
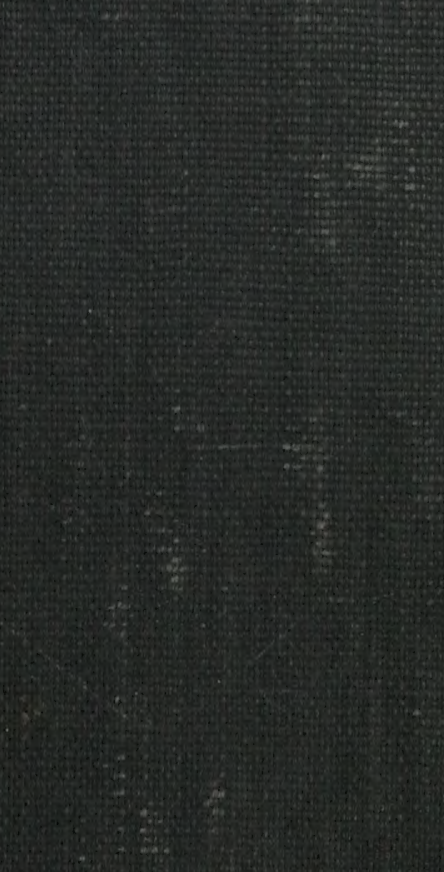



$$
D-1
$$







\title{
Die Vögel
}

\section{der paläarktischen Fauna.}

\author{
Systematische Übersicht \\ der
}

in Europa, Nord-Asien und der Mittelmeerregion vorkommenden Vögel.

Von

Dr. Ernst Hartert.

Band I.

Mit 134 Abbildungen.

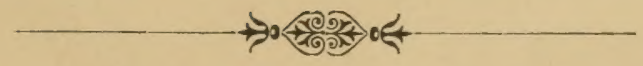

\section{Berlin 1910.}

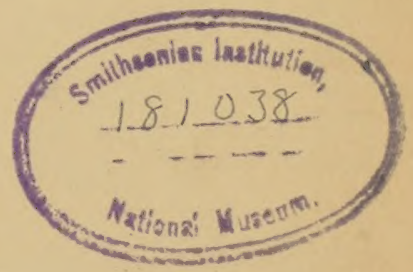

Verlag von R. Friedländer und Sohn.

Agents in London: Witherby \& Co., 326 High Holborn. 



\section{Einleitung.}

Es war ohme Zweifel der grobe Reformator der srotematisulien Natur-

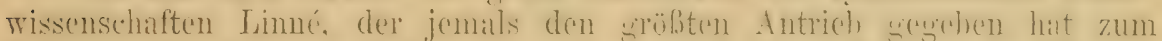

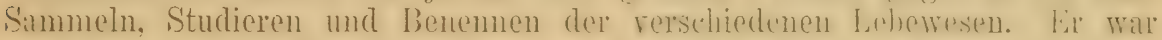

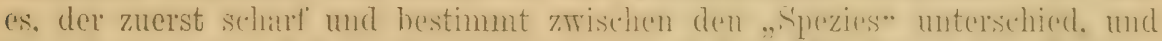

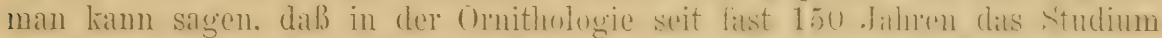
der Arten mit groliem Eifer und lifolg hetrielen worden ist. Hente lamen

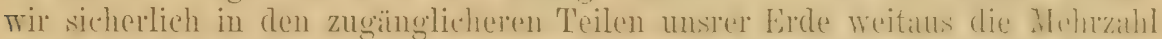
der Arten, ohwohl es auch noch maluche newe zu (Antdecken gibt. ${ }^{1}$ ) lis hat

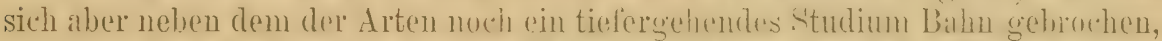
nämlich das der geographischen Vartiation. Limn sall dir Natur an als

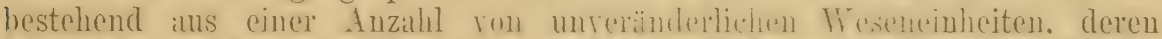
Individuen nur bis zu einem geringen Grade abroblerten. Diese Treseneinleden namnte er Spezies Arten) und erfind für sie die ïh(raus prabtische hinäre Nomenklatur. 1)ie Entseheidung. on es sich um Irten ader Tarrotiiten ] a delte. Wurde zumeist ziemlich willkürlich und lediglieh nateh dem Mab der lnterschiede getrofien. Eine frrupne run Individuen. die sivb gut definieren B. war eine Art. ihr in wesentlichen ähnliche oder sir durch Ühereänge wirkliche und rermeintliche) rerhundene Formen wurlen (ntweder gar nicht. oder als Varietäten benaunt. Auf die geographisehe Verbreitung wurde dabei gar lein, oder nur ein geringes Gervicht golegt - das wat alleh damals nicht anders mö̈glieh. deun das rorlicgende Material wall goring. selten genau und oft ganz filsed etilettiert, die Kenntnisse physikilischer Geogmaphie waren gering. Die sogenanuten Varietäten waren zum T'eil wirkliche individuclle

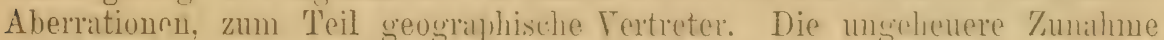
unster Kenntuis von Formen und die Menge des gesammelten Materials mubte notwendigerweise zu cins. Tertiefung das Studiums fiilnem. Lis mulite sich herausstellen. dab mauches sehr abmliche forh nicht dissellue. und manches auffallend rersehiedene doch noch nicht spezitich rerstheden war. Man erkannte, daß gewisse äuferdich sehr äbuliche Tiere rerschiedenen drten

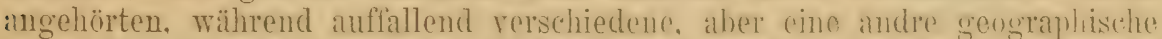

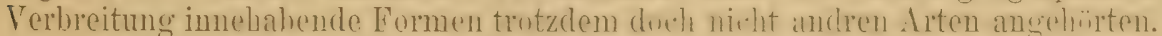

Auffallenderweise hatte dir gewaltige liovolntion are Erolution: lehe

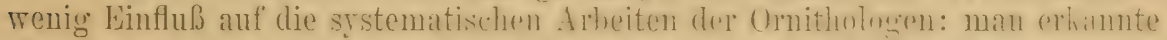
die neue Lehre zwar meistuns ans. zog ahor keine Kunsequenzen thï die Systematischen Details aus iłr, ausegenommen in neuerer Zeit fïr die systemutits der höheren Gruppen.

1) In der 10. Ausgabe seines Systema Naturae, 1758, also in dem Jahre, mit dem wir unsre Nomenklatur beginnen, kannte Liuné 554 Vögel, wir unterscheiden heute mehr als 15000. 


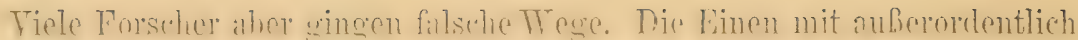

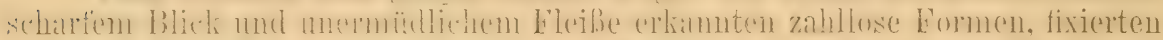

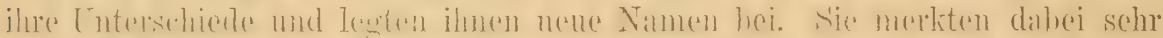

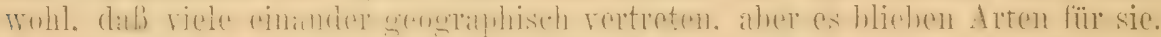

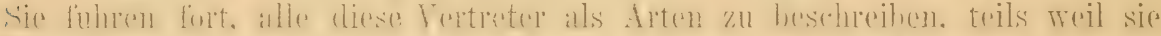

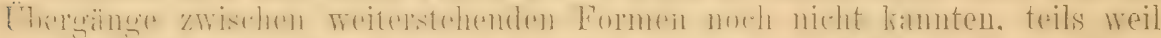

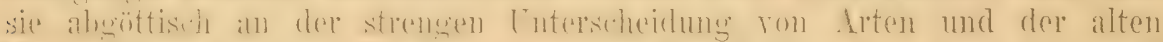

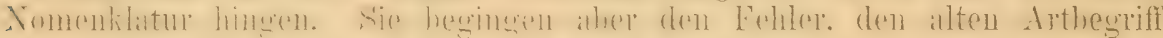

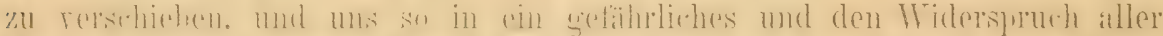

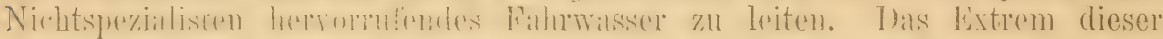

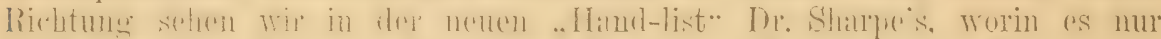

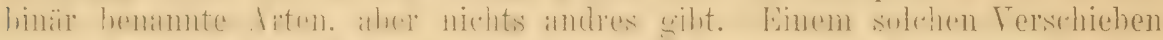

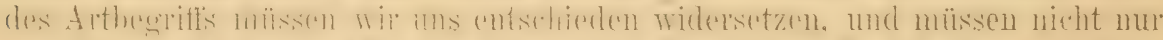

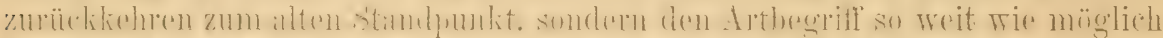

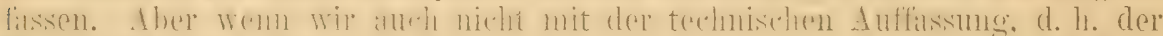

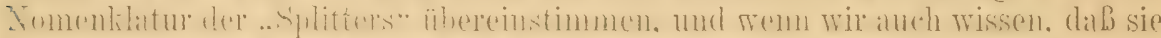

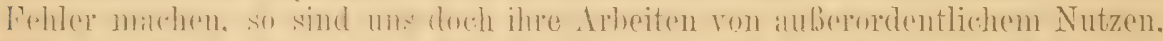

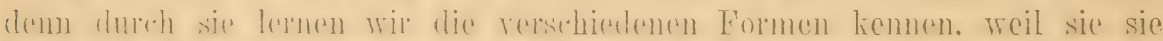

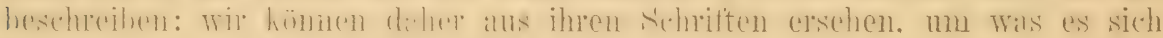
handelt, daraus lernen und Schlüsse ziehen.

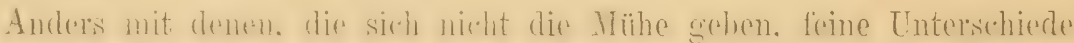

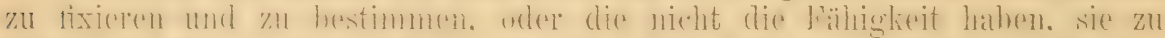

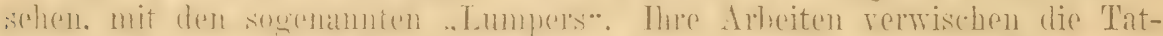

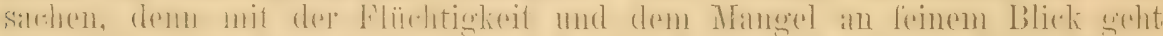

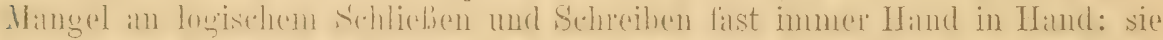

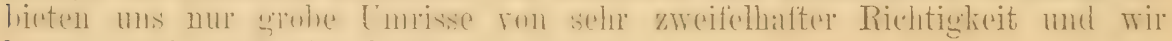
lermen wenig und oft falsches von ihnen.

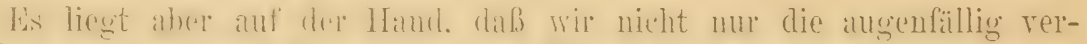

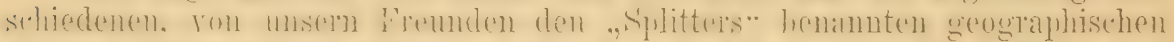

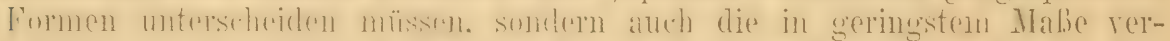

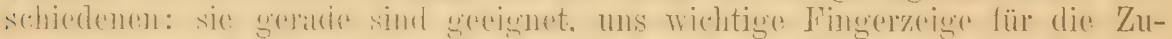

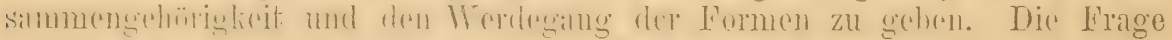

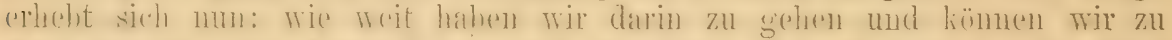

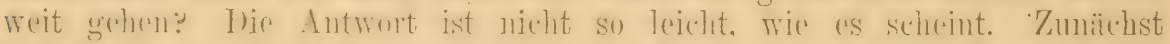

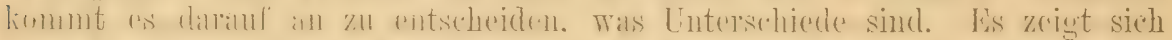

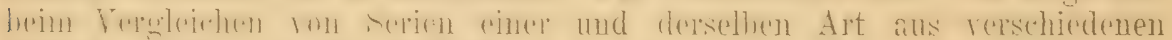

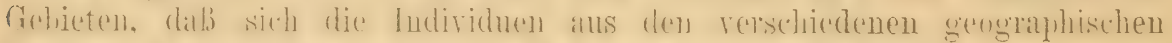

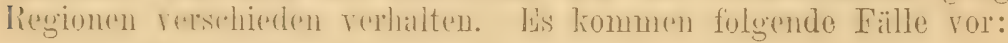

1. Sie gleichen einander vollständig.

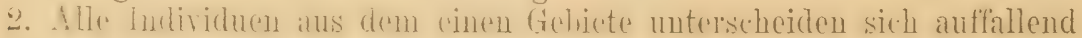
von allen aus dem andern Gebiete.

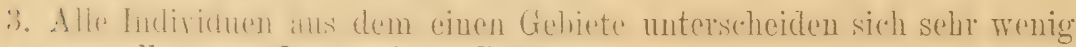
von allen aus dem andern Gebiete.

4. Nuir cin Troil der [ndividuen alus dem einen Gebrete unterseheridet sich von denen aus dem andorn Gebiete.

Im arstem Falle crluth sich naturlich lisine Frage, d. h. wir kömnen nicht mehrere Formen unterscheiden.

In zreitcrn linlle müssen wir sie henenuen, ohne dilb sich weitere Schwierigkeiten darbieten. 
Der rritte Fall ist natiurlich schon sehwiericre. Fin grühter Sestematiles. sieht mehr Entrehsherle, als ein Anfinger, nud wer sich linne intensiv mit

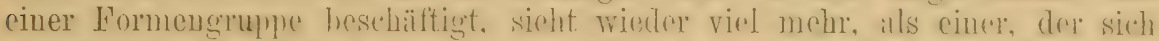

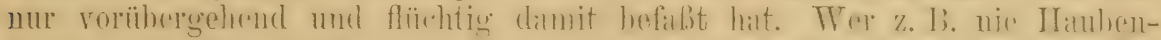

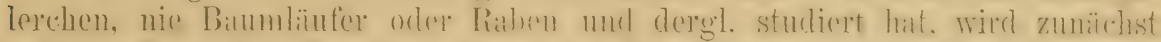

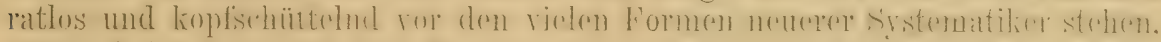

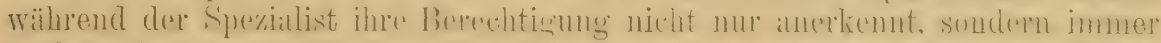

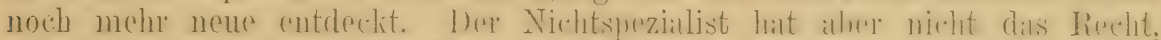

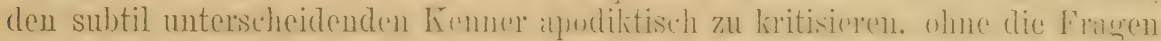

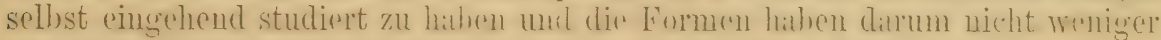
Bedeutung, daß man sie ohne ticferes Studium nicht sehen kann.

Noch sehwieriger ist der vierte fiall zu behandeln. Um zul entseheiden,

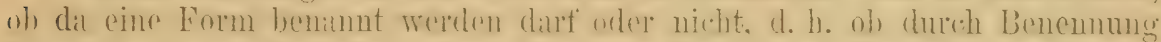

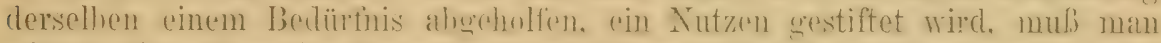
wissen, fin wie grober Prozentsitz zu moterseheiden ist, und man wired gen zugehen, dab eine gengraphisele Form mit Vorteil hename werelen wird,

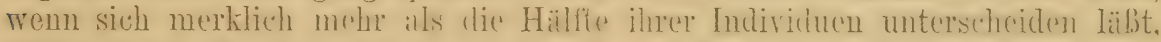

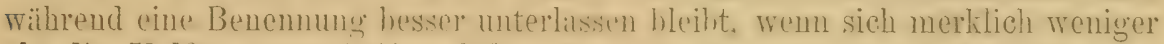
als die Hälfte unterscheiden läbt. Da wir aber ron ren tatsäichlich vorhaudenen Indivichen nur rinen rersehwindend geringen 'Teil untersuchen kömnen. su liegt es auf der Hand. dab wir in solehen Fällen ïborhant mur

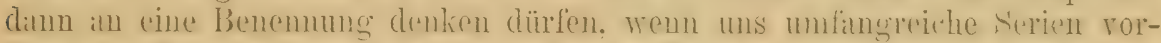

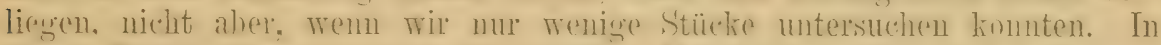
diesen Fïllen liamn es schon rerschiedene Meinungen gohen und man hiann uft gezwungen soin. seine ursurüngliehe Ansivht ämlen zu müssen.

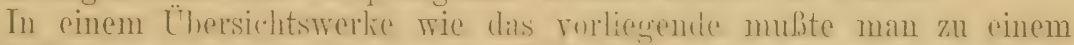

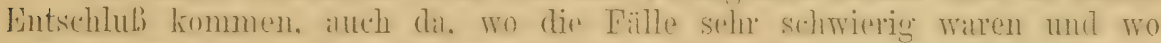
rersehiedene Sprezialisten ihne gegenseitigen Mrinungen helïmplfen. Wo es irgeud möglich wan. wurden eigene studien an möglichst mufangredehom Material gemacht. Terfissere howamn seine Studien an den Vögeln der Heimat

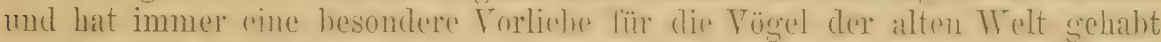
und manche Stuncle daran geallheitet, es steht ihm aher auch ein reiches paläarlitisches Maturial in dom von ihm verwalteten Rothschild'seden Museum

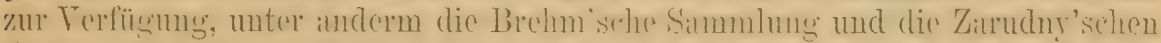
Śerien russischer, turkestanischer und persischer fïgol n. a. m. Auberdem

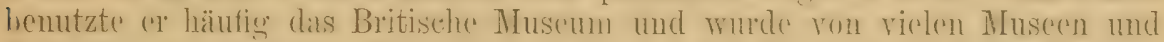

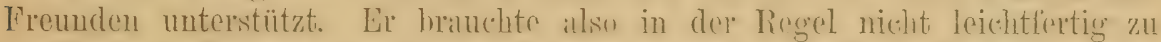

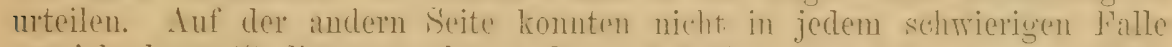

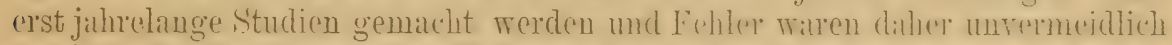
- das aber ist immer der Fall. nur ein aufgehlasener Nan wird ghluben können, daß er keine Fehler machen kann.

Fine gleichnäBige Behandhung wurde ancestreht, alber oft nicht erreicht,

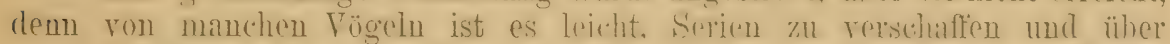
manche Gattungen liegen unfangreiche Arheiten, Resultate jahrolangen Fleifes vor, von andern Arten fehlt es ïherall an Material mud niemand liat sich fïr sie hesonders interessiert. Solche Inkonsegnenzon abor. wie sic sich bei mehreren modernen Autoren findem, hat der Ferfisser zu relmeiden acsucht.

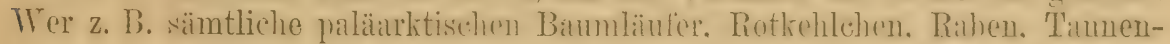

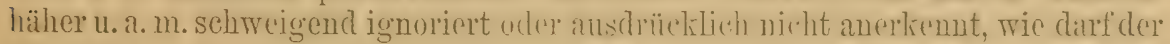
die uicht cin bischen mehr rerschiedenen Tasserimseln und staro untersehoiden! 


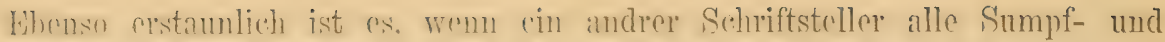

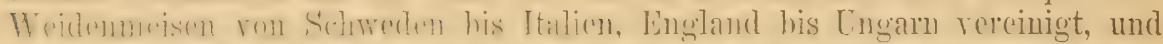

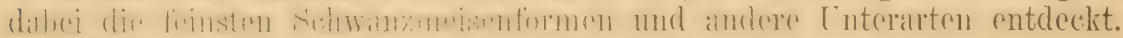

Das oben gesagte beantwortet eigentlich schon eine Frage, die viele

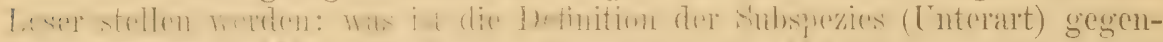

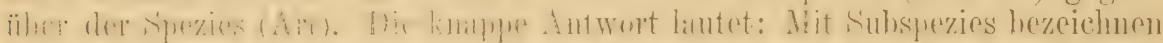

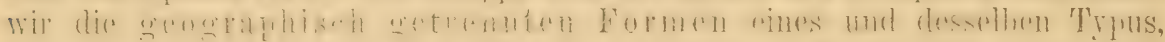

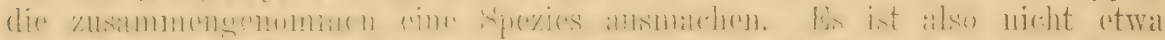

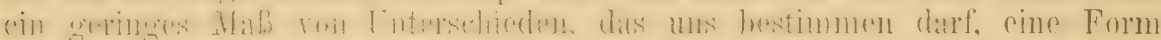
als Subspezics aufufassen, sondern Unterschiede verbunden mit

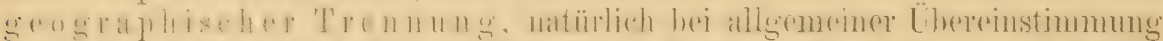

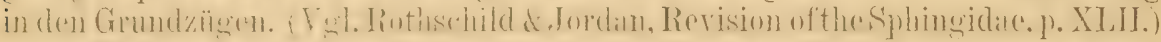

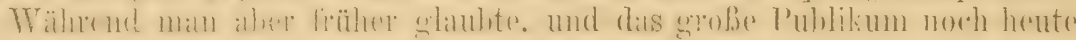

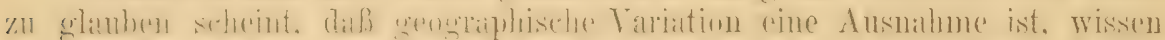

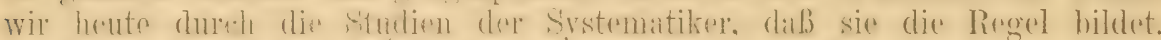

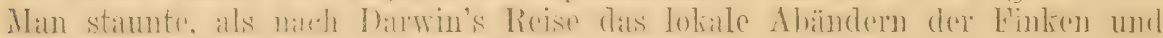

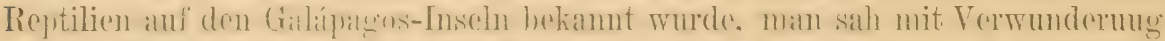
auf die Philippinem, wo fist jectr Insel andro Formen anfweist - hente wissen

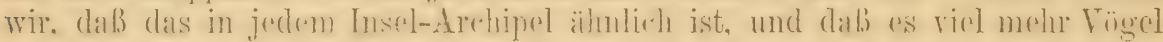

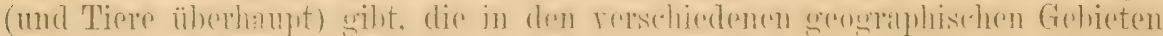

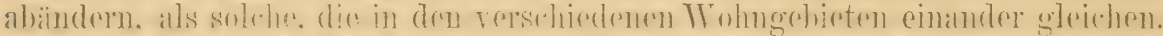

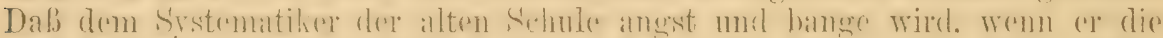

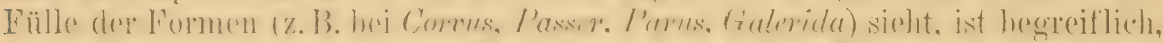

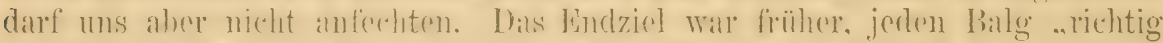

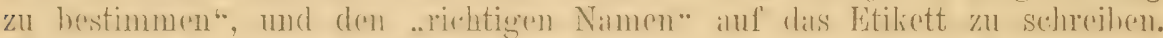

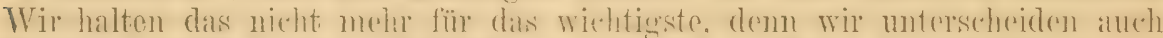

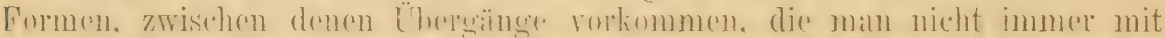

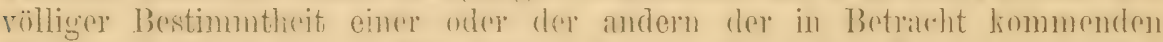

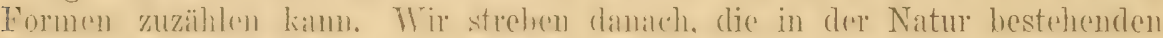

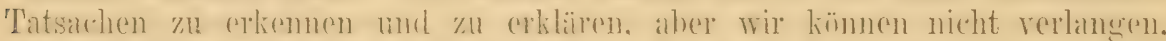

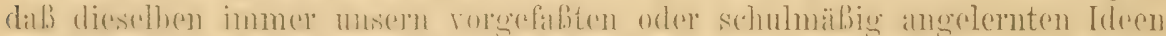

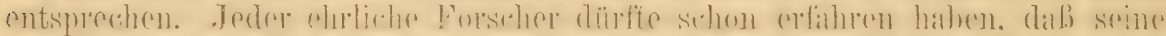

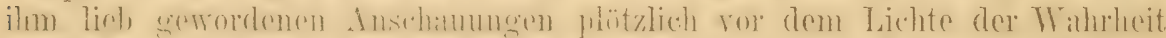

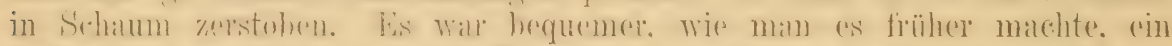
System zu wronlinu und dir Natur in dassedhe rimzuschalten - wie as Limné, Oken, Strainson und viele andre machten - als aus den eigenen

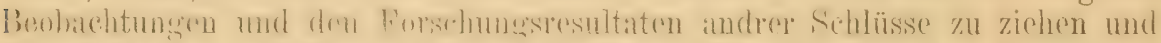

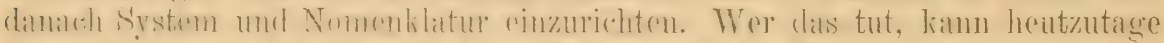

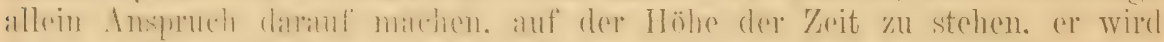

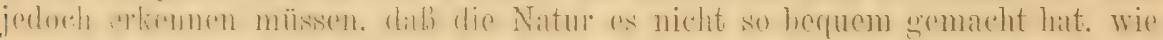
man frïher wähnte und wie man es gern möchte, or wird aber auch ein-

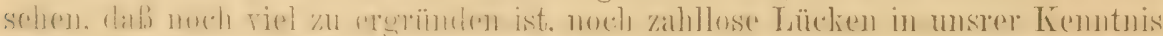

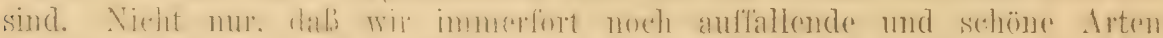

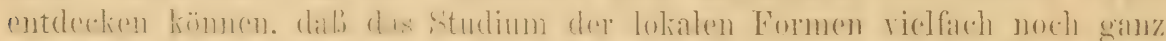

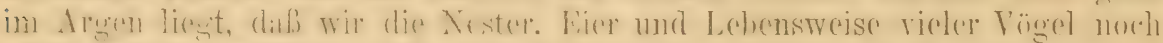

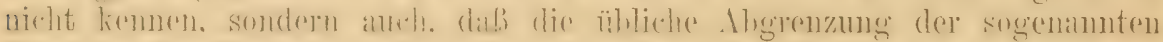

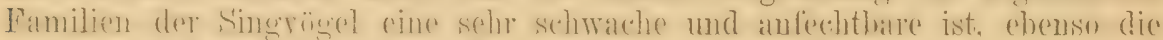

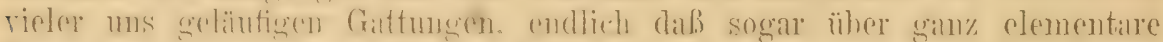

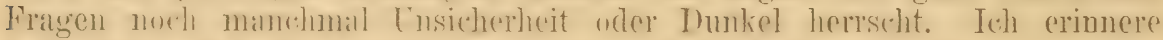

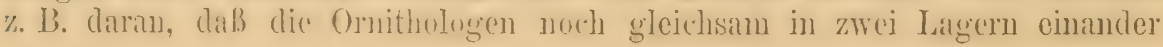




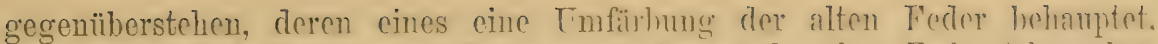

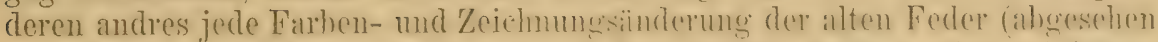

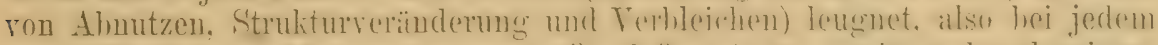

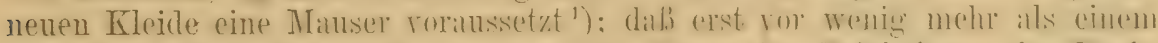

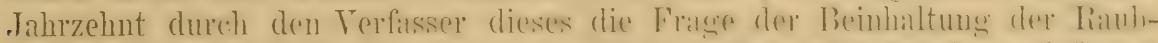

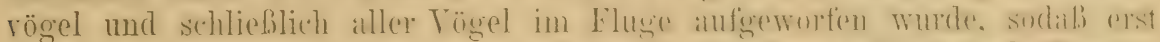

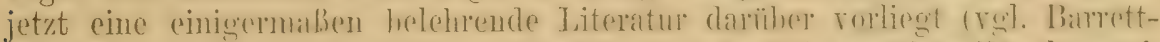

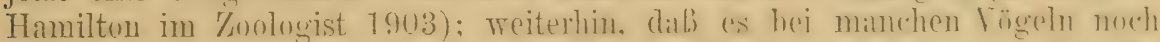
nicht sicher festgestellt ist. wir oft. Wamn und wo sie malusem - cine für das Studium der lokiten Formen ganz hesonders wiehtige Flagen! Anch

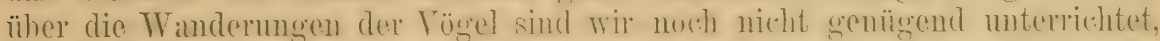
und gerade für die Liforsehung dieser ist das genaure Studium der Interanten

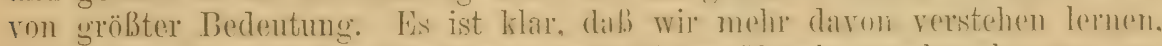
wemn wir den auf der Tranderung hefindlichen Vïgeln ansehen kïmmen, wo ihre Heimat ist. d. h. Wo sie hrüten. F̈herenthusiastisthe Gunssen müssen freilich darauf aufmerksam gemarht werden, dali wir dies nicht in allen Fällen werden armöglichen kömmen, demn nicht hei jeder Togelart sind lokale Formen ausgebildet.

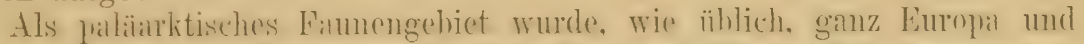

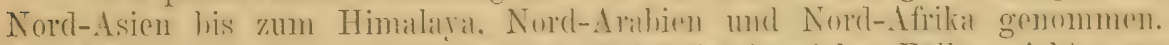
Die Alngrenzung dieses Gelietes math süren ist in vielen Fällen nicht ganz sicher und keineswegs scharf. In Tresten hildet die Salnara die Sï̈dgrenze.

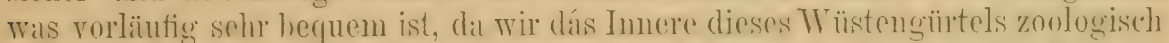
noch nicht lienuen. Im Niltal verwischt sich dio (roenze, dat tropische Formen dem Nil mach Norden, paläarktische jhm südwïrts gefolgt sind. Wrir gehen mit den paläarlitisehen Formen. soweit sie sïdwairts renchangen und nehmen lieher zu vicl, als zu wenig anf. Auch in Arabien ist die Grenze nieht

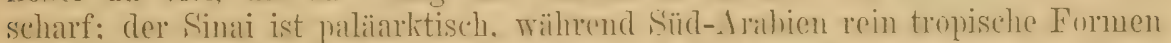
zeigt. Im Himalaya sind alle deu palianktisehen Fomem nahestehenden Töged erwithnt, rein trojische Formen aher meist unerwilhnt golassen. anch wemn sie hoch in die kïhlen Regionen aufstrigen. In ('hina fehlt es an einer scharfen Grenze, im allgemeinen vingen wir im Westen his in die Berge rom Szetschwan. inn Osten lis in die Breite von I'eking und nalumen soviol wie möglich auf. Jilpan dufte uatürlich nicht fohlen. Wir gehen zu. daß

1) Praktische Naturbeobachter im allgemeinen und anatomisch arbeitende Zoologen haben von jeher der letztern Ansicht beigestimmt. Es sind vorzugsweise bloße Balgforscher, die eine Farben- und Zeichnungsveräuderung in der alten Feder behaupteten. Davon kann aber keine Rede sein. Nur so lange die Feder noch wächst, ist ein Zufluß von Pigment überlıapt möglich und findet vielleicht in einigen Fällen statt. In solchen Fällen kann dann möglicherweise eine Farbenveränderung einer Feder stattfinden. Die Behauptung von Sehlegel, Sharpe, Grant, Millais u. a., daß eine im Herbste erwachsene Feder nach Mlonaten im Frühling ihre Farbe und sogar ihre Zeichnung ändere, z. B. statt Längsstreifen Querbänder bekomme usw., ist in keinem Falle bewiesen und beruht auf falscher Schlußfolgerung, indem aus dem

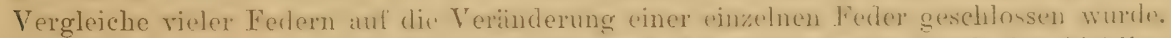
(iewaltig sind aher dir. Teränderungen. die dureh Alwetyung sowie dureh das Abfiallen der Seitenästchen der Federfahuen oder ihrer filamentösen Anhängsel hervorgebracht werden. Das vorher wie mit einem Duft üborzogene, matte Gefieder erhält dadurch

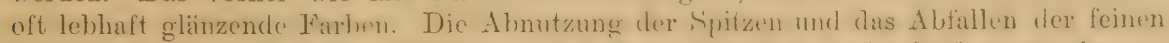
Seitenzweiglein ofler ihrre Anhängsel geht in viclen Füllen in trockenheibem. smmigerem Klima rascher vor sich, als in höheren Breiten. 


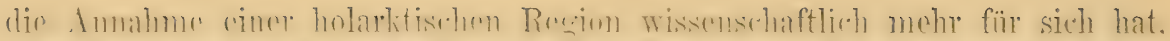

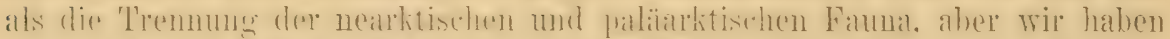

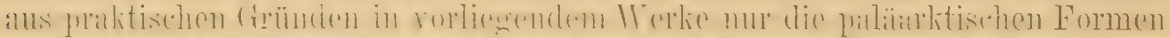

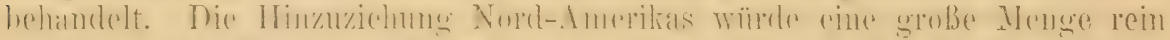

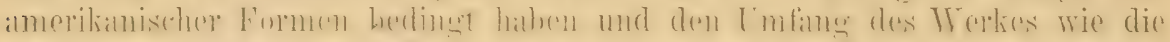

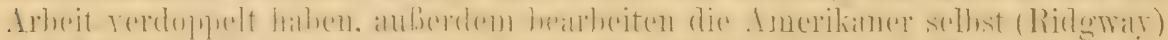

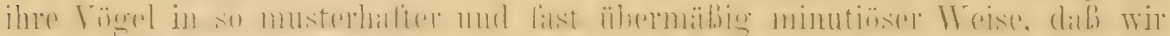

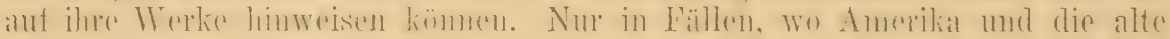

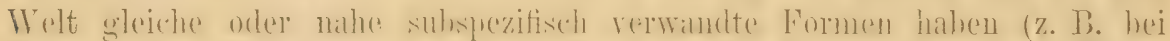

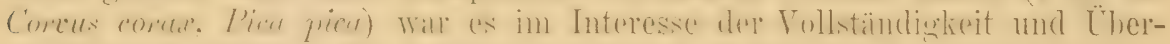

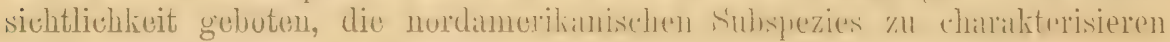
oder wonigstens kurz zu erwähnen.

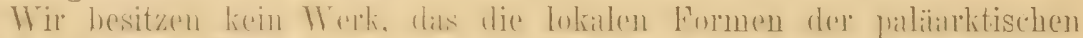

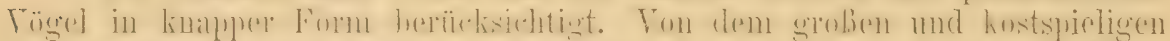

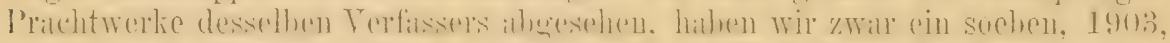

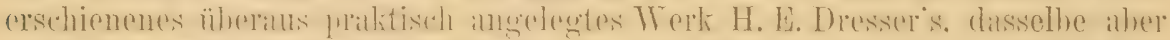

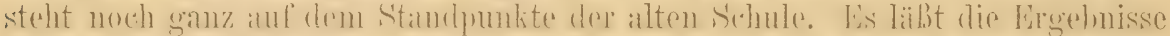

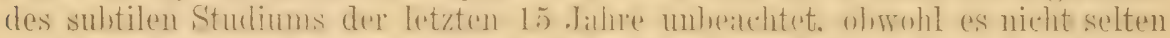

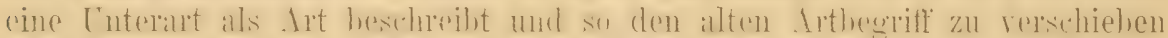

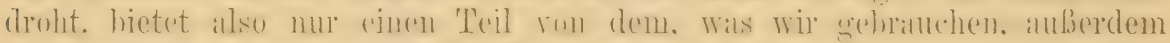

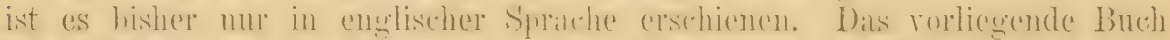

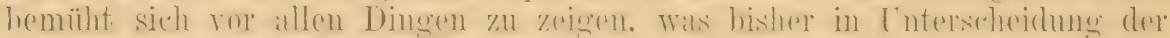

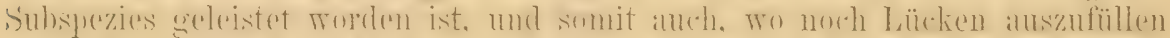

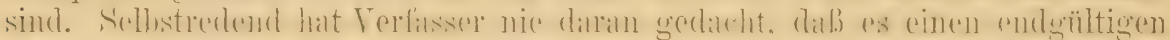

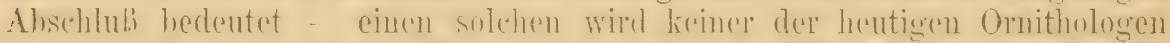

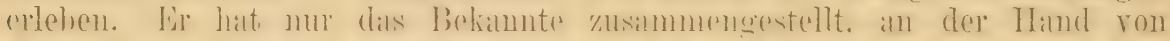

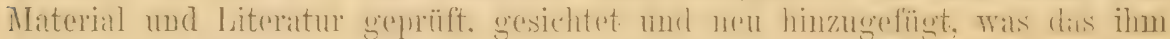
rorliegende Material ergab.

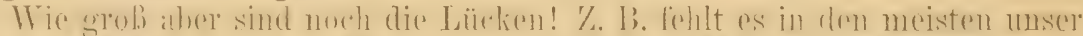

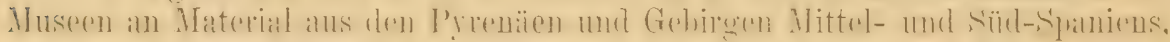

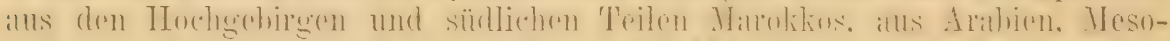

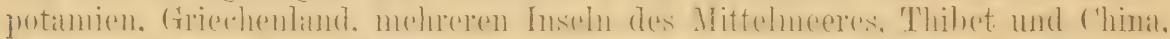

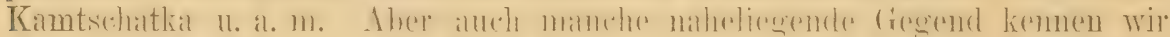

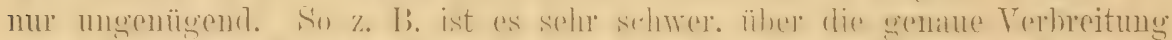

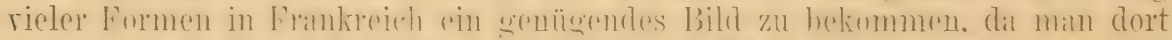

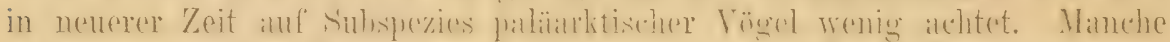

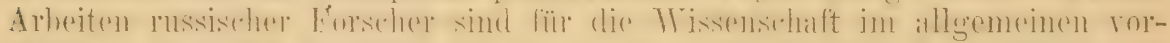

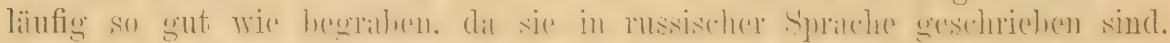
Bezüglich der speziellen Behandlung sei folgendes bemerkt.

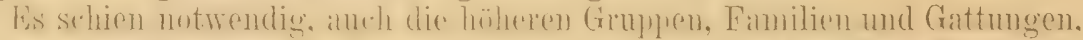

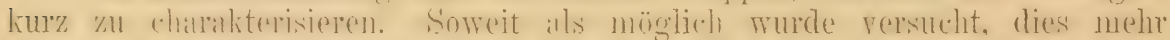

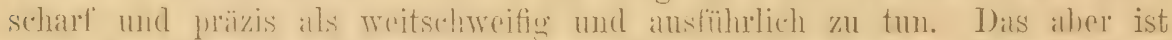

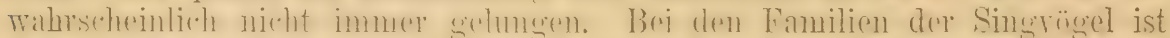

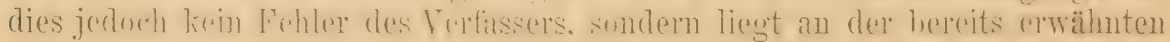
Schwäche dieser Familien.

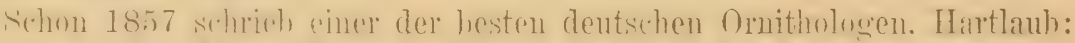

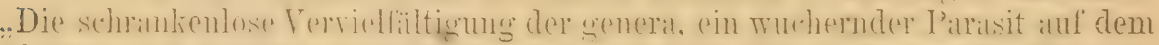

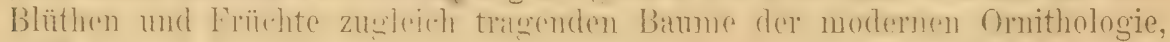

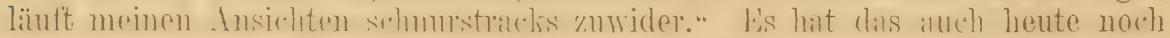
riniga berechtigung und ist dem Verlitsser recht sympathisch, ex bemühte 
sich jednch mö̈lichst dem Gebrauch zu folgen mol nur dil zu änclern. Wu ihm die rorgenommene Gattumsspraltered durellas nicht halthar arselien.

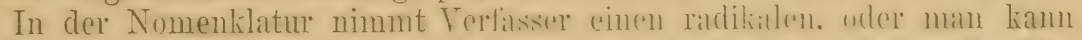
auch silgen streng konservatiren Standpunkt ain. indem or sich hemëht. den

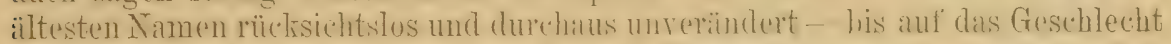

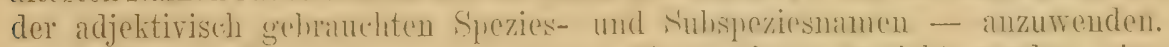

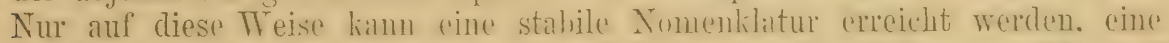

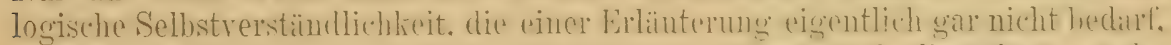
die aber trotzdem tamsendlatele hestritten. rentiliert und disputiert wuris. "Nomina nuda" mulden zwar zitiert. alwe als solche gekemuzeichnet. Dilb sic nieht angersandt wurden. hraureht nicht amseinandergesertat zu werden. Bei den Zitaten wurde es zur herel gematcht, sie nachzusehlagen umel den ersten Fundort riner Form, die "typische Lukalititu eines jeden Nannens lest-

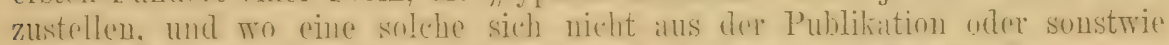

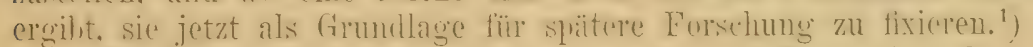

Die Beschreilumen warden, wo mux irgend Material rorlag, wach der

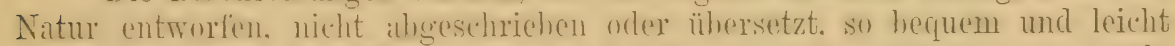

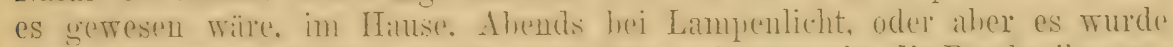
das. Wo es unvermeidlieh maur, homerkt. Es wude rersueht, die Buschreibungen möglichst knapp. lim\% aber chalrakteristisch zu marhen. eine Aufgahe, dio sich oft als recht selower herausstellte und unx teilweise einigermalsen gut gelist morden sein mas. Dis Malie sind. Wrum irgend mëglich. an rorliegenden Bälgen vom Verfasser selbst genommen.

Die Verbreitung wurde möglichst genan gegoben, aber auch das ist nicht so leicht getan. wie man es cich lenkt und die Lülken sind grob geblichen, was der Verfasser selbst am besten weib.

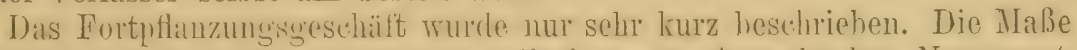
der Eiel wurden teils selhst genommen, teils der nenen dusgahe des „Namman" entlehnt, wo ihnen besondre Sorgfalt gewidmet wurde.

Schtrer war es. hei den lierheschreihumgen und norh mehr bei den Andentumgen der Lehensweise gleichmailig zu verfahren und Mals zu halten.

1) Verfasser hätte gern alle Synonymien und Zitate vermieden, aber das war mmö̈glich. Die größten allgemeinen If erke (Catalogue of Bircls. Birds of Europe) haben die Prioritit nicht ernst genug wenommen, auberdem hei der XII. statt der. X. Ausgabe Limés begonnen. Alle Synougue mubten zitjert werlen, damit man schen kanu, was für Namen existieren, und die typischen Fundorte mußten eruiert werden, damit man bei Abtrennung never Unterarten nieht in den of gemachten Fehler verfalle, neut Namen zu schaffen, obwohl schon Namen da waren, die sich auf die nene Form bezogen, aber bisher als Synonyme galten. Es ist traurig, aber wahr, daß die deutschen Vögel sich durch hesonders viele Synonyme und natite Xamen herrortum, meist durch die Publikationen C. L. Brehm's in dem, "Vogelfang", noch mehr durch das von A. E. Brehm herausgegebene Verzeichnis der Sammlung seines Vaters. Dasselbe war deutschen Ornithologen bekannt und wurde ron denen, die es kannten, mit Recht totgeschwiegen, Dresser aber fand is niitig. die darin enthaltenen zahllosen Nomuina muda (ohne sie als solche zu bezeichnen!) in den "Birds of Europe" zu zitieren, sodaß wir sie nun als nutzlosen Ballast mit herumschleppen müssen. In allen Fällen wurde nur die den Ausgang bildencle erstr. l'ublikation angegeben. Das Zitieren ron allbeliamnten Werken wie Catalogue of Birds. D)resser's Birils of Europe u, a., wie es (besonder's in England) ïblich ist, erschien nutzlos, denu jeder weib, dab clort die betr. Tögel zu funden sind. Auf diese Weise wurte viel Ballast remieden, dagegen wurden die ersten Beschreibungen ausführlich zitiert. 
7/u leicht kam man in die Gefahr, zu breit zu werden. Lis tanchten die Kiefernforsten und sumptigen Eirlenwälder (Ostrueußens, die Gärten am Rhein, wogende S'ee. wilde Klipren, Palmen- und ()amgenhaine in Gedanken auf,

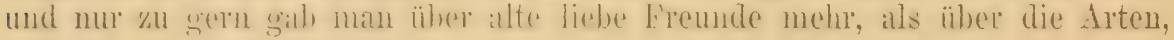
die man nur aus Büchern kannte.

Für die geographis:chen formen haben wir natürlich den Ausdruck Sulnspezies (['nterirten) beihehalten, der sich allgemein eingebürgert hat. Lis hat nicht den geringsten Zwerk. gilht leineswegs einen hesseren Begrifl

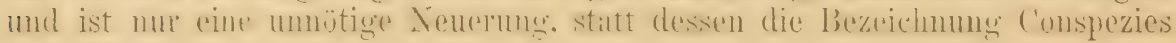
einzufühlen.

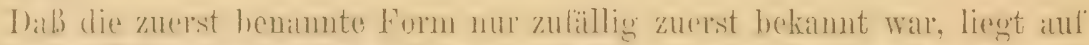
der Hand. Wir nelnnen ihren Xamen ledightich darum für die Art an, weil

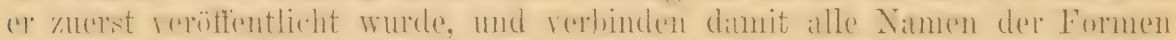

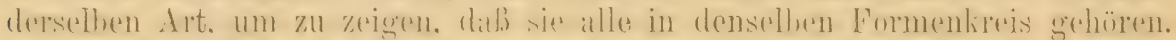

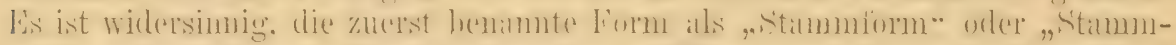

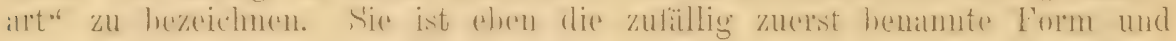
darum nehmen wir ihren Namen für die Art an. Jedes andre Verfahren wïrde zu endlesen Streithatgen mihren. Weil wir selten ohne weiteres lest-

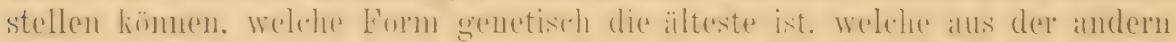
hervorgegangen ist.

Dit nun die zuerst lomannte Form matürlich keinen andern Rang ciu-

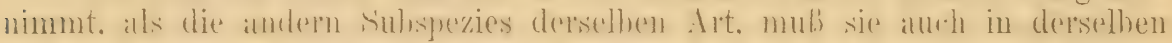
Art und Weise wie jene henthnt werdens. d. h. wir këmnen nicht lïr sie

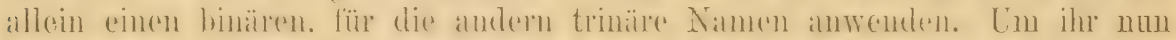

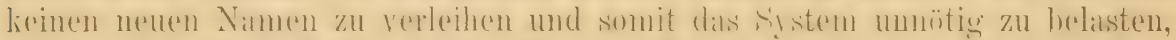

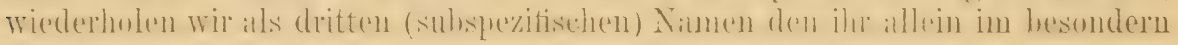
zulkommendeu.

Als Beispiel möge die Wasseramsel dienen. Sie wurde von Linné

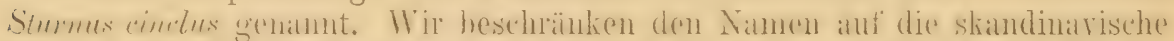

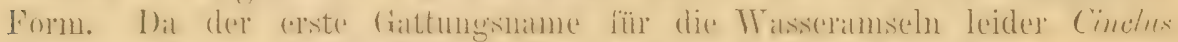

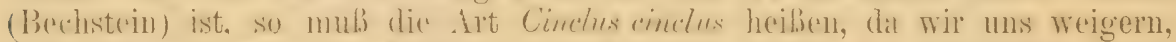

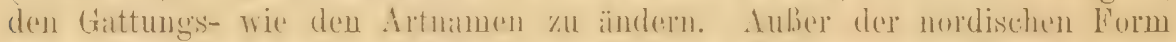

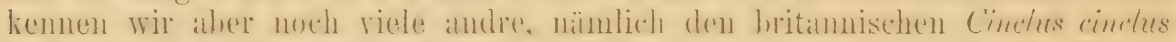

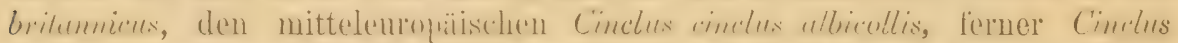

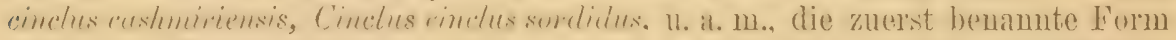

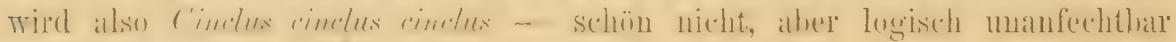
und praktisch.

Bezüglich der technischen bohandlumg sei noch folgendes bemerkt.

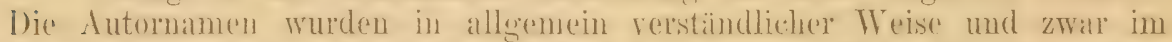

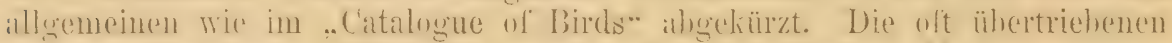
und unpraktiseh gewählten Ablärzungen des rom lierline Museum heraus-

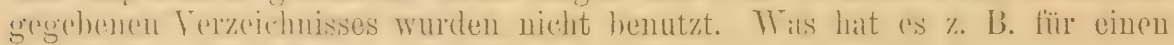

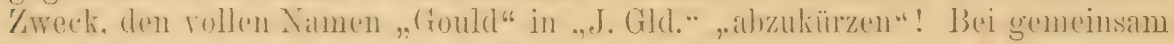
rerlibten Arbeiten wurden die Autenemamen dureh dis Zejehen id rerbunden.

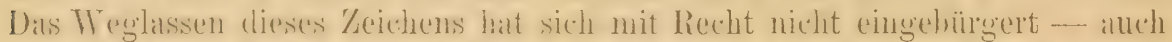
die Rediktion des ..'Tleereich" hilligte es nicht - . da es keinen Vorteil bringt,

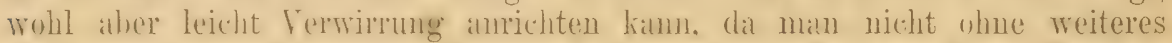
wissen katun, uhe es sirh un Vor- und Nachnamen orler zwei Leute handelt. Die Antorennamen wurden eingeliammert, wenn der Art- resp. Ginterartname ursprünglich mit einem andern, als dem nun angewandten Gattungs- 
nimmen publiziert worden war. Fin stetes Finkiammorn ist ein sehe nïner'flïssiger Ballast.

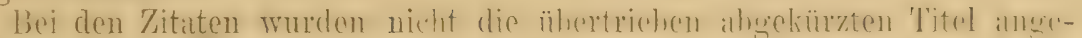
wandt, wio sie in England und anderswo ïblich sind. Anstatt „P. \%. S.".

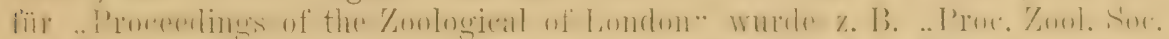
London", statt „J. f. O." für "Jourual für Ornithologie" wurde ,.Journ. f.

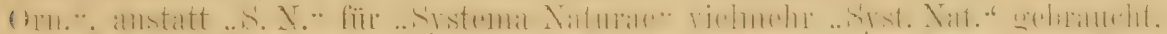

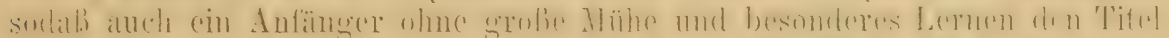

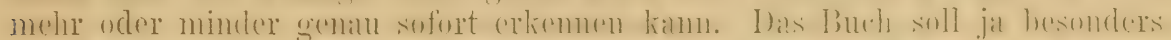

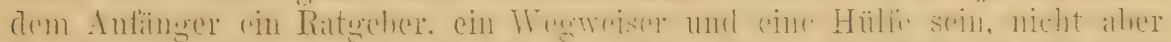

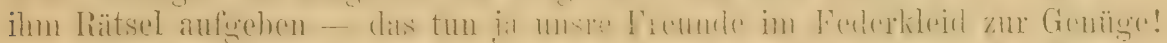

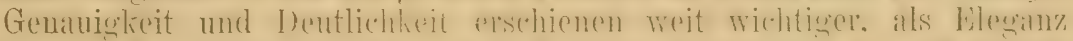

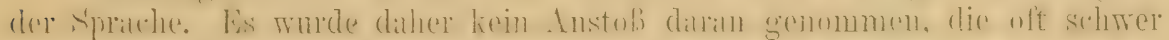

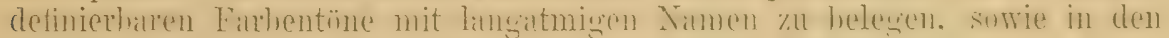
Beschreibungen sich oft wiederholende Ausdrücke anzuwenden. 


\section{Kunstausdrủcke.}

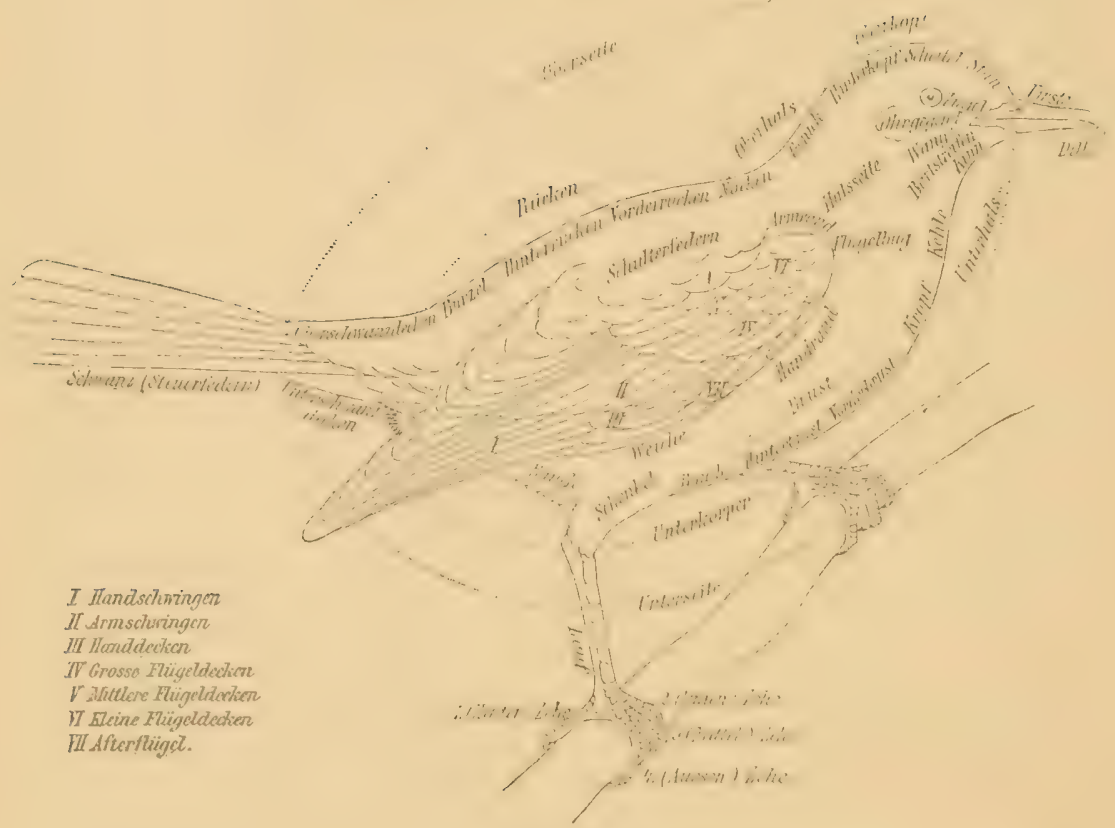

Figur 1.

Stirn und Scheitel $=$ Vorderkopf.

Ohrogend = Ohrdecken.

Unterhals $=$ Vorderhals.

Oberhals $=$ Hinterhals.
Oberkopf $=$ Pileum.

Sehulterfodern $=$ Schulterfittichc.

Unterkörper $=$ Abrlomen.

Steiß $=$ Aftergegend.

Ein ïber den Zhigeln und über das Auge hinziehender Streif wird gewöhnlich als Supereiliarstreif oder Supercilium bezeichnet.

Der Schuabel ist wenn nicht ander's gesagt vom Ende der Stirnbefiederung bis zur Spitze gemessen (Reichenow's und anderer ILethode); wenn gesagt wird "von der Wurzel" ocler ,von der Stirn", ist er aber vom Beginn der Schnabeldecke gemessen. Bei cinigen Arten schien das erstere, bei andern das letztere genauer zu bewerkstelligen.

Der Fliigel ist rom Bug bis zur Spitze auf dem Lineal gestreckt gemessen.

Der Schwanz ist von der W Wurzel, d. h. ron da wo die mittleren Steuerfedern aus der Haut heraustreten bis zum linde der längsten Stenerferler gemessen.

Der Lauf ist ron der hintern Gelenkvertiefung zwischen Lauf und Untersehenkel (F'ersengelenk) bis zum Énde des letzten Laufschildes gemessen. 


\section{Inhalt des I. Bandes.}

[Seit der Zeit des Frscheinens der 1. Lieferung der "Tög. der paliarkt. Fanna" hat die Tätigkeit anf diesem Gebiete gervaltig' zugenommen, nameutlich hat man in nenerer Zeit angefangen mehr auf geriuge Lutersehede in den verschiedenen Ländern und Faunengehieten zu achten. Dies ist ein erfrenliehes Zeichen für die Weiterentwicklung unserer Lieblingswissensehaft, wenn auch nicht alles Gold ist was dafiir allswegehen wird, und wenu alueh mitunter im Übereifer fehlgeschossen wird.

In den Anmerkungen zu vorliegendem Inhaltsverzoichnis sind dio seit Funde 1903 als neu beschriebenen Formen (bis knde 19(19) erwähnt, aher fast nur in Fïllen, wo ich mir ein auf Unterstchung ron Material gegriunctetes Urteil orlatuen zu dürfen glauhte, habe ich mich dariiher ansgesprochen, ob) die betreffenden Namen neuen Spezies oder Sulspezies zukonmen. oder oh sie don Symonymen hinzuzufügen sind. Ẻbeuso habe ich in den Überschriften rorgekommene oder sonstige wichtige Fehler rerbessert und Überschenes machgetragen. Beschreiloungen und Beurteilung aller der hiuzugekommenem Formen, neuere Entdeckungen und Firgänzuvgen der Terbreitung, Fortptlanzung und Lobensweise usw. werden in den später zu reröffentlichendon Nachtrëgen erfolgen.]

Die 6 Hefte des I. Bandes erschienen wie folgt:

Heft 1: (Seite I-XII und 1-112): November 1903.

:. 2: Seite 113-240: Juni 1904.

"3: Seite 241-38t: Juni 1905.

, 4: Seite 385-512: März 1907.

., 5: Seite 513-640: Februar 1909.

". 6: Seite $6 \pm 1-817$ : Juni 1910.

Einleitung . . . . . . . . . . . . . I-XIII

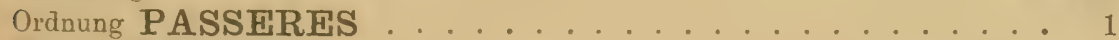

Fanilie CORVIDAE . . . . . . . . . . . . . . . . 1

Gattung Corvus L. . . . . . . . . . . . . . . 1

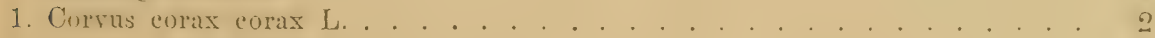

2. $"$ " varius Brünn. $\left.{ }^{1}\right) \ldots \ldots \ldots \ldots$

3. $"$ " tibetanus Hodgs. .................... 4

4. " $"$ sibiricus Tacz. ................... 4

5. $"$ " ussurianus Tacz. . . . . . . . . . . . . . . . . 4

6. " " kamtschaticus Dyb. . . . . . . . . . . . 5

1) Hinzufügen ist: C. corax islandicus Hantzsch, Orn. Yonatsber. 1906, p. 130; Island. - Der grönländische Rabe ist C. corax principalis Ridgw.

E. Hartert, Die Vögel der paläarktischen Fauna. 
7. Corvus corax behringianus Dyb.1)

8. $"$ " hispanus Hart. \& Kleinschm. . . . . . . . . . . . . 5

9. $"$ " sardus Kleinschm. ............... . . 6

10. $"$ " canariensis Hart. \& Kleinschm. . . . . . . . . . . . 6

11. $"-\%$ tingitanus $\operatorname{Irby}^{2}$ ) . . . . . . . . . . 6

12. $"$ laurencei Hume .............. . . 7

13. " " umbrinus Sund................ 8

14. $"$ affinis Rüpp.................. 8

15. cornix cornix L. ${ }^{3}$ ) .................. 9

16., sardonius Kleinschm. . . . . . . . . . 10

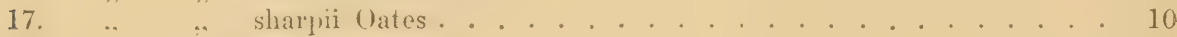

18. ., "apellanus šcl. . . . . . . . . . . . . . 11

19. $"$ corone corone L......................... 11

20. , , orientalis Eversm. . . . . . . . . . 12

21. "macrorhynchus japonensis $\mathrm{Bp}{ }^{4}$ ) .............. 12

22. " frugilegus frugilegus L................ 13

23., tschusii Hart. . . . . . . . . . 14

24. $"$ " pastinator Gould ............. . . . 14

(iattung Coloeus Kaup. . . . . . . . . . . . . . . . . 15

25. Coloeus monedula monedula (L.) . . . . . . . . . . . . . 15

26. $" \quad$ spermologus (Vieill.)............ . . 16

27. $" \quad$ collaris (Drummoud) ................. 17

28. " dauuricus $\left.(\text { Pall. })^{5}\right)$. . . . . . . . . . . . 18

29. " neglectus (Schleg.) . . . . . . . . . . . . . 18

Gattung Pica Vieill, (oder Schäffer 1789) . . . . . . . . . . 19

30. Pica pica piea (L.) . . . . . . . . . . . . . . . . 19

:31. .. " melanotos Brehn. . . . . . . . . . . . . . . . . . . . 21

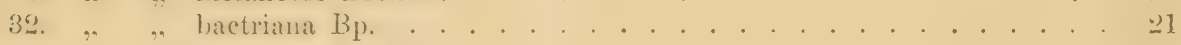

3:3. .. " hudsonius (Sah.) . . . . . . . . . . . . . . . 21

34., sericea Gould ........................ 22

35. " . mauritanica Ialh. . . . . . . . . . . . . . . . . 22

36. .. .. bottanensis I) less. . . . . . . . . . . . . . . 22

37. .. .. nuttalli Aud. . . . . . . . . . . . . . . . . . . . . . . . . 22

Gattung Cyanopica Bp. .................. . . 23

38. Cyanopica cyanus eyants (Pall. i. . . . . . . . . . . . . . 23

39. ., .. swinhoci Hart. . . . . . . . . . . . . . . . 24

40. $"$ cooki Bp. .................... 24

1) Synonym: C. grebnitskii Stejueger, Proc. Biol. Soc. Washington II (1884), p. 97.

2) Vgl. C. corax lirausei Zedlitz, Orn. Monatsb. 1909, p.178 (Sinai. - Nach Ansicht des Verf. vermutlich der östliche Vertreter von tingitanus, dagegen umbrimus weniger ähnlich. Wenn eine besondere Rabenform den Sinai bewohnt, muß sie aber wolıl infumatus heißen. Vgl. Parrot, Zool. Jahrb. XXIII, p. 287.

$\left.{ }^{3}\right)$ Die südosteuropäische Nebelkrähe wurde als C. cornix valachus Tschusi (Orn. Jahrb. 1904, p. 121, Typus Rumünien) unterschieden. Synonym: C. cornix balcanicus Rzehak, Orn. Monatsber. 1906, p. 189 (Serbien). - Die Form von Cypern wurde als C. c. pallescens (Madarász, Orn. Monatsber. 1906, p. 528) abgetrennt.

$\left.{ }^{4}\right)$ Die bereits angedeutete kleinere festländische Form wurde als "Corvus hassi" (Reichenow, Orn. Monatsber. 1907, p. 11, Typus von T'singtau) beschrieben. - Die Form der Riu-Kiu-Inseln wurde als C. macrorhynchus osai (Ogawa, Annot. Zool. Japon. V, 1905, p. 196, Typus ILus. 'Tring) getrent.

5) S. Coloeus daunricus lchamensis Bianchi, Bull. B. O. Club XVI, p. 68, 1906. (Mir unbekannt.)

$\left.{ }^{6}\right)$ Die japanische Form, auf deren mögliche Verschiedenheit ich schon hinwies, wurde als C. cyanus japonica Parrot (Orn. Monatsber. 1905, p. 226) abgetrennt. 
Gattung Nucifraga Vieill, (oder Schaeffer 1789)

41. Nucifraga caryocatactes caryocatactes (L.) . . . . . . . . 25

42. macrorhyuchos Brehm .......... 26

43. japonicus Hart. . . . . . . . . . 27

44. "4. $"$ kamtchatkensis Barrett-Ham. ....... 27

- $45 . \quad$ rothschildi Hart. ........... 27

46. .. $\quad$.. hemispila Vig. ............... . 28

47. $"$ multipunctata Gould . . . . . . . . 28

(iattung Garrulus Vieill. (oder Schaeffer 1789) . . . . . . . . . . 28

48. Garrulus glandarius glandarius (L.) . . . . . . . . . . 29

49. $"$, rufitergum Hart. . . . . . . . . . 30

50. $\quad " \quad$ kleinschmidti Hart. $\left.{ }^{1}\right)$. . . . . . . . . 30

51. " $"$ " ichnusae Kleinschm. . . . . . . . . . 30

52. $"$ glaszneri MIad. ............ 31

53. $, \quad, \quad$ hyrcanus Blanf. .............. 31

54. "

55. $", \quad$ minor Verr. ............... 31

56. " $"$ " krynicki Kalenicz. ${ }^{2}$. . . . . . . . . 32

57. $" \quad$ " atricapillus Geoffr. ${ }^{3}$ )............. . . 32

58. $"$ " japonicus Schleg. .......... 34

59. $" \quad$ " $"$ brandtii Eversm. ${ }^{4}$ )............ 33

60. $", \quad$ whitakeri Hart. .............. 33

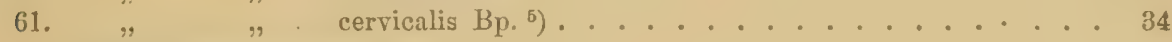

Gattung Perisoreus Bp. . . . . . . . . . . . . . 34

62. Perisoreus infaustus infaustus (L.) . . . . . . . . . . 34

63. $" \quad, \quad$ sibericus (Bodd.) ........... 8 . . .

Gattung Pyrrhocorax Vieill. . . . . . . . . . . 35

64. Pyrrhocorax pyrrhocorax (L.) . . . . . . . . . . . . . . . 35

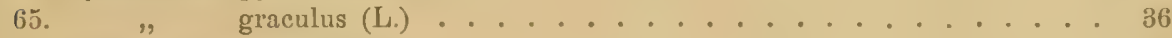

Gattung Podoces Fisch. . . . . . . . . . . . . 37

66 . Podoces hendersoni Hume . . . . . . . . . . . . 38

67. " biddulphi Hume . . . . . . . . . . . 38

68., panderi Fisch. . . . . . . . . . . . 39

69. " pleskei Sar. ..................... 39

70., humilis Hume.................. 40

1) Hierfür muß der ältere Name fasciatus Brehm (Allg. D. Naturh. Zeitung 1857, p. 446) angewandt werden.

2) Synonym: G. nigrifrons Buturlin, Ibis 1906, p. 425, 426, 736. - Hierher dürfte auch als ferneres Synonym zu stellen sein: G. lendlii Madarász rom T'aurus (Orn. Monatsber. 1907, p. 77 - mit minor (!) verglichen) nach ungenügendem Material beschrieben. Serien alter Vögel sind zu untersuchen.

3) Vgl. Salvadori, Boll. Mus. T'orino XXV 1909, No.607!

$\left.{ }^{4}\right)$ Synonyme: G. glandarius taczanowistii Lönnberg, Journ. Coll. Sc. 'Iokyo, XXII, Art. 14, p. 7 (1908 - Sachalin) und G. g. bambergi Lönnberg, Arkiv för Zool. V, Nr. 9, p. 12 (1909 - Transbaikalien, Nord-Alongolei).

$\left.{ }^{5}\right)$ Syronyun: G. glandurius lioenigi T'schusi. Orn. Jahrb. 1904, p. 99 - Tunis. - Die Untersuchung von 28 Stück erwies die Nichtigkeit der meisten der vermeintlichen Untersehiede; nach der IBrutzeit trift das dunkle Froptband in der Regel mehr hervor, die Seiten werden dunkler, die Unterseite schmutziger. Falls sich dennoch die Form aus Nord-Tunesien von der der Aurès Berge (Batna), die kleiner zu sein scheint, unterscheiden lassen sollte, würde letztere zu benennen sein, da Nordalgier mit Nordtunesien übereinstimmen und sicher nordalgerische Stücke zuerst cervicalis genannt. wurclen. Näheres a. a. $\mathrm{O}$. 
Familie STURNTPAT\&

. . . . . 11

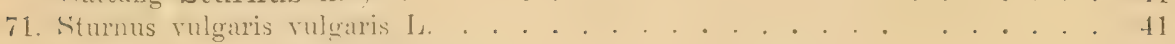

72. $"$ " granti Hart. ............. 43

73. $"$ poltarntski Finsch ............ 44

74. $"$ faroensis Feilden ............. 44

75. $"$ "lumii Brooks ................. 45

76. $", \quad$ nobilior Hume.............. . . 45

77. $"$ " caucasicus Lorenz ............ . . . 46

78. $", \quad$ purpurascens Gould .............. 46

79. $"$ " porphyronotus Sharpe ........... 46

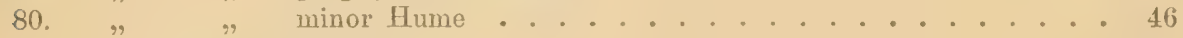

81. $"$ unicolor T'emm. . . . . . . . . . . . . . . 46

Gattung Pastor Temm. . . . . . . . . . . . . . 47

82. Pastur rosers (L.) . . . . . . . . . . . . . . . . . . . 47

Gattung Spodiopsar Starpe . . . . . . . . . . 48

83. Spodiopsar cineraceus ('T'emm.) . . . . . . . . . . . . . . 4 48

Gattung Sturnia (Pall.) . . . . . . . . . . . 49

84. Sturnia sturnina (Palli) . . . . . . . . . . . . . . . . . . . . 4! 4 !

85., violacer $($ Bodd.) . . . . . . . . . . . . 50

Familie ORIOLIDAE ${ }^{3}$ ) . . . . . . . . . . . . . 51

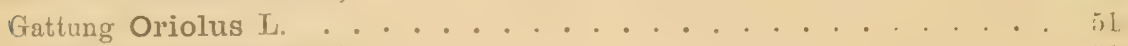

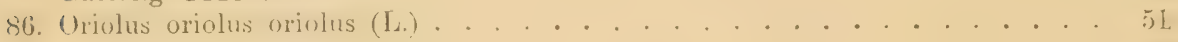

87. " kundoo Sykes..................... 53

s8. . . indieus tert. . . . . . . . . . . . . . . . . 53

Familie FRINGILLIDAE .............. 54

(rattung Coccothraustes I'all. (oder Sehaefier 17s9) . . . . . . . . 55

89. Coccothraustes coccothraustes coccothraustes (L.) . . . . . . . . 55

90. $"$ " japonicus Temm. \& Schleg. . . . . . . 57

91 . $\quad$.. hurrri Cab. ............ 57

92. $", \quad$ humii Sharpe .......... . 57

Gattung Eophona Gould . . . . . . . . . . . . . . . 57

93. Eophona personatus personatus (Temm. \& Schleg.) . . . . . . . 58

؛1. .. $\quad$.. mignirustris llart. . . . . . . . . . . . . . 58

95. " melanura melanura (Gm.) ................. 59

96. " $"$ migratoria Hart. . . . . . . . . . . . . 59

Gattung Mycerobas Cab............... . . 60

97. Mycerobus carnipes (Hodgs.) . . . . . . . . . . . 60

1) Hier ist einzufügen: Amydrus tristami Scl, stahlblau mit rostroten Schwingen. Palästina und Sinai. S. Cat. B. Brit. Mus. XU, p. 168.

2) Die Gattung bedarf einer völligen Umarbeitung, die in den Nachträgen nach Vollendung dieses Werkes erfolgen soll. Im Orn. Jahrb. 190t, p. 206-213 beschrieb Buturlin neun neue Formen, teilweise ron ganz neuen Fundorten; Vergleichung der Typen ist notwendig. 1905 beschrieben Tschusi \& Reiser noch S. vulgaris graecus. - S. ferner S. balcanicus Buturlin \& Härms, Orn. Mlonatsber. 1909, p. 56.

3) Hier würde die Familie DICRURLDAE einzufügen sein, die mit einer Art bis ins paläarktische Gebiet reicht: Dicrumes atra (Herm.) - Muscicapa atra Hermann, Observ. Zoolog. p. 208 (1804) - geht bis in die Tsinling-Berge, wo sie häufig zu sein scheint. Da nur juuge und wenige alte nicht gute Vögel vorliegen, ist nicht zu entscheiden, ob es sich um typische indische atra, oder eine der siidchinesischen cathoeca näher stehende Form handelt. Vgl. Nov. Zool. 1910, p. 249. 
Gottung Chloris Cay -

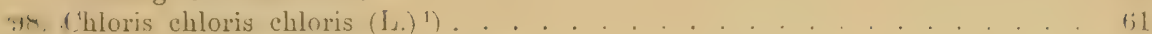

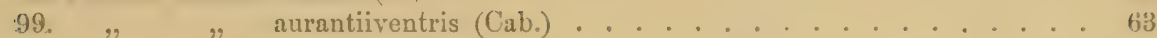

100.,$\quad$ chlorotica (Bp.) ................. 63

101. sinica kawarahiba ('Temm.) . . . . . . . . . 63

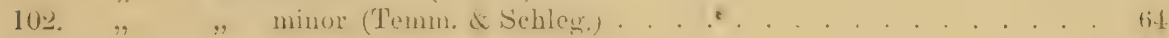

10:3. " $"$ sinien (L.) . . . . . . . . . . . .

104. ". ussurieusis Hart. . . . . . . . . . tit

105. kittlitzi (Seeb.) . . . . . . . . . . 65

(Hattung Acanthis Borkhausen $1797^{\circ}$ ). . . . . . . . . . . . . . (iล́

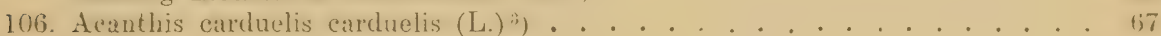

107. .. .. britannicus Hart. . . . . . . . . . . . . lis

108., " tschusii (Arrig.) . . . . . . . . 68

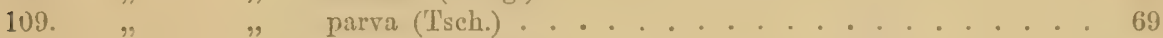

110. $"$ africanus Hart. . . . . . . . . . 69

111. $"$ major (Tacz.) . . . . . . . . 69

111 a. ". $\quad . . \quad$,brovirostris" (7ar.) . . . . . . . . . . (An11.) 70

112. $"$ caniceps caniceps (Vig.) . . . . . . . . . 70

113. $"$ orientalis (Eversm. . . . . . . . T0

114. . spinus (L.) . . . . . . . . . . . . . . . 71

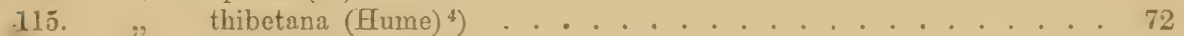

11t. ". spinuides (Vig. . . . . . . . . . . . . . . 73

117., cannabina cannabina (L.) . . . . . . . . 73

118. $"$ mediterranea Tschusi ........... 75

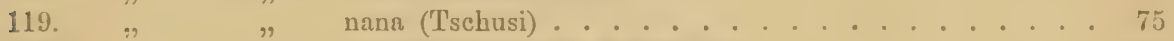

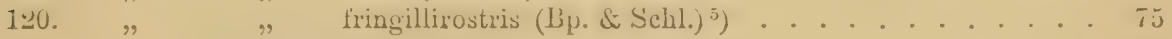

121. $"$ flavirostris flavirostris $(\mathrm{L}$ ) ........... 76

122. $"$ " brevirostris (Hoore) .......... 77

123. $" n$ stoliczkae Hart. ${ }^{6}$ ) ............ 77

1) Hinzugekommen: C. chloris turkestanicus Sarudny, Orn. Monatsber. 1907, p. 61. - Ferner „mïhlei" Parrot, Journ. f. Orn. 1905, p. 649 (Griechenland; unauffällig im Text vorgeschlagen!). - Als Synonym von 98 betrachte ich C. c. rossika Sar., ebenda p. 63.

2) Vgl. Schalow, Orn. MLnatsber. 1910, p. 53. - Hinzuzufïgen: A. ambignu. (hrysomitris umbignu Onstalet, Bull. IIus. Paris 1896; p) 186 (Junuan)). Diese merkwürdige Art kommt auch in Szetschwan (Ta-tsien-lu) vor. Kopfplatte schwarz, sonst

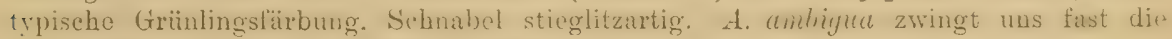
Grattungen Acanthis und Chloris zu vereinigen.

3) Neu beschrieben sind: Carduelis carduelis loudoni Sarudny, Orn. Monatsb. 1906, p. 18 (Schilan und Kaswin in Persien) (ebenda anch C. c. minor wieder beschrieben - indessen ist der Name minor ebenso wie brevirostris rergeben!); Carchuelis carduelis

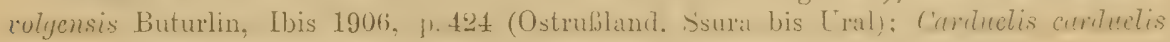
niediecki Reichenow, Journ. f. Orn. 1907, p. 623 (Kleinasien).

4) Vgl. ferner: Chrysomitris bieti Oustalet, Nouv. Arch. Jus, Paris (3) VI, p. 41 (1894- T'a-tsien-lu).

5) Hinzugekommen: A. cannabina merzbacheri Schalow, Orn. MLonatsb. 1907, p. 3 (Tianschan); kritische Bem. ebenda p. 46-47, 58-59!

c) Hierfïr wird wohl der Name montanella angewandt werden müssen: tinota montanella Hume, Lahore to Yarkand, p.261 (1873 - Yarkand. Unauffällig im 'Text einer Anmerkung erwähnt! Abbild.: Taf. 26. - Als interessante neue Form ist hinzu-

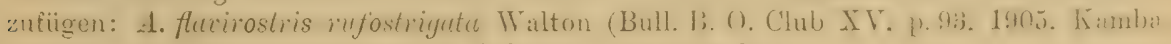
Dschong in Tibet. Etwas größer, Schnabel etwas stärker). 
12t. Acanthis flammea flammea $(\text { L. })^{1}$. . . . . . . . . . . 77

125.,$\quad$ holboelli $(\text { Brehm })^{2}$. . . . . . . . . 79

126. $"$ " rostratus (Coues) ${ }^{3}$. . . . . . . . . 80

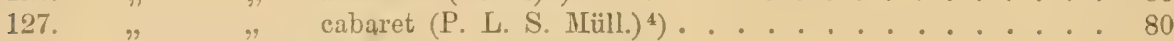

128. $"$ hornemannii hornemannii (Holb.) ........... 81

129. $\%$ exilipes (Coues) ............ 81

130.

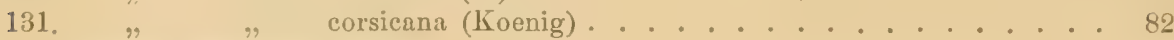

(rattung Serinus liveh. . . . . . . . . . . . . . . . . 82

132. Serinus serinus serinus $(\mathrm{L}$.$) . . . . . . . . . . . . 83$

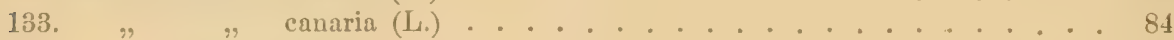

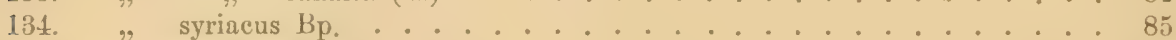

135. .. [millus (Pall.). . . . . . . . . . . . . . . . . . . . . 85

Gattung Uragus Keys. \& Blas. . . . . . . . . . . . . . . . . sit

136. Uragus sibivica sibirical (Pall.) . . . . . . . . . . . . . . . غ6

137. $" \quad "$ sanguinolenta (Temm. \& Schleg.) . . . . . . . . 87

138. $" \quad$ " lepidus Dav. \& Oust. ............ 88

Gattung Erythrospiza Bp................ . 88

139. Erythrospiza githaginea githaginea $(\text { Licht. })^{5}$. . . . . . . . 88

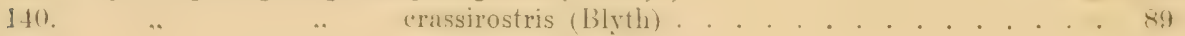

141.,$\quad$ amantum Hart. . . . . . . . . 89

142. $"$ mongolicus (Swinh.) . . . . . . . . . . 89

Gattung Rhodopechys Cab. . . . . . . . . . . . . 90 90

143. Rhodopechys sanguinea sanguinea (Gould) . . . . . . . . . . . 90

144. $"$ " aliena Whit. . . . . . . . . . . 91

Grttung Rhodospiza Sharpe . . . . . . . . . . 91

145. Rhodospiza obsoleta (Licht.) . . . . . . . . . . . . . 91

Gattung Pyrrhula Pall. . . . . . . . . . . . . . . . 92

146. Pyrrhula pyrrhula pyrrhula $\left.(\text { L. })^{6}\right)$. . . . . . . . . . . . 93

147. $"$ " europrea Vieill. $\left.{ }^{7}\right) \ldots \ldots . . . . . . . . .94$

148. " $"$ kamtschatica Tacz. .............. . . 95

149. $"$ " griseiventris Lafr. . . . . . . . . . . . . 95

150. $"$ " kurilensis Sharpe ............ 95

151. $"$ " cassini Baird ............. 96

152.,$"$ murina Godm. ................. 96

1) Dieser Name wurde durch ein unglückliches, durch Störung während der Arbeit hervorgerufenes Versehen angervandt, wie ich Orn. Monatsberichte 1907, p. 97 erklärt habe. Diese Form muß somit Acanthis linaria linaria (L.) heißen. Hinzuzufïgen: A. linaria islandica Hantzsch, Orn. Monatsb. XII, p. 32, 1904, scheint aber nicht ron A.l. linaria unterscheidbar zu sein.

2) MLßB A. linaria holboelli heißen.

$\left.{ }^{3}\right)$ Muß A. linaria rostratus heißen.

$\left.{ }^{4}\right) \mathrm{ML}$ B A. linaria cabaret heißen. - Die englische Form ist von Schmiedeknecht (Wirbelt. Eur., p. 128, 1906) als A. linaria britannica abgesondert worden, scheint mir aber nicht trennbar zu sein.

5) Hinzufügen: E. githaginea zedlitzi Neumann, Orn. Monatsb. 1907, p. 145, 146. Die Form von Algerien und Tunesien ist rosiger und meist etwas größer.

$\left.{ }^{6}\right)$ Hinzuzufïgen: P. pyrrhula rossikowi Derjugin \& Bianchi, Ann. Mlus. Zool. Ae. Sc. St. Petersburg V, 1900, p. 43. Russisch! Vgl. innere Seite des Titelblattes von Heft III dieses Buches, sowie Buturlin, Ibis 1906, p. 420-422. Kaukasus, Transkaukasien, - Ferner: P. pyrrhula caspica Witherby, Bull. B. O. Club XXITI, p. 48 (1908).

7) Die britische Form ist als P. pyrhula pileata MIacg. zu trennen. S. Hartert, British Birds II, p. 130 (1908). 
153. Pyrrhula erythaca Blyth ${ }^{1}$ ) . . . . . . . . . . . 96

154. $"$ erythrocephala Vig. ............................ 97

155. " aurantiaca Gould ................ 97

156. "nipalensis nipalensis Hodgs. ${ }^{2}$. . . . . . . . 93, 97

Gattung Pyrrhoplectes Hodgs. . . . . . . . . . . . . 98

157. Pyrrhoplectes epauletta (Hodgs.) . . . . . . . . . . . . 9 98

Gattung Carpodacus Kaup. . . . . . . . . . . . . 98

158. Carpodacus rubicilla (Güld.) . . . . . . . . . . . . 99

159. $"$, severtzori Sharpe ............ 100

160. $" \quad "$ rubicilloides Przew. ............ 100

161. rhodochlamys rhodochlamys (Brandt) . . . . . . 100

162. " grandis Blyth ............ 101

163. " thura thura Bp. \& Schl. ${ }^{3}$. . . . . . . . . . 101

164., blythi (Bidd.) ...................... 102

165.

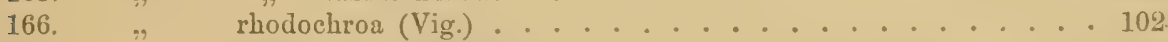

167. $"$ pulcherrimus (Ioore) ${ }^{4}$. . . . . . . . 103

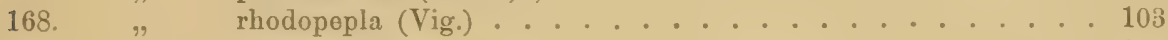

169. .. edwardsii Verr. . . . . . . . . . . . . 104

170., vinaceus Verr. .......................... 104

171.,$\quad$ trifasciatus Verr. ..................... 10 .

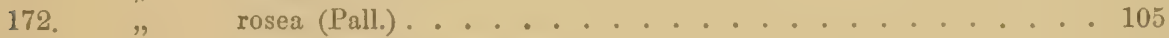

173.,$\quad$ erythrina erythrina (Pall.) . . . . . . . . 106

174. $"$ grebnitskii Stejn. ........... 107

175. $\%$ roseata $(\text { Hodgs.) })^{5}$. . . . . . . 108

176. " synoica synoica (Temm.) . . . . . . . . . 108

177. $"$ 178. stoliczkae (Hume) .................. 109

178. $"$ verreauxi (Dav. \& Oust.) . . . . . . . . 109

Grattung Haematospiza Blyth. . . . . . . . . . . . 110

179. Haematospiza indica $(\mathrm{Gm}$.$) . . . . . . . . . . . 110$

Gattung Pyrrhospiza Hodgs. . . . . . . . . . . . 110

180. Pyrrhospiza punicea punicea Hodgs. . . . . . . . . . . . 111

181. $"$, humii Sharpe .............. . . 111

182. $", \quad$ longirostris Przew. ${ }^{6}$ ) . . . . . . . . 111

Gattung Procarduelis Hodgs. . . . . . . . . . . . . . 111

183. Procarduelis nipalensis (Hodgs.) . . . . . . . . . . . 112

184., rubescens Blanf. . . . . . . . . . . 112

Gattung Propyrrhula Hodgs. . . . . . . . . . . . . 112

185. Prophyrrhula subhimachalus (Hodgs.) . . . . . . . . . . . 113

(iattung Pinicola Vieill. . . . . . . . . . . . . . . . . 11:;

186. Pinicola enucleator enucleator (L.) . . . . . . . . . . 114

187. $"$ kamtschatkensis (Dyb.) . . . . . . . 115

1) Man vergleiche: P. altera Rippon, Bull. B. O. Club XIX, p. 19, W. Junnan.

$\left.{ }^{2}\right)$ MIan vergleiche: P. ricketti La Touche, Bull. B. O. Club XVI, p. 21, S. O.

China; $P$. victoriae Rippon, Bull. B. O. Club XVI, p. 47, Mt. Victoria in Birmah. W. Junnan).

3) Ilan vergleiche: C. femininus Rippon, Bull. B. O. Club XIX, p.31 (1906--

*) Die hier rorgenommene Vereinigung von C. pulcherrimus und davidianus halte ich auch jetzt für richtig, dagegen kommt hinzu: C. p. valtoni (Sharpe) (Propasser waltoni Sharpe, Bull. B. O. Club XV. p. 95, 1905) aus Tibet.

5) Hinzuzufügen: C. erythrina laetissimus Walton, Bull. B. O. Club XV, p. 93

(1905- Tibet). Ob von C. e. voseata zu unterscheiden? p. 189.

6) Hinzuzufügen: P. punicea szetschuana Bianchi, Bull. Ac. St. Petersburg 1907, 
Gattung Chaunoproctus Bp. .............. 115

188. Chaunoproctus ferreirostris (Vig.) . . . . . . . . . . 115

Gattung Loxia L. . . . . . . . . . . . . 116

189. Loxia currirostra curvirostra L, ${ }^{1}$ ) . . . . . . . . . . . 117

190. .. $\quad . . \quad$ hispana Hart. . . . . . . . . . . . . . . . . . . . . 119

191. $" \because \quad$ anglica Hart. ${ }^{2}$. . . . . . . . . . . 119

192. $", \quad$ scotica Hart. . . . . . . . . . . 120

193. " " balearica Hom. . . . . . . . . . . 120

191. .. $\quad .$. poliogyna 1 hit. ................. 121

195. .. $\quad . \quad$ guillemardi Mat. . . . . . . . . . . . . . . 121

196.,$\quad$ albiventris Swinh. . . . . . . . . . . 121

1!17. .. $\quad . . \quad$ himalayonsis Blyth . . . . . . . . . . . . . . . . 121

19S. " pytyopsittacus Borkh. . . . . . . . . . . . . 122

199. " leucoptera bifasciata (Brehm) . . . . . . . . . . . 123

200. " $"$ elegans Hom. . . . . . . . . . . . . 124

(iattung Fringilla L. . . . . . . . . . . . . . . . . . . . . . . . 125

201. Fringilla coelebs coelebs $\mathrm{L}^{3}{ }^{3}$. . . . . . . . . . . . . . 125

20\%. " $"$ spodiogenys Bp. ................ 127

203. " " africana Levaill. . . . . . . . . . . . . . 127

204. " " koenigi Rothsch. \& Hart. . . . . . . . . . . 128

205.,$\quad$ maderensis Sharpe . . . . . . . . . . . . 128

206. " $"$ moreleti Puch. . . . . . . . . . . . 128

207. " $"$ canariensis Vieill. . . . . . . . . . . 129

208. $"$ " palmae Tristr. . . . . . . . . . . 129

204. " teydea Webl, Berth. \& Hoqu-Tiandon" . . . . . . . . . 129

210. $"$ montifringilla $\mathrm{L}^{5}{ }^{5}$. . . . . . . . . . 130

Gattung Montifringilla Brehm ${ }^{6}$ ) . . . . . . . . . . . 131

211. Montifringilla nivalis nivalis $\left(\mathrm{L}_{\text {. }}\right.$. . . . . . . . . . . . . . 133

212. $"$ " alpicola $(\text { Pall. })^{7}$ ) . . . . . . . . . . . 133

213. " $"$ adamsi Adams ............... 134

214. mandelli Hume .............. 134

215. $"$ davidiana (Verr.) ................ 134

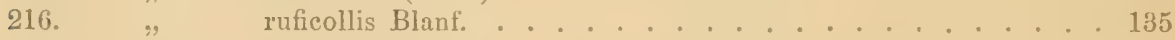

1) S. Loxia curvirostra caucasica Buturlin, Orn. Monatsb. 1907, p. 9.

2) Vermutlich nicht zu trennen; da es schwierig ist, sichere englische Brutrögel zu bekommen, ist die Frage schwer zu entscheiden. L.c. scotica ist zwar variabel, aber eine sehr kenntliche Form.

3) Kleinschmidt trennte die englischen Brutrögel als $F$. coelebs gengleri ab (Falco V, 1909, p. 13), die Form muß aber als fraglich betrachtet werden, bis größere Serien englischer Brutrögel untersucht worden sind. Gran Canaria.

4) Hinzuzufügen: F. teydea polatzeki Hartert, Orn. Monatsb. 1905, p. 164, von

$\left.{ }^{5}\right)$ Hinzuzufügen die noch näher zu untersuchende: $F$. montifringilla subcuneolata Kleinschmidt, Falco V, 1909, p. 13, Ostasien (Terra Typica Japan).

$\left.{ }^{6}\right)$ Eine (leider russische) Übersicht der Gattung - die der Verf. in 5 Genera trennt! - findet sich Ann. Mus. Petersburg XII, 1907, p. 555-597.

Übersehen wurde von mir: Mont. henrici (Oust.) - Eurhinospiza Henrrici Oustalet, Ann. Sci. Nat. XII, 18, p. 291, 293, Taf. XI, Platean von Thibet. Scheint wohl unterschiedene Art nahe adamsi zu sein.

${ }^{7}$ ) Sarudny \& Loudon trennten (Orn. Jahrb. 190t, p. 215, 216) ab: Montifi. alpicola groum-gizimaili (aus Beisehan) und M. alpicola gaddi (aus Luristan in Persien), Bianchi, 1. c.. p. 580-ñ82, 588, aber hält beide für synonym mit alpicola. Derselbe trennt „M. alpicola hiventunensis" ab (1. c., p. 583, 588). 
217. Montifriugilla blanfordi IIme . . . . . . . . . . . . . 135

218. $"$ kansuensis $(\text { Przerv. })^{1}$ ) . . . . . . . . . . 136

219. $"$ nemoricola nemoricola (Hodgs.) . . . . . . . . 136

220. $"$ altaica (Eversm.) . . . . . . . . 137

221. $"$ brandti brandti $(\text { Bp. })^{2}$. . . . . . . . . . 137

222. $"$ " $\quad$ " haematopygia Gould ${ }^{3}$ ) $\ldots \ldots \ldots \ldots$

223. " " $"$ walteri Hart. . . . . . . . . . . 138

224. $"$ arctous $(\text { Pall. })^{4}$. . . . . . . . . 138

225. $"$ roborowskii $(\text { Przew. })^{5}$. . . . . . . . . . 139

226. $"$ gigliolii (Salvad.) . . . . . . . . . . 139

227. $"$ brunneinucha (Brandt) ................ 140

228. $"$ tephrocotis griseonucha (Brandt).......... 140

Gattung Petronia Kaup. . . . . . . . . . . . . . . . 141

209. Petronia petronia madeirensis Erl. . . . . . . . . . . . . . . 141

230. $", \quad$ petronia (L.) ................... 141

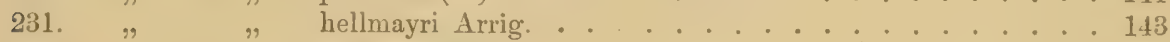

232. $"$ " barbara Erl. ${ }^{6}$................ 143

233. $" \quad$ exiguus (Hellm.) . . . . . . . . . . . 143

234. $", \quad$ intermedia Hart. . . . . . . . . . . 144

235. $" ~ "$, brevirostris Trez. . . . . . . . . . . 144

236. $" \%$ puteicola Festa ............... 144

Gattung Gymoris Blyth . . . . . . . . . . . 144

237. Gymnoris flavicollis transfuga Hart. . . . . . . . . . . 145

238. $"$ "flavicollis (Frankl.) . . . . . . . . . . 145

(rattung Carpospiza Müll. . . . . . . . . . . . . . . 145

2:39. Carpospiza brachydactyla (Bp.) . . . . . . . . . . . . . . . . 145

Gattung Passer Koch. . . . . . . . . . . . . . . . . 147

240. Passer domestica dornestica $(\mathrm{L} .)^{7}$ ) . . . . . . . . . . . . 147

241. . . . biblicus Hart. . . . . . . . . . . . . . 14!

242. $"$ tingitanus Loche .............. 149

213. " . ahasrer Kleinschn." . . . . . . . . . . . 1.50

244. $" \quad$ arboreus $(\mathrm{Bp}.) \ldots \ldots \ldots \ldots$

1) Diese mir unbekannte Form ist nach Bianchi gleich davidiana.

2) Eine fernere, aber wohl unterschiedene Subspezies dieser Art scheint zu sein: 1. murguritucea Madaris\%. Orn. Junatsb. 1904. 1. 196, Katon Karagai (Altai); Syuonym: Lencosticte annae Suschkin, Bull. B. O. Club XVI, p. 56 (1906- Tarbagatai).

3) Vgl.: Leucosticte haematopygia pallidior Bianchi, Ann. HIus. Zool. Petersb. XIII, 1. 45,55 (Russisch!).

4) Synonym: M. cognata MIadarász, Ann. Hist.-Nat. MIus. Hungar. VII, p. 176, mit impressionistischer Abbild. auf Taf. IV (1909- Tunkan-Berge, Nord-MIongolei). Taf. 1.

$\left.{ }^{5}\right)$ Kozlovia nov. gen. nach Bianchi, Aves exped. Kozlowi, p. 21, 1907; Abbild.:

b) Synonym: Petronia petronia algeviensis Kollibay, Ora. Honatsb. 1905, p. 42. Yrenes Material aus Algurien zeigt deutlich die Xichtigkeit der mgeblichen Interschicde.

$\left.{ }^{2}\right)$ S. Passer domesticus rar. Valloni Chigi, Boll. Soc. Zool. Ital. XV, p. 50, ron Udine in Italien. Nach Salvadori (Atti Acad. Sci. Torino XLI, 1906, p. 728) Bastard von $P$. d. domestica und italiae. S. auch Boll. Soc. Zool. Ital. 1907, fasc. 1, 2, 3.

s) Augenscheinlich Bastard von P. domestica tingitanus und P. hispaniolensis. "Passer italiae bergeri" Zedlitz (Orn. Monatsb. 1908, p.42) aus Süd-Tunesien ist dasselbe wie "P. hispaniolensis /lücligeri" (259) und seheint ebenfalls cin Mischprodukt zu sein; eine eingehende Besprechung der komplizierten algerischen und tunesischen Sperlinge, auf Grund sehr umfungreichen, gröbtenteils von D). Rothschild und mir grsammelten Materials, erfolgt demnächst a. a. 0. 
245. Passer domestica subsp. ${ }^{1}$ ) . . . . . . . . . . . . . 151

246. $", \quad$ indicus Jard. \& Selby . . . . . . . . . . 151

247. $"$ pyrrhonotus Blyth ............. 151

248. $"$ italiae italiae $(\text { Vieill. })^{2}$ ) . . . . . . . . . . . . 152

249. $"$, senckenbergianus Hart. . . . . . . . . . . 152

250. $"$ griseigularis Sharpe .............. . . 153

2.1. .. eniguaticus Sar. . . . . . . . . . . . . . . . . . 154

252. .. moabiticus muabiticus Tristr. . . . . . . . . . . . . . . . . . 155

253.,$\quad$ yatii Sharpe ${ }^{3}$ ) . . . . . . . . . 155

254. " hispaniolensis hispaniolensis (Temm.) . . . . . . . 156

255. .. arrigonii Tsehusi . . . . . . . . . . . . 157

256.,$\quad$ transcaspicus Tschusi ......... 157

257. $"$ malta Hart. .......... 157

258. ".

259. $, \quad, \quad$ flückigeri Kleinschm. . . . . . . 158

260. " ammodendri ammodendri Gould ............ . . . 158

261. $"$, korejewi Sar. \& Härms . . . . . . . . . 159

262., stoliczkae Hume . . . . . . . . . 159

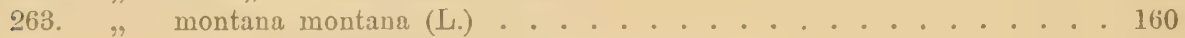

saturatus Stejn. $\left.{ }^{4}\right) \ldots . . . . . . .161$

malaccensis Dubois . . . . . . . . . . 161

twimensis Hart. . . . . . . . . . . . . . . . . . 1 tri

261., dilutus Richm. ................ 161

265. ". rutilans rutilans (Temm.) . . . . . . . . . . . . . . 14il

266. .. . cinnamomea (Gould) . . . . . . . . . . . . . . 1620

267. . .. debilis Hart. . . . . . . . . . . . . . . . 142

268. $"$ simplex simplex (Licht.) . . . . . . . . . 162

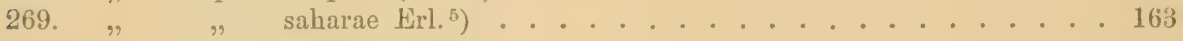

270. " $"$ zarudnyi Pleske ............. . . . 163

Gattung Emberiza L. ${ }^{8}$ ) . . . . . . . . . . . . . 164

271. Emberiza calandra calandra L. ${ }^{7}$. . . . . . . . . . . . 165

272. $"$ " thanneri Tschusi . . . . . . . . . . 167

273. $"$ citrinella citrinella L. ${ }^{8}$ ) ................ 167

27ı. $", \quad$ erythrogenys Brehın............ 169 102 (1909).

1) Passer domesticus niloticus Nicoll \& Bonhote, Bull. B. O. Club XXUI, p. 101,

2) Vgl.: P. donestica italice var. Romae und var. subalpina Chigi, Boll. Soc. Zool. Ital. XIII, p. 145.

3) Vgl.: P. mesopotamicus Sarudny, Orn. Jahrb. XV, 1904, p. 108.

4) Die Vögel „vom Kaukasus bis Tsingtau“ werden von Reichenow wegen durchschnittlich etwas kürzerer Flügel getrennt: $P$. montanus iubilaeus Reichenow, Journ. f. Orn. 1907, p. 470.

5) Fraglich ob von $P$. s. simplex zu trennen!

$\left.{ }^{6}\right)$ Hinzuzufügen: E. koslowi Bianchi, Bull. B. O. Club XIV, p. 80 (1904- Oberer Ilekong). Diese prachtrolle Art ist auf Taf. 1 der Ares Exped. Koslow. abgebildet (1907). - Ebenfalls in die Gattung Emberiza gehört die interessante "Junco" siemsseni Ilartens, Orn. Monatsb. 1906, p. 192, aus Futschau in China. Westsibirien).

7) Hinzuzufügen: E. calandra buturlini Johansen, Orn. Jahrb. 1907, p. 202 (Kastek,

8) Vgl. „E. citrinella palukae" Parrot, Orn. Jahrb. 1905, p.45, im T'ext. (Konstantinopel - ungenügend begründete Form.) - Bei den Flügelmaßen von E. c. citrinella (p. 168) ist ein bedauerlicher Schreib- oder Druckfehler untergelaufen: es muß heißen Flïgel 85-93 mm. Ebenso bei E. c. erythrogenys (p. 169) 91-94, nicht 61-64 mm! 
275. Emberiza leueocepte

275. Emberiza leucocephalos S. G. Gm. . . . . . . . . . . 169

276. $"$ melanocephala Scop................... 170

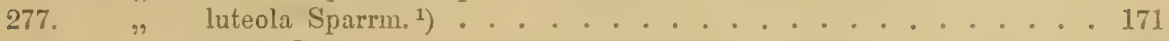

278. $"$ rutila Pall. . . . . . . . . . . . 172

279. $"$ aureola Pall. ..................... 173

280. $"$ elegans T'emm. . . . . . . . . . . . 174

281.,$\quad$ cirlus L. . . . . . . . . . . . 175

282. $"$ spodocephala spodocephala Pall. . . . . . . . . 176

283. " $"$ melanops Blyth ........... 177

284. $"$ " $"$ personata Temm. . . . . . . . 177

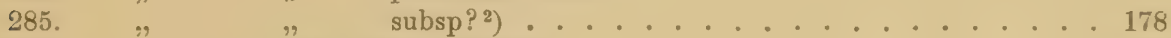

286. $"$ sulphurata Temm. \& Schleg. . . . . . . . . . . 178

287. $"$ cinerea Strickl. ${ }^{3}$ ) . . . . . . . . . . 178

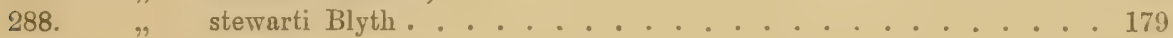

289. $"$ hortulana L. . . . . . . . . . . 180

290. " buchanani Blyth ${ }^{4}$ ) ....................... 182

291. $"$ caesia Cretzschm. . . . . . . . . . . . . 182

292. $"$ cia cia L. . . . . . . . . . . . . . . 183

293. " " stracheyi Moore ............... 184

294. " " par Hart. . . . . . . . . . . 184

295. ., $\quad$ godlewskii Тaсz. ${ }^{5}$. . . . . . . . . . . . . 185

296. $"$ cioides cioides Brandt .............. 185

297. $"$ " castaneiceps Moore . . . . . . . . . 186

298. $", \quad$ ciopsis Bp. ................. 186

299. $"$ jankowskii Tacz. . . . . . . . . . . 186

300. $\because \quad$ fucata fueata Pall. . . . . . . . . . . . . . 187

301. $", \quad$ arcuata Sharpe ............... 187

302. " rustica Pall. . . . . . . . . . . . . 188

303. $"$ pusilla Pall. ................. . . 188

304. $"$ chrysophrys Pall. . . . . . . . . . . . 189

305. $"$ striolata sahari Lev. . . . . . . . . . . . 190

306.,$\quad$ striolata (Licht.) . . . . . . . . . . 191

307., variabilis Temm. . . . . . . . . . . . . 191

308. $"$ tristrami Swinh. . . . . . . . . . . . 192

309. ., yessoënsis (Sirinh.) . . . . . . . . . . . . 1913

310. $\quad$ pallasi (Cab.) . . . . . . . . . . . . 191

311. $"$ schoeniclus schoeniclus $\left.(\mathrm{L} .)^{6}\right)$. . . . . . . . . 194

312. $"$, pallidior Hart. ........... 197

313. $" \quad$ pyrrhulinus Swinh. ........... 197 nennen.

1) Sparrmanns Name ist doch nicht sicher, die Art ist daher besser icterica zu

2) Lönnberg (Journ. College Sci. Univ. 'Tokyo XXIII, Art. 14, p. 14) verglich eine Serie von Sacchalin, die er nicht von $E$. s. personata zu trennen vermochte.

3) Hinzuzufügen: E. cinerea semenowi Sarudny, Arabistan in Persien und Syrien. E. semenowi Sarudny, Orn. Jihrb. XV, 190.t, p. 117. Synonym: F. citinivntris Selater. Bull. B. O. Club XVI, p. 39 (1905- Syrien); Abbild., Ibis 1906, Taf. 15.

*) Den Synonymen ist hinzuzufügen: "E. buchanani Blyth rar. obscura subsp. иог." Zarudny \& Korejer, Om. Monatsb. 190:3, p. 130, Semiretsehje-Gebiet in Turkestum.

$\left.{ }^{5}\right)$ Hinzuzufügen: E. cia yumanensis (E. ynunanensis Sharpe, Bull. B. O. Club XIII. 1. 12, 1902, Junnan); ist rütlicher und etwas kleiner, vertritt youllenstiii in ('hima. von den Tsinling-Bergen bis Schensi, Schansi. Szetschwan und Junnan.

6) Hinzugekommen: E. schoenichıs zarudnyi Härms, Orn. Monatsb. 1909, p. 1 (Kuldscha am Ili-Strom). You mir nicht gesehen. - (Vgl, auch Arieula II. p. I25-130.) 
314. Emberiza schoeniclus eanneti (Brehm) :315.

316.

317.

318.

319.

320.

321.

Gattung Calcarius Bechst.

tschusii Reis. \& Amisy . . . . . . . . . 198

" pyrrhuloides pyrrhuloides Pall. . . . . . . . . . . . . . . . . 198

" $"$ reiseri Hart. . . . . . . . . . . . 199

$" \quad$ centralasiae Hart. ${ }^{1}$ ) . . . . . . . . . . 199

$" \quad "$ subsp. ${ }^{2}$. . . . . . . . . . . . . . 199

", palustris Savi .............. 199

332. Calearins lapponica lapponica (L.) . . . . . . . . . . . . . . 2000

323. $"$ " coloratus Ridgw. . . . . . . . . . 201

Gattung Passerina Vieill. . . . . . . . . . . . 202

324. Passerina nivalis nivalis (L.) . . . . . . . . . . . . . . 202

Gattung Urocynchramus Przew. . . . . . . . . . . . . . 204

325. Urocynchramus pylzowi Przew. . . . . . . . . . . . . . 205

Familie ALAUDIDAE ${ }^{3}$ ) . . . . . . . . . . . . 205

Gattung Rhamphocorys Bp. . . . . . . . . . . 206

326. Rhamphocorys clot-bey (Bp.) . . . . . . . . . . . . . 206

(iattung Melanocorypha Brim. . . . . . . . . . . . . . . . 207

327. Mlelanocorypha calandra calandra (L.) . . . . . . . . . . . 208

328. $"$ psammochroa Hart. $\left.{ }^{4}\right)$. . . . . . . . . . 210

329. $"$ bimaculata (Ménétr.) . . . . . . . . . . 210

330. $\quad$ maxima Gould ${ }^{5}$ ) . . . . . . . . . . . 211

331. $\quad$ sibirica $(\mathrm{Gm}$. . . . . . . . . . . . . 211

332. ", mongolica (Pall.) . . . . . . . . . . 212

333. $"$ yeltoniensis (Forst.) . . . . . . . . . . 213

Gattung Calandrella Kaup . . . . . . . . . . . . . . . . . . 214

334. Calandrella brachydactyla brachydactyla (Leisl.) . . . . . . . . . . 214

335. $" \quad$ longipennis $(\text { Eversm. })^{6}$ ) . . . . . . . 216

336. $"$ dukhunensis (Sykes) $)^{7}$. . . . . . . 217

1) Verschieden aber sehr nahestehend: E. myrrhuloides harterti Suschkin, Bull. B. O. Club XVI, p. 56 (1906- Saissan-Noor).

2) E. pymhuloides korejewi (Sar.) (Cynchramus pyrrhuloides korejewi Sarudny, Orn. Monatsb. 1907, p. 83). (Seistan und Persisches Baluchistan).

3) Vgl. Bianchi, Cat. Alaudidae in Bull. Ac. Imp. Sci. St. Petersburg (5) XXV, 1906, p. 1-98; höchst wichtige Arbeit in der nur leider Verf. eine Anzahl überflüssiger neuer Gattungen aufstellt, u. a. auch Otocorydopsis für Otocorys berlepschi. Ferner werden einige wohl unterscheidbare Formen unrichigerweise rereinigt. S. auch Bull. Ac. Imp. Sci. St. Petersburg (5), XXIII, 1905, p.20б̆-240, wo u. a. Ammomanes in Psendammomanes, Ammomanes, Ammomanopsis und Ammomanoides gespalten wird.

4) Bianchis Ansicht, daß dies eine individuelle Varietät sei, die auch anderswo auftreten könne (?) - s. Ref. in Orn. Nonatsb. 1907, p. 85 - ist irrig. - MI. calandra ruddei Sar. \& Loud., Orn. Jahrb. 1904, p. 221 (Dézember) aus Südwestpersien ist augenscheinlich synonym; M. c. psammochroa variiert natürlich auch.

$\left.{ }^{5}\right)$ „Melanocoryphoides maxima" Bianchi 1906.

B) Bianchi (1. c.) gibt an, der Typus ron longipennis sei typische brachydactyla, was aber des Fundortes wegen kaum glaublich erscheint. Er trennt ferner wieder C. tibetana (Tibet) und "C. tibetana acutivostris" ('Tianschan, Pamir, Karakorum und Kaschmir), was einer erneuten Prüfung bedarf, aber vielleicht richtig ist, nur daß die Nomenklatur verfehlt ist, da der Name acutirostris älter ist als tibetana.

$\left.{ }^{7}\right)$ Nach Bianchi Brutrogel in der Wïsto Gobi, rom Lob-Nor bis Ala-schan ust. (t. c., p. 50). 
337. Calandrella minor rufescens (Vieill.) ${ }^{1}$ ) . . . . . . . . 217

338. $"$ " polatzeki Hart. . . . . . . . . . . 217

339. $" \quad "$ " baetica Dress. ${ }^{2}$ ) . . . . . . . . . . 218

340. minor minor $\left.\left(\mathrm{Cab}_{0}\right)^{3}\right) \ldots \ldots . . . . . . . .218$

341. $", \quad$ heinei $(\text { Hom. })^{4}$ ) . . . . . . . . . . . . 219

342. " " $"$ leucophrea Sew. ............. 219

343. " " $"$ seebohmi (Sharpe) . . . . . . . . . 220

314. " " persica $(\text { Sharpe })^{5}$ ) . . . . . . . . 220

345. " " $"$ cheleënsis (Swinh.) . . . . . . . . . 220

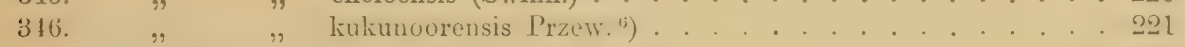

Gattung Ammomanes Cab. . . . . . . . . . . . 221

347. Ammomanes deserti algeriensis Sharpe . . . . . . . . . 221

348. " " erythrochroa Rchm. . . . . . . . . . . 222

349. $", \quad$ deserti (Licht.) . . . . . . . . . 222

350. " $"$ isabellina (Temm.) ${ }^{7}$ ) . . . . . . . . 223

351. $"$ " fraterculus Tristr. ............ 223

352. $", \quad$ parvirostris Hart. ${ }^{8}$ ) . . . . . . . . . . 223

353. $"$ " subsp. nov.?............... . . 223

354. $", \quad$ phoenicuroides (Blyth) . . . . . . . . 224

355. $"$, subsp. nov.? $\left.{ }^{9}\right) \ldots \ldots . \ldots . \ldots . . \ldots 24$

356. " phoenicura arenicolor (Suncler.) . . . . . . . . . . 224

357. $"$ cinctura (Gould) . . . . . . . . . 225

358. $"$ " $"$ zarudnyi Hart. . . . . . . . . . . 225

359. " " phoenicura (Frankl.) . . . . . . . . 226

Gattung Galerida" Boie ............... . . 226

360. Galerida cristata nigricans Brehm ${ }^{10}$ ) . . . . . . . . . . 227

361. " cristata cristata (L.) ${ }^{11}$. . . . . . . . . . . . . . 208

362. $" \quad$ subsp.? $)^{12}$. . . . . . . . . . . . . . 229

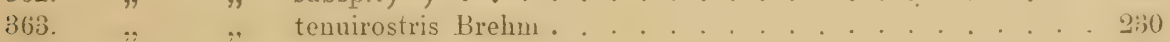

364. " $"$ caucasica Tacz. .................. 230

365. " " ". . . . . . . . . . 230

1) Hinzuzufïgen: C. minor distincta Sassi, Orn. Jahrb. 1908, p. 30-32 (Gran Canaria. Der Fundort ganz neu).

2) Der Name muß durch den älteren Namen apetzii ersetzt werden: Melanocorypha Apetzii Brehm, Naturh. Zeit. 1857, p. 455 (s. Zool. Ann. IU, 1, p. 66).

${ }^{3}$ ) Hinzuzufügen: C. minor nicolli Hartert, Bull. B. O. Club XXV, p. 9 (October 1909 - Nil-Delta).

4) Vgl. C. minor minuta Sarudny \& Loudon, Orn. Jahrb. 1904, p. 224. - Winterrogel in Persien. Nach Bianchi identisch mit no. 341.

5) Die Form aus Seistan, auf deren Unterschiede ich schon hinwies, wurde als C. minor scistanica Sarudny \& Loudon, Orn. Jahrb. 1904, p. 222 abgetrenut.

$\left.{ }^{6}\right)$ Diese mir nur aus der Beschreibung bekannte Form ist nach Bianchi partieller Albino ron C. m. seebohmi.

3) Die Deutung und Verbreitung von Nr. $3 \stackrel{1}{ }$ und 350 bedarf ferneren Studiums und wahrscheinlich einiger Ergänzungen.

8) Vermutlich synonym: A. deserti orientalis Sarudny \& Loudon, Urn. Jahrb. XV, p. 224 (1904- S. W. Buchara und Nordostecke Persiens).

$\left.{ }^{9}\right)$ Wahrscheinlich $=354$.

$\left.{ }^{10}\right)$ Hinzuzufügen: G. cristata moeritica Nicoll \& Bonhote, Bull. B. O. Club XXIII, p. 101 (1909- Fayum, Ägypten. Steht G. c. nigricans sehr nahe).

11) Hinzuzufügen: G. cristata neumanni Hilgert, Orn. MIonatsb. 1907, p. 63 (Kömische Campagna).

12) G. cristata cypriaca Bianchi ex Hartert no. 362, Bull. Ac. Scci. Petersburg $\mathrm{XXV}$, p. 6ŏ, 1907. 
366 .

367.

Jallirla Brehm. . . . . . . . . . . . . 231

368.

kleinschmidti Erl. . . . . . . . . . 231

riggenbachi Hart. . . . . . . . . 231

369.

macrorhyncha Tristr. $^{1}$ ) . . . . . . . . . . . 232

370.

arenicola Tristr. ${ }^{2}$ ) . . . . . . . . . . 232

371.

senegallensis (P. L. S. Müll.) ${ }^{3}$ ) . . . . . . . . 233

372.

isabellina Bp............... . . 233

373.

altirostris Brehm $^{4}$ )................. 233

374.

caroli Hart. . . . . . . . . . . . . 231

375.

brachyura Tristr. . . . . . . . . . . . 234

376 .

subsp. ? 5) . . . . . . . . . . . . 234

377.

cinuamomina Hart. . . . . . . . . . . . 235

subsp. ? . . . . . . . . . . . . . . 235

tardinata Hart. . . . . . . . . . . 235

magna Hume ${ }^{7}$ ) . . . . . . . . . . . . 235

iwanowi Loudon. . . . . . . . . . . . 236

chendoola (Frankl.) . . . . . . . . . . 236

leautungensis (Swinh.) ......... . . 236

coreensis Tacz. .............. . . 236

theklae theklae Brehm .............. . . 237

erlangeri Hart. . . . . . . . . . . . . . 237

ruficolor Whit. . . . . . . . . . . 238

harterti Erl. ${ }^{8}$ ) . . . . . . . . . . . 238

1) Hinzuzufügen: G. cristata carthaginis Kleinschmidt \& Hilgert, Orn. Mlonatsb. 1905, p. 188; Hilgert, Kat. Coll. Erlanger, p. 102. Neuer Name für G. c. macrorhyncha Erl. aus N. Tunesien. Das Bedürfnis, diese Form zu benennen, entsprang geographischen Gründen; wenn auch die Autoren recht haben werden (wovon ich überzeugt bin), so ist doch eine Neubenennung aus lediglich geographischen Gründen nicht empfehlenswert, wenn nicht greifbare Unterschiede angegeben werden können. Die allerdings noch rätselhafte Verbreitung von macrorhyncha hoffe ich demnächst zu ergründen.

2) Synonym dürte sein: G. cristata gafsae Kleinschmidt \& Hilgert, Orn. Monatsb. 1905, p.189; Hilgert, Kat. Coll. Erlanger, p. 103. Die angeblichen Unterschiede sind nach dem von mir verglichenen Material nicht stichhaltig, auch ist das Gebiet geographisch und der Bodenbeschaffenheit nach dasselbe. - Über die noch fragliche, aber wahrscheinlich doch verschiedene G. c. reichenowi s. Hilgert, Kat. Coll. Erlanger, p. 104.

3) Die angegebene Verbreitung ist rermutlich zu groß. Neumann (Bull. B. O. Club XXIII, p. 45, 1908) trennte G. cristata alexanderi von Bautschi im Haussalande. im Text.

1) Synonym: „Var. aegyptiaca von Ägypten" Reichenow, Vög. Afr. III, p. 361,

5) G. cristata mbica Bianchi ex Hartert Nr. 376, Bull. Ac. Sci. Petersburg XXV 1906, p. 69.

$\left.{ }^{6}\right)$ G. cristata somaliensis Bianchi ex Hartert Nr. 378, Bull. Ac. Petersburg XXV, p. 69 (1906); G. cristata somaliensis Reichenow, Journ. f. Orn. 1907, p. 49 (Zeila).

7) Vgl, G. cristata vamberyi Härms, Orn. Monatsb. 1907, p. 49 (Utsch-Adschi in der Sandwiste Kara-Kum in Transkaspien). Scheint zwischen G. c. magna und cancasica zu stehen.

s) Hierher gehört wohl wenigstens teilweise „Galerida schliteri" Kleinschmidt, Orn. Mlonatsb. 1904, p. 196, Bône und Kerrata in Nordalgerien. — Es scheint mir, daß das übrigens zoogeographisch überhaupt übereinstimmende algerisch-tunesische Küstengebiet und die nördlichen 'Teile des Atlas nur von einer Form von Galerida theklae, nämlich von $G$. $t$. harterti bewohnt werden. Serien von Tunis, Hammam Meskoutine und Umgebung, Kerrata und der Sahel-Region bei Alger scheinen mir nicht trembar zu sein. - Damit stimmen auch Stücke von Bône überein, während andere viel heller 
Seite

389. Galerida theklae superflna Hart. ${ }^{1}$ ) . . . . . . . . . . . . . . 238

390.,$\quad$ " carolinae Erl. . . . . . . . . . 239

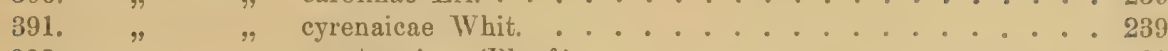

392. $"$ " praetermissa (Blanf.) ............ 239

393. $", \quad$ ellioti Hart. . . . . . . . . . . . . 240

394., malabarica (Scop.) . . . . . . . . . . 240

Gattung Lullula Kíñ. . . . . . . . . . . . . . . . . . . . 241

395. Lullula arborea $\left(\mathrm{L}_{\mathrm{c}}\right.$. . . . . . . . . . . . . . 241

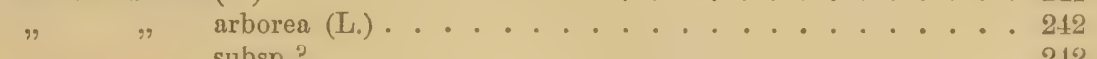

" $\quad$ subsp.? . . . . . . . . . . . 242

" $\quad$ flavescens Ehmeke . . . . . . . . . . . 242

"Gattung Alauda L

396. Alauda arvensis arvensis L. . . . . . . . . . . . 244

397. ,,$\quad$ cantarella Bp................... 246

398. $"$ cineren Ehmcke ${ }^{3}$. . . . . . . . . . . 247

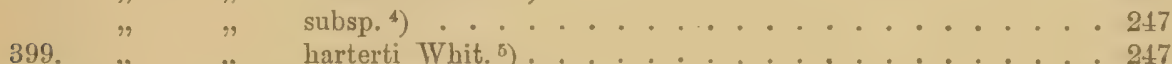

400. " " $"$ pekinensis Swinh. ${ }^{6}$. . . . . . . . . . 248

401. " " japonica Temm. \& Schleg. .......... . . 248

402. $"$ intermedia Swinh. ............... 248

403. " gulgula gulgula Frankl. . . . . . . . . . . . . 249

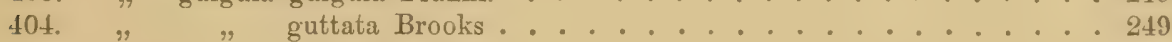

405., inconspicu Serr. ................. 249

406.,$"$ australis Brooks ............... 249

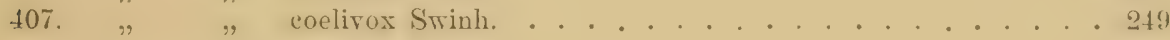

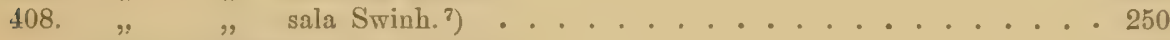

Gattung Alaemon Keys, \& Blas. . . . . . . . . . . . 250

409. Alaemon alandipes alnudipes (Desf.) . . . . . . . . . 250

410. $"$ desertorum (Stanl.) . . . . . . . . 251

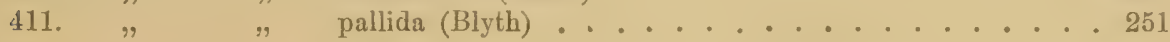

sind und mit solchen von G. t. superflua übereinstimmen, es frägt sich jedoch, ob der Fundort "Bône" richtig ist.

1) Wie wir uns 1909 auf der Reise von Biskra nach Tuggurt überzeugten, habe ch unrichtigerweise $G$. $t$. deichleri mit $G$. $t$. superflua vereinigt; erstere ist eine wohl verschiedene Subspezies, über die eingehend a. a. 0 . berichtet werden wird. Sie variiert wie alle Formen von G. theklae einigermaßen.

$\left.{ }^{2}\right)$ Über diese Formen kann ich auch heute noch nicht zu einem befriedigenden Resultat gelangen. Daß sie alle lediglich „auf verschieden abgetragenes Gefieder zurückzuführen" sind, ist eine unbegründete Annahme. - Die tunesischen Brutrögel wurden L. arborea harterti benannt; Hilgert, Kat. Coll. Erlanger, p. 113 (1908).

${ }^{3}$ ) Vermutlich ist die ostpersische Form als A. a. schach Ehmcke zu trennen.

4) Diese Vögel sind nicht identisch mit der europäischen Form. Sie müssen wohl A. arvensis dulcivox Brooks (1873) heißen.

Hinzuzufügen: A. inopinata Bianchi, eine durch die stumpfe Flügelform seln ausgezeichnete Art (oder Subspezies von arvensis). - A. japonica inopinata Bianchi, Ann. MLus. Zool. St. Petersburg IX, p. XXXI. Ost-Iibet: Nan-Schan, Kulku-Nor, oberer Mekong, oberer Brahmaputra, Gyantse, Lhassa.

5) Eine noch sehr unsichere Form. Näheres darüber a. ฉ. 0 .

$\left.{ }^{6}\right)$ Den Synonymen ist hinzuzufügen: A. buxtoni Allen, Bull. Am. MIus. N. H. XXI, p. 247 (1905- Anadir, N. O. Sibirien), - Nach Untersuchung des Typus muß diese Form pelinensis heißen und nicht blakistoni.

7) Beschrieben von Formosa und Hainan. 
Seite

Gattung Chersophilus Sharpe ............. 252

412. Chersophilus duponti duponti (Vieill.). . . . . . . . . . 252

413. " " margaritae (Koenig) . . . . . . . . 253

(Gattung Eremophila Buie. (Otocorys auct.) . . . . . . . . . 25:3

414. Eremophila alpestris alpestris (L.) . . . . . . . . . 255

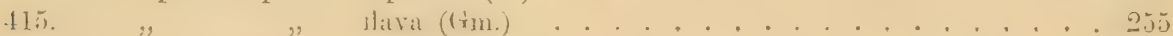

416. ", atlas (Whit.) .....................

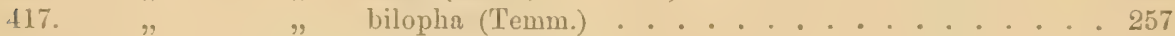

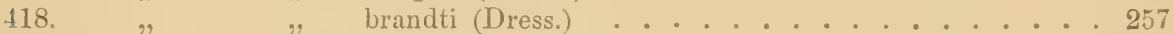

419. " montana (Bianchi) . . . . . . . . 258

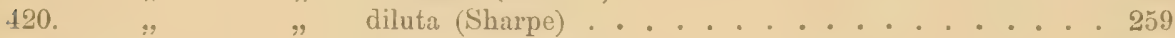

421. $", \quad$ przewalskii (Bianchi) . . . . . . . 259

422. $"$ " longirostris (Hoore) . . . . . . . 260

423. $", \quad$ elwesi (Blanf.) ............. 260

424. $"$ "kliamensis (Bianchi) . . . . . . . . . 260

425. $"$ " teleschowi (Przew.) . . . . . . . . . 261

426. $" \quad$ " penicillata (Gould) . . . . . . . . 261

427. $" \quad$ " balcanica (Rchw.).......... . . 262

428. $" \quad "$ albigula (Bp.) . . . . . . . . . . 262

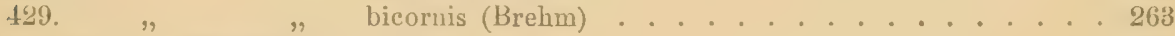

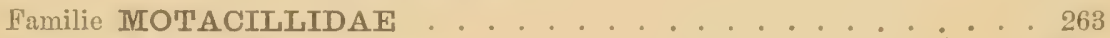

Gattung Anthus beehst. . . . . . . . . . . . . . . Itit

430. Anthus richardi richardi Viesill. . . . . . . . . . . . . . 265

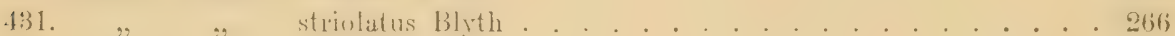

432., campestris campestris $(\mathrm{L}.) \ldots \ldots . \ldots . . . . . .267$

433. . .. minor (Ki. Blas.) . . . . . . . . . 269

434. , leucophrys eaptus Hart. . . . . . . . . . . . 269

435. , , jerdoni Finsch ........... 270

436. , berthelotii berthelotii Bolle ${ }^{1}$. . . . . . . . . . 270

437. " madeirensis Hart. . . . . . . . . . 271

438., trivialis trivialis (L.) . . . . . . . . . . 272

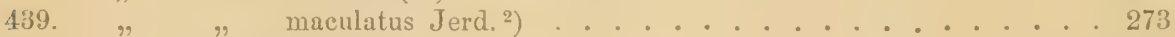

440. " gustavi Swinh. $\left.{ }^{3}\right)$. . . . . . . . . . 274

441. $"$ pratensis $\left.(\mathrm{L})^{\frac{1}{2}}\right) \ldots \ldots \ldots \ldots \ldots . \ldots . \ldots . \ldots 275$

442. $\%$ cervina $(\text { Pall. })^{5}$ ) . . . . . . . . . . . . 277

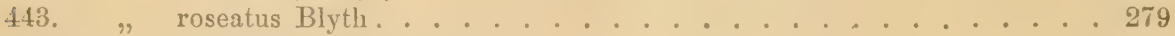

44. $"$ spinoletta spinoletta (L.) . . . . . . . . . . . 279

445. $" \quad "$ coutellii Sav. . . . . . . . . . . . 281

446. $"$ blakistoni Swinh. . . . . . . . . . 282

1) Tschusi \& Polatzek (Orn. Jahrb. 1908, p. 191) beschränken A. berthelotii berthelotii auf T'enerife, Gran Canaria und Gomera und trennen die Form der Inseln Fuertaventura, Lanzarote und Graciosa unter dem Namen A. berthelotii lanzaroteae ab. Ich konnte ron dort nur einige wenige stark abgenutzte Sommervögel vergleichen.

2) Sarudny (Orn. Mlonatsb. 1909, p.41, ex Beresowski \& Bianchi) trennt Stücke ron S. W.-Kansu als $A$, muculatus berczowstii ab.

$\left.{ }^{3}\right)$ Den Synonymen ist hinzuzufügen: Anthus stejnegeri Ridgrvay, Proc. U. S. Nat. Mus. 1883, p. 95 (Bering Insel).

4) Sarudny (Orn. Monatsb. 1909, p. 56) unterschied bei Taschkend (Turkestan) durehziehende Vögel als A, pratensis enigmaticus. Sie gleichen der Beschreibung nach Stücken ron A. cervina ohne rote Kehlen.

5) Den Synonymen ist hinzuzufügen: A. anadyrensis Allen, Bull. Am. MIus. XIII, p. 254 (1905- Gichiga in Nordost-Sibirien). 
447. Anthus spinoletta japonicus Temm. \& Schleg. ${ }^{1}$ ) . . . . . . . . 282

448. ." pensilvanica (Lath.) . . . . . . . . . . 2n3

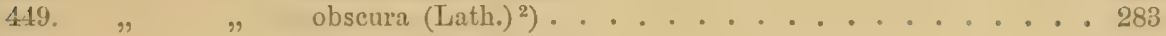

450. " $"$ kleinschmidti Hart. . . . . . . . . . 284

451. $", \quad$ littoralis Brehm ............ 284

Gattung MTotacilla L. . . . . . . . . . . 285

45:. Irotacilla flava Hara $\mathrm{L} .^{3}$ ) . . . . . . . . . . . . . 207

453. " $"$ dombrowskii (Tschusi) . . . . . . . 289

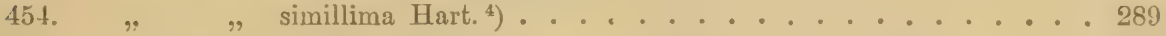

455.,$\quad$, alascensis (Ridgw.) . . . . . . . . 290

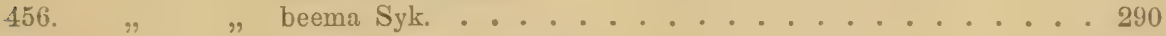

457. $"$ " leucocephala (Przew.) . . . . . . . . . 291

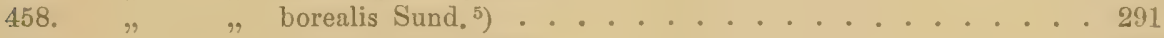

459. " $"$ cinereocapilla $\left.\mathrm{Savi}^{6}\right) \ldots \ldots . . . . . . . .292$

460. $"$ " tairanus (Swinh.) . . . . . . . . . 293

461. $" \quad$, rayi $\left.(\mathrm{Bn} .)^{2}\right) \ldots . . . . . . .294$

462. $"$, campestris Pall. ............. 294

463. $"$ " melanocephala Licht ${ }^{8}$ ) . . . . . . . . . 295

464. " " melanogriseus (Hom.) . . . . . . . . 296

465. citreola citreola Pall. ${ }^{9}$ ) . . . . . . . . . 296

466. $"$ " citreoloides (Gould) . . . . . . . . 298

467. boarula boarula L. . . . . . . . . . 298

1) Sarudny unterscheidet drei Durchzugsvögel aus 'Taschkend wegen etwas geringerer Größe (Flügel $85.7-87 \mathrm{~mm}$ ) als A. japonicus härmsi (Orn. MIonatsb. 1909, p. 40).

2) Nach Collett (Nyt. Mag. Naturw. XXIII, 1877, p. 144, XXVI, 1881, p. 3́06) soll obscurc auf den Inseln und an (ten Küsten Norwegens bis zum Varaugerfjord brïten, während im südöstlichen Nortregen die „baltische" Form, i. e. littoralis, brïtet. — (?) -

3) Motacilla flava pygmaeus (Brehm) ist eine ausgezeichnete, kleine, weißkehlige Subspezies, die in Ägypten brütet. Ich hielt das einzige s. Z: untersuchte Stück irrtümlich für aberrant. - Den Synonymen von MI. f. flava ist hinzuzufügen: Budytes fasciatus Brehm, Vogelfang, p. 141.

3) Synonym: Motacilla barnardi North, Proc. Linn. Soc. N. S. Wales XXX, p. 579 (1906- Dawson River, Queensland). - Nach einem Zugvogel, ohne jedes Vergleichsmaterial, trotz der dem Verf. bekannten Schwierigkeit der (iruppe selbst fïr Ornithologen, die "ein lebenslanges Studium der Gattung" hinter sich haben.

5) Hierfür muß der ältere Name thunbergi Billberg, 1828, angewandt werden; s. Journ. f. Orn. 1906, p. 351.

$\left.{ }^{6}\right)$ Vgl. Budytes plumbeiceps Azzolini, Publ. Mus. Rovereto 42, p. 20 (1906Italien). S. auch Giglioli, Avif. Itnl. 1907, p. 111.

7) Den Synonymen ist hinzuzufügen: Budytes neglectus Brehm, Vogelfang, 1). 142 (1855- "England, selten in Deutschland").

s) Härms beschreibt "Exemplare aus 'Transkaspien und der Wolganiederung", von denen er vermutet, daß sie in der "unteren Wolgagegend" brüten als $M$. flava raddei (Orn. Monatsb. 1909, p.2). Sie haben weißen Superciliarstreifen und schiefergrauen Nacken und ebensolches Genick. Hit dieser Beschreibung stimmt der 'Iypus von A. E. Brehms superciliaris (paradoxus C. L. Brehm) überein. Wenn diese Form also wirklich ein besonderes Brutgebiet inne hat (untere Wolga), muß sie demnach M. Hava superciliavis heißen. Ich hielt sie für eine Aberration.

$\left.{ }^{9}\right)$ Budytes citreola verae Buturlin, Orn. Monatsb. 1907, p. 197. (Brïtet in Rußland „rom Weißen Meere und Kasan, Simbirsk und Astrachan Gouvern. östlich bis Ural, aber nie im Mloskauer Gouv.", und unterscheidet sich (nach Buturlin) durch geringere Größe.) (S. Pallas, Reise Russl. III, p. 69b!)

E. Hartert, Die Vögel der paläarktischen Fauma. 
468. Motacilla bonrula melanope Pall. . . . . . . . . . . . . . . . . . 300

469. " schmitzi Tschusi ............. 301

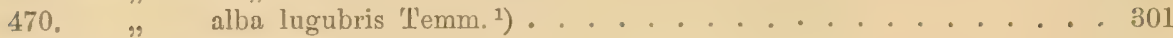

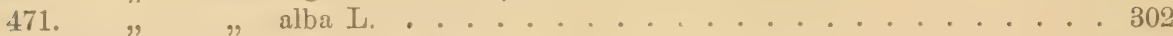

472. $"$ " dukhunensis Syk. . . . . . . . . . . 304

473. $"$ " baicalensis Swinh. ............ . . 304

474. $"$, leucopsis Gould . . . . . . . . . . . . . . 304

475. $"$, subpersonata Meade-Waldo ......... 305

t76. .. .. persica Blanf. . . . . . . . . . . . . . . . . $301 \%$

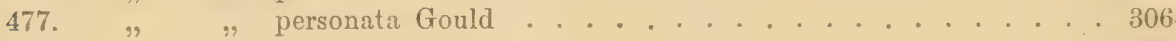

478. $"$ " hodgsoni Blyth ............. . . . 307

479. $"$ " ocularis Swinh. . . . . . . . . . . . 307

480. $"$ " lugens Kittl. . . . . . . . . . . . . 308

481. " " grandis Sharpe ............. . . . . 309

(rattung Dendronanthus Blyth. . . . . . . . . . . . . . . . 30\%

482. Dendronanthus indica $(\mathrm{Gm}$.$) . . . . . . . . . . . . 309$

Familie MNIOTILTDAE . . . . . . . . . . . 311

Familie NECTARINIIDAF . . . . . . . . . . . 311

Gattung Cinnyris Cuv. ............... 312

483. Cinnyris asiatica brevirostris (Blanf.) . . . . . . . . . . 312

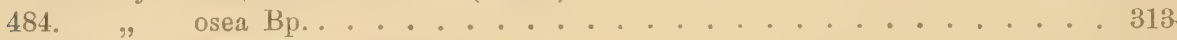

Gattung Nectarinia Ill. . . . . . . . . . . . . . . 313

485. Nectarinia metallica Licht. . . . . . . . . . . . 313

Familic ZOSTEROPIDAE . . . . . . . . . . . . . 314

Gattung Zosterops Vig. \& Horsf. . . . . . . . . . . . . 314

486. Zosterops palpebrosa stejnegeri Seeb............. . 315

487. $"$ loochooensis Trisr. . . . . . . . . 315

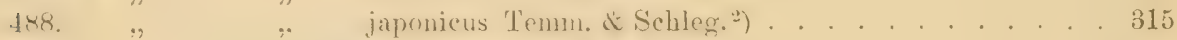

489. erythropleurus Swinh. ${ }^{3}$. . . . . . . . 315

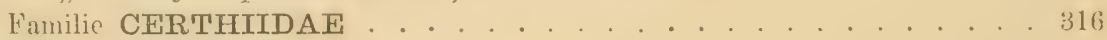

Gattung Certhia L. . . . . . . . . . . . . 316

490. Certhia familiaris familiaris L. ${ }^{4}$. . . . . . . . . . 317

491. $\quad$.. japonica Hart. . . . . . . . . . . . . . . . . 319

492. ", macrodactyla Brehm .............. 319

493. " $"$ brittanica Ridgw. ............ . . . . . . . . . . . .

494. $"$ corsa Hart. . . . . . . . . . . . . 320

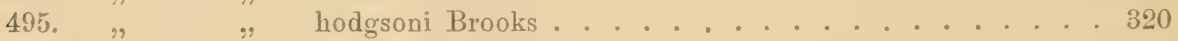

496. $", \quad$ bianchii Hart. . . . . . . . . . 321

1) Nistet nach Collett zurveilen im westl. Norwegen bei Stavanger und Bergen.

2) Hinzuzufügen ist: Z. palpebrosa alani Hartert, Bull. B. O. Club XV, p. 45 (1905- Vulkan-Inseln, südöstlich von Japan). - Ferner: Z. p. insularis Ogawa, Annot. Zool. Japon. V., p. 186 (1905- Tanegaschima und Jakuschima).

3) Hinzuzufügen ist: Z. moussoti Oustalet, Ann. Sei. Nat., Zool. XII, 19, p. 289 (1891- Szetschwan). Ebbenfalls Subspezies von palpebrosa.

4) Hinzuzufügen ist: 1. C. familiaris persica Sarudny \& Loudon, Orn. Monatsb. 1905, p. 106 (Nördliche Provinzen Persiens: Ghilan, Masanderan, Astrabad). Ich konnte diese Form nicht untersuchen. - 2. C. familiaris caucasica Buturlin, Orn. Monatsb. 1907 , p. 8 „Kaukasus und Transkaukasien“. Untersuchung von 5 Bälgen aus dem Nordkaukasus ergab, daß sich diese $V$ ögel weder durch längere Schwänze noch längere Schnäbel unterscheiden, daß aber die Füße auffallend dunkler sind und der Oberschnabel fast schwarz erscheint; ob die Unterseite weniger rein weiß ist, ist schwer zu entscheiden, da einige nicht ganz rein sind, doch könnte es der Fall sein. 


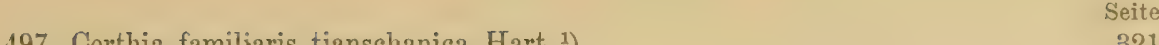

497. Certhia familiaris tianschanica Hart. ${ }^{1}$. . . . . . . . . . 321

498. $"$ "khamensis Bianchi .............. 321

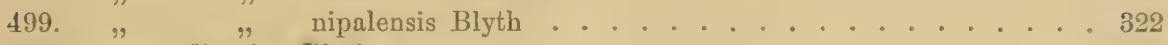

500. " discolor Blyth . . . . . . . . . . . . . . . . 322

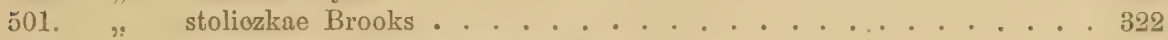

502. " brachydactyla brachydactyla Brehm ............ 323

503. $"$ ultramontana Hart. . . . . . . . . . 324

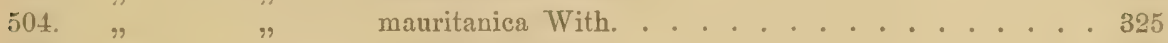

505. .4 dorothene Hart. . . . . . . . . . . 325

506. " " $"$ harterti Hellm. . . . . . . . . . . . 325

๖(17. " himalayana taeniura Sew. . . . . . . . . . . . . . 329

508. " " himalayana Vig. . . . . . . . . . 326

Gattung Tichodroma Ill. . . . . . . . . . . . . . . 326

509. Tichodroma muraria (L.) . . . . . . . . . . . . . . . . . . . 327

Familie SITTIDAE . . . . . . . . . . . . 328

Gattung Sitta L. . . . . . . . . . . . . . . . . 328

510. Sitta curopaca curopaea L. . . . . . . . . . . . . . . . . . 329

511. ., .. homeyeri Hart. . . . . . . . . . . . . . . . . . . . 330

512. " " $\quad$ uralensis $\left(\mathrm{l} l o g .^{2}\right)$. . . . . . . . . . . . . 330

513. . . $\quad . \quad$ albifrons Tacz. ${ }^{3}$ ) . . . . . . . . . . . . . . . . 331

514. . ., amurensis Swinh. . . . . . . . . . . . . . . 331

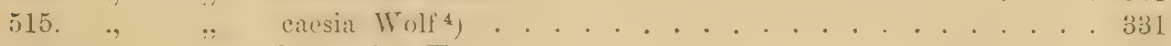

516. " $"$ britannica Hart. . . . . . . . . . . . 332

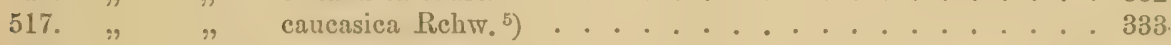

518. $"$ " levantina Hart. . . . . . . . . . . . . 333

519. . . persicit With. . . . . . . . . . . . . . 333

520. $" \quad "$ sinensis Verr. . . . . . . . . . . . . 333

521. " $"$ nagaensis Godwin-Austen ........... 334

522. " $"$ montium La Touche ............... 334

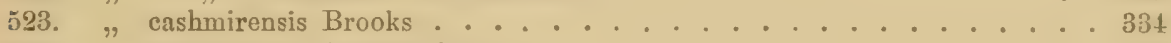

524. " himalayensis Jard. \& Selby . . . . . . . . . . . 335

525. " canadensis whitcheadi Sharpe .............. 335

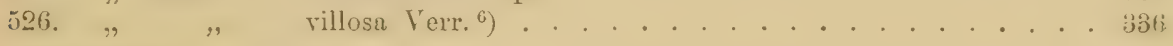

J) Vgl. C. familiaris albomaculata Johannsen, Orn. Jahrb. 1907, p. 202 (Kreis Dscharkent in Turkestan). - Diese Form bedarf fernerer Bestätigung, denn es lag dem Verf, nur ein of vor. Zwei von mir untersuchte $ᄋ$ von Dscharkent (von Sarudny gesammelt) zeigen die angegebenen Unterschiede nicht.

$\left.{ }^{2}\right)$ Den Synonymen ist hinzuzufügen: S. biedemanni Reichenow, Journ. f. Om 1907, p. 312 (T'elezlky-See, Altai. - Auf individuelle Unterschiede begründet). S. uralensis kann übrigens nicht "sibirica" genannt werden, da dieser Name nicht in nomenklatorischem Sinne gebraucht wurde! - Verschieden ist "S. aretica", Buturlin, Psovaia i Ruzheinaia Okhota XUI, no. 6, p. 87, Febr. 1907, und Orn. IIouatsber. Mai 1907. p. 79 (Werchojansk. - Äuberst schmalschnäblig, Zeichnung der Steuerfedern auffallend!).

$\left.{ }^{3}\right)$ Schwach verschieden scheint zu sein S. e. bedfordi (,S. bedfordi" Grant, Bull. B. O. Club XXIII, p. 59) von der Quelpart Insel südlich von Korea.

$\left.{ }^{4}\right)$ Synonym: S. caesia var. sordida Reichenow, Journ. f. Orn. 1907, p. 312 (Nördliches Deutschland!).

5) Hiervon verschieden (Schnabel viel, Flügel etwas länger, Unterseite dunkel ocker-röstlichgelb) ist wieler: S. curopac mbiginosa Tschusi \& Sarudny, Orn. Jihrb. 1905 , p. 140 (Nordpersische Gebirge).

o) Trefflich unterschieden ist: S. canadensis corea, etwas kleiner als villosa und Abdomen rahmfarben (S. corea Grant, Bull. B. O. Club XVI, p.87 (1906- Korea). Die Form bekräftigt meine Auffassung ron der subspezifischen Verwandtschaft ron. S. c. canadensis und whiteheadi, da sie in rieler Hinsicht in der Mitte steht. 
527. Sitta krüiperi Pelz. . . . . . . . . . . . . 336

528. . lencopsis leucopsis Gould . . . . . . . . . . 337

529. " przewalskii Berez. \& Bianchi . . . . . . . . 337

530. neumayer neumayer Michah. ${ }^{1}$. . . . . . . . . . 338

531. striaca Temm. . . . . . . . . 338

532. ". tephronota Sharpe 2 . . . . . . . . 339

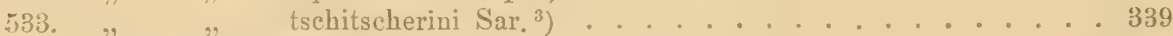

Familie PARIDAE . . . . . . . . . . . . . . 339

Gatlung Parus L. . . . . . . . . . . . . 310

5i3t. Purtis majur !najor L. . . . . . . . . . . . . . . . . . . . . . 341

535. newtoni Pražák . . . . . . . . . . 343

536. .. .. excelsus liurry . . . . . . . . . . . . . . . . 343

$537 . \quad . \quad$.. corsus lilemschun. . . . . . . . . . . . . . . 34:3

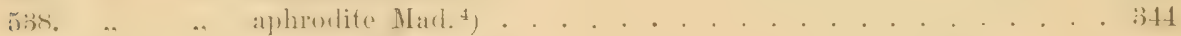

539. .. .. blanlordi l'razik") . . . . . . . . . . . . . . . . 344

540. ", bokharensis Licht. ${ }^{6}$ ) . . . . . . . . . 345

5+1. .. .. internedins sir. . . . . . . . . . . . . . . . . . . \$35

1) S. neumayer neumayer durfte auf Südost-Europa beschränkt sein! Die kleinasiatische Form ist kleiner und unterseits blasser. Sie muß S. neumayer zan udnyi heißen (Buturlin, Mitt. Kauk. MIus. III, p. 69 (1907- Typus aus Kleinasien)).

2) Die Verbreitung wurde ron mir zu groß angenommen: Die nordpersische Form (Elbursgebirge, Armenien, Transkaukasien) ist trotz meiner Auseinandersetzungen zu trennnen: Schnabel kleiner, feiner, schlanker, u. a. m. Sie muß S. neumayer rupicola Blanford heißen, denn Blanfords Diagnose und der zuerst genannte Fundort ,in mont. Persicis praesertim in Elburz saxa..." beziehen sich auf diese Form und es ändert nichts, dab der Autur irrigerweise auch Vögee aus Isfahan und Sehiras dazu rechnete. Buturlins Name S. syrica parva (Ibis 1906, p. 417 , typus ron Tiflis) ist also

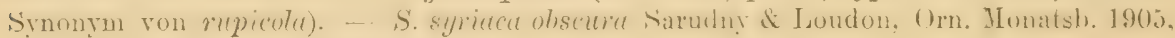
p. 86 ist Synonym von tephronote.

3) Buturlin unterscheidet von der "kleinen" S. tschitscherini noch eine "große" S. Iresseri (Orı. ILonatsb. 1906, p. 132). Seine tschitscherini wurde aus Ispahán beschrieben, dresseri soll Faristan, Schiras und Luristan bewohnen, ich halte sie indessen nicht für verschieden, denn sie scheint mir nicht geographisch getrennt zu sein. (Vgl. Ibis 1907, p. 91.)

4) $P$. m. aphrodite wird in Griechenland durch die etwas größere P. major peloponnesius Parrot, Journ. f. Orn. 1905, p.547, vertreten. Der Unterschied ist aber nur bei Untersuchung ron Serien festzustellen und nicht immer konstant. - Dalmatinische Stücke wurden als Parus major sulfureus Kollibay, Journ. f. Orn. 1904, Süddalmatien (!) unterschieden, scheinen aber nicht ron mitteleuropäischen Stücken unterscheidbar zu sein.

${ }^{5}$ ) Synonym von $P$. m. blanfordi ist $P$. maior caspius Sarudny \& Loudon, Orn. MIonatsb. 1905, p. 109 , indessen ist $P$. m. blanfordi nicht so weit verbreitet, wie ich annahm: sie bewohnt Nordpersien: Teheran, Ghilan, Mrasanderan, Asterabad und die Wälder des Tieflandes von Talyseh, während die Form des südwestlichen Persiens, Parus major zayrossiensis rerschieden ist (P. m. zayrossiensis Sarudny \& Loudon, Orn. Monatsb. 1905, p. 108. Terra typica: Sagroschgebirge). (Hellmayr in litt.) - Verschieden ist ferner auch die Kohlmeise ron Palästina. Sie gleicht in jeder Beziehung der südwestpersischen $P$. m. zayrossiensis, ist aber kleiner: Flügel o $71-72, q 69.5 \mathrm{~mm}$, bei $P$. m. zayrossiensis dagegen ơ über 75, $q 71$ und mehr. Ich benenne die Form ron Palästina

Parus major terraesanctae subsp. nот.

Typus ô Jerusalem. 2. Februar 1899, No. 177 im 'lring ALuseum.

${ }^{6}$ Ist beschränkt auf Buchara, Transkaspien (Amu Darja, Merr, 'Tedschen), Nord Afghanistan und wird in eigentlicheu Turkestan (Dschungarei, Semiretsehje [Dscherkent] und Syr Darja) durch die viel großschnäbligere und iiberhanpt größere $P$. major turkestanicus (Sarudny \& Loudon, Orn. Monatsb. 1905, p. 109) vertreten. 
Seite

512. Parus major caschmirensis Hart. . . . . . . . . . . . . . . . . . . 315

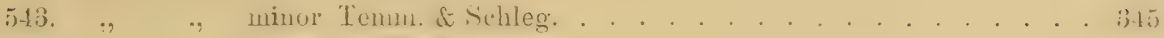

5.4. . . " tibetanus Hart. . . . . . . . . . . . . . . . . . . . 346

j4.5. . . . commixtus Sivinh. . . . . . . . . . . . . . . . . . . . . 311;

5t6. " , okinawae Hart. . . . . . . . . . . . . . . . 346

5.7. " monticolus monticolus Vig. . . . . . . . . . . . . . . . . . 347

548. 9 caeruleus caeruleus L. ${ }^{1}$ ) . . . . . . . . . . . . . . . 347

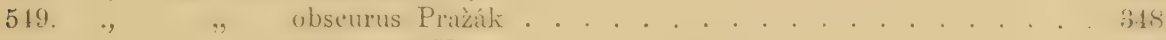

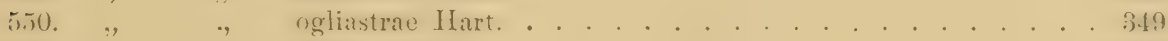

551. .. $\quad . . \quad$ sibsp. nor.?. . . . . . . . . . . . . . . . . . . . . 3413

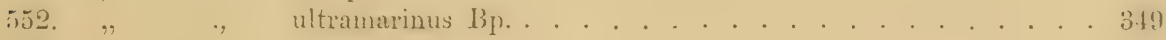

553. . $\quad$.. degener liart. . . . . . . . . . . . . . . . . . . 350

554. $"$, teneritfae Less. . . . . . . . . . . . . . . . 350

555.,$\quad$ ombriosus Meade-TValdo ............... . . 350

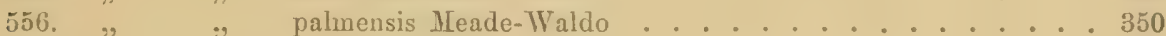

557. . $\quad$.

558. ". pleskii Cab. . . . . . . . . . . . . . . 351

559., cyanus cyanus Pall. . . . . . . . . . . . . . . . . 352

$560 . \quad$., .. tiansehanicus (Menzl.) . . . . . . . . . . . . . . . . . . 353

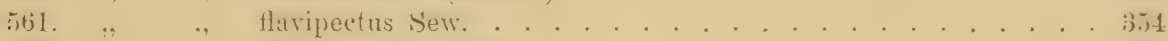

562. .. $\quad$.. berezowskii (Pleske) . . . . . . . . . . . . . . . . . . . . 354

563. " varius varius Temm. \& Schleg. . . . . . . . . . . . . . . 354

56 t.,$\quad$, owstoni Ijima . . . . . . . . . . . . . 355

565. ., .. castaneoventris Gould . . . . . . . . . . . . . . . 35

i66. . . varius subsp. nor.?3) . . . . . . . . . . . . . . . . 355

567. $"$ venustulus Swinh. . . . . . . . . . . . . 355

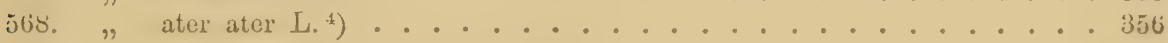

569. " " britannicus Sharpe \& Dress. . . . . . . . . . . . 357

570. ",, sardus Kleinschm. . . . . . . . . . . . . . . 358

571., 9 atlas Meade-IValdo . . . . . . . . . . . . . 358

572. .,, pekinensis David ${ }^{5}$ ) . . . . . . . . . . . . . . 358

57:3.,$"$, aemodius Hodgs. . . . . . . . . . . . . . . . . . 35s

574. .,, insularis Hellm. . . . . . . . . . . . . . . 359

1) Sarudny \& Loudon (Orn. Monatsb. 1905, p. 105̃) beschreiben unter dem Namen Cyanistes coeruleus orientalis eine anscheinend lichtere Subspezies aus den östlichen Gouvernements Rußlands (Orenburg, Ufa, Samara, Kasan, Simbirsk). - P. coeruleus calamensis Parrot, Verh. Urn. Ges. Bayern, VIII, 1908, p. 28 ist vielleicht zu unterscheiden, aber noch zweifelhaft. Scheint ebenfalls hell zu sein.

2) Ich machte auf wahrscheinliche Unterschiede von Kaukasus-Stïcken aufmerlisau. Sarudny (Naša Okhota 1908, 10, p. 5 \& Oru. Monatsb. 1908, 1). 5, 6, beschreilut

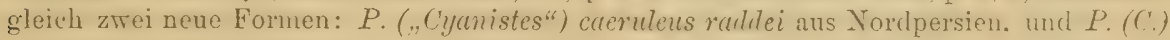
c. scutunini aus Lenkoran bis Nordpersien, also ,südlich, westlich und östlich" von P. c. raddei.

$\left.{ }^{3}\right)$ Einige Exemplare von Okinawa und Amami scheinen sich nicht von $P$. varius varius zu unterscheiden, noch weniger gehören sie zu $P$. v. castaneoventris, die von neueren Sammlern nicht wiedergefunden wurde und vielleicht gar nicht von Formosa kun:

4) P. vieirae Nicholson (Mem. \& Proc. Manchester Lit. \& Philos. Soc. L, III No. 13, p. 16, mit Tafel, 1906- Portugal) ist augenscheinlich auf ein aberrantes Stück mit stark rostbraunen Weichen begründet, doch sind vielleicht andre portugiesische und spanische Stücke auch etwas verschieden. - Im Zitat ron P. ater schuederi muß es heißen 1905̆, nicht 1904. Die sogenannten schvederi gleichen vollkommen den typischen Skandinaviern.

5) $P$. ater amurensis Buturlin, Orn. Mlonatsb. 1907, p. 80 (Amur \& Ussuri), steht zwischen ater und pelinensis (vgl. p. 357 und $P$. ater ater ${ }^{\circ}$ ). 
575. Parus ater rufpectus Sew. Seite

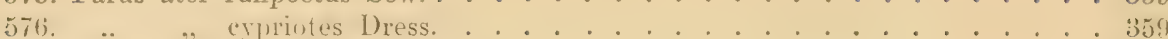

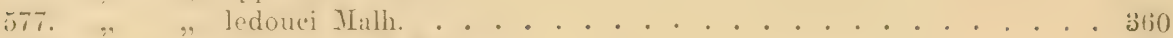

ธъь. ", moltsehanori Menzb. . . . . . . . . . . . . 360

$579 . . . \quad$. derjugini (Sar. \& Loudon) . . . . . . . . . . 3650

580. ". miehalowskii Bogd. . . . . . . . . . . . . . 36(0)

581. " phaeonotus Blanf. ........................ 361

582. " rufonuchalis rufonuchalis Blyth ............. 361

583.,$\quad$ beavani (Jerd.) ................... 361

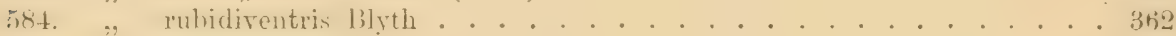

585. " melanolophus Vig. ............................. 362

586. ", dichrous dichroides (Przerv.) . . . . . . . . . . 363

587. , , dichrous Hodgs. . . . . . . . . . 363

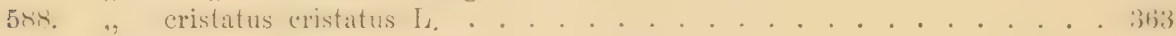

68\%. . mitratus Bronn . . . . . . . . . . . . . 3641

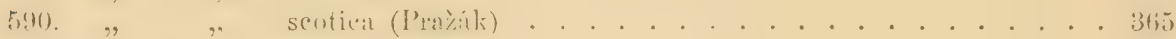

591. $"$ cinctus cinctus Bodd. . . . . . . . . . . . 365

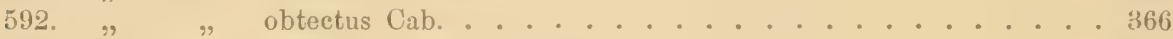

593. $" \quad$ sayana $(\text { Suschk. })^{1}$. . . . . . . . . . . 367

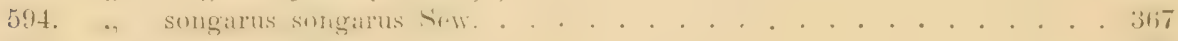

$595 . \quad$.. affinis l'

596. ", lugutris lugutris T'mmm. . . . . . . . . . . . . . . 366

597. " " lugens Brehn . . . . . . . . . . . . . . 366

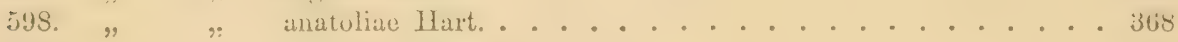

599. " " hyrcanus (Sar. \& Loudon) . . . . . . . . . . 369

600. $"$, dubius Hellm. . . . . . . . . . 369

branttii (Bogri.) . . . . . . . . . . . . . . . . . . 36!

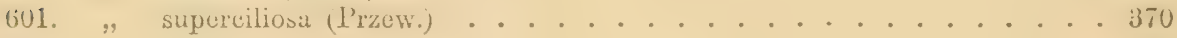

602. " davidi (Berez. \& Bianchi) . . . . . . . . . 370

603. " palustris palustris L. . . . . . . . . . . . 370

604. $", \quad$ stagnatilis Brehm ................. 371

605. $" \quad$ korejewi Sar. \& Härms ........... 372

60t5. ., "

807.,$"$ longirostris Kleinschm. . . . . . . . . 373

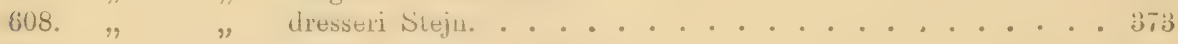

609. " " italicus T'schusi \& Hellm. . . . . . . . . . 374

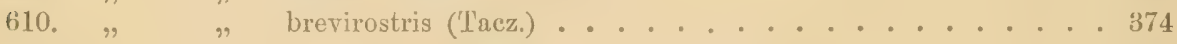

611. " " crassirostris (Tacz.) . . . . . . . . . 374

612. " $"$ hensoni Stejn. ........................... 375

613. " $"$ hellmayri Bianchi .................... 375

614. " $"$ hypermelaena (Berez. \& Bianchi) . . . . . . . . 375

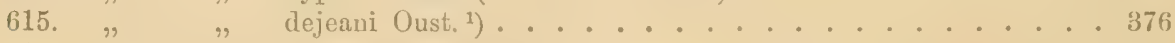

616. " atricapillus salicarius Brehm ............ . . 376

617. $"$ rhenanus Kleinschm. ........... . . 377

618. " " kleinschmidti Hellm. . . . . . . . 378

1) Hinzugekommen: Poecile kolymensis Buturlin, Journ. f. Orn. 1908, p. 284. Augenscheinlich wohl unterscheidbare Subspezies ron P. cinctus (N.O. Sibirien - Kolyma - bis zum Ochotskischen Meere).

$\left.{ }^{2}\right)$ Es ist nicht ausgeschlossen, daß hypermelaena und dejeani und vielleicht auch noch hellmayri (letztere nicht nach Untersuchung ron Material, sondern ex Hellmayr \& Kleinschmidt benannt) ein und dieselbe Form sind: durch Abnutzung der Federspitzen an den Kehl- und Halsseiten tritt der im frischen Gefieder teilweise verdeckte schwarze Kehlfleck mehr hervor. Wir erhielten alte Vögel aus den 'T'sinling-Bergen. 
619. Parus atricapillus borealis Selys . . . . . . . . . 378

620. $"$ " assimilis Brehm .................... 379

621. " $"$ bianchii (Sar. \& Härms) ........ 379

622. " montanus Baldeust.............. 380

623. $"$ baicalensis (Swinh.) ${ }^{1}$. . . . . . . . . 380

(i24. . " restrictus Hellm. . . . . . . . . . . . . . . . 380)

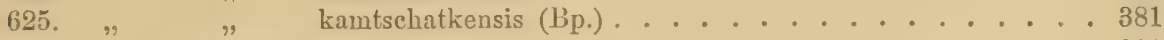

626. " modestus (Burton) . . . . . . . . . . 381

Gattung Aegithalos Herm. (Acredula auct.) ${ }^{2}$. . . . . . . . . 382

627. Aegithalos caudatus caudatus $\left(\mathrm{L} \mathrm{s}^{3}\right)$. . . . . . . . . 382

628. $" \quad$ europaea (Herm.) . . . . . . . . . . 384

629. $"$ " $"$ rosea (Blyth) . . . . . . . . . 384

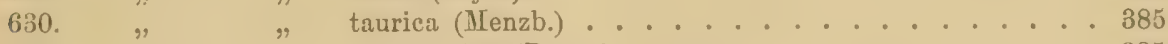

631. $"$ macedonica (Dress.) .................. 385

632. $"$ " $"$ trivirgatus (Temm. \& Schl.) . . . . . . 385

633. " $"$ irbii (Sharpe \& Dress.) . . . . . . . . 386

634. $"$ sicula (Whit.) ....................... 386

635. $", \quad$ major (Radde) ............ 386

636. " " $"$ tephronotus (Günther) ${ }^{4}$ ) ......... 387

637. $"$ " passekii (Sar.) ...................... 387

638. $", \quad$ glaucogularis (Hoore) . . . . . . . 388

639. ".

Gattung Anthoscopus Cab. ............. . 388

640. Anthoscopus pendulinus pendulinus (L.) . . . . . . . . . 389

641. . . . caspius (Poelzam) . . . . . . . . . . . . : 390

612. $"$ jaxartensis (Suschk.) ............... 391

643. $"$ stoliczkae (Hume) ................. 391

644. $"$ consobrinus (Swinh.) ${ }^{5}$ ) ........... 391

645. $"$ yenisseensis (Suschk.) .......................... 392

616, $\quad, \quad$ coronatus (Sew.) . . . . . . . . . 392

6i-17. macronyx $(\text { Sew. })^{6}$. . . . . . . . . . . 393

1) P. atricapillus sachalinensis Lönnberg, Journ. College Tokyo, XXII Art. 1t, 1. 20 (1908) von Sachalin steht dem dutor zufolge zwischen baiculensis und liantschutliensis. - Synonym ron baicalensis ist wohl Poecile tunlanansis Madarász, Anm. Mus. Hung. VII, 1909, p. 177 (Tunkan-Berge).

\%) Durch Versehen wurden $A$. iouschistos und $A$. fuliginosus nicht beschrieben - ich war damals Kongreß-Selretär! - A. iouschistos (Parus iouschistos Hodgson, Journ. As. Soc. Bengal XIII, 2, p. 943, 1844- Nepal) bewohnt den östlichen Himalaya Abbild.: Gould, B. Asia, II, Taf. 68. - A. fuliginosa (Mecistura fuliginosa Verreaux, Nouv. Arch. MIus. Paris V, Bull. p. 36, 1869) lebt in den westchinesischen Gebirgen, Szetsehwan. Tsinling-Berge (Tapaischan) und Kansu. Abbild.: Nour. Areh. Mus. Paris VIII, Bull, Taf. T, Fig. f. Ausfihhrliche Beschreibung wird in den Yachtrïgen erfolgen.

3) Synonym: Acrechula trivirgata magna (sic!) Clark, Proc. U. S. Nat. IIus. XXXII:

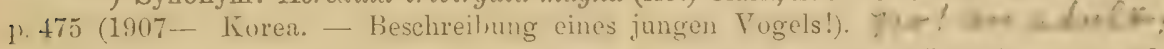

4) Leider muß hierfür der ältere Name A. caudatus alpinus (Hablizl) angewandt werden: Purus alpinus Hablizl, Nene Nordische Berträge IT, p. 19 (1783- Gebirge der Provinz Ghilan in Nordpersien).

$\left.{ }^{5}\right)$ Synonyme: Remiz consobrinus suffusus Clark, Proc. U. S. Nat. MIus. XXXII, p. 474 aus Korea und $R$. c. japonicus Clark, ebenda p. 475 aus Japan, letztere aufs Gerathewohl beuannt.

$\left.{ }^{6}\right)$ Sarudny, Orn. IIonatsber. 1908, p.162, 163, beschränkt $A$, macronyx macronyx (die er A. rutilans mutilans nennt) auf Turkestan und trennt die Form von Seistan als A. rutilans nigricans, die aus den Rohrväldern vou Lenkoran, Ghilan, Masanderan 
Gattung Cephalopyrus Bp. .............. . 393

648. Cephalopyrus flammiceps (Burton) . . . . . . . . . . . 314

Gattung Regulus Vieill. . . . . . . . . . . . . 394

619. Kegulus regulus regulus $\left(\mathrm{L}_{0}\right)$. . . . . . . . . . . . . . 391

650. " anglorum Hart. . . . . . . . . . . . . . . 39t

651. azoricus Seeb. ............. . . 39

652 . interni Hart. . . . . . . . . . . 396

653. . himalayensis Jerd. . . . . . . . 397

654., japonensis Blakist. . . . . . . . . . . 397

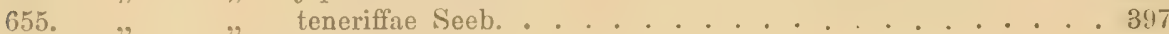

656.

657. $"$ ignicapilla ignicapilla (Temm.) . . . . . . . . . . 398

658. madeirensis Harc. . . . . . . . . . . . 399

Gattung Leptopoecile Sew. . . . . . . . . . . . . . . . 400

659. Leptopoecile sophire sophiae Sew. . . . . . . . . . . . . 400

660.4 deserticola Hart. . . . . . . . . . . . 4(1)

$661 . \quad$ obscura Przew. . . . . . . . . . . 401

Gattung Lophobasileus Pleske . . . . . . . . . . . . . . 102

662. Lophobasileus elegans (Przet.) . . . . . . . . . . . . . . . . 4 (12

Gattung Panurus Koch .................. . f(1)3

663. Panurus biarmicus biarmicus (L.) . . . . . . . . . . . . 403

664.,$\quad$ russicus (Brehn) . . . . . . . . . . . 405

Gattung Cholornis Verr. . . . . . . . . . . . . . 405

665. Cholornis paradoxa Verr. . . . . . . . . . . . . . . . 406

Gattung Suthora Hodgs. . . . . . . . . . . . . . . . 406

666. Suthora unicolor (Hodgs.) . . . . . . . . . . . . . . . $4(17$

667. $"$ ruficeps ruficeps $($ Blyth) . . . . . . . . . . . . . . 407

668. $"$ nipalensis Hodgs. . . . . . . . . . . . . . . . 408

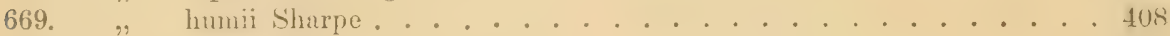

670. " gularis Verr................... . . 409

671. " przervalskii Berez. \& Bianchi ............... . 409

672. " fulvifrons fulvifrons (Hodgs.) . . . . . . . . . . . . 409

673., cyanophrys David................ . . 410

674. . conspicillata David ............... . . 410

675. "webbiana mantschurica Trez. ........... 410

676. $"$ webbiana Gray .............. . 411

677. $" \#$ alphonsiana Verr.............. 412

Gattung Psittiparus Hellm. . . . . . . . . . . . . . 412

678. Psittiparus ruficeps ruficeps (Blyth) . . . . . . . . . . 412

679. $"$ gularis gularis (Gray) . . . . . . . . . . 413

Gattung Conostoma Hodgs. . . . . . . . . . . . . 413

680. Conostoma aemodius Hodgs. . . . . . . . . . . . . 413

Familie IANIIDAE ................. . . 414

Gattung Lanius L. . . . . . . . . . . . . . . . . 414

681. Lrnius minor $\mathrm{Gm}$. . . . . . . . . . . . . . . . 416

682. \% excubitor excubitor L. . . . . . . . . . . . 418

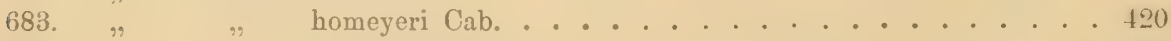

684. .. $\quad$., przewalskii Bogd. . . . . . . . . . . . . 420

685. :. . mollis Eversm.............. . 422

und Asterabad als A. rutilans neglectus ab. - Johansen, Orn. Jahrb. 1907, p. 201, beschreibt ein $0^{-}$von den "Ufern des Balchasch, westlich vom Flusse Karatal" als $A$. saposhnikowi. ("Nach der Abbildung wahrscheinlich ơ jur. von macronyx". - Hellmayr in litt.) 
68t. Lanius exeubitor borealis V'ieill. . . . . . . . . . . . . 463

687.,$"$ bianchii Hart. . . . . . . . . . . 424

48R. ., meridionalis Temm.............. 124

689.. algeriensis Less. . . . . . . . . . . 425

690. " dodsoni Whit. . . . . . . . . 426

691. " " koenigi Hart. . . . . . . . . . . . 426

692. " $\quad$ " elegans Swains. ${ }^{1}$ ) . . . . . . . . . . 427

693. ",$\quad$ leucopygos Hempr. \& Ehr. . . . . . . . . . 428

694. $", \quad$ pallidirostris Cass. . . . . . . . . . . 429

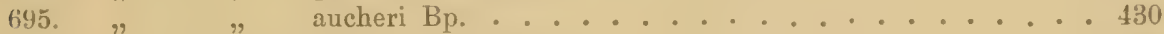

696. $" \quad$ " buryi Lor. \& Hellm. . . . . . . . . . 432

697. " sphenocercus sphenocercus Cab............. 433

698. ., . giganteus Przew............... . $4: 34$

699., senator senator L. ${ }^{3}$ ) . . . . . . . . . . 433

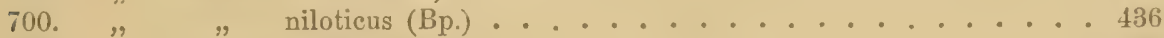

7)1.

702. $"$ nubicus Licht. . . . . . . . . . . . 438

703. $"$ collurio collurio L. . . . . . . . . . 439

704. $"$ kobylini (But.) ${ }^{3}$. . . . . . . . . . 441

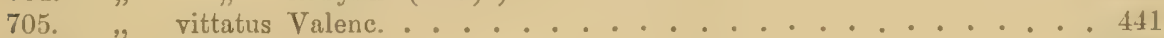

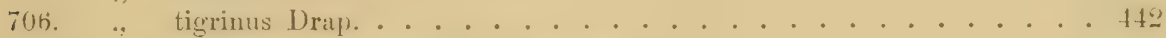

707. " eristatus phoenicuroides (Schalow) ${ }^{4}$ ). . . . . . . . 4:3

708,, isabellinus Hempr. \& Ehr. . . . . . . . . . 444

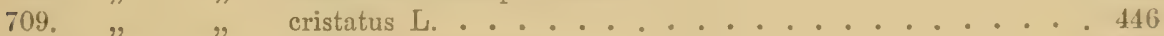

710. superciliosts Lath. . . . . . . . . . . 447

711. .. lucionensis L. . . . . . . . . . . . 447

712. ., bogdanowi (Bianchi) ${ }^{5}$ ) . . . . . . . . . . . . . 448

713. , darwini (Sew.) .......................... 44

714. " bucephalus Temm. \& S'chleg. . . . . . . . . . . 450

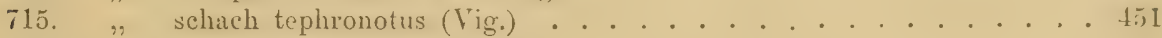

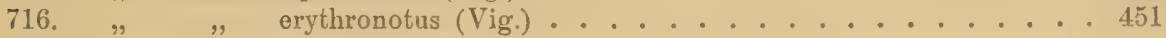

Gattung Telophonus Swaius. ${ }^{6}$. . . . . . . . . . . 452

717. Telophonus senegalus cucullatus (Temm.) . . . . . . . . 452

Gattung Hypocolius Bp. . . . . . . . . . . . 453

718. Hypocolius ampelinus Bp. . . . . . . . . . . . . tǒt

1) Brütet ostwärts bis Eigypten.

2) Kleinschmidt unterscheidet den algerischen Rotkopf-Würger als $L$. senator. flïckigeri (Falco 1907, p. 68), die angegebenen Untersehiede sind aber m. E. nicht stichhaltig. Näheres an anderem Orte.

${ }^{3}$ ) Buturlin trennt ferner L. loudoni von Nord-Turkestan (ILitt. kaukas. MIus. 1907, p. 78). Ich konnte keine Stücke von dort untersuchen.

4) Buturlin schuf noch einen neuen Namen für den von ihm für verschieden gehaltenen "Otomela varia"s (s. siebentes Synonym), und zwar L. zarudnyi (Naša Okhota 1908, 90, p. 9. Persien).

5) ? Otomela salina Zarudny, Mém. Ac. Imp. Pétersb. ser. 8, X, s. 187 (1900- N. O.

6) Vgl. Reichenow's Ansicht über diesen Namen, die ich indessen nicht ganz teile. Boie sagt, ,Pomatorhynchus Horsf.", und da er Pomatorhimus Horsf. nicht erwähnt, kann es - er stellt die Gattung auch in dieselbe Verwandtschaft wie Timelia keinem Zweifel unterliegen, daß er nur Horsfields Namen falsch, oder seiner Ansicht nach besser, wiedergab. Swainson dagegen schrieb selbst 1831 Telophorus, dagegen 1837 Telophonus. Vielleicht ist es am besten, auch diesen Namen zu verwerfen, und Harpolestes Cab. fïr die (rattung anzuwenden, ein Name, der jedenfalls einwurfisfrei ist. Ich hatte Telophorus 1831 übersehen. 
Gattung Bombycilla Vieill. ............... . . 455

719. Bombycilla garrulus garrulus (L.) . . . . . . . . . 456

720., japonica (Sieb.) . . . . . . . . . . . . 457

Familie BRACHYPODIDAE . . . . . . . . . 459

Gattung Pycnonotus Boie . . . . . . . . . . . . 459

721. Pycnonotus barbatus barbatus (Desf.) . . . . . . . . . 460

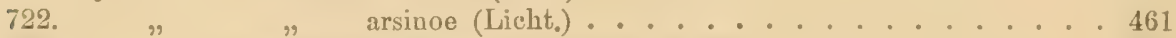

723. " capensis xanthopygos (Hemr)r. \& Ehr.) . . . . . . . . . 4 til

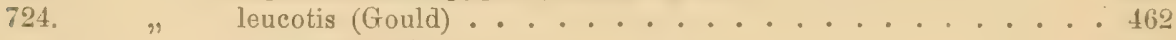

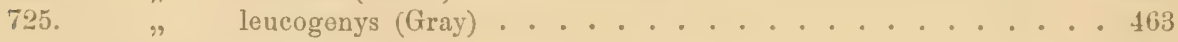

Gattung Hypsipetes Vig. . . . . . . . . . . . . 163

726. Hypsipetes amaurotis amaurotis (Temm.) . . . . . . . . . 463

727. $"$ hensoni Stejn. ............ . . 464

728. ".

729. $", \quad$ stejnegeri Hart. . . . . . . . . . 464

730. $"$ " ogawae Hart. . . . . . . . . . 465

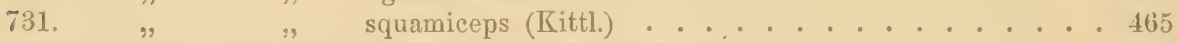

732. " $"$ magnirostris Hart. ......... 465

Familie CAMLPOPHAGIDAE ${ }^{1}$ ) . . . . . . . . . 466

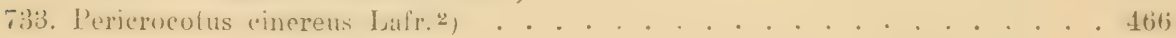

734. $"$ tegimae Stejn. ................. 467

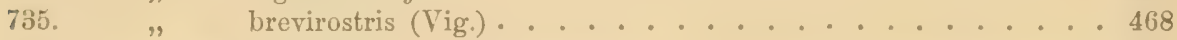

736., solaris solaris Blyth ............. 468

Finwilie MUSCICAPIDAE (einschlieblich "Sylizilue", "Timeliidue" und ,Turdidaces) . . . . . . . . . . . . . . 469

Gattung Tchitrea Less. . . . . . . . . . . . . . 469

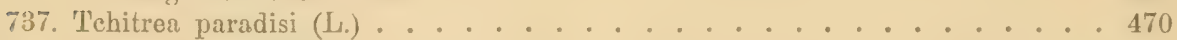

738. " incei (Gould) . . . . . . . . . . . . 471

739.,$\quad$ princeps princeps $($ Temm.). . . . . . . . . 471

740.,$\quad$, illex (Bangs) . . . . . . . . . 4 472

Gattung Rhipidura Vig. \& Horsf. . . . . . . . . . . . . . 472

741. Rhipidura albicollis (Vieill.) . . . . . . . . . . . 473

frattung IVIuscicapa L. (einsehließlich "Hemichelidon", ,Alseonax", „Nen-

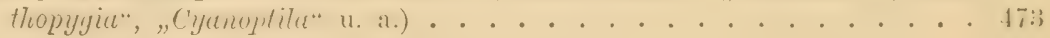

742. Muscicapa striata striata (Pall.) (M. grisola auct.) . . . . . . . . 475

743. $"$, neumanni Poche ............. 477

7H. ". latirostris liafl. . . . . . . . . . . . . . 477

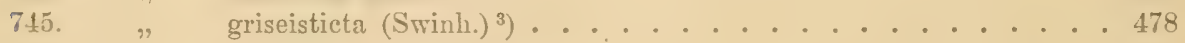

746. $\quad$ sibirica sibirica Gm. ................... 478

747. $"$ " fuliginosa (Hodgs.) . . . . . . . . . 479

748. $"$ ferruginea (Hodgs.) . . . . . . . . . . 479

1) Hinzuzufügen: Campophaga melanoschista melanoptera (Rüpp.) (Ceblepyris melanoptera Rüppell, MIus. Senckenberg. III, p. 25, Taf. II, Fig. 1 (1839). Chinesische Gebirge bis ins Tsinling-Gebirge. Schiefergrau, Unterschwanzdecken hellgrau bis weißlich, Schwingen schwarz, Steuerfedern schwarz mit weißen Spitzen. Etwa von Starengröße. Die Form der Tsinling-Berge gehört entweder zu melanoptera oder bildet eine besondere Subspezies, sie gehört aber nicht zu saturata von Hainan.

$\left.{ }^{2}\right)$ Die (mir nicht vorliegende) Form von Korea wurde als $P$. cinereus intermedius abgetrenut (Clark, Proc. U. S. Nat. Nus. XXXII, p. 474, 1907).

3) Parrot beschreibt die Form ron Iturup (Kurilen) nach einem am 30. August 1900 gesammelten ô als $M$. griseisticta habereri. Größer als $M I$. g. griseisticta, Flügel $90 \mathrm{~mm}$. 
Seite

749. MLuscicapa atricapilla atricapilla L. ${ }^{1}$ ) . . . . . . . . . 480

750.

751.

752.

753.

754.

755 .

756 .

757.

758.

759 .

760.

761.

762.

763.

764.

765 .

766 .

767.

768.

speculiger Bp. $^{2}$ ) ............ 482

semitorquata Hom. ${ }^{3}$ ) . . . . . . . . . . . 4 483

collaris Bechst. . . . . . . . . . . . . 483

strophiata (Hodgs.) . . . . . . . . . . . . . . . . 484

ruficauda Swains. . . . . . . . . . . 485

parva parva Bechst. ............. 485

" albicilla Pall. ............. . . 487

" hyperythra (Cab.). . . . . . . . . 4 487

superciliaris Jerd. . . . . . . . . . . . . 488

hodgsonii (Verr.) . . . . . . . . . . . 488

leucomelanura leucomelanura (Hodgs.) . . . . . . . 489

cerviniventris (Sharpe)....... 489

narcissina zanthopygia Hay . . . . . . . . . . . 490

" narcissina Temm. ........... . . 490

" jakuschina Hart. . . . . . . . . . . . . 491

, owstoni (Bangs) . . . . . . . . . . . 491

mugimaki Temm. . . . . . . . . . . . . 492

cyanomelana Temm. . . . . . . . . . . . 493

melanops Vig. ................ . . 494

Gattung Chelidorynx Hudgs. . . . . . . . . . . . . . . 4 (t)

769. Chelidorynx hypoxantha (Blyth) . . . . . . . . . . . 494

Gattung Culicicapa Swinh. . . . . . . . . . . . 495

770. Culicicapa ceylonensis (Swains.) . . . . . . . . . 495

Gattung Cryptolopha Swinh. . . . . . . . . . . 496

771. Cryptolopha burkii tephrocephalus (Anders.) . . . . . . . . 496

772. $"$ " burkii (Burt.) ............. 497

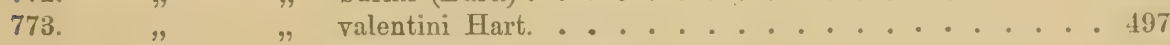

774. " $"$ intermedia La Touche............ 497

775. $"$ affinis (Rossf. \& Moore) ............ 498

776. $"$ xanthoschistos xanthoschistos (Gray) ........ 498

777. $", \quad$ jerdoni (Brooks) . . . . . . . 498

Gattung Abrornis Hodgs. . . . . . . . . . . . . 498

778. Abrornis albogularis albogularis Hoore . . . . . . . . . 499

779: $\quad$ " $\quad$ fulvifacies Swinh. . . . . . . . . . . 499

Gattung Phylloscopus Boie . . . . . . . . . . . . 499

780. Phylloscopus collybita collybita (Vieill.) . . . . . . . . 501

781. " . abietina (Nilss.) . . . . . . . . . . 503

782. $", \quad$ tristis Blyth ................... 503

783. $"$ " canariensis Hartwig . . . . . . . . 504

" $", \quad$ axillaris Suschk. . . . . . . . . . . 504

781. $"$ " exsul Hart. . . . . . . . . . . 505

785. $"$ " sindianus Brooks ............... 505

786. $"$ neglectus neglectus Hume . . . . . . . . . 506

7.

788. $"$ trochilus trochilus $(\text { L. })^{4}$. . . . . . . 507

1) Hierfür muß der ältere Name M. hypoleuca hypolenca eintreten (Motacilla hrpotereca Pallas, Troegs Cat. Verzam. Vogelen, Adumbratiuncula, p. 3; 1761- Holland).

2) Миß $M$. hypolerca speculigera heißen.

3) MLß M. rypoleuca semitorquata heißen.

4) Den Synonymen ist hinzuzufügen: Phyllopseuste curvirostris Madarász, Journ.

f. Orn. 1880, p.326 (Budapest). 
789. Phylloscopus trochilus eversmanni $\left.(\mathrm{Bp} .)^{1}\right)$. . . . . . . . 509

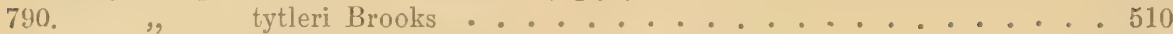

791. $"$ nitidus nitidus Blyth .................... 510

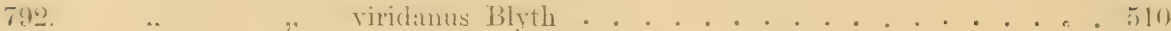

793. $"$ " plumbeitarsus Swinh............... 511

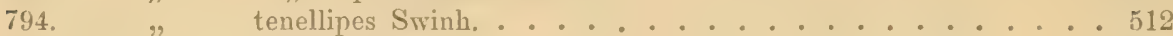

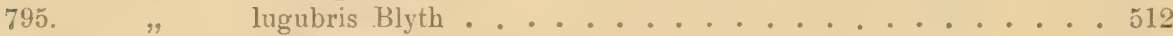

796., magnirostris Blyth ............... 513

797.,$\quad$ bonelli bonelli (Vieill.) ............ 513

798.,$\quad$ orientalis (Brehm) ................. 514

799.,$\quad$ sibilatrix sibilatrix (Bechst.) . . . . . . . . 515

800. $"$ " erlangeri Hart. . . . . . . . . 516

801. $"$ borealis borealis (Blas.) .......... . . 517

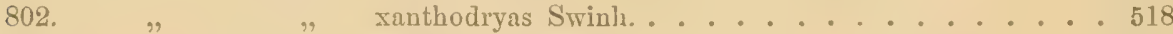

803. $\quad, \quad$ superciliosa superciliosa $\left(\mathrm{Gm}_{.}\right) \ldots \ldots \ldots \ldots$

804. $"$ humei (Brooks) . . . . . . . . 519

805. $"$ mandellii (Brooks) . . . . . . . . 520

806. $\quad " \quad$ subviridis (Brooks) . . . . . . . . . . 520

807. $\quad " \quad$ occipitalis coronata (Temm. \& Schleg.) . . . . . 521

808. $" \quad$ occipitalis (Blyth) . . . . . . . . 521

809. $"$ trochiloides (Sund.) . . . . . . . . . . 522

810., ijimae (Steju.) . . . . . . . . . . . 522

811. $"$ proregulus proregulus (Pall.) ........... 523

812. $"$ newtoni Gätke . . . . . . . . . 524

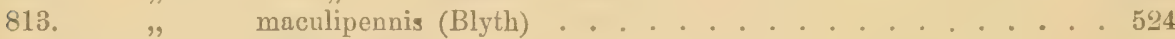

814. $"$ pulcher Blyth .................. 524

s15. .. atfinis (Tick.) . . . . . . . . . . 525

816.

817., armandii (Milne-Edw.) . . . . . . . . . . 526

818. $"$ indica (Jerd.) . . . . . . . . . . . 527

819. $\%$ fuscata $($ Blyth) . . . . . . . . . . 528

820 homeyeri $\left.(\text { Dyb. })^{2}\right)$. . . . . . . . . 528

821. $"$ fuligiventer (Hodgs.) . . . . . . . . . . 529

Gattung Herbivocula Swinh. . . . . . . . . . . . 529

6.2. Herbivocula schwarzi (liadle) . . . . . . . . . . . . . . . . . 530)

Gattung Horeites Hodgs. . . . . . . . . . . . . 530

5:3. Horeites cantuns cantans (Termm \& schleg.) . . . . . . . . . . . . . . 531

824. $"$ " canturians (Swinh.) . . . . . . . . . . 532

825. $"$ " $"$ borealis (Campbell) . . . . . . . . . 532

826. $"$ " diphone (Kittl.) . . . . . . . . . 533

827. $"$ flavolivacen flavolivacea (Blyth) . . . . . . . . . . 533

828. $" \quad "$ intricatus Hart. . . . . . . . . . . . 533

829. $"$ major Hoore .................. . . 534

830., acanthizoides brunnescens Hume . . . . . . . . . 534

831. $"$ acanthizoides (Verr.)................ 584

832. $"$ fortipes fortipes (Hodgs.) . . . . . . . . . 535

833. " $"$ ".................... 535

834. " pallidus Brooks ............................. 536

835. " brunnifrons (Hodgs.) ....................... 536

1) Hierher gehört wahrscheinlich auch der von Erlanger im Dezember bei Wonda im südlichen Abessinien (nicht im "südafrikanischen Seengebiet" wie Reichenow schreibt) gesammelte Vogel: „Var. murina" Rchw., Vög. Afr. III, p. 645.

2) Vgl. Novitates Zoologicae-1910, p. 239. 
Gattung Cettia Bp.

836. Cettia cetti eetti (Jirm.) . . . . . . . . . . 537

837. $"$, cettioiles Hume . . . . . . . . . . . . . 538

Gattung Urosphena Swinh. ............ 539

838. Urosphena squameiceps (Swinh.) . . . . . . . . . . 539

Gattung Lusciniola Gray ............ . . 540

839. Lusciniola melanopogon melanopogon (Temm.) . . . . . . . 540

840.,$\quad$, mimica Mad. . . . . . . . . 541

841..$\quad$ thoracica (Blyth) . . . . . . . . . . . 541

842. $"$ tacsanowskia (Swinh.) .......................... 542

843. " major (Brooks) .................. 543

844. " luteoventris (Hodgs.) ${ }^{1}$ ) ............. 543

Gattung Locustella Kaup ... . . . . . . . . . . . 544

845. Locustella fasciolatus (Gray) . . . . . . . . . . . . . . 545

846.,$\quad$ ochotensis (Midd.) . . . . . . . . . 545

847. " fluviatilis (Wolf) ............... 547

848. $"$ luscinioides luscinioides (Savi) . . . . . . . . 548

849. $" \quad$ " fusca (Sew.)............... 549

850. $"$ certhiola (Pall.) . . . . . . . . . . 550

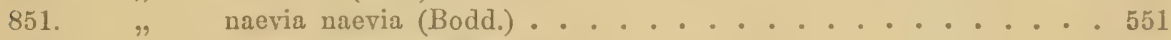

852. . .

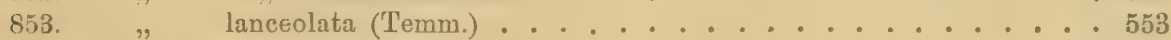

Gattung Phragamaticola Jerd. ............. 554

854. Phragamaticola aëdon (Yall.) . . . . . . . . . . . . 554

Gattung Acrocephalus Naum. ............. 555

855. Acrocephalus arundinaceus arundinaceus (L.) . . . . . . . 556

856. $" \quad$ zarudnyi Hart. ......... 558

857. $"$ orientalis (Temm. \& Schleg.) . . . . . . 558

858. $" \quad$ stentorea stentorea (Hempr. \& Ehr.) . . . . . . . 559

859. $"$ " brunnescens (Jerd.) ......... . . 560

860. $\quad \because \quad$ strepera strepera $(\text { Vieill. })^{2}$........... 560

861. $"$ macronyx (Sew.) .............. 561

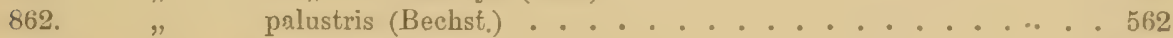

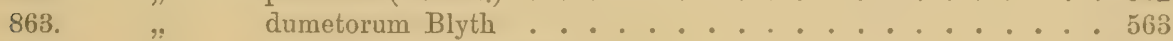

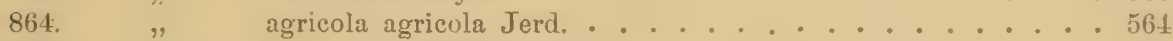

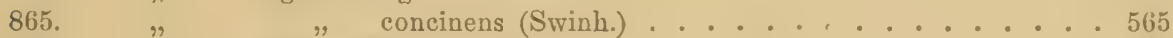

866. " orinus Oherh. ............. 56i

867. $"$ bistrigiceps Swinh. ................ 565

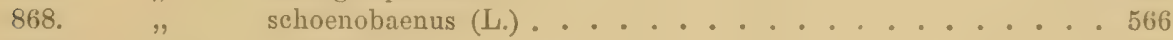

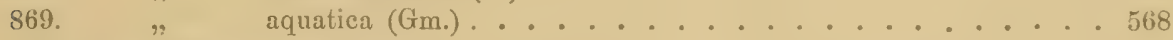

Genus Hippolais Brehm . . . . . . . . . . . . . 569

870. Hippolais icterina (Vieill.) . . . . . . . . . . . 570

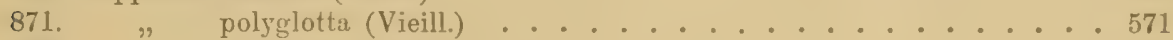

872., olivetorum (Strickl.) . . . . . . . . . 572

873. $"$ languida (Hempr. \& Ehr.) . . . . . . . . . . 573

874. $"$ pallida pallida (Hempr. \& Ehr.) ${ }^{3}$ ) . . . . . . . . 574

875.,$"$, reiseri Hilgert .............. 574

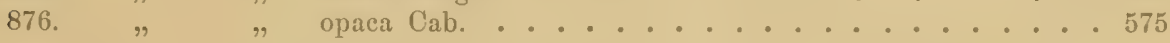

1) In den 'Angaben ïber die Verbreitung muß es heißen: Bergländer südlich des Brahmaputra.

2) Den Synonymen ist hinzuzufügen: Calamoherpe arborea Cretté de Palluel, Le Naturaliste, 6. année, p. 469 (1881- Descriptio nulla! Gärten in Paris).

3) Häufiger Brutvogel in Ägypten! 
877. Hippolais rama (Sykes) . . . . . . . . . . . . 575

878., caligata (Licht.) . . . . . . . . . 575

Gattung Sylvia Scop. .............. 576

879. Sylvia nisoria nisoria (Bechst.) . . . . . . . . . 578

880., . merzbacheri Schal. . . . . . . . . . . . . .

881. " hortensis hortensis (Gm.) (S. orphea auct.) . . . . . . . 580

882. ",$\quad$ crassirostris Cretzschm. . . . . . . . . 581

883. " borin borin (Bodd.) (S. hortensis auct, errore!) . . . . . . . 582

atricapilla atricapilla $\left(\mathrm{L}_{\mathrm{c}}\right)$. . . . . . . . . . . 583

heineken (Jard.) . . . . . . . . . . . 5 5 . . . . . . . . . .

885., communis communis Lath. . . . . . . . . . 586

886. $"$. icterops ILénétr. . . . . . . . . . . . . . . . . . . . . .

887. $"$ curruca curruca $(\mathrm{L})$. . . . . . . . . . . . 588

888. " $"$ affinis Blyth . . . . . . . . . . . . . . . . . . . . . . . . .

889. " $"$ halimodendri Suschkin . . . . . . . . 589

890. . $"$ minula Hune . . . . . . . . . . . . . . j8!

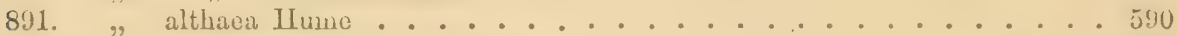

892. " nana nana (Hempr. \& Ehr.) . . . . . . . . . 590

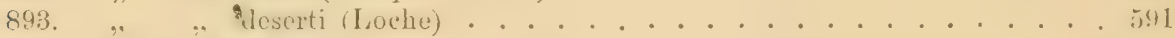

894. . ruppeli Temm. . . . . . . . . . . . 592

895. " melanocephala melanocephala $(G \mathrm{~m}.) \ldots . . . . . . . . .593$

896. $" \quad "$ leucogastra (Ledru) . . . . . . . . . . 594

897. " $"$ momus (Hempr. \& Ehr.) ${ }^{1}$ ) . . . . . . . 594

898., melanothorax Tristr. . . . . . . . . . 595

899. $"$ mystacea Hénétr. . . . . . . . . . . . . . 595

900. ", subalpina subalpina Temm. ${ }^{2}$. . . . . . . . . 596

901. $" \quad$ inornata Tschusi ${ }^{3}$. . . . . . . . . . 597

902. $\quad$.. albistriata $\left(\right.$ Brehur $\left.{ }^{4}\right)$. . . . . . . . . . 5 597

003. . conspicillata comspicillata 'Temm1. . . . . . . . . . . . 54s

904.,$\quad$. hella Tschusi . . . . . . . . . . . . . . . . . . . . . .

905. " deserticola Tristr. . . . . . . . . . . . 599

906. ", undatia undata (Bodll.) . . . . . . . . . . . . . . 600

907. $" . \quad$ dartfordiensis Lath. . . . . . . . . . . . 601

\$os. $" . \quad$. trit Hart. . . . . . . . . . . . . . . . . 602

609. ., sarda Temm. . . . . . . . . . . . . . . . . 602

Gattung Agrobates Swains. .............. 603

910. Agrobates galactotes galactotes (Temm.) . . . . . . . . . 603

911. $"$ syriaca (Hempr. \& Elr.) . . . . . . . . 605

912. " $"$ familiaris (Ménétr.) ............... 605

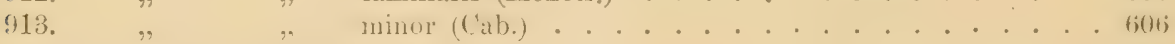

Gattung Scotocerca Sund. . . . . . . . . . . . 606

914. Scotocerca inquietus inquietus (Cretzschm.) . . . . . . . . 606

915. $"$ platyura (Sew.) . . . . . . . . . 607

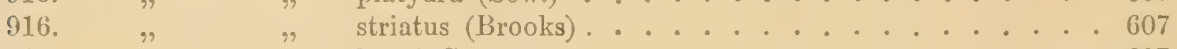

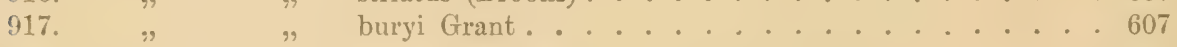

918. $"$ saharae (Loche) . . . . . . . . 608

1) S. semenowi ist Synouym.

2) Hierfür - nicht aber für S. undata! - muß der ältere Name Sylvia cantillans cantillans (Pall.) angewandt werden: Motacilla cantillans Pallas, in Vroeg's Cat. rais. Coll. Ois., Adumbratiuncula p. 4 (1764- Italien).

3) ILu S. cantillans inornata heißen.

4) Richtiger S. cantillans albistriata. 
919. Prinia gracilis gracilis (Licht.) . . . . . . . . . . . . . . . 608

920. $", \quad$ deltae Rchw. . . . . . . . . . . . . . . . . 609

921. " " $"$ yemenensis Hart. . . . . . . . . . . . . . . . . . 609

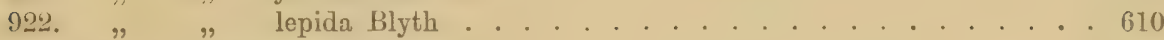

Gattung Cisticola Kaup. . . . . . . . . . . . . . . . . . . . . . 610

923. Cisticola cisticola cisticola (T'emm.) . . . . . . . . . . . . . 610

$924 . \quad " \quad$ arquata (Müll.)................. 611

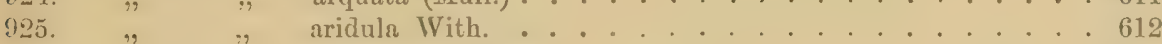

926. " $"$ uropygialis (Fras.) . . . . . . . . . . 612

927. $", \quad$ cursitans (Frankl.) . . . . . . . . . . . . 613

928. " " $"$ brunniceps (Temm. \& Schleg.) . . . . . . . . . 613

229. " " $"$ tintinnabulans (Swinh.) . . . . . . . . . . . 613

930. $"$ fuscicapilla Wall. . . . . . . . . . . . . . 613

Gattung Rhopophilus Gigl. \& Salvad. . . . . . . . . . . . . . . 613

931. Rhopophilus pekinensis pekinensis (Swinh.) . . . . . . . . . . . 614

932. $"$ albosuperciliaris (Hume) . . . . . . . . 614

Gattung Proparus Hodgs. . . . . . . . . . . . . 615

933. Proparus nipalensis hueti (David) . . . . . . . . . . . . . 616

934. $" \quad$ "13. naleusis (Hodgs.) . . . . . . . . . . . . . 616

935. " vinipectus vinipectus (Hodgs.) . . . . . . . . . . . . 617

936. " $"$ bieti Oust................. . . 617

937. " $"$ cinereiceps (Verr.) . . . . . . . . . . . . . . . 617

938. " striaticollis (Verr.). . . . . . . . . . . . . 618

939. . ruficapilla (Verr.) . . . . . . . . . . . 618

940. $"$ chrysotis Blyth ................. . . 619

941. " swinhoii Verr. . . . . . . . . . . . . . 619

Gattung Moupinia David \& Oust. . . . . . . . . . . . . 619

942. Moupinia poecilotis (Verr.) . . . . . . . . . . . . . . . 619

Gattung Leiothrix Swains. . . . . . . . . . . . . . . 620

9.13. Leiothrix lutea lutea (Scop.) . . . . . . . . . . . . . 620

१1. $"$ " calipyga (Hodgs.) ............. . . 621

Gattung Crateropus Swains. . . . . . . . . . . . 621

45. Crateropus squamiceps squamiceps (Cretzschm.) . . . . . . . . . 621

4. 46 . $"$. . . . . . . . 622

9 4 . $"$ caudatus huttoni (Blyth) . . . . . . . . . . . 622

9.18. $"$ " altirostris Hart. . . . . . . . . . . . 623

949. " $"$ caudatus (Drap.) .................... 623

950. $"$ fulvus fulvus (Desf.) . . . . . . . . . . 623

951. $", \quad$ acaciae (Licht) . . . . . . . . . . 624

Gattung Ianthocincla Gould . . . . . . . . . . . . . 624

952. Ianthocincla maximus (Verr.) . . . . . . . . . . . 625

953. $"$ ocellatum artemisiae (David) . . . . . . . . 626

4.54. $" \quad$ ocellatum (Vig.) ........... . . 627

95\%. .9 lunulata Verr. ................ . . 627

4.5ti. $\quad . \quad$ lanceolitus lanceolatus (Verr.) . . . . . . . . . 627

95\% $"$ " bonvaloti (Oust.) . . . . . . . . 628

958. $"$ waddelli (Dress.) . . . . . . . . . . . 628

959. $"$ koslowi (Bianchi) . . . . . . . . . . . 629

960. $" \quad$ sukatschewi (Berez. \& Bianchi) . . . . . . . . . . . 629

(11)1. $"$ davidi (Swinh.) . . . . . . . . . . . 630

912. $"$ cinereiceps styani (Oust.) . . . . . . . . . . 630

963. $"$ " $"$ cinereiceps (Styan) . . . . . . . . . 631

961. $"$ elliottii elliottii (Velr.) . . . . . . . . . . . . 631

965. $" \quad "$ prjevalskii (Menzb.) . . . . . . . . . 632 
Selte

966. Ianthocincla elliotti bonvaloti (Oust.) ${ }^{1}$ ) . . . . . . . . . . . 632

967.,$\quad$ lenrici (Oust.) ................... 636

968, 9 affinis blythii (Verr.) . . . . . . . . . . . . 633

(1ti!).

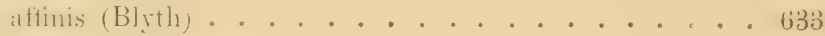

970.

971. oustaleti Hart. . . . . . . . . . . 633

172.

973 .

974.

975.

976.

977.

978.

979.

980.

Gattung Pomatorhinus Horsf. subunicolor (Blyth) . . . . . . . . . 633

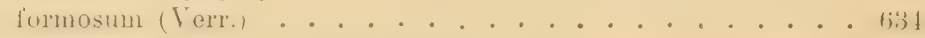

rufogularis rufogularis Gould . . . . . . . . . 634 assamensis Hart. . . . . . . . . 635

$" \quad$ occidentalis Hart. . . . . . . . . 635

lineatum lineatum (Vig.) . . . . . . . . . 635 grisescentior Hart. . . . . . . . 636 gilgit Hart. . . . . . . . . . . 636

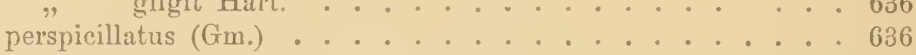
albogularis Gould. . . . . . . . . . . . . 637

981. Pomatorhinus erythrogenys erythrogenys Vig

$982 . \quad$ ferrugilatus Hodgs. . . . . . . . 638

983. $"$ macclellandi gravivox David........... 638

981. $" \#$ dedekensi Oust. . . . . . . . . 638

985. " $"$ ruficollis ruficollis Hodgs. . . . . . . . . . . 639

$986 . \quad " \quad$ " styani Seeb. . . . . . . . . . 639

(inttung Turdus L. . . . . . . . . . . . . . 6 tit0

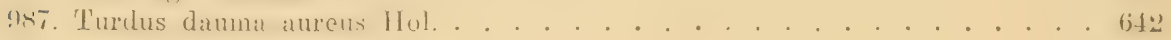

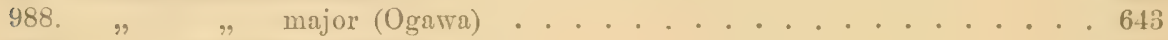

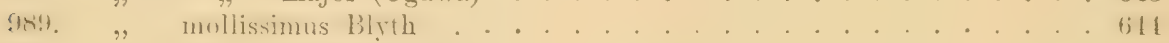

990. " sibiricus sibiricus Pall. . . . . . . . . . . . . 614

$991 . "$. davisoni (Hume) . . . . . . . . . . . 645

1)

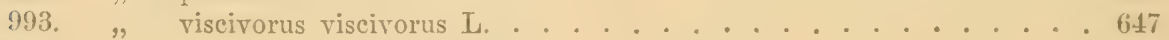

994. $" \quad$ deichleri Erl. . . . . . . . . . . . . 648

995. $"$ " bonapartei Cab. . . . . . . . . . . . 649

$996 .$, auritus Verr. . . . . . . . . . . . . 64t9

997. " philomelos philomelos Brehm (T. musicus auct., erroro!) . . . 650

998. " $"$ elarkei Hart . . . . . . . . . . . 651

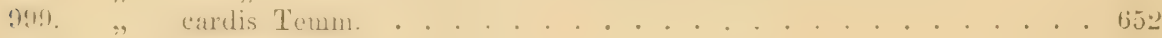

1000. $"$ musicus L. (T. iliacus anct.) . . . . . . . . 653

1001. " hortulorum Scl. . . . . . . . . . . . . 654

1002. " pallidus Gm. . . . . . . . . . . . . 655

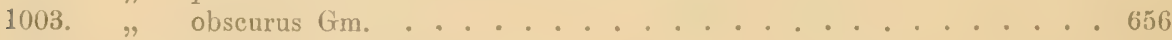

1004. $"$ chrysolaus Temm. . . . . . . . . . . . . 656

1005. $"$ celaenops celaenops Stejn. ............. . . 657

1006. $" \quad$ yakushimensis (Ogawa) ......... . 657

1007. " naumanni Temm. .................. 657

1008. " fuscatus Pall. . . . . . . . . . . . . . 658

1009. " ruficollis ruficollis Pall. . . . . . . . . . . . . . 659

1010. $" \#$ atrogularis Temm. ............660

1011. " castanea castanea (Gould) . . . . . . . . . . . 661

1012. " $"$ gouldi (Verr.) . . . . . . . . . . 662

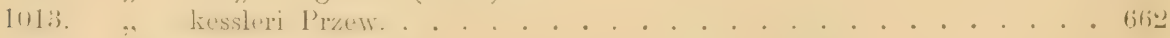

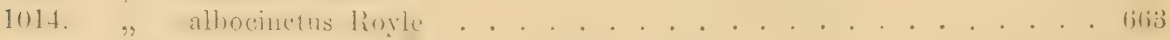
ich vor:

1) Präokkupiert durch I. bonvaloti (antea p.628). - Als neuen Namen schlage 
1015. Turdus torquatus torquatus $\mathrm{L}$.

Seite

1016.

orientalis (Seeb.)

663

1017.

alpestris (Brehm)

664

665

1018. " hispaniae Kleinschm. . . . . . . . . 667

1019. $"$ cabrerae Hart. ${ }^{1}$ ) . . . . . . . . . 667

1020 . a a . . . . . . . . 668

1021. " mauritanicus Hart. . . . . . . . . . 668

1022.,$\quad$ algira (Mad.) . . . . . . . 669

1023. . .. aterrima (Mad.) . . . . . . . . . . . 669

1024. ", syriaca Hemper. \& E'hr. . . . . . . . . . . 669

1025. . , intermedia (Richm.) ........... 670

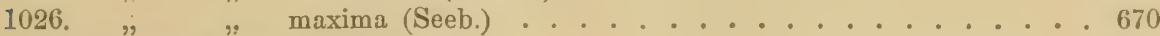

Gattung Monticola Boie . . . . . . . . . . . . 671

1027. Monticola saxatilis (L.) . . . . . . . . . . 671

1028., gularis (Swinh.) . . . . . . . . . 673

1029.,$\quad$ solitarius solitarius (L.) (M. cyanus auct.) . . . . . . . 674

1030. " $"$ transcaspicus Hart. . . . . . . . . 670

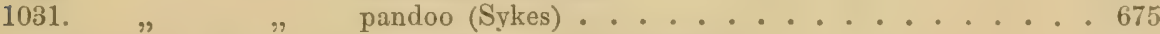

1032.,$"$ philippensis (P. L. S. Müll.) . . . . . . . 675

Gattung Myiophoneus Temm. . . . . . . . . . . . 676

1033. Myiophoneus temminckii temminckii Vig. . . . . . . . . . 676

1034. $", \quad$ turcestanicus Sar. . ........ 677

1035. $"$ caerulea (Scop.) . . . . . . . . . 677

Gattung Saxicola Bechst. . . . . . . . . . . 678

1036. Saxicola oenanthe oenanthe $(\mathrm{L}$.$) . . . . . . . . . 679$

" $\quad$ " argentea Lönnb. . . . . . . . . . 680

1037. " rostrata Hempr. \& Ehr. . . . . . . . . . 681

1038, " $"$ seebohmi Dixon .................. 682

1039. $"$ deserti deserti Temm. . . . . . . . . 683

10.10. .. $\quad$, atrogularis Blyth ${ }^{2}$ ) . . . . . . . . . . 684

1041. $"$ hispanica hispanica (L.) ................. 685

1042. $"$ " xanthomelaena Hempr. \& Ehr. . . . . . . . 687

1043. $" \quad$ gaddi Șar. \& Lond. . . . . . . . . . . 688

1044. $\%$ pleschanka pleschanka (Lepech.) . . . . . . . . 688

10Ł5. ". " cypriaca Hom. . . . . . . . . . . . 689

1046., melanoleuca melanoleuca (Güld.) . . . . . . . . 690

1047. $"$ finschii Heugl . . . . . . . . 690

10t8. $"$ isabellina Cretzschm. . . . . . . . . . . 691

1049. " xanthoprymna chrysopygia (De Til.) . . . . . . . . 693

1050. $" \quad$ xanthoprymna Hempr. \& Ehr. . . . . . . 693

1051.

1052. moesta Licht. . . . . . . . . . . 693

1053. " lugens lugens Licht. . . . . . . . . . . . 694

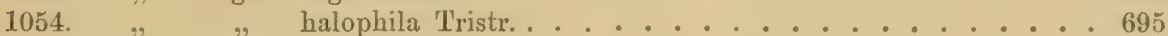

1055.

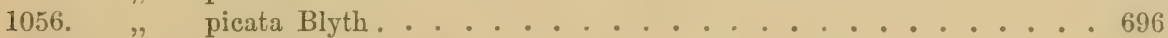

1057., opistholeuca Strickl. .................. 697 ('Tenerife).

1) Synonym: T. m. brachyptera Floericke, Aus der Heimat des Kanarienvogels

2) Wird S. deserti albifrons heißen müssen: Saxicola albifrons Brandt, Bull. Acad. Petersburg II, p. 139 (1844- " "Westsibirien").

E. Hartert, Die Vögel der paläarktischen Fauna. 
1058. Saxicola leucurus leucurus (Gm.) . . . . . . . . . . 697

1059. , , syenitica Heugl. . . . . . . . . . 698

1060. $"$ riggenbachi Hart. . . . . . . . . . 699

1061. " leucopyga $(\mathrm{Brehm})$. . . . . . . . . 699

1062., alboniger Hume.............. 700

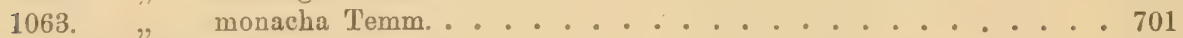

Gattung Pratincola Koch. .............. 701

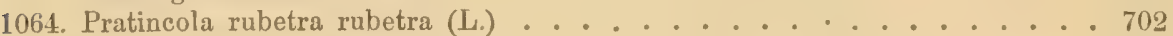

1065.

1066., noskae Tschusi ................... 703

1067.

1068. dacotiae Meade-Waldo . . . . . . . 704

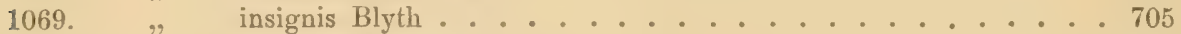

1070., torquata rubicola (L.) .................. 706

1071. $"$ " hibernans Hart. . . . . . . . . 707

1072. $, \quad, \quad \operatorname{maura}($ Pall.) .............. 707

1073., stejnegeri Parrot ........... 708

1074. $", \quad$ indica Blyth ............. 708

1075.,$\quad$ " przewalskii Pleske............. 709

1076. $"$ caprata rossorum Hart. . . . . . . . . 709

1077. $" \quad$ " bicolor (Sykes) .......... . 710

1078. " $\quad$ "eaprata (L.) . . . . . . . . . . 710

Gattung Oreicola Bp............... . . 710

1079. Oreicola ferrea ferrea (Gray) . . . . . . . . . . 711

1080., haringtoni Hart. . . . . . . . . . . 711

Gattung Tarsiger Hodgs. . . . . . . . . . . 712

1081. Tarsiger cyanurus (Pall.) . . . . . . . . . . . . 712

1082.,$\quad$ rufilatus (Hodgs.) . . . . . . . . 713

1083.,$\quad$ indica indica (Vieill.) . . . . . . . . . 713

1084. $"$ hyperythra (Blyth) ................ 714

1085. $"$ chrysaeus Hodgs. ............... 714

Gattung Chaimarrornis Hodgs. . . . . . . . . . . 715

1086. Chaimarrornis leucocephala (Vig.) . . . . . . . . . 715

1087. $"$ fuliginosa fuliginosa (Vig.) .......... 716

Gattung Phoenicurus Forst. . . . . . . . . . 717

1088. Phoenicurus phoenicurus phoenicurus (L.) . . . . . . . 718

1089. $", \quad$ algeriensis (Kleinschm.) . . . . . 719

1090.,$\quad$ mesoleuca (Hempr. \& Ehr.) . . . . . 720

1091.,$\quad$ ochruros gibraltariensis (Gm.) (tithys auct err!) . . . . 720

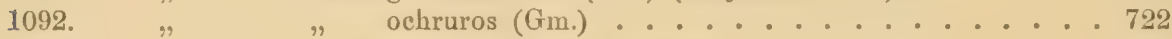

1093. $"$ semirufa (Hempr \& Ehr.) . . . . . . . 723

109t.,$"$ phoenicuroides (IIoore) . . . . . . 723

1095. " $"$ rufiventris (Vieill.) ......... 723

1096. $"$ hodgsoni (Hoore) ................. 724

1097.,$\quad$ aurorea aurorea (Pall.) ................. 725

1098. $", \quad$ filchneri (Parrot) ........... 725

1099.,$"$ leucoptera Blyth ........... 726

1100.,$\quad$ erythrogastra erythrogastra (Güld.) . . . . . . 726

1101. $"$ " grandis (Gould) ........ 726

1102. $"$ erythronota (Eversm.) .............. 727

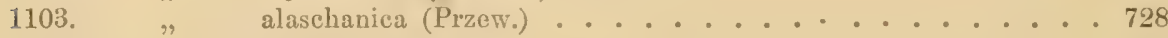

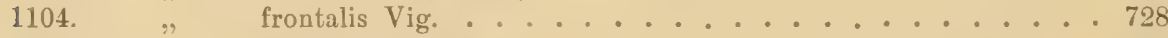

1105. " schisticeps Gray ................ 729

1106. $\quad$ coeruleocephala Vig. ........... 730 
Gattung Diplootocus Hart . Seite

1107. Diplootocus mousieri (O............ 731

Gattung Luscinia Forst.

1108. Luscinia megarhynchos megarhynchos Brehm (L. Luscinia auct. errore!) • . 733

1109.

1110.

1111.

1112.

1113.

1114.

1115.

1116.

1117.

1118.

1119.

1120.

1121.

1122.

1123.

1124.

1125.

1126.

1127.

1128.

1129.

1130.

1131.

1132.

1133.

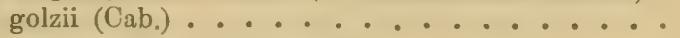

africana (Fisch. \& Rchw.)
735

735

luscinia $\left(\mathrm{L}_{\text {. }}\right)(\mathrm{L}$. philomela auct.) . . . . . . . 736

calliope (Pall.) . . . . . . . . . 738

pectoralis pectoralis (Gould) . . . . . . . . . 739

ballioni (Sew.) . . . . . . . 739

confusa Hart. . . . . . . . . . 740

tschebaiewi (Przew.) . . . . . . . . 740

davidi (Oust.) . . . . . . . . . . . 740

obscura (Beres. \& Bianchi) . . . . . . . . . 741

ruficeps (Hart.) . . . . . . . . . . 741

akahige ('lemm.) . . . . . . . . . 742

komadori komadori (Temm.) . . . . . . . . . 742

namiyei (Stejn.) ............ 743

sibilans (Swinh.) . . . . . . . . . . 743

cyane (Pall.) . . . . . . . . . . . 744

svecica gaetkei (Kleinschm.) . . . . . . . . 745

svecica (L.) . . . . . . . . . . . 745

pallidogularis (Sar.) . . . . . . . . 747

discessa (Mad.) . . . . . . . . . . 747

robusta (But.) ........... . . 748

cyanecula (Wolf)............. . . 748

volgae (Kleinschm.) . . . . . . . . . . . . . . . . 749

magna (Sar. \& Loud.) . . . . . . . . . 750

abbotti (Richm.) ........... 750

Gattung Erithacus Uuv. .............. . . 750

1134. Erithacus rubecula rubecula (L.) . . . . . . . . . . . 750

1135.,$\quad$, melophilus Hart. . . . . . . . . 752

1136. $"$ sardus Kleinschm. ............. 753

1137. $"$ witherbyi Hart. . . . . . . . . 753

1138. " $"$ superbus Koenig............. . . . 754

1139. .. $\quad$,. hyrcanus Blanf. .............. 754

1140.,$"$ caucasicus But. ............ 755

Gattung Irania De Fil. . . . . . . . . . . . . 755

1141. Irania gutturalis (Guérin) . . . . . . . . . . . 755

Gattung Hodgsonius Bp. ............. 756

1142. Hodgsonius phoenicuroides (Gray) . . . . . . . . . . 756

Gattung Grandala Hodgs. . . . . . . . . . . . . . . . 757

1143. Grandala coelicolor Hodgs. . . . . . . . . . . . . 757

Gattung Enicurus T'emm. . . . . . . . . . . 758

1144. Enicurus maculatus maculatus Vig. . . . . . . . . . . . . 759

1145. $"$ guttatus Gould ............ . 759

1146. $"$ sinensis Gould ............... . 759

1147. $"$ leschenaulti indicus Hart. . . . . . . . . 760

Gattung Microcichla Sharpe . . . . . . . . . . 760

1148. Microcichla scouleri (Vig.) . . . . . . . . . . . . 760

Familie ACCENTORIDAE . . . . . . . . . . 761

1149. Prunella collaris collaris (Scop.) . . . . . . . . . . . 762

1150. " $"$ subalpinus (Brehm) ........... 763

1151. " " $"$ caucasicus (T'sch.) .................. . . . . .

1152. ", rufilatus (Sew.) .............. 764 
1153. Prunella collaris tibetanus (Bianchi) . . . . . . . . . 765

1154.

1155 .

1156 .

1157 .

1158 .

1159

1160.

1161.

1162.

1163.

1164.

1165 .

1166.

1167.

1168 .

1169 .

1170 .

1171.

erythropygius (Swinh.) .

765

" nipalensis (Blyth) ............ 765

, himalayanus (Blyth) ........... 766

rubeculoides (Moore) . . . . . . . . 767

strophiatus strophiatus (Blyth) . . . . . . . . 767

multistriatus (David) . . . . . . . . . . . 768

jerdoni (Brooks) . . . . . . . . 768

montanella (Pall.) . . . . . . . . . . 768

fulvescens fulvescens (Sew.) . . . . . . . . . 769

dresseri Hart. . . . . . . . . . . . . . 770

dahuricus (Tacz.) ........... 770

ocularis (Radde)........... 770

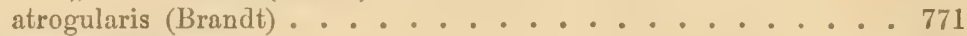

koslowi (Przew.) . . . . . . . . . . 771

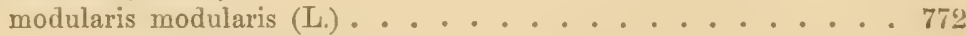

" occidentalis (Hart.) . . . . . . . 773

" orientalis (Sharpe)............ 774

blanfordi (Sar.) . . . . . . . 774

rubidus (Temm. \& Schleg.) ........... 774

immaculatus (Hodgs.) . . . . . . . . . 775

Familie TROGLODYTIDAE . . . . . . . . . . . 77 ,

Gattung Troglodytes Vieill. . . . . . . . . . . . 776

(Iroglodytes troglodytes taivanus Hart.) . . . . . . . . . . . 776

1172. Troglodytes troglodytes islandicus Hart. . . . . . . . . 776

1173.

zetlandicus Hart. . . . . . . . . 777

1174.

borealis Fisch. . . . . . . . . 777

1175 .

subsp.. . . . . . . . . . . . . 777

1176.

hirtensis Seeb. . . . . . . . 778

1177.

troglodytes (L.).......... . . 778

1178 .

kabylorum Hart. . . . . . . . . . 780

1179 .

eypriotes (Bate) . . . . . . . . 780

1180.

hyrcanus Sar. \& Loudon . . . . . . . 780

1181 .

1182.

pallidus Hume . . . . . . . . . . 781

zagrossiensis Sar. \& Loudon . . . . . . 781

nipalensis Blyth......... . 781

tibetana (Walton) .......... 782

neglectus Brooks ......... 782

dauricus Dyb. \& 'l'acz. . . . . . . . 782

tarbagataica (Suschk.) . . . . . . 782

peninsulae (Clark). . . . . . . . 783

idius (Richm.) .......... 783

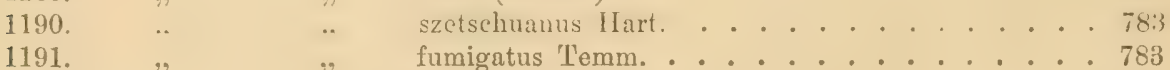

$1192 . \quad "$ " ogawae Hart. . . . . . . . . . 784

1193. $"$ kurilensis Stejn. . . . . . . . . 784

1194.,$\quad$ " pallescens Ridgw.) ......... . . . 784

Gattung Spelaeornis Dav. \& Oust. . . . . . . . . . 785

1195. Spelaeornis troglodytoides (Verr.) . . . . . . . . 785

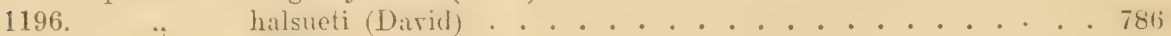

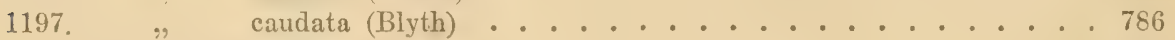

Gattung Pnoepyga Hodgs. . . . . . . . . . . . 786

1198. Pnoepyga squamata (Gould) . . . . . . . . . . 787

1199. :, pusilla pusilla Hodgs. ............. 787 
Gattung Cinclus .................. 788

1200. Cinclus cinclus cinclus $(\mathrm{L}.) \ldots \ldots \ldots$. . . . . . 788

1201. , , britannicus 'Tschusi ........... 789

1202. $"$, hibernicus Hart. ............ 790

1203. ., ., pyrenaicus Dress. . . . . . . . . . . . 790

1204. $\Rightarrow \quad$ subsp. . . . . . . . . . 790

1205. . ., sapsworthi Arrigoni . . . . . . . . . . . . . 791

1206.,$"$ aquaticus Bechst. ............ 791

1207. , , meridionalis Brehm ............ 793

1208. ", minor Tristr. . . . . . . . . 793

1209. . caucasicus Mlad................. 794

1210. . . rufiventris Tristr. ................ 794

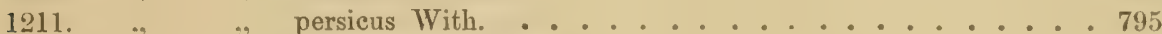

1212., cashmeriensis Gould .......... 795

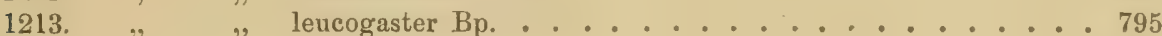

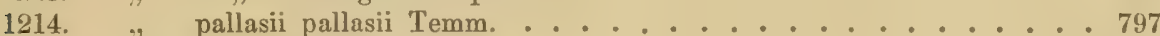

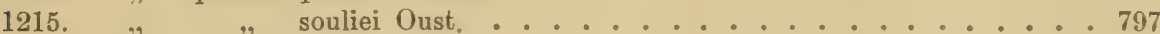

1216.

Gattung Tesia Hodgs. . . . . . . . . . . 798

1217. Tesia castaneocoronata (Burton) . . . . . . . . 798

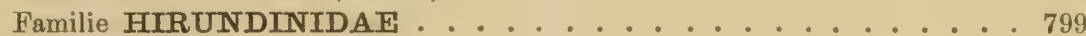

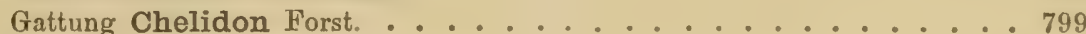

1218. Chelidon rustica rustica $\left(\mathrm{L}_{0}\right) \ldots \ldots \ldots$............. 800

1219.

1220. " savignii (Steph.) .......... 802

1221. $"$ gutturalis Scop.) ........... 803

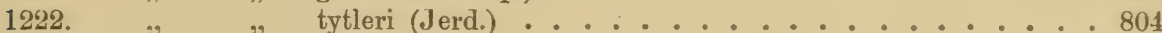

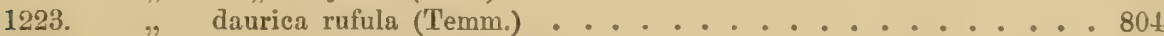

1224., nipalensis (Hodgs.) . . . . . . . 805

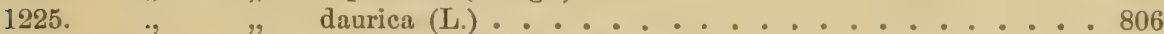

1226. $" \quad$ striolata (Temm. \& Schleg.) . . . . . . . 806

1227. $", \quad$ erythropygia (Syk.) . . . . . . . . 806

Gattung Hirundo I. . . . . . . . . . . . 807

1228. Hirundo urbica urbica $\mathrm{L}$. . . . . . . . . . . 807

1229. $"$, meridionalis Hart. . . . . . . . . . 809

1230. $"$ " whiteleyi (Swinh.) ............. 809

1231. $" \quad$ cashmeriensis (Gould) ........... 809

., nigrimentalis Hart. ........... 810

Gattung Riparia Forst. .............. 810

1233. Riparia riparia riparia $\left(\mathrm{L}_{0}\right)$. .............. 811

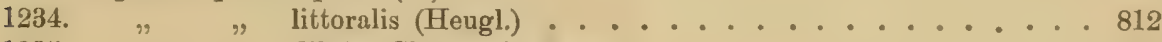

1235. $"$ diluta (Sharpe \& Wyatt) . . . . . . . . . 813

1236. $"$ " ijimae (Lönnb.) . . . . . . . . . . 813

1237. $"$ paludicola minor (Cab.) ............. 813

1238. $" \quad$ mauritanica (Meade-Waldo) . . . . . . 814

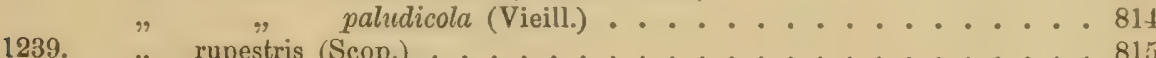

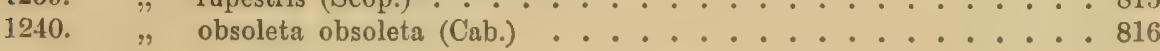





\title{
Die Vögel
}

\section{der paläarktischen Fauna.}

\author{
Systematische Übersicht \\ der
}

in Europa, Nord-Asien und der Mittelmeerregion vorkommenden Vögel.

Von

Ernst Hartert.

-Heft I.

Mit 22 Abbildungen.

Berlin.

Verlag von R. Friedländer und Sohn. Ausgegeben im November 1903. 
Alle Rechte rorbehalten. 


\title{
Die Vögel
}

\section{der paläarktischen Fauna.}

\author{
Systematische Übersicht \\ der
}

in Europa, Nord-Asicu und der Mittelmeerregion vorkommenden Vögel.

Von

Ernst Hartert.

Heft I.

Mit 2: Ahhildungen.

\section{Berlin.}

Verlag von R. Friedländer und Sohn.

Ausgegeben im November 1903. 
„Der Naturforscher soll nie die Wahrheit der Klarheit zum Opfor bringen, dem was heute unwahr ist, bleibt immer unwahr, was aber hente nicht klar ist, kann spät ('r klar werden." 


\section{Ordnung PASSERES.}

Gaumenknochen aegithognath. Halswirbel nicht mohr als 15. Ohne Basipterygoidfortsitze. Von Schenkelmuskeln fehlt der Ambrims. Zehenstellung immer normal, d. h. die Hinterzehe (Hallux) ist nach hinten, die übrigen Zehen sind nach vorn gerichtet. Die tiefon Zehenbenger frei, der flexor

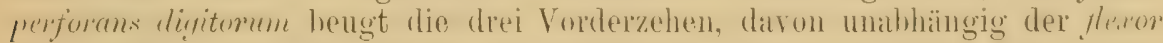

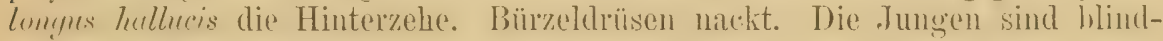
geborene Nesthocker:

Die Passeres oder Passerifommes bilden die weitaus größte Ordnumg: der Vögel. Sie umfassen die Oscines oder eigentlichen Singvögel und die

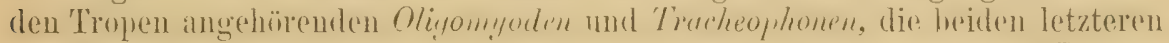
die Clamatores Cabanis', der aber auch die meisten unsrer heutigen Coraciae dazu rechnete.

Die Linteilung der Passeres ist äuberst schwierig und noch keineswegs zufriedenstellend. In der Anordmung derselben, wie in der ganzen ststematiseden Reihenfolge in diesem liuche, folgen wir mit wenigen unwesentlichen Ausnahmen Sharpe's Klassifikation, wie er sie in seiner Hand-list anwendet. Fis sind lediglich Arheits- und Raumverhailtnisse (nicht wissenschaftliche Gründe!), die dazu bestimmten, mit den höheren Formen zu beginnen.

\section{Familie CORVIDAE.}

Die größten unsrer Pusseres. Flügel mit 10 Handschwingen, von denen die erste verkürzt ist, immer aber länger als die Handdecken, meist etwa halb so lang wie clie zweite. Lauf hinten mit einer fortlaufenden Schiene bedeckit. Geschlechter nicht wesentiich verschieden. Die.Jungen den Alten

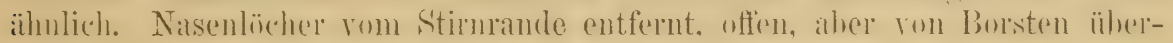
deckt. Nur eine meist im Herbste stattfindende Mauser.

\section{Gattung CORVUS L. (1758).}

Urmfaßt die Raben, Krähen und Saatkrähen. Gefieder schwarz oder grau (his milchweiblich) und sehwill\%. Fiste Sthwinge mormal, nur wenig im der Innenfihne verjü̈ngt, mindestens hall, so lang wie die zweite. Sichwanz ahgerundet oder wenig gestuft, kïrzer als der Flügel. Nester frei auf Bämmen oder an Felsen.

E. Hartert, Die Vögel der paläarktischen Region. 
Fast kosmopolitisch, nur in Südamerika, Neuseeland und den meisten Siidsee-Inseln (aber nicht auf den Sandwichs-Inseln) fehlend.

In unserm Gebiete 6 Arten mit vielen Unterarten.

\section{Übersicht der paläarktischen Arten.}

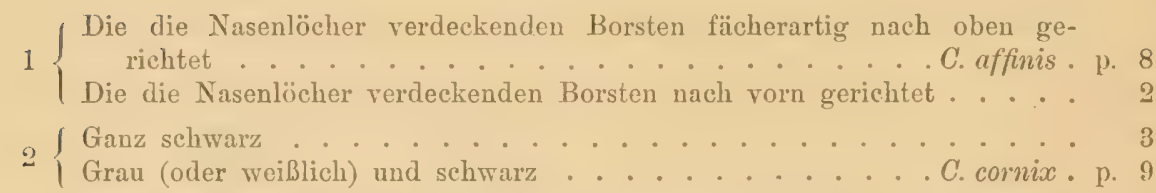

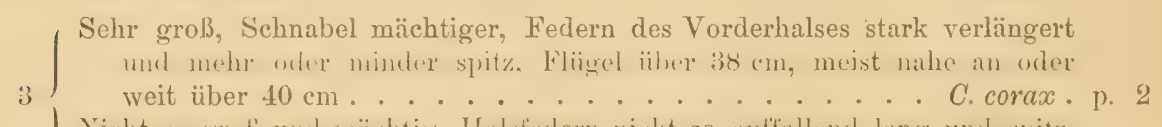

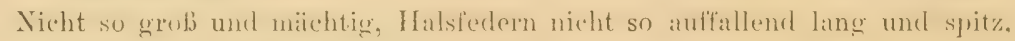
Flïgel unter $38 \mathrm{~cm}$, meist viel kürzer . . . . . . . . . . . 4 4

Schnabel gestreckt, spitzig, Halsfedern weitstrahlig, zerschlissen, Gefieder

4 stark glïnzend . . . . . C. . . . . . . . . . . 13

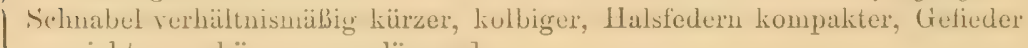
nicht so schön purpurglänzend . . . . . . . . . . . 5

Schnabel länger als der Kopf, von der Stirn an nach der Mitte der Firste zn etwas ansteigend; im allgemeinen mehr grünlich schimmernd

C. macrorhynchos . p. 12

5 Schnabel nicht länger als der Kopf, die ganze Firste absteigend, oder doch nirgend ansteigend; im allgemeinen etwas mehr bläulich schimmernd

C. corone. p. 11

\section{-1. Corvus corax corax L. ${ }^{1}$ ) (Fig. 1.)}

Der europäische Kolkrabe.

Corvus Corax Linn., Syst. Nat. Ed. X, p. 105 (1758- „Hab. in Europa“. Lirstes Zitat: Fauna Suecica 69, typ. Lok. daher Schweden).

Corvus maximus Scopoli, Annus I Hist. Nat., p. 34 (1769- Linué's C. corax.)

Corvus Clevicus Sparrm., Mus. Carlson. Taf.2 (1786- Aberration mit weißem Kinn). Corcus sylcestris Bretm, Haudb. Jaturg. Vüg. Deutsch., p. 163 (1831 - Tyjus Renthendorf). Corvus peregrinus Brehm, 1. c. p. $16+$ (1831- Typus Renthendorf).

1) Das Studium der Kolkrabenformen ist ein sehr schwieriges, weil es viele lokale Formen gibt und das sonst so bequeme Hilfsmittel der Farbenunterschiede fast gänzlich fehlt, außerdem ist es schwer, aus manchen Gegenden Serien zu erhalten, und die Formen sind tüchtige Flieger, die zur rauhen Jahreszeit oft ihre Wohnsitze wechseln. Die sibirischen Formen sind mir fast unbekannt geblieben, ich führe daher ihre Unterschiede nach 'Taczanowski an, es sei jedoch bemerkt, dass die von diesem Autor zur Untersuchung benutzten Schwingenverhältnisse auch bei einer und derselben Form stark variieren, und daher die sibirischen Formen noch nicht feststehen. Überhaupt sei darauf aufmerksam gemacht, daß die Kenntnis der Kabenformen mit rorliegender Übersicht jedenfalls noch nicht abgeschlossen ist. Eine äußerst kleine Rabenform (C.edithac) bewohnt Somaliland; in Amerika wohnen mehrere wohl unterscheidbare Formen: C. c. sinuatus Wagler (Isis 1829 p. 748) aus den westlichen Vereinigten Starten, C. c. principalis Ridgw. (Man. N. A. B. p.361, 1887) N.W.-Amerika, Kanada usw., C.c. cryptoleucus Couch (Proc. Ac. Philad. 1854, p. 66) T'exas bis N.-Mexiko, eine wohl unterscheidbare, anscheinend noch nicht benannte Form rou Alaska, C. c. clarionensis Rothsch. \& Hart. (Nor. Zool. 1902) von der Clarion-Insel im Stillen Ozean. 
Corvus littoralis Brehm, 1. e. p. 164 (1831- Typus Rügen).

Corvus montanus Brehm, 1. c. p. 165 (1831- 'T'ypus T'irol).

Corax nobilis, pityocorax, planiceps, minor A. Brehm, Verz. Samml. p.3 (Nom. nuda!) $\left.{ }^{3}\right)$

Engl.: Karen. Franz.: Corbeau. Schwed.: Korp. Ital.: Corvo imjeriale.

Ad. Großer, hoher Schnabel, sehr starke Füße, Kehlfedern verlängert

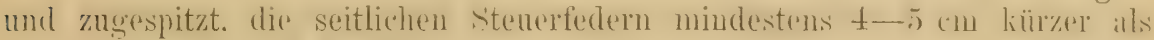

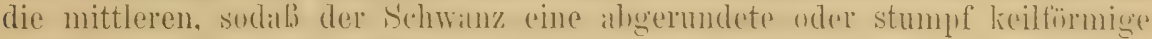
Gestalt hat. Glänzend schwarz, stahlblau bis bräunlich-purpurn schimmernd, am Halse manchmal etras ins bräunliche zichend. Das Kleingefieder an der Wurzel aschgrau, dam mattschwarz, darauf metallisch glïnzend, auf dem Oberrücken noch wieder mit bräunlichem Findsamm. Iris dunkelbraun, Schnabel und FüBe tiefschwarz. Grölste Flügellänge $43-45 \mathrm{~cm}$. Schrvanz $24-25 \mathrm{~cm}$, seitliche Steuerfedern etwa

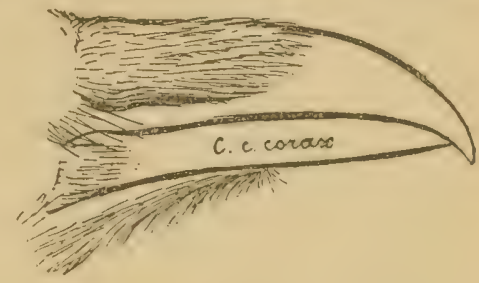

Figur 1. $20-21 \mathrm{~cm}$. Schnabel $70-84 \mathrm{~mm}$, grölite Hölı etra $31 \mathrm{~mm}$, Lauf $70-7$ ร mm. o wie 07 , aber im allgemeinen etwas kleiner.

Juv. Mattschwarz, ohno viel Glanz, die Kehlfedern kuiz und abgerundet.

Nord- und Mittel-Europa — Skandinavien, Rußland, Polen, W.-Sibirien, Inentsebland, die hritisehen Inseln his zu den Hebrelen. Frankreich his zu

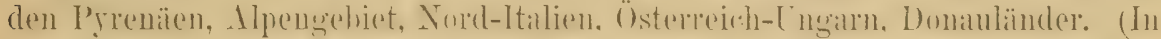
Griechenland lehen mehrere Rishenformen, deren studium noch aussteht.)

Schon auf den Färöer vertritt don typischen corax eine andre Unterart, auch der grönländische woicht etwas al). In den I)onauländeru, im Ballkan

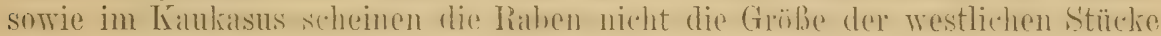
zu creichen, in Amerik. Nort-Afrika und in Symien sïdlich der l'yrenten kommt der typische Kabe sicher nicht mehr vor. Außer den bisher unterschiedenen Formen dürften sich noch mehr unterscheiden lassen. wenn genügendes Studienmaterial sorgfältig geprüft wiıd.

Bewohner der felsigen Meeresküsten, höheren Gebirge und ausgedehnten Wälder seines Verbreitungsgebietes. Stand- und Strichvogel. Scheu und flüchtig. Omnivor: Fische an den Meereskïsten, Aas, lebendige Tiere, rom jungen Vogel, Rel, Schaf, Ziege und Hasen bis zum Wurm, Schneeke und Insekt, Vogeleier, Pflanzen, Korn. In den Kuiturländern meist selten geworden, daher trotz gelegentlicher Räubereien an Wild und Vögeln dort dringend des Schutzes bedürftig. Stimme ein tiefes, sonores krach, krach; in der Paarungszeit hört man auch ein weitklingendes klong, klong und ein krächzendes Geschwätz.

Nester je nach des Ortes Gelegenheit an F'elsen oder auf hohen Bäumen. Eier rom März bis April, wanchmal in mildem Klima (West-Europa) schon Ende Februar, 3-6 (meist 4-5) an der Zahl. Genau wie große Kräheneier, hellgrïn oder bläulichgrïn mit grünlichen Schalentlecken und bräunlichen Flecken und Punkten, zuveilen auch Strichzeichnungen, $47 \times 31.5,49 \times 32.8$, selten bis zu $53 \times 34.5$, seltener nur $43 \times 33$, oder gar $43 \times 29 \mathrm{~mm}$.

1) Die Drucklegung dieser zahllosen Namen ist bedauerlich. Sie ist entstanden durch den Mangel an Finst, mit dem man Prioritäts- und Nomenklaturfragen zu behandeln pflegte. Ilan könnte vielleicht das Verzeichnis als Verkaufsliste ignorieren, dies würde aber im Hinblick anf Lichtenstein's Dublettenverzeichnis 1 . a. m. nicht konsequent sein, außerdem hat Dresser die Namen bereits in seinem großen Werke zitiert, sie sind also nicht mehr totzuschweigen. 


\section{Corvus corax varius Brïn.}

Der Färöer-Rabe.

Corvus varius Brimnich, Orn. Bor., p. 8 (1764- „E feroensibuis insulis", Beschreibung der weiß und schwarzen Aberration).

Corvus leucophaens Vieillot, Nouv. Dict. d'Hist. Nat. VIII, p. 27 (1817).

Corvus leucomelas Wagler, Syst. Av̀., Genus Corrus, sp. 4 (1827).

Corvus ferroensis Schlegel, Bijdr. tot de Dierk., Genre Corvus, p. 6 (1858).

Corvus corax varius Hartert \& Kleinschm., Nor. Zool. 1901, 1. 44, Abb.

Dem C. c. corux äußerst ähulich, größte Flügellänge der bisher

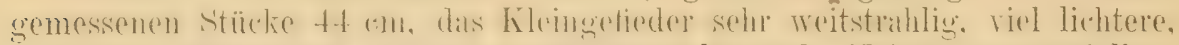

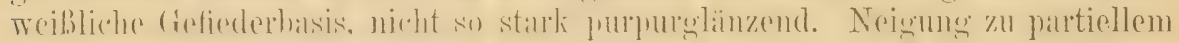

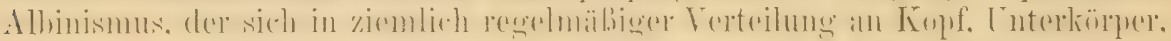

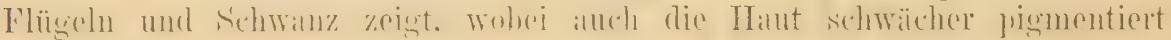
erscheint.

Färöer. - Auf diesen Inseln kommt natürlich nur diese Form vor.

Nistet an den Felswänden und lebt von ans Ufer geworfenen Fischen, jungen Seevögeln, Eiern und Abfällen aller Art. Standvogel.

\section{Corvus corax tibetanus Hodgs.}

Corvus Tibetanus Hodgson, Ann. \& Mag. Nat. Hist. (2), III, p. 203 (18t9 "Libet": jedenfalls nördlich von Sikkim).

Ausgezeichnet durch seine bedentende Größe, besonders riesige Flïgellänge, die bis $497 \mathrm{~mm}$ reicht! Großer; besonders in der Mitte sehr hoch gewölbter Schnabel, verhältnismäßig kleine Füße.

Lebt im Himalaya in Höhen von ïber 13000 engl. Fuß.

\section{Corvus corax sibiricus Thez.}

Corvus corax sibiricus 'Taczanowski, Faune orn. Sib. Orient. I, p. 526 (1891- Ost-Sibirien).

Flügellänge $447 \mathrm{~mm}$, erste Schwinge kïlzer als siebente und $86 \mathrm{~mm}$ kỉrzer als die zweite, $1 \mathrm{~cm}$ vor der Spitze $9 \mathrm{~mm}$ breit, äußere Stenerfedern 56 kürzer als die (längste) mittelste.

Ost-Sibirien bis zum Ussuriland, genaue Verbreitung nicht bekannt. (Nach 'T'aczanowski.)

\section{Corvus corax ussurianus 'lacz.}

Corvus corax ussmianus Thez⿰nоwski, Fame oru. Sib. Orient. I, p. 527 (1891- russ. Mandsehurei).

Flügellänge $445 \mathrm{~mm}$, erste Schwinge länger als die siebente und $86-90 \mathrm{~mm}$ kürzer als die zweite. $1 \mathrm{~cm} \mathrm{vor} \mathrm{der} \mathrm{Spitze} 10 \mathrm{~mm}$ breit, äußere Steuerfedern $70 \mathrm{~mm}$ kïrzer als die (lïngste) mittelste.

Russische Mandschurei, besonders im Süden. (Nach Taczanowski. Ich

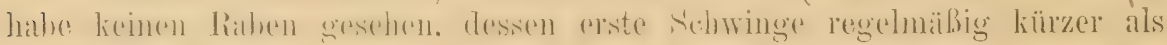
die sicbente ist.) 


\section{Corvus corax kamtschaticus Dyb.}

Corvus corax kantschaticus Dybowski, Bull. Soc. Kool. France 1883, p. 362, 863 (Kamtschatka).

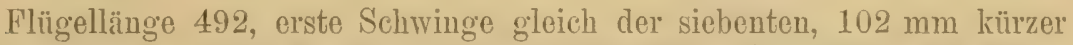

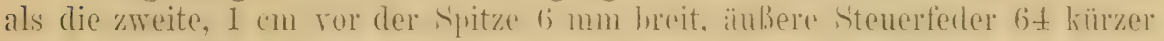
als die mittelste.

Kamtschatka, gemein. (Nach Dyborsski und 'Taczanowski.)

\section{Corvus corax behringianus Dyb.}

Corvus corax behringianus Dyborski, Bull. Soe. Zool. France 1883, p. 363 (Behrings-Insel).

Flügellänge $44-46$, erste Sibwinge kïrzer als die siebente und 95 mm

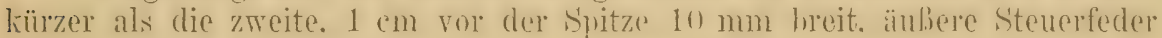
65 kürzer als die mittelste.

Kommandem-Inseln (Behrings- und Modni-Insel). (Nalch 'Tirbanomshi.)

Die Unterschiede dieser Formen bedürfen der Bestätigung. Auf den Kurilen wohnt und brïtet ein Rabe, der zu lamtschaticus gehören sollte, ein

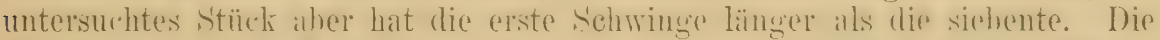

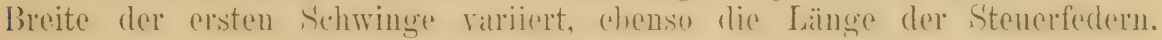
Es liegen mix 2 Raben von Jesso, Nord-Japan, vor, bei denen auch die erste Sidnwinge länere als die siohente ist. Es sind gemaltige Raben, hede

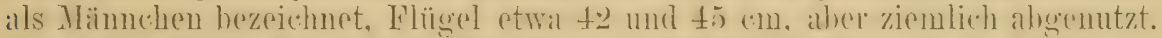

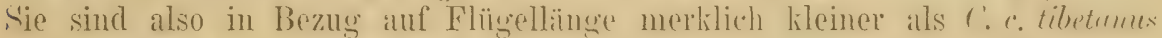
und seheinen am meisten dem kinrilischen Raben zu gheichen. (Möghicherweise wrerden C. c. sibiricus, ussuriamus, lamtschaticus, behringiams und die Form von den Kurilen und Yesso zı einer und derselben Subspezies zu zählen

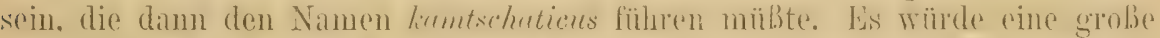

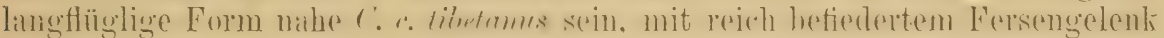
und kurzem Lauf, langem Flïgel, der meist den von C. c. corax übertrifft, aber hinter dem von C. c. tibetanus zuriickbleibt.)

\section{Corvus corax hispanus Hart. \& Kleinschm. (Fig. 2.)}

Der spanische Rabe.

Corvus corax hispanus Hartert \& Kleinschm., Nor. Zool. 1901, 1). 45 (Spanien, Typus Aguilas bei Murcia).

Zeichnet sich durch großen, hohen, an der Schneide stark gebogenen Schnabel, kurzes, engstrahliges Gefieder, das am Fersengelenke besonders auffüllt, und geringe Allgemeingröße, besonders kurzen Flügel, aus. Naximum der Flügellänge nur $43 \mathrm{~cm}$. Diese Form steht zwischen $C$. corax corax und $C$. c. tingitanus, unterscheidet sich aber von beiden durch den im Verhältnis zu seiner geringen Größe sehr kräftigen. hohen Schnahel. der hei C. "orme gestreckter, bei C. c. tingitumus kiirzer ist.

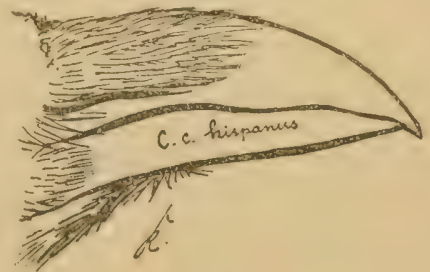

Figur 2.

Spanien. 


\section{Corvus corax sardus Kleinschm.}

Corvus sardus Kileinschmilt,. Orn. Monatsber. 1903, p. 92 (Sardinien).

Steht zwischen Corvus corax corax und $C$. c, tingitumes und ähnelt anch C. c. hispemus auBerordentlich. Unterscheidet sich von C. c. corax durch

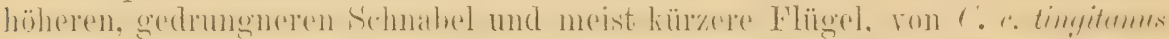

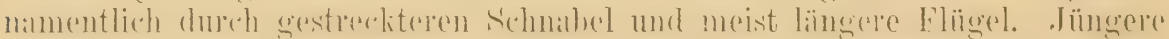
Vögel und Weibchen können ohne gutes Vergleichsmaterial leicht mit C.c. tingitums verwechselt werden, und die meisten Angaben vom Vorkommen letzterer Form auf Sardinien usw. diurften sich auf $C$. c. surclus beziehen. obwohl ein gelegentliches Verfliegen ron C'. c. tingitanus auch nicht unwahrscheinlich ist. Im allgemeinen ïhnelt $C$. c.sardus dem C.c. hispanus am meisten, hat aber längere Flïgel. Der Schnabel ist auch meist gestreckter, einzelne Stücke aber haben Schnäbel, die denen vou manchen C. c. hispanus gleichen.

Sardinien. (Wahrseheinlich auch noch andre mediterrane Inseln.)

10. Corvus corax canariensis Hart. \& Kleinschm.

Der canarische Rabe.

Corvus corax cenariensis Hartert \& Kleinschm., Nor. Zool. 1901, p. 45 (Canarische Inseln, 'Typus Palma). ${ }^{1}$ )

Schnabel von der Form des Schnabels von C. co corax, aber kileiner, der ganze Vogel viel kleiner. Flügel 390--415, Schwanz $240-250 \mathrm{~mm}$. Unterscheidet sich von C. $\therefore$ tingitanus, womit er von vielen Autoren verwechselt wurde, durch viel schlankeren, gestreckteren, weniger hohen Schmabel (Schnabelhöhe bei 8 gemessenen Exemplaren nicht ïber $27 \mathrm{~mm}$ ), durch viel

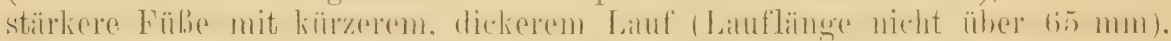

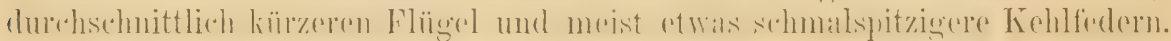

Bewohnt die westlichen Canarischen Inseln — vermutlich anch die östliche Gruppe (Fuertarentura und Lanzarote), aber welcher Form die dortigen Raben angebören ist noch nicht ausgemacht.

Unterseheidet sich vom europäischen Raben wie die meisten siidlichen formen durch größere G'eselligkeit und mindere Scheuheit, obwohl er auch noch vorsichtig genug ist. Außer dem charakteristischen Rabenlockruf hört man oft ein klangvolles „kloang, kloang". Nistet an Felsen, angebliclt auch auf Bäumen. Wier typische Rabeneier, $47 \times 30,48 \times 32,45 \times 31,54 \times 33,48 \times 33 \mathrm{~mm}$.

\section{Corvus corax tingitanus Irby: (Fig. 3.)}

Nordafrikanischer liabe.

Corvus tingitanus Irby, Ibis 1874, p. 264 ('l'anger, Marokko).

Der sehr kurze, aber hohe, gekrïmmte Schnabel ist für diese 1 rorm

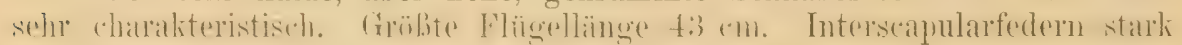

1) Vielleicht müßte für diese Form der Name leptonyx (Corvus leptonyx Peale, U. S. Expl. Exp., p. 105, 1818) angenommen werden. Sie wurde von Madeira beschrieben, später von ('assin für umbrinus erklärt. Da späterhin Raben nicht auf Madeira gefunden wurden, nnd sich ebensowohl tingitanus wie canariensis oder hispanus nach Madeira rerflogen haben konnten, war der Name höchstens nach Untersuchung des 'lypus zu deuten. Nenerdings sind aber, besonders auf den Desertas, nach Schmitz Raben öfters beobachtet, die jedoch alle nur gelegentliehe Gäste zu sein scheinen. Es muß also auf Material zur Lösung der Frage gewartet worden. 
abgerundet. Gefieder stark glänzend, der hei allen liaben mattere Hinterhals

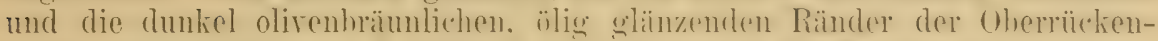

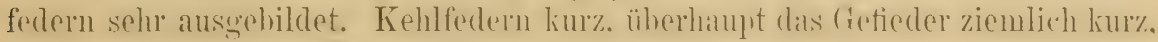
die Ferse ziemlich weit nackt lassend. Schneiden des Oberschnabels oft merklich hervortretend, was man aber auch bei andern Raben findet. Schnabelhöhe bis $28 \mathrm{~mm}$ bei einer Länge von nu $60-$ $64 \mathrm{~mm}$.

Atlasländer: In T'unis, sowohl in den Gebiro'szïgen im Norden des Landes, als anch in den Gebirgen südlich der Atlaskette häufiger Brutvogel" (Erlanger), in Algier weitschichtig verbreitet, sogar bis in die Wüste hinein (Koenig),

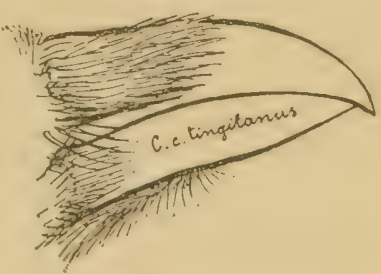

Figur 3. in Marokiko von Tanger his ('asihlancat und Mogador. Bei Mazagan und iiberall in den ebenen Umgebungen ungemein häufig:

Vögel von Tunis bis Marokko sind die gleichen. C. c. tingitamus ist hesser zu unterscheiden als manche der andern Rallenformen. aller das Studim der mediteramen Formen zeigt, dab es mmöglich ist, ihn artlich zu tremnen.

Ein echter Rabe in Flug, Bewegungen und Wesen, klug und scheu, omniror und räuberisch. Vom europäischen Kolkraben durch mehr geselliges Wesen unterschieden, wie alle südlicheren Rabenformen.

Nistet je nach des Ortes Gelegenheit auf Felsen und Bäumen. Erlanger fand die Horste in Tunis nur an Felswänden, Koenig bei Batna in Algier auch auf Bäumen. Ich fand sie am Kap Blanco in MIarokko an einer Felswand, während am Oum Rbiah bei Mazagan fast jede Dattelpalme einen Horst trug. Von mir in Marokko Mitte April gesammelte Eier messen von $54 \times 35.6,50 \times 34.6,53.1<33,50<35.3$ (das größte Gelege), bis $46.9 \times 32,44 \times 32.5,45 \times 32.1,45.1<32.1,45.1<32 \mathrm{~mm}$ (das kleinste Gelege). Die Gelege bestehen aus $1-5$ Eiern. Letztere variieren wie die von $C . c$. $\operatorname{corax}$ - hellbläulichgrỉn mit nur schmalen, hellbräunlichen Linien und Kritzcln, bräunlichgrün mit fast das ganze Ei bedeckenden braunen Flecken usw.

\section{Corvus corax laurencei Hume.}

Corvus Laurencei Hume, Lahore to Yarkand, p. 335 (1873-. Punjab).

Steht gervissermaßen zwischen $C_{\text {. c. corax, C.c.tibetanus und } C . c . u m b r i n u s}$ und ist bisweilen kaum ron diesen Formen zu unterseheiden. In frischen Herbstgefieder ist el schwarz und sieht dann C.c. corax so ähulich, daß man ihn manchmal nicht sicher unterscheiden kann: "o ähnelt dimn auch C. c. tibetanus sehr, ist aber kleiner und hat viel kürzere, aber spitzere verlïngerte Kehlfedern. In der Brutzeit (vor der Mauser) rerhleichen die Halsfedern oder rrerden viehnehr hraun; damn ähneln diese Tügel C. c. mulrims his auf die hedeutentere Gröbe aufallend. Die GröBe ändert rielfach und es ist möglich, dab noch mehrere Formen alstreunbar sind. wem bedeutenderes Ilaterial untersucht wird. Flügellänge t20 (Indien), $410,425, \pm 40, \pm 50$ (Kandahar), 147 ((quetta), 440 (Jerusalem), Maximum also his $450 \mathrm{~mm}$.

In N.W.-Indien (Punjab. Baháwalpur. Bikaneer. Jodhpur und .Jaipur. Sambhar, Sindh), Baluchistan und Ost-Persien, dam aber wieder im nördlicheren Palästiua. (Einige ostgriechische Ralun scheinen auch zu diesel Form zu gehören, doch fehlt es noch an genügendem Material.) 


\section{Corvus corax umbrinus Sund.}

Corvus umbrinus Sundevall, Oef. k. Vet. Akad. Förh. Stockh. 1838, p. 199 (Ex Hedenborg MS., Sennar).

Corvus infumatus Wagner, Mïnch. gel. Anz. 1839. (teste Sund.)

Corvus umbrinus, fuscicollis, nigricollis, crassirostris, minor A. Brehm, Verz. Samml., p. 3 (1866, nomina nuda!).

Gekennzeichnet durch geringe Größe, schlanken Schnabel, chokoladefarbenen Ton im Gefieder, der am Halse und Nacken am stärksten ist.

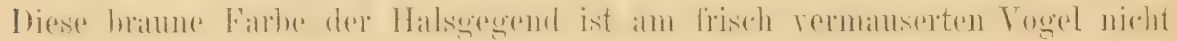
deutlich, demn die frisch gewachsenen Federn sind schwarz, wird aber vor der Mauser sehr' auffallend. Andre südliche Rabenformen werden auch am Halse bräunlich, aber nicht bis zu dem Grade. Federwurzeln ziemlich hell. Maße variabel, vielleicht lassen sich noch mehr geographische Formen tremnen, so z. B. sind die von den Kapverden meist sehr klein. Sollten diese Vögel sich unterscheiden lassen, würde der Name muficollis Lesson ('I'raité d'Orm., p. 329 - Kapverden) dafür anzuwenden sein, es scheinen aber keine

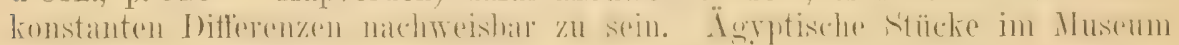
zu Tring messen 380—420, fünf ron den Kapverden 370-390, zwei aus Arabien bis 357 (?jun.), eins südlich vom toten Meere 380, 1 Sokotra 395, 1 Lahej 357 Flügelmab.

Bewohnt das Saharagebiet von den Kapverden durch die tunesische

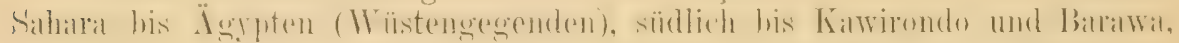
durch Arabien und Sokotra bis in das südliche Palästina (Senke des toten

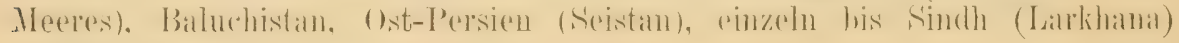
und Jacobabad.

Eier typische Rabeneier, $44 \times 31.5 \mathrm{~mm}$.

\section{Corvus affinis Rïpp.}

Corvus affinis Riippell, Neue Wirbelth. Hauna Abyssin, Vögel, p. 20 (1835- Massaua und S'chendi).

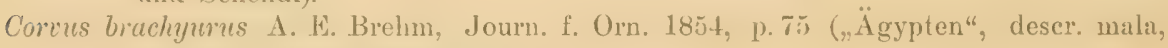
typus ex Luxor in Mlus. 'Tring).

Corvus brachyrhynchos (errore) U. L. Brehm, Vogelfang, p. 414 (1855, deser. mala).

Corvus brevicandatus Miiller, Journ. f. Om. 1855, 1).456 (descr. nulla).

Schnabel kurz, stark gebogen, an der Wurzel hoch, nach der Spitze

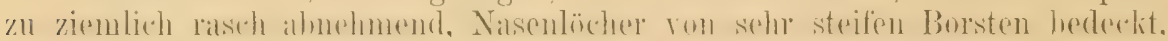
die nur ganz vorn mach vorne, sonst a ufw ürts gerichtet sind. Kehlfedern nur

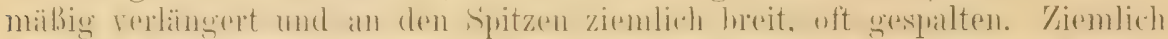

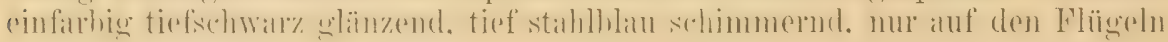
etras Purpuischimmer. Flügel $340-370$, Schwanz kurz und breit, 140 bis $160 \mathrm{~mm}$ lang, Lauf etwa 55, Schnabel ron der Wurzel an 50-60 mm.

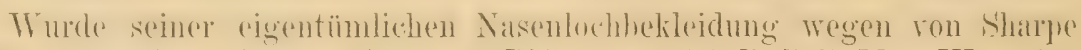

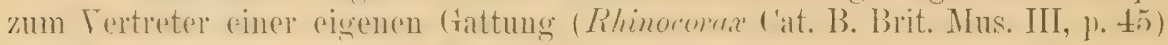
erhoben.

C. affinis, von den Engländern als "Fantail-Raven" bezeichnet, ist von Palästina, dem südlicheren und mittleren Ägypten, Nubien, Kordofan, ganz 


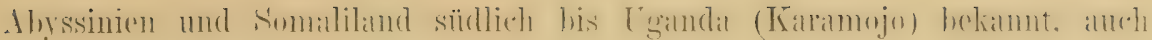
von Sïdarabien.

Der Flug wird als eigenartig geschildert und soll namentlich durch das viele Schweben ausgezeichnet sein. Die Stimme rabenartig. Teils in Paaren, teils in Flügen. In der. Wïste des Somalilandes folgt dieser Rabe den Karawanen und nährt sich von Abfall. Nistweise noch nicht bekannt.

\section{Corvus cornix cornix L. ${ }^{1}$ )}

Die Nebelkrïhe.

Corvus Comix Lim., Syst. Nat. Ed. X. p. 105 (1758- "Hab. in Europa", erstes Zitat Fauna Suecica 71, typ. Lok. daher Schweden).

Corvus cincreus Leach, Syst. Cat. Mamm. etc. Brit. MLus, p. 18 (1816- nomen nudum!).

Corvus subcomix Brehm, Haudb. Vög. Deutschl., p. 168 (1831 - nordöstl. Deutschl., namentlich Ahlsdorf).

Corvus cinereus Brehm, I. c. p. 169 (1831 - im Vinter in Mittel-Deutschland).

Corvus tenuirostris Brehm, Naumannia 1855, p. 273 (Nomen nudum, auberdem schon von Yoore vergeben!)

Corvus comix ulgaris, planiceps A. Brehm, Verz. Samml., p. 3 (1866, nomina nuda!)

Engl.: Hooded Crow. - Franz.: Corneille mantelée. -- Ital.: Cornacehia.

Gestalt ganz wie die von C. c. corone, aber nur der Kopf, Vorderhals und Kropf, Flügel, S'chenkelhetiederung und Schwanz sechwarz, das übrige

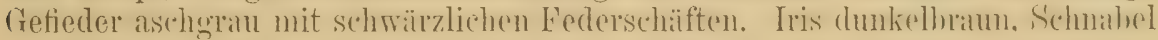
und Füße schwarz. Flügel 320-340, Schrvanz 185-212, Lauf 55-64, Schnabel von der Stirn an gemessen $47-54 \mathrm{~mm}$.

(Nath Süd-osten sollen die Nehelkrähen im allgemeinen heller werdeu.

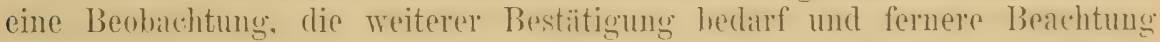
verdient.)

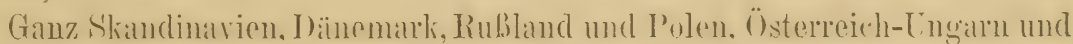

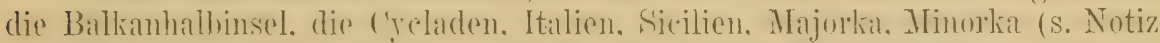
unter Nr. 16), am Eulie der Alpen his Nizzal. In ästlichen Dentschland etwa his

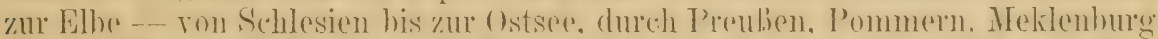
his zur ITestküste Jütands. in Sohlesmig-Holstein etwal his zu rinel in sïd-

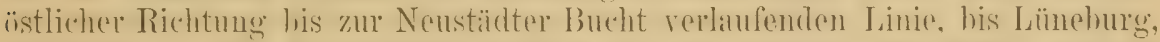

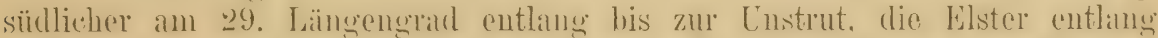

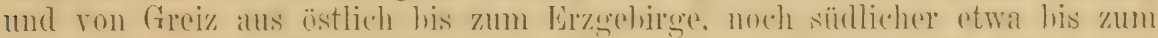
Egertal und zum Bähmerwald und der harerischen Gienze an der Donan. äher den Hanstuck die Salzach hinauf, Nordost-Tirol bis Innshruek. Von

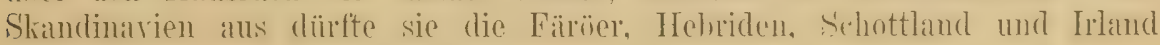
bevölkert haben, wo sie häufig ist.

Die nördlich wohnenden Nebelkrähıen sind Zugrögel, die in ungeheueren Massen beim Beginn des Winters fortziehen. Sie sind aber nicht Wandervögel im Sinne der

1) Es ist meines Erachtens absurd, die Artselbständigkeit der C. cornix und corone zu verneinen. Obwohl beide dieselbe Gestalt haben, sind sie in der Gefiederfärbung total verschieden entwickelt. Beide Arten haben mehrere Unterarten und verbastardieren sich, wo ihre Verbreitungsgebiete zusammenstoßen. Gerade dieser Umstand spricht fïr und nicht gegen ihre V erschiedenheit, denn wenn nicht tiefbegründete Unterschiede zwischen beiden beständen. wïrden sie ihre Selbständigkeit unter den obwaltenden Umständen längst aufgegeben haben. So aber erhalten sie sich rein, trotz der Häufigkeit von Bastarden in MIittel-Deutschland, in Sibirien und Schottland. 
Sehwalben, Segler, (rrasmücken, rotrickigen Würger, Mandelkrähen und zahlreicher andrer, die weit über das Mittelmeer nach Süden, in die Tropen, ja bis in das südlichste Afrika wandern, sondern sie überwintern schon in den Ostseeprovinzen und im südlichen Skandinavien, und nur die ganz nördlich wohnenden ziehen nach Sïden. mehr aber noch nach Westen, milderen Gegenden zu. Ganz West-Deutschland, Frankreich, England, Spanien, sowie die niedrigeren 'T'eile der Schweiz werden im Winter ron ihnen überschwemmt. \Lan sieht sie in diesen Ländern etwa von Mitte oder Ende Oktoher an, oder später, in strengen Wintern mehr, als in milden.

Die Nahrung besteht aus Insekten, Würmern, Mäusen. Schnecken, Feldfrïchten, Obst, Abfall aller Art, bis zu Kartoffelschalen, Knochen und Menschenkot. Zur Brutzeit sind sie die allerabscheulichsten Eierdiebe, die nicht nur den Eiern der kleinen bodenbriitenden Singvögel, sondern auch denen der Rebhühner, Fasanen, Enten, Wasserhühner und Taucher nachstellen und stellenweise großen Sehaden tun. Sie rauben auch junge Vögel und junge Hasen und werden im Winter bei tiefem Schnee allem schwachen Wilde gefährlich, überfallen alle Arten Federwild, Hasen usw. Am Meeresufer finden sie reiche Nahrung an dem ausgeworfenen Seegetier und bei Ebbe. Muscheln und auch wohl Knochen heben sie auf und lassen sie auf Steine, Felsen, Dächer herabfallen, um zu dem Inhalte zu gelangen. Am Seestrande kann man dies leicht beobachten. Sie fischen auch nicht selten, watürlich nur an der Oberfläche des Wassers.

Die Nebelkrähe ist ein hochbegabter, mutiger und vorsichtiger Vogel, der wohl meiß wo und wie wenig er dem größten Feinde der Tierwelt, dem Menschen, trauen darf. Sie ist daher in Europa nur bei tiefem Schnee und am Neste leicht zu erlegen. Ihre Stimme ist ein rauhes Kräh oder Kraah, das sie oft sehr lang zieht. Bei Verfolgung von Raubrögeln oder Neckereien läßt sie ein eigentümliches Knarren hören, und zuweilen einzelne höhere, wie jauchzende 'Töne, die man wohl als Mißtöne bezeichuen kanu.

Die Nester stehen immer einzelu, wenu auch oft nicht weit voneinander - an besonders günstigen Orten, wie z. B. in Reiherkolonien, wo sie sich mit Vorliebe ansiedeln und den Reihern eine Geißel werden - , fast stets auf Bäumen, meist hoch, selten niedrig, nur wo es an höheren Bäumen fehlt atch ganz niedrig in Büschen, oder sogar auf den Sanddünen und auf den Färöer und andern nordischen Inseln an Felswänden. Die Nester gleichen denen andrer Krähen und sind stets oben frei. Die Eier gleichen denen der Rabenkrähe und Saatkrïhe, sind aber meist etwas dicker und größer als die der letzteren. Sie nistet ungestört nur einmal im Jahre. Das Gelegre besteht aus 3-5, selten 6 und nur aulerordentlich selten aus 7 Eiern. Die Eier messen durchschnittlich $41.79 \times 29.04$ und $41.2 \times 29$, herab bis zu $37.5 \times 26.5$ und $38.2 \times 28.7$, und hinauf bis zu $45 \times 30$ und $45.5 \times 30.5 \mathrm{~mm}$. Die Eier schmecken ausgezeichnet.

\section{Corvus cornix sardonius Kleinschm.}

Corvus sardonius K̉leinschmidt, Orn. Monatsber. 1903, p. 92 (Sardinien).

Ganz wie C.c.comix, aber etwas kleiner und die graue Ober- und Unterseite mit einem leichten hellbrïunlichen Schimmer.

Sardinien und Korsika, von letzterer Insel im Museum zu Tring. (Bewohnt vielleicht auch Cyrern und noch audle Inseln des Mittelmeeres. Von den Balearén und Sizilien konnte ich keine Stücke vergleichen.)

\section{Corvus cornix sharpii Oates.}

Corvus sharpii Oates, Fauna Brit. India, Birds I, p. 20 (1889- „Siberia, Turkestan, Afghanistan, and a portion of India" - typische Lokalität daher Sibirien).

Vollkommen wie C.c. comix, aber die grauen Teile heller, weniger aschgrau. mehr hräunlichgratu. auch ist im allogmeinen der Schnabel atwas schwächer. 
Bewohnt West-Sibirien etwa his in die Gegend ron 'Tomsk (nur vereinzelt am Jenissei und noch weiter östlich), Turkestan, Afghanistan, im Tinter weiter südlich, his Mesopotamien und N.W. -Indien. Die mesoputamischen

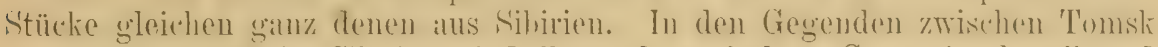
und Krasnoyarsk in Sibirien sind Bastarde zwischen C. comix sharpii und C. corone orientalis häufig. Diese Form steht C. c. cornix sehr nahe, beim Vergleichen einer Serie aber ist der Unterschied sehr auffallend.

Einige Schwierigkeit bieten die in Ägypten (und Syrien) brïtenden Nebelkrähen. Sie sind meist nicht von C. c. sharpii zn unterscheiden, aber zurveilen etwas dunkler.

Die Untersuchung größeren frischvermauserten Materials ist nötig zu entscheiden, ob man sie von C. c. sharpii trennen kann, was ich vorläufig nicht wage.

\section{Corvus cornix capellanus Sel.}

Corvus capellanus Sclater, Proc. Zool. Soc. London 1876, p. 694 'Tab. LXVI („Arabia 'I'urcica, ad ora Sinus Persici").

Unterscheidet sich sehr auffallend von C. c. comix und C. c. sharpii dureh die nur ginz schwach graulich angehanchte rahmweibe oder milchweilse Firhung der hellen T'eile, mit deutlich hervortectenden schwarzen schäften,

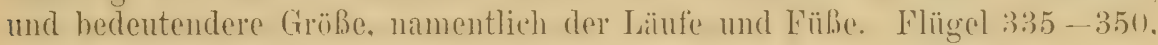
Schwanz 215-225, Lauf $64-70 \mathrm{~mm}$.

Die milchweiße Farbe der hellen Teile und die GröBe unterseheiden diese Form sehr ron der Nehelkrïhe und die meisten ornithologen hetrachten sie als "gute Art". Sie mit C. cornix comix zu vereinigen ist schon ein starkes Stiinck. trotzdem hat Dresser dies in seinem ..Manual of Palaearetic Birds" getan.

Wie es scheint nur vom Persischen Meerbusen durch Mesopotamien hin bekannt.

\section{Corvus corone corone L. (Fig. 4.)}

Die Rabenkrähe.

Corvus Corone Linn., Syst. Nat. Ed. X, p.105 (1758-- Ex Rajus, Albin. „Hab. in Europa". Typ. Lok. England, ex Raj., Albin.).

Corvus subcorone Brehm, Handb. Vög. Deutschl., p. 167 (1831 - Mittel-Deutschland). Corvus hiemalis Brehm, 1. c. p. 167 (1831- seltener Wintervogel, Mittel-Deutschland). Corvus assimilis Brehm, Vogelfang, p. 57 (1855-Deutschland).

Corone andayensis Olphe-Galliard, Faune orn. Europe occ. IV, Coraces, p. 60 (Henday -jedenfalls individ. Aberr.)

Corvus corone major, minor, longirostris, brevirostris, intercedens, montanus A. Brehm, Verz. Samml., p. 3 (1866- nom. nuda!).

Engl.: Carrion-Crow. Franz: Corneille noir. Ital.: Cornacchia nera.

б o ad. Starker Schnabel, wie ein Rabenschnabel im kleinen (Fig. 4), Nasenlöcher wie bei den Rahen mit borstenartigen Federn ver-

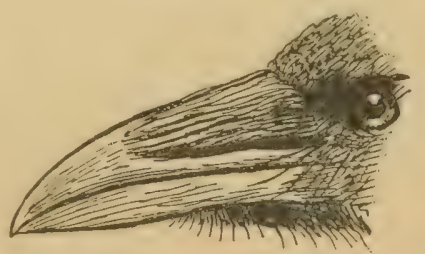

Figur 4. deckit. die nie ausfillen, Färhung schwally. O)herseite mit purpurnem schimmer.

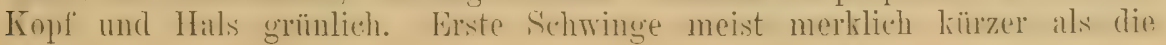




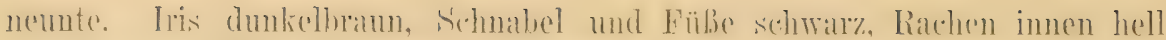

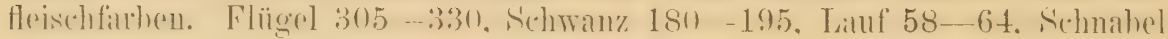
von der Stirn an gemessen $46-56 \mathrm{~mm}$.

Ganz England, Frankreich, Spanien, West-Dentschland bis dahin, wo die Nebelkrähe sie vertritt, die auch in einzelnen Stationen in das Gebiet

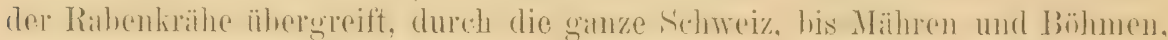

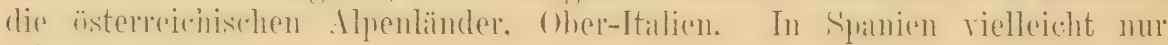
Wintervogel.

Unterscheidet sich in der Lebensweise nicht wesentlich von der Nebelkxähe, ist aber nirgends so ausgesprochener Zugvogel, sondern mehr Stand- und Strichvogel. IVo sie in strengen Wintern fortziehen, vereinigen sie sich auch in großen Flügen.

Die Eier unterscheiden sich nicht von denen der Nebelkrähe.

\section{Corvus corone orientalis Eversm.}

Corvus orientalis Eversmann, Add. Pall. Zoogr. fase. II, p. 7 (1841- , eirca Huvium Narym, ultra oppidum Buchtarma").

Durch viel bedentendere Größe in allen seinen Teilen und etwas mehr gestuften Sehwanz von C.c. corone unterschieden. Meist scheint auch die Allgemeinfïrbung etwas weniger tiefschwarz zu sein.

Sibirien, vom Jenissei bis zum Stillen Ozean, Kamtschatka, Mongolei. Nord-China und Japan. Einzeln in Turkestan und Nord-Indien erlegt.

\section{Corvus macrorhynchos japonensis $\mathrm{Bp}$.}

[Corvus Mracrorhynchos (ex 'Temminck IIS. in IIus. Lugd.) Wagler, Syst. Arium, gen. Corvus, sp.3 (1827 - „Hab. in Nova Hollandia, Nora-Guinea et in insulis

Sumatra et Java". - - Als typische Lokalität ist Java (T'emminck MLS. in

Iseyden) anzusehen, Australien und Neu-Guinea sind irrtïmliche Angaben).] Corvus japonensis Bonaparte, Consp. Av. I, p. 386 (1850- „Japon").

Schwarz, Stirn grïnsehimmernd, Hinterkopf und Hinterhals matt,

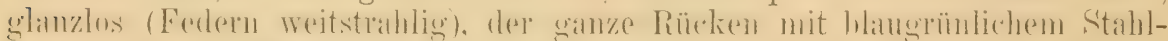

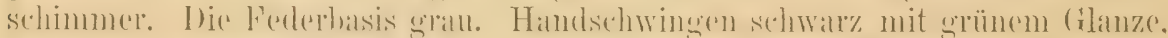

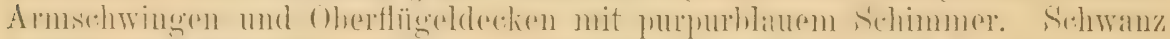

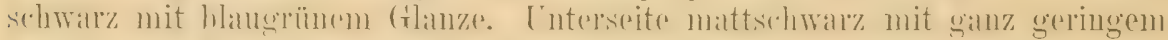

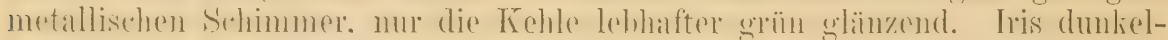
braun, Schnabel und Fübe schwarz. Flügel 340-376, Schwanz 220-246, Schnabel ron der Stirn an bis zu $75 \mathrm{~mm}$, Lauf $60-67 \mathrm{~mm}$.

Diese Krähenform weicht bedeutend von den europäischen Formen ab.

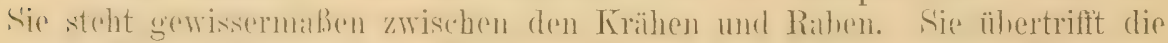

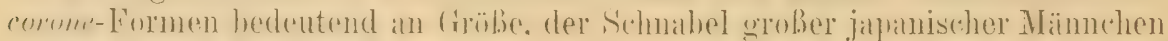

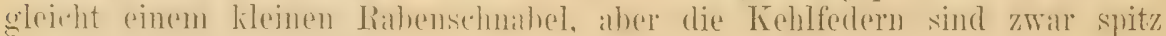
und an den Spitzen oft zweigeteilt, nie aber stark verlängert wie bei den Kolkraben (corax-Gruppe).

Japan, Korea, Nordost-China und Ost-Sibirien (Ussurien). Im Durch-

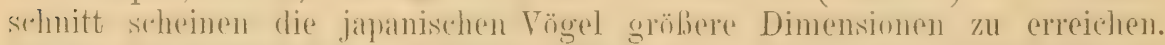
sollte die Intersuchung grölserer Serien eine Tremumg rechtfertigen. su wïrde wohl für die festlindische Form ein nener Nime gemacht werclen 


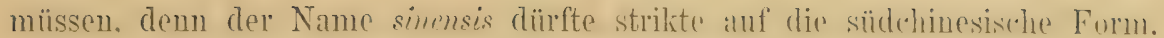
welche der indischen gleicht, zu beziehen sein.

C. macrorhynchos macroihynchos bervolint die Sunda-Inseln und unterscheidet sich auf den ersten Blick von C. m. japonensis durch niedrigeren,

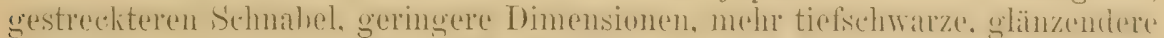
Lnterseite, schwarzen. glänzenden Hinterhals und weilie Federhasis, die nur bei ganz jungen Vögeln grau ist.

C. m. levaillantii Less. (1831 - typische Lokalität Bengalen) ist C. m. macrorlymolus sehr ähnlich, hat aher wieder graue Eederhasis. Bewohnt Indien bis Sïd-China.

Lebenștreise mehr krähenartig als rabenartig; sehr gesellschaftlich, in Baumpflanzungen und Wäldern, auf dem Felde und in Städten und I)örfern. Nester stets auf Bäumen, nach Art derer der Rabenkrähe. Eier großen Kräheneiem völlig gleichend. Die Stimme ist melur rabenartig als krähenartig.

\section{Corvus frugilegus frugilegus L. (Fig. 5.)}

Die Saatkrähe.

Corvus fingilegus Linn., Syst. Nat. Ed. X, p. 105 (1758- "Hab. in Europa". Erstes Citat Fauna Suecica 70, typ. Lok. daher Schweden).

Corvus agrorum Brehm, Handb. Yög. Deutschl,, p. 170 (1831- „Nord- und IlittelDeutschland").

Corvus granorum Brehm, 1. c. p. 171 ("Mittel-Deutschland auf dem Zuge").

Corvus advena Brehm, 1. c. p. 171 („Koburg, F'bruar 1827“).

Corvus agricola Tristram, Proc. Zool. Soc. London 1864, p. 444 (Nablous, Palästina).

Corvus frugilegus major, gregarius, longi-, angusti-, tenui-, crassirostris, planiceps

A. Brehm, Verz. Samml., p. 4 (1866- nomina nuda!).

Engl.: Rook. Franz.: Corbeau-Freux. Ital.: Corvo nero. Schwed.: Raka.

ơ $q$ ad. Glänzend schwarz mit prachtvollem purpurnem Schimmer; hesonders an Konf. Hals, Brust und Flügeldechent. Die Haut um die Sclmabelwurzel herum. Zingel und Kinn mit einer hellgranen. grindigen Haut bedeelit und unbefiedert, am Kinn meist etwas Flaum- und Federstoppeln. Iris nußbraun, Schmabel und Füße schwarz. Nund innen schieferfarben.

Voll der Rabenkrähe (C. corone) durch folgende Merkmale himmelweit verschieden: Schnabel viel gestreckter und spitziger, Schnabelwurzel im Alter nackt und grindig; Halsfedern weniger kompakt, zersehlissener, das ganze Gefieder glänzender, Gestalt und Flügel schlanker,

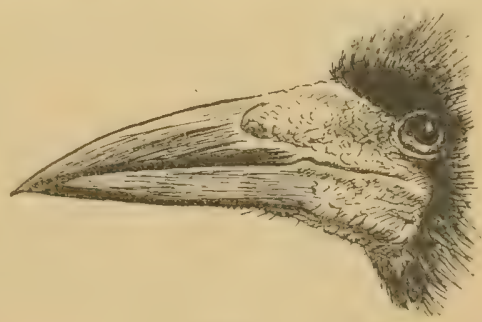

Figux die erste Sehwinge etwal ehen so ling oder sogar etwas lïyger als die neunte. Flïgel 30-33, Schwanz 16-18, abgerundet, die äuliere Stenerfeder $-2-2.5 \mathrm{~cm}$ kïrzer, Lauf $4.8-5.4$, Schmabel $5.2-6{ }^{1} / 4 \mathrm{~cm}$. Q wie $0^{\text {T }}$, nur etras kleiner.

Jus. Matter schmarz, viel weniger glänzend, Schnahelwurzel betiedert, Niasenlïeher ron Borsten üherdeckt. (Die Federn um die Schnahelwurzel fallen mit zunehmendem Alter aus und werden ilvgenutzt.) Jris gratuhram, Mund innen dunkel fleischfarben. 
Einige Ornithologen (Bonaparte, Sundevall, Sharpe und viele Nachfolger) stellen die Saatkrähen in eine eigene Gattung, Trypanocorax.

Vom $62^{1} / 2$ Grad nördl. Br. in Finland und etwa $60^{\circ}$ in Schweden, von Cholmogory in Arehangelsk und der unteren Petschora in Rußland über

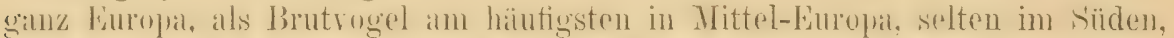

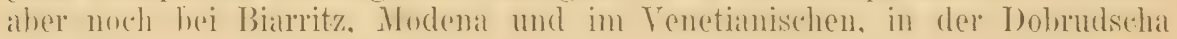
und Krim. In den südlicheren Juändern, wo der Boden im Sommer so steinhart wird. dab sie darin nicht buhren killm. fehlt sie als Brotrogel. In mittleren und südlichen Italien. in der ganzen iberischen Habinsel und den Vittehmeerlindern im allgemeinen nur Wintergast. In den nördlichen und kïlteren Gegenden ihres Wohngohirtes ist die Sibathrähe Zugroggel.

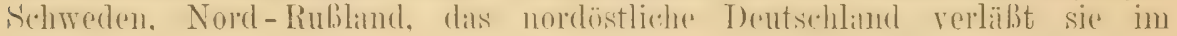
Oktober und November in Scharen, aber in England ist sie Standvogel,

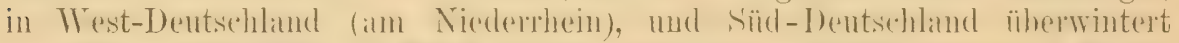

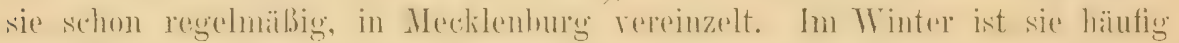
am Dittelneer, in Italien, Sprnien, ansmahmsweise erscheinen einzelne in

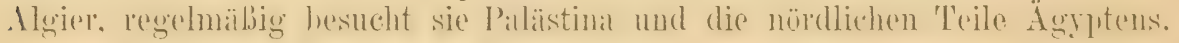

In der Lebensweise weicht die Saatkrähe ron der Rabenkrähe wesentlich ab. Sie ist immer gesellschaftlich, geht in Flïgen ihrer Nahrung nach, ïbernachtet in Scharen und nistet in größeren oder kleineren Kóolonien. Nährt sich meist auf Äckern von Wiirmern und Insekten und allen Arten Korn. Sie verschmäht anch Aas nicht und frißt am Seestrande ausgeworfene Fische und andres Getier, plïndert Obstbäume und ist besonders ein lästiger Walnußdieb. Nur ausnahmsweise in trocknen Sommern als Eierdieb und Nestplïnderer beobachtet.

Nester in Kolonien von mur wenigen Paaren bis zu T'ansenden, olt hart beieinander, nicht selten viele auf einem Baume. Fast immer auf sehr hohen Bäumen. Eier da wo sie überwintern sehon im März, im Norden erst Linde April, 3-5, wie die andrer Krähenarten, aber meist etwas kleiner und oft gestreckter als die von Corvus comix und corone, sehr oft am spitzen Ende am meisten gefleckt. Maßße der Eier im Durchschnitt $40.7 \times 27 \mathrm{~mm}$, Maximum $44.5 \times 29$, Minimum $36.5 \times 27.5$ und $40 \times 27 \mathrm{~mm}$. Rot grefärbte Varietäten sind änßerst selten.

\section{Corvus frugilegus tschusii subsp. nov.}

C. frugilegus fruyilegus dicto simillimus sed minor, rostro graciliore, rectiore, pedibus paullo infirmioribns, alis brevioribus.

Im allgemeinen schwächer, mit. dünnerem, gestreckterem Schnabel, etwas kleineren, schwächlicheren, ein wenig kurzzehigen Füßen und oft

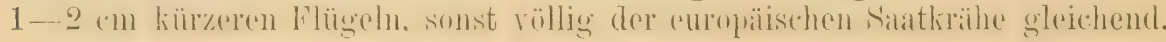

Typus o ad. Gilgit 7. Dezember 1879, J. Scully, Nr. 711, in Mus. linthschild, Tring. Nistet in Nord-l'risien. Turkestan und dem sïdwestlichen

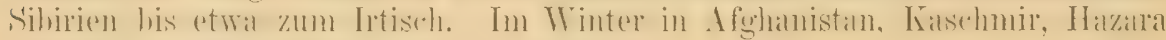
und dem nordwestlichen Punjal in Indien.

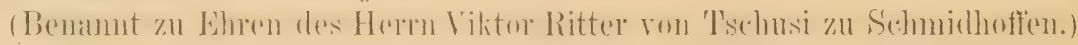

\section{Corvus frugilegus pastinator Gould.}

Corvus pastinator Gould, Proc. Zool. Soc. Lond. 1845, p. 1 (Chusan, China).

Unterscheidet sich von C. fingilegus fingilegus durch folgende Merkmale:

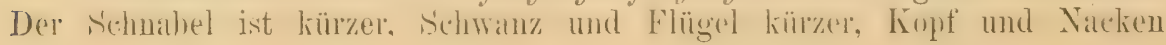




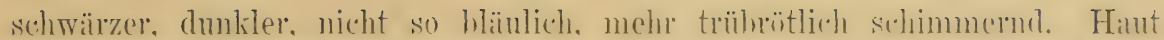
nur ummittelhar an der sehnibelwurzel grindig und im Alter von Feedern

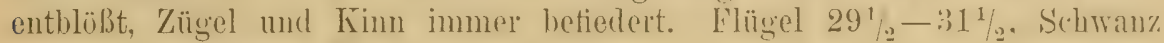
$16-17^{1 / 2}$, Schnabel $4^{1 / 2}-5^{1 / 2} \mathrm{~cm}$.

China, nōrdlich bis Ost-Sibirien, westlich bis Gansu; Korea, Japan; suidlich bis Formosa, aber dort wohl nur im Winter.

Lebensweise und Nisten wie bei C.f. frugilegus ('l'aczanowski, Orn. Sibérie oxient. I, p. 537).

\section{Gattung COLOEUS Kaıן. (1829). $\left.{ }^{1}\right)$}

Lmfaßt nur die eigentlichen Dohlen des Nordens der alten Welt. Der nordamerikanisehe Corres osxifurus hat nichts mit den Dohlen zu tun. Ton den meisten Oruitholngen mit Cortus rereinigt. aber doch durch folgende Merkmale einigermalien charakterisiert: Schmabel kurz, kolhig, kaum so laug wie der Kopf. Ohersthnabel wenig gelirimmt. Fedeen am Hals und Oherkopf wie zerschlissen, weitstrihlig; Innenfilhne der ersten s'chwinge ron der Mitte an stark ausgehuchtet. so lang wie nder linger als die lïngsten Armschwingen; der Schwanz, gerade, die einzehen Steuerfedern gar nicht ahgerundet, sondern am linde wie ahgeschnitten. Nisten stets in Hïhlungen, nur ausnahmstreise in alten Kirähennestern. Lïer meist anffallend hell und spairlieher. alser größer gefleckt, als die der Rahen und Kribihen. Alle Dohlen haben einen starken, ganz eigenartigen, auch noch an Bülgen und lange ausgestopften Stïcken hemerklichen mosehusartigen Geruch. Labhen, und rtwas weniger die Krï̈hen, hahen anch einen Geruch, der ather ganz anders und nicht so auffallend ist.

2 Arten, von denen eine in mehrere Unterarten geteilt worden ist. Europa und das nördliche Asien.

Übersicht der Arten:

Unterkörper schnärzlich . . . . . . . . . . . . . monedula . p.17

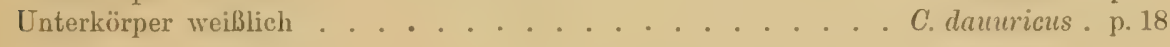

\section{Coloeus monedula monedula (L.).}

Die schwedische Dohle.

Corvus Monedula Linné, Syst. Nat. Ed. X, p. 106 (1758 - „Hab. in Europae agris“, erstes Citat Fauna Suecica, daher typ. Lok. Schweden).

Monedula septentrionalis Brehm, Handb. Naturg. Vög. Deutschl., p. 173 (1831- Nördl. Europa, namentlich bei Helsingör).

Schwed.: Kaja.

Alle europäischen Dohlen sehen folgendermaßen aus: Im frischen Gefieder, kurz nach iler Herbstmauser, sielit der ganze Togel schwïrlich aus. Die Kopfplatte ist hauschwarz mit etwas purpurnem Schimmer; diese Kopfplatte ist seitlich scharf hegreuzt, am Nacken aher meist etwas in den schiefer-

$\left.{ }^{1}\right)$ Coloeus und Lycos wurden beide erst 1829 (Lycos nicht 1822) zuerst veröffentlicht. Coloeus ist vorzuziehen, weil schon 1787 der Name Lycus (allerdings mit u) gegeben wurde. 
farbenen Hals ïbergehend. Zïgel und Fleck an der Wurzel des Unterschmahnels schwärzhich. Ohrdechen, Halsseiten und Hinterhals düster schiefergrau. hinter den etwas helleren Ohrdedien ein dïsterer Schatten. Oherseite

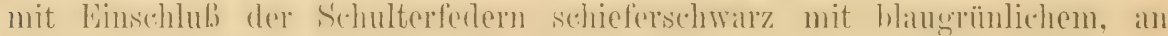
den lï̈ndern stïrlerem Glanze. Handschwingen sehwall\% mit älgrünlichen Glanze. Armschwingen und gröbere Flügedderten an den Aubensïmmen sebön

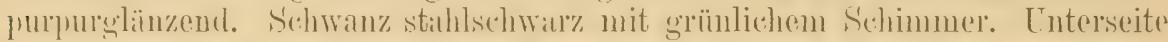
dunkel aschgran, die Federn an Krimn mit weibgrauen s'baftstrichen, Kehle und Vorderhals dunkler, fast schwarz. Schnabel und Füße schwarz.

Im Laufe des Jahres, namentlich in Frühjahr, erleidet dies Gefieder anffillende Veränderumgen. I) ie Federrïnder mutzen sich al), didturch werden

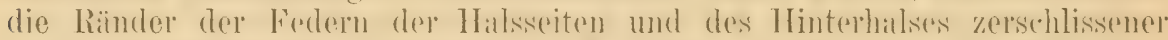

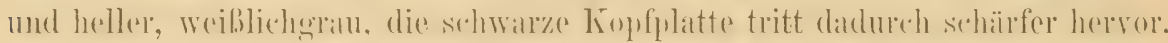
Auch die Federn der ïhrigen oherseite werden aln den liändern alvgenutzt, sodaß sie auffallende graue Säume bekommen.

Im ersten Jugendfieder sind Ober- und Unterseite brïunlich schiefer-

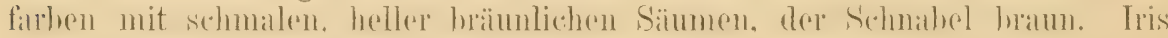
in der Jugend braun, im Alter bläulichweiß.

Flïgel 230-250, Schwanz 135-140, Lauf 42-45, Schnabel $29-36 \mathrm{~mm}$.

Die schwedische Form der Dohle gleicht vollkommen der westcuropäischen, aber das Kleingefieder ist heller, was namentlich auf der

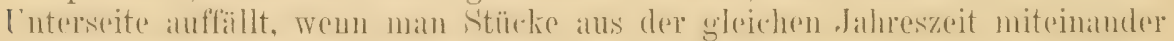
vergleicht. Auch die Federwurzeln sind meist etrvas heller. Nur selten rerigt sich ein sechmaler, meist undeutlicher weiber Fleck an den Halsweiten nach dem Flïgelbug zu.

Bewohnt Skandinavien bis etwa $63^{1} / 2$ Grad nördlicher Breite. Die genaue Grenze nach Osten zu vermag ich nicht auzugebeu.

\section{Coloeus monedula spermologus (Vieill.). (Fig. 6.)}

Die westeuropäische Dohle.

Corvus spermologus Vieillot, Nouv. Dict. d'Hist. Nat. VIII, p. 40 (1817- Ex Frisch, Latham, Buffon, typ. Lok. Süd-Frankreich).

MLnedula turrinm Brehm, Haudb. Naturg. Vög. Deutschl., p.172 (1831_ „ . . unseres Vaterlandes", (d. h. Hittel-Deutschland).

Monedula arborea Brehm, Handl). Naturg. Vög. Deutschl., p. 173 (1831- ,bewolnt die

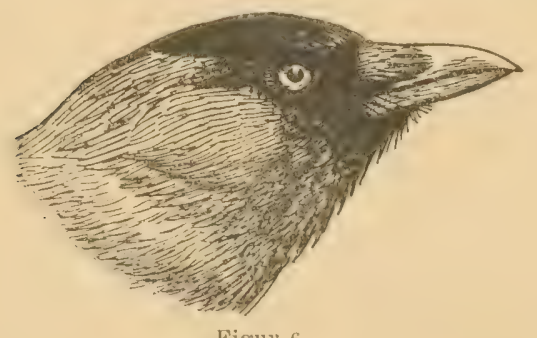

Figur' 6. hiesigen W:ilder", typ. Lok, daher Renthendorf).

Monedula vulgaris alticeps, planiceps, crassirostris, occidentalis A. Brehm, Verz. Samml., p. 4 (1866- nom. nuda!). Engl.: Jackdaw. Franz.: Choueas.

Gleicht vollkommen der schwedischen Dohle, aber das Kleingefieder ist dunkler, was sich an der Unterseite beim Vergleich einer Serie bald zeigt. Nur selten ist ein weißer

Fleek an den Halsseiten ausgebildet.

Verbreitung: (irobloritamnien und Irland. Deutsehland, Belgien, Holland,

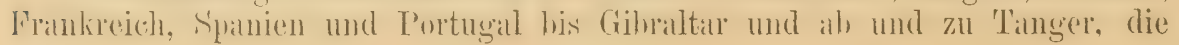


Alpenländer, Italien, Sardinien, Malta, Österreich und Lngarm, gemane Gremze gegen Osten nicht festgestellt. Ausnahmsweise auf den (anaren beobachtet, mach älteren Angaben auch in Algier, wo neuere Forscher sie aber nicht fanden. (Die meditermen Dohlen sollten genauer untersucht merden. Lis seheint, als wenn solche vou Spanien und (Yypern sehr kleinwïchsig wälen, Verf. hatte aber kein nennenswertes Material.)

Bewohner der verschiedenartigsten Gegenden, wenn sie nur Gelegenheit zu gesellschaftlichem Nisten bieten. So finden wir die Dohlen an Kalksteinfelsen und andern höhlenreichen Felswänden, besonders an der Meeresküste, in altem Gemäuer, an Türmen, Burgen, Schlössern und andern hohen Gebäuden, in den Schießscharten von Festungsmanern (Glatz, Wesel) und Blockhäusern, auf Böden, auf Gebälk und Sparrwerk, sehr oft auch in den Schornsteinen, wo sie durch das Anfüllen mit Reisig sehr lästig werden können, ausnahmsweise an Lehmstcilufern, noch seltener in Kaninchenhölılen, sehr oft aber, wo alte Bäume Gelegenheit dazu bieten, im Walde, in Höhlungen von Eichen und andern Bäumen. Schließlich nimmt sie auch in geringerer Anzahl von alten Krähennestern Besitz und baut sich in den Klumpen von Saatkrähennestern an. Immer aber sind die Dohlen Höhlenbriiter, außer wenn sie in Saatkrähennestern brüten. Dadurch unterscheiden sie sich von allen Krähen. Einzelne Paare findet man sehr selten brüten, gewöhnlich sind ihrer mehrere, meist sogar sehr vicle nahe beieinander.

Die Nester sind meist große Klumpen ron Reisig und Strol, mit Haaren, Heu, Lappen, Papier, Fetzen und Federn weich ausgefüttert. Beim Verlassen des Nestes werden die Eier oft locker zugedeckt. Volle Gelege findet man in West-Deutschland und England oft schon Mitte April, sonst meist Ende April bis Anfangs Mai. Die Brutzeit dauert etwa 18-20 Tage. Gelege 4--7, meist 5. Die Wier sind Jeicht von denen aller Krähen und Raben zu unterscheiden. Sie sind in der Regel rundlicher, weniger spitz, hellblau mit einzeln stehenden größeren bräunlichen und grauen UnterHecken geziert, oder auch hellblau mit lauter kleinen schwärzlichen Punkten bedeckt, sehr selten ungefleckt. Maße $33 \times 23,30 \times 22.3,34.9 \times 24.6,33.7 \times 25.2,38 \times 25.5$, $37.7 \times 23.3 \mathrm{~mm}$. Durchschnittsgewicht $0.763 \mathrm{~g}$.

Die Dohle ist ein lebhafter, munterer Vogel, hurtiger und gewandter als dic Krähen, durch raschen, oft schwankenden und geschickten Flug ausgezeichnet. Wo man sie verfolgt bald sehr scheu, sonst vertrauter. Gesellig zu jeder Jahreszeit. Stimme ein lustiges, hohes Kjäck, Kjah, und ein Krächzen, vielfach moduliert. Nahrung mannigfach: Insekten, Larven, Würmer, Korn, F'rüchte, Kerne, besonders gern Walnüsse, leider auch sehr gern Eier und junge, kleine Vögel, am Strande auch Muscheln, Crustaceen, Fische, im Winter jede Art von Abfall. Das Fleisch der jungen Dohlen schmeckt ansgezeichnet, viel besser als das der in England beliebten Saatkrähen.

\section{Coloeus monedula collaris (Drummond).}

Die osteuropäische Dohle.

Corvus collaris Drummond, Ann. \& MIag. Nat. Hist. XVIII, p. 11 (18t6- "Macedonia, Thessaly, Albania", typ. Lok. Macedonien).

Unterscheidet sich ron der westeuropaiischen Dohte durch hellere Lnterseite. worin sie der schwedischen etwa gleichliommt, ron der schwedischen durch einen mobr oder miuder ausgedehnten, oft halb halshandfürmigen rahmweißen Fleck an den Halsseiten. nach dem Flügelhug zu. Dieser weile Fleck findet sich hei westeuropliischen Brutdohlen nicht, bei skandinavischen nur angedentet, hei dentschen Brutdohlen selten angedentet. im Osten Deutschlands vielleicht mehr.

Verbreitung: Rußland, wahrscheinlich das ganze Rejch in buropa, Nacedonien, Bulgarien, Serhien, Griedheuland, Kilukasus, Mesopotamien, Persien

E. Hartert, Die Vögel der palïarktischen Region. 
bis 'Turkestau, Afghanistan, Kaschmir, im Winter bis in das nordwestliche Punjab in Indien, ja sogar bis Umballa, Ferozapur, Jhelum und in den Gázi Khan Distrikt, im Norden bis West-Sibirien, etwa bis zun Jenissei.

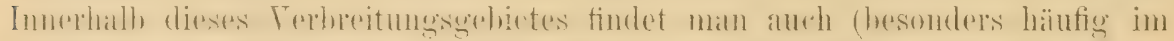

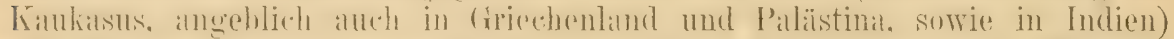

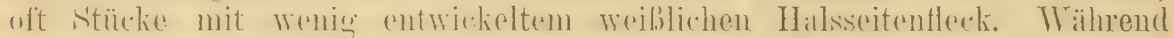

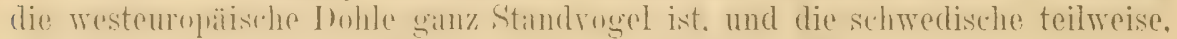

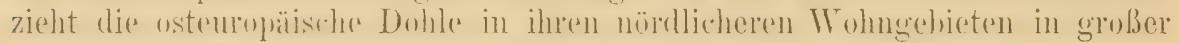
Menge bei Beginn des Winters gen Süden und Osten. So erscheint sie in Ost-Preußen (wo die dort brïtende Dohlenform noch die mehr. oder minder typische westeuropäisehe Form zu sein scheint) rom Ende Oktober

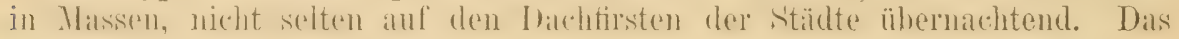
gleiche findet in Polen statt.

\section{Coloeus dauuricus (Pall.).}

Corvus daurricus Pallas, Reise Russ. R. III Anhang, p. 694 (1776- „Ex Mongolia Chinaque advolat, in reg. circa Baïkalem sitas, circa oppida et pagos usque ad Lenaxn frequentissima, ubi rarior Monedula, et rarissima Cornix." Typ.

Lok.: Baikal-Gegenden).

Corvus capitalis WVagler, Syst. Ar., Corrus, sp. 19. (1827 - ex Pallas).

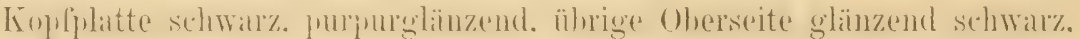

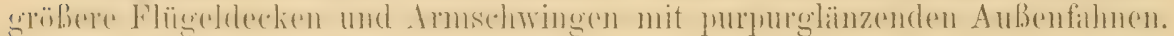

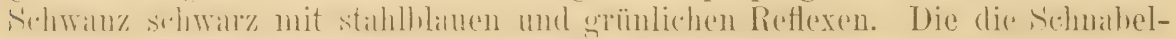
wurzel bedeckenden Borsten schwärzlich mit hellen Schaftstrichen. Federn hinter dem Auge und ïber den Ohrdecken und Ohrdecken schieferfarben mit grauweiben Spitzen, die zuweilen spärlich sind oder fast fehlen. Kinn und Kehle tief blauschwarz, die ganze übrige Unterseite und ein breiter

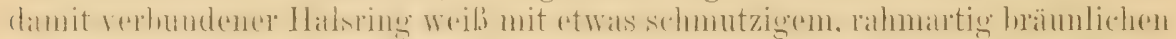
Anflug. Federwurzeln grau. Achselfedern, Unterflügeldecken und Unterschwanzdecken schicferschwarz. Größe wie die von $C$. moneclula. Schnabel und Irïbe schwarz, Iris graubräunlich. of nicht wesentlich vom Weibchen verschieden, junge wie die alten, aber die schwarzen Gefiederteile weniger glänzend, mit granen Säumen, die Unterseite stark mit grau getrïbt.

(Nach der auch in der neuen Bearbeitung des ,Naumann" wieder-

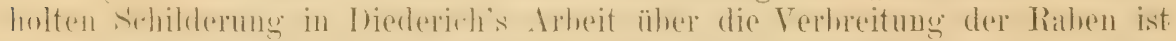
zu verstehen, dab sich dieso ganz verschiedene Dohlenart von $C$. monedula nur durch den breiten Halsring unterscheidet und daß die Jungen wie „unsre jungen typisehen Dohlen“ aussehen!)

Vom 'Tale des Jenissei und vom Altaigebirge nach Osten durch ganz Sibirien, die Mandschurei, Mougolei, Nord-China bis Kansu und Ost-Libet, Korea, Japan und Formosa (Exemplare vom 25. November 1896 in 'Tring').

Jedenfalls in den nördlichen I'eilen ihres Wohngebietes Zugvögel. In l'ormosa vielleicht nur Wintergast.

Lebensweise, Fortpflanzung und Eier wie bei den europäischen Dohlen.

29. Coloeus neglectus (Shlhleg.) (Höchstwahrschemlich lieine Art.)

Corvus neglectus Schlegel, Bijdr. Dierk. Amsterdam, Afl. 8, Corrus, p. 16 (1859-Japan. Basiert auf dem Corvus daunicus jun. Faun. Jap. Taf. 40). 
Wie C. denuricus, aber der weiße Halsring dureh tief schiefergraue

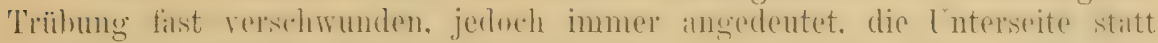
weiß aschgrau mit dunkleren Federmitten. Die Färbung der Unterseite scheint etwas zu variieren.

Kommt anscheinend ïberall vor, wo C. danuricus vorkommt, und ist in einzelnen Stïcken in den Schwärmen der letzteren beobachtet worden.

Pallas beschrieb diese Form sehon als Aberration von $C$. danuricus, andre haben sie für die junge dumurens gehalten. Höchstwalhscheinlich nü melauistische Varietät der letzteren. Dalli Dresser sie (Hanulal T'al. 13. p. 420) als Subspezies von C. monedula beschreilht, während er $C$. deunnicus artlich trennt, hat durchaus keiuen Simn.

\section{Gattung PICA Vieill. (1816).}

Die eigentlichen Elstern. Ansgezeichnet durch langen, keilförmigen Schwanz mit besonders langen mittleren Stenerfedern und eine eigenartig

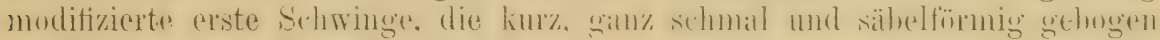
ist (Fig. 7). Mit nur weißen und schwarzen, teils prachtvoll metallisch glänzeuden Farben.

Alle echten Elstern stimmen in ihren Hauptmerkmalen überein und

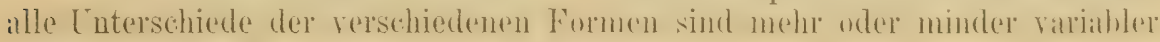
Natur. Die Gröb s schwonlit auch imnerhalb - derselben Form mehr oder weniger, die Bürzelfärbung ist nicht immer konstant, die Ausdehnung der weißen Farbe auf den Handschwingen. sehr veränderlich. Wir müssen

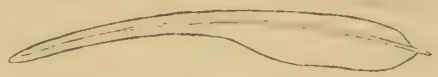

Figur 7.

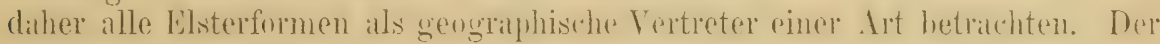
ganz schwarze Bürzel tritt heieinander sonst ferustehenden l'ormen auf. Man kamn die folgenden künstlichen Gruppen unterscheiden:

I Oberseite einfarbig schwarz, ohne helles Biirzelband . . . . . . . . 2

I Oberseite mit hellem Bürzelbande ... . . . . . . . . . . . 4

2 I Mit grobem blanen Fleck hinter den Auge . . . P. p. manitanica . 1.22

2 \} Ohne großen blauen Fleck hinter dem Auge . . . . . . . . .

$3\{$ Viel größer . . . . . . . . . P. p. bottanensis . 1.22

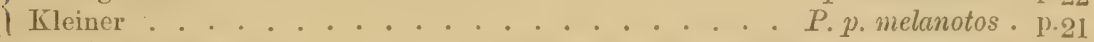

4 Schnabel schwarz. . . . . P. p. pica, hudsonius, bactriana, sericea . 19.19-22

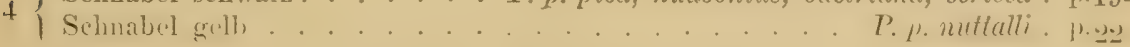

\section{+ 30. Pica pica pica (L.).}

Die europäische Elster.

Corvus Pica Linné, Syst. Nat. Ed. X, p. 106 (1758- Hab. Europa, erstes Citat Fauna Sueciea, typ. Lok. daher Schweden).

Corvus musticus Scopoli, Ann. I Hist. Nat., p. 38 (1769- "Carniolia").

Pica melanolenca Vieillot, Nouv. Dict. d'Hist. Nat. XXVI, p.12l (1818- neuer Name für Corvus pica).

Pica albiventris Vieillot, Faune firanc., 1). 119 (1828).

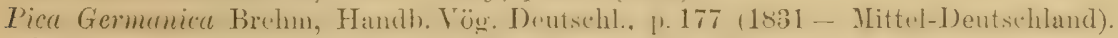

Pica septentrionalis Brehm, Handb. Yög. Deutschl., p. 178 (1831- Nord-Europa).

Pica hiemalis Brehm, Handb. Vög. Deutschl., p. 178 (1831- Winter in Deutschland).

Pica caudata Keyserl. \& Blas., Wirbelth. Europ., p. XIV, 168 (18t0- Europa.). 
Pica varia Schlegel, Rev. Crit., p. LIV (1844).

Pica pinetorum Brehm, Vogelfang, p. 62 (1855).

Pica vulgaris Brehm, Journ. f. Orn. 1858, p. 173 (ganz Deutschland).

Pica leuconotos Brehm, Journ. f. Orn. 1858, p. 173 (partim: Exempl. aus Deutschland, nicht die aus Kamtschatka).

Pica curopaea major, minor, hortorum, montana, robusta, brachypus, alticeps, planiceps, macrorhynchus, crassi-, parvirostris, valida, Hungariae, orientalis A. Brehm, Verz. Samml., p. 4 (1866- nom. nuda!).

Pica Linnéi MIalm, Göteb. och Boh. Fauna, p. 211 (1877- Bohuslän).

Engl.: Magpie. Franz.: Pie ordinaire. Schwed.: Skata.

Alle Elstern sehen folgendermaßen aus: Schnabel und Füße schwarz, Konn, Hals, Rüelien, Oher- und Lnterschwanzdecken. Bauch, Steiß und Schenles, Kinn. Kehle und Krople glämzend schwarz. Ëher dem Bürzel ein grauliches oder weißes Band, das nur wenigen Formen fehlt. Schwingen

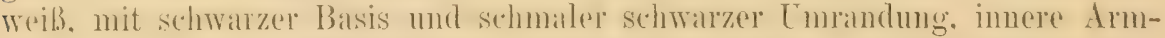
sehwingen und Oberflïgrelderen glänzend stahlblau, Schulterfedern weib. Sehwanz dunkel metaligrïn mit blauer Spitze, vor welcher ein kupfrig purpurn- und violettschimmerudes Band sich himzieht, Inuenfahnen der

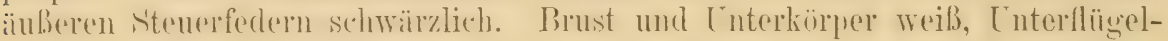
decken schwarz. Der junge Vogel hat die schwarzen I'eile matt, ohne jeden Glanz. Das Weibchen gleicht dem Männchen, ist nur etwas kleiner.

Die europäische Form ist wie folgt gekennzeichnet: Größe mittel;

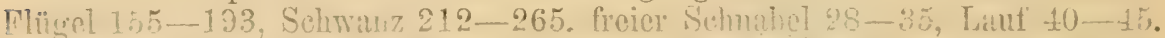
Tohledern meist ohne, manclumal aber auch mit weibem Querstreifen nabe der Basis. Anf dem Bürzel ein breites, meist hellgranes, bisweilen roin weibes, sehr solten (England, Renthendorf) fehlendes band. Handselwwingen meist ziemlich breit schwarz umsäumt. Dies letztere Merkmal wechselt sohr. demn hisweilen kommen Stürke in Europa ror (Dentschlaud, Fngland),

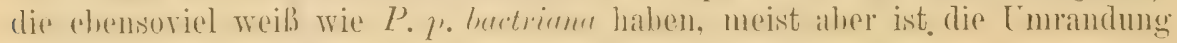
in Europa viel breiter.

Verbreitung: Gauz Europa von Irland und vom Nordkap bis in die Pyrenäen, Italien, Griechenland, Rußland bis zum Ural, Klein-Asien bis Persien und 'lrauskaspien.

Bewohnerin baumreicher Gegenden, im hohen Gebirge und inmitten großer Waldbestände aber fehlend. Flug nicht gut, bei starkem Winde sehr unbeholfen. Stimme ein rauhes schack, Schackirali, Schatcherack, schak, sehak, in Frihling mehr moduliert. dann auch oft ein amiisantes Gesehwätz. Nahrung sehr mannigfach, Würmer, Inseliten, Sehnecken, Früchte, Vogeleier und junge Vögel, im Winter in. der Not auch Aas, Getreide, Pferdemist und allerlei Abfall. Weil meist verfolgt sehr sehen und sehlau. „Sagax, loquax, furax." Nester immer auf Bäumen, meist hoch, oft auf den unersteiglichsten schwauken Spitzen der höchsten Bäume, nicht selten aber auch kaum mannshoch in Hecken, dichten Dornbïschen und Schonungen. Nest durch eine "Haube" von Dornen und Reisern ausgezeichnet, die immer vorlanden ist, ganz ausnahmsweise aber auch fehlen soll. Eier frih, oft schon im März, meist aber erst Mitte oder gar Ende April. Gelege 6-8, manchmal auch 9. Einmal sind sogar 10 beobachtet, Nachgelege (nach dem Raube der ersten) oft nur 4-5. Die Eier sind grïnlich oder weißlich mit graubräunlichen oder grünbräunlichen helleren und dunkleren Flecken und Punkten iiber und über gesprenkelt, meist an einem Ende reicher. Oft sind hellgraubräunliche

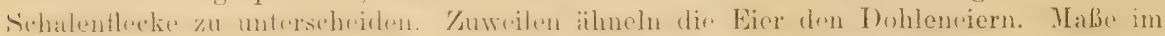
J) urchschnitt $32.9 \times 23,33.8 \times 23.28$, Maximum $35>21,37 \times 25$ und sogar $44.9 \times 26.5$ (Rödernsche Sammlung, 'Tring Museum), Mlinimum $32 \times 22.5,28 \times 22.5,28.5 \times 23.4$, $29.6 \times 24 \mathrm{~mm}$. Die Eier der verschiedenen Unterarten sind teils größer, teils kleiner, sonst aber im wesentlichen iibereinstimmend. 


\section{Pica pica melanotos Brehm.}

Pica melanotos Brelum, Journ. f. Orn. 1858, p. 174 (Umgebungen ron Madrid und Toledo).

Ganz wie Pica pica pica, aber der ganze Rücken und Bürzel rein schwarz, oder mit Andeutungen eines hellen Bürzelbandes.

Taluscheinlich die ganze iberische Halhinsel sïdlich der Pronenien. Ich untersuchte Stüche- rou Madrid, Toledo, Sü̈-Spanien und Portugal.

(Das 'T'otschweigen dieser Form ist nicht zu billigen. ${ }^{1}$ ) Thr Volhandensein ist grade ron bëehster Wiabtigkeit fül unser Vurständnis der Elsterformen und ihrer mutmaßlichen Terwandtschaft. Nerkwürdiger Wreise kommen auch in übrigen Juropra (Deutschland. England) als grobe Seltenheiten gamz schwarzrïckige. den spanischen völlig ähuliche Flstem vor. während die Form in Spanien recht konstant zu sein scheint.)

\section{Pica pica bactriana Bp.}

Pica bactriana Bonaparte, Consp. Av. I, p. 383 (1850- Ost-Persien).

Pica leucoptera Gould, B. Asia V, pl. 55 (1862- Ost-Sibirien).

Pica lemtschatica Stejneger, Proc. Biol. Soc. Washingt. II, p. 97 (1884) (cf. Stejn. Res. Orn. Expl. Commander \& Kamtschatka p. 241).

Merkmale: Bürzelhand inmel sehr markiert, meist weif, nie fehloud. Kehifedern meist mit dentlichen weilien (quellinden nahe der Wrurzel, Handsehwingen in der Regel mit sehr schmalem schwarzen Saum, das schwarz an der'Sehwingenhasis seh' gering; ziemlich grob und langflüglig. Flügel $210-227 \mathrm{~mm}$.

Ganz Nord-Asien vom Ural und Ost-Persien durch Turkestan bis Kalschmir, Baluchistan durch Sibirien. Wo sie am .Jenissei his ïher den Polarkeis hinatufeht. soust aher nicht ann̈̈hernd soweit nach Norden reicht, im (Isten bis zum Amur, Lssuri und Sidemi. Kantsolathad. (Es ggelang mir

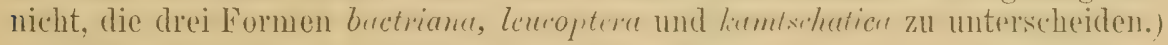

Eier $37 \times 25.4,38 \times 25,36.3 \times 25,33 \times 23 \mathrm{~mm}$.

\section{↔33. Pica pica hudsonius (Sab.).}

Corvus hudsonius Sabine, App. Frankl. Journ., pp. 25, 671 (1823).

Pica media Blyth, Journ. As. Soc. Bengal XII, p. 393 (1844- Andes, Chili, errore, aber wohl amerikan. Exemplar).

Der P. p. bactriana sehv ähnlich, die Kehlfedern bald olne bald mit weiben Querlinien nahe der Trurzel, Flügel 190-212 mm. Handschwingen mit schwarzem Rande.

Testliches Nord-Ameriki his zu den Rocliy Mountains, ron Neu-Mexilio und Arizona bis Alaska.

1) „Ich halte es nicht für nützlich, weiter verbreitete Lokalrassen, auch wenn sie nur geringe Unterschiede aufzuweisen vermögen, durch Totschweigen von der Bildfläche verschwinden lassen zu wollen. Die Kenntnis und Berücksichtigung solcher Rassen trägt größeren Nutzen, als der leidige Kampf um die Lösung der Frage, ob ein gewisser Vogel als Art oder nur als Varietät zu gelten habe. Die Rassen gerade sind es, welche uns die Bewegungserscheinung der Verbreitung einer Art aus dem heutigen Resultate deuten helfen. Sie rernachlässigen, heißt sich selbst der Stufen berauben, die am leichtesten und sichersten den Gipfel der Erkenntnis erklimmen lássen." (Diederich, Ornis 1889 p. 281.) 


\section{Pica pica sericea Gould.}

I'ica sericea Gould, Proc. Zool. Soc. London 1845, p. 22 (Amoy, China).

Pica varia juponica Schlegel, Famna Japonica, Ares, p. 81 (18t8).

Gekennzeichnet durch dunkle Färbung von Schwanz und Flïgeln. Das schwarz der Schwingenbasis sehr weit ausgedehnt. Auch die Handschwingen fast blau, nicht lebhaft griun, die mittleren Steuerfederu meist stahlblau, selten grïnlich. Täufo und Fübe sehr stark, Bürzelband immer vorhanden, meist grau, selten weib. Basis der Kehlfedern meist ohue alles. bisweilen aber auch mit sehr viel weil.s.

You Ober-Birma durch China bis in's südliche Japan (Insel Kiuschiu), Hainan, Formosa, nördlich bis Korea.

\section{Pica pica mauritanica Malh.}

Die maurische Fister.

Pica manvitanica Malherbe, Mém. Soc. d'Hist. Nat. Mus. de Metz, 1).7 (18.43--. Algerien).

Unterscheidet sich von allen andern Flstern durch ganz schwarzen

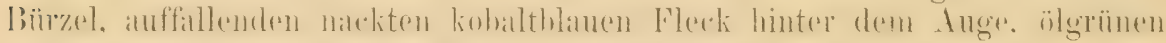

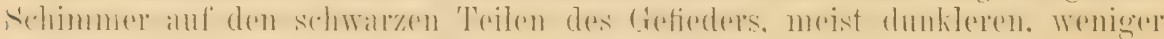
griinlichen Schwanz und geringe Größe. Flïgel nur 155-165 mm.

Marokko, Algier und T'unis; in Tumis fast nur sïdlich der Atlaskette. in Marokko rou Tanger bis Mogador, und vielleicht noch weiter südlich.

(Wird von den meisten Ornithologen als ,gute Art" bezeichnet, da aber alle ihre Merkmale bei den Elstern sehr variable Charaktere sind, kann man sie lediglich als ,Subspezies“. (t. h. geographische Form auffussen. Der schwarze Rücken findet sich hei der südspanischen Form und ausuahmsweise sogar in Deutschlaud und England, der nackte Fleck hinter dem Auge ist hei $P$. $\%$. sericea und melanotos meist angedeutet, die atuffallende geringe Größe kamn nicht als Artkennzeichen dienen, da die Elstern auch in den Malsen schwanken.)

\section{Pica pica bottanensis Deless.}

Pica bottanensis I) clessert, Rer. Zool. 1840, p. 100 (Butan).

Pica meguloptera Blyth, Journ. As. Soc. Bengal XI, p. 193 (1842 - Butan).

Pica tibetana Hodgson, Aun. \& Mag. Nat. Hist. 1819, p. 203 (Tibet).

Gekennzeichnet durch ganz schwarzen Bürzel ohne Andeutung eines hellen Bandes und seln' bedeutende Größe. Flügel bis 250 und sogar $265 \mathrm{~mm}$ (P.p.bottanensis, manritanica und mitalli sind die henntlichsten Formen der Art).

Sikkim, Bhutan und Ost-Tibet bis Kausu.

\section{-37. Pica pica nuttalli Aud.}

Pica nuttalli Audnbon, Orn. Biog. IV, p. 450, Taf. 362 (1838).

Unterscheidet sich vou allen andern Elsterformen durch den gelben Schnabel, der nur an der Basis mehr oder minder dunkler ist, und einen kleinen gelblichen nackten Fleck hinterm Auge.

Nur in Kaliformien westlich der Sierra Nevada, rom Sakramento-Tale his etwa $34^{0}$ nördl. Breite. 


\section{Gattung CYAINOPICA Bp. ${ }^{1}$ )}

Die Blauelstern ähneln im allgemeinen, namentlich durch den langen,

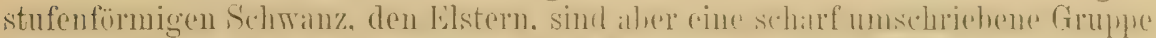

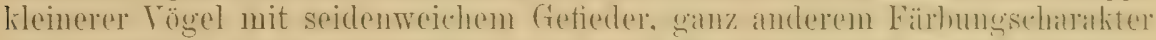

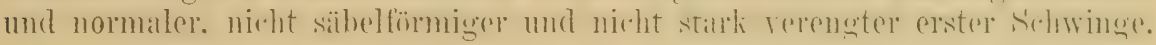
Die Verbreitung ist sehr merkwürdig, da wir sie nur von der iberischen Halbinsel und ans Ost-Asien kennen. Die beiden bekannten sotveit von einander entfernt wohnenden Formen sind zwar sehr leicht kemntlich, aber doch so ähnlich, ihre Nerkmale so wenig tiefeingreifond, daß wir sie nur als Unterarten auffassen können, aulierdem werden sie durch die dritte

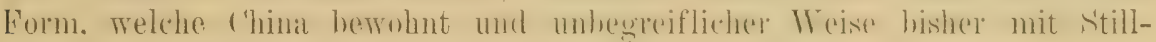
schweigen übergangen wurde, eininder stark genähert.

\section{Cyanopica cyanus cyanus (Pall.).}

Sibirische Blanelster.

Corvus Cyanus Pallas, Reise Russ. R. III, ]).694 (1776- Daurien).

Cyanopica Pallasii Bonaparte, Proc. Zool. Soc. London 1850, p. 85 (crwähnt).

Oberkopf bis auf den Nacken und Kopfseiten rein schwarz, ïbrige

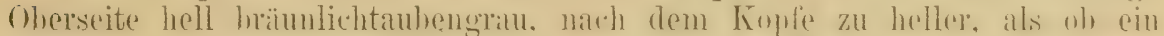
undeutlich begrenzter weiblicher Ring sich um den Hinterhals zingre. Habd-

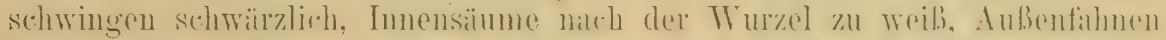

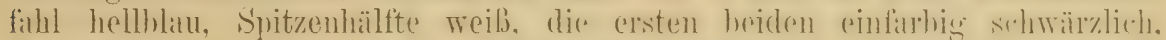
Armsthwingen an dere ganzen Aufenfihne hellhlun, die letzten an beiden

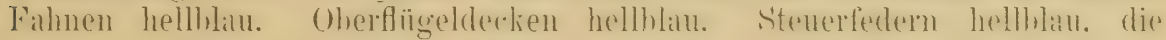
mittelsten mit ausgedehnten weißen Spitzen. Unterseite weil mit sehr schwathem aschgrauen dnflug. Cnterflügeldecken hell hoüulichgrau. Iris

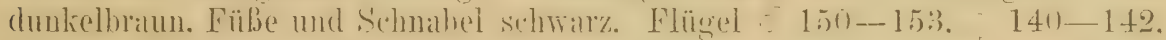
Schwanz ơ 240-260, o 215-225, Lauf etrva 35. Schnabel etrra $30 \mathrm{~mm}$, o außer der geringeren Größe ganz wie ơ, Junge brüunlicher mit fahlhrïunlichen Kanten an Flügeldecken und Rückenfedern. weibrn Surtzen an allen Steuerfedern und weißen F'ederrändern auf dem Kopfe.

Ost-Sibirien bis Korea und die südlicheren Inseln des eigentlichen Japan, aber nicht Jesso. (Es konnten nur wenige japanische Stücke untersucht werden, die noch dazu zum Teil nicht ganz alt sind. Tielloreht

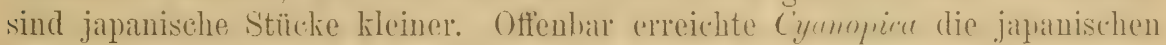
Inseln über Korea, da sie auf Jesso fehlt.)

Soll nach Przewalski ziemlich scheu sein, in Scharen die Wälder durchstreifen, und fortwährend ein schnarrendes biji. bijij. dijin, dijiin. dijiin heiren lassen. Das Xest ähnelt einem kleinen Krähennest und steht auf Bäurnen. Die Eier ähneln denen von C. c. cooki, sind aber meist etwas größer und oft heller. Maße: $30 \times 20,29 \times 22$, $29 \times 19.5,28.8 \times 22,28.5 \times 20.4,28.2 \times 19.3,28.2 \times 21,27.3 \times 20.3,27 \times 20,26 \times 20.5$, $25.5 \times 20,25.2 \times 19.2,25 \times 20,25 \times 19 \mathrm{~mm}$.

1) Cyanopica Bonaparte, Proc. Zool. Soc. London 1850, p.85, Consp. Av. I, p. 382 (1850) ist der älteste Name dieser Gattung! 


\title{
39. Cyanopica cyanus swinhoei subsp. nov. $\left.{ }^{1}\right)$
}

\author{
Chinesische Blamelster.
}

Unterscheidet sich von C. c. cyanus durch dunklere, viel mehr bräunliche

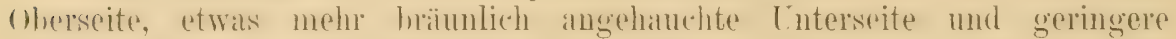
Größe, steht also in diesen Punkten zwischen C. c. cyames und C. c. cooki. Oे Flügel anscheinend nicht ïber $145 \mathrm{~mm}$.

Typus: (?०) Kiukiang 26. November 1882 (Nr. 351), im Nuseum zu T'ring. Benamnt zum Andenken an den Ornithologen Swinhor. dessen Verdienste um die Ornithologie rom ('hina, Hainan und Formosa unsterblich sind. Die Form wurde schon vor 5 Jahren vou Kleinschmidt und mir als verschieden erkaunt, aber bisher nicht publiziert.

China mit Ausualıme der südlichen und südöstlichen 'I'eile.

Stïcke aus der Gegend von Pekin scheinen sich C. c. cyanus etwas zu mähelı.

\section{Cyanopica cyanus cooki Bp.}

\section{Spanische Blauelster.}

Cyanopicu cooki Bonaparte, Proc. Zool. Soc. London 1850, p. 86 (Spanien).

Cyanopica Cooki alticeps und planiceps A. Brehm, Verz. Samml., p.4 (1866- nom. nuda!).

Noch dunkler und bräunlicher auf der Oberseite, als C. c. swinhoei, Interseite noch mehr und sehr stark fahlaschbrïunlich äherlaufen. Kehle aher weil, beihend, das blau der Flüger und des Schwanzes rotwas dunkler, die mittleren Steuerfodern ohme ausgedehute weile Spitzen, ansmahmsweise aber mit kleineren weißen Endflecken. Kleiner als C. c. cyamus. Flïgel o 142-145, o 130-135, Schwanz o 190-195, o $205-208$, Lauf etwa 35 , Schnabel etwa $25 \mathrm{~mm}$. O genau wie $\sigma^{\pi}$, nur kleiner, Junge unten und oben diisterer. hräunlicher, die Flügelderken mit fahlgelhmö̈unlichen Śritzen.

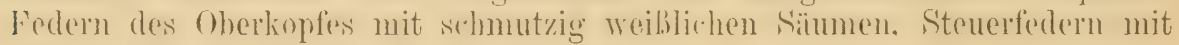
schmalen weißen Endsäumen.

\section{Sïd- und Mittel-Spanien und Portugal.}

I) ie spanische Blauelster ist eine Bewohnerin der immergrïnen Eichenwälder, deren dichte Kronen sie besonders liebt. Gesellig, aber dem Menschen gegeniiber scheu. Im Betragen den Elstern ähnelnd, klug, vorsichtig wie diese aber anch etwas an die Häher erinuernd. Die Stimme klingt ungefähr wie "krrrih" oder "prrrih", oder wenn der Vogel schwatzt wie "klikkiklikkiklikki“. Brutzeit von Anfang Mlai an. Nest einem kleinen Krähen- oder großen Würgerneste ähnelnd, meist mehrere nahe beieinander, ja bisweilen sogar zwei auf einem Baume. Der Unterbau besteht aus dürren Reisern, die innere Ausfütterung aus Kräutern, weichem Gras, Ziegenhaar und Wolle. Eier 5-9. Sie sind auf hellolivenbrüunlichem Grunde mit aschgrauen tiefer liegenden und dunkelolivenbraunen Oberflecken gezeichnet. Haße etwa $28.5 \times 21.4,28.5 \times 20.8,27.4 \times 21$, $26.6 \times 21.4,24.9 \times 21.2,24.5 \times 20,25 \times 19.5 \mathrm{~mm}$.

1) Pica melanocephalos W agler, Syst. Ar., Pica, sp. 7 (1827- Ex Levaillant: China) kann nicht auf diese Form bezogen werden, da der Name sich auf Levaillant's Vogel mit schwarzer Kehle und lauter ausgedehnt weiß gespitzten Steuerfedern bezieht, der wohl ein Phantasiegebilde sein dürfte. Cyanopica vaillanti Bonaparte, Proc. Zool. Soc. 1850, p. 85 im Text erwähnt, bezieht sich gleichfalls auf Levaillant's Vogel. 


\section{Gattung NUCIFRAGA Vieillot 1816.}

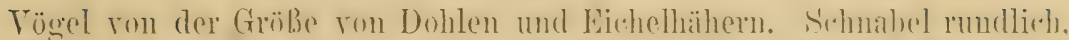
lang, so lang wie oder länger als der Kopf, whe eine de'utliehe Kante anf dem Obersehnabel, der meistens etwals ïher den L'nterschnalhel hinanstagt.

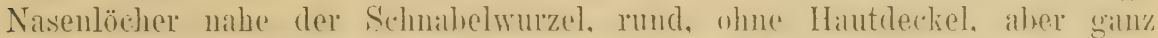
ron kurzen, borstenirtigen. nach vorn gerichteten Federn üherdecht. Getieder lang, voll und weich, schwarzbraun mit weißen Flecken. Die vierte bis serhste Sichwinge etwa gideich und am längsten, die dritte nur ganz wenigg kürzer, die erste nicht viel über halb so lang wie die zweite. Schwanz etwa $3 / 4$ so lang wie der Flügel, nur wenig gerundet, fast gerade. Eehte Corviden im Bau und in der Lebensweise, bauen offene Nester und legen gefleckte Vier. Die Gattung hewohut den Norden der alten Irelt. nur eine Art mit ungefleckter, hellgrauter Oborseite und ganz, weiber äulierer Stenerfeder in Nord-Amerika. In Deutschland zwei Formen, eine seltener Brutrogel, die andre Winterhesucher. Alle altwelthichen Tamnenhäher këmnen als Sulsplezies einer trt betraditet werden. während die nordamerikanisele Art (Nucifraga columbiana) ganz für sich stelit.

\section{Nucifraga caryocatactes caryocatactes (I..). (Fig. 8.)}

Der dickschnäblige T'annenhäher.

Corvus Caryocatactes Linué, Syst. Nat. Ed. X, p.106 (1758- Europa. 'lyp. Lok. Sehweden, ex Fauna Suecica, erstes Citat).

N'ucifraga guttata Vieillot, Nouv. Diet. d'Hist. Nat. V, p. 354 (1817, partim).

Caryocatactes maculatus Koch, Syst. baier. Zool., p. 93 (1817- Hochgebirge Baicins).

Caryocatactes nucifraga Nilsson, Orn. Suec., p. 90 (1817).

Nucifraga brachyrhynchos Brehm, Lelırb. Naturg. europ. Vögel I, p. 10.t (1823- "Scheint d. nordöstl. Eur. zu bewohnen und sich selten nach Deutschl, zn verirren". Typus Thüringer Wald 10. X. $182 \mathrm{l}$ ).

Nucifvage platyrhynchos Brehm, Isis 1833, p. 973 ('Typus Rodatal).

Nucifiaga caryocatactes pachyrhynchus R. Blasius, Ornis II, J.536 (1886).

Nucifraga caryocatactes crassirostris Hartert, Mitth. Orn. Ver. Wien XI, p. 146 (1887).

Nucifraga arquata Brehm, Vogelfang, p. 66 (1855, olne Isokalitätsangabo).

Nucifraga relicte Reichenow, Journ. f. Orn. 1889, p. 288 (Alpen).

Nasenborsten und Zïgelfedern etwas unrein weiß, an der Basis schwirzlich. Kopfplatte und Genick einfarbig dunkelıraun. Kopfseiten und Rücken heller braun, jede Feder an der Spitze mit einem länglichen, tropfenförmigen, dunkel umschatteten weißen Fleck, der auf den Bürzelfedern ganz klein wird oder fast ganz verschwindet, Oberschwanzdecken bräunlichschwarz. Schwingen schwarz, Flügeldecken mit weißen Flecken, nur die längsten einfarbig. Steuerfedern schwarz, mit weißen, nach der Mitte zu kleiner werdenden

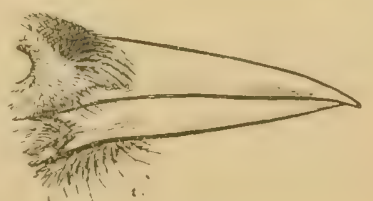

Figur 8. Spitzen, an dem äußeren Paare etwa $1 \frac{1}{2}-2 \frac{1}{2} \mathrm{~cm}$ lang. Unterseite dunkelhraun. Kehle mit schmalen weißen Schaftstrichen, Kropf- und Brustfederu mit großen. eifömigen. weißen Endflecken. Cuterkürper mit schmäleren solchen Flecken. Unterschwandecken weil. Interfügeldecken schwarzbraun mit weißen Spitzen. Tris braun, Schnahel und Fübe schwar\% 
Flïgel 180-190, Seliwanz etrva 125-130, Schmabel $40-45 \mathrm{~mm}$. O ad. wie $O^{-1}$ ad. nur ein wenig kleiner, Flügel $1 / 2$ bis $1 \mathrm{em}$ kürzer. Die Jungen im ersten Nestkleide sind oben von einem hellen, an Milchschokolade erimmernden graubraun, die 'I'ropfenflecke sehr klein, mur etwa $1 \mathrm{~mm}$ breit, die Kehle weißlich.

Die europäische Form des Tamnenhähers zeichnet sich folgendermaßen aus: Schnabel sehr dick, kurz, nicht merklich länger als der Kopf, stumpfspitzig, weibe Schwanzspitzen weniger ausgedehnt, $1 \frac{1}{2}-21 \%$, selten über $2 \mathrm{~cm}$ weit. Kleingefieder braun, am hellsten auf dem Rücken. Das braune Kleingefieder, namentlich auf dem Rücken, verbleicht im Laufe des Jahres ziemlich auffallend. Die Alpentannenhäher lassen sich nicht von den nordischen unterscheiden.

Diese Form brïtet in Skandinavien, Bornholm, Lappland, Finland, den

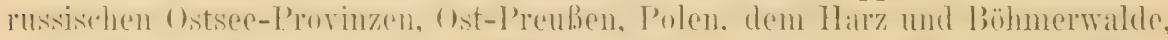
vermutlich alteh im 'Thüringer Walde. sicher im galnzen Alpengehiete. dem Jura, Siebenbürgen, der Tatra und den Karpathen, jedenfalls auch in den

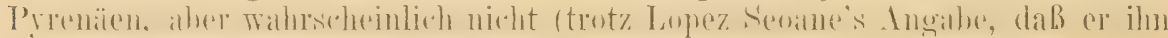
dort im Mai gesehen) in der Sierra Nevada.

Stand- und Strichvogel. In Ostpreußen Standvogel, in den Alpen mehr Strichvogel, der in der kalten Jahreszeit in die Vorberge und Ebenen Süd-Deutschlands und Frankreichs himabgeht.

Bewohner von Nadelwäldern, besonders wo Hichten und Edeltannen allein oder mit Laubholz gemischte Bestände bilden, oder Zirbelkiefern stehen. Reine Kiefernoder Laubwälder scheint er nicht zu bewohnen.

Wenig scheu, phlegmatisch, fällt am Brutplatze dureh sein tiefes Körr, körr, körr auf, das hauptsächlich Paarungsruf ist, hat sonst einen wie Kräk, kräk, kräk klingenden Lock- und Warnungsruf und in Frühjahr noch bisweilen ein elsterartiges Geschwätz. Die Nahrung besteht aus Insekten, Würmern, Schnecken, den Samen der Nadelhölzer, Nüssen, Früchten, Beeren, aber auch bisweilen Eiern und jungen Vögeln.

Der 'T'annenhäher brütet schon sehr frühzeitig, im März, in Nadelbäumen, wo er ein offenes Nest nahe am Stamm baut. Die tiefe für die Größe des Vogels geräumige Mulde ist mit trockenem Grase, Stengeln, J Bast von verrotteten Zweigen, hauptsächlich aber mit Flechten, namentlich Bartflechten, dick und weich ausgefüttert. Brutzeit 18 'ane. Gelege 3-4 Eier. 'T'annenhähereier sind eiförmig, meist ziemlich gestreckt, $24 \times 34$ bis $26 \times 36.5 \mathrm{~mm}, 34.18 \times 24.67,31.2 \times 24.5,33.1<23.8,36.7 \times 24.4$, $31.2 \times 25.2 \mathrm{~mm}$. Gewicht etwa $0.557 \mathrm{~g}$. Schale ziemlich glatt und etwas glänzend, błaß grünlich- oder bläulichweiß, mit blaß griinlichbraunen und tieferliegenden blaß bläulichgrauen Punkten und Flecken meist nur spärlich gezeichnet.

\section{4.․ Nucifraga caryocatactes macrorhynchos Brehm. (Fig. 9.)}

\section{Der schlankschnäblige 'T'annenhäher.}

Nucifraga macrorlynchos Brehm, Lehrb. Naturg. europ. Vögel I, p. 103 (1823_ „Gebirgswälder mittl. nördl. Eur. u. Asien“, selten nach Deutschland. Typus ein asiatischer Wandervogel).

Nucifraga hamata Brehm, Isis 1833 , p. 975.

Nucifraga minor Gourcy-Droitamont, Isis 1833, p. 970.

Nucifraga caryocatactes leptorhynchus R. Blasius, Ornis II, p. 536 (1886).

Nucifraga caryocatactes tenuirostris Hartert, Mitth. Orn. Ver. Wien XI, p. 146 (1887)

Diese und die rorige Form heißen auf Engl.: Nuteracker. Franz.: Casse-noix.

Schwed.: Nötkråka. Ital.: Nocciolaja. 
Unterscheidet sich von $N$. c. canyoratactes durch den viel schlankeren,

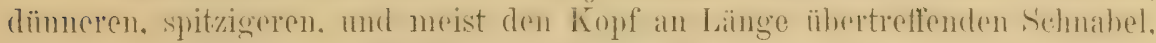
sowic ausgedehntere weiße Schwanzspitzen, die an den seitlichen Steverfedern etra $2^{3 / 2}-3^{1} / 4 \mathrm{~cm}$ lang sind.

Sibirien bis Korea. (Auch Nord-China, doch sollten nordchinesische Stïcke genau studiert werden!) Wandert im Herbste und Winter westwiirts bis Deutschland, Skandinavien, Frank-

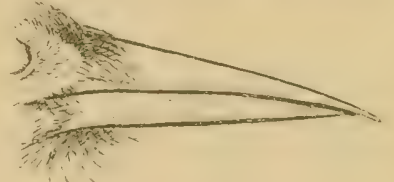

Figur 9 . reich, Dänemark und sogar England, wo schon über 30 Stücke mit Sicherheit festgestellt wurden.

\section{Nucifraga caryocatactes japonicus Hurt.}

N. e. japonicus Hartert, Nov. Zool. 1897, p. 134 (Japan).

Sehnabel intermediair zwisehen dem von $N$. c. caryocatactes und

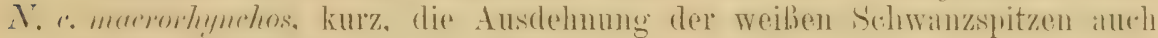
intermediär, Brustflecke meist größer.

Nördliches Japan und Kurilen.

\section{Nucifraga caryocatactes kamchatkensis Barrett-H:m.}

Nucifraga kamchatkensis Barrett-Hamilton, Bull. B. O. Club VII, p. XLVI (April 1898Kamtschatka).

Unterscheidet sich von den drei vorhergehenden Formen dureh $1-3 \mathrm{~mm}$

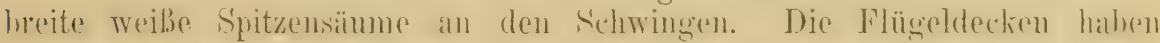
dreieckige weilse S'jitzenflecke. Die cimmlfithe ist sehr chunkel, die weibe Fleckung groß und grob. Von $N$. c. multipunctata durch kleinere weiße

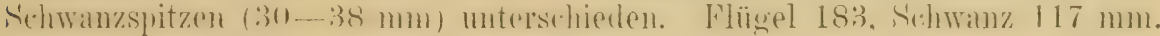
Schuabel intermediär, aber mehr schlink.

Kamtschatka. (Der Typus im British-Nuseum vou mir untersucht.)

\section{Nucifraga caryocatactes rothschildi sulssp. nюr.}

Unterscheidet sich von $N . c$. coryorutactes, macrorhynchos und japonions

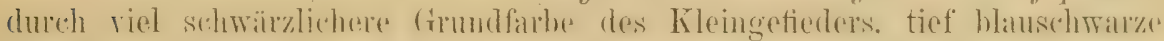
Flïgel und Sehwanz, ziemlich große, breite Flecke an der Unterseite und lingere Flügel. loer Shlubahel ist stark, mittellang, kïnnte als intermediär zwischen dem von macrorhynchos, caryocatactes und japonicus bezeichnet werden, bisweilen aber so dünn wie bei macrorhynchos. In der schwarzen

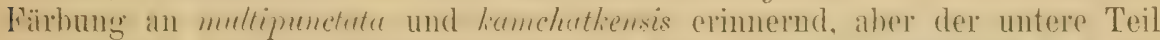
des Bürzels und die Oherschwanzdecken sind gainzlich ungeffeckt und die Sehwingen haben keine weißen Spitzen. Flügel $19-19^{1} / 2 \quad(q)$ bis $20-21\left(0^{-1}\right) \mathrm{cm}$.

Gehirge des mittleren Turkestan: Tian-Sehan und Wahrscheinlich die Ala-Tau und Terskej-Tau Ketten.

Typus: Ô ad., südlich des Issik-Kul im Februar 1901 von Tancrés Sammlern erbeutet. Nr. J. K. 44 im Tring-Museum. 14 Exemplare untersucht. (Vgl. W. Rothschild, Nov. Zool. 1902 p. 166, wo die dunkle Färbung schon hervorgehoben wurde.) 


\section{Nucifraga caryocatactes hemispila Yig.}

Nucifraya hemispila Vigors, Proc. Zool. Soc. London 1830, p. 8 (Himalaya).

Noch brïunlicher als $N$. c. caryocatactes, macrorkynchos und japonicus, die weißen Flecke klein, kury, nur an den Spitzen der Federn, Bürzel ungefleckt, die äußeren Steuerfedern etwa $6 \mathrm{~cm}$, d. h. zirka zur Hälfte woiß. Flïgel etwa $20-22 \mathrm{~cm}$.

Himalara rom Sutlejtale bis Butan.

\section{Nucifraga caryocatactes multipunctata Guuld.}

Nucifiaga multipunctata Gould, Proc. Zool. Soc. 1849, p. 23 (:Simla).

Grundfarbe schwärzlich. Schnabel selı dünn, die weiBen Flecke des Kleingefieders sehr lang, auf der Únterseite auch sehr breit, Bürzel

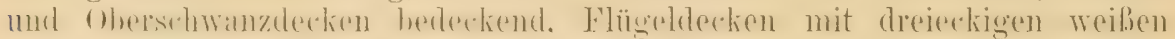
śritzenflechen. alle Selnwingen mit weilien Endspitzen, Sehwanz lang. die äuBeren Steuerfedern falst zur Hälfte weil. Flügel etwa 200, Schwanz,

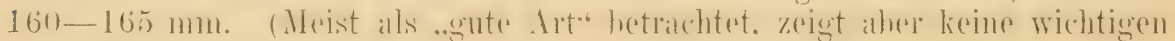
nenen Merkmale.)

Kaschmir und westliche 'l'eile des Himalaya bis Kumann, in Höhen bis weit über 8000 engl. Fuß.

\section{(Gattung GARRULUS Vieill. (Hix Brisson) 1s16. ${ }^{1}$ )}

Gekennzeichnet durch die auffallend lebhaft hellblauen, schwarz-

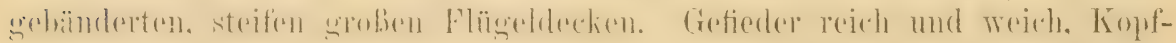
federn mehr oder minder haubenartig rerlängert. Die groben rundlichen oder ovalen Nasenlöcher von borstenartigen Federn verdeckt. Flügel

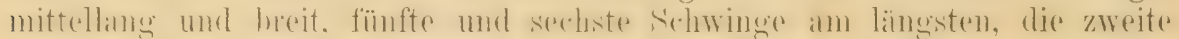
etwa so lang wie die Armschwingen, die erste fast halb so lang wie die

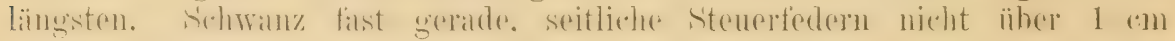
küızer. Hüỉe kräftig. Bauen offene Nester in Bäumen, Eier graulich oder griunlichweiß mit graugriinen Flecken bedeckt.

Alle palïaritischen Formen lassen sich als Unterarten einer Art betrachten. (Vgl. Kleinschinidt, Neue Bearl). des „Nauman"“6 p. 70, 71.)

Luropa, Nord-Afrika, Asien bis zum Himalaya, Japan und Formosa.

1) Man hat regen seines rermuteten Vorkommens in Japan einen wunderbaren Häher in die Liste der paläarktischen Vögel aufgenommen:

\section{Garrulus lidthi Bp.}

Dieser merkwürdige Vogel hat den Kopf, Hals, Flügel und Schwanz azurblau, Flïgelspitzen und Kehlstreifen weiB, Ober- und Unterseite braunrot.

Das Vaterland dieses seltenen Vogels ist noch unbekannt. Zwei lebend nach Florenz und Antwerpen (Paris) gelangte Stücke sollen aus dem "Innern ron Japan" gekommen sein. Da die Angabe der Insel fehlt, und der Vogel bisher nicht von Japan nachgewiesen ist, diirfte die sowieso Mißtrauen erweckende Angabe "aus dem Innern ron Japau" anzuzweifeln sein. (Siehe Bonap., Consp. Ar. I, p.376, P. Kool. Soc. London 1850, p. 80, Taf. XVII; Salvad., Atti Acc. Torino VII, 1872, p. 473; Cat. B. II, p. 102.) 


\section{Garrulus glandarius glandarius $\left(I_{i_{*}}\right)$.}

Der Eichelhäher.

Corvus glandarius Linné, Syst. Nat. Ed. X, p.106 (1758- Europa. 'J'yp. Lok. Selnweden. demn erstes Citat: Fauna Suecica 74).

Glandarius pictus Koch, Syst. Baier. Zool., p.99 (1816).

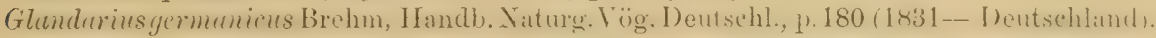
Glandarius septentrionalis Brehm, p. 180 (1831- „im Herbst nach Deutschland“).

Glandarius taeniurus Brehm, Vogelfang, p. 63 (185̌- "Wandert durch Deutschland"(!)).

Glandarius robustus Brehm, Vogelfang, p. 63 (1855- Deutschland).

Glandarius leucocephalus Brehm, Naumannia 1855, p. 273 (Nomen nudum!).

Glandarius vulgaris major, minor, alticeps, fasciatus, verus, brachyr.hynchus, A. Brehm, Verz. Samml., 1). 4 (1866 - nom. nuda!).

(Garrulus severtzowi Bogdanow, Vög. d. Wolga p.114- russisch, daher der Majorität der wissenschaftlichen Welt unzugänglich. Aus Kasan und Simbirsk, soll intermediär zwischen glandarius und brandti sein, mit rötlichem Oberkopfe, scheint aber nicht konstant zu sein.)

Engl.: Jay. Franz.: Geai. Schwed.: Nötskrika).

Sehmahelhorsten weiblich, Vorderkopf his fast zum Genich weiblieh mit hreiten schwarzen streifun. Oherseite hell rötlichgrau. der Rärken deutlich gratu, ron dem Hinterbalse mehr vder minder abstehend. ()helectien. Hals-

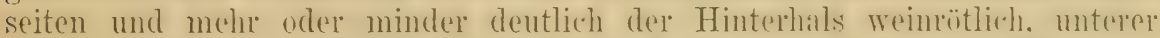

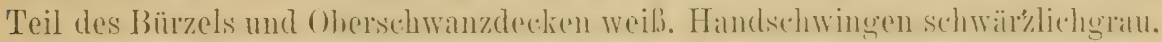

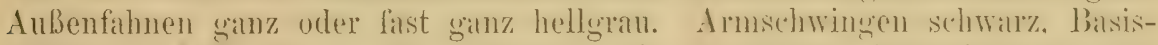

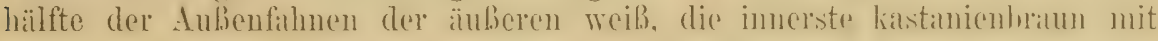
schwarzer Spitze. Schwanz schwarz, an der Basis bläulichgrau, schwarz oder hlau gehändert. Is leinste oberflügeldecken rötlichgrau, dic ïhrigen schön hellhlau mit scharfen schwaren. durch hergleitende, oft undentliche ganz schmale weife Linien gehohenen (Querhändern. Trangen schwall\%. einen kurzen. hreiten Bartstreifen hildend. Kinn und Kohle wriblicb, ührige

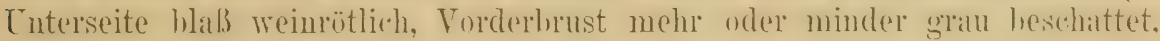
bauch und [nterschwanzdecken weil. Schnahel schwatr. Iris meist hläulichweils. Füße brëunlich fleischfarben. Flügel o 172-180, o 185-196, Schwanz

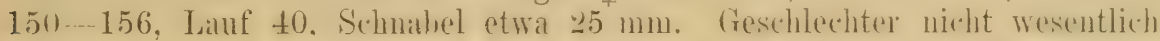
rerschieden, aher das o etwas kileiner. Junge den Alten ähnlich, aber oben dunkler, mehx rotbräunlich, Kopf nur wenig schwärzlich gesprenkelt.

Der Fichelhäher variiert sehr: Oberkopf bisweilen fast ganz schwarz,

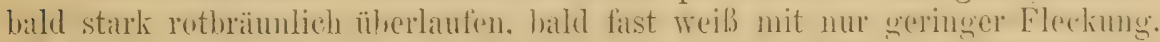

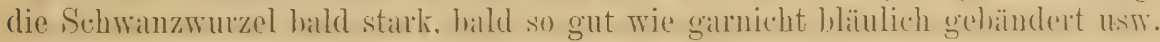
(Vgl. Kleinschmidt in Ornithol. Jahrbuch 189\%.)

Bewohnt Europa südlich des P'olarkeseses in Skimdinarien und südlich vom $63^{\circ}$ nördl. Breite in Rußland, östlich bis zum Ural und TVolgatal, sïdlich his ans Mittelmeer, wird aher anf den Inseln des Mittuhneeres mod

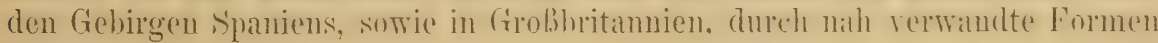
vertieten.

In der Lebensweise stimmen alle Häher überein. Sie sind unruhig, scheu, laut. Ihr rauhes, durehdringendes rrää, räätsch, und ihr der Stimme des Bussards und der einer Katze täuschend ähnliches Mianen sind allbekannt. Bewohner von Wäldern aller Art, nur in der Zugzeit und im Winter mehr in Gärten und offenem Gelände, in ganz baumlosen Gegenden unbekannt. Nahrung Insekten, Wiirmer, Niisse, Eieheln, 
Früchte, Eier und junge Vögel, besonders Zerstörer vieler 1)rosselnester. Nest offen. immer auf Bäumen, meist nahe am, aber auch oft weit rom Stamm, bald hoch, bald niedrig, ein grober, lockerer Bau aus 'Zweigen, mit wohl ausgefiitterter; weicher Iulde. Eier Mitte April bis Mitte MIai, 5--7 an K/ahl, auf hellgranem, gelblich oder grünlich grauweißem Grunde, meist über und iiber, oft mehr am stumpfen Pole mit blassen, braungrauen Flecken und Punkten bedeckt. Heist finden sich einzelne schwarze Haarziige oder Punkte, ungefleckte Kier sind äußerst selten. Maße normaler Eier etwa $34.1 \times 24$ bis $29.2 \times 21.4$ und $31.6 \times 23 \mathrm{~mm}$. Brutzeit 17 ' lage.

\section{Garrulus glandarius rufitergum suls1. nor.}

Ganz wie Garmlus glandarius glandurius, aber die Oberseite fast

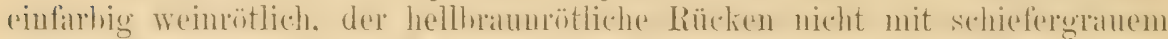

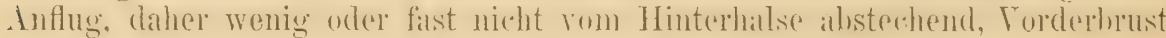
fast immer ohne grauen Schatten, Unterkörper meist etwas heller.

Großbritannien und Irland. Häufig in den waldreichen Gegenden Englands, lokal und seltener in Schottland und Irland.

Nach Untersuchung von fast 100 grobbritamischen Hühern und ïber 200 aus dem gesamiten Europa babe ich mich entschlossen, die englische

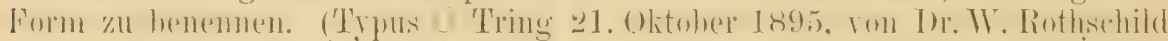
erlegt, Nr. 'T. 116 im 'Tring-Museum.) Die Unterschiede fallen in einer Serie sofort auf, und man findet kaum unter 50 ein Stïck, das typischen

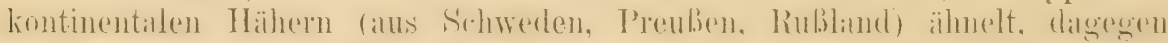

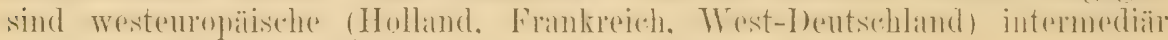
und bald mehr wie typische Schweden, bald wie rufitergum.

\section{5). Garrulus glandarius kleinschmidti sulıi. "m.}

Gilandarius vinlgaris obscuricapillus A. Brehm, Verz. Samml., p. 4 partim (1866-nomen nudum, nach Ausweis der Sammlung meist spanisehen Stïcken gegeben).

Wie Ġ. g. glandanizs, aber Schnabel auffallend stark, Oberschnabel etwas gebogen, Kropfgegend stark mit dunkel sehicfergrau überzogen, Oberkopf sehr breit und weit nach hinten scharf gestreift, Flügel kurz, o 180,181 , o $175 \mathrm{~mm}$.

\section{Süd-Spanien (Sierra Nevada).}

('Typus ơ ad., Nr. 182 Sierra Nevada, 21. November 1856, Dr. A. H. Brehm coll. Aus der Brehm'schen Sammlung, jetzt in Tring.) Benannt zu Ehren

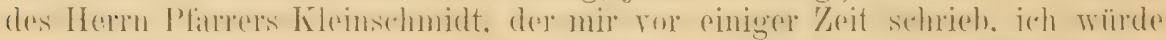

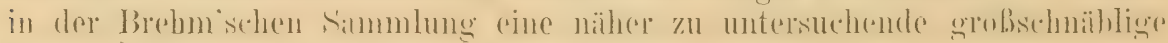
Form dès Eichelhähers finden. Drei Stücke untersucht.

\section{Garrulus glandarius ichnusae Kleinschm.}

Gavulus ichnusae Kleinschmidt, Orn. Mlonatsber. Juni 1903, p. 92 (Sardinien). Garvetus glandarizs sardus 'I'schusi, Orn. Jahrb. Juli 1903, p. 140 (Sardinien).

Dem G. g. glandarius sehr ïhnlich, aber etwas kleiner, was besonder's

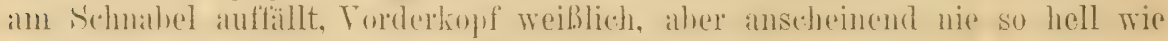
er meist bei jener Form ist. Genick und Hinterhals rötlich, sonst aber die

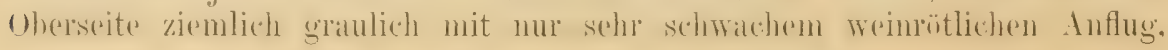




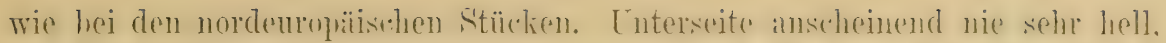
der (Oherseite ziemlich ähnlich, aher nicht ganz so gran. Torderbrust mit

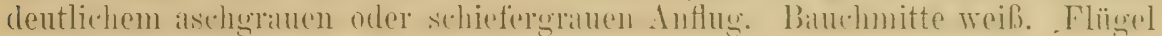
von fünf alten Yögeln $170-181 \mathrm{~mm}$.

Sardinien.

\section{Garrulus glandarius glaszneri Mad.}

Garulus glaszneri Madarász, Ornith. Monatsber. 1902, 1) 163 (Cypern).

Im ganzen kloiner als G.g.glandarius, besonders der Schnabel klein,

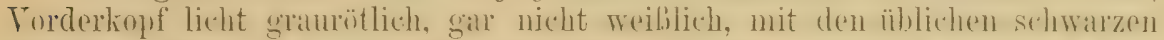
Streifen; frenick und Hinterhals graurätlich. Rücken graulich. vicelleicht noch etwas dunkler als hei Skitndinaviem. Unterseite dunkler, Kehle weiblich mit

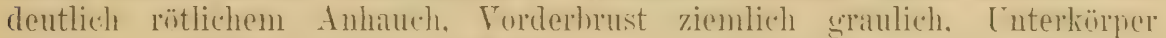
dunkler. Madarász gibt die Maße von 12 . Münnchen aus den Monaten Mai und Juni an: Flügel 165-176, Schwanz 155-168, Lauf 39 mm.

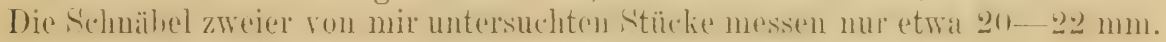
(Unterseite und Rücken viel mehr graulich als bei hymcams.)

Cypern.

\section{Garrulus glandarius hyrcanus Blanf.}

Garrulus hyrcenus Blanford, Ibis 1873, p. 225 (Mazandaran in N.-Persicn).

Kleiner als G. g. glandarius (Flügel etwa 160--170), die weintote Fïrhung intensiver, Enterseite dunkel weinrot-löünlich. Keble mu wenie heller (nicht weiß), Ober- und Torderkopf wie der Rücken mit schwarzen

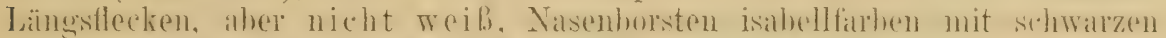

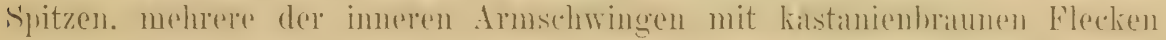
an den Außenfuhuen. Läufe kïrzer, etwa $40 \mathrm{~mm}$. (Unterseite und Rücken viel mehr rötlich als bei gluszneri.)

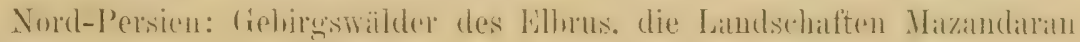
und Ghilan.

\section{Garrulus glandarius caspius Seeb.}

Garrulus atricapillus subsp. caspius Seebolm, Ibis 1883, p. 8 (Lenkoran).

Sehr ähnlich hyrcanus und meist mit dieser Form vereinigt, aber die sehwaren Elecke auf Scheitol und Hinterkopt sanz zusammenflichend (wie bei lrynicki und atricupillus), außerdem größer. Flügel $180-185 \mathrm{~mm}$.

Die Ebene von Lenkoran am Kaspischen Meere, also zwischen den

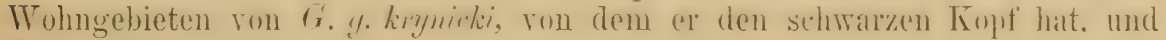
G. g. hyreancs, dem er sonst sehr gleicht, sitzend.

\section{Garrulus glandarius minor Verr.}

Garrulus minor Verreaux, Rev. \& Mag. Zool. 1857, p. 439, pl. XIV (Algérie).

Garrulus oenops Whitaker, Bull. B. O. Club VII, p. XV'III (Marokko. 'I'yp. Lok. 'lilula. Typus im Brit. MIus.). 
Ähnlich G. g. glandarius, aber viel kleiner, Oberkopf graurötlich oder

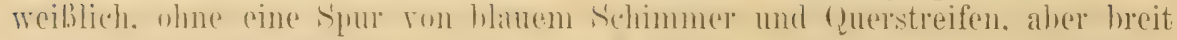

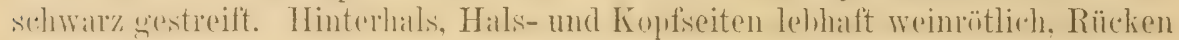

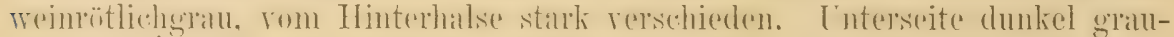
rötlich. Ánlich G. g. hyreanus, aber etwas kleiner und mehr rötlich an Hals und Kopfseiten. Flïgel 165, Schwanz etwa 145, Lauf 38-40, Schnabel 25-26 $\mathrm{mm}$.

Tilula und Enzel im marokkanischen Atlas und „Sïd-Algier".

Die Beschreibung und Abbildung von G. minor paßt vortrefflich auf den von Whitaker-als oenops beschriebenen Vogel. Auf die vermutliche Identität hrider hat sehon Kleinschmidt im neuen .. Naumanin" aufmerksan gemacht.

\section{Garrulus glandarius krynicki Kalenicz.}

Garmulus Krynicki Kaleniczenko, Bull. Soc. Mosc. XII, p.319, Taf. 9 (1839-- Kaukasus, typ. Georgiersk, l. c. p. 325).

Garrulus atricapillus subsp. anatoliae Seebohm, Ibis 1883, p.7 (Klein-Asien).

Dem G.g.glandarins im allgemeinen sehr ähnlich, aber größer, Haube sehr reich und lang, ganz schwarz, Stirn weil mit mehr oder minder rötlichem Anflug mod mit sehwarzen oder kisstanienhramen Flecken. Oherseite

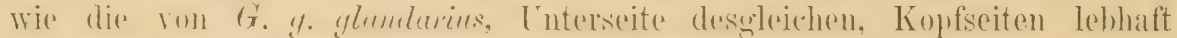
rötlich. Flïgel $186-205 \mathrm{~mm}$.

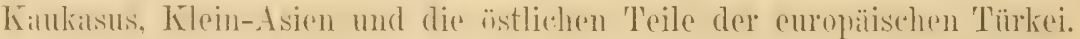

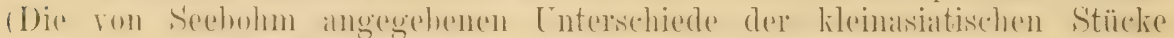

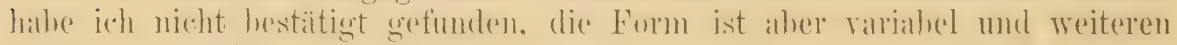
Studiums wert.)

\section{Garrulus glandarius atricapillus Geoffi'。}

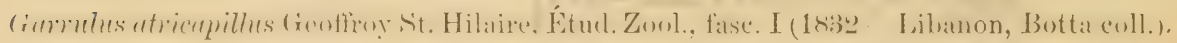
Pica stridens Hempr. \& Ehrenberg, Symb. Phys., Av, fol.z. (1833 $\left.{ }^{1}\right)$ - Syria).

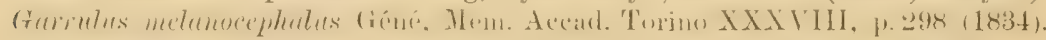
Garmlus iliceti Lichtenst., Nomencl., p. 9 (1854- nomen nudum, Syrien).

Vorderkopf rein weib, durch schwarzgefleckte Federn in die rein schwarze Haube übergehend. Ohrdecken und Kopfseiten rein weiß mit schmaler hell weinrötlicher Streifung. Kehle weiß. Oberseite sehr licht

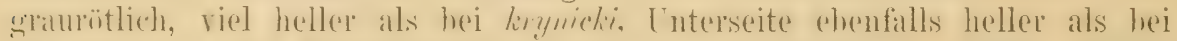

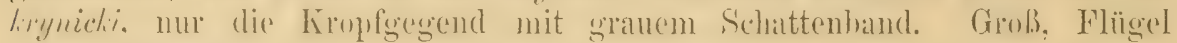
$180-190 \mathrm{~mm}$.

Syrien und Palästina bis in die Eichenwälder Südwest-Persiens.

\section{Garrulus glandarius japonicus Schleg.}

Gurvulus glundarius japonicus Schlegel, Hauna Japon, Aves, p. 83, 'Taf. 43 (18.18 - Japan)

Nasendecken schwarz mit weißer Basis, Zü gel größtenteils schwarz. Haube reich und weich, Federn breit, aber meist nicht sehr lang, bald

1) Auf dem 'Titelblatte ist 1828 angegeben, aber nur fol. a \& b und alle 'Tafeln erschienen in dem Jahre, der übrige Text mit den Sängetieren erst 1833. (B. B. Woodward \& Sherborn in litt.) 
schwarz mit schmalen weißen Ränderu, sodaß der Oherkopf vorwiegend schwarz erscheint, bald weil. mit schwarzem Mlittelstreif, sodil. der Oherkopt vorwiegend weib erscheint, Basishälfte der Aufenfahuen der meisten Handschwingen schwarz (eine Figentümlichkeit, die auch sinensis hat) sonst $G$. y. glumdarins ähulich, aber der schwarze Backenstreif aufwärts his zum Ange reichend, Kopfseiten dunkler, die Ohrdecken schwiirzlich übergossen, Oberseite dunkler, Brust und Kropfgegend dunkler, letatere mit schiefergrauem Anflug, Teichen lehhaft rimmtartig rotbraun. Flïgel etwa $160-170 \mathrm{~mm}$.

Die sïdlichen Inseln von Japan, auf Jesso fohlend.

In Lebensweise und Fortpflanzung unserm Häher gleichend, Nester meist ziemlich hoch auf Fichten und andern Bäumen.

\section{Garrulus glandarius brandtii Lversm. ${ }^{1}$ )}

Garrulus brandtii Eversmann, Add. Pall. Zoogr. fasc. III, p. 8 (1842- Altai).

Gefieder sehr weich und weitstrahlig, Oberkopf fuchsrötlich, mit schwarzen Jängsflecken, aher ohne alles weiB, Nasenfedern schwarz gespitzt, Hinterliopf und Hinterhals bis auf den Oberrïcken lebhaft liell fuchsrot, Cnterseite etwas mehr lotbräunlich, Kehle rotgellolich ïberlanfen, sonst unserer Form sehr ähnlich, auch von derselben Größe.

Sibirien östlich des Cral his Korea, Maudschurei, allernördlichstes China und die Nordinsel von Japan, Jesso.

Lebensweise und Fortpflanzung wie bei unsrer Form.

\section{Garrulus glandarius whitakeri sulsp. nor.}

Garmulus minor (non Verreaux!) Hartert, Orn. Monatsber. 1895, p. 169-171.

Nasenfedern weißlich mit dunklen Spitzen, Vorder- und Oberkopf schwarz, die vorderen Federn meh" oder minder auffallend weiBlich, die hinteren weinrötlich gesïumt, Nacken und Hinterhals hell weiurötlich braun, viel heller als hei 'rvicalis, davon scharf abstechend die ïbrige Oherseito hellgrau, ganz oder fast ohne rötlichen Anflug, Unterseite hell grauweiblich, Kropf und Seiten grau verwaschen, die letzteren auch etwas rötlich angeflogen, aber, wie auch die Unterflügeldecken, heller als bei crviculis. Kehle weiß, Federu rings um das Auge weiß, Ohrdecken rein weiß, nur die Spitzen von der Farbe des Hinterhalses. Größe wie die von cervicalis.

Nord-Marokko (Tanger, genaue Verbreitung unbekannt).

(Typus Ō, Mai 1894, Tanger, Marokko, Vaucher coll. Nr. 6348.)

Benaunt zu Ehren von Mr. Joseph I. S. Whitaker, und seine Terdienste um die Ornithologie der Atlasländer.

1) Im British-MIuseum befindet sich ein auf einer Auktion erworbenes Stück von Garrulus sinensis Swinh., das aus einer von Capt. St. John in Nagasaki angelegten Sammlung stammt. Es ist nicht nachzuweisen, daß es tatsächlich in_Japan erlegt wurde. G. sinensis gehört in die Gruppe von bispecularis und taivanus, die alle einen einfarbigen Oberkopf haben und einander sehr ähnlich sehen.

E. Hartert, Die Vögel der paläarlitischen Region. 


\section{Garrulus glandarius cervicalis $B p$.}

Garrulus cervicalis Bonaparte, Compt. Rend. Paris XXXVII, p. 828 (1853- Algerien).

Der ganze Oberkopf rein schwarz, nur an der Stirn die weißen Federwurzeln ansgedehnter und sichthar, Nacken und Hinterhals lehhaft rothraun, viel dunkler als bei whitakeri, von der grauen, mehr oder minder rötlich angehauchten Rückenfarhe scharf ahstechend. Körperseiten dunkler und mehr rötlich als bei whitakeri.

Nor(-Algerien und Nord-Tumesien, Bewohner der Korkeichenwïlder.

Lebensweise, Stimme und Fortpflanzung genau wie bei G. g. glandarius.

\section{Gattung PERISOREUS Bp.}

Der Gattung Garmelus am nächsten stehend, aber Schuabel gerader,

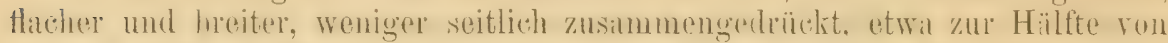
hreiten, steifen Niscuhorsten hedeckt. I) as ginze Gefieder sehr weitstrablig,

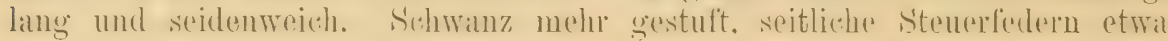
$2 \mathrm{~cm}$ kï̈rzer als die andern.

Nur eine Art in 2 einander sohr ähnlichen Formen in unserm Gebiote. Eine zweite Art in 5 Formen in Nord-Amerika.

\section{Perisoreus infaustus infaustus (L.).}

Unglïckshäher.

Corvus infaustus Linné. Syst. Nat. Ed. X, p. 107 (1758- „Hnb. in Europae alpinis sylvis" - typ. Lok. Schweden: erstes Citat Fauna Suecica).

Corvus Nimus $\left.{ }^{1}\right)$ Pallas, Koogr. Rosso-Asiat. I, p. 395 (1811- partim).

Perisoreus infaustus verus, brachyrhynchus, microrlynchus A. Brehm, Verz. Samml., p. 4 (1866- nom. nuda!).

Selıwed.: Lafskrika, Rödtjuxa.

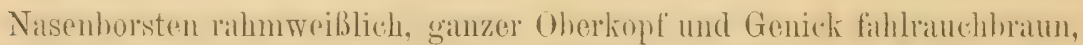
Rücken hellgrau mit braumem Anflug. Schwingen tiefhraun. Auliensäume hellgralu, Innensäume und Basis hell fuchsrot. die meisten größeren Obelflügeldecken hell fuchsot mit grauen Spitzen, Afterflügel aher hrïunlichgrau. Sehwanz hell fuchspot, Śpitzen und mittelstes Paal ganz gralu. Cuterseite hellgran. allmählich in den hell rötlich gelhhramen Dnterkörper ïbergehend. Iris bratun. Schmahel und FüBe schwarz. Flügel $140-145$, Schwanz 135- 140 , Lauf 35-37, Schnabel von der Wurzel an $23-25 \mathrm{~mm}$. o wie das $0^{*}$, nur etras kileiner. Junge auf dem Rücken düster braun, an der Enterseite fast einfarbig hell zimmtfirben, aber nicht blasser, wie Dresser (Mamual 1). 410 ) sast.

Bewohnt den Norden von Guropal von Christiania und dem sïdlichen Telemarken, his zur Birkenregion hinauf, Nord-RuBland, Estland und Livland. (Weilumathten 1857 in der Tatra, angehlich einmal auf Helgoland und in Schlesien und Dïnemark(?) vorgekommen.)

Bewohner der Nadelwälder des Nordens. In seinem ruckweisen, wie unsicheren, aber dabei ganz lautlosen Fluge erinnert er an unsern Eichelhäher. Er ist aber nicht

1) Im Cat. B. Brit. Mus. III, p. 103 wohl dureh einen Sehreib- oder Druckfehler als "C. russicus" zitiert. 
so scheu und klug und nähert sich ohve Scheu dem Menschen und seinen Wohnungen. Im Herumklettern hat er etwas meisenartiges. Hat einen rauh miauenden und einen mehr kreischenden 'L'on. Nahrung etwa die unsres Garulus.

Nest friil im Jahre, wenn die Wälder des Nordens noch voller Schnee liegen, nach Häherart, offen, mit Flechten und Haar ausgelegt, 3-4, ausnahmsweise 5 Eier, schmutzig oder blab grïnlichweiß mit tiefer liegenden granen Zeichnungen und oberfläehlichen braunen Flecken und Punkten bald mehr, bald weniger, meist aber nur am stumpfen Ende gehäuft. Im ganzen kleinen hellen Elstereiern ähnelnd. Maße: 20.5 <27.3, $22.8 \times 31.8,29.9 \times 21.8,31.8 \times 22.8,30.6 \times 23.6,30.5 \times 22.9,27.5 \times 22,33 \times 22.5$ usw:

\section{Perisoreus infaustus sibericus (Bodd.).}

Corvus Sibericus Boddaert, Labl. Pl. Enl., p. 37 (1783- Eix Daubenton \& Buffon).

Ganz wie P. i. injaustus, aber Vorderhals, Kropfgegend und Brust, wie

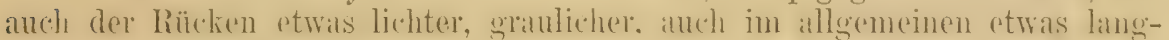
schwänzig’er und langflügliger.

Ganz Sibirien bis zum Amur und Sachalien, aber in Kamtschatka anscheinend fehlend.

\section{Gattum PYRRHOCORAX Vieill. (1s16).}

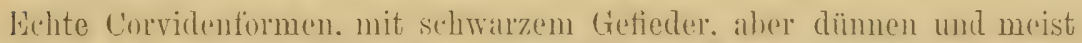

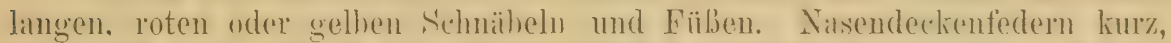
dicht und hart. Flügel lang. Schwanz fast quadratisch ahgeschnitten. Lä̈ufe hinten und vorn mit einer ungeteilten Schiene bedeckt, ein in dieser Familie ganz eigenartiges Merkmal. Nur ganz junge Tügel zeigen nech einige Anteilungen von sehildern, die aber bald anch verwatsen. Ich halte es mit Reichenow. Dresser. Hennicke. Arromi u. a. für umnötig die

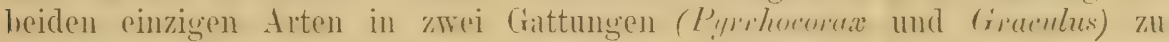
stellen. Gebirgsvögel. Europa, Nord-Asien und Nord-Afrika.

\section{Übersicht der Arten:}

Unterschnabel ungelähr ebensoweit befichert wie der Oberschnabel, Schnabel rot, so lang oder länger als der Kopf . . . . . . . P. pyrrhocorax . p. 35

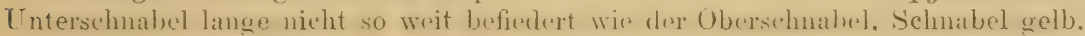

kürzer als der Kopf . . . . . . . . . . P. graculus . p. 36

\section{Pyrrhocorax pyrrhocorax (L..). $\left.{ }^{1}\right)$}

\section{Steinkrähe, Alpenkrähe.}

Upupa Pyrrhocorax Limné, Syst. Nat. Ed.X, p. 118 (1758- Ex Hasselquist's Iter, Albin t. 24, Ray, Will., "Hab. in Angliae, Aegypti maritimis“. Ich nehme als typ. Lok. Eingland an).

Coracia erythrorhamphos Vieillot, Nouv. Dict. d'Hist. Nat. VIII, p.2 (1817-- Alpes etc.). Fregilus europaeus Lesson. Traité d'Orn., p. 324 (1831- „l'Europe").

1) Oates, Fauna Brit. India, Birds I, p.43 nimmt für diese Art den Namen eremita (Corvus eremita 1766, p. 159) an. Wie sich das mit der Diagnose ("C. virescens, capite flavescente(!), occipite subcristato") rereinigen läßt, ist unverständlich, noch schlimmer aber ist, wenn anno 1902, also lange nach den Auseinandersetzungen von Rothschild, Hartert \& Kleinschmidt, Dresser C. eremita noch als Syuonym ron P. pyrrhocorax zitiert. Vgl. Manual Pab. Birds, p. 405. 
Pyrhocorax rupestris Brehm, Handb. Naturg. Vüg. Deutschl., 1. 175 (1831- höchste deutsche Alpen) (= Fregilus alpestris Brehm, Vogelfang, p.61, 1855. Brehm änderte seine Namen oft teils nach Belieben, teils aus Vergeßlichkeit).

Fregilus graculus major, macrorhynchus, microrhynchus A. Brehm, Verz. Samml., p. 4 (1866- nom. nuda!).

Engl.: Chough. Franz.: Crave.

Rein schwarz mit stahlblauem, die Flügel und der Schwanz mit metallgrïnem sehimmer. Sehmahel und Fïbe mangerot. Sehmahed so laug

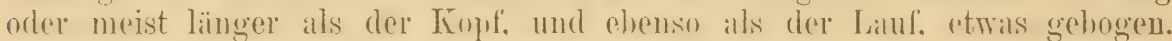
Cntersehuabel an der Basis fast ehemson weit hetiedert wie der Ohersehuahel. Iris braun. Flügel 27--31, Schwanz 15-17, Schuabel 45-58, Lauf $45-53 \mathrm{~mm}$. \& wie o, nur kleiner, besonders der Schnabel kürzer. Junge wie die Alten. nur das Gefiedex matter, der Sohnahel sehmutzig orange, die Fïße braungelb.

Nord-Asien (den hohen Norden ausgenommen) von Ost-Sibirien bis Kloin-Asien. Nord-Afrika his zu den ('anaren. die Mittelmeerländer, an dex westfranzösischen Kü̈ste lis zu den Normannischen Tnseln nud nordwärts bis England. Sehottland, den IIehriden und Irland. Auberdem im Alpengehiete, seltener Gast in den bayerischen und österreichischen Alpen. ${ }^{1}$ ) Augenscheinlich seltener als frïher. Sowohl in den Alpen, wo sie lukal und lange nicht so hänfig wio die Alpendohle rortimmut, als anf den englischen Inseln.

Gebirgsvogel, nur an den Seekiusten auch mit niedrig gelegenen Felswänden vorlieb nehmend (England, Irland, Normannische Inseln, Canaren). Flug schwebend, graziös, gewandt, Ruf klar und schrill, wie kria oder dla, dla, Nahrung ebenso mannigfaltig wie die andrer Corviden. Heist wenig scheu. Nester nach Krähenart an Felswänden, seltener an alten Burgen, 'Türmen, und selbst bewohnten Häusern, im April und Mai 4-5 lier, die olivenbräunlich weile Grundfarbe haben und mit olivengraubraunen Schalenflecken und dunkler olivenbraunen Zeichnungsflecken geschmïckt sind. Sic messen etwa $40.78 \times 27.97,36.5 \times 27.8,40 \times 21.5$ bis $43.2 \times 28,40 \times 28$ usf.

\section{Pyrrhocorax graculus (L.). $\left.{ }^{2}\right)$}

Alpendohle.

Corvus Graculus Linué, Syst. Nat. Ed. XII, p. 158 (1766- Ex Gesner Aldr., Alb., Will., Raj., Synon. partim! - "Hab. in Helretiae alpibus").

$\left.{ }^{1}\right)$ Es scheint mir nach dem von mir untersuchten Material nicht möglich zu seiu, mit einiger Befriedigung im paläarlitischen Faunengebiete von West-Luropa bis OstSibirien hin Unterarten zu trennen. Die Himalaya-Vögel wurden von Gould als Fregilus himalayanus (P. Z.S. 1862, p.125) getrennt. Zwweifellos haben sie die Tendenz, größer zu sein, denn meist sind die Himalaya-Vögel sehr groß, besonders haben sie längere Flïgel und Schnäbel. Ihre Maße werden aber von Europäern (Canaren) oft erreicht und Sharpe, Oates u. a. sprechen sich gegen T'rennung aus. Die chinesischen Vögel wurdeu als var. brachypus (Swinhoe, P. Z. S. 1871, p. 383) beschrieben, weil sie kleinere Füße haben sollen. In der T'at ist dies oft der Fall, aber nur teilweise, die Form wird daher ron den meisten neueren Ornithologen nicht unterschieden. Wenn man sie auf Grund größerer Serien doch trennen sollte, dürften aber die ost-sibirischen Vögel kaum dazu gehören, obwohl T'aczanowski sie dazu rechnet.

2) Man nimmt jetzt ziemlich allgemein diesen Namen für die Alpendohle an, denn wenn auch nur ein Teil der angegebenen Bücherstellen paßt, so stimmt doch die Diagnose. Corvus pyrrhocorax Syst. Nat. Ed. XII (1766), p.158 ist ein Gemisch, 1758 aber ist der Name unanfechtbar für die Alpenkrähe gut festgelegt. 
Pyrrhocorax alpinus Vieillot, Nouv. Diet. d'Hist. Nat. VI, p. 568 (1816- Alpes).

Pyrhocorax alpines var, digitutus Henupr. \& Ehrenhurg, Symb. Ihys. fol. z. (1833-Syrin). Pyrrhocorax montanus Brehm, Handb. Naturg. Vög. Dentschl., p. 176 (1831- Schweiz und Tirol).

Pyrrhocorax Forsyth $\imath^{3}$ Stoliczka, Stray Feathers 1874, p). 462 (Ladak).

Pyrrhocorax planiceps Brehm, Naumannia 1855, p. 273 (Nomen nudum!).

Pyrrhocorax alpinus major, gregarius, alticeps A. Brelım, Verz. Samml., p.4 (1866nom. nuda!).

Engl.: Alpine Chough. Franz.: Chocard. Ital.: Gracchio.

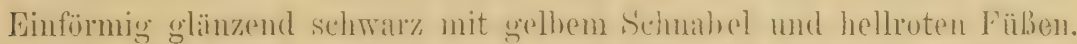

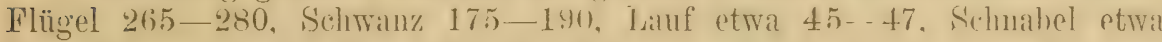

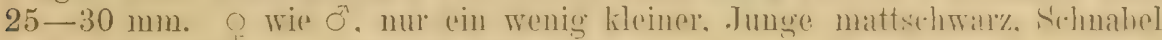
und Füße mehr oder weniger brïunlich.

Die Borgo Süd-Europas von den Alpen bis in die Apennineu, die iherische Halbinsel, Griecheuland. P'alïstinat und Klein-Asien his zum Kankasus und im Himalaya von Kaschmil bis Bhutan.

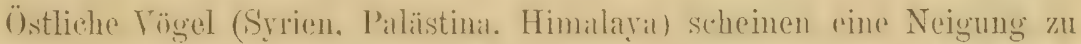
größereu Dimensionen zu haben. hefricaligende [nterartun aluen sind nach dem von mil untersuchten Material nicht abtreunbar.

Obwohl lokial in Sü̈l-Spamien rerhreitet. ist das Torkommen in Marokko

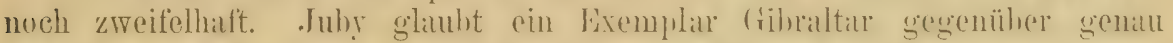
erkannt zu haben und im Rothschild'schen Musem hetinden sich zwei

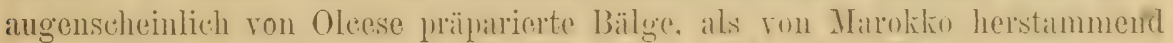

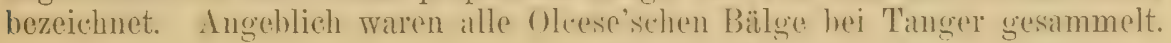

Die Alpendohle ist ein strikter Grebirgsbewohner, der im Sommer bis in die Gletscherregion aufsteigt. Immer gesellschaftlich. Flug gewandt und sehr oft mit ausgebreitetem Schwanze schwebend, in Schneckenlinien auf- und absteigend. Stimme ein eigenartiges krui, krui, selten ein dohlenartiges Jauchzen. Nahrung krähenartig. Nisten gesellschaftlich von der Schneeregrion bis in die obersten Ansläufer der Waldregion in Spalten und Löchern schroffer Felsenwände, bisweilen auch in Ruinen, Nester gut und dicht mit Haaren gefüttert, auf großer Unterlage. Eier 4-5, April und Mai, denen der Alpenkrähe ähnelnd, aber kleiner. Maße: $35.9 \times 25.6,39.5 \times 25.1$, $38.7 \times 26$ bis $41.8 \times 26.4 \mathrm{~mm}$.

\section{Gattung PODOCES Fischer (1823).}

Die Gattung Podoces umfaßt 5 Arten, die man am passendsten als "Laufhäher" bezeichuen dürfte. Sie hahren lange, starlie Läiufe. hintum mit. zwei langen, parallelen Platten, vorn mit etwa s' groben duertaloln bodeckt.

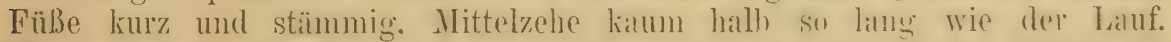

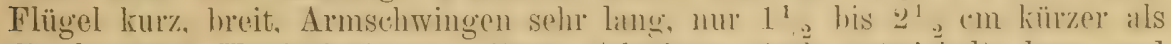
die längsten Handsehwingen. Histe S'hwinge stark entrickelt, limg und breit, etwa $2 / 3$ der $z$ weiten, nur bei $P$. hrmilis etwa $1 / 2$ der zweiten, die 3.-5. oder 3.-6. fast gleich und an längsten. Schwanz mäl.jig ahgerundet, ziemlich weich, das ganze Gefieder sehr wereh. mehr vder minder ri üstenfallig. Schnabel gestreckt, dümn, otwas gelongen. die ganze Basis mit dirhten Nasenborsten, Zügel mit anfstehenden, kuren Federn bedeckt.

Alle Arten sind Bervohner der centralasiatischen Steplen oder wüstrnartigen, sandigen, spärlich bervachsenen Hochebenen. 
Übersicht der Arten:

1 f Flügel unter $100 \mathrm{~mm}$, etwa Steinschmätzergröße . . . . P. humilis . p. 40

\{ Flügel über $100 \mathrm{~mm}$, etwa Drosselgrößse . . . . . . . . 2

2 $\int$ Oberseite lichtgrau . . . . . . . . . P. panderi . p. 39

2 Oberseite rötlichsandfarben . . . . . . . . . . . 3

f Oberkopf schwarz mit stahlblauen Schimmer ... . . . . . . 4

3) Oberkopf wie der Rücken . . . . . . . . . . P.pleskei. p. 39

1 Schwanz stahlblau .............. P. hendes'soni. p. 38

4 Schwanz weißlich mit schwarzem Schaftstrich ..... P. biddulphi. p. 38

\section{Podoces hendersoni Hume.}

Podoces hendersoni Hume, Ibis 1871, p. 408 (Yarkand).

ơ ad. Oberseite röthich sandfarben, die Schulterfedern dunkler, etwa

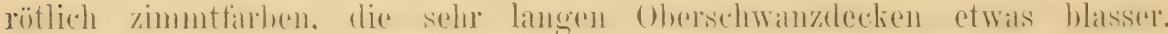
Oherkoff und Genick hausshwar\% in frischem Gefieder mit weiben Spitzenflecken, die sich nachher abuutzen. Handschwingen weiß mit schwarzer

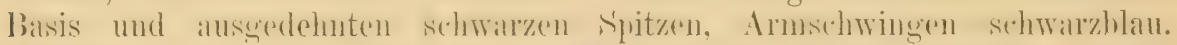

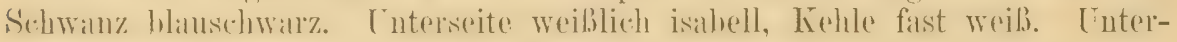
flïgeldecken schwarz. Flügel 140-145, Schwanz 110-118, Schnabel von der Wurzel 38-42, Lauf 39-42, Mittelzehe ohne Nagel etwa $19 \mathrm{~mm}$.

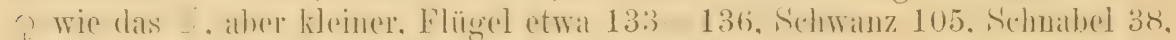
Lauf $36 \mathrm{~mm}$, auch in der Farbe etwas dunkler.

Von Yarkand bis in die Mongolei, Nord-Tibet und Wüste Gobi.

Bewohner der offenen Wüste, wo sie in den Wagenspuren, auf den Wegen umherlaufen und Insekten (oft am Pferdedünger) und Sämereien auflesen. Rapide Läufer, schwer zum Fliegen zu bewegen. Nest und Eier noch nicht beschrieben.

\section{Podoces biddulphi Hume. (Fig. 10.)}

Podoces biddulphi Hume, Stray Feathers II, p. 503 (1874- Ost-'Turkestan, typ. Lok. Haralbash).

Dem P. hendersoni ähnlich, aber gröber, die Keblseiten schwarz, Kehle schwall und weilis gemiseht, indem die Federn mattsehwarz sind mit langen

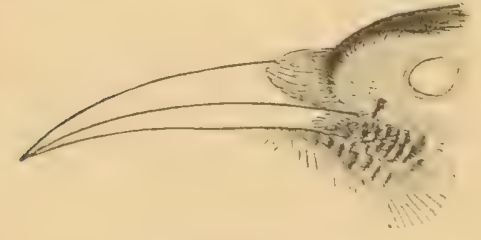

Figur 10. weißen, die schwarze Grundfarbe in unabgenutztem Gefieder fast ganz verdeckenden Spitzen. Die drmschwingen sind nicht ganz blauschwarz wie die rou $P$. hendersomi, sondern haben breite weiBe Spitzen, die inneren auch großenteils weiße Innenfahmen. Schwanz weiß, die Schäfte schwarz, die mittleren mit breiten schwarzen Schaftstreifen. Flügel etwa $152-154$, Schwanz

110-114, Schmibel 45-51 (von der Basis), Lauf 47-48 mm.

Ost-Turkestan.

In der Lebensweise seinen Gattungsgenossen rollkommen ähnlich. Oberst Biddulph traf sie mehr in buschreichem Gelände an. Aufgeschreckt setzten sie sich auf die Spitzen der Büsche, waren aber auch vortreffliche Renner. Der lilug ist beschwerlich, wellentörmig, kurz. Eier noch unbeschrieben. 


\section{Podoces panderi Fisch.}

\section{Saxaul-Häher.}

Podoces panderi Fischer, Mém. Soc. Imp. Nat. Moscou VI, p.251, pl. XXI (1823 - Sandwüste Kysil-Kum, Eversmann coll).

Farbenverteilung wie bei $P$. pleskei, aber Oberseite hellgrau und Schmabel kürzer. - Oherseite hellgrau, auf dem Bürzel ins rötlich Fahmfirbene ziehend. Die kurzen Oberschwanzdecken sehwarz. Handschwingen an der Wurzel und Spitze schwarz, in der Mitte $2 \%$ bis $5 \mathrm{~cm}$ weit weiß. Aruschwingen weils mit schwarzen Schäften und schwarzer Wurzelhälfte. Kleme Elügeldectien wie der Rürlien, die groben selowarz mit 6 bis $9 \mathrm{~mm}$ weiten weiben Spitzen. Schwanz schwarz mit starkem stahlhlauen Glanze. Yü̈gel schwarz. Ohrdecken und Halsseiten wie der Rücken, Kehle weiblich, auf dem Kropfe ein grober, fast dreieckiger schwarzer Fleck. Die übrige Cnterseite rötlich isabell, Mitte des Lnterkörpers weißlich, Cnterschwanzdecken und Lnterflügeldecken weils. Schmabel schwar\%, Fübe hräunlichorau. Flïgel 116 (๑) bis 125 (ठ̋), Schwanz 92-102, Lauf 40-42, Schnabel 28-31 mm. Q ganz wie $\sigma^{\pi}$, nur etwas kleiner. Der junge Vogel ist oben blasser und sandfarhigere, die Lnterseite hlasser und ganz ohne den schwarzen Kropffleck, auch fehlt der schmarze Zügelfleck, Oberschnahel braun. Tnterschuabel gelblich. (Nach 15 Exemplaren im Rothschild'sehen Musemm.)

Transkitspien und 'Turkestau. Bewohner der mit Saxaulbüschen (Aludusis ammodendron) bervachsenen Wüstensteppe.

Über die Lebensweise dieser Art sind wir durch Bogdanow, Zarudny und Floericke gut unterrichtet. Er läuft mit großer Schnolligkeit auf den mit Saxaul bestandenen sandigen Steppen herum, sitzt auch wohl auf Büschen, fliegt ungern, nie sehr weite Strecken, häherartig, bogenförmig, ruckweise. Stimme ein überraschend lautes Schwirren, das mit dschi-dschi-dschi, oder türr-türr-türr übersetzt wird. Es ist ganz eigenartig und merkwürdig. Dann hat er (nach Floericke) auch noch einen wie glick, gliick klingenden, spechtartigen Lockruf. Den Schwanz breitet er oft fächerartig aus. Sehr munter, unstet, rauflustig. Das ziemlich große Nest steht in Büschen, meist nicht höher als höchstens ein Nieter hoch, ausnahmsweise auch in Erdlöchern (nach Zarudny), besteht aus dürrem Reisig und ist mit feinen Gräsern, Haaren oder Federn ausgefiittert und nach Elsternesterart mit einer Haube versehen, sodaß es nur durch ein Flugloch erreicht werden kann. Es enthält im Februar bis März 4-5 (oder auch nur 3) Eier, die blaß grünlichgrau bis sehr hell gelblichgrün sind, mit graubraunen und olivenfarbenen Flecken, etwas an die von Perisoreus erinnernd. Sie messen etwa $27 \times 19 \mathrm{~mm}$. Nach Floericke werden 3 Bruten im Jahre gemacht(!). Die Nahrung des Saxaulhähers besteht aus Käfern und deren Larven und andern Insekten, später im Jahre melır aus Sämereien, besonders den Samen des Saxaul.

\section{Podoces pleskei Zar. (Fig. 11.)}

Podoces pleskici Zarudny, Annuaire Mlus. zool. Acad. Imp. Sc. St. Pétersb. I, 1896, p. XIX (Alkor in Ost-Persien). Härms, Orn. Monatsber. 1897, p. 182.

Hat die Farbenverteilung und dir kuren, schwarzen Oherschwanzdecken des I'. premeleri, Sehmilux aluer länger und Grundfarhe nicht gratu. sondern rötlich sandfarben, wie bei $P$. hendersoni und $I$. biddulphi. - Ganze Oberseite rinfërmig rötlich sandfarhen. Oberschwanzdecken ganz kurz und selhwarz wie bei $\ell$. panderi. Zügelfleck schwarz, um das Auge herum weißlich. Handschwingen: Wurzel, Spitzen und Schäfte sthwilm. in der Mitte :3-tem 
weit weiß. Armschwingen schwarz, Spitzen $1 \frac{1}{2}-2 \frac{1}{2} \mathrm{~cm}$ weiß. Kleine Flügeldecken wie der Rücken, die gröberen scluwar\% mit weiben spitzen, die eine lureite Binde bilden. Schwinz schwarz mit starkem stahblatuen Glinze. Kimn und obere Kehle weiß, anf dem Kropfe ein grober dresedkiger

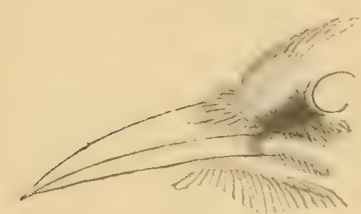

Figur 11. schwarzer Fleck, die übrige Unterseite wie der Rücken, in der Mitte des Unterkörpers und an

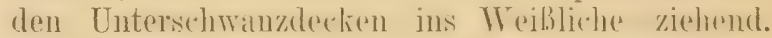
Unterflügeldecken weiß. Q ad. ganz wie ôad. Flïgel 120-12:3. Shwallz st-94. Laituf 43. Schnabel von der Wurzel $35-38 \mathrm{~mm}$. Der junge Vogel ist blasser, nicht so rötlich, der schwarze Fleck vor dem Auge ist undeutlich und der grobo schwarze Kiropffleck fohlt ganz. (Der junge Vogel wurde von Dresser, Mimual Pal. B. p. 407, irrtümlich als das o beschrieben.) (Beschreibung nach 4 von Zarudny gesammelten Bälgen im Rothsehild'schen Museum.)

Das nördliche Ost-Persien (östlicher 'Teil der Wüste Lut).

Gleicht in der Lebensweise seinem nahen Verwandten $P$. panderi, von dem er vielleicht nur ein geographischer Vertreter ist, doch soll er noch rascher laufen können. Nest niedrig in Büschen, aber auch bis $3 \mathrm{~m}$ hoch ïber dem Boden. Das Nest gleicht dem von $P$.panderi, die Eier 4-6, von lehmgelber Grundfarbe mit graubraunen und olivengrauen Flecken und Punkten, messen $26^{1 / 2} \times 20 \mathrm{~mm}$.

\section{Podoces humilis Hume. (Fig. 12.)}

Podoces humilis Hume, Ibis 1871, p. 408 (Yarkand, typ. Lok. Sanju-Pass).

Oherseite bab bramn, an sehmutzighranen simd erimnerud. Hinterhals

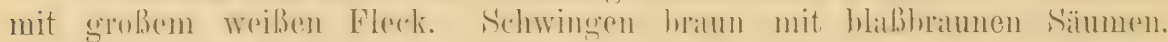
Steuerfedern weiß, die beiden mittelsten Pare dunkelbraun mit brïunlichweißen Anßensäumen, die sich abreiben. Zügel weiß, die Federn in der Mitte mit schwarzen Spitzen. Unterseite rahmweil, Unterflügel schmutzig rahmfarben. Iris braun. Schnabel und Füile schwarz. o wie das ${ }^{r}$. Junge den Alten ähnlich, aber unten etwas gelblicher, oben etwas dïsterer, Schmabel

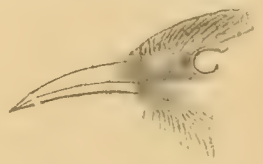

Figur 12. braun. Flügel $90-93$, Schwanz etwa 65, Lauf 28, Schnabel $23 \mathrm{~mm}$.

\section{Yarkand, 'Libet bis zum Kuku-Nor und Kan-su.}

Bewohnt grasbewachsene Hochflächen, wo er am Boden herumläuft, aber sich auch auf Büschen niederläßt. Briitet in Löchern an Erd- und Felsenwänden und legt reinweiße, denen der Montifringilla-Arten ähnliche Eier, welche $21.6 \times 16.2,23.5 \times 16$, $22.5 \times 16.5$ messen. Weil diese Eier so völlig von denen von Porloces panderi abweichen, haben viele Eierkenner die richtige Bestimunung derselben angezweifelt. Rückbeil aber, der bekannte entomologische Sammler 'T'ancré's, versicherte in mehreren Briefen, daß ein Irrtum nicht vorliegen könne, da er viele Nester gefunden. Es ist interessant zu erfaluren, daß er Podoces humilis, dessen Namen er nicht kennt, als "Steinschmätzer" bezeichnete.

P. humilis weicht etwas von den andern Podoces-Arten ab, ich ziehe aber vor, ihn nicht generisch zu trennen. 


\section{Familie STURMIDAE.}

Flügel mit 10 deutlichen Handsehwingem, erste Handschwinge aber sehr kurz. 12 Stenerfedern. Nisenlioher frei. alle palïarktischen Formen ohme Schnaloelborsten. Lauf hinten ron zwei rollkommenen. ghatten Schienen unschlossen. Schnabelränder glatt oder mit einem flathen Zahm an ()her-

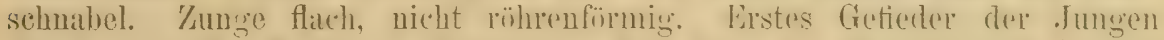
meist gestreilt. Nester in Höhlungen. Hier hlau. hei Eiv'nde's und Culurnis gefleckt. Nur eine Mauser im Jahre. Berrohnen die gesimnte alte IV elt.

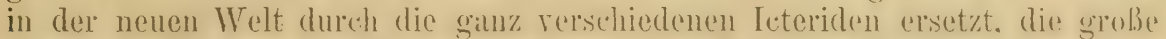
hängende Röhren oder híngehn wehen, oder (Holothrus) Brutpatisiten sind.

\section{Gattung STURNUS L. 1758.}

Umfint die allbekimuten Stare. nit verlïugerten und spitz'n Federn an Kopf, Hals und Vorderhrust, in Aiter mehr oder minder stirk metallisch

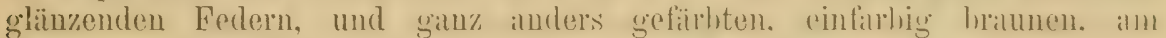
Unterkörper weiblich gestreilten .Jungen. lieschlechter nicht wescutlich

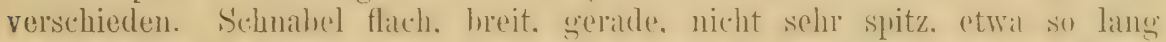

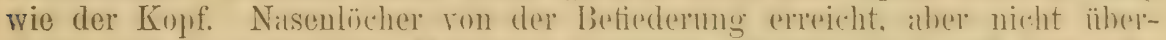
deckt, von einer hornigen Memhlian heschützt. H'lügel lings und spit\% die? erste Schwinge ganz kurz, nur etwa 1-2 cm lang, die zweite am längsten, dritte nur sehr wenig kürzer, von da an ziomlich regelmäßig bis zu dou Armschwingen hin abnehmend. Schwanz etwa halh so limg wie der Flïgnl.

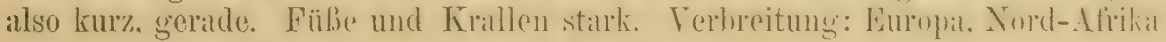
und der größte Teil des asiatischen F'estlaudes.

Alle Stareuformen mit Ausnahme von Sturnus unicolor sind zweifellos als Unterarten einer Art zu betrachten. Weder die verschiedenen bunten Farben, noch die Gröbenunterschiede hahen mehr als sulsipezitischen IV ert. Die Subspezies vertreten einander in den Brutgehieten. kommen aher' and" der Wanderung und in den Winterpuntieren trilweise zusanmen ron.

Man könnte schließlich auch $S$. unicolor als Cnterart von S. vulyaris auffassen, denn als Brutvogel rertritt ar den letateren im Mittehneergehiete, er ist aber weiter von den übrigen Stumus-Formen getrennt, als jene von einander. Die roten. Grïnen und stahlblatuen Farben sind bei ihm nicht nebeneinander verschieden verteilt. sundern gleichmäbig gemischt. sodilfs sie ein unreines, glänzendes Schwarz ergehen, die Federn sind viel stärker verlängert. die weibe F'leckung sehr gering, das Herthsthleid gran ïhoryenten.

\section{Übersicht der Arten:}

Ad.: Mit sehr verschiedenen metallisch glänzenden Farben. . . . S. vulgaris . p. 41 Ad.: Ëinförmig graphitschwarz mit schwachem Purpurschimmer, nur die Flügel-

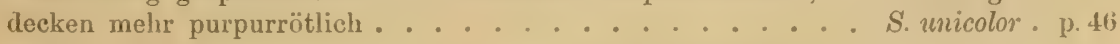

\section{+71. Sturnus vulgaris vulgaris L.}

\section{Der Star.}

Sturnus vulgaris Linné, Syst. Nat. Ed. X, p.167 (1758 - 'Iyp. Lok. Schweden, ex F'auna Suecica, erstes Citat).

Sturnus varius Meyer, Taschenb. Vög. Deutschl, I, p. 208 (1810). 
Turdus solitarius Montagu (nee Latham, Gmelin!), Orn. Dict. Suppl., Art. "Ihrush" (1813- errore! Beschreibung und Abb, eines jungen Stars!).

Sturnus domesticus Brehm, Handb. Naturg.Vög. Deutschl.. p.398 (1831- mittl. Deutschl.). Sturnus sylvestris Brehm, Handb. Naturg.Vög. Deutschl., p.398 (1831- mittl. Deutschl.). Sturnus nitens Brehm, 1. e., p. 399 (1831- Renthendorf auf dem Zuge).

Sturnus septentrionalis Brehm, Handb. Naturg. Vög. Deutschl., p. 400 (1831-- „bewohnt die Färöer-Inseln und andre nördliche Länder, besucht das mittl. Deutschl. im Februar, März und Oktober usw." Dn Brehm's Beschreibung nichts für den Färöer Star charakteristisches enthält, Brehm offenbar auch Schweden, die typische Lokalität fiir vulgaris, in seine Verbreitung einschließt, und der Färöer Vogel nie Deutschland besucht, auch Brehm's Sammlung nur deutsche vulgaris unter dem Namen septentrionalis enthält, ist es nicht angebracht, den Namen septentrionalis für den Färöer Star zu verwenden).

Sturnus Hollandiae Brehm, Handb. Naturg. Vög. Deutschl., p. 1016 (Holland).

Sturnus guttatus Macgillivray, Hist. Brit. B. 1, p. 595 (1837).

Sturnus vulgaris intermedius Prazák, Orn. Monatsber. 1895, p. 144 (Mittel-Europa).

Sturnus sophiae Bianchi, Ann. Mus. zool. Ac. Imp. Se. Petersburg 1896, p. 129 (T'wer \& St. Petersburg).

(Sturnus longirostris, batavorum und tenuirostris Brehm sind nomina nuda.)

Engl.: Starling. Franz.: Etourneau. Ital.: Storno. Schwedisch: Stare.

Oad. nach der Herbstmanser: Schwarz mit bunten. metallischen Reflexen: Kopf und hehle dunlelgrün. mit wher whe Purpursthimmer. ohrdecken

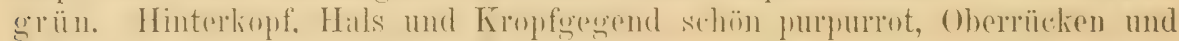

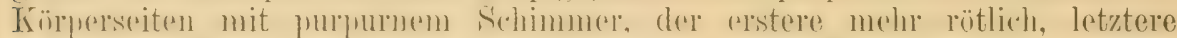

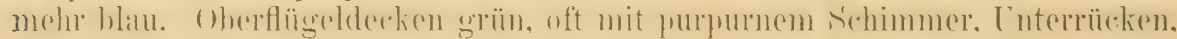
Bürzel, Oberschwanzdecken, Brust und Unterkörper grün, die F'edern der Oherseite mit hell sandighramen. die dere Interseite mit weiben spitzen, sodak die Grundfarbe nieht gut zu sehen ist. Im Laufe des Jahres nutzen sich die Federn sehr stark ab, die Fahnen werden schmäler, die weißen Spitzen

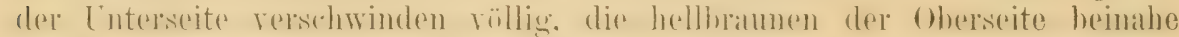

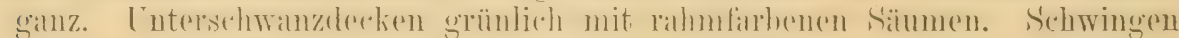
tiefluamm mit liehthramnen Sïmmen. vor den Sirtzen mit groben aschgranen

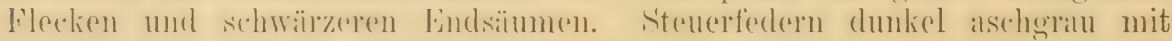
hell lichtbraunen Säumen. Unterflïgeldecken immer braun mit hell

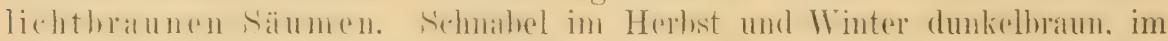
Frühling und Sommer gelb. Füße rotbraun, Iris hellbraun. Flügel etwa 128-134, Schwanz 64-68, Schnabel 22-25, Lauf 28-30 mm. 우 wie

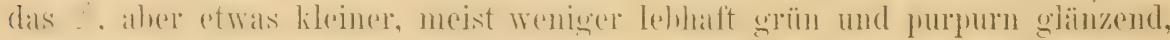

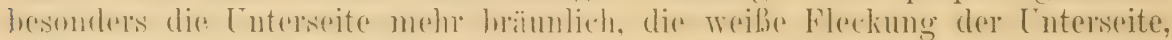

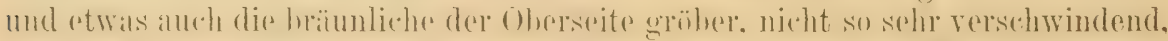

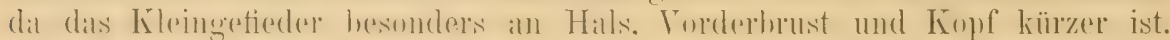
Jung: Ganz verschieden, einfarbig erdbraun, Schwingen und Schwanz mit

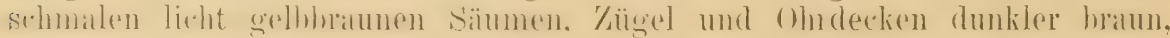
Kehle in der Mitte weiß, Unterkörper mit weißen Streifen.

(Schon C. L. Brehm machte durch die verschiedenen von ihm benannten Staarenarten den Nachdenkenden auf eine große Variation in Maßen und

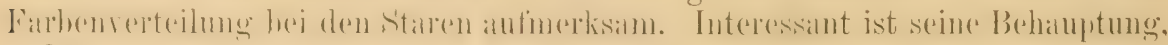
daß bei Renthendorf während seines dortigen Aufenthaltes eine andre langschnäbligere Starenform eingervandert sei. Die Belege in seiner Sammlung aber zeigen, daß die von ihm gesehenen Verschiedenheiten nicht artliche oder subspezifische waren, sondern höchstens vielleicht Familien- 
cigentümlichkeiten darstellten. Nenerdings hat Sharpe behauptet. daß in England die von ihm als ..typisch" hezeichnete, ganz grünkïpfige Form heimiseh oder doch rorhertschend sei, und dab eine ,intermediare" Form mit mehr oder weniger purpurotem Kopf und Kehle, aher noch grönen Ohrdecken, in Europa zwischen den Wohngehieten des ..echten englischen,

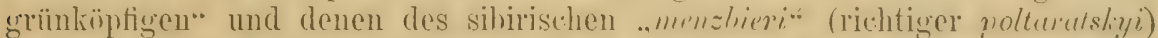
wohne. die auch Fingland, hesmulers die ëstlichen Grafichaften, ,hesuche". Prazák bename diese Form intrmedine, Bianchi cin Jabr spaiter rophine. Die Untersuchung sehr groben Materials, hantsiichlich zu Tring und im BritishNuseum, hat mich zu der C̈herzeugung gehracht. dab diese Form nicht halthar ist. denn auch schwedische mol englische Brutvingel haben schr oft ehenso viel purpurroten Schimmere wir jene, und dab anch letatere (Rubland) nicht selten eiuen ganz, grünen hopf hahen. C̈herhaupt ist die Färbung dieser' 'Teile sehr' variabel.)

Europa rom nördlichen Norwegen und etwa 64 bis $60^{\circ}$ nördl. Breite in RuBland his Süd-Europar. Pyrenien. Italien, in S'́̈dost-Europa durch S. v. purpurascens vertreten. Auf dem Zuge bis nach Madeira und den Canaren, sowie ganz Nord-Afrikit ron Marokko bis Ägrpten. In Eingland und Süd-Lurona immer, in den milderen westlichen T'eilen Dentschlands häufig überwinternd, und Stand- oder Strichvogel. Sonst Zugvogel.

Der Star ist ein Bewohner von lichten Laubwäldern mit hohlen Bäumen, besonders Eichen, zumal wenn Wasser oder ausgedehntes Wiesenland in der Nähe, man findet ihn aber auch in baumarmen oder selbst baumlosen Gegenden, wenn er Felsenwände oder Gebäude hat, an denen er nisten kann. Wasserloses Gelände liebt er nicht. Ein lebhafter, muntrer und kluger Vogel, außerordentlich gesellig. Flug rauschend, schnell, gradlinig, ror dem Niederlassen schwebend, in Schwärmen dicht gedrängt. Lockstimme dem Worte star ähnlich, Gesang schnatternd, leicrnd, pfeifend, zischend, schnurrend, mit nachgeahmten Locktönen und Rufen andrer Vögel untermischt, z. B. oft Mliauen, Pirolruf, Flöten. q singt auch, aber leiser. Nahrung Insekten, Engerlinge und andre Larven, Würmer, Schnecken, Bremsen, weiche Früchte, Beeren. Der ursprüngliche Nistplatz sind Baumhöhlen, jetzt nisten aber Millionen in Nistkästen, mit denen sie gar nicht wählerisch sind, andre unter Dächern, an Tiümen, in Ruinen, T'aubenschlägen, Felsspalten. Das aus allen möglichen Baustoften zusammengefügte kunstlose Nest enthält 4-7 blaß bläulichgrïne, glänzende Eier, die 14 l'age bebrïtet werden. Die Eier messen $31.5 \times 20.6,27>20.1$ bis $28.3>20.84$ und $31.2<22.8 \mathrm{~mm}$.

In Süd-Deutschland, IVest-Europa, kurz in milderen und sonst günstigen Gegenden werden regelmäßig zwei Bruten gemacht, in andern Ländern (Nordost-Deutschland, Skandinavien, Schleswig-Holstein, usw.) machen sie ungestört nur eine Brut. In Dänemark hat man ausuahmsweise beobachtet, daß Stare freie Nester in dichten Bäumen bauten (Ornis 1886, p. 60). Man muß große Starenschwärme beobachtet haben, ilar donnerartiges Gebrause gehört, wenn sie auffliegen oder niedersausen, die Verwüstungen gesehen, die sie im Rohr anrichten, worin sie gern ïbernachten, muß sie in Kirschbäumen und Weinbergen gesehen haben, um ihre Jenge zu verstehen, den Schaden, den sie trotz ihrer sonstigen Nïtzlichkeit zu Zeiten an gewissen Orten tun können, zu begreifen. In Siid- und West-Deutschland wird der Star noch heute vielfuch gegessen. Viele sogen. gebildete Leute wissen nicht, daß die noch heute sehr geschïtzten "Sprehen" junge Stare sind.

\section{Sturnus vulgaris granti subsp. nov.}

Dem nord- und mitteleuropäischen Sturnus vulgaris vulgaris gleich, aber die erste Schwinge noch mehr reduziert, nur etra $10-13 \mathrm{~mm}$ lang, meist volle $2 \mathrm{~mm}$ kürzer. Der Sehnabel ist weniger breit, oft sehr kurz, durch- 
schnittlich jedenfills auffillend kleiner. Die Läufe neigen zu geringer Länge. Die Färbung ist vällig wie heim gemeinen Star, Konf und Kehle grïn, ohne

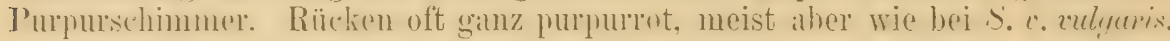

Azoren. (Pico, Sta. Cruz, Sta. Maria, San Miguel, Terceira, Graciosa,

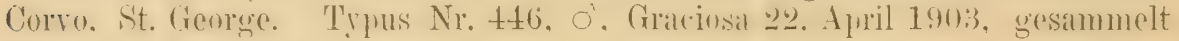
von R. Ogilvie Grant.)

(Trotz der geringen Unterschiede ist es durchaus angemessen, diese Form zu benennen. Fis ist nicht ohne Interesse zu sehen. dial. hier anscheinend cine Form anfïngt. ihre Flugwerkzenge z.u rerringern, wïhrend anf den Färöer cine mit gekräftigten Flügeln wohnt. Es scheint, als ob Inselformen die Neigung lathen. entweder flugles zu werden, oder so kräftig, daß sie den Stïrmen widerstehen kömnelı. Auf den kahlen stürmischen Färöer trat heim star dats letztere ein. anf den milderen, hewathsenen und melr Schutz bietenden Azoren die erstere Eigentümlichkeit.)

\section{Sturnus vulgaris poltaratskyi Finsch.}

Sturnus poltaratsliyi Finsch, Proc. Zool. Soc. 1878, p. 712 (See Marka-Kul im chines. Altai. Typus im Brit. Museum von mir untersucht).

Sturnus menzbieri Sharpe, Ibis 1888, p. 438 ("Asia Minor, Persia, is the starling of Krasnoyarsk where Seebohm found it, Afghanistan, India to Assam." Der 'Iypus nicht bestimmt. Der erstgenannte Fundort Klcin-Asien ist irrtiunlich, denn Sharpe selbst fiilhrt im Cat. B. XIII das klein-asiatische Stïck richtig unter purpurascens an. Ich acceptiere als typische Lokalität für Sharpe's menzbieri Krasnoyarsk. Die Stare von Krasnoyarsk sind wic die vom Altai).

Von S. v. vulgaris dureh konstant purpurnen Kopf und Kehle und mehr oder minder rein purpurne Ohrdecken unterschieden. Der ganze

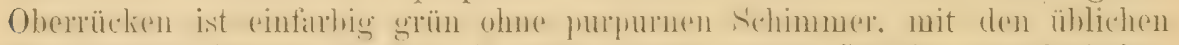

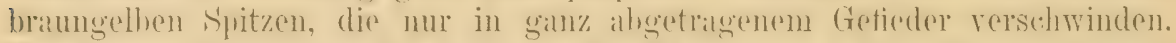

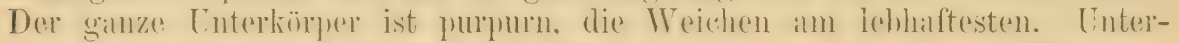

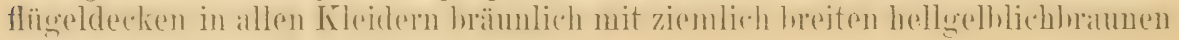
Säumen, wie bei S. v. vulyaris.

Bewohnt Sibirien mit Einschluß des Altai bis zum Baikal, wandert im Winter in die Elbenen Indiens. wo er von Kisthmir südwärts bis in die Breite von Barrodat und östlich his nach Ober-Assam äherwintert, sowie

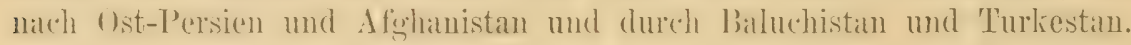

\section{Sturnus vulgaris faroensis Feilden.}

Sturnus faroensis Feilden, Zoologist 1872, p. 3257 (Färöer).

Sehr kenntliche Form: Im allgemeinen größer als der gemeine Star, erste rudimentäre Shehwinge länger und hreiter. Flügel und Schwanz etwas lïnger. ${ }^{1}$ ) l'ülie liräftiger, S'chuabel merklich gröber. Knnf und Kehle grün,

$\left.{ }^{2}\right)$ Es ist sehr interessant, daß eine sedentäre Form gegenüber einer wandernden Form größere Flugwerkzeuge hat, während sonst die wandernden Formen oft längere Flügel aufweisen. Man kann ja leicht verschiedene Zweckmäßigkeitsgründe für diese Erscheinung beim Färöer-Star anführen, es fragt sich aber, welche die wahren Gründe sind. Die bedeutendere Größe und weniger reduzierte erste Schwinge mögen auf hohes Alter der Form hindeuten, oder aber noch wahrscheinlicher auf eine Anpassung an das waldlose stiirmische Inselreich, das sie bewohnt. 
schr selten mit Purpurschimmer, (Oherseite im allgemeinen etras dunkler und dïsterer als die ron S. c. melguris. Flügel 134-136, erste S(hwinge etwa 16-20 $10 m$ (gegenüber etrat 12-1t beim gemeinen Star), Schnaliol 25-30 mu. Die. Jungen sind erhehlich dunkler und mehr graulich hraun, als die des gemeinen Stars, die Kehle weniger weib, Enterkïrper nur schwath und wenig weib gestreift. Die .Tungen allein würden zur Ahtremung der Form genügen!

Standvogel auf den Färöer-Iuseln. wo er sehr häufig ist und an Felswïnden und Gehäuden nistet. (S. Knud Andersen in Saertryk Vidensk. Meddel. nat. Foren. Kbhvm. 1898 p. $358-374$.

\section{Sturnus vulgaris humii Brooks.}

Sturnus nitens (non Brehm 1831) Hume, Ibis 1871, p. 410.

Sturnus humii Brooks, Ibis Oct. 1876, p. 500 (Cashmere).

Sturnus ambiguus Hume, Stray Feathers IV, p. 512 (Dezember 1876).

(Sturnus indicus und St. splendens sind nomina nuda, daher nicht verwendbar.)

Oherkopf tief jurpurblan. (ienick. Hinterhals und Kehle lebbafter und mehr rötlich purpurblau. Ohrdecken dunkel metallisch griün, Rürcken und Forderbrust kupferrot mit Bronzeschimmer, Bürzel und Oberschwanzdecken hronzegrün, Flügeldecken dunkel bronzegrün. Unterflügeldecken schwärzlichbraun mit schmalen weiben Sämmen. Handsehwingen mit weiben Aubensäumen. Flügel 123-125 mm.

Brïtet in Himalaya rom Kirsehmir his Nepal und im nordwestlichen Punjab, zieht im Winter in die Ebenen N.W.-Indiens.

\section{Sturnus vulgaris nobilior Hume.}

Stumes nobilior Hume, Stray Feathers 1879, p. 175 (Kandahar).

Sturnus poltoratskyi (non Finsch!) Sharpe, Cat. B. XII (partim), Oates u. a.

Dem S. $v$. poltaratslyg sehr ähnlich, aher ohne weiteres durch die heim alten Togel stets (und Wahrscheinlich in allen Kleidern) schwärzlichen, schmal weißlich gesïmmten Lnterflügeldecken zu unterscheiden. Kopf und Hals rötlich purpmrn. deю Oberrüclien rein dunkelgrün, Oberflügeldecken prächtig purpurm. Bürzel meist mit purpurhlauem Schimmer, längste Oherschwamzdecken mehr oder minder jurjurn. Üher die Torderhrust zieht sich ein metalliseh grïnes Band, der ganze Tnterkörper ist prïchtig purpurn. Flügel $130-133 \mathrm{~mm}$. - Von S. v. poltaratskyi durch gestreckteren, meist lämgeren und sehmäleren Schmahel. die Farhe der Cnterflügeldecken und Oberflïgeldecken. sowie mehr rötlich purpurnen Enterkörper unterschieden.

Afghanistan und Ost-Persien (Mesched his Seistan, ron Zarudny gesimmelt), im Winter rereinzelt in N. IT.-Indien, Punjah und Sind.

(Dic eigentliche Brutheimat ist nicht mit voller Sicherheit hekannt. Ich glauhe es ist Afghanistan und ()st-Persien, aher auch ron dort liegen mir nur Serien aus den Wintermonaten vor:) 


\section{Sturnus vulgaris caucasicus Lorenz.}

Sturmes caucasicus Lorenz, Beitr. Orn. Faun. Caucas., p. 9, Taf. V, Fig. 1 (1887- typ. Lok. Kislowodsk).

Steht S. v. nobilior sehr nahe und das alte Männchen hat wie jener

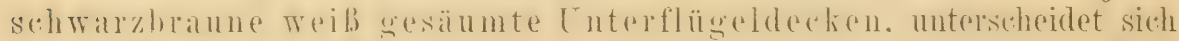
aber anf den ersten Blick durch den tief grünen, nicht pupumoten Kopf und Kehle. anch sind die Cutersehwanzdectien nicht so jurpmrittich, sondern meist vorherrschend grün. (Die in Dresser's „Mammal of Pal. B.“ p. 401

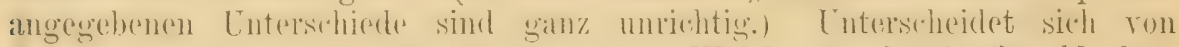

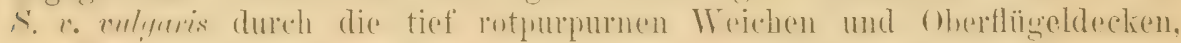

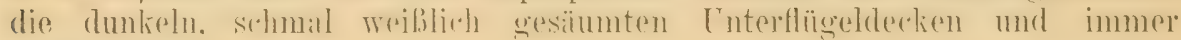
grrünen Kopf.

Kaukasus und Nord-Persien, auch in den Gebirgen Südwest-Persiens noch Brutrogel, von 4000 engl. Fuß aufwärts bis 7000 oder mehr.

\section{Sturnus vulgaris purpurascens Gould.}

Sturnus purpurascens Gould, Proc. Zool. Soc. London, p. 219 (Typ. Lok. Lrzeroum).

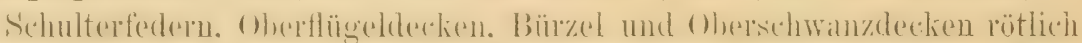

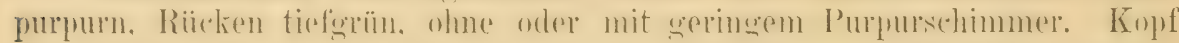
and Kehle grïn, mit oder ohne Purpurschimmer. Unterkörper purpurn,

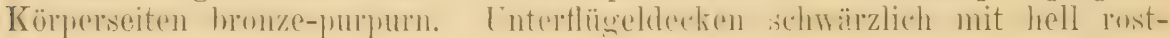
farbenen Säumen.

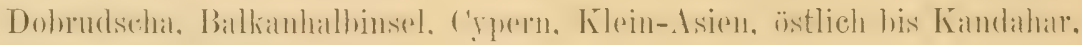
vereinzelt bis N.W.-Indien.

\section{Sturnus vulgaris porphyronotus Sharpe.}

Sturnus porphyronotus Sharpe, Ibis 1888, p. 438 ('Turkestan, typische Lokalität Yarkand, s. Cat. B. Brit. Mus. XIII, p. 38).

Von S. v. purpurascens durch ganz rötlich purpurnen Rücken wie die ganze (Oherserite. grïne Kehle und noch mehr grö̈nlichen Kopf rerschieden.

Brïtet bei Ferghana und Yarkand in 'Iurkestan, nördlich bis zum I'ian-Schan und besucht Afghanistan und Indien im Winter.

\section{Sturnus vulgaris minor Hume.}

Sinrmus minor Hume, Stray Feathers 1873, p. 207 ('lyp. Lok. Larkhana).

Geringe Größe! Kopf, Kehle und Vorderhals dunkel bronzegrün. Vorderhrust rötlich riolett oder purmurn. Hinterhals und Rüicken rötlich

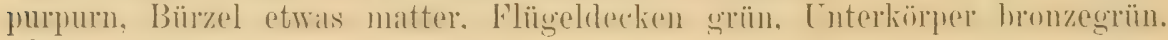
Flügel $115 \mathrm{~mm}$.

Standvogel in Sind, östlich bis Etawah in Indien.

\section{Sturnus unicolor 'Temm.}

Sturnus unicolor Temminck, Man. d'Orn., p. 133 (1820- Sardinien).

ôd. Unterscheidet sich von $S$, vulgaris in allen seinen Formen dureh die noch riel längeren und spitzigen. schmalen Kehl-. Brost-, Kopf- 
und Rückenfedern, die am der Brust und ann Vorderhalse bei sehr altun

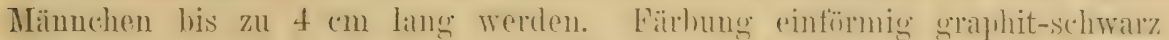

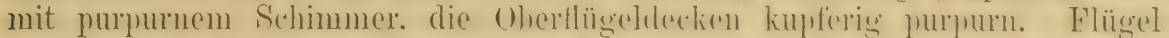

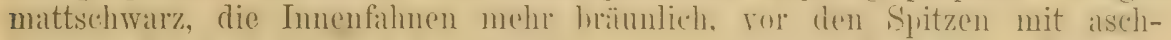
bramen Flecken und mit sehwärzerem. sammetartigen Endsamm. Sichmahel

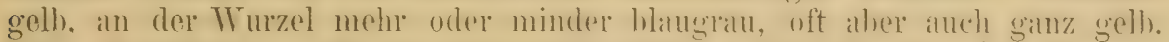
Fïbe fleisehfarhen. Flugel 132-137. Schwanz 68-70. Sehnabul 26-30, Lauf etwa $31-32 \mathrm{~mm}$.

Das $O$ ad. gleicht dem $0^{\text {a }}$ ad, ist aber ein wenig kleiner und meist nicht so tief schwarz, etwas mehr grau angelaufen, auch sind im Herbst-

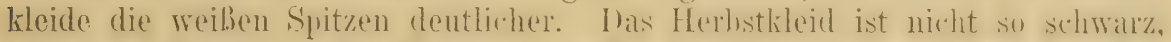

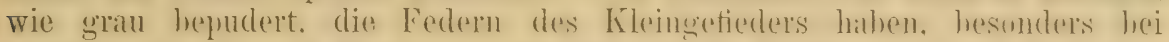

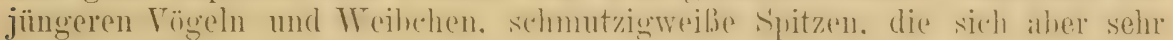
bald abnutzen. Schnabel schwärzlich, die Füße rötlichbraun. Das erste

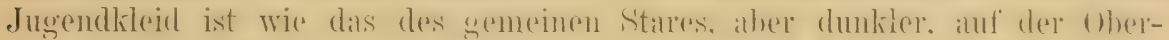
seite ebenso dunkel wie das von $S$. vulgaris faroensis.

Bewohner von Spanien und Portugal, Sardinien, Korsika, Sizilien,

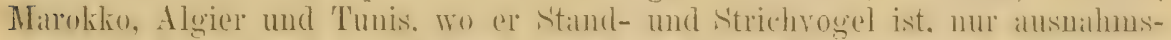

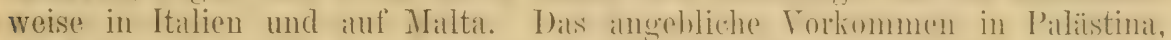

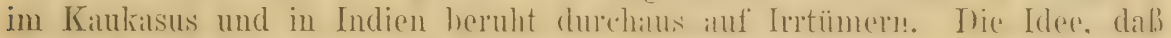
er im Orient ïherwintere. ist daher schom deswegen allein simmlos. aluberdem findet man ihn in den Atlas-Ländern sowohl als in sïd-Europa das ganze Jahr hindurch.

Die Lebensweise des Einfarbstares ist im großen und ganzen die unsrer Stare. Sein Pfiff ist etwas stärker, voller. Die Nahrung ist die aller Stare, aber er scheint Schnecken ganz besonders zu lieben. Er nistet teils einzeln, teils in kleinen oder größeren Gesellschaften in Löchern an den Felswänden, Ruinen alter Wasserleitungen oder sonstiger Gebäude, unter Dächern, an T'ïrmen, auch (selten) in Baumlöchern, oder sogar in Bienenfresserröhren, und legt 4-6 Eier, die denen unsrer Stare gleichen, nur meist etwas heller sind.

\section{Gattung PASTOR Temm. 1815.}

Enthält nur eine sehr kenntliche Art. Lokale Formen sind bisher nicht unterschieden, nath dem von mir gesehenen Material scheimen solche auch nicht zu existieren. Die Geschlechter sind fist gleich, das Jugendleid ganz verschieden. Das rosige Gefieder und die grolie Haube der Alten sind sehr kennzeichnend. Frübe auberordentlich krältig. Mittelzehe etwal so lang wie der Lauf. Flügel lang und spitz. Schwanz kurz und gerade. Nur eine Mausel:

\section{Pastor roseus (L.).}

\section{Rosenstar:}

Turdus rosens Linné, Syst. Nat. Ed. X, p. 170 (1758- „Hab. in Lapponia, Helvetia"). Turdus seleucis Forskål, Descr. Anim., p. VI no. 16 (1775).

Pastor roseus rosans, subroseus A. Brehm, Verz. Samml. p. 4 (nom. nud!).

Engl.: Rose-coloured Starling. Franz.: Martin roselin. Ital.: Storno marino.

Ad. Kopf und Hals his auf den Kropf schwarz mit etwas purpurnem Schimmer. Elügel. Schwanz. Flügel- und Schwanzdecken, Steil.s und Schenker- 
hefiederung sehwarz, mit stahlgrinnem Shehmmer, die Innenfihnen der Schwingen

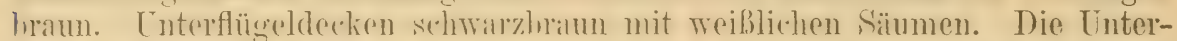
schwanzdecken in frischem Geffeder mit kleinen weiben syitzen. Am Oberrand der sichulterfedern zieht sirh je ein sehmaler sehwalrzhraumer streif an den Śeiten des Rü̈ckens entlang. das ührige (iefieder ist hell rosenrot. Flügel rtwal 28 -31. Sehwanz 71-73. Shehnahel (unbedeckte Firste) 17-20, Lauf etwa $30-32 \mathrm{~mm}$. o ad. wie ơd., aber ein wenig kleiner, Farben etwas wenigere leholhaft. Hanthe kïrzer. Der junge Vogel ist ganz rersehieden. Lir ist oben grandich erthramm. auf dem Konife mit dunkieren Eedermitten, auf dem Mintel mit gellhräunlichen Sïumen. Flügel und S'chwanz dunkelbraun mit hell rostgelhlichen silumen. Lnterseite hrälunlichweil., Kehl- und Unterkörnermitte am weißesten. Kropfgengend dured dunkelhrame Federmitten wie gestreift. Weichen und Cutersehwanzdectien auch mit dunkleren Federmitten. Nath der Herhistmansere hahen die sehwallzen Kropfedern helle, bräunliche Spitzen, die sich gegen den Frühling hin völlig abnutzen.

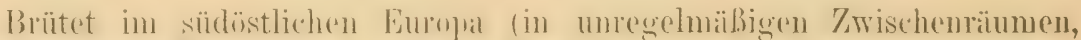
wie man sagt in C̈hereinstimmung mit dem Massenaultreten seine Liehlingsmahnung. der Henschrecken. his Bulgarien und Ost-[ugarn). Klein-Asien bis Turkestan. Hält sirh ron kinde .Juli his Anfang Mai in Indien in Menge

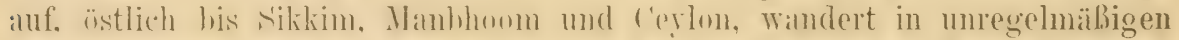
Zwwischenrïumen weit monher. ist in fast allen Teilen von buropa (einmal 1875 zu Tiusendeu hei Veronal liritend!) heohachtet, nördlich alusnahmsweise his ost-P'reuben. Lisland. Finland. Latplland, Grobhritannien. Belgien, öfters in Deutschland, immer in Flügen.

In seinem Wesen ein echter Star, mit dem or auch ungefähr die gleiche Nalırung hat. Als Heuschreckenfresser bekannt und hewundert, aber auch als Fruchtvertilger, namentlich in den Maulbeerpflanzungen, und weil sie die Reishalme umknicken und unreife Ähren fressen, stellenweise gefïrchtet. Nicht gauz so lärmend wie der Star und ein etwas besserer Flieger. Eine Schar Rosenstare bietet ein prächtiges Bild dar. In Rajputana sah ich sie zu Tausenden in den rotblïhenden Bäumen der Butea frondosa, am Fuße der Aravalli-Berge - ein unvergeßlicher Anblick. Nistet ebenfalls wie die Stare, aher besonders gern auch an steilen Eirdwänden. Eier 4-6, ausnahmsweise bis 8, denen des gemeinen Stares gleichend, aber viel heller. Maße nach Rey durchschnittlich $27.97 \times 20.91$, im MLaximum $29.5 \times 20.6$ bezw. $26 \times 21.3$, im Minimum $26 \times 21.3$ bezw. $27.1 \times 20.6 \mathrm{~mm}$. Durchschnittliches Gewicht $0.412 \mathrm{~g}$.

\section{Gattung SPODIOPSAR Sharye 1889.}

Der Gattung Sturms sehr nahestehend, aber das Gefieder weicher,

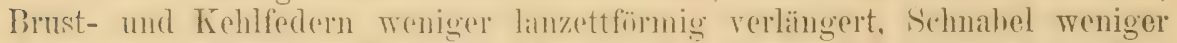

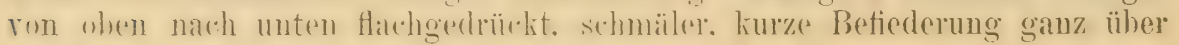
das Nasenloch himeichend, Fülßse schwächer.

bie Formen dieser Gattung gehören dem indisch-chinesischen Faunengebiete an, nur eine reicht in die paläarktische Zone hinein.

\section{Spodiopsar cineraceus ('Temm.).}

Stu'nus cineraceus Temminck, Pl. Col. 556 (1832- Japan).

ond. Kopf und Hals schwarz, Stirn bis in Augenhöhe, Kopfseiten und Ohrgegend weik und schwart gestreift, Kimn oft weib, die weiße 


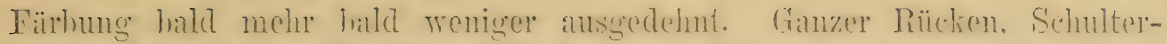

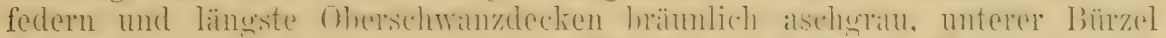
und kürzere Oherschwandedene weib. Shwingen schwilrlich. Handschwingen

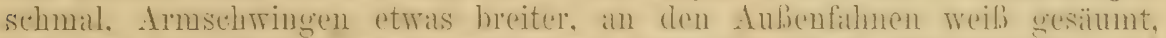

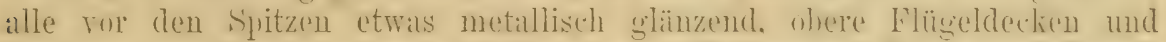
die imnersten drmschwingen mit bronzenem Schimmer. Finhle und hiropf-

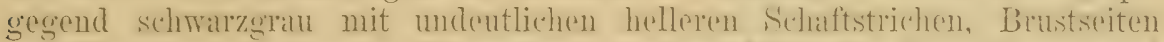

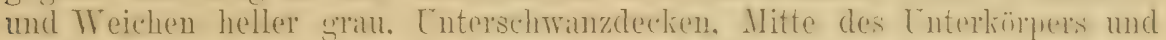

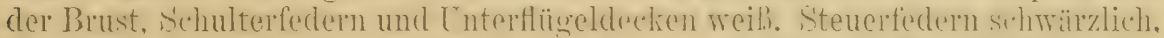
Innenfahnen mit durchsehnittlich etwa $1 \mathrm{~cm}$ meiten weilsen sintzen. das

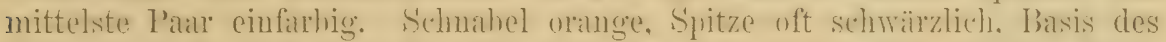

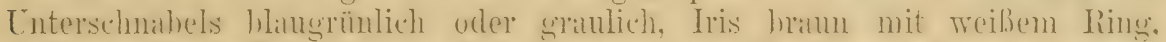

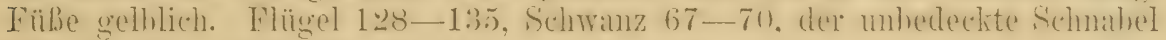
24-25, Lauf etrra 28-30 mm.

o ad. Dem ơ ad. ähnlich, aber alle Farben weniger roin, Kehlmitte

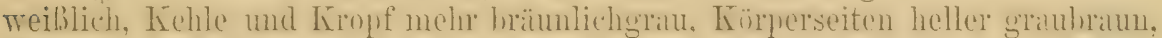
Mitte des Lnterkörpers schmutzig hrïmulichweils; ein wenig kinemer. Junge den 으 ähnlich, aber noch bräunlicher.

1.5. rolletti Shatre (Ihis 1888 p. 477) roin unhekimntem liunderte, ist wahrseheinlich nur eine melanistische Aberration.)

Tom sïdlichen Diturien durch die Essuri-Lünder und die Ost-1Iongolei bis Japan und China. In Sibirien, der Mongolei, Nord-China und Jesso Zugrogel, in südlicheren Jilpan angehlich standrogel. C̈herwintert im südlichen ('hina, Hainan und Formmsat. wurds eimmal in Birmah erlegt.

Bewohnt mił Bäumen bestandene Ebenen, wo er nach Starcnart in Baumlöchern nistet und 4-7 Eier legt, dio denen unsrer Stare ähneln, aber dunkler blau sind, auclı oft etwas kleiner. Die Maße sind nach Taczanowski (Haune Sib. Orn. I, p. 5t6): $28 \times 20,28.5 \times 20.6,29 \times 20,29 \times 20.8,30<20.2,30<21,29.5 \times 20.4,27.2 \times 21$, $28.1 \times 20.3 \mathrm{~mm}$.

\section{Gattung STURIIA Lesson 1837.}

Starenartig; aber das Gefieder viel weicher, der Schnabel viel höher und schmalspitziger als hei Stmms. an der Wrurzel merlilich hreiter, etrat wie geschwollen. 3 Arten, von denen 2 unser Gebiet bewohnen. Dio alten Männchen lassen sich wie folgt unterscheiden:

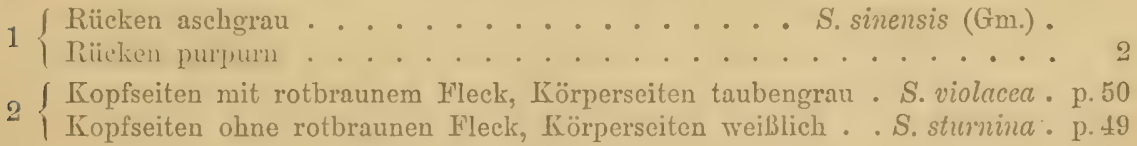

\section{Sturnia sturnina (Pall.).}

Gracula sturnina Pallas, Reise Russ. Reich. III, p. 695 (1776- „In salicetis Dauuriae australioris, circa Ononem et Argunum").

Stumus dauricus Pallas, Acta Holm. 1778, p. 197, Taf. VII (Daurien),

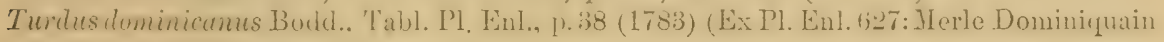
des Philippines).

Turdus striga Raffles, Truns. Linn. Soc. London XIIT, p. 311 (1820- Sumatra).

Pastor malayensis Eyton, Proc. Zool. Soc. London 1839, p. 103 (Mlalakka).

E. Hartert, Die Vögel der paliarktischen Region. 
Oad. Oberseite: Kopf und Hals aschgrau, im Genick ein purpurvioletter

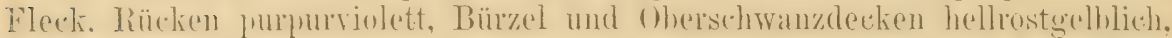

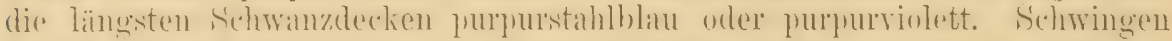

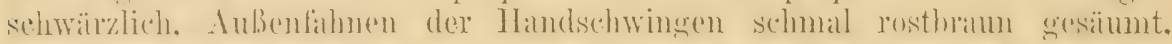
Inuenfahnen breit weiblich rostgelh, Śpitzen metallisch glinzend und mit

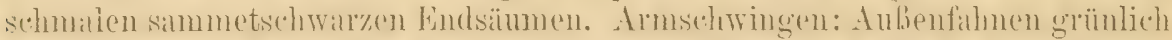
metallghänzend. Basishailte dere Innenfahnen gröbtenteils weiblich. Aufendahnen

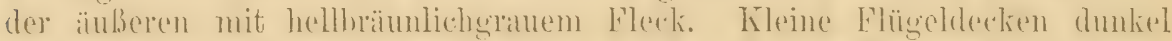

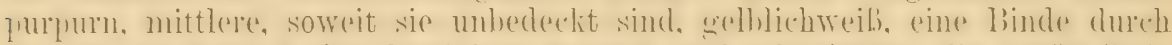

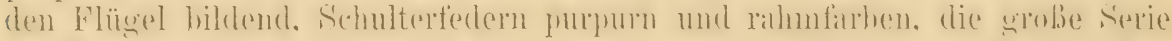

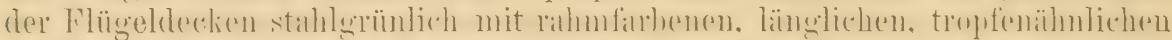

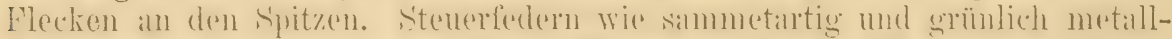

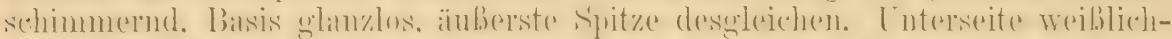

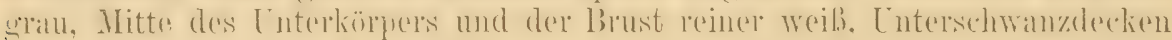
und Aftergegend mit rostfirbenem Anflug. Conterflügeddecte'n weiblich. Flïgel 105-110, Schwanz 52-54, Schnabel 14-15, Lauf etra $25 \mathrm{~mm}$.

o ad. Oberseite aschbraun, am Kopfe heller und mehr graulich, der

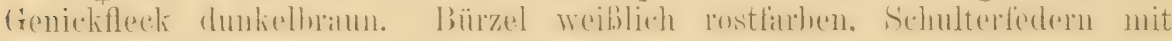
weißlichen Spitzen, Flügel viel bräunlicher und matter als beim ỡad, Schwanz desgleichen, Unterseite wie beim ỡ ad.

Die roströtliche Färbung auf dem Bürzel, an den Spitzen der Flügel-

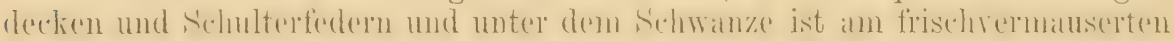

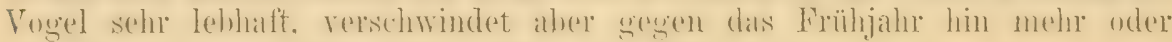
minder. Der junge Vogel soll dem o ähnlich sein.

Ost-Sibirien, die Mongolei und Nord-China, durchzieht im Herbste

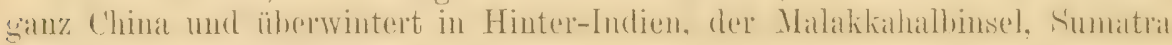
bis Java und den Nikobaren.

Bewohnt baumreiche Ebenen und findet sich oft in Gesellschaft von Spodiopsar cincraceus. In Ost-Sibirien trifft er nach Godlewski erst gegen Ende MIai cin, und soll schon Ende Juli wieder von seinen Brutplätzen fortziehen. Die 5-7 Eier findet man um die Bitte des Juni in Baumlöchern. Sie haben Starencharakter, sind aber dunkelblau und messen nur $24 \times 17.2,24.1 \times 16.8,24.2 \times 18,24.5 \times 20,24.8 \times 17.3$, $25 \times 18,25 \times 18.2 \mathrm{~mm}$.

\section{Sturnia violacea (Bodd.).}

Motacilla violacea Boddaert, Tabl. Pl. Enl., p. 11 (1783- Ex Daubenton Pl. Einl. 185: "Le Grand 'Traquet des Philippines").

Pastor ruficollis Wagler, Syst. Av., Genus Pastor no. 19 (1827-- Manilla). Lamprotomis pyrhoyenys 'Temminck \& Schleg., Fauna Japonica, Aves, p. 86 (1850Japan). (L. pyrrhopogon unter Tafel 46, wohl Druckfehler.)

orad. Oberseite der voll S. sturnina ähnlich, aber der Kopf nicht

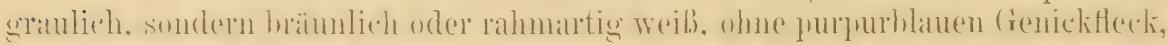

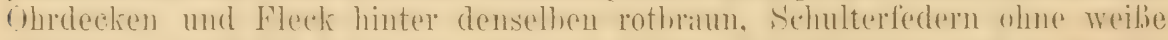

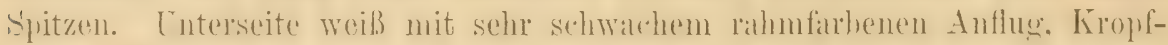

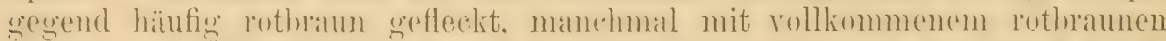

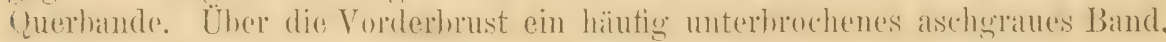
Brust und Körperseiten aschgrau. Das o ähnelt dem von S. sturnina, aber die Schulterfedern sind einfarbig hram. Crablic etwa wie die ron ș stumine. 
Man kömute S. violacea als geographischen Vertreter (Subspezies) von

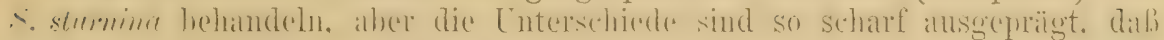
die beiden Formen schr gut nebeneinander vorkommen könnten, daher ändere ich die bisher übliche binäre Nomenklatur derselben nicht.

Brïtet in Japan und richtet seinen Zug im Herbste direkt nach

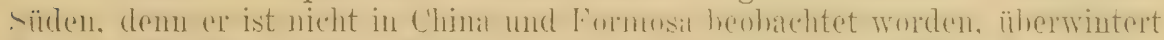

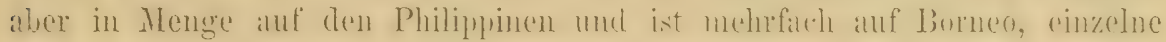
in Celebes und oinmal auf Batjan gefunden worden.

Brütet nach Art seiner Verwandten und legt dunkelblaue Eier, die nach Nehrkorn $25-25.5 \times 18 \mathrm{~nm}$ messen.

\section{Familie ORIOIIDAE.}

Flügel mit 10 Handschrvingen, die crste Handschwinge wohl entrvickelt, in Oriohs etwa halb so lang wic die z⿰氵еite, die dritte am lüngsten. 12 Stenerfedern. FülBe stark und kurz, Lauf hinten ron 2 glatten Schienen

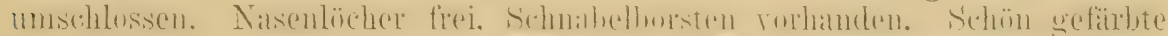

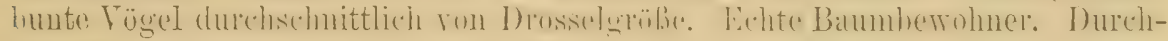
aus 'Tropenvögel, nur eine Art berohnt Europa. Hängende kurze Nester. Junge mehr oder minder gestreift. Nur eine Mauser im Jahre.

Europa, Asien, Afrikin und die malayische Inselwelt bis Australien. In Amorika fehlend.

\section{Oriolus oriolus oriolus $\left(\Lambda_{\star}.\right)$.}

[rimol.

Coracias Oriolus Linné, Syst. Nat. Ed. X, p. 107 (1758- „Hab. in Europa, Asia." 'Yyp. Lok. Schweden, nach dem ersten Zitat).

Uriolus Galbula Liuné, Syst. Nat. Lid. XII, 1) 160 (1766).

Oriolus Galbula varietas virescens Hemprich E Ehrenberg, Symb. Phys., fol. 2 (1833"Nubia et Dongala“. Irrtum!).

Oriohıs aureus Brehm, Handb. Naturg. Vög. 1)eutsehl., p. 156 (1831-- Nord-Deutschland). Oriolus garmlus ${ }^{1}$ ) Brehm, Handb. Naturg. Iög. Deutschl., p. 157 (1831-- MittelDeutschland).

Oriolus Galbula musicus, tibicen, minor, ulticeps, pluniceps, crassirostris, septentrionalis A. Brehm, Terz. Samml., p.t (nom. nuda!).

Engl.: Golden Oriole. Franz.: Loriot. Schwed.: Sommargylling. Ital.: Rigogolo.

Orad. Oberseite und Unterseite goldgelb. Zügel schwarz. Flïgel

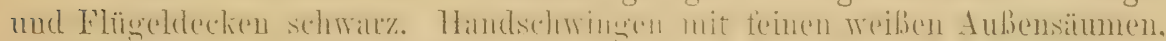
alle Schwingen im frischen Gefiedor mit weißgelben Spitzensänmen, die aber dureh Abuutzung in Frühling verschwinden. Handdecken gelb, an

1) Brehm's Oriolns gariulus ist keineswegs eine besondere Art. Der Name beruht auf (namentlich unten) blassen Individuen, die Unterschiede des Schmabels und Scheitels, die der Autor angah, sind nicht stichhaltig. Solche helle Stücke scheinen nicht immer jüngere zu sein. Sie brïten in dem liellen Gefieder und sind nur individuelle Aberrationen, die in allen Ländern ihres Aufenthaltes vorkommen. Ich kenne sie aus Renthendorf, Ost-Preußen, Schlesien. 


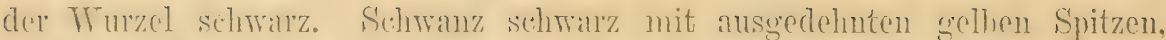

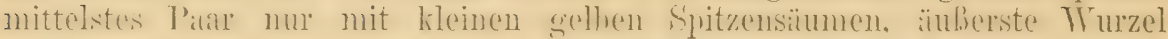
schmutziggelb. Die Ausdehnung des Gelb im Schwanze variiert etwas.

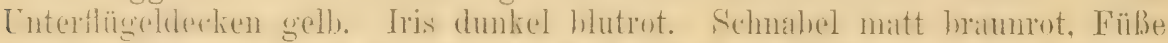

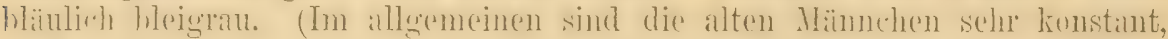
es kommen aber auch Stïcke vor, dio unten viel heller, fast weiBlichgelb sint. Solche pflamzen sich nach Auswejs der Brehn'schen Simmonlung fort, können also nicht ganz jung sein. Ich sehe ïberhaupt nicht ein, daß es jüngere Stücke sein müssen, sondern halte sie für alte, aber abweichend gefärbte Individuen. Aus Süd-RuBland liegt mir ein oben schwarzgestreiftes Stück v01.) Flügel 149-158, Selıwanz 85-93, Lauf 21-23, Schnabel $23-26 \mathrm{~mm}$.

o ad. Hell olivengrün mit gelblichem Anflug (etwa Zeisigfarbe),

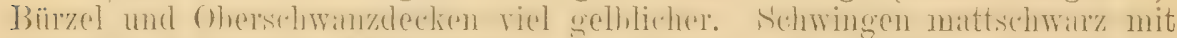

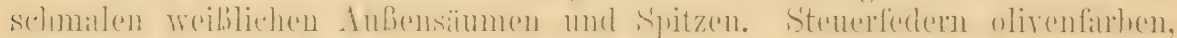
Wurzel gelb, nach der Spitze zu schwarz, Inmonfahnen mit ausgedehnten, Außenfahmen mit kleinen gelben Spitzen, mittelstes Paar nur mit ganz

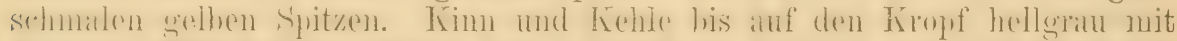

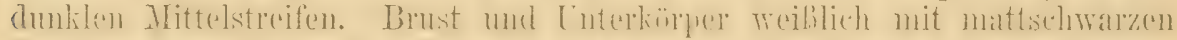

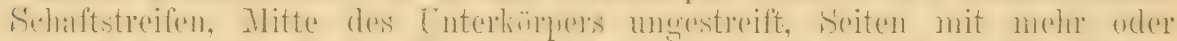

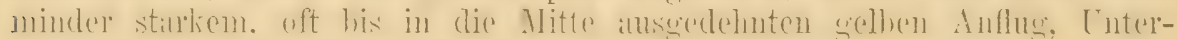
schrvanz- und Unterflügeldecken gelb. (Die o ändern vielfach ab. Die

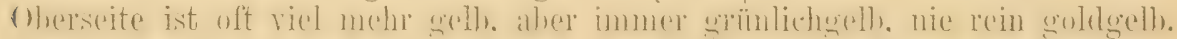
Die Unterseite ist oft lebhaft gelb, nur Kehle und Kropf mit grauem

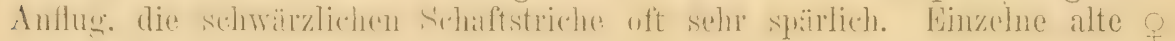
ähneln den ot etwas und sind wohl als sterile, hahmenfedrige o anzusehen.

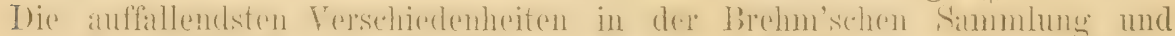

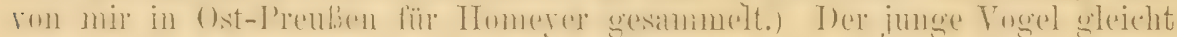

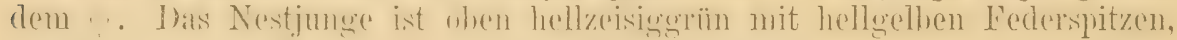
die Unterseite weiß mit schwärzlichen Schaftflecken.

Europa im allgemeinen, in Schwedon bis zum 63. Grad, in Rußland bis zum 60. Grad. Ob in N.TV.-Afrika nur Zugvogel oder auch brütend,

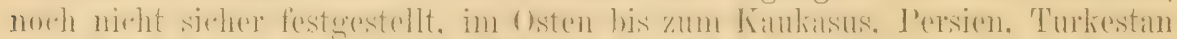

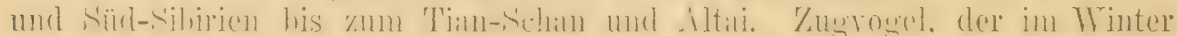

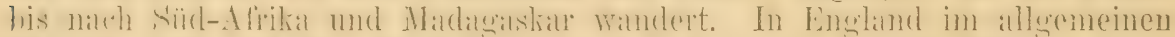

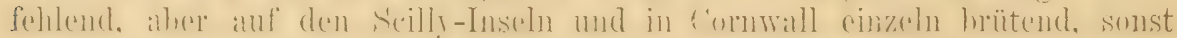
nur ausuahmsweise und auch nur in den südlicheren 'Teilen. Einzelne

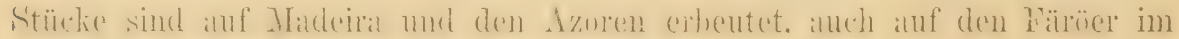
Mai 1893. Als selteuer Wintergast in Sind.

Zugrogel, der meist erst im MIai (in Deutschland) kommt und uns im August schon wieder verläßt.

Bewohnt nur Wälder und andre baumreiche Gegenden, besonders Laubwälder (Eichen), aber auch gern Kiefernwälder und Erlenbestände.

Scheu, wild, zanksüchtig und unstet, fast immer im Gelaube der Bäume sich aufhaltend, besonders in den Kronen hoher Bäume. Wenn ausnahmsweise auf dem Erdboden, sich mit sehwerfälligen Sprüngen fortbewegend. Flug meist in großen, flachen Bogenlinien. Am meisten wegen seines herrlichen, flötenden, weithin klingenden Paarungsrufes bekannt, das wie gidlio, gitadidlio, gipliagiblio klingt und von den Landleuten mit "Vogel Bülow" oder "Pfingsten Bier holn, aussaufen mehr holn" u. dergl. mehr verglichen wird. Lockstimme ein helles gjäk, jäk, jälk oder rauhes Schräk, Angstruf 
ein unangenehmes krächzendes Schnarren. Außerdem hat der Pirol noch einen schwatzenden, schnalzenden, wie hinrieselnden Gesang, auf den zuerst C. L. Brehm und später Heinrich Seidel aufmerksam machten, den aber nachher Viele beobachtet haben. Ich glaube, daß er diesen Gesang nicht immer und nicht regelmäßig hören läßt. Nahrung Insekten, namentlich glatte, bisweilen aber auch behaarte Raupen und Käfer, später im Jahre auch Kirschen und andre weiche Baum- und Buschfrüchte.

Brïtet natïrlich nur einmal im Jahre. Das Nest weicht $\nabla$ on denen aller andern europäischen Vögel ab, denn es hängt derart in einer Zweiggabel, daß die Ränder fest an die Zweige befestigt sind. Es ist tief napförmig, meist aus bandartigen Gräsern, Bast, Fäden, Birkenrinde, auch gelegentlich Papierstreifen u. dergl. geflochten, mit weichem Grase, Wolle und Federn ausgefüttert. Meist hängt es sehr. hoch in Eichen, Erlen, Birken, Kiefern und andern Bäumen, nicht selten aber auch nur $1 \frac{1}{2}-3$ oder $4 \mathrm{~m}$ hoch, so besonders in den Rheingegenden und Westfalen in jungen Eichenschonungen. Ende Mai (sehr selten) bis Ende Juni findet man die $4-5$ wundervollen, rein weißen, frisch rosa angehauchton oder rahmfarbig weißen, glänzenden Hier, mit tief purpurbraunen, fast schwarzen Flecken, seltener auch mit hellgrauen Schalenflecken geziert. Maße: $28 \times 20.3,30.8 \times 21.34$ bis $32.2 \times 20.7 \mathrm{~mm}$. Durchschnittliches Gewicht nach Rey $0.386 \mathrm{gr}$.

Natürlich findet nur eine volle Mauser im Jahre statt, diese dauert aber anscheinend sehr lange.

\section{Oriolus oriolus kundoo Sykes.}

Oriolus kundoo Sykes, Proc. Zool. Soc. London 1832, p. 87 (Dukhun).

Oriolus galbuloides Gould, Proc. Zool. Soc. London 1841, p. 6 (Alpine Punjab nomen nudum!).

Das o unterscheidet sich von 0 . o. oriolus wio folgt: Del schwarze Zügelfleck ist etwas hreiter und his hinter dis Iuge fortgesetzt. sodalli dort

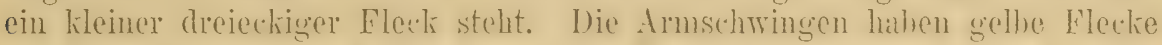
an den Enden der AnBensä̈nne, die Fanddeclien ansgedelnutere gellie Fïrbung, sodab der Flügelspiegel gröber ist. die schwarze bisis der stenerfedern ist viel beschüinkter, sudali. die äuberen liast ganz gelh erscheinen, der Flügel ist kürzer: $140-142 \mathrm{~mm}$. o dem von 0. o. oriolus ähnlich, aber kleiner und unten viel gelber.

bewohnt ganz Indien, bis zu 9000 engl. Fuli im Himalaya, Káschmil bis Afghanistan und 'Turkestan.

Lebensweise wie bei unserm Pirol. Eier $3-4,28>20 \mathrm{~mm}$.

\section{Oriolus indicus Jerd.}

Oriolus indicus Jerdon, $\left.{ }^{1}\right)$ Ill. Ind. Orn. T'ext zu Taf. XV (1817- Malabar, Travancore ete.). Oriolus diffusus (nom. emend.) Sharpe, Cat. B. Brit. Hus. II, p. 197 (1877).

$\sigma^{\top}$ gelb, ron den Nasenlöchern über die Augen ein breiter tiefschwarzer Streif, der dum einen his zu 2 em meites schwarzes Feld am Hinterkenfe verbunden ist. Handsehwingen schwar\% mit schmalen weißen dubensiiumen, drmschwingen mit breiten gelhen Aulicusämmen. Stencredern schwarz, alle mit Ausnahmo der beiden mittelsten mit breiten gelben Spitzen.

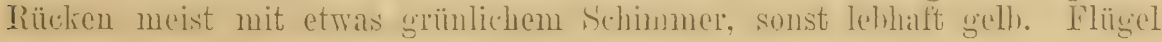

1) Es liegt durchaus kein Grund vor, den Namen Jerdon's zu verwerfen. Er hat die Art gut beschrieben und abgebildet und fïgt hinzu, daß, the $O$. indicus of Brisson and others may possibly refer to this though faultily described". 
153-160, Schwanz 95-99, Schubel 30-32, I auf etwa $37-38 \mathrm{~mm}$. Sehnabel rosemrot. o dem o ähnlich, aber der ganze Rücken grüulich und

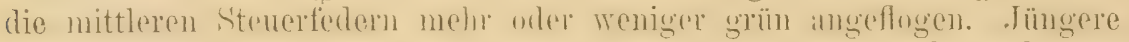
oft ron den alten o kaum zu unterscheiden. Der junge Togel ithuelt dem o vou O. galbula. Er ist oben gelbgrün, die Kopfferlern mit gelben Quer-

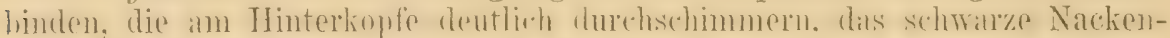

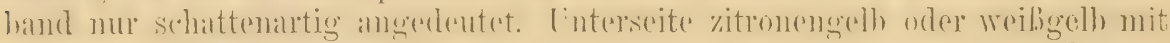

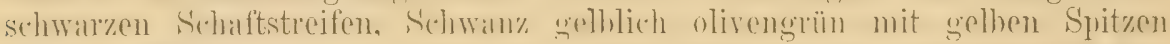

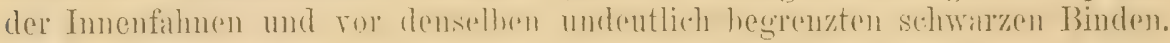
Schnabel schwärzlich.

Dieser Pirol gehört einer ganz andern Gruppe an als O. oriolus. In ihr sind die o vou den o nur wenig, oft kaum verschieden. $O$. indicus, tenuirostris, und mehrere andre dürtten wohl nichts mehr als Subspezies einer Art sein. Die zuerst benannte Form dieser Gruppe ist der Oriolus chinensis Linn. ex Brisson des Cat. B. Brit. Mus. III. p.203. Man kamn im Zweifel ïber diesen Namen sein. Brisson gibt als Vaterland Cochin-China an, aber

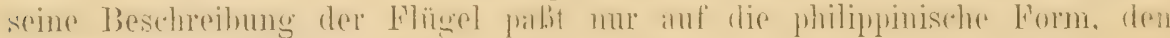
O. acrorhynchus Vigors P. Z. S. 1831, p. 97.

O. indicus berwohut als Brutrogel Ost-Sibirien (Ussuri), Süd-Damien, China und Formosa, anscheinend auch Hainan, und iiberwintert in Birmah, der Malakkahalbinsel, Indien und Ceylon.

Der Gesang soll lauter sein, als der yon O. oriolus, sonst aber ähulich, Nest und Eicr ähnch cbenfalls denen unsrer Art, letztere sind aber etwas grölier, indem sie $30 \times 22.8,30.7 \times 22.4,31 \times 22.3,31.2 \times 22.3 \mathrm{~mm}$ usw. messen.

\section{Familie FRINGIIIIDAE.}

Kegelschnäblige Singrögel mit neum Handschwingen, d. h., daß die erste ganz rerkümmert, nicht sichtbar ist. Der Unterschmabel sehr oft stark

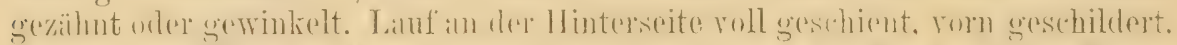

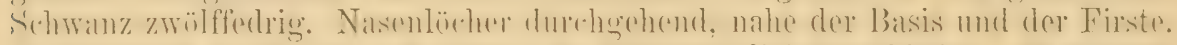

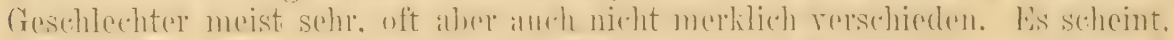

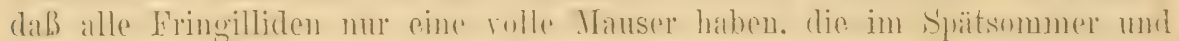

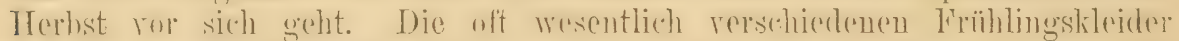

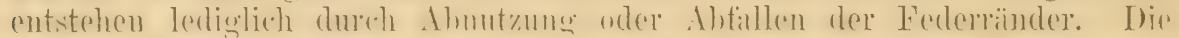

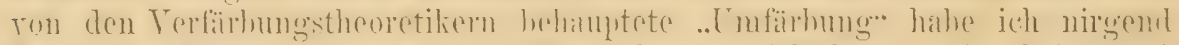

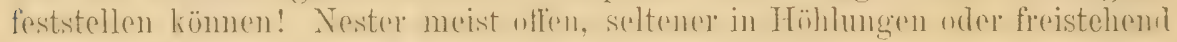
und riberwölbt, Eier meist gefleckt, selten einfarbig:

Amn nächsten steht den Fringilliden die lediglich amerikanische, schlecht abgegrenzte Familie der 'Tanagriden, mit der wir in diesem Werke nichts zu schaffen haben. Die auch nahestehenden Webervögel (Ploceidae) lassen sich an der langen ersten Schwinge erkennen, sind alle .zohnhandselnwingig"; sio hewhom die Tropenländer der alten Wrelt und

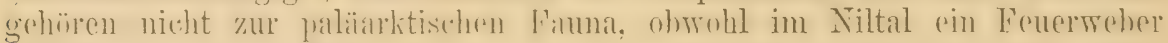
(Pyromelana), eine Witwe (Vidur), eine Lagonosticta und Hypochaera ultra-

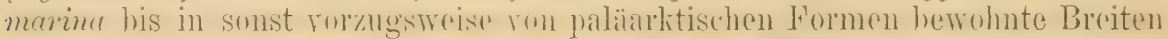

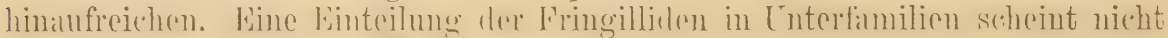

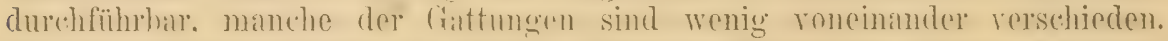

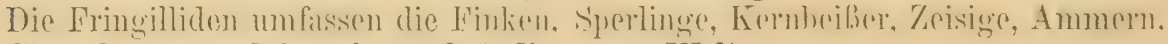
Gimpel usw. und bewohnen fast die ganze Welt. 


\section{Gattung COCCOTHRAUSTES Pall. 1811.}

Gekennzeichnet durch den gemaltig dicken, hreiten und hohen Schmahel, bei dem die Länge. Breite an der Basis des Unterschnahels und Höhe fast ganz gleich sind. Schwanz kurz und gerade, etwa halb so lang wie der Flïgel. Im Flügel sind die erste (entwickelte) bis dritte Schwinge fast gleich lang und am lüngsten, die vierte wenig kürzer, die folgenden viel kürzer und höchst merkwürdig am Ende ausgeschweift (siehe Fig. 13). Lauf und Fïßß kurz

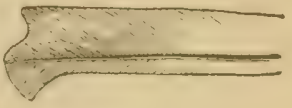

Figur 13. und stark, Lauf etwa so ling wie Mittelzehe. Feschlechter nur wenig rerschieden, Junge ganz anders, auf der Unterseite quer gefleckt.

Bewolnt fast die ganze paläarktische Region.

\section{Coccothraustes coccothraustes coccothraustes (L.).}

Kirschkernbeißer.

Loxia coccothraustes Linné, Syst. Nat. Ed. X, p. 171 (1758- ex Gesner, Aldrovandi, Albin, Willoughby, Ray n. a. m. "Habitat in Wuropa australiori").

Coccothraustes vulgaris Pallas, Zoogr. Rosso-Asiat. II, J. 12 (1811- Süd-Rußland bis Sibirien -? partim).

Coccothraustes deformis Kocli, System d. baier. Zool., p. 226 (1816- Bayern).

Coccothraustes fagormm Brehm, Handb. Naturg. Vög. Deutschl., p. 256 (183L- Laubhölzer mit Steinbuchen).

Coccothraustes cerason um Brehm, Handb. Naturg. Vög. Deutschl., p. 257 (1831 - Laubhölzer und Gärten).

Coccothroustes planiceps [Brehm, Ifandb). Naturg. Väg. Dentschl., p. 258 (18:31-- im Winter bei Renthendorf).

Coccothraustes atrogularis Macgillivray, Hist. Brit. B. I, p. 356 (1837-Großbritannien).

Coccothraustes Europaeus Swainson, Class. B. II, p. 227 (1837- auf Selby's Abbildung zu bezichen).

Coccothraustes minor Brebm, Vogelfang, p. 94 (1855- Ungarn und Renthendorf).

Engl.: Hawfinch. Hranz: Grosbec. Ital.: Frosone.

ôad. Oberkopf und Kopfseiten zimmtbraun, an der Stirn heller, am Hinterkopf etwas dunkler. Der ganze Hinterhals aschgrau. Rüeken, Schulterfedern und kleine Flügeldecken schokoladenhraun, mittlere und grobe Flügeldecken zum gröBten Téile grauweib, cine breite weibliche längshinde dureh den Flügel bildend. S'chwingen, Handdecken und henachbarte grol.se Flügeldecken schwar\%, die änbern Handschwingen mit weibem Fleck in der Mitte der Innenfulhe, die innern an der Basis der Innenfahnen zu etwa " : wrib, Armsehwingen mit kleinerem weilsen Fleck an der Innenfahne. Spitzen der Handsehwingen stahlblau, AuBenfihnen der Armschwingen an der Spitzenhälfte mit hreitem violettblanen Aubensium, die imersten Armsehwingen braun. Stenerfedern: Aubenfahnen schwirzlich, Innenfahnen schwarz, Spitzo zu etwa $\% / 5$ weiß. nach der Mitte zu weniger, mittelstes Panr brïuulich, an den Spitzen weiblich. Bürzel heller, Oherschwanzdecken dunkler zimmtfarhen. Zügel und ein ganz sehmaler Streif um den Schnahel herum schwarz; Kehle schwarz, bisweilen seitlich weißlich hegrenzt, ührige Unterseite graburaun mit weinrötlichem Anfluge. Bauchmitte weißlich, Cuterschwanzdeckeu weil. Achselfedern und U'nterflügeldecken weiB, letztere am Außemrande dureh die hervortretenden brauschwarzen Federwurzeh mit schwarz gefleckt. Iris 


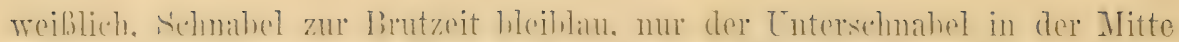

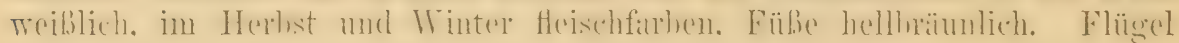
100-105, Schmanz 53-57, Schuabel 19-22, Lauf etra 21--22 mm.

o dem ôd. ähnlich, aber weniger lebhaft gefürbt, Oberkopf und Kopf-

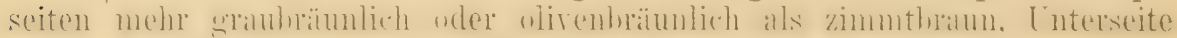
ebenfalls melır graubräunlich, Nitte des Unterkörper's mehr weißlich.

Der junge Togel ist sehr rerschieden: Kopf bräunlich grïnlichgelb,

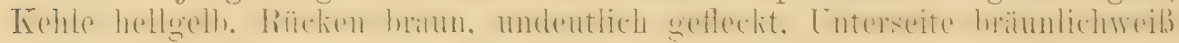
mit schwarzbraumen Federspitzen.

Die Unterscheidung von Unterarten in Europa steht noch aus. Im IIuseum zu 'Tring ist ein Paar aus Corsica, ron Thitehead gesammelt,

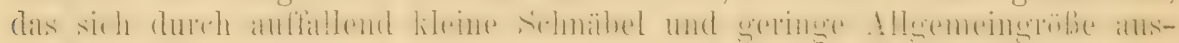
zeichnet. Diese Korsikaner aber baben nicht den hellgrauen Bürzol der

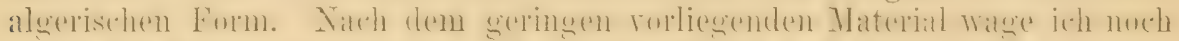

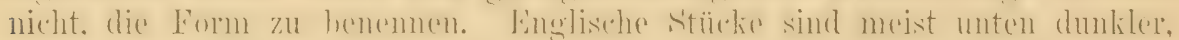
was aber von dem russigen Zustande des Landes herrühren dürfte, denn

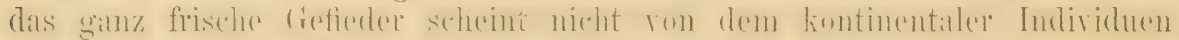

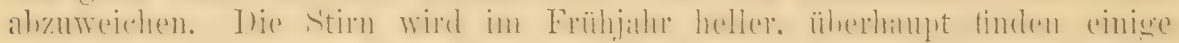
Variationen im Farbenton und in der Größe statt. Daß suidosteuropäische

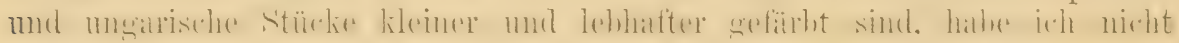
gefunden; italienische sind meist, aber nicht immer, sehr licht und groß.

In Skaudinavien nur im Süden und auch dort ziemlich selten, in England (an Zahl in vielen Grafschaften zunchmend) fast überall, wenn anch lokal und meist in geringer Anzahl britend, in Irland nur seltener Wintergast. In Rußland mach Norden bis St. Petersburg, in Mittel-Europa allgemein

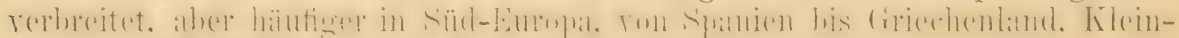

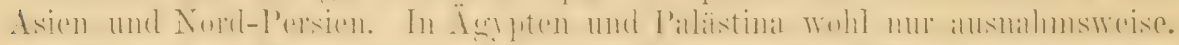

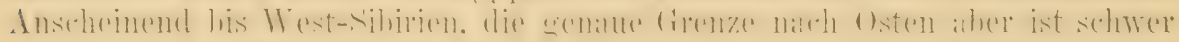
zu bestimmen, denn die östliche Form (C. e.japonicus) ist sehwer zu unterscheiden und vielleicht findet ein allmählicher Übergang statt.

In England und andern milden Gegenden Stand- und Strichrogel, in rauheren Klimaten Strieh- und Zugrogel, aber kein großer Wanderer.

Der Kirschkernbeiber ist ein Bewohner ron Parks, baumreichen, stillen Gärten, gemischten und reinen Laubwäldern und Feldhölzern. Er ist ein schener Vogel, der sich in diehten Baumkronen wohl zu rerbergen weiß. Auf dem Boden sieht man ihn seltener. Der Flug geschieht in flachen, weiten Bogenlinien, schnell und ruckweise. Dic Lockstimme ist ein kurzes scharfes ,zicks zicks" und ein gedehntes durchdringendes „zilh". Der Gesang ist klirrend und schirkend, nicht laut. Nahrung allerlei Sämereien, namentlich aber die Kerne der Kirsehen, Schlehen, Buchen und Hainbuchen, Unkrautsamen, Taxusbecrein, besonders gern auch Erbsen, im Frühling auch Baumknospen, wodureh er schädlieh werden kann, und Insekten, namentlich grolie Käfer. Die Jungen werden teilweise mit Insekten, namentlich mit Raupen gefüttert. Ende April wird meist mit dem Nestbau begonnen und wenn die Bänme belanbt sind, findet man die Gelege. Sie bestehen aus 4-6 Eiern, welche hellgrau oder hellgelbbräunlich, oder auch blänlich bis olivengrïnlich sind und mit hellgrauen Schalenflecken und tiefbrauneu Schnörkeln, Linien und Flecken gezeichnet sind. Durch die Strich- und Schnörkelzeichnung älneln sio den Eiern von Emberiza miliaria und unterscheiden sich dadurch ron allen heimischen Fringillideneiern. Sie messen $23.52 \times 16.8,24.46 \times 17.50$, $27.1 \times 16.7,22.7 \times 17.3,23 \times 16.6 \mathrm{~mm}$. Das durehschnittliche Gewieht beträgt nach Rey 0,236 gr.

Das 우 brïtet 14 Tage. Das Nest steht auf Bäumen, meist ziemlich, oft sehr hoch, selten niedrig in Büschen. Es erinnert an ein vergrößertes Gimpelnost, denn es 
besteht aus einem Unterbau ron trockenen Reisern, ist ziemlich flach und die MIulde mit feinen Gräsern, Würzelchen, Flechten, Moos und einigen Haaren ausgefüttert. Es findet nur eine Brut im Jahre statt. Zur Brutzeit rersteckt und paarweise, später in kleinen Flügen und mehr bemerklich.

90. Coccothraustes coccothraustes japonicus T'emm. \& Schleg.

Coccothranstes vulgaris japonicus 'Temminck \& Schlegel, Faun. Jap., pl. 51 (1850).

Kaum vou C. c. coccothraustes zu unterscheiden, doch ist der Rücken meint etwas lichter, die Kónfseiten heller. der Luterkïrjer in der Alitte heller und sehr oft sind die reiken Spitzen der Stenerfedern weniger ansgedehnt $(15-20 \mathrm{~mm}$.)

Japan, Corea, Nord-China, Ost-Sibirien, Genane Grenze wach Westen hin nicht sicher festgestellt, auch wohl schwer festzustellen. weil rielloulht

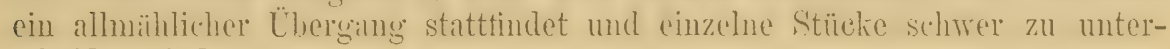
scheiden sind.

\section{Coccothraustes coccothraustes buvryi ('ih.}

Coccothraustes buvryi Cabanis, Journ. f. Orn. 1862, p. 259 (Algerien, im Mai von Burry gesammelt).

Wie C.c. coccothraustes, aber etras blasser, Oberkiopf nicht so braun, mehr cratulich, Mantel etwas lichter. IBürzel und Oherschwanzdechen lichter und fast rein grau. Nach Cabanis anch etwas kleiner, was die beiden von

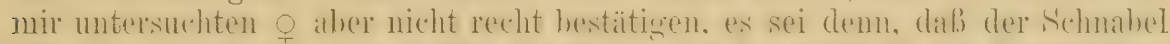

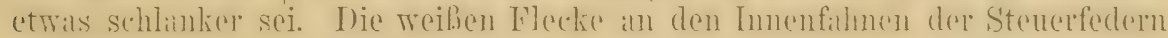
sind viel woniger ausgedehnt, indem sie nur etra $\mathrm{zu} 1 / 4$, nämlich $12 \mathrm{~mm}$, statt zu $\%$, nämlich etra $20-22 \mathrm{~mm}$ weiß sind.

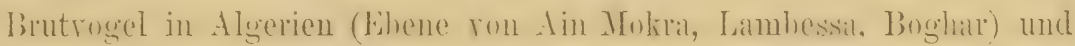
wahrscheinlich auch in Tunis ${ }^{1}$ ) und Narokko.

\subsection{Coccothraustes coccothraustes humii Sharpe.}

Coccothranstes humii Sharpe, Proc. Zool. Soc. London 1886, p. 97 (N. W. Punjab); id. Cat. B. Brit. MIus., p. 40, pl. I (1888).

Im ganzen sehr viel lichter, besonders auf dem Bürzel, die Unterseite und Körperseiten heller und mehr rostfarben, nicht so weinrötlich, das o viel blasser, oben mehr graulich, namentlich auf Kopf und Bürzel. Sehr kenntliche Form.

Nördlichster Teil des Punjab in Indien, Afghanistan und Turkestan.

\section{Gattung EOPHONA Gould.}

Der Gattung Coccothroustes schr wahestehend, namentlich der Schmahel

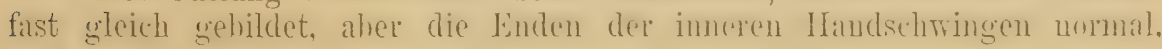

1) Ein Paar von Gabes in 'Tunis obne Datum, aber augenscheinlich TVinterrögel, in Prof. Koenig's Sammlung, gehören nicht zu C. c. buvryi und sind vielleicht Zugrögel. 
der Shawnz riel länere mud tief ausgehuchtet. die Geschlechter mehr verschieden.

2 Arten in China, Japan und Ost-Sibirien.

Größer, Körperseiten lichtgrau, Schwingenspitzeu ganz schwarz . E. personatus . p. 58 Kleiner, Körperseiten rostrot, Schwingenspitzen ganz weiß oder weiß gesäumt

E. melanura . p. 59

43. Eophona personatus personatus (Temm. \& Schleg.). (Fig. 14.) Coccothraustes personatus Temminck \& Selhlegel, Fauna Japon., Av., p. 91, 'Taf. 52 (1850).

Schnabel dunkelgelb, ringsum an der Wurzel graugrünlich. Um

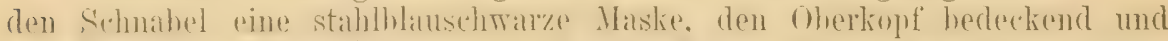

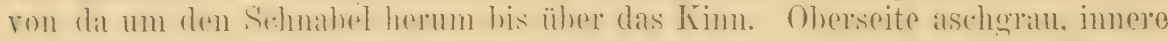

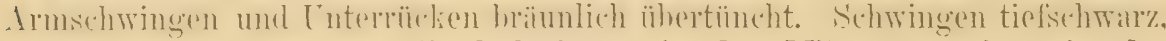

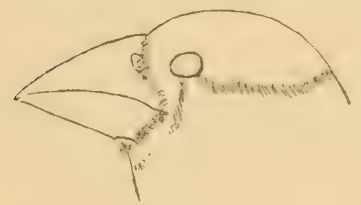

Figux it. Handschwingen in der Mitte von einer in der Mitte etwa $1 \mathrm{~cm}$ weiten, am Schafte jeder Feder unterbrochenen weißen Querbinde durchschnitten, Oberflügeldecken und der größte Teil der Außenfahnen der Armschwingen stahlblau. Schwanz sehwarz mit stahlblauem Schimmer, die Innenfahnen der äußeren Steuerfedern an der äußersten Basis schmutzigweiß. Unterseite etwas heller grau, als die Oberseite, Mitte des Cnterkin̈lers, Schenkelhefiederung und Cunterschwanzdecken rein weiß. Unterflügeldecken weiß. Iris braun. Füßse

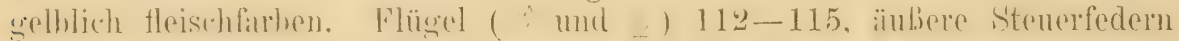
80-82, mittlere 60-63, Iauf etra 22-23, Schnabel 22-24 mm. ㅇ rom o nicht wesentlich versehieden. nur ein wenig kineiner. etwas dunkler auf der (Herseite, L'nterrïrken unil Weichen retwas mehr brïunlich angeflogen.

Die japanischen Inseln von Jesso bis Nagasaki.

Die Fortpflanzung scheint nicht beschrieben zu sein. Der Gesang wird als melodisch und abwechslungsreich beschrieben. Der Flug ist kräftig; im Herbste und Winter in Scharen. Nahrung Beeren, Früchte, Kerne, besonders Erbsen und Bohnen.

\section{Eophona personatus magnirostris Hart. (Fig. 15.)}

Eophona personata magnirostris Hartert, Bull. B. O. Club V, p. XXXVII (April 1896Sibirien. Typus Amur-Bai 10. IV. 1894, Dörries leg.).

Von E. \%) personatus auf den ersten Blick durch bedeutendere Größe, namentlich mächtigeren Schmabel, zu unterscheiden. Oberseite reiner grau, die weiße Flügelhinde etwas schmäler. Flügel o 123 , ㅇ $116-118$, Schmabel ơ $27-29$, o $23-25 \%$, Schwanz or $90-92 \mathrm{~mm}$.

Ost-Sibirien (Ussuri-Länder) und große

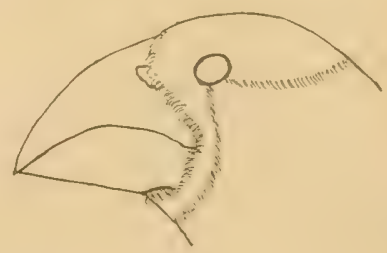

Figur 15.

Teile ron (hina, im Winter ricmlich weit nach Süden, Brutrogel wohl nur im Nordwesten.

(Lebensweise: 'Taczanowski, Faune Orn. Sibérie Orient. I, p. 624.) 


\section{9.). Eophona melanura melanura (fm.). (Fig. 16.)}

L.oxia melanura Gmelin, Syst. Nat. I, p.853 (1788 - Ex Sonnerat \& Latlam — "Habitat in Sina").

ơnd. Kopf, Kopfseiten und ganze Kéhle schwarz mit stahlblauem shimmer. Oherseite grauhran. Hinterhals und Bürzel bräunlicherau, nateh dom Schwanze zu fast weiblieh. Sehwingen schwart. Hondsehwingen mit "twa 2 cm langen weiben Spitzen, deren Ausdehmung alser rielfixch athändert, indem hisweilen noch schrarze Lindspitzen rorhanden sind und die erste Schwinge meist fast ganz schwarz ist. Armschwingen mit etwa $1 / 2 \mathrm{~cm}$ weiten weißen Spitzen, die letzte aber nur ganz schmal weiß gesäumt. Flügeldecken und breite Außensïume der Armschwingen stahlartig glüuzend, Handdecken weiß mit schwarzer Wurzel und Spitze. Schwanz und die längern Oberschwanzdecken schwarz mit bläulichem, stahlartigem Sehimmer. Kropfgegend hellaschgrau, Unterkörper weißlich, Körperseiten rostrot. Unterschwanzdecken weiß, Unterflügeldecken

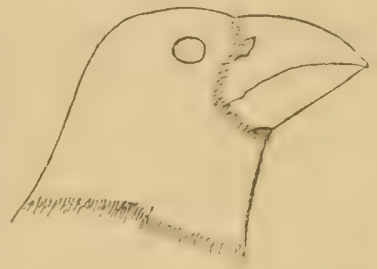

Figur 16.

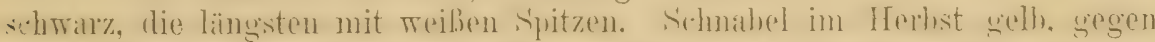
den Frühling hin gelb mit schwarzer spitze und schwarzen Scitenrindern.

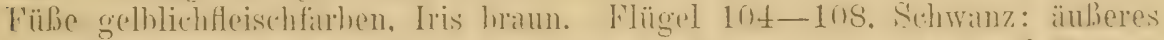
Steuerfederpara etwa 80-83. mittelstes 64. Schmahel 22-24. Lauf $2.3 \mathrm{~mm}$.

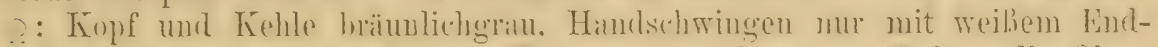
und Auliensaum an den Spitzen. Körperseiten hasser rostlarben. die Oher-

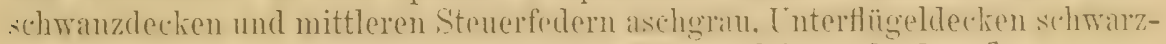
grau, zum Teil mit weißlichen Spitzen. Etwas kleiner als das ${ }^{7}$.

Seleint fast ganz China zu hewohnen, mit Ausuahme der sïdwestlichen

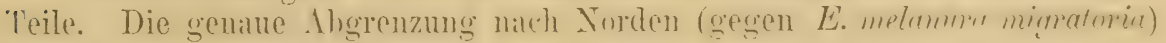
konnte ich noch nicht feststellen.

Auch diese Art hat einen wundervollen Gesang; wenn er auch dem von E.personatus nachstehen soll. Bewohuer von Laubwäldern, wo sie nach Kernbeißerart nistet. Von den Eiern sagt Nehrkorn (Kat. Eiersamml., p. 104, 1899): „Während die Eier des gemeinen Kernbeißers (Coccothraustes coccothraustes) eine grobe Fleckung aufweisen, haben diese feine violette und schwarze Schnörkel und Haarlinien. $23.5-25 \times 18-19 \mathrm{~mm}$.

96. Eophona melanura migratoria suhsp. nor. (Wig. 17.)

Diese merkw ürdiger: Weise hisher üherschene Form unterscheidet sich

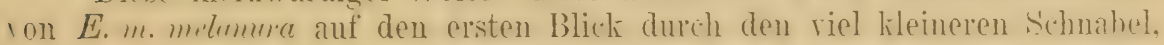

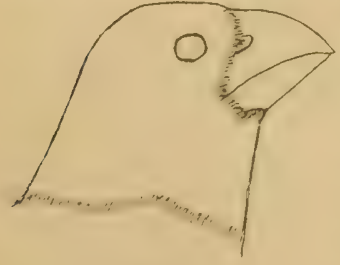

Figur 17. auch sind die Mraße sonst geringer. Schnabel 17 bis allerhöchstens $20 \mathrm{~mm}$, Flügel 97-102, Schwanz $73-75 \mathrm{~mm}$.

Bewohnt die Ussuri-Länder Südost-Sibiriens und die Insel Askold, streift his Corea, ganz vereinzelt auch nach Japan (Rikuzen) und findet sich im Winter in Scharen in Nittel- und Süd-China (Amoy, Foochow usw.).

(Typus von E. m. migratoria: OTad. Sidimi 24. Mai 1884. Gesammelt von Gehr. Dirries. Nr. 698. im Museum Rothschild zu Tring.) 


\section{Gattung MYCEROBAS Cabanis 1847 .}

Schnabel dem von Coccothraustes ganz ähnlich, nur hat der Oberschuabel

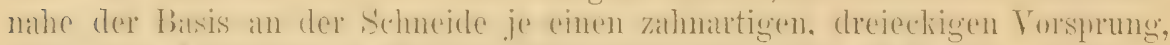

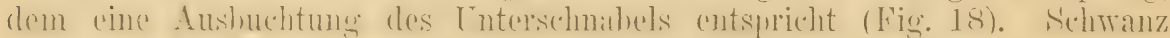

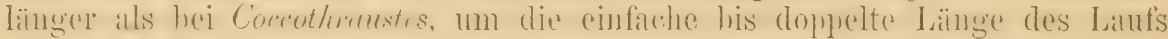

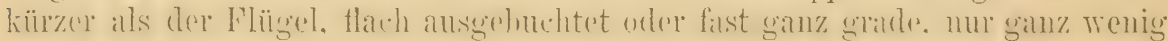
abgerundet. o dem ò ähnlich, aber viel heller, oder gestreift.

Der Typus der Gattung Dycerobas ist melanozanthus. $\left.{ }^{1}\right)$ Viele Ornithologen vereinigen damit generisch die Art camipes und das halte ich für ganz

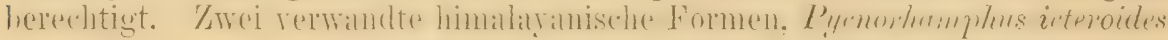

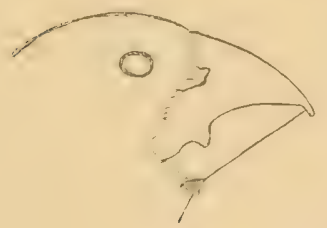

Figur 18. icteroides") und $P$. icteroides affinis:) haben einen riel gestreckteren Schnabel, langen, etwas ausgebuchteten Schwanz und völlig verschieden gefärbte Geschlechter. Wemu man daraufhin die Gattung Pycnorhamphus abtrennt, so dürfen in ihr jedenfalls nur die boiden Formen ietroides und affinis stehen, die nur don Grenzen des paläarktischen Faunengebietes angehören. Wenu man wegen des weniger flachen Unterschnabels und lïngeren Schwanzes, sowic des ungestreiften

Weibchens, M. camipes von Mycerobas melanozanthes generisch tremnen will, so muß ein neuer Gattungsname dafür gemacht werden. Wir bemühen uns

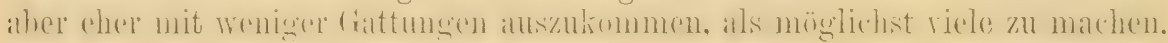

\section{Mycerobas carnipes (Hodgs.). (Fig. 18.)}

Coccothraustes eanipes Hodgson, Asintic Researches XIX, p. 151 (1836- Nepal). Coccothranstes speculigenes Brandt, Bull. Sc. Acad. Petersb. IX, p. 11 (1842).

ơ ad. Schnabel braun, Untersehnabel fleischfarben mit dunkler Spitze. Kopf, Hals, Brust und Rücken schwarzgrau, die Federn mattschwarz mit dunkel aschgrauen S̈̈umen. Luterrücken und Bürzel grünlichgelb, Oberschwanzdecken mattschwarz mit grünlichgelben Säumen. Handschwingen mattschwarz, die AuBenfihnen an der Basis etwa zu einem Drittel weiß,

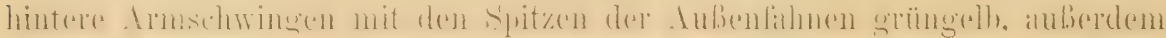

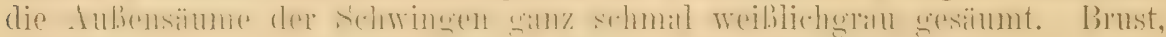

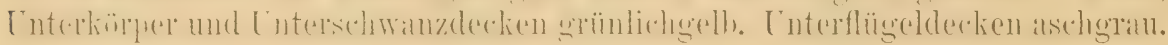

1) Mycerobas melcnozanthus (Coccothraustes melanozanthus Hodgson, As. Res. XIX, p. 150, 1836) bewolnt den Himalaya rom äußersten N IV. bis Sikkim, kommt aber auch in den Bergen von Szechwan in WV. -China ror und zieht im Winter bis Manipur. ôad. Oben schwarz, Armschwingen und große Flïgeldecken mit hellgelben Spitzen der Außenfahnen, Kinn und Kehle schwarz, übrige Unterseite gelb. 우 oben schwarz, gelb gefleckt, unten gelb, schwarz gefleckt.

2) Coccothraustes icteroides Vigors, Proc. Zool. Soc. London 1830, p. 8 . - o ad. Kopf, Kehle, Hals, Schwanz, Fliigel und Schenkelbefiederung mattschwarz, das iibrige Gefieder gelb und schwarz gestreift. ㅇ bräunlichaschgrau, Bürzel und Unterkörper hellrostbräunlich. Westlicher Himalaya.

$\left.{ }^{3}\right)$ Hesperiphona affinis Blyth, Journ. Ac. Soc. Bengal XXIV, p. 179, 1855. Unterscheidet sich von P. i. icteroides durch golbe Schenkelbefiederung des of und bewohnt den östlichen Himalaya von Sikkim bis Jupin in China. 
Beine und Füße bräunlichfleischfurhen. Iris hraun. Flügel 116-125, Scilwanz 100-104, Schnabel 21-23, Lauf etra $25 \mathrm{~mm}$.

qad. und juv. Verteilung der Farben wio beim ôd. aber statt schwarzgrau hell aschgratu, der Reïcken mit gelhgrünilehem Schimmer, das gello nicht so dunkel, die Ohrdecken mit weiblichen sidaftstreifen, die brust mit helleren Schaftstrichen.

Von Turkestan und Afghanistan durch den Himalaya bis Kansu und

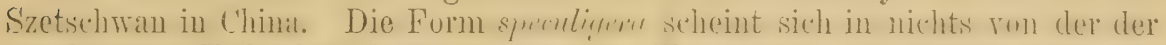
westlicheren Teile des Himalaya oder von Kimsu usw. zu unterscheiden, nur in Siklim (nieht aler in Nepal) kommt eine kleine Forme ror, (c) Flïgel nur 103-115,) deren genaue Verhreitung aher nicht leststeht, da aus Siklim anch Stälelie der groben Form rorliegen. Es ist anzunehmen. dials die kileine form ein hesonderes Brutgentiot hat und subspezifisch unterschieden werden sollte.

II. camines ist ein Bergbewohner, der in Nadelwäldern und Wachholderdickichten, meist in Höhen über 8000 engl. Fuß lebt, und im Himalnya anscheinend nie unter 5000 herabgeht. Am 20. Mai 1899 wurde in Turkestan das Nest gefunden. Es stand etwa $1^{1 / 3} \mathrm{~m}$ hoch in einem Wachholderbusehe. Es erinnert in der Bauart (außen trockene Zwweige, innen mit feineren Zwweiglein ausgelegt) an Kernbeißernester, und enthielt 4. Eier, die ungefähr wie Kirschkernbeißereier aussehen, nur etwas größer sind, indem sic etrra $28 \times 19$ bis $29.3 \times 19 \mathrm{~mm}$ messen. (Dresser, Ibis 1903 T'af. 10, p. 406.) Der Flug wird als rasch und rauschend beschrieben, während des F'luges hört man einen häufig ausgestoßenen schwatzend melodischen Lockruf.

\section{Gattung CHLORIS Cuv. 1800.}

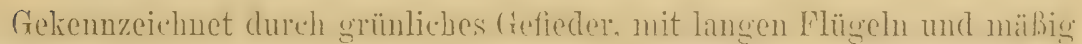
langem, merklich ausgeluchtetem Schmanze. Selunahel kurz und kulhig diek.

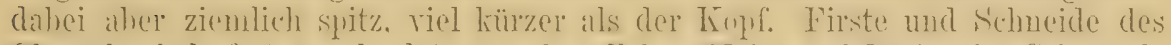

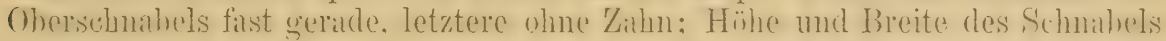
an der Basis gleich und nur etra $2-3 \mathrm{~mm}$ weniger als dio Lünge. Nester

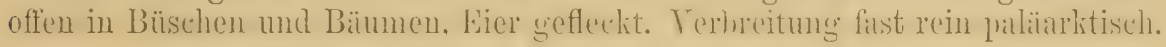

$$
\text { Übersicht der Arten: }
$$

$1\{$ Schrvingen an der Basis nur gelb gesäumt . . . . . . . 2

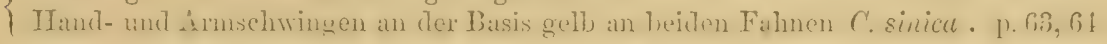

. f Õad. oben gelbgriin, Geschlechter nicht gleich, Fliigel über $8 \mathrm{~cm}$ C. chloris . p. 61

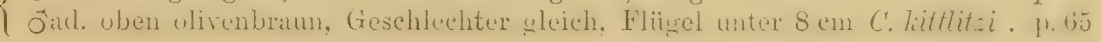

\section{Chloris chloris chloris (L.).}

Der Grïnling:

Loxia Chloris Limné, Syst. Nat. Ed, X (1758), p. 174 („Habitat in Europa“. - Typ. Lok. Schweden: ex Fauna Suecica, erstes (itat).

Chloris pinetornm Brehm, Handb. Naturg. Vög. Deutschl., p. 259 (1831- Nadelwälder, Jittel-Deutschland).

Chloris hortensis Brehm, Handb. Naturg. Vög. Deutschl., p. 260 (1831- in deutschen Gärten und Laubholz).

Chloris septentrionalis Brehm, Handb. Naturg. Vög. Deutschl., p. 261 (1831- NordDeutschland, z. B. Kiel, Winter in Mittel-Deutschland).

Chioris curvirostris Brehm, Vogelfang, p. 95 (1855- "Schweden und Deutschland". Aberration mit gebogenem Oberschmabel). 
Chlorospiza chloris montuna und megarhynchos A. Brehm, Verz. Samml., p.9 (1866 nomina nuda!).

(Chloris incerta Brelum, Vogelfang, p. 95, aus Siid-Europa, ex Bonaparte und Rissu. dürfte nicht hierher gehören.)

Chloris Linnéi Malm, Göteborgs Fauna, p. 195.

Engl.: Greenfinch. Franz.: Verdier. Ital.: Verdone. Schwed.: Grönfink.

O̧ad. Oberseite gelblicholivengrün, durch graubraume Federänder ver-

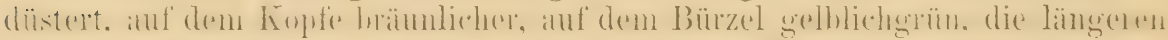

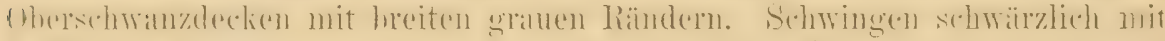

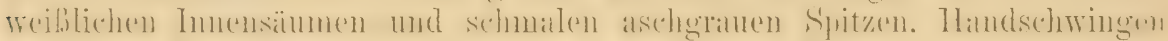
zu 2/3 ron der TVurzel mit breiten, fast die ganze Breite der Außenfahne

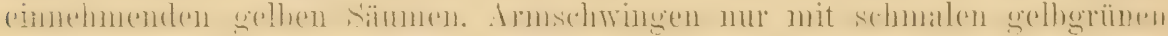
Säumen nahe der Basis der Außenfahmen und aschgrauen Aubenrändern,

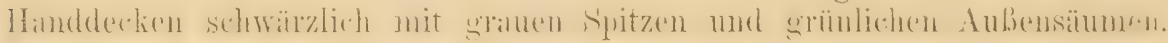

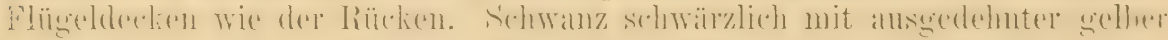
Basis und aschgramen Sïumen, das mittelste Paar ohne gelbe Basis. Unter-

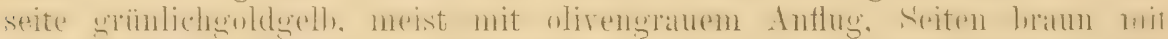

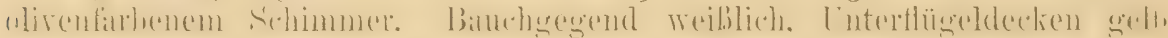
mit graulichen Twuzeln. Flügel 87-90, Schwanz etwa 57, Lauf 88-89, Schuabel $12-14 \mathrm{~mm}$.

ad. Oben viel brauner, Mitte der Federn dunkler, wodurch ein etwas

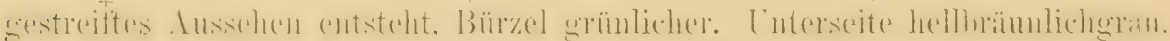

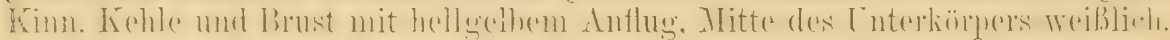
Die gelben Säume der Handschwingen reichen nie bis an den Schaft, die

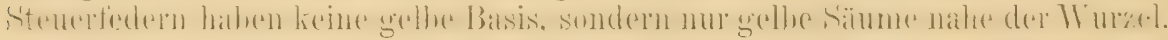

Der junge Grïnling hat grïnlichgelbbraune Oberseite, durch braune

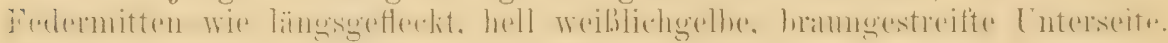

Berrohnt ganz Europa (im S.W. durch C. c. aurantïventris vertreten). von etwa $65^{\circ}$ mördl. Breite in Norwegen und $60^{\circ} \mathrm{im}$ Ural bis Italien, die

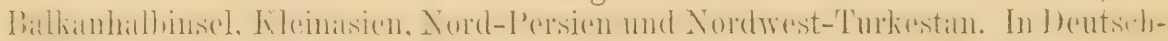
land und Eugland ïberall häufig, rerbreitet sich mit dem Zunehmen vou Gartenanlagen mehr und mehr, demu er ist ein Bewohner von Gärten und

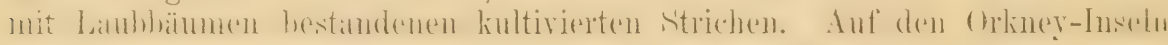
jetzt hïufig, woraus man aber nicht auf ,ein allmähliches Vordringen nach Norden " zu schließen hat. In den meisten Gegenden Stand- und Strichvogel, nur im höheren Norden, bis Norddeutsehland, allenfalls als halber

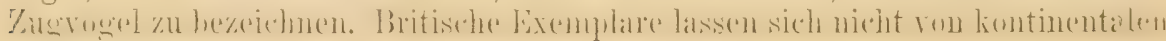
unterscheiden.

Dieser allgemein bekannte, häufige Vogel bewohnt Gärten, Alleen, lichte Litul. wälder und dergl., besonders in fruchtbarer, bebauter Gegend. Er ist im allgemeinen wenig scheu, aber auch nicht gerade besonders vertraut. Der Lockruf ist ein girrendes "giirrü̈rürm", seltener ein etwas zischendes ,zih", die Flïge rufen häufig ,jick, jich jick jick". Der Gesang ist ein eigenartiges, klirrendes Trillern und Pfeifen, das keinen Anspruch auf Schönheit machen laun. Die Lahrung besteht hauptsächlich aus Sämereien, namentlich gern ölhaltigen, den Kernen der Buchen, Vogelbeeren, Taxusbeeren, auch Baumknospen und Blattrieben, teils am Boden, teils an den Bäumen aufgelesen.

Der Grünling macht in der Regel zwei Bruten im Jahre. Mãn findet die Lier der ersten Brut schon Mitte oder Ende April, die der zweiten im Juni oder Juli. In nördlicheren Gegenden, merkwürdigerweise auch, wie es scheint, in dem milden Klims Englands, wird nur eine Brut gemacht. Das Nest steht in Büschen und auf Bäumen $1-5 \mathrm{~m}$ hoch, meist in Reichhöhe oder etwas darüber. Nicht selten findet man 2-i: 
ganz nahe beieinander. Das Nest ist ein prachtroller, dichter Bau aus Moos, Flechten, Wolle, Würzelchen, Gräsern, Federn und Haren, mit tiefem, warmen Napf. Die Gelege bestehen ans 4-6 Eiern. Sie sind trübweiß mit meist sehr schwachem grünlichblauen Schimmer, von mattem Głanze, und mit blassen graurötlichen oder mattrotbräunlichen Schalenflecken und darüber liegenden tief rotbraunen Flecken, Punkten und manchmal Schnörkeln geziert und messen nach Rey im Durchschnitt $20.2 \times 14.5$, im MIximum $22.7>15.3$ bezw. $20 \times 16$, im Minimum $17.2 \times 13.5 \mathrm{~mm}$. Ich habe zwar kleinere Eier gefunden, die aber wohl als abnorm gelten dïrften. Das Durchschnittsgewicht beträgt $0.123 \mathrm{gr}$.

\section{Chloris chloris aurantiiventris (Cab.).}

Ligurinus aurantiiventris Cabanis, Mlus. Hein. I, p. 158 (1850- Sïd-Frankreich). Chloris chlorotica einiger Autoren - errore!

Unterscheidet sich von C.c. chloris lediglich durch tiefere und gleichmäBigere groünlichgoldgelhe [nterseite. die in der Nitte des Cnterkïrpers

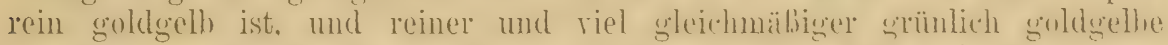

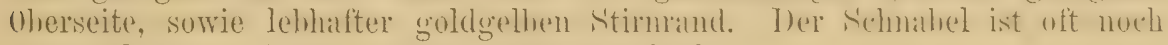
etwas klobiger. In der Regel etwas kurzflügliger.

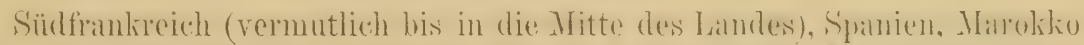

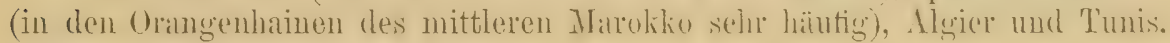
Azoren (San Michrel) eingefülnt.

Lebensweise wie bei C. c. chloris.

\section{Chloris chloris chlorotica (Bp.).}

Chlorospiza chlorotica Bonaparte (ex Licht. IIS.), Consp. Av. I, p.514 (1850_ „As. occ." Typische Lokalität Syrien: Hempr. \& Ehrenberg).

C. c. chloris und noch mehr C. c. atrantiuventris äußerst ähnlich, aber etwas kurzflügeliger, im ganten viel heller und reiner geelblich oken und unten. Im frisehen Gefieder sind Hinterkopt und Hhrdecken hellgran ïherthgen, im abgetragenen Brutgefieder von dem von C. c. aurantiiventris kaum zu unterscheiden, nu sind die Flügel kïryer, anch ist das gello dere Handschwingen meist heller.

Syrien und Palästina.

\section{Chloris sinica kawarahiba ('Temm.).}

Fringilla lkauarahiba 'Temminck, Pl. Col. 588, Fig. 1 (1835- Japan).

Fringilla laumahibu mujor Temminck is Schlegel. Fauna Japon.. Aves, pl. 48. 11. 88 (1850).

OTad. Schnabel braun. Oberkopf und Hinterhals dunkel graubraun

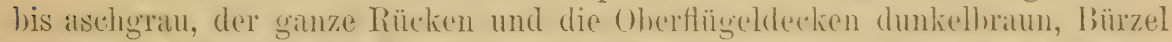
heller, in dass gram der (Bherschwanzdechen ïhergehend. Śchwingen: durehschnittlich last die Basisuälfte gell, die Spitzenhailfte schwar\% mit schmilen weillichen Suitzensäumen, innere Armsehwingen mit breiten hellhräunlichgranen

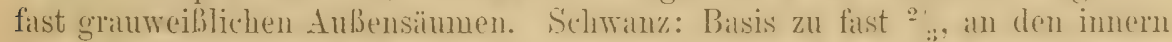
Stenerfedern nur etwa ${ }^{1}$ agelh, Spitze sthwailzhich mit schmalen graubramen Süumen, mittelstes Parar nur an der Basis dor Aubenfihmen gelh. Zü̈gen rauchschwarz, Kopfseiten und Fehle aschgrau mit hrïmnlichem Schimner, übrige Cnterseite lebhaft hraun mit etwas helleren Sämmen, Kohle und Brust 


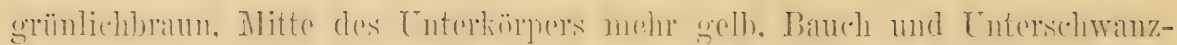

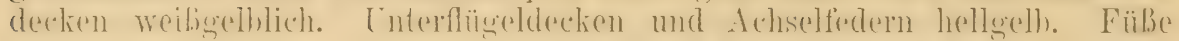
hellbraun, Iris braun. Flïgel 87-92, Schwanz etwa 60, Lauf etwa 17-18, Schuabel 12-13 $\mathrm{mm}$.

o ad. Kopf nicht graubraun, sondern braun, Oberschwanzdecken mehr

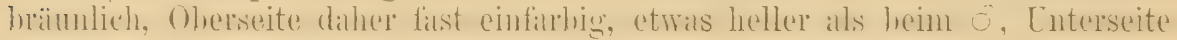
heller braun, ohne grün.

Juv. Oberkopf braun, Oberseite durch dunklere Federmitten etwas streifig, Unterseite mit dunkelbraunen Schaftstrichen.

Kamtschatka und Kurilen. Zuerst von Japan beschrieben, wo er läufig:

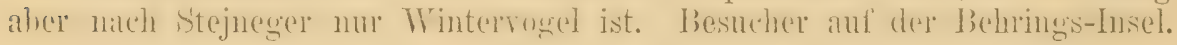

Lebensweise grünlingsartig, über die Fortpflanzung ist nichts genaues bekannt.

\section{Chloris sinica minor (Temm. \& Schleg:).}

Fringilla kawarahiba minor. T'emminck \& Schlegel, Fauna Japon., Ares, pl. 49, p. 89 (1850-- Japan).

(Chloris sinica Sharpe u. a. -- partim, ex Japan).

Genan wie C. s. lawaratiba, aber erheblich kleiner, Flïgel 81-84, Sehwanz 55-56, Lauf 15-17, Schmabel etwa 10-11.5 mm, Rücken mehr

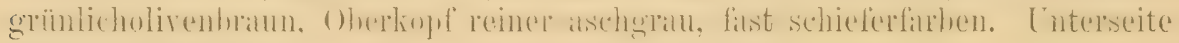
meist mehr grünlich.

Japan, nach Stejneger nur dort Brutrogel.

Lebensweise grünlingsartig, nistet nach Art der Grünlinge auf Bäumen, meist Nadelbäumen. Die Eier ähneln denen der Grünlinge, sind aber etwas zarter gezeichnet. Exemplare der Rey'schen Sammlung messen $19 \times 13.2,19 \times 13 \mathrm{~mm}$. Gewicht 0.111 und $0.110 \mathrm{~g}$.

\section{Chloris sinica sinica (L.).}

Fringilla sinica Linné, Syrst. Nat. Ed. XII, rol. I, p.321 (1766-. Ex Brisson: China).

Noch kleiner als C. s. minor und auch in der Färbung sehr abweichend.

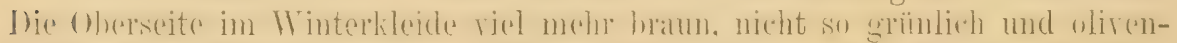

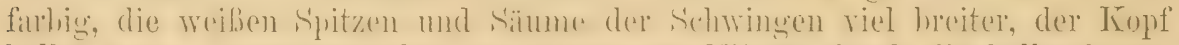

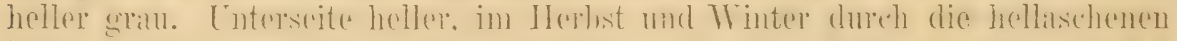

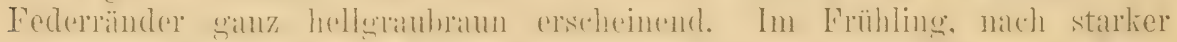

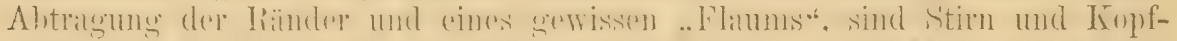

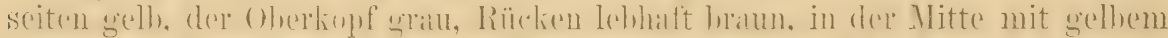

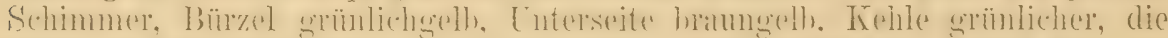

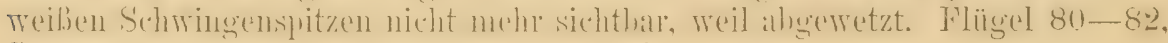
Schwanz etwa $47-48$, Schmabel $10-11 \mathrm{~mm}$.

Berrohnt China, wo er ein häufiger Vogel ist.

Der Gesang wird von Père Darid als noch schlechter als der des Grünlings geschildert, Styan aber nennt ihn gut. Soll ziemlich scheu sein, brïtet auf Nadelbäumen und streift nach der Brutzeit in Seharen umher.

\section{Chloris sinica ussuriensis subsp. nor.}

Ganz wio C. s. sinica, aber der Schmabel an der Wurzel, besonders des Entersehnahels, weniger lureit und dick. was beim Anblick einer serje leicht 
auffällt. Flügel in der Regel 1-2 mm länger. Herbstkleid heller, Rü̈lien

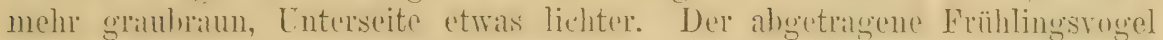
oben mehr leberbraun, nicht so gelblich, unten viel blasser. Typus ỡ ad. Sidemi-Mündung, Ostsilirien (Cssuri), 30. April 1884, G(e)r. Incirries coll., ill Mus. Tring (Nr: 2116).

Bewohnt die östliche Mandschurei bis zum Ammr, Korea und die Inschn Sachalin und Askiold.

\section{Chloris kittlitzi (Seob.).}

Fringilla kittlitzi Seebohm, Ibis 1890, p.101 (Nakondo-Shima und Haha-Shima, 2 der Bonin-Inseln).

ôad. Oberseite olivenbraun mit dunkleren Federmitten, Kopf mehr

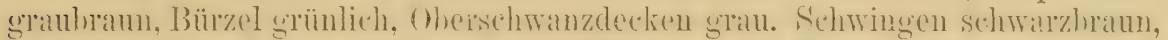

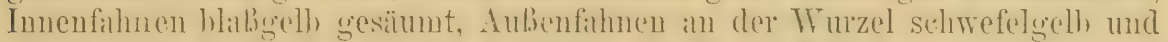
writer natch den Suitzen hin nit sehmalen grünlichen Süumen. Armschwingen mit aschgranen duliensïmmen. Flügalderonen olivengrün, die mittleren und

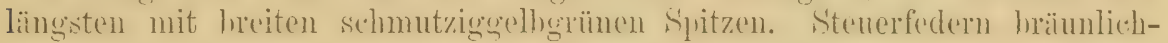
schwarz mit schmalen aschfarbenen Rändern, Wurzel etra $1-1^{1 / 2} \mathrm{~cm}$ weit

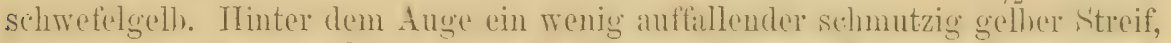

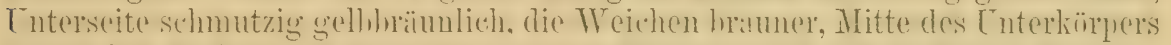

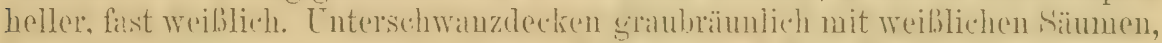
Enterflügeldreken sehmutzig hellgelh. Schmahel mol Fïlie (im Balge) sehmutzig

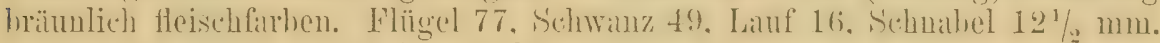
ㅇ (wenn richtig bestimmt) wie on nur. Flügel $2 \mathrm{~mm}$ kïrzer.

Bouin-Insoln südöstlich von Japan.

Wahrscheinlich von C. sinica abzuleiten aber zu auffallend verschieden, um nicht als Art betrachtet zu werden. Obige Beschreibung scheint die erste einigermaßen ausfülurliche zu sein.

\section{Gattung ACANTHES Bechstein 1803.}

Die (Catalogue of Birds XII, Oates, Birds of India, Neue Ausgabe von Naumann, Reichenow's Kennzeichen der Vögel Deutschlands, u. a.) ählieh wewordene Finteilmes der Gattungen der Hönflinge und Zeisige ist ein Unding. Fs ist allgemein anerkannt, daß wil Gattungen nicht nach der: Fürbung allein abgrenzen kömmen, sonderu mach ihrem äußeren und

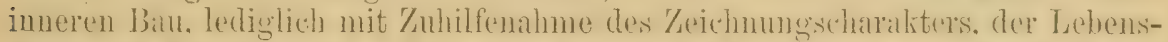
weise und Fortuflanzung. Tie man danath die Leinzesige mit ihnem feinen, spitzen Schuahel (Fis. 19, 2) mit dom dickschnähigen Hänlingen (Fig. 19, 1)

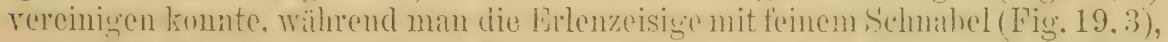

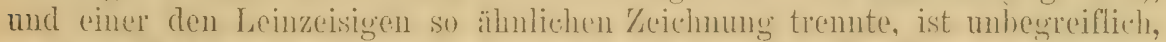
anch sind keine strukturellen Entraschiede hei den stienlitzen rorhanden,

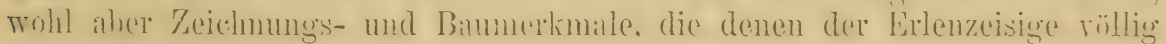
entsprechen. Faßt man nur die europäischen Arten ins Augo, so ergibt

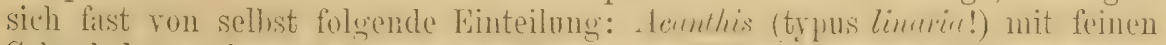
Sehnäbehn, unfassend Leinzeisig, Lirlenzeisig, Distelzeisig und (itronenzeisig. Linota umfassend die dickschnäbligen cannabina und flacirostris. Leider 
wird diese so plausible Teilung erschïttert, wenn wir die Auslïnder mit betrachten. Sehen wir nur z. B. barbata aus Chile und magellanica (icterica) an, so haben wir einen echten gelbgrünschwarzen Zeisig mit dem Schnabel vines Hänflings, und den C'bergatug rom Zeisig- zum Hänflingsschuabel.

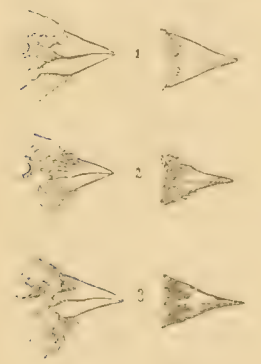

Fign11 19. Da die Gattungen nur gemacht werden, um die Übersicht zu erleichtern, nicht aber, um das Studium zu erschweren, so vereinige ich die Genera 26 („Carduelis"), 27 ("Chrysomitris") und 31 ("Acanthis") des XII. Bandes des Catalogue of Birds unter letzterem Namen. Will man dies nicht tun, so muß man in das viel schlimmere Extrem gehen, nämlich nicht nur statt der drei Gattungen des Cat. B. deren vier, Carduelis, Chrysomitris, Acanthis und Linota annehmen, sondern auch noch die amerikanischen Zeisige weiter in Spinus, Astragalinus und Hypacanthis zersplittern - ich meine aber, das sei mehr Last als Nutzen. Meine Gattung Acanthis kömnte man folgendermaßen beschreihen:

Schnabel hart, fast kegelförmig, mit scharfer, bald kurzer, dickerer, bald langer, dümnerer Spitze, Basis merklich stïrker, wie geschwollen. Ober-

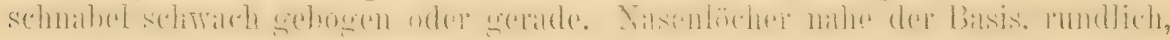
durch nach vol'n gerichtete Federchen bedeckt. Flügel lang und ziemlich spitz, die erste Schwinge ganz verkïmmert, die zweite bis vierte fast gleich

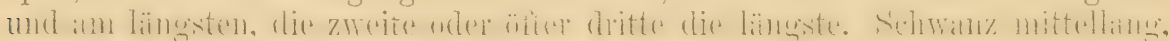
mindestens $1 / 2 \mathrm{~cm}$ tief ausgeschnitten. Lauf kurz und kräftig, vorm mit Schildern, an den Seiten mit ununterbrochenen Schienen bedeckt.

$$
\text { Übersicht der Arten. }{ }^{1} \text { ) }
$$

I Rings um den Schnabel herum rot. . . . . . . . . . . . 2

1 Kopf, Brust oder Bürzel mit rot............... 3

Ohne alles rot......................... 4

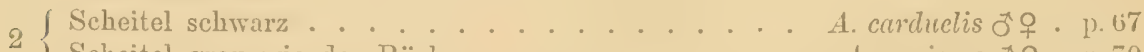

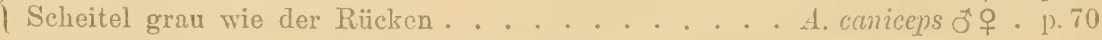

Oberkopf und Brustseiten rot, Bürzel ohne rot, Körperseiten ungestreift braun . . . . . . . . . . A. cannabina ơ. p. 73

Vorderkopf, Vorderhals und Brustseiten rot, Bürzel gestreift A. flammea ơ . p. 77

3 Vorderkopf rot, Brustseiton ohne rot, Bürzel gestreift . . A. flammea 우 . p. 79 Vorderkopf rot, Brust ohne oder mit wenig rot, Bürzel ungestreift weiß A. homemannii ડํㅇ. . p. 81 Nur Bürzel mit rosenrot ............. flavirostris o . 1). 76

1) Über die folgende Zieisigart fehlt bisher weitere Nachricht:

Chrysomitris pistacina Bonaparte, Consp. Ar. I, p. 515 (1850- Ex Erersmann MS. im Berliner MIus. "Sibiria"). ,Minor: rufo-olivacea; subtus oliracea-flara, tectricibus alarum caudaeque inferioribus albis: alis, caudaque fuscis; tectricibus omnibus, remigibus secundariis, rectricibusque interne apice albicantibus." Prof. Reichenow schreibt mir iiber den Typus wie folgt: „Ein ganz eigenartiger Zeisig, am ähnlichsten dem o ron mexicana, Schnabel aber schlanker, Oberseite heller, Rücken ins rotbräunliche zichend, der Farbe von totta sich nähernd, nur sehr schmale, weißliche Endsäume an den großen und mittleren Deckfedern, keine Säume an den inneren Armschwingen; Oberschwanzdecken grau. Steuerfedern mit länglichem weißen Fleck am Lnde der Innenfahnen, Unterschwanzdecken weiß. - Ich kann den Vogel auf lieine bekannte Art deuten." Da es schwer glaublich ist, daß es sich um eine nie wieder gefundene sibirische Art handelt, so liegt die Vermutung nahe, daß es ein Bastard (aber woron?) oder eine Aberration sei, oder daß der Fundort nicht richtig ist. 
f Oberseite rostbraun, schwarz gestreilt ............. 5

4 Oberseite grünlich oder olivenbraun, gestreift ......... 6

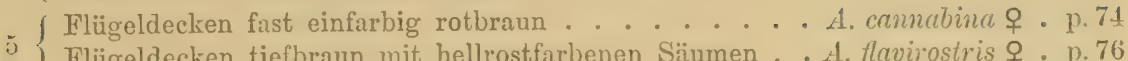

Flïgeldecken tiefbraun mit hellrostfarbenen Säumen . A. flavirostris o ? p. 76

, Oberkopf schwarz oder schwarzbraun ............. 7

\{ Oberkopf meist mehr oder minder gestreift, nieht schwarz . . . . . 8

7 f Rücken grün, Flanken gestreift .............. spinus ô. p. 71

\{ Rïcken olivenbraun, Flanken ungestreift ......... spinoides ơ. p. 73

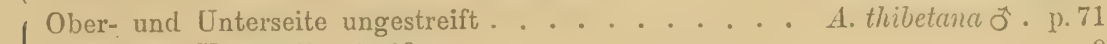

8 Ober- und Unterseite streifig ............... . . . . . . . . . . . .

Oberseite streifig, Unterseite ganz ungestreift . . . . . . . . 10

Unterseite weißlich . . . . . . . . . . . spimis o . P. 71

9 Unterseite hellgelb, Flügel unter $70 \mathrm{~mm}$...... A. thibctanc 우 . p. 72

Unterseite hellgelb, Flügel über $70 \mathrm{~mm}$....... A. spinoides 우 . p. 73

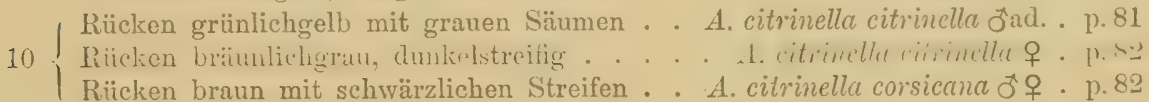

\section{Acanthis carduelis carduelis (L.).}

Distelzeisig, Stioglitz, Distelfink.

Fringillc Carluclis Linné, Syst. Nat. Ed. X, p. 180 (1758- „Habitat in Europae juniperetis" - typische Lokal. Schweden: Ex Franna Suecica, erstes Citat).

Carduelis elegans Stephens, in: Shaw's Gen. Zool. XIT, 1).30 (1826).

Carduelis septentrionalis Brehm, Handb. Naturg. Vög. Deutschl., 1). 288 (Nördl. Europa).

Carductis Germanica Brehm, Handb. Naturg. Vög. Deutschl., p. 28:) (1831).

Carduelis aurata Eyton, Cat. Brit. B., p. 20 (1830- lediglich neuer Name für Fringilla carduelis).

Carduelis communis Blyth, Journ. As. Soc. Bengal XIV, p. 5 n̆ 4 (1845- neuer Name für den europäischen Stieglitz, vielleicht nur lapsus calami).

Carduelis vulgaris Döderlein, Avif. Siciliens, p. 81 (1869- ex Linné Ed. VI!).

Carduelis accedens, aurantii-pennis, meridionalis Brebm, Vogelfang, p. 109 (1855Deutschland und Ungarn).

Carduelis elegans minor A. Brehm, Verz. Samml., p. 9 (1866-- nomen nudum!).

Carduelis Limnéi IIalm, Göteborgs Fauna, p. 195 (1877).

Fringilla albigularis Nadarász, Zeitschr. ges. Orn. I, p. 145 (1884- Ungarn).

Fringilla sylvestris, alpestris, hortensis Prazák, Ornith. Jalurb. 1894, p. 82-85.

Engl.: Goldfinch. Franz.: Chardonneret. Ital.: Cardellino.

onad. Schnabel weißlich mit schwarzer Spitze. Vorderkopf und Kopfseiten bis hinter die Augen und obere Kehle dunkelrot, einen zusammen-

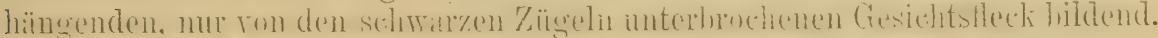

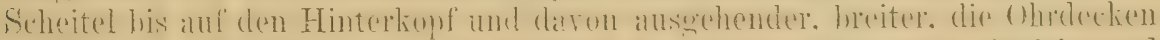

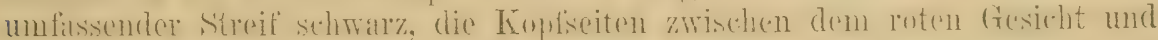
diesem schwarzen Streifen weiß. Dentlich weißer Fleck anf Nacken und

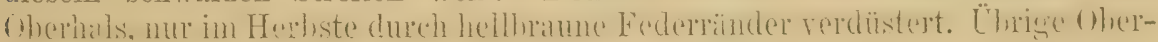
seite braun, unterer Bürzel und Oberschwanzdecken weiß, an den Spitzen im

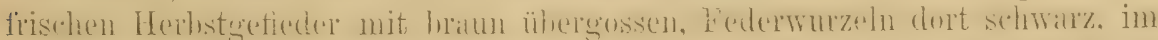

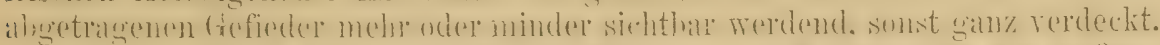

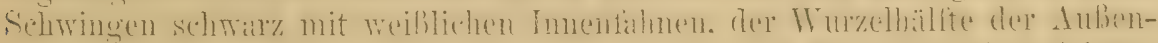

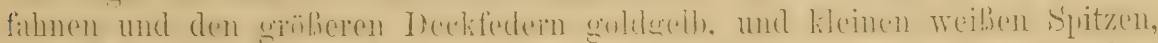

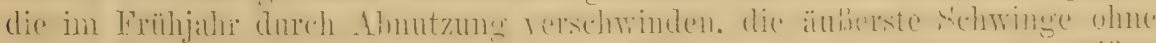

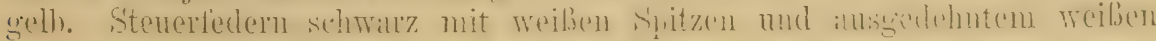




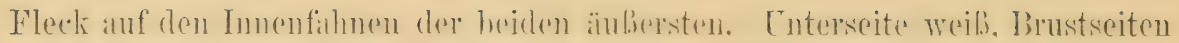

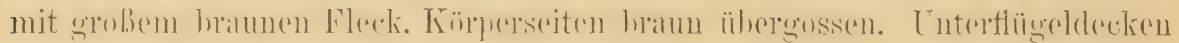
und Achselfedern weiß. Flügel o $79-84$, o 76-78, Schwanz etwa 50, Lauf, $14-15 \mathrm{~mm}$. O wie ơ nur etwas kleiner. Der junge Vogel ist oben licht erdbraun mit dunkleren Federspitzen, Flügel wie beim alten Vogel,

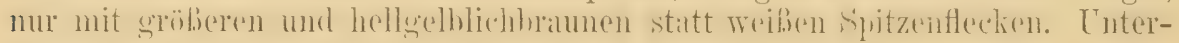

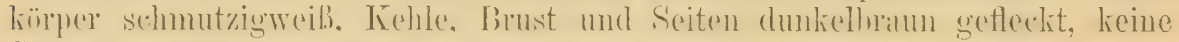
Spur von rot und schwarz am Kopfe.

Eine mehr oder minder weißkehlige Aberration war schon vor 100 Jahren als "Cheverel" in Frankreich und England bekannt und wurde 1884 von

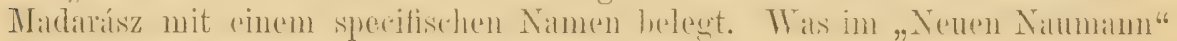
III, 293 dlarüber gesagt ist, ist nicht zutreffend.

Europa vom mittleren Sehweden ( $65^{\circ}$ nördl. Breite) bis an das Mittelmeer, wo aber andere Formen die typische Form ersetzen. Im allgemeinen Stand- und Strichvögel, im Winter in Flügen das Land durchstreifend.

Bewohner baumreicher Gegenden, wird aber fast nie in Nadelholzwäldern bemerkt. Seine Lebhaftigkeit, Schönheit, sein niedlicher Gesang und seine guten Eigenschaften als ausdauernder Käfigrogel machen ihn zu einem der beliebtesten Vögel. Er sucht seine Nahrung auf Bäumen, Büschen und Unkrautstauden, geht aber nicht oft auf den Boden. Sie besteht vorzugsweise aus Sämereien, namentlich ölhaltigen. Eine besondere Vorliebe hat er für die Samen der Disteln und Kletten. Grüne Knospen und Blattspitzen, sowie Insekten sind in der Freiheit wohl nur Zukost, aber die Jungen werden teilweise mit Insekten gefüttert. Der charakteristische Lockruf erinnert an das Wort "Stieglitz", das also ein Klangbild seines Namens ist. Der fröhliche, viel zwitschernde Töne enthaltende Gesang ist laut und angenehm, und im Fliegen und Sitzen schwatzen und locken die Scharen wie pick, pick-pickelnick und pickelnickneia usw.

Das tiefe, dickwandige, entzückend gebaute Nestchen steht auf Bäumen und hohen Büschen und enthält im Mai 4-6 Eier, die sehr dïnnschalig sind, weißlich mit schwachem bläulichen Schimmer und mit blaßrötlichbraunen Flecken und tief rotbraunen, fast schwarzen Punkten, Flecken und Kritzeln gezeichnet. Sie messen nach Rey etwa $17 \times 12.6,17.3 \times 12.3,17.4 \times 12.6,17.5 \times 13.5,17.9 \times 12.7 \mathrm{~mm}$. Das Gewicht ist durchschnittlich $0.085 \mathrm{gr}$. Zwei Bruter sind die Regel. Ich habe in Wesel beobachtet, daß dasselbe Paar zweimal im selben Nest briitete.

\section{Acanthis carduelis britannicus subsp. nov.}

Wie A. c. carduelis aber die Oberseite düsterer, mehr mit olivenbraunem

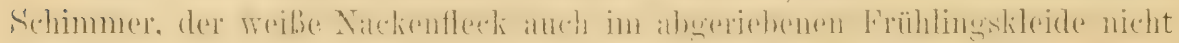

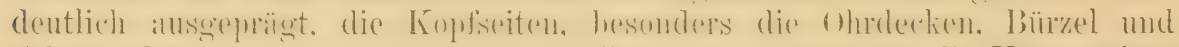

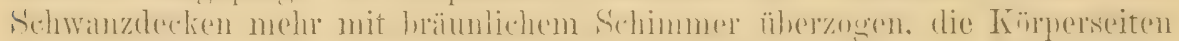

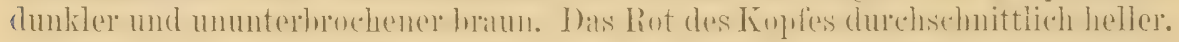

Diese sehr kenntliche Form bewohnt als Brutvogel dio britischen Inseln. Sie ist Stand- und Strichvogel, auch teilweise Zugvogel.

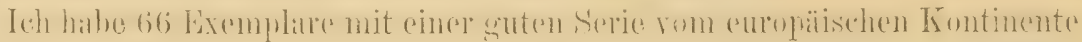
verglichen. (Der Typus ist Nr. $1100 \mathrm{im}$ Museum zu Tring, ein ò rom April 1902, Rottingdean in Sussex, erworben ron Brazenor.)

\section{Acanthis carduelis tschusii (Arrig.).}

Carduelis carduelis Tschusii Arrigoni, Aricula 1902, p. 101 (Sardinien).

Von A.c.carduelis durch dïstere, mehr olivenbraune Oberseite, rerdiusterten, kitum hemerkitren weililichen Nitchenfleck, sehe dumkle Brust- und 


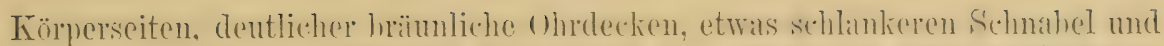

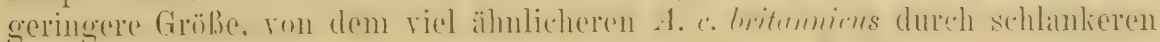

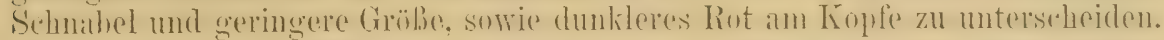
Das Flügelmaß des Männchens scheint 78-79 $\mathrm{mm}$ nicht zu überschreiten.

Sardinien und Korsika. (Exemplare von Sicilien, Cypern u. a. sollten studiert werden!)

\section{Acanthis carduelis parva (Tseh.).}

Carduelis carduelis parva Tschusi, Orn. IInnatsber. 1901, p. 129 ("Südliche Form" typ. Lok. Madeira!).

Carduclis carduelis nana Hartert, Wanderj. e. Naturf., p). 105 (1902- Schreibfehler für C. c. parva!).

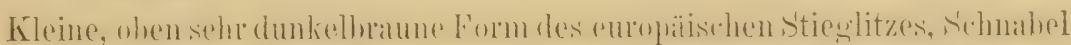
kleiner, Flügel kürzer, Nackenfleck verdüstert. Flügel $74-78$, meist $75-76$

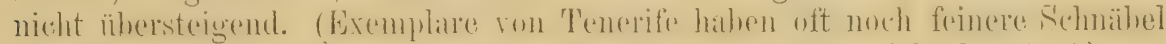
als die von Madeira, der Unterschied ist aber durchaus nicht konstant.)

Madeira, westliche Canaren Stücke von Tenerife (v. Thanner coll.), Gran Canaria und Gomera (Polatzek coll.), und Azoren (San Miguel und Terceira, Grant coll.) untersucht. Auf den Azoren augeblich eingeführt. In diesem Falle sicher von Madeira aus, nicht von Portugal, denn die iberische Form ist nicht parva.

\section{Acanthis carduelis africanus subsp. nov.}

?Carduelis meridionalis Brehm, Vogelfang, p. 109 (1855- nomen nudum!).

Der Stieglitz Nordafrikas, den Tschusi (Orn. Nonatsber. 1901 p. 129) und ich (A.d. Wanderj. e. Naturf. p. 313) filix dieselbe Form wie die von

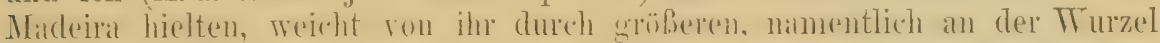
dickern Schnabel, lüngere Flügel, nicht so tiefe, weniger rotbraune, mohr

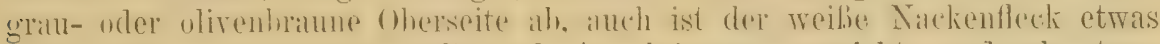
deutlicher. Von A.c. earduelis und A.c. britannicus weicht er durch etwas

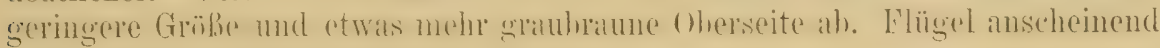
nicht über 78 , ausnahmsweise $79 \mathrm{~mm}$.

Spanien (Aguilas), Marokko, Algier und Tunis. (Mir liegen 17 in Marokko von Riggenbach und mir gesammelte Stïcke vor, 5 aus T'unis,

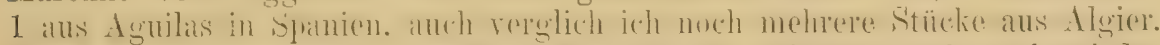

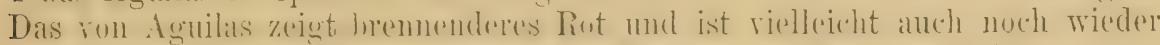

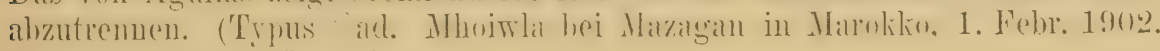
Riggenbach coll. N1. 78.)

Diese Form ist in den Atlasländern sehr häufig und nistet hauptsächlich in den Kronen der Olivenbäume und Orangen. Die Gelege bestehen aus 4-6 Eiern, die denen der europäischen Form völlig gleichen, wenn sie auch oft, aber kaum im Durchschnitt, etwas kleiner sind.

\section{Acanthis carduelis major (Tacz.).}

Carduelis major Taczanowski, Proc. Zool. Soc. London 1879, p. 672 (Turkestan).

Von A. c. carcluelis durch die bedentendere Größe, namentlich größern Si-hnaliel. und dis ausgedehutere und reine Teif. des Bürzels unterschieden. 


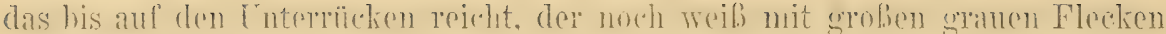
ist, hellere WVeichen, sowie die längeren, rein weißen Oberschwanzdecken. Flïgel $83-89$ mm.

Vermutlich rom Ural an durch Westsibirien bis Omsk und Krasnoyarsk, Turkestan und Persien. Genaue Grenze gegen A. c. corduelis schwer anzugeben, in Rußland (Orenburg) scheinen Exemplare vorzulsommen, die zwischen A.c. carduelis und major stehen, und letztere Form zieht im Winter westrärts und wird damn in Ost-Europa, vereinzelt bis Polen und Preußen gefunden. ${ }^{1}$ )

\section{Acanthis caniceps caniceps (Vig.).}

Carduelis caniceps Vigors, Proc. Zool. Soc. London 1831, p. 23 (Himalaya).

Ähnlich Acanthis carduelis, aber der Schnabel langspitziger, das Rot

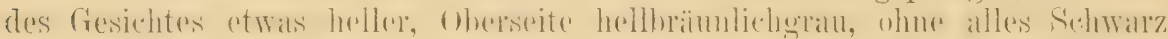
auf dem Kopfe. Bürzel und Oberschwanzdecken weiß Spitzenhälfte der

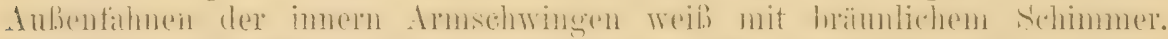

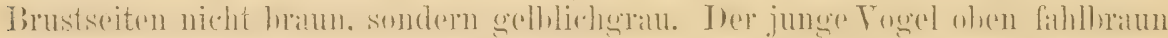
mit dunkleren Federmitten, Kopf ohue Rot. Flügel o $79-81$, o 77, Sehwanz $50-52 \mathrm{~mm}$.

Westlicher Himalaya von Kaschmir (Hazara und Gilgit) bis Kumaon.

\section{Acanthis caniceps orientalis (Eversm.).}

Fringilla orientalis Eversmann, Addenda ad Pall. Zoogr. fasc. II, p. 9 (1841- Typische Lokalität Jenissei, ex Pallas Zoogr. II, p. 16.

Ganz wie A. caniceps caniceps, aber merklich größer. Flïgel ò 84-88, o $81-82$, Schwanz $54-58 \mathrm{~mm}$, die Oberseite reiner und weniger bräunlich-

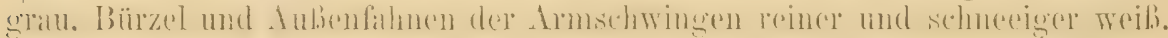

Sibirien rom Baikalsee bis Krasuoyarsk, Turkestan, Transkaspien, Afghanistan bis zum östlichen Persien.

Am Jenissei nicht selten mit A. carduelis major verbastardiert.

Gewohnheiten und Nistweise wie bei unserm Stieglitz. Eier vom Altai in Nehrkorn's Sammlung gleichen denen ron A. carduelis.

\section{1) $111 \mathrm{a}$. Acanthis carduelis brevirostris (Zar.).}

Carduelis elegans brevirostris ou C. elegans minor (sic!) Zaroudnö̈, Bull. Soc. Imp. Nat. MIoscou 1889, p. 133 (1890-- Baku).

Carduelis minor Zarudnoï, op. cit. 1893, p. 505 (russisch) (1894- Bergwälder bei Asrabad).

Diese mir unbekannt gebliebene Form ist augeuscheinlich eine Unterart ron A. carduelis. Sie unterscheidet sich nach Zarudny's ausführlicher Beschreibung von $A$. $c$. carduelis durch geringere Größe und die wie bei A. caniceps hellbrüunlichgraue Oberseite und nicht braune, sondern wie bei $A$. caniceps erdgrane Flecke an den Brustseiten. Der Nackenfleck ist sehr verdüstert, die Wangen stark bräunlich. Die sonst noch angegebenen Unterseliede dürften nicht ron Bedeutung sein. Flügel (nach Zar.) ot $75-78$, ㅇ $70 \mathrm{~mm}$.

Wurde im Winter bei Astrabad in N.O.-Persien und an der Grenze von Transkaspien gefunden, Brutplatz noch nicht festgestellt. 


\section{Acanthis spinus (L.). (Fig. 19,3.)}

\section{Zeisig, Erlenzeisig:}

Fringilla Spinus Linné, Syst. Nat. Ed. X, p.181 (1758- „Hab. in Europae juniperetis". Typ. Lok. Schweden: erstes Zitat Fauna Suecica 203).

Fringilla fasciata P. L. S. Miiller, Natursyst. Suppl. p. 165 (1776- Europa, ex Buffon) Spinus vividis Koch, Syst. d. baier. Zool., p. 235. ("In den Gebirgen gemein.")

Spinus alnomum Brehm, Handb. Naturg. Vüg. Deutschl., p. 284 (1831 — ,die deutschen Fichtenwälder" ${ }^{\text {) }}$.

Spinus medius Brehm, Handb. Naturg. Vög. Deutschl., p. 285 (1831- „auch er lebt zuwcilen in unsern Nadelwäldern".)

Spinusbetularum Brehm, Handb. Naturg.Vög. Deutsehl., p.286 (1831— „die Nadelwälder"). Spinus obscurus Brehm, Yogelfang, p. 108 (1855- Deutschland. Ein einziges sehr merkwïrdiges Stïck ohne alles grün und mit schneeweißer Schwanzwurzel und weißer, statt gelber Flïgelbinde. Jedenfalls nur Aberration. 1819Thüringer Wald).

Chrysomitris Dybouskii Taczanowski, Journ. f. Orn. 1876, p. 199 (Askold. ô ohne schwarzen Kehlfleck).

Engl.: Siskin. Franz.: Tarin. Ital.: Lucarino. Schwed.: Grönsiska.

ôad. Oberkopf schwarz, vom Auge an nach hinten zu durch einen

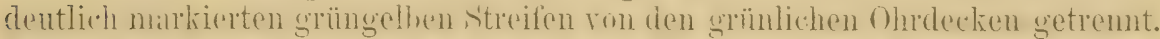

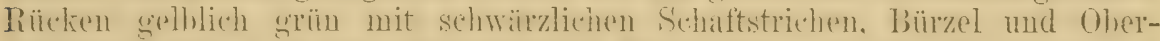

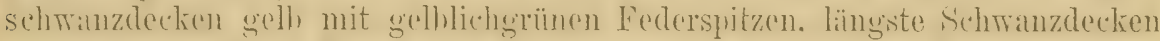

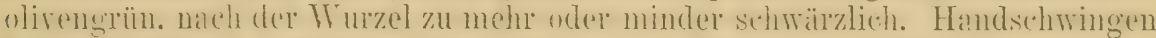

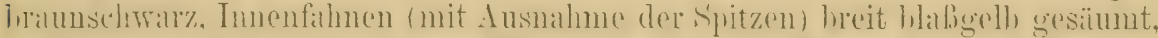

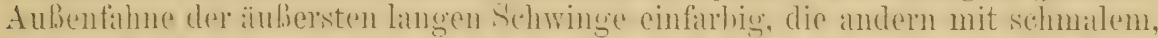

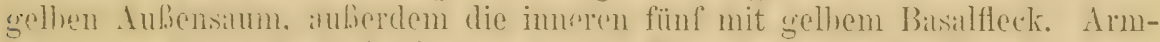

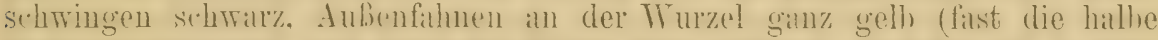

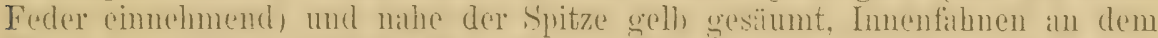

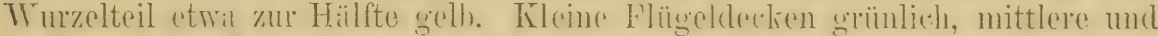

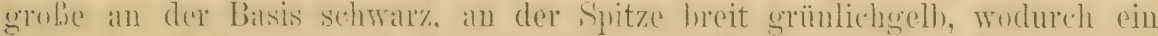
s.hwarz und grimlichgelh muergestreifter Oherflïgel entsteht. Struerfedern

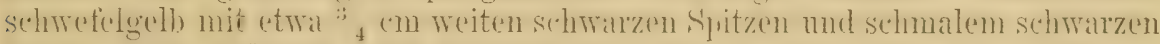
Silum an der äubersten. dis mittelste Palar dunkel olivengrün mit gelhlichen Säumen. Unterseite gelb mit schwarzem, meist durch helle Federsäume

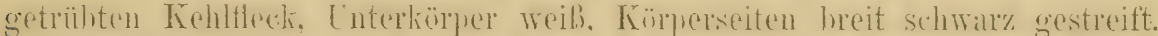

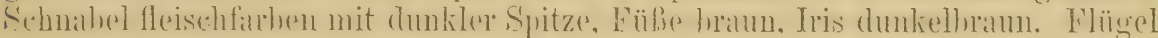
73-75, Schwauz 45-49, Lauf 14-15, Schnabel etwa $10 \mathrm{~mm}$. Im frisch-

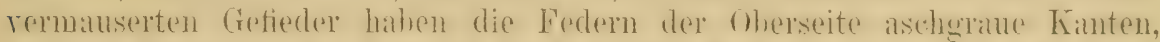
wodurch hesonders dere schwarze hopf getrüht wird. Dicse nutzen sich spätel mehr oder minder ab.

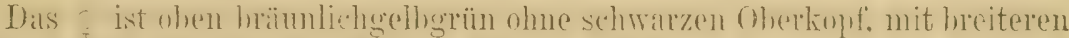

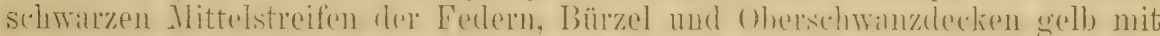
schwarzen Streifen. Flügel und Schwanz ähnlich gezeichnet wie beim or,

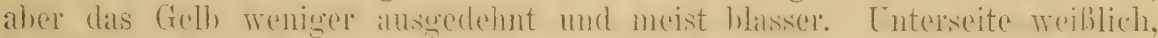

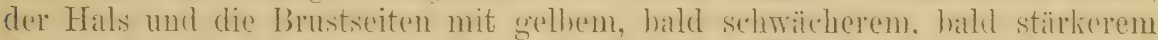

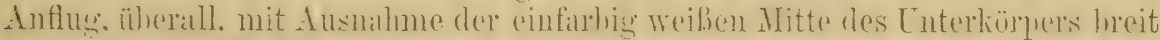
schwar\% gastreift. Junge dem : ت̈hnlich, aher ohen viel mehr hellhrïunlich, unten ebenfalls mehr brëunlich gestroift, die Grundfurbe gelblicher.

Der Zeisig bewohnt Europa vom hohen Norden, soweit die Nadelholzwälder reichen, als Brutrogel his üher die Fichtemualdwälder von Dentsehland, 


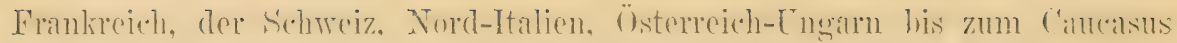
und zieht im WVinter in Scharen durch die Ebenen, häufig südwärts bis in

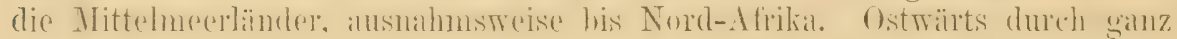
Sibirien bis Nord-China und Japan, auch von Kleinasien und Nord-Persien angegenen. In Eingland im IVinter hïufig. als Butrogel in Sehottland. Friand und selten in Nord-England.

Bewohner von Nadelwäldern. Überfuß und Mißraten der Baumsamen scheinen iliren Aufenthalt zu becinfußen. sodaß sie an denselben Orten manchmal selten, oder häufig sind. Munter und zutraulich, im Winter leicht bemerklich, zur Brutzeit ziemlich still und zurückgezogen, meist in hohen Bäumen. Érinnert in vielem an den Stieglitz. Die Locktöne sind rerschiedener Art: es gibt einen schnarrenden Ruf wie tettett, tetetrett, außerdem einen pfeifenden, wie didei, didlei, oder wie Zeising klingenden'. Wemn eine Schar auffliegt, hört man noch einen sonderbar heiser zwitschernden, oder sngen wir "tschätschenden" 'Ton. Der Gesang ist zwitschernd, niedlich, aber nicht berïhmt. Die Nahrung besteht aus Sämereien, namentlich Samen von Nadelhölzern, Erlen, Birken und vielen niederen Pflanzen. Im Sommer werden Inseliten mit rerspeist, die Jungen aber großenteils damit gefüttert, namentlich aber mit den Blattläusen von Tannen, Lärchen und Erlen.

Das Nest steht in Bäumen, fast immer Nadelhölzern, selten auf Lrlen und andern Laubbäumen, meist sehr hoch, selten niedrig in Büschen. Hs ist tief und schön gebaut, meist sehr schwer zu finden, daher das Härehen von seiner Unsichtbarkeit. Die 4-6 Eier ähneln denen des Stieglitzes vollkommen, sind aber viel kleiner. Die der Rödern'schen Sammlung (meist in seiner Vogelstube gelegt) messen $16.6 \times 12.5$, $17 \times 11.7, \quad 17 \times 12.2, \quad 17.1 \times 11.8, \quad 15.9 \times 11.5, \quad 16.5 \times 13, \quad 16 \times 13.4, \quad 17.5 \times 12.5$, Dr. Rey gibt an $15.5 \times 11.78,15.8 \times 13.1,14.4 \times 13.3 \mathrm{~mm}$. Durchschnittsgewicht $0.088 \mathrm{gr}$.

\section{Acanthis thibetana (Hume).}

Chrysomitivis thibetana Hume, Ibis 1872, p. 107 („obtaiued by Handelli on the borders of Sikkim and "Thibet").

ơad. Oberseite gelblicholivengrïn; Federn des Genicks und Hinter-

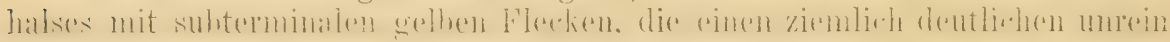
gelben Fleck hervorbringen. Federn des Rückens vor den Spitzen mit schwärzlichen Mittelflecken und je 2 kieinen grauen Flecken an den Spitzen der Fahnen, wodurch ein etrvas geschecktes Aussehen entsteht, Bürzel und Ober-

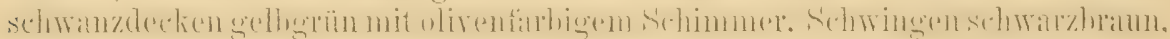
Innensäume heller, Außenfahnen dunkel gelbgrün gesäumt. Ohrdecken und

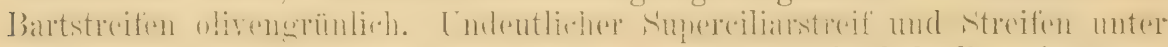
den Augen und Ohrdecken trüb gelb. Unterseite dunkelgeib mit etwas bräunlichem Schimmer. Weichen und Unterschwanzdecken gelb mit schwarzbramen Strichen. Steuerfedern schwärzlich mit grïngelben Säumen. Unterflügeldecken matt gelbgrünlich. Schmabel und Füße (im Balg) bräunlich fleischfarben. Flïgel 70, Schwanz 41, Lauf 12, Schmabel 8\% mm, zeisig-

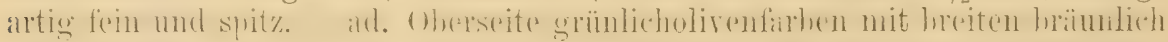

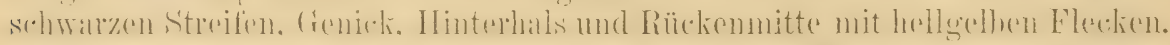

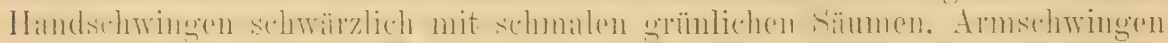

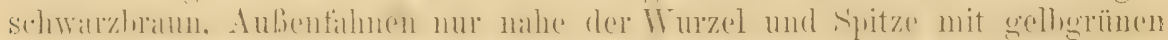

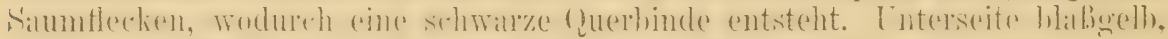
am Unterkörper fast weiß, Brustseiten und Unterkörper breit schwarzbraun gestreift. 
Lebt in gewaltigen Höhen in Sikkim, an und jenseits der tibetanischen Grenze. Wie es scheint nur you seineru Eintelecker. dem rerstorhenen Mandelli. in den siebziger Jahren gesammelt.

Fortpflanzung unbekannt.

\section{Acanthis spinoides (Vig:).}

Carduelis spinoides Vigors, Proc. Zool. Soc. London 1831. p. 44 (Himalaya).

oad. Oberseite dunkel schwarzbraun mit grünlichem Schimmer, Stirn

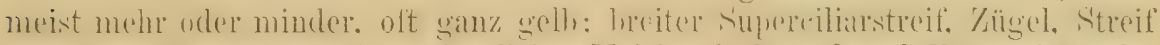

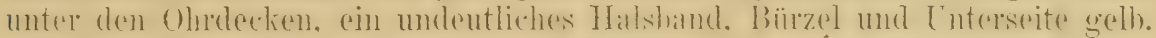
Schwingen schwarz mit gelber Basis, Spitzen der Armschwingen weißlich. Kleine Flügeldecken und Spitzen der groben gelb, zwei Binden bildend,

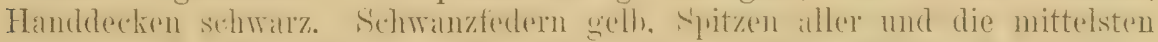

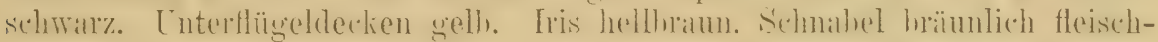
farben, Füße desgleichen. Flügel 78-81, Schwanz t5̃, Lauf 17, Schmabel $10 \mathrm{~mm}$. Sehmabel dick, klotzig, kolbig, hänflingsartig. O. Oben trïbgelb

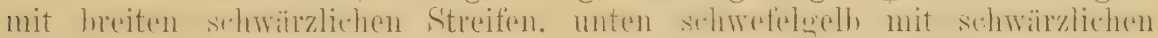
Streifen, die jungen Vögel den o ähnlich aber vicl bräunlicher und blasser.

Bewohner der Bergwälder des Himalaya (bis 9000 engl. Fub hoch) von Kaschmir his nach (hinil hinein (Nzetschwan). Wurke aluch in Manipur erhentet.

Brütet „im Juli und August", baut ein tief napfförmiges Nest aus feinem Grase, Mloos und Haaren auf Bäumen und legt 3 Eier, die blaßgrüinlich sind, mit tiefbraunen Punkten und Flecken und $17^{1 / 2}>13 \mathrm{~mm}$ messen.

\section{Acanthis cannabina cannabina (I.). (Fig. 19.1.)}

\section{Hänfling, Bluthänfling:}

Fringilla cannabina Linué, Syst. Nat. Ed. X. p. 182 (Europa - typ. Lok. Schweden, denn erstes Zitat Fauna Suecica 210). ${ }^{1}$ )

Fringillc vitis P. L. S. Müll., Natursystem, Suppl., p. 163 (1776- Ex Daubenton Linotte des vignes. Hab. Frankreich. Jerkwürdigerweise bisher fälschlich als Synonym von A. linaria zitiert!).

Fringilla Linota Gmelin, Syst. Nat. I, p. 916 (1788- Europa. Ex Brisson, Buffon, Pennant ete.).

Fringilla argentoratensis Gmelin, Syst. Nat. I, p.918 (1788- "Hab. circa Argentoratum“. Ex Brisson: La Linotte de Strasbourg, Buffon).

Passer Papaverina Pallas, Zoogr. Rosso-Asiat. II, p. 26 (1811- Süd-Rußland, Wolga).

Cannabina pinetorum Brehm, Handb. Naturg. Vög. Deutschl., p.276 (1881- ,in den (leutschen Fichtenvorhölzern").

Cannabina arbustornm Brehm, Handb. Naturg. Vög. Dcutsehl., 1. 277 (1831- Felder, Bïsche, Weinberge).

Linaria vulyaris Rüppell, Neue Wirbelth., p.95 (1835-40- Name für den "gewölnnlichen Hänfling“" - nomen nudum!).

Cannabina major und minor Brehm, Vogelfung, p. 106 (1855- ohne besondere Vaterlandsangabe, nach Ausweis der Sammlung aus Renthendorf!).

Cannabina Limnéi Jalm, Göteborgs Fiuna, p. 197 (1877).

Ëngl.: Linnet. Franz.: Linotte. Ital.: Fanello.

1) Linné's Beschreibung ist so schlecht, daß weder Gmelin noch Pallas in ihr den Hänfling erkannten, da aber der Name cunnubinu heute ausnahmslos angenommen wird und sich anch wohl auf den Hänfling bezieht, so haben wir ihn beizubehalten. 
çad. Vorderkopf mit blutroter Platte, die aber im frischvermanserten Ge-

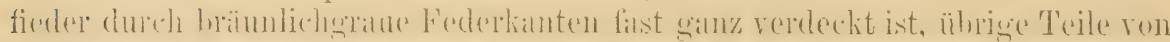

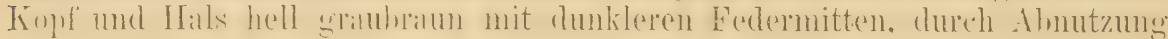
der bräunlichen Ränder und Ausfallen der Seitenpartikel der Fahnen im Sommer ganz gruu werdend. Rüeken lebhaft kastanienbraun mit helleren Säumen und dunkleren Federmitten, auf dem Bürzel viel lichter braun unterer 'Teil des Bürzels und Oberschwanzdecken weiß mit dunklen, fast schwarzen Federmitten, der erstere manchmal mit rosemrotem Schimmer, die längsten Schwanzdecken schwarz mit weißen Säumen. Handschwingen schwarz mit schmutzigweißen Innen- und reinweißen Außensïumen, Am-

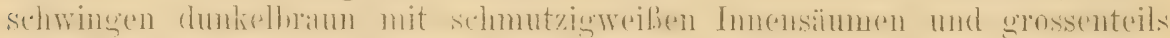
kastanienbraumen Außenfahnen. Steuerfedern schwarz mit schmalen weißen

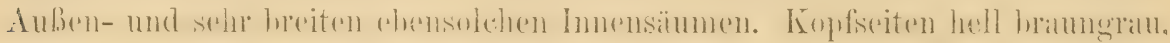
unter dem Auge, in der Mitte der Ohrdecken und unter denselben bräunlich-

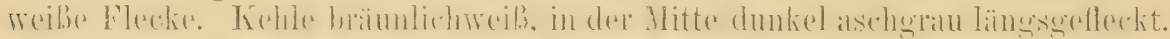
Kropf und Brustseiten blutrot, im frischvermanserten Gefieder durch hell grauliche Partikelchen verdeckt, die nachher verschwinden und die rote Farbe rein hervortreten lassen. Übrige Unterseite. weißlich, Seiten rotbraun mit dunkleren Federmitten. Schuabel bräunlich, Füße braun, Iris dunkelbram. Flügel 82-85, Schwanz etwa 55-58, Lauf 16-17, Schmabel dick und kolbig, etwa $10 \mathrm{~mm}$. (Kaum bei einem andern Vogel bringt die Abnutzung;

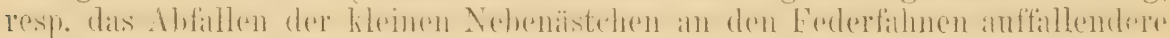
Veräinderungen hervor: Das wie bepudert aussehende, matte Hellrot wird dadurch bremnend rot - von einem plötzlichen Influx ron Pigment zur Zeit der Liebe oder sonstigen mysteriösen Yorgängen ist nichts wahr: die Feder verliert nur und dadurch entsteht das veränderte Aussehen.) o ad. Wie das $\delta$, aber ohne alles Rot, Kropf und Seiten breit dunkelbraun gestreift, Rücken meist dunkler und Bürzel weniger weiß, etwas kleiner. Junge Vögel ähneln den Weibchen.

Vom 64" in Skandinavien und vom $60^{\circ}$ in Rußland sïdwärts ïber

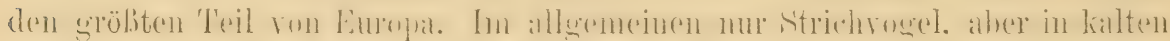

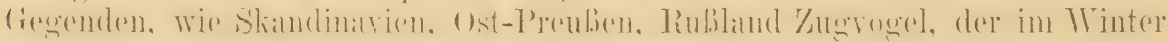
als seltener Gast bis Egypten und Abyssinien geht. Die Behauptung, daß, englische Stïcke dunkler seien, fand ich nicht bestiitigt. Sie sind bisweilen, besonders die aus der Nähe von Städten stammenden, schmutzig, wie alles

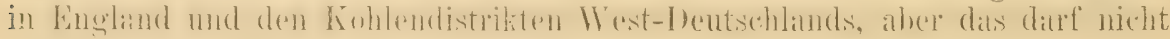
mit natürlicher Färbung rerwechselt werden.

Bewohner baumreicher und freier Gegenden, aber nicht ausgedehnter Hochwälder. Ein munterer und flüehtiger Vogel und ziemlich gesellig. Der Flug ist raseh und bogenförmig. Die Lockstimme ist kurz, hart und ganz charakteristisch, man hört sie an meisten im Fluge. Der Gesang ist ausgezeiclunet, flötend, aber von harten, locktonartigen Tönen eingeleitet und unterbrochen. Ziemlich reiner Samen- und Körnerfresser, der nur ausnalumstweise auch Insekten frißt, auch die Jungen werden zwar neben Sämereien auch mit einigen Inseliten gefüttert, aber nicht in dem IIße wie die andern Fringilliden.

Das Nest steht meist in Büschen, $1 / 2-3 \mathrm{~m}$ hoch, bisweilen aber auch hart am Boden in Ginsterbüschen, Grasbïscheln, Heidekraut, mit Vorlicbe aber in Dornhecken und toten Reisighecken und -Haufen, in 'Torfhaufen und Holzklaftern, auf kahlen Dünenrücken, 'Torfmooren und Wiesen, wie in Gürten, Laubhölzern und Nadelholzschonungen. Namentlich zur ersten Brut werden mit Vorliebe immergrüne Büsche benutzt. Die Eier der ersten Brut findet man im April, bisweilen sogar sehon Ende 
MIärz (in milden Gegenden), eine zweite Brut findet regelmäBig statt. Die Eier sind weißlich mit bläulichem oder grünlichem Schimmer bis hellblau, mit bleichen violettgrauen Schalenflecken und tief blutroten bis braunschwarzen Punkten, Flecken, Kritzeln und Strichen. Sie sind äußerst variabel, zuweilen ganz ungefleckt, sehr dünnschalig, manchmal von denen des Stieglitzes nicht zu unterscheiden, meist aber größer und schwerer. Krohn berichtet von einem ungefleckten weißen Gelege bei Hamburg. Die Gelege bestchen aus 5-7, die der zweiten Brut aus 4-6 Eiern. Sie messen nach Rey im Durchschnitt nach 80 gemessenen Exemplaren $18.3 \times 13.1 \mathrm{~mm}$, im Maximum $20.3 \times 14.9$, im Minimum $16 \times 12$, das durehsehnittliche Gewicht ist $0.098 \mathrm{gr}$. Das Weibchen scheint meist allein zu brüten, Helm aber beobachtete regelmäßiges Brüten des ơ in den Abendstunden und ich sah in England ein ơ am Nachmittage nach 5 Uhr auf den Eiern sitzen. Brutzeit 13-14 T'age.

\section{Acanthis cannabina mediterranea T'schusi.}

Acanthis cannabina mediterranea T'schnsi, Ornith. Jahrb. 1903, p. 139 ('Typ. Lok. Cattaro, Dalmatien).

Schwer kenntliche Form. Etwas kleiner als die nordeuropäische, was

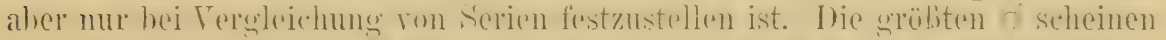

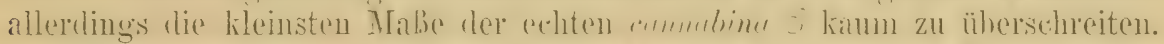
Im allgemeinen alleh lobhafter geförlt. Was aher vielledeht nur Folge des im

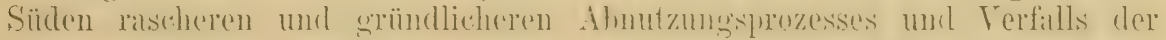
Federn in der Brutzeit ist.

Nördiche Küsten des Mittelmecres: Malnatien, Süel-Italien, Süul-Syanien. Genaue Verbreitung: Z. Z. nicht festzustellen.

\section{Acanthis cannabina nana (Tsch.).}

Cannabina cannabina nana Tschusi, Orn. Monatsber. 1901, p. 130 (Madeira).

Acanthis cannabina meadewaldoi Hartert, Nor. Zool. 1901, p. 323 und A. d. Wanderjahr. e. Naturf., p. 104: (T'enerife).

Sehr kenntliche Form. Ganz wio 4. c. camabina, aber orheblich kleiner!

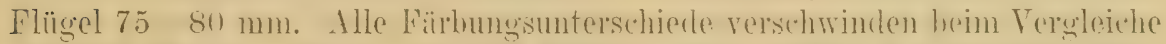

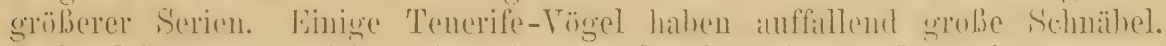
Auf solche basierte ich meine A. c. meadewaldoi, die großen mir nun vorliegrnden Serien aher beweisen die Enhaltharlest dieser Form. (52) Exemplare mit 110 von A.c. cannabina verglichen.)

Madeira, Camaren, Marokko, Algier und Tunis.

\section{Acanthis cannabina fringillirostris (Iip. d schleg.).}

Linota fringillirostris Bonaparte \& Schlegel, MLonogr. Loxiens, p. 45, Taf. 49 (1850"Népaul" errore. Der Typus wird wohl ron Kaschmir stammen).

Cannabina bella Cabanis, Mus. Hein. I, p. 161 (1850-51- Ex Hempr. \& Ehrenb. IIS., Syrien).

Tat. wie das von A.c. camabina, aber die Färbung im allgemeinen etwas lichter, namentlich iler Hals hellex, and rom Seheitel meist mit einigeu

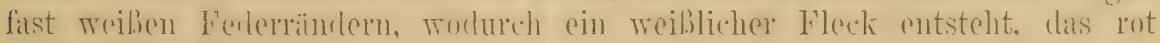
heller, die weißen Federïnder des Bürzels meist breiter. Flügel 83-87, also durchschnittlich etwas lïnger, oft aber gleich.

Vertritt A. c. camalina vom Kaukasus und Kleinasien nach Osten hin, clurch Turkestan, Persien, Afghanistan bis in das nördliche Kaschmir. 


\section{Acanthis flavirostris flavirostris (L.).}

Berghünfling.

Fringilla flavirostris Linné, Syst. Nat, Ed, X, p. 182 (1758- "Europa". Typ. Lok. Schweden, denn einziges Zitat Fauna Suec. 204).

Fringilla montium Gmelin, Syst. Nat. I, p.917 (1788- Ex Brisson, Buffon, Pennant u. a. „Europa").

Cannabina media Brehm, Handb. Naturg. Vög. Deutschl., p. 279 (1831- ,selten, wie im Winter 1826, in Nord-Deutschland").

Linaria montana Selby, 1ll. Brit. Orn. I, p.318, pl.55, Fig. 5 (1833-Norway, Sweden etc.) Cannabina microrhynchos Brehm, Vogelfang, p. 106 (1855- Mittel-Deutschland).

Cannabina montium major A. Brehm, Verz. Samml., p. 9 (1866- nomen nudum!).

Engl.: Twite. Franz.: Linotte montagnarde, linotte à bee jaune.

ơad. Oberseite tiefbraun mit rostbraunen Federrändern, sodaß sie hell- und dunkelbraun gestreift erscheint, Bürzel rosenrot mit sehr hellbräunlichen Federspitzen. Schwingen schwarzbraun mit bräunlichweißen

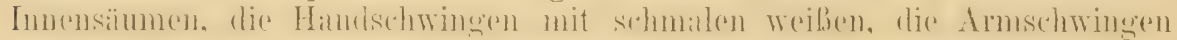
mit breiteren hellhramen Außensïmmen. Stenerfedern schwarzbraun mit

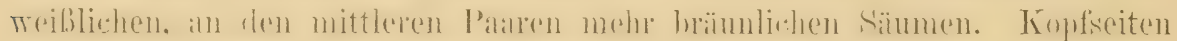
hell zimmetbraun, dunkelbraun gestrichelt, ïber den Augen ein deutlicher

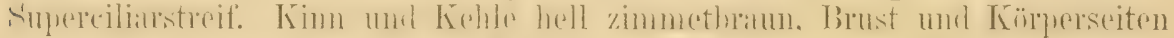

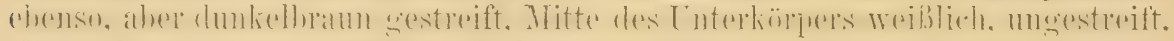
Unterschwanzdecken brïunlichweiß mit schmalen, an clen längsten Federn

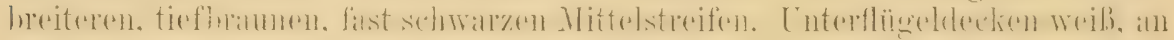
den Wurzeln schwairzlich. Schmabel wachsgelb mit dunkler Spitze, Iris braun, Füße dunkelbraun mit fast schwarzen Krallen. Flügel 76-81, Schrvanz etwa 64-66, Lauf etwa 16, Schmabel 8-9 mm. Im Frühjahr stoBen sich die Federkanten ab, die Oberseite erseheint dadurch dunkler und ein schon vorher angedentet gewesener weiBlicher Nackenfleck tritt mebr herror, die dunkle Streifung der Unterseite wird auffallender. o und junge Vögel ähneln den alten, aber der Bürzel ist wie der Rücken, ohne rot, der Flügel kürzer, $72-76.5 \mathrm{~mm}$.

(A. Havirostris unterscheidet sich rou dem ungefïlur gleich großen

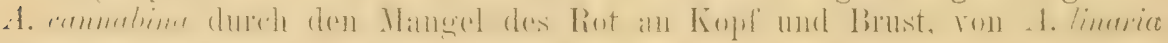

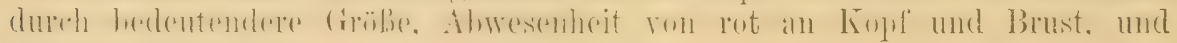
lïngeren Schwanz.)

Brutrogel rom mittleren England (einzeln im Seengebiot) ïber Schottland, Irland, die Shetlands-, Orkney-Inseln und Hebriden, auf den Inseln und an der Westkïste von Nortwegen bis etwa $70^{\prime \prime}$ nördl. Breite, seltener in Schweden und Nord-RuBland. Auf der Tanderumg in Süd-England, Nord-

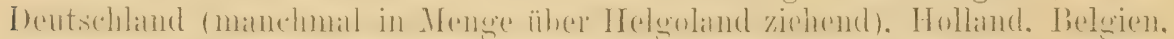

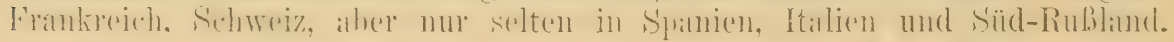

Bewohner offener, nur mit Gras, MLos, Heidekraut und niederm Gebüsch bewachsener, meist felsiger Gelände. Äußerst lebhaft und munter, in F'luge und anderweitig dem Hänfling ähnelnd, sucht seine Nahrung meist auf dem Boden. Der Lockton ähnelt bald dem des Hänflings, bald dem der Leinzeisige — bald ist er ein flötendes daii, bald ein tschätschender 'Ton. Der Gesang hat flötende, zischende und knarrende 'löne. Nahrung Sämereien, besonders ölhaltige, im Sommer und zumal bei der Aufzucht der Jungen mit Insekten gemischt. Das Nest steht meist am Boden unter Steinen, Büschen, Heidekraut usw. und ist dem des Hänflings ähnlich, aber meist etwas dickwandiger und mehr mit Federn und Renntierhaaren ausgefüttert. 2 Bruten sind 
nicht selten, vielleicht die Regel. Es enthält $4-5$, selten 6 oder nur 1 Eier, die denen des Hänflings ähneln, aber öfter blaß rotbraune Strichelung zeigen. Sie sind hell grünlichblau und messen nach Rey im Durchschnitt $167 \times 12.1$, bis $18 \times 12.4$ oder nur $15.3 \times 12.3$, bezw. $16.8 \times 11.8 \mathrm{~mm}$. Das durchschnittliche Gewicht ist etwa $0.073 \mathrm{gr}$.

\section{Acanthis flavirostris brevirostris (Noore).}

Linota brevirostris Moore, Proc. Zool. Soc. London 1855, p. 216 („Erzeroum and Afghanistan". - Typus von Erzeroum im Brit. Mus. Ex Bonaparte, Geogr. \& Comp. List, p. 34 (nomen nudum) falsche Vaterlandsangabe, nämlich „Southeastern Europe", wenn diese Form gemeint war).

Linota erythropyga Seeb., teste Sharpe, Cat. B. Brit. Hus. XII, p. 238 (1888- synonym).

Von A. f. flavirostris auf den ersten Blick durch hellbräunliche, fast waißliche Federänder der Oherseite, heller losenroten, meln ins woilibhe ziehenden Bürzel mud hellere nieht so hrame Lnterseite unterschieden. Schnabel kleinel. (Zeutralasiatische Stüche haben oft lï̈zere liügel, ler Lnterschied sebeint aher nicht konstint und nicht lokalisiert gemug zu sein, um - nach dem untersuchten Material — darauf einen Namen zu gründen.)

Tom Kankasus und Keleinsien durch P'ersien, Turkestan und Tiliet bis in die Mandschurei.

Gleicht in seiner Lebensweise $L$. f. flavirostris. Nest und Eier ebenfalls äußerst ähnlich. Ein Gelege von Erzerum in Dressor's Sammlung ( 4 tier) mißt durehschnittlich etwa $15.5 \times 17.5 \mathrm{~mm}$. Gelege vom Kuku-Noor zu 5 und (5 Eieru gleichen denen ron $A$. f. flavirostris und messen nur $12.4 \times 17$ und $12.6 \times 17.1 \mathrm{~mm}$.

\section{Acanthis flavirostris stoliczkae sulsp. nor.}

?Linaria pygmaec Gray, Hand-list II, p. 109 (1870 - „Ladakh", nomen nudum! Nach Sharpe, Cat. B. Brit. Mus. XII, p. 238 synonym von brevirostris).

Oberseite viel mehr blaß sandig-braun, die Eedermitten viel heller braun, Unterseite blasser und matter.

(Typus: Oొad. Gilgit, 7. März 1880, J. Scully Nr. 738, in Nus. Tring.)

Termutlich St:mdrogel, jedenfalls aher Butrogel in Kischmir (Gilgit, Ladelkh. Shandur Yassin). Nach Stoliczkil in deu Kulu- und Sutlej-Täleru im Winter, sowie bei Chindi.

\section{Acanthis flammea flammea (L.). (Fig. 19, 2.) Birkenzeisig, Leinfink, Leinzeisig. ${ }^{1}$ )}

Fringilla flammea Linné, Syst. Nat. Ed. X, p. 182 (1758- "Habitat in Europa". Typische Lokalität Norrland in Schweden, ex Fauna Suecica no. 201. Man hat es sich bequem gemacht, indem man diesen Namen entweder gar nicht

1) Dis Studium der" "Leinfinken" oder "Birkenzeisige" ist ein besonders schwieriges, weil einige Formen ungemein verbreitet sind (circumpolar), andre lokal, außerdem diese Vögel während der Brutzeit durch Abnutzung und Verfall des alten Gefieders sich gewaltig verändern. Es ist daher notwendig, aber nicht immer möglich, Serien aus den verschiedenen Gebieten von der gleichen Jahreszeit, besonders frisch vermauserte Vögel, zu vergleichen. Literatur: Stejneger, Auk 188t, pp. 145-155. - Sharpe, Cat. B. Brit. Mrus. XII, pp. 245-256. - Deichler, Naumann's Naturg. Vög. Mittel-Europas, pp. 301-312. - Ridgway, B. North \& Middle America I, pp. 78-92. - Mit der ron 
oder als Synonym ron linaria zitiert hat. Linné selbst kannte den Vogel nieht, sondern beschreibt ihn nach Rudbeck's Bilde und nach Klein - Hist. Ar. Prodr., p. 93 - wo dentlich der Birkenzeisig beschrieben ist. Da fammea ror linaria steht, nehmen wir den Namen ohne Bedenken an. Nicht wir, die wir Nomenllaturfragen ernst nehmen, sondern die, welche leichter Hand flammea unbeachtet ließen, sind an der Namensänderung schuld).

Fringilla Linaria Linué, Syst. Nat. Ed. X, p. 182 (1758 - „Habitat in Europa“. Typ. Lokal.: Erlenwälder Schwedens, ex Fauna Suecica no. 210).

Linaria borealis Vicillot, Mcm. R. Accad. Sci. Torino XXIII, 1816, Sci. Fis., p. 199.

Linaria agrom und betulan (1831- Herbst in Deutschland).

Linaria canescens Gould, B. Europe III, pl.193 (1834- als häufiger Wintergast in England besehrieben, Brutgebiet unbekannt).

Linaria dubia, assimitis, lenconotus, septentrionalis, pusilla Brehm, Vogelfang, p. 107 (1855- nomina nuda(!), nach Untersuchung der Exemplare ganz oder teilweise hicrher gehörig. Brehm selbst unterschied die groß- und kleinschnäbligen Formen uicht als solche, sondern teilte nach dem Rot der Brust ein!)

Aegiothus mber crassirostris, tenuirostris, microrhynchus A. L. Brehm, Verz. Samml., p. 9 (1866- nomina nuda(!), nach Untersuchung der Exemplare hierher gehörig), (Kidgway, B. N. \& Middle Amer. I, p. 88 u. a. rechnet hierher auch: Aegiothus fuscescens Coues, Proc. Ac. Nat. Sci. Philad. 1861, p. 222, typ. Henly Harbor, Labrador, was ich auch für richtig halte. Deichler, Naumann's Naturg. Vög. Mittel-Europas IH, 1900 , p. 310 unterscheidet diese Form, aber die ron ihm angegebenen Linterschiede siud nicht zu erkennen).

Linaria americane Wied, Journ. f. Orn. 1858, p. 338 (Missomi).

Acantlis intermedius Dybowski, Bull. Soc. Zool. France VIII, 1883, p. 365 (Kamtschatka). Acanthis innominatus Dybowski, Bull. Soc. Zool. France VIII, 1S83, p. 366 (Kamtschatka).

Engl.: Mlealy Redpoll. Franz.: Sizcrin boréal. Schwed.: Gråsiska.

ơad. Schnabel wachs- oder horngelb mit dunkelbrauner Spitze, Vorderkopf bis etwa in die Mitte des Kopfes rot; Federn von Hinterkopf, Hals

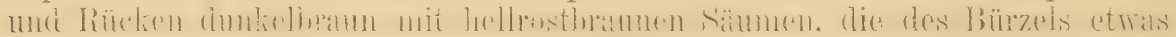
dunkler mit weißlichen oder weißen Säumen, mehr oder minder rötlich angehaucht, und die des untern Bürzels rosemrot mit weiblichen Spitzen.

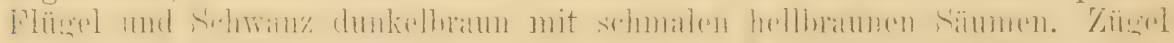

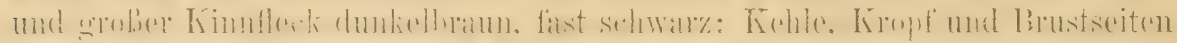

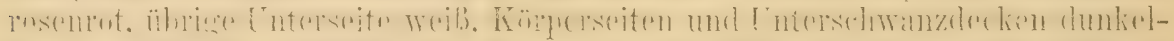

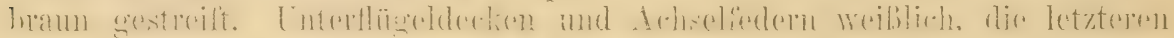
oft mit rötlichem Schimmer. Füße dunkelbraun. Flügel 74-78, Schrvanz etrva 57-58, Schnabel 8, Lauf $15 \mathrm{~mm}$. - Jüngere oे haben kein Rot an der Kehle und Brust. Es scheint, daß das Rot erst im zweiten Jahre völlig ausgebildet ist. Im Frülijahr untzen sich dic Federïuder ab, dic Fahnen verlieren ilne kleinen Anlängsel, die Oberseite wircl dadurch viel schwärz-

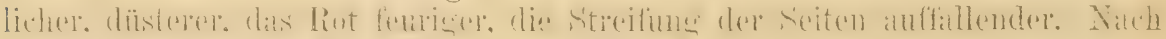

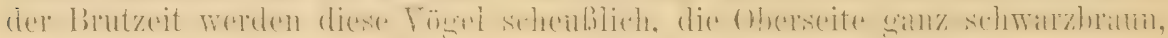

Deichler vorgeschlagenen, teilweise nur vermuteten Einteilung in 12 verschiedene Formen bin ich nicht einverstanden. És scheint, daß der Verfasser dio jahreszeitlichen Veränderungen nicht genug gewïrdigt hat. Nach Vergleichung bedeutender Serien muß ich Sharpe, Stejneger, Ridgway u. a, beistimmen, die eine circumpolare Verbreitung mehrerer Formen annehmen und die englische und alpine Form rereinigen. Acanthis homemannii muls artlich getrennt werden, da Formen derselben mit solchen von flammea in gleichen Gebiete zu nisten scheinen und sich trotz gelegentlicher Bastarde erhalten und ron $A$. holboellii gilt vielleicht dasselbe! A. brevesterii ist offenbar cin Bastard. 


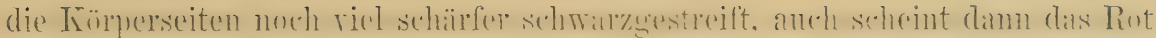
an der Unterseite wieder zu verbleichen. Das o hat den roten Vorderkopf wie das $0^{2}$, aber nie rot an der Unterseite. Fs ist etwas kleiner als das o Junge Vögel sind wie die $Q$, aber brauner und ohne rot am Kopfe, das erste

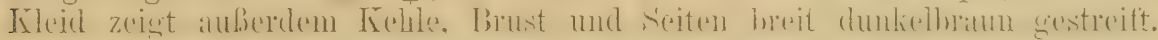

Der immer deutlich gestreifte Bürzel, die zwar brüunliche, aber nicht rostbraune Oberseite, mittlere Größe und kleiner Schuabel keunzeichnen diese Form.

Brutrogel im Norden der Erde. Die nördlichsten Brutplïtze (z. B.

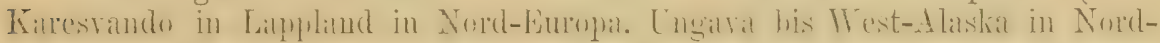
Amerika) fallen mit den sïdlicheren von Acanthis homemanni exilipes zusammen, und in diesen Gegenden kommen sogar Fxemplare vor, die man nur als Bastarde zwischen A. $f$. flammea und A. $\%$. exilipes deuten kann, da das Brïten der letzteren beiden und einer intermediären Form in derselhen Gegend nicht gut angenommen werden kann. In Europa südlich bis in das nördliche Ost-Preußen, dort in der Nähe der Ostsee brütend. A. f. flammea

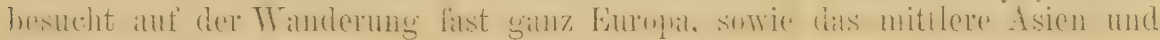
Teile Nord-Amerikas.

(Es ist mir unmöglich, die amerikanische und sibirische Form zu trenneu.

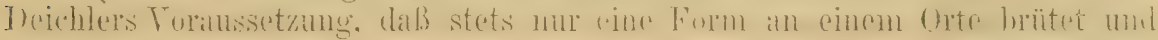
daher alle Leinzeisigo Subspezies einer Art seion, ist eine unberviesene An-

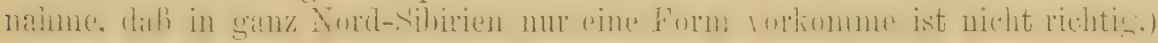

Ein hübscher, unruhiger, lebhafter, aber nicht scheuer Vogel, Bewohner nordischer Birken- und Erlenwälder, sogar nördlich der Gronze der Birkenwälder noch nistend; nördlich des 58. Grades regelmäßiger Brutrogel. Die Lockstimme ist ein eigenartiges T'schätt, tschätt, das sie sitzend und fliegend hören lassen. Außerdem haben sie noch einen angenehmen flötenden Ruf und einen zwitschernden, kunstlosen Gesang. Die Nahrung besteht aus Sämereien vieler Art und im Sommer wohl auch aus Insekten. Das dicht gefütterte Nest steht in Büschen und Bäumen oder zwischen Gras und Steinen und enthält ziemlich spät im Jahre $4-5$, selten 6 Eier. Diese sind hellblau oder grinlichblau mit rotbraunen Flecken und Punkten. Sie messen etwa $16.8>12.2$ bis $18 \times 12.5$ und $18.2 \times 12.3 \mathrm{~mm}$. Die Jungen werden zumeist mit Insekten und deren Lurven aufgefüttert.

\section{Acanthis flammea holboellii (Brehu). (Yit statt Lnterat.)}

Lincuric Holboellii Brehm, Handb. Naturg. Vög. Doutschl., p.280 (1831- ,selten, wie Nor. 1822 und 1825 im mittleren Deutschland").

Linaria alnonum Brehm, Handb. Naturg. Vög. Deutschl., p. 281 (1831- Vorkommen wie bei L. holboellii).

Linaria longirostris Brehm, Vogelfang: p. 107 (1855- „kommen aus dem Norden nach Dentschland").

Fringilla linaria magnirostris Holmgren, Scand. Fogl. I, p.328 (1866, Nord-Schweden).

Linaria brumescens Homeyer, Journ. f. Orn. 1879, p. $18 \pm$ ("Lappland, Grönland, Schweden").

Linaria robusta, canigularis Brehm, Vogelfang; p. 107 (1855- nomina nuda(!), nach den Exemplaren der Sammlung hierher gehörig).

Ganz wie A. f. flammea aber größer, der Flïgel länger, Schnabel stürlier und meist merklich lïnger. Flügel $75-81^{1} / 2$, Schnabel $9-11 \mathrm{~mm}$.

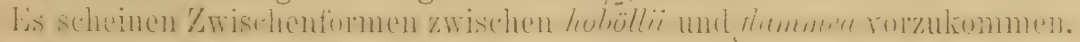

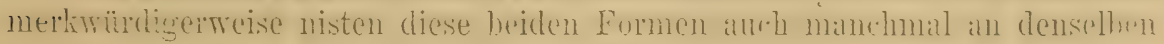




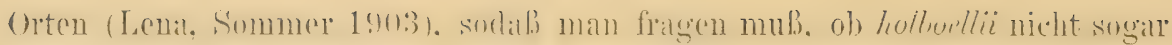
als Art aufzufassen ist.

Äußerster Norden der alten und neuen Welt, in der Regel nördlich von A. $f$. Hammea, kolonientreise hier und dort. Auf der Wanderung teils in getrennten Flügen, teils mit flammea gemischt, in Süd-Schweden, England

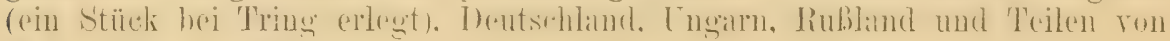
Mittel-Asien, Nord-Japan und dem nordöstlichen Amerika.

\section{Acanthis flammea rostratus (Cones).}

Aegiothus rostratus Coues, Proc. Ac. Nat. Sei. Philadelphia 1861, p.378 (S.-Grönland). Acanthis linaria $\gamma$. lanceoiata Dubois, Consp. Av. Eur. 1871, p. 18 (Ex Selys-Longchamps MS.).

?. Acanthis groenlandica Bonaparte, Rer. et Mlag. Zool. 1857, p.55 (Nomen nudum!).

Sehr große Form mit starkem, lünflingsartigem Schnabel, Oberseite sehr dunkel, Streifung der Unterseite sehr auffallend dunkel und kriftig.

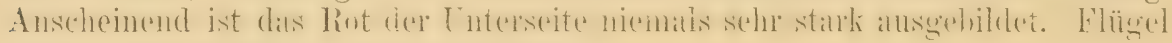
77.5-83.8, Schnabel 8.5-10.5 mm.

Brut- und Standrogel in Grönland. Im WVinter in südwestlicher Richtung sïdwärts wandernd durch Canada und 'T'eile der Vereinigten Staaten. In Europa nicht nacingewiesen!

\section{Acanthis flammea cabaret (P. L. S. Müll.).}

Kleiner Birkenzeisig.

Fringilla Cabaret P. L. S. Iiiller, Natursystem, Suppl., p). 165 (1776- ex Daubenton \& Buffon. „Europa" - Dentschland und Frankreich nach Buffon). (Die Beschreibung und Abbildung ron Buffon und Daubenton passen nur auf die mittel-europäische Form und das Habitat spricht nicht dagegen. V'orsichtige Nomenklatoren wie Salradori, Stejneger, T'schusi (in. litt.) haben auch den Namen cabarel unbeanstandet acceptiert).

Fringilla minima Boddaert, Tabl. Pl. Enl., p. 28 (1783- Daubenton's, pl. 485, Fig. 2 "Le Cabaret" benannt).

Linaria rufescens Vieillot, Mem. R. Acead. T'orino XXII, Sc. Fis, p. 202 (1816).

Linaria minor Leach, Syst. Cat. IIamm. \& B. Brit. MLs., 1). 15 (1816- nom. nudum). Engl.: Lesser Redpoll.

Auf den ersten Bliek dureh geringe Größe, rotbraune Federränder der Oberseite, die überhaupt sehr dunkel ist, sowie sehr braune Kehle, Hals und Brustseiten der o und Jungen gelienmeichnet. Flïgel of 69-73, ᄋ 66 bis $70 \mathrm{~mm}$.

Bewohnt als Brutrogel Mittel- und WVest-Europa. In Mittel-Europa nur Gebirgsvogel (Alpen, ?Karpathen, Balkan), in Schottland, Irland undEngland, aber hier auch in der Ebene. Im Herbst und Winter Strichrogel. (Englische und kontinentale Stïcke sind nicht zu unterscheiden.) Tschusi, Deichler u. a. nehmen allerdings an, daß erstere bräunlicher sind. Würde man sie tremnen wollen, müBte ein neuer Name für sie gemacht werden.

(Gätke erwälnnt das Brïten eines Pares von Leinzeisigen auf Helgoland, die Form aber ist nicht festgestellt. Radde beschreibt das Briten einer noch ununtersuchten Form im Kaukasus.)

Gleicht in seinen Gewohnheiten und seiner Lebensweise den nordischen Formen. aber die Nistzeit ist frïher. Sowohl in England als auch in der Schweiz, wo diese 
Form bis fast $1900 \mathrm{~m}$ hoch brïtet, findet man schon Ende April und in der ersten Hälfte des Mai die Eier, die denen von A. f. flammea gleichen, aber im allgemeinen wohl noch etwas kleiner sind. Der Gesang scheint kräftiger, wohllautender zu sein, als der der nordischen Form.

\section{Acanthis hornemannii hornemannii (Holl.).}

Linota hornemannii Holböll, Naturk. Tidskr. IV, 18ł3, p. 398 (Grönland). (Acanthis canescens, non Gould!, mehrerer Autoren).

Die größte und hellste Form der Leinzeisige. Bürzel ungestreift, schneeweili, hei alten cे zart rosia angeflogen, ehenso die Brust. die nie lehhaft rot wird. Flankeu weil.s. mit sehr geringer strichelung oder ganz olne dieselhe. Federänder des Rückens bräunlichweib. S'chuahel sehr kurz und dick. Im .Jugendliteide sind Hals und Nactien golhlich angeflogen. Fliigel ठै $84-90$, o $80-84 \mathrm{~mm}$.

Brut- und Standvogel in Grönland bis zum $73^{\circ}$ nördl. Breite; Island, Splitzhergen, Jan Magen. Im Winter in Teilen von Nord-Amerika. Soll atuch zreimal in England und eimmal in Erankich rorgeliommen sein.

\section{Acanthis hornemannii exilipes (Coues).}

(Linaria canescens, non Gould!, mehrerer Autoren.)

Aegiothus exilipes Coues, Proc. Ac. Nat. Sci. Philadelphia, Nov. 1861, p. 385 (Fort Simpson, Arktisches Amerika).

Linaria sibirica Homeyer, Journ. f. Orn. 1879, p. 185 (Onon und Baikal).

Linaria pallescens Homeyer, Journ. f. Orn. 1880, p. 156 (= sibirica!).

Gleichsam eine verkleinerte Ausgabe von $A . h$. homemannii, auch im ganzen dunkler, der Bürzel ungestreift, aher nicht so ausgedehnt weib, Köry)erseiten und Cuterschwanzlecken mehr gestreift, das Rot der Cuterseite in der Regel mehr entwickelt. Flïgel ơ $74-77.9, \circ 69.6-74.6 \mathrm{~mm}$.

(In Lappland kommen Exemplare ror, die zwischen dieser Form und A. f. Hammea stehen und vermutlich Bastarde sind.)

Circumpolarer Brutvogel. In Amerika von Ungava bis West-Alaska hrïtend. im Winter die nördlichen Tereinigten Staten hesuchend. In der alten Welt ron Lappland durch Sibirien bis Nork-Japan, auf der Wanderumg weiter südlich bis Ost-Preußen (ausnahmsweise).

\section{Acanthis citrinella citrinella (L.).}

\section{Zitronenzeisig:}

? Fringilla Citrinella Vroeg. C'atalogus Ver\%am. Vogel. dier., Adumbratiuncula, 1. 3 (1761"hier", d. h. Holland).

Fringilla Citrinella Linné, Syst. Nat. Ed. XU, p. 320 (1766- Ex Gesner, Aldror., Will, etc. "Hab. in Europa australi". Ich nehme als typ. Lok. die Alpen an, nach vorhergeh. Autoren).

Emberiza brumalis Scopoli, Annus I, p. 145 (1769- Tirol).

Citrinella alpina Bonaparte, Cat. Metod. Ucc. Eur., p.48 (1842- nomen nudum!) (vgl. Bonap., Consp. Av. I, p. 520 (1850).

Engl.: Citril Finch. Franz.: Venturon alpine. Ital.: Venturone.

Fad. Oherlinpf his hinter die Augen, rund um den Schnahel his hinter die Angen, Enterseite, Obersehnanzdecken und Bürzel gुelhgrïn. Naclien und

F. Hartert, Die Vögel der paläarktischen Region. 


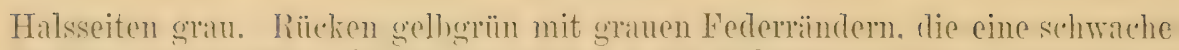
Streifung hervolufen. Sehwingen tiefhram mit hellhramen Imen- und sidnmal-

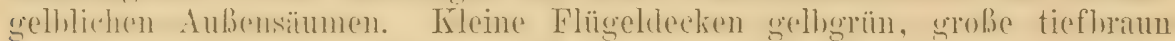

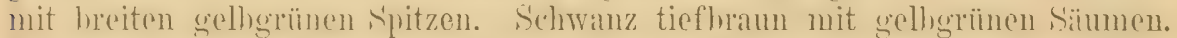

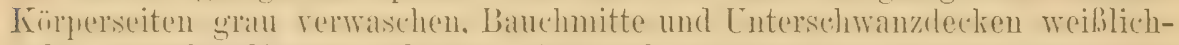

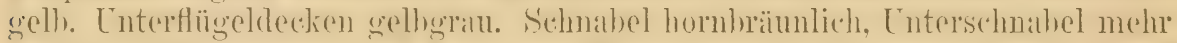

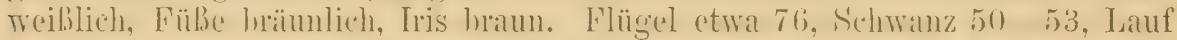
14-15, Schnahel etwa $8.5 \mathrm{~mm}$. Im Herbste ist das Gefieder dunkler, grauhrämulicher, in Frühling viel mehr grüngelhlich, weil sich die Ferleränter

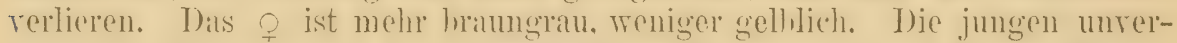
mauserten Vëgel hahen rosthräunlichgrane ()herseite mit sehwarzen Shehaftstrichen, die Lnterseite ist hrïmulichweil.s mit hramen Flecken. ()here Fü̈geldecken mit breiten nekergelhlichen Spitzen, Steuerfedern hraun mit grauwoißen Säumen und Spitzen.

Bervohner der Berge vou Zentral- und Süd-Europa. Alpen, Pyrenäen, Vogesen, Gelinge Italiens, Sehwarzwald, aber wahrocheinlich nicht im Harze,

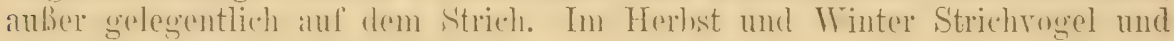
gelegentlich auch in den Ebenen.

Bewolıner von Nadelwäldern, wo er zeisigartig lebt. Der Lockruf ist ein sanfter, etwas schwermütig klingender Pfiff, der Gesang aber ziemlich wohllautend. Das Nest steht in verschiedener Höhe, meist ziemlich hoch, fast immer auf Nadelbäumen. Es enthält 4-5 zeisigartige Eier, die nach Rey im Durchsehnitt $16.35 \times 12.64$, im MIaximum $17.2 \times 13.1$ bezw. $16.2 \times 14.1$, im Minimum $15.4>12$ bezw. $16.1<11.7 \mathrm{~mm}$ messen. Ihr Gewicht beträgt im Durchschnitt $0.0744 \mathrm{gr}$.

\section{Acanthis citrinella corsicana (Koenig).}

Citrinella corsicana Koenig, Orn. MLonatsber. VII, p. 120 (1899- Korsika).

Unterscheidet sich von A.c. citrinella wie folgt: ôad. Rücken rostbraun mit dunklen Mittelstreifen, Stirn und Bürzel etwas lehhifter gringelh, [nter-

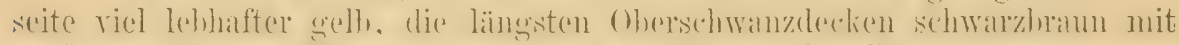

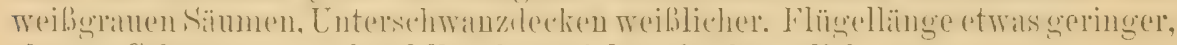
ebenso Schwanz. o ebenfalls oben viel mehr brïunlich.

Vertiitt A. c. citrinella auf Korsika und violleicht auch in T'eilen des italienischen Litorales.

\section{Gattung SERINUS Koch 1816.}

In allgemeinen zeisigartig (ocler hirlenzeisigartig) gefüht. Gefieder sehr weich, Flügel und Schwanz ziemlich lang, erste bis dritte Schwinge fitst gleich und am längsten, Sichwan\% tief ansgeschuitten, Schmahel kurz und dick. etwas wie gescluwllen (Fig. 20).

Figur 20. Afrika, Süd-Europa bis Nord-Deutschland, Mittel-Asien.

Übersicht der paläarktischen Arten.

1 Stirn und Bürzel gelb oder grünlichgelb . . . . . . . . . 2

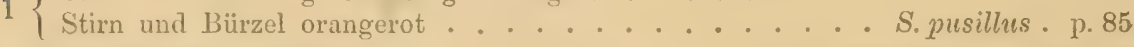

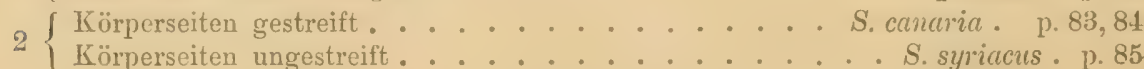




\section{Serinus canaria serinus (L.). (Fig. 20.)}

Girlitz.

Fringilla Serinus Linné, Syst. Nat., Ed. XII, p. 320 (1766- „Hab. in Europa australi"). Serinus hortulanus Koch, Syst. d. baier. Zool., p.229 (1816- "In Gebirgsgegenden selten. Gerne in Gärten.")

Serinus orientalis Brehm, Handb. Naturg. Vög. Deutschl., p. 254 (1831- S.O.-Europa bis Wien).

Srinus meridionalis Brehm, t. c., p. 255 (1831- 'l'irol und Schweiz).

Serinus Islandicus Brehm, t. c., p. 255 (1831- Island, aus Faber, Isis 1824, p. 792) (Typus verloren).

Serinus flavescens Gould, Birds Europe III, Taf, 195 (1837).

Serinus occidentalis Brehm, Vogelfang, p. 93 (1855- S.-Frankreich).

Serinus luteolus A. v. Homeyer, Journ. f. Orn. 1873, p. 223 („Der Girlitz" - descr. nulla. Schlesien).

Engl.: Serin Finch. Franz.: Serin, Cini. Ital.: Verzellino.

sad. Stirn gell, mit grauhaumen Fecterspitzen, oherkopfledern tiefhraun mit hellen Säumen, namentlich die in der Mitte an den Wureln gelh. Rü̈clienfedern tiefbraun mit hellhräunlichen, tejineise gelben Rändern. Bürzel zitronengelb, Oberschwanzdecken wieder haum mit grünlicherauen Ründern. Schwingen und Stenerfedern sedıwroham mit hellnö̈unlichen Inneu- und gelhlichen Aubensäumen und brïunlichweiben Śpitzen. Unterseite gelh, Kopfseiten granhraun gestreift. Körperseiten breit schwarzhaun und hellgrauhrïunlich gestreift, nur die Mitte des L'nterkïrpers gelb lassend. Batuch und Tntersehwanzdecken weililich. letztere mehr oder minder gelh) rerwaselyen und mit einigen schwarzhraumen Schaftstrichen. Tris, Fïlie und Schnahel wie bei S. c. canuria. Flügel 72--75, Schwanz etwa 50-52, Lauf etra 14, Schnabel $7-7^{1 / 2} \mathrm{~mm}$. o ein meniy kleiner, oben etwas matter. unten meistens nicht so lehhalt gell und Torderhals his zum Lnterlörper hin mehr oder weniger schwarz gestreift. Das erste Jugendkleid hat gar kein felh, sondern ist ohen tieflram mit breiten rosthräunlichen Federkanten, unten hell rosthranngellilich mit schwärzlichen Streifen, Mitte des Unterkörpers ungestreift.

Brut- nud Standrogel in den Atlasländern und in gianz Süd-Europra ron Spanien his Griechenlaud, Klein-Asien und Pallestina. Natch Norden zu reichte der Girlitz solange wir Nachrichten darïher hesitzen. also seit mehr als 300 .Jahren (Gesner, Aldrovandi), his S. Wr.-Deutschland und war, wie uoch hente, häufig hei Frankfurt. Wo er als firlitz, Hirugrill helsannt war; und woher er auch das Frankfurter Tögelchen genamnt wurde. Zalhlreiche Beohathumgen scheinen zu hewcisen, daf die Art sich (in den letzten 50 . Jahreu wenigstens) weiter nach Norden verhreitet hat und noch verhreitet. dem heute ist sie am Rhein mindesteus his Köln Brutrogुel (in Bom ungemein bäufig). in der Nark hïutig, in Pommen nicht selten, in den Niederungen WestPreubens geradezu ('haraliterrogel. ustr. In Sehlesien ist sie seit 1860) hekanut, mig aber auch früher sehou rorgekommen sein. Es sebeint wie gesilgt, festzustehen, dab wir es hier mit wirklicher rezenter Wreiterverlueitung zu tum halen. olwohl einzelne der angeführten Fäle sheptiseh anfzunehmen sind. weil sie anffullend mit zufïlliger Anwescmheit ron Beohachtern zusammenfallen. Faher's isländischer Girlitz war sicher keine andre Art, sonclern ein rerirrtes Stück. In Fngland nur sehr seltener Gast. In Deutschland Zugvogel, der in Nord-Afrika iiberwintert. 
Bewohner von Gärten, Parks, Alleen, Flußufern, Weinbergen, Laubwäldern. Im Friihling leicht bemerkbar, da er gern auf den Spitzen der Bäume und Büsche sitzt und seinen wie zitherartig klirrenden Lockruf girlitz, hitzriki hören läßt, und sich baumpieperartig in die Luft schwingt, um wie ein Federball anfgebläht, sein klirrendes, anmutiges Liedchen singend, herabzuschweben. Nahrung Sämereien aller Art, vom Boden und von den Pflanzen aufgelesen. Dis Nest steht vorzugsweise auf Obstbäumen, Eichen, Tannenbüschen, Eiben, Wachholder, Thuja, Weinstöcken, Roßkastanien, Linden, Gartenlauben aus verschiedenen Schlingpflanzen und dergl. m. Es ist ein tiefer Napf, prächtiger Bau aus Würzelchen usw., meist etwas mit Flechten verziert, weich und warm mit Federn, Haaren, Pflanzenwolle, gern aus alten Finkennestern entnommen, ausgefüttert. Eier meist blaßbläulich bis rahmweißlich, mit feinen Punkten, Flecken oder kritzeligen Linien gezeichnet, sehr dünnschalig. Von mir in Marokko gesammelte Eier messen $15.6 \times 12,15.6 \times 11.8,15.6 \times 10.9 \mathrm{~mm}$ usw. 18 Eier der Rey'schen Sammlung messen im Durchschnitt $16.06 \times 11.88$, im Maximum $17.2 \times 11.6$ und $15.9 \times 12.7$, im Minimum $14.4 \times 11$ Das durchschnittliche Gewicht $0.070 \mathrm{~g}$. Zwei Bruten.

\section{Serinus canaria canaria (L.).}

Kanarienvogel.

Fringilla Canaria Linné, Syst. Nat., Ed. X, p.181 (1758- "Hab. in Canariis insulis" Beschreibung des gelben Stubenrogels!).

Crithagra butyracea (errore) Grant, Ibis 1890, p. 441 (Madeira).

Engl.: Canary-bird. Franz.: Serin, auch canari.

Dem Girlitz sehr ähnlich, aber otwas größer, der Rücken vorwiegend grau, mit schwarzen hehaltsterifen, fast ohne gellygün, Bürzel nicht schwefolgelh sondern gelhlichgrïn, ror dem Flügelhug ein deutlicher sraner streif, die Streifuug der Kärperseiten viel mehr al diese heschränlit. sordal.s die Lnterseite mugestreift erseheint. Die Konfzeichumb ist aine andere, indem die Stimfedem ulivengelh (mit goldigen Sehimmer) sind und dunkle Schaftstriche zeigen, am Hinterkopfe sind die Federn reingran, mif schwärzlichen Schaftlinien, am Nablien wieder mehr grünlichgell), in der Mittr des Kopfes feht das

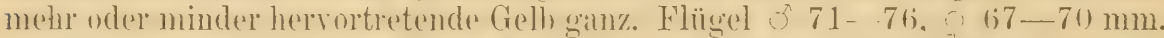
S.hwamz etwa 55-59 mm. Tris bran, Füße hornhraum, Oherschnabel dunkel hornfarben, Unterschnabel blaß fleischfarben.

Auf den Canaren (mit Ausnahme von Fuertarentura und Lanzarote), Madeira und den Azoreu Sam Miguel. Tereenia. St. Jorge. (irateiosa, Nta. Maria, Pico, Fayal).

Ähnelt in seiner Lebensweise dem Girlitz, bewohnt Gärten, mit Bäumen bestandene Wegränder, Wälder, Weingärten. Nahrung Sämereien, Früchte (Feigen), in der Fortpflanzungszeit wohl auch Insekten. Der Gesang ist einschmeichelnd, abwechslungsreich, mit größerer Zartheit in Rollern und Trillern, aber sonst wie der des Käfigvogels, wenn auch weniger laut. Auf Tenerife brütet der wilde Kanarienvogel in der Küstenregion anfangs März, vielleicht schon im Februar, weiter oben in den Bergen später, macht aber sicher in der Ebene zwei Bruten, ja man hat sogar von mehr als zwei Bruten gesprochen, damit aber wohl übertrieben. Daß die Küstenvögel zu späteren Bruten in die Berge ziehen, dïrfte Phantasie sein, denu man findet die Kanarienvögel auch im Sommer noch in den tieferen Regionen.

Das Nest steht in Büschen und Bäumen (Erica, Cytisus, Scinus, Cypressen, Orangen u. a.m.) besteht äußerlich aus Stengeln und Halmen, mit (weißlichen) Haaren und Pflanzenwolle ausgefüttert. Eier 4-5, seltener 3, auf blaß meergrünem Grunde teils hellweinrötlich gefleckt, gewässert und gewölkt, teils tief rotbraun gepunktet, bekritzelt und gefleckt. Die Maße variieren nicht sehr und betragen im Mittel etwa $13 \times 17 \mathrm{~mm}$. (Lebensweise: Bolle, Journ. f. Orn. 1858, p. 125, Koenig, Journ. f. Orn. 1890, p. 432). 


\section{Serinus syriacus Bp.}

Serimus syriacus Bonaparte, Consp. Av. I, p. 523 (1850, ex Hempr. \& Ehr., IIS. in Berlin Mus, - „ex As. oce. Bischerra". Daß der 'Typus nicht mehr existicre ist ein Irrtum. Prof. Reichenow hat ihn untersucht und teilt mir mit. Jaß er diese Art repräsentiere. Der Name muß daher angenommen werden, obwohl die Diagnose nicht gerade gut ist).

Serinus aurifrons (non Blyth 1847) 'Tristram, Proc. Zool. Soc. London, 1864, p).447, Ibis 1868, p. 207, Taf. VH. (Berg Hermon).

Serinus canonicus Dresser, B. Europe III, p. 558 'Taf. 171 (1876).

Erinnert an S. canaria serinus, dessen palestinensische Bergform er sein diurfte, unterscheidet sich aber in vielem, namentlich durch die ganz ungestreifte Cnterseite, die dunkelgelb mit fihlhräunlichem Schinmer ist, hellfihlhräunlichen Bauch und Unterschwanzdecken. Stirn und Natekenhand goldgelh, Bürzel desgl. Schwingen tiefluaun mit gelhen Säumen, Armsehwingen mit gelber Basis der AuBenfahnen. Steuerfedern tiefhraun mit gelhen Aubenund weiblichbramen Immensäumen, letztere Firles nach den äubern Federn hin an Ausdehumg zumehmend, sodaß das äuberste Pan ganz bräunlichweiß. mit dunklem Schaftstriche ist. Flügel $77 \mathrm{~mm}$. Der junge Togel ist ohen sebr viel hlasser und mehr rostluäunlich, nit rosthramer Stirn, die Enterseite ungestreift wie heim alten cie dichwingensïume sind grïulichgelh. o wie o, nur etwas weniger lehhaft, im allgemeinen etwas mehr aschbrimulich.

Palästina. Anscheinend lokal und nur im Gebirge.

\section{Serinus pusillus (Pall.).}

Passer pusillus Pallas, Zoogr. Rosso-Asiat. II, p. 28, Taf. XLIII, Fig. I (1811- „Circa Caucasum et mare caspium frequens avis, .....").

Fringillu rubrifions Hay, Journ. As. Soc. Beng. AV. 1).38 (1846-Simla).

Emberiza aurifrons Blyth, op. cit. XVI, p.476 (1847- oberhalb Simla).

Oraegithus indicus Homeyer, Journ. f. Orn. 1880, p. 152 („Indien").

ơad. Kopf. Kinn und Kohle schwarz mit schwachem olivenhräunlichen Schimmer, Stim his über das Auge hinaus lebhaft orangerot, diese orangeroten Federn an der Wrurzel orangegelh. Ürige Oherseite schwarzhaum mit goldgelhen Ründeru, Bürzel fast rein dunkelgelh. Oberschwanzdecken mit weißlichgrauen, schwach grelblich schimmeruden Süumen. Oherflügeldecken schwarzbraun mit dunkelgelbeu Sï̈men, die an den kleinen so hreit werden, diß diese ganz gelh aussehen, die grol.en auberdem mit weil.en Spitzen. Schwingen schwarzhaun, Handschwingen mit schmalen dunkelgolhen, Armschwingen mit breiteren weiblichen dufensäumen, Imnenfahnen nach der IV'urzel zu hellhräunlichgrau gesäumt. Steuerfederu schwärzlich mit dunlielgelben Aubenund schmalen hellgrauen Endsäumen. Kehle bis zul Keoffgegend schwarz, ïbrige Luterseite gelh und schwarz, die Federu in the Mitte schwarz, an den S'eiten und śnitzen dunkelgell). Nitte des Lnterköryers hellgelh. Unterschmauzund Unterflügeldeclien ggell. Schmahel schwarz, IVurzel des Cuterschmabels bram, Füße schwalz, Iris tiefhraun. Flügel 75-77, Schwanz 58-60. Schuahel etwa 6, Lauf $15 \mathrm{~mm}$. Das frisch vermauserte Gefieder sieht infolge der breiten hell weißlichgramen Süume viel holler aus, diese Sümme aher nutzen sjeh bald ah und das Gelb tritt damn dumkler hervor. O etwas kleiner, nicht ganz so lehlaft gefïrbt, das Schwarz der Kehle nicht so tief hinahreichend. Juv. Auf der Oberseite blaß sandartig braun, die Federn in der Mitte 
schwarhraun. Fopf hrum mit dunklern Federmitten, ohne eine Sinur des manseroten stimlleckes. Cuterseite hellhram. an den Seiten mit schwaryhramen Längstlecken. an ["ntertiorper heller, fast reiblich. Bei den jungen 0 ist infolge der schwärzlichen Federwurzeln die Tichle schon schwärzlich.

Bewohner von Gebirgswäldern, in Höhen ïber 3000 und 3500 bis zu 10500 engl. FuB, im Winter in tieferen Lagen. Brutvogel im Kaukasus,

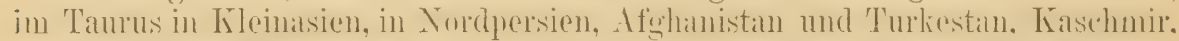
morelwestlieher Himblaya hei Ladilkh. Spiti. Garkwál und Lahul. Im Lihanom und in den niedrigeren Regionen des Himalaya nur Wintervogel. Nach Angaben eines Vogelfängers, dem das Stïck aber entkam, soll cines auf Helgoland vorgekommen sein (Neuer Naumann III p. 278).

Brïtet in den hohen Wachholderbäumen und anderen Nadelhölzern seines Brutgebietes, besucht im Winter auch Laubholz und Gärten. Das Nest ist größer als das des Girlitz und besteht aus feinen Halmen, mit einigen Flechten oder Holzstïckchen durchwebt, weich mit Federn und Haaren ausgefuittert. Man fand $3-5$ Eier in den Nestern. Sie älneln den Eiern des Kanarienvogels und Girlitz, sind bläulichweiß oder blaßblau, mit einigen tief braunen und zahlreicheren rötlichbraunen Flecken und kurzen Strichen, meist mehr oder minder kranzförmig um das stumpfe Ende herum. Sie messen $17.2 \times 13.2$ und $16 \times 12.1 \mathrm{~mm}$. Die Lockstimme ähuelt der des Girlitz, der Gesing ist nach Radde sehr angenehm.

\section{Gattung URAGUS Keys. \& Blas. 1840.}

Eine höchst auffallende Gattung, die man sehr treftend als Meisengimpel bezeichnet hat. In ihrem sehr weichen und reichen, vollen Gefieder, sowie dem langen, dureh die etwa 1 cm kïrzeren Seitenfedern abgestuften

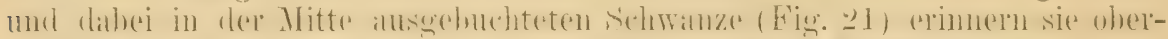

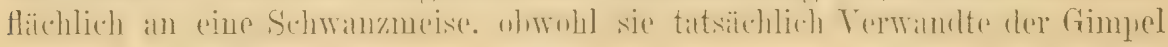

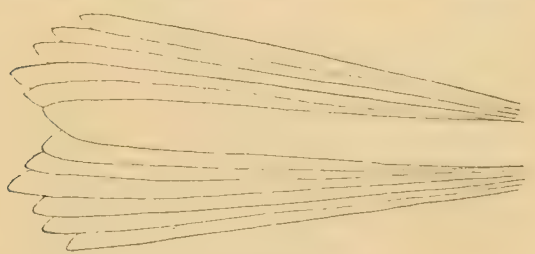

Figur 21.

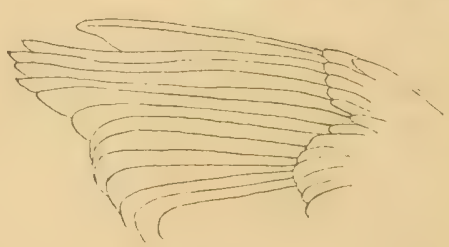

Figur 22 ,

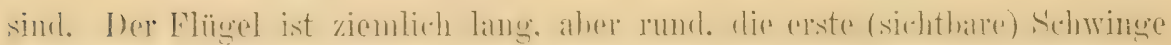
ist merklich kiurzer, die folgende auch noch deutlich kïrzer als die längsten,

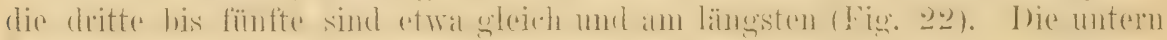

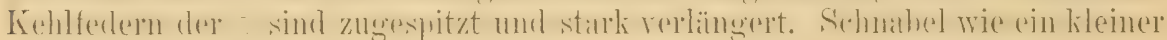

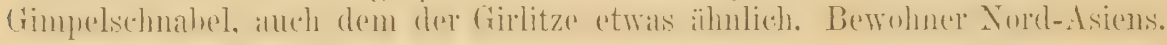

\section{Uragus sibirica sibirica (Pall.). (Fig. 21, 22.)}

Loxia sibirica Pallas, Reise d. versch. Pror. d. Russ. Reichs II, Anhang, p. 711 (1773„... frutic. dens. ca. riros et terr. mont. australioris Sibiriac").

Pyrrhula caudate Pallas, Zoogr. Rosso-Asiat. II, p. 10 (1811- „... jugi Altaïci, Sajanensis, et totius Sibir. or, frequens ..." Als typ. Lok. Altai zu betrachten).

Pyrmula longicauda 'Temminck, Han. d'Orn. I, p.340 (1820- "les contrées boréales, trés abondant en Sibérie; en hiver il émigre vers 1. pror. mér. de l. Russie, et passe en Hongrie"). 
OTad. im Herbste: Zïgel und Federn um den Oberschnabel weinrot,

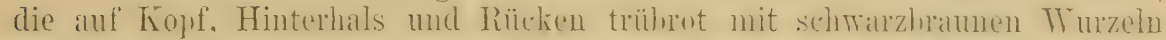

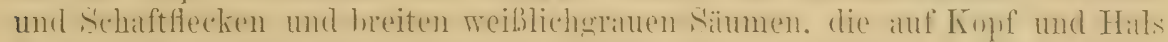

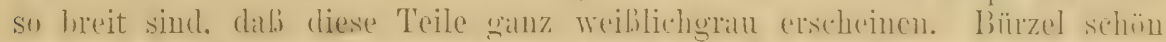

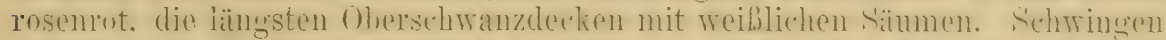
granschwar\%, die Handschwingen mit schmalen. die innern Armschwingen anit

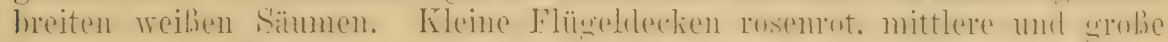

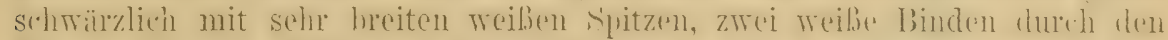

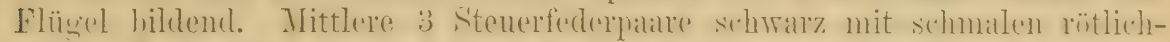

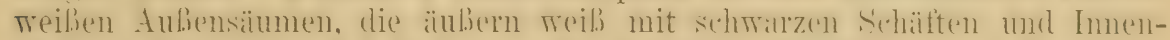
sïmmen. letztere an den äubersten viel schmailer. Kiehlfedern und Ghrdecken

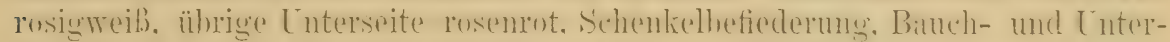

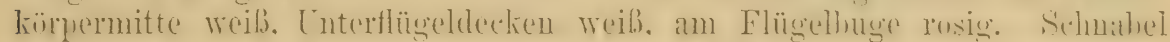
horubräunlich, Füße hellbraun. Iris braun. Flïgel 73-79, Schwanz etra 85, Lauf 16-17.5, Schnabel etrva 8-9 mm. Durch die Abnutzung des

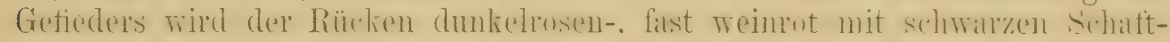
flecken und die Unterseite lebhafter rot, wïhrend der Oberkopf sein Aussehen nicht wesentlich verändert, im Sommer ist der Schnabel fast.gelb. o kleiner als 0 , oben lichtbrïunlichgrau, nur auf dem Unterrücken ein

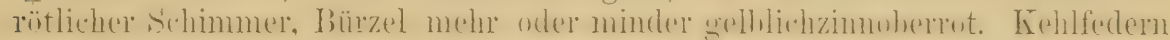

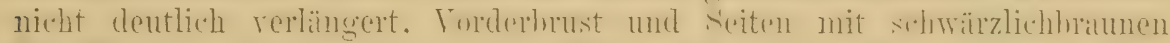

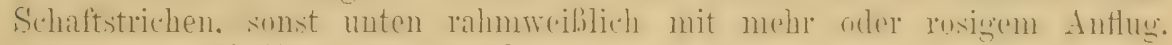
Juv. dem o ähnlich, aber bräunlicher.

Der größte Teil von West- und Ost-Sibirien, bis Turkestan, Tibet und

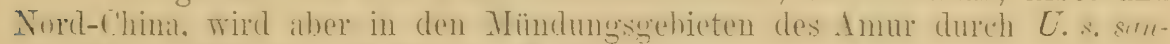
guinolenta vertreten und fehlt in Kamtschatka.

Bewohner bebuschter Flußufer und Berghänge, aber nicht der großen Waldungen. Stand- und Strichrogel, im Winter in mildere Iäler ziehend. Singt leise aber lang und melodiös, die Lockstimme ein leises fit, fit, fit. In Daurien findet man das Nest, Tenn die Büsche grün werden, d. h. dort im Juni, 1-2 Meter hoch in Büschen. Es ist prachtroll gebaut, meist mit weißlichen trockenen Kräutern, Gespinsten und Bast bekleidet, so daß es äußerlich an die Nester der Gartenspötter (Hypolais) erinnert. Die 4-6 Eier ähneln denen ron Carpodacus erythrinus, sind aber etwas kleiner und etwas weniger intensiv blau und meist nicht allzu reichlich und läufig nur um das stumpfe Ende dentlich, schwarz punktiert, bekritzelt und gefleckt, oft auch einfarbig. Sic messen $18-18.5 \times 14,18.5 \times 13.6,17.8 \times 13.5,18 \times 14.3,18.2 \times 14.1,19 \times 13.7$, $19 \times 13,20.2 \times 12.5,19 \times 14 \mathrm{~mm}$. Godlewski berichtet, daß man den Flug weit liören kanı - das ist auch bei den Schrwanzmeisen der Fall.

\section{Uragus sibirica sanguinolenta (Temm. it sichl.).}

Pym rulda sanguinolenta Temm. \& Schlegel, Fauna Japon., Ares, p. 92, Taf. $5 \pm$ (1850— Japan).

Ganz wie U. s. sibinica aber merklich kleiner, die Oberseite im frisch-

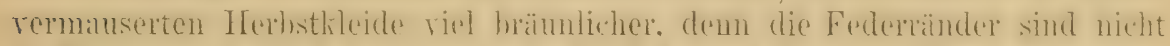

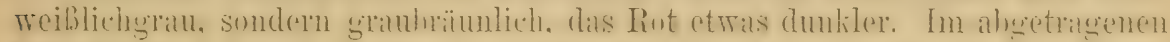

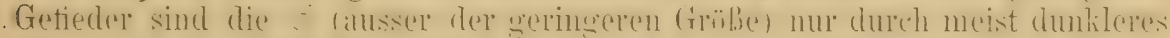
und feurigeres Rot, die o durch viel bränulicheren Farbenton ron denen von $U$. s. sibirica zu unterscheiden. Flügel ôad. 68-71, ansuahmmeise bis $74 \mathrm{~mm}$. 
Tertritt $L$. so silivice am unteren Amur (Lssurien), auf den Inseln Askold und Sachalin, und in Japan und wurde auf den Kurilen und in NordChina beobachtet.

Die Eier sind wie die der vorigen Art. MIaße (nach Nehrkorn) $18 \times 13 \mathrm{~mm}$, die genauen Lokalitäten sind aber beim letztern Autor nicht angegeben, was doch gerade hier erwünscht gewesen wäre.

\section{Uragus sibirica lepidus Dav. \& Oust.}

Uragus lepidus David et Oustalet, Ois. Chine, p. 359, Taf. 98 (1877- "Isinling, Chensi").

Nach Sharpes Besehreibung des Typus und der Abhildung in den .Ois.

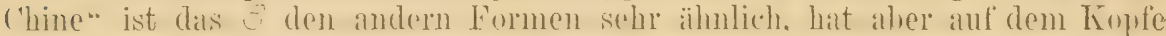
mehr hraun, die ganze Oherseite ist hramer. und hat sthmälere weiße Flügelhinden und bräunliche Kärperseiten mit dunkelnamen streifen, Gröbe etwas geringer. Fin mil rorliegrendes, im Musem zu 'Tling, in Kansu im Januar 1885

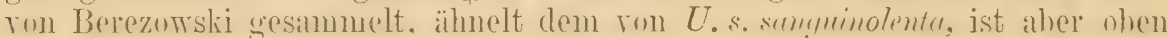
retwas hreiter und auf der gimzen ['nterseite mit Disnahme der Vitte des Cnterköpers scharf dumkelluraun crestreift, der Bürzel ist dunkel erdhraun,

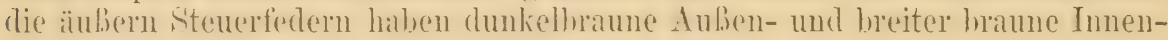
säume, nirgends zeigt sich eine Spur von Rot.

Dïrfte U.s.sanguinolenta (beziehungsweise U.s. sibirica) in den Gebirgen Nord-Chinas - 'T'sinling, Schansi, Kansu - vertreten.

\section{Gattung ERYTHROSPIZA B1. 1841.}

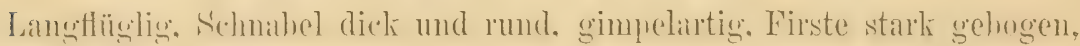
Schwanz deutlich ausgebuchtet.

Außenfahnen der Armsehwingen und großen Flügeldecken cinfarbig graubraun mit hell rosenroten Säumen, Flïgel etwa $85-90 \mathrm{~mm}$. . . E. githaginea . p. 83 Außenfahnen der Armschwingen und großen Flügeldecken mit großen bräunlichweißen Flecken, Flügel etwa $95 \mathrm{~mm}$. . . . . . E. mongolicus . p. 89

\section{Erythrospiza githaginea githaginea (Licht.).}

Fringilla githaginea Lichtenstein, Verz. Doubl., p. 24 (1823- "Prope Deram Aegypt. super.").

Pyrrhula payrandaei Audoniu, Expl. somm. Pl. Ois. Egypte, p. 369, 'Taf. V, Fig. 8 (1825Egypten).

Nach der Herbstmauser ist der Kopf und die Unterseite sehr hellgrau mit foinem It assehimmer und losigem Anflug. übrige oherseite und Hals-

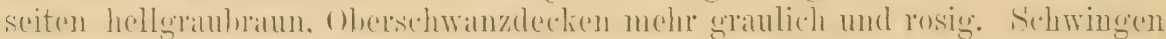

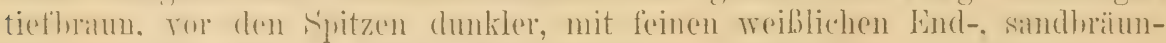

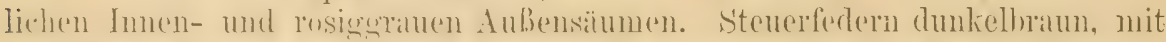

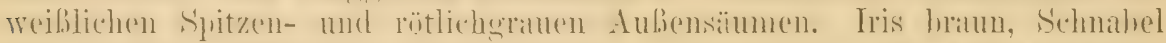

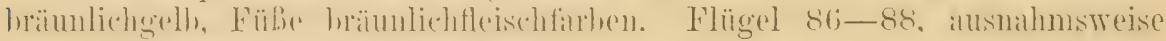
nur 89 (1 Exemplar), Schwanz 48-50, Lauf etwa 27, Schmabel $9-10 \mathrm{~mm}$.

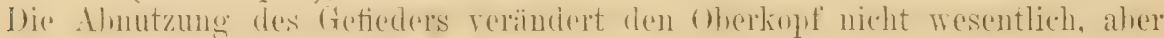
um den Schnabel herum bringt sie das Rot der ledern zum Vorschein, und

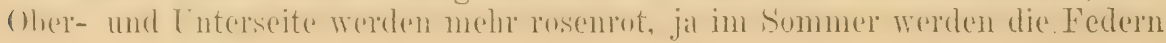


am Schnahel. Oherschwanzdecken. Flügcl- und Schwanzä̈nder feurig haminrot. c merklich kleiner. Flügel fast 5 mm kürzer. unten meln hrüumlich und nie so rosig, meist fast ohne rot. IuF. Olorseite. Flügel- und Schwanzsïume rosthrüunlich-sandfarben, Cuterseite chenser, aher heller, Ilitte des Unterkörpers weißlich.

Algier, Tunis, Tripolis, his Oher-Egyten. Stücke aus Arahien gohören vielleicht auch zu dieser Form. In Marokko ist die Art anscheinend noch nicht uacherewiesen: wem sie dort fehlt. Würde die Ahgeschiedenheit der canarischen Tögel deren Terschiedenheit erlilüren. Auf Malta im Trinter oft heohachtet. sonst nur ausuahmsweise in Süd-Eurn!r (Italien. Griechenland, ? Süd-Frankreich.)

Bewohner steiniger, dürrer Gegenden. Im Winter in Flïgen und etwas mehr herumstreichend, aber eigentlich doch Standvogel.

Die Stimme, die ihm die Namen Wüstentrompeter, Trombettiere, Trampeter Bullfinch u. a. eingetragen hat, ähnelt dem 'I'on einer Kindertrompete, sonst hat er auch noch Locktöne, die wie kek-kek, kä, kä, oder schack schak, klingen. Ende Februar und im Mrärz findet man die Eier, eine zweite Brut ist nicht unwahrscheinlich. Das Nest steht unter Steinen oder Erdschollen und in Felsenspalten, ist flach aus Grashalmen und Rispen gebaut, die Mulde mit feinen Würzelchen, Haaren, Wolle und Federn ausgefüttert. Es enthält 4-5 ovale Eier, blab blaugrünlich, am stumpfen Ende mehr oder minder mit dunkel- und rotbraunen Flecken und Punkten gezeichnet. Sie messen etwa $18 \times 14$ bis $19 \times 14 \mathrm{~mm}$.

\section{Erythrospiza githaginea crassirostris (Blyth).}

Carpodacus crassirostris Blyth, Journ. As. Soc. Beng. XVI, p. 476 (1847-Afghanistan).

Ganz wie E.g. githaginea, aber etwas größer, der Flïgel 88 -92 mm, ein Maß, das von der Sahara-Form, von der ich über 20 o messen konnte, nie erreht wird. Im ganzen neigen die Schuähel zu gröberer I)icke, die Oherseite ist meist etwas mehr graulich und weniger stark rosa üherflogen, wie auch die Unterseite, diese Unterschiede aber sind nur bei Serien zu elkennen.

Paliastina, Ost-Persien, Afghanistan, Baluchistan, Sind. Rajputana bis Gurgaon im Punjab.

\section{Erythrospiza githaginea amantum sulspi. nor.}

Unterscheidet sich vou den anderen beiden Formen auffallend dureh geschtwolleneren, klohigeren Schnibel. dunklere. hrämlichere Oherseite, und vielleicht auch viel stïlieren rosaroten Anflug. Ictzteres sicher festzustellen fohlen mir allerdings noch frisch remauserte stïnke. foribe viel geringer: ठ Flügel $83-87 \mathrm{~mm}$. (Typus ơ Oliva, Fuertaventura, 22. III. 1889. Nr. $1211 \mathrm{im} \mathrm{Tring} \mathrm{Mfusenm.)}$

Fuertaventura. Lanzarote und Gran (amaria. (Bolle. Tammania 1858.)

\section{Erythrospiza mongolicus (Swinh.).}

Carpodacus mongolicus Swinhoe, Proc. Zool. Soc. 1870 p. 447 (Nankow Pass.).

Erythrospiza incarnata Severtz., Turkest. Jevotn., p. 64, 117 (1873). 


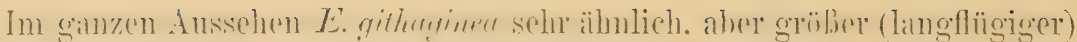

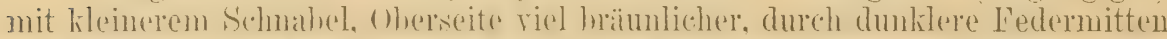

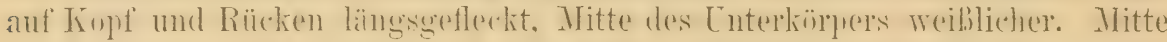

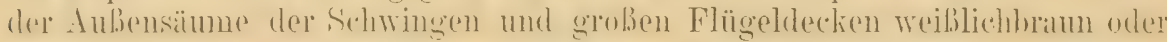
Dräunlichweiß, im abgeriebenen Gefieder rahmweiß. Flügel o 93 -96, of $86-90 \mathrm{~mm}$.

Zentral-Asien vou Afghanistan, Baluchistan, Iurkestan, Ost-Persien bis

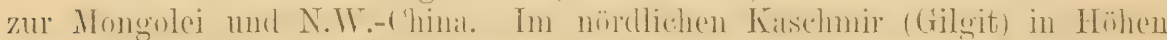

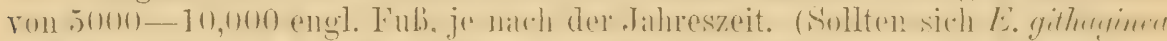

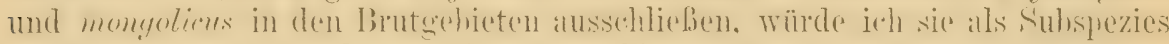
auffassen, aber, obwohl mongolicus entschieden mehr Bergvogel ist, ist dies nicht erwiesen).

Berrohnt steiniges Gelände und nährt sich ron Sämereien. Der Gesang soll flötend, angenehm, melancholisch sein, Lockstimme wie tuck, tuck. Przewalski will das Nest in einem Busche gefunden haben. Es enthielt grünlichweiße Eier mit schwärzlichen Flecken und Strichen, die 20.2-22 $\times 17.8-14.6 \mathrm{~mm}$ messen.

\section{(Gattung RHODOPECHYS Cab. $\left.1550 .{ }^{1}\right)$}

Schmabel ungemein stark, etwa zwischen denen von Petronia und Coccothraustes stehend, Firste leicht gewölbt. Flügel sehr lang, Schwanz

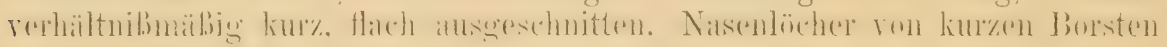
bedeckt. Bervohner steiniger, felsiger Gebirge.

\section{Rhodopechys sanguinea (Gould).}

Fringilla sanguinea Gould, Proc. Zool. Soc. London 1837, p. 127 (Erzerum).

Erythrospiza plactenicoptera Bomaparte \& Sehlegel, ILon. Loxiens, 1). 27, Taf, 30, 31 (1850 - ex Bonap., Comp. Liste, p. 34 nomen nudum! Hab. Libanon).

Carpodacus rhodopterus Lichtenst., Nomencl. Ar. Berolin., p. 48 (1851- nomen nudum!).

Oొad. Pileum brïunlich schwarz mit schmalen braunen Säumen, übrige

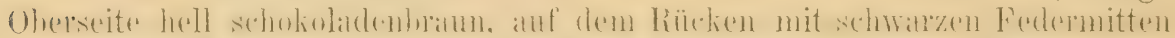
und meist mehr oder minder sichtbaren roten Spitzen, Bürzel einfarbig und

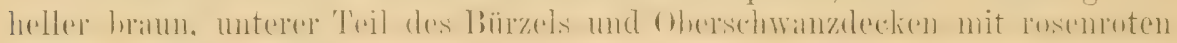

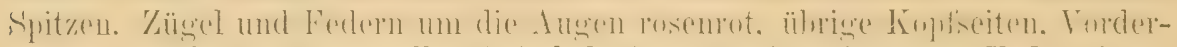
hals und Körperseiten hell schokoladenbraun mit schwarzen Federmitten, übrige Unterseite weiß mit leichtem rosemroten Schimmer. Schwingen braunschwarz mit breiten weillichen Innen- und schmäleren am Spitzendrittel

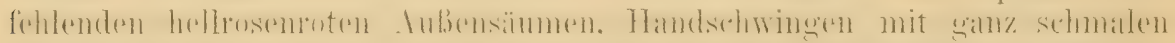

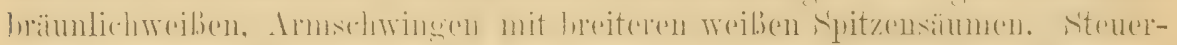
federn schwarz mit weißen Sätmen und mehr oder minder weiß an der Wurzel, das äußere Paar ganz weiß mit schmalem schwarzen Schaftstrich.

$\left.{ }^{1}\right)$ Es wäre rielleicht zu rechtfertigen, wenn man Rhodlopechys, Rhodlosyiza und Erythrospiza unter letzterem Namen rereinigte, wir wollen aber diese wicht ganz zwanglose Änderung nicht cinfïhren, und folgen der ïblich gewordenen Dreiteilung. Auf jeden Fall sind Erythrospiza yithayinea und mongolicus die niichsten und in der Tat sehr nahe Verwandte. Die Einteilung Dresser's (JIan. Pal. B., p. 328-331) ist ganz verfehlt, abgesehen clavon, daß als Typus ron Bucanctes (Cab., MIns. Hein. I, p. 16t) auf jeden Fall githaginea anzusehen ist. 
Enterflügeldecken weil., am Flügellug mit einigen rosenroten Flockichen. Achselfeclern weilo mit rosenroten Aubensïumen. Selnubel bräunlichgeil, mit dumkler Spitze, Fübe schwärzlich. Iris hraum. Flügel 11)6-110. Gehwanz. etwa 58, Lauf 19-20, Schnabel 11.5-12 mm. Dnreh Almutzume wird das Pileum reiner schwarz, die reten Spitzen der İ̈̈clienfedem werden deutlich. das Rot an Flïgeln, Bürzel usw. wird fenriger, llunkler. of etwas kleinex. das P'ilem mehr hraun, Rü̈cken etwas heller hraun. ['nterkïrper wriblicher, äußere Steuerfeder an der Inmenfilme mit melu vder weniger hram. .Jur. Ohen ganz, rost- oder sindbraun. Flïgel und Sobwanz mit hreiten hellhrïunlichen Sämmen, Torderhals und Kärperseiten cinfarlig hell rosthraun, Innterkörper weiß.

Von den armenischen Gebirgen (Erzerum, Lenkoran) und dem Libanon his Persien. Afghanistan, Ferghama und Ost-Turkestan. (I) is Torkummen in Arabien ist noch nicht sicher. Vgl. Heuglin Orn. N.O. Afr., p. 655.)

Im Sommer Bewohner großer Höhen, im Winter mehr talwärts ziehend. Scheu und flüchtig. Ein Nest, dessen Inhaber erlegt wurde, will ein JIr. Cochrane auf dem Libanon auf einem Baume gefunden haben. Das Nest war ähnlich dem eines Grünlings gebaut, das in Dresser's Sammlung befindliche Ei ist weiß mit grünlichgrauem Schimmer und feinen grauen Flecken, meist am stumpfen Ende und mißt $22 \times 15$ mm.

\section{Rhodopechys sanguinea aliena Whit.}

Rhodopechys sanguineus (non Gould!) Loche, Expl. Sci. Algérie, Ois. I, p. 163 (1867Algier).

Rhodopechys aliena Whitaker, Bull. B. O. Club VII, p. XVIII (Nov. 1897), Ibis 1898, p. 601 (Glaoui, Atlas, Marokko).

Unterscheidet sich von $R$. sangrinea wie folgt: Hinterhals aschgrau, Tehle weiblich mit rosigen s'chimmer. Schwingern auben nul sehmal rot

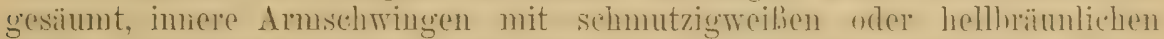

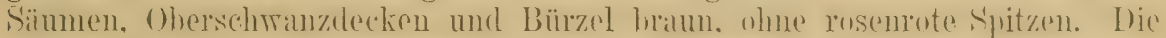

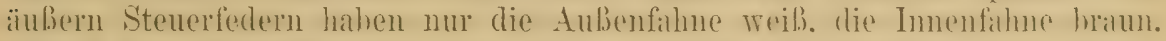

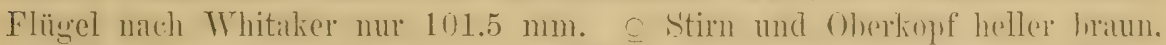

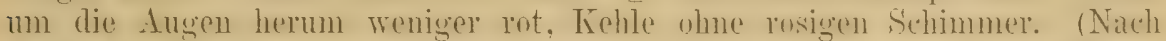
Trhitaker. T'ou mir nur flülutigg gesphen. Jedenfills gengr. Tertrester ron Rh. sanguinea und daher besser als Unterart zu behandeln.)

Wurde am 28. Mai zu Glaoui im Atlas, südöstlich ron Marrakesh, etwa 5000 engl. Fuß ïber dem Meere, erbeutet.

\section{Gattung RHODOSPIZA Sharpe 1888.}

Steht Rhodopechys auBerordentlich nahe und kömnte allenfalls damit vereinigt werden, der Schnabel ist aber spitziger, die Firste gerader, der

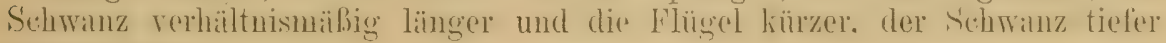
ausgeschnitten.

\section{Rhodospiza obsoleta (Licht.).}

Fringilla obsoleta Lichtenstein in Eversmann's Reise, Anhang, p). 132 (1823- bei Buchara).

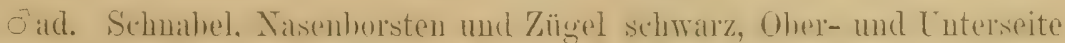

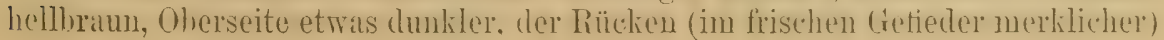


mit granem S'bhimmer, Oherschmanzdecken lehbafter und mehr rostfarhen, Luter-

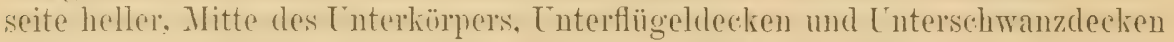
weil.) vder woiflich. Schwingen schwarz, scharf und schön weiß umsäumt, Handdecken. grobe Flügeldecken und Armschwingen mit hellosemroten AuBensïumen, die letateren an den Spitzen etwa $5 \mathrm{~mm}$ weit weil. Steuerferleru schwar\%, clas äuberste Par mur mit schmalem, das mittelste mit breitem weißen Aubensaum, die ̈̈brigen mit ganz weiben AuBensämmen und Spitzen.

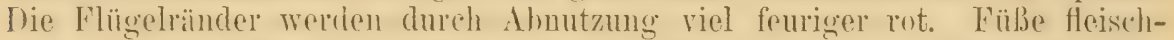
hraun. Flügel 86-90). Sehwanz ctwa 60-62, Iauf etwa 16, Schmahel 11 his $12 \mathrm{~mm}$. Q Flügel etwas kïrer. Farbe hasser, weniger lehhaft, Bürel wie der

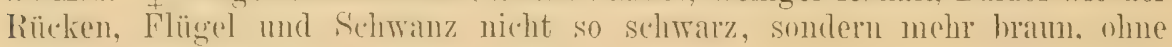
schwarz an Nase und Zügeln. Juv. wie das $q$.

Ton J'alästina und Syrien dureh Persien und Afghanistan bis 'Turkestan und in die Mongolei.

Lebt auf spärlich bewachsenen Höhen, frißt Sämereien und hat einen angenehmien Gesang. Die Lockstimme klingt wie ein sanftes, leises pink, pink oder fink, fink. Brïtet 2 mal, in Ilai und Juli, Nest aus 'Zweiglein, Pflanzen- oder Schafwolle, Haaren und Gras wohlgefügt, in Bïschen. 4 bis 6 Eier, trüb blaßblau, mit purpurbraunen Flecken und Strichen, zumal um das stumpfe Ende, messen etwa $19.5 \times 14.9 \mathrm{~mm}$.

\section{Gattung PYRRHULA Pallas 1811.}

Unsre Gimpel oder Dompfaffen. Gekeunzeichnet durch ihren dicken, kurgen. rundlichen Schmbhel: die erste (sichthare) Schwinge etwa gleich der fünften, die. 2.-4. etwa gleich und am längsten, wenn auch nur einige $\mathrm{mm}$ länger als die 1. und 5., 2. (lange) bis 5. nach der Mitte dentlich verengt. Schwanz serate (hei der emopäischen Art und ihren Formen) oder tief ansgebuchtet (Himblara-l'ormen). Dio oberschwandecken (hei der europäischen

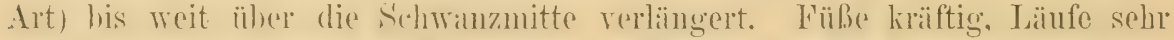
liur., nicht viel länger als Vittelzehe mit Nigel. (ieschlechter meist merlich verschieden ( $\sigma^{\pi}$ unten rot, $\bigcirc$ bräunlichgrau) oder fast ganz gleich (beide unten grau oder bräunlich). Bewohner des europäischen und asiatischen Nordens, in Asion moch im Himalara in mohreren sehr eigenartigen Formen und nemerdings in je aner sehr aigenartigen Form in den Hochgehirgen der Malakkahalbinsel und von Luzon (Philippinen) entdeckt.

(Die nordasiatischen Formen dürften hier richtig als Formen von P.pyrrhula behandelt sein, denn sie scheinen einander in iluren Brutgebieten auszuschließen, obwohl sie im Winter teilweise zusammen vorkommen.)

Übersicht aller bekaunten Formen der Gattung.

1 Nittleres Steuerfederpaar mindestens $13 \mathrm{~mm}$ kürzer als das äußere. . . . 5

| Mittleres Steuerfederpaar nicht oder wur sehr wenig kürzer als das äußere 2

I Kopfplatte schwarz . . . . . . . . . . . . . . . . 3

$\because$ I Nur die Stirn schwarz............. P. aurantiaca . p. 97

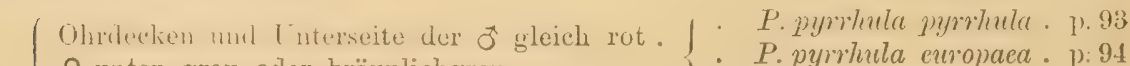
o unten grau oder bräunlichgrau .... . P. pyrtula en Popaea . p: 94

:) Ohrdecken der ơ rosenrot, Unterseite grau (P. pyrrhula griseiventris . 1). 95 oder rosig angelaufen, o Ohrdecken und $\left\{\begin{array}{l}\text { P. pyrrhula griseiventris. 1).95 } \\ \text { Lnterseite griulich. . . . . . . . . . }\end{array}\right.$

Ohrdecken und Unterseite in beiden Geschlechtern grau oder graubräunlich 4 
$4\{$ Unterschwanzdecken und Bürzel weiß . . . . P. pyrrhula cassini . p. 96

Unterschwanzdecken und Bürzel graubraun ... P. pymrhela murina . p.96

Ganzer Oberkopf blauschwarz ..... P. leucogenys Grant (Luzon).

Scharf begrenate schwarze IIaske um den Schnabel. $\vec{j}$ mit riel fint im

5\{

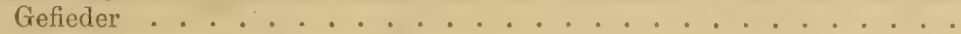

Unscharf begrenzte schwärzliche Maske oder gar keine, beide Geschlechter ohne Rot. . . . . . . . . . . . . . . . 7

(i) $\{$ Oberkopf und Hinterhals zinnoberrot, o ebenda grüngelb $P$. erythrocephala • p. 97

$\{$ ơ und $q$ Oberkopf grau, ơ aber Brust zinnoberrot, o + bräunlich P. erythaca . p. 96

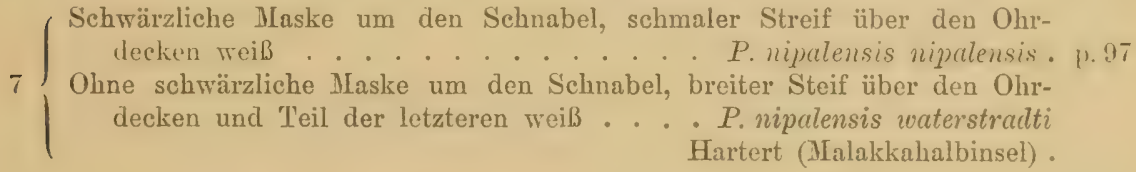

\section{Pyrrhula pyrrhula pyrrhula (L.).}

\section{Großer oder nordischer Dompfaff oder Gimpel.}

Loxia Pyrrluta Linné, Syst. Nat. Ed. X, p. 171 (1758- „Hab. in Europae sylvis" erstes Zitat „Fauna Suecica 178“6, typ. Lok. daher Schweden).

Pyrrhula Rubicilla Pallas, Zoogr. Rosso-Asiat. If, p. 7 (1811-- „In omnia Rossia et Sibiria". Aus der Anm. p. 8 geht hervor, dab Pallas cassini u. a. mit seiner rubicilla vereinigte, als deren typ. Lok. aber Rußland anzusehen wäre).

Pyrrhula major Brehm, Handb. Naturg. Vög. Deutschl., p. 252 (1831- „Er kommt nur zuweilen im Winter nach Deutschland").

Pyrrhula coccinea Selys-Longch., Faune Belge, p. 79 (18t2).

Pyrrhula Limnéi Malm, Göteb. och Bohusl. Faun., p. 194 (1877- Göteborg etc.).

Pyrrhula minor gracilis (sic!) A. Brehm, Verz. Samml., p. 9 (1866- nomen nudum die Stïcke der Sammlung gehören meist der großen Form an!).

Pyrrhula coccinea $\beta$. var. atavica Menzbier, Bull. Soc. Imp. Natur. Moscou 58, p. 111 (1883- ex Sewertz. M.S.: Aberration des of ohne rot an der letzten Armschwinge).

Schwedisch: Domherre.

Ĉad. Oberkopf his zum Genick und maskenartig rings um den Sehnahel blauschwarz, ührige Oberseite nebst kleineren und mittleren obertlügeldecken rein aschgrau. Bürzel weilb. Kopf- und Halsseiten und die ïbrige Unterscite lis anf den Unterkörper lebhaft bellrot, hinterster Teil des Lnterkörpers und Lnterschwanzdecken weiß. Oberschwanzdecken und Schwanz blauschwarz. Die äußerste Steuerfeder hat oft einen mehr oder minder breiten weilien Strich am Schafte. Sehwingen sthwarz, der ganz greride Aubensilum der äußersten und das verengte Spitzendrittel der folgenden vier Silhwingen fein hellgrau gesäumt, die letzten Armschwingen blinschwarz, die letzte kleine mit grauer, meist mehr oder minder sehön rosenrot üherkufener Außenfahne. Hinddecken dunkelgrau, längste Flügeldecken bluschwarz mit ausgedehnten hellgranen Spitzen, die eine auffallende Binde dureh den Flügel hilden. Inmensïtume der Schwingen und Cuterflügeldecken weilich. Schmahel schwarz. Iris ind Fïße braun. Flügel 93-98, Schwanz etrva 68-72, Lauf etwa 18-19, Schuabel etwa $10 \mathrm{~mm}$. etwas kleiner, Rücken mit hräunlichem Schimmer, unten hellgran mit brïunlichem (oder vielnehn weinrötlichem) Sehimmer statt rot. Jur: beide Gesehlechter oben und unten resthräunlich. muten heller, ohne Gran oder Rot, Kopf ohne Schwarz, wie Rücken. (Der 
Rü̈cken der c ist manchmal rötlich angehaucht, Käifigröged (namentlich durch Hanffütterung) werden oft schwarz).

Brutrogen in Skandinarien, den Ostseeprovinzen bis OstureuBen, RuBland, Trest-Sibirien his südlich rom Baikal-See und loaurien. In Winter wandert er weit nach sïlden mol mach Westen, ïher ganz Deutschland his West-Enroph, vereinzelt his Ost-lingland, noch seltener lis Italien. Griechenland und Kleinasien.

Lebensweise und Fortpflanzung ganz wie bei P. p. europaca, nur Nest und Eier meist etwas größer. Eier (Rey) $21.22 \times 14.73,23.2 \times 14.8,19.7-14.7,20 \times 15$, $20.1 \times 14.9,19.6 \times 14.7,20.1 \times 14.1 \mathrm{~mm}$ usw.

\section{Pyrrhula pyrrhula europaea Vieill.}

\section{Gemeiner oder kleiner Dompfaff oder Gimpel.}

Pyrmhla europaea Vieillot, Nour. Diet. d'Hist. Nat. IV, p. 286 (1816- die große nordische Form ist deutlich auf Seite 293 von der gemeinen unterschieden).

Pyrrhula rufa Koch, Syst. d. baier. Zool. I, p. 227 (1816-- „In Waldungen, gemein“6). Pyrrhula vulgaris Temminck, Mlan. d'Orn. I, p. 338 (1820- ex Brisson, partim).

Pyrrhula germanica Brehm, Handb. Naturg. Vög. Deutschl., p. 252 (1831- „bewohnt deutsch. Nadel- und Buchenwälder").

Pyrrlula peregrina Brehm, t. c., p. 253 (1831- „kommt gew. erst im Okt. und brütet nur höchst selten in uns. IVäldern'").

Pymhula pileate Macgillirray, Hist. Brit. B. I., p. 407 (1837- ,Generally distributed in Britain).

Pyrrhula vulgaris minor Schlegel, Vog. Nederland, p. 347 Taf. 165 (185t-58 - Holland, W.-Europa).

Pyrrhula minor Brehm, Vogelfang, p.91 (185̄ō- Deutschland, selten).

Pyrrhula minor pusilla A. Brelım, Verz. Samml., p. 9 (1866- nom. nudum!).

Engl.: Bullfinch; Franz.: Bourreuil; Ital.: Ciuffolotto. Holl.: Goudvink.

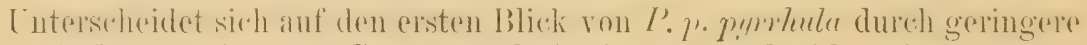
GröBe. Außerclem ist das Grau der Oberseite etwas dunkler, das Rot der Unterseite in der Regel (aber nicht immer) trüber, weniger lebhaft. Der

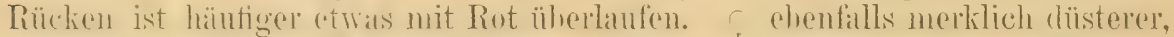
hrïunlicher. Flügel $₫ 81-88.5 \mathrm{mmm}$. (In den Togesen kommen anffallend

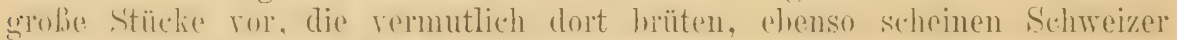
bxemplane oft recht grob zu sein, ohne alher deshalh cetwa der gyoben nordischen Form anzugehören.)

Mittel- und West-Europa bis ins nördliche Italien und (nach Bocage) Sord-Portugal. Auf den hritisehen Inseln mohr oder minder häufig, in sehottland seltener, aber noch bis zu den Hebriden und vereinzelt den Orkneys und Shetlands Inseln.

Bewolmer baum- und waldreicher Gegenden. Samen- und Knospenfresser, die Jungen werden nebenbei auch mit Raupen und Insekten gefüttert. Ein sanfter, ziemlich zutraulicher Vogel, der sich nicht allzu bemerklich zu machen pflegt. Lockstimme ein sanftes, flötendes, etwas melancholisches diü-diü, das sehr bezeichnend, aber nicht sehr weit zu hören ist. Oft ist diese Lockstimme ron einem noch sanfteren, leiseren büt-büt gefolgt, das viele Beobachter gar nicht kennen. Der Gesang ist sehr gedämpft, quietschig und knatterig, das o singt auch. Das überaus reine Flöten der Käfigvögel ist durchaus kïnstlich angelernt, dadurch aber ist der Gimpol ein so geschätzter Stubenvogel geworden. In Deutschland vorzugsweise im Hügellande und Gebirge brütend. Das Nest steht in Büschen und Bäumen, meist nicht hoch. Es ist 
sehr charakteristisch, da es keineswegs finkenartig schön ist, sondern eine lose Plattform aus Zweigen mit einer nicht sehr tiefen Mulde aus feinen Würzelchen, oft auch mit Haaren, seltener mit Wolle und noch seltener mit wenigen Federn ausgelegt. Die Eier, 4-5 an Zahl, findet man von Ende April an. Sie sind blaßblau, mit rötlichgrauen und hellrötlichbraunen tiefer liegenden und dunkel rotbraunen, fast schwarzen Oberflächen-Flecken, Punkten und Kritzeln, meist mehr am stumpfen Ende gezeichnet. Sie messen im Durchschnitt etwa $18.86 \times 14.15$ (Rey), IIaximum $20.3 \times 13.8,18.7 \times 15$, Minimum $17>14.2,19.2 \times 13$ (Rey), $20.4 \times 15.4,20 \times 15.1,19.6 \times 15.1 \mathrm{~mm}$ usw.

\section{Pyrrhula pyrrhula kamtschatica Tilc.}

Pyrrhula kamischatica 'Taczanowski, Bull. Soc. Zool. France 1882, p. 395.

Der nordeuropäischen $P \cdot P \cdot p y r \eta h u l a$ äußerst ähnlich, aber vielleicht etras größer, jedenfills der Rü̈cken heller. die Flügell,inde ISpitzen der groben Deckfedern) reiner weil, der weilie Schaftstrich an den seitlichen Stenerfedern anscheinend nicht nur manchmal, sondern regelmäbig entwickelt. Flügel ơad. 94-96 mm.

Kamtschatka, einmal von Jankowski am Ussuri erbeutet, sonst nicht auBerhalb Kamtschatka bekannt.

\section{Pyrrhula pyrrhula griseiventris Lafi.}

Pyrrhula griseiventris Lafresnaye, Rev. Zool. 1841, p. 241 (Fundort? - Ich nehme als die typ. Lok. Japan an).

Pyrrhula orientalis Temminck \& Schlegel, Fauna Japon., p. 91, Ares T'af. 53 (1850 Japan, die rötlichen Stücke für ad. im Hochzeitskleide gehalten).

Pyrrhula rosacea Seebohm, Ibis 1882, p. 371 (Yokohama, auch Askold und Kurilen. ''yp. Lok. Yokohama - Kurilen errore!).

Größe wie die von 1.p.europaea; Kopfseiten und Binde unter dem Kimn liehlich rosenrot. ührge Unterseite entreder rein grau oder mehr oder minder stark mit rosemrot ühergossen, hïufig auch der Rücken mit rosenroten Federrindern. Zwischen den unten remgranen und unten rosenrot angehanchten Stïcken finden sich alle möglichen Ühergünge und die rötlichen und grauen Tügel kommen aus denselhen Gegenden. Temminck und Schlegel hielten die rïtlichen ö für die alten im Hochzeitskleide, Tatranowski hoilt sie tür weniger adult. Jedenfalls irren alie Ornithologen, die sie mit Sceehohm und sharpe für verschiedene Arten nder ("nterarten ${ }^{1}$ ) halten. Die durch die hellen Spitzen der groben Flïgeldecten gehildete Plïgellinde ist schmäler und weniger hell als bei $P \cdot p$. europaea. o dem von $P . p$. europaea ïuberst ähnlich, aber unten etwals lichter, Konfseiten und unter dem Kümu lichter und rötlicher.

Bewohnt die nördlichen Insehn des japanischen Fariserreiches (Jesso und Hondo his Nigalsaki), auch Konrea, die Miundschurei, den unteru Amur und Teile ron Nord-China.

\section{Pyrrhula pyrrhula kurilensis Sharpe.}

Pyrrhula kurilensis Sharpe, Zoologist 1886, p. 485 (Kurilen).

Kaum ron $P \cdot p$. ariseiventris zu untersheiden, aber Oherseite lichter grau, Lnterseite auch etwits holler, rein gran oder mehr oder minder ritlich üherflogen. Kurilen Inseln nördlich von Japan.

1) Bei gleicher Verbreitung!!! 


\section{Pyrrhula pyrrhula cassini Baird.}

Pyrrhula coccinea var. cassini Baird, Trans. Chicago Ac. Sci. I, p.316, Taf. 29 (1869Nulato, Alaska, Typus im U. S. Nat. Mus.).

Pyrrtula cineracea Cabanis, Journ. f. Orn. 1872, p. 316 (Baikal-See).

Pyrrhula cineracea pallida Secbohm, Ibis 1887, p. 101 (Altai und Ussuri).

(Der Typus ron cassini war jedenfalls ein verflogener Vogel. Nach dem Urteil ron Stejneger, Ridgway u. a. handelt es sich tatsächlich um die später ron Cabanis cineracea genannte Form).

Von allen bisher behandelten Formen dadurch unterschieden, daB das o nie rote Farbe bekommt, sondern daß Kopfseiten und Unterseite rein aschgrau sind, nur Banch und unteror 'Teil der Weichen weißlich, Unterschwanzdecken weib. Flügel s8--90.7. S(hwanz 68-69. Latul 15.5, Selunahel etwa $9 \mathrm{~mm}$. ㅇ kaum kleiner (Flügel 86-89), aber Unterseite mehr oder mincler lehhaft weinbräunlich üher\%gen. Rücken oft mit hräunlichem sehimmer. Jüngere ô scheinen den o zu ähneln.

Bewohut die Gegend südlich des Baikal-Sees.und Daurien bis zum Jenissei und Altai, wo nur diese Form zu brüten scheint, streicht aber im Winter weiter nach sïden. Osten und Westen. angehlich ansmahnstreise lis. Rußland, jedenfalls regelmäBig bis zum untern Amur (Ussuri).

\section{Pyrrhula pyrrhula murina Godm.}

Pyrrhula murina Godman, Ibis 1866, p. 97 'Taf. 3 (San Higuel, Azoren).

Unterscheidet sich von allen anderen Formen dieser Gruppe durch den nicht weilien, somdern gamz redüsterten. nur etwas heller asth-gratuhanen

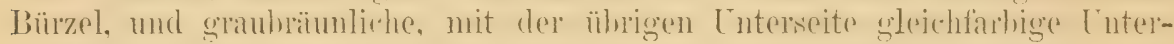
schwanzdecken. In dem Mangel an Rot (nur die letzte Armschwinge hat

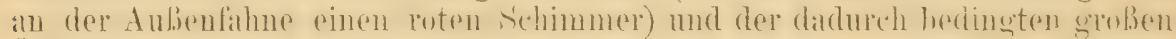
Ähnlichkeit der Geschlechter ähnelt diese Form P.p. cassini. Der Rücken ist düster graulnaun, die Interseite hellgraulichlaum mit etwas rosthrämnlichem Sehimmer. ơ: Filügel 88-90.5, Schwanz etwa $68-71.5 \mathrm{~mm}$, Lauf etwa $20 \mathrm{~mm}$. Q etwas kleiner und auf der Unterseite lichter, etwas weniger bräunlich. Iris braun, Schuabel schwarz, Füße sehr dunkel hornbraun.

Bewohnt die Bergitilder der Azoreninsel San Miguel (Sankt Michael), wo sie fiüher häufig, jetzt sehr selten ist. Wegen des Knospenbeißens ron den Gartenbesitzern rerfolgt worden.

\section{Pyrrhula erythaca Blyth.}

Pyrrhula erythace Blyth, Ibis 1862 p. 389 (Sikkim).

Pyrrhula erithacus Blyth, Ibis 1863, p.411, T'af. 10 (und auctorum).

Mittlere Steuerfederu $15-20 \mathrm{~mm}$ kïrzer als die äußeren. Ring rings um den Schnabel schwarz, Oberseite und Kopfseiten düstergrau, von der schwarzen Stirn durch einen weißlichen Streifen, von dem weißen Bürzel durch ein breites schwarzes Band getrennt. Handschwingen schwarz, Arm-

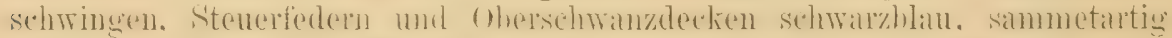

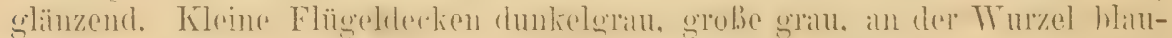
schwarz. Ganze Brust bis an den Hals orangerot. Mitte und unterer Teil

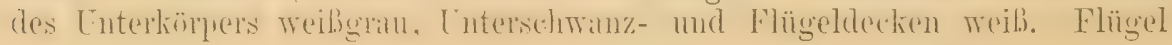




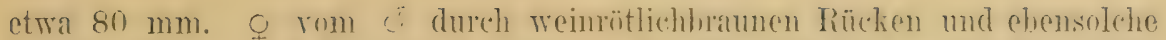
Schulterfittiche und Spitzen der langen ()herflïgeldedien, somie Unterseite

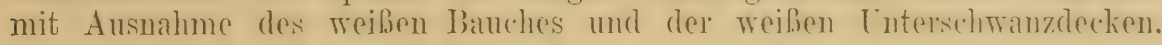
unterschieden.

Sikkim im Himalaya östlich bis Kansu und West-China.

\section{Pyrrhula erythrocephala Vig.}

Pyrrhula erythrocephala Vigors, Proc. Zool. Soc. London 1831, p. 174 (Himalaya).

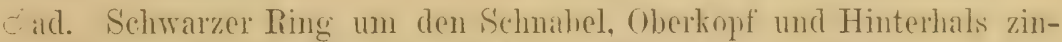
molerrot. Rücken. Selunterfittiche und kileine Fï̈geldecken dumkel aschgrau. große an der Trurzel blauschwarz, S'pitzenhälfte grau. Bürzcl. Schwanz und Schwingen wie hei $P$. eryllace. Kónfseiten hellgrau mit rötlichem sehimmer.

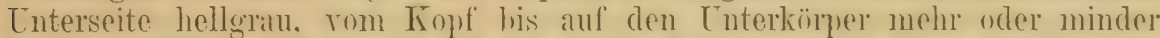
hell zimmoheret ïhertüucht. Luterschwanzdecken weif. Interflügeldecken schmutzigweiß. Flügel etwa 80 - $82 \mathrm{~mm}$. O unterseheidet sich rom 0 durch grrünlichgraugelhlichen Oherkopf und Hinterhals, hräunlicheren Rücken mul brïunliche Unterseite. olne cine Spur ron Rot. Flügel etwal $75-57 \mathrm{~mm}$.

Bewohnt den Himalaya von Kaschmir bis Butan.

\section{Pyrrhula aurantiaca Gould.}

Pyrvluela aurantiaca Gould, Proc. Zool. Soc. London 1857, p. 22 (Kaschmir).

Sehwarzer ling um den Schnahel. Oher- und Vinterseite schïn orangefarhen. Bürzel weils, Oberschwanzdecken schwarz. S'chwanz, mur schwach ansgeschnitten, sehwar. Flügel sehwirz, kleine und mittlere Flügeldecken dunkelgrau mit urangeroten. große sehwar, mit ausgedehnten orangefarhenen, die äubern mit klemeren weiblichen Spritzen. Euterschwanz- und Interflügeldeclien weiBlich. Jüngere (?) o sind mehr ader minder gell statt orange, und es finden sich zwischen den gelhen und loten alle möglichen Zwischenstufen. (Tielleicht ist die gelloe und rote Farhe auch nicht rom Alter abhäugig: sondern individuell.) Flügel etwa $81 \mathrm{~mm}$. c: Kopf und Hinterhals aselhraum. Rückeu und Schulterfittiche gelhlichloram, Kehle mol Brust hlal.s rotbraun, Unterkörper trübgelblich, sonst wie $\sigma^{\pi}$.

Kaschmir und Hazara-Distrikt bis nach Afghanistan.

\section{Pyrrhula nipalensis nipalensis Holgs.}

Pyrrlula Nipalensis Hodgson, Asiatic Researches XIX, p. 155 (1836- Nord- und Zentral-Nepal).

Stirn und Federu rings um den Schuahel schwilrzlichhramu, Oherkopf aschbräunlich mit hervortretenden schmäl'zlichen Federwurzeln, wodurch dieser Teil gefleckt erscheint. Rücken. Schulterfittiche und kleine Flügeldecken erdhraun, vordere In̈̈lfte des Bürzels schwar\%, hintere weiß. Tunterseite hell erdbraun oder grauhräunlich. Mitte des Enterkïryers, Bauch. Lnterschwanz-, Unterflügeldecken und Achselfedern weib. Unterm Auge ein weißer Streif. Schwanz. dessen mittelstes Steuerfeclerpar 2 cm kïumer ist als das äuberste. Oherschwanzdecken und Almschwingen tief sammetartig stahlhlin mit sammetschwarzen Spitzensänuen. Die inmerste likine Armschwinge mit tiefrotem

E. Hartert, Die Vögel der paläarktischen Region. 
Strich an der Aubenfahne. Flïgel etwa 9 0, Schwanz $75 \mathrm{~mm}$, also sehr laug. o etwas kleiner als ơ der Strich an der AuBenfahne der letaten Schwinge hellgelb, sonst wie $0^{\pi}$.

Hinnalaya ron Galrwhál his Siklim. wo Blanford sie $10(10 n$ engl. Fub hoch beobachitete.

\section{Gattung PYRRHOPLECTES Hodgson 1844.}

Diese Gattung enthält eine Art von höchst eigener Fiirluung. Das o ist sehwarz mit verlängerten Scheitel- und Genickfedem von orangegelber Farbe und sehneeweißen Innenfahnen der innersten Armschwingen, welche letzteren sich auch bei dem rothranen 2 finden. Der Schnalbel erinuert am meisten an den ron Pyrrlulu, ist aber gestreckter und weniger geschwollen, dagegen flacher als del von Curpodurus, womit sonst die Struktur am neisten übereinstimmt. Die erste (lange) Schwinge ist merklich kïrzer als die näthste.

\section{Pyrrhoplectes epauletta (Hodgs.).}

Pyrorula Epauletta Hodgson, Asiatic Researches XIX, p. 156 (1836- „nothern and central regions of Nepal“). (Abbildung in Nov. Kool. 1903, Heft UI).

Oad. Mattsehwarz, Federn des S'cheitels und Hinterkopfes orangegelh eine breite, kurze, lockere Haube bildend. Innensïume der drei letzten Armschwingen größtenteils weiß. Unterflügeldecken und Innensïume der Schwingeu weißlich, Achselfedern zimmthraun. Flügel 77 -81, S'chwanz 60, Lauf 19, Schnahel 11-11.5 mm. ? Stirn und Hinterhals bis auf den Oberrïcken aschgratu, Scheitel- und Genickfederh und Kopfseiten grüulichgelb, Rücken und Obersehwanzdecken kastanienbraun, Sehwingen schieferfurben, Innensäume der letaton Armschwingen weil, AuBensïume derselhen kastanienbraun. Unterseite zimmtbraun, Schwanz sehieferfarben.

Himalaya rom Sutlej Tale bis Sikkim. wo Blanford sie 11000 engl. Fuß hoch fand.

\section{Gattung CARPODACUS Kinup 1829.}

Schnabel kürzer als der Kopf, konisch, dick, an der Basis höher als breit, die Höhe etwa gleich der Lünge des Oberschnabels vom Nasenloch zur Spitze. Culmen deutlich gehogen oder fast gerade. Flügel zicmlich lang. dif ersten drei Schwingen (die nicht sichthare verkïmmerte eigentliche erste natürlich nicht mitgezihllt) am lïngsten, die erste meist der vierten gleich, manchmal so lang wie die zweite (und dritte.) Sehwanz deutlich ausgeschnitten, oder (hei vielen amerikanischen Formen) gerade. Gefieder viel weniger reich und weich, als bei Pymlula, küirzer, fester, etwa wie bei Passer. Von den europäischen Vëgehn steht Pinirolu amn nächsten, womit einige Ornithologen Curpoduches veremingen, doch hat Pinicola einen geschwungeneren und gebogeneren Schnabel, sowie viel reicheres weicheres Gefieder, auch sind die bier ganz anders gezeichnet. o immer grobenteils rot, o sperlingsartig grau und hraun, mehr oder minder streifig. Nester lorkere Binten, frei in Büschen. Eier blau mit tiefbraunen Flecken. 
Verbreitet ron Ost-Europil (ron Polen und Ost-Preuben an) übre NoredAsien und Nord-Ameriki, sïdlich his Mexilon. In Nord-Amerikil unterscheidet man 12 Formen, die Ridgway in 5 Arten verteilt. Der c'atalogue of Birds zïhlt 26 Arten auf.

\section{Übersicht der ơ der paläarktischen Arten. ${ }^{1}$ )}

$1\{$ Größer, Fliigel weit iiber $100 \mathrm{~mm}$. . . . . . C. rubicilla . p. 99

Kleiner, Flügel weit unter $100 \mathrm{~mm}$............. . . 2

2) Oberseite auffallend dunkelbraun oder schwarz gestreift........ 3

Y Oberseite gar nicht oder nur undeutlich gestreift . . . . . . . 9 9

3 I Bürzel braunrot wie der Rücken ........ C. edwardsii . p. 104

| Bürzel rosa . . . . . . . . . . . . . . . . . . 4

4 Kehle von der Brust nicht wesentlich verschieden ........ 5

4 Kehle mit atlasweiben, nur rosa angehauchten Federu oder Fudermition 8

$5\left\{\begin{array}{r}\text { Ober- und Hinterkopf graubräunlich mit braunschwarzen Federmitten } \\ \text { C. pulcherrimus . p. } 103\end{array}\right.$

I Ober- und Hinterkopf rotweinfarbig . . . . . . . . . . 6

6 I Rücken bräunlich rotweinfarben . . . . . . . . . . 7

\{ Rücken trübrosa mit graulichen Säumen . . . . . C. rhodochlamys . p. 100

7 Flügel über $80 \mathrm{~mm} \ldots \ldots$. . . . . . . . . . . . . . . . 103

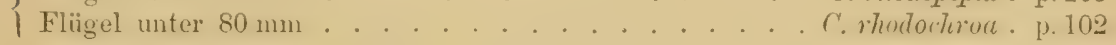

8 Scheitel rosa . . . . . . . . . . C. rosea . p. 105

Scheitel dunkelbraun ............. C. thura . p. 101

9 Rïcken blabbräunlich oder aschbräunlich mit oder ohne schwache dunklere

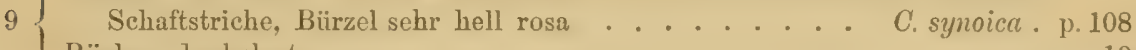

Rücken dunkelrot ........................ 10

10 Kehle und Kopfseiten mit weißlichen Strichen . . . C. trifuscintus. 1. 104

I Kehle und Kopfseiten ohne weißliche Striche . . . . . . . 11

11 Kehle und übrige Unterseite dunkel weinrot . . . . . C. vinaceus . p. 104

\{ Kehle brennend rot, Unterkörper hell rosa....... C. crythrina . p. 106

\section{Carpodacus rubicilla rubicilla (Gïld.).}

Loxia mbicilla Güldenstädt, Nouv. Comm. St. Petersb. XIX, p. 463, Taf. XII (1775Kaukasus (typ. Lok.) und. "Altai", in letzterem Gebirge wohnt aber eine andere Subspezies).

Coccothranstes Cancasicus Pallas, Zoogr. Rosso-Asiat. II, p. 13 (1811- Kaukasus).

jad. Der ganze Kopf glänzend blutrot, Obrdecken etwas heller. Oherkopf mit weiBen kleinen subterminalen Flecken. Rürken und Flügeldecken. rosiggram mit dunlilen Sohaftstrichen und im frischen Gefieder roten Sämmen, Bümel und Oberschwanzdecken lehhatt rosenrot, die längsten Schwanzdecken aschhraun mit rötlichen Säumen. Schwingen dunkelhrann mit schmalen weißlichen, rosig angehauchten, Säumen, innere Almschwingen mit rosigweiBlichen Flecken nahe den Śpitzen der Aufensäume. Schwanz dunkelhrium mit helleren, rosiog angehauchten Säumen. Federu der Lnterseite an Hasis und Schäften dunkelbraun, vor den Spitzen rosig-rveiblich. breit glänzend blutrot gesïumt, Kehle ron tieferem Rot mit kleineren, viel schärfer markierten

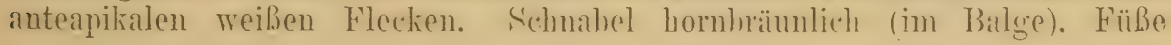

1) Das ơ ron C. verreauxi ist noch nicht bekannt. 


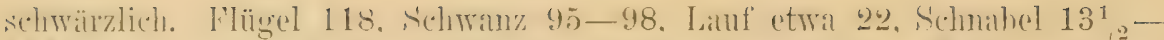

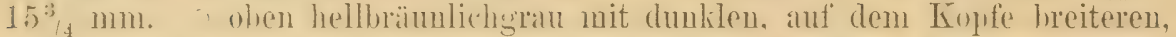
anf Rücken und Bürzel weniger sichtharen S'chaftstreifen. S'chmanz dunkelhämn mit hellgranem. an den inneren Armschwingen breiteren und weiblicheren Aulensïmmen. Enterseite licht, fist weiblich grambräunlich mit dunkelhramen Federmitten. Kleiner als das ơ, Flügel höchstens $115 \mathrm{~mm}$.

Im Hochgebirge des Kaukasus.

\section{Carpodacus rubicilla severtzovi Shrrpe.}

Carpodacus scvertzovi Sharpe, Proc. Zool. Soc. London 1886, 1). 351 ('Turkestan und Yarkand).

Im ganzen $C . r$.rubicilla und von denselben Dimensionen, aber oben viel

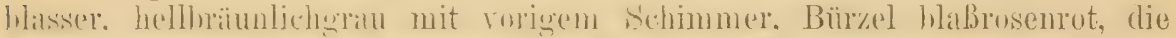

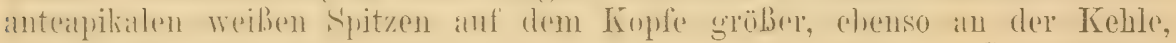
ganze ïbrige Unterseite heller und blasser rot. O wie das von C. r. rubicilla, aber unten meist etwas bräunlicher oder gelblicher. Juv. viel bräunlicher, sonst wie das $q$.

Bermohner der zentralasiatischen (rehirese, fon Norel-Kasehmir (Gilgit. Ladak) durch Turkestan und Tibet bis zum Altai und Sajan.

Stoliezka scheint das Nest in westlichen Tibet gefunden zu haben, aber die Identität ist nicht sicher.

\section{6i. Carpodacus rubicilla rubicilloides l'rzer.}

Carpodacus rubicilloides Przevalski, Mongoli Strana Tangut II, p. 90, Taf. XII (1876, russisch - Kansu); engl. Übersetzung in Rowley's Orn. Mlisc. II, p. 299, 'Taf. LIV (1877).

Ơ dem von C.r.mibicilla atm ähnlichsten, aber merklich kleiner (Flügel nur etwas über 105), die Federn der Oberseite in der Mitte ausgedehnt

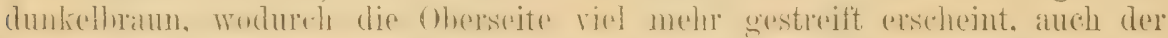

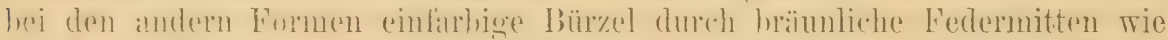
stroitig esscheinend. : ohen und unten mit alusgedehnteren dunklen Federmitten, auch natürlich kleiner; sonst wie das der andern Formen.

Ost-Nan-Schan, die Gebirge ron Kukunor und Nord-Kansu.

Bewohnt hohe, buschreiche Lagen; die Lockstimme soll der von Pyrrhula pyrvtuta ähneln. Die Eier (ein Gelege von 3 vom Kukunor) haben die charakteristische schön lellblaue Farbe der Carpodacus-Eier mit einigen tief schwarzbraunen Punkten, Haarlinien und Flecken am dickeren Eude. Sie messen 21.2, 21.4 und $21.6 \times 15.3,15.4$ und $15.5 \mathrm{~mm}$.

\section{Carpodacus rhodochlamys rhodochlamys (Brandt).}

Pyrrhule (Corythus) rhodochlamys Brandt, Bull. Sci. Acad. Imp. St. Petersbog. 1843, p. 27 (Altai).

Propasser thodometopus Biddulph, Ibis 1881, p. 156, Taf. VI (Yarkand).

ơad. Oberkopf und Genick dïster graurot, Zügel und breiter Streif

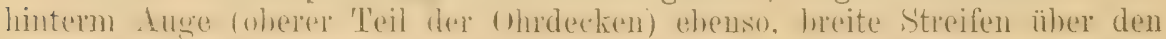
Ausen his zum Nalcken, durch ein Band ïher die Torderstirn rerhunden, 
und Kopfseiten glänzend hellrosa, die Federn dieser hellrosa geförloten Teile schmäler und steifer. Federn des Rückens, Schulterfittiche und Oherflügel-

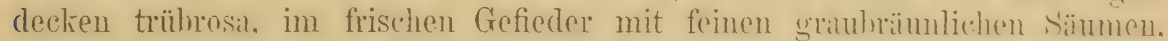
alle mit sehwarzhraunen Sehaftstrichen. Bürzei mon (Ihersehwanzdecken sehön rosenrot. die längsten Ohersehwamzlecken dumkler. Lntersoite rosil mit dunkingranen Federwurehn und schwärzhehen shö̈ften. Sehwingen dunkel selieforbraun mit trührötlichen Säumen. Tuterthügeldecken und Achselfeclern weil.s mit dunkeh Schiften und rosigen Sohimmer. Iris hellhram, ()hersehnahel

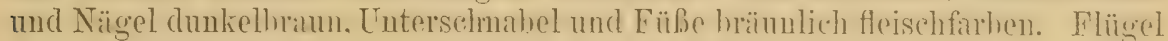
87-91, Schwanz 84-87, Lauf 32-33, Schnabel 12.5-14.3 mm. o ohne rot im Gefieder. Oherseite dunkelhram mit hreiten hell graulichloramen Federänderu, Lnterseite hell gelbhrïmnlich mit tiefhraunen hreiten Lüngsstreifen, die die Mitte der Federn aimehmen. Flügel und Sehtranz tiefhramu mit hellhräunlichen Ränderı. Dimensionen nur unhedeutend g̈eringer als die des $\sigma^{r}$.

Bewohnt die Gehirge Mittelasiens. den Altai, Tarbayatai, Alatau, Tian-

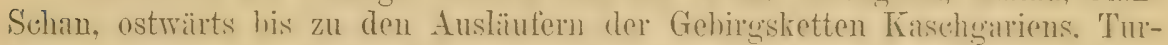
kestan südlich bis Yarkand, Iskander-Kul und Zamin.

\section{Carpodacus rhodochlamys grandis Blyth.}

Carpodacus grandis Blyth, Journ. As. Soc. Bengal XVIU, p. 810 (1849 - „Range beyoud Simla, near snow line").

Carpodacus sophia Bonaparte \& Schlegel, Monogr. Loxiens, p. 22, Taf. 24 (1850-.. Himalaya).

Unterscheidet sich von C.r.rodochlamys im of durch mehr bräunlichrosige als gratulichrosige Oherseite. merklich längeren Flügel. etwas gestrekteren Schuabel und über der Schnahelwurzel in der. Jitte merhochene. nicht üher die Stim hin rerhundene hellrosil Sunereiliarstreifen. Fiügel 94-97 mm. Das o gleicht in der Färbung dem von C.r.rhodochlamys, aber der etwas längere Flügel $(92-94 \mathrm{~mm})$ und meist etwas gestrecktere S'chmabel lassen es unterscheiden.

Von Pushut in N.O.-Afghanistan und dom Karaliorum Gehirge dur.h Kaschmir den Himalaya entlang bis Kmnaon. (Weiter nach Osten nicht nachgewiesen, der Fundort Sikkim ist wahrscheinlich falsch.)

\section{Carpodacus thura thura Bp. \& Schl.}

Carpodacus thura Bonaparte \& Schlegel, Monogr. Loxiens, p. 21, Taf. 23 (1850Himalaya).

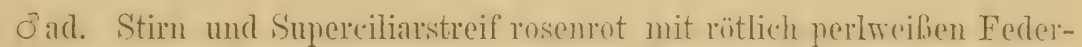
mitten, hinter dem Superiliarstreif üher den Ohrdecken ein weifer Fleck. Oberer Teil der Ohrdecken dumkelhraun. Oherseite mann, die Federmitten sehwarzhraum. Bürzel und Oherschwanzdecken rosenrot. dio längsten Sehwanzdecken mit dunkelhraunen spitzen Sebaftflecken, die ünrgen nur mit sehwarzem Schaft, soweit die Federu verdeckt sind. Flügel und Śchwanz, sehwarzloralum mit braunen Sïmmen, die imern Armselwwingen mit hreiteren. gellichbraumen Sümmen, die kleinen Flügeldecten mit schmalen dunkelvosa Pändern. 


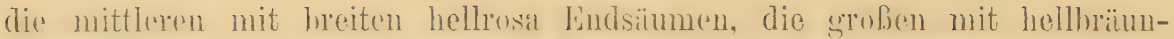
lichnesuitzen. Ganze Enterseite rosenent, Kehlfedern etwas steifer und

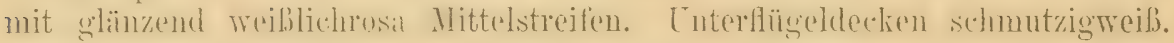
Schnabel und Füße braun. Flïgel 83-86, Schwanz 74-76, Lauf 25, Schnabel 12-13 mm. o Oberseite braun mit braunschwarzen Mittel-

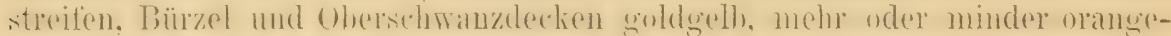

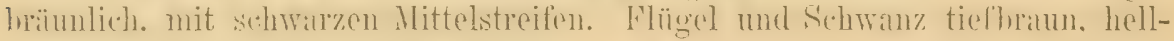

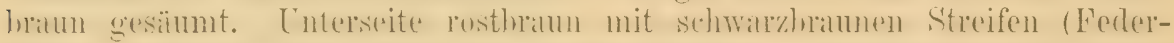

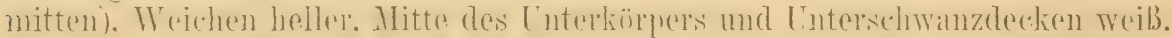

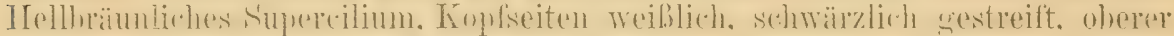
Teil der Ohrdecken schwarzbram. (Beim o ist das Rot des Superciliums und der unteren Ohrdecken durch einen breiten tief'braunen Streifen getrennt.)

Himalaya von Nepal bis Sikkim.

Bewoluner der Hochfä̈chen (10000 und 12800 engl. Fuß) des mittleren Himalaya, wo Rhododendron und Wachholderbüsche den Baumbestand bilden, oder Gras und niedrige Bodenpflanzen stehen. Der Lockruf soll ein eigentümlich schnarrendes briji, brijj sein. Mandelli fand das Nest in Nepal im August. Es bestand aus Gras; außen mit MIoos rerziert, innen mit Haaren ausgefüttert. Es enthielt 3 matt grünblaue Eier mit spärlichen braungrauen Zeichnungen, die etra $22 \times 16.3 \mathrm{~mm}$ messen.

\section{Carpodacus thura blythi (Bidd.).}

Propasser blythi, Biddulph, Ibis 1882, p. 283, Taf. 9 (bei Gilgit).

On wie das von $C$. $t$. thura, aber oben etwas lichter braun, hinterm Auge oin zwar schmaler (nicht breiter), aber doch deutlicher tieflorauner Streif. o Kehle und Brust rostbraun, wenig heller als bei C.t. thura.

Gebirge bei Gilgit im nördlichen Kasehmir.

\section{Carpodacus thura dubius Przew.}

Carpodacus dubius Przewalski, Mongoli Strana T'angut II, p. 92, Taf. XIII (1876russ., bewaldete Berge in Ala-schan und Kansu); engl. Übersetzung in Rowley's Orn. Misc. II, p. 301, 'T'af. 53 (1877).

Cै wie das von C. th. thura, aber etwas langflügliger (Flügel etwa $88 \mathrm{~mm}$ ) und mit kleinerem Schnabel, das Braun der Oberseite lichter, das rosenrote Supercilium und die rosenrote Farbe der Ohrdecken ausgedehnter, hinter den Augen zusammenkommend, nicht durch

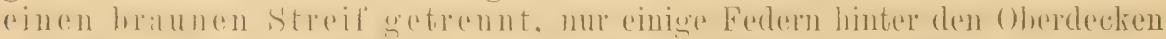

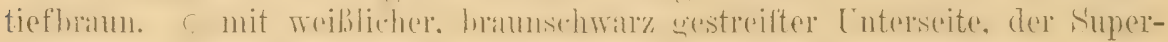
ciliarstreif im vorderen Teile rötlichbraun, im hinteren isabollfarben.

Alaschan und Kansu bis Szetschwan im nordwestlichen China.

\section{Carpodacus rhodochroa (Vig.).}

Fringilla rhodochroa Vigors, Proc. Zool. Soc. London 1831, p. 23 (Himalnya).

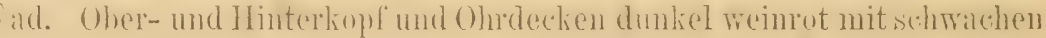

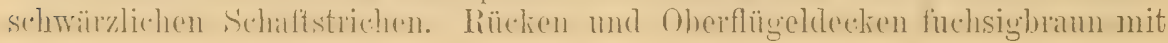


h)eiten schwärzhichen Mittelflecken der Federn. Büızel hellrosa. Lüngere Ober'seluwauzdecken dunkelosa. Stirm. lueiter Superoiliastreif, Trangen mol ganze Interseite hellosa, Stim und Supereiliarstreifen mit silherweiblichem S. (himmer. Flügel und Schwanz sehwarzham mit fuchsighranen Rändern. Cnterflügeldecken meißlich. Flügel $72-75$, Sehwanz etwa 60-62, Lauf 19. Schunahel 9 num.

o Oherseite gelblich olivembram mit lneiten sehwarzhaunen Mittelflecken. Breiter ockerfarhener Supereiliarstreif. Cnterseite hellockerfarben mit dunkelbraunen Schaftstreifen.

Himalaya von Kaschmir bis Nepal.

\section{Carpodacus pulcherrimus (Moore).}

Propasser pulcherrima Hodgson, Gray's Zool. Mlise., p. 85 (18t4-- nomen nudum!) unde: Propasser pulchevimus Mloore, Proc. Zool. Soc. London 1855, p. 216 (Nepal).

Carpodacus Davidianus Milne-Edwards, Nouv. Arch. Mus. I, Bull., 1. 19, T'af. 2 (1864China, Armand David coll.).

Federn der Oherseite schwarzhram mit hreiten granbrïunlichen, schwach rosig ïberlaufenen S:̈̈umen, Oberkopf dunkler und stärker rosil ühertüncht, Bürzel hellosa. Schr hreiter Strepif über den Augen und Unterseite hellrosa, Seiten hell- und dunkelhram gestreift, Unterseite mit dunklen Schäften. Flïgel 78-86, Sehwanz etwa $66-77 \mathrm{~mm}$. O dem von C. rhodochous sehr ähnlich, aber oben und unten viel lichter, Tnterseite weiblichlomun mit dunklen Schaftstrichen.

Himaliya von Nepal his Sikkim, Ost-Tihet, Central- und Nort-C'hina bis Ordos, S.O.-Momgolei und Nan-Schan. (Stücke aus dem Himalaya sind vielleicht meist etwas kleiner?)

Bewohnt lichte Bergwälder und nährt sich von Samen und Knospen. Das Nest steht in Büschen und besteht aus Farnkrautstengeln und Grasstämmehen, mit Haaren und Federn ausgelegt. Die Eier (etwa 5) sind denen von Carpodacus erythrina ähnlich, aber etwas kleiner, indem sie nur 19.1 bis $19.6 \times 14$ bis $14.3 \mathrm{~mm}$ messen. Sie sind von einem reinen hellen Blau, am stumpfen Ende mit äußerst feinen Punkten oder größeren Fleckchen, manchmal auch mit Haarzügen und Kritzeln gezeichnet. Der Lockruf ist ein melancholischer Pfiff, der Gesang angenehm, aber eintönig.

\section{Carpodacus rhodopepla (Vig.).}

Fringilla rhodopepla Vigors, Proc. Zool. Soc. 1831, p. 23 (Himalaya). (Abbildungen: Gould, Cent. Himalay. B., Bonap. \& Schleg., Monogr. Lox. 22.)

ơ ad. Oherseite dunkel rotwein-oder portweinfarbeu, die Federmitten viel dunkler, auf dem Linterrïcken mehr rosig, Bürzel mit breiten rosa Federrïndern. Flïgel und Schwanz tiefhram mit rothranen Säumen. Nittlere Flügeldecken mit rosa Nipitzen, grobe Flügeldecken und innero Armschwingen mit rosa Spitzen an den Aulenfahmen allein. Breiter hell gläuzend rosenroter Superciliarstreif. Kopf- und Halsseiten wie der Oherrïcken. Unterseite rosa, die dunlielrotbraunen Wurzelteile üherall sichtbar, die Kehlfedern zugespitzt, etwas steifer und glïnzend hellosi. Flïgel etwa 85, Schwanz 72, Laut 23, Schmabel ungefïhr $11 \mathrm{~mm}$. O Oherseite olivenbraum, alle Federn in der Mitte hreit dunkelhraum, die Federrïnder in der Mitte des Rückens lichter, mehr gelhlich angeflogen, unterer Bürzel und Ober- 
schwanzdecken fast einfarbiy bramn. Über deu Angen cin hreiter rostgell)-

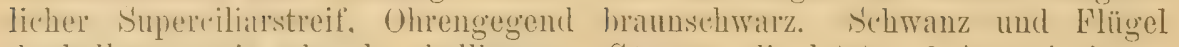
dunkelhrimu mit schmalen hellbramen Sämmen, die letzten 3 Armschwingen sowie die mittleren mud groben Oberflïgellecken an den Spitzen der AuBenfilhuen helhostgelh. Cuterseite rostgell mit dunkelhramen, an den Cuterschwauzlechion mol in der Mitte des Unterkörpers schmäleren Streifen längs der Felermitten. Unterflügeldecken schmutzig gramweils. Śchmbel und Fiibe braun.

Himalaya von Garwhál bis Sikkim.

\section{Carpodacus edwardsii Verr.}

Carpodacus echwardsii Verreaux, Nouv. Arch. Mus. VI, Bull., p. 39 (1870- „Les montagnes du 'Thibet Chinois“); op. cit. VIII, 'T'af. 3 (1872).

Propasser saturatus Blanford, Journ. As. Soc. Beng. XLI, II, p. 168, 'I'af. VIII (1872-Tonglu, nördlich von Darjiling, 10000 Fuß hoch).

ơad. Oberkopf und Nacken dunkel weimrot mit schmalen, schwäl"zlichen Sohaftstrichen, ïbrige Oberseite hraunot mit schwarzbranen ferlermitten, Wangen. Stirn und Supereiliarstreif hellowsi. Schwanz und Flügol dunkelbraun mit lothramen Sïumen. Ohnelecken trïhweinut. Unterseite hellweingt mit dunkeln Sehaftstrichen. Bauchmite und Unterschwanzdechen heller. Seiten hräunlich verwasthen. Flügel etwa 81-8:3. Sohwanz etwa 68, Jauf 22-23. Schualol $12 \%$ mm. Im fristhvermatuserten fofieder ist die Oherseite hrïunlicher, die Unterseite heller rosa, im abgenutzten Kleid die erstere dunkler und mehr rot, letztere viel lehhafter und feuriger rot. (Himilaval Stücke sind möglicherweise meist atwas dunkler?) - WVie das von C. rhoilo-

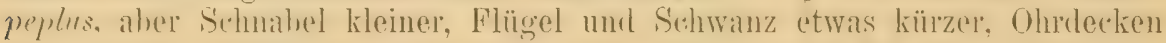

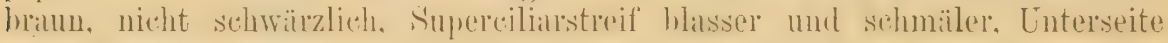
etwas weniger lebhaft.

Himalaya von Nepal bis Butan, Kansu und Sze-tschwan.

\section{Carpodacus vinaceus Verr.}

Carpodacus vinaceus Verreaux, Nouv. Arch. Hus. VI, Bull. p.39 (1870 - „Les montagnes du 'Thibet Chinois").

రึad. Oberseite von der Schnabelwurzel an tief burgunderrot, auf dem Bürzel heller, mehr rosenrot. Breites schmalfedriges rosigrveibes sujercilium. Sehwingen und S'chwanz schwarzbraun mit dïstern, schmalen rotbrannen Sïumen. die beilen letzten Armsthwingen mit groben weiblich-rosemoten Flecken an den Spitzonteilen ler Anbenfuhnen. Unterseite burmulemot mit breiten heller roten Säumen. Schnabel und Füße braun. Flügel 70-74,

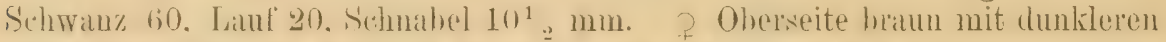
F'edermitten. Bürzel ainfarbig bram. Unten ockerhram mit schmalen clunkeln Schaftstrichen.

Diese uobelste drt der hübschen Gattung hewohnt die Berge ron sü̈dKansu und Sze-tschwan in N.W.-China.

\section{Carpodacus trifasciatus Verr.}

Carpodacus trifasciatus Verreaux, Nouv. Arch. MIus. VI. Bull., p. 39 (1870- „Les montagnes du 'Thibet Chinois"); op. cit. VIII, 'Taf. 4, Fig. 3 (1872). 


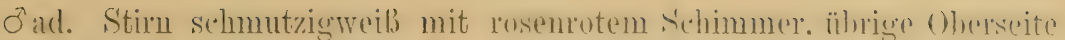
und Zï̈gel duuled weimot. Oherschwanzdecten sehicterschwaln mit helloren, dunkelgratuen Spitzen. äubere Reihe der Shehulterfittiche mit satuz weilfen Außenfahmen, wodureh ein langer weilser sterif gehilutet wird. Selowingen mattschrarz, innere Armschwingen mit dem gröheren Teil der Aubenfalmen weiß. Schwanz sehwarz. Kleinste Elügrelectien dunkel weimot, mittlere nus grobe sehwarz mit ausogelehnten helloxia Śnitzen, wodur.h 2 losa Binlen gebildet rerden. Kopfseiten und Kehle mit zugespitzten. steifen silhermoilin. rötlich gesäumten Federu hedeckt, ührige Lnterscite kitrminnt, nur die Vitte des Unterköruers his auf die Brust hin. Banch uml Cinterschwanzdechen weil., letztere mit dunkelgramen TVumelteilen. Selmaher und Fübe hraum. Iris

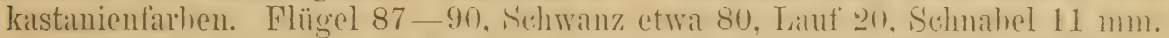
o Oberseite aschgrau mit breiten mattschwalmen Ferlemitten, golblich angohaucht, Bürzel durch hreite kurkmmagelhe Snitzen gelh exscheinemel. ()herschwanzdecken schiefergrau mit hellen spitzen. Flïgel wie heim ò, abrex die weißen Außensämme der Schulterfittiche mit gelhem S̈́hinmer, kileme Flügeldechen schieferschwilr\%, mittlere und gröbere mit gelhen statt rosenroten Spitzen. Kehle sehmutzig graugelhlich, ührige [uterseite kurkmagelh, Nitte des Cnterkörpers usw. Weilich. Körperseiten grau mit dunklen. matten Streifon.

Kansu und Sze-tschwan in China.

\section{Carpodacus rosea (Pall.).}

Fringilla rosea Pallas, Reise d. versch. Prov. d. Russ. Reichs III, p. 699 (1776 — „.. in salicetis ad Udam et Selengam occurrit").

ơad. Vorderkopf bis zur Mitte und Kehle mit eng geschlossenen, etwas steifen Federn bedeckt, die atlaswein mit posenentem Schimmer sind. Oberkopf und Hinterhals rosenrot, jede Feder schwarygran mit hreitem rosenroten Samme. Rücken losil und schwalmbraun gestreift, die Rückenund Schulterfedern rosa. ror den syitzen mit undeutlich hegrenzten woik-

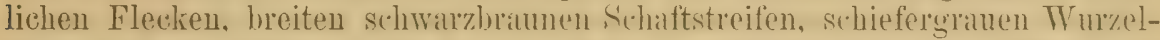
teilen und im frischen Gefieder mit feinen graumeiben Sïumen. Bürzel und Oberschwanzdecken schön rosa, im ahgenutzten Gefieder feurger. Schwingen bräunlich sehieferfarben mit schmalen trïh-rosa, die inneren drmschwingen mit hreiteren schwach rosig angehauchten weiben sämmen. Kleinste Flüg(xdecken dunkel rosa, mittlere und grobe dunkelbram mit hreiten weibon, rosa schimmernden Säumen. S'chwanz hräunlich schieferfarben mit rosenroten dußen- und sehmutzig weißlicheu Endsäumen. Zïgel. Kontiseiten, Konpfgegend und ïbrige Unterseite rosenrot, Bauch, [nterschwamzderelen und Mitte des Lnterkörpers heller, letztere fast weib, an den Weichen einiger

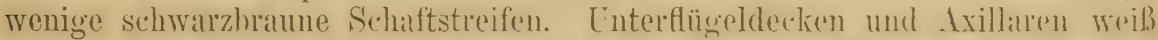

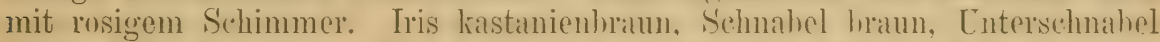

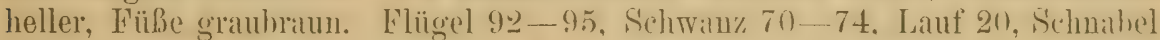
10-12 mm. qad. Oberkopf blaß rosa mit schwarzbraunen Federmitten, Hinterhals und Rücken dunkelhram mit hellbramen Federsïmmen und rosigem Schimmer, an der TVurzel statu. Bürzel mud Oherschwanzdecken rosenrot, auf dem oberen Teile des Bül\%els mit dunkelbaunen. konischen Schaftflecken, die längsten Obersehwanzdecken hram mit rosigen Säumen. Selıwingen dunkelbran mit rötlichweilien. an den Armsthwingen riel heritren Säumen. Oberflügeldecken dunkelhram, die kleineren mit losemoten. die? 
gräberen mit hroiten weiblichen. rosig angeflegenen Süumen. I'nterseite hell

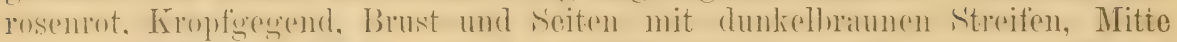

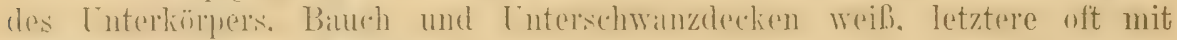

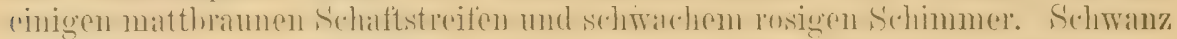

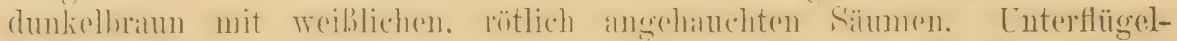

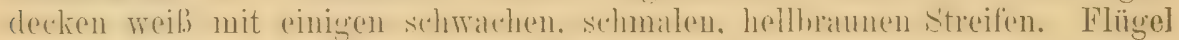
88-92, Schwanz 69-72, Lauf 20, Schnabel 10-12 mm. Der jungo Vogel ähnelt dem o ad., hat aber zuerst weniger rosa im Gefieder, das or

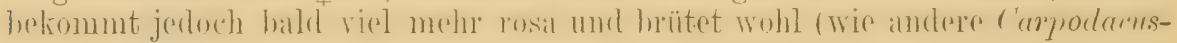
Arten) auch in diesem, dem des $o$ so ähnlichen Kleide.

Vom Jenissei bis Sachalin, wandert im Winter südlich bis in die

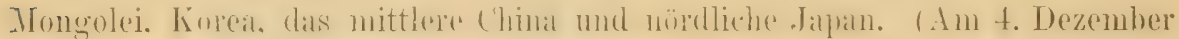

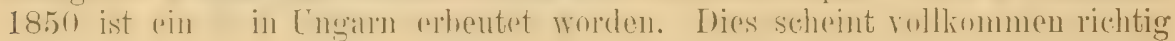
zu sein, doch ist es auf jeden Fall das einzig bekannte Vorkommen der

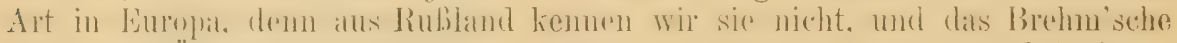
Stück aus Österreich sowohl, als das Helgoländer gehören zu emythrina.)

\section{Carpodacus erythrina erythrina (Pall.).}

Der Karmingimpel.

Loxia erythrina Pallas, Nov. Comm. Acad. Sci. St. Petersb. XIV, p. 587, I'af. 23, Fig. 1 (1770- Sïdrußland und Sibirien. 'Typ. Lok.: Wolga, als erstgenannter Fundort).

Loxia erythraea Endler \& Scholz, Naturfreund I, p. 17, 'Taf. 5 (1809- bei Breslau 1789 erlegt).

Fringilla incerta Risso, Hist. Nat. Eur. Mérid. III, p. 52 (1826).

Erythrothorax rubrifrons Brehm, Handb. Naturg. Vög. Deutschl., p. 249 (1831- Pallas' crythrina neubenannt, „kommt selten aus N.O. nach d. nördöstl. Deutschl. bis nach 'Thüringen").

Engl.: Searlet Grosbeak, Searlet Finch. Franz.: Roselin cramoisi.

Die europäische oder westliche Form des Karmingimpel ist gekenn-

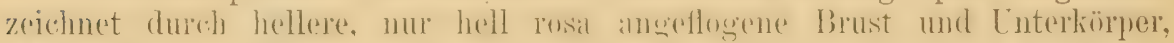

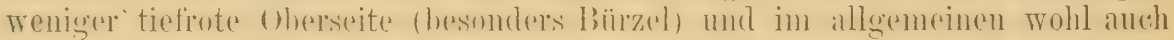

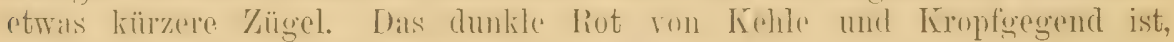
ziemlich scharf von der nur rosa übertünchten Brust abgeschnitten.

$0^{2}$. Im frisch vermauserten Gefieder ist das alte $0^{x}$ auf dem Unterrücken und Bürzel, an Wangen, Kehle und Vorderbrust rosa, Oberkopf

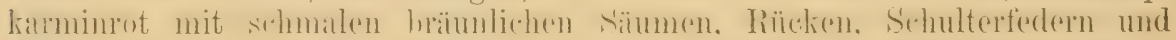

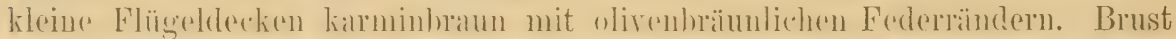

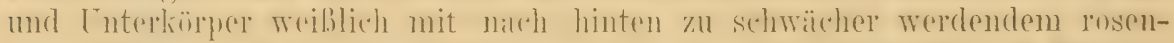

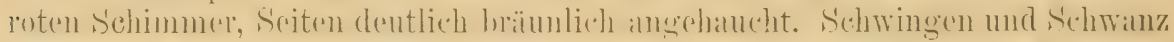

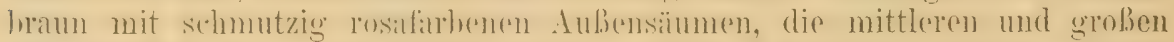

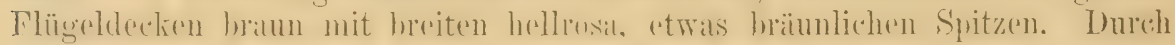
Abreiben der braunen Säume wird die Oberseite mehr karminrot, das

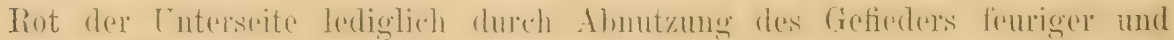

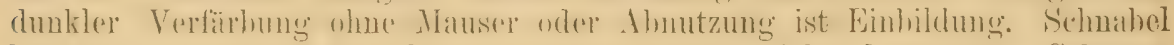
bräunlich hornfarben, Füße braun, Iris braun. Flügel 84-87, Schwanz 57-60, Schnabel 10.5-11.5, Lauf $19 \mathrm{~mm}$. - o oben olivenbraun mit

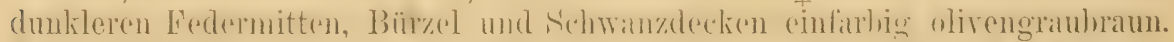

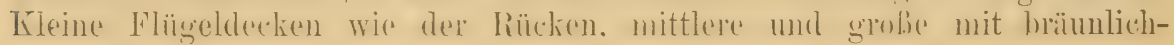




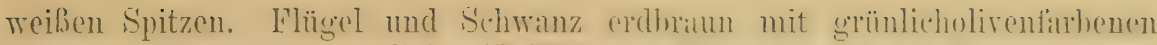

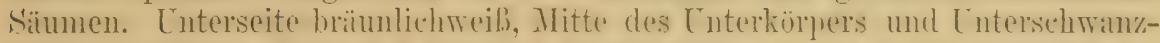
decken einfarbig, sonst mit hramen kedernitten. die an der Turderbrust am dunkelsten und dentliehsten sind. In fiseh vermaluserten frefieder ist das ?

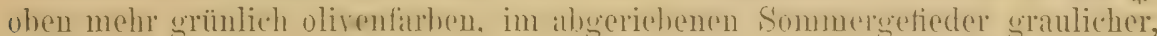
unten weißlicher. oे und jur. unterscheiden sich ron den alten o durch

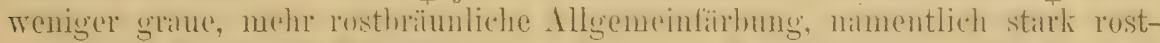

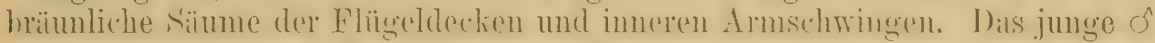
mausert nieht immer (? nic) im ersten . Iahre in das Altriskleid. und hrötet (wie auch andere Arten der Gattung) lisweilen in gratulnatumen, dem des? so ähnlichen Gefieder:

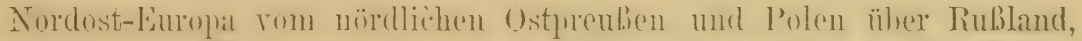
his alu die untere Trolgal und diss ehene Sibirien his zur Lena. Hat frïher einige Male in Schlesien (Iausitz) gebrütet und wurde des öfteren in

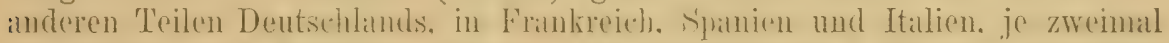
in Holland und burbland rhentet. In Dentschland 7. Zt. mit Sicherheit

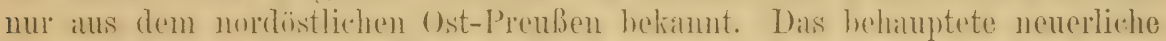
Tonücken nach IV esteu ist reine I'hantasie. man kïnnte in Gegenteil ehor

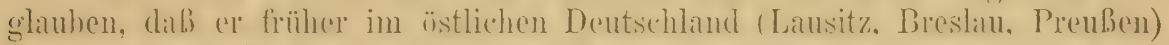
häufiger war, als jetzt. (Tul. den ..Nenen Namman" III, 1. 247 his 252.)

Bewohner feuchter Erlenwälder mit dichtem Unterholze von Erlen-Stockausschlag, Johannisbeerbiischen, Brombeerranken, Nesseln, mittlerer Weißbuchenbestände, buschreicher Gärten, Uferdickichte und ähnlicher Plätze, immer in der Nähe des Wassers, oft in sumpfigem Gelände. Einer der spätesten Ankömmlinge im Frühjahr, denn in den russischen Ostseeprovinzen, Polen und Preußen trifft er nicht vor Mitte Mai ein. Die laute, weithin hörbare, flötende Strophe verrät die Anwesenheit am Brutplatze auch dem ungeiibtesten Beobachter unfehlbar. Wer diese Stimme einmal gehört hat, kann sie nie vergessen oder verwechseln. Sie ist durch hit hüt jehütja, hüi thu et jeluetja, tiu tiu fi tiu und dergl. $\mathrm{m}$. nicht schlecht veranschaulicht worden. Dieser Pfiff ist der eigentliche Gesang, doch hört man auch bisweilen (wie beim Pirol) einen hänflingsartig zwitschernden Gesang. Der Lockruf ist kurz, wenig auffallend, an den des Kanarienvogels erinnernd, beim Neste hört man bisweilen auch einen zirpenden Angstruf. Nahrung durchaus vegetabilisch, auch die der Jungen, die nur ab und zu auch ein Räupchen oder Käferchen erhalten. Die Nester stehen meist niedrig im Gebü:sch. Sie bestehen äußerlich aus dürren Stengeln, dann folgen meist einige Grashalme und die Ausfütterung besteht aus feinen WVurzeln, Haaren, Blïtenrispen, Pflanzenwolle und dergl. Die Nester erinnern in ihrer flachen Bauart äußerlich an die der Dorngrasmücke, doch fehlon die jenen eigenen weißlichen Gespinste oder P'llanzenwollelüuschehen, innen an die des Dompfaffen. Das früheste Gelege fand ich in Ost-Preußen am 7. Juni, die meisten Mitte Juni bis anfangs Juli. Eier meist 5, zweites Gelege nach Zerstörung des ersten meist 4, regelmäßig natürlich nur eine Brut. Eier frisch von einem prächtigen, wenig grünlichen Blau, das mit der Zeit stark verbleicht, mit tiefscholsoladebraunen, fast schwarzen, meist spärlichen und kleinen Punkten, Flecken, Stricheln, gewöhulich mehr an stumpfen Ende, selten Kranz bildent. bisweilen fehlend. Ostprenbische Stïclie messen $19 \times 14.5$ bis $22 \times 15.5$, zehn Eier des Dr. Rey im Durchschnitt $16.69 \times 14.52$, im Maximum $21.5 \times 15,19.5 \times 15.5$, im MLinimum $19 \times 13.5 \mathrm{~mm}$. Gewicht etwa $0.123 \mathrm{~g}$. Das brütende 우 sitzt sehr fest.

\section{7t. Carpodacus erythrina grebnitskii Stejn. (Frigliche Lorm.)}

Carpodacus erythrina grebnitskii Stejneger, Orn. Expl. Command. Is. \& Kamschatka, p. 265 (1885- Kamschatka und (?) Sibirien). 
Soll lehlatter lot soin. namentlich anf dor Oherseite. Fohle und brust. Flügel (nach Stejneger) $79-84 \mathrm{~mm}$.

Kamtschatka und vielleicht Ost-Sibirien.

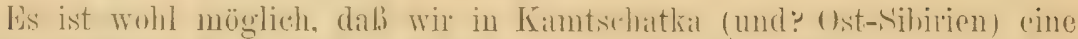

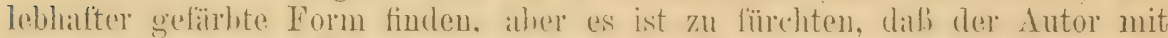

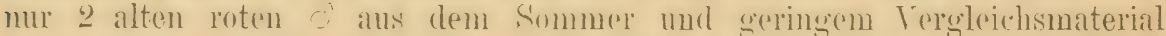

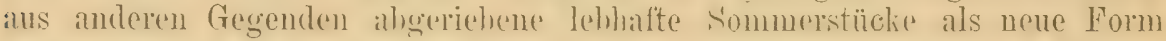
betratehtere. Auf der anderen Seite ist es nicht wahrseheinlich. daß diese Form aus dem fernen Osten diesellue ist wie die dop zentralasiatischen und

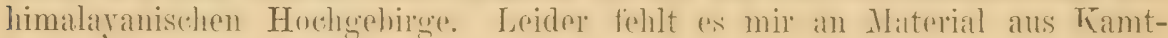
schatka und Ost-Sibirien.

\section{Carpodacus erythrina roseata (Hodgs.).}

? Pyrriulinota rosaecolor Hodgson, Gray's Zool. Misc., p. 85 (nomen nudum!).

? Propasser sordida Hodgson, ebenda (nomen nudum!).

Pyrrhulinota roseata Hodgsun, Proc. Zool. Soc. London 1815, p. 36 (Nepal und Hindustan).

Wie C. erythina erythrina, aber das ơ viel tiefer rot, namentlich auf Kopp, Büızel. Rülisen, die Enterseite dunkler rot. die rote Kehle umel Vordel-

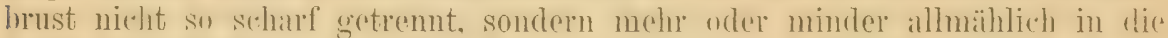

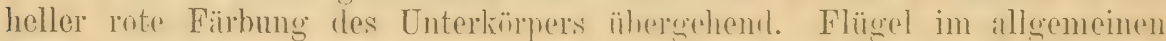
etwas länger; 85-90 mm.

Im allegemeinen Bewohner der zentralasiatischen Gelirege und des Himalava.

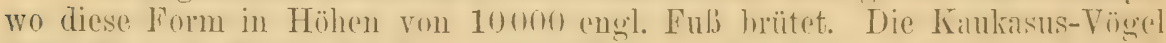
gehören auch dieser Form an. obwohl sie in der Fürhumg manchmal stark zur westlichen Form hinneigen. Im Winter in Inelien his zu den Nilgimi Bergen, Arrakan und Pegu. Ob C. e. grebnitskii von dieser Form zu unterseheiden ist, ist moeh nicht ansgemacht. daher wissen wir atuch noch nicht

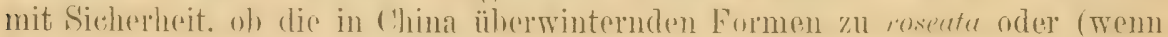
trembar) zu grebnitsliii gehören.

\section{Carpodacus synoica synoica (Temm.).}

Pyrrhula synoica 'Temminck, Pl. Col. 375 (1825- Sinai, Hemprich \& Ehrenberg coll.). (Es ist sinnlos, den Namen synoica, der wie jeder Tertianer weiß, gesellig bedeutet, in sinaiticus umzuwandeln. zumal Temminck noch besonders seine Art „Bourreuil social" nennt. Ob Lichtenstein ,in litt." den Namen sinaiticus anwandte, kommt doch nicht in Betracht.)

Pyrrluela sinaica Rüppell, Neue Wirbelth., Vög., p. 101 (1835- nomen nudum!).

Carpodacus sinaiticus Bonaparte \& Schlegel, Monogr. Loxiens, p. 17 (1850- Sinaï).

and. Oherseite blaßhriunlich mit etwas dunklern schaftstreifen und rosemotem Influs. Oberkopf etwas lebhafter rot. Zü̈gel und Stirn dumkel rosemrot, ïber Stirn und Augen glänzend weiße, sehx schwach rosig angehauchte. etwas steife. schmale fiedern. Konfseiten rosenrot mit silberigem Sehimmer: Lnterer Bümel ainfarhig hell rosenrot. ohere Schwanzdecken graubrämlich mit rosigem sehmmer. Kehle wir die Koptseiten. übrige Unterseite rinförmig hell rosenot, Bauch und Lntersehwanzdechen lichter.

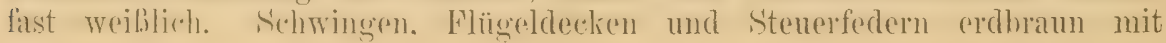


lichthlabbraumen. kaum merklich rosig angehauchten Säumen. Tenterflügeldecken weißlich mit schwachem rosigen Schimmer. lilügel 86-84. Schmanz. etrat 62. Lauf etwat 20, Schmahel $10 \mathrm{~mm}$. Selmahel und Fïbe hellhraun. gratubrïunlich isabell, when dunkier und mit dunklen Shathtstreifen, unten heller, in der Mitte des Enterkürpers ins Weibliche zichend, an der Torderlnrust mit einigen schwachen dunkleren Sehaftstreifen, ohne alles Rosenrot.

Linzig und allein von der Sinä̈-Halhinsel natchgewiesen. (Heuglin lïlit ihn keineswegs inderwïrts im steinigen Arahien rorkmmen, sondern

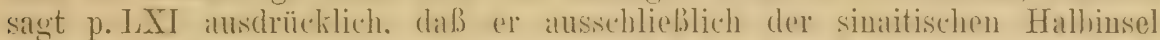
angehöre; Tistram ist zwar üherzeugt. dal.s er die Art in Palïstina sah, erthachte aher keinen Beweis. diss angehliche Vorkmmmen in Griechenland ist ganz unwahrscheinlich.)

Lebt nach Heuglin auf Felsen, sonnigen Hängen, Viehtriften und an Regenbetten, ist lebhaft und schiichtern, nährt sich von Grassamen, sitzt meist am Boden und auf Felsen.

\section{Carpodacus synoica stoliczkae (Hume).}

Propasser stoliczlice Hume, Stray Feathers 1874, p. 523 (Yarkand). (Abbildung in Berezowski \& Bianchi; Aves exped. Potanini p. prov. Gansu, Taf. III. (1891).

5 Oherseite bab aschloraun. whe alle dunklere Zeichnung, Bürzel blab rosa. Flügeldecken wie die Oberseite, am Bug etwas rosa ïberflogen. Schringen hraun mit hräunlich-treißlichem Aubensamm der Handschwingen und brïmnlich-weiblichen siritzen der Armschwingen. Oherschwanzdecken

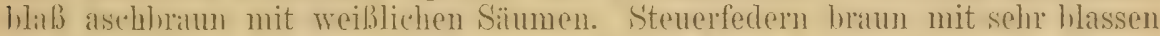

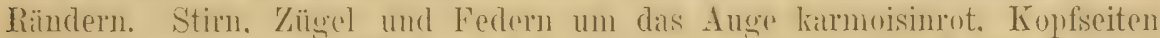
und Ohrdecken rosil. Kiehle und Torderbrust rosid, an der hehle dunkler, Tnterkürper, seiten und schenlellnefiederung hell aschbrämnlich, Cinterschwanz-

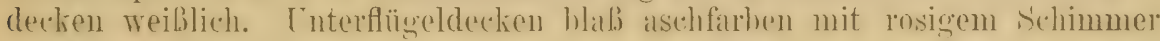
am Bug: Flïgel 92, Schwanz 67, Lauf $20 \mathrm{~mm}$. Q ohne Rosa und Rot, im allgemeinem sandhrïunlich. anf Bürzel und Enterseite heller. Konf und Tehle mit dunkleren schaftstriehen. Ltwas kideiner (Flïgel $8: 3 \mathrm{~mm}$.)

Ton Yarkand dureh die Wüste Gobi bis Kansu.

\section{Carpodacus verreauxi (Dav. \& Oust.).}

Carpodacus verreauxi David, Nouv. Arch. MLus. VII, Bull., p.10 (1871- nomen nudum!). Propasser verreauxi Darid ot Oustalet, Ois. Chine, p. 355 (1877).

Nur ein o (oder ơ im grauen jugendlichen Kleide) dieser Art im Pariser Museum ist bekannt. Es scheint C.rhodopeplus nahe zu stehen, ist aher kleiner. Oherkopef und Genick whenbum, alle Federn in der Mitte schwarzhraun uestreift, Rï̈clen ebenso mit rahmfurbenen oder bräunlichgelhen Silumen. Bürzel und oherschminzdecten heller und mehr einfarbig. mit mur sehwach markierten dunklen Federmitten. Ton den dugen nach rückwirts ein breites gelbhriunliches Superciliarband. Kleine Flügeldecken hram. Mittlere und grobe Flügeldecken. Sethwingen und Sehwanz dunkelbraun mit helleren Rändern. dic letzten Armschwingen nach der Spitze der Außenfahne dentlich weiblich. Zügel weißlich aschgrau. Wangen und Kehle

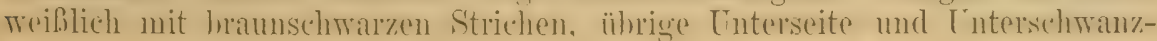


decken hell gelhbrïmnlich, wie dic Kehle gestreift. Mitte des Lnterkürpers nngestreift. Tnterflügeldecken und Achselfedern hräunlich isalhellfarben. Culmen 10, Flügel 71, Schwanz 71, Lauf 17.7 mrn. (Nach Sharpe und Oustalet.)

Mupin in NW.-China.

\section{Gattung HAEIMATOSPIZA Blyth 1844.}

Diese Gattung ist von Sharpe inkonsequenter Weise nit C'arperlurns vereinigt worden, da er doch sonst die Fringillidengattungen genïgend zersplitterte. Das (refieder ist fester, der S'chwanz rerhïltnismü̈Big viel küurer, der Flïgel sehr liug und nicht so spitz, der Abstimd ron den Spitzen der Handschwingen zu denen der Armschwingen viel geringer (etwa 22-2:3 1um), die erste (ausgebildete) Scluwinge ist $7-10 \mathrm{~mm}$ liürzer als die lïngste, 2. bis 5. am längsten, 5. wenig kürzer. Fürbung eigenartig. Eine Art.

(Dies Genus steht vielleicht Loxiu wïher, als Carporturn., der Schnabel ist sehr dick, aber nieht gekreuzt.)

\section{Haematospiza indica (Gm.).}

Loxia indice Gmelin, Syst. Nat. I., p. 847 (1780 - ex Seba, Brisson, Latham, hab. India) ${ }^{1}$ ).

Loxia boetonensis Latham, Index Orn., p. 377 (1790 - ex Seba, India insula Boetonense). Corythus Sipahi Hodgson, Asiat. Research: XIX, p. 151 (1836- Nepal).

OTad. Ganze Ober- und Unterseite lebhaft seharlachrot, die Federwurzeln grau, vor den roten Spitzen ein weißer Streif, auch längs des Schaftes am Irurzelteile weib. Flügel und Schwan\% schwarzhraun mit

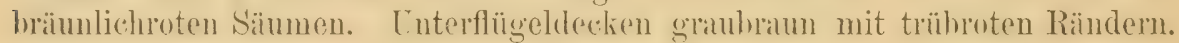
Schmolbel brïunliehgelb. Fübe hellhraun. Iris braun. Flügel 100-105. Schwanz 66-69, Lauf 29-31, Schmabel 14-16 mm. O oben olivengrünlichbraun, jede Feder wit weiBlicher Basis und brïunlicher, gelblicholivengrün gesiiumter Spitze. Bürzel goldgelb. Schwingen und Schwanz.

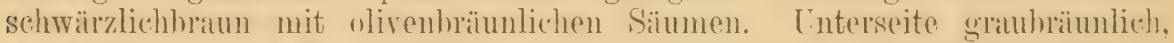
die Federn nach der Basis zu weiß, dimn graubraun mit hellhräunlichen Sïumen,

Himalaya von Nepal bis Sikkim, in Höhen von 5000 bis 10000 engl. Fub, je nach der Jahreszeit, und Kilasia-Berge südlich des Brahmaputra.

\section{Gattung PYRRHOSPIZA Hodgs. 1844.}

Diese Gattung steht unbedingt Carpodacus am näehsten und könnte ohne groben Zwang mit ihr rereinigt werden, ather alle nemeren (ornithologen

1) Gmelin's und Latham's Namen sind von allen neveren Schriftstellern übergangen worden. Sie beruhen auf Seba (I, Taf. 60, Fig. 4), der dentlich einen ganz roten Vogel mit dem kernbeißerartigen Schnabel von Haematospiza abbildet. Er stellt. inn zwar mit einer Haube dar, der man aber ansicht, daß sie gezwungen und augenscheinlich ein Kunstprodukt ist. Als Lokalität wird die Ivsel Boeton (Buton) angegeben, da aber in der celebesischen Inselwelt kein solcher Vogel vorkommt, ist anzunehmen, daß Buton ein Versehen für Butan ist, und daß der Vogel aus dem Himalaya stammte, vielleicht lebend aus Indien gekommen, oder daß sonst eine Verwechselung damit vorgekommen war. 
trennen L'mphospizu wegen des viel lïngeren und schlanlieren Schnahels generisch alh. Abgesehen ron der Sehmabelform steht Pyrrhospizal im Bau der Gattung Propyrohula nahe. Eine Art in mehreren Unterarten.

\section{Pyrrhospiza punicea punicea Hodgs.}

Pyrrhospiza punicea Hodgson, Journ. As. Soc. Beng. XIII, p. 953 (1844- Nepal). Abbildg. Bp. \& Schleg., Monogr. Loxiens 27, 28.

ò ad. Stiru, kurzer Superciliarstreif, Kopfseiten, Kehle und Brust lehhaft karmoisinrot, die Federn an der Basis schwärzlich. ror den Spritzen weißlich rosi, Bürzel rosenrot. ührige Oberseite sraubraun mit schwarzbranen Federmitten, Flügel und S'chwanz dunkelhraun mit heller brameu Śäumen. Lnterkörper aschhram mit cinigen an den Seiten breiteren dunkelbraunen Streifen, Unterschwanzdecken hraun, die kïrzeren mit rosigen Spitzen. Schmahel hornbraun. Fülise dunkelhraun. Flügel 112-114, Schwanz 81-83.5, Schmabel 15-18. Lauf etwa $25 \mathrm{~mm}$. Oherseite gxaubraun mit schwarzhaumen Federmitten, Cnterseite hell gelbbrim mit schwarzhramen Schaftflecken.

Himalaya von Nepal bis Sikkim.

\section{Pyrrhospiza punicea humii Sharpe.}

Pyrhospizc humii Sharpe, Cat. B. Brit. Jlus. XII, p. 433 (1888- „Interior of N.W.Himalayas").

$O^{7}$ dem von $P$. p. punicea älnnlich, aber etwas langschnäbliger und blasser. das Rot am Vorderkopfe etwa so weit wie hei I'. l'. longinestris.

N.W.-Himalaya.

\section{Pyrrhospiza punicea longirostris Przew.}

Pyrrhospizu longirostris P'rzewalski. IInngol i Strana Tangut. II, p. 95 'T'af. XIV' (russisch);

Übersetzung in Rowley's Orn. Misc. II, p. 304, Taf. VI (Kansu).

Ist $P$. p. homii äußerst ähnlich, aber mit noch lüngerem Schnabel $(20 \mathrm{~mm})$, das Rot des $\sigma^{\pi}$, das bei $P . p$. punirea in der Kopfmitte nicht weiter reicht, als eine Linie zwischen den rorderen Augenründern, geht weiter nach hinten, bis zu einer die hinteren Augenränder verbindenden Linie, die Fïrbung ist im allgemeinen etwas hasser und graulicher, hesonders am Unterkörper, der auch sehmalere dunkle Schaftstriche hat.

Kansu und Sze-tschwan, in der alpinen Region.

\section{Gattung PROCARDUELIS Horlgs. 1844.}

Die Gattung Procarduelis ist sehr schwer im System unterzuhringen. In der viel Rot enthaltenden Fürbung der Mämnehen mud der Versehiedenheit der Geschlechter gleicht sie den Arten der Gattung Cirpoducus, aher der Schnabel ist viel schlanker, mehr Fringilla-artig. fast an einen CinduelisSchnahel erimernd. Das Gefieder ist seidenaltig, alher nicht ilmorm reich, der Schwanz nur wenig ausgebuchtet. Zwei Arten:

Schnabel schlanker, ơ Vorderkopf rot, Hinterkopf tief braunrot: P. nipalensis . p.112 Schnabel klumpiger, ơ ganzer Oberkopf rot........ P. mbescens . p. 112 


\section{Procarduelis nipalensis (Hodgs.).}

Carduclis Nipalensis Hodgson, Asiatic Researches XIX. p. 157 (1836- „central \& north. reg. of Nepal").

Linota saturata und fusca Blyth, Journ. As. Soc. Bengal XI, p. 193 (1842- Darjiling).

otad. Oberkopf etwa bis zur Mitte losig weinrot, vom Auge nach

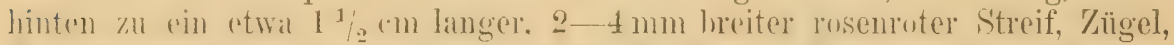
Tinpliseitenstreif his zum Halse. hintere Hälfte dles Oherkinfes und Hinterhals sehr dunkel weincot. fist sehwarzot, Rïicken tief schwärzlich braun mit düster rosig weinroten Federrïndern. die anf Bürzel und Oherschwanz-

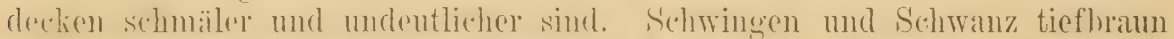

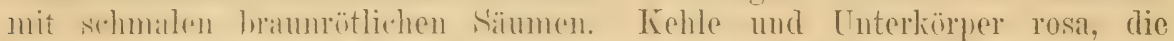
ganze Torderhust und Seiten breit düster hä̈unlich weinmot. Enterschwanz-

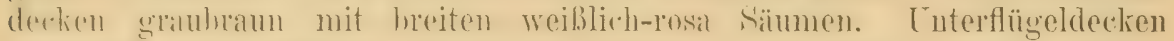

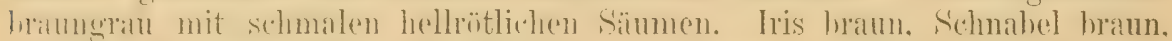

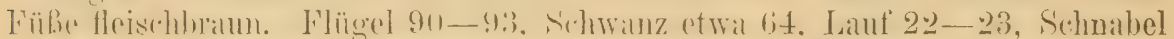

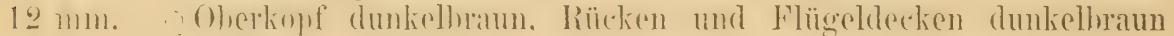
mit hellbramuen Sïmmen, Bürzel einfarhig hraun. Gamze Tnterscite einfarhig röstlichbraun. Juv. wie 0 aber etwas mehr rotbrïunlich.

Himalaya bis Kansu und Mupin in W.-China. (Vielleicht sind Stïcke aus, dem westlicheren Himalaya etwas bleicher?)

\section{Procarduelis rubescens Blanf.}

Procarduelis rubescens Blanford, Proc. Zool. Soc. London 1871, p. 694, 'Taf. 74 (Sikkim). Procarduelis mandellii Hume, Stray Feathers 1873, p.14 (im Winter bei Darjiling, ges. v. Mandelli).

Oberseite matt karmoisinrot, auf dem Kopfe lehhafter, auf dem Rücken bräunlicher, weil dort die bramen (nur rot gesäumten) Federn durch-

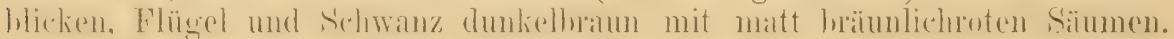

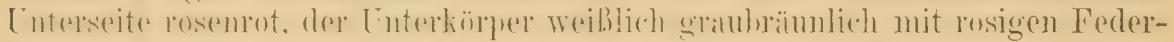
rändern. Schnabel und Füsse hellbrann. Flügel 80-83, Schwanz 54-60, Lauf etwa 20, Schnabel etwa $12-13 \mathrm{~mm}$. O ̈̈lnnlich dem von $P$. nipalensis,

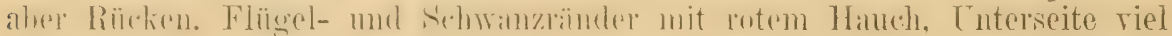
heller. (Das ô ähnolt einem Carpodaens enythinus mit schlankem, längerem

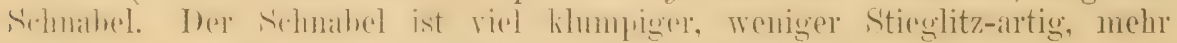
dem, von Campodacus sich nähernd, als bei $P$. nipalensis.)

Nördliches Sikkim, im Sommer in Höhen von 12800 engl. Fuß (Oberstabsarzt Pearse), im Winter his etwa 8000 FuB abwärts, dann auch in den Bergen von Kausu. (Vgl. Berezowski und Bianchi ,Aras exped. Potanini p. p. Gansu ete." p. 131 - russisch!)

\section{(rattung PROPYRRHULA Hoigs. 1844.}

Line eigenartige, nicht gauz leicht im System unterzubringende Form, die anscheinend aber nächst Pinicola zul stellen ist, der Schmabel aber ist

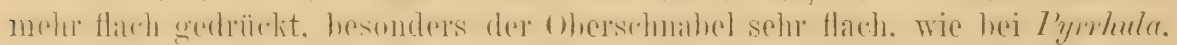

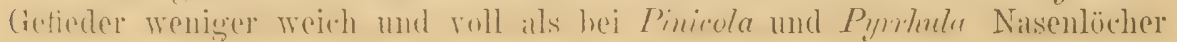




\section{R. Friedländer \& Soln in Berlin NW. 6.}

In unserem:Verlage erseheint:

\section{Das Tierreich.}

\section{Eine Zusammenstellung und Kennzeichnung der rezenten Tierformen.}

Begründet von der Deutschen Zoologischen Gesellschaft.

Im Auftrage der

\section{Königl. Preuß. Akademie der Wissenschaften zu Berlin} herausgegeben von

Franz Eilhard Schulze.

I) Heransgalle findet in Lieferungen (in Grob-Lexikon-Oktar mit Abbildungen in Texte) statt. die je eine oder nehrere nabestehende Gruppen behandeln, jedoch unabhängig rou einer systematischen Folge erscheinen. Jede Lieferung ist einzeln käuflich.

Bei Subskription anf das ganze Werk tritt eime P'reisermäbigung (aiu. Aus der Gruppe der

\section{Vögel (Aves)}

sind bisher ersehienen:

Lieferung 1: Podargidae, Caprimulgidae und Macropterygidae. Benrbeitet von.E. Hartert ('Tring). 1897. VIII und 98 Seiten mit 16 Abbildungen und Beilage: Terminologie des Vogelkörpers von A. Reichenow, 4. Seiten mit Abbildung.

Einzelpreis Mark 7,-

Lieferung 2: Paradiseidae. Bearbeitet ron The Hon. Walter Ruthsehild. 1898. VI und 52 Seiten mit 15. Abbildungen. - Einzelpreis Mark 3,60.

Lieferung 9: Trochilidae. Bearbeitet von E. Hartert (Tring). 1900. X und 254 Seiten mit 34 Abbildungen.

Einzelpreis Mark 16,-.

Lieferung 15: Zosteropidae. Bearbeitet von O. Finsch (Leiden). 1901. XIV und 55 Seiten mit 32 Abbildungen. Einzelpreis Mark 4,80.

Lieferung 18: Paridae, Sittidae und Certhiidae. Benbeitet ron C. E. Hellua yr (München). 1903. XXXI und 255 Seiten mit 76 Abbildungen:

Einzelpreis Mark 16,--

Weitere Lieferungen erscheinen in ununterhrochener Folge. Bestellungen

Subskriptionen können durch jede Buchhandlung bewirkt werden.

Berlin, November 1903. 
Wir hesitzen hisher kein Werk. dis die lokalen Formen der palïarktischen Vögel in knapper Fassung berücksichtigt.

Fron dem gronken und kestspieligen Prachitwerke H. Fi. Dresser's ahgesehen. hahen wir zwall ein sochen (19113) erschienenes selur praktisehes Handhuch dessellen Verfixsers.s. welches indes noch ganz auf den Standmunkt der altem s'chule steht. lis läht die Firgebnisse des sultilen Studiums leer letzten 15 . Jahre unbeachtet. obwohl es nicht selten eine Tuterart als Lit heschreiht, und so den alten Arthegriff zu rerschichen droht. hietet also unr einen Teil yon dem. Was wir gehrathenen, außerlem ist es hisher nur n englischer Sprache ersehienen.

I)as forliegende Buch hemuilht sir-h vor allen Dingen zu zeigen. was isher in Cntersirheidung der Sulsperzies greleistet woirden ist. und somit uch. wo noxh Lücken anszufüllen sind. Selhstverständlich hat Verfiasser ie daran gedacht, daßs sein Werk einen condgültigen Alschluß hedeutet, men solchen wird keiner der heutigen Ornithologen erleben. . Er hat nur das Bekiumte zusinmengestellt, an der Hand rom Misterial und Literatur geprifift. gesichtet und nen hinzugefiugt. was dis ihm rorliegende. freilich sehr reichhaltige Material ergab. -

Hartert's Vögel der paläarktischen Fauna werden in Lieferungen ron je 8 Bugen, zum Preise von 4 Mark für die Lieferung erseheinen. Das (xanze wird in 10 Lieferungen (zusammen 1200 his 1300 Seiten in 2 Bänden) ahgeschlossen sein. Die Vollendung des ganzen Werkes ist für $1905 \mathrm{zu}$ errarten.

Berlin, NW: 6 ,

Karlstr. 11.

\section{R. Friedlånder \& Sohn.}




\title{
Die Vögel
}

der paläarktischen Fauna.

\author{
Systematische Übersicht \\ der
}

in Europa, Nord-Asien und der Mittelmeerregion vorkommenden Vögel.

Von

Dr. Ernst Hé

Heft 1.

Seite $113-240$.

Mit 22 Abbildungen.

Berlin.

Verlag ron R. Friedländer und Sohn. Ausgegeben im Juni 1904 . 
Es galn bisher kein Werk, welches die lokalen Fomen aller palïarktischen Vögel in knapper Form berïeksichtigt, und überhaupt kein Werk in deutseher Sprache über die Ornis der paläarktischen Fauna.

Yon dem seln kostspieligen Prachtwerke H. E. D) resser's allgesehen, haben wir zwar ein soeben erschienenes pralktisch eingeriehtetes $\mathrm{Handbuch}$ desselhen Verfissers. Dieses ...Manual of P'alaearctic Birds" hat aher die Ergehnisse des subtilen studiums der letzten 15 . Tahlure unlreachtet gelassen, und bringt fast nur die leicht unterscheidharen Formen, hietet also nur einen Teil von dom, was wir gebrauchen, und ist nur in englischer Sprache erschienen:

Das vorliegende Werk, bemüht sicb vor allen Dingen zu zeigen, was hisher in Cuterscheidung der Subspezies geleistet worden ist. und somit auch. Wo noch Lü̈(ken auszufüllen sind. I)is Bekannte ist zusimmmengestellt, an der Hand ron Mriterial und Literatur geprifift. gesichtet und viel Nenes hinzugefügt morden, wozn die hedrutende rou dem Terfasspr verwaltete

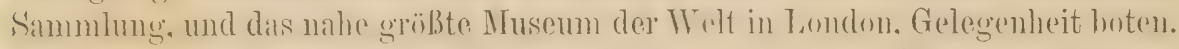

Die Synonymien sind nicht in der herkömmlichen Weise zusammengestellt. sondern hei jedem Zitit ist der ursunüngliche F'undert. die sngenamute terra typica. sorghailtig ermittelt. D)er Ballist unnitiger und unwieldiger l,iteraturangalien ist rermieden. Ihie Beschreihungen sind. wemn nicht anders

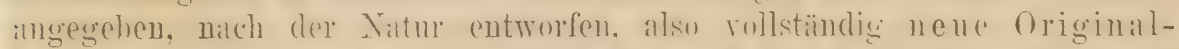
hesehreibungen: sie sind möglichst kur, und kinily' gehalten. Nicht nur r. t.. in enthalten Bestimmungssehlüssel der Arteu.

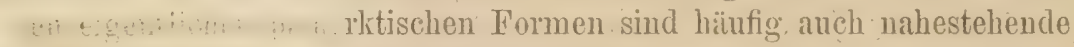
eliete kurz erwähnt.

so konservativ wie möglich, d. h. der. ïlteste stung, Art und Unterart in jedem. Falle ohne susuatume angewandt, sodal.s. Streitigkeriten un die Namen in Zuluinft nicht melre stattzufinden brauchen.

Das Werk wird in Lieferungen von je 8 Bogen, zum Preise ron 4 Mark für die Lieferung, erscheinen. Das Ganze wird in 10 Lieferungen (zusammen etwa 1200 his 13010 S'siten in 2 Bänden) abgeschlossen sein. Die Vollendung des ganzen. Werkes ist zu Ende 1905 zu erwarten.

Berlin, NW. 6, Karlstr. 11.

\section{R. Friedlinder \& Soln.}




\title{
Die Vögel
}

\section{der paläarktischen Fauna.}

\author{
Systematische Übersicht \\ der
}

in Enropa, Nord-Asien und der Mittelmeerregion rorkommenden Vögel.

Von

Dr. Ernst Hartert.

Heft II.

Seite $113-240$.

Mit 22 Abbildungen.

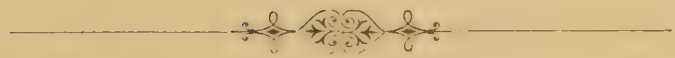

\section{Berlin.}

Verlag von R. Friedländer und Sobn.

Ausgegeben im Juni 1904 . 
"What's hit is history",

What's missed is mystery."

Druck von A. Hopfer in Burg b. I. 
Kleiu, aber kaum ganz vou den kurzen Nasenborsten überdeckt, wïlirend letztere bei I'yrrhula etwas und bei Pinicola weit hinüberreichen. Fürbung mehr an C'mpolacus crinnernd, das of dem von Llamatospiza ähnlich. Schwanz länger als bei letzterer Gattung. Nur eine Art bekannt.

\section{Propyrrhula subhimachalus (Hodgs.).}

Corythus? Subhimachalus Hodgson, Asiat. Research. XIX, p. 152 (1836- Nepal).

Propyrohula subhemachalana Blyth, Journ. As. Soc. Beng. XIII, p. 952 (1844).

Propyrrhula subhimalayensis (sic) Sharpe, Cat. B. Brit. MLus. XII, 1. 462 (1888- Name geändert, damit er einen besseren Begriff gäbe).

Oad. Stiru und kurzes Supercilium his üher die Augen lehhaft karmoisimrot. Wangen, Kinn und Kehle weniger lebhaft karmoisinrot, Federn der Vorderhrust brïunlichrot mit dreieckigen, rosa Federspitzen. Oberseite grünlichliaun, stark mit Rot ühergossen, hesonders auf Kopf, Hals und Oherrïcken. der Bürzel und die vorderen Obersehwanzdecken ganz rot. Brust und Cnterkörper bräunlichgrau. Brustseiten meist rosa angehaucht. Enterschwanzdecken grau mit weißlichen Säumen. Sehwingen und Schwauz. dunkelhraun mit rötlichluaungrünlichen Sïumen. S'chnahel und Fïße hellbraun. Flügel 95-98. Schwanz 80, Lauf 2.5.5, Schnabel 12.5-13.5. Schnabelhreite $10 \mathrm{~mm}$. Stirn und grolier Kropffeck dunkelgelb, Hinterkopf grau mit gelblichen Kanten, ülnige Oherseite gelblich olivengrün mit dunkelgrauen Federmitten. Bürzel und Oberschwanzdecken lehhaft olivengrüngell. Brust und Unterkörper bräunlichgrau.

Himalaya von Nepal und Siklim.

\section{Gattung PINICOLA Vieillot 1807.}

Grobe baumbervohnende Finkenvögel, o mehr oder minder lebhaft rosemrot, o grau und olivenhräiunlich oder olivengelhich, stets olme Rot. Junge den o ähnlich. S'thnahel sehr dick und kurz. der ganze Oherschnabel gekrïmmt. Nisenborsten lang und auffallend, die Nasenlörher röllig zudediend. Flügel lang. spitz, \& äußerste Handschwingen fast gleich und am längsten. die erste (lange) wenig kürzer als die folgende. merklich länger als die fünfte von außon, Handschwingen etwa $3 \mathrm{~cm}$ länger als Armschmingen. Schrianz lang (nur etwal um die halhe Lauflänge kürzer als der Flügel), merklich ausgeschnitten. Lauf kul\%. (etwa wie die Mittelzehe mit Nagel). Füße stämmig. Fine Art in mehreren [nterarten, verbreitet iiher den bohen Norden der alten und neuen Telt, in Amerika (ine Form südlich bis zur Sierra Nevada in Kalifornien. ${ }^{1}$ )

1) In Amerika unterscheidet man folgende Formen, die z. T., namentlich die 오, sehr kenntlich sind:

Pinicola enucleator lencura (P. L. S. Mïll.) 1776 (canadensis auctorum), nordöstl. NordAmerika.

P. e. alascensis Ridgw., Brutrogel im Innern von Alaska.

P. e. flammula (Homeyer), Insel Kadiak und Küste von Alaska bis Sitka.

P. e. californica Price, Sierra Nevada von Kalifornien.

P. e. montana Ridgw., Felsengebirge von Nord-Amerika.

E. Hartert, Die Vögel der naliarktischen Region. 


\section{Pinicola enucleator enucleator ( $\mathrm{I}_{\text {.. }}$.}

Hakengimpel, Fichtengimpel.

Loxia Enucleator Linnaeus, Syst. Nat. Ed. X, p. 171 (1758- „Hab. in Suecia summac, Canadae Pinetis .... migrat hyeme ad australes Sueciae provincias ....". Basiert vorzugsweise auf Fauna Suecien 176, als typische Lokalität ist daher Schweden zu betrachten).

Loxia Flamengo Sparrman, Mus. Carlson. I, Nr. XVII mit 'T'af'el (1786- Upsala. Albinistische Var!).

Loxia psiltacea Pallas, '/oogr. Rosso-Asiat. II, 1). 5 (1811- „In Rossiae totiusque Sibiriae pinetis ....").

Corythus angustirostris Brehm, Handb. Naturg. Vög. Deutschl., j). 247 (1831- X.Europa, zuweilen nördl. Deutschl.).

Corythus Enucleator minor Brehm, Vogelfang p.89 (1855- „.. zuweilen aus dem. hohen Norden nach N.-Deutsehland").

Corythus Enucleator latirostris, macrorhynchos, microrliynchos A. E. Brehm, Verz. Samml., p. 10 (1866- nom. nuda!).

(Corythus splendens Brehm (Isis 1810, p.590), ist eine amerikanisehe F'orm, und zwar die jetzt unter dem Nimen Pinicola emucleator canadensis (Uab.) (1850) lrekannte Form. Der Name Pinicola vubra Vieillot, Ois. Amér. Sept. I, p. IV, 'l'af. I, 13, ohne Besehr. und Fundort, ist nicht zu deuten, die Figur zeigt aber, daß eine Form dieser Art gemeint ist).

Engl.: Pine Grosbeak. Französ.: 1)ur bee vulgaire. S'chwed.: Tallbit, Dumsnut.

Oad. Kopf, Hals, Kropf, Brust und Seiten losemrot, die Federu soweit

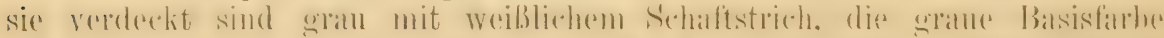

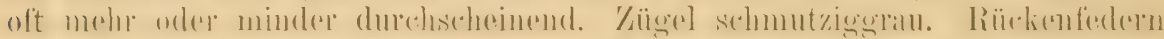

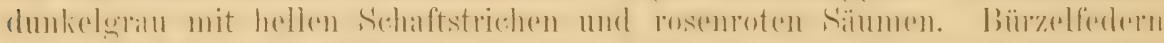

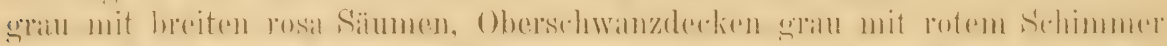

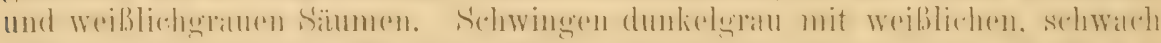

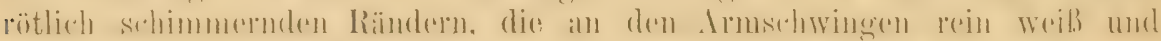

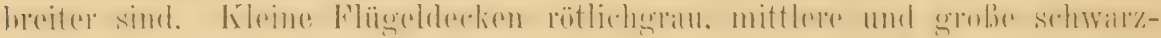
bratun mit breiten weilsen, schwach rosa schimmernden Säumen. Schulter-

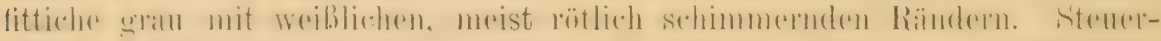

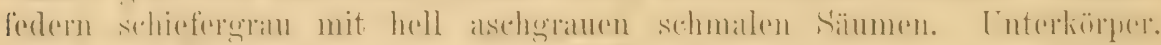

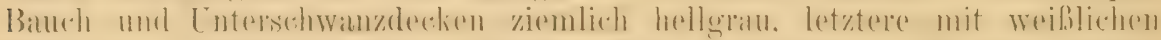

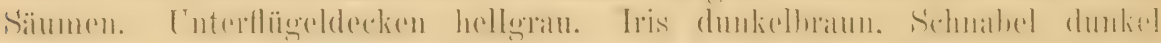
hornbraun, Unterschnabel heller, Fïße dunkelhraun. Flügel 109-113. Schwanz 87-90, Lauf etwa 22, Schnabel 16-17 mm. Ober- und Unterseite aschgrau mit olivenfurbenem Schimmer, der Rücken mit helleren Säumen; auf Kopf, Hals und Oberrïcken dunkler olivenfarben verwaschen

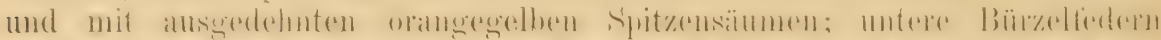

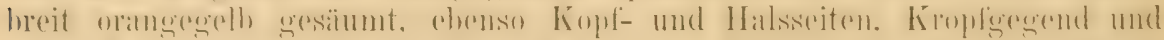

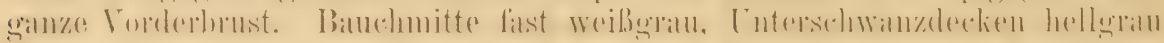

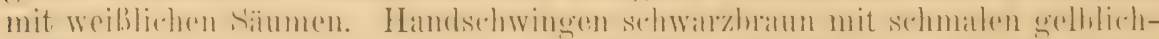

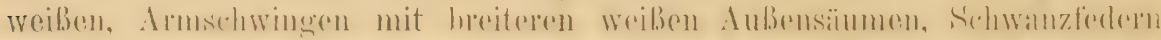

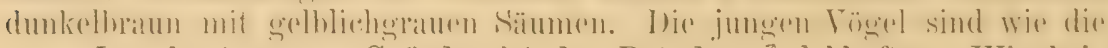

Im abgetragenen Gefieder ist das Rot der of lebhafter. Wie bei den Arten der Gattungen Carpoducus und Loxia brïten manchmal die or im grauen und gelben Gefieder, wie es die o und Jungen tragen, oft auch

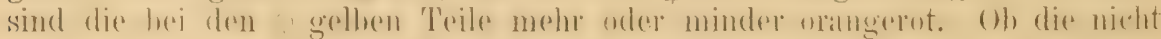
roten ơ je cin rotes Kleid amnehmen, dürfte sehwer festzustellen sein. 
Bewohner des hohen Nordens der alten Welt, ím Winter mehr oder minder regelmäßig weiter nach Süden. In Europa nur im nördlichen

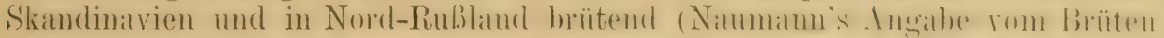

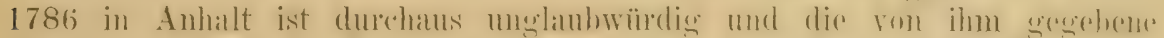

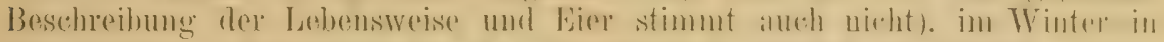

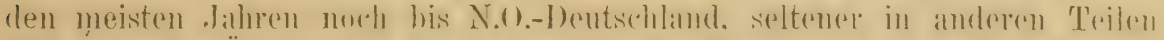

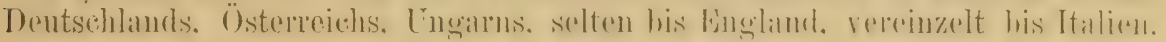

Hält sich in den Wäldern, besonders Nadelhölzeru des Nordens auf, ist ein sehr wenig scheuer, geradezu dummdreister Vogel, um IBrutplatze aber vorsichtiger and schlamer. Nahrung Coniferen-Samen und Beeren. Eier 3-4, ausnalnmsweise 5 , Nest auf Nadelbäumen, nicht sehr tief, den Charakter der Nester andrer gimpe]artiger Vögel tragend, aus feinen Kweigen, innen mit Wurzeln, feinem Giras. Flechten und Haaren ausgefüttert. Die Eier sind himmelblan, meist dunkler als Gimpeleier. mit rötlichgrauen und hellbraunen, ticfer liegenden, und tiefbraunen, fast schwarzer Oberflecken, manchmal auch Schnörkehn und Punkten, meist mehr un das stumple? Ende herum, gezeichnet. In der Größe gleichen sie denen von Coccothraustes coccothraustes. Die Lockstimme ist ein ansprechender, Hötender 'T.on. der Gesang laut und 'flötend. Das Fleisch dieser Vögel schmeckt sehr gut.

\section{Pinicola enucleator kamtschatkensis (1) W.).}

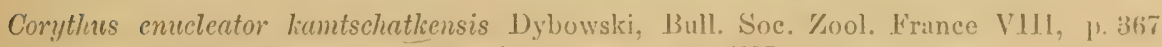
(1883 - Kamtsehatka, Beschreihung op. ('it. VII, p. 394, 1882).

Der ostsibirische Hakengimpel unterscheidet sich von der curopäisch-

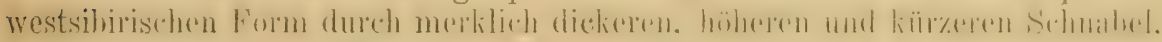
auch seheinen in der Regel dic Farben otwas lichter zu sein, das liot der Ò etras heller, der Unterkörper vielleicht heller gran. Die Fïbe scheinen etwas kräftiger zu sein. Schmabel $15 \mathrm{~mm}$.

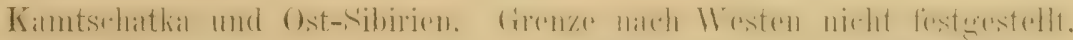
doch ist zu vermuten, daß sie, wie bei andern in Ost- und West-Sibirion

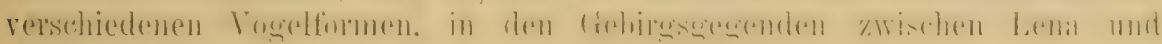
Jenissei -liegt.

\section{Giattung CHAUNOPROCTUS' Bן. 1850.}

Orad. mit teilweise rotem Gefieder, o oben und unten bram, Schmabel

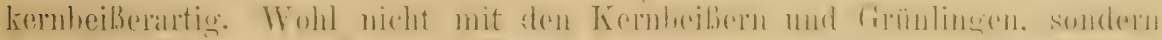
mit den Haliengimpeln und Karmingimpeln verwandt, aber dureh den ungeheueren Schmabel sofort lienntlich.

\section{Chaunoproctus ferreirostris (Vig.).}

Coccothraustes ferreirostris Vigor's, Kool. Journ. 1828, p. 354 (Ohne Heimatsangabe typus von den Bonin-Inseln).

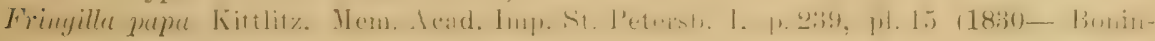
sima).

ơd. Oben braun. Rücken mit rotem Sehimmer und dunklen Feder-

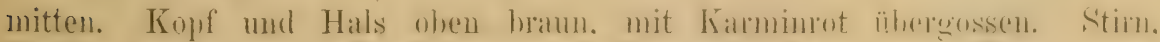

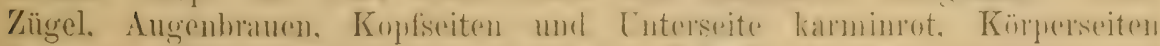

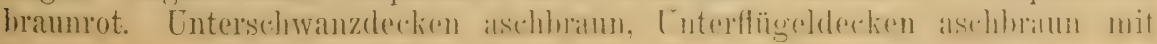


rosigem Śchimuer. Flügel 110. Schwanz 70, Schnahel ㄴ4, Lauf $28 \mathrm{~mm}$. ad. Oherseite braun. Rückenfedern mit dunklen Centren und olivenfurbenem Anflug. ['nterseite ockerbräunlich, Cnterkörper heller, Körperseiten braun.

Bonin-Inseln, südöstlich ron .Juran. Wurde 1827 während der Reise de's Schiffes. .Blossom" entdeckt und im folgenden .Jahre chenfalls von Kittlitz gefunden. Finer der seltensten aller Vögel, von neneren Sammlern nicht erbentet.

\section{Gattung LOXIA Linn. 1758.}

Dir Grittung der Kreuzschnähel ist unter allen palïarlitischen Vügehı aut den r'sten Blick an dem eigenartigen Schuahel zu erkennen; derselbe ist vorn stark seitlich zusammengerlriickt. (her- und Entersehnibel stark gebogen und einander ror der Spitze kireuzend. meist so, dab der Ginterschnabel nach links, ahere auch nicht selten sor. dia er nach rechts gehogen ist. (Fig. 23-27.) Nasenborsten auffallend dicht, die Nasenlöcher ganz

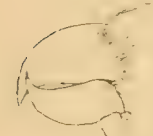

Figur 23.

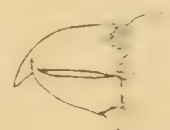

Figur 24.

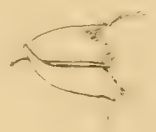

Figur 25.

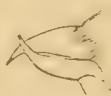

Figur 26.

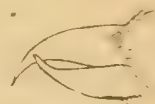

Figur 27.

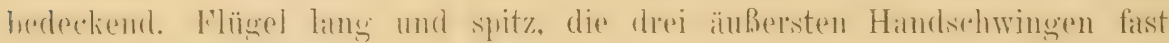
gleich und am längsten. Schwanz tief ausgeschnitten, kurz, aber lünger als der halbe Flügel. Lauf kurz, kürzer als die Mittelzehe mit Nagel. otad. rot oder grünlichgelb, o grünlich oder gelblich, Junge gestreift.

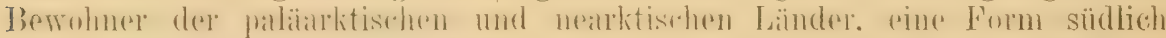
bis zu den Bergen der Philippinen, eine andre (in Amerika) bis Guatemala. Offene Nester in Bäumen, gefleclite Eier. Wir unterscheiden drei Arten (mit vielen Unterarten): ${ }^{1}$ )

1) Die Kreuzschnäbel neigen sehr zur Bildung lokaler Formen und wenu man Jahre daranf verwendet, Serien aus verschiedenen Läindern zu sammeh und eingehend zu studieron, so werden wohl noch mehr Formen unterschieden werden können. K. Z. konnte ich nicht melr feststellen, als hier geschehen. Am meisten Schwierigkeiten machten mir die englischen und schottischen. Sie sind es offenbar vorzugsweise, die Sharpe zu dem freilich vereinfachenden, aher nicht zu billigenden Schritte veranlaßten, alle bindenlosen Kreuzschnäbel ron Nord-Europa, Nord-Asien und Amerika zu vereinigen und ihnen , nicht einmal subspezifischen Rang" zu geben (Cat. B. Brit. Mus. XII, p. 439). Die nordemopäischen Formen des liontinentes bicten keine Schrvierigkeit dar. C. I. Brehm hat zwar unter Verkennung des geographischen Prinzips und mit Überschätzung individueller Variationen eine ganze Anzahl vermeintlicher Spezies und Subspezies benannt, die die Frage endlos schwierig erscheinen lassen (Naumannia 1853, mit 'Tafel), ein Studium seiner Stiicke alser zeigt, dnb + seiner Formen sich auf pytyopsittucus, die andern (abgesehen ron den wirklichen Bindenkreuzschnäbeln und Amerikinern) auf curvirostra beaichen. Loxiu pytyopsittacus und curvirostra müssen als Arten behandelt werden. Jedenfalls ist erstere eine nordische Form, die sich ursprïnglich aus $L$. cuvirostra entwickelt hat, mit der '/eit aber so scharf differenzierte, dalh sie neben $L$. curvirostra bestehen und beide wieder dieselben fiebiete hewohnen konnten. Daß sie durchaus auf. die Kicfer angewiesen sei. finde ich nicht bestätigt. 
Flïgel einförmig dunkelbraun, ohne, nur ausnahmsweise mit schmalen, meist undentlichen, roten orler weißlichen Binden

Flügel mit zwei auffallenden, breiten weißen Binden

L. leucoptera . p. 124

Schnabel dicker, an der Basis etwa so hoch, wie der Unterschnabel lang; Unterschnabel an der Basis hreiter, als die Dille lang, Flitgel iiber $103 \mathrm{~mm}$. . . . . . . . . . . . . . L. pytyopsittacus

Schuabel schlauker, an der Basis niedriger, meist nur etwa $3 / 4$ oder $2 / 3$ so hoch wie der Unterschnabel lang, selten ebenso hoch wie jener lang, Untersehnabel an der Basis selmäler, als die Dille lang, Flïgel unter $10: 3 \quad$ inu

L. rervirostin

189. Loxia curvirostra curvirostra I. (Fig. 25.)

Gemeiner oder Fichtenkreurschmahel.

Loxia Curvirostra Limnacus, Syst. Nat., Ed. X, p. 171 (1758- „Hab. in Luropae Abietis“ typ. Lok. Schweden, ex Fauna Suecica 177. Der Name wurde ron späteren

Autoren bisweilen in cricirostr( verändert).

Crucirostra abietina Meyer, Vögel Liv- u. Esthlands p. 72 (181n̆- Livland).

Crucirostra media, montana, pinetorum Brehm, Handb. Naturg. Vög. Deutschl., 1).212 .244 (1831 - alle aus Deutschland. Der Name montana kinn nicht lediglich auf die alpine Form bezogen werden, wie aus Naumannia 1853, p. 189 lịervorgeht. wo Schweden, Thüringen, Tirol als fiundorte angegeben sind).

Laxia europaea Macgillivray, Brit. Birds I, p.417 (1837- ex Leach, Syst. Cat., p. 12. nomen nudum. Hlacg. beschreibt zwar die große schottische Form, sein Name aber sollte ein passenderer Name für Linné's curvirostra sein, und kann daher leider nicht fïr die schottische fiorm allein angewandt werden).

Loxia mbrifasciata Bonap. \& Sehlegel, Mlon. Lox. p.5 Taf. 5 (1850- ex Brehm IIs., Lentraleuropa).

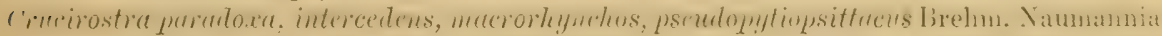
1853, p. 185, 187, 190, 192 (Nadelwälder bei Renthendorf, Thïringen usw.).

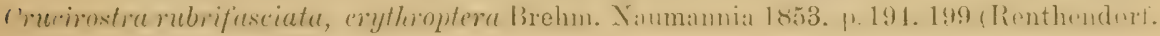
Thüringen, Harz).

Crucirostra dubia, assimilis A. E. Brehm, Verz. Samml., ]) 10 (1866 -. nom. nuda!).

Engl.: Common Crossbill. Französ.: Bec-croisé. Italien: Crociere. Schwed.: Korrsuäbb, Kryssnäbb.

ơad. Rot, meist ziegelrot, Rücken etwas dunkler und mehr mit hraun

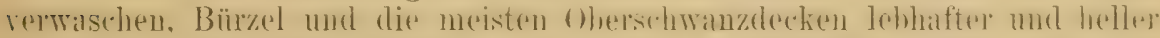

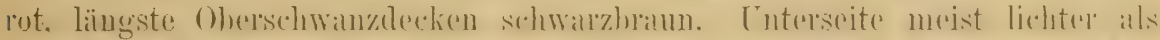

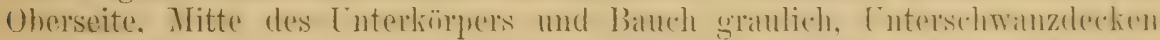

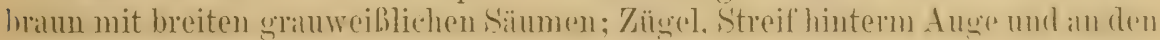

In Großbritannien (wo alle Kreuzschnäbel dickere Schnälsel hahen), findet eiue ähnliche Entwickelung statt. Auch hier hat sich Loxia curvirostra anglica im Norden zu einer urolischnäbligeren form (scoticu) anserehildet, ihr. Entwickelumg ist aher nicht so schart und weit gegangen und nicht so vorgeschritten, daß sie als eigene Art neben der andern (anglica) bestehen kann - denu wir finden bisweilen Exemplare, von denen man kaum zu sagen wagt, za welcher Form (scotica oder anglica) sie gehören. Solche sind aber selten, in der Regel können die großschnähligeren Schotten von den kleinschnäbligeren Engländern leicht unterschieden werden. - Das von mir untersuchte siideuropäische Haterial ist zu mangelhaft gewesen, um alle dortigen Formen auch nur annähernd endgültig zu besprechen, auch fehlt es noch an größern Sammlungen aus vielen T'eilen Mittelasiens usw. Während ich dies schreibe, stchen mir 405 Ḱrenzschnäbel zur Verfügung, woron über 300 dem Tringer Juseum gehören, außerdem sah ich die großen Serien im Britischen Museum durch. 


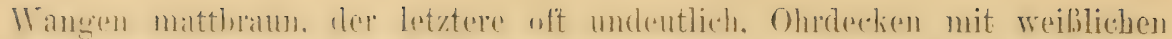

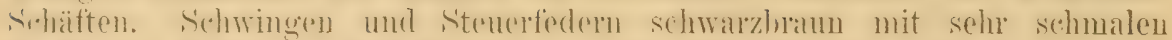

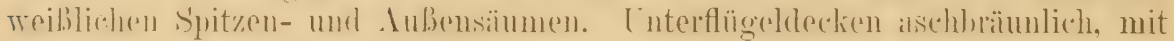
hellgrauen, meist rosig angehauchten Säumen. Iris, Schnabel und Füße braum. Flügel 99-102, Schwanz 59-73, Lauf etwa 27-28, Länge des

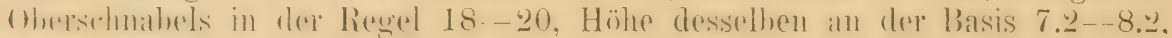
Breite des Unterschmabels an der Basis 10.8-11.4 mm.

ad. Oberseite fleckig olivengelblich, jede Feder olivenbraun mit

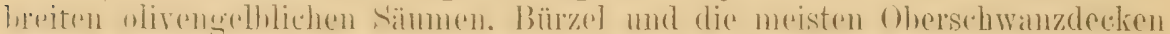

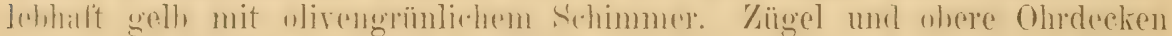

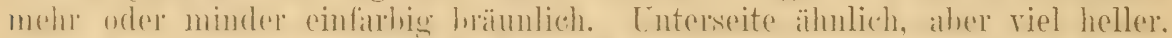

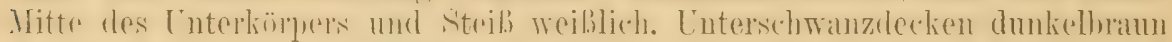

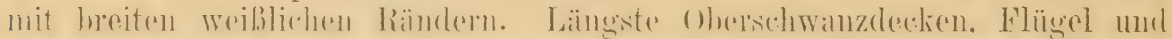

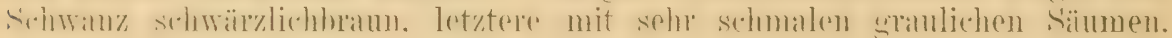
Kleiner als das ơ, Flïgel $94-97.5 \mathrm{~mm}$.

Das Jugendkleid ist ganz verschieden, denn Ober- und Unterseite sind dunkelbraun gestreift. Junge haben keine Spur von Rot, sondern sind oben

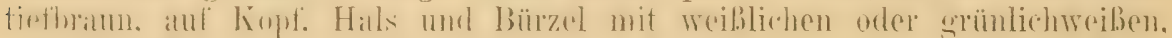

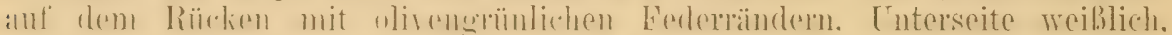

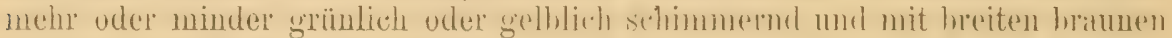
Streifen in der Mitte der Federn.

Das alte o variiert in der Tebhaftigkeit der gelblichen und griulichen

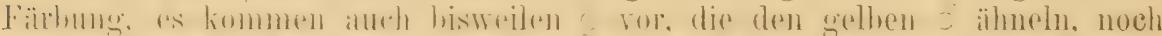

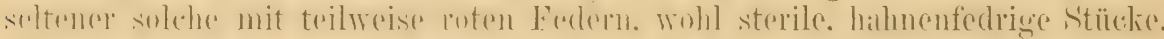

Das Gefieder der ơ variiert noch viel mehr. Alte Brutvögel sind meist rot, es kommen aber auch ganz gelbe vor, d. h. wo statt der roten Farbe

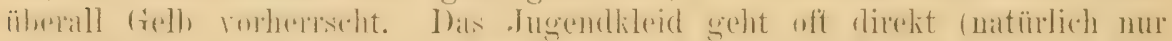
(dureh Mauser) in das rote ïber, oft aber erst in ein gelbes oder dem der o

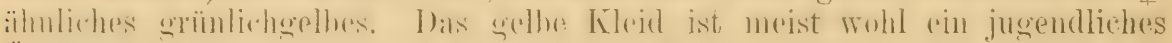

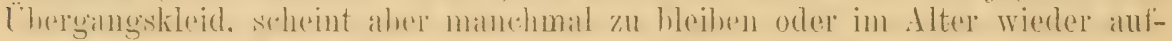

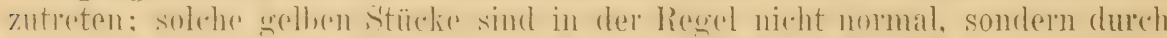

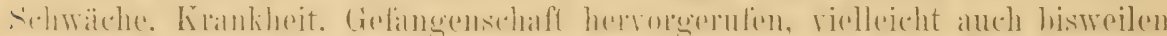

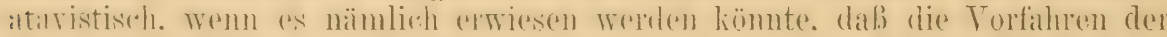

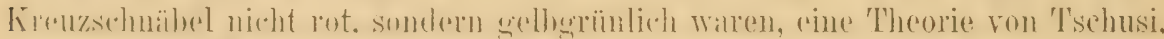

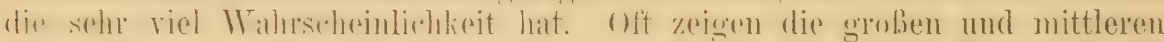

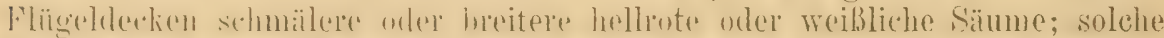

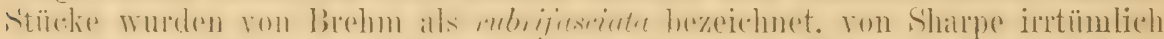

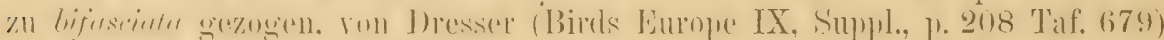

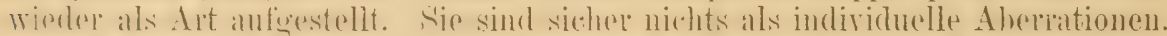
Als "Subspezies" kamu diese Form nur betrachten, wer noch nicht hegriffen

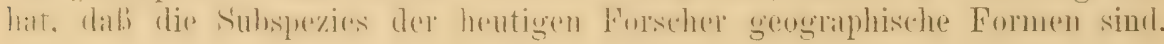

Huropa vou Lappland bis Italien und Korsika, ganz Rubland bis

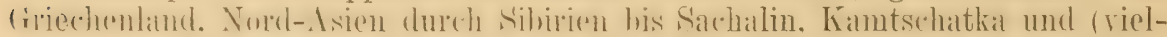
leicht nul im Winter) Nord-Japan, südlich anscheinend bis Yokohama. In Europa wirl L. e. curvirostre in GroBbritannien, Spanien, auf Cypern und

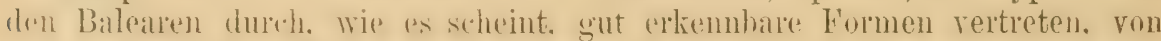
anderu Inseln des Mittehmeeres lionnten keine. oder nur wenige untersucht worden. Im fernen Osten Asiens (celexentlich Ost-Sihirien, Nord-.Japan.

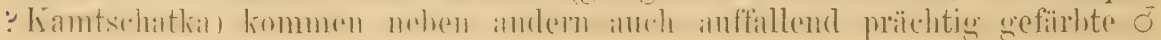


vor. und es wäre möglich. daß man dort (? Kamtschatká) eine loblaftere Interalrt - eiur Parallele zu L. lencoptera elerums - wird abtrenuen kömnen, deren Verbreitung und Beständigkeit aber noch ganz unsicher ist.

Der Grundzug dles Wesens dieser merkwürdigen Vögel ist das nomaden-, zigeunerhafte, denn sie ändern ihren Aufenthalt gern: In Gegenden, in denen man sie Jahre lang nicht sah, treten sie plötzlich auf und nisten dort auch; ebenso verlassen sie auch ihre Brutplätze plötzlich. Dieser Wechsel der Wohnsitze scheint mehr oder minder mit dem Geraten der Nadelholzsamen in Verbindung zu stehen. Im allgemeinen sind es mehr gemischte als reine Nadelhölzer, die sie bewohnen. Dort treiben sie sich in kleineren Trupps oder großen Flïgen herum. Sie sind meist gar nicht scheu, immer geschäftig herumflatternd oder kletternd, wobei sie wie Papageien den Schnabel zu Hilfe nehmen. Ihre Lockstimme ist sehr charakteristisch, wie plüt, plüt, plütplüt oder küpküpküp, der Gesang ist abwechselnd, zwitschernd, klirrend und flötend. Außer Nadelholzsamen fressen sie auch andre Baumsamen und Beerenkerne gern, sowie Blattläuse, die sic ganz auffallend lieben. Wechselnd nach Ort und Keit ist auch ihr Brïten. Meist brïten sie im frühen Frühjahr, und selbst schon im Winter, aber manchmal auch im Sommer und Herbst - ja es gibt nach Brehm keinen Mlonat, in dem man nicht schon Eier oder Junge gefunden hat. Es scheint, daß, im Gegensatzè zu fast allen andern Vögeln, auch die Manserzeit verschieden ist, wahrscheinlich nach der Zeit, in der die Vögel ausgebrïtet sind. Brehm allerdings gibt an, mausernde Kreuzschnäbel sich paaren, Eier legen und Junge füttern gesehen zu haben. Fernere Beobachtungen hierüber sind sehr ervünscht. - Das Nest ist dicht und warm, anscheinend immer auf Nadelbäumen, meist ziemlich hoch, gern von Zweigen überdeckt. Die Eier sind 3-4, öfter 3 an 'Zahl. Sie ähneln denen des Grünlings, sind aber etwas größer, đünnschalig, glatt, schmutzig oder grünlichweiß mit einigen violettgrauen Schalenflecken und rotbraunen oder fast schwarzen Punkten, Flecken oder Schnörkeln, meist wenig und klein gezeichnet. Sie messen $20<15,22.13>15.79-23.5 \times 16 \mathrm{~mm}$. Das 우 brütet 14-16 Tage allein. - Das Fleisch der Kreuzschnäbel schmeckt nach Harz.

\section{Loxia curvirostra hispana subsp. 110r. (Fig. 27.)}

Subspeciei L. c. curvirostra dictae simillimus, sed rostro graciliore, longiusculo.

Aus Spanien konnte ich nur fünf Stück im Museum zu Edinburgh untersuchen. allo aus Aguilas bei Mureia. rom Juli 1897. Alle fünf sind etwas sehmutzig und hahen augenseheinlich kure Zeit im Kätig gesessen. Zwei

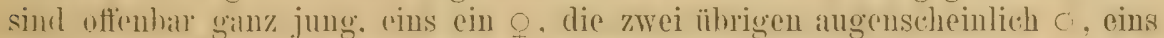
gerfirht wie rin - das andre mit sehr wenig rot. Ton der Färhung kann daher nivhts Bestimmtes gesagt werclen, ohwohl alle ziemlich düster erseheinen; anch sind dir mehr oder minder alogestoBenen Flügel und Schwänze zum IIescen nicht tallghioh, aher die Sohmähel machen einen so schlanken, langen Eindruck. disb ich nicht umhin kam, die spanisehe form aloutremen. Srlunahellänge der of 21. Höhe des Obersehnabels nicht ganz 7. Breite des Lutersehmahrels an der Basis 11 mm. ('Typus no. 1897, 91, 14, im binburgh Museum.)

Spanien, wahrscheinlich ziemlich weit in Lande verbreitet.

\section{Loxia curvirostra anglica subsp. nor.}

Suhspeciei L. c. curvirostra dictae similis, sed colore rubro remissiore, rostro hebetiore, ad crassitiem majorem vergente.

Unterscheidet sich von L.c. arvirostra im frischen Gefieder durch (twas mattere Fïrhung: I bis 5 hat ein matteres, mehr mit Grau und weniger 
mit Orange gemischtes Rot, das nie die Lebhaltigkeit der alten o row Kontinente erreicht; das o ist etwas düsterer, Brust und Bürzel im frischen Gefieder mehr grïnlich, fast nie so gelblich und lebhaft. Der Subuabel ist stumpfspitziger, weniger schlank und gestreckt, neigt auffallend zu bedoutender Stärke und kommt oft dem der schottischen Form nihle. Flügel wie die von L. c. curvirostru, nur hisweilen etwas länger, etwa 99-102.5 mm. Schnabel alter $17.5-19$, Höhe des Obersehmabels meist etwa 8.2. Breite des Unterschnabels an der Basis etwa 12-12.8 mm. (Trpus o 110.1890 im Rothschildschen Museum, Tring 7. XII. 1897.)

Unregehmäßig, nomadenartig umherstreifend, alher alljährlich in gomischten und reinen Nadelwäldern in England (und Irland. Serien aus Irland aber nicht untersucht) nistend. Vom Herhst his Frühijalır in Flügen und mohr bemerkbar. daun anch ofter in Schottland, wo sein Nisten aher nicht erwiesen zu sein scheint. ( $L$ 。 e curvirostra verirrt sich nur selten nach Grob)britannien.)

\section{Loxia curvirostra scotica subsp. nov. (Fig. 2t.)}

Subspeciei L.c. curvirostra dictae similis, sed rostro multo crassitiore, colore maris remissiore.

Färbung wie bei L. co anglica, nur selten lebhafter, Schnabel dicker,

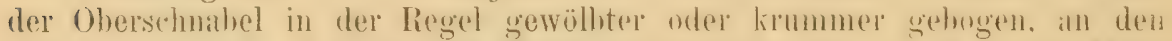

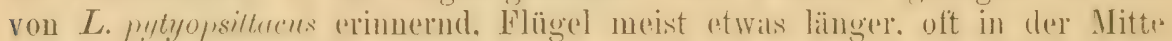
zwischen dem von L. pytyopsittacus und L. co curvirostra stehend. Flügel

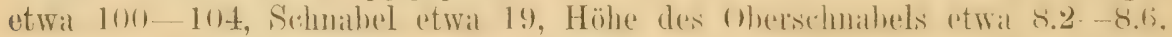
Breite des Untersehnabels an der Basis etwa 12.5-13.6 mm. Die Untersebiede fallen anf den r'sten Blick mehr auf, als die Malbe remuten lassens. (Siehe Ammerkung 1. 117.) ('Typus no. a. in dee simmlung lon Feilden d Harvir Brown. East Rossshire 26. XII. 1870.)

Brutvogel in den Bergwäldern Schottlands, im Winter zuweileu bis

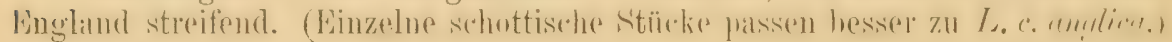

\section{Loxia curvirostra balearica (Hom.).}

Cmeirostra curvirostra var, balearica A. v, Homeyer, Joum. f. Orn. 1862, p. 2ăt (Mullorku, Balearen).

Wird von Homeyer beschrieben als sehr dickschuäblig - er sagt, der

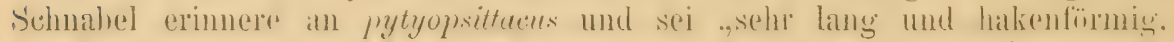
der Lnterschnilhel ganz kurz und rerdickt". Wals sich einigermaben willerspricht - schr liurzflïglig, . und Junge mit eigentümlich granem liolorit. Es sind mir nur die Typen im Berliner Museum (ein o jur. und ein ?) und zwei jüngere os (noch mit Spuren des Jugendlkleides) in .Tr. Hontard Saunders Simmmlung bekaunt. Letatere haben durchans keine selur dicken

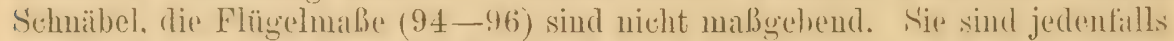
von $L_{0}$ c. curvirostra verschieden, müssen aber $L$. $c$. poliogyna sehr nahe stehen, sind aber möglicherweise knryflïgliger und etwas langschnibligen.

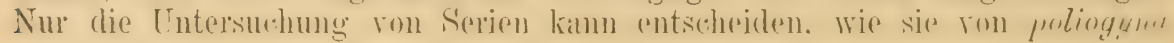
abreichen.

Insel Mallorka (Balearen). 


\section{Loxia curvirostra poliogyna Whit.}

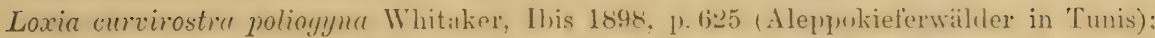

Erlanger, Journ. f. Orn. 1899, p. 461 und Abbildung 'T'af. 15.

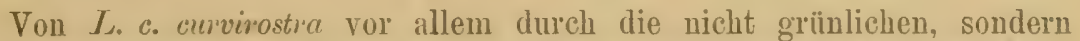
brämlich aschgrauen 7 . die nur au der Brust einen ganz schwachen und auf dem Bürzel deutlichen gelhgriünen S'himmer hathen. zu unterseheiden. Auch junge Vögel zeigen schon den Mangel an Grïn. Rote alte sind rerhiiltuismüBig

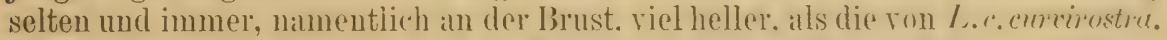

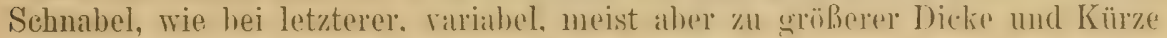
hinneigend, bisweilen dentlich kürzer und dicker.

Bewohnt die Wälder der Aleppokieferm in 'L'unis und Algier.

\section{Loxia curvirostra guillemardi Mad.}

Loxia guillemarli Mladarász, Orn. MLnatsber. 1903, p. ̄ (Cypern).

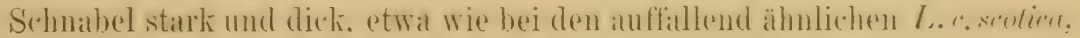
Gefieder durch pinen unewissen dunklen Ton rharaliterisiert. Was hesonders hei frischvermanserten alten - anffält. die einen dunkeln Rëicken hahen und deren Rot ein dunkles Lirschrot çenannt werlen kimn, sowie hei jüngeren und in dem ersten Jugendkleide, wïhrend of ron denen von L. «. scotica wohl kaum zu unterscheiden sind.

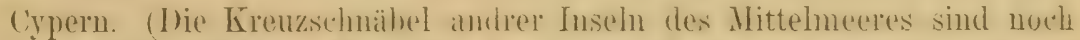
nicht genügend bekannt. Nir liegt tin o und jun. ron Korsika ror, die

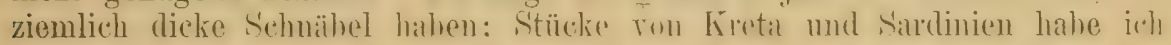
nicht gesehen.)

\section{Loxia curvirostra albiventris Swinh.}

Loxia albiventris Swinhoc, Proc. Zool. Soc. Lond. 1870, p. 437 (Peking).

Loxia cuvirostra japonica Ridgway, Proc. Biol. Soc. Washington II, p. 101 (1885Jарап).

WVie L. c. curvirostra aber kleiner — ôad. Flïgel $94-97 \mathrm{~mm}$ Sehmahel ebenso proportioniert (nicht merklich s(hlauker). aher kleiner. Gelhe : scheinen (in Turkestan namentlich. ron wo fist alle geelh sind) rerhältnismäBig häufig zu soin.

Turkestan bis ('hina und Japan, uördlich bis zum Amur und Hakodate. Japanische Exemplane gleichen denen aus (China und Turkestan. im mörellichen Japan kommt aher auch eine grobe Form lor (siehe I.. a arrevesta).

\section{Loxia curvirostra himalayensis Blyth. (Fig. 26.)}

Loxia himalayana Hodgson, Gray's Kool. Misc., p. 85 (1844- nomen nudum!).

Loxia himalayensis Blyth ex Hodgson M.S., Journ. As. Soc. Beng. XIII. p. 952 (1844Nepal).

Ein wahrer //werg: Flügel etwa 85. Schwamz ctwa 52, Schuahel $14-15$. Höhe rles Oberschnabels 5, Breite des Lnterschnabels an der Basis $7 \frac{1}{2} \mathrm{~mm}$. Färbung wie hei anderu Kreuzsehnäheln. aher schulterfeder'n und Rüreken 


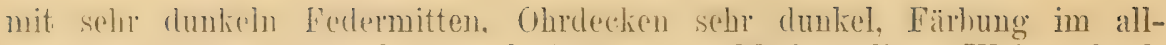

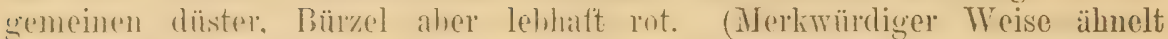
1. c. americanct (= minor Brehm) der L. c. himalayensis ganz auffallend.

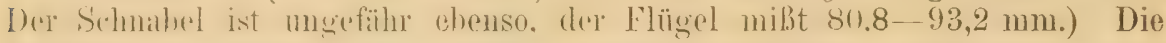
Färbung ist ebenfalls seh" dunkel, aber der Rücken nicht mit so sehr dunkeln Federmitten. Ohrdecken meist mehr mit Rot übergossen.) ${ }^{1}$ )

Himalaya.

\section{Loxia pytyopsittacus Borkh. (Fig. 23.)}

Großer oder Kiefernkreuzschnabel.

Loxia Pytyopsittacus Borkhausen, Rheinisches Magazin I, p. 139 (1793- Exemplar „im Leskischen Kabinete in Marburg". Bercits ron Gmelin, Syst. Nat. p. 843 var. $\gamma$ und ron Otto in Naturforscher XII p. 96, beschrieben, aber nicht benannt. Der Name, in der Schreibweise pytiopsittacus, später oft in pityopsittacus rerändert, wird sonst Bechstein - Orn. Taschenb. I p. 106, 1802 - zugeschrieben, Borkhausen aber benannte die Art zuerst. Eine Lokalität ist nicht angegeben. Wahrseheinlich war der Typus in Deutschland erlegt, aber die eigentlich regelnäßige Brutheimat ist Skandinavien, als terra typica ist daher am richtigsten Schweden zu substituieren).

Crucirostra pinetorum Meyer, Yög. Liv-u. Esthlaud, p. 71 (1815- Livland).

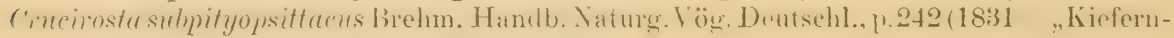
und Fichtenwälder Deutschlands").

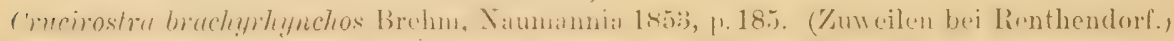
Concirestra pityogs. mujor A. Brehm, Xammanua 1853. 1. 181. (Thiiringen.)

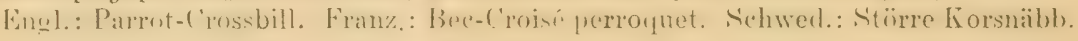

Riesenform der Gattung. Färbung von del vou L. c. curvirostra nicht

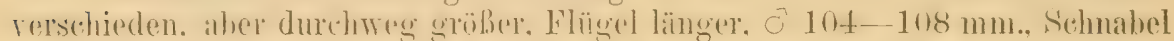

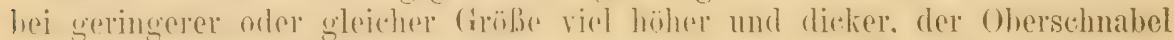

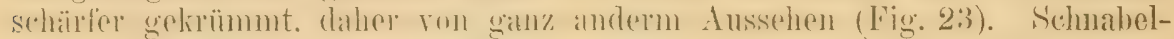
lïnge 19-20, ganz ausuahmsweise vielleicht, nur abnorm 21; Höhe des Oberschmabels $9-10$, Breite des Unterschnabels an der Basis $13-16 \mathrm{~mm}$.

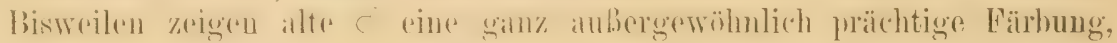
indem sie, mit Ausuahme von Sehwanz und Schwingen, ganz rot werden, gerade wie bei $L$. curvostra; doch sind solehe, wie bei jener nicht häufig.

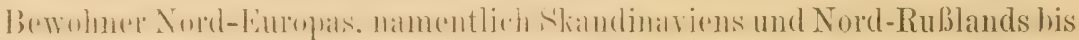

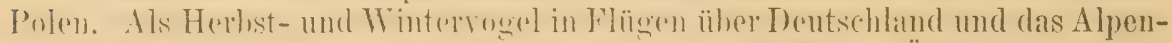

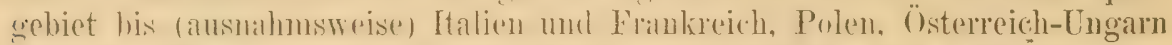

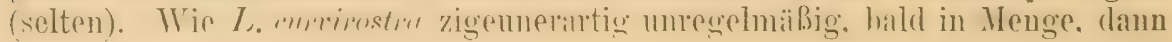

1) In Amerika wohnen folgende Formen:

Loxia curvirostra anericana Wils. 1811 (= minor Brelm 1853) bewohnt das nördliche und östliche Amerika.

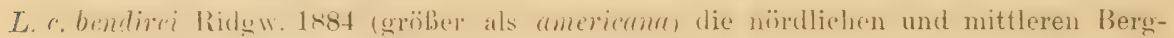
länder der westlichen Vereinigten Staaten,

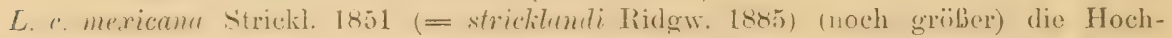
gebirge von Neu-ILexiko und Arizona. (Vgl. Ridgway, Birds North \& Middle Amer. I, p. 46, 1901.)

Merkwïrdiger Weise wohnt in den Hochgebirgen der Philippinen-Insel Luzon noch eine Loxia, L. hzonensis Grant, die der L. c. americana auch sehr ähnelt, aber gedrungeneren Schnabel und riel grauere of hat. 
jahrelang fuhlend. Nistet anch mehr oder minder unegehmäbig in Dentrehland, mamentlich dem Nordosten, auch in Stulesien. vor Yaiten in Roda- und Orlatal (C. I. Brelım, 1817, 1819 u. a. m.). In West-Deutschland im all-

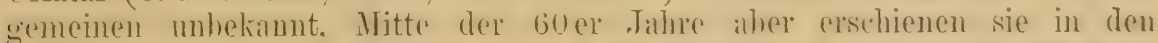
Finforntaldungen lea Darmstadt in groferen, num atus dieser Art hestehenden Flügrn. sodab) Kublunam (der Tater) in einem Trinter etwa 2on Stïrk erhielt: pinige blieben zurvirk und cin cinzelnes T'alr mindestens schritt lanseheinend im März) zum Nesthatu. Auch in del Selneiz und Oherhalyern

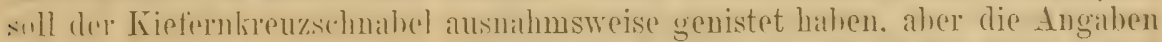
dariiher sind wenige und nielut immer heweisend. Englische Stüclie sind mil nicht hekimnt. dic Insiben darriber seheinen sich meist odere alle auf L. c. seotica zu bezielien.

L.ebensweise wie die ron L. c. curvirosta, aber der Lockton auffallend lauter und tiefer, mehr wie plöp, plöp und zok, manchmal ein sehr leises gip, Gesang lauter. aus schmarronden, schwirrenden und flötenden 'Tönen zusammengesetzt. Bewohner ron Nadelholzwaldungen, besouders wo Kiefern und Fichten zusammenstehen, nicht gern ganz reiner, weiter Kiefernforsten. Im allgemeinen besonders der Kiefer zugetan, deren Samen er auch zu seiner Nahrung bevorzugt; doch frißt er auch Fichtensamen und andre Sämereien. Nistweise wie die von L. c. curvirostra, Nest auf Kiefern und Tannen, Eier wie die ron L. cuvvirostra, aber größer, dicker, $21 \times 16.5$ bis $23 \times 17.7 .20 \times 16.5,23.04 \times 16.69$ bis $25 \times 17 \mathrm{~mm}$. Das $q$ brütet allcin.

\section{Loxia leucoptera bifasciata (Brehm).}

Weißbindiger Kreuzschnabel.

[Loxiu lencopter, Gmelin, Syst. Nat. I, p. 844 (1788- „Hab. in sinu Hudsonis et Norehoraco".) ] ${ }^{1}$ )

Cincirostra bifasciate C. 1. Brehm. Ornis III, p. 85 (1827-Thüringer Wald und Wien, Typen erhalten); id. Isis 1827 p. 714.

Luxin tremingtera (ilogen, Isis 18ะ7. p. 411 (Sehlesien): Ahbild. Namman XII, Tat. 385, u. a. Concirostre orientalis Brehm, Naumanuia 1853, p. 251 ("Himalaya“ - nach Gould, wahrscheinlich irrtümliche Angabo -, Wien und Thüringen. Sind typische bif(esciata).

Crucirostra trifasciate Brehm, Naumamnia 1853, p. 243 (Renthendorf und Roda).

Crucirostre assimilis Brehm, Naumannia 1853, p. 253 (Roda).

Jingl.: Two-barred Crossbill. Franz.: Bec-croisé bifascié. Schwed.: Bände Korsnäbb.

Unterscheidet sich von L. curvirostra und pytyopsittacus, denen er in dre butwickelung und allgenceinen Fïrlung (o ad. rot, of gellogriulich, juv. den zihnlich. sellue ad. selten) gleicht, dureh die heiten weißen Binden ant den Flïgreln. Dic kleinsten Flügeldecken sind selhwar\%hraun mit röt-

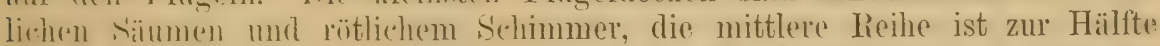

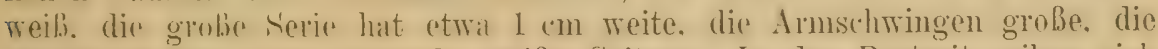
Handsehwingen san\% selmmale weiße Spitzen. In der Brutzeit reilien sieh

1) Loxic lencopterc leucoptera Gm. 1788 bewohnt das nördliche Nord-Amerika und ist der europäischen Form zwar oberfläichlich ähnlich, unterscheidet sich aber auf den ersten Blick durch viel dïnneren, niedrigeren Schnabel, geringere Größe (Flügel etwa 5) mm kürzer) und ticfer schwarze Flügeldecken, Schulterfedern und Rückenmitte, auch ist das Rot anders, mehr johannisbeerrot. Bewohnt die Koniferenwälder des nördlichen Nord-Amerikas und ist 3 - oder $4 \mathrm{mal}$ in Großbritannien vorgekommen, diese Fälle mögen aber zum Teil bezweifelt werden, da es sich in einigen um entflohene Käfigrög̣el handeln kann. Angeblich auch auf Helgoland vorgekommen. 
die weiken Śpitzen der Shawingen ganz, die der Flügeldectien teilweise ab. Junge or und o habeu schmälere weibe Elügelhinden. Das lot der $\hat{\sigma}$ ist variabel, aber anders als bei amrostre. mehr losil, dic sehulterledern sind schwarhlaum, mit rot gespitzt und ïbertüncht. Flügel 92-95. Schwauz. ctwa 65 , Schnabel $17-20 \mathrm{~mm}$.

Nadelwaldungen des nörllichsten Nolel-kuropas, umregelmäbig schanenweise - und zwar nicht nur im Winter - nach Sïden streifend, selten bis

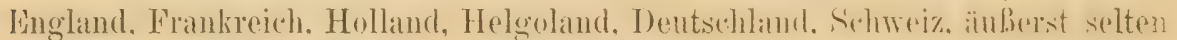
bis Italien, häufiger Polen, Östereich-Ungarn.

In der Lebensweise wie die andern Kireuzschnäbel, abcr schr wenig schen, fust dummdreist. Nester und Eier vielleicht kleiner als die von L. curvirostro, ein Ei in Dr. Rey's Sammlung mißt $21 \times \mathbf{1 4 . 6} \mathbf{m m}$. - C. L. Brehn erbentete Serien im August, und es ist durchaus nicht unmöglich, daß sie damals ausnahmsweise einmal in Deutschland gebriitet haben.

\section{2()0. Loxia leucoptera elegans Hom. (Now finglich. Fim.)}

Loxia eleyans E. v. Homeyer, Journ. 1. Orn.-1879. p. 180 (Amur).

Loxia leucoptera elegans T'schusi, Orn. Jahri). 1903, 1). 163 (Sibirien).

Loxia amurensis Dubois, Bullet. Hus. Roy. d'Hist. Nat. Belg. T, p.85 (1882- Amur).

In Ost- und West-Sibirien kommen of mit gauz erstaunlich lebhaftem, lenchtenden Rot vol: wïhrend die Mehrzahl. namentlich alleds dio s. den

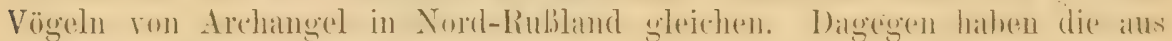

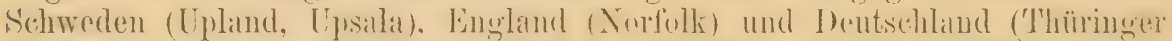

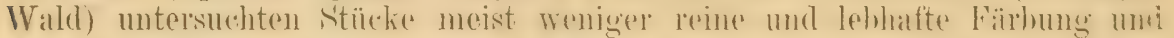

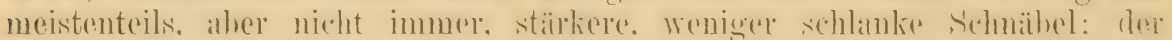

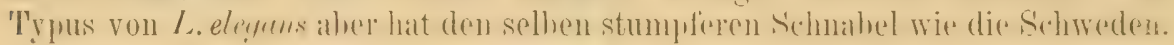

Falls es sich wirklich um eine konstante Form handelt (was noch

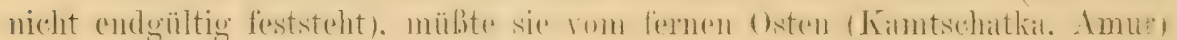
his Archangel reichen und die trpische bifusciata nu Nord-Skandinavien (Lappland) bewohnen.

\section{Gattung FRINGILI,A L. 1758.}

UmfaBt unsre Buchfinken nebst Verwandten in N.W.-Afrika und anf

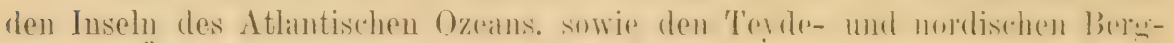
funken. Äuberlich. namentlich in dem harten. gaeralen. spitzes sthnibul,

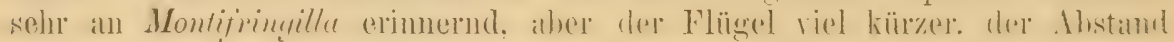
von den Arm- zu den Handschwingen geringer. Gefieder voll und weich.

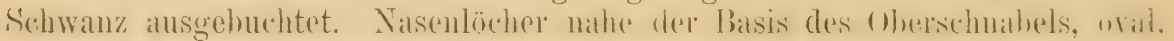
gröBtenteils ron kleincn, steifen, nach rorn gerichteten oder etwas umsebogenen Federehen hederkt. In Flägel sind dic arsten Arei stohringan oder die zrveite bis vierte (entwickelte), etwa gleich, und am längsten,

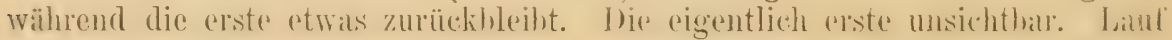
rom mit groben, aber meist nur muten seharfyotrenuten 'ateln, seitlich mit fortlaufenden Sehienen hedeckt. Nester kumstroll gedbut, frei anf Bämmen

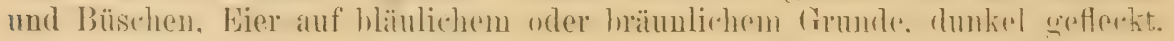
Huropa, N.W.-Afrika, Altantiden, Nord-Asien. 
Ubersicht der Arten (̋):

1 Ganze Oberseite und 'leil der Unterseite graublau . . . . F' teydea p. p. 129

\{ Ohne Blau an der Unterseite.................. 2

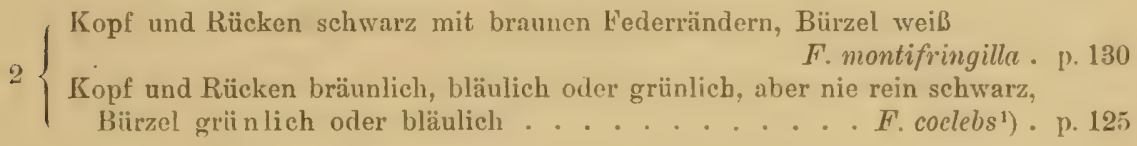

\section{Fringilla coelebs coelebs $\mathrm{L}$.}

Der Buchfink.

Fringilla coelebs Linnaeus, Syst. Nat. Ed. X, p. 179 (1758- "Habitat in Europa“. Als typische Lokalität ist Schweden anzusehen, denn die Diagnose gründet sich auf Fauna Snecica 199. Die ursprïngliche Schreibweise coelebs wurde aus sprachlichen Gründen vielfach in ccelebs verändert).

Fringilla nobilis Schrank, Fauna Boica, p. 176 (1798).

Passer Spiza Pallas, Zoogr. Rosso-Asiat. II, p. 17 (1831²)-- „Per omnem Rossiam et Sibiriam occurrit").

Frvingilla hortensis Brehm, Handb. Naturg. Vög. Deutschl., p. 272 (1831 - „In Gärten und mit Laubbäumen besetzten Orten des mittleren Deutschlands").

Fringilla sylvestris Brehm, Handb. Naturg. Vög. Deutschl., p. 273 (1831 - „Fichtenwälder unseres Vaterlandes").

Fringilla alpestris und minor Brehm, Vogellang, J. 102 (1855- alpestris „auf den Alpen“, minor „in Deutschland").

Fringilla coelebs septentrionalis A. E. Brehm, Verz. Samml., p.9 (1866- nomen nudum!) Fringilla coclebs tristis Floericke, Mitteil. Osterr. Reichsb. f. Vogelk. u. Vogelsch. UI, p. 21 (1903- im Wintes auf der Kurischen Nehrung, Brutheimat unbekannt).

Engl.: Chaffinch. Franz.: Pinson ordinaire. Ital.: Fringuello. Schwed.: Bofink.

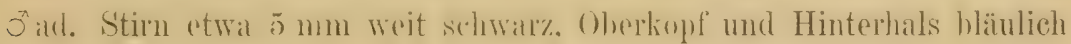
aschgrau, im Herhstleide dureh später sich abnutzende rosthrämliche Feder-

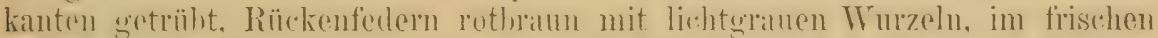

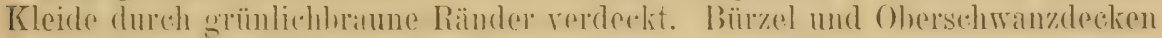

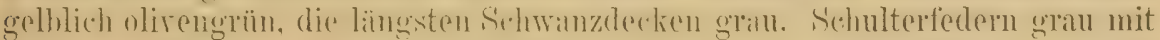
rothraunen Sïumen. Schwingen hräunlichss:hwar\% mit mattgelhlichen. an den

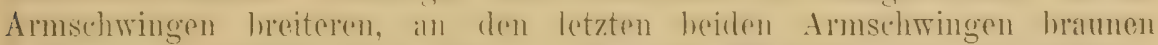

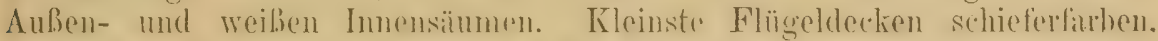

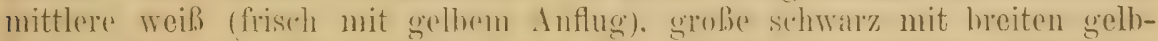

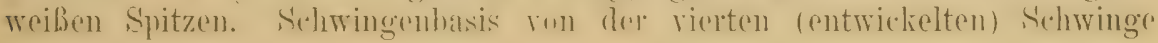

1) Ich habe mich erst nach sehr eingehender Prifung und reiflicher Überleguug

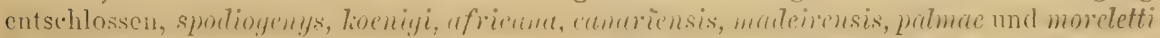
als Subsperies ron corlels aufzufassen. halte dies aber nun lär unbedingt riehtig. Alle diese Formen lassen sich, wenn man frische Herbströgel ron allen Lokalitäten vergleicht, ohne Z Krang von einander ableiteu. Die nordafrikanisehen F'ormen (namentlich die kleine, lebhaft gefärbte koenigi) steht $F$. c. coclebs schon schr nahe, nur fehlt das Rotbraun des MIantels und die Unterseite ist heller. Bei den atlantischen Formen sehen wir das Rotbraun auf dem Mantel ron maleirensis auflallend angedeutet - die Weibchen aller der Formen sind einander sehr ähnlich, zum 'l'eil nicht zu unterscheiden. Übrigens stehe ich mit meiner Ansicht durchaus nicht allein.

2) Pallas' Zoogr. Rosso-Asiat. wurde bisher mit der. Jahreszahl 1811 zitiert, das Werk erschien aber, wie festgestellt wurde, nieht vor 1831, obwohl auf dem Titelblatt fälschlich 1811 gedruckt wurde. Tgl. Ibis 1882, p. 611. 


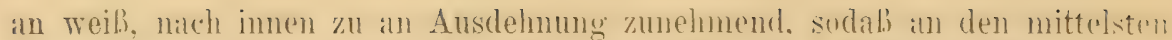
Armschwingen fast die halben Fahnen weils sind. Mittelste Stencrfedern

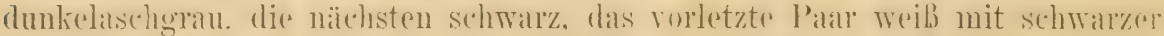

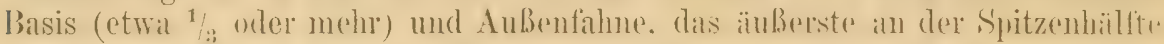

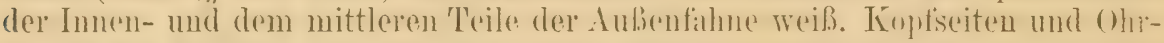
decken wie die Brust. Unterseite von einer schwer zu heschreihenten nath hintr.m zu hlasser werdenden, hä̈unlich-weinrötlichen, im Hertostgetieder mehr graulichen.

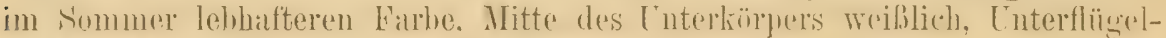
decken waib mit gelblichem Schimmer. Schnahel im Horbste hä̈unlich, im

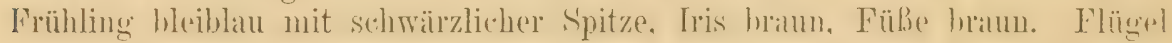
87-92 (höehstens), manchmal küızer, nur etwa 82, Schwanz 67-71 (kleine Stĩcke 62), Schnabel 11.5-13.5, Lauf etwa $18 \mathrm{~mm}$. O Oberseite olivbram

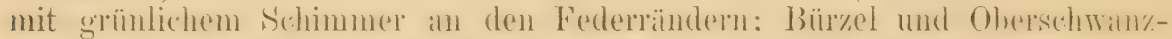

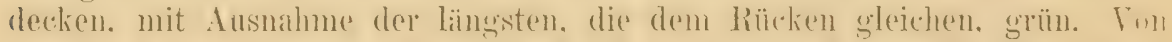

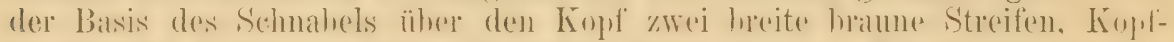

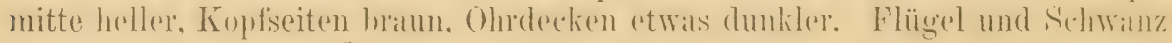

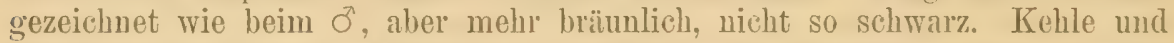

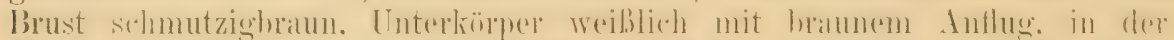

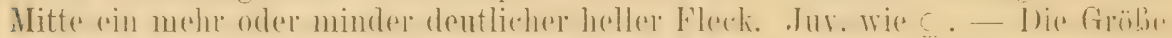
der Buchfinken variiert. Im Herlst und Winter kommen in Deutschland und England viele kleine Stïcke vor (o Flügel nur etwa $82 \mathrm{~mm}$ ). Auf solehe hat man Brehm's minor bezogen, und darauf dürfte atuch tristis sich beziehen. Is kommen aber auch alle möglichen Übergänge zwischen den kleinen und großen Vögeln vor, und vage ,biologische Beobachtungen" beweisen nichts, demn auch dieselben Individuen sind während des Zuges

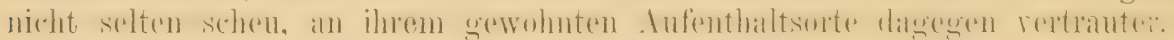
Geringere Größe an nordischen Stïcken habe ich nicht feststellen können. lihle wir daher durch Serien von den Brutpliitzen darïber helehrt werden, daß es "irgendwo im Norden" cine bestindig kleine Form gibt, könuen wir eine solehe nicht als 'Tatsache himnehmen. Das Benennen solcher vermeint-

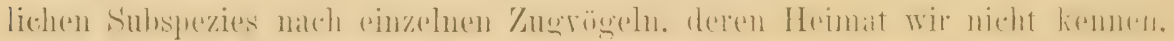
ist nicht zu billigen, da wir an ihnen keinen festen Anhalt, keine sicheren Ausgang'spunkte habeu.

Der Buchfink bewohnt Europa. In Norden geht er in geringer Anzahl bis fast zum Nordkap, südlich des Polarkreises ist er häufiger, südlich bis zum Mittelmeer, aber in Süd-Spanien selten. Im Winter besucht er NordAfrika, aher nicht in groBer Menge, die Mehrzahl überwintert in Luropra. Nach Osten zu geht er in Sibirien bis Omsk, fehlt in Ost-Sibirien ganz,

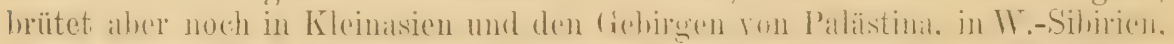

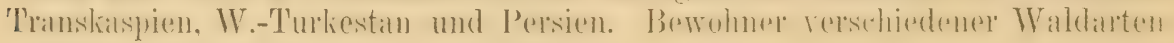
unterscheiden sich nicht von einander.

Bewohner aller möglichen Örtlichkeiten, wo Bäume wachsen, rom hohen Laubund Nadelwald-bis zum Garten, Plantage, Baumallee, in der Ebene sowohl als im Gebirge, so hoch Laubwald und Obstbäume gehen. In vielen Gegenden die häufigste Vogelart nächst dem Sperling. Jedermann kennt das meist im F'liegen ausgestoßene jüpp, jüpp und den lauten hellen, muntern, wie fink oder pink klingenden Kuf, wie auch den lustig schmetternden Schlag der Buchfinken. der lokal abweicht, in einigen Gegenden melodischer, in andern rauher und anderweitig rerschieden klingt. Auch der Lockton soll nicht überall derselbe, z. B. (nach Jourdain u, a.) in Skandinavien langgezogener, gröber sein. Die Nalırung besteht aus Sämereien, Beeren und Körnern und im Sommer größtenteils aus Insekten, womit auch die Jungen gefiittert werden. 
Das meist den Ästen durch die äußere Bekleidung nit Flechten wunderbar ähnliche Nest ist durch dichte, weiche Wände und tiefen Napf ausgezeichnet. Die Behauptung, daß manche Nester "alljährlich vergrößert werden", ist wohl unhaltbar, dagegen war" es der Buchfink, der in Wesel zweimal im Jahre im selben Nest brïtete und ein gleicher Fall wurde von meinem Vater bei Marburg beobachtet. S. 68 ist die Notiz dureh Irrtum unter A. carduelis geraten. 2 Bruten sind die Regel. Das Nest steht immer auf Bäumen und enthält 4-7 Eier, die in 2 Färbungstypen vorkommen. Sie sind (am öftesten)

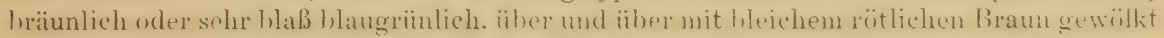
und mit schwarzbraunen und braunroten Zeichnungen versehen. Die andere 'Type ist hellblau, mit ähnlicher Zeichnung. Besonders charakteristisch sind die sogenanuten lirumbflecke, d. h. dunkelbraune Flecke mit verwischten Rändern, wie bei Brandlöchern in Papier. Manchmal kommen auch ungefleckte, sehr selten einfarbig hellblaue Eier vor. Maße von 100 Eiern nach Rey im Durchschnitt $19.3 \times 14.6$, im MIaximum $22.8 \times 15.5$ oder $22.5 \times 15.8$, Minimum (von Spureiern abgesehen) $17 \times 13.7$ bezw. $17.7 \times 13.2 \mathrm{~mm}$. Durchschnittsgewicht $0.125 \mathrm{~g}$. - Während des Zuges findet eine teilweise T'renuung

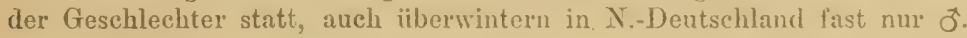

\section{Fringilla coelebs spodiogenys Bp.}

\section{Del' Miaurenfink.}

Fringilla spodiogenys Bonaparte, Rer. '/ool. 1841. p. 146 (Sfax in 'I'unis, an der Grenze von 'I'ripolis. -- Der Name wurde später oft in spodiogenia und spodiogena verïindert).

Oberer. 'I'eil der' '/ï̈'gel und schmales Stirnband schwar\%, Oberkopt',

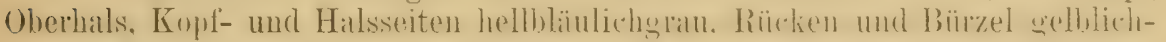

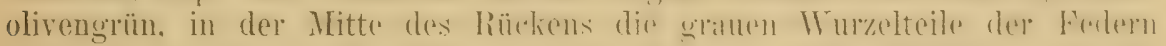

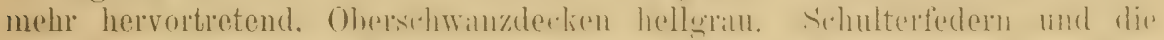

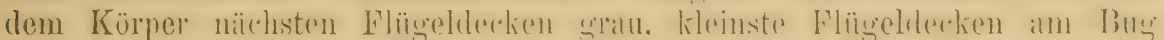

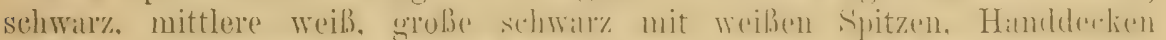

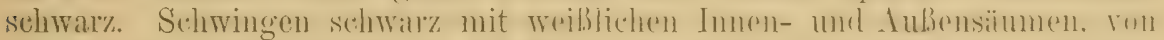

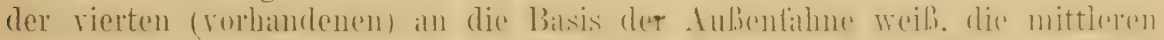

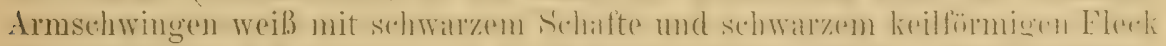

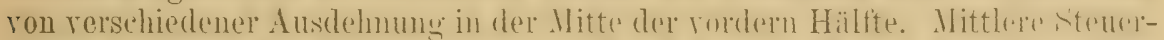

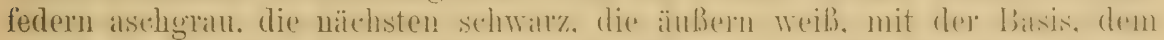

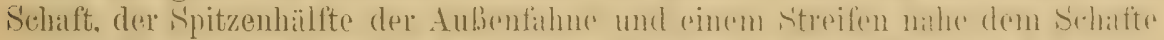

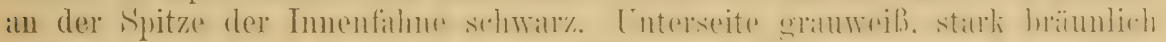

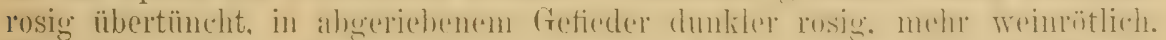

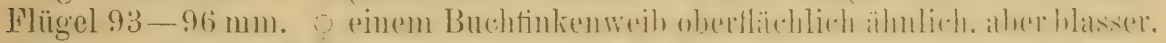

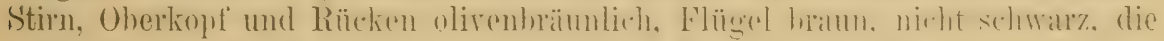
mittleren Armschwingeu ausgedehnt (meist etwa $3 / 3$ ) weib.

'lunis (Sfax, Tripolis, Gafsa, Stadt 'Tunis, Hamam el Lif, Ostküste, Feriana, Nord-Tunis).

Vertritt unsern Buchfink, mit dessen Lebensweise die seinige ïbereinstinmt. Das Nest steht mit Vorliebe auf Olivenbüumen. Es ist im wesentlichen ganz wie ein Buchfinkennest und die 4 (selten 5) Lier gleichen ebenfalls Buchfinkeneiern. Sie messen etwa 19 bis $22 \times 14.5$ bis $16 \mathrm{~mm}$. (Vgl. Journ. f. Orn., 1888, 1899). Die Hauptbrutzeit fällt in die Monate April und Mai.

\section{Fringilla coelebs africana Levaill.}

Fringilla africana Levaillant, Expl. Algér. Tat. VII (1850- die 1850 erschienenen Tafeln waren von keinem Text begleitet, sie wurden aber später dem Werke voñ Loche beigegeben). 
Gauz wie $F$. c. spocliogenys, mit ganz oder fast ebensoviel weib an den innem Armschwingen, aber die Oherseite atwas dunkler, hesonders der Oherkopf mehr schiefergrau, die Ohrdecken dunkler. Flügel 91-9t mum. o an den Ohrdecken etwas dunkler, sonst wie dats ron tr. ce spodioneny.s. Wenn man diese Form unterscheidet, muß der für die algerische Form angervandte Name africana dafür gebraucht werden.

Algerien (besonders in der Provinz ('onstantine hei Lambessia häufig). Genaue Verbreitung nicht hekannt. namentlich auch nicht die Grenze gegen $F$. c. spodiogenys im Osten- und $F$. c. koenigi im Westen.

Bewohnt Steineichen- und Pinienwälder, Aleppokieferngehölze, Gärten- und Olivenpflanzungen. (Journ. f. Orn. 1896, p. 114.)

\section{Fringilla coelebs koenigi Rothsch. \& Hart.}

Fringilla spodiogenys koenigi Rothschild \& Hartert. Om. Nlonatsber. 1893, p. 97, 1894, p. 75 (llarokko - Typus ron 'Tanger).

Auf den ersten Blick von $F$. r. spodiogenys durch viel dunklere Farben, namentlich anf der Obresseite, untersehieden. Die mittleren Armsthwingen sind nicht grobenteils. sonderm viel weniger, nur and der Trurzel, if his höchstens 1/3 weiß. Flügel nul $87-90.5 \mathrm{~mm}$. dunkler als bei $F$. c. spodiogeny.s und ufricana.

Marokko. ('T'unger, El Kasar, Marrakesch, 'Tilula, Ras-el-Ain. Bei Mazagan nicht gefunden.)

\section{Fringilla coelebs maderensis Sharpe.}

Fringilla maderensis Sharpe. Cat. B. Brit. MLus. XII, p. 175 (1888-- Nadeira); Journ. f. Orn. 1890, 'Taf. V'1.

ơad. Stirnband schwarz, Pileum und Oberhals graublau, übrige Oberseite lebhaft olivengrün, über die Rückenmitte ein für diese Form selir charakteristischer breiter olivenbrauner Sattel. Unterseite wie bei $F$.

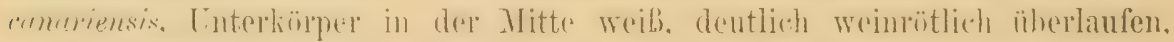
an den Seiten hellschiefergrau. Sonst wie F. c. canariensis, dessen o auch das o gleicht.

Insel Madeira, wo er Laubstald (Lorbeer, Eichen) und Gärten, sowie spiirlicher die Fichtenbestände bewohnt.

\section{Fringilla coelebs moreletti Puch.}

Fringilla Moreletti Pucheram, Rev. \& Mag. de Zool. 1859, p. 409-412. 'Taf. 16 (Azoren).

cad. dem ron Fr. c. maderensis ähnlich. unterscheidet sich abęr

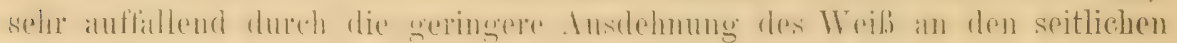
Stenerfeder'n. Diese sind, anstatt mindestens halb weiß zu soin, schiefer-

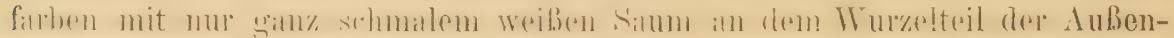

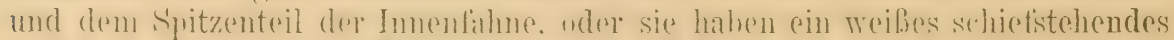
Querband - unter über 80 untersuchten Stïcken sind nul 5-6, die in

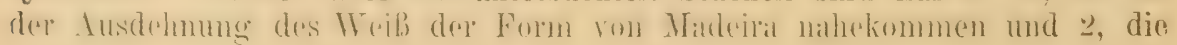
ihr darin gleichen. AuBerden ist mebr der ganze Rücken olivengrünlich, 
1)hne so deutlichen Sattel. am woiberen Cnterkïruer fohlt der weinrötliche Schimmer, die Brust ist meist efwas hräunlicher. Der Schmahel ist oft beträchtlich, fast immer merklich größer.

Die Inseln San Miguel, Griciosa, Flores, Santa Maria, Pico, Fayal, San Jorge, Corvo, San Pedro und 'Terceira im Azoren-Archipel.

\section{Fringilla coelebs canariensis Vieill.}

Fringilla canariensis Vieillot, Nour. Dict. d'Hist. Nat. XII, p. 232 (1817- Tenerife, Typus im Pariser MLuseum).

Fringilla Tintillon Webb. Berthelot \& Ifnunin-'Tumblon. Hist. Nat. Thes ('inar., (Ornith., p. 21, Taf. 4 (1836-41- Canaren. Beschreibung der 'Tenerife Form); Journ. f. Orn. 1890, 'I'af. VI.

ơad. Oherseite grauhlau (hlïulich schicferfuhen). P'ileum hlauschwarz (dunkel stihlhlau), Bürzel olivengrün, längrste Oherschwanzdecken schiefer-

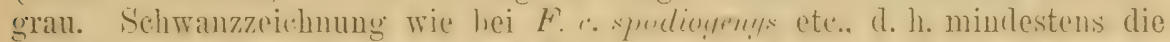
Hälfte der änbern steuerfeder woib. Enterseite hellrustgelhich mit wein-

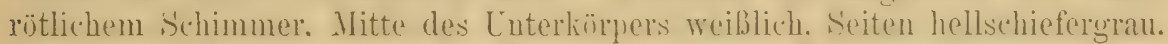
Zïgel und Kopfseiten wie die Brust, der hintere Teil der Ohrdecken und Halsseiten wie der Rücken. Flügrel 85-8s. Śchnahel 13-1+ mm. Q ähulich denen der andern Formen, aber oben dunkel olivenhan. Bürzel gुrün.

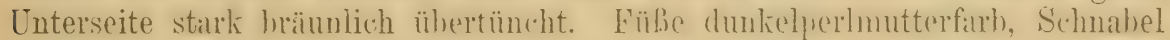
licht schieferfarb, in's Violette spielend, Spitze schwarz, Iris braun.

Tenerife, Gran Canaria und Gomera in der Canarengruppe.

Bevorzugt Kastanienhaine und Gärten, findet sich aber auch in Lorbeer- und Pinienwäldern. Lebensweise und Fortpflanzung der ron $F$.c. coelebs ähnlich. (Vgl. Koenig, Journ. f. Orn. 1890.)

\section{Fringilla coelebs palmae Tristr:}

Fringilla palmue T'ristram, Ann. \& IIag. Nat. Hist. ser. 6, III, p. 489 (1889- Palma); Ibis 1890 , Taf. III.

Fringilla coerulescens Koenig: Journ. f. Orn. 1889, p. 183, 1890, p. 479, T'af. VII.

Ganz wie F. c. canariensis, doch unterscheidet sich das o wie folgt: Das Schieferhlau des Rückens (das ührigens ron genau derselhen Farbe ist) erstreckt sich ïhel den ganzen Bürzel his zu den Oherschwanzdechen. nur im frischen Gefieder hahen die schieferhlaten Bürzelfederı grüne Sïume, die aber gregen das Frühjahr hin rerschwinden. Die rüstliche Kehlfïrbung hört an der Brust auf, die nur etras rosig angehaucht ist. uud erstreckt sich nicht wie bei $F$. a cumurimsis über die Brust und an den Suiten entlang.

Vertritt $F$. c. canariensis auf den Inseln Palma und Hierro (Ferro).

Gleicht in der Lebensweise seinen Verwandten. Ër lebt auf Palma in Lorbeerleständen, sonstigem Tralde und Pinien. P'olatzek fand ihn and Hierro hauptsä̈hlich in den Pinienwäldern. Nest und Eier wie die ron $F$. c. canariensis. Koenig gibt unbedeutende Unterschiede in den Locktönen an.

209. Fringilla teydea Trehb.. Berth. \& Moqu.-T'andon.

Fringilla teydea Webb, Berthelot \& Moquin-Tandon, Hist. Nat. Iles Canar., Ornith., p. 20, Taf. 1 (1836-44- T'enerife).

E. Hartert, Die Vögel der paläarktischen Region. 
3 ad. Gefieder lang; die einzelnen Federn weich und zart, die ganze

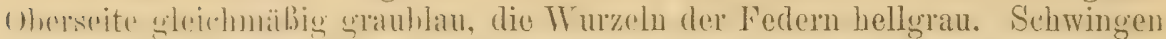
und Schwan\%, schwar\%. hellbläulichgrau gesüumt, die seitlichen Steuerfedern mit sthmalem wablichen Auliensaum und Spitye. sowie großem schiefergramen Flork wor der Spitze der Innenfahme. Kleine Flügeldecken wie der

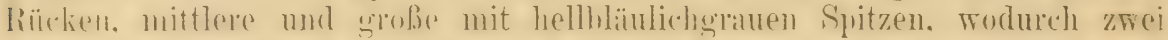
Guerbinden entstehen. I'nterseite hellhlïnlidigratl. der Nitte entlang und

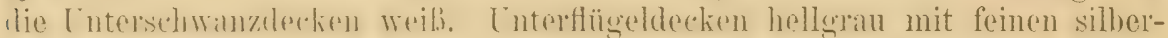
weißen Säumen. Flïgel 103-105, Schwanz 83-85, Schnabel 16-17, Lauf etra $24 \mathrm{~mm}$. O dem ö ïhnlich, aber etwas kleiner, heller, matter, when matt hiulicheralu mit rosthräunlichem Sthimmer und solchen Federrïndern im frisehen Gefieder. Jur. dem o ähnlich.

AusschlieBlich Bewohner der Wälder von Pinus canariensis, die sich um den Pik von Teneriffa an der S.-, S.W.- und N.-Seite der Insel befinden, wo er Standrogel ist und hrütet.

Lehensweise im allgemeinen finkenartig. Auberordentlich zutraulich. Lockton melodisch, ron den andrer finken mohl rerschieden. Der finkenartige, dabei aber sehr charakteristische Schlag wird ron Kioenig mit "tschin, tin-tini ri-vi-vi-ri-vi" übersetzt. Nahrung rorzugsweise Fichtensamen und Insekten. Das Nest steht 2-14 m hoeh in Fichten. Es besteht aus Piniennadeln, trockenen Stengeln, Maultierharen, Federn, Pllanzen- und Schafwolle und ist innen mit Tauben- und andern Federn ausrekleidet. Es ist der Größe des Vogels entsprechend größer als ein Buchfinkennest, weniger fest und schön gefügt und nicht so tief gemuldet. Eier immer nur 2, hellblangrün mit rötlichweingranen tiefer liegenden und tiefschwärzlich rotbrauneu darüber liegenden Flecken, mehr am stumpfen Ende. Sie glcichen riesigen, länglichen Iompfaffeneiern. 2 von 'Thanner gesammelte messen $24.5 \times 16,24.8>16.1$, Koenig gibt an $26 \times 17$, $23 \times 17 \mathrm{~mm}$. Die Brutzeit ist der Juni, das of britet 14'Tage allein. Nur eine Brut im Jahre.

\section{Fringilla montifringilla L.}

Der Bergfink.

Fvimille Montifingilla Limnaeus, Syst. Nat, Ed. X, 1).179 (1758- "Habitat in Europa". Typische Lokalität Schweden, denn die J)iagnose ist aus Fuma Succica 198 entnommen).

Frinyilla lulensis Linnaeus, Syst. Na1. Li. X, p. 180 (1758- „Habitat in Suecia").

Fringilla septentrionalis Brehin. Handb. Naturg. Vög. Deutschl., p. 274 (1831- NordEuropa).

Froingille major; borealis Brehm, Vogelfaug, p. 101 (1855-- Schweden ma Lappland, durch Deutschland ziehend).

Fringille montifringilla alticeps A. Brehn, Verz. Samml., p. 9 (1866- nomen nudum!) Engl.: Brambling. Franz.: Pinson des Ardennes, des montagnes. Schwerl. : Bergfink.

ơad. Kopf, Kopfseiten, Hinterbals und ganzer Rücken blauschwar\%,

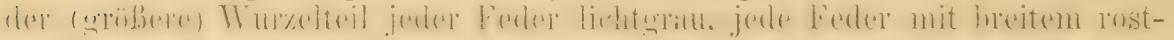
braunen Saum, der sich im Frühling größtenteils verliert, im Nacken ein

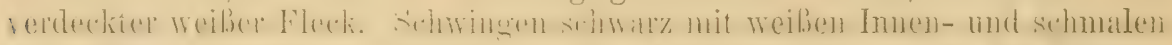

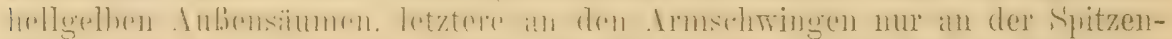

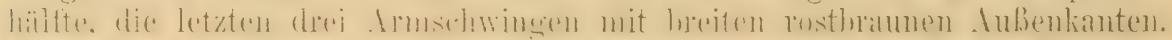

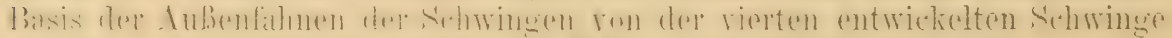

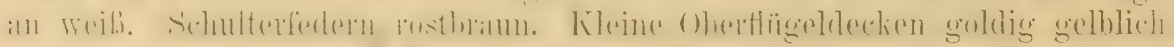

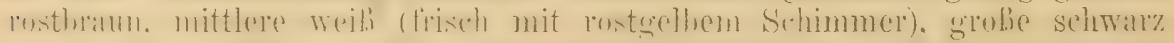

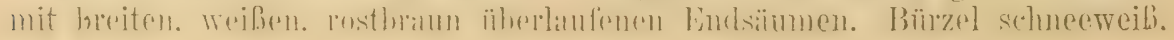




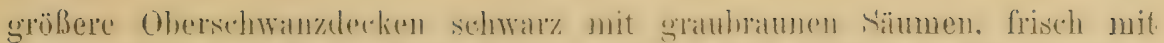

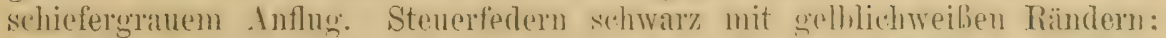

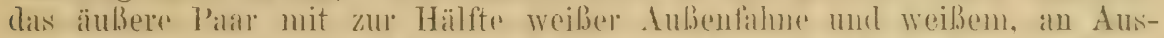

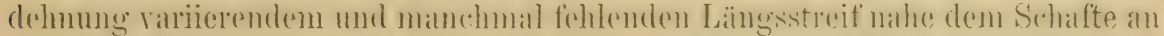

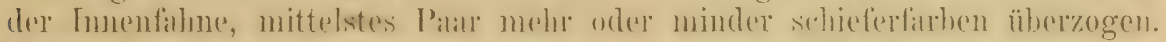

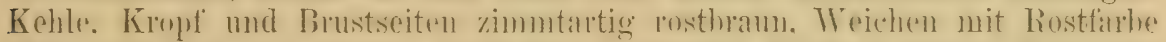

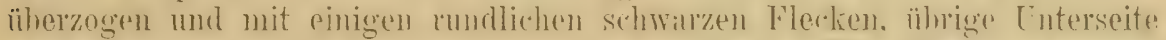

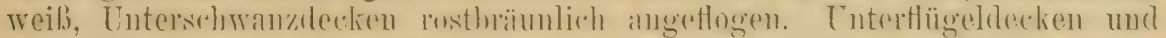

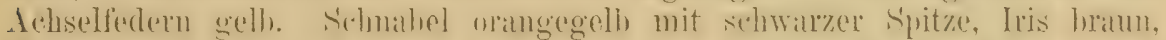

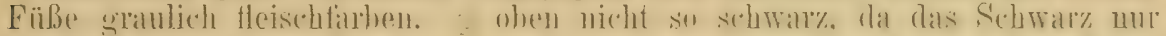

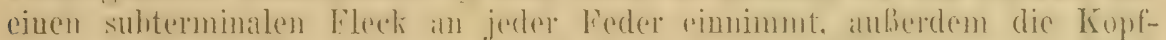

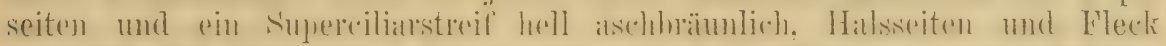

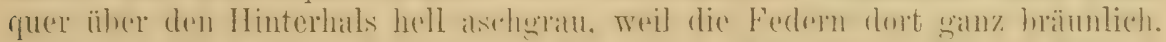

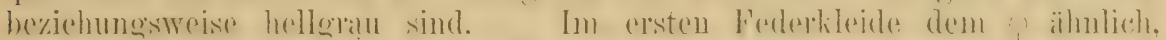

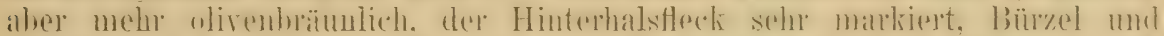

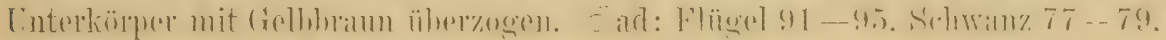
Schmabel etwa 13, Lauf 20-26 $1 \mathrm{~mm}$.

Brutrogel im Norden der Alten Welt, in den subarktischen Nadelund Birkenwäldern, ron Norwegen bis Kamtsehatka. '/ugvogel, der im

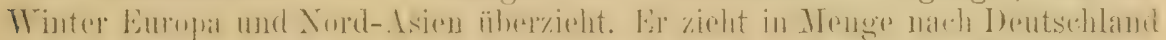

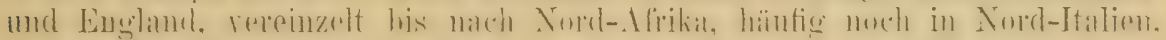
in Asien bis 'Turkestan und sogar his N. W.-Indien, im Osten bis nach Chinal und Japan.

Kräftig, nicht so scheu wie Buchtinken, auf dem 'Zuge in großen Flïgen, auch die Nester gern nahe beieinnnder. Loekton ein gezogenes lautes Quäken, auch ein kurzes jäck, jäck, sowie ein kreischendes Schriik. Gesang kreischend, klirrend, an das „Dichten“ der Buchfinken erinnernd. Nalnung allerlei, besonder's ölhaltige Sämereion, Bucheckern, daher sie in Buchenwäldem in guten NuBjahren massenhaft auftreten. Im Sommer verzehren sie vicle Insekten. 1)as Nest steht meist in einer Astgabel nahe am Stamm auf Birken, 'Lannen, Kiefern, W'achholder; in Bäumen oder Bïschen, ist loser und umfangreicher, sonst aber wie das des Buchfinken. Die 5-7 Eier sind ganz wie die gewöhnlichen bräunlichgrinlichen Buchfinkeneier, blaue Varietäten, die den Dompfafteiorn ähneln, seheinen aber nicht vorzukommen. 56 Eier der Rey'schen Sammlung messen $16.8 \times 13.8,17.3 \times 13.5,19.3 \times 14.6$ bis $21.5 \times 14.5$ und $19.8 \times 15.5 \mathrm{~mm}$. Das Durchschnittsgewicht ist $0.127 \mathrm{gr}$. l'jergfinken waren friher eine beliebte speise, sie sind die . Bohämmer" der Eilsïsser.

\section{(em- MONTIFRINGILLA lirehm is2s.}

Umfang wie in XII. Bande des Catalogue of Birds, also Ieneosticte

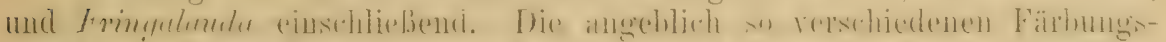

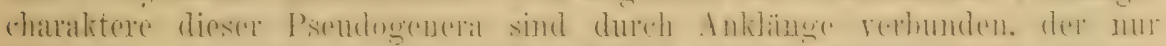

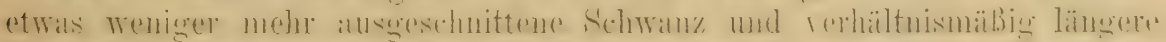

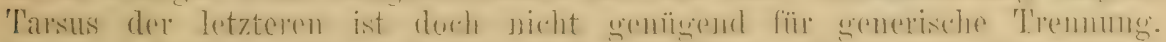

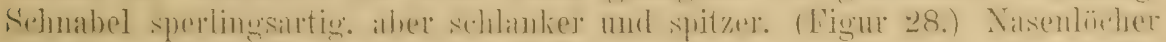

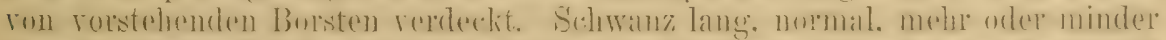

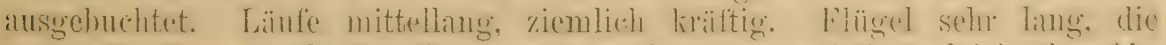
ersten 2-3 alusgelildeten Schwingen an lïngsten und fast glejed. der Ah-

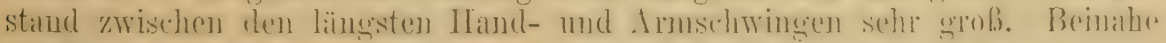

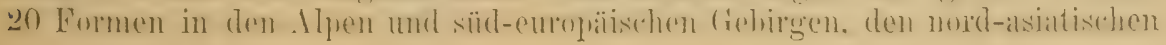


Bergen, N.O.-Asien und Nord-Amerikit. Nisten in Felslöchern und an Gebäuden und legen (soweit die Nistweise hekannt ist) reinweiße glattschalige bier!

$$
\text { Übersicht der paläarktischen Arten (Ja d.): }{ }^{1} \text { ) }
$$

Außere Steuerfedern reinweiß mit weißen Schäften, mit oder ohne schmale schwarze Spitzen. Halsseiten ohne rostrot. . . . . . . . . 2 Stenerfedern graulichweiß mit schwarzen Schäften . . . M. arctous . p. 138

1 Äußere Stenerfedern größtentuils weif mit hreiten sehwärzlichen Sutzen, Halsseiten rostrot. . . . . . . . . . . . . . 3 Äußere Steuerfedern wenigstens an den Innenfahnen ohne alles weiß. . 4

2) Bürzel schwarz, Zügel grau. . . . . . . . . M. nivalis . p. 132

| Bïry. weiß, Zïgel sehwarz. . . . . . . . . M. muntellii. p. 131

flehle weib, stirn ohne sehwarz........... M. ruficullis . p. 135

$3\{$ Kehle schwarz, Stirn mit schwarzem Strich ...... M. Ulanfordi . p. 135

Kehle schwarz, Stirn ganz schwarz ........ M. davidiana. p. 134

OHerseite sperlingsartig gestreift. ohne rot . . . . . M. nemoricolu . p. 136

4 Oberseite fast einfarbig blaß bräunlichgrau . . . . . M. brandti . p. 137

Oberseite braun, nie olne rot ................. 5

5 O Oberknt haminmt . . . . . . . . . . M. roborowstii. p. 13!)

\}-Oberkopf schwarz oder braun. . . . . . . . . . . . 6

6) OOhere Sehwanzlectien sehwazbrau ohne rot . . . . . M. gigliolii p p. 1:s!

| Obere Schwanzdecken mit roten Spitzen . . . . . . . . 7

7 I Hinterkopf grau. . . . . . . M. tephrocotis griseinucha . p. 140

\{ Hinterkopf braun ............. M. brunneinucha . p. 140

\section{Montifringilla nivalis nivalis (L.). (Fig. 28.)}

Schneefink.

Fringilla nivalis Linuaeus, Syst. Nat. Ed. XII, I (1766), p. 321 („Hab. in America errore! Ex Brisson II, p. 162 - Fundort nicht angegeben, als typ. Lok. sehe ich Schweiz an.)

Fringilla saxatilis Koch, Syst. baier. Zool., p. 216 (1816- „Hochalpen von Tyrol, Salzburg").

(„Plectrophanes fringilloides" Boie, Isis 1822, p. 554 ist ein ganz unsicheres nomen nudum!) Montifringilla glacialis Brehm. Handb. Naturg. Vög. Deutschl., p. 270 (1831- Alpen Tirols: erste Beschreib.).

Engl.: Snow-Finch. Franz.: Pinson des Neiges. Ital.: Fringuello alpino.

ơad. Oberkopf und Kopfseiten aschgrau, Rücken braun, die Federrä̈nder lichter, unterer Bürzel und ohersehwanzdecken schwarz mit bräunlichen Sïnmen, die oheren soitlichen (Oherschwanzdecken teils ganz weiß, teils mit weiBen $A$ ubenfahnen. Handschwingen schwallz mit weiblichen, an den juneren Schwingen breiteren Spitzensäumen, Armschwingen weiß, die

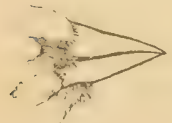

Figur 28. äußerste Bisis schwarz. die innersten größtenteils. braun. Oberflügeldecken weiß, Handdecken mit schwarzen Spitzen, Afterflügel schwarz. Äußerste Steuerfeder ganz weiß, die andern mit schwarzen Spitzen, das mittelste Paar schwarz mit brëunlichweißen Säumen. Ganze Unterseite weiß mit gelblichem Schimmer, die schwarzen Federwurgehn an der Kehle, infolge der dort grobenteils schwarzen Federn mehr oder minder sichthar, die lïngsten Lnterschwanzdecken mit

1) Die mir unbekannt gebliebene M. kansuensis konnte ich in der Übersicht nicht einfügen. 
tiefbramen sinitzen. Unterflügeldecken weiß. Iris dunkelkistanienbraun, Fübo sehwar\%, Sehmalrel orangegelh mit schwärzlicher Spitze. Dureh das Ahtragen

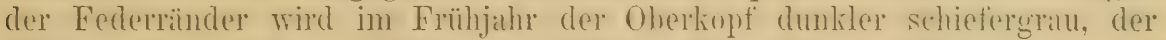
Rücken reincl hraun, Flügel und mittlere Struerfeclem rein schwarz, die Nitte der Kehle gamz schwar\%. Schmabes im Sommer schwar\%. o wie o

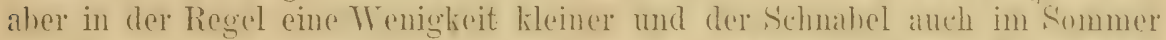
nicht schwarz, sumdern bräunlichgolh mit schwarzer Spitze. Flügel 117 bis 125, Schwanz 73-75, Iauf etwa 22, Schnabel 13-14 mm. Juv. Dem alten Vogel sehr ähnlich, aher Handelectien gounz schwarz, die weiben Almsehwingen mit lïnglichem schwaren Fleck aul der Aubenfahne, die meisten struerferlen'n mit mehr Sohwarz nahe eler spitze, Cuterseite mohr

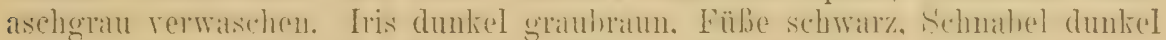
zitrongelb mit schwärzlicher Spitze (Elüela-Paß, 9. Juli).

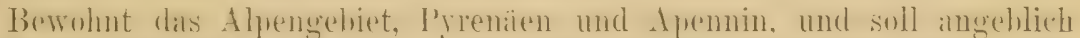
ostwillts his Palästina varkommen. eine Angalue, die aber durehalus der Bestittigung bedarf.

Hält sich das ganze Jahr hindurch nur in sehr hohen Lagen auf, immer oberhalb des Baumwuchses, zwischen Stcinen und an Felsen, noch mehr vielleicht an Gebäuden, in Mauerlöchern und unter den Dächern der hochgelegenen Hospize, wie z. B. auf dem Fliiela-Paß, dem St. Bernhard, Splügen, Simplon, Gemmi, Grimsel, St. Gotthard u. a. m. nistend. Nach der Nistzeit zieht er sich noch höher, bis in die Gletscher-Region zurück, wo er sich in Flügen bis über 60 Stück heruntreibt, kommt aber in der kalten Jahreszeit als selur seltener Wintergast in die niedrigeren Berge und Täler herab, während die meisten auch den strengsten Winter durch an den hochgelegenen Hospizen, Klöstern und Dörfern ausharren.

Am Brutplatze vertraut, sonst aber sehr scheu. Im Gebahren buchfinkenähnlich, aber durchaus kein Baumrogel, sondern am Boden, an Felsen und auf Gebäuden sitzend und herumhüpfend Nahrung suchend. Die Locktöne sind kurze, piepende, etwas an die der Kreuzschnäbel erinnernde Laute, der Gesang ist nichts wert. Nahrung Sämereien und im Sommer auch Insekten, namentlich (anf dem Flïelapab) Diphterenlarven.

Das Nest ist groß und dickwandig, aus Gras und Hoos, mit Federn und Haaren sehr dicht ausgefuittert. Es enthält anfangs Mlai das erste Gelege von $4-6$ mattglänzenden, dichtporigen, schneeweißen, ungefleckten, feinkörnigen Eiern, die von $22.7 \times 16.9,24.3 \times 16.8$ und $22.3 \times 16.9$ bis $23.5 \times 16.6$ und $24.3 \times 16.8 \mathrm{~mm}$ messen. Manchmal sollen zwei Bruten stattfinden.

\section{Montifringilla nivalis alpicola (Pall.).}

Passer alpicola Pallas, Zoogr. Rosso-Asiat. Il, p. 20 (1831- „In alpibus summis Caucasi atque mont. Cerauniorum Caspicum lacum ambientium").

Montifringillu leucura Bonnparte. Compt. Rend. XLI, p. 657 (1855- Indien. Persien. Typische Lokal. Erzerum, ex Gould M.S.).

Montifringilla fringilloides J)resser, Ibis 1875, 1. 242 (crrore, descr. nulla-- - Turkestan).

Ganz wie M. nivalis nivalis, aber der Oberkopf nicht grau, sondern etwa so braun wie der Rücken, die Ohrrseite etwas heller braum: etwas kleiner, Flügel etwa 2--5 mm kürzer, Schnabel aloer meist etwas länger und stärker, also relativ größer.

Kaukasus, durch Persien und Afghanistan his Ost-T'urliestan, brïtet in der alpineu Region, in Höhen von $10-14000 \mathrm{FuB}$, kommt aher im Winter bis 3000 FuB herab. 


\section{Montifringilla nivalis adamsi Adams.}

Montifringilla adansi Adams (ex Moore M.S.), Proc. Zool. Soc. London 1858, p. 482 (Ladakh).

Wie M. nivalis alpicola, aber etwas kleiner, die kleinen Oberflügel-

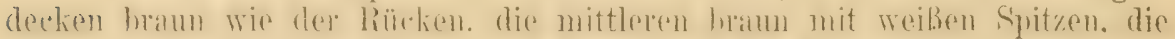

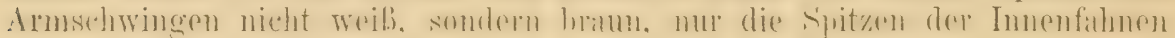
7u etwa einem Drittel weils.

Bewohnt die Schneeregion des westlichen Himalava ron Kasehmir,

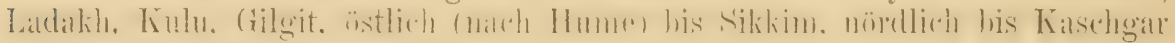
und auch noch 'Teile ron 'lihet.

Häufig bei Ladakh auf kahlem Felsgelïnde. Ruf lerchenartig (nach Adams), Nester in Froldämmen. die die 'Tataren iiber den (iräbern banen.

\section{Montifringilla mandelli Hume.}

Montifringilla Mandelli Hume, Stray Feath. 1876, p. 488 („Borders of Thibet, north of Native Sikkim").

Onychospiza taczanowsliii Przewalski, Mongol. i Strana Taugut. II, 1).81, 'Taf. XT (1876Russisch! Übers. in Rowley's Orn. Ilise. II, p. 290. 1877. Tetunga und KukuNor Steppen in N.-'Tibet).

Ähnlich M. ruficollis, aher ohne alles Rostbraun, Stirn und Streif über

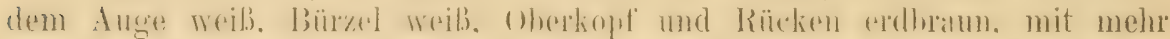

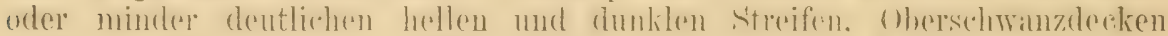

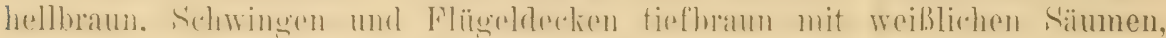
die an den Armschwingen breiter und bräunlicher sind. Zïgel schwarz,

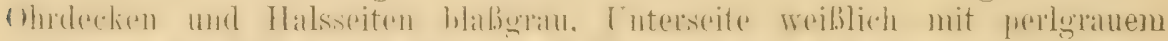

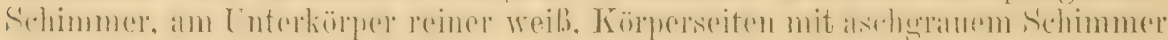
und etwas undeutlicher Streifung. Flügel etwa $105 \mathrm{~mm}$.

'Tibet, von den Nan-Sehan Bergen bis rum Himalaya, soll aher in 'L'saidam fehlen.

\section{Montifringilla davidiana (Verr.).}

Pyrgilanda daviliana Verreaux, Nouv. Arch. Mrus. VI, Bull., p. 40 (1870 - „Montagnes du Thibet Chinois", Armand David coll.) op. cit. VII, T'af. 1.

I'asser ouratensis Swinhoe, Proc. Zool. Soc. Lond. 1870, p.430 (Fx David M.S.. Oulashan. Ungenïgende Beschreibung!).

Oberkopf brïunlichsandgrau, Stirn, breiter Streif um den Sehmabel

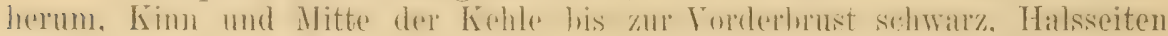
und Unterseite weib) mit rötlichem Schimmer. Obersoite sandhraun mit

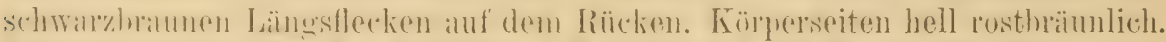

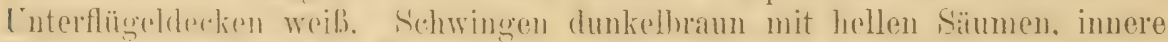
landschwingen an der Wurel mit weiBem (Querhande. Mittelste Steurfedern dunlielluann, hreit hellhrann umsiumt und mit subterminaler weißer linie, die übrigen schwar\% mit weibs an der Basis der Innenfahnen und hreiter suhterminaler schwarzer Binde. Flügel 84-85, Schwanz etwa 43, Iauf 17, Selunabel etrva $12 \mathrm{~mm}$.

Die hohen Berge der chinesischen Mongolei. 


\section{Montifringilla ruficollis Blanf.}

Montifringilla meficollis Blanford, Proc. Asiat. Soc. Bengal 1871, P. 227 (Kangra Lama Paß, 15500 engl. Fuß hoch, nördl. Sikkim), Gould, B. Asia V, Taf. 5.

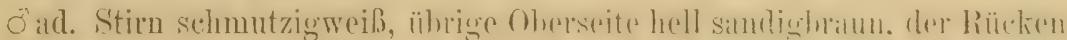
dureh Federn. deren eine Fahne dumkellutun ist, dunkelerestreilt. Ton den

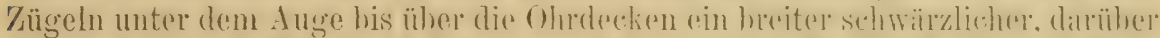
ein nach vorn weiber, nach hinten zu holl restroter Strif. Lépe- und Hals-

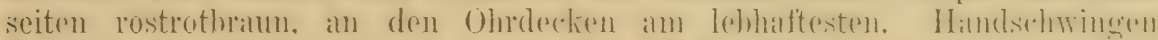

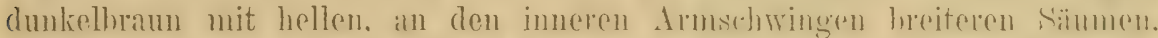

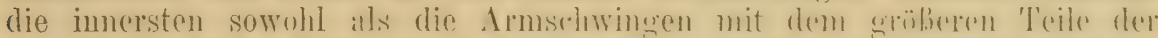

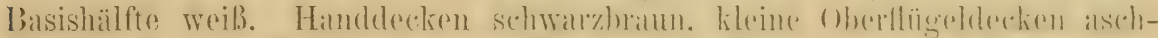

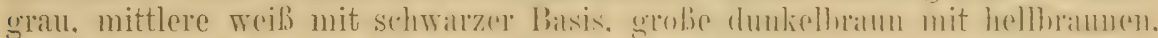
nach der Wurzel zu mehr grauen Sü̈mmen. Nittelste Stenerfodern dunkel-

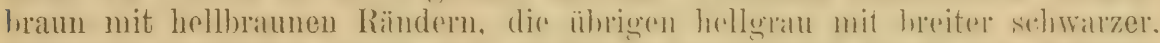

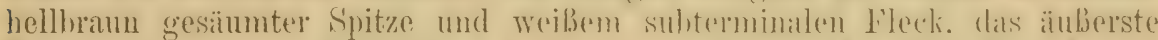

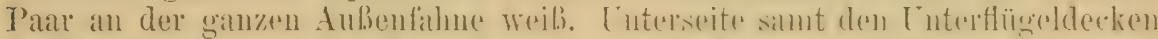

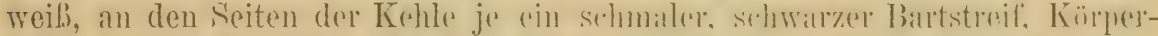

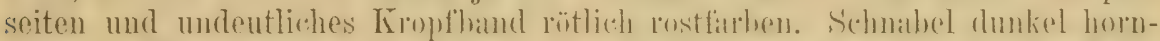
farhen. Fübe sehwärzlich. Flügel !t -96. Sichwanz etwa 5) т-58, Latuf 201,

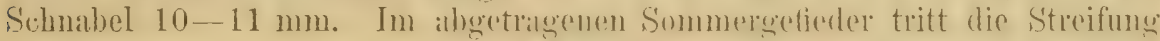
des Rückens mehr hervor. o ad. wie o, aber etwas matter gefärht, Stirn

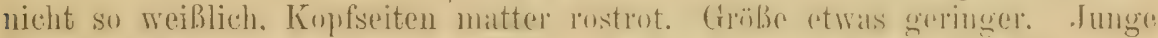

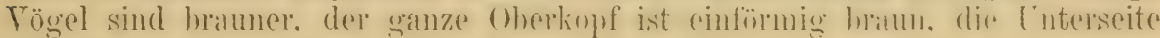
rostfarb verwaschen.

Tibet von Sikkim bis zum Kukunor und Kausu.

Bewohner großer Höhen ron 15-16000 engl. Fiul.s. Im Winter in groljen Fliigen. Nistet in den von Lagomys gegrabenen Höhlen.

\section{Montifringilla blanfordi Hume.}

Montifringilla blanfordi Hume, Stray Feathers 1876, p. 487 ('libet, gesammelt von Mandelli), Cat. B. Brit. Mus. XII, Taf. 4.

Pyrgilauda barbata Przewalski, Ibis 1887, p. 412 (Über's. a. d. russ., Kansu).

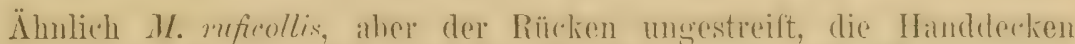

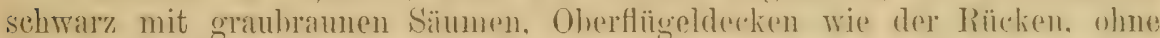

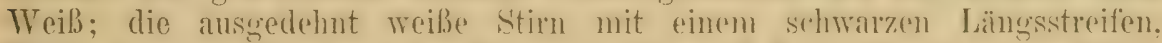
Zügel, schmaler Strieh an den Schnabelseiten und Kehlmitte sehwarz: ïhrige Kehle und Kopf- nnd Halsseiten woils. Flügel 98 mm. Nehrerens Stïcken im British Mhseum fehlt die schwarge Kohlunitte. Virlleicht sind es die o. Junge Vägel sind ohen hranner. der Kunf ist hrimnlich, die schwarzen Zeichnungen grau.

Sikkim und das nördlich davon gelegene Tibet, bis Kansu im westlichen China.

Wurde in Höhen von 12-14000 engl. Fub beobachtet. Benehmen wie das ron M. ruficollis. Wahrscheinlich auch in den Höhlen von Lagomys brütend. Im Winter in Flügen ron $20-40$ Stück. 


\section{Montifringilla kansuensis (Przew.).}

Pyrgilauda kansuensis Przewalsky, Journ. f. Orn. 1887, p. 285, Ibis 1887, p. 414 (aus d. russ., Kansu).

8 o al. Zweite Shwinge die läugste. erste gleich der dritten. manchmal gleich der zweiton. Schwanz leicht ausgeschnitten, die äußersten Federn

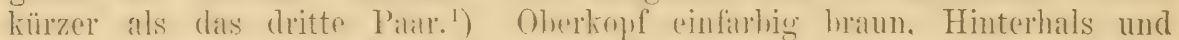

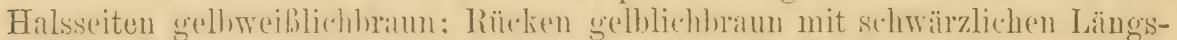
flecken, Bürzel und Ohersehwanzdecken rothram. Kä̈gel und undeutlicher Supereiliarstroif wriblichliram. Ohrderken lichthram. Wangen und Lnterseite schmutzigreils, an Wangen und Kronf unit rothannem Sohmmer. Flanken

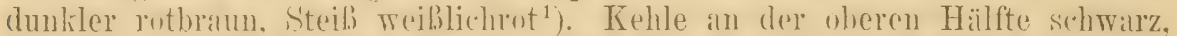
im frisehen Crefieder dureh weiße Eederlianten verderlit. Flügel schwarz-

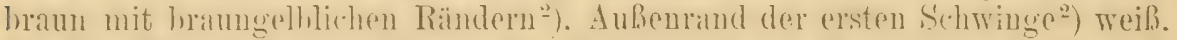
In der Mitte der Inmenfahmen der sehwingen, hei der vireten besinnend, sind meilie Fleclien, die ainen Spieged hilden. der hei zusimmengrelegtem

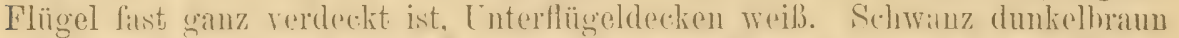
mit hämulichgelhen Rändrm²). Das äuferste Stenerfederpan ist meiß, mit

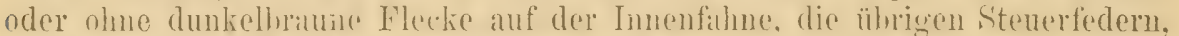
mit Ausuahme der 2-4 mittelsten einfarhig dunkelhraunen. mit weiBem Fleck in der Mitte der Inmenfahne, matuchnal auch anf der Aubenfalme.

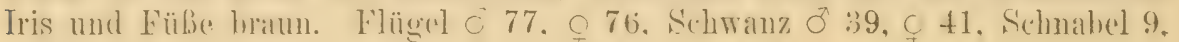
Lauf 17.1-17.3 mm. (Nach Przewalsky!)

Kansu, Steppe und Hïgel nördlich des Chagrin-gol.

Brütet in den Löchern von Spermoplituss.

\section{Montifringilla nemoricola nemoricola (Hodgs.).}

Fringalauda nemoricola Hodgson, Asiat. Res. XIX, p. 158 (1836-- ,central \& north. regions of Nepal"), Abbild. Bp. \& Schleg., Mlonogr. Lox., Taf. 47.

ô o ad. Oberseite dunkelbraun und hellor braun gestreift, jede Feder in der Mitte tiefluam, an den Rändern heller und nehr rosthrame einge

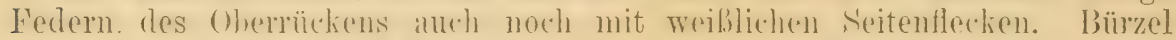

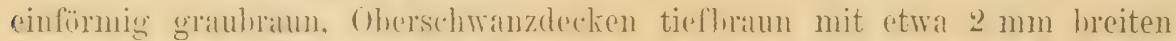
Spitzensïmnen. Schwingen tiefhram mit hellhrämnlehen, in der Mitte der Außenfinhenen der Armschwingen fist wriben säumen. Oberflügelderlien braun, eine Reihe der mittleren und die großen mit schmalen weißen s'̈̈̈men. 'Zügel und hreiter Supereiliarstreif hräunlich aschgrau, Ohrdecken braum mit feinen gramen Linien. Cuterseite schmutrig glaubraum, Mitte des Cuterhörners mud [nterflügeldecken heller, fast weiblich. Lnterschwanzdechen dunkelhram mit soln hreiten weifen Rändern. Sehuahel und Füfor hraun. Iris rot. Arhselfedern zitrongelb, an den śpitzen weib. Flügel 99-105. Schwanz 66-71, Lauf 21, Schnabel 11-12 mm.

Juv. Oberkopf und Ohrdecken einfarbig rostbraun, Oberseite mehr rostbräunlich, Unterseite rostbraun, etwas heller als der Kopf.

Östlicher Himalaya von Nepal ostwärts bis Kansu und Mupin im westlichen China, nur im _Hochgebirge.

3) Die englische Übersetzung ist hier offenbar ganz fehlerhaft.

2) Die deutsche Übersetzung ist hier falsch, statt „Rändern" ist „Bändern" gedruckt, u. a. m. 


\section{Montifringilla nemoricola altaica (krersm.).}

Fringilla altaica Eversmann, Bull. Soc. Imp. Nat. ILosc. XXI, p. 223 (1848- Altai).

Propasser murrayi Blyth, Journ. As. Soc. Beng. XXXI, p. 458 (1863- Tonglu Berg 10000 FuB, Grenze von Sikkim).

Fringillauda sordida Stoliczka. Journ. As. Soe. Beng. XXXVII, 2, 1.68 (1868- nïrdl. von Simla).

Passer pulverulentus Severtz., Turkest. Jevotn., p. 64, 116 (1873); Übers. Ibis 1875 , p. 270 (Turkestan).

Wie M. n. nemoricola aber die Achselfedern weißgrau ohne eine Spur von Gelb, die Säume der grïbern und mittlern Flügeldecken hellrostfarben, nicht weiBlich.

Westlicher Himalaya von Kumann bis (rilgit und Afghanistan, Turkestan bis zum Altai, im Sommer nur in großen Höhen.

\section{Montifringilla brandti brandti (Bp.).}

Leucosticte brandti Bonaparte, Consp. Av. I, p. 537 (1850 - „ex Sibiria or" — errore! Die typische L Lokalität dürfte I'urkestan sein).

Leucosticte pamirensis Severtzow, Ibis 1883, p. 58 ('Tian-Schan).

Ad. Torderkopf his zur Konfmitte und Zïgel sthwarz mit weilinäunlichen Säumen, Hinterkopf und Nacken düster ramehfirthen mit brï̈nlichen Säumen, übrige Oherseite lichtgrau mit dunkleren Shchaftstrichen und rostgelblichen Säumen, Bürzelfedern mit oft kaum hemerkaren hellosenroten Süumen. Oberschwanzdecken etwas reiner grau. Lnterseite lichtgrau mit schwachem. bräunlichen Schimmer. Rleine oherflügeldecken mit rosenroten Säumen. Flïgel und Schwanz schwärzlich mit weißlichen Sämmen. Tris braun, Schnahel braun, Füße schwar. Im ahgetragenen Sommergetieder sieht der Rücken mehr gestreift aus, die weißbräunlichen Süume auf dem Kopfe und Rücken sind rersthwunden, der Schnabel ist schwarz. Die rosenroten Bürzelsäume fehleu nicht selten, zumal bei jüngeren und weihlichen Tögeln. Flügel 115 (O) bis 120 und $125\left(0^{7}\right)$, Schwanz etwa $79-84$. Lauf 21-23 ${ }^{1 / 2}$, Schnabel $12^{1} / 2-13^{1} / 2 \mathrm{~mm}$.

Juv. Viel mehr rothräunlich, die kleinen Flügeldecken ohne Rosenrot,

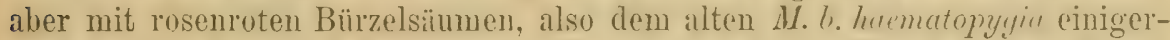
maßeu ähnlich. (Im ahgetragenen Gefieder wird das Rot auf dem Bürzel durch das Tersehwinden rerdeckender Federfahnempartikeldhen feuriger, dio roten Säume der kleinen Flügeldecken aber stoßen sich ab.)

Tian-Schan, Pamir-Gebirge, Alai und Trans-Alai-Ketten in Ost-Turkestan, im Sommer nur in großen Höhen bis zur Schneegrenze, im Winter his 6500 engl. Fuß herab.

\section{Montifringilla brandti haematopygia Gould.}

Montifvingilla haematopygia Gould, Proc. Zool. Soc. London 1851, p. 114 (von Lord Gifford in "Tibet" erbeutet).

Gauz wie W. U. brandti, aher die kleinen Oherflügeldeckenganz obne rote Süume, dagegen der Bürzel mit breiten roten Sïumen, Oberseite bräunlicher und deutlicher gestreift, Flügel durchschnittlich 3-5 mm kürrzer. Himalaya von Gilgit his Sikkim, im Sommer in Höhen ron 12-19000 engl. Fuß. 


\section{2:3. IVontifringilla brandti walteri suhsp. nw.}

Montifingilla formae M. b. haematopygia dietae similis, sed ubique obscurior, pileo nigro, dorso schistaceo-fusco, uropygii plumis fusco-nigresentibus, angusto roseomarginatis, supraeaudalibus fuseis, albido terminatis.

Tiel dunkler als irgendwelche Exemplare vou M.. . Lrandti und $M . b$.

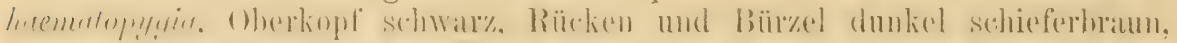

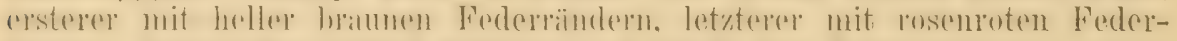

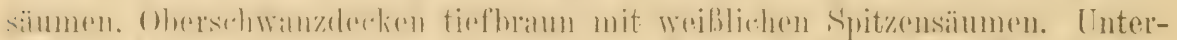

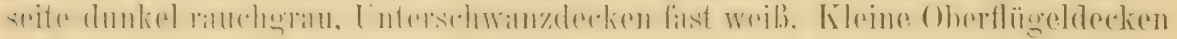
hräunlich olıne rote Säume! lïhgcl $118 \mathrm{~mm}$.

Diese atufallende neue Form liegt in einem Balg (, of "?) vor, rou Berezowsky am 6. April 1894 zu Sung-pan, Sue-shan, in Szetsehwan im

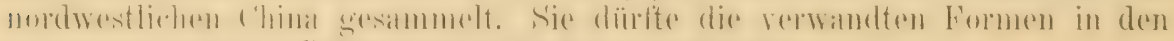
Hochgebirgen von Szetschwan und Kansu vertreten.

(Benannt zur Grinnerung an Dr. Walter v. Rothschild, der die Form nuerst in Nov. '/ool. 1902, p. 167 erwïhnte).

\section{Montifringilla arctous (Pall.).}

P'asser (tvetous P'allas, Zoogr. Rosso-Asiat. 11, p. 21 (1831 - „Ad Jeniseam ot in orientali Sibiria", etc.).

Fringilla (Limariu) gebleri Brandt, Bull. Sci. Acad. St. P'étersb. X, p. 251 (1842).

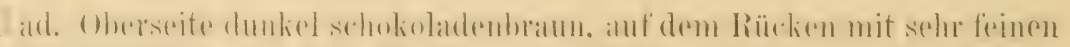

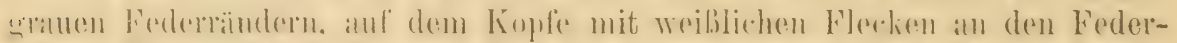

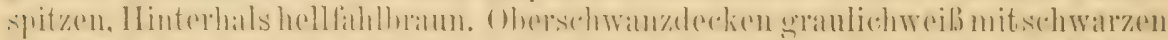

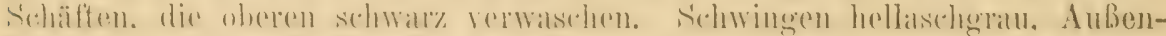

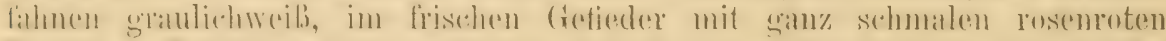

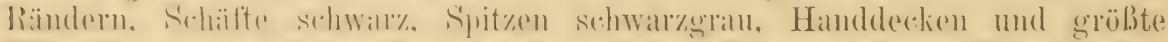

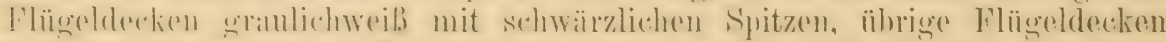

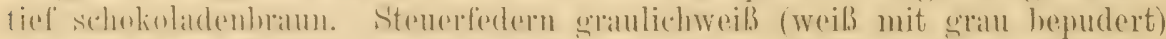

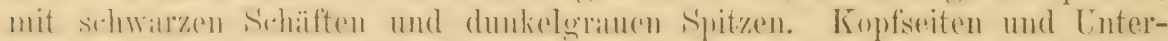

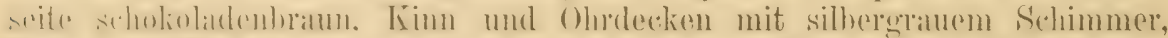

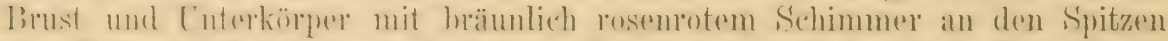

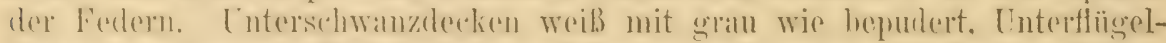

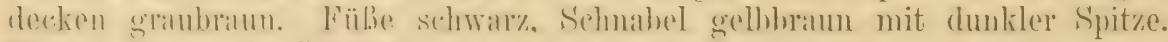
Flügel 113-116, Schwanz 76, Lauf $21-22$, Schmabel $11-12 \mathrm{~mm}$. Q vom

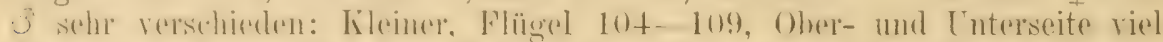

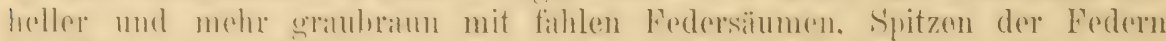

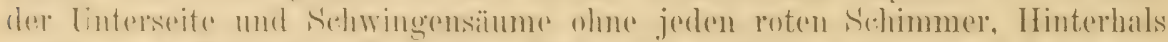
nicht so anffallend viel heller, S'chwingen und sehwanz etwas mehr mit grau getrïbt. Jur. dem o ganz ähnlich, aber noch brïunlicher und mit breiteren rostfahlen Sïumen.

Mittlere 'l'eile des sïdlichen Sihiriens. Genaue Fundorte: im Winter mach l'allas am Jenissed (jedenfalls mur an den sïullehen Teilen des Elusses),

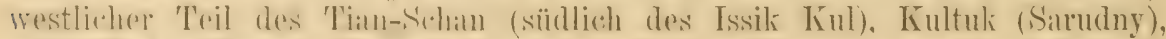

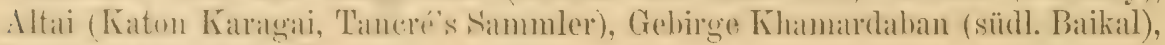
Biriussa (Stubendorff). 


\section{Montifringilla roborowskii (Przew.).}

Leucosticte roborowskii Przewalski, Ibis, 1887, p. 411 (Übersetzung a. d. russ. BurkhanBudda-Zug).

Oherkopf und Hals kamenent mit silberweilsen filecken im Genick.

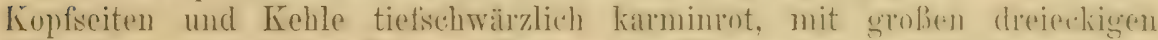

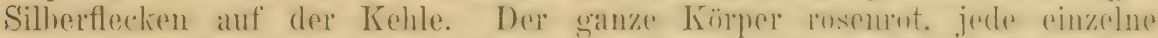

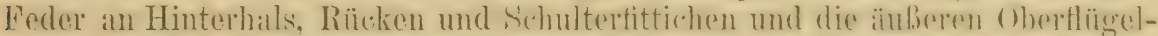
decken mit kamminoten Rändern. Sehwingen und Stenerfedem dumkelhramn mit hell rosemroten Sïmmen, die äulierste stenterforler mit weiliem dulien-

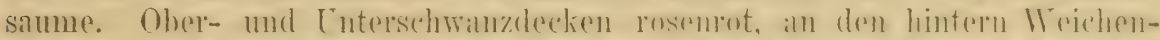

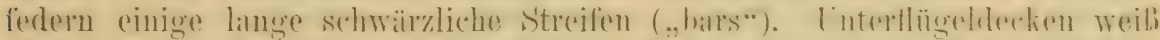

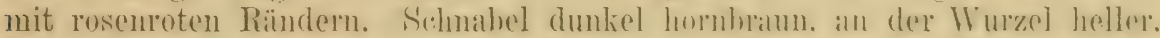

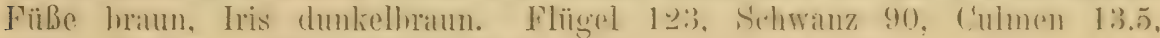
tarsus $21 \mathrm{~mm}$. (Nach Przewalski!)

Dits einzige Exemplat wurde ron General Przewalshi auf dem Marsolue rom I'lateau von Tihet durch deu ëstlichen Teil des Burkhan-Buddal Kuses erbeutet. 2-3 Paare wurden in den Höhen von 15-16000 cngl. Fuß heobachtet.

\section{Montifringilla gigliolii (Salvad.).}

Lencosticte gigliolii Salvadori, Proc. Zool. Soc. London 1868, p. 579, 'T'af. 44 ("Dauria", Typus in Mus. 'Turati, Mailand).

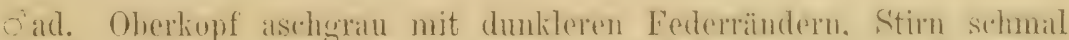
dïsterot, hinterm Auge ein breiter rötlichgrance Streif., Ohrelecken silhergrau. Hinterlals fahl hellbraum. Rï̈cken brammot mit sehmalen hollhramnen säumen, Bürzel und Schulterfedern dunkel kirschrot. Ohersehwanzdecken schwarzhram

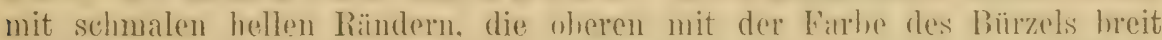
gesätumt. Schwingen und Schwanz tiefhram mit schmalen hellweiblichhramen Rändern. Oherfligendecken sehwarzhran, die kleinsten mit hreiten ticfroten Sïumen. Kimn, Kohle und Vorderhals bräunlichasehgrau. die ribrige Cinterseite rot, jede Feder tiefgran mit answedehnten mattroten śpitzen. Unterschwanzlecken schwämlich mit feinen brannen sïumen. [interflügeldeeken dunkelgrau. Sehnahel hellhräunlich mit dunkler Spitze, Fübe schwarz. Im Frühling versehwinden natürlich die Fodersäume mehr oder minder, das Rot tritt aber dureh die Abuntzung lehbafter hervor. Flïgel $1116-111$. Schwanz 70-75, Lauf 20, Schnabel 10-12 mm.

I)as ( con Siharpe in (at. B. Brit. Mus. Xul und D) resser im Mamual wie auch hei anderen Arten ganz morehtig als dem - efoich heschriehen) ist oben rostbraun mit dunkleren Federmitten, der Hinterlanls cinförmig hellhraun, aher dunkler als beim s, Bürzel graulich, Unterseite hrïunlich aschgrau - weder oben noch unten irgend welches Rot. Eibwas kleiner, Flügel etwa $5 \mathrm{~mm}$ kïrzer. Tuv. dem o ähulich. Ist ein naller Verwandter vou $\boldsymbol{M}$. arctous, weniger von $\boldsymbol{M}$. brumeinucha.

In Sommer Bewohner der Gehirge un den Baikilsec, im Winter weiter niber die Baikalgegenden und Daurien verbreitet. 


\section{Montifringilla brunneinucha (Brandt).}

Fringilla (Linaria) brunneinucha Brandt, Bull. Sci. Acad. St. Petersb. X, p. 252 (1842Ex Pallas Passer arctous var. $\beta$ : Kurilen).

3ad. Oherlonf grau (wie schuppig), jede eiuzehe Feder an der Wurzel sehwärzlich, dimn silhergran und wieder mit dunklerm saume, die hinteren F'deru oft noch mit ganz feimen rosenroten Rändern. Genick und Nacken rosthaun, in meh* ahwotrageuen Gefieder weiblich, Rücken tiefhram mit hellhramen s̈̈unnen, Federn des Bürzels und Oherschwamzdecken mit amsgedehnten rosemoten Spitzen und hellgramen anteapikalen Querbinden. Schwingen und Oberflügeldecken ticfhram mit rosenroten Außensämmen. Federn des Lnterkërpers wie die des bïrzels. das Rot rerliert sich aber nach der Brust zu, und Hals und Kropferegend sind schwarhan mit silhergrauen Federspitzen. Untersohwanzdrelien hraun mit ausuedehnten weiBlichen, mehr oder mindel rosemrot ïhertünchten und im ganz frischen Gefieder röstlich gesämmten Splitzen. Interflïgrdecken weiblich mit rosemroten Sämmen. Sohnabel hellmäunlich mit dunkler Spitze, in Sommer dunkelbram. Fülie schwar\%, Flügel 110-112, Schwanz etwa $74-75$, Lauf 20, Schnabel 21-22 mm. O etwas libiner, viel heller. hlasser und nur an den Seiten des Conterkörpers mit etwas hlassem Rosemot. auch der Bürzel mit weniger und hlasserem Rot. Juv. dem o ähnlich.

Kantsthatka, Kurilen, Nord-Japan, ästliches Sibirien und die Berge des nördlichen China.

\section{Montifringilla tephrocotis griseonucha (Brandt).}

[Linaria (Leucosticte) tephrocotis Swainson, Fauna Bor.-Amer. I, p. 265 (1831- Ebene des Saskatschewan, Mai)]. ${ }^{1}$ )

Fringilla (Linaria) griseomecha Brandt, Bull. Sci. Acad. St. Pétersb. X, p. 252 (1843auf Pallas, Passer arctous var. $r$ basiert. Pallas, Zoogr. Rosso-Asiat. II, p. 23 - Unalaschka).

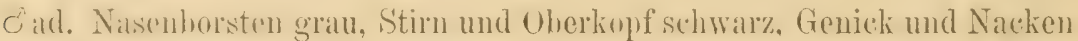
hell aschgratu. (ehenso die Konfieiten. Keble bräunlichschwallz, am Kimn mehr sian. Oher- mol C'nterseite scholioladenbram mit atwas helleren

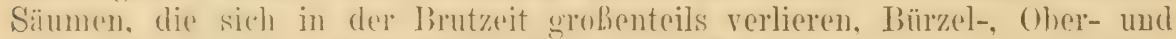
Untersehwanzderelin. Cnterkirper. Seiten und Flügeldeclien mit breiten rosenroten Säumen. S'chwingen tiefloraun mit schmalen helhosenroten Außen- und weiben Innemä̈men, S'teuerfedern tiefbraun mit weiBlichen, meist rötlich angehauchten Rändron. Cnterflïgeldeken weib mit schmalen rosemoten Sïmmen. Schnaluel im Sommer schwarz, im Winter gelblich mit schwärzlicher Spitze, Füße schwarz. Flügel 117-127, Schwanz 75-83, Lauf 23.5-25.5, Schnabel 13.5-15 mm. o soll ganz wie das o sein, aber etwas kleimr, Flügel 169-122. Jur. ganz graturam, Flügel und Schwanz. schieferfurben mit helleren Sämmen, keine Spur ron Rot oder Schwarz unct Grau am Kopfe.

1) Montifringilla tephrocotis tephrocotis ist viel kleiner und heller und hat die Kopfseiten nicht grau, die Kehle nicht schwärzlich. Sie bewohnt große Teile des Innern von Nord-Amerika. Eine dritte Form, M. tephrocotis littoralis (Baird) ist ebenfalls viel kleiner und heller als M. . griseonucha, hat aber die Kopfseiten grau wie bei letzterer. Sie bewohnt die Berge des nordwestlichen Nord-Amerikas. 
Standrogel auf den Inseln des Bering Meeres (St. Matthews. Otter. Pribilof, Alenten und Kommindeur Insehn), Shumbinin, unterer Teil der Aliaska Halbinsel von Alaska, Kadiak Inseln im Winter.

Bewohner der Felsenkiisten. Legt 3-6 schneeweiße Eier, die $24.5 \times 17 \mathrm{~mm}$ messen.

\section{Gattung PETRONIA Kaup 1829.}

Der Gittung Prtsser am närchsten stehend, aher durch Schunabelform und Verhältnis ron Schwanz und Flügehn genügend unterschieden. Der Schnabel ist an der Basis sehr hreit, verjüngt sich aber rasch und hat eine ziemlich lange Spitze, sodaß er nicht so klobig aussieht wie ein Sperlingsschnabel. Die Firste ist nicht gewölbt, sondern fast gerade, in der Mitte ein wenig eingesenkt. (Fig. 29.) Flügel sehr lang, fast das Sehwauzende erreichend, die ersten 3 Schringen am längsten und etra gleich lang, etwa $2.3-3.7 \mathrm{~mm}$ lünger als die

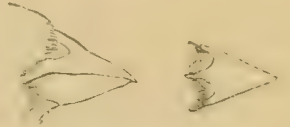

Figur 29. längsten Armschwingen, die an den Spitzen breit sind und nur wenig üher die mittlern hinausragen. Śchwanz liurz, etwat " so lang wie der Filugel. Fine Art in vielen Unterarten.

\section{Petronia petronia madeirensis Erl.}

Petronia petronia madeirensis Erlanger, Journ. f. Orn. 1899, p.482, 'Taf. XIII, (IIadeira). Passer petronins idae Floericke, Mitt. Österr. Reichsb. f. Vogelk. u. Vogelsch. IVien II, p. 100 (1902 - 'T'enerife, 3 der Typen im Mus. Rothsch., nämlich Nr. 1142, 1144, 1277. Keiner der angeblichen Unterschiede besteht).

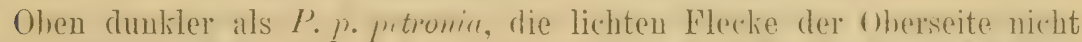
so hell, mehr lebmbrïunlich, fist sephabraun, hesonders Kopfmittr und Bürzel merklich düsterer, Unterseite schmutziger, mehr grauhrüunlich. Flügel 90$97.5 \mathrm{~mm}$. also kleiner.

Madeira und C'inaren ('lenerife, Gran ('anaria. I'alma, Gomera und Hierro).

Nistet auf obengenannten Inseln häufig unter den Dachpfannen einzeln stehender Bauernhäuser, Kirchen und Kapellen, von wo er gern in Flïgen in die Getreidefelder streicht, um sich dort gütlich zu tun. Solche Flüge sind scheu, am Nistplatze aber ist er sehr vertraut. Hier meist etwas heller und kleiner als die ron P.p. petronia.

\section{Petronia petronia petronia (I..). (Fig. 29.)}

Steinsperling.

Fringilla Petroniu Linnacus, Syst. Nat. Ed. XII, p. 322 (1766-- Wr Brisson, Will., Aldror., Frisch. "Europa". Ich nehme Nord-Italien als typische Lokalität an, da aus den Zitaten von Linné eine solche nicht sicher feststellbar ist, die Stiicke, die Brisson beschreibt, ebenso wie Aldrovandi's $u$. a. aber wohl aus Italien gewesen sein mögen).

2? Fringilla stulta Grmelin, Syst. Nat. I, p.919 (1788- „Habitat circa Bononiam". Es ist m. E. ganz verkehrt, auf jeden Fall aber höchst unsicher, diesen Namen auf den Steinsperling zu beziehen. Brisson, auf den sich Gmelin in erster Linie bezieht, beschreibt den Schnabel als rot, die ganze Unterseite als ,jaunâtre" (,flavescunt"), den Schwanz ohne weiße Flecke, usw. „Passera mattugia“, der ital. Name des ,Moineau fou", ist der des Feldsperlings. Gmelin's Diagnose ist zusammengestoppelt). 
?. Fringilla bononiensis Gmelin, Syst. Nat. I, p.919 (1788- ,Hab. circa Bononiam". Auch dieser Name (Ex Brisson, Will., Ray, Latham) ist mehr als unsicher).

Fringilla leucure Gmelin, Syst. Nat. I, p.919 (1788- „Hab. circa Bononiam. Ex Brisson usw. Ziemlich wahrscheinlich ist hiermit - Brisson schöpfte aus Aldrovandi - der Steinsperling gemeint).

Pyrgita rupestris Brehm, Handb. Naturg. Vög. Deutschl., p. 264 (1831- selten und nur in manchen Jahren im Saaletale).

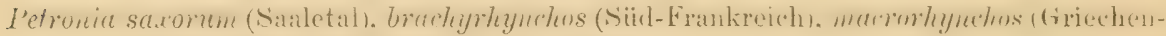
land) Brehm, Vogelfang, p. 97 (1855).

Petronia sylvestris Jaub. et Barth. Lapomm., Rich. Orn.. p. 112 (1859-

Petronia rupestris communis A. E. Brehm, Verz. Samml., 1).9 (1866- nomen nudum!) Engl.: Rock-Sparrow. Franz.: Moineau fou, Soulcie. Ital.: Passera lagia.

ơad. Erinnert im Ganzen an das o des Haussperlings, hat aber in

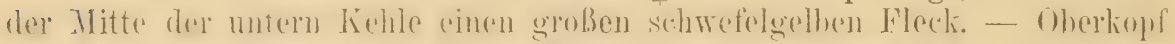
in der Mitte "rellnatun mit hellern Federspitzen. danehen anf jeder Seite ein

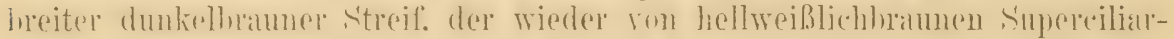

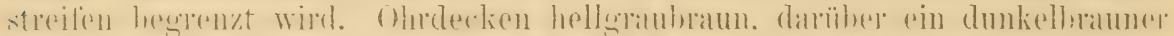

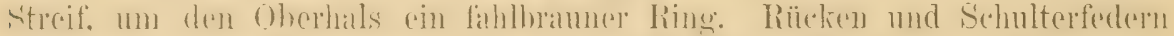

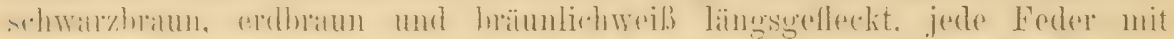

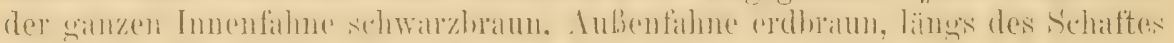

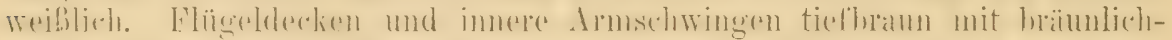

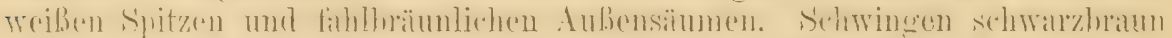

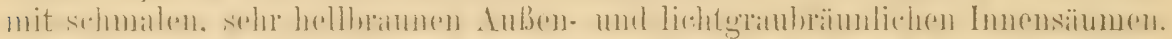

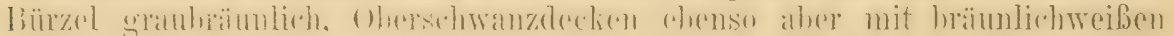

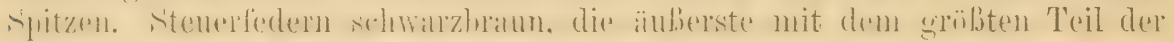

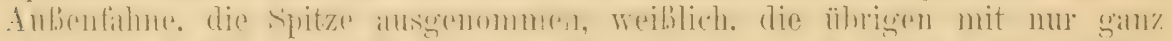

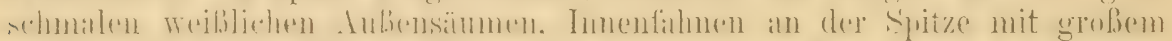

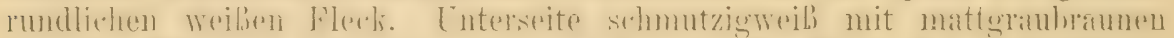

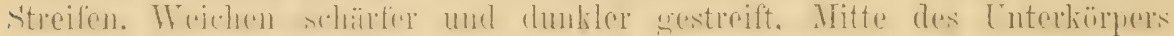

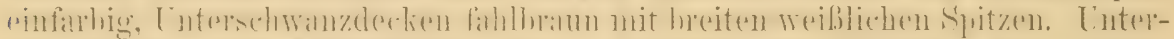

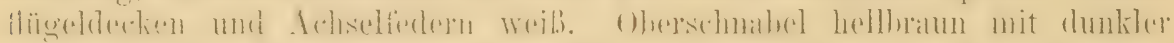
Spitze, im liübling etras melı gelblich, Lnterschnabel gelb mit brauner Spitze. Iris braun, Füße bräunlichgelb. O wie 0 , nur etwas kleiner. Flügel 93-100, Schwanz 54-58, Schnabel 13.5-15, Lauf etwa 19-21 mm.

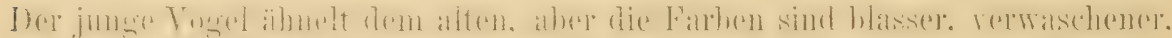

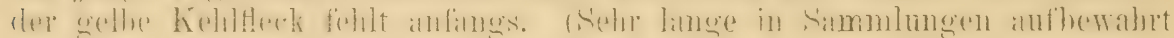
gewesone Stïcke - namentlich die aus den Jahren 1819, 1826 stammenden der Brehmschen Sammlnug - werden fuchsiger, mehr rötlichbraun.)

Bewohner des südlichen Euronas rou Spanien durch Süd-Frankreich und einzelner rerstrenter Orte der Vorberge der Alpen und Österreichs, Italien,

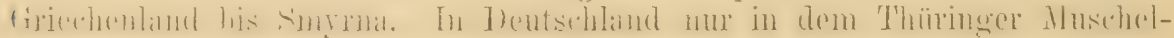
kalkgebiet, an der Saale und ihren Zuflüssen, der Unstrut, Ilm und Gera. Nach alten Angaben auch in der Wetterau und im Rheintale,(?) dort aber

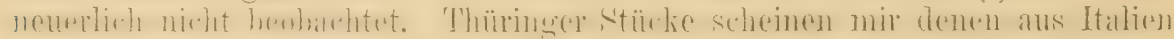
usw. völlig zu gleichen, sie sind, soweit ich feststellen kanu, nicht dunkler

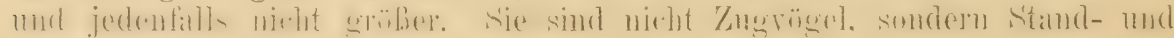
Strichiögel.

Betrohner offener oder halboffener Gegenden, wo alte Burgen, Ruinen, Felswände, im Sïden auch Häuser, unter deren Dächern sie nisten können ( $P$. p. madeirensis z. B.), ihnen Gelegenheit zum Briiten bieten. Das Betragen ist ganz sperlingsartig, 
aber sie sind oft recht schen, nur am Brutplatye vertrauter. Der Lockton ist meist zweisilbig, deutlich sperlingsartig, aber breiter, mchr quäkend, vielfach moduliert, sie zetern auch (beim Neste u. a.) wie Spatzen und haben einen ganz unbedeuteuden, gequetschten Gesang. Nahrung sperlingsartig. Flug schnell, leicht, wellenförmig. Das Nest steht in engen und tiefen Löchern im Gemäuer von alten Burgen, Ruinen. Schlössern, Kirchen oder unter Dächern (die cmarische Unterart), sowie an Felsen und Erdwänden, nach älteren Beobachtern in Deutschland (neuerdings nicht bestiitigt) und in Sardinien auch in Baumlöehern. In diese Höhlungen schleppen sie wie Sperlinge allerhand Baustoffe, an deren hinterm Finde die eigentliche Nestmulde aus Federn sich befindet. Sie legen meist nur 3-6 Eier, die wie Sperlingseier unssehen, aber in der Regel glänzender sind und in der Größe etwa zwischen denen der Hans- und Feldsperlinge stehen. Sie messen von $20.1>15.5$ bis $22.2 \times 16 \mathrm{~mm}$. Mittleres Gewicht $0.216 \mathrm{~g}$.

\section{Petronia petronia hellmayri Arrig.}

Petronia petronia Hellnayri Arrigoni degli Oddi, Arieula VI, 1. 104 (1902 - Sartinia).

thine schwer erkennbare Subspezies, die sich ron $\ell^{\prime}$ \% petronia aus

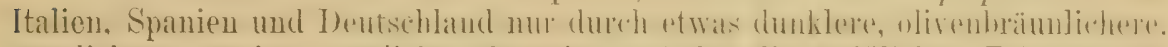

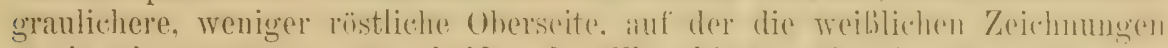

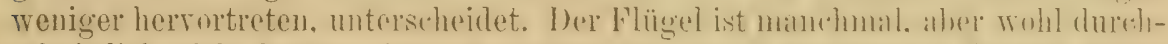

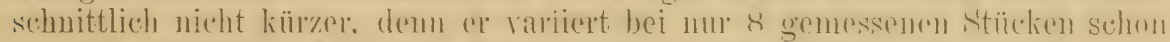

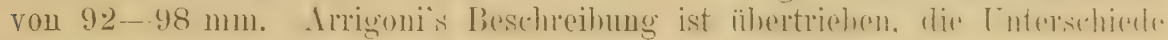
lassen sich abér beim Vergleiehen ron Serien feststellen.

Sardinien und Korsika.

\section{Petronia petronia barbara kirl.}

Petronia petronia barbava Erlanger, Journ. 1. Oru. 1899, p. 481, Taf. XUL (Oued Kasserine, T'unis).

Fürbung mit einem sehr kemneichnenden aschgrauen Anflug, der be-

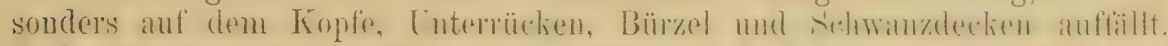

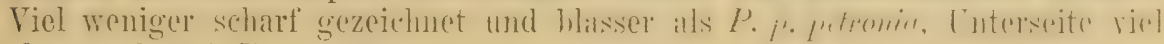
blasser als bei $P . p$. petronia, P.p.madteinsis, $P$.p. intermedius, $P$.p. exiguns

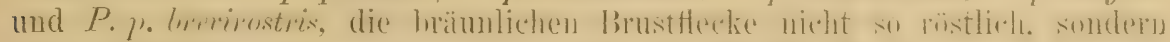
mehr graulich als bei P.p. puteicola, der gelbe Kehlfleck sehr blaß. Die

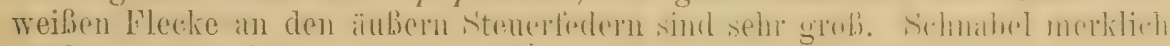
größer als bei P.p. petronia. Flitgel etra gleich, $93-100 \mathrm{~mm}$.

\section{Tunis und Algier bis Marokko (Glaoui im Atlas).}

Erlanger fand sie am Ufer des Oned Kasserine in steilen Sandwänden. anch ein Gelege in einem usurpierten Schwalbenneste.

\section{Petronia petronia exiguus (Hellm.).}

Passer petronius exiguus Hellmayr, Orn. Jahrb. 1902, iv. 128 (Rostow am Don und N.-Kaukasus).

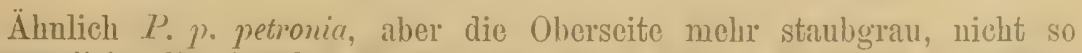

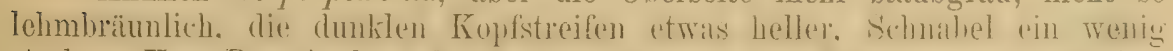

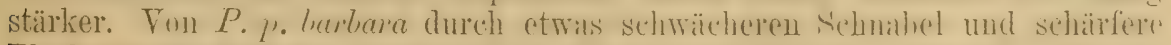
Fleckung der Oberscite unterschieden. F'lïgel (uach Hellmalyr) etwa 96 - $99 \mathrm{mmm}$.

Don-Mründung, Kaukasus bis Erserum in Armenien. 


\section{Petronia petronia intermedia Hart.}

Petronia petronia intermedia Hartert, Nor. Zool. 1901, p. 324, A. d. Wanderj. e. Naturforsch., p. 324 (1901-1902) (Kaschmir, Typus aus Gilgit, und Kandahar).

Viel größer als P.p. petronia, der Schnabel stärker, Färbung lichter, schwarze Fleckung etwas undeutlicher. Flïgel $102-106 \mathrm{~mm}$.

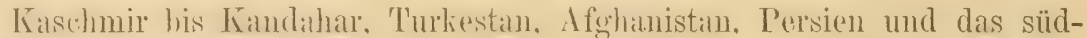
liche 'Tramskisprien (Kópet Dagh. Goudan, Flub Duriaugar). (S'erien frischer Herbströgal aus den verschiedenen Gegenden sind noch nicht genügend untersucht.)

\section{Petronia petronia brevirostris Tacz.}

Petronia brevirostris 'T'aczanowski, Journ. f. Orn. 1874, p.323 (Argunfluß in Ostsibirien).

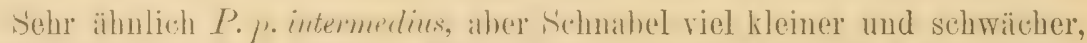
ähnlicher dem ron I'. l' petronie, Flügel etwas kürzer als hei $P$. p. intemelius.

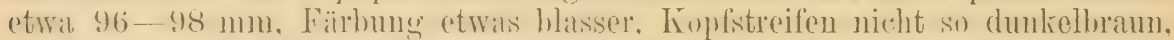
dech sind diese Firrhungsunterscherle noch weiter zu untersuchen, da bisher nur abgeriebene Frïhlingsvögel untersucht wurden.

Ost-Sibirien und Mongolei, Mandschurei.

\section{Petronia petronia puteicola Festa.}

Petronia stulta puteicola Festa, Boll. Mus. Zool. Anat. comp. Torino IX, no. 174, p. 3 (1894- Palästina); Journ. f. Orn. 1899, Taf. XIII.

Die alledalfallendste der Strinsperlingsformen. Sehn groß, viel liehter, gelblich sandfarlener. Was hesumder's auf Rürken und Bürzel hervortritt, die dunkeln Kopfstreiten heller hram, diher viel weniger auflillend, die dunkeln Streifen der Lntreseite mehr röstlieh, Sehnahel gewaltig. Klügel $100-104 \mathrm{~mm}$.

Palästina.

\section{Gattung GYMNORIS Blyth ex Hoclgs. MI.S., 1844.}

Von Petroniu durch langen, sehr schlanken Schmabel mit deutlich gebogener Firste unterschieden (Fig. 30), Oberseite nur auf den Flügeln gefleckt. Flïgelbildumg nicht wesentlich von der von Petronia verschieden (Fig. 31). Eine Art im paläarktischen Gebiet. $G$.dentata (am Nil bis Schendi, Bajudasteppe), pyrgita (N.O.-Afrika) und petronella (S.O.Afrika) dürften auch ohne Zwang zu Gymmris zu rechnen sein, obwohl sie dickere Schnäbel haben und von Sundevall, Heuglin u. a. wiederum als Xasthodira

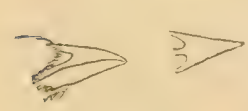

Figur 30. getrennt wurden. (Man könnte allenfalls 'iymnoris mit l'etroniu vereinigen, da auch die Lebensweise ähnlich ist, die 'Teilung ist aber praktisch, und leicht. Carpospiza ist ganz anders

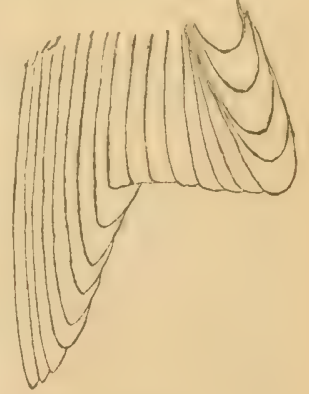

Figur 31. und kam ummöglich mit den Steinsperlingen zusanmenbleiben). 
237. Gymnoris flavicollis transfuga sulsp. nut. (Fig. 311, 31.)

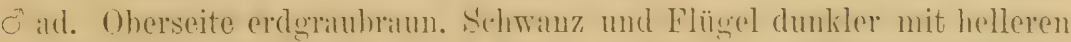
Sämmen. kleine Oberfiügaldecken hell kiastanixmotlıam, mittlere mit hreiten. grobe mit etwas weniger scharf hegrematen, solmäleren weiblichen spitzen,

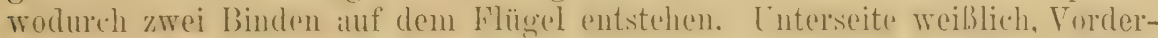
brust und Kärperseiten hell grambram. lichter als die (oherseite. in der Mitte

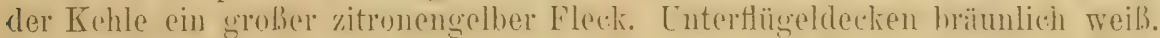
Schnabel in der Brutzeit schwarz. in Herbste meist hroun. Iris und Fübe

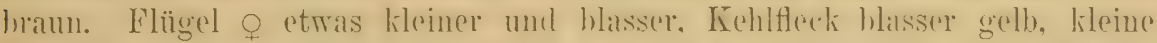

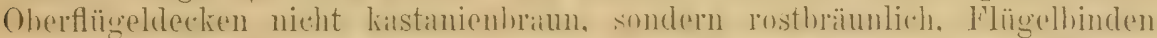

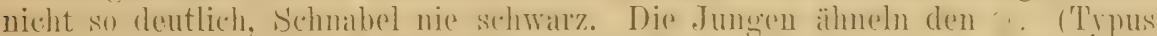

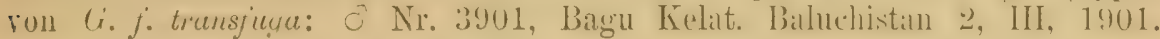
N. Sarudny coll. im Rothschild-Museum.)

Sindl, Baluchistan, sïdliches Afghanistan und Persien.

\section{Gymnoris flavicollis flavicollis (Frankl.).}

Fringilla flavicollis Franklin, Proc. Zool. Soc. Lond. 1831, p. 120 (Indien, Zentralprovinzen).

Fringilla xanthosterna Bonaparte, Cionsp. Ar. I, p.512 (1850- Bengalen, 'Typus im Berliner Iluseum).

Von G.f.transjuga durch dunklere, bräunlichere Oberseite und dunklere, mehr kastanienbrame kleine oberflügelderken untersehieden, nur in NordwestIndien kommen zu $G$. $f$. transfuga hinneigende Fixemplare vor.

Die Ebenen Indiens, im Himalaya nui bis 4000 engl. Fuß, sïdlich bis Travancore, nach Osten bis Midnapur unweit Calcutta.

Bewohner von Gärten und Buschwald, im allgemeinen sperlingsartig. Brütet in Indien vom März bis Juli in Baumlöchern, manchmal auch unter Dächern, nach Art der Sperlinge, und legt 3--4 Eier, die matt griinlichweiß sind, uiber und über mit braunen Flecken und Punkten gezeichnet, in Durchschnitt etwa $18<14 \mathrm{~mm}$ groß.

\section{Gattming CARPOSPIZA Miiller 1854.}

Hächst eigntümliche Form. mit starkem. sperlingsartigem, aber oben

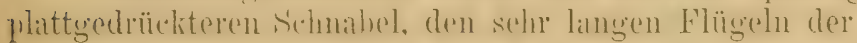
Steiusperlinge, in dem aber nur die ersten beiden (alusgebildeten) Schwingen fast gleich sind, die dritte merklich kürzer ist, die inneren Armsehwingen an den Spitzen verschmälert, über die mittlern merklich hervorragend (Fig. 32, 33). Nistet in offenen Nestern in Büschen, also ganz anders, als die Steinsperlinge. Nur eine Art bekannt.

\section{Carpospiza brachydactyla (Bp.).}

(Fig. 32, 33.)

Petronia brachyclactyla Bonaparte, Consp. Av. 1, p. 513 (1850Ex Hempr. M.S.: ,A Arabia, Abyssinia ${ }^{66}$, in Mlus. Berolinens. Typ. Lok. Konfuda, IV. Arabien).

Pyrenestes? Gray, Carpoducus Bp., lacteus (Sic) Müller, Naumannia I, Heft 4, p. 24r (1851- ,Ex Abyssinia $\left.{ }^{66}\right)$.

E. Hartert, Die Vögel der paläarlstischen Region.

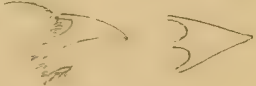

Figur 32.

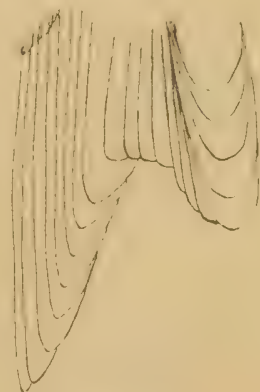

Figur 33. 
Euplectes (?) grisens Ilenglin, Syst. Übers. Vög. N.O.-Afr., p. 39 (1856- nom. nud.). ("arpospiza longipennis Mïller, Deser. nour. Gis. d'Afr. (Beitr. Orn. Afr.), p. 21, Taf. 10 (185t- Abyssinien).

ad. Wherseite fahl sind-granhriunlich, ein nur angedenteter weib-

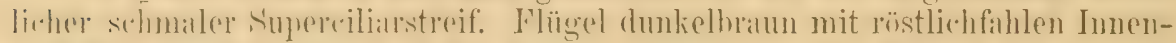

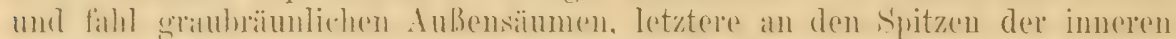

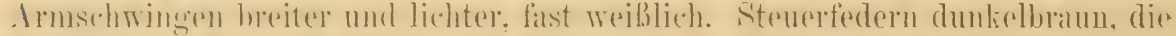

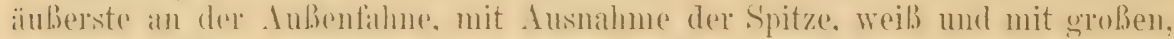
nach der Nitte zu kleiner werdenden weißen rundlichen Flecken an den

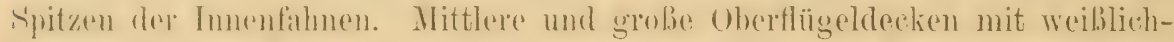

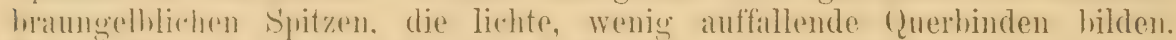
Kehle. Mitte der Brust und des Tnterkïrpers und Intersehwanzdecken rahmweiblich. Konf- Hals- mod Körperseiten und hreites band üher die Kropfsegend hell fahlhräunlich. heller als die oherseite. Oherschnabel (wenigstens hrei in Frühling) dunlelhornbraun. Interschualnel und Füba hell horn-

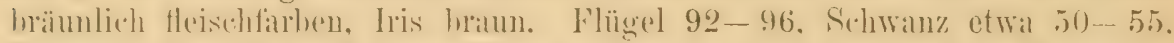
Sehmahel $11-12$, Latuf etwa $20 \mathrm{mmm}$. Junge viel lichter, mohr hell samdig-

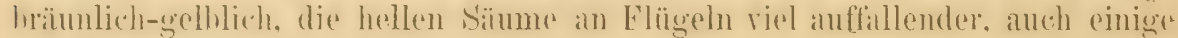
am Kleingefieder der Oberseite.

Vom persischen Baluchistan durch Süd-Persien nach Palästina und Arabien, jensedts des Roten Merees im abessinischen Kö̈stenlande und nach Heuglin sogar im südöstlichen Kordofan.

Bewrohner offener wiistenartiger Steppengefilde, wo Mimosen und andre Büsche nur spärlich wachsen, in der Ebene und im Gebirge in S.W.-Persien bis fast 8000 engl. FuB. Der Lockruf ist ein sehr langgezogenes, monotones zirpendes wiiiiis. Das Nest steht nahe dem Boden in Bïschen, ist wohl gefügt und enthält 4-5 weiße Eier mit kleinen schwarzen Punkten, wie ganz kleine Pirol-Eier.

\section{Gattung PASSER Koch 1816.}

Lmfaßt die Haus-, Feld-, Weiden- und Wüstensperlinge des palï-

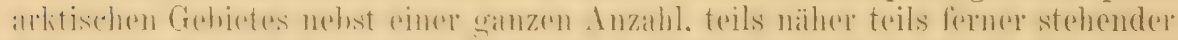

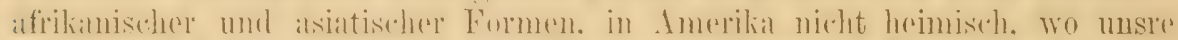

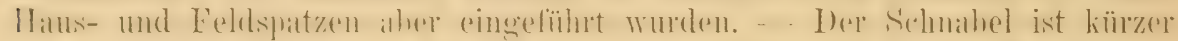

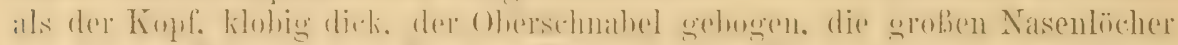

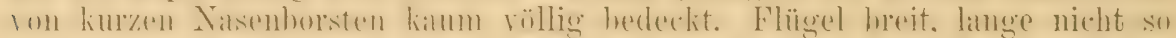

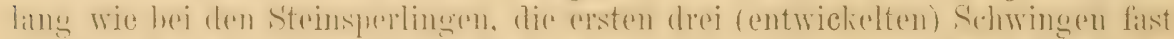

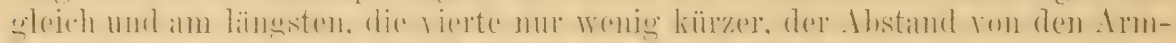

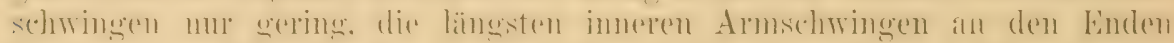
breit und nicht sehr weit und plötzlich ïber die ïbrigen hinausragend.

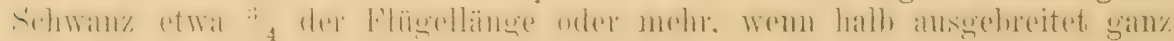
gerade. Jauf kurz und stark, Fül.e krüftig. Geschlechter meist sehr rel-

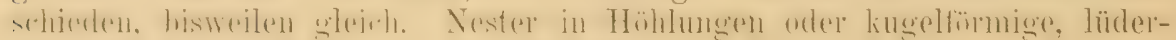
liche Klumpen in Bäumen. Hier gefleckt.

$$
\text { Übersicht der ô aller Arten der Gattung Passer: }{ }^{1} \text { ) }
$$

1) Uherseite gefleckt oller gestreift 
? $\left\{\right.$ Körperseiten schwarzgestreift ${ }^{1}$ ) . . . . P. hispaniolensis . p. 156

Körperseiten ungestreift . . . . . . . . . . . . . 3

3 I Unterseite kastanienbrammot . . . . . . . P. cmini-bey ${ }^{2}$ ).

I Unterseite weißlich, gelb oder granbrüunlich . . . . . . . . . . I

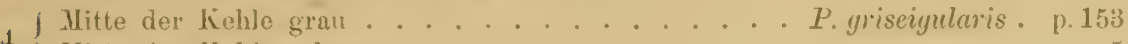

I Mitte rer Kchle schwarz. . . . . . . . . . . . 5

Oberkopf ju der Mitte schwalz . . . . . . P. ammodendri. p. 158

Oberkopf und Rücken zimmtbraun .......... P. rutilenss . p. 161

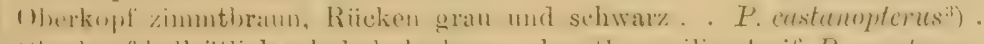

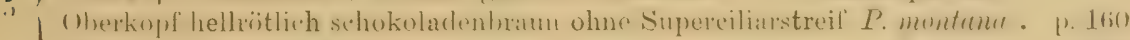
Uberkopl kastanicubraunrot . . . . . . . . . . ituliete p. 152

Oberkopf aschgran oder bräunlich mit Superciliarstreif . . . . . . 6

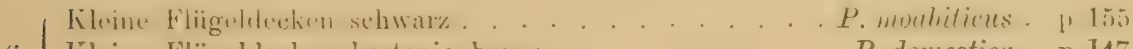

6 Kloine Fliigeldecken kastanienbraun......... P. domestica . p. 147

Kleine Eliigeldecken zimmtfarben ........ P. motitensis ${ }^{\dagger}$ ).

7 Kopf, Rïckien und Bïrzel gleichgefürbt . . . . . . . . . . . \&

| Kopf, Räicken und Büirel nicht gleichgefärbt ... . . . . . . . ก

8 \{ Oberseite kantriengelh. . . . . . . . P. enchlor $\left.a^{5}\right)$.

| Oberscite hellgran (ठ) oder isabell (ㅇ)........ P. simplex . p. 162

Ganzer Kopt und Bürzel gelb . . . . . . . . . . . P. lutea ${ }^{\text {) }}$.

9 Kopfmitte und Kehle schwarz .......... P. melanura ${ }^{7}$ ).

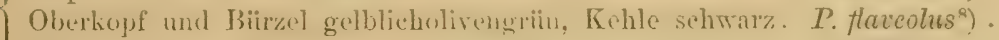

Oberkopf grau, Biirzel zinmtfarben, Kehle weißlich . . P. (liffusus ${ }^{\theta}$ ).

\section{Passer domestica domestica ( $\mathrm{I}_{\text {L. }}$.}

Haussperling, Hausspatz.

Fringilla domestice Linuaeus, Syst. Nat. Ed. X, p. 183 (1758- Europa. 'Typ. Lok. Schweden, nach dem ersten Citat: Fauna Suecica 212).

Pyrgita pagorum Brehm, Handb. Nat. Vög. Jeutschl., p. 265 (1831-mittl. Deutschland).

Pyrgita rustica Brehm, Hondb. Nat. Vög. Dentschl., p. 266 (1831- Norden, bei Greifswald).

Pyrgita validu, minos, brachyrhynchos, intercedens Brehm, Vogelfang, 1) 98 (1855„Dentschland, Schweden, Lingarn, Frankreich und Egypten").

1) Über Yariation sielse unter Mr. 254-259.

?) Sorella Emini Bey Hartl., Journ. f. Orn, 1880, pp. 211, 325: Südlich von Abyssinien bis Lado und Massailand.

3) P.castanopterus Blyth, Journ. As. Soc. Beng. XXIV, p.302 (1855) N.-Somaliland.

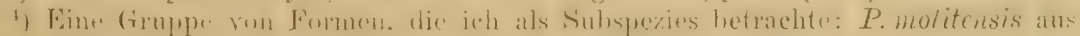

Siid-Afrika, I' mot. nuficinctus Mrssailand, P. mot. shelleyi Lado bis Kordofan, P. mot.

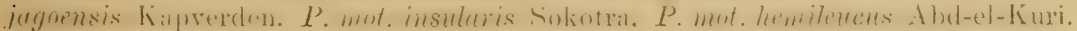

5) Auripasser euchlora Bonuparte, Consp. Ar. I, 1850, p. 519: Süd-Arabien.

*) Fringilla luten Licht., Vorz. Doubl., 1823, p. 24: N.O.-Afrika bis Nubien.

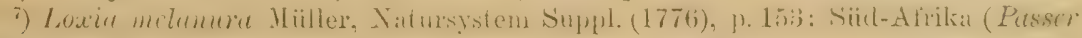
arcuatus (Gm.) (1788) auctorum). P. melanua damarensis Reichenow ist eine kleinere, lebhafter gelärbte Form.

s) P. flaveohus Blyth, Journ. As. Soc. Bengal 1844, p.946: Birmah bis Cochinchina.

9) Afrika siidlich der Sahara in einer ganzen Anzahl ron Subspezies. (V'gl. Orn. Mowatsber. VIT, [. 190, Nor. \%onl. 1900, p. 44.) 
Passer domesticus familiaris, crassirostris, macrorhynchos, microrlymchos, Passer midorsalis longirostris, major A. E. Brehm, Verz. Samml., 1).9 (1866-- nomina nuda! gehören nach Maßgabe der Sammlung hierher, nicht aber $P$. ruficlorsalis C. I. Brehm 1856 und P. brachypterus). ${ }^{3}$ )

Passer domesticus var. caucasicus Bogdanow, Vög. Kaukasus, p. 60 (1879- ungenïgende Beschreibung, russisch).

Engl.: House-Sparrow. Franz.: Ioineau domestique. Ital.: Passera oltramontana. Schwed.: Hussparf. Holländ. MInseh.

O’ad. Oberkopf aschgrau, die Federwurzeln daselbst auch grau. Zügel,

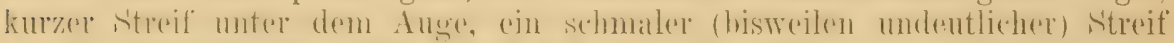

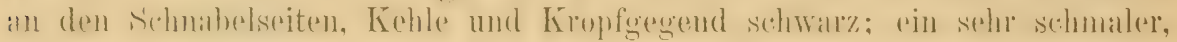
oft ganz undeutlicher weißer Superciliarstreif. Am Auge entspringt ein am Hinterhalse verbundener sehr breiter kastanienbramer Streif. Rücken

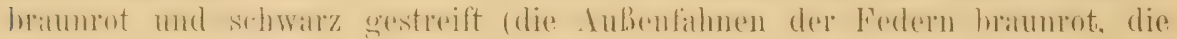
Innenfahuen schwarz), bald mit bald ohne weißliche Flecke, Bürzel und

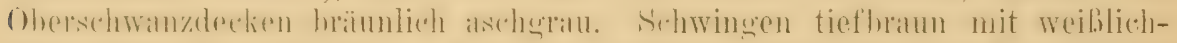

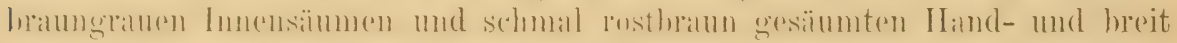
rostbraun gesïumten Armschwingen. Schwauz dunkelbraun mit röstlich-

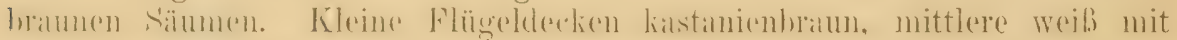
schwarzbramen Wurzeln, grolse kastanienrostbram mit helleren Spitzen. Kopfseiten weiBlichgrau, Halsseiten mehr weißlich. Unterseite mit Aus-

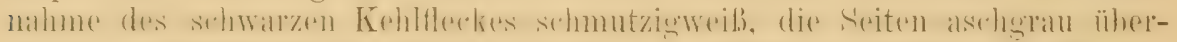

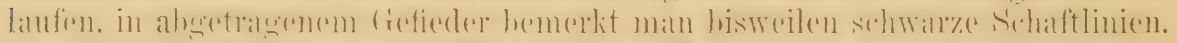

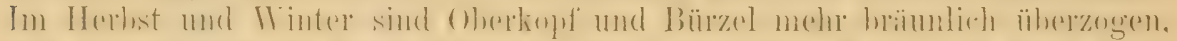

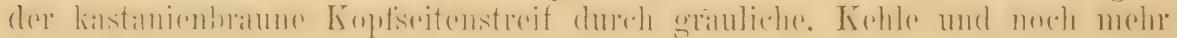

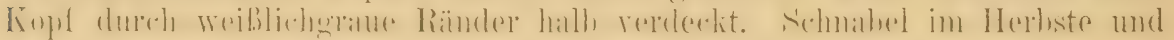
Vinter braun, Frïhjahr und Sommer schwarz, Iris und Füße braun. o und

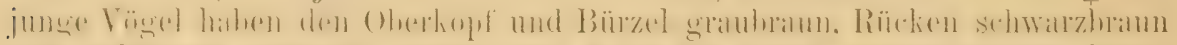

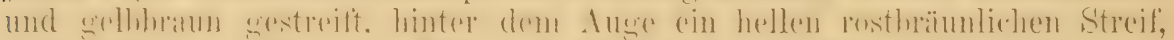

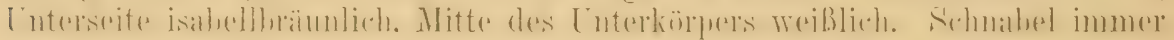
braum. Oad. Flügel etra 76-82.5, ja sogar 83 (Ost-Preußen).

Die Verbreitung der typistien Form des Haussperlings und seine $\mathrm{Ab}$ -

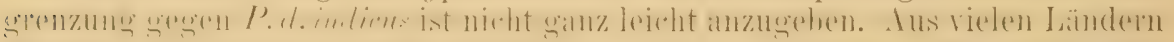

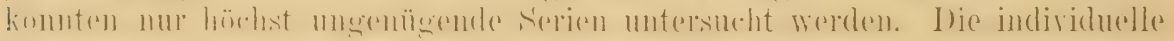

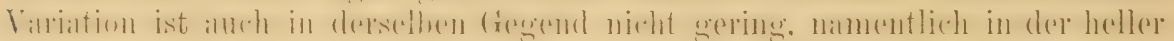
und dunkler, mehr oder minder mit weiß gemischten Rüickenfärbung und in den Maßen. Das von mir untersuchte Material ermöglichte mir nicht,

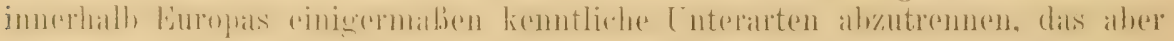
mag zum 'L'eil an der Tnzulänglichkeit des Materials liegen und nicht end-

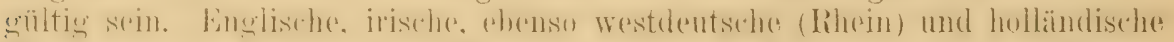

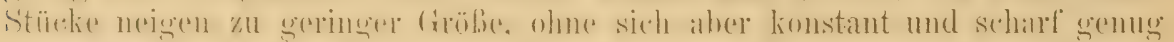
abzugrenzen. Das größte vou mil gemessene $\sigma^{\top}$ stammt aus Ost-Preußen, wo aber nicht alle so groß sind. Stïcke aus S.O.-Europa sind sehr lebhaft

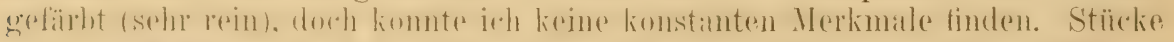
aus dem Kankasus sind ebenfalls sehr rein in den Farben, solche aus Trans-

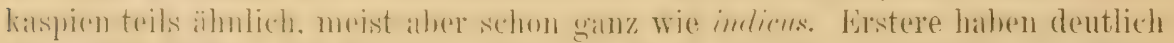

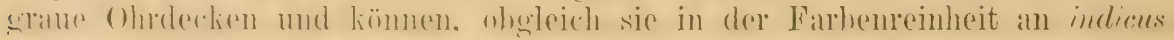

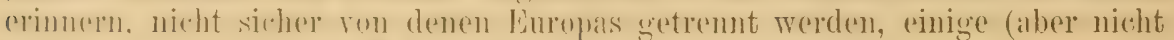

1) Im Catalogue of Birds XII, p. 309 sind als Synonyme falsch zitiert: Passer rufipectus Bonaparte, Fringilla pyrrhoptera Lesson. 


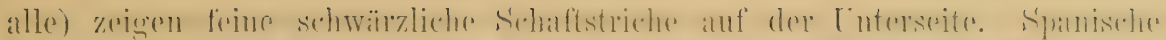

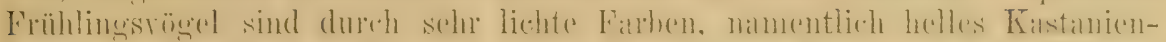

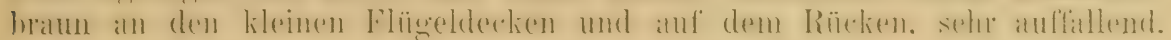
Herbströgel scheinen aber nicht unterscheidbar zu sein.

Ganz Luropa mit Ausmahme Italiens, wo er nur vereinzelt (etwas öfter in Friaul und Udine) erscheint. In Skandinavien bis etwas über den Polar-

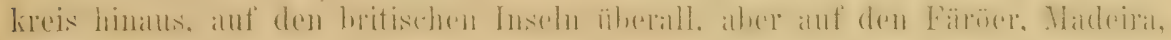
Azoren und Camaren fehlend. Durch Rußland und Sibirion bis Irliutsk und Daurien ostwärts, in Städten und Dörfern, soll sich aber in Sibirien erst. verbreitet hahen, seit feste IVohnsitze gegründet wurden, den lediglich von

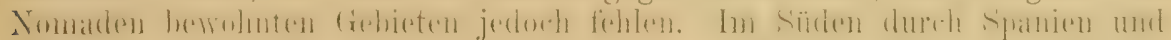
Portugal bis Gibraltar, Tauger, anf der ganzen Ballsanhalbinsel, mach A.V. Homeyer auch auf den Balearen. (Durch Nensehen nach Nordamerika, Neusceland und in andere Linder verbreitet.)

Der Haussperling ist ein Begleiter des Menschen. denn die Mehrzahl brïtet hentzutage an (iebäuden und nälurt sich an meisten von (retreide, Gartenprodukten und Abfall. Die Jungen werden teilweise mit Inselitenlarven und dergl, geliittert. Frech, laut, gclräßig, üherall. Jeclermann kenut sein lantes schilp, schilp, dieb, trenk und seiu Gezcter. Wr nistet jetzt zuneist an Gebäuden, bant aber auch in großen Städten sowohl als anf clem Lande kugelförmige, schr liederlicho Nester, in Ephen und in Bäumen, ${ }^{1}$ ) atuch bisweilen in Storchnestern und andern groben Horsten, an Uferwänden (zumal in Uferschwalbenlöchern), in Nistkästen, in Rauch- und IIehlschwalbennestern usw. Eier 5-6 Lier, selten 7, ausualumsweise 8, variabel, von lust ganz weib, nur mit kleinen grauen P'unkten bis braun, iiber und iiber mit dunkelbruun gefleckt, ziemlich groß fiir den Yogel, von $17 \times 14$ und $19.2 \times 14.8$ bis $22 \times 15.5,23>17$. $24.8 \times 15.7$ und sogar $25.2 \times 15.6 \mathrm{~mm}$. Durchsehnittliches Gewieht $0.207 \mathrm{~g}$. Es finden jährlich 2, oft auch drei Bruten statt.

\section{Passer domestica biblicus subsp. nov.}

Groß (Hlïgel $82-84 \mathrm{~mm}$ ), Schmabel so groß und manchmal größer;

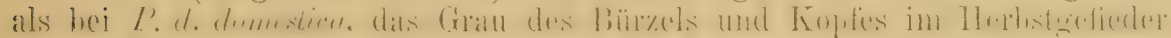

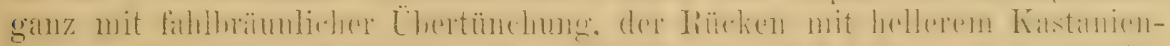

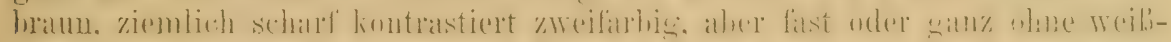

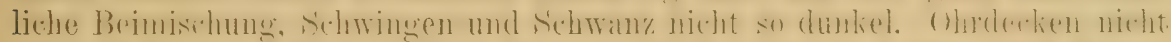

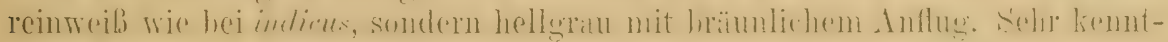
liche Form, die mehr auffällt, als man beschreiben kanm. Ich konnte 60 untersuchen, darunter die von 'Tristram gesammelten.

Syrien mit Palästina, von Beerseheba bis Beirut. Weitere Verbreitung:

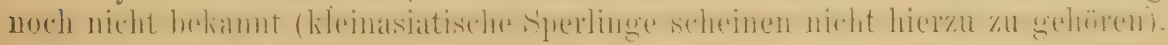

(Typus Nr: 143 o "Sueme" 2, IV, 1897, von Schlüter erworben.)

\section{Passer domestica tingitanus Loche.}

Pusser domesticus A. Tingitanus Loche, Expl. Algér., Oiseaux, p) 132 (1867-- aus Bonnp. Cat. Parzudaki Coll., p. 18, nom. nud., descr. prima: Algier!) (Es ist auffallend,

1) Das war wahrscheinlich die ursprüngliche Nistweise, wofür auch die Eier-

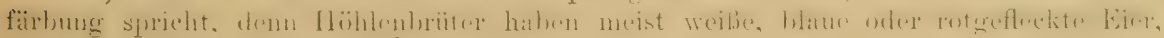
Theorien darüber gehören aber nicht hierher, wo es sich um Tatsachen handelt, ebenso-

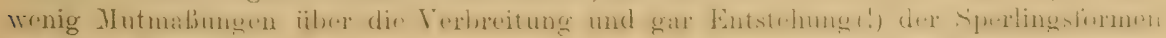
mit dem ylensehen. 
dab Loche sowohl $P$. domesticus als auch „P. d. A. Tingitanus" angibt. Dessen ungeachtet und trotzdem die Beschreibung nicht besonders bezeichnend ist, bezicht sich doch der Name Tingitamus auf Haussperlinge aus Álgier und muß daher für die dortige Form angewandt werden. obwohl Loche auch die echte domestica rorkommen liißt.)

Älnnelt P. d. domestica sehr, aber die grauen Oberliopffedern des ơ in der Mitte (unch der Bisis zu) schwarz, was beim frisch vermauserten Vogel nur beim dufheben der Federn gesehen werden kann, wodurch aber im Frühling, wenn die Federränder sich ahnutzen, ein dentlich schwar\% gesprenkelter Oherkopf entsteht. Außerdem sind die Ohrdecken weniger grau verwaschen und wie die Lnterseite lichter, etwas rahmfarben iiberlaufen, der Bürzel vielleicht atrvas lichter, der Flügel zu grölerer lä̈nge neigend, meist 1-2 mm lïnger. O nieht sicher zu unterscheiden, aber unten etwas lichter, weniger graulich.

'I'unis, Algier und Marokko. Auscheinend kommt in den nördlichsten 'l'eilen dieser Länder auch $P$. d. domestica ror, denn die aus 'Tauger stammenden Stücke scheinen dazu zu gehören, wïhrend in und bei Mazagan nur typische tingitanus leben. Aherrante Stïcke des echten I. d. domesticu mit der Kopfzeichnung ron tingitame kommen ansnahmsweise anch in Deutsehland vol (Kleinschmidt's Sammlung).

\section{Passer domestica ahasver Kileinschm.}

I'asser ahasver Kk leinschmidt, Orn. Monatsber. 1904, p. 7 (Marmkesch).

Wie P.d. domestica, aber nur ein rundlicher Heck in der Mitte des Soheitels grau, der rundherum, auch rorn schmal über die Stiru him, von Braumot umgehen ist. (Fhe Serien vorliegen - der Autor hat nur ein S'tück - kamm diese Form nicht als sicher hetrachtet worden. doch ist die Wahrscheinlichlieit, dab es eine Subspezies ist. gröher, als daß es pine Bastardhildung darstellt.) Museum).

Süden der Atlasländer: Marrakeseh, Lagouat in S.-Algier (Liverpool

\section{Passer domestica arboreus (Bp.).}

I'tsser arborens Bonaparte, Consp). Ar. I, p. 510 (1850- ex Lichtenstein M.s. in Mns. Berlin: Sennaar).

Passer mfidorsalis Brehm, Naumannia 1855, p. 277 (,N.O.-Afrika").

P'esser rufidorsulis megarhymchos und microrhynchos O. L. Brehm, Naumannia 1856. 1) 376. 377 (,Beide Subspezies leben in Ostsudan und sind bei Chartum nicht eben selten".)

? Pyrgita pectoralis Paul Wilh. v. Wïrtemberg, Naumannia 1857, p. 1333 (Nom. nudum! Nubia, Korosko, Dar el Bind); Heuglin, Journ. f. Orn. 1867. p. 299. (Beschreibung paßt auf arboreas, Fundorte des Herzogs mehr auf Nr. 245.)

Dieser reizende Sperling ist eine kleine, auberordentlich lebhaft ge-

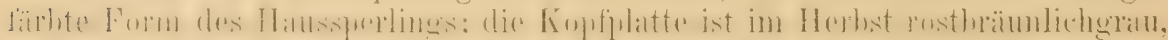

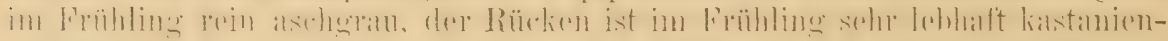
rotbraun, mit nur sehmalen schwarzen Streifen, nur im Herbstkleide sind

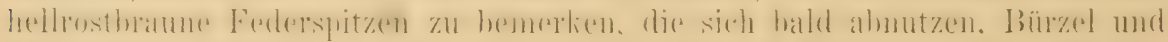

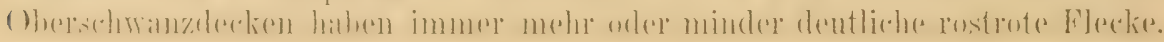


Die kleinste Form, Flügel der ठ 72 bis höchstens $74 \mathrm{~mm}$. O von denen der andern Formen nur durch geringere MIaße zu unterscheiden.

Am Nil, von Dongola und Berber südlich bis zum $12 .{ }^{\circ}$ uördlicher Breite. Bei Khartum häufig.

Lebensweise und Stimme wie die ron $P$. d. domestica, Nester (bei Sehendi), Klumpen von trockenem Gras und Federn an den Steilufern des Nil. Eicr nur 3, wie die andrer Sperlinge, olne Glanz, etwa so groß wie K'eldsperlingseior. (N. (:) Rothschild, Ibis 1902, [).9).

\section{Passer domestica subsp.?}

? Pyrgita Calivina Paul Wilh. v. Württemberg, Naumannia 1857, 1. 4333 (Nomon nudum! "Egyptia, Nubia, Shelaal, Wadi Halfa"); Heuglin, Joum. f. Orn. 1867, p. 299 (Sehr ungenügende Besehreibung. Später - Orn. N.O.-Afr. - stellt Henglin den Namen als Synonym zu P. hispaniolensis, Prof. Reichenow aber sah, wie er mir selrreibt, in der Sammlnng des Herzogs Stiicke von arboreus als calivina bezeichuet).

Ganz wie P.d. imlicus, aber die Ohrdecken nicht so rein weils, sonderu an ihrem obern 'Teile deutlich aschgrau, Flïgel etrar $73-76 \mathrm{~mm}$, also durehschnittlich etwas kleiner als bei $l$. $d$. indicus. Das untersuehte Material ist gering, dahor wage ich nicht, einen neuen Namen zu schaffen, und der Name

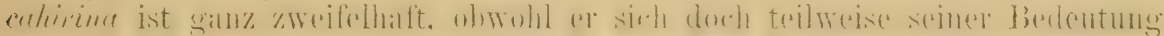
und der dafür angegebenen Fundorte nach auf diese nördliche Nilform bezogen haben mul.s.

Niltal südlich mindestens bis Wadi Halfa.

\section{Passer domestica indicus Jard. \& Selby.}

Passer indicus Jardine \& Selby, Illustr. Ornith. III. 'T'al:. 118 (Etwa 18:35-1848Indien. T'ypus im Tring Museum).

Passer confucius Bonaparte, Compte Rend. 37, p.915 (1853- Mus. Paris. "ex China, a Botta". Jedenfalls auf einen Haussperling zu beziehen, Lokalität violleicht ungenau).

Passer domesticus buryi Lorenz \& Hellmayr, Journ. f. Orn. 1901, p. 233 (Yeshbum, Siid-Arabien).

Merklich keiner, F'lügel $74-78 \mathrm{~mm}$, die Kopfseiten der o meist rein

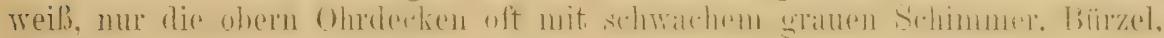
Kopf und allgemeine Fälbung lichter.

Von Cochinchina dureh Birmah (in T'enasserim sïdlich bis Moulmein),

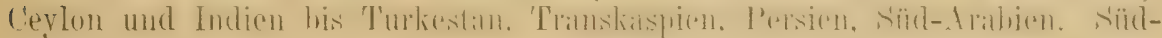
arabische Stilcke kann ich nicht von den indischen nnterscheiden. 'I'ranskaspische Stücke können zum Teil als intermediür zwischen domestice und indicus angesehen werden, sind aber meist reime inclicus.

\section{Passer domestica pyrrhonotus Blyth.}

Passer pymhonotus Blyth, Journ. As. Soc. Bengal XIIT, p. 946 (1814-- Sinclh.); Cat. B. Brit. Mus. X I1, 'Taf. 5 .

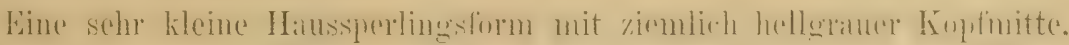

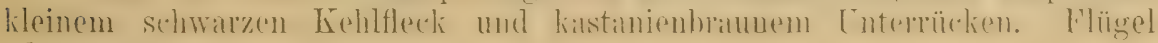
oี ad. $68-69 \mathrm{~mm}$.

Sindh (Narra). 


\section{Passer italiae (Vioill.).}

Fringilla italiae Vieillot, Nouv. Dict. d'Hist. Nat. XII, p. 199 (1817- Italien).

Fringilla cisalpina Temminck, MIaunel d'Orn., p. 351 (1820-Italien von den Alpen an). Pyrgita Italica Bonaparte, Geogr. \& Compar. List B. Europe \& N.-America, p. 31 (1838). Passer italiae gallicte Tschusi, Orn.-Jahrb. 1903, p. 19 (Nizza).

Das o unterscheidet sich ron dem von 1 . d. domestica nicht sicher,

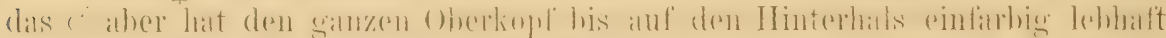

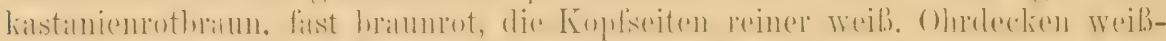
licher. Der Rücken ist wie bei I’. $/$. domestica, aber Stiicke mit nur rotbraun

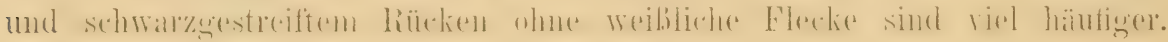
Neist ziemlich groß, aber nicht immer gröher als $L$. d. domestira.

Vertritt den nord-europäischen Haussperling von den Süd-Abhängen

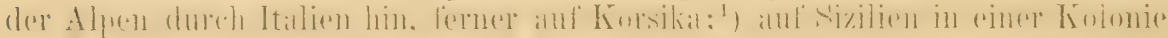
zu Messina. An der Riviera bis Nizza, vereinzelt bis Lyon. Wo soust $l$. (l. domestica wohnt. Süd-'lirol bis zum Ridnauntal, Sarntal, Bozen, Meran, im Eisacktal mit $P$. d. clomestica zusammen, cbenso bei Monfálcome (Gradiska). Fimmal bei 'Triest und Pontafel (Kärnten), 1837 in Genf erlegt, soll auch einzeln im Inntal vorkommeu, wo bis ïber Innsbruck hinaus (vou oben her) aber domestica rorkommt. (Vgl. 'I'schusi, Orn. Jahrb. 1903, p. 18.)

\section{Passer italiae senckenbergianus subsp. nov.}

Subspeciei $P$. italiae ituliae dictae similis, sed minor, gracilior, coloribus rividioribus. N.O.-Afrika - genauer Fundort unbekannt, Typus Nr. 903 im Senckenbergischen Iuseum zu Frankfurt a. M.

Auf S. 60 des Katalogs der Senckenbergischen Vogelsanmlung führte

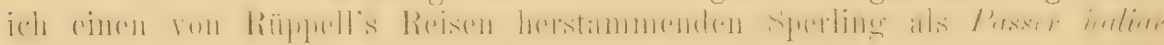
mefodorsalis an. Er gehört jedocb nicht zu mijodorsalis (= mboreus), dem

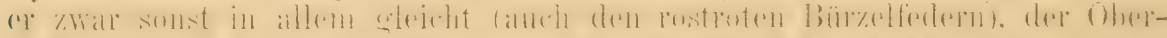

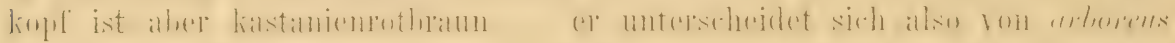
genau wie italiae von clemestica. Da wir solche Aberritionen nicht liemmen, müssen wir annehmen, daB es sich um eine besondere Form handelt. Fs ist eine Aufgabe der Sammler in N.O.-Afrika, diese Form wieder zu entdecken und ihren Wohnort zu ergrïnden. Da Rïppell die verschiedenen

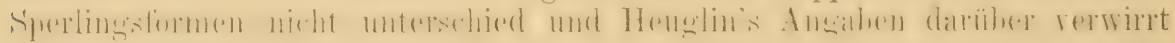
und teilweise unrichtig sind, haben wir keinen Anhalt, woher das merkwïrdig'e Stück stammt.

1) Von Korsika liegt mir außer typischen italiae ein von TWhitehead gesammeltes ot mit dunlelgrauer, schwarzgesprenkelter Kopfmitte vor, das also tingitanus täuschend filmlich ist, aber kürzere Flügel und dunkle Seiten hat. Das Vorkommen von italiae in Palistina berulht anf Irrtum. Die Angaben vom Vorkommen in Algier und T'unis dürften sich meist auf P. lispun. flïckigeri bezichen, möglicherweise auch auf Bastarde(?) zurïckzuführen sein, oder anf leichtfertiger Bestimmung von jungen hisponiolensis beruhen. - Die Frage, ob italicue als Subspezies von domestica zu behandeln ist, ist nicht leicht zu entscheiden. In größeren Gebieten kommen sie sicher nicht zusammen ror, doch aber in Sïd-Tirol und Süd-Frankreich (anscheinend auch im Inntal im Engadin). Übergänge sind nicht festgestellt, sondern bisher nur vermutet. 


\section{Passer griseigularis Sharpe.}

Passer griseigularis Sharpe, Cat. B. Brit, MLus. XII, p.313 (1888- Kandahar); Bianchi, Anumaire Mus. Zool. Petersbg. 1896, p. 126 (russisch: Übers. Orn. Mlonatsber. 1897, p. 162).

„Ơ ad. im Sommerkleide. Der Oberkopf und der Hinterhals rötlich-

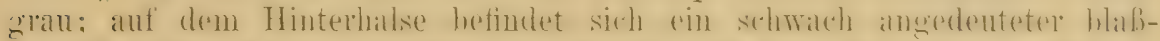

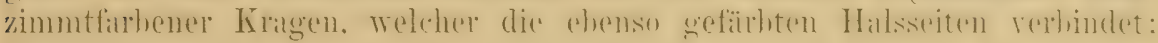
die Interscarpular- sorvie die Scapularfeder'n roströtlich, auf den Außenfahnen blasser gesïumt und mit schwarzen Innenfahnen; der Bül'zel

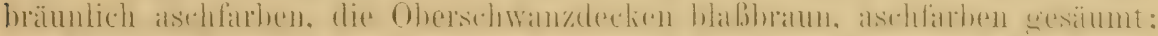

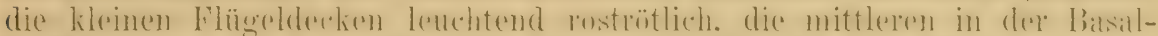

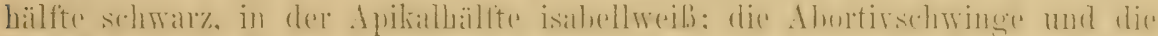

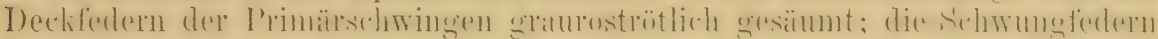
dunkelbraun mit rötlichisabellfarbenem Saun, welcher auf den 'Tertiürschwingen schr breit, auf den Primärschwingen aber weißlich ist; auf den letzteren ist der Saum vor dem Ende der Deckfederm und an der Verschmälerung der Aubenfahne am breitesten (ebenso wie bei den andern

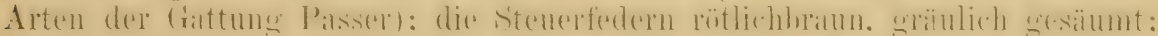
vom Auge elstreckt sich lïngs den Scheitel- und Genickseiten ein sehr blasser isabellzimmtfurbener Streifen, welcher sich auf den Halsseiten erweitert und in der Mitte durch die weiBlich-isabellarbene Augenbraue

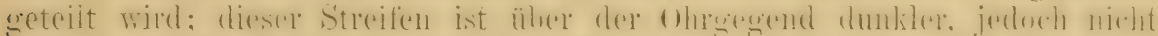

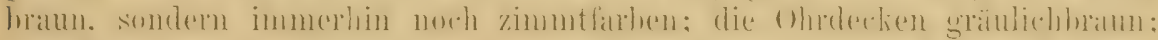
der Zügel und die Federn unter dem Auge schmutzigweiß; die Wangen,

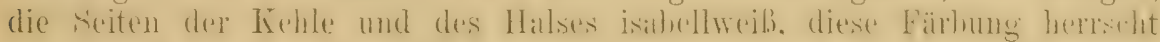
jedoch nur in der oberen Hälfte vor, in der unteren dagegen tritt die weiße

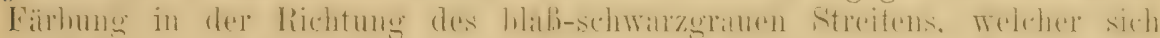
rom Kinn auf den Unterhals elstreckt, scharf hervor; die Kropfgegend

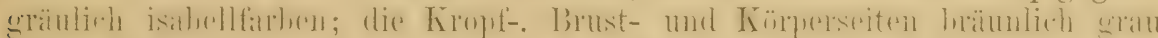
mit rötlicher Beimischung; die Brust, der Bauch und die Unterschwanz-

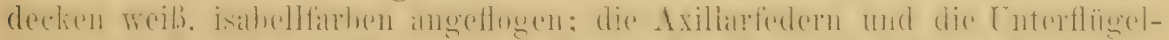

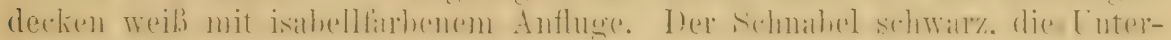
lieferbasis gelb; die FüBe gelblichbraun.

qad. Die Oberseite äbulich dem on, nur blasser gefärbt; die rost-

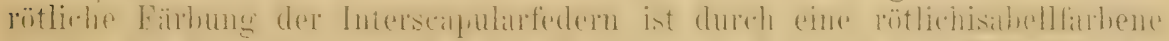

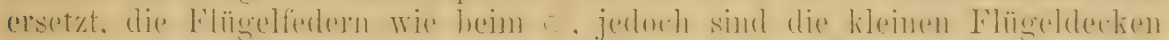

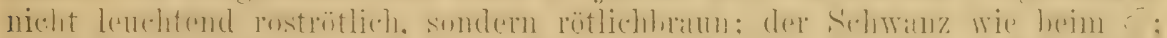

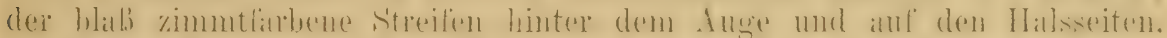

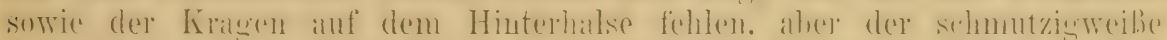

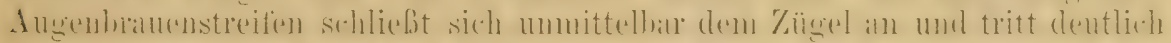
hervor: ein hinter dem Auge hefindlicher; zwischen der Angenbrane und den

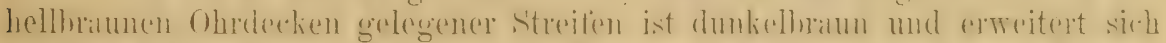

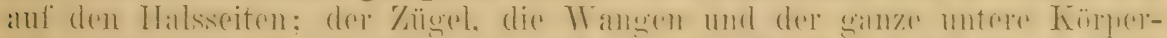

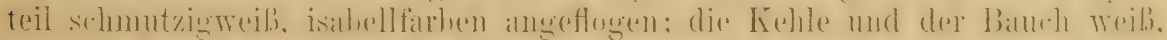

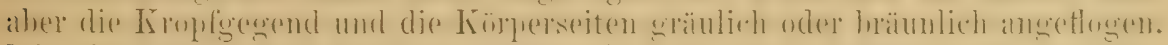
Der Sehnabel dunkelbraun. Flügel o $074 \mathrm{~mm}$; Schrwanz $58-61 \mathrm{~mm}$. 'Tarsus 18-19 mm." (Nach Bianchi. Ich konnte nur das nicht ganz alte 0 in London untersuchen.)

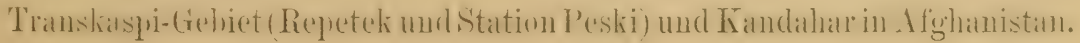


Diesem Sperling begegnete X. Sarudny ${ }^{1}$ ) in Trankaspi-Gebiet sowohl zur Zugals auch zur Britezeit. Er nistet in der Oase Merw, wo er ihn im Sommer in den Rohrbeständen antraf; auch in Buchara, in der Kultur-Zone des Amu-I)arja, bei den Aulen Kara-Ohous und Mukuri in wasser- und rohrreichen Gegenden ist er gefunden. Den Zug beobachtete Sarudny im \%weiten I)rittel des April (a. St.) 1892 in der Wüiste zwischen Merw und dem Amu-Darja, am 14. (26.) IV. bei der Station Peski und vom 18.-20. IY. (30. IY.-2. V.) bei Repetek. Ein Stïck wurde aus einem ungeheuren, sehr schnell und sehr hoch gegen X.O. fliegenden Schwarm erlegt.

\section{Passer enigmaticus Sarudny.}

Passer eniqmuticus Sin'udny, Orn. IIonatsber. 1903. p. 130 (Porsisches Baluchistan).

"Oberkopl und Hals graubraum, Halsseiten mit rostfarbener, wemn anch schwacher Beimischung. Der untere l'eil des Rëckens einfarbig graubraun. Die Federn der Schulterpartie an der AuBenfahne rostbraun, schwarz an der Tnnenfahne. Die Fïrbung des Bürzels ehenso wie die des Oberkopfes und des Halses, nu' mit stark entwiekelter grauer Beimisehung. Die oberen Schwanzdeckfedern dunkler, mit seh" undentlichen, rerwischten, graubräunlichen Elecken. Die kleinen oberen Flïgeldeckfedern roun bleich-kastanienrosthramer Wärbung. Die mitteren oberen Deckfederu in der Wurzelhälfte schwarz, in der Kudhälfte isabellfarhig. Die rorderen groben Deckfedern seliwarzbraun und graubraun in der Wrurzelhälfte. Die hinteren groben Deckfedern schwarzbraun mit isabellrostfarbigen Enden mo ebensolehen breiten Rändern auf den Aubenfahuen. Sehwingen dunkel-graubraun mit isabellfurhigen Randungen (sehr breit an den Federenden und den AuBenfalunen der Schwingen dritter Ordnung, bleicher und schmäler an den AuBenfahnen erster Ordnung). Die isabellfarbigen Borden an den Schwingen erster Ordnung sind am hreitesten iu der Gegend der Spitzen der Deckfedern und vor der Linbuchtung der AuBenfinhe. Tou hinteren Winkel des Auges, längs der Kopfsseiten und am Hinterkopfe sich sehr erweiternd, an don Vorderseiten des Halses, erstreckt sich ein bleich isabellfarbiger Streifen. der einen dentlichen, wenn auch sehr schwachen, kastanienbraunen Stich hat. Zügel und Federn muter dem Ange sind grauweib. Die Obrgegend ist hellgrambraun, Kinn und Jitte der Kehle sind mehr oder weniger reiuweißer Firbung. Der ïbrige 'Teil der Kehle, Vorderbrust, die Seiten derselhen und Bauch sind isabellfurbig mit grauer Beimischung, hesonders stark an den Seiten der Oherhust. Die unteren Schwanzdeckfederu sind weib mit dentlichem isibellfarbigem Stich. Die Mitte der Unterbrust und die Mitte des Bauches sind

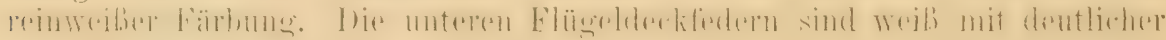
isabellfarbiger Beimisehung, dieselben Federn des Buges sind hell isabellfarbig. Der Schmabel, außer der Wurzel des Unterschnathels, die hellhornfarbig ist, schwar\%. Füße sehr hellgrau mit etwas dunkleren Nägeln. Iris dunkelgraubraun. Winterkleid: Die kleinen oberen Flïgeldeckfedern mit weniger entwickelter kastanienbramer Fïrbung; dor Schubel hellhornfarhig. In den

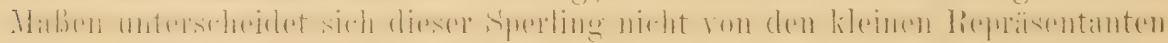
des T. indicus." (Nach Sarudny.)

Sarudny erbeutete diesen allerdings noch rïtselhaften Sperling iu einigen $\sigma^{\top}$ in persischen Baluchistam.

$\left.{ }^{1}\right)$ In der 1. Lieferung dieses Buches wurde der Nane mit $\mathbf{Z}$ geschrieben, nach Mitteilung russischer Freunde aber ist die Schreibweise mit $\mathbf{S}$ im Dentschen vorzuziehen. 


\section{Passer moabiticus moabiticus 'Tristr.}

Presser moabiticus Tristram, Proc. Kool. Soc. London 186t, p. 169 (Am 'Loten Mleere), Ibis 1867, p. 370, 'iaf. 7.

ô ad. Ganzer Oberliopf und Hinterhals, sowie die Kopfseiten ascherau,

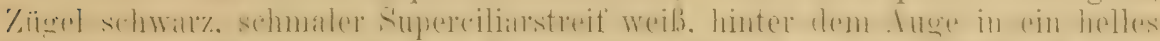

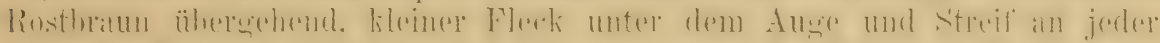

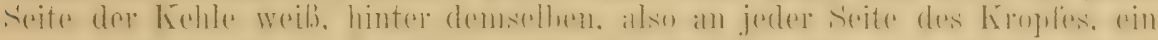
schwefelgelber Fleck, Kehle bis anf den Kropf schwarz. Rücken lobhatt

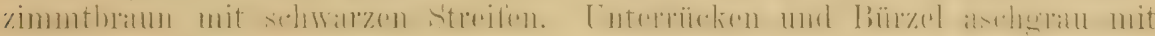
rosthräunlichem Schimmer. Oherschwanzdecken in der Mitte dunkelhraum. Sehwingen und Schwanz schwarzbraun mit fihl weiblichbraunen Säumen.

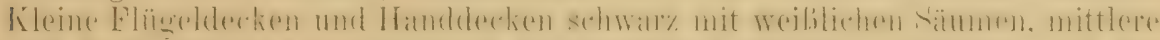

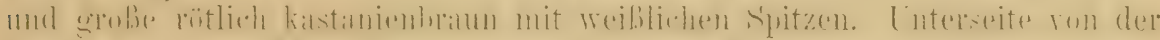

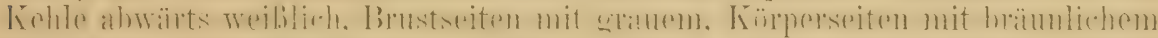

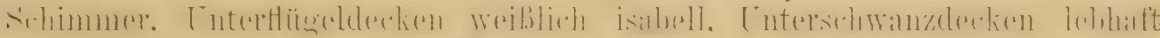
rimmtbraun mit breiten weißlichen Säumen. Schenkelbefiederumg außen schwarz. Im frischen Herbstgefieder sind Kehle, Kopf und Bürzel durch hellrostbräunliche Federrïnder halh verdeckt. Die Unterseite hat hisweilen

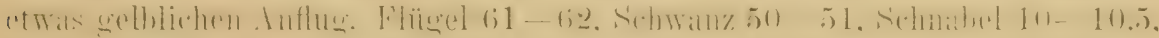
Lauf $17-18 \mathrm{~mm}$. Das o sieht etwa wie ein lileines gemeines Sperlings-

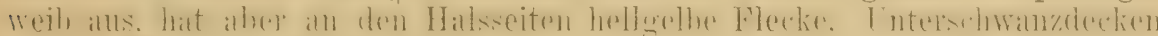
in der Mitte dunkler, aber nicht zimmtfarhen. Juv. wie o. Die Eier sind wie die voll Passer montama.

Bewohnt die Rohrdichichte westlich und sïdlich des Toten Meeres in l'illïsting.

\section{Passer moabiticus yatii Shlirpe.}

Passer yatii Sharpe, Cat. B. Brit. MIus. XII, p. 322 (1888- Dedarli in WV.-Afghanistan); Trans. Linn. Soc.. 2. ser., Zool. Y., p. 80, T'af. VI.

Von oben P. m. moabiticus zum Verwechseln ähnlich, doch ist im

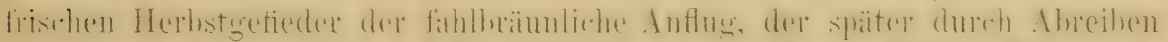

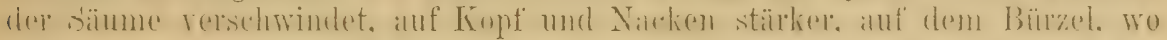

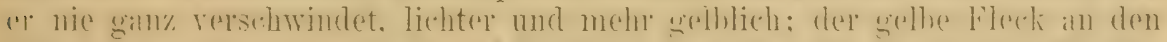

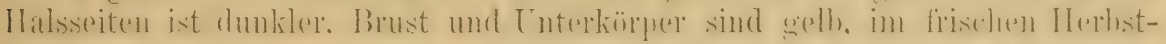

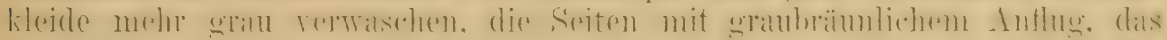
Vimmtbraun an den Unterschwanzdecken ist blasser und mehr auf den Wurzelteil beschränkt. Etwas gröBer, Flïgel $64-68 \mathrm{~mm}$. o wie das von I’. m. moubiticus, aher gröBer, auf dem Rücken lichter, im frischen Gefieder

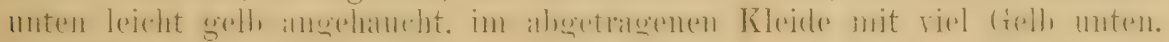
Jur. wie 0 .

\section{Bervohnt das westliche Afghmistan und Ost-Persien (Seistan).}

Sarudny fand diesen reizenden Sperling im Juni häufig in Seistan brütend. Gelege 4-6, Eier variabel wie andre Sperlingseier: weißlich, ganz oder an der oberen Hälfte mit aschgranen Flecken bedeckt, ebenso aber mehr bräunlich, bis rein weiß mit einzeln

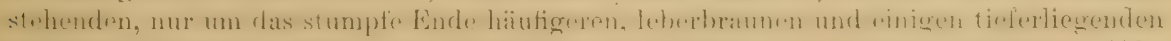
hellgrawen Flecken. Haße $18 \times 13.3,18.7 \times 13.3,18.4 \times 13.1,18.4 \times 12.9 \mathrm{~mm}$. (Abbildung Ibis 1903, Taf. 10.) 


\section{2.). Passer hispaniolensis hispaniolensis (T('mm.). \\ Weidensperling.}

Fringilla hispaniolensis Temminck, MLan. d'Orn., p. 353 (1820- typ. Lok. Gibraltar, Typen in Wien.)

Fringilla espaniolensis Werner, Atlas Ois. Europe, Granivores, 'I'af. 41 (1827- Spanien).

Fringilla salicicola Vieillot, Faune Franc., p. 417 (1828 - „très rarement en Provence, commun dans l'Espagne" ).

Pyrgita hispanica Brehm, Haudb. Naturg. Vög. Neutschl., p. 266 (1831- Spanien bis Sardinien).

Pyrgita Salicaria Bonaparte, Compar. List B. Eur. \& N.-Amer., p.30 (1838- augenscheinlich Schreil,fehler für salicicola, aber später oft so geschrieben. Nom. nud.).

Passer rufipectus Bonaparte, Consp. Ar. I, p. 509 (1850_- ,ex Ägypto". Bezieht sich auf eine nicht eben seltene Aberration von $P$. hispaniolensis mit rotbraun gemischter Kropfgegend aus Egypten).

Pyrgita oricntalis Brehm, Vogelfang, p. 98 (1855- „Im Morgenlande").

Passer salicarius major, minor, elegans, magnirostris, longirostris, brevirostris, A. E. Brehm, Verz Sanml.. p. 9 (1866- nomina nuda!).

Passer hispaniolensis washingtoni 'T'schusi, Oru. Jahrb. 1903, p. 9 (Agypten, Sinai, Ḱlein-Asien: Typus Damiette).

Engl.: Spanish Sparrow. Franz.: Aloineau espagnol. Ital.: I'assera sarda.

Unterscheidet sich von allen Formen der domestica-Gruppe durch auffallende Merkmale und bewohnt grobe l'eile desselben Gebietes. Ober-

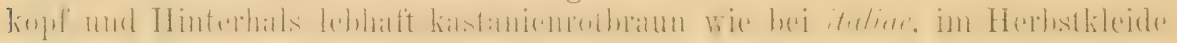
durch bräunlichgraue Rïnder fast verdeckt, eine schmale weiße Linie von der Stirn bis linter das Auge. Zügel, schmaler Streif unter dem Auge bis zur Schlälengegend und an den Seiten der Untersehuabelbasis sehwarz. Rücken und Schultern schwarz, ersterer durch die gröBtenteils fahlrostgelhlichen Inmenfahmen der Federm hell gestreift, im Herbst durch fille Säume ganz, fabl erscheinend. Bürzelfedern schwarz mit fahlrostbräunlichen Säumen, Oberschwanzdecken braun. Die ausgedehnt schwarze Kehle und Kropfgegend setzen sich gleichsam auf die Seiten fort. indem dort die Federmitten cler Jänge nach schwarz sind, im Herbste durch weibliche Säume mehr verdeckt, im Krïhjahr um so sichtbarer. Die schwarze Seitenstreifung variiert, ja es liommen Stücke vor, denen sie fast gauz fehlt - ebenso bei den andern Subspezies der Art. o wie das des Haussperlings, aber die Seiten zeigen meist dunkelgrane Streifung angedentet. Flügel der o $76-82 \mathrm{~mm}$.

Spanicn, auf den östlichen Canaren und Gran Canaria, Capverden, ganz,

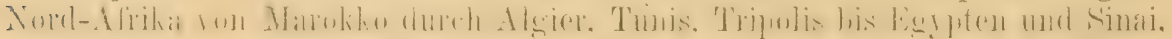
nördlich des Mittelmeeres von Kleinasien dureh Griechenland und die 'Tïrkei bis Bulgarien. Ob die Weidensporlinge, die in der Provence vorkommen, hierzu gehören, oder zu arrigonii, ist nicht festgestellt.

I'schusi unterscheidet die Form von „Egypten, Sinai, Kleinasien", die ron ihm angegebenen Unterschiede finde ich aber keineswegs bestätigt, die

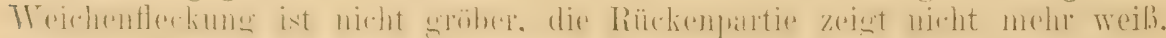
der Kopf ist nicht dunkler bramrot. Einige Verschiedenheit lïßt sich in

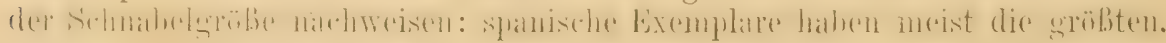
die von N.W.-Afrika teils gleich große, teils lileinere, die von Egypten und Kleinasien meist etras kleinere Schnäbel - die Unterschiede sind aber sehr

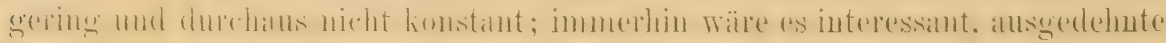


Serien daraufhin ferner zu betrachten. Wenn man die egyptische Form unterscheiden könute, müßte man sie rufipectus nennen. Stücke von den

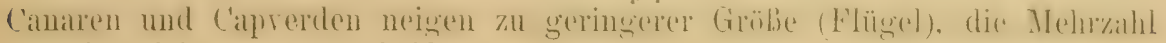
aber ist nicht zn unterscheidon.

Der Weidensperling ist im allgemeinen Stand- und Strichrogel, aber in Nord-Indien erscheint die dortige lorm (Nr.256) nur als IVintervogel, wahrscheinlich von 'Turkestan her. In Stimme, Nahrung und Gewohnheiten ist wenig Unterschied vom Haussperlinge, doch schien mir die Stimme etwas höher, sunfter. Zum Nistplatz wählt diese Art Bäume, Gebüsch, Uferdickichte, Palmenkronen, wo sie kugelförmige Nester nach Art der Haussperlinge baut, in Nord-Afrika finden wir sie aber zuweilen an Materwerk und dergl. nistend, aber doch wohl ausnabmsweise. Die Eier gleichen denen der Haussperlinge,

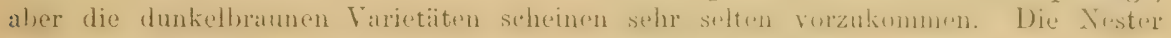
stehen meist nahe beieinander, oft geraclezu kolonienweise.

\section{Passer hispaniolensis arrigonii 'Ischusi.}

Passer hispaniolensis arrigonii Tschusi, Orn. Jahrb. 1903, p.8 (Sardinien).

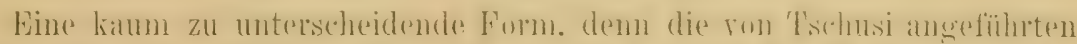

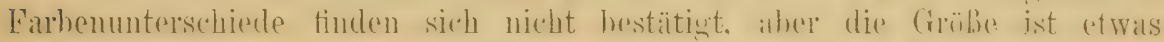
geriuger, als bei $P$. h. hispaniolemsix. Ich messe die Flügel vou 10 o 75-78, Tschusi die von 27 o $75-77 \mathrm{~mm}$.

Sardinien und Korsika.

\section{2.)ti. Passer hispaniolensis transcaspicus 'l'shusi.}

Passer hispaniolensis transcaspicus T'schusi, Orn. Jahrb. 19033, p. 10 ('Transkaukasien, 'Transkaspien bis P'unjab, Typus Jelotau, 'Transkaspien).

Passer hispaniolensis palaestinae T'schusi, Orn. Jalnrb. 1903, p. 11 (Palästina).

Schnabel meist etwas kïrzer, einzelne Stiicke und selbst Serien im abgetragenen Sommerkleid nicht von $I^{\prime}$. h. hispaniolensis zu unterscheiden,

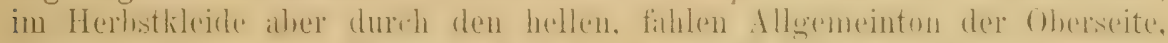

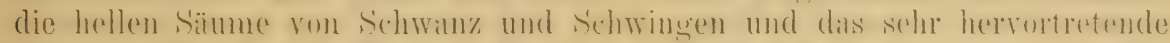

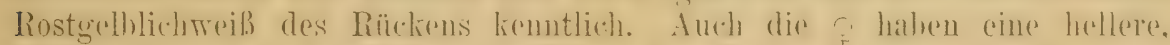

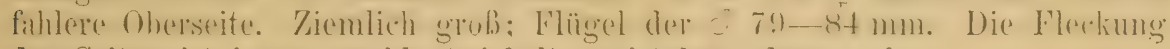
der Seiten ist immer wohlentwickelt, meist besonders grob.

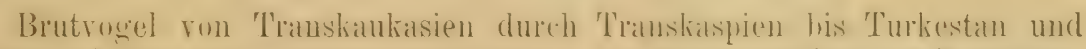
Kaschmil. Af

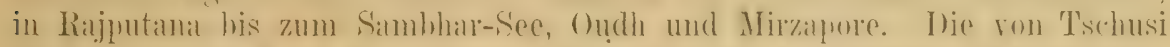

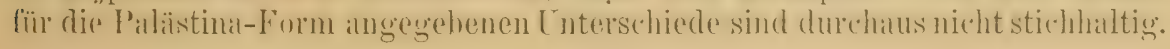

\section{Passer hispaniolensis maltae Hart.}

Passer hispaniolensis maltae Hartert, A.d. Wanderj. e. Naturf., p. 315 (1902- IIalta); Nov. Zool. 1902, p. 332; 'I'schusi, Orn. Jahrb. 1903, p. 12.

Wie 1'. h. hispaniolensis aber die Seitenstreifung sparsamer bis zur gäinzlichen Ermangelung derselhen. Flügel im allgemeinen, aber nicht koustant kürzer, etrva $74-79 \mathrm{~mm}$.

Malta und Sizilien. Stïcke mit mangelnder Seitenstreifung wurden wiederholt für italiae gehalten. 


\section{Passer hispaniolensis brutius liore.}

Passer italiae (Vieill.) var, brutius C. Fiore, Materiali per un'Avitauna ('alabra, p. 28, 296 (1890 - typische Lokalität Calabria).

Vou allen anderen Formen von $P$. hispaniolensis dureh ganz lehlende

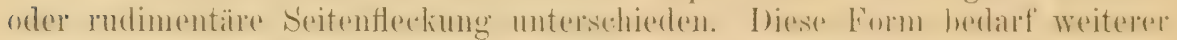

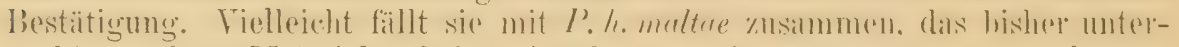
suchte geringe Material scheint sie aber zu einem Extrem von maltue zu stempeln. Die Stücke sehen in der T'at atus wie Hybriden ron itrliae und hispaniolensis. Man lese 'Tschusi's genaue Auseinandersetzungen im Ori. Jahrb. 1903, p. $14-16$.

Süd-Italien (Calabrien und 'T'arent).

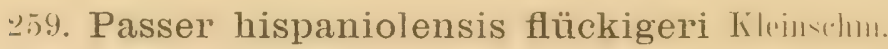

Passer" flïckigeri Kleinschmidt, Orn. MLonatsber. 1904, p. 7 (Tugurt)

ơ: Äbnlich P. h. hispaniolensis, aher mit verschwindender vder gan\% ohne Seitenstreifung. Auf dem Rücken mehr braun, fist wie bei $P^{\prime}$. 1 . domestica. Lichter als $P$. h. maltar, scheint $P$. h. brutius am nächsten $\%$ stehen. O (nach Kleinschmidt) heller, als das der nördlichen Form, die aber in der Brutzeit auch sehr verbleicht.

Süd-Algier (Erlanger's Gebiet III - 'T'ug'urt, Zouia, Guerrera u. a. m.).

\section{Passer ammodendri ammodendri Gould.}

Saxaul-Sperling.

Passer ammodendri Gould, Birds of Asia Y, 'Taf. XV und 'Iext (1872- ex Dode nomen nudum Proc. Zool. Soc. 1871, p. 481 und Severzow II.S., als Fundort ist irrtïmlich "montagnes Célestes" angegeben, die terra typiea ist abor tas: 'Tal des Syr Darja in T'urkestan-Perowk, Djulek).

ơad. Kopfmitte vou der Schuabehwurel his anf den Hinterhals, wo

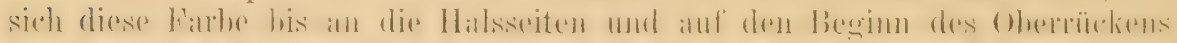

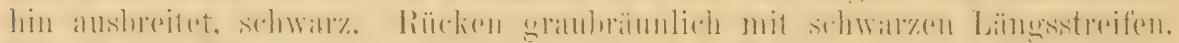

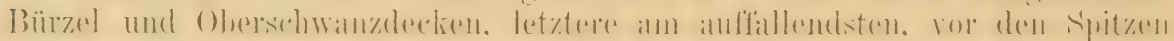

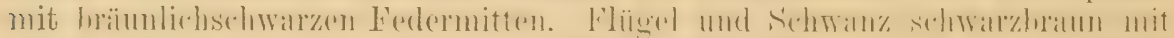

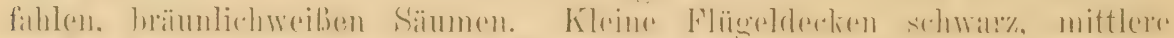

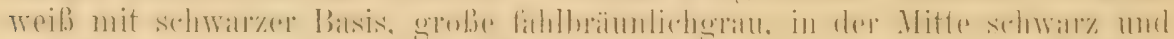

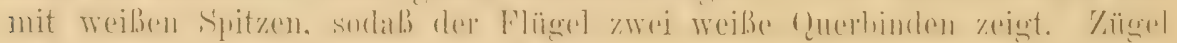
und Streif hinter dem Auge sehwar, darüber ein schmaler weiber, vou Auge bis auf den Hinterhals ein sehr breiter zimmbrötlicher Streif. Kopl-

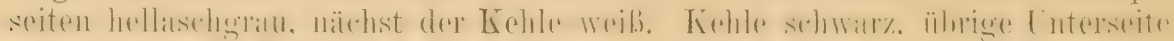

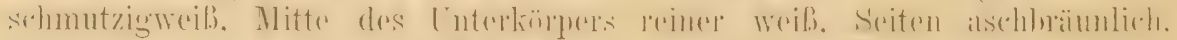

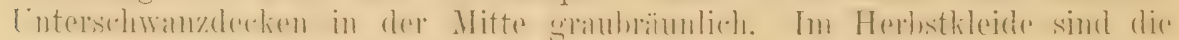

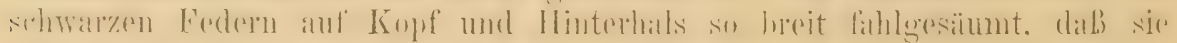
die schwarze Grundfarbe fast ganz verdecken, auch auf Unteriticken und

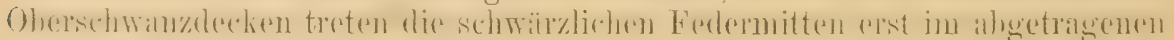
Gefieder dentlich hervor. Flïgel 78.5-82. Schwanz 67-69.5, Lauf 20 , 
Schmabel 10-11 mun. Iris bram, Sehnabel im Frühjahr und Sommer ganz schwall\%, in Herhst und Winter. an der Wur\% heller. dem ähnlich. ather kleiner: (Flïgel etwa 77 ). Kehle nicht sehwar\%, sonderm sediefergrau. Koptmitte nicht schwar. sondern aschbrïmlich und nur an den lexderwurzeh

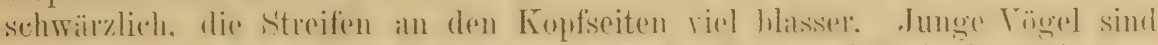

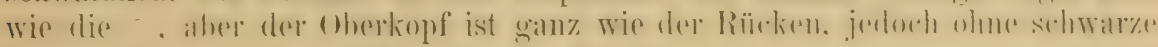
Streifen, die Kehle weißlich wie die Brust.

Russisches 'Turkestan, besonders das 'T'al des Syr Darja bis Ferghana

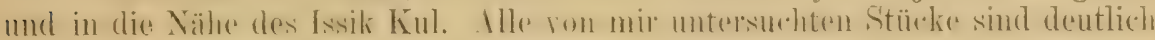

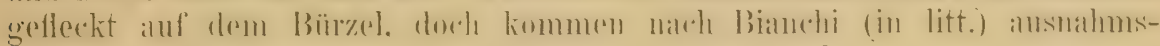
weise atuch Stiicke vor, die der folgenden Form älmoln.

Die Saxaul-Sperlinge sind Bewohner lehmiger und sundiger Fibenen, besonders in der Nähe der Flußlänfe. Thre Lebensweise und ihre Stimme sind durchaus sperlingsartig. Sie lieben besonder's die Saxaulbüsche, von deren Sumen sie auch hauptsächlich leben. Thre Yester banen sie nach Sperlingsart in den Saxaulbüschen, an Lehmwänden. Gebäuden oder in der Unterlage von Kaubrogelhorsten. Die 3-5.5 Eier gleichen Hanssperlingseiem. (Abbildung Ibis 1903, T'af. 10.)

\section{Passer ammodendri korejewi Silmụ d Hirms.}

Passer ammodendri lorejewi Sarudny \& Härns, Orn. Monutsber. 1902, p. 53 (Östl. Transkaspien, zwisehen Paropamisus und Amu-Darja).

Steht $P$. a. ammodendri äußerst nahe, der untere Bürzel und die Obersehwanzdecken sind abor in heiden deschledhtern immer ungefleckt, auch hat die Oberseite rinen sehwatehen rö̈tlichen Sehimmer, ohue darin aher auch

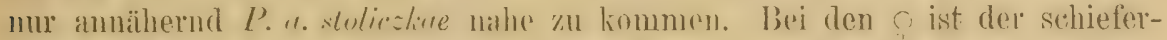
farbene Kehlffeck nicht dentlieh. Diese Form. von der ioh rine gute Serie untersuchen komnte, ist sehr kemntlich.

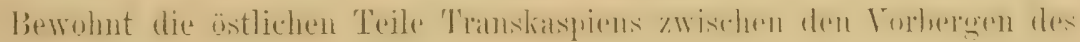
Paropamisus und dem Amu-Darja.

\section{Passer ammodendri stoliczkae Hume.}

Passer Stoliczlicte Hume, Stray Feathers II, p. ó16 (187. L- Yarkand, Kaschgar).

Passer timidus Przewalski, Iz. Zais. Khami \& 'Tibet, pp.94, 95 (russisch! 1883- Oasen Chami und Sa-tschen in der Wïste Gohi). Übersetzung . Deditius, Journ. f. Orn. 1886 , p. 529.

Untersuleidet sich anf den ersten Blick ron l’. a. ammodendri durch

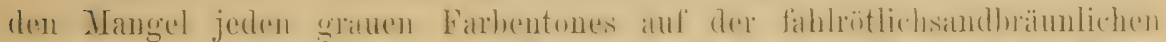

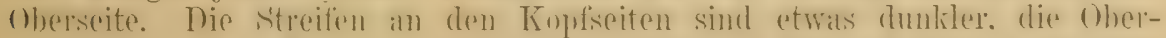

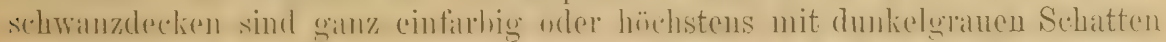

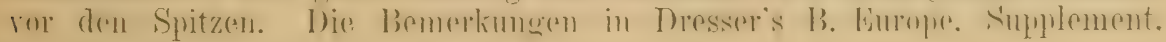
p. 185, sind unzutieffend.

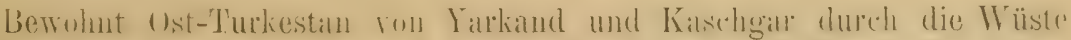

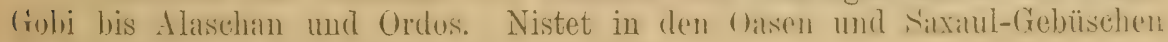
an den Rändern der eigentlichen Sandwüste. 


\section{Passer montana montana (L.).}

Feldsperling:

Fringilla montana Linnaeus ${ }^{1}$ ), Syst. Nat. Ed. X, I, p. 183 (1758 - Ex Aldrovandi, Olina, Rajus. "Habitat in Europa". Als terra typiea nehme ich Nord-Italien an, ex Aldrovandi).

Loxia hamburgin Gmelin, Syst. Nat. I, p. 854 (1788 - Ex Brisson, Albin, von Hamburg). Fringilla campestris Schrank, Fauna Boica, p. 181 (1798).

Passer Montanina Pallas, Zoogr. Rosso-Asiat. II, p. 30 (1831 - „In Rossiae et Sibiriae apricis ubique frequens").

Pyrgita septentrionalis Brehm, Handb. Naturg. Vög. Deutschl., p. 268 (1831- „Er bewohnt den Norden, namentlich Dänemark bis Kiel").

Passer arboreus Blyth in Rennie's Field-Naturalist I, p. 467 (1833- nomen nudum!).

Passer montanus vulgaris, hortonm, macrouns, microrhynchos, montanoides A. E. Brehm, Terz. Samml., p. 9 (186t)- nomina riuda!).

Engl.: 'Tree-Sparrow. Franz. : Friquet. Schwed.: Piefink. Ital.: Passera mattuggia.

Unterseheidet sich von 1 . domesticu und der Mehrzahl der Sperlinge dadurch, daß die Geschlechter ganz gleich gefürbt sind. Der ganze Ober-

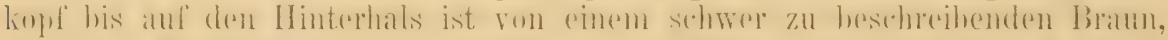

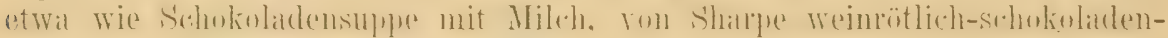

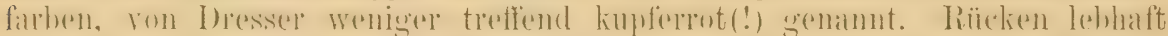

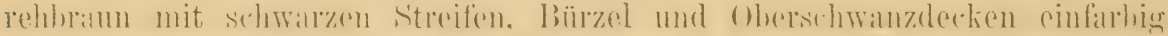

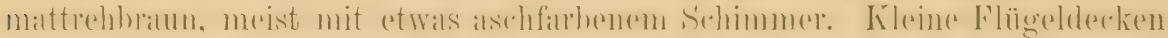

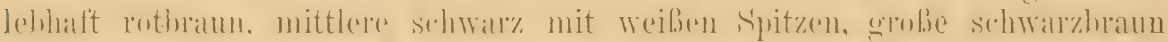

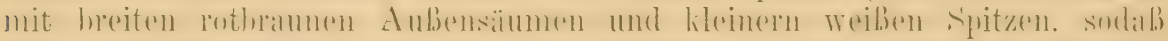

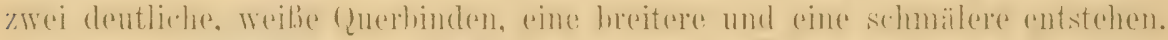

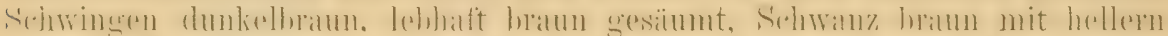

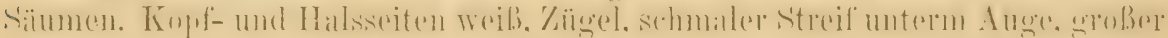
Fleck in der Ohrgegend und Mitte der Kehle bis zum Kropf sehwarz.

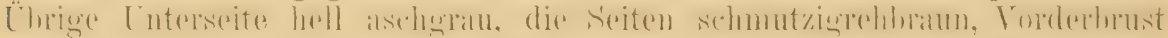
mehr aschgräulich, Mitte des Unterkörpers weißlicher. Achselfedern und

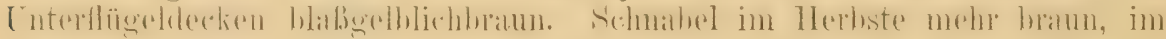

Frühjahr sehwarz, Füße hellbraun, Iris braun. O etwas kleiner als das o Flïgel otwa $73-76$, o etwa $69-72$, Schwanz etwa 55, Schnahel etwa 9-10 mm. Juv: im allgemeinen dem alten Vogel ähnlich, aber der Kopf

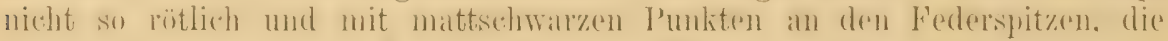
ganze Oberseite matter, Kehle nur in der Nitte mit etwas Schieferfarbe.

Europa vou 68" $30^{\prime}$ nördlicher Breite bis Italien und Spanien, soll jedoch in l'ortugal und anf den Inseln des Mittelmereres fohlen und ist ron zweifelhaftem orler doch andiserordentlich seltenem Vorkommen in Nordafrika; dureh Sibirien his r'hina und Japan. Auber der zentralasiatischen form

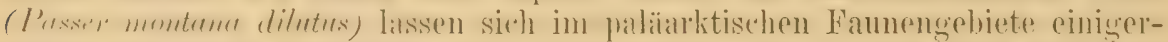
malien liemutliche Gnteralrten nicht muterscheiden, doch haben sehom sibirische

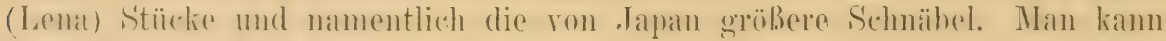
sie daher allenfalls als

1) In der 1. Lieferung wurde, dem deutschen Gebrauch folgend, der. „Archiater" áls "Linné" zitiert, er nennt sich aber auf dem Titelblatt und weiterhin "Linnaeus". Ein Autor muß aber auf alle Fälle so zitiert werden, wie er als Autor des betreffenden Werkes im Druck erscheint. 


\section{P'asser montana saturatus Steju.}

unterscheiden. Der Name wurde rou Stejneger nach einem Stïck (!) von

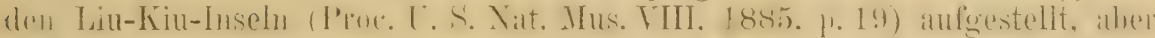

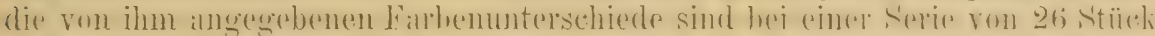

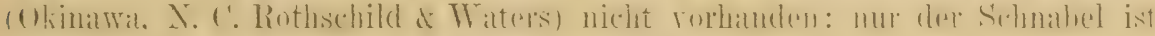
etwas größer, wio bei den Japanern und Sibirieru.

Anders ist es, woun wir die 'lropen Asiens betreten: durch das tropische

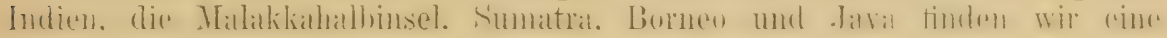
kleine und merklich rötlichere Form, die heiben muls:

\section{Passer montana malaccensis Dubois. 1885.}

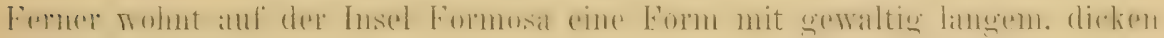
und hohen Sehnabel (11-12 mm lang; etra 81/2 hoch), die ich als

\section{Passer montance taivanensis subsp. nor.}

bezeichne ('Typus $\mathrm{Nr} .4 \pm 8$ Daihoku 9. Oktober, von Japanern gesammelt). 28 Exemplare untersucht, uneist seho typisch.

Der Feldsperling bewohnt in Europa vorzïglich Gärten, Aulagen, lichte Laubwälder, Chausseebäume usw. und nistet bei uns fast ausschlicßlich in Baumlöchern, während er in Indien und anderwärts im Osten ganz wie unsre Haussperlinge lebt and rorzugsweise unter den Dächern der Häuser brütet. Jourdain u. A. fanden ihn in England und anderwärts auch im Unterbau der Nester von Saatkrähen, Reihern u. a. Vögeln brittend. Die Laute sind alle echte Sperlingstöne, aber dic Locktöne sind weicher, angenehmer, etwas kiirzer, daher von denen des Haussperlings fïr einen nur cinigermaßen Geübten zu unterscheiden. Nahrung sperlingsartig. Die Nester bestehen wie die der Hausspatzen aus großen Kmmpen von Federn, Stroh. Heu, Wolle, Fasern, sehr gern (wie auch beim Haussperling) mit bunten Fäden, Lappen, und bisweilen frischen Blüten vermengt. Die Hier sind wie die des Hausspatzen, aber meist etwas glänzender und bedeutend kleiner und viel öfter über und über braun. Sie messeu in Durchschnitt $19.7 \times 14.1$, im Minimum $18 \times 13.2$, im Ilaximum $22.2 \times 14.1$ und $20.2 \times 14.8 \mathrm{~mm}$. (Rey.) Beide Eltern brüten. Es finden stets 2, manchmal, wie es scheint, sogar 3 Bruten statt.

\section{Passer montana dilutus Richm.}

Passer montunus dilutus Richmond, Proc. U.S. Nat. ILus. XVII, p. 575 (1895- Kashgar). Pusser montanus, Briss. var. pallidus Sarudny, Ois. Perse Oriental, p. 262 (russisch! .1903"t, scheint aber erst Februar 1904 ausgegeben zu sein - Ost-Persien).

Unterscheidet"sich auffallend von 1 . m. montana durch die lichtere

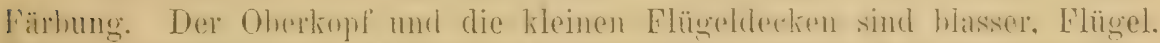

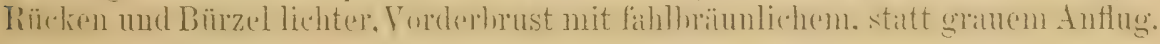

Ost-Turkestan, Turkestan und östlichstes Persien, jedenfalls auch

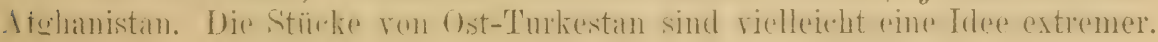

\section{Passer rutilans rutilans (Temm.).}

Fringillı rutilans Temminck, PI. Color. III, 488 (1829- Japau).

Passer russatus 'T'emminck \& S'chlegel, Fauna Japon., Ares, p. 90, 'T'uf. ร0 (1850- Japan).

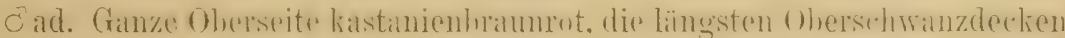

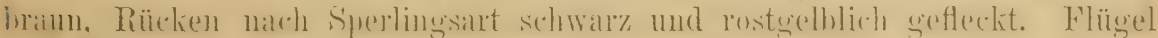

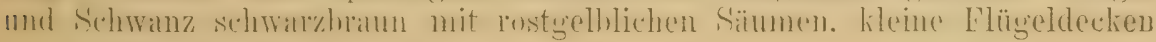

E. Hartert, Die Vögel der paläarktischen Region. 


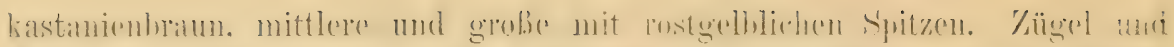

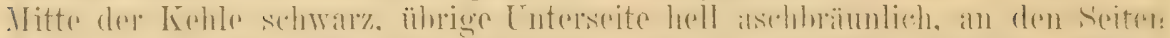

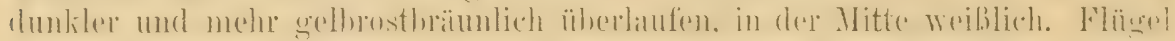
72-74 mm. Im Herbste ist die Oberseite durch hell aschbräunliche Feder-

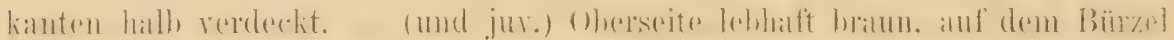
ins Rotbrame ziehend. Vom Auge zum Hinterhals ein schmaler, schwarz-

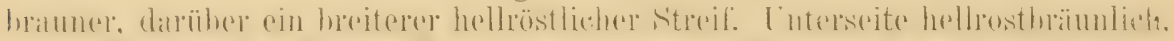

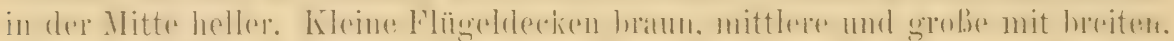

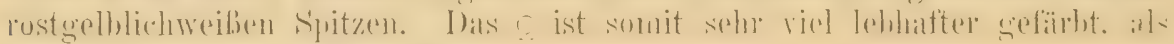
unsere Hausspatzenweiber.

Japan, mittleres China (fehlt aber nördlich schon bei Peking und in

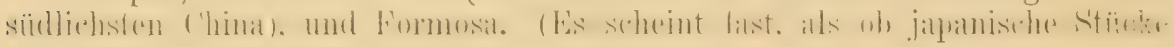
otrvas gröber seien.)

Nisten meist unter Dächern, Lier wie dichtgefleckte Feldsperlingseier.

\section{Passer rutilans cinnamomea (Gould).}

Pyrgita cinnamomea Gould, Proc. '/Hool. Soc. London 1835, p. 185 („Himalaya", ich nehme als terra typica Bhutan an).

Ist $P . r$ rutilans äußerst ähnlich und vou oben nicht zu unterseheiden,

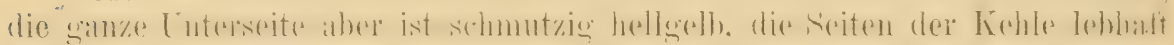
gelb. Flïgel länger: o $77-79 \mathrm{~mm}$. O wie das ron $P$. r rutilans, aber unten mit etwas gelblichem Schimmer.

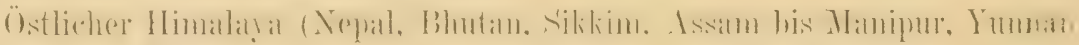
und die Karen-Berge).

\section{Passer rutilans debilis subsp. nov.}

..Passer cinnamomeus" Hume \& Heuderson, in Lahore to Yarkand, p. 252, 'Taf. 25 (1873Sind-'Tal in Kaschmir').

Ganz wie $P$. $\%$ cinnamomea, aber die Flügel kürzer, of $70-73 \mathrm{~mm}$, und im Sommer auf der Oberseite viel heller werdend, als jene Form, obwohl das frischvermauserte Gefieder ebenso dunkel ist. ('Typus ôd. SindThal in Kaschmir 19. VII. 1873, ges. v. Oberst Biddulph, 'Tring Museum: Nr. $7265 \mathrm{~g}$.

Kaschmir bis in das nördliche Sindh und östlicher Himalaya.

Diese und die vorige Form sind baumberwolnende Sperlinge, die ihre Nester in Baumlöchern, seltener unter Düchern, haben. Die Wier tragen ganz den Charakter von Sperlingseiern und haben etwa die Größse der Feldsperlingseier. Während manehe eine weißliche Grundfarbe haben, und nur mäßig gefleckt sind, sind andre so dieht braungestreift und gefleckt, daß die Grundfarbe nicht mehr sichtbar ist.

\section{Passer simplex simplex (Licht.).}

Fringilla simplex Lichtenstein, Verz. Doubl. Zool. Mus. Berlin, p. 24 (1823- Ambukol an Nil); Abbild. 'T'emminck's Pl. Col. III, 358, 1825.

Passer Lichtenstinii ILeuglin, Journ. f. Orn. 1868, p. 88 (Bajuda-Steppe, N. Kordofan, Sennar). 
Sad. Ganze Oberseite aschgrau mit einem Stich ins Bräunliche.

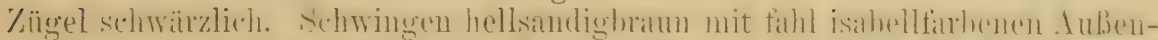

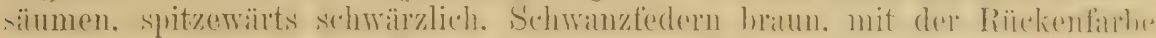

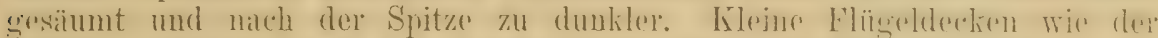

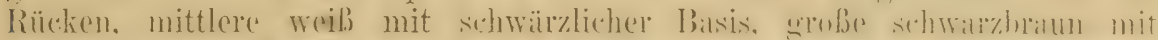

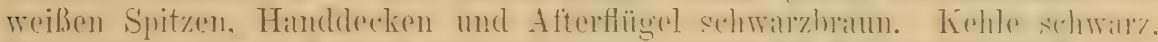

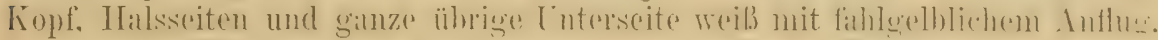

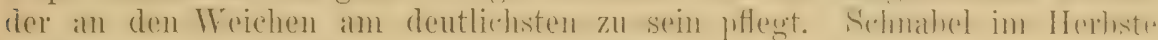
hollbraun, im Frühling bei alten ơ schwarz. Fülo hellbraun, Iris braun. Flügel 73-77, Schwauz 58-62, Schnabel etwa 10, Lauf 19-20 mm.

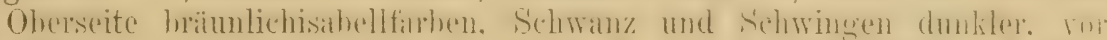

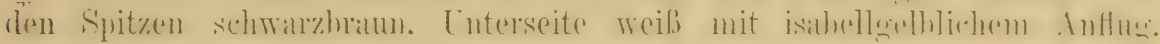
Schnabel hellbraun. Juv. wie

Nach Heuglin an den Wüstenbrumen des südlichen Nubiens, in der

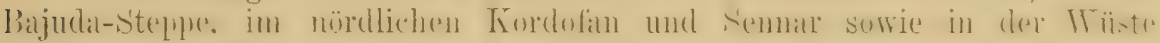
üstlich von Berber. (Von neueren Forschern nicht beobachtet.)

Lebt in deu oben angegebenen Gegenden als Standvogel in kleinen Flügen und paarweise, nährt sich von Grassamen und ist im Gebahren ganz ein Sperling.

\section{Passer simplex saharae Erl.}

Passer simplex saharae Erlanger, Journ. f. Orn. 1899, p.472, T'af. 14 ('Tumesische Sahara); Abbild, auch in Dresser's B. Europe III, 'I'af. 179.

Das ơ unterscheidet sich von $I^{\prime}$. s. simplex durch hellere, im frischen

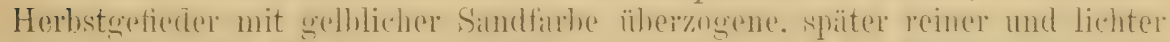

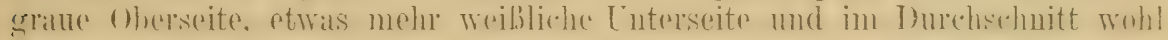
auch etwas gröbere MaBe, Flügel $77-81 \mathrm{~mm}$. o oben heller, nicht so

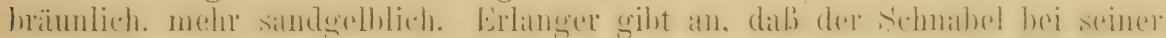

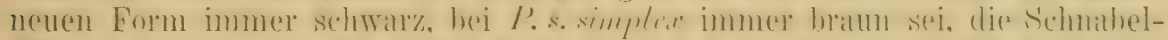

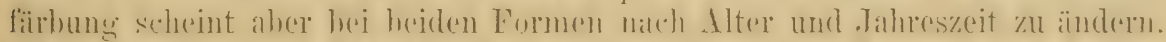

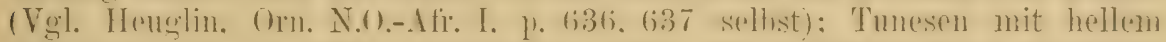
Sehmilnel habe ich selhst untresucht. (T)iese Form seheint kamm genëgend begriundet zu sein.)

Bewohnt die Sandwüsten von Algier, 'I'unis und 'I'ripolis.

IIan findet den W Üstensperling hauptsïchlich an den Brunnen und meist aut dem Boden, auf Steinen oder Felsen sitzend und hïpfend, und er ist ganz und gar feldsperlingsartig in seinem Betragen und seiner stimme. Das Nest ist ein grober Bau von trockenen Halfastengeln, Gräsern, Granuen, Wolle, Federn, Lappen. Es steht im Gemäuer der Wüstenbrunnen, in hohlen Baumstämmen und Raubvogelhorsten. Die Gelege scheinen aus 3 Eiern zu bestehen. Diese sind ganz wie Feldsperlingseier, aul hellem Grunde braun gestrichelt und gewölkt, oder auf lehmbräunlichem Grunde mit bräunlicholivenfarben und tiefer liegenden grauvioletten F゙lecken größtenteils bedeckt. Maße: $20>13,19>13,18 \times 14,19 \times 14 \mathrm{~mm}$, Gewicht 0.122 und $0.125 \mathrm{~g}$.

\section{Passer simplex zarudnyi Pleske.}

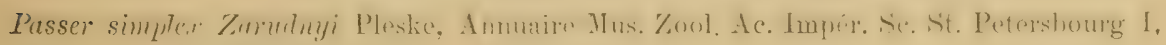
p. 31 (1896 Russisch! - Transkaspien.).

Ganz rom Charakter der andern Formen von Passer simplex, das o

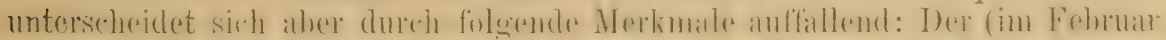

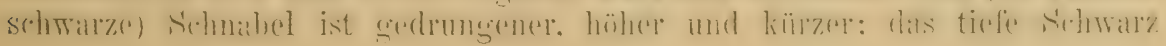




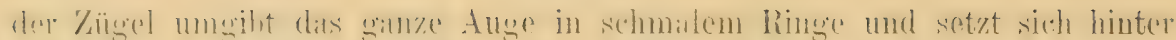
demselben in schmaler, spitzer Linie fort. Die Oberseite, besonders die

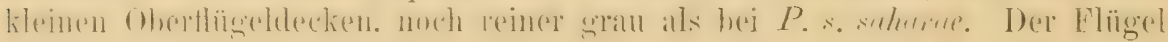
eiues mir vorliegenden alten $\delta$ mißt $75 \mathrm{~mm}$. der Schwanz 63. Fübe (im Balge) dunkel, nicht hellbraun.

T'urkmenen-Steppe in 'Transkaspien, zwischen dem Amu Darja und den Auslïufern des Paropamisus.

\section{Gattung EMBERIZA L. 1758.}

Umfalit alle altweltlichen Ammern mit Ausnahme des Sehnecammer

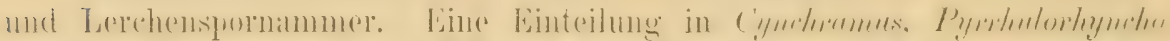

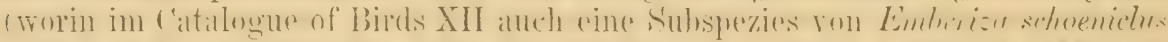

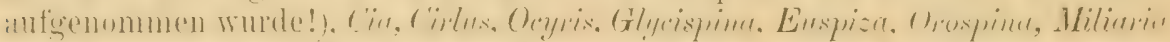

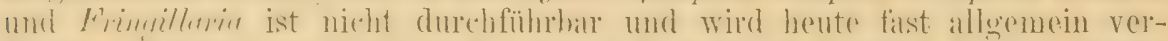
warfen. Dic typisehen Ammern zeichmen sich dureh ziemlich ku\%en, kegel-

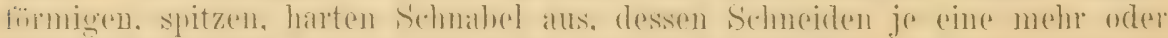

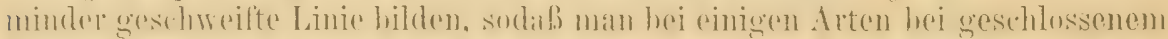

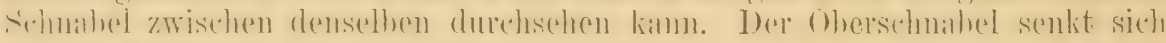
an der Wurzel in scharfem Winkel abwärts (Fig. 34). Am Gaumen findet

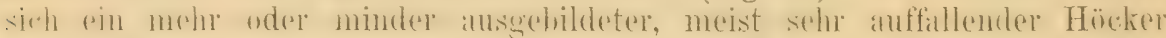
(Fig. 35), der nur wenigen Arten fast ganz fehlt, von denen alle Über-

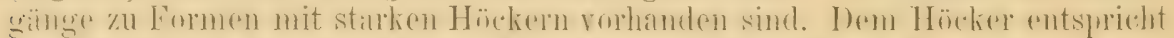

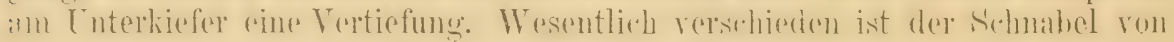
Emberiza pyrmhloides, es findet aber zwischen ihm und dem von $\mathbb{E}$. schoenichs

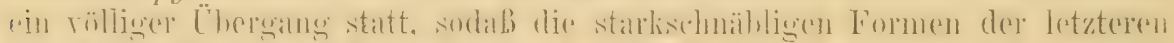

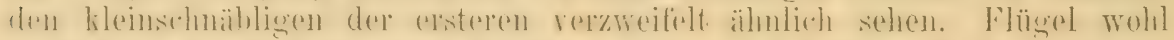
entwielielt. die wirkliche erste schwinge winzig. die ersten vier anseghildeten

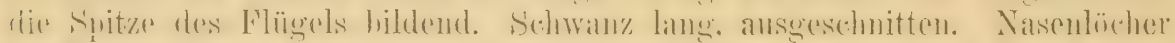

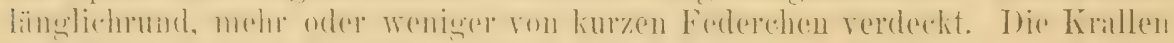
der Zehen kurz und krumm. Die am typischsten entwickelte Ammer ist

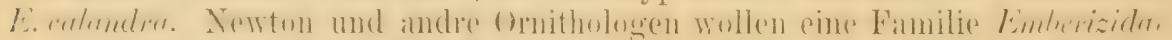

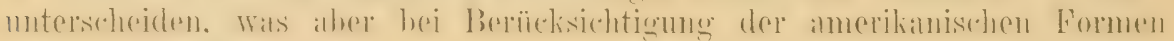
zuг Unmöglichkeit wird.

Über die ganze paläarktische Region verbreitet, sowie in Afrika und Indien. In der indo-australischen Region fehlend, in Amerika durch zum

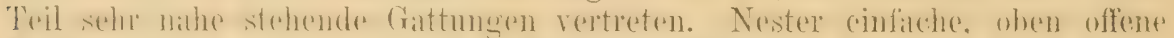

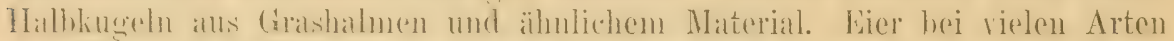

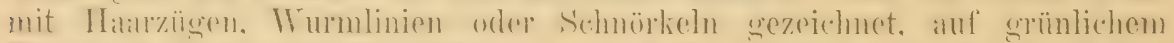

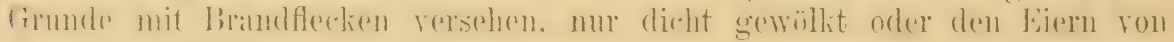
Passer und Motacilla alba ähnlich. - Wir unterscheiden im palärktischen Fannengebiete 29 Arten mit vielen Unterarten.

Übersicht der alten ơ der paläarktischen Arten:

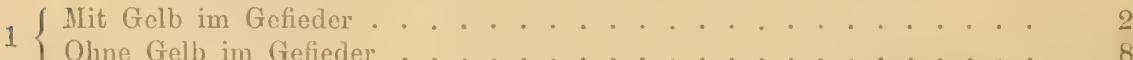

2 $\{$ Nur die Kehle gelb. . . . . . . . . . . . . . 3

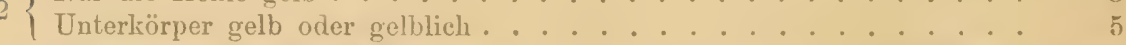

8) Unterkörper bräunlich zimmtfarben . . . . . . E. hortulana . p. 180

3 Unterkörper weiß .......................... 
Kopf ohne Schwarz oder nur an Zügeln und obcrer Kehle schwarz . . i

Kehle orangenartig zimmtbrau, Bürzel gelb. . . . . E. Luteola. p. 171

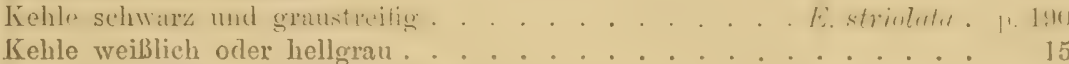

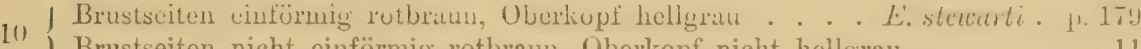

| Brustseiten nicht einförmig rotbraun, Oberkopf nicht hellgrau... . . . 11

11 ) Bürzel zimmtartig rotbraun . . . . . . . . . . . . 12

| Biirzel graulich oder weißlich . . . . . . . . . . . 13

12 Grobe Oberflïgeldecken zimmtrot gesïumt....... E. yessoënsis . 1. 193

\{Große Obertlïgeldecken graulich ............... tristrami. 1. 192

13 f Schnabel dick, breit, mit stumpfer Spitze . . . . E. pym thuloides . p. 198

I Schnabel weniger dick, oft dïnu, mit schärferer Spitze . . . . . . 14

14 I Kleine Flügeldecken grau . . . . . . . . . . E pallasi . 11. 194

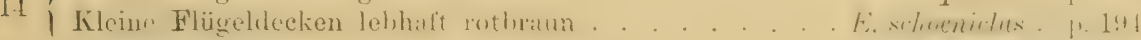

Ohrdecken schwarz

H. mistica. p. 188

TOhrdecken nicht schwar'. ................. 16

f Mit gelbem Superciliarstreif ........... E. chrysolhrys . 1. 189

\{ Ohne gelhen Superciliarstreif . . . . . . . . . . . . 17

17 O Ohrdecken rotbraum . . . . . . . . . . . 18

f Ohrdecken nicht rotbraun ................ 19

Bürzel zimmtartig rotbraun, Pileum kastanienbraun . . . . . . cioides . 3. 185

Bürzel braunrot, Pileum grau und schwarz gestreift. . . . E. fucata . p. 18 T

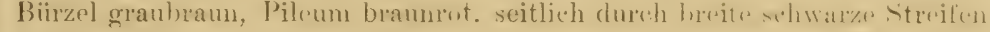
begronzt. . . . . . . . . . . . . p. pisilla .

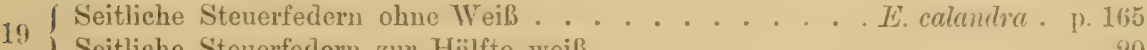

| Seitliche Steuerfedern zur Hälfte weiß. . . . . . . . . . 20

20 Kropfgegend hellgrau, Zïgel schwarz . . . . . . . . . . . . cia . p. 183 Kropfgegend weiß.................. junkouskii . 1). 186;

\section{Emberiza calandra calandra 1. (Fin. 3+. 35).} Gerstenammer, Giraummer.

Emberiza Calandra Linnaeus, Syst. Nat. Ed. X, 1). 176 (1758 - „Habitat in Europa“. Als typische Lokalität ist Schweden anzusehen, denn Linné bezieht sich in erster Linie auf Famna Suecica 206 and It. Scan. 292, 'Taf. 4).

Emberiza Miliaria Linnaeus, Syst. Nat. Ed. XII, p.308 (1766- einfache Umtaulung der E. Calandra von 1758 !).

1) Über Aberrationen siehe 1. 168-170. 
Fringilla projer P. L. S. Mü̈ller, Natursystem, Suppl., 1) 164 (1776- ist Daubenton's "Bruant de lírance appellé le Proyer", Pl. Énl. 233 - Frankreich).

Miliaria septentrionalis Brehm, Handb. Naturg. Vög. Deutschl., p. 291 (1831- Schweden und Rügen, also Linné's Calandra und Mitiaria).

Miliaric Germanica Brehm, Handb. Naturg. Vög. Deutschl, p. 292 (1831- Ebenen Nordchentschlands).

Miliaria peregrina Brehm, Handb. Naturg. Vög. J)eutschl., p. 292 (1831 - seltener Wintervogel in ,unsern Gegenden“).

Milieria Europaea Swainson, Nat. Hist. \& Classif. of Jirds II, p. 290 (1837- der Name ist nur zum Iirsatz für Linné's miliaria gemacht, da man nach damaliger Auflassung Miliaria miliaria nicht sagen mochte. Kitiert ist Sclby's Abbildung (des enclischen Vogels).

Miliuria valida, meridionalis, minor Brehm, Vogelfang, p. 111 (1855- keine genaue Lokalität, alle Formen "Von Schweden bis nach Afrika").

Crithophaga miliaria var, minor Radde, Ornis Cancasica, p). 196 (1881- T'iflis und 'l'alyseli).

Engl.: Coru-Bunting, Bunting Lark. Franz: Proyer. Italien: Strillozzo. Spanisch: 'I'riguero.

ơ ad. Oberseite olivenbraun, bald mehr (besonders, aber nicht nur, in England) mit Rostbram, bald mehr mit Gran durchzogen, die Federn an den Rändern am hellsten, in der Mitte mit hreiten schwarzbramen, auf

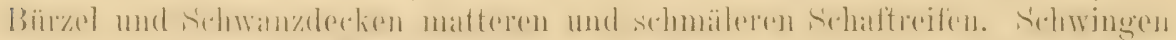

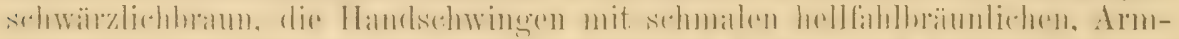

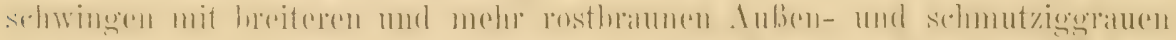

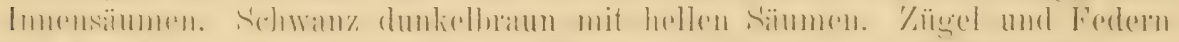

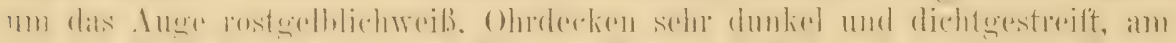

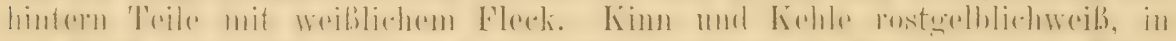

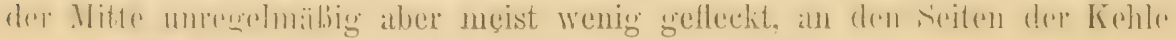

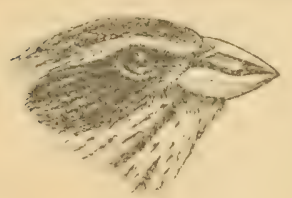

Figur 31. eine dunkle Fleckenreihe, Kiop) dicht dunkelbraun gefleckt, übrige Unterseite rostgelblichweil. bis rahmweißlich. anden Seiten dunkelbraun gestreift. Unterflügeldecken gelblichweib, nahe dem Bug einige braune Flecke, Untersehwanz-

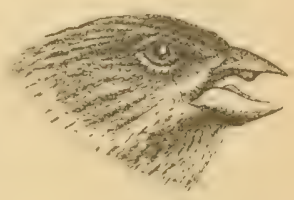

Lijgur 35.

decken mit bramen Sehaftstrichen. Iris braum, Schmahel hellgell. Firste

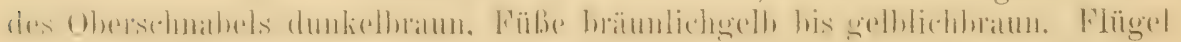
95-105, nur ausuahmsweise und wohl nur bei 0 91-92, Seliwanz 67-75,

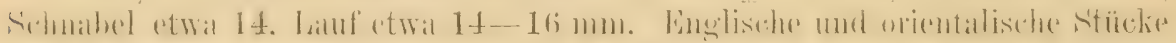

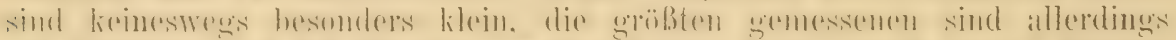

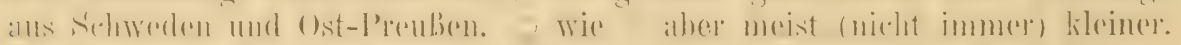

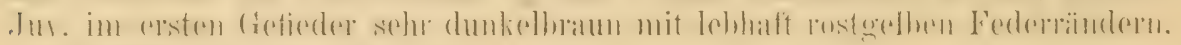
unten etwa wie der alte Vogel.

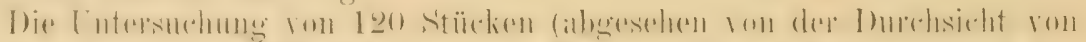

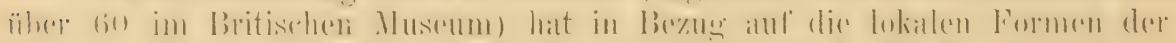

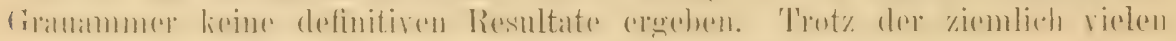

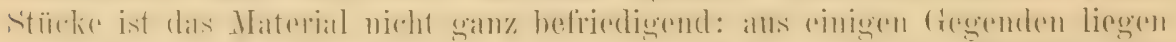

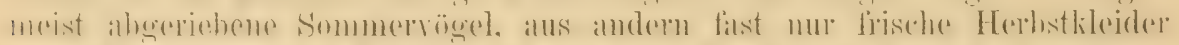

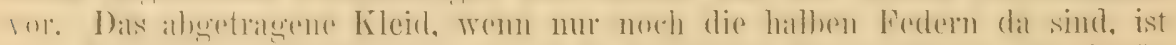

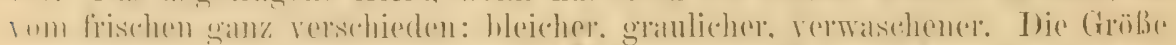

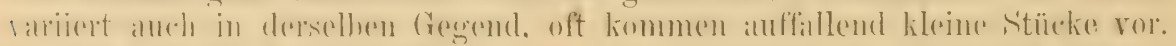

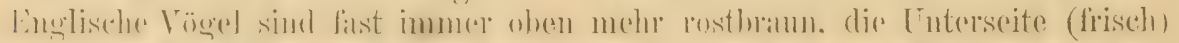

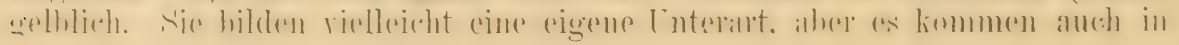




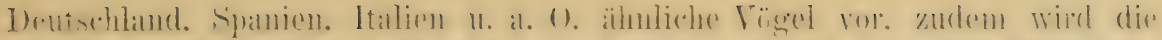

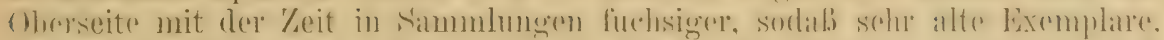

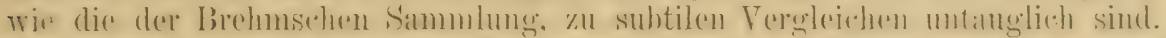

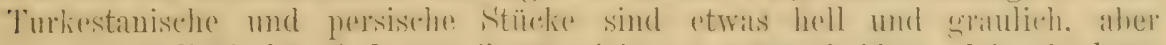

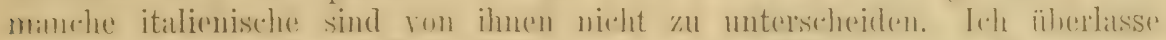

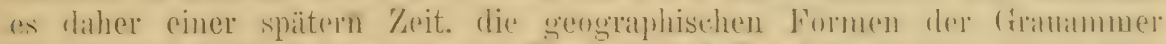

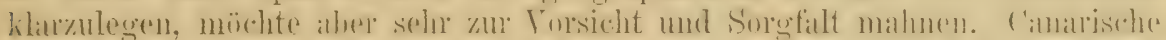

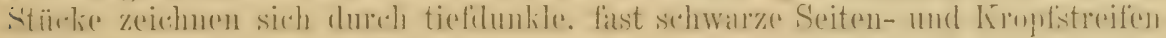
aus. Sie wurden ron 'T'schusi henannt. Um mich nicht scheinbar gegen

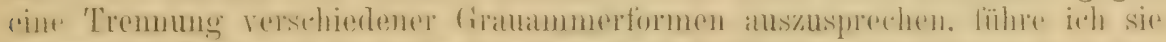

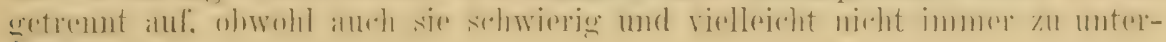
sehpiden ist.

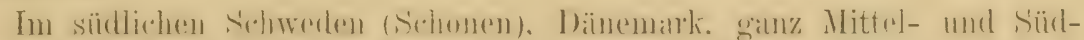

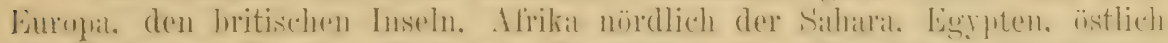

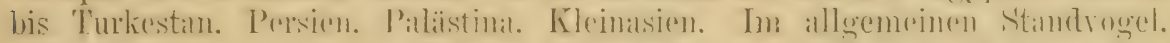

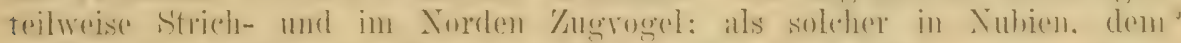

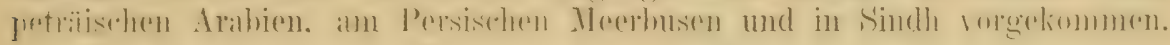

Bewohner kultivierter Ebbenen, der da, wo Getreide gebant wird, namentlieh wenn es mit Buschwerk, (iräben, Hirse- und Rapsfeldern, WViesen und einzehen Bänmen abwechselt, selten fehlt, und namentlich in Spanien und N.W.-Afrika sehr hïufig ist. Hacht einen trïgen, plumpen Eindruck, sitzt meist auf freien Ästen einzelstehender Bäıme, Büsche, Steine, Pffïlıle oder dergl., von wo er sein höchst eigenartiges Lied rorträgt, das mit zick zick zick anhobt und mit eincm aus 1 und $r$ gemischten Klirren endet. Nahrung Getreide und andre Sämereien, im Sommer und \%um Auffüttern der Jungen auch Insekten. In Nord- und Mittel-Luropa findet man die Eier selten vor dem 1. Mai in einem lose aufgebanten Nest am Erdboden, meist in Feldern, oft anch an Wiesen und Wegrändern oder am Fuße ron Büschen und Bäumen. Die 4-6 Eier sind sehr variabel, matt graulich, schmutzig fleischfarben, hellbräunlichrot oder fast weib, mit rötlichgrauen Schalenflecken und jurpursehwarzen Oberflecken, welehe die den meisten Ammereiern eigene kritzel- und schnörkelförmige Gestalt mehr orler minder olt annehmen. Janchmal sind die Kier ganz mit Dunkelbraun iiberzogen, iiberhaupt kionnte man zahlreiche Varietäten beschreiben. Anch die Form variiert - ich messe extreme schlesische Stiicke: $22 \times 18.2,22 \times 18.4$ (also ein äußerst rundliches Gelege), $27 \times 18.5,27.8 \times 18.5$ (also sehr grob und lang), $24 \times 16.2$ (also sehr klein), Rey gibt als Durchschuitt von 100 Exemplaren an: $24.3 \times 17.6$, als IIaximum $28 \times 19$, als Minimum $21 \times 17$ und $22 \times 16 \mathrm{~mm}$. Durchschnittsgewicht $0.206 \mathrm{~g}$. Meist britet das + nach Naumann hilft das ơ briiten.

\section{Emberiza calandra thanneri T'schusi.}

Emberiza culandra thannewi Tschusi, Orn. Jahrb. 1903, p. 162 ('Tenerile).

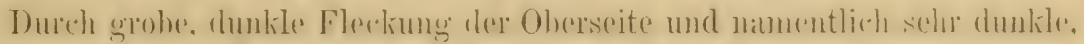

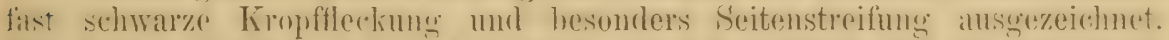

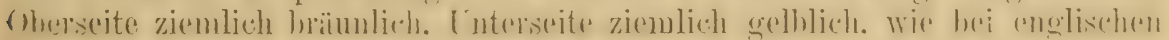
V̈̈gelu. Sonst durchaus wie Huropäer.

Sehr häufig anf den Canaren.

\section{Emberiza citrinella citrinella $I_{\text {. }}$}

\section{Goldammer.}

Emberiza citrinella Linnaeus, Syst. Nat. Ed. X, p. 177 (1758- „Habitat in Europa" Typ. Lok. Schreden, denn Diagnose beruht auf dem ersten Zitat: Fauna Suecica 205). 
Emberiza sylvestris Brehm, Handb. Naturg. Vög. Dentschl, p. 294 (1831- .nur in Nardelwäldern").

Finberizu septentrionalis Brehm, Handb. Naturg. Vög. Deutschl., p). 295 (1831- ,bewolnt den Norden ").

Emberiza major, longirostris, planorum, brachyrhynchos 13rehm, Vogelfang, 1. 113 (1855-"Schweden bis Kïrnthen"6).

Emberiza citrinella pratorum, campestris A. Li. Brehm, Ver\%. Samml., p. 8 (Istitinomina nuda!).

Emberiza citrinella var. brehmi Popham, Ibis 1901, 1. 453, Taf. X (Ex Homeyer M.S., nomen nudum, olme Fundort. Abgebildet ist ein Stïck der Aberration mit braunrotem Bartstreifen aus Eingland).

Engl: Yellowhammer. Franz: Bruant jaune. Ital.: Kigolo giallo. Schwrel.: Gulsparf.

Şad. Kopf und Vorderhals schön gelb, eine durch dunkel olivengratue Federspitzen gebildete Linie verlänft von der Stirn über die Augen his an

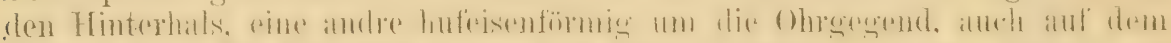

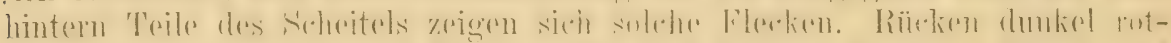

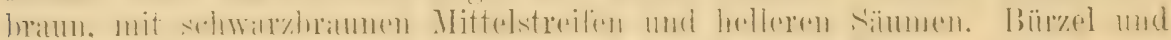

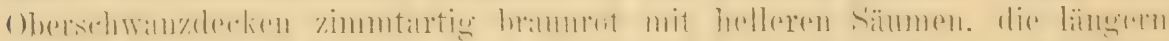
Schwanzdecken dunkler und mit sehwärzlichen Schaftstrichen. Schwingen

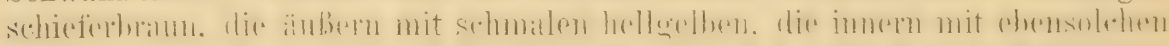

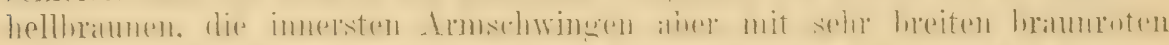

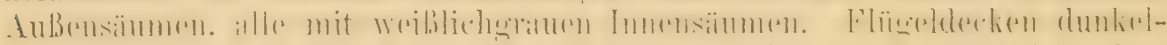
braun. mittlere und grobe mit licht rothramen Säumen. Unterseite schön

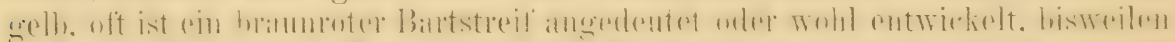

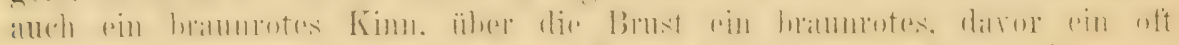

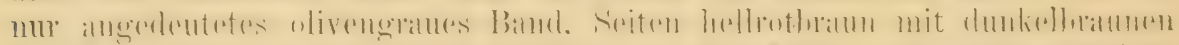

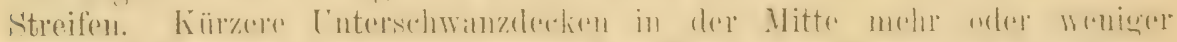

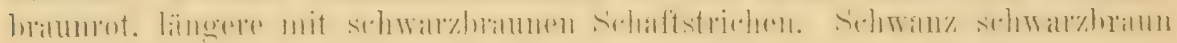
mit bramen, oft sehr lichten Sïmmen. die heiden äubern Stenerfedern nut

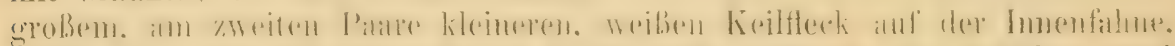

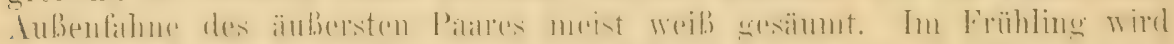

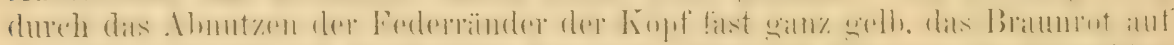

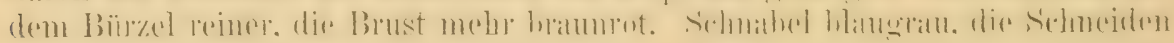
heller, Iris dunkelhraum, Beine hellbraun. I’lïgel 58-63. Schwanz 76-80,

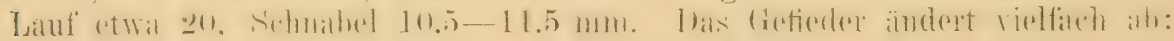
Fin branmoter Bartstreif findet sich oft; anf der Oberseite herrseht oft ein

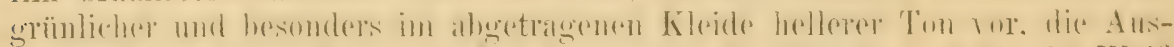

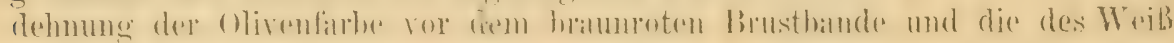
an den äußern Stenerfedern sowie die Größe u. a. m. variiert. - o. Weniger

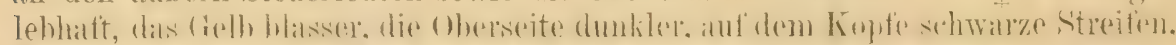

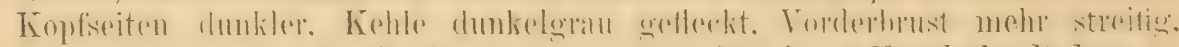

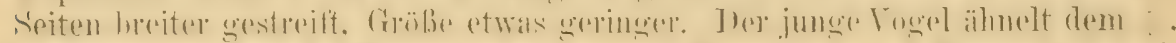

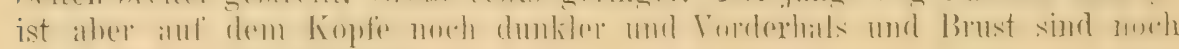
dentlicher dunkel gestreift.

Nord-Furopa, in Norwegen bis etwa $70^{\circ}$ nördl. 13reite, östlich his Nord-

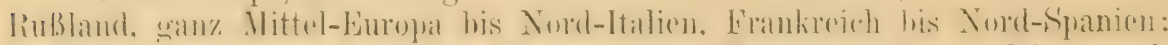

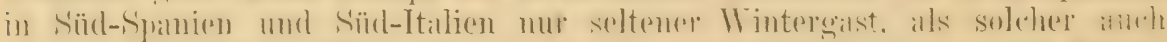

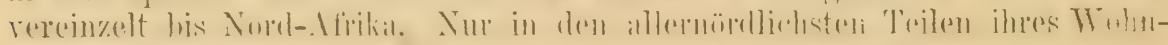
gehiotes Viturogol. 
Bewiohner ron Feldhölzorn, buschreichen Grabenrändern, Waldrändern usw., weun nur Unterholz vorhanden ist. Jedermann kennt das niedliche, anspruchslose Liedehen, das der Volksmund verschiedentlich ïbersetzt. Sämereieu verschiedener Art bilden die Nahrung, im Sommer auch Insekten. Das Nest stelit am Boden, in Büsehen manchnal his zu $2 \mathrm{~m}$ hoch. Ws besteht ans Grashalmen mit etwas Moos, innen ist es feiner und meist mit Pferdehaaren ausgelegt. 'Zwei Bruten im Jahre. Jan kann Lier ron Mitte April bis Anfang August (so spät aber nur ausnahmsweise) finden. Grelege $4-5$ (in Derbyshire in England nach Jourdain meist nur 3) Eier, dic aulserordentlich variieren. Ieist sind sie rötlichweiß, weißlich oder bläulichweiß mit zahlreichen braunen Pünktchen und Kritzeln und grauen Schalenflecken. Dariber ziehen sich tiefbrame bis schwarze Haarlinien hin, wie sie für diese und viele andre Ammereier so charakteristisch sind. Nur selten fehlen diese letyteren. Von aberranten Fiern sind weilje mit grauen Fleckion und rein weiße an seltensten. Die Durchschnittsmaße ron 100 Eiern gibt Rey 21.2 $>$ $15.9 \mathrm{~mm}$ an, das Maximum $24.2 \times 17.1$ und $23.5 \times 17.7$, das Minimum $18.5 \times 14.3 \mathrm{~mm}$. Das mittlere Gewicht normaler Hier betrïgt $160 \mathrm{mg}$.

\section{7 . Emberiza citrinella erythrogenys liwh.}

Emberiza erythrogenys Brehm, Vogelfang, p.414 (1855- „Bei Sarepta:").

Emberiza mollessoni Sarudny, Orn. Jahrb. 1902, p. 58 (aus dem Russischen .,Ergänz. z. Orn. Fauna Orenb. Geb.6:, p. 74, 1897 - Orenburg). (Abbildung Ibis 1901, T'af. 10.)

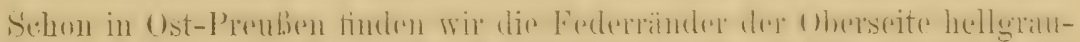

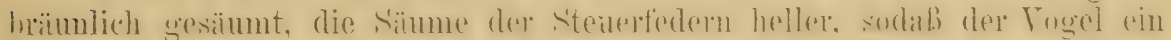

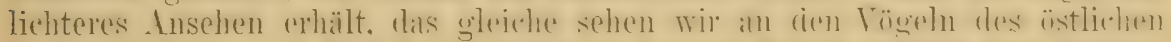

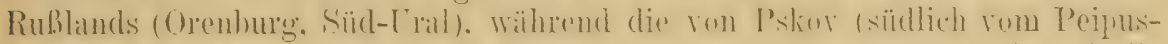

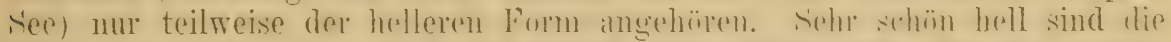

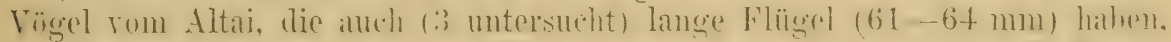

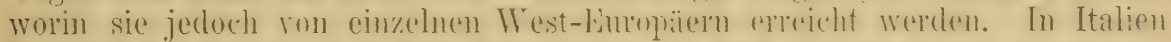
kommen im Winter atuch helle Stïcke ror, die aher Yagriggel sein mögen. -

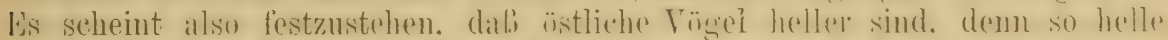

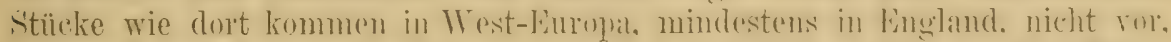
während im Osten so dunklu. Wir sie sich dort tinden. tohlon. Der Nimur Brehm's heruht auf einem Sarepta- Togel. der leider in der Sammlung nield

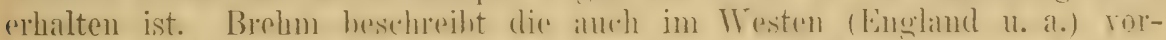
kommende. Aheration mit braumenten Bartstreifen und Kinn. alher der Fundort und Brehmis Ausdruck .. etwas weniger schön. mit weiliblehen Flïgelhinden* deuten auf die isstliche Fom hin. Dor Name E. mollessomi hezicht sich atuf stürke

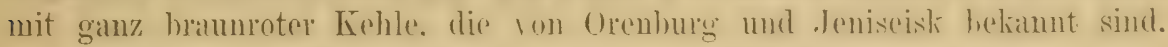

RuBlind und Irest-Sihirien. westlich his ()st-I'louben, niirdlich lis zum 640 nördl. Breite, astlich his zum . Altai und Jenssei: gelecontlinh in Turliestru, Persien und Kleinasion. (Ungeningend bekannte Form.)

\section{† 275. Emberiza leucocephalos S. G. Gm.}

\section{Fichtenammer:}

Emberiza leucocephatos S. G. Gmelin, Nor. Comm. Acad. Sci. Imp. Petrop. XV, 1. 480. Taf. 23 , Fig. 3 (1771-Astrachan). $\left.{ }^{1}\right)$

$\left.{ }^{1}\right)$ Fringilla dalmatica Gmelin, Syst. Nat. I, p.920 (1788- Ex Brisson MIoinem d'Esclavonie usw. - Dalmatien), und Emberiza sclavonica Degland, Orn. Eur. 1849 I, 1. 252, welcher Name ebenfalls auf Brisson's Moineau d'Esclaronie beruht, wurden als Synonyme ron E. leucocephalos zitiert. Sie berulen ant Aldrovandi's Passer Illyricus, den ich nicht zu denten vermag. 
Emberiza Pithyomus P’allas, Reise d. versch. Prov. d. Russ. Reichs II, p. 710 (1773"Habitat in Sibiriae etiam borealioris, primo vere advolans).

Lineverizu albila Blyth, Journ. As. Soc. Bengal XVIII, pt. 2, J.811 (1849-- oberhalh, Simla im Himalaya).

Emberiza bonapartii Bonaparte, Cat. met. Uce. Eur., 1) 45 (1842 - ex Barthélemy de la Pomm., Marseille, nomen nudum! Vgl. Ker. \& Mag. Zool. 1857, p. 161).

?? Emberiza himalayensis Tytler, Ibis 1868, p. 201 (Nomen nudum! Nach Sharpe Synonym von E. leucocephalos).

Oे. Auffallend ähnlich einer weißen (statt gelben) L'. cirrinellu, aber Zïgel und breiter Streif hinter dem Auge braumrot, ebenso die gamze

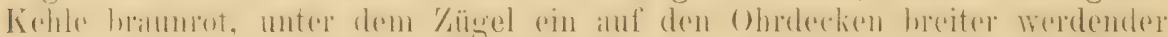
weißer, ïber und unter den Ohrdecken ein schwarzer Streif. Auf dem

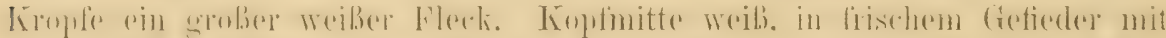

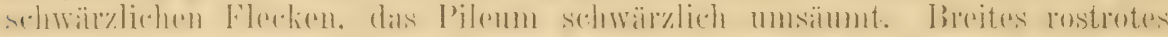

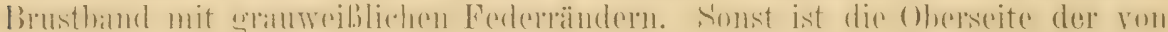
L. citrinella ïhnlich, nur etwas ausgedehnter rostrot auf dem Bürzel, dio Unterseite aber weiß statt gelb. dem einer Goldammer gauz ähulich, aber alles Gelh dureh W

Brutrogel in Sibirien rom Ural bis zur Anur-Mündung, - Nord-China. Mongolei und 'lurkestan, aber wohl mur als Wintervogel. Vereinzelt bis

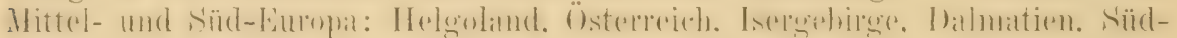
Frankroich, etwas öfter (aber auch mur sehr selten) in Italien. ITegen der

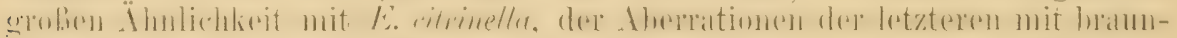

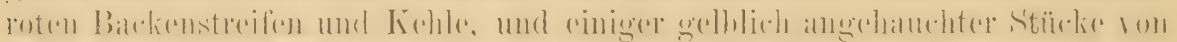

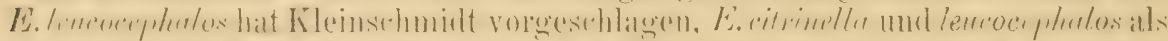

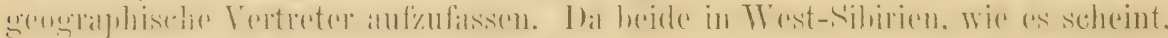

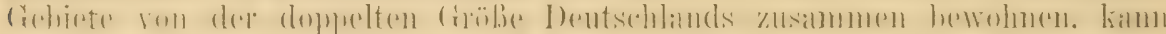

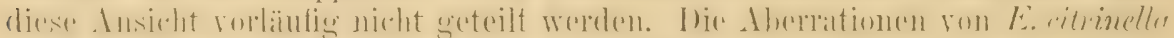
mit bramuroter Zoichnung an Kehle und Wangen finden sich nicht mur in

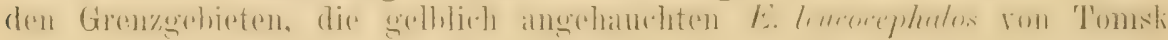
aber kömnten Bastarde seim. ( $\mathrm{Vgl}$. das p. 168 unter E. citrinella Gesagte und Jouln. f. Om. 1903, Taf.' VII.)

Lebensweise und Fortptlanzung sollen mit der der Goldammer ïbereinstimmen. anch die Eier scheinen den ihrigen zu gleichen oder ihnen wenigstens sehr ïhnlich zu sehen und sehr zu variieren. Maßs $20.5-63>15.5-16.5,21.5>17 \mathrm{~mm}$.

\section{Emberiza melanocephala Scop.}

Kappenammer:

Emberizu melanocephala Scopoli, Annus I Hist. Nat., p. 142 (1769- IYyous wahrscheinlich aus Kärnthen. Vgl. Aum. 1). 14.).

Trancryo melanictera Güldenstädt, Nov. Comm. Acad. Imp. P'etrop.XIX, p. 466 (1775

N.- \& Mittel-Kaukasus, heiße Quellen am Torek in Georgia, Tiflis).

Fringilla erocea Vieillot, Ois. Chant., 'Laf, 27 (1805 - Senegal! errore!).

Tanthornus caucasicus Pallas, Zoogr. Rosso-Asiat. I, 1). 428 (1831 - Kaukasus und 'liflis).

Wmberiza granativora Ménétries, Catal. rais., ]. 40 (1832- zwisehen Baku und Kuby am Kaspischen Mecre, Juli).

Fuspiza simillima Blyth, Journ. As. Soc. Bengal XVIII, pt.2 p.811 (1849-S.-Indien). Euspira atricapilla Brehm, Vogelfang, p. 112 (1855-Griechenland).

Euspiza melanocephala macrorhynchos, brachyrhynchos A. E. Brehm. Verz. Samml., p.9 (1866- nomina nuda!). 


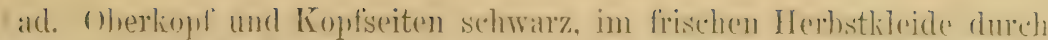

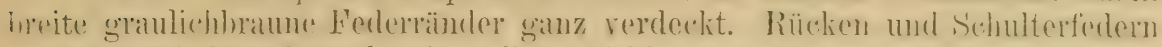

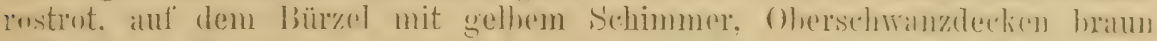

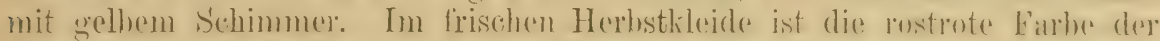

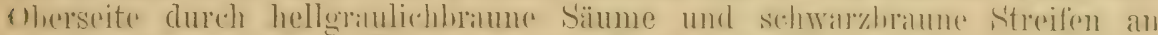

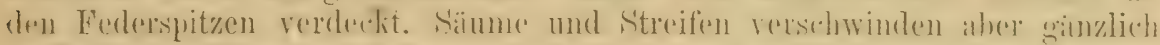

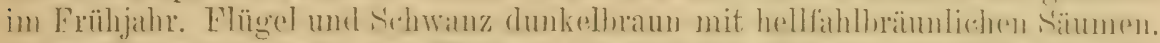

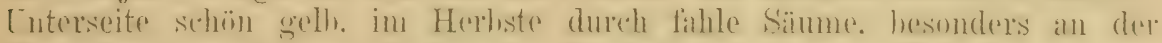

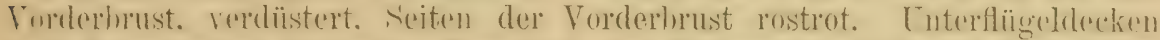

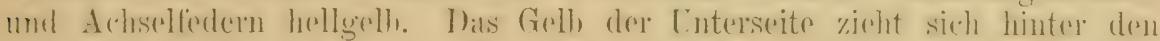

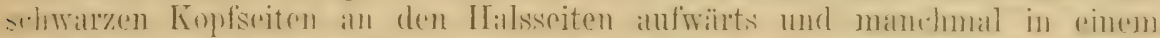

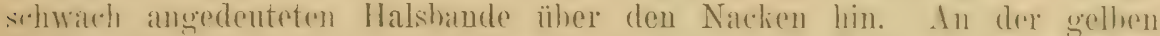

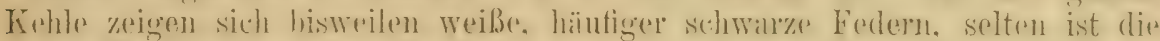

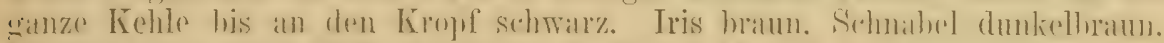

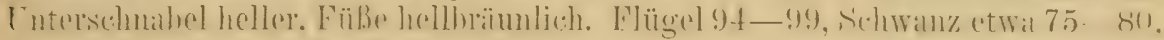
Schmahel etwa 14, Lauf $21-22 \mathrm{~mm}$. O ad. Oberseite brïunlichgrau mit

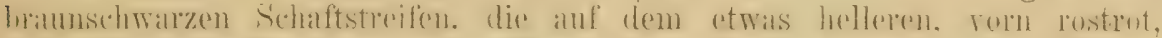
weiter hinten gell schimmenden bürzol fast oder ganz versehwiuden. Cinter-

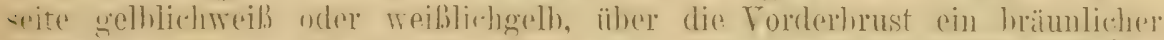
s.himmer. Junge ähnelu den jüngere of haben nikht die fracht alter.

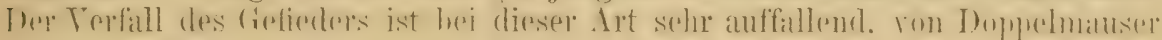
ist keine Rede.

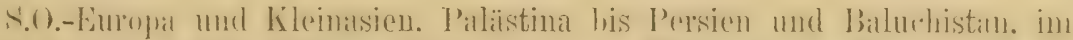

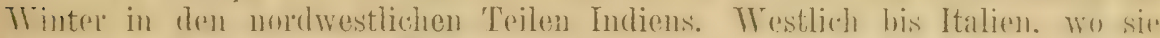

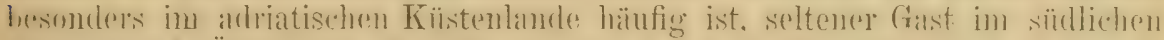

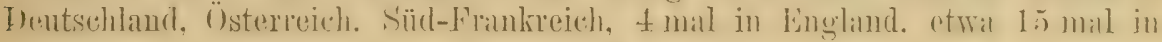
Helgoland. Nordwiirts bis zur untern Wolga.

Bewohut buschreiches Gelïnde, Weinberge, Gärten und ist ein Zugvogel. Stimme anmerartig: Lockton ein scharfes ,zitt", Angstruf ein leises ,zih", Gesang dem der Goldammer ähnlich, von Naumann mit, "dzi der ïh-zi zi zih" versinnlicht. Das grolie lockere Nest, das sehr leicht zu finden ist, steht meist in Büschen oder Baumausschlag. nie sehr hoch, manchmal am Boden. Die 5 Kier haben nichts von den Schnörkehn und Hieroglyphen der meisten Ammereier, sondern sind sehr blaßbläulich oder bläuliehgrïu, fast weiß, mit aschbraunen. und hellgraulichen Schalenflecken gezeichnet, an helle Sperlingseier erinnernd, bisweilen ungefleckt. Haße durchschnittlich $22.5 \times 16.1$, I:ıximum $25 \times 16.5$ oder $22 \times 17.7$, Minimum $19 \times 14.5 \mathrm{~mm}$. Gewicht $0.172 \mathrm{~g}$.

\section{Emberiza Iuteola Sparm.}

Enberiza luteola sparman, IIus. Carlsonian., fasc. 4. 'laf. 93 und 'Text (1789-- ohne Fundort. Vermutlich erhiclt ihn Carlson aus S.-Indien; woher er viele Vögel hatte. Die Beschreibung bezieht sich sicher auf unsre Art, die Abbildung aber ist so gräßlich, daß man glauben kann, sie sei von einem andern Vogel genommen).

Emberiza icterica Lversmann, Addenda ad Pallas, Koogr. Rosso-A siat. II, p. 10 (1841„Hab. in campis elatis et in lit. sax. orient. mar. Caspii, nec non in loc. clivosis sub montium Altaicorum radicibus, circa Bist, etc." ).

Emberizu bruniceps Brandt. Bull. Sei. Acad. St. Petersb. IX, 1) 11 (1842-Turkomanen Gebict).

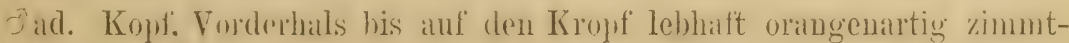

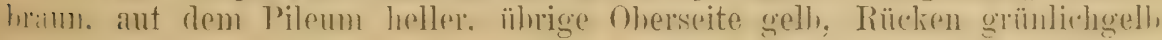




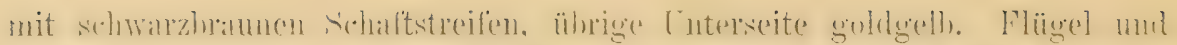

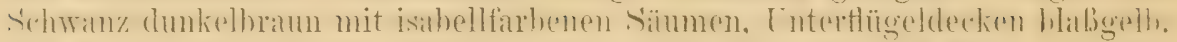

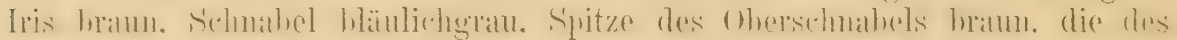

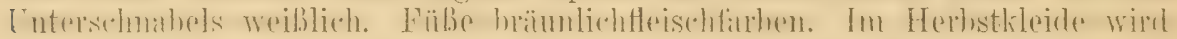

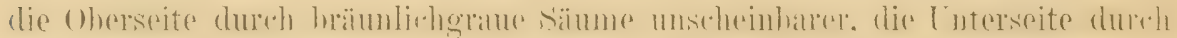
weißlichfilhle Federänder halb verdeckt. Flügel 87-90. sehr selten 91, Schwanz etwa 72-75, Schnabel etwa 12-13, Lauf $21 \mathrm{~mm}$. Abgesehen

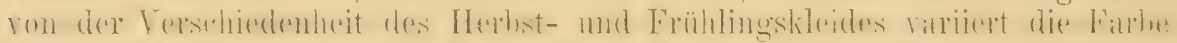

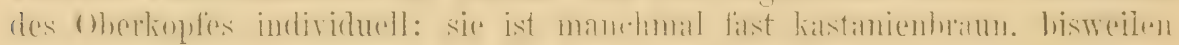
nur orangegelb, ausnahmsweise überzieht sie T'eile des Rückens. o. Oberseite im frischen Gefieder aschbrüunlich bis zimmtbraun, in Sommer gran-

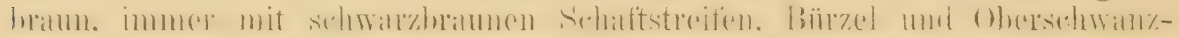

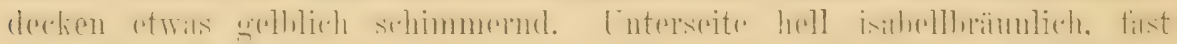

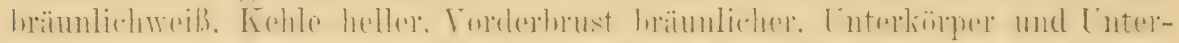

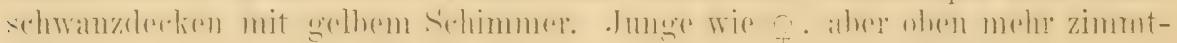
bräunlich, breiter gestreift, am Kropfe mit schwärzlichen Längsflecken.

Transkaspien, Afghanistan und 'Turkestan, nördlich his in das sïdwestliche Sibirien und zum Altai. Im Winter am Persischen folf und in den

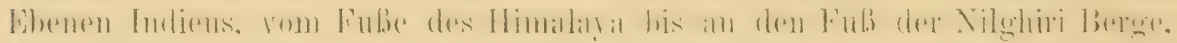
von Sindh bis Chutia Nagpur. In Kaschmil aut' dem Durchzuge. 'Zneimal auf Helgoland erbeutet.

Bewohner ron Eeldrainen. Gehölzen und einzolnen Büschen zwischen Feldern und Gïrten, sucht seine Nahrung meist an Hoden, auf und bei den Feldern. Nicht besonders scheu, partrweise, nur auf dem '/uge in kleinen Flügen. Nester aul oder nahe dem Lirdboden. Das Nest gleicht andern Ammernestern und enthïlt (neist im Mai) 3-4 Hier, die bis auf ihre geringere Größe denen von E. melanocephala gleichen. somit also denen der weißen Bachstelze ïhnelu. Sie messen nach Rey $20.7 \times 15.3$ und $20 \times 14.9 \mathrm{~mm}$. Gewicht $0.138-0.150 \mathrm{~g}$.

\section{Emberiza rutila Pill.}

Emberiza vutila Pallas. Reise d. versch. Prov. d. Russ. Reichs III, 1) 698 (1776-- ..In salicetis ad (Ononem, versusque Mongolian fines").

Abbildung: T'emminck \& Sehlegel, Tiama Japonica, T'at. 56 г.

Õad. Kopf, Hals und ganze Oberseite rotbram, zwischen kastanienbranu und rimuthratun,

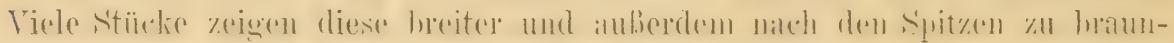

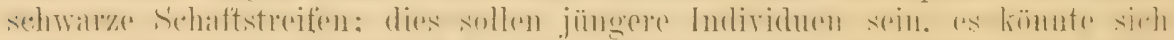

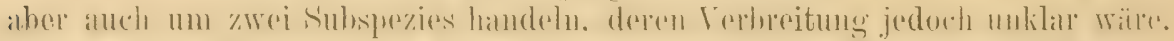

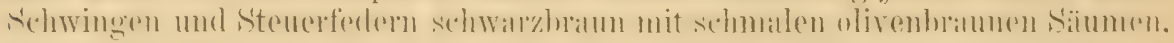
innere Armschwingen mit ganz oder teilweise rothramen Außenfahnen.

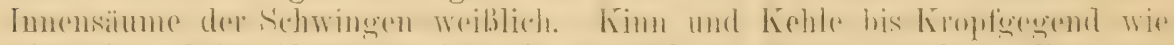

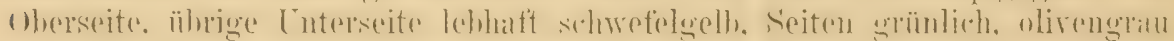

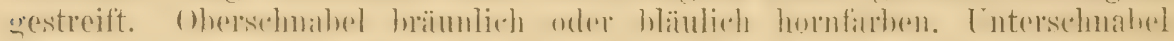
heller, Iris braun, Fül.se hellbraun. Fügel 73-74.5, Schwanz etwa 58. Śchnabel 10-11, Isauf $19 \mathrm{~mm}$. Q ad. Kopf und Bürzel wie der Rüicken

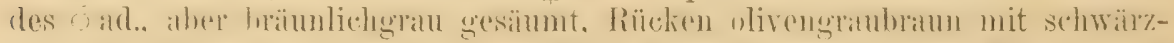

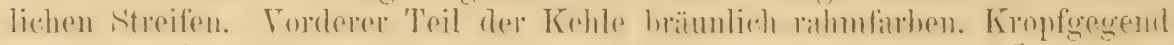
rotbraun mit fahlen Federïndern, übrige Unterseite wie beim ô ad. Juv.

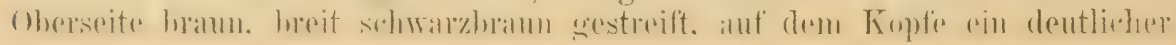




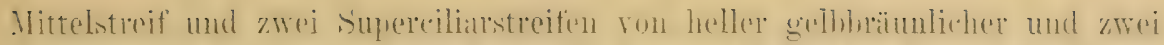

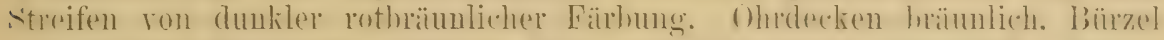

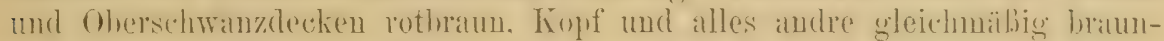
sohwary gestreift. Flügel und Schwanz etwa wie beim ơ ad. Unterseite

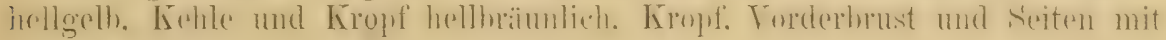
kurzen sehwarzen Streifen.

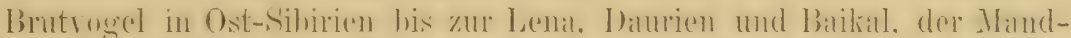

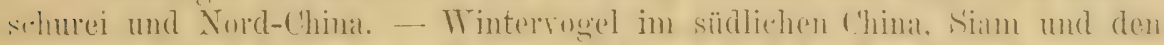
isstlichen Teilen Indims. Westlirh his Sikkim. Sull $1-2$ mal in .Jalnan rorgekommen sein.

Gesang verschieden beschrieben. Nest ammerartig. Eier sandgelblich mit grau-

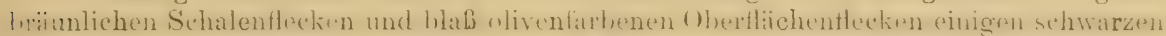
Zickzack- und Sehnörkellinien und kurzen Strichen. Eier aus Daurien (nach 'Taczanowski). $17>14.2,18.3>13.7 \mathrm{~mm}$.

\section{Emberiza aureola Pall.}

Weiden-Ammer.

Emberiza Aurcole Pallas, Reise d. versch. Prov, d. Russ. Reichs I1, Anhang, p. 711 (1773"Hab. in Populetis, insulisque salice luxuriantibus ad Lrtin aliosque Sibiriae Huvios"i).

Passerina collaris Vieillot, Nour. Dict. d'Hist. Nat. XXV, p. 9 (1817- Südamerika(!), errore!).

Mirafia flavicollis McClelland, Mroc. Zool. Soc. London 1839, p. 163 (Assam).

Emberiza dolichonia Bonaparte, Atti della sett. Adun. Sci. Ital. 1845, p. 715 (teste Salvadori).

Eimberiza selysii Verany, Atti de Congres Sci. Ital. Napoli 1848 (teste Salvadori).

Euspiza flavogularis (,flavocollaris" irrtiimlich in Gray's Hand-list II, p. 112) Blyth, Journ. As. Soc. Bengal XVIII, p. 86, 811 (1849- Indien).

Abbildungen in Dresser, Naumann u, a. $\mathrm{m}$.

tad. (Hochzeitskleid). Stim his an die Augen. Kopfseiten und oherem

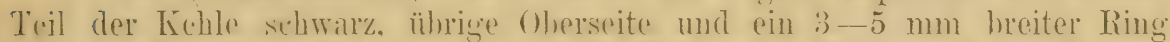

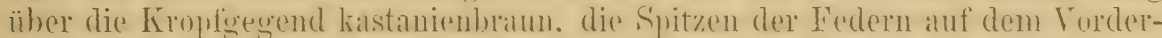
rücken mit schwa\%en Nittelfeclen und schmalen fahlen Säumen. Selnwingen und Schwanz ticfhram mit aschhräunlichen Aubensïmmen. äuberstes Steurle frelerpar mit hreitum, zmeites mit schmälerem weilien Mittelstreifen. kileine

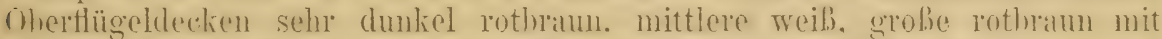

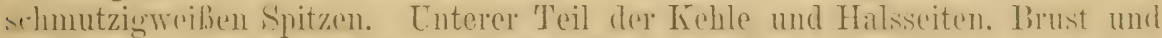

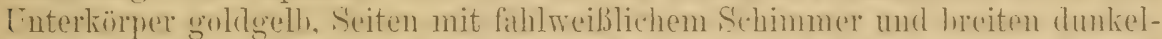

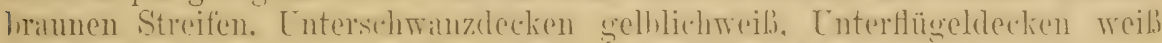

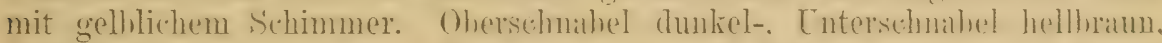

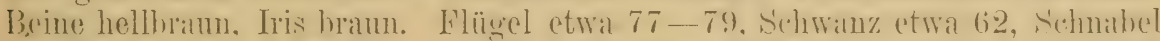

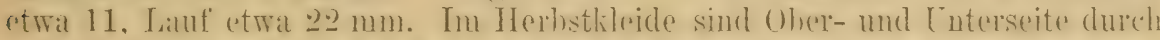

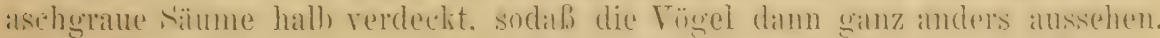

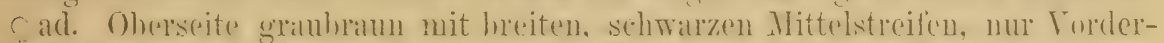

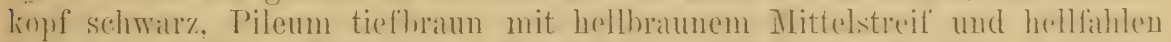

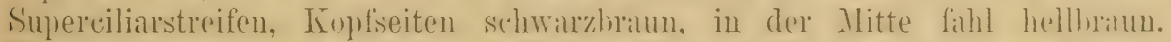
Bürzel rothraum, sebwargestreilt. Furdere Kehle meiblichgelh. Kileine Flügel-

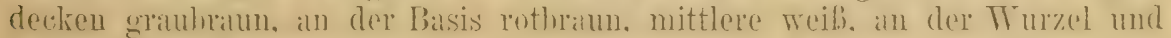
in der Mitte hraunschwarz, grolos sehwarzhratun mit breiten aschloüunlich- 
graueu Sïumen. Unterseite etwas heller, als heim ơd., das Kropfband

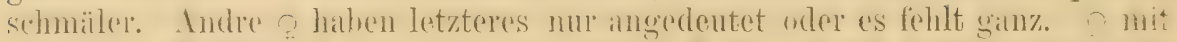

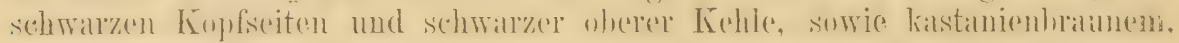

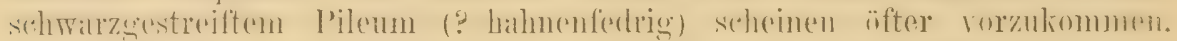
Flügel kürzer. Im Winter ist das Gefieder durch aschfalıle Säume schr rerdïstert. Junge Vögel ähneln den O, hahen aber ein gleichförmigeres

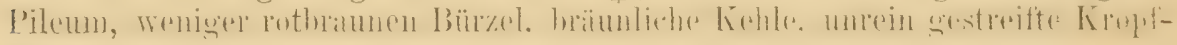
gegend.

Nord-Rußland (Dwina, nur veremzelt noeh weiter westlich, südlich

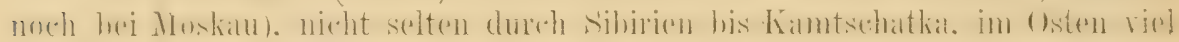
häufiger als im Westen, und bis auf die Kommandeur-Iuseln, selten bis Japan reichend, soll aber auf Jesso auch noch brïten. Auf dem Zuge durch China bis Siann, Indien vom Norden bis zum Süden, streicht auch

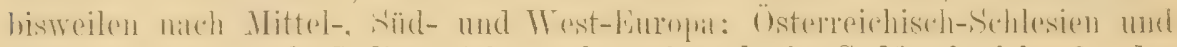
Böhmen je einmal, Italien siebenmal, mehrmals in Suidfrankreich. 2 oder 3 mal anf Helgoland.

Bewohnt besonders Wiesen mit Gebüsch. Weidendickichte und andres Buschwerk an Flußufern und dergl. m. Lockton ein scharfes zip, zip, Gesang dem ron Eimberiza hortulana äußerst ähnlich, aber etwas höher und rascher. Nester mit Eiern fand man nicht ror dem Juni, wie der Vogel auch erst im Mai an seinen Brutplätzen eintrifft. Das Nest steht am Boden oder niedrig dariiber im Gras oder in Büsehen und ist ein echtes Ammernest. L's enthält 4-6 Eier. Sie sind auf grïnlich- oder bräunlichgranem. hellbläulichgrauem oder grautreißem Grunde mit fast schwarzen Flecken und Figuren, häufiger aber nur mit braunen Flecken und Punkten, seltener Krritzeln bedeckt und immer mit tief'erliegenden hellgrauen oder hell bräunlichen F'lecken gezeichnet und messen von $18.6 \times 148,20 \times 14.5$ bis $19 \times 15,20.7 \times 15.2,21 \times 15.5$ und $22 \times 15 \mathrm{~mm}$.

\section{Emberiza elegans 'T'emm.}

Emberiza elegans 'T'emminck, Pl. Col. 583 (1835- Japan).

Emberiza clegantula Swinhoe, Proceed. Zool. Soc. London 1870, p. 134 (..Kweichow, the westernmost city of Hoopih province on the Yangtsze").

ơd. Kopfmitte, ganze Kopfseiten und grober Fleck auf dem Kropfo schwar\%. Schmaler Streif über den Zügeln weiß, hinter dem Ange in einen

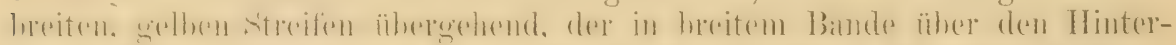

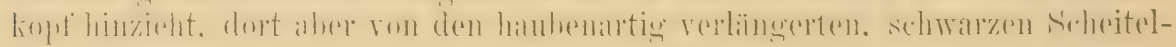
federn fast ganz verdeckt wird. Obere Kehle gelb, ron dem schwarzen

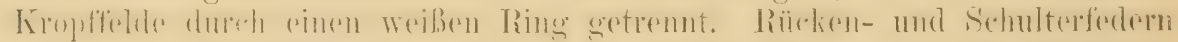
rotbraun mit schmalen schwarzbraunen Schaftstreifen und hell fahlbräun-

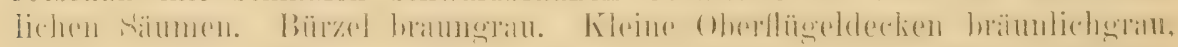
mittlere und große braunschwar'z mit hellröstlichen bis weißlichen Spitzen.

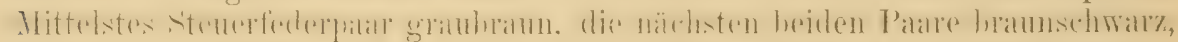
die beiden Seitenpare mit der bei den meisten Ammern bekannten weißen Zeichnung. Brust und Unterkörper weiß, Seiten hell rostbraun mit dunkelbrannen Streifen. Im frischen Herbstkleide ist der Rücken bräunlicher, das

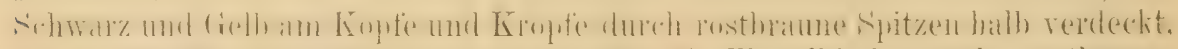

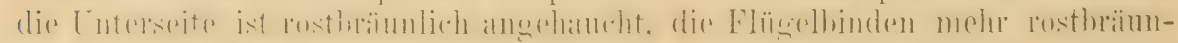
lich. Schnabel schwarz, Iris braun, Füße bräumlieh fleischfarben. Flügel 74-79, Schwanz etrva 70, Seluabel etwa $9 \frac{1}{2}$. Lauf $18 \frac{1}{2} \mathrm{~mm}$. O etrvas kleiner, Oberkopf braun mit braunschwarzen Federmitten, das Gelb an den 


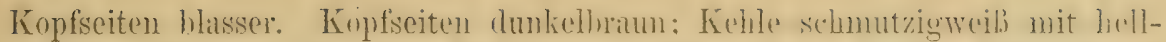

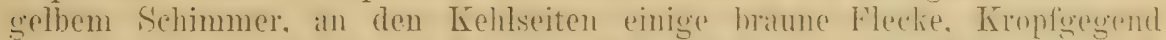

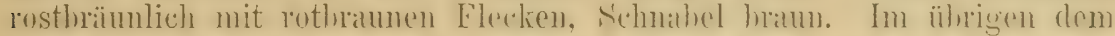

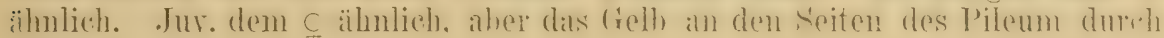
helles Rostbraun ersetzt.

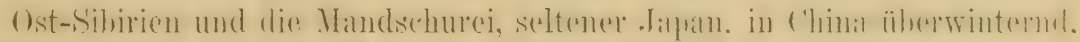
im Norden dieses Landes (Nupin, nach Père David) noch nistend.

Bewohner der Waldränder und buschreicher Gelände, Lockton dem andrer Ammeru gleichend, Gesang der beste aller Ammerngesänge. Die verlängerten Scheitelfeclern oft haubenartig erhoben. Das Nest steht im Grase, unter Büschen und Krautwerk am Boden und enthält (am Ussuri) in der zweiten Hälfte des Mai 5-6 Eier. Sie sind hell rötlichgrau init violetten S'chalenflecken und scharf markierten, braunschwarzen Punkten und Kritzeln, meist aber ohne die letzteren! Sie messen $17 \times 15$ (Radde), $17-18.5 \times 14.5-15.5$ (Nehrkorn), bis $19 \times 14.8,19 \times 15 \mathrm{~mm}$ (Taczanowski). Es ist. möglich, daß die mit Kritzeln beschriebenen Eier fälschlich dieser Art zugeschrieben wurden. Abbildung: Radde, Reisen i. S. von O.-Sibirien, II (1863), 'T'af. 5.

\section{Emberiza cirlus I.}

\section{Zaunammer, Zirlammer.}

Emberiza Cirlus Linnaeus, Syst. Nat. Ed. XII, I, p.311 (1766-ex Brisson ete. - „Hal). in Europa australi").

Emberiza Elneathorax Bechstein, Orn. Taschenb. I, p. 135 (1803- „in den mittleren Rheingegenden, in Hessen und Thü̈ringen").

Engl.: Cirl-Bunting. Franz.: Bruant zizi, Ital.: Zigolo nero.

ơad. Oberkopf und Hinterhals grünlich olivengrau mit schwarzen, am

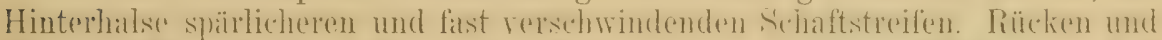

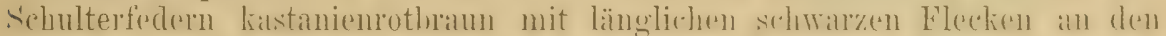

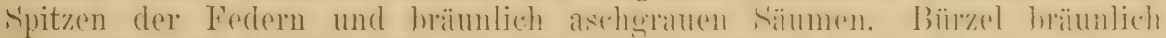

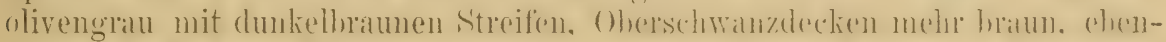

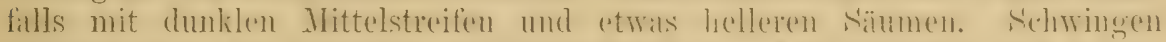

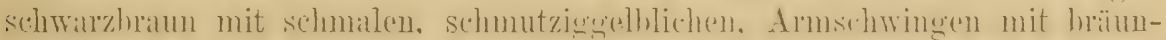

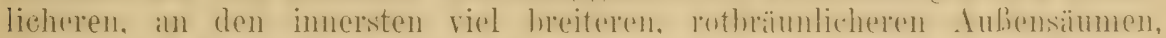

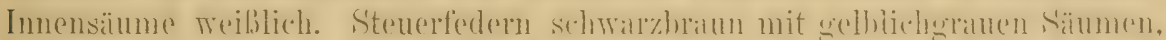

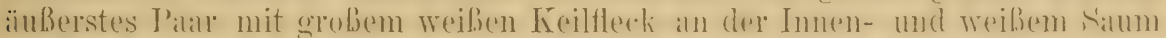

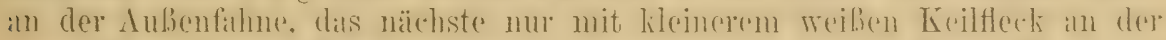
Innenfahme. Supereiliarstreif, Streif unter dem Auge bis in die Mitte der

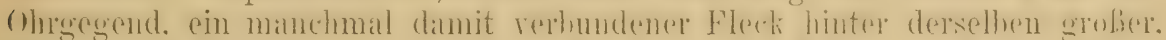
bis an die Halsseiten ausgedehnter Fleck in der Mitte der Kehle, Brustmitte und Unterkörper gelb. Ohrdecken größtenteils schwärzlich. Obere

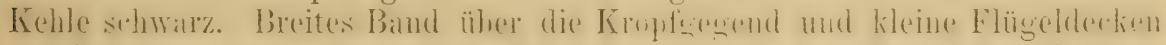

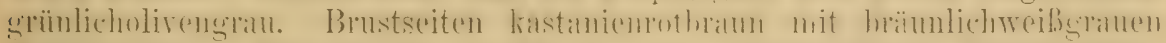

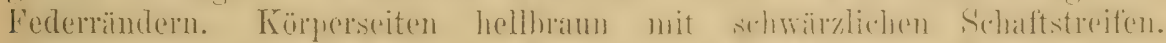

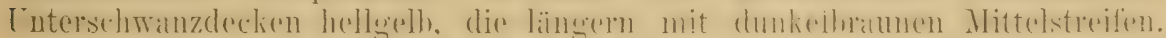

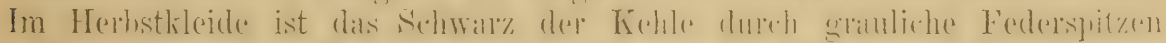
rerdeckt, die ganze Oberseite matter, melir verwaschen, im Frühling durch Abnutzung leblafter. Flügel 79.6-83.6. Schwanz 70-75, Lauf etwa 17.5,

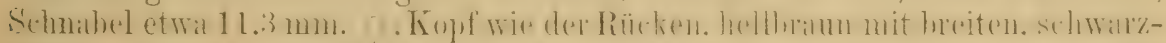

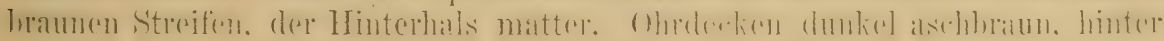
und über denselben ein mattgelber Fleck, über dem Auge ein meist nur im 


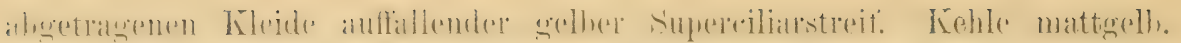

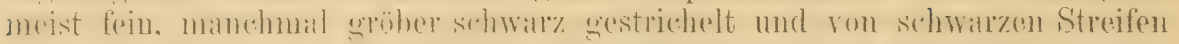

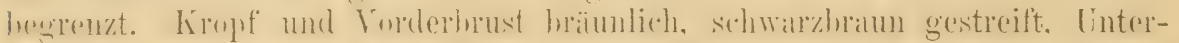

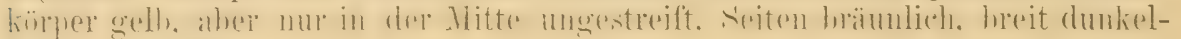
braun gestreift.

Bewohner der Mittelmeerlïnder, durch Griechenland und die 'I'ürkei his zur Krim, Kleimasien, selten bis zum Kaukasus; in Österreich-Ungarn,

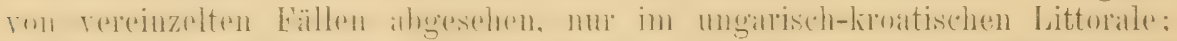

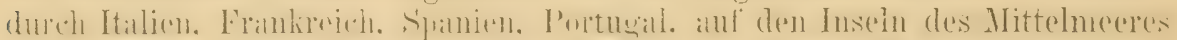

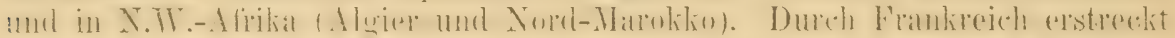

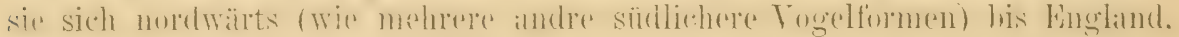
wo sie die südlicheren Grafschaften bewohnt: das 'Themse-I'al und ihre

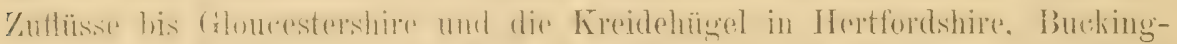

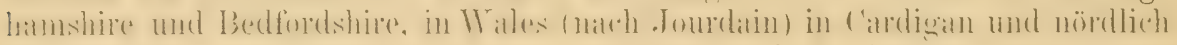
bis Denbigh. In Deutschland nu vereinzelt im S.TV. (Rhein-, Mosel- und Satirtal).

Bewohner buschreichen Gelïndes, namentlich im Hügellande, wo sie auch steinige, spürlich mit Wachholder bestandene Hïnge liebt, in Algier bis hoch in die Berge, aber auch an Flußufern, Hecken, in Gärten und Feldhölzern. Neist Standrogel, so auch in England, soll aber an seinen sonstigen nördlicheren Wohnorten (S. W.-I Deutschland) Zugvogel scin. In der ganzen Lebensweise ein echter Ammer. Lockton ein feines zib, zib oder zi, zi, Gesang dem des Goldanmer ähnlich, jedoch ganz ohne die Endstrophe, leiser und mehr klirrend, melnr wic aus $\mathrm{r}$ und $\mathrm{l}$ zusammengesetzt. Nest niedrig in Büschen, meist fast am Boden, einem Goldammerueste ähnlich. Zwei Bruten, in England früh im Mrai und Juli Eier. Dic 1-5 Eier sind charakteristisch; in Sammlungen: schmutzig grauweißlich, frisch: schwach grüulich oder graubläulich, sehr selten rötlichweiß, mit fast schwarzen und braunen Punkten, Klecksen und feinen, oft labyrinthisch verschlungenen Haarzïgen oder Wurmlinien iiberzogen. 25 Eier der Rothschildschen Sammlung messen $19 \times 15.1$ (abnorm klein), $20.3 \times 16.4,20.4 \times 15.9,20.8 \times 16.1,21 \times 16.8,21.5 \times 16.4$, $21.6 \times 17,21.7 \times 16.6,21.7 \times 17.4,22.2 \times 16.4,22.5 \times 16.4,22.2 \times 16.6,22.4 \times 16.8$ bis $23.1<16.4 \mathrm{~mm}$. Gewicht nach Rey $166 \mathrm{mg}$.

\section{․ㅡ‥ Emberiza spodocephala spodocephala I'all.}

Emberiza spodocephala Pallas, Reise d. rersch. Pror. d. Russ. Reichs III, p. 698 (1776Daurische Alpen).

Emberiza sordida vel chlorocephala? Gray's Zool. Miscell., p. 81 (1814- nomina nuda(!). ex Hodgson's M.S.).

Abbildung in Schrenck's Reise etc. Amurland, 'laf. 12 (1859).

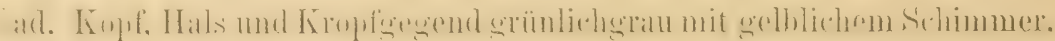
auf dem Kopfe braume Federspitzen, die aber im Frühjahr verfallen. Um den Schnabel herum eine schwarye Maske. Rücken- und Schulterfedern rostbraun mit lichteren Räudern und breiten braunschwarzen Längsflecken.

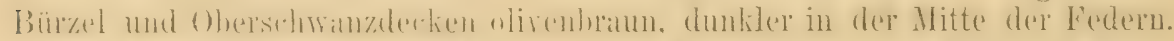

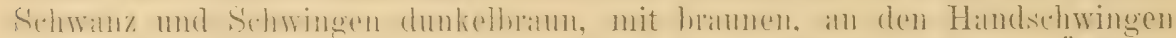

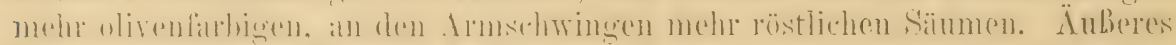

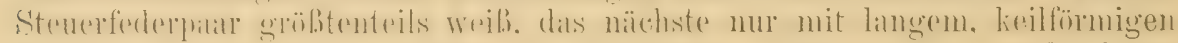
Fleck an der vorderen Hälfte der Innenfahne. Mittlere und große Ober-

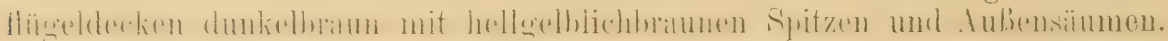

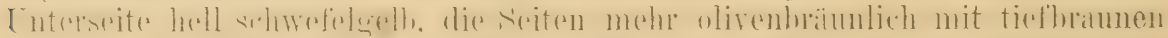

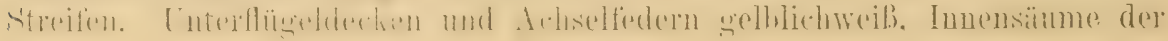


Schwingen meißlich. Im abgetragenen Gefieder sind lie Seiten lichter, diu Kiehle etwas gelhlicher, wenger mit grau vermaschen. Flügel 70-75. Schrvanz etrva 65-68, Schnabel $10 \frac{1}{2}-11 \mathrm{~mm}$. - o ad. Oberkopf und Oherhals im Herbst und Winter etwits hä̈unlicher und mehr geflerkt, im Summer wie heim 3 . Kehle hellgelh, mehr oder minder dunkelhraun grefleckt. \%ügel graubraun. darïher pin oft undentlicher, kurzer, hellgelber superciliar-

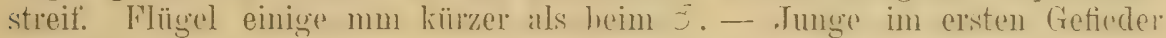
ähneln den 0 , aber oben viel mehr rostbramn, beinahe rotbräunlich, der Oherkopt braum, rorn und an den seiten dicht dunkelloraun geflectit und gestreift. Mitte des Hinterlenfe's heller. der Supereiliarstreif deutlicher. rostbäunlich von Farhe. Ohrolecken streifig. Enterseite gralblich, die Seiten mit hräunlichem Schimmer, Kehle und Kropf mit hamsehwarzen, peilspitzenartigen Strichen.

Ost-Sibirien. Mandsehurei und Koreal, westlich bis Irkutsk. nördlich bis zum Ochotskischen Meerhusen. Clhorwintert in Chiua und im nördlichsten Indien, am Fuße des Himalaya. Jouy erlegte ein Stïck im Januar bei Tlokio. Zur Brutzeit erlegte Stücke von Kol'er, wo sie häufig ist, haben

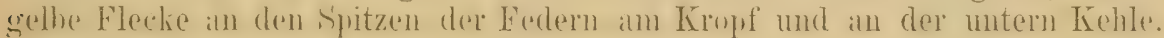
(Vielleicht Subspezies?)

Bewohnt Waldränder und buschreiche Flußufer. Kommt an seinen Brutplätzen in der zweiten Hälfte des Mai wieder an. Der Gesang wird als kurz, leise aber angenehm geschildert, genauere Angaben habe ich nicht darïber gefunden. Das Nest steht in Büschen, meist $1 / 2-1 \mathrm{~m}$ hoch, oder an Boden. Es enthält 4-6 Eier, wrelche weiß mit braunen Flecken sind und $18.2 \times 14,18 \times 14,18.3 \times 14,18.5<14,18.6 \times 14.3$. $19 \times 14,19 \times 14.2, \quad 19 \times 14.6,19 \times 15,19.2 \times 14.8$, ausnalımsweise $21.6 \times 15.2 \mathrm{~mm}$ messen. Sie gleichen also sehr in der Färbung den Eiern ron Emberiza melanocephala und striolata, nicht den bekritzelten Eiern der meisten Ammern. Nur ausnahmsweise zeigen sie feine schwarze Linien. Abbildung: Ibis 1904, Taf. III, Fig. 10.

\section{8:3. Emberiza spodocephala melanops Blyth.}

Emberiza melanops Blyth, Journ. Asiat. Soc. Bengal XIV, p. 554 (1845- Tipperah, Hinter-Indien).

Unterscheidet sich von E. sp. spodocephala nur durch etras lebhaftere und srïnlichere Förhumg an Konf. Hals und hropfgergend und lebhifter gelbe Unterseite, das $q$ nur durch letztere.

Brütet nach Styan im Gebiete des Jaug-tse-kiang (Mupin) und überwintert in Hinterindien, rou Assim und IIanipur his IBima. Weitere Forschungen über die Verbreitung sind notwendig!

\section{8t. Fmberiza spodocephala personata T'emm.}

Eimberiza personata Temminck, PI. Col. 580 (1835- „.. les part. septentr. du Japon et probabl. Ia Corée." Korea ist ein Irrtum, die typische Lokalität also N.-Japan).

Auf der Oberseite nicht vou E. sp. spodocephala verschieden, aber der

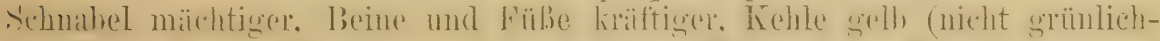

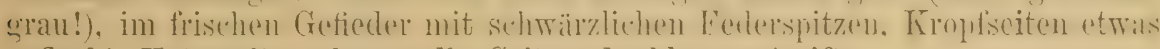
gefleckt, Unterseite schön gelb, Seiten dunkler gestreift.

F. Hartert, Die Vögel der paläarktischen Region. 
Japan von Iturup (der südlichsten der Kurilen) bis zu den Liu-KinInseln. In den nördlicheren T'eilen ihres Wohngebietes Zugvogel.

Das Nest steht in Grasbüscheln, auf oder nahe über dem Boden. Die Eier werden ron Jouy, der sie selbst gesammelt (Proc. U. S. Nat. Mus. 1883, p. 298) beschrieben als weißlich, mit blaßlila und braunen Punkten und Flecken, haben also augenscheinlich den Charakter derer der andern spodocephala-Formen. Nach Seebohm sind Eier in der Pryerschen Sammlung denen von $\mathbb{E}$. hortulana ähnlich - ich möchte diese für unecht halten. Nach Jouy messen sie $20 \times 16 \mathrm{~mm}$.

\section{Emberiza spodocephala subsp.?}

Emberiza personata (non 'Temminck!) Taczanowski, Faune Sibérie orient. I., p. 567 (1891Sacchalin!).

Nikolski und Taczanowski besehrieben "Emberiza personata" als häufigen Brutrogel auf der Insel Sacchalin, aus der Beschreibung geht aber hervor, daß es sich dort nicht um die japanische personata, sondern eine anscheinend der $E$. sp. melanops sehr wahestehende Form mit gelberer Unterseite und grünlicherer Fürbung auf dem Kopfe haudelt.

Sacehalin.

\section{Emberiza sulphurata 'Temm. \&t Schleg.}

Einberiza sulphurata 'T'emminck \& Schlegel, Fauna Japonica, Ares p. 100, Taf. 60 (1848Lokalität nicht angegeben, 'Typus von Japau).

ơad. Oberseite grünlichgrau (im Herbstkleide stark mit Rostbraun

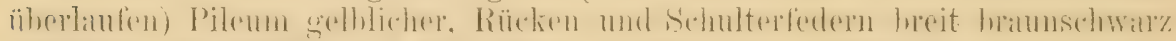

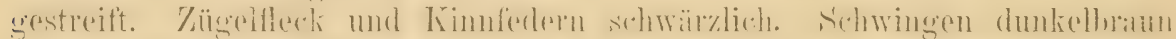

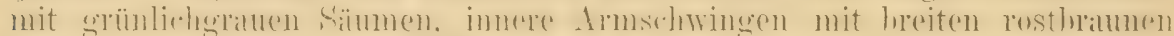

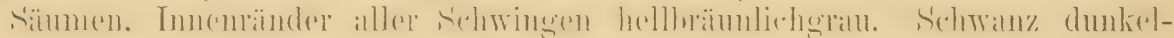

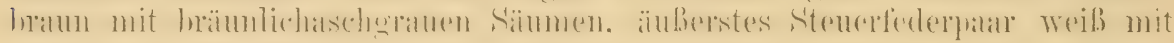
schwarzhramer Wurzel und ebensolchem Saumfleck an der Spitze, zweites Paar mit laugem keilförmigen weißen Streif an der Innenfahue. Kleine

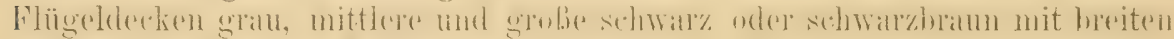

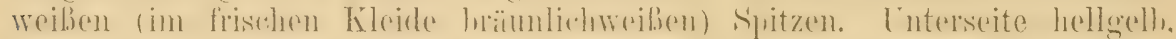

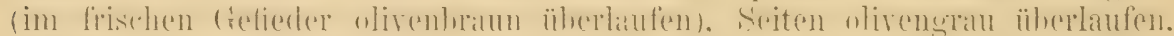
Weichen mit braunschwarzen Streifen. Flügel 70-74, Schwanz 65-68, Schnabel 10-11, Lauf etwa $18 \mathrm{~mm}$. 2 oben bräunlicher, Kehle, Kropf und Seiten bräunlicher, '/ügel ohne Schwarz. Junge Vögel den o ähnlich, aber noch brïunlicher. und Formosa.

Brutvogel in Japan (Jesso bis Nagasaki). - Wintergast in Süd-China

Häufig auf dem Fudschi-Jama, wo er in Büschen nahe dem Boden ein mit Pferdehaaren ausgelegtes Nest ans Grashalmen und etwas Moos baut, in dem man von Iai bis Juli etwa 4 Fier findet, die denen der Gartengrasmücke älneln. Sie messen nach Nehrkorn $20 \times 15 \mathrm{~mm}$.

\section{Emberiza cinerea Strickl. Btehrn}

Emberiza cinerca Strickland, Proc. Zool. Soc. London 1832, p.99 (Smyrna), frecC, Emberiza cineracea Brehm, Vogelfang, p. 114 (1855- „Smyrna, rerirt sich nach Griechenland").

Abbildung: Dresser, B. Hurope IV, T'af. 207. 
Ead. Konf hellgran mit schwefelgelhem Anfluge. Tonderhals sehwefolgelh, dies Gelh in einem leichten Anfluge aluf die Tordertnust fontgesetzt.

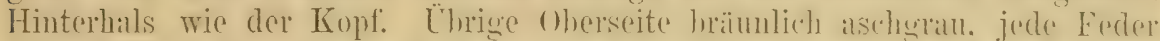

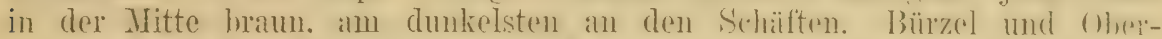

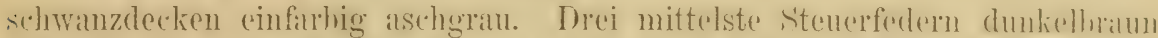
mit schmalen, am mittelsten P'aare viel hreiteren hell bräunlichwrilien siinmen.

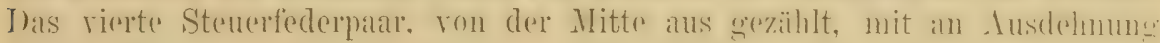
wechselnden, aber immer kleinen weißen Spitzen, das vorletzte mit fast zur Hälfte, das äußerste mit zur Hälfte veißer Innenfilhne und einem

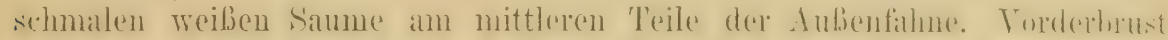

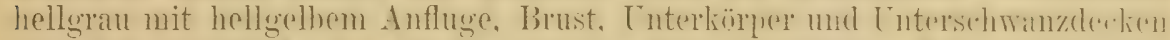
hell bräunlichweils, die Brust zuweilen mit hellgedlem. Tïrnersciten mit bräunliehem Anfluge. Schwingen dunkelbaun, Handschwingen mit sethr

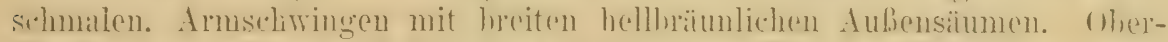
flügeldecken tieflnaun mit breiten weiBlishbramen Rändern. Interflügederken

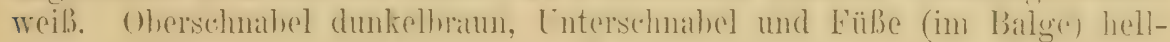
braun. Flïgel 95-97, Schwanz 76-78, Schnabel 12, Lauf $21 \mathrm{~mm}$. Jüngere ot haben weniger Gelb an Kopf und Kohle. oad. kleiner als das $\overbrace{}^{\top}$, Oberkopf graubraun, die Federu in der Mitte dunkelbraun und

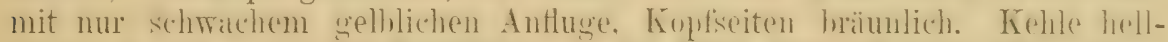

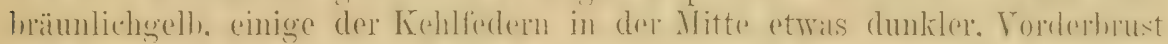

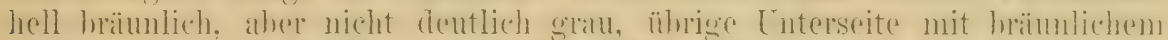

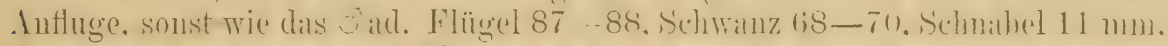
I) junge Togel im ersten Köleide ist viel mehn hram und es fehlt hei ihm

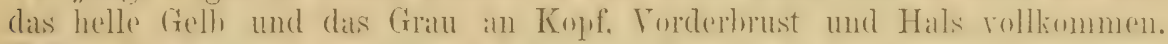
Kehle. Forderhrust und Brust hellbrä̈mlieh mit dunkelbaunen länglichen

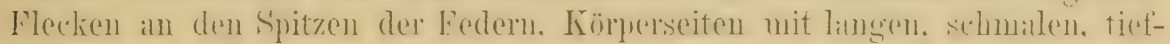

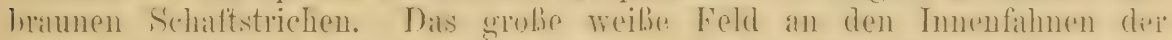

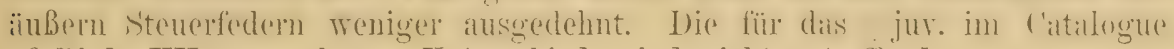
of Birds XII angegebenen Unterschiede sind nicht zutreffend.

Kleinasien (Smyrna und Südküste) brütend. Osträrts bis Persien, wo

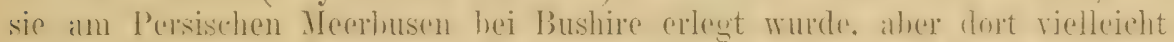
nur als Zugrogel. Trurde ron Heuglin hei Keren in Boges (Aluessinient) und

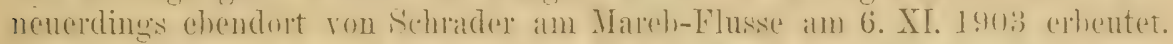

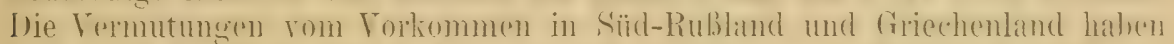

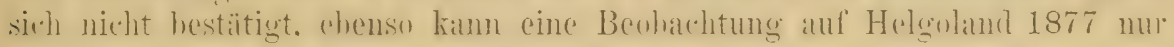
als unbewiesene Vermutung hingenommen werden.

Bewohner felsiger, steiniger Lagen mit spürlicher Vegetation. Die vertikale Verbreitung reicht vom Fuße der Berge bis iiber die Kiefernwälder hinaus. Lockruf ein kurz ausgestoßenes "küp", Gesang aus kurzen, verschieden modulierten, etwa wie "dir dir dir didl de" klingenden Strophen bestehend. Am 10. Mai 1889 fand Krüper ein Gelege bei Smyrna. Die Eier sind weiß mit bläulichem Schimmer, spärilich mit schærarzen Punkten und Flecken und einigen blassen Schalenflecken nahe dem stumpfen Ende gezeichnet. Ein Ei in Dresser's Sammlung mißt etwa $20.7 \times 15.5 \mathrm{~mm}$. Abbildung: Ibis 1904, Taf. III.

\section{Emberiza stewarti Blyth.}

Eimberiza stewarti Blyth, Journ. As. Soc. Bengal XXTI, p. 215 (Februar 1854 - Himalaya). Emberiza caniceps Gould, B. Asia V, Taf.6 (1854- Agra in Indien). 
Tad. Oberkopl bis auf den Nacken und Kopfseiten weil', '/ügel und

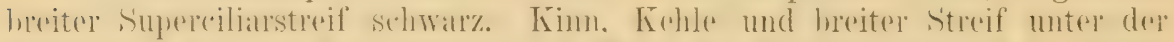

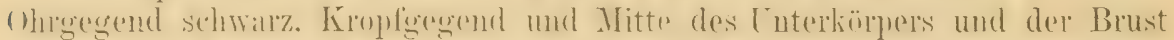
rahmweil.s. Brusthand. an den Seriten herit, in der Mitte sehmal, rotbram.

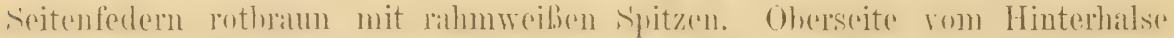

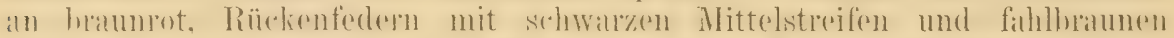

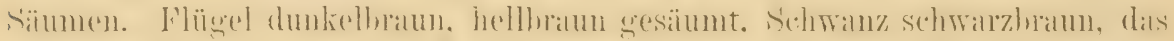

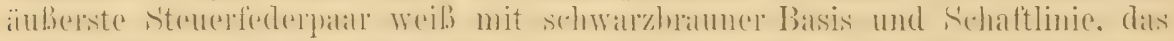

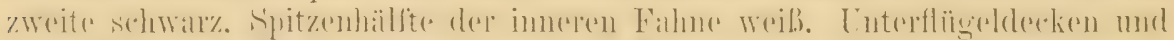

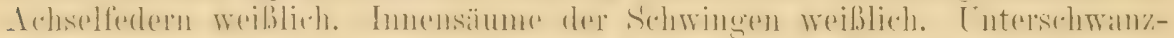

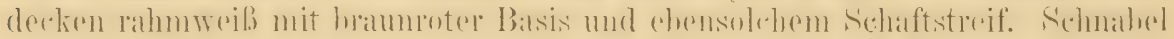

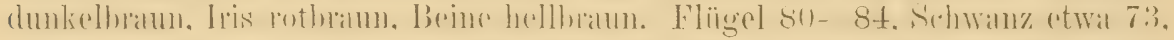
Schnabel etra $10-11 \mathrm{~mm}$. Im Herbstkleide ist das ganze Gefieder durch

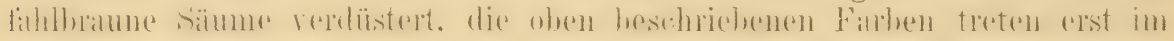
Frühjahr schön hervor, wenn die Ränder verschwinden. o gauz rersehieden

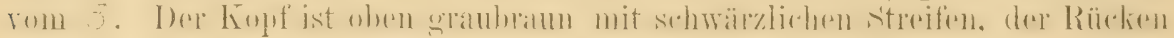

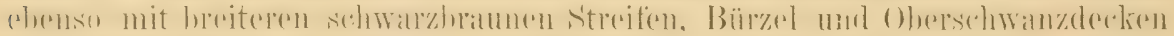

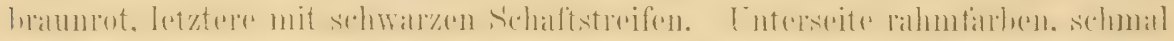
graubraun gestreift, nur an den Brustseiten etras rotbraun, Mitte des Unterkörpers und der Brust einfarbig. Jur. dem o ganz ähnlich, aber unten etwas gelbbräunlicher und kräftiger schwarzbraun gestreift.

Himalaya von Hazara, Gilgit und Kaschmir bis Almora, weiter nördlich in Turkestan und Afghanistan, im Winter in den Ebenen Indiens bis Sindh.

Brïtet im Mai und Juni, im Himalaya in Höhen ron 5-7000 engl. Fuß. Das nipfförmige Nest steht in Büschen nahe über dem Boden und ist ans Gras und Wurzelfisern gebaut. Die +-5 Eier sind schmutzigweiß oder grauweil mit tief rotbraunen, fast sehwarzen, und tiefer liegenden violett-bläulichen Punktein und Strichehn, die den größten 'T'eil der Oberfläche bedecken. Maße etwa $20 \times 15 \mathrm{~mm}$.

\section{Emberiza hortulana I.}

Gartenammer, Ortolan.

Emberiza Hortulana Limmens, Syst. Nat. Ed. X, p. 177 (1758-- „Habitat in Europa". Erstes Zitat: Hauna Suecica 208. Wir acceptieren daher als typische Lokalitït: Schweden.).

Emberiza maelbyensis Sparrmann, Mus. Carlson. I, Taf. 21 (1786 - Landgut Maelby in Schrveden).

Emberiza chlorocephala Gmelin, Syst. Nat. I, p. 887 (1788- ex Brown \& Latham, Fundort London).

Limberiza Badensis Gmelin, Syst. Nat. I, p.873 (1788- ex Sander, Naturforscher 13, p. 198, Fundort Baden).

Emberiza tunstalli Latham, Index Orn. I, p. 418 (1790- bei London gefunden. Neuer Name für chlorocephala!).

Linberiza jinguescens Brehm, Handb. Naturg. Vög. Deutschl., p. 295 (1831 - „, Deutschland, z. B. bei Berlin'b).

Kinberiza antiquorum Brehm, Handb. Naturg. Vög. Deutschl., p. 297 (1831- Italien). Limberiza shah Bonaparte, Consp). Ar. I, p.465 (1850- Persien).

Emberiza delicata \& intercedens Brelim, Vogelfang, p. 113 (1855- Deutschland).

Glycispina hortulana major \& planiceps A. E. Brehm, Verz. Samml., p. 8 (1866- nom. nud.!).

Engl.: Ortolan. Franz. Bruant-Ortolun. Italien: Ortolano. 


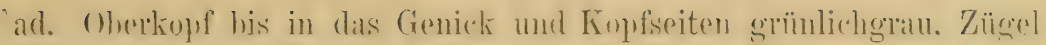
mohr gelhlich. schmaler Ring um das Auge hellgelh. Rëcken hraun mit hatunschmarzen Streilen. Bürzel und Oherschwanzdecken hraun mit schmalen, seluwarzgramen Sohaftstrichen. Schwingen. Flügelelecken mod Sohwanz dunkelhram mit hellhramen Sämmen. letzterer fast schwarz, äulieres Sehwanzfoder-

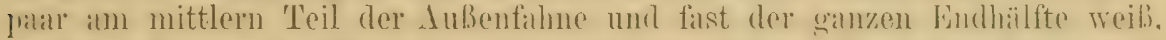

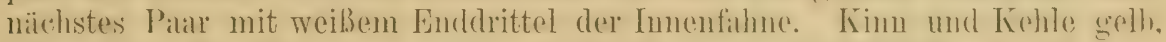

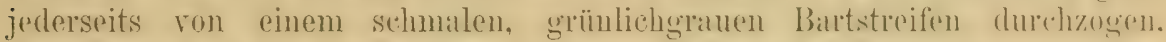

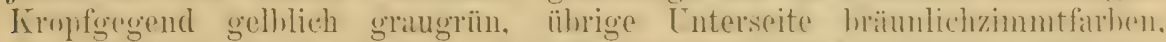

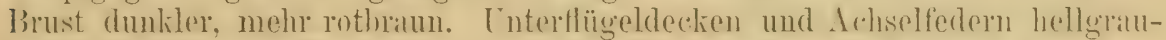
grelh. Im frischen Herbstkleide ist das Pilem etwas heller und hat dent-

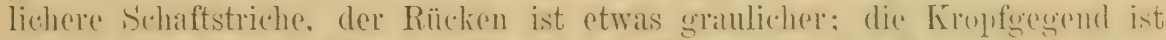

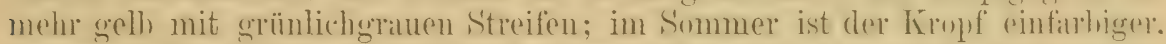

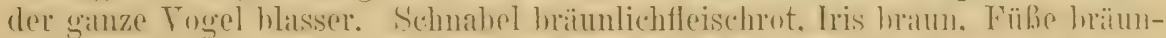
lichtleischfarhen. Flügel etwa 85-91, Sohwanz etwa $65-71$. Schmiluel $9-11$. Latuf 19-20,5 mm. Oal. blasser. P'ilem brïunlicher und mit sehwarzhrammen

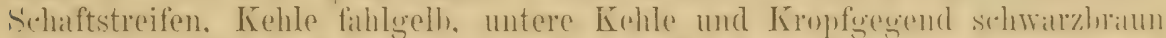
gestreilt. - Jur. dem - Z̈hnlich. aher I'ilemm breiter gestreift. oherseite mit

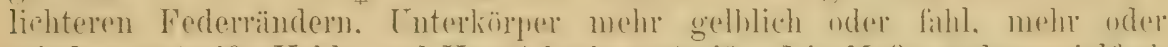

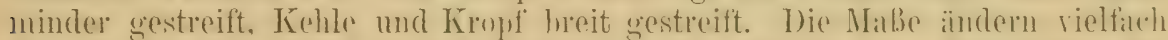

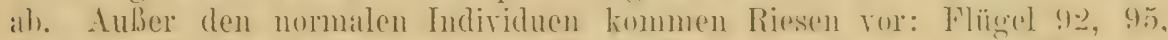
$96 \mathrm{~mm}$. Solche wurden aus dem Kohdo-Tale in der westlicheril Mongolei und Palästina untersucht. Es könnte sich viclleicht um eine östliche Form handeln, aber die Verbreitung ist unklar und das vorliegende Material ungenïgend; die aus Pabästimal mindestens sind nicht immer wn

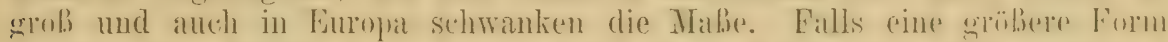

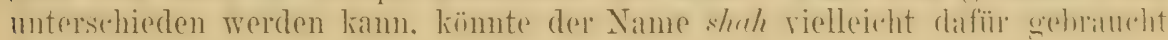
wercten.

Bewohnt Europa vom Polarkeise bis zum Mittelmecre, N.W.Afrika, Asien ron Kilein-Asien und Syrien his ()st-Persien. Afghanistan und Folulu in der Mr.-ALongolei, im Minter his Ahyssinien und rereingelt in Gilgit (Kaschmir). In England nicht heimisch, nur menige Male wurlen verimte IV auderer erlegt, in Schottland nux zwei, in Irland friglich rimmal. In den nördlichen Teilen ihres Wohngebietes Zugvogel.

Lebt in buschreichem Gelände, fehlt im höhern Gebirge. Eine jetzt noch stattfindende Weiterverbreitung ist durchaus nicht erwiesen, Vorkommen in Gegenden, aus denen man sie rorher nicht kannte, fallen meist mit der Ankunft guter Beobachter in den betreffenden Gegenden zusammen. Indessen ist der Ortolan vielleicht nicht so regelmäßig, wie manche andre Vögel verbreitet, sondern fehlt hier und da und ändert zuweilen seine Wohnsitze, woran ebensowohl eine Veränderung des Geländes, als der Umstand, daß der Ortolan "ein Neuling in unsrer Fauna ist" schuld sein kann. Der Lockton ist ein echt ammerartiges, ,jiih ji", manchmal wiederholt und moduliert. Der Gesang ist eine melancholische Ammerstrophe, trefflich mit „trii trii trï, tri tri tri ürr" wiedergegeben, bisweilen verlängert, aber wo ich ihu hörte selten merklich anders, immer der erste 'Teil tiefer als cler zweite, während der Schlußtor wieder um eine kleine Terz fällt. Nahrung wie die andrer Ammern. Das Nest am Boden oder wenige Zoll darüber; es enthält im Mai 4-5, ausnahmsweise 6 Eier, die ziemlich wenig variieren. Sie sind mattgrau oder blaß graurötlich mit einigen wenigen dunkleren, grauen wolkenartigen Schalenflecken und braunschwarzen Punkten, F'lecken und meist nur kurzen und wenigen Kritzeln. Unter den zahlreichen mir vorliegenden Eiern messen die kleinsten $18.3 \times 15.3$, das größte $21.8 \times 16.8$, Rey gibt als $D$ urchschnit 
von nur 29 Stück $19.9 \times 15.6$, als Maximum $22 \times 16.25$ bez. $19.5 \times 16.75$, als Minimum $18.25 \times 16$ bez. $18.5 \times 14.75 \mathrm{~mm}$, das Gewicht mit $0.158 \mathrm{~g}$ an. In Deutschland dürfte nur eine Brut stattfinden.

\section{Emberiza buchanani Blyth.}

Emberiza Buchanani Blyth, Journ. Asiat. Soc. Bengal XIII, p. 957 (1844- uach einer Abbildung vou Buchanan Hamilton. Indische Halbinsel. Die Beschreibung ist kurz, aber, in Verbindung mit dem Fundorte, vollkommen bezeichnend und genügrend.).

Emberiza Huttoni Blyth, Journ. Asiat. Soc. Bengal XVIU, 2, p.811 (1849-Afghanistan. - Blyth erklärt hier seine buchanani fiir identisch mit hortulana, ist aber damit durchaus im Irrtum, denn er hat in der ursprünglichen Beschreibung einen der Hauptuntersehiede hervorgehoben, auch kommt hortulana nicht auf der indischen Halbinsel vor. Man vgl. anch Stray-Feathers VH, p. 150.).

Emberiza Cervuttii De Filippi, Arch, per la Zool. ete. Genova II, fase. 2, ]). 383 (1863Persien).

Abbildung: Dresser, B. Europe, Suppl. (IX), Taf. 681.

Erinnert sehr an $E$. hortulana, unterscheidet sich aber namentlich wie folgt: Oberkopf und Bartstreifen rein grau, ohne eine Spur von Grün, Ohr-

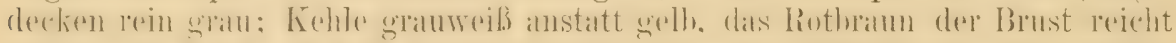

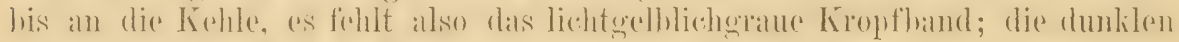

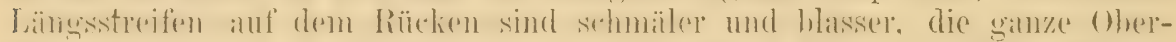

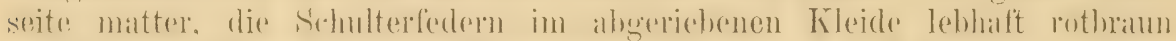

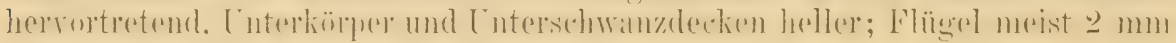
kürzer, oft aber ganz wie bei $t$. hortulana.

Vom Altai bis 'lurkestan, in den Gebirgen Persiens, Afghanistans, 'Tramskitsulens, ansmahmsweise mestlich his lowhent am Katukasus und in der

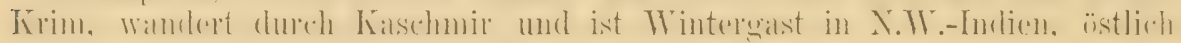
bis Ltawah, südlich bis Khandála und Chanda.

Lebensweise wie die andrer Ammern. Blanford fand ( 9 erlegt) das Nest 8000 engl. Fub hoch in Persien. L's war etwa einen Fub über dem Erdboden in dichtem Busche angebracht und enthielt 3 Eier. Die Eier sind blaßgriin mit tief purpurschwarzen Punkten und Flecken und blasseren rötlichgranen Zeichnungen, die letzteren meist am stumpfen Ende. Sie messen $24 \times 16.5 \mathrm{~mm}$, sind also merklich anders und größer als Ortolaneier. Nehrkorn gibt au, daß Eier rom Altai denen des Ortolans "sehr ähnlich" seien, gibt aber weder den Sammler noch die Art der Identifizierung an.

\section{Emberiza caesia Cretzschm.}

Emberiza caesia Cretzschmar, Atlas z. Reise von E. Rüppell, Vögel, p. 17, Taf. 10 (1826im Winter bei der Insel Kurgos im Nil).

Emberiza rufibarba Nordmaun in Erman's Reise, T'af. 8, Fig. 1, 2 (1835- ex Lichtenstein M.S.: N.O.-Afrika).

Emberiza nufigularis Brehm, Vogelfang, p. 113 (1855-.- Syrien).

Glycispina caesia longirostris, crassirostris, tenuirostris A. E. Brehm, V'erz. Sammlung; p. 8 (1866- nomina nuda!).

ơad. Oberkopf und Hals, durch ein breites Kropfband rerbunden,

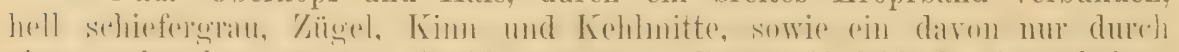

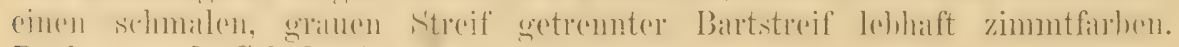
Rücken und Schulterfedern röstlich braun mit breiten schwarzbraunen 


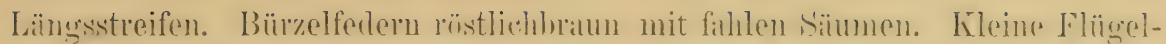

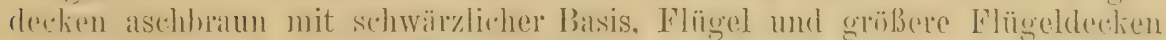

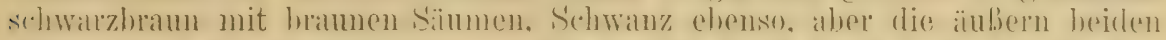

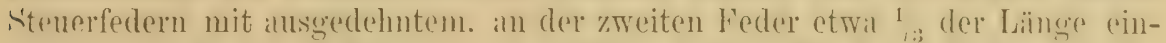

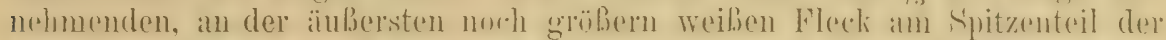

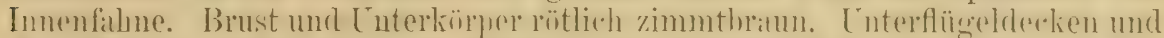

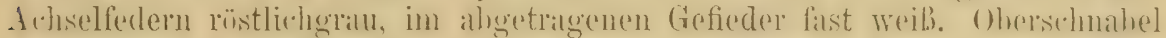

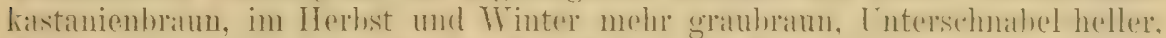

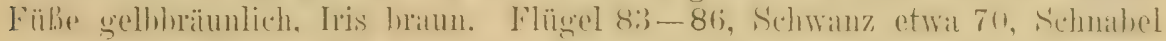
19-20, Lauf etwa $20 \mathrm{~mm}$. O. Oborkopf brïunlichgrau mit tiofbraunen

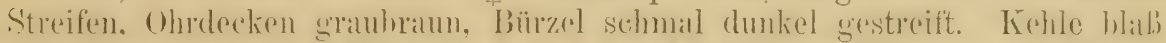
zimmthrann, an den Kohlseiten je ein schwärylicher Fleckenstreif, hropf

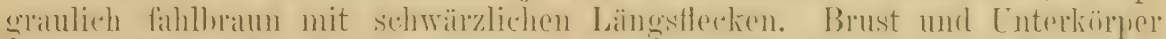

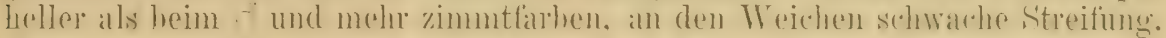

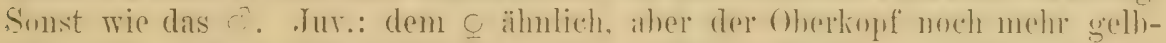

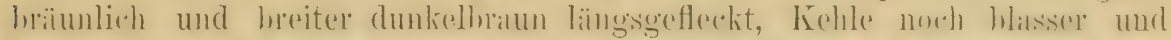

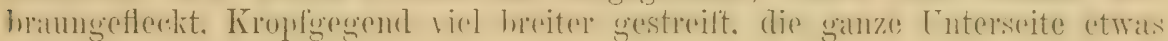
selewarzbraun gestreift.

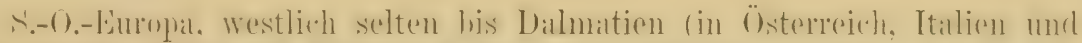

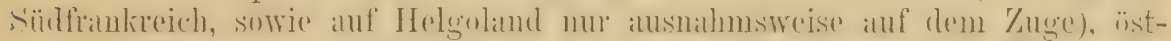
linh his Kleinasien, nörtlich his zum südlichen Kaukasus. Im Minter his Nordost-Afrika und Sïd-Arabien.

Bewohner felsigen Geländes mit spärlichem Buschbestande. Das auf dem Boden stehende Nest besteht aus Grashalmen und ist mit Pferdehaaren ausgefüttert. Es enthält 4-6 Eier, die denen der E. hortulana täuschend ähnlich sehen. Sie sind meist rötlichgrau, manchmal aber auch ohne den rötlichen 'Ton. 4 Eier aus Griechenland (Krüper) messen $22.5 \times 17,20.6 \times 16.2,21.6 \times 16,20.6>16.1 \mathrm{~mm}$. Rey gibt fïr 28 Lier aus derselben Quelle als IIaximum $21 \times 16$, als Durehschnitt $19.08 \times 14.72$, als Minimum $17.8>14.3$ und $18.5 \times 13.5 \mathrm{~mm}$, als mittleres Gewicht $0.138 \mathrm{~g}$ an. Krüper fand frische Gelege rom April bis Juni und rermutet danach, daß diese Vögel zwei Bruten machen.

\section{Emberiza cia cia L. (Fig. 36, Lii).}

\section{Zip-Ammer.}

Eimberiza Cia Linnaens, Syst. Nat. Ed. XII, I, p. 310 (1766- ex Kramer, Gesner, Aldror., Brisson. "Habitat in Europa australi." Als typische Lokalität ist NiederÖsterreich anzuschen, aus ilem 1. Zitat: Kramer, Elench. Vegetab. \& Animal. per Austriam infer. observ., p. 371, 1756.).

Emberiza barbata Scopoli, Annus I Hist. Nat., p. 143 (1769- neuer Name für E. cia L., Kärnthen).

Éniberiza lotharingica (Kmelin, Syst. Nat. 1, p. 882 (1788- ex Buffon; Lothriugen).

Enberiza meridionalis Cabanis, ILus. Hein. I, p.128 (1850- Bischerre in Palästina). (unterscheidet sich gar nicht von E. c. cia, sehr abgetragener Sommervogel). Eimberiza hordei Brehm, Handb. Naturg. Vög. Deutschl., p. 298 (1831- S.O.-Europa), Emberiza canigularis Brehm, Vogelfang, 1). 114 (1855- S.-Deutschland bis Italien).

Emberiza cia major A. E. Brehm, Verz. Samml., p. 9 (1866- nom. nud!).

Engl.: Meadow-Bunting. Franz.: Bruant fou. Ital.: Zigolo muciatto.

ad. Oherseite. mit Ausuahme des ganz anders gezeichneten Konfes der ron E. c. cioides sehr ähnlich, aber die Federränder mehr bräunlich, biirzel und ()herschwamzdectien nicht so lehhaft und dunkler rothraum. ['ilemm

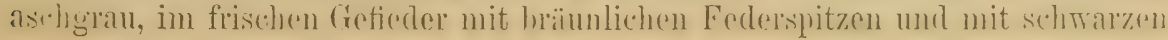


rehaftstreifen, an jeder Scite des I'ileum rin breiter schwarzer, nach der Mauser hranngerïnderter Streif; Zïgel, in einem Streifen hinterm Ange fortgesetzt, schmaler Bartstreif von der sishalielwurzel an und unter der Ohrgegend mach dem Genick hinziehend schwall\%. Flügel etwat wie hei cioides, aber die mittleru

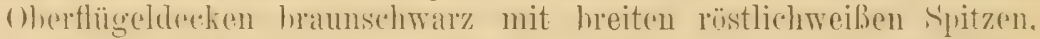
whe subterminale rotbrame Fïrlung. Supereiliarstreif weißlich, im frisehen Herhstlieide hräunlich, Ohrgegend und Kopfseiten weiblichgrau, Fleck unter den Ohrdecken, an den Halsseiten weiß. Kinu, Kehle und Vorderbrust hellgrau, übrige Unterseite röstlich zimmtFigur 36. braun, in der Mitte heller. Schwanz wie bei cioides. Flügel 82-85, Schwanz etwa $75-77 \mathrm{~mm}$. o kleiner, Pileum graubraun mit schwarzen Streifen, ()hrgegend und Zügel hraun. Kehle brïunlichgran. kederspitzen mit drececkigen schwärzliehen filecken. wie anch die Brustseiten. I'nterseite und Rücken nicht so lebhaft gefürbt.

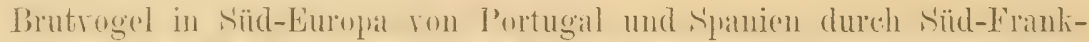
reich, Italien, die Balkanhalhinsel his Kilein-Asien, nördlich in Deutsehland im Neckartal und Rheintal bis in die Gegend von Bingen, in der Österench-Ungarischen Monarche his an den Fub der siebenbürgischen Alpen und his Nieder-österreich reichend. - Nur die nördlich wohnenden Individuen sind Zugvögel, die im Winter bis Nord-Afrika ziehen.

Bewohner warmen, sonnigen Berg- und Hügellandes, namentlich der Weinberge. Nahrung wie die andrer Ammern. Lockton ein feines zi, zi, zi, Gesang dem der Goldammern ähnelnd, aber etwas klarer, etwa wie $\ddot{i}$, $\ddot{i}$, $\ddot{u}-i h$, oder bisweilen $\ddot{u}, \ddot{u}$, $i-$ i, i. i. Das Nest steht meist zwischen Steinen und Grasbüscheln, oft auf und an den Mauern, die die verschiedenen Weinberge abgrenzen, und enthält im Mai oder Juni 1--5 Eier. Diese sind sehr charakteristisch (Fig. 36). Sic sind gräulichweiß, manchmal schwach bläulich oder rötlich angehaucht und mit irrgartenartig hin- und herlaufenden und sich kreuzenden tief braunen bis schwarzen Haarlinien reichlich bekritzelt. Dazwischen sielnt man noch tieferliegende grauliche Linien und einzèlne Punkte. Größere Flecke sind selten. Maße von 14 Eiern nach Rey $22.5 \times 16.5,20.87 \times 16.37$ bis $20 \times 15.75$ und $20.5 \times 15.25 \mathrm{~mm}$, Durchschnittsgewicht $158 \mathrm{mg}$.

\section{Emberiza cia stracheyi Moore.}

Emberiza stracheyi Moore, Proc. Zool. Soc. London 1855, p. 215, 'Taf. 112 (Liumaon).

Wie E. c. ciu, aher die mittleren libugeldecken nicht mit röstlichweißan, sondern mit hell rothraunen Spitzen. Interseite dunkler, Rürken dunklar rotbraun, die Kopfzeichnung schärfer weiß und schwarz.

Himalaya von Kaschmir bis Kumaon.

\section{Emberiza cia par subsp. nov.}

Wie $E$. cia cia, aber die Oberseite merklich lichter, was besonders im ahgetragenen Crefieder auffillt, die Spitzen der mittlen Flügeldecken dagegen rothräunlich, nicht so weißlich, Flügel lïnger: ó etwa $88-91 \mathrm{~mm}$. ('T'Yus. vou E. cia par: Nr. 1767, bei Gudan, Transkaspien 13. V. 1892. N. Sarudny coll. $0^{\pi}$.)

Mittleres Asien, vom nördlichen Kaukasus durch Transkaspien his 'Turkestan, Afghanistan, (sst-Persien und Baluehistan, vielleicht im Winter bisweilen in N.-Indien. 


\section{Emberiza cia godlewskii Tac\%.}

Emberiza Godlewskii Taczanowski, Journ. f. Orn. 1874, p. 330 (Ostsibirien).

Abbild.: Cat. B. Brit. Mus. XU, Taf. 12.

Unterscheidet sich sehr von den andern Formen von cia: Kopf und Hals sind hläulich aschgrau, Pileum mit dunkeln Sehbïften und an jeder Séeite einem kastanienbramen his anf den Hals reichenden Streifen. Kï̈gen und Bartstreif sehwärzlich: Ohrgegend etwas dunliere iiher dersolben ein kastanienhramer Streif. Nabe sehr valliahel. of Fliggel 87-95 mm in derselhen Gegend. o auf Oberkopf und Vorderbrust gestrichelt, Kehle isabell.

Ost-Sibirien, Mongolei his Ala-Sehaln und Kinnsu, im Süden des BaikilSees. westlich his ()st-Turkestan, im Irinter in (hina ('Tat-tsien-lu), cimmal nörllich ron Kaschmir im Arär erlegt. - Das Brutgehiet dieser Ammer ist nirhit genau bekannt, doch scheint sie die andern ciu-Formen nordöstlich zu vertreten. daher ich sie als subspegies aufzufasion rorschlage. Vielleicht lissent sich noch wieder hellere und dunklere Formen davon unterscheiden.

Eier nach Nehrkorn wie die von $E$. cia cia.

\section{Emberiza cioides cioides Brandt.}

Emberiza cioides Brandt, Bull. Scient. Acad. Imper. St. Pétersb. 18.13, I, p. 363 (Sibirien). Abbild.: Ibis 1889, Taf. X, Dresser, B. Europe, IX, Taf, 683.

ơad. Pileum und Ohrgegend vom Auge an kastanienbraun, Federn des ersteren an den Spitzen etwas sehwärzlich und im frischen Herlostgefieder hreit hell aschhrämulich, die der letzteren nur schmal aschgram gessiumt.

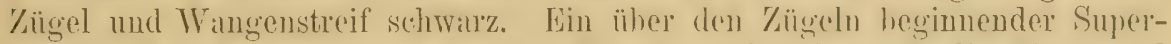
riliarstreif und ein anderer von den Mundwinkeln his nuta die olnrogegend hinziehender grauweib. Rïichen rothaun mit dunkelsehwarghaunen Streifen und breiten aschbräunlivhen Rïnlern, die sich in der IBrutzeit grobenteils abmutzen. Bürzel und (Oherschwanzdecken zimmontig rothram, im frischen (iefieder. mit schmalen, helleren Sämmen. Sohwingen sehwalzhrann. Hanr-

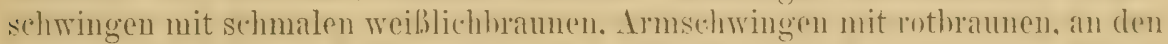
immeren viel breiteren Auben-, alle mit weißlichbranen Inncnsäumen. Kileins Oherflügeldecken aschhraun mit aschgratuen sätmen. mittlere und grobe dunkelbaum mit bellrosthä̈unlichen Spitzen und subterninalen baumboten Fleclien. Äubere zwei steuerfederparo weils mit schwärzlichem Schaft und an der äubersten weniger ausgedehntem, an der inneren Fahne his zur Hälfte ader writer sehrïg hinauflaufenden hraunschwarzem Wurzelfeck, die näldsten drei l’are schwaryhraun mit schmalem, hellen Aubensaum, das mittelste ringsmm mit seho hreiten braunroten Säumen. Kehle und Halsseiten hellgrau, an den vordern Halsseiten ein woiber Flock. Kronfgegend kistanionhanm mit hreiten. hell aschhräunlichfahlen Sämmen. C̈hrige Enterseite rostgenhlichwrib. die Séiten ausgedehnt hrïunlich zimmtfarben. an den Wrichen undeutliche dunklere streifung. Lntersehwanzdecken weil. mit röstlichem Shehmmer. Cutcrefïgeldecken weib. Schnahel dunkel hornfarbig. Lntersehnahel heller, Fübo bram.

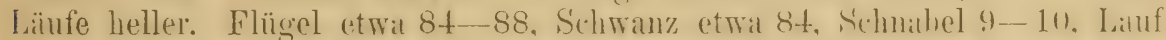

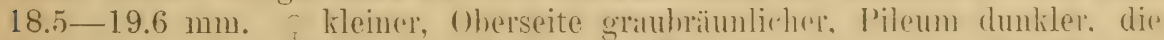

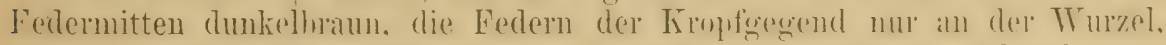
und auch dort heller rothram, nicht lehhaft kastanimblam. Flügel ofwa $78-80 \mathrm{~mm}$. 
West-Sibirien und T'urkestan. Genaue Grenze nach O. nicht sicher. doch scheinen typische cioides bis Daurien zu gehen, und am Altai- und Baikit-ree allein rorzukommen, auch scheint es in mittlern Sibirien Chelgänge zu geben. Sehr hoch nach Norden geht die Form nicht.

Stand-, Strich- und teilweiser Zugvogel. Bewolnner offenen, buschigen Landes, aber nicht von Wäldern. Nest echtes Ammernest, am Boden. Die 4-5 Eier sind denen von E. cia gleich oder sehr ähnlich, munchmal aber mehr gefleckt, meist auch etwas größer: $20.5 \times 16, \quad 19 \times 15.2,19.5 \times 15.6,19.6 \times 15,20 \times 14.8-15.4,20.1 \times 15$, $21 \times 16,21.5 \times 16.2 \mathrm{~mm}$. Gesang zweistrophig; angenehm, melodiös.

\section{Emberiza cioides castaneiceps Hoore.}

Enberiza castaneiceps Moore, Proc. Zool. Soc. Loudon 1855, p. 215 (China).

Merklich kleiner und rötlicher. Der Unterschied in der Größe ist auffallend genug, wenn man nur wirklich Exemplare der heiden Formen und ; mit. o. mit rergleicht, die viel rötliehere Fïrbung im frischen Herbst-

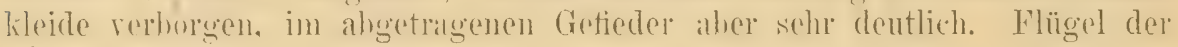
ơ $78-82$, der o $73-76 \mathrm{~mm}$.

Bewohnt das östlichste Sibirien (den untern Amur und Ussuri, die Insel

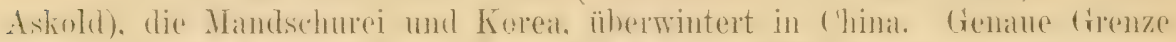

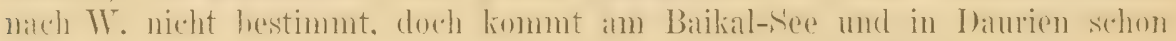
E. c. cioides vor: (Im November 1886 in England erbeutet.)

\section{Emberiza cioides ciopsis Bp.}

Emberiza ciopsis Bonaparte, Consp. Ar. I, p. $466^{\circ}$ (1850-- Japan).

Emberiza cioides ijimae Stejneger, Proceed. U. S. Nat. Mus. X VI, p. 638 (1894- Insel 'I'schusima).

Abbild.: 'T'emm. \& Schlegel, Fauna Japonica, T'af. 59, unter dem Namen cioides.

Unterscheidet sich von den andern Subspezies der Art im männlichen

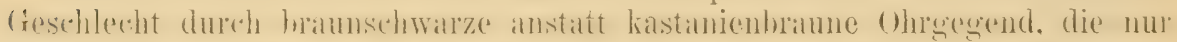

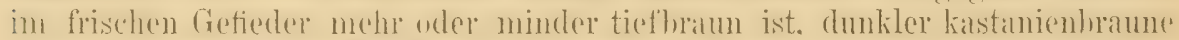
Grundfilbe auf dem hopfe (abgeriehen tief hastanienbraun). Weniger ausgedehnten, aber viel dunkler braunen (nicht blasseren wie Dresser sagt!) Kropffleck, oft auch kürzere Flügel, die beim on nur etwa $76-81 \mathrm{~mm}$ betragen. O wie das ron E. c. castaneiceps, nur die Mittelstreifen auf Kopf und Rïcken dunkler.

Japan, häufig auf Jesso und Hondo brïtend, sorwie auf 'T'schusima, wo sie völlig denen aus Japan gleichen.

Nest auf oder nahe ïber dem Boden, Eier wie die von $E$. $C$. cioides, nach Nehrkorn $22 \times 16.5 \mathrm{~mm}$.

\section{Emberiza jankowskii Taez. (Fragliche Art.)}

Emberiza jankowskii Taczanowski, Ibis 1888, 1. 317, Taf. 8 (Sidemi).

Im allgemeinen E. cioides ähnlich, ist aber kleiner, die Oberseite ist riel heller, die Knptseiten. namentlich die ohrdeckens, sind weib, dise Lnterseite ist heller und mehr granlieh, mit einem kastanienhranuen Fleck in der Nitte des Unterkörpers, aber ohne kastanienbraune Farbe an der Brust. 
Ein einziges Stuick vom Sidemi, an der Grenze von Korea und der chinesischen Mandschurei bekannt. lis läbt sich mit keiner der bekinnten Formen rereinigen, aber es ist sehwer zu glauheu, dafis ein soleher Toget in jener Gegend nie wieder gofunden sein sollte. Die Zukunft muls lehren, ol, ('s sich um eine wirkliche drt, Aberation. Bastard (?) onter was sonst handelt.

\section{Emberiza fucata fucata Pall.}

Enberiza fucata Pallas, Reise d. verseh. Prov. d. Russ. Reichs III, p. 698 (1776-_ „Ad Ononem et Ingodam in ripis").

Abbildungen: T'eum. \& Schleg., Fauna Japonica, Taf. 57, Gould, B. Asia V. Taf. 9 \& B. Europe III, Taf. 178.

òad. Oberkopf grau mit sehwarzen Schaftstreifen, Rücken braun mit sehr breiten schwarzen, Bürzel braunrot mit einigen braunen Streifen.

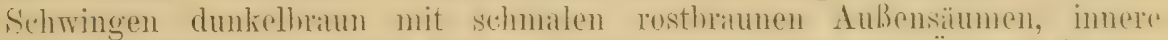

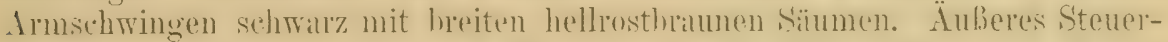

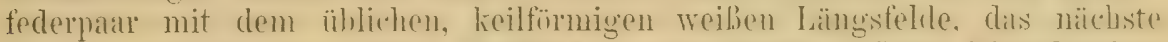
aher nur mit kurem weiben Keilfeck an der suitze. Kleine Flïgeldeckern hell rothraun, mittlere und grense sehwarz mit hell prosthaumen spitzen.

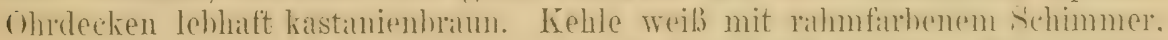
an den Tehlseiten je ein schwarzer, durch eine breite schwarze Flectienreihe wher die Kropfgegend hin verhundener Streif. C̈her die Vorderhust zieht sich

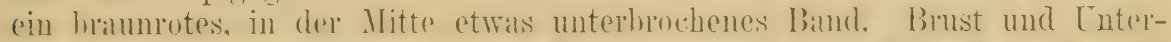

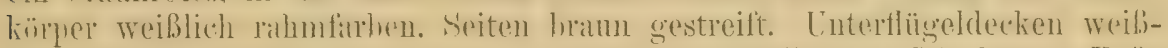

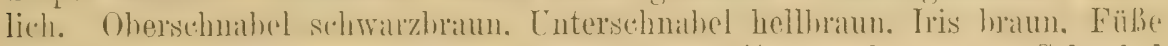
fleischfarben. Flügel $74-78$, Schwanz $75-77 \frac{1}{2}$, Lauf $41-43$, Schuabel etrva $11-12 \frac{1}{2}$ mm. . o etwas kleiner, Oberkopf bräunlicher, schwarze und hraunrote 7eidhnungen in Kehlseiten, Kropf und Torderhrust heschrïnliter. In Herhstlieide ist in heiden Geschlechtern der oberkopf durch rothrame

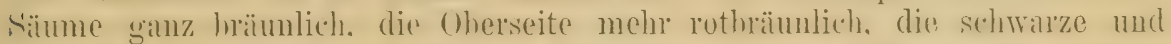
rothrame Zeichnung an Kropf und Torderhrust durch gelhbrïunliche Ründer etrvas verborgen, Brust und Unterkörper rostgelb.

S.O.-Sibirien (siidliches Damrien, Cssuri), Mandschurer. Korea, Jalpun. Nord-1 hina, Wintervogen durch ganz Süd-C'hina his Hainan und Hinter-Indien.

Bewohnt offenes steiniges, mit niederm Buschwerk bestnndenes Gelände und hat einen der besten und längsten aller Ammerngesänge. Nest am Boden oder nahe daruber, 4-6 Eier im Juni. Diese sind denen der weißen Bachstelze (Motacilla alba) ïhnlich, blaßgrünlich bis weiß rnit mattbraunen, dunkelgrauen und fuchsigen Flecken dicht bedeckt, olne Kritzel und Haarzüge. Maße 17.t-19.6 $<14.7-15.6$ (Taczanowski), $19-23 \times 16 \mathrm{~mm}$ (Nehrkorn).

\section{Emberiza fucata arcuata Sharpe.}

Emberiza arouata Sharpe, Cat. B. Brit. Hus. XII, 1).494, im Text (1888- Himalaya).

Das of unterscheidet sich auf den ersten Blick durch cinfïmig hrann-

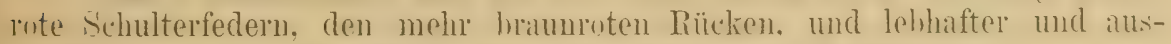
gedelnter lehhaft zimmetartig hammote Brust- und Kïrperseiten.

Himalaya vou Kaschmir bis Assam. 
Britet im Himalaya in Höhen von 6-8000 engl. Fuß, im Mai und Juni. Die 4 Eicr sind grünlichgrau, über und über rotbraun oder purpurbraun gefleckt. Sie messen etwa $20.7 \times 15 \mathrm{~mm}$.

\section{Emberiza rustica Pall.}

Waldammer.

Emberiža rustica Pallas, Reise d. versch. Prov. d. Russ. Reichs III, p. 698 (1776 - „In salicetis Davuriae").

Enberiza lesbia Gmelin, Syst. Nat. I, p.882 (1788- ex Buffon \& Daubenton Pl. enl. 656 fig. 2: Provence. Irrtiimlich für $E$. fucata gehalten!)

Enberiza borealis Zetterstedt, Resa Sver. och Norr. Lappm. I, p. 107, Taf. 1, 2 (1822 Haparanda).

Engl.: Rustic Bunting. Schwed.: Videsparf.

O’ad. Oberkopf und Kopfseiten schwarz, breiter Postokularstreif und kloiner Fleck in Gronick woils. Hinterhals, Bürzel und Oherschwanzdecken

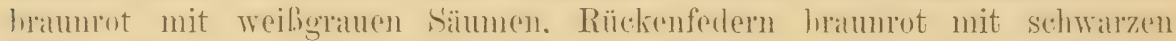
Mitfolstreifen und rostgelblichen Sümmen. Schwingen und Schwanz dunkelhram mit fahlhamen S̈̈umen, die beiden ïubern Steuerfedern mit den

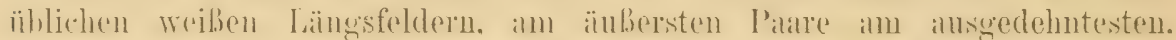

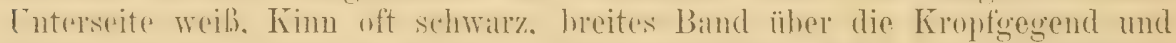

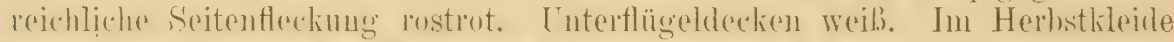
hahen das Shehwar\% des Lonfes, das Braumrot und die ganze olherseite fahlhatum Ränder. Wodureh das fresamtaussehen ein mesentlieh anderes wird. Elïgel $77 \frac{1}{2}-83$, Schwanz 62-63, Lauf etwa 19, Schnabel $20-21.5 \mathrm{~mm}$. kleiner (Flïgul etwat 5 mu kïrmer). ()herkopf sehwarghaun mit fahlluramen Säumen, die auch in der Brutzeit nie ganz verschwinden, das Kropfband

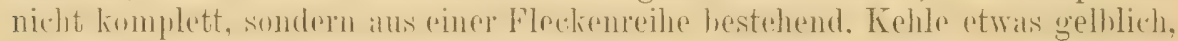
an den Kehlseiten ein schwärzlicher Streif. Ohrdecken hraun. Sonst dem Herhstkleide des ơ ähnlich.

Von Kamtschatka und Ost-Sibirien bis Ost-Finnland, wo sie noch

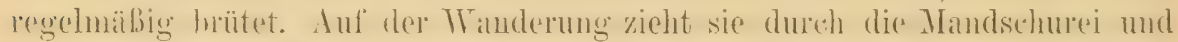
Mongelei. nath ('hina mud Japan, Thrkestan, erseheint hisweilen in Schweden,

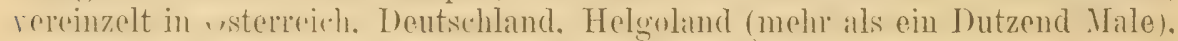
Italien, Süd-Frankeich, Holland und in England (etwa dreimal).

Bewohner feuchten, busch- und baumreichen Geländes. Das leicht gebaute Nest steht auf oder mahe dem Erdboden und besteht meist aus Grashalmen. Im Juni findet man die 5-6 Eier, die fälschlich als denen des Rohrammer ähnelnd beschrieben wurden. Sie erinnern viel mehr an Bachstelzeneier, sind auf bleigranem oder grüulichgranem, seltener olivenbräunlichem bis rötlichem Grunde, ïber und über mit wolkenartigen bräunlichgrauen Längsflecken bedeckt. Haarlinien und Schnörkel fehlen. Maße mach Sandman (Rey) durchschnittlich $20.57 \times 15.01$, Maximum $21.8 \times 15.2$ und $21.3 \times 15.3$, Mlinimum $19 \times 14 \mathrm{~mm}$. Gewicht $0.117 \mathrm{~g}$.

\section{Emberiza pusilla Pall. Zwergammer.}

Emberiza pusilla Pallas, Reise d, versch. Prov, d. Russ. Reichs HI, p. 697 (1776Daurische Alpen).

Emberiza Durazzi Bonaparte, Fauna Ital., Uecelli, 'T'af. 35, Fig. 1, 2 und 'T'ext (1832-41 Ligurien).

Ocyris oinops Hodgson, Proc. Zool. Soc. London 1815, p.35 (Nepal).

Engl.: Little Bunting. Italien: Zigolo minore. Franz: Bruant nain. Sehwed.: Drägsparf. 
Oad. Mitte des Oberkopfes bis auf den Nacken, ganze Kopfseiten mit EinsehluB der Ohrdecken und Zï̈gel brauneot. An heiden Seiten des Pilemn ron den Zügelu his zum Hinterhalse ein breiter schwar\%er Streif. hinter den Ohrdecken eiu schwarzer Bogen. Rückenfedern und Schulterfittiche in dè Mitte schwarz, daneben bram dot, damn hellbraun, Bürzelferlern und oherschwanzdecken braungratu, in der Mitte dunkelhraum. Sohningen dunkelhramn mit schmalen, hellhramen Rïndern, die imneren Arnschwingen dunkler, fast schwar\%, mit breiteren und mehr rothramen Sïmmen. Kleine Oherflügrdecken braungrau, mittlere und grobe schwarzhau wit weililich fuhlhrumen spitzen. Stenerfedern dunkelbraum mit granbramen Rüudern. das änberste l'all mit dem bei den meisten Ammern rorkommenden, den gräberu T'eil der Ferler

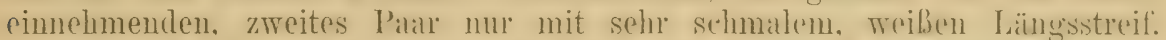
Interseite weib, an den Seiten der Kehle eine sehmalrze Flechenreilue. Brust

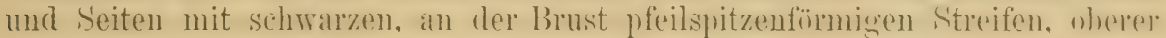
Tril der Kohle meist, aher nieht immer, rostrot. Euterflügelderien und

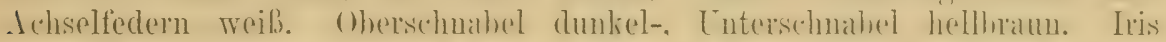

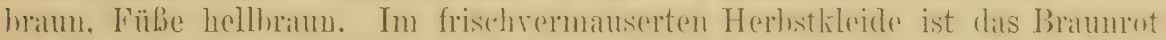
am Kopfe heller, dis Schwarz halhwerderlit, die ganze ohrerseite mit Rost-

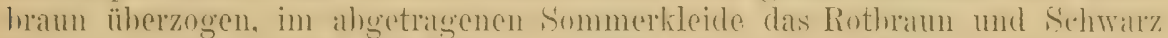

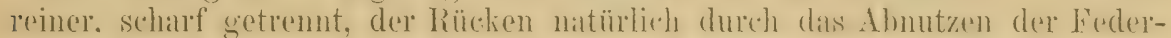

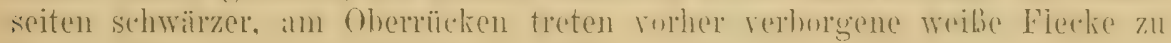
'Iage. Flügel 72-76, Schwanz etwa 60, Lauf etwa $17-18$, Selnabel $10 \mathrm{~mm}$. 5 wie ơ, nur etrvas kleiner, Elügel meist nu 69-71 mm. Juv.: Oben

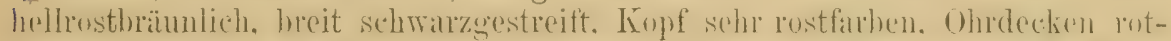
ham. Tnterseite weib mit rostfabenem Silhmmer, schwargestreift. Mittr des Unterkörpers ungestroift.

Nord-RuBland bis zum Onega und durch ganz Sibirion bis zur AmurMändung, Turkestan mnel Mongolei. - Im Winter durch ( hima his Nord-Indien und Birmah, vereinzelt nath don Andamanen und Philipunene sowie im

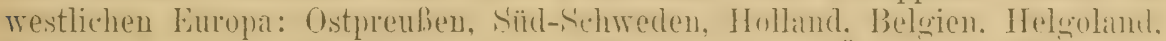
Frankeich, dreimal in England, anch öfter in Italien. Österreseh, Kleinasien und Algier.

Bewohner bebuschter Gegenden, namentlich sumpfiger Wälder und Ufergelände. Die Lockstimme wird als ein leises tick tick tick, der Gesang als melodisch, mehr dem cines Rotkehlchens als einer Ammer ähnelnd bezeichnet. Unter den Eiern finden wir äußerst verschiedene Typen. Einige ähneln nach Popham ganz denen von E. schoenichus, andre denen von $E$. spodocephala, andre den grïnen Varietäten von $E$. rustica. MIiddendor' fand schon vor langen Jahren dieselbe T'Tatsache, daß nämlich zwei Gelege (die Wcibchen in beiden Fällen erlegt!) einander durchaus unähnlich waren. DIaße 17.5 $<14,20<14$, $20.2 \times 14.3 \mathrm{~mm}$, Gerwicht $0.130 \mathrm{~g}$. Das Nest steht am Boden und ist mit feinen Gräsern und Haaren gefiittert, das Gelege besteht aus $4-6$ Eiern.

\section{Emberiza chrysophrys Pall.}

Emberiza chrysophrys Pallas, Reise d. rersch. Prov. d. Russ. Reichs III, p. 698 (1776Daurische Alpen).

Abbildungen: Dresser, B. Europe IV, 'Taf. 212, Neuer Naumann, III, T'af. 22.

OTad. Oberkopf und Kopfseiten schwarz, die schwarze Kappe in der Mitte durch einen von der Stirn zum Nacken reichenden, schmalen rein-

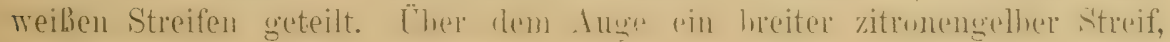




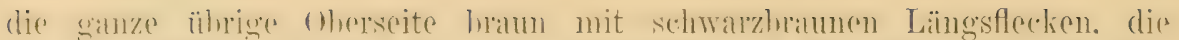

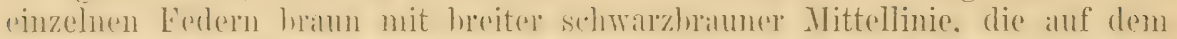

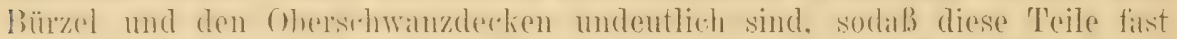

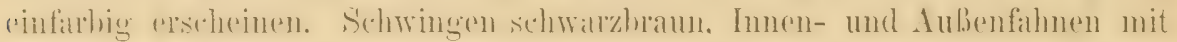

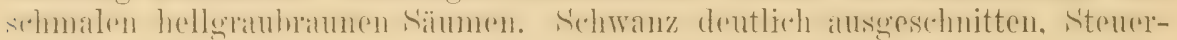
feder'n schwarzhraun, das mittelste Paar mehr braun. das äulierste mit der Wurzelhälfte der Außenfahne und etwa der Hälfte der Innenfahne dem

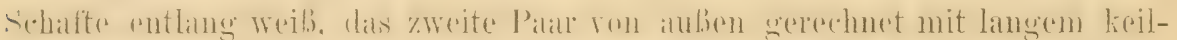

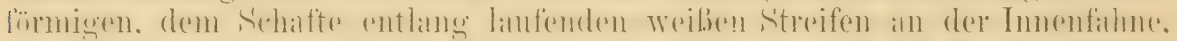

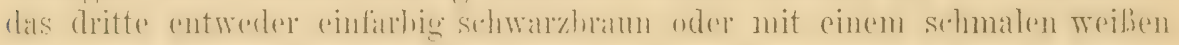
Strich nahe der Spitze der Innenfahne. Unterseite weiß, an den Kehlseiten

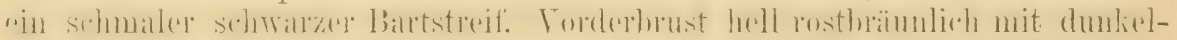
braunen Schaftstreifen, Körperseiten ebenso. Iris braun, Schnabel dunkel hornbraun, nach der Wurzel des Unterschuabels zu hellbraun. Füße bräunlich fleischfarben. Flügel etwa 80, Schwanz 63, Lauf 20, Schnabel $11 \mathrm{~mm}$. Q ad.: Oberkopf und Kopfseiten braun, der Mittelstreif in der Kopfmitte

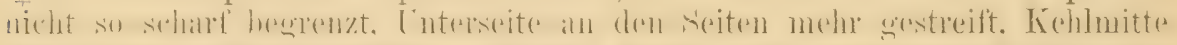

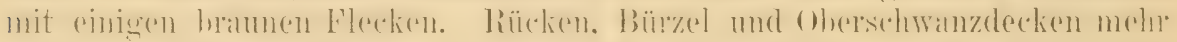
rotbraun. Etwas kleiner. Sonst wie ơad. Jur. dom o ad. ähnlich, aher

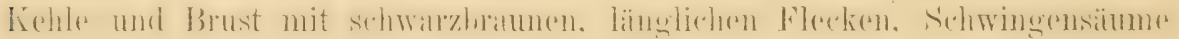
und Stenerfedern melir rostfarhen.

Bewohnerin des östlichen Sibiriens: Damren, T'arei-Nor, an den Flüssen

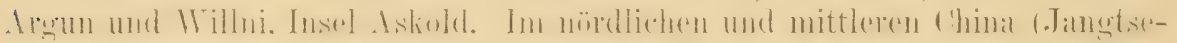

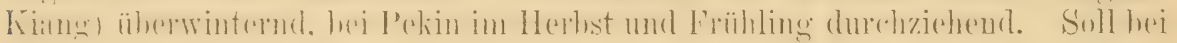
Lille und in Luxemburg je einmal crbentet sein (iiber die teilweise widersprechenden Angaben s. Neuausgabe des "Naumann" III, p. 202).

Lebt in buschreichem Gelände, besonders in Weidengebiisch. Lockruf zippend, nach Radde sanfter und mehr pfeifend, als bei andern Ammern. Gesang angenehm. Fortpflanzung unbekannt.

\section{Emberiza striolata sahari Levaill.}

Emberiza Sahari Leraillant jun., Expl. Scient. de l'Algérie, Atlas, Ois. 'Taf. IX bis, Fig. 2 (1850- als typ. Lok. ist Algier anzunehmen, die 'Tafeln erschienen aber olnne 'l'ext).

Fringillaria saharae 'l'ristram, Ibis 1859, p. 295 (ex Bonaparte, Cat. Parzudaki, nomen nudum - M'zab, Algier, erste Beschreibung).

Fringillaria Sahara Loche, Expl. Scient. de l'Algérie, Oiseaux I, p. 182.

ơnd. Oberkopf hellgran mit bräunlichem Schimmer und schwarzen

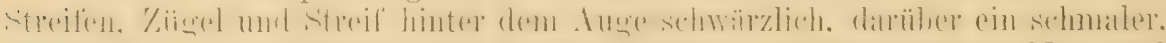

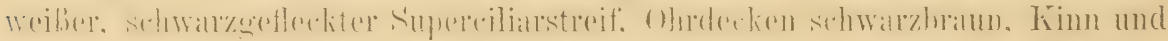
Kehle bis auf den Kropf grau und schwarz, jede Feder schwarz mit breiten

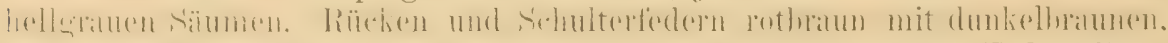
nicht scharf begrenzten und nicht sehr scharf hervortretenden Federmitten, hintere Bürzelfedern und vordere Oberschwanzdecken einfarbig rotbraun.

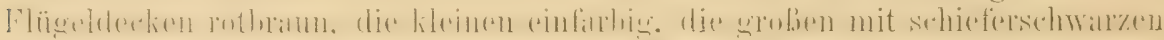

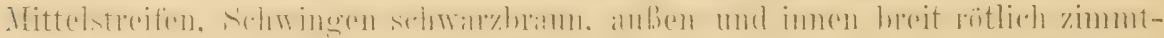
braun gesiiumt. Schwanz schwarzbraum, schmal rötlich zimmtfarben gesäumt.

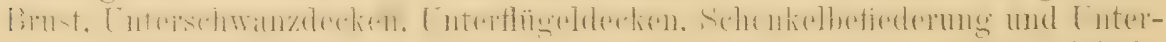
lärner rötlich zimmtbram. Iris bräunlich orange, Fübe bräunlich fleisch- 


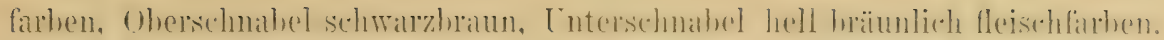
Flügel 75-80, Schwanz 65-70, Lauf etra 18-19, Schnabel 10-11 mm.

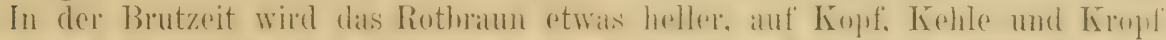

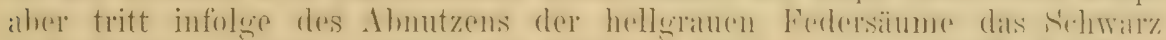

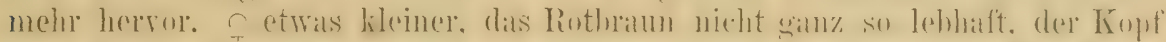

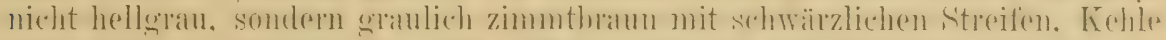

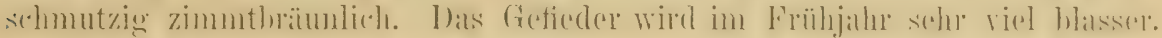

N.IT-Afrika: 'Tunis, Algier, Marokko. In Tunis und Algier nur südlich des Atlas, in Narokko aber nördlich desselben, in Marakesch, Mogador, Mazagan (in letzterer Stadt aber nicht Brutrogel), im Norden (z. B. hoi 'Tanger) fehlend. (Angeblich als Irrgast in S.-Spanien.)

Bewohnt Oasen, Dörfer, Städte, Brunnen und felsige Sahara. Überaus vertraut. so zahm wie wenig andre Vögel. Der Gesang liann ein Mittelding zwischen Finkenschlag und zwitschernder Ammerstrophe genannt werden. Dis ordentlich und festgebaute Nest wird unter Dächern, an Mauern, auf Ballken in Häusern, in Brunnenwänden, an Felsen und unter Steinen angelegt. Es enthält im April und März 3, selten 4, Eier, die zartschalig, fast glanzlos sind. Sie sind grïnlich oder gelblich weiß mit lebhaft lehmbraunen Flecken und Punkten und matt violettgrauen Schalenflecken, meist nicht allzu dicht gezeichnet. Sie sind der Größe des Vogels angemessen, $18 \times 13$, $18 \times 14,19 \times 13,19 \times 14,19 \times 14.5,20 \times 14,20 \times 13.5 \mathrm{~mm}$.

\section{Emberiza striolata striolata (Licht.).}

Fringilla striolata Lichtenstein, Verz. Doubl. zool. ALus. Berlin, p. 24 (1823- Ambukol in Nubien).

Glycispina striolata crassirostris \& tenuirostris A. E. Brehn, Verz. Sammlung, p. 9 (1866- nomina nuda!).

Ähnlich E. striolata suhuri, aber die Oberseite viel blasser, die Federu

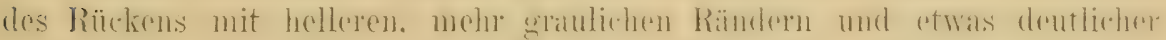
schwarzbraun gestreift. In der Nitte des Oberkopfes kim man oft, be-

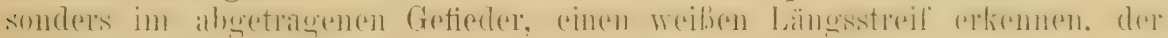
bei E. s. saluari nicht markiert ist. Flïgel of $75-79 \mathrm{~mm}$.

.. Standvogel im mittleren und südlichen Nubien, in Kordofan, am Atbara und in den Gebirgen der Hadendoa- und Bischarin- Araber,

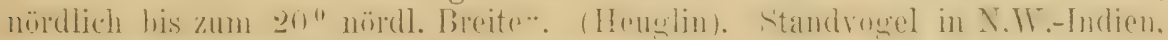
rom Punjab bis Sindh und Cutch, östlich bis Saugor; Baluchistan, SüdPersien bis Palästina und Arabieu.

Im Gegensatze zu dem vorzugsweise Städte und Dörfer bewolnenden Vertreter in N.W.-Afrika (E. str. sahari) lebt diese Form in inenschenarmen Steppen und vegetationsarmen Felsbergen, wie der Bajuda-Steppe, den Aravalli-Hügeln in Rajputana, wo sie besonders bei Ajmir häufig ist, und ist lange nicht so vertraut und zahm, sondern duckt sich hinter Steinen, Grasbiischeln, Euphorbiastöcken, bis man fast auf sie tritt, und huseht dann daron. Das Nest besteht in Rajputana aus dornigen Akazienzweiglein und trockenem Gras, und ist innen mit feineren Halmen und Federn gefüttert. Is enthält (in Indien) im Norember und Dezember; wahrscheinlich aber auch noch im Juni cin erstes (oder zweites) MIal etwa 3 Eier, die denen ron $\mathbb{E}$. str. sahari ähneln. Sic messen zirka $18.5 \times 12.7 \mathrm{~mm}$.

\section{Emberiza variabilis T'emm.}

Emberiza variabilis Temminek, Pl. Col. 583 (1835- Nord-Japan).

Zonotrichia musica Kittlitz, Denkwürd. Reise II, p). 201 (1858- zwisehen Peter-PaulsHafen und Awatscha auf Kamtschatia). 
Õad. Oberseite schiefergrau, im frischen Gefiedor mit braunen und gell,ichlnamene Federspitzen, Rü̈cken und Schultertittiche mit schwarzen Längsflecken und hreiten rostugellen Süumen. Fileine Flügeldecken dunkel ascheratu, in frischem Gefieder mit rostgelblichen Süumen, mittlere und

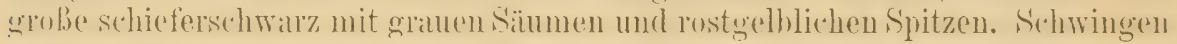
schieferfirhen mit hrïunlichen dubensïmmen, imnere Armschwingen mit breitern

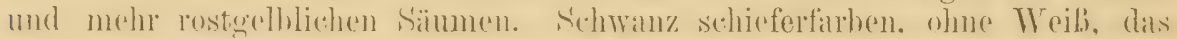
mittelste stenerferlerpalar bräunlich, oft fuchsig bram. Enterseite alschgrau.

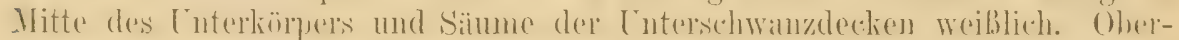

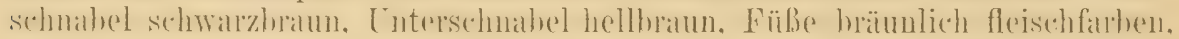
Iris braun. Flïgel 85-92, Schwanz etwa 75, Lauf etwa 22, Schnabel $13 \mathrm{~mm}$. O kleiner (Flügel 80-88), an den Seiten des Pileum ein rostbramer Streif, Rücken mehr mit Rotbraun überzogen, Bürzel und Ober-

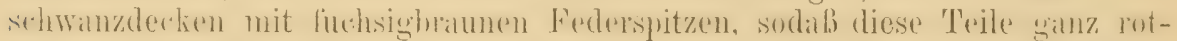

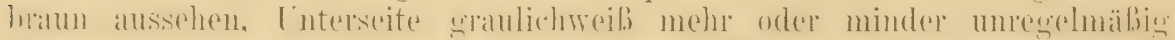

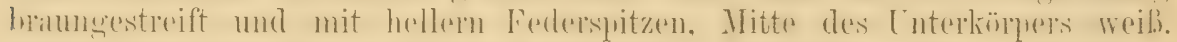

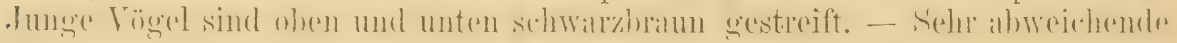

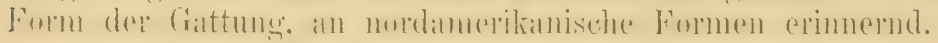

Bewohner der großen Inseln Japans und der Kurilen-Insel Iturup) (Münchener Museum), auch mehrere Male auf Kamtschatka, Askold, der Berings-Insel und in der Ebene des Sungatschi gefunden. Seltene Art.

Lebenstreise und Fortpflanzung scheinen nicht beschrieben zu sein.

\section{Emberiza tristrami Swinh.}

Emberiza tristrami Stwinhoe, Proc. Zool. Soc. London 1870, p. 441 (Amoy in China). Enberiza qninquelineata 'Taczanowski, Journ. f. Orn. 1874, p. 323 (Argun - ex David II.S., nomen nudum! Synonym von lristrami teste David \& Oustalet).

(Abbildung fehlt.)

ơad. Kopf bis anf den Hinterhals sehwarz, eine etwas unregelmïBige Mittellinie und Supereiliarstreifen weiß. Kopfseiten schwarz. Streif vom

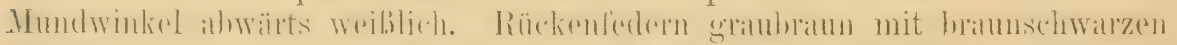

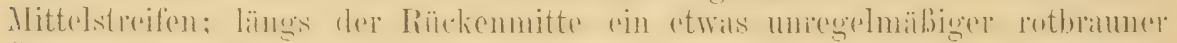
Streif. Bürzel und Obersehwanzdecken dunkel zimntfarben. Sehwingen

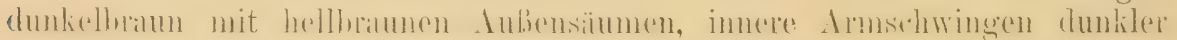
und außen breit zimmtbraun gesïumt, Innensäume aller Schwingen hell aschbräunlich. Steuerfedern schwarzbraun, das mittelste Paar zimmtbraun.

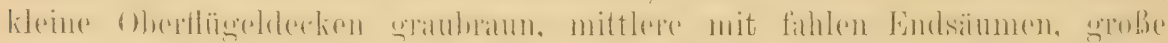
schwärzlich mit graulichen Säumen, das äuberste mit dem üblichen breiten

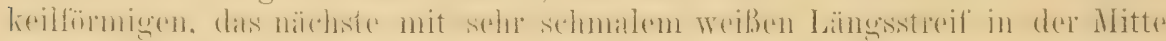
der Endhälfte. Kehle schwarz. Unterkörper weiß, Kropfgegend und Seiten hellrostbraun. Iris dunkelbraun, Oberschmabel braun, Untersehnabel gelbbräunlich, Füße rötlich fleischfarben. F'lügel 72-73, Sehwanz etwa 54, Iauf 20, Schmabel $10 \mathrm{~mm}$. O: das Weil der Kopfstreifen weniger rein, Kopfseiten braun, nur üher der Ohrgegend etras schwarz. Kehle weiß mit bräunlichem Schimmer, an jeder Seite derselben ein dunkelbrituner Streif. Kropfgegend und Seiten hell rostbraun mit dunkler rostbramen Streifen.

Süd-Daurien, am Amur und Ussuri und Korea. Wandert durch die Mandschmee und Nord-China in das mittlere und südliche China. 
Diese seltene Ammerart bewolnt waldreiches Gelände. Das Nest ähnelt dem ron Emberiza citrinella, die Eicr ähneln denen von Emberiza hortulana, sind aber kleiner. Eier von der Ussuri-Mïndung messen nach 'Taezanowski $18.5>14.8,19.3>14.5$, $19.33 \times 14.8 \mathrm{~mm}$.

\section{Emberiza yessoënsis (Sivinl..).}

Emberiza mino" (non Midd!) IBlakiston. Ibis 1863, p.99 ("Hakodadi, Yesso"- erste Beschreibung).

Schoenicola yessoënsis Swinhoe, 1bis 1874, p.161 (ex Blakiston Ibis 1863, 1).99).

Abbild.: Ibis 1879, 'Iaf. I, Fig. 2.

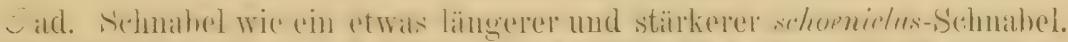

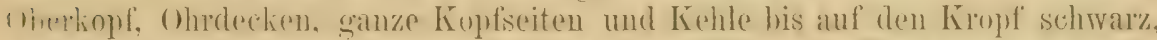

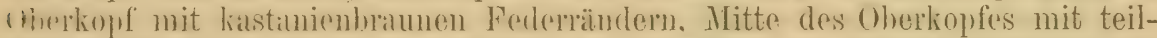
wrise sich almutzdndem zimmothöunlicheu streifun, im frischen Gefieder mit hellbämlichem Supereilianstreit. die ganze Kehle mit hreiten. hellgrau-

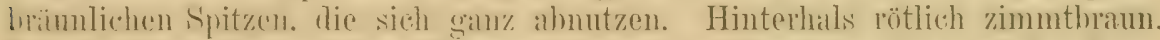
frisch mit vrauhrïunlichen Sammen. hinter den Ohrdecken his auf die Halsseiten ain weililicher Fleck. Rücken hreit schwargestreift, jede Eeder im

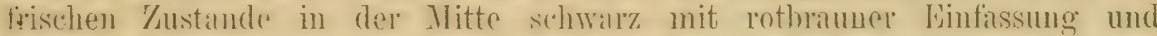
hräunlichweiben Aubensä̈men. Hand- nnd äubere Amschwingen dunkel

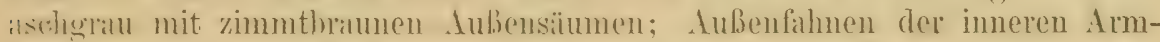
schwingen rötlichzimmthram mit groliem schwalrzen Basalfleck und licht rahm-

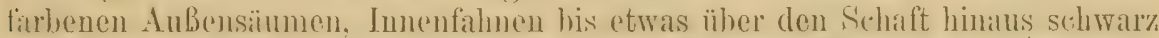

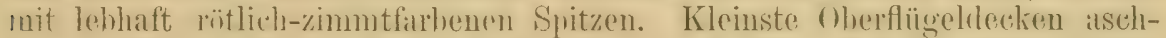
arau. mittlere und grobe schwallz mit sehr hreiten. fast die ganze Feder pimmehmenden lehhaft rötlich zimmtfubenen Rändern. Bürzel und obershwanzdecken zimmtfarhen, frisch mit helleren Sïumen. Mittolstes Stener-

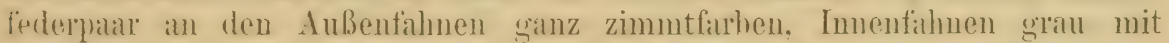
zimmtlarbenem Anflug und ehensolchen Außensäumen, ïbrige Steuerfedern schwarzhran mit hraunen Sämnen, äuberes Palar mit groben weiben hängsHock wie die Rohrammern, volletztes nur mit weibem dreierkigen Längsteck an der Imnenfilune. Aubenfalhue ohne weib. Tnterseite vom Kropf his zu den Enters:hwanzdecken licht zimmtfarhen, Mitte des Lnterkörpers weiblich, Brustseiten mit scharfen, hreiten, Weichen mit weniger herortreteuden kastanienrothramen Streifen. [nterflïgeldecken und Axillaten weiß. Iris hram. Sehmahol dunkelhraun, Interschnabel heller, Fübe hellrötlichbram. Plïgel etma 68, der Ahstand von der Flügelspitze zu del der längsten Arm-

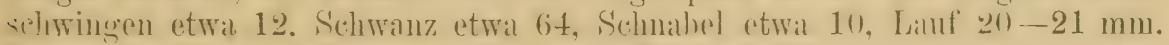
rotwas kileiner, Pilem meln hraun, Kehle hell zimmtirben mit zwei schwärzlichen Bartstreifen.

Japan (Jesso und Hondo), vielleicht nur auf Jesso brïtend.

(E. yessoënsis ist keineswegs eine Form von E. schoeniche, denu (rstens brïtet sie im gleichen feliete mit ciner solchen, zweitens ist sie durch die sehr kurzen. Ireiten Flügel, gïnzliches Fehlen der weißen Wangenstreifen und des weißen Hinterhalses, sowis einfirloig zimmtfarhenen Bürzel sehr wesentlich verschieden. E. yessünsix dürfte nächstverwandt mit tristrami sein.)

E. Hartert, Die Vögel der paläarktischen Region. 


\section{Emberiza pallasi (Cab.).}

Cynchramus Pallasi Cabauis, Mus. Hein. L, p. 130 (1851- ex Pallas Emberiza Schocnichus $\beta$, Zoogr. Rosso-Asiat. II, p. 48: Transbaikalien, besonders in Weidendickichten am Flusse Selenga). ${ }^{1}$ )

Emberiza polaris MLiddendorff, Sibir. Reise II, p. 146 (1851-- Boganida).

Emberiza schoenichts var. minor Middendortf. Sibir. Reise II. p. 14t (1851 - StanowojGebirge bis Udskoj-Ostrog ïberall).

Emberiza canescens Swinhoe, Ibis 1860, p.62 (Amoy in China).

Emberiza Alleonis Vian, Rev. \& Mag. Zool 1869, p. 97 (Daurien -und wiederum ex Pallas $E$. Schoenichus $\beta$ ).

Abbild.: Ibis 1879, 'Taf. I, als E. passerina.

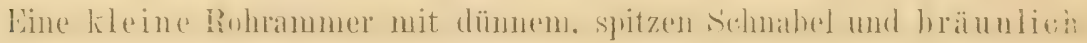
aschgrauen anstatt rotbraunen kleinen Oberflügeldecken, was bein Oad. im allgetragenen Frühlingskleide an atulfallendsten, ab) aluch heim frisch remauserten f im Herbste zu hemerlien ist. dal diese Federn dort

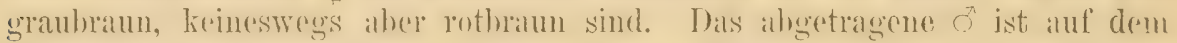

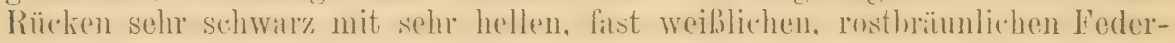
rändern. Das frische Herbstkleid ist ziemlich licht und rostfarben. Die beiden äubern Stenerferlerm halen meist rinen groben Teil der Aubenfahne: weiß. Flügel ơ ad. $72-73.5 \mathrm{~mm}$. - Da (rgl. Taczanowski u. a. Autoren)

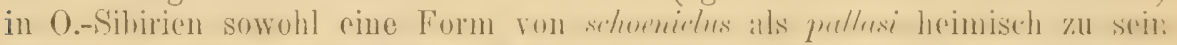

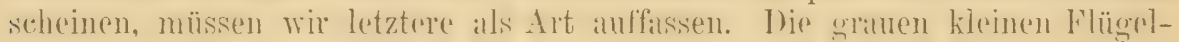
decken bieten ein scharfes Merkmal dar.

Brütet im östlichen Sibirien. Genaue Grenze gegen Westen nicht

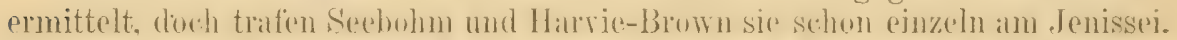
IVie weit nath Norden ehenfalls noch nicht sicher, doch fand Hall heine an der untern Lena. Häutig in Inanrien. Lssurien (Khanka-See), hei Oudskui Ostrog, inn Stanowoi-Gehirese, an der Buganida mod am Baikal-Sée. — Üherwintert in der Mindschurei. Acr Mongolei. im nördlichen und mittleren China und Korea, angeblich auch zur Zugzeit in T'eilen von Turkestan. aber kleiner.

Lebensweise wie die der schoenichı-Formen, auch die Eier ebenso gezeichnet,

\section{Emberiza schoeniclus schoeniclus (L.).*2) (Fig. 37.)}

Rohrammer:

Fringilla Schoeniclus Linnaeus, Syst. Nat. Ed. X, p. 182 (1758- "Habitat in Europa." Typische Lokalität Schweden, denn Linné bezieht sich in erster Linie auf Fauna Suecica 211).

1) Diese Form wird meist fälschlich als E. passerina bezeichnet, denn E. passerina wird ausdrücklich mit rostroten kleinen Flügeldecken beschrieben, E. schoenichus $\beta$ aber mit grauen. Außerdem stimmte ja die Lokalität nicht! (S. unter schoenichus.)

$\left.{ }^{2}\right)$ Die Gruppe der Rohrammer-artigen Vögel bietet z. Z. noch mancherlei Schwierigkeiten dar. Die Formen derselben sind noch nicht genügend untersucht worden, die Angaben in der vorhandenen Literatur oft falsch und irreführend. Die Schnäbel variieren von den dünnen, spitzen der eigentlichen Kohrammern (schoeniclus) bis zu dem hochgewölbten, breiten, an der Spitze runden (,bee bombé") der gimpelschnäbligen Rolırammer (pyrrhuloides), in den Formen palustris, canneti u. a. m. merkwürdige Mittelstufen zeigend. Fliichtige Benbachter haben daraus folgern wollen, daß 
E'mberizu provincialis Gimelin, Syst. Nat. I, p. 881 (1788 - ex Buffon \& Daubenton P1. Enl. 656 fig. 1: Provence. Bisher irrtümlich für E. rustica gehalten!)

? Emberiza arundinacea S. G. Gmelin, Reise Russl. II, 1).175 (1774- Astrachan. Wird stets als Synonym von schoenichus zitiert, die aber Gmelin auch kannte! Soll vielleicht p!yrrhuloides sein!).

Einberiza passerina Pallas, Reise d. verseh. Prov. d. Russ. Reichs 1, p. 456 (1801- „Ad Jaicum autumno", also S.-Rußland, Herbstkleid).

Cynchramus stagnatilis Brehm, Handb. Naturg. Vög. Dentschl., p.301 (1831- „ron Wien bis Kiel hinauf, wandert").

Cynchramus septentrionalis Brehm, Handb. Naturg. Vög. Deutschl, p. 302 (1831„bewohnt das nördliche Europa").

Cynchranus pseudo-pyrrhuloides Brehm, Vogelfang, p. 115 (1855-- 'L'riest).

Cynchramus riparius Brehm, Vogelfang, p. 115 (1855- Dentschland).

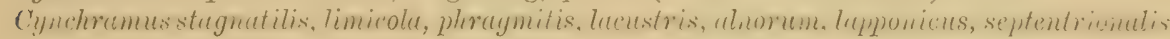
Brehm, Vogelfang, p. 116 (1855- ,von Lappland an in Deutschland" - nur vage vergleichende Angaben über Allgemeingröße und Schnabelform).

Cynchramus micror/hynchos Brehm, Vogelfang, p. 116 (1855-. "wandert sehr selten durch Deutschland").

Emberiza scotatı Bonaparte, Rev. \& Mag. Zool. 1857, p. 164, Taf. 7 (Breseia - merkwürdige Aberration oder Artefakt, sicher aber nicht junge lentcocephala, wie der Autor meint!).

Emberiza schoenichus Valloni Arrigoni, Atlante Ornitolog., p.267 (1902 - kleine Varietiit der Rohrammer benannt, augenscheinlich von Italien, typ: Lok. und Typus nicht angegeben, aber wohl bei Udine gesammelt).

Engl,: Reed-Bunting, Reed-Sparrow. Franz.: Bruant des Roseaux. Ital.: Migliarino di palude. Schwed.: Säfsparf.

$\because$ ad. Kopl, Kopfseiten und Fehle his anf den Kropif schwall\%, Kehle vou den Konfiveiten dureh einen weiben Mangeustreifun getrennt, ron den Kopfseiten zieht sich ein breiter weiber Ring über las Cienick hin. Rücken schwal\% und rosthaun gestreift, Bürzel und Oherschwauzdechen aschgran mit rosthraunen Streifen. Shwingen tiefhraun mit helleren, schmalen, :m den Aruschwingen breiteren und mehr rothranen Sämmen, kleine Oberflügreldecken lehbaft rothraun, mittlere bramschwarz mit lehbaft rothramem Spitzendrittel. grobo hraunsehwar\% mit breiten, hell rosthraunen Aubensäunen. Mittleres Stenerfederpan tiebraun mit hreiten rostbraneu Aubensïumen. die nä̈hsten beiden Pare schwarz, das vorletzte schmarz mit grobem. langen, fast die halbe Feder entlang laufenden weißen Keilfleck an den Innenfahnen, die Aulenfahne schwarz, neist mit sehr schmalem, leicht algeuntzten Aufensaum; das äußerste Stenerfederpar weib mit langem schmarzen Keilfleck am basalen Sammteile der Innenfahne, sehwarzer äulerster Basis und Spitzo

alle diese Formen derart ineinander übergehen, daß man überhaupt nur 1-2 unterscheiden kann, das ist aber falsch, denn trotz einer gewissen, das Studium etwas erschwerenden individuellen Aberration sind alle diese Formen in ihren Brutgebieten recht konstant. Neuerdings hat man nun - im Gegensatze zu der ganz veralteten und unhaltbaren Auffassung, die dickscluäbligen Formen in eine besondre Gattung (Pyrrhulorhyncha Gigl.) zu stellen - alle als Subspezies einer Art ansehen wollen. Dem steht aber die Verbreitung im Wege, denn in vielen Ländern brüten dick- und dünnschnäblige Formen nebeneinander, z. B. in Italien schoenichus und palustris (Salvadori, Giglioli, Arrigoni, u. a.), in Griechenland canneti und reiseri, usw. It:n muB daher 2 Arten, eine dickschuäblige (pyrthulvides) und eine dünnschnäblign (schoenichus), jede mit mehreren Unterarten, unterscheiden. 


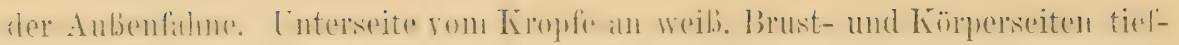

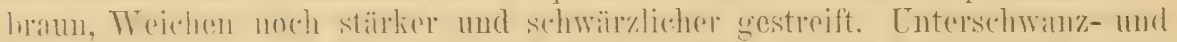

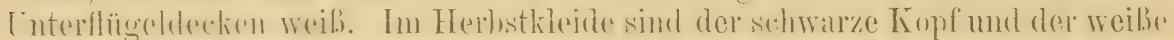

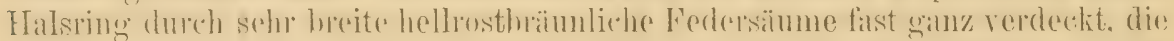

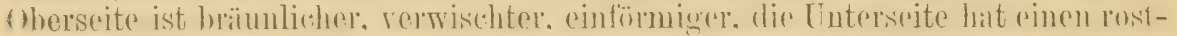

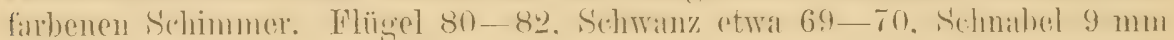
lang, 5-5.5 hoch, 4-5.5 breit, Lauf etwa $20 \mathrm{~mm}$ lang. - Das o ist etwas lileiuer, der (Oherloper ist lothraun, die Mitte desselhen mit lichteren Sïumen, die

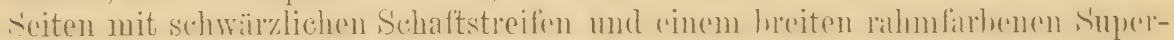

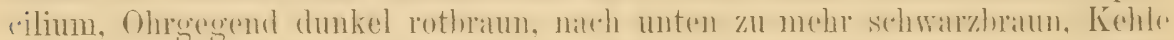

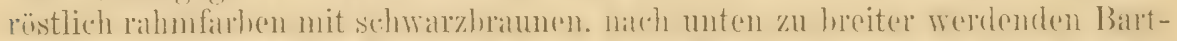
streifen. Ohne weibes Halshancl. nur aln den Eoderwurzeln zejegt sich dort ein weiblichere Flark. Krepfgegend und Körperseiten reichlich dunkel rothram

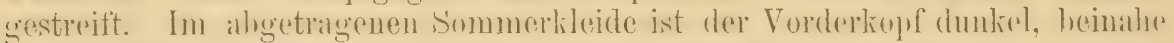

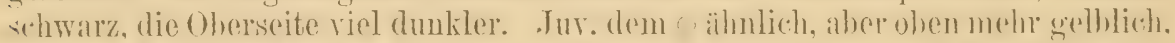

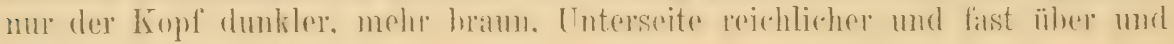
iiber gestreift.

Brutvogel in Europa, mit Ausnahme des Südostens; britische Inseln

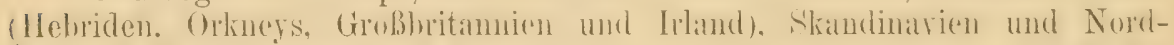
Rubland, Nold-Spanien und ganz. Italien, in Südost-Europal nur bis in das

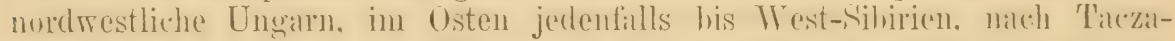

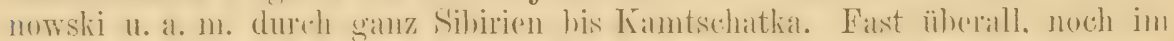
nördlichen Italien. Zugrogel, alser in Mittel- mod Sïd-Italien, sowir teilwejse in dem milden Klina Englands, stand- und striehvogel. .. G̈herwintert in Siid-Spanien, Italien, Sü̈dust-Luroprat. am S.hwarzen Meere, in Krleinasien, der Türkei und Griechenland, in geringerer Anzahl in Nord-Afrika, sowie anscheinend in Asien bis in das nördliche Punjab in Indien.

Wolnt immer am Wasser, wo Weiden und Erlen oder andre Büsche mit Rohr, Schilf und Binsen, oder auch Getreide abwechseln, auf dem Strich und Zuge trifft man sie aber auch an andern Orten. Man sieht sie meist auf niedern Büschen, Rohr und Schilf sitzen, nicht oft auf höhern Bäumen. Unruhig und munter, aber nicht eigentlich scheu. Lockstimme ein helles, hohes, gedehntes Zih oder 'Ischih, auch hört man ein leises Zirpen. Gesang ziemlich laut, den ammerartigen Charakter nicht verleugnend, von Naumann mit "zja, tit, tai, zississ-tai, zier, zississ" übersetzt, wie mit Anstrengung herrorgequetscht. Nahrung allerhand Sämereien, namentlich die der Rohrarten und andrer Sumpfptlanzen, im Sommer größtenteils Käfer und andre Insekten. Nisten auf sumpfigem Terrain, besonders da, wo Salweiden und andre Weidenbïsche stehen. Das Nest steht meist am Boden, meist gut versteckt zwischen den Stämmen und Wurzeln der Weidenbüsche, auf Seggenkufen, im Gras oder zwischen Sumpfpllanzen, selten und nur wo diese sehr dicht stehen, einige Fuß über dem Boden. És ist wie andre Ammernester nicht sehr gut gebaut, besteht aus Halmen, Stengeln, Schilfstïcken, dürren Blättern, die W $W$ ände locker, meist mit Haaren und Pflanzenwolle ausgelegt. Die Eier unterscheiden sich von unsern andern Ammern-Eiern, denn sie sind braun, oft dunkel, wie Schokolade mit Milch, bräunlich oder hell bräunlichgrau, nur selten mit grünlich olivenartigem Schimmer. Die Zeichnungen sind charakteristisch, aber schwer zu beschreiben: die hieroglyphenartigen Figuren oder Schnörkel dick, die Flecke grob, plump, oft wie umwölkt oder verlaufen. Mleist ist die Form ziemlich rund und dick, seltener spitz. Nach Rey messen 37 Eier seiner Sammlung im Durchschnitt $19.3 \times 14.3 \mathrm{~mm}$, im Maximum $22 \times 15$ bez. $19.5 \times 15.5$, Minimum $17.75 \times 13.75$ bez. $18 \times 13.5 \mathrm{~mm}$. Das Gewicht beträgt etwa $0.135 \mathrm{~g}$. Brutzeit 12-14 Tage, das 우 brütet meist allein, soll aber vom $\sigma^{t}$ in den Mittagstunden auf kurze Zeit abgelöst werden. Meist zwei Bruten im Jahr, die zweite manchmal bis in den August hinein. 


\section{:312. Emberiza schoeniclus pallidior sulw1. nu.}

Heller als E. sch. schoenichs, die Federrïnder auf der Oberseite hellriistlich oder hrïunlichweib (anstatt rosthraui). Flïgel otwas länger. 80-84. meist etwat $8.2 \mathrm{~mm}$. ('Trpus im Mus. 'Tring c. Nr.1298. Aiserli in Trurkestin 11. XI. 1899, gesammelt von Sarudny.)

Im Münchener Museum (Hellmayr in litt.) vom Baikal-S'see. Sehr

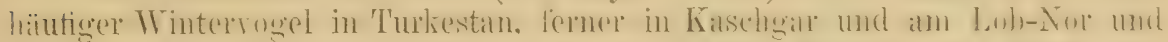

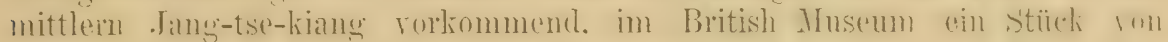
Omsk. - Brutgebiet noch nicht erforseht, aber vermutlich am Baikal-See.

\section{Emberiza schoeniclus pyrrhulinus kwinh. (Lik. 3.'.)}

Emberiza pyrrhulinus Swinhoe, Ibis 1876, p. 333, 'Taf. VIII, 2 (Hakodate, Japan).

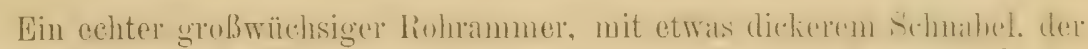

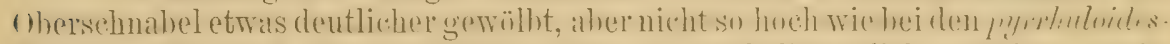

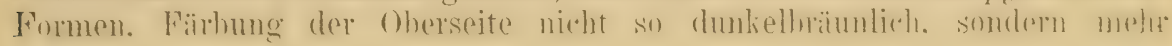

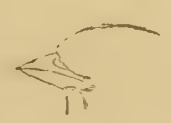

Figur 37 .

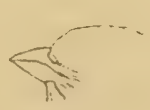

Figur 38.

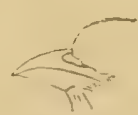

Figur 39 .

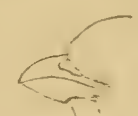

Figur 40.

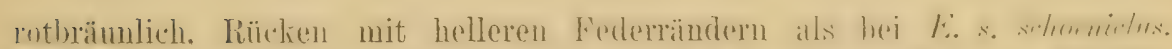
Bürzel mit dunklen śchaftstreifen. Ściten mit schmalen, rothrannen s'treifen. Flïgel ōad. etwa 86, Schnabel etwa 10, Schwanz etwa $70-71 \mathrm{~mm}$. -

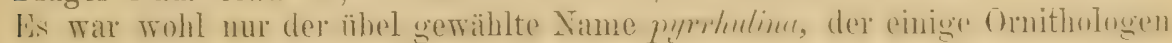
verleitete, diese Form in die Nähe von pyrrhuloides, weit entfernt ron schoenichus, zu stellen, oder sie gar mit palustris zu identifizieren.

Jabaln, wo sie anf Jesso und den Bergen ron Homdo Britrogel sein soll. -

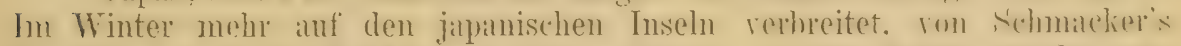

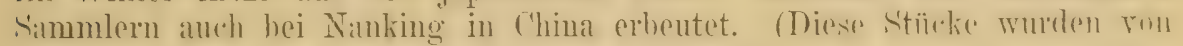
Hartlaub irrtïnlich als pyrrhuloides verzeichnet.)

\section{Fmberiza schoeniclus canneti (Brehm). (Fig. 39.)}

? Sehoenicoia intermedia Bonaparte, Rer. Crit. Eur., p. 39, 164 (1850) \& Consp. Ar. I, p. 465 (1850- ex Michahelles MI. S. „Dalmatia“; nomen nudum!!).

Cynchramus canneti Brehm, Vogelfang, p. 115 (1855- Dalmatien).

Abbild.: Neuausgabe des „Naumann", III, T'af. 26.

Der E. schoenichus schoenichs :ilnnlich, ąher der Schuabel gerwölbter, dicker. der Oberschmahel (atwal so hoch wie der I'nterschmahel. ersterer gan\% gehogen, wemn auch nieht aunähernd so hoch gewöllht wie der von $\mathbb{E}$. $\%$

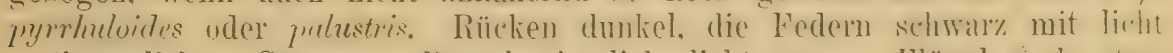
restbrïunlichen Süumen. Bürzel ziemlich licht glau. Flügel ad. ntwal 81-83, Schnabel $5.5-6.5 \mathrm{~mm}$ loch, etwa 10 lang. 


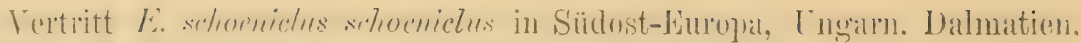
Bulgarien, Serbien, Bosnien und Griechenland (Thessalien).

Im Winter Stand- und Strichrogel und dann manchmal in dic Brutgebiete andrer Formen streichend. Wier wie die ron E. s. schoenichus; $20.1 \times 14.9,20.9 \times 15.1 \mathrm{~mm}$.

\section{Emberiza schoeniclus tschusii lieisen d Ilmásy. (Fig. 41).}

Emberiza schoenichus tschusii Reiser \& Almásy, Aquila V, p. 122 -125 (1898 - Dunavat in der Dobrudscha 18. IV. 1897).

Eine dick- und hochschnäbligere canneti, aber anf der Oberseite viel heller, fast so licht wie L. pyrrh. pyrrhuloides. Flïgel 81-82, Schwanz

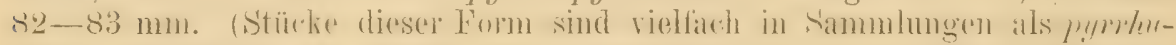

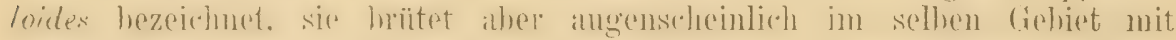
letzterer, auch ist der Schuabel, obwohl hoch und kurz, lange nicht so

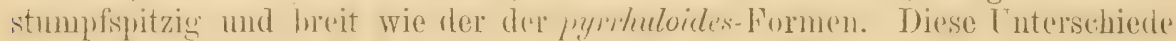

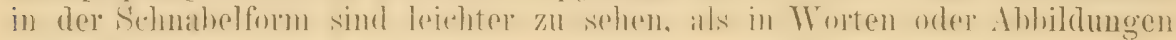
darzustellen.)

Von der nördlichen Dobrudscha (Donaudelta) bis Süd-Rnßland und

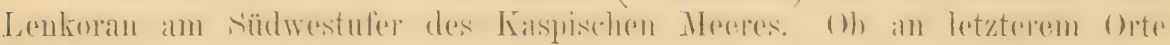
britend oder nur Wintervogel, konnte nicht sicher festgestellt werden.

\section{Fmberiza schoeniclus othmari whis. nor.}

Wie E. sch.tschusii, aber mit dunklerer Oberseite mud größerem S'chmabel.

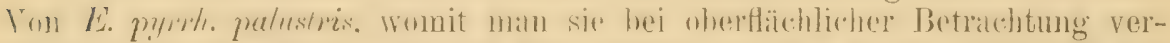

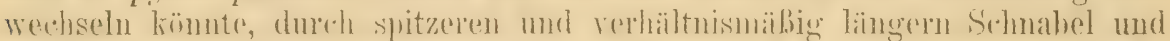

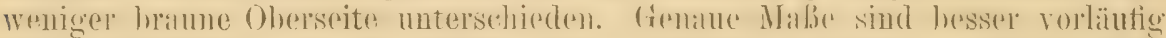

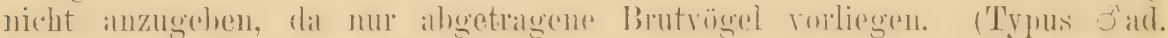
Sultanlal in Bulgarien 19. VT. 1890. im Bosnischen Landes-Minsemm zu Sarajevo, gesammelt von 1'. Reiser; dem Bruder vou Othmar Reiser.)

Vertritt augenscheinlich $E$. sch. tschnsï weiter südlich im östlichen Bulgarien als Brutvogel. - Im Winter mehr umherstroichend, vereinzelt bis Egypten (Nildelta).

\section{Emberiza pyrrhuloides pyrrhuloides l'all. (Tig. +1.)}

Limberiza pyrrhuloides Pallas, Zoogr. Kosso-Asiat. II, p. 4h (1831- ,ad Volgam et Rhymnum, versus inare caspium").

Eimberiza caspia Ménétries, Cat. Raisonné, j).41 (1832- .prìs du Bìchebermak, non loin de la mer Caspienne, au mois de juillet").

Abbild.: Dresser IV, Taf. 222; Neuausgahe des "Naumamu" III, Tal. 26.

Von allen andern Ammern. vamentlich aber den Rohrammern. durch den außerordentlich dicken, hochgewölbten Schnabel,

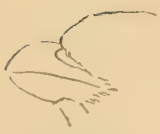

Figux 41 dessen oluerkiufer höher ist als der Luterkiefer. und dessen Spitze nicht spitz, sondern rund und stumpf ist, unterschieden von den Rohxammern durch sehr bedentende Allgemeingröße, sehx lichte, rostgelblichgraue, durch die sehr

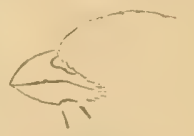

Figur 42.

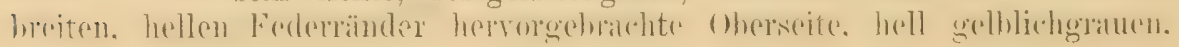


muneklich gestreiften Bürzel. weibe Unterseite mit ungestreiften Seriten, an denen man nur ganz ausnahmsweise Andeutungen von Streifen hemerkt. A bienfahne der. heiden äußern Steuerfederu weib. Flügel ổ ad. 90 -92, Schwanz mindestens 85. Höhe des geschlossenen Schnabels 9-10.5, Lauf etra 21-22 mm.

An den Küsten des Kispisthen Mexes rom Fubr des N.-Kaukibus durch die Wolgat-Auen nach Tramskaspien und Turkestan. his zum Issik-Kul und Semiretschensk. Eiumal auf Helgoland vorgekommen.

Die Lebensweise und Fortpflanzung scheint ganz die der schoenichus-Formen zu sein. nur sind Nest und Wier etras größer.

\section{Emberiza pyrrhuloides reiseri sulspp. nor.}

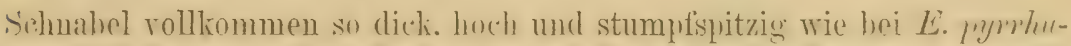

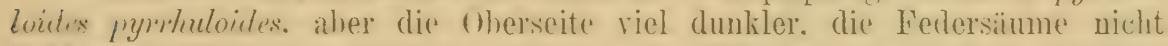
licht rostgelblichgrau, sondern rosthraun. die Jiügeldecken dunkler rothraun. Bürzel dunkler grau. Seiten sehmal aher dentlich und regelmäbig gostreift.

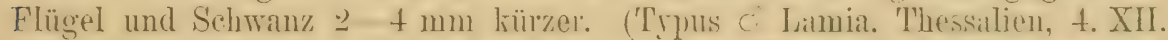
19011. Nr. 10009) Tring Musem.) Benannt zu Silnen des fleibigen nenern Erlorschers Griechenlands, Othmar Reiser.

Brutrogel in Thessalim (Lamia. Vulo). wo man ihn anch im Winter findet.

\section{:39. Emberiza pyrrhuloides centralasiae :uhsp. nю.}

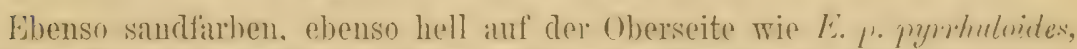
julwh oler Schnahel merklich kleiner. rerhälnismäBig kïmer. aher fast ebenso stumpfspitzig, der [utersehmabel nicht so hreit. ('Typus Nr. 47. 12. 11), 589 im British-Museum, Maralhasehi in Ost-Turkestan. Tamull 1874. uesammelt ron Oberst Biddulph.)

Bewohnt Zeutral-Asien mol Ust-Turkestan (Maralbischi, Kaschgall, Yarliand) bis Tsadiam. Alaschan und Karal-nssu in der nordwestlichen Mongolei.

\section{Emberiza pyrrhuloides subsp.?}

In Seistan im östlichen Persien (ron Saruduy gesammelt) und merkwïrdigerweise auch in Saisan in West-Sihirien (von Finsch gesammelt) kommen Formen vor, die dunkler und liteiner als E. pyrrh. pymmuloides zu sein scheinen. Die ron Seistan sind vielleicht noch etwas schwiilzlieher auf der Oherseite und etwas grobsehmähliger als die von Saisam. Ls liegen nur wenige, sehr abgetragene Brutrögel atus heiden Gegenden rox. und unsre Kenntuis ihrer Terbreitung ist noch zu unvollkommen, als dab maln wagen diurfte, diese Formen zu benemuen. doch scheinen sie nicht anffallend vonrimander verschieden, aher mit $E$. p. l'ymhluloides katum zu rereinigen zu sein.

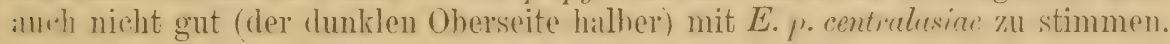

\section{Emberiza pyrrhuloides palustris Savi. (Fig. $4 \div .1$}

Emberiza palustris Savi, Orn. 'Toscana II, p.91 (1829- Toskana).

Abbild.: Neuausgabe des "Naumann" III, Taf. 26.

Wie eine grobe Rohrammer, aher etwas größer, Flügel etwa 8:3,

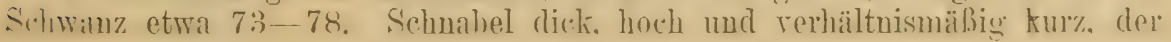




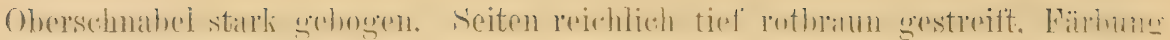
dunkel und braun. ${ }^{\text {) }}$

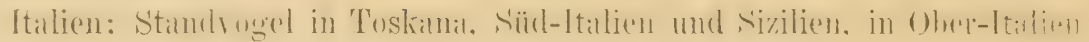
nur zur Brutzeit; im südlichsten Frankreich und Spanien.

Lebenstreise und Fortptlanzung wie die ron E. schoenichs.

\title{
Gattumg CALCARIUS Bechst. 1 so:3.
}

Sebr ähnlich der Gattung Emberizu, aber der Flügel länger und spitz, die drei ersten Schwingen fast gleich und am läugsten, von Emberizu und Passerina durch die flach gebogenen Nägel der Vorderzehen und die rer-

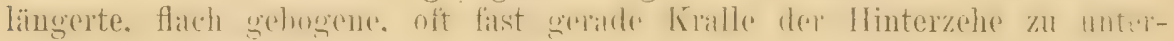
scheiden. Färbungscharakter von dem ron Passerina sehr verschieden. N'ur eine Art in der Alten Welt, von der eine sehr dentliche Subspezies in N.W.-

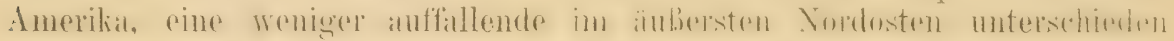
werden kamn, wälurend noch 2 andre Arten. ('. pictu (Swains.) und C. ornatu: ('I'owns.) in den thenen von Nord-Amorika und Nexikn leben. - Dio Gattung steht Emberiza viel näher als I'asserina, womit sie sonderbarerweise oft vereinigt und rerglichen wurde.

\section{2\%. Calcarius lapponica lapponica $\left(\Pi_{\text {. }}\right)$.}

\author{
Lerchen-Spormammer.
}

Fringilla lapponica Linnaeus, Syst. Nat. Ed. X, 1. 180 (1758- Lappland).

Fringilla calcaratu Pallas, Reise d. versch. Prov. d. liuss. lieichs II, J) 710 (1773)"Nidulatur in Sibiriae borealibns". Der Name ist nit Unrecht angezweifelt worden, denn er ist so sicher wie nur möglich).

Emberiza calcarata 'Temminck, Manuel d'Orm. 1, p. 322 (1820- „Les régions boreales"). ? Hortulanus montamus Leach, Syst. Cat. Mamm. \& Birds in Brit. Mus., p). 16 (1816nomen nudum(!), Somerset) muß zweifelhaft bleiben, dem der Name „. IountainBrambling" ist kein sicherer Name der Lerchen-Spornammer.

Plectrophanes Groenlendicus Brehm, Handb. Naturg. Vög. I)eutschl., p. 307 (18:31Grönland).

Centrophanes calcaratus major, latirostris, angustirostris, lrachymhynchos, microrhynchos: A. E. Brehm, Verz. Samml., p. 8 (1866-- nom. nuda!).

lingl.: Lapland-Bunting. Franz.: Plectrophane lapon. Sehwed.: Lappspart.

ơad. Oberkopf und Kopfseiten, mit Ausualmme cines breiten rahm-

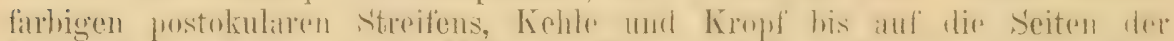

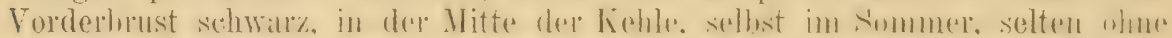

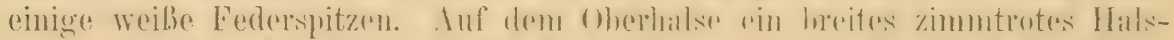

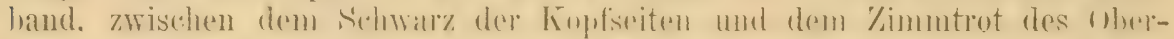

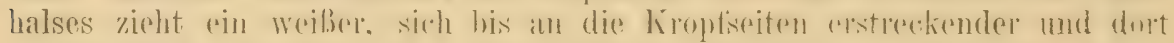

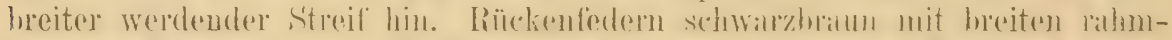

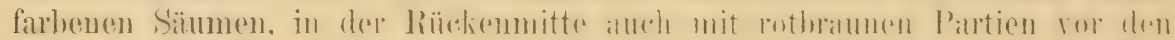
helleren Säumen. Der Rücken sieht somit blaumschwar\% und rahmfarhen gestreift aus, auf dem Oberrïcken, namentlich in der Mitte, rotbram

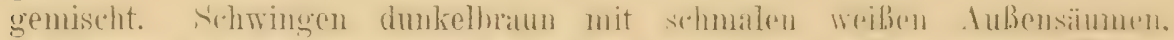

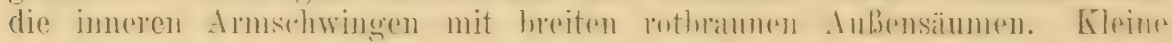

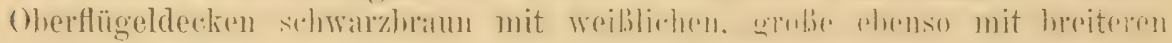

1) Es ist höchst interessant, dab diese kleinschuäbligste Form von E.pyrrhuloicles der grolsschnäbligsten Form von $\boldsymbol{E}$. schoenichus (nïmlich $F$. sch. othmari) äußerst nahe fiommt. 


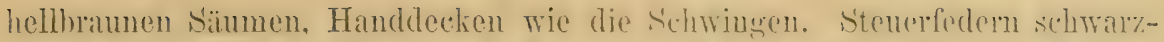

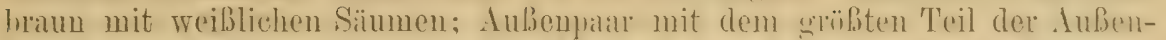

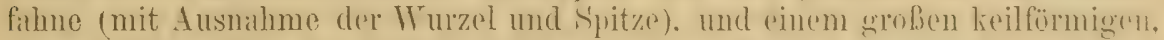

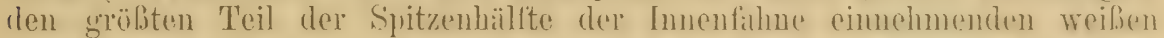

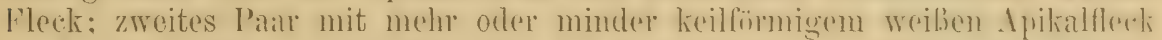
an der Inuenfahne. Unterseite vou der Vorderbrust an nebst Unterschwanzund Unterflïgeldedien wrib, Seiten hreit schwar\% gestreift. Sichmahes hell-

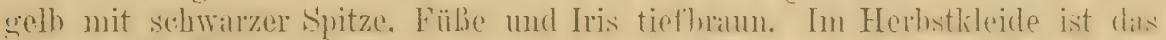

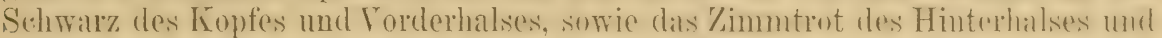

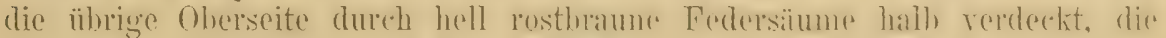

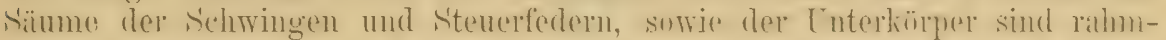

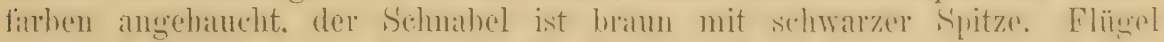
94-99, Schwanz etwa 64-67, Lauf 20.5-22.3, Schuabel 10.4-12 mm. o ad. Tom of sehr verschieden durch weiße. von schwarzem Fleckenkiranz,

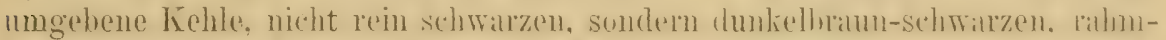

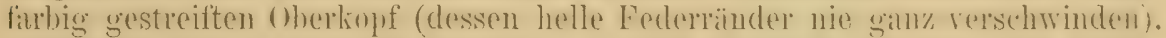

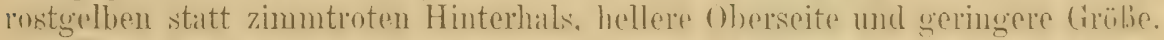
Das Herhstkleid sicht infolge der rahnufarhemen ferlersïume gimz anders aus. Der junge Vogel ist auf der ganzen (1)erseite sehwarz mit hell gelhhraturen

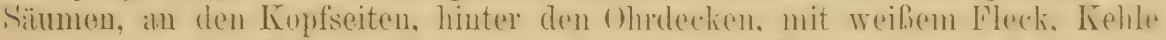

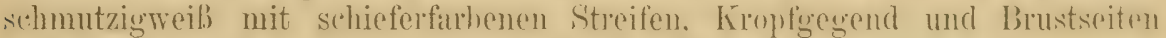

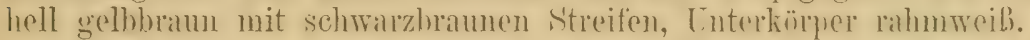

Brutrogel in den arktischen und subarktischen Inreiten der Alten und Neuen Welt: an den Kü̈sten Grönlands, Lalpuland, Jan Mayen, Kolgujew. Waigatseh, Novajal Śemlja, Framz-onsef-Laud, Nord-Sibiriem. Nord-dmerikia. Sü̈dlich des l'olarkreises nur auf hohen Gehirgen. wie dem Dorre-lyelel in Norwegen. - Zieht im Herhstr in südlichere Gogenden. ist damn im ästliehen Europa nicht allzu selten, in westlichen dagegen selten. In bughand utwa 40 mal his 1892 und 1893 rorgalommen, in welchen heiden dahren sie sehr zahheich erschienen. Südlich in Enropal nur ganz reremzelt lis

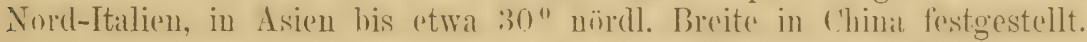

Bewohner der Tundren und sumpfigen Flächen iiber der Grenze des eigentlichen Baumwuchses, wo Z/wergweiden, Zwergbirken die einzige höhere Vegetation bilden, seltener auf trockenem Boden. Das ot singt nach Baumpieperart meist im Fluge, der Gesang erinnert an einen stümperhaften Feldlerchengesang. Der Lockruf ist meist ein klagender, etwas trillernder Pfiff, an den der Schneeammer erinnernd. Nahrung: Sämereien und Insekten. Das Nest steht am Borlen, meist in Grasbïscheln wohl versteckt und ist inuen reichlich mit Federn ausgelegt, äußerlich aus Halmen und Moos gebant. Es enthält im Juni 5-6 Eier, die auf olivbraunem, oft hellerem und stark ins Grïnliche ziehenden Grunde dicht braunrot gewölkt und sparsam mit schwarzbruunen Haarzügen, Kritzeln und Schnörkeln versehen sind. Dic Durchschnittsmaße von 36 lapp)ländischen Stücken in Dr. Rey's Sammlung betragen $20.7 \times 14.8$, das Maximum $22.5 \times 15.5$ und $20.5 \times 16$, das Minimum $19 \times 14.8$ und $19.3 \times 14 \mathrm{~mm}$. Das Durchschnittsgervicht $0.149 \mathrm{~g}$.

\section{Calcarius lapponica coloratus Ridgw.}

Calcarius lapponicus coloratus Ridgway, Auk XV, p. 320 (1898- "Commander Islands, Kamtsehatka, in summer; Plover Bay, Siberia, and other parts of northeastern Asia in summer?" 'Typus von "Copper Island, Kamtschatka".).

Nach Ridgway ist die Oherseite stark rostlarbig überlaufen, die Aulden-

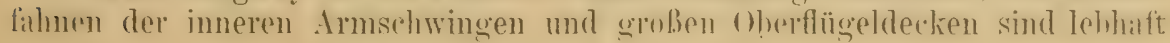


rostbraun oder hell kastanienfurben, das o ad. mit sehr deutlichem rot-

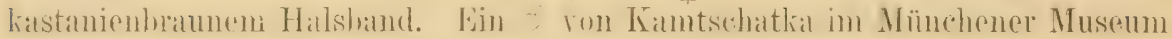
(Hellmayr in litt.) bestätigt die angegebenen Merkmale.

Auf den Kommandeur-Inseln und Kamtschatka briitend. Vermutlich auch in andern Teilen Nordost-Asiens. (Nach Ridgway.)

Außerdem kommt noch eine oben hellere Subspezies in Alaska und auf' den umliegenden Inseln vor: C. Lapponica aluscensis Ridgw.

\section{Gattung PASSFRINA Vicill. 1816.}

Enthalt lediglich die nordische Schneeammer mit circumpolarer Ver-

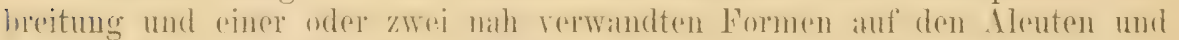
Inseln des Bering-Meeres. Plectrophanes und Plectrophenax ïlterer und

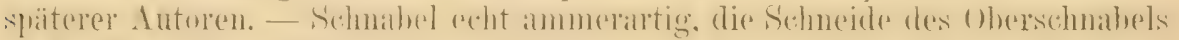

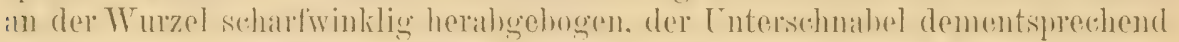

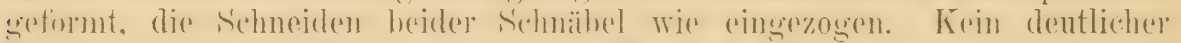

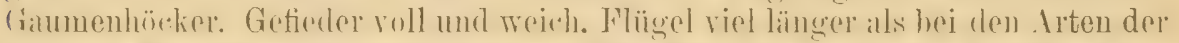

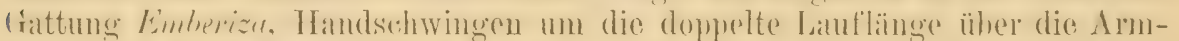

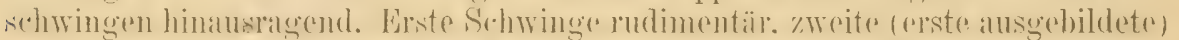
am längsten, die nitchiste gleich wher nur sehr wenig. die folgende schon

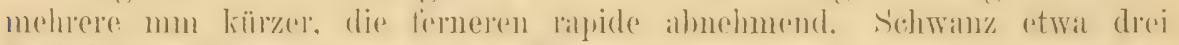

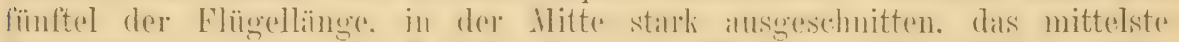

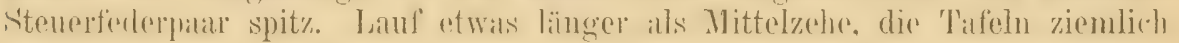
stark verwachsen. Hinterkralle etwa so lang wie die Hinterzehe, schwach

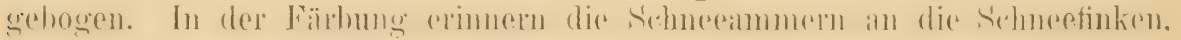
ohne jedoch näher mit ihnen verwandt zu sein.

\section{Passerina nivalis nivalis $\left(\mathrm{I}_{.} .{ }{ }^{1}\right)$ \\ Sehneeammer.}

Fimberiza nivalis Limaeus, Syst. Nat. Ed. X, p. 176 (1758- „Hab. in alpibus Lapponiae, Spitsbergae ad sinum Hudsonis alibiqne." - Basiert auf Act. Stockh. 17.40, p. 368 und Fauna Suecica, typischer Fundort daher Lappland.).

1) Amerikanische Ornithologen unterscheiden noch eine zweite Art und eine Unterart von E. nivalis:

1. Passerina hyperhoreus (Ridgway), welche P. nivalis auf der Hall- und St. MatthewsInsel im nördlichen zentralen Berings-Nleere als Brutvogel vertritt, und im Winter im westlichen 'T'eile von Alaska erscheint. Sie ist leicht durch die grobe Ausdehnung des Weiß auf der Oberseite (Rücken und Schulterfedern weiß) und an den Schwingen zu unterscheiden, welche mindestens zur Hälfte weiß sind. Vielleicht auch nur Subspezies von nivalis.

2. Passerina nivalis tounsendi (Ridgway), welche auf den Alenten, einschließlich der Kommandeur-Inseln, den Pribilof- und Schumagin-Inselı, sowie an der sibirischen Küste des Berings-Meeres vorkommen soll. Sie soll sich lediglich durch bedeutendere Größe unterscheiden - Flügel nach Ridgway 108.71-120.40 gegenïber 106.43-116.33 hei $P$. n. nivalis --, ich finde aber die Haße mir rorliegender Stiicke von den PribilofInseln und Alaska durchaus nicht größer. Ich kann daher die Berechtigung der Subspezies tounsendi rorläufig nicht ancrkennen, doch scheint es, als ob die Stücke ron den Pribilof-Inseln und Alaska, wie die von Kamtschatka und Wintervögel aus Ussurien den Unterricken immer weiß haben. (Vgl. Ridgway, B. North and Middle America I, 1. 147-153; 1901.) 
Eimberiza notata P. L. S. Miüler, Syst. Nat. Suppl., p. 157 (1776- basiert auf Buffon). Emberiza mustelina Gmelin, Syst. Nat. 1, p. 867 (1788- basiert auf Ray, Willughby, Albin, Pennant und namentlich Latham. „Habitat eum nivali, ejus, ut videtur, varietas.").

Eimberiza montana Gmelin, Syst. Nat. I, p.867 (1788- basiert anf Willughby, Pennant und Latham. „Habitat in Anglia.").

Enberiza glacialis Latham, Ind. Orn. I, j).398 (1790- nener Name für E. mustelinu und nivalis der Fauna. Suecica).

Plectrophanes hiemalis Brehm, Handb. Naturg. Vög. Deutschl., p.304 (1831- „in sehr schneereichen Wintern in Ylittel-Deutschland").

Plectrophanes borealis Brehn, Handb. Naturg. Vög. Deutschl., p. 305 (1831- ., bewohnt Grönland, wahrscheinlich auch Island ....").

Plectrophanes nivalis major, macrodactylus A. F. Brehm, Ver\%. Sammlung, p. 8 (1866nomina nuda!).

Engl.: Snow-Bunting. S'elwwed.: Snösparf. Franz.: Ortolan de neige.

onad. im Sommer. Kopf und Hinterhals, die meisten Oberschwanzdereken. Oherflïgeldecken. die meisten der Armischwingen ganz und die Hand-

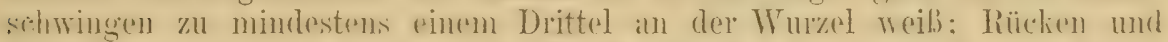
[Bürzal, manchmal rin Streif auf' den s'chwanzdereken, die letzten Armschwingen

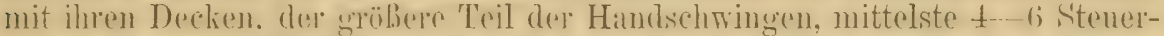

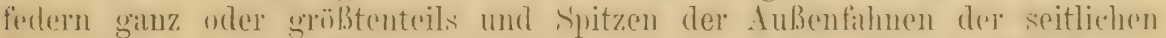

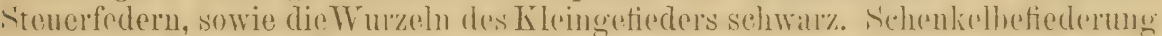

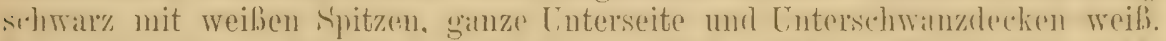

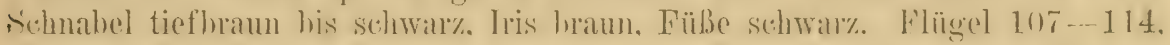
Schwanz 65-70, Lauf 12-14.2, Schuabel 9.6-10.5 mm. Die Fürbung der variient vielfach: ganz ansmahmsweise sind der" ganze Bür\%el und die

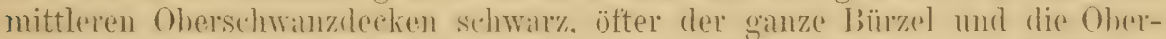

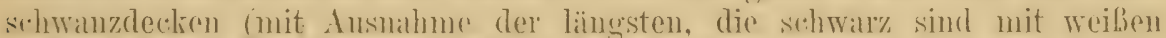
Rändern) rein weiß: letztere Form scheint in Ost-Sibirien im Tinter die worherschende zu sin. kommt aloer anch in Nord-Amerika und seltener in Europa vor. Dir weiben drmsehwingen hahen hisweilen etwas s'chwarz an darn Außenfahnen. add. im Sommer. Oherkopf und ährige Oherseite mit

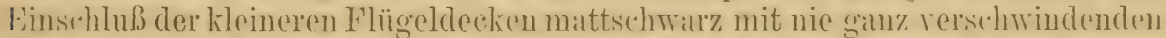

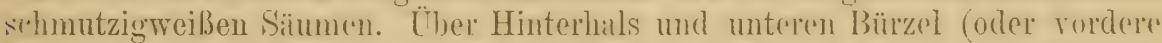
(berschwanzdecken) je (in weikes, mehr oder minder mattschwarz gefleckites Banc. Handschwingen dunkelbraun mit weiben Anben- und sthmutzigweiben

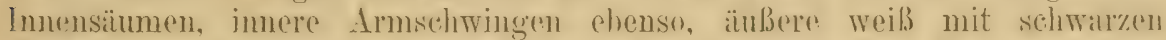
Flecken an den Spitzen, namentlich an den Aufenfahmen. Sonst etwa wie

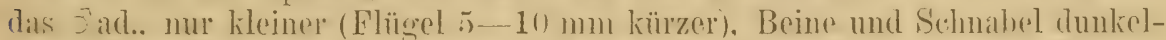
Traun. Im Herhstlidede hahen alle Eedern der Oherseitr rosthraune Śpitzon, wodurch Oberkopf. Bürzel und (Ohersehwanzdecken rosthraun erscheinen und aurh diss Schwarz des Rärekens mehr oder minder verdeckt wird. Cuterseitr weili, ein grober Fleck an den Suiten der Torderbrust, die ganzen Körperseiten uder nur ein Teil derselhen, bisweilen anch ein Bimd üher die Vorderbrust resthraun. Das Rostbram ist variahel in Ausdehnung und Farbenton. Man nimmt obne rechten Grund an, dilb jüngere Vögel mehr und tieferes Ronthraun hahen. Sehnahel gelhbraun, Füibe sehwarz. In der Mitte des Winter: ungrefïhr sind die braunen Säume schon zum Teil fort, dis schwarze Gefieder der Oherseite aber zeigt noch Überreste davon in Gestalt schmälerer weilien Tïnder, denm jene hraunen Süume gehen wahe dem Schwar\% in bräumliches,

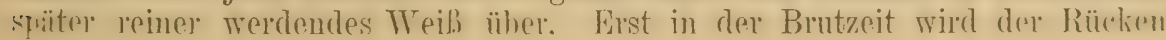


rein schwarz, der Kopf rein weiß. Juv. Oberseite brïunlichgrau, der

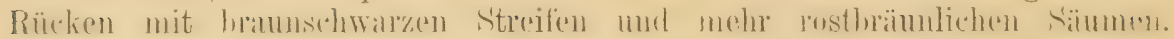

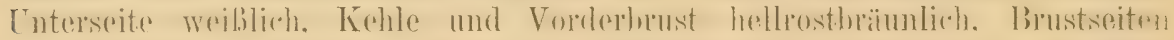

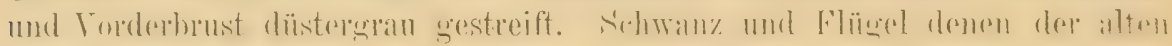
Vögel ïlnnlich.

Brutvogel im Norden der Alten und Nenen Welt, in den arktischen

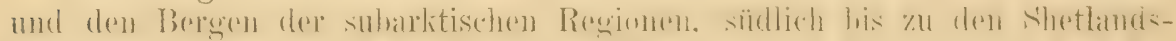

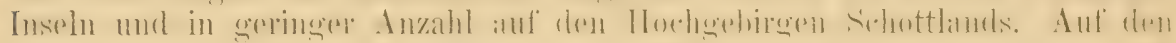
Färöer und Island bäufig brïtend. - In Winter südlich wandernd, in oft

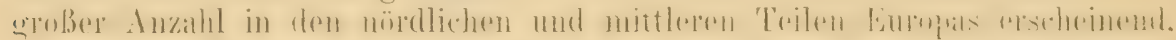
in geringerer Anzahl bis zum Nittelmeer, vereinzelt his zu den. Canaren, Azoren und Nord-Afrika. Im Osten im Winter in Japan und Nord-china. in Amerika über einen großen 'Teil der Vereinigten Staten.

Rasch laufender: meist scheuer Bodenvogel, der sich olt nach Art der lierehen rerbirgt und nur sehr selten auf Bäume und Zäune setzt. Flug sehr raseh und kräftig. Größere Scharen wälzen sich gleichsam fort, indem die hinteren die vorderen ïberfliegen. Nahrung wie die der Ammern. Lockruf ein langgezogenes 'l'sirrr, Warnruf ein flötendes füd, fid, der Gesang zwitschernd. Das Nest steht am Boden oder an Kelsen, meist verdeckt oder doch geschützt, in Spalten, unter Steinen oder Holzklötzen. His ist ammeruartig gebaut, meist aus Grashalmen, aber weich und dicht mit Federn, Hataren 11. dergl. ausgefüttert. Die Fier, 1-6 an Z/ahl, fundet man im Juni. Sie sind ziemlich variabel. Thre Grundfarbe ist grünlichweiß, weniger oft gelblich, rötlich oder gelbbraun. Die oft am stumpfen Ende ringförmig gehänfte //ueichnung besteht oft nur aus blassen, bräunlich-rostroten, zahlreichen Flecken von verschicdencr Größe, oder aus spärlicheren von tief purpurbrauner Fïrbung, nebst helleren, mehr violettorauen Unterflecken. Kritzelförmige Linien und Haarlinien sind sehr selten. Bisweilen sind die Fier über mol ïber rotbräunlich gefleckt und gewölkt. 27 frier in J)r. Rey's Sammlung messen durchschnittlich $22.37 \times 16.8 \mathrm{~mm}$, das größte $24 \times 17$, die beiden kleinsten $21 \times 15.5$ und $21.2 \times 14.9$. Das durchsehnittliche (iewicht beträgt $0.168 \mathrm{gr}$.

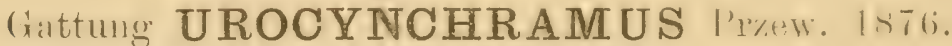

Diese merkwürdige Gattung steht sehr isoliert. Der Schnabel ist lang

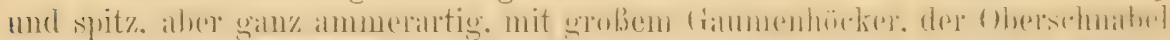

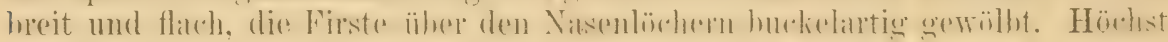

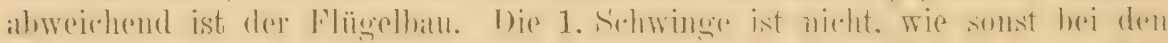

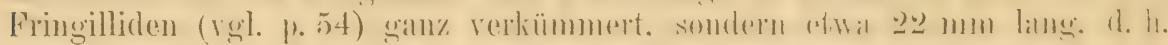
etwas über halb so lang wie die 2. Der Flïgel kann somit nicht ,neun-

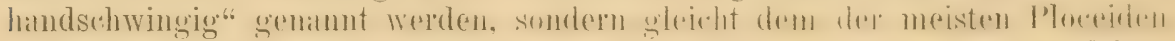
oder Webervögel! Die 2. Schwinge ist etwa $: / 4 \mathrm{~cm}$ kiüzer als die dritte.

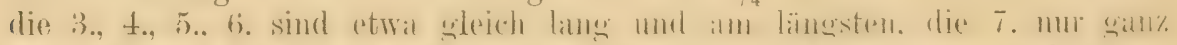

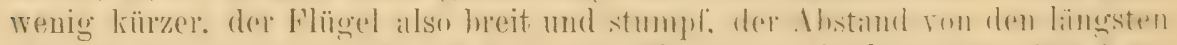

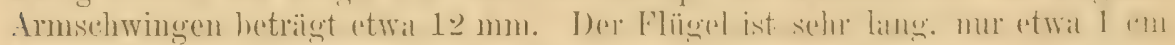
kïrzer als der Sohwanz, der infolge seiner länge und starken dbstufume

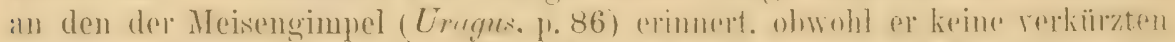

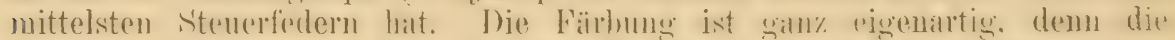

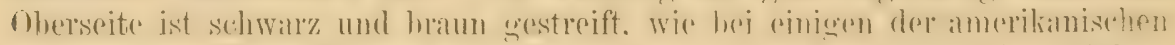

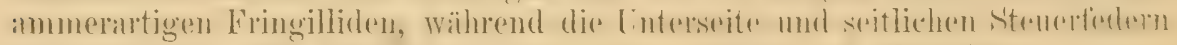

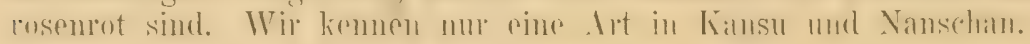




\section{Urocynchramus pylzowi Przew. ${ }^{1}$ )}

Urooynchramus pylzowi Przewalski, MIongol i Strana 'Tangut, II, p. 99, 'Taf. XV (1876, russisch!); Übersetzung in Orn. Hisc. II, p. 309, T'af. 7. (Am Tatung-Elusse in der $\mathbf{N}$.-Mlongolei.)

jacl. Ohersite fihl aschloram mit breiten, hransehwarzen streiten. sonwingen schwarzhann mit habhrïunlichen, natch der Wurzel zu mehr lost-

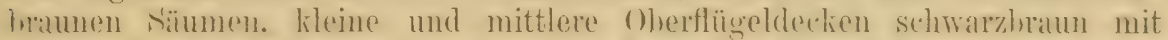
meiten, futhsig rothramuen Säumen. Die mittleren 4 Steuerfedern dunkellorau mit fahlgrauhraunen Sïmmen. die ïhrigen schön rosenrot mit weil.un Schäften und Spitzensämmen. Zügel. Supereiliarstreif. Handrand und ganze Cunterseite

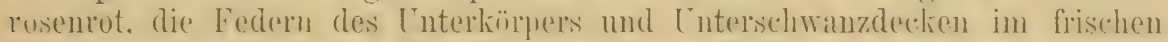

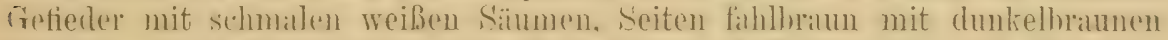
strichen. Enterflïgrolerelien und Achselfedern hellhnäunlich, mit leichtem,

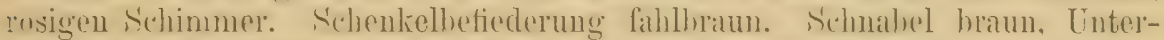
shuahel heller. Füfer schwall. Flügel (etwa 78. S(hwanz etwa 80-90), Lauf 25,

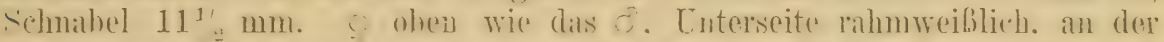
Forderhrust mit schwachem rosigen Schimmer, an Kehle, Vorderhrust und soiten mit hremuschwarzen Streifen, äubere Steuerfedern rosenrot wie hein $\bar{b}$. Etwas kleiner als das $0^{r}$.

Am 'Tatung-Flusse in Nan-Schan und in Kansu.

Wurde in alpinen Höhen in den mit Büschen der Potentilla tenuifolia bestandenen Strichen gefunden. Die Lockstimme erinnert an die ron Emberiza schoenichus, der Flug an den des Uragus.

\section{l'amilie AIAUDIDAE.}

Die Alaudidae oder Familie der Lerchen bilden im Gegensatze zu mehreren andern Singrogelfamilien, an deren Lnterscheidung wir uns wahrscheinlich mit Cnecht gewöhnt haben, eine wohl unterscheidlaare Gruppe. ÄuBerlich zwar den Piejern (Authus) aus der Familie Motucillidue ähnlich, unterscheiden sie sich von diesen durch die aus vierseitigen sichildern

1) Mit Urocynchramus schließt die Liste der paläarktischen Fringilliden. In der Nähe von Acantlic hätte vielleicht noch der eigentïmliche

\section{Callacanthis burtoni (Gould)}

Platz finden können. Er ähnelt einem riesenhaften Stieglitz (Acanthis carduelis). Der Schnabel ist dick, oben flach; das ơ ad. hat Stirn, Zügel und Augenstreifen rot, Kopfplatte schwarz, übrige Oberseite braun mit rötlichem Schimmer, Schwingen und große Flägeldecken schwarz mit weißen Spitzen, Sehwanz schwarz nit weiben Supizen, äußere Steuerfedern großenteils weiß, Unterseite braun mit rotem Schimmer. Flügel etwa 98, Schwanz 6ā-70 mm. - Bewohner des Himalaya ron Mlurree bis Garwhál und Kumaon.

Ein nordamerikanischer Fink

\section{Junco hyemalis (L.)}

wurde von den Sammlern der Vega-Expedition in einem Stück am 4. VI. 1879 an der Küste der. T'sehulstschen-Halloinse), nïralieh rou Kamtschatha gefunden (Pahmin. VecraExped., p. 284). Das ot ist oben, wie auch Kehle und Vorderbrust dunkel schiefergrau, Unterkörper und äußere Steuerfedern weiß, das + etwas blasser, sonst wie das 0 . 


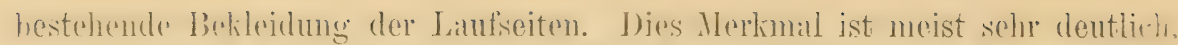
nur selten finden wir. hei sehr alten Vïgehn, die Schilder etwas rerwathisen. Fast alle und teilweise sonst sehr konstante Charaktere variieren bei den Lerchen ungemein: Der Schnabel von dem kurzen dünnen, an den der Hotacillidae erinnernden von Alauda, Lullnda u. a. m., bis zu dem gewaltigen.

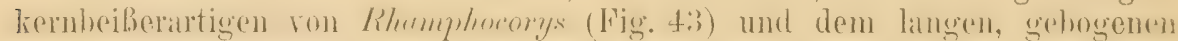
von Alaemon (Fig. 45); die bald höheren, bald kürzeren Lüufe und Füßße hahen eincen versehieden geformten Nagel all der Hinterzehe: derselle ist bald kurz und gebogen, wie bei Calandrella bractiydactyla, hald lang und gerade; die erste (rudimentäre) Schwinge ist bald so klein, daß man sie

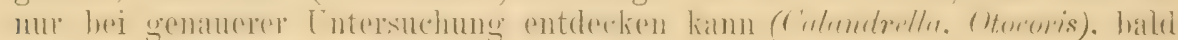
deutlich sichtbar, wenn anch noch sehr klein, bald grob, bis zu 1/3 und

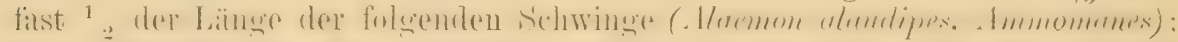

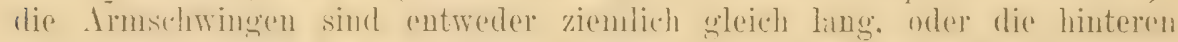
sind stark verlingert wie bei den l'iejern (.Imlluss). Creschlechter meistens rinander ganz, ithnlich, nur selten merkileh repsedieden. Die Jungen mesist gefleckt, selten (z. B. bei Limmomanes) ungefleckt, den Alten ähnlich.

Die Lerehen mansern nur einmal im Jahre. Sie sind meist Bervohuer

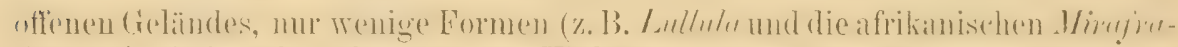
Formeni sind mohr oder weniger Waldhewohner. Thre Nahrung suchen sive am Boden, auf dem sie geschwind zu rennen rermögen, die meisten Arten sieht man selten oder nie auf Büumen. Nester kunstlose, offene Bauten

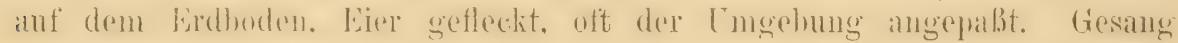
meist schön. Europa, Asien, Afrika, in Amerika nur durch die Gattung Otocoris, in Australion nur durch Mirafiri vertreten. In Afriki am artenreichsten.

\section{Gattung RHAMPHOCORYS 13p. 1s.).}

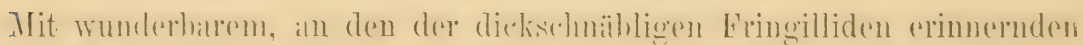

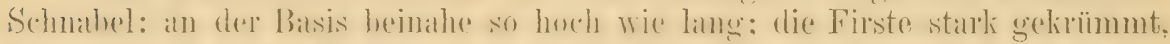

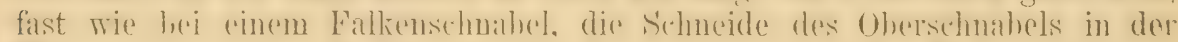

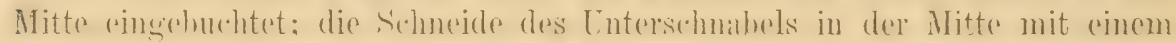
vorspringenden Zahn, vor dem eine Einsenkung ist, bei welcher man bei

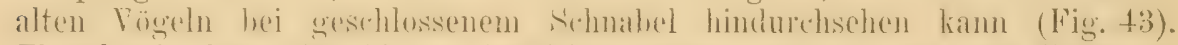

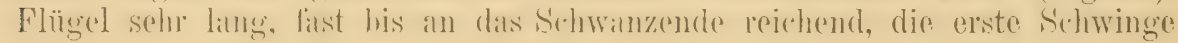
etwa $3 / 4$ der Handdecken, nämlich zirka $1 \frac{1}{2} \mathrm{~cm}$ lang, dritte Schwinge am längsten, 2. und 4. nur wenige $\mathrm{mm}$ kürzer. Schwanz kurz, nur ganz flach ausgesehnitten. etwa loalh so lang wire der Flügel. Laluf liurz nud stimmig, otwis lingere als Vittelzohe mit Nager. \%ehen kur\% und kräftig; Nagel der Hinterzehe beinuhe so lang wie jene, dick, sehr flach gebogen. Eine Art in der nördlichen Sahıra.

\section{Rhamphocorys clot-bey (Bp.). (Fig. 43.)}

Melanocorypha clot-bey Bonaparte, Consp. Ar. I, p. 242 (1850- ex 'T'emm. MI.S. "ex Deserto Egypt.").

Ierapterlina C'avaignacii Des Murs et Lucas, Rev. et Mag. de Zool. 1851, p. 25, 'Taf. 1 ("Kecours D'Aïn Séfra, Sahara algérien").

Hierapterhina Clot-Bekii Heuglin, Journ. f. Orn. 1868, p. 220.

Abbild.: Journ. f. Orn. 1893, Taf. II, 1895 'laf. XIV. 


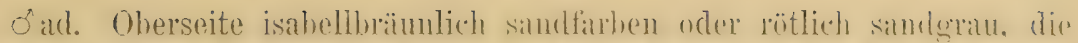
Federränder etwas lichter, die Gedern des Oherkoptes in der Mitte dunlielslatu, die Oherschwanzdecken lichter, ins Rahmfarhene zichend. Zü̈gel weif., Fleck unterm duge und oberes Augenlid weib. Kopfseiten schwall\%, in rler.

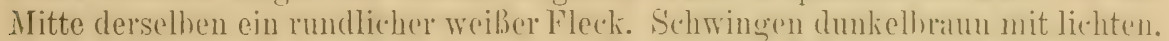

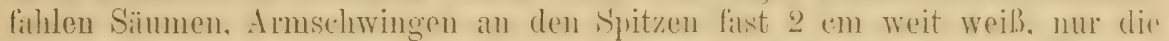

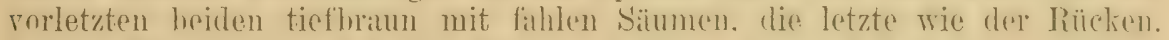
Kleme lin̈geldecken wie der Rürken, mittlere branschwatr\% mit schmalen. grobe braun mit breiten fihlhräunlichen Sämmen, sodit.s dio mittlerm eine dunkle Fleckenxeihe üher den Flügel bilden. Stenerfedern rabmweib. an den Sppitzen mit groben länglichrundlichen, narh der. Mitte zu an duschehmung von Feder zu Feder zunehmenden, selwarmen Flecken, dis mittelste Pair ganz, das angrenzende an den Rändern fahlbräunlich wie der Rücken. Unterseite rahmweiß, die Seiten graurötlich-sandig: ïberlaufen, an der Basis des Unterschnabels jederseits ein kleiner, am Kinn ein großer weißer Fleck, unter dem das Schwarz der Kopfseiten sich fast oder ganz begegnet. Die Mitte der Unterseite dicht und groß, nach den Seiten zu kleiner schwarz gefleckt, nur der' hinterste 'Teil des Unter-

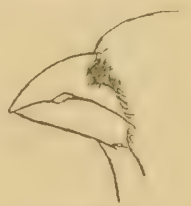

Higur 43

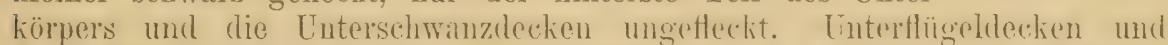

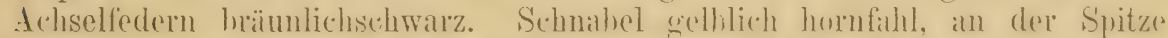
schwärzlich. Iris hraum. Fïße fahl hläulich grau. Flïgel 123- 127, Schwanz etwa 61, Lauf etwa. 24, Schnabel $18 \mathrm{~mm}$ lang; an der Wurzel 13--15 mm hoch. Getwas kipiner, ohen mehr rötlich sandiarlen, ohme den beigemischten

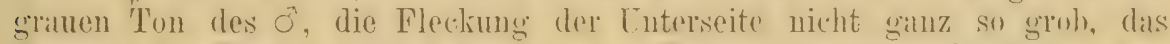

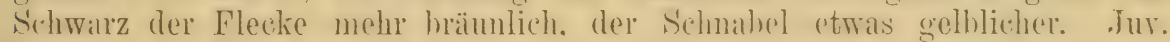
(Beschr. Konenig, Jouru. f. Orn. 189:) p. 47) unten whe sehwarze Fleckung. Kehle weils mit gramen Schatten, Vorderbrust golblich zimmtfarben, oben blasser und gelblicher, der Schnabel noch olne den eigenatigen Tahnansschnitt der alten Vögel.

Der 'Typus der Art soll aus der Libyschen IVüste westlich vom Nil stammen, dio von ()rnithologen hisher uicht ordentlich durchforscht wurde. Wir kemen die Art jetzt mur als Bewohmerin steiniger Plateass und Hügelreiben am Nordrande der Sahara in Tunis und Algier. Der 'I'ypus im Jeidener Museum stimmt ganz mit Vögeln aus I'unis überein.

Ein Vogel der peträischen Wüste. Nahrung Sämereien und Insekten. Duckt sich gern vor dem Verfolger und fliegt meist niedrig über den Boden. Das von Koenig entdeckte Nest stand am Boden unter einem Halfabüschel. Fs bestand aus Pflanzenstengeln, Gras und feingekräuseltem Bast und war von kleinen Steinen umringt. Dic beiden Eier sind von gedrungener, banchiger Gestalt, mattglänzend, zartschalig. Die Grundfärbung ist rahmfarben mit zartem Aprikosenschimmer, iiber und über mit matt. violetten Schalenflecken und rostroten Flecken bedeckt. $M$ Laße $24 \times 19$, $24 \times 18 \mathrm{~mm}$, Gewicht 0.22 und $0.25 \mathrm{gr}$. (Journ. f. Orn. 1895, 'Taf. 14.)

\section{Gattung MEIANOCORYPHA Boie 1828.}

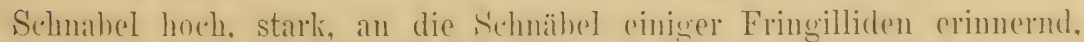

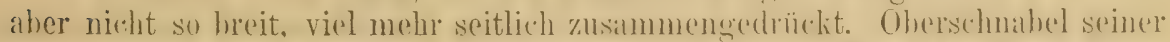

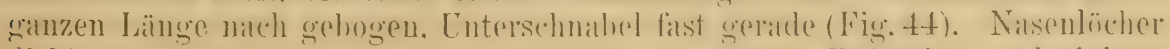

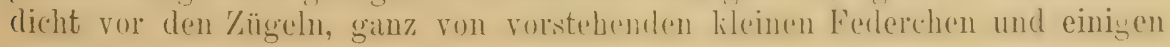




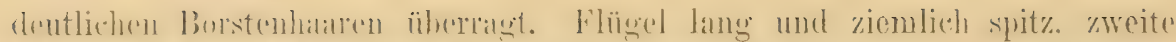

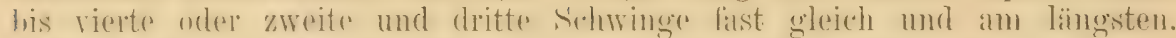

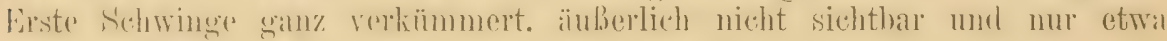

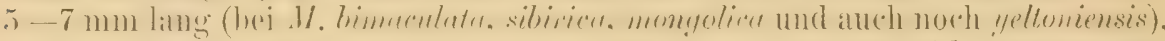
oder von unten deutlich zu sehen und etwa $1 \mathrm{~cm}$ lang (bei $M$. calandra und

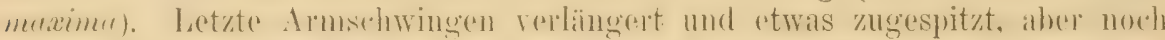
weit von der Flügelspitze zurïckbleibend. Füße stark, Lauf länger als

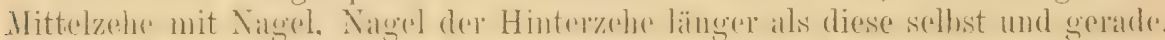

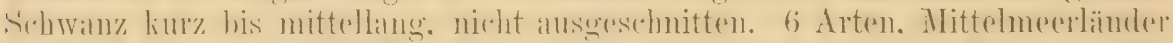

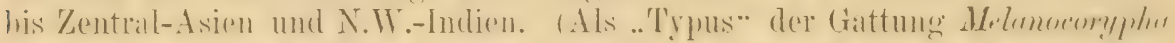

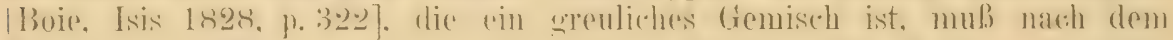

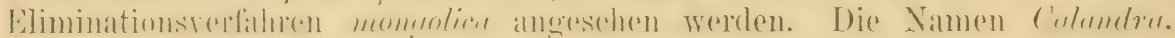
Londra, Calandrina, Saxilauda, Nigrilauda und Pallasia sind Synonyme, von denen sich die ersten beiden auf calandra, der dritte anf bimaculata, der

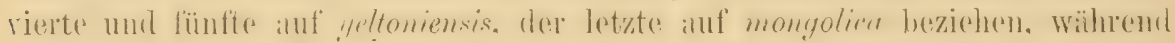
die durch ihren schlanken Schuabel recht abweichende maxima noch ohne synonyme Gattungsbezeicbnung dasteht.)

$$
\text { Übersicht der ô der Arten: }
$$

1 Unterseite weißlich ... . . . . . . . . . . . . 2 2

1 \{ Unterseite schwarz .................. Meltoniensis. 1. 213

, Kleine Flügeldecken rostrot . . . . . . . . . . . . 3

2 Kleine Flügeldecken sehwarzbraun mit fahlen Säumen ........ 4

3 Kropfseiten schwarz. . . . . . . . . . . M. mongolica . 1. 212

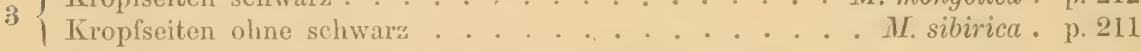

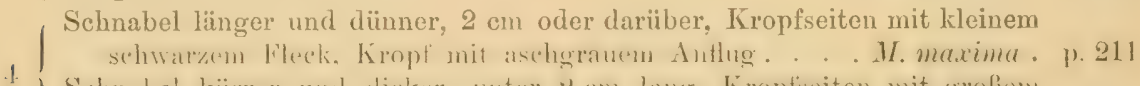

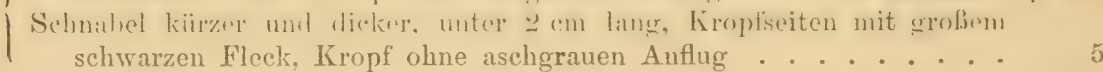

5 \{ Innere Armschwingen mit ausgedehnten weißen Spitzen. M. calandra . p. 208 I Innere Armschwingen ohne weiße Spitzen..... M. bimaculata. p. 210

\section{3ะ7. Melanocorypha calandra calandra (L.). (Fig. 44.)}

Kalanderlerche.

Alende Calandia Linnacus, Syst. Nat. Ed. XII, 1, p. 288 (1766-- ans Brisson, OMn. III, p. 352 , и. a. "Habitat circa Pyrenaeos.").

Alauda colleris P. L. S. Miiller. Natursystem, Suppl.. P. 137 (1776 Ex Edwards, Gleanings II T'af. 268. "Carolina" errore!).

Melanocorypha subcalandra C. L. Brehm, Handb. Naturg. Vög. Deutschl., p. 310 (1831"lebt im südöstlichen Europa und in Asien, kommt äußerst selten nach Deutschland." In Naumannia 1856, p. 37.t: "Griechenland und Dalmatien“.).

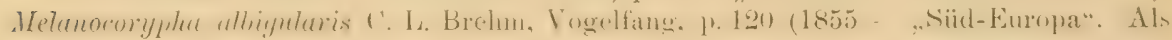
typischer Fundort ist Dalmatien anzunelimen, nach Naumannia 1856, p.374.).

Melanocorypha calandra megarhynchos O. L. Brehm, Naumannia 1856, p. 374 („, in Algerien und auf Sardinien").

Melanocorypha semitorquata C. L. Brehm, Naumannia 1856, p. 374 (Sarepta. Der 'lypus ain Vorderhalse beschädigt, daher "semitorquata“.).

? Melanocorypha Calandra torquata, longirostris, tenuirostris A. E. Brehm, Verz. Sammlung, p. 8 (numina mula! Jedenfalls mu individuelle Abweichungen ron calandra, aber in der Sammlung nur tenuirostris erhalten.).

Engl.: Calandra Lark. Franz.: Calandre. Italien.: Calandra. 
ơad. Oherseite graulich sepiahnaun mit schwarzhaunen Federmitten. die auf dem Vordertïken, wo sich auch hell gelhlichfahle Ecelersïume zeigen, am breitesten und dunkelsten sind. Oherhals utwas gratulicher. Hinterer Teil des Bürzels und Oherschwandecken fast einfarbig, letztere mit hlalsfahleu Sïumeu. Schwingen schwäl\%lich, Außenfuhnen schmal, an den inneren Armschwingen breiter und brïunlicher, rahmfirben gesäumt, Al'msehwingen, mit Ausnahme der letaten (verlängerten), mit etwa $6-9 \mathrm{~mm}$ lreiten weilin Spitzen. Stenerfedern schwarzhran mit schmalen, nach den änberen lectern zu größer werdeuden weiBen Spitzen, das mittelste Paar weniger schwïrzlic.] und mit fahlbräunlichen Säumen, das äuberste gröbtenteils wrib, an del basis aber ein sehiefer, keilförmiger. dunkellnauner Fleck, das zweite Paar mit etwa $1 \mathrm{~mm}$ breitem weißen Außensaum. Zügel graulich weifs; ein schmaler rahmweiBer Superciliarstreif. Kopfseiten graubaum, schmal fahlhrïunlich gestrichelt, unter dem Auge ein hellerer Fleck. Unterseite weil, an den Kropfseiten ein sehr großer schwarzer Fleck, Vorderbrust mit gelbbräunlichem Schimmer und kleinen dunkelbraunen Längsflecken, Seiten fahl erdbraun. I'nterflügeldeclien und Achselferern bräunlichgrau mit schmalen fahlen Sänmen. Oberschnabel und Spitze des Unterschnabels dunkel horngrau, Schneide des Oberschmabels und Cntersehmabel hlab bräunlichgelh. Iris blatun, Fülis

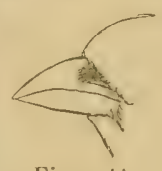

Figur 44. hellbraun. Flügel 127--134, Schwanz etwa 62-66, Schmahel etwa $1+-17$. Lauf etwa $17-18 \mathrm{~mm}$. O wie $0^{\top}$, nur etwas kleiner, Schnabel und Flïgel kïrzer, meist anch die schwarzen Flecke an den Kínopfseiten nicht galluz so groß. Das Herhstkleid ist lehhafter, die fahlen Federsäume machen es hühscher, im Sommer wird die Färbung matter, hräunlicher. Die Variation ist namentlich in Bezug auf Schnabel- und Flügellängo grol.s, anch der dunklere, und hellere, bramere und grauere Ton der Oberseite ist etwas rechsehud, ohne ilver. geographiseh beschränkt zu sein. Der junge Togel im ersten Crefioder ist oben lebhaft gelhbram mit braunscbwatzen Federmitten und fahlgelhen

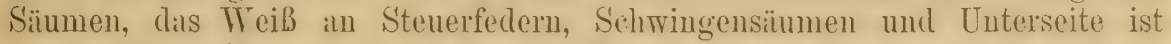
dureh Rahmgelh ersetzt, die dunklen Flecke an den Kropfseiten sind hraun und kleiner:

Das Brutgebiet der Kalanderlerche erstreckt sich von Sïd-Frankreich üher Süd-Europa und Nord-Afrika bis Kleiussien, Kaukasus und Armenien. hïutig in Spanien und Portugal, Nittel- und S̈̈d-Italien, in Nord-Italien jedoch nur selten und zufällig, in Korsika, Sirdinien, Sizilien, Dalmatien, Montenegro (bei Podgorica), Bulgarien, Dohrudscha, Sürl-Rußland bis zum Kaspischen Neere, Türkei und Griechenland, Ḱ̉einasien his Armenien, NordKaukasus (aber nicht im Bakudistrikt), Palüstina bis zum Tihanou, in den nürdlichen und mittleren Teilen ron Marokke, Algier und Tunis (aher in Ägypten anscheinend nicht Brutrogel, sonderm nur eine ansmahmsmeise Erscheimung). - Stand- und Strichvogel, daher nicht oft außerhalb ihres Wobugebietets heobachtet. Da sie oft in der Gefangenschaft gehalten wird, sind vereinzelte Torkommnisse mit Torsicht aufzunehmen. Ist nach Leisler eimmal bei Frankfurt a. M., uach Glocer eimmal in Schlesien, nach Gïtie einmal anf Helgoland rorgekommen, in Fughand nicht mit Sicherheit festgestellt.

Lebensweise feldlerchenartig. Bewohnt mit Gras, Steinen und Gestrüpp bedeckte steppenartige Ebenen, aber auch, besonders in Nord-Afrika, Gerste- und Haferfelder, in denen sie sehr gemein ist. Im Winter vereinigt sie sich zu großen Schwärmen, aber

E. Haxtert, Die Vögel der paläarktischen Region. 
schon im März beginnen sich die Paare zu sondern. Lockstimme viel kräftiger als die der Feldlerchen, Gesang schnarrend und flötend, häufig ron dem laut und klar gepfiffenen Worte "klytra, klytra", sowie mit den wunderbar nachgeahmten Strophen andrer Singrögel durchsetzt. Das Nest steht am Boden in kleinen vorgefundenen oder gescharrten Mulden, meist von überhängendem Grase mehr oder minder verborgen. Im MIai oder schon Ende April findet man meist 5, seltener 4 oder 6 Eier. Letztere sincl in der Regrel gröber gefleckt als Haubenlercheneier und immer größer und dieker als Feldlercheneier. Grundfarbe meist weißlich oder gelblich, sehr selten schwach grünlich, fast immer zwischen den zahlreichen, meist graubraunen Flecken deutlich hervortretend. Selten ist eine Kranzzeichnung ausgebildet, selten die Fleckung fein, wie bei Heidelercheneiern, bisweilen erinnern die Eier an die der großen Grauwürger. Maße von 78 Eiern in Dr. Rey's Sammlung im Maximum $27.1 \times 18.9$ und $26.8 \times 19.2$, im Durchschnitt $24.3 \times 17.9$, im Minimum $24 \times 17.2$ und $22.8 \times 18 \mathrm{~mm}$. Gewicht etwa $239 \mathrm{mg}$.

\section{Melanocorypha calandra psammochroa sulıp. nor.}

Unterseheidet sich von $M$. calandra calandra durch hellere, mehr sandgelhliche. weniger gratue Oherseite, nicht so schwärzliehe, sondern mehr brause Federmitten und gelhlichere Sïmmen, namentlich an den Fiügeldechen, und liehtren Bärzol anf den ersten Blick. Auch die Körperseiten und Achselfedern sind etwas heller.

Ost-Persien. Af (Typus $5 \mathrm{Nr}$. 14. N. Fitudny coll., hei L)u-Badom 14. XI. 1898. Im Rothschildschen Museum.)

\section{Melanocorypha bimaculata (Ménétr:).}

Alauda bimaculata Ilénétries, Cat. Rais., p.37 (1832- Berge bei Talysch).

Melanocorypha torquata Blyth, Journ. As. Soc. Bengal XVI, p. 476 (1847- Afghanistan). Melanocorypha alboterminata Cabanis, Mus. Hein. I, p.124 (1851- „Abyssinien").

Melanocoryphe rufescens C. L. Brehm, Vogelfang, p. 120 (1855- Sudan).

Melanocorypha bimaculata $\beta$ minor. Sewertzow, 'Turkest. Jevotn., p. 67 (1873- nomen nudum! Turkestan; ef. Journ. f. Om. 1875, p.174, Ibis 1876, p. 183.).

(? Melanocorypha intercedens Brehm, Isis 1845, p. 343 ["bewohnt das Morgenland"] ist nicht sicher zu deuten, dürfte aber hierzu oder zur vorigen Art gehören. 'Typus nicht mehr in der Sammlung.)

Abbild: Dresser, B. Europe IV 'T'af. 238.

Oberflächlich betrachtet einer M. calandra sehr ähnlich, aber durch folgende Merkmale seharf unterschieden: den Armschwingen fehlt die weiBe Splitze: die äubere Stunerfeder ist dunkelbraum. die AuBenfahme rostgelh šesiumt, an der Spitze der Innenfahne mit einem kleinen rahmweißen oder schmutrigfahlgelhen Fleck; die Fleckmug der Vorderhrust ist spällicher, mehr anf die Seiten hesehrïnkt. Der Sehwanz ist etwas kïrzer, etwa 5:3-61 mm. Die schwarzen Flecke an den Kroptseiten nähern sich mehr in der Mitte, ohne aher ctwa ein ganz geschlossenes Band zu hilden. Die Größe variert individurll (aller, so viel ich feststellen komnte, nicht geographiseh) ziemlich bedeutend.

Brutrogel in Transkaspien (westlich um den sïdlichen Teil des Kaspischen Meeres his in das 'Tiefland ron Talysch), T'urkestan, Afghanistan, Baluchistan, Persien (in Fars his gono engl. Fub üher dem Meere) his zum Libanon 
und Taums in Kleinasien. - Inf dem Kuge durch Kaschmir, üherwintert im P'unjab) in Sindh, Raijputana, Bahaiwilpur, den N.W.-P'rorinzen Indiens und Ondh einerseits, Arabien und N.O.-Afrika (Sudan, Blaunr Nil, Ahessinien) andrer'seits.

Bewohnt baumlose, grasige 'I'riften und Felder. Der Gesang ist wundervoll, wie der von M. calcundra. Soll ziemlich scheu sein. Fortpflanzung wie die von M. calandra, aber die Eier sollen meist etwas kleiner sein und öfter einen griulichen Ton haben.

\section{Melanocorypha maxima Gould.}

Melanocorypha maxima Gould, Birds of Asia IV, Taf. 72 mit Text (1867- [schlechtes Bild]. ?Afghanistan. Irrtum! Ich nehme als terra typica die Grenze von Sikkim an).

Ton 1\% calandra und himaculata dureh deu langen, gestrecliten, diumen Schnahel sehr verschieden. -- Oad.: Federn der oherseite dunkelluraun, in der Rückennitte first schwarz, röstlich fahlhraun gesämmt, Oherhals etwals graulicher und einförmiger, unterer Bürzel und Olserschwanzdecken brïunlicher und einfarbiger. Sehwingen dunkelbraun, die erste (entwickelte) mit weiben, die übrigen mit bräunlich rahmfarhenem Außensaum: Armschwingen, mit Ausnahme der letzten, die dunkelbran sind, mit breiten weißen Śpitzen. Ilittleres Stenerfederpaar dunkelbraun mit gelblichbramen Sïmmen. die ährigen schwarzbraun mit weißen, nach außen zu an Ausdebnung zunchmend('n S.jpitzen.

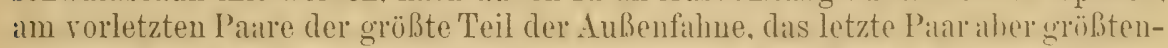
teils weiß mit keilfürmig sehiefem schwarzhraunem Basalfleck. Zïgel und Streif hinter dem Auge schmutzigweiß. Thuterseite weißlich, Kropfgegend mit aschgrauem Anflug, Kropfseiten braun, nach oben mit einem oft undentlichen, menig bemerkbaren schwarzen Fleck. Weichen rostbrann. Lnterflügeldecken bräunlichgran, dehselfedern etwas blasser. Schuahel (am Balge) bram mit dunklerer Spitze, Füße braun. Flügel etwa 150), Schwanz etwa 89. Latuf etwa 28, Schnahel etwa 22 lang, an der Wurzel 8-9 $\mathrm{mm}$ hoch. o wie of. aber kleiner, Flügel etwa 135-138 mm lang. Im Herhstkleide siud die gelhhraunen Federsitume breit und aufallend, in ahgetragenen Sommergefieder stark ahgenutzt, solaß letzteres damn viel dunkler und einförmiger aussieht. Der junge Vogel im ersten Gefieder ist sehwarzhaun mit hell gelblichweißen Säumen, die Unterseite schwefelgelb, Seiten und breites Kropfhand sehwarzbraun nit gelhhrïunlichen Sïmmen und Federwurzeln.

Hochehene von Tibet, rom Nordabhange des Himalaya bei Sikim bis zum Kuku-Nor und Kansu.

Lebt auf feuchten Wiesen in großen Höhen und ist ein rortrefflicher Sänger und Nachahmer andrer Gesänge. Im Winter in großen F'lügen.

\section{Melanocorypha sibirica (Gm.).}

Alauda sibirica Gmelin, Syst. Nat. I, p. 799 (1788- ex Pallas' Reise II, p. 708, N1: 15*, III, p. 697: "Abundat in campis apricis ad Irtin").

Alauda lencoptera Pallas, Zoogr. Rosso-Asiat. I, p. 518, T'af. 33 (1831- „In desertis Barabensis, ab Om fluv. usque ad Altaïca juga, secundum omnem Irtin copios. prim, observata").

ơad. Oberkopf zimmtrot, Rücken und Bürzel schwarzlrian mit sehr breiten fahlgelblich-grauhraunen Federrändern, die am Halse am hreitesten 
sind. sodab die Oherseite fahlgraubraun, auf dem Halse schmal, auf dem Rë̈lien hreit schwarzhriun gestreift alussieht. Oherschwanzdecken graubraun mit schwalrzhaunem s'chaftstreif und zimmtrotem Wrurzelteil. Handschwingen sehwar\%bram mit schmalen rahnwelben Sämmen, Armschwingen zur Hälfte reinweils. die Basishialfte dunkelhrann, die letzten drei braun, an der Spitze fihler und mit schmalen weiblichen siumen. Kleine und mittlere Oherflïgreldecken und Handdeden zimmtrot, letztere mit hramen Streifen an der Innenfahne. grobe Flägroddecken dunkelhraun mit weißlichen Sä̈men. Stenerfedern schwarzhraun, das mittelste l'are breit hellfablhraun gesïumt, alle mit weiben Sïumen, Aubenfilhe des vorletzten mod ganzes äuberstes laatr weib. Ziiggel und Streif hinter dem Auge weiß. Ohrdecken zimmtrot mit braunen und weiblichen strichen. Enterseite weib, Kehlseiten und Kropfgegend mit habbramen Fleclien; Brustseiten zimmtrot. Körperseiten mit fahlbranem Anflug und dunkelhramen Strichen. Tnterflïgeldeceken und Achselfedern

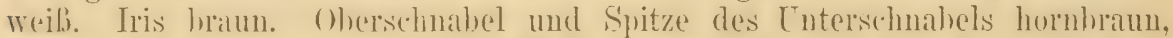
Trurzel des letzteren rahnfarben. Fübe hräunlich fleischfarben. Zehen dunkler. Flügel 120-126, Schwanz 67-72, Schmahrel 12-14. Laluf etwa 2:3-24 mm. Infolge der Abuntzung der hellen Federsïmme sieht dis Sommerkleid ohen viel dunkler alus. der zimmrote (oherkenf erscheint einförniger, reiner. Dis o ist auffallend kleiner (Flügel etwa $112-11: 3 \mathrm{~mm}$ ), die Oherseite ist ein wenig graulicher: der (oherkopf ist nicht zimmtrot, sondern hell bräunlichgrau mit schwarzhraunen Streifen, ehenso die ohrdecken, die kleinen und mittleren Oherflïgelderlien sind hlisser rimmtrot und weiblich gesätunt, die Brustseiten schwarzhram gefleckt. die Kehle reichlicher gefleckt. Die Jungen ähneln den o die iuberste steuerfeder hat mahe der spitze einen braunen Fleck, den man auch bei alten Weibchen manchmal findet.

Bewohnt die südrussischen Stepuen, Transkaspien, dis westliche Turkestan bis zum Jenissei. - Im Herhst und Winter mehr umherstreichend, dann nicht selten in der Türkei, einmal in Lngarn, Polen, Galizien, 'l'irol, vereinzelt bis West-Furopa, z. B. zweimal auf Helgolind, dreimal in Nüd-Fingland, dreimal in Belgien, melnrfach in Italien u. a. m. festgestellt.

Lebt auf Steppen und grasigen 'l'riften. Kommt an ihren Brutplätzen wieder an, wenn das Gras grün wird. Im Winter in großen Flügen. Singt ein schönes kräftiges Lied, steigt aber nicht so hoch in die Lüfte wie die Feldlerche, sondern kehrt nach kurzem Fluge wieder zum Lrdboden zurïck. Nistweiso wie die der Feldlerche. Die 3-5 Eier sind meist etwas grünlich und grobgrefleckt und gleichen ganz denen der Kalanderlerehe, nur daß sie viel kleiner sind. Rey mißt 72 Eier aus der Gegend ron Astrachan wie folgt: Durchschnitt $22.6 \times 16.3$, Maximum $24.3 \times 16.8$ und $23.5 \times 17.2$, Minimum $21.6 \times 16$ und $23 \times 15.5 \mathrm{~mm}$. Hittleres Gewicht $213 \mathrm{mg}$.

\section{Melanocorypha mongolica (Pall.).}

Alauda mongolica Pallas, Reise d. versch. Yror. d. Russ. Reichs III, p.697 (1776- „in campis salsis inter Ononem et Argunum abundat").

Alanda sinensis Waterhouse, Proc. Zool. Soc. London 1839, p.60 ("China“, nach zwei im Zool. Garten gestorbenen Stücken, Typus im Brit. IIuseum).

Abbild, in Radde's Reise S.O.-Sibirien, Vögel II, Taf. 3 (1863).

Im allgemeinen $1 /$, silhivice ähnlich und möglicherweise als geographische Form der letzteren anzusehen, aber durch folgende zum T'eil sehr seharfe Merkmale

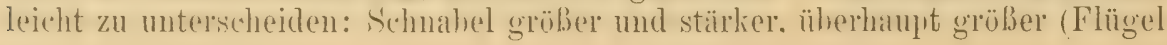


etwa 132-1:36 mu); anf dem dunkler lebhaft renthraunen P'ilenm cin hräunlich।

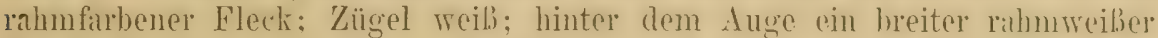
Streif, der sich mit einem das Hinterhanut umfassenden Halhkireise von bräunlicher Rahmfarbe rereinigt; äubere Armschwingen fist bis zur Wurzel weiB; Rüchenfedern lichter, weiBlicher gesïunt; Obersehwanzdecken zimmtbram; an den Kropfseiten ein grober schwarzer Fleck, der sich am Vorderhalse in schmaler Binde vereinigt. dem ơ ähnlich (also der Oberliopf

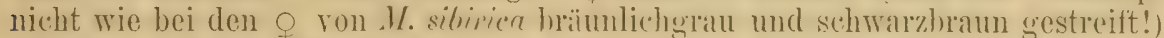
aber das schwarze Kropfband in der Mitte ganz unterlorochen, der Oberü̈cken etwas graulicher, Flügel etwa 10-_-12 mm kïrzer. Winterkleid ohen mehr bell aschgrau gesäumt. die Federn des schwarzen Kropfhandes mit weiblichen Rändern, solab dasselbe oft in der Mitte scheinbar unterhochen ist.

Daurien, Mougolei bis Mandschurei. - Im Minter anch in Nord-China.

Nur teilweiser Strich- und Zugvogel, wie $M$. sibirica, auf den Hochebenen und hochgelegenen Steppen ihres Verbreitungsgebietes. Singt wie andre Lerchen meist im Fluge, der eigentliche Gesang soll nicht so lang und laut wie der andrer MelanocoryphaArten sein, sondern kurzstrophiger und etwas an den der Feldlerche erinnern, aber diese Lerche ahmt wie die Kalander andre Gesänge nach. Fortpflanzung und sonstige Lebensweise wie die andrer Lerchen. Eier denen der Haubenlerchen ähnlich, $\mathrm{Maße}$ nach 'Taczanowski $24 \times 18.3,23.5 \times 18.1,23.4 \times 17.5,23.2 \times 18.2,23.2 \times 18,23 \times 18$, $22.7 \times 17,22.3 \times 17.2,22.2 \times 17 \mathrm{~mm}$.

\section{Melanocorypha yeltoniensis (Forst.).}

Molrenlerehe.

Alundu ycltoniensis Forster, Philos. Transat. LVII, p. 350 (1767 - Suid-RuBland, untere Wolga beim See Yelton oder Elton).

Alauda tatarica Pallas, Reise d. versch. Pror. d. Russ. Reichs II, p. 707, Tab. C (1773.

"Hab. in desertis aridissimis, salsis inter Volgam et Jaïcum, itemque in toto deserto tatarico australiore .......).

Alauda mutubilis (imelin, Syst. Nat. I, p. 796 (1788 ex S. (i. Gmelin und Latham: „Habitat in desertis Astracanicis ....").

Alauda nigra Stephens, in Shaw's Gen. Zool. XIV, p. 25 (1826- ex Levaillant, Ois. d'Afr. IV, "Le T"ncal": Ar moblich aus Süd-Afrika, was natürlich unrichtig ist). Nigrilaula nigra Bogdanow, Vög. Cau asus (russisch), p. 76 (1879).

Abbildungen im „Neuen Naumann“ III, T'af, 3 und anderwärts.

Oad. Das gesante Gefieder brännlichschwarz, die Federn der oherseite und der Körperseiten mit hreiten, die des Vorderhalses, der Kropfgegend mud Brustseiten, die [Tnterschwanzdecken und Schwingenspitzen mit schmalen filhlhräunlichweißen Sämmen. Schuahel bräunlichgrau, an der Trurzel gellolich, Füße grauschwarz. Im Frïhjahre nutzen sich die hellen Federsïune derart ah, daß sic sich unten ganz verlieren und oben sehr schmal werden, ja schließlich nur yoch auf dem Rücken als schmale Ränder zu bemerken sind. Flügel $128-136.5$. Sehwanz etwa $70-75$, Schubliel $14-15$, Lauf $25 \mathrm{~mm}$. o rom Oेganz verschieden; Federn der Oherseite hellfahlbräunlichgrau, in der Mitte dunkelbraun. Schwingeu dunkelhraun, die änßeren und immern mit hreiten, die mittlern mit schmalen weißlichen Süumen. Stenerfedern schwarzbraun mit reißlichen, an dem äußern Parr die ganze Anßenfahne cinnehmenden Säumen. Unterseite weiß, Federn der Kropforegend und Seiten in der Mitte tieflraun. Lnterflügeldecken brämnlichschwall\%. Kleiner als das O. Flügel 
etwa 1 cm kürzer. Die Jungen sind den o älınlich, erscheinen aber noch mohr gefleckt. dir die federsiume dor Oberseite rostfarbiger sind und sehen daher mehr einer jungen Ohrenlerche ähnlich.

Die Mohrenlerche bewohnt die Salzsteppen von Transkaspien, die Kirghisensteme his zur Wolga, ïstlich his Turkestan. nördlich his WestS'ihirien. - In Wrinter in scharen und mehr umherstreichend, z. B. mitunter

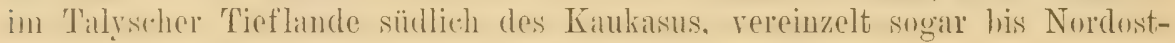
galizien (Schauer), Helgoland und Belgien.

Brehm nennt diese Lerche eine der anmutigsten Erscheinungen der Steppe. Der Gesang ist wundervoll, an den der Kalanderlerche erinnernd, und wahrscheinlich wie jener mit den nachgeahmten Liedern andrer Vögel gemischt. Das kunstlose Nest steht wie das andrer Lerchen am Boden und enthält meist vier Eier, die denen der Kalanderlerche ähneln, aber, wie es scheint, infolge noch gröberer und weniger zahlreicherer Fleckung die Grundfarbe mehr erkennen lassen. Sie messen durchschnittlich von 25.5 bis $26 \times 18.5$ bis $19 \mathrm{~mm}$ und wiegen 300 bis $350 \mathrm{mg}$.

\section{Giattung CAIANDRELLA Kiml) 182\%.}

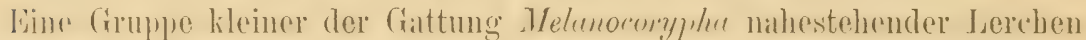

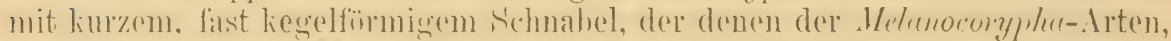

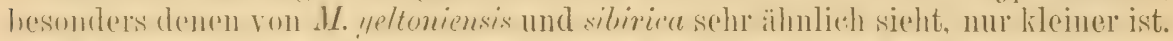

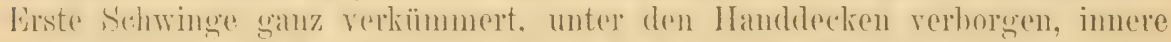
Armschwingen stalk rerlïngert. oft so lang wie die Handschwingen, nutzen sich ather viel mehr ah). Flïgel und Sr.hwanz mittellang his ling, die zweite bis vierte Schwinge meist retwal gleich und am lingssten. Nagel der Hinter-

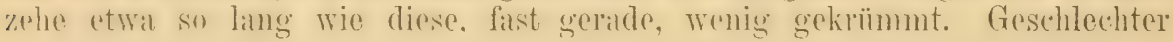
gleich. Die minor-Gruppe generisch zu tremen, hat keinen praktischen IV ert. Dire Cutersehiede sind tredflich z.n spezifisther, ather nicht wohl z.u

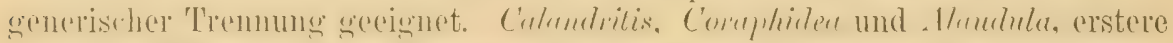

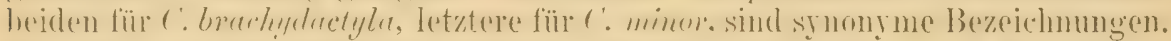

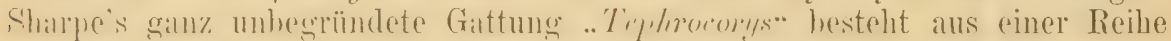

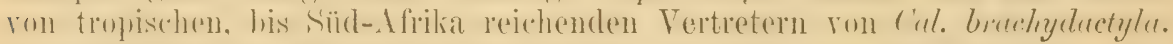

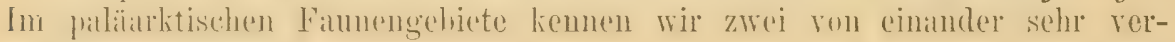
schiedene Arten.

Übersicht der paläarktischen Arten:

Innere Armschwingen so lang wie die Handschwingen oder wenig kürzer, Kropfseiten mit dunklem F'leck, Kropfgegend nicht merklich gefleckt C. brachydactyla . p. 214 Innere Armschwingen merklich kürzer als die Handschwingen, Kropfgegend scharf geflectit . . . . . . . . . . . . . C. minor . p. 217

\section{Calandrella brachydactyla brachydactyla (Leisler).}

Die kurzzehige Lerche.

?? Alauda testacea Gmelin, Syst. Nat. I, p.797 (1788- ex Latham, Syn. II, 2, p. 393: Gibraltar! Der Name testacea ist m. E. ganz undeutbar, da er sich fast ebensogut auf Agrobates galactodes u. a.m. beziehen könnte).

Alauda brachydactyla Leisler, Annalen der Wetterauischen Gesellsch. III, p. 357, Taf. 19 (1814- „Frankreich und Iţalien. Typischer Fundort Montpellier in SüdFrankreich".). 
Alauda arenaria Vieillot, Nouv. Diet. d'Hist. Nat. I, p. 343 (1816- Frankreich: siidliche Provinzen und Champagne).

? Alauda Kollyi 'l'emminck, Pl. Col, 305 (1824- nach einem bei Dijon gefangenen Käfigvogel. Wahrscheinlich eine C. brachydactyla, aber die gefleckte Brust erinnert an $C$. minor.).

Alauda calandrella Savi, Orn. Toscana II, p. 67 (1829- 'Toskana).

Melanocorypha Itala Brehm, Handb. Naturg. Vög. Deutschl., p.311 (1831- „Italien, besonders Sardinien").

Phileremos moreatica Mïhle, Oru. Griech., p. 38 (1844- Griechenland).

Melanocorypha affinis Brehm, Isis 1845, p. 343 (Griechenland).

Melanocorypha Gallica Brehm, Isis 1845, p. 345 („Süd-Frankreich, namentlich bei Montpellier").

Mclanocorypha tenuirostris Brehm, Isis 1845, p. 346 (ohne Vaterlandsangabe, nach Vogelfang, p. 121, "in Griechenland und bei 'Triest").

Calandritis Kollyi (?Temminck) Cabanis, Mus. Hein. I, p.123 (1851- N.O.-Afrika).

Alauda macroptera A. E. Brehm, Journ. f. Orn. 1854, p. 77 (N.O.-Afrika).

Melanocorypha graeca Brelim, Vogelfang, p. 121 (1855- „, Griechenland bis Sennaar6). Calandrella hermonensis 'Iristram, Proc. Zool. Soc. London 1864, p. 434 (Hermon und Libanon).

Calandrella brachydactyla albicollis und bifasciata A. E. Brehm, Verz. Samml., p. 8 (1866- nomina nuda!).

Calandritis immaculata Homeyer, Journ. f. Orn. 1873, p. 194 (ex Brehm M.S.-Spanien). Engl.: Short-toed Lark. Franz.: Calandrelle. Ital.: Calandrino.

Sad. Oherseite erdhraun mit hreiten, fihl simdfubenen Säumen, unterer

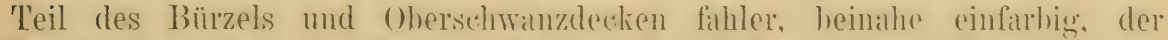
Oherkopf meist stark rothräunlich. 7ägel und Superciliastreif rahmnfurben. S'chwingen dunkelgraubraun, die äuberste (entwickelte) mit rahmfirbener Aubenfabue, die übrigen mit ehensolehen sehmalen Sïumen. innere Amsehwingen breit fahlsandbräunlich umsäumt. Alle Schwingen mit weiblich-

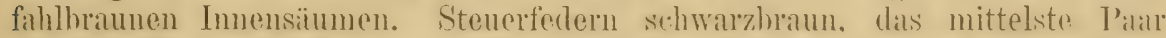
wie der Rürken, dab äuberste P’ar mit dem Sehafte, der Aubenfahne, mit Ausmahme dex Trurzel, und grobem leilfömigen Flecti an der Innenfihne weiß, oft, hesonders nach der Syitze zu rahmfardig angehaucht. zweites Pala mur an der Aubenfahne weiß. Cuterseite weil. mit rahnfirbenem Anflug; ()hrgegend bellhaum, in der Mitte am bellsten, nahe dem Sumereilium am duukelsten,

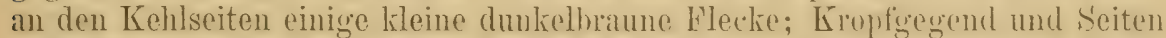
hellrötlichfahlhraun, an den Halsseiten jederseits ein grober schmalzhrauner Fleck. Unterflïgeldecken rahmweib. Iris bram. Oherschabel dunkel hormbram. Unterschmabel hell hornfarben. FüBe hräunlich fleischfirhen. Flügel 9:3-96, Schwanz etwa 62, Lauf 20-21. Sehnabel etwa $11 \mathrm{~mm}$. f wie d', mur wenig kleiner. Dis erste Jugendkleid ist oben gefleckt, indem die dumklen Federn scharfe weißliche Säume haben.

(Diese Lerche ist sehl rariabel und rariert angenscheinlich nach der Färbung des Bodens, auf dem sie leht, ohue aber (auBer in Asien) geographisch ahorenzhare Formen zu hilden. Sehr rötliche Stücke findet man in Frankreices. Italien, Spanien. Portugal. der Her\%egowina, Griechenland, Palästina (sogenaunte hermonensis, nach abgetragenen Brutexemplaten beschrichen): ebenso rötliche. bisweilen noch lichtere, zum Teil sehr helle in Marokko, Algier. Tunis. Einige frisch rermauserte Stücke aus Palästina (Jerusalem) sind auffallend graulich, weiter nach Osten hin aber nimme die graue Firhumg zu, sodab wir dort

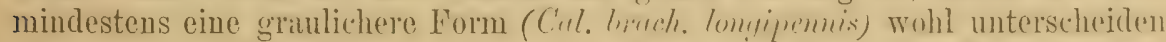
kömneu. In Afrikia finden sich mehrere Subspezies dieser Art, dio sich durch 


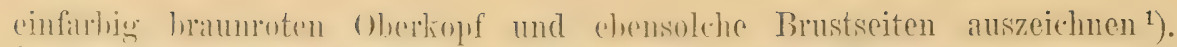
Sie wurden irrtïmlieher Weise unter lem Namen Trphrororys generisch

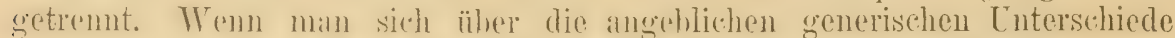
informieren will, mag man den Sehlüssel der Lerehergattungen im Catalogue of Birds XIII, p. 512-513, nachsehen, wo die Nummern $b^{4}$ und $a^{6}$ rinander wirlersprechen, solal.s die Intersehiede weglallen, oder die GattungsDiagnosen in Shelley's Birds of Africa III, p. 122 und 128, die fast gleich lauten.)

Süd-Europa: Süd-Frankreich, nördlich noch in der Champagne bis

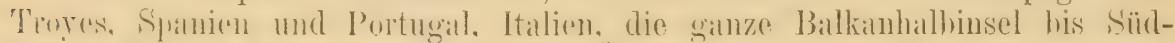

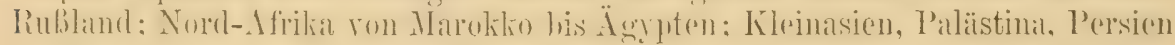

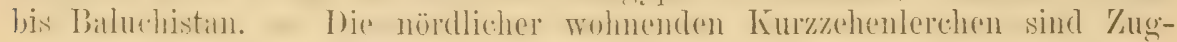
vïgel, die his in den siudiun und nalch N.W.-Indien Wandern. Terfliegt sich vereinzolt weiter nach Norden, z. B. melıfath anf Helgoland und in England, eimmal in Irland, Nord-Frankreich, der Schweiz und bei Metz erlegt.

Bewohner trockenen, sandigen, spärlich bewachsenen Geländes, namentlich in wüstenartiger Steppe. Gesang laut flötend, wenig zusammenhängend, mit den oft wiederholten Locktönen durchsetzt, soll auch andre Gesänge nachahmen, was aber einige Beobachter leugnen. Das Nest steht am Boden wie das andrer Lerchen, ist lose zusammengeschichtet und mit Haaren und Pflanzenwolle weich ausgefüttert. Im April und Mai findet man die Gelege von 4-5 Eiern, die außerordentlich variieren. Sie sind meist weißlich, gelblich, bräunlich, seltener blaß grünlich, mit blaßbräunlichen, gelbgrauen oder bräunlichgrauen Flecken über und über bedeckt, manchmal kranzförmig gezeichnet. Bisweilen sind die Eier fast weiß. Durchschnittsmaße von 14 ausgewählten Gelegen aus Montenegro nach Reiser im Mittel $19.7 \times 14.6$, im Maximum $23.8 \times 15.2$, Ninimum $17.5 \times 13.4 \mathrm{~mm}$. Gewicht $12-18 \mathrm{cg}$. Das Durchschnittsmaß der ron Koenig in 'I'unis gesammelten Eier ist etwa $22 \times 16 \mathrm{~mm}$, Gewicht durchsehnittlich $14 \mathrm{eg}$.

\section{3:35. Calandrella brachydactyla Iongipennis (Frersm.).}

Alanta longipennis Eversmann, Bullet. Soc. Imp). des Natural. Moscou XXI, p. 219 (1848Songarei). ( $\mathrm{V}$ gl. Journ. f. Orn. 1877, p. 95.)

Calandrella acutirostris Hume, Lahore to Yarkand, p.265 (1873- Yarkand).

Calandrella brachydactyla $\beta$ temuirostris Severtzow, Turkest. Jevotn., p. 67 (1873nomen nudum! 'Turkestan. - Übers.: Journ. f. Orn. 1875, p. 174.).

Calandrella tibetana Brooks, Stray Feathers VIII, p. 488 (1880-, "Thibet beyond Silkin.1.").

Unterscheidet sich von C. b. brachydactyla durch merklich graulicheren Ton der oherseite, welehe ganz der rötlichsandfahlen Färbung enthehrt. Der

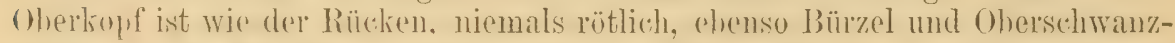
decelen. I)er weibliche Surereiliarstreif ist sehr dentlich! Der Sehmabel ist meist etwas schlanker, der Flügel 3 bis $5 \mathrm{~mm}$ kürzer. - So leicht es ist, rine Serie von der Grenze rou Siklim ('Tihet) oder ron T'urkestan zu unterseheiden. so wenig leieht ist es, die Grenze natch Westen genau anzugehen. demn anch ostpersische Stäcke (die ich aller im allgemeinen nicht ron $t$. b.

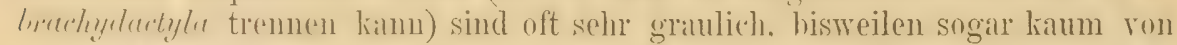
den turkestanischen zu unterseheiden, anf der andern Seite finden sieh in Turkestan und noch mohr in Transkilspien hrïunlichfihle kxemplare, die der

1) Calandrella brachydactyla cinerea, mficeps, blanfordi (auctorum!) u. a.m. 
typisehen lrachychrtylie ganz nabe kommen. (Die zur Enterscheidung von acutirostris und tilntener henutzte Ausdehnung des Teib an den Steucrfedern ist ganz variabel.)

Transkaspien, Turliestan, Afghanistan und 'T'ihet. - Im Minter in den westlichen T'eilen Indiens.

\section{Calandrella brachydactyla dukhunensis (Sykes).}

? Emberiza bagheira Franklin, Proc. Zool. Soc. London 1831, p. 119 (nom. nudum). Alauda dukhunensis Sykes, Proc. Zool. Soc. London 1832, p. 93 (Dukhun, Indien).

Ähnlich C. b. Urachydactyla, unterscheidet sich aber durch die mehr fahlhräunliche, fist gelbliche Fïrbung der Unterseite, besonders der Kropfgegend, dunklere Körperseiten und hrïunliche Oberseite. Flügel meist riemlich lang, oft mehrere mm länger, als hei $(\vdots$. b. brachydurtyle im Durehschnitt.

Wintervogel in Indien, mit Ausnahme der westlichen Teile. -- Brutheimat unbekannt, wahrscheinlich in einem Teile Tibets.

\section{Calandrella minor rufescens (Vieill.).}

Alauda rufescens Vieillot, Tabl. Enc. et Méth. I, p. 322 (1820- "Ténériffe").

Alaudu tigrina Bonaparte, Compt. Rend. Séances Acad. Paris XXXYII, p. 67. Anmerk. (1854- nom. nudum).

Calandrella pispoletta canariensis Hartert, Bull. B. O. Club 1901, p.6t (Tenerife). Calandrella pispoletta rufescens Hartert, Aus d. Wanderj. c. Naturf., p. 106 (1901- Geschichte, Synonymie, Kritik); Nov. Zool. 1901, p. 325.

Enterscheidet sich ron allen Verwandten durch die zimmtartig riotlichbraume Färbung der Oherseite. Die schwarzhramen Federmitten sind sehr ausgedehnt, die Fleckung der Kropfgegend gröher und dunkler als hei C. m. minor, aber meist nicht ganz so grob wie bei $C$. m. baetica. Dio ralımweibe Cuterseite ist fist immer dureh den rothaunen Ackerboden, anf dem diese rögel lehen, heschmutzt, mu frische Herhstrïgel sind fiei ron dieser Beschmutzung: o: Flïgel etwa $88-91^{1} / 2 \mathrm{~mm}$.

Bewohnt die fruchtbare Hochehene vom Lastuma anf Tenerife, wo sie sehr häufig ist.

\section{Calandrella minor polatzeki sulsp. nor.}

Eine große Serie (32 Stück), die ich mit einer ebenfalls guten serie ron Tenerife reroleichen kounte, zeigt, dab sich (entgegen meiner früheren Ansicht) die Lerehen der ïstlichen Canaren gut unterscheiden lassen. Sie sind ohen hellel (nicht so zimmtartig) lütlich sandfuben und etwas kileiner als C.m. mufescens. ơ: Flügel $87-88$, nul in einem Stücke $91 \mathrm{~mm}$. Der junge gefleckte Vogel hat rötlich rahmfarhene Spitzen an den Federn der Oherseite. - Benaunt zu Ehren des cifrigen Sammlers Herrn Hauptmann Polatzek. 'Typus o'. Nr. 1178, Lanzitrote 3. III. 1902. gestmmelt von Polatzek.

Lanzarote und Fuertaventura, also die östlichen Inselu der ('anaren-Gruppe.

Die zahlreich vorliegenden Eier ähneln denen der verwandten Formen, doch ist die Grundfarbe meist etwas weißlicher, fast nie so grünlich, sodaß die Flecke sich stärker abheben. 54 Stücke von Fuertarentura messen im Maximum $23.5 \times 14.7,21.7 \times 15.4$, $21.5 \times 14.8$, im Durchschnitt $19.7>14.2$, im Hinimum $20<13$ und $17.6 \times 14 \mathrm{~mm}$ und wiegen etwa $136 \mathrm{mg}$. 


\section{Calandrella minor baetica Dresser.}

Calandrella bactica Dresser, B. Europe IV, p. 351, Taf. 236, fig. 2 (1873- Sevilla).

Auf der (Oherseite riel dunkler und hramer als C: m. minor und C. m. heinei, anlinedem ron heiden dureh die viel gröberen, dunkleren, sehwaryhraunen Längsflectie dex Kropfugegend zu unterscheiden, die sich üher die Kehle hin his fast an den simabel und an den Körperseiten entlang ziehen. Größe etra wie die von C.m. minor. Die Färbung der Oberseite variert wie bei allen Verwandten, ohne aher den charateristischen dunklen Ton zu verlieren.

S'̈̈d-Spanien (die Provinzen Andalusien, Granada, Mureia, Valeneia). ${ }^{\mathbf{}}$ )

Bewohnt zur Brutzeit hauptsächlich die Marismen. Fortpflanzung wie die der verwandten Formen, aber die Eier scheinen meist etwas gröber gefleckt zu sein als die von C.m. minor und C. m. heinei.

\section{Calandrella minor minor (Cab.).}

Calandritis minor Cabanis, Mus. Hein. I, p. 123 (1851- „N.O.-Afrika“).

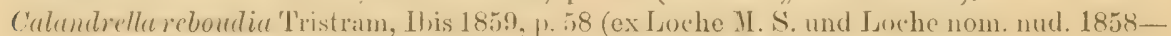
"In Sahara Algeriensi“").

Calandrella deserti 'Tristram, Ibis 1866, p. 286 (Sahara - nomen nudum).

Abbildung: Dresser, B. Europe IV, 'T'af. 236, fig. 1.

ơ ad. Oherseite hell rötheh sandfarben, die Federmitten schwar\%haum. B̈̈r\%clfedern und (Oherschwanzdecken rötlicher, in der Mitte nicht schwarzhram, somelem mehr rosthraun. S'chwingen dunkelhram mit licht isalhellfarbenen Auben- nud Innensïmmen und Śpitzen, die letzten Almschwingen von der Fïrbung des liückens. Steuerfedern sehwarzhraun mit sehmalen woiben

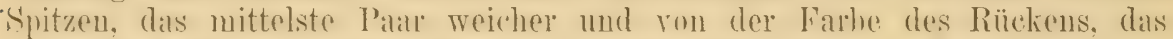

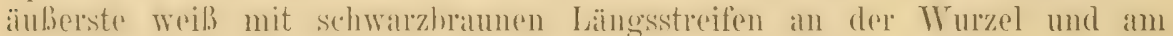

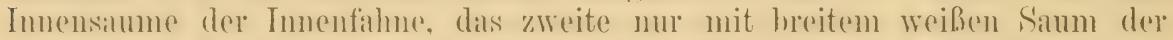

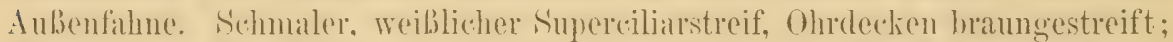
Interseite weif mit leichtem isahellarhenen Schimmer, die Seiten der Kehle, Kropfugerend und Brustseiten mit dunkelhamen, schmalen Längsflecken in der Vitte der Federn. Körperseiten isabellhrämble?, dunkel gestreift. Tnterflügeldecken weil.s mit isabellfarbenem S'chimmer. Schnabel hornartigg gratubran, unten geelblich, Fübe hröumlichfleischfarhen, Iris bram. Flügel 90-94, Schwanz etwa 55-60, Lauf $20-22$, Schnabel $9-9.5 \mathrm{~mm}$. O wie $0^{7}$, nur etwas kleiner. Durch die breiten hell isibellfubenen Foderänder erscheint das Herbstkleid lichter. Zitrter, während nach der Brutzeit die dunkeln Federmitten mehr hervortreten. Sitücke von Algier (Medeah) scheinen etwas dunkler als tunesische.

Bewohner der nürdlich des großen Wüstengürtels golegenen Lüuder, von Maroklo, dureh Algier und 'Tunis bis Ägynten (Unter-ägypten, selten) und l'alästina, atuch in cinem Stücke vou Fao am Persischen Golf im British Museum. Bei Fa wohl mu auf dem Zuge, dem dort brïtet C.m. pessica oder eine sehr nahe Form. Vereinzelt in Malta und Italien.

1) Zwei mir rorliegende, angeblich von den Balearen stammende Stiicke, leider ohne Datum, sehen auf der Oberseite aus wie C.m.bactica, aber die Fleckung der Kropfgegend ist feiner, mehr wie die von C. m. minor. Vielleicht wäre die BalearenForm zu sondern. Was A. v. Homeyer (Journ. f. Orn. 1862, p. 266) C. brachydactyla nannte, ist vielleicht diese Form der minor-Gruppe gewesen. 
Man findet diese niedliche Lerche nur an gewissen Örtlichkeiten, nach Koenig meist in der Nähe des Wassers. Sie ist auf dem rötlichen Stepuenhoden, den sie bevorzugt, schwer zu sehen, meist aber gar nicht scheu. Wie die Feldlerche „klettert sie an ihren Liedern in die Luft" und singt wunderschön, wenn auch sehr abwechselnd an Stärko und Klang. Die Nester sind kunstlos, wie die andrer Lerchen, meist mit Pflanzenwolle ausgepolstert. Die Gelege bestehen wahrscheinlich nur aus drei Eiern. Man findet die Eier vom April bis Juni. Sie sind auf weißlichem oder graugrünlichem Grunde mit lehmbraunen Flecken besät, zwischen denen man hier und da violettgraue Schalenflecke bemerkt. Sie sind gedrungen eiförmig und messen $18 \times 14,19 \times 15,20 \times 14$, $20 \times 15,20 \times 16 \mathrm{~mm}$.

\section{Calandrella minor heinei (Hom.).}

Calcendritis Heinei E. v. Homeyer, Journ. f. Orn. 1873, p. 197 (Wolgagegend).

(Calandrella pispoletta auctorum. - Dieser Name ist von Alauda Pispoletta J'allas, Zoogr. Rosso-Asiat. I, p. 526 genommen. Pallas adoptierte Linné's Namen Alauda spinoletta, dessen Schreibweise er, der italienischen angemessen, in pispoletta veränderte. Linnés Name gehört einem Anthus an, wurde also von Pallas mit Unrecht auf die von ihm beschriebene Lerche angewandt. Dieser alteingewurzelte Irrtum ist somit zu beseitigen und der nächst alte Name einer Stummellerche, minor Cab., muß für die Art mit ihren F'ormen in Anwendung kommen.)

Abbildung: Dresser, B. Europe IV, Taf, 237.

Wie C. ninor minor, aber die Oberseite nicht so sandfarben, sondern mehr gläulich, hesonders der Bürzel weuiger ritlich, meh" sandgrau; außerdem gröBer als C. m. minor. Flügel ơ ad. 95-100, Schwanz etwa 63-66, Lauf 21-22.5, Schnabel $9-10 \mathrm{~mm}$.

Stepuen Süd-Rublands und Transhaspieus. - In Herbst und Winter mehr umherseliweifend und damn ausnahmsweise anch in anderen Ländern, so einmal anf Helgoland. RegelnüBig in Klein-Asien, aber wahtstheinlich nur als Wintergast.

Fortpflanzung wie die von C. m. minor, nur sind die Eier meist etwas trïber und grünlicher, durchschnittlich auch etwus größer. 54 . Eier aus Südrußland messen nach Rey: Durchschnitt $18.8 \times 14.6$, Mrximum $20.1 \times 15.2$, Ninimum $17 \times 13.8 \mathrm{~mm}$. Durchschnittliches Gewicht $139 \mathrm{mg}$.

\section{Calandrella minor leucophaea Serertz. ${ }^{1}$ )}

Calandvella leucophaca Sewertzow, Turkest. Jevotn., p. 142 (1873- Turkestan); vergl. Dresser, Ibis 1876, p. 182.

Wie C. m. Teinei (C.. pispoleth auctorum), aber auf der Oherseite heller, mehr graulich, der Schnahel sehr klein. Äußeres Stenerfederpar weiß, schmaler Innensaum und äuBerste Basis del Innenfahne braungrau, diese Farbe aher am Innensaume nicht ganz bis zur Spitzo reichend.

1) Im Cat. B. Brit. Mus. XIII, p. 593, ist diese Form als Subspezies zu Calandrella raytal (Blyth) gestellt, während die nur schwer zu unterscheidende, lediglich oben etwas mehr gelbbräunliche seebohmi als Subspezies zu "pispoletta" (minor) aufgefaßt ist! Diese lediglich auf Vergleichung der Färbung der. Oberseite beruhende Trennung ist unrichtig. Culandrella raytal raytul (Blyth, 1844) und C.raytal adamsi (Hume, 1871) bilden eine indische Art, die sich durch geringere Größe, dünneren und gestreckteren Schnabel und längere innere Aimschwingen von den asiatischen Formen der minorGruppe selı wesentlich unterscheidet. 
West-Turkestan (Amu Darja, Syr Darja). - Im Winter anscheinend weiter natch Süden ziehend, 7. B. nach Ost-Persien. Genaueres diurïher ist schwer festzustellen. weil man sich auf die Angaben in der Litteratur nirht immer verlassen kamm, wie es häufig hei schwieriger zu hestimmenden Formen der Fall ist.

\section{Calandrella minor seebohmi (Sharpe).}

Alaudula scebohmi Sharpe, Cat. B. Brit. Hus. XIII, p. 590 (1890- „Central Asia from Yarkand and Kaschgar to Mongolia“. Diese Verbreitung ist nicht richtig, denn das angeblich mongolische Stück, ungliicklicher Weise der Typus, ist irrtïmlicher Weise „Mongolia“ etikettiert; es stammt vielmehr aus Turkestan, wo es ron Sewertzow gesammelt wurde).

Genau wie C.m. lencophaea, nur auf der Oberseite nicht so graulich, sondorn gelb-bräunlich sandfarben.

Ost-Turkestan (Yarkand, Kaschgar, Aksu). - Im Winter hisweilen in Nord-Indien.

\section{Calandrella minor persica (Sharpe).}

Alaudula persica Sharpe, Cat. B. Brit. Mus. XIII, p. 590 (1890- „From Persia to Afghanistan and N.W.-India". Diese Verbreitung ist nicht richtig, denn die Stücke von Afghanistan und N.W.-Indien gehören einer andern Form an. Typus: Niris östlich von Schiras, Persien, terra typica also: Niris in Persien).

Ëine sehr grofschmählige Form, Flïgel his $100 \mathrm{~mm}$. Äußeres Steuerfederpaar weiB, an der Innenfahne hreit braunschwarz gesiumt. (Oberseite licht sandbrïunlich.

Persien. - Genaue Verbreitung nicht bekannt. Der Typus von Niris hat dinen sehr lingen und starken Schnahel. Fïn alter Brutrogel von Fin an I'ersischen (iolf hat einen etwas kürzeren und dabei dickeren, geschmolleneren S'Chnahel. Fine grobe in S'eistan in Ost-Persien von Sinudny gesimmelte serie hit auch stirliere Schnähel als alle andern Formen dieser (trupure, aber sie stehen hinter denen des Stiickes ron Niris und dem von F'an zurück. Lis dürfte sich bei Vergleichnng einer Serie ron Niris und Fan ergeben, dab in P'ersien 2 his 3 Formen vorkommen: eine kleinsehnähligere von Seristan und Afghanistan. die vielleicht im Winter auch in Nord-Indien

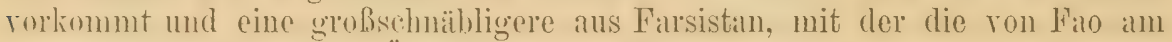
Persischen Golf grobe Ähnlichleit hat, aher vielleicht anch nicht ganz ïhereinstimmt. Im Winter scheint anch noch C. m. Lencophae in Ost-I'ersien vor'zukommen.

\section{4.). Calandrella minor cheleënsis (Swinh.).}

Alandula chelec̈nsis Swinhoe, I'roe. Zool. Soe. Lourlon 1871. p.390 (Talien Bay" in China).

Ziemlich kileine, feinsehnäblige Form mit fein und schwach grefleckter Kropfgegend.

Brutrogel in der sïdöstlichen Mongolei und Nord-('hina. - Im Winter in großen Flügen bei Peking. 


\section{Calandrella minor kukunoorensis Przer.}

Calculrelle kuknoorensis Przewalski, Jlong. istrana 'T'angut II. p. 10:3(1876-- Kukunonr); (russisch!) vgl. Übersetzung in Rowley's Orn. Misc. II, p. 316 und Journ. f. Orn. 1877, p. 93, Anm.).

Nach Przemalski und Bogdanow eine hlab isabellfarbene Form ron

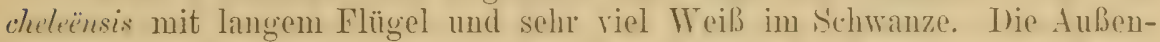
fahne des dritten Steuerfederpares soll weib sein, die Inuenfahne weib mit dunkelbraunem Saume.

Kuku-Nor:

\section{Gattung AMIMOMANES Cab. 18.51.}

Schmabel, Schwanz und Füße nicht wesentlich ron denen von culumdrella verschieden, aber Flügelbau und Körperhefiederung ganz andrers. Das Gefieder ist sebr weich und zalrt, die Federn nicht in der Mitte dunkel, ()her- und Lnterseite erseheinen daher meist ungefleckt. Die erste Schwinge ist ungeführ $=1 / 3$ der zweiten, die bei den meisten Formen merklich kiurzer ist als die dritte bis fünfte, welche meist etwa gleich lang sind und die Spritze des Flügels bilden. - Die jungen gleichen den Alten, sind also nicht gefleclit. Bewohmer der wïstenartigen Landstriche ron den Kapverdischen Inseln durch die Sahara bis Somaliland und Indien. In Süd-Afrika wohnen noch drei zu dieser Gattung gezählte Formen, die zum Teil derart ron den typischen Arten alweichen, dab man sich fast wundern mub, weBhalls sie ron deu großen Gattungsspaltern noch nicht generisch getrennt wurden. Die auf den ersten Blick sehr rerschiedene tropisch indische A. phomicure wird durch zarulnyi mit cinctur rerhunden, sodaß man alle diese Formen als Subspezies einer Art behandeln muß.

\section{Übersicht der paläarktischen Arten:}

Innere Armschwingen nicht länger als die übrigen, Schwanz ohne scharf begrenzte schwarze Spitze ................. deserti. p. 221

Innere Armschwingen meist merklich verlängert, Schwanz mit scharf abgegrenzter schwarzer Spitze.................... phoenicura. p. 224

\section{Ammomanes deserti algerieusis Sharpe.}

? Alauld lusitana Gmelin, Syst. Nat. I, p.798 (1788- ex Latham, Gen. Syn. II, p. 393 : "Portugal". Der Name lusitana kann nicht angenommen werden, da die Beschreibung der Oberseite auf keine dieser Ammomanes paßt und keine derselben Portugal bewohnt).

Ammomanes algeriensis Sharpe, Cat. B. Brit. Mlus. XIII. p. 645 (1890- „Algerian Sahara, ranging into Nubia"). Abbildung: Journ. f. Orn. 1895, T'af. VIII.

Innere Armschwingen nicht merklich länger, als die ührigen, zweite (erste lange) Schwinge erheblich kürzer, als die dritte.

ơad. Oberseite von einem schwer zu beschreibenden rosigen sandgrau, auf dem Kopfe etwas matter und mit Andeutungen dunkler Federmitteu, Bürzel und Oberschwanzdecken am rötlichsten. Schwingen graubaun, AuBeufahme mit Ausnalmme des Spitzenteiles rötlich zimmthram, an den Spitzen schmal weißlich gesäunt, Imuenfahnen an der Basalhälfte hreit zimmtrot 
gesäumnt, letzte Armschwingen dem Rückeu ähnlich, aber etwas bräunlicher. Stenerfedern sehwarzhraun, Spitzen und breite Außensïume lıell zimmtrot, vorletztes Par mit der ganzen AuBenfahme, das äuBerste nur an der Innenfilme mit hraun, oft fast ganz hell zimmtrot. Unterseite rötlieh rahmfarben, Kehle weiß, Kropfgegend matt hraungrau geffeckt. Unterflügeldecken, Achselfedern und Seiten hell rosig zimmtbrälnulich. Schnabel oben hornbraun, unteu weißlich, Fïl.se licht fleischartig hellhraun, Iris lraun. Flügel 99-103.5, Schwauz 68-72.5, Lauf etwa 22-23, Schnabel 13-15.5 mm. o meist etwas kleiner: Flïgel 91-99, Sehnabel 12.5-13.5 mm. Jur.: wie der alte Vogel, nur auf der Oherseite nicht so graurötlich, sondern mehr gelblich, Unterseite blasser. Gänzlich ungefleckt.

Algerien und 'Tunis südlich der Atlas-Wrasserseheide, von da nach Westen bis Tripolis und durch die libysehe Wïste his an den untern Nil, wo sie in steinig-wüstenartigem Gelïnde hart nehen al. d. deserti vorzukommen und sich mit letzterer manchmal zu vermischen scheint.

Bewolner steiniger Höhenzüge und spärlich bewachsener Abdachungen der Berge in der nördlichen Sahara oder vielmehr an deren Rändern, nicht auf dem fliegenden Sande der eigentlichen Wüste. Der Gesang ist ein lullend weiches, oft wiederholtes viersilbiges "Krieüe", das in den trostlosen Einöden, die das Vögelchen berwohnt, nicht verfehlen kann, den Lauscher zu entzücken. Nester halb unter und neben Steinen, aus feinen Grashalmen, Pfanzenwolle und Blütenrispen wohl gefügt. Hauptbrutzeit Mai. Gelege 3, seltener 4 Eier. Sie sind auf rahmfarbenem oder milchweißem Grunde mit hellgrauen Schalenflecken und rotbräunlichen Flecken und Punkten bedeckt. Sie messen nach Koenig $20 \times 15,21 \times 15,21 \times 16,22 \times 15,22 \times 16 \mathrm{~mm}$, nach Erlanger $21 \times 15$ bis $23>16 \mathrm{~mm}$. Gewicht nach Koenig im Durchschnitt etwa $0.13 \mathrm{~g}$.

\section{Ammomanes deserti erythrochroa Rehw.}

Ammomanes lusitana erythrochroa Reichenow, Journ. f. Orn. 1901, p. 307 (Ambukol).

Wie A. d. deserti, aber der Schnabel meist noch etwas stärker (lünger), die Fïrbung ausgesprochen rötlixher, fast ganz wie bei A. d. algeriensis namentlich auch die Lnterflügeldecken und Lnterseite des Körpers (mit Ausnahme der weiben Kehle) im ahgeriebenen Gefied(x sehr stark isabell-rötlich und dio Shehwanzwumel rötlicher. In dar Färhung A. d. algeriensis äuBerst ähnlich, aber etwas mehr zimmtrötlich, der Schnahel merklich stärker und länger.

Südliches Nubien rom Dongola-Bogen des Nils an (Ambukol, Schendi, Bajuda-Steppe).

\section{Ammomanes deserti deserti (Licht.).}

Alumiu deserti Lichtenstein, Verz. Doubl,zool. Mus. Berlin, p. 28 (Sept. 1823- „ex Aegypto super". Partim! Lichtenstein hatte auch Stücke von erythrochroa vor sich). Melanocorypha galeritaria Brehm, Vogelfang, p. 122 (1855-- "Nordost-Afrika").

Ammonanes deserti macrorhynchos A. E. Brehm, Verz. Samml., p.8 (1866- nomen nudum!).

Ammomanes isabellina minor A. E. Brehm, Verz. Samml., p. 8 (1866- nomen nudum!).

Abbildung: Dresser, B. Europe IV. 'Taf. 233, vordere Figur!

Sehr ähnlich 1. I. algerénsis, aber die Oherseite nicht so rötlich isabell, sondern melı Iräunlichgrat. Einigermaßen variahel, in frischem Gefieder lichter und graulicher, im abgetragenen Kleide dunkler, bräunlicher.

Niltal, von Kairo durch gamz Ober-Ägyten, lis fast nach Dongola, jedenfalls bis Wadi Halfa. 


\section{Ammomanes deserti isabellina ('T'emm.).}

Alauda isabellina 'T'emminck, Pl. Col. 244, Fig. 2 (Oct. 1823, dem Wortlaute des T'extes nach später als Lichtenstein's Beschreibung erschienen. Asaba in Arabien; von Rüppell gesammelt).

Melanocorypha arabs Brehm, Vogelfang, p. 122 (1855 - „Verirrt sich aus dem steinigen Arabien zuweilen nach Europa". Typus aus dem Peträischen Arabien).

Die Stücke ron der Sinai-Halhinsel sind etwals lichter als die meisten von $A$. deserti deserti; sie sind nicht so rosig angehtucht wie die von ulgeriensix; sie werden im abgetragenen Kleide nicht so rötlich wie die von emythrochrou und sind im frischen Gefieder nicht ganz so licht; sie sind groBschnähliger als fruterculus und weniger graulich. Stïcke von Unteregypten stimmen ganz mit solchen rom Sinai überein.

Sinai-Halbinsel (Asiba, Sinai) und Unter-Ägyten. (Berechtigung dieser Form und Verbreitung zweifelhaft, ebenso die von $\mathrm{Nr}$. 351 und 352. Finige Stücke aus dem Niltal, wo sonst die graulichere echte deserti wohnt, sind von solchen vom Sinai nicht zu unterscheiden.)

\section{Ammomanes deserti fraterculus Tristr.}

Ammomanes fraterculus Tristram, Proc. Zool. Soc. London 1864, p.434. (Ohne genuue Lokalität. - W Wüstengegenden Palästina's, nach ,Fauna und Flora of Palestine ${ }^{65}$, p. 80. 'l'ristram's Name muß natürlich für die palästinensische Form benutzt werden, obwohl er die 우 von den ơ, die er deserti nannte, artlich trennte!)

Ganz wie A. d. deserti, aber im frischen Gefieder ist die Oberseite eine Nuance meln graulich, die Kropfgegend meist deutlicher gefleckt, die Ohrgegend ziemlich dunkel und streifig, der Schuabel etwas plumper und kïrzer, bei alten ô etwa $13 \mathrm{~mm}$ lang:

Von Palïstina bis zum Persischen Meerbusen.

\section{Ammomanes deserti parvirostris Hart.}

Anmomanes lusitanica parvirostris Hartert, Journ. f. Orn. 1890, p. 156 („Aschabat". Diese Angabe beruhte auf einem Irrtum. Die Typen sind vom Kuba-dagh bei Krasnowodsk).

Ganz wie A. 1. phoeniruroiles, aher die Oherseite vielleicht eine Nuance leller, der Schmabel merklich feiner und kïrzer. Schnahel 1.5-2 mm kïr'zer.

Transkaspien (Krasuowodsk, Turkmenen-Steppe).

\section{Ammomanes deserti subsp. nov.?}

Anmomanes phoenicuroides (?! non Blyth) Whitaker, Ibis 1902, p.654 (Djebel Soda in 'Tripolis).

Whitaker erwähnt, l. c., daß in den Schwarzen Bergen (Djebel Soda) von Tripolis eine Form der Wüstenlerehe wohnt, die ganz A. d. phoenicuroides gleicht, aber vielleicht etwas kleiner sej, besonders kleiner' S'chabel habe. Ls ist nicht denkbar, daß dies typische phoenicuroides sind oder daß sie mit einer der andern dunkeln Formen völlig übereinstimmen. Diese Form dürfte daher zu benennen sein. 


\section{Ammomanes deserti phoenicuroides (Blyth).}

Mirafor phocnicuroides Blyth, Journ. As. Soc. Bengal XXII, p. 583 (1853- Kaschmir).

Abbildung: Dresser, B. Europe IV, 'T'af. 233, hintere Figur!

Wie A.d. fraterculus und A.d.parvirostris, aber der Schnabel stärker, die Oherseite mit noch gratulicherem T'on, Cnterseite dunkler hrämulich fahlgell. Sichnabel o'ad. etwa $14 \mathrm{~mm}$ lang. Das erste. Jugendlileid ist seho hell, fast rahmfarben.

Bewohnt das Indus-Tal und umliegende Gebiete, ron der Mündung bis in clas nördliche Punjab und südlichste Kaschnir sowie Teile von Afghanistan. ${ }^{1}$ )

\section{Ammomanes deserti subsp. nov.?}

Oberseite noch merklich dunkler und mehr bräunlichgrau, was beim Tergleich einer Serie sehr anflält. Auch das erste Jugendkleid ist oben hräunlichgran mit lichten Federë̈ndron. Obersehnahel dunkel hormbraun, Tnterschnabel gelhlich nit dunkler Spitze. Noch zweifolhafte Form. Stücke

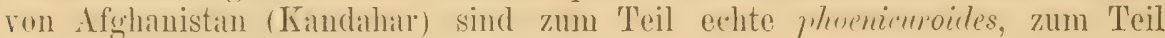
gleichen sie den ostpersischen Stïcken.

Ost-Persien, von der Strabe ron Hormus bis Baluchistan und $\mathrm{A}$ fohanistan.

Die Eier sind unter Nr. 216 (A. phoenicuroides) von Sarudny in Ois. Perse Orientale, 1). 197-200 (1903- russisch!) beschrieben.

\section{Ammomanes phoenicura arenicolor (Sundev.).}

Alanda arenicolor Sunderall, Oefv. K. Vet. Akarl. Förh. Stockholm 1850, p. 128 („in arenosis Aegypti inferioris vel Arabiae petraeae").

Ammomanes pallida Cabanis, Mus. Hein. I, p. 125 (1851- "Arabien").

Melanocorypha elegans Brehm, Vogelfang, p. 122 (1855- "Nubien". 'Iypus von Abu-Hamed.).

Ammomanes regulus Bonaparte, ('ompt. Rend. XLIV, J) 1066 (1857-Algerische Siahara). Abbildung: Journ. f. Orn. 1893, Taf. IX.

Auf den ersten Blick wie eine kleine 1. dezerti alyeriensis aussehend, unterscheidet sich aher sehr wesentlich: Die Handschwingen sind an heiden Fahmen zimmtartig rötlich isabell, mu die äubersten Spitzen rauchschwärzlich

1) Die Liste der Subspezies von A. deserti ist auch hiermit noch nicht erschöpft, denn das tropische Afrika und Arabien beherbergt noch mehrere Formen:

A. deserti akeleyi Elliot, Field Columbian Mus. Yubl. Nr. 17, Orn. Nr. 2, p. 39 (1897-Somaliland. Sehr ähnlich A.d.phocnicuvoides, aber kleiner (kurzfligliger), Unterseite rötlicher. - Mehrfach fälschlich als "A. deserti" angeführt - es soll aber auch eine deserti-ähnliche helle Form im Somalilande vorkommen, iiber die es aber noch an sichern Nachrichten fehlt.

A. deserti samharensis Shelley, B. of Africa III, p. 99, 'T'af. 21, 1 (Mai 1902). Abyssinien: Amba. Damit ist assabensis Salvadori, von Assab an der abessinischen Küste beschrieben, identisch (ef. Bollet. IIus. Zool. et Anat. 'Torino XVII, Nr. 425 p. 2. Juni 1902). Noch dunkler, etwa so groß wie phoenicuroides. Steht saturatus am nächsten und ist von letzterer nur schwer zu unterscheiden.

A. deserti saturatus Grant, Nov. Zool. 1900, 249. - Süd-Arabien. Die dunkelste Form, außerdem sehr groß. Von A. $l$ samharensis kaum zu unterscheiden, aber nicht ganz damit identisch. 
mit schmalen weißlichen Endsïmmen. die Ammsthwingen ganz zimmotritlichisabell. Die inneren Armseliwingen ragen in frischem Getieder etwal I cm über die vordern himas. Schwanz zimmtrötlieh isahell mit schwarzem isathellweiblich gesiumten Fleck an der Spitze, der an dem äuberen Stencrederpan nur klein ist, nach der Mitte zu an Austehnung zunimmt. Fï̈gel 92-97. Sehwanz 56-59, Schnibel 11-11.5. Iauf $21-23 \mathrm{~mm}$. O meist, aher nicht immer, etwas kileiner, sonst wie $0^{-}$. Jur. wic ad., um noch lichter, hlasser; fast rahmfarben.

Ton Algier und Tunis durch die nördliehe Sahnara his in die Wüsten-

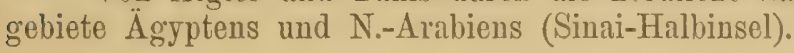

Standrogel auf steinigen Hochplateaus und am Rande der Sanddïnengebiete der Sahara. Das ơ steigt (uach Koenig) wie das von Ammomanes deserti algeriensis kerzengerade in die Luft und wiegt sich ruckweise im klaren Äther, wobei es pfeifend

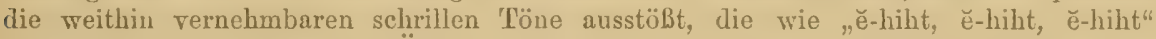
klingen und eine aufallende Ähnlichkeit mit den bei physikalischen Demonstrationen durch Schwingung erzeugten Tönen einer Glasröhre oder eines Holzstabes haben. Das Nest steht in einer kleinen Mulde des Bodens, an oder unter einem schützenden Stein oder Strauch. Der Rand des aus Gräsern und Stengeln gebauten, mit Pflanzen- und. Tierwolle und Lappen ausgefütterten Nestes ist mit Steinen umpflastert, augenscheinlich zur Befestigung des Nestes. Eier 2-3. Mattreiß mit aschgramen Flecken und graubraunen Punkten, meist äußerst fein, am stumpfen Ende gezeichnet. Mabe mach Koenig $19 \times 14,19 \times 15,20 \times 14 \mathrm{~mm}$, Gewicht 0.11 bis $0.12 \mathrm{~g}$.

\section{Ammomanes phoenicura cinctura (Gould).}

Melanocorypha cinctura Gould., Zool. Voy. Beagle III, Birds, p.87 (1841- Insel St. Jago, Kapverden).

Obwohl oberflächlich ïhnlich, doch mit A. ple. arenicolor gar wicht zu verwechseln: Oherscite dunkler, ein tieferes braungran seheint wie untergelegt, wie darauf getragen eine hell rötliche Zimmtfarbe, Schramz und. Flügel dunkler rötlich zimmtfarhen; Lnterseite riel dunkler, der C'nterkiöner nicht fast weiß, sondern hell zimmtartig isabell, die Kropfgegend dunkler und deutlich aschgrau gefleckt.

Kapverden (São Thiago, Boavista).

\section{Ammomanes phoenicura zarudnyi Hart.}

Ammomanes cinctura zarudnyi Hartert, Bull. B. O. Club XII, p. 43 (Januar 1902Mudjnabad in Ost-Persien).

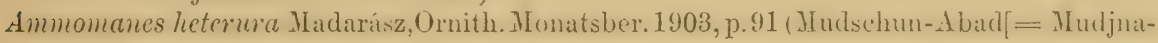
bad] in Ost-Persien).

Von $A . p h$ arenicolor und $A$. ph. cinctura durch die staubartig brälnnlich erdgraue Oherseite auf deu ersten Blick zu unterscheiden. Schwanzwurzel und Oberschwanzdecken rötlich isahell, noch dunkler als hei cinctura. Handschwingen graulich isahell, Basishälfte der Außenfahine und breiter Satum am Basalteile dex Innenfahne hell rötlich zimmtfarben, Spitzen rauchschwarz. Spitze des Sehwanzes viel weiter schwarz als bei $A$. ph. arenicolor und eineture, an den mittelsten Stenerfedern fast bis zur Hälfte. Cnterkörner rahmfarben, Unterschwanzdecken in der Mitte bräunlich-isabell, am Schafte dunkelbraun.

E. Hartert, Die Vögel der paläarktischen Region. 
Kehhnitte weiß, Kreplgegend stark aschgrau gefleckt. Flügel etwa $5 \mathrm{~mm}$ länger als hei A. pho arencolen, FüBe answeinend dunkler. Jur. heller, liehter!

Ost-Persien (Mudschun-Abad, Nusi, Bamrud. Mian-Basaar, PendschSara, Schur-ab) und westliches Baluschistan (Maschkid-Ebene).

\section{Ammomanes phoenicura phoenicura (Frankl.).}

Mirafra phoenicura Franklin, Proc. Zool. Soc. London 1831, p. 119 (am Ganges zwischen Calcutta und Benares oder Vindhya-Berge zwischen Benares und Narbudda. Ich acceptiere letztere Lok. als typ. Lok.)

Von den übrigen Formen der Art sehr versehieden: Der Schnabel viel

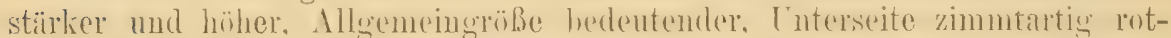
hram, Kedhe bis ïher die Kropfgeggend heller und dunlel gratubaun gatfeclit; Oherseite dunlelgraubraun: Schwanzwur\%el und (Obersehwanzdecken lehbaft zimmtrot, die sehwalrbuanne Sehwanzspitze an den mittleren Stenerfedern

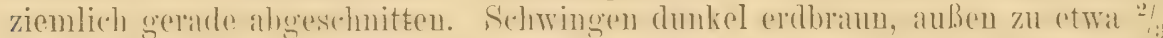
ganz schmal, innen ehensoweit hreit zimment gesüunt. Flïgel etwa 108

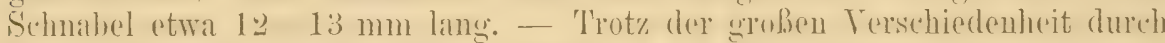

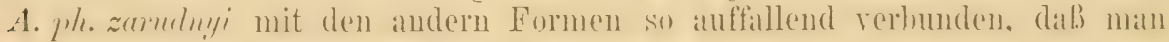
sie nicht artlich trennen solite.

Staulvogel in e'inem groben T'eil der vorderindisthen Hallinsel; dem paläarktischen Faunengebiete fremd.

\section{Gattung GALERIDA Boie 1828.}

(Der Name wurde von Boie Galerida (mit d) geschrieben, oder ist wenigstens so im Druck erschienen. IIan hat ihn verworfen, weil es einen älteren Gattungsnamen Galerita (mit t) für eine Käfergattung gibt. 1844 bezeichnete Hodgson die Haubenlerchen als Heterops, aber auch dieser Name war bereits vergeben. 1900 zeichnete sich Madarász durch die Schaffung von Ptilocorys, 1902 Dresser durch die von Corydus für die Gattung aus. Keiner dieser Namen braucht angenommen zu werden, denn jeder Grund, jede Entschuldigung muß gelten, einen alten Namen zu retten, solange er nicht irrtümlicher Weise auf eine Gattung oder Art angewandt wurde.)

Von den übrigen Lerchengattungen sind dic „Haubenlerehen" dureh eine etwa in der Konffuitte entspringende, ans cinigen stark verlüngerten l'elerm bestehende spitze Haube (Schopf) zu unterscheiden. Sehmahel von wechselnder Lünge und stiirle. Lirste (verkümmerte) Schwinge deutlich sichtbar, etwa so ling wie, oder etwas kïrzer oder lïnger als die Handdecken. Die ersten (vier) entwickelten Schwingen nicht wesentlich verschieden lang. Hinterzehe mit riemlich langem, fast geraden Nageel (Sporn). - Im paläarlitisehen Faumengebiete 2 oft rerwechselte und nicht immer leicht zu unterscheidende Arten ("rishuta und theldae) in weiten Gebieten neleneinander. Fine ron diesen (cristutu) in rerinderter Form bis Kineal, in Indien noch eine dritte Art, (G. deva) die weder als Form von theklae noch als solche von cristata auf-

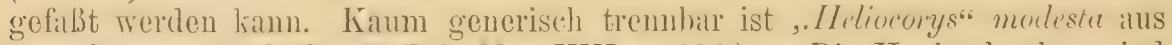
dem Sudan. (Vgl. (at. B. Brit. Mus. XIII, 1) 623.) - Die Haubenlerchen sind meist Standyögel und sehr zur Bildung lokaler Formen geneigt, sodabi ihr Studium 
zu den allerschwierigsten gehört, wenn man sich nicht leichter Hand nuwissenscbaftlich darüber hinwegtäuscht. ${ }^{1}$ )

\section{Übersicht der Arten:}

$2\left\{\begin{array}{c}\text { Schnabel länger, Untertlügeldecken rötlich isabell ohne grauen Anflug, } \\ \text { erste (rudimentäre) Schwinge nie länger, als die Handdecken G. cristata. } \\ \text { Schnabel kürzer, Unterflügeldecken mit deutlichem grauen Anfluge, erste } \\ \text { (rudimentäre) Schwinge so lang wie oder länger, als die Handdecken }\end{array}\right.$

\section{Galerida cristata nigricans Brehm.}

Galerita nigricans (partim) Brehm, Vogelfang, p. 123 (1855- „Ägypten und Thüringen". Brehm gibt im Vogelfang und Naumannia 1858, p. 206, die Kennzeichen der Form des Nildelta an, vermengt damit aber wunderbarer Weise eine Anzahl von deutschen Stïcken).

Galerida cristata deltae Hartert, Nov. Zool. 1897, p. 144 (Nil-Delta, Typus von Damiette).

Weitans die dunkelste aller Formen von G. cristatu. Grundfarbe der Oberseite sehr dunkel aschenirtig graubram, die Federmitten fast rein schwarz. Unterer Bürzel etwas einfarbiger graubram, Ohersehwanzdecken mit hreiten fast schwarzen Schaftstreifen, nur die Aubenränder etwas ins rötlich-Sinclfarbene ziehend. Kopfseiten dunkel schwarzhran gefleckt. [uterseite in frischen Gefiedeo bräunlich rahnfithen, die Fleckung der Kropfgegend anffallend dunkel, fast rein schwarz und grob, bei manchen Stücken ïber den größten Teil der Unterseite ausgedehnt, immerandenSeiten dentlich. Unterschranzdechén hell bräunlich, die längsten mit dmukelbranen I'edermitten. Unterflügeldeclien dunkler rostbräunlich als hei irgend einer der andern liormen der Art. Flïgel ôd.: 104-107, ad. etwa 97--100 nmm. (22 verglichen. dirunter den T'yus.)

Wohnt auf dem dunklen Boden des Nildelta von Damiette his Kailro.

1) Die hier anerkannten Formen scheinen mir festzustehen, obwohl es in einigen Fällen kaum möglich ist, ihre Unterschicde mit Worten so zu beschreiben, daß man sie danach „bestimmen" kann. Dazu ist die Vergleichung von Serien in Vereiu mit der Kenutnis der geographischen Verbreitung notwendig. Nur das kann wissenschaftlich wertrolle Resultate ergeben. Wie schon früher (Einl. p. VI) gesagt wurde, ist die "richtige Bestimmung" einzelner Bälge nicht das Endziel unsrer Forschungen. Der Zweck dieses Buches ist nicht der, dem Ornithologen alle Arbeit zu ersparen, denn dazu sind die Formen in der Natur zu kompliziert entwickelt. Einen .,Abschluß" bedeutet diese Übersicht natürlich auch nicht. Die südeuropäischen Formen bedïrfen noch weiteren Studiums, die Wolgn-Form ist unsicher, aus Kleinasien und Palästina ist das vorliegende Haterial ungenügend, im nördlichen Afrika dürften noch neue Formen zu entdecken sein, vielleicht auch (doch weniger wahrscheinlich) im Innern Asiens, wo die Verbreitung der Formen noch ungenau bekannt ist. Aus der Literatur über die Haubenlerchen ist am wichtigsten: Erlanger, Journ. f. Orn. 1899, p. 321-352. Außerdem: Whitaker, Ibis 1895, 1896; Hartert, Nov. Zool. 1897, p. 142-147; Lebensweise und Verbreitung in Algier: Koenig, Joum. f. Orn. 1895; u, a. m. - Abbildungen: Journ. f. Orn. 1899, Taf. IX.

2) Alauda deva Sykes, Proc. Zool. Soc. London 1832, p. 92: Vorderindische Halbinsel. (Spizalauda deva des Catalogue of Birds XIII.) 


\section{Galerida cristata cristata (L.).}

Haubenlerche.

Alauda cristata Linnaeus, Syst. Nat. Ed. X, p. 166 (1758- Ex Raius, Syn. MIeth. Avium, p. 69: ohne Lokalität. [1713], "Will." [Raius] Orn. lib. II, p. 151: "Viennae Austriae visa \& deser.", Olina, Albin, Aldrov. - "Habitat in Europae viis." - Als terra typica ist Wien anzunehmen, nach dem zweiten Zitat Linné's, da das erste keine genaue Angabe enthält).

Alanda cochevis P. L. S. Müller, Natursystem, Suppl., p. 136 (1776- ex „Buffon“: "Europa")

Alauda matutina Boddaert, 'Tabl. Pl. Enl. Daubenton, p.40 (1783- ex Daubenton's "Coquillade". - Provence. Da südfranzösische Stïcke sich nicht von denen aus Mittel-Europa unterscheiden lassen, diirfte die "Coquillade" trotz des abweichenden Aussehens des Bildes nichts als cristata sein).

Alanda plumata P. L. S. Müller, Natursystem, Suppl., p. 137 (1776--- ebenfalls ex Daubenton's "Coquillade". - Provence).

Alauda undata Gmeiin, Syst. Nat. I, p. 797 (1788 - auch ex Daubenton's „Coquillade“! Provence).

(?partim.) Alauda Galerita Pallas, Zoogr. Rosso-Asiat. I, p. 524 (1831 - „in Rossia et Sibiria ....").

Alauda movincialis Schrank, Fauna Boica I, p. 161 (1798- Umbenenuung von Gmelin's undata. "Ingolstadt". Autor scheint eine junge Haubenlerche vor sich gehabt zu haben).

Galevida viurum Brehm, Handb. Naturg. Vög. I)entschl., D. 315 (1831 - „N. W.-Dentsehland, namentl. in Westfalen, im Winter bei Saalfeld").

Gaterida major Brehm, Isis 1841, p. 123 („in der Nähe von Berlin, geht wenigstens bis an die Elbe").

Galerida viarum Brehm, Isis 1811, p. 123 („zwischen Leipzig und Delitzsch, in Vinter mehr südlich und besucht das Saaltal").

Galerida pagorum Brehm, Isis 1841, p. 123 ("lebt im nordwestlichen Deutschland“. Typen von Witten in Westfalen).

Galerida Karinthiaca Brehm, Isis 1841, p. 124 (Klagenfurt).

Galeritu eristuta vulguris Brehm, Naumannia 1858. 1. 207 ("hei Leipzig und Written").

Galerita cristata gallica Brehm, Naumannia 1858, p. 208 (Lyon).

Galerita cristata communis und longirostris A. E. Brehm, Verz. Samml., p. 8 (1866nom. nuda! Gehören nach der Sammlung hierher).

Galerita varia Rey, Eier d. Vög. Mitteleuropas, p. 256 (1902-- nomen nudum! angeblich ein Brehm'scher Name. Unde?!)

Engl.: Crested Lark. Franz.: Cocheris, Alonette huppée. Italien.: Cappellaccia.

Erste Showinge dentlich $(2-4 \mathrm{~mm})$ kïrzer als die Handdecken. Oad. Oherseite filhl sand-oder stumbartig-graubraum, Federmitten dunlel schwärzlichbram; P'ileum mehr gestreift, Haubeufederu hranschwarz mit schmalen Rändern von der Rï̈kenfarbe; Bürzel einfarbigger, weil dort dic dunklen Federmitten weniger dentlich sind, die Obersehwanzdecken (mit Ausmilıme der längsten, die wieder molı dunlielhraun sind) etwas ins Rostfurhene ziehend. Schwingen

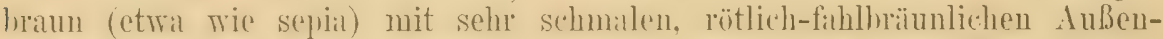
und sehr hreiten hell rötlich zimmtiorhenen Innensïmmen an der Trurzelhälfte; die inncrsten Armschwingen dem Rücken ähulich. I)as mittelste S'tenerfederpuar dem Rücken ähnlich, die ührigen schwalrzlunum, das vorletzte mit schmalem isabell-lahlimfirhigen Aubensaum, das letzte an der AuBenfahme und cinem groben Teil der Innenfithne bräunlich isabell-rahmfarbig. Ohrgegend dunlielbraum nit hellbraumen Strichen. Tuterseite bräunlich rahmfarhen. an den Kehlseiten zwei kurze dunkelhrame Fleckeureihen, Kropfgegend durch dunkelbraune 
Federmitten stark gefleckt, Seiten fahlbräunlich, selmmal dmnkelhraun gestreift. Unterschwanzdecken mit deutlichen dunkehn Federmitten. Schnabel hell hornbraun, Unterschmabel etwas heller. Fïße sehr hell hram. Iris maun. Flïgel ô etwa 105-110, Schwauz etwa 6t-70, Liuf etwa 27-29, Schuibel $17.5-19.9 \mathrm{~mm}$.

O wie On, nur etwas kleiner, namentlich Schnabel und Flügel merklich kürzer. Flügel etwa 97-109 mm.

Durch die Abnutzung im Frühjahr wird die Oherseite stirlker gefleckt, da die dunkehn Federmitten sich schürfer ahhehen, die Hleckung der Kropfgegend kleiner und schïrfer. Der junge Togel im ersten Kleide hat an den Spitzen der Federu der Oherseite kleime meiße, (lavor anteapikile schwarzbraune Flecke, an den Flügeldecken und Schwingen rahnweiße Stiume und anteapikale schwarzbraune Linien, ist also "gefleckt". (86 Stück untersucht.)

Europa rom südlichen Sehweden (ansuahnsweise bis Drontheim) bis Italien, im S.O. bis zu den Pyrenäen, in S.TT. bis au den Balkan. östlich bis Süd-Rublind. (Norditalienische Stücke sind typisch, in der römischen ('ampagna kimmen sehr dunkle Stücke vor:) Fehlt auf Sardinien und Korsikal. Fehlt in Großbritannien und Irland - kaum ein halbes Dutzend Vorkommuisse verflogener Stücke sicher beglaubigt.

Unsre Haubenlerche lebt zur Brutzeit in offenem Gelände mit wenig Vegetation, auf trockenen, unfruchtbaren Plätzen, besonders auf Sandflächen, mit niedrigem Unkraut bewachsenen Brachen, trockenen Exerzierplätzen, Schuttablagerungsstätten, Sandgruben, an Bahnhöfen, Ladeplätzen, auf den Landstraßen usw. In Deutschland hat sie sich durch die Anlage von breiten Chausseen und Eisenbahnen im vergangenen Jahrhundert weiter verbreitet. Höhere Gebirgslagen meidet sie gänzlich. Sie ist ausgesprochener Standvogel, nur tiefer Schnee treibt sie in Städte, Dörfer und weiter im Lande umher. Sie läuft meist nur am Boden, sitzt gern auf kleinen Bodenerhebungen, Erdschollen, Steinen, Mauern und niedrigeren Haus- und Scheunendächern, aber nicht auf Bäumen. Sie hat einen sanft flötenden Lockton, der nicht übel von Naumann durch "diididria" veranschaulicht wurde. Der Gesang wird bisweilen im Sitzen, meist aber in der Luft, und zwar in unregelmäßigerem, meist weniger himmelanstrebenden, mehr flatternden Fluge, als bei der Feldlerche vorgetragen. Er hat nicht die schmetternde Kraft und Stärke des jubelnden Feldlerchenliedes, sondern ist sanfter, flötender, schwermütiger, für Viele angenehmer. Nahrung Sämereien und Insekten. Die meist schwer zu findenden Nester enthalten 4 bis 5 Eier. Man findet sie von der letzten Woche des April bis Anfang Juni (in Deutschland). Sie sind typische Lercheneier, meist etwas grob gefleckt, nach Art der Kalanderlercheneier, oft feiner und den Feldlercheneiern sehr ähnlich. 100 Eier in Dr. Rey's Sammlung (ob alle von der echten cristata?) messen im Durchschnitt $22.7 \times 16.8$, im Jaximum $24.7 \times 17$ und $22 \times 18.3$, im Minimum $19 \times 15 \mathrm{~mm}$. Ihr mittleres Gewicht ist $192 \mathrm{mg}$.

\section{Galerida cristata subsp.?}

Die crpriotische Haubenlerche gleicht so auffallend der mitteleuropäischen G. c. cristata, daß ich mich nicht entschließen kann, ihr cinen Namen beizulegen. Allenfalls ließe sich sagen, daß die Schnähel bei durchschnittlich ziemlich geringer Stärke zu größerer Länge neigen und daß das frische Herbstgefieder einen gewissen rötlichen Anflug der grauen Oberseite hat, während dieser bei $G$. c. cristata mehr lehmbräunlich ist. Obwohl ich 28 Stïck untersuchte, möchte ich diese Form doch noch unbenannt lassen und fernerem Studium anheimstellen.

Cypern. 


\section{Galerida cristata tenuirostris Brehm.}

Gulerite cristate temirostris Brehm, Naumannia 1858, p. 208 (Sarepta).

Lie südrussischen Hauhenlerehen sind etwas graulicher als $(\dot{r} . \cdots$ cristata, fast so grau wie G. c. cancasica und zeichnen sich durch auffallend dünne

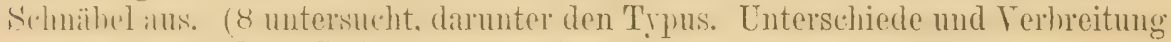
sind durch größere Serien zu bestätigen!)

Süu-Rubland his Limmänien (Sareptat, Toltava, Cernavoda, Baragana).

\section{Galerida cristata caucasica Tacz.}

Galerida cristata caucasica 'l'aczanowski, Bull. Soc. Zool. de France 1887, p. 621 (Lagodechi im Kaukasus).

Galerida cristata magdae, Loudon u. Sarudny, Ornith. Jahrb. XIV, p. 172 (1903-Petrowsk bis Baku u. Lenkoran).

Wie G. c. cristata, aber die ganze Oberseite mit einem so deutlichen granen Influge, im ganz frischen Gefieder etwas wie grau hepudert, diß der Untersehied heim Vergleiche einer Serie sofort in die Augen füllt. Flïgel ơad. 106-110, o ad. etwa 99-104 mm. Sehwanz ot etwa 64, o etwa $133 \mathrm{~mm}$. Nath den ronliegenden Bbilgen z.n urteilen scheint der Schnilhel etwas dunkler, mehr horngrau zu sein als hei (i. e. cristutu. (26 untersucht.)

Kitukasus und Westufer des Kaspischen Mecres: Lagodechi, Wladikawkils, von Petrowsk bis Baku und Lenkoran.

\section{Galerida cristata meridionalis Brehm.}

Galerida meridionalis Brehm, Isis 1841, p. 124, 128 (Dalmatien).

Galerita cristata planorum Brehm, Naumannia 1858, p. 207 (Dalmatien).

Galerita cristata brevirostris A. E. Brehm, Verz. Samml., p. 8 (1866- nomen nudun! Auf dem Etikett ist der Name planorum in brevirostris geändert).

Galerita cristata balcanica Arrigoni, Atlante Ornitologico, p. 241 (1902-- ex Brusina IL.S., unauffällig im T'ext erwähnt als Name für die von MIadarász unter dem Namen $G$. senegalensis beschriebene dalmatinische Haubenlerche).

Galerida cristata-madarászi (sic!) Herman, Aquila 1903, p. 274 (Name für die ungarischlitorale Form, unauffällig im 'Text. 'Trotz Versicherung der Ernsthaftigkeit des Verfassers beabsichtigte er doch wohl nicht einen neuen Namen zu schaffen, da ihrer schon drei vorhanden waren.).

Im frischen Herhstgefieder uben lichthratun mit röstlichem Anfluge, AuBenfihnen der seitlichen Stenerfectern sehr rötlich rostfarhen, Unterseite mit rosthräunlichem Anflugre in alrgetragenen Brutgefieder ganz anders atussehend, alufiallend hell und mehr grialulich. (Tgl. Mildarász, Magyal Maldarai, p.51 und t74.) (32) untersucht, darunter deu remutlichen Typus.)

Ballkanhalhinsel (Griechenland), Dalmatien (his Fiume), Helzegowina (Mostar). Montenegro (Joflgorica). Die Fxemplare aus den versehiedenen Gehieten sind zwal nicht alle sleich, aber doch ohne Zwang miteinander zu vereinigen und sie variieren auch am selben Orte, und zwar ebenso sehr, wie die aus verschiedenen Gegenden stammenden Stücke. 


\section{Galerida cristata pallida Brelim.}

Galerita cristata pallida Brehm, Naumannia 1858, p. 207 („Spanien").

Galerita cristata angustistriata (partim) Brehm, Naumannia 1858, p. 208 ("Spanien, Griechenland und Nubien").

Galerita mufescens Brehm, Vogelfang, p. 124 (1855- ohne Lokalitätsangabe).

Galerita cristata rufescens Brehm, Naumamnia 1858, p. 209 ("Süispanien“).

Galerita cristata maculuta und altirostris Brehm, Naumannia 1858. 1. 208, 209 (gehören teilweise hierher, d. h. die spanischen Stücke).

Galerita cristata gigantea und striata A. E. Brehm, Verz. Samml., p. 8 (1866- nomina nuda!, gehören nach der S̊mmlung hierher).

Wie G. c. cristata, aber die Oberseite heller, mit fahleren, blasseren Federrïndern, was sowohl im frischen Herbstkleide als im abgetragenen Frühlingskleide auffiillt. Flügel meist $2-4 \mathrm{~mm}$ kï̈zer. (18 untersucht, darunter den Typus.)

Spanien (Valencia, Murcial, Grumadil, Sevilla) und Portugal (Beira, Estremadura).

\section{Galerida cristata kleinschmidti Erl.}

Galeritu cristuta kleinschmidti Erlanger, Journ. f. Om. 1899, p. 345 (Nord-MIarokko).

Von derselben Größe wie G. c. pallida, aber Oberseite dunkler, die Federmitten schwärzlicher, Federrinder nicht so isibell, sondern mehr grau, Vorderbrust sehr scharf und dunkel, fast schwarz, gefleckt, wie bei Gr. theklae. Durch diese schatfe Fleckung, die dïstere Oberseite und etwas geringere Größe von G. c. cristata unterschieden. (8 untersucht.)

Nord-Marokko (Gegend von Tanger).

\section{Galerida cristata riggenbachi Hart.}

Galerida cristata viggenbachi Hartert, Nov. Zool. 1902, p.333; G. c. viggenbachi und G. macrorlynncha randoni Hartert, A. d. Wanderj. e. Naturf., p. 316, 317 (1902- Mazagan, W.-Küste von Marokko).

Erste Schwinge nur wenig, bisweilen kaum kïrzer als die Handdecken. Von den bisherigen Formen durch bedentendere Größe, nimentlich längern Schnahel, unterschieden. Unterseite in frischeu Herbstkleide nicht weißlich, sonderu isahell-bräunlich-rahmfarhen. Iris rothraun, Selunabel hormartig granbraun. Füße hellbraun. O Flügel 107-113, meist etwa 110. Schnibel meist 20-22, seltener 18, ausuahmsweise 17.2 mm lang. o : Flügel 98-102. Schnabel 15.8-18 mm. (60 untersucht, darunter den Typus.)

Mittleres und südliches westliches Marroklio (Gegend ron Mazagan: Mrazagan, Djebel Chedar, am Oum-R-biah, Rabamna, Zania Sidi Abas hem Omar, Aounat; Mogador).

Bewohnt hauptsächlich die Getreidefelder, worin sie bei Mazagan ganz die Feldlerche ersetzt, grasiges und offenes Gelände. Von Riggenbach gesammelte Eier sind meist nicht sehr grob, bald reichlich, bald spärlicher gefleckt und messen $25.5 \times 17.5,25.2 \times 17.5,23.8 \times 17.6,23 \times 16.6 \mathrm{~mm}$. 


\section{3(19.) Galerida cristata macrorhyncha Tristr.}

Galerita randonii Loche, Cat. MIamm. Ois. Algérie, p. 85 (1858- nomen nudum!); descr.: Rev. et Mag. Zool. 1860, p. 150, 'Taf. XI, fig. 2.

Galerida macrorhyncha 'Tristram, Ibis 18599, p.57, 426 (Nordrand der Sahara. - Der Typus ist aus Laghouat!).

Gauz wie G. c. riggenhachi, aber die Oberseite heller, die Unterseite

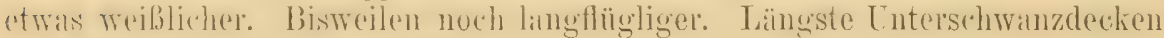
mit hammen Federmitten. Flügal his 117. Schnalhel his $18 \mathrm{~mm}$. (12 untersucht, darunter den Typus.)

Mittleres und nördliches Algier und nördliches Tunis. In Tunis nur nirrollich der Ausläufer der Atlaskette, im mittleren Algier aber sü̈llich bis Laghouat (el Arhouat). Erlanger führt sie nur für sein "Gebiet I" an (siehe die Zongeographische Kiate der Itlasländer im .Jum. f. Orn. 1898), aher Lilghoult liegt in seimem .. Gehiet II". Die Verbreitumg scheint sich also hier nicht genau nach der Wasserscheide zu richten.

Bewohnt die mit Halfa und niedern Sträuchen bewachsenen Ebenen und Saatfelder. Eier gelblichweiß oder grünlichweiß, dicht mit violett-aschgrauen Schalenflecken und braunen, lehmbraunen oder gelbbraunen Flecken mehr oder minder dicht besetzt. Maße von Stïcken aus Oned Kasserine nach Erlanger $23-24 \times 17 \mathrm{~mm}$.

\section{Galerida cristata arenicola Tristr.}

Galevida arenicola 'Tristram, Ibis 1859, p.58, 426 (Algerische sandige Sahara).

Galerita cristata reichenowi Erlanger, Journ. f. Orn. 1899, p. 351 (Kebilli und Tozer im Djerid (Typus) in 'Iunis. Nach nur 2 Exemplaren).

Von G. c. macrorhyncha sofort durch die viel lichtere Färbung der Oherseite zu unterseheiden. die viel mehr hellhräunlichsindfarben ist, aluch dureh geringere Gröhe. Die Cntersehwanzdecken sind vällig einfurbig, fast

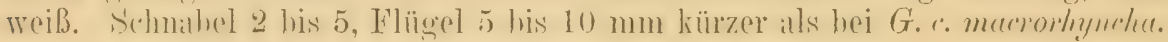
(36 untersucht, darunter den Typus.)

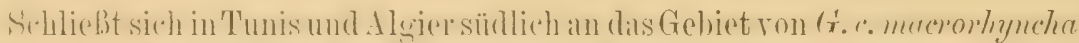
:11, in 'Tunis sufort sïdlich der Atliskette. in Algier offenbar erst etwals weiter südlich atuftretend, von Biskist an (noch nicht hei Latghonat) und bis Ghardatia (Guardaia), weiter im Osten auch in T'ripolis. Ein Stück von der Insel I) jerba (Githes gegenüher) ist rosthräunlicher, aher ein ganz ähnliches liegt

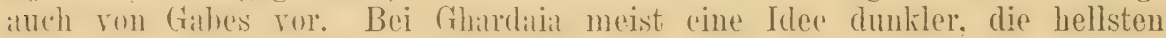

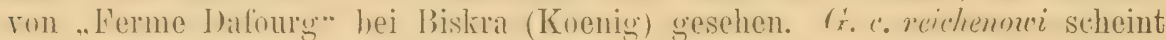
mir ununterscheidbar z.1 sein. Wrlanger gilnt sie für" sein "Gehiet III" (siehe Karte. Journ. f. Orn. 1898) an. T'ozer (woher der Typus stammt) liegt aber in seinem Gehiet II, Kehilli, woher das zweite bxemplar kam, an der Grenze desselhen, auch schemen einige Strïcke aus der Gegend von Biskra in Koenigs Sammlung ebenso hell zu sein.

Bewohnerin der mit Halfa und andern niedrigen Sträuchern bewachsenen Steppe. Der Vogel ist der Bodenfärbung wunderbar angepaßt. Das Nest steht meist an einem Halfabiischel und enthält 4-5 Eier. Sie gleichen denen andrer Haubenlerchen und messen etwa $23 \times 16,23 \times 17,25 \times 17,26 \times 16,26 \times 17 \mathrm{~mm}$. Gewicht nach Erlanger $0.18-0.22 \mathrm{gr}$. 


\section{Galerida cristata senegallensis (I. I. S. Mü̈ll.).}

Alauda senegallensis P. L. S. Müller, Natursystem Suppl., p. 137 (1776- ex „Buffon“richtiger Daubenton's Taf. mit Text von Montbeillard. "Senegal").

Sïdlich der Salhatra finden wir in TV.-Afrika eine belle, licht sindhranne Hambenlerehe, die sich namentlich dureh ihre geringe Größe von den meisten Verwandten auszuzeichnen scheint. Sie ist oben hell, nicht sehr verschicden von G. c. arenicola, aher etwas kleiner und kurzschnähliger. Oherschwanzdecken und mittlere Stencrfedern rötlich satndfarhen. Tris nuBhraun, Fïlic sror hellbrämnlich, fast weißlich fleischfarben. Flügel 92-102. Tauf 21. Sichwanz etwa 60, Schnabel bis $15 \mathrm{~mm}$. (8 untersucht.)

W.-Afrikia: Senegambien, Sierra Leone his zum nördlichen Hantssalande. Genaue Verbreitung nicht festgestellt, erstreckt sich vielleicht an Sïrdrunde der Silharia entlang bis Nordostafrikil, wie so mathe andere Vogelformen.

\section{Galerida cristata isabellina $\mathrm{Bp}$.}

? Galerida abyssinica Bonaparte, Consp. Av. I, p. 245 (1850- angeblich ,G. cristata ex Abyssinia, Rüpp." Diese Angabe ist nicht mit der Diagnose in Einklang zu bringen, die nichts enthält, als die Worte: „Similis praeced. (d. h. G. cristata L.) at distincta colore deserti sequentisi. Rüppell's abyssinische Haubenlerchen sind eine ganz dunkle, nicht wüstenfarbige Form. Wahrscheinlich hatte Bonaparte sudanische Stücke (? aus Chartum) vor sich).

Galerida isabellina Bonaparte, Consp. Av. I, p. 245 (1850- „ex Nubia aegyptiaca").

Galerita flava A. E. Brehm, Journ. f. Orn. 1854, p. 77 („Ost-Sudan, südlich des 16. Grades nördl. Br." ).

Galerita lutea \& flava Brehm, Vogelfang, p. 124 (,Nordostafrika“6); Naumannia 1858, p. 209,210 .

Galerita flava tenuirostris \& crassirostris Brehm, Naumannia 1858, p. 210 (Chartum und Berber).

Oberseite hellsindbrïmulich mit ziemlich stitrken rötlich-sumdfitrhenem 'Ton. Fleckung der rahmfarbig ïberlaufenen Vorderbrust sehr blal, nicht schwärzlich, sonderu hellothrïunlich. Längste Unterschwanzdecken mit licht rotbräumlichen Täugsstreifen. Groß: Flügel ởal. 106-113. Schnahel $18-20 \mathrm{~mm}$. Ist $\dot{G}$. c. seneyallensis auberordentlich ähulich, aher merkich größer (langflügliger) und die dunklen Federmitten sichtharer. (Fitwa 25 untersucht, darunter die Typen der Brehm'schen Formen.)

Südliches Nubien uud ïgyptischer Sudan (Bajudit-Stepure lis zum Blauen und weißen Nil), unterer Atbara. Stücke von Sehendi sind zum Teil etrvas weniger rötlich als solche ron Khartum, stimmen aber in allgemeinen so genau damit überein, daß man sie ohne Bedenken zu einer und derselhen Form rechnen kann.

\section{Galerida cristata altirostris Brehm.}

Galerita altirostris Brehm, Vogelfang: p. 124 (1855— ,in Oberägypten").

Galerita cristata maculata (partim) Brehm, Naumannia 1858, p. 208 (Assuan und Masnou in Spanien. Terra typica: Assuan.).

Galerita cristata altirostris (partim) Brehm, Naumania 1858, p. 209 („Ober-ägypten, Nubien und bei Murcia"). 


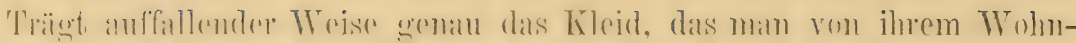
gebiete, zwvischon dem von $G$. c. nigricans und $G$. $c$. isabellina, vermuten sullte. demin sige steht zwisehen diesen beiden Formen. Im Kolorit ist sie

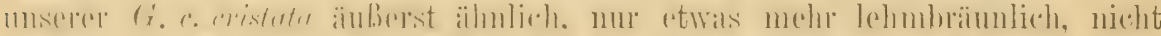

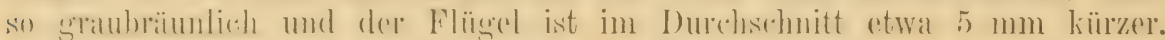
(18 untersucht, darunter die Typen.)

Bewohnt das Niltal südlich von Kairo bis ins nördliche Nubien. Süd-

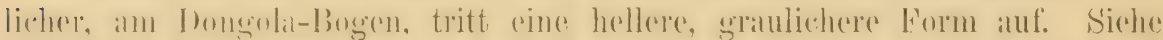
Nr. 376.)

\section{Galerida cristata caroli subsp. nov.}

Im Natron-T'Tal westlich von Kairo und vielleicht weiter verbreitet in

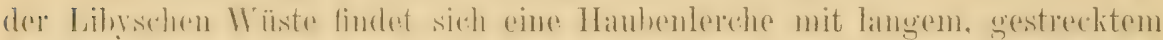

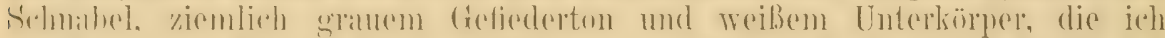

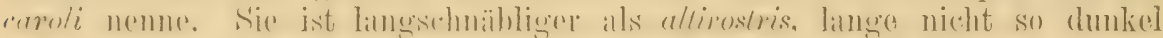

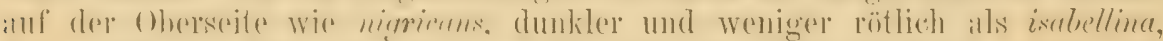

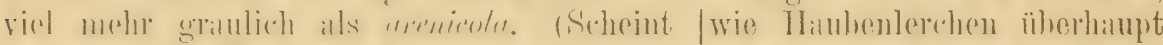

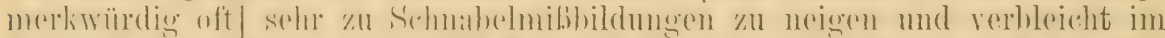

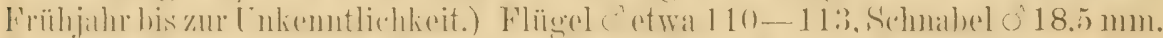

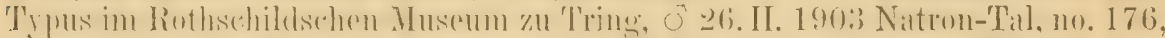

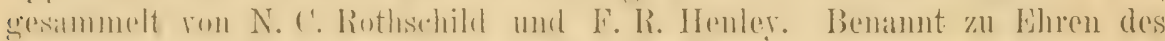
Lirstgenannten. (4 untersucht, dirlunter den 'I'ypus.)

Natron-Tal in Unter-Ägypten.

\section{Galerida cristata brachyura 'I'ristr.}

Galevida brachynu Tristram, Proc. Zool. Soc. London 1864, p.435 (Ghor am Südende des 'I'oten Meeres).

Galerita cristata var. deserticolor Festa, Boll. Mus. '/ool. Anat. comp. T'orino LX, Nr. 174, p. 4 (1894- Palïstina).

Oherseite fahl sumelbrïunlich, ziemulich rötlich, nicht so gelblich und wïstenfarbig wie G.c. arenicola; mit etwas mohr grauem Schimmer und

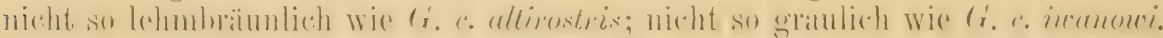
Oben in der Fïrbung wohl kaum von $G$. c. magnce zu unterseheiden, aber

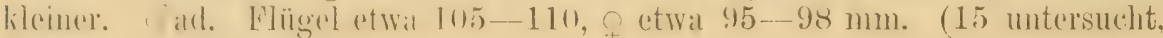
darunter den 'Typus.)

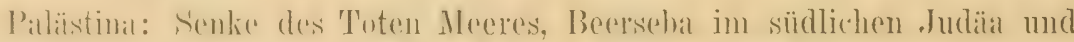
Jortintal. (bei fortusilem und ant dem Berge ('armel liommen andere Formen vor:)

\section{Galerida cristata subsp.? ${ }^{1}$ )}

Die abessinisehen Kä̈stenländer, vielleidet sngar heide l'fer des Roten

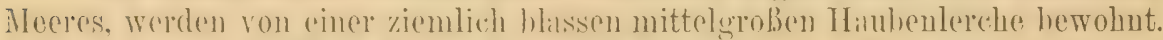

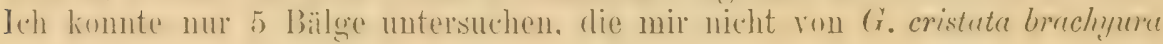

') Der Name abyssinica Bp. kann nicht etwa auf diese Form bezogen werden, denn wahrscheinlich gab Bonaparte diesen Namen Stücken von der hier isabellina genannten Form, die abor nicht aus Abessinien, sondern aus dem Sudan (? Khartum) stammten. Siehe G. c. isabellina. 


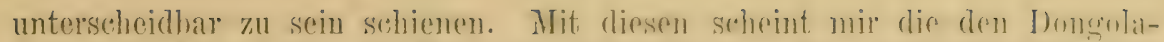
Bogen des Nil hewohnende Form ähereinzustimmen. Lihe sie mit lostimmtlenis

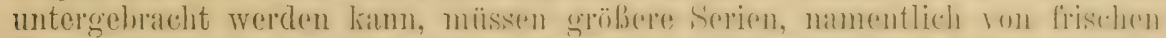

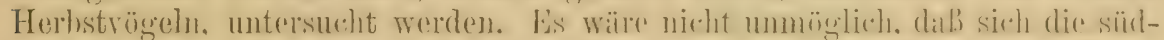

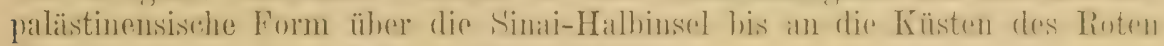
Neeres und an den mittleren Nil erstreckt.

\section{Galerida cristata cinnamomina sulsp. 1101 .}

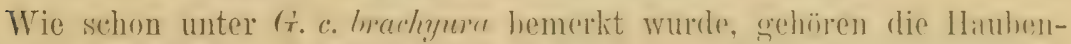

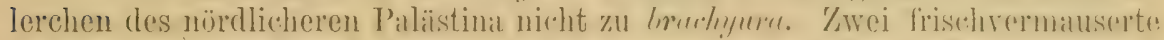

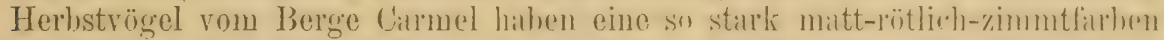
überlatufene Oberseite. dab ich sie gestrost nen heneme. Sie stimmen in

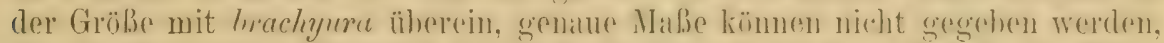
da sie matuserm. Sehmahel zicmlich kur\% und stark. ('Tyjus im Tring Museum, Carmel 28. VIII. 1897. O Nr. 151a.)

Nord-Palästina: Berg C'armel. Vom nördlicheren Jurliä und . Terusalem liegen num ahgetragene Stüclie vor (.Jerusillem 7. III., 27. III.), die scher wohl zur selben Form gohören liönten, aber des zimmtfarbenen Anflugs entherhron.

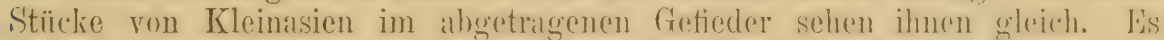

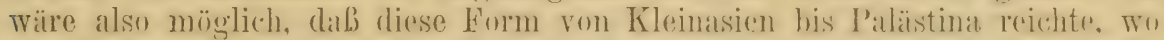
sie im Jordantal und dem äubersten Sïdrn durch die hellere brachenter vertreten wird. Das untersuchte kleinasiatische Material ist leider nu1 seh" ungenuigend.

\section{Galerida cristata subsp.?}

Auber der limaschü̈bligen (x. thrlilae ellioti (siche p. 24(1) leht in Somalilande noch eine langschnählige, oben sehe hlasse, nicht aber rötliche

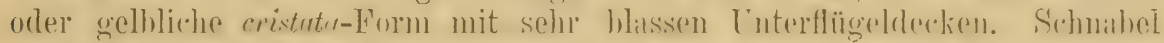
ziemlich lang und merklieh gehogen. reh komnte nur wenige Stïclie untersuchen, die mir nicht zur Charakterisierung der Form genïgten.

\section{Galerida cristata tardinata subsp. nov.}

(Siehe Nov. Zool. 1900, p. 248 u. Denkschr. math. naturw. Cl. Kais. Ak. Wiss. Wien LXXXI, p. $7,8,1902$.

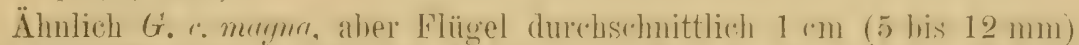

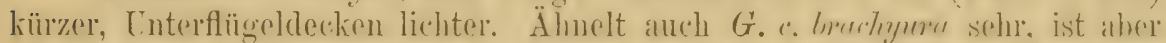
im frischen Gefieder oben viel heller, ohne den rötlichen 'Ton. 'Tyus im

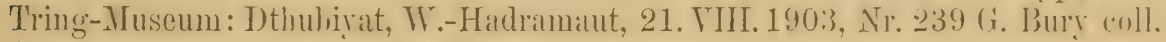
(26 untersucht, darunter don Typus.)

Süd-Alabien: Westliches Hadramuant. Iden. (T/wwei Stüclie ron Marrith im Hadramaut, östlich vou Malkallat, unterseheiden sich nach Torenz of Helhnarl

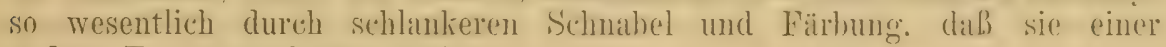
andern Form angehören duirften.)

\section{Galerida cristata magna Hume.}

Galerida magna Hume, Ibis 1871, p. 407 (Yarkand).

Fine sehr große, ohren sehr hell bräunlichgelhlivhe, unten dentlich rostgelblich überlitufene Subspezies. Flügel alter c $110-117 \mathrm{~mm}$ ! 
Zentral-Asion: Luh-Noner, Ost Turkestan (Tankand, Kalschgar), die südlichen Teile von Thukestan und Transkaspien (Tal des Amu Darja), uach Süden his Ost-Iersien. A fohanistan und Baluchistan. Im Winter durch das rauhe Klima aus Ost-Turkestan teilweise bis N.W.-Indien vertrieben.

\section{Galerida cristata iwanowi Loudon.}

Galerida cristate iwanowi Loudon ,und Sarudny“, Ornith. Jahrb. XIV, p. 171 (1903"Syr-Darja-Gebiet, Ferghana- und Sarafschan-Gebiet").

Ist G. c. magna äußerst ähnlich, aber die Unterseite samt den Unterschwanzdecken ist weißlicher. Die Oberseite hat einen deutlichen grauen Ton, der bei typischen magna ganz fehlt. (Etrva 15 untersucht.)

Vertritt G. c. magna in den nördlichen Teilen von Russisch-Turkestan und Transkisprien: Issik-Kun. Dscharkent. Ferghana. Sarafschan und Tal des Syr-Darja, vielleicht auch im östlichen Buchara.

\section{Galerida cristata chendoola (Frankl.).}

Alauda chendoola Franklin, Proc. Zool. Soc. London 1831, p. 119 (Ganges und Nerbudda).

Certhilauda Boysii Blyth, Journ. As. Soc. Bengal XV, p.41 (1846- ohne Lokalität. Nach Ibis 1867, p. 48 bei Lahore).

Im nordwestlichen Indien wohnt eine kleine, auf der Oberseite im frisch vermauserten (isfiecter gelburämlich staubgraue Haubenlerehe. Die Enterseite ist weiblich, fast ohme brälmlichen Anfug, die C'nterflügeldecken

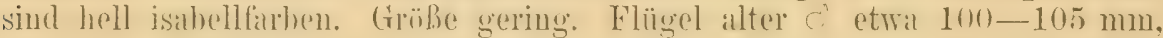
oft kürzer, Schnabel etwa $13-15 \mathrm{~mm}$. Im alogetragenen Kleide ist die Oherseite nichte se ansigesprochen stanhgran. sondern mehr wie rersehossen bräunlich. (Über 20 untersucht.)

Nordwest-Indien, besonders das Indus-T'Tal von Kaschmir bis Sindh, P'unjah, Raijnutanla, ästich etwa bis zmm 85. längengrade, südlich etwa bis Hatidabad. (Im Winter scheint (i. c. mume im Nordwesten vorzukommen.)

Brütet in Indien etwa rom März bis Juni und legt meist drei Eier, die denen andrer Haubenlerchen-Formen gleichen.

\section{8:3. Galerida cristata leautungensis (Swinh.).}

Alauda leautungensis Swinhoe, Ibis 1861, p. 256 (Talienwan in der Provinz Liautung).

Kleiner und viel mehr graurötlich, als magna. Flügel ò 101-110 mm. (10 untersucht, darunter den Typus.)

Nördliches und westliches China bis in die Provinz Szetschwan.

\section{Galerida cristata coreensis Tacz.}

Guleritu cristuta corcensis Taczanowski. Proc. Zonl. Soc. London 1887, p. 603 (Seoul, Korea).

Ebenso gloß wie leautungensis, also kleiner als magna, aber wieder vicl mehr grau, nur der ()berrïcken etwas rötlich und heller. (3 untersucht.)

Korea. 


\section{Galerida theklae theklae Brehm.}

Galerita Thelilae Brehm, Nammannia 1858, p. 210 (,, in der Umgegend ron Jatira, nieht weit von Valencia und auf der Sierra Nevada66).

Galerida Miramarae Homeyer, Journ. f. Orn. 1882, p. 316 (,Scheint an einzelnen Orten Südspaniens nicht gar selten, wurde jedoch bisher nicht unterschieden". Offenbar hatte Homeyer $G$. thelilae ganz vergessen. Die von Kronprinz Rudolfs Reise stammenden Cotypen im Braunschweiger MLuseum gleichen völlig den typischen theklae, der im Wiener Museum aufberrahrte, aufgestellt gewesene und wieder zum Balge gemachte "I'ypus" ist in sehr schmutzigem und sehr abgetragenem Gefieder, gleicht daher fast den dunklen Stücken von Tanger).

Wie alle Formen von $G$. theklae von denen von G. cristata durch kï̈rzeren und verhältnismäBig dickern Schmahel, sehr stark und seharf (..Heidelerehem-artig"“) gefleckte Kropfgegend und nicht rötlich isibellfarbene. sondern sehmutzigrahmfarbene, de utlich gria üherlaufene Cnterflügeldecken zu unterscheiden. Die erste (rerkïmmerte) Schwinge ist nicht merklich kürzer als die Handdecken. sondern chenso lang oder 1-2 mm länger. - Die Oberseite von $G$. th. thelitue ist der einer mitteleuropüischen critulu ähnlich, aber etras blasser und nicht so braun, sondern etwas graulieher; sie ist also dunkler als hei $G$. c. pullide. Dire Unterseite hat keine Spur vou röstlichem Schinmmer, sondern ist weil. mit gauz schwathem rahmgelblichen Anflug; die Kropfgergend ist galnz wie der Cnterkïrper. ohne einen deutlichen röstlichen Schimmer, daher tritt die schwalrze Fleckung schärfer hervor. Lnterschwanzdecken ganz, cinfarbig. Sichuabel heim od 14-15.5 mm, Flügel etwa $100-104 \mathrm{~mm}$. O nur ein wenig kleiner. Das Nestjunge liat auf der Oherseite einen stauhgrauen Auflug. (15 untersucht, darunter den Typus.)

Spanien, ron Murcia und Valencia his Süd-Spanien, und Teile ron Portugal. $\left.{ }^{1}\right)$

Die Formen von G. theklae weichen in ihrer Lebensweise von denen von G. cristata im allgemeinen nicht untresentlich ab. Sie berorzugen nicht wie die cristata-Formen flache, sandige Triften oder Getreidefelder (wie in Marokko u. a.), sondern steinige Höhenrücken, Gebirge, Abhänge und setzen sich oft und gern auf Sträucher und Bäume. Ihr Gesang ist noch schöner, voller, länger, lauter, mehr an den der Feldlerchen erinnernd. Es scheint, daß die Eierzahl in der Regel 3 nicht überschreitet. Die Eier sind meist feiner gefleckt als die ron $G$. cristata, aber oft nicht von ihnen zu unterscheiden. Wegen der häufigen Verwechselung der verschiedenen Formen ist das von Händlern bezogene Material wertlos und ich verzichte darauf, Maße anzugeben.

\section{Galerida theklae erlangeri subsp. nov.}

Ganz wie G. theklae theklae, aber die Oberseite dunkler: die Grundfïrbung eine Schattierung bräunlicher. die dunkle Fleckung etwas schwöl'zlicher und gröher: Vorderhust sehr groh und reichlich schwargeflectit.

1) Auf den Balearen lebt eine vielleicht noch zu benennende Form von G. theklae, die anscheinend mehr mit $G$. theklae harterti übereinstimmt, als mit der typischen spanischen thelklae. Ich konnte nur ein Exemplar vergleichen. Es muß eine Serie untersucht werden, um sie klarzustellen. (Vgl. Journ. f. Orn. 1862, p. 267.) 
(Typus im Tring-Museum: "O " Nr. 1177, Tanger 16. III. 1897, Olcese

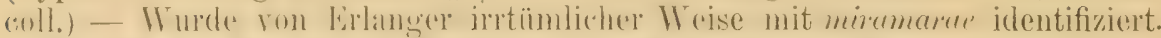

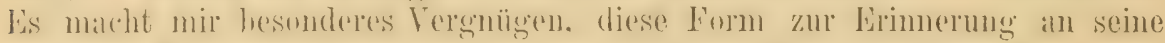
wertrolle Hambenlerehenarbeit im Journ. f. Orm. 1899 nateh Banom ('arlo rom Ellanger zu beneunen.

Nord-Marokko: Gegend von 'T'anger.

\section{Galerida theklae ruficolor Whit.}

Galerida thelklae ruficolor Whitaker, Ibis 1898, p. 603 (,Central and Southern Marocec").

Ähnlich G. th. theklae und erlangeri, aber die Oberseite bräunlicher, oft stark ins Rothrame zirhemel, unterer Bärzel und Oherschwanzolecken matt zimmtforben. Interseite, namentlich Sesten und Kropfogegend mit lejohtem isibellfurbenen Anflug. Cuterflügeldecken hellgrau mit isabell-

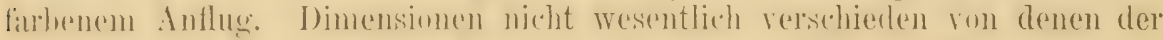

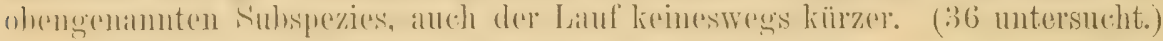

Mittleres und sïdliches Marokko. (Eine älnliche, abor anscheinend

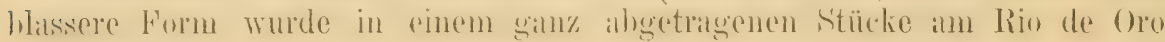
gesammelt.)

Obwohl diese Haubenlerehe mit $G$. cristata riggenbachi dieselben Gebiete bewohnt, so bevorzugt sie im Gegensatze zu der vorzugsweise feldbewohnenden riggenbachi hauptsächlich steinige Höhenrücken mit Buschwerk und Gras. Ihr Gesang ist prächtig. Eier fand ich am 10. April. Das Golege scheint nur aus 2, höchstens 3 Eiern zu bestehen. Die Eier sind typische Haubenlerchen-Eier und könnten ebensogut kleine Stïcke deutscher Feldlerchen sein. Maße vou 4 Hiern: $23.6 \times 17.7,22 \times 16.5$, $21.6 \times 16.4 \mathrm{~mm}$.

\section{Galerida theklae harterti 13rl.}

Galerita theclclae harterti Erlanger, Journ. f. Orn. 1899, p.332 („Nord-Algerien und 'Tumesien bis zum Nordrand des Atlasgebirges").

Kaum von $G$. th. mufiolor zu unterscheiden, aber beim Vergleich einer

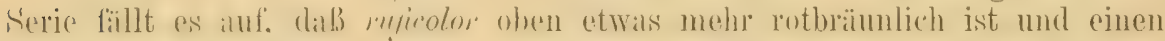

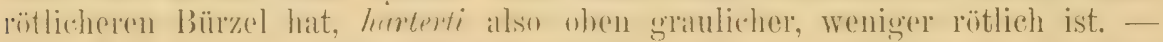

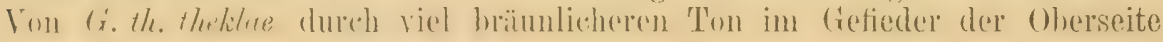
unterschiedeu. (12 untersucht.)

Nord-Algier und 'Tunis bis zum Atlasgebirge. (Angeblich von Bône stammende sind trils typisehe huterti, teils intermediä, teils wie supreftum).

Erlanger fand Gelege von drei Eiern bei Kasserine. Die Eier sind verhältnismäßig fein und matt punktiert und messen nach Erlanger $22 \times 17,23>16,23 \times 17$ bis $24>17 \mathrm{~mm}$. Gewicht $17-21 \mathrm{cg}$.

\section{Galerida theklae superflua Hart.}

Galerida cristata superfua Hartert, Nov. Zool. 1897, p. 144 (neuer Name für Whitaker's Alauda cristata pallida (non Brelim), Lbis 1895, p. 100 ,South of Tunis"6).

Gulerita thecklae deichlevi Erlanger, Journ.f. Orn. 1899, p. 339 (soll Erlanger's Gebiet III [s. Karte im Journ. f. Orn. 1898] bewohnen. Typus von Douz in T'unis. Ist von G. $t$. superflua nicht zu trennen. Aus "Giebiet II" liegen zu viele Stïcke vor, die denen. aus "Gebiet III" gleichen, an denselben Orten kommen Ixemplare vor, die mehr voneinander abweichen, als "deichleri" von superflua. Eine 'Trennung scheint daher nicht geraten. S. auch Ibis 1898, p. 603.). 
Dies ist die von 'Taczanowski und Koenig intümlich als G. arenicola bezeichnete form. Sie ist dureh ihren Sohmahel und die ïhrigen Morkmale

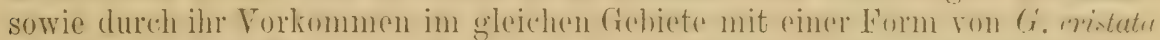

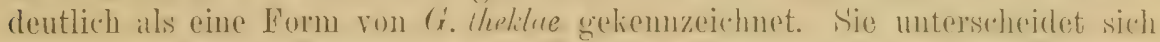
von allen übrigen Subspezies von Ge. Uhethe durch die helle, dem Wüsten-

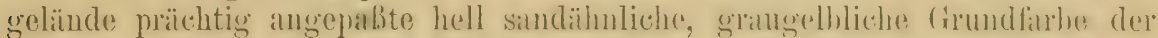
Oberseite, die der im selhen Gehiete wohnenden G. cristutu arentroln gleichkommt. Die dunkeln Flectie der Oberseite sind braun, nicht selwwirmlich, auch die Kropffleckung ist nicht so dunkel. Die C:nterflïgoddecken licht isaluell, ather nicht so rötlich wie hei den gheichgefürbten hellen rrisuln-liormen, sondern immer noch mit einem deutlichen gratuliehen Anflug. (Nohen typischen Stä̈cken kommen, z. B. am I) jehel Batoum, auch sehr rötliche vor.) (30 untersucht.)

Bewohnt Algier und Tunis von den Ausläufern der Atlaskette bis in die Sahara. Vielleicht sind südalgerische Stücke im allgemeinen dunkiler und subspezitisch zu sondern, was ieh aher vorliutig unterlasser, da mir krine

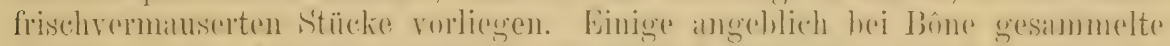

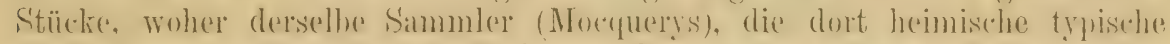

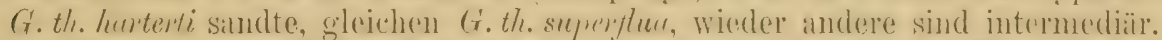

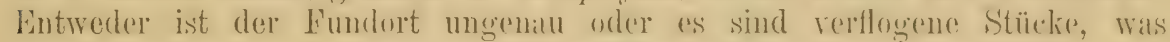
bei der sedentären Lehensweise dieser Yägol nicht allzu wahrscheinlich ist, oder aber die Form ist in Algier variabler als in T'unis.

Erlanger fand anfangs Juni mehrere Gelege von 3 Wiern. Diese sind auf weißem Grunde fein punktiert und messen $22 \times 17,23 \times 16,23 \times 17-24>17 \mathrm{~mm}$ und wiegen nach Erlanger etwa 17, 18-21 $\mathrm{cg}$.

\section{Galerida theklae carolinae Frl.}

Galerila cristata carolinae Erlanger, Orn. MLonatsber. 1897, p. 186 („Hab. in Sahara petraica Tunesiae, Typus ex Oued-oum el Graf".) Vergl. Journ. f. Orn. 1899, p. 342 (peträische Sahara von 'Tunis und Süd-'l'ripolis).

Unterscheidet sich von der ähnlichen G. th. suproflum durch die rostrote Oberseite. (1 untersucht.)

Bewohnt die öde, fast vegetationslose peträische Sahara von SüdT'unis und dem angrenzenden 'Tripolis (Gehiet IV, linlinger's Kirte, Journ. f. Oru. 1898).

\section{Galerida theklae cyrenaicae Whit.}

Galerida theklae cyrenaicae Whitaker, Ibis 1902, 1).654 (Cyrenaica).

Wie die andern Subspezies vow $G$. theklae, aber von ganz andrer Fürbung, die Oberseite mehlig grau, wie bepudert, ïhnlich den graneren zentralasiatischen Formen von G. cristata.

Barka (oder Cyrenaica): Bir 'l'abilleh, Bischer, Sidi Sweya.

\section{Galerida theklae praetermissa (Blanf.).}

Alauda praetermissa. Blanford, Ann. \& Mag. Nat. Hist. (4) IV, p. 330 (Nov. 1869Tigré in Abessinien); Blanf. Geol. \& Zool. Abyss., Taf. VI. 
Alauda (Galerita) arenicola? Tristram, var. fusca Blanford, Geol. \& Zool. Abyssinia, p. 387 (1870- "Abyssinian highlands at Ashangi").

Galerita mycrocristata Homeyer, Journ. f. Orn. 1873, p. 202 (Abessinien. Typus im Museum Heine).

Galerida riippelli Hartert, Journ. f. Orn. 1890, p. 102 (.,Simen in Abyssinien"*).

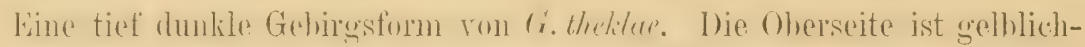

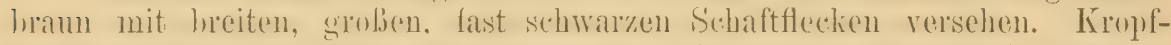

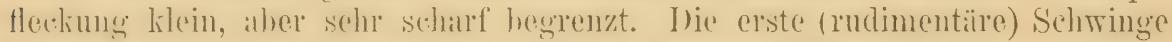
überragt die Handdecken um beinahe $4 \mathrm{~mm}$. Haube breit und kurz. Flïgel 104-105, culmen 14, Lauf etwa 25, Schwanz $67 \mathrm{~mm}$. (8 untersucht, darunter den Typus.)

Hochgebirge Abessiniens ('ligré, Simen). (Es scheint, als wenn in T'eilen ron thessinien \%. I). Sumafe| noch rine brömnlichere puicht aber

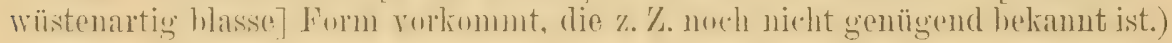

\section{Galerida theklae ellioti Hart.}

Galeriela ellioti Hartert, Nov. Zool. 1897, p. 144 (neuer Name für G. pallida Elliot [non pallida Brehm] aus dem Somalilande).

Schnabel kurz, stark und spitz, also echter thelilae-Schmabel, erste (rudimentïre) Schwinge lang. Tnterflügeldecken hell rostfarben. ohne erine

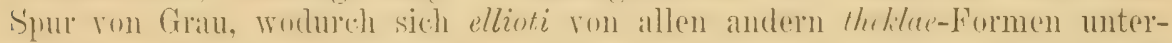
scheidet. Oberseite blaß, etwa wie bei $G$. cristata senegallensis, aber mehr rötlich, die dunkeln Federmitten sehïrfer hervortreteud. Eirste (rudinentïre) Sehwinge rällig so lang wie die Handdectien. Scheint $G$. the curolinue sehr ïhnlich, aber nicht ganz so rostrot zu sein.

Somaliland.

\section{Galerida malabarica (Scop.).}

Alanda malabarica Scopoli, Del. Flor. et Faun. Insubr. II, p.94 (1786- ex Sonnerat, Voyage I. O. \& Chine II, p.203, Taf. 113, "Côte de Malabar").

line sehr wohl unterscheidhare Form, die nach den p. 227 gegebenen Kennzeichen unter $G$. theklae kommen würde. Es ist aber nicht leicht zu sagen, ob man sie als eigene Art oder als Subspezies einer der hier angenommenen Arten aufzufissen hat. (Sollten maluburian und thekler sub)spezitisch rerwandt sein. so mülite ersterer Name anstatt thelke für die Art angewandt werden.) Der Schnabel ist kurz wie bei ellioti, an der Wrurgel hreit. nich dex spitze zu sehr merklieh verjüngt und ziemlich spitz. Allgemeinfïrhung sehr rostrütlich. Enterseite ganz hellrostfartien, der Kropf stark geffectit. die mittleren Steuerferdern sehr dunkel. dagegen die AnBen-

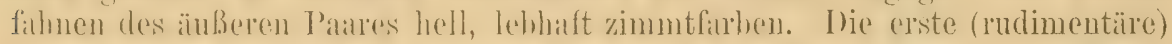
S'chwinge sn lang wie nder otwas linger als die Handdecken. Unterflügeldecken dunkel restlintren odrer zimmtfirben. meist mit leichtem graulichen Schimmer. Flïgel etwa 95-99 $\mathrm{mm}$.

Westliche T'eile der vorderindischen Halbinsel, zum Teil in denselhen Gebieten wie Galerida deva. 


\section{R. Friedländer \& Sohn in Berlin NW. 6.}

In unserem Verlage erscheint:

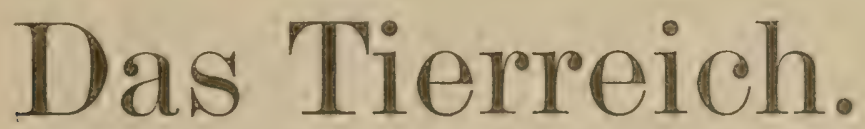

Eine Zusammenstellung und Kennzeichnung der rezenten Tierformen.

Begründet von der Deutschen Zoologischen Gesellschaft

Im Auftrage der

\section{Königl. Preuß. Akademie der Wissenschaften zu Berlin herausgegeben von}

Franz. Eilhard Schulze.

sind bisher erschienen:

Die Herausgallo findet in: Lieferungen (in Grob-Lexikon-Oktat mit

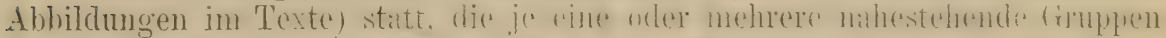

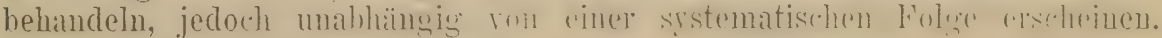
Jede Licferung ist cinzeln küuflich.

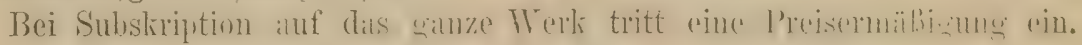
Aus der Gruppe der

\section{Vögel (Aves)}

Lieferung 1: Podargidae, Caprimulgiclae und Macropterygidae. betrlutet von E. Hartert (Tring). 1897. VIII und 98 Seiten mit 16 dbbildungen und Beilage: Terminologie des Vogelkörpers ron A. Reichenow, 4. Seiten mit Abbildung:

Einzelpreis Mark 7,--

Lieferung 2: Paradiseidae. Bearbeitet von The Hon. Walter Rothschild. 1898. VI und 52 Sciten mit 15 Abbildungen. Einzelpreis Mark 3,60 .

Lieferung 9: Trochilidae. Bearbeitet von E. Hartert (Tring). 1900. X und 254 Seiten mit 34 Abbildungen.

Einzelpreis Mark 16, -

Lieferung 15: Zosteropidae. Bearbeitet ron O. Finsch (Leiden). 1901. XIV und 55 Seiten mit 32 Abbildungen. Einzelpreis Mark 4,80.

Lielerung 18: Paridae, Sittidae und Certhiidae. Lical xitet von ('. E. Hellmayr (München). 1903. XXXI und 255 Seiten mit 76 Abbildungen.

Einzelpreis Mark 16,-.

Theitere Liefermgen erscheinen in ununterhochener Folge. Bestellungen und Subskriptionen können durch jede Buchlandlung hewirlit werden.

Berlin, Juni 1904. 


\section{R. Friedländer \& Soln in Berlin NW. 6.}

In unserem Kommissions-Terlage erschien 1902:

\section{Aus den \\ Wanderjahren eines Naturforschers.}

\section{Reisen und Forschmngen}

in Afrika, Asien und Amerika

nubst daran anknüpfenden meist ornithologischen studiun voli

\section{Eirnst Hartert.}

Lin Band von XV und 329 Seiten mit 17 Abbildungen in l'ext mol 13 'Tafeln (- L loutenkarten, Landschaftsbilder, ethnographische 'Typen, Abbiliungen nener Fische -). klein-t.

In geschmackvollem Lieinenband.

$$
\text { Preis } 25 \mathrm{Mark} \text {. }
$$

\section{Inhalt:}

I. Reise nach Sokoto und Kano im wostlichein Sudan (Trestküste. Flubfiahrten auf dem Niger und Benue. Ton loko his Krano, Śokoto und Gandu dureh rother unerforschte Gehiete, damm zuriick zum Benue. Loko

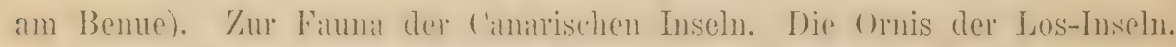
Terzeichnis der hisher helianuten Vügel des Haussalandes. C̈hersicht der im Hatussalande beohatehteten Nut/piflanzen. - II. Reise nach Sumatra. Malialika und Indien. (D)ie Insel Pening. Sumatra. Naturgeschichtliches

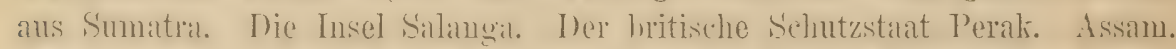
Indien.) - III. Reise nach den Inschn des ('aribischen Aleeres (Jeise nach Westindien und Venezuela: St. Thomals. Famistisehes. Porto Rico. Venczuela. Canateas. Antinnano. Curaţan. Aruba und Bunaire. Flora und Fauma dieser Inseh. Hațti). Die Tägel der Inseln Aruha, ('maţan und Bunaire. neue Formen. - IV. Frühlingsausfug uach Marokko und Tenerife. (Reise nath Marokik und den Camarem. Vugelleben. Der Oum Rhiah. Futdecliung nener Fische. Tenerife. Orotiria.) Notizen üher die Vügel der (regend um. Mazagan im mittleren Marokko. 


\section{Die Vögel}

\section{der paläarktischen Fauna.}

\section{Systematische Übersicht \\ der}

in Europa, Nord-Asien und der Mittelmeerregion vorkommenden Vögel.

Von

Dr. Frnst Hartert.

Heft III.

Seite $241-384$.

Mit 16 Abbildungen.

Berlin.

Vorlag von R. Friedländer und Sohn. Ausgegeben im Juni.1905. 
Es gab bisher kein Werk, welches die lokialen Formen aller paläarktischen V̈̈gel in knapper Form berücksichtigt, und ïberhaupt kein Terk in deutscher Sprache über die Ornis der paläarktischen Fauna.

Ton dem sehr kostspieligen Prachtwerke H. E. Dressor's abgesehen, haben wir zwar ein soehen erschienenes praktisch eingerichtetes Handbuch desselhen Verfassers. Dieses, ,Manual of Palaearetic Birds" hat aher die Ergehuisse des suhtilen Studiums der letzten 15 Jahre unbeachtet gelassen, und bringt fast nur die leieht unterscheidharen Formen, hietet also nur einen Teil ron dem, was wir gebrauchen, und ist nur in englisch Sprache erschienen.

Das vorliegende Werk bemüht sich vor allen Dingen zu zeigen, was hisiner in Cnterscheidung der Sulsprezies geleistet wordeu ist, und somit auch, To inch Lüldien auszufüllen sind. Das Bekiunte ist zusammengestellt, an der Hand ron Material und Literatur geprüft, gesichtet und riel Nenes linzugefïgt morden, wozu die bedeutende ron dem Verfisser rerwaltete Sammlung, und das nahe gröBte Museum der Trelt in London, Gelegenheit boten.

Die Synonymien sind nicht in der herkïmmli then Weise zusammengestellt, sondern hei jedem 'Zitat ist der ursprüngliche f'nndort, die sogenamnte terra typiea, sorgfïltig ermittelt. Der Ballast unnöiger und unmichtiger Literaturangahen ist remieden. Die Beschreihungen siud, wemn nicht anders angegelien, nath der Natur entworfen, also vollstindig neue Originalhesehreilungen; sie sind möglichst liurz und knaply gehaltev. Nicht nur die Arten und Lnterarten, sondern anch Familien und Gattungen sind charakterisiert, die Gattungen enthalten Bestimmungsschlüssel der Arten. Aufer den eigentlichen palïaritischen Formen sind häufig auch uahestehende Formen der angrenzenden Gebiete kurz errwähnt.

Die Nomenklatur ist so konservativ wie möglich, d. h. der älteste ermittelte Name ist für Gattung, Art und Uuteralrt in jedenn Falle ohne Ausnahme angervandt, sodaß. Streitigkeiten um die Namen in Zukunft nicht mehr stattzufinden brauchen.

Das Werk wird in Lieferuugen von je 8 Bogen, zum Preise von 4 Mark für die Lieferung, erscheinen. Das Ganze wird in 10 Lieferungen (zusammen etwa 1200 bis 1300 Seiten in 2 Bänden) ahgeschlossen sein. Die Vollendung des ganzen Werkes ist zu Ende $1907 \mathrm{zu}$ erwarten.

Berlin, NW. 6, Karlstr. 11.

\section{R. Friedländer \& Sohn.}




\title{
Die Vögel
}

\section{der paläarktischen Fauna.}

\author{
Systematische Übersicht \\ der
}

in Europa, Nord-Asien und der Nittelmeerregion vorkommenden Vögel.

Von

Dr. Ernst Hartert.

Heft III.

Seito $241-384$.

Mit 16 Abbildungen.

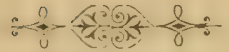

Berlin.

Verlag von R. Friedländer und Sohn.

Ausgegeben im Juni 1905. 


\section{NACHTRÄGR.}

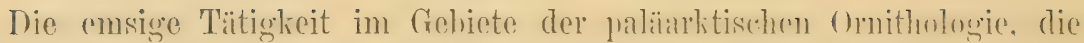

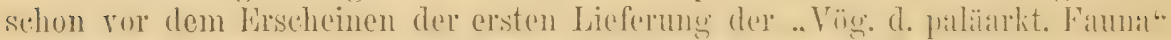
gröber war, als zuror, hat seither merklich zugenemmene. Nimentlich werden dis, wo durch meine Ühersicht der bisher hekamnten Formen Lü̈ckene ersichtlieh wurden, neue Formen beschrieben.

Die neueren Entdeckungen und Frginnungen, Ühersehenes und Varbesserungen werden in einem Nachtrag nitch Tollendung des burhes rrgänzt werden. Folgendes sei schon hier erwähnt:

Auf p. 5 ist als Synonym von Corvus corax behringiams einzufügen:

Corvus grebnitskii Stejneger, Proc. Biol. Soc. Washington II, p. 97 (188.1"Commander Islands").

7u p. 25--27: Die Ühersicht der Vucifuge-Formen hat sich nach Prifung ferneren Materials als vollkommen richtig erwiesen. Die Furmen sind leicht zu unterscheiden. Die Kritik Reichenows, der sich hemiilit, seine relicta aufrecht zu erhalten, ist nicht zutreffend.

Zu p. 41-46: Die Gattung Sturmus mulb vollkommen neu bearbeitet werden. Seit bischeinen meiner Ühersicht sind neun neme Formen heschriehn worden!

Zu 1). 65: Der Name der (xattung, die ich Accullis namnte, mul.s Curduelis lauten, wenn die von Schaeffer 1789 aufgestellten Gattungsnamen angenommen werden. Ich verwarle sie, weil Sithatefer nicht durchgehends binäre Nomenklatur anwandte. Die Ansichten über diesen Fall sind verschieden. Man rgl. Ibis 1905, p. 85 -88, namentlich aher p. 86, 87 .

Auf p. 94 ist einzufügen:

\section{6 a. Pyrrhula pyrrhula rossikowi Derjugin.}

Pyrrhula pyrrhula rossikowi Derjugin, Ann. Mus. Zool. Acad. Imp. Sci. Petersb. V, p. 285 (1900-- Salolet-Topass, Caucasus \& 'Transcaueasia. Russisch!).

Unterscheidet sich von der sehr ähnlichen P. pyrrhula pyrrhula durch die sehr lehhafte, weniger rosen- und melur ziegelrote Unterseite, auch ist der Sehnabel wohl meist dicker.

Transkaukasien, von Lasistan und Provinz Tiflis bis Askhabad in Transkaspien. Wahrscheinlich im gauzeu (auch nördlichene) Kaukasus.

Auf p. 168 und 169 sind die Flügehnaße verdruelit oder verschrieben: sie sollten sein: E. c. citrinella 85-93, E. c. erythrogenys 91--94 mm.

7u p. 182: Sarudny \& Korejew untersehieden eine dunklere Form ron Limberiza Luchumeni aus dem Semirotschje-Gredret in T'urkestan. die sie als "obscura" bezeichneten (Orn. Monatsber. 1903, p. 130). 


\section{Gattung LULLULA Kaup 1829.}

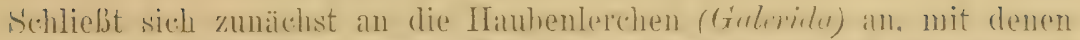

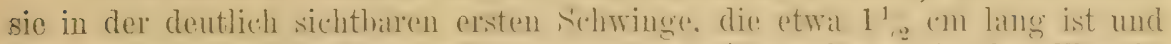

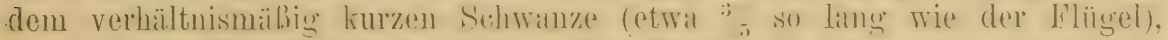
sowie einer Haube ähereinstimmt. Die Himbe ist aller nicht ein spitzer,

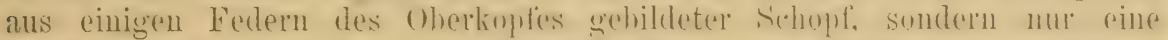

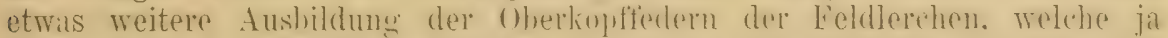
anch ...

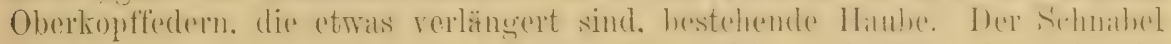
ist nur halb so lang wie der Kopf, gerade, foin und liinn, fast wie ein Sylvien-Schnabel. Geschlechter gleich.

\section{Lullula arborea (L.).}

Heidelerche.

Alauda arborea Linnaeus, Syst. Nat. Ed. X, p. 166 (1758- "Habitat in Europa". Typische Lokalitït Schweden, denn die Diagnose basiert auf dem ersten Citat: „Fn. suec, $\left.192^{66}\right)$.

Alauda nemorosa Ġ̀melin, Syst. Nat. I, p. 797 (1788- ex Rajus, Brisson, Buffon, Latham, Willughby. „Habitat in Italia, Austria, Silesia, Polonia, Anglia, solitaria, cristata minor, in silris et dumetis nidificans" $)$.

Alauda cristatella Latham, Index Orn. II, p.499 (1790- „Habitat in Europa; frequens in Italia; in Anglia, comitatu Eboracensi, rarius").

Galerita anthirostris Landbeck, Syst. Aufz. Vög. Württ., p).36 (1834- auf den höchsten Bergen der Alp. Vgl. ,Nener Naumann"6 IU, p. 33).

Galerite nemorosa, arborea, musica Brehm, Vogelfang, p.12+ (1855- ,In Deutschland bis Dalmatien":).

Corys nemorosa sylvestris, ?brachyrhyncha, anthoides A. E. Brehm, Verz. Samml., p. 8 (1866- nomina nuda!).

Lullula arborea chemeli Prazák, Oru. Monatsber。1895, ]). 143 (Deliblater Sandwüste in Ungarn. Vgl, „Neuer Naumann" HI, p. 33).

Engl.: Woodlark. Franz.: Cujelier, Alouette lulu. Italien: 'Tottavilla. Schwed.: Trädlärka, Skogslärka.

ond. Oherscite rosthraun mit graubrimulielem Sehimmer, die Mitte jeder Feder alusgedehnt bramsehwarz: Federn des Hinterkopfes heller, mehr

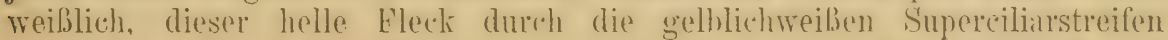
verbunden; Bürzel und Ohersehwanzdecken ptwas mehr olivenbrïunlich und olme die bratunsehwalren Federmitten. Schwingen dunkelhraun mit ralumweißen, an den Armsehwingen hellhranen Anben- und gratureililichen Innensäumen, Armsehwingen mit schmalen weiblichen Spitzen. Handdecken tiefbratun mit weiblichen Śpitzen; Oberflügeldecken wie der [Bürzel, an der Wurzel dunklex, die mittlere Serie dunkelhrimu mit rahmfarhener Spitzenhälfte, die große hellhrämulich mit tieflhrumer Basis; Steuerfedern dunkelbraun, das änßerste Parr mit hellerer, rahmfarben gesämmter AuBenfahne und Spitzenhälfte, die ander'n mit nach der Nitte zu an Ausdehnung abmehmenden weißliehen Spitzen, das mittelste wie der Bürol, nur in der Nitte dunkler. Ohrdecken rosthriun, nitch dem Supereilium zu dunkler. Unterseite rahmfarhen, an den Kehlseiten kleime bramschware Elecke, Kropfgegend mit abensolchen größeren Flevken, Kürperseiten mit schmalen bramen Schaftstrichen. - Elügel 92-99, meist etwa 95-96 mm, die of in der

E. Hartert, Die Vögel der paläarktischen Region. 


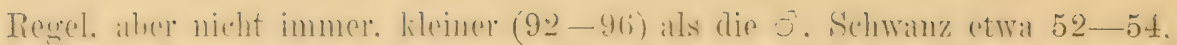

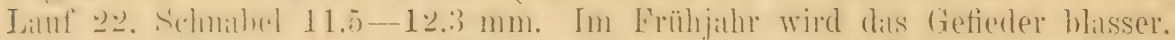

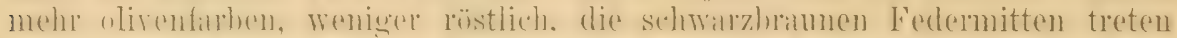

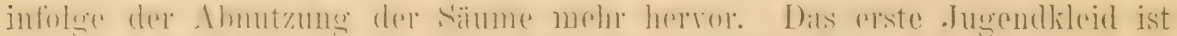

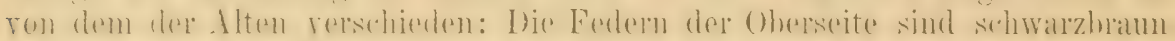

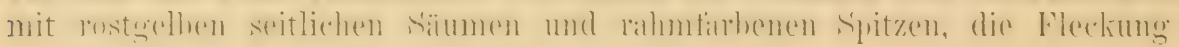
der Kropfgegend ist kleiner, mehr tropfenartig.

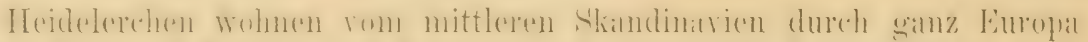

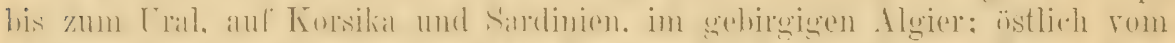

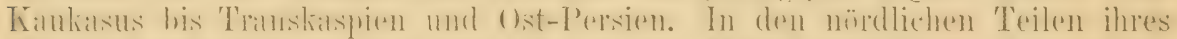

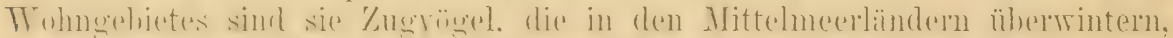

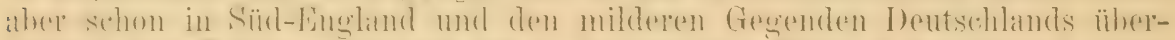

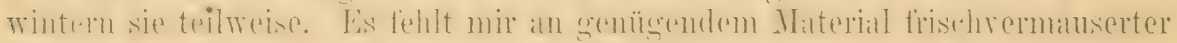

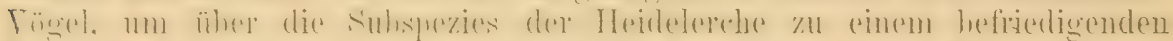

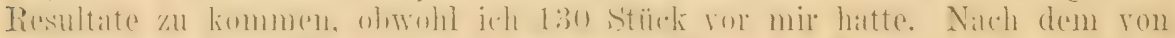

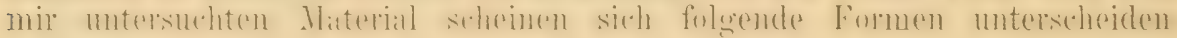
zu lassen:

\section{a) Lullula arborea arborea (L.).}

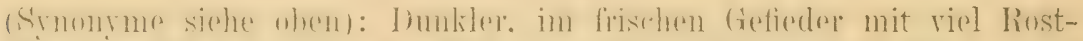

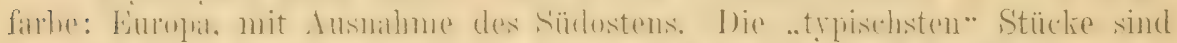

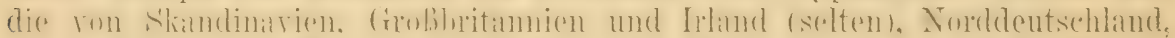

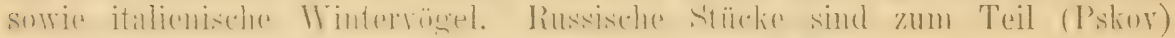
schon auffiallend hell, aber anscheinond nicht durchgehend.

\section{b) Lullulu arborea subsp.?}

Stücke von Sardinion und Korsika sind oben sehr wenig rostfarben,

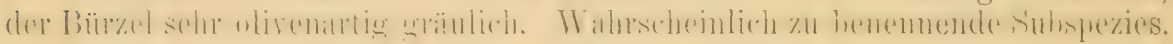
es liegen aber mur Wintervögel vor, deren Brutheimat zweifelhaft ist.

\section{c) Lullula arborea subsp.?}

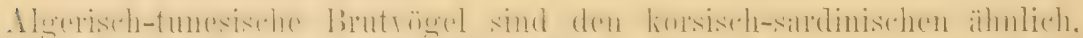

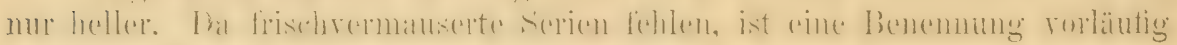
nicht angebracht.

\section{d) Lullula arboren favescens Ehmeke.}

? Corys nemorosa tenuirostris A. E. Brehm, Verz. Samml., p). 8 (1866- nomen nudum!). Lullula flavescens Ehmcke, Journ. f. Orn. 1903, p. 152 („Rumänien“. - A us der teilweise nach Käfigvögeln entworfenen Beschreibung ist wenig für die eventuelle Subspezies bezeichnendes ersichtlich. Der von mir verglichene Typus stimmt mit griechischen Stücken überein.).

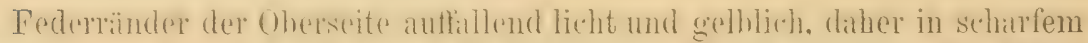
Gerensitze zu den fist schwalmen Federmitten. Hierin stimmen die Vägel

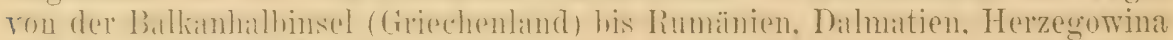
äherein. Einige dentsche Friblingsvögel (Fenthenderf) der Brelmeschen Simmilung seheinen ununterstheidhat zu sein. sind aher vielleicht durch das hohe Alter der Exemplitre etwas rerindert. Die Berechtigung dieser Form ist jedenfalls noch fraglicb, ihre Verbreitung unsicher. 


\section{e) Lullula arborea pallida Sarudury.}

Inlluda arborea pallida Sarudny, Orn. Monatsber, 1902, p. ŏ4 (,1Berge Transkaspiensi:).

Ostpersische und transkaspische Brutrögel sind auffallend hab, iber die ron N.W.-Afrika sind ähnlich, weun auch nicht so blik. Die ron

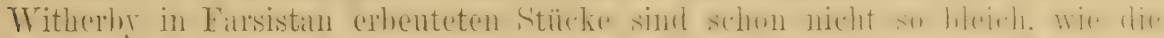

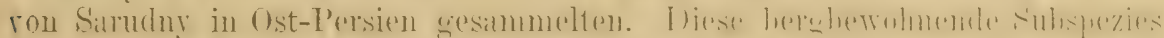

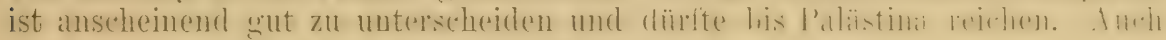
Sarudny sammelte keine frischen Herbströgel.

Die Heidelerche bewohnt lichte Wälder, namentlich mit Heidekraut und Farnkräutern bestandene BlöBen im Nadeholze, besonders Kiefernheiden, auch Brachen mit Gestrüpp und niederm Gebïsch orler steinige, dünn bebuschte Hochflächen, immer nur da, wo der Boden trocken, besonders sandig: ist, im Hügellande und im Gebirge bis zu ziemlichen. Höhen. Nie in sumpfigem Gelände. Verläßt die nördlichen IVohnbezirke im Oktober und kehrt Ende Februar oder im März wieder heim. Die Lebensweise ist echt lerchenartig, aber die Heidelerche ist im Gegensatze zu den ïbrigen europäischen Lerchenarten mehr Waldrogel und setzt sich oft auf Bäume. Der Gesang, der am besten als , lullend:6 bezeichnet wird (woher der Name Lulllerehe und das französische Lulu), äbertrifft durch seine sanft flötenden und doch in der stillen Kiefernheide und namentlich in der Nacht weithin klingenden Strophen alle andern Lerchengesïnge. Niemand kenut die einsamen, weiten Kiefernforsten Norddeutschlands, der nicht von dem Zauber des wunderrollen, schwermütigen Liedes ergriffen wurde. Das Nest besteht aus Mloos, Wurzelı und Halmen und steht wunderbar versteckt unter Grasbïscheln orler Büschen. Es enthält in Dentschland im Mai und Juni frische Gelege, in Enghland oft schon im MIärz. Regelmäßig werden zwei Bruten gemacht. Gelege 4--5 Ficr. Die Eier unterscheiden sich ron den andern dentschen Lercheneiern durch die zarte, feine fleckung, die nur selten gröber ist. Die Schale ist sehr fein und glänzend, weiß, trüb weiß, manchmal etwas rötlich, mit braunen, rötlichen, graubraunen, bräunlichgrauen (Ober- und blaßgrauen Schalenflecken gezeichnet. Oft bilden die Flecke einen Kranz nahe dem stumpfen Ende. Bisweilen kommen ganz weiße Eier mit nur wenigen grauen Flecken vor, sowie weiße mit roten Flecken, an die der Rauchschwalbe erinnernd. 46 ron Dr. Rey gemessene Stücke aus Deutschland ergaben: Durchschnittsmab: $20.7>15.5$, Maximum $22>16$ und $20.5>16.5$, Minimum $19.5 \times 15.5$ und $21.5 \times 14.7 \mathrm{~mm}$. Mittleres Gewicht $156 \mathrm{mgg}$.

\section{Gattung ALAUDA L. 1758.}

Schnabel viel stärker als bei Iullulu, gestreckter und feiner als bei

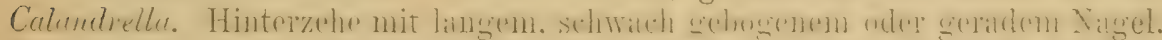

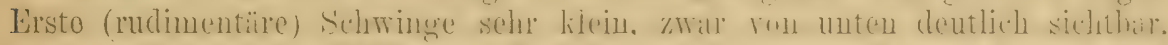
aber weit unter der Hallte der Handdeclien. Innerste Arnsebwingrus stark

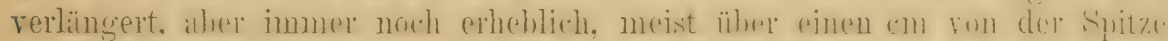

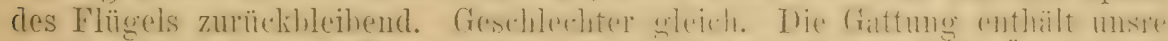

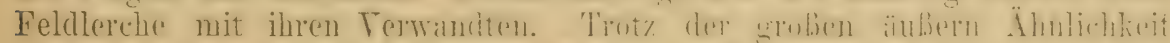

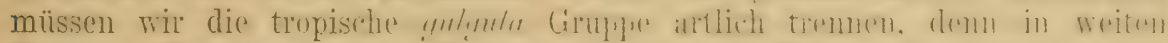

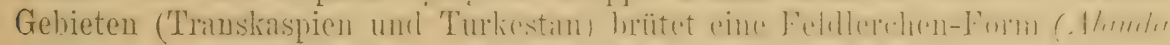
arvensis cantarella) und eine gulgula-Form (Alanda gulgula inconspionu).

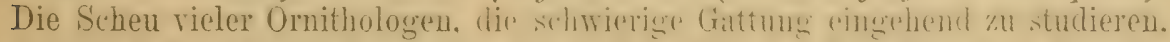
erschwert das Terständnis sehr. ein grolin' Toil der Literatur ühre dieselhe ist systematisch seln minderwertig. 


\section{ïbersicht der Arten:}

Größer, Fliigel und Schwanz meist länger (Flügel bei den meisten Formen weit iiber $10 \mathrm{~cm}$ ), Lanf etwas über $1 / 3$ der Schwanzlänge, fïnfte Schwinge (die erste rudimentäre nitgezählt), $5 \mathrm{~mm}$ oder mehr kürzer als die längste: A. arvensis .

Kleiner, Fliigel und Sehwanz meist kürzer (Flïgel bei den meisten Formen unter $10 \mathrm{~cm}$ ), Lauf beinahe $1 / 2$ der Schwanzlänge, fünfte Schwinge (die erste rudimentäre mitgezählt) $n$ w wenig (unter $5 \mathrm{~mm}$ ) kürzer, als die längste: . A. gulgula .

\section{- 396. Alauda arvensis arvensis $\mathrm{L}$.}

Feldlerche.

Alaula crvensis Linaens, Syst. Nat. Ed. X, p. 165 (1758 - "Habitat in Europae apricis." Terra typica: Schweden, nach dem ersten Zitat).

?Alandu italica Gmelin, Syst. Nat. 1, p. 793 (1788- Italien. Ex Brisson u. a. m. Wahrscheinlich übertriebene Beschreibung einer jungen Feldlerche).

?Aluuda arvensis ruficeps Bechstein, Gemeinn. Naturg. Deutschl. IV, p.120 (1795Waltershausen. Man hat diese rotköpfige Lerche zu Melanocorypha sibirica gezogen, aber es scheint mir cher, daß Bechstein eine Feldlerchen-Varietät vor sich hatte). ${ }^{1}$ )

Alauda coclipeta (partim!) Pallas, '/uongr. Rossu-A siat. I, p. 524 (1827- „Per omnem Rossiam et Sibiriam." Pallas gab den Namen nicht etwa den östlichon Feldlerchen im Gegensatze zu den europäischen, sondern ersetzte Linnés Alauda arvensis durch Alauda coelipeta.).

Alaudavulyaris Leach, Syst. Cat. Mamm. Birds in Brit. Mus., 1. 21 (1816- nomen nudum!). Alanda ayrestis Brehm, Handb. Naturg. Vög. Dentschl., p. 320 (1831— „erscheint bei uns im März und Oktober"*).

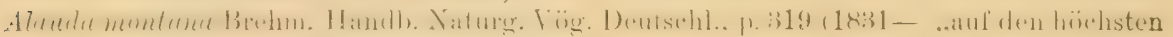
Bergen des Thïringer Waldesi).

Alanda segetrom Brohm, Handb. Naturg. Vög. Deutschl, p. 318 (1831 - ,sie bewolnnt die Felder ebener und hügeliger Gegenden unsres Vaterlandes"6).

Alauda pratorum Brehm, Isis 1841, p. 136, 141 (Brinnis).

Alauda robusta Brehm, Isis 1841, p. 137, 145 (Mittel- und Nord-Dentschland).

Alauda Bugiensis Brehm, Isis 1811, p. 137, 150 (Bug auf Rügen und 20 Hlinuten von Renthendorf).

Alauda galevidaria Brehm, Isis 1841, p. 137, 151 (Nerdin in Pommern und bei Renthendorf). Alauda albigularis (partim!) Brehm, Isis 1811, p. 137, 152 (Ragusa und Klagenfurth). Alauda gracilis Brehm, Isis 1841, p. 137, 153 (Kärnthen).

1) Bechstein hat (t. c., 1). 121) anch noch eine, ,langbeinge Feldlerche. Alauda arvensis longipes." Ich habe in diesem Buche die zahllosen Bechsteinschen und Naumannschen, zum großen T'eile immer wiederkehrenden Aberrations-Namen für Albinismen, Luteismen, Melanismen und gescheckte Stïcke (alba, latea, nigra, variu, rufa, candida, albida usw.) ausgelassen. Ihre Zitierung würde den Umfang des Buches sehr vermehrt haben und ich folgte mit der Weglassung derselben dem allgemeinen Gebrauch aller Ornithologen. Diese Namen haben nicht die (wenn auch oft nur vermeintliche) Bedeutung der Brehmsehen Namen, d $\Omega$ sie ausdrücklich nur individuellen Aberrationen beigelegt wurden. Nomenklatorischer Wert wurde ihnen niemals beigelegt, denn sie kehren bei vielen Arten in derselben Gattung wierler, oft auch wurden sie weggelassen, oft waren sie nur Übersetzungen von 'Trivialnamen in andern Sprachen. Die meisten Ornithologen werden sich daher freuen, daß ich diesen Ballast fortließ: Trotzdem wäre es vielleicht besser gewesen, sie zu zitieren, denn es könnte die Frage aufgeworfen werden, ob nicht diese Namen den Gebrauch derselben (für Spezies und Subspezies) innerhalb der Gattung fernerhin ausschließen. 
Alauda tenurostris Brehm, Isis 1841, ]. 137, 153 (Brinnis bei Leiprig britend, bei Renthendorf nur zur Zugzeit).

Alauda crassirostris Brehm, Vogelfaug, p. 125 (1855- Deutschland).

Alauda minor Brehm, Vogelfang, p. 125 (1855- Deutschland).

Alauda arvensis planomu, major A. E. Brelm, Verz. Samml., 1).8 (1866- nomina nuda!).

Alandu nana Giglioli, Avif. Ital., p. 68 (1886- bei Hlorenz. ['Zwerg.]).

Alanda subalpina Ehmeke, Journ. f. Orn. 1903, p. 150 ("Savoyer Alpen"6).

Alaude arvensis scotica T'schusi, Orn. Jahrb. XII, p. 162 (1903- Schottland).

Alauda sordida Ehmeke. Ann. Mus. Nat. Hung. 1904, p.300 (Hiddensee bei Rügen und Ungarn).

Engl.: Skylark. Hranz.: Alouette des chaups. Ital.: Lodola. Schwed.: Sanglärka.

óad. Oberseite braum, alle Federn in der Mitte schwarzbraun. Hinter-

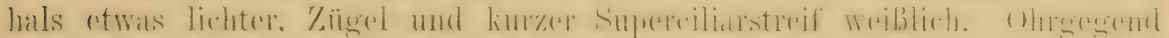

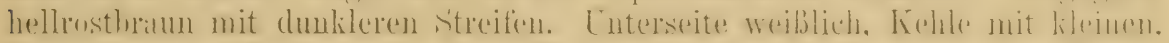

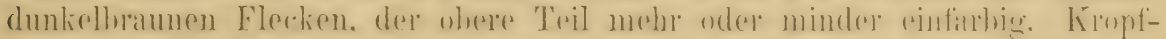

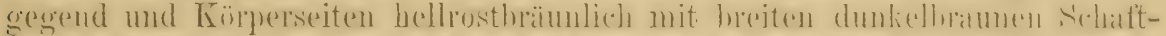

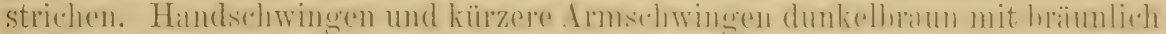

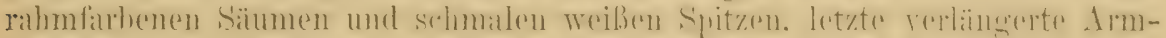

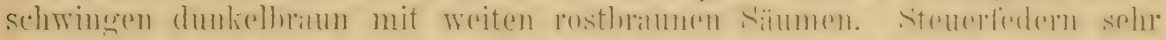

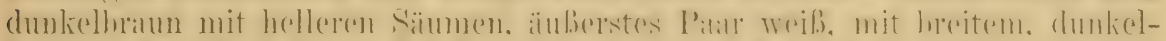

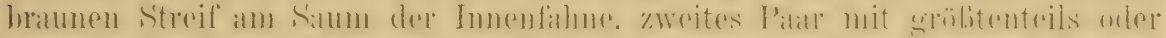

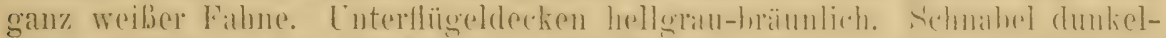

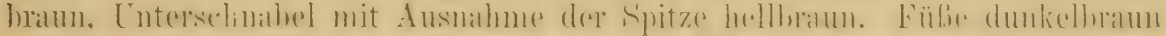
mit schwälzlichen Gelenken. Jris britun. Flügel alter ơ etwa 110-120. Schwanz, etra 70-75, Lauf etwa 25, Sclinabel $10-12 \mathrm{~mm}$. Nagel der Hinter\%ohe

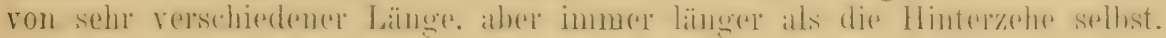

o ad. wie O', nur etwas kleiner. Flügel etwa 95-105 (meist circa 100),

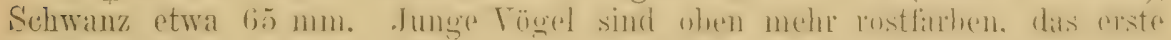
Federkleid ist oben dunkelbraun mit sehr hreiten rosthriunen Säumen und

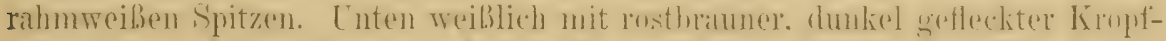

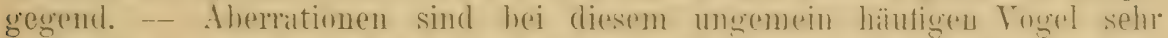

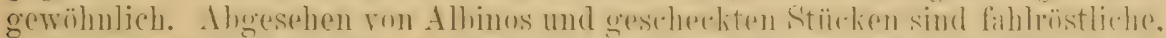

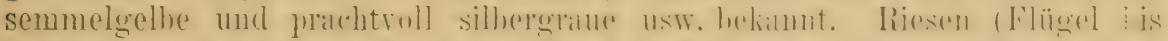

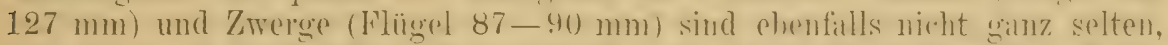

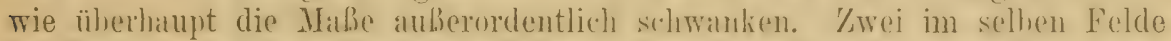

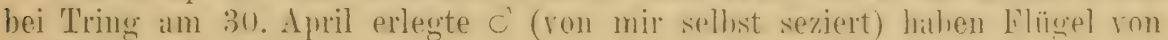
112 und $116.5 \mathrm{~mm}$.

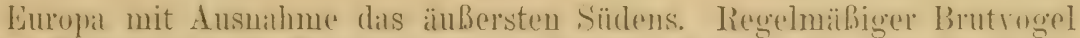
bis zum T'olarkerese, in Sliandinavien in geringer Anzahl his zum 70. Craide

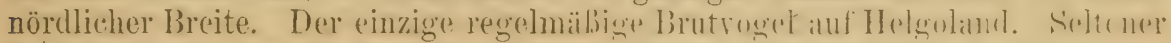
Brutvogel auf den Farier. In den märllichen If ohngehieten \%ugroged, der iu Nord-Afrika und Süd-Furopa üherwintert. Schon in den milderen Teilen Deutschlands in geringer Anzahl, in Fngland in Menge tiberwinternd, aber noch aus Nord-Italien fortziehend. In Sün-Europa dureb gratuere Formen

- ersetzt. Schon Sharpe und Dresser spratehen ron der rostbrïmlichen Firrbung

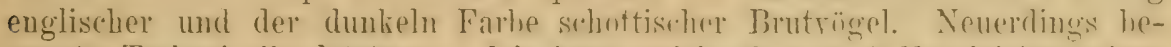

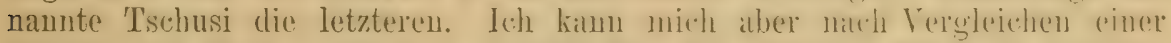
ungeheneren Serie nicht dazu entschlieben, die britische Form zu sumclem. Es ist wahr, dab hritische Lerehen (die englisehen somoln] wit diu whthishen) 


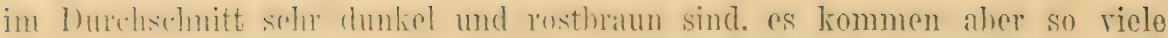

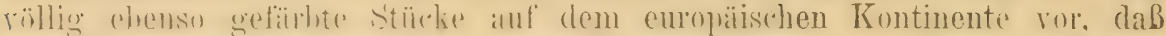

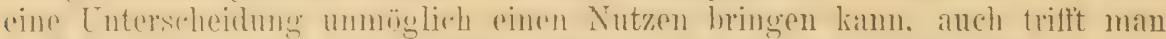
in England hisweilen ptwas hellere Stücke hrïtend an, gerade wie anf dem Kontinente. Iuf Rëgen und ant dem dunkeln Masschboden einiger Gegenden

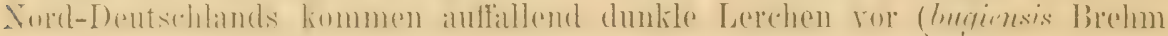
1841. sorlid, Ehmeke 1904!). Sie sind aber nicht konstant und nicht geographisch begrenzt genug, um sie subspezitisch zu unterscheiden.

Die Feldlerchen bewohnen Felder. Wiesen und offenes Ödland. Im Winter streichen sie in Flïgen umher und die nördlicher wohnenden wandern in großen Massen in mildere Gegenden. Sie halten sich fast immer an Boden auf, sehr selten sieht man sie nuf einem Busche oder Baume sitzen. Ẻben so selten hört man eine sitzende Feldlerche singen, fast immer steigen sie in die Luft, weun sie ihren jubelnden Gesang hören lassen. Das locker gebaute Nest steht meist in einer kleinen Vertiefung des Bodens und ist in der Regel der Umgebung so ähnlich, daß es nur schwer su sehen ist. Die 3-5 Eier findet man von Mitte April bis Mlitte Juli; es werden sicher zwei, angeblich bisweilen auch 3 Bruten im Jahre gemacht. Die Eier variieren außerordentlich. In der Regel sind sie anf rahmfarbenem oder weißlichen Grunde über und über mit braunen und dunkelgrauen filecken bedeckt, die nach dem stumpfen Ende hin größer werden und dort manchmal einen Kranz bilden. Bisweilen sind sie fast steingrau oder hellkaffeebraun mit undeutlicher Fleckung, hellbräunlich, mit wenigen kleinen Flecken und tief dunkelbraumen Kranze oder fist weil. Sehr selten haben sie einen rötlichen Schimmer. 100 Eier in Dr. Rey's Summlung messen durchschnittlich $24.1 \times 16.8$, die beiden gröliten $25.5 \times 17$ und $24.3 \times 18.5$, die kleinsten $20.6 \times 16.6,22.7 \times 15.3 \mathrm{~mm}$. Durehschnittsgewicht $182 \mathrm{mg}$.

\section{Alauda arvensis cantarella Bp.}

? Alanda cantarella Bontparte, Geogr. \& Compar. List B. Europe \& N. America, p. 37 (1838 - nomen nudum!).

Alauda canturella Bonaparte, Ieonogr. Fauna Ital., Uecelli, Introd., j). 5 (1832-1841 Italien. Mittelitalien: nach Consp. Ar. I, p. 245. Uf. Bp., Rev. Crit., p. 57). Alaude albigularis (partim!) Brehm, Isis 1841, p. 137, 152 (Ragusa und Klagenfurth. Beschreibung nicht für die siidöstliche Form bezeichnend.).

Alaula lunata, Brehm 1842, p. 342 (Unterungarn, Ragusa, Türkei, Griechenland. Besehreibung palst auf die südliche Form.).

?Alaudu flavescens Ehmeke, Journ. 1. Orn. 1903, p. 151 (W'alrscheinlich zu cantarella grehörend, aber unsicher, da nach Käfigrögehn beschrieben!!).

Alauda intercedens Ehmeke, Ann. MLus. Nat. Hung. 1904, p. 296 (Attika).

Alauda balcanica Ehmcke, Ann. Mus. Nat. Hung. 190t, p. 297 (Balkan).

Alauda minutu Ehmeke, Ann. MLus. Nat. Hung. 1904, p. 298 (Corfu, Kankasus und Balkan!). Alauda cypriaca Elmueke, Ann. Mus. Nat. Hung. 1904, j). 300 (Cypern).

Alauda insularis Elnmeke, Ann. Mus. Nat. Hung. 1904, p. 300 (Cypern - wie cypriaca nach Winterrögeln beschrieben. die zum Teil auch der nordöstlichen Form angehören dïrften).

Diese Form ist A. a. arvensis sehr ähnlich, unterscheidet sich aber

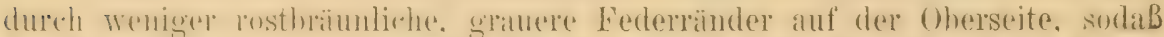

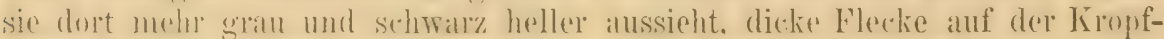
gegend, zismlich weililichen ["nterkïrper und im allgemeinen wohl anch etwas geringere Gröbe.

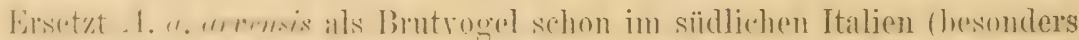

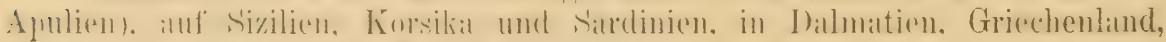
der Türkei bis Sïd-Ungarn und Süd-Rußland. 
398. Alauda arvensis cinerea Ehmeke.

Alanda cinerea Ehmcke, Journ. f. Orn. 1903, p. 149 (Barnoul in Sibirien).

Alauda cinerascens Ehmeke, Journ. f. Orn. 1904, p. 313 (Umänderung des Namens cincrea). ? Alauda schach Ehmeke, Ann. Ilus, Nat. Hung. 1901, p. 299 (Ost-Persien).

? Alauda beludschistana Ehmeke, Ann. Mus. Nat. Hung. 1904, p. 299 (Dus-Ab in Persisch Beludschistan und Hussein Abad in Ost-Persien).

Meist lileiner, merkilich lichter und gräulicher als südenropiaische rantmella, doch gibt es Stücke, die sich kaum oner nicht unterseheiden lassen, und dio geographische Verbreitung ist noch unsicher.

A. a. cinerea dürfte Brutvogel sein in West-Sibirien (mindestens bis Krasnoyarsk). Turkestan, Persion his (?) Pallastinat. (Ther die kininasiatischo Form hin ich nicht unterrichtet.) Im Winter häufig an (ler Nordscite des Kankasus und his Algier. 'Tunis und Ägypten. Ostrussisehe Stürlie (o)renburge) scheinen intermediar zu sein. In ()st-l'ersien und lailuehistan sind viele

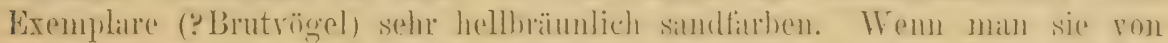

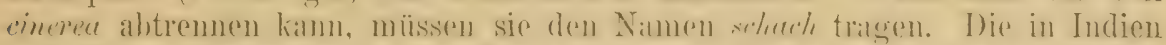

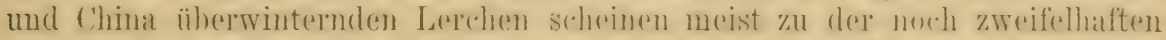

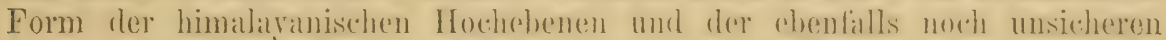
intermedic $(\mathrm{Nr}, 402)$ zu gehören.

a) Alauda arvensis subsp.?

? Alauda leiopus vel orientalis (?partim) Hodgson, in Gray's '/ool. Mlisc., p. 84 (1844nomina nuda!).

Alauda leiopus (?partim) Hume, Stray Feathers 1, p. 10 (1873-- „High Himalayan Platenus.").

Alauda dulcivox Hodgson, in Gray's Zool. Nisc., p. 84 (1844- nomen nudum!); Brooks, Stray Feathers I, p.484 (1873- Alpine Regionen Nord-Indiens).

Auf den alpinen Matten des Himalitya hritet eine Feldrorehe, die meist einfach Alauda arvensis genannt oder zu canturella gezogen wurde. Sio

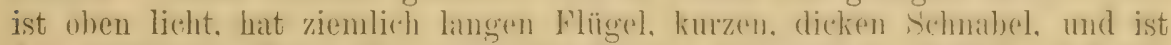

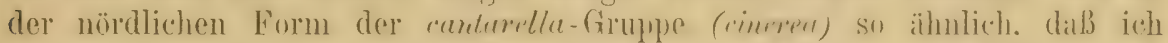
sichere linterscheidungsmerkmale nicht angehen kamn - es fohlt jedoch

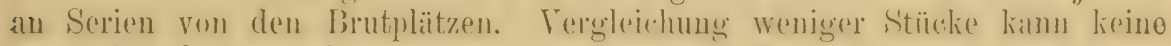
neuen Resultate ergeben.

In Sikkim und an andern Plätzen in Himalaya ersehcinen zur Zugzeit Lerchen. die teils 1. ". jeponier (Nr. $t^{\prime \prime 1)}$ sehn ithnlich sehen, teils wie dio

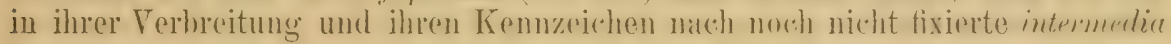
aussehen. Sio dürften von der auf' diesen Hochehenen brïtenden Form anch wieder verschieden sein.

\section{Alauda arvensis harterti Whit.}

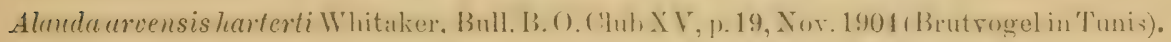

Ton der ihr sehr ïhnliehen, im selhen Gehicte im Winter erseheinendeu nordöstlichen rantarella-Form (rineren) sowie von A. a. mernsis auf den proten

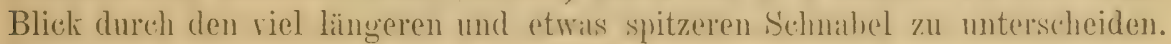
Färbung nicht so grau wie die von $A$. $a$. cinerea und heller als die von A. a. arvensis.

Nord-T'unis, Algier und vielleicht 'Teile von Marokko. (Nordmarokkanische und namentlich spanische. Brutlerchen dürften nicht hierzu gehören und sind noch genauer zu untersuchen.) 


\section{- 400. Alauda arvensis pekinensis Swinh.}

Alanda pekincnsis Swinhoe, I'roe. Zool. Soc. London 1863, p. 69 (P'eking).

Alanda blakistoni Stejneger, Proceed. Biol. Soe. Washington II, p. 98 (1884- Kamtschatka. Vgl. P'roe. U.S. Nat. MLus. XV, p. 303, 1892- Kurilen, Japau).

Sehr grobe, lebhalt rostrote Form. Vou allen hior unterschiedenon linormon A. arrensis arvensis am ähnlichsten, aber im frisch vormauserton

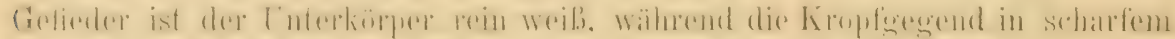

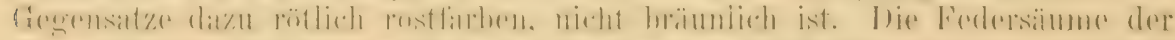

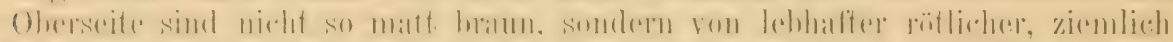

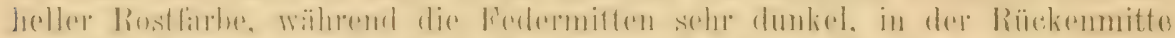

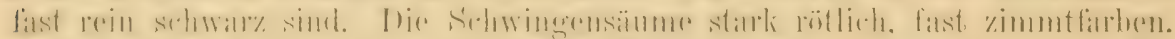

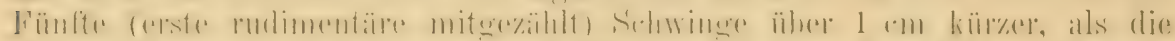

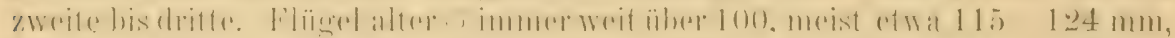
Schwanz 69-76, Schnabel 12-13, Jauf 26-27, Nittelzohe mit Kralle $22-24 \mathrm{~mm}$.

Brutrogel in Kamtschatka, dem nördlichen Ost-Sibirien mit Sachalin,

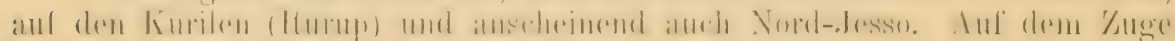
auch auf andern japanischen Insein und in Nord-China (Jeking).

Lebensweise ganz wie die unsrer Eeldlerehe. Thezanowski gibt die Maßse von Jiern von Darasun, die vermutlich zu dieser Eorm gehören, wie folgt an: $21.3 \times 17$, $22.2 \times 16.8,23 \times 16.1,23.3 \times 16.6,24 \times 16,24.2 \times 16.3,24.2 \times 17.2 \mathrm{~mm}$.

\section{Alauda arvensis japonica 'l'emm. \& Schleg.}

Alauda japonica 'T'emminek et Schlegel in Siebold's Fauna Japonica, Aves, p. 87, T'af. 47 (18.18- Japan).

Ganz wio A. arvensis prekinensis, aber viel kleiner, meist auch oin wenig dumkler auf der Oberseite. Wlügel alter o unter oder höchstens $3-4 \mathrm{~mm}$ über $100 \mathrm{~mm}$ lang. Schwan\% 63-66, Schulbel 11-12.5, I tauf 23-25, Nittelzehe mit Nagel etwa $19-22 \mathrm{~mm}$.

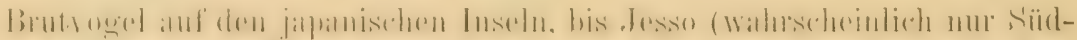

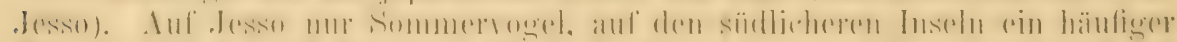

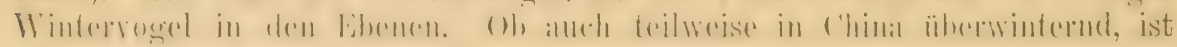
nicht sicher, woil die als japonica bestimmten Jerchen wohl meist zu intermedia gohören.

Nistet anscheinend in Gebirge und in der Eibene. Eier rom April bis Juli.

\section{Alauda arvensis intermedia Swinh.}

Alauda intermedia Swinhoe, Proc. Zool. Soc. 1863, p.89 (Shanghai).

A. intermedia ist eine noch gan\% fragliche Form, aber wahrscheinlich

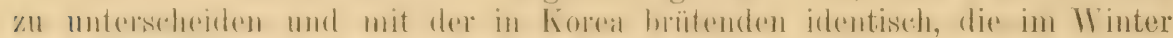

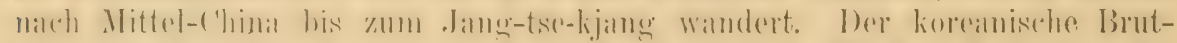

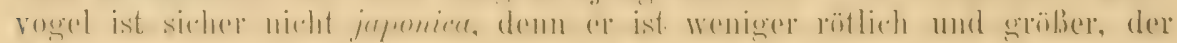
Flïgel dor or miBt etwa $105-115 \mathrm{~mm}$, or ist atleh nicht pekinensis, denn er ist nicht so rötlich und kleiner.

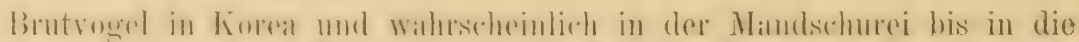

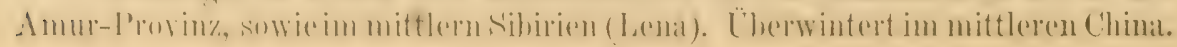




\section{Alauda gulgula gulgula Frankl.}

Alauda gulgula Franklin, Proc. 'Lool. Soe. 1831, p. 119 (am Ginges zwisehen Calcutta und Benares oder Vindhya Berge).

? Alaula triborhyncha (partim) Hodgson, in Gray's Zool. Hise., p. 81 (1814 - nomen nudum!). Alauda gracilis Blyth, Journ. As. Soc. Bengal XI, ]. 201 (1842- Calcutta).

Alauda Gangetica Blyth, Journ. As. Soc. Bengal XIl, p. 181 (18.43- (ranges Ébene). Alauda peguensis Oates, Stray Feathers III, p.343 (1875- l'egu).

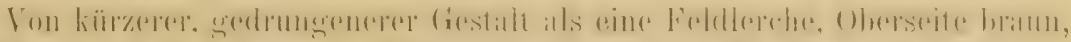

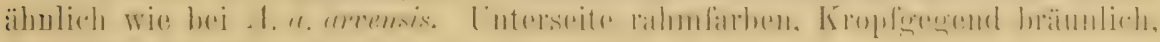
solr foin gofleckt. Flïgel $83-97 \mathrm{~mm}$.

Bewohnt das tropische Indien vom Himalatya sïdwärts, wird aber im äußersten Sïden durch australis vertreten.

\section{Alauda gulgula guttata Brooks.}

Alauda guttata Brooks, Journ. As. Soc. Bengal XLI, 2, p.84 (1872- KuschmnT).

Ganz wie A.q. gulyula, aber gröBer, Obersoite dunklor, weniger röstlich,

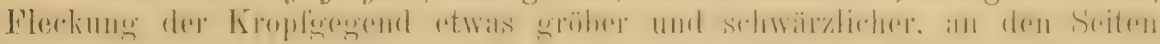
in oinen größern schwarzen Fleck zusammenfliebend. Flügol 95-102, ansmahmsweise his $107 \mathrm{~mm}$.

Bowohnt Kaschmir:

\section{Alauda gulgula inconspicua Sever\%.}

Alauda inconspicua Severzow, 'lurkest. Jevotn., p. 142 (1873- 'T'urkestan. Russisch!). Alauda transcaspica Eihmeke, Ann. Mus. Nat. Hung. 1904, p.301 (Tedschen in 'Transkaspien).

Abbild.: Dresser, B. Ėurope Suppl., 'I'nf. 68.1.

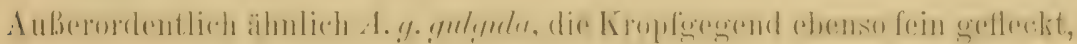
aber oben etwas lichter, mehr sandbräunlich, fingel etwa $97-100 \mathrm{~mm}$.

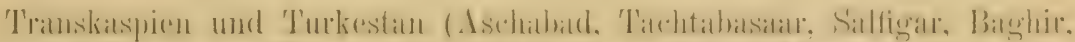

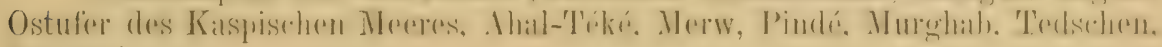
Bucharia).

\section{Alauda gulgula australis Brooks.}

Alauda anstralis Brooks, Stray Feathers I, 1).486 (1873- Ootacamund).

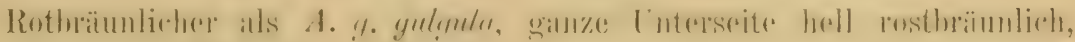
Federmitten der Oberseite sehr dunkel.

Südindien und Ceylon.

\subsection{Alauda gulgula coelivox Swinh.}

Alanda coelivox Swinhoe, Zoologist 1859, p. 6724, Ibis 1860, p. 52, 132 (Amoy).

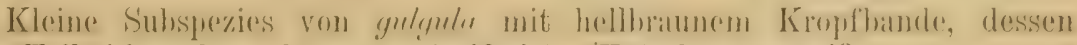
oberer 'Teil foin schwarzbraun gestreift ist. Unterkörper weiß.

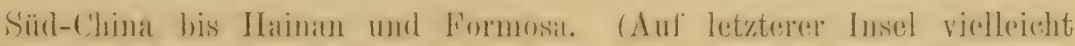

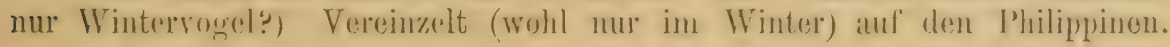




\section{Alauda gulgula sala Swinh.}

Alaula sala Swinhoe, Ibis 1870, p. 355 (Hainan).

Alanda vattersi Swinhoe, Proc. Kool. Soc. London 1871, p. 389 (Süd-Formosa und Pescadores).

Eine sehr dunkle. "twas langflügeligrere und merklich dick- und großschnäbligere Form.

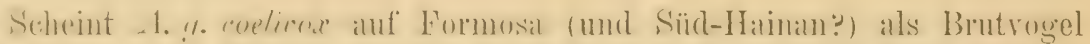

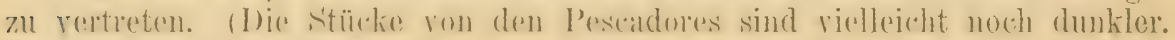
Vgl. Ibis 1895, p. 335.)

\section{Gattung ALAEMON Keys. \& Blas. 1 \& 11.}

Von allen hisher hesprochenen Leredengattungen dureh den langen,

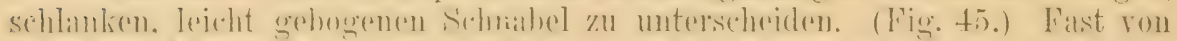

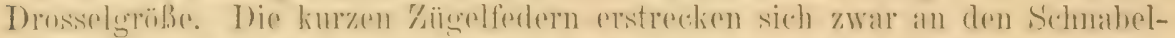

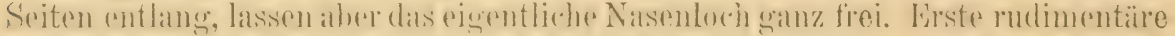

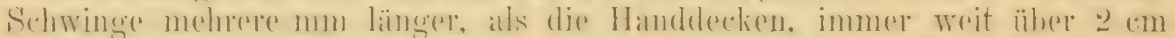

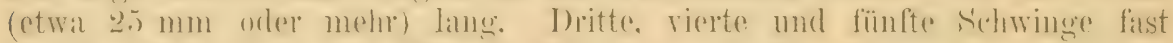

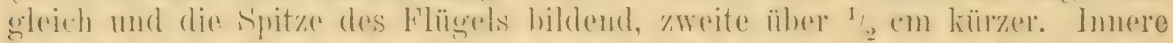

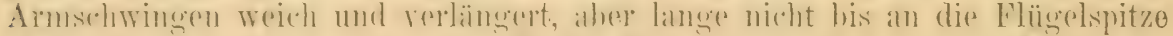

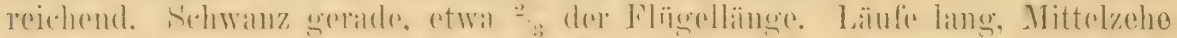

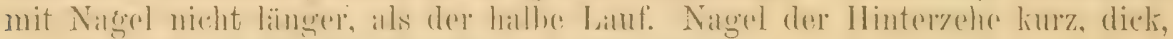
gerade, so lang wio die Hinterzehe oder kürzer.

\section{Alaemon alaudipes alaudipes (I)esf.). (Fig. 45.)}

Upupa alaudipes Desfontaines, Hén. de l'Acad. 1787, p. 50.t (Gafsa \& 'T'ozer in 'Tunis). Alauda bifasciata Lichtenstein, Verz. Doubl. Zool. Mlus. Berlin, j). 27 (1823- „Nubia“). Certhilauda meridionalis A. E. Brehm, Journ. f. Orn. 1854, p. 77 (Dongola in Nubien). Certhilauda salvini 'Tristram, Ibis 1859, p. 57 (Algerische Sahara).

ชึad. Oberseite blaß gelblich oder bräunlich isabell, auf Kopf und

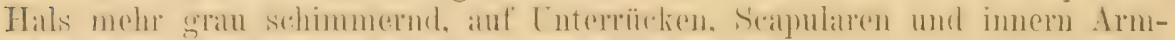

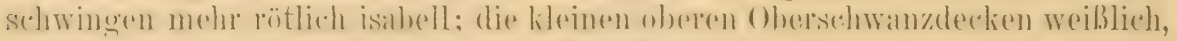
die längern isabell mit dunkelhramen behaftstrichen. Mandsehwingen sedowarz-

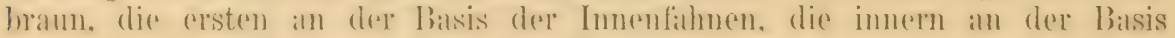
beider Fahnen weiß. Armsehwingen braumschwarz, Außen-

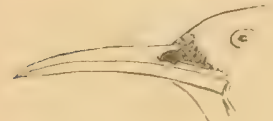

Figur 45. fahne isabell gesïumt, Basis und Spitze ausgedehnt weiß. Letzte verlängerte Armschwingen dunkelbraun, sehr breit lichtisabellfarben gesäumt. Kleine Oberflügeldecken isabell, mittlere fallbraun mit isabellfarbenen Säumen, große dunkelbraun mit weiten woiben Spitzen. Steuerfedern

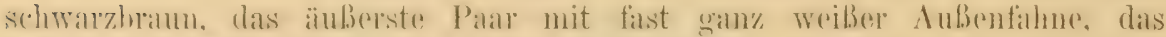
zweite mit ganz sthmalem weiben dubensanme. die folgenden mit ganz schmalem, fihlhrammem dubentamde. das mittelste I'all weich und spitz (fast wie verlängerte Schwanzderelen). lehhaft isahell mit schwar\%em sehafte mod dunlielgranem Sehatten entlang dem Schalte. Jederseits an der Basis

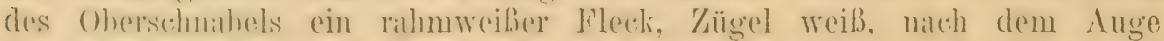
zu cinige sohwarge Federu. Kurzer weiber Supereiliarstreif, ohregegend 


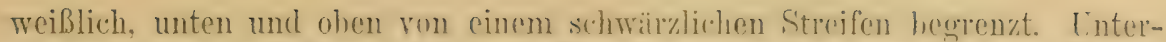

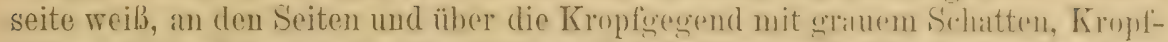

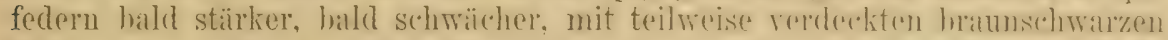

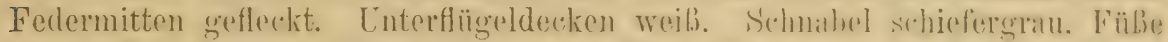

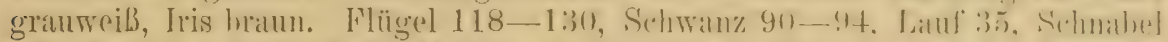

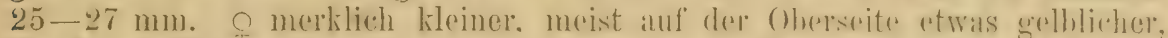

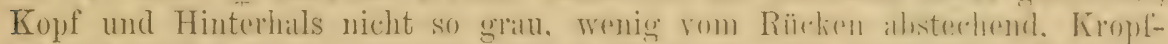

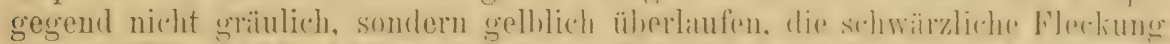

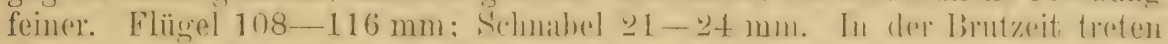

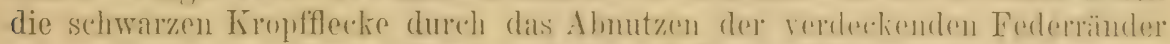

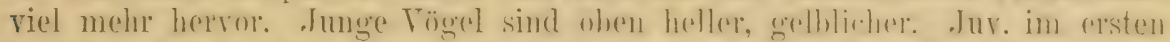

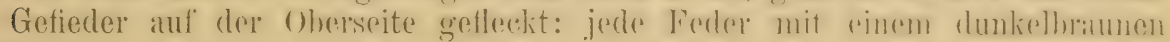
Fleck vor dem rahmfarbigen Endsaum.

Sahara vom Rio de Oro bis Egypton. Soll sich ausnalumsweiso nach

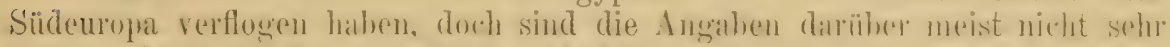

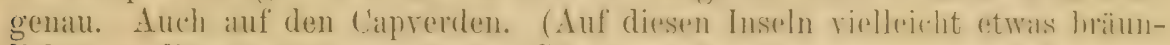
licher, es liegen aber nur wenige Stïcke vor.)

Ausgesprochener Wüstenvogel, Fürbung dem Wüstenboden wunderbar angepaßt. Der klangvolle, nach Lerchenart in langsam aufsteigendem Hluge nusgestoßene, wehmütige Gesang hebt an mit einer aus 3-4 'Tönen hestehenden aufwärts steigenden Scala, an den sich ein lebhafter Triller anschließt. Jeder Reisende bewundert die überaus liebliche Hrscheinung dieser zutraulichen "Wüstenläuferlerche". Die Nahrung scheint fast ganz aus Insekten zu bestehen; Nest (Kíoenig u. a.) frei auf dem Boden oder auf niedrigen Büschen. (ielege 2- \$3 (nach Erlanger auch 4) Eier. Diese sind milchweiB, mit matt lila Schalenflecken und gelbbraunen oder dunkellswunen Oberflecken bedeckt. Sie messen $20 \times 15,20 \times 16,21 \times 15,21 \times 16,22 \times 17 \mathrm{~mm}$ und wiegen etwa 0.15 bis $0.17 \mathrm{~g}$, wach Nehrkorn $24 \times 16.5 \mathrm{~mm}$.

\section{Alaemon alaudipes desertorum (Stunl.).}

Alauda Desertorum Stanley in Salt's Exped. Abyssinia App. IV, p. XLIX und LX (1814- Insel Hamphilah im roten Meere und abessinische Kïste).

Certhilauda doriue Salvidori, Atti R. Accad. Torinn III, p. 292 (1868).

Alaemon Jessei Finsch, 'Trans. \%ool. Soc. London VII, p. 273 (1870 .. "Koulla" an der abessinischen $\mathrm{K}$ ïste).

Ganz wie A. a. chundipes, aber Oberseite viel gräulicher, die kleinen

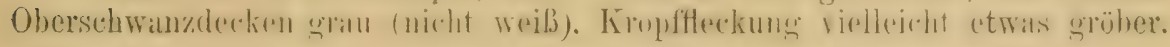

Inseln und Küsten des roten Meeres, bis Süd-Arabien.

\section{Alaemon alaudipes pallida (Blyth).}

Saxicola (?) pallida Blyth, Journ. As. Soc. Bengal XVI, p. 130 (1817- Sindh).

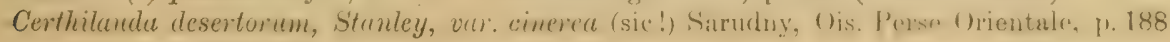
("1903" (?1904) - Ost-Persien. Russisch!).

Wie A. r. desertorum gefärht, aber viel größer. Hlügol alter ơ 138 bis $141 \mathrm{~mm}$, Schnabel $28-30 \mathrm{~mm}$. Flügel alter o etwa $128-130 \mathrm{~mm}$.

Persien, Afghanistan, Cutch und Sindh. 


\section{Gattung CHERSOPHILUS Sharp? 1890.}

Steht Alaemon sehr nahe, unterscheidet sich aber wie folgt: Die kurzen

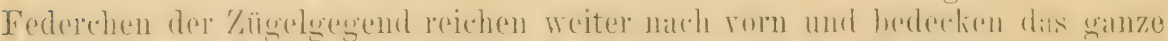
Nasenloch vollständig. Erste Schwinge nur etwa 10-12 mm, kámm mehr als halb so lang wie die Handdecken. Steuerfedern schmal und spitzig:

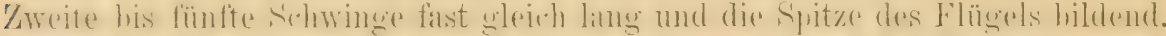

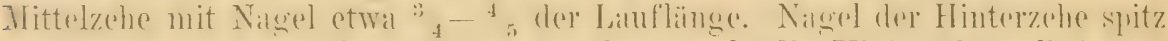
und schlank, etwa so lang oder etwas länger als die Hinterzebe sellost.

\section{Chersophilus duponti duponti (Vieill.).}

Alauda Duponti Vieillot, Faune Franc., p. 173 T'af. 76, Fig. 2 (1820- Provence!). ?Certhilanda Duponti, var. lusitanica Bocage, Journal Sci. Hath. Phys. e Nat. XI, Nr. XLIV. p. 214 (Febr. 1887 - „Qointa do Alfeite, au sud du Tage, vis-à-vis de Lisbonne")

(Alauda ferruginea v. d. Mühle, Beitr. Orn. Griechenl., p. 35 (18.14) ist mit Unreeht als. Synonym zitiert. És ist eine aberrante Haubenlerehe.)

Abbild.: Dresser, B. Europe IV, Taf. 227 ; Journ. f. Orn. 1899, 'Taf. VIL, linke Figur.

ơad. Oberseite dunkelbraun. die. Federn rahmfarben umsäumt, der

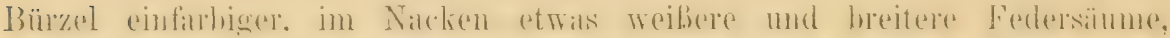

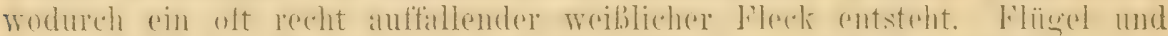

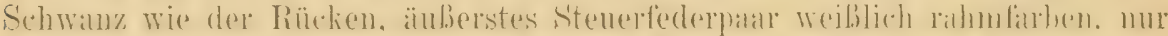
die Inmenfihne mit breitem sehwarzhramen Streffen. zweites l'alar dunkelhram,

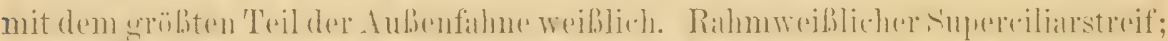

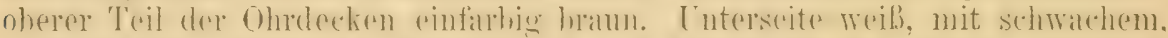

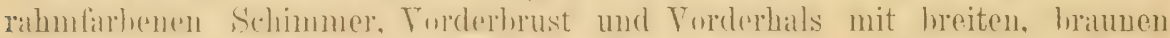
Länsstreifen, nur der ohere 'Teil der Kohle eiufarbig. Körperseiten bran

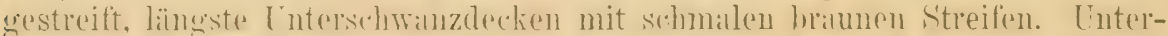

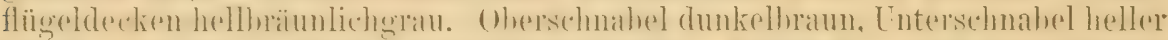

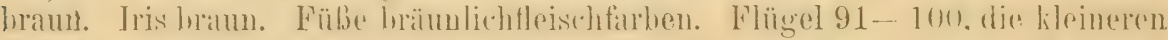

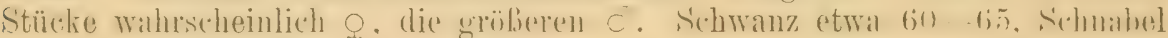
17-19, Lauf $13-14 \mathrm{~mm}$. In der Brutzeit nutzen sich die hellen Feder-

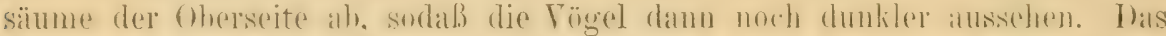

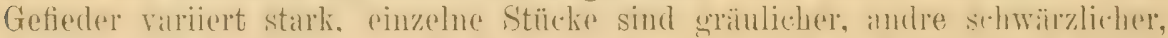

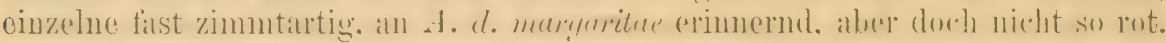

Iner Norden von T'unis und Algier, in Algier ansebeinend his über dio Atlaskette hinaus, in Tunis nur his zu den Ausläufern derselhen. In nenerer Zeit kommen durch einen Händler in Nizza viele Stücke in den Handel, die ron den balearen stammen sollew. Sie sind zwar variahol, aber alle sehe dumkel. 1. r. Homerer und ande Oruithologen trafe'n die drt nicht auf den Balearen an. Wemn die Art in Portugal wirklich hemiseh ist, wird die dortige Form wohl untersehieden werden liömen. Eines der typischen Stückre. das ich vor einigen Jahren sah, schien mir aber zur trpischesl deponti zu gehören. Die angehlich geringere Gröbe ist nicht 'Tatsalehe. Verirto

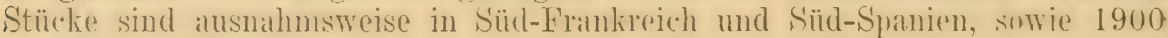
in 'Toskana ellegt.

Lier 3-4, Grundfarbe bräunlichweiß oder hell rötlich graugelb mit feiner braungrauer oder gelbbrauner, oft verschwommener Zeichnung und wenigen bläulichaschgrauen Schalenflecken. Sie messen nach Erlanger $23<17,24 \times 18,24 \times 18$, $24>18 \mathrm{~mm}$ und wiegen 0.20 bis $0.23 \mathrm{gr}$. 


\section{Chersophilus duponti margaritae (Kinenis).}

Alaemon Margaritae Koenig, Joum. f. Om. 1888, p. 228 (Gabes in 'Lunis).

A bbild.: Journ. f. Om. 1888, T'af. II, 1899, T'af. VIII, beide Figuren reehter Hand.

Typische Fixemplare unterscheiden sich auf den ersten Blick von C.d.

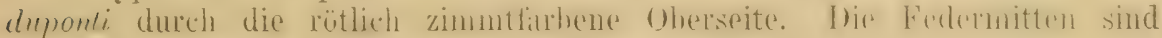

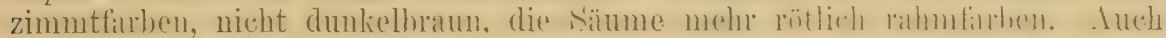

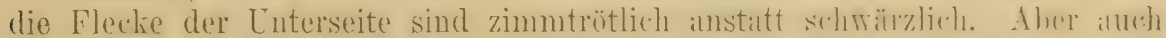

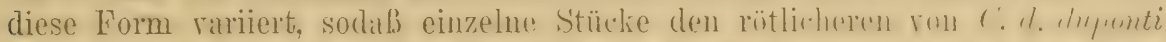
etwals nälier kommen. Der Sehnalnel ist merklich länger. hei alten his 25 und $26 \mathrm{~mm}$.

Vertritt C. d. duponti südlich der Ausläufer des Atlas in 'Tunis und im südlichsten Algerien.

Bewohnt den Nordrand der Sahara, mehr die peträische Wüste als die eigentlichen Flugsandfächen. Auch ihr Gesang ist prachtvoll und wird im aufwärts steigeuden Fluge ausgestoßen. Die Brutzeit ist von Mitte März bis Mitte April. (ielege 3 bis 4 Eier. Diese sind weiß mit schwachem grüngelblichen oder bräunlichen Schimmer, trübgelblichweiß bis blaß gelbgrünlich. Wie Zeichnung besteht aus zarten bräunlichgrünen, graugelben bis braunen Flecken und blaB violettgrauen Schalenflecken, ausnahmsweise bemerkt man feine dunkle Haarziige. Mabe nach Erlanger $31 \times 17,22 \times 17$, $23 \times 17,22 \times 16,22 \times 17 \mathrm{~mm}$. Gewicht $0.19-0.20 \mathrm{gr}$.

\section{Gattung EREIOPHILA Boie 1内ำ.}

Eremoplila wurde unnötigerweise wegen des Namens Erenoplitus Huml. (1811), der eine Fischgattung bezeichnet, verworfen, 1831 von Brehu durch Phileremos ersetzt, ein Name der wegen Phileremus Latr. (1826) nicht angenommen wurde. 1838 schuf Bonaparte den Namen Otocoris, den spätere Autoren in Otocorys rerbesserten.

Ton allen anderu Lorehen dureh spitze. verlingerte... Federohren" ïhnehde Federhüschel in der Schläfengegend ansgezeichnet. (Fig. fli.) Sithabel viel kïrzer als der Kopf, stark, hei vielen Formen fast kegellömig, hei andern spitzer, gestreckter. Nisenlïcher rundlich, ganz, ron liurgen. nach rom geriehteten Federehen bederkt. Imere Armschwingen zwar rerlingert, aber nicht annühernd so lang wie die Handschwingen. Sichwanz, sehwalch insgehuchtet, obere Schwanzdecken bis zur Mitte des Schwanzes oder darriber hinaus reichend. Geschlechter ziemlich ähnlich. Junger gefferelt. Verhreitung: Nord-Amerika und Mexiko, nördliche Anden his Bogntíl. Europna. Nord-Afrika und Nord-Asien his zum Himalaya. Aın formenreiclisten in Nord-Amerika. Das Vaterlind von E. Lerelepechi Hart. (Journ. f. Orm. 18901. 1. 103) ist nicht bekannt. - Nach unsrer heutigen Kenntnis dürfen wir anmehnen. dab alle Formen der Gattung einander in ihren Brutgelicten rertreten. Finige varieren auffallend individuell. Die sogenannten Artcharaktere sind oft mehr oder minder auffallend durch C̈hergänge oder Anklänge rerhunden, ${ }^{1}$ ) es ist also willkürlich, weun Oberholser (Proceed. L. S. Nit. Mus. XXIT, 1902) bei den ihm weniger hekannten. meist in sehr geringer Anzahl ron ihm

1) Außergewöhnliche, die Artmerkmale nicht gut aufwcisende Stücke wurden von Sharpe, Bianchi u. a. als. Bastarde bezeichnet. Ob das im allgemeinen richtig ist bei diesen Vögeln, mag dahingestellt sein, sicher aber ist es bei den meisten sogrenannten Hybriden im Britischen IIuseum nicht zutreffend. 
untersuchten Asiaten mehrere Spegies amnimmt. während er alle Amerikaner

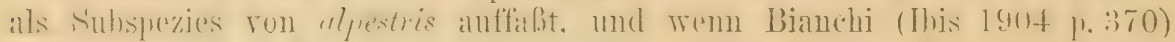

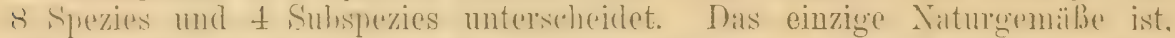

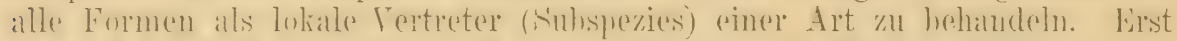

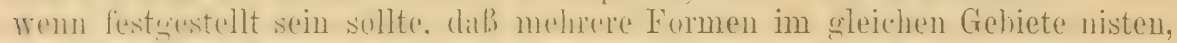
kïnnte diese Auffissung geändert werden. Sicheinhare in der Literatur nachmeishare Wideriprïche digegen sind nicht anzuerkennen, denn die Formen sind nur zu oft lalseh hestimmt worden. soddal., mall durehaus nicht alle

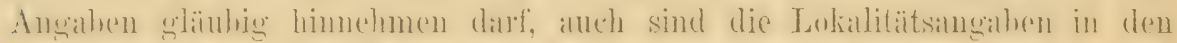

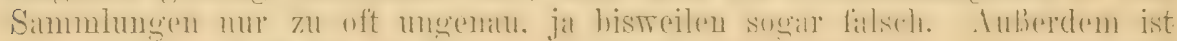

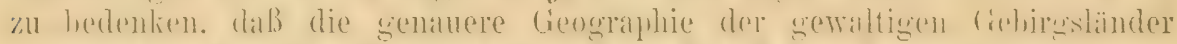

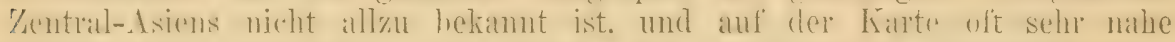
ersebeinemele Lokialititen nieht relten ganz verschiedenen Gebirgssystemen und Klimaten angehören.

\section{Übersicht zur Bestimmung der ỗ der paläarktischen Formen:}

1) Das Schwarz der Kropfgegend mit dem der Kopfseiten verbunden...

\{ Das.Schwarz der Kropfgegend von dem der Kopfseiten getrennt . .

(Kinn und Kehle schwarz . . . . . . . E. berlepschi ${ }^{1}$ ).

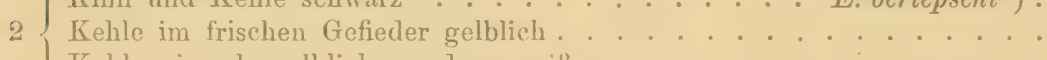

Kehle niemals gelblich, sondern weilj............. . 4

3 f Oberseite reiner grau . . . . . . . E. a. balcanica p. 262

\{ Oberseite etwas bräunlicher ................ a penicillata. p. 261

4 S Schnabel dïnner und länger . . . . . . . . E. a. bicomis . p. 263

\{ Schnabel kürzer und dicker ............ E. a. albigula. p. 262

5 f Oberseite ohne dunkle Federmitten . . . . . . E. a. bilopha . p. 257

I Oberseite mit dunklen Federmitten .......... 6

$6\{$ Kehle gelb . . . . . . . . . . . . . . . . . 7

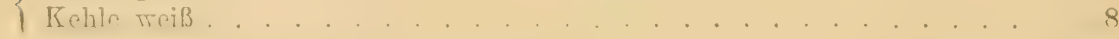

Kleine Oberflügeldecken sandbräunlich . . . . . . . E. a atlas . p. 257

7 Kleine Oberfliggeldecken graulich rosa........... E. a. fava. p. 255

Kleine Oberfligeldecken braunötlich .......... a. alpestris. p. 255

$8\left\{\begin{array}{l}\text { Vorderkopf rom Schnabel bis zum Scheitel schwarz . E. a.teleschowi . p. } 261 \\ \text { Mit breiter weißer Stirnbinde. }\end{array}\right.$

I Mit breiter weißer Stirnbinde. . . . . . . . . . . . 9 9

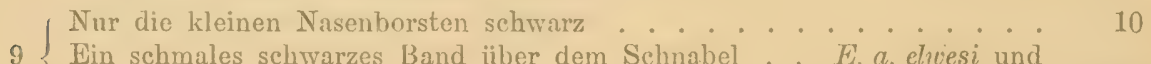

$9\left\{\begin{array}{l}\text { Ein schmales schwarzes Band ïber dem Schnabel . E. a. elviesi und } \\ \text { E. a. khamensis . p. } 260\end{array}\right.$

$10\{$ Oberseite viel lichter und rötlich-sandfarbener . . . . E. a. przewalskii . p. 259

\{ Oberseite mehr graubräunlich. . . . . . . . . . . 11

11 I Kurzflïgeliger, Flügel des of meist merklich unter $120 \mathrm{~mm}$. E. a. brandti 1 . 260 und E. a. montana. p. 257,258

(E. a. diluta, p. 259, wird meist unter 11 fallen, man beachte aber, was über ihro Varbation in Bezug auf stimhinde, Ausdehnung des Schwarz und Größe gesagt ist.)

1) Otocoris berlepschi Hartert, Journ. f. Orn. 1890, p. 103, Ibis 1892, p. 522, Taf. 13. Nach fincm Siticke mit unsicheren Fundorte im Senckenbergischen Museum zu Frankfurt a. ML. beschrieben. Angeblich aus "Caffraria"! 


\section{-414. Eremophila alpestris alpestris (L.).}

Arktisch-amerikanische Alpenlerche, Ohrenlerche.

Alauda alpestris Limnaeus, Syst. Nat., Ed. X, p. 166 (1758 - beruht anf Catesby's Alauda gutture flavo von der Küste ron Carolina).

Phileremos vufescens Brehm, Vogelfang, p.122 (1855- Nord-Amerika).

Ganz wie E. alpestris flava, aber der Sehnabel größer, meist erheblich lïmger, wemn aher ausuahmsweise ku\% gewohnlich stärer. lileine Flügel-

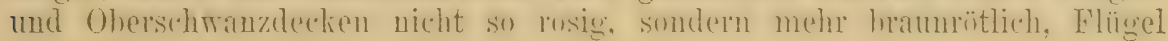
im Durchschnitt 2-3 $\mathrm{mm}$ lünger.

Zur Brutzeit im nordïstlichen britischen Nort-Amerilia restlich bis

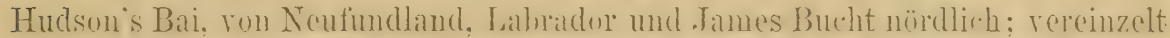

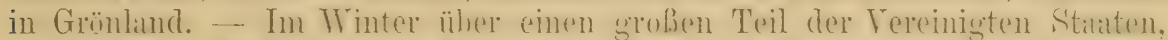

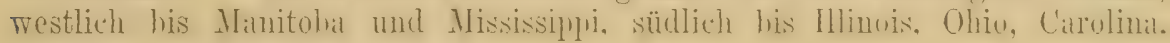
Louisiana und Bermudas Inseln.

(Außer dieser, der nord-europäischen Form ( $E$. a. flava) so nahe stehenden und meist mit ihr vereinigten Subspezies werden in Nord-Amerika noch etwa 18 weitere und eine in den nördlichen Auden Süd-Amerikas unterschieden. Die beste Auskunft hierüber gibt Oberholsers Artikel in Proc. U. S. Nat. IIus. XXIV, p. 801-883, 1902. Während die meisten der unterschiedenen Formen sehr auffallend keuntlich sind, scheinen. einige wenige derselben nicht unterscheidbar zu sein.)

\section{Eremophila alpestris flava (Gm.). (Fig. 46.)}

Nordeuropäische Alpenlerche, Ohrenlerche.

Alauda flava Gmelin, Syst. Nat. I, p.800 (1788- beruht auf „Buffon's" und Daubenton's Ceinture de Prêtre ou Alouette de Sibérie. 'Typ. loc. Sibirien.).

Alauda nivalis Pallas, Zoogr. Rosso-Asiat. I, p. 519 (1827- Europa und Sibirien bis zur Lena).

Phileremos striatus Brelum, Vogelfang, p. 122 (1855- Europa).

Phileremus alpestris macrourus, brachyurus A. E. Brehm, Verz. Samml., p. 8 (1866nomina nuda!).

Engl.: Shore lark. Franz.: Alouette de la Sibérie, Ceinture de Prêtre. Schwed.: Berglärka. Ital.: Lodola gola gialla.

ơ ad. Stirn, größter Teil der Kehle, Streif überm Auge und hinter den sehwarzen Trangentlecken an den Halsseiten his zur Kehle hinziehend schmefelgelh. Die mitch rorn stehenden kinginen Federn üher den Nasenlöchem und Zügel schwarz. unter dem Auge mit dinem groben schwalrzen Kopleseitentfeck verbunden, von dem schwarzen Kroptfleck breit getremnt. (Gner über den Scheitel eine breite sehrvarze Rinde, aus der die ebenfalls schwarzen "Federohren" entspringen. Im frischen Herbstkleide baben die schwarzen Scheitelfedern und Kopfseitenflecke bräunlichgelbe Säume. Oberkopf von der schrwarzen Scheitelbinde an und Hinterkopf gräulich-rosa mit graubräunlichen Federspitzen und Säumen, Rücken braun, in der Mitte der Federn dunkler, an den Seiten der Federn mit rosigem

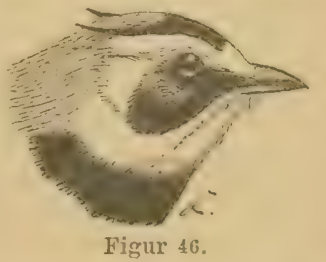
Anflug, die Schwanzdecken au der Basis ansgedehnt rosit und mit helleren, fast weiBlichen Spitzen. Schwiugen dunkelbram. beide Fihnen weib gesiumt, die inneren verlüngerten Armschwingen mehr röstlich braun und mit röstlichen 


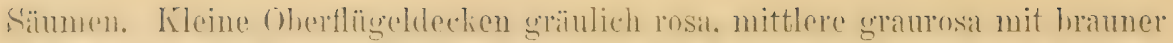

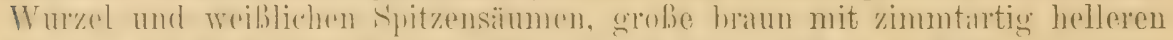

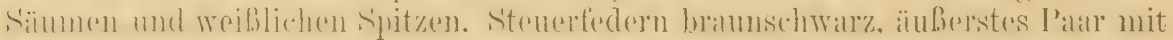
heritem, zweites mit sehmalem weibem Aubensamm, s'pitzen aller Steuerfedern

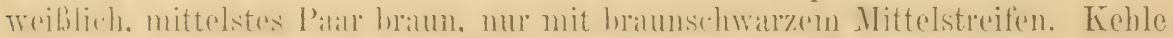

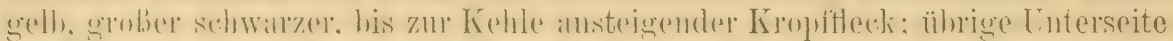
weili. unter dem sehwarzen Kroptflects rinige. dureh grane Federspitzen

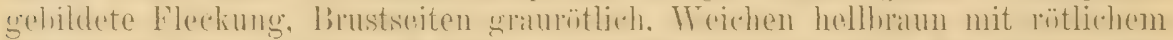

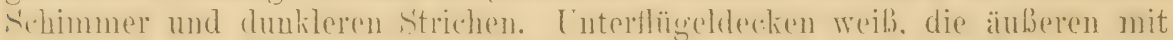

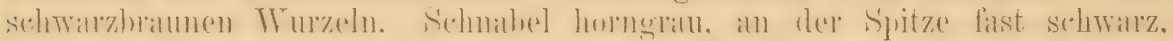

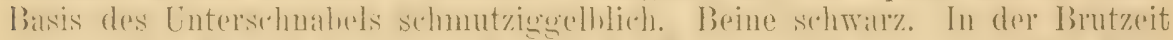

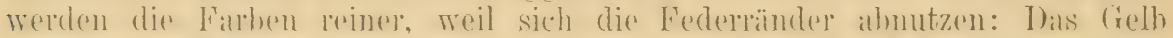

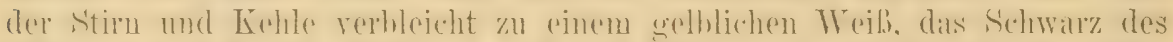

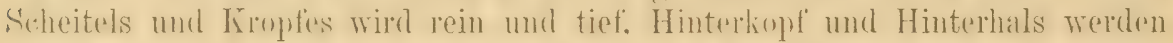

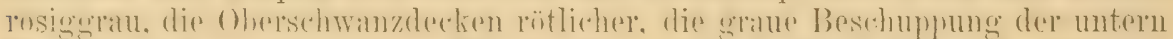

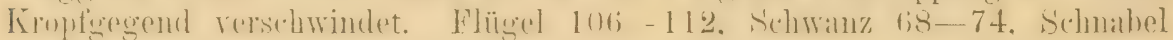
9-11, Lauf 21-23 mm. Das o ad. ist merklich kleiner (Flïgel etwa

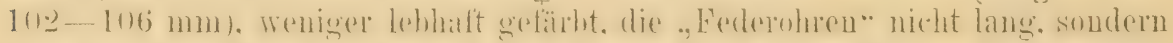

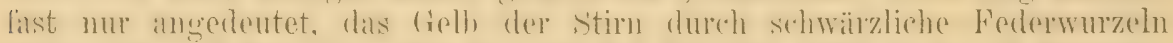

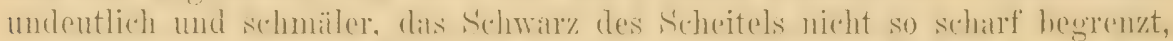

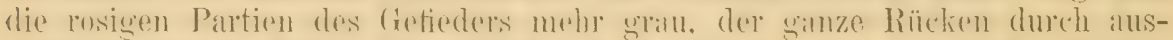

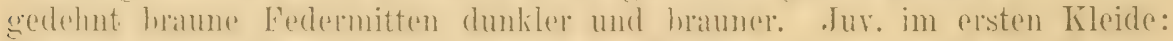

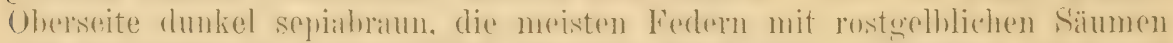

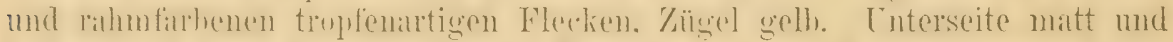

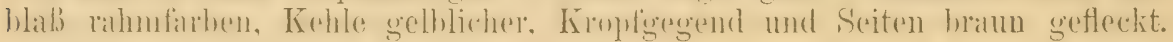
Schuabel und Füße gelblich fleischfarben.

Bewohnt zur lirutzeit das nördlichste Nord-kuropa, fast nur imnerhalb

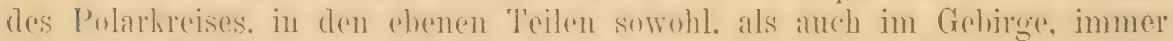
üher der Baumregion. und die 'Thundren und waldlose'n Nordlandsgehiete Nord-Asioms. - Auf dem Zugn erseheint sie in Mittel-Europal, \#̈herwintert aher sedon an den Kü̈sten Nord-Dentsehlands und in Süd-RuBland, erseheint nur selten in Italien, im ()sten südlich his zum Amur und NordGhina. Die Behauptung von rezenter Weiterverhereitung vom Amerika nach Westen hin ist nicht anfrecht zu crhalten, denn nicht nur sind die annerikanischen Formen verschieden, sondern die Apenlerche war auch schon 1736. 1747 und 1767 in Dentschland bekannt.

In der Lebensweise lerchenartig; läßt ihren lieblichen, weichen, im Vergleich zu dem der Feldlerche kurzen und unbedeutenderen, weniger schmetternden Gesang auch während des kalten Mitternachtsonnenscheins von erhöhten Gegenständen und in der Luft schwebend ersehallen. Am Brutplatze zutraulich, auf der Wanderung in Scharen, mit Vorliebe auf Bracben. Steppen, und namentlich am Seestrande, ziemlich scheu; sie fliegen dann rasch und gewandt, mit hellem, vernehmlichen Lockruf. Die Nester stehen in kleinen Bodenvertiefungen im offenen Gelände. Sie sind je nach des Orts Gelegenheit aus Zweiglein, Pfluzenstengeln, Halmen und Wolle gebaut, mit Werdenkätzchen und Haaren ausgefüttert und enthalten (in Lappland) in der zweiten Hälfte des Mai und im Juni 3-5 Eier. Diese ähneln bis auf die meist geringere Größe den Feldlercheneiern, sind jedoch in der Regel grünlich, obwohl auch oft graulich und überhaupt recht variabel. Sie messen nach Rey's MLssungen an 17 Exemplaren im Maximum $25.1 \times 15.9$ und $22.1 \times 16.8$, im Durchschnitt $22.7 \times 16.4$, im Minimum $21.2 \times 16.3$ und $25.1<15.9 \mathrm{~mm}$. 


\section{Eremophila alpestris atlas (Whit.).}

Otocorys atlas Whitaker, Bull. Brit. Orn. Club. VII, p. 47 (1898), Ibis 1898, 1).604, T'af. 13 (Glaoui, 5000 Fuß im Atlas, Marokko).

Das Schwarz der Kopfseiten wie bei E. a. flava getrennt. Hat die

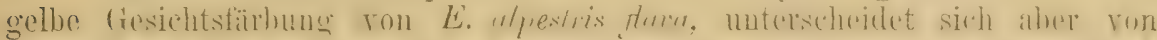

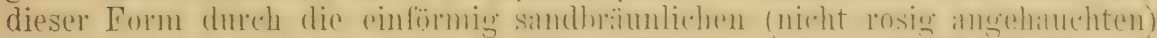

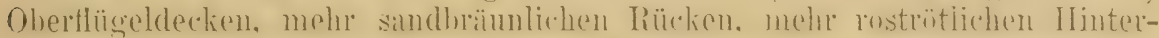
hals und Hinterkopf, und längere "Federohren", die mehr denen von E. a. penicillate ähneln. Iris braun, Schmabel grauschwarz, Beine schwarz. ô Flügel 111.2, Culmen 15, Lauf $20 \mathrm{~mm}$. o kleiner (Lilügel 102.5 mm),

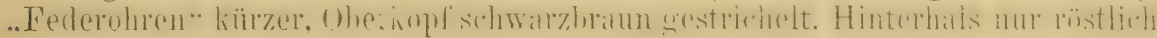
angehaucht, der schwarze Kopfseitenfleck nicht so scharf markiert.

"Glaoui" etra 5000 und Jebel Ogdimt $8-10.500$ engl. FuB im marokkanischen Atlas.

\section{Eremophila alpestris bilopha (Temm.).}

Alauda bilopha Temminck, Pl. Col. 244 (1823 - Akaba in Arabien).

Der' schwarze Wangenfleck reicht weiter nach unten, als bei $E$. a. Anva, ist aber doch ron dem schwarzen KroptHeck deutlich getrement. Stirn. Kehle,

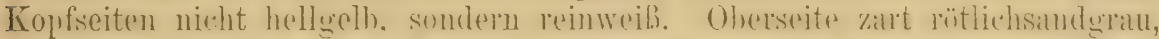

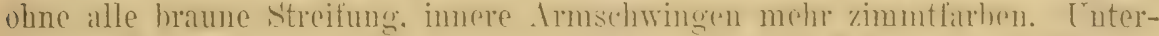
hörjer. Lnterflügel- und Lnterschwanzdecken rein woib. Seiten wie der läucken. Stenerfedern brannschwarz, dic äubern heiden l'tare schmal weib gesïunt, das mittelste wie der Rüclien. das näthste nur an der Murzel rötlich. ,Federohren: sehr litng und spitz. Klïgel cetwa $96-1001 \mathrm{~mm}$. o etwas Kleiner, die schwarze Stheitelhinde und die Koptseitentheken weniger scharf. Die Jungen im ersten Gefieder sind oben hell rot-isilhell. jede Feder mit weißer Endspitze, unten weiß mit zartem rötlichem Anflug.

Bewohner der steinjgen 'Teile del Silhallat rom Atlantischen Orean (Rio de Oro, südlich von Marokko. ron Ifo allerdings nur zwei sehr abgenntzto Weibehen aus dem Sommer untersucht werden komuten) his Egyten (NatronTal) und Nord-Arabien (Akaba). Terirte Stücke rurden in Süd-Spanien beobachtet.

In den hochplateauartigen 'I'eilen der Sahara findet man dies iiberaus anmutige Vögelchen namentlich da, wo Helianthemum, Erodium und distclartige Pflanzen spärlich den Boden bedecken. Standvogel, außer der Brutzeit in kleinen Flügen und etwas mehr umherstreichend. Das ơ läßt bisweilen eine aus zwitschernden und gurgelnden Tönen zusammengesetzte Strophe hören, das 우 lockt etwa wie "tíri-tíri-tíri-tíri“. Die Nester fand Koenig am Boden unter distelartigen und andern Pflanzen. Sie enthielten meist 2, seltener 3 Eier. Die Nester sind aus feinen Stengeln und Halmen gebaut und mit wolligen Blüten oder Haaren ausgepolstert. Die ziemlich variablen Wier sind milchweiß oder hell rötlichweiß, mit braunen, lehmbraunen, rostbraunen, rötlich graubraunen Punkien und Flecken und violettgranen S.chalenflecken bedeckt, oft so dicht, daß die Grundfarbe nicht zu erkennen ist. Sie messen im Durchschnitt etwa $21<15 \mathrm{~mm}$ und wiegen etwa $0.16 \mathrm{gr}$.

\section{Eremophila alpestris brandti (Dress.).}

(Otocorys albigula einiger Autoren, aber nicht 0 . albigula Bp.)

Otocorys brandti Dresser, B. Europe 1V, p. 397, 402 (1874- Kirgisen-Steppe).

E. Hartert, Die Vögel der paliarktischen Region. 
Otocorys parvexi 'Taczanowski, Bull. Soc. Zool. France I, p. 161 (1876-- Daurische Steppen und bei Kiachta).

(?) Otocorys petroplile Sewertzoff, Journ. f. Urn. 1873, p. 379 (nomen nudum! Tjan-Shan, partim).

Diss sthwarze Kropfland von dem Schwarz der Kónfseiten dureh einen

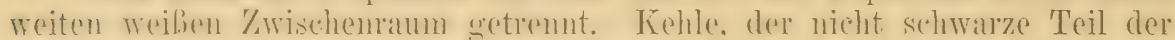

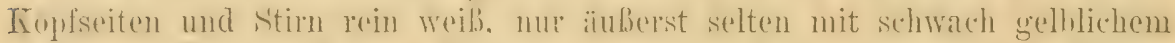
Anfluge. Hinterkopl und Hinterhals weimrötlich (graurosia), der Rö̈chen

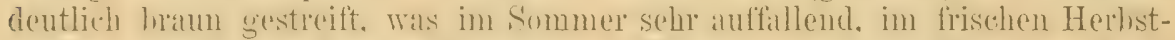

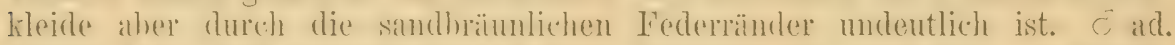
Flïgel 110-115. seltence his $118 \mathrm{~mm}$. Schnabel $10-11.5 \mathrm{~mm}$. o kleiuer,

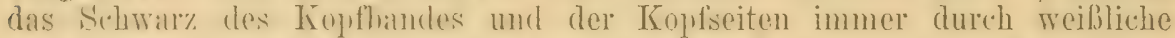
Folerainder geschuppt. Hinterlope mit haunen Fedemitten, Hinterhats mur mit sehwathem weinrötichen Hauche. Rücken hreiter und dunkler haun gestreilt. Flügel ctwa 101-104 mm. Bisweilen ist die 'Themmug der beiden schwarzen Elärehen durch sehlechte Präparation der Bälge nicht zu selsen,

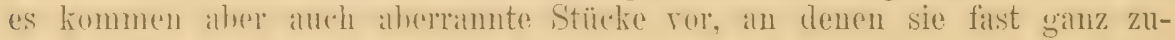
sammenfließen.

Stemen Asiens von aler Kirgisensteppe his Damien. Südlich bis zur Mongolei und dem nördlichen Teil der Wüste Gobi(口). Im Winter mehr umherstreifend und damn his an dir Mrolga, his Ost-Turkestan und Nord-China. Tielleicht gaht dats Brutgeliet nur his zu den Vorherwen des Tian-Sehan nud Altai und ist sio in der Mongolei und Gobi auch nicht melu Brutvogel.

Diese Form ist Stand- und Strichrogel. Wenn auch im Winter weit umherschweifend, doch kein eigentlicher Zngvogel. Im Winter in oft großen Flügen. Gesang schwach, in Sitzen, meist von einem Erdhügel oder Stein herab. Es scheint, dab die Eier Ende Hai gelegt werlen und die Jungen Eude Juni das Nest verlassen. Wahrscheinlich werden zwei Bruten gemacht.

\section{Eremophila alpestris montana (Biauchi).}

\section{(Unsicher begrenzte Form.)}

? Otocorys silviricu Swinhor. Proc. Zonl. Sore. London 1871, p. 390 (nach einem angeblieh Eversmannschen M.S.-Namen in Gould's Sammlung. Der Typus ist ein von Fleming bei Tientsin gesammeltes oder erworbenes Stück, das im Cat. B. Brit. IIus. XII, p. 536, irrtümlich als E. a. elwesi aufgezählt wurde. Zu letzterer Form gehört es auf keinen Fall. Es sieht ganz aus wie eine auffallend lang- und schlankschnäblige brandti, ist aber abnorm, denn die erste (ausgebildete) rechte Schwinge ist weiß, Flïgel und Schwanz abgestoßen, so daß man sie nicht messen kann; rielleicht ist das Stück ein Käfigrogel gewesen. Es könnte sehr wohl zu montana gehören, einer Form, die im Winter gelegentlich nach China streichen kann).

Otocorys fromiti montana Bianchi, Ihis 190.4, 1. 331 und Ares Przewalskianae, p. 227 ("Alps of the northern parts of Central Asia". Typ. Lok.: Julduss im zentralen Tian-Schan, nach Av. Przew.).

Gamz wie E. alpestris brandi, aber der Sehnabel dünner und länger, der weibe Zwischenram zwischen dem schwarzen Kropffleck und den Kópfseiten schmäler, die "Federohren" des ơ sehr laug, Flügel des ơ (nateh Bianchi) 106-119.5 mm. Unterscheidet sich von L. a. elwesi durch den fehlenden schwarzen Stimstich. 
Nach Bianchi Bewohner des nördlichen Zentral-Asiens: Palmir, Alai und Trans-Alai Ketten. Tian-Sehan, Tarhagatai, Altai, Tamm-nlia Bergen nördlich rom Sajan-Gehirge. Soll Brutrugel auf den hördisten (iehirgen sein.

Diese Verbreitung ist a priori eine auffallende, Bianchi nennt E. $a$. montana in den "Wissensch. Result. d. Przewalsk. Roisen" eine schwach differenzierte Form, die man ,nicht als eine wohl abgesonderte Form

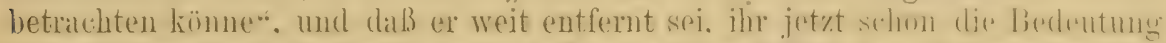

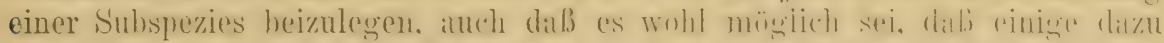

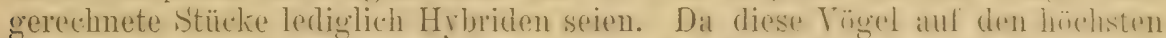
Gehirgen brüten sollen. dürften sie schon deshalh nicht lejeht zu brandti gehören. Es scheint, dab in der Tat im zentralen und ästlichen Tian Schan eine der

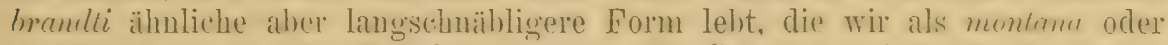

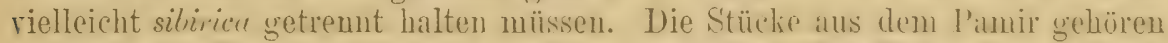
vielleicht zu Sharpe's dihutu. Aus dem westlichen Tian-Sidhan-Grebiet (Issik Kul. Karakol, Aksn-Tal) erhielt das Tring Museum typische. im Trinter

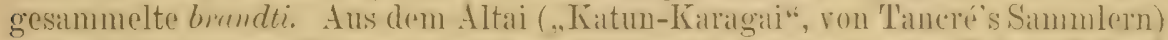
untersuchte ich zum Teil ganz mit bromdli ühereinstimmende. zum Teil auffillend dickschnäblige Exemplare.

\section{Eremophila alpestris diluta (Sharpe).}

Otocorys pullida (nicht O. alp. pallide Dwight 1890) Sharpe. Cat. B. Brit. Mus. XIII, p. 533 (1890 - „Central Asia“6. Typ. Lok.: Kaschgar (Dezember 1873) und Yarkand in Ost-'Turkestan).

Otocorys diluta Sharpe, Cat. B. Brit. Mus. XIU, p. 670 (1890- Ersatz fïr O. pallidu).

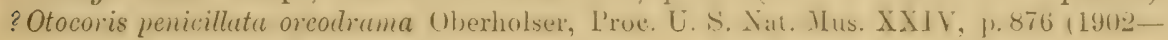
Tagdumbash Pamir).

Trie E. u. rlwe:i, aher kleiner (Flügel 116-124 1um), das S'chwarz der Kopfseiten ron dem der Kropfgegend meist mehr oder minder dentlich getreunt, hisweilen ineinander laufend. Stim meist weiß. hisweilen aher ist ein deutlich ausgebildeter schwarzer Stirnstrich vorhauden.

Ost-Turkestan: See Pandjong (Henderson), Kaschgar, Yarkand (Biddulph), Karakorum, Akthag (Stoliczka), anscheinend Teile de's Pamir. ahe das Brutgebiet ungenügend festgestellt.

\section{Eremophila alpestris przewalskii (Bianchi).}

Otocorys brandti przewalslii Bianchi, Ibis 1904, 1).371 (Zaidam).

Wie E. alpestris Imandit, aber der Schnahel viel länger, unoch feiner als der von E. ulpestris montumu ( $0^{7} 1 t-14.5 \mathrm{~mm}$ ), die Oberseite sehr viel heller, der Rücken sehr licht sandfarhen, die Bürzelferdern mit hreiten reißen. licht rosig angehanchten Sïunesu. Flïgel sehr lang (114-117 mm).

Im südlichen und westlichen Troile des Zatidam im nördlichen Tihet.

Die von Przewalski am 9. Mai 1884 in südöstlichen Zaidam gefundenen Eier dürften wohl zu dieser Form und nicht zu elwesi gchören. Sie waren auf schmutzigweißem oder grünlichen Grunde mit unregeluäbigen, „rrißßren und kilcincren Flecken bedeckt und hatten einige wenige schwarze Sprenkel. Sie messen $26.5 \times 16.5$ und $24.5>16.5 \mathrm{~mm}$ und wiegen $0.20-0.22 \mathrm{gr}$. (Bianchi.) 


\section{2․ Fromophila alpestris longirostris (Monre).}

Otocoris longirostris ILoore, Proc. Zool. Soc. London 1855, p. 215, Taf. Ares 111 (ex Gould M.S. - „Agra“. Irrtümliche Angabe: Die 'lypen stammen ron Kulu!).

Otocoris longirostris perissa Oberholser, Proc. U. S. Nat. Nus. XXIV, p. 869 ('Tsokr Chumo Lake, Ladak).

Otocoris lonyirostris aryalea Oberholsèr, Proc. U. S. Nat. Mus. XXIV, p. 871 (Suget Paß im nördlichen Káaschnnir).

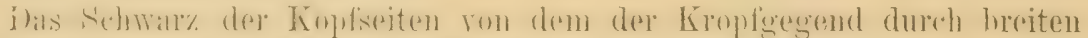

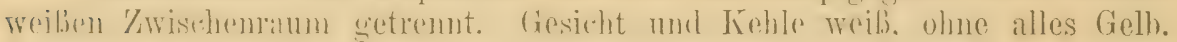

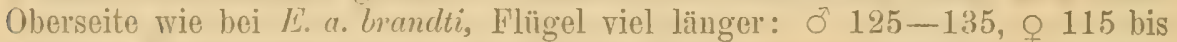

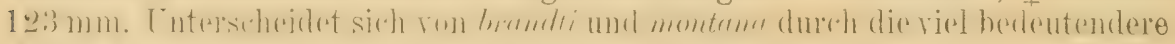

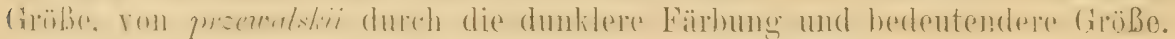
Schmabel länger und schlanlier, als der von E. a. brandit.

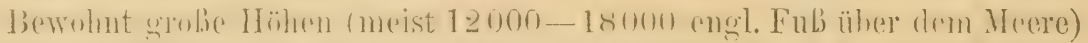

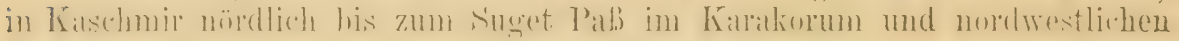
Himalaya (Kulu, Sutlej-Tal, nördliches Kumaon).

\section{Eremophila alpestris elwesi (Blanf.).}

Otocoris Elwesi Blanford, Journ. As. Soc. Bengal 1872, p. 62 (.,Kongra-Lama pass, between 15000 and 16000 feet, in Sikkim(6).

Otocorys nigrifrons Przewalski, Mongol i Strana Tangut. II. p. 103 (1876- Kanșu, Kuku-Nor, Zaidam und Nord-Tibet. IRussisch! Siche Ühersetzung in Rowley's Orn. Misc. II, p. 313).

Das Schwar" der Kopfseiten ron dem des Kropfes getremut, Kehle

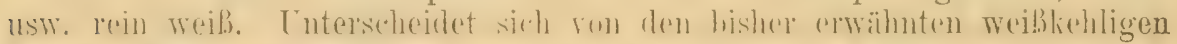
Formen dureh ein dentliches. Wrum anch sehr selmales, sehwarzes Stimband.

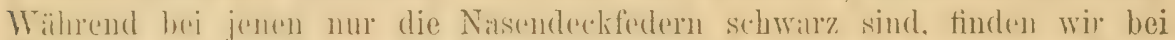

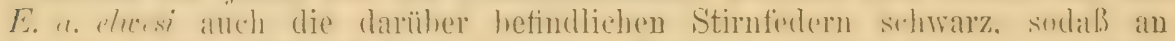
der stirn aine schwallze Linies entsteht. Flügel des on etwa 115-1:25 mm.

Tibet von Nan-Schan und Kuku-Nor bis auf die Hochflächen des IImalatyal ron Sikkim und Nepal. Im nordöstlichen Zaidam vertritt rhesi die im Südwesten dieses Landes lebende przevoalshii.

E. a. clwesi ist eine Form des tibetanischen Hochlandes, wo sie Stand- und Strichrogel ist. Sie bewohnt im Sommer Höhen ron 16-18000 Fuß, im Winter kaum unter $8000 \mathrm{FuB}$ herabgehend. Przewalski beschreibt am Kuku-Nor gefundene Eier als denen von Melanocorypha mongolica sehr ähnlich. Sie waren sehr langgestreckt und maßen $24.5 \times 16 \mathrm{~mm}$. Hell olivenfarbig mit bräunlichen, verschwommenen kleinen Flecken reichlich bedeckt: Nest in einer Vertiefung des Bodens unter einem Strauche, aus trockenem Grase, mit Schafwolle ausgekleidet. Von Koslow im Juni am nördlichen Abhange des Humboldt-fiebirges gefundene Eier messen nur $23.5 \times 16$ und $2.25 \times 16 \mathrm{~mm}$ und wiegen nur $0.14-0.16 \mathrm{gr}$. (Bianchi). Wahrscheinlich nistet $E$. a. eluesi zweimal im Jahre.

\section{4⒋ Eremophila alpestris khamensis (Bianchi).}

Otocorys eluesi lihumensis Bianchi, Ibis 190.1, 1. 372 (,Kham, South-eastern 'Tibet").

Sehr ïhnlich $E$. a. eluesi und wie jene mit ziemlich breitem schwarzen Stiruhand, aber dunkler, auf dem ǧanzen Rücken viel rostbrüunlicher, dio 


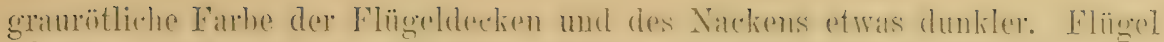
o $117-126$, o 112.5-114 mm. Erstes Jugendgefieder: Federn der Ober-

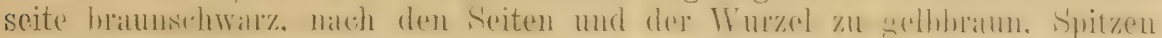

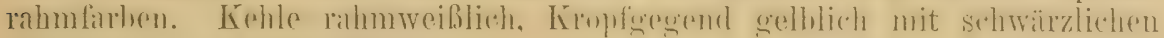
Flecken, Unterkörper weiß.

Gebirgslaud Kham im südöstlichen Tibet.

\section{Firemophila alpestris teleschowi (Przew.).}

Otocorys teleschowi Przewalski, Journ. f. Orn. 1887, j. 2 und Ibis 1887, p. 416 - aus dem russischen! (Bergländer an der Nordgrenze von Tibet, am Cherchen, Khoten und Keria).

Unterscheidet sich vou allen andern Folmen duxch den Mangel des

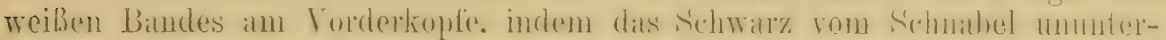

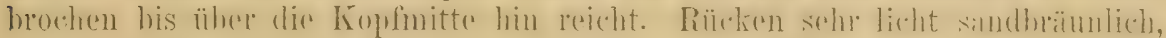
aber nicht so licht und nicht so rötlich wie bei E. a. przervalskii. Flügel o '108-116.5 mm, o 99-105. Beim o haben die Federn der Stirn und

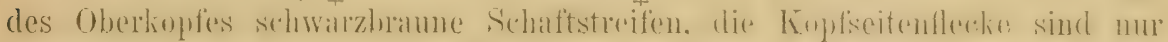

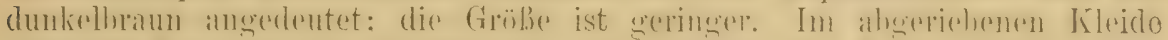

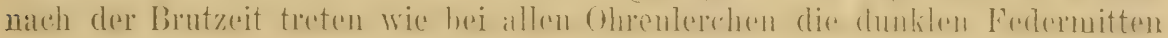
der Oherseite viel mehr hervor.

Gebingszïge des Kwenlun (Küen Iiüu), Chamen-Tag und Altyn Tag, im Winter ron Stoliezka hei Karohalik erbentet.

'T'ancré's Sammler find mehrere Gelege von je 4 Eiern im Altyn 'I'ing im ILai 1903. Sie varieren wie die Eier andrer Ohrenlerchen, denen sie gleichen. Einige haben hellrötlichen, andre rahmweißlichen Grund, alle sind mit dunkleren, der Grundfarbe entsprechenden Flecken über und über bedeckt. Sie messen $22.2 \times 16.5,22.7>16$, $23 \times 16.5,23 \times 17.3,23.5 \times 16,23.2 \times 16.2 \mathrm{~mm}$.

\section{t2ti. Eremophila alpestris penicillata (Gould).}

Alauda penicillata Gould, Proe. Zool. Soc. Fondon 1837, 1). 126 (Eirzerum).

Otocoris scriba Bounparte, Consp. Ar. I, p. 246 (1850- partim! Descr. nulla! Beruht auf Gmelin, Reise, Taf. XII, I, p. 62, wo das Winterkleid von 0 . alpestris flava dargestellt ist, und der Abbildung von Gould's penicillata in Gray \& Mitchell, Gen. B., 'Taf. 92).

Von sïntlichen bisher erörterten Formen daturch unterschieden, dalb das Schwarz der Krophegegend mit dem der Kopfseiten rerhunden ist.

Der Rücken ist griu mit rothräumliehem Schimmer. nareh dem Ahmutren

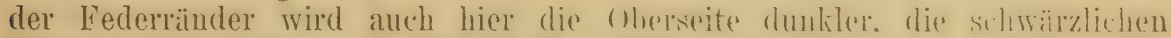
Federmitten auffullender, Oherkopf uml Hinterhals rötlicher. Federn der Kopfseiten hinter dem S'chwar\%, Stirn und Kehlfleck im Herhst- und Winterkleide hell schwefelgell, willuend der Brutzeit in Treif verhleichend. Der gelblichweiße Kehlfleck viel herehränkter als hei allen rorhergehenden Formen, das schwarze Kropfhand hreiter. Säume der mittelsten Stenerfedern cratubräunlich. Die "Federobren" sehr lang und schmal, an den Spitzen mach innen geschweift. or Flïgel etwa $117-122 \mathrm{~mm}$.

Kaukasus und Kleinasien. 
Brutrogel im gesanten Hochgebirge der Kaukasusländer und des Taurus bis zu 14000 Fuß über dem Meere. Im Herbst und Winter steigt sie immer weiter abwärts. Der Lockruf ist ein etwas klagender Pfiff. Radde besehreibt das Nest als flach und kunstlos, grobe Gräser bilden die Basis, verfilzte Schafwolle dient als schwaches Polster. Die 4 Fier sind nach demselben Autor auf grüngelblichem Grunde fein und dicht rotbräunlich punktiert. Sie gleichen denen von E. a. flava, sind aber etwas gröber.

\section{Eremophila alpestris balcanica (Rchw.).}

Otocorys penicillata balcanica Reichenow, Orn. Monatsher. 1895, p. 42 (Balkan. Reichenow's "Typen" stammten aus Bosnien).

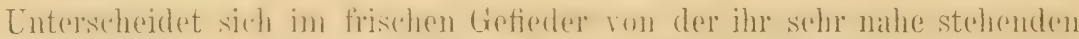

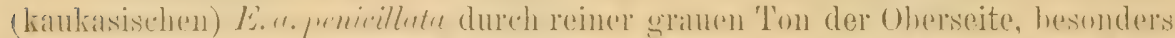
der sïmme dex mittleren Stenerfodern, sowie dureh dunkles gello Kohles

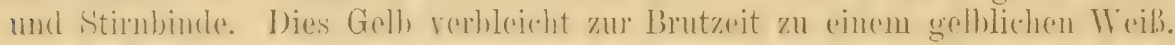

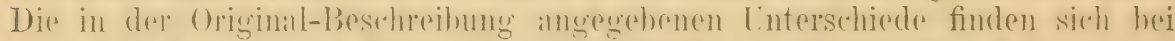

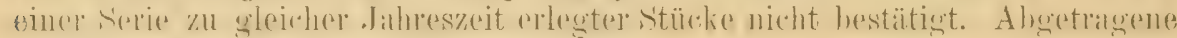
Sommerstücke der beiden Formen dürften kaum zu unterscheiden sein.

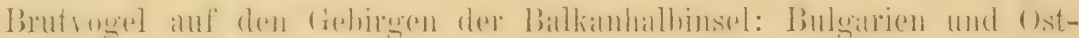

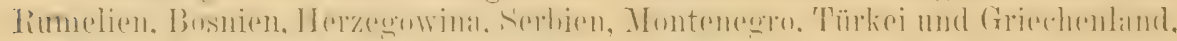
besonders häufig auf den bulgarischen Gebirgen.

Die ơ steigen am Brutplatze (nach Reiser) ebenso trillernd in die Höhe wie die Feldlerche. Die Nester sind geräumiger und diekwandiger als die der Feldlereho am gleichen Standorte und aus Gras, Hieracium, Verbascum, Luzula und andorn Alpenpflanzen gebant. Jie Ėnde IIai gefundenen 3-4 Eier variieren stark und ähneln bis auf die bedeutendere Größe denen von $E$. a. Hava. Die Schale ist ziemlich glänzend. Maße: $23.7 \times 17.7,23.6 \times 17.4,23.2 \times 17.3,23.1 \times 17,22.9 \times 16.8,22.8 \times 16.5$, $22 \times 16.5 \mathrm{~mm}$, (ietrielit $18-21 \mathrm{gr}$. ((). Reiser).

\section{Eremophila alpestris albigula (13p.).}

Otocoris alligula Bonaparte, Consp. Ar. I, [). 246 (1850- ex Brandt M.S. ,Mus. Lugd. ex Alp. Ross.-Asiat," Das Original im Leidener Musenm trägt die Aufschrift "Alpes de liussie“6. Es hat rein weiße lichle und gehört sicher zur asiatischen F'orm, auch schon der Diagnose nach. Der genaue Fundort ist leider unsicher).

Otocoris larvatu Filippi, Arch. Zool. Anat. \& Phys. II, p. 382 (1863-- Berge um den Demarend in Nord-Persien. Vgl. Note di un Viaggio in Persia, p. 348).

Otocorys pennicillata transcaspica Flöricke, Gefiederte Welt 1898, p. 46 (Hochmatten des Gebirges bei Gudan im südlichen 'Transkaspien, hart an der persischen Grenze).

Otocorys penicillata iranica Sarudny \& Härms, Ornith. Honatsber. 1902, p. j33 (,nördliches Persien, ostwärts von der Elbrus-Kette und nach Siiden bis zur IV iiste Lut und den Bergen der Gegend Sarhad in Beludschistan").

Abbild. : Dresser, B. Lurope IV, 'l'af. 244.

Ton F.a. penicillata und E. a. balcunica auf den ersten Blick durch die

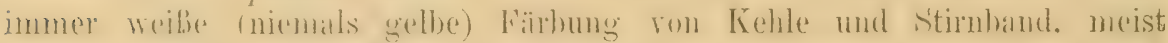

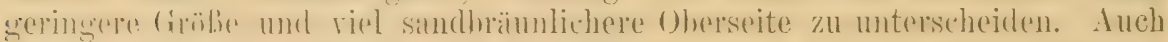

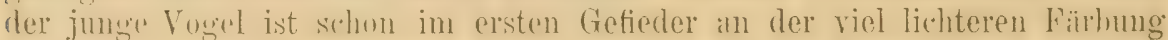
kenntlich. Bei H. a. baleanica (woron Reiser mir eine Serie aus dem

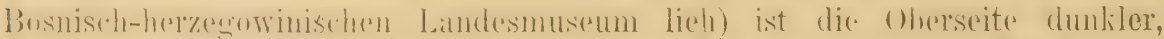

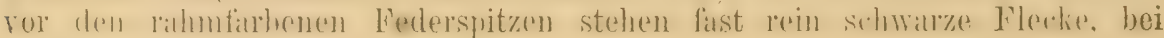


E. a. lamuta ist sie lichter hraun. die anteanikalen lilecke sind nicht so dunkel hraum, die Torderhrust ist hei $E$. ". bulemina dunkel hraun gefleckt, hei E. a. larvertr rahmfarben mit hellhramen Flectien, dir Kehle ist bei E. a. balcanica oft schon deutlich gelb, bei $E$. a. larvata nie. Flügel der o ad. 114-120, ausuahmsweise bis $125 \mathrm{~mm}$. Es kommen Stïcke im

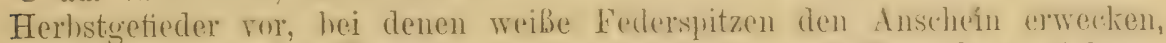
als sei das Shellwarz an den Halsseiten getrennt, alıer anch Exemplare. hei denen eine solehe Tremmung wirklich angerlentet ist. I th halte diese fö̈ abreranto Stücke, nicht aher notwendigerweise fül bastarie zwischen $E_{2}$ "l. lmameli

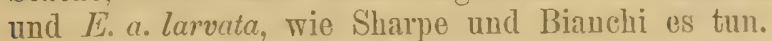

Sollte diese Form wirklich (im Pamir und Tian-Schan) mit einer

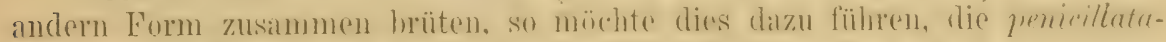

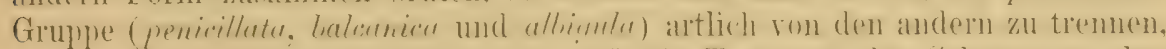

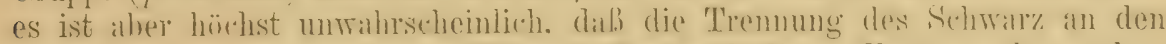
Halsseiten - das einzige auffallende Merkmal dieser Furmen. das zudem noch manchmal nicht scharf auscoloiledet erseheint - wirklich mehe als pin

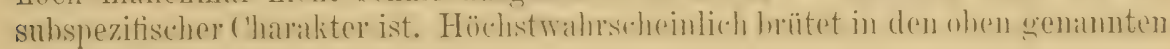
Gebieten nur eine Folm.

Hochgebirge von Nord-Persien und T'urkestan, bis zum Pamir und Tian-Schan.

Steigt bis in gewaltige Höhen, aber nicht höher, als wo noch flielendes Wasser und Moos gefunden wird. Biologisches bei Sarudny, Mém. Soc. Impẻr. Russe de Geogr. XXXVI, no. 2, „Ois. Perse Orient.", p. 202 - russisch!

\section{Eremophila alpestris bicornis (Brom).}

Phileremos bicornis Brelım, Vogelfang, p. 122 (1855--- ex Hemprich 1L.S. „kommt wahrscheinlich aus Syrien nach den griechischen Inseln $\left.{ }^{66}\right)$.

Ähnlich E. a. albrimela. Kehle und stimband obenfalls meib, allore der Schnahel etwas lïnger und dünner, der Nackon heller weinmïlich, der Rücken rötlicher, blasser, die dunklen Federmitten hlisser mol wenigger dentlich.

Bewohnex der hörhsten 'Teile des lihamm und Hermon. ummittelhatr an der Schucegrenze.

Tristram beschreibt ihren vollen und doch gedämptten Gesang, den er nie von fliegenden, sondern nur von sitzenden Vögeln rernahm. Die auf dem Libanon gefundeven Eier sind denen der E. a. flava ganz ähnlich, aber größer. Dic Nester sind kompakt und wohlgebaut, tiefer als die andrer Lerehen zu sein ptlegen.

\section{Familie MOTACIIIIDAE.}

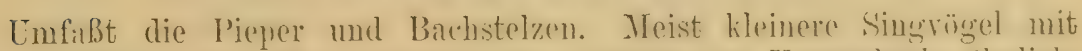
weichem Gefioder, zum Teil (.lnthus) den Lerehen z,um Verwechseln ïhnlich. aber durch die mit ungeteilten Schienen hedeckten laufseiten sofort zu unturscheiden. Die Forderseite des Laufes ist mit mehr oder minder verwachsenen Schildern, dic oft nur am untern Teil erlienubar sind. bedeclit.

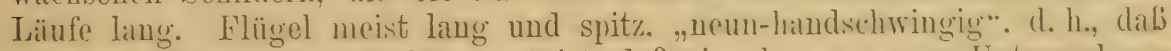
die erste Sulnwinge su verhämmert ist, dab sie ohne genauce Untersuchumg 
nicht zu lumerlen ist, innere (most drittletzte) Armschwingen so verlüngert, dab

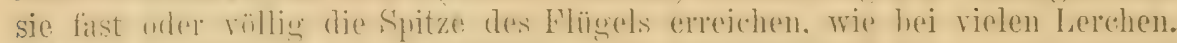

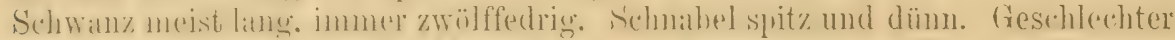

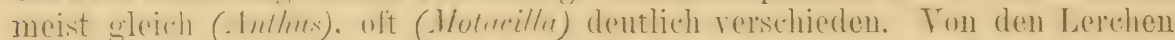

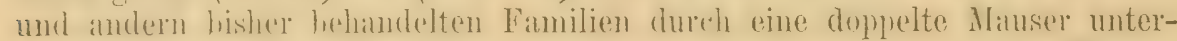
schieden: rime vollständige Spätsommermauser, und eine Ausgang des Wrinters bis Anfang des Fröhlings stattindende Mauner. bei der aher nur das Klein-

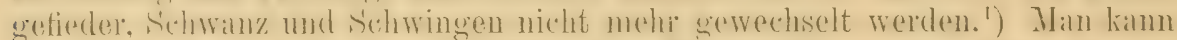

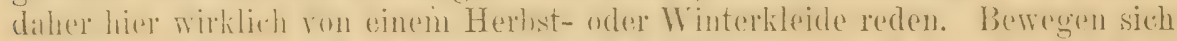

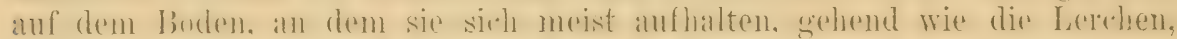

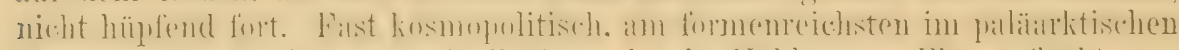

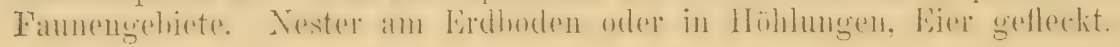

\section{Gattung ANTHUS Bechst. (1807).}

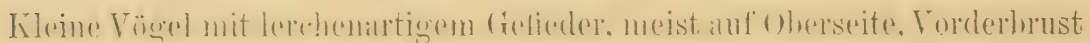

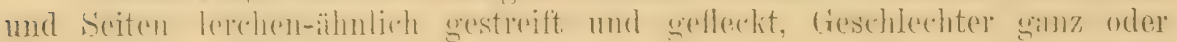
fast gleich. Sehwanz meist erheblich kïrzer als Flügel, fast gerade

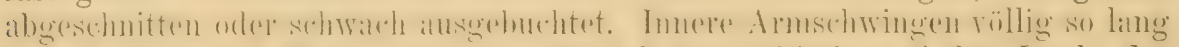

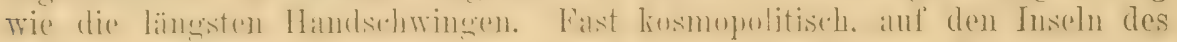

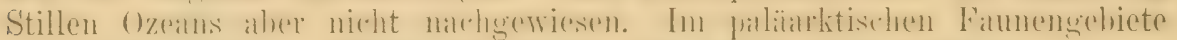

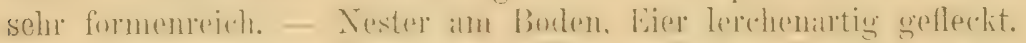

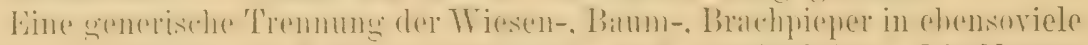

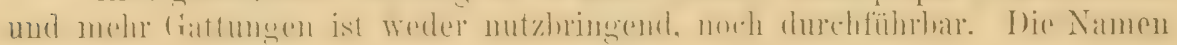
Corydalla, Pipastes, Agrodromu u. a. m. sind daher nux Synonyme von Anthus.

Übersicht der ơ im Frühlingskleide:

Achselfedern grïnlichzitronengelb . . . . . . . A. roseatus . p. 279

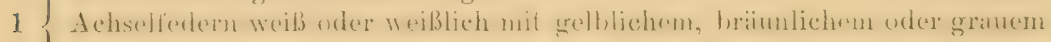
Anflug . . . . . . . . . . . . . . . 2

2 Ganze Kehle lebhaft rostrot . . . . . . . A. cervina . p. 277

2 Kehle weißlich, rötlich angehaucht oder trübrötlich........ 3

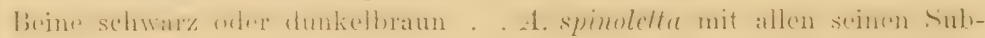

Beine hellbrau spezies außer juponicus . p. 279

Oberseite olivenartig graubraun, schwach und undentlich gestreift, Kropf-

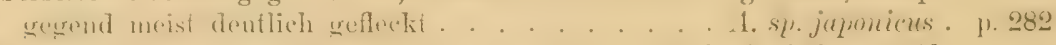

Oberseite rötlich tehmlathen, schwath mol moleutlich dmbel gestreift, Kropfgegend nur schwach gestrichelt. . . . . . . . . . 5

()hersite athallend dunkel gestreilt, 2 ) Krofifgegend mit sehr dentichen schwärzlichen Längsflecken . . . . . . . . . . . .

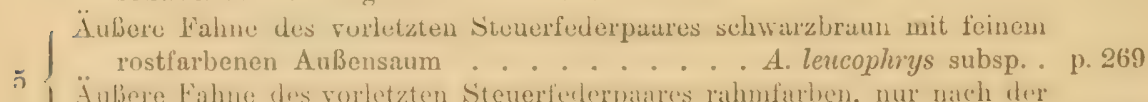

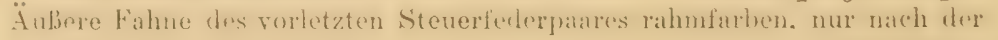
Wurzel zu dunkelbraun. . . . . . . . . A. campestris . p. 267

1) $\mathrm{Ob}$ diese zmeite (olt unregelmäßige) Mlauser auch allen in heißen Ländern wohuenden Formen eigen ist, ist noch nicht festgestellt. Bei A. berthelotii konnte sio bisher nicht beobachtet werden!

2) Bei dem sonst A. trivialis trivialis sebr ähnlichen maculatus sind die Streifen weniger deutlich. 


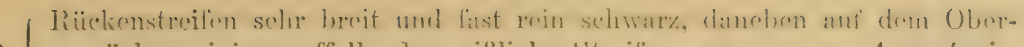
rücken einige auffallende weibliche Streifen. . . . A. gustavi. p. 274

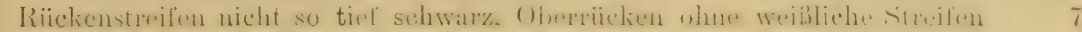

Rïckenfärbung im ganzen lehmfarbig, ohne olirenfarbenen Anflug, Lauf $25 \mathrm{~mm}$ oder melır . . . . . . . . . . A. richardi. p. 265

Rückenfïrbung mit olivenfarbenem, aber ohne röstlichen oder lehmfarbigen Anflug, Lauf unter $25 \mathrm{~mm}$

Nagel der Hinterzehe gekrümmter, in gerader Linie gemessen kürzer als

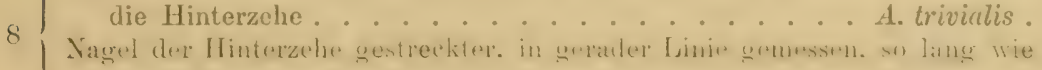
oder länger als die Hinterzehe

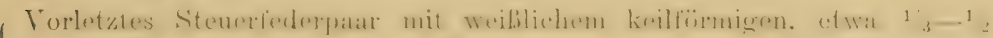
der Feder hinabreichenden Fleck ........ A. berthelotii. p. 270

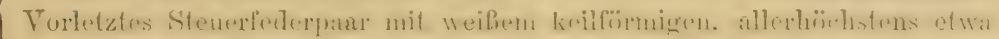
$1 / 8-1 / 2$ der Feder hinabreichenden Fleck . . . . A. pratensis

\section{Anthus richardi richardi Vieill. (Nig. 47.)}

Spormpieper.

Anthus Richardi Vicillot, Nouv, Dict. d'Hist. Nat. XXVI, p.491 (1818- Frankreich). Anthus macronyx Gloger, Vollst. Handb. Naturg. Vög. Hirop)., p. 269 (183t- eine Umbenennung von A. vichardi!).

Anthus longipes Holandre, Faune de la Moselle, p. 84 (1836).

Corydalla sinensis Bonaparte, Consp. Av. 1, p. 247 (1850- Süd-China).

Anthus maximus Blyth, in Blyth' Ausgabe von White's Nat. Hist. Selborne, p. 262 (1858).

Abbild.: Naumann, Vög. Deutschl., 'Taf. 371, Fig. 3, 4; Dresser, B. Europe III, Taf. 138.

Kralle der Hinterzehe $15-22.5 \mathrm{~mm}$ lang, selten so lang wie, meist

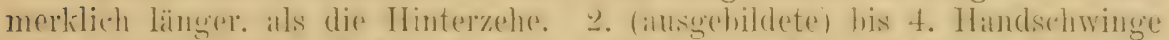

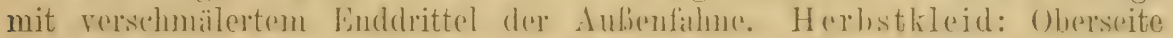

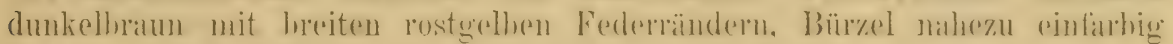
braun. Supereiliarstreif hell gelblichbraun. Ohrdecken braun, streifig. Unterm Auge und an den Seiten der oberen Kehle je ein schmaler sehwarzbrauner Stroif. Schwingen dunkel schieferbraun mit schmalen, an den letzten Armschwingen breiten Säumen. Kleine Oberflügeldecken wie der Rücken, mittlere und große dunkelbraun, mit breiten gelbbräunlichen Säunen. Steuerfedern dunkelbraun mit sehr schmalen hellen Säumen, das mittelste Paar wie die letzten Armschwingen, das äußersto Paar weiß mit weißom Schaft, Innensaum mit breitem graubraunen Saum, vorletztes Paar weiß mit

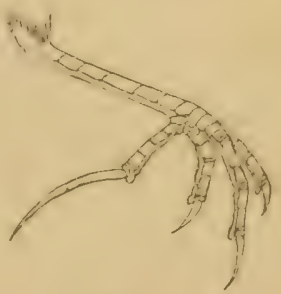

Figur 47 .

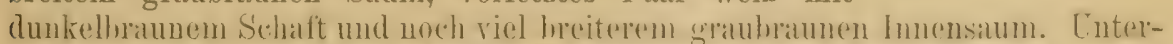
seite weib mit brïunlichem Anflug. Inilssoiton mit dunkelhranner Fleckenreihe, Kropfgegend mit dunkeltmanen Tropfenflecken. Seiten mehr brïunlich. Lnterflügeldecken bräunlich rahmfarben. Iris dunliclhrann, Ohurschnahel tiefloram,

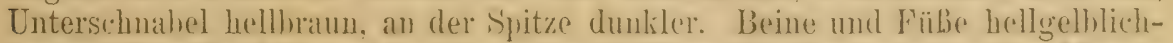
braun. Das Erühlingskleid ist wie das Herlostlileid. aher natch der Mauser verhleichen die Farhen und die Federränder nutzen sich ah, sudat. die Oberseite riel heller, weniger rostfarhen. die Cuterweite weiblicher erscheint. Das 


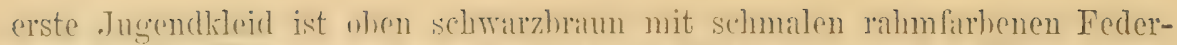
sïumen. die hropfgegent noch stärker gefteckt. Sïmme der Flïgeldecken weiblich. Siciten und Treichen mit dentlichen dunkien Streifen. of ad.:

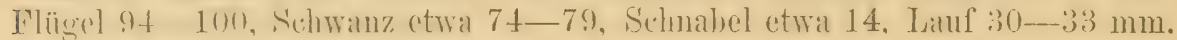
O wie ơ, nur etwas kleiner, Flïgel etwa $88-91 \mathrm{~mm}$.

Brutvogel in Sibirien (Jenissei, Oberlauf der Lena) bis zum Altai,

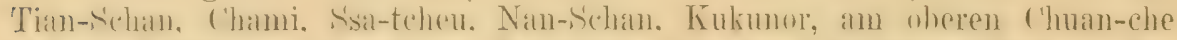
und in Kansus. - (iewaltiger Wanderes, der seine Winteryuartiere in den

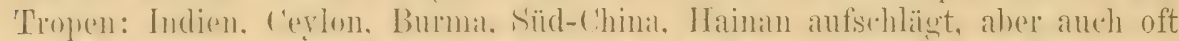
mach Wresten hin streift. Wo er heinahe 70 mal in bingland. sehr häufige auf Helgoland. anf Borkum. selten in Ientsehland. in P'ersirn, Kleinasien,

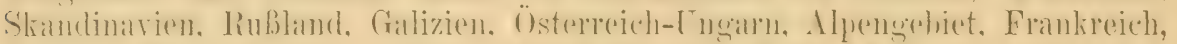

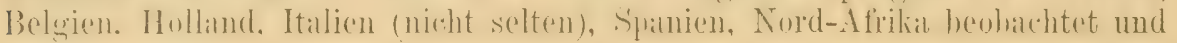
erlegt wurde.

J)ie Sporupieper bewohnten wohlbewässerte Ebenen, Wiesen und dergleichen. Der Zug findet schon früh statt, denn auf Helgoland treffen sie meist schon im August ein. Lockton lauter und tiefer als der andrer Pieper, wie rrrüp klingend, manchmal auch hört man einen doppelten schirpeuden Ton. Der Gesang soll unbedeutend sein. Das Nest steht in einer Vertiefung am Erdboden und enthält in Daurien in der ersten Hälfte des Juni 4-6 Eier. Dybowski behauptet, daß in der zweiten Hälfte des Juli eine zweite Brut folge(?). Die Eier sind blaß olivenfarbig, grïlichgrau oder blaß schmutzig rosa. Die meist etwas strichförmige Fleckung ist dunkel olivenbraun, braun oder violettgrau. Sie messen nach Dybowski $2.3 \times 16,22.8 \times 17,23 \times 16.2,23 \times 16.2$, $23 \times 17.2,20.8 \times 15.8,20.8 \times 15.4,20.8 \times 15.8,20.6 \times 16.4 \mathrm{~mm}$. Ein Ei in Nehrkorns Sammlung wiegt $167 \mathrm{mg}$.

\section{Anthus richardi striolatus Blyth.}

Anthus striolatus Blyth, Journ. As. Soc. Bengal XVI, p. 435 (1817 - I)arjiling).

Agrodroma godlewskii 'Taczanowski, Bull. Snc. Zool. France 1876, p. 128 (Argun-Fluß in Siid-Daurien).

Sehr ähulich A.r. vichardi, aber kleiner, der Flïgel zwar nur wenige

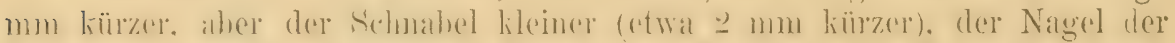

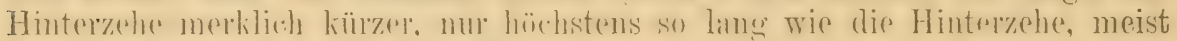

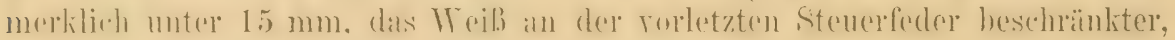
oft nur ein kurzer Keilfleck an der Imnenfahne.

$(O b)$ rohl im allgemeinen leicht von vichardi zu unterseheiden, sind

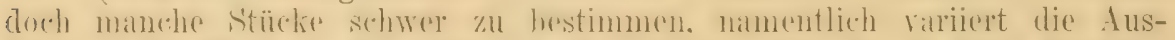
dehnung des Weib an der vorletyten Stenerfeder sehr. Lis ist katum denkbar,

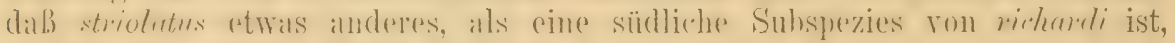
olwohl die gengraphische Verlurestung der beiden formen in Mittel-Asien norch nicht ganz festgestellt ist. Wahrscheinlich ist anch der tropisehindisehe A. rujulus num Suhsperies dieser Art; dimn wïrden natiorlich aluch

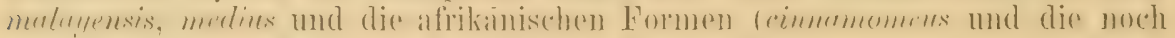
zu bestätigende camaroonensis) $\mathrm{H}$ olge leisten müssen).

Wintervogel in Indien, der sieh im Frühling in die höheren 'Teile des IIimalatya zum Brüten zuritckzicht. Wie weit sein Wohngehiet natch Norden reicht. stebt noch nicht fest. wir anch hei andern l'iepern. deren Jestimmung

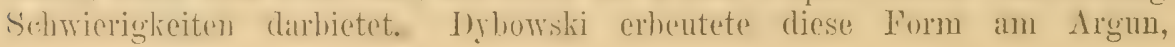


Przerralshi ein Stück im August im Alit-Schan in der südlichen IIongolei, Radde (nach Taczinowsti) hei Kulussutajewst. In tropischen Indien zur Brutzeit durch rufilus vertreten.

\section{Anthus campestris campestris $\left(I_{\text {L. }}\right)$.}

Brachpieper.

Alauda campestris Linnaeus, Syst. Nat. Ed. X, p. 166 (1758- "Habitat in Europa". Als typische Lokalität nehmen wir Schweden an, nach dem ersten Zitat „Fn. suec. 193". - Linnaeus zitiert noch die "Alauda minor campestris" von Ray: Der Name campestris ist keineswegs sehr sicher, zumal die Beschreibung der Schwanzzeichnung und Füße bei Linné ungenau ist; ihn zu verwerfen würde aber eine unnötige Beunruhigung der Nomenklatur sein, da er nicht mit Sicherheit als unzutreffend bezeichnet werden, sondern höchstens zweifelhaft sein kann).

Alauda mosellana Gmelin, Syst. Nat. I, p. 794 (1788 - ex Daubenton \& Montbeillard \& Latham. Vorzugsweise auf der vortreftlichen Abbildung der "Alouette des marais" ron Daubenton beruhend. "Habitat in Germania, Alsatia et Lotharingia, ad Mosellam.").

?. Motacilla maculata Gmelin, Syst. Nat. I, p.965 (1788- ex Daubenton's \& Buffon's "Pivote ortolane". "Habitat in Galloprovincia." Mit Sicherheit rermag ich diesen Namen keineswegs auf den Brachpieper zn bezichen).

Motacilla massiliensis Gmelin, Syst. Nat. I, p.965 (1788- ex Daubenton \& Buffon's „Fist de Provence". "Hubitat in G'ralloprovincia").

Alauda Paludosa Bonnaterre, 'Tabl. Enc. \& Méth., Orn. I, p.313 (1791- „.. octobre dans le pays Messin; elle se trouve aussi en Alsace \& en Pologne").

? Spipola agrestis Leach, Syst. Cat. Indig. Mamm. \& Birds Brit. MLus., p. 22 (1816-nomen undum!)

Anthus rufescens 'T'emminck, Nanuel d'Orn. I, p. 267 (1820 - neuer Name für A. campestris).

? Alauda grandior Pallas, Zoogr. Rosso-Asiat. I, p.525 (1827- ,Frecuentissimus circa lacus et lacunas salvas deserti Mongolici". - Ich kann aus der Diagnose keineswegs mit Sicherheit Anthus campestris erkennen und bezweifle, daß es sich ïberhaupt um einen Pieper handelt!).

Anthus brachycentrus Hemprich \& Ehr., Symb. Phys. fol. dd (1828 - „MIoileh“").

Anthus agrom Brehm, Handb. Naturg. Vög. Deutschl, p.324 (1831- bei Renthendorf). Anthus subarquatus Brehm, Handb. Naturg. Vög. Deutschl., p. 325 (1831- östliches Deutschland, Wien, auf dem Zuge bei Renthendorf).

Anthus flavescens Brehm, Handb. Naturg. Vög. Deutsehl., 1. 325 (1831-.. Nubien).

Corydalla gracilis Brehu, Handb. Naturg. Vög. Deutschl.. p. 138 (1831 „Griechenland").

Corydalla vierthaleri Brelım, Vogelfang, p. 137 (1855-., , ,im Winter in Nordost-Afrika“");

Naumannia 1856, p. 338.

Anthus campestris temirostris Brehm, Naumannia 1856, p. 338 (.Griechenland").

Corydalla arenaria Brehm, Naumannia 1856, p. 337 (Holland).

Corydalla campestris arvensis Brehm, Naumannia 1856, p. 338 ("brutet in NordDeutschland").

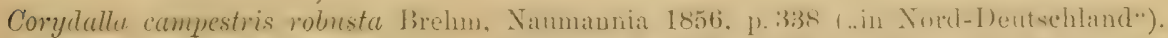

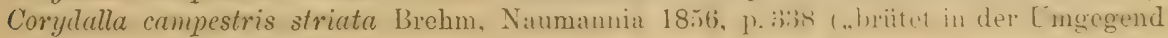
von Leipzig").

Corydalla campestris vera Brehm, Naumannia 1856, p. 338 ('Thiiringen).

Corydalla campestris septentrionalis Brehm, Naumannia 1856, p. 338 (Skandinarien).

Corydalla campestris rufescens Brehm, Naumannia 1856, p. 339 ("er wandert durch Nordost-Afrika"). 
Coryclalla campestris vulgaris, hispanica A. E. Brehm, Ver\%. Samml., p. 7, 8 (1866nomina nuda).

Engl.: 'L'awny Pipit. Franz.: Pipi rousseline. Ital. : Calandro, Schwed. : Fialtpiplärlka.

ơ ad. Herbstkleid: Oberseite fahl sandbraun mit gramem Schimmer,

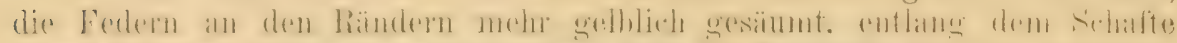

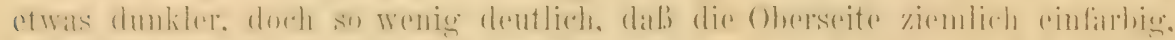

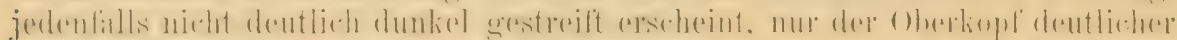

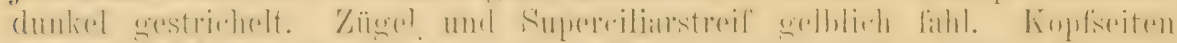

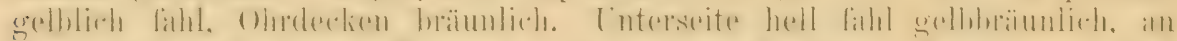

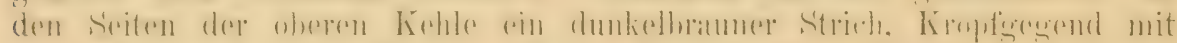

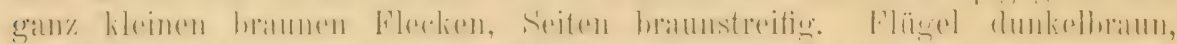

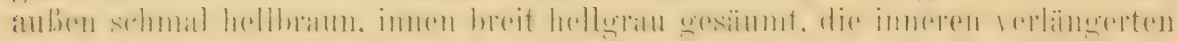

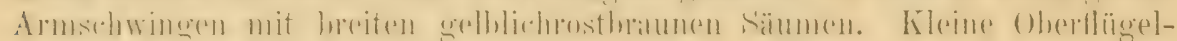
decken wie der Rücken, mittlere und grobe tiefbram mit breiten ralım-

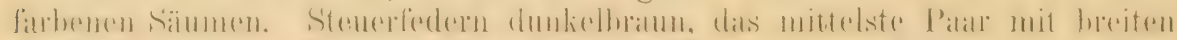

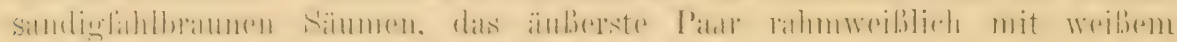

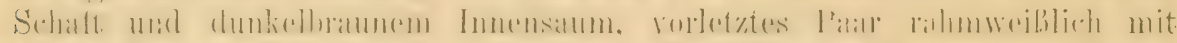

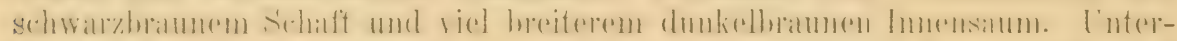

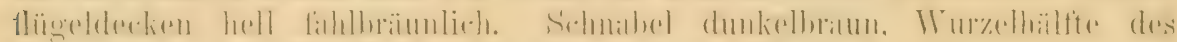

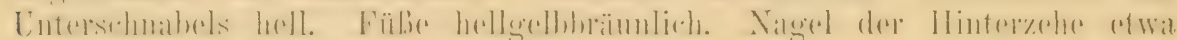
so ling wie diese, sehr dick und wenig gekriummt. Isauf sehr lang. Frühlingskleid wie Herbstkleid, wenn das Gefieder abgetragen ist, ist die Oberseite aber noch einfarbiger als rorher. Der junge Vogel sieht wesentlich anders aus: Federn der Oberseite tiefhraun, rahmfarben

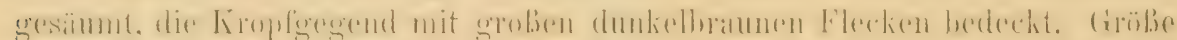
sehr variabel. Oे ad. Flügel $87-97 \mathrm{~mm}$. In der Regel sind dio größeren

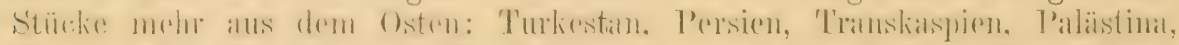

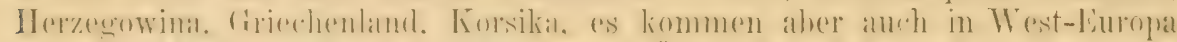

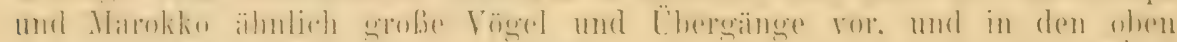

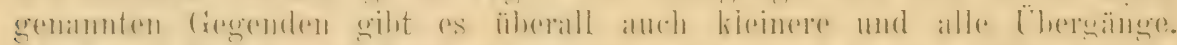

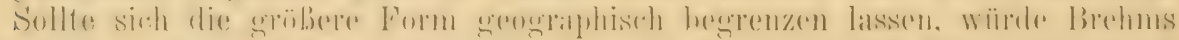

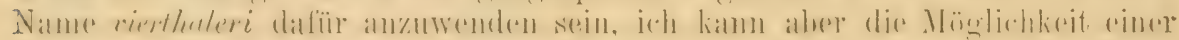
Trennumg nieht einsehen. Schwanz etwa $69-76$, Schmabel 1+-16. 'Lauf" 25-27 mm. O wie on 11 w wenig kleiner, Flügel etwa $3 \mathrm{~mm}$ kïrzer.

Brutvogel vom mittleren und südlichen Schweden über ganz Europa

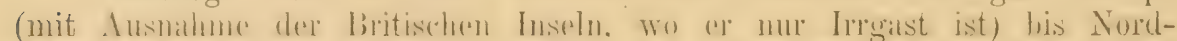

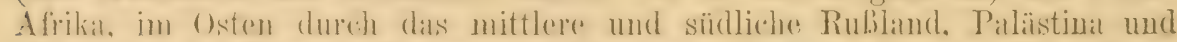

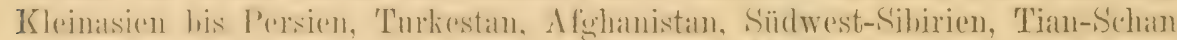

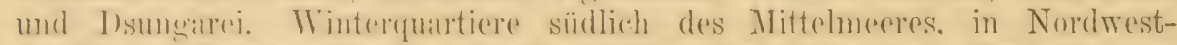

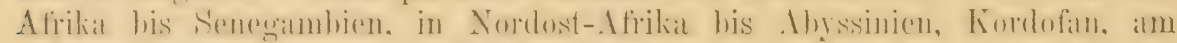

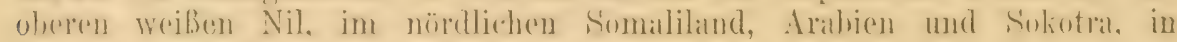
Indien in den Bbenen des Nordwestens.

Der sehr bezeichnend so genannte Brachpieper bewohnt trockenes, brachliegendes Land, dïrre Sandsteppen, Heiden, freie Schliige in den Kiefernwäldern und dergleichen. Meist am Boden, sehr selten auf Bäumen sitzend. Gesang einförmig, meist in flatterndem Fluge ausgestoßen, Lockrufe sehr verschieden, am häufigsten wie ein kurzes wit, oft zweisilbig, breiter, rauher, als die andrer Pieper, manchmal fast an Sperlingsrufe erinnernd. Das Nest steht meist treff lich versteckt neben Steinen, unter Kiefernbüschen, in Wngengeleisen oder an Grasbüscheln und ist ein großer Bau aus Wurzeln, Stengeln, Gras und dergleichen, innen meist mit Pferdehaaren ausgelegt. Die 4-5, selten 6 Eior 
findet man in Deutschland von Ende Mai bis Anfang Juli. Sie varieren auberordentlich, sind ziemlich glänzend und unterscheiden sich ron den ander'n deutschen und den meisten Pieper-Hiern überhaupt durch die schärfer hervortretendere, weniger verwascheno und gewölkte, sparsamer aufgetragene Fleckung. Grundfarbe weißlich, grïnlich, seltener gelblich oder rötlich. I'lecke braun, dunkelbraun, rotbraun, dazwisehen hellgraue tieferliegende. Malie nach 40 Wiern (Key): Maximum $23 \times 17$, Durelischnitt $21.17 \times 15.74$, Minimum $19.4>15.9$ und $20<15.5 \mathrm{~mm}$. 1lit1leres (iewieht $158 \mathrm{mg}$. Ich maß Eier von $24.6 \times 17.4$ und $19.5 \times 15.8 \mathrm{~mm}$.

\section{Anthus campestris minor (R. Blas.).}

(Noch fragliche Form.)

Agrodroma campestris minor L. Blasius, in "Naumann, Naturg. Vög. Mitteleuropas" IrI, p. 74 (1900 - ex Homeyer M.S. \& nomen nud. Grabowski 1893 - Eitawah, N.W.-Indien).

In Nordwest-Indien erseheinen im Winter - dre Tyjus ist, anselueinend

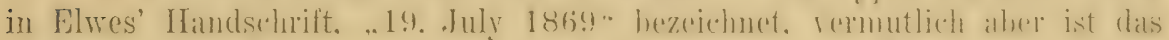

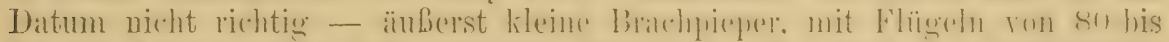

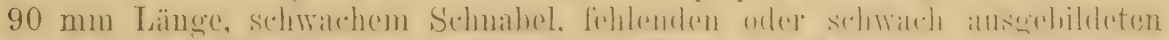

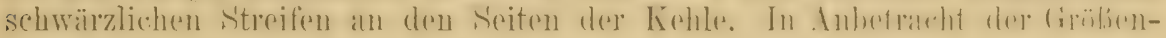
variabilität beim typischen A. campestris und unsrer Unkenntnis von der

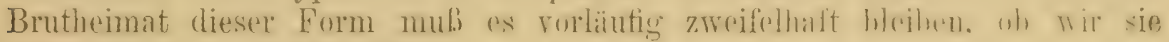
subspezifisch absondern können.

\section{Anthus leucophrys captus subsp. $110 \mathrm{v}$.}

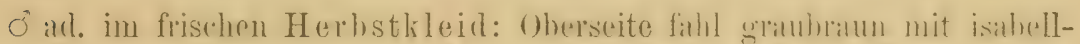

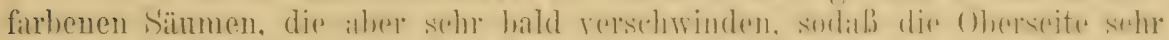

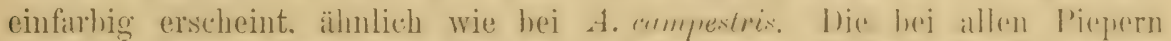

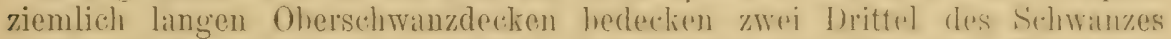

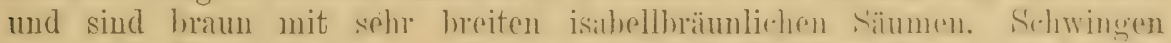
bram, die Handschwingen mit sanz schmalen, die Amschwingen mit sehr breiten lebhaft isabellfulrenen Aubensämmen. Oherflïgeldecken wir dio

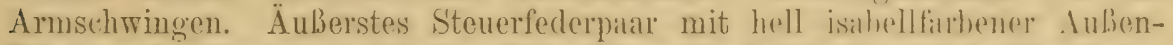
fahne und schwarzem Schafte, Innenfihne dunkelhram mit keilfïmuiem, isabellfubenem Fleck, der von der Spitze etwa (iu I)rittel lis zur Hälfte der Feder entlang läuft. Vorletates Stenerfederpar dumkelham mit schmalem isabellfarbenem simum und kleinem Keilfeck an der Syitze, mittelstes Paar

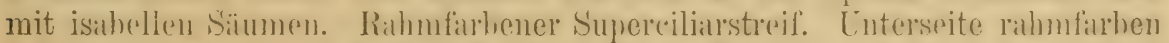
mit isabelluräunlichem Anflug, Kohle weiBlich, Kropforgend etwas lü̈unlicher und mit schmalen dunkelhramen Schaftflecken. Ohersehmahed und Spitze des Untersthnabels schwïrlich hormbram, Unterschnahel hrimulich weib. Läufe und Fäße hell brïunlich Heischfarhen. Flügrel retwa 100-110. Schwanz etwa 85-90, Sehnabel 15-17, Lauf etwa $28 \mathrm{~mm}$. o wie das 0 , nur etwas kleinel. Flügel etwa 97 ..101 mm. Frühlingskleid wip das Herbstkleid. Im ahgetrigenen Gefieder oben einfurbig schmutzig graubram oder bräunlichgrau, die Fleckung der Kropfgegend undeutlich. I)er junge Vogel im ersten Gefieder sieht oben viel hunter aus, da die Federn dunkler braun sind mit sehärfer ahgegrenzten rahmfarhenen Ränderu, die Kropf- 


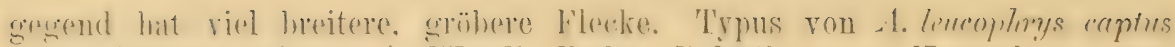
"ơ" (wahrscheinlich o) Waadi Zerka, Palïstina 27. November 1897, Nr. 158, von Sehlüter erhalten.

Pallistinal (Jordan-Tal, im Winter), Persien, A foghanistan, Baluedristan, im Winter im Indus-Tal bis in die Nähe von Karachi. Russisch!)

(Vgl. Sarudny, Ois. Perse Orientale, p. 286-289, sub nomine "Anthus similis".

\section{Anthus leucophrys jerdoni Finsch ${ }^{1}$ ).}

[Anthus lencophrys Vieillot, Nouv. Dict. XXVI, p.502 (1818 - "Cap de Bonne Éspérance"). - Anthus lencophrys leucophrys bewohnt Süc-Afrika. Im Cat. B. Brit. Mus. X, p. 555, ist diese Form Anthus pyrrhonotus genannt, ein Name, der aber nicht anwendbar ist. Vgl. Reichenow, Vög. Afr. III, p. 316, 328. Im Iransvaal lebt A. lencophrys vaalensis Shell., in Nordost-Afrika A. leucophrys sordidus Rüpp.] Anthus jerdoni Finseh, 'Trans. Zool. Soc. Loudon VII, p. 241 (1870- Kotegurh, N.W.Himalaya).

Corydallu grisemufesens Hume. Lbis 1870, 1. 286 (Indien, nördlich vom Nerbudda und Himalaya).

Abbild.: Henderson \& Hume, Lahore to Yarkand, Taf. XXI.

Wie A. leuc. captus, aber die Oberseite dunkler und viel bräunlicher;

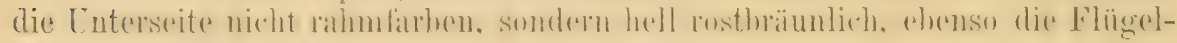
säume viel brïunlicher.

Himalaya, im Winter in Nord-Indien nördlich des Nerbudda.

Nistet im Himalaya, wahrscheinlich kaum über 6000 Fuß, vom Mlai bis Juli, macht ein großes, lockeres Nest aus Gras und legt 4 brïunlich oder graulich weiße, braun und tief rotbraun gefleckte Eier, die etwa $21.8 \times 15.9 \mathrm{~mm}$ messen. Die Lockstimme soll der von $A$. richardi ähneln.

\section{Anthus berthelotii berthelotii Bolle.}

Anthus Berthelotii Bolle, Journ. f. Orn. 1862, p. 357 (Canaren).

Abbild.: Dresser, B. Europe II; Taf. 133.

(IIan hat in A. berthelotii eine Form der Wasserpieper-Gruppe sehen wollen, aber ohne Grund. Die deutlicher gefleckte Oberseite, scharf gefleckte Kehle, verhältnismäßig große Schnabel und Beine, sehr kurze Flïgel, Mangel eines verschiedenartigen Frühlingskleides u. a. stempeln $A$. berthelotii zu einer wohl unterschiedenen Art.)

of ad. ()herseite dunkel grauhraun mit schwarghraumen Federmitten, sodab sie deutlich längsegefleckt erseheint, unterer Bürzel und Ohersehwanzdecken fast cinfullig. Schwingen dunkellraun mit schmalen, an den innern Armschwingen aher hreiteren hräunlich rahmfarhenen Säumen, kleine Flügeldecken wie der lï̈cken, mittlere und grobe wie die inneren Armsehwingen. Steuerfedern schwarzham mit schmalen, an dem mittelsten Paare hreiten

$\left.{ }^{1}\right)$ Südlich schließt sich in Indien A. leucoplirys similis Jerd. an. Er ist viel dunkler als A. l. jerdoni, dem A. l. sordidus aus Abyssinien sehr ähnlich, aber merklich größBer und finst noch lebhafter gefärbt. Err bewohnt als Standvogel die Gebirge der siidindischen IIalbinsel, sïdlich des Nerbudda. Synonymie: Agrodroma similis Jerdon, Madras Journal XI, p. 35 (1840- Gulna, cfr. Jerd., Ill. Ind. B., Text zu 'I'af. 45). Anthus cockburniae Oates, Fauna Brit. India, Birds II, p. 503 (1890 - Nilgiris). 


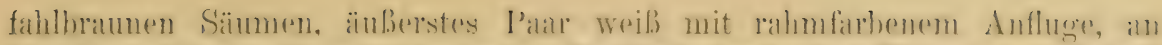

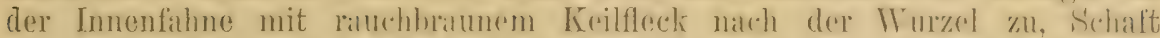

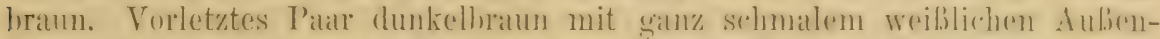

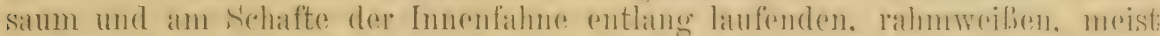

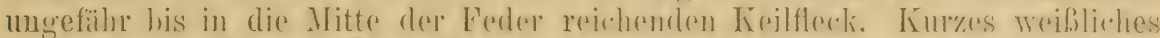

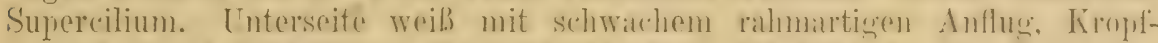

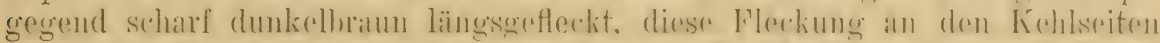

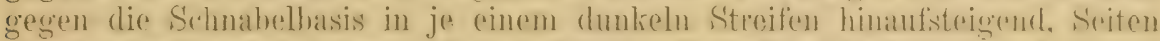

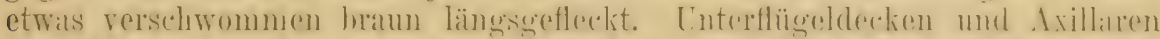

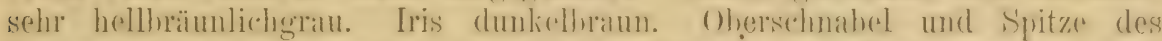

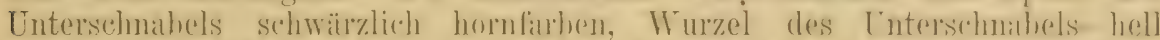

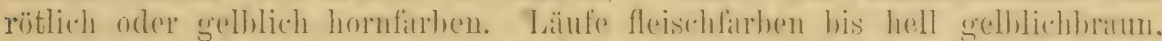

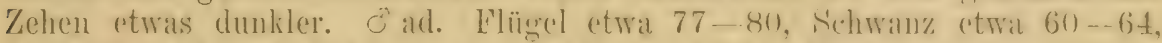

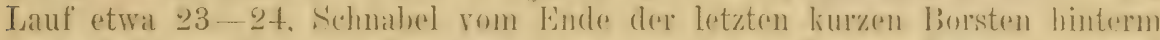

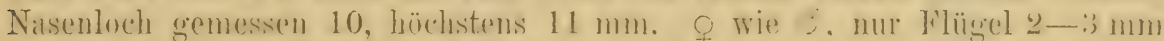
kürzer. r/wischen Herhst- und Fröhlingskleid soheint kein anflallender Dnterschied zu hestehen. Jur.: Wir hei andern l'iejerm ohen hunter. Weil dies Federn ganz dunkel. sehwarzhraun mit schall alogegrenzten rasthraumen Sämmen sind, die Fleckung der Kroplgegend reichlicher mal graber. (D)iese Vögel heschmieren ihn Gefiedor hisweilen so mit rostfubenen Erduatikelehen, dab sie unten rötlich aussehen.)

\section{Canarische Inseln von Lanzalrote bis Ferro.}

Der canarische Pieper lebt vorzugsweise auf und an den Chausseen und Landwegen (woher der auf den Canaren übliche Name "caminero"), auf Feldern, Trümmerhalden und Felsen, besonders in den tieferen Lagen am Mleeresstrande, aber auch bis etwa in die Mittelhöhe der Berge. Hr ist besonders auf Tenerife und Gran Canaria sehr häufig und leicht bemerkbar. Als ich 1885 zuerst meinen Fuß auf Gran Canaria setzte, war er der erste Landvogel, den ich sah. Ein Pieper auf den ersten Blick, pieperartig auch der Lockton, der gedehnter ist als beim Wiesenpieper. Gesang kurz, etwas hart, am meisten an den der Wasserpieper, allenfalls an den des Wiesen-, aber gar nicht an den des Baumpiepers erinnernd. Der Gesang wird von Steinen, Errdhügeln, Sträuchern herab, oft aber auch im Fluge vorgetragen. Das ziemlich große, lose aus I'flanzenstengeln zusaunen geschichtete. innen mit feinm Wür\%elchen, Halmen und Haaren ausgelegte Nest steht wohl versteckt am Boden. Es enthält im Mlärz und April 4 Eier, die wie fast alle Piepereier stark variieren. Sie sind auf weißlichen, hellgranem, grïnlichgranem oler isabellfubenem, selfst rötlichuranem (iruude dunkelgrau und branu getïp felt, gefleckt und gewöllst und spärlicher tiefpurpurbraun, fast schwarz gezeichnet. Sie messen von $18 \times 15,18.2 \times 15.1,18.3>14.7,18.6 \times 15.2$, $18.8 \times 14.5,19 \times 14,19 \times 14.9,19.4 \times 14.4,19 \times 15,19.8 \times 14.5$ bis $20 \times 14.5$, $20 \times 15$ und $20.1 \times 14.6 \mathrm{~mm}$. (Vgl. Journ. f. Orn. 1890, p. 398, Zeitschr. f. Ool. XII, p. $148, \mathrm{XIV}$, p. 8 .)

\section{Anthus berthelotii madeirensis sulisp. nor.}

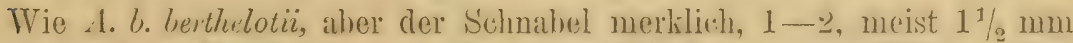
länger, was heim Vergleich einer Serie sowohl, als einzrlner Stritclie sofort auffällt. (Typus o ad. Poizo, 4000 Fub hoch, 20. Fehruar 190:), W. R. Ogilvio Grant coll., Nr. 1344.)

Madeira und Porto Santo.

Häufig. Beginnt sein Brutgeschäft unglanblich frïh. Eier schon vom 20. Felsruar an, Gelege 3-4 Eier. Gestreckte Eier und solche mit zugespitztem kleinen Pol sind 
seltener, melr oder minder rundliche herrschen vor. Ein Li mißt $18.5 \times 16.5 \mathrm{~mm}$, andere $17.5-21 \times 14.5--16.5 \mathrm{~mm}$. Grundfarbe hellgrau, schmutziggrau, grünlichgrau, violettgrau, braungrau bis schwarzgrau, die Piinktchen, Flecke, Strichel dunkelgrau, braun, violett, fast schwarz, meist der Grundfarbe ziemlich entsprechend. Lebensweise, Nest usw. wie die ron A. b. berthelotii.

\section{Anthus trivialis trivialis (I.). (Fig. 48.)}

Baumpieper.

Alauda trivialis Linnaeus, Syst. Nat. Ed. X, p. 166 (1758- „Habitat in Suecia, in arborum summitate").

Alaula minor Gmelin, Syst. Nat., p. 793 (1788- ex Will. und Latham. „Habitat in Europa, pratensi multum affinis, et aequalis").

Anthus arboreus Bechstein, Gemeinniitz. Naturg. Deutschl. III, p. 706 (I807- „ganz Europa"; Beschreibung nach mitteldeutschen Stiicken).

?Spipola sepiariø Leach, Syst. Cat. Indig. MIamm. \& Birds in Brit. Mus., p. 22 (1816nomen nudum!).

Motacilla Spipola (partim!) Pallas, Zoogr. Rosso-Asiat. I, p. 512 (1827 - „in nemorosis Rossine et Sibiriae omnis frequens occurrit". Jedenfalls beschrieb Pallas den Baumpieper, vereinigte damit aber seine östliche Form maculatus.).

Anthus folionnu Brehm, Handb. Naturg. Vög. Deutschl., I. 326 (1831- Lảubhölzer). Anthus juncorum Brehm, Handb. Naturg. Vög. Deutschl., p. 326 (1831- „auf den mit Binsen und Gras bewachsenen freien Schlägen der Nackelwälder, geht auf dem Thüringer Walde bis auf den Rücken des Gebirges, in Tyrol bis anf die Ilittelgebirge hinauf ...").

Anthus herbarum brehm, Handb. Naturg. Vög. Dentschl., p. 327 (1831- „ . lebt auf freien, mit Gras bewachsenen trockenen Schlägen der Nadelwälder, nicht sehr. hoch hinauf").

Anthus agilis Sykes, Proc. Zool. Soc. London 1832, p.91 (Typus aus dem Decean im Britischen IIuseum).

Anthus arboreus validus Brehm, Naumannia 1856, p. 339 (bei Halle).

Anthus arboreus luteigularis Brehm, Naumannia 1856, p. 339 („er streicht selten durch die hiesige Gegend und wandert bis Ägypten").

Anthus arboreus saxorum Brehm, Naumannia 1856, p. 340 (Erfurt, Wittenberg).

Anthus arboreus microrhynchos Brehm, Naumannia 1856, p. 340 (Skandinavien).

Pipastes trivialis major A. E. Brehm, Verz. Samml., p. 7 (1866 - nomen nudum!).

Anthus microrliynchus Severtzow, Ibis 1883, p. 63 (Pamir). Cf. Dresser, Ibis 1876, p. 180.

Engl.: Tree-Pipit. Franz.: Pipi des arbres. Schwed.: Trädpiplärka. Ital.: Prispolone.

(Oherftälilich hetrichtet einem Wiesenpieper sehr ähnlich, aber in vielen Eigentümlichlieiten, namentlich den folgenden, verschieden: Merklich größer; Schnahel stïlire; erste drei Schwingen etwa gleich, die vierte hedentend (4.5-6 mm etwa) kürzer; Kralle der Hinterzehe kürzer und mehr gekrümmt, etras kürzer als die Hinterzehe; Oberseite etwas heller; Unterkörper weißlich, mehr im Kontrast zu der rahmfarbenen bis hell rostfarbenen Kehle, Kropfgegend und Körperseiten. Flügel ơ etwa $86-92$, o $81-87$ mm.

Stiick aus dem Osten (Turkestan, Indien) sind meist

Figur 48.

sehr blaß, dies scheint aber nur dem abgetragenen Gefieder im. Süden eigentümlich $z u$ sein und nicht einer geographiseben Form.

Brïtet in Europa von Tromsë (69") und Nord-Rußland bis zu den I'yrenäen, den höber gelegenen T'eilen Italiens und der Krim, in Asien von 


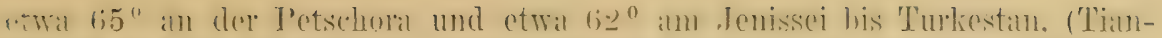

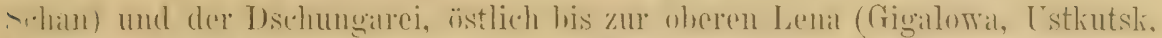

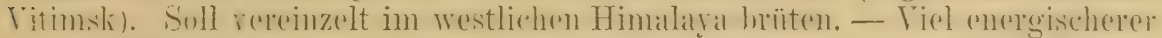

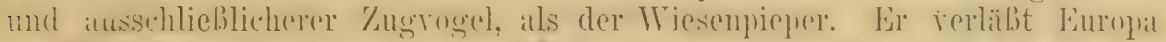

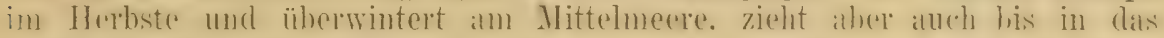
tropische und sogar südliche Afrika. Ebenso wandert er weiter im Osten his nach Nordwest-Indien.

Unterscheidet sich in der Lebensweise schr rom Wiesenpieper, denn er bewohnt trockene, mit Gebiisch bestandene Wlächen, Blößen und Lichtungen im Walde, breite We e- und (irabenränder, dichte Laub- und Nadelholzwälder, Festungswälle in der Nähe waldartiger.Glacis, Parks und große Gärten, vou der Tiefebene bis in die Gebirge, manchual bis in die Nähe der Grenze des Baumwuchses (z. B. in Urseren-'Tal im OberEngadin). Der ('esang ist gut, erinnert an den des Kanarienrogels, beginnt mit einer kurzen, zwitschernden Strophe, der ummittelbar einige quirlig pfeifende Töne folgen, worauf eine schöne trillernde Strophe den Vortrag beschließt. Er singt meist im Fluge, in schiefer Richtung von einem Baume oder Busche aufsteigend und sich dann wieder langsam herablassend, auch im wagerechten Hinsehweben oder sitzend. Lockstimme ein etwas schnarrendes psihb. Nester gut rersteckt am Boden, im Grase oder unter kleinen Bïschen, manchmal auch in Getreide. Eier 5, selten 4 oder 6, von Mitte Mai bis Anfang Juli; meist wohl nur eine, manchmal aber auch zwei Bruten. Eier ungeheuer variabel: hellbläulichgrau mit dunkelbraunen, sogenannten Brandflecken und hellbraunen Schalenflecken; schrnutzig blaßrot mit großen helllila Schalen- und dunkelrotbraunen Oberflecken und Kritzeln; rötlich mit ziegelroten, verwaschenen und tieferliegenden hellila Schalentlecken, sowie tiefbramen Punkten und Brandflecken; hell ulivenfarben mit großen dunkelolivenfarbenen Schatten und dunkelbraunen Flecken und Harzïgen; rötlichgrau mit feinen rötlichbraunen Längstlecken über und ïber bedeckt, olne Brandflecke; auf weißgrauem, bläulichem oder bräunlichem Grunde fein graubraun und braun punktiert und gestrichelt, manchen Eiern von Motacilla alba sehr ähnlich; auf weißlichem (irunde mit zahlreichen braunen und tieferliegenden hellgraulichen Flecken dicht bedeckt, den Sperlingseiern ähnlich; hellrot, ïber und iiber (lunkelbraunrot punktiert und gefleckt: hellila mit brauner Punktierung, an Eier von Locustella fluviatilis erinnernd. Manchmal häuft sich die Zeichnung kranzartig am stumplen Ende. Diese Varietiiten finden sich natïrlich nicht bunt in den Nestern rerteilt, sondern die Gelege sind immer unter sich gleichmäßig grau, rötlich usw, Jedenfalls legt ein $q$ immer dieselbe Sorte von Eiern. Die Baumpiepereier sind ziemlich glatt und matt gliinzend und ändern auch in Größe und Gestalt ziemlich stark ab. 72 Exemplare messen nach Rey im Maximm $22.5 \times 16.5$, im Durchschnitt $20.18>15.37$. im Minimum 18.4 $<14 \mathrm{~mm}$, das mittlere Gewicht beträgt etwa $135 \mathrm{mg}$. Das größte mir rorliegende Ei mibt $22.6 \times 16.8$, das kleinste $18.8>15.9 \mathrm{~mm}$, von Spureiern abgesehen.

\section{-439. Anthus trivialis maculatus Jerdon.}

Anthus maculatus of brevivostris Hodgson, Zool. Mlisc., p. 83 (1814- nomina nuda!). Anthus maculatus Jerdon, B. India IH, p. 873 (1861- ex Hodgson, 1. c., Indien). (Anthus agilis vieler Autoren, aber nicht A. agilis Sykes 1832.)

Abbild.: Gould, B. Asia IV, 'Laf. 65.

Man hat sich in neuerer Keit daran gewöhnt, diesen Pieper als eine Cubspezies ron trivalis zu betrichten, und clas ist wahrseheinlich alleh das lichtige. angesichts der Ähnlichlicit mehrerer zweifellos antlich rerschiodenen

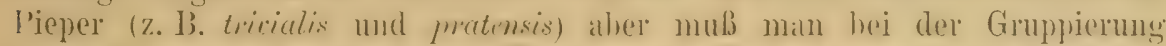
dieser Formen sehr vorsichtig zu Trerke gehen. In der kurzen, stark gुelogenen Iinterkialle und dem allgemeinen Aussehen stimmt murulatus mit tririelis 
ïberein. Die vierte (ausgebildete) Schwinge ist nicht so stark verkürt. sondern nur etwa 2-3 mm kürzer, als die dritte; die Oberseite ist grün-

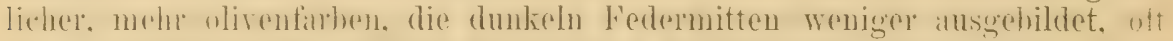
gatuz undeutlich. der weiblich rahmfarbene supereiliarstreif hinter dem Angr

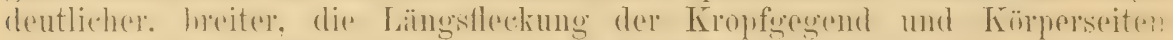

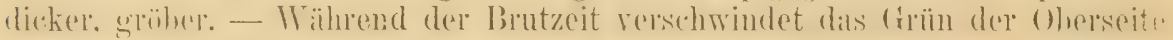
fast ganz, sodal. letztere dann fast grau erscheint. Der junge Vogel ist oben viel brä̈ulicher, nicht so grünlich.

Vertritt A. trivialis trivialis sozusagen in weitem, das Brutgebiet des letzteren halhmondfïmig unfissenden lBogen: im nördichsten sibirien rwm Unterlauf des Jenissei und der Lena (an deren oberen 'Teilen noch trivialis rorkommt). his zum stanowoi Gehirge und Kimtschatlial. ant dem Kurilen. in Jesso und den Bergen von Hondo, ebenso aber auch in der östlichen

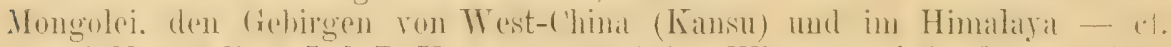

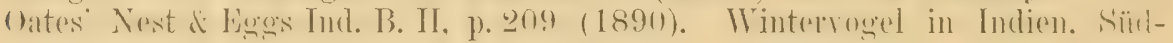
China, Cochinchina bis Hainan, sowie in den südlichen T'eilen von Japan. Vereinzelt bis zu den Philippinen. ${ }^{1}$ )

Nistet nach Dybowski's Beobachtungen in lichten Gehölzen und am Rande von Wäldern und sitzt meist auf Bäumen, wie unser Baumpieper. Nester auf der Eirde unter einem Grasbüschel oder dergleichen. In der ersten.Hälfte Juni (in Daurien. Ost-Sibirien) 4-5 Eier, die den mehr großgefleckten Varietäten des Baurnpiepers völlig gleichen. Nach den Beobachtungen von Anderson u. a. im Himalaya in Höhen von 7-12000 engl. Fub rom Mai bis Juli nistend. Nest in jenen Höhen ein großer Bau aus Moos, unter Grasbïscheln verborgen.

\section{Anthus gustavi Swinl.}

\section{Petschorit-Pieper.}

Anthus gustuvi Swinhoe, Proe. Zool. Soc. London 1863, p. 90 (Amoy).

Anthus batchiancensis Gray, Handlist B. I, p. 251 (1869- "n. sp.? Batchian Island * Nomen nudum!).

Anthus seebohmi Dresser, B. Europe III, p. 295, 'T'af. 131 (1875- Petschora).

Kralle der Hinterzehe schlank, nur wenig gekrümmt, meist lïnger als die Hinterzehe. Die ersten heiden ansgehildeten Sichwingen etwa gleich. die dritte ganz wenig, oft kaum, die vierte viel kürzer. Nur die zweite und dritte ansgebildete Schwinge mit dentlich verengtem s'pit\%endrittel. Firste des (Oberischnalyels ror der Mitte etwas eingesenlit, somit an eincus

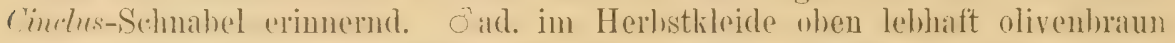
mit ansgedehnten tief' dunkelhramen Federmitten. Federn des Oberrückens. meist mit auffallenden rahmweiBen Seitenstreifen. Säume der mittleren und eroben Oherflügeldecken rahmweiblirh. Äubere steuerfeder schief längs:

1) Im Ornithol. Centralblatt 1882, p. 34, berichtet Böckmann, daß er am 18. Mai 1875 bei Hamburg (Winterhude) ein Exemplar dieses Piepers erbeutet habe. Das jetzt in Tring befindliche Stück nurde aber erst 1880 in Wiebke's Sammlung als maculatus erkannt, bis dahin für trivialis gehalten. Zweifellos liegi hier ein Irrtum vor: das Stück war aufgestellt und hatte kein Etikett. Es befindet sich in ganz frisch vermausertem Gefieder, wie es schon Stücke vom April nicht mehr haben. Da Böckmann viel für Wichkes atusstopfte und da letztere Herren viele ostasiatische Tögel ron Dörries erhielten. so dürfte eine Verwechselung stattgefunden haben. 


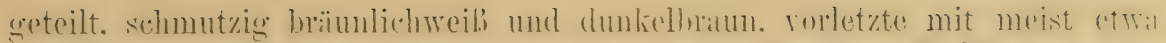

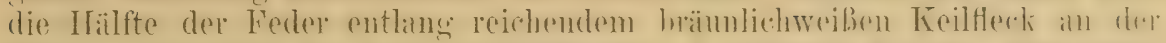

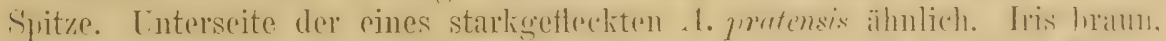

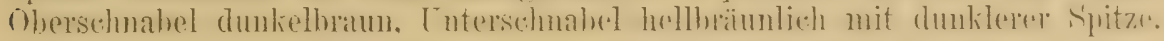
Füße brïunlich floischfarben. Oेad. Flügel etwa $82-85 \mathrm{~mm}$, ᄋ etras kleiner, Flügel etwa $79-82 \mathrm{~mm}$.

Brutvogel im hohen Norden, von den Kommandeur-Inseln umd Kamtschatkat his in das 'lad der f'etschoria im nördlichen linbland. südlioh his zum Altai. - Wanderungen in östlicher Richtung; dureh Daurien und

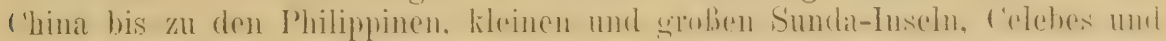

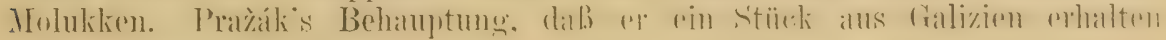
habe, ist molaubwürdig.

Bewohner tiefliegender, sumpfiger, aber auch sandiger Striche. Gesang aulberordentlich lang, aus zwei T'eilen bestehend, erst einem 'Trillern, dem von Tringu temmincki oder der Endstrophe von Phylloscopus sibilatrix älnlich, daun einem gutturalen Schlagen, an den zweiten 'I'eil des Blaukehlchenschlages erinnernd. Dieser Gesang wird ron dem Vogel meist in der Luft schwebend vorgetragen. Nahrung Insekten. Nester am Borlen, aus Hachen Gräsern, Blättern usw. zusammengesetzt. Eier in cler zweiten Hälfte des Juni und der ersten des Juli, 5 an der Zahl, denen der Wiesenpieper ähnelnd, die bräunliche oder weißliche Grundfarbe durch die dichte grauliche und braune Fleckung fast ganz verdeckt. Manchmal finden sich fast schwarze Flecke, oft eine kranzförmige Zone um das stumpfe Ende. Maße $20.2 \times 14.6 \mathrm{~mm}$.

\section{-441. Anthus pratensis (I.). (Fig. 49.)}

IViesenpieper:

Alanda pratensis Linnaens, Syst. Nat. Ed. X, p.166 (1758- „Habitat in Ėuropae pratis“. Als typische Lokalität ist Schweden zu betrachten. Vgl, erstes Zitat. Linne unterschied deutlich zwischen Wiesen- und Baumpieper und seine Namen müssen ohne Bedenken angenommen werden. In den Zitaten war er dagegen unsicher (vgl. Ed. XII, p. 287), zumal mehrere seiner Gewährsmïnner die Arten verwechselten).

Anthus sepiarius Vieillot, Nour. Dict. d'Hist. Nat. XXVI, 1) 486 (1818- nener Name fïr den Anthus pratensis von "Bechstein et Meyer").

Anthus palustris Brehm, Lehrbuch Naturg. a. eur. Vög. I, 1.24.4 (1823- „auf' sumpfigen IViesen").

Anthus stagnatilis Brehm, Handb. Naturg. Vög. Deutschl., p. 332 (1831- ,MLrïste, Sumpfiriesen und stehende Gewïsser Nord-Deutschlands").

Antlus Danicus Brehm, t. c., p. 333 (1831- „Dänemark u. a. nordische Länder").

Anthus pratorum Brehm, t. c., p. 333 (1831 - "stumpfige Wiesen des nördlichen Deutschlands").

Anthus alticeps Birehm, t. c., p. 335 (1831— "scheint den Norden zu bewohneu“).

Anthus tenuirostris Brehm, t. c., p. 335 (1831- Deutschland).

Anthus musicus Brelim, t. c., p. 336 (1831 - "er wandert durch Mittel-Deutschland"). Anthus virescens Brehm, t. c., p. 337 (1831- Mittel-Deutsehland).

Anthus Lichtensteinii Brehm, t. c., p. 338 (1831- „..... wüste Plätze Westfalens").

Anthus desertorum Brehm, t. c., p. 338 (1831- „.... Heiden des nordwestlichen Deutschlands, ron Flensburg bis nach Dortmund ....").

Anthus montanellus Brelım, t. c., p. 339 (1831- „.... auf dem Rücken des 'Thüringer TValdes ....").

Anthus tristis Baillon, Mém. Soc. d'Ĺmul. Abbcrille, p. 14 (1834- Abbeville. Vergl. Naumannia 1856 , p. 389, 396). 
Anthus communis in Blyth's Ed. ron G. White's Nat. Hist. Selborne, 1). 261 (1850-England).

Antluts acurostris Brehm, Isis 1841, p. 207, 208 (im Winter und ersten Frühjahr in Deutschland).

Authus hydrophilos Brehm, Isis 1841, p. 207, 211 (seltener Zugrogel).

Authus limicola Brehm, Isis 1841, p. 207, 213 (zur Zugzeit Lirdmannsdorter Wiesen). Anthus alaudarius Brehm, Isis 1841, p. 208, 215 (bei Renthendorf).

Authus pratensis minor Brehm, Naumannia 1856, p. 346 (.,wandert durch Deutschland" ").

Leimoniptera Lichtensteinii brachyrhyncha A. E. Brehm, Verz. Samml, p. 7 (1866nomen nudum!).

Anthus intermedius Dresser, ex Sewertzow IL.S., Ibis 1876, p. 179 ('Turkestan).

Anthus pratensis var. borealis R. Blasius, Naumann, Naturg. Vög. Mitteleur. III, 1. ¿8 (1900- ex Homeyer H.S. - Anklam, gleicht pratensis).

Engl.: Titlark, Meadow-Pipit. Franz.: Pipi des Prés. Ital.: Pispola. Schwed.: Ängpiplärka.

Kralle der Hinterzehe gestreckt, schwach gebogen, etrvas lïnger als

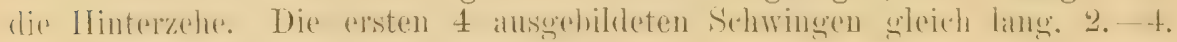
mit verschmälertem Enddrittel der Außenfahne.

ord. Herbstkleid: Oberseite auf hellbraunem. ins olivenfarbene

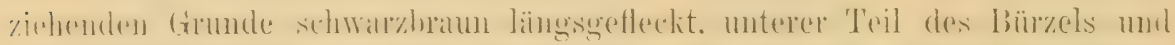

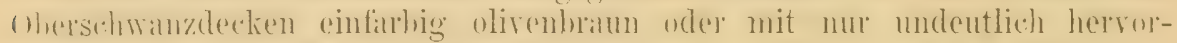

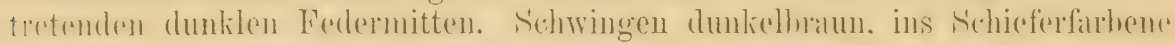
ziehend, mit schmalen, an den letzten Armschwingen aber

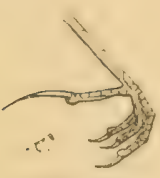

Jimill I'! breiten blaßbraunen Säumen. Mittlere und großse Oberflügeldecken breit blal.s gelblichbraun gesïumt. Untere Flügeldecken und Achselfedern weißlich, in der Mitte blaßbräunlich, mehr oder minder (besonders die Achselfedern) gelblich angehaucht.

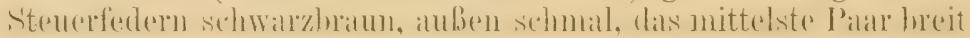
olivenbrïunlich gesĭumt, Außenfahme des ïußersten Steuerfeder-

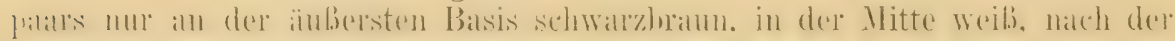

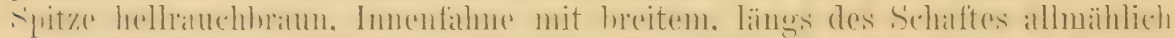

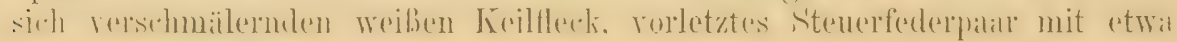
5 -15 mm langem weißen keilförmigen Fleck an der Spitze. Unterseite

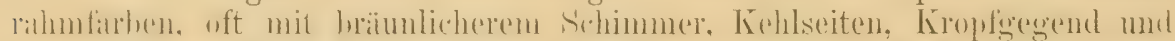

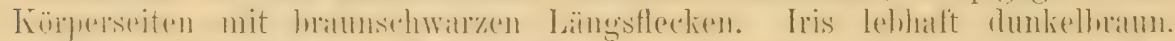

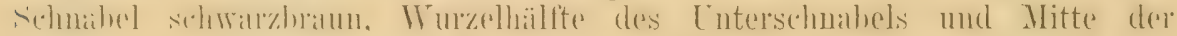

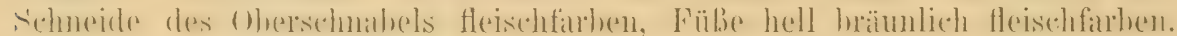
Hlügel etwa $80-84$, Schwanz $60-70$, Lauf etwa 20-23, Schnabel etwil 11-12.5 mm. O wie o Frählingskleid nicht wesentlich vom Hertostkleide versehieden. Einzehe Stïcke sind auch im frischen Gefieder unten fast weib, immer aber sind

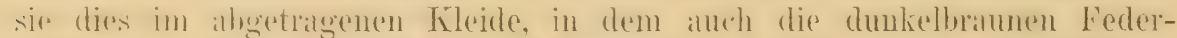

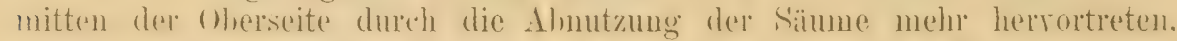

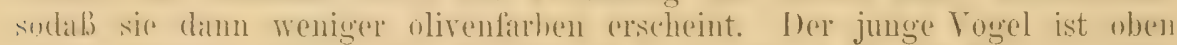
retwats dïsterer und an der Vorderbrust (audh retwas an der Fiehle) gröber und mehr gefleckt. - Die Gröbenverhältnisse varieren etwas. aher nieht mehr, als bei vielen anderen Vögeln.

Brïtet in Europa von Island und deu Faröer, rom Nordkap bis zu den P'yeniten. Italien (in den südlicben Teilen aher nur sehr seltener Brut-

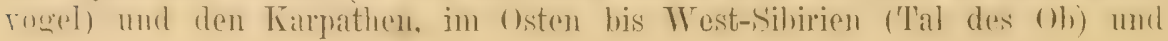




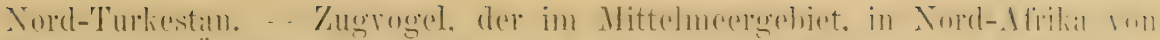

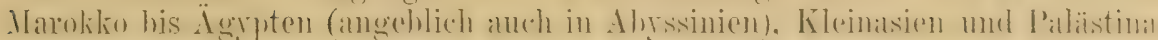
ïberwintert. Fine geringe Anzahl bleiht im Wintel auch in nördlicheren

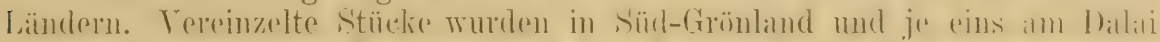

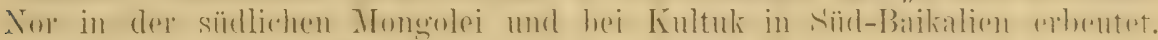

Der Wiesenpieper ist ein wahrer Wiesenrogel. Zum Briten berorzugt er lenchte Gelände, Brüiche und Sumpfwiesen, namentlich wo Binsen und Schachtelhalme gredeihen, aber auch allerlei, oft reeht dïrre, grasige Flächen in der Niilıe ron Bächen. ()bwohl hauptsächlich ein V'ogel der Ebene, briitet er doch anch im Gebirge, jul aul ihm zusagenden Bergwiesen und Mooren bis mindestens $1500 \mathrm{~m}$ hoch. Die Loekstimme ist ein feines, oft ausgestoßenes, ist"; am Brutplatze hört man ein sanftes „dwit" und ."zerrit". Der Gesang erinnert an den des Baumpiepers, ist aber leiser, feiner, unbelentender, weniger melodiseh. Das Nest steht am Boden und ist sehwer zu finden. lis ist finst inmer mit Haaren ausgelegt und enthält in England oft schon Finde April, in Deutschland erst im Mai und Juni 4-6 Eier. Diese sind meist auf blaßgranem oder bräunlichem Grunde dicht dunkelbraun gefleckt und gewölkt, manchmal auch grünlich. Rote Varietäten scheinon äußerst selteı zu sein - meist mögen Verwechslungen mit Baumpiepereiem vorliegen. Mittleres (rewicht nach Rey $11 . \mathrm{mg}$. Malie $20.3 \times 14.7$. $20 \times 15.1,18.99 \times 14.27,17.7 \times 13,17.5 \times 1411 m$.

\section{-442. Anthus cervina (Tall.).}

Rotkehliger Pieper.

Motacilla Cervina Pallas, Kongr. Rosso-Asiat. 1, p. 511 (1827²) (1). e. in Sibiria tantum maxime orientali, circa Coryma $\mathrm{fl}$. itempue in Cantschatea et ins. vers. Amerieam sitis frequens est.." ).

Authus cecilii Audouin, Deser. Egypte, p.360, T'af. 5), Fig. 6 (1828 - ..en Égyte, en Syrie, en 'lurquie, en Barbarie").

Anthus pratensis mubicus Hemprich \& Ehr., Symb. I'hys. fol. dd (1828- ex Licht. II.S., als Synonym zu A. cecilii gestellt, Stiicke aus Aribien).

Anthus rufogularis Brehm, Handb. Naturg. Vög. Jeutschl., j).340 (18:31- ,er bewohut den Siiden, besonders Nubien, kommt abel auch bisweilen in Deutschland vol**).

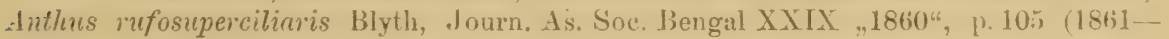
Pegu).

Leimoniptera cervina und rufigularis major und minor A. E. Brehu, Verz. Samml., Ir.7 (1866--.- nomina nuda!).

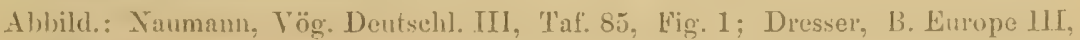
Taf. 136.

Die ersten drei alusgebildeten Sehwingen fast gleich, die vicrte aher schon merklich kïrzer! Das Gefieder dieses Piepers ist sehr rersehiedenartig: im allgemeinen ist das Herbstkleid dem eines 1. pratensis so ïlnnlich, daß es leicht damit verwechselt werden kann und sich eigentlich nu dureh die scharfe und sich gleichmäßig stark ïber Bülrzel und Ober-

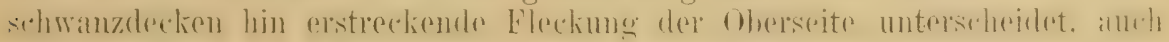
sind die Flecke der Kropfgegend und Śeiten meist merklich größer. Aus

1) Pallas: Werk wurde in Heft I ( $1.1-112$ ) mit dem Jahre 1811 zitiert, wie es auf dem Titelblatt steht. In Heft II (p. 113-240) wurde als Lischeinungsjahr 18:31 angegeben (vgl. Anm.2 p. 125). Aus der 1831 in Königsberg erschienenen Schrift „Berichte iiber die Zoogr. Rosso-A siat." von $K$. E. v. Baer geht aber klar herror, daß wir als Erscheinungsjalur, also das .Jahr, rou dem an das Werk erhältlich war, 18:7 annelımen miissen. Man rgl. 11. a. p. 16, 22 und die Anmerkung p. 23. 


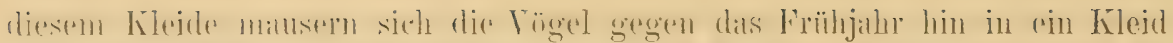

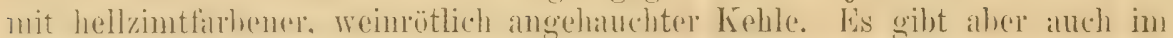
Herlst und Trinter viele Individuen mit prïchtig ansgebildeter zimtroter

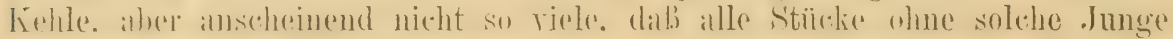
srin limmtru. In Fröhjahrskleide ahere tinden wir anch rine anfallende Tariation: hald ist nur die Kehle rot, Kropfgegend und Seiten aber

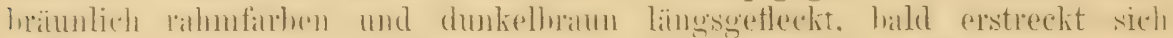
die rote Furbe bis zur Brust und die Fleckung der Kropfgegend wird spärlich oder rersehwindet ganz, die der Seiten etwas sparsamer. Dab es

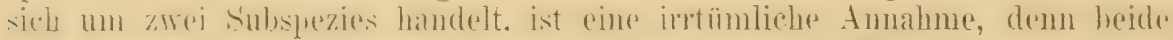
Variationen finden side an denselluen bintulätzen in Nopel-Guropa sownhl. als in Sibirien, anBerden finden wir alle Kwischenstadien. Main kann

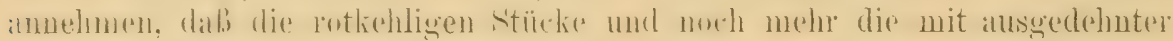

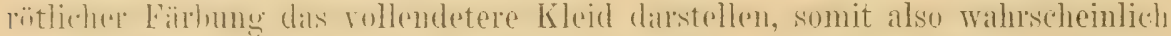
die ältesten Stïcke sind. Vielleicht verhält es sich mit diesen Piepern ïhulieh wie mit den meisten Arten vou Carpodacus u. a., die zwar ihr

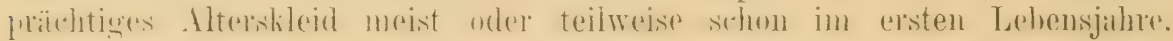
oft aber erst nach 2-3 Jalıen anlegen, bisweilen vielleicht gar nicht, nur dal.) diese P'ieper auch ein intermediäres Kleid (das mit nur roter

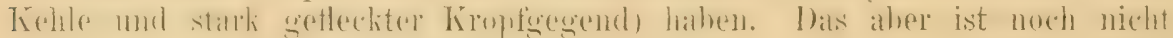
hewiesen und die Behauptung; dals diese Pieper ,in drei Jahren völlig adult seien und bis dahim Jahr für Jahr in der Frühlingsmauser meh"

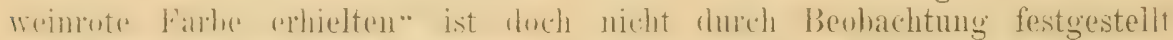

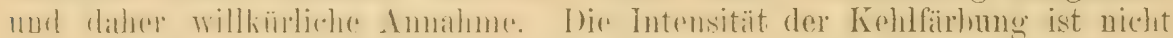
vanz konstint, meist ist sie stark weimrötlich, manchmal mehr zimtfarbig. Die ofcheinen den $\sigma^{2}$ völlig zu gleichen, nu ist der Flügel meist wenige nmm kilirzel:

Bervohnt zur Brutzeit den hohen Norden buropas und Asiens ron Skandi-

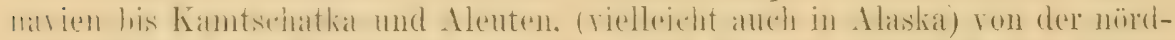

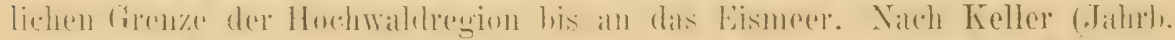

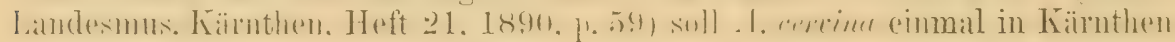
gुebriitet hahen! Dil ein Beweiseremplar (ein Junges hätte doch leicht

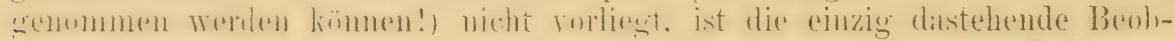
achtung weder zu heweisen noch zu widerlegen. - Gewaltiger Wanderer,

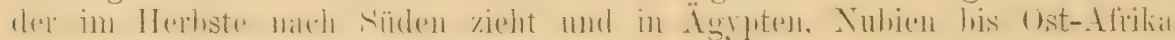
und Indien, sowie rereinzelt bis zu den malaiischen Inseln überwintert. In England und auf den Fäöer sehr selten, in West-Europa nicht häufig.

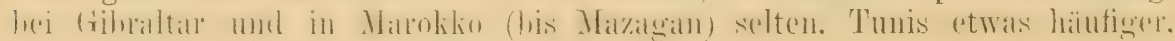
Italien häutig, Ägypten in Nenge, Persien usw.

Hauptsïchlich Bewohner der Tundren. In der Lebenswoise A. matensis, mit dem er im nördlichen Skandinarien die gleichen Bezirke bewohnt, zwar ähulich, aber nach ïbcreinstimmenden Beobachtungen verschiedener Forscher sind die Locktöno langsamer und gedehnter, weniger scharf, der Gesang melodischer und länger. Die Art trifft erst spät (anfangs .Juni) im Yorden ein und verweilt in seinen Winterquartieren (Ägypten) bis in den Mai. Das am IBoden stehende Nest enthält erst von Jitte Juni an meist 5 , seltener 4 oder 6 Eier. Diese variieren vou einem fast cinfarbigen Mahagoni-rotbraun bis zu einem grïnlichen Grau mit brauner Fleckung. Sie gleichen denen des Wiesenpiepers, sind aber meist gröber und dunkler gewöllt. 33 Eier in Reys Sammlung messen im Maximum 20.5 $<14.3$, im Durehschnitt $19.2 \times 14.3$, im Minimum $17.9 \times 13.7 \mathrm{~mm}$, das mittlere Gewicht derselben beträgt $127 \mathrm{mg}$. 


\section{Anthus roseatus Blyth.}

Anthus rosaceus, $v$. mfogularis? Hodgson, Zool. Miscellany, p. 83 (184t- nomen nudum!).

Anthus roseatus „Hodgson“ Blyth, Journ, Asiat. Soc. Bengal XVI, p.437 (1847 -- Nopal).

(I)ieser Pieper ist vielleicht am nächsten mit A. cevvinus rerwandt,

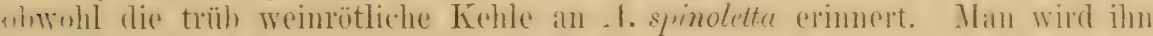
roxläufig jedenfalls als Spezies betrachten müssen.)

I)ic ersten rier ausgebildeten Handschwingen ganz gleich lang? Herhst-

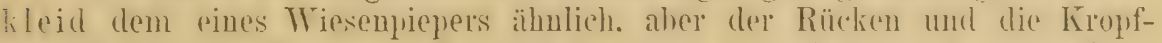

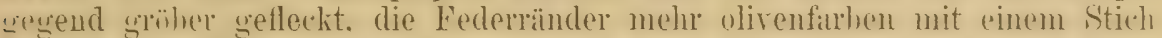
ins Grünliche. Flügel etwas länger: die klemen Flügeldeclitn hahen grüuliche

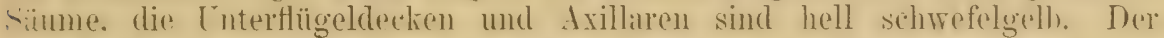
alte Frïhlingsrogel ist ohen etwas hlasser. am Hinterhilse zeigt sich dentlich rin asehgratuer Anflug. Kehle und Kropfogegend, oft andeh die Brust

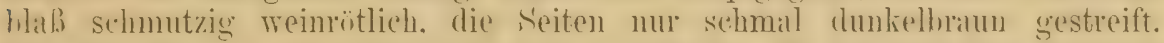
lie Kroplgegend ist manchmal gimz ungeflectit. oft mit einzelnen wengen Elerken repsehen, in anderen Stücke'n ist wieder nur die Kehle ritelieh, die

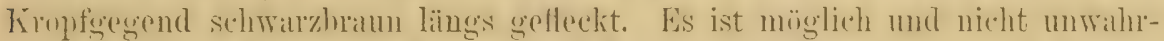
$\therefore$ heinlich, aber lieineswegs hewiesen. dath erstere die ältesten. letatere jüngore

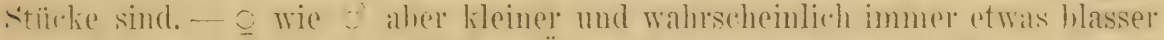

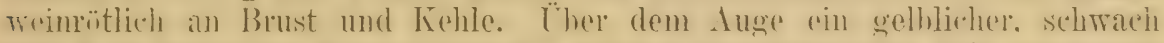

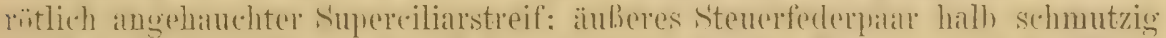

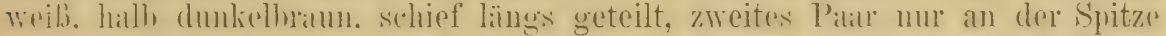
mit dinem keillämigen. mehr ofler minder kurzen schmutzigmeiben Fleck.

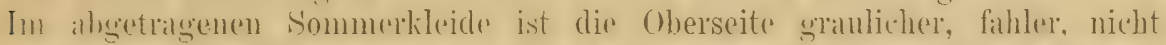

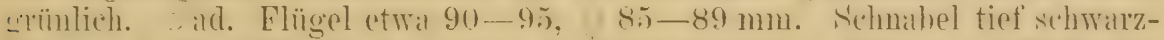

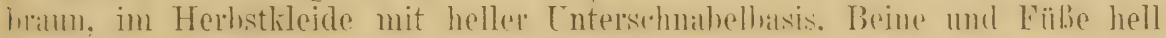
hrïunlich fleischfarben.

Britet in den Gebirgen ron Kansu, am oberen Clunanche, im Chotantagh. Kukumor und der Kerian-Kette bis zum Himalaya. - Überwintert in Indien, von Afghanistan bis Manipur und Arrakan.

Bewohuer hoher Alpenwiesen. In Frühjahr singt das of selır gut. Nach Art der W'iesenpieper erhebt es sich in die Luft und senkt sich von dort zitternden Fluges auf den Boden herab. Am 9. Juni 1880 wurde auf dem Berge Dschachar ein Nest mit $\&$ unbebriiteten Eiern gefunden. 1873 kamen die ersten Vorziigler in Kansu am 1U. April, $1880 \mathrm{am}$ Chuanche am 17. April an. (Ares Prowalskianae p. 194.) Riickbeil find an Kukunor Gelege ron 4 und 5 Eiorn. Die des einen Geleges sind weißlichgrau, über und ïber dicht braun und graubraun gesprenkelt, manchen Eiern von Anthus arboreus sehr ähnlich. Sie messen etwa $20.6 \times 16 \mathrm{~mm}$. Die des andern Freleges sind heller, trüb weiß mit blaß erdbramen und ticfer liegenden hellgraten Flecken, an kleine Lercheneier erinnernd. Ialße: $20.5 \times 16,21.2 \times 15.5$ bis $21.3 \times 15.8 \mathrm{~mm}$.

\section{Anthus spinoletta spinoletta (L.).}

\section{Wasserpieper:}

Alculde Spinoletta Linnaeus, Syst. Nat. Ed. X, 1) 166 (1758 - ex liaiius, Syn. Meth. Ar., p. 70 [1713] und Raius, Willughbeii Ornithol., p. 152 [1676]. „Habitat in Italia." Der Name ist später oft dem ital. Sprachgebrauch gemïß.3 in spipolette und pispolette umgeändert worden). 
Anthus aquaticus Bechstein, Gemeiun. Naturg. Deutschl. III, 1).745 (1807- Umbenemmung von Limné's Alauda spinoletta.)

Anthus montamus Koch, System der baier. Zool. I, 1) 179 (1816- „ein Alpenrogel, der noch auf den höchsten Alpen angetroffen wird." Koch beschreibt das Frïhlingskleid, während er den Vogel in Herbstlileide A. aquaticus nennt).

Anthus hiemalis Brehm, Handb. Naturg. Vög. Deutschl., p. 329 (1831- ,er lebt nördlicher als A. aquaticus, kommt im Winter bei Greifswald, bei Witten in Westfalen, Süd-Frankreich, aber Thüringen nicht ror"i).

Anthus alpinus Brehm, Handb. Naturg. Vïg. Deutschl., p.329 (1831- ,Alpen Tyrols und Kärnthens"),

Anthus major, minor Brehm, Naumaunia 1855, p. 279 (nomina nuda!).

Anthes aquaticus rivalis, montium A. H. Brehm, V'erz. Sanmlung., 1. T (1866- nomina nuda!).

Anthus spinoletta carpatica Grabowski, Mus. Homeyer., 1). 13 (1893- ex Homey. M.১., nomen nudum!).

Anthus spipoletta reichenowi Prażak, Journ. f. Orn. 1897, p. 326 (Karpathen).

Engl.: Water-Pipit. Franz: Pipi spioneclle, Farlouse spioncelle. Ital.: Spioneello, Pispolia di padule.

Herbstkleid: Oberseite hraum, Kopf und Rücken mit dunkelbramen

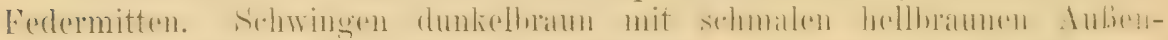

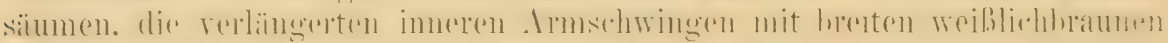

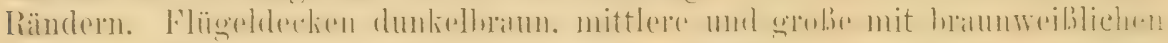

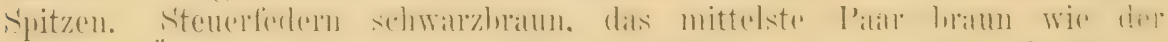
Rïcken. Äußerstes Par mit meist rein weißer, nur an der Wruel hrauner und nach der Spitze zu bräunlicher AuBenfahne und grobem weiben Keilfleck an der Innenfahne, zweites Par mit weibem Keilfleck an der Spitze. Unterseite weil mit rahmfarbenem Anflug, Kropfgegend, Kehl-

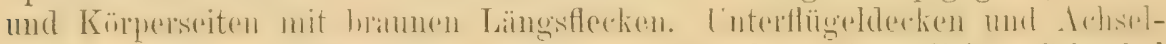
federn weißlich, Federmitten nach der Wurzel zu brïunlich. Schmahel

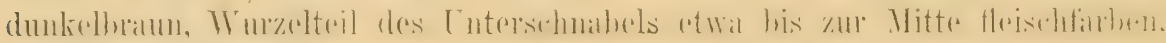
Eüiße dunkelbraun.

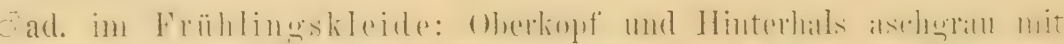

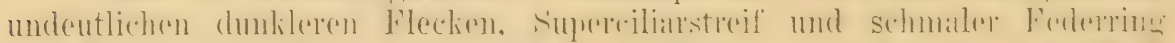

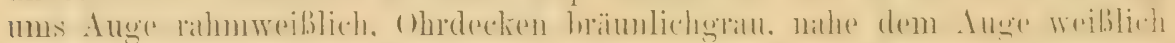

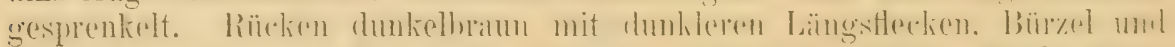

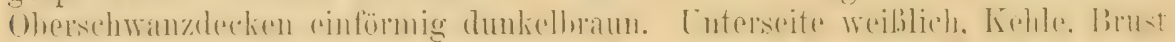

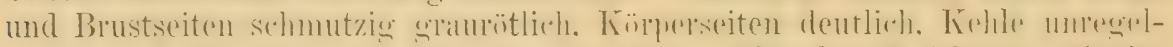

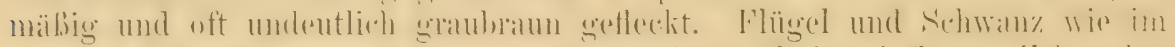

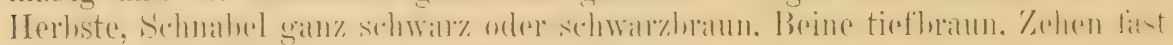

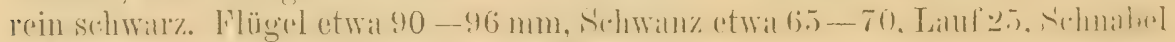

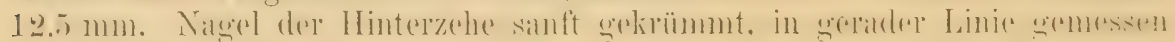
so lang wie oder ctwas lünger als die Hinterzehe. wie of. nur etwas kleiner, Flïgel etwa $86-92 \mathrm{~mm}$. Das erste Jugendlkleid ist wie das oben beschriebene Winterkleid der Alten, nur erscheint die Fleckumg auf der

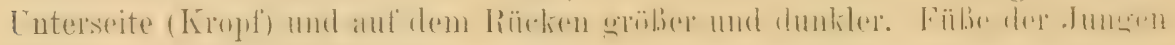
hollbraun. fast fleischfarben.

Der Wasserpieper bewohnt zur Brutzeit die Gebirge Mittel- und Sücl-

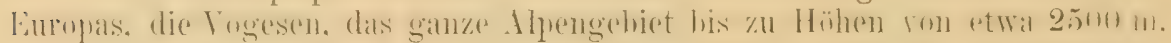
den Schwarzwald, Harz, die Sudeten, den 'Thüringer Wald, die Pyrenien. und hohen Bergziige Spaniens, die Karpathen und Berge der Balkanhalh- 


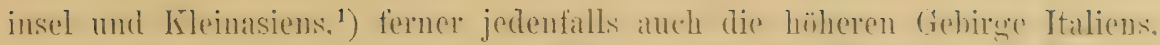
und sicher die Sardiniens. - Im Winter zieht die Mehrzahl der Wasserpieper in die Ehenen hinah, mol man findet sie dimn in den süddentschen Whenen, seltener am lihein, in ësterreich-[ugarn, rereinzolt his Nord-

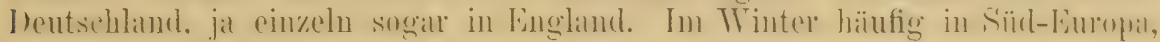
his an die Küsten Nordwest-Afrikas (Algier, Tunis).

Brütet in der alpinen Region, besonders an Bächen und 'T'eichen in der Knicholzregion, wo Flächen mit kurem Grase und sumpfige Wiesen sich finden, auch ant steinigen Kuppen, wenn nur Rinnsale in der Nähe sind. Das Nest steht am Boden, im Schutze überhängender Steine, Grasbiischel oder Büsche und enthält oft schon Ende April, meist aber erst im Mai 4 -6 Eier, die denen anderer P'ieper gleichen, aber weniger variieren. Sie sind hellgrau, seltener grünlich, dicht bedeckt mit dunkelgrauen und braunen Flecken und Wolken, sowie manchmal mit einigen schwarzen Punkten und Linien. Rote Varietäten scheinen nicht beobachtet zu sein. I)ie Eier messen nach Rey (55 Stück) im Ilaxinum $23.7>15.8$ und $22.4 \times 16.3 \mathrm{~mm}$, im Durchschnitt $21.3 \times 15.6$, im 1 linimum $19.3 \times 14.9 \mathrm{~mm}$. Die gewöhnliche Lockstiname ist ein selur pieperartiges fit, fit-fit, fit, der Angstruf am Brutplatze ein rielfach rariiertes heiseres spieb, der wie Hi, Hi, Hi, fi, fi, fi, pi, pi, pi, thi, thi, thi klingende feine Gesang wird im Auffliegen, selten sitzend, ansgestoben.

\section{Anthus spinoletta coutellii Saviguy.}

Anthus coutellii Savigny, in Deser. de l'Égypte XXXIIT, 1.360, Taf. 5, fig. 5 (1828Ägypten).

Anthus orientulis Brehm, Vogelfang, p.138 („Aus Asien rerirrt er sich uach OstEuropa". (Sic!) Die Sammlung enthält nur Stücke aus Ägypten und dem peträischen Arabien. Als typische Lokalitiat betrachte ich Agypten).

Die Wasserpieper, die in Ägypten und Palästina im Winter erlegt

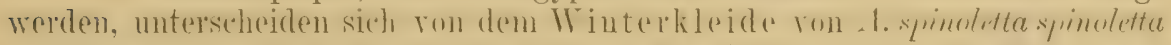
auf den ersten Blick durch die Förlung der Oherseite, wo die Federn aut

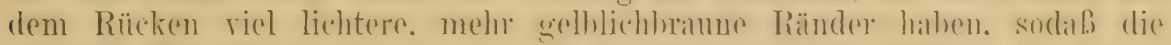

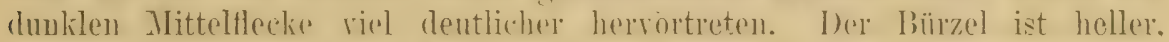
mehr gelhlichuraun. der Konf deutlicher gestreift. Tie Einterseite seheint

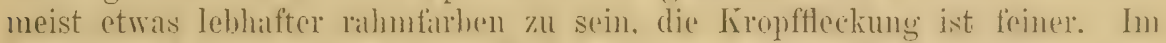

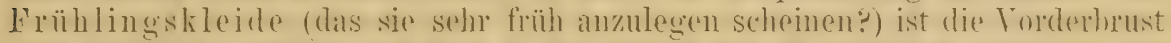

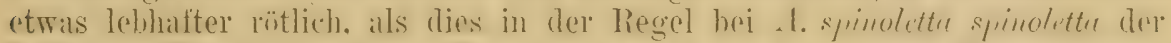

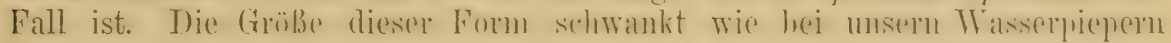
ziemlich sehr, doch neigt sie keinesweg's zu geringerer Gröle, sondern stimmt eher mit den größeren spinoletta überein.

Die geographische Terbreitung ist noch etwas unklar. Es liegen Wintervägel aus Ägrpten und Palistina ror und die persischen Vögal

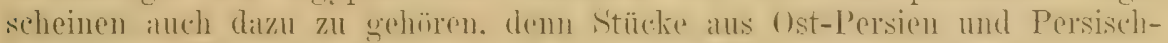
Baluchistan (Härms) scheinen nicht unterscheidhal zu s(iu. I)as Brutgeloiet

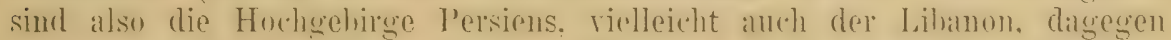

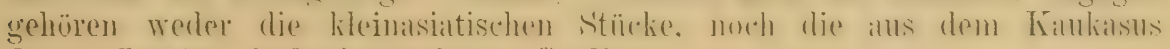
dazu. Letztere hedïrfen weiteren Studiums.

1) Die kleinasiatischen Stïcke (Smyrna und 'laurus, wo sie anscheinend brïten) scheinen mir nicht ron denen Europas abzuweichen, es sei demm, daß sie etwas kleiner seien. Um dies festzustelien, müßte eine große Serie verglichen werden. Die Vorderbrust ist im Friihjahr lebhalt rötlich. 


\section{Anthus spinoletta blakistoni Swinh.}

Anthus blakistoni Swinhoc, Proc. Zool. Soc. London 1853, 1).90 (, On the banks of the Yangtsze River, 150 miles iuland. $\left.{ }^{6}\right)$.

Anthus neglectus Brooks, Ibis 1876, p. 501 (, lixtensive swamps and lakes in the northern parts of Inclia during the cold season.").

Herbstkleid oben viel heller, als das' von A. spinoletta spinoletta, ja

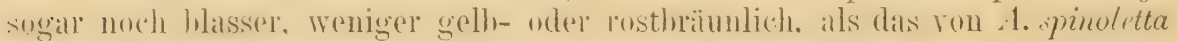

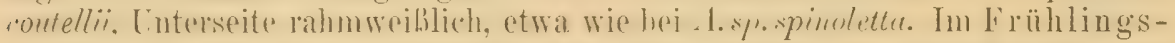
kleide ist die ganze Unterseite bis zum Banche hin hellhöimnlich mit rosigem Anflug. an Vorderlnerust und Hals etwas lehhafter, whe alle Fleckung.

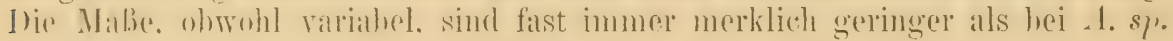
spinoletta und coutellii. ơad. Flïgel meist etwa 89-90, selten bis 92 und $93 \mathrm{~mm}$, o etwa $81-83$.

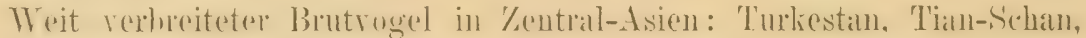
Altai, Njan-Schan, am Chuanche usw. Im Winter in wärmere Gebiete hinalssteigend: häufigere Winterrogel in Nordwest-Indien his Sindh. Katschmir, Himalaya, am Lob-Nor, in Tarim und Tsaidam und Teilen von Chint. (1)ie wenigen untersuchten Kankasus-Firmplare scheinen merkwirdiger-

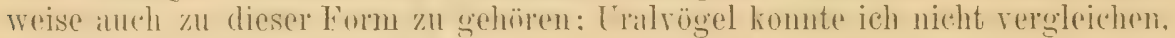
doch soll anch im südlichen Ural ein Wasserpieper rorkommen.)

Przewalski fand am 17. Juni 1879 ein Nest mit 5 stark bebrüteten Eiern im Njan-Schan in einer Höhe von 11200 Fuß über dem Meere.

\section{Anthus spinoletta japonicus Trmm. it hichleg.}

Anthus pratensis japonicus 'l'enminck \& Schlegel, Siebold's Fauna Japon., Ares, p. 59, T'af. $2 \pm$ (1847- „Japon").

Herhstkleid: Oberseite braun, nicht wesentlich ron der unserer

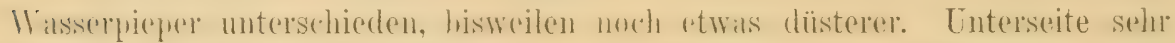

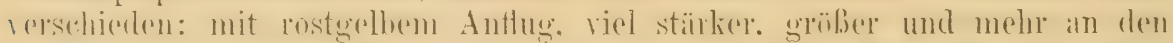

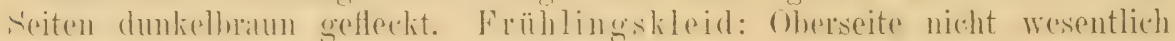
rou dem von A. sp. spinoletta verschieden, also viel dunkler als bei coutelli

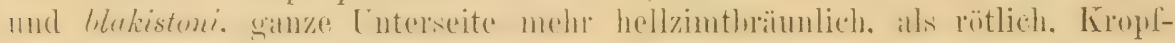

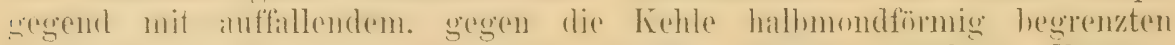

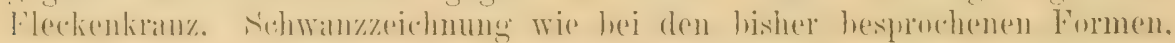

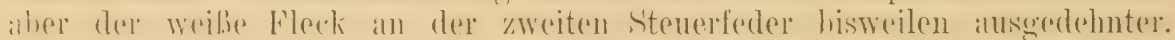
Die Beine und Fübe heller, als hei den ïbrigen Formen, nie schwarz. Gröbe wie die von A. sp. spinoletta.

Briitet in Kamtschatka, Ost-Sibirien (mindestens bis zur Lena) und auf. den Kurilen. - Auf den japanischen Inseln anscheinend nur Winterrogel; ïberwintert auberdem anch in Teilen von Chini, und kommt aus* nalımsweise in Indien vor:

\section{- H४. Anthus spinoletta pensilvanica (Lith.).}

Alarda pensilvanica Latham, Synops. Suppl. I, p. 287 (1787- ex Latham, Gen. Synops. II, 2, p.376 , Red Lark:, nach Edwards, Gleanings II, p. 185, Taf. 297. Hab.: ,North Ameriea".). 
Alenede ludoviciana Gmelin, Syst. Nat. I, p. 793 (1788- ex Buffon, Latham. „Habitat in Louisiana.").

(Hernere Synonymie vgl. (at. B. Brit. Mus. X, p. 596).

bem 1. sp.juponicus selı ähulich, aber lileiner, Flügel $81-89 \mathrm{~mm}$, Interseite im II interlileide noch mehr hellrïstlich. fist hellhrïunlich.

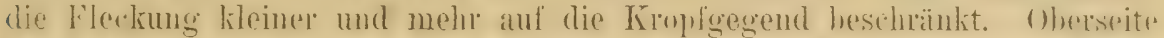
hilum von der von japonims rersehieden. Enterseite hell zimtfarben. Kuhlu "twats hlasser. Kropifgegend mit dmokelhramen Längstlecken. Beinn und

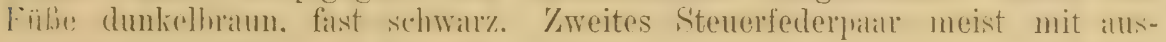
gedehuterem WVeil.), als bei den übrigen Formen, und bei der Nehrzahl roll juponicus.

Brutrogel im subarktischen Nord-Amerika, von Grönland bis Alaskar, ant den Höhen des Felsengebirges und der Berge ron Colorado. - Im Winter in den Golf-Staaten. Mexiko und Zentral-Amerika. Ist zweimal ant Helgoland erlegt.

\section{Anthus spinoletta obscura (Lath.).}

Strandpieper:

Alueda obscrwa Latham. Index Om. II, p. 494 (1790- "Habitat in Angliae paluclosis"). Alaude petrose Montagu, 'Lrans. Linn. Soc. London IV, p. 41 (1798- Wales).

Anthus rupestris Nilsson, Orn. Suec. I, P. 245 (1817 - partim).

Anthus immutubilis Degland, Ornith. Europ. I, P.429 (1849- Dieppe, Bretagne).

Engl.: Rock-l'ipit. Franz: Pipi obseur.

Lnterseheidet sich sofort ron allen bisher besprochenen Wasserpieperformen durch die sehr beschränkte. fast rerschwundene weiße Farbe der

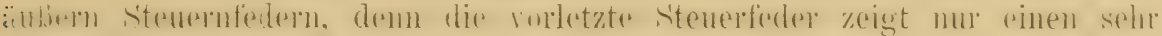

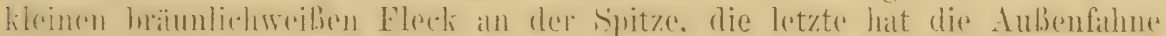

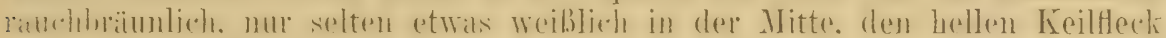
an der. Innenfalnne verdüstert und rerschwommen, nie rein weib. Das

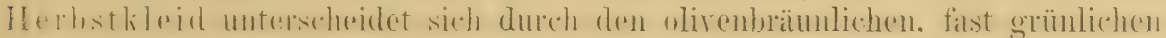

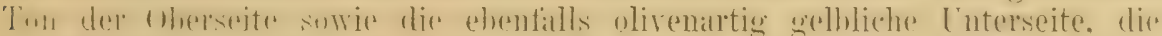

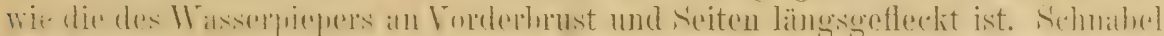

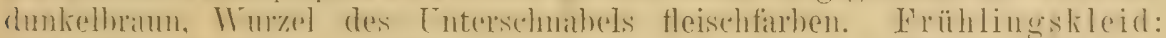

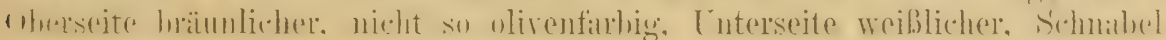
ganz schwalr. Brust und Seiten ebenso stark gefleckt wie im Herlost. Iris

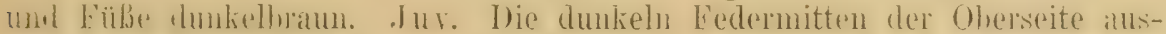

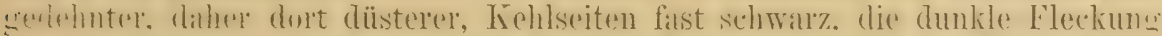

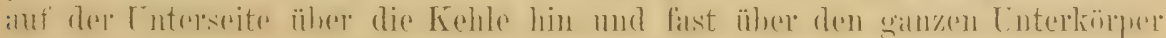
ansgedehnt.

Häufiger Standrogel an den Küsten der britischen Inseln, der Nor-

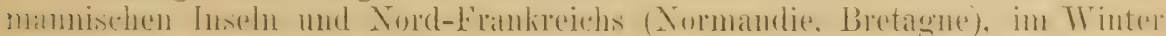

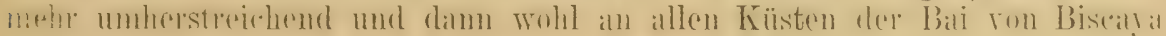
und ausnahmsweise auch im Bimenlande angetroffen.

Der Strandpieper bewohnt die Kiisten der britischen Inseln, wo hohe Felswände düster aus den Wogen emporragen, oder (bei den normanischen Inseln) kleine steiluferige, mit Gras und Blumen bedeckte Eilande. Hier geht er unbekümmert um Wind und Wetter seinor Nahrung nach, die aus allerlei Insekten, kleinen MLollusken und Schnecken, seltener S̈̈mereien besieht und singt meist im Aufsteigen und Niedel- 
schweben wie andere Pieper sein anspruchsloses, feines Liedchen. das wie dsit, dsit, dsit, dsit, dsi, dsi, dsi, dsi klingt, gegen das Ende hin abfallend. Ende April und Mai, zum zweiten Male im Juni, findet man die Eier. Das Nest ist ziemlich grob und steht in Löchern und Ritzen an Felswänden, in Mauerlöchern, unter Steinen oder an irgend welchen anderen geschützten Plätzen, selbst unter firasbüschelu und im Jloose, auf kleinen Filanden rom Rande des Wassers bis auf die höchsten Spitzen, auf großen Inseln aber nur an der Kïste. Die 4-5 Eier ähneln denen des Wasserpiepers, sind aber meist etwas bräunlicher. Nach hey wiegen sie (8 Stïck) etwat $1.55 \mathrm{mg}$ und messen $23 \times 15.7,22.1 \times 16.5,21.5 \times 15.8,20.8 \times 15.7 \mathrm{~mm}$. Nach Saunders kommen auch rote Varietäten ron Kiern, wie beim Baumpieper, ror.

\section{4.). Anthus spinoletta kleinschmidti :ukp. пю.}

(Vgl. Notiz in „Naumann, Naturg. Vög. Mittel-Europas" III, 1900, p. 81.)

Wie das Herbstkleid von duthu: spinoletu obscure, aber Oher-

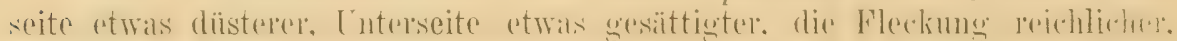
anscheinend etwas mehr nach del Nitte hin reichend. Schnahel anseheinend immer so lang wie bei den langschnäbligsten obscura. Wurzel des Unter-

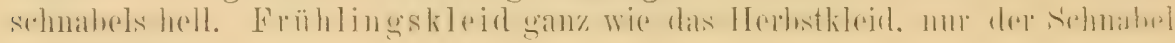
ganz schwar\%.

(Benamnt zu Ehren des Herrn Pastor Kleinschmidt, der zuerst anf die Unterschiede anfmerksam machte. Typus von Nolsö, F'aröer.)

Far̈er:

\section{Anthus spinoletta littoralis lirelim.}

\section{Felsenpicper.}

Anthus rupestris Nilsson, Orn. Suec. I, 1, 2ti), Taf. 9, fig. 1, 2 (1817- purtim! 1)er Name ist nicht der schwedischen Form im Gegensatze zur englischen gegeben, sondern eine Nenbenenmung ron obscura, die Beschreibung pabt auf beide Formen.).

Anthus littoralis Brehm, Handb. Naturg. Vög. Deutschl.. p.331 (1831- .,er leht an den hohen Sandklintufern einiger dïnischen Inseln und kommt selten an den deutschen Küisten der Nordsee ror:"i).

Anthus obscurus longirostris of microrhynchus A. E. Brehm, Verz. Simml., ]) 7 (1866nomina nuda!).

Norweg.: Skjaer-piplaerki. Schwed.: Skäipiplärka.

Das Herbstkleid ist dem ron A. sp. obscure so ïhnlich. dal.s ich keine sicheren Untersehiede anzugeben vermag. Im Frïllingskleide hat die

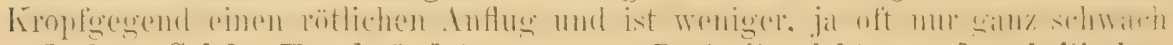
gefleckt. Solche Vögel findet man zur Brutzeit nicht an den britischen

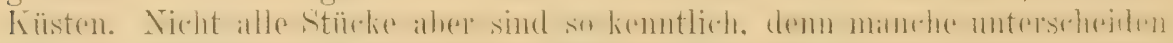

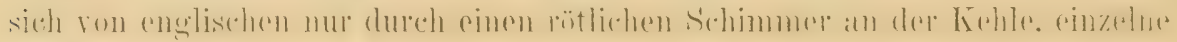
fist gar nicht.

Diese Form hervohnt die Küsten Skandinaviens und soll aneh im

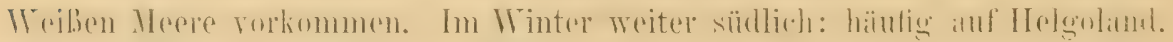

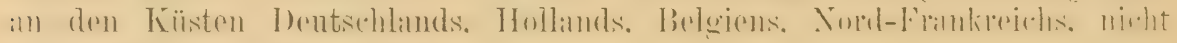
selten auch an denen Englands.

Lebensweise und Fortphlanzung wie die ron A. sp. obsenro. 


\section{Gattung MOTACILLA L. 1758.}

Umfaßt die weißen und schwarzen, grauen, gelben und Gebirgsbach-

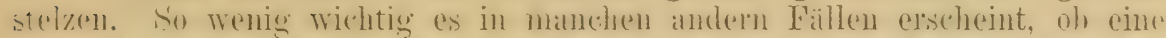
fiattung getrenut wirl oder nicht, so wichtig ist e's hier. dies nicht zul tun.

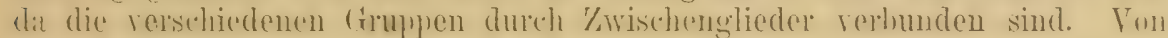
den palïarktischen Arten ist $\mathbf{1}$. boanulu noch am meisten unterschieden, eine generisehe 'Trennung ist ahere nicht durchführbar. Die Formen von M. albu und melanope haben eine kurze, stark gekrümmte, die vou $M$. Hava und

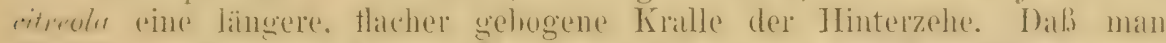

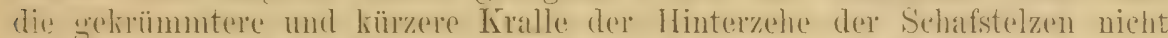

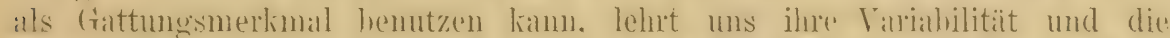
Verschiedenheit derselhen in der mald repwandten Gattung Authes in frap-

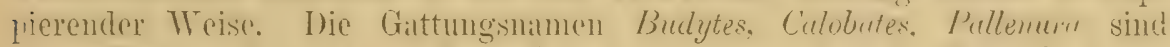

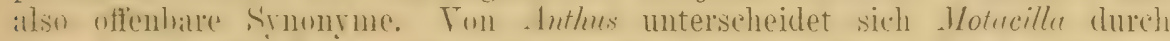

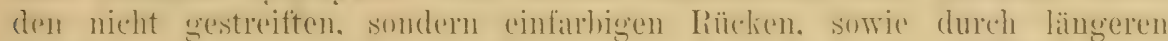
Schrvan\%, der nümlich so lang wie oder länger als der Flügel ist, in der Mitte nieht cingekerht, sombern am linde etwas alhgerundet, die Steuerfedern schmailer. Inas Gesamthild ist ein anderes: die gratziös trippelnde. s.hwamzwiplende Batchstelze erscheint aluch dem laien wesentlich rersehieden

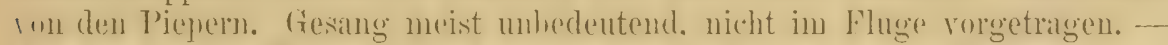
lie ganze alte Walt. auber Australien und Polynesien. in den siidlichen Teilen Asiens alleh nur Wintervogel, während in Afrikia Balchstelzen noch am Kap der guten Hoffuung und in Madagaskar heimiseh sind.

Übersicht der alten ơ im normalen Frïhlingsgefiecler:

1 $\int$ Unterkörper gelb . . . . . . . . . . . . . . 2

| Unterkörper weib. . . . . . . . . . . . . . . 10

Kehle schwar' . . . . . . . . . . . . . . . 3

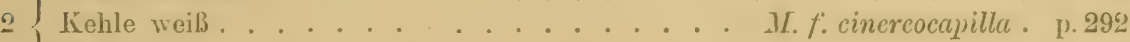

Kehle gelb .................... . . . . 5

3 f Sehwanz etwas kiirzer.............. . . melanope ${ }^{1}$ ) . 1.300

I Schwanz etwas länger . . . . . . . . . . . . . . 4

4 O Oberseite und Ohrdecken heller .......... M. b. boamula . p. 298.

4 Oberseite und Ohrdecken dïsterer ............ b. schmitzi. p. 301

Oberkopf weil................... lencocephala. p. 291

5

Oberkopf rein schwarz. . . . . . . . . . . . . . . 6

Oberkopf grau . . . . . . . . . . . . . . . . . 7

Oberkopf grïnlich, gelblich oder gelb . . . . . . . . 8

6 I Unterseite tief gelb, Kinn auch gelb..... M. f. melanocephala . 1.295 Unterseite blasser gelb, Kinn weiß ....... M. f. melanogriseus . p. 296

(Wherkopf dunkel sehiefergrau, Supereiliatstreil fehlend . M. f. boreulis . 1. 291

7

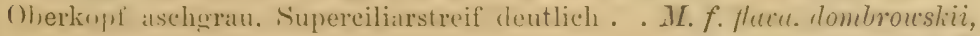
simillimu, aluscensis. p. 287-29u

Oberkopf hellgrau, Superciliarstreif deutlich . . . . . M. f. beenu . p. 290

1) Die nächste Verwandte der paläarktischen Formen von M. melanope ist M. flaviventris Hartl. Sie hat eine starke, kurz gebogene Hinterkralle; weiße Kehle, schwarzes liropfband, gelben Unterkörper, graue Oberseite und bewohnt Madagaskar. 
Oberkopt olivenfarben, gelber Supereiliarstreif scharf ron den dunkelschieferfarbenen Ohrdecken sich abhebend . . . M. f. taivanus .

Oberkopf gelbgrünlich, gelber Supereiliarstreif sich deutlich von den grïingelblichen Ohrdecken abhebend . . . . . . M. f. rayi .

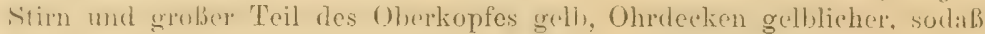
der gelbe Superciliarstreif mehr oder minder undentlich wird oder ganz verschwindet

M. f. campestris .

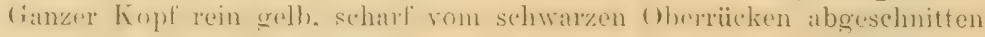

Ganzer Riicken schwarz . . . . . . . M. c. citreoloides.

Unterrücken grau . . . . . . . . II. c. citreola

1). 298

Rücken gran .

Rücken schwarz . . . . . . . . . . . 11

Äußere Armschwingen ganz oder größtenteils weil. . . . . . . . 12

$11\{$ Äubere Armschwingen größtenteils dunkelbraun oder schwarz . . . . . 13

12 Ohrgegend weiß

Ohrgegend sthwarz

M. a. litgens . 1, 308

Obere Kehle weiß.

1. a. yromtis .

Obere Kehle schwarz

M. a. leucopsis .

f Ohrgegend weiß.

M. a. lugubris . j. 301

f Ohrgegend schwarz

M. a. horlgsoni.

p. 307

Ohrdecken und Halsseiten ganz schwarz...... M. a. personata.

1). 306

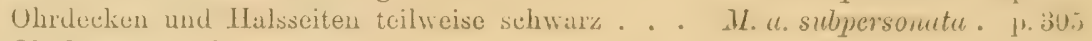

Ohrdecken weiß

D) as Schwarz des Oberkopfes mit dem der Kropfgegend rerbunden

Das Schwarz des Oberkopfes ron dem der Kropfgegend getrennt

M. a. persica . p. 306

1) Die folgenden beiden weiß und grauen Arten sind tropisch und berïhren mur sozusagen das paläarktische F'aunengebiet:

1. Motacilla vidua Sunderall, Öfv. Kongl. Vetensk.-Akad. Förl. 1850, p. 128 (1851- Stid- und Nordostafrika). Ad.: Oberseite und Kopfseiten schwarz, breiter Superciliarstreif und Halsseitenfleek weiß, Fliigel mit sehr breitem weißen Lïugsstreif. Unterseite weil3 mit breitem schwarzen Kropfbande. Fast ganz Afrika und Arabien, nördlich bis zum ersten Nilkatarakt und Süd-Palästina. Vielleicht ist eine nördliche etwas kleinere Subspezies unterscheidbar. Vergl. Reichenow, Vög. Afr. III, p. 296-299 Abbild. Reichenow, Vög. Deutsch-O.Afr., p. 200.

Auf der Wasserscheide zwischen Orangeflub und Limpopo vertreten clurels 11. vaillanti Cab. (= nigricotis Shelley, B. Afr. II, 1). 266, 1900). - Mr. capensis L. bewohnt ebenfalls Afrika und bildet eine gauz andere Art, desgleichen M. longicauda.

2. Motacilla maderaspatensis Gmelin, Syst. Nat. I, 1). 961 (1788 - ex Buffon, Brisson usw. - "India"). Ad.: Oberseite, Hals und Kehle bis zur Kropfgegend, schwarz. Breiter Superciliarstreif, der nur einen schmalen Streif von der Schnabelwurzel zum Scheitel freiläßt, breiter Längsstreif auf dem Flügel und Unterseite vom Kropfe bis zum Schwanze weiß. Sehr groß, Flügel etwa 100-105, Schwanz $110 \mathrm{~mm}$ !Vielleicht auch als Subspezies von alba aufzufassen. - Indien von Ceylon bis zum Himalaya. Sewertzow führt sie auch als Brutrogel in Teilen von Turkestan an, es erscheint aber zweifelhaft, ob sie dort regelmäßig mit personata zusammenbritet? Merkwïrdigerweise nent Sewertzow sie Motarilla personata ; materaspatensis ciould: Vergl. Sharpe, Cat. B. Brit. Mus. X, p. 490, Dresser, Handb. Pal. B., p. 169, Abbild.: Gould, B. Asia IV, Taf. 61.

Auf der kleinen Insel Abd-el-Kuri bei Sokotra entdeckten Grant \& Forbes eine alba-ähnliche Bachstelze mit grauer Stirn. Diese Form ist ungenügend bekannt, da nur ein 우 ad. und ein junger Vogel gesammelt wurden. Sie wurde M. forkoodi genannt. 
17 f Obere Kiehle weiß............... U. Uaicalensis . 1. 304

† Obere Kehle schwarz .................. 18

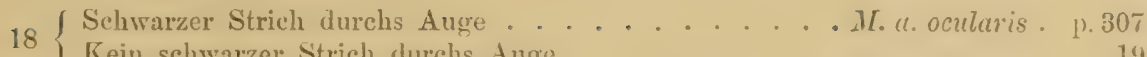

\{ Kein schwarzer Strich durchs Auge. . . . . . . . . . . 19

19) Flïgeldecken mit mehr Weiß, Rüicken ctwas heller. M. a. duthunensis . p.301

I Fliggeldecken mit weniger W WeiB, Rïcken etwas dunkler. . M. a. alba . j. 302

\section{- 452. Motacilla flava flava $]$.}

Gelhe Baclistelze. Schafstelze.

Motacille flava Limaeus, Syst. Nat. Ed. X, p. 185 (1758- „Habitat in Europa“. Typ. Lok.: Süd-Schweden. Limné beschreibt dentlich den weißen Superciliarstreifen, es kann sich also nicht um die im nördl. Schweden heimische Form handeln).

Paris luteus S. G. Gmelin, Reise durch Rußland III, p. 101, Taf. XX, Fig. 1 (1774am Kaspischen Meere, Astrachan, aber über die Wolga hin nach Rußland ziehend, um dort zu brüten).

Motacilla chrysogastra Bechstein, Joh. Lath. allg. Uebers. IV, 1 (kurze Übersicht a. bek. Vög. nach Latham), p. 327 (1811- Europa).

Motacilla flaveola Pallas, Zoogr. Rosso-Asiat. I, 1). 501 (1827- partim! "Ln ommi Rossia et Sibiria abundat.").

Motacilla neglecta Gould, I'roc. Zool. Soc. Tonclon 1832, 1. 129 (Europa: Sehweden, Paris).

Budytes Gouldi Macgillivray, Man. Brit. B. I, p. 163 (1840- Europ. Festland, rereinz. S.O.-England).

Motacilla flava rar. 2 villgaris Sunderall, Kongl. Vetensk. Acad. Handlingar, Stockholm för 1840 , p. 53 (1842 - Schweden, Stockholm).

Budytes boarulus Brehm, Isis 1842, p. 578 (Nord-Deutschland).

Budytes chrysoyaster Brehm. Isis 1812. 11.582 (mittleres und nördliches Dentsehland).

Budytes chlorocephalus Brehm, Naumannia 1851, 2, p.24 (Renthendorf. Diese Stücke gehören nicht zur englischen Form, sondern sind nur Herbströgel mit grünlichen Federspitzen an den Kopffedern).

Budytes pallidus Brehm, Naumannia 1851, 2, p. 25 (Renthendorf).

Budytes pygmaeus A. E. Brehm, Journ. 1. Orn. 1854, p. 74 (N.O.-Afrika: zwerghaftes aberrantes Stiick).

Budyte's flacus alticeps, phumbiceps, brachyshynchus. Budytes cinerencapillus ovium. atrigenalis (?partim), B. pygmaens longivostris, brevirostris, B. campestris major (partim), olivaceus, brevirostris, microrhynchus (partim), B. calcaratus, B. giganteus A. E. Brehm, Verz. Samml., p. 7 (1866- nomina nuda).

Englisch: Blue-headed Wagtail. Franz.: Bergeronette printanière. Italien: Cutrettola gialla. Schwed.: Gulärla.

Ơad. im Frühling: Oberkopf aschgrau, Zügelfleck vor dem Auge dunkler, Ohrdecken aschgrau, am untern Ende meist mit weib gestreift. Deutlicher, meist ziemlich breiter weißer Supereiliarstreif, L'nterseite mit Einschlub der Kehle hochgelb. Diss Grau des Kopfes erstrectit sich bis auf den Hinterhals. Die übrige ()herseite gelblich olivengrïn, auf dem Bürzel lehhafter. Schwingen dunkelhraun mit helleren Innensïmmen und schmalen. an den imnersten Armsehwingen breiten, schmutzig hellgelblichen Außensïumen. Kleine Oberflügeldecken wie der Rǘken. mittlere und große dunkelhraun mit breiten hellgelben Süumen, die zwei Biuden auf dem Flügel bilden. Steuerfedern schwarzhraun mit gauz schmalen grünlichen Außensäumen, äußerstes Patar weiß. Innenfahne mit hreitem. etwa cin Viertel 


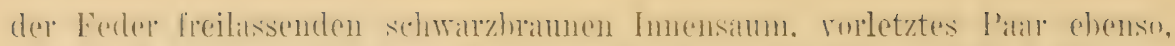

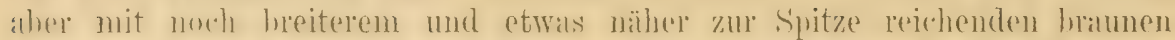

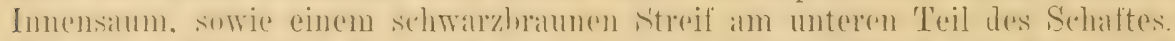

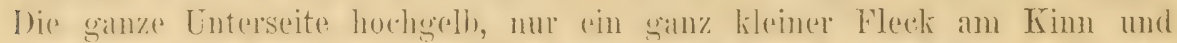
ein schmaler, oft undeutlicher Strich jederseits der nheren Kohle weils. An den Halsseiten und auf dem hropfe meist einige olivenfirlene sidhatten.

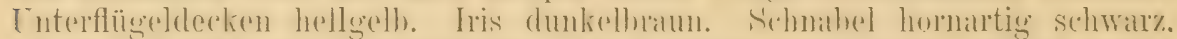

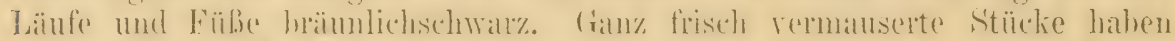

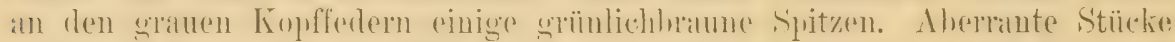

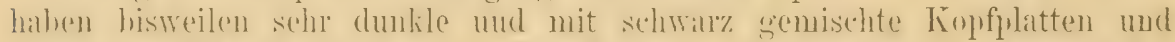

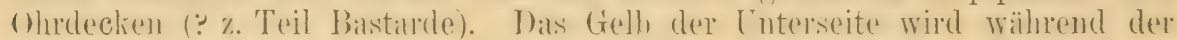

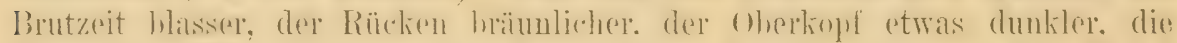

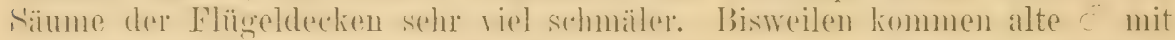

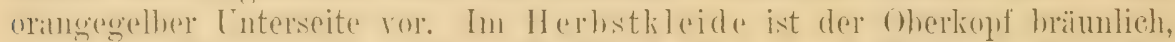
die Ganze oherseite hrïmbliehere die Kehle oft "twas weiblich. das Gelh der

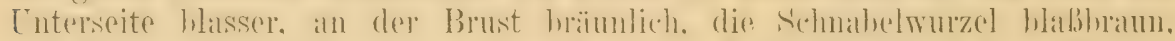

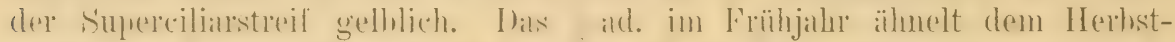

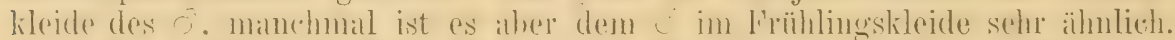

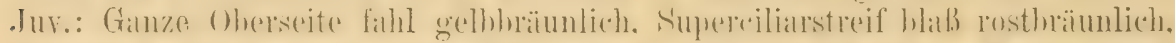

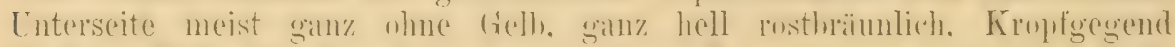

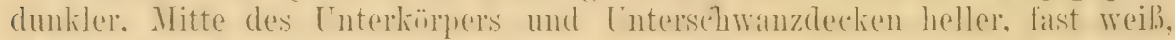

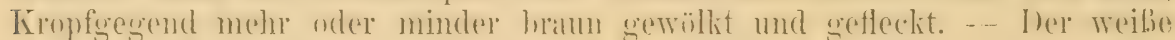
Superciliarstreif des $o^{t}$ ad. ist immer dentlich ausgeprïgt, nur selten schmäler, als gewöhnlich, schr selten ist er gelb (z. B. Ex. in 'Tschusi's

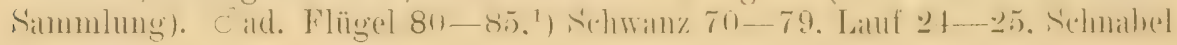
$12-13 \mathrm{~mm}$.

Brutrogel im größten Teile Luropas: rom mittleren Skandinavien bis

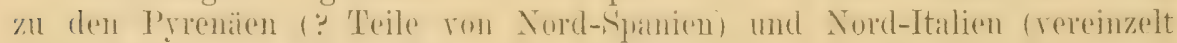
oder nur in den Bergen?) und im Osten durch RuBland und Ungarn his zur Doman- und save-Niedermeg." In lingland nur unregelmäBiger Wandervogel, der aber auch 2-3 mal gebritet hat. - Auf dem Zuge häufig in Süd-Europa. Sicheint sehon in geringerer Anzahl an Mitteheere

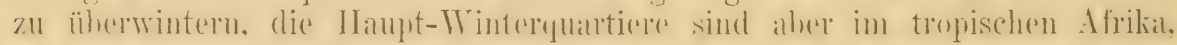
wo sie bis zum Kaplande hin vorkommt. - $M$. $f$. Have kommt auf den

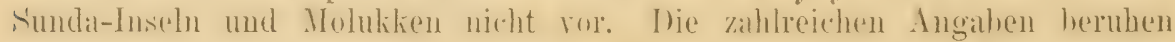
auf Verwechselungen mit simillima und trivamus. Finzelue flava mögen

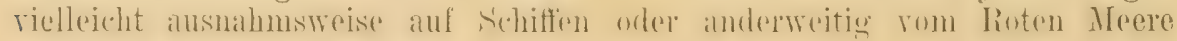
nach Indien gebracht werden.

Bewohner von feuchten Wiesen, wo Vieh woidet, IIarschländern, See- und T'eichufern, auch von Raps-, Erbsen-, Wieken- und Weizenfeldern und grasiger Raine.

1) Die Größe variiert bei diesen und verwandten Formen oft beträchtlich. In der Brehmsehen Sammlung befindet sich ein alter Herbstrogel ( $\left.{ }^{\top}\right)$, gesammelt ron Alfred Brehm zu Mureia am 10. September 1856, dessen Flïgel völlig $88 \mathrm{~mm}$ mißt. Die Kropfgegend hat einen orangefarbenen Anflug.

$\left.{ }^{2}\right)$ Infolge der oft ungenauen und unzuverlässigen Bestimmungen war es oft schwer und bisweilen unmöglich, die Brutgebiete der einzeluen Formen genau anzugeben. Daß mehrere Formen im gleichen Gebiete brüten, ist nirgends sicher nachgewiesen. U. a. schreibt mir Othmar Reiser, daß er „auf der Balkan-Halbinsel nirgends zwei verschiedene Schafstelzen-Formen zusammen brütend antraf ${ }^{\sharp}$. 
Nach der Brutzeit sehr gesellig, sich gern bei Schafherden aufhaltend. Laufen graziös, raseh, schwanzwippend einher, oft Insekten in der Luft fangend. Lockruf ctwa wie psïip oder psijjip, mehr zwei- als einsilbig. Im Frïljahr rufen sie viel und lauge hintereinander srie, srie und lassen manchmal einen unbedeutenden Gesang hïren - ein Gezwitscher, in dem die oben genannten psüip- und srie-Laute vorhrrrschen. Nahrung lediglich Insekten: Jiücken, Fliegen, kleine Käfer, bis $2 \mathrm{~cm}$ lange Raupen, kleine Orthopteren und Neuroptereu. Nest immer in eirier kleinen Bodenrertiefung an Erdboden, im Grase, anch in Raps-, Wicken- und Erbsenfeldern, mit hesonderer Vorliebe an Eisenbahndämmen, Deichen oder sonstigen abschïssigen Hängen. Es besteht aus ILoos und Halmen und ist mit Haaren, selten mit Federn ansgefiittert. Die 5-6 Eier der einzigen Brut findet man selten vor Anfang Juni, oft bis in den Juli hinein. Sie sind meist auf bräunlichgelbem oder gelblichweißem firunde ïber und ïber so dicht dunkelgraubraun gewölkt, daß von der Grundfarbe wenig zu sehen ist, selten bemerkt man feine schwärzliche Haarzüge, Punkte oder Kritzel, oder eine kranzïhnliche Häufung der Flecke am stumpfen Ende. Ebenso selten treten die Flecke schärfer herror und sind größer und rereinzelter. Etwas weniger selten, aber immerhin nicht oft, kommen Gelege mit hellrötlicher Grundfarbe nul dunklerer graurïtlicher kleckung vor. Einige der dunkleren Varictäten sind von den Eiern des Schilfrohrsängers kaum zu unterscheiden. Maße nach Rey (72 gemesseu): Maximum $19.6 \times 12.9$ und $19.2 \times 15.2$, Durchseluitt $18.7 \times 13.8$, Jinimum $16.3 \times 12.8 \mathrm{~mm}$. (iewieht im Durchschnitt $105 \mathrm{mg}$.

\section{MTotacilla flava dombrowskii (Tschusi).}

Inulytes flavus dombrowskii 'L'schusi zu Sehmidhoffen, Orn. Jahrb. XIV, p. 161 (1903Rumänien).

Ist M. f. flava äuBerst ähnlich, aber die Ohrdecken so schwärzlich, wie

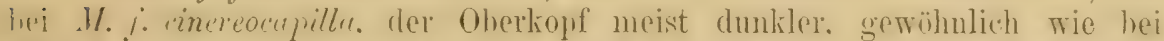

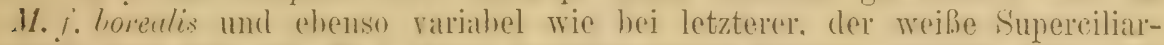

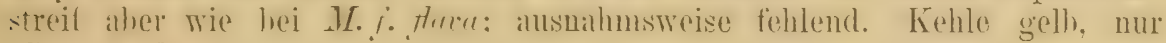
Kinn weiß. Unterseite gelb, bisweilen, wie bei andern Formen, orange-

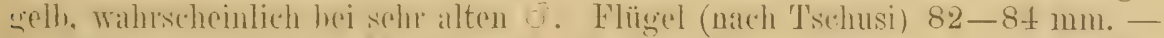
In der Regel leicht von .1\%. t. fluou durch obige Kemmedehen zu unterscheiden. doch kommen Stürele von letzterer aus anderen fregenden vor. die sich mohl nicht unterseheiden lassen und ron einzelnen I)olnulschal-Fxemplaten liamm

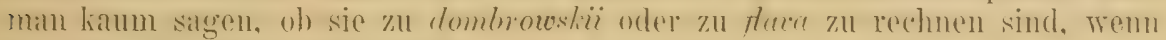
man den Fundort nicht kennt.

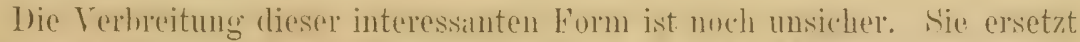

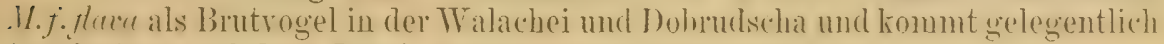
(wenigstens auf dem Zuge) auch in der Herzegowina vor.

\section{-454. IMotacilla flava simillima subsp. nov.}

Brudytes leucostriatus (non Homever!) amerikanischer Ornithologen. ${ }^{1}$ )

In Kamtschatha hrïtet eine Schafistelze, die der mittremengïischen

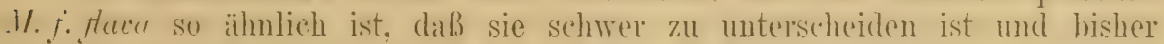
sun europäischen Ornithologen nicht daron untersebieden wurde. Der weibe smereilianstreif ist ror dem Auge sche schmal. hinter dem Auge hreit und

1) Der Name leucostriatus kann auf keinen Fall auf diese Form bezogen werden, auch wenn man mir nicht beistimmen sollte, daß der Typus eine aberrante 1I. f. taivanus ist.

E. Hartert, Die Vögel der paläarktisehen Region. 
dentich, die Federn vor dem Ange sind schwarz, die Ohrdecken meist

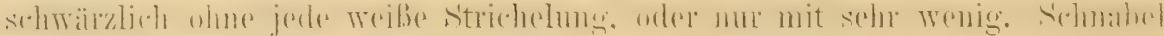
und Laul meist etwas länger, Kralle der Hinterzehe oft etwas länger, d(י Kropf immer mit großen, deutlichen schieferfarbenen Flecken.

Briitet wahrscheinlich nur in Kamtschatka. - Sie zieht ïher die Bering-Insel, durch Ost-Sibirien und Korea und überwintert in China, auf den Molukken und im malayischen Archipel, von wo sie meist als tence

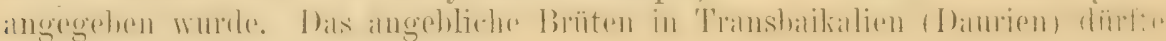
anf Verwechselungen herulien.

\section{- 455. Motacilla flava alascensis (Ridgw.).}

Bulytes flavus alascensis Ridgway, P'roc. Biol. Soc. Washington XVI, 1. 105 (September 1903 - West-Alaska).

Ist M. f. simillime äuBerst ähulich, aber die Oberseite etwas brüunlicher, das Gelb der Unterseite etwas blasser. Die dunkle Fleckung und Wölkung der Kropfgegend meist noch gröber, besonders bei den 0 , dis manchmal ein breites olivengraues Band quer über die Vorderhrust hahen.

Briitet im westlichen Alaska.

\section{Motacilla flava beema Sykes.}

Iotacilla Becmu Sykes, Proc. Zool. Soc. London 1832, p. 90 (Dekkan, Indien).

Budytes dubius vel anthoides Hodgson, in (iray's Zool. Mise., p. 83 (184t- noms nud.! Nach Vergleich der Exemplare gedentet).

Budytes brevicaudatus F. r. Homeyer, Journ. A'. Orn. 1878, p. 131 („Indien“. 1)ic 'Yypen sind Wintervögel aus Etawah in N.W.-Lndien).

Abbild: Cat. B. Brit. Mus. X, T'af. VI, 6 (Kopf); Neuausgabe des ..Naumanr" III, I'af. 15, 2.

Das ơnd. unterscheidet sich von M. f. tlara durch den helleren Kope ${ }^{1}$ )

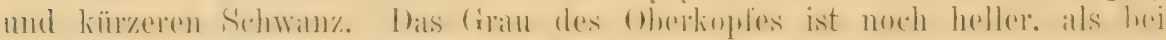
11. f. Have, manchmal beinahe weißlich, aber wie bei $M . f$. borealis und

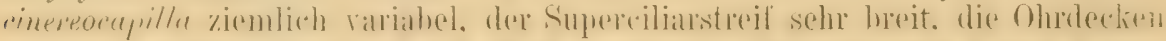

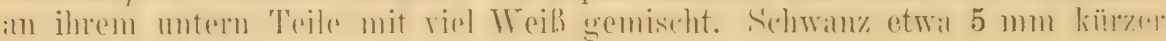
als bei $1 \%$. f. Hava.

Brutgebiet West-Sibirien von Oreuburg bis zum Jenissei. - Auf dem zuge dureh Turkestan his Indien, wo sie massenhaft äberwintert, südlich

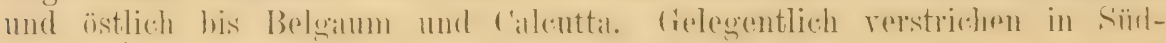
Europa (bis Thugrme und 1 oder 2 mal in Süd-England.

1) Dic Kopffürbung rariiert selr, manchmal ist sie nicht merklich heller als bei II. f. flava, manchmal fast weißlich. Solche außerordentlich hellköpfige Stiieke werden nicht selten auf dem Friihjahrszuge bei Sarepta erbentet. Es wäre möglich, daßs sie einer noch unbenannten ferneren Subspezies angehören, aber wir kennen ihre Brutheimat noch nicht und es gibt Stücke, die intermediär sind. Bei Orenburg scheinen Stïcke vorzukommen, die intermediär zwischen flama und beema stehen. Beide Namen, beema und brevicaudatus beziehen sich anf die indischen Wintervögel, die den Oberkopf meist lange nicht so hell haben, wie jene aus der Gegend von Sarepta. 


\section{Motacilla flava leucocephala (Przew.)}

Bulytes lencocephula I'rzewalski, Zapiski Imper. Akac. Nauk. St. Petersburg LV, n. 85 (1887- Dsungarei); Uebersetz. Ibis 1887, p. 409.

Abbild.: Ares P'rzewalskianae I, 'Taf. X, Fig. 3, 4.

„Ơ ad. in Frühlingskleide. Stim, Scheitel, Ohrdecken, Wangen, Zügrel

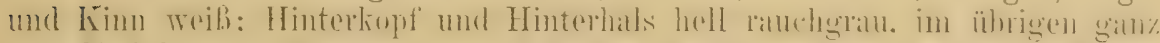

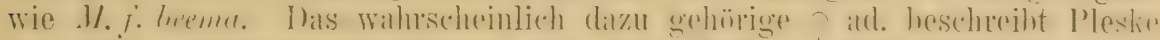

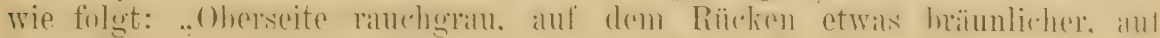

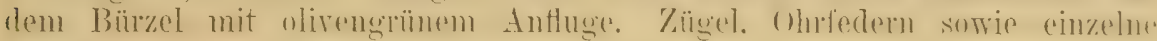
Flecke auf den Halsseiten und der Brust von derselben Färbung. Fin

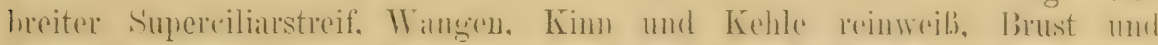

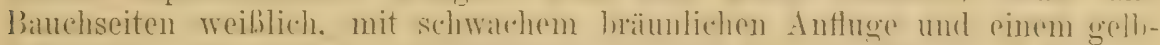

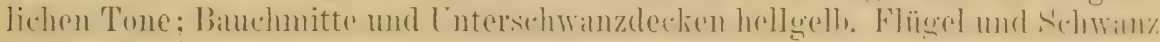
wie beim $\sigma^{2}$, jedoch ohne gelblichen Anflug:

Prjewalski entdeckte diese Stelze auf dem Frïhjahrs-Durchzuge in der Dsungarei, am Hlusse Urumga und im siidlichen Altai. Sarudny will

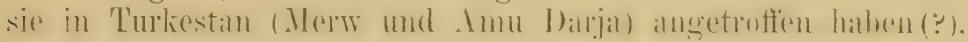

Ich komnte die oben zitierte, (noch nieht erschienene) I'afel vergleichen.

\section{Motacilla flava borealis Sund.}

Nordische Schafstelze:

? Pans Caspicus S. G. Gmelin, Reise durch Rußland III, 1) 104, Taf. XX, Fig. 2 (1774- „bei Enzeli." IVegen des mangelnden Superciliarstreifens ist der Name nicht auf flava zu beziehen, sondern wahrscheinlicher anf borealis oder eine andere Form.).

?.Motacilla viridis Gmelin, Syst. Nat. 1, p. $\$ 62$ (1788- ex Brown, I11. Zool. Taf. 33. Fig. 2: zweifelliate Art).

Motacilla flava var. 3 borealis Sundevall, Kongl. Vetensk, Acarl. Handlingar. Stockholm för 1840, p. 53 (1842- „e Lapponia Suec.").

Budytes atricapillus Brehm, Isis 1842, p.511 (Partim- Brehm erwähnt Hemprichsche Stüeke, die die 'Iypen von melanocephala Licht. sind, auberdem beschreibt er aber auch eine Anzahl von Renthendorfer Exemplaren, die jedoch zu borealis gehören, wie sowohl aus der Beschreibung als auch aus Untersuchung der Stücke hervorgeht).

Budytes melanocephalus Brehm, Isis 1842, p. 566 (Partim- Brehm's Renthendorfer Stücke waren sicher borealis).

Budytes rinereocrpillus (non Savi!) Brehm, Isis 184:- 11.572 (Renthendorl. Durehzug). Budytes caniceps Brehm, Isis 184: 1. 57t (Friesnitzer See und Ronthenderf. ?Partim). Budytes schisticeps \& fulviventer Hodgson, Gray's Zool. Misc., p. 83 (1814- nomina nuda! Nach den vorhandenen Ex. bestimmt).

Budytes dubius Zander, Naumannia 1851, 3, p. 17 (ex Brehm M.S. Fundort nicht angegeben.).

Budytes atricapillus planiceps, alticeps, dubius A. E. Brehm, Verz. Samml., p. 7 (1866partim. Nomina nuda).

Abbild.; Cat. B. Brit. Mlus. X, Taf. VII, 1-3; Dresser, B. Eur. Taf. 129, 3; "Neuer Naumann" IU, Taf. 15, 3.

Das alte $\sigma^{\pi}$ unterscheidet sich auffillend von dem von $M . f$. flar $u$

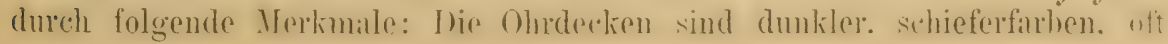




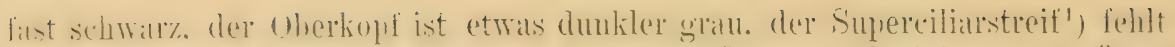

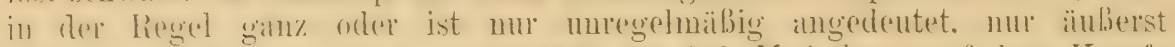

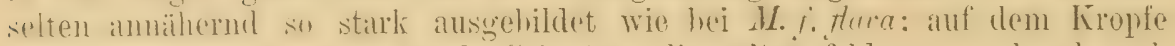
sioht man meist vinige dunkle Schatten, die selten fehlen. manchnal anch

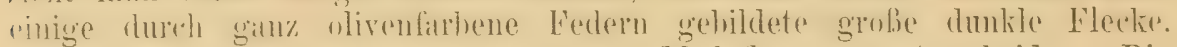
Junge Vögel sind nicht von denen voul M.f. flava zu unterscheiden. Die

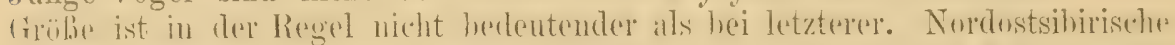

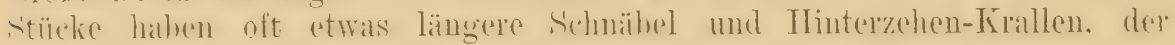
Unterschied ist aber nicht konstant genug, um darauf eine Unterart zu

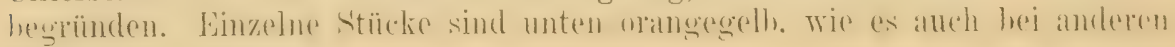
Formen vorkommt.

Brïtet im Norden von Skandinavieu, RuBland und Sibirien, ostruärts

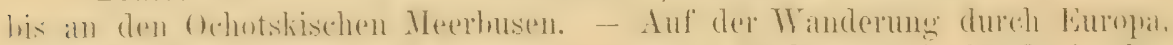

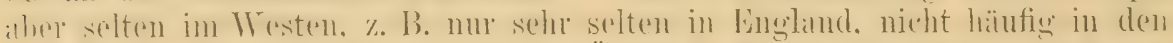

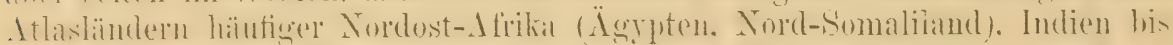

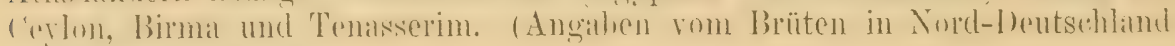
beruhen auf Irrtum.)

Lebensweise und FortpHlanzung wie die ron M. f. flavı. Auch die Wier gleichen drunen unserer dentschen Schafstelze vollkommen, variieren ebenso und haben dieselhe Größe. Rey gilht für 77 Lier seiner Sammlung als Naximum $19.6 \times 15.4$, uls Durehschnitt $18.3 \times 14$, als Minimum $16.1 \times 12.9 \mathrm{~mm}$ an.

\section{Motacilla flava cinereocapilla Sari.}

Wotacilla cinereocapilla Savi, Nuovo Giomale dei Letterati no. 57, 1. 190 (1831Italien); Orn. I'oscan. III, p. 216.

Notacilla flava var. 4 Dalmatica Sundevall, Kongl. Vetensk. Acad. Handlingar, Stockholm för 1840, p. 54 (1842- Dalmatien).

Budytes megarhynchos Brehm, Isis 1842, p. 578 (1)almatien).

Budytes flavus albicollis, B. cinereocapillus pallidus, albicollis (partinı) A. E. Brehm, Terz. Samml, p. 7 (1866- nomina nuda!)

Abbild.: Cat. B. Brit. Mus. X, 'Taf. VII, 4-6; „Neuer Naumann" IJ1, Taf. 16, 1.

o acl. Unterscheidet sich ron $M . j$. borealis durch die ganz woibe

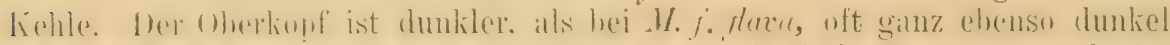

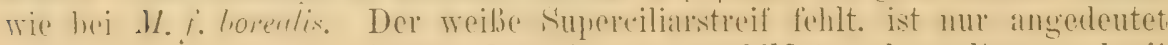
oder schmal und nur hinter dem Auge ausgebildet, sehr selten so breit wie bei 1 . $\dot{f}$. flave. Die Ohrdecken sind gleichmäBig schiefergrau, sehr

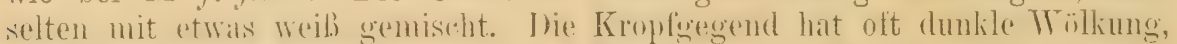

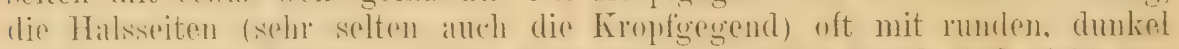

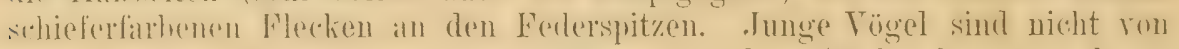

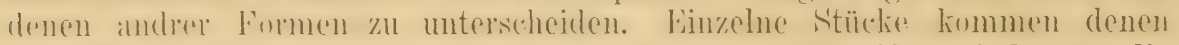
ron $M . f$. borealis so nahe, daß sie kaum zu unterscheiden sind, nur die weilie Keble ist eim fast nie. leim alten $c$ wohl nimmer trïgentes Mrermal. l)ie Conterseita ist hisweilen orangefarhen. 'Tsehusi (in litt.) hält solehe für sehr alte Stiicke.

1) Die Supereiliarstreifen gehören wohl dem Urtypus der Art an, denn auch bei den Formen, denen sie in der Regel fehlen, kann man sie bei einzelnen Stiicken rudimentär wiederfinden, besonders (aber nicht nur) bei jüngeren Vögeln. 
Brutrogel in Italien (besonders häufig in Venetien, T'oskana. Sizilien.

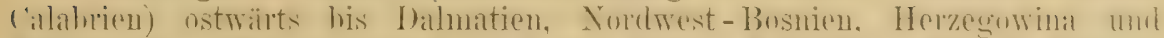

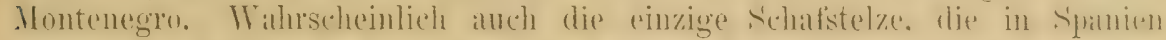

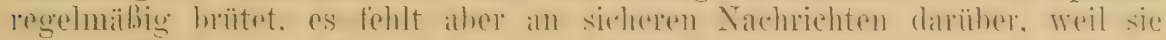
oft mit $\mu . f$. Have und borealis rerwechselt wurde. Auf dem Zuge in NordAfrika, im W'esten bis zum Senegal, im Osten his Lado. (Irrtïmlich fïr Deutschland und Belgien angegeben.)

Lebensweise und Fortptlanzung augenseheinlich ganz wie bei M.f. flava. (I)ie

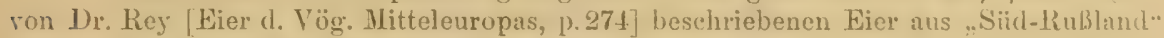
kömmen nicht solche von cinercocapilla sein.)

\section{IMotacilla flava taivanus (Sivinhoe).}

? Motacilla flavescens Stephens, in Shaw, Gen. Zool. X, 2, p). 559 (1817- ex Jutham \& ILontbeillard: 'Limor! - Der Name flavescens ist fälschlich als Synonym ron M. Hava flave betrachtet worden. Wenn or sich iiberhaupt anf eine Bachstelze bezieht, kam dies nur unsre M. $f$. taivanus (schon wegen des Ausdrucks ,superciliis Havis“) sein. Da aber keine Maße angegeben sind, die Beschreibung des Sehwanzes („rectricibus nigris") ungenau ist und damals viele kleine Vögel als Motacillen bezeichnet wuxden, ist es nicht angebrachi den sicheren Namen taivums für den might sicheren flarescens aufzugeben.).

Bulytes taivanus Swinhoe, Proc. Zool. Soc. 1863, J334 (Formosa).

Bulytes melanotis Swinhoe, Ibis 1864, j) 422 (Singapore, 14. Dezember).

Burlytes leucostriatus E. v. Homejer, Journ. I. Om. 1878, p. 128 (Baikalgegend". Das kein Originaletikett tragende und schmutzige Stiick ist ein aberrantes Exemplar von M. f. taivanus mit schwärzlichem Oberkopf und wcißem nur gelblich angehauchtem Superciliarstreifen. Dies beweist schon die bedoutende Gröbe aller" 'Teile).

Abbild.: "Nouer Naumanu" Ill, Taf. 15, ‥

Òad. Oberseite mit kiuschlußs der Kopfplatte olivengrïn, im frischen

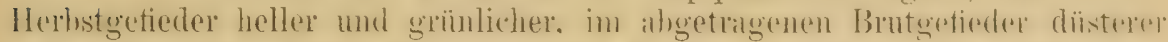
und hrïunlicher. Zügel und ohrgegend dunkler, manchmal fist schwärzlich. s'uperciliarstreif gelb. Ganze ['nterseite mit Finschlub ron hohle und Finn gelb, in Herbstkleid heller als im Sommer. Mittlere und grobe Ober-

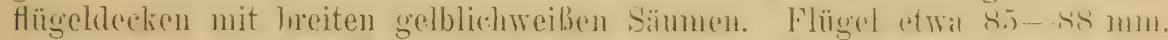

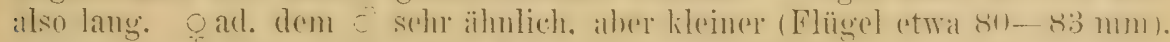
und unten blasser gelb, oben kaum etwas hräunlicher. Der junge Togel

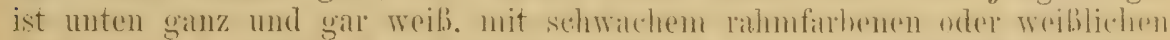

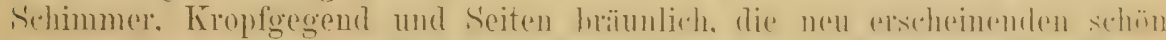

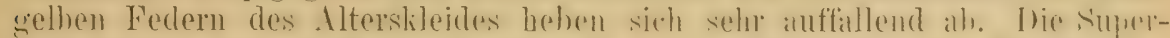

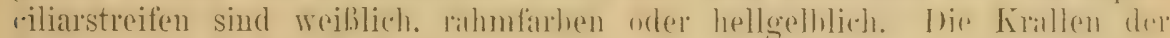
Hinterzehen sind bei $M . f$. tuivanus meist auffallend lang, lïnger als hei andern Schafstelzenformen, etwa $12-15 \mathrm{~mm}$. Fast den ganzen Winter

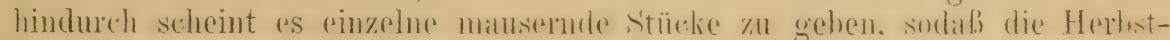

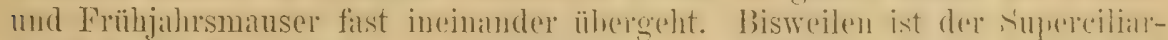

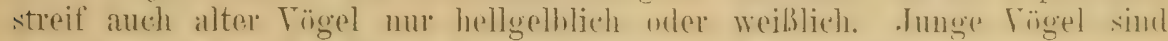

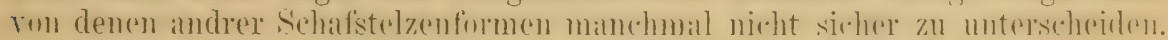

Das Brutgebiet erstreckt sich von den Baikalgegenden (obere Lenil)

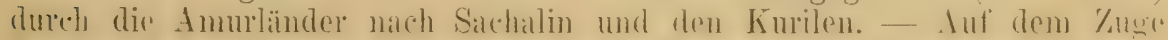

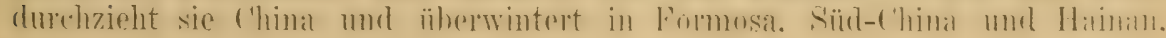


anch auf den Molukken bis zu den Key-Inseln, 'T'enimber. Celebes, den Sunda-Inseln und der Malakkahalbinsel. - Das von Almásy im Orn.

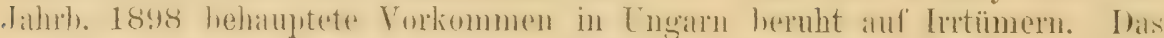
..schöne alte o " vom 22. Apri] 1895 ist eine flava mit aberrantem

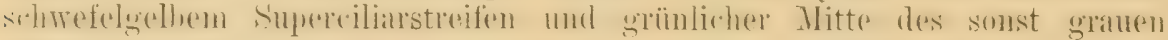
Oberkopfes. Ws hat nichts mit tuirams zu tun, ebensowenig wie das $\sigma^{7}$ ron Temes Kubin.

\section{Motacilla flava rayi (Bp.).}

"Budytes flavu, or better, perhaps flavissima" Blyth, MIag. Nat. Hist. VII, p. 342 (1834 -.. nomen nudum, descriptio nulla! - looting, Surrey).

Budytes Rayi Bonaparte, Geogr. \& Comp. List of B. Hurope \& N. Amer., p. 18 (1838 "British Islands". Der Name beruht aul (rould's 'J'af. 145 in den B. of Europe II).

Motacilla flava var. 1 anglica Sundevall, Kongl. Vetensk. Acrd. Handlingar Stockholm för 1840, p. 53: (1842- Èngland).

Motacille Anglomem Degland. Orn. Eur. I, j. 442 (1849- ex Prérost M.S.).

Budytes Rayii alticeps, planiceps, flavicapillus (partim) A. E. Brehm, Verz. Summl., p. 7 (1866- nomina nuda!).

Engl.: Yellow Wagtail.

ơad. Oberseite hell olivengrün, viel heller und gelblicher als bei

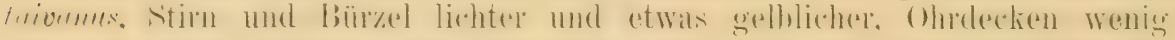
oder gar nicht dunkler, an ihrem untern 'Teile mit gelb gemischt und

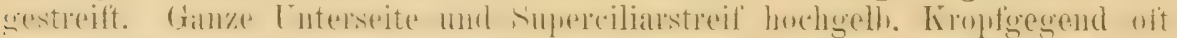

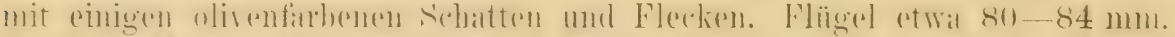

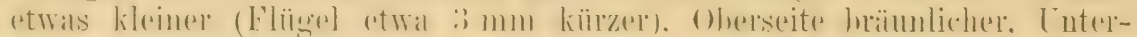

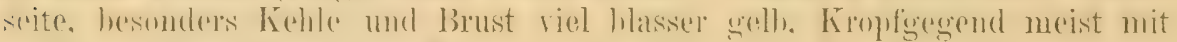

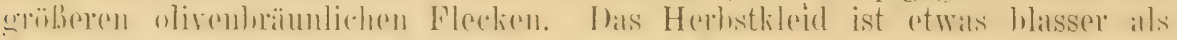

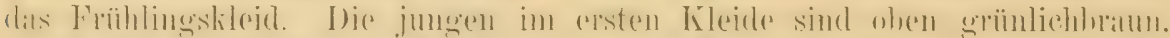

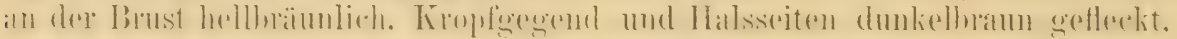
Cnterschwanzdecken hell gelblich. Superciliarstreif weiblich.

Brïtet in England und nordwärts lis etwa zur Mitte von Schottland,

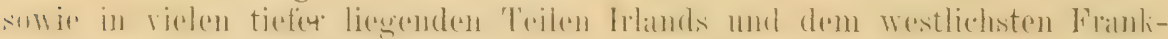

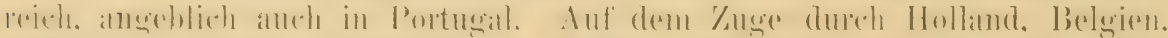

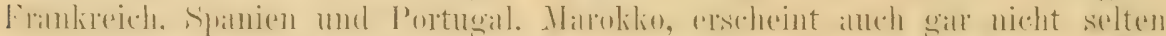

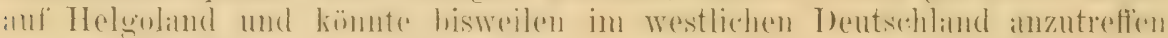
sein. Überwintert in West-Afrikia von Sü̈l-Marokko bis zum Congo, ann meisten aher wohl ron Senegambien his zum Benuë.

I)as Nest wird in Lingland schon früh im Mai gebaut, angeblich findet auch manchmal eine zweite Brut statt. Stimmt in der Lebensweise mit ihren Verwandten iiberein.

\section{Motacilla flava campestris Pall.}

Motacilla compestris P'allus, Reise d. ver'sch. Prov, d. Kuss. Reichs III, p. 696 (1776keine Lokalität); Zoogr. Rosso-Asiat. 1, f. 50.1 (1827- „In campis desertis Rossiae et Sibiriac australioris". - Pallas' Beschreibung paßst nur auf ciuen Herbstrogel und ist meines krachtens nicht absolut sicher, da der Name aber allgemein angenommen ist und immer noch am besten anf diese Form palst, so krinnen wir ihn beibehalten). 
Budytes flava var. flavifrans Sewertzow, 'l'urk. Jevotn., p. 67 (1873- T'urkestan. Nomen nudum!).

Budytes flavifions Sewertzow, Stray Feathers III, p.424 (1875- erste Beschreibung. "Breeding only in Eistern Russia and Western Siberia, passing through T'urkestan.").

Gauz wie M. $\dot{f}$ rayi, aber am Kople mit mehr gell, die Ohrdecken meist ganz gelb, der Oberkopf bei alten o im Frülling ganz gelb, nur

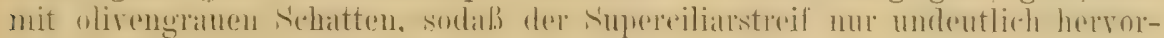
tritt oder ganz verschwindet.

Wahrseheinlich nistet diese, merkwürdigerweise hartnäckig mit der

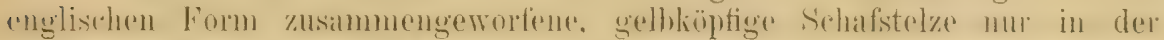

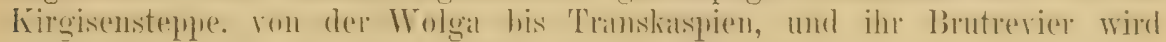
im Norden voun Bezirk der M. $f$. beemu, im Osten ron dem vou M. $f$. melanogriseus, siidwestlich you dem ron $M$. $\dot{t}$. melanocephala begrenzt. - Auf

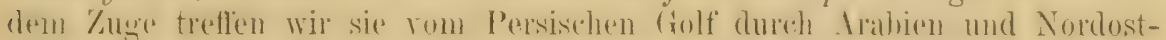

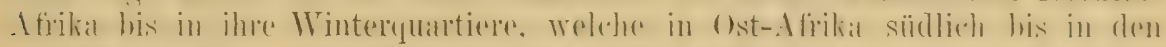
'Transval liogen. Win Stiick ist aus Ungann bekannt.

\section{Motacilla flava melanocephala Licht.}

Motacilla melanocephala Lichtenstein, Ver\%. Doubl, Zool. Mus. Berlin, \}) 36 (1823Nubien).

Motucilla Feldegg Michahelles, Isis 1830, p.812 (..Thäler des siidlichen Dalmatiens". Man hat mehrfach intiimlich diesen Namen anf cinereocapillt bezogen, aber die beschreibung libist gar keinen Kweifel, dab es sich um melanocephala handelt).

Motacilla Kaleniczenliii Kaleniezenko, Bull. Soc. Imp. Nat. Moscou 1839, p. 229. 'I'af. XX (ex Krynicki II.S.; Krim).

Motacilla flava var. 5 Africana Sunderall, Kongl. Vetensk. Acad. Handlingar för 1840, p. 54 (1842 - Sennar und Nubien, ron Herlenborg gesammelt).

Bulytes nigvicapilla Bonaparte, Consp. Av. I, p. 249 (1850- „ex Dalmatia. Italia, Seandin.. Lapponia". Skandinavien \& Lappland ist ein Irrtum, Verwechslung mit borealis).

Budyles superciliaris A. E. Brehu, Journ. f. Orn, 1851, p. 74, Anm. (Bei Chartum. Dies ist eime Aberration mit weißem Supereiliarstreifen).

Budytes paradoxus Brehm, Vogelfang, p. 142 (1855- kein Fundort. Der Name bezieht sich auf die ron $\mathrm{A}$. E. Brehm sehon superciliaris genanute Aberration).

Budytes melanocephalns vulgaris, cervicalis, brachyrhynchos A. E. Brehm, Verz. Samml, 1. 7 . (1866- nomina nuda!).

Bulytes puradoxus longirostris, brevirostris (partim) A. E. Brolm, Verz. Samml, p. 7 (1866- nomina nuda!).

Motucilla xanthophyss Sharpe, Cat. B. Brit. Mus. X, p. 532, 'Lal. VIII, Hig. 6 (1885Lenkoran. Aberration mit gelben Superciliarstreifen).

Abbild.: Cat. B. Brit. Hus. X, 'Taf. YII, 1-t (Kopl); Dresser, B. Hur. III, T'af. 160; "Neuer Nammann" III, Taf. 16, 2.

ond. Ton allen hisher behandelten Formen anf den ersten Blick

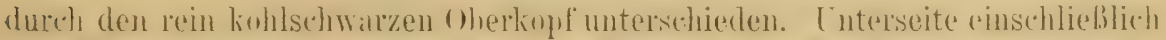

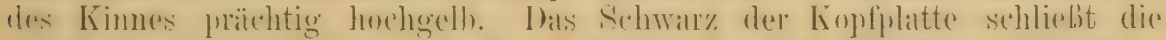

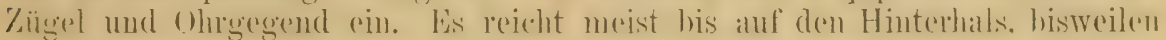
nur bis ins Genick, manchmal his auf den Oberricken. Von einem Super-

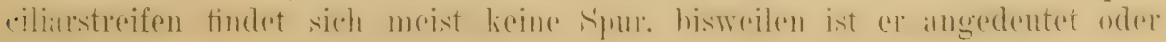




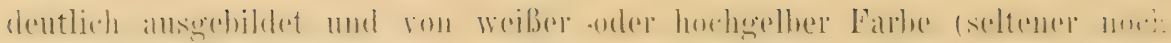

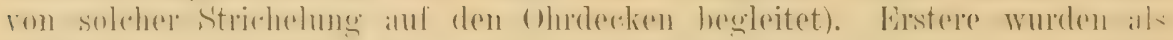
superciliaris und paradoxus, letztere als xanthophys beschrieben. Die Sïume der Flïgeldecken sind schön gelh. Hlïgel $8 \pm-90 \mathrm{~mm}$.

Brutrogel in Griechenland und der 'Türkei, nördlich bis Sophia, Niseh und zum Nordende des Skutari-Sees (Reiser in litt.), his in die Suidspitze

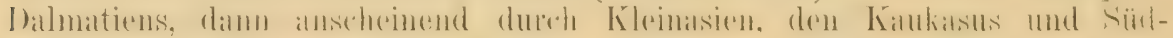
Rußland, ungefilı bis zur Donaumündung. - Verfliegt sieh hisweilen nördlich, so \%. I). (diese oder meleneqrisens) nath Melgoland. Tn SïnUngarn wurden im Sand-Gebiet hei 'I'emes Kubin Stïeke ron melano-

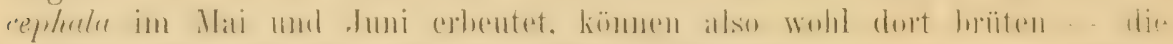

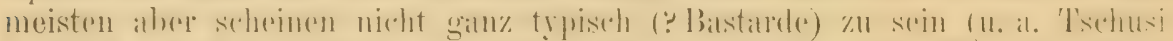

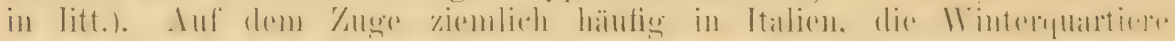

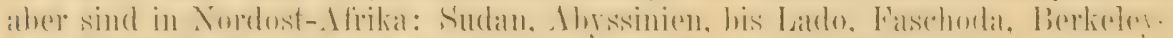

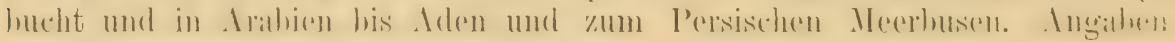

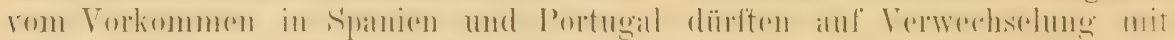
borealis beruhen. Am 13. Mai 1903 wurte ein altes of bei Willingdon in Sussex, Süd-linglind, erbeutet.

Lebensweise und fortpltanzung angenseheinlich nicht wesentlich von der der andern Subspezies abweichend. Der Lockton soll rauber, heiserer sein.

\section{Motacilla flava melanogriseus (Hom.).}

Budytes melanogrisens E. v. Homeyer, Journ. I. Orn. 1878, 1).128 („Indien". I)ie Tyjen sind Wintervögel ans N.W.-Indien.).

Budytes aralensis L. v. Homeyer, Journ. f. Orn. 1878, p. 128 („Aralsee").

Budytes melanocervix Homeyer \& Tincré, Mitth. Orn. Vereines Wien V'lI, p. 86 (188:3(partim) „Altai, 'lurkestan und an kaspischen Heore“.).

Las alte $O$ dieser merkwürdigerweise in Catalogue of lirds $\mathrm{X}$. p. 529 und von allen nachfolgenden Autoren mit $1 \%$. . melanocephalu rer-

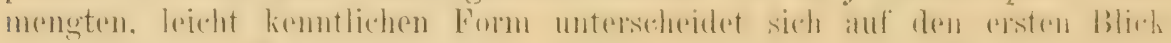
von dem vou M. i. melanocephala durch die heller gelbe Unterseite mit. weibem Kinn und weiber Tinie an den Halsseiten. Auberdem ist sie kleiner und die Oberseite ju der kegel nicht so gelblich, sondern matter und grünlicher. Flügel ठิ ad. $80-85$ mm.

Brutvogel in größten 'l'eile von 'T'urkestan, aber wahrseheinlich nicht

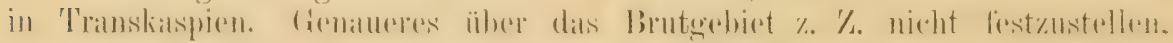

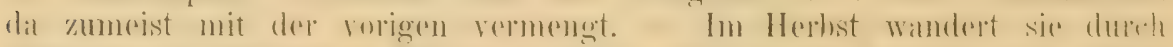

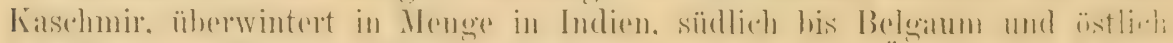

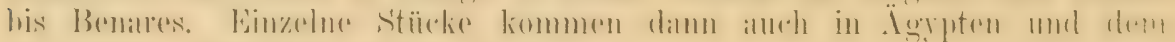
Sudan vor (Brelmo'sche Sammlung).

\section{6.). Motacilla citreola citreola P’all.}

Motacilla citreola P'allas, Reise d. versch. P'roy. d. Russ. Reiches 1II, J.696 (1776"In Sibirir orientaliore frequens, rarior minorque in Russia.").

Motecille Citrinella Pallas, Koogr. Rosso-Asiat. I, P. 503 (1827- neuer Name fïr (vitreola). 
? Motacilla Calcarata Hodgson, Asiatic Researches XIX, p. 190 (1836-- Nepal. Beschreibung eines jüngeron Vogels, die sich mit riemlicher Wahrscheinlichlkeit auf citreola bezicht.).

Abbild.: Dresser; B. Eur. III, 'Taf. 127; Neuausg. d. „Namman" III, Taf, 13.

(11. citreola und cibreoloides stehen viel entfernter von allen Formen der Harce-Gruppe, als irgend welehe der letzteren voneinander: Sie sind

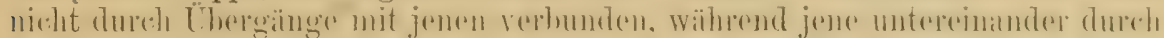
đlie völlige Ähnlichkeit der o, jüngere und aberrante Stïcke melr oder

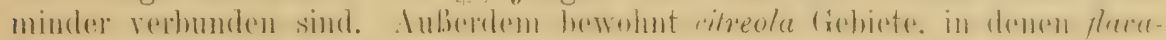
Formen ebenfalls nisten.)

O๋ ad. im frischen Fröhlingskleide: Del ganze Kopf bis auf den Hinter-

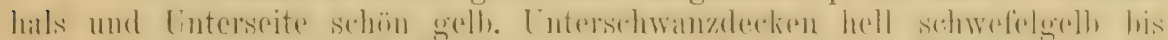

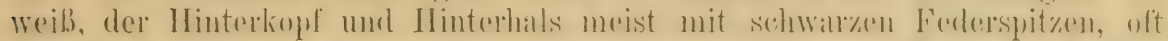

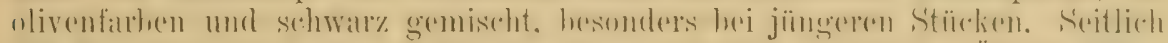

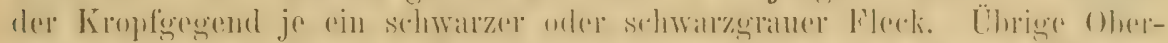

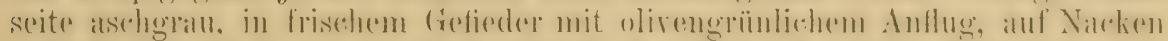

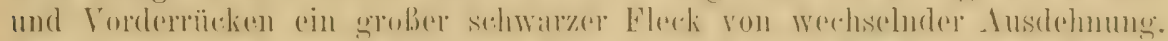

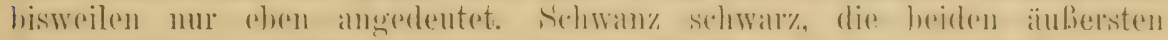

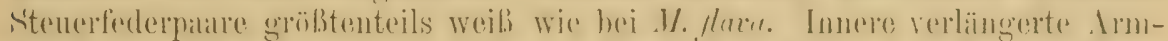
schwingen mit sehr hreiten weiben Aubensimmen, mittere mel grobe oher-

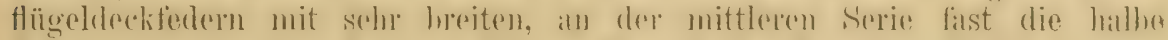

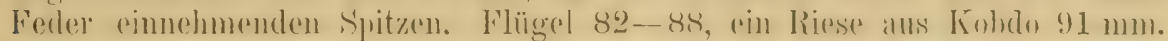

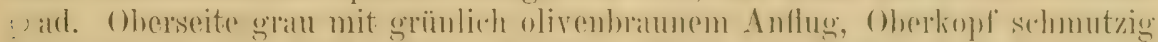

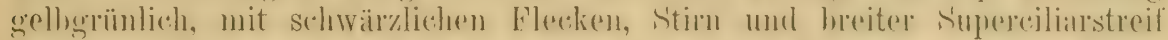

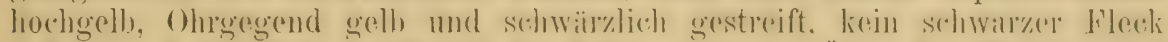

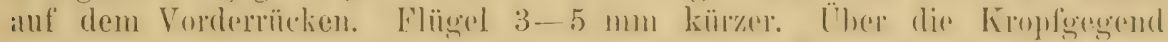
oft ein mehr oder mincler dentliches sehwarzes Fleckenband. Unterseite

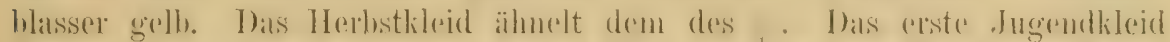

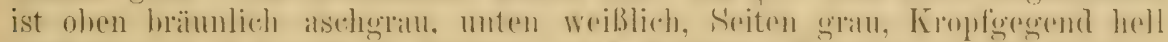

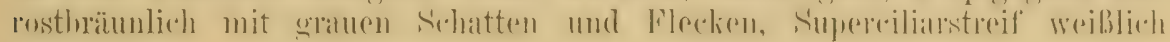
rahntarben.

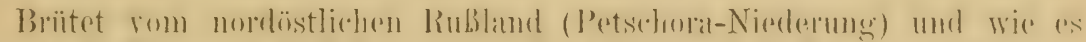

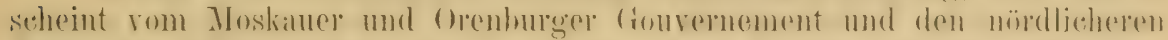

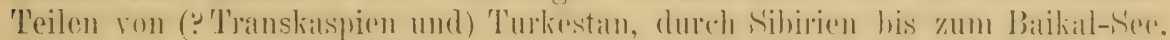

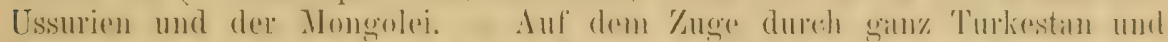

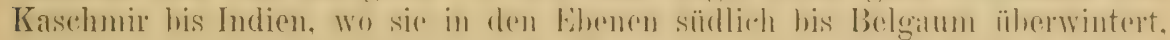
in geringerer Anzalı in Chini. In luropa nur veroinzelt, \%. B. mehrfach anf Helgoland und in Italien. Versehiedentich ist diese Ait wohl irrtiondich angegeben worden: so \%. I3. findet sich im .Jomm. f. Orn. 1885, p. 92 cine Notiz, wonach sie in Ostpreuken zur Brutzeit getroffen wïrde. Acloque

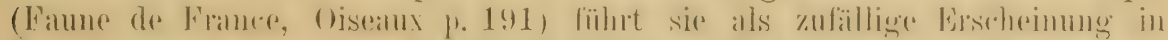

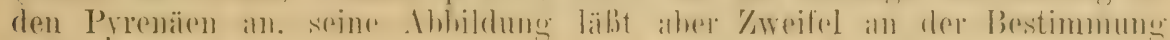
aufkommen.

Diese Bachstelze bewohnt haup tsächlich 'T'eilo der' 'T'undren mit moorig-schlammigem Gruncle, wo dieht verfilzte Wollweidendickichte stehen, und die Ränder ron Gräben und Wassertiumpln. Sie hïlt sich meist aluseits von andern Bachstelzen und ähnelt an meisten ciner S'chafstel\%c. Nicht ror dem Juni legt das $q 5$, selten 6 Eier. Das Nest steht auf der Erde oder im Moose der Moore, meist sehr versteckt. Die Wier sind weibgelblich, mit kleinen, blassen, rostfarbenen, schwach ausgeprägten dunkleren

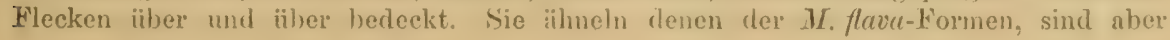


anscheinend noch einfarbiger', weniger tentlich gefleckt. Mabe nach 'T'uczanowski $20.2 \times 1.1 .8,18 \times 14 \mathrm{~mm}$, wach Dybowski $19 \times 14.5,19.2 \times 14,19.3 \times 14.4,19.8 \times 14.5$ his $20 \times 14.4,20 \times 14.5,20.2 \times 14.8 \mathrm{~mm}$, ein (Helege in 1)r. liey's Sammlung milst fast olme Schwankung $20 \times 14.5$, Gewicht $127 \mathrm{mg}$.

\section{4titi. Motacilla citreola citreoloides ((imuld).}

? Buelytes citreoloiles IIorlgson, in Gray's Zool. Mise., p. 83 (184t- nomen nudum!) Budytes citreoloides (iould, 13. Asia IV, Tat. 6.t (1865-- ex Hodgson nom. nud. N.-Indien).

Bullytes citreole var. melunota Sewertzoff, Turkest. .lovotn., 11.67, 139 (1873).

Unterscheidet sich von $\boldsymbol{M}$. c. citreola dadureh, dab das alte. $\sigma^{\pi} \mathrm{im}$

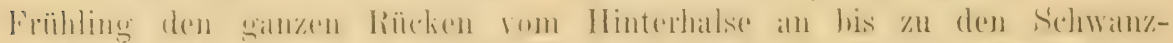

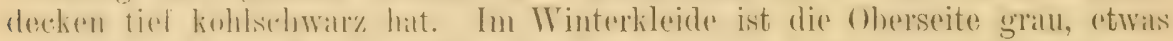
dunkler, als bei 1\%. ce citreolu. Die Jungen im Herbste sind denen von

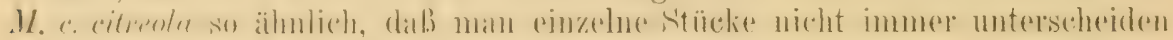

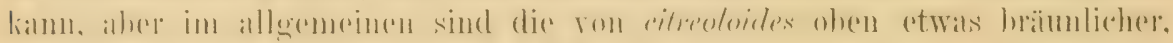
bei etwas dunkleren Federwurzeln, die von citreole etwas heller, etwas mehr aschgrau, bei etwas lichteren Federwurzeln.

11. c. citreoloides scheint cine südlichere Gebirgstorm von IL. ce citreolu zu seiu. Sie hrütet augenseheinlich vom Altai bis zu den nördlichen $A b-$

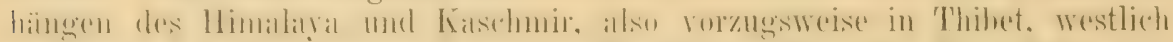

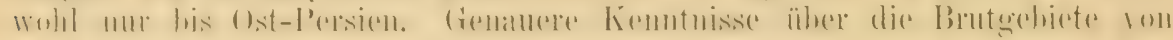
M. c. citreola und citreoloides sind noch sehr erwïnseht.

Wurde in Katschmir im Mai brïtend gefunden. Die + Hier waren hellgrau mit graubraumen und und mattgrauen Flecken und maken $24 x 18$ mm (Oates).

\section{Motacilla boarula boarula I.}

\section{Schwefolgello oder Gebirgs-Bachstelze.}

Motacille boculule Linnacus, Mantissa Pautarum, p.527 (1771- Habitat in Furopa: Snecia. - Lis Beschreibung kann nur auf diese Art bezogen werden, obwohl er Citate und Biologisches verwechselte).

Motacille grised I'. L. S. Milller, Natursystem Suppl., 1) 175 (1776- Ex Edwards, fileanings Nat. Hist. (V), Taf. 25\%. - Xiiller gibt als Heimat irrtïnlich dmerika an. Wdwards sagt aber ausclrieklich, dab der von ihm abgebildete Vogel bei Lundon gesehossen sei).

Motacilla sulphureu Bechstein, Gemeinn. Naturg. Deutschl. III, 1).459 (1807- "Europa und Asien |er. . . . In Dentschland nicht selten und in Thüringen gemein." Als typ. lindort betrachten wir 'Thiiringen).

Motacilla cincrea loach, Syst. Cat. Indigen. Mamm. \& B. Brit. Mus. p. 22 (1816nomen nuclum!)

Motacilla montium Brehn, Handb. Naturg. Vög. Deutsehl., p. 345 (1831- deutsehe (tebirge).

Motacilla lunulate Prórost \& Des Murs, in Lefebre, Yoy. Abyssinie, Atlas \%ool. Iaf: VII, Untersehrilt (18-15).

Motacilla ophthalmica Des Mur's \& l'revost, in Lelebve, Voy. Abyssinie, Hist. Nat. "Koologie (VI), p. 9.4 (1845- "ilans le Choho, ì 'T'schélenkote").

Motacilla Lindermayeri Brohm, Isis 1815, p. $3+1$ (Griechenland).

Motacilla montana und rivalis Brehm, Vogelfung, p.143 (1855-Dentsehland). 
Wotacillu bocrula ceturensis Harterf, Nor. Zool. 1901, p. 332, A. d. Wanderj. c. Nat,

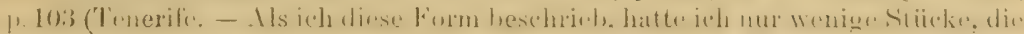
z.' 'I. schlecht präpariert waren. Die von mir behauptete Redultion des Superciliar- und Wangenstreifs ist lediglich der schlechten Präiparation der Koprseiten der Typen zuzuschreiben. Mit. M. b. schmitzi ist die canarische Form keineswegs identisch, ieh kaun aber keine brauchbaren Merkmale finden, sie von der emropäischen (iebirgshalchstelze zu unterscheiden. Die Ohrdecken sind nur bisweilen, die Oberseite durchutus nicht dunkler; die Grölse variert. Bemerkenswert ist eventuell die Lebhaftigkeit der grelben Unterseite. die Häufigkeit prachtvoll sehwarzkehliger Stücke. Der Laul ist meist nur $20 \mathrm{~mm}$ lang. Die drittletzte Steuerfeder hat last immer einen of sehr breiten sehwarzen Innensaum, der nur bei 2 ron 18 verglichenen ô fehlt, und ist bisweilen zur Hällte und großenteils schwarz. Lsetzteres wïre vielleicht eine Eigentiimlichkeit ter (anaren-Form, ist aber auch variabel).

Eingl.: Grey Wagtail. Franz: Bergeromette jaune, Hocheguene boarule. Italien: Ballerina gialla. Selnwed.: (iraiäla.

atd. Frïhjahr: Oberseite aschglatu in frisehem Gefieder, mit grün-

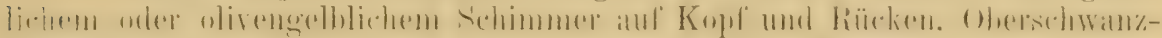
decken olivengelh, die seitlichen fist rein gelb. Ohrdecken etwas, aber meist nicht viel dunkler; als der Oherkopf; selmaler Superciliar- und etwas ireiterer Wangenstreif weib. Schwingen sehwarzbrau, Armschwingen an der Basis (fast zur Hälfte) weil., imere (verlängerte) mit breiten, in der Brutzeit sich abmutzenden. gelblich-grall-weißen AuBensiumen. Die dritt-

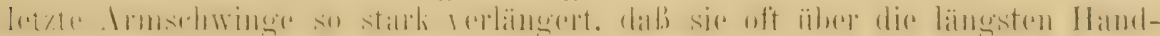

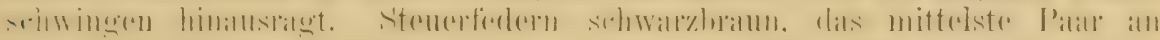
den Aubenfuhnen dentlich, die nichsten nur sehr schmal olivengelblich

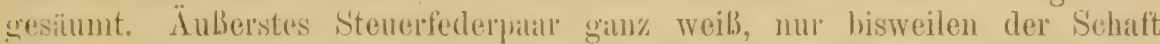
nahe der Wurzel hraun: vorletztes l'ar mit gan\% weilser Innenfahme und

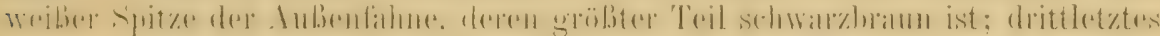
l'ar wio das vorletre, aber manchmal mit sehmalem hramem Streif in der. Mitte der lunenfilume. äubarst selten mit breitem solehen Streif oder gar einem groben 'leile der Innenfahne sehwärzlich. Gatuze Kehle bis an

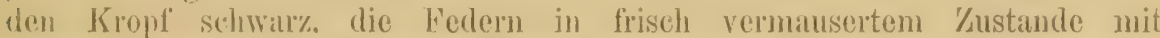
scinnalen wriben Endsänmen. Ührige Unterseite gell, an den Untersehwanzdecken am lehhaftesten, Seiten etwas olivengran angeflogen. Banchseiten

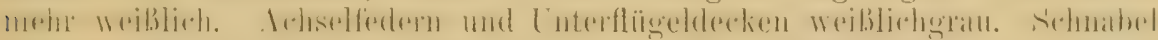
schwar". Iris dunkelhraun. FüBe dunkel hräunlich fleisehfarhen oder lehhaft hellbraun. Flïgel 80-85, Schwanz 95-105, Latuf etwa 20-22, Schnabel etwa $11.5-12.5 \mathrm{~mm}$. Die Kehle ist nicht immer rein sehwar" sondern oft mit ganz oder teilweise weiben Federn gemiseht; es scheint, dab die grauz. schwarzkehligen Stücke die ältesten sind. Oad. wie das ơ ad., abuer

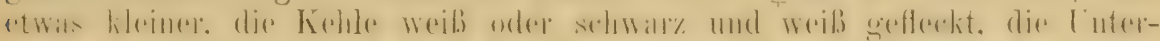

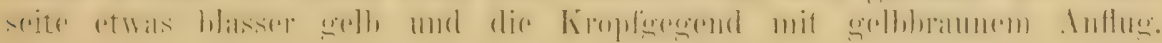
Herbstlileid der $\sigma^{*}$ : Kehle weib odre weiblich. Torderbust hrimlich. Mitte des Unterköpers seho hell, fast weiblich. Bauch und Untersehwan\%-

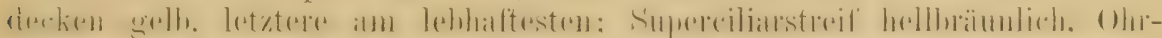

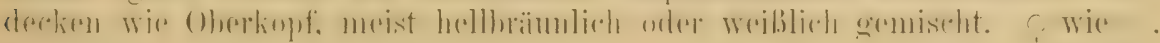
nur etwas weniger lobhalt und kleiner. Hrstes Jugendkleid: Oberseito

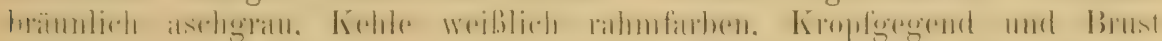

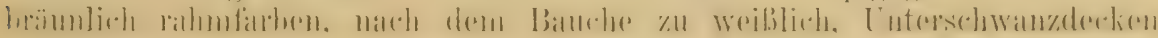
zitronengelb. - Die schwarze Kehle wirk dureh Mauser erlangt, aher die 


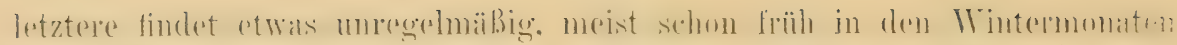
statt. Nach C. I. Brehm werden anch die imneren (verlingerten) Arunsehwingen ein zweites Mal vermausert, was mir aber nur ausuahmsweise der Fall zu sein scheint.

Brutgebiet: Europa vom sïdlichsten S'chweden bis in die Mittelmeor-

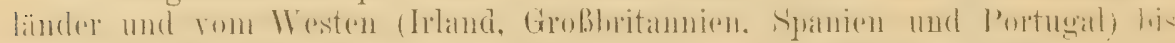

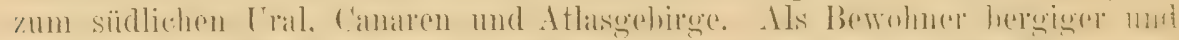

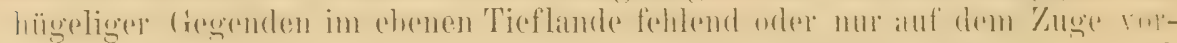
kommend. - In den nördlicheren 'Teilen ihres Trohngebietes 'Mugrogel. der in Nord-Afrika, südlich in geringer Anzahl bis Senegambien und Britisch-Ostafrikı, überwintert.

Die Gebirgsbachstelze lebt zur Brutzeit nur im Hiigel- und Berglande, wo sio in der Nähe schnelltießender Bäche, in ILauerlöcherm, unter tiberhängenden Uferı, in Felsen-und Erdlöchern, besonder's gern unmittelbar neben kleinen Wasserfällen, Schleusen. Wehren usw. nistet. Das Nest ist ein unordentlicher Haufen ron diinen Reisern, IInos, WẄ̈rzelchen, Halmen und Blättern, in dessen Mitte sich ein weich und reichlich mit Haaren ausgelegter halbkugelförmiger Napf findet. Das erste Gelege ron 4-6 Kiern findet mari in Europa im April, in der liegel ein zweites ron meist nur 4 Liem im Juni und Juli. Die kier ähneln denen ron $M$. flave außerordentlich (obwohl die Gebirgsbachstelze in ihrem Bau viel näher der Gruppe ron $\boldsymbol{M}$. alba steht), sind alher meist etwas heller und gelblicher, sehr selten rötlich und noch seltener so stark gefleckt, daß sie denen ron 1 . alba ïhnehn. 61 Exemplare in Rey's Sammlung messen von $18 \times 14.4$ und $19.7 \times 13.1$ bis $19 \times 14.5$ (Durehsehnittsmab), $19 \times 15$ und $20.4 \times 14.3 \mathrm{~mm}$. Gewicht $114 \mathrm{mg}$. - Nahrung Inseliten. Lockton meist im Fluge ausgestoßen, dem von $\boldsymbol{M}$. albe ziemlich ähnlich, ein scharfes ziss-si, Gesang unbedentend, aus den Locktönen zusammengesetzt. Jeder Beobachter ist ron der Anmut dieser Vögel entzückt.

\section{Motacilla boarula melanope Pall.}

Motacilla Melanope Pallas, Reise d. verseh. Prox. Russ. Reichs III, J).696 (1776- ,.In Daouria circa ripas glareosas").

Motacilla bistrigata Raffles, 'T'ans. Linn.-Soc. London XIJI, p.312 (1820- Sumatra. Beschreibung nicht gut.).

Motacilla xanthoschista Hodgson, in Gray's \%ool. Hisc., p. 8:3 (18.4- Nepal; nomen nudum!)

Pallemura javensis Bonaparte, Consp. Ar. I, p. 250 (1850- nomen nudum!)

Calobates melanops Ball, Stray Feathers 187.4 p. 416 (? Schreibfehler).

Budytes Novae Guineae Meyer, Sitzungsber. Isis, Dresden 1875, p. it (Arfakgebirge in Neuguinea).

Wie .\%. b. bocmela, aber der Schwanz ist kïrzer mel milst nur etwa $88-95 \mathrm{~mm}$. Die änßerste Stenerfeder hat sehr oft etwas hrau in der Mitte des Schaftes, die vorletzte oft etwas briun am Innensaume und die drittletzte fast immer mebr oder weniger schwar am Innensaume.

Die Verbreitung dieser sehr wenig ausgebildeten und an einzolnen

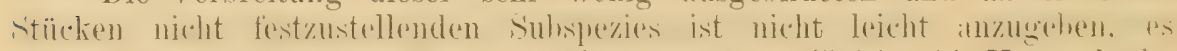

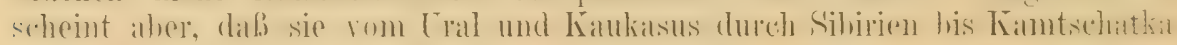
und zu den Kurilen reicht, aber nicht nördlich des 64. Grades geht. -

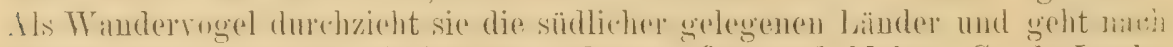
Indien und bis zu den Andamanen, den großen und kleinen Sunda-Inseln. Celebes, Molukken, Nouguinea, Hainan, Formosa. 


\section{Motacilla boarula schmitzi T'schusi.}

Motacilla boarula schmitzi 'Tsehusi zu Schmidhoffen, Orn. Jahrb. XI, p.223 (1900Madeira).

Unterscheidet sich auf den ersten Blick von U. b. boamla durch dumklere,

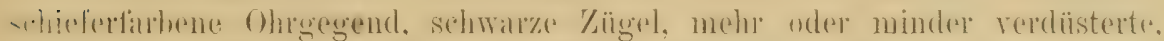

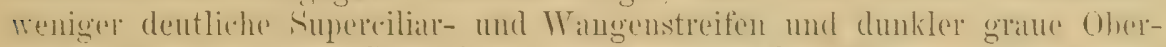
suite. Die drittletzte Stenceferler neigt zu dunkler Förlumg. fast immer

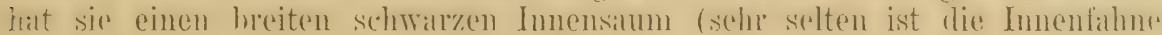
gamz weiß) und ist oft zur Hälfte oder fast ganz schwarz. Das Gelb der

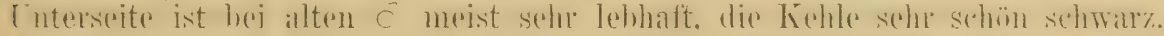

ad. mit sehr viel. Sehwarz an der Kehle. Schon die Nestjungen sehen dunkler aus als die von $\%$. b. boumela.

Standrogel auf Madeira und den Azoren.

\section{Motacilla alba lugubris 'T'emm.}

Motacille lugubris 'l'emminck, Man. d'Orn. I, p. 253 (1820- ex Pallas ML.S. - Partim! 'Temminck spricht von Stïcken die ihm von Pallas' aus Rußland [gemeint ist Sibirien] gesandt wurden und solchen aus Fraukreich, Egypten, der Krim und Ungarn! Einige dieser Fundorte sind zweifelhaft, Pallas Vogel war sicher nicht unsere Form, sondern wohl lugens. Da die Beschreibung aul die englisehe Bachstelze paßt und der Name allgemein angenommen ist, sollte er beibehalten werclen.).

Motacilla Yarrellii Gould, B. Europe .List of Plates" in Bd. II, p.2 (1837- Grobbritannien).

Motacilla Algira Selys-Longchamps, Nammannia 1856, f).391 (dem Namen nach zu schließen aus Algier).

Fingl.: Pied Wagtail.

Unterscheidet sich vou M. u. ulba im Sommer dureh die ganz schwarze

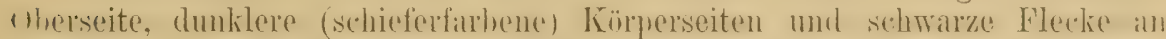

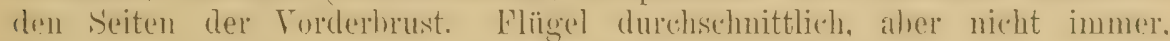
$2-3 \mathrm{~mm}$ lïnger. Das $q$ ist etwas kleiner, der Rücken ist nicht so rein sehwar\%, sondern mohr dunkel schieferfarben oder fleckig. I)ie. Jungen sind

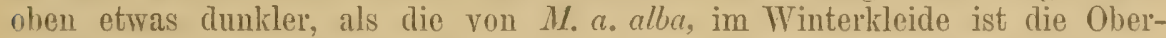
seito grau, aher viel dunkler, als hei ./. ". ullu. Bisweilen crhalten (? jüngere)

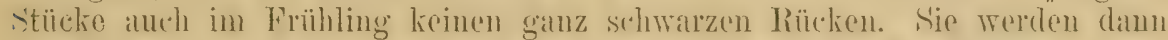

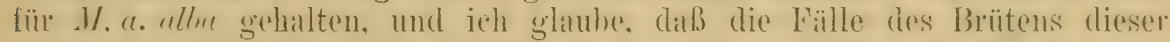
letzteren in Grobloritamien seltener sind, als man glauht. da die brlegung und Lntesuchung der Pare manchmal ergehen wïrde, dab es sich nicht min reine alba oder nur um aberrante lugubris handelt. (Vergl. unter Nr. 471.)

Das Brutgebiet von $\boldsymbol{M}$. a. lugubris sind die britischen Inseln, aber auf st. Kildat und den Shetlands ist sio nul gelegentlicher Giast. AuBerelem hritet sie in sehr garinger Anzahl nahe der Küste in westlichsten Holland. Belgien und nordwestlichen Frankicich. - Sic wird nicht selten in sïdwestlichen Schwedeu beohachtet. wo man ihr Briiten auch remutet bat(?). in Dänemark und häutig auf Helgoland. Aus den nördlieheren 'Teilen (irohbritauniens und Irlands zicht sic im Winter fort und ïberwintert in sï̈lFrankreich. Portugal, Spanien und Marokkr. Man hat hehauptet, dal.s sie 
in Portugal und Spanien brüte, was aber zu bezweifeln ist. Im suidlichen und mittleren Eingland Standvogel.

Lebensweise und Fortpflanzung wie die von $\boldsymbol{M}$. $\boldsymbol{a}$, alba. Zwei Bruten sind die Regel, die ersten Gelege findet man gegen Ende April. Nester nicht selten in den verlassenen Nestern andrer Vögel (Zoologist 1904, p. 421). Eier wie die ron $M$. u. albu.

\section{-71. Motacilla alba alba T. (Fig. 50.)}

Weiße Bachstelze.

Motucillu alba Linnaeus, Syst. Nat. Ed. X, p. 185 (1758 - "Habitat in Europa." Als typische Lokalität hetrachten wir Schweden, nach dem ersten Zitat: Fauna. Suecica 214).

Motucilla cinerea (tmelin, Syst. Nat. I, j. 961 (1788-- ex Brisson. Buffon \& I athan. Hab. in Europa).

Motacilla Albeola Pallas, 'Loogr. Rosso-Asiat. I, p. 506 (1827- Partim: „Per universam Rossiam et Sibiriam, ut in Europa omni ..." Neubenennung von Jinnés 1. alba).

1Lotacilla septentrionalis Brehm. Handb. Naturg. Vög. Dentsch., 17.347 (1831 _ „Sie lebt vom nördlichen Deutschland bis Island hinaut").

Motacilla sylvestris Brehm, Handb. Naturg. Vög. Deutschl., 1. \$348 (1831- Nadelwälder Deutschlands).

Motacilla brachyrlıynchos Brehm, Haudb. Naturg. Vög. Dentschl., p.348 (1831_ ..Sie scheint östlich ron Deutsehland zu wohmen, kommt bei Wien ror, und erscheint hier sehr selten auf der Wanderung").

Motacilla gularis Swainson, B. WV--Africa II, p. 38 (1837-- Senegal).

Motacilla Brissoni Macgillivray, Manual of Brit. O'n. I, J. 160 (1840-- Umbenennung von Linné's $M_{\text {. alba). }}$.

Motacilla alba nigromaculata Zander, Naumannia 1851, 4. 1.13 (exp. 11 - Mecklenburcr).

Motacilla cervicalis Brehm, Vogelfang, p.143 (1855- "Ungarn und Deutschland").

Motacilla fasciate Brehm, Vogelfang, p. 143 (1855- Gralizien).

Motacilla major, pratorum Brehm, Naumannia 1855, p. 280 (nomina nuda!).

Wotacilla alba minor, cervicalis alticeps, planiceps und matorum A. E. Brehm, Verz. Samml., p. 7 (1866- nomina nuda!).

Engl.: White Wagtail. Franz.: Larandière, Hochequene grise. Ital.: Ballerina. Schwerl.: Ringärla, Sädesärla, Linärla.

ôa. Frühling: Stirn und Seheitel bis über die Augen, Zügel, Ohrdecken und breiter Streif an den Halsseiten weil., Hinterkopf etrva von der Mitte des Scheitels und Genick glänzend schwarz. Rücken, Bürzel,

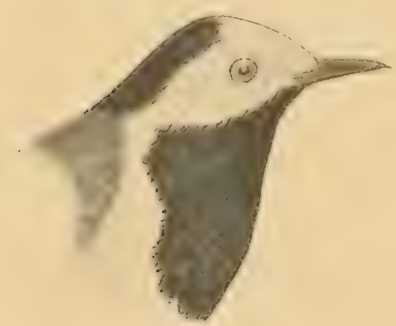

Figur 50. Schulterfedern und kleine Oberflügeldecken grau, Oberschwanzdecken schwarzgrau, die längsten schwarz mit grauen Sämmen. Kinn, Kehle und Kropf glänzend schwarz. Brust und übriger Unterkörper, Untelschwan\%- und Unterflïgoldecken weiß, Brust- und Körperseiten gräulich. - Mittlere Oberflügeldecken grauschwarz mit weißen Spitzen, große grauschwary mit breiten weißen End- und Außensïtumen. Handdecken und Afterflügel schwarzgrau. Schwingen schwarzbraum mit weißen Innen- und schmalen weißgrauen

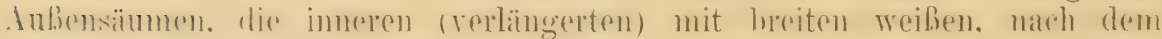
Schafte zu bräunlich verwaschenen Außensäumen. Steuerfedern schwarz. mittelstes Par mit schmalem weißen Lußensaum, äußerstes weiß mit 


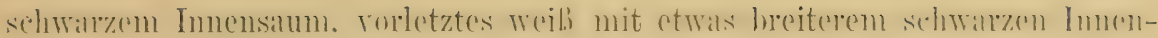
satum und ebensolcher Basis. Schmabel schwar'z, Fïße braunschwarz, Iris brauu. Flügel etra 87--90, selten bis 93, Schwanz etwa 86-91, Laul etwa 22-24, Schuabel etwa $13 \mathrm{~mm}$. Im Herbst-(Winter-)Kleide ist die Kehle weiß, über die Kropfogegend zieht sich ein breites schwarzes,

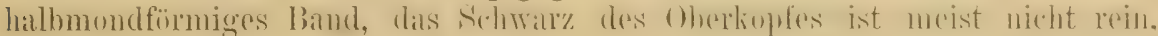

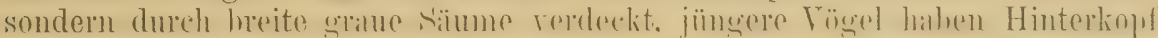
und Genick sehmutriggran. o wio ò, nur etwas kleiner, Flügel etwa 5-7 mm kïrzer, der lin̈cken eine Schattiermo brïmulicber, das IVeiß des

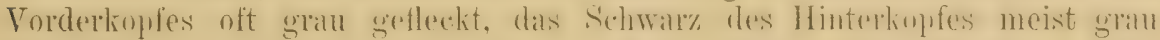
gemischt, aber nicht immer. Die o, denen diese graue Mischung fehlt, sind wahrscheinlich sohr alte Vögel. Im orsten .Jugendkleide ist die

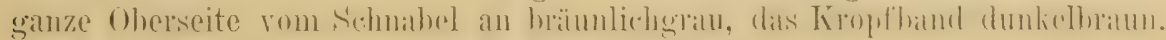
das Weil der Unterseite mit gelblichem Anflug.

Das Schwarz des Hinterkopfes variert an Ausdehnumg und reicht manchmal bis auf den Oherrïcken hinah. Brehm nannte solche Stricke cervicalis, es sind aber nul Aberrationen. Es kommen aber auch Stücke

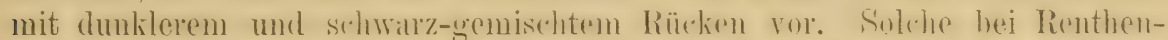

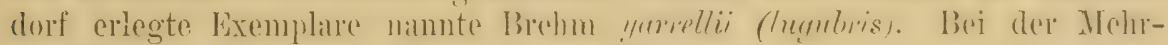
zahl der von Brehm so bezoichneten Stïcke sehe ich keinen Grund ein. sie von $M$. a. alba zu tremen. Zivei derselben sind allerdingrs auf dem Rücken fast (aber lange nicht ganz) schwarz. Sie sind als o bezeichnet und am 20. März 1854 und am 4. April 1837 erlegt. Man könnte sie fül luguluris (-yerrellii) halten, aher ioh erachte sie fï̈ Aherrationen, demn es

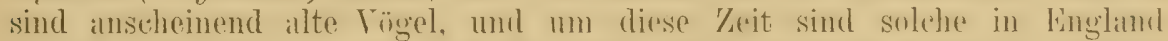

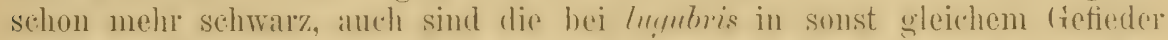

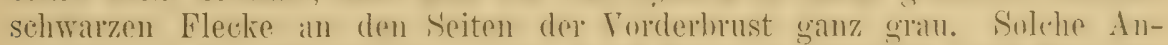
nähermngen einer Subspezies an die andre kommen mitunter aurle feru von den Grenzgebieten vor, ohne etwa Bastarde zu sein.

Brutvogel in Europa, von Island und dem nördlichen Skandinavien bis zum Mittelmeer, in Usten his zum Cral, im äulersten Wresten (Hingland) durch W. a. lneguluris exsetzt. In Fingland und sehottland vereinzelt nistend. aber nicht regelmälig und hisweilen mit lugulwis gegatat. (Vergl. untel Nr. 470). Auf Jan Maven und in Sïd-Grönland wahrseheinlich nul cine ausnahmstveise Erseheinumg. - Üherwintert in Afrika, im Westen südlich bis Hanssaland und Niger, in Osten bis British Ost-Afrikil, herïhrt ausnahmsweise die Azoren, hänfig Madeira und die C'anaren. C̈herwintert anch vereinzelt im westlichen Deutschland.

Die weiße Bachstelze ist an allen möglichen Orten zu finden, zumeist aber wo Weiden stehen, an Brücken, Mïhlen, Wehren, Bachufern, in Dörfern und Gärten, auch anf freien Schlägen in Walde, wo Holzhaufen ihnen Gelegenheit zum Nisten bieten. lsockstimme ein hohes, dünnes, ziemlich scharfes, zweisilbiges ziuitt, ziuwiss, zississ. Gesang zwitschernd, wie aus den Locktönen zusammengesetzt, wenig auffallend. Nahrung Insekten. Nest in allen möglichen Löchern an Gehäuden, llauerwerk, Felsen, Erddämmen, in Reisighaufen, Holzklaftern, Kopfweiden und andern hohlen Bäumen, in Bretterhaufen, unter J)ichern. J)as Nest selbst ist ein wirrer Haufen aus Reisern, Heu, Moos, Wïrzelchen und Blättern, der halblugelförmige Napf mit Federn ausgelegt. Die Eier der zwei Bruten findet man rom April bis Juli, ausnahmsweise bis in den August, Gelege 5-6, seltener 7 Eier. Die Eier erinnern etwas an Sperlingseier; sie sind bläulichweiß, gränlichweiß oder hellgelb-bräunlichweiß mit 
feinen dunkelgrauen l’unkten ïbersät oder gröber braun gefleckt, mit hellaschgrauen Schalenflecken. Mabe nach Rey ron $21.5 \times 15$ und $20 \times 16.2$ bis $18 \times 15$, im Iurchschnitt $20.5 \times 15.1 \mathrm{~mm}$. Nittleres Gewicht $136 \mathrm{mg}$.

\section{Motacilla alba dukhunensis Srkes.}

Motacilla Dukhunensis Sykes, Proc. Zool. Soc. London 1832, p. 91 (Dekkan, Indien). Motacilla alba L. var. orientalis Zarudny et Korejew, Orn. Monatsber. 1903, p. 130 (Nördl. 'Lurkestan).

Von M. a. alba durch die heller grane Oberseite und ausgedehnteres

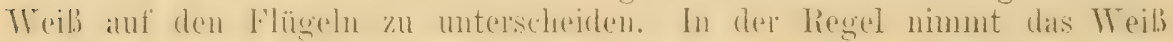

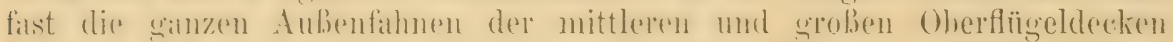

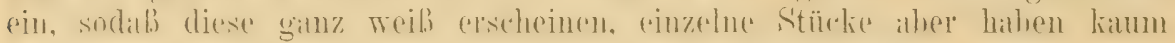
mehr Weiß auf den Flügehn als trpische alba, die ja auch hierin einigermaßen variiert.

Das Brutgebiet seheint West-Sibirien bis zum Jenissei und Altai zu

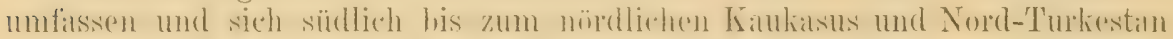
zu erstrecken. - Wandert durch 'Turkestan und überwintert in Indien, in

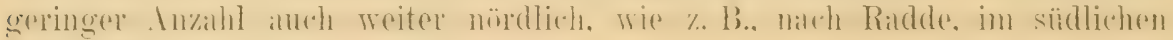
Kaukasus.

Die Fortpflanzung und Lebensweise dieser und andrer verwandten Formen gleicht der ron $M$. a. alba.

\section{Motacilla alba baicalensis Swinl.}

Motacilla baicalensis Swinhoe, Proc. Zool. Soc. London 1871, p. 363 (Easteru Asia).

Motacilla baicalensis var. temporalis Swinhoe, 1. c. ('Irans-Baikal. Varietät, bei der eine schwarze Linie rom Schwarz des Hinterkopfes zum hinteren Augenrande zieht).

Gleicht $M_{\text {. }}$. dukhunensis, aber die obere Kehle bleibt auch im Frühling

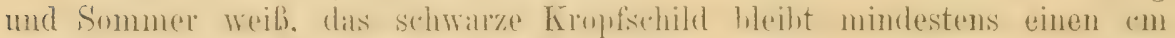

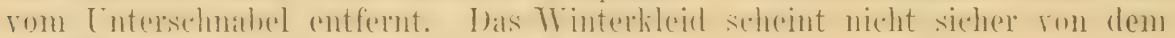
ron 1 . a. dutihunensis unterseheidbar zu sein.

Brütet im mittleren Ost-Sibirien, ron der oberen Lena (Gigalowa) durch Transhaikilien (I)anrien). Cienaure (trenzen wedere nach Norden und Süden, noch nach Osten und Westen festgestellt. - Überwintert im mittleren China.

\section{Motacilla alba leucopsis Gould.}

? Motarilla Alboides Hodgson, Asiat. Researches XIX, p. 191 (1836- partim! Hodgson vermengte leucopsis und hodgsoni so, daß sein Name nicht sicher gedeutet werden kann).

Motacilla leucopsis Gould, Proc. Zool. Soc. London 1837, p. 78 (Indien).

Motacilla alba, var: paradoxa (non Brehm!) Schrench, Reise Amurland, Vög. p. 341, Taf. XI, fig. 2 (1859- Amurland: Nertschinsk und Südlicher Amur).

Motacilla felix Swinhoe, Proc. Zool. Soc. London 1870, p. 121, 122, fig. 1 (Canton bis Schanghai). 
Motucilla felix var. sechuenensis. Swinhoe, Proc. Zool. Soc. London 1870, p. 122, fig. 2, 123, (Szetschwan).

Motacilla francisci Swinhoe, Proc. Zool. Soc. Londou 1870, p. 123 (Szetschwan).

Motacilla frontata Swinhoe, Proc. Zool. Soc. London 1870, p. 129 (Amoy). ${ }^{1}$ )

Ad. wie M. a. baiculensis, aber die ganze Oberseite nicht grau, sonderu ghïnzend schwarz: (Hhrgegend rein weils. Oberschwangdecken mit weiben

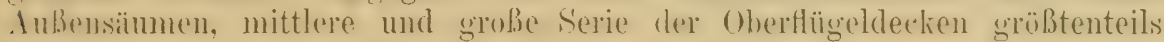
weiß, oberer 'T'eil der Kehle weiß, Schwingen dunkler, als bei M. a. alba mul iben graturïckigen Verwandten, fist schwary aher mit sehr breiten rein weiben Innen- und reju weiben Aubensïumen. Äuberes stenerfederpaar bei ganz alten ơ, gamz oder fast ganz weiß. ơ ad. Flügel etwa 92-96 mm, o etwas kleiner. Im Winterkleide ist dio Oberseite, mit Ausnilhme des Hinterlinfers und Nickens, nicht so rein schwaluz, sondern durch graue Federä̈nder und Federwureln mit grau gemischt, nur selten tinden sich Stücke. die fast rein schwall sind (angenseheinlich sehr alte). wibluend andre, anscheinend jumge Fxemplare, oben ganz gratu, oder nur wenig mit schwarz gemischt sind. Größe etwa wie die von M. a. ocularis.

lirutgehict: Imurland, Mandschurei, östliche Mongnlej bis nach N.W.(Wina und zum nordöstlichen 'Tibet (Chuanche, Ganssu, Kukunor). Wandert in Tintel nach sü̈d-('hina, Formosa, Hainan, Cochinchina, Birma, Assimu. Westlich bis Nepal und Mirzapur, atuch hisweilen his natch den Andamanen.

Nach Yrzewalski ist die Lockstimme anders als die von $M$. a. alba und $M$. $a$. personata. Die Eier (Kuku-Nor) gleichen ganz denen von M. a. alba, nur sind sie vielleicht im Durchschnitt eine Kleinigkeit größer $(21.2>15.8 \mathrm{~mm}$ und sogar noch etwas größer).

\section{Motacilla alba subpersonata Meade-Waldo. (Fig. ól.)}

Motacilla subpersonata Meade-Waldo, Bull. B.O. Club XII, p. 27 (1902- Wad Moorbey, mittleres IIarokko); Ibis 1903, p. 208, fig. 11a; 1905 , p. 98, fig. 10 .

ơd. Obersoite miudestens so hellgrau wie bei $H$. a. alba, das Schwarz des Hinterkopfes reicht bis in den Hinterhals, in der Mitte des Kopfes etwas weiter nach voln, soweit wie der vordere Augemrand. Durch das Auge zieht ein schwarzer Strich, wie bei M. a. ocularis, das Schwarz

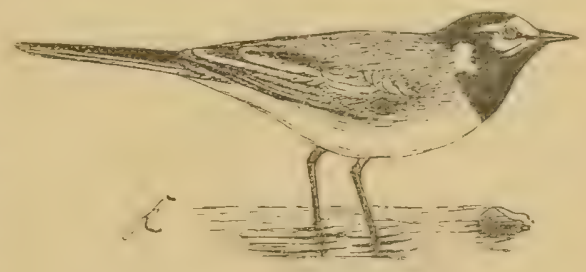

Figur 51. (Etwa 1/3 nat. Gr.) der Kehle zieht in breitem itreifen über den hinteren 'I'eil der ohrdecken zu diesem Strich hinauf, der wieder mit dem S'Shwarz des Hinterkoptes in Yerhindung steht. Hinter dem schwarzen Verbindungsstreifen steht aln den

1) Zweifelhaft bleibt: Motacilla luzonensis Scopoli, Del. Faun. et-Flor. Insubr. II, p. 95 (1786- ex Sonnerat, Voy. Nouv. Guin. 1766, p. 61, 'T'af. 29: "Bergeronette ì collier de l'isle de Lucon". Man hat den Namen vielfach auf $\boldsymbol{M}$. a. lencopsis bezogen, was aber nicht richtig ist, denn diese hat kein Kleid mit grauem Rïcken und ganz weißer Kehle, bei dem das Schwarz des Oberkopfes nit dem Kropfbande zusammenhäingt. Daß Scopoli, der lediglich aus Sonnerat schöpfte, die Beschreibung falsch wiedergab, berührt den von ihm gegebenen Namen nicht.

E. Ha rtext, Die Vögel der paläarktischen Region. 


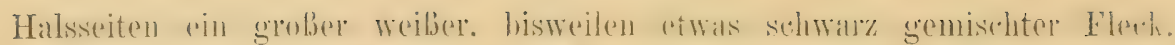

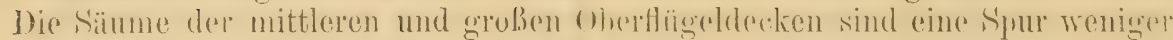
rein weiß, mehr grïulich, als bei M. a. alba. Das erste Jugendkleid wie das von U. a. albu, nur die Ohrdecken dunkler.

Vir kenmen diese Form bisher mit Sicherheit nur vom Oum-R-biah

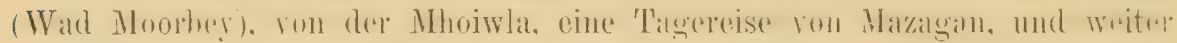
stromaufwärts, wo sie Standvogel zu sein scheint.

\section{Motacilla alba persica Blanf.}

Motacilla personata Gould, var. Persica Blanford, Eastern Persia II, Zool. \& Greol., p. 232 (Persisches Hochland. 'T'ypus von Niriz, östlich von Schiraz).

Abbild. (Köpfe): Cat. B. Brit. Mus. X, Taf. V, Fig. 5, 6.

Ein merkwürdiges Bindeglied zwischen $M$. a. albu und $M$. a. personata: die Ohrdecken sind weiß wie bei alba, das Schwar\% des Genickes und das

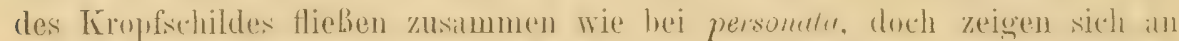

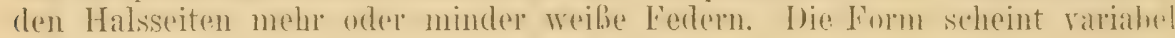
zu sein und wir wissen über ihre Jerbreitung noch sehr wenig. Flügel etwa $93 \mathrm{~mm}$, also länger als bei alba.

Nistet nateh Blanford in den frehirgen ron Fansistan (Niris und Sirján.

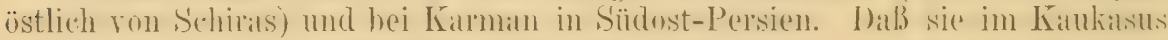

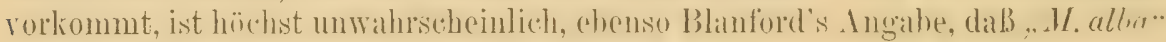
(richtiger M. a. dukhunensis) in derselben Gegend wie persicu brüten soll!

\section{Motacilla alba personata Gould. (Fig. 52.)}

Motacilla personata Gould, B. Asia IV. 'T'af. 63 (1861- Indien).

Motacilla Cashmeriensis Brooks, Proc. As. Soc. Bengal 1871; p. 210 (nicht 289), (Kaschmir).

Abb.: Dresser, B. Eur. Taf. 663; der Köpfe: Cat. B. Brit. Mus. X, Taf. V, 3 und 4.

Unterscheidet sich ron den vorhergehenden Formen durch die grobe

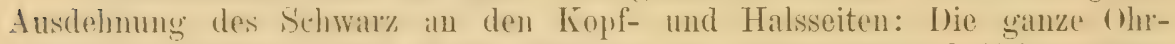
gegend ist schwar\%: diese Farhe zieht von der Sehmabelwurzel dicht unterm Auge hin, nu den Forderkopf his in dio scheitehnitte und einen höchstens

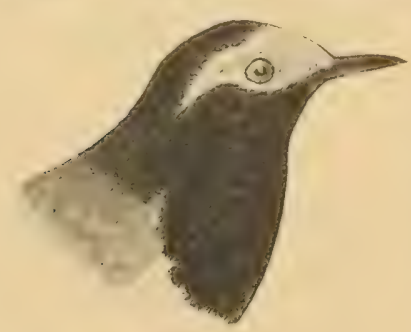

Figux 6.2.

$1 \mathrm{~cm}$ hinter dem Auge in spitzem Winkel endigenden weißen Streif freilassend. An den Halsseiten ist das Schwarz des Vorderhalses mit dem des Genickes breit verbunden. Die mittleren Flügeldecken sind fast ganz, die groben so ausgedehnt weiß, daß von den schwärzlichen Federteilen nichts zu sehen ist. Die Farbe der Oberseite ist bald reiner und lichter grau, bald etwas dunkler, bisweilen etwas durch schwarze F'ederränder verdüstert. Im Herbst-Kleide sind die Ohrdecken ebenfalls schwarz, aber der Oberliopf nur anf der sicheitelmitte und an den Seiten schwärzlich, in der Mitt² dunkelgrau vder gemischt; Kimn und Kehle schwarz mit weißen Flecken, oder weil. mit einigen schwarzen Flecken, demn die Federn sind dort weils mit mehr uder minder ausgedehnten sehwarzen Spitzen. Auch das erste 


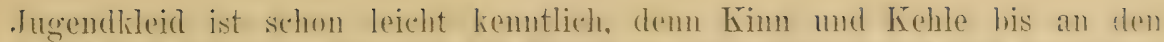

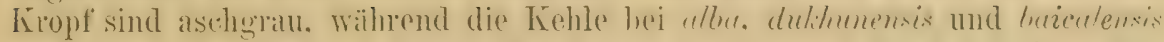

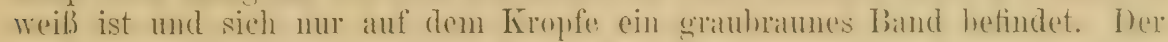
weiBe Streif hinter dem Auge hebt sich scharf von den dunkelgrauen

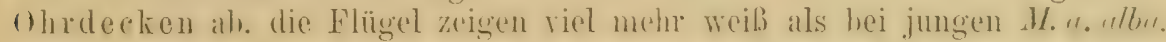
Flügel alter c $92-96$, bisweilen aber bis $100,102,102.5 \mathrm{~mm}$. Die gröbten von Nord- mu! Ost-Persion (Sarudny). Junge Vägel erlangen ihr Alterskleid wahrscheinlich erst im zweiten .Jahre.

Brutgeloiet: Turkestan, ron 'Transkispien lis zum Altai und Süulendo dres Batkal-Sees, an Nordende des ('hotan Tagh, in den Oasen Nija, Kerial und Ssampulat. südlich his in das nördliche Kasehmir. Aghanistan, Noxdmol Ost-l'ersien, wo sie aher nicht mehr häutig zu sein scheint. - Mintervögel in Indien, ostriärts bis Caleutta, südlich bis Belgaum.

Nest unter Steinen, in Baumlöchern orler zwischen Wurzeln und dergl., Eier wie die ron M. a. alba.

\section{Motacilla alba hodgsoni Blyth.}

? Motacilla Alboides Hodgson. Asiatic Researches XIX, p. 191 (1836- partim! Da Hodgson hodgsoni und leucopsis rermengte, kann sein Name nicht sicher gedeutet :werden).

Motacilla horlysoni Blyth, Ibis 1865, p. 49 (Erste Beschreibung! Hodgson 1844 u. a. m. ist nomen nudum. - Nepal und Sikkim).

Motacilla personata var. melanota Setrertzow, Turkest. Jerotn., p. 67, 139 (1873Turkestan. Russisch!)

Abbild. (Köpfe): Cat. B. Brit. Mus. X, 'Taf. V, Fig. 1, 2.

Im Sommergefieder ganz wie $M$. a. personata, nur daß die Oberseite rou der Mitte des Oberkopfes his auf deu Schwanz schwarz anstatt grau ist. Die Oherschwanzdecken hahen weiße Aubeusämme, das seitliche Stenerfederpaar ist ganz weib oder weib mit schmalem schwarzen Immensam. Das Herbst-(Winter-)Klejd gleicht dem rou M. a. pereonuta, nur ist das Gran der Oherseite meist etwas dunkler und häufig mit Sehwarz untermischt, ja es kommen Herbströgel vol (z. B. (ein von mir am 20. Olitober in den Patkai-Hügeln südlich des Brahmaputra geschossenes ó), die ohen yanz schwarz sind, mit nur wenigen schmalen dunkelgrauen Federrïndern; dies sind wahrscheinlich sehr alte, die ganz gramen jüngere Stücke. - Ton 11. a. lencopsis im Sommer und Wiuter dureh die schwarzen Ohrdecken und im Sommer durch die schwarze obere Kehle unterschieden.

Das Brutgebiet scheint dits sïdliche Tihet und die Nordahhänge des Himalaya zu sein, östlich von Kaschmir. Die gzenauen Grenzen des Brutbezirkes sind nicht bekamnt. - Überwintert in den Hügelländern am Fulie des Himalaya, in Assam, Manipur, Birma und Tenasserim, vereinzelt in den Ebenen Indiens.

Nistweise und Eier wie die der andern alba-Formen.

\section{-479. Motacilla alba ocularis Swinh.}

Motacilla ocularis Swinhoe, Ibis 1860, p. 55 (Amoy in China).

Abbild. Turner, Contr. N. H. Alaska I, Taf. XI; Köpfe: Cat. B. Brit. Mlus. X, Tal. IV: 5,6 . 
Ad.: Kenntlich zu allen Jahreszeiten an dem reinschwar\%en Strich. der von der Schnabelwurzel zum Ange und vom Auge nach den Halsseiten hinzieht. I) as Schwarz der Kropfgegend zieht sich im Frïhlingskleide die ganze Kehle entlang, verengt sich aber an dem oberen 'T'eil derselben etwas, und das Kinu zeigt meist einen kleinen weißen Fleck oder einige weilor Federwurehn. Rïrken immer gratu. Flügel mit ehensonviel Weiß wie bei 1 . a. personata. Im Winterkleide ist der Hinterkopf bei ganz alten Vögeln auch schwarz, die ganze Kehle aber rein weiß, nur

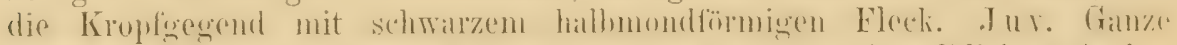

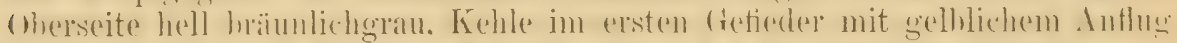

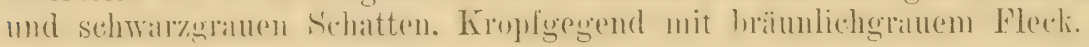

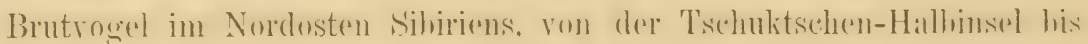
zur oberen Iena, vielleicht auch noch etwas weiter westlich. - Zieht durch

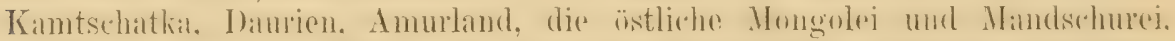
berïhrt gelegentlich Korea, Askold, die Bering-Inscl, rrscheint ansmahmsweise anf den Aleuten und im nordwestlichen Amerika und ïberwintert in

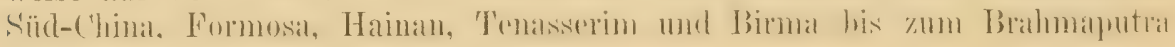
und am Fuße des Himalaya.

\section{Motacilla alba lugens Kittl.}

Motacilla lugens „Pallas" Kittlitz, Kupfertafeln zur Naturg. (l. Vög., 2. Heft, p. 16, Taf. XXI, Fig. 1 (1833- Kamtschatka).

"Motacilla albeola var. camtschatcae Pall." Schlegel, Rev, Crit,, p. 68 (1814- Kamtschatka).

Motacilla leucoptera Zander, Naumannia 185̆1, IV, p. 14 (ex Brehm MS. - Japan) Motacilla japonica Swinhoe, Ibis 1863, p. 309 (Japan. Swinhoe - vergl. Ibis 1874, p. 156 - unterschied nicht zwischen der auf den japanischen Inseln durchziehenden lugens und dem dortigen Standvogel, M. a. grandis. Auf keinen Fall aber kann Swinhoe's Name allein auf letztere bezogen werden).

Motacilla kamtschatica Stejneger, Naturen 1872, p. 182 (Kamtschatka).

Motacilla amurensis Seebohm, Ibis 1878, p. 345, 'Taf. IX, (Japan, "Oorogan Island", Amur. Typus: "Gulf of Abrek in the Sea of Japan").

ILotacilla blakistoni Seebohm, Ibis 1883, p.91 (T'yp. Lok. Japan).

.Motacilla mutabilis Blakiston" Stejneger", Proc. U. S. Nat. Mus. X V, p. 305 (1892ex Blakiston M.S., unter den Synonymen ron higens aufgezählt).

Abbild. (Köpfe): Cat. B. Brit. Mus. X, Taf. IV, 1-4, Flügel t. c., p. 475-477.

Ad. im Sommerkleide: Unterscheidet sich von H. $_{\text {. ocularis durch }}$ gaṇz schwarze Oberseite, sowie die ganz oder fast ganz weißen äußern Armschwingen, ist auch atwas gröber. Ine oherste 'Tril der hehle hleibt liast immer "twas weib, mindestens hleiht vin weiber Kinnfleck. Jüngere Fixemulare haben die inneren Armsthwingen dumkelbatun mit weilis an Wurzelteile, ather zwischen diesem Starlium und dem mit ganz weißsn immeren Amsehwingen findet man alle Überginger. Iner Riicken ist hei

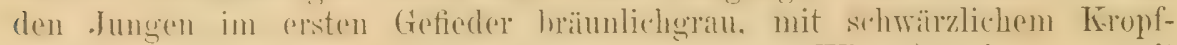
bande, nach der ersten Mauser (also im ersten Winter) rein grau mit

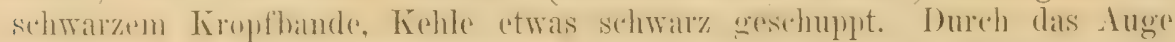
zieht sich bei allen alten Vögeln ein schwarzer Streif wie bei $\boldsymbol{\mu}$. $\boldsymbol{a}$. oculuris, wovon das grauriekige Stadium im Winter sich fast nur durch etwas

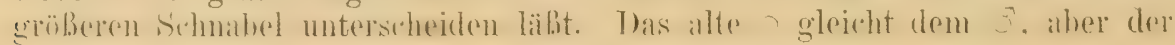


Rïcken ist in der legel nicht so rein schwarz und es ist etwas kleiner.

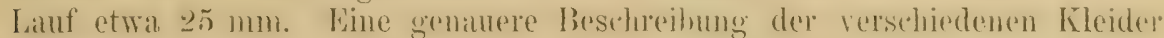
findet sich bei Sharpe, Cat. B. Brit. Mus. X, p. 47t, 478. In diesem Bande sind äherhaupt de weiben Batchstelgen mit grolier. Sorghalt und staunens-

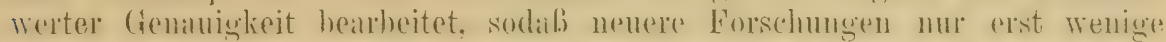

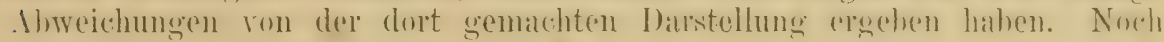
eingehender sind die Kleider von $\boldsymbol{M}$. a. lugens von Stejneger in Proc. U. S. Nat. Mus. XV, 1892 (erschienen 1893) 1. 305-312 beschrichen. Flïgel oad. 92-97, Sehwanz 92-100 $\mathrm{mm}$.

Brïtet in Kamtschatka, auf den Kommandeur-Inseln, Kurilen, Askold und (? nur Nord-)Jesso. - Zugvogel in Ost-Sibirien, der Mandschurei, Chima, Korea und auf den japanischen Inselı; südlich bis Formosa.

Wier wie die yon M. a. alba, rielleicht etwas gröber.

\section{Motacilla alba grandis Sharpe.}

Motacilla japonica [uon Swinhoe] von Seebohm und mehreren andern Antoren.

Motacilla grandis Sharpe, Cat. B. Brit. Mus. X, 1).492 (1885-- Japan).

Abbild.: 'T'emminck \& Schleg., Fauna Japonica Ares, Taf. 25 (unter dem Namen 1I. lugens).

Oad. Oberseite schwarz, nur Stirn und Streif über dem Auge weilß.

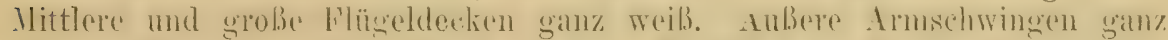

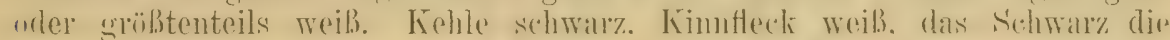

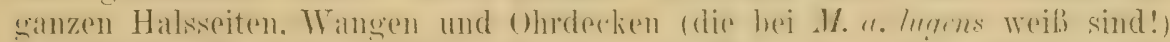

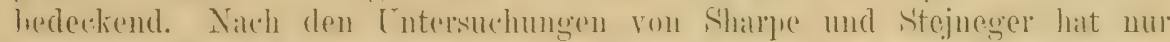

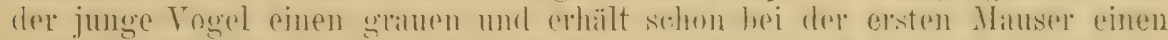

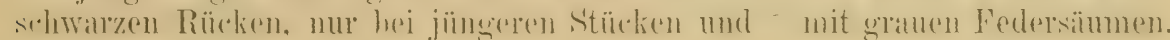
Tauf etwa $2.63 \mathrm{~mm}$.

Brutrogel (angeblich vou Sïd-Jesso an) auf den japanischen Inseln lis zu den Rin-Kiu (Lu-Tsehu) Tnselu. Soheint kein Zugrogel zu sein. Turkommen aukerhalb Japan's nicht sicher.

\section{Gattmg DENDRONANTHUS Blyth 1844.}

(Dendronanthus Blyth. Aum. \& Mag. Nat. Hist. (1) XIII, p. 116 |1844|:

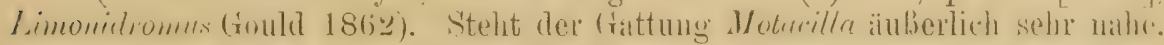
unterscheidet sich aher wie folgt: Das mittelste Stenerfoderpan ist morklirh (rtwa $7 \mathrm{mmn}$ ) hïr\%er, als die ührigen. resschmälert und dïmmsehäftig. (Eig.5:3.) lon dey inneren Armsehwingen ist nur die drittletzte starli rerlängert mud

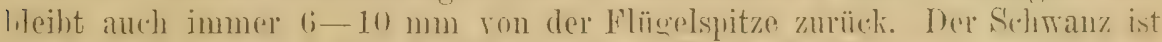
uir.ht so lang wie der Flüg(el. Sehuahed lang. Kralle der Hinter\%ehe gekrïmmnt. höchstens so lang wie die Hinterzehe.

\section{Dendronanthus indica (Gm.). (Kig. 53).}

Motacilla indica Gmelin, Syst. Nat. I, p.962 (1788 - ex Sonnerat und Latham: Indien). Motacilla variegata Vieillot, Nouv. Dict. d'Hist. Nat. XIV, p. 599 (1817- yau Cap de

Bonne-Espérance [errore ex Levaillant, Ois. Afr. pl. 179!] et au Bengale"). Abbild.: Gould, B. Asia, 'Taf. 67. 
Oैad. im Frübling. Oberseite olivengrau, Obersehwanzdecken schwarz-

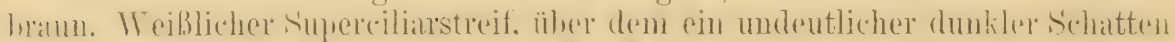

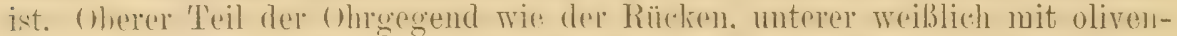

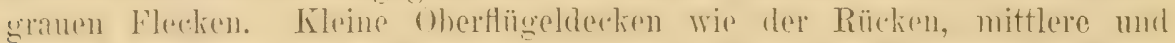

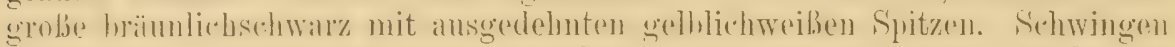
dunkelbraun, Armschwingen schwärzlicher, alle an der Basis weiß, mit Ansmahne der ersten :3 Handschwingen, die aher an der Trumel der dußen-

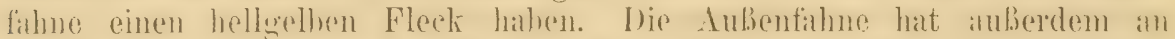

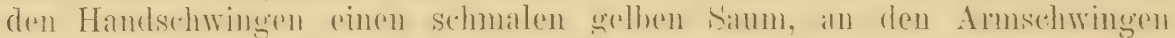
cinen gelblichweißen Fleck vor der Spitze, die imnersten drei

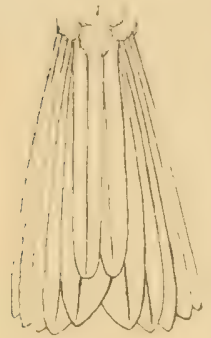

Figur 53. Armschwingen haben ausgerlebute olivengraue Spitzen. Die äußersten beiden Steuerfederpare weiß mit bräunlichgrauer Außenfahne und ausgedehntem keilförmigen dunkelschwarzbraumen Basalfleck über heide Fahnen. Die nächsten drei Parre schwarzbraun, das mittelste olivengrau. Unterseite weiß, an der Brust mit schwachem gelblichen Schimmer, Seiten olivengrau verwaschen. Kropf mit breitem halbmondförmigen schwarzen Fleck, der sich in der Mitte in einem kurzen Streif auf die Brust fortsetzt, an den Brustseiten noch ein kurzer schwär\%lich olivenfarbener Halbbogen. Unterflügeldecken gelblichweiß mit olivengrau überlaufenen Spitzen.

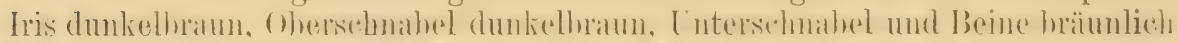

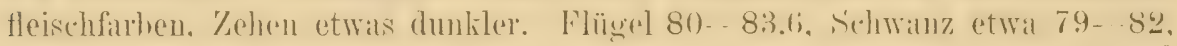
Lauf etwa 21-22, Schnabel etwa $13 \mathrm{~mm}$. O nur etwas kleiner, Flügel

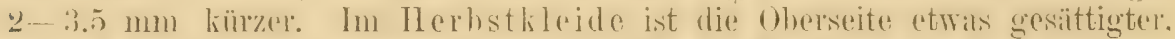
mehr bräunlich. Im ersten .J ugendlideide ist die Oherseite dumbel olivenhraun mit rostbramen Federkanten, ïher dem hell rostgellulehen, breiten Sunereiliarstreif ein hreiter sehwarzer Strich; die Sohwingen sind dunkelhram mit reiblichen Aubensäumen. Armsehwingen nit weiber Basis der Innenfihme. Interseite weiblich. Brust bräunlich rahmfarhen. Kehle vou brammschwarzem bande umsehlossen; äuberstes stenerfederpat weib mit schwarm

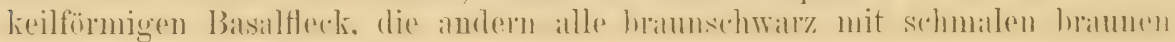
AuBenkanten.

Brutvogel in Ostsibirien, auf der Insel Askold (wie weit nach Westen nicht sicher festgestrellt, aber vermutlich his zum Altai) and horeal und in der Mandschurei. - C̈herwintert in den westlichen 'L'eilen Iudiens, auf ('eylon, den Andamanen, in Malakka. aluf den Sunda-Tusehn. in S'iam. Cochinchina und Süd-China bis Hainan.

Die Bewegungen dieses merkw ïrdigen Vogels sind bachstelzenartig, namentlich auch das Schwanzwippen. Nach den Beobachtungen Godlewski's hält er sich im Ussuri-Lande in Laubwäldern auf, besonders an den Waldrändern. Wenn man sich ihm nähert, beginnt er ein fortwährendes Geschrei, worauf er schwanzwippend auf einem Aste entlang läuft. (Vermutlich wurde diese Beobachtung, in der Nähe des Nestes gemacht.) Nach demselben Beobachter steht das Nest auf Ästen, vom Stamme entfernt, und ist außen so mit Mloos bekleidet, daß es kaum vom Aste zu unterscheiden ist. Von Dörries am mittleren Ussuri (5. Mai u. a.) gefundene Eier sind dunkelgrau, mit tiefer liegenden grau-violetten und schwarzbrannen Flecken und Wurmlinien, außer in der geringeren Größe unsern Kirschkernbeißer-Eiern ähnlich. Nach Nehrkorn $20>14 \mathrm{~mm}$. (Nistweise und Eier sind so ganz verschieden von der aller IIotacillen und Pieper, dab man an einen Irrtum glauben und weitere Forschungen wünschen möchte.) 


\section{Familie MNIOTIITIDAE.}

Kleine dünnschnäblige Singvögel. "Neunhandschrvingig;" d. h. die urse sichwinge ganz rerkïmmert. Innere Armsehwingen nielt rerlingert

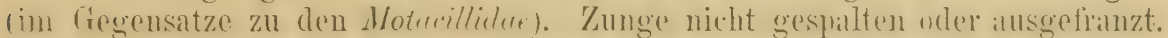
Kralle der Hinterzehe stark gelirümnt, kiirzer als dis Bascilghied der Zehe.

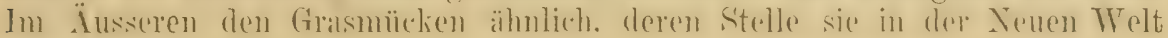
einnelsmen.

Die artemreiche Familie ist rein amerikanisch. Die folgeuden 3 Arten murden je eiumal im palïarktischen Faunengebiete erbentet:

Dendroica coronata (L.) Nordamerika, im Winter südlich bis I’anama. Wurde von den Naturforschern der Vega-Expedition am 25. Mai 1879 am K'ap der'l'schuktschenHalbinsel gefangen. Das ơ ad. ist oben bläulich aschgrau mit schwarzen Streifen, goldgelber Scheitelmitte und gelbem Bürzelfleck. Unterseite weilh mit schwarzem Kropf und Brustseiten, an denen ein großer gelber Fleck steht. Flïgel etwa $75 \mathrm{~mm}$. Vgl. Sharpe, Cat. 13. Brit. Jus. X, p. 311 ; Ridgway, Birds North \& Middle Amerien II, p. 546 . Abbild.: In allen Bilderwerken iiber nordamerikanische Vögel.

Dendroica virens (Gm.) Östliches Nordamerika, im Winter südlich bis Panama. Trurde am 19. November 1858 auf Helgoland von einem Knaben geschossen. ठ̋ad. Oberseite lebhaft oliven-gelbgrïn mit schwarzen Flecken, Oberkopf uugestreift, Oberschwanzdecken grảu. Zügel, breiter Superciliarstreif und Halsseiten goldgelb. Kinn und Kehle bis an den Kopf, sowie Brustseiten sehwarz, Unterkörper in der Mitte blaßgelb. Flügel mit zwei breiten weißen Querbinden. Schwanz weiß und schwarz. Vgl. Sharpe, Cat. B. Brit. Mus. X, p. 297; Ridgway, B. North \& Iliddle America II, p. 562. Abbild.: In allen Bilderwerken nordam. Vögel u, im ,Neuen Naumann "I I, 'Taf. 16, Fig. 5.

Seiurus noveboracensis (Gm.) Nordamerika, im Winter in Westindien und dem nïrdlichen Südamerika. Wurde ron der Vega-Expedition am 14. Juni 1879 auf der 'I'schuktschen-Halbinsel erbeutet. Sieht fast aus wie eine kleine Singdrossel: Oberseite olivenfarben, Supereiliarstreif rabmfarben. Unterseite blabgelb mit dunkel olivenfarbenen Streifen, die in der Mitte des Unterkörpers fehlen. Fliigel etwa $76-80 \mathrm{~mm}$. Vgl. Sharpe, Cat. B. Brit. Mus. X, ]).343 (sub nomine Siuvns naevius); Ridgway, Birds North \& Middle Ameriea II, p. 642. Abbild.: Baird, Brewer \& Ridgway, Hist. $\mathrm{N}$. Amer., B. I. I'af. 14, Fig. 12, auch bei Wilson, Audubon u. a. m.

\section{Familie NFCTARINIIDAE.}

Gine wohl umschlossene Gruppe kleiner Vögel mit meln oder minder lingum und meist gekrimmtem, dimmen. 7ylundrischen Schmahel, dessen Fnddrittel an heiden Schnahelhälften an den S(hneiden fein sägezïhnig ist. ${ }^{1}$ ) Zunge lang, vorschiehhar, in eine gespaltene Rïhre endigend, womit kleine Bliiteninseliten und Nektar aufgesogen werden. Nasenlücher frei, nicht rou Federn rerdrekt, aher mit einem Hautdeckel versehen. Ohne oder fast whu Sehnahelborsten. 1. Sohwinge immer deutlich rorhanden, wenn auch sehr restehieden lang und viol litirzer, als die folgenden. 3.- o. Schwinge dir Flügelspitze bildend. Lauf dentlich geschildert. - Mau kamn die - Vurturirden die Kolibris der alten Welt nemnen, dem sie rertreten gleichsam ilne stelle in den Tropen Asicns und Afrikas, indem sie wie jene ihre

1) Was man aim besten mit starker Lupe oder beim Auf- und Abstreichen mit einer Nadel oder dergl. bemerkt. 


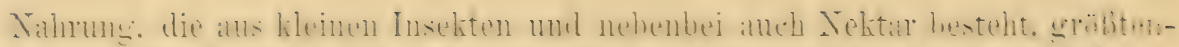

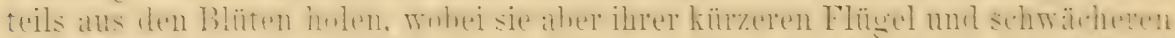

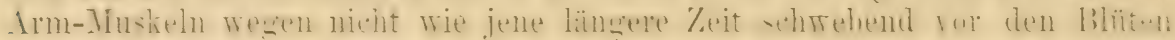
stehen, sonderu sich setzen oder anklammer.n. Die ó sind zumeist in ein

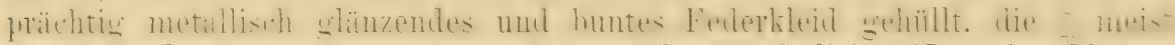
ron den ô sehr rersehieden, die Jungen den ö̈lhulieh. Nur eine Mausur im Jahre.

Die Vectarinäden hewohnen die heiben Lünder der Alten Wolt. Zwwei

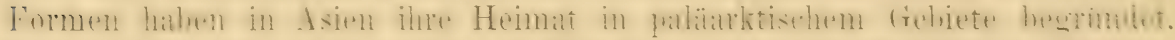
eine andre afrikanisehe geht am Nil bis an den 1. Katarakt. (Shelley. Monograph Nectariniidae 1880.)

\section{Gattung CINNYRIS Curier 1817.}

Schmabel gehrümmt, Schranz kiilzer als der Flügel, finst gerade oder

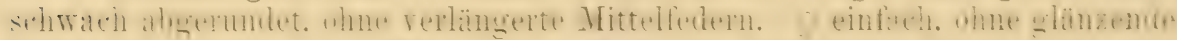
metallische Farhen. - Man hat vielfach die asiatischen Formen ron den

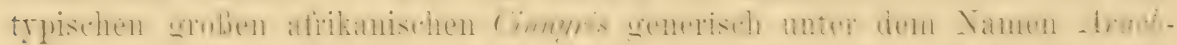
nechthra (nicht zu vertrechseln mit Arachnothera) getrennt. Ieh hin daggegen.

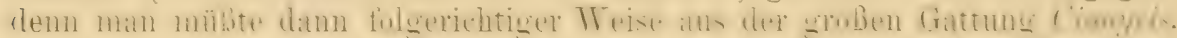

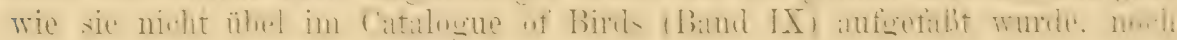
mehrere andre machen, wobei man aber hald in Enzulingliehkeiten sterit. 2 paläarktische Formen:

ơ Ohrdecken schwarzbraun, Halsseiten stahlbläulich, Kehlmitte purpurblau. 오 unten grelt!

of Ohrdecken und Halsseiten metallgriin, ganze liehle blangriin, 오 unten bräunlichgran

\section{Cinnyris asiatica brevirostris (Blauf.).}

Certhia asiaticu Latham, Ind. Orn. I. p. 288 (1790- Indien. Ich folge dem allgemeinen Gebrauch, diesen Namen für die Art anzuwenden, der infolge der unvollkommenen Diagnose zwar nicht abzuweisen ist, aber auch nicht sicher erscheint I. Tectarinia (Arachnechthra) brevirostris Blanford. Lis 1873. p. St (Baluehistani.

Abbild.: Blauford. Eastern Persia, 'Iaf. 14.

Sad. Oberseite glänzend stahlhliu mit grünlichem Schimmer. dic

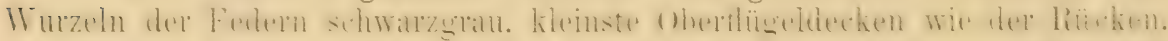
die ührigen matt braumschwarz. Ohrgegend braunsehwil'z. Sehringen schwarzbraun. Schwanz dunkel stahlblau. Nitte der Fehle (scharf und

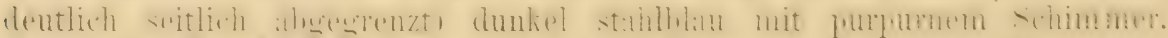

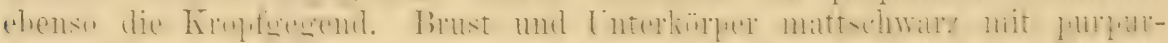

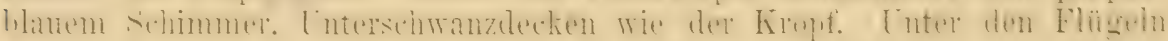
an den Brustseiten ein groBer gelber. rorn orange- his feneroter Federbüschel. Iris braum. Sehmabel und Fübe schwarz. Flügel 56-59. Schwanz. etra 37-38, Sehuabel ungefähr 15. Lauf 14.5 mm. حad. Oherseite grünlich

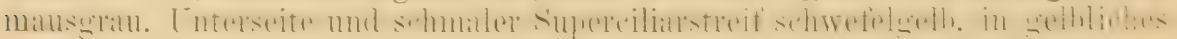
Hellgran rechleichend. Jur. wie aber of in der Mitte der hehle nit einem sehwarzen Streif. 
Ost-Persien. Baluehistan und Afghanistan. - Cimmpis asiatien asiatica

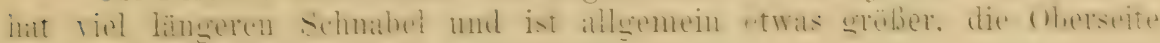
des $0 \overrightarrow{i s t}$ dunkler und mehr stahlbläulich.

Das Nest ist ein ungefäh birnenförmiger, ron einem Zweige an Bïschen herab. hïngender Bau mit seitlichem, runden Eingangsloch, das oft von einem Dache beschiïzt ist. Es besteht aus Gras, Bast und anderem geeigneten Material und ist auben mit Spinnweben, Raupenhäuten, Rindenstückehen und trockenen Blïttern bedeckt. Es enthïlt 3 (selten 4 ) weibe bis hellgrane Eier mit grauer bis brauner Elechung. Mlaabe $16.1 \times 11.4 .16 \times 11.5 \mathrm{~mm}$.

\section{t8t. Cinnyris osea Bp.}

Cimmris oseu Bonaparte, Compte Rend. Aead. Se. 12, p. 765 (1856- Ebene ron Jericho). Abbild.: Sheller: Monogr. Nectarin.

Şad. Oherseite dunkel glïnzend metallgrüu, jede Feder sehwarzbraun

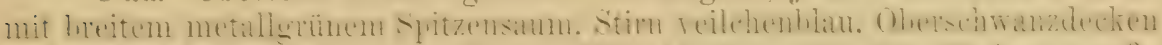

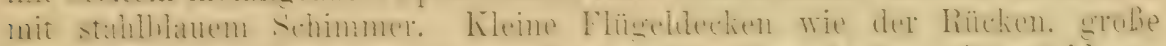

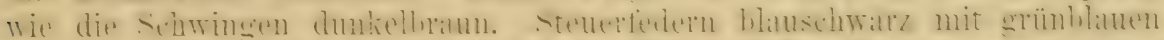

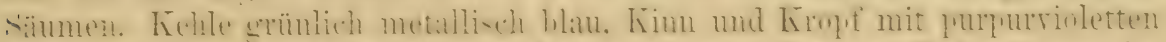

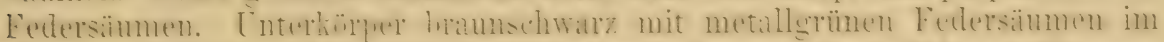

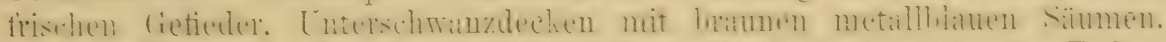

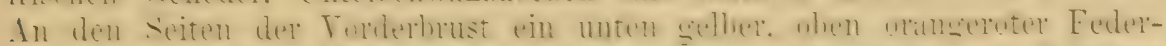

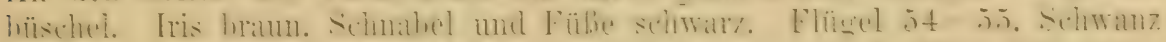

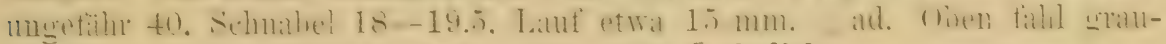
braum, unten hell bräunlichgrau. Jur. dem ổ ähnlich.

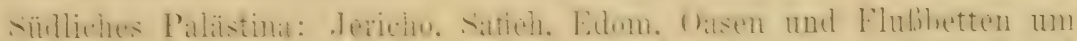

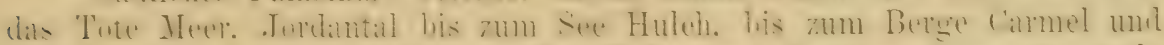

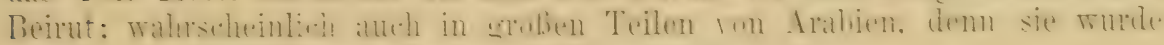
mehrfach in Sïd-Arabien (? nur im Tinter) erbeutet.

Lebensweise wie die andrer Nectariniiden. Nahrung Insekten, die meist aus Bliiten, manchmal auch in der Luft gefangen werden. Lockton ein monotoner, heller Ruf. Jest beutelförmig mit seitlichem Flugloch am oberen Teile. Eier meist 3 , hellgrau bis weiblich mit kleineren oder gröberen, nie aber selı großen. nschgranen oder olivengranen Punkten und Flecken, $16>10.5 \mathrm{~mm}$.

\section{Gattung NECTARINIA Ill. 1811.}

Ton Cimmpres dadurch untersehieden, daß heim ó die beiden mittelsten

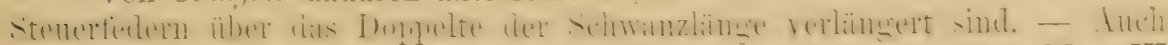
lier muB ieh mich der Auffassung des Autors rou Cat. B. Brit. Mus. IX

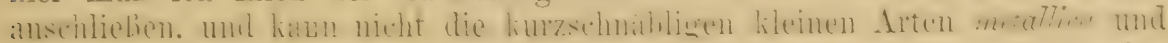
plature generisch sondern. Dies wïre ratsam. wem wir nur die riesige

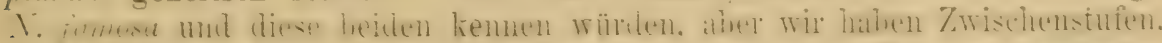

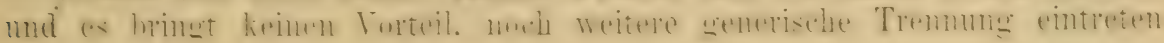
7.1 lassen.

\section{Nectarinia metallica licht.}

Tecturiniu metallica Isichtenstein, Verz. I)oubl.. p. 15 (1823- Dongola).

? Tectarinia muelleri Lorenz \& Hellmayr. Orn. Monatsber. IX, p. 38 (1901-- Yeshbum. s.-drabien).

Abbild.: Shelley, Monograph Xectarin. 
Ōad. Kopf, Hals, Oberrïcken und kleinere Flïgeldecken glänzend

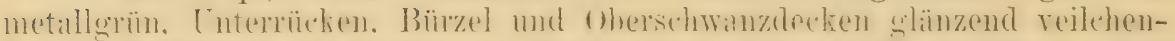

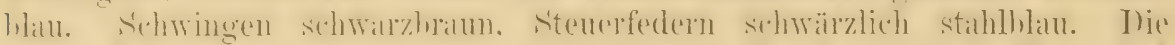

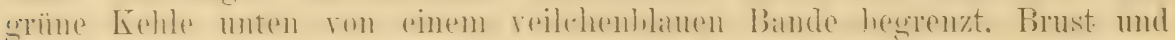

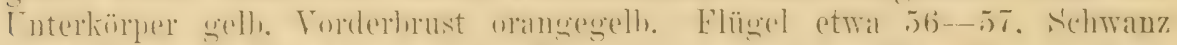

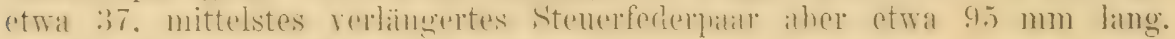
2 und juv. oben grau, unten schwefolgelb.

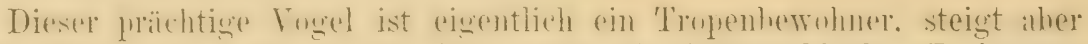
am Nil bis in die paläarktische Zone, etwa bis Assuan himah. Er ist von

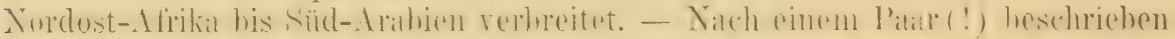

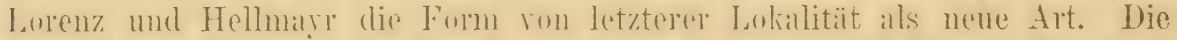

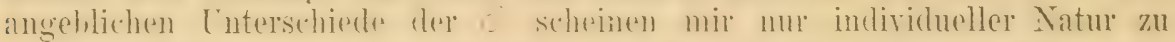
sein, südarabische o aber scheinen durchweg unten heller zu sein. Die

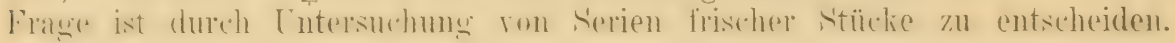

Baut ebenfalls ein hängendes, beutelförmiges Nest mit seitlichem Eingang. Die (meist) $3 \mathrm{Hier}$ sind reinweil oder weil. mit winzigen roten Punkten — abweichend ron denen anderer Nectariniiden!

\section{Fanilie ZOSTEROPIDAE.}

Fine ïher 150 bekamnte Formen enthaltende Familie etwa meisen-

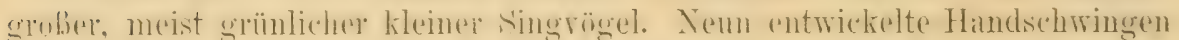

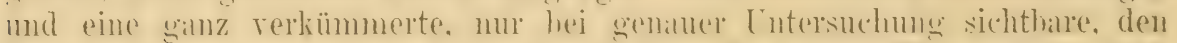

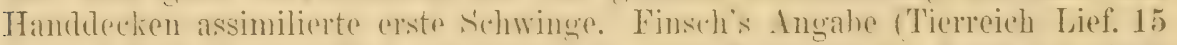
1. 1). dab diese ganz fehle, ist irrtümlich. Die Mehrzahl der Arten hat einen

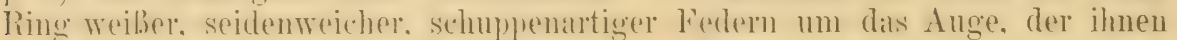

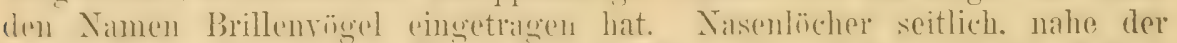

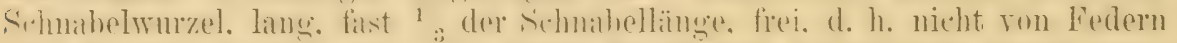
uder Borsten hedeckt. ahe mit rimem Hatutedel gäbtenteils rersehlossen. Zunge protraktil. am Eme wespalten und in kure homartig steife Fasern

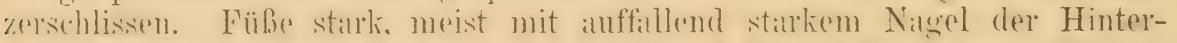

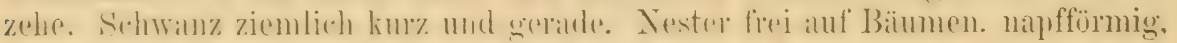

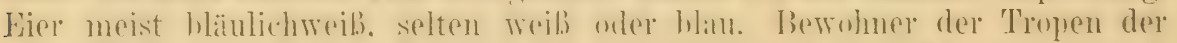

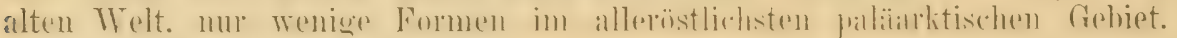
(Finseb, Tierreich Lief. 15, 1901.)

\section{Gattung ZOSTEROPS Vig. \& Horsf. 18.26.}

Umfaßt nach der meist üblichen Auffassung alle Zosteropiden mit Iusnahme der coehäuhten Loghozosterogs Hart. ron den kleinen Sunda-Inseln. (Einsch, 1. c. p. 48), Shelley u. a. trennen ahel auch die westafrikanischen Speirops 11. a.

1 Körperseiten rahmfarben, bräunlichgrau verwsehen. Z.p. loochooensis p. p15

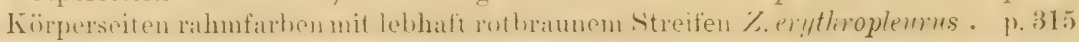

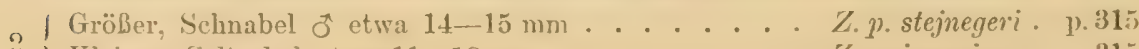

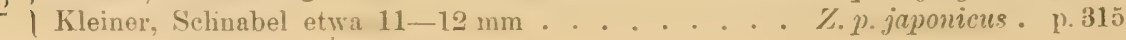




\section{Zosterops palpebrosa stejnegeri Seeb.}

Zosterops stejnegeri Secbohm, Ibis 1891, p. 273 ( .Fatsizio or Hatchi-now-sima“).

Färbung wie die von juponicus, aber Make, namentlich der Schnabel. bedeutend gröber: Schnabel 14-15, Flügel 63.5-65, Schwanz ungefälır $45 \mathrm{~mm}$. Q etwas kileiner.

Bewohnt die kleinen Inseln Mijake und Fatsidschio südlich von .Tokohama.

Tester wie die ron $\% . p$. japonicus, nur etwas gröber, meist auf Ilex oder Clevera Bäumen, Eier 3-4, April und Maai, bläulichweiß, $19>15.5 \mathrm{~mm}$.

\section{Zosterops palpebrosa loochooensis Tristr.}

Zostciops simplex rar. Inochooensis L'ristram, Ibis 1889, p. 221 (Riu Kiu Inseln).

Oberseite wie die vou Z/. $\%$ japonicus, unter den Augen ein dunklerer

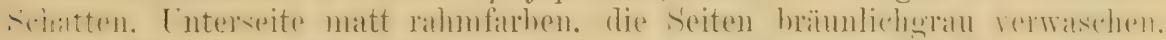
in der Nlitte des Unterkörpers meist ein undentlieher gelber Streif. Kinn

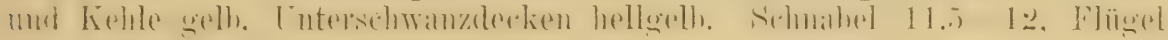
$58-6() \mathrm{mm}$.

Riu Kiu Inseln (Süidl. Japan).

Der \%. pr. simplex aus Süd-Chinal ist merklich kleiner; \%. mussoti

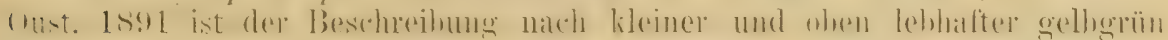

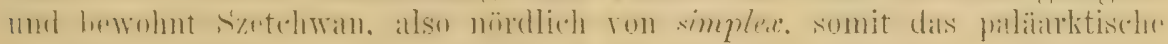
Gebict berïnend. - Z. \% palpebrosa ist oben viel gelblicher und ist der Vertreter in Indien. wie Z. p. nicobaricus aut den Nikoharen und Andamanen.

\section{Zosterops palpebrosa japonicus T'emm. \& S Shlew.}

Zostcrops juponicus Temminck \& Schlegel, in Sicbolds Fama Japoniea, Ares, p. 57. Jaf. 22 (1848- Japan).

Oben einförnigg gelblich olivengriun, uni das Auge cin vorn schmal

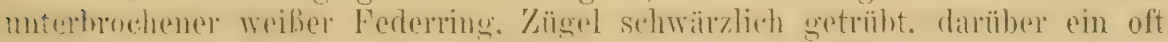

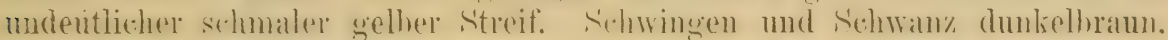

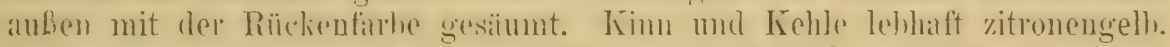

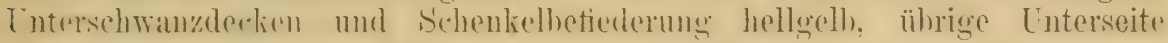
isahellhram, längs der . Vitte heller. fast gelblichweib. Enterflügeldecken. Achelfedern und Innensäume der Schwingen weil., erstere gelhlich angehancht.

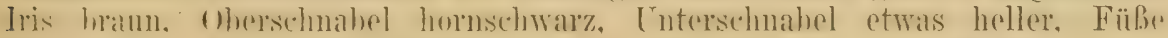
loraungrau. Flügel 59-62, Schwanz 38-43, Schnabel $11-12 \mathrm{~mm}$.

Bewohnt das eigentliche Japan bis Süd-Jesso.

Nahrung Insekten und weiche Frïchte. Nest 4-10 Ful. hoch auf kleinen Bäımen, ein fester, ziemlich dünner, glatter, flacher Napf aus Moos, auBen mit Flechten bekleidet, innen mit Haaren ausgelegt. Eier vom April bis Juli, 4-5 an Zahl, bläulichweib, etwa $16,5 \times 12 \mathrm{~mm}$.

\section{Zosterops erythropleurus Swinh.}

Zosterops erythropleurus Swinhoe, Ibis 1863, p.29.4 (N.-China); Abbild.: Gould, B. Asia II. Tat. 35. 


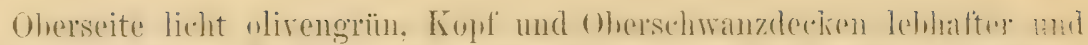

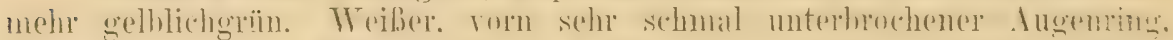

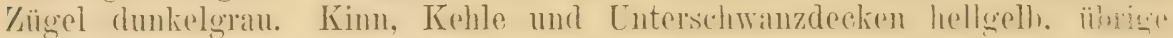
Unterseite rahmfarben, Seiten von Kropf und Vorderbrust mit grauom

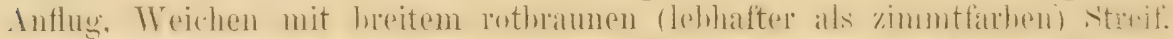

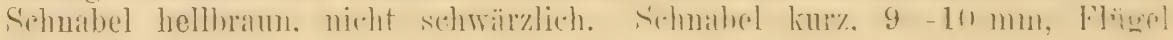
$60-63 \mathrm{~mm}$.

Bewohnt das nöldliche China, wie es scheint sïdlich bis Mupin und Peking: Wurde einmal am unteren Amur bei Dondon erbeutet.

\section{Fumilie CERTHITDAE.}

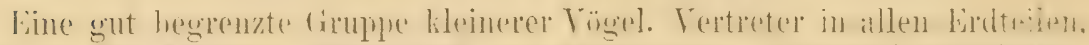

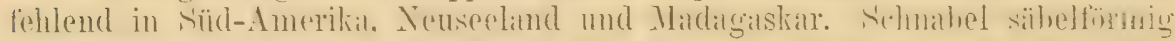

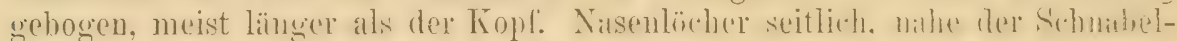

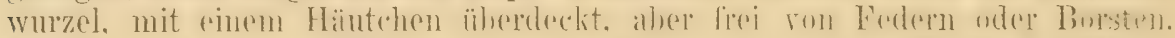

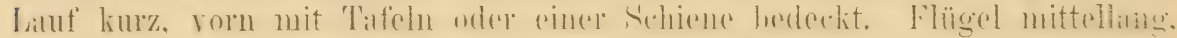
meist merklich länger als der Schwauz. Hand- und Aruschwingen jo 10.

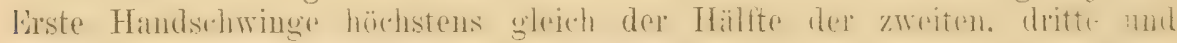
vierte oder vierte und fünfte am längsten. Schwanz zwölffedrig. Zehon

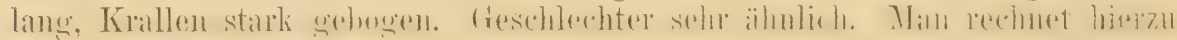
die Gattungen Certhia, Tichodroma, Salpornis und Climacteris. Oh, die letztgenamnte mit Recht, mag dahingestellt sein.

\section{Gattung CERTHIA L. 1758.}

Schmabel so lang wie oder länger als der Kopf, sübelförmig (mehr

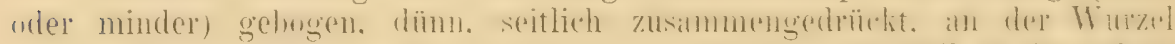

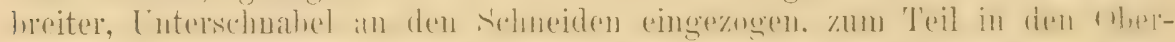

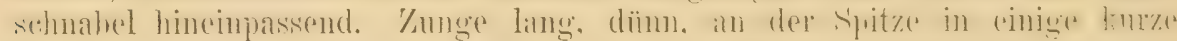
Borsten endigend. Flügel abgerundet, 1. Sehwinge ctwas kiurzer, als die

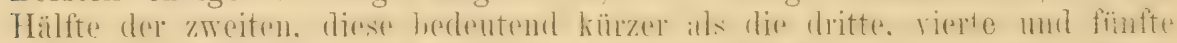

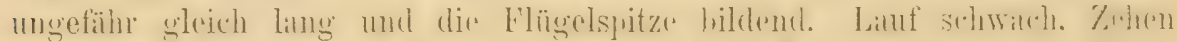

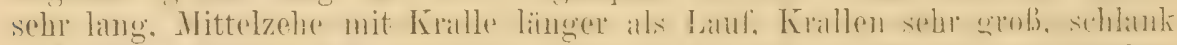

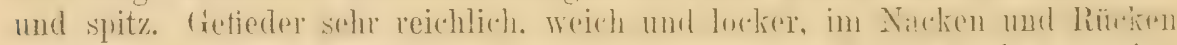

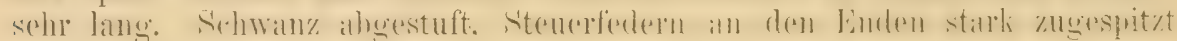
und steif und elastiseh. (Fig. 54.) Geschlechter gleich gefärbt, Junge den Alten ähnlich.

Stand- und Strichvögel. Nur pine im Herbste stattfindende Mauser. Norden der alten und neuen Welt. - Die Banmläufer bilden viele. zum Teil nur dureh Vergleich von Serien klar festzustellende, geographisehe

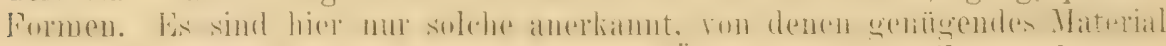
untersucht werden kounte, um danach mit Überzeugung urteilen zu kümnen.

\section{Übersicht der paläarktischen Arten:}

| Schwanz mit etwa 20 scharfen Querbinden ...... C. himalayana. I. 326

1 I Schwanz ohne oder höchstens mit schwacher Andeutung von Querbinden . 2 
Unterseite rein weiß oder weißlich ............. 3

2 Unterseite fahl erdig graubraun............ C. discolor . 1). 322

Kehle rostgelblich, Weichen dunkel rostgelb...... C. stoliczkae. p. 322

Kralle der Hinterzehe größer und flacher, Unterflügeldecken meist (aber nicht immer) ohne, nur bei einigen asiatischen Subspezies mit dunklem Fleck vor der ersten Schwinge, Stirn mit scharfer Längsfleckung, Schnabel bei den europäischen Formen kïrzer . . C. familiaris .

Kralle der Hinterzehe kürzer und gekrümmter, Unterflïgeldecken immer mit großem dunklen Fleck vor der ersten Sclwinge, Stirn mit nur undeutlicher, verwaschener Längsfleckung, Schnabel länger als bei den europäischen Formen ron C. familiaris . . . C. brachydactyla .

p. 323

491. Certhia familiaris familiaris $\mathrm{L}$. (Fig. $5.55,56$.

Nordischer Baumlïufer.

Certhia familiaris Linureus, Syst. Nat. Ed. X, p. 118 (1758- Europa. Wir betrachten. Schweden als terral typica, nach dem ersten Zitat).

Motacilla scolopacina Ström, N. Saml. Norske Solsk. Skr. II, p. 367, Abbild. (1788).

Certlic Scandulaca Pallas, Zoogr. Rosso-Asiat. I, p. 432 (1827- "In sylvestribus Rossiae et Sibiriae". Umbenennung ron Linné's familiaris!).

Certhia septentrionalis Brehm, Handb. Naturg. Vög. Deutschl., p. 210 (1831 - ?partim. „Er bewohnt die ron Deutschl. nördl. lieg. Wälder").

Certhia longicauda Reichenbach. Handb. Scansoriae, p. 263 (185̌3- ex Brandt M. S., Sibirien, "in keinem Punkte von C. costae zu unterscheiden"6).

Certhia fasciata David, Nour. Arch. ILus. Paris III, Bull., p.36 (1867-- Peking).

Certhia familiaris candida Hartert, Mt. orn. Ver. Wien XI, p. 161 (1887- O.-Preußen).

Schwed.: Trädkrypare.

Oad. Oberseite hell tabaksbraun, auf Kopf und Hals dunkler, die Feden mit weißlichen Läugsflecken, die auf Knpf und Oherhals schmïler und licht hrïunlich verwaschen. an den Hilsseiten und auf dem Rücken hreiter und viol weiflicher sind. Bürzel und Oherschwanzdecken licht lohfarlig oder .,talbalisgelh," jede Feder dieser 'Teile an der Basis dunkel schicferfarhen. dann mit ausgedehutem weißen Fleck. die Spitzen licht

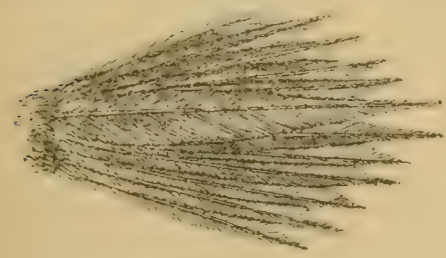

Figur 54. lohfarbig und meist noch wieder mit einem weißlichen Streif an der äußersten Spitze.

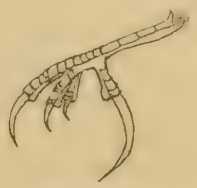

Figur 55.

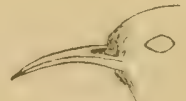

Figur 56.

Weiber Superciliarstreif. Flügeldecken mit dem liücken harmonierend, Handdecken und Afterflügel dunkelbriun mit kleinen, scharfhegrenzten gelbhräunlichen Suitzenflecken. Schwingen dunkelhranı. die ersten drei pinfarhig, vierte nit großem lüüulichgelhen Fleck auf der Außeufithe, die folgenden mit breiter solcher Binde üher heide Fithnen; diese Binde versebieht sich an den Armschwingens mehr oder minder nach hinten, so daß sie ron der Nitte an gekuickt orler ganz, gehrochen erscheint. Anf der Aubenfahne befindet sich in der Spitzenhailfte ein an den Armschwingen und inneren Handsehwingen seharf hegrenzter, an deu äußeren Hindschwingen wenig 


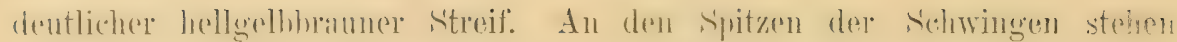

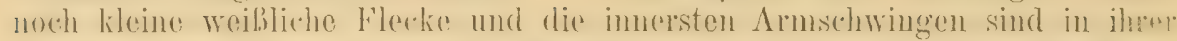

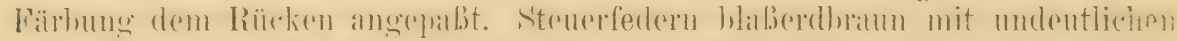

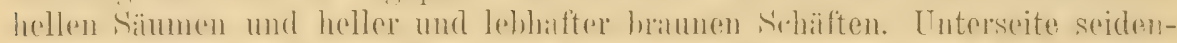

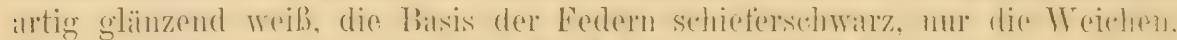

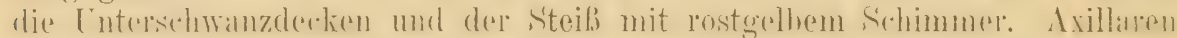
und Unterflïgeldecken rein weiß, oder mit schwacher Andentung eines

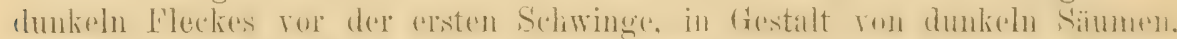

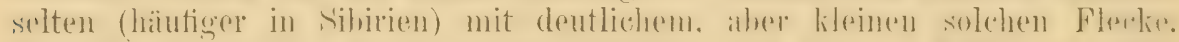

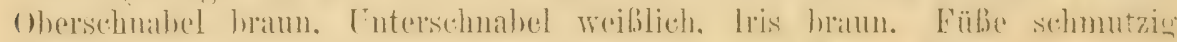

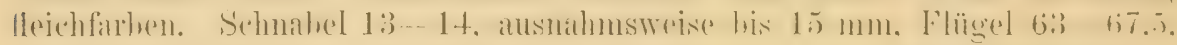
Schwanz ungeführ 60-65. Lauf $14-16 \mathrm{~mm}$. O wie $\sigma^{2}$, nur etwas kleiner. der Schnabol viel kürzer: Schnabel etwa $11-13 \mathrm{~mm}$. Jnx.: Alle Federn der

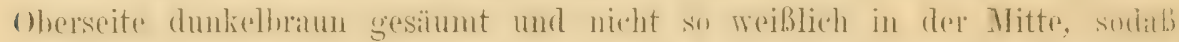

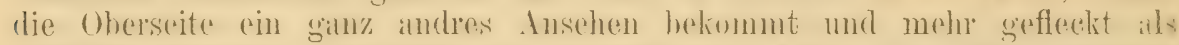

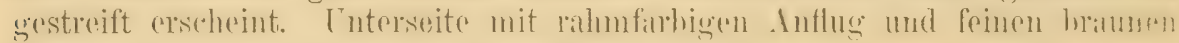
F'ranzen.

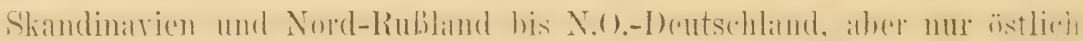
der Oder, also Ost- und West-Preußen, Polen und Rußland bis in den nördlichen Kankasus. Kantrathen und Rumänien, ganz Nord-Asien südliwh his

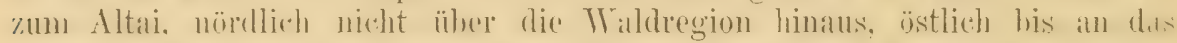

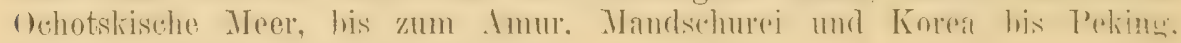
Sachalin, Kurilen und Jesso. ${ }^{1}$ )

Sucht seine fast nux aus Insekten bestehende Nahrung an Baumstämmen, man sicht ihn daher selten anders, als an den Stämmen aufwärts rutschend, die er von unten anfliegt; dabei stïtzt or sich auf seinen Schwanz und untersucht die Ritzen der Rinde mit dem Schnabel. Wie Meisen u. u. macht er regelmäbige Runden und kann meist zur selben 'Tageszeit am gleichen Platze getroffen werden. Die feine Lockstimme klingt etwa wie srih, srilh, der Gesang ist eine feine zwitschernde Strophe. Das Nest findet man hinter loser Baumrinde, in Spalten alter Bäume, halbvermoderten Baumstümpfen, Holzstößen usw: Es besteht aus Reisern, Halmen, Gespinsten, Federn. Zwrei Bruten, je 5-8 Eier, erste Hälfte April und Juni. Lier trübweiß mit bräunlichroten, meist einen Kranz um das stumpfe Ende bildenden Punkten und Flecken. In der Regel ziemlich fein gefleckt und oft kleiner, als die ron C. b. brachydactylu, zuweilen aber ebenso groB gefleckt. Es fehlt in Sammlungen meist an wisseuschaftlich, d. h. mit dem Vogel gesammelten Serien. Sichere Gelege ron dieser Form messen

1) Auf Korea fand ihn Kalinowski im Winter. Tel konnte Stïcke von dort nicht untersuchen. Auch bei Peking wohl nur als Strichvogel im Winter. Die von Jesso sind meist kleiner (Flügel ơ 63.5-65.5, 우 62-63 mm), also zu japonica hinneigend, aber nicht so dunkel. Whe die Jesso-Form getrennt wird, sollten größere Serien verglichen werden. - Vielleicht bewohnt eine noch zu benennende Form Süd-Baikalien. Ein Stück ron Kultuk am Südl. Baikal-See (im Braunschweiger MLuseum) hat fast ganz weibe flecke und änBert lichten Bürzel. - Sihirische Vögel gleichen den Skandinaviern und Nordrussen, jedoch ist in Ost-Sibirien der dunkle Unterflïgel-Fleck vor der ersten Schwinge fast immer sichtbar, wenn auch oft nur angedeutet. Während einzelne sibirische Stücke auffallend hell sind, finden sich am Amur auch solehe, die dunkler sind. Nach dem bisher untersuchten Material kann ich keine Tremung der Ost-Sibirier (oder der Sibirier überhaupt) verantworten. Der allerdings meist sichtbare UnterHiigel-Fleck ist nicht ganz konstant und kommt auch in Europa vor, ebenso gibt es dort auch aberrant gefärbte Individuen - es sei an Brehm's "C. rufidorsalis" (s. in der Synonymie von $C . b$. brachydactyla) erinnert. 
$15.5-16.5 \times 12.5 \times 13$, in Durchsehnitt etwa $15.9 \times 12.9$ und $16.1 \times 12.7 \mathrm{~mm}$. Vou den sehr ähnlichen Kiern der Meisen meist (namentlich die grolggefleckten) dureh die etwas mehı bräunlichen und verwascheneren Flecke, zwischen denen auch manchmal einzelne gräuliche Schalenflecke sichtbar werden, und glänzendere Schale, von denen der Haubenmeise oft nicht, überhaupt nur dureh geübte Sammler zu unterscheiden. - Dieser Baumläufer ist ein echter Waldvogel, der zur Brutzeit die großen Nadelwälder, gemischten und Laubwälder des Nordens bewohnt. Im Winter sieht man ihn oft in Gesellschaft von Meisen. Goldhähnchen usw.

\section{Certhia familiaris japonica Hart.}

Certhia familiaris japonica Hartert, Nov. Zool. 1897, p. 138 (Hondo, Japan).

Steht C: $f$. familiaris am nächsten, ist aber etwas kleiner und die Farhen der Oherseite stehen in lehhafterem Gegensatze zueinander lioustrastiert. die Crmolfurbe ist dunkler bram, die hellen Lälusstlecke sind stharf hegrenzt und weiBlich. Die Anlesufihuen der Steurefoelen hahen hellere Sämme. Flauken und Batuch siud gräuliehrostfurhen rerwischen, dir Tutersehwanzdecken hell rostbräunlich. Flügel 59-61, Schnabel nur $11-12 \mathrm{~mm}$.

Insel Hondo oder Nipon.

\subsection{Certhia familiaris macrodactyla lirehm.}

\section{Langkralliger oder Wald-Baumläufer.}

Certhia macrodactyla Brehm, Handb. Naturg. Dentschl., p. 208 (1831- „Bewohnt die Nadelwälder, im Sommer selten im mittleren Deutschland, häufiger im Herbste und Winter").

? Certhia Nattereri Bonaparte, Comp. List B. Europa \& N.-Amer., p. 11 (1838- nomen nudum. Dalmatia (!); Consp. Ar. I, p. 224 (1850- Partim!! Die Diagnose paßt z. 'I'. auf diese F'orm, z. 'T. auf brachydactyla. Jedenfalls war sie nach dem Gedächtnis gemacht und konfus geworden; zum Vergleiche mag sowoh! macrodactyla als brachydactyla gedient haben! Savoyen, Schweiz).

Certhia costae Bailly, Observ. s. l. moeurs et 1. hab. Ois. Savoie: Descr. nouv. esp. Grimpereau (18.17 - Sayoyen, bei Chambéry. — Die Beschreibung dieser oft erwähnten Art beruhte insofern auf einem Irrtum, als sie mit der für familiaris gehaltenen brachydactyla verglichen wurde. Vergl. Bailly, Orn. Savoie II, p.478-494, 1853).

Certhia brachyrhynchos Brehm, Naumannia 1855, p. 274 (nomen nudum, aber es ist angegeben, daß dies die C. costae auct. sei.); Naumannia 1856, p. 358 (Witten, Görlitz, Renthendorf).

Certhia familiaris vera Brehm, Naumannia 1856, p. 357 (Deutsche Nadelwälder).

Certlia fumiliaris pusilla Brehm, Naumannia 1856, p. 358 (1)almatieu u. Renthendorf.

Lediglich beruhend auf 2 auffallend kleinen ㅇ).

Certhia rhenana Kleinschmidt, Orn. MLnatsber. VIII, p. 169 (1900- ,am Rhein“).

Französ. Grimpereau. Ital. Rampichino alpestre.

Unterscheidet sich von C. $f \cdot$ jumiliuris leicht durch die dunklere Firbung der Oberseite, die sowohl durch die dunklere Farbe der Wurzelteile der Federn, als auch durch die geringere Ausdehnung und sehmutzigeren, bräunlich angehauchten Mittelflecke der Federn (besonders in der Rüickenmitte) entsteht.

Deutschland, etwa yom Odergebiet im Osten bis an die Westgrenze, Belgien, Frankreich, Pyrenälen, Alpengebiet, Österreich-Ungarn bis Bosnien, Herzogowina und vielleicht noch weiter nach S.O.-Furopa. In Italien nur 


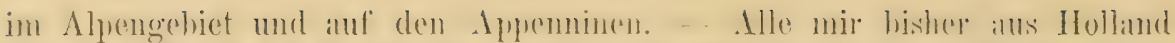

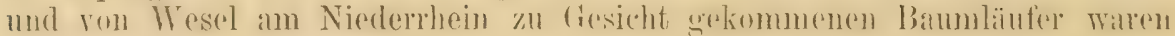
C. brachydactyla, ebenso alle griechischen und spanischen.

Bewohnt die Nadelwälder der Gebirge, aber anch größsere genischte und Laubwaldungen, namentlich Buchenbestände, in den Ebenen und Bergen. Stimmt in Iebensweise und Fortptlanzung vollkommen mit C.f. familiaris iiberein.

\section{Certhia familiaris brittanica Ridgw.}

Certhia brittenica Ridgway, Proc. U. S. Nat. MLus. V, p).113 (1882 - England).

Engl. 'Tree-Creeper'.

C. f. macrodactyla auBerordentlich ähnlich, nur ist die Bürzelfärbung

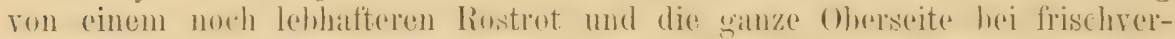

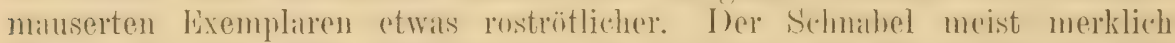

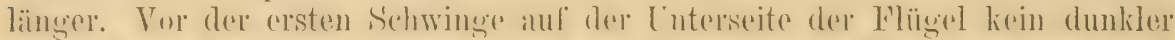
Flerek oder nur die Andeutung aines solehens. vierte hehwinge immer mit großem rostfurbenen Fleck. Sehmabel o $13.5-17 \mathrm{~mm}$.

GrolBbritannien, Insel Man, Irland.

Bewohnt Wälder, Parks und größere, alte Gïrten, aber nicht die modernen, glatten Zier-, Erwerbs- und Zwergobstgärten, wo jedes lose Stïck Rinde, trockene Blatt und dergl entfernt wird. Stimme wie die von C. f. familiaris und macrodactyla, daher wundern sich englische Ornithologen, wenn sie in Frankreich usw. Baumläufer (zweifellos brachydactyla) anders locken hören! Nester meist hinter Rinde, aber auch in Holzstößen, an Holzschuppen, Sommerlauben, in Ritzen und unter Dächern, ausnahmsweise in Steinmanern (Jourdain, Bidwell u. a. in litt.) Die 5-6, selten 7 Eier bald mehr oder minder glänzend oder glanzlos; bald grob, bald fein gefleckt. Maaße (Jourdains Sammlung): $16.5 \times 12,16.5 \times 12.3,16 \times 12,16.8 \times 11.9,16.2 \times 12.1$, $15.5<12.7$ usw.

\section{Certhia familiaris corsa subsp. nov.}

Subspeciei C. familiaris macrodactyla dictae maxime affinis, sed paullo major, rostro longiore, necnon striis albidis magis terminatis, clarius circumseriptis.

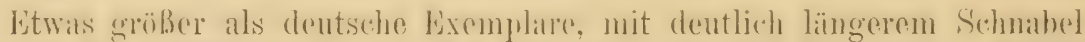
und sethïfer markierten hellen Längstlerken anf der oberseite. Flïged $0^{7} 68-70$, o etwa $64-66.5 \mathrm{~mm}$. Schmabel $0^{7} 15.5-16.5$, o $15-15.5 \mathrm{~mm}$.

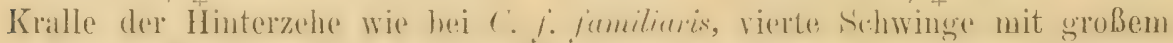

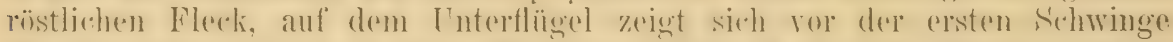

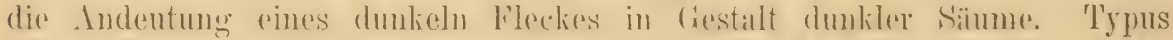
oidd. Corsieal 6. I. 1884, ges. v. John Whituhead. (Mus. Tring.) (No.6184.)

Bewohnt die Bergwälder von Korsika.

\section{Certhia familiaris hodgsoni Brooks.}

Certhia hodgsoni Brooks, Journ. Asiat. Soc. Bengal XLI, p. 74 (1872-- Kasehmir).

Färbung der Oberseite etwa wie bei C. f. macrodactyla, die AuBenfaline

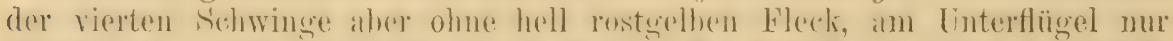
ein kleiner, meist nur angerdenteter dunklire F'leck ror der ersten Schwinge. GröBe fast oder ganz wie bei C. $t$. tianschanica. (Die in Lief. 18 des 
"Tierreich" gegebene Beschreilumg ist nicht ganz zutreffend, weil ansehninend von jungem Vogel entnommen.)

Kaschmir. (Nadelwälder unterhalh der Schneegrenze, Astor und Gilgit in Höhen von 10000 engl. Fuß.)

Sehr dicht gefleckte Eier von $15.6 \times 14.8 \mathrm{~mm}$ wurden im Juni gefunden.

\section{Certhia familiaris bianchii subsp. nor.}

Subspeciei C. familiaris familiaris dictae similis, sed supra minus albescente, magis subspeciei C.f. macrodactyla dictae colore, abdomine luteo tincto, subeaurlalibus luteis, subalaribus macula fusca, necnon alis caudaque longioribus distinguenda.

Oberseite viel dunkler, als bei C. $f$. familiaris, nicht so weißlich, mehr wie bei C: i. murrodurtylu, der Bürzel viel dunkler rosthraun. Lnterschwanzdecken rostgell, Enterkörper mit hrälulich-rahmfarbenem Anfluge. AuBenfahne der vierteu Schwinge mit grobem rostgelhen Flerk. Schwanz utwas dunkler, vor der erstent schwinge ant den linterflügetderele'n ein wohl

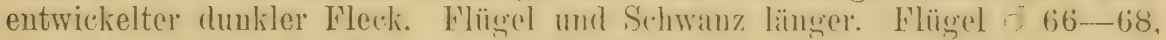
Schwanz o 69-71. Benannt zu Ehren von Dr. Talentin Bianchi in St. Petershurg. Typus Nr. 12114 des Potershurger Museums: siidliche TretungBerge, Kansu, ges. vou Przervalski.

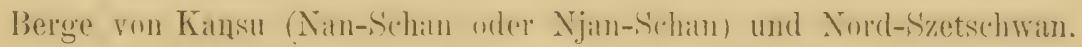

\section{Certhia familiaris tianschanica subsi. nor.}

Subspeciei C.f. bianchii dictae similis, sed supra pallidior, inaculis latioribus, albescentioribus.

Wie $C . f$. bianchii, aber die Oherseite heller, die hellen Lüngsflecke, besonders anf dem Konfe. Ineiter und weißlicher. der Bürzel lichter. -

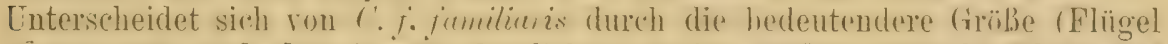
C 66-69!) und den immer dentlichen, meist groben dunkehn lileck auf den Lnterflügeldecken. unmittelbatr ror der ersten s'chwinge. Tierte schwinge an der Aubenfihne mit grolsom restgelhen Fileck. Typus ad. Mk-śu (?Fluß) siidl. Tlian-Schan, 19. II. 1902 (Nr. 1801, Tring Museum).

Gebirgssystem des 'liun-S'chan, von Semire, Dsharkent bis zum östlichen 'Tian-Schan.

\section{Certhia familiaris khamensis Bianchi.}

Certhia lihamensis Bianchi in Sharpe's Hand-list B. IV, p. 355, $36^{\circ} 0$ (1903- "Kansu, Sze-chuen, Upper Mlekong“, nach Sharpe. - Kansu und Szetzschwan errore!! Typ. Lok. Kham am oberen Mekong).

Grundfarhe der Oberseite sohe dunkel. diast schwar\% dir Längsflectie

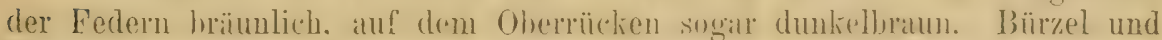
Oberschwanzdecken dunkel rosthraun. S'oiten und Lnterschwanzdecken bräunlich ranchgran. Cuterkörper mit grauem Anflug. Tehle seilenartig weib. Vierte Handschwinge ohne Andrutung eines rostgellen Elrekes an der Aubenfahne, Stenerfedern braungriu, an den Aulensïumen etwats heller.

E. Hartert, Die Vögel der paliarktischen Regiou. 


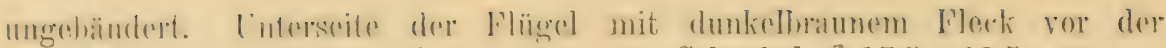
ersten Schwinge. Flïgol of 70-72, o 67, Schmabel o 17.5-18.5 mm.

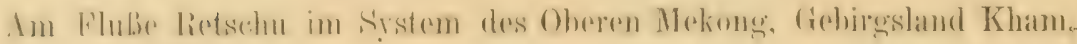
im südöstlichen 'libet.

\section{Certhia familiaris nipalensis Blyth.}

Certhia nipalensis Blyth, Journ. Asiat. Soe. Bengal XIV, 2 p. 581 (1815- Nepal). Certhia Mandellii Brooks, dourn. Asiat. Soc. Bengal XIII, p. 256 (1873- Sikkim).

Von allon anderen Formen von C. jamiliaris durch die tiof dunkel-

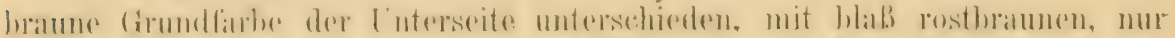

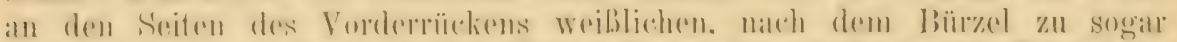

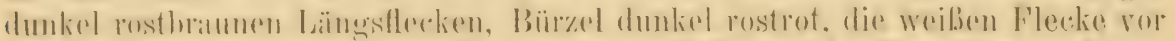

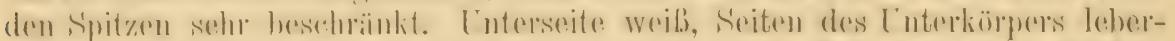

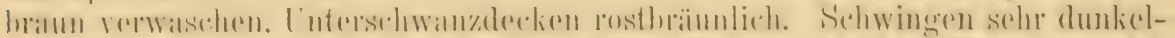

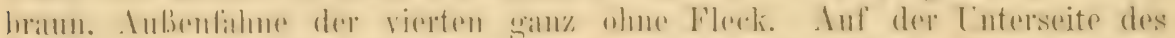

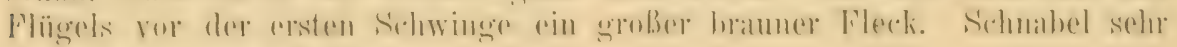
kurz, nur his $\%$. $13 \mathrm{~mm}$.

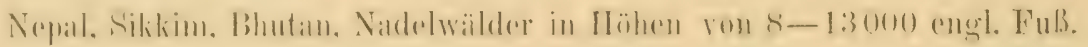

\section{Certhia discolor Blyth.}

Certhia discolor Blyth, Journ. As. Soe. Bengal XIV, p. 580 (1845- Dnrjiling).

Oberseite dunkelbraum, dio Federn in der Mitte filhl rosthrüunlich, die

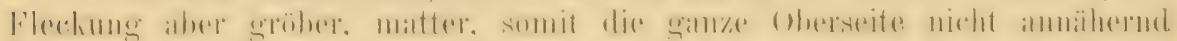

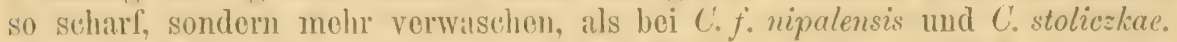

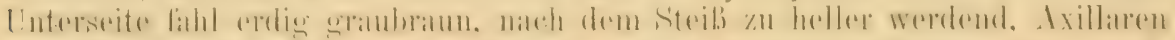

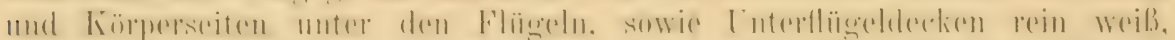

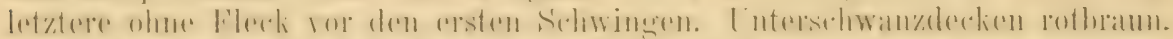

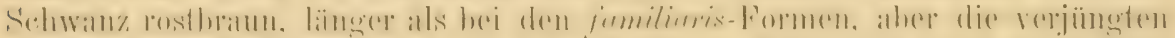

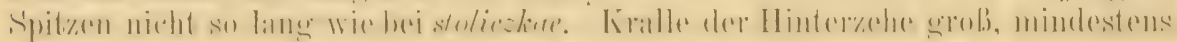
wio die 7/ehe. Sehuahel $14-15.5 \mathrm{~mm}$, Sehwanz ô $78-82 \mathrm{~mm}$.

Himalaya von Nepal, Sikkim, Bhutan, Ober-Assam bis in die NagaBorge und Karenneo. - Anscheinend nicht in so groken Höhen wie

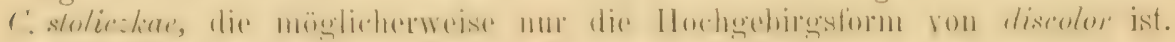

Fine kaum untersehoidhare, anf der Interseite aber vielloicht etwas

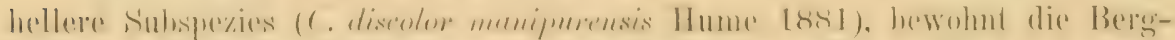

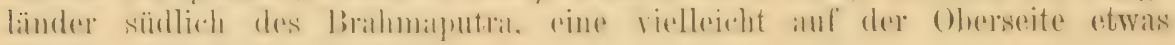
dunklore die Schan-Staten.

\section{Certhia stoliczkae Brooks.}

Certhia Stoliczkae Brooks, Journ. As. Soc. Bengal XLII, 2 p. 256 (1873- Sikkim).

Färbung der Oberseite wio dio von $C$. familiaris nipalensis, von dieser

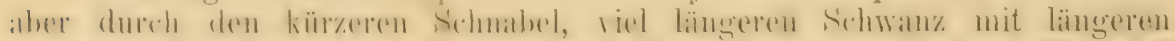

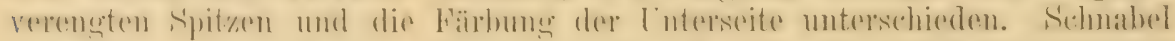
nur etwa 11.5-13 $\mathrm{mm}$, Schrvanz etwa $74-78$, die verjüngten Spitzon

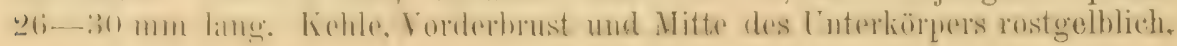




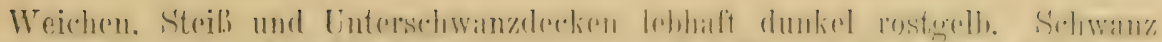

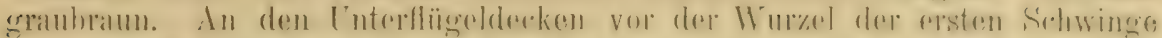

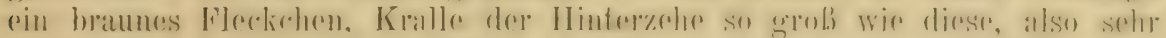
grob, wio bei C. familiaris. Dio 4 ersten Schwingen ohno l'leck an del

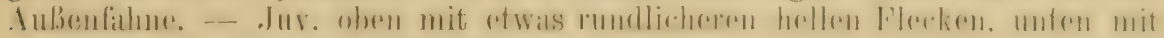
schmalen dunkelhramen léedersïumen.

Himalaya von Sikkim und Bhutan, in Höhen von 10000 und 11000 eng1. Fub, also in selben Gehiete, in den $C \cdot f \cdot$ mipulensis wolnt.

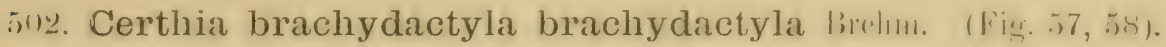
Kurkiralliger orler Garten-Baumliufer.

Certhia brachydactyl( $\left.{ }^{1}\right)$ Brehn, Beitr. \%. Vögelkunde I, 1.570)(1820- Rorlatal).

Certhica longirostris Brehm, Beitr. \%. Vögelkunde II, J.709 (1822- es ist mur gesagt, dab unser Vogel auch C. l. Jeiben köunte!)

Certhin megarhynchos Brehm, Handb. Naturg. Vög. Deutschl., p. 211 (1831 - bewohnt das westl. Deutschland, namentl. Westphalen).

Certhia paradoxa Brehm, Vogelfang, 1. 76 (1855- ,verirt sich aus Ungarn sehr selten nach Deutschland").

Certhia brachydactyla vera und media Brehm, Naumannin 1856, 1. 3599 (Iaubholz in Deutschland, „Nordunerika usw." )

?Cerllia rufi-dorsalis Brehm, Naumannia 1856, p.359 (Win einzigres Stiick von Witten in Westphalen. - Jïn sehr merkwürdiger V'ogel: sicher keine familiaris, im allgeneinen mit den Herkmalen von brachydactyla, aber Oberseite noch lebhafter rostrot als bei Irittunicu. Diirtte cin ganz aberrantes Stiick von brechydactyle sein, das wohl Unicum - wenigstens anf lange Kcit hin bleiben wird).

Certhia brachydactyla commenis A. Ji. Hrehm, Ver\%. Simmul.. p. 10 (1866- nomen nudum!)

Franz. Grimpereau.

Unterscheidet sich von C. jumiliaris macrodaclylu (sowie von C.j. fami-

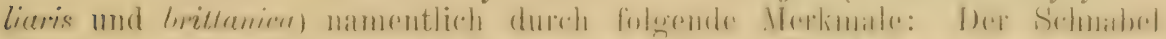

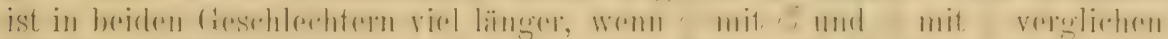

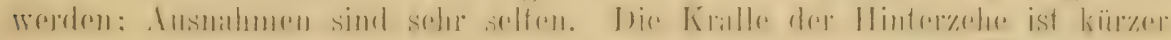

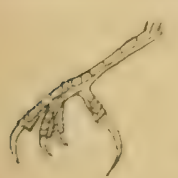

Figur 57 . und verhältnismälbig stärker grekrïmmt; auch dies Konnzeichen ist meist dentlich und konstant. (Lig. 57.) Dic Oberseite ist dunkler, mehr graubraun, da die hellen Streifen in der Mitte der liedern woiblicher, die Federä̈nder dunkler, weniger" röstlich sind, die rostgrelbe (,tabakisgelbe," "lohfarbige") Färbung des Bürzols erscheint weniger

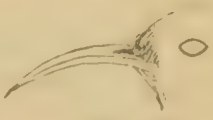

Figur 58.

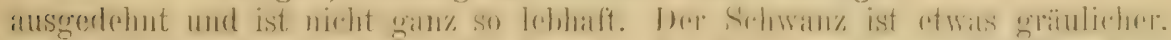

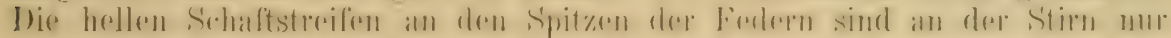

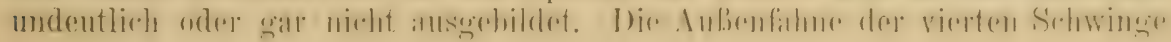

1) Diese Art wurde nach C. 1. Brelm auch von Bailly, Degland 14 a. richtigr unterschieden, nur dab letztere sie C'familiaris uannten und die hellere Art als C. costae beschrieben! Merkwürdigerweise bekïmpften Naumann, J. H. Blasius u. a. Brehm's brachydactyla energisch. Erst nach liingerer l'ause, 1882, 1887 und später wurden die beiden europäischen Arten wieder erörtert, und es zweifelt heuto kein kompetenter Ornithologe mehr daran, dab es in ILittel-Europa 2 Arten von Baumläufern gibt. 


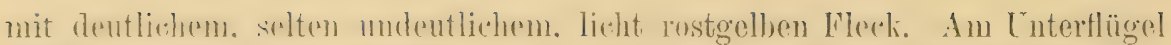

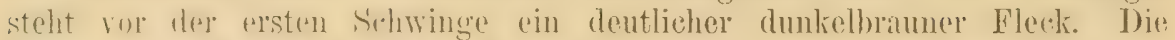

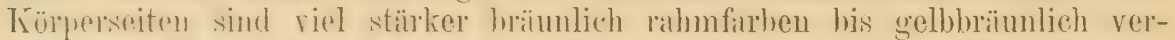
Waschen: dient lähumg erstrecht sich auch üher Bauch und Entersehwan\%-

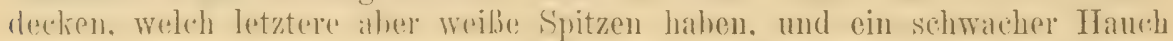

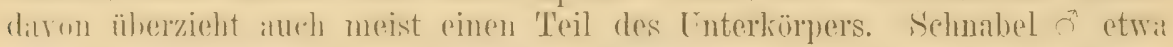
15.5-19.5, o etwa $13.5-16.5 \mathrm{~mm}$, Oberschnabel im Leben fast schwarz, dunkler als bei $C \cdot f \cdot f^{\prime}$ umiliaris und macrodactyla.

Dentsehland - änBerst selten in Ost- und West-Prenken sowie in Hinter-Pommeru, bäufig in Nittel- und Süd-Dentschland. der häufigste Bammläufer in West-I)entschland Holland. Belgien, Frankreich, die niedrigen

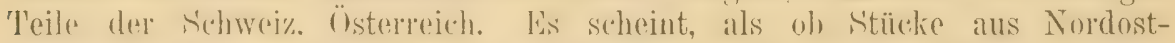
bentsehlanch uhen heller, mit weiblicheren und hreiteren Wlecken. seien. leh konnte aloer nur wenjoge stüche untersuchen, dagegen auch pinzelne

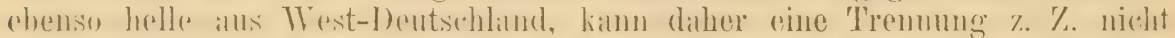

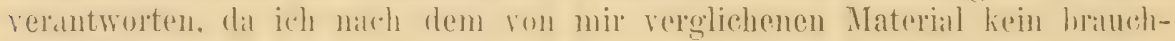
bares Merkmal anzugeben vermag.

Bewohnt zur Brutzeit Gärten, Parkanlagen, Kopfweideu, unit Bäumen bestandene Festungsglacis, Jörfer, Laub- und gemischte Waldungen, Feldhölzer, Alleen. Stimme von der von C. familiaris ganz rerschieden und klingt mehr wie ein rasch hintereinander ausgestobenes twih twih twih tw twiht oder tit tit tit tit, auch der Gesang ist lauter und härter. Nester hinter abgesprungener Baumrinde, in Ritzen, Holzklaftern, Löchern und Ritzen an Gebäuden und unter Dächern, ausuahmsweise auch an Laub. sängernester erinnernde lose Klumpen ron Blättern und Halmen in dichten Hecken nahe am Boden. Die 6-7 (angeblich manchmal 8-12!) Eier unterscheiden sich ron denen ron familiaris und macrodactyla durch durchschnittlich gröbere Fleckung; ein sicheres Herkmal ist dies aber nicht, denn man findet auch ganz ähnliche Gelege ron familiavis. Da die Sammler meist nur die Hier ,ausheben“, ohne die dazu gehörigen Vögel zu sammeln, sind sichere Angaben nur vereinzelt rorhanden. Von Deichler gesammelte tier sicherer brachydactyla messen $16-16.6 \times 12-12.5 \mathrm{~mm}$, im Durchschnitt $16.4 \times 12.4$ und $16.3 \times 12.4 \mathrm{~mm}$.

\section{1): Certhia brachydactyla ultramontaua subs|. mus.}

1tal.: Rampichino.

Unterscheidet sich von C. b. Erachydactyla durch dunkler braune Ober-

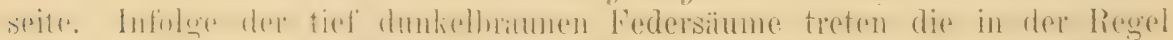

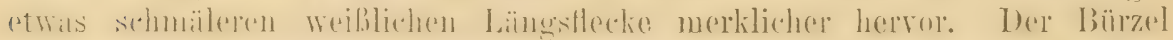
ist von einem dunkleren, mehr rostbraunen, als rost- oder "tabaks"-gelben 'Ton. Die Unterseite ist schwach rahmfarben angehaucht, nicht von dem kälteren, reineren, oder fast bläulich gemischten weiß der Unterseite vou C. L. Irechyductyla. Dio Weichen und der Bauch sind noch dunkler graumauu verwaschen. 'Iypus ơ 3. X. 1902 Panzano bei Chianti, Italien, Nr. 656,

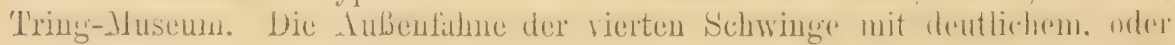
nur angodenteten, selten fohlendem rostgelben Fleck.

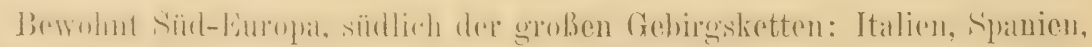

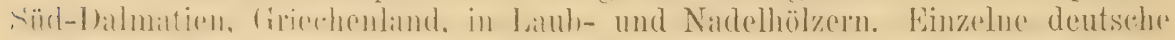

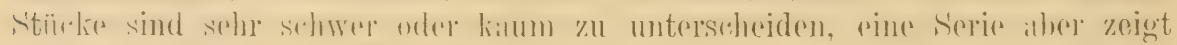
die Versehiedenheit an. (Ich untersuchte über 30.) 


\section{5) 4 . Certhia brachydactyla mamritanica Wither!.}

Certhia brachydactyla manvitanica Witherby, Bull. B. O. Club, 1).35 (1905-Algier \& Tunis).

Ähnlich C.b. ultrumontana, aber die Oberseite noch dunkler, fast sehwarz,

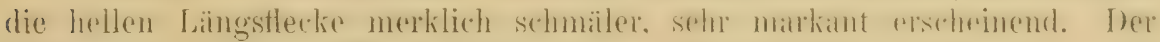
Bürzel noch etwas dunkler rotbräunlich. Schuabel des ç etwa 15.5-17,

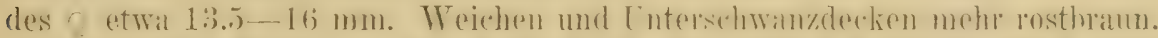

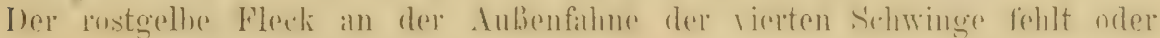
ist nur ingedeutet. (24 untersucht.)

Bewohner der Korkeichenwälder, Kieferu- und C'edernbestände von 'Tunis und Algier. (T'erra typica: Aïn Draham, I'unis.) Auch die I3aum-

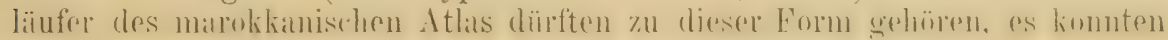
aber hisher nur Sommerstïcke von dort verglichen werden.

\section{0อ. Certhia brachydactyla dorotheae Hurt.}

Certhice Urachydactyla dorotheae Hartert, Bull. Brit. Orn. Club XIV, p). 50 (1901- Giebirge I'roodos anf (ypern).

Ist C. b. manritrenicu sehr ähnlich, die Grundfarbe der Oberseite ebenso

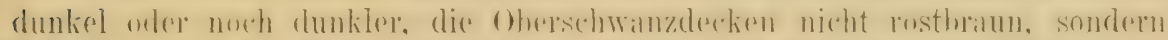

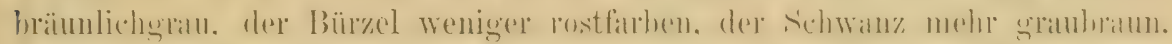

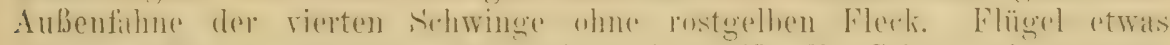
kürzer, etwa $63-65 \mathrm{~mm}$. Unterseite rein weib, die Seiten mit grauem,

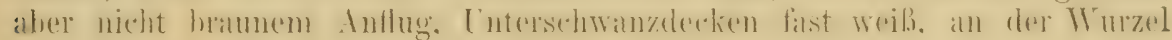
bräunlichgrau. (20 untersucht.)

Bewohnt die Kiefernwälder des 'l'roodos-Gehirges auf Cypern, wo er ein sehr hïufiger Standrogel ist.

\section{Certhia brachydactyla harterti Hellm. ${ }^{1}$ )}

Certhia familiaris harterti Hellmayr, Journ. 1. Oru. 1901, 1).189 (Kleinasien).

Gherseite dunkel rothraun, der Bürzel seln reitlich, die weilsen Längsflecke ziemlich scharf unterenzt und dunkel pingefibt. Stenerfedern sehr röstlich. Kehle reinweil, ährige Enterseite trühweih his sehmutzig rahmfarhen.

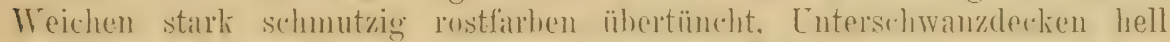
rostfarben. Tierte Sohwinge ohne rostgelben Eleck an der Innenfahue, Hinterkialle stark geliümmt: deutlicher hramgrauel Flecti ror der ersten Schwinger auf der Unterseitr des Vlügrels. Die Mittrlflecke der Federu sind

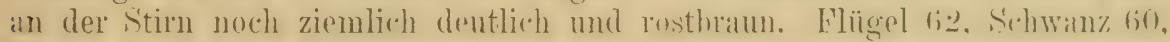
Schnabel 15.5, Lauf $14 \mathrm{~mm}$.

Kleinasien (Smyrna, Alumdagh).

1) In Nordamerika unterscheidet man ferner noch 6 Subspezies. (Vgl. Helimayr, Tierreich Lief. 18.) Sie wurden bisher als Formen von $C$. familiaris betrachtet. Daß sie alle Formen einer Art sind, scheint mir unzweifelhaft, aber nach Naßgabe der ziemlich kurzen Hinterkralle, meist dunkeln Färbung und des großen, allen Formen eigenen dunkeln Fleckeș am Unterflügel möchte ich sie vielmehr als Unterarten ron C. brachydactyla ansehen. 


\section{Certhia himalayana taeniura Serwertz.}

Certhia taeniura Sewertzow, Turkest. Jevotn. (in Izy. Obshch. Moshov.), p. 138 (1873'lurkestan).

Auf den ersten Blick von $C$. h. himulayana durch die graue Oberseite

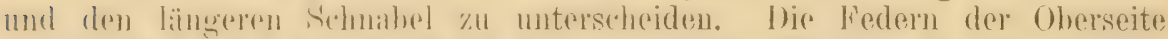
sind asehgratu, alul dem Konf mit hreiten, auf dem Rï̈cken nur mit sechmalen

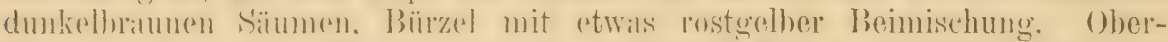

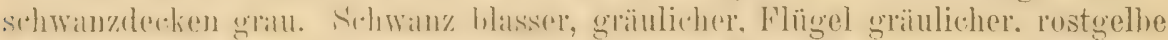
Flügelhinde hasser. Intreseite milehweilo, vom Kropfe an mit rahmfarbenem Anflug, Seiten gräulicher, nicht so bräunlich wie bei $C$. h. himalayana. Schnabel ơ 22-25 $\mathrm{mm}$.

'Turkestan und Afghanistan.

\section{Certhia himalayana himalayana Vig.}

Certhia himalayana Vigors, Proe. Zool. Soc. London 1831, p. 174 (Himalaya).

Certhia Asiatica Swainson, Animals in Menag., p. 353 (1838- India).

Abbild.: Gould, B. Asia 11, Tat. 17.

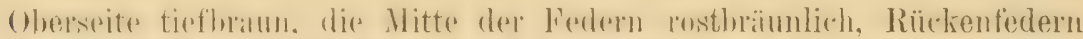
hrämbleheram mit dunlilem S'amm und nach der Basis zu mehr rosthraun,

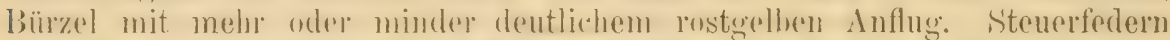

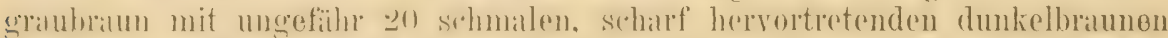

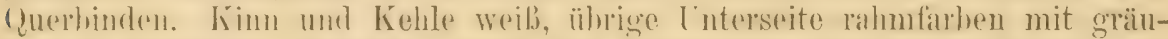

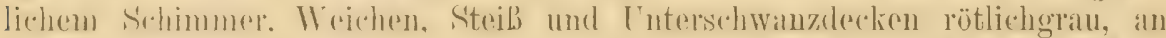

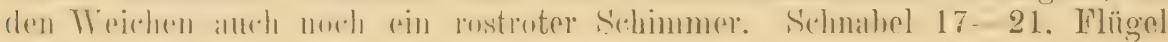
66-71. Sehwanz 63-68 $\mathrm{mm}$.

Himalilya von Kilsthmir his . Issim und Gohirge des westliohen ('hinal bis Kansu. Hine etwas dunklere Form bewohnt Yun-nan (C. himalayana yumanensis Sharpe 1902).

In Kaschmir wurden Nester in Baumlöchern etwa 40 cugl. Fulb hoch gefunden. Fier weib mit roten P'unkten, $15.2 \times 11.5 \mathrm{~mm}$.

\section{(xattmig TICHODROMA III. 1811.}

Schmabel lang, dümn, rundlich, nur an der Wurzel verbreitert. Nasen-

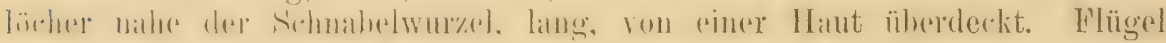

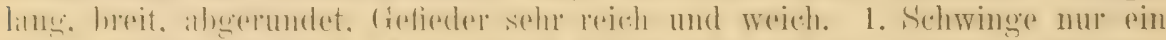

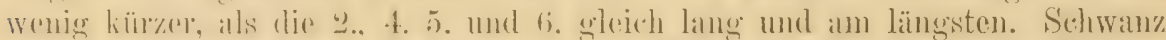

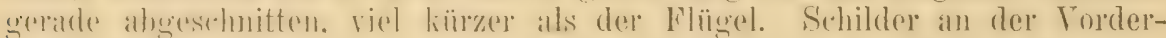
seite des taufes zu einer Schiene verwachsen. Tauf und Tohen für einen

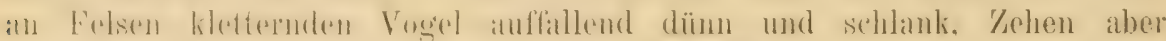
lang. Mittelzuhe otwas längere als dis: Hinter\%ehe, alle mit starken und

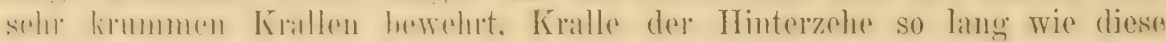
oder etwas länger. Nur eine Art bekannt. Mausern das Kleingefieder »weimal in .Jahre! 


\section{Tichodroma muraria (L.).}

Manerliüer.

Certhia muraria Linnacus. Syst. Nat. Ed. XII, p. $18+$ (1766- Siid-Europa).

Metacilla longirostra Gmelin, Reise Rußı. III, p. 100, 'Taf. XIX, 2 (1774- Gebirge Yersiens).

Tichodroma alpina Koch, Syst. baier. Zool., p. 80 (1816- „Hochberge").

Tichorlroma phoenicoptera 'Temminck, Hanuel d'Orn. Ed. II, 1, p).412 (1820- Unbenennung von Certhia muraria).

Tichodroma Europaea Stephens, in Shaw, Gen. Zool. XIV, I, p. 187 (1826- Umbenennung ron Certhia muraria. Deser. nulla. "South of Europe"

Tichodroma Lrachyitynchos Brehm, Handb. Naturg. Vög. J)eutschl., p.213 (1831"Alpen 'Tyrols und Kürnthens").

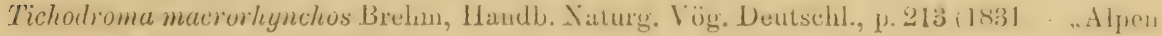
der Schweiz und Salzburg's, wahrscheinlich nicht in Tyrol").

Tichodroma phoenicoptera? var. subhemalayana Hodgson, in Gray's Zool. Misc., p. 82 (1814- Nepal. Nomen nudum!)

Tichodroma nepalensis Bonaparte, Consp. Ar. I, J.225 (1850- „ex Asia centr."

Tichodroma Hoff meisteri Reichenbach, Handb. Orn., Scansor., p. 271 (1853--- Namgiah (Indien)).

Tichodroma media Brehm, Vogelfang, p. 77 (185̃ - "Tyrol und Kärnthen bei Salzburg usw."

Tichodroma muralis David \& Oustalet, Ois. Chine, p. 88 (1877 - ex Brisson).

Engl.: Wall-Creeper. Französ.: Grimpereau de muaille. Ital.: Picchio muraiolo.

ơad. Herbstkleid: Oberkopf hell graubraun, einige der Federn

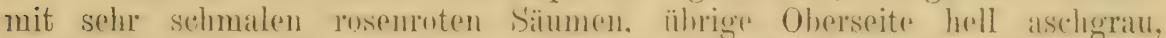
nnterer Bïrzel und Ohersehwanzdechen schieforfalhen, letztere am dunkelsten

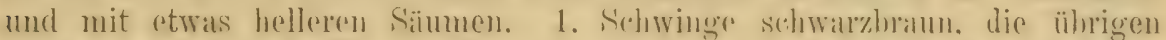

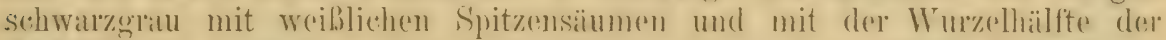

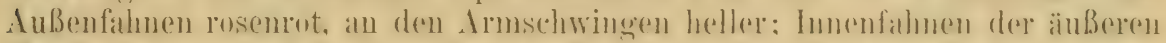

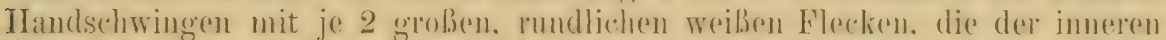
meist ohne oder mit nur 1 weilien. dir der Almselhwingen meist ohne oder

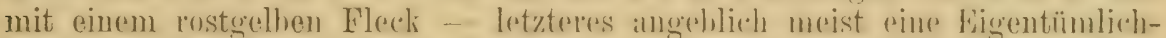

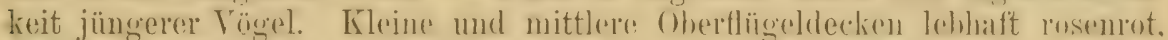

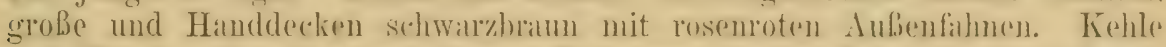

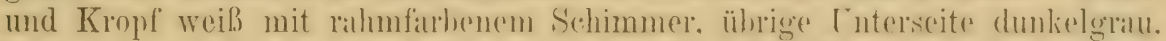
Unterschwanzdecken mit weifen Spitzen. [nterfligendecken gralu mit roten

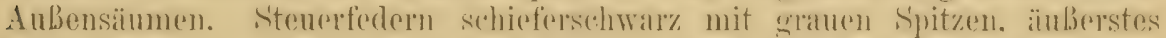

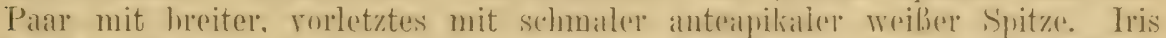

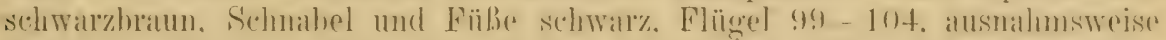
$110 \mathrm{~mm}$, Schwan\% etwa 55-65, Lauf 20-22, Schuabel 23-35 mm.

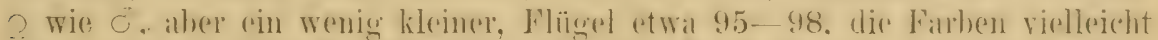
etwas weniger lohbaft. Frählingskleid: Kojof dunkel aschoran, öhrige

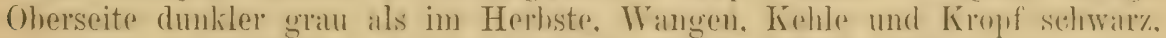
sonst wie in Herhste. atwas weniger lehhaft gefïrlet. Flüger] ringer mm kuirzer, Kehle und Kropf nicht so rein schwarz. Jur. dem o ad. sehr

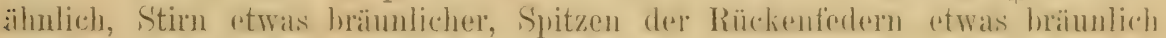
verwaschen, die hellen Schwingenspitzen etwas breiter.

Hochgehirge Mittel und Süd-Furopats (Alpen, Sierra Nevada, P'yrenäten, Apenninen, Karpathen. Balkan), Kaukasus, 'Tukestan, Nord-Persien. Aluhanistan, Tihet, Mongolei und Himalaya his natch Bhutan, im Winter liswoilon his in 
das mittlere Indien. Soll anch in Nord-Afrika (Atlas, Abessinien ?) rorkommen. Verfliegt sich bisweilen in ehenere Is̈̈nder (Süd- und Mittel-Deutschland, Bretagne, Normandie, dreimal England).

HIan sieht diesen Vogel selten anders als an steilen Felswänden ruckweisè emporkletternd, wobei er fortwährend Schwanz und Flïgel lüftet. Die Lockstimme klingt etwa wie $=$ pli, pli pli pli pli pli. Die Nester stehen in den Ritzen steiler, oft unzugänglicher Felsenwände. Fs sind große Klumpen aus allerhand weichem Itaterial. Dic drei oder mehr (meist 4 ) Eier sind oral birnfömig, matt- oder schwachglänzend weiß, mit oft nur wenigen, kleinen, braunroten, gegen das stumpfe Ende hin zahlreicheren Punkten, zureilen auch mit einigen bläulichgrauen Pünktchen. Die Maße von 15 Eiern in verschiedenen Sammlungen ergeben einen I) urchschnitt ron etwa $21.3 \times 14.3$. ein Haximum ron $22.7 \times 15.7$ und ein Minimum von $20 \times 14 \mathrm{~mm}$. Gewichte 130 und $145 \mathrm{mg}$.

\section{Familie SITTIDAE.}

Mehrfach als Interfimilie der L'aridue angesehen. Meisenähnliche kleine Vögel, deren Fïß㇒e aher mehr zum Klettern geeignet sind: Zehen, hesonders Mittel- und Hinterzehe stark und lang. mit mïchtigen, seitlich zusammengedrïckten Krallen. Lauf kurz, bei den paläarktischen Formen mit deutlichen Gïrteltafeln bedeckt. S'chnabel grelade (bei . Veositta Hellm. auf der Firste sinft eingesattelt). keilföming, an einen rundlichen Spechtschnahel erinnernd. (Fig. 59.) Nasenlögher frei oder mit Federborsten bedeckt. Zunge seitlich fein gezilhnt, an der Spitze kleine Fisern. Gefieder weich und locker. Schwan\% kurz, werch. gerade. 12 Stenerfedero. Firste Schwinge sehr kinz, aller deutlieh entwickelt, ron auben zu sehen, im Dunkehn zu fühlen. 2.-4. oder 3.-5. Schwinge am längsten, immer 10 Hand- und 10 Armschwingen. dieschlechter nicht wesentlich rersehieden. Innge deu Alten ganz ähnlich. Kletternde Tilgrïgel. Nahrung Inseliten und Larren, Kerne. Nüisse. Frü̈lıte. Nisten in Lürchern mol Höhlen, deren Lingang einige Formen durh Lehm oder derghl. rerkleinern, Fier weiß mit rötlichen Flecken. Die austrialischen Vroxittu diugegen, deren Zugehörigkeit 7.11 der Familie vielleicht hezweifelt werden kimm, batuen ein wundervoll den Ästen angrepabtes, oben offenes (keineswegs röhrenförmiges!) Nest und legen blïulichweiße, braun- und graugefleckte Eier.

\section{Gattung SITTA L. 1758.}

Nasenlïcher größtenteils mit Federn und nach rorwärts gerichteten Borsten hedeckt. Flïgelspitze von der 3.-5. Handsehwinge gehildet, 4. am längsten, im übrigen gelten die Merkmale der Familie Sittidae.

\section{Übersicht der paläarkisehen Arten:1)}

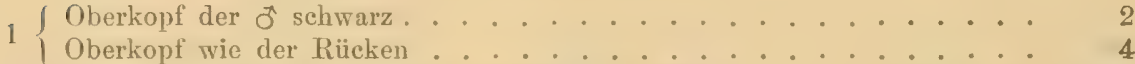

2 Kropfgegend mit grobem kistanienbraunem Fleck . . . S. krïperi. p. 336

2 Kropfgegend olne kastanienbraunen Fleck........... 3

1) Die neueste und beste systematische Behandlung der ganzen Gattung gab Hellmayr, Lief. 18 des „Tierreich“, p. 169-195 (1903). 
Oberkopf in beiden Geschlechtern schwarz, Weichen lebhaft kastanienbraun

Oherkopf nur bei den of rein schwarz, Wreichen gräulich his rostgelh

S. leucopsis . p. 337

S. canadensis (whiteheadi, villosa) . p. 335

4

(Wurzelhälfte der mittelsten beiden Steuerfedern größtenteils weiß

Wurzelhälfte der mittelsten beiden Stenerfedern wie der- Rest derselben

Unterschwanzdecken, Unterkörper und Weichen kastanienbraun

S. cashmirensis .
Unterschwandecken weißlich mit kastanienfarbener. Wurzel und ebensolchen

Seitenrändern, Weichen der ơ kastanienbraun . . S. europaea.

Unterschwanzdecken blaßrostfarben oder rahmgelblich, nach der WVurzel

zu meist grau, Weichen ohne Kastanienbraun . . . S neumayer . p.338

\section{Sitta europaea europaea $I_{\text {. }}$.}

Sitta europaea Linnaeus, Syst. Nat. Ed. X, p.115 (1758- Europa, Amerika, letzeres irrtümlich! Als typischen Fundort sehen wir Schweden an, nach dem ersten Zitat).

Sitta suecica Brehm, Vogelfang, p. 74 (1855- Skandinarien).

Sitta europaea sordida A. E. Brehm, Verz. Samml., p.6 (1866-- nomen nudum!).

Schwed.: Nötväcka.

Cad. Oberseite bläuliehgratu; von den Nasenlëchern durh das Augre und an den Halsseiten entling verläuft ein schwaller Streif, üher demselhen hinter dem Auge und an den vorderen Stirnfedern läbt sich oft die Andeutung einer weißen I,inie erkennen. Schwingen hran mit schmutzigweiben InnenSäumen, dic äußerste Basis weif, 3.-5. von der Mitte der Aubenfahne an verschmïlert und an dem Wurcelteile mit weißlichen AuBensïmmen, innere Armschwingen blänlichgrau, die übrigen mit ehensolehen Säumen. Mittelstes Steuerfederpar wie der Rücken, die nächsten heiden schwarz mit grauen Spitzen, die darauffolgenden beiden an der Imuenfahme mit grobem anteapikalen weißen Fleck, das äußerste Paar auf beiden Fahmen mit großem anteapikalen weißen (Querfleck, der aher nicht gerade durch die l'eder verläuft, sondern auf der Aufenfalue mehr nach der Wurzel zu steht, da die graue Sitze ausgedehnter ist. Halsseiten und Cuterseite weih, Weichen lehlaft kastanienhraun. Cnterschwanzdecken weib, nach der $T^{\top}$ urzel zu kastanienbran und heiderseits mit derselben Farbe, einige auberdem noch am Wurzelteil der Imusufinem hellgran. Axillarew grau, Unterflügeldecken mittschwarz, nur die vorderen Unterbanddecken weib, Flügel ungeführ 78 -91.5, Schwanz 47-48, Schnibel 18.5-19.5, Lauf $17-20 \mathrm{~mm}$. O dem ö zwar ähulich, aher sofort durch die viel hellere, mehr zimtartig rotbramue Fähmu an den Enterschwauzdecken und Treichen zu unterscheiden, auberdem ist der beim of reinweiße Cinterkürver lell ockergelblich oder dunkel rahmfarhen verwaschen. Jur. wie die Alten.

Ganz Skandinavien, Nordrußland ${ }^{1}$ ) und die dänischen Inseln his Middelfart auf Fünen und Fanï im kleinen Belt (uicht zu relwechseln mit Fanö nördlich von Sylt).

Lebensweise und Fortpflanzung ganz wie die von S. eur, caesia.

1) Herr Dr. G. v. Burg erlegte am 31. Dezember 1901 zu Rumpel bei Olten ein Stück, daß sich nicht von ơ $S$. e. envopaea unterscheiden läßt. Es ist ein altes ô, irrtümlich als "우 "etikettiert. Wenn es nicht etwa eine aberrante caesia ist, duirfte das Vorkommen ein ganz ausnahmsweises sein. 


\section{Sitta europaea homeyeri Hart.}

Sitta caesic homeyeri Seebohm, B. Japanese Eimpire, p.92 (1890- „Pomerania, the Baltic Provinces of Russia, Poland, and the Crimea," nomen nudum! Seebolim gab weder eine Beschreibung, noch die Verbreitung richtig an. In Pommern kommt nur S. e. caesia vor).

Sitta caesia homeyeri Hartert, Ibis 1892, p. 364 (Ost-Preußen).

Abbild.: Neuausgabe des Nanmann II, 'T'af. 23, 3.

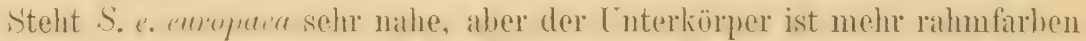

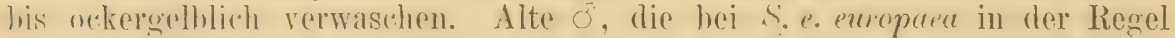
anf dere L'nterseite ganz weil.) sind, baben pinen deutlichen rahmfarbenen Anflus. währond die dunkler und his in die Kropfgegend rostgelblich verwasehen sind, sodib, sie manchmal s. e. lnitumien und hissen Stücken von S. e. caesia ähneln!

Russische Ostser-Provinzen. Ost-Preuben, Polen. (Selie aus der Krim nicht untersucht.)

Lebensweise und Fortpflanzung ganz die von S. e, caesia.

\section{Sitta europaea uralensis Glog.}

..Sitta europaea, var. sibirica P., S, uralensis Lcht.; uralscher Kleiber" (sie!) Gloger, Vollst. Handb. Naturg. Vög. Eur., p. 378 (1834- partim! Augenscheinlich vereinigte Gloger unter seiner gleich doppelt [ex Pallas und Licht. A. S.] benannten neueu Form sowohl unsere S. e. uralensis, als anch S. e. amurensis Von den beiden in derselben Keile publizierten Namen nehme ich den allgemein angenommenen zweiten Namen an, weil die demselben zu Grunde liegenden 'Typen vorhanden sind, und wenigstens die Beschreibung „unterhalb .... ganz weiß", in Verbindung mit dem Vorkommen „im ganzen außereuropäischen Rußland", sich sicher auf die westsibirische Form bezieht).

Sitta Asiatica Gould, B. Europe HI, Taf. 236 (1837- ex 'Temminck M. S. „Russia“).

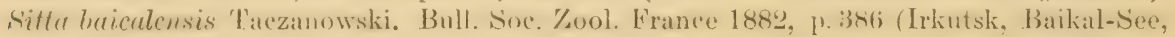
Daurien).

Sitta ammensis clara Stejneger, Proc. U. S. Nat. MIus. IX, p.390, 392 (1886- Jesso. Die Beschreibung beruht auf Irrtum, indem anscheinend $q$ mit ô verglichen wurde).

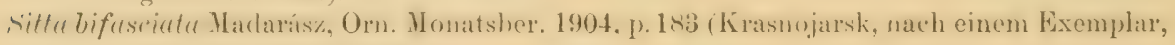
das ich untersuchte).

Wie S. e. erropaea, aber viel kleiner, Flügel ơad. 80-84, meist

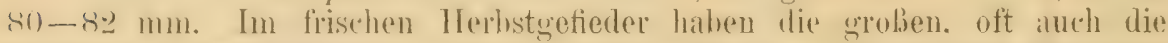
mittleren Oherflügeldecken sehmalo woike s̈̈̈ume. I) vordere Stimrand ist dentlich woiblich. Interseite der e rein weil., nu dio Weichen hastanionrothlaun. Interkürper der o nur sehr leicht rostgelhlich angehaucht, die

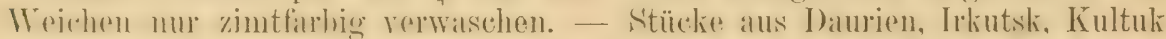
haben meist frinere, sehlankere Sehnibel. Fihenso sehlanke Schuähel liommen

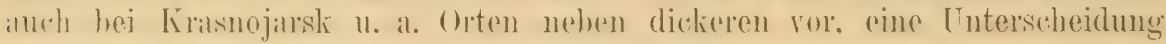
der sogenamnten baicalensis ist daher unmöglich.

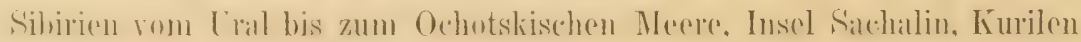
ind .Tesso.

Fortpflanzung wie die von'S. e. europaea, aber die Eier etwas kleiner. Eier nach "Thezanowski $17.3 \times 13.2,17.4 \times 14,17.3 \times 13.5,18 \times 13.3,18.6 \times 14$ bis $19 \times 14 \mathrm{~mm}$. 


\section{Sitta europaea albifrons Tacz.}

Sitta albifrons 'l'aczanowski, Bull. Soc. Zool. France VII, p.385 (1882 - Kamtschatka).

Sehr ähnlich s. e. laciculensis, aher dureh anffallendere, breitere. weibe Stirn und wohl ausgehildete breitere Supereiliastreifen. heller hlangraue (Oberseite und nur schr wenig (? C) oder ganz fehlendes (? o) Kastanienrotbraun an den Flanken leicht zu unterscheiden. Auch haben die inneren Armsthwingen und groben Flügeldecken breitere, deutlichere weibe Spitzensïume.

Kamtschatka.

\section{Sitta europaea amurensis Swiuh.}

? Sitta roseilia Bonaparte, Consp. Av. I, p. 227 (1850- Japan).

Sitta amurensis Swinhoe, Proc. Zool. Soc. Lond. 187, p. 350 (Amur, im Winter südl. bis Peking).

Abbild.: Pleske, Ares Przewalskianae, 'Taf. IX, Fig. 3.

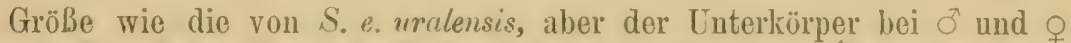
ockergelh. Kohle und Brust weih. letatere nur lisweilen (wohl meist o) mit ockergelhlichem Sohimmer. Weiber Supereiliastreif meist wohl entwickelt.

Amur, Issurien, Mandschurei his Nord-china (im Irinter nach Swinhne bis Peking), Koren, Insel Hondo oder Nipon, nicht aber Jesso!' $)$

Eier vach Taczanowski wie die der verwandten Formen und $17.5 \times 13.6,18 \times 13.3$, $18 \times 13.4$ bis $18.2 \times 13.4 \mathrm{~mm}$ messend.

\section{Sitta europaea caesia Wolf. (Hig. 59.)}

\section{Spechtmeise, Kleiber (mitteleuropäische Form).}

Sitta caesia Wolf, in Meyer \& Wolf's 'l'aschenb. deutsch. Tögelk., p. 128, 'Taf. 15 (1810I) eutschland).

Sitta pinetorum Brehm, Handb. Naturg. Vög. Deutschl., 1. 205 (1831- Deutsche Kiefernwälder).

Sitta folionm Brehm, Handb. Naturg. Vög. Deutschı., p. 206 (1831- Deutsche Laubwälder).

Sittc septentrionalis Brehm, Handb. Naturg. Vög. Deutschl., p. 206 (1731- „bewohnt den Norden, kommt im Winter bei Kiel vor").

Sitta advena (verdruckt adversa bei Giebel) Brehm, Handb. Naturg. Vög. Deutschl., p. 207 (1831- ,zeigt sich nur zuweilen in den Wäldern des mittleren Deutschlands").

Sitta affinis (partin!) Blyth, Asiat. Soc. Bengal XV, p. 289 (1846- bezielit sich auf die im Dict. Class. beschriebene Form aus Frankreich. die der Beschreibung nach für identisch mit der britischen gehalten wurde. Der Name kann also nicht für die britische Subspezies augenommen werden, sondern ist Synonym von caesia).

Sitta coerulescens Brelım, Vogelfang, p. 74 (1855-- Deutschland).

Sitta caesia major, longirostris, hungariae A. E. Brehm, Verz. Samml., 1.6 (1866nomina nuda!)

Sitta cinerea Doderlein, Giorn. Sci. Palermo V, 1, p. 192 (1869- Sizilien).

Franz.: 'Torchepot. Ital.: Picchiotto.

1) Sitta europaea subsp.nov.? Hin im 'I'ring-Aluseum befindliches of von Hiuga auf der Insel Kiu-schiu, am 5. Mai 1894 erlegt, ist bis zur Kropfgegend hin bräunlich ockergelb und gehört wahrscheinlich einer unterscheidbaren Subspezies an. Teider konnten weitere Exemplare nicht untersucht werden. 
[nterseite. mit Ausuahme der mehr oder minder rein weiben oberen Tíhle und Wimgen. lehhaft veliergelh. Weilbliche Torderstim und Superciliarstreifen gar nicht oder nur wenig wahrnehmbar. Im übrigen wie S.e. europaea. Oft, aber nicht immer, etwas kleiner. Flügel alter ơ etwa $75-79 \mathrm{~mm}$.

Europa von Jïtland bis zu den Pyrenäen (?Spanien) ${ }^{1}$ ). Italien und Sardinien, (vielleicht nur vereinzelt) bis Sizilien,

Figur 59. im Osten bis Rumänien. Südlich bis Griechenland, von wo. aber nur wonige Stücke (Reiser) untersucht werden kounten, die ziemlich klein zu sein scheinen. Wurde vor rinem halhen Jihlonndert in den Bergen hei 'T'anger von Oleese gesammelt (?subsp.). Luche erwähnt Algier, wo die Art aber neuerdings nicht festgestellt wurde. Italienisehe und

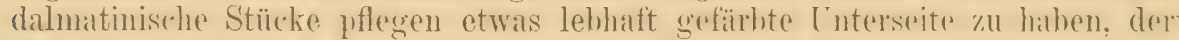
Unterschied ist aber nicht konstant genug zur Trennung.

Stand- und Strichvogel, der sich im Winter oft umherstreifenden Meisenscharen anschließt. Bewohner von Wäldern und Parkanlagen; meist nur auf hohen Bäumen, wo er sich auf- und abwärts kletternd in steter Bewegung aufhält. Er hat einen weithin vernehmbaren etwa wie twiet, twiet, twiet klingenden Ruf, außerdem einen feinen, wie sit klingenden meisenartigen Lockton. Im Frühjahr hört man laute, denen von Menschen auffallend ähnliche Pfiffe, ferner ein trillerpfeifenartiges Pfeifen und quäkende Laute. Nahrung Insekten und Sämereien, Eicheln, Nüsse, Bucheckern usw. Mauser Juli bis September. Nester oft hoch, meist mittelhoch (3-t m), selten niedrig.

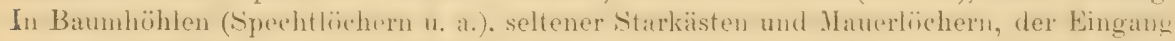
durch mit Speichel rermischte Erde verklebt, sodaß der Vogel eben noch durchschlüpfen kann, eine Eigentümlichkeit, die er mit seinen näberen Verwandten teilt, aber lange nicht mit allen "Gattungsgenossen." Das Nest selbst ist ein unordentlicher Haufen ron Blättern, Bast, Rinde usw. Es enthält im April und Mai $6-8$, selten 9 Eier, die etwas glänzend weib sind. Die Zeichnung besteht aus zahlreichen feinen oder weniger zahlreichen groben rostroten Flecken, zwischen denen meist einige tieferliegende violettgraue Schalenflecke stehen. Die Größe ist ziemlich variabel. 42 Eier der deutschen. Form messen nach Rey rou $22.25 \times 14.5$ und $19.9 \times 14.6$ (Durchschnitt) bis $18.75 \times 15$, $20.25 \times 14$ und $17.5 \times 14.8 \mathrm{~mm}$. Durchschnittsgewicht $132 \mathrm{mg}$.

\section{Sitta europaea britannica Hart.}

Sitta curopaea Zritannica Hartert, Nor. Zool. 1900, p. 526 (England, Typus ron Tring). Engl.: Nuthatch.

Abbild.: Lilford, Col. Fig. Brit. B. II, 'Taf. 51.

Das Kantanionbram der Weichen nicht so dunlicl, die Linterseite meist etwas lieller, oft anffallend blab. der Sehuabel etwas schlanker, spitzer. die Firste meist etwas schärfer und höher. Sonst ganz wie S. e. caesia.

In England, seltener in Schottland. (Nicht in Irland.)

Lebensweise und Fortpflanzung wie die von S. e. caesia. Nester sehr oft mit den blättchenartigen Rindenstücken von Pinus sylvestris ausgelegt. Eier gewöhnlich. 6-8 aber 9,10 und 11 wurden gefunden (Jourdain).

1) Fraglich ist: Sitta europaea minor A. E. Brehm.

Sitta caesia minor A. E. Brehm, Allg. D. Naturh. Zeitung 1857, p. 447 (Spanien). Brehm erbeutete nur ein 우 am 14. Februar bei Madrid, das sich noch in der Sammlung befindet. Es hat auffallend matte Unterseite und kurzen Schnabel, sodab man die Vermutung haben muß, daß es sich um eine spanische Subspezies handelt. Dagegen stimmt ein von Olcese bei Tanger gesammeltes Sïuck im Brit. MIus. wesentlich mehr mit caesia überein. Die Untersuchung von mehr Material allein kann entscheiden. 


\section{Sitta europaea caucasica Rehw.}

Sitte caesia caucasica Reichenow, Orn. Monatsber. 1901, p. 53 (Naltschik im 'T'erekgebiet, N.-Kaukasus).

Ist $S$. e. caesia äußerst ähnlich, aber der Schnabel ist etwa $2-3 \mathrm{~mm}$ liürer und seln stumpefspitzig. am Porderande der Stirn und üher den Augen hefindet sich ein mehr oder minder undentlich angedenteter weiber Streif, die Unterseite ist oft dunkler und ansebeinend nie heller als hei den lebliaftest gefärbten S. e. cacsia.

Kaukasus.

\section{Sitta europaea levantina subsp. nor.}

Sitte sulspeciei S.e.cesiu diet ae colore simillima. sed rustro graciliore facile distinguendat.

Unterseite lebhaft ockergelb wie bei S. e. caesia, nur obere Kehle

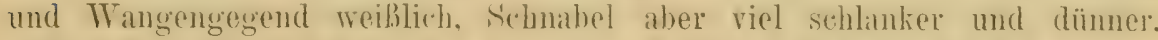

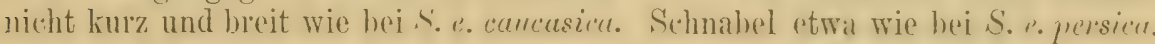

Kileinasien ('T'aurus) ('Typus 'T'aurus. April 1876. im Brit. Mus.. ron Hanford gesammelt) und Palistina: westlich des Jordan in waldigen 'levilun Galiläas.

\section{Sitta europaea persica Witherlyy.}

Sitta europaca persica Witherby, Ibis 1903, p. 531 ("Oak-woods of S. W. I'ersia").

Von S. e. britannica, die ihr in der Färbung der Unterseite nahekommt,

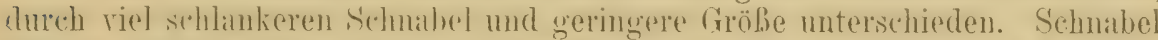

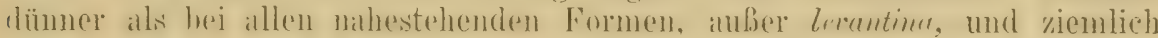
lang, beim of etwa $17 \mathrm{~mm}$, das ganze Culmen 20 (aber nicht ,200") mm

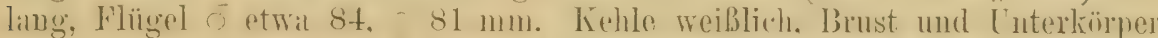
rahmfarben mit orkergelblichem Aufluge; am Torderrande der Stirn und äher den Augen ist ein weilier Streif angedentet. .. Iris lohbaft hamm. Fübue brüunlichgrau. Schuabel bläulichgrau."

Eichenwälder S.W.-T'ersiens.

Nester wurden in alten Löchern des Sankt-Johannes-Spechtes gefunden, die ̈̈ffnungen waren von innen mit Pferdedïnger rerkleinert. Am 9. April wurden 7 stark bebrütete Eier gefunden, dic denen ron S.e.caesia gleichen, am 18. Mai flogen Junge aus.

\section{Sitta europaea sinensis Verr.}

Sitta sinensis Verreaux, Nour. Arch. Mlus. Paris VI, Bull. p. $3+(1870-\ldots .$. dans les montagnes du Thibet Chinois". Als Typen dienten Stücke von Kiukiang und Mupin, ron denen die letzteren aber zu S. e. montium gehören).

Lnterscheidet sich von S. e. caesia durch die viel geringere Gröhe, nicht woif.jiche. sondern lostgelhe Ohrdeckes und uicht so lehbafte. sondern

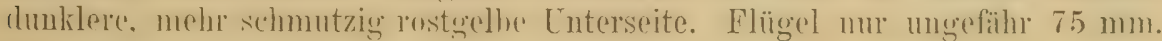

Hügelland von China (und Ost-libet?). 


\section{Sitta europaea nagaensis Godwin-Austen.}

Sitta nagaensis Godwin-Austen, Proc. Zool. Soc. London 1874, p. 44 (Naga-Berge).

Wie S. e. sinensis, aber die Interseite schmutzig grau. mit rostgelbem Anfluge, Mitte des Lnterkörpers deutlicher rostgellolich, dic Kíastanienfarhe der Unterschwanzdecken sehr dunkel.

Naga-Berge in Assam und suidliche Schan-Staaten.

\section{Sitta europaea montium La 'Tonche.}

Sitta montium La Touche, Ibis 1899, p. 404 (Kuatun [typ. Lok.] und andere Berggegenden Chinas. Nur mit sinensis, nicht mit nagaensis verglichen!).

Von S. e. nagaensis kaum zu unterscheiden, vielleicht aber auf der Interseite meist etwas rüstlicher. Kinige stäclie hilden C̈hergänge zu $S$. e. sinensis und kommen lotzterer sehr nahe. - Noch ganz zweifelhafte Form.

Berggegenden Chinas.

\section{Sitta cashmirensis Brooks. ${ }^{1}$ )}

Sitta cashmirensis Brooks, Proc. Asiat. Soc. Bengal 1871, p. 209 (Kaschmir).

Oberseite wie bei S. e.caesia. Zügel, Wange, Ohrgegend und Kinn Blal. rustlarben oder weiblich, Kehle und Brust hell rostfurhen, in den kastanienrothramen Lnterkörper ühergehend. Cnterschwanzderelen kastanienhraun, moist an der Wruzel mit hlïulichgrauem, oft undeutlichem Eleck.

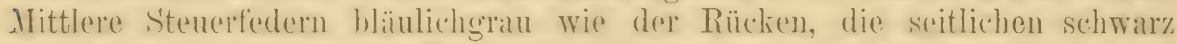
mit ausgedehnter graluer spitze und liceitem anteapikalen weiben, nicht

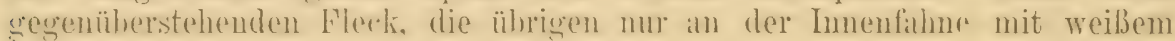
Anteapikalfleck. Flïgel ơ etwa $85 \mathrm{~mm}$.

Tammenwälder ron Kaschmir und den angrenzenden Teilen von dfghamistan.

1) Sitta cashmirensis steht den beiden indischen Kleibern: S. castaneoventris und S. cinnamoventris nahe. Letztere beiden sind nur Subspezies, denen sich vielleicht auch S. cashmirensis anschließen ließe. Ich möchte es dahin gestellt sein lassen, ob man diese alle als tropische Unterarten der europaea-Gruppe aufassen kann. S. castaneoventris castaneoventris Franklin 1831 hat bläulichgraue, kastanienbraun ges:iumle Lntersehwamzdecken und bewohnt Vorder-Indien rom Fube des Himalaya bis Wynaad; S. castaneoventris cinnamoventris Blyth 1842 hat einen breiten weißen Anteapikalfleck an den sonst ebenso gefärbten Unterschwanzdecken, ist viel kleiner, mit viel schlankerem Schnabel und bewohnt den Himalaya. Beide Formen haben o mit dunkel kastanienbrauner Unterseite, die nur Kinn und Wangen weißlich läßt, und 우 mit rötlichzimtfarbener Unterseite.

In Birma schließt sich S. c. neglecta Walden 1870 an, die S. cashmirensis sehr ähnlich sieht, unterscheidet sich aber von letzterer durch die Unterschwanzdecken, welche grau sind, mit ausgedehntem weißen, rostrot umsäumten Fleck, von cinnamoventris durch die rahmweißliche, allmählich in den kastanienfarbenen Unterkörper übergehende Kehle. 


\section{Sitta himalayensis Jard. \& Selby.}

Sitta himalayensis Jardine \& Selby, Ill. Orn. III, 'Taf. 144 (1835- Himalaya). Sitta nipalensis Hodgson, Journ. As. Soc. Beng. 5, II, p. 779 (1836 - Nepal).

Lnterscheidet sich leicht durch die hreiten sehwarzen, his an die Seriten

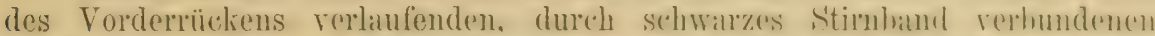
Augenstreifen, kurzen, dicken Schnabol. weilien Sichaft und hreiten weiben Mittelstreifen an der Wurgelhälfte der mitteren heiden Stenerfeden und

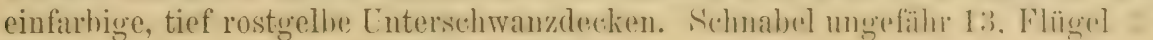
etwa $74-76 \mathrm{~mm}$. . O Unterseite blasser.

Himalaya, 5000-11000 engl. Fub, bis in das westliche 'Tibet.

Brütet vom April bis Juni in Baumlöchern, baut ein Nest ans Moos und logt 5 -6 weiße, rostrot gefleckte Eier, die etwa $18.5 \times 14.3 \mathrm{~mm}$ messen.

\section{Sitta canadensis whiteheadi Shlarpe.}

Sitta whiteheadi Sharpe, Yroc. Zool. Soc. London 1881, p. 233, 414, 'Taf. 36. Dresser. B. Europe IX, 'T'af. 662. Ibis 1885, Taf. 2.

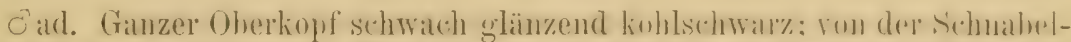

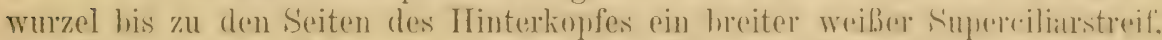

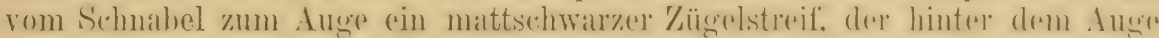

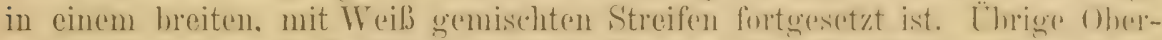
seite häuliehgralu, allmählich in das Sellwarz der Konfjulatte ïherogehend.

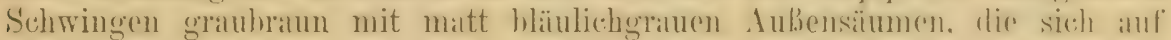
den innersten Armsehwingen ühor die ganze Iubenfinhe arstredien. Mittleres

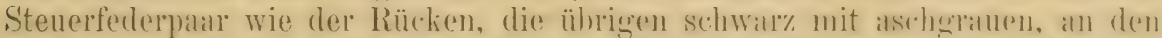

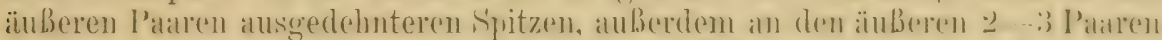

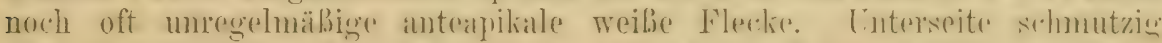

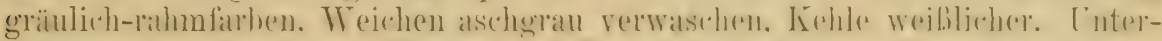

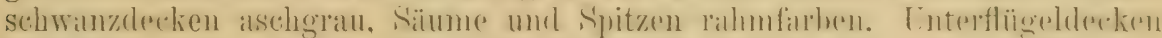

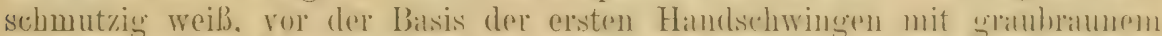

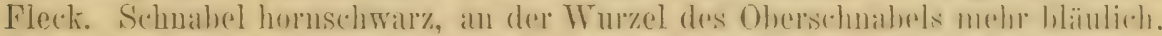

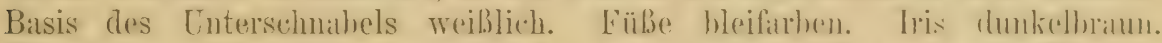

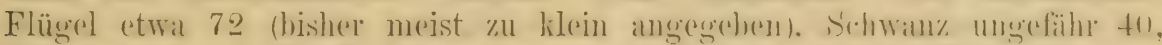

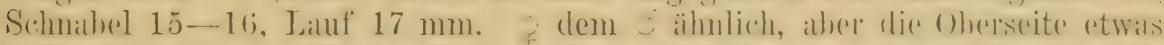
heller bäulichgrau. Oberkonf nicht sehwarz, sonderen nue cin hisehen dunklor als der Rï̈cken, und mit schwärlichen statt hellgranem Basiltrilen: Pntreseitu mit geringerem gratuen Anfluge, Weichen weniger grall rerwatsehen: Grïlio geringer. Flügel etwa $70.5 \mathrm{~mm}$.

\section{Berrohner der hohen Berge auf Korsika.}

Standvogel in hochgelegenen Koniferenwäldern. Ruf' ein sanfter P'fiff; der in einen zischenden Laut, etwa wie sch-wer, sch-wer, übergeht, aus der Ferne an die Stimme der Haubenmeise erinnernd. Nester meist in großer Höhe in halbvermoderten, abgestorbenen Kiefern- und Lürchenstämmen. Nesthöhlen augenscheinlich rom Vogel selbst ausgehöhlt, Hingang ohne Verklebung! Im Mai 5-6 glanzlos weilie, braunrot gefleckte Eier, die denen andrer Kleiber ähneln, aber reichlich und teilweise grob gefleckt sind, so daß sie mehr an groBgefleckte Baumläufer- und HaubenmeisenLier erinnern. Ein ( $17.1 \times 12.9,17.8 \times 13.1,17.7 \times 12.9 \mathrm{~mm}$. Die Nesthöhle ist rcichlich und weich mit Bast, Moos, Federn und manchmal. auch Haaren ausgefïttert. 


\section{Sitta canadensis villosa Verr. ${ }^{1}$ )}

Silta villosa Verrenux, Nouv. Areh. Mus. Paris I, Bull. p. 78, T'af. 5, Fig. 1 (1865nördlich von Peking).

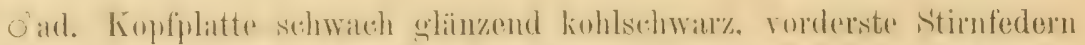

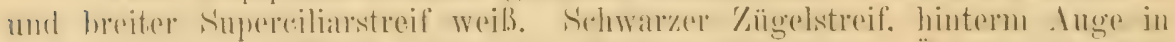

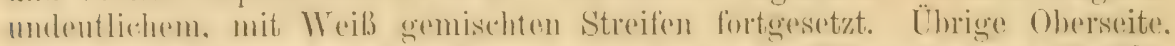

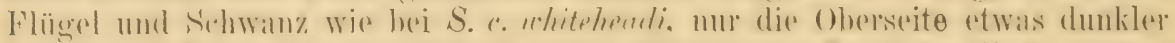

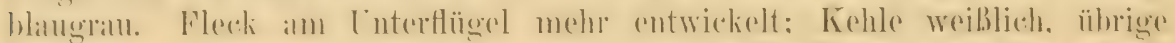

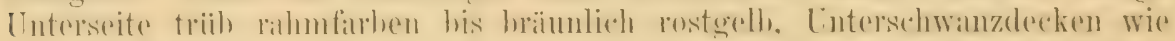

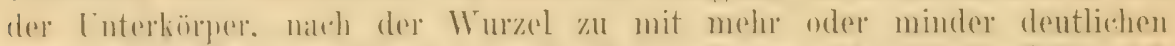

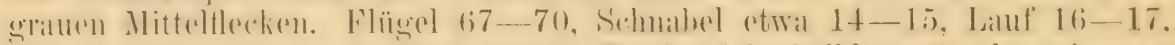

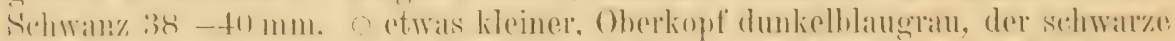

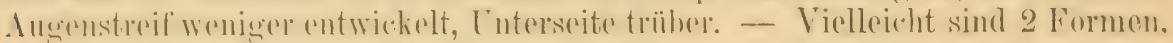

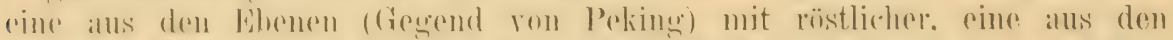

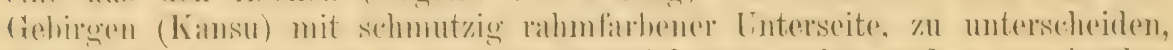

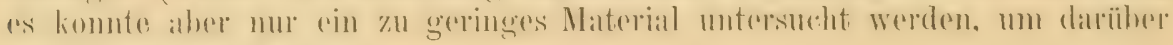
zur Klarheit zu kommen.

Nord- und Nordwest-China, Nongolei (Kansu, Ala-Sehan).

\section{Sitta krüperi J’elz.}

Silte Kriiperi Pelzeln, Sitzungsber. Akad. Wien 48, I, p. 149 (1863- Simyrna).

Abbild.: Ibis 1865, Taf. 7 ; J)resser, B. Europe III, T'af. 121.

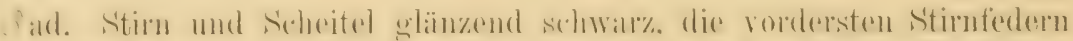

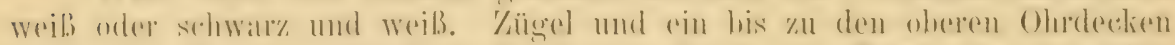

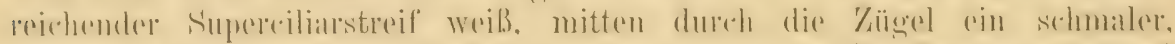

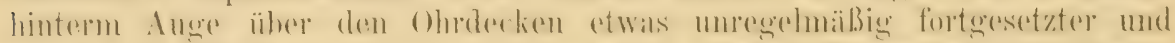

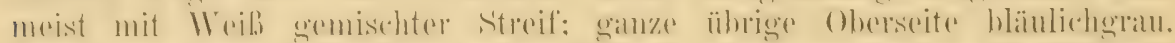

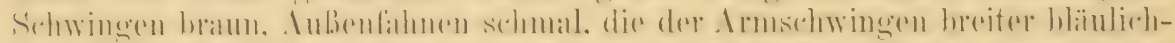

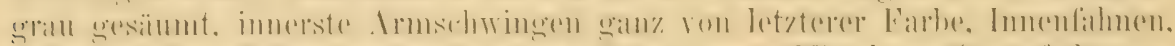

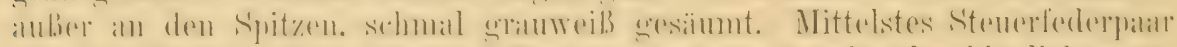

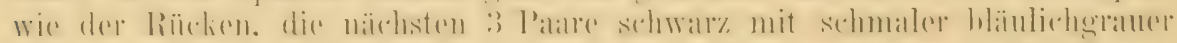

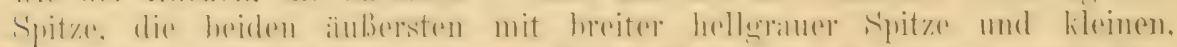

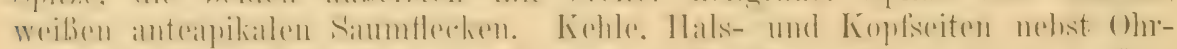

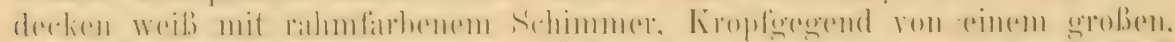

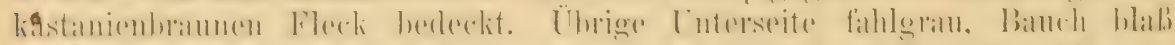

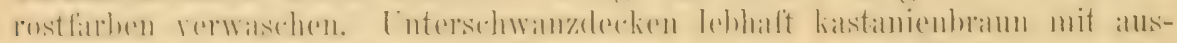

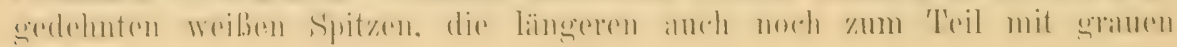

1) Sitta canadensis canadensis I innaeus, Syst. Nat. Ed. Xll, I, p. 177 (1766-_exBrisson, hab. Canada; schlecht wiedergegebene Dingnose!), unterscheidet sich durch lolgende Merkmale: ơ Oberkopf von noch glänzenderem Schwarz, das sich etwas weiter unf den Nacken erstreckt und schïrfer von der blaugrauen Oberseite abgeschnitten ist; schwarzer lileck hinterm Auge scharl, rein, viel größer; Unterseite lebhafter: Kehle gelbbrïunlich, Brust, Bauch und Seiten lebhaft rostgelb, Mitte des Unterkörpers mehr weißlich; Unterschwanzdecken lebhaft rostfarben, snit weißen Spitzen, die an den längsten ansgedehnter sind; die seitlichen Steuerfedern mit durehgehender breiter anteapikaler weißer Binde; der dunkle Fleck auf dem Unterflïgel noch reiner und schärfer. + muten etwas blasser als das $\sigma^{7}$, Oberkopf schiefergrau, anstatt schwarz. - Bewohnor des nördlichen Nordamerikas. 


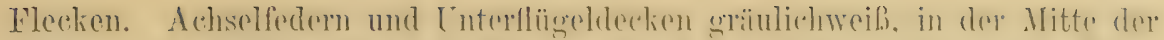

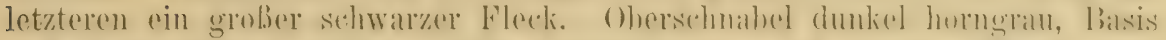
und Entersehnabed heller. Fübe sehieferfarben. Iris hrann. Flïged etwa 76-77, Sehrwanz otrva 41, Schnabel etwa $15-16$, Lauf $17-18 \mathrm{~mm}$. o etrvas

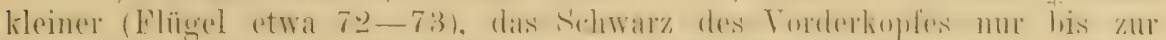

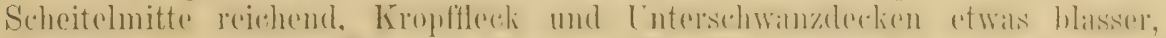

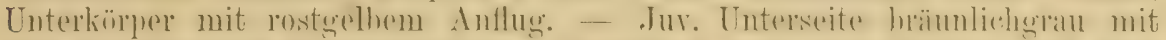

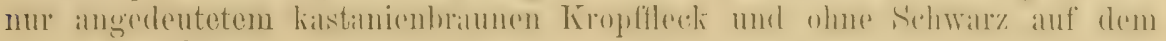
Kopfe. - S. krïperi steht der cancdensis-Gruppe sehr nahe!

Kleinasion bis zum Kaukasus (Lorenz, Orn. Kaukasus, p. 35). (Von

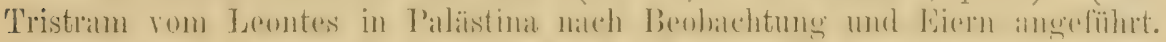

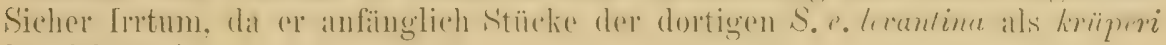
bezeichnete.)

Hauptsïchlich Bewohner von Kiefernwäldern, Cedern- und Wachholderbeständen, soweit die Waldregion reicht, in denen sie nach Art der europäischen Kleiber lebt. Paarungsruf ein lutes, vielfach abgeändertes, oft an das von Parus major erinnerndes aber mehr gurgelndes und längeres Geschrei, Warnungs- und Lockton an den des Kanarienvogels, Klageton an den (les Wendehalses erinnernd (Krüper). Nest in morschen Bäumen, wie ein großes MIeisennest, Eingang nicht verklebt. Eier natürlich kleiner als die der deutschen Kleiber, in der Fleckung mehr an Haubenmeiseneier erinnernd. Maße etwa $16.8 \times 13.1,17.2 \times 13.3$ bis $17.5 \times 13.4 \mathrm{~mm}$, Gewicht etwa $100 \mathrm{mg}$.

\section{Sitta leucopsis leucopsis Gould.}

Sitla leucopsis Gould, Proc. Kool. Soc. London 18ł9, p. 113 (Himalaya).

Abbild.: Gould, B. Asia III, Taf, 46.

ơad. Stirn, Oberkopf und Nackenseiten glüuzend schwarz, übrige

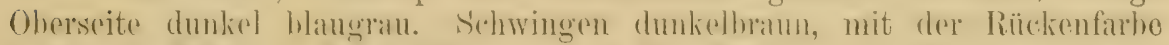

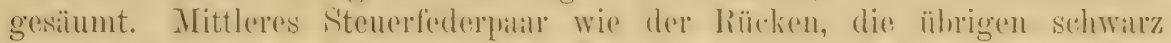

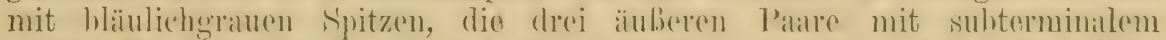

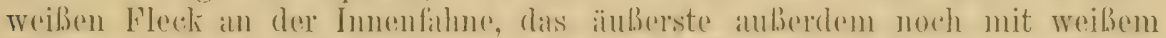

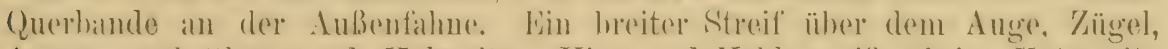
Augen- und ()hrgegend, Halsseiten, Krimn und Kohlo weib, übrige ITnterseito

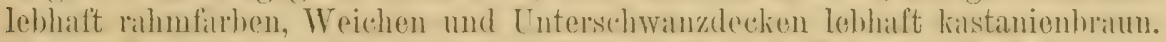
O wio 5, mur unten atwas liehter. Flïgel $76-81$, Sehwanz etwa 41)-45, Culmen 18, Lauf 17-19 mm. - Auch S. lencopsis stoht der canadensis sehr naho!

Nordwestlicher Himalaya, in Mähen von 7000 - 10000 engl. Fußrütend.

Bewohner von Nadelwaldungen, Stimme ein lauter, melancholischer Ruf. Nahrung u. a. die Zapfen von Pinus gerardiana. Eier Mai und Juni. Sie gleichen anderen Kleiber-Eiern und messen ungefiihr $18 \times 14.1 \mathrm{~mm}$.

\section{Sitta leucopsis przewaiskii Berez. \& Bianehi.}

Sitta Ekloni Przewalski, Tret. pyt. no. Cent. Asi., p. 368 (1883 - nomen nudum!).

Sitta Przewalskii Berezowski \& Bianchi, Av. Exp. P’otanini (ransu usw., p. 119 (1891am oberen Chuanche. Russisch!); Pleske, Av. Przew. I, p. 174.

Abbild.: Pleske, Aves Przewalskianae, Taf. IX, Fig. 4.

Ist S. l. leucogris schr ähnlich, unterscheidet sich aber dureh kürzeren Schnahel und Flïgel, sowic dunkleren Unterkinpler. Dio Unterseite, mit

E. Hartert, Die Vögel der paläarktischen Region. 


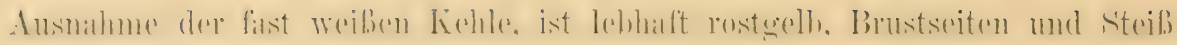
kastanienrothraun.

Nordwestliches China; am oberen Chuanche. Kansu, Patong im nordwestlichen Hupe.

\section{Sitta neumayer neumayer Michab.}

Felsenkleiber.

Sitta Neumayer Nichahelles, Isis 1830, ]).814 (Ragusa in Sïd-Dalmatien).

Sitta rupestris 'lemminck, Man. d'Orb. Ed. 2, 1II, p. 287 (1835- ex Cantraine II.S. ?partim. Deser. nulla).

Sitta rufescens Gould, B. Europe III, Taf. 235 (1837- ex T'emminck M.S. - Dalmatien). Sitta saxatilis Schinz, Europ. Fauna I, p. 266 (1810- Dalmatien).

Abbild.: Dresser, B. Eur. III, Taf. 120.

ơad. Oberseite bläulich aschgrau. Von den Zïgeln dureh das Auge

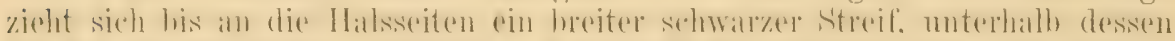

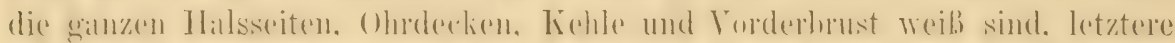

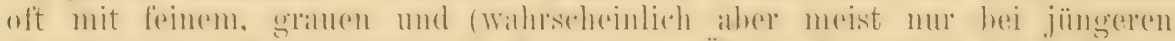

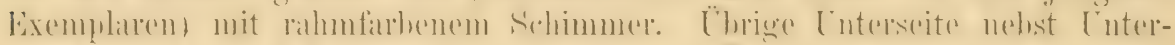

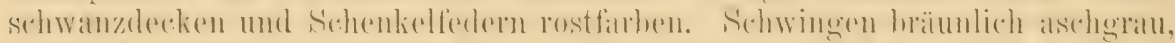

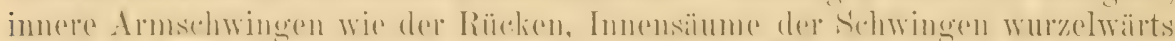

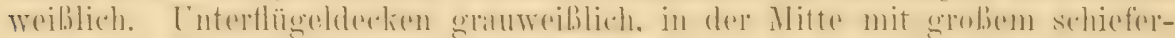

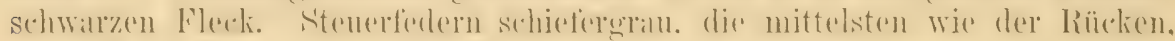

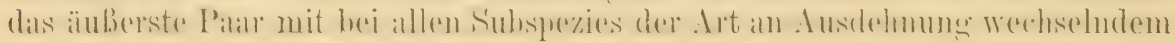

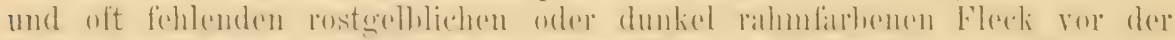

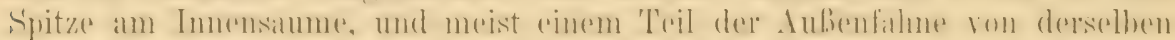

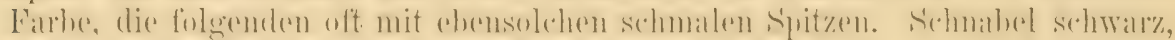

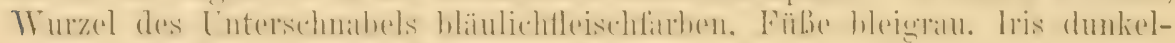
braun. Flïgol 77-83, Sehwanz etwa 48-52, Lauf 19--20.5, Schnabel etwa 19-22 mm. - o wie ó, nu ein wenig kleiner. - Juv. Brust mit

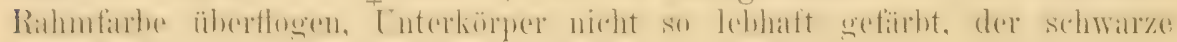
Augenstroif weniger entwickelt, Schnabel und Flügel kiüzer.

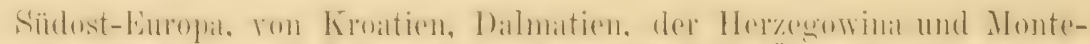

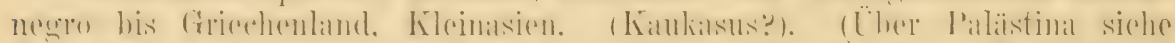

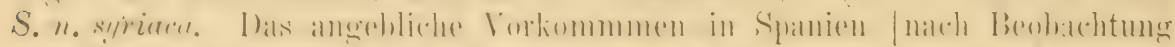

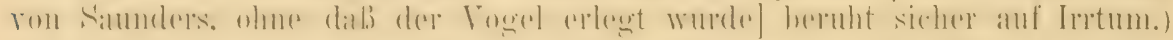

Sehr lebhafter, stimmreicher, lauter Vogel, den man meist an Felsen, selten an Bäumen umherklettern sieht. Er nistet in Felslöchern, deren Eingang er mit Erde und Lehm rerklebt, sodaß nur ein zum Einschlïpfen genügendes Loch bleibt, und macht nicht selten sogar einen ganzen retortenförmigen, am Felsen angeklebten Lehmbau. Das eigentliche Nest ist mit MLos, Haren, Heclern u, dergl. ausgefiittert und enthält im April und Mai 6-8, seltencr bis 9 und 10 Eier. Diese sind rein weib, glänzend, mit rostroten und tiefer liegenden blaß rötlichen bis lehmfarbenen und blaß rioletten Flecken spärlich bedeckt. Sie unterscheiden sich von denen ron S. europaea durch höheren Glanz und meist geringere Fleckung. Geübte Eierkenner werden den Gesamtcharakter durchaus verschieden nennen. 33 Eier in Rey's Sammlung messen durchschnittlich $20.6 \times 15.3$, im Naximum $22.75 \times 16.0$ und $20.75 \times 16.25$, im Minimum $19 \times 14.25 \mathrm{~mm}$. Das mittlere Gewicht $156 \mathrm{mg}$.

\section{Sitta neumayer syriaca ''emm.}

Sitte syriaca 'Temminck, Man. d'Orn. İd. 2, III, p. 286 (1835- ex Ehrenberg M.S.: "Commun en Syrie et dans le Levant"). 
Oberseite etwas heller, fahler, sonst in keiner Weise von S. nermayer

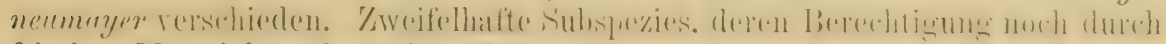
frisches Material zu bestätigen ist.

Syrien und Palästina.

\section{Sitta neumayer tephronota Sharpe.}

Sitta tephronota Sharpe, Ann. \& Mag. Nat. Hist. ser. 4, X, p. 450 (1872- Kohand im Ferghana-Gebiete, 'Turkestan).

Sitta rupicola Blanford, Ibis 1873, p. 87 und E. Persia II, Zool., p. 225, Taf. XV. 2 (partim! Typus aus dem Elbruz-Gebirge. Die auch dazu gerechneten Stiicke von Ispahán und Schiraz gehören zu tschitscherini. Blanford beschrieb junge Stücke als mipicola. 'Lypus und Cotypen untersucht).

Sitta syriaca obscura Sarudny \& Loudon, Orn. Monatsber. 1905, 1). 76 (N.\& O.-Persien).

ơ ad. Oberseite fithlgrau, bedeutend heller als bei S. n. nemmayer,

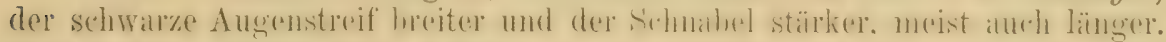
Viel gröBer: Flügel alter ơ etwa 85-92, Schwanz 50-53, Lauf 21-22, Schnabel ungefühl $21-25 \mathrm{~mm}$.

S'ïdliches'Turlestan bis zum 'Tian-S'chan, Afuhanistan, nördliches Lbaluchistan Ost- und Nord-Persien (Elburs-Gebirge).

\section{Sitta neumayer tschitscherini Saludny.}

(Sitta mupicola Blanford, partim. Siche Nr. 533.)

Sitta tschitscherini Saruduy, Orn. Jahrb. XV, p. 218 (1904- Ispahán in I'ersien).

Wie S. n. tephronota, aber mit noch viel hellerer, weißlichgrauer Ober-

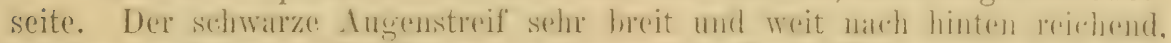

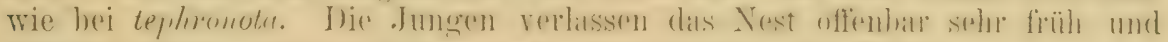
klettern umher, ehe sie fliegen, wie man es auch bei Certhien u. a. findet.

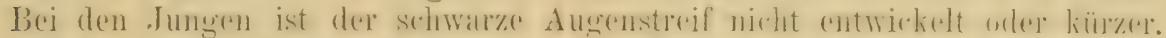

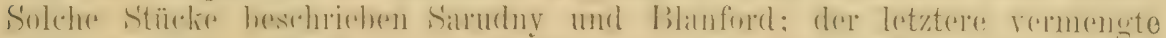

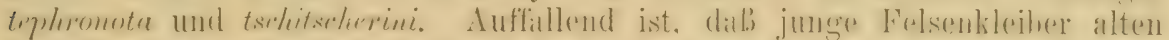

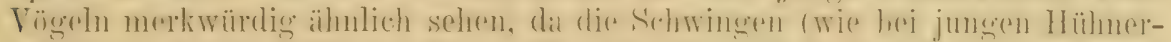

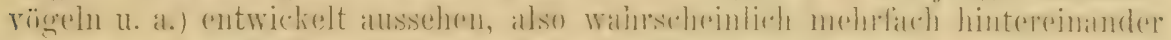
mausern, ehe der Vogel erwachsen ist. Fübe grtünlichrrau.

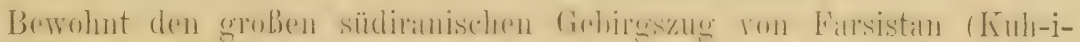

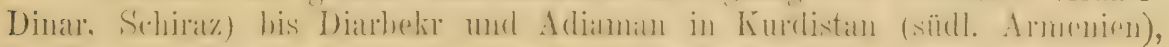
nördlich bis Isfahau.

An Felsen, oft aber auch an Bäumen herumkletternd; lärmend, pfeift laut wie ein Mlensch, miaut wie eine junge Katze und hat einen trilleruden l'fiff, der an ein hohes Nachtschwalben-Schnuren erinnert, gibt aber auch noch viele andere Töne von sich.

\section{Familie PARTDAD.}

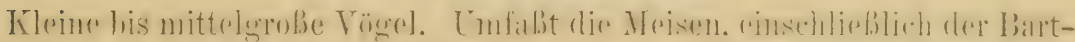

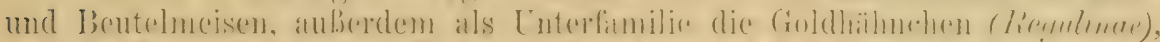

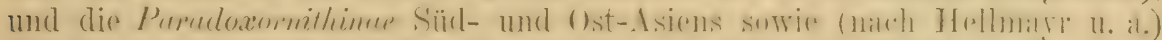

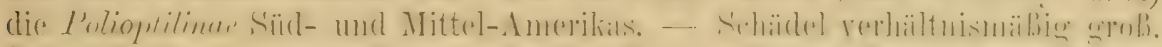

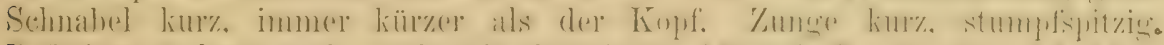

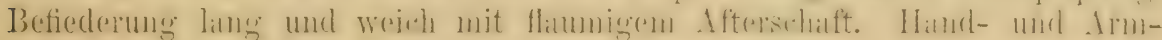


sehwingen jo 10. Erste Handsehwinge sehr reduziert, so lang wie oder etras linger als die Hailfte der zweiten. Flïgel meist kurz, Flug diher mangerhaft.

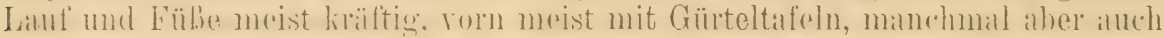

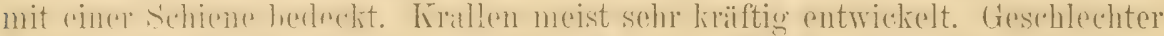

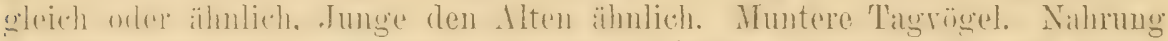

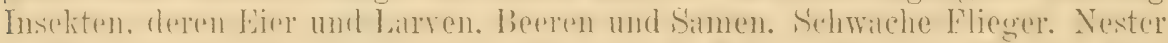

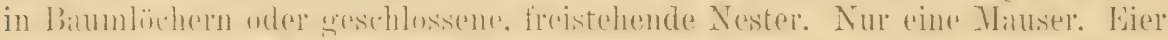

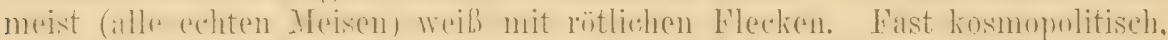

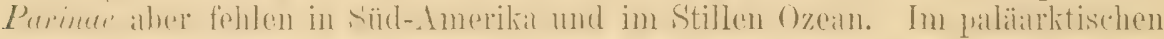
Faunengebiete haben wir es mit 3 Unterfamilien zu tun:

A. Schnabel mehr oder minder kegelförmig, dick und stımpf oder spitz, Oberschnabel meist ungekerbt . . . Parinae (Gattungen Parus, Aegithalos, Antloscopus, Pamurus).

B. Schnabel fein, fast wie ein Sylvienschnabel, Firste gerade, gekielt, Schneide des Obersehnabels ror der Spitze etwas gekerbt

Regulinae (Gattungen

Regulus, Leptopoecile, Lophobasileus).

C. Sehnabel hoch, kurz, seitlich zusammengedrückt, Oberschnabel meist mit einer grolien Ausbuchtung, Firste schon von der Wurzel an stark nach unten gebogen ....... Paradoxornithinae (Gattungen Paradoxomis, Cholornis, Suthora, Conostoma).

\section{Gattung PARUS L. 1758.}

Umfaßt die eigentlichen Meisen, die Kohl-, Blau-, Sumpf-, Weiden-,

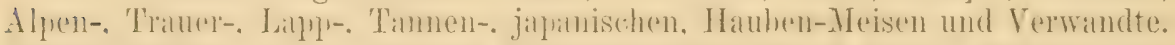

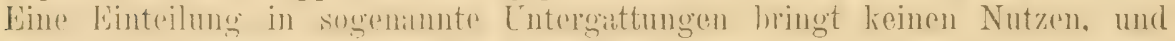

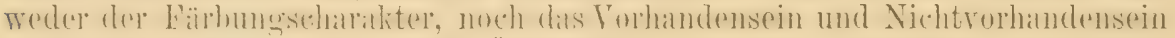

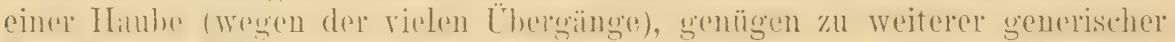
Trenuung. - - Der Schnabel ist kurz, von der Länge der Hälfte oder eines Inittels des Koufes. sehr krältig. Nasenlächer rund, ron dichten Borsten

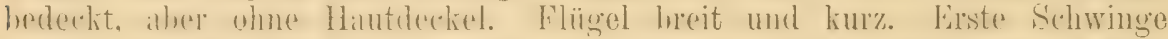
kï̈rer. als die Hälfte der zweitrn, aher lïnger, als die Iranddecken, zweite kïirzere als die dritte, vierte! und fünfte meist am längsten. Selhwanz gerade, abgerundet oder "twals allsgerandet. Lauf" vorn mit Gürtaltafeln hedeckt. die bei cinigen Formen in Alter rerschmelzen. (ieschlechter wenig rerschieden.

$$
\text { Übersicht der alten ơ der paläarktischen Arten. }{ }^{1} \text { ) }
$$

$1 \int$ Gefieder laubsängerartig griinlich . . . . . . . P. modestus . p. 381

Gefieder nicht laubsängerartig grünlich . . . . . . . . . 2

$\left(\begin{array}{c}\text { Kehle weiß wie die übrige Unterseite; Oberseite blau und weiß; ohne } \\ \text { Schopf . . . . . . . . . . P cyanus. p.352 }\end{array}\right.$

2) Kehle rahmfarben his isahell und graubraun verwaschen; ()herseite oliven-

braun bis mausgrau; mit Schopf........... P. dichrous . p. 363

Kehle schwar\% oder bram, seharf ron der ïbrigen Unterseite abstechend 2

(3) Unterkörper grau; Kehle und Kropf schwarz . . . . . . . . . . . 3

3 | Tnterkörper nicht grau . . . . . . . . . . . . . . 4

1) Eine Form der tropischen gehäubten Meisengruppe (..Machlolophus"), Parus xanthogenys Vig., bewohnt den westlichen Himalaya bis zu $2300 \mathrm{~m}$, eine andre, P. spilinotus Blyth, den östlicheren Himalaya bis zu $2000 \mathrm{~m}$. Man vgl. Hellmayr, Tierreich, 18. Lief. p. 93 und die Abbildungen in Gould's B. Asia II.

Die zweifellnafte brandtii (1).369) konnte nicht in die Übersicht aufgenomnen werden. 


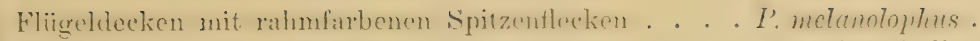

1. .3692

Flïgeldecken ohne rahmfarbene Spitzenflecken . . . P. rufonchalis . p.361

5 Oberkopf blau, Unterseite ganz oder teilweiso gelb. . P. caevuleus . p. 347

\{ Oberkopf nicht blau. . . . . . . . . . . . 5

J Mit hellem, meist weißem Nackenfleck ........... 6

6 Y Ohne hellen Nackenfleck. . . . . . . . . . . . 10

Stirn rahmfarben oder kastanienbraun, auf dem Vorderrieken ein.

............ Parius , p. 354

f Oberschwanzdecken schwarz . . . . . . . P. vemustulus . p. 355

8 \} Oberschwanzdecken grau oder graubräunlich........... . . 8

9 Unterseite mit schwarzem Mittelstreifen . . . . . . . . . 9 9

\{ Unterseite olne schwarzen Mitlelstreifon.......... P. ater . p. 356

10 S Mittlere Flügeldecken mit weißen Säumen....... P. monticohıs , p. 347

X Mittlere Flügeldecken ohme weiße Säume ........ P. major p. 341

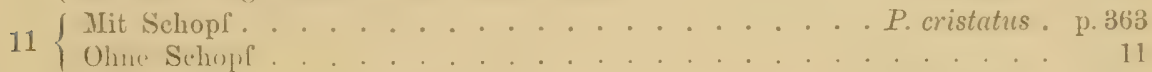

$12\{$ Mit weißem Superciliarstreifen . . . . . P. superciliosa . p. 370

Ohne weißen Supereiliarstreifen.............. . . 12

$13 .\left\{\begin{array}{r}\text { Unterseite mit Ausnahme der schwarzen Kehle lebhaft rötlich zimtfarben } \\ \text { P. davidi . p. } 370\end{array}\right.$

Unterseite mit Ausnahme der schwärzlichen Kehle nicht rötlich zimtfarben 13

14 Oberkopf schwarz mit metallischem Glanze . . . . . P. palustris . p.370

Oberkopf bräunlich oder sehwarz ohne metallischen Glanz . . . . . 14

Körperseiten lebhaft rostfarbig . . . . . . . . . . 15

15 Körpersciten weiblich, nicht aufiallend ron der ibrigen Luterseite abstehend, bis fahl röstlich . . . . . . . . . . . . 16

Oberkopf bräunlich mausgran bis erdfahl, Schnabel klein, dünn, etrra

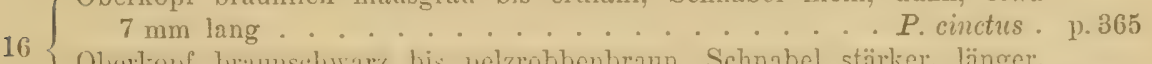

Olerkopf hramsehwar\% his pelzmbbenhrnun. Schnahel stärker. länger, etwa $9.5 \mathrm{~mm}$ lang. . . . . . . . . . P. songarns . p. 367

Größere Formen, Schnabel dick und klotzig. Fliigel etwa $70-77 \mathrm{~mm}$
P. lugubris . p. 368

Kleinere Formen. Schnalwl kleiner, dem der gumeinen Sumpemeisen (palustris) ähnlich, Flügel $60-70 \mathrm{~mm} \quad P$. atricapillus (montanus usw.) • p. 376

\section{Parus major major L.}

Kohlmeise.

Parus major Linnaeus, Syst. Nat. Ed. X, p. 189 (1758- "Habitat in Europa“. Wir betrachten Schweden als typ. Lok, nach dem 1. Zitat).

Panes Fringillago Pallas, Zoogr. Rosso-Asiat. I, 1. 555 (1827- Umbenennung von P. major L. "Per omniam Rossiam et Sibiriam").

Purus robustus Brehm, Handb. Naturer. Vög. Dentschl., 1'.461 (1831 Dentsehland).

Parus cyanotus Brehm, Vogelfang p. 241 (1855-- Deutschland).

Parus intercedens Brehm, Vogelfang, p. 241 (1855-- "Mitteldeutschland“. Typus von Greiz. Blasse Aberration).

Parus perniciosus Brehm, Naumannia 1855, p. 285 (Nomen nudum!).

Parus major verus Brehm, Naumannia 1856, p. 367 (Skandinavien, Deutschland).

Parus pallidus Brelım, Naumannia 1856, p. 367 (ein früher als boliharensis erwähntes aberrantes Stück von Greiz, das allerdings oben kaum grïnlich, unten fast weiß ist, somit wirklich einer bokharensis auffallend ähnlich sieht). 
Parus major paraloxus, cyanotos eximius, cyanotus accedens A. E. Brehm, Verz. Samml., p. 6 (1866- nomina nuda!)

? Parus glanconotus Olphe-Galliard, in Brief von C. L. Brehm ron 1857, Orn. Jabrb. 1892, p. 128 (Spanien - nomen nudum!)

Schwed.: 'Talgmees.' Französ. Hésange charbonnière. Ital. Cinciallegra.

ơ ad. Oberkopf und Genick glïnzend blauschwarz, durch ein breites,

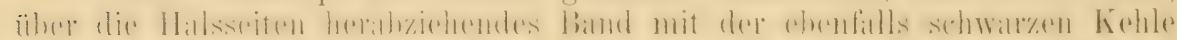

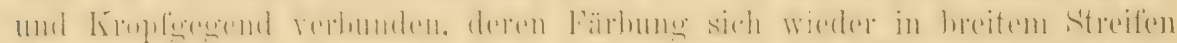

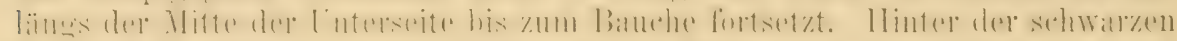

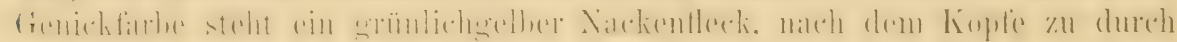
eine mehr oder minder deutliche weiße Linie begrenzt. Rücken gelblich

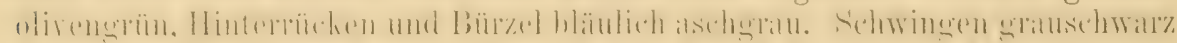

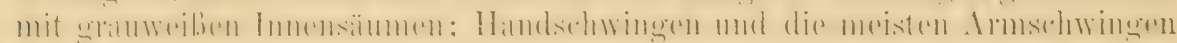
mit schualen graublauen, die 3.-6. in der Endhälfte mit woißen Anßen-

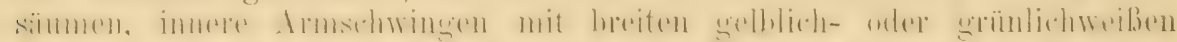

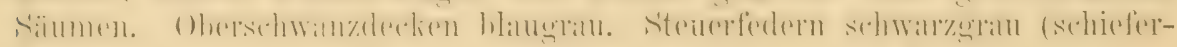
farben), das äußerste Paar mit weißer Außenfahne und damit zusammen-

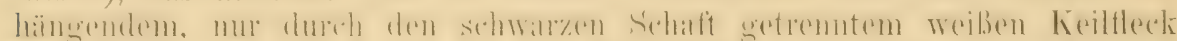

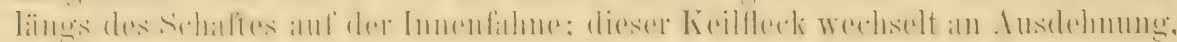
reicht aher meist üher ein Drittel der Feder hinaus. 1)as zweite Stenerfeder-

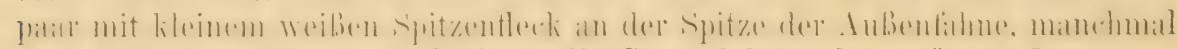
anch an beiden Fihnen, anBerdem alle Stenerfedern, das ïuBerste Par aus-

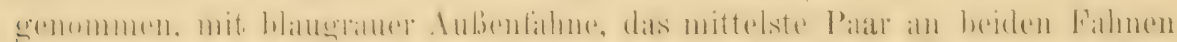

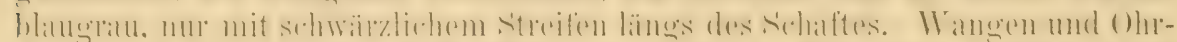

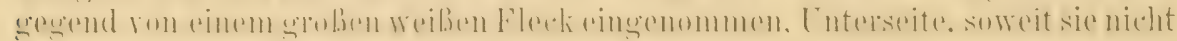
wie oben beschrioben sehwarz ist, sehwefolgelb, Weichen etwas schmutzig oder grünlich überlaufen. Steil. und Unterschwanzdecken weiß, von den letateren die in der Mitte stehenden fast ganz sehwarz oder mit schwarzen

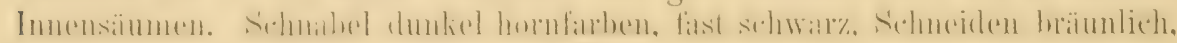
Iris duukelbraun, Füßse bleifarben. Flügel 75-78, Schwan\% etwa 63-68, Lauf 20-22, Schubbel ungefïh $9-10 \mathrm{~mm}$. o etwas kleiner (H'lïgel

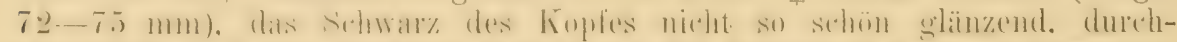

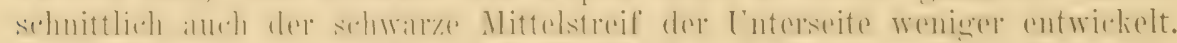

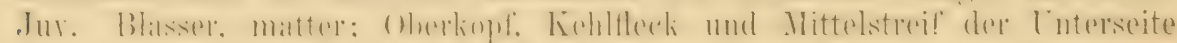

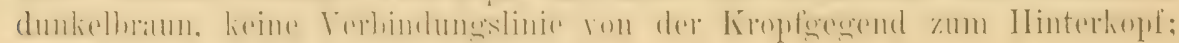
Kopfseiten und Flïgelhinde blaßgelb.

Europa rom Polintreise in Norwegen bis zum Mittelmecre im Süden,

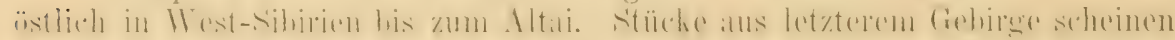
zu gröBerer Flügellänge zu neiğen; eine Serie mit genauen Geschlechtsangaben ist zu untersuchen. Hxemplate aus Spanien sind teilweise sehr blaß. einzelne aber so lebhaft wie solche aus Dentsehland; eine Serio

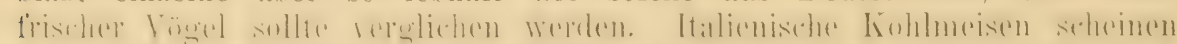

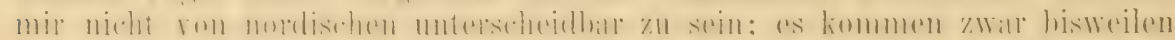
unten gauz lielle, fast ralumfarbene Strieke vor; daraul alloin ist aber kein

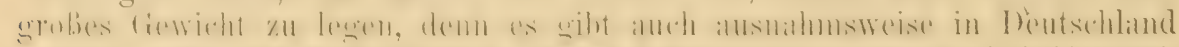

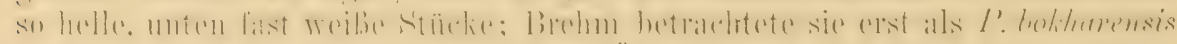
und benannte sie spaiter 1'. pallidus. Über die aus Griechenland rgl. man das untel $P$. mujor aphodite Gesilgte.

Bewohner ron Wäldern, Parkanlagen und Gärlen, wo sie in steter Bewegung umherklettern und -hüpfen. Die Lockwejse ist sehr veränderlich. Die häufigste, aber 
wenig anfallende Stimme ist ein zischencles si oder sit. Ileist hört man cin helles, dem des Buchfinken älnliches pink, pink oder ein sanfteres tivïlivüdi, im Schreck pink tscherrerrerrerrer. Der Gesang ist ein glockenreines sitti sitti sitti, sitzidi sitzidi oder sititn, sititn, sititn, riellach abgeändert und moduliert. Nahrung Insekten und Sämereien, Baumfrüchte, Kerne u. dergl., sehr gern anch Fett und Fleisch. Nester in allen möglichen Hölılungen, besonders Astlöchern, Spechthöhlen, Nistküsten, Pumpen, Mauer- und Erdlöchern. Blumentöpfen, Wichhörnchen- und Vogehnestern. Nest aus Moos, Wurzeln, Halmen, mit Haaren, Wolle, Hedern ausgefuittert. Eier 6-10, ausnahmsweise 12 und 14; weilb mit mattroten bis ziegelroten, in der Regel ziemlich groben, oft aber auch feineren, meist ïber die ganze Fläche verteilten Flecken, selten auch noch mit blassen, rötlich violetten Schalenflecken. Sie sind von denen von Sitta eur. caesia durch noch weniger Glanz und geringere Größe unterschieden. ILaße (Rey): Durschnitt $17.3 \times 13.5$, Maximum $19.6 \times 13.3$ und $17.6 \times 14.8$, Minimum $16.4 \times 12.9$ und $17 \times 12.6 \mathrm{~mm}$, mittleres Gewicht $95.5 \mathrm{mg}$. - Stand- und Stricluvogel, im Norden aber Zugrogel. Mauser Juli bis September.

\section{Parus major newtoni Pražák.}

Parus major nevtoni Prażák, Orn. Jahrb. V, p. 239 (1894- Ẻngland).

Dureh auffallend groben, klotrigen Schmabel ron $P$. m. major unter-

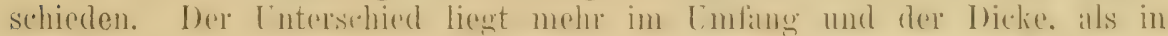

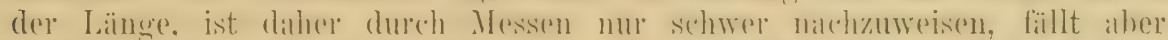

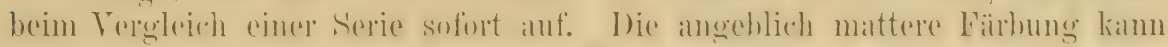

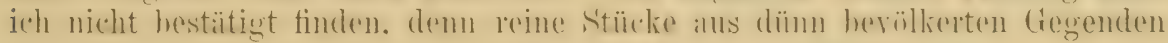
Grobbritamiens sind ebenso lebhaft gefürbt wie nordeuropäischo.

England, Schottland und Irland.

Lebensweise dieser und der übrigen nahe verwandten formen wie die von P. m. major. Die englische Subspezies ist infolge der dicht bevölkerten, stark kultivierten Gregenden, die sie bewohnt, noch weniger wählerisch in ihren Nistplätzen, so z. B. brütet sie gern in Briefkästen, Erdlöchern, an Häusern usw.

\section{Parus major excelsus Buvry.}

Parnes major excelsus Burry, Journ. f. Orn. 1857, p. 194 (Ex Brehm II.S.- Wald Nrakta-el-abbia in Nord-Algier).

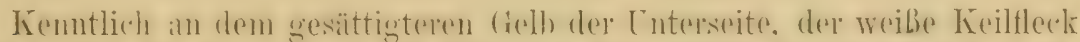

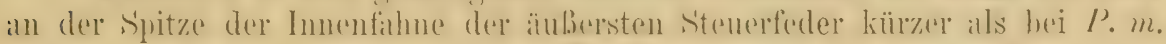
mujur, meist zu liurzem rundliehen Fleck reduziert, dire zweite stenerferder

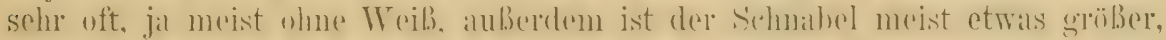
aber nicht so klobig wie der von I'. m. newtoni. Von I'. m. aphlerodite dureh längeren Lauf zu unterscheiden $(20-22 \mathrm{~mm})$.

Bewaldete Teile ron Algier, 'I'unis und Marokko.

\section{Parus major corsus Kleinschm.}

Parus corsus Kleinsclimidt, Orn. Monatsber. 1903, p.6 (Korsika).

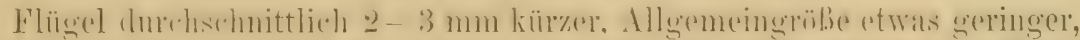

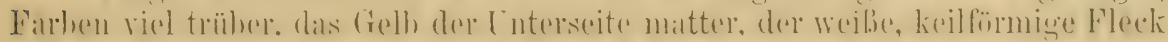

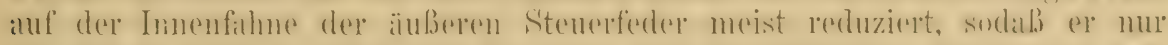

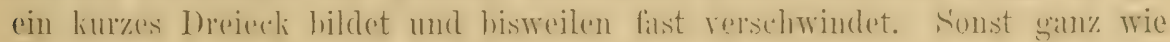
P. m. major. 


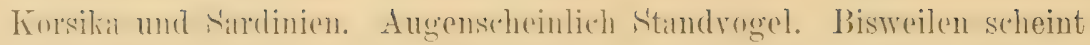
die festländische form sich nach Sardinien zu verirren, denn ein am

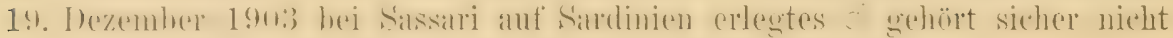
zu corsus, wozu alle übrigen untersuchten Stücke gehören.

\section{Parus major aphrodite Mad.}

Panss aphrodite Xadarász, 'T'erm. Füzetek XXIV, p. 272 (1901- Cypern).

Madarász beschrieb seine aphrodite nach einigen auf der Unterseite

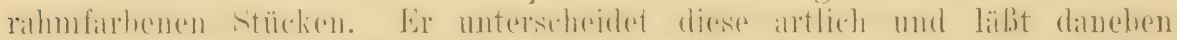

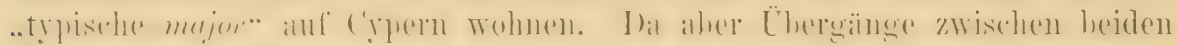
vorkommen, kann vou artlicher 'Iremnung nicht die Rede sein. Da aber'

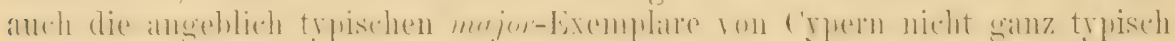

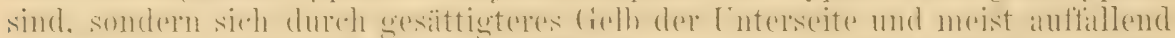

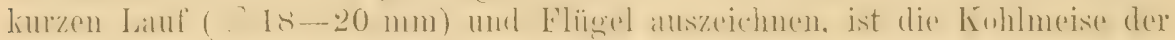
Insel Cypern als Subspezies zu unterscheiden. Außer allen Stïcken von

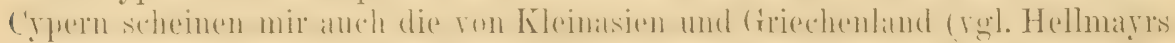

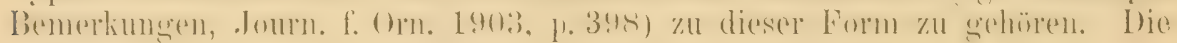
mediterranen Formen sind aber noch weiter zu studieren.

\section{Parus major blanfordi Pražílk.}

Parus major blanfordi Pražák, Orn. Jahrb. V, p. 240 (1894- Persien. Typen ron Teheran in Wiener ILuseum).

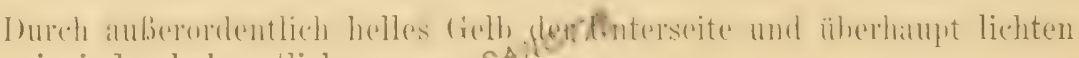
Allgomeineindruck kenntlich.

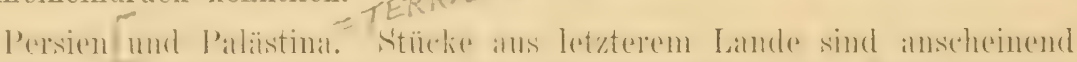

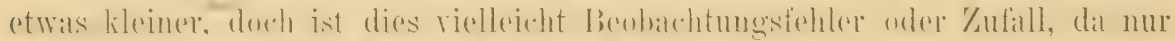

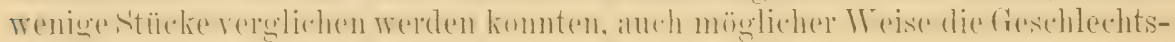
angabe nicht immer richtig war.

\section{Parus major bokharensis licht.}

$P$ an'us bokharensis (oft fälschlich bockharensis, bockhariensis, bocharensis, bochariensis, bacharensis geschrieben), H. Lichtenstein, in Eversmanns Reise Orenburg Buchara, p. 131 (1823 - Buchara).

Parus bocharensis typicus Zaroudnoï, Bull. Soe. Imp. Nat. Iloseou 1890, p. 789 (Ebenen von 'ledschend, Murgab, Merw, Kara-ben usw.)

Yon P. m. major durch den günzlichen Nangel aller grünlichen und

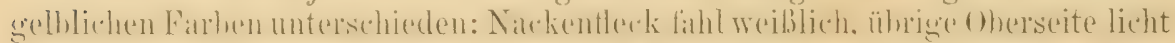

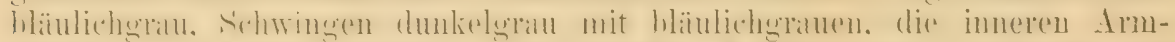
sehwingen mit viel breiteren blïnliehwriben Aubensiümen. Enterseite mit Ausnahime der sehwarzen Kehle und Kropfgegend und des schwarzen

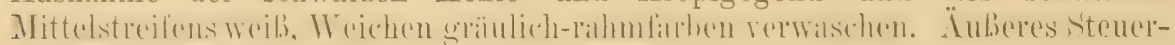

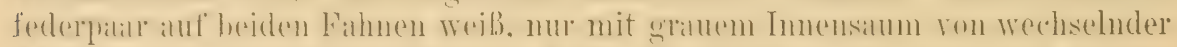

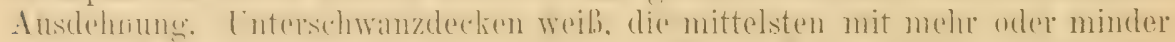

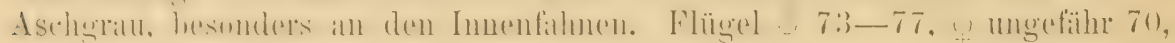
Schwanz or etwa $77-80 \mathrm{~mm}$. Juv. den. alten Vögeln äußerst ähnlich, nur

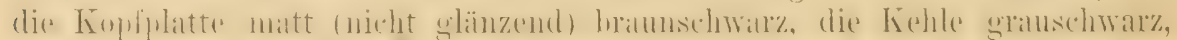

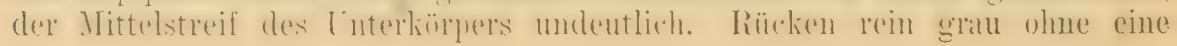




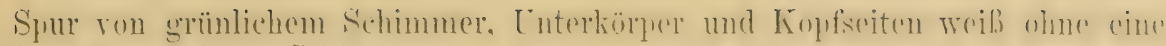
Spur von gelbem Schimmer.

Von der Dsungarei bis Turkestan, Buchara und Amu Darja (Oxus), Murgab, Merw und T'edschen sowie im nürdlichen Afghanistan.

Fortptlanzung und Eier wie die ron $Y$. m. major.

\section{Parus major intermedius Sarudny.}

Parus bocharensis var: intermedins Zarondnoï, Bull. Soc. Imp. Nat. MIoscou 1890, p. 789 (Berge der Gebiete des "Karguy-Sou, Firousé, Gujarmaou, Soumbar \& T'chandyr", also das siidwestl. 'T'ranskaspien).

Parus transcuspins Zaroudnoï, Bull. Soc. Imp. Nat. Aloscou 1893, p. 36t. (Dieselben Gegenden - Umbenennung vou P. b. var, interm.)

Ist $P . m$. bokharensis sehr ähnlich, unterscheidet sich aher durch etwas

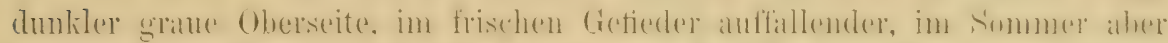

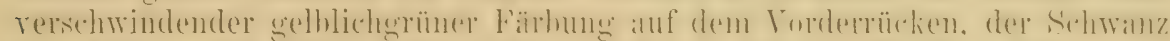

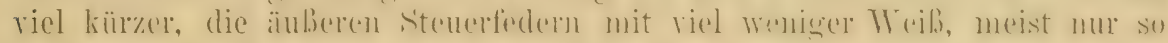
viel wie bei $P$. m. mijor, oder wie bei $P$. m. corsus, die Ausdehung der weißen Farbe variert aber einigermaßen. Schwanz of ad. nur etra bis

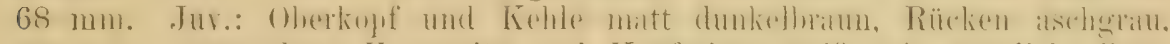

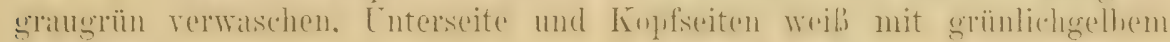
Sehimmer.

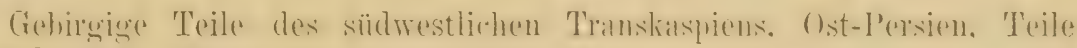
des südlicheren Afghanistan und Baluchistan.

\section{Parus major caschmirensis subsp. nor.}

Steht $P$. m. bokharensis nahe, und lat rein graue aber etwas dunklere

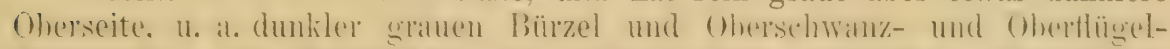

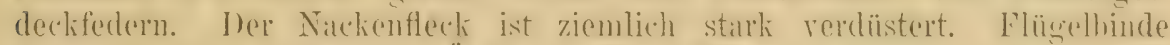

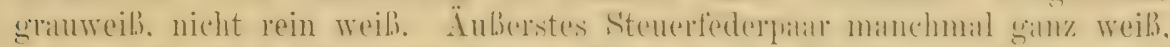

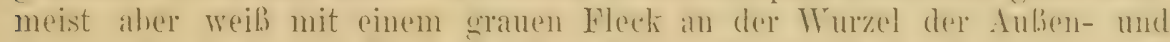

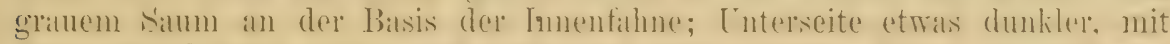

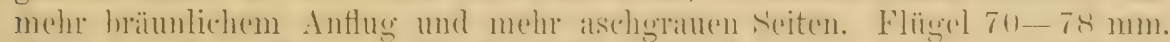

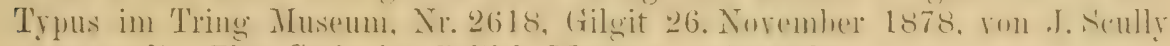
gesammelt. Fine Serie im British Museum untersucht.

Bewohnt die Gehirge ron Kaschmir. Genaue (irenzen des Verhereitungsgebietes mach Norden und Osten noch zu ermitteln.

Im eigentlichen Himilarat, schon ron Simlis, schliebt sich cine retwas kleinere und dunklere Form an. die durch Assimn und Birmal geht und ron

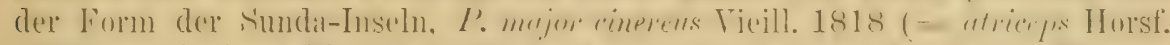
1821. = nipulensis Ifotgs. 1837) nicht zu unterseheiden ist. Andere Fomen schließen sich in Sïd-Indien usw. an.

\section{Parus major minor 'T'emm. \& Schleg.}

Parus minor 'T'emminck \& Schlegel, in Siebold's Fauna Japonica, Aves, p. 70 Taf. 33 (1848- „Japon").

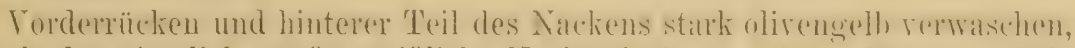

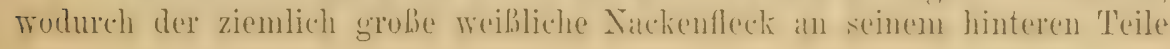




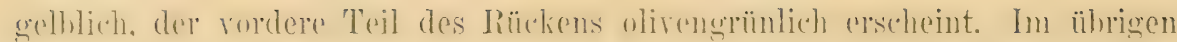
fast ganz wie $P$. m. intermedius, aber die bei letzterer triib gräulichmeißen

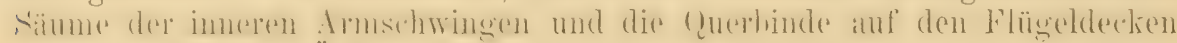

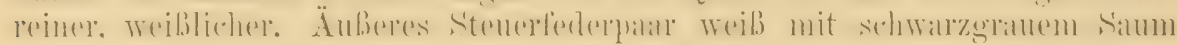
an größten 'Teil der Innenfahne, zweites Paar mit einem an Ausdehnung sehr variierenden weißen Keilfleck, oder nur kurzen Fleck an der Spitzo beider Fahnen. Flügel 69-74, Sehwanz ungefähr 62-67 mm.

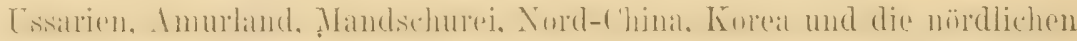
japanisehen Inseln (Jesso, Hondo und Kinschiu).

\section{Parus major tibetanus subsp. nor.}

Vorderrücken grünlich wie bei $P$. m. minor, die genaue Ausdehnung des Grïn aber wegen des schlechten Zustandes des Tyrus nicht sieher. Fionst

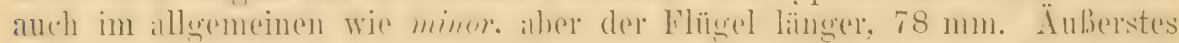

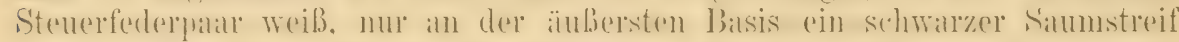
an dere Innenfiahne, zweites Stenerfeederpatar chenfalls weib. nur mit einem schiefersehwar\%en Simmotreifen an der Innenfihne, drittes mit grobenteils woibcr Aubenfahne und ainem weiben Keilfleck an der śpitze der Imnenfilme. J)urh diese sehwanzzedehnung sofurt rom minor u. a. zu unterscheiden, dureh

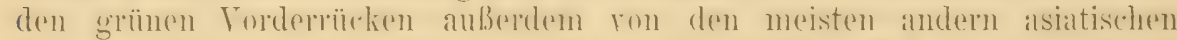

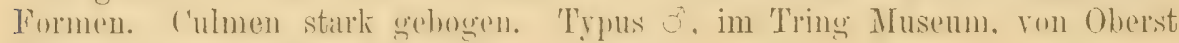
Waddell gesammelt.

Chaksam im 'Tsongpo-Tale in Tibet.

\section{Parus major commixtus Swinh.}

Parns commixtus Swinhoe, Ibis 1868 , p. 63 (Amoy in China).

Wie $l$. m. minor, aber viel kleiner. Flügel nur etwa $65-70 \mathrm{~mm}$. Auberdem ist das olivengrün des Vorderrüdelens weiter nateh hinten ausgedehnt und die Weichen sind trïher, mehr schmutzig rahmfarthen oder bräuulichgrau verwaschen.

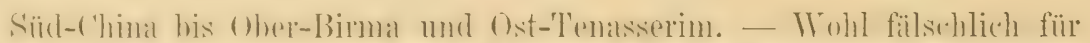

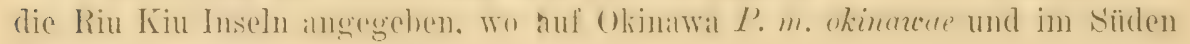
Hellmayr's nigriloris vorkommt.

\section{Parus major okinawae subsp. nov.}

Hat die geringe (irible und sehmutzig rahmfarbigen Weichen und Seiton

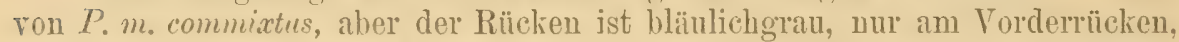

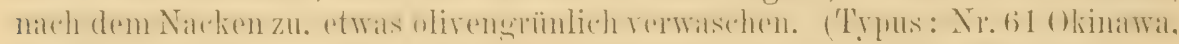
14. März 1902, gesammelt von N. C. Rothschild, Gayner und Waters.)

Insel Okinawa und vielleicht noch andre Inseln der nördlichen Riu-Kiu Gruppe. ${ }^{1}$ ) Herr N. C. Rothsehild brachte elf Exemplare heim.

1) In der sïdlichen Gruppe der Riu-Kiu Iuseln (Ischigaki) findet sich P. vigriloris Hellm. 1900 (= stejnegeri Bangs 1901), deren ganze Oberseite ron dem blauschwarzen Halse abwärts einförmig dunkel blangrau ist. Das Weiß an Schwanz und Flïgeldeckensäumen auf ein Minimum beschränkt. Ist trotz ihrer großen Verschiedenheit vielleicht der Vertreter der major-Formen auf Ischigaki. 


\section{Parus monticolus monticolus Vig. ${ }^{1}$ )}

Parus monticolus Vigors, Proc. Zool. Soc. London 1831, p. 22 (Himalaya).

Siebt aus wio ein sehr kleiner und sehr lebhaft gefürbter $P$. major.

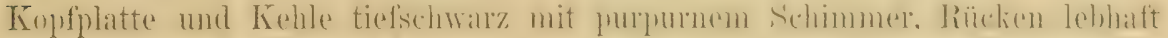

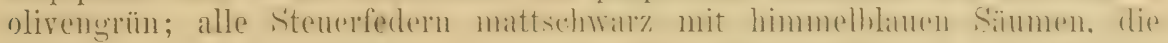
Spitzen weiß, die, äußeren 7-11 mm weit, die imeren nur mit kleinen

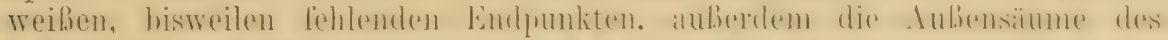

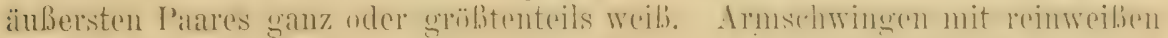

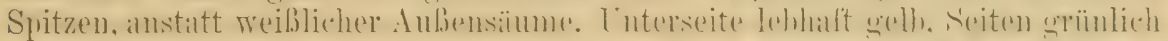

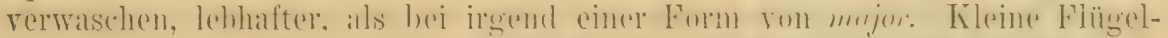

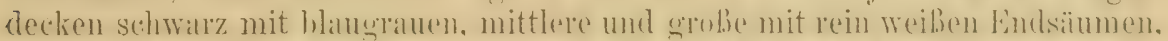

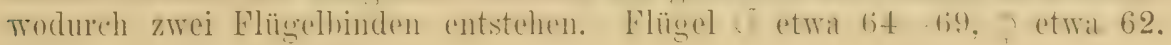
Schwanz etwa 54-59 $\mathrm{mm}$.

Himalaya von Kaschmil bis Assam, Manipur und Gebirge des westlichen China (Mupin, Szetschwan).

\section{Parus caeruleus caeruleus $\mathrm{I}$.}

Blaumeise.

Parus caeruleus Linnaeus, Syst. Nat. Ed. X, p. 190 (1758- „Habitat in Europa“. Als typ. Lok. sehen wir Schweden an, nach dem ersten Zitat.)

Parus erectus P. L. S. Jï̈ller, Natursystem, Suppl,, p. 178 (1776-- ex Buffon, Europa.) Parus coevulescens Brehm, Handb. Naturg. Vög. Deutschl., p. 463 (1831 - Mitteldeutschland.)

Cyanistes salicarius Brehm. Naumannia 1855 p. 285 (Nomen nudum!).

Cyaristes coeruleus glaucopterus, megarhynchos A. E. Brehm, Verz. Samml., p. 6, 7 (1856- nomina nuda!).

Parus caeruleus pallidus (non P. pallidus Brehm!) Grote, Orn. Monatsber. 1902 p. 181. (Nach lebenden, bei St. Petersburg gefangenen Stücken beschrieben). Parus caeruleus languidus Grote, Journ. f. Orn. 1904, p. 307. Orn. Honatsber. 1904, p. 177 (Umbenennung ron pallidus. - Der glücklicher Weise im Berliner Museum aufbewahrte Typus ist eine typische nordrussische Blaumeise [die mit der skandinavischen Form ïbereinstimmt], lediglich, wie alle in Gefangenschaft gehaltenen Blaumeisen, mit etwas rerdiistertem Rücken und blasser, aber noch inmer gelber Unterseite. Älnnliche Stïcke kann man auch in Holland, Deutschland $u$, a. schießen, sie bilden aber keine Subspezies, sondern sind nur blasse, durch Übergänge mit andern verbundene Individuen.)

Franz.: Mlésange bleue. Ital.: Cinciarella. Schwed.: Blåmes.

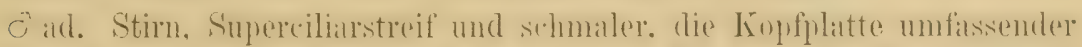

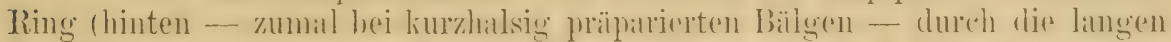

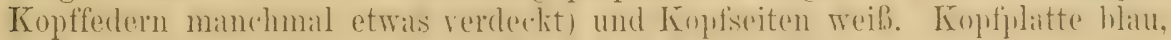

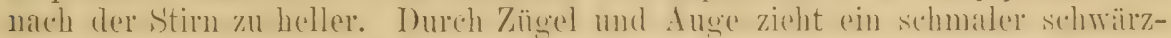
licher, nach linten 7, in dunkles Blan ïhereghender und mit rinem hreiten dunkelhlanen, his zu den Kohlseiten heralniehemlen, dort mit dem schnärz-

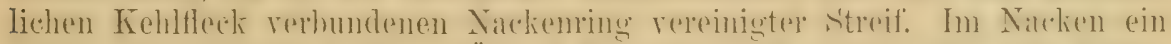

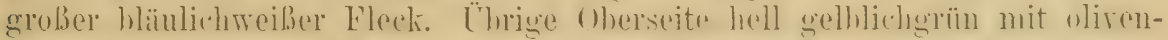

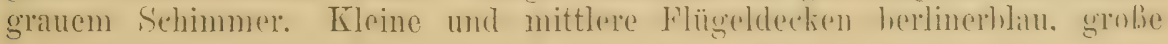

1) Eine sehr älnliche Subspezies, Pames monticolus insperatus Swinh. (Ibis 1866, p. 308, 402) bewolnt Formosa. Sie unterscheidet sich fast nur durch die ausgedehnteren weißen Säume und Spitzen der Flügeldecken und Armschwingen. 


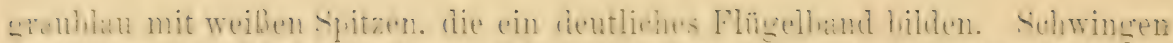

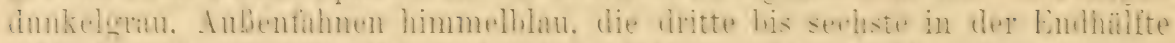

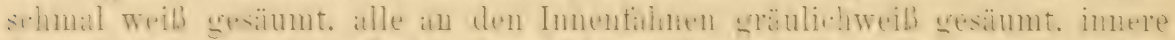

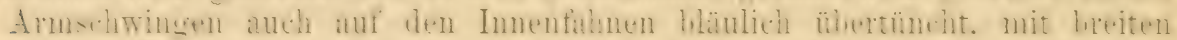

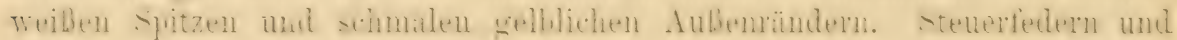
Oberschwanzdecken himmelhlan mit sehwärzlichen Schäften. Unterseite schwefelgelb, am Kropfe am lebhaftesten, nach hinten zu matter und mit etwas grünlichem Anfluge; in der Mitte ron Brust und Tnterkörper ein

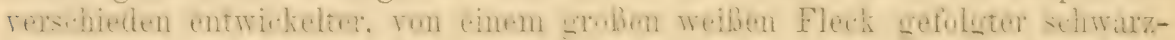
blauer Luingsfleck. Schnabel dunkel hornbriun. an den Schneiden heller,

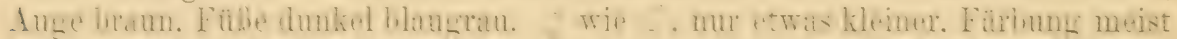

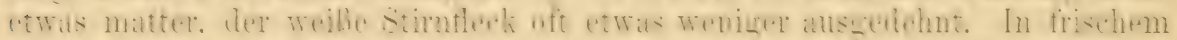

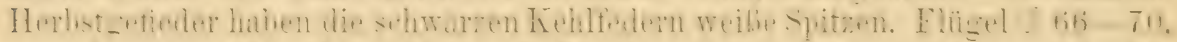

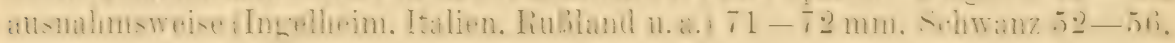
Sehmabel etra $\overline{7} .5$, Lauf $16-1 \bar{\tau}$. Jur. matter und blasser, Kopfplatte dunkel olivengrau mit gelbgrünlichem Schimmer, Kopfseiten usw. blabgelb.

Tom $64^{\circ}$ in Skandinarien und etrra $60^{\circ}$ in RuBland durch den gröBten

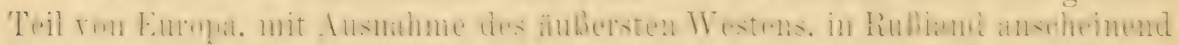
his zum Crial und Nord-Kaukasus, auch in Griechenland und Kleinasien. In England mu als Wintergast. - Im allgemeinen finden mir die

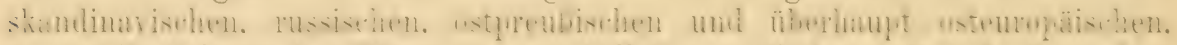

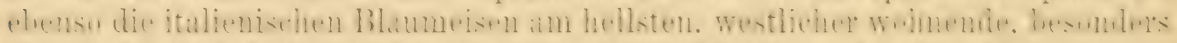

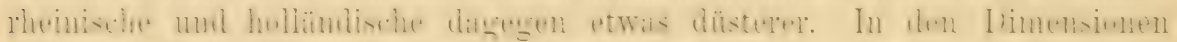
stimmen diese letzteren mit den trpischen und nicht mit den kleineren, außerdem noch düstereren. britischen obscurus überein. Da auberdem die

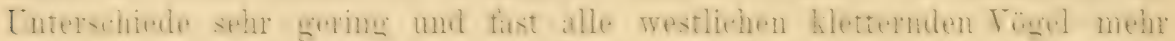

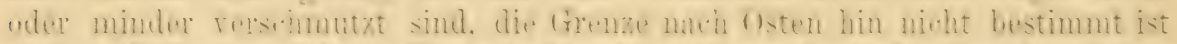

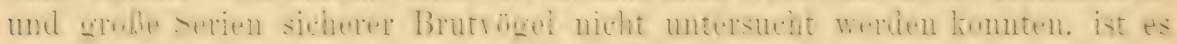
niht ratsm. eine kuthentale wetliche Form abrutremen - dies mag einer späteren Zeit, mach eingehenderen Studien rorbehalten bleiben.

Die Blaumeise bewohnt Laubhölzer, gemischte Wälder, sehr selten Xadelwälder, um so mehr größere Gärten. Alleen usw. Sie ist so munter wie andere Mleisen, ihre Laute sind fein, aber durchdringend. Im Früllling hört man ein feines titi tetetete, ein Schnurren und ein glöckchenhelles zizizizizirrrr. Das ..Zetern" ist auch feiner als bei P. major und in der 'Tonhöhe autsteigend. Alle Laute rielfach rariiert individuell rerschieden. Das Nest steht in engen Astlüehern und anderen Höhlungen, meist niedrig. oft aber in sehr beträchtlicher Höhe. IIan findet in demselben Ėnde April und Mai $7-9$, selten bis 10 und 12 Eier, die meiß sind mit hellroten (hell bräunlichroten) Flecken und Punkten. 44 Eier messen nach hey in llaximum $17 \times 12$. 1) urehschnitt $15.4 \times 11.9$, Jinimum $14.3 \times 11.7$ und $15.5 \times 11.5 \mathrm{~mm}$. Mittleres Gewicht $69.7 \mathrm{mg}$.

\section{Parus caeruleus obscurus Prażák.}

Parus caeruleus obscurus Pražák, Orn. Jahrb. 1894. p. 246 (England).

Eugl.: Blue Titmonse.

Cnterscheidet sich ron $P$. c. ccreruleus durch riel dunkleren. mehr

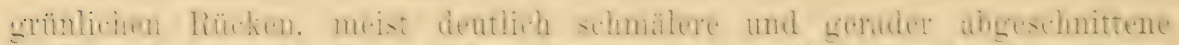

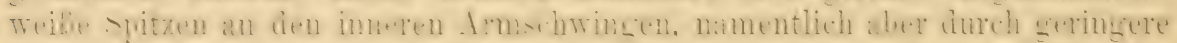

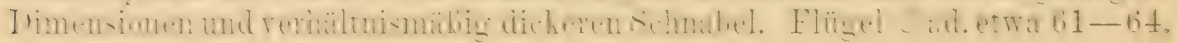
seltener $65-66 \mathrm{~mm}$.

Grobbritannien und Irland. 
(1)ie Lebensweise und Fortpflanzung dieser und anderer Blaumeisenformen stimmen so genau mit der ron P. c. caeruleus überein, daß Winzelheiten darüber in einem notwendigerweise kurz gefaßten Handbuch fortbleiben können.)

\section{Parus caeruleus ogliastrae subsp. $110 \mathrm{v}$.}

Von I’. c. cuerulens dureh dïsterere Fïrbung (dunkler grïno Oberseite,

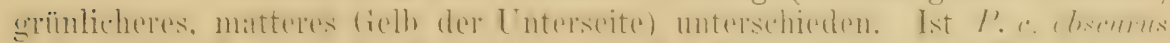

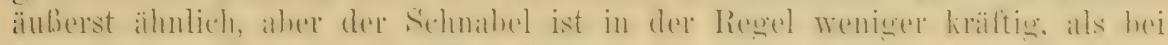
letzterer, auch sind die weißen Spitzen der imneren Armselewingen etwas

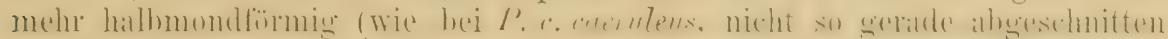
wie bei I'. c. olsenmes). ('Typus im 'lring Museum: ơ ad. Tanusei im Distrikt

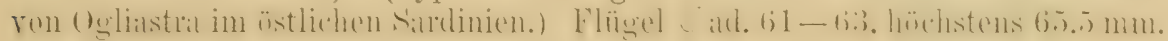
(14 Exomplare untersucht.)

Sardinien und Korsika. (Im Winter kommt bisweilen [z. 13. bei Sassari im Norden ron Sardinien sowohl als bei Lanusei] anch $P$. co cueruleus vor.)

\section{วั5̆1. Parus caeruleus subsp. nor.?}

Cyanistes coeruleus meridionalis A. E. Brelım, Verz. Sammlung p. 7 (1866- Nomen nudum! Der Sammlung nach waren spanische Stïcke mit dem obigen, bereits vergebenen Namen bezeichnet).

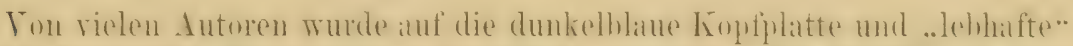

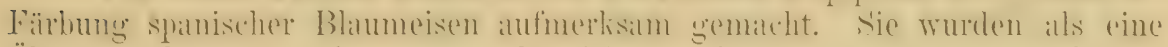
Übergangsform zu ultramarimes bezeichnet. Ich konnte nur alte Stücke (Brehm. Silunders) untersuchen. D)il der Rü̈cke'n grïn ist, kimn mann nicht von nïchster Verwandtschaft mit ullramarinus sprechen, dagegen ist die

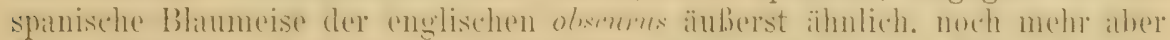

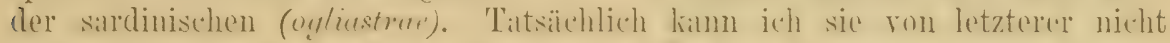

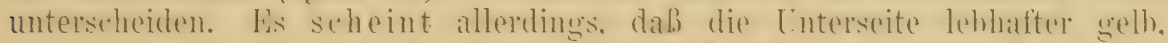

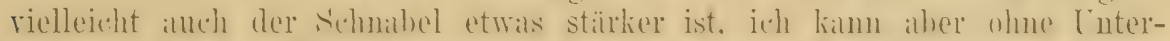
suchung frischer Herbströgel niebt rerantworten, daraufhin einen neuen

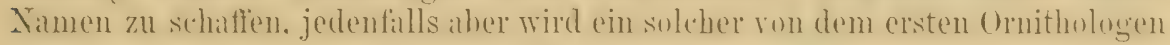
gegeben werden, der genïgendes Naterial untersuchte.

Ich sah Exemplare von Granada, der Sierra Nevada und Madrid.

\section{Parus caeruleus ultramarinus Bp.}

Parus ultramarinus Bonaparte, Rer. zool. IV, p. 146 (1841- „Tunis, et notamment à Sfax").

Pamıs caeruleanus Malherbe, Bull. Soc. Moselle III, p. 58 (1845- Bône in Algier). Abbild: Journ. f. Orn. 1890, Taf. IV.

Ton allen europiiischen Blaumeisenformen anf den ersten Blick durch die zwar durelatus nicht ultrimarinhlaue, aher tief dunkel herlinerhlane,

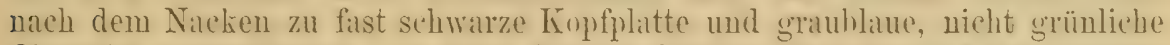
Oberseite unterschieden. Im ganz frischen Gefieder sieht man anf dem unteren Bürzel einen grünliehen Sehimmer. I)er rseiße, die Típpfplatte eimrahmende Ring ist schmal und scharf begrenzt. Die Jungen sind ron denen rou $P$. c. caeruleus nicht sicher oder nur durch dunklere Kopplplitte und geringere 


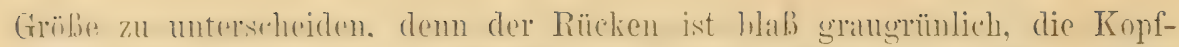
plitte dunkel olivengrau. Konfseiten und ganze Cnterseite hellgells. Flügel ơ ad. 63-67 $\mathrm{mm}$; die größten von Tamarouth im marokkanischen Atlas gemessen. Vielleicht werden sich noch lukiale Intershiede feststellen lassen.

Tunis, Algier und Marokko. Einige bei Mazagan, an der Westküste

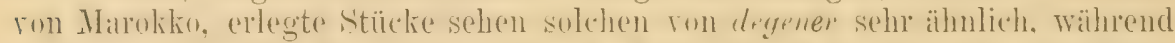

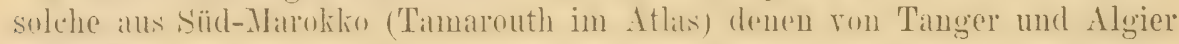
gleichen.

\section{Parus caeruleus degener Hart.}

Parus caeruleus degener Hartert, Nor. Zool. 1901, p. 309, 322 (Fuertaventura und Lanzarote).

Panus ultramarinus insularis Bianchi, Ann. Nus. St. Péterb. VII, p. 252 (1902- ex Meade-Waldo! Lanzarote \& Fuertaventura).

Ganz wie I'. c. ultramarimus, aber die Oberseite ist etwas blasser blüulichgran, die Unterweite heller gelh. Gribe nicht koustant geringer, als die von $P$. c. ultramarinus.

Inseln Fuertaventura und Lanzarote, östliche Canaren.

\section{Parus caeruleus teneriffae Less.}

Parus Teneriffae Lesson, Traité d'Orn., p. 456 ('T'enerife).

Parus violaceus Bolle, Journ.f. Orn. 1854, p. 455 (Kanarische Inseln).

Abbild.: Dresser, B. Europe IX (Suppl.) Taf. 660; Journ. f. Orn. 1890, Taf. IV.

Wie $P$. c. ultramarinus, aber ohne weiße Spitzen an den Armschwingen und ohne Flügerlhinde, da die groben Flügrolderelen lieine weiben spitzen haben. Nur lixi jüngeren Vüguh sieht man Andentungen darou. Im übrigen gleichen die Jungen auch denen vou $P$. c.ultramarinus.

Inseln T'enerife, Gran Canaria und Gomera in der Canarengruppe.

\section{Parus caeruleus ombriosus Mende-Taldo.}

Parus ombriosus Meade-Waldo, Ann. \& Mag. Nat. Hist., ser. 6, vol. 5, p. 103 (1890Hierro).

Abbild.: Dresser, B. Europe IX (Suppl.) Taf. 661; Ibis 1890 Taf. 13.

Hinterhals und Nacken blaugrau, die übrige Oberseite olivengrün

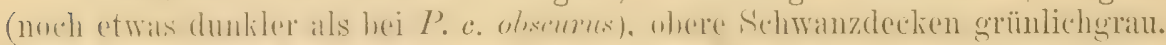

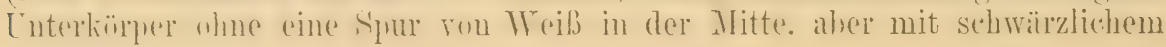
Bi'ustfleck.

Insel Hierro (Ferro) in der Canarengruppe.

\section{Parus caeruleus palmensis Meade-Waldo.}

Parns palmensis Meade-TValdo, Ann. \& Mag. Nat. Hist., ser. 6 vol. 3 p. 490 (1889Palma).

Abbild.: Dresser. B. Europe IX (Suppl.) T'af. 660; Ibis 1889 Taf. 16.

Kopfplatte tief blauschwarz, Oberseite dunkler als die von tenerifjae,

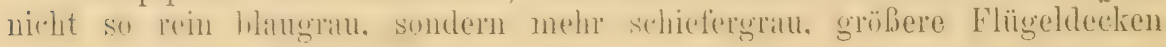




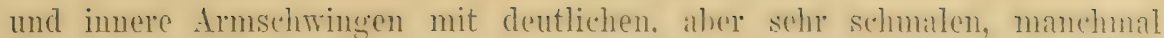
etras umeinen weiben Spitzen. Forderhrust. Seriten, Steil. und Futerschwanzdedien hell und rein schmefelgell, Brust und Lnterköruer weib. nach den Seiten zu grau mit rahmfarbenem schimmer. Brustmitte mit wenig entwickeltem, oft undeutlichem schwärzlicben Längsfleck.

Insel Palma in der Canarengruppe.

\section{Parus caeruleus persicus Blanf.}

Parus persicus Blanford, Ibis 1873, p. 89 (Schiraz).

Unterscheidet sich von $P$. c. cueruleas durch mattere, hellere Farben: der Rücken ist hell grünlichgrau, die Unterseite sehr hell gelb.

Persien und Kurdistan. Stïcke aus dem südlichen und mittleren Kamkatsus stuhen provicus sehr nahe. gehören aber viclleicht einer noch zu benennenden 'Zwischenform an.

\section{Parus caeruleus pleskii Cab.}

(Noch zweifelluafte Form, da Brutplätze noch unbekannt.)

Parus (Cyanistes) Pleskii Cabanis, Journ. f. Orn. 1877, p. 213 (Ex Pleske MI.S., St. Petersburg.)

Parus pleskei var, pallescens Hellmayr, Journ. f. Orn. 1901, p. 175 (Nord-Rußland. Die sogenannten "pallescens" dïrften meist Bastarde von P. c. pleskii und $P$. cyanus sein, da es aber Stäcke gibt, die intermediär zwischen pleskii und "pallescens" sind, so mögen sie teilweise auch aberrante pleskii darstellen). Abbild.: Dresser, B. Burope IX. 'Taf. 659; Neuausgabe des Naumann II, Taf. 18.

Oberseite wie die einer Blaumeise ( $P$. c. caeruleus), deren Rücken das Gelh entzogen ist - der Rücken also nicht grïnlich, sondern helibläulichgrau. in frischem Gefoder meist mit ainem ginz feinen grünlichen Anflug.

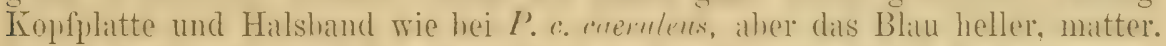
Inmere Armsehwingen mit riel hreiteren meiben Spitzen, als hei $l$ '. cartules,

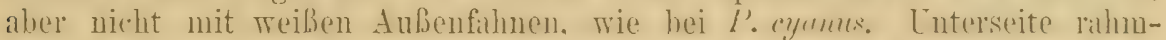
artig weils, an den seiten etwis schmutziger und gollolichers, in der Mitte reiner weib. Koble mit schmälerem schwarzen Flech, als hei aremlens, das Fehlhand hisweilen fehlend. der hehlfeck oft kleiner. als gerwhnlich, manchmal fehlend, Torderhrust hell schwefelgelh, hisweilen sehe blat. oder wic der Lnterkörper, in der Brustmitte der den Terwanden eigene schiefer-

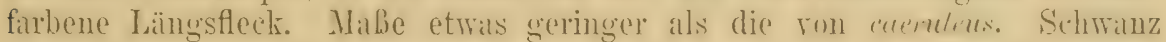
wie bei caemleus, nicht so lang wie bei cyans. Bisher nur als Herbstund Tiuterfogel in Nord- und Ost-Rubland hekimnt (O) renhumes, Muskialu, st. Petershurg). noch nicht hrïtend benhatehtet. - Tiel ist über. I'urus plestii gesehriehen. Minn hat ihre Selhstïndigheit als Ant wder [nterart gelengnet, iudem man sie als Frenzungsereghinis ron l'. aremlens und aymus hinstellte.

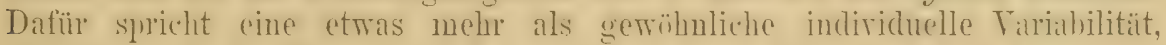

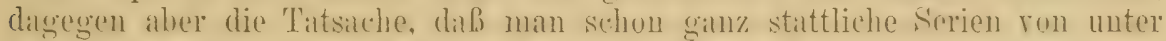
sich im wesentlichen gloichen stïrken gesammelt hat, ihrer also virle Hunderttausende existieren müssen, da zwischen den menigen Punkton des groben russischen Reiches. wo gesammelt murde. Gehiete fast von der dusdehnumg Deutsehlands liegen! I)ie prïchtigen Studien rom Memzhier (Bull. 
Soc. Zool. de France IX, 1884, p. 261 ff.) u. a. m. (auch das von mir untersuchte Interial), scheinen zu beweisen, dals Bastarde ron plexlizi und ryame. nicht selten sind. Austahmsweise liommen aller anch stüeke vor, die man fuir Bastarde von pleskii und caerulens halten muß. Da sich nun pleskii sehr wesentlich (auch in den Dimensionen) ron cyanus unterscheidet, in

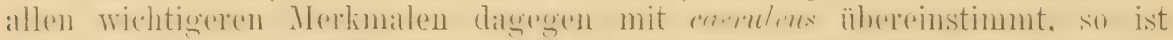

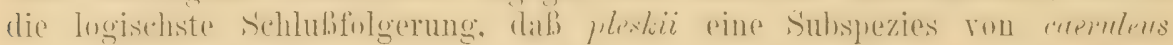
ist, deren Brutheimat noch unbekannt ist. Aus dem relativ häufigen Vorkommen ron Bastarden zwischen pulestii und cyumes müssen wir schlieben. daß die Wohngebiete von pleskii mit denen von ryamus zusammenfallen, :us den anseheinend sehr seltenen (wenn sicheren) Vorkommen von Bastarden

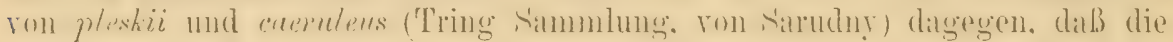
Heimat von pleskii an die von caeruleus angrenzt. Die Heimat dürfte also

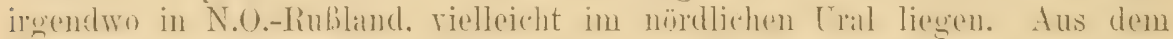

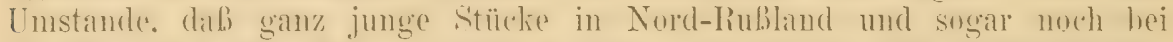
St. l'etershurg (Bianchi) gefunden wurden, geht hervor. dial die Brutpliitze nicht sehr weit ron dort (also wahnscheinlich nieht in W'-Silhirien) liegen.

\section{Parus cyanus cyanus Pall. $\left.{ }^{1}\right)$}

Lasurmeise.

Parnis cyanus Pallas, Nor. Comment. Ac. Petrop. XIV, I, p. 588, Taf. 23,1 (1770- „.. a Volgensibus regionibus datur anicula, cuius patria, qua latissime ad orientem patet Sibiria estenditur, ubi ab accuratissimo quondam Messerschmidio passim observata et pro Paro caeruleo descripta fuit". Als terra typica ist also die Wolgagegend anzusehen, doch unterschied Pallas die asiatische Form nicht). Parus saebyensis Sparmann, Mus. Carlson. I, Taf. 25 (1786- „dd Praedium Carlsonianum Saeby in Sudermannia detecta est").

Parus cyanus und ? P. clegans Brehm, Vogelfang, p.242 (1855- „beide kommen aus Asien sehr selten nach Europa, bis Deutschland").

Cyanistes cyanus major A. E. Brehm, Terz. Samml., p.6 (1866- nomina nuda!)

ơad. Oberkopf weiß, in ganz frischem Gefieder mit schwachem, bäulichen Schimmer. Ein hatuschwallzer schmaler Strich durch Zü̈gel und Auge his fiest zum Natken. Quer üher den Hinterhals, von einer Halsseite zur anderen ein breites tiefhlaues Band, hinter dem sich ein grober weiber, schwach grau üherflogener Fleck hrefindet. Übrige ()herseite hell grauhlau. anf dem Bürzel in Treiß ühergehend. Oherschwanzolecken dunkelhliu mit weißen Spitzenflecken. Kleinere (Oherflügeldecken dunkelhlau, einige mit weiben Spitzen, grobe weiß mit schwarzhläulichen WVurelu. Schwingen sehwärzlich grambraun mit weißen Innenfahnen, die heiden ersten mit weileu, die folgenden Handsehwingen im Wurzelteil mit himmelhinen, im Fndteil mit weiben Außenfahnen; Armschwingen mit blauen AuBenfahnen und weiben Spitzen, die an den immeren Armschwiugen mehr und mehr an Ausdehnung zunehmen, die innersten drei Armschwingen mit ganz weiben Innenfahnen. Äußerstes Stenerfederpar meili, nur an der Trurzel der Innen-

1) Die ganz verschiedene Kopffärbung, die gänzliche Abwesenheit des schwärzlichen Kehlfleckes und Bandes an den Halsseiten, der lange Schwanz, das Brüten in Nord-Rußland, wo auch noch $P$. caeruleus zu brüten scheint, und der wesentlich andere Eindruck, den sie im Leben machen, sprechen gegen die Annahme, daß die Gruppe der Lasurmeisen als Subspezies der Blaumeisen zu betrachten sei. 
fahnen ein dunkelgraner Fleck, das zweite T'an an den Tmenfahnen noch fast zur Hälfte weiß und mit etwas Blau an der Basis der Aufenfahnen, dann vou Paar zu Patu mit mehr abnehmendem Treiß, das mittelste auf beiden Fahnen blat, nul mit mehr oder minder beschänliter weifer Spitze. Euterseite schneeweib, nur in der Nitte der Brust ein dunkel hïulich-ascherrumer Streif. Schnahel schwärzlich hornfarben. an den Schneiden hell. Iris hraun, Füße schmutrig graublau. Flügel 68-72, Schwanz 63-66. Isauf $15-16$, Sehuabel $7-9 \mathrm{~mm}$. F wie $\delta$, nur sehr wenig lileiner. Firben liamu matter. Jur. dem alten Togel ähnlich, aher die Oherscite viel dumkler, mehr selniefergrau, nicht so bläulich. Oherliopf mit Ausnalme der Stirn schieferorau: Unterseite ohue schwärzlichen Brustfleck und mit schwachem, gellulichem s.chimmer.

Brutrogel in östlichen Rubland und wahrscheinlich in West-Sibirien.

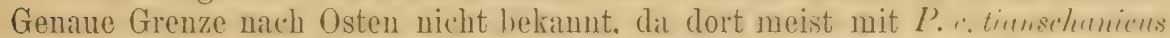
rerwechselt. - Im $\Pi$ intel weiter umherstreifend. nicht selten auch im mestlicheren Rublaud. Schweden, Polen, Schlesien, Prenben, amsmansweise anch weiter westlich. Die weiter westlich erlesten Stücke gehören 7. 'T. der Subsp. I'. '. tianschunimes an, in wie weit dies ahel der Fall ist, kianu nicht aus der Litteratur, sondern nur dureh sorgfältiges Tergleichen der Exemplaro festgestellt werden.

\section{Parus cyanus tianschanicus (Menzb.)}

?Parus Inujuescik Gmelin, Srst. Nat. I. p. 1013 (1788- ex Lepeehin 1770. „Hab. in Sibiriae quercetis".)

Cyanistes cyaneus minor A. E. Brehm, Verz. Samml., p.6 (1866- nomen nudum!) Parus cyamus tianschanicus Severzow, Journ. f. Orn. 1873, p. 347 (nomen nudum!)

Cyanistes cyames var. tian-schanicus Menzbier, Bull. Soc. Zool. France IX, I). 276 (188t-„.. dans les montagnes qui bordent les déserts de l'Asie centr. au nordouest et à l'ouest". Eirste Beschreibung.)

Kleiner als $P$. a. rycoms, Kopfplatte und Nackenfleck bläulichgrau verwaschen, Rücken trïber, mehr schiefergrau, äubere Steucrfedern mit ausgedehnterer grauer und beschränkterer weiBer Färbung; auch die inneren Armschwingen meist mit etwas beschränkterem Weiß.

Bewohnt Sibirien bis zum fernen Osten des Laudes (Grenze nach Testen noch nicht sicher), den Altai, die Gebirgszüge des Ala-tau, Tarbagatai, Tian-Schan, Kwen-lun (Küen-Lün) Ost-Turkestan. - Streicht im Tinter auch nach Europa, daher die Beschreihungen bellerer und dunklerer Fremplare. Gin am 12. Oktober 1821 bei Ohrdruf bei Gotha erlegtes ơ der Brehmschen Sammlung gehört sicher dieser Subspezies an.

Bewohnt lichte Laubhölzer, besonders gern Weidendickichte an den Stromuferu. Munter und lebhaft wie andere Meisen und mit vielfach variierten Stimmlauten. Im Fluge hört man oft ein entfernt an den Ton des Seidenschwanzes erinnerndes, schnarrendes tirr, tirr, sonst ein lautes tscherpink, tscherpink und kohlmeisenartige Rufe. Brütet im Mai in Baumlöehern. Nest aus Hataren und dünnen Gräsern. Gelege 10 bis 11 Eier. Letztere sind größer als Blaumeisen-Eier und ähneln in der Fleckung mehr denen der Sumpfmeisen. Manchmal sind sie nur ganz fein punktiert. Maße nach Dybowski $18.5 \times 12.5,17 \times 12, .16 .5 \times 12,16 \times 11,15.5 \times 11 \mathrm{~mm}$, nach Rөy (5 Eier) $15.3 \times 12.2,14.8 \times 11.5,15.1 \times 12,15.9 \times 11.7,15.6 \times 12 \mathrm{~mm}$, mittleres Gewicht $74 \mathrm{mg}$. Die Maße zweier ron mir gemessenen Stiicke betragen $16.5>12$ und $16.4 \times 12.1 \mathrm{~mm}$. 


\section{Parus cyanus flavipectus Severtz.}

Parus fluripectus Severtzow. Izv. Obsheh. Moskov. V11I, 2, p. 133, I'af. 8, fig. 7, o (1873). Abbild.: Menzbier, Orn. 'Turkestan, Taf. 10.

Oherspite sauz wie die typischer $P$. c. tianschanirus, die Kopfplatte meist noch etwas dumkler. Cuterseite aber durch die lehhaft schwefelgelbe Fïrbung von Kropf und Brust auffallend verschieden. Juv: Oherseite noch düsterer, als hei jungen I'. c. tums'lumirus, mit mehr oder minder bemerlibarem grünlichen Schimmer, ganze Enterseite aher hell schwefelgelb!

Bewohnt das Tal von Ferghana in Turkestan und britet in den dasselhe einschließenden Gebirgen (Kurhach, Tara, Jassil, an den Quellen des Kara-l)irja und Ak-huru), im Winter in die Fhenen hinalsteigend.

\section{Parus cyanus berezowskii (Pleske).}

Cyanistes berczouskii Pleske, BuIl. B. O. Club III. p. XIII (Dezember 1893- . Cprer Chuan-che, China); Cyanistes Beresowkii Pleske, Aves Przewalskianae, p.163, Taf. VII, 3 u. 4 (1894).

Sehr ähulich l'. '. Alavijuechs, aher die Kopfllatte ist mebr sehmutziggrau angeflogen, der dunkle Zügelstreif nicht hinter dem Auge fortgesetrt, das dunkel hlanglatue Nackenband ist viel schmäler, oft in der Mitte unterbrochen, oder nur angedeutet.

Trest-('hina (Oherlanf des ('huanche $=$ Hwang-ho), wo el in Tralddickichten bis zu einer Höhe von 8000 Fub vorkommt.

\section{Parus varius varius Temm. \& Schleg.}

Parus varius 'T'emminck \& Schlegel, Siebold's Fauna Japon., Ares, p. 71, Taf. 35 (1848- „Japon". Als terra typica ist zu betrachten: Hondo).

Parus sieboldi Seebohm, B. Japanese Empire, p. 85 (1890- neuer Name für varius substituiert).

Panıs rubidus Blakiston, Ibis 1862, p.321 (Schreib- oder Druckfehler).

Kinn, Koble bis auf den Krouf, Scheitel und Natienseiten schwarz; Stim fast his an die Augen, Zü̈gel. Ohrgegend, Halsseiten und unregelmälBiger Nickenstreif rahnfarben. Auf dem Torderrücken rin großer hell kastanienrothrauner lileck. Ülnrige Oberseite bläulichgrau. Schwingeu schiefergrau mit weißlichen Imnen- und hellgramen, nach der Spitze zu weißlichen Außensüumen. Sehwanz aschgriul mit etwas belleren Säumen. Lnterkörper hell kastanienothram, handartiger Fleck unterhall der schwarzen Kehle, Mitte des Cunterkïrpers, Cnterschwanz- und Lnterflügeldecken lahmfarben. Schnithel dunkel hornfirben, Füsse dunkel blaugran, Iris braun. o wie ơ, nur sehr wenig kleiner. Juv.: Stirn und Kopfseiten mehr rostfarhen, Küicken sehmutziger. Grïunlichgratu. d: Flügel etwal 77-80, Schwanz etrat 55, Lauf 16-18, Schnabel 10-11, Culmen $12.5-13.5 \mathrm{~mm}$.

\section{Japan (Jesso, Hondo) und Colea.}

Soll sich hauptsächlich in Nadelholz aufhalten, die Stimme soll der des kleinen Buntspechtes ähneln. 7-8 Eier, im April und 1lai, in Baum- und Steinwall-Löchern. Eier weiß mit mattroten Flecken, etwa $17.5>14.2 \mathrm{~mm}$. 


\section{Parus varius owstoni Ijima.}

Panus Oustoni Ijima, Dōbutsugaku Zasshi, Yokohama, Nr. 62 (1893 - „Mị̧akeshima. Seven Islands"): Abdruck in Ornith. Nonatsber. 1897, p. 143.

Unterseheidet sich sehr auffullend von I'. e. v'n ins durch den ungehenereur Schnabel, einfarbige, lehbaft zimmtfarbene, fast kastanienbrame Stim. Kopfseiten und Brust und Unterkörper. Nackenstreif und Vorderrïcken sind kastaniemotbraun, der Rücken ist grau mit olivenbrïumlicher Beimischung: Fiügel ơ 80-86, o 76 , Schnabel etwa 13.5, culmen 17, Nchwanz etwa $5+-55$, Lauf etwa $21 \mathrm{~mm}$.

Sieben-Inseln östlich ron Süd-Hondo (Mijake und Fatsidschio).

\section{Parus varius castaneoventris Gould.}

Parus castaneoventris Grould, Proc. Zool. Soc. London 1862, p. 280 (Formosa).

Parus cinnamomeiventris Gray, Hand-list I, p.231 (1869- nomen nudum! Jedenfalls nur Schreibfehler).

Abbild.: Gould, B. Asia II, Taf. 49.

Viel kleiner als P. v. varius, Schnabel spitziger. Der rahmfarbene Stirnfleck sowie der Nackenfleck mehr reduriert, ehenso das kistanienhliume Feld auf dem Vorderrïcken. Das Grau der (Oherseite dunkler. Lnterseito von dem schwarzen Kropffelde an einförmig kastanienbraun. Flügel ungeführ 59.5-61,5 mm. (Typus im Liverpooler Museum untersucht.)

Formosa.

566. Parus varius subsp. nov.?

Stejneger (U. S. Nat. Mus. 1886 p. 650 , beschreibt ein of von Okinawa, mittlere Riu Kiu Gruppe, welehes kleiner sei (Flïgel $67 \mathrm{~mm}$ ) ils 1 ?. c. rurius, mit reduziertem kastanienrotem Vorderrückenfleck und hellem Kropflande

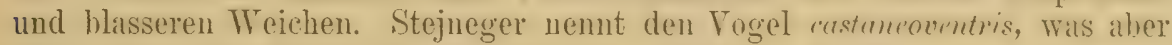
falsch ist. Es scheint sich um eine neue Form zu handeln.

\section{Parus venustulus Swinh.}

Parus vemustulus Swinhoe, Proc. Zool. Soc. London 1870, p: 133 („From Kweifoo in Szechuen to Ichang in Hopih").

Pardaliparns potaninae Bianchi, Ann. Alus. Zool. Petersbourg VII, j. 247 (1902- S. IV.Kansu. Ein offentar junger Vogel wurde 1891 von Berezowskí \& Bianchi in Av. Exp. Potanini, p. 108, T'af. 2 als richtig P. venustulus juv. beschrieben und abgebildet. Eiff Jahre später kam Bianchi zu der Überzeugung. daß dieser junge Vogel einer selbständigen Spezies angehöre, eine Ansicht, der ich mich nicht anschließen kann).

Abbild.: Gould, B. Asia II, Taf. 48.

ôal. Oherkopf und Nackenseiten lis auf den Vorderrïuken ylünzend hlausehwarz, voun Hiuterliopfe ïber den Nacken zieht sich ein weilier, mehr oder minder gelb angehauchter und auf dem Torderrïcken in Flecken aufgelöster Streif, ein andrer breiter weiber Streif verläuft ïher Wange und Ohrgegend. Hinterücken, Bürzel und Schulterfedern blaugrau, meist mit Ausnahme des Bürzels etwas grünlich verwaschen. Oherschwanzclecken schwarz, Schwingen schwarz, Innenfahnen grauschwarz mit weiblichen Säumen, duben- 


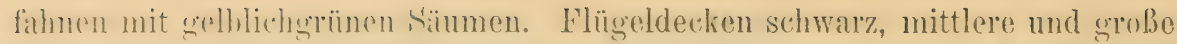

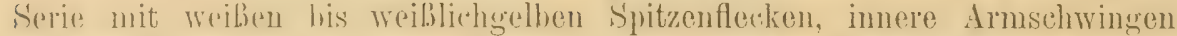
mit weiblicherellen Spitzen. Steuerfedern schwarz mit sehr kleinen weiben

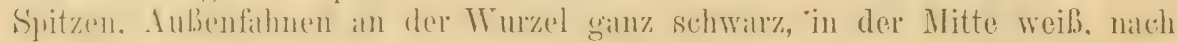
der spitze zu selhwall\% mit sechmalen blaugranen Sümmen. Gamze Kehle

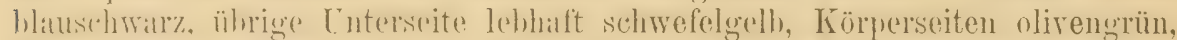
Eintersehwanzdecken hellgelh). Unterflügeldecken gelblichweiß mit granen Flectern. Flügrel otwa 633-66, Schwanz etwa 36-37, Lauf 14, Schnabel 8-8.5, ('ulmen 10 10.5 mm. ostim und s'cheitel gräulich olivengrïn. Nackenseiten grauhratun, Natekennitte weibliehgelh. Wangen und Ohrgegend weiblich. Kehle weils. Bartstreifen gran. Torderücken und śdnulterfedern olivengrün,

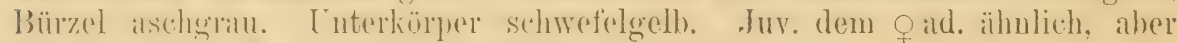
Timbe nicht weils. sondern sehwefelgelh, über den Augen ein kurzer gelhlicher Supereiliarstrenf, Lenfmitte grünlich, nicht srüulich, Bürzel weniger grau.

China, von Kansu bis Szetschwan, Hupeh und N. W. Fohkien.

Styan's Sammler fanden bei Kuatun ein dieser Meise zugeschriebenes Nest mit 3 Eiern. Diese waren weiß mit hell schmutzigroten Flecken und Punkten, sowie tiefer liegenden hell rötlich lila Flecken. Sie maßen $16.8 \times 13$ und $16.6>13 \mathrm{~mm}$. Mir scheint die Identität unsicher zu sein, da die Maße sehr groß und die lila Flecke auffallend sind.

\section{Parus ater ater $\mathrm{L}$.}

Tannenmeise.

Parus ater Linnaeus, Syst. Nat. Ed. X, p. 190 (1758- „Habitat in Europa“. Wir betrachten als typ. Lok. Schreden, nach dem ersten Zitat: Fn. Suec. 241).

Parus carbonarius Pallas, Zoogr. Rosso-Asiat. I, p.557 (1827- Umbenennung von Linué's Parus ater).

Parus abietum Brehm, Handb. Naturg. Vög. Deutschl., p. 466 (1831- „Sie bewohnt die gebirgigen deutschen Schwarzwälder").

Parus pinctorum Brehm, Naumannia 1855, p. 285 (Nomen nudurn!).

Parus ater schwedevi Loudon \& 'I'schusi, Orn. Jahrb. 1904, p. 140 (Liviand).

Französ.: Mésange noire. Italien.: Cincia mora. Schwed.: Svartmes.

ơad. Scheitelfedern etwas verlängert, die hinteren oft eine mehr oder minder undentliche Haube bildend. - Stirn, Oberkopf und Nackenseiten, sowie die ginze Kehle und daron nach den Halsseiten hinziehende Felder glinzend hiuschwallz. die Kehle matter, im alogetragenen Gefieder ganz glanzlos. linterer Teil der Zügel und gesamte Kopfseiten sorvie ein großer Wleck in der Nackenmitte rein weib. Übrige Oberseite bläulich aschgrau, auf dem Bürzel und den Ohersehwanzdecken rostgelblich verwasehen, mittlere und grobe Oberflïgeldecken mit weißen Spitzen, die somit zwei breite weiße Flügelhinclen bilden. S'chwingen schiefergrau, Innensä̈ume schmutzig weib, Aubensïume hell aschgrau, etwas silberig glänzend, oft röstlich angehaucht, an den ïußersten Schwingen weiBlicher, Armschwingen mit schmalen weißlichen Spitzen. Steuerfedern dunkelgrau, Außenfahnen heller und mit mehr oder minder olivenfarbenem Sehimmer. Lntere Kehlfederu mit weiben, in der Brutzeit sich ahnutzenden Spitzenflecken. Übrige Unterseite weißlich, Seiten, Bauch und Unterschwanzdecken fahl rostgelblich, die Intensität letzterer Färbung sehr variabel. Sehnabel braunschwarz, Iris dunkelbraun, Füße blaugran. Flügel etwal $61-64$, ausuahmswoise bis 66 , Schwanz etwa $45-48$, Schnabel 7-8.5, Lauf etwa $16-17 \mathrm{~mm}$. O wie 0 , aber etwas kleiner, 
Flügel etwa 2-4 mm kïrzer. - Juv. Kopf und Kehle dunkel olivenhrann, Nackenfleck, Flügeldeckensäume, Kopfseiten und Lnterseite schmutrig hibsgelb, Rücken olivengrünlich grau.

Europa und Nord-Asien. In Europa ungeführ bis $65^{\prime \prime}$ nördl. Br., im Osten anscheinend durch das nördliche Sibirien his Kantschatkia. in Lurnar bis in die Gebirge von Spanien. Italien und Sizilien, von wo ide allerdings keine serie vergleichen konnte. Im Norden strich- und teilweiser Vungvogel, der aber nur bis in die Crebiete seiner südlicher wohnenden Artgenossen hinalbzieht. Im Süden Stand- und höchstens strichroggel. Auferhalb der Brutzeit vereinzelt in Großbritannien. -- Varlationen in Plügellïnge, Schuabelgröße, Entwieklung des sichopfes. Farbenton der Körperseiten. der Oherseite und namentlich des Bürzels sind anch in Europa häutig. whe dilb ich andere cinigermaben konstante und geographiseh begrenzte finmen feststellen livunte, als die folgenden. In allgemeinen sind skandinatrisebe, nordrussische, baltische und ostpreuBische Stücke auf dem Rüclien am reinsten, deutsehe, alpine, italienisehe u. a. weniger rein gratu, und man liömote diher vielleicht eine mittel- und siddeuropiiische Sulsplezies (I'. a. abietum Brehm) ahtremnen. doch scheint die individuelle Tirtiation z.u serof zu sein. Auffullend lange Flügel find ich bei einigen Italienern, andere italimische Stücle aller hatten recht kurze, wieder andere näherten sich in der leihhaften Teichenfürbung und Rürckenfarbe I'. us surdus. Sehr lehhafte S'eitenfärhung zoigten u. a. Stïcke aus der Dobrudscha, Ungarn. Sichweiz und Inentschland. In ()stsibirien (Amur) kommen auffallend stark gehä̈ubte stücke vor. die an I'a. pelinensis erinnern, doch scheint die europriische Form his zum Anur und bis Kamtsehatkit zu reichen. (Spanisehe Vögel sind vielleicht rersehieden!)

Der Name dieser Meise ist sehr bezeishnend, denn sie bewohnt zur Brutzeit nur reinen und gemischten Nadelwald, findet sich daher in Norden in den Ebenen. dagegen in vielen Ländern, besonders in Süd-Europa nur im Gebirge. Der Lockruf ist ein heller Pfift, fast immer hört man das bekannte sit, der G'esang ist aus dem hellen glöckchenartigen Rufen und zwitschernden und klirrenden 'lönen zusammengesetzt. Das Nest findet man oft sehr hoch, oft aber auch niedriger und sogar bisweilen in ganz niedrigen Stümpfen und in Erdlöchern. Es ähnelt dem anderer Meisen, enthält aber anscheinend keine Federn. 2 Bruten sind die Regel. Eier meist mit sehr kleinen Flecken und Punkten, die bald gleichmäßig verteilt sind, bald deutliche Kranzform zeigen. Größe wie die der Blaumeiseneier, von denen sie nicht sicher zu unterseheiden sind. 44 Stüick in Dr. Rey's Sammlung messen im Durchschnitt $14.8 \times 11.6$, Maximum $16.5 \times 12$, Minimum $14>10.7 \mathrm{~mm}$, das mittlere Gewicht ist $65 \mathrm{mg}$.

\section{Parus ater britannicus Sharpe \& Dresser.}

Parus britunnicus Sharpe \& Dresser, Ann. \& MIag. Nat. Hist. ser. 4, VIII p. 437 (1871England).

Engl.: Coal Titmouse, Coal Tit.

Abbild.: Dresser, B. Europe UI, p. 93, Taf. 107, fig. 2.

Wie $P$. a. ater, aber leicht dureh den gelblich olivenfarbenen Anflug der Oberseite zu unterscheiden, der allerdings im Frühjahr durch Almutzung der Federn minder deutlich wird. IDie Körperseiten sind meist deutlich

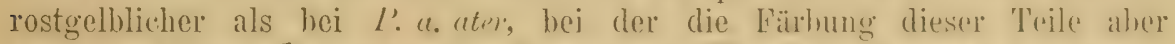
variicrt. Flïgel onad. etwa 60-62, also im Durehsehuitt etwas kürzer. als bei ater. Iinige schottische und irische Stüclie sind sehr dunkel, ather nitelt konstant verschieden.

GroBbritannien bis Nord-Schottland, Irland. 
Bewohnt keineswegs nur Nadelwald, sondern allerlei Wälder, Parkanlagen, Gärten, alte Hecken zwischen Feldern und Wegen, brütet in Baumlöchern, an Gartenhäusern, in Erdlöchern, Stümpfen, Nistkästen und dergl. Eier meist 7-10.

\section{Parus ater sardus Kleinschm.}

Parus sardus Kleinschmidt, Orn. Monatsber. 1903, p. 186 (Sardinien).

Rücken nicht so rein bläulichgrau wie bei $P$. a. ater, sondern mit deutlichem, aber viel weniger rostgelblichem Anflug als bei I'. a. Initumicus, Körperseiten mit etwals varbabeler, aher stark rosthräunlicher, mehr rötlicher Seitenfïrhung als bei I’. a. lnitnmirus. Wenn das Geschlecht der vorliegenden vier Exemplare ('Typen) richtig hestimmt wurde, ist der Flügel noch kürzer, als hei l'. u. Lriftuniens. - Cutersuchung gräBerer Serien ist nötig, um dio Form sicher zu stellen.

Sardinien. (Zwei in der Brutzeit von Whitehead erlegte Frühlingsvögel aus den Bergen von Korsiliat sowohl, als mehrere Wintervögel aus Silrdinien scheinen natch Gröbe und Fïrhung nicht zu l'a a. surdus zu gehören.)

\section{Parus ater atlas Meade-Waldo.}

Parus atlas Meade-Waldo, Bull. Brit. Orn. Club XIr, p. 27 (1901- Marokkanischer Atlas 6-8000 FuB).

Abbild.: Ibis 1903, 'Taf. VI.

Sehr ähnlich $I^{\prime}$. a. savelus, wenigstens dieser F'orm in der Färbung der Oheresite am ähnlichsten. soweit natch den vorliegenden Frühlingsvögeh zu urtrilen ist, ahes die Kö̈repersciten mehr olivengräulich, nicht röstlich, das Sidhwarz des Konfers nichte so blatuschwarz, sondern mehr mit grüulichstahlfirbenem cilanze, der untere Tril der weiter ausgedehnten Kehle mit runden weiben , 'jitzen flecken, die sich aher später völig albnutzen, die IIaße bedeutender: Flügel $66(? \circ)$ bis 69.5 , Lauf ungefähr $19 \mathrm{~mm}$.

Bewohnt die Waldungen des marokkinischen Atlas ron etwa 6000 engl. Fuß bis zur Baumgrenze.

\section{Parus ater pekinensis David.}

Parus pekinensis David, Ibis 1870, p. 155 (Peking).

Unterscheidet sich ron $P$. a. arr. durch stark entwickelten Schopf auf dem siebritel. wo einige Federn 16 mm (und meln?") lang sind. und durch

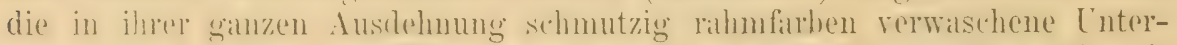
scite mit filhl rïstliehen Seriten, auch soll der weibe Narkenfleck oft mit schwarzen Flecken gemischt sein.

Nord-China und Mandschurei, vielleicht auch westwärts durch den Norden der Mongolei bis in das Quellgebiet des Jenissei.

\section{Parus ater aemodius Hodgs.}

Parus aemodius Hodgson. Journ. Asiat. Soc. Bengal 13, II p.943 (1844- Nepal). Lophophanes Humei Brooks, Journ. Asiat. Soc. Bengal 42. p. 57 (1873- Sikkim). 
Ist $P . a$. pekinensis am ähnlichsten, aber der Schopf ist noch ausgebildeter und seine Federn sind an den Spitzen aufwarts gebogen. Das Grau der Oberseite ist etwas dunkler. Unterseite chamois, Seiten dunkler und grau verwaschen. Die Flügellïnge scheint zu viriieren, meist aber unter $60 \mathrm{~mm}$ zu bleiben.

Östlicher Himalaya von Nepal und Sikkim ostwärts lis in die Gebirge von Kansu und Schensi in W.-China.

\section{Parus ater insularis Hellm.}

Parus ater insularis Hellmayr, Orn. Jahrb. XIII, p. 36 (1902- Japan. Typus von Suruga im mittleren Hondo).

Ähnlich $P$. u. uter, aher die Endflecke an den mittleren Flïgeldecken merklich, die der großen etwas größer und ralhmfarben oder mit rahmfirhenem Schimmer, die ganze Linterseite rahmfarhen his olivenrostgellh. Die Hatuhe noch weniger als oder wie bei $P$. u. uter entrickelt, Größe wie bei letzterer.

Japan: Jesso, Hondo; auch von den Riu-Kiu-Insehn angegehen, aber dort wohl kaum Brutvogel.

\section{Parus ater rufipectus Sewertz.}

„Parus ater var. rufipectus (asiatica, Catal.)" Sewertzow, Izv., Turkest. Jerotu., Obshch. 3loskor. VIII, 2 p. 134 (1873- Turkestan, Russisch!); Dresser, Ibis 1876, p. 93. Parus piccae Sewertzow, Journ. f. Oxn. 1873, p. 346, 373 (Nomen nudum!); Stray Feathers 1875, p. 423 (Erste Beschreibung).

Abbild.: Ares Prezewalskianae I'af. IX, 1.

Auf der Oberseite wie $P$. a. ater, aber das Grau ein wenig dunkler, die Spitzenflecke der mittleren und groben Flügelderen rahmfarben his rostgelb, Cuterseite lehhaft chamois, die Seiten ausgedehnt röstlich olivengrau, an den Śeiten der Tinderhrust ein aschgraure Fleck. Flügel ò ad. etwa 61 (? o) bis $65 \mathrm{~mm}$.

Tian-Schan, vom ïstlichen Tian-Schan his zum Issik-Kul, Mritet in Höhen von 8--10000 FuB, im Winter bis in die Kulturzone hinab.

\section{Parus ater cypriotes Dress.}

Parus cypriotes Dresser, Proc. Zool. Soc. London 1887, p. 563 (Cypern).

Abbild.: Dresser, B. Europe IX, 'T'af. 658.

Diese Subspezies weicht in vielen Punkten von den hisher hesprochenen ab. Das matt hlauglänzende S'chwarz des Kopfes ist sehr auscredehnt und zieht weiter an den Kunfseiten hinab, das Treiß im Naklien und an den Kopfseiten ist reduzierter. I)ie Oberseite ist bräunlich olivangrau, viel dunkler als hei lritumicus. Lnterseite rihmfarhen. Kärperseiten ziemlich dunkel braun. das Schwarz der Kohle sehr weit ausgedehnt. Kleine Fiügeldecken grau mit deutlich hervortretenden röstlichen Sïumen. Snitzen der mittleren Flügeldecken hell chamois, die der oroben woib mit mehr oder minder rahmfarbenem Sehimmer. Flügel ơ etra $61-64 \mathrm{~mm}$.

Cypern. 


\section{Parus ater ledouci Malh.}

Parus ledouci MIalherbe, Bull. Soc. Moselle III, p. 57 (1845- Algerien).

Ton allen anderen Subsuezies von Purus nter durch die schwefolgelbe Fïrhung der brust und des Unterkäruers sowie der Kopl- und Halsseiten unterschichlen. Nitelienfleck hlabgelh, Körperseiten schmutziggrau verwaschen, Spitzenflecke der Flïgchderken weib oder weiblich, Rücken aschgrau mit olivengrünlichem Anfluge. Flügel ơ etwa $65-68.5 \mathrm{~mm}$.

Nord-Algier und Nord-Tunis, in Natel- (Aleppokicferm) und Laubwäldern (Steineichen).

Brïtet in Baum- und Erdlöchern, Eier denen von $P$. a. ater gleichend, meist sehr fein gefleckt.

\section{Parus ater moltchanovi Menzb.}

Parus moltchanovi Menzbier, Bull. B. O. Club XIII, p. 49 (Febr. 1903- „Hab. in sylvis montium Yaïla peninsulae Tauricae").

Oberseite fast ganz wie bei $P$. a. ater, nur das Grau etwas lichter. Unterseite last uhne röstlichen Seitenanflug. Flügel und Schwanz so lang wie hei mirlotonstii, der Schnabel aber viel längè und schlanker, etwa 10 , Culmen etwa $11.9 \mathrm{~mm}$.

Bergw:̈̈lder der südlichen Krim.

\section{Parus ater derjugini (Sarudny \& Loudon).}

Peripurus ater L. ver. derjugini (sic!) Sarudny \& Loudon, Orn. MIonatsher. 190:3, p. 129 ("I'schorochgebiet im Kaukasus").

Hat den anberordentlich langen Shehnihel von moltedernovi, unterseheidet sich aher von letzterer didureh, dab der Rü̈clen nicht rein aschgrau, sondern

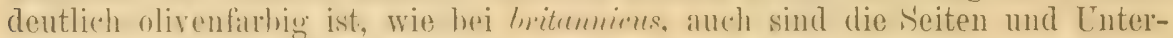
schwanzdecken nicht so weiblich, sondern deutlich rosthräunlich-rahmfarben

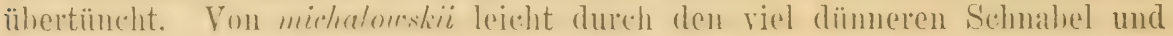
die Fïrhung der Gherseite, dis mehr gräulich allsieht, zu unterscheiden. Schnabel etwa 10.5, Culmen $12-12.4 \mathrm{~mm}$.

Laisistan in nördlichen Armenim, im I)schoroch-Grebiet, also lieineswegs im eigentlichen Kaukasus.

\section{Parus ater michalowskii Bogd.}

Parus ater Michalowskii Bogdanow, Trudui Kazan. Univ. VIII, 4 p. 87 (1879- SuramPass. Kirschalewi im West-Kaukasus, Russich!); Sehalow Journ. f. Orn. 1880, p. 268.

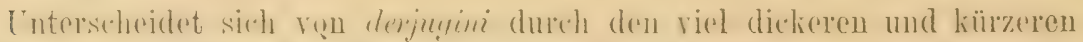

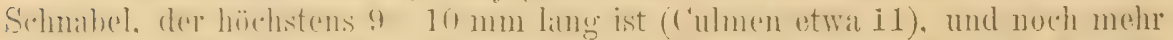

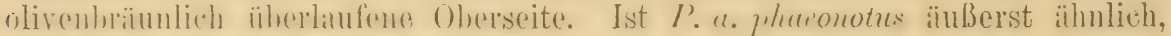
aher dureh dir etwals weniger lehhifte, nicht so ristliche, sondern mehr olivenbrämliche ()herseite von letzterer zu unterseheiden, anch ist der Schmabel 
etrvas dicker. P. e. michalowstii und pharonotus sind einander ähnlich und von allen anderen Tannenmeisenformen an der Farbe der Oherseite mul den dicken Schnäbeln zu unterscheiden.

Sïdlicher Kaukasus, im ganzen FluBgebiet der Kura, Sekarsk bis Kedabeg und Lenkoran. 1 ô aus dem Nord-Kitukilsus (Laibil) scheint (riner nenen Form anzugehören.

\section{Parus ater phaeonotus Blanf.}

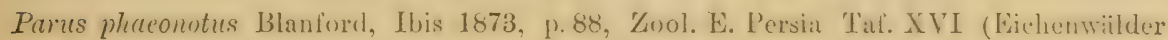
bei Schiraz).

Erimnert in der Fïrbung der Oherseite an eine Sumptineise, denn der Rüeken ist bis zu den Oberschwanzdecken röstlich olivenbraun, die Federn an der WVurzel natürlich wie hei allen Terwandten schwärzlich. vor den ausgedehnten röstlich olivenbraunen spitzen aber mit undeutlichen weililichen Flecken. Das Schwar\% der Kopfplatte nicht so stark blansehwarz, wie bei $P$. a. ater, britanimes u. a. m., die Spitzen der mittleren Oherflägeldecken mit rahmfarbenem Schimmer. Unterseite weil, Seiten fahl rostfarhen verwasehen. Malde sehr bedeutend: Flügel Sad. etwa 67-70. Sehuahel stark und lang, 9-10, Culmen 11-11.5 mm.

Persien und südliches Transkaspien.

\section{Parus rufonuchalis rufonuchalis Blyth.}

Parus rufonuchatis Blyth, Journ. Asiat. Soc. Bengal 18, II, p.810 (1849- „Range beyond Simla, near the snow-line").

Abbild.: Gould, B. Asia II, 'Taf. 60.

ơad. Federn des Oberkopfes lang, die mittleren in einen langen Schopf verlängert. Oherkopf und Nackenseiten schwarz mit stilhllhauem Schimmer. Vom Schnabelwinkel erstreckt sich üher die Wangen, Ohrgegend und Halsseiten ein weißer Fleck. In der Nitte des Nackens ein weißer, mach binten zu blass rostfarben verwaschener Fleck. Ülrige Oherseite grau mit olivengrïnlichem Anfluge. Flügeldecken grau, die kleinen nach der Wurzel zu schwärzlich. Schwingen und Schwanz braungtan mit blïulichaschgrauen Sïumen. Kinn, Kehle und Brust schwarz, ührige ['nterseite aschgrau mit olivenbräunlichem Anfluge; Achsclfedern und Unterschwanzdecken rostrot; Lnterflügeldecken grau mit weilsen Süumen, nach dem Körrer zu hell rostrot, Innensïmme der Schwingen weiß. Sichnabel schwarz, Fü̈ße grau, Iris braun. Flügel 70-77, Schwanz etwa 50-53, Lauf 18-20, Schnabel etwa 9 (Culmen 12) mm. - c wie o , nur etwas kleiner. - Juv. Oberkopf und Kehle schwarzhraun, der weißliche Nackenfleck ohne liostfarbe am hinteren T'eile, Unterschwanzdecken blaß röstlich.

Turkestan und Himalaya von Gilgit his Ghurwal. Im Summer im Himalaya in Höhen ron 7-12000 engl. Fuls, im Tinter bis 50)(1) Fuß oder weiter abwärts.

\section{Parus rufonuchalis beavani (Jerd.)}

Lophophuncs Beavani Jerdon, B. India II, p. 275 (1863- ex H3!̣th II.s., IIt.-Tongloo, Silkkin, 10000 Fuß hoch).

Parus Atkinsoni Jerdon, B. India II, 1. 276 (1863-, interior of Sikkim, at u considerable elevation"). 
Ähnlich wie I’r.rujommchalis, unterscheidet sich aber wie folgt: Das Schwall\% der Kehle reicht nicht his an die Brust, nur Kinn und Kehle schwar\%. Rücken dunkler, bläulichgrau ohne röstlichen Śchimmer, Nackenfleck rahmweib, aber ohne rostfathenen Schimmer, Kopf- und Halsseiten nicht rein weib, sondern rahmfarben. Schopf etwas länger; Gröbe geringer: Flïgel ot $68-70 \mathrm{~mm}$.

In groben Hühen in Treilen von Nepal, Siklim und von dort weiter östlich bis in das westliche (hima ('Tsinling, Süd-S'hensi). (In West-Junnan leht eine andere, auffallend rerschiedene fiorm: "Lophophemes poesilopsis" Sharpe, Bull. B. O. Club XIII p. II 1902.)

\section{Parus rubidiventris Blyth.}

Pame mubidiventris Blyth; Journ. Asiat. Soc. Bengal 16, I p.445 (Nepal)

Abbild.: Gould, B. Asia II, 'Taf. 59.

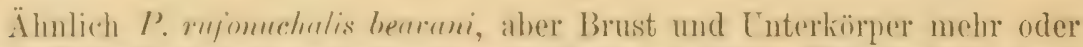
weniger lohblalt restrot. manchmal mit Graul gemischt, Körperseiten grau

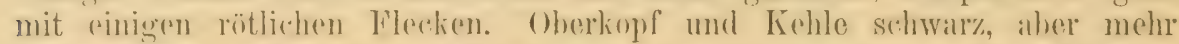
branuschwarz, niemals so tief sehwary wie hei den rerwanden formen. Kopf- und Nirkemseiten sowie Fleek im Nakken weils. (Somit jungen beuvani sehr ähnlich!)

Nepal. . . Lingenügend und nu in wenigen bxemplaren bekamnte Fom.

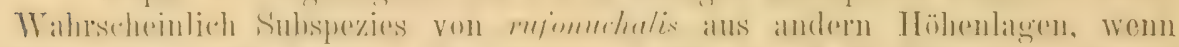

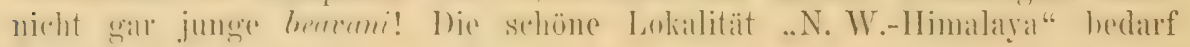
weiterer Frkliirung.

\section{Parus melanolophus Vig.}

Parus melanolophus Vigors, Proc. 'Zool. Soc. London I, 1831, p. 23 (Himalaya).

Abbild.: Gould, B. Asia II, 'Taf. 61.

Ähnlich P. mifommalis, aber viel kleiner, der ans den Scheitel-

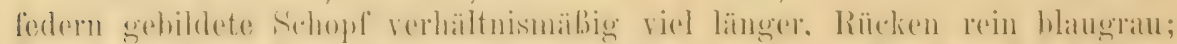

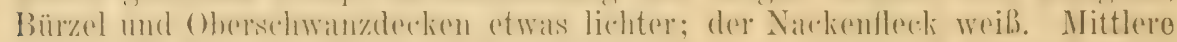

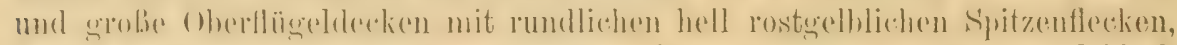
Seiten rostrot, Achselfedern und ein Fleck an den Brustseiten lebhaft

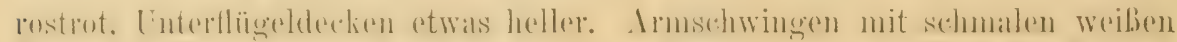

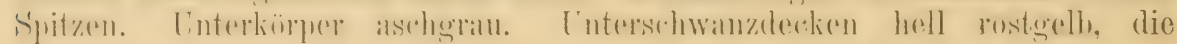
längeren grau mit rostgelben Spitzen. Flügel ungeführ $60-63 \mathrm{~mm}$. -

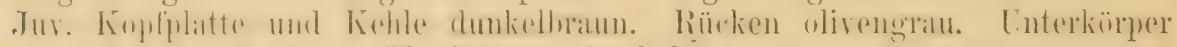
roströtlich verwaschen. Kopfseiten rahmfarben.

'Teile von Afghanistan und der westliche Himalaya von -Gilgit bis Nurreo und Kumaon.

Bowohnt zur Brutzeit Höhen von 2000 bis $4000 \mathrm{~m}$. Nistet im Himalnya von Mlärz bis Juni und baut in Bammlöehern, Steinritzen u. dergl. auf einer Grundlage von Moos, ein weiches Nest aus Haaren und Wolle. Wier $6-8$, rötlich weiß mit lebhaft braunroten I'lecken und Punkten. Hrbe ungefähr $15.6 \times 11.94 \mathrm{~mm}$. 


\section{Parus dichrous dichroides (Prow.)}

Lophophanes dichroides Prowalski. Hongol i Strana Tangut. II. p. 5.t (1877- Kansu) (Russisch!); Rowley's Orn. Misc. II, p. 189 (1877- engliseh).

Abbild.: Aves Przewalskianae, 'I'af. IX, 2.

otad. Oberkopf mansgrau, mit breiter, langer Haube. Vordere Stirnfedern rahmfarben mit gramen Wurzeln, ührige (Oherseite hell olisenhraun, Bürzel und Oherschwanzdecken mit schwatchem röstlichen schimmer. Flïgeldecken wie der Rübken. Schwingen und Steuerfedern braungran mit helleren Säumen. Ohrgegend gelblich rahmfarben mit brämlichen foxlerspitzen. Halsseiten hell rahmfarhen. Linterseite rahmfarben. Seritern und Unterschwanzdecken rostgelh. Cuterfïgeldecken röstlich rahmogh. Sirhnahel braunsehwarz, Fübe sehiefergrau. Iris zimgelrot. Flügel etwa 69474 , selıwallz etwa 55-56, Lauf 18-19, Schnabel etwa 9 (culmen $11-11.5)$ mm. ? wie os, aher kleiner. Juv. Oherseite dunkler. Cnterseite rinfömiger und bräunlicher.

Kansu, Tetung-Gelorge. - In den Taunenwïldern der unteren Gerirgszono.

\section{Parus dichrous dichrous Hodgs.}

Parus diclvous Hodgson, Zool. Misc., p. 83 (1844- nomen nudum!); Journ. As. Soc. Bengal 13, II p. 943 (1844- Nepal).

Abbild.: Gould, B. Asia II, Taf. 58.

Sehr ähnlich $P$. d. dicleroiles, aber die Oberseite mehr grau, so dab.

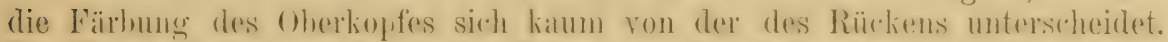
Die Cnterseite ist dunkler. isalhellfarben. an den Suiten kimm dumkler als in

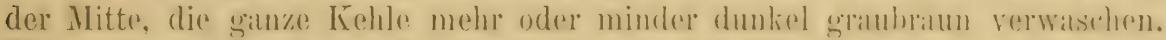
Flügel etwas $(2-3 \mathrm{~mm})$ kür\%er.

Himalaya von Dharmsala bis Sikkim, von 2500 bis 4000 m Höhe.

\section{ว88. Parus cristatus cristatus $I_{i}$.}

Nordische Haubenmeise.

Parus cristatus Linnaens, Syst. Nat. Ed. X, p. 189 (1758 - „Habitat in Europa“. Als typ. Lok. betruchten wir Sichweden, nach dem ersten '/itat).

(? Partim) Lophophanes cristatus septentrionalis A. E. Brelim, Verz. Samml., p. 7 (1866nomen nudum!).

Scliwed.: 'Tofsmes.

OTad. Federn des Kopfes breit und lang, die des Scheitels zu einem

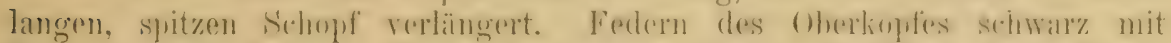

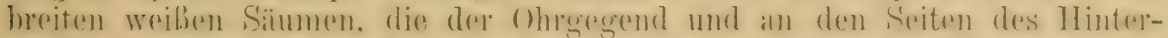

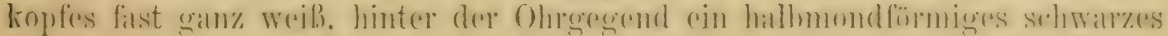

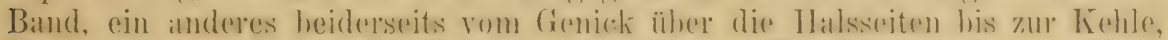

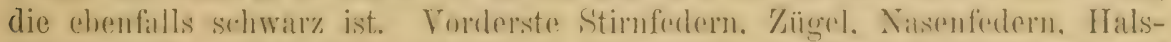

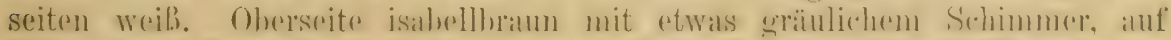

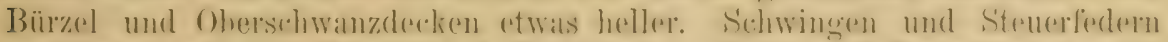

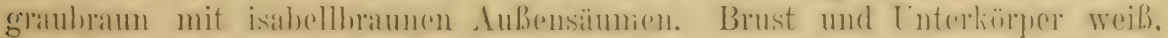

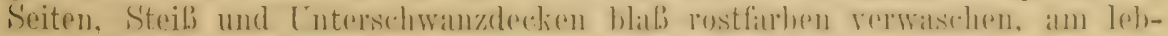

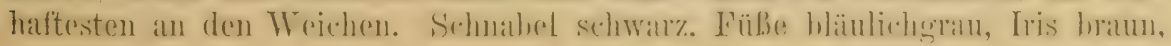




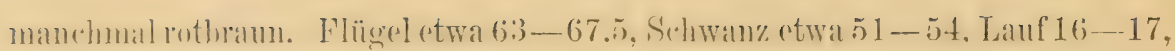
Schnabel etwa 7 -8.1 (Culmen 10-12) $\mathrm{mm}$. - o wie ơ, aber kleiner (Flügel meist atwal 3 mm liüz(r), Hauhe kï̈zer. - Jus. Wie die Alten,

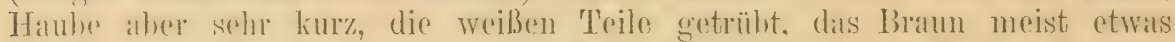

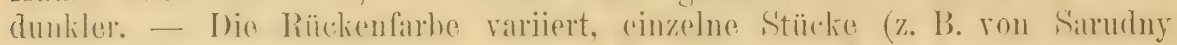
hei Pskov gesammolte) sind vou denen der folgenden form kianm zu unterscheiden.

Skandinavion, nördliches, westliches und mittleres Rubland, wahrseheinlich

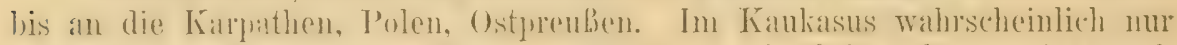

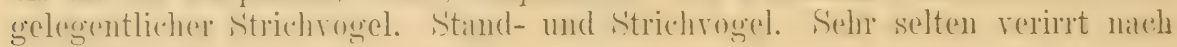
Süd-England.

Im Freien durch die große Haube (Schopf) kenntlich, außerdem durch ihre ganz eigenartige, etwa wie törrrrl, gürrrrr oder zick gürrrr klingende, gurgelnde Stimme weithin bemerkbar. Andere Stimmen hört man seltener, der Gesang ist ein leises Zwitschern und Klirren. Zur Brutzeit fast ausschließlich im Nadelholz, auch sonst meist an Nadelbäumen. Nester bald niedrig, bald hoch, in Baumlöchern oder alten Eichhörnchennestern, auch in morschen Zaunplählen, Baumstümpfen und dergl. Die Eier zeichnen sich durch grobe Fleckung von braumroter Farbe und meist sehr ausgebildete Kranzzeichnung aus. Rey gibt als Maße an: Haximum 17.5 $<12$, Durchschnitt $16.3 \times 12.4$, Minimum $15.8 \times 12 \mathrm{~mm}$, mittleres Gewicht.mg. (J)iese Angaben werden sich natürlich meist auf Eier der folgenden Form beziehen. Da Rey seine Fundorte nicht angibt, kann man selten ersehen, um welche Subspezies es sich bei ihm hamble doch sind dir. Wier solcher naher Subsperies fast niemals nerklich versehieden.)

\section{Parus cristatus mitratus Brehm.}

Mitteleuropäische Haubenmeise.

Parıs mitratus Brehm, Handb. Naturg. Vög. Dentschl., p. 467 (1831- "deutsche Sehwarzwälder" $)$.

Parus rufescens (non Townsend 1837!) Brehm, Vogelfang, p. 243 (1855- \#itteldeutschland").

Lophophanes cristatus brunnescens Pražák, Journ. f. Orn. 1897, p. 347 (Neuer Name für rufescens Brehm, Heimat "West-Europa". Was für MIaterial dem Autor vorlag, ist nicht klar, "West-Europa" ist ein unsicherer Begriff, Brehm jedenfalls beschrieb seine rufescens von Renthendorf. Im "Neuen Naumann"II, p. 269 spricht Pražak vou französischen, westdeutschen und schottischen Vögeln und fügt dann hinzu "diese westlichen braunen Vögel werden brunnescens benannt". Hier also ist der Name brunnescens auf die schon vorher "scotica" getauften schottischen, die westdeutschen und französischen Stücke bezogen.)

Französ.: Mésange huppée. - Ital.: Cincia col ciuffo.

Entersehedet sich von dep nordischen Hanbemenese dureh weniger

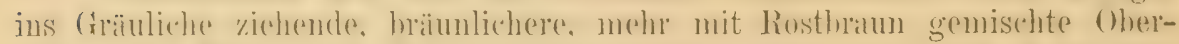

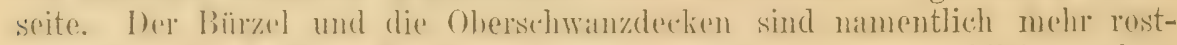

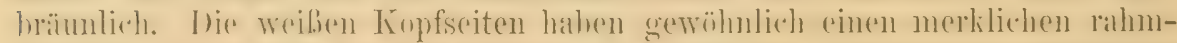

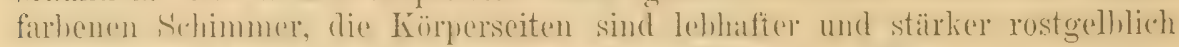

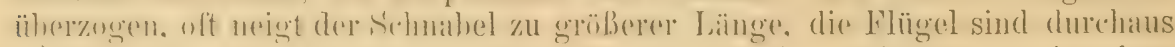
nicht küuzer, sondern völlig so lang wie die von $P$. c. cristatus. - An ciner

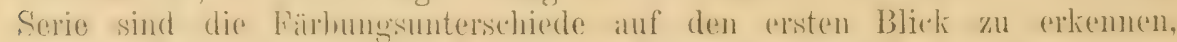
pinzelne Stücke alber sind oft kaum und manchmal nicht zu unterseheiden. So \%. 13. ähneln einzelne westrussisede bxemplare denen rom Rhein roll- 
lommen, auch sehen westeuropäische nach der libutzeit, in aloenutztem und verhleichtem Gefieder, den nordischen Tögeln mamehmal seln ähnlich. Auch in denselben Wäblem finden sich rothräunlichere und sräulichere Individuen, doch hat die Vardition natiolich wie fist immer hestimmte Grenzen. Die von I'rabik vorgesthlagene writere 'Trenmung in eine .westeuropäische*, auf der Oherseite angehlieh noch mehr rosthä̈unliche Eorm kamn ich nicht anmehmen, ohwohl jeh nur wenge framzïsische stüclie mutersuchen kounte. Brohm hatte auch gar nicht die Auffassung von P'rabak, dom soine mitrutus und "rufesems" kamen beide bei Renthendorf vor. Die schottische Form ist gut zu unterscheiden.

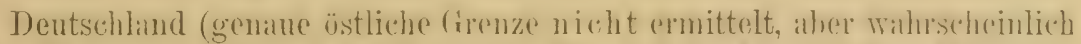
an der Wreichsel), Jïtland, Niedertande. Frankresich, Alpenländer, Pyren̈en, Östereich-Lugatrn his zur Batlianhalhinsel und Spanim his in dio Niller von

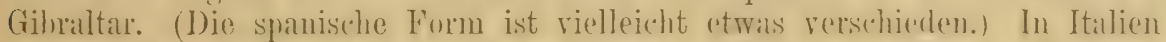
nur im Alpengebiet, rereinzolt, ausmahmsweise und mu anber der Brotzeit südlich der Alpen.

Lebensweise genau wie die ron P.c. cristatus.

\section{Parus cristatus scotica (Pražák).}

Lophophanes cristatus scotica Prazák, Journ. f. Orn. 1897, p. 347 (Schot1land).

Engl.: Crested 'Titmouse.

Leicht ron den Formen des Kontinents durch viel dunklere, mehr olivenbrälunlich verwaschene Oherseite zu unterseheiden. Eitwas kleiner (Flügel anscheinend nux etwa $60-63 \mathrm{~mm})$. Treichen etwas hrämlicher. Es komnten nur wenige Stücke dieser seltenen, aber sehr kenntlichen Form untersucht werden.

Ton heschränktem Torkommen im nördlichen Śchottland und viclleicht hentzutage nur in Tale des Flusses Spey (Strathspey) Brutrogel. In anderu T'eilen Schottlands werden hisweilen cinzelne im Heriste und Winter hemerlit. Die renigen in Süd- und Ost-Fugland beobachteten Haubenmeisen sind zweifellos vom Kontinent verstrichen gewesen.

\section{-591. Parus cinctus cinctus Bodd.}

Parus cinctus Boddaert, 'Tabl. Pl. Enl., p. 44 (1783 - ex Daubenton, 'Taf. 708, "Buffon“ [rectius Mlontbeillard], Brisson. -- Sibirien).

Parus sibiricus Gimelin, Syst. Nat. I, 2, p. 1013 (1788- ex Daubenton. ILontheillard, Latham. - Sibirien).

? Parus Lathami Stephens, in Shaw's Gen. Zonl. 10, I, p.4. (1817 -- Lokal. unbekannt). Panus lapponicus Lundahl, Notiser Sällsk. Fauna Fenn. I, p.4, Taf. 1, fig. 1 (1848Lappland).

Parus septentrionalis (non Harris 18t5) Brehm, Vogelfang, p. 243 (1855- RuBland). Poecila sibirica vera Brehm, Naumannia 1856,1 , 369 ("Verirrt sich aus dem asiatischen Rußland nach Europa, kommt aber auch in Norwegen vor").

Poecila sib. microrhynchos Brehm. Naumannia 1856, 1).369 (Neuer Name für septentrionalis). ${ }^{1}$ )

1) Dieser Name wurde von Gadow im Cat. B. VIII, p. 35 irrtümlich als „Poecile submicrorhynchus" und in Ridgway's B. N. \& Middle Amer. III, p. 396 als "Poecila sibmicror/hynchos" zitiert! 
Parus melanothorax Olphe-Galliard (Brehm. in litt.), Orn. Jahrb. 1892, p. 138 (Norwegen).

? Parus sylvicus Rae, White Sea Penins., p. 326 (1881 - Nomen nudum!)

Cal. Die his auf den Vorderriblien fortgesetzte Koufplatte graubraun (bräunliches matusgrau). Torderste Stimfedern und ein mehr oder minder deutlicher, hinter dem Auge nur noch angedeuteter Supralorilstreif dunkelbraum. Zügel. Wangen und Halsseiten weib. Kleine Flügeldecken graubaun, große schiefergrau mit fahlgrauen his röstlichen Säumen, Schwingen sthiefergrau, mit fahlgrauen, an den inneren Armschwingen hreiteren und mehr hell bräunlichgelben Aubensämmen und hrätulich-weibgrauen Imensäumen. Übrige Uherseite rötlich fillhraun. Oherschwanzderken dunkler, mehr grauhraun. Steuerfedern schiefergrau mit hell aschgramen Sïmmen. Kehle tiefhran, nicht scharf von dem Wriß der Brust getrennt. Dies wird dildureh bewirkt, daß das I)unkelbratune an der Basis der Federn an Ausdehnung zunimmt, bis es zuletat (an der Kehle) die sanzen Federn pinnimmt. Brust und Mitte des Lnterkörvers weiß, Seiten, Steib und Lnterschwanzdeclien lehhaft hell rustfarhen. Schmahel braunschwar\%, Fübe häulichgrau. Iris dunkelbram. óad. Flügel ungeführ 68-70, Schwanz etwa 65-67, Lauf 16-18, Schnabel ungefähl $7 \mathrm{~mm}$ (Culmen 10-11). Q anscheinend ganz wie $0^{\circ}$, nur ein wenig kleiner.

Nord-Siandudinaren, I,appland, Nord-Rubland und West-Sibirien. - Im Winter herumstreichend und dimn südlich his P'etershurg und Moskau.

Bewohner von Laub- und Nadelwäldern. Eier Ende Mai und Juni in Baumhöhlen, besonders alten Spechtlöchern. Die Eier sind meist sehr grobfleckig und glänzend, denen von Phylloscopus trochilus ähnlich, aber größer. Sie haben etwa die Größe der Kohlmeiseneier. 25 Exemplare messen nach Rey im Durchschnitt $16.5 \times 12.6$, im Maximum $17.1>12.2$ und $15.7 \times 13.1$, Minimum $15.7 \times 13.1,16.2>12.1 \mathrm{~mm}$ und wiegen durchschnittlich $82 \mathrm{mg}$.

\section{Parus cinctus obtectus Cab.}

Parus (Poecila) obtectus Cabanis, Journ. f. Orn. 1871, p. 237 (Südlich vom Baikal-See, Sibirien).

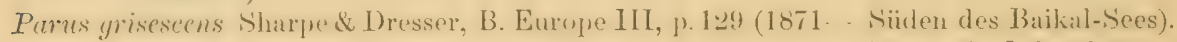
? Poecile cincta alascensis Pražák, Orn. Jahrb. 1895, p. 92 ("Alaska \& Ochotsk". Der Name bezieht sich natïrlich in erster Linie auf den Alaska-Vogel, der angeblich denen von den Küsten des Ochotskischen Meeres gleichen soll. Vielleicht beruhen Pražák's Angaben nur auf denen früherer Schriftsteller!)

Oberseite etwas matter, Kopfulatte fahler, mehr erdgrau. Körperseiten, Steib und Tuterschwanzdecken nicht rostfarben, sondern blasser, mehr rostgelblich verwaschen. Schnabel anscheinend etwas größer.

()st-Sibirien, anseheinend schon rom .Jenissei an, his Kamtsebatka. Anscheinend sind Fxemplare ron den Küsten des Ochotskischen Meeres wieder etvas rötlichere, als typische obtectus und die von Nord-Alashal sollen den ersteren gleichen. Die nordamerikanischen Formen von Purus huelsonicus sind den altwelthelen Formen von $I^{\prime}$. rinetus so ähnlich, daß man die Frage erwïgen mub, uh sie nivht als Subspezies zu derselhen Siezies zu rechnen sind. In Nord-Alaskia soll ahor sumohl die uoch näher zu bestïtigende .. I'. rinctus alascensis", als auch $P$. hudsoniens stoneyi Brutvogel sein! Ob wirklich in demsellon Gebiete? Die folgenden nordanerikanisehen Formen wurden bisher unterschieden: 
1. P. hudsonicus hudsonicus Forst. 1772: Südöstliches Canada und östliche Vereinigte Staaten. - 2. P. h. evura Coues 1884: Mittel- und Süd-Alaska. - 3. P. h. stoneyi Ridgw. 1887: Tal des Kowak-Flusses in N.W. Alaska. - 4. P. h. colımbianus Rhoads 1893: Rocky Mountains.

\section{Parus cinctus sayana (Suschkin).}

Poecile cincta sayana Suschkin, Bull. B. O. Club. XIV, p.44 (1904_, ..Sayan recidentalis, Altai“).

Ähulich $P$. co cinctus, aber der Schnabel länger und dicker. Unterflügeldecken und Axillaren einfarbig, rosthraun überwaschen. Stenerfedern mit undeutlichen aschgraueu (nicht gelblichgrauen) Säumen. Oherkopf mehr grïulich, wie in $P$. «obcectus. Flügel 73 , Schwanz 69, Culmen 11, Schnabel vom Nasenloche bis zur Spitze $9.5 \mathrm{~mm}$. (Nach Suschkin!) Östliche Sayan-Kette, Altai.

\section{Parus songarus songarus Severtz.}

Panus songarus Severtzow, Turkest. Jevotn. (in Izv. Obshch. Mloskov. VIII, 2), p. 134 (1873 - Tian-Schan. Russisch!); Dresser, Ibis 1876, p.93 (Engl. Übersetzung). Abbild.: Aves Przewalskianae, T'af. VII, fig. 1.

Schnabel schlank, Kopf ungehäuht, in allgemeinen rom Halıitus einer Sumpfmeise. - o ad. Kopfplatte mattschwarz. spitz his in die Mitte des Tordrerückeus rellängert. Ührige Oberseite isahellfarhen, natch rorn zu lehluafter. Schwingen braungrau, die inneren Armschwingen hreiter. mit der Farhe des Rückens, die übrigen sthmäler und gräulicher gesïumt. Steuededern wie die Shhwingen, schmutrig isahellfarben gesïumt. Zïgel, Trange und Ohrgregend weib mit schwahem rahmfarbenen Schimmer, an den Halsseiten in röstliche Rahmfirbe oder lichtes Isabell übergehend. Kinn-, Kichl- und Kropffedern mattschwarz. letztere mit schmutzigweißen Śritzen. Brust und Mitte des Lnterkürpers triib rahmweißlich. Seiten ausgedehnt dunkel isahellfarben, ebenso Steiß und Lnterschwanzdecken. Lnterflïgeldecken isahell, Innensäume der Schwingen weißlich. Schnabel schwarzhraun mit helleren Schneiden, Füße bleigrüulich. Flügel etwa 69-72, Schwanz etwa 58-60, Lauf etwa 20, Schnabel etwa 9.5 (C'ulmen 11.5-12.2) 1mm. O etwas kleiner. Flügel ungeführ 65-68. - - Einige von Sarudny erhaltene Stücke aus Turkestan (Nusart-Berge, Kar:i-tau, I)scharkent) hahen merklich Iräunliche Kopfplatten und anscheinend etwas rötlichere Oberseite. Fis sind teils abgetragene, teils frisch gemauserte Sommerstücke. Einige haben auch sehr schlanken Schnabel. Es dürfte sich katum um eine weitere Sulspezies handeln, da die Verbreitung nicht verständlich wäre, anch liegen fast nur Wintervögel zum Vergleich vor.

Nördliches 'Turkestan: Lob-Nor, Ssairam-Nor, Issik-Kul, Tian-Schan. _ Nadelwaldungen.

\section{Parus songarus affinis Przew.}

?? Parus on ratensis Swinhoe, Proc. Zool. Soc. London 1870, 1. 430 (Alaschan. Beschreibung ungenügend. Ex David M.S.).

Poecile "ffinis P'rzewalski, Jongul i Strana Tangut II, 1. 52 (1876-. Alaschan \& Kinsu. Russisch!); Rowley's Orn. Mlisc. II, p. 188 (1877- engl. Übersetzung).

Abbild.: Pleske, Aves Przewalskianae, Taf. VHI, fig. 2; p. 158. 
Sehr ähnlich $P$. s. songcirus, aber der Oberkopf "pelzrobbenbraun" (Ridgrwily"s Nomencl. Colours III, 1), der Kehffeck etwas größer und auch braun, Rücken weniger röstlich, mehr fahlbraun.

Ala-Schan und Muni-ula bis Kansu und Dichu.

\section{Parus lugubris lugubris Temm.}

Parus lugubris Temminck, Man. d'Orn. Ed. II, I, p. 293 (1820- Dalmatien und Ungarn. Name ex Natt. M.S.).

Abbild.: Naumann, Vög. Deutschl. 13, II, Taf. 379, fig. 1; Dresser, B. Eur. UI, Taf. 111.

Yom ungefïhren Aussehen einer gewaltigen Sumpfmeise. - Òd. (ianzer Oberkonf his an den unteren Augenrand und Genick dunkel rubhram. Gesamte Kohle lis an den Kropf wie die Kopfplatte, aher etwas matter, im frisehen Irerhstkleide mit hell braunen Federspitzen. Zïgel, Wange und Ohrgegend his an die Halsseiten weiß, ührige Oberseite mausartig graubraun. Oberflügeldecken wie der Rücken, die groben mit hellen Süumen an den AnBenfahnen. Schwingen schwärzlichgran, Handschwingen mit sebmalen, Armschwingen mit breiteren bräunlichweißen Auben- und weißlichen Innensïumen. Stenerfederu dunkel aschgrau mit hell aschbräunlichen, das äuberste Par mit fast weißen und breiteren Außensïumen. Lnterseite trülhweiß, Körperseiten, Steils und Cnterschwanzdecken mit lräunlich rahmfarhenem Anflug. Sehnibhel dunkel horngrau. Schneiden weißlich. Füße häulichhleigrau, Iris hraun. Flügel etwa 72-76, Schwanz 65-68, Lauf 20, Schuabel etwa 10-11 mm. - o kleiner, Scheitelplatte schokoladenhraun, also viel heller als beim $\overrightarrow{0}$, im allgemeinen etwas matter gefïrbt. - Juv. Scheitelplitte matt schokolidenhraun, Kehlfleck fihl graubraun, Kopfseiten und Unterseite mit rahmfarbenem Anflug.

Istrien, Illyrien, Dalmatien, Bosnien, Herzegowina, Serbien, Süd-Ungarn, nördliche Ballkanhalbinsel, einzeln ansnahmstreise in Nord-Italien. Gärten.

Sehr beweglicher, unruhiger Vogel, Bewolner von Laubwäldern, Gebüschen und

\section{Parus lugubris lugens Brehm.}

Parus lugens Brehm, Vogelfang, p. 213 (1855- Griechenland).

Parus lugubris graeeus Reiser, Orn. Jahrb. 1901, 1.216 (Griechenland und Türkei. Reiser und Hellmayr [Tierreich Lief. 18 p. 68] haben Brehm, l. c., mißverstanden: er vergleicht lugens nicht mit lugubris, sondern mit „sibiricus“. Sein Name muß ohne Zweifel angenommen werden).

Ganz wie I. l. lugulris, aber etwas kleiner (Flügel etwa $70-73 \mathrm{~mm}$ ), die Kopfplatte etwas matter und brïunlicher.

Griechenland.

Die Eier gleichen großen Kohlmeiseneiern, sind fast glanzlos weiß und messen $18.5 \times 13.7$ und $17.8 \times 13.8 \mathrm{~mm}$. (Von Krüper, aus Attika.)

598. Parus lugubris anatoliae subsp. nov.

Subspeciei $P$. lugubris lugubris dictae persimilis, sed pileo nigrescente, nee nigro-brunneo distinguendus. 
Das o ad. unterscheidet sich ron den alten on von $P$. l. lugubris durch viel dunklere, brinuschwarye, manchmal fist rein schwarz rrscheincende Kopfplatte. Auch die Kehle ist dumliler und andertem von der weiblichen

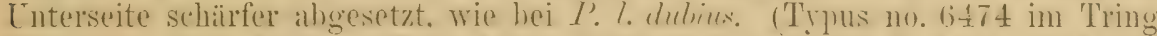
Museum; carl. Ahoory, Ḱlein-Asim, 5000 Fub hroh am 6. April $187 t$ rom

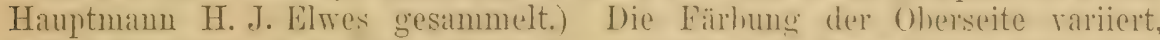

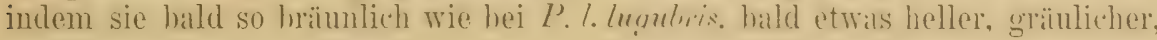
erscheint, aber nicht annähernd so hell wie bei $P$.l. dubius. Dio o sind wie die von P. l. lugubris. Außer dem Typus lionnte ich eine Anzahl von Stücken im British Nuseum, und andere aus dem Taurus. Fom Jamaular Dagh und von Smyrna untersuchen.

Tíleinasien; berghewohnend. Eim in Nizza ron Giorlioli erworhenes Stück des Florenzer Musemms dürfte kiam auf nitürlichem Wege narch Nizzil gelangt sein.

\section{Parus lugubris hyrcanus (Saruduy \& Loud.)}

Poecile hugubris hyrcanus Sarudny \& Loudon, Ornith. Monatsber. 1905, p. 76 (Rustum Abad, Prov, Ghilan).

Wie P.l. lumbris, aber Bauch, Banchseiten und Cnterhnust nicht weib, sondern deutlich rostfarbig. Die weibon Ränder an den Aubenfabnen der kleinen Schmingen schwächer entwicliclt. Mabe (nilch S. \& I.): Schnahel rou der Stirn 11.2, Flïgel 71, Schwanz 55, Lauf $19.2 \mathrm{~mm}$.

Die Persichen Provinzen Ghilan und Massanderan am Süidufer des Kaspischen Meeres, also wohl das Elhurs-Gelhirge. (I)iese Form wurde schon ron Blanford, E. Persia, Zool., 1. 2.9, beschrichen, aher nicht henannt. Siehe auch Pražák, Orn. Jahro. 1895, p. 83, uach Blanford.)

\section{Parus lugubris dubius Hellm. ${ }^{1}$ )}

Poecile lugubris persica (nicht Parus persicus Blanf. 1873!) Prazák, Orn. Jahrb. 1895, p. 81 (Persien, Palästiua \& Syrien).

Parus lugubris dubius Hellmayr Journ. f. Orn. 1901, p. 173 (Umbenennung von persica).

Diese sehr atuffallende Form unterscheidet sich (Inhänger alträterlich binäler Nomenklatur müssen sie als gute Spezies anerkemen) ron $P$. l. lugulmis und lngrms dureh die tief sammetartig hraunschwarze Förbung der Kopfplatte und Kehle, die in scharfer Linie von der weißen Luterseite ahgegrenzt ist, auch ist der Rüclien fast rahmfarbig hellgrau. Flügel etwa $75-77 \mathrm{~mm}$.

Sïdpersische Gebirge. (Eichenwälder.)

\section{1) Parus brandtii (Bogd.) (Fragliche Art!).}

Poecile Brandtii Bogdanow, Trudui Kazan. Univ. VII, 4, p. 89; russisch! (1879Borschom im Kaukasus).

Übersetzung: Schalow, Journ. f. Orn. 1880, p. 269.

Ähnlich P. palustris aber mit viel dickerem und stärkerem Schnabel, wodurch sie sich $P$. lugubris nähert. Kopfplatte schwarzbraun, schon auf dem Nacken endend. Ohne schwarzen Kehlfleck! - Das einzig bekannte Exemplar ist in sehr schlechtem Zustande und hätte gar nicht benannt werden sollen. Es ist sicher keine kaukasische Form von lugubris, sondern eine Form einer mattköpfigen Sumpfmeise. (Nach Bianchi und Beschreibung.)

Kaukasus.

E. Hartert, Die Vögel der paläarktischen Region. 


\section{Parus superciliosa (Przerv.).}

Poecile supercilios P'rzewalski, Mlongol i Strana 'Tangut II, p. ถ3. Russisch! (1876Alpine Regionen der Kansu-Berge); Rowley's Orn. Misc. II, p. 189 (1877engl. Übers.).

Abbild.: Ares Przewalskianae, Taf. VIII, fig. 3, 4.

Oad. Vordere Stirnfedern und ein von den Zïgeln bis zu den Seiten des

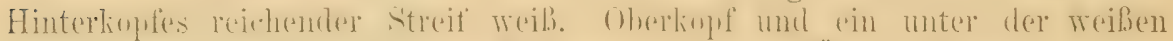

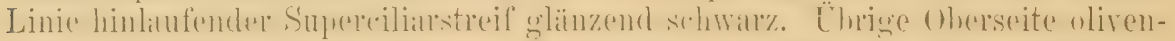

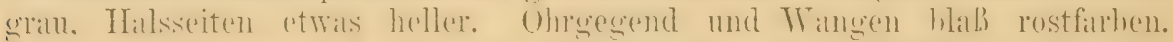

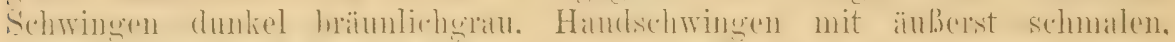

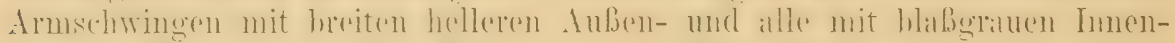

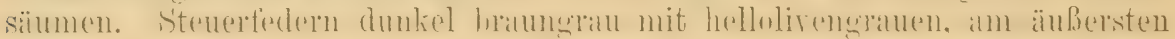

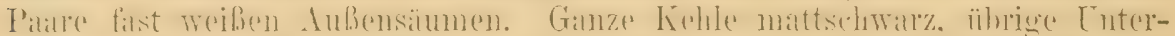

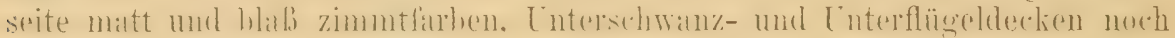
heller und blasser. Schmabel schwarzbraun. Füße dunkel bleifarben. Iris

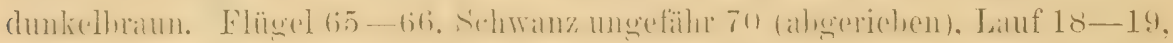
Sehnabel etwa $7-8 \mathrm{~mm}$ (Culmen 12.5). - o ad. wie ō, nur etwas kleiner. -

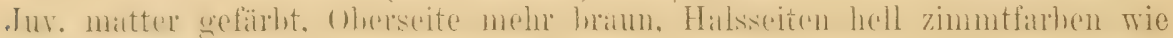
die Unterseite.

Kansu und Szetschwan in West-China, im Buschwald der Alpenzone.

\section{Parus davidi (Berez. \& Biauchi).}

Poecile Davidi Berezowski \& Bianchi, Ares Exped. Potanini, p. 113, 'Taf. II, fig. 4 (1891- Süd-Kansu. Russisch! Abbild. schlecht koloriert!); Übersetz. Deditius, Journ. f. Orn. 1897 , p. 73.

ôad. Die bis über den Nacken ausgedehnte Kopfplatte rein schwarz

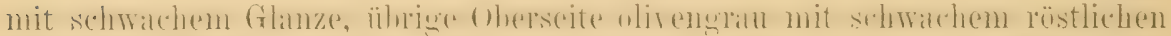

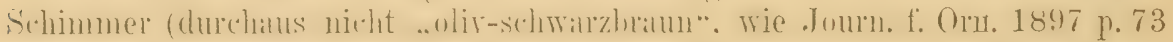
ïbersetzt und auch Tierreich, Lief. 18 p. 53 wiederholt ist). Flügel und

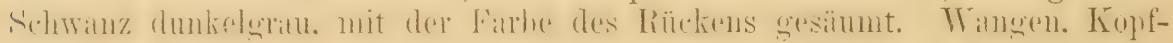
seiten und rorderer 'Teil der Halsseiten rein weiß. Kinn und Kehle bis auf

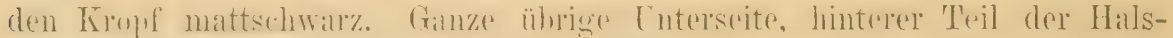
seiten und [nterflïgedilecken lehbaft rötlich zimmtfarben. Flügelbng und

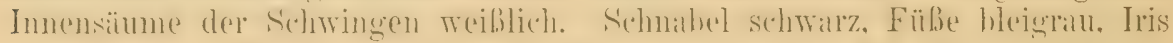

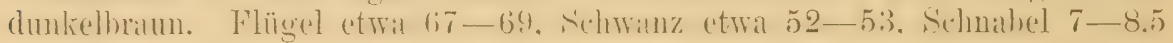
(Culmen 10-11), Lauf $15-16 \mathrm{~mm}$. O wie $\sigma^{7}$, aber etwas kleiner: Flügel etwa 64-67 mm. Juv. ähnlich den Aiten, aber Kopfseiten gelblich.

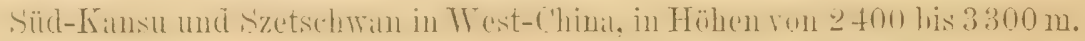

\section{Parus palustris palustris L.}

Die nordische glanzköptige Sumpfmeise.

Parus palustsis Linnaeus, Syat. Nat. Ed. X, p. 190 (1758- „Habitat in Europa“. Als terra typica betrachten wir Schweden, nach dem ersten Zitat "Faun. suec. 242". Die von Jinné angefügten Zitate beziehen sich wie gewöhnlich auf mehrere Formen. 1827 unterschied Baldenstein zwei Formen, von denen 
aber keine die schwedische war. Von den nordischen Arten wurde später zuerst der MLattkopf von neuem benanut, wir beschrünlien daher Linné's Namen auf den schwedischen Glanzkopf).

Parus meridionalis (partim!) Liljeborg, Naumannia 1852, II, p. 100 (der Name basiert auf den von Selys und Nilsson als palustris bezeichneten Formen, genauer Fundort fehlt, also ein unsicherer Name).

Pamus fruticeti Wallengren, Naumannia 185\%, p.141 (,im sïdl. und mittleren Schweden (gemein").

Poecila palustris vera Brehm, Naumannia 1856, p. 368 (partim - „in der hiesigen Gegend und in Schweden, namentlich bei Stockholm").

Schwed.: Kärrmes.

Abbild.: Journ. f. Oru. 1897, 'Taf. IV, obere Figur. Neuer Naumann II, Taf. 21, 5.

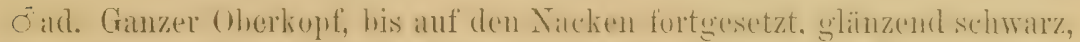

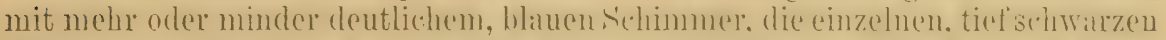

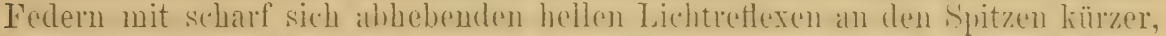

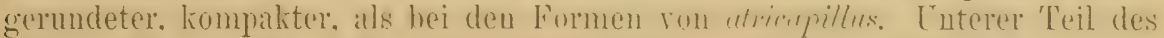

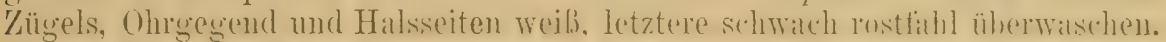

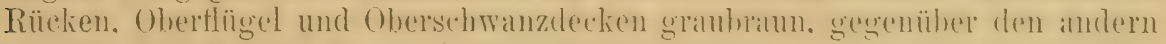

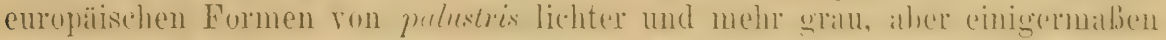

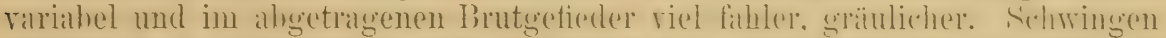
graubraun, Handschwingen mit weiblichgrauen. Armsehwingen mit hreiteren

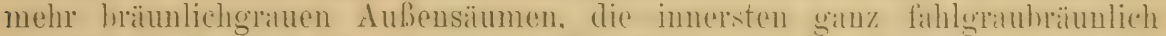
verwascben, Imneusämme schmutzigweib. Struerfedern hräunlichohnledgratu mit

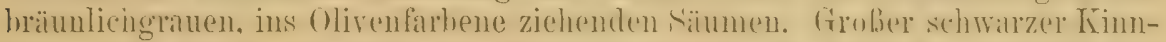
fleck, etwa bis in die Mitte der Kehle reichend: im Erälijalne rerselewinden die weiblichen Spitzen der unteren Kohlferlern mehr. wodureh der schwarze

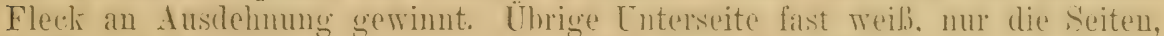

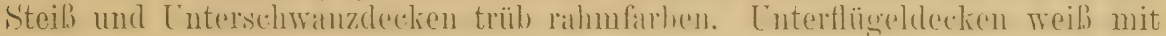

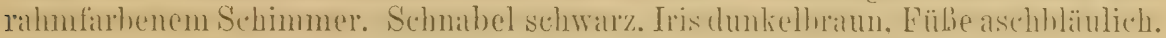
Flügel etwa 65-67, selten 69, Schwanz 56-60, Lauf 15-16.5, Schmabel etrva 7.5, Culmen etrwa 9.6-10.6 mm. 'o wie 0 , nur meist etwas kleiner: Flügel etwa 62-6t mm. Jur.: Kopfulatte mattschwatr whe Glimz. Räicken brätunlicher, Sïume der Sohwingen mehr rostfarhen. Lnterseite trïher, Kelhlfeck meist weniger ausgelildet. Soleho junge Tügel sind an der strulitur der

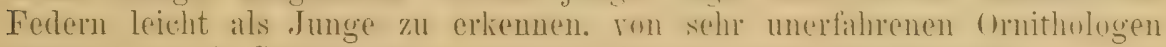
aber schon mit Stücken der atricupillus-Gruppe verwechselt worden.

Ost-Preußen.

S'ïdlicheres nnd mittleres Shandinarien, russische (Ostser-T'rorinzen,

Die Lebensweise ist ganz wie die von $P$. palustris communis. Überhaupt gleichen die Subspezies dieser Art sich darin so wesentlich - soweit wir darüber unterrichtet sind - daB Wiederholungen der Angaben bei den einzelnen Formen fortbleiben können,

\section{Parus palustris stagnatilis Brehm.}

\section{Parus stagnatilis Brehm, Vogelfang, p. 242 (185̌- Galizien).}

Südostemopäische glanzköpfige Sumpfmeisen halen in der Regel einen

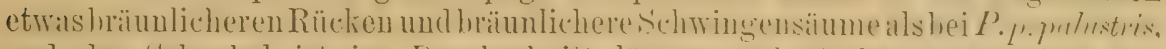
und der Sehnahel ist im Durebschnitt länger und stärler. namentlich das

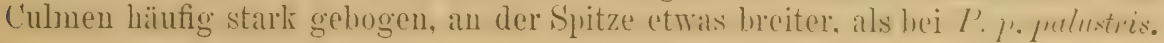


Schnabel etra 7.5-8, Culmen 10-11 mm. - Die Unterschiede sind sehr

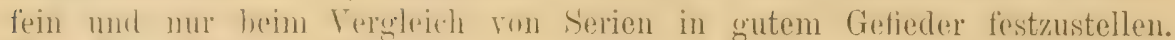

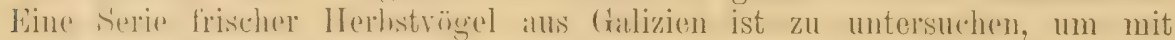

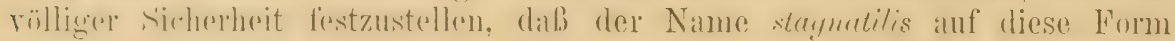

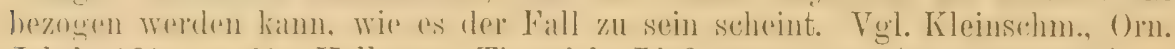
Jahrb. 1897, p.69; Hellmayr, Tierreich, Lief. 18, p. 59. (20 untersucht.)

Balkanhallhinsel, Rumänien, Serrben, Bosnien, Lngarn und Galizien, his

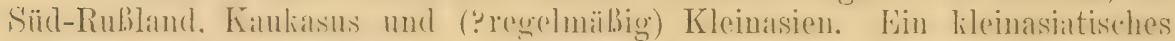

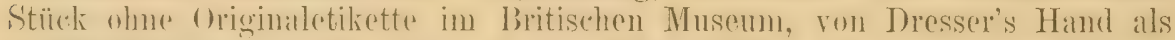

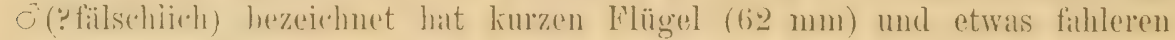
Rücken, stimmt aber am besten mit dieser Form überein.

\section{Parus palustris korejewi Sarudny \& Härms.}

Parus communis korejewi Zarudny \& Härms, Orn. MLonatsber. X, p. 54 (1902- Karatau, T'urkestan).

Ist I’.p. palustris und stagnalilis äuBerst ähnlich, aber das Braun der Oberscite und der Flügeldectien ist etwas reiner, weniger verdüstert; der

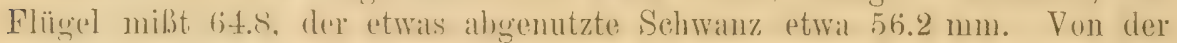
geographisth nahen hrenirostris und ron crassirostris anf den ersten Blick durch die braune Oberseite zu unterscheiden. - Die Autoren hatten nur ein lixemplar, das mir gütigst geliehen wurde. I) ie Form ist dureh ferneres Material zu bestätigen.

1)er Typus wurde am 20. Januar in Kara-tan in Turkestan gesammelt.

\section{Parus palustris communis Baldenst.}

\section{Mitteleuropäische glanzköpfige Sumpfmeise.}

Parus cinerens communis Baldenstein, Neue Alpina II, p.31 (1827 - "Überall in unsern 'Tälern ... selten bis in die Mittelberge hinauf". 'Terra typica: Graubünden). Parus subpalustris Brehm, Vogelfang, p. 242 (1855- "Deutschland." Terra typica: Renthendorf).

Poecila palustris sordida Brehm, Naumannia 1856, p. 369 („Mitteldeutschland“. 'Terra typiea: Renthendorf).

Poëcila palustris vulgaris A. E. Brehm, Verz. Samml., p. 7 (1866- Nomen nudum! Cf. Kleinschmidt, Orn. Jahrb. 1897, p. 67).

Abbild.: Neuer Naumann II, Taf. 20,4. Journ. f. Orn. 1897, 'Taf. III.

Ton den bisher hesprochenen Formen von palustris dureh dunklere, brimnlichere (Herseite zu unterscheiden. I)ie Kopfseiten sind meist deutlicher rahm-oder licht restfirhen getrüht, die Armschwingensäume etwas mehr olivenbräunlich. Flïgel lang, of meist etwa $65-67.5$ selten his 69 mm. - Von I.p. longirostris dureh etwas helleren Rücken unterschieden. Die Abtrennung dieser Form ist beim Vergleich ron Serien nicht schwierig, eine Unterscheidung der Yögel aus den Vor- und Mittelhergen der Alpen aber anscheinend nicht möglich. Große Serie von mir verglichen.

Deutschland (mit Ausnahme der Rheingegenden und Ost-Prenßens) und Alpen his durchsehnittlich 1000 und $1200 \mathrm{Meter}$, fast ganz Österreich 


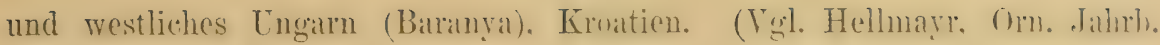
1902, p. 30.)

Der alte Name Sumpfmeise rührt vielleicht ursprünglich von einer Verwechselung mit Parus atricapillus salicarius her, denn er ist nicht bezeichnend. Die "Sumpfmeisen" bewohnen Laubwald, Gärten, Alleen, überhaupt baumreiches Gelände aller Art, nur im Innern einförmiger Nadelholzwälder wird man sie meist vergeblich suchen. Sie sind Stand- und Strichvögel und brïten in Baumlöchern, meist in mäßiger Höhe, manehmal ganz niedrig. In morschem, mulmigem Holze soll manchmal ein Nestloch gezimmert oder erweitert werden; es ist jedoch möglich, daß diese Gewolınheit lediglich eine Eigentümlichkeit der "Weidenmeisen" (salicarius, rhenamus, kileinschmidti) ist. Das Nest ist je nach der benutzten Höhlung größer oder kleiner und aus Hoos, Federn und Halmen weich gebaut. Die 6-10 Eier sind auf weißem Grunde etwas matt schmutzigrot gefleckt und von denen der Blau- und l'annenmeisen nicht immer zu unterscheiden, obwohl oft die Flecke etwas dunkler und schärfer markiert aussehen. Man findet sie von Mitte oder Ende April an. Der Lockruf ändert rielfach ab, ist aber kurz und rauh, ungleichmäßig betont, wie spit dä dä, spitzi dä dä, oder tschi tschü, dä dett dett dett dett, oder därredett. Der Gesang ist ein eigenartiges, kaum zu beschreibendes, etwas zischendes Klappern, daß man mit dem von Sylvia curveca verglichen hat. Kleinschnidt beschreibt es als dă dă dă dă dă. Dem Klappern ptlegen ganz feine wie sit sit klingende Laute roranzugehen, bisweilen soll man auch ein mehr moduliertes Gezwitscher hören (? Herbst).

\section{Parus palustris longirostris Kleinschm.}

Parus dresseri longirostris Kleinschmidt, Orn. Jahrb. 1897, p. 65 („Frankireich und Rheingegend“. 'lerra typica: Latour, nach Kileinschm. in litt.).

Franz.: Nonnette.

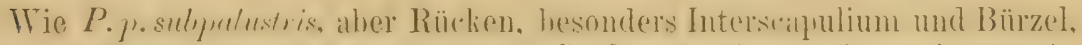

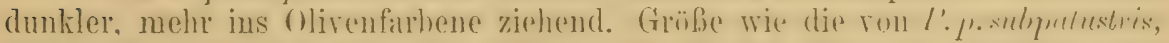

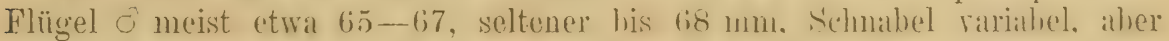
zu gröBerer Länge und Dicke neigend. - Die Form hann wegen ihrer bedentenderen Gröbe nicht mit dresseri verwedhelt werden. dagegen steht sie sulyuluxtris so nahe. dab man sehon einc serie bei gatem lichte rerghleichen

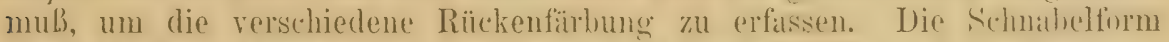
ist zwar bemerkenswert, aber so wenig konstant. dal.j sie kein heruemes Kriterium abgibt.

Rheingegenden und Frankreich, Belgien und Holland. ()h, dio in Sinanien

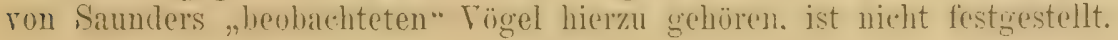

\section{Parus palustris dresseri Stejn.}

Englische glanzköpfige Sumpf̣meise.

Parus palustris dresseri Stejneger, Proc. U. S. Nat. AIus. IX, p. 200 (1886- England). Abbild.: Dresser; B. Europe III, 'laf. 109, 2; Neuer Naumann II, Taf. $21,4$.

Engl.: Marshtit.

Oberseite noch dunkler. oder vielmehr etwas melu und sehr gleichmïBig

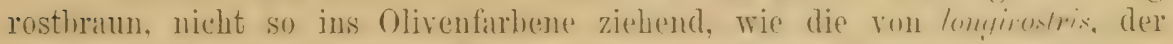

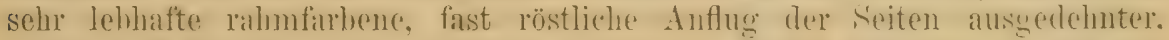
meist anch dio Halsseiten merklich getrïhter. Groble geringer. als die ron longirostris und allen anderu bisher hesprochenen Subspezies. Flügrel of etwa 


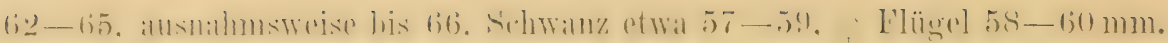
Schmabel im allgemeinen sehr dick und kurz.

Ganz England und sïdlicheres Schottlaud. In Irland nicht als Brutvogel, und auch sonst nur ausuahmsweise vorkommend.

\section{Parus palustris italicus 'l'schusi \& Hellm.}

Parus communis italicus 'T'schusi \& Hellmayr, Orn. Jahrb. 1900, p. 204 (Siena in Toskana). Pemus communis tschusii Hellmayr, Orn. Jahrb. 1901, p. 110 (Terra typica: Cremona).

Ital.: (Hincia bigia.

Sehr ithulich 1.p. commmis, aber dio Oberseite röstlicher und lebhafter,

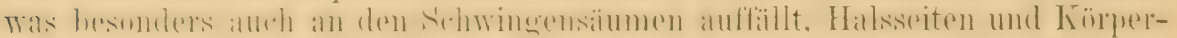
seiten reiner rahmbrïmnlich angeflogen. - Dic beiden 'I'ypen von italicus

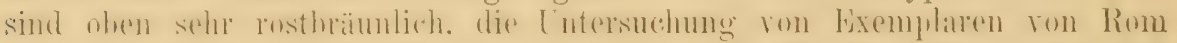

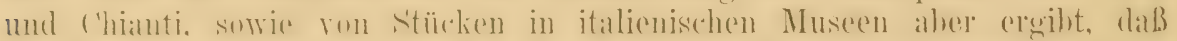

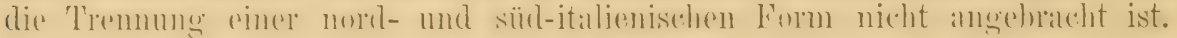

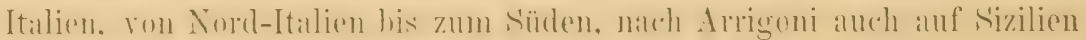
und Sardinien (?regelmäßig).

\section{Parus palustris brevirostris (T'acz.).}

Poecilia brevirostris T'aczanowski, Journ. f. Orn. 1872, p. 444 (Süd-Baikal).

Ähnlich P.p. palustris, aber der Rücken viel lichter, gelblicher und mehr

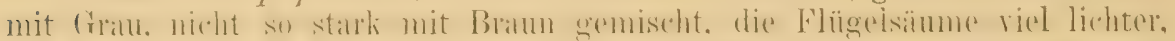

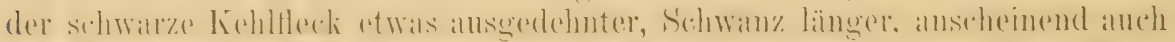

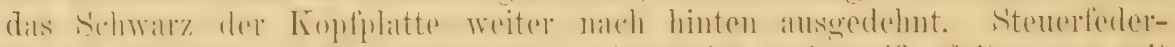

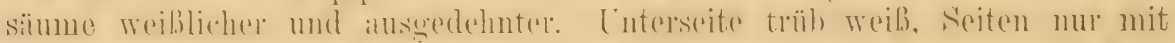

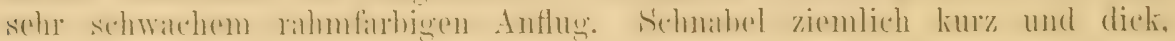
Culmen etra 8.3-8.9 mm. Flügel o.etwa 68-69.5, Schwanz o etwa $67-69 \mathrm{~mm}$.

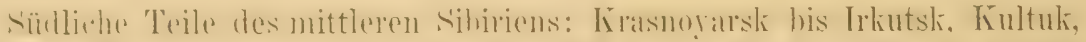

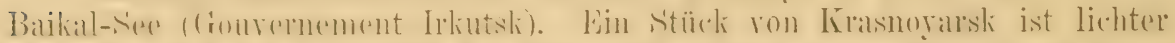

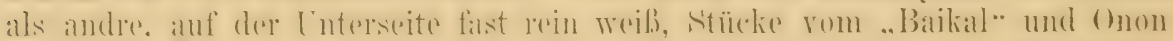

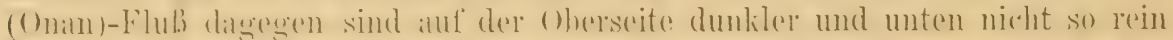

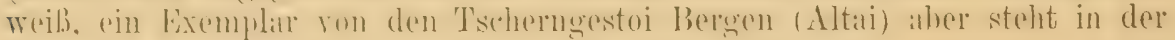
Mitte. Alle diese scheinen zu einer Form zu gehören.

\section{Parus palustris crassirostris (Tacz.).}

Poecilia palustris, crassirostris Taezanowski, Bull. Soc. Zool. France, X, p. 470 (1885Sidemi-Fluß).

Wie brevirostris, der Schnabel ebenso geformt, aber an der Wurzel

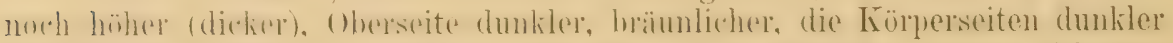

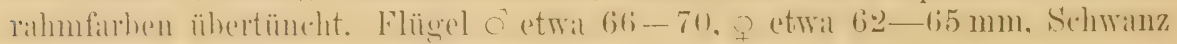
ơ $66-70$, o etwa $62-64$.

Südost-Sibirien: Ussuriland, Sachalin, Korea. 


\section{Parus palustris hensoni Stejn.}

Parus hensoni Stejneger, Proc. U. S. Nat. Ins. XV, p. 342 (1892- Hakodate aut Jesso). Parus scebohmi Stejneger, Proc. U. S. Nat. Mus. XV, p. 343 (1892- terra typica: Sapporo, Jesso).

Von P. p. arassirostris und I'. pr. Grevirostris durch etwa 5-10 mm

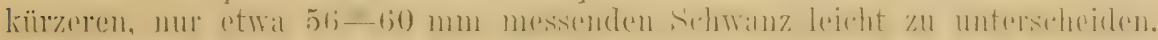
Die Färloung der Oberseite ist etwas heller, als bei crassirostris, aber nicht so licht, wie bei den hellsten brecirostris, der Schuabel nicht so hoch, wie der ron crassirostris, aber nicht viel verschieden.

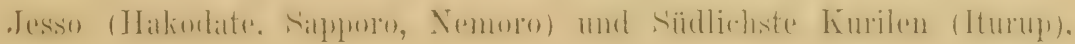
wo Biutrogel.

\section{Parus palustris hellmayri Bianchi.}

Panus pahustris hellnayri Bianchi, Annuare Ylus. Zool. Acad. Imp. Se. Petersburg VII, p. 236 (1902- P'eking. Lx Kleinschm. ete.).

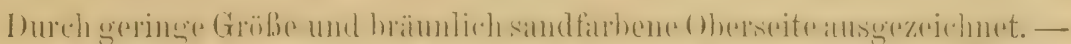

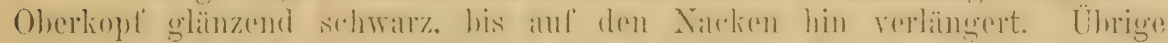

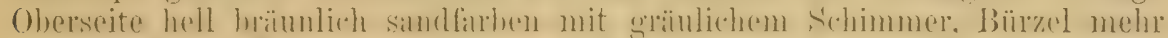

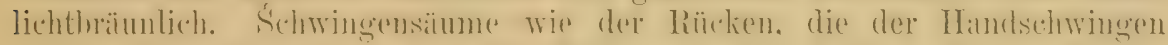

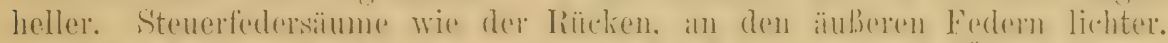

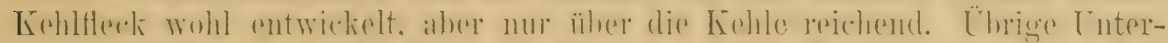

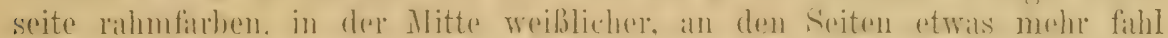
röstlich. Flügel 59-62, Schwanz bis 55, Schuabel etwa 8-9, Culmen

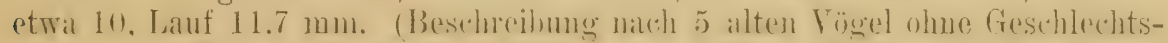

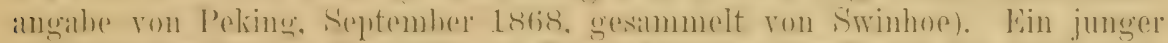

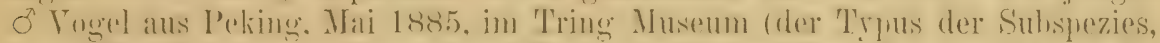

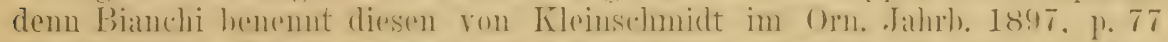
beschriebenen Vuerel) stimme im wesentlichen ïberoin. ist nul anf dem

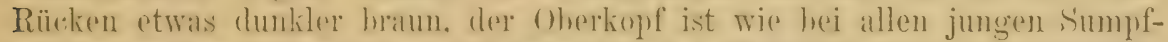

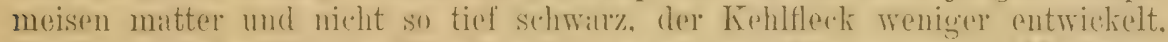

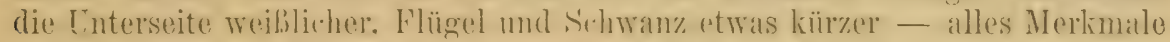
von Jugenul. - Mit keiner der ambern asiatischen Formen zu rerwerbseln,

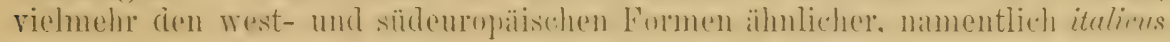
sehr ähnlich, aber auf dem Rücken noch heller und fahler.

Nord-China: Peking und Korea. (Stücke in London, Turin, Tring).

1;14. Parus palustris hypermelaena (B('r\%. (E Iimm.hi).')

Poecile hypermelaena Berezowski \& Bianchi, Ares Exped. Potanni (I'titz-Gansu) p. 112, Taf. II, 2 (1891- russisch! Schensi an der Grenze von Kansu); Übersetzt: Deditius, Journ. f. Om. 1897, p. 72.

1) Parus hypermelaena und dejeani (deren Typen ich konfrontierte und welche beiden möglicherweise zusammenfallen) haben eine auffallende Ähnlichlieit mit Parus sclateri Kleinschm, aus Mexiko, (P. meridionalis Scl. 1856, non Liljeborg 1852 - sieho Hellmasr, Lierreich, Lief. 18, p. 52), von der sie sich aber durch etwas dickeren Schnabel und bräunlichere, nicht so olivengräuliche Seitenfärbung unterscheiden. - Ich nehme keinen Anstand, diese Formen als Subspezies ron palustris aufzufassen, denn sie stimmen 
Ad. (Geschlecht?) Töopf glänzend schwarz. die schwarze Zeichnung

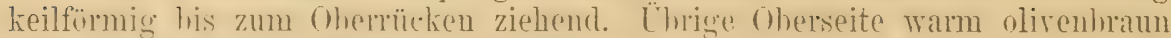
mit sandhräunlicher Nüance. $\left.{ }^{1}\right)$ Kopfseiten und Halsseiten wriß. letztere mit hraunem Anflug. Kimm. Kehle und Liropf schwarz. diese Förbung his an die Halssciten reichend und dort sowohl wie gegen die Brust hin scharf abgegrenzt. Brust- und Banchmitte, sowie Stcil. schmutzig weiß. Seiten ansgedehnt fihllbrïunlich. Flügel 63. Schwanz (etwis abgenutzt) t?. Lauf etwa 16, Schnabel 8, Culmen $9 \mathrm{~mm}$.

Lan-tschja-kou in Schensi an der Grenze von Kansu.

\section{Parus palustris dejeani ()ust. (? = hypermelaona).}

Parus dejeani Oustalet, Bull. MLus. Paris III, p. 200 (1897- 'Tatsienlu).

Die von mir mit dem Typus von hypermelaena verglichenen 3 Original-

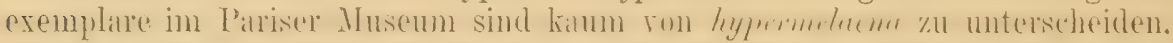

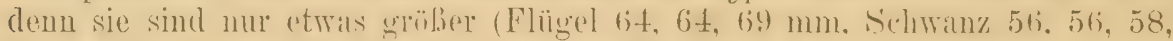
Schuahed 5. ('ulmen 9.6. Lauf $16 \mathrm{mmm}$ ), die Seiten sind dentlich etwas reistlieher,

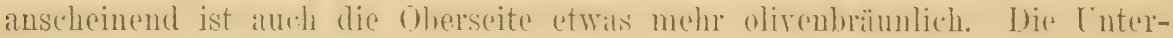
suchung vou melur Material (weder vou den Stïcken vou dejeani noch von

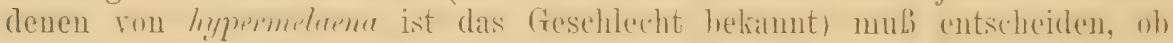
dejeani von hypermelaena zu trennen ist.

Tatsienlu in Szetschwan, im westlichen China.

\section{Parus atricapillus salicarius Brehm.²)}

Mitteldeutsche Weidenmeise, mattköpfige Sumpfmeise.

Parus salicarius Brehm, Isis 1828, p. 128t (Nomen nudum!); Brehm, Handb. Naturg. Vög. Deutschl., p. 465 (1831 - ,lebt in unsern Tälern, besonders an den mit Weiden besetzten Bach-, Fluß- und T'eichufern“. 'Terra typica: Renthendorf).

mit letzterer in den glänzenden Spitzen und der Form der Ḱopffedern, sowie in dem wenig gerundeten Sehwanz überein. Auffallend ist die große Ausclehnung und scharfe Abgrenzung des Kehlfleckes. Dies Merkmal allein aber kann ohne weitere geographische und andere Bestätigung nicht als Artkennzeichen dienen. Es variiert bei anderen Formen und besteht auch nur darin, daß die Spitzen der betreffenden Federn keine weißen Säume haben, denn die Kehlfedern sind bei allen Sumpfmeisen an der. Wurzel schwarz und die Größe des schwarzen Kehlfleckes ist tatsächlich nur durch weißliche Federspitzen mehr oder minder verschleiert. - P. palustris sclater $i$ ist anseheinend der einzige Vertreter der Glanzköpfe in Amerika. Vgl. Ridgwny, B. N.\& Middle Amer. III, p. 407.

1) Journ. f. Orn. 1897 , p. 72 ist fälschlich übcrsetzt „oliv-schwarz-braun“, ebenso wurde Tierreich, Lief. 18, p. 53 wiedergegeben.

$\left.{ }^{2}\right)$ Die nordamerikanischen Sumpfmeisen, d. h. atricapillus mit den nahverwandten Formen septentrionulis, turneri, occidentalis, carolinensis, agilis, impiger stimmen mit den europäischen "Mattköpfen" in der Strulitur der Oberkopffedern, Stufung des Schwanzes und allen andern wesentlichen Ierkmalen so überein, daß man nicht umhin kann, sie alle als Subspezies einer Art zu betrachten. Die amerikanischen Formen weichen hauptsächlich in der großen seitlichen Ausdehnung des Kehlfleckes ron allen altweltlichen Vertretern ab. MIerkwürdigerweise findet sich diese Eigentümlichkeit auch bei der glanzköpfigen amerikanischen sclateri und bei einigen ostasiatischen Formen (hypermelaena, dejeani). Über die nordamerikanischen Formen vgl. Hellmayr, Tierreich, Lief. 18, p. $54 \mathrm{ff}$. und Ridgway, B. N. \& Middle Amer. IH, p. $397 \mathrm{ff}$. 
Parus accedens Brehm, Vogelfang, p. 242 (1855- "Deutschland". T'erra typica der Sammlung zufolge: Berg mit Nadelholz bei Renthendorf).

Parus murinus Brehm, Vogelfang, p. 242 (1855- „Deutschland". T'erra typica der Sammlung zufolge: Renthendorf).

Poecila salicaria vera und murina Brehm, Naumannia 1856, p. 370 ("In den hiesigen Tälern". Terra typica: Renthendorf).

Parus musicus Homeyer (Brehm in litt.), Orn. Briefe p. 76 (1881- "Lebt und britet im Nadelwalde". Terra typica: Renthendorf).

Parns saticarius communis Olphe-Galliard (Brehm in litt.), Orn. Jahrb. 1892, p. 146 („Deutschland“. Terra typica: Renthendorf).

(Vgl.: Ǩleinschmidt, Orn. Jahrb. 1897, Hellmayr, 'lierreich, Lief. 18, u. a. m.).

Enterscheidet sich wie alle andern .. mattlinptigen Sumpfueisen:" von den dent Enkundigen sehr ähulich erscheinenden ${ }^{1}$ ) Formen vom pulustis rorzugsweise dureh folgende Merkmale: Der oherkopf ist fast glanzlos, braunschwarz, die einzehen Federn schwäther pignentiert, länglicher. Feniger kompalit, etwas mehr zelsehlissen. ohne scharf sich ahhehende Lichteflese. Der schwarze Kehlfleck ist etwas ausgedehnter. Sehnahel länger. gestrerliter.

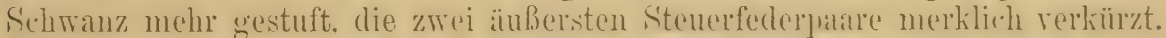
Kleiner als assimilis und mit dunklerem Rücken. Rücken baumgrau mit rostfarhener Beimischung. Halssciten bis an die ()hedeclien schmutzig rahmufirben übertüncht. Körperseiten rosthuben verwaschen. lebhafter als bei der im gleichen Gebiete wobnenden P. palustris commanis. Flügel o etrva

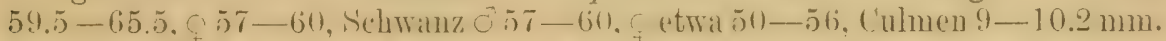
Manchmal sind die ô so klein wie dip gröberen a größer.

Bewohnt Mittel-Isutschlaud und Österreioh, ron den Tiefehenen bis in die Vorberge der Alpen, stellenweise bis etra $1000 \mathrm{~m}$ hoch.

Bewohnt Nadelwald, besonders Kiefernwald, dichtes Stangenholz, Fichten-, Tannenhölzer, Mischwald, in den Ebeneu und Bergen, anscheinend auch Dickichte an Flußund Seeufern. Hat einen feinen, meisenartigen, wie "sit" klingenden Ton und lockt gedehnt und laut "djäh, djäh" oder "däh däh". Der Gesang ist gänzlich verschieden vou der klappernden Strophe unsrer glanzköpfigen Sumpfmeisen und besteht aus einigen pfeifenden 'Tönen, die wie „tjye, tjye, tjye“ klingen. Die Nester stehen in Baumlöchern und die Nesthöhlungen werden (?immer) von den Vögeln ausgepickt oder wenigstens erweitert. Weitere Einzelheiten können z. Z. nicht festgestellt werden, da der gewöhnliche Beobachter und Eiersammler die verschiedenen Arten und Formen der schwarzköpfigen Meisen nicht kennt. Die Eier dürften in manchen Sammlungen als "Sumptimeiseneier" liegen.

\section{Parus atricapillus rhenanus Kleinschm.}

Pans *henamus Kleinschmidt, Orn. Honatsber. 1900, p. 168 (Rhein. Terra typica: Rheinufer zwischen Mainz und Worms).

Abbild. Journ. f. Orn. 1897, 'T'af. III. Neuer Naumann II, 'Taf. 21, 1.

Äuberst ähulich $P$. a. sulicurius, aber die Oherseite etwas diesterer und der Flügel durchschnittlich kïrzer: etwa 58-63 mm.

1) Es ist sehr interessant und beachtenswert, daß die im selben Gebiete wohnenden Formen der beiden Arten einander am ähnlichsten sind, sodaß z. B. von beiden Arten in Skandinavien eine sehr helle Subspezies, in Mittel-Deutschland je eine dunklere, am Rheiu je eine noch dunklere und kleinere, in England von jeder Art die dunkelste und kleinste forkonmt. Die Kurzsichtigkeit zieht darans die merkwiirligsten Trugschliisse. 
An Mihrin ron Thorms und Mainz his Tresel und Holland, Walmseheinlich

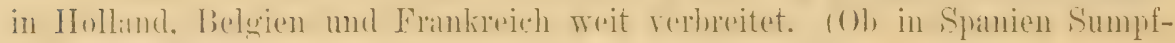
meisen heimisch sind, wissen wir nicht.)

Auf dem Pariser Vogelmarkt wurden in friilerer Zeit ron den Vogelfängern zwei Sumpfmeisen, nommette und cocotte genannt, unterschieden, deren eine lebhafter und stimmreicher war, als die andre, daher einen höheren Wert hatte (Keulemans). Jedenfalls waren dies $P$. palustris longirostris und $P$. atric. rhenamus.

Bewohnt in der Brutzeit Kopfweidenpflanzungen, Weidendickichte, Erlenanlagen. dichtes Gebïsch und Gehölz am Ufer von Strömen, Altwässern, Teichen, wo auf schattigem, sumpfigem Grunde, oft im Wasser selbst, dichtes Unterholz, Schilf und Gerank wuchert. Schener, flüchtiger, als unsre glanzköpfige Sumpfmeise. Lock- und Warnruf lang gedehnt, etwa wie däh, däh, deh, deh, die Silben gleichmäßig betont, oft mit vorangehendem feinem si si. Der Gesang besteht aus einem hellen-tschi-tschi-tschi klingenden Pfeifen, das viel musikalischer klingt als das Klappern von $P$. pal. communis. Die Eier fand Kleinschmidt Anfangs Juni. Das selur spärliche Nest stand in ausgepickter Höhle im morschen Weidenstumpf. Eier wie Sumpfmeiseneier, aber wohl gefleckt. Vergl. Kleinschm., Journ. f. Orn. 1903, Taf. V. Über andere Einzelheiten ist keine Gewißheit zu erlangen, solange die Sammler nur "Eierrarietäten" sammeln, statt auch den Erzeugern derselben die nötige Aufmerksamkeit zuzuwenden und sie in zweifelhaften Fällen zu erlegen und Kennern zu unterbreiten.

\section{Parus atricapillus kleinschmidti Hellm.}

Parus montanus kleinschmidti Hellmayr, Orn. Jahrb. 1900, p. 212 (England. Terra typica: Coalfall Wood bei Finchley, bei London).

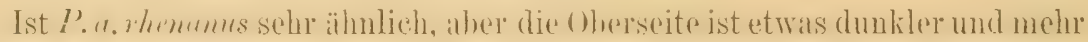

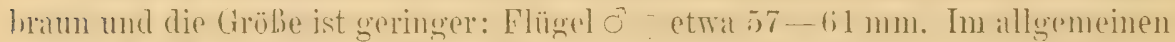

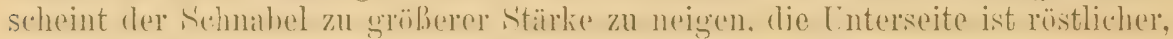
die Ohrdecken mehr mit röstlicher Rahmfarbe überflogen.

England und Schottland. Bewohnt in Schottland, wo sie briitet und Standrogel ist, (Tiiler des Tweed, Forth. Sper), anscredehnte. mit Firlen und

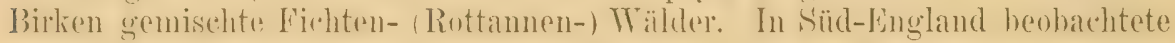
man sie in Laubholz, bei 'T'unbridge Wells in dichtem Ufergehölz.

Ein bei T'unbridge Wells am 10. Mai gefundenes Nest euthielt acht Eier, welche sich von einer Serie von Eiern von Parus palustris communis und dresseri durch sehr große, hell ziegelrote Fleckung am stumpfen Ende unterscheiden. Vielleicht ist diese große Fleckung charakteristisch für die Eier dieser Form. Ein Ei des erwähnten Geleges mißt $16.7>13 \mathrm{~mm}$. Das sehr spärliche, fast nur aus Moos bestehende Nest stand in einem kleinen Weidenstumpf am Rande eines Baches, in dichtem Gehölz. Das Loch war etwa $15 \mathrm{~cm}$ tief und augenseheinlich durch Wegpicken des Holzes entstanden. Evans fand in Schottland Gelege ron 7 und 8 Eiern in der Mitte des MIai, Er berichtet gleichfalls, daß die Nestlöcher von den Vögeln selbst ausgepickt oder doch stark erweitert waren.

\section{Parus atricapillus borealis Selys.}

Nordische mattköpfige Sumpfmeise.

Paris borealis Selys-Longchamps, Bull. Ac. Bruxelles X, 2 p. 28 (1843- Island, errore!! 'Terra typica: Norwegen). ${ }^{1}$ )

1) Selys-Longchamps beschrieb auch noch eine andre Form von Island, eine -. wie sich später herausstellte - - amerikanische Form, die er Parus frigoris nannte. Auch in diesem Falle ist der Fundort sicher falsch gewesen. 
Panss colletti Stejneger, Proc. U. S. Nat. II

Parus borealis minor Kleinschmidt, Orn. Jahrb. 1897, p. 89 (Ex Brehm II. S., in der Synonymie ron colletti $=$ borealis).

Abbild.: Dresser, B. Europe III, Taf. 113; Kleinschmidt, Journ. f. Om. 1897, Taf. 4; Neuer Nammanu U, Taf. 21, 3.

Schwed.: Gråmes.

çad. Kupfplatte tiefschwarz, dunkler als bei montames und assimilis, obne oder mit sehr schwathem hraunen Anfluge, mit etwas seiclenartigem Sehimmer. Wangen, Ohrogenend und Halsseiten fist ganz rein meil.), diese

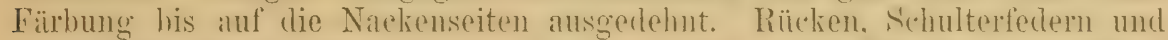
Oberschwanzdechen hräunlichgrau, etwas rariabel, meist fist gratu, manchmal aber bräunlicher, als in der Regel. Äufere Handschwingensïume gräulichweiß, die sïnmo der Aruschwingen riel hreiter. Lnterseite trübreils, dio

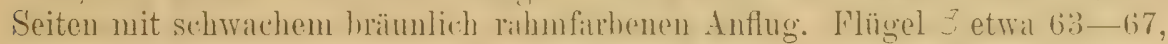
selten bis 68, Schrvanz etra 59-64, Culmen 10-11, Lauf 15-16 mm. o wie $\delta$, nux etwas kleiner: Flügel ungefähr 60-63 mm. -- Der Schnabel

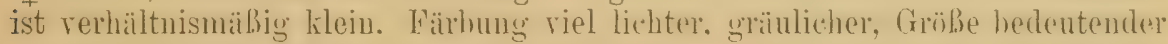
als bei salicarius, geringer als bei montanus. Schnabel dicker und kïrzer, Färbung weniger rostgelblich, als bei assimilis.

Skandinavien, Nord- und Nordmest-Rublind, Russische Ostreeproviuzen und Ostpreuben, wo sie (mindestens hisweilen an den L fem masurischer Seen) noch brïtet. Tn Winter wie alle Meisen mehr vagahondierend und dann nicht selten in Polen, ja sogar bis Orenburg. Stücke aus Orenburg, von Silrudny gesammelt. sind tyrische bomerlis. (bh dort anch im Sommer, rermig ich nicht zu sagen.

Bewohnt Nadelwälder, aber auch Birken- und sumpfige Erlenbestände. 31 finnische Wier gleichen im wesentlichen denen von $P$. pal. communis und messen nach Rey im Maximum 16.7n $>12.75$, im Durchschnitt $15.81 \times 12.14$, Minimum $15 \times 11.4 \mathrm{~mm}$, Gewicht etwa $74 \mathrm{mg}$. Das Gelege ron meist 8 , seltener bis 10 Eiern findet man im IIai.

\section{Parus atricapillus assimilis Brehm.}

Parus assimilis Brehm, Vogelfang, p. 242 (1855- "Galizien". 'T'erra typica: galizische Karpathen.)

(Vgl. Kleinschmidt, Orn. Jahrb. 1897, Hellmayr, T'ierreich, Lief. 18, u. a. m.).

Sebr ähnlich $P$. a. borcalis, aber Schuabel gestreckter, schlanker, etwas länger, Flïgel so lang wie oder lïnger als bei horrelis, Körperseiten etwas lebhafter rostgelhlich, anf dem Rüclien elonfills lieht, aher mit mehr ristlicher Beimischumg, somit diese Teile mäunlicher. Kopfilatte etwas brïunlicher als hei boreulis. Flügel ô etwa 66-1j9.5 o 63-65, Schwamz etwa 60, Culmen etra $11 \mathrm{~mm}$.

Katpathen, Transsilvanische Alpen und Gebirge Bosuiens und Serbiens. In hochgelegenen Nadelwäldern.

\section{Parus atricapillus bianchii (Śarudny \& Hälms).}

Poecile salicaria neylecta (non P'arus rufesens neylertus Ridgw. 1879) Zarudny \& Härms, Orn. Monatsber. 1900, p. 19 (Pleskau = Pskov).

Poecile salicaria bianchii Zarudny \& Härns, Orn. ALnnatsber. 1900, D. 67 (L̈mbenennung von $P$. s. neglecta). 


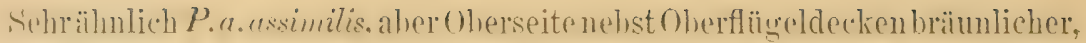

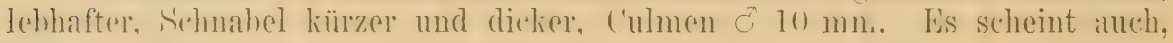
daß die Seiten blasser sind. (Originalexemplare untersucht.)

Bisher sind nur wenige Wintervögel von Pleskau (Pskov) in Westlinfiand hekannt. Las Vorkommen ist in Anhetrakht der Verbeitung rom

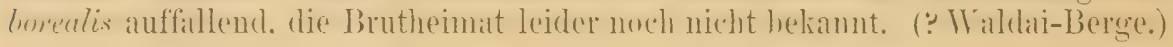

\title{
622. Parus atricapillus montanus Baldenst.
}

\author{
Alpenmeise.
}

Pamus cinereus montanus Baldenstein, Neue Alpina II, p. 31 (1827- Gebirgswälder Graubündens).

Parus alpestris Bailly, Bull. Soc. Savoie 1851, p. 22 (Savoyen).

Poecila salicaria alpina Brehm, Naumannia 1856, p. 370 („Auf den Alpen der Schweiz"). Parus Baldensteinii Salis, Jahresber. Naturf. Ges. Graubïnd. VI, p. 107 (1861- In

Nadelwäldern von 4000-7000' in Graubünden, z. B. St. Moritz im Engadin).

Abbild.: Neuer Naumann II, T'af. 21, 2.

Nerklich größer als alle andern Formen, Oberseite dunkler, bräunlicher. Steuerfedem hreriter. Kopfilatte mehr mit hram gemischt, als bei borealis. Oberseite dunkler braun, trüber als die von assimilis, viel heller als bei salicarins und deren westlicheren Vertretern. Größer. Flügel ơ bis 70 , ja sogar 71 , bis jetzt gefundenes Minimum bei $964 \mathrm{~mm}$.

Bewohnt die Wälder des Alpengebietes, in Höhen von über 1200 Iletern, bis an die Grenze des Waldwuchses, im Engadin bis etwa $2000 \mathrm{~m}$. Die Lockstimme klingt wie gräh, gräh, etwas rauher als däh, däh, meist mit vorangehendem feinen dsi, der Gesang ist ein pfeifendes tü-tü-tü-tü- oder ti-ti-ti-ti-ti, oder djüs-djüs-djüs, die einzelnen Silben viel mehr pfeifend, wohllautender als die klappernden von communis, es gibt aber anch einen noch etwas mehr modulierten, noch hiibscheren Gesang. Eier nach Fatio 6-10, etwas größer als die ron P. p. communis.

\section{Parus atricapillus baicalensis (Srinh.).}

Poecile baicalensis Swinhoe, Ann. \& $M$ lag. Nat. Hist. ser. 4, VII, p. 257 (1871- „TransBaikal" (sic) zweifelloser Typus im Brit. IIus. von Kultuk, was allerdings nicht "Trans-Baikal"“ ist).

Poecilia pahestris macroura 'Taczanowski, Faune Orn. Sibér. Orient. I, p. 436 (In Mém. Acad. Imp. Scienc. St. Petersburg ser. 7, XXXIX, 1891- Gouvern. Irkutsk und Daurien).

Ist $P$. a.borealis äußerst ähnlich, aber die Färbung ist lichter, reiner, der Rüreken noch mehr gratu. weniger hrïunlich. Flügel der of bis $70 \mathrm{~mm}$, eine Länge, die borealis nicht erreicht. Schmanz ơ $64-68 \mathrm{~mm}$.

Sibirien his zum Oehotskischen Veere, Mandschurei und Nord-Japan (Jesso), westlich bis in das nordöstliche Rußland.

\section{Parus atricapillus restrictus Hellm.}

? Parus palustris japonicus Seebohm, Ibis 1879, p. 32 (? Partim. Ohne Fundortsangabe, ungenuigende Beschreibung. Nach B. Japan. Empire, p. 81 soll japonicus aus Siid-Japan (sic!) stammen, die ebenda p. 82 gemachten Bemerkungen siud 
verworren und es geht nur daraus hervor, daß der Autor diese Meisengruppe nicht kannte und die Formen der palustris- und atricapillus-Gruppen vermengte. SchlieBlich ist cler Name japonicus durch Parus japonicus Stephens, in Shaw's Gen. Zool. X, 1, p. 55 präokkupiert. Was Parts japonicus Stephens ist, wissen wir nicht. Die Beschreibung beruht auf zwei Vögeln, die an Bord eines Schiffes bei Japan geflogen waren. Stephens kannte den Vogel nicht, sondern gab lediglich Latham's Beschreibung wieder, leider aber ganz falsch! Vgl. Latham, Gen. Syn. B. II, 2, p. 542).

Parus borealis restrictus Hellmayr, Orn. Jahrb. 1900, p. 215 (Nipon).

Ist $P$. a. baiculensis zwar thnnlich, aber der Rücken viel dumkler und brätunlicher, der S.hwanz kürzer. Ist I’. a. berealis (dessen brutgehiet durch ganz Nord-Asien ron dem ron restrictus getrenut ist) durch etwals kïrzeren Schwaluz zu unterscheiden, aber nicht immer nach einzelnen Stücken. Die Körperseiten sind rïstlich rihmfarhen ïhertüncht. Flügel ctwa $6: 3-65$, selten bis 67 und gar $68 \mathrm{~mm}$. Schwanz ó etwa 58, o $55 \mathrm{~mm}$.

Insel Hondo odel Nipon. ( 22 untersucht.) Die ron mir untersuchten Stücke von Jesso gehïren wicht zu dieser Form, sondern zur liontinentalen bairulensis.

\section{Parus atricapillus kamtschatkensis (Bץ.).}

Poecila kamtschatkensis Bonaparte, Consp. Av. I, p. 230 (Ostasien. 'T'erra typica: dem Namen zufolge Kamtschatka).

Parus viemuthi Dybowski MIS., teste Stejneger, Bull. U. S. Nat. MIns. XXIX, 1885, p. 297).

Abbild.: Madarász, Zeitschr. ges. Orn. 1, Taf. VII.

Unterscheidet sich von allen andern Formen von montanus dureh die außerordentlich hell brïunlichgraue, fast weißo Rückenfärhung. Schwingen und Steucrfedern schiefergrau mit fast rein meißen. infolge der dunklen Farbe der Federn sebr anffallenden Sämmen. Oberschwanzdecken asehgrau. Die schwarze Kopfplatte rejeht weit nach hinten. Kíehlfleck ziemlich groß, ganze übrige Enterseite aher rein weil, Seiten ohme bräunlichen oder rihmfarbenen Anflug: O wie ô, aber etwas kleiner und der Rücken nicht so weiblich, mehr bräunlichgrau verwaschen. Flügel etwa $61-65 \mathrm{~mm}$.

Kamtschatka.

\section{Parus modestus (Burton). ${ }^{1}$ )}

Sylviparus modestus Burton, Proc. Zool. Soc. London 1835, p. 154 („apud montes Himalayenses").

Parus? mimutus Jerdou, MIadras Journal XI, p. 8 (1840 - "edge of northern (Ghauts"). Parus serioplirys Blyth, Journ. Asiat. Soc. Bengal 13, II, p. 942 (1814-- ex Hodgson II. S.: "Nepal").

1) Burton, Jerdon, Blyth, Oates (B. India I, p. 53) und Hellmayr ('lierreich Lief. 18, P. 15) trennen Parus modestus generisch als Sylviparus morlestus, letzterer stellt sie sogar zur Unterfamilie Regulinae. Außer der für eine Meise ganz auffallenden, laubsängerartigen Färbung kann ich jedoch nichts finden, das nicht mit Parus vereinbar wäre. Die richtigste Stellung dürfte nahe dichrous sein. 
ơ ad. Oberseite olivengrün, die Federn des Oberkopfes breit und zu:

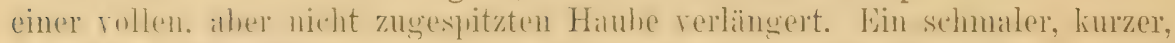

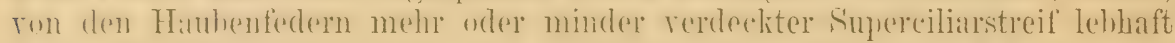

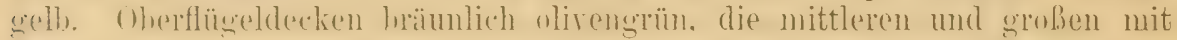
Greiten hell olivengrünliehen Sipitzen. Handrand hellgelb. Sehwingen dunkelgraubrann. mit der Rüekenfarhe gesäunt. Schwanz bram mit hell oliven-

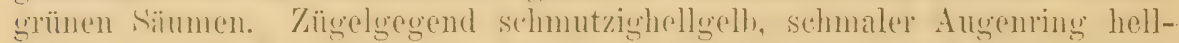

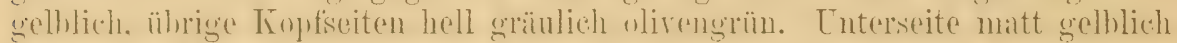

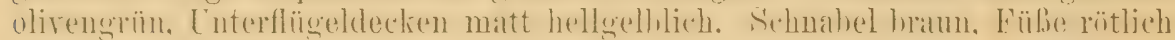
bleigrau. Flügel 60-64, Schwanz 35-38, Lauf 14-15, Schuabel 6, Culmen $9 \mathrm{~mm}$. of wie $\sigma^{2}$, aber kleiner, die Haube etwas kïrrzer, Flïgel 55-59, Stirnfedern heller. in China.

Himalita ron Kaschmir his Blutan und Gehirge ron Nordwest-Folien

\section{Gattung AEGITHALOS Hermann 1804.}

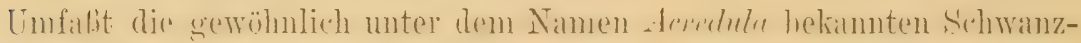

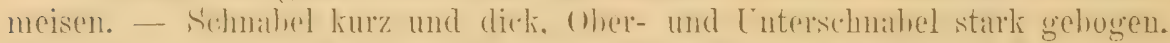
Flügel meist ziemlich kurz und atheremetet. Sidhwanz meist viel linger, als der Flügrl. dists mittelste Paar meist verkiüzt. die seitlichen Palare noch stärker und stufenfürmig rerkilizt. Bei den amerikanischen Eormen, die ron Vielen generisch getrement werden. sind die mittelsten steuerfederm nicht

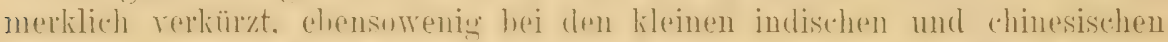

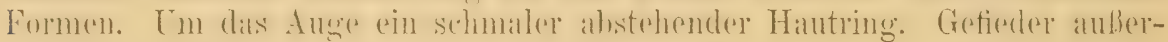
ordentlich weich, locker und weitstrahlig. - Banen ein kunstrolles rundliches, mit seitlichem Flughoche versehenes Nest. Vier meist wenig gefleckt. Lebensweise auch sonst etwas verschieden von der anderer Meisen, z. B. hacken sie in der Regel nicht wie jene mit dem Schuabel die mit den Füßen festgehaltenen Kerme auf.

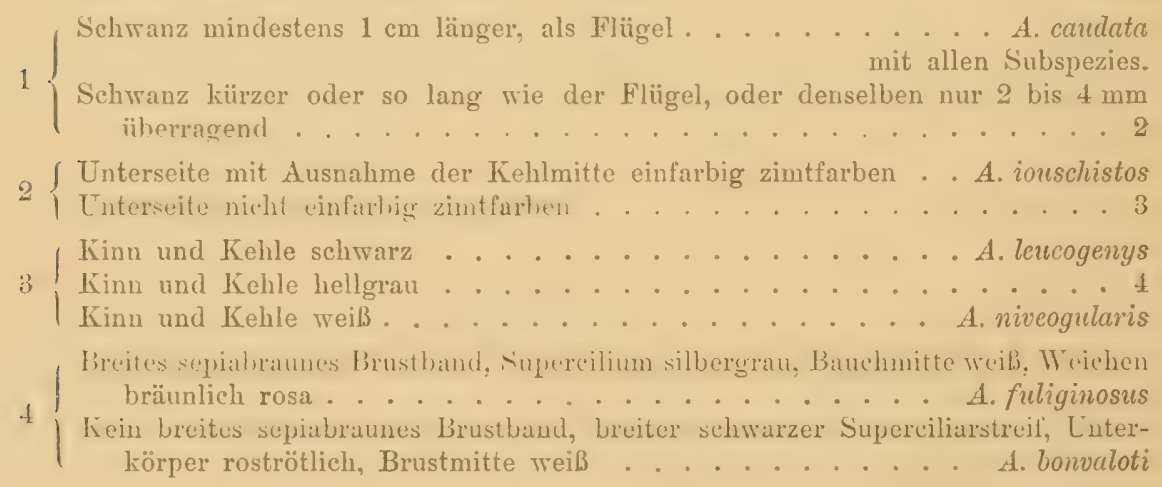

\section{Aegithalos caudatus caudatus (L.).}

Weißlöpfige oder nordische Schwanzmeise.

Parus candatus Limnaeus, Syst. Nat. Ed. X, p. 190 (1758- Wir betrachten als typische Lokalität Schweden - ex Fauna Suec. Nr. 243). 
Lanius biarmicus (nec Panes biamicus 1758!) Linnaeus, Fauna Suec. ed. II, p. 29 tab. 1 fig. 84 (1761 - errore! Beschreibung, excl. Citate Albin \& Edwards!).

Paroides pinetorum Brehm, Vogelfang, p. 243 (1855- Partim! "In einem großen 'Teile von Europa").

Acredula macrura Seebohm, Hist. Brit. Birds Eggs I, p.487. im Text (1883- „from St. Petersburg eastwards").

Acredula caudato sibirica Seebolim, Birds Japan. Emp., p. 88 (1890-- "Central Siberia"). Aegithalus caudatus japonica Praz̀ak, Journ. f. Ornith. 1897, p. 291 („im nördlichen Japan“).

Schwed.: Stjürtmes, Stjärttita.

Abbild.: Dresser, B. Europe III, Taf. 104, rechts oben.

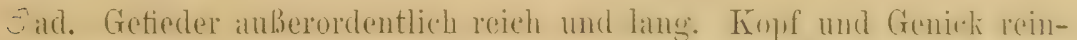

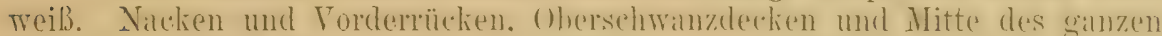
Rü̈liens schwarz, Hinterüleken und Bür\%el nit weinrütlichen und weililichen Federn gemischt. Sehulterfedern weimeötleh, gegen dio Flügeldechen hin mit weißen Spitzen. Bürzelseiten weinrötlich mit weißen Federspitzen. Sehwingen schwarzbraun, gröbtenteils mit sehr schmalen, oft undentlichen Außen- und breiteren Innensäumen ron weißer Farbe, die inneren Armschwingen mit breiteren Außensäumen, die letzten an den Außenfahnen größtenteils oder ganz weiß, die Inmenfahmen ebenfalls mit meln oder weniger Weiß. Stenerfedern schwarz, die äußeren drei Pare mit weißer Außenfahne und damit zusammenhängendem weißem Keilfleck an der Innenfahne, die AuBenfahne des drittletzten Paares aber meist nach der W Wurzel zı braunschwarz. Unterseite rein weiß, nur die Weichen blaß weinrötlich, Unterschwanzdecken weimötlich mit weißen Spitzen.: Schnabel schwar\%, Füße dunkelbraun, Augenlidrand golb. Flïgel etwa 65-68, Schwanz etwa 88-104, Lauf 17-18, Schuabel (Culmen) etwa $7 \mathrm{~mm}$. - o wie $\sigma^{n}$, aber Flügel meist 2-3 mm kürzer (nicht immer). - Juv. Kopf-

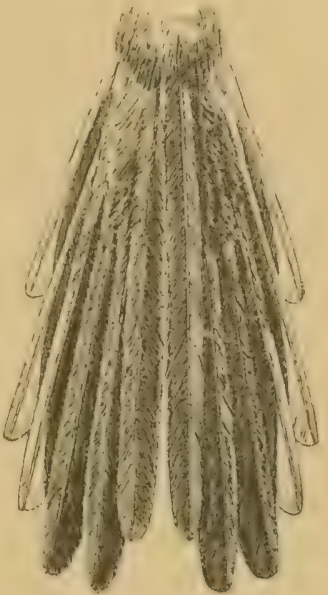

Figur 60. seiten, Nacken und Rücken schwarzbraun, Schulterfedern dunkelhram olme Weimot, Cnterseite schmutrigreif. Batuch und Entersehwanzdecken sehmutzig weinrötlich. Augenlidrand indisch-lont. - Äulierst selten kommen bei alten Vägel dnileutungen rom fiopfistreifen ror.

Nord- und Ost-Europa, Sibirien bis Iturup und Nord-Japan (Jesso). In Dentschland ron Osten her ungefäln his in die Mitte. genalue Grenze gegen Guropa nicht heliamnt. Im Osten im Winter lis zum Kiulkasus und Rumänien. - In Wrestsihirien sollen die Schwänze länger serin, dies aher ist nicht konstant der Fall. In kuropra kummen hisweilen stücke vor, die

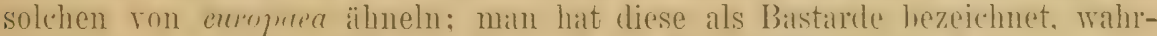
scheinlicher aber handelt es sich meist um Rürkschlïge oder Auliänge. Im Tinter mehr unherstreifend und dam auch his Test-kuropa, \%. B. Hessen. Rhein. Belgien (eimmal in England) und Frankrexch, aber meist um in g'eringerer Anzahl.

Stand- und Strichvogel in gemischten und Laub-IVäldern, Parkanlagen und Gärten und überhaupt wo es riel Gebüsch und Bäume gibt. Der lange Schwanz 
macht sie ron weitem kenntlich. Flug bogenförmig. Gern folgen sie einander „wie Indianer auf dem Kriegsfade". Der gewöhnliche Ton (Lockton) ist ein feines "si si", aber man hört zumeist das auffallende, nicht zu rerwechselnde "dscherrrp", das sie immer hören lassen, wonn sie in Gesellschaften umherstreifen, und das hauptsächlich Warnruf ist. Ein ganz merkwürdiges leises, kurzes, nicht in Buchstaben auszudrückendes Schnalzen drückt wohl hauptsächlich Neugierde aus. Nest-ein großer, länglich runder, dickwandiger Bau aus Moos, Bast, Gespinsten, außen mit Flechten wunderhübsch bekleidet, innen mit Federn ausgepolstert, mit seitlichem Flugloche. Es steht 2 bis $3 \mathrm{~m}$ hoch auf Bäumen, den Stämmen und Asten angeschmiegt, oder frei in Büschen, oft nur $1 \mathrm{~m}$ hoch. Eier 7-10, manchmal auch noch melur. Erstes Gelege in Mittel- und Westdeutschland schon gegen Mitte April, zweites Ende Mai und Juni. Eier glanzlos schmutzig weiß, selten ungefleckt, meist mit schwacher, manchmal mit sehr ausgebildeter blaßroter Punktierung und feiner Fleckung. 33 Stück aus der Gegend ron Halle messen nach Rey von $12.8 \times 10.2,13 \times 10$ bis $14.2 \times 11.8$, im Durchschnitt $13.6 \times 10.9 \mathrm{~mm}$ und wiegen etwa $47-59$, durchsehnittlich etwa $51 \mathrm{mg}$.

\section{Aegithalos caudatus etzropaeus (Herm.).}

Pipra? europaea J. Hermann, Observ. Zoolog., p. 214 (1804- Basel).

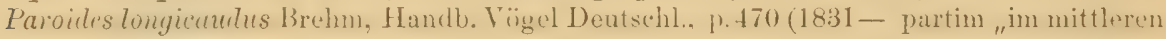
Deutschland").

Paroides pinetorum Brehm, Vogelfang, p. 243 (1855 - partim! - „In einem großen 'Teile von Europa").

Mecistura caudata longicunda, pinetorum und microrhynchos, A. Brehm, Verz. Samml. p. 7 (1866- nomina nuda!).

Abbild.: Journ. f. Orn. 1886 'laf. XVI, 1893 Taf. IV (sehr instruktiv).

Franz: Mlésange à longue queue. Ital.: Codibugnolo.

Wie A. caudatus caudutus, aber Gefieder nicht ganz so lang und reich, die Kopfsciten rom Torderrande des Auges an oder "rest hinter dem Auge mit mehr vder minder breiten schwarzen oder briunen Streifen, Ohrdecken getriiht. an der Torkerorust eine mehr oder minder kemntliche brame Fleckenreihe, Handsehwingen hörhstens mit angedeuteten schmalen weiben Aubensämmen, meist aher gamz ohne solche. Sibwanz meist etwal $11 m 5 \mathrm{~mm}$ oder noch kürzer. Flügel etwa $62-67 \mathrm{~mm}$.

Verhreitung eigentümlich: Sïdlicheres Mittel-Europa ron Rumänien und Bulwarien dureh Serhien und Bosnien, Norditalien, Schweiz, Franlireich, das westliche Dentschlame, ostwïrts his Hessen mol Thüringen, (am Rhein ausschliefilich diese Form als Brutrogel). Holland und Belgien. Genaue Abgrenzung in Dentschland nicht sicher. Im westlichen umd mittleren Deutschland kommen bisweilen auch meilkïpfige: Stücke vor (Hessen — von Berlepsch mit kopfstreifigen gepaat gesehen - und Thüringen), die aber deshall, noch nicht .1. re cumcatus, sondern wohl nur ausnahmsweise weil.sköpfige Individuen sind.

Lebensweise und Aufenthalt wie bei der vorigen Form. Sieben Eier rom Rhein messen $12.8 \times 10.4,12.9 \times 10.6,13 \times 10.7,13.3 \times 11.0$ bis $13.5 \times 10.5 \mathrm{~mm}$.

\section{Aegithalos caudatus roseus (Blyth).}

Mecistura vagans Leach, Cat. Mamm. Birds Brit. IIus., p. 17 (1816 - nomen nudum! Devonschire).

Ilecistura rosea Blyth in: Gilh. White. Nat. Hist. Selbome, p. 111 (1836- England). Mecistura longicaudata MIacgillivray, Hist. Brit. B. II, p. 454 (1839- England).

Abbild.: Dresser, B. Europe II, Taf. 103.

Engl.: Long-'Tailed 'Titmonse. 


\section{- Friedländer \& Sohn in Berlin NW. 6 .}

In unserem Verlage erscheint:

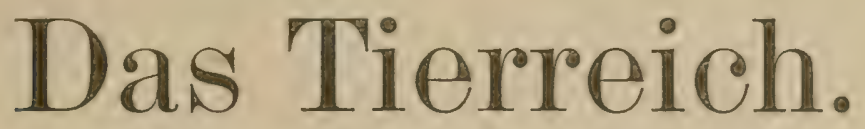

Eine Zusammenstellung und Kennzeichnung der rezenten Tierformen.

A Begründet von der Deutschen Zoologischen Gesellschaft. As

Im Auftrage der

önigl. Preuß. Akademis der Wissenschaften zu Berlin herausgegeben von

Franz Eilhard Scliulze.

Die Herausgahe findet in Lieferungen (in Groh-lexilinn-Oktar mit . bhildungen im Textei statt. die je eine oder mehrere mahestehende Gruppen behandeln, jedoch mabhängig ron einer sistematischen Folge erscheinen. Jede Lieferung ist einzeln käuflich.

Bei Subskription auf das ganze Werk tritt eine Preisermïßßgung ein.

Aus der Gruppe der

\section{Vögel (Aves)}

sind bisher erschienen:

Lieferung 1: Podargidae, Caprimulgidae und Macropterygidae. Bearbeitet von E. Hartert (Tring). 1897. VIII und 98 Seiten mit 16 Abbildungen und Beilage: Terminologie des.Vogelkörpers von A. Reichenow, 4 Seiten mit Abbildung.

Einzelpreis Mark 7, 一.

Lieferung 2: Paradiseidae. Bearbeitet von The Hon. Walter. Rothschild. 1898. VI und 52 Seiten mit 15 Abbildungen. Einzelpreis Mark $3,60$.

Lieferung 9: Trochilidae. Bearbeitet von E. Hartert (Tring). 1900. X und 254 Seiten mit 34 Abbildungen.

Einzelpreis Mark 16,--.

Lieferung 15: Zosteropidae. Bearbeitet ron O. Finsch (Leiden). 1901. XIV und 55 Seiten mit 32 Abbildungen. ... Einzelpreis Mark 4,80.

Lieferung 18: Paridae, Sittidae und Certhiidae. Bearbeitet von C. E. Hellmayr (MIünchen). 1903. XXXI und 255 Seiten mit 76 Abbildungen.

Einzelpreis Mark. 16, -

Weitere Lieferungen erscheinen in ununterbrochener Folge. Bestellungen und Subskriptionen können durch jede Buchhandlung bewirkt werden.

Berlin, Juni 1905. 


\section{R. Friedländer \& Soln in Berlin NW. 6.}

In unserem Kommissions-Verlage erschion 1902:

\section{Aus den \\ Wanderjahren eines Naturforschers.}

\section{Reisen und Forschungen}

in Afrika, Asien und Amerika

nebst daran anknüpfenden meist ornithologischen Studien

von

\section{Einst Hartert.}

Ein Band von XV und 329 Seiten mit 17 Abbildungen im Text und 13 Tafeln (- Routenkarten, Landschaftsbilder, ethnographische Typen, Abbildungen neuer Fische -). klein-4. In geschmackvollem Leinenband.

Preis 25 Mark.

\section{Inhalt:}

I. Reise nach Solroto und Kavo im westlichen Sudan (Westkïste. Flußfahrten auf dem Niger und Benue. Ton Loko bis Kano, Sokoto und Gandu durch rorher unerforschte Gebiete, dam zurïck zum Benue. Loko am Benue). Zur Fauna der Canarischen Inseln. Die Ornis der Los-Inseln. Terzeichnis der bisher hekannten Vügel des Haussalandes. Ühersicht der im Haussalande beobachteten Nutzpflanzen. - II. Reise nach Sumatra, Malakka und Indien. (Die Insel Penang. Sumatra. Naturgeschichtliches aus Sumatra. Die Insel Salangi. Der britische Schutzstaat Perak. Assam. Indien.) - III. Reise nach den Inseln des Caribischen Meeres (Reise nach TTestindien und Venezuela: St. Thomas. Faunistisches. Porto Rico. Venezuela. Caracas. Antimano. Curaçao, Aruba und Bonaire. Flora und Fauna dieser Inseln. Harti). Die Vögel der Inseln Aruba, Curaçao und Bonaire, neue Formen. - IV. Frühlingsansfug uach Maroklio und Tenerife. (Reise nach Maroklio und den Canaren. Tugellehen. Der Oum Rhiah. Eutdeckung nener Fische. Tenerife. Orotavil.) Notizen üher die Vügel der Gegend um Mazagan im mittleren Marokko. 


\title{
Die Vögel \\ der paläarktischen Fauna.
}

\author{
Systematische Übersicht
}

der

in Europa, Nord-Asien und der Mittelmeerregion vorkommenden Vögel.

Von

Dr. Ernst Hartert.

Heft IV.

Seite. $385-512$.

Mit 32 Abbildungen.

Berlin.

Verlag yon R. Friedländer und Sobn. A usgegeben im März. 1907. 
Es gab lisher kein Werk, welches die lokalen Formen aller paläarktischen Vögel in knapper Form berïcksichtigt, und überhaupt kein Werk in deutscher Sprache üher die Ornis der palïarktischen Fauna.

Von dem sehr kostspieligen Prachtwerke H. F. Dresser's abgesehen, haben wir zwar ein soeben ersehienenes praktisch eingerichtetes $\mathrm{Handbuch}$ desselben Verfissers. Dieses, ,Manual of Palaearctic Birds" hat aher die Frgebnisse des subtilen Studiums der letzten 15 Jahre unbeachtet gelassen, und bringt fast nur die leicht unterscheidharen Formen, hietet also nur einen Teil von dem, was wir gebrauchen.

Das vorliegende Werk bemüht sich vor allen Dingen zu zeigen, was bisher in Unterseheidung der Subspezies geleistet worden ist, und somit auch, wo noch Lü̈cken auszufüllen sind. Das Bekannte ist zusammengestellt, an der Hand ron Material und Literatur geprifft, gessichtet und viel Neues hinzugefügt worden, wozu die bedeutende von dem Verfasser rerwaltete Sammlung, und das nahe gelegene größte Museum der Welt in London, Gelegenheit boten.

Die Beschreihungen sind. wem nicht anders angegeben, nach der Natur entworfen, also vollständig neue Originalbeschreibungen; sie sind möglichst kur\% und knapp gehalten.

Die Nomenlklatur ist so konservativ wie möglich, d. h. der älteste ermittelte Name ist für Gattung, Art und Unterart in jedem Falle ohne Ausnahme angewandt.

Das Werk wird in Lieferungen von je 8 Bogen, zum.Preise von 4 Mark für die Lieferung, erscheinen. Das Ganze wird in etwa 10 Lieferungen (zusammen etwa 1200 his 1300 Seiten in 2 Bünden) ahgeschlossen sein. Die Vollendung des ganzen Werkes ist zu Ende 1908 zu erwarten.

Während der Arbeit, die infolge der in den letzten Jahren rapide wachsenden Tütigkeit der Ornithologen auf dem Gebiete der paläarktischen Fauna einen immer größeren Umfing annimmut, wurde Verf. von vielen Museen und Freunden mit Material und Notizen unterstïtzt. Er möchte schon hier vorläufig allon seinen Korrespondenten seinen Dank aussprechen, ins besondera den Herren Valentin Bianchi, Dr. Paul Suschkin, Sergius Buturlin, Professor Reichenow, Pastor Kleinschmidt, Prof. Sehauinsland, Othmar Reiser. Dr. Julius vou Madarísz, Ritter von Tschusi zu Schmidhoffen, Dr. Lorenz ron Liburnau, Prof. Wilhehm Blasius, Dr. Louis Bureau, Prof. Trouessart, Dr. Ménégaux. Joseph Whitaker, Dr. H. O. Forbes. Dr. Hoyle, W. Eagle-Clarke, Prof. Giglioli, C. E. Hellmayr und anderen.

Berlin, NW. 6, März 1907. Karlstr. 11.

\section{R. Friedländer Sohn.}




\title{
Die Vögel
}

\section{der paläarktischen Fauna.}

\author{
Systematische Übersicht \\ der
}

in Europa, Nord-Asien und der Mittelmeerregion vorkommenden Vögel.

Von

Dr. Ernst Hartert.

Heft IV.

Seite $385-512$.

Mit 32 Abbildungen.

\section{Berlin.}

Verlag von R. Friedländer und Sohn. Ausgegeben im März 1907. 


\section{NACHTRARGE.}

Die emsige T'ätigkeit auf dem Gehiete der paläarktischen Ornithologie, die sehom zur Zeit des Frscheinens der 1. Lieferung der . Vög. d. paläarkt. Fauna" größer war. als je zuvor, hat seither gewaltig zugenommen. Wro durch meine Ühersichten der hekannten Formen Iücken ersichtlich wurden, werden diese in mehr oder minder befriedigender Weiso ausgefüllt. Seit langer Zeit wurden nicht si vicle neue Formen heschriehen. wie jetzt. Has minutiöse Studium der lokalen Formen tindet immer mehr Interesse und Verhreitung. Die Irisseuschift wird durch die riclen neuen Tatsachen in erfreulicher Weise herejehert. wenu anch mitunter üher das riel hinausgeschossen wird. Sohr unhequem für das Studium sind aher unauffällig im Text erwähnte neue Namen, ungenïgende Kémnzeichnungen nener Formen, Cnklarheit über das rom Beschreiher untersuchte Material, ungenaue Vaterlandsangaben. Pullikationen in anderen als romanischen und germuluschen Spratehen und in fast monckannten und pupulitren \%eitschriften. Durch dergleichen wird die Arbeit ungemein reschwert. - Nenere Lintdockungen. Ergüuzungen, Übersehenes und Beriehtigungen werden in einem Nachtrag wach Vollendung des Buches ergänzt werden.

\section{E. Hartert.}


Kann als Extrem von A. c. europaea bezeichnet werden, von der sie sich durch den viel kürzeren Flügel (58-62 mm!) unterscheidet. auch ist der Schwanz meist noch einige mm kï̈z'?. Die schwarzen Streifen an den Kopfseiten sind breiter, sodaß das Wriß der Kopfmitte beschrïnltel ist, auch ist letzteres meist getrülot und bisweilen schwalrzhralun gefleckt, die Vorderbrust zejgt fast immer eine dentliche Fleckenreihe, die Ohrgegend ist hramu getriabt und meist deutlich dunkelbriun gestreift. I) dugenlidrand anch bei alten Vügeln nicht gelb, sondern matt orangerot. im Frühjahr im Lehen lebhaft orangerot.

Grobhritamien und Irland, rielleicht anch in ganzen westlichen Frankreich. denn eine Serie von Bälgen aus den Pyrenïen (Herhst und Trinter) ist nicht ron euglischen Stïcken zu unterseheiden, gehirt also keinestregs zu europaea. Farbe des Augenlides "orange clair" (in litt.).

Lebensweise wie die der vorigen. Eier der ersten Brut meist in der zweiten Hälfte dos April. 100 Eier (Jourdain u. a.) messen im Durchschnitt $14.17 \times 11$, ein abnorm langes $17.2 \times 10.5 \mathrm{~mm}$. Sonst ist das Mlaximum etwa $15.1<11.8$ und $15 \times 12$, das Minimum $13.2 \times 10.7$ und $14 \times 10.1 \mathrm{~mm}$. Sie sind also etwas größer als die der rorigen Formen. Durchschnittliches Gewicht von 25 Eiern $51.5 \mathrm{mg}$.

\section{Aegithalos caudatus taurica (Menzb.).}

Acredula rosea taurica Menzbier, Bull. Brit. Orn. Club XIII, p. 49 (1903- „in sylvis montium Yaïla peninsulae 'Tauricae").

Sehr ähnlich .1. c. rosen, aher die Schulterfectern stark mit grau gemischt und die Kopfmitte rein weib. Fleckenbinde an der Brust sehx undeutlich. Ton A. ¿ maredonicu dadurch unterschieden. dialb diss Schwarz der Kopfseiten nieht bis an den Sehmahel reicht. anch soll dis Sehwarz auf dem Rücken ausgedehnter sein. (Nach Menzbier:)

In den Bergwäldern der Yaïla-Berge auf der Halbinsel Krim.

\section{Aegithalos caudatus macedonica (Dress.).}

Acredula macedonica Dresser, Bull. Brit. Orn. Cl. I., p. 15 (1892-- „in monte Olympo"); Ibis 1893, p. 240 ("Mount Olympus in Mlacedonia," späteren Angaben zufolge aber aus Griechenland!).

Abbild.: Dresser, B. Europe IX (Suppl.), Taf. 655, Fig. 1.

Unterscheidet sich von der ähnlichen A. c. rosea dadurch, daB das tiefe und noch breitere Schrvarz der Kopfseiten bis fast an die Schnabelwurzel, also weit vor das Auge reicht. In der Mitte der Kehle ist ein grauer Fleck angedeutet, rou dem sich das weibe Kimn scharf ahheht. ...Augenlidrand schön schwefelgelb" (Reiser).

Griecheuland (Olymp, Othrys. Thessalien, Lamia, Akinnimien usw., aher nicht im I'eloponnes), nördlich his Monastir in der Türkei (Ihis 19(16, p. 29:2).

\section{Aegithalos caudatus trivirgatus ('Temm. \& Schl.).}

Parus (MCgisturus) trivirgatus Temminck \& Schlegel, Faun. Japon., Ar. p. 71, Taf. 34 (1848- Japan).

E. Hartert, Die Vögel der paläarktischen Region. 
Ist am ähnlichsten A. c. europaea, aber der schwarze Kopfseitenstreif reicht hei den meisten Stücken his vor dis Auge, sodaß nur der allerrorderste Teil der Zügel weiB heilnt. Alle weißen Teile sehr rein, dio Kopfmitte sehr heit und rein weib, seharf gegen die schwarzen Streifen alogegrenzt, die Brust sehr selten mit einer rerwaschenen braunen, nie mit einer deutlichen

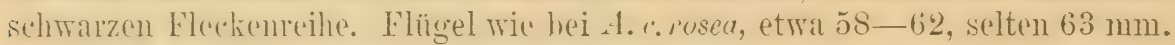

Südjapanische Inseln Hondo und Kiuschiu.

\section{Aegithalos caudatus irbii (Sharpe \& Iress.).}

Acredula irbii Sharpe \& Dresser, Proc. Zool. Soc. London 1871, p. 312 (Gibraltar).

Abbild.: Dresser, B. Europe III, 'Taf. 105, Fig. 1.

Stimfedern hellnwaun, anch die Scheitehnitte mehr oder weniger mit Branu ühurwaschen. die sehr hreiten, schwarzhraunen Kópfeitenstreifen auf dem Nilken zu eincm ansegedehnten schwarzen Flecke rereinigt, Rüeken

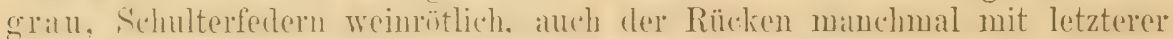
Farthe gemischt, die seitlichen Rücken- und Bürzelfedern mit weimrötìchen Spitzen. Oherschwanzderken schwarz, meist mit grauen Spitzen. Kopfseiten

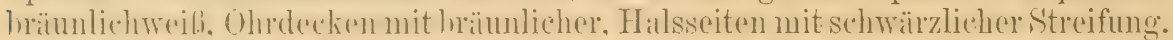

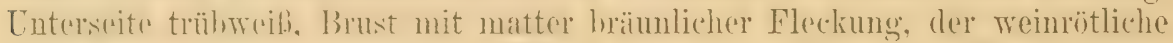
Anfluge der Seiten ausgedehnt. Flügel etwa 58-62 mm. - Das Schwarz

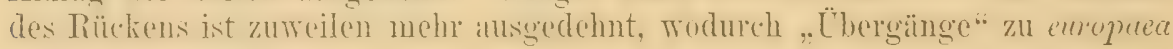
und rosea entstehen.

Sü̈d- und Yittel-Italien, an der Küste der Adria his Venetien hinaufreichemel, an der Riviera. Südi-Frankreich. Portugal und Spanien. Kiorsikil und

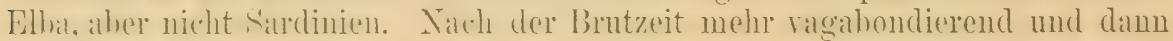
bis Poschiaro, vereinzelt in Tirol und einmal bei Paris erlegt.

12 Eier aus Korsika im Tring-3Iuseum messen im Durchschnitt $14.1 \times 10.6 \mathrm{~mm}$.

\section{Aegithalos caudatus sicula (Whit.).}

Acredula sicula Whitaker, Bull. Brit. Orn. Cl. XI, p. 52 (1901- Sizilien); Ibis 1902, p. 54, Taf. II.

Auffallend ähnlich A.c. major, aber kleiner, Flügel nur etwa 56 bis $57 \mathrm{~mm}$, Konfmitte stark mit Bran getrüht, sorkb kein reiner weiber streif in der Mitte heilht. das schwarze Rürclenfeld moist heschränkter. I)ie Stenerfedern sind merklich schmäler. der schwanz etwas kïrzer $(73 \mathrm{~mm})$. Augenlid gelblich.

Sizilien.

\section{Aegithalos caudatus major (Radde).}

A'rentule tephnote in. major Radde, Ornis Cancas., 1. 144, Taf. 6, Fig. 1 (1884- Tiflis und Schamchor, Kaukasus).

Mecistura irbyi var. cancasica T. Lorenz, Beitr. Orn. Nordseite Kaukasus, p. 60 (1887Podkumok, Nord-Kankasus).

Acredula dorsalis ILadarász, T'ermesz. Füzetek XXII, p. 202, Taf. VII, Fig. 1 (1900Pjatigorsk, Nord-Kaukasus).

Acrectula senex Mladarász, Termesz. Füzetek XXIII, p. 202, 'Taf. VII, Fig. 2 (1900Pjatigorsk, Nord-Kaukasus).

Abbild,: Dresser, B. Europe IX (Suppl.), Taf. 655 Fig. 2. 
Leicht von A. c. irbii dureh die keineswegs schwarzen sondern hellbranuen Kopfseitenstreifen zu unterscheiden. Diese werden nach hinten zu dunkler und vereinigen sich auf dem Hinterhalse zu einem an Ausdehnung wechselnden schwarze'n Flecke. Auf der Kohle findet sich manchmal eim undeutlicher graner Fleck angedeutet. Flügel etra 60-63 1mm. - Fïm Stück mit sehr hellen Konfstreifen und sehr schmalem. schwarzem Rürclenhande wurde als .esnex". ein anderes mit sehr dunklen Konfstreifen und stark sehwarz gemischtem Rüclien als ..doratis" heschriehen. Das Torkommen vou 3 Arten(!) bei Pjatigorsk, von wo viele "typische" major

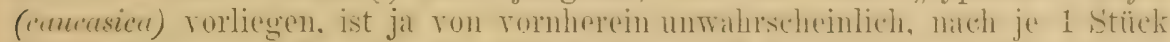

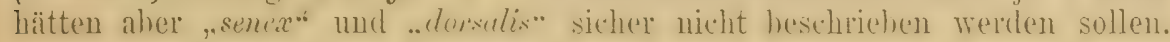

Kaukasus (nördliche Ausläufer, Kura-Tal).

\section{Aegithalos caudatus tephronotus (Günther).}

Orites tephronotus Günther, Ibis 1865, p. 95, Tal. IV (1865- "Asiatic side of the Bosphorus").

Mecistura pöltzami Sewertzow, Iurkest. Jevotn. in Izv, Obshch. MIoskov. VIuI, p. 135, Tab. 8, Fig. 1 (1873- Astrabad, Nord-Persien).

Abbild.: Dresser, B. Europe III 'Taf. 105, Fig. 2.

Unterscheidet sich von A. c. irbii und Verwandten durch den großen schicfergrauen Fleck an der Kehle. Bei andern schwanzmeisen sind die

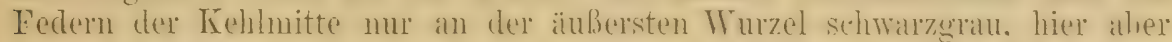
ganz. ron letzerer Farhe, nur mit schmalen weililichen Spitzen. die sich im Sommer almutzen. Die schn schwarzen Künfseitenstreifeu hegimen üher oder manchmal eben ror den Augen und fließen am Nacken nicht oder nur unvollkommen ineinander. sodils kein sehwarzes Nackenband, oder nur eine schwache Andeutung eines solchen entsteht. Stim und schmaler

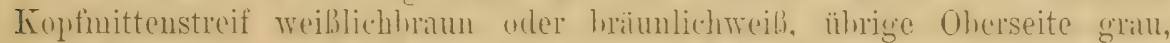
olune schwarz, nur der Vorderrülden etwas hraun rerwaschen. Enterseite schmutzigweiß mit rahmfarlenem sedimmer, auf der Kehle ein grober schiefergrauer Fleck. anf der Brust eine Reihe hellhrauner Lüngsflecte. Köruerseiten, Bauch und [nterschwanzlechen meinriotlich. Augenlid orange.

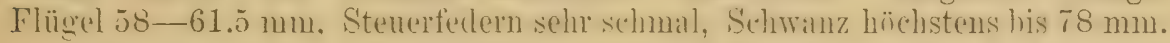

Lmgegend ron Konstantinopel (Pera, Bujuliclere. Bachtscheischköi, Belgrad, ${ }^{3}$ ) Cíleinasien lis zum Taturus. am südufer des Kispischen Meeres cutlang his (Fhilin. Misinteran und Astrabad in Persien, nach Re iser eimmil im Herbst in Griechenland erlegt.

Lebensweise wie die der europäischen Formen.

\section{Aegithalos caudatus passekii Sarudny.}

Acredulu tcyhronotu pusschii Sarudny, Ornith: \[onatsber. 1!04, 1. 164 (..Gelirge zwisehen dem Iranischen Hochlande und der Ebene Mesopotamiens").

Sehr ähnlich $A$ c. tephlironotus, aber Rücken und Bürzel heller grau, Kopfstreif und Unterseite reiner Teiß, das Rnsa der Seiten und Lntersehwanzdeckèn aber ebenso lebhaft wie bei $A$. c. tephronotus.

Churistan.

Bewohnt die Eichenrällder des südiranischen Gehiruszuges - Farsistan,

1) Aber niclit Belgrad in Serbien! 


\section{6:34. Aegithalos caudatus glancogularis (10ure).}

Orites? glancogularis $\left.{ }^{2}\right)$ F. Aloore, Proc. Zool. Soc. London 1854, p. 140 (1854- "China “). Mecistura swinhoei Pelzeln, Reise Novara 1 II., p. 66, Tab. 3, Fig. 1 (-juv.) (1865Schanghai).

Abbild.: Gould, B. Asia II, Taf. 69.

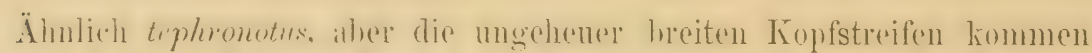

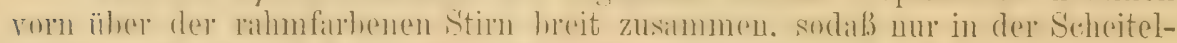

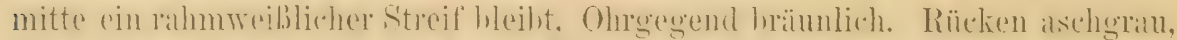

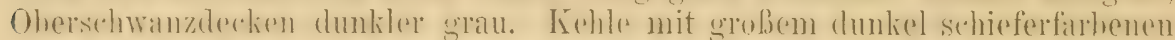

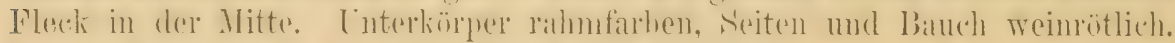

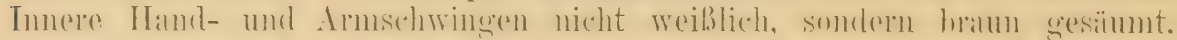
Flïgel 5̌6-60, Schwanz 60-64 mm. - Juv.: Kehle und Brust rosigziegelrot, Kopfstreifen sepiabraun.

Mittleres China (Gebiet des Jangtsekiang; Ningpo).

\section{Aegithalos caudatus vinacea (J. Verr.).}

Mecistura vinacea Verreaux, Nouv. Arch. MLus. Paris VII, Bull. p. 56 (1871-- Ourato. - Juv.). Orites ouratensis Swinhoe, Proc. Zool. Soc. London 1871, p. 362 (nomen nudum!).

Acredula calva Pleske, Bull. Brit. Orn. Cl.1II, 1.13 (1893- „Upper Chuan-che, China“).

Abbild.: Wissensch. Res. Przewalskis Reis. Il Taf. VII Hig. 1, 2.

Ähnlich A.c.glanecogularis, aber viel größer, Flïgel 62-63, Schwanz

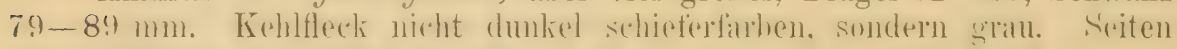

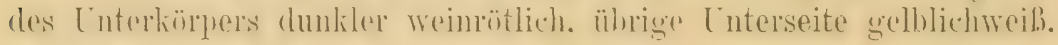

Nordwestliches China (Kansu, Ourato).

\section{Gattung ANTHOSCOPUS Cal). 18.1.}

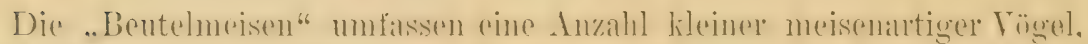

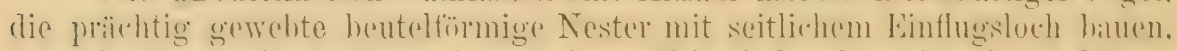

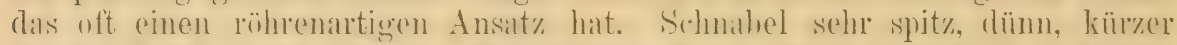
als der Kopf. Firste gerade. Nasenlöcher klein, rund, seitlich. von Ferlern

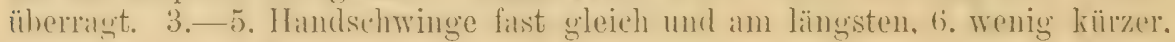
ebenso 2. Gefieder nicht so voll und weich wie bei Pams. Frste Handschwinge klein, linzettlich, nieht oder nur ganz wenig, hei maeronye schon sehr stark die Handderkn ïherrigend. hei den afrikanisehen Arten jedoch noch mehr entwickelt, beinahe, halb so lang wie die zweite. Die nordanerikanische Bentelmedse hat anbere der wie hei den afrikinischen Formen ausgehildeten 1. Ifandsehwinge anch etwas läingeren Schwanz und gekrümmiteren

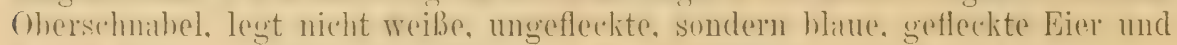
wurde daher generisch, als Auriparus Baird (1864) getrenut.

Im Alterskleide nur Stirn und Kopfseiten solıwarz . . . . A. pendulinus . p. 389

Im Alterskleide Stim, Kopfseiten und Hinterkopf schwarz . . A. coronatus . . p. 392

Im Alterskleide der ganze Kopf schwarz . . . . . . A. macronyx . p. 393 (Von der zweifelhaften A. yenisseensis isty das Alterskleid noch nicht bekannt.)

1) Nicht "glaucovirens" wie Orn. Monatsber. 1894, p. 28, steht. 


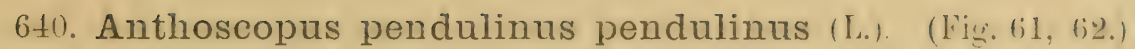

\author{
Südenropäische Bentelmeise.
}

Motacilla Pendulimes Linnaeus, Syst. Nat. Ed. X, p. 189 (1758 - „Habitat in Polonia, Lithuania, Hungaria, Italia, missa a DD. Montio").

Panes narbonensis Gmelir, Syst. Nat. I, p. 1014 (1788- "Habitat in Gallia Narbonensi." Ex Buffon).

Penclulimes Polonicus Brehm, Handb. Naturg. Vög. Deutschl., p. 476 (1831- "Sie lebt in den Rohrwäldern Polens" usw.).

Pendulinus medius Brehm, t. c. p. 477 (1831- "Sie kommt bei Wien ror").

Pendulims macrourus (sic) Brehm, t. c. p. 477 (1831- „Sie lebt an der Donau, zeigt sich auf der Wanderung in der Nähe ron Wien").

Parus minimus Gloger, Gemeinu. Naturg., p. 281 (1842).

Remizus pendulinus vadlei Prażák, Neuer Naumann II, j).242 (1897- partim? "Südeuropa (Südrußland, Ostgalizien)." Ganz konfus!)

Engl.: Penduline 'lit; Französ.: Mlésange rémiz; Ital.: Pendolino.

ơ ad. im Frühling. Stirn, Zügel und Kopfseiten schwarz, Mitte des

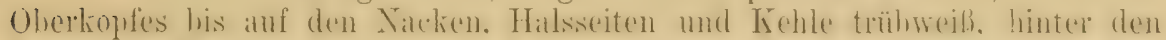

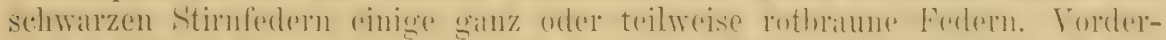

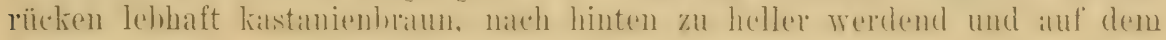
Hinterrücken in Oekergelb ïbergehend. Oberschwanzdecken graubraun mit breiten rahmfarbenen

Säumen, Schrvingen und Steuer-

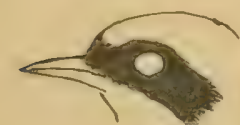

Figur $61(1 / 1)$.

federn schwärzlich graubraun mit weißlich-rahmfarbenen Außenund Imensïumen, die sich auch um die Spitzen herumziehen und an den immeren Armschwingen

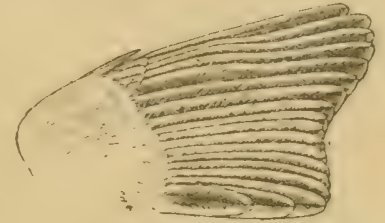

Figur $62(2 / 3)$.

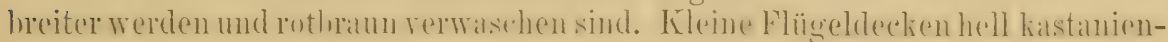
braun, an der Wurzel schwarggrat, die groben schwarzgrau mit dunkel

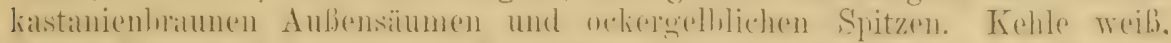

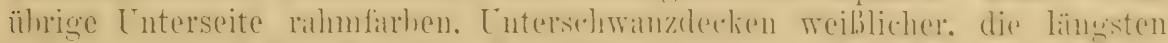

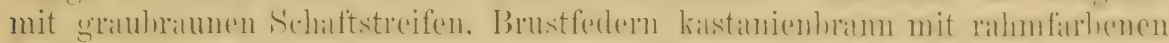

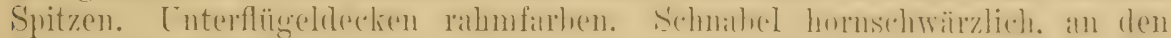

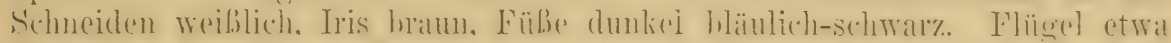

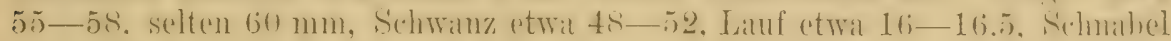
(Culmen) 9.6-12 mm. o ad. wie ơ ad., wie es scheint nur im allgemeinen

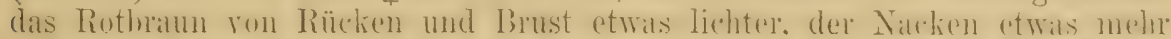
gräulich, Gröbe alser nicht geringer. Im frisch rermauserten Herhstlibide

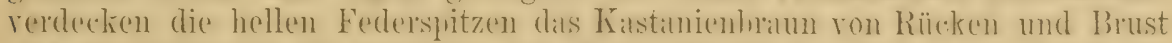

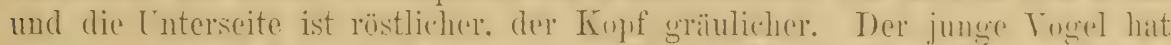

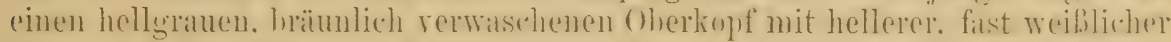

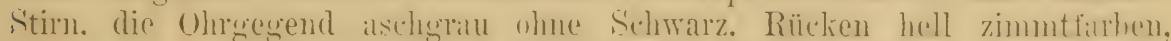

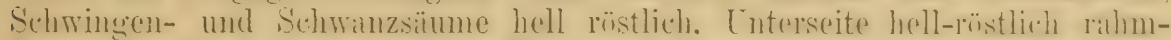
firben. - Fis scheint nur eine (Herhst-) Mathser stattzufinden, jedoch findet

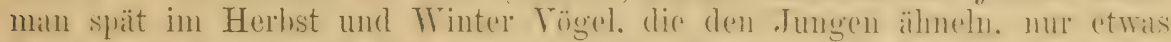
dunkler sind und mit Spurean ron oder trilweise antwicheltem sehwarmen

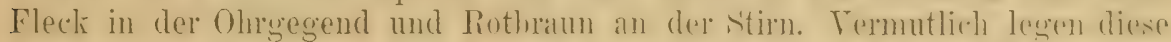
auganscheinlich jüngeren Tögel ihr Alterskleid arst im folgenden Herhste an.

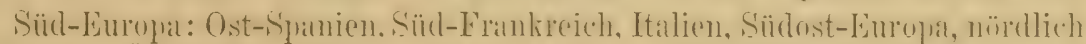

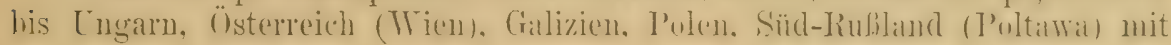


Ausnahne des äußersten Ostens, Kleinasien. Früher hier und da in Deutsehlinnd: Sehlesien. Magdeburg, Gothil. Mark Brandenburg, Mecklenburg, Thorn, Eisleben, ?? Mosel. Jetzt noch vereinzelt in Schlesien.

Bewohner der Weidendickichte und anderer Buschwälder an den Ufern von Strömen und Seen, nicht aber ausgedehnter Röhrichte. Stand- und Strichvogel. Nahrung Insekten, im Winter Rohrsamen u. a.m. Nest auf Büschen und Bäumen, ein am Ende von Zweigen aufgehängter ovaler Beutel, der an seinem oberen Ende ein Eingangsloch hat. Die Ränder des Loches sind mehr oder minder dachartig vorgezogen oder gar zu einer Röhre verlängert. Die Materialien des filzartig weichen Nestes bestehen aus Pflanzenwolle, besonders der Bliitenwolle von Zitterpappeln und Weiden, sowie Sehilfkolbenwolle, Fasern und Haaren. Das Gelege besteht aus 5-8, ausnahmsweise 9 und 10 weißen, glanzlosen, sehr langgestreckten Eiern. Maße von 50 Eiern ron der Balkanhalbinsel und aus Kleinasien (37 Jourdain, 13 Reiser) im Durchschnitt $15.52 \times 10.53$, Maximum $17.4 \times 10.3$ und $15.6 \times 11.2$, Jinimum $14 \times 10 \mathrm{~mm}$. Gerwicht ron 13 Eiern (Reiser) 55-75, im Durehschnitt $65.7 \mathrm{mg}$.

\section{(it1. Anthoscopus pendulinus caspius (Poelzam).}

Aegithahus caspius Poelzam, Protok. Kazan. Univ. I, p. 141 (1870-- Astrachan).

Aegithahus castrneus Sewerzow, T'urkest. Jevotn. in: Izr. Obshch. MLoskor. VIII, 2, p. 136 (1873-Astrachan); Übersetz. in: ILadarász, Zeitschr. Ges. Orn. IV, p. 104, 1888. Aegithahus galliardi d'Hamonville, Cat. Ois. Europe, p.35 (1876- ex Olphe-Galliard, Ibis 1875, p. 268, 269: „Russie méridionale“).

? Aegithalus altaicus Radde, Samml. Kaukas. IIus., p. 147 (1899- Nomen nudum! "Lenkoran").

Abbild.: Dresser, B. Europe III Taf. 117

Das of ad. ist auffallend rersehieden von A. pend. pendulinus: Stiru

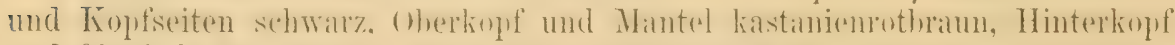

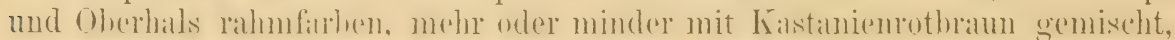
die rahmfarhene Fïlehe oft zul einem simz sehmalen Natelinhand reduziert.

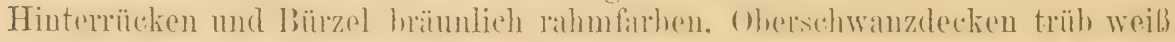

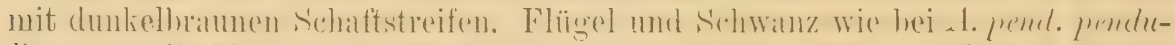

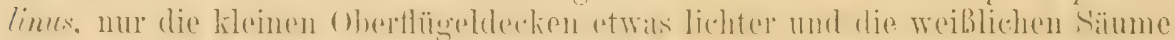
breiter. Unterseite wie hei A. pend. peudulinus. - Zweifellos jüngero Vögel,

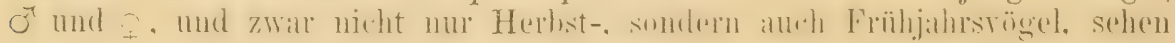
ganz auders aus und tun augenscheinlich dar, dab sie ihr Alterskleid nicht schon im ersten Jahre anlegén, wie dies auch bei andern Bentel-

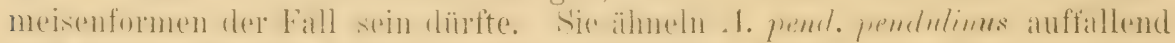

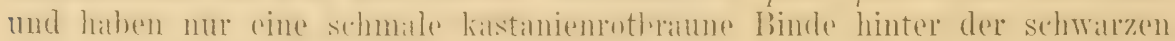
Stiru, wie man sie auch bei 1 . proul. penduliuns findet, die kastanienbraune Pärbung zieht sich aber ferner noch in einem mehr oder minder schmalen. Supereiliarstreifen bis über die Ohrdecken hin, eine Zeichumng, die bei A. pend. pendulinas fehlt; meist finden sich auch noch einige rotbraune

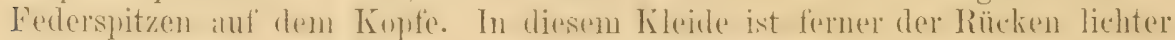

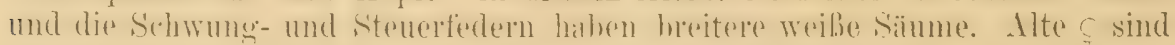

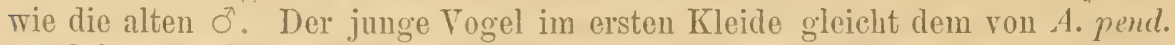
pendulime, außer dab er auf der Oberseite ein wenig blasser ist.

Tertritt die siddeurnaitisehe Bentelmeise in den Niederungen um das Kaspische Meer, nordwärts bis Orenburg, wo sie nicht selten brütet.

Lebensweise und Fortpflanzung wie bei A. p. pendulinus. Auch die Eier sind wie bei jener. 61 Eier ans der Gegend von Astrachan messen im Durchschnitt $16.1>$ 10.8, im Maximum $17.7 \times 11$ und $16.2 \times 11.3$, im Mininum $15 \times 10.7$ und $15.5 \times 10.3 \mathrm{~mm}$. Ihr durchschnittliches Gewicht ist $67.8 \mathrm{mg}$. 


\section{Anthoscopus pendulinus jaxartensis (Susehk.).}

Aegithalus pendulinus var. jaxartica Sewerzow, Turkest. Ievotn. in: Izv. ()bsheh. Iuskor. VIII, 2, p. 135 nomen nudum, unter einer unkolorierten, nicht charakteristischen Abbild. auf Taf. IX (1873).

Remiza pendulina jaxartensis Suschkin, Bull. B.0. ('lub XIV, 1).45 (1904 . . "Turkestan”. T'erra typica Syr Darja).

Unterscheidet sich von A. p. pendulinus durch viol kleineren, feineren Schnabel, goringere Größo und hellere, mehr zimmtfarhene obertlügeldecken. ÄuBerst ähnlich 1. \%. stoliczlue, aber heim alten Vugel brefinden sich hinter dem schwarzen Stirmbaude stets einige rothiame Flecke. welche das schwarze Stirnband von dem triih- oder rahmweiben oherlingle trennen. Meist ist diese rothraune Linio sehr deutlich, hiswrilen nur angerlentet. Außerdem sind die kleinen Oherflügeldecken dunkler, mehr zimmtfarhen. nicht isabellfurhen wie bei stoliczler: dies Kiennzeichen ist meist sehr dentlich, nur sehr selten nicht deutlich ausgeprägt. Intermediäres Kleid: Stirn weiblich, dahinter eine rothrame Linie wie bei dem alten Togel, Ohrgegend nicht schwarz, sondern nur mit mehr oder minder verhoschenem schwärzlichen

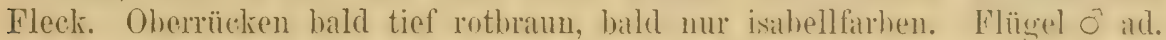
und f etwa 54-57, Sehwanz etwa 45-49, Iatuf $1 \pm-15$, C'ulm(2) $7.5-9 \mathrm{~mm}$ (11 Exemplare).

Turkestan: Tal des Syr Darja und Umgegend.

\section{Anthoscopas pendulinus stoliczkae (Hum( ).}

Aegithalus stoliczkae Hume, Stray Feathers II, p. 521 (1874- Keine Lolsal. angegeben! 'Terra typica: Bora südlich von Yarkand in Ost-T'urkestan).

Remiza pendulina centralasiae Suschkin, Bull. B. O. Club XIV, p.45 (1904- „Asia centralis." Terra typica: Sa-tschu in der suidöstl. Mongolei).

Abbild.: Scient. Res. Second Yarkand Jlission, Ares Taf. VII, unter dem irrtümlichen Namen Aegithalus coronatus.

Ebenso klein- und feinschnäblig wio A. p) juxartensis, aber die kleinen Oberflügeldecken isabellfurben. Auf die sehallfe schwarze Stirnbinde heinn alten Vogel folgt ummittellate der weibe Oherkopf, whe spur einer rotbraunen Binde. Ton A. pendulimes pendulims durch viel kileineren, feineren Schmabel, geringe Gröbe und isabellfarbene oder dech nur mit blassem

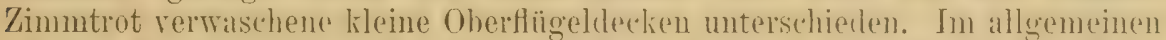
ist das Kastanienhraun des Torderrïlekens weniger ausgedehnt, die Mitte des Ĺnterkörper's etwas weiblicher. Die rahmfirhenen chpitzen der groben Oberflügeldecken sind hreiter als hei pendulims aus Europil. Flügel etma 52-55, Schwanz etwa 43-46, Culmen $7-8 \mathrm{~mm}$ (15 Exemplare).

Ost-'Turkestan (Kaschgarien) bis Dschungarei.

\section{4t. Anthoscopus pendulinus consobrinus (Swinh.).}

Aegithalus consobrinus Swinhoe, Proc. Zool. Soc. London 1870, p.133 (Scha-schi am Jangtse-kiang).

Abbild.: Gould, B. Asia II T'af. 70.

Leicht kenntlich an dem nicht weiblichen, sondern hell aschgratuen Oherkopfe. Die Federn in der Mitte des Oherkopfes hahen dunklere Sichatt- 
streifen und hellere. fist weibliehe Ränder. Sechwäryliche stimbinde deutlich,

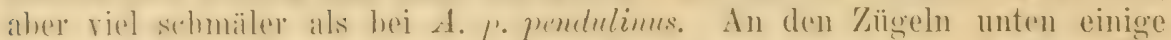

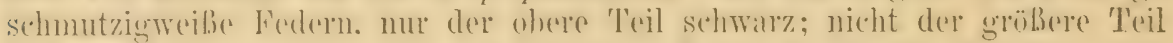
der Koprifeiten, sondern nur ein hördhstens 4 mm hreiter streif hinter dem Auge sthwal\%. Hinter der sehwarzen stimbinde lieine rotbranne, sondern

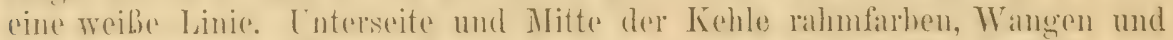

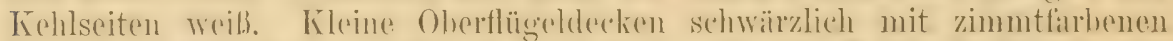

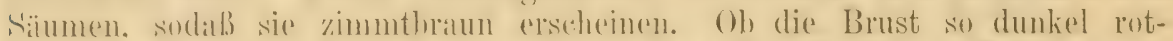

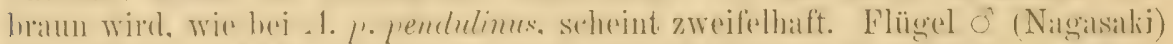

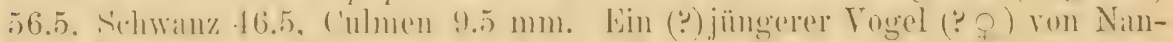

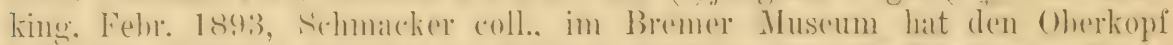

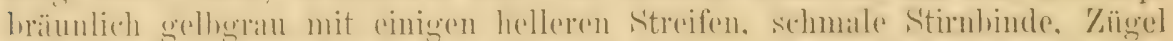
und streif hinterm Auge dunkelhomen; hinter der dunkehn Stirnbinde e'in

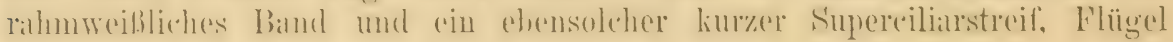
$55 \mathrm{~mm}$. (5 Exemplare.)

(hina: Tal des Jangtse-kiang. Jajan: Nalgassalki. (Sehr wenigg bekamnte und ïußerst seltene Form, aber wohl kaum etwas anderes, als der südöstlichste Vertreter unserer pendulimus.)

\section{6i.5. Antioscopus yenisseensis (Suschlin). Fragliche Furm!}

Remiza yenisscensis Suschkin, Bull. B. O. Club XIV, p. 44 (1904- „Mongoliae septentrionalis pars inter juga Sayan et Tannu-ola posita, ad cursum superiorem fluminis Yenisei").

Es liegt kein ausgefürbtes Stïck vor, nur viex junge Vögel im ersten

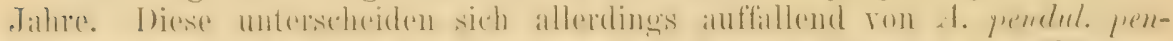

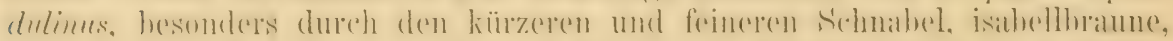

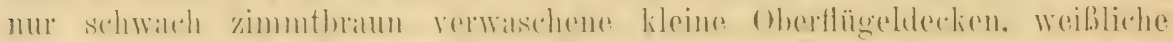

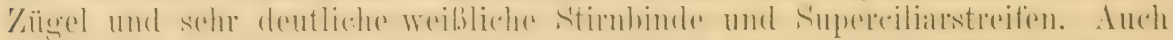

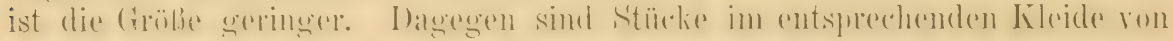
A. p. jaxartensis nur dureh eine mehr oder minder deutliche rostrotbraune

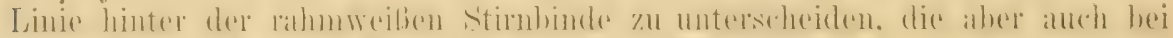

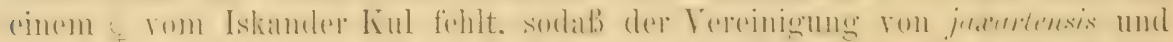

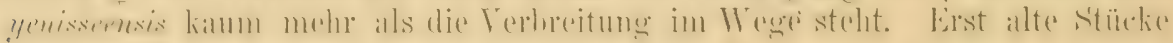
lönnen zeigen, was "yenisseensis" ist. Flügel 53-55, Schwanz 44-48, Culmen 7.5-8.5 $\mathrm{mm}$.

Oberer Jenissei (Fluk Kemtschik, Berg Chairehan).

\section{Anthoscopus coronatus (Sewerz.).}

Aegithalus coronatus Sewerzow, Turkest. Jevotu. in: Izv. Obshch. Moskov. VIII, 2, p. 136, Taf. IX Fig. 3 (1873- Nau bei Chodjent am Syr Darja); Übers. in: Madar. Zeitschr. Ges. Orn. IV, p. 103

degithalus atrieapillus Sewerzow, t. c. p. 137 Taf. IX Fig. 4, 5 (1873- Syr Darja bei Perowsk; auch 'Tschimkent und Ouigoum-Berge); Übers. in: Madar. Zeitsehr. Ges. Orn. IV, p. 105.

Ist A. pendulinus pendulimus ähnlich, aber in allen Kleidern durch den

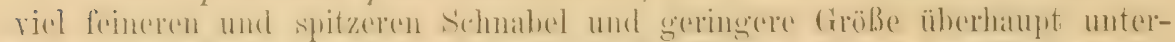

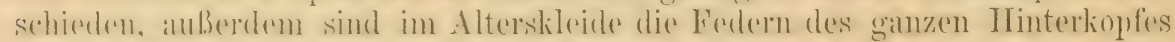

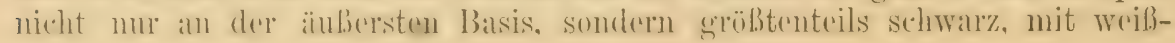




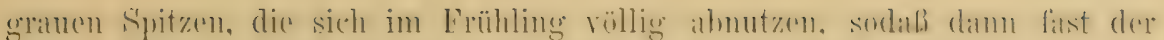
ganzo Oberkopf schwar\% orscheint und nul auf dem vorderen 'Teil des.

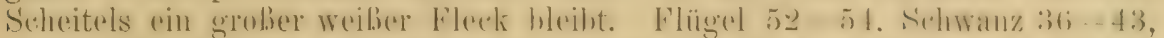

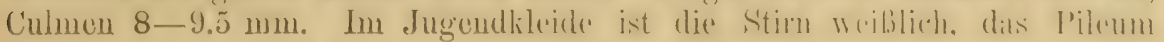
holl graubraun. (50 Exemplare.)

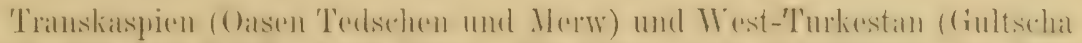

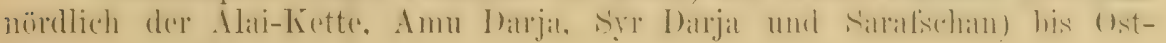
Persien und Persisch Balluchistan.

\section{Anthoscopus macronyx (Sewerz.).}

Aegithalus macromyx Sewerzow, 'l'urkest. Jerotn. in: Izr. Obshel. Moskov. VIII, 2, p. 137,

'Taf. IX Fig. 8 (Übers. in Madarász' Zeitschr. Ges. Orı. IY, p. 106) (1873-

'I'schimkent am Syr I)arja. Die Abbildung ist zwar nicht für vorliegende Spezies churakteristisch, die Beschreibung aber enthält melureres, das auf keine andere form palst. Sewerzow nennt seinen Typus , Oే ad. hyemal". Dies ist kaum richtig, da es sich aber doch um ein Kleirl vorliegender Form zu bandeln scheint, werden wir am besten den allgemein angenommenen Namen macromyx beibehalten. V'gl. Ibis 187t, p. 173. 174).

Aegithalus rutilans Sewerzow, 'Turkest. Jerotn. in: Izw. Obsheh. Mloskov. VIII, 2, p. 137, 'Laf. IX Fig. 6, 7, wo als se. rutilans var. cucullata und var. pectoralis bezeichnet (1873- Syr Darja, T'schimkent): Übers. in: Mad. Zeitschr. Ges. Orn. IV. 1). 107.

In allen Kleidern von allen übrigen Beutelmeisen dureh die die Hand-

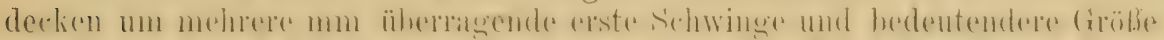

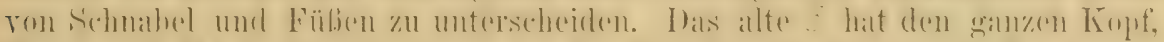

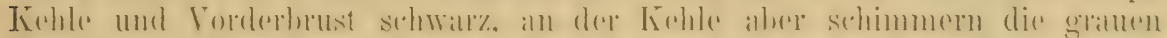

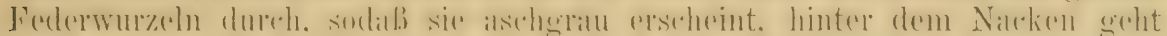
die schwarze Farbe allmählich in das dunkle Kastanienbraun des Mantels

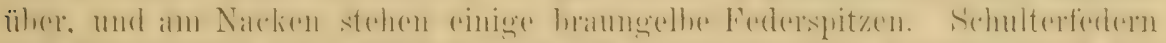

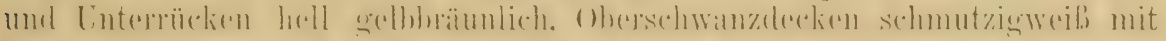

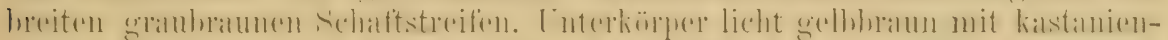

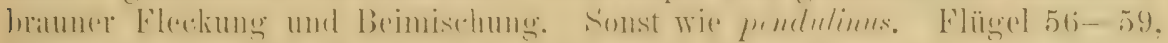
Sehwanz etwa 48-52, Lanf 15, Culmen 10.5-11.5 mm. - Außer dem

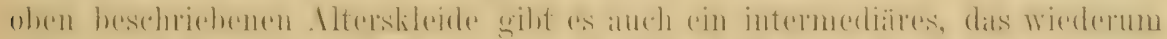

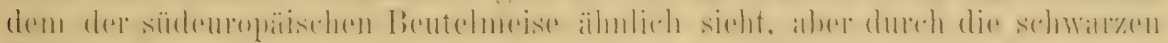

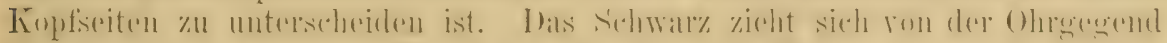

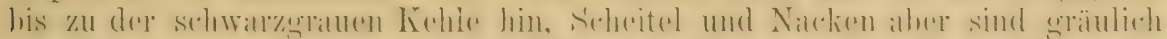

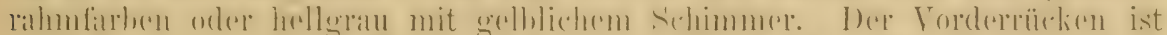

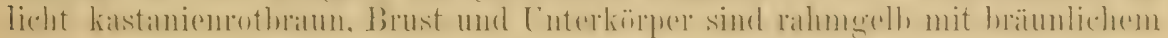
Selimmer: - Der junge Vogel im ersten Getieder unterseheidet sich von

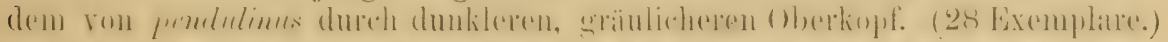

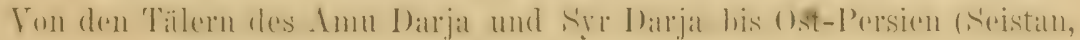
von Sarudny gesammelt).

Saruduy gibt in dem leider russisch gesehriebenen Werke über die Vögel Ost-Persiens (1903) p. 331-342 eingehende biologische und nidologische Notizen und bildet die interessanten Nestbauten ab. Die Hier sind wie die der anderen Beutelmeisen.

\section{Gattung CEPHALOPYRUS Bl. 1854.}

Von Anthoscopus sowohl morphologisch als biologisch verschiecten:

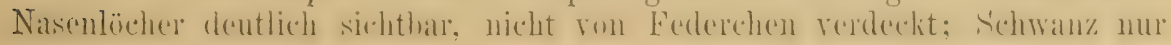


ungefähr halh so lang wie Flügel, also verhältnismäiBig kïrzer. Flügel dagegen rerhältnismälbig länger; Federn des Vorderkopfes steif und schmal; Nester in Baumlïchern; Eier einfarbig dunkelhlau (Nehrkm'n in litt.).

\section{Cephalopyrus flammiceps (Burton).}

Aegithahus flammiceps Burton, Proc. Zool. Soc. London 1835, p. 153 (Himalaya). Abbild.: Gould, B. Asia Ir, Taf. 71.

ơad. Stirn, Vorderkopf bis zur Scheitelmitte und Kinn glänzend feuerrot. Wangen, Kiehle und Vorderh'ust goldgeld. ïhrige Interseite holler gellh, Nitte des Bauche's und L'nterschwanzdecken weiblichaelh). Rest

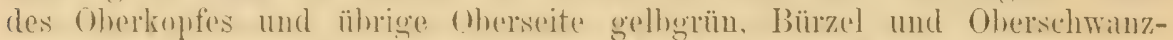

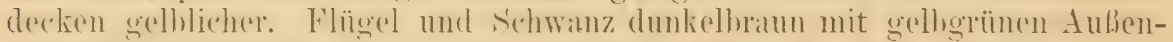

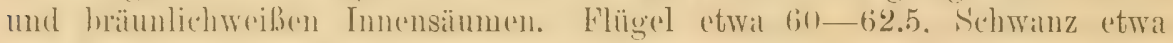
30-34, Lauf 12-13, Culmen etra $9 \mathrm{~mm}$. o und Jur. Oberkopf, Kinn und Kehle gelbgrïn, Oberseite etwas grünlicher, Unterseite blasser.

Himalaya von Gilgit bis Butau, in Höhen vou 3000-9000 engl. Fuß, im nördlichen Juman mot westlichen Szetsehwan. Komment anch in Afghanistan vor und zieht im Winter in die indischen Ebenen hinah.

\section{Gattung REGULUS Vieill. 1807 (vgl. 1) 340 ).}

Die Goldhähnehen haben einen dünnen, schlanken Schnabel mit fast

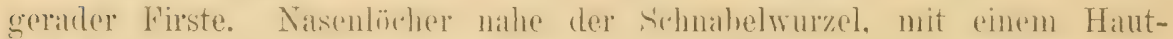
deckel und ron winer nach rorn gerichteten Feder mit Burstenhataren an der Spitze, bei R. calendula aus Nordamerika von mehreren Borsten überdeclit. Ciefieder äuberst weich und reich. Sedmahnelspalt mit einigent Borsten. 4.-6., bei $R$. calendula 3.-5. Handsehwinge fast gleich und am längsten, 2. immer viel kürzer, 1. ein Drittel bis Hälfte der zweiten. Schwanz aus-

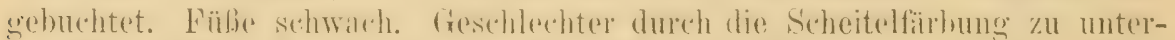

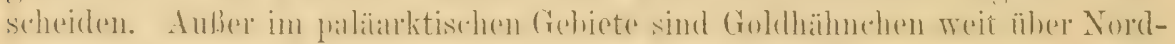
amerika verbreitet: Regulus culendulu, bei dem das $0^{\pi}$ einen sehön gleich-

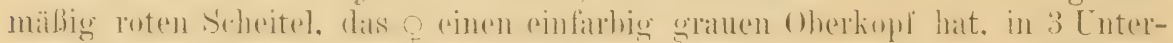
arten, und líegulus sulrapa in 2 Formen. Der von Audubon beschriebene

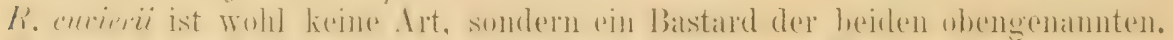

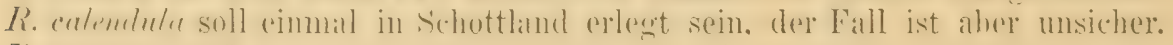
R. satrapa muß als Unterart von Riegulus vegulus bzetrachtet werden.

\section{Regulus regulus regulus (I .). (Fig. 63.)}

Gelbköpfiges oder Winter-Goldhïhnchen.

Motacilla Regulus Linnaeus, Syst. Nat. Ed. X, p. 188 (1758- „Habitat in Europa.“ Als typ. Lok. betrachten wir Schweden, nach dem ersten Zitat: „Fn. suec. 236").

Regulus cristatus (non R.c. Vieillot 1807!) Koch, Syst. Baier. Zool., p. 199 (1816Umbenennung ron Mot. regulus. Bayern).

Regulus vulgaris Leach, Cat. Mamm. B. Brit. Mus., p. 25 (1816- nomen nudum).

Regulus aureocapillus Meyer, Heyer \& Wolf's 'Taschenb. deutsch. Vögelkunde III, p. 108 (1822- Umbenennung von Motacilla regulus).

Regulus crococeplualus Brehm, Beitr. z. Tïgelkunde II, 1). 120 (1822-- Limbentenumg ron Motacilla regulus). 
Regulus favicapillus Natumann, Ÿ̈g. Deutsehl. IlI. p.9188, Taf. 9:3. Fig. 1 -.3 (1823Umbenennung von Motacilla regulus).

Regulus septentrionalis Brehm, Handb. Naturg. Vög. Deutschl., p.479) (1831- „Es bewohnt die nordeurop. Wälder, namentlich Skandinavien").

Regulus chrysocephalus Brehm, t. c., 1. 481 (18:31 — „Wandert im Okitober durch VIitteldeutschland").

Regulus auricapillus Selby, Ill. Brit. Orn. Erl. II, I. p. 229 (18:33- Umbenenunng von Motacilla regulus. "It is found throughout Europe, and as far to the northward as the Aretic Circle").

Regulus Limnéi Malm, Göteb. Bohusl. Fanna, p. 170 (1877- Bohus).

Engl.: Goldcrest, Golden-crested Wren. Franz,: Roitelet. Ital.: Regolo. Schwed.: Kungsfogel.

ơad. Schmaler Stirnstreif und Zügel bräunlichweiß, dabinter ein etwas breiterer Stirnstreif olivenbräunlich, Mitte des Oherkopfes gelh, in der Mitte brennend orangregelh, an den S'eiten von einem schwarzen Streifen hegreuzt. Übrige Oberseite gelblich olivengrün, Halsseiten und Nacken leicht brïunlich rerwaschen, Bürzel lehhafter, mehr gelhlichsriün. 2.-6. Hindschwinge dunkelbraun mit olivengelhlichen Außensäumen, die folgenden Hand- und Armschwingen haben dio Außenfahme an der Basis (etwa $1 / 4$ der Lü̈nge) rübweiß, dann für etwa $1 / 2 \mathrm{~cm}$ schwarzbraun und für den Rest braun mit olivengelben Säumen, wodurch an der Basis eine weißliche, von einer schwärzlichen gefolgte Querbinde ent-

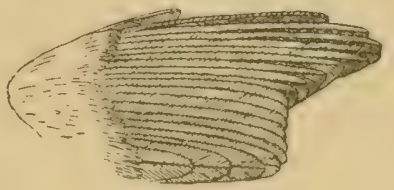

Figur $63(3 / 4)$. steht. Armschwingen mit schmalen, innere mit breiten trübweilen śritzen. Flïgeldecken dunkelbraun mit olivengrïnlichen Säumen, mittlere und große mit trülıreißen Spitzen. Innensïume der Schwingeu und Lnterflügeldecken trühweiß. Stenerfedern hrimu mit olivengelhgrïnen Süumen. Unterseite mäunlich rahmfarben. Schmabel schwarz oeter schwarzhraun. Fübe gelhlich olivenbraun his hell hornbraun, Iris braun. Fliggel etwal 53.5 bis 55.5, ausnahmsweile 56.5 und 57, Sehwanz etwa 40-42, Lauf 17-19, C'uhmen 10-11 mm. o wie ot, aher etwas kleiner (Flügel etwa $51-53 \mathrm{~mm}$ ) und der Scheitelfleck einfarhig gell, olne orangefarbene Mitte. -- Erstes Jugendlieid: Oberseite grünlich olivenhraun, Oberkopf wie der Rü̈cken, ohne eine Surn von Gelh oder von schwarzen Streifen. (C̈her 100 Exemplare.)

Europa, im allgemeines im Norden so weit die Tamnenwiilder reichen, im Süden bis zu den Pyrenäen, in Italien und Griechenlind his zum Mittelmeer, Kaukasus und Kleinasien. Stand-, Stridl- und teilwriser Zugrogel, wanigstens ziehen im Herbst oft Schwälme üher Helgoland. nach England. Deutsehland. mnd man trifft diese Vögel dam atuch in Śpanien, Portugall und äherhaupt an Orten, wo man sie zur Brutzeit rergehens sucht. Nach Angahe älterer Autoren auch in Algier; wo neuere Forscher sie nicht fanden.

Meisenartig unruhige Baumvögel, die Nade hölzer, besoñders 'Tannen und gemischte Wälder, Parks und Gärten mit Xadelholzbäumen bewolnen, aber nur außer der Brutzeit auch in reinen Laubwäldern vorkommen. Stimme ein meisenartiges, sehr feines, aber scharfes si-sih, Gesang mit den Locktönen beginnend und in ein angenehmes wisperndes Gezwitscher übergehend, alles äußerst fein und nicht weit hörbar. Nahrung Insekten, im Winter auch Sämereien, die aber immer ganz verschluckt werden. Nest offen, aber oben eng zusammengezogen, die dicken, weichen Wände aus Hoos, Flechten, Raupengespinsten, Spinnengeweben, dicht verfilzt, mit Federn und Haaren ausgefüttert, bald hoch, bald (seltener) niedrig, am Ende wage- 
rechter oder herabhïngender Zweige, in denselben versteckt, meist in der Sehwebe hängend, seltener oben auf den Zweigen. Wier 8-11, auf mattgelblichem oder gelblich rahmfarbenem, manchmal schwach fleischfarbenem, bisweilen fast weißem Grunde über und ïber etwas dunkler gewölkt. Am stumpfen Ende verdichten sich diese Wölkchen meist stark oder bilden einen Kranz. Manchmal sind die Wölkehen auch größer und bilden mehr vereinzelte gelbbräunliche Flecke, die deutlich von der weißlicheren Grundfarbe abstechen. 51 Eier messen nach Rey im Durchschnitt $13.65 \times 10.31$, im Maximum $14.2 \times 10.3$, resp. $14 \times 11$, im Alininum $12.1 \times 9.7 \mathrm{~mm}$. Durchsehnittsgewieht $40 \mathrm{mg}$. 2 Bruten im Jahre.

\section{Regulus regulus anglorum Hart.}

Regulus regulus anglonum Hartert, Bull. B. O. Club XVI, p.11 (1905- Großbritannien und Irland).

Unterscheidet sich von Regulus regulus regulus durch dunklere, etwas

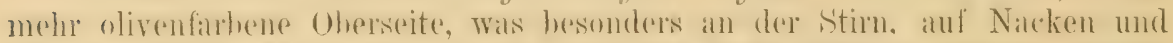

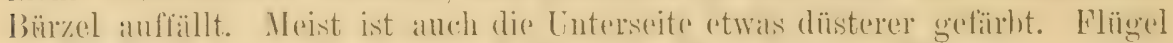

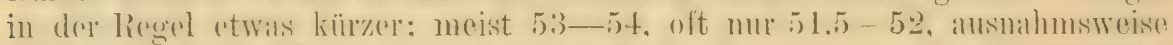

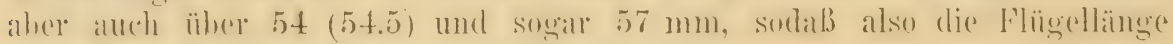
kein gutes Nerkmal bildet. (26 Lxemplare.)

GroBbritannien von der Insel Wight bis Schottland und Irland.

Lebensweise und Fortpflanzung wie bei R.r.regulus. Nester nicht sehr selten auf den Ästen, auch im Efeu an Baumstämmen und Gebäuden.

\section{Regulus regulus azoricus Seeb.}

Regulus cristatus var: azoricus Secbolım, Hist. Brit. B, I, D.454 (1883- Azoren).

Unterscheidet sich von K. r. regulus dureh merklich längeren Schnabol,

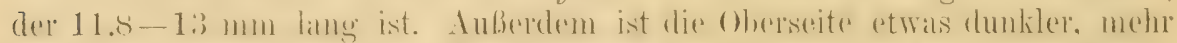

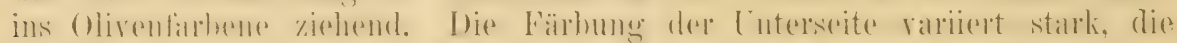

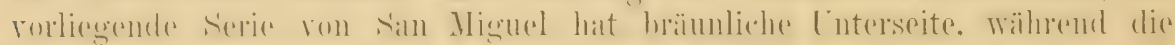

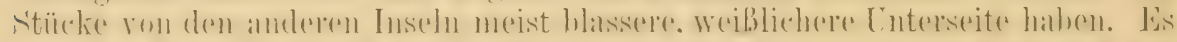

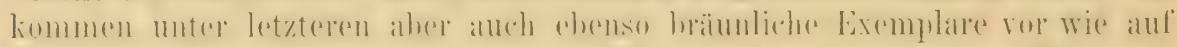

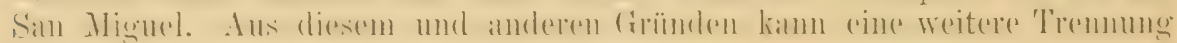
nicht stattfinden (rgl. Nov. Zool. 1905, p. 120). (50 Exemplare.)

Azoren: Sta. Maria, San Miguol, 'Terecira, San Jorge, Pico, Fayal, Flores, besonders in Tammen und Beständen von Cryptomeria japonica.

\section{Regulus regulus interni Hart.}

Regulus regulus interni Hartert, Bull. B. O. Club XVI, p. 45 (Januar 1906--. Sardinien und Korsika. 'lypus Sardinien).

Vou R.r. regulus durch graue Seiten des Oberkopfes und grauen

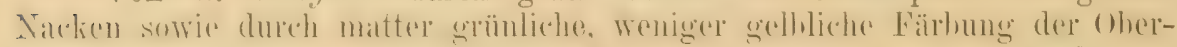
seite unterschieden. Sehr ähnlich K. $r$ japonensis, aber die woißlichen Flïgrelhinden nicht so breit, der orangefarbene Seheitelfleck nicht so intensir rot-orange, soudern mehr gelblich, von li. $x^{*}$. himalayanus dureh weniger

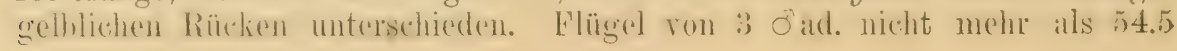


his 5; mm (rier von Whitehead. Koneng und Syuilloni gresammelte Stüleko untersucht).

Korsika und Sardinion. - Im Winter scheint gelegentlich auch $R . r$. regulus auf diesen Inseln vorzukommen.

\section{Regulus regulus himalayensis Jerd.}

Regulus Himalayensis Jerdon, B. India II, J. 206 (1863- ex Blyth, ML.S. - „N. W. Himalayas").

Regulus himalayanus David, Nouv. Arch. Mus. Paris VII, Bull. p. 7, 196 (187i).

Regulus eristatus orientalis (partim!) Seebohm, B. Japan. Emp., p. 80 (1890-- Asien! Gernisch)

Abbild.: Gould, B. Asia IV, Taf. 60.

Ist $R . r$ regulus sehr ähnlieh, aber gröBer! Flügel 55-58.5, Culmon

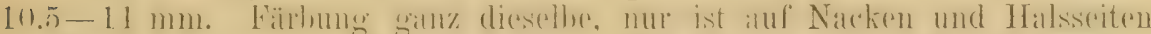

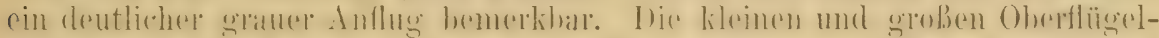

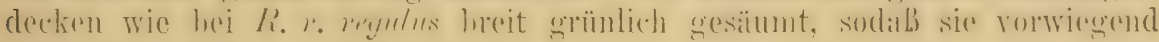
grïnlich erscheinen. (6 Exemplare.)

Himalaya von Kaselimir bis in das nordwestliche China.

\section{Regulus regulus japonensis Blakist.}

Regulus japonicus Bonaparte, Compt. Rend. Acad. Sci. 42, 1).767 (1856- Nomen nudum!).

Regulus japonensis Blakiston, Ibis 1862, p. 320 (Hakodati, Jesso. Lrste Beschreibung). Regulus cristatus orientalis (partim!) Seebohm, B. Japan. Emp., p. 80 (1890- Asien!) Regulus cristatus coatsi Suschkin, Bull. Brit. Orn. Club XIV, p. 44 (1904- „Jugi Sayan zona subalpiua").

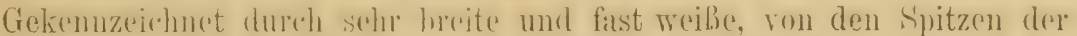

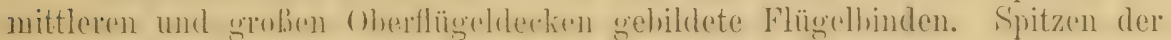

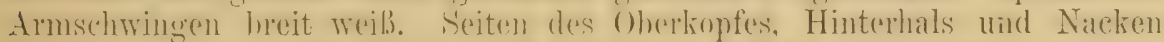

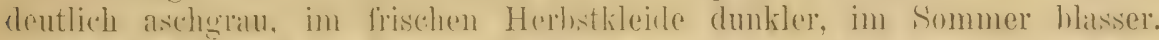
Rücken und bürzel im frischen Gofieder zimnlich dunkel, ungefähr wie bei anglomem. Flügel ơad. etwa $56-58 \mathrm{~mm}$. Scheitelmitte im Herbst sehr

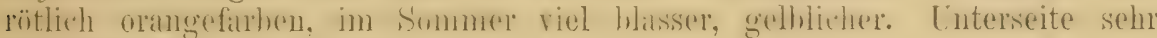
gelbbrïunlich. (13 Stïck.)

Jayan, Norel-China, Mandsehurei, sibirien his zum Nitai und Tomsk, genaue Grenzen noch unbestimmt.

\section{Regulus regulus teneriffae Seeb.}

Regulus teneriffae Seebohm, Hist. Brit. B. I, p.459 (1883- Canaren). Regulus satelles Koenig, Journ. f. Orn. 1889, p. 263 (Canaren. Terra typica 'Tenerife). Abbild.: Journ. f. Orn. 1890, 'Taf. V, Fig. 1; 'T'af. VIII, Hig. 9, Ei.

Enterseheidet sich ron $K$. r. regulus dadurch. dal.s die schwar\%en Streifen an don Seiten des Ohrerlenfes hreiter sind und ïhre der Vorderstim dureh

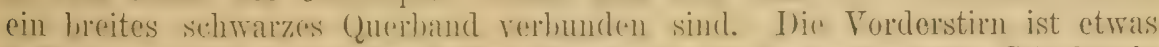
heller, wats noch mehr dureb den Gergensitz zu dem schwar\%en Stirnhando

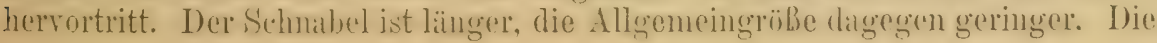


Tairloung ist rotwas dunkler, gesïttigter, dir Oherseite mehr ins Olivenfarbene ziehend, wie hei $R$. $r$ anglomen. der Nacken mit aschgranem Anflug; die

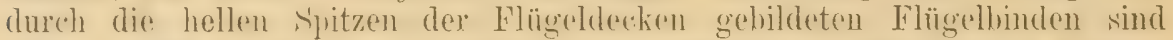
etwas sehmäler und mehr gelhhräunlich verwaischen. Bei frischen Stürcken

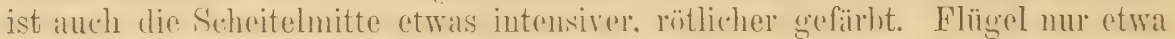
$50-51$, Selowinz ctwa 37 - 38, (uhmen etwal 11-11.5 mm. (12 Exemplare.)

\section{Bewohner der westlichen Gruppe der Canaren.}

Standrogel in den dichten Beständen der Baumheide (Erica arborea) und in den Pinienwäldern der Berge. Lebens- und Nistreise wie bei den Verwandten. Gelege 5 -8 Eier, die denen von $R$. $r$. regulus gleichen. Maße vou 23 Eiern (20 von Jourdain, 3 ron Kutter gemessen) im Durchschnitt $13.73 \times 10.56$, Maximum $14.7 \times 10.2$ und $14 \times 11.2$, Jinimum $13 \times 10.6$ und $14 \times 10 \mathrm{~mm}$. Gewicht $4.5 \mathrm{cg}$.

\section{Regulus regulus tristis Pleske.}

Reguhus tristis Pleske, Bull. Acad. St. Petersb. XXXV, p.146 (1892- 'Transkaspien und I'urkestan).

Őad. Auf den ersten Blick ron allen anderen Formen ron Regulus

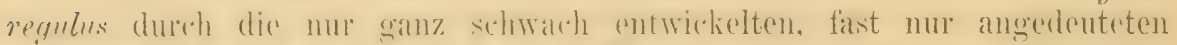
schwar\%en Streifon an elen Seiten des Pileum zu unterseheiden. Auberolem

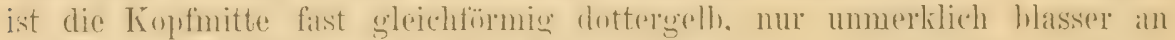

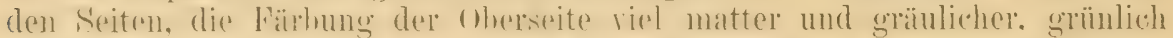

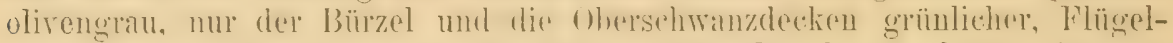
säume viel düsterer, sonst nicht wesentlich von Regulus regulus regulus verschieden. : Scheritelnitte mit einem hlibegellen streifen, nur von etwas dunkleren Schatten eingefaßt. (25 Exemplare.)

Bewobnt Turkestan von Aksu und Karakol bis Transkaspien.

\subsection{Regulus ignicapilla ignicapilla ('Temm.). (Fig. 6it.)}

\section{Feuerköpfiges oder Sommer-Goldhïhnchen.}

(Regulus cristatus Vieillot, Ois. Amér. sept. II, p. 50, Taf. 106, 1807, kann nicht für irgend eine Art angenommen werden. Es ist ein Gemisch von drei Formen! Der Name sollte Motacilla regulus Linné's ersetzen, weil Regulıs zum Gattungsnamen erhoben wird und wurde auch für unsern Regulus regulus später von Vieillot benützt, außerdem wird das amerikanische Goldhähnchen mit dem europäischen vereinigt, und aus Unkenntnis nicht $R$.regulus, sondern $\boldsymbol{R}$. ignicapilla beschrieben und abgebiletet).

Sylvia ignicapilla 'Temminck, Man. d'Oxn. Ed. II, I, p. 231 (1820- ex Brehm M. S., teilweise. Frankreich, Deutschland usw.).

Regulus mystacerts Vieillot, Faune franç. Uis., p. 231, 'Taf. 102, Fig. 3 (1822- Europa [Frankreich] und N.-Amerika-errore).

"Regulus pyrocephalus, mihi (früher Sylliu ignicapillı mihi)" Brehm. Beitr. z. Vügelkunde II, p.130 (1822- „Deutschland, Holland, Frankreich und Amerika“).

Regulus Yilsonii Brehm, Handb. Yaturg. Vïg. J) utschl.. p. 482 (1831-. "Scheint nordöstl. von hier zu wohnen, zieht.im April, usw.").

Regulus brachyrlynchos Brehm, t. c., p.483 (1831- „zieht im April und September durch die hiesige Gegend").

Reyulus pyroceptealue rommunis A. E. Brehm. Verz. Samml., P.7 (1866- nomen nudum).

Engl.: Firecrest. Franz.: Roitelet triple bandeau. Ital.: Fiorrancino. 
Von Regulus regulus wie folgt unterschieden: Die glimzend orangerote Fürhung der Kopfmitte ist etwas lehhafter und ausgedehnter, der Stirmmend hellbräunlich (brïunlich rahmfurlen), die schwarzen Könfseitenstreifen üher dem Stirnband vereinigt, üher den Augen ein weiber Streif; Zïgelstreif und einige Federn hinter dem Auge schwarz; an den Halssciten ror dem Flügelhug steht ein grober olivengelher Fleck; Ohrgegend olivengräulich, nach oben zu dunkler; Unterseite truibweiß mit matt graubräunlichem Anflug, Mitte des Unterkörpers weißlicher. Flügel of $53-55 \mathrm{~mm}$. 오 Scheitelfedern alle gelb (38 untersucht).

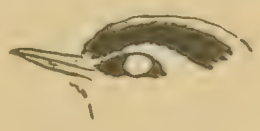

Figur $64(1 / 1)$.

Bewohner der MitteImeerländer: Algier. Tunis, Südenropar his Kíleinasien, dureh G̈sterreich-[ngarm bis Galizien, Frankreide und Deutsehland his an die Ost- und Nordsee: in Polen und Tittanen selten. In Inentsehland und Frankieich Zangogel. der nur vereinzolt iiherwintert, in den Mittelmererländem Standrogel. In lingland (hesonder's an den sïd- und Ostlï̈sten vorkommender) seltener Irrgist ron Olituher his April, nicht hrütend.

Noch lebhafter, beweglicher, als das gelbköpfige Goldhähnchen, Lockton und Gesang etwas schärfer und lauter. Nest wie bei jener Art, aber die 8-10, selten bis 12 Eier sind nicht gelblich, sondern rötlich, entweder über und ïber mattrötlich gesprenkelt oder glanzlos weiß mit breitem matt roströtlichen Fleckenkranz um das stumpfe Ende, oder auch zur Hälfte weiß, zur Hälfte roströtlich. Manchmal finden sich (wie auch bei $R . r$ regulus) feine schwarze Linien und graubräunliehe Flecke. Durehschnittswab ron 100 Eiern (71 Rey. 29 . Jourdain) $13.57 \times 10.28$. 11 iximum $14.3 \times 10.5$ und $13.8 \times 11$, Minimum $12.5 \times 10.3$ und $13.5 \times 10 \mathrm{~mm}$.

\section{Regulus ignicapilla madeirensis Hare.}

Regulus madeirensis Harcourt, Sketch of Madeirn, p. 118 (1851- Madeira).

Abbild.: Dresser, B. Europe II, Taf. 73; Eier: Journ. f. Orn. 1890, Taf. 8.

Vorderstirn weiblich, Kopfnitte ron einem einfarhigen, leicht brïunlichen Inottergell, nach dem Nacken zu gelhlicher: wer weibe Superciliallstreif lï̈rer. mur wenig hinter dem Auge fortgesetzt: Oherseite etwas dunkler, mehr olivenfarben; sonst wie R. i. ignuirapillu. Flügel $55-57 \mathrm{~mm}$. o wie $\sigma^{2}$, mur die Scheitehnitte etwas matter und nach hinten zu nicht so deutlich gelh rerdend. auberdem kleiner: Flügel $52-5.3 \mathrm{~mm}$. S'thabel sthwar\%. Iris braun. Füßse hellbraun mit gelben Sohlen (16 untersucht).

\section{Madeira, häufig in den Bergwäldern.}

Lebensweise wie bei den Verwandten, Stimme noch etwas stärker als bei $R$. $i$. ignicapilla. Das mir rorliegende sehr große Nest sieht aus als ob es keineswegs unter einem Zweige gehangen habe, sondern auf einem solchen befestigt gewesen wäre, ein hoher, dickwandiger Bau aus Moos, Flechten, Fasern u. dgl., mit nur wenig eingezogenem finde, Napl klein, aber tief. Eier etwas rïtlich rahmweiß mit dentlichen, rötlichen Flecken, die sich nahe den dicken Ende verdichten oder einen Kranz bilden. Sie sind von den Eiern von R. $r$. ignicapilla leicht durch die deutlicher einzelnen, nicht so ineinander versehwommenen Flecke zu unterscheiden und sind wohl auch etwas größer. 2 Eier eines Geleges messen nach Kutter $14.8 \times 11$ und $14.1 \times 11.1$, 5 Eier eines mir vorliegenden Geleges $15.4 \times 11.2,15.1 \times 11.2,14.9 \times 11.4,14.8 \times 11.4$, $14.7 \times 11.5 \mathrm{~mm}$. Durchschuittsmabe von 12 Eiem (Jourdain) $14.36 \times 11.1 \mathrm{~mm}$. Gewieht etwa $50-55 \mathrm{mg}$. 


\section{Gattung LEPTOPOECIIE Sewertz. 1873 (vgl. 1). 340).}

Tom den (toldhähnehen (Kegulus) dureh den vich längreren und dentlich.

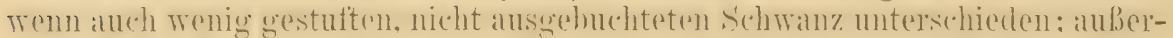
dem ist der Flïgel weniger spitz. dadureh. dalb die längsten Handschwingen nicht so weit rorragen; die 4., 5. und 6. Handschwinge sind etra gleich

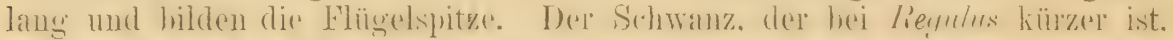

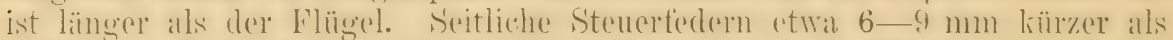

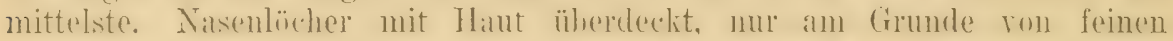

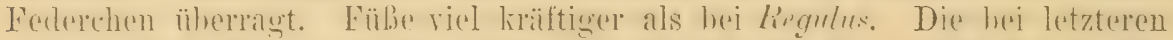

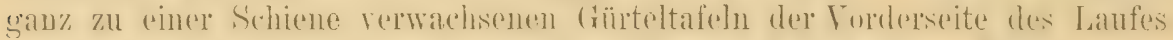

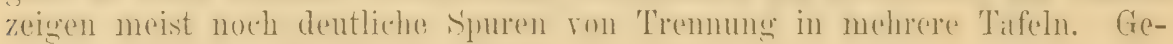
schlechter etwas verschieden gefärbt. - Inner-Asien.

\section{Leptopoecile sophiae sophiae Semert\%. (Fig. 65). (iti).}

Leptopoecile Sophiae Sewertzoff, I'urkest. Jevotn., in: Izv. Obshch. Moskor. VIII, 2, p. 135, 'laf. VIII, Fig. 8, 9 (1873- Fichtenwälder am Issik-Kul); Übersetz. in: Madarász, Zeitschr. Ges. Orn. IV, p.99 (1888); Journ. f. Orn. 1873, p.346, 373,386 .

Stoliczkana Stoliczkae Hume, Stray Feathers II, p. 513 (1874- olıne genaue Lokalitätsangabe. Als terra typica ist das Karakasch-'Tal, 11-14000 engl. Fuß, anzuschen).

Leptopoecile sophiae major Menzbier, Ibis 1885, p. 353 (Tauschkan Darja, bei UtschTurfan in Ost-Turkestan).

Abbild.: Gould. B. Asia II, Taf. 62; Pleske, Wiss. Result. Przewalsk. Reis., Ares II, I'at: VI.

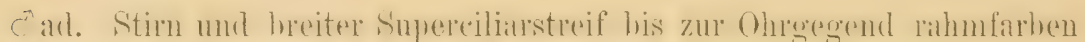
in der Mitte der Stim mit dunkeln Forlerspitzen. Zü̈el sehwärzlich. (H)e-

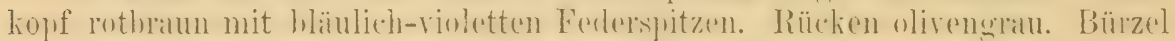

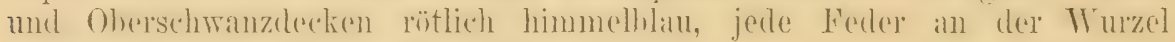
schwäl\%lich, in der Mitte kupferartig braunrot, au der Spitze violett-himmelblau. Oberflïgeldecken wie der Rücken. Schwingen dunkelbraun, Außen-

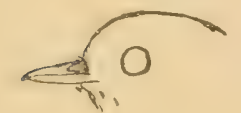

Figur $65(1 / 1)$. fahmen mit schmalen, blaß olivengrünlichen, die inneren Armschwingen mit breiteren Säumen vou der Farbe des Rïckens. Steuerfedern schwarzbraun mit glänzend

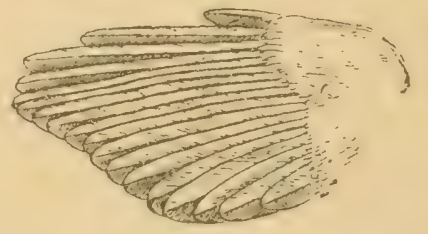

Figur $66(1 / 5)$.

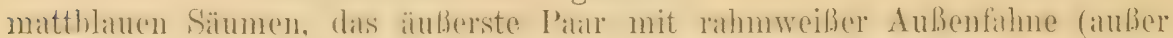
an der Basis) und Spritze. Tramgenn und Konfseiten olivenloraun mit hlänlichen Federn egemischt. Kinn. Kehle. Hals- und Kürperseiten kupferigg

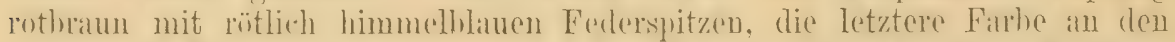
Hals- und Kürperseiten remer, nach der Ditte zu das kupferige Rothraum

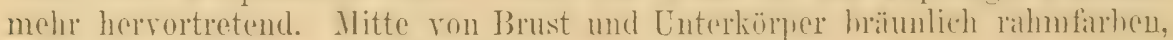
Untersehwanzdecken wie die Kehle. Innensïmme der Schwingen dunkel

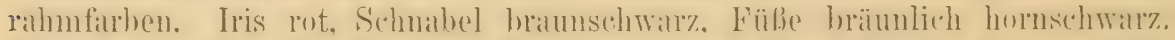

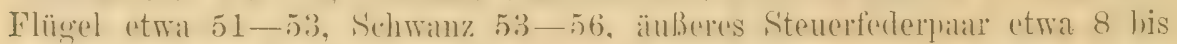
$10 \mathrm{~mm}$ kürzer, Lauf etwa 18-20, Culmen etwa $10-11 \mathrm{~mm}$. oad. Oberkenf nicht so lebhaft gefiirht, diss Braun fast bis zur Schnabelmur\%el 
gehend, Bürzel und Oberschranzdecken nicht so lehhaft rötlichhlau, sonst auf der Oberseite dem ơ ähnlich, dagegen die Unterseite bräunlich rahmfarben Kehle und Körperseiten mit blïulichgrauem Anflug. nur die Teichen mit oinem lila-kupforroten Flecke. Juv. Dem ö̈hnlich, aher ganz ohne rötlichblaue Farben auf Bürzel und Unterseite. - Im alogetragenen Frühlingsgefieder tritt die liupferigo Färbung an Kehle und Seiten mehr herror und der Oberkopf ist ganz kupferbriunlich. Viele frisehe Herbststïclie sind auffallend blab. (Etra 40 untersucht.)

Turkestan: Dsharkent. Issik-Kul, Tian-Schan, östlicher Tian-S'chan, his Kansu (Gebiet des oberen Hwang-ho), im TTesten südlich his Gilgit.

Bewohner von hohen Bergzügen von 3000 bis 14000 Fuß Höhe, wo man ihn in dichtem Gestrüpp von Berberitzen, Weiden, Schlehen, Tamarix, Rhododendron, Caragana, Potentilla, Weiden, Myricaria, Nitraria usw. findet. Klettert im Dickicht äußerst gervandt umher und bewegt sich auch schnell auf dem Boden. Stimme ein leises Piepen. Am 16. IV. 1880 fand Przewalski ein fertiges Nest ohne Eier. Es stand $7 \mathrm{FuB}$ über der Erde, war an einem Wachholderzweige befestigt und durch einen ebensolchen gestützt. Es war aus Mloos, Schaf- und Weidenwolle erbaut und mit weichen Federn von Crossoptilon ausgefüttert. Gestalt kugelförmig, oben mit engem Flugloch. Zwvei Gelege zu je 5 Eiern wurden von Rückbeil bei Karakol am Issik-Kul gesammelt. Sie sind sehr schwach glänzend reinweiß und mit dunkel rotbraunen Fleckeu und Punkten gezeichnet, auch siud wenig auffallende blassere Schulenflecke vorhanden. Die Eier gleichen bis auf die geringere Größe Eiern rom Zilpzalp. Sie messen: $13.6 \times 10.8,13.6 \times 10.9,13.9 \times 11.3,14 \times 11.1,14.1<11.5$ und $13.8 \times$ $11.6,14.5 \times 11.5,14.7 \times 11.5,14.8 \times 11.2 \mathrm{~mm}$.

\section{Leptopoecile sophiae deserticola sulsp. nor.}

(S. Pleske, Wiss. Result. Przewalsk. Reis., Aves p. 90-92.)

ơ. Wie I. sophiae sophiae, aber überall blasser, der Oberkopf mehr woinrötlich, der Rücken nicht olivengrau, sondern gräulich sandfarben, die Säume dor Armschwingen mehr isahell, dio Spitzen der Bürzelfeclern von einem helleren Blau. Kropfgegend, Brust und Unterlïrper rahmfarben, nur Kehle, Kopf-, Hals- und Körperseiten bräunlich weinfarben mit hellblanen Federspitzen. o wie dis von L. s. sophiau aber blasser; beller. Von einigen blassen Herbststücken der I. s. sophiae aus dem Tian-Schan und Kaschgarien nur bei sorgfïltiger Vergleichunc, im allgemeinen aber leicht zu unterscheiden. (5 Stück untersucht.)

Gebirge am Südrande des Tarimn-Beckens und der Wrüste Gohi: Russische Kette, Atyn-Tagh, Nan-Schan, T'saidam, Naidschin-gol. — Diese Form scheint cine sehr beschränkte Terbreitung zu haben und nu die wïstenartigen Geläude südlich der Gobi, um das Tsaidau-Becken herum zu hewchneu. Die von mir untersuchten Typen ron "S. stoliczlae" und "L. major" gehören zur dunkleren soptiac.

\section{Leptopoecile sophiae obscura Przew.}

Leptopoecile obscura Przewalski, Zapiski Imper. Akad. Nauk St. Petersb. LV, p. 80 (1887lat. Diagn., sonst russ.; Gebirgswälder des nordöstlichen Tibet, am Oberlauf des Ditschu; Übers. Journ. f. Orn. 1887, p. 277).

E. Hartert, Die Vögel der palïarlstischen Region. 
Leptopoecile Henvici Oustalet, Ann. Se. Nat., ser. 7, XII. p. 287, Taf. X, Fig. 1 (1891Hochplateau von 'Tibet [5000 m]. - Der Typus im Pariser Inseum ist in sehr schlechtem Zustande, worauf das fast gänzliche Fehlen des Superciliarstreifens und hellen Stirnbandes wahrscheinlich zurïckzufübren ist).

Abbild.: Pleske, Result. Przewalsk. Reis., Ares 'l'af. VI, Fig. 5.

ơ. Unterscheidet sich von L.s. sophiae durch die gesättigtere und eintünigere Färbung der Luterseite. die liuperig hraunot mit himmelhlauen

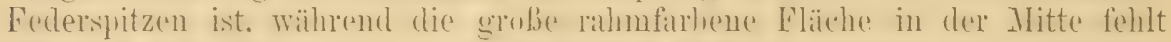

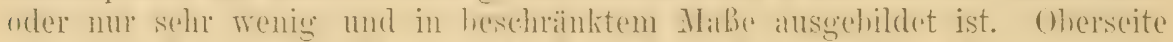

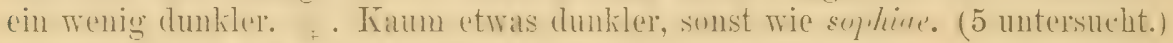

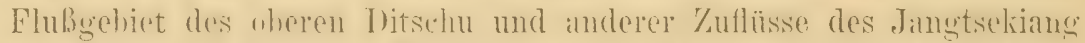
his Tatsienlu mel tihetanisehes Hochplatean his (iyantse nörllieh ron siklim. Die Angabe rom Torkommen bei frilgit heruht anf einem Irrtum: es handelt sich um stark abgeriehene und dather dunklere summerstïclie ron sopline.

Drei Eier eines bei Gyantse in Tibet gefundenen Geleges in Dressers Sammlung gleichen denen von L. s. sophice, nur sind die rotbraunen Zeichnungen etwas blasser, und sie messen $16>11,15.7>11.6$ und $15.7>11.5 \mathrm{~mm}$.

\title{
Gattung LOPHOBASILEUS l'leske 1890
}

\author{
(
}

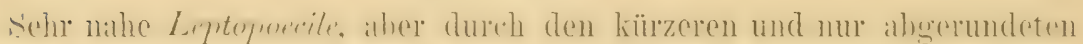

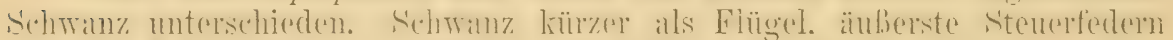

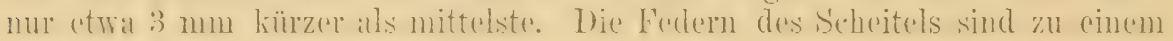
seidenweichen spitzen Schopf verlängert. West-China.

\section{Lophobasileus elegans (Przew.).}

Leptopoecile elegans Przew'alski, Zapiski Ak. Nauk St. Petersburg, LX, p. 77 (1887- Zuerst am oberen Gelben Flusse); Übersetz. Journ. f. Orn. 1887, p. $275,276$.

Abbild.: Pleske, Wiss. Result. Przewalsk. Reis., Aves, I, Taf. VI, Fig. 1, 2.

ơad. Oberkopf und Schopf blaß lilagrau, Stirnfedern und Ende des Schopfes beller, fast weiß. Zügel und kurzer, nur bis zur Augenmitte

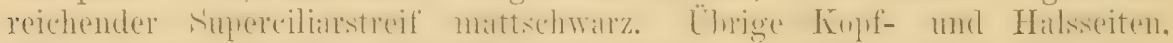

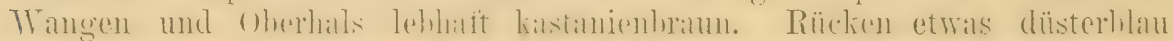

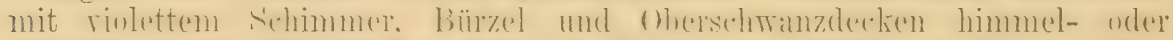

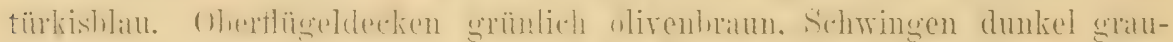

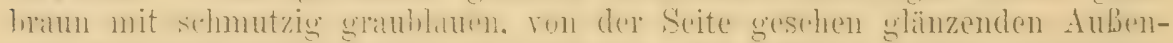

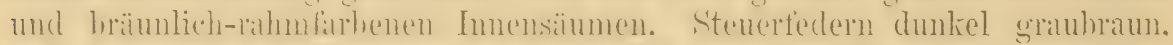
mit ehensilelen dulensänmen wie die Schwingen. Enterseite reinrötlich-

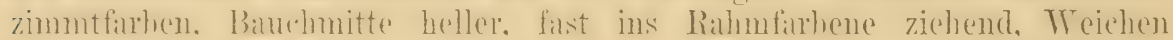

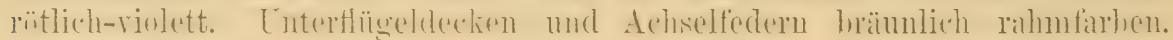

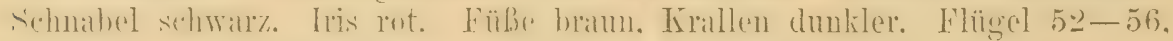
Schwanz: von mir gemessen ( $\left.1 \sigma^{7}\right)$ 44, nach Pleslie 47-50!, Lauf 20-21,

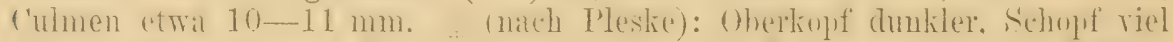

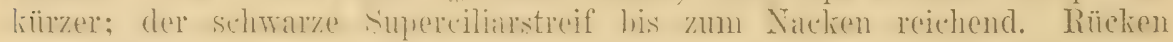

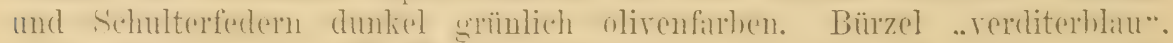
olivengränlich genischt. Trangen. Halsseiten und Enterseite schmutzigmeil.. 
Seiten mit weinrötlich-7immtfarbenem Antug, Banchseiten auberdem nuch violett verwaschen. ( 1 ơ untersucht.)

Gebirgsland am oberen Laufe des Chuanche (Gelben Flusses).

Lebt in Tannenwäldern, in Höhen von 7500-11000 Fuß, nicht selten in Gemeinschaft mit Meisen und Goldhähnchen umberstreifend, mit denen sie das muntere Wesen und Herumklettern gemein hat. Stimme ein leises Piepen, manchmal ein schrillerer 'Ton, an den des Zaunkönigs erinnernd (nach Przewalski).

\section{Gattung PANURUS Koch 1816.}

(Symon.: Calamoplitus Leach 1S16, Mystacinns, Biarmicus usw.) Nasen-

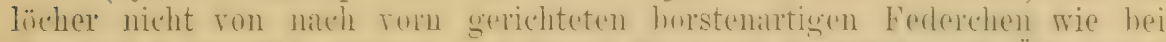

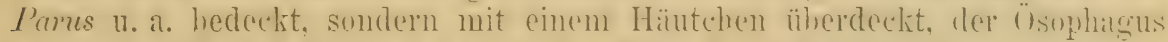
im zweiten I)rittel schwach erweitert. Diese Gigentümlichleiten rerankssen ainige Antoren, die Gattung von den Pariden zu tremen. Jir scherint sio

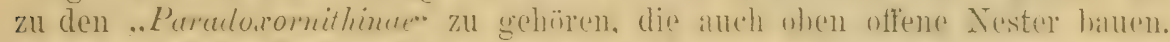

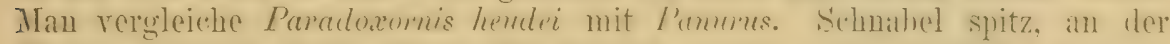

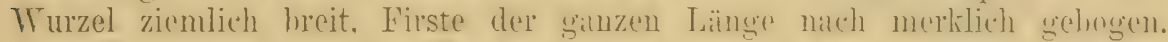

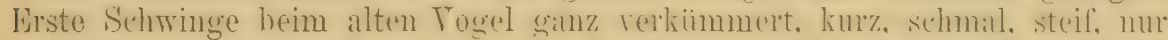
$6-8 \mathrm{~mm}$ lang, kürzer als die Handdecken, 3.-5. Schwinge fast gleich und am läugsten. Seluwanz lang. viel länger als der Flügrel mul stark ge-

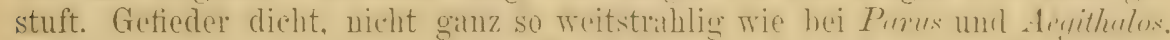

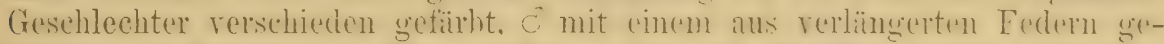
hildeten Bartstreifen, = ohne solehen. Tur. mit längorer erster schwinger.

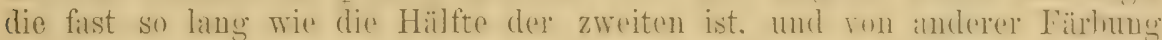
als die Alten. Nest oben offen! 1 Art in 2 Unterarten. Europa, Asien.

\section{Panurus biarmicus biarmicus (1..). (Fi. 67.)}

\section{Bartmeise.}

Parns biamicus Linnaeus, Syst. Nat. Ed. X, p. 190 (1758- „Habitat in Europa " Ex Albin \& Edwards: Beide Autoren beschreiben Stïcke, die aus Dänemark nach England gebracht worden waren und erwähnen auch das Vorkommen in England. Im heutigen Dänemark sollen nie Bartmeisen vorgekommen sein, wohl aber in dem früher zu Dänemark gehörigen Holstein, woher also die 'Typen der alten Autoren gekommen sein dürften. Edwards' Tafel zeigt anf jeden Fall die dunkle westliche Form, während die von Albin zu gräulich ist, um mehr als die Art erkennen zu lassen).

Parus barbutus Pullas. Zoogr. Rosso-Asiat. I. I. jt9 (1827- Sïdrubland, der Mame ist aber nur eine Neubenenuung von Linnés $P$. biarmicus und nicht etwa der östlichen Form im besonderen gegehen. obwohl der Autor russisehe Stücke beschreibt).

Mystacinus armandinaceus (?partim) Brehm, Handb. Naturg. Vög. Deutschl., p. 474 (1831- „N.O. der alten Welt, wandert aber im Herbste an die Küsten der luutsehen Ostsee. häufig nach Fiolland, sogar, jeduch sclten, an den Eisleher und an andere große Seen unseres Vaterlandes." - Ganz falsche Annahmen, wahrscheinlich lagen nur holländische Stücke der Beschreibung zu Grunde). Mystacinus dentatus Brehm, Handb. Naturg. Füg. Deutsehl., 1. 47t (1831- Holland). Panurus biarmicus occidentalis Tschusi, Orn. Jahrb. XV, p.228 (1904- terra typ: Venetien).

Engl.: Bearded Titmouse. - Franz: Mésange barbue, Mlésange des roseaux, Ilésange à moustaches. - Ital.: Basettino. 
ơad. Ganzer Oberkopf aschgrau, nach unten zu etwa von der Ohrgegend an heller werdend. Yü̈gel und die zu dinem Bartstreifen verlüngerten Wangenfedern tiefschwally. Nitcken und ührige Oberseite lehhaft zimmthraum. Schulterfittiche weißlich, hä̈unlieh ïhertüneht. Oberschwanzlecken meist mit etwas rosiggem Hauch. Schwiugen dunkel graubraun mit hallhrämnlichen Spitzensäumen. crste mit schmalem, dritte bis sechste mit breitem weißen Aubensaum. Amonsehwingen dunkler, fust rein schwarz. mit hreiten zimmtbramen Aubensïumen, die innersten deei mit dem weitaus gröBten Teil

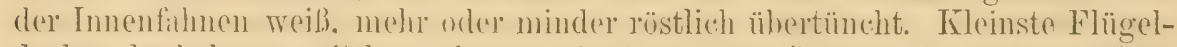
decken dunkelgrau. mittleresehwar\% mit zimmtroten syitzen, einige der gröbten

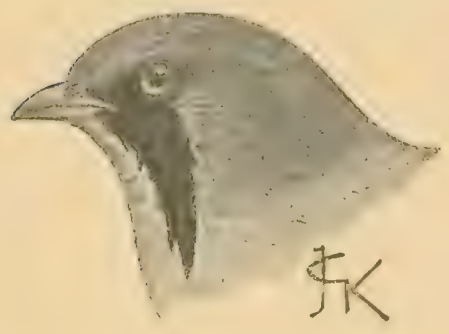

Figur 67. ganz zimmtrotbraun. Steuerfedern zimmtbraun mit ebensolchen Schäften, die äußeren drei bis vier mit mattgrauen Spitzen, die äuBerste an der Wurzel schwarz, worauf keilförmig abgesetzt die weißgraue Spitzenhälfte folgt, die zweite nur an der Wurzelhälfte der Außenfahne schwarz, mit zimmtfarbener Innenfahne. Kinn, Kehle und Mitte der übrigen Unterseite weiß, Brustseiten woinrosa, Körperseiten lebhaft zimmtbraun, Unterschwanzdecken schwarz. Unterflügel decken schmutzigwoiß. Schuabel dunkelgelh, Iris gelhhraun, Füße schwallz. Flügel 59-62. Sehwanz 80 -87. äuberste Steuerfeder etrva 43-46, Schnabel etwa $7.5 \mathrm{~mm}$ - - ad. Oberkopf hellbram, oft mit schwarzgrauen Federn gemiseht. ührige Oherseite zimmthraun, in der Mitto des lï̈ckens einige oft undeutliche sthwäraliche schaftstreifen. Kein schwarzel Bartstreif! Brustseiten mit sehwächerem, oft fast ganz fuhlenden rosigen Anflug. Luterschwanzdecken rosthräunlich, nicht schwarz. Sonst dem ơ ad. ähnlich. Jüngere Vögel haben mehr sehwärzliche Streifun auf Kopf und Rürken. Jux. im ersten Gefieder: Rürclienmitte fast ganz selowar\%, (irste Selhwinge fast hallh so lang wie die zweite, Stenerfelerm, mit Ausulmue des mittelsten laares, gröbtenteils schwärzlich. (38 Exemplare.)

Süd-limopar von Griechenland durch Italien, Ost-Spanien, Süd-Frankech. Enstand (frïher an vielen Orten, jetzt nur noch in Norfolk brïtend) mel Holland, frïhne dureh Ost-Friesland his Holstein und Necklenburg. Tahrstheinlich war es auch die westliche Form, die früher an deu Mansfolder Seen bei Eisleben genistet haben soll.

Die Bartmeise bewohnt nur ausgedehnte Rohrdickichte und ist daher natürlich überall lokal. Sie bewegt sich kletternd und laufend im Rohrwalde umher und fliegt nur ungern und selten. Die Lockstimme ist ein helles ping ping, der Warn- und Angstruf ein schnarrendes tschirr oder i-errr, auch hört man feine, meisenartige Laute wie sit-sit und einen unbedeutenden, aus den Locktönen und anderen Lauten zusammengesetzten Gesang. Nahrung Insekten, kleine Mollusken usw., und Rohrsamen. Nest ein tiefer Napf, aus dïrren Rohrfasern, Schilfblättern, Gras lose zusammengefügt, innen mit den Blütenrispen des Rohres und oft auch mit einigen Federn ausgelegt. Es steht immer am Boden oder auf umgeknickten Rohrstengeln, hängt nicht und ist oben ganz offen, nur am Kande etwas zusammengezogen. Die 5-7 Eier findet man im April und Mai, eine zweite Brut im Juni und Juli, bis anfangs August. Die Eier sind etwas glänzend weiß oder rahmweiß und mit feinen kurzen Linien und Kritzelchen von schwarzbrauner 
Farbe versehen. Sie sind bauchig, oft fast gleichhälftig. 106 Eier aus Holland und England (83 Jourdain, 23 Rey) messen im Durchschnitt 17.2.2 $>13.91$, Iaximum $19 \times 15$, Jinimum $14.5 \times 13.2$ und $15.8 \times 13 \mathrm{~mm}$.

\section{Panurus biarmicus russicus (Brehm).}

Mystacimus Russicus Brehn, Handb. Naturg. Vög. Deutschl., p. 472 (1831 - Rußland. - Obwohl Brehm, nach J.F. Gmelin [Syst. Nat. I, p. 1011, Synonyme] den Namen russicus dem Reisenden S. Gmelin [II, p. 164] zuschreibt, ist der Name dort nicht zu finden).

Calamophilus sibiricus Bonaparte, Compt. Rend. Ac. Sci. 43, p.414 (1856- „Kamtschatka". Wahrscheinlich beruht der Fundort auf einem Irrtum).

Panurus biarmicus raddlei Pražák, Journ. f. Orn. 1897, p. 288 (Nach Radde, der [Ornis 1887, p.477] irrtümlich einen ganz jungen Vogel als alten beschrieb, und mit phantastischer Übertragung auf' 54 eingebildete galizische Stücke).

Viel heller, lichter, besonders auf dem mehr fahlen Rücken. Obelschwanzdecken immer mit deutlichem rosigen s'chimmer. Innensilume der. inneren Armschwingen meist reiner weiß. (39 Exemplare.)

Von Ost-(7alizien durch Cngarn. Rumänien, Sü̈l-Rußland, Kleinasien, Persien, Turkestan his Zaidan, Fokn-Nor und Ordos, sowie ëstliche Mand-

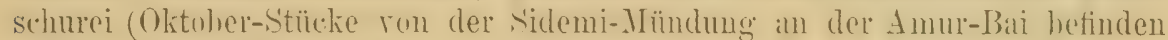
sich im Tring-Museum).

13 Eier aus Ungarn messen im Durchschnitt $17.47 \times 14.06 \mathrm{~mm}$, sind also etwas größer, als englische und holländische Stïcke (Jourdain).

\section{Gattung CHOLORNIS Terreaux. 1870.')}

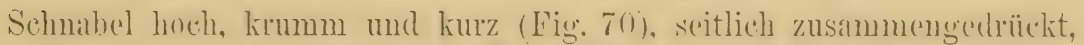
die runden, mahe der Basis gelegeneu Xiasenlireher von nach rorn gerichteten Federu gauz üherragt. I) Aufenzehe der starlen, mit liniftigen Nägchn hewaffueten Fübe rerkïmmert. ohme Nagel, mit der Nittulzehe halh verwachsen, mur halb so lang wie letatere (Fig. 71). Flügel laug. (erste Schwinge etwa halb so lang wie der ganze Flügel, fünfte his siohente ungefïhr gleich und am lïngsteil. Almsehwingen ziemlich lang, allmählich abnchmend. Schwanz

1) In unmittelbare Nähe gehört Paradoxomis. Diese Gattung (Fig. 68) hat einen noch größeren, seitlich zusammengedrückten Schnabel, aber keine rerkümmerte

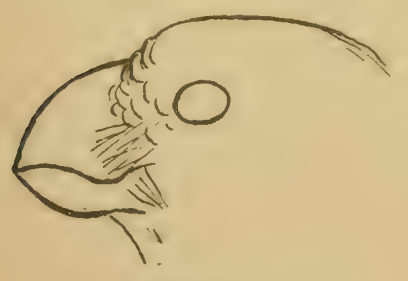

Figur $68(1 / 1)$. Außenzehe (Fig. 69). -- P. heudei Dar. 1872 (Oberkopf hellgrau, jederseits ron einem schwarzbraunen Streifen begrenzt, Kinn und Kehle ohne Schwarz) kommt im südlichen China vor. P. flavirostris Gould 1836 (Oberkopf und Nacken rotbraun, Kehle und Ring über den vorderen Teil der Brust schwarz) bewohnt die TeraiWälder des östlichen Himalaya

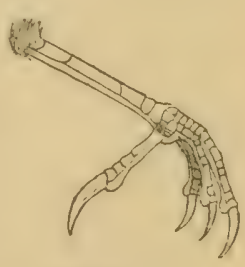

Figur $69(1 / 4)$.

und Assam. P. guttaticollis Dav. 1871 (etwas kleiner als flavirostris ohne schwarzen Ring in der Kropfgegend, vielleicht nur Subspezies) scheint vom südlichen Assam bis Szetschwan und Kansu rorzukommen. Letztere Form berihrt das paläarktische Gebiet, die übrigen beiden nicht. 
stark enstuft. liinger als der Wliggel. Gefiede' auberordentlieh weich und reich. Kunffederu etwas verlingert. Nur eine Art hekinnt. - Die Gattungen Cholomis, Paradoxomis, Suthora, Psittiparus und Conostoma sind ihrer ab-

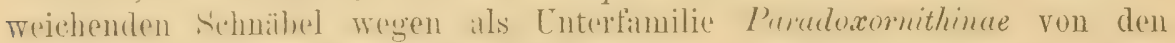
eigentlichen Meisen gesthieden (vel. p. 340). Im Gefieder erimert Paradoxomis heudei auffallend an Panums. Nester offen.

\section{Cholornis paradoxa Verr. (Fig. 70, 71).}

Cholornis paradoxa Verreaux, Nouv. Arch. Mus. Paris VI, Bull., p. 35 (Mupin); Abbild. op. cit. VII, Bull. Taf. 1, Fig. 1, David \& Oust., Ois. Chine, Taf. 62.

Oad. Stirn graubram mit weiblichem Schimmer. ron den Zügehn his

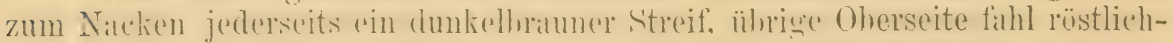

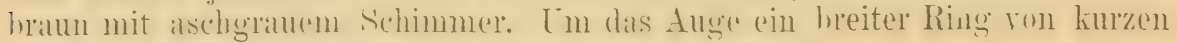
weißen Federn. Kopfseiten fahlbraun mit weinrötlichem Schimmer und helleren, fast weißlichen Streifen.

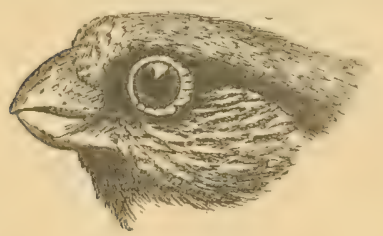

Figur $70\left({ }^{2} / 1\right)$.

Unterseite fahlbraun, die Seiten dunkler und bräunlicher, die Mitte heller, mehr bräunlichgrau mit weiurötlichem Schimmer.

Kehle dunkelbraun.

Schwingen braungrau, Außenfahnen reiner grau, die der Armschwingen zum

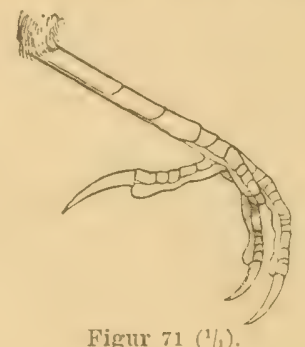

Figux $71(1 / 1)$.

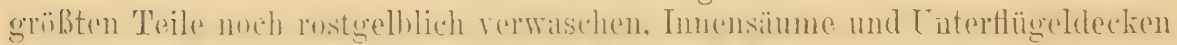
sehmutzig rahmfarhen. Steuerfedern. gran mit lnamuen Schäften. Schmahel dunkelgelb. Iris weißlich. Füße bräunlich. Flïgel etwa 96, Schwanz,

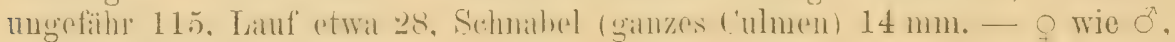
nur ein wenig kleiner.

Mupin und Kansu im nordwestlichen China.

\section{Gattung SUTHORA Hodgson 1838.}

Strukturell ganz wie Cholomis, nur die Aubenzebe vollkommen ent-

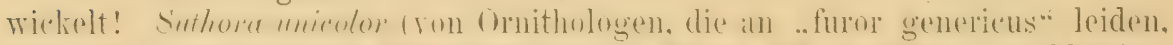

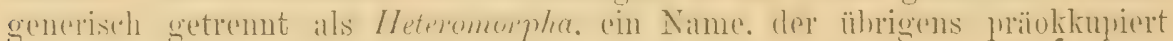
ist) ist auch etwa so grob wie Cholomis und letzterem zum Verwechseln

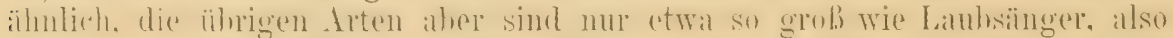
sehr viel kloiner. Mehrere Arten hahen einen krummen Oberschnabel mit

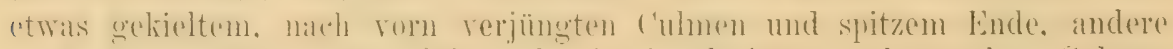

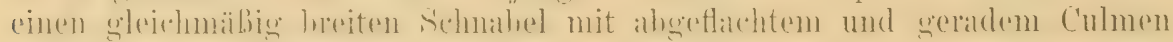

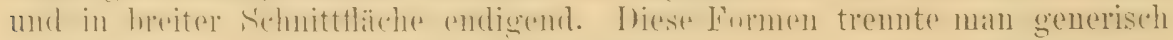
als Chlenasicus, was aber nicht durehzuführen ist, da S. humii etrvas in dev Mitte steht und in der shluahelform variert. sudal.s man nicht immer mit Bestimmtheit sagen kann, ob Stücke davon zu Sulhora s. s. oder "Chleu-

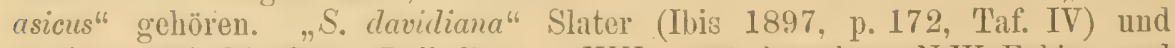

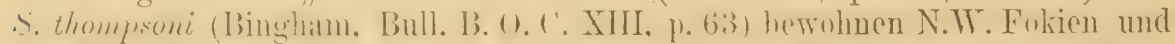
die Shan-Staiten, also nicht mehr paläiulitisches (rohict; sie hallen einen kïrzeren und fast gill nieht gestuften Schwanz und sind daher hesser zu Psittiparus oder in eine besondere Gattung zu stellen. 
Übersicht der paläarktischen Arten: ${ }^{1}$ )

1

Größer, Flïgel über 80, S'chwanz etwa $100 \mathrm{~mm}$, Oberseite graubraun

. . . . . . . . . . . . . S . . . . . . . . . . . . . . .

Kleiner, Flïgel etwa $70-75$, Sehwanz nicht iiber 84 mm, ()berkopf lehhuft hell rot, Rïcken hell olivenbraun......... S. ruficeps . p. 407

Viel kleiner, Flïgel nicht iiher 58 , Schwanz nicht ïher $80 \mathrm{~mm}$, meist aber

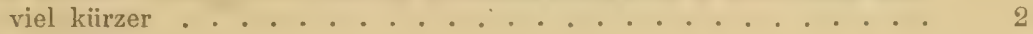

1 Kehle schwarz ... . . . . . . . . . . . . 3

Kehle nicht schwarz .................. . . 5

3 f Oberkopf schmutziggrau, Rücken gelblichbraun.... S. nipalensis . p. 408

| Oberkopf und Rücken ockergelb oder orangebräunlich . . . . . . 4

4 S Breiter schwarzer Superciliarstreif . . . . . . S. hmmii. p.408

4 \{ Nur kurzer weiber, aher kein sehwarzer Supereiliarstreif . . s. guleris . 1) 409

5 I Ein weiber Ring un das Auge wie hei Zesterops. . S. nnspicillutu p. 410

5 I Kein weißer Zosterops-artiger hing um das Auge . . . . . . . . 6

6 I Oberkopf grau, 'Jügel. Stirn und Superciliarstreif rotbraun: S. pracualskii. p. 40?

\{ Oberkopf braun oder rotbräunlich ............ 7

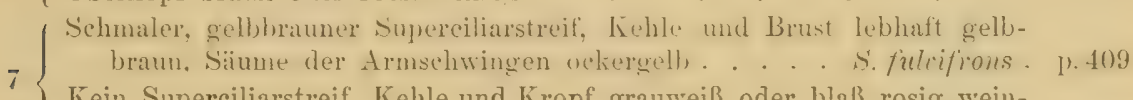

Kein Superciliarstreif, Kehle und Kropf grauweiß oder blaß rosig weinfarben, Schwingensäume kastanienrotbraun . . . . . . . 8

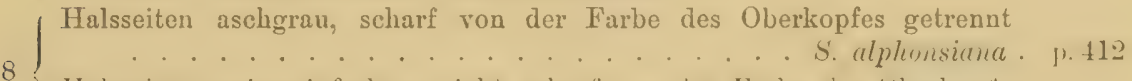

Halsseiten rosigweinfarben. nicht suharf rou der farhe des (oherknptes geschieden ......................... w. 410,411

\section{Suthora unicolor (Hodgs.).}

Heteromorpha unicolor. Hodgson, Journ. Asiat. Soc. Bengal XII, 1, p. 448 mit Abbild. (1843 - Nepal).

Abbild.: Gould, B. Asia III Taf. 76.

Ist Cholomis mondoxa äuberst ähnlich, nur die oherseite utwas bräunlicher, alle Schwingen an den Aubenfahnen lehhaft rothrimn, Inmensämme

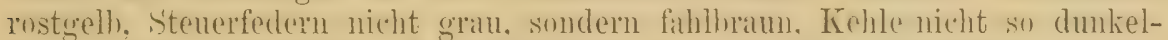
braum. Der sehtärzliche Supereiliarstreif nicht su breit. Kupfieiten dunkler. Füße braungrau, Iris braun. Flügel 87 - 95, Schwanz etra $100 \mathrm{~mm}$. Das o scheint kleiner zu sein als das ơ.

Bewohnt Nepal und Sikkim, wo man sie in Höhen ron 7000 bis

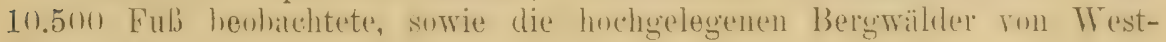
China (Mupin, Ia-tsien-lu).

\section{Suthora ruficeps ruficeps (Blyth). $\left.{ }^{2}\right)$}

Chlenasicus ruficeps Blyth, Journ. Asiat. Soc. Bengal XIV, 2 p. 578 (1845- Darjiling).

1) S. poliotis Blyth aus den Naga- und Dufla-Bergen südlich des Brahmaputra und S. poliotis feae Salvadori aus Birma können nicht als paläarktisch betrachtet werden.

2) In den Hügelländern von Nord-Katschár und Ober-Assam (Margherita, Sadiya, Grenze ron Yunnan bei "Ponsee") kommt die verwandte S. ruficeps atrosuperciliaris Godwin-A.usten (Proc. As. Soc. Bengal 1877 p. 147) ror, die sich nur durch einen kleinen schwarzen Fleck überm Auge und gauz röstlich rahmfarbene Unterseite unterscheidet. Flügel 70-74, Schwanz $83-84 \mathrm{~mm}$. Nest aus Gras, Ei lebhaft hellblau. (Baker, 1bis 1895, p. 44.) 
Típffectern haubenartig verlängert. Schnabel am vorderen Ende sehr breit. In der Fïrhung zum Verwechsehn ähnlich Psittipurus ruficens mficeps, niimlich Oherkopf und Kopfseiten lebhaft hell rostrot, letztere heller, übrige Oherseite heil olivenbraun. Schwingen dunkellbraun, außen rosthraun gesäumt. Lnter dem Auge cin weißlicher Fleck. Lnterseite weiß, nur Kohle, Torderlorust und Seiten mit rahmfarbenem Schimmer. Oberschnabel hellbrälunlich, Cnterschnahel Heischfarhen, Iris hellhram, FüBe lileigrau. Flügel 75. Schwanz etwa 80, Lauf 23, Schnabel (Culmen) $12 \mathrm{~mm}$.

Silkim, wo augenscheinlich äuBerst selten. Lis konnte nur ein Stiick untersucht werden.

\section{Suthora nipalensis Hodgs.}

Suthora nipalensis Hodgson, Indian Review II p.32 (1838- Nepal).

Temmoris atrifrons Hodgson, Proc. Zool. Soc. London 1845 p. 31 (Nepal).

Abbild.: Gould, B. Asia III Taf. 70, ohere Figur.

Oberkopf und Narcken schmutziggrau, hreiter schwarzer Supereilianstreif ron der Schublyelwurel his zum Hinterkopf. Zügel. Wange und Federu um das Ange weib. Übrige Köpfseiten schiefergran. Rücken gelblichbraun, Hinterrïcken stark rostgellhlich rerwaschen, (oberschwanzdecken orangerostrot. Sehwingen schwarzgrau, Handschwingen an den AuBenfuhmen weiß, im Trurgeldrittel glämend kastanienhraun gesäunt, Armsehwingen mit hell kastanienbranen Aubensïumen und weiben Spitzen. Stenerfedern kastanienbraun mit beriten schwarzen spitzen. Kinnfleck rein schwarz, Kehle schwarz mit ausgedehnten rostroten Siimuen, sordaß sie gebändert erscheint. Ührige Unterseite orangefirben. an den Seiten lehhafter. Lnterflügeldecken und Innensïume der sichwingen weilis. Flügel etwa 46-48. Schwant etwa 56, Lauf 17-18, Culmen $7-8 \mathrm{~mm}$. bekannt.

Seltener Vogel der Berge von Nepal. Genauere Verbreitung nicht

\section{Suthora humii Sharpe.}

Suthore lumii Sharpe, Cat. B. Brit. IIus. VII p. 487 (1883- „Eastern Himalayas." Als terra typica haben wir Sikkim zu betrachten. Die angeblichen NepalStücke von Hodgson sollen aus Sikkim [Darjiling] stammen).

Abbild.: Gould, B. Asia III Taf. 70, untere Figuren).

ơ ad. Oberschnabel schwach gebogen, Spitze rundlich breit. Woite, nach hinten sich rerbreiternde und an der Stim hreit zusimmentliebende schwarze Supereiliarstreifen. Im die Augen herum weili, Zügel weib. Ohrgeegrend ansgedehnt mangegrelh. Halsseiten alschgran. Oherseite ron der

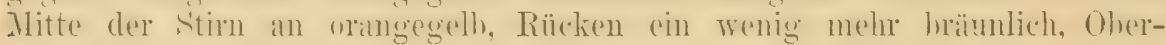
schwanzdecke's lehhafter und mehr orangerot. Śchwingen schwarzgralu, Schaifte schwarz, die äußersten rier mit weilhen, die folgenden fünf mit

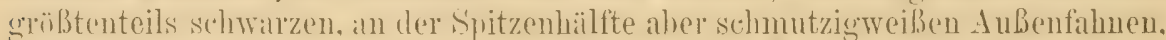
die fünfte auberdem noch mit schmalem weiben Aubensaum, alle aher mit dem Basisteil (etwa ${ }^{1}{ }_{4}-{ }^{1}$ ) der Aufenfahnen lehhaft orangehraun. Armschwingen nit breiten orangehraunen Aubensïnuen und alle mit weißen Innensïumen. Afterflügel und Handdecken schwarz. Stenerfederm graubraun, Spitzen trülggrau, Aubenfahnen und Basis orangehman. Kimn- und Kehlfedern sehwarz, im frischen Gefieder mit weiblichen Spitzen. Übrige Unterseite schmutzig weib, Kürperseiten rostgelh rerwaschen und geflammt. 
Schenkelbefiederung und Tnterschwanzdecken rostgelhlich. Schnabel schwïrlich. Füße (im Balg) hellhrïunlich. Bei einigen Stücken ist der schwarze Superciliarstreif schmäler, die Stirn hrïunlich. Inies sind vielleicht o. Iler junge Togel hat ehenfalls weniger ausgebildeten Supereiliarstreif und Kehlfleck, die Fïrbung der Oherseito ist weniger lehhaft, die Brust grauhrïmnlich verwaschen. der Schwanz viel kürzer. Flügel (ad.) 48-5o, Schwanz etwa 50-57, Schnabel (Culmen) 7-8, Lauf $17-18 \mathrm{~mm}$.

Bei und oberhalb Darjiling in Sikkim (Himalaya).

\section{Suthora gularis Verr.}

Suthora gularis Verreaux, Nouv. Arch. Mlus. Paris VI, Bull. p. 35 (1870- Terra typica: "Mloupin.")

Suthora verreanxi Sharpe. Cut. B. Brit. MIus. VII p. 488 (1883- Umbenennung ron S. gularis, ohne die Art gesehen zu haben).

Abbild.: Nouv. Arch. VIII. Bull. Taf. 3, Fig. 1. (1872).

Ad. Oberseite lehhaft gelhbram. Stim sehr wenig. Hinterkopf etwas lebhafter. Yä̈sel und schmaler, kurzer Superciliarstreif weib. Schringen dunkelhraun, Handschwingen mit weiblichen. Armschwingen mit lebhatt

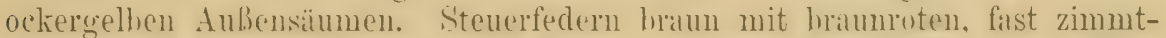

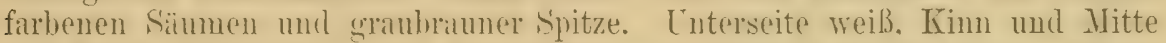
der Kehle aber schwarz und Ściten hrämnlich ockergelh üherwaschen. Flügel

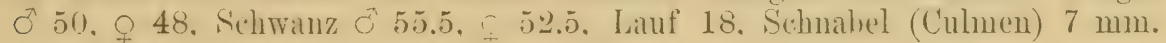

Berge von West-Szetschwan (Mupin) und Nordwest-Fokien.

\section{Suthora przewalskii Berezowski \& Bianchi.}

Suthora Przewalshii Berezowski \& Bianchi, Aves exp. Potanini p. p. Gansu, p. 67, Taf. II, Fig. 1 (1891- südl. Gausu. Russisch!); Übersetz. Deditius, Journ. f. Orn. 1897 p. $69,70$.

o ad. Oberkopf und Nacken hell aschgrau, Züg'el, Stirn und ein bis zum Halsanfing verlaufender supereiliastreif tief rothram. Torderrïcken

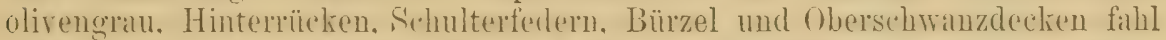
olivenfarben. Angengegend. Kinn. Kehle und Torderhust lohlaft zimmtfurben. Lrustmitte ptwas heller. Hals- und Brustseiten hellgrau mit schwachem zimmotfuhenen Anthug. Seiten des Luterköruers, Bauch und Cnterschwanzdecken fahlbräunlich. Schwingen dunkelgraubraun, aulen hell fablbraun, innen "lichtfihl" gesä̈mut. Enterflügelderlien ,.lichtfahl". Achselfedern weib-

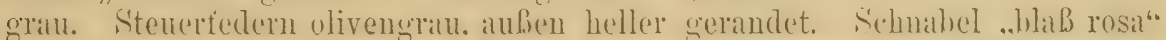
Lïufe hläulich gran. Iris rot. Flügel 55-56. Sohmanz 7(1-_80. Sehnahed S, Tauf 18-19 mm. (Nach Deditius Chelsetzung und nath Ahbihung.) Die Geschlechter sollen gleich sein, juv. mit ockergelber Iris.

Lichte Laubwälder auf hohen Bergen im sïdlichen Kansu.

\section{Suthora fulvifrons fulvifrons (Hodgs.).}

Temoris fulvifrons Hodgson, Gray's Zool. Misc. p. 83 (1844- nomen nudum!); Proc. Zool. Soc. London 1845 p. 31 (Erste Beschreibung - Nepal).

Abbild.: Gould, B. Asia III Taf. 71 (1852).

Ad. Schnabel an der Spitzo mit hreiter Schneide. wie alygeschnitten, also zur sogeuamuten Gattumg ".'Whemicus" gehörig. — Stirn und Mitte des 
(Hherkopies hell gelhblatum. hinter dem Auge ein kurzer, sehmaler hell gellbramer, dartihter ein breiter brïmulich olivengraner streif. Rücken grambrä̈unlich mit rostenclhlichem Anfluge, der auf dem Bürzel und den Oberschranzdecken lebhalter herrortritt. Schwingen dunkel graubraun, Handschwingen an der Wurzelhälfte mit hell gelhbrïunlichen, nach den Spitzen zu mit weilblichen. Armschwingen mit breiteren lebhaft brïunlich ockergelben Außensïumen. Struerfedern bram mit sehr breiten, den grö̈Bten Teil der Aubenfahmen eimnehmenden, ockergedhlichen Sämmen. die nach den Spitzen zu verhldichen und sehlieBlich in Gran ïbergehen. Kinn, Kehle und

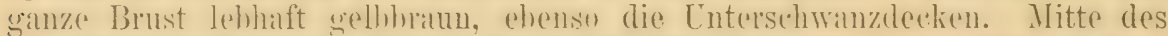

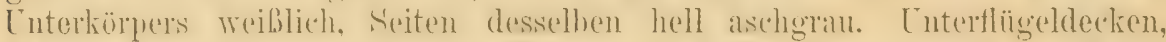
Axillaren und Innensiume der S'chwingen weib. Obnersehnahed (im Balge)

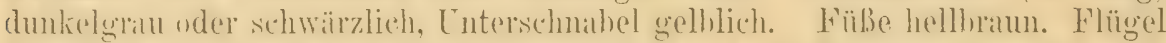
53-57.5 (vielleicht sind die kleineren Strieke ?). Schwanz etwat 63-69, Schuabel (Culmen) 7.5, Lauf etwa $19-20 \mathrm{~mm}$.

Bewohnt die Berge ron Nepal und Sikkim (selten).

\section{Suthora fulvifrons cyanophrys David.}

Suthora cyanophrys David, Journ. trois. Voy. Chine I p. 345 (1875- terra typica "Chensi mériclion.")

Abbild.: David et Oustalet, Ois. Chine Taf. 66.

Ähnlich S. $\dot{f}$. fulvifrons, aber Streifen an den Seiten der Kopfplatte entlang, etra vom Auge bis zum Nacken, sebiefergrau. Brust blasser, Schwanz etwas kürzer (etwa $60 \mathrm{~mm}$, aber etras abgenutzt).

Südöstliches Schensi, Szetschwan (Tatsieulu).

\section{Suthora conspicillata David.}

Suthora conspicillata David, Nouv. Arch. Mus. Paris VI, Bull., p.14 (1871- 'Terra typ.: "Setchuan occidental." )

Abbild.: David \& Oustalet, Ois. Chine Taf. 65.

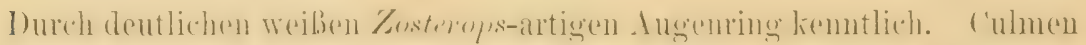
oben abgerundet, nach der Spitze zu etwas verjüngt, aber nicht sehr spitz.

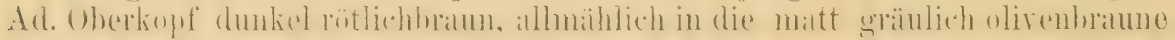

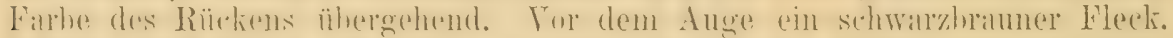

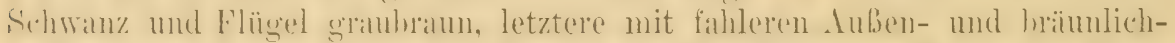
weiben Immensïumen. Oherfü̈geldecken wis der Rüelien. Kopf- und Hals-

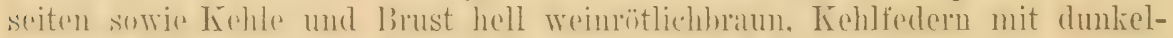

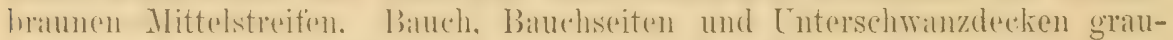

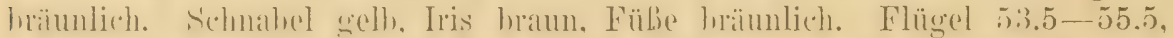
Schwanz etwa 70-79, Lauf 18-22, Schmabel (Culmeu) etwa $7 \mathrm{~mm}$. q scheint ganz wie or nur etwas kleiner zu sein.

Westliches Szetschwan, südliches Kansu und süclliches T'sin-ling:

675. Suthora webbiana mantschurica Tilez. (Fig. 72. )

Suthora vebbiana mantschurica 'Taczanorski, Bull. Soc. Zool. France X p. 470 (1885Alamanowka in Ussurien). 
Sehmabeltirste gehogen, Suitzo ziemlich spritz. - o ad. Ganzer (1)herkopf und Nacken fahlrötlichbram mit atwas rosigem Schimmer, allmählich in die fahl hellbranne Farbe des Rächens ühorehend. Oberschwanzdretien fahl hellbram. Innenfahnen der Selwwingen gräulieh erdhraun, die inneren Armschwingen rothram überwaschen, Innensämme hlabrosig lahmfarhen. Außenfahnen der Schwingen kastanienrotbraun, die der immeren Armschwingen auberdem noch mit hell brïunlichcolben, fast rahmfarbenen Sïumen. Sehwanz fahlhraun. Kleine Oherflügeldecken wie der Rücken. grobe hreit kastanienrotbraun gesïumt. Zügel, Kopfseiten, Kinu, Kehle und Vorderhrust hlab rosig weinfarben, die meisten Federn mit dunkleren Schaftstrichen, Ohrgegend etwas dunkler.

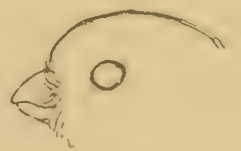

Figur 72,11 . Unterkïrper hräunlich rahmfarhen, seiten mehr gelhbräunlich. [ntreffïgel-

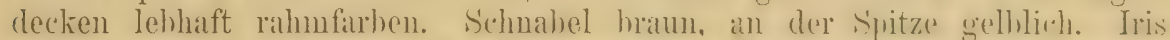
rötlichlraun. Fübe braun. Dais o seheint dem of zu gleichen. Jus. Sehwanz. kïrzer und viel mehr lostrotbaun. Kehle mit rerwaschenen, haum siehtharem Schaftstreifen. Flüg(el etwa 52-54. Sehwanz etwat (j+--71), C'ulnuen 8-9, Lauf etwa $20 \mathrm{~mm}$.

\section{Ussurigegend.}

Munterer, streitsüchtiger Bewohner buschreichen Geländes, im Winter in Scharen und Strichrogel. Nest ein tiefer Napf in Büschen und Stauden. Eier blau, Maße nach Taczanowski (Faune Orn. Sibér. Orient. I p).451) $15<12.4,15.2<12.3,15.8 \times 12.2$, $15.8 \times 12.5,16 \times 12.4, .16 \times 12.8 \mathrm{~mm}$.

\section{Suthora webbiana webbiana Gray. ${ }^{1}$ )}

Suthora Webbiana Gray, Proc. Zool. Soc. London 1852 p. 70, Taf. 49 (Shanghai).

Suthora fulvicauda Campbell, Ibis 1892, p. 237 (Chemulpo, Corea. Jur!).

Suthora longicanda Campbell, Ibis 1892, p. 237 (30 Jeilen östl. Söul in Corea. ㅇ ad!).

Abbild.: Gould, B. Asia III, Taf. 72.

Sehr ähnlich S. $w$. mantschurria, aber die dußensäume der inneren Armschwingen mehr braun, nicht rahmfarben, wie bei S. v. mantschurica.

1) Folgende geographische Vertreter bewohnen tropische Gegenden:

Suthora vebbiana suffusa Swinh. (Suthora suffusa Swinhoe, Proc. Zool. Soc. London 1871 p. 372). Äußerst ähnlich S. w. webbiana, aber der Oberkopf etwas lebhafter und rötlicher. 'Zweifelhafte Form, vielleicht nicht von S. w. webbiana zu unterscheiden. - Oberer Jangtsekiang bis Fokien (Kiukiang, Ichang, Puching, Kuatun).

Suthora webbiana bulomachus Srinh. (Suthora bulomachus Swinhoe, Ibis 1866 p. 300 Taf. 9). Hit größerem Schnabel $(9-9.5 \mathrm{~mm}$. lang) und vielleicht etwas kuirzerem Schwanz, sonst wie S. v. suffusa, woron schwer zu unterscheiden. - Insel Formosa.

S. vebbiana styani Rippon. (Suthora styani Rippon, Bull. B. O. Club. XIII p. 54, 1903). Oberkopf lebhaft zimmtrot, Kehle schön weißlich-rosa mit scharf hervortretenden rotbraunen Schaftstreifen. - Tali-Tal in West-Yunnan.

Suthora webbiana brunnea Anders. (Suthora brunnea Anderson, Proc. Zool. Soc. London 1871 p. 211). Kehle rosa mit brauuen Streifen. - Westliche Grenzgebiete ("Kauri Kachin-tract, Momien") von Yunnan. 
AuBerdem ist die Firlumg im allgemeinen dunkler, besonders auf Kopf, Rücken und Ǩ̈̈rperseiten. Schwanz, meist etwass kürzer, etwa $58-65 \mathrm{~mm}$.

Nittleres (hina (Shanghai, Ningpo, Hupei, bis Kansu), nördlich bis Korea.

Frische Stïcke aus Korea im Britischen Mluseum scheinen mir ganz den typischen webbiana zu gleichen und nicht zu mantschurica zu gehören!

\section{Suthora alphonsiana Verr.}

Suthora alphonsiana Verreaux, Nouv. Arch. Mus. Paris VI, Bull. p. 35. (1870-- „Thibet chinois".)

Abbild.: Nouv. Arch. Mus. Paris VIII, Bull. 'Taf. 3, Fig. 2.

Unterscheidet sich von den Formen von S. webbiana durch mehr zimmtartig brammoten Oherkopf und bräunlich-aschgraue, scharf ron der Kopfiplatte abgesetzte Kopl- und Halsseiten. Unterseite hell rostloräunlich, Kohle und Kropf grauweil.s mit feinem rosigen Schimmer. Rücken und Bürzel nehst Oherschwanzdecken bram, fist olivenbraun. S'chwanz oliven-

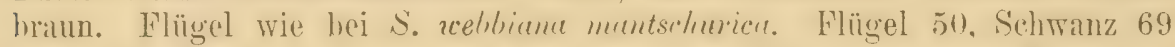
(nicht 50), Lituf 21 , Sehnahel $6 \mathrm{~mm}$. - Der anffillenden grauen Halsseiten weggen möchte ich dieste Form artlich von der webianu-Gruppe tremnen.

Szetschwan (Tschentu, Tatsienlu).

\section{Gattung PSITTIPARUS Hellmayr 1903.}

Scaeorhynchus Oates 1898 nee Scaeorlynchus Wilson 1881. - Von Suthora dureh viel kïrzern und nicht gestuften, sondern nur ahgerundeten

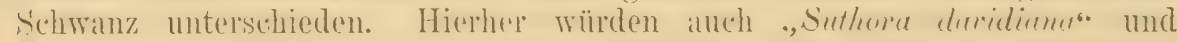

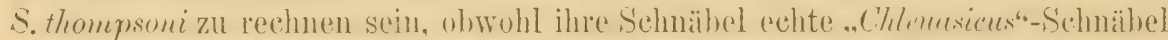

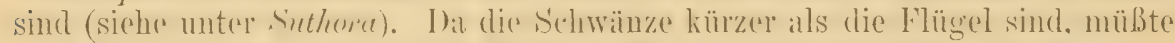
man eigentlich dine besondere (iattung für diese heiden Arten schatfen.

Oberkopf hellrostrot................ P. ruficeps . p. 412

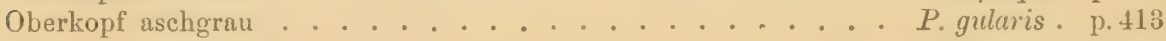

\section{Psittiparus ruficeps ruficeps (Blyth). ${ }^{1}$ )}

Paradoxornis ruficeps Blyth, Journ. Asiat. Soc. Bengal 1842, XI, 1, p. 177 („Bootan“). Abbild.: Gould, B. Asia III Taf. 78.

Färbung fast ganz wie die von Suthora ruficeps! - Ad. Oberkopf, Nidcken, ganze Konf und Inalssuiten lebhalt hollowstrot. Rürken hell olivenbram. Schwingensïume filı rötlichlraun. Enterseite weiB. nur an den Brust-

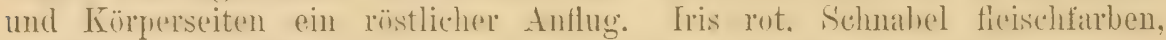

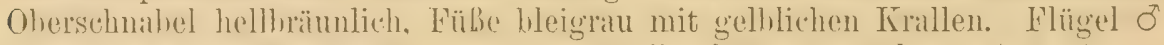

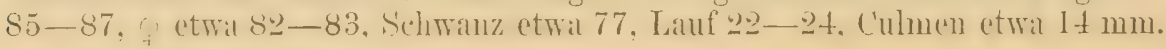

\section{Butan und Sikkim.}

Nest ein tiefer Napf, die Eier weiß mit gelblichbraunen und gräulichen Flecken. Bewohnt besonder's Bumbusdickicht", anch Buschwerk und nicdrige Bäume, Bewegungen meisenartig. Ruf wie tschirr, tschirrp, außerdem ein klagender Laut wie der einer jungen Ziege.

${ }^{1}$ ) In Katschár, Assam und Birma wohnt P. r. bakeri Hartert (Nov. Zool. 1900 p. 548 ) mit etwas stärkerem und dunklerem Schnabel und rostgelblicher Unterseite. 


\section{Psittiparus gularis gularis (Giay). ${ }^{1}$ ) (Fig. 73.)}

Purudoxornis guluris Gray, Gen. B. II p.389. Taf. 94 Fig. 2 (18t5- Keine Lokalität!

Als terra typica betrachte ich Sikkim).

Paraloxorniscanireps Blyth, Journ. Asiat. Soc. Bengal X VIII, 2, p. 810 (1849-Darjiling).

Ad. Oberkopf hell aschgrau, Fedem üher den Nasenlöchern und rorn an der Stirn sowie schmaler, his zu den Nackenseiten reichender Supereiliarstreif schwarz, die kuren Federchen vor und über dem Auge weiß, hinterer 'Teil der Ohrgegend und Nackenseiten hellgrau, ganze übrige Oberseite hellrötlichbraun. Außenfahnen der Schwingen und beide Fahnen der innersten Armschwingen hellrötlichbraun, Innenfahnen der Schwingen schwärzlichbraun mit blaßröstlichfahlen Säumen. Steuerfedern graubraun

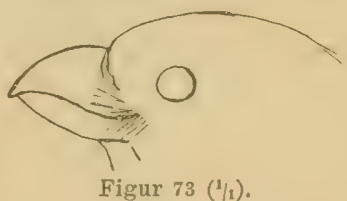
mit schmaleu gelbhäunlichen Kanten. Timge. Bartgegend und ganze Unterseite weif, nur an den Brustseiten und Trichen ein ganz schwather rahmgelhlicher Hameh. Kehle mit schwarem Eleck. Schuabel orangegelb, Fübo sehiefergrau mit gelbliehen Kralleu, Iris graubram. Flügel etwa 90-95, Schwanz 80-85, Lauf 25, Culmen $13 \mathrm{~mm}$.

Sikkim und Butan.

Nest ein tiefer Napf in Bïschen, Eier weißlich mit bräunlichen Flecken.

\section{Gattung CONOSTOMA Hodgson 1841.}

Schnabel nicht so kurz und hoch wie bei Paradoxomis, Cholomis, Suthora. Schwanz. lange nicht so stark gestuft, Zehen sehr liräftig, mit sehr krätigen Krallen, hesunclers die der Hinterzehe sehr lang, stark und lirumm. Eine Art.

\section{Conostoma aemodius Hodgs. (Fig. 74.)}

Conostoma Aemodius, Oemodius, Omodius Hodgson, Journ. Asiat. Soc. Bengal X, 2, p. 856, 857, mit Abbild.: (,1841", wohl aber erst 1842 erschienen! "Northern Region of Nepal).

Abbild.: Gould, B. Asia III, Taf. 31.

ơ ad. Oherseite matt rötlichhrain, Stirn weißlichhraun, Zügel und Federn un den rorderen Teil des Auges dunkelhraun. Sehwingen grambraun. AuBenfahnen der Handschwingeu hräunlichgrau, die der Armschwingen rotbraun. Steuerfedern grau, läings des lonthraunen Schaftes lothraun rerwasehen. Unterscite fabl graubraun. Keble unleutlich hell gestreift, Mitte des Unterkürpers

1) P. gularis transfluvialis (Hartert) (Nov. Zool. 1900 p. 548) bewohnt die Hügelländer südlich des Srahmaputra, nämlich Katsehír, Ober-Assam (bei Margherita in den Patkai-Hügeln) und Karenni. - Unterseite rostgelblich, Schnabel schwächer.

P. gularis fokiensis (David) (Ann. Sci. Nat. 1874 Nr. 9 p. 4) bewohnt Süd-China (Berge von Fokien). - Größer, als die übrigen Formen, der schwarze Kehlfleck größer.

P. gularis hainanus Rothschild (Bull. B. O. Club XIV p. 7, 1903) bewohnt Hainan. - Die kleinste Form, Kehlfleck groß, Oberkörper dunkler braun, Unterseite reinweiß. 


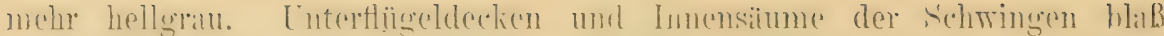

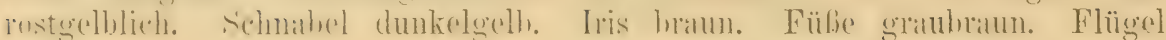

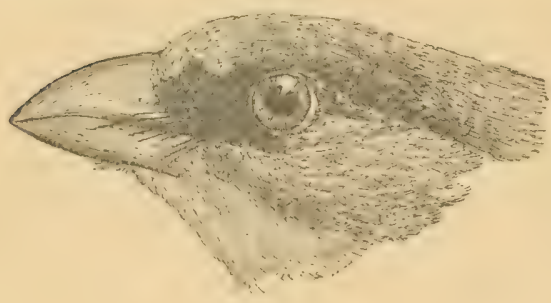

Figur $74(1 / 2)$. 122-132, Schwanz etwa 140, Lauf etwa 40, Culmen $23-24.5 \mathrm{~mm}$.

In großen Höhen (10.000 und 11.000 engl, Fuß) im Himalaya von Nepal und Sikkim, sowie in den westchinesischen Grenzgebirgen von Kansu his S'zetschivan.

Baut ein halbkugeliges oben offenes Nest aus Stengeln, Bambusblättern und Grashalmen auf einem Bambusrohr. Es enthält im Mai (3) Eier. Dieselben sind matt reiß mit gelbbraunen Flecken und Stricheln, sowie mit einigen purpurschwarzen Flecken und Wolken am stumpfen Ende. Das Ei mißt $28.19 \times 20.32 \mathrm{~mm}$.

\section{Familie I. ANIIDAE.}

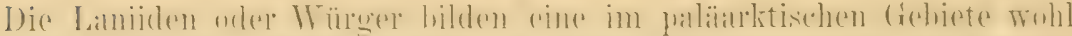

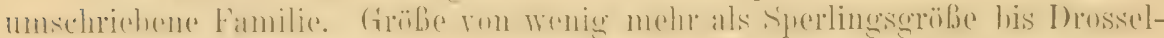

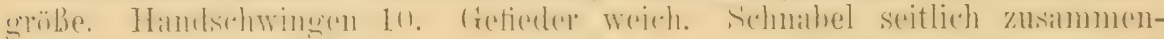

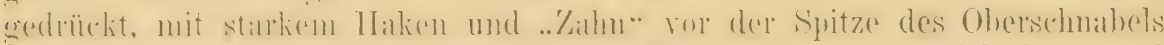
(Fig. 75), Läufe ziemlich kurz, vor'n gotäfelt. Flügel ziomlich kurz und

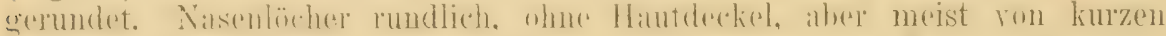

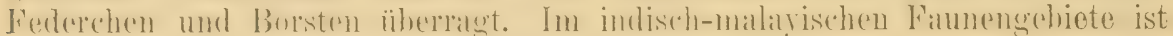
die Familio nicht so scharf getronnt, denn dort finden wir Formen, die in einer den Systematiker in Verlogenheit setzenden TVeise zu den Corvidae und Muscicapidae hinïborleiten, und zeigen, wio unvollkommen oder wie wonig richtig unsre übliche Einteilung der Familien der Passeres ist. - Verbreitung: Fast die ganze "Alte Welt" und Nord-Amerika bis Mexiko. Die hauptsächlich dem tropischen Amerika angehörenden

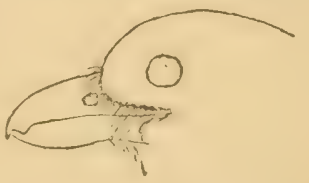

Figur 75.

L. excub. aucheri $(2 / 3)$.

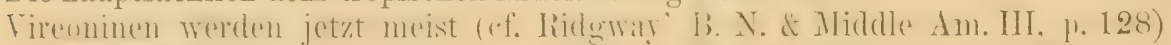

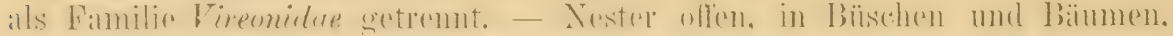

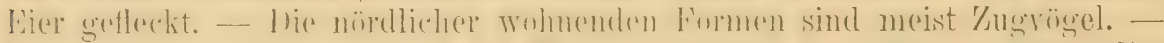

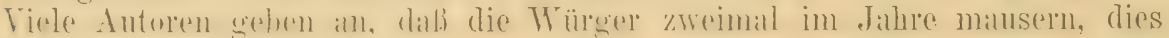
aber seheint mil ein Irrtum zu soin: sie mausern wohl nur eimmal, und

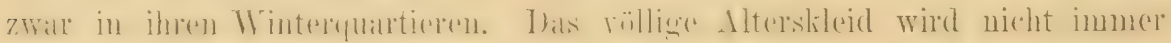
im elsten Jahre angelegt.

\section{Gattung LANIUS Linné 1758.}

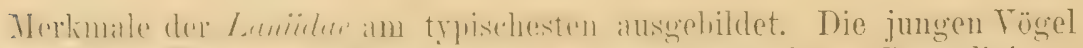

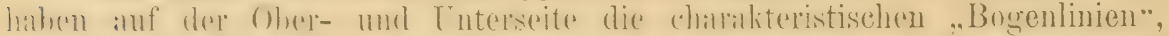

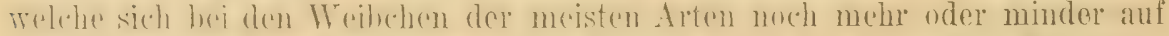
der Unterseite, alner num hei wenigen Furmen atwh hei den alten Männehon 
(z. B. L. e. mollis und horealis auf der Unterseite, L. tigrimus anf dem Rïekern) finden. Wahrscheinlich ist diese Bogenzeichnung ein ancestraler Chalrakter. - Eine Weitreinteilung in Collurio, Enneoctonus, Phoners, Fiscus, Leneomitopon, Olomela und Cephaloplıoneus ist nicht durchführbar.

\section{Übersicht der alten ơ der paläßrktischen Würger:}

Scheitel und Rücken schwarz nubicus

Scheitel rothraun, Rücken grau mit rostiarbenem Anlhug. Uncephalus. Scheitel und Rücken gleichmäßig fahl sandbräunlich, Schwanz braunrot isabellinus.

Scheitel intensiv rostrotbraun, Rücken etwas heller und mehr rostbraun, Schwanz rostrotbraun. . . . . . . . superciliosus. Scheitel und liiicken schmutzig graubraun, Stim weils. Schwanz braun

Scheitel mit roströtlichem Anflug, Rücken fahl bräunlichgrau mit sehr schwachem röstlichen Anflug, Sckwanz rotbraun - phoenicuroides .

Scheitel und Rücken graubrïunlich, lebhaft rostrotbraun verwaschen,

Schwanz größtenteils rotbraun. . . . . . . . . . . .

Seheitel grau, Riiekenmitte lehhaft rothraun, Sehwanz schwarz und weif

Seheitel grau, Lï̈cken matt graubräunlich, Schwanz an der IT urzel weib, mit anteapikalem Schwarz und mehr oder minder lebhafter mattrötlicher Fläche vor dem Sehwarz....... . bogdanowi .

Scheitel gran, Rïcken hraun mit sehwarzen Bogenlinien . tigrieus .

Scheitel grau mit rostrotem Anflug, Schwanz braun, mittelste Steuerfedern fast schwarz . . . . . . . . . . . . . . . . .

Scheitel braunrot, Oberrücken schwarz, Schwanz schwarz und weiß . .

Seheitel und lïicken grau, Bïrzel weib oder gran. Selhwanz schwarz

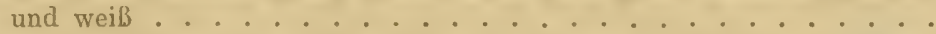

Scheitel und Rückeц grau, Bürzel rostrot, Schwanz dunkelbraun, mittelste Steuerfedern fast schwarz . . . . . . . . tephonotus .

Seiten röstlich isabell, Flügel $96 \mathrm{~mm}$. . . . . . darvini .

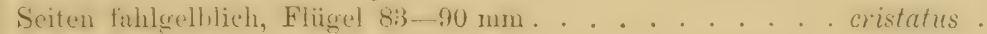

$3 \int$ Breites schwarzes, von weißer Linie begrenztes Stirnband. vittatus .

Schwarz an der Stiru ausgedehnter, Größe bedeutender (Flügel etwa

Ohne weibem Fliigelspiegel. . . . . . . . . . budius.

$6 \int$ Basis der beiden mittelsten Steuerfedern 2-3 cm weiß . . niloticus .

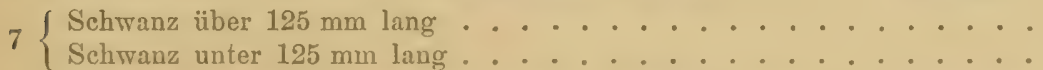

Stirn und schmaler Superciliarstreif weißlich, Flïgel $116-125 \mathrm{~mm}$

$8\{$ Stim und Federn ïber den Augen dunkelerau, Flïgel $140 \mathrm{~mm}$ uder länger ................ gigantens.

Erste S'chwinge etwa so lang wie die Handdecken, zweite nur etwa 20 mm lï̈rzer als chritte. . . . . . . . . . . . minor .

Erste Schwinge riel länger als die Handdecken, zweite viel kïrzer als die dritte. 
$10\left\{\right.$ Unterseite auch bei alten $\delta^{\top}$ mit Bogenlinien . . . . . . . . . 11

0 \{ Unterseite bei alten ô ohne Bogenlinien............ 12

11 Oberseite reiner grau, Bïrzel meist mit grauem Anflug . . borealis . p.423

| Oberseito mehr bräunlichgrau, Bürzel meist reiner weiß . . . mollis . p.422

J Brust gräulich rosa . . . . . . . . meridionalis . p. 424

Brust mit merklichem grauen Anflug . . . . . . . . . . 13

Brust weiß. mit oder ohne rosigen Anflug. . . . . . . . . 16

$13\{$ Kehle meist so grau wie die Brust . . . . . . . . buryi . p.432

Kehle stuts weißlich, in dentlichem Kontrast zu der hellgrauen Brust . 14

Oberseite dunkel schiefergrau. . . . . . . . . . . . 15

14 Oberseite hell schiefergrau ............ dodsoni . p. 426

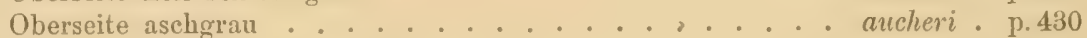

15 f Etwas größer, Flügel etwa $104-112 \mathrm{~mm}$. . . . . algeriensis . p.425

\{ Etwas kleiner, Flügel etwa $99-105 \mathrm{~mm}$. . . . . . koenigi . p. 426

16 I Kleiwe ()herlïgeldeckn größtenteils schwar, die ührigen grau. .lahtora . p. 430

Kleine Oberflügeldecken alle grau ............ 17

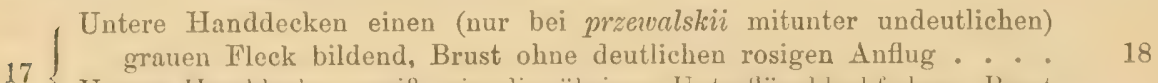

Untere Handdectien weiß we die iibrigen Unterfliggeldeckfedern. Brust mit deutlichem rosa Anflug. . . . . . . pallidirostris . p.429

18 Fliigel mit grobem ineinandertlebenden Doppelspiegel . praexalstii . 1. 420

$\{$ Flïgel mit einem Spiegel oder mit zwei deutlich getrennten Spiegeln . 19

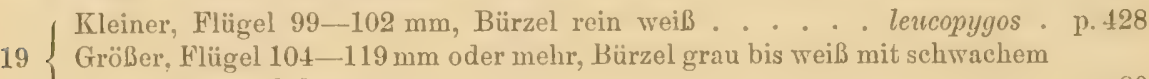

Größer, Flügel $104-119$ mm oder mehr, Bürzel grau bis weiß mit schwachem
gräulichen Schimmer. . . . . . . . . . . 20

$20\{$ Größer, Flügel $113-119 \mathrm{~mm}$ oder mehr. . . . . . . . . . 21

Kleiner, Flügel 104-107 mm . . . . . . elegans . p. 427

Oberschwanzdecken fast rein weiß, mit nur einem Fliigelspiegel, manchmal mit Andeutungen eines zweiten, Flügel 110-114 mm (östlichste Form)

bianchii . p. 424

21 Oberschwanzdecken grau, meist mit zwei Flïgelspiegeln, oft aber auch mit nur einem, Flügel 110-116 mm (westlichste Form) excubitor . p.418

Oberschwanzdecken weißlich grau, fast immer mit zwei großen Flïgelspiegeln, Flïgel $112-120 \mathrm{~mm}$......... homeyeri . p. 420

\section{Lanius minor Gm.}

Kleiner Würger, kleiner Grauwürò̀er, schwarzstirniger Würger.

Lanius mino Gmelin, Syst. Nat. I, p.308 (1788- „Habitat in Italia, Hispania, Russia“.

Ex Butfon, Daubenton Pl. Enl. 32. Als terra typica betrachten wir Italien). Lanius italicus Latham, Ind. Orn. I, p.71 (1790- Europa).

Lanius Vigil Pallas, Zoogr. Rosso-Asiat. I, p. 403 (1827- Südrußland).

? Lanius flavescens Hemprich \& Ehrenberg, Symb. Phys. Aves I, fol. e (1828 - nomen nudum!).

Lanius nigrifions Brehm, Handb. Naturgesch. Vïg. Dentschl, p. 236 (1831- Thüringen).

Lanius medius Brehm, 1. c., p. 236 (1831- Norddeutschland).

Lanius pinctorum lBrehm. Isis 1842 , p. 65. 659 (Berlin, Hecklenturg, Ahlstorf).

Lanius eximius Brehm, Isis 1842, p.652, 662 (Thüringen, Vien, Kärnthen).

Lunius lonyipennis B1yth, Journ. As. Soe. Bengal X V. p.300 (18t6 - Fundort unbekannt).

Lanius Roseus Bailly, Orn. Saroie II, p. 26 (1853- Savoyen, Frankreich, Spanien, Italien. Neuer Name für L. minor). 
Lanius graecus Brehm, Vogelfang, p. 84 (1855- "Griechenland". 'Typus aus Attica). Lanius minor arboreus, septentrionalis, microrhynchos, A. E. Brehm. Verz. Sammlung, p. 3 (1866- Nomina nuda!).

"Lanius minor Gml. typ. et var.: obscurior Radde" Radde, Orn. Cauc., p. 282 (1884Kaukasus).

Engl.: Lesser Grey Shrike. Franz.: Pie Grièche d'Italie. Ital.: Averla cenerina.

Unterscheidet sich von den eigentlichen Grauwürgern ( $I_{\text {. }}$ caxrubitor und Verwandten) fundamental durch den Bau des Flïg(s): die hei den groben Würgern etwa die Hälfte der zweiten S'chwinge erreichende erste Srhwinge ist viel kül\%er, nämlich nur etwa so lang wie die Handderken, wohneregen dio zweite Schwinge, dio hei exculitor und seinen Verwandten erhehlich (meist etwa $1 \%$ cm) hinter der dritten zurïckhleibt, nur etwa $2 \mathrm{~mm}$ kürzer ist als die dritte, die allein die Spitze des Flügels bildet. da die vierte wirder merklich kürzer ist. - O ad. Zügel und Stim mindestens his in die Augenhöhe, sowie damit zusammenhängender Streif überm Ange und grobrr. Fleck hinterm Auge rein schwar\%. Ührige Oherseite hellghrau, meist auf dem [Bürze] etwas heller, äußerste Außensäume der Sehulterferlern weiblich. Schwingen schwarz, Handsehwingen mit ausgedehnter weißer Basis, Spjitzensïume der Armsehwingen weib, die der Handschwingen nur äuberst sthmal hellbrïunlirh. Schwanzzeichnung wie bei allen Grauwïrgern varierend: meist sind die beiden äußeren Paare weiß mit größtenteils schwarmen Schïftru, das dritte Paar hat einen ausgedehnten, an Form und Ausdehumg wechselnden inteilpikilen schwarzen Fleck, das vierte ist schwarz mit weiber Basis und Spitze; oft hat indessen schon dis zweite Pallr von außen einen mehr oder minder großen schwarzen Querfleck in der Eindhälfte. Luterseite wrib. Torterhust und Seiten rosig angehaucht bis lebhaft wein-rosig. Schmahel und Fübe schwarz, Iris nubbraum. Flügel etwa 115-123, Sehwauz $85-95 \mathrm{~mm}$. Tauf etwa $25 \mathrm{~mm}$. O wie $\sigma^{\top}$, aber meist etwas kleincr. Cnter den westeuropiaischen Exemplaren findet man die kleinsten, unter den östlichen die grablen, die Maße aber schwanken so, dab dalaufhin keine versehiedenen Formen unterschieden werden können. Jur. Oberseite brïunlichgrau, mehr oder minder weißlich und grau quergewellt, Stirn wie der Rücken, also nicht schwarz. Flügoldecken mit weißlichen Spitzensåumen.

Brutrogel in Sïd- und Mitteleuropa, nördlich bis in die Ostsecprovinzen und selhst Livland, und in West-Sibirien his 57" nördl. Bl\%. ïstlivh durch Süd- und Mittelrußland, Klein-Asien, Persien und West-T'urlestan his zum Altai. In Deutschland sporadisch, aber überall als Brutrogel rorkmmmend, mit Ausnalme der nordwestlichsten Landesterle. In Hollind und Belgrien nur rereinzelt auf dem Zuge, in Grobloritamnien sehr seltener Irrgast. Im mittleren und südlichen Frankreich nicht selten, fehlt jedoch im Norden und Nordwesten des Landes und ist nur eine zufällige lirscheinung in der Sïdwestecke (Lot, Tarne et Garonne, Gars, Halutes Pyreness, Basses P'yrénien, Landes, Gironde - L. Bureau in litt.). Nicht selten in Italien. Korsika, Sardinien, Südost-Europa, sehr häufig in Cugarn. - Zugrogerl, der uns frïh verlïßt und in Afrika, südlich bis Dentsch S. IT. Afrika und Oranje-Fredistat überwintert.

In Ėuropa in Ebenen und hügeligem Gelände, im Kaukasus nach Radde vereinzelt bis $1800 \mathrm{~m}$. Bewohnt Feldhölzer, Waldränder, Parkanlagen, Auen und fïrten, besonders wenn solche an Wiesen angrenzen. Warnrufe und Lockstimme wie schäck, 
sclıäck cder kjäck, auch pfeifend wie kwiä, kwiell, und quätsch, scharrek, scharrek. Der Gesang ist ein gepreßtes Zwitschern, mit den Lock- und Angstrufen untermischt, manche Individuen haben aber ein wunderbares Nachahmungstalent und ahmen die Gesänge vieler Vögel trefflich nach. Nahrung Käfer, namentlich Arten von Geotrupes, Helolontha, Carabus, Elateriden, kleinere Carabiden, Aphodius, Necrophorus, auch Orthopteren, Raupen, mitunter auch Schnecken, selten und wohl nur ausnahmsweise junge Vögel und Häuse. Nester meist hoch, bis 8 oder $9 \mathrm{~m}$, selten unter $3-4 \mathrm{~m}$, gern, aber nicht immer, nahe am Stamm von Laubbäumen, selten auf Nadelbäumen. Nester mit Vorliebe aus weißlichen Reisern und Wurzeln, die mit grünen oder sonst unverändert bleibenden und besonders auch wohlriechenden Pflanzen und Blumen, wie Salvir, Gnaphalium, Capsella, Chelidonium, 'Thymian, Achillea, Potentilla, Mentha, aber auch andern, untermengt und geziert sind. Die innere Ausfütterung besteht aus feinen Halmen und Würzelchen. Die Ëier sind charakteristisch, typische Würgereier, Grundfarbe fast immer hellgrïnlich, selten weißlich, nach Rey auch bisweilen, aber nur ausnahmsweise rötlichgelb, Flecke olivenbran, Schalenflecke hellgrau oder grünlichgran, meist groß, oft ringförmig angeordnet. IIaße von 100 Eiern (Rey, Jourdain, Blasius) im Durchschnitt $25.10 \times 18.24$, Maximum $28.2 \times 20$ (also größer als normale Eier von excubitor), Minimum $23 \times 17$ und $23.3 \times 16.6 \mathrm{~mm}$. In der Rödernschen Sammlung (T'ring) aber befinden sich auch noch Eier von $22.8 \times 18.3$ und ein Riesenei von $29 \times 19 \mathrm{~mm}$. Das mittlere Gervicht ist nach Rey $0.257 \mathrm{~g}$.

\section{Lanius excubitor excubitor L.}

\section{Großer Würger, Grauwürger, Krickelelster.}

Lanius Excubitor Linuaeus, Syst. Nat. Ed. X, p.94 (1758 - „Habitat in Europa“. Als

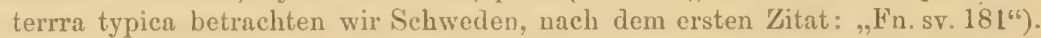

Lanius major Gmelin, Syst. Nat. I, p. 300 (1788- Europa; ex Brisson, Will., Frisch 'Iaf. 59). ${ }^{1}$ )

Lanius cinereus Leach, Cat. Hamm. \& Birds Brit. Ilus., p. 19 (1816- „Wiltshire“. Nomen nudum! ? ex Brisson, Orn., p. 141).

Lanius rapax Brehm, Journ. f. Orn. 1854, p. 144 (Deutschland, Typus untersucht).

Lanius excubitor conmunis, crassirostris, tenui-, longi-, brevirostris A. E. Brehm, Verz. Samml., p. 3 (1866- Nomina nuda!).

Lanius borealis europaeus Bogdanow, Würger der russ. Fauna (in Faun. Zapiski Imp. Nauk XXXIX), p. 102 (1881- Nordeuropa. Russisch!).

Engl.: Grent Grey Shrike. Französ.: Pie-Grieche, Pie-Grièche grise. Ital.: Averla maggiore. Schwed.: Större Törnskata.

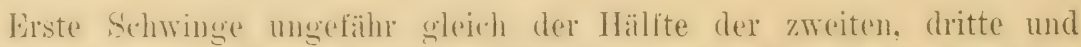
vierte gleich lang und am längstrn, fünfte nur wenigg kürzel als die dritte und vierte. - Cial. Oherseite hell ascherall. Srohultertittiche an den Spitzen heller, fast weib, Oherschwanzdechen meist etwas. manchmal auffallend heller grau. Die nach vorn geriehteten, die Nasenlöcher üherlagenden Borsten ganz oder gröbtenteils schwarz. sehualer Streif ummittelbar unter dem Auge und hroitur. die ohren Ohrolecken einsehliediender Streif hinter dem Alige schwarz. An der Torderstirn Andentung cines weiblichen Schimmers, ein undentliches'

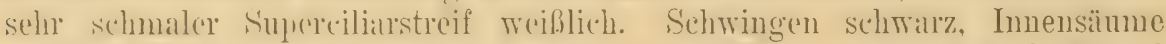
woißlich, Spitzen der Amuschwingen und inneren Handsehwingen weiß, IT urzel der Handschwingen immer, Wurzol der Armsehwingen meist weib, wodurch entwoler (im letzteren Falle) zwei weibe spiegul, oft (im ersteren Falle) un cin Flïgelspregel entsteht. Kleime Flügeldecken grau mit schmarzer

1) Wahrscheinlich gehört hierher Lanius albus Gmelin, 1. c., ex Brisson - nach. Aldrovandus \& Johnston. Dies ist vermutlich ein Albino gerresen. 
Basis, mittlere und große schwarz. Mittelstes Steuerfolerpuar schwarz mit nur ganz schmalen, meist abgenutzten weiken Śpitzeusïumen, die folyenden mit immer mehr an Ausdehnung zunehmenden weißen Enclen, so daß das äußerste Paar nur etwa zur Hailfte oder weniger sehwarz hleiht, oft auch fist ganz weil. wird mit nichts als eincm unregehmäßigen sehwal'zen Fleck in der Nitte, einem medianen sehwarzen Schaftstreifen oder nur in der Mitte schwarzem Solnaft; die Außenfahne des äußursten P'alle's ist stets ganz, die des folgenden meist gröbtenteils weil. Äuberste Basis der Steuerfedern weiß, das mittelste Par aber ganz oder fast bis zur Wurzol schwarz. Ganze Unterseite milehweiß, Brustseiten im frisehvermanserten Gefiecler mit zartem rosigen Sehimmer, Weichen etwas gräulich verwaschen. Luterflügeldecken weiß, untere Handdecken aher grau. Schnahel und Füles schwarz. Iris dunkelhram. Flïgel 113-116, selten his 118 und $119 \mathrm{~mm}$, Silhwillz

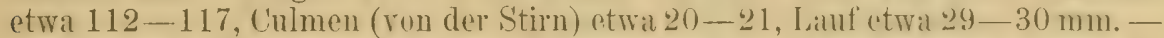
ad. wie ơad., nur etwas kleiner, Flügel etwa $1111-113$, seltener 115 mm. Juv. im ersten Gefieder: Oherseite hräunlichurau, Zügel gröbtenteils valu, Unterseite milehweiß mit graubrumen Tollenlinien an Iirust und Sciten. I)as völlige Alterskleid wird augenstheinlich nicht im ersten, sondern erst im zweiten oder dritteu Jalue angolegt, elem man findet anch noch einoder zweijührige Stücke mit deutlichen hraungranen Trellenlinien auf der Interseite, bisweilen auch schon brïtende Tägel, namentlich Wreihehen mit solchen. - (82 Exemplare untersucht.)

Brutrogel in Europa ron NordruBland mod Skandinarim, im Tresten his an den Fub der Prrenäen. im Zentrum his zu den Alpen. im Südosten his L'ngallu; nordöstlich his Ohdursk am unteren Oh. In Frankrejch, wenn auch nicht häufig, sedentïr und I)urchzugsvogel im Herbst und Frïhjahr, nistend in allen Tandesteilen mit Ausmahme der Bretagne, von I'oitou und den am Mittelmeere gelegenen I'rovinzen, wo L. e. merilimulis hrütet. (T. Burean in litt.) In den Alpen nicht häufig und mohr in den 'Tälern. sehn vereinzelt in hïheren Lagen, his 1400 (Lrseren-Till) und sogar 1800) m

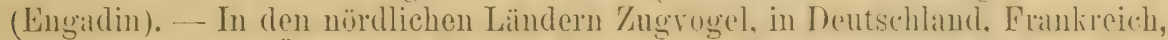
der Schweiz und Österreich-Lngaru Stand- und Śtrichrogel. Auf dem Zuge anf Helgoland, in Grobbritannien und Irland, in Sï̈-Frankreich, Italien. SüdostEuropa und im nördlichen Kaukasus.

Der große Würger bewohnt Feldhölzer, Gärten, Waldränder u. dergl., nie das Innere größerer Wälder. Er ist ein munterer, lebhafter Vogel und sitzt gern frei und weithin sichtbar. Raubvögel, Krähen usw. markiert er durch Geschrei, neckt und verfolgt sie. Er hat eine laut pfeifende wie truii klingende Lockstimme und ein wie schäck, schäck klingendes Geschrei, manchmal hört man u. a. auch ein klagendes Quäken. Der Gesang ist ein schwätzendes Schäckern, mit den Locktönen vernischt, sie ahmen aber auch manchmal andere Vögel nach und einzelne Individuen entwickeln prachtrolle Gesänge. Nahrung Käfer u. a. große Insekten, Eidechsen, kleine Frösche, Iläuse, kleine Vögel. Seine Beute spießt er zum Verzehren an Dornen oder klemmt sie zwischen Zweige und in allerlei Ritzen ein und verläßt sie sehr oft halb gefressen oder unangerührt, wenn er genug Nahrung findet. Standort des Nestes meist hoch auf Eichen, Obst- und anderen Laubbäumen, seltener niedriger, sehr selten ganz niedrig. In Holland fand Jourdain sie auch auf Kiefern. Das Nest besteht aus trockenen Reisern und Stengeln, gern mit grünen oder hellgrauen Pflanzen wie Heidekraut, Achillea u. dergl. vermischt, die flache Nulde mit Haaren und Federn ausgelegt. Gelege meist 5-7, selten weniger oder mehr Eier. Durchschnitt von 100 Eiern aus Deutschland und Holland (Jourdain, Rey, blasius. Tring sammlung) $26.25 \times 19.5$, 
Maximum $30.5 \times 19$ und $28 \times 20.5$, Minimum $23 \times 18.9$ und $25.1<18 \mathrm{~mm}$. Nittleres Gewicht etwa $0.283 \mathrm{~g}$. Die Lier sind auf trübweißlichem, rahmfarbenen oder matt bräunlichweißem Grunde mit braunen Flecken und hellgrauen Unterflecken gezeichnet, die Zeichnung meist am stumpfen Ende gehäuft, seltener aber deutlich kranzförmig. Grünlich ist die Grundfarbe niemals.

\section{Lanius excubitor homeyeri Cab.}

Lanius Homeyeri Uabanis, Journ. f. Om. 1873, p. 75 (Wolga und Krim. 'Terra typica: Untere Wolga. Typus untersucht).

Unterscheidet sich von L. e. excubitor durch etwas hellere Oberseite, hesmuders fällt ein lichter, weiblicher Sthimmer an der Stirn und übrer den Augen auf, die Ohorschwanzdecken sind weiblicher. Der zweite Flügelspiegrel ist fast immer vorhanden, d. h. die Basis der Armsehwingen ist ebenfalls weißs; Stücke mit nur einem deutlichen spievel, d. h. weißre Basis der Handschwingen allein, sind änberst selten; etwas Weili ist sogar stets auch an

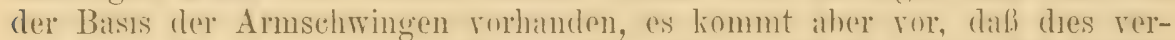
deckt ist. Basis auch der mittelsten Steuerfedrm mit Winschlub der Schälfte etrva 2 cm weit weib. I)ie meisten, auch viele ganz alte ("weilhliche) Vügel hahen etwas Wreil., an den Kä̈geln. was hei $L$. e.exculiter stets ein Zeichen von Jugend ist. Flïgel $111-120 \mathrm{~mm}$. (48 untersucht.)

Das Brutgeniet seheint ron Rumänien und Bulgarien durch die Steppen Südrublands (Astrathan. Sarepta. Cralsk, Kisatn. Gurjew) his in die westsibirischen Stepuen (Barabil). bis Tomsk und Krasmojarsk am Jenissei zu reichen. in Rubland nürdlich wohl mindestens his Mloskan. - Im Winter unstet, uminerstreifend. rereinzelt lois weit nach Westen, 7. B. in Ungarn,

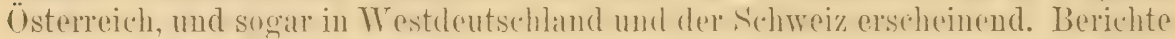
von solchen sind jedoch mit Vorsicht anfzunchmen, da aubergewöhnlich helle

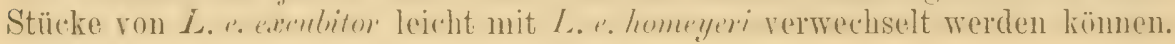

\section{Lanius excubitor przewalskii Bugd. (Fig. 7i.)}

Lanius leucopterus Sewertzow, 'Turk. Jevotn. (in Izv. Obshch. Moskr. VIII, 2), p.67 (1873- 'Turkestan. Nomen nudum! Vgl. Madarász's Zeitschr. ges. Orn. IV, 1888$, p. 16,24$)$.

Lanius Przeualskii Bogdanow, Würger der russ. Fauna, (in Faun. Zapiski Imp. Nauk XXXLX), p. 147, Taf. III fig. 2. Russisch! (1881- beim Saissanski-Posten, bei Karaschar, in Taschkent, I'schinas).

Abbild.: Dresser, B. Europe IX, Suppl., Taf. 668 fig. 2; Bogdanow 1. c. „Neuer Naumann" IV, Taf. 16 sub nomine homeyeri.

Von L. e. homeyeri (und somit natïrlich umsomehr von L.e.exculitor) durch hellere Allgemeintähumg und mehr IT eibs an Schulterfittichen, Oherschwanzderken, Flïgehn und Schwanz untersehieden. -.. Thie Färbung der Oberseite ist von cinem noch helleren Grau als bei L. e.homeyeri, die Stirn ist deutlich und noch ausuedehnter weili, der weilie sumereciliarstreif noch

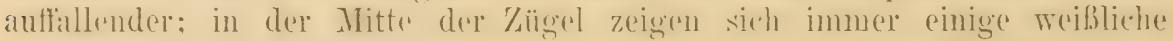
Federn. Die Schulterfittiche sind fast ganz weiß. Das Weiß an den sehwingen ist viel ausgedehnter: die Handsehwingen sind mehr als zur

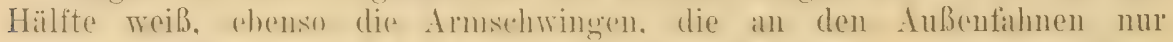
ror den Spitzen einen an Ausdehnung sehr variorenden schwarzen Flectí 
haben, und deren mittlere an den Innenfilunen oft gamz weiß sincl, oder nur kleine, manchmal aber auch gröbere und grolie schwarze Flecke haben; es entstehen auf diese Weise immer 2 miteinander verbundene Spiegel, oder eigentlich nur einer, der die Trurzeln der Arm- und Handschwingen umfaßt. Sïmtliche Oberselswanzdecken sind rein weiß, oder doch nur die dem Bürzel nä̈hststehenden grau verwaschen. Die änßerste Stenerfeder ist ganz weib, nur selten ist der Schaft selbst in der Mitte der Feder schwarz; die zweite Steuerfeder von außen ist mitunter rein weiß mit weißem
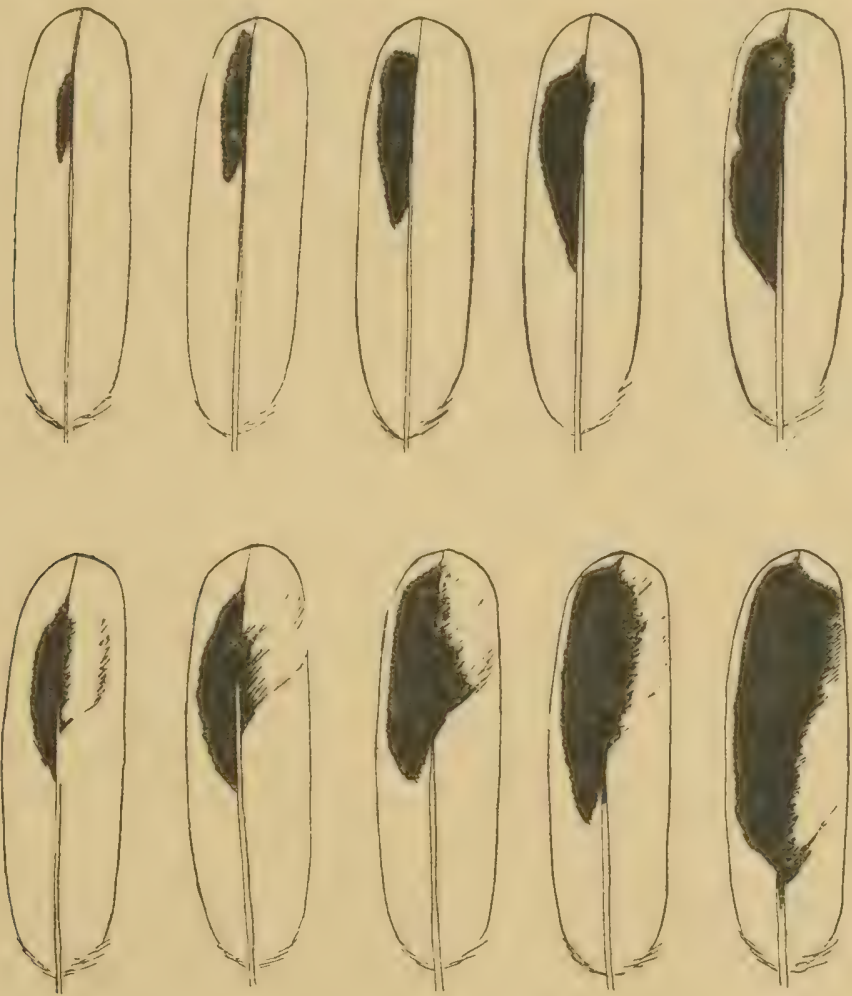

Figur 76 .

Viertletzte Armschwinge von $L$. exc. prevoalshii $\left({ }^{2} / 3\right)$.

Schaft, meist weib mit schwarzem Schafte in der Mitte der Feder, manchmal aher zeigt sich ein schwarzer Fleck am Silum der Innenfilne, selten wird dieser Fleck gröber, äuberst selten erreicht er den Schaft oder zeigt sich auch an der Außenfahne etwas schwarz; das dritte Par ist weiß mit in der Nitte sehwarzem Schaft und an Auschehung sehr wechsehnden schwarze'n Flecken nahe den Säumen in der Mitte beider Fahnen. Ibie folgenden Steuerfedern sind schwalrz mit weiber Basis und weiben spitzen, die an mittelsten Pare zu cinem ganz schmalen Spitzensamne zusimmensehmelzen.

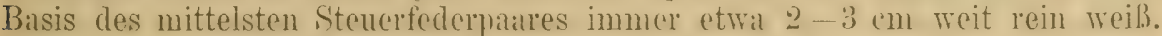
Cnterflïgeldecken weil, untere Handdecken hellgrau, oft fast weilbich. Jüngere 
Tögel haben auf der Oberseite einen sandgelblichen Anflug. Flügel 118-122, bei cingen Treibchen nur $113 \mathrm{~mm}$, wïhrend andere - wenn richtig als $c$ bezeichnet - so groß wie die o sind. (66 Exemplare untersucht.)

Scheint die Ischungarei. Turkestan ron Samarkand und Ferghana bis Seminalatinsk und Semirjetschensk, Kuldscha, den Tian-Schan, Ost-Turkestan, die Grenzgehiete und Oasen der Wüste Gobi zu bewohnen. - Im Winter unstet und damn rereinzelt his Gilgit, in Tsididam und selbst SüdostRußland (Orenburg).

\section{Lanius excubitor mollis Eversm.}

Lanius major (non L. major Gmelin 1788) Pallas, Zoogr. Rosso-Asiat..I, p.401 (1827"In Rossia boreali, omnique Sibiria frequens, .....").

Lanius mollis Erersmann, Bull. Soc. Imp. Nat. HIoscou XXVI, p. 498 (1853- SüdI. Altai, an der T'schuja. Beschr. des jungen Vogels! Typus untersucht).

Lanius borealis sibiricus Bogdanow, Würger d. russ. Fauna (in Faun. Zapiski Imp. Nauk XXXIX, p. 102 (1881- 'T'schuktschen-Halbinsel, Ochotsk, Chanka, in Winter in Baikalien). (Russisch!)

Lanius borealis asiaticus 1. c., p. 115 (1881- wohl lapsus für L. b. sibiricus).

? Lanius seebohmi Gadow, Cat. B. Brit. Mus. VIII, p. 243 (1883- Amur-'Tal. 'I'ypus untersucht). ${ }^{1}$ )

Lanius funereus Menzbier, Ibis 1894, p. 378 (Tian-Schan: Ulugschat, Kuldscha).

(Man vgl. Taczanowski, Faune Orn. Sib. orient. I, p. 488, wo allein die Kleider von $L$. e. mollis richtig beschrieben sind.)

Abbild. des jungen Vogels: Bogdanow, Würger d. russ. Fauna Taf. II; Dresser B. Europe, IX, Suppl. 'Taf. 667, 668 fig. 1; Ibis 1882 Taf. XI.

$\delta^{x}$ ad. Bürzel und Obersehwanzdecken weißlicher als bei L..e.excubitor,

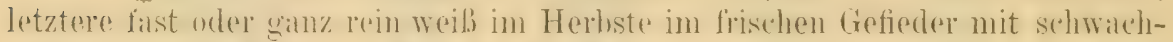
rostgelbliehem Aufluger. Nur die Fasis der Handschwingen weib, also stets

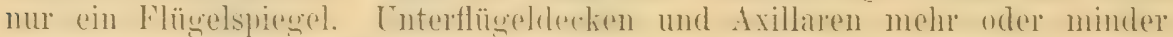

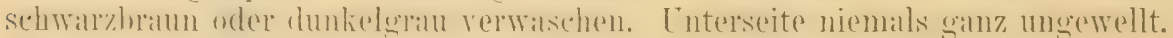
Flügel etwa $113-122$ mm. - Juv: Oberseite graubraun, die Ränder der

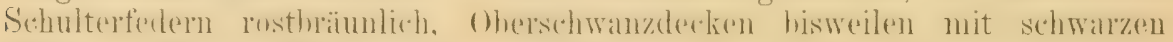

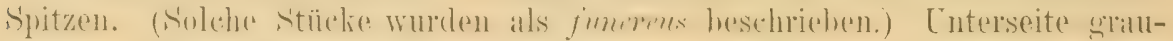
hräunlich bis resthräunlich uler sohmutzig zimmthäunlich rowaschen und

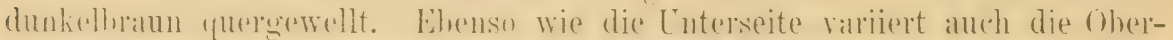

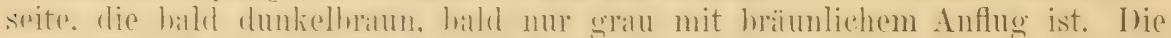
moter dem Nimen mollis als alte Tögel heschriehenen und als Art aufrecht

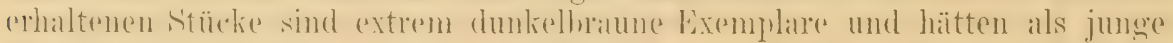

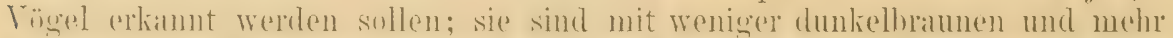

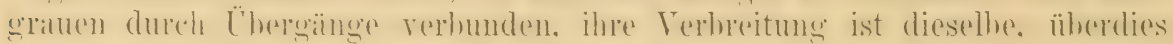

1) Das als L. seehohmi beschriebene Stück hat eine bräunliche, anscheinend ungewellte Unterseite und die Schulterfiltiche haben keine weißen Säume. außerdem lraben die Stenerfedern sehr wenig Weiß: das änßerste Paar nur einen $2 \mathrm{~cm}$ langen weißen Fleck an der Spitze der Innenfahne. Der l'ogel ist indessen in sehr abgenutztem Gefieder, die Unterseite beschmutzt; bei genauerer Untersuchung findet man an derselben deutliche Spuren vou Bogenlinien. Die Schulterfedern sind auf einer Seite unvollständig. Der Bürzel hat kein Weiß. 1 ch glaube, daß es sich um ein schmutziges, abgenutztes, dabei aber durch das reduzierte Weiß an Schwanz und Skapularen aberrantes Stück von L. e. mollis handelt. 
sind manche junge nordamerikanische borealis chenso braun wie sogenannte mollis und mitunter nicht ron denselhen zu unterscheiden. (52 untersucht.)

Brïtet in Sibirien von Kamtschatka bis zum unteren Jenissei. - Im Winter Strich- und Zugvogel und dann regelmäbig süllich his Ost-Turkestan, Turkestan, in der Mandsehurei, an der Amur-Mïndung, vereinzelt und selten in Japan. Geuaue Grenzen des Brutgebietes z. Z. noch unsicher.

\section{Lanius excubitor borealis Vieill. ${ }^{1}$ )}

Lanius borealis Vieillot, Hist. Nat. Ois. Amér. Sept. I, p.80, Taf. 50 (1807- ohne genaue Lokalität: Nordamerika).

Lanius septentrionalis (non Gmelin) Shaw, Gen. 7.ool. VII, p. 331 (1809-

Collyrio chemungensis Gregg, Proc. Elmira Acad. I, p. 9 des Separatabdr. (1870Chemung im Staate New York).

Lanius borealis americanius Bogdanow, Würger d. russ. Fauna, in Faun. Zapiski Imp. $\wedge$ auk XXXIX, p. 102, 115 (1881- Nordamerika).

Lanius borealis invictus Grinnell. Pacific Coast Avif. Nr. 1 p. 54 (1900- Alaska).

Ist $L_{0}$ e. mollis ïußerst ähnlich und nicht leicht zu unterscheiden, die Cnterseite wie bei jenem immer gerwellt. niemals einförmig, aher die oberseite ist hei alten Fïgeln reiner graul und der Bürzel meist mehr mit Gran üherlanfen. Oft sind die weiben Aubensüume der S.hulterfittiche undeutlich oder fehlen gaun. Der Flügel ist moist etrvas kürzer; bei 26 von mir gemessenen Stüclien $111-118 \mathrm{~mm}$, jedoch giht Riclgway (B. N. d Mithle Amei. III p. 238) für ơ 112-121, ᄋ 110-118 mm an.

Nördliches Norelamerikil ron Labrador bis Alaskia. erenatue Grenze des Brutgehietes nach Sï̈len noch nivht festgestellt. - Im Winter in den Vereinigteu Staten. südlich his Nen-Mexilo. Arizona und Mittel-Kálifornien.

1) In Nordamerika leben noch andre Graumiirger-Formen, von den Amerikanern (Ridgway, B. North \& Middle Amer. UI, p. 235-252) wie folgt unterschieden:

A. Lanius ludovicianus lulovicianus L., 1766- Südatlantische und Golfstaaten.

B. L. l. migrans Palmer, 1898- nördliche Vereinigte Staaten und siidliches Canada östlich der großen Ebenen.

C. L. l. gambeli Kidgw., 1887 - Kalifornien, Oregon und siidl. Britisch-Colombia, im Wiuter siidlicher.

D. L. l. excubitorides (Swains.), 1831-- Trockene innere Teile der Vereinigten Staaten und östliche Staaten von Canada, im Winter siidlich durch Hexiko.

E. L. l. mexicanus (Brehm), 1854- Südliches Mexiko.

F. L. l. meansi Ridgw.; 1904- Inseln San Clemente und Santa Margarita an der kalifornischen Küste. (Vermutlich, wenn überhaupt zu unterscheiden(?) auch auf andern Inseln. E. H.)

G. L. l. anthonyi Mearns, 1898- Santa Cruz Insel an der kalifornischen Küste. (Hierher gehört vielleicht auch mearnsi.)

Alle diese haben im Alter eine ungewellte Unterseite, sind erheblich kleiner und meist auf der Oberseite dunkler, als der nördlicher wohnende $L$. excubitor borealis, da sie aber zur Brutzeit andere Gebiete bewohnen und in den Hauptmerkmalen ganz mit den paläarktisehen Grauwürgern übereinstimmen, dürften sie als Subspezies zu $L$. excubitor zu rechnen sein. 


\section{Lanius excubitor bianchii subsp. nov.}

(Benannt zu Ehren des Petersburger Ornithologen Dr. Val. Bianchi. Typus im Petersburger Iluseum: Nr. 9061. Gesammelt von Dr. Suprunenko.)

Merkwürdigerweise tritt im äubersten Osten wieder eine der europäischen ähnlichere Form mit im Alter ginzlich ungewellter Cnterseite auf. Sie ist anf den ersten Blick rom L.e. mollis durch die im Alter einförmig weiße Unterseite unterschieden; der Flügel ist kürzer. Schnahel schlank, Spitze sehr lang hakenfërmig wie bei anderen Inselformen, oder doch dazu neigend; ()herseite rein aschgralu. Spitzen der Schulterfittiche und Oherschwanzdecken weil. mit schwachem gräulichen Schimmer. Basis der Handschwingen weib, meist nicht sehr ansegedehnt, Basis der äuberen Armschwingen hei etwa einem Inittel der untersuchten Stücke mit eimem von den Flügeldecken ühredeckten weilien Fleck - also ein Himneigen zur "Zweispiegligkeit." Sunst sind die Almsthwingen gianz schwarz nur mit weiken bindsäumen und grauen Innensïmmen. Unterseite einförmig weiß, hei fünf anscheinend jüngeren und weiblichen Stücken mit Andentungen von Bogenlinien, bei eincen jungen Vogel stark gewellt. ÄuBere Stencrfeder meist ganz weiß mit dem mittleren Teil des Schaftes oder noch einem den Schaft hegleitenden Jïngsteck im mittleren Teile schwar\%. hei cinzelnen Stücken mit noch mehr Schwarz an der Innenfahne. bei decien mit der Imnenfahne im mittleren Teile etwa $3 \%$ em weit schwalrz. Die übrigen Steuerfectern mit an dus-

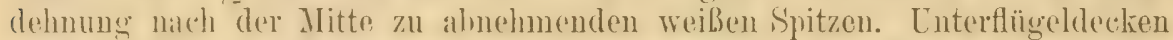
weib, diw Lnterbanddecken einen groben grauen Fleck bildend. Achselferlern brïunlichgran mit gribtenteils weiben Aubenfahnen. Flügral $110-11+\mathrm{mm}$. (Keins der vorliegenden Stücke hat eine Geschlechtshestimmung.) Schwanz mugefïh $115 \mathrm{~mm}$. (I)ie serie von 16 Stück besteht aus ahgeriehenen Sommer-

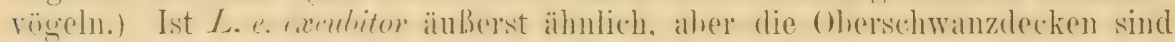

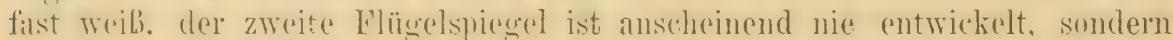

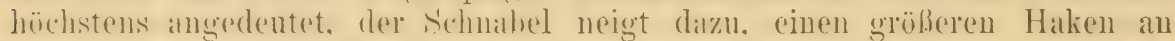
der Spitze zu entwickeln.

Insel Sathalin. (Wieder ain Fall, in dem die westlichste und ïstlichste Form einander am meisten ähnelı.)

\section{Lanius excubitor meridionalis 'Temm.}

Lanius meridionalis 'Temminck, Man. d'Orn., Ed. 2, I, p. 143 (1820- ,le midi de l'Italie, la Dalmatie, le midi de la France, le long des bords de la Méditerranée et l'Espagne". 'Teilweise unrichtig! Als terra typica betrachten wir die Provence, von wo 'Temminck Stiicke vorlagen).

Abbild.: Temminck, Pl. Col. 143, Dresser B. Eurnpe III Taf. 147 u. a. m.

Schnahel durchschnittlich wie der von l. p. excubitor. Lnterscheidet sich anf den ersten Blick von L. excubitor excubitor und dessen nächsten Terwandtem (homeyeri usw.) dureh die dunkelgrane Oberseite, gräulich rosal seförlote Cnterseite und kurzen Flügel. - Oberseite dunkel hleigrau, nach Bürze] und Ohrersthwanzdecken zu etwas heller werdend; an der Mrurzel des Oherschnahels ein weiblicher Fleck, der über den oberen Teil der Zä̈gel hinziehend mit einem schmalen. kurzen. scharf hervortretenden weiben Supercilialstreifen in Verlindung steht. Flügel etwa 102-105. selten his $110 \mathrm{~mm}$. - 
Jur. Oberseite aschbräunlich, Luterseite blasser, wellenförmige Zeichnung nur angedeutet.

Spanieu und Portugal, Südfrankreich (die am Mittilmeere gelegenen Provinzen, bis Nizza, dagegen nur zufïllig anf dem Striche in den I)epartements Aude, Tarn, Arriège, Haute Garomne, Hautes et Basses Pyrénées. Eimmal bei Gien an der Loire erlegt. - L. Bureau in litt.); vereinzelt in Italien (Ligurien, Toskuna, Umbrien his Rom). Sull nach Kolombatories hei Spalato in Dalmatien, nach Gütlie (Vogelwarte 2. Aufl. p. 229) eimmal anf Helgoland vorgekommen sein, die beiden letzteren Angaluen aher hedürfen der Bestätigung. Lord Lilfords Angabe rom Vorkommen auf Corfu dürfte ebenso irrtïmlich sein wie andere Angahen rom Vorkmmen auf den griechisehen Inselu, denn ein Belegstiick ist nicht vorbanden.

Lebt in den Ebenen, an Plätzen wo genïgender Bestand lichter Hölzer, einzelne Bäume oder Obstgärten ilım Gelegenheit zum Nisteı bieten. Jourdain fand die Nester 1-2 $\mathrm{m}$ hoch in Büschen, nicht auf Bäı!men, wie die von $L$. excubitor und senator. Lebensweise die von $L$. e. excubitor. Eier meist etwas lebhafter und mehr rötlichbraun gefleckt, sonst wie die der deutschen Form. Maße von 62 Eiern (35 Jourdain, 25 Rey, 2 Blasius): Durchschnitt $26.22 \times 19.58$, Mlaximum $28.2 \times 19.8$ und $26 \times 20.5$, Minimum $24 \times 18.2$. Durchschnittliches Gewicht $0.298 \mathrm{~g}$. Gelege 5--6 Eier, März und April.

\section{Lanius excubitor algeriensis Less.}

Lanius algeriensis Lesson, Rev. Zool. 1839, p. 134 (Uran).

Collurio ludovicianus var. robustus Baird, Amer. Naturalist. VII, p. 608 (1873-- "California"! Errore!).

Abbild.: Dresser, B. Europe III, I'at. 148.

Schnabel merklich stärker (höher) als hei L.e.exculitor. [nterscheidet sich ron allen hisher hesprochenen Formen durch weder weibliche moch rötliche. sondern graue Lnterseite. - Oherseite dumlel hleigrau. [nterseite hell aschgrau, Lnterschwandecken lichtgrau mit weiben Sïumen. Kehle und Nitte des Cnterkörues weiBlich. Lmmittellitr ïher dem Auge oft ein kleiner weiBlicher Strich, ein dentlicher Superciliarstreif aber nicht ausgehildet. Nur die Basis

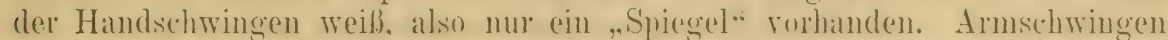
sehwallz mit werißen Spitzensïumen und hä̈unlichweißen Imensäumen. Schwanzzeichnung für eimen Würger sehr konstant: Äuberste stemerfeder: Aubenfilnne ganz oder fast ganz weib, Innenfahne an der Spitzenhälfte (oder etwas mehr oder weniger) weib, das Schwallz am Schafte meist his fast zur Suitze auslaufend; zweites und drittes Pallo mit nach immen zu an Ausdehmung ah)nehmenden weißen Spitzen; 4. und 5. Pałr mit schmalen weißen Säumenmittelstes Paar ganz schwarz. Flügel etwa 104-112 mm. - Juv. Oberseite bräunlich, Schwanz- und Schwingenspitzen rusthräunlich verwaschen, Cnterseite mit hrïunlichem Schimmer und gimz schwacher Trellenzedchnung, Kehle rahmmeiß.' ${ }^{1}$ (Über 25 untersucht.)

$\left.{ }^{1}\right)$ Ein Exemplar aus der Nähe der Stadt Tunis, in Whitakers Sammlung, vom Präparator Blanc in Tunis gekauft, hat Brust und Seiten gräulich-rosa, ähnlich wie L. e. meridionalis! Rücken dunkel wie bei typischen algeriensis, aber nicht so dunkel wie bei meridionalis. Unterkörper in der Mlitte weiß, weißer Flügelspiegel sehr ausgedehnt, viel Weiß an den Armschrringen, äußere beiden Steuerfedern weiß, an elegans erinnernd. 
Nord-MIarokko ('Tanger) und Nord-Algier. Genaue Grenze nateh Südeu nicht festgestellt, in Marokko wohl nur an der Nordküste entlimg, nicht mehr südlich ron Fe\%, in Algier anseheinend his zum Atlas. In Tunis nur ganz im Norden, bei der Stadt Tunis. Am 2. Juli 1892 wurde ein Stïck bei Florenz erlegt. C̈ber ein angeblich im Elsaß erlegtes Stück vergl. Blisius Notiz im Neuen Naumann IV p. 155.

Lebensweise wie die der Verwandten. Bewohnt offene Gegenden, besonders wo hohes Dorngestrüpp wuchert. Das Nest steht meist tief in den dornigen Büschen von Crataegus und Zizyphus. Die 4-6 Eier sind meist etwas heller als die von L.e. excubitor, oft ist die Grundfarbe weiß. Whitaker gibt als Durchschuittsmaß dasselbe wie bei $L$. e. elegans, nämlich $25 \times 19 \mathrm{~mm}$ an. Brutzeit April und Mai, ansnahmsweise bis in den Juni.

\section{Lanius excubitor dodsoni Whit.}

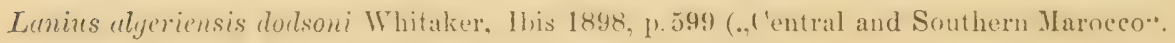
'Typen untersucht).

Oberseite etwas heller, soust ganz wie /.exc. algriensis. AuBerdem

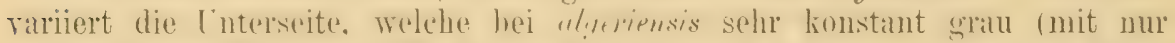
weiber oberer Koble und Mitte des Lnterkïrpers) zu sein seheint, ron dentselhen Gran wie bei chervensis his zu rahmweiblich mit nur greringem grauen Anfluge an Brustsciten und Weichen. (Etwa 50 verglichen.)

Bewohnt Mittel- und Süd-Marokko bis zum Atlas. Dio Würger aus

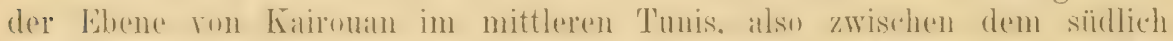

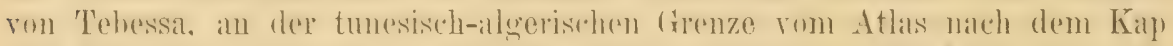

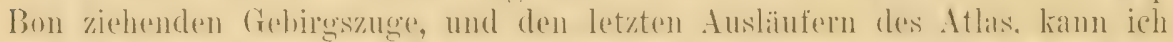

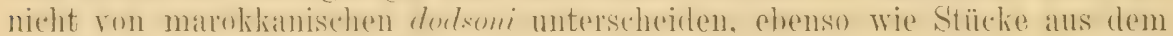

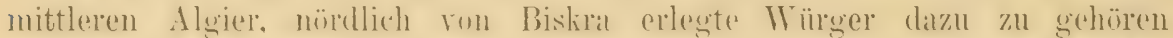

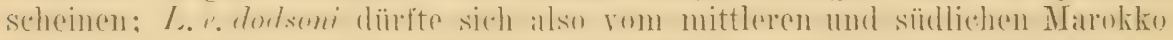
bis zum mittleren 'T'unis erstrecken und somit einen Streifen zwischen den

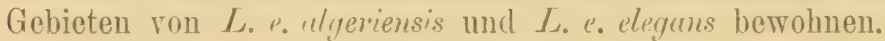

\section{Lanius excubitor koenigi Hart.}

Lanius alyeriensis linenigi Hartert, Nor. Zool. 1901, p. 309, 310 (Camaren: terra typica: 'Tenerife).

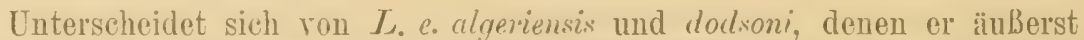

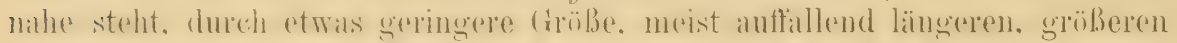
Sehmahel mit wröberem Haken und mit mehr oder minder dentlehen wenn anch sehmalen aher immer vorhandenen weiben Streffen ïher dem inge.

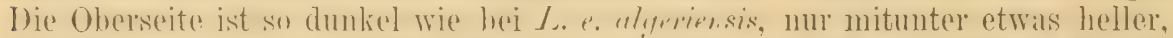
die Lnterseite aber raribert ähnlich wie hei dodsoni. indem sie hald so dunkel wio bei l.e. algeviensis, bald viel lichter ist. Flügel on o etwa $99-105 \mathrm{~mm}$. Wie bei allen diesen Würgern, sind die o kleiner, bei mehreren Formen aber lagen so wenig ganz zuverlässig sezierte Stücke ror, daß ich vorzog; die Mabe der Geschlechter nicht getrome anzugehen. - Jur.: (Oberseite sand-

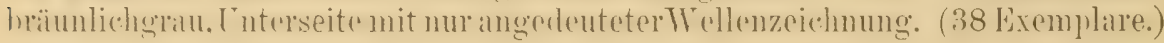

Canaren. Anscheinend alle Inseln. Stücke von 'Tenerife, Gran Canaria, Fuertaventura, Lanzarote ron mir rerglichen. 
Bewohnt buschreiches Gelände, besonders wo riesige Euphorbien aus dem Felsgestein aufragen, vom Littorale bis hoch hinauf auf den Pik von 'J'enerife. Lebensund Nistweise wie die der Verwandten. Durchschnittsmaß von 15 Eiern von Tenerife (Jourdain in litt.) $25.36>19$, Maximum 2 r.2 $>18.3$ und $26 \times 20$. Minimum $24>19.8$ und $25>18.2 \mathrm{~mm}$. Gewicht $268 \mathrm{mg}$.

\section{Lanius excubitor elegans Swains. (Fig. 77.)}

Lanius eleyans Swainson, Fauna Bor.-Amer. II, p. 122,1831- „Fur ('ountries". Errore! Der von mir untersuchte Typus stammt augenscheinlich aus Algier oder Tunis). Lanius hemileucurus Finsch \& Hartlaub, Vög. ()st-Afr. (г. d. Deekens Reisen IV). p.329 (1870 - Algier).

Abbild.: Cat. B. Brit. Mus. VIII, Taf. VII.

Schnabel hoch und dick wie bei algeriensis und dodsoni. Von diesen, seinen näehsten geographischen Nachbarn unterscheidet sich eleyuns wie folgt: Oberseite heller. Bürzel manchmal weißlich, viel mehr weiß in Schwanz und Flïgeln, Cnterseite ganz oder fast rein weib. Die Handschwingen sind
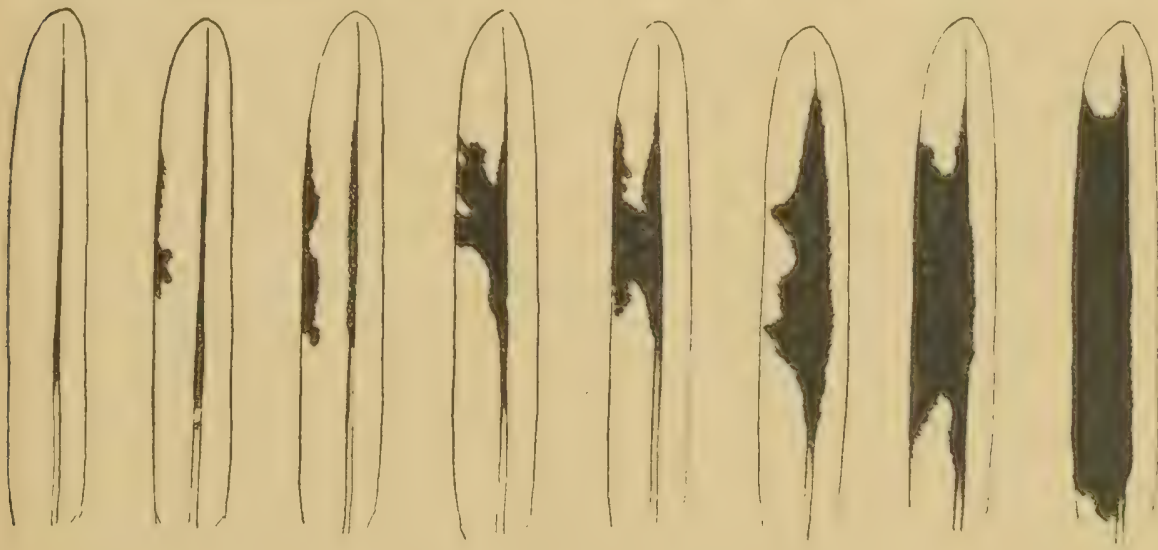

Figur 77.

Dritte Stenerfeder voll L. exc. elegans $(" / 3)$.

zur Hälfte oder mehr weiß, so dab cin sehr grober spiegul entstelst; die angrenzenden Armschwiugen hahen meist schwarze Aubenfahmen, sudab diesere

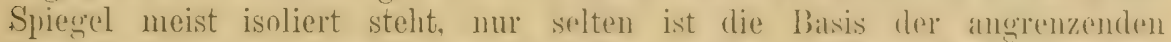

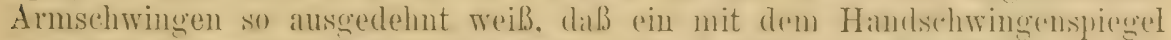
rerhundener zweiter Śpiegel entsteht. Die Iuschehnung des Meib an den mittleren Armsehwingen variert anderorelentlich; die Immentane ist hei den extremsten Stücken gaum weib, die Aubenfilne weil.) nit schwarzem, alm Schafte entlang laufenden, aher nicht his zur Spitze reichenden strejfen, der manchmal an seinem oberen Ende anf die Aubenfahne äherereift. Bej den am wenigsten typischen Stücken ist die Inmenfalne und die Aulienfalme grabitenteils sehwarz, die Spitze der Feder aher hat einen weilien saum. Fhensin rariabel ist das Weil des Schwanzes. Dic heiden äubersten Steuerfederpulare sind meist ganz weiB mit gröbtenteils schwallen selnäteu. das dritte variert von gamz weiß mit schwarzem Schafte his schwarz mit weilher Spitze und ehensolehen äußerster Basis. Eimzelne lixemplane haben div Schmanzzeichnung an 
deu beiden Seiten ungleich, indem die zweite oder dritte Steuerfeder an der linken oder rechten Yeite mehr sehwarz zeigt als an der andern. Das Gran der Oherseite variert, ist aber meist sebr viel heller, als hei dodsemi. Enterseite weiB, nur an den Wreichen oft ein graner Anflug. Oft (aber nicht immer) stimme die größere Ausdehnung von Weiß an Flügeln und Schwanz mit hellerer Oherseite ïherein, und umgekehrt. Die Ausdehnung des Weiß dürfte nur individuell, nicht aher nach dem Alter variieren, denn Neströgel zeigen schon dieselhen Cniterschiede wie alte Tögel. Flügel etwa 104-107, selten his 110, an einem gemessenen c $112 \mathrm{~mm}$. (Etwa 50 Exemplare verglichen.)

Vertritt die anderen Formen sïdlich der Ausläufer der Atlaskette in Tunis und Algier, und erstreckt sich bis Tripolis und Barka.

Bewohnt die Sahel-Region, wo sandiges Gelände mit meist dornigen Sträuchern spärlich bewachsen ist. Lebensweise wie die der Verwandten. Nest in dornigen Zizyphus-Büschen oder Mimosen, in den dornigen Zweigen wohl verwahrt. Nest aus meist hellgrauen Zweigen von Wüstenstrüuchern, die Julde mit Pftanzenwolle, Federehen und Spinngeweben ausgepolstert. Das Gelege, das man vom März bis Mai findet, besteht meist aus 4-6 Eiern. Diese sind weißlich bis isabell, mit grauen oder gelbbraunen, ausnahmstweise rostroten Flecken bedeckt, sowie hellgrauen bis lila-farbenen Schalenflecken. Die Eier messen im Durchschnitt nach Whitaker $25 \times 19$, nach König ron $22 \times 17,23 \times 18$ bis $27 \times 19$ und $28 \times 19 \mathrm{~mm}$. (Abbild. Journ. f. Orn. 1896 Taf. VI Fig. a-f.)

\section{Lanius excubitor leucopygos Hempr. \& Ehrenl).}

Lanius leucopygos Hemprich \& Ehrenberg, Symbolae Physicae fol, e und fol. dd, Beschreibung fol. d (1828 - Dongola, Egypten. Die Autoren hatten zwar die sonderbare Idee, dab diese Vögel Bastarde zwischen L.excubitor und minor wären, aber sie beschrieben dieselben kenntlich und nannten sie Lanius leucopygos. Der Name muB also bedingungslos angenommen werden. Dagegen ist $L$. maculatus, fol. e, dd nomen nudum, das sich vermutlich auf lencopygos juv. bezieht).

Lanizes pullens Cassin, Proc. Acad. Philad V, p. 245 (1852 - „Fazogloa, Eastern Africa“). Lanius pallens Cassin, Journ. Acad. Philad, 2nd ser. II, p. 258 'Taf. 23 fig. 1 (1854).

Lanius dealbatus Defilippi, Rer. \& IIag. Zool. 1853, p. 289 (Weißer Nil, von Brun Rollet gesammelt. 'Typus verglichen).

Lanius orbitalis Lichtenstein, Nomencl. Av. Mus. Zool. Berol., p). 12 (1854- Nomen nudum! Nubien. Vgl. Finsch \& Hartl., Vög. Ost-Afrikas, p. 329).

Lanius lenconotus Brehm, Journ. f. Orn. 1854, p. 147. (Im Winter in Sennaar am Blauen Nil. 'I'ypus verglichen.)

Abbild.: Cat. B. Brit. Mus. VIII, 'Taf. VI.

Leicht kenntlich an folgenden Merkmalen: Tnterer Bürzel und Oberschwanzdecken weib, nur die lïngsten S'chwanzdecken hellgrau; Größe gering, Shohathel klein. Flïgel kum: Cnterseite rein weiß, Brust mit einem feinen rahmbarhenen Hauche: die gewöhnliche schwarze Zeichnung der Kopfseiten reicht beim alten Togel in schmaler Stimbinde ïher den Schnabel hnn; Handschwingen utwa z.ur Hülfte weib. wodurch ein grober .Spiegel" entsteht. Innenfahnen der Armschwingen (mit Ausuahme der letzten) galnz oder doch gröbtenteils weib, Aubenfahnen schwalrz mit weißem Außensann und weiber Syitze, oft gribtenteils schwarz mit nur einem schwarzen Fleck in der Mlitte. Enterflügreldecken. rinschlieblich der Cnterhanddecken rein weiß, nur die eine grobe Lnterflïgeldedifeder an der Basis der ersten Schwinge hellgrau. Im 
Schwanz sind in der Regel die äußersten beiden Steuerfederpare ganz weiß mit schwarzen Schüften, die dritte weiß mit dem gröBten Teil der Innenfahne schwarz, selten mit etwas Schwarz an der Aubenfahne. Schnahel hei jungen Tögeln hraun, bei alten schwarz. Flügel etwa (ad.) 99-102, Schwanz meist etwa 113, Schmabel 15-16.5 mm. - Unterscheidet sich von dem ähnlichen I. e. elegans durch rein weiße Oberschwanzdecken und geringere Größe. (10 untersucht.)

Dieser Würger ist eigentlich nicht mehr paläarlitisch, dem er hewohnt Nubien etwa rom Atbara an, siidlich his Sennatr, Kordofan, zum Blauen und Teifen Nil. Er stheint in diesen Lïndern Standrogel zu sein und als alleiniger Tertreter dieser Gruppe die paläarktischen Grauwürger zur Brutzeit $z$ vertieten.

\section{Lanius excubitor pallidirostris Cass.}

Lanius pallidirostris Cassiu, Proc. Acad. Philad. V, p.244 (1852- „Eastern Africa“. Exemplar der Sammlung Rivoli).

Lanius assimilis Brehm, Journ. f. Orn. 1854, p. 146 (Oktober bis Frühjahr in Sennaar am Blauen Nil. 'Typus vor mir).

Lanius palliclus Antinori. Cat. deser. Coll. Uce., p.56 (186t- Trockene Sandhügel bei Kadaref an Blauen Nil; November. Typus untersucht).

Lanius Grimmi Bogdanow, Würger der russ. Faunn, in Faun. Zapiski Imp. Nauk XXXIX, p. 151 Taf. IV (1881- Atrek-Fluß an der persisch-transkaspischen Grenze, Ust-Urta, Taschkent, Alaschan, östl. bis Amu Darja, Syr Darja und Buchara. Russisch, Diagn. lat. - L. grimmi Bogdanows und späterer Autoren ist trotz gegenteiliger Angaben ein jüngerer Vogel, Der Typus, den ich nicht vergleichen konnte, scheint zu dieser Form, pallidirostris zu gehören, Stücke andrer Autoren teilweise zu aucheri. (Vgl. Dresser, B. Europe IX, Suppl., p. 153, Taf. 666 ).

Abbild.: Journ. Acad. Philad. 2nd ser. II 'Taf. 23 fig. 2.

Unterscheidet sich ron dem sehr ähnlichen I. e. eleguns aus Sï̈l-Algier und Süd-Tunis durch das Fehlen des großen grauen Fleckes am Unterflügel und rosigem Schimmer an Kropf und Brust; von L. excubitor aucheri durch nicht im geringsten graue oder gräuliche. soudern rosige Brust. Fehleu des grauen Fleckes am Unterflïgel, mehr Weib an den Armschwingen, gänzlich fehlenden oder nur angedeuteten schwarzen Querstreifen am vordersten Stirmande, weißen Strich an der Vorderstirn und üloer den Augen und durchsehnittlich auch etwas kürzeren Schmahel. Das Gratu an den kleinen Oberflügeldecken etwas ausgedehnter. Der Name pallidirostris ist unglücklich, denn ganz alte Tögel hahen auch bei dieser Art einen schwarzen Sehnahel. Die Oherseite ist hellgrau, etwa wie bei L. raxhlitor eleyans, meist zieht der Bürzel wie hei jencr etwas ins Wreißliche, was hei ancher nie der Fall ist. Treif im Flügel variahel. Handsehwingen etwa zur Hälfte veiß, so daß ein grober Flügelspiegel entsteht. Innere Armsehwingen meist an den Inuenfahnen ganz weib, Anßenfahneu grüßtenteils schwarz mit ausgedehnter weiber Spitze: auch im dunkelsten Extrem sind die Imneufahnen nath der Basis z, weil. ÄuBerstes Steuerfederpar immer weib mit schwarzem Shafte; zweites chenso oder mit einigen. meist umegrelmäbig hegrenzten schwarzen Zeichnungen, drittes meist schwarz mit weilon' Spitze. Schmabel meist etwas kïrzer, als hei l. exul. anrheri. hei einem ron 
Erlanger bei Daddal im nordëstlichen Sumalilande gesammelten Stïcke abnorm croß. Flügel etwal 10i)-112, selten bis 117, schwanz $10 t-116 \mathrm{~mm}$, die kleineren Stüreke die größeren C. Äußerstes Steuerfederpalar $25-30 \mathrm{~mm}$ kürzer als mittelstes. - Die Jungen sind auf der Cnterseite nicht gewellt, die Brust ist blaß isahell his isabell-rötlich oder gräulich weinfarben, nicht rein rosig. Oherseite und alle weißen Zeichnungen mehr oder minder isabell. (52 Exemplare untersucht.)

Nach dem vom mir untersuchten Material, namentlich den vou Sarudny und Härms gesammelten Serien, muß ich amnehmen, daß dieser Trürger trotz gewenteiliger Angahen in ganz anderen Gebieten brütet als L. e. aucheri, nïmlich in den Stepuengebieten ron Transkispien, östlich mindestens bis zum Syr Darja. Lis liegen zwalr auch fast vällig rermauserte Stïcke aus Persisch Baluchistan (allso dem Brutgebiet von aurheri) aus dem Juli vor, aher ein Beweis des Brïtens daselhst ist nicht erhracht. Im Herbst und Winter ist er unstet und schweift weit umher. Während cin Teil schon in Persien und Baluchistan äberwintert, ziehen andere nach Nuhien, zum Blamen und Wrißen Nil und sogure his in die Gallaländer und das nördliehe Somaliland. Es ist hemerkenswert, daß diese Furm auf dem '/uge nieht selten am IssikKul und am Loh-Nor, sonve im zentralen 'Tian-Sehan und in der Russischen Kette im westlichen Kü̈en-Lün (Kwen Isun) erheutet wurde (Petershnurger Museum). Ein Stïek der Przewalshischen Sammlung, cin $q$ jur. ist sogar Alischan etikettiert - doch sind anseheinend keine dieser Stiuclie Brutvögel jener Gegenden.

\section{Lanius excubitor aucheri Bp. ${ }^{1}$ ) (Fig. 75, 78.)}

Lanius ancheri Bonaparte, Rer. \& Mag. Zool., 1853, p. 294 (Persien! Die Untersuchung der Typen im Pariser und des Cotypus im Britisehen Museum haben ergeben, daß es sich zmeifellos um diese Form handelt).

Lanius fallax Heuglin, Orn. N. O. Afr. I, p.482 (1869- ex Finsch M.S., Bogos-Länder); Finsch, Traus. Zool. Soc. Loudon VII, p. 249 Taf. 25 (1872- Rairo [Typus untersucht] und Ain im Bogosland, Abessinien).

1) Südlich schließt sich an, ist aber Tropenbewohner und berïhrt nur die Grenzgebiete der paläarktischen Fauna:

\section{Lanius excubitor lahtora (Sykes).}

Collurio Lahtora Sykes, Proc. Zool. Soc. London 1832, p. 86 (Dekkan).

Gekennzeichnet durch die ganz, oder fast ganz schwarzen kleinen Oberflügeldecken, verhältnismäßig breites schwarzes Stirnband und bis an die Halsseiten verlängerten schwarzen Fleck der Ohrgegend. - Die schwarzen Zügel sind durch ein mehr oder minder breites Stirnband verbunden; dies variiert zwar an Breite, ist aber meist so breit wie bei keiner andern Form. Die Oberflügeldecken siud alle schwarz, oder nur die dem Armrande zunächst stehenden haben hellgraue Spitzen und sind bisweilen ganz grau; bei den andern Formen sind die kleinen Flügeldecken alle grau. Unterflügeldecken und Axillaren reinweiß, oder doch nur einige der Unterhanddecken grau verwaschen. Basis der Handschwingen weiß, Armschwingen mit ganz oder größtenteils weißer Innenfahne, ausgedehnten weißen Spitzen und breiten weißen Außenfahnen. Schwanz ziemlich lang, etwa 114--130, Flügel 106-113 mm.

Bewolnt die Ebenen Indiens, aber nicht weiter südlich ala Goa und nicht östlich von Calcutta, westlich bis Sindh, Afghanistan und Baluchistan. 
Von den auf der Unterseite älnhlichen nordwestafrikanischen Formen, L. $e$. algeriensis und $L$. e. dodsoni auf den ersten Blick dureh die zwar variierende aber immer viel heller graue Oberseite untersehieden, vou allen andern asiatischen
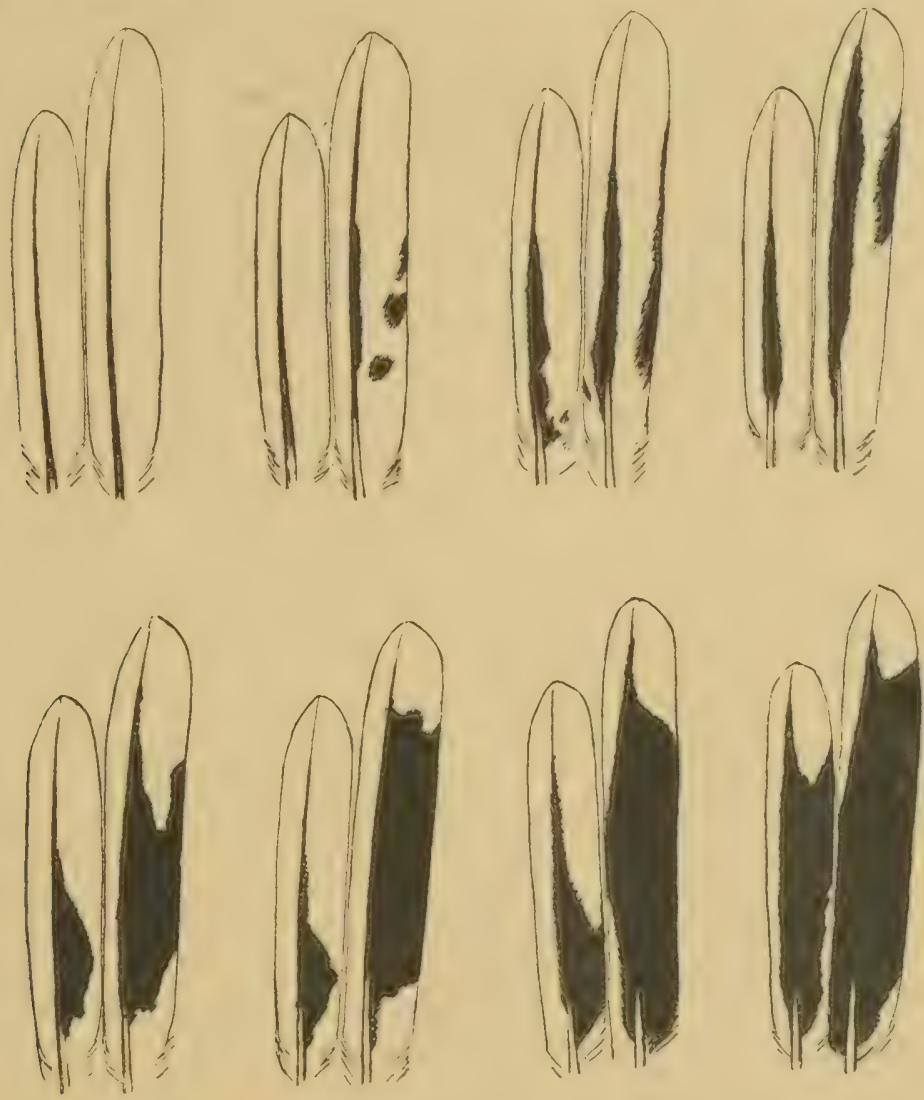

Figur 78.

Äußerstes Steuerfederpaar von $L$. exc. aucheri $(2 / 8)$.

und nordostafrikanischen Graumürgern durch die mehr oder minder gräuliche Unterseite. Bald ist der größere Teil der Unterseite, besunders die Brust-und

Außerdem bewohnt noch eine Form dieser Würger die Insel Sokotra:

\section{Lanius excubitor uncinatus Scl. \& Hartl.}

Lanius uncinatus Sclater \& Hartlaub, Proc. Zool. Soc. London 1881, p. 168, fig. 1 (Sokotra).

Sehr ähnlich L. e. aucheri, aber etwas kleiner, kurzflügliger, schmalschwänziger, das Weiß an der Basis der Handschwingen viel beschränkter. Schuabel dünn, gestreckt, meist in einen merklich größeren Haken ausgezogen. Flïgel $98--100 \mathrm{~mm}$. Insel Soliotra.

Von den übrigen bisher beschriebenen Grauwürgern des tropischen Afrika kann keine als geographische Form rou L. excubitor betrachtet werden. (Vgl. Reichenow; Vög. Afr. II, p. 605-623.) 
Körperseiten hellgrau (ïhnlich wie bei dem nordwestafrikanisehen dodxoni), sodaßB eigentlich nur die Kehle, Nitte des Unterkörpers und Unterschwanzdecken fast weiß bleihen, bald ist die Lnterseite weils zu nennen, und nur an den Brust- und Körperseiten zeigt sich ein grauer Schimmer, der besonders beim Aufheben der Brustferlern sichthar wird. Unterhanddecken grau, wodurch ein meist sehr deutlicher grauer Fleck am Unterflügel entsteht. Ad.: Oberseite rein assehgran; schmaler Stirnstreif, Zügel, sehr schmaler Streif ïher. hreiterer unter, und großer Ohrfleck hinter dem Auge zusammenhängend sehwarz. Nur im alogetragenen Gefieder bemerkt man eine weißliche Linie überm Auge. Aubenfihnen der Schulterfittiche weiß. Kleine Oberflügeldecken grau, meist etwas weniger ansgedehnt als bei pallidirostris, die ührigen schwarz. Schwingen schwarz, Basis der Handsehwingen ungeführ zur Hälfte weiß; Armschwingen an den Spitzen weiß, Sam der Innenfahnen weib oder weißlich. Schwanz: meist ist das Aulseupar weiß mit schwarzem Sehaft, das zweito schwarz mit ausgedehnter weißer Spitze. Fariation: Bald sind die zwei äuberen Paare weil mit sehwarzem Schafte, bisweilen ist das Aubenpare zu zwei Dritteln schwarz, das folgende ebenfalls schwal\% mit einer kitum 2 'm langen weißen Spitze. Zwische'n diesen Lixtremen finden sich alle Cherginnge (Fig. 78), in letzterem Falle ist das Schvalrz am ïubersten l'are nicht gerade ahgesehnitten, sondern verlüuft unregelmißBig, meist am Schaite am weitesten hinauf. Schmabel nur im Alter gamz sehwal\%. Flügel etwa $107-116$, meist $108-110 \mathrm{~mm}$, Schwanz etwa 106-118. Juv. Seiten und Vorderhrust gräulich-rosa oder hell schmutzig weinfarben, (Cherseite mehr oder minder sandfarthen oder rostgelhlich, Spitzen der mittleren und groben Oherflügeldeckfedern weiBlich sindgelb, Schnabel bräunlich. Das Nestkleid hat Andeutung von Querwellung an Oberseite, Kropf und Brustseiten. (Nach 129 Exemplaren.)

Hat angenscheinlich ein weites Brutgehiet: von Ost-Persien und PersischBaluchistan durch Persien und Mesopotamien his Palïstina und den Inseln des roten Meeres (Dithlak), vielleicht anch an der West-Küste des roten Neeres. - Im Winter heiben viele in P'ersien und Baluchistan, andere aber ziehen bis Abessinien und Somaliland.

\section{Lanius exœubitor buryi Lorenz \& Hellm.}

Lanius buryi Lorenz \& Hellmayr, Orn. II onatsher. 1901 p. 39, Denkschr. Akad. WVien IAXI p. 112, 1902 (Yeshbum in Südarabien). Typus untersucht.

Lanius arabicus Grant, Bull. B. O. Club XV, p.78 (Mlai 1905- Amiri-Distrikt in Südarabien, Typus untersucht).

(ranze Oberseite einfarbig schiefergran, nur die Spitzen der längsten Sehulterfedern weißlich, Oherflügelderken sehwarz, nur die lileinsten, nahe dem Yorderrande. mit sehiefergratten Spitzen. Handsehwingen mit ausgralehnter weiber Basis, die somit einen groben Spiegel bildet, und mit schmalen weißen spitzensäumen. Armsehwingen mit etwas breiteren weißen Sifitzrn. Aubenfahnen rein schwarz, Imnenfihnen mit graubräunlichen Imensilumen. Nittelstes steneriederpar ganz schwarz oder mit nur sehr schmalen weiben spitzen, die übrigen mit nach außen zu ron Feder zu Feder an Ausdehmung zunchmenden weiben Spitzen. Torletates Stenerfederpan mit einem grolben Teil der Aubenfahme, äuberstes mit der ganzen Aubenfahne weiß. 
Unterseite, meist einschließlich von Kinn und Kehle grau, Unterschwimzdecken weißlich, Mitte des Bauches, oft ein groler Teil des Lnterkörpers weils. Enterhanddecken dunkelgrau bis schwärzlich, ührige U'nterflügeldecken nud Axillaren mehroder minder sehiefergrau verwasehen und getrüht. Flügel 103 - 111), Schwanz etwa 102-108, Lauf 28 -30 mm. - Tou dem ihm sehr älmlichen algeriensis meistens durch graue Kehle und sehmales schwarzes Stirnhand. ron dem ihm genetisch wohl am nächsten stehenden aucheri durch riel dunklere Ober- und Unterseite sorwie durch das viel hesechränktere Weiß an den Spitzen der Schulterfittiche unterschieden. (20) untersucht.)

Brutvogel in Sïd-Arabien. Yeshlum, Amiri-Gebiet istlich der Grenze von Yemen (Hl Kubar, Ithala, Gerba, Iranat). - Das Brüten in Sï̈l-Arabien wird durch ganz junge Vögel im Britischen Museum berviesen.

\section{Lanius sphenocercus sphenocercus (ah.}

Lanius sphenocercus Cabanis, Journ. f. Orn. 1873, p. 76 (,angeblich von Canton“6).

Abbild.: David \& Oustalet, Ois. Chine Taf. 76.

ơad. Oberseite einsehließlich des Bürzels und der Oherschwanzdecken einförmig grau, Außensïume der Schulterfittiche weiß. Zügel und Fleck unterm Ange bis über die Ohrgegend hinaus schwarz: lieine Sipur rou einer schwarzen Stirubinde, dagegen vorderste Stirnfedern und Linie üher Auge und Ohrdecken weiß. Schwanz erheblich lïnger als Flïgel, stark gestuft, mittelstes Steuerfederpar mehr als sonst üher dils nüchste Paar hinaus verlïngert. Drei äußerste Steuerfederparre meist ganz weil, selten mit etwas schwarzer Zeichnung. Handschwingen mit ansgedehnter weißer Basis, Armschwingen meist weiß mit großem, schwarzem Felde, das sich tränenförmig von der Wurzel her sehmal am Schafte entlang fortsetzt und sich nach der Spitze hiu so verbreitert. daß die Spitzenhälfte sehwarz ist mit weißem Saum. Kleine Oberfügeldecken grau. [Tnterseite weiß, Brust und Seiten im frischen Gefieder mit trüb rosa Schimmer. Lnterflügeldecken und Achselfedern weib, nur die Lnterhanddecken teilweise grau. Flügel etwa 116-125, Schwauz 130-148 mm, äußerstes Steuerfederpar mehr als $50 \mathrm{~mm}$ kürzer als mittelstes! o und juv. mit größtenteils weißen Zügeh. Juv. mit stärkerem und mehr gelh-rötlichem Schimmer an der Brust. (11 Stück untersucht.)

Bewolnnt zur Brutzeit die südöstliche Mongolei, Ordos. Schensi, Ussurien und Korea. Przewalski fand ihn auch im Kreise Turfan am Südabhange des östlichen Tian-Schan und im Ala-Schan. -- Im sücllicheren I'hina. wo er bis zum Jangtsekiang, Nanking und Canton vorkommt, jedenfalls nur Wintervogel. - Unterscheidet sich von den anderen Grauwürgern wesentlich durch den sehr langen und stark stufigen Schwanz. Trotzlem wïrde ich geneigt sein, ihn als Vertreter der excubitor-Gruppe anzusehen, er scheint indessen mit excubitor-Formen zusammen zu leben (Turfu, Ala-Schan, ? Cssurien). ") daher behandele ich ihn der Torsicht halber z. Z. (wie bisher in diesem Werke) als „artlich" verschieden.

1) Man vgl. L. e.przewalskii und (?) mollis.

E. Hartert, Die Vögel der paläarktischen Region. 


\section{Lanius sphenocercus giganteus Przew.}

Lanius giganteus Przewnlkki, Zapiski Imp. Akad. Nauk St. Petersburg LV, p. 86 (1887lat. Diagn.. sonst russisch. Mai 1880 am ob. Gelben Flusse, 1884 am Kukunor nistend). Übers.: Journ. f. Orn. 1887 p. 280 . Typus untersucht.

çad. Größer und dunkler als I. sph. sphenocercus, ohne weiße Linie an der Stirn und ïher den Augen. Oberseite dunkel grau, etwa wie bei I. e. merilionclis, auf Bürzel und Oherschwanzdecken etwas heller. Zügel, Partie unter dem Auge und Ohrgegend schwarz. Schulterfittiche mit weiBer Suitzenhälfte. Schwingen schwarz, Basis der Handschwingen ausgedehnt weiß, Armschwingen nur mit weißen Śpitzensäumen und weißlichem Außensaum. Kleine Oherflügeldecken grau, die übrigen schwary. Mittelstes Stenerfederpaar schwarz, die nächstfolgenden mit weißen, nach außen zu von Feder zu Feder an Ausdehnumg zunehmenden Spitzen, sodaß das äußerste Paar nur noth an der Inuenfahne einen schmalen schwarzen Fleck hat. Kehle weiß, ïhrige Cuterseite waiß mit rosigem Schimmer. Lnterflïgeldecken weiß. Flügel etwa 140-141 mm, Schwanz 16(1)-173. - Jur. Oberseite heller, bräunlich siudgelh verwaschen. Kehle weiß, ührige Cnterseite mit gelbbräunlichrosigem Schimmer. (3 Exemplare.)

Kansu, am oberen Gelben Fluß, Kuku-Nor.

\section{Lanius senator senator L.}

\section{Rotköpfiger Würger, Rotkopfwürger.}

Lanius Senator Linnaeus, Syst. Nat. Ed. X, p. 94 (1758- Einzig und allein aus Albin, Birds II, p. 15 Taf. 16. „Habitat in Indiis" Errore! Obgleich Abbildung und Beschreibung Albin's nicht schön sind, unterliegt es doch durchaus keinem Zweifel, daß er den rotköpfigen Würger vor sich hatte. Albin gibt keine Lokalität an, soudern sagt nur, er habe den Vogel aus der Sammlung ron Sir Thomas Lowther gehabt, und fügt hinzu, daß Willoughby ein Stück vom Khein beschreibe. Wie Linné zu der Angabe, "In Indiis" kam ist unerfindlich, ähnliche Flïchtigkeiten aber kommen bei ilım mehrfach vor. Wir fixieren als terra typica: Rhein).

Lanius miceps Pallas, Vroeg's Cat. Verzam. Vogelen, dieren, Adumbratiuncula, p. 1 (1761- Holland).

Lanius auriculatus P. L. S. Müller, Natursystem, Suppl., p. 71 (1776- Partim! Unzulängliche Beschreibung, aber auf Buffons, resp. Daubentons „Pie-Griêche rousse" (Taf. 9 fig. 2, X fig. 1) basiert. Muillers Schlußsatz von einer ,gewisseu Verschiedenheit mit roter Brust" bezieht sich jedenfalls auf $L$. colluvio, auf dessen 9 sich übrigens auch 'Taf. 31 fig. 1 bezieht).

Lanius mfus Gmelin, Syst. Nat. I, p.301 (1788- Europa! Basiert auf Brisson's „PieGriesche rousse" [Orn. II p.147]. Man hat wegen der Beschreib. d. Schwanzes als halb weiß, halb schwarz den Namen rufus auf die richtig niloticus zu nennende Form angewandt; dies ist falsch, denn Gmelin beschreibt, wie seine Zitate zeigen, den europäischen Vogel, den rotköpfigen Würger von Ray, Schwenckfeld, Klein, Frisch [T'af. 61 ausgezeichnetes Bild], Albin usw. Einige von Brissons Zitaten beziehen sich auch auf $\boldsymbol{L}$. collurio. Die Schwanzbeschreibung ist natürlich cum grano salis zu nehmen und es ist dadurch nicht die nubischnilotische Form gekennzeichnet. Von diesem Fundorte ist kein Wort erwähnt!).

Lanius senegalensis (imelin. Syst. Xiat. I. p.301 (1788- Senegal. Ex Buffon's [rectius Daubenton's] Pl. Enl. 477, fig. 2; eine greuliche Abbildung, von der man aber annehmen muB, daß sie einen Rotkopfwürger darstellt). 
Lanius rutilus Latham, Ind. Orn. I, p. 70 (1790- „Habitat in Europa6. Ex Brisson, Gmelin, Ray, Frisch, Klein, Buffon usw.).

Lanius pomeramus Sparrman, M useum Carlson. Fasc. I Nr.1. Taf. I (1798- „Pomerania“). Lanius ruficollis Stephens, in Shaw's Gen. Zool. VII, p. 316 (1809- Europa).

Lanius melanotos Brehm, Isis 1828, p. 1275 (nom. nud.); Handb. Naturg. Vög. Deutschl., p. 238 (1831-, ,in den deutschen Ebenen ${ }^{66}$ ).

Lanius rutilans Temminck, Man. d'Orn. IV, p. 601 (1840- beruht auf dem von Daubenton, PI. Enl., Taf. 477 fig. 2 abgebildeten Pie-Grièche rousse du Sénégal. Siehe oben).

Phoneus rufus longirostris, brachypterus, medius. pluniceps, superciliosus A. E. Brehm, Verz. Samml., p. 3 (1866- nomina nuda!).

Engl.: Woodchat Shrike. Franz: Pie-grièche rousse. Ital.: Arerla capirossa.

Sad. Stim in rechselnder Ausdehnumg ron 5-15, meist etwa $10 \mathrm{~mm}$ schwar\%, diese Farbe in breitem Bande von der Stirn durch die Augen, üher die Ohrdecken und Nilckenseiten his an die Rückenseiten fortgeführt. Zügel mit größerem oder lileineren rahmweißen Fleck, der manchnal jederseits isoliert steht, manchmal in sehmalem, aber etwas an Ausdehnumg wechseluden Querbande über der Schahelwurzel hinzieht. Scheitel. Oherkopf und Nacken braumot. Oberrïcken schwarz, im frischen Horbstleide mit schmalen rotmaunen Federrändem; Hinterï̈ken grau; Oberschwanzdecken weil, mehr oder minder röstlich ülertüncht, die längsten grau, nach den Spritzen zu sehwärzlich. Schwingen braunschwarz, Innensäume weiblich, Basis der Handschwingen etwa ${ }^{1 / 3}$ bis $1 / 2$ weib. sudab ror den Handdeckem ein grober weiBer "Spiegel" entsteht, innere Handschwingen im frischen Gefieder mit schmalen weißen Spitzen. Armschwingen mit bell röstlichen End- und Außensäumen, die sich später ahtragen. Oberflügeldechen hramsehwarz, im Herbste mit hellhraunen Ränderm. Schulterfittiche weib. Mittelstes Palar Stenerfedern schwar\% his zur Wrurzel, die folgenden mit an Ausclohmung zumehmendem weißen Basalteil. äußerstes Stenerfederpala weib mit etwa $1^{1 / 2}$-2 (em weitem schwarzen anteapikalen Fleck. Äuberes Paar mit meist etwa 1 c'm langer weißer Śnitze, die übrigen mit immer schmäler werdenden weiben Fndsäumen, die am mittelsten Palare nur eine schmale. spüter sich abtragende Linie bilden. Ganze Lnterseite weib mit rustgelbem, an der Torderbrust und besonders an den śeiten stärkeren Anflug. der im Sommer

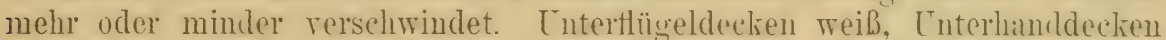
und Flecke nahe am Flügelhug schwärzlich. Iris braun, Sehnahel und FüßBe schwarz. Flügel 93-100.5, Sichwanz etwa 75-85, Lauf 23-25, Schulhel 15-17 mm. o dem C’ähnlich, aber der Rücken dunkel graubraun austatt schmarz, die weißen Teile stärker rostgelb ühertüncht, der schwarze Streif an den Kopfseiten meist etwas schmaler und weniger rein schwarz. meist aber nicht immer - das Braumot des Kopfes heller. Seln alte o hahen einen fast schwarzen Rücken. Jüngere Vögel haben Ancleutungen von Quelwellen auf der Lnterseite. Jur. Nestkleid: Federn der Oberseite an der Trurzel grau, an der Spritze meiBlich mit hraumschwarzer anteapilialer Bugenlinie, Unterseite brïunlichweib, schuppeuatig mit dunkelhaunen anteapilialen Linien gezeichnet, Mitte des Enterkürpers einförmigrer. Auf dieses erste Kleid folgt ein sehr ähnliches mit bräunlichem Rücken und rötlichbramem Oberkopfe, darauf erst das Alterskleid. (Üher 100 Exemplare untersucht.)

Bewohnt als Brutrogel die Mittelmeerländer: Tripolis. Tunis, Algrier, besonders nördlich des Atlas, Marokio someit es durehforscht wurde, 


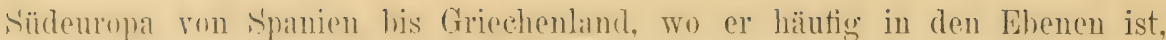

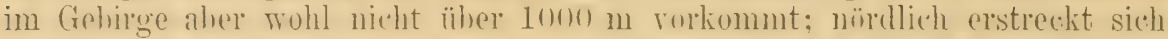
das Brutgelset durch Frankexich his nawh Belgien und Holland, dureh Italien

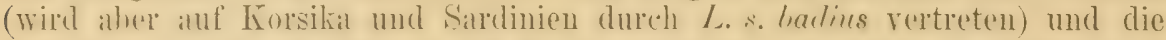
niedrigeren 'Trile der S'chweiz his Torddentschlaud (ist jedoch in I)entschland sehr lukial und in Torden sehr selten), durch Österreich-Tugirn (ehenfills sehr lokial) his Griechenland, Sürdrubland, Kaukasus. Kleinasien. Genaue

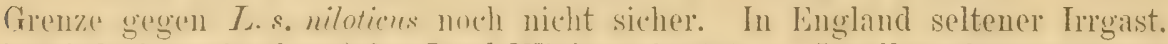
hat jedorh zweimal auf der Insel Wight gehritet. - In allen obengenamnten Isändern Zngrogel. der wie 's seheint nur in nordwestlichen Afrika sï̈llich der Sahara üherwintert (Senesumhien, Haussaland, Nigerien). ('alnera und 'Thamner erheuteten vereinzelte Stüche anf 'I'nerife. - Verschiedene Antoren (atuch ich früher, unterscheden subspezifisch oder gat spezifisch die norelafrikanischen Brutrögel. Kuenig gahl an. sie hätten hellere Köpfe. Hrlanger fand in einem stälieren lostfarbenen Influg der I'nterseite cin Kenuzeichen, Wiss aher durehaus nicht richtig ist. Kleinsehmidt (in litt.) glauhte in dem helleren Bümel mancher Afrikaner ein Merkmal gefunden zu haben. Hilgert (in litt.) meint, die geographisehe Terbreitnng sei zu bedenkeu, himm aber nur wenige stücke an lohbalterem, dunkleren Rot der Kö̈nfe (also dis Gegenteil von Koenigs Kennzeichen) unter,heiden. Nich Lntersuchung von ïher 100 Stücken kimu ich keine Interschede feststellen. dem die helleren Köpfe sind nur bei Tögeln während nud nitch der Brutzeit vorhanden, aher nicht nur in Afrikit. wo allerdings das Verhleichen der Farben in etwas stärierem Mabe stattfindet. Trh kamn also eine Tremmung nicht billigen. Übrigens ist kein Name für die nordwestafrikanischen Brutvögel verwendbar.

In der Lebensweise stimmt der rotköpfige Würger im allgemeinen mit seinen Gattungsgenossen ïberein. Er bewohnt Feldhölzer, Waldränder. Blößen im Laubwalde, Alleen, Parkanlagen usw. Stimme rauh wie krähts, kjäck, kjäck, im Gesange andere Vögel nachahmend. Nest auf Bäumen, ähnlich dem von Lanius minor aber kleiner, oft mit immergrinen und grauen, weichhaarigen, wolligen und duftenden Pflanzen und Bliiten geschmückt. Standort meist hoch, in Deutschland selten unter $4 \mathrm{~m}$, im Mediterrangebiet oft niedriger. Gelege in Deutschland im Mai, im Sïden schon im April. Die 5-6, selten 7 Eier, sind denen von Lanius collurio sehr ähnlich, aber durchschnittlich größer, jedoch sind die rötlichen Eier mit roter Fleckenzeichnung selten und werden in Deutschlund fast nie gefunden. Durchschnitt von 100 europäischen Eiern $22.88 \times 16.98$, Maximum $29 \times 19,27 \times 17$ und $23.9 \times 17.8$, Minimum $18.3 \times 22.8,21 \times 15.9$ und $22.1 \times$ $15.7 \mathrm{~mm}$. Koenig mißt 23 nordafrikanische Eier: Durchschnitt 23.74 $\times 17.17$, Naximum $27 \times 18$ und $25>19$, Ninimum $22>18$ und $23 \times 17 \mathrm{~mm}$. Gewicht 0.170 bis 0.240 , im Durchschnitt $0.191 \mathrm{~g}$.

\section{Lanius senator niloticus (Bp.).}

Enneoctonus niloticus Bonaparte, Rev. Zool. 1853, p. 439 (Weißer Nil. Die Typen im Pariser. Museum haben $30 \mathrm{~mm}$ weite weiße Basis der beiden mittelsten Steuerfedern).

? Enneoctonus pectoralis v. Miüller, Journ. f. Orn. 1855, p. 450 („,Sennaar". Die Diagnose lautet: „Simillimus $E$. rufo, sed pectore eiunamomeo, speculo alari minore". 1899 bezog ich [Nov. Zool. p.416] diesen Namen auf die nordwestafrikanische Form, die angeblich auch in den Nilländern vorkommen sollte. Ich bin nun überzeugt, daß der Name nicht sicher gedentet werden kann).

Enneoctonus Jardinii v. Müller, Journ. f. Orn. 1855, p. 450 („Sennaar und Nubien“". Diagnose konfus, aber auf niloticus zu beziehen). 
Lanius paradoxus A. E. Brehm, Journ. f. Orn. 1854, p. 75, Anm. (Kein Fundort); C. L. Brehm, Vogelfang, p.84 (1855- .Im Winter in Ägypten, auch in Sïdeuropa". Letztere Behauptung anscheinend ganz unbegründet. Die 'I'ypen stammen rom Blauen Nil).

Lanius cognatus Brehm, Vogelfang, p.81 (1855- ,Verirrt sich nach Siideuropa". Vermutlich nach einem aus Nubien oder vom Blauen Nil stammenden Stïck beschrieben, die Angrabe rom Verirren [wie oftmals ähnlich lautende im Vogelfang] unbegrïndet).

Unterscheidet sich auffallend von $L$. s. senator dadurch, daß die Basis der mittelsten Stenerfedern 2-3 (m weit rein weils ist: dies ist schon hei

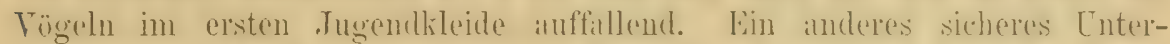
scheidungsmerkmal gilit es nicht, indessen ist der stehmahel in der Regel

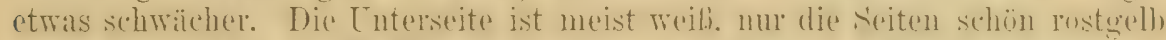
rerwischen. Der meibe Flügelspiegel an der basis der Handschwingen ist immer groß und deutlich. - Bisweilen, wenn auch sehr selten, tritt die weilie Basis der mittelsten Stenerfedern auch in andern frecenden auf. demn mir liegt ein o ans 'Tunis (P. Spatz) vom 21. Juni 190:3, und ein ô aus der Turiner Gegend rom 2. Mai 1885 mit etwal of em langer weriber sehwanz-

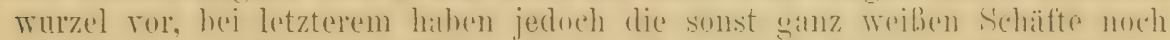
eine schwarze Linie. - Ein junger Yogel aus S. W. Persien (Witherby) ist sehr hell.

Brutrogel im südlichen Persien und l'alïstina: äherwintert in X.o. Afrikil ron Nubien his Ladde und Tord-somaliland, anch hisweilen in Arahien. Sönll einmal in Sindh vorgekommen sein.

Eier wie die ron L. s. senator: (Vgl. Ibis 1905, p. 527, Taf. XI fig. 4, 7.)

\section{Lanius senator badius Hartl.}

Lanius badius Hartlaub, Journ, f. Orn. 1854, p. 100 (Goldkïste):

Abbild.: Journ. f. Orn. 1906, Taf. H fig. 4 (das Rot des Kopfes nicht gut).

Unterscheidet sich ron I. senator senator dureh das Fehlen des weiben

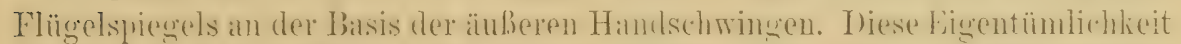
ist heim è sehr auffallend, hei cinigen stärken. namentlich hei den meisten

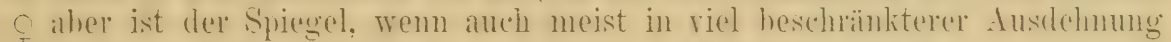
vorhanden. Außerdem ist der Schnabel meist stärker, als bei $L_{\text {. }}$ s. senator und im frisch vermanserten Gefieder ist die Firlonumg alter ce dunkier: das Rothraun des Tonfes ist bei alten e im frischen Gefieder sebr dunkel, im Sommer dagegen sehr hell. das meibe Bürzelhand erseheint schmiller, Büryel und Cinterseite sind meist schr stirti rustegelh üherlaufen. Ihas Flïgehmal. ist grob, indem e's sich mit $98-104 \mathrm{~mm}$ an der wheren Grenze von I. s. senator und darïber hält. - Juv. Auf der Oberseite heller,

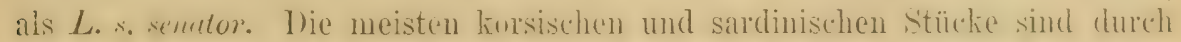
obige Eigrentümlichkeiten sehr kenntlich. einige aher sinu nielit sicher von L. s. senator zu unterscheiden. Diese sind den Daten mach z. 'T. Zugvögel, einige aher scheinen doch aherrante. vielleicht atavistische. ludins zu sein. Auch ans Aord-Tunis liegen mir zwei d ror, die keinen weißen Elügedsyiegel haben - eins im Norember, eins am 21. Juni erlegt!

Bewohnt zur Brutzeit die Inseln Finsikit und Saldinien und üherwintert im nördlichen Westafrika (Goldküiste bis zum Niger). 
Ende Mai und erste Hälfte Juni fand Whitehead auf Korsika viele Gelege. Die Vögel trafen dort erst von Mitte April an wieder ein, auf Sardinien ebenfalls Zugvogel. Gelege 5-6 Eier, wie die von L. s. senator.

\section{Lanius nubicus licht.}

Lanius nubicus Lichtenstein, Verz. Doubl, p.47 (1823- Nubien).

Lanius personatuis Temminck, Pl. Col: III, Taf. 256, f. 2 (Dezember 1823- später als Licht., Verz. Doubl., das Temm. schon zitiert- Akaba in Arabien).

Lanius leucometopon v. d. Mïhle, Beitr. Orn. Griechenl., p.78 (1844- Griechenland). Lanius gruecus Lindermayer, Ahh. naturh. Ver. Passau 1859. p. 132. Vögel Griechenlands (Separatabdruck 1860), p. 115 (Griechenland).

Lanius lencopterus et albicollis Heuglin, Orn. N.O. Afr. I, p. 485 (1869- ex Paul v. Württemberg M.S., in der Synonymie ron L. nubicus).

Lanius caudatus Brehm, Vogelfang, p.84 (1855- keine genaue Lokalität).

Lencometopon personatus medius, magnirostis, brevirostris, tenuirostris A. E. Brehm, Verz. Samml., p. 3 (1866- nomina nuda!).

Lanius atticus Reiser, Mater. Ornis Balcan. 1II, p. 262 (ex Lindermayer MIS.- 1905!). Abbild.: Dresser, B. Europe IU, Taf.417; Journ. f. Orn. 1906, Taf. H fig. 6, 7.

3 ad. Stim his zur Scheitelmitte. kurzer Superciliarstreif, sowie Schulterfittiche weib. Ührigo Oherseite, Ohrgegend und Zügelfleck schwarz, Bürzelfedern in frischem Gefieder mit schmalen graumeiben Rändern; seitliche ()herschwanzdeclien mit breiten weiben Aubensïumen. Schwingen schwarz, Basis der Haudschwingen zu etwa $1 / 3{ }^{2 / 3}$ meili, einen gloßen "Spiegel" bildend. Oberthügeldecken mit schmalen grauweißen Ränderm, Armschwingen

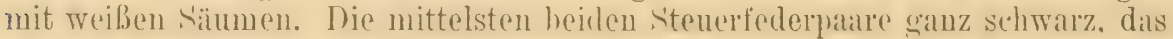

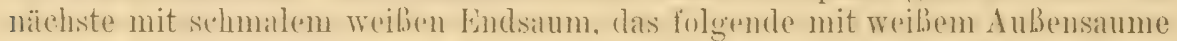
und ehensoldher Spitze. das vorletzte weib mit schmalem sehwalzen s'aum

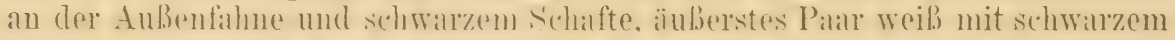
Schalite. Luterseite weil. mit röstlichem S'chimmer, S'riten lehhaft hell rostrot, Kehle und Lutersehwanzderlien rein weils. Cuterflügeldechen und dehser-

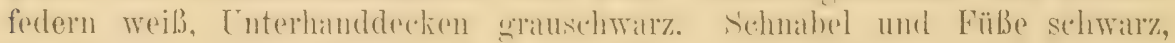
Iris braun. Flügel (19 o') etwa 89-92.5, sehr selten nur 87, Schwanz etra 89-93, Isauf $21-23$, Schnabel (Culmen) etwa $16.5-17.5 \mathrm{~mm}$. o ad.

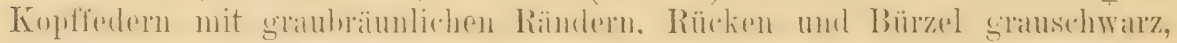

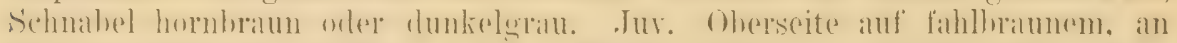

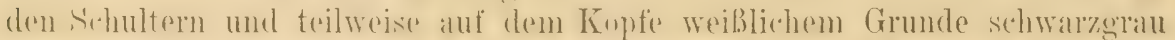

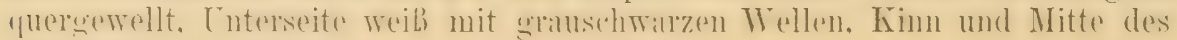
Unterkörpers rein weiß.

Brutroged rom sïdwestlichen I'ersinn dureh Fileinasien und Palästinat. Bis 1864 hẩug bei Athen brütend, seither dort verschwunden. - Über-

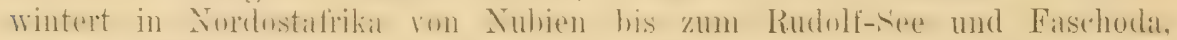

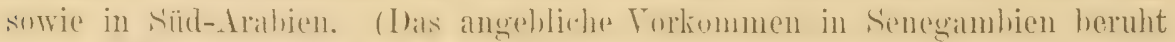
nur anf liehauntung des in seine'n Fundortsangaben notoriseh unzurerlitssigen Verreaux und einem Stïck unsicherer Herkunft im British Museum.)

Ziemlich spät am Brutplatze ankommender Zugrogel. Lebensweise typisch würgernrtig. Bewohner buschreichen Geländes. Angenehmer Sänger, Insektenfresser, namentlich Käfern nachstellend. Brïtet mit Vorliebe auf Oliven, Granatapfelbäumen u. a. m., meist in mittlerer Höhe. Nest wie andre Würgernester ein ziemlich lockerer Bau, innen mit allerlei grauen, weiBlichen u. a. Würzelchen, Rindenstreifen, Blütenrispen u. dergl. ausgelegt. Die i;-7 Eier sind rom Charakter audrer Würgereier, aber 
sehr kenntlich: Hellbraun, blaß gelblich olivenbraun, mitunter rahmweißlieh, mit, schwachem, wachsähnlichen Glanze. Die oft kranzförmig gehäufte Zeichnung besteht aus olicenbraunen und tiefer hegenden hell asehgrauen Fleeken. 48 von 1899-1901 bei Suyrua gesammelte Eier messen nach Jourdain im Durchschnitt $20.55 \times 15.7$. Yraximum $23>15.2$ and $22 \times 16.4$, Jinimum $19 \times 15.3$ und $20.5 \times 14.4 \mathrm{~mm} .10$ ron Krïper bei Smyrna gesummelte Eier aus der Röderuschen Sammlung (jetzt in Tring) messen ron $19.1 \times 15.9$, resp. $19.5 \times 15.5,19.6 \times 15.6,19.8 \times 15.7,20>15,20 \times 15.7,20.6 \times 16$, $20.8 \times 16$ bis $21.3 \times 16.4$ und $22 \times 16.6 \mathrm{~mm}$. Gewicht etwa $15-16 \mathrm{cg}$.

\section{Lanius collurio L.}

Rotrückiger Würger oder Neuntödter, Dorndreher.

Lanius Collario Linnaeus, Syst. Nat. Ed. X, p.94 (1758- "Habitat in Europa". Wir betrachten Schweden als die typ. Lok., nach dem 1. Zitat ,Fauna Suecica 180: - Linnés Diagnose ist teils nichtssagend, teils falsch, da er aber die Art ,Fn. SF. 180:6 unzweifelhaft beschreibt, und die folgenden Zitate (,Will. ornith. 5t, Raj. av. 18, Alb. av, 2, 1. 14 t. 14, 15") sich zweifellos auf den rotrückigen Würger beziehen, müssen wir den Namen collurio annehmen, obwohl als letztes Zitat angegeben ist Frisch. t. 60, wo als Lanius medius das $\sigma^{7}$ von $L$. minor und das + von $L$. excubitor dargestellt ist. Ähnliche falsche Zitate findet man bei Linné sehr oft).

Lanius varius Gmelin, Syst. Nat. I, p.301 (1788- basiert auf Brissons Écorcheur varié, II, p. 154, der das Junge von $L$. collurio ist).

Lanius Spinitorquens Bechstein, Gemeinnütz. Naturg. Deutschl. II, p. 392 (1791Deutschland),

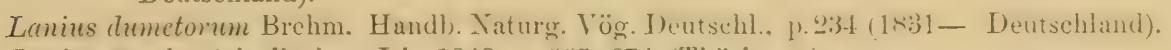
Lanius tenuirostris Brehm, Isis 1842, p. 665,674 ('Thüringen).

Lanizes misicus Brehm, Isis 1842, p. 665, 679 ('Thüringen, Süddeutschland, Wien).

Lanius gracilis Brehm, Isis 18+2, p. 665, 680 (Kap der Guten Hoffnung).

Lanius brachiwos Brehm, Isis 1842, p. 665, 681 (Kap der Guten Hoffnung).

Enneoctonus anderssoni Strickland \& Sclater, Jardine's Contr. Orn. f. 1852, p. 145 (1853Damaraland).

Enneoctonus collurio communis A. E. Brehm, Verz. Samml., p. 3 (1866- nomen nudum!). Lanius affinis Fischer \& Reichenow. Journ. f. Orn. 188t, p. 2 til (Lindi, Ostafrika, April 1882 - höchst eigentümliches Stïck, das statt des regelrechten Alterskleides nur teilweise dieses uud teilweise ein dem Jugendkleide ähnelndes Gefieder augelegt hat).

Enneoctonus reichenovi Shelley, Bull. B. O. Club III. p. 42 (1844- neuer Name für den vorweggenommenen Namen $L$. aftinis).

Engl.: Red-backed Shrike. Franz. Écorcheur. Ital.: Arerla piccola. Schwed.: Brunryggad lörnskata.

O ad. Schmales Band über die Stirn, Zügel, feine Linie um das Auge und Ohrdecken schwar\%. Oherkopi, Hinterhals und Viaken glan. natch der Stiru zu weiblicher. Rücken, Achselfedern und oherflügeldecken rostrot; der Farbenton dieses Rostrot valriert, manchmal ist er filst kadstanienrothaun, im alogeriehenen Sommergefieder oft sehr hell. anscheinend atheh hei jüngeren Stüclien hellex, als bei alten Vuggeln: aluch die Ausdehnung des rostroten Rückenfeldes rariiert einigermaben. Bürzel und Ohershwanzilecken asehgrau. Schwingen dunkelbran mit schmalen, an den Armschwingen nach imen zu breiter werdenten rostfarbenen Aubensïumen; imnere Armschmingen mit schmalen weißlichen Spitzensïumen, die letzte auf heiden Fahnen rostfarben rerwaschen. Manchual hefindet sich an der Wurzel der Hand- 
sthringen etwas Treib. das aher sehr selten ror den Handdecken einen kleinen weiben Spiegel hildet. Mittelstes Steuerfederpaar ganz schwarz, nur selten mit etwals Wreiß näehst der Wrurzel, nächstes Paar mit an Ausdehnung wedselndem Weib nahe der Wurzel, manchmal bis zu $2 \mathrm{~cm}$ Lä̈uge: fulgendes Palar etwa zur Hälfte weib. das äuberste etwa $1 \%$ cm schwarz, aher mit dem gröiten Teil der Aubenfahne und einem sehmalen Spitzensaume weiß. Laterseite weiß mit starkem trülorosa oder haßs weinrötlichen Anflug. Kehle. Banchmitte und Untersehwanzdecken weißlicher.

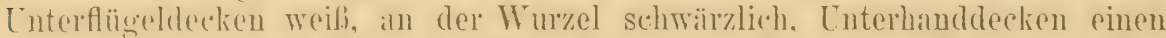
schwirzlichen Eleck hildend. Innensïmme der sthwingen blab und fahl scrïulich rostgelh. [ris hram, S'chnahel und Fübe hlïulich schwarz. Flïgel etwa $89-98 \mathrm{~mm}$ (75 alte $0^{7}$ gemessen), meist etwa 92-96, Schwanz etwa 75-80, Lauf etwa 23-25, Culmen 14-17, also sehr variabel. Q ad. Oherkinf resthraun. mamehmal mit aschgranem Anthug. Hinterhals immer mit deutlichem grauen Anflug. Rücken rosthraun, Bürzel und Oherschwanzdedien mehr graubräunlich, oft noch mit mehr oder weniger deutlichen Bogenlinien. Stenerfedern hraun, clie äuheren mit schmalem weilien oder weißlichen Auben- und Śpitzensium. Zä̈gel weiblich. Ohrdecken rothraun, Unterseite weib mit rahmfarbenem Anflug. Torderspiten und Seiten nit durkelhrannen Bogenlinien. Entersehmahel an der liasis weißlich. - Junge Vägel hahen im Nestlkeide auf der ganzen Olnerseite bogenlinien, in ersten darauffolgenden Kileide sind letrtere am oherrücken undeutlich. Im ïhrigen ähneln die Jungen den 0 .

Brïtet rom 64. Grad nördlicher Breite durch ganz Buropa, im Westen his zu den Prrenien, im Italien his zum Nittelmeere. auf Kórsika und Sardinien, aber fraglich anf sizilien: in Griechenlund häufge. In Kelein-itsien und Paliastina nur im Gehirge, ostwirts im westlichen Asien lis 'Transkispien und Nord-Persien. I)iese letzteren bilden anscheinend rine eigene subspecies (rgl.

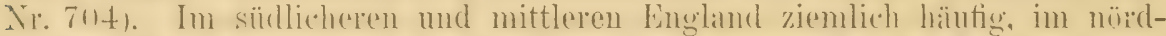
licheren 'Trike selten. in shehottland nur norh rereinzelt im äuBersten sïden briitend. Fehit in Irland, wo er nur einmal erlegt wurde. - Gewaltiger Tranderer, der durch Arahien und Nordust-Afrikia his in's tropisehe und sindliche Afrika zieht und dort überwintert.

Eiu Sommervogel, der in Mittel- und Nord-Europa nicht vor anfangs Mai eintrifft und kaum vier Monate bei uns verweilt. Die Mauser findet in Afrika statt. Jedermann kennt den hübschen Vogel, der auf den höchsten Spitzen der Büsche oder frei auf Seitenästen sitzend seinen wie gwä oder gäk gäk gäk klingenden heiseren Ruf ausstößt. Gesang zwitschernd, manchmal sehr gut, äußerst variabel. Ist auch ein guter Nachahmer. Er liebt besonders Dornbüsche aller Art, denn er hat die Gewohnheit seine Beute an Dornen oder spitzen Zweigenden aufzuspieben. Man findet ihn daher besonders in Hecken, auf einzelnen Bïschen, an Waldrändern, kleinen Feldhölzern, Parkanlagen und Gärten. Nahrung größere Insekten, besonders Käfer, Hummeln, Orthopteren; kleine Eidechsen, Frösche und Mäuse, er raubt aber auch nicht selten junge Vögel aus ihren Nestern und tötet mitunter kleine Singvögel. Nester ${ }_{12}^{1 / 2}$ bis 3, meist aber $1-11 / 2 \mathrm{~m}$ hoch in Bïschen, besonders Dornbüschen, groß, aus Stengeln, W urzeln und Halmen, meist mit Moos durehsetzt, mit lockerem Unterbau und reich mit Haaren und Wolle gefuittert. Eier 4-7, Mitte Mai bis Mitte Juni, Nachgelege bis in den Juli hinein. Eier sehr variabel. Grundfarbe rahmfarben, gelblich, gräulichweiß, grünlich, rötlich, seltener bräunlichgelb, sehr selten lebhaft rot, lebhaft hellgrün oder (die schönsten) rein weiß. Die Zeichnung bildet fast immer einen Kranz und entspricht wie bei andern Würgereiern der Grundfärbung, von blaßgrauer Unterfleckung und dunkel graubraunen Oberflecken, bis zu 
hellrötlicher Schalenfleckung und schön roter Oberfleckung. Rey erwähnt ein ganz weißes Ei, ich sah mehrere mit nur wenigen feinen Punkten. Maße von 360 von Rey gemessenen Eiern im Durchschnitt $22.1 \times 16.4$ im Maximum $25 \times 16$ und $22.6 \times 18.3$, im Minimum $18.3 \times 15$ und $22.2 \times 14 \mathrm{~mm}$. Mittleres Gewicht $0.186 \mathrm{mg}$.

\section{Lanius collurio kobylini (Buturl.).}

"Enneoctonus collurio L., var. fuscatus" (sic) Saruduy (non Lesson 1831), Vögel OstPersiens, p. 368 (1903- Ost-Persien).

Enneoctonus collurio kobylini Buturlin, Hbis 1906, p. 416 (Kutais und Ssuram).

Schon Radde (Orn. Cancas. p. 283) gibt an, daB. bei ,kaukasischen"

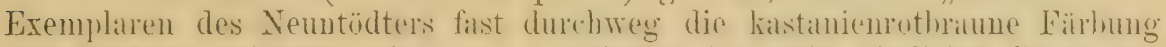
des Rückens reduziert oder nul angrelentert ist. Ein ähnliches Strïck beschreibt Sarudny aus Ost-Persien unter obigem Namen, und Buturlin

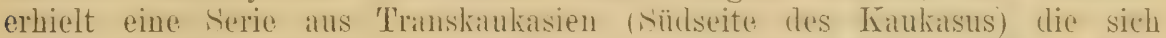

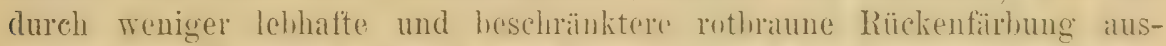
zeichnet. - Is scheint danath eine unterscheidhane transkitukasiseh-persisehe

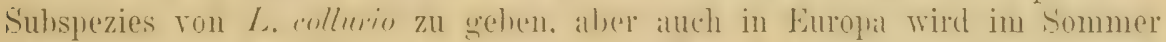

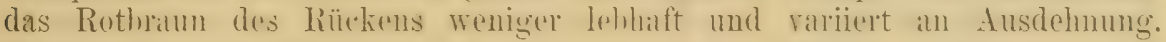
Stücke, die mit Sarudnys, „vur. fuscutus" übereinstimmen liegen mir vor aus Ost-P'ersien. Sür-Arahien. Wr aluch ..t!rische" rollurio rortommen, aus Ost-Afrika, S.IV.- und S.O-Afrika und ? Griechenland (April).

\section{Lanius vittatus Talenc.}

Lanius vittatus Valenciennes, Dict. Sci. Nat. XL, p. 227 (1826- Pondicherry). Collurio hardwickii Vigors, Proc. Zool. Soc. London 1831, p. 12 (Himalaya).

Lamius margaritaceus Lesson, Suppl. Buffon, Deser. Mamm. Ois., p. 329 (Ëd. Lévêque, 1847 - Indien).

Abbild.: Gould, Cent. Himal. B. Taf. 13, fig. 1; Journ. f. Orn. 1906, Taf. F fig. 7.

ôad. Zügel, Stirn bis in die Mitte des Scheitels und von dort ein

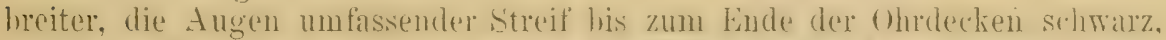
sodal. das Gesicht wie mit einer sehwarzen Maske hedeckt erscheint; Sebeitel ummittelhatr hinter der schwallon stimhinde weib. allmählich in das foran

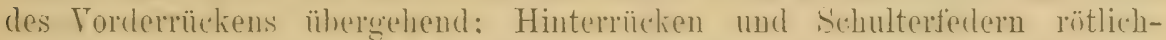

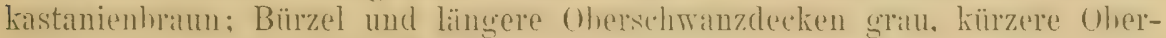

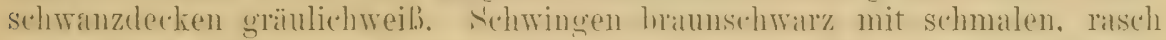
ahecutzten hellhamnen Sämmen. Basis dex Haudschwingen ausgedehnt meib,

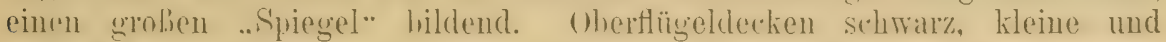
mittlere mit rosthramen Sämmen. Nittelstes Steuerfelorpar ganz schwarz mit nur schmalem weiblichen Endsium, die ührigen mit asugedehnter weiber Wurzel mul etwal 1 em laugen weiben sintzen. das vorletzte Palar meist

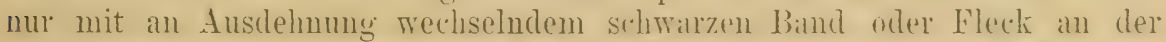
Imnenfahne, das Aubenpala ganz weili oder mit einem kleineu sehwaren Fleck an der Innenfahme. Cnterseite weib mit rahmfarhenem Anflug. Suiten hell rütlich-kastanienhrann. Tris hraun. Schnaluel mud Fülie schwarz. Flügel (36; oे) etwal 86-92 mm. Bisweilen kommen (in Indien) Stïclie mit

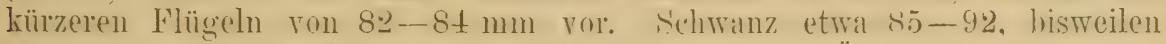
nur 82, Lauf 23-24.5, Culmen etwa $14-16 \mathrm{~mm}$. Über das alte o sind die Ansichten sehr versehieden! Natel von Härms in Baluchistan gesammelten 
Stücken ist das auf dem Rücken heller rotbraun, hat eine etwas schmïlere schwarze Stimbinde und mit WTeiß gemischte Zügel; diese Tögel könuen kaum etwas andres sein als $q$ ad. Daß die o den or völlig gleichen (Grant, Oates) scheint mir nicht richtig, es sei denn, daß die oben erwähnten sehr kleinen Stïcke o seien; Stïcke ganz ohne Schwarz an der Stirn sind nicht alt. Juv. Oberseite hellhräunlich mit schwarzhraunen Querwellen, Bürzel und Oberschwanzdecken röstlicher; Schwanz rostbraun, Seitenfedern mit weißlichen AuBenfahnen. Unterseite weib, Seiten und Brust mit grauen Querwellen.

Indien ron Mysore his zum westlichen Himalaya, westlich his Afghanistan und Persisch Baluchistan.

Bewohnt buschreiche Ebenen und steigt im Himalaya bis 4000 oder 5000 engl. Fuß hoch. Brütet in Indien rom April bis September, hauptsächlich aber im Juni und Juli. Das typisch würgerartige Nest steht in Hecken, Büschen und Bäumen und enthält 4-6 grünlichgraue oder gelblichbraune Eier, die mit hellbraunen oder olivenbraunen und tiefer liegenden mattgrauen Flecken, oft kranzförmig gezeichnet sind. Sie gleichen bis auf die geringere Größe Eiern von $L$. collurio, rötliche Gelege aber sind nicht bekannt. Sie messen von 19-22, ausuahmsweise $24 \times 15-17.5$ und 18.5, durchschnittlich etwa $21 \times 16.5 \mathrm{~mm}$.

\section{Lanius tigrinus Drap.}

Lanius tigrinus Drapiez, Dict. Class. Hist. Nat. XIU, p.523 (1828- Java).

Lanius ferox Drapiez, Diet. Class. Hist. Nat. XIIL. p. 523 (18:8 - Java).

Lanius magnirostris Lesson, in Bélanger Voy. Ind. Orient., p. 251 (1834- "L'Inde“). Lanius strigatus Eyton, Proc. Zool. Soc. London 1839, p. 102 (Malakka).

Enneoctonus crassirostris Bonaparte, Consp. Av. I, p. 362 (1850- ex Kuhl II.S.-Jara). Lanius waldeni Swinhoe, Proc. Zool. Soc. London 1870, p. 131, Taf. XI (Szetschwan). Lanius incertus Swinhoe, Proc. Zool. Soc. London 1871, p. 376 (Amoy. - Vgl. Ibis 1875, p. 115, Anm.).

Abbild.: Ibis 1867, 'Taf. VI; Journ. f. Orn., Tuf. C, fig. 1.

ơad. Eine Maske, bestehend aus einer 4-5 mm breiten Stirnbinde, welche die salnz: Zïgrelgegend hederkend und die Augen umschliebend bis

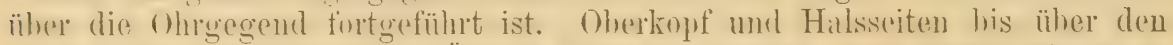
Nacken hin rein ascheriul. Ëhrege oherseite restrot, jede Feder mit 2-3, in der Regel 2) rollständigen und einer weniger ansgehildeten Bogrenlinie, die in der Mitte meist pfeilspitzonartig atusläuft. Gehwingen tiefhram mit schmalen losthramen Aubensüumen, innere Almselowingen ganz rostrothraun. Kiein ..Spregel". Steuerfedern fahl rothram mit sehmalen weiblichen Spitzen, äubere Fahnen mit undentlichen, nur bei gewissem Iivehte auffallenden dunkleren Qunhändern. Tuterflügoldecken weib, Enterhandereken und Inuensä̈mue der Schwingen hellröstlichrahmfarben. Ganze Unterseite wejl.s. Iris

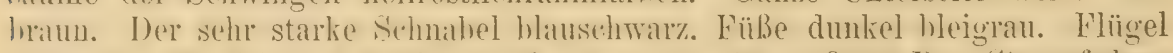
etwa 84-88. Sihwanz stark gestuft, etwa 7j-81), äuferes Pair Steuerfedern retwa 2 cm kïr\%er als mittelstes, Iauf etwa $22-25$. ('ulneu etwa $17-18 \mathrm{~mm}$.-qat. Ähmlich dem C all., aber das Grau des Oberkopfes umeiner, bräunlicher, der Rückron bräunlichrr, nicht so rothraun, Zügel weiBlich, S'eiten der Unterseite schwärzlich quergewellt. Unterschnathel an der Trurzel hell. - Jur. Oherkopf wie der Rüchen rötlichbram und weißlieh gemischt mit sehwärzliehen Bogenlinien, Unterseite weiß, Seiten schwilrzlich gewollt. 
Brutvogel im Essurilande, Korea, Nord-China. Auf den japanischen Inseln selten, wahrscheinlich nur auf dem Zuge. - Üherwintert auf den großen Sunda-Inseln und in der Malakka-Halbinsel.

Lebensweise und Nahrung die unseres $L$. collurio. Ich fand in den Mägen in Sumatra nur Käfer und Orthopteren. Nester in Büschen, Eier wie die rötlichen Varietäten des L. collurio.

\section{Lanius cristatus phoenicuroides (Schalow).}

Lanius phoenicuroides Severzow, Journ. f. Orn. 1873, p. 347 (Tomen nudum! Man kanu beim Vergleich mit Sewerzow's russischer Arbeit vermuten, und wir werden drei Jahre nachher versichert, daß dies sein früherer phoenicurus aus dem Tian-Schan sein sollte, aber davon ist 1. c. kein Wort gesagt. Da er früher seinen phoenicurus nicht beschrieben hat, bleibt der Name nomen nudum).

Otomela phosnicurointes Schalow, Journ. f. Orn. 1875, p. 148 (Erste Beschreibung. Terra typica: 'l'schimkent. „Bewohnt nach Sewerzow das ganze turkestanische Gebiet, in der Saxaulzone und in der Kulturzone").

Lanius phoenicurus var. montanu Sewerzow, Turkest. Jevotn., p. 144 (1873 - russisch); Dresser, Ibis $1876^{\circ}$, p. 185 („inhabits the mountains." Ex Sewerzow).

Lanius phoenicurne var. ruficeps Sewerzow, Turkestan. Jevotn., p. 145 (1873- russisch); Dresser, Ibis 1876, p.187 (,mountain form" - scheint also dasselbe wie "montana" sein zu sollen. Ex Sewerzow).

Lanius phoenicurus var. caniceps Sewerzow, Turkest.Jerotn. p. 144, 143 (1873- russiseh), Dresser. Ibis 1876, p. 187 ("lowland form").

L. canescens (Subspecies von phoenicuroides) Schalow, Journ. f. Orn. 1875, p. 150 (Nornen nudum, wohl lapsus für caniceps; ex Sewerzow).

Otomelt phoenicuroides subsp. Romanoui Bogdanow, Würger Russ. Reichs, in Zapiski Imp. Akad. Nauk. XXXIX, p. 14, 19, 201, 215, Taf. I, fig. 2 (1881- „Altai, 'T'arbagatai, beim Nor Saissan, Dsungarei, im östl. Tian-Schan, Transkaspien." Russisch.).

Otomela phoenicuroides subsp. Karelini Bogdanow, 1. c. p. 14, 23, 201, 202, 216, 'Traf. I, fig. 3 (1881 - Syr Darja, Ili, Buchara, Tian-Schan, am Aral-See, schwarzen Irtisch, 'Transkaspien. Russisch).

Otomela varia Sarudny, Orn. Fauna Transkaspiens, in Mater. Kenntn. Fauna \& Flora Kuss. Reichs. zool. Teil II p. $19+$ (1896-- Russisch); Übers. Orn. Monatsber. 1897 p. 183 (Grebirge Kirchjar" in Transkaspien. Der neue Name vorgeschligen, falls etwa neu! Soll mit Ausnahme des Schwanzes wie Bastard von romanowi und karelini aussehen und wohl an den betr. Fundort verschlagen und mit o romanowi gepaart sein!!!).

Abbild.: Ibis 1867 Taf. V, fig. 1 (sub nomine L. isabellinus); Dresser, B. Europe IU, Taf. 152 (sub nomine $L$. isabellinus!); Journ. f. Orn. 1906 'Taf. B, fig. 6.

Oad. Ganz schmale Linie an der Vorderstirn. ganzer Zügel und grober Ohrfleck sehwarz, dies Sehwarz durch eine sehr auffallende, wenn auch schmale weiße Linie ringsum gूegen den melu oder minder lehhaft brammenten Oherkojf abgegrenzt. Übrige Oherseite zimtartig haun, manchmal mit granem Schimmer. Oberschwanzdecken und Stenerfedern hraumot, letztere nach dem Fude zu brïunlicher und dunkler, und mit schmalen, weißlichen Spitzen. Schwingen dunkelhiau, heim frisch rermauserten Tugel fast schwarz. im Sommer filhler braun, schmale AuBen- und Spitzensämme liell fahlhraun, imnere Armsehwingen bräunlicher und mit hreiten. hell rïstlich-filhlhramen Sïmmen, Innensämme der Sehwingen fahl bräumlichmeil. Basis der Handschwingen weiß, einen ror den Handecken sichtbaren Spiegel bildend. Lnterseite weib. Kehle 
reinweib, der ïhrige Teil mit mehr oder minder ansgenrägtem isabellartigen vder hesser hell zimtrötlichen oder weinrötlichen Schimmer, Weichen zimtrötlich his lohhaft rostrot. Iris hraum, Schuahel und FüBe sehwar\%. Flügel 91-95, ausmahmsweise nur 90 oder his 96 und 97, Sohwanz etwa 79-85, Lauf etwa 23-25, Schmabel (Culmen) etwa 15-17 mm. - o ad. Unterseheidet sich rom oे ad. dadurch, dab. die Brustseiten mehr oder minder reichliche (bisweilen nur schwatch angectentete) grambanue Bogenlinien haben, die Yäger nicht rein schwarz, sondern meho oder minder weiblich sind. Die Basis des Lntersehnahels ist nicht rein sehwalrz, sondern hräunlich oder fleischforhen, anch ist meist die Firhuug des Oberkopfes nicht so lebhaft rothram. Nesthleid: Oherseite fahlgrauhraun mit schwälzhehen. Unterseite rahmfarhen mit hramen Bogenlinion, Mitte der Kohle und des Lnterkïrpers, sowie dir Cnterschwanzdecken einfarbig, Schnoled hraun mit heller Basis des Cnterschuabels. Das darauffolgende Jugendkleid ist oben fuchsig braunrot mit helleren Spitzensïumen und sehwärzlichen Bogenlinien, die Interseite wie heim Nestkleide, alher die Bugenlinien schärfer. Die Handsehwingen haben im Jugendkleide keinen weiben spiegel oder nur eine Andeutung desselhen. Die. Jungen sind ron denen ron Lanims collmio liaum zu muterseheilen. meist aher ist lle S'Chwanz rötlicher. (Etwa 160) untersucht.)

Brütet in Transkinspien. 'Turkestan. Afuhanistan, Baluchistan und Persien (Ost, Südwest). Östlich his zum Altai. (Niche Bemerkung hei isuluellimes.) Als Zusrogel in Süd-Alabien. Alsssinien und Somaliland. Teremzelt bei Gilgit und in sindh aheutet. Tehbufter gofürbte, rötlichere und hallkëpfige, sowie hlassere und ariulichere Individuen sind benannt worden, doch sind diese angehlichen fiomen weder gengraphisch hegrengt noch unterseheidbar, da mim alle möglichen C̈hergïnge findet. Lis handelt sich dabei also nur um individuelle Versehiedenheiten. ${ }^{1}$ )

Lebensweise wie die andrer Würger, Eier wie kleinere rötliche Eier von $L$. collurio, aber auch bräunlich bis grünlichgrau. Maße eines ostpersischen von Sarudny gesammelten Geleges: $21.7 \times 17,21.9 \times 16.7,22.2 \times 17,22.5 \times 16.8,22.6 \times 16.9 \mathrm{~mm}$.

\section{Lanius cristatus isabellinus Hempr. \& Eihrenl.}

?Lanius phoenicunus Pallas, Reise d. verseh. Prov. d. Russ. Reichs III, p. 693 no 6 (1776- . In rupestribus ad Ononem semel observ. vere6. Kurze Beschr. nach einem leider verloren gegangenen Stück. Bogdanow u. a. haben den Namen für die hier L. c. cristatus genannte Form angenommen, was unrichtig ist. Dem Fundorte nach [dort kommt zur Brutzeit nicht cristatus sondern isabellinus vor] und der Beschr. des Schwanzes nach [„,canda.... tota cum uropygio intense rufa"] scheint der Name phoenicums sich ziemlich sicher auf isabellinus zu bezichen. Von letzterem ist der Typus rorhanden, vor ersterem jedoch nicht, und wir dürfen bei diesen schwierigen Formen ohne absolute Sicherheit keine nomenklatorische Änderung einführen).

1) Suschkin (in litt.) teilt mit, daß karelini mit phoenicuroides durch Übergänge verbunden sei und in einigen Gegenden (Zaissan, Tarbagatai) mit ihm zusammen brüte, daß aber letzterer höher in die Gebirge ginge, und dab es Plätze gibt, wo nur eine der beiden Varietäten vorkommt. Daß in einer oder der anderen Gegend die eine derselben vorwiegt oder bisher allein gefunden wurde, ist ein interessantes Detail, kann aber die Auffassung dieser Form nicht beeinflussen. 
Lanius isabellinus Hemprich \& Ehrenberg. Syrmb). Phys. fol. e, Aum. (1828- Kumfuda [Gonfode] im mittl. Arabien).

Lanius arenurius Blyth, Journ. As. Soe. Bengal XV, p.304 (1846- , between Sind and Ferozepur'i).

Lanius ruficaudus Lichtenstein, Nomencl. Ar. HIus. Berol., p. 12 (1854- Arnbien; nomen nudum!)

Lanius ruficaudus A. E. Brehm, Journ. f. Orn. 1857, p. 79 (Blauer Nil).

Lanius speculigerus Taczanowski, Journ. f. Orn. 1874, p. 322 (Alt-Tsuruchaitui am Argun-Fluß in Ost-Sibirien. Es scheint mir sicher zu sein, daß Taczanorski seine neue Art nicht mit isabellinus, sondern mit phoenicuroides verglichen hat. Die angeblichen Unterschiede von $L$. isabellinus [blassere Oberseite, großer Spiegel] sind sonst unverständlich. 1891 [Faune orn. Sib. Or. I, p. 504] sagt 'Tacz. daß speculigerus sich von isabellinus durch schwarze Zügel mnterscheide. Der Typus ron isabellinus, den ich mit dem von speculigerus und dem von phoenicuroides im Berliner IIuseum verglich, hat einen größeren Spiegel, als die meisten sogenannten speculigerus, letzterer Name ist also offenbares Synonym).

Otomela isabellina var. major Bogdanow, Würger d. Russ. Fauna, in Faun. Zapiski Imp. Nauk. XXXIX, p. 35, 38, 204 (1881- Tarim).

Otomela isabellina var. orientalis Bogdanow, 1, c. p. 38, 204 (1881- = speculigera; Alaschan, Ordos u. a.).

Otomela isabellina typica s. occidentalis Bogdanow, 1. c. p. 202, 203 (1881- keine Beschreibung, Arabien, Persien bis West-Sibirien).

Abbild.: Hume \& Henderson, Lahore to Yarkand, Birds 'Taf. III; Journ. f. Orn. 1906 Taf. B, fig. 6 (우 ad.).

$0^{\pi}$ ad. Unterscheidet sich von dem von I. c. phoenicrioides durch folgende Nerkmale: I)er Oherkopf ist nicht so rothraun oder hraunot, soudern gauz oder fast gauz rou der Farbe des Rückens, der viel fabler, hlasser, ".wïstunatiger". ist. Die Zügel sind nicht ganz his zur Stim hin, sonderu nur ror dem Ange und am unteren Rande schwarz, auBerdem haben die schwarzen Zügelfederu meist mehr oder minder deutliche weiße spitzen. Die gुanze L'nterseite ist schön rötlich isablll, auch die Kehle hat diesen Anflus, nur die Bauchmitte bleiht weiB. In der Brutzeit verhleicht die Färbuug der Unterseite in eine hlasse, fast gelbliche Ralumfarbe. Der Soluwanz ist in der Regel etwas heller. - Die Basis der Handschwingen hildet meist einen weiben ...Spiegel", oft alher fehlt dieser ..Spiegrel" oder ist nur angedentet. Flügel etwa 89-100 mm. — o ad. Ohrdecken hraum, Zügel weiblich, nicht schwarz. An den Kehl- und Brustseiten oft Überreste von Bogenlinien, Schwinz oft mit Andeutung ron schmaler Querhänderung. Der weiße Flügelspiegel ist meist reduziert uder fehlt. Die Schwingen nicht dunkel sehwarzbraun, sondern mehr fahlbramu. - Juv. Oberseite etwas mehr rostbräunlich, der Spiegel feult. Oherseite, Brust und Seiten mit dunkelbrauner Bogenzeichnung. (60 Exemplare untersucht.)

Seheint als Brutrogel die Steppen der Mongolei und Süd-IDauriens (Algun, Onon) zu bewohnen, westlich his zur Dschungarei und Ost-Turkestin. Die genaneren Grenzen des Brutgebietes sind bei dieser Form und den Terwandten zur Zeit hitum zu eruieren, wegen der oft unsicheren Bestimmung: derselben und daraus resultierenden zweifelhaften Angaben. - Überwintert schon in Persien, N.WT.-Indien, Afghauistan. Siudh, Arabien und N.O.-Afrika, südlich bis Deutsch-Ostafrikat. Am 25. Oktoher $185 \pm$ ein Stück auf Helgoland erlegt. 
Lebensweise und Fortpflanzung die der Verwandten. Eier etwas kleiner, als die meisten Eier von L. collurio, sonst nicht ron denselben verschieden. Aus 9 Eiern der Nehrkornschen, Blasiusschen und Reyschen Sammlungen ergibt sich nach Rey ein Durchschnittsmaß von $22.84 \times 16.86 \mathrm{~mm}$, ein $M$ aximum von $24.5 \times 17.3$ und $23.9 \times 17.6$, Minimum $21.3 \times 16.9$ und $22.2 \times 16 \mathrm{~mm}$. Ob alle diese Eier zu dieser Subspecies gehören, dürfte unsicher sein, denn bei keinem derselben dürfte das Elternpaar im Balge vorliegen. Die Maße scheinen mir zu groß zu sein. Südlich des Issik Kul gresammelte Fier, angeblich von isubellinus, möglicherweise aber von phoenicuroides sind teils rötlich, teils grünlichweiß. Sie sind kleiner, als die von $L$. collurio: $21 \times 16.4$, $21 \times 16.2,20.8 \times 16.2,20.6 \times 16.1,20.5 \times 16.4$ und $21.2 \times 16.2,20.5 \times 16.4,20.4 \times 15.5$, $20 \times 16,20 \times 15.6 \mathrm{~mm}$. Sonst ganz wie Eier von L. collurio.

\section{Lanius cristatus cristatus L.}

Lanius cristatus Linnaeus, Syst. Nat. Ed. X, p. 93 (1758- Bengalen. Ex Edwards Nat. Hist. Birds Taf. 54 p. 54; die Abbildung ist zwar ganz miBlungen, aber die Beschreibung genügt in Verbindung mit dem Fundorte, um die Beibehaltung des darauf begründeten Namens zu rechtfertigen).

Lanius brachyurus Pallas, Reise d. versch. Prov. d. Russ. Reichs III, p. 693 no. 5 (1776„In rupestribus Dauuriae ${ }^{i 6}$; Zoogr. Rosso-Asiat. I, p. 405. Die Beschreibung scheint mir gut auf vorliegende Form zu passen).

Lanius melanotis Valenciennes, Dict. Sci. Nat. XI. p. 227 (1826- Pondicherry).

Lanius ferrugiceps Hodgson, Indian Review 1837, p. 446 (Nepal).

Otomela phoenicura $\beta$ var. intermedia Bogdanow, Würger d. russ. Fauna (in Faun. Zapiski Imp. Nauk. XXXIX) p. 3 (kurze Diagnose) p. 9 (1881- Nach einem von Middendorf bei Udskoi-Ostrog erbeuteten Stiicke).

Abbild.: Bogdanow, t. c. Taf. 1, fig. 1 sub nomine Otomela phoenicura (Unterseite zu rötlich, nicht gelblich genug, sonst ziemlich gut; Journ. f. Orn. 1906

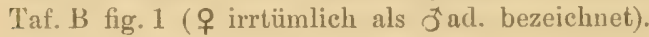

0 ad. Unterscheidet sich von L.c. phoenicuroides und I. c. isabellinus durch die keineswegs rötlich-isahellfarhene. sundern immer fahlgelhliche Cuterserite, wolvei Kehle und Baturhmitte meist ziemlich rein weib hleiben. Die Oherseite ist der von L. e. phoenimuroides ähnlich, aber dal die Kónffürbung eiue Nuance bräunlicher und der Rücken eher etwas rotbräunlicher ist, erscheint der Togel von obeu geschen etwas gleichförmiger, zumal auch der Schwanz und Bürzel nicht so l(hhaft braumrot. sondern etwas dunkler, etwa selmmutzig kastanienliaun sind. Weiber Stirnand und Supereiliarstreifen schmal aher sehr deutlich ausueprïgt. Schuabel im allgemeinen etwas krältiger. Flügelspiregel fehlt oder ist nur ginz ausnahmsweise schwach angedeutet. Hlügel etwal $83-$-91) mm. Während der Brutzeit verändert sich das Gefieder nicht allzu sehr, wird jedueh etwas inatter. blasser. - - ad. Dem o ad. sehr ähnlich, aher div Farben etwas matter, Enterseite mit mehr oder minder zahlreichen, manchmal anf die Brustseiten heschrïnkten und fast rerschwindenden Bogenlinien. Der Ohrfleck bräunlicher. - Juv. Oberseite dunkler und mehr rothraun, Lnterseite nit Ausnalnme ron Kehle und Mitte des Unteriörpers mit dunkelhramen Bogenlinien. Jas Nestkleid ist obeu dunkelhraun, jede Feder mit mehreren schwärzlichhranen Bogenlinien, Unterseite lichthrïmulich mit schmalon schwärzlichen Bogenlinien. (Über 80 untersucht.)

Brïtet in Nordsihirien von Kamtschatkil und Amurland bis zum BaikillSée und Krasnojarsk. Die Angaben vom Brïten im Ala-schan erscheinen mir zweifelhaft. - Auf der Wanderung durch China und die östlicheren 
Teile Zentralasieus bis Süd-China, Cochinchina, Siam, Indien mit Ausnahme des äußersten Westens. Die Vermutung, daß er auch auf den Audamanen brüten dürfte, kann ich durchaus nicht teilen!

Kommt erst spät, Mitte und Ende Mai, an seinen Brutplätzen an und brütet etwa Ende Juni. Die Jungen verlassen das Nest Ende Juli und Anfang August. Die Eier gleichen denen von $L$. collurio und varieren ebenso, sind jedoch meist etwas kleiner. MIaße nach Taczanowski $20 \times 15.5,20 \times 16,20.2 \times 16,20.2 \times 16.2,20.4 \times 16.2$, $20.6 \times 16.2,21 \times 16.8,21 \times 16,21.6 \times 16.6,22 \times 16.2,22 \times 17.3,22.2 \times 16.7,22.4 \times 16$, $22.8 \times 17,23 \times 17.23 \times 17.2,23 \times 18,23.3 \times 17.4,23.6 \times 17.8$ bis $24 \times 17.5 \mathrm{~mm}$. Nester und Lebensweise wie die von L. collurio. (Ibis 1905 Taf. XI, fig. 6, 9.)

\section{Lanius cristatus superciliosus Lath.}

Lanius Superciliosus Latham, Ind. Orn. Suppl., p. XX (1801- ex Levaillant, Ois. Afr. II, Taf. 66 fig. 2. p. 60. - Batavia, Java).

Abbild.: Ibis 1867 Taf. V fig. 2, sub nomine L. phoenicuvus; Journ. f. Orn. 1906 Taf. $B$ fig. 2, 3, 4.

Ơ ad. Dem von L. c. crislatus ühnlich, aber der Schnahel länger, das Rotbraun auf Kopf und Bürzel viel lebhafter, der Rücken rotbräunlicher, bei sehr schönen alten Stücken die ganze Oberseite fast gleichmäßig rotbraun. Hinter der schmalen schwarzen Linie an der Vorderstirn ein weißer, meist 4-8 mm breiter Streif, der nicht wie bei lurionensis in helles Grau übergeht, sondern unmittelbar an das Braunrot des Oberkopfes angrenzt. Unterseite nicht rötlich, sondern fahlgelh wie hei L. c. cristatus. Kein deutlicher Flïgelspiegel, wenn Weiß an der Basis der Handschwingen, von den Hauddecken verdeckt. - $q$ ad. Dem ơ ad. sehr ähnlich. wie es scheint nur durch mehr weißliche Zügel, etwas weniger rötliche Olserseite und nieht ganz so tiefschwarze Ohrdecken zu unterscheiden - mir liegen aber nicht genug Stïcke mit zurerlïssigen Geschlechtsangahen vor. - Die jungen Tögel sind auf der Oberseite sehr dunkel hraun und auf der Luterseite quergewellt. Das erste Kleid, das auf der Oherseite jedenfalls auch Querwellen hat, habe ich nicht untersuchen können.

Brütet in Japan, wurde einmal auf Sichalin erhentet. - C̈herwintert im malayischen Arehipel, auf Hainan, der Malakkahalhiusel uud wohl auch im südlichsten China usw.

Lebensweise und Nistweise wie bei den Verwandten. Nester $1-3 \mathrm{~m}$ hoch auf Dornbüschen und Bäumen. Eier wie rötliche Eier der Verwandten, vermutlich aber auch in grünlichen Varietäten vorkommend.

\section{Lanius cristatus lucionensis $\mathrm{L}$.}

Lanius lucionensis Linnaens, Syst. Nat. Ed. XII I, p. 135 (1766- Ex Brisson, II p. 168, Taf. XVIII fig. 1. - Luzon, Museum Réaumur).

Enneoctomus schwaneri Bonaparte, Consp. Av.1 p.363 (1850 - Borneo, MLuseum Leyden). Abbild.: 'Trans. Zool. Soc. London IX Taf. 29, fig. 1 (1875).

ơ ad. Sehr ähnlich dem ron L. c. cristatus, aber augenseheinlich in jeder Hinsicht weiter entwickelt. Die Stirn ist nicht am rorderen Rande ummittellar hinter der schwarzen, dic Zügel verbindenden Linie schmal weißlich, sondern diese weiße Fürbung erstreckt sich, allmählieh in lichtes Grau übergehend, 
bis zur Mitte des Oherkonfes. Die übrige Oberseite ist etwas gräulieher, die Cuterseite etwas lehhafter, oft sogar viel rostgelber, sodal.s die weiße Kehle dagegen auffallend ahsticht, die Lntersehwanzlecken und Banchmitte aher sind nicht weib. Der Schmahel ist etwas größer (lïnger und dabei reichlieh so hoch und dick). Flügel und S.hwanz etwas länger. Treifer Flügelspiegel nicht ror-

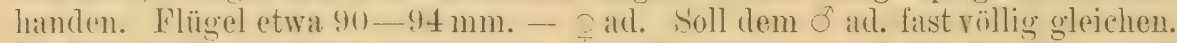
In der. That stheint bei gamz alten o die Bogenzeichnung anf dor Cuterseite nicht mehr vorzukommen, die doch hei den Terwandten, wenn aluch manchmal nur noch ganz rudimentär, immer zu rerfolgen ist. I)ie Ohrdeclen scheinen aher hei den $\bigcirc$ etwas hräunlicher, die Zü̈gel weniger rein schwarz zu sein. Jur. Ton den verwanden Formen durch viel weniger rothrame Oherseite zul unterscheiden.

Dats Brutgehiet dieser Form ist oftenhar (hina mit Ausuahme des änersten Sïclens, nördlich his Koreal. Jinkowski erbentete ein Exemplar am Sidemi und eins auf der Insel Askold. - Im Trinter aul den Philippinen. in Süd-China, vom südlichen T'enasserim durch die Hallinsel Malakía bis zu den Andamanen, Sunda-Inseln und ('elehes. D) il Stëreke aul den Andamanen spät im Mai und vereinzelte noch später erherutet wurlen, hat man die Vermutung alusgesprochen, dab sie dort brüten, was aher durehaus nicht glaubhaft erscheint.

\section{Lanius bogdanowi (Bianchi).}

Otomela Bogdanowi Bianchi, Bull. Acad. Imp. Sei. Pétersbourg XXX, p. 514 (1886Aber, Prov. Astrabad in Nord-Persien); Mél. Biol. XII, p. 581. (Typus untersucht.)

Lanines raddei Dresser. Proc. 'Jrol. Soe. London 188, 1. 291 (hulkulais im Fopet-I)ag in 'Transkaspien). ('lypus untersucht.)

Lanius dichrourus Menzbier, Ibis 1894, p. 382 (Kenderlik-Fluß am Zaissan See). ('Typus untersucht.)

Lanius elaedgui Suschkin, Bull. Soe-Lmp. Natural. Moseou 1895, 1).41 (Flub Emla in der Kirgisensteppe). (Vom Autor bestimmte Stïcke untersucht.)

Lanius infuscatus Suschkin, Ann. Ilus. St. L'etersh. 1s9f, p.40 (Kenderlik-kluß). (Typus untersucht.)

Lanius phenimoides pesudorollurio Suschlin, Bull. Brit. Orn. Club XVI. p) (30 (1906Altai und Tarbagatai). ('I'ypus untersucht.)

Abbild.: der Typus von L. raddei in Dresser, B. Europe IX, p. 171, Taf. 669 (schön aussehend, aber übertrieben und daher irreführend).

Es ist für mich ausgemacht, daß die von Bianchi, Dresser, Mlenzbier und Suschkin (unter drei weiteren Namen) beschriebenen phoenicuroides-artigen Würger mit Schwarz im Schwanze und mehr oder minder grauem Oberkopfe dasselbe sind. Han könnte einwenden, daß raddei und dichrourus einander gleichen, aber gegenüber bogdanowi, elaeagni, infuscatus und pseudocollurio eine viel mehr grate Oberseite haben, indessen vermittelt ein abgeriebener "pseudocollurio" den Übergang, außerdem stammen gerade raddei und dicliroums nicht aus derselben Gegend! Man könnte auch einwenden, daß bogdanowi gegenüber allen anderen einen viel mehr rostbraunen Oberkopf hat (der keineswegs nur beschmutzt ist, wie Grant annahm), aber einer der sogenannten elaeagni Fermittelt auch hier den Übergang. Da bogdanowi und radilei die beiden Extreme der Serie vorstellen, so war Dresser nicht zu tadeln, daß er letztereu benannte, die Benennung von dichrourus dagegen hätte schon rermieden werden können, aber die von elaeagni und gar erst die von infuscatus und pseudocollurio ist durchaus zu verurteilen. - Weun es nun aber auch meiner Meinung nach feststeht, daß alle diese Namen 
sich auf eine Form beziehen, so ist darum doch die Frage, was diese Form bedeutet, noch nicht erledigt. Nach Suschkin's Meinung (Bull. B. O. Club XVI p.59-61) sind raddei, infuscutus, psendocolhurio und elacugni, "sulspecies" von phoenicuriodes, während bogranoui identisch mit varius (') und eine indiriduelle A berration von phoenicurailes sein soll. Diese Ansicht tut dar, daß Suschkin eine ähnliche unhaltbare Auffassung von ,Subspecies" hat, wie sie C. L. Brehm hatte, während wir heutzutage die geographischen Vertreter ternär benennen, aber nicht mehr Aberrationen. Da L. bogdanowi nun mit L. phoenicuroiles (unter verschiedenen Namen) zusammen brütet (vgl. die Fundorte und Suschkins und Sarudnys wertvolle Forschungen), können wir ihn nur als Art auffassen, deren Merkmale einigermaßen variieren.

Ő ad. Oberseite aschgrau, mit mehr oder minder starkem rostbraunen Anflug, der boi dem Typus von I. radilei am schwächsten, bei denen von

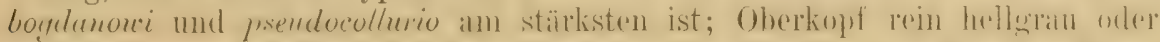

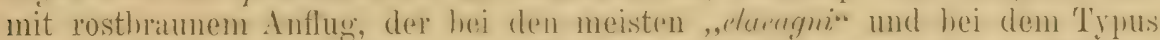

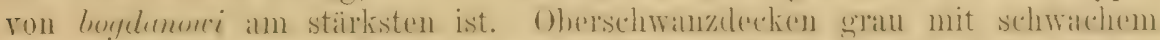

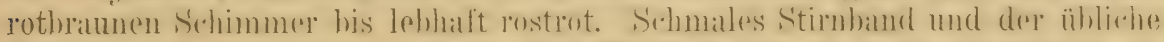
Kopfseitenstreif sehwar\%. Ibasis del Handsehwingen weili, mamehmal so

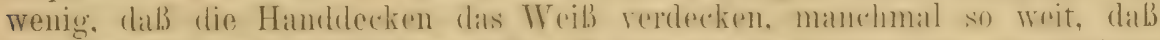

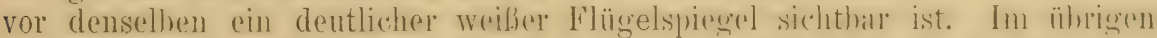
sind die Schwingen wio bei phoenienroides. Unterseite wie bei phoenicuroides.

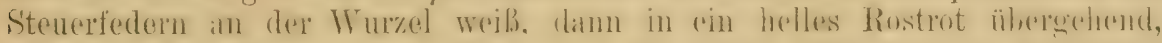

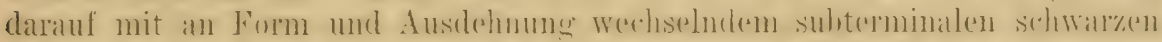

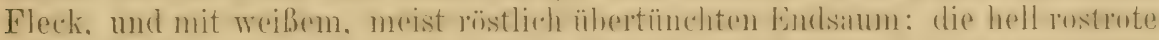

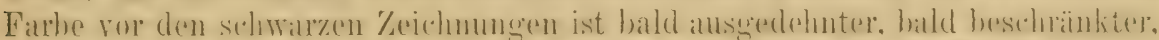

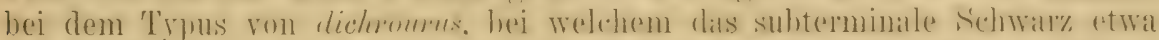

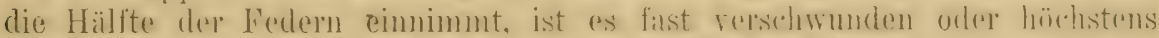

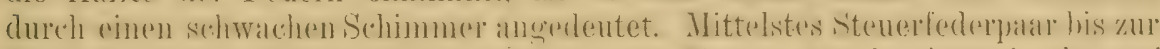
Wurzel bräunlichschwarz odler (wio bei den I'ypen von bogdanowi, elaeagni

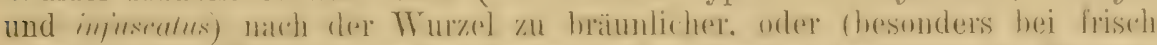

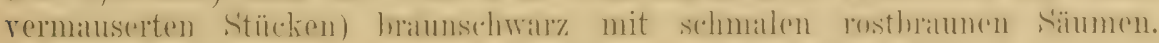
Größe etrva wie die von L.c. phoenicuroides. Flügel $89--97 \mathrm{~mm}$.

Brütet mach Suschkin (l. c.) an den Nord- und Südabhängen des

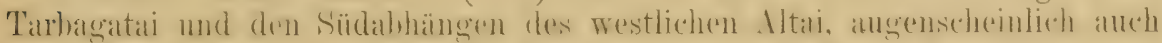
bei Vernoje und am Kenderlik-Flusse am Saissan-Nor. Der 'I'ypus von boadanowi wurde am 22. Juni bei Asterabad in Nord-Persien (also doch wohl zur Brutzeit), der von raddei in Transkaspion, der von elatagni in der

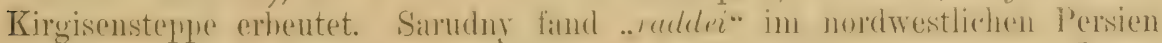
bruitend. Osear Neumann erlegte ein noch nicht vermausertes of am 15. November 189:3 bei Lmhugwe in ost-Afrika das mit dem 'Tyuns ron infuscatus und einem sogenannten psezulocollurio ïbereinstimmt.

Sarudny fand am 13.-25. Hai das Nest in einem Berberis-Busche, etwa $1^{1 / 3} \mathrm{~m}$ hoch. E's war nach Art anderer Wirgernester gebaut, auben aus stacheligen Zweigen und Blättern, mit feinen Würzelchen, Schafwolle und Ziegenhaar ausgefüttert. Die 4 Eier sind typische Würgereier. Dresser beschreibt sie nicht, bildet aber drei Stück ab, die rahmfarbenen Neuntödter-Eiern gleichen. (Ibis 1905 Taf. XI fig. 1-3.) IIae $23 \times 17$ bis $22 \times 16 \mathrm{~mm}$.

\section{Lanius darwini (Sewertz.). (Noch fragliche Art.)}

Collyrio darwini Sewertzow, Tashkent-Zapiski I, 1 p.51 (1879- Verni [Vernoje] in Semiretschensk) (Russisch).

E. Hartert, Die Vögel der paläarktischen Region. 
Tinterseheidet sich ron I. phoeniemoides durch lehhafter und mehr rothraume, fast hell kastanienbranne Schulterfittiche. Bürzel und Oberschwanzdecken und sehr lehhaft rötlich rahmfarlone Seiten. I)er Schwanz ist rötlich zimtfarben, die mittelsten beiden Steuerfedern rötlich dunkelbraun. In der Fürbung der Oberseite erimnert das Stück an l.e e. superciliosus, aber der Hinterhals ist deutlich gräulich. Flügel lang, nümlich 96.5, Schwanz 95, Lauf $26 \mathrm{~mm}$.

Ein ơ am 30. April bei Vernoje in der Provinz Semiretschje erlegt. Ob es sich hei diesem stäkek um rine Sulspezies von cristutus. deren Brutheimat wir noch nicht kennen, um ein aherrantes Exemplar oder einen Bastard himdelt. lïbt sich ohme ferneres Haterial nicht feststellen.

\section{Lanius bucephalus 'Temm. \& Schleg.}

Lanius bucephalus 'T'emminck \& Schlegel, Siebold's Fauna Japonica, Aves p. 39 'T'af. 14 (1814- Japan).

Abbild.: Journ. f. Orn. 1906 'Taf. C fig. 4, D fig. 1.

ad. Ohertionf rou der Stim his zum Nateken lebhaft rothatun, diese Färbung allmählidh jn das Aschgrau des Rürliens und Bürzels üherochend, das aber immer mehr oder minder lotbratu überlaufen ist. Ton den Nasen-

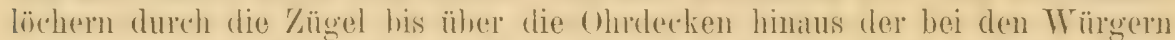
ähliche sehware Koprseitenstreif. Worüber sich eine sehmale weibliche Linie befindet. Schwingen sehwar\%, vor den Handdecken ein etwa $5-7$ mm großer weiber, durch die weibe Basis der Handschwingen gebildeter spiegel. Armschwingen und grölere Flügeldecken mit hreiten röstlich rathmfarbenen

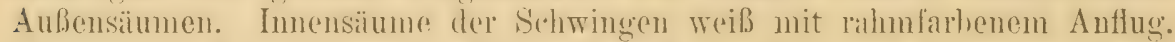
Stenerfedern dunkelgrau, die mittleren nach der Spitze zu schwall, alle mit Ausnalme der mittelsten mit schmalen etwas schmutzig waben Spritzen-

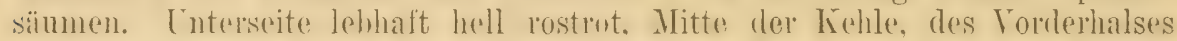

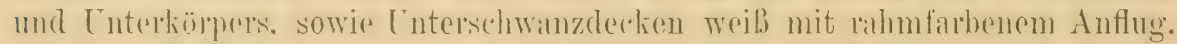
Brust- und Seitenfedern mit sehmalen antrapikalen dunkelhraumen Bogenliniran. Conterflügelderken weils, Handderken und einige hemathbarte Federn einen genben sehiefersehwarzen Fleck bildend. - In der Brutzeit rerhleicht

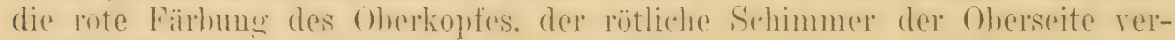
schwindet mehr nder minder, die Bogenlinion anf der Conterseite verschwinden fist oller im ganz alngetragenen Getieder hisweilen gänzlich. Sehnahel und Füße schwalz. - Flügel etwa 87-91, Sehwanz etwa $89-96 \mathrm{~mm}$. - o ad. Die '/ägol weißlich, Olıdeckenfleck dunkelhrann, Rücken his aluf die Schwanz-

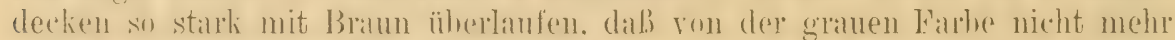

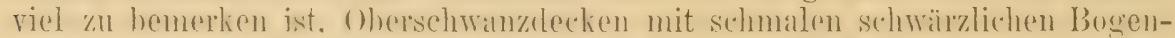
linien, Cnterseite stälier gewellt, jode Feder mit mindestens zwei schwäl\%-

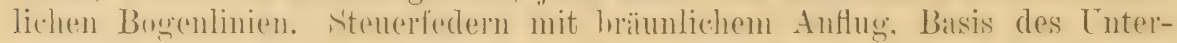
schnabels weißlich. - Juv. Auch auf der Oberseite gewe'llt.

Brïtet auf den nördlichen japanischen Inseln, in Nordchina, Korea,

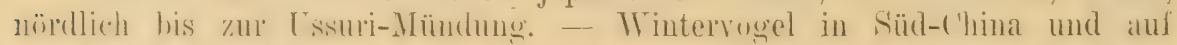
den Riu-Kiu Inseln.

Nest auf Büschen und Bäumen in geriuger Höhe. Eier 4-6, von Ende März bis Ende Juni, vom Aussehen und den Dimensionen der Eier von Lanius senator; aber meist sehr länglich, teilweise dickbauchig rundlich. Rötliche Varietäten scheinen nicht bekannt zu sein. Exemplare im Brit. IIuseum messen $22.9 \times 16.9,23 \times 18.5$, $23.8 \times 17.4,23.8 \times 16.4,24.4 \times 16.2,24.4 \times 17.3,24.4 \times 18.4,24.5 \times 167 \mathrm{~mm}$. 


\section{Lanius schach tephronotus (Vig.). ${ }^{1}$ )}

Collurio tephronotus Vigors, Proc. Zool. Soc. London 1831 p. 43 (Himalaya).

Lanius nipalensis Horsfield, Indian Review I p. 445 (1837- Nepal).

Collurio obscurior Hogdson in Gray's Zool. Misc. p. 8t (1844- nom. nudum!)

Lanius lama Dresser, Proc. Zool. Soc. 1905, I p. 55, T'af. V fig. 1 (T'sangpo-T'al in 'libet).

Abbild.: Dresser, l. c., Journ. f. Orn. 1906 Taf. E fig. 1.

ơ ad. Die schwaren Kopfseitensteifen gamz sehmal, manchmal nur undentlieh. ̈̈ber dio Torderstim hin verbunden, ührigo Ohersaito rein sehiefergrau, hintere Bürzelfoleru und Oberschwanzdecken rostrot, letztere etwas dunkler. Showwingen schwarz mit äulherst schmalen, an den Almschwingen breiteren röstlich weiben Aubros̈umen. Kein sichtharer Flügelspirgel, dis Treif an der Basis der Handschwingen (wemn vorhanden) von den Hand-

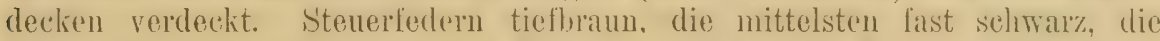

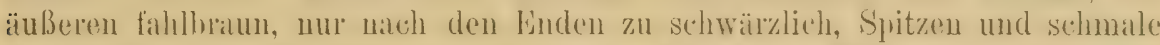
Aubensämme der Aubenpalre rahmfarben. Kehle und Mitte des Lnterkörpers weil. mit schwatchem rahmartigen Anfluge, Seiten und [uterschwanzdecken lehbaft rostgelh. Cnterfï̈geldechen und Achselfederu weib mit rahmgelbem und bisweilen gräulichem Anfluge, [ntrohanddecten cinen schicterfirbenen

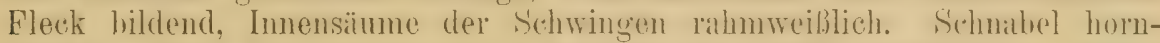
schwarz, Basis des Cuterschmaliels hellbrüunlich, Eüle schwärzlich. Flïgel etwa 97-104, Schwanz etwa 115-123 mm, Lauf etwa 30, Culmen etwa 17-19 mm. - o. Ohrdecken nicht schwarz, sondern tiefbraun, Zügel schwärzlichgrau, Rücken mit bräunlichem Anflug, Schwan\%, hräunlicher als beim c. Flügel meist (aber nicht immer) einige mm kïlzer. Schmabel schwärzlich, Basis des [nterichnabels hell. - Jur. Oberseite dunkelhraun mit fahlbrïunlichun, Bürzel und ()hersehwinzdeclien rostlarhen mit schwälzlichen Querwellen. I'nterscite. mit Ausnahme ron Kehle und Batuchmitte, dunkelhraun quergewellt. (26 Exemplare vor mir.) - Alle andern Subspezies ron L. schach haben hellere Oberseite als tephronohs.

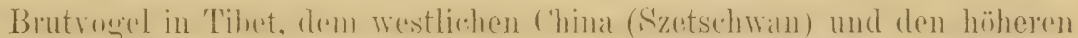
Regionen des Himalayi. - Wintervogel im Himalaya und in den nordindischen Hïgolländern und Fhenen.

Gelege you 5 Eiern gleichen in Färbung und Größe denen von $L$. senator oder sind etwas größcr. Die rötlichen Varietäten scheinen nicht selten zu sein.

\section{Lanius schach erythronotus (Vig.).}

Collurio erythronotus Vigors, Proc. Zool. Soc. London 1831, p. 42 (Himalaya). Collurio jounotus Hogdson, Gray's Zool. Misc. p. 84 (1814- nomen nudum!)

Abbild.: Gould, Cent. Himal. B. Taf. XII fig. 2; Journ. f. Orn. 1906 Taf. E fig. 2.

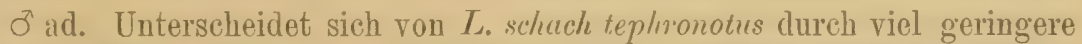
Gröber viel hellere Oberseite und dadureh. dal. das hellore Rostrot des Bürzels

1) Lanius schach schach L. 1758 bewohnt Süd-China, Formosa und Hainan und ist durch seine bedeutende Größe, besonders den außerordentlich langen Schwanz, leicht von L. S. erythronotus zu unterseheiden. Die Ausdehnung des Schwarz sehr variabel, meist ist der ganze Vorderkopf, oft nur die Stirnpartie breit schwarz. (Journ. f. Orn. Taf. E fig. 3).

Lanius schach bentet Horsf. 1822 bewohnt die Sunda-Inseln (bis 'Timor und Wetter) und ist wieder L. s. erythronotus ähnlicher, aber namentlich durch den langen Schwanz und ausgedehnteres Schwarz an der Stirn kenntlich. 
sich his anf den Rïcken und die Schulterfedem erstreclit. - I)ie heiden schwarzen Koplseitenstreifen durch eine ungelähr $3 \mathrm{~mm}$ breite, mitunter breitere, scharf hegrenzte Binde üher die Torderstirn hin verhunden, rer dahinter hefindliche Stirnteil heller als der grane Vorderrïeken. Ohersehwamz-

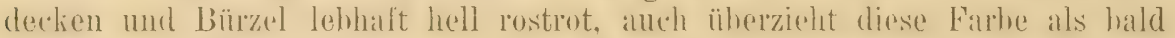
stärkerer, bald schwächerer Anflug die Sehulterfedern und den Rü̈cle'n. Flügel etrva 86-92, Schwanz 105-115 mm. Unterseite wie bei L.s. tephronotus. Basisis der Jindsehwingen wrib. sodatis die Andeutung eines

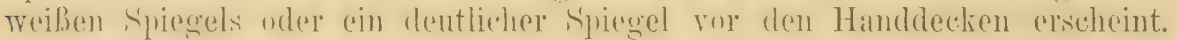

Brutrogel im nordwestlichen Indien von den Ebenen bis in die mittlere Höhe der Gebirge, in Afghanistan und Teilen von Turkestan. [Wird in Sïdindien und Ceylon durch den etwas kleineren und auf Rïcken und

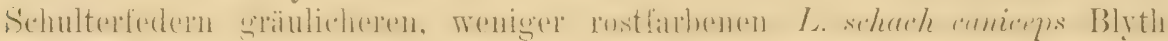
vertrotess.]

Nistet in Indien rom März bis Oktober. Nester in Bïschen und Hecken. Die 4-5 Eier sind meist rahmweißlich mit nicht seln großer, oft feiner, selten grober dunkel bräunlicher Zeichnung. Mitunter ist die Grundfarbe schwach grünlich angeflogen, ein Gelege (Afghanistan) liat warm rötlich ralımfarbene Grundfarbe mit rötlichen Flecken. Die Gröbe variiert von der der Eier von Lanius collurio bis zu der von L. minor.

\section{Gattung TELOPHONUS Swains. 1837.}

(Nan hat den Namen Pomatorlynchurs Boie 1826 für diese Gattung angenommen, aber mit Unrecht. Boie - Isis 1826, p. 973 - zitiert "Pornatorhynches" Horsfield" und verweist aus Unkenntnis den 'I'schagra

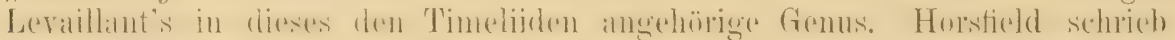
Pomatorlinus, eine Schreibweise, die Boie in Pomatorlyngehus verbesserte. Telophonus wurde meist in 'Telephonus verbesset).

Sehmabel gestreckter, als bei Lanius, erste Schwinge lang, Flïgel

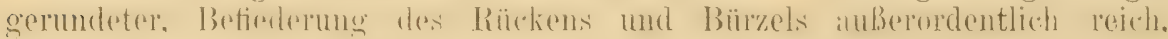
weicher und länger, als bei Lunius, Schwanz stark gestuft, Läufe länger. Hinter dem Auge ein kibine mbefiederter Fleck. - Etwal 18 Formen bekannt. Afrika bis Nubien, eine Form in Marokko, cine andro in Süd-Arabien. Eier weiß mit Flocken und eigenartigen Kritzoln.

\section{Telophonus senegalus ctacullatus (Temm.). ${ }^{1}$ ) (Fig. 79.$)$}

Lanius cucullatus 'T'emminck, Man. d'Oru. 2 nd. ed., IV p.600 (1840- Andalusien. ?errore; vermutlich aus Marokko!).

Abbild.: Dresser, B. Lurope III, 'Taf. 154.

1) Telophonus senegahus senegalus Linnaeus (Syst. Nat. Ed. XII p. 137, 1766Senegal) ist sehr ähulich, aber auf der Oberseite heller, an Brust und Körperseiten viel dunkler aschgrau. Bewohnt das tropische Afrika mit Ausnahme der nordöstlichen Teile, südlich bis zum Kaplande.

T. senegalus habessinicus (Hempr. \& Ehrb.) (Symb. Phys. fol. e) ist dem T. s. senegalus sehr ähnlich, aber kleiner und hat auf den mittleren Steuerfedern noch 
Ôd. Oberkopf von der Stirn bis zum Hinterhalse tiefschwarz, ein

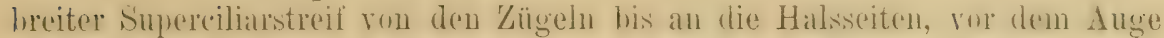
fitst rein weib. hinter demsellen in ein bräunliches Rahmegeld ïhergehend, unter diesem Streifen ein schwallzer Zügrelfleck und schwarzer Streif hinter dem Auge. Räicken dunkelbraun, Bürzel und Oberschwanzdecken melr graubraun, letztere mit mehr oder weniger deutlichen schwarzen Spitzen. Außenfahnen der Schwingen rostrot. nur die Spitzon und die Außenfahnen der beiden ersten Schwingen größtenteils dunkelbraun, die inneren Armsehwingen an beiden Fahmen braunschwarz, mit rostroten Säumen. Schulter-

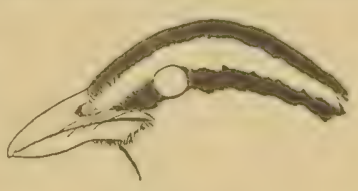

Figur $79\left({ }^{2} / 3\right)$.

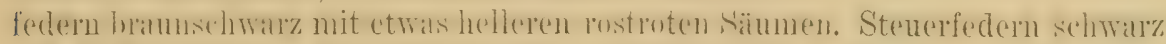

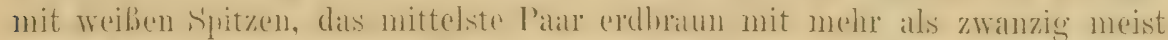

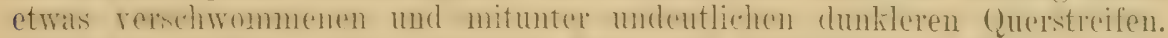

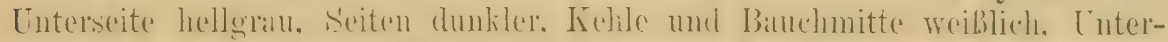

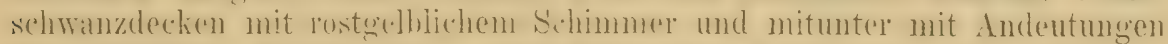
ron dunkteren lingenlinien. Innensiume der schwingen hell zimtlarben.

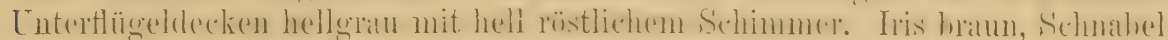
schwarz, Füße bleigrau. Flïgel etwa 90-93, Schwanz etwa 110-120, Lituf 32-33. cuimen 22-24 mm. - - wie d. - Juv. Oherkoph und dunkler Augenstreif braun.

Marokikn (Tamger his Mrogador), Algien und Tunis, wie es scheint lokal, vorzugswerise in hügeligem Gelinde und hisher noch nicht sïdlich des Atlas festgestellt. Das von Temminck und Favier herichtete Torkommen in Spranien ist sonst nicht bestätigt worden.

Bewohnt buschreiches Gelände mit Thuja, Iandel- und Olivenbäumen, weicht in der Lebensweise in vielfacher Hinsicht von den Lanius-Arten ab. Läuft viel am Boden, verbirgt sich im dichten Gebiisch. hat einen aus vollen Flötentönen bestehenden Gesang, den er auch im Fluge, schwebend in der Luft von sich gibt, und einen würgerartig rätschenden Lockton. Nahrung Käfer und andre Insekten. Nest würgerartig in Büschen und Bäumen, die 4-6 Eier glanzlos weiß mit blaß bläulichgranen Schalenfleckes und braunen und grauen Óberflecken, von denen viele eigenartige Strich- und Kritzelform haben, die für die meisten Telophonus-Eier bezeiclnnend ist. Die . Eier. sind etrra in der Größe derer ron Lanius minor.

\section{Gattung HYPOCOLIUS Bp. 1850.}

I) iese merkinurdige Gattung ist an verschiedenen Stellen in Systrm unter-

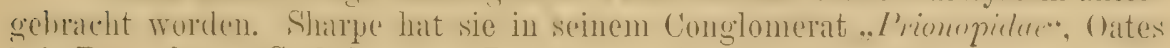
bei Psaroglossa, Cepplalopyrus, Leptopoecile(!) usw. in dem Gemisch, das er

weniger deutliche Querlinien. Bewolnt N.-O.-Afrika von Abessinien bis Nord-Somaliland. [T. blanfordi auet.]

T. senegalus remigialis Finsch \& B artl. (Vög. O. Afr. p. 340). Viel heller, Vorderrücken fahl gelbbrnun, Unterseite weiß mit rahmfarbenem Anflug, Schwingen größtenteils braunrot. Gebiet des weißen Nil, nördlich bis zum Atbara (N. C. Rothschild).

T. senegalus percivali Grant (Bull. B. O. Club X p. 50, 1900). Sehr viel mehr verschieden von den übrigen Subspezies, als letztere untereinander: Unterseite, mit Ansnahme der Kehle grau, Rücken dunkelbraun, mittlere Steuerfedern schwarz, Schnabel dünner und gestreckter, überhaupt kleiner. Südarabien. 
Liolrichime nennt (Lnterfamilie seiner Cuteropodidue). Mir scheint eine Verwandtschaft mit den . Impolidue am wahrseheinlichsten, eine solehe mit den Wïrgern nicht ganz ausgeschlossen zu sein. Der Schnahel ist an der Trurzel sche hreit, nicht seitlich komprimiert wie hei Lanins, vor der Spitze des Oherschnahels befindut sich ein ganz kleiner Ausschnitt. Culmen gehogen. Nasenlöcher gron. frei ror den kurzeu, borstenartigen Federscheppen der Stirn, der where 'Teil der Nasenöllnung von einer Hatut überdeckt. Keine Schnalielhorsten. Fïbe liurz und stämmig, Lauf rorn mit scharf getrennten Schildern, and die Seitensehienen zeigen Andentungen oder besser C̈berhleibsel ron einer Eintrilung in Schilder. Schwanz zwölffedrig, lang, nur wenig ahgermudet. Flügel stumpf. Sjpitze des Flïgels nur $1^{1}{ }_{2}-2 \mathrm{~cm}$ ïher das Ende der Armschwingen hinatragend. arste schwinge klein. schmal, steif. spit\%, kïr\%er als die Handdecten. ‥, 3., 4. linst gleich und am lïngsten. Getieder weich. alue linang auliegend. Fïrlung die eines Wüstenvogels. Nester offen, Wier schwach gefleckt.

\section{Hypocolius ampelinus Bp. (Fig. 80.)}

Hypocolius ampelinus Bonaparte, Consp. Av. I p.336 (1850- "California"! Errore! Die Typen wurden von Botta im abessinischen Küstenlande erbeutet).

Ceblepyris iscubellina Henglin, Syst. Übers. im Sitzungsher. K. Akad. Wiss. Wien XIX. p. 284 (1856- Abessinisches Küstenland. Nomen nudum!).

Abbild.: Ibis 1868 'Taf. V (Ei: Cat. Birds Eggs Brit. Mus. IV, Taf. XII fig. 6).

o ad. Oherseite hellgrau mit schwachem gelhbräunlichen Auflug, Vorderkopef heller, fast isahell-rahmfarben. An der Stirn hinter den Nasenlöchern ein Büschel kurzer schwarzer Federchen, von dort eine schmale Linie über die Zügel zum Auge, von wo ein hreites schwarzes feld über

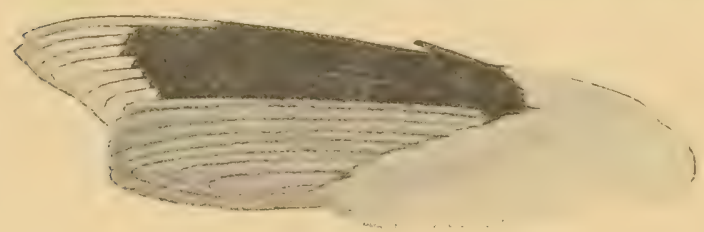

Figur $80(2 / 3)$. die Kopfseiten und Ohrdecken sich erstreckt und den Hinterkopf umfaßt. Scheitelfedern etras verlängert. Oberflügeldecken und innere Armschwingen wie der. Rücken, äußere Armschwingen an den Innenfahnen größtenteils schwarz. Handschwingen

schwarz mit hreiter weißer S'pitze, die an der zweiten (ersten langen) Shchwinge hraun getriiht ist. Handdecken sehwarz. Steuerfedern grau (etwas reiner als der Rücken), mit etwa $1^{1} / 2-21 / 2$ cm langen schwarzen Endteilen. Kéhle. Interkörper unl Unterschwanzdecken hell isabell mit schwach rosigem Anflug; Brust und Cinterflügelderken wio der Rä̈cken. Iris hraun, Schnabel fleischfarben mit sehwar\%er Spitze, zur Brutzeit ganz schwar\%. Füße im Leben fleischfarben (Cumming), an Bälgen hell gelbhraum. Flïgel etwa 98-101.5), Schwanz. etwa 110-116, Lauf 23-24, Culmen 16-19 mm. - o ad. Ohne Schwarz an Kople, Handschwingen an den AuBenfihnen wie der Rëcken, nur etwas gräulicher, Spitzen schwal\% mit schmalen weißen Endsäumen, das Schwanzende schwarzhraun und nicht so scharf ahgesetzt, Handdecken brïunlich grau mit braunschwarzen Spitzen. - Juv. dem o ad. ähnlich, aber mehr isabellfarben, die ơ mit weißem, grau gespitzten Flügelende. 
Brutrogel am Nordende des Persischen folls (Buschir. FuphratMündung). TTie weit sich das Brutgehiet erstreckt, ist nicht sicher. Einzehe Stücle wurden in Khelat und in den Khirtar-Bergen an der Grenze ron Sindh erbeutet. Barnes will die Art bei Aden "gesehen" haben. In Afrika ist kein genauer Fundort bekamnt. Die ron Botta und Goutin gesimmelten Stücke stammen abel vermutlich ans dem ahessinischen Küstenlande (Massaua). Das Torkommen in Niamniam beruht auf Irrtum.

Nach Cumming's Beobachtungen am Persischen Meerbusen nur Sommerrogel, brïtet daselbst ron Ende Mai bis Juli. Es sind Baumvögel. Ihr Ruf ist ein angenehmer Pfiff. Nahrung Früchte und lusekten. Nester meist auf Blättern niedriger Dattelpalmen, 3-5, seltener bis $10 \mathrm{FuB}$ über dem Erdboden. Nester groß, napfförmig, innen mit feinen Gräsern, Pflanzenwolle, Tierwolle und Haaren ausgefiittert. Eier $4-5$, spitz-oval, wie Würgereier gestaltet, glänzend, weiß mit bläulichgrauem Anflug, bisweilen ohne Zeichnung, meist mit blassen hellgrauen oder bräunlichgranen Flecken, besonders am stumpfen Ende. Gegen das Licht gehalten meist mit schwachem grünlichen Schimmer. Maße von 16 Eiern im Brit. Mus, und in Tring (2): $24.6 \times 19$, $24.8 \times 19.2,25.4<188,25.4 \times 19,25.6 \times 20.2,25.9 \times 20.5,26 \times 19,26.3 \times 19.8$, $26.4 \times 20.2,26.5 \times 19.1,26.7 \times 19.2,27 \times 19.6,27.1 \times 18.7,27.2 \times 19.1,27.4 \times 20 \mathrm{~mm}$.

\section{Familie AMPEIIDAE (1831).}

Die Seidenschwänze bilılen eine so eigenartig modifizicrte. fïr sich allein stehende Gruppe, dab man sie nach der heute üblichen Finteilumgsweise der l'asseres als eigene Familie hetrachten mub, deren nächste Verwandte die Lamiidue und Muscicupridae zul sein scheinen. Die ron den meisten Autoren dizu gerechneten amerikanischen Gattungen IJulus, I'hainoptila. Pluinopepla und l'iloyonys meichen so wesentlich ah. dib man sie hinfort nicht mehr mit den Ampelidae vereinigon sollte. - Größe kleinerer Drosseln. Gefieder seidenweich und reirh. Finffeclern in eine wie zerschlissme Haube verlüngert. Flügel lang und spitz, erste Schwinge ganz rudimentïr. steif, spitz, nicht hallh so lang wie die Handdecken, 2. und 3. Schwinge fast gleich und am lïngsten, Armsehwingen kurz, Flïgelspitze fast um die halbe Flügellänge über die innern Amschwingen hinausragend. Zahl der Handsehwingen 10. Śchwanz zwölffedrig, gerade. kurz. Śchnabel stark, kurz uncl hreit, Oberschuahel ror der Syitze mit einem Aussehnitt (..gezälint*), an der Irurzel die grolien, ron simtartigen F'edern hedeckten Nasenlöchergruben, an deren vorderem Ende die eigentlichen Nasenlërher liegen. Schuabelhorsten mur angedentet. Iauf liurz, mit dentlichen Schilderu. Zehen stark mit starken Krallen. -.. Terhreitung holarktisch. -- offene Nester auf Bäumen, Eier gefleckt. — Junge unten schwach gestreift.

\section{Gattung BOMBYCILLA Vieillot 1807.}

Kenuzeichen der Fimilic. - Der neuerdings angenommene Gattungsname Ampelis ist unrerwendhar, weil el durels krin liminationsverfahren auf den Seidenschwanz bezogen werden kann. 
Schwanzspitze gelb, Flügel weit ïber $100 \mathrm{~mm}$, weile Flïgelhinden:

Schwanzspitze gelb, Flügel unter oder höchstens bis $100 \mathrm{~mm}$,

olne weiße Flügelbiuden ............... g. cedrorum ${ }^{1}$ )

Sichwinzpitze rot

B.g. garmilus - p. 456

B. japonicu . . 1. 457

\section{Bombycilla garrulus garrulus (L.). (Fig. 81.)}

\section{Seidenschwanz.}

Lanius Garrulus Linnaeus, Syst. Nat. Ed.X. p. 95 (1758-- Habitat in Europa. Terra typica Schweden. (f. Fauna Sueciea 179).

Parus Bombycilla Pallas, Zoogr. Rosso-Asiat. 1, p. 548 (1827- Umbenennung ron Lanius Garrulus).

Ampelis lientericus Meyer, Ann. Wetterau. Ges. f. Naturk. I, p. 270 (1790- Umbenennung von Ampelis garrulus).

Bombyciphora poliocoetia Meyer, Vög. Liv, u. Esthlands, p. 104 (1815-- Livland).

Bombycilla bohemica Leach, Syst. Cat. Hamm. B. Brit. Mlus., p. 18 (1816-- nomen nudum!); Brehm, Handb. Naturg. Vög. Deutschl., p. 219 (1831- N.O.-Europa).

Bombycilla brachyrhynchos Brehm. Vogelfang, p. 79 (1855- Europa).

Bombycilla garrula vulgaris A. E. Brehm, Verz. Samml., p.3 (1866- nomen nudum!).

Engl.: Waxwing. - Franz.: Jaseur de Bohême. - Ital.: Beccofrusone. Schwed.: Sidenswans.

Gad. Oberseite grau mit rötlichbranuem Anflug, Kopf und Hals hrameroitlich, Stirn und streif ühere den Augen zimtartig lastanienluaumrot, Rüleken

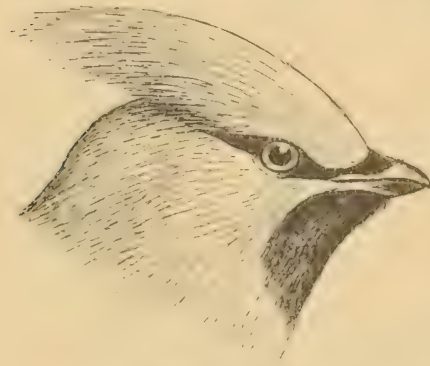

Figur $81(2 / 3)$. bräunlicher, Bürzel und Oberschwanzdecken fast rein grau. Schmale Linio über dem Schnabel, Zügel und dreicckiger länglicher Fleck hinter dem Auge schwarz. Handschwingen schwarz, zweite (erste lange) meist mit sehr kleinem weißen Strich an der Spitze der AuBenfahne, 3. und 4. mit etwa 5-7 mm langem weißen Strich an der Spitze der AuBenfahne und weißem Spitzensaum, übrige mit weißem Spitzensaum und an der Spitze der AuBenfahne etwa $1-1^{1} / 4 \mathrm{~cm}$ gelb. Letzte Armschwingen wie der Rücken, die übrigen schieferfarben mit hreitem weibon Silumstreifen an der Spritze der Aubenfahne und

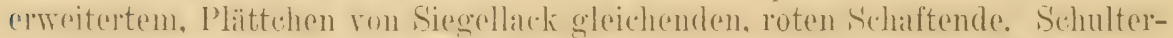

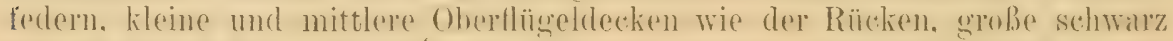

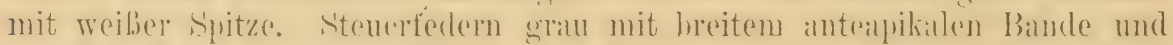

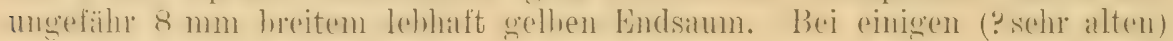

1) Bombycilla cedrom Vieillot, Ois. Amer. Septentr. I p. 88, Taf. 57 (1807N.-Amerika). Viel kleiner als B. g. gamulus, Flügel $92-99$, selten bis 100 , große Flügeldecken und Armschwingen ohne Weiß an den Spitzen, Handschwingen olne Wejß oder Gelb an den Spitzen der Außensäume, das Schwarz an der Kehle auf einen weniger scharf abgeschnittenen Fleck an Kinn und oberer Kehle beschränkt, Mitte des Unterkörpers gelb, Unterschwanzdecken weiß mit rahmfarbenem Schimmer. Nord-Amerika. Brütet südlicher als B. g. garrulus: von Virginien, Nord-Carolina, Kentucky, Kansas, den Bergen von Neu-Mexiko und Arizona nördlich bis Prince Edwards Insel, siidliche Kïste der Hudson-Bay, Saskatschewan und Manitoba. Im Winter in allen Vereinigten Staaten bis Costa Rica und West-Indien. Eier wie die von B. g. garrulus, aber kleiner. durchschnittlich $22<15.5 \mathrm{~mm}$. 
Stiicken sind die Schäfte an der Spitze erweitert und rerlïngert und triagen somit rotem Siegellack gleichende Blïtchen, wie die Armschwingen. Sulche Stücke sind sehr selten. Am Mundwinkel und am hinter'm Augenlide je ein weilser Strich, hinter arsterem ein rütlicher Streif. Kinn und Kehle tiefsehwarz, Brust und Seiten rütlichgrau, I'nterköryer grau, Ditte hollgrau. Unterschwanzalecken sehr lang, rotbraun. Achselfedern. Cnterhlüghtechen und innere Sehwingensitume hellgritu. Iris hram. Sehnahel sehwarz. an der Wurzel blaugrau, Füße sehwarz. Flügel etwa 110-120, Schwanz 62-70, Lauf 20-21.5, Schuabel 11-12 mm. Jüngere ô ähneln den o. - o ad. Trie ô ad, aber die weißen bndsämme der Handschwingen fehlen neist. wenn auch nicht immer. die gethen Striche an den sintzon der Aubenfiahnen

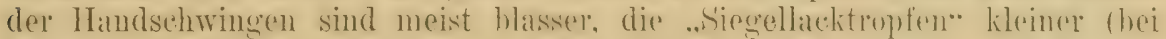

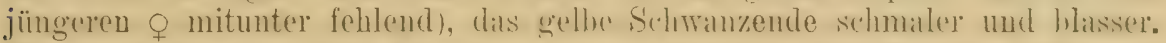

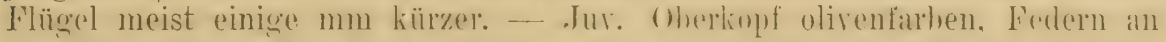
der stirn mit weiber Basis. liärken mit olivenfarbenem Anflug und hell-

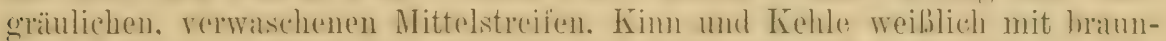
granen Strichen, ährige ['nterseite dunkel olivengran mit verwasehenen weiblichen Streifen. Batuchnitte trübweib. ["ntersehwanzdecken hasser. - Ein

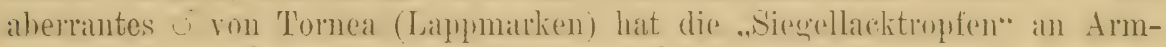
schwingen und Steuerfedern wohl entwickelt, aber gelb.

Brutvogel in der arktischen Zone der Alten und Neuen Welt. In Europa südlich bis etwa zum $65 .^{0}$, in Amerika bis zum $68 .{ }^{0}$ nördl. Breite. Streicht im Winter südlicher, in manchen . Tahren nur wenig, in einzelnen Jahren in Nenge in Lünder, die ar sonst nirht wder mur sehr selten besucht. In (Astpreuben noch alljährlich, olere doch annïhernd so, in Italien nur in grtïbren Zwischenüumen. In Grobbritmuien unregehnibig arseheinend. In Amerika bis ins nördliche Kalifornien und bisweilen Arizona.

Baumvogel, still, wenig beweglich, gesellig, nicht scheu, zum Trinken und zum Fressen von Beeren verschiedener Taccinizm-Arten mitunter auf den Érdboden gehend. Hïufigste Stimme eine Art feinen Triller's oder ein klirrendes Zirpen, das man mit ssir-ssir-ssirr oder rhiss verdeutlicht hat, seltener hört man einen tiefen, an den der Gimpel erinnernden Flötenton. Gesang ein quetschendes, zirpendes 'Trillern. Nahrung im IVinter hauptsächlich Beeren der verschiedensten Art, im Sommer größtenteils nur Insekten. Nester in Tannen oder Birken, meist 4 bis $5 \mathrm{~m}$ hoch, auf einer Unterlage aus dünnen 'Lannenreisern aus Hoos und Flechten, mit feinen Flechten und Renntierhaaren ausgelegt. Brutzeit der Juni. Die Eier sind blaß bläulichgrau oder hellgrau, mitunter mit einen schwachen rötlichen oder bräunlichen Schimmer, bisweilen fast weib. Die Zeichnung besteht aus tiefbraunen, fast schwarzen rundichen Flecken, die oft einen graubraunen Schattensum zeigen, sowie aus tiefer liegenden hellgrauen oder rötlichgraue Flecke. Mitunter finden sich kurze Harlinien, bisweilen fehlen die schwarzbramen ḱlecken zum großen 'Teile. Maße von 100 Eiern nach Jourdain durehsehnittich $24.03 \times 17.29$, Maximum $28.3 \times 18$ und $24.8 \times 18.8$, Minimum $21.1<16.3$ und $25>15.7 \mathrm{~mm}$. Durchschuittliches Gewicht $0.208 \mathrm{~g}$. (Vgl. Newton, Ootheca Wolleyana I, 2, Taf. X, Dresser, Ibis 1861, p. 102, Newton, ebenda, Taf. IV.)

\section{Bombycilla japonica (Sieb.).}

Bombycivora Juponica Siebold, De hist. nat. in Japon. statu etc., p.13 (1824 ... „... in prov. 'I'yko et 'I'sikusen habitat."): cf. Férussac, Bull. Sci. nat. et. géologie IV, 1825, p. 87 (Referat).

Bombycilla phoenicoptera 'Temminck, Pl. Col. (II) 450 (1827- Japan). 
Ampelis Maesi Oustalet, Nour. Arch. Mus. Paris, sér. 3., IV p. 213 (1892- „? Japan." Der Typus war ein japanischer Handelsbalg, augenscheinlich ơad., er gleicht dem von 'T'emminck abgebildeten Vogel und wurde wegen der weißen Endsäume an den Handschwingen benannt, da zum Vergleich Vögel mit nur weißem Streif an der Spitze der Außenfahne (ㅇ und jur.) gedient hatten).

Abbild.: Temminck \& Schlegel's Fauna Japonica, Aves Taf, XLIV ; David \& Oustalet, Ois. Chine, Taf. 74.

Oे ad. Unterscheidet sich von $B . q$. garrulus hauptsächlich durch die geranium-rote statt gelhe Sichwanzspitze. hlutrot remaschene Unterschwanzdecken, blutroten, durch die Spitzen der Anßenfahnen der groben Flügeldecken gebildeten Querstreifen am (Oherflügel, mattgelhliche Nitte des Unterlïirpers und etwals geringere Grïbe. Anf dem Kopfe ist nicht nur die Stirn. smondern anch der seheitel, allmählich in das rötliche Gran der Oberseite rerlaufend, zimtartig hraumrot. Die unteren Haubenfederen sind teils seldwarz, teils grau mit sehwarzen Silumen. Dir groben (Oherflügeldeckfedern hahen ungefïhr das Spitzendrittel der Aubenfahuen blutrot, sodab eine breite rote Querbinde entsteht, die hläulichgrauen Armsehwingen rine breite, durch die Spitzen der Aubeufahnen gehildete schwalrze bindhinde. Die Handschwingen hahen in der Regel, mit Ausnahme der ersten. einen weilen Findsium und eineu roten Fleck an der spitze; bei jüngeren ò fehlt der weiße Findsaum und dafür hat die Spitze der dulienfahne einen kurzen weiben Strich, oft auch sehon eine Andeutung des weiBen Endsaumes. Mitunter fehlt der weibe Endsaum auch anseheinend ganz alten 0 . Die Armschwingen hahen einen mitunter mit weib gemisehten, manchmal fehlenden dunkel rusenroten Fleck an der śpitze der Aulienfilmen. Vitte des [nterkörpers sehr hlabs schwefelgelh. Linterschwanzdecken lehhaft zimtfarben mit butrotem Anflug. manchmal grïistenteils rot. Sonst

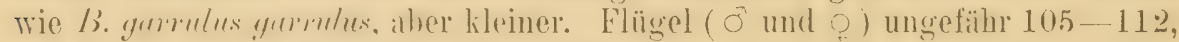
wohl nur ansuahmsweise bis 114, Schwanz etwa $55-60 \mathrm{~mm}$. - o ad. Dom of ähnlich, scheint sich ahrer durch ständiges Fehlen der weißen Endsälume an den Innensämmen der Haudschwingen, schmälere rote Flügellinde, weniger Sihwar\% und kleinere rote Fleetiehen an den spitzen der Armschwingen, zimtfarbene J'ntersehwanzdecken ohne roten Anflug. hlasser gedbliche ulitte des ['nterkiarpers. hitsser und weniger rïtliche Wingen und sheitel, sowie geringere Gröbo zu unterscheiden. - Jus. Oherseite schmutzig brüunlichGran, Hanhe nicht entwickelt. der schwarze Kehllfeck fehlt, Kehle, Brust und seiten brämulich aschgralu mit weiben oder weiblichen Sïmmen, Mitte des Unterkirpers rahmfarben. Cintersehwanzalecken bell zimtfarben. Schon in der Jugend scheinen sich die Gesthlechter durch die versehientene weibe Zeichnung an den Spitzen der Handschwingen zu unterscheiden.

Bewohnt das sïdliche Ostsibirien, d. h. die Ussuriländer, von der Japanischen See his zum Amm, im Winter im nördlichen Japan und Nord('hina, mitunter südlich lis P'eking. - Soll im Cssuri-Gehict nisten, Nest

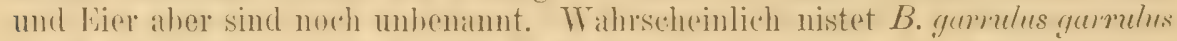
nicht im gleichen (iehiet und B. jupenica sollte auch als geographischer Vertreter des letzteren angesehen werden. 


\section{Familie BRACII PODIDAE Swains. $\left.1837 .{ }^{1}\right)$}

Die „Haarvögel“ oder „Kurzfubdrosselu“ sind in einer tahularen Reihenfolge der Familien der Passeres wie manche andre Gruphen schwer unterzuhringen. Sie sind vielfitch umbergetrorfen worden und heweisen wiederum die Unvollkommenheit unsres Systems. - Sie hahen einen starken, meist etwas gehogenen Sehnabel mit deutlichem Aussehnitt und zahnartigem Vorsprung vor der spitze des Oberschnabels. Nasenlöcher in einer groben Grube frei vor den Stirnfedern, selten (Irenu) mit Federn bedeckt. Befiederung weich, auf dem Bürzel lang. Tollig, schr reich, am Hinterkopfe in der liegel einige auffallende seheinhare Hanre, d. h. dünne, rerlängerte fahnenlose Federschiilte. Erste Schwinge etwa gleich der Hällte der zweiten oder linger. Flïgel lang; breit, gerundet. Itäufe kurz, rorn getafelt, manchmal aher auch trilwcise oder ganz geschient. Zehen kurz und stark. - Gesehlechter meist gleich. Offene Nester, Fier bunt, rot gefleckt. Stimme stark, Gesang laut, wohltönend. Baumvögel. Nahrung hauptsïtchlich Früchte. - Heiße und warme Länder der Alten Welt.

\section{Gattung PYCNONOTUS Boie 1826 (ex Kuhl MS.).}

Keunzeichen der Familie. Sehmahel stwas kïrzer als der Kopf, Kehlfedern breit, rund, nieht zugespitzt. Zahlreich in den Tropen Afrikis mud Asiens, fünf Formen paläarktisch.

Übersicht der paläarktischen Formen: ${ }^{2}$ )

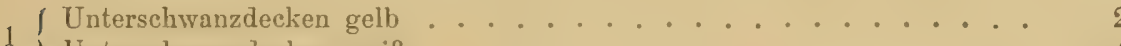

I Unterschwanzdecken weiß .................... 4

1) Eine eigenartige Form Spizixus semitorques Swinhoe, bewohnt das tropische südöstliche China und geht nach IJavid bis in das vorwiegend paläarktische Grebiet von Mupin (bei Ta-tsien-lu in Szetschwan). Sie ist kenntlich an dem kurzen, dicken, starkgehogenen hellgelben S'hnabel, gelblichgrïner Oberseite, schwärzlicher liehle und ebensolchem Oberkopf, grauem Nacken und Hinterhals, schwärzlicher Endbinde am Schwanze, weißem Kehlbande und gelbem Bauche.

2) Eine Gruppe von „Bülbüls“ mit schwarzem Kopfe, weißlichbraunen bis weißen Oberschwanzdecken, braunschwarzem Schwanz mit weißer Ėndbinde und karminroten Uutersehwanzdecken bewohnt in ungrefähr if Formen Indien und süd-China. Pycnonotus haemorrhousa, burmunicus, nigropiteus, bengalensis und intermedius dïrften Vertreter einer Art sein.

Pycnonotus haemorrhousa intermedius Jerdon (B. India II, p. 95. „Wuzeerabad, in the Punjal.:) bewohnt die Siidahlïnge des westlichen Himalaya his in mittlere Höhe. den nördlichen Punjab und die Nordwest-Provinzen Indiens. Im Cat. B. Brit. Mus. VI. p. 130 ist unter $e$ ein Stuick aufgezählt mit der Angabe „Afghanistan (Griffith)". Auf Grund dieses Exemplares ist die Art wohl in Dressers "Manual"6 aufgenommen. Die Etikette im Brit. Ius. trägt aber die Angabe Himalaya, nicht Afghanistan! Aubexdem ging Griffith's Expedition dureh Kaschmir nach Afghanistan, seine V̈̈̈gel wurden nicht etikettiert und der genaue Fundort derselben ist nicht bekannt.

Pycnonotus xanthorrhous Anderson, mit hochgelben Unterschwanzdecken, schwarzer Kopfplatte, braunem Rücken, winzigem roten Fleck an der Basis des Linterschnabels und weiber Unterseite mit brannem Brustbande, bewolnt Süd-China bis Szetsehwan, :grenzt also an paläarktisches Gebiet. 
2 Unterschwanzdecken blaßgelb, Olirdecken schwarz . P. c.xanthopygos . p.461

2 Unterschwanzdecken hochgelb, Ohrdecken weiß ......... 3

3 Oherkonf schwarz. Kopfedern ntr wenig verlingert. . . L'. lencotis . 1.462 Oberkopf braun, Kopffedern zu einem langen Schopf verlängert . . . . . . . . . . . . P. lencogenys . p. 463

4 \{ Stirn und Kehle braun, Fliigel ïber $100 \mathrm{~mm}$. . . . P. b. barbatus . p. 460 Stirn und Kehle braunschwarz, Fliigel unter $100 \mathrm{~mm}$. . P. b. arsinoe . p. 461

\section{Pycnonotus barbatus barbatus (Iesf.). (Fig. 82.)}

Turdus barbatus Desfontaines, Mém. Acad. Roy. Sci. France MDCCLXXXVII, p. 500 Taf. III (1789- ,... environs d'Alger."6)

Ixos obscurus Temminck, Man, d:Orn. 2nde ed. IV, p. 608 (1840- „A été trouvé en Andalousie, ete." $)$.

Haematomis lugubris Lesson, Rev. zool. 1840, p. 98 (, a été décrit par Ml. T'emminck sous le nom d'Ixos obscurus" ).

Abbild.: Dresser, B. Europe III, 'Taf. 142.

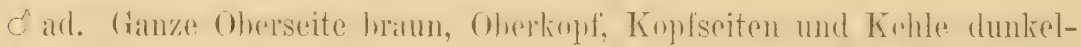
braun, im Frïhjahr und Sommer aber mehr verbleichend, das Braun der

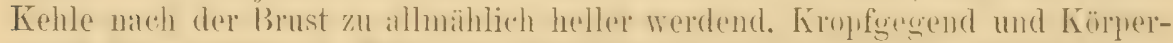

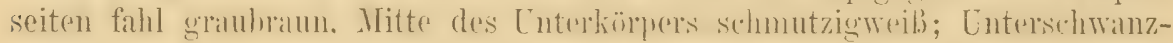

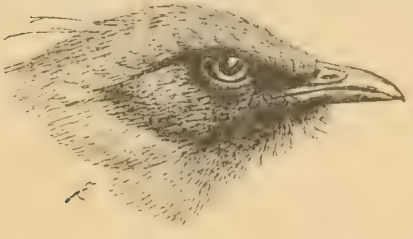

Figur $82(2 / 3)$. decken weil., an den Schäften oft ein bräunlicher Streif, Sïume oft (besonders bei ơad.) sclıwefelgelb. Sehwingen dunkelbraun mit sehr schmalen etwas helleren AuBensäumen und fahlen Inmensüumen. Steuerfedern sehr dunkel braun, Spitzen der äußeren Paare mit undeutlichen graubramen Endsäumen. Unterflügeldecken und Achselfedern hell graubraun. Iris dunkelbraum. Füße und Schnabel sehwärz-

lich. Das (rotiesler rerhloicht im Erïhjahr stark und wird dimn viol mehr graubräunlich. Flügel etwa 104-107, Schwanz 98-102, Lauf 23-24, Culmen etwa 21-23 mm. - o wie o aber kleiner: Flügel etwa 93-96 mm.

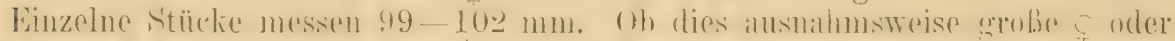

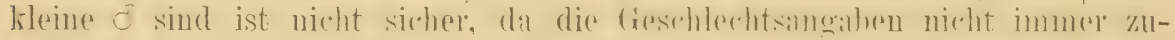
verlässig sind. - Juv. wie die Alten, nur blasser, der Kopf kaum dunkler, Unterseite vielleicht etwas grïulicher. (18 Exemplare.)

Marokko von 'T'anger bis Mogador und vielleicht noch südlicher, Algier, Tunis. In letzterem Lande anscheinend nur nördlich des Atlas?1) — Soll

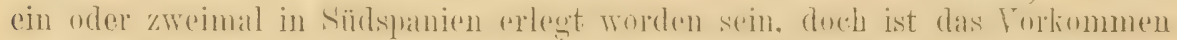
daselbst auf jeden Fall um ein ausnahmsweises, wenn überhaupt sicher.

$\left.{ }^{1}\right)$ In West-Afrika von Senegambien bis zum Niger wird $P$. b. barbatus vertreten durch: P. barbatus inomatus: Wie $P$. b. barbatus, aber Fligel etwa 2-5, Schwanz etwa $10 \mathrm{~mm}$ kiirzer.

In Kamerun und Gabun schließt sich an:

$P$. barbatus gabonensis: Kenntlich an den weißen, aber breit gelb gesäumten Unterschwanzdecken.

Noch weiter südlich und im zentralen und östlichen Afrika wird P. b. barbatus durch Formen mit ganz gelben Untersehwanzdecken vertreten. (Vgl. Nov. Zool. 1906.) 
Kein Vogel Nordwest-Afrikas erinnert mehr an die Tropen, als der" „Naranjero“ mit seinem lauten, etwas metallischen, schönen Schlag und lärmenden Schwatzen. Die volle Strophe erinnert an die Silben ,guit, huit, huit, hwitera, hwitera". Man sieht diese Vögel außer der Brutzeit immer in kleineren Trupps und sie fallen von weitem durch ihren Lärm auf. Die Nahrung besteht hauptsächlich aus Früchten, namentlich reifen Orangen, die sie ganz ausfressen. Sie bewohnen daher vorzugsweise Orangenhaine, Gärten und Laubholz, nach Meade- Waldo im marokkanischen Atlas bis 7000 engl. Fuß hoch. Die Nester stehen in Büschen und niedrigeren Bäumen, sind aus Wurzeln, Stengeln und Gras gebaut, mit feineren Würzelchen ausgefüttert und man findet von Mai bis Juli die 3-4 Eier. Diese sind weil mit rötlichem Schimmer, reichlich mit dunkel rotbraunen Flecken und Punkten und einigen hellgrauen Schalenflecken gezeichnet. Größe ungefähr $23 \times 16-24 \times 18 \mathrm{~mm}$.

\section{Pycnonotus barbatus arsinoe (Licht.).}

Turlus Arsinoe Lichtenstein, Verz. Doubl, zool. MLs. Berlin, p. 39 (1823- „Fryum in Aegypto:).

Untreschwanzdechen weili, anscheinend nie mit gelhen sïumen. ()herkopef. Kopfseiten und Kehle braunschwarz, das Schwally dey Kehle in dals Frdbram des Kroples ïhergehend. Hinter der (Hhrgegend ist mehr uder

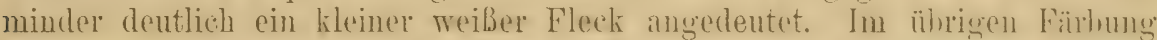
wie bei $P$. b. barbatus. Flügel etwa $87-95$, wobei die kleineren Stïcke zweifellos $\circ$ sind, doch liegen nur wenige Stäcle mit sicher fistgestelltem Geschlecht vor. (16 Exemplare.)

Ton Fajum im mittleren Egypten his zum Wreiben und IBlauen Nil. ${ }^{\text {) }}$

Lebt nach Heuglin parweise oder in Familien, hat einen lauten, drosselartigen Gesang, mit schwätzenden oder wispernden Lauten vermischt. Nahrung Insekten, Beereu und Friichte. Nest meist niedrig, in den dichtesten Palmenbüschen; es ist groB, diclıt und dick aus Pflanzenstoffen zusammengefügt, die Mulde mit Wurzelfasern und Pferdehaaren ausgelegt. Eier wie die anderer Pycnonotus-Formen: Grundfarbe weiß mit bräunlich-rosigem Anflug, lebhaft rotbraunen Flecken und hellgrauen Schalenflecken.

\section{Pyenonotus capensis xanthopygos (Hempr. of Lihrenh.) ${ }^{2}$ )}

Ixus xanthopygos Hemprich \& Ehrenberg, Symbolae Physicae fol. bb (1828 - 'Terra typica: „Syria". Die Autoren beschreiben die Art ron Syrien und fügen hinzu: "In Arabia frequens.")

Ixos Taillantii (errore, non levailluntii T'emm.) Brehm, Vogelfang. 1. 221 (1856- Arabien, womit Sinai gemeint ist, woher Brehm Stïcke hatte).

1) In Abessinien, dem Hauaschgebiet und nördlicben Gallaland durch den äußerst ähnlichen, aber im frischen Gefieder oberseits merklich dunkleren $P$. b. schoanus Neum. vertreten. - Reichenow beschreibt einen $P$. barb. somaliensis ( $P$. arsinoe somaliensis bei Reichenow) der bei Zeila und Somadu vorkonmt und kleiner ist.

2) $P$. capensis capensis bewohnt das südliche Kapland und ist durch größtenteils rauchbraune Unterseite und braunen (nicht schwarzen) Kopf unterschieden.

$P$. capensis nigricans mit orangerotem Augenringe bewohnt Benguela, SüdwestAfrika, die nördlicheren Teile des Kaplandes bis Transvaal.

P. capensis reichenowi ist über Süd-Arabien östlich bis Muskat verbreitet. Ist P. c. xunthopygos sehr ähnlich, aber auf der Oherseite mehr gräulich, das Schwarz der Kehle ist nicht so scharf abgesetzt, das Augenlid bräunlich. (Vgl. Journ. f. Orn. 1901, p. 241, Nov. Zool. 1906.) 
Ixos vallombrosae Bonaparte, Compt. Rend. Acad. Sci. Paris X LII, p. 766 (1856- „dans les jardins de Jaffa").

Abbild.: Dresser, B. Europe III, Taf. 143, Fig. 1.

Ist im allgemeinen 2 . barbatus arsinoe ähnlich, aber die Unterschwanzdecken sind lebliaft gell, und das Auge ist von einem vorstehenden. im Alter wargigen mbefiederten Hantringe umgehen, ein Herkmal, das alle Formen von I'. repenxis anszeichut. - Oberknf, Kopfsciten und Kehle bramsehwarz, Geniek und übrige Oherseite fahlbraun, Flügel dunkler, Selnwanz sehwar\%hram mit fahl graubrämmlichem Endsimm. Lnterseite hell fahlhräunlich. Bauchmitte etwas weiBlicher. Hautring um dis Auge grau. Flïgel, ơ ungefähr 99-102, o $90-95 \mathrm{~mm}$.

Brutrugel in Syrien umel Palästina, nördlich his Krleimasien ('Taurus).

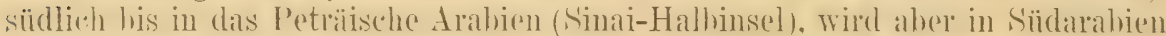
durch $Y$. c. reichenowi vertreten. - Die Angaben vom Vorkommen auf den griechischen Inschn beruhen auf Irtum (vgl. Reiser. Ornis Balcan. III, p. 559-561). Auf Cypern kommt die Art nicht vor. Guillemard will ihn einmal gesehen haben, erlegte ihn aber nicht.

Bewohnt fruchtbares Gelände und Gartenland. Der laut flötende Gesang wird als wundervoll geschildert. Das wohlgebaute Nest steht in Büschen und Bäumen. Die Eier gleichen denen von P. b. barbatus; sehr variabel, Fleckung oft sehr dunkel. 25 Eier (Key, Jourdain, Hartert) messen im Durchsehnitt $24.38 \times 16.97$, Maximum $27.2 \times 17.3$ und $25.1 \times 17.7$, Minimum $22 \times 16.5$ resp. $23 \times 15 \mathrm{~mm}$. Gewicht im Durchschnitt 0.173, Maximum 0.200, Minimum $0.155 \mathrm{~g}$ (Rey). Abbild.: Rey, Eier Vög. Mitteleuropas, 'Taf. 57, Fig. 5-8, helle Var. Cat. Eggs Brit. MIus. III, Taf. X. Fig. 19.

\section{Pycnonotus leucotis (Gould).}

Ixos lencotis Gould, Proc. Zool. Soc. London 1836, p. 6 (,In India Orientali"i).

ơ ad. Kopffedern etwas verlängert. Oberkopf von der Stim bis zum

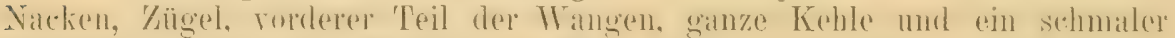

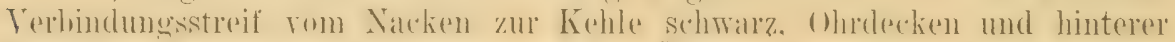
Teil der Koplseiten sridenartig weib. Ëhrige (1)herseite fahl grambanu,

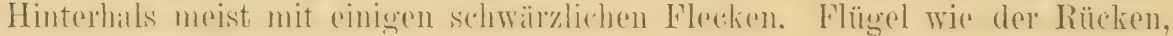
mit blisseren Innensämmen. Sehwanz an der Ituryel wie der Kürken, dann

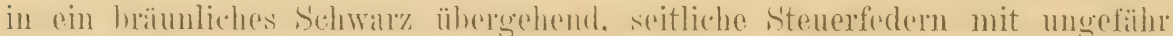
1 cm langen. weißen Spitzen, die an den inneren Federn etwas schmäler werden, die mittelsten beiden Patre mit undenthehen schmalen hräunlichen

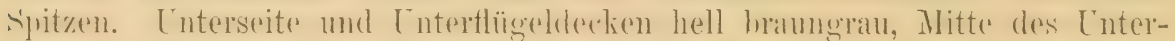
kïrpers weiblich, nahe der schwarzen Kehle etwas dunkler. Lntersehwamz-

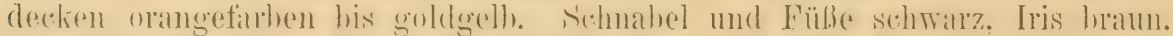
Flügel etwa 91-94, Schwanz etwa 86-92, Lauf 20-21, Culmen etwa

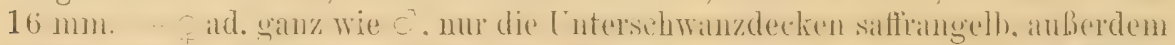

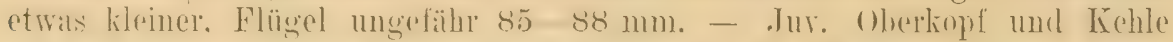
nicht sehwarz, sundern bram, etwas dunkler als der Rü̈clen. Enterschwanzdecken beim of blaßorange, beim o zitronengelb.

()stpersien. Baluchistan und das westliche Indien von Sind, Rajjuntana und Punjab bis Etawah, Jhansi, Saugor und Hoschangabad.

Briitet in Indien rom Mai bis August. Nest in Büschen, aus Würzelchen und Stengeln zusammengefïgt und mit feinen Gräsern ausgefiittert. Die 3-4 Eier gleichen denen anderer Pycnonotus-Arten. Albild.: Ibis 1904, Taf. VII, Fig. 1, 3 (nicht 4, 5). 


\section{Pycnonotus leucogenys (Gray).}

Bratlypus lencogenys Gray, Hardwicke's I11. Ind. Zool. II. Taf. 35 tign. 3 (18:30- Indien).

on ad. Federn des Oherkoptes sehmal und spitz. matthram mit graulubramen Sïumen, die der Scheitelmitte zu einem üher 2 cm langen schoufe verlïngert und einfarbig braun. Zägel, schmaler ling um das Auge, Trohle und Kropf tief schrarzbraun, über den Zügeln cime schmale weißse Linie, Ohrgegend weiß, hinter den (Mhrdecken ein braunschwarzer, unter denselben ein braun und weiß gestreifter Fleck. Ülorige oherseite gräulichliaun, Flügel etwas dunkler mit blasseren Innensïumen. Steuerfedern brannschwarz, nach der Wurzel zu allmählich in Braun ühergehend; das mittelste stenerfederpaan mit sehmalen hellbranen, die übrigen mit etwa $4-10 \mathrm{~mm}$ langen, an den äußersten Paaren ausgedehnteren, weiben Spitzen. Brustfedern hran mit schmutzigweiben säumen, Seiten fahl braun, Nlitte des Unterkörper's schmutzigweiß. Cnterschwamzdecken lehhift gelh. Lnterflügeldecken schmutzighraun mit weiBlichen Säumen. Schmahel schwarz, leübe brüunlich bleifarben. Iris hraun. Flügel 89-95, einzelne bis 98.5, selhwanz, $80-90$ und sogar 95, Lauf $21-23$. Culmen etwa $19 \mathrm{~mm}$. - o wie 0 , aher "twas kleiner: Flügel $85-88 \mathrm{~mm}$.

Afghanistan und nordwestlicher Himalaya bis Butan, im Sommer in Höhen von $3-7000$ engl. Fuß, im Winter in niedrigeren Lagen.

Nest und Eier wie die andrer Arten der Gattung, Eier 3-4, weißlich, mit roten und rötlichgranen Flecken dicht bedeckt.

\section{Gattung HYPSIPETES Vigor's 1831.}

GröBere Vögel als die Arten der Gattung Pyrnonotus, Schnabel so

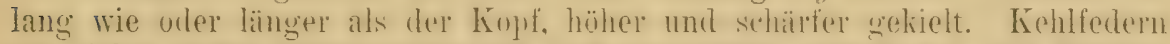
hei vielen drten etwas verlingert und zugespitzt. Länfe hei den Fonmen

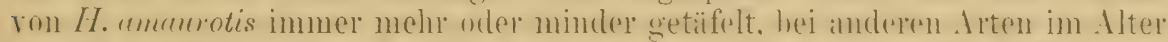
gesehient. Hinter dem Nasenlech rinzelue nateh som gerichtete Borsten. Indien, ('hina, Jipan und umliegende Insehn. - Van hat erworgen, ob nicht die japanischen Formen wegen des nie geschienten Laufes und anderes Eigentünlichlieiten generiseh zu trenuen sind, in welchem Falle sie wohl

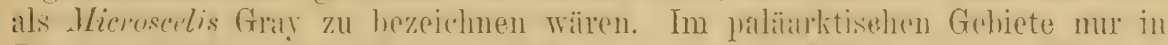
Japan und den umliegenden Insel-Gruppen. wo eine Alt in mehreren Eormen

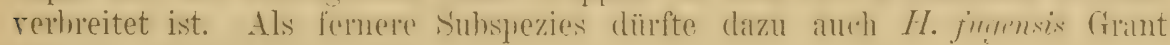
von den Philippinen gehören.

\section{Hypsipetes amaurotis amaurotis (T'emm.).}

T'urdus anuarotis Temminck, Pl. Col. II. Taf. 497 (1830- Japan).

ơ ad. Federu anf Tim f und Hinterhils rerlïngert, schmal und zugespitzt. grau mit etwas helleren Spitzen und dunkleren Schlaftstrichen, die des Räickens etwas dunkler grau, an den Sïunnen etwats heller, hinterer Teil des Bürzels und Oberschwanzdecken mit mehr röstlich olivenfarbenen Säumen. Kleine Flügeldecken wie der Rücken. mittlere bräunlicher und mit hell rostfarhenen. hei ganz alten Tögeh fast verschwindenden Spitzensïumen, große grambrau 
mit hellhräunlichen Sä̈mon. Schwingen dunkelhraun mit schmalen hräunlicholivenfurbunen Auben- mnd röstlich-rahmfarbenen Innensäumen. Steuerfedern tirfhran mit sehmalen olivengranen Aubensümmen. Tohle sehr hell grau, mutere Kehlfedern mit weiblichen Spitzen; Ohrolecken dunkel kastanienhraun, durch cin undentliches, oft nur angedentetes liastanienhloumes Band, das um

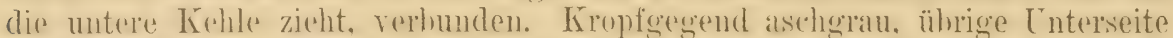

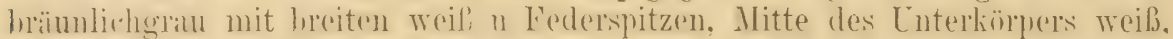

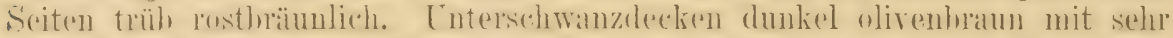

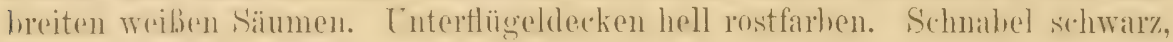
Füße braun, Iris nußbraun. — o wie ó, nur etwas kleiner. - Juv. Oberseite hrämolich, nicht sn gräulich-schieferfarhen. Schwanz. Ohorflïgohlechen und Schwingen mit hesten hell rosthramen Sämmen. (to untersucht.)

Hondo, Kinschiu, 'Tselnuschima, Siehen-Inseln, Tamegat-sehima und Yakuschima. - Kein eigentlicher Wandervogel. soll aber zur Brutzeit mehr anf den [Bereen wohnen mol zioht im Winter teilweise nath Korea und OstChina, sowie in geringer Anzahl nach den Riu Kin-Inseln (Okinawa) die Mohrzihl dieser Kusrögel aber dürften der Form ron .Jesso angehören.

Nest in Büschen und Bäumen, 2-6 m oder höher, aus Halmen, Zweigstückchen, Wurzeln und Blättern. innen mit feineren WÜ̈rzelchen ausgelegt. Eier rötlich weiß oder rötlich rahmfarben, mit rotbraunen Flecken und hellgrauen schalenflecken. Größe ungefähr die von Amsel-Eiern. Zwei von mir gemessene Stïcke messen $31>20.5$ und $30 \times 21 \mathrm{~mm}$. Nehrkorn gibt an $28 \times 20-21 \mathrm{~mm}$. (Ibis 1904, Taf. VII, fig. 6, 8.)

\section{Hypsipetes amaurotis hensoni Stejn.}

Hypsipetes amanrotis hensoni Stejueger, Proc. U. S. Nat. Mus. XV, p.347 (1893Hakodate (u. a. Orte) auf Jesso).

Oberseite eine Schattierung heller als bei H. a. amaurotis, obenso die Weichen: Sohnahel etwas schlanker und schwächer. - Eine nur dureh Ter-

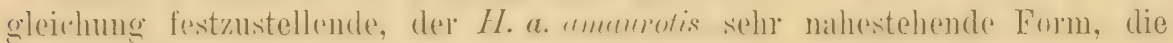
aber bei Untersuchung mehrerer Stïcke auffällt (4 verglichen).

Jesso. - Vielleicht gehört die Mehrzahl der im Winter in Korea, China urd auf den Riu-Kiu-Inseln erlegten Stïcke zu hensoni.

\section{Hypsipetes amaurotis pryeri Stejn.}

Hypsipetes pryeri Stejneger, Proc. U. S. Nat. Mus. IX, p. 612 (1887- Okinawa).

Unterscheidet sich von $H$. a. amaurotis wie folgt: Oberseite dunkler, hesonders der Kupft dumkler, der Rüldien bräunlichor, der Bürzel ganz oliven-

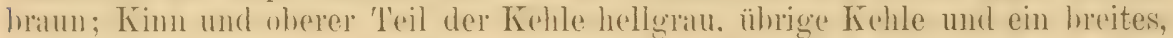

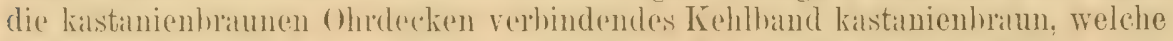
Farbe nach dor Brust zu weniger lehhalt und löiunlicher wircl; Seiten rosthratun; Lnterselıwanzdeclien röstlich olivenhaum mit breiten hräunlichweißen bis fast rein weißen Säumen. (20 untersucht.)

Bewohnt die Inseln der mittleren Riu-kiu Gruppe: Okinawa, Iheya.

\section{Hypsipetes amaurotis stejnegeri suhsp. nог.}

Subspeciei $H$. amaurotis pryeri appellatae simillimus, sed major, rostro validiore.

In der Färbung nicht wesentlich von $H$. a. pryeri unterschieden, nur durchsehnittlich noch lebhafter rotbraun auf der Lnterseite, aher größer. 
Wlügel zwas nicht immer lünger (c etwa 123-127, o etwa $115-116 \mathrm{~mm}$. diese Maße aher sind ungenan und vermutlich zu gering, weil nur stark alhgenutzte Brutvügel rorliegen), ahrer Schmahel auffallend größer. Culmen :30-35 mm (Tyjus c ach Ischigaki 26. Nai 1904. No. 174, Tring-1Iuseum).

Benannt nach Lemulard Stejneger, dem Beschreilser ron zwei HysipetesFumen und kritischesten Irheiter ïher japanische Vügel. (10 untersucht.)

Bewohnt die Insehu lschigalkj und Iriomote in der südlichen (Namhuschoto)

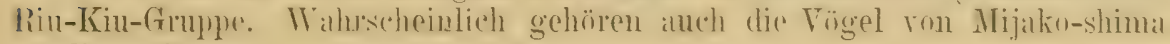
$2 \pi$ dieser F'orm.

\section{Hypsipetes amaurotis ogawae sul)sp. nor.}

Subspeciei $H$. amurotis prycri dictae similis, sed torque gualari rufo angustiore magis restricto, haud difficile distinguendus.

Das rotbriune Band, das die ebenso gefärbten Ohrdecken, über un unteren 'Teil der liphle hinziehend. verhindet. ist scharf begrenzt und nur etwa cinen 'm hreit. oft noch schmäler, mitunter fist verschwindend; unter demselben lrefinden sich mehr oder minder sehiefergraue Federn. wïhrend hei pryeri die rothraune Fïrbung mehr oder minder anf die Kropfgevend hin verläuft und in dlas röstliche Braun der Seiten ähergeht. Flügel C. etwa 122-125. ungefïhr 114-118 mm. (Тypus o $\mathrm{Nr}$. 192, Amamiu-shima 13. Dezemher 1914, Tring-Nusemm.) Benaunt nach dem Ornithologen Ogawa, Ferfasser einer Ahhandlung üher Rin-Kiu-Vüggel. (20 Exemplare.)

Bewohnt die Insel Amami (Amami-o-shima) in der nürdlichen Riu-KiuGruppe. - Es ist interessant, daß diese Form, die zwisehen H. a. cmumotis ohne Kehthand und $H$. ". pryeri mit breitem Kehlbande wohnt, auch in der Fürbung gewissermaßen zwischen beiden steht.

\section{7:31. Hypsipetes amaurotis squamiceps (Kittl.).}

Oriohus squcmiceps Kittlitz, Ilém. Acad. Imp. St. Pétersb. I, p. 241 'Taf. XVI (1830Boninsima).

Äußerst ïhulich $H$. " ogazcae aber viel größer und das kastanienbraune Kehlband nach dem Kropfe zu weniger scharf hegreuzt. Flügel co etwa 135-140, 우 124-126 mm. (6 untersucht.)

Boniu-Inseln südöstlich von Japan.

Bewohnt Gebiasch und Bäume. Nahrung Beeren, Insekten und C'rustaceen. Stimme nach Kittlitz ein holer, pfeifender, aber etwas heiserer Ton. Flug schnell, gewandt, flach bogenförmig.

\section{Hypsipetes amaurotis magnirostris Hart.}

Hypsipetes amaurotis magnirostris Hartert, Bull. B. O. Club XV. p. 16 (1905- S. Dionisio, Vulkan Inseln).

Ähnlich H. a. squaniceps, aber der Schnabel viel stärker und länger. ('ulmen 31-34 mm. Auf der Kropfgegend ist viel weniger Rotbraun, anch seheint die Oberseite etwas lichter zu sein, jedoch läßt sich über die Fürbungs- 
unterschiede wenig Bestimmtes ságen. dil die rorliegenden Vögel in sem. abgenutztem Gefieder sind. (7 Exemplare.)

Süd-Dinnisio, eine der Vulkan-Inseln, südlich der Bonin-Inseln.

Ein vorliegendes Nest besteht aus Wurzeln, Halmen und nach außen zu größtenteils aus dürren Blättern mit von der Wolle umgebenew. Baumwollenkernen, und ist innen nur nit Wnrzeln ausgelegt. Es enthält zwei Eier, die auf rötlich schimmernden. rahmweißen Grunde mit dunkel rotbraunen Flecken gezeichnet sind, die um das stumpfe Ende einen dicken Kranz bilden und sonst nur spärlich verteilt sind. Außerdem haben sie einige hellgraue Schalenflecke. Maße $30.5 \times 22$ und $30 \times 21.7 \mathrm{~mm}$.

\section{Familie CAMPEPHAGIDAE.}

Schnahel breit, fliegenfängerartig, Spitze mehr oder minder hakenfürmigg. Befiederung sehr reich. besnnders auf clem Bürzel, wo die Schlïte nach dèr Wurzel zu verstärkt und steif sind, was man leicht fühlen kaun, wenn man gegen die Federn zu streichen versucht. Diese Federn sitzen anch sehr lose in der Haut. Füße ziemlich schwach, Lauf kurz. -- Fast 200 Formen hewohuen die Tropen der Alten Welt, in das paläarktische Futunengehiet reichen nur wenige Formen der Gattung Pericrocotus.

\section{Gattung PERICROCOTUS Boie 1826.}

Eine Gattung, die in den 'Tropen Asiens in etwa 30 Formen verhreitet ist, die meist in lebhaften roten (O) und gelben (q) Farben prangen. Iи das eigentliche paläarktisehe Faunengehiet reichen nur wenige Formen. Jie grau, weiß und schwarzen Formen unterscheiden sich durch die viel kürzere erste Schwinge, welche die Handdecken nur wenig ïherragt, während sie bei den tropischen Arten in der Regel etwa halb so lang wie die zweite ist. Hier hat die Gattungsmacherei noch ein Fold für ihre Spielerei. - Der S'chwanz von allen P'ericrocotus-Formen ist so lang wie oder länger als der Flügel und sehr stark gestuft, die seitlichen nur ein Viertel bis ein Drittel. der Länge der mittelsten Steuerfedern.

Ganze Unterseite weiß .............. P. cinereus . p. 466

Unterseite weiß mit grauem Brustbande........ P. tegimae p. 467

Unterseite feurig rot, Kehle schwarz . . . . . . P. brevirostris . p. 468

Unterseite orangerot, Kehle gelblich . . . . . . . . P. solaris . P. 468

\section{Pericrocotus cinereus Lafi.}

Pericrocotus cinereus Lafresnaye, Rev. Zool. 1845, p. 94 (Luzon).

Pericrocotus modestus Strickland, Proc. Zool. Soc. 1846, p. 102 (Halakka).

Ceblepyris luctuosus De Filippi, MIus. Mediol. Anim. Vert., Aves, p. 31 (1847).

Pericrocotus japonicus Stejneger, Proc. U. S. Nat. Mlus. IX, ,1886 p. 649 (1887--

Hondo, Japan. Japanische Stücke lassen sich nicht trennen.)

Pericrocotus motacilloides Swinhne. Ibis 1860, p.58 (als Synonym von cinereus).

Abbild.: Gould B. Asia II, Taf. 11. Eier: Ibis 1904, 'Taf. X, Cat. Eggs Brit. Mus. III. 'Taf. LX, 19.

ond. Stim his fast in die Mitte des Scheitels $(10-15 \mathrm{~mm}$ weit) weiß. die die Nasculöcher üherragenden borstenartigen Federehen, eine Linie 
ron dort über die Zïgel zum Auge, Seheitel und Nacken his an den Hinterhals, oft auch letzterer, schwarz, ührige Oberseite aschgrau. Iubere Hanclschwingen ganz braunschwarz, 3. und 4. mit weibem Saumfleck am Rande ler Mitte der Inmenfahne, die übrigen mit dreieckigem Fleck vor der Basis der Innenfahnen und kleinem weißen Fleck nahe dem s'chafte der Außenfahne, Armschwingen reiner sehwarz und nit geraderer weiljer Querhinde ror der Basis, innerste Armschwingen gröBtenteils schiefergrau. Kleine Oherflügeldleckeu grau, große schieferschwarz mit grauen AuBensäumen. Handdecken schwarz. Mittelstes Stenerfederpaal schwal\%. folcendes mit weißem oder lichtgrauem Schaftflecke an der Spitze, die ïhrigen an der Wurzel. schwar\%, die apikale Hälfte oder mehr weiß. Ganze Unterseite weib. Die mahe dem Flügelbuge hefindlichen Interflügeldecken fist gunz wveiß. die übrigen schieferfarben mit ausgedehnten weißen Spitzen, Handdecken schieferfarben. Schnabel und Füße schwarz, Iris braum. Flügel (2) o ) (1 \pm -96. Schwanz 93-99, äuBerste Steuerfedern nur etwa $33-36$. Lauf $15-16$. Schnabel vom Ende der weißen Stimbefiederung $14-16 \mathrm{~mm}$. - o ad. Nur der Zügelstrich schwarz, auf dem Kopfe aschgrau wie auf dem hï̈cken, die rordersten Stirnfedern mit weißen Spitzen; Brustseiten mit mehr oder mindrr dentlichen grauen Querlinien. - Juv. Federn der Oberseite mit schwarzen Endsäumen, vor denen sich eine weißliche Linie befindet. Unterscite mit gelblichem Anflug, Brustseiten mit grauem Fleck. (38 Fixmplare.)

Brutgebiet: Amurland, Mandschurei, Korea, auch im mittleren Jalran. Zieht durch Japau, China, Formosa, im Winter in Birma, Malakka, auf den groben Sunda-Inseln, Palawan und. Plilippinen. - In Sïd-China dureh Pericrocotus rantonensis Swinhoe (Ibis 1861, p.42) vertreten, der wohl nu. Subspezies von cinereus sein dürfte, sich aber sehr wesentlich durch dunkelgrauen statt schwarzen Scheitel, bräunlichen Bürzel. kïrzeren Schwanz und hellbraune Steuerfederschäfte unterscheidet.

Nahrung Insekten. Halten sich in Laubwäldern fast immer hoch auf Bäumen auf, kommen um Mitte Nai an und bauen im Mai ein tief napfförmiges Nest auf Bäumen. Die Eier sind nach Nehrkorn blaugrau mit großen violetten Schalenflecken und graubraunen und gelblichen Oberflecken, dunklen Eiern von Lamius collurio nicht unähnlich; Maße $21<15.5$ bis $16 \mathrm{~mm}$. (Kat. Eiersamml. 1899, p. 23.)

\section{Pericrocotus tegimae Stejn.}

Pericrocotus teginue Stejneger, Proc. U. S. Nat. Mus. IX „1886“ p. $648(1887$. Okinawi. mittlere Riu Kiu Gruppe).

$\sigma^{-}$ad. Nasenborsten und Zügel schwarz, schmaler, über den Zügelı bis zum Auge fortgeführter Stirnstreif weiß. Oberkopf und Nacken glänzend schieferschwarz, allmählich in das dunkle Schiefergrau des Rückeus übergohend. Handschwingen schieferschwarz, Inuenfahnen mit großem weißen Fleck, Armsehwingen auch auf den AuBenfahnen mit weiliem Fleck, die innersten ganz schieferschwarz. Mittelste heiden Steuerfederpare giuz schwarz, das folgende mit schwarzer Wurzel- und weißer Spitzenhälfte, die übrigen (kürzeren) schwarz mit schiefstehendem weißen Spitzenfleck. Kehle, Mitte des Unterkörpers und Unterschwanzdecken weiß, breites Band über die Vorderbrust und Seiten schiefergrau. Die kleinen Unterflügeldecken nahe dem Flügelrande und dio Achselfedern weiß, die übrigen Unterflïgeldeckfedern schwarz mit weißen Spitzen. Iris bratun, Schnabel schwarz, Füßo 
schwärzlich. Flïgel stwal 86--90), Sichwan\% rtwal 96-10\%, Schuabel etwil 11-12 mm. - ad. Oherkopf nicht schwal, sondern schiefergrau, Rücken heller grau. - dur. Federu der Oherseite mit weißen Endsäumen. (18 Exemplare.)

Süd-Japran ('T'anega-schima und Yakku-schimal) und Rin Kin Insedn (Amami, Okinawa, Ischigaki, Iriomote).

\section{Pericrocotus brevirostris (Vig:).}

Iruscipete brevirostris Vigors, Proc. Zool. Soc. London 1831. p. 43 (Himalaya).

Abbild.: Gould, Cent. Him. B. 'T'af. 8.

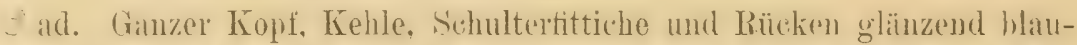
shwal\%. Hinterrücken, Bürzel, Oherschwanzdecken und L'nterseite mit Ausmahme der Kehle feurig rot, jede Feder ror der ausgedehnten roten Spitze zelhlieh, damn weif und an der Basis sehiefergtan. Oherflügeldecken wie der Rürcken, die großen mit roten śpitzen, Handdecken mit oder ohne kleinn rote Flecke an den Spitzen. I) ae sten drei Sehwingen sthwarz, die 4 m mit rntem Saumstrich in der Mitte der Aubenfibue. 2.. 3.. 4. mit blaßrotem Fleck an der Innenfahne, die ährigen rot, Basis etwa 1 cm und Spitzendrittel schwal\%, letzte Armschwingen wieder fast ganz schwar\%. Stenerfederin rot mit schwarzer Bassis, mittelstes Paar ganz sehwar\% oder schwar\% mit

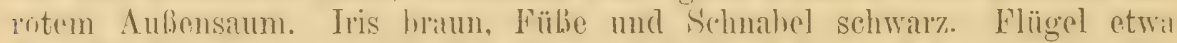
85--89, Schwanz etwal 89-_-94. Schnaluel 9, Lauf etwa $14 \mathrm{~mm} . \quad$ : I) heim of roten 'T'eile gelb, Stirn gelblich. Rücken nlivengrau.

Himalaya his in Höhen ron loguo engl. Fuld astlich bis Kansu, Mandschurei und Nord-China.

Die Angaben, daß diese Art im Gebirge nisten und in den Ebenen uiberwintern soll, sind zweifelhaft. Nistet im Himalaya im Mai und Juni. Nest ein tiefer, außen mit Flechten und Spinnengeweben bekleideter Napf, auf einem hohen Aste stehend. Eier 3-5, weißlich mit braunroten Flecken und hell graulila Schalenflecken. Mabe etwa $18-19.5 \times 14-15 \mathrm{~mm}$. Lockton ein silberhelles ti-ti-ti.

\section{Pericrocotus solaris solaris Blyth.}

Pericrocotus solaris Blyth, Journ. As. Soc. Bengal XV, p.310 (1846- Darjiling).

Ähnlich P. Irevirostris, aher Oherkopf und Rücken schieferfarben, Bürzel. Basis der Sehwingen. Enden der äuferen Steuerfedern und Unterseito orangerot, Kinn grau, Kehle gelblich. Beim sind die beim of orangeroten Teile gelb.

Bewohnt Birmal, soll aber im Himalaya in Sikkim bis 10000 Ful.3 hoch vorkommen (Blinford)(?). - I. soluris 'griseiguluris Gould bewohnt Formosa und Teile von Süd-China. 


\section{Familie IMUSCICAPIDAE (nelust SYIVIIDAE, "TIMEIIIDAE“ und TURDIDAE).}

Es ist m. E. unmöglich, die Familien Muscicapidae, Sylviidae und Tiudida zu tremnen. Die sogen. Muscieapiden gehen allmilhich in die sugen. Sylviiden sowohl als in die sogen. 'Turdiden üher. Man vgl. и. а. die Gattung Ciryptolopha: sie wird allgemein zu den II sciespiden gerechnet, dennoch haben augenscheinlich ihre Jungen kein geflecktes Nestkleid. was doch fast das emzige Merkmal der Museieapiden gegenüher den sylviiden ist: ferner Pratincolu: herrnragende Ornithologen stellten sie zu den Muscianpiden. andere z.1 den Turdiden, in die Nïhe ron Saxirolı; eine Art. lliplootocus monssieri, wurde abwechsehd zin Rinticilla und Pratineoln gestellt. ron sharpe jedoch zu Pinarochroa (Fimilie Timelielue.'). his ich jhr einen I'latz in einer eigenen Gattung anwies, aher nachdrieklich hetonte, dab sipe den Ruticillen auberordentlich nihe stehe. Rhyymornis wurde bald zu den Fliegenfängern, bald in die Nähe der Rotsehwänze gestellt. Die (rattung Chinurrhornis wurde ron Sharpe zu deu T'imeliiden gestellt: dies war zwar sicher ein Milsgriff, aher ol man sie zu den Srlvio-Turdiden oder zu den

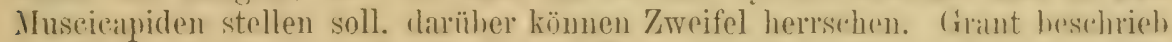
ron Luzon einen neuen Togel, den er Chimurhomis bicolor namnte. der aher rine Form ron lihyocomis juliginose ist: das Wiehtige dabei ist, dal.) man letztere liattung zu den Muscicapiden rechnete, erstere zu den 'Turdiden. Seebohm auberte sich schom dahin, dab MInscicapiden und Sylvio-Turdiden nicht trembar seien. Reichenow rereinigte sylviiden, 'I'imeliiden und Turdiden, und stellt sie an das Ende der Passeres, während er die Muscieapiden fast an den Anfang derselben stellt. Dis Gros der lishore Timeliidae genamnten Tögel (am besten gekennzeichnet dureh dir Parodie: .. Was man nicht unterhringen kamn, sieht man als Timeliiden an") muli anch in diese grobe Formengruppe eingeschlossen werden. wïhrend mil scheint, dab man die Zaunkönige und Verwandte als eigeme Familie hetralditen kann, deren Abgrenzung noch näher zu studieren ist. Soweit wir wissen, ist

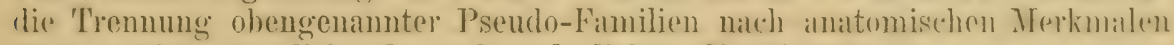
noch weniger möglich, als nach äußerlichen Charakteren.

\section{Gattung TCHITREA Lesson 1831.}

Terpsipheme vicler Autoren, doch kamn dieser Name nicht angewandt werden. V'gl. Proc. C. S. Nat. MIus. XXII, p. 245. Schuahel groli und flach, SChmahelhorsten lang und kräftig (Fig. 83). Schwanz stark enestuft, die mittelsten Stenerfedern bei den of aller paliatrktischen mod der meisten tropischen Arten enol'm rerlüngert (Fig. 8-4), bei den o mur wenig. Lim dis. Auge ein hei vielen Arten selur stark (besonders U. it. bei minures und

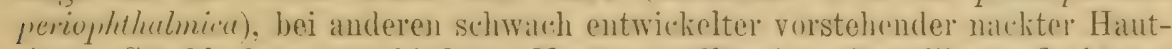
ring. Geschlechter rerschieden. Nester napförmig, offen. lier gefleckt, an Tö̈rgereier erimnernd. Bewohner der Tropen tfrikas und Asiens. südlich his zu den kleinen Sunda-Inseln. nur wenige im paläarkitischen Grehiete. In

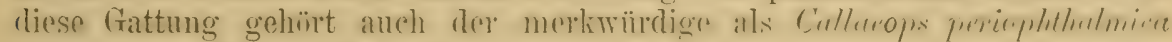
beschriebene Vogel ron Iuzon. 
ఫొad. Oberseite weiß mit einigen schmalen schwarzen Linien und blauschwarzem Linpfe: etwas grciber. Jomed. Oherseite und Schwanz zimtfarben T. paradisi . ơad. Wie das von $T$. paradisi, aber mit breiteren schwarzen Linien auf der Oberseite und etwas kleiner. ômed. Oberseite und Schwanz kastanienrotbraun mit purpurnem Schimmer ........... T. incei. ơad. und ơmed. Nie weil, sondern Rücken purpurbraun, Schwanz schwarz

\section{Tchitrea paradisi (L.). (Fig. 83, 84.)}

Corvus paradisi Linnaeus, Syst. Nat. Ld. X, p. 107 (1758 - ex Edwards 113, Rajus und Seba. "Habitat in India").

Muscipeta Indica Stepheus, in Shaw's Gen. Zool. XIII, 2, p. 111 (1826- India).

Muscipeta rastanea Temminck, Pl. Col. III, im Text zu Taf. 584 (1835- Benennung einer Abbildung ron Levaillant).

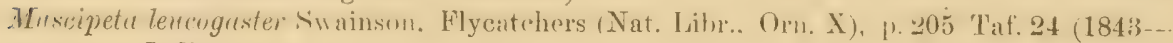
Indien, 우).

Abbild.: Gould, B. Asia II, Taf. 18. Eier: Dresser, Ibis 1904, Taf. X, 9, 10; Cat. E'ggs Brit. Mlus, IV, 'Taf. VIII, 21.

Juv. ( ). (Dherkopf nelsst Haube und Nacken metallisch blauschwar\% mit grïnlichem Schimmer. ganze ïhrige Oherseite nelost Schranz lebhaft rïtlich zimmtfarben. S'hwingen dunkelbraun, Außenfahnen und Innensäume wic der Rürcken. Kéhle und Kropf bräunlich aschgrau, allmählich in das Weiß des Cnterkörpers ühergehend. Schwanz nur wenig länger als der Flïgel: ctwa $10 \mathrm{~cm}$. - Iuf dieses Kleid folgt heim o ein anderes, das sich durch ganz binsechwatren Kont. Kohle und Hals und enorm rerlängert. mittlere Steuerfedern (his etwa $36 \mathrm{~cm}$ )

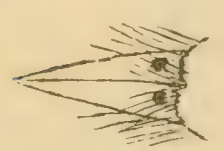

Figir $83(1 / 1)$. unterscheidet. Darauf folgt eins, das eine rein weilse Ynterseite, nicht melre aschgraue Vorderhrust, zeigt. Dies Kleid geht schließlich in das

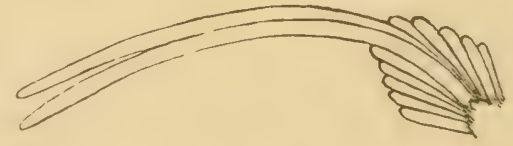

Figur $84(1 / 8)$.

letter schwal\% und weilie Alterskleid äber. das folgendermaben aussieht: fianzer Kinf und Hals gliuzend schwarhhian. übrige Oberseite weiß mit mehr oker minder dentlichen schwärzlichen Sehäften; Schwingen schwar\% mit weiben Innen- und Aulsensäumen. die an den letzten Armschwingen so hreit werden, dat. nur noch ein schwarzer Schaftstreif übrig bleibt. Stenerfedem weib nit schwalmen Shchïften und Aubensäumen, beim mittelsten Patar sind rlie Shehäfte nur an der Wur\%el und mitunter wieder an der äußersten Spitze schwar\%. Unterseite mit Ausnahma der Kehle weib. Sehnabel und sechmalcr Hautring um das Auge hellblau. Schmahelspitze schrwïrzlich; Fübe loleigrau: Iris hraun. Flügel etwa 94-. 98, Culme'u ctra 25, Lauf 15-17 mm. - Die Angaben darüber, in welchem Jahre das weiße Kleid angelegt wird, sind jedenfalls nur Vermutungen. Die Behauptungen. daß dor Cloergang ron dem rotbraunen Gefieder in das weiße durch Farbenveründerung ohne Mauser stattfände, enthehren jeden Grundes, indessen finden sich viele Individurn, die nicht nach dem rothraunen gleich das reine. rolle weißse Kleid. sondern ein weißes. mit zinmtrot gemischtes, unregelmäßig hespritates. rerwaschenes anlegen. Solehe Stïcke werden als Beweise fü̈ .. Tmbirbunge whe Manser" paradiert, es liegt aber durchaus kein Grund ror. 
arzunehmen. dab das gemisehte Kleid nicht unverändert ron einer Mausex bis zur anderen getragen wird. Oh das gemischte Kleid regelmäßig und mehrfach im Lohen angelegt wird und ob nicht manche oे das braunrote Gefieder bis in ihr Alter heihehalten, ist schwer zu bestimmen. - Das o ad. gleicht dem oben hesehriehonen jüngeren Vogel. Das Nestkleid liegt mir nicht vor:

Bevohnt Indien von Ceylon und Nepal bis Kasehmir und Afghanistan. Sewerzow simmelte die Art im Russischen Turkestan im Gehiet des Flusses Alis, Russow in Tschinas am Srr Darja und am Sarafschan, Regel und Lidshy in Ost-Bucharil. - Es scheint sich allerdiugs um zwei Formen zu handelu, deren o und im rothraunen Stadium im sïden (Ceylon!) dunkler, im Norden (Kaschmir. vermutlich auch Afghanistam und Turkestam. woher ich keine stïcke untersuchen kmuntr) heller sind, doch kounte ich diesse Frage nicht befriedigend lösen. Wegen dieser Cnklarhoit henemus ieh dic Form in der C̈herschrift rorläufig nur hinär. (Im Osten. rom Fulie des östlichen Himalara dureh Assam. Birmal und Tenasserim his Malakka und den groben Sunda-Inseln wohnt die etwas kleiner" T. pradisi affinis.)

Vom Mai bis Juli findet man in verhältnismäßig kleinem, napfförmigen Neste, das aus Gras, Würzelchen und Moos zusammengesetzt ist, 4--5 Eier. Diese sind schön rahmfarben oder lachsfurben, selten weil., mit rotbraunen Ober- und hell hliuliehgrauen Unterflecken, die Zeichnung meist am stumpfen Ende gehäuft oder kranzförmig. Sie messen $19-22 \times 14.5 \times 16.5 \mathrm{~mm}$. Die Stimme ist ein rauher, lanter Ruf, die Nahrung besteht aus Insekten.

\section{Tehitrea incei (Gould).}

Muscipeta Tneei Gould, B. Asia II, Taf. 19 (1852- Schanghai).

Sad. Im weißen Gefieder dem von 'T. paradisi sehr ähulich, aber etwas kleiner (F)ügel etwa 5 mm kïrzer), dir Haubenfedern nicht so lang und ineiter, Ohersuite nicht so rein weih. sondern mit mehr oder minder auffallenden schwargen Shehäften. Das ơ im rotbraunen Kleide unterscheidet sich ron dem ron 'T. paradisi durch riel dunklere Oberseite, die nicht rötlich zimmtfarben ist, sondern kastumien-rothraun mit etwas purpurnem Schimmer. c. Ehenfalls ron dem rou T. purudisi durch die dunklero Färhung der Oherseite unterschioden, sewie durch dunkler graue Kohle. - Vielleicht ist incei nur geographischer Vertreter von paradisi.

China. nördlich his Patl-ting-tu in der Provinz Tehili. Die Angaben vom Forkommen in der "Mandschurei" sind unsicher. Berezowski glauht, dab. sie im ästlichen Kansu rorkomme erheutete sie dort aher. nieht (Bianchi in litt.). In der Malakka-Halbinsel und anf Sumatra, ahep in diesen beiden Läinderu wohl nur Wintervogel.

Eier last ganz wie die von T. puradisi, schön rahmfarben mit scharf markierten rothraunen Flecken und hellgrauen Unterflecken. $19.8 \times 14.2,20<14.7 \mathrm{~mm}$.

\section{Tchitrea princeps princeps ('I'emm.).}

Muscipeta princeps 'Temminck, Pl. Col. III. 'T'af. 584 (1835- nördliche 'leile von Japan; Korea).

Muscipeta principalis Temminck \& Schlegel, in Siebold's Fauna Japon, Aves p. 47, Taf. XVILE (1847). 
Jad. Luterscheidet sich vou den im rotbramen fefieder hetindlichen der rorhergehenden Formen durch nicht so stark metalliseh gläuzenden. purpursehwar\%en Kopf; diese Farbe ist im Unterrande der Kehle nicht seharf aligeschnitten. sondern reicht his zur Brust und erstreckt sich an den Śeiten his zu den Wrichen hin, wo sie in cin dunkles Bram ühergeht. Rï̈cken und Oherflïgeldecken purpurbraun, Obersehwangdeckens und Sehwanz. sehwar\% mit Andentung ron purpurnem Schimmer. Mitte des Cuterkinjeris und Tntersehwanzdecken weiß, letztere meist mit roströtlichem Anflug. Sie nehmen nie ein weilos Gefieder an! - o ad. 乡herknuf mattschwarz mit glänzend stahlhlauen Federspitzen. Rücken und Oherflügeldecken zimmt-

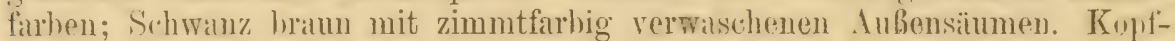
seiten und Kehlo dumkelgrau. Treichen rostbrïmlich. Introkörper und Unterschwamzdecken woib, letztere mit schwarhem rostgalblichen Anflug. öarl. Flïgel etwa $89-93$. ausmahmsweise 94. mittelstes Stemerferlerpair etwa 300 -340, seitliches etwal 80. Lauf etwa 15. ('ulmen etwa $20-21 \%$ mm.

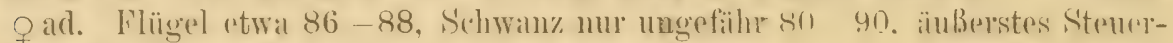
federpaar 7--10 $\mathrm{mm}$ kïrzer als das mittelste.

Brutrogel anf Hondo und Kiuschiu. Wandert durerh das ästliche l'hinit

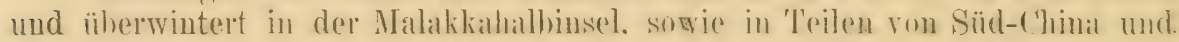
seinen Insoln.

Britet im Juni und Juli. Nest in Astgabeln auf Bäumen, etwa 2-4 in hoch, aus trockenen Gräsern, Baststreifen, Hoos, mit Klechten und Insektengespinsten durchwebt. Die 4-5 Ëier sind fast gleichhälftig, schwach glänzend, rötlichweiß oder lachsfarben mit rötlichen und tiefer liegenden blaßblangran Flecken, dir an stumpir.u Ende sich häufen. Sie ähneln rötlichen Neuntötex-Ëiern und messen etwa $20-22 \times$ 15-16 mm. Die laute Stimme wird von den Japanern (nach Owston) mit den Worten. 'T'suki-Hi-Hoschi verglichen.

\section{Tehitrea princeps illex (Bangs).}

Terpsiphone illex Bungs, Bull. Mus. Comp. Zool. Harvarl XXXVI, p. 264 (1901- Ischigaki, sidl. Riu-Kiu-Gruppe).

Unterscheidet sich durch nichts von $T$. $\%$ monceps als durch etris

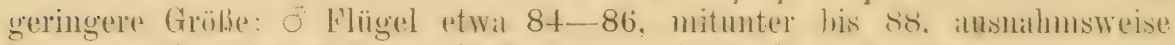
() 1 mm. Eine sichere Cinterscheidung ist hei sinzelnen stäcken nicht immer

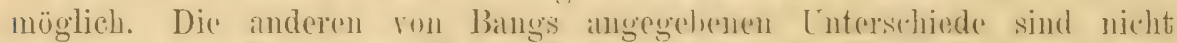

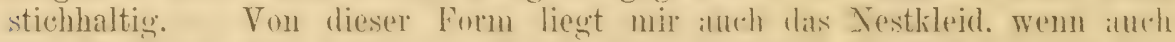

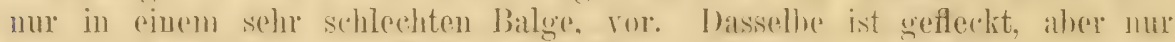

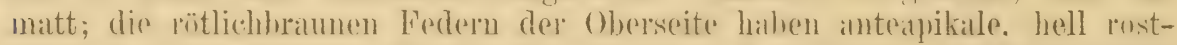
rötliche. fast woibliche Flecke. dio kleinen und mittleren ()herflügeldecken

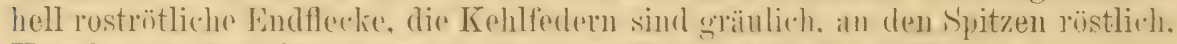
Kropf- und Brustfedern an der basis weiblich. nateh log sitze zu brämulich.

Riu-Kiu-Inseln.

\section{Gattung RHIPIDURA Vig. ¿ Horsf. 1826.}

Die Arten des von Indien his Australien weit verhreiteten Genus lihipidure sind krmutlich all dem lamgen, stark westuften oder gerundeteri

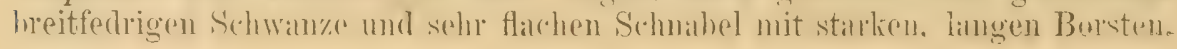


Gefieder sehr weich. Nehmen oft merkwürdige Stellungen ein, breiten den Schwanz fücherförmig aus. Bauen prächtige. feste. dümnwandige offene, auf wagerechten Zweigen befestigte Nester und legen sehr chalrakteristisch grob gefleckte Eier. Tropenbownhner, ron denen uu eine so hoch im Himalaya aufsteigt, daß man sie fast als paläarktisch betrachten kann.

\section{Rhipidura albicollis (Vieill.). (Fig. 85.)}

Plutyrhynchus albicollis Vieillot, Nour. I)ict. d'Hist. Nat. XX V II. 1. 13 (1818- ..Bengalen". Typus im Pariser Museum).

Rhipidure fuscorentris Franklin, Proc. Znol. Suc. Lundon 18:31. 1. 117 (Bengalen, genauer Fundort nicht angegebeu).

Q ad. Oleerkopf. Stirn, Kopfseiten und Kimn schwarz. kurzer S'uperciliarstreif seidig weil.s. C̈lorige Oherseite dunkel rußhran. Stenerfedern dunkelhraum, alle mit Ausmahme del heiden mittelsten Paare mit breiten weißen Spitzen, das mittelste cinfarbig dunkelbraun, das nächste nur mit schmalen weißlichen Spitzen. Sehwingen dunkel rauchhraun. Kehlfedern mit weiben Spitzrn. Kropfgegeur schwarzhramm. ührige Cnterseite matt rußfarlen. Schnabel und Füle schwarzbraun, Iris tief braun. Flïgel etwa 74-83, Sehwanz 95-108 mm, die o meist etwas kleiner. - Juv. Oberseite mit rothraunen Federspitzen. Cuterseite mit ehrensoldhen Süumen.

Bewohnt einen grofen Teil rom Indien. im Himalaya his 5000, nach Stoliezka sogall his snou engl. Fuf, die Berge der Malakka-Hallinsel und Borneos.

Eier, meist drei an '/ahl, hellbräunlich oder mattgelblich bis fast weiß mit einem Ring ron leberbraunen und grauen Flecken. Ein mir vorliegendes Stück mißt $17 \times 12.6 \mathrm{~mm}$.

\section{Gattung MUSCICAPA L. 1766 (Ex Brisson).}

In keiuer Familie ist meiner Jeinung nach mehr unnötige Gattung'sspralterei hetrieben worden. als hei den Muscicapiden im Simne der hisherigen Autoren. Wie wenig halthar ricle der hisher angenommenen (ienera sind, wird am besten dadurch hewiesen. daß jeder Autor die Arten andess anordnet und die Gattungen anders begrenzt. rermindert oder vermeht. Zwischen geringen Unterschieden in der Schuabellänge. Schnabelbreite und -höhe. der Länge und Anzahl der Barthorsten, Schwanzlïnge usw. finden meist eklatante C̈hergänge statt. die Färhung laum ebenfalls nicht als Gattungsmerkmal dienen. Infolgedessen sind wir genötigt, die Gattungen Hemichelidon, Alseonax, Medymele

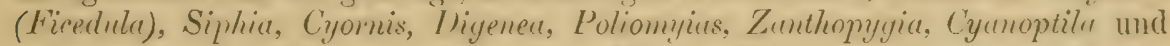
mehrere tropische Gruppen unter dem Namen Husciripa zusammenzufisseru. In dieser Gattung sind die Geschlechter teils gleich, teils anfallend verschieden. Viele Arten haben eine ainfache Itatuser. andere, und zwar meist die bunteren, mit verschieden gefürloten Geschlechtern. cine doppelte. Die erste Schwinge ist mitunter liürer. meist aher linger als die Handdecken. erreicht aher fist nie die Hälfte der zweiten: 3., 4.. 5. vder 3. und 4. Sichwinge in der Regel

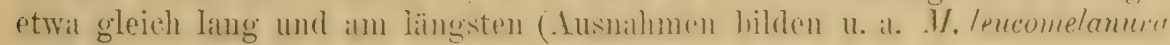
und I. strophiater). 


\section{Übersicht der paläarktischen Arten: ${ }^{1}$ )}

Unterseite hellgrünlichblau, Schwanz blau, Zügel schwarz M. melanops ō. Unterseite mattgrïnlichblau, Schwanz grünlichblau, Zïgel grau ....

Unterseite ganz oder größtenteils gelb, Bürzel gelb. M. narcissina ơ. p. 490

Unterseite weißlich mit hellschwefelgelbem Anflug . M. narcissina 우 p. p.490

Kehlezimmtrot.Brust undUnterkïrperweib, Schwanzwurzel weiß M.parkỡ . p. 48:

Unterseite orange-rotbraun, Oberseite schieferblau . . M. hodgsoni ơ . p.488

Kehle und Brust lebhaft ockerfarben, Oberseite schieferschwarz ....

M. mugimaki ơ . p. 492

Kiehle und Brust matt ockergelb, Oberseite olivenbraun M. migimaki o . p.492

Unterseite nebst Kehle reinweiß . . . . . . . . . . . 2

Unterseite nebst Kehle weiß, ganz oder teilweise mit bräunlichem Anflug, Sehwanz dunkelbraun ..............

Unterseite weiß mit Fleckung oder Strichelung ..........

Unterseite grau mit orangefarbenem Kehlfleck, Schwanzwurzel weiß

M. strophiata ơ? . p. 484

Kinn und Kehle schmutzigweiß, ibrige Unterseite blaß schmutzig gelbbräunlich, Schwanz schwarz mit weißer Basis. M. leucomelanura ơ. Kehle weißlich, übrige Unterseite bräunlich ockerfarben, Schwanz rotbraun ohne weiße Basis ........ M. leucomelanura .

linterseitr mämulich aschfarben. Oberseite olivenhran, Schwanz braun M. hodgsoni o . p. 488

Unterseite hellgraubräunlich, Steuerfedern zirumtrot. M. ruficanda ơ 오 - p. 485

1) In Höhen bis zu 7000 und bisweilen 8000 engl. Huß kommen im Himalaya zwei farbenprächtige Hliegenfänger mit abgerundeten Schwänzen vor:

1. Niltava sundara Hodgs. 1837. - o Zügel, Stirn, Kopfseiten und Kehle schwarz. Oborkopl, Fleck an den Halsseiten, kleine Ol,erfligeklecken, Bärel und Oberschwanzdecken glänzend hellblan. Rïcken und schmale Schwingensäume schwarzblau. Schwingen schwarz. Mittelstes Stenerfederpaar und Aufenfuhnen der iibrigen blau. Unterseite lebhaft orange-ockerfarhig. S'chenkelhefiederung schwarz. Flïgel etwa $80-85 \mathrm{~mm}$. 우 mit demselluen schuppenartigen glänzend hellblauen Fleck an clen Halsseiten, aber die Oberseite rös(lich olivenluraun, Bürzel rostfurbig, Schwanz rostrot, Kehle und Vorder'brust bräunlich, auf dem Kropfe ein großer weißer Fleck. (S. Oates, Fauna Brit. Ind., Birds II p. 41.)

2. Niltava grandis (Blyth) 1842. - ot Oberseite dunkelblau, Oberkopf, Halsseitenfleck und Biirmel glïnzend hellblau. Kehle und Kropf schwarz, Brust bläulieh. Unterkörper aschgrau. Fliigel etwa $105 \mathrm{~mm}$. ㅇ Ober- und Unterseite braun, Scheitel mit grauem Anflug, Halsseitenfleck glänzend hellblau. (S. Ortes, t. c. p. 40.)

Ferner ein selır schmalschnäbliger kleiner Flingenfänger, deu man ebenfalls in eine besondere Gattung gestellt hat:

Nitidula hodgsoni (Moore) 1854. (Abbildung Proc. Zool. Soc. 185̌4 T'af. 62.) of/ïgel und Stimrand rom tiefsten Blau. ()berkopt dunkel himmelblau, in das dunkle Blau der ïbrigen Oberseite übergehend. Schwingen schwärzlich, Außensäume trüb blau. Imensäume und Intertligeldecken gelblich weib. Steverfedern schwarz mit blauen Auben- und blaßgelben Innensäumen. Unterseite lebhaft hell rostgelb. Flügel etwa 49-50, Schwanz 35-37, Lauf 15-16, Culmen 10.5-11 mm. 우 Oberseite und Schwanz röstlich olivenbraun. Schwingen schwarzgrau, mit der Rückenfarbe gesäumt. Unterseite blab. rostgelblich. Axillaren und Unterfligeldecken seidenweib. Unterschnabel hellbraun. (S. Oates, t. c. p. 27.)

Auberdem strigen noch hoch im Himalaya auf: Muscicupa melanolenca, vgl. Oates, Fauna Brit. India, Birds II p. 18, M. sapphiva, vgl. t. c. p. $20, M$. unicolor, t. c. p. 22 ,

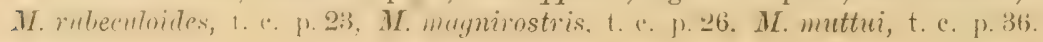


Kehlmitte weiß mit rostgelbem Anflug, übrige Unterseite ockerrostgelb, Schwanz zimmtartig rostrot........... ferruginea ơ o . 1.,479

Kehle blauschwarz, Abdomen weiß, Schwanz schwarz und blau mit weißer Basis ................... cyanomelana ठ . Kehle bräunlich rahmfarben, Brust und Seiten aschbräunlich, Schwanz

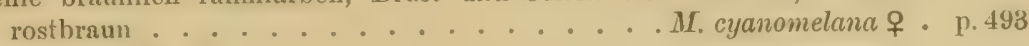

Oberseite blan .......................... superciliaris ô. p.488

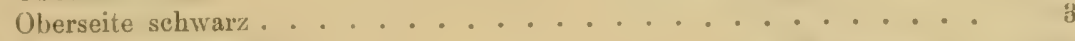

3 Mit weißem Halsbande . . . . . . . M. collaris ơ p. 483

Ohne weißes Halsband ............... M. atricapilla ơ . p. 480

f ishwanz schwärzlich, Aubentahnen der ïuberen Stenerfedern meist un

5 der Basis weiß...... M. atricapilla q und $M$. collaris ? . p. 480,483

Schwnnz braun, auch an der Basis nie mit weißen Säumen . . . . 6

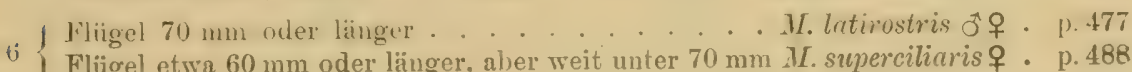

Flügel etwa $60 \mathrm{~mm}$ oder länger, aber weit unter $70 \mathrm{~mm}$ M. superciliaris $q$ - p. 488

- Oberkopf deutlich gestreift............... striata ơ . p. 475

7 Oberkopf nicht deutlich gestreift ................. 8

Schnabel etwa so breit wie lang, Brustfleckung breit, fast die ganze Brust

fichnahel nicht so breit wio law. Brustfleckung sthmäler und nicht so p. 478 scharf hervortretend .............. griseisticta ơ . p. 478

\section{Muscicapa striata striata (1'all.). (Fig. 86.)}

Grauer E'liegentänger, Fliegenschnäpper.

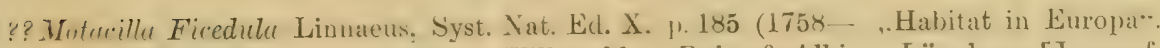
Ex ,Fauna Suecica 2316, TVilloughby, Rajus \& Albin. Lönnberg [Journ. f. Orn. 1906, p. 529] will den Namen für den grauen Fliegenfänger annehmen, indem er sich lediglich auf die Diagnose beruft, er scheint mir aber nicht sicher genug zu sein, um diese Änderung einzufïhren. Man vgl. die der Diagnose in der Fauna Sueciea beigefügte Beschreibung [,Color supra totus e fusco eastaneus"6 und die Citate, die ich Ibis 1906, p. 571 kritisch besprochen habe. In der Diagnose ist nichts ron der Stirnfleckung gesagt).

Motarilla striata Pallas, Vroeg's Catal. Verzam. Vogelen, dieren. Adumbratiuncula, 1. 3 (1761 „hier", d. h. Holland. Beschreib. zweifellos auf den Fliegenfänger zu beziehen, aber holl. Name und Bemerkung "cantu excellit" fälschlich hinzugefügt, offenbar rom Gartensänger entnommen).

Muscicupa Grisola Linnaeus, Syst. Nat. Ed. XII, I, p. 328 (1766- ex Brisson, Aldrov. u. a. "Habitat in Europa").

Butalis montana Brehm. Handh. Naturg. Vïg. Deutschl., f. 220 18:1_- ..die deutsehen gebirgigen Wälder ..."i).

Butalis pinetorum Brohm, Handh. Naturg. Vög. 1)entschl. 1.221 1831- ,.Schwarzwälder Deutschlands").

? Butalia ufircanc Bonaparte, Compt. Rend. Acad. Paris XXX VIII, 1.652 (1854- Cap. - Beschreibung ganz ungenügend. Handelt sich vielleicht um eine ganz andere Art).

Butalis montanu, pinetorum, alpestris et domestica Brehm. Vongelfang. 11.80 (1855"Alle in Deutschland". Nomina nuda!)

Butulis Finschii Bocage, Jorn. Acad. Se. Lisboa XXIV, p. 257, 270 (1878- Caennda).

Engl.: Spotted Flycatcher. — Franz. Gobe-mouche gris. - Ital.: Pigliamosche. Schwed.: Grå Flugsnappare. 
Nur eine Hauser! - ôd. Oberseite fahl graubraun, Federn des. (Wherkopfes in der Mitte tiofhraun, die ron Stirn und Forderkonf außerdem mit mehr oder minder deutlichen weililichen Säumen. S'chwingen sehwall\%hraun mit sehr feinen, an den inneren Armschwingen und Flügeldecken aber hreiteren fahl weißlichbranuen S'üumen: Lmensiimme fihl röstlichwejl. Stenerfedern dunkelhraun mit feinen fahlen S:äumen. Tuterseite wrißlich. Vitte des Thuterkïrpers fist rein weib. Seiten fahlluraun mit dunklerer Strichelung: Keblseiten. Kropfgegend. manchmal auch dir in der Regel rinfarbig weibliche Kehlmitte, hram gestrichelt. Interffügelderelen und

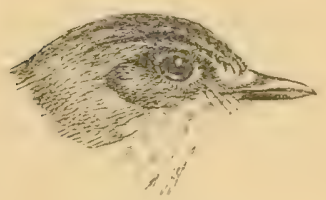

Figur $86(1 / 1)$. Achselfedern isabellfarben, nach der Basis zu braun. Iris dunkelbraun. Füße schwärzlich. Schnahel sehieferschwarz, Basis des Unterschnabels brïunlich fleischfarben. Flïgel etwa 85-89, Schwanz etwa 60-64, Culmen 16-18, Lauf $14: 5-16 \mathrm{~mm}$. - $q$ wie $0^{2}$, aber oft etwas kleiner (Flïgel $83-87 \mathrm{~mm}$ ). Nestkleid: Federn der Oberseite fahl gelbbräunlich, fast rahmfarben, breit schwarzbraun gesäumt, die der Lnterseite weils. Kropf, Vorderhrust und Suiten mit schwïmlichen Seitensünmen. Listes Jugendkleid: f'edern des (Bherseite fahl staubraun mit

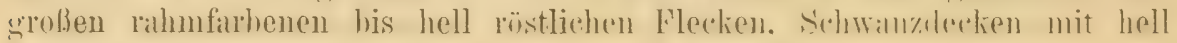
röstlichen Endsätumen. Unterseite wio beim Nestlileide.

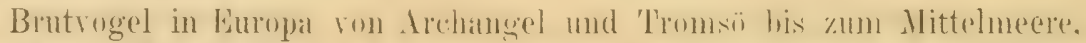
in Nordwestafrika nördlich der Atlaskette. und in derselhen his ins sïdliche Matrokko. - ... Zieht dureh den ganzen dunkien lirkteil und überwintert im mittleren und südlichen Afrika. -- I)ie meist dinfurlige Kehlmitte ist mitunter deutlich gestrichelt. hesonders scheint dies hei Stärken ans Sardinien der Fall zu sein, ïhnliche aher finden sich andh in anderen liegendent. Auf solche Stücke dürfte sich „Butalis finschiio beziehen.

'Zugrogel, der bei uns Ende April oder (meist) Anfangs Jai, in England in der Regel Anfangs Mai, erscheint und meist Anfangs September wiecter fortzieht. Er hält sich vorzugsweise in Gärten, an Waldrändern und in Laubwäldern auf. Der Lockruf ist ganz eigenàrtig und mit keinem anderen zu verwechseln: ein etwas rauher „schirpender“", etwa wie tschie oder tschrie klingender Pfiff, dem in der Hrregung noch ein tieferes reck, teck, angehängt wird. Auch der unbedeutende Gresung ist charakteristisch, da in ihm der Lockruf immer auffallend vertreten ist, sonst besteht er aber nur aus zwitschernden, schirpenden Tönen und ist nicht sehr laut. Auffallend durch seine Gewohnheit, auf frei emporragenden Gegenständen zu sitzen, ron wo or fliegende Insekten fängt, und in graziösem Bogen auf denselben Platz zurïckkehrt. Auffallend ist auch das eigenartige Flügelwippen. Nahrung Insekten, im Herbste auch mitunter Beeren.

Das atus Halmen, Wurzeln, Joos, Haaren, Federn u. a. m. gebaute Nest steht mit Vorliebe an Spalieren und mit Schlingpflauzen bewachsenen Mauern, auch in den halboffenen Höhlungen von Kopfweiden, Kopfakazien, Pappeln, Mauerspalteu, auf Balken in und an Gebäuden, besonders Gartenlauben, Kegelbahnen usw, in Laternen, an Warnungstafeln und an ähnlichen Plätzen. Wier meist 5 (seltener 4, selten 6). Grundfarbe blaß hellblau bis rahmfarben, mit braunroten, manchmal lebhaft ziegelroten bis matt rostbraunen Flecken und helleren, manchmal bläulichgrauen SchalenHecken meist ïber die ganze Fläche, manchmal fast nur un den stumpfen Pol herum, oder kranzförmig gezeichnet. Mitunter kommen blaß-blaue Eier ohne alle Zeichnung vor. Durchschnittsmaß von 58 Eiern nach Rey $18.55 \times 13.79$, Haximum $21.3 \times 14.3$ und $19.2 \times 14.8$, Minimum $16.4 \times 13.5$ und $17.7 \times 13.2 \mathrm{~mm}$, mittleres Gewicht $115 \mathrm{mg}$ - 


\section{Muscicapa striata neumanni Poche.}

Muscicapa grisola sibirica (non $M$. sibirica Gm.) O. Neumann, Journ. f. Orn. 1900, p. 259 (N.W.-Massailand, Ukamba, Nguruman, Taweta, Kilimandscharo usw., teils auch nach Radde und 'T'aczanowski).

.. Butulis grisolu, L., vur. pullida" (sic) (non M. pallirla Müll.) Sarudny, Vöger Ust-P'ersiens. in Mém. Soc. Imp. Géogr. XXXVI, 2, p.363 (1903- Ost-Persien und Transkaspien; russisch;); Übers. Orn. Monatsber. 190ฎ, p. 135.

Mrescicapa grisole nermami P'oche, Orn. Monatsber. 1904, p. 26 (Umbenennung ron 1. g. sibiricu).

Ganz wie M. s. striutu, aber auf der Oberseite etwas blasser, die Stiru lichter. dagrgon dir rumkeln Striche auf dem Torderkopfo sehr deutlich, diu Kronfstreifung hialis. der. Flügel riemlich latus. meist etwa 86-90).5 mmm.

Ls scheint. dal.) die Tägel. welehe Westsihirien his zum südlichen bialkal-See und Daurien. 'Turkestan. Transkaspien, Persisch Baluchistan, Persien und Ifghanistan sowie den undwestlichen Himalitya hewohnen, alle zu dieser rtwas blasseren Form gehön'en. Auch die ron mir untersuchten Stücke aus Palästina (nach Tristran dort hrüteud) rechne ich hipher. Sie wandert rlurch Südarabion nach Ostafrika, wo sie üherwintert - loch gehören nicht alle ostatikiknischen Mintervigel ihr an. Sie hesucht anch Nordwest-Indien im Winter.

\section{IVIuscicapa latirostris Raffl.}

Wuscioupa lutirustris Ratłles. Trans. Linn. Šoc. Londou XIII, 2, p.312 (1821 - Sumatra). Muscicapa Poonensis Sykes, Proc. Zool. Soc. London 1832, p. 85 (Dekkan). Butalis terricolor Blyth, Joum. As. Soc. Bengal XVI, p. 120 (1847- Nepal).

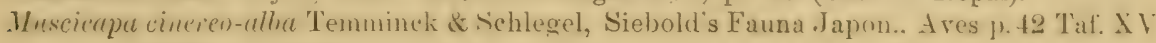
(1847- Japan).

Abbild.: Hume \& Henderson, Lahore to Yarkand, Orn. Taf. V. Ei : Journ. f. Orn. 1873, Taf. I. 16.

(Schnabel meist etwas kürzer und an der Basis oft $1 \mathrm{~mm}$ breiter als der ron IV. striata. Schwanz und Flïgel verhältnismäßig länger. Aus diesem Grunde meist. zur afrikanischen Gattung Alsconax gezogen, was aber wegen der dort längeren ersten Schwinge u. a. m. abgelehnt wurde - darum schuf Oberholser für $\mathbf{M}$. latirostris eine neue Gattung: Arizelomyia. Ton solcher Gattungsspalterei müssen wir uns allmählich losmachen.)

Oे o arl. ()herseite bräunlich aschgrau, im Sommer etwas blässer und gräulicher, Kopffederu in der Mitte dunkler braun. Flügel dunkelhraun. kleine Oberflügeldecken dunkelbraun mit graubraunen süumen, große Flügeldecken und imnere Armschwingen mit bräunlichweißen Säumen. Steuerfeclern dunkelbraun mit gau\% schmalen woißlichen Spitzensäumen. Um das Augre (ein schmaler weißlicher Federring. Unterseite weiß, Kehlseiten. Kropfgegend. Brust- und Körperseiten fahl bräunlich aschgrau. Iris brann. Schnabol schwarz, Basishälfte des Unterschnabels gelhlich. Füßße schwärzlich. Flügel etwa $67-72$, nul ausnahmsweise (Borneo . " - wohl o7 ad.) bis $75 \mathrm{~mm}$. Schwan\% etwa $45-50 \mathrm{~mm}$, Lauf $13-14$, Culmen $13.5-14.5 \mathrm{~mm}$. - Jur. oherseite mit rostgelhen Flerken, an der Unterseite mit braumer Fleckung:

Bewohnt Ostsibirien bis zum Baikalsee, Korea, die nördlichen Teile rou China, den Himalaya westlich bis Chamba. - Im Winter Indien, Ceylon, Malakka. Andamanen, Hainan. Sürt-China, Philippinen und große Sunda-Inseln. 
Soll anch in den Tropen Indiens nisten. Dies scheint fon rornherin unglaublich. doch wollen verschiedene Simmler dort Nester und Eier gefunden hahen. Vgl. Ihis 1906 p. 277. Möglicherweise liegt eine Terwechslung mit $M$. sibirica fuliginosa vor.

In seinen Lebensäußerungen ein echter Fliegenfänger. Nest in Astwinkelu, auf Weidenköpfen und dergl. Die 4-5 Eier sind nach Dybowski weiß mit röstlichem Anfluge am stumpfen Ende, nach Dresser mit schrachem olivengräulichem Anfluge, nach Nehrkoru denen vou Motacilla fluva ähulich. Maße nach Dylnowski $17.5 \times 13$, $17.2 \times 13,16.3 \times 13$, nach Nehrkorn $17.5 \times 13.5 \mathrm{~mm}$. Im Britischen Museum befinden sich dieser Art zugeschriebene Eier aus Japan, die hell matt lläulichgrün sind. mit schwachen hellröstlichen Zeichnungen und $16>12.4$ bis $17>13 \mathrm{~mm}$ messen.

\section{Muscicapa griseisticta (Swinh.).}

? Butalis manillensis Bonaparte, Compt. Rend. Aead., Paris XXXVIII, p. 652 (1854Manila. Nomen nudum!).

Hemichelidon griseisticta Swinhoe, Ibis 1861 p. 330 (Amoy and T'aku).

Butalis hypogrammica Wallace, Ibis 1862, p. 350 (Ceram und Morty).

? Butulis pallens Stejneger. Proc. U. S. Nat. Ilus. X, p. 144, im Text (1887 -.. Bering-Insel).

Nur eine Manser. Eiste Śchwinge hedentend kïrzer als die Handdecken. ofad. Oherseite düster rauchbraun, grobe Oberflügeldecken und innere Armschwingen mit hräunlichweißen Säumen. Schwingen schwarzhraun mit fahlgranhannen Inneusäumen. Stenerfedern schwarbloraun mit sehr schmalen fahlhrïunlichen Bndsäumen, längere Oherschwauzdecken mit weißlichloraunen Spitzen. Zügel schmutrigweil.s. Unterseite weiß mit hreiten lanchbraunen Läugsflecken, Kehlmitte, Mitte des Unterkörpers und Interschwanzdecken ungefleckt, Körperseiten fast ganz hraun. Unterflïgeldecken und Achselfedern matt rauhbraun mit fahlröstichen Sämmen. Schnabel sehwarz, Basis des Cuterschnabels bräunlich, Füße schwarz, Iris tiefbraun. Flïgel c etwa 84-87, o etwa $81--86$ (wem alle richtig seciert), Schwanz etwa 48-52, Lauf etwa 14-15, Culmen 13-14 mm. - o wie $\sigma^{7}$. Nestkleid unheschrieben. junge Vägel ohen mit weißlichen Filecken. - Im Frïljahr rerhloicht das Gefieder der Oherseite hedentend. Die Breite der Śtreifen an der Lnterseite rariiert etwas. Stejneger benannte einen am 17. Juni auf der Bering Insel erlegten ,strigglem clessen Geschlecht nicht festgestellt wurda bedingungsweise pullens. Es diurfte sich $\mathrm{mm}$ das abgetragene Sommerkleid handeln. (Üher 50 Fxemplare, aher sichere Brutrögel nur aus Ussurien untersucht.)

Verbreitung zur Brutzeit nicht ganz klar. Brïtet jedenfalls im Ussurilande, an den Suifun- und Sidemi-Mündungen, hei Thladiwostok, sowie auf den Kurilen und in Nord-China (nach Inavid und Oustalet in ganz ('hina?!), vielledeht atuch auf der Bering-Tnsel ts. olsen). - Er zieht durch China und

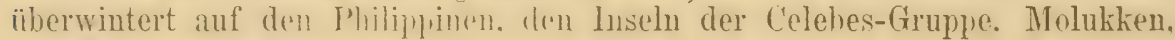
Key-Inseln und Neuguinea (IVaigiu).

\section{Muscicapa sibirica sibirica Gm.}

Muscicapa sibirica Gmelin, Syst. Nat. I, p.936 (1788- „Habitat circa lacum Baikal, et in orientali Sibiria ad Camtschateam usque").

Muscicapa Fuscedula Pallas, Zoogr. Rosso-Asiat. I, p. 462 (1827- Daurien his zum Baikal-See). 
òad. (Oherseite bräunlich rauchgrau, Schwingen und Steucrfedern dunkelbraun, innere Armsehwingen und größere Oberflügeldecken mit schmalen, hräunlichweißen Außeusïumen. Zügel und Augenlidbetiederung weißlich. Mitte der Kehle, Kropf, Mitte des Unterkürpers und Unterschwanzdecken weiß, die Federwurzeln grau. Kehl- und Brustseiten größtenteils fahlbraun, durch weiBliche Federrïnder mehr oder minder dentlich gestreift. UnterHügeldecken und Achselfedern fahlbraun mit hell rostfarbenen Säumen. Innensäume der Schwingen hell rostfarben. Füße und Schnalbel schwar\%hraun, Wurzel des Unterschmabels fleisehfarben, Tris dunkelhraum. Flügel (ठ゚ 우) $76-82$, Schwanz $48-52.5 \mathrm{~mm}$. O wie ō, nur etwas kleiner. Juv. Oberseite braun mit hell rostfarbenen Flecken. Kopf und Hals mehr weißlich gestreift, Unterseite weiß, Kehlseiten, Brust und Körperseiten schwä1\%lich gefleckt. Das Nestkleid liegt mir nicht vor.

Ostsibirien von Kamtschatka bis zım Baikal-See, Berings-Iusel, Maudschurei. - Zugrogel, der in der Malakka-Halbinsel, auf den Natuma-Inseln, Borneo und Palarvan überwintert und alljährlich das südlichere China durchzieht.

Benehmen wie das von $\boldsymbol{M}$. striata. Sie sollen nach Dybowski erst anfangs Juni an ihren Brutplätzen ankommen und gleich mit dem Nestbau beginnen. Das Nest steht in den Gabeln der Stämme und Äste von Birken und Weiden, 4-8 m hoch. Es ist außen mit anscheinend den Stämmen entnommenem Hoos und Flechten bekleidet. sodaß es schwer zu entdecken ist. Eier meist kurz und gewölbt, das breite Ende merklich dicker: seltener mehr gleichhälftig. Sie ähneln denen des Blaukehlchens, bisweilen aber mehr denen von $\boldsymbol{M}$. striata, sind mattgrünlich, reichlich mit blaß rostfarbenen Flecken und Punkten gezeichnet, meist ziemlich gleichmäBig verteilt. Sie messen nach Dybowski von $15.8>12.7$ bis $18 \times 14$, nach Taczanowski von $16 \times 12.3$ und $16 \times 12.4$ bis $17.2>13,17.8 \times 12.2,17.8 \times 12.3 \mathrm{~mm}$. (Journ. f. Oru. 1873, Taf. I, f. 15.) Im Britischen Museum sind zwei von Dybowski gesammelte Stiicke, die $18.2 \times$ 12.9 und $18.6 \times 13.2 \mathrm{~mm}$ messen.

\section{Muscicapa sibirica fuliginosa (Hodg's.).}

Hemichelidon fuliginosa Hodgson, Proc. Zool. Soc. London 1845, p. 32 (Nepal).

Abbild.: Hume \& Henderson, Lahore to Yarkand, Orn. Taf. IV.

Unterscheidet sich auffallend von . M. s. sibirica durch lïngere erste Schwinge, die so lang wie die Handdecken ist, ferner durch merklich kürzeren Flügel und ausgedehnteres Graubraun an den Federu der Unterseite, sodaß diese verdüsterter erscheint und namentlich die Brustseiten fast einförmig graubraun sind. Flügel $70-75 \mathrm{~mm}$. Neist ist die Oherseite etwas brïunlicher:

Himalaya von Afghanistan und Kaschmir bis Sikhim und rermutlich durch den östlichen Himalaya und die tibetanisch-ehinesisehen Gehirge nordwärts bis Kansu, wo diese Form nach Berezowski und Bianchi vorkommt.

Im Sommer bis 13000 engl. FuB, im Winter in den niedrigeren Lagen. Nest (in Kaschmir) an Baumstämmen oder in der Vertiefung eines abgebrochenen Astes, groß und locker. Eier blaß grünlich mit blab rotbrannen Flecken, denen von II. striatu ähnlich.

\section{Muscicapa ferruginea (Hodgs.).}

Hemichelidon ferruginea Hodgson, Proceed. Zool. Sise. London 1845, p. 32 (Nepal)." " Hemichelidon cinereiceps Sharpé, Ibis 1887 p. 441 (Kina Balu auf Borneo). 
Sad. Oherkope his auf den Nacken mäunlich schiefergrau. Rö̈cken und Shipularen dunkel zimutbraun, unterer Bürzel und Ohersehwauzdecken lohhaft zimmtrot. Schwingen bräunlichschwarz, zweite Schwinge und äußsere Armschwingen mit etwas Rostfathe an der AuBenfahne, innere Armschwingen hraum mit röstlich zimmtfarheuen Säumen. Innensüume aller Schwingen hell zimmtartig rostfarben. Handdecken schwarz, ührige Oherflügeldecken hraunselnwarz mit rostfarhenen Sämmen. Steuerfedern zimmtartig rostrot. dir mittle'('n ginn, die ïhrigen nach den s'yitzen zu mehr oder minder sehwärzlich rerwaschen. Kehle weil. mit rostgelbem Anflug. ïhrige Enterseite ocherrostgell, in der Nitte heller, fast weiBlich, Vorderbrust graubraun gefleckt; Unterflïgeldecken ocker-lostgelh mit grauhraumen Flecken. Schnahel sehwarz. Basis des Unterschmabels fleischfarben. Füße hlaß geblüumlich. Iris hram. Flügel etwa 70-75, Schwanz etwa 51, Lauf 12.5-13.5, Culmen etwa $13 \mathrm{~mm}$. O wie oे. $11 \mathrm{~m}$ vielleicht etrats kleiner. Juv. Oherseite dieselhe

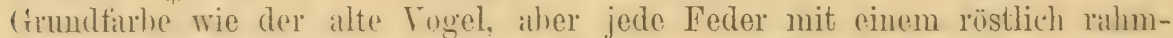
farheneu orler rostroten länglichen Fleck an der Spitze. Ferleru der Cnterseite meist mit dunkelhraunen Endsäumen.

Bewohnt den Himalara in Höhen von 4000 bis 8000 engl. Ful. und die Westubinesischen Gelirge von Kansu und ist in den Bergländern von Assam, Birmah, Sü̈l-thima. aluf den, Bergen der Malakka-Halhinsel, Java. Sumatra, Bormen und P'aliman sesammelt worden, ist aher in letzterm Gegenden augenscheinlich nur Wintervogel.

Unter Hodgsons unveröffentlichten Abbildungen im Britischen Huseum befindet sich Abbildung von Nest und Ei dieses Vogels. Das Nest ist ein dicker runder Bau aus Hoos und Flechten mit kleinem Napf, auf einem Stamm befestigt. Das Lii ist bräunlich, wie Milchkaffee, mit feinen blassen rötlichbraumen Flecken. Nehrkorn beschreibt die Eier ("aus Assam") als rötlichbraun mit undeutlicher F'leckung, gewissen Varietäten der Eier von M. striata ähnlich, und $17-17.5 \times 13-14.5 \mathrm{~mm}$ messend.

\section{Muscicapa atricapilla atricapilla L.1) (Kig. 87. 88.)}

\section{Schwarzrïchiger oder 'Trauer-Fliegenfänger.}

.Hascicapa Atricapilla Linniteus, Nyst. Nat. Ed. XII, p.326 (1766 "Hahitat in Europa". Wir betrachten als die terra typica: Schweden, nach dem ersten Zitat: Fauna Suecica I, n. 230 t. 1 f. 229).

Emberiza lnctuosu Scopuli, Annus I Hist.-Nat., p. 146 (1769- Nach einem im Kaiserl. Vivarium lebenden Vogel).

Museicupa mueulatu P. L. S. Miiller. Natursystem, Suppl. p. 171 (1771;-- Europa. Ex "Buffon", rectius Daubenton \& Buffon).

IIuscicapa muscipeta Bechstein. Lathams allgem. Übers. d. Vögel H, p. 319 (179.

Beschr. jüngerer(?), nicht schwarzer Vögel. Gebirgige Geg. Deutschlands, besonder's Hessen).

Muscicupce obscura Brehm. Lehrbuch Nat. aller eur. Vög. I, 1.382 (182:3 Deutsehland. Muscicapa alticeps Brehm, Handb. Naturg. Vög. Deutschl., p. 225 (1831 - ,in den deutschen Laublö̈lzern").

Muscicapa fuscicapilla \& atrogrisea Brehm, Handb. Naturg. Vög. Deutschl., p. 226, 227 (1831 -.. ,im mittleren Deutschland“).

Iruscicapa picata S'wainson in Flycatchers, Natur. Libr, p. 254 (1838-- Westafrika).

1) Oberholser nimmt für diese Art den Namen ficedula an (Linn., Syst. Nat, Ed. X, p. 185) an, was aber nicht angängig ist, wie ich an anderem Orte auseinandergesetzt habe. (Ibis 1906, p. 571.) S. auch p. 475 unter M. s. striata. 
"Mitscicapa nigra liriss." Degland \& Gierbe, Orn. Europ., Ed. 1I, I, 1. 580 (1867).

Aruscicupa atrogrisea Brehm, Vogelfing, p. 81 (1855- Westfaleu).

Muscicapa atricapilla vulgaris, microrhyncha A. H. Brehm, Ver\%. Samml., p. 33 (1866) nomina uuda!).

Engl.: Pied Flyeateher. Fran\%: Gobe-Monche noir. Ital.: Balia nera. Sehwed.: Srart och hivit Flugsnappare.

Doppelte Mauser. - 2. Schwinge meist merlich kürzer als 5 , in

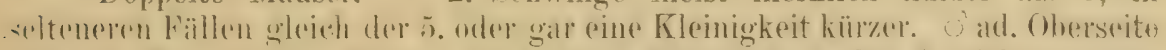
s.hwal\%. Wurzeln dor Federn dunkelgrau, Stirufleck in der. Ausslehmung von

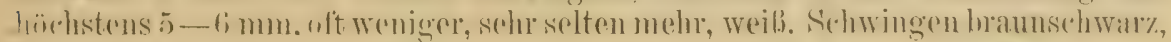
Innensäume weißlich. Handschwingen an der Basis der Aubenfahmen oder beider Fahnen von der 5.-6. (4.-5. langen) an rveib, sodab vor den Handdecken in der Regel vin Kleiner weiber Heck sichthar wird oder doch angredentet ist. Innerste drei Armschwingen an den Aubenfahnen und einem an Ausdehnung sehr wechselndeu Teile der Immenfahnen weib, die ïbrigen nur an der. Basis, wenigstens der AuBenfahnen, weiß. Oberflügeldecken schwar\%, die inneren der größten Serie weib, an der Basis schwillz.

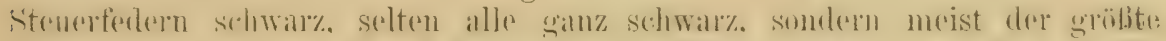

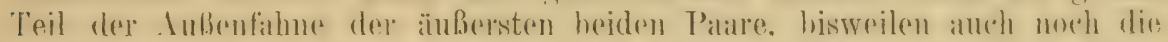

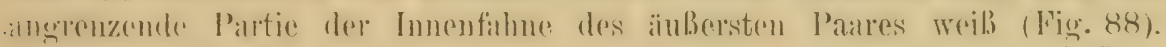
1)as dritte Paar ist meist ganz schwal\%, bisweilen zeigt sich an del Auben-
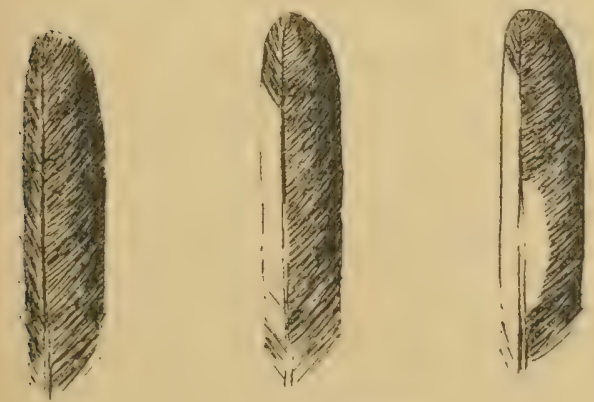

Figur $88(1 / 1)$

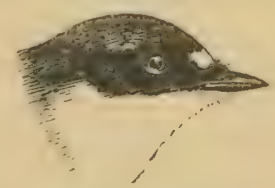

Figur si $(2 / 3)$. falhe etwas, selten viel Weil. Ganz. Unterscite. weib, Federwurzeln schieferschwar\%. Unterfligeldecken weib mit mehx oder minder hervortretenden schiefergrauen oder schwär\%lichen Basalteilen. Schnabel und Fïbe schwar\%, Iris dunkelbraun. Flügel etwa $78-82$, selten 84 , Šchwanz etwi $52-55$, Lauf etwa 18, Culmen 12-13 mm. O ad. Oberseite . Hunkel granhram. im F'rühjahr und Sommer hlasser, otwas gräulicher. Die inneren hahen breite rahmfarhene, im Frühjahr reiner weiße Außensäume und Bassis, Armshwingen die crobrn Oherflügchecken chensolche Śpitzen; die ()herschwanzrecken sind schwär\%lich. S'hwingen tiefhraun; Stenerfedern braunschwar\%, di» äußoren drei, manchmal nur zwri, mit dem größeren Teil der Aubenfahnen weik unler im Herbste rahmweiblich. Tinterseite hell rahmfarben. Kropfgegend und Seiten mehr grambäunlich überlaufen, Kehle und Bauchmitte wrißlicher; im Frühling fast rein weil. auf der Cnterseite. - Die jungen o nach der r'sten Mauser und dis schon früh im Herbste angelegte Winterkleid gleichen last ganz d(m o. nur sind Schwanz, Sehwingen und Oberschwanzdecken sohvärzlicher. Aus diesem Kleide mausern die o im Frühling in das oben

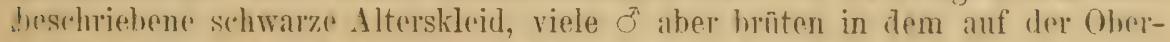


scite lnaunen Winterkleide und legen diss sehwal\%-WeiBo Alterskleid arst in: höherem Alter (oder vielleicht überhaupt nicht?) an. - Nestkleid mit gefleckin. Oberscite. dem ron M. shrutu ïhnlich. (110 im Tring-Mluseum untersucht.)

Brutvogel in Europa vom 69. oder 70. Grad in Skandinavien, rom 65. (irat in Fimnland und ungefähr 60). Grad in Nordrubland bis Spanim. Italien und sardinien. Im Nordosten angenscheinlich bis zum Ural, im Südosten nur bis Österredeh. In England sehr lokal (aber häutig in Norit-

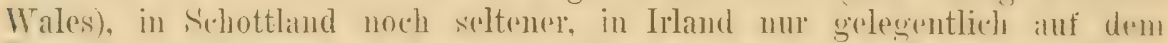
Zuge. - Im Winter in Afrikil südlich his zum Benur und zweimal am ('nngu beobachtet, sowie am Nil.

Bewohner von Wäldern und stillen, großen Parks, Gärten und Anlagen. Nahrunm Insekten, die er meist im Fluge längt, im Herbste auch weiche Beeren und ebensolche

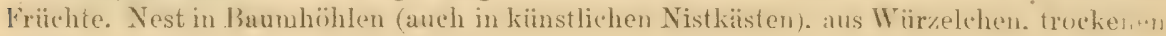
Blättern, Baststreifen und dergl. gebaut. Die 5-7, angeblich auch bisweilen 8-9 Fier. einfarbig hellblau. Es sollen auch mitunter Stücke mit blassen rötlichen Punkten vorkommen. Die Eier ähneln denen des Gartenrotschwanzes, haben aber feineres Korn. sind meist etwas kleiner, schlanker und von hellerem, zarteren Blau. Man findet sie in Mittel-Europa von ungefähr Mitte oder Ende Mai bis Mitte Juni. Nach Bau messen 54 Eier im Durchsehnitt $17.6 \times 12.7$, Maximum $18.6 \times 14$, Minimum $15.9 \times 12$ nm. nach Rey messen 39 Eier durchsehnittlich $17.16 \times 13.47$, Maximum $18.4 \times 13.3$ resp . $17 \times 14.1$, Minimum $15.7 \times 13.6$ und $17.7 \times 12.6 \mathrm{~mm}$. Durchschnittliches Gewicht etwa 89-92 mg. Der Lockton ist ein feines „bitt-bitt". Der etwas schwermütig klingende tiesang wechselt vielfach ab. enthält aber immer "ine unverkemnhare Sirophe. die ungefilar wie ein taktmäßig auf- und abziehendes "wu tiwn tiwn tiwu" oder „widiirvi, widliwi" lautet.

\section{Muscicapa atricapilla speculigera 131.}

Muscicapa speculigera Bonaparte, Consp. Av. I, p. 317 (1850- ex Selys H.S. „ex Afr. sept." T'erra typica Algier; siehe Selys).

Muscicapa speculifera Selys Longchamps, Naumannia 1856, p.393 (Algier).

Das ad. unterscheidet sich von dem ihm ähnlichen ron ./. a, atricapiin wie folgt: l)ie Form des Flïgels ist atwas anders. indem die 5. Schwinge nicht num etwas, sonderen herlentemel (etwa $5-7 \mathrm{~mm}$ ) länger ist als dis zweite. Das scharf alugegrenzte Weib an der Basis dor Handsehwingen int in der liegel ansyedehnter und restreckt sich bis zur Innenfalme der zweitrn (ersten langen) Schwinge: es zeigt sich daher vor den Handdechen ein meist.

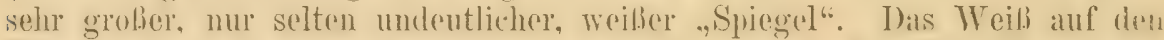
Flügeh ist meist etwas amsgedehnter: dic inneren grolin Oherflügeldeckn sind fast gan\% weilb, mur die äulierste basis schwarz, das IV oilj der innersten Armsehwingen erstreckt sich stets auf einen malle ofler minder groben Ti:il

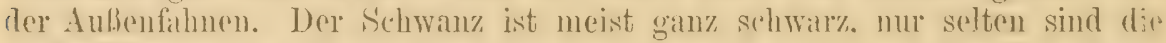
Aubenfahmen der äuleren Steuerfedern zum groben Teile weil.s. Der Stiru-

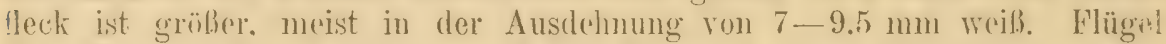
$79-82 \mathrm{~mm}$. Die o scheinen anf der Uherseite etwas gräulicher zu sciu. doch liomnten keine frischrrmanserten Vägel untersucht werden. (16 Gxempling? wurden verglichen.)

Brutroged in den Wäldern (besonders Korkerichen) ron Nord-Thunis umb Algiar. Wirweit und ol) diese Form ihr Brutgelnet in don marokkanischeri Atlas restreckit, ist noch nicht listgestellt. of vom 22. April von Ain Musia gehören noch der nordeuropäischen Form an. 


\section{7j1. Muscicapa atricapilla semitorquata $\mathrm{Hnm}$.}

Mescicapa semitorquate E. v. Homeyer, Zeitschr. ges. Orn. II, p. 185, 'L'af. X (1885-Kaukasus).

Muscicapa var. Raddei, M. caucasica Raddei (sic!) R. Blasius, "Nener Naumann" IV. p. 173 (1901- als Synonyme).

Selur interessante Form, die zwall kein weilies Halshand hat, hei der sich aber das Woils an den Halsseiten in Form einer Finbuchtung I, lis: $1^{1 / 2} \mathrm{~cm}$ weit nach oben $z u$ erstreckt. Außerdem haben die äuß̈eren

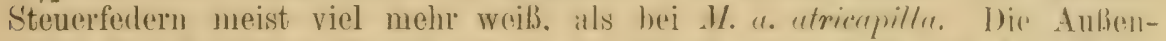
fabne des äul.sersten Paares ist in cler Regel ganz weil., die Inn(nfuhur weib mit schwarzem Fleck nahe der Spitze, bisweilen aber mit itus-

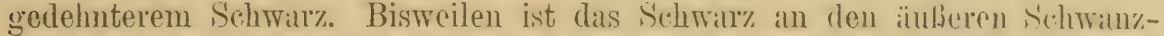
federn so ausgedehnt wie oder ausgedehnter als bei manchen s'tïcken ron. II. a. atricapilla, indem heide Fahnen sehwal\% sind und nur llie äuBere einen langen weißen Streifen zeigt ( $1 \sigma^{\text {r }}$ Attika, gesammelt ron strimeneas, im Bosnisch-herzegowinischen Landesmusemm). Die weilor Basis der Handsehwingen hildet einen dentlichon Spiegel. Flïgel rtwit $81-84 \mathrm{~mm}$. (11) Lxemplare untersucht.

Seheint nur im Kaukasus, in Kleinasien, Persien und direchenland zu brüten. - Am Persischen Meere vorgekommen, dort aher vielleicht nu: Wintervogel.

\section{Muscicapa collaris. Bechst.}

Halsbandfliegenfünger.

Muscirupa collaris Bechstein. (remeinn. Naturg. Deutschl. IV. 1. 495 (1795)- .. Europa und Deutschland; in den tiefen Gebirgen des Thüringerwaldes noch am häufigsten". Als terra typica betrachte ich (len 'Thüringerwald).

Muscicapa albicollis Temminck, Man. d'()ru., p.100 (1815- Lmbenemung von M.colluris Bechst., weil Latham schon eine Muscicapa collaris schuf, die aher in eine ganz andere Gattung [Platysteira Jard. \& Selby] gehört).

Muscirapa streptophora Vieillot, Faune Francaise, p. 145, Taf.63, fig. 2 (um $1828-$ Lothringen, Paris und Süden).

Muscicupa albifrons Brehm, Handb. Naturg. V̈̈g. Deutsehl., 1. 223 (1831- Laubhölzer Thüringens).

Muscicapa melanoptera Heckel, Isis 1833, p.458-459 (bei Wien).

Muscicapa collaris microrhyncha \& ? atroshriatu A. E. Brehm, Verz. Samml., 1. 3 (1866Nomina nuda!). ${ }^{1}$ )

Engl.: Collared Flycatcher. Franz.: Gobe-Mouche à collier. Ital.: Balia del collare. Schwed.: Halsbands Flugsiappare.

ơal. 2. Schwinge meist merklich länger als (selten nul so lang wie sehr selten etwas liürzer als) die fünfte. Über den Oberhals zieht sich ein hreites veißes Halshand, üher den Bürzel ain ehenso breites schmutrig grauweiBliches Band. Der weiße Stirnfleck variert sehr an Ausdehnumg, ist aber

1) Eine $M$. collaris atrostriata existiert nicht in der Sammlung. Vermutlich sollte der Name unter atricapilla stehen. -- Man hat mein Zitieren der Namen A. E. Brebms von 1866 bemäkelt, es ist aber höchst wichtig hier festzustellen. dab sie nom. nuda sind, weil sie von Dresser, Sharpe u. a. zitiert wurden, ohne als nom. nuda gekennzeichnet zu sein! 
meist so grob. wie oder noch ansgedehnter als bei M. atricapilla speculigera. Tor den Halldsehwingen \%oigt sich meist rin sehr ansgedehnter weiber Spicegel,

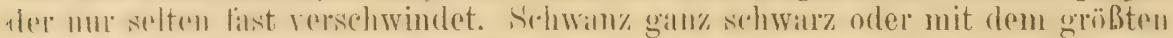

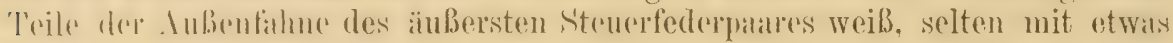
TVeib an der Aubenfahme des zweiten Paares. Sonst wie $\boldsymbol{M}$. alricapille. Flïgel etwal $80-84.5 \mathrm{~mm}$. Das $\bigcirc$ gleicht dem vou $M$, abricapilla, aber die

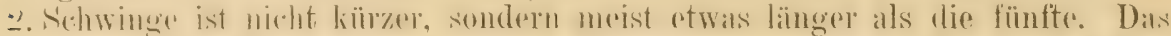

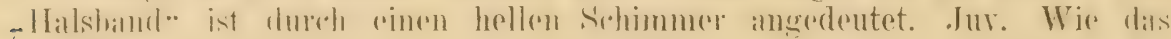
ron $1 \%$ atricurille, doeh ist auch hior das Halshand meist mehr oder minder atngerlontet.

lis ist schwer. (las Brutgebict genall zal bescimmen. Nördlich brïtot

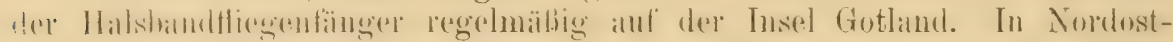

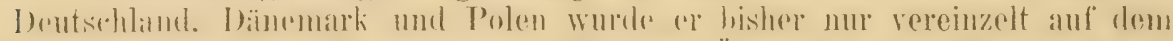

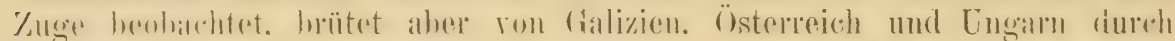

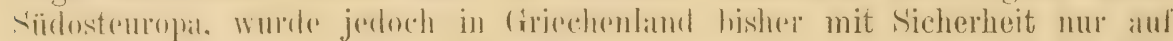

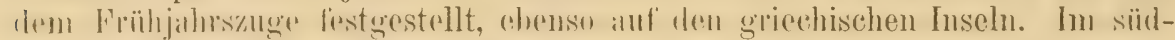

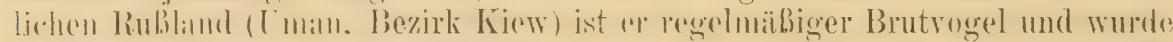

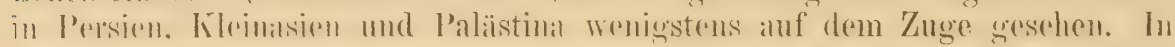

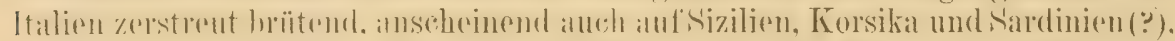

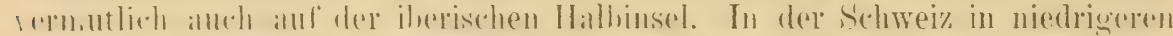
latgen. Herstrent in Frankreich. Bulgien und Holland, im sïdwestlichen

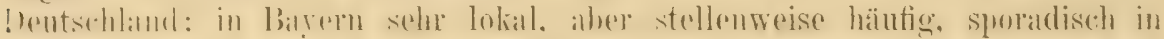

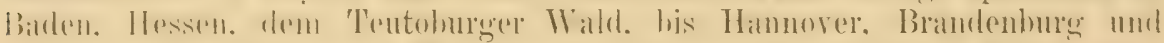

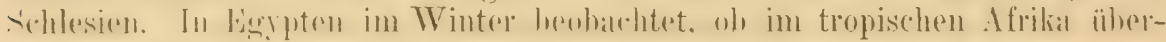

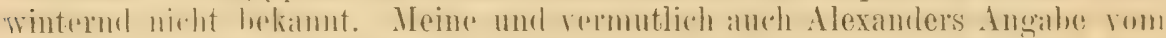

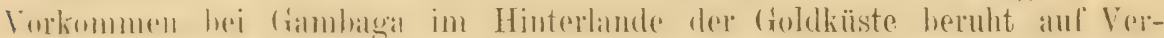

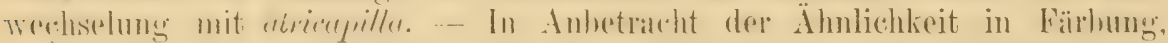
Fortpflamzung und Lebensweise mit der von $1 /$ atricapilla und der etwas

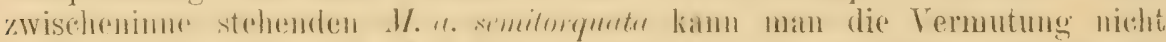

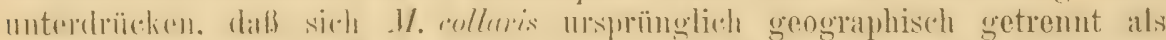

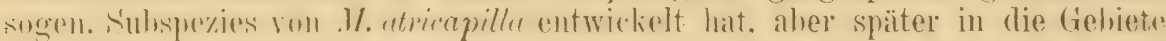

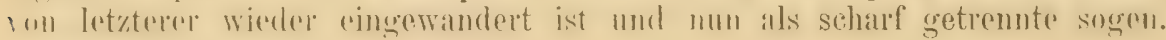
Art nehen ilor wohnt.

Lebensweise uud liortpflanzung ganz wie die von M. atricapilla atricapilla, aber iler Gesang ist augenscheinlich etwas abweichend. Parrot drückt ihn durch die Silben ..Hed (hied), zidjedjedje-doi" aus, er ändert aber vielfach ab. Die Lockstimme klingt nach Parrot wie "hees", "zieszieß", auch vernimmt man ein einfaches "zig, zig". Mewes drijekt den Gesang wie folgh aus: ., Hit-tsih hety, tao tao tsitt-tse tse quing “.

\section{Muscicapa strophiata (Hodgs).}

Siphice strophiatu Hodgson, Indian Review I, p. 651 (1837- Nepal).

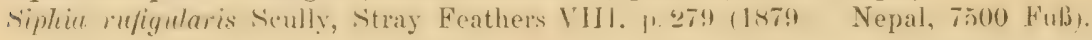

ơacl. Eirste Schwinge halb so lang wie die zweite. Stirnband und liurzrr, lis zum dugr reichender supereiliarstreif weib, gegen den Seheitel hin dureh rine sehieforfarbene Linie hegrenz: ährige Oberseite olivenhram. äuBere Shehwiugensiume etwas lebhafter und röstlicher. Oberschwanzalecken schwar\%. Mittelstes Steuerfederparr gan\% braunsohwar\%, die übrigen an der Basishälfte weib. Kimn und Kehle mattsehwarz. Kropfgegend mit grobem,

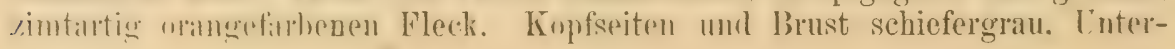




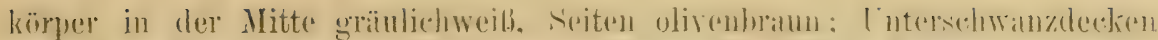

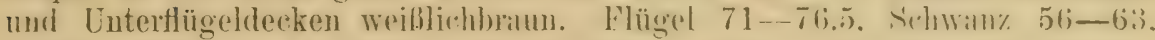
Culmen etwa 13, Lauf etwa $19-20 \mathrm{~mm}$. o dem ò ilnnlich, alher Vorderstirn ohne oder nur mit rerdecktem Wrili. Kins. Kolle unel hopfseiten

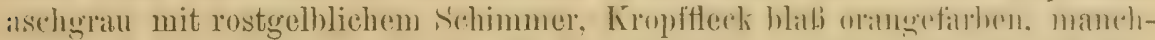

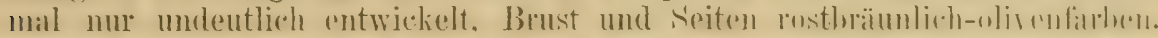
Basis des Schwanges gelbliehweili. Flügel nur utwal bis mm. Jur. Bram

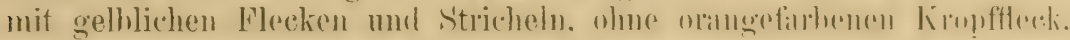

Brutrogel im Himalaya vom östlichen Kaschmir bis in den istlichen

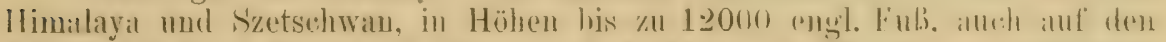

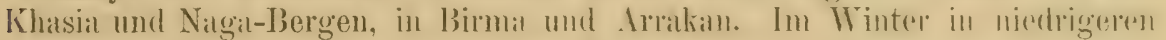
Lagen. - Die von Slater und La 'Touche aus der Gegend von Swatow

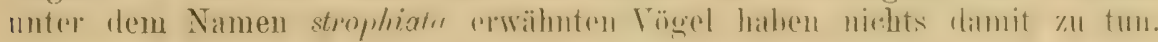

Osmaston berichtet, dab er Nest und lier gefunden habe. Die V̈̈icr waren weib. $O b$ ries richtig ist? Vgl. Ibis 1900 1. 270.

\section{Muscicapa ruficauda Swains.}

Muscicapa ruficaula Swainson, Flycatehers, in Nat. Library, p. 25) (1838- Andia').

ơ ad. Oberseite bratun, Oberschwamzdecken lebhaft yimmtrot, Stenel-

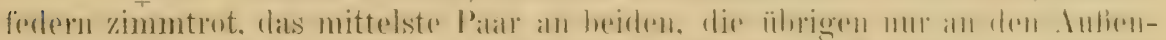

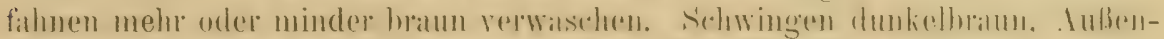

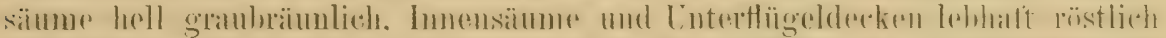

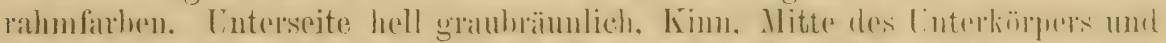

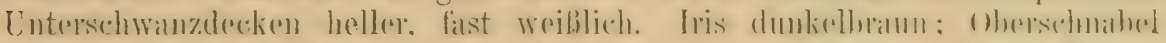

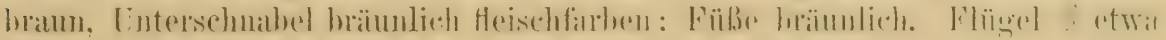
78-80, O etwa 74-75 mm. - Juv. Oberseite olivenhrïunlich mit röstlich

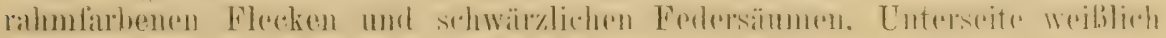
ralumfarben mit sehwärlichen Federsiumen.

Im Sommer im westlichen Himalaya mol angrenzenden Afghamistan, bis in Höhen yon $6000-10000$ engl. Fub. Im IVinter in den westliehon

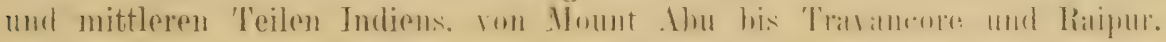

Nester aul Baumstïmpfen und in dichten Baumkronen. Eier blab olivengrïn mit matten bräunlichen Fleckenzeichnungen (His 1906 J. 279).

\section{Muscicapa parva parva Bechst.}

\section{'/swerfliegenfünger:}

Mascicapa purva bechstein, Isathams allg. Uebers. d. Vögel II, p. 356, Abhildung a. d. 'Iitelblatte (1794-- 'Ihüriuger Wald. - 9 oder ơ jun.)

Ifuscicupa vefogularis Brehm, Handi). Naturg. Vög. Deutschl., 1). 228 (18:31- (i)sterreich und Deutschland).

Muscicapa Lais Hemprich \& Ehrenberg, Symb. Phys. fol, t (um 18:3- „Amlukul*. Nach Reichenow (MS.) ist der Fundort unsicher, da auf dem Etikett .. Arabien." steht).

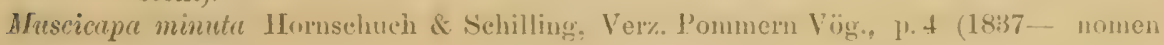
nudum!)

Erythosterna pave meficollis, rufigularis A. W. IBrehm, Ver\%. Samml., ]. 33 (1866 nomina nuda!). 
Lngì.: Red-breasted F'lycatcher. F'ranz: Gobe-mouche rougeâtre, Ital.: Pigliımosche pettirosso.

ơal. Oberseite fahlbraun, im Frühling verbleichend und dam mohr gräulich wertend. Oherliopf und Hinterhals etwas gräulicher. Oherschwanzsecken sehwar\%haum mit hraunen spitzxn. Kopf- und Halsseiten aschgratu, Federn an Augenlide weiBlichgratu. Schwingen dunkelbram mit fahlluramen Auben- und weiblichen Inuensïmmen. Äubere Sitenerfedern weib. Śpitzon etwa zu einem Drittel braunschwarz, die mittelsten beiden Pare in der

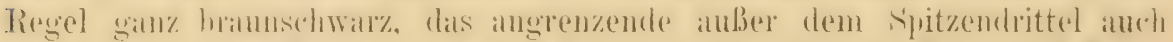

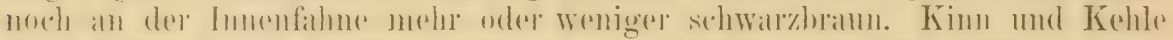

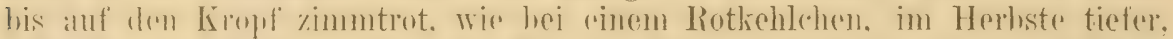

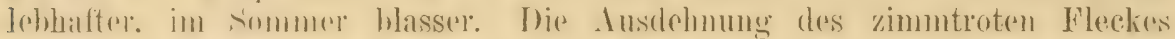
varibert ringermaben. anscheinemel ohne sich geograthisch hegrenzen zu

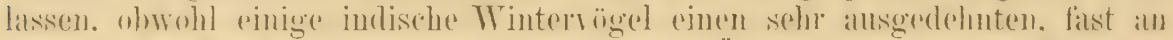
den rom hyyeryther erinnernden Fleck haben. Ëhrige Lnterseite weib. Seiten

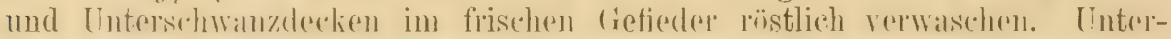

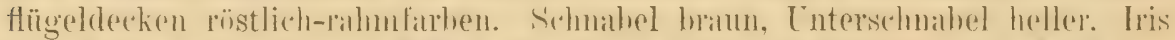

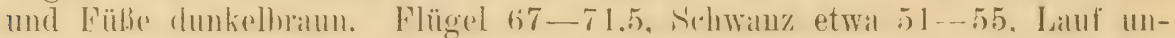
gefähr 18, Culmen 12.3-14.5 mm. - o ad. Oberseite wie beim ơ, Kehle

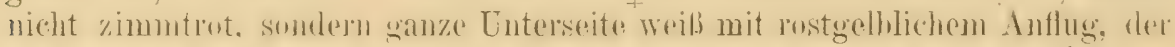
im Sommer fast rersehwndet. im Herhste dagegen sehr stark ist. - jur.

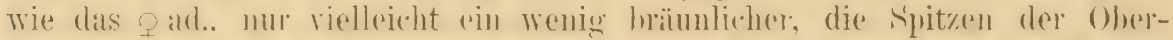

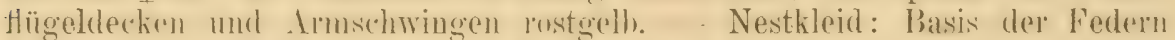

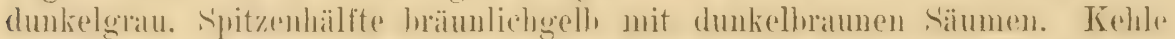

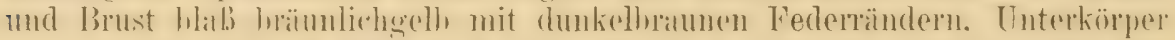
und Untersehwanzlecken weil. Anscheinend sind die Stïcke mit he-

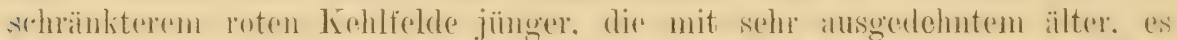

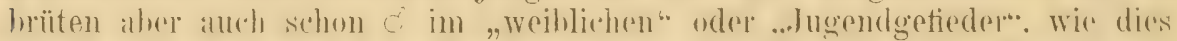

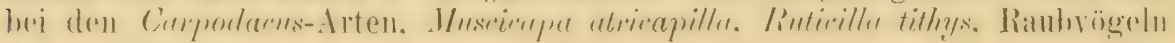
и. a. vorkommt.

Brutvägel ron St. Petersburg, den russischen Ostsee-Provinzen, Rïgen

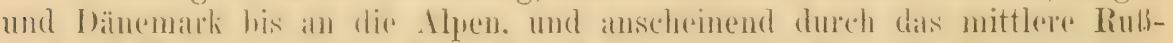

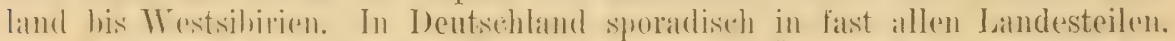

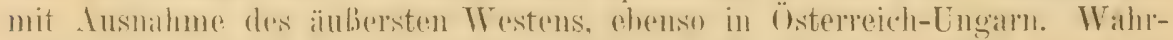

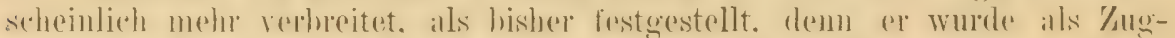

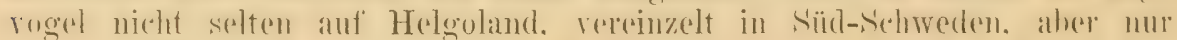

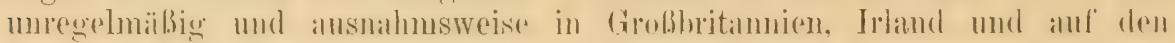

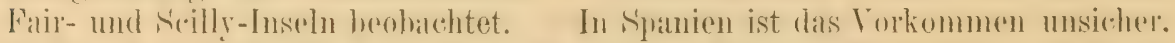

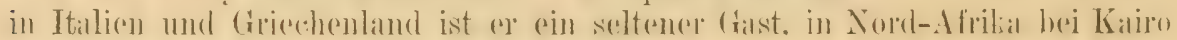
sirher festgestellt. As Winteryuartiore liemen wir mit kieherheit sonst nur die westlichen Teile Indiens.

Bewohner von Wäldern, besonders Buchen- und Hainbuchenbeständen mit viel Enterholz, sowie von gemischten Wäldern und hier und da auch fast reinen FichtenWaldungen. In der Ebene sowohl als im Gebirge, bis in Höhen von $1000 \mathrm{~m}$. Luekton ein wohllautender, an den des schwirrenden oder Waldlaubsängers erinnernder, deutlich zweiteiliger, etwas gegen das Ende hin absteigender Pfiff, dann wird auch von einem schnarrenden Laut, der Angstruf sein dürfte, berichtet. Der Gesang ändert vielfich ab, bezeichnend aber ist immer eine glockenhelle, wunderschöne, wie tink, tink, tink, eida, eida, eida klingende Strophe. Das Nest besteht aus MLos und Halmen und ist. mit Haaren ausgelegt. Es steht in weiten Baumhöhlungen, auch in der Gabel starker 
:Zweige. Gelege 5-7. Eier im Juni, auf blaß grünlichem oder rahmfarbenem Grunde mit rötlichbraunen od mattrił lichen Wölkchen und P'unkten iiber und iiber, am stumpleu Ende etwas dichter, bedeckt. 46 Eier messen nach Alex. Bau im Durchschnitt $16.7 \times$ 12.7. Maximum $17.6 \times 13.2$ und $17.3 \times 13.4$, Ninimum $15.8 \times 12 \mathrm{~mm}$. 14 Eier der Rödernschen Sammlung (Museum zu Tring) messen $14.7 \times 12.6,16 \times 13,16.1 \times 13$, $16.2 \times 12.3, \quad 16.5 \times 12.2, \quad 16.8 \times 13, \quad 17 \times 13, \quad 17.2 \times 12.5,17.2 \times 12.6,17.5 \times 13$, $17.6 \times 12.5,17.6 \times 12.6,1.7 .7 \times 12.3,18 \times 12.7 \mathrm{~mm}$. Gewicht etwa ron $64-92$, im Durchschnitt $74.5 \mathrm{mg}$.

\section{Muscicapa parva albicilla Pall.}

Muscicapu Albicilla l'alkss, Zoogr. Rosso-Asiat. I, p. 462 (1827- ,in salicetis rivulorum Dautriae apricae, maximae circa Ononem". Besehr. des $q$ ).

Motacille Luteola Pallas, Zoogx. Rosso-Asiat. I, 1. 470 (1827-, ,ad Tunguskam It. Messerschmidius obserwavit. Hihi nuncuan fuit oblata". Aus Messerschmidts IS. Auf keinen Fall kann dieser Name auf M. muginaki bezogen werden, aber ob M.p. albicilla oder M. 1\% pave an der 'lunguska nistet, konnte ich nicht feststellen, rermute jedoch ersteres).

Saxicola mbeculoides Sykes, P'oc. Kool. Soc. London 1832, p. 92 (Dekkan).

Muscicapa lencura Swainson, in Eklyeatch., Nat. Libr., XVII. 1. 253 (1843- "India"6).

Ei: Dybowski, Journ. f. Orn. 1873, 'L'af. II, Fig. 17.

Onac. Äbnlich $2 \mathrm{~L}$ p. purca, aber nur Kinn und Kehle bis an den Kropf,

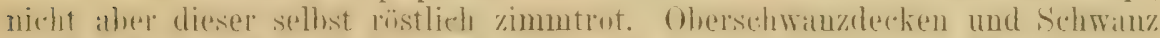

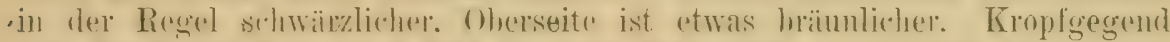
und Brust des Wrihdhens und jüngeren Mämnchens bräunlieher als hei den entsprechenden Kleidern von 1\%. p. purea. Flügel ôad. etwa $68-73 \mathrm{~mm}$.

Vertritt I\%p.p pare im ästlichen Sibirien, ron der Bering-Insel und Timntschatkit remutlich his zum Jenissei. im së̈len his zmm südufer des

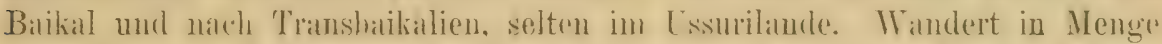

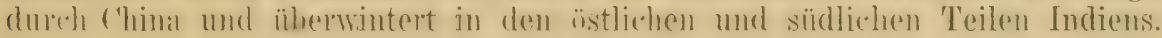

Die Lebensweise scheint dieselbe zu sein wie die von M.p.parva. Das Nest steht in Baumlöchern, die Hier ähneln denen von $M . p$. parva, haben aber nach 'Laczanowski eine weißlichere Grundfarbe und messen $17 \times 13$ mm. Nach Nehrkorn sind sie den vorigen ..sehr ähnlich" und wessen $18>13.5 \mathrm{~mm}$.

\section{Muscicapa parva hyperythra (Cib.).}

Siphit hyperythre Uabanis, Journ. f. Orn. 1866, p. 391 (Ceylon).

Abbild.: Proc. Znol. Soce. London 1872. 'Taf. 17.

3a ad. Ähnlich K. p. parea, aber die Oberseite viel dunkler braun,

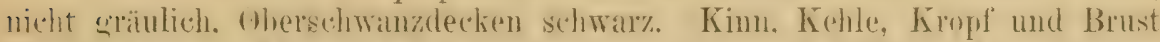
Tostrut. viel dunkler. als hei den vorigen. S'eiten und Interschwanzdecten

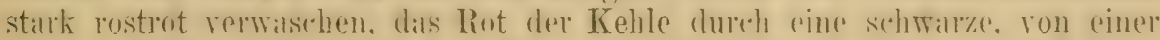

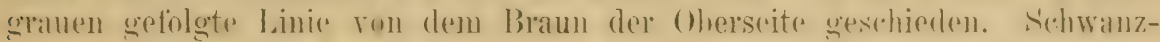
zeichnung wie bei den vorigen. Flügel $67-69.5 \mathrm{~mm}$. - o oben etras dunkler als die ron albicilla, Flügel etwas kiirzer.

Brätet in Höhen von 6-7000 engl. Fub in Kaschmir und ist im Winter häufig in Ceylon. 


\section{Muscicapa superciliaris Jerd.}

Ifuscicapa superciliuris Jerdon, Hadras Joumal XI, 1). 16 (1840- nördliche Ghats in Indien).

Dimorpha albogularis Blyth, Journ. Asiat. Soc. Bengal XI, p. 190 (1842- Dariiling). Muscicapa ciliaris \& hemileucura Hodgson, in Grays Zool. Jise., p. 84 (184t - nomina nuda!).

Erythrosterna acornans Blyth, Jouru. Asiat. Soe. Bengal XVI, p. 127 (1847 - ,S. E. Himalayas and Central India").

Ei: Cat. Lggs Brit. IIus. III, Taf. VU, Fig. 19.

Oad. Oberseite, Kopf- und Halsseiten und Seiten der Vorderhrust dunkel himmelhin, S'tirn und Bürzel atwils heller. K/ügel sehwärzlich, rom

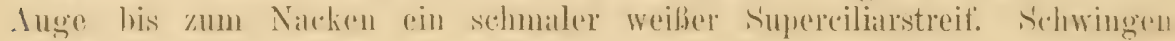

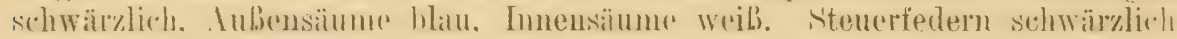

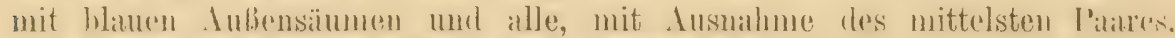
mit weiber Bassalhälfte. Kinn, Kehle, Mitte der Corderhrust und iibrier

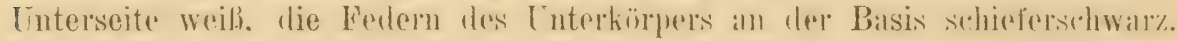

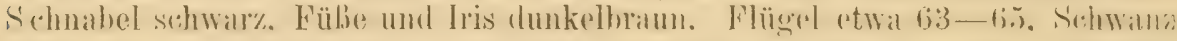
etwa 46-51. Latuf etwa 16, Culmen ungefäh $14 \mathrm{~mm}$. - o ad. Oberseite

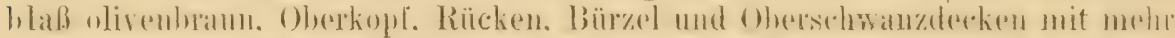

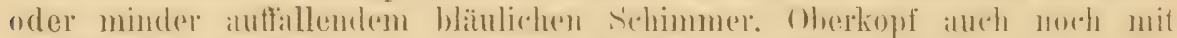

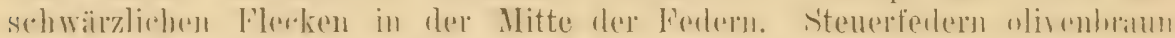

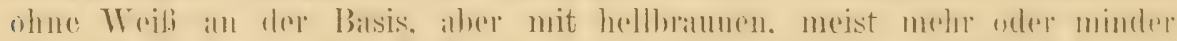

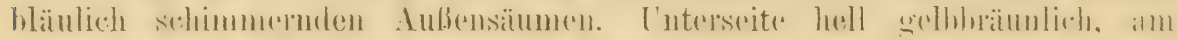

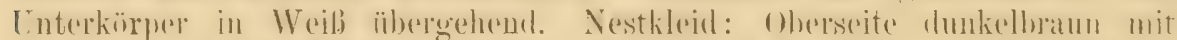

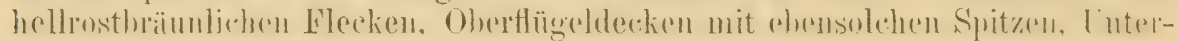
seite hell posthräunlich mit hraunen Wollonlinien. Basis des Schwamzes beim os sehon mit Weilh.

Himalaya von Kasehmir und Hazala bis Sikkim, im Sommer in groben Höhen, bis zu 12000 engl. Fub, im Winter in die niechrigeren Berge und Ehenen des westlichen Vorderindiens heribsteigend.

Briitet rom April bis Juni und legt in einem weichen, in Baumlöehern oder in Steinwällen angebrachten Moosneste ó Eier. Die Eier sind kurz oval, aul fahlgrallbräunliehem oder matt grünlichem (irunde mit bräunlichen Flecken so dieht bedeckt. daß sie fast einfarbig erscheinen. Sic messen etwa $15-17.5 \times 12.5-14 \mathrm{~mm}$.

\section{Muscicapa hodgsonii (Verr.).}

Siphice hodysonii Verreaux, Nouv. Arch. Mus. Paris VI, Bull., 1).3t (1870- Mupin). Erythosterna sordida Godwin-A usten, Journ. A siat. Soc. Bengal XLIII, II, 1. 158 (1874Japvo Peak, Naga Berge).

Abbild.: David, Nouv. Areh. Mus. P’aris IX, Tal. 4, Fig. 4.

Oेad. Oberseite nebst Kopf- und Halsseiten schicferblatu, Zügel, Waugen.

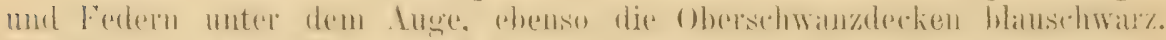

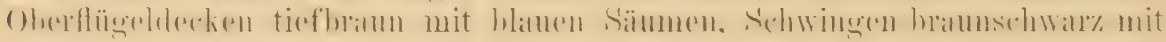
hramen Außensäumen. Steuerfedern schwar\% allo mit Ausurhme des

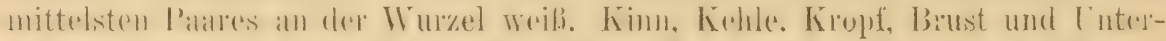

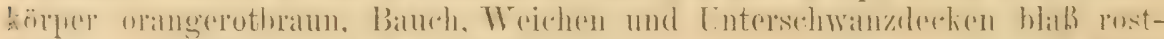

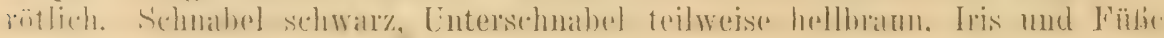
bramn. Flügel etwa 70, Sehwanz $55 \mathrm{~mm}$. - o id. Oberseite olivenbraum, 
()hersehwanzdecken mehr rothrïunlich. Schwanz uach der Basis \%u mit melur rostbraunen Säumen. Sehwingen und ()herflügeldecken tiefbram mit rostbraunen Säumen und Spitzen. Yä̈gel weiblich. [ntersute aschluräunlich. Unterkörper weißlicb. Jugendkleider umbekannt.

Hisemplare sind aus dem nördlicheren Sretschwan (.Mupin). und hausu

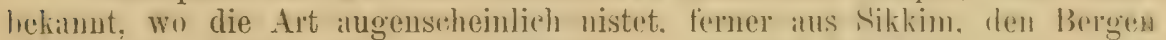

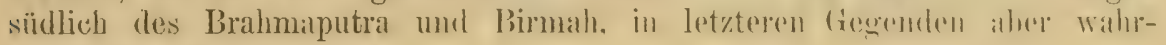
schoinlich nur Zugvogel.

\section{7iv. Muscicapa leucomelanura leucomelanura (Hodw's)}

Digenea lencomelanua Hodgsou, l'roe. Zuol. Soc. London 1845, p. 26 (Berge von Nepall). Digenoa tricolor Hodgson, Proc. '/ $/ 00$. Soe. London 1815, p. 26 (Berge von Nopal). Siphia minuta Hume, Ibis 1872, p. 109 (IIt. 'I'ongloo in Sikkim).

ond. Flñgel starkgerundet, 4., 5., 6. Schwinge etwa gleich und am

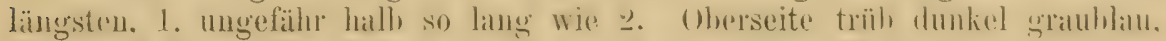

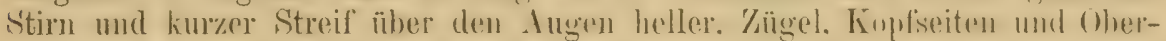

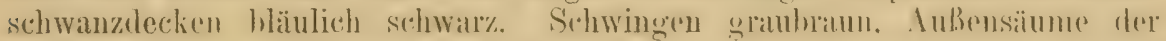

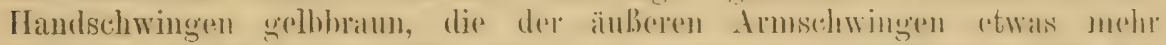

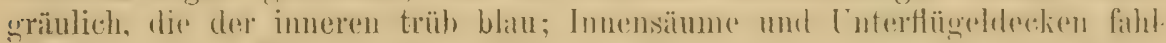
arelbbräunlich. Mittlere Stenerforlern schwal\% mit schwarlien häuliehen

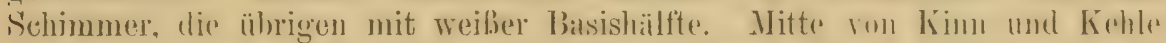

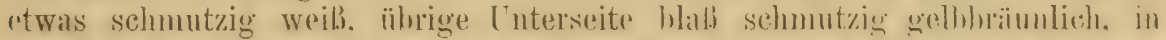

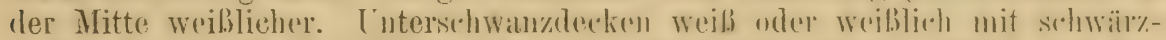

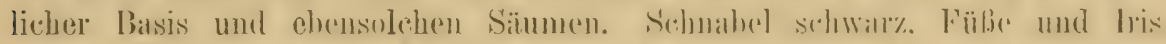

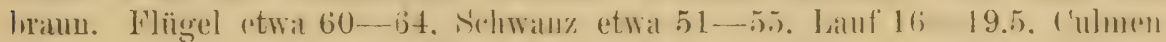
11.5-12 mm. - o ad. Oberseite röstlich olivenbraun, auf dem B̈̈r\%el

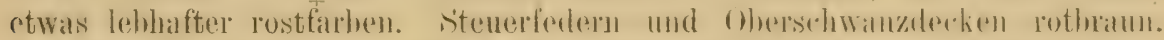

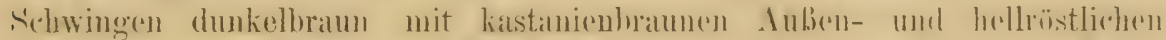

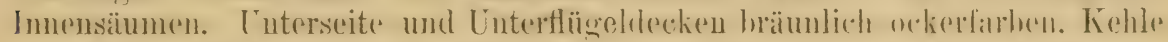

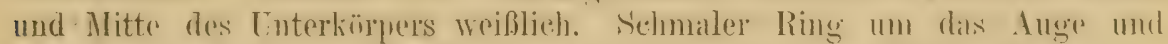

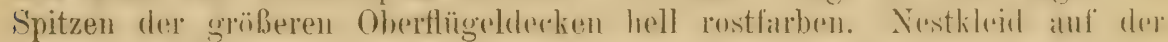

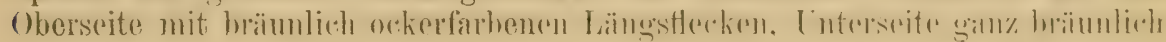
ockerfarben.

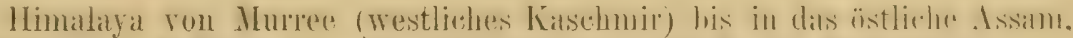

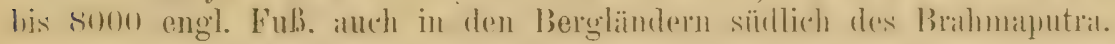

Nest ein dicht gewebter Nap aus Noos, Haaren und Wolle, in Bammhöhlungen. Dic 4 Eier sind rahmfarben, entweder eiufurbig oder mit matten, blals rötlichen H'lecken. Mabe etwa $15 \times 12.5,15.5 \times 12,15 \times 11.5,15.8 \times 12,14 \times 12,17 \times 12,15.4>1.5 .4$. $17 . t \times 12.3,14.5 \times 12.2 \mathrm{~mm}$.

\section{Muscicapa leucomelauura cerviniventris (N)}

Digenea cerviniventris Sharpe, Cat. B. Brit. Ilus. IV, P. 460 (1879-_ .. Khasia and neighbouring ranges of hills". Dem Autor lag anscheinend nur der 'Yypus aus Manipur vor, terrat typica daher Manipur).

Unterseite dunkler, mehr bräunlich, Kehle kaum weiblicher:

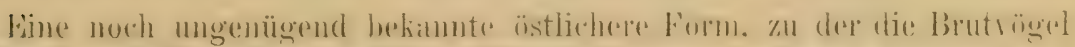

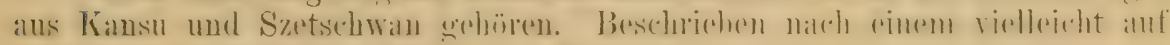
dem /uge befindliehen Stïcke aus Mauipur. 


\section{Muscicapa narcissina zanthopygia Hay.}

Muscicapa Zanthopygia Hay, Madras Journal XIII, 2, p. 162 (1845- Malacca. Beschr. d. ㅇ. Jedenfalls anfangs 1845 erschienen, da Teil 2 das Datum Dec. 1844 trägt. Neuere Autoren verbesserteu den Namen in das richtigere xanthopygia). Muscicupa (Muscicapula) tricolor Hartlaub, Rev. Kool. 1845), p. 406 (..Malacea?6 Jeden falls erst Ende 1845 oder wahrscheinlich anf. 1846 erschenen, da in derselben No. Sitzungsberichte rom 24. Nov, mitgeteilt sind.)

Muscicupa hylocharis 'Temminck \& Schlegel, Fauna Japonica, Ares 1). 44, 'I'af. 17 (1847- Japan).

Mauser doppelt. - Ôad. Oberkopf, ZZügel, Kopfseiten, Hinterhals,

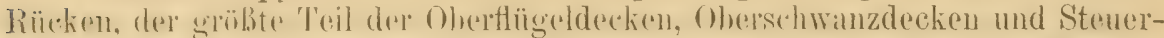
fedem sehwall. Shehwingen bräunlichsehwar\%. innere mittlere und grobe

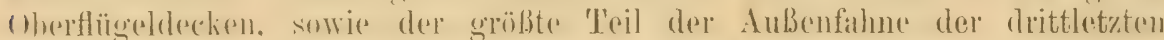

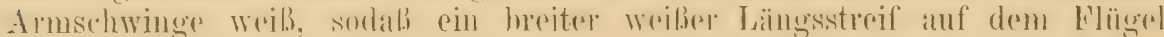
arseheint. Breiter Supereiliarstreif weils. Hinterrïcken und Bürzel geth.

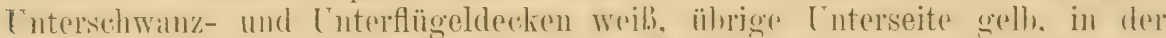

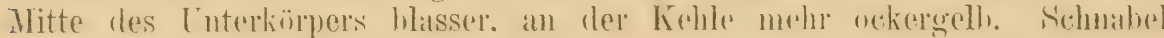
sehwarz, Iris und Fübe braun. Flügel 69-73, seltener 74-75, Schwanz otwa 45-50, Culmen etwa 13-14. Lauf 16-17 mm. Zweite Schwinge nngefähr so lang wie die sechste. - o ad. Oberseite olivengrünlich, am

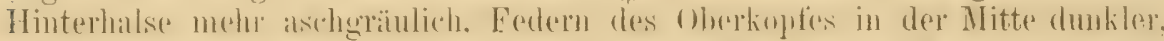

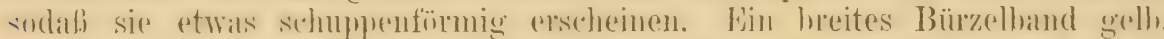

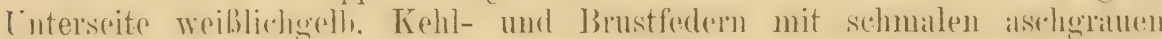

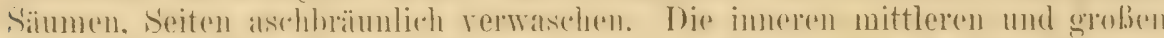

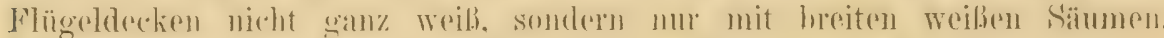

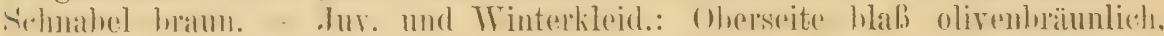

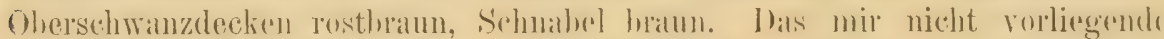

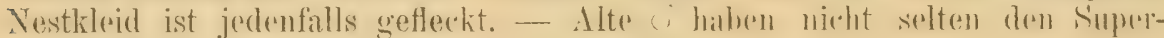
ciliarstreifen mehr oder minder gelb überlaufen.

Brutrogel in. Süd-Ianrien ('Transbaikalien), Ussurien mit der Insel

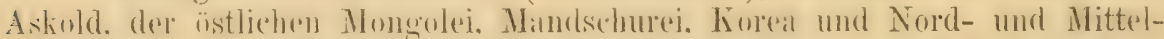

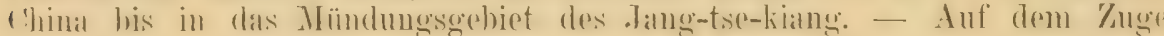
dureh China wandernd, äberwintert in der Malakka-Halbinsel.

Anfeuthalt in Dickichten an F'lußufern, 'Teichen und Waldrändern, wo sich alte Bäume finden, in deren Höhlungen sie ein loses Nest bauen. Dies enthält Ende Mlai und Juni 5-6, manchmal 7 Eier. Diese sind weiß oder rötlichweiß; mit feinen oder größeren blaß rotbraunen Punkten und Flecken, meist auch mit hellgrauen oder blaß lila Schulenflecken gezeichnet, bald Eiern von Mruscicapa striata ähnehnd, bald mehr an Meisencier erinnernd. Mlaße nach T'aczanowski ron $17 \times 13.3,17.2 \times 13.2,17.5 \times 13,17.6 \times 12.3$ und $18 \times 12.8$ bis $18 \times 12.2,18 \times 13.6$ und $18.2 \times 14$, meist etwa $17.8 \times 13.2$ bis $13.8 \mathrm{~mm}$. (Cat. Egggs Brit. Mus. III, Taf. VIII, Fig. 8.) Im Britischen Museun von $16.5 \times 13.4$ bis $18 \times 13.8 \mathrm{~mm}$. Nach La Touche ein eifriger Sänger mit kurzem, aber kräftigem und wohlklingenden Schlag. Lebhaft und kampflustig.

\section{6i:). Muscicapa narcissina narcissina 'T'mm.}

Muscicapa narcissina 'L'emminck, Pl. Col. 577, fig.1 (1835- Japan).

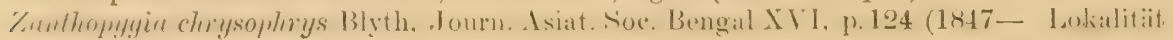
unbestimmt).

Abbild.: 'Temminck \& Schlegel in Siebolds Fauna Japon, Ares Taf. $17 \mathrm{C}$ 
Oad. Ähulich dem ron M. n. zanthopygiu, aber größer, Supereiliarstreif hochgell, nur die inneren mittleren und groben Oberflügeddecken, nicht aber die Anbenfahne der drittletzten Almsehwinger weilb: Brustseiten mit sehwarzen fileck. Kö̈perseiten mit Sedhefersehwar\% rerwasehen; Kohle und

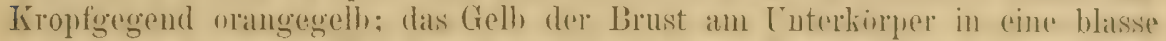

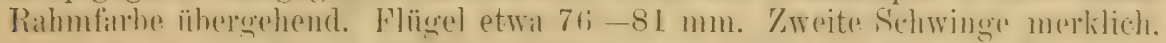
meist 2-6 mm länger als die sechste. - o Größer als das von $\mu . u, z a n-$

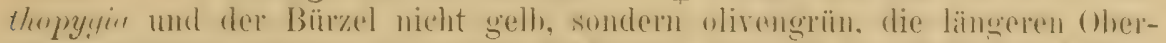

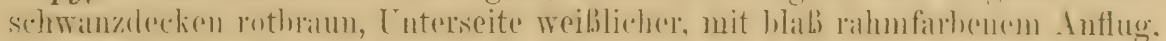
die Flügel whe den groben wriben Pleck, der jederh dureh einige weibliche Federainder angedentet. areheint. Stenerfedern hran mit rosthaunen Auben-

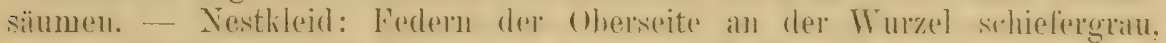

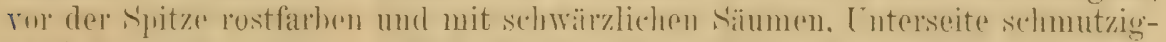

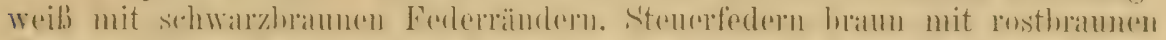

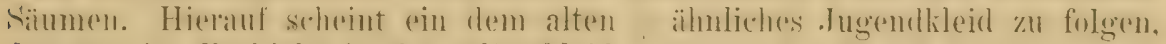
das arst im Frähjahr in das Altersklesid rermansert. Lis ist wahrecheiuliele. daß hei allen Formen ron $M$. narcissina anch die alten of ein Winterkleid

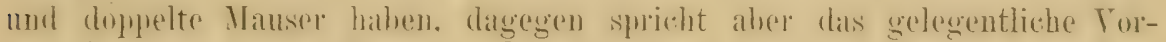
kommen ron oben selıwarzen of im Herbste, das nach von Swinhoe ge-

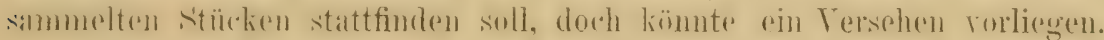

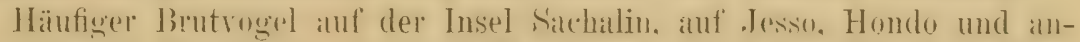

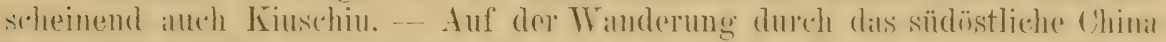
nach Hainan ziehend und auf letzterer Insel, sowie auf den Philippinen iiherwinternd.

Lebt in Wäldern und nistet wie M. n. zanthopygia in Baumlöchern. Die Wier werden beschrieben als blaß grünlichweiß mit blaß rotbraunen Flecken und von der Grïbe derer ron $\boldsymbol{M}$. $n$. zanthopygia. Der Gesang wird als kurz und angenehm geschildert.

\section{Muscicapa narcissina jakuschima subsp. แюr.}

I'nterscheidet sich ron ./. n. nurcissinu dureh olivengrüne. nieht schwar\% werdende Oherseite. I)ie zweitr Sehwinge ist glejeh der sechsten, nicht kï̈rzer. Filügel o etwa $74-75.5$, o $69-72 \mathrm{~mm}$. Schwanz o $50-53$.

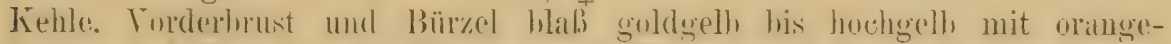
farbenem Anflug. In der Firbung mit .11. n. onstomi ähereinstimmend, abee viel größer: Typus: ơ ad. 18. X. 1904. No. 1064, Tring Museum. (8 o 12 o verglichen.)

Insel Jaku (Yaku-no-shima, Yaknshima) südlich von Kiuschin. -- $30^{7}$

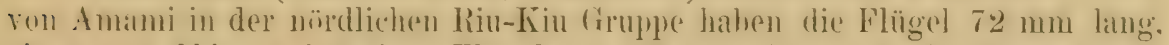
rin ron Okinawa hat einen Flïgel ron $68 \mathrm{~mm}$, die zweite Sehwinge gheicht ungefihh der sechsten uder ist mubedeutend kïrzer. Ferneres Material mub entscheriden. oh (wie es seheint) die mittleren und nïrdlichen Riu-Kin-Insedn

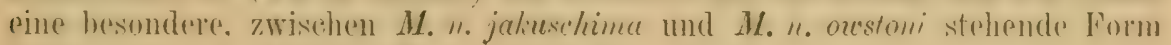
hahen. oder ob diese zu M. no orstoni z.u rechmen ist.

\section{Muscicapa narcissina owstoni (Bangs).}

Zunthopygia oustoni Outram Bangs, Bull. Mus. Comp. Zool. Harvard XXXVT, p. 265 (1901- Ishigaki).

Unterscherdet sich von $M, n$. narcissina durch geringere Gröbe und

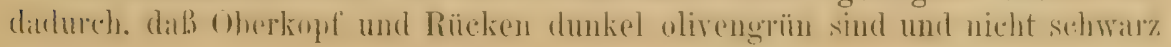




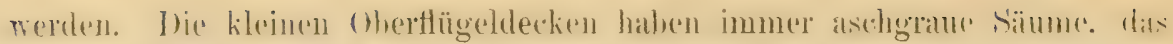
fielh von helle und Kropf ist hochgelh his goldgelb, abre nicht orange-

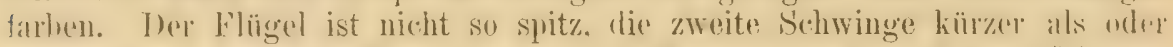

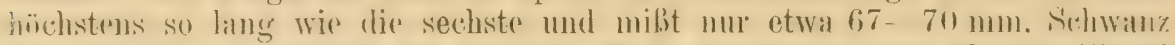

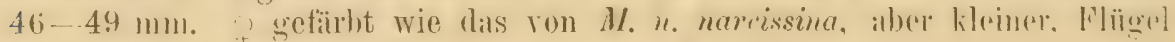
nur etwa 65--66 $\mathrm{mm}$. Tuv. wie die ron $M$. n. nureissinu.

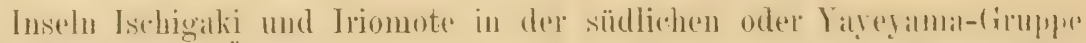

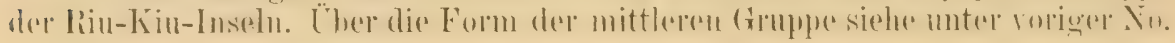

\section{Muscicapa mugimaki 'T'emm.}

(Poliomyius luteola anctorum: errore, non Motacilla luteola Pallas! Siehe Musc. purve albicilla.)

Muscicapa Mrugimaki l'emminck, Pl. Col. 577, Hig. 2 (1835-- Japan).

Mriscicapa rufigula (unde Erythrosterna rufigularis Gray, Hand-list 1, 1.319) S. Müller, Tijdschr. voor Natuurl. Geseh. \& I'hys. II, p. 351 (1835- nomen nudum! S. Not. Leyden Mus. I, p. 27).

Siphia erythaca Blyth, Journ. As. Soe. Bengal XV1, p. 126 (1847- Malakka. J'eschr. (l. jurgen ठ).

Abbild.: Siebolds Fauna Japonica, Ares, 'Taf, XYLIB; Eier: Journ. f. ()'n. 1873. T'af. 11. 18.

Doppelte Mauser. - o ad. Oberseite mattschwarz, die meisten ledern

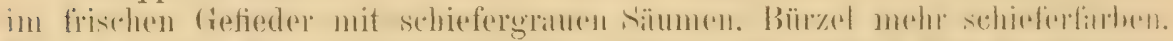

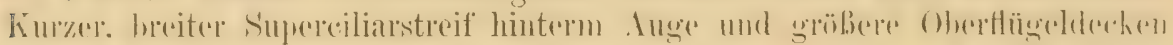

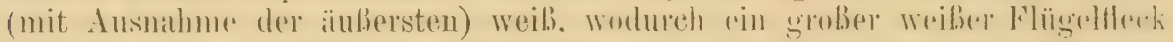

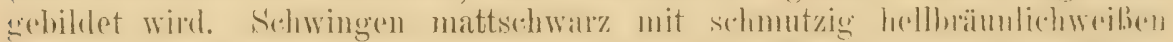

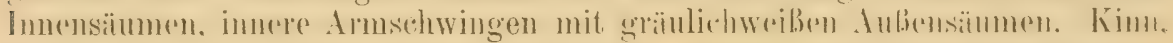

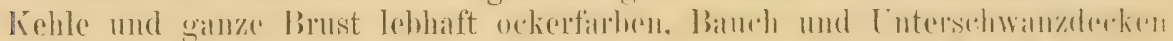

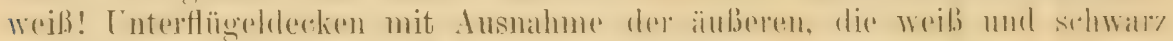

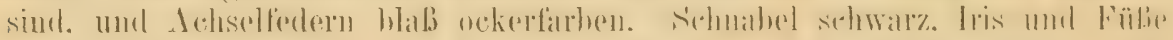
hraun. Flügel etwa 7:3-79, Sehwanz etwa 50-53, Ianf ctwa 14.5-15.8. Culmen 12-13 mm. o ad. Oberseite oliveubraum, der Vorderkopl dured

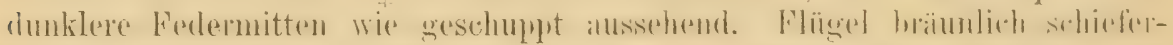

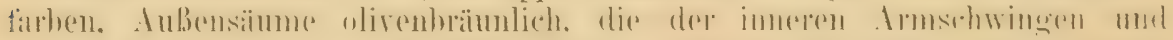

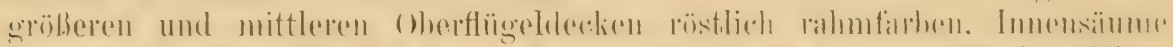

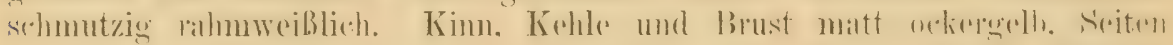

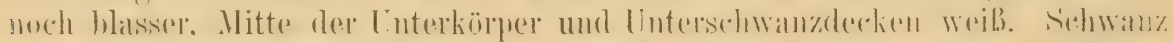

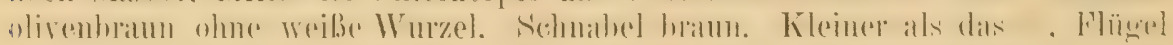
etwa $70-75 \mathrm{~mm}$. Ojuv. dem o ad. ähulich, aher mit dunklerem Sohwanze

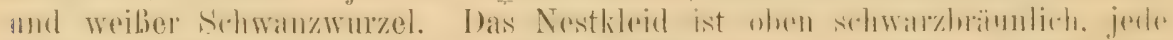

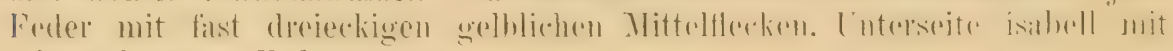
sehwarzbramen ledersäumen.

Ostsibirien von der Amurmündung bis zum Baikil-see. - Auf dem

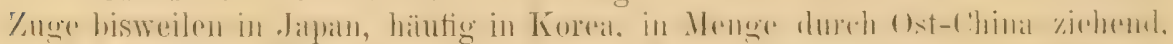

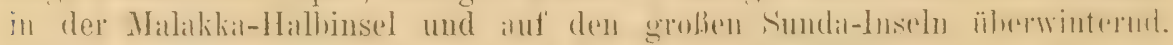
Beccari erlangte ein Exemplar auf 'Temate in den Molukken, wo die Art sonst nicht gefunden wurde.

Kommt uach Godlewski in der zweiten Mälfte des Mai an seinen Brutplätzen an. Brütet in den mit Zirbelkiefern und Fichten bewaldeten Tälern. Die tiel naplfïrmigen Nester landen die polnischen Forscher in verkrüppelten, mit $\mathbf{H}$ oos bedeckten 
Fiehten 2-6 m iber der Erde. 1/3um Nestban wird viel Mloos von den Fichtenzweigen verwandt, sodab clas nahe am Stamme stehende Nest schwer zu sehen ist. Um die Mitte des Juni findet man die 4-8 Eier, die blab olivengrïn sind mit unregelnäßig verteilten kleinen blab rotbräunlichen Punkten und Flecken und denen der Blaukehlehen ähneln. Make nach T'aczanowski $16 \times 12.3,16 \times 12.4,16 \times 12.5,16.2 \times 12.2,16.3 \times$ $12.3,16.6 \times 13,17 \times 13.3,17.2 \times 13,17.8 \times 12.2,17.8 \times 12.3 \mathrm{~mm}$. Hin ron $\mathrm{mir}$ gemessenes bi milit $17.7 \times 12.9$.

\section{Muscicapa cyanomelana 'l'emm.}

Muscieripu cyanomelana (von neueren Autoren in cyanomelaena verbessert) 'l'emminek, I1. Col. 470 (1828- Japan. Ô).

Muscicupa guluris 'T'emminek \& Sehlegel, Siebold's Launa daponica, Ares, 1. 43, 'I'al'. XVI (1847- Japan. + ).

Muscicapu Bella Hay, Madras Journal XHI, 2, p. 158 (1844- Hongkong).

C'yanoptile cyanomelanura (errore) Blyth, Journ. A siat. Soe. Bengal XVI, p. 125 (1847Java).

ơad. Stirn lebhaft himmelblau. Hinterkopf und Nacken kobalthlau,

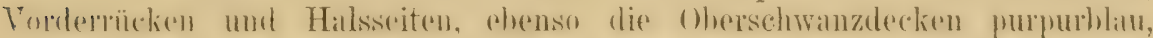

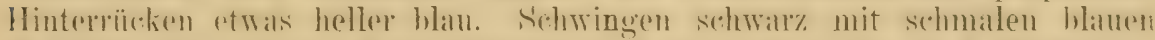

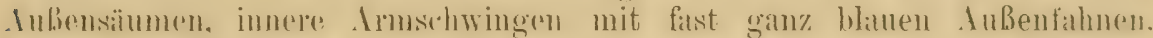

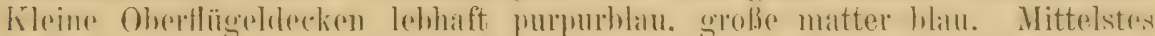

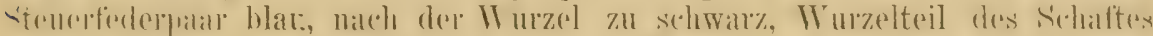
and änberste basis weilis: die übrigen struerfedern schware mit blaturn

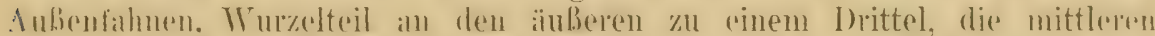

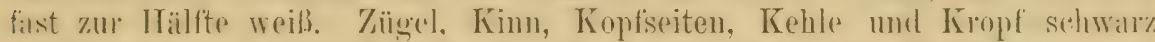

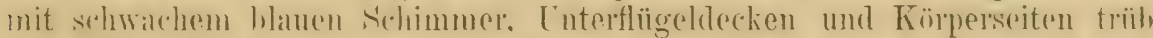
hlan, Schenkelluefiederung sehwärzlich, ülnrige Interseite und Entersehwanz-

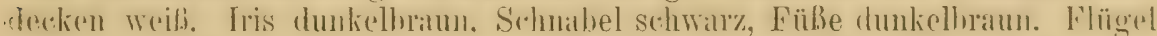
stwa 90-100, meist $93-96 \mathrm{~mm}$, Schwanz etwa 59-68, Tauf $15-17$. fulmen 15-17 mm. Nach dem mir vorliegenden Material von 41 o und

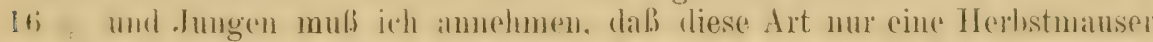

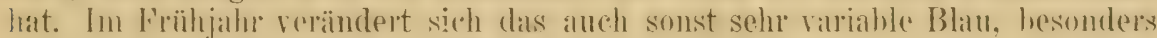
wird die Stirn heller, der Rücken matter und blasser. o al. Oberseite brann, im frischen Herbstkleide stark mit Rostfarbe äberlaufen, in Frühling blassere, nicht mit so deutlichem röstlichen. sondern eher mit etwas srïlllichem Anflug. Bürzel und Obersehwanzdecken immer lebhafter und moh rosthräumlich. Ohrdecken mit hellun S'chaftlinien. Stenerfedern wie dis Ohersehwanzlecken, Schwingen dunkelbraun, Aubenfahnen mit der Farbe



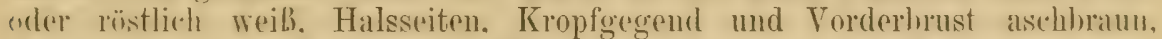
Käprerseiten matter aschhram. Mitte des Cnterkörpers und Tutersehwan\%-

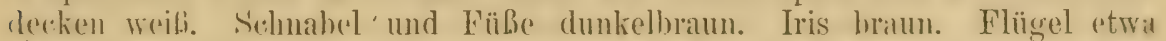

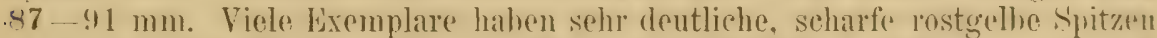
inn clen grofien Oberfligerderken, die aber im Frühling rerblassen und sirh simutzen. - Jüngere of haben l'nterseite, Kopf und Rücken wie dio. Bürzel und Wherschwanzdecken aber blau. Schwanz und Flïgel wio die aul. bies ist vielloweht das erste anf das Nestkleid folgende Ciefieder der ó, während die : damn schon ein dem Alterskleid gleichendes angelegt haben, es fehlt mir indessen an genügenden Serien, um die Aufeinanderfolge der Kileider genau zu beschreiben. Das Nestkleid soll geflerkt sein. win\% jungu of haben fast schwarze Oberschwanzdecken mit braunen Spitzen. 
Brutroged im ïstlichen Amurlande, in der ästlichen Mandseburei, in Korea und aul den japanischen Inseln, aber nicht anf den Riu-Kiu-Inselu. Nach BBanchi auch in Kansu. - Yicht dureh ('hina und ïherwintert in Borneo, Palawan, Java, Hainan u. a.

Bewohner gemischter Wälder. Kehrt am Ussuri im Mai an seine Brutplätze zurück. Soll auf Hondo im Juni brüten. Eier rahmfarben, ungefleckt oder (in der Regel) mit feinen, kaum bemerkbaren hell rötlich rabmfarbenen Flecken. Maßr vin 6 Hiern $19.5 \times 15.8,20 \times 15.5,20.2 \times 16.2,20.5 \times 15.6,20.5 \times 16.2 \mathrm{~mm}$.

\section{Muscicapa melanops Vig.}

Muscicapa melanops Vigors, Proceed. Zool. Soc. London 1831, p. 171 (Himalaya).

Abbild.: Gould, Century Himalay. B. Taf. 6.

Sad. Oher- und Cuterseite lem Lichte zugewandt mattblan mit geringem grünlichen s(himmer ("verlitel-hlau"), rom lichte abgewandt hell

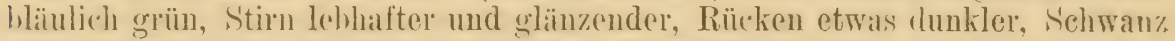
mol Aulenfabnen der schwingen sowic Oberflügoldecken dunkler und hlän-

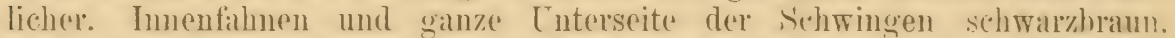
Zï̈gel mol sehmaler Federring um dis Auge sehwar\%. Fnterflügeldrelien sehmutzig matthlau. Interschwanzdecken mit grünlich weilien spitzen. Iris

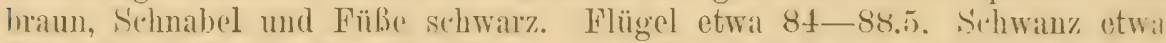

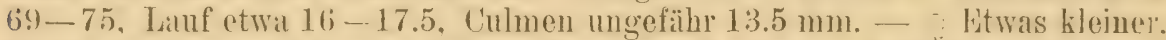
Farhen matter, mehr grangrimlich, Zügel nicht schwar\%. sonderu dunkelgran. Kinn und ohere Keble mit weiblichen Federspitzen. — Juv. Fülü hell. Fredern mit rostgelben Anteapikalflecken und s'hwärzlichen Endsämmen.

Brutrogel in Himalaya ron Kasthmir his zur Tihetanischen Hocin-

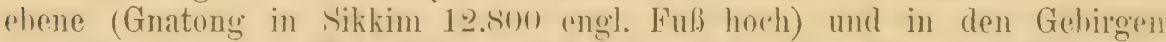
ron Szetseluwan in West-china. Seheint anch in den Bergen siüllich des Brahmapnutra, in denen von Birmah und in anderen B(ryzügen zu hrüten. dïrfte aber in den Ehenen Indiens (südlich his zu den Nilgiris) nur IVintervogel soin.

Baut in Baum-, Lrd- oder Mauerlöchern ein lockeres Nest aus Moos und legt kur\% ovale glänzende fast rein weiße, rötlich weiße oder hell lachs- und rahmfarbene Eier, bald ungefleckt, bald mit rotbräunlichen, meist etwas verwischten Flecken, mehr oder minder dicht bedeckt. Maße ron etwa $17.2 \times 13.6$ und $18.7 \times 14.1$ bis $19 \times 14.8$ und $21 \times 16 \mathrm{~mm}$.

\section{Gattung CHELIDORYNX Hotgson 1844.}

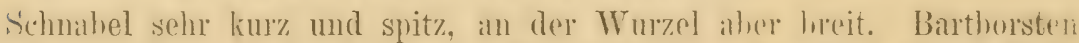

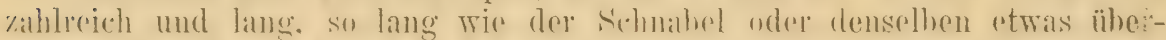
ragend (Fig. 89). 4. und 5. Sohwinge uleich mud am längsten, erste sein? breit und etwa halb so ling wie die zweite; Schwanz länger als dlor Flïg(t) und sehr woich, merklich abgerunelet.

\section{Chelidorynx hypoxantha (Blyth). (Fig. 89.)}

Rhipidure hypoxtenthe Blyth, Journ. Asiat. Soc. Bengal XII, p.935 (1843- Darjiling).

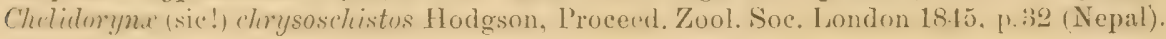

ôad. Vorderrand der Stirn, Zügel, Ring um das Auge und vorderer 'T'ril der dhrgegend schwar\% mit etwas grünlichem s'chimmer. Breites. in 
einen kurzen. his hinter die Augen reichenden superciliastreifen Lortogetztes Stirmband hochgelh. C̈hrige Oberseite olivenfarben. Oherschwanzolecken heller. Schwingen schieferschwarz mit olivenfarbig sehimmernden, an den inneren Armschwingen breiteren Außen- und weißhräunlichen Inuensänmen. ()herflügreldecken wie die S'hwingen. mit helleren Süumen, die größte Serie mit. weiblichen Spitzen. Steuerfeclem bräunlich sehieferfarben, Schäite, Spitzen und Innensïume nach der S'pitze zu weiß, das mittelste Paar mur mit weißen Shathtinien. Lnterseite hochgelh, Tnterschwomzdecken etwas blasser. Tuterflügel-

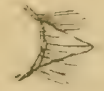
decken weiBlichgelh. Iris und Füße lnam, Oherschmahel schwar\%, Untrischnabel hellgelhlich. Flügel etwa 55-57. Schwan\% etwa 55-58, Laul etwa 13--14, Culmen ungefäbr $10 \mathrm{~mm}$. - ad. wie $\sigma^{7}$, aber die Farben rtwats weniger lehhaft und etwas kleiner. Flügel etwa 53-5t mm. - Erstr Jugendstadien nicht bekannt.

Himalaya vou Simla nach Osten zu, in Höhen von 6-12000 engl. FuB, Birmesisethe Gehirge und Bergzüge sïdlich des Brahmaputra.

Das Nest ist ein kompakter, dickwandiger Napf aus Moos und steht auf wagerechten 'Zweigen. Die Angaben über die Eier widersprechen einander. Vgl. Oates. Humes Nest \& Eggs, 2. Ausg. II, p. 30, Baker, Journ. Bombay Nat. Hist. Soc. IX, p. 18.

\section{Gattung CULICICAPA Swinhoe 1871.}

Dic Schmabelhorsten zahlreicher und riel stäker entwickelt als hei Muscirapu, fast so lang wie der Schmalwel. der lïnger ist als bei C'helidorynu, mit hakiger, herahgehogener Spitze (Fig. 90). Schwanz gerade, nomal. 3. his 5. Schwinge etwa gleich lang und am längsten. 1. lang und hreit, etwas kürzer als die Hälfte der zweiten. Eime Art im Himalayal usw., eine rerwaudte Form mit weniger grau all der Kehle auf den kleinen Sunda-Inseln, einc noch wehr rerschiedene ohme grau anf' linerseite und Kopf auf l'elehes.

\section{1). Culicicapa ceylonensis (śwains.) (Fig. 90).}

I'latyrlynclus Ceylonensis Swainson, Zool. Ill., ser. I, 1, Taf. 13 (1820-21- Ceylon). Cryptolopha pojocephala Swainson, Flyeateh., in Nat. Lihrary, 1. 200, Taf, 23 (1843ohne Lokalitätsangabe).

Cryptolopha cincreocapilla ..Vieill." Hutton, Journ. As. Soc. Bengal XVII, p.t89 (1848 der Name wird Vieillot zugeschrieben, aber dies scheint ein Irrtum zu sein.) Abbild. d. Ei : Cat. Eggs Brit. MIus. III, Taf. IX, 6.

cat. Oberkopf und Hinterhals dunkel aschgrau, Federn des Oherkepfes in dex Mitte fast schwarz, übrige Oberseite gelbgrüu, auf dem Bürzel melr gelh. Schwingen und Oherflïgeldecken schwarzhraun mit grüngelhen, an den Flügelderken griunlicheren Sïumen. S'teuerfedern schwarzhraun mit grüngelhen Aubensä̈umen. Kopfseiten, Kinn und Kehle bis auf len Krouf hellaschgrau, ührigo LnterFigur $90\left({ }^{1}, i\right)$. seite lebhaft gelb, an der Brust und an den Seiten mit olivenfarbenem Anflug: Linterflügrldecken schmutziggelh, Inmensïmme: ler Schwingen hell brïunlich. Iris rothraun. Schmabel schwärzlich, Basis les Unterschnabels weißlich. Fübe hräunlichgell. Flïgel etwa $60-65.5$, Schwanz etwa 54-57, Lauf $13-15$, Culmen etwa $12-13 \mathrm{~mm}$. O wio ơ, nur etwats kleiner, Flügel etwa 56--60. S.hwan\% 49-51 mm. Mir vol- 


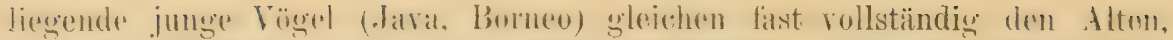

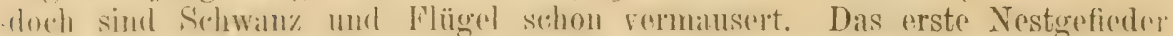

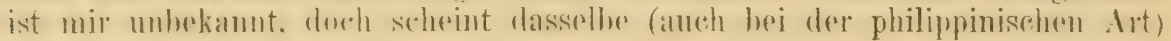
ungefleckt zu sein!

Bewohnt die Wilder Indiens rom Punjab und Coylon bis in den

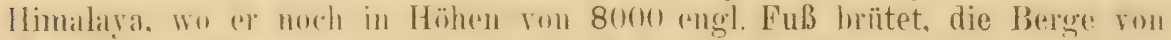

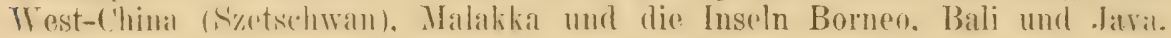
Bei Stïcken von Borneo ist das Gran der Kehle meist sehr dunkel. Auf

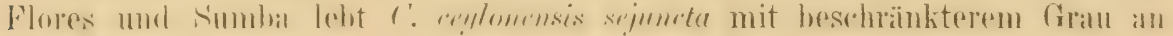
der Kehle.

Nest ein kleiner Napf aus Mloos, an Baumstämmen oder Maucru, 3- + Hier, Mär"z bis oluni. Mattweiß mit olivengrauen oder braunen, meist einen Ring bildenden Flecken und blasseren Schalenflecken. Maße der im Britischen ILuseum befindlichen Fier $15.4 \times 11.9,15.5 \times 12,16.2 \times 12.1$ bis $17 \times 12.8 \mathrm{~mm}$.

\section{Gattung CRYPTOLOPHA Swainson 1.337.}

Schnabel breiter Hliegenfängerschmabel, etwa halb so lang wie der Kopt oder länger. Selmabelhorsten stark entwickelt, Nasenlöcher ron Borstrn

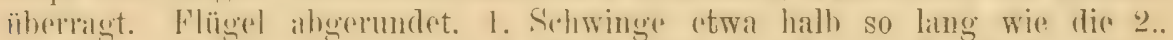

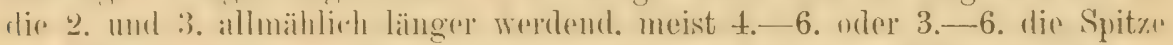

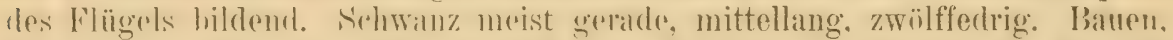

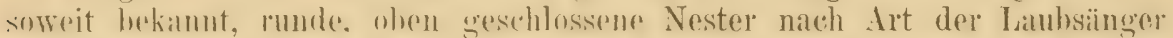

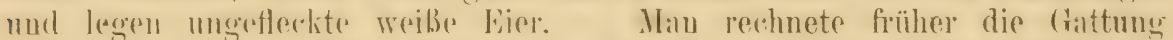

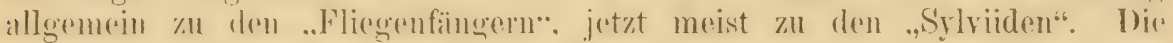

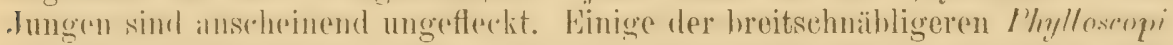
sind den ('ryptolophen nicht mïhulich und wurden fröber allgemein und werlen noch hente oft hierher gestullt: sie haben indessen eimen weniger

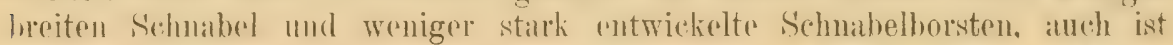
hei den Phyllosenpi (mit Ausnahme weniger Arten) die 1. Schwinge kürmer.

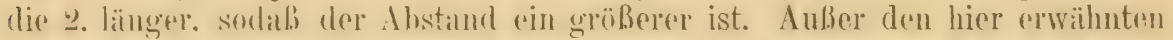

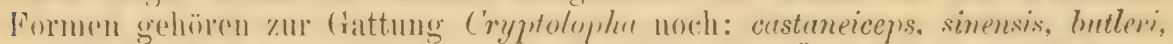

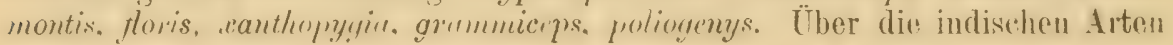
gibt Oates, Fauma Brit. Ind., Birds I, p. $421-428$ Aufschlub.

1 | Rücken grau oder graubraun . . . . . . . C. xanthoschistos . 1) 498

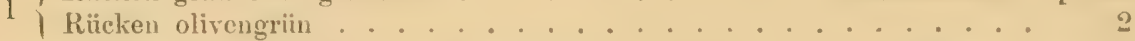

J Schmaler Federring un das Auge gelb......... C. burkii. p. 497

2 S Schmaler Federring un das Ange weiß ......... C. affinis ${ }^{1}$ ) . p. 498

\section{7i1. Cryptolopha burkii tephrocephalus (Anders.).}

Culicipeta tephrocephalus Andersun. Proc. Z/3ool. Soc. London 1871, p. 213 (Bhame in Birma).

Cryptolopha burmanica Berezowshi \& Bianchi, Ares Exped. Potanini Gan-su (189)1Birma. Typus aus Unter-Pegu untersucht).

Abbild.: Anderson. Yunnan Expedition, Ares Taf. 50 (s. auch p.626).

1) Eine Art mit kistanienrotbrannem Oberkopfe, hellgrauer Kehle und breitem gelben Bürzelband, C. castrneiceps (Gray), bewohnt Nepal, Sikkim, die Dafla- und Hanipur-Berge. 
Õad. Torleve Stirn, Superviliarstreif und Kopfseiten gelhlichgrün, Oberkouf schieferschwat\% mit einem unregehmäBigen aschgrauen Mittelstreifen, um das duge ein schwefolgelber Federring, ïhrige Oberseite olivengrün. śchwingen dunkel bräumlichgrau, Außensäume gelhlich olivengrün. Steuerfedern graubraun, Außenfatumen olivengrün, das mittelste Par auch au den Innenfahmen olivengrünlich: äußerstes Paur mit weißer, nur au der Basis brauner. zweites mit etwa zur Hälfte keilförmig weißer Innenfahue. Oberflügeldecken wie der Rücken. dic längste Serie im frischen (iefieder mit oft mndentlichen hellgelhen Spitzen. Unterseite gelh, s'eiten mit olivengrünlichom Influg. Obersehnahel dunkelhornbraun, Cntersthnahel gelhlich fleischfarben. Iris braun. Füße geelblich fleischfarben. Flügel oे etwa 55-60, o 50 his $55 \mathrm{~mm}$, Sehwanz nugeführ $45-48$. Saluf $18-19$, Culmen etwa $14-15$. c. wie $\overrightarrow{0}$, uur etwis kleiner und der Scheitel nicht rein grau, sondern mohr oder minder grïnlich, mit Grau verwaschen.

Birma, P'egu, 'Tonatsserim, Schan-Staaten, bis in die Berge ron Szetschwan. In Süd-China wie es scheint nur im Winter.

\section{Cryptolopha burkii burkii (Burt.).}

Sylvia Burkii Burton, Proe. Zool. Soc. London 1835̃, p. 153 (Himalaya).

Ähnlich. C. l. tephroesphahs, aber Scheitelmitte nicht aschgrau, soudern gelhlich olivengrïn, meist nur beim o mit Andeutung eines grauen Schimmers. Körperseiten mit olivenhrïunlichem Anflug. Flügel etwa $5 \pm(f)$ bis $60\left(\sigma^{2}\right) \mathrm{mm}$.

Himalaya rom Sutlej Flusse his Butam, auch Assam und die Bergketten südlich des Brahmaputrit. - Soll im Winter in den Whenen Indiens vorkommen, doch liegen keine Exemplare aus denselben vor.

\section{Cryptolopha burkii valentini subsp. nov.}

Cryptolopha teplurocephala (non Anderson!) Berezowski \& Bianchi, Aves Exped. Potanini Kansu, p. 74 (1891- Kansu).

Die irrtümlich für C. b. tephrocephulus gehaltenen Vögel von Kansu unterscheiden sich von letaterer durch heller und weniger reingrauen Scheitel, kurzen Schuabel und lange Flügel, von intermedia durch die weniger deutlicho Flügelbinde und längere Flügel. Die Stirn ist grüngelb, der Scheitel hellgrau mit grüngelhlichom Anflug. Filugel o otwa 62-64.5, o $57-60 \mathrm{~mm}$. Typus $\sigma^{\pi}$ ad. no 13205. Taipaischan 2. Juni 1905. Benanut zu Ehren von Valentin Bianchi.

Süd-Kansu und S'chensi; Tsin-ling-Gebirge, im Waldgürtel.

\section{Cryptolopha burkii intermedia La Touche.}

-Cryptolopha intermedia La T'ouche, Bull. B. O. Club VII, p. XXXVII (Februar 1898Fokien).

Äußerst ähnlich dem o vom C. b. teplırocephalus, aber die großen Oberflügeldecken mit schurf hervortretenden, eine deutlich markiorte Bindo bildenden, Fudflecken. der Scheitel hellgrau mit mehr oder weniger grünlichgelbem Schimmer, Stirn ausgedehnt gelbgrïn. Unterseite gelb. Flügel etwa .51 ( q) bis 5.6 ( (ठ) $\mathrm{mm}$.

Süd-China (Kuatun, Provinz F'okien).

E. Hartert, Die Vögel der paläarktischen Region. 


\section{Cryptolopha affinis (Horstield \& Movre).}

Abrornis affinis (ex Hodgson MIS.) Horsfield \& Moore. Cat. B. Mus. Hon. E. Indiw Comp. I, p.341 (1854- "Nepal“).

Oberkonf dunkelgrau wie hei C. b. teph/hocephahs aber dunkler und an: den Seiten breiter schwarzgestreift. Federring um das Auge weiß, nicht gelb. Kopfseiten sehiefergrau. Die Spitzen der groben Flügeldecken lehbaft schwe felgelb.

Sikkim, aulierdem Nepal, wenn Hodgson's stücke wirlich aus lotzterem Lande stammten, sowie in den Bergen südlich des Brahmaputra (Naga-Bergen, Khasia und Manjpur).

(Sehr ähnlich ist C.poliogenys (Blyth) mit weiblichgrauem Kinn und schwarzem. in der Mitte unregelmäßig graugeflecktem Oberkopfe. Sikkim und die Khasia-Berge).

\section{Cryptolopha xanthoschistos xanthoschistos (Gray).}

Phyllopneuste xanthoschistos Hodgron, (Yray's Zool. Alise., 11.82 (1844- nomen nudum!); Gray, Cat. Iamm. B. Nepal and Tibet, p. 151 (1846- Nepal).

Abrornis albosuperciliaris Blyth, Jerdon, B. India II, p. 202 (1863-

Abbild.: Hume \& Henderson, Lahore to Yarkand, 'Taf. XX, Fig. 1.

Oberkopf, Nacken und Rücken aschbräunlich, auf dem Kopfe ein undeutlicher holler Längsstreif. Schulterfittiche, Bürzel und Oberschwanzdecken gelblichgrün. Gräulichweißer Superciliarstreif ron der Basis des Oberschnabels zum Nacken. Zügelstreif und Fortsetzung dessolben binterm Auge schieferbraun. Unterseite gelb. Stenerfederu braun nit gelhgrünen Süumen. die beiden äußeren mit weißen Innenfahnen. Flïgel etwa 53-58 mm.

Himalaya von Nepal bis Kaschmir.

Unterhalb der Schneeregion in Wäldern. Das überwölbte Nest steht am Erdboden. Eier rein weiß. (Vgl. Hume's Nest \& Eggs of Indian B., Edit. II, I, p. 270.)

\section{Cryptolopha xanthoschistos jerdoni (Brooks).}

Abromis Jerdoni Brools, Proc. Asiat. Soc. Bengal 1871, P. 248 (,The enstern representative of $\mathrm{A}$. Xanthoschistos".

Abbild.: Hume \& Henderson, Lahore to Yarkand, Taf. XX, Fig. 2, sub nomine. Abrornis albosuperciliaris.

Wie C. x. xanthoschistos aber kleiner, Oborkopf und Nacken dunkol aschgrau mit dentlicherem hellgrauen Scheitelstreif, Rücken grau, unterer Bürzel und Oberschwanzdecken gelblich griin. Flügel etwa $47-52 \mathrm{~mm}$.

Himalaya von Sikkim ostwärts. AuBerdem Khasia-Berge, Manipur und nach Blyth in Arrakan (? Winter).

Das überwölbte Nest enthält wie das ron $C, x, x$, keine Federn. Eier weib (vgl. Hume's Nest \& Eggs Ind. B., Edit. II, I, p. 271).

\section{Gattung ABRORNIS Hodgs. 1844.}

Diese indische Gattung steht Cryptolopher sehr nahe, unterscheidet sich aber durch kïrzeren, hreiteren Schnabel mit verhältnismäßig längeren, stärkeren Borsten (Fig. 91), namentlich aher dadureh, dab die Arteu nur 10 Schwanz- 
federn haben. Sie legen, soweit bekannt, gefleckte Lier. Aulier den hier erwähnten Formen gehören zu Abrornis: flarigularis, schucaneri, vordermanni, nicht aber olivacea und nigromem. (Oates, Fauma Brit.-India, Birds I 1. 429.)

Nahe steht ferner die Gattung Tichellia. Sie hat ebenfalls nur 10 Steverfedern, aber einen eigenartig gleichmäBig breiten, nach rorn zu sehr wonig verschmïlerten, stumpfspitzigen Schnabel. Einzige Art T. hoolgsoni. Unbegreiflich ist, warum Bianchi (Bull. Ac. Imp. Petershg. Ser. 5, XXII, p. 64) Abrornis alligularis und jollifacies in die Gattung Tickellu stellt.

\section{Abrornis albogularis albogularis Monre.}

Abrornis alboguluris Moore, Proc. Zool. Soe. London 1854. p. 106 tex Hodgson IIs. Nepal).

Abromis albicentris Jerdon \& Blyth, Proe. Zool. Soc. London 1861, p. 199 (Sikkim).

Oberkopf in der Mitte fahl rotbräunlich, an den Seiten je ein breiter schwarzer Streif. Stirn und Kopfseiten lebhaft zimtfarben. Ührige Oberseite olivengrün, der Bürzel aber seidig gelbweiß. Kehlfedern schwarz mit weißen Spitzen, über die Brust ein breites hellgelbes Band, übrige Lnterseite seidig weiss. Flügel otwa $43-47 \mathrm{~mm}$.

Nepal und Sikkim, bis zu den Garo- und Naga-Bergen (Patkai-Hügel) und Ost-Manipur.

Über die Fortpflanzung vgl. Oates, B. India I, p. 431, Oates in Hume's Nest \& Eggs Ed. II, I, p. 275. Nest und Eier wie die von fulvifacies.

\section{Abrornis albogularis fulvifacies Swinh. ${ }^{3}$ )}

Abromis fulvifacies Swinhoe, P'roc. Zool. Soc. London 1870, p. 132 (Szetsehwan).

Abbild.: David \& Oustalet, Ois. Chine, Taf. 23.

Unterscheidet sich von $A$. a. albogularis durch etwas mehr rostgelhlichen, meist leicht grünlich angeflogenen Oberkopf, etwas dunkler olivengrünen Rücken und viel schmäleres hellgelbes Brustband.

China von Mupin in Szetschwan bis Fokien.

Über die Fortpllanzung s. La Touche, Ibis 1899, p. 428. Die Eier sind rötlichweiß mit dunkelroten, lïnglichen Flecken und matt violettgrauen Schalenflecken. Nester in löchern von Bambusrohr-Stämmen.

\section{Gattung PHYLLOSCOPUS Boie 1826.}

(Der Gattungsuame Phyllopseuste, den Oberholser vorschlug, ist nicht 1822 gegeben, denn dort - Meyer, Zus. und Bericht. zu Moyer \& Wolfs

1) Andere Arten sind:

A. schisticeps (Gray) (Culicipeta schisticeps Gray; Cat. Mamm, B. Nepal, p. 67, 153, 1846), (Fig. 91), durch breite gelbe Superciliarstreifen, schwarze Zügel und schwarze Umgebung des Auges kenntlich. - Bewohnt mittlere Höhen im Himalaya.

A. super ciliaris Tick. (Journ. As. Soc. Bengal XXVIII, 1859, p.414), mit gelber Unterseite, weißer Kehle, weißem schmalen Superciliarstreifen,

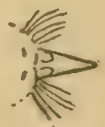

Figur $91(1 / 1)$. braungrauer Stirn, olivengelber Unterseite. - Himalaya von Sikkim an, südlich bis Manipur, Tenasserim und Mergui. 
Tascheuh. p. 95 - wurde der Name nicht in generisehem Simne gehraucht.) Synonyme sind ferner: Trochilus und Asilus, die beide präokkupiert waren. Sibillatrir, Phyllopmenste, Reyuloidrs, Oreopmenste, Arunthopmenste. - Unterseheiden sich ron Cryptolop,he dureh weniger breiten, mehr dem der Sylvien : ihnlichen Schnabel. weniger entrickelte Schnabelborsten. und meist viel kïrzere 1. Schwinge. sodab der Flïgel spitzer erscheint. Bauen ïherwölhte Nester und legen reinweiße oder mit roten und rothraunen Zeiehnungen rersehene Fier. Fine Abgrenzung der Gattung dronthopmenste ist numüglich, da die rerschiedenen Sthnabelformen durch Übergänge vorbunden sind, dir Eier der breitschnibligeren Arten teils gefleckt teils ungefleckit sind und biologische Versehiedenheiten fehlen. In clie Gattung P'hylloseopus gehören auber den hier hehaudelten paliarktisehen Formen: I\%. ricletti, tricirgata.

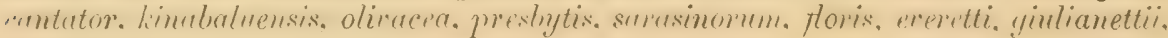
nigromem.

\section{Übersicht der Arten: ${ }^{1)}$}

Mit hellgelbem Bürzelband

I Spitzen der groben Oberflïgeldecken blab orangefarben. . P.pulcher . p. 5yt

2 Spitzen der großen Oberflügeldecken hellgelb

3 Innenfahnen der ̈̈ußeren Steuerfedern weiß . . . P. maculipennis . p.524

I Innenfahnen der äußeren Steuerfedern dunkelbraun. . P. proregulus . p. 523

4 Mit deutlichem hellen Scheitelstreifen oder Andeutung eines solchen. .

Ohne jede Spur eines hellen Scheitelstreifens . . . . . . . 8

f Ganzer Untersehnabel hell . . . . . . . . . . . . .

5 Unterschnabel dunkelbraun, nur an der Basis hell ......... 7

6 Flügelbinden breit, 2. Schwinge zwischen der 8. und 10. . C. trochiloides . p. 522

\{ Flïgelbinden schmal, 2. Schwinge zwischen der 6. und 8. . P. occipitalis . p. 521

7 Unterseite lebhaft rahmgelb . . . . . . . P. subviridis . p. 520

7 Unterseite weiblich mit gellem oder büunlichen Auflug . P. superciliosa. p. 518

f Oberseite tiel dunkel olivenhaun........ P. fuligicenter. p. 529

| Oherseite grïnlich oder hruun, aber nicht dunkel olivenbraun . . . . 9

9 f 1. Sehwinge kiirzer als die Handdecken oder hüehstens $1 \mathrm{~mm}$ länger . 10

9 † 1. Schwinge bedeutend länger als die Handdecken . . . . . . . 11

10 Oberseite hell gelbgrïn, Unterkïrper rein weiß. . . . P. sibilutrix . p.515

\{ Oberseite bräunlich olivengrün, Unterkörper gelblichweiß . P. borealis . p. 517

Unterseite weiß, Bürzel und Oberschwanzdecken olivengelb, in auffallendem

$11\left\{\begin{array}{c}\text { Gegensatze zum Rücken } \\ \text { Unterseite weniger rein weib, Biirzel nicht olivengelb in auffallendem }\end{array}\right.$ Gegensatze zum Rücken...............

Ober- und Unterseite ohne allen grünlichen oder gelben Farbenton . .

$12\left\{\begin{array}{l}\text { Auf der Ober-oder Unterseite ein mehr oder minder grünlicher Farbenton } \\ \text { (bei tenellipes äußerst schwach, doch ist diese Art an dem stark rost- }\end{array}\right.$ bräunlichen Bürzel zu erkennen).

13 f Füße braun, Unterflügeldecken braun . . . . . . . . . 14

\{ Fïße dunkelbraun, Unterflügeldecken weißlich . . . P. neglectus . p. 506

14 Schnabel größer und breiter .......... P. fuscata . p. 528

\{ Schnabel kürzer und schmäler ........... P. homeyeri. p. 528

1) Die mir durch eigene Anschauung unbekannte ijimae und "axillaris" sind nicht aufgenommen. Vgl. p. 522 und 504. 
Mitte der Unterseite lebhaft gelb . ........P. affinis: p. 525

15) Mitte der Unterseite lebhaft bräunlichgelb oder wachsqelb . . . . . 16

Unterseite weißlich, mattgelblich, oder bräunlich . . . . . . . 17

16 Oberseite granbraun ................ . . indica . p. 527

Oberseite grünlich olivenfarben . . . . . . . P. subaffinis . p. 526

17 Oberflïgeldecken mit mehr oder minder deutlichen hellen Querbinden . 18

| Oberflügeldecken ohne eine Spur von Querbinden ........ 21

18 I Unterseite weiß, an den Seiten bräunlich . . . . . . I' tenellipes . 1.512

| Unterseite mit mehr oder minder gelblichem Anflug . . . . . . 19

2. Schwinge zwischen der 7. und 8, wenn nicht zwischen der 6. und 7. . . 20

$19\{2$. Schwinge zwischen der 9. und 10, seltener zwischen der 8 . und 9.

P. lugubris . p. 512

Unterseite gleichmäßig blaßgelb. . . . . . . . P. nitichs . 1.510

20 Unterseite blaßgelb, Kehle und Kropf mit gräulichem Schimmer

P. magnirostris . p. 513

$21 \int$ Außenrand der 3. bis 6. Handschwinge deutlich verengt . . . . . . 22

A Außenrand der 3. bis 5. Handschwinge deutlich verengt ....... 23

22 f Flägelbug zitronengelb, Mitte des Unterkörpers weißlich . P. collybita . 1.501

\{ Flügelbug hellbräunlich, Mitte des Unterkörpers blaßgelb. P. rrmandii . p. 526

23 Unterseite trübweiß mit gelblichem Anflug . . . . . P. trochilus . p. 507

Unterseite matt gelblich rahmfarben, Seiten und Kropfgegend bräunlich-

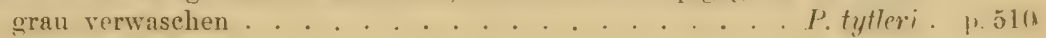

\section{Phylloscopus collybita collybita (Yieill.).}

\section{Zilpzalp, Weiden-Laubvogel.}

"Phylloscopus rufus" ist ein vielfach fälschlich für diese Art angewandter Name. Bechstein (Gem. naturg. Deutschl. IV, 1795, p. 682) benannte keineswegs den Zilpzalp, sondern wandte irrtümlich dafür Gmelin's Namen „Motacilla rufa et lotharingica" (sic!) an. Gmelin's "Mot. mifa" aber ist kein Phylloscopus und "lotharingica" kein nomenklatorisch verwendbarer Name.

Ebensowenig kann für den Zilpzalp der Name "Trochilus Minor" Forster's (Syn. Cat. Brit. B., p. 14, 54) angewandt werden. Trochilus Minor ist Forster's never Name für Linné's "Sylvia hippolais", dem er als Synonyme "Lesser Pettychaps", "Chiff Chaff" u. a. beifügt. Eine Beschreibung ist nicht gegeben. Der Name kann also unmöglich angewandt werden).

Sylvia collybita (von Salvadori 1887 in das sprachlich richtigere collybiste verbessert) Vieillot, Nouv. Dict. d'Hist. Nat. Nouv. Ed. XI, p. 235 (1817- Gute Beschr., auch Gesang und Wier unzweifelhaft gekennzeichnet. Frankieich).

Sylvin sylvestris Meisner, Ann. allg. sehweiz. Ges. f. Naturw. Bern 1824, p. 172 (Bern. Gute Beschr. des Zilpzalps. Eine der Typen Meisners in der Brehmschen Sammlung).

Sylvia nemorosa Baldenstein, Neue Alpina II, p. 83 (1827- Graubünden).

1'hyllopneuste solitaria (?partim) Brehm, Handb. Naturg. Vög. Dentschl. p. 436 (18:31"Laubhölzer, häufig bei Wien, bei Renthendorf nur auf dem '/uge". Das Iaterial der Sammlung sehr ungenügend).

Phyllopneuste pinetorum Brehm, Handb. Naturg. Vög. Dentsch1., p.432 (1831 „Fichtenwälder unseres Vaterlandes").

Sylvia loquax Blyth, in Rennie's Field Natur. I, p.425 (1833- nomen nudum).

Phyllopneuste Brehnii Homeyer, Erinnerungsschr. Vers. deutsch. Ornith. 1870, p. 48 (Portugal. Scheint mir ebensowenig wie Stücke aus Algier verschieden zu sein. Übrigens scheint es sich nicht um Brutrögel,zu handeln). 
Phylloscopus rufus oceidentalis Flöricke, Vers. Avif. Pror. Schlesien, 1. Lief., p. 114 (1892 - "westliche Form").

Ihylloscopus rufus splendens Tsehusi, Ornith. Beobachter V, p.98 (1906- Aarau. Es ist doch nicht anzunehmen, daß mitten im Verbreitungsgebiet von $P h . c$. collybita eine eigene Form vorkommt, sondern vielmehr, daß es sich um ein ausnahmsweise lebhaft gefärbtes Individuum handelt).

Engl.: Chilfchaff; Franz.: Pouillot oder Becfin véloce; Ital,: Lui piccolo.

Außenfahne der 3., 4., 5. und 6. Schwinge vor der Mitte verengt. 1. Shrwinge $12 \quad 18 \mathrm{~mm}$ lang. immer hedentend länger als die Handdecken, 2. in der Regel zwischen der 7. und 8.; Ausuahmen, in denen sie so lang wie die 7. oder kïrrzer als die 8. ist, sind selten. 3., 4., 5. fast gloich (dio 5. meist ein wenig kïrzer) und am längsten. Flügel also gerundeter, kürzer als bei Ph. trochilus. - Fürbung variahel, bald gelher orler brïunlicher, bald matter, im allgemeinen wie bein Fitis-Laubsänger, nur meist etwas bräunlicher, nicht so lebhalft grünlich und gelhlich. Flügel etwa 55-60, wobei die kleineren Malbe den $Q$. die größeren den ôn angehören, oft atuch his 62 und ansuahmsweise his nahe an 65 , doch frägt es sich, ob nicht solehe Stücke 7ugröggel sind und der größeren Form angehören. Schwanz 46-55, Lauf etwa 18-21, Culmen 11-12 mm.

Brutrogel in Großbritannien (aber seltener in den nördlichen Teilen) und Irland, Frankreich. Rhein, Westdeutsehland (genane Grenze nach Osten nicht festgestellt). Pyrenien, Spanien und Italien, mit Linschlu(3) der Berge Sardiniens und Siziliens — doch hehauptet Whitehead, ihn auf Korsika uur als Wintervogel heobachtet zu hahen. Witherby (Ihis 1905) sah nicht identifizierte, aber von ihm hierher gerechnete Fier in Algier, das Brïten in Nordwest-Afrika wurde nie festgestellt. - In den Mittelmeerlündern schon teilweise Standvogel, iı West- und Mittel-Europa dagegen Zugvogel, der in Südwest-Europa, Seneanmbien und Nordwest-Afrika überwintert. Windert in großer Menge durch Marokko und zeigt sich gelegentlich auf Fuertaventura (Thamner sandte Bälge ron letzterer Insel). Einzehe üherwintern ausnahmsweise im südlichen England, Fraukreich und dem südwestlichen Deutschland. Meine Angabe rom Vorkommen in Sü̈l-Afrika (A. d. Wanderj. e. Naturf. p. 102) beruht auf einem Irrtum.

Schon früh im Jahre, in Süd-England oft schon anfangs, in Westdeutschland in der zweiten Hälfte des März hört man an sonnigen 'T'agen den lauten Lockruf, der wie das hüid des Fitis klingt, aber etwas härter ist, und das einförmige, weithin klingende zilp zalp, zilp zalp, oder besser dilm delm, dilm delm des Weiden-Laubvogels. Sein Aufenthalt sind Wälder, gröBere Parks und Gärten. Nester meist in Bïschen, besonders gern Tannen. ganz nahe ïber dem Boden, mitunter $1 \mathrm{~m}$ oder sogar bis 2 und $3 \mathrm{~m}$ hoch, selten auf dem Boden oder an Grabenrändern. Nest wie beim Fitis-Laubsänger, aber die etwas nach oben gerichtete seitliche Ölfnung meist größer, sodaß man in das Nest hineinsehen kann, mitunter sehr grob, selten klein. Meist mit vielen trockenen Blïttern. Die 6-7 Eier sind rein weiß (äußerst selten ungefleckt) mit dunkel rotbraunen, meist zerstreuten, tief dunklen, fast schwärzlichen, seltener etwas Jelleren Punkton und Flecken gezeichnet und von den Eiern der übrigen europäischeu Laubsänger immer zu unterscheiden. 100 von Rey und Jourdain gemessene Eier messen im Durchschnitt $15.45 \times 12.1$, Naximum $17.7 \times 12.6$ und $17.1 \times 13.7$, Dinimum $13.3 \times$ 10.8, doppeldottrige Eier in Jourdain's Summlung $19.2 \times 13.6 \mathrm{~mm}$. Das Gelege findet man meist in der ersten Hälfte des Mai, ein zweites im Juni, Jourdain bezweifelt aber, dab letzteres eine regelmäbige zweite Brut bildet und glaubt, daß es sich, in England wenigstens, nur um Nachgelege handelt. 


\section{Phylloscopus collybita abietina (Nilss.).}

Syliva rbietinu Nilsson. Egl. Vet.-Akad. Handl. 1819, p. 115 (Schweden, 'Trondjem u. a.). Sylvia brevirostris Strickland, Proc. Zowl. Soc. London 1836, 1. 98 (Smyrna, im Winter). Phylloscopus habessinicus (in Geol. \& Zool. Abyssinit, Ares. p. 378 in abyssinicus verändert) Blanford, Ann. \& Mlag. Nat. Hist., ser.4, IV, p. 329 (1869- Abyssinien. Die Ex. im Brit. Mus. sind wohl falsch seziert: „우 "Flüg. 65, „б“ $63 \mathrm{~mm}$ ). Phylloscopus mufus var. obscurus Radde, Orn. Caucas, p. 233 (1881- Tiflis. Anscheinend melanistische Aberration).

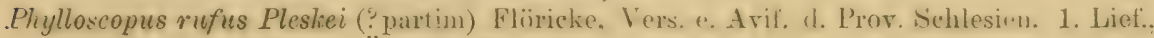
p.114 (1892- "Östliche Form").

Im Norden und Osten Europas wobnt rine langflïgligere, gröliere und im Gefioder meist etwas lichtere Form, was wenigstens bei Frühjahrsviggeln auffällt. Flügel der ơ etwa $62-67.3$, der o $56-60 \mathrm{~mm}$.

Diese Form, ehenso wie die ästliche Form ron Phyllostopus truchilus (eversmumi) sind uach Merkmalen und Terbreitung noch ungenügend bekannt und bedürfen weiteren Studiums. Es wäle zwar cinfucher. aber nicht wissenschaftlich; ihre Namen als Synonyme zu trochilus und collybita zu stellen und mit Stillschweigen zu ïbergehen.

Bowohnt Skandinavien. Ostprentien, vermutlich auch Pommern und Śchlesien, (̈)sterreich-Ungilrn. südwestlich bis Bosuien und Montenegro, Rußland vom 65.0 nördl. Br: his in das Gouvernement Perm und Orenburg und den Kaukasus. Die genauen Grenzen nach Westen z. \%. nicht festzustellen. Zur Zugzeit in Sürlwest-Europa, gelegentlich auch, wie es scheint, in TrestEuropa; ïberwintert in Griechenland. Transkaukisien und Transhaspien (in geringer Anzahl), Kleinasien. Palästina, Nordost- und Ost-Afrika. Finzelne Stücke aus Palästina und Kleinasien (wohl nicht Brutrögel) sind auffallend klein, nicht mit Sicherheit vou westlichen zu unterscheiden.

\section{Phylloscopus collybita tristis Blyth. (Fig. 92.)}

Phylloscopus tristis Blyth, Journ. As. Soc. Bengal XII, p. 96h (1843- Calcutta).

Ficedula fulvescens (und rar. atevia) Sewertzow, Turkest. Jerotn. (in Izv. Obsheh. Iloskov. VIII, 2, p. 126 (1873- T'urkestan). Übers, in Madarász, Zeitschr. ges. Orn. IV, p. 74.

Abbild..: Gould, B. Asia IV, Taf. 59; „Neuer Naumann" II, T'Taf. 5 Fig. 4 (nicht gut!).

Schwingenverhältnisse wio hei $1 \%$. roll. collylitu, die 2. in der Regel .zwischen der 7. und 8., mitunter jedoch auch gleich der 8. oder noch etwas hürzer. Cnterflügcldecken, Axillaren und Flügelhug ähnlich wie hei Pl. coll. collybita, aber etwas gelblicher, mehr schwefelgelh, nicht so grünlich. Auf den ersten Blick von den westlieheren Formen durch den Mangel der gelbgrünlichen Färbung im Gefieder unterschieden, dic auf der Lnterseite gänzlich fehlt, sodal diese schmutzigrahmfarben, an Vorderhrust und Seiten hräunlich verwaschen aussieht, und auf der gräulichlorumen Oherseite nur an den Schwingensäumen und auf dem Bürzel noch herortritt. Superciliarstreif nicht gelb, sondern rahmfarhen. In Frühlingskleide ist die Oherseite noch blasser und gräulicher, dic Unterflügeldecken heller blakgelb, bei den Jungen im Herhste zieht die Oherseite mehr in's ockerbräumliche. Flügel o ungefïhr $.55-60$ (wenn alle richtig seziert), ơ $60-67 \mathrm{~mm}$. 
Das Brutgebiet erstreckt sich ron der P'etschora und dem mittleren. und südlichen Ural (Jekaterinenburg, Orenburg) über das westliche Sibirien. und das Altai-System bis an die Westufer des Baikial-Sees ${ }^{1}$ ). Wandert in Menge durch Turkestan und überwintert in den westlichen und mittleren Teilen Indiens, südlich etwa bis Bombay, östlich bis in die Gegend von Calcutta. Am 26. September 1902 wurde ein Stïck am Suliskerry-Lueuchtturm, 33 engl. Meilen westlich der Orkney-Inseln, gefunden. Im Oktober $18 \pm 6$ auf Helgolaud erbeutet, nach Giithe daselbst außerdem mehrfach beobachtet.

Der Gesang ist monoton, an den vom Zilpzalp erinuernd, von Seebohm mit den Silben tschiwit, tschiwit verglichen, der Lockton soll auch anders klingen. Der Aufenthaltsort sind Wälder und Ufergebüsch. Die Nester stehen nahe am Erdboden oder wenige Fuß über demselben, in Büscheln abgestorbenen Grases oder in Weiden-, Erlen-, Wachholder- u. anderen Büschen. Sie enthalten 6-7. weiße Eier, die mit kleineren oder größeren tief dunkel rotbraunen Punkten und Flecken gezeichnet sind, also denen des Zilpzalp ähneln. Sie messen nach Blasius (ein Gelege) von $14.9 \times 11.8$ und $14.8 \times 11.7$ bis $15 \times 11.5,15 \times 12$, und $15.1 \times 11.7 \mathrm{~mm}$.

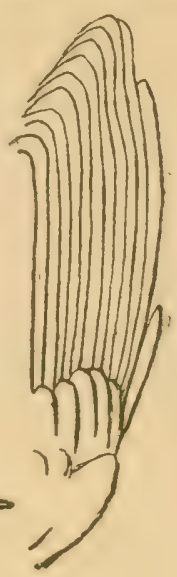

Figur $92(1 / 1)$. Andere Maße sind $14-15 \times 11-12$ und $15 \times 11.9 \mathrm{~mm}$. Win Ei in Rey's Sammlung wiegt $55 \mathrm{mg}$.

\section{Phylloscopus collybita canariensis Hartwig.}

Phyllopneuste rufa canariensis Hartwig, Journ. f. Orn. 1886, p. 486 (T'enerife).

Phylloscopus fortunatus Tristram. Ibis 1889, 1. 21 ((iran Canaria). (Vgl. Hartert,. Wanderjahre e. Naturf., p. 101-102.)

Unterseheidet sich von Pl.c. collybita durch geriugere GröBe und viel dunklere, oliven-bräunlichere Oberseite. Die Unterseite ist ebenfalls viel hräunlicher. Selhst zur Brutzeit erlegte Stücke sind ehenso dunkel oder dunkler als frisehe Herbströgel ron 7\%.c. collybitu aus Europa. Der Flügel. ist breiter, kürzer, weniger spitz, gerundeter, da der Abstand zwischen Handund Armsehwingen ein geringerer ist, die 3. Schwinge kürzer als die 4. und 5., und die 7. und selbst 8. mur ganz wenig kürzer sind. Die 2. ist so rerkürzt, daß sie kürzer ist als die 8 . Flügel der $553.5-56$. der $048 \ldots-50 \mathrm{~mm}$. Iris braun. Füße dunkelbraun, Zehen etwas lichter, Sohlen oliven-gelhlich. Schmabel dunkelbraun, Unterschnahel fleisehforhen, Spitzo braun.

Standrogel auf deu westlichen cantrisehen Inseln. sowohl in baumund buschreichen Gärten. als in Wäldern, von der Küstr (hei Orotava) his.

1) Suschkin beschreibt in Bull. B. O. Club XIV, p. $44_{5}(1904)$, wie folgt eine angeblich neue Form:

\section{„Phylloscopus tristis axillaris n. sp.}

A $P h$. tristis subalaribus et axillaribus isabellino-albidis straguloque magis. grisescenti distinguenda.

Hab. Ad cursum medium fluminis Yenisei $\left(55^{\circ} \mathrm{N}\right.$. lat.)."

Diese Diagnose paßt auf das verblichene Brutgefieder von tristis; es ist kaum anzunehmen, daß an dem angegebenen Orte eine besondere Subspezies wohnt, da die. von Seebohm am Jenissei gefundenen und andere vom Altai stammende Stïcke noch zu tristis zu rechnen sind. 
in beträchtliche Höhen. Ich untersuchte Stücke ron Tenerife. Aram Cianilial, Palma und Hiol'o.

Der Gesang weicht auffallend vou dem unseres Zilpzalps ab. Err besteht aus einem lauten diep diep diep diep. das in eine kurze mehr flötende Strophe ïbergeht, man hört nichts von dem schwermütigen dilm delm unseres Zilpzalys. Der Lockruf ist rauher, schriller. Die Nester stehen in der Regel, aber nicht immer, höher uiber dem Boden als die der europäischen Formen und bestehen aus dïrren Gräsem, Stengeln und ähnlichem Material, innen weich mit Federn ausgefüttert. Dus Eingangsloch ist hei den von mir untersuchten Nestern sehr groß. Die 3-4, nicht selten auch 5 Eier sind weiß mit dunkel braunroten Flecken und Punkten, mitunter auch ganz weiß oder mit nur wenigen feinen Punkten, die mir vorliegeuden ohne graue Schalenflecke, doch fand Koenig Gelege mit solchen. Die Zeichnungen sind in der Regel heller; als bei den Eiern des Zilpzalp, denen sie aber im allgemeinen Charakter gleichen. Die Maße ron 44 von Koenig und Jourdain gemessenenen Eiern sind im Durchschnitt $15.6 \times 12 .(i 5$. Maximum $17 \times 12.5$, Minimum $15 \times 12$ und $16 \times 11.5 \mathrm{~mm}$. Das kleinste mir vorliegende Ei mibt $15.2 \times 11.4 \mathrm{~mm}$. Sie variieren stark in der Größe. Es dürften mehrere Bruten stattinden, da Eier vom 28. Februar bis 19. Juni gefunden wurden.

\section{ist. Phylloscopus collybita exsul suhsp. nor.}

Subspeciei $P h$. collybita canariensis dictue persimilis, sed minor. colvere supra pallidine, subtus minus ochrascente.

Unterscheidet sich ron dem sehr ähulichen Vogel der westlichen Canaren durch etwa:s geringere Größe, etwils lichtere, weniger olivenbrïunliche Oberseite und weniger röstliche, mehr fahlgelhliche Unterseite. Die Tnterflügeldecken scheinen etwas blasser gell zu sein. Flügrel o 50-52, ?7-48.5 mm. Typus ơad. Lanzarote 22. I)ezember 1903. Gesammelt ron Hauptmann Polatzek, No. 2223.

\section{Lanzarote (östliche Canaren).}

Auf Fuertaventura kommen keine brütenden Laubsänger vor, Polatzek aber sandte ron Lanzarote sieben Exemplare der neuen Form. Er beschreibt den Oberschnabel als schwärzlich olivenbraun, den Unterschnabel matt oder hell olivenbräunlich, die Iris dunkelbraun, den FuB dunkel olivenbraun. Den Ruf schildert er als gedehnter und rauher, als bei P.c.canariensis, an den von Anthus berthelotii erinnernd, den (resang als weniger gellend, auch fehle ihm "das Überschlagen der Strophe“.

\section{Phylloscopus collybita sindianus Bronks.}

Phylloscopus sindianus Brooks, Stray Feathers VIII, 1' 476 (1880 Sind); I'leske, Ornithogr. Rossica, p. 284 (1891 - partim! Pleske vermengte mit den Vögelu. aus der Russischen Kette die aus dem Kaukasus, die lorenzii sind).

Sehr ähnlich tristis, aber ohue den hei letzterer immer mehr oder minder bemerkbaren grünen Schimmer an den Flügelu. 1. Selhwinge rerhältnismäBig groß, lang und breit, was aber kein sicheres Kennzeichen ist. da mitunter Stïcke von tristis mit ähnlich oder selbst gleich grol.jer 1. Schwinge vorkommen. Flïgelbug und Unterflügeldecken sehr blaßgelb, aber richt. rein weiß; auch dies ist kein gutes Merkmal für einzelne Stiicke, da tristis mitunter ähnlich und im abgetragenen Gefieder fast ahemso hlasse Unterflügeldecken zeigt. Größe wie die von tristis. Nach Brooks ist der Lockton. sownhl ron dem rou tristix als anch ron dem ron neglecins rerschieden. 
Brütet ingenscheinlich in der Russischen Kette (Kwenlün südlich der ostturkestanischen Wüste), und vielleicht ist es auch diese Form. die im Karakorum nisten soll. Wintervogel in Sind.

\section{Phylloscopus neglectus neglectus Hume.}

Phylloscopus neglectus Hume, Ibis 1870, p. 143 (Punjab).

Abbild.: Pleske, Ornithographia Ross., T'Taf. III, Fig. 3, 4 (leidlich).

3. bis 6. Schwinge an der Außenfahne verengt, wie bei den Formen ron I'. collylita, doch ist cliese Verengung an der 6. Sehwinge mitunter etwats undentlieh. Die 1. Sehwinge rerhältnismäßig riel größer als bei $l$ '. c. tristis. Tnterschoidet sich ron dem etwas ähnlichen Phyll rollybite tristis durch gar nieht gelbe. sondern lahmfarbene, fast weibe Unterflügeldecken, Flügelbug und Axillaren, sowio durch heleutend geringere Größe. Die Fïrbung der Oberseite ist fahler. graubrïunlich ohme jeden grïnlichen Ton, anch auf dom Bürzel und an den Flügelsäumen. Die FüBe sind sehr dunkelbraun, fast schwill. Flügel $0^{7}$ ○ $51-55 \mathrm{~mm}$. Unterseite kaum etwas lichter als boi $P$. tristis. - Bei jungen Herbströgeh sind die [nterflügeldecken und Axillaren leicht gelb überflogen.

Bewohnt zur Brutzeit Transkaspien. Buchalra und Persien und üherwintert im Punjab, in Rajputana und Sind.

In Anbetracht der Ähnlichkeit dieser Formen und des Aussehons von sindiams, der zwischen tristis und neylectus zu stehen seheint, liönnte man vermuten. dab neglectus und lorensii als Subspecies zu der Zilpzalp-Gruppe (collybitu) gehören; dieser Amuahme steht clas liriten von $P$. c. abietinu und P. n. lorenzii im Kaukasus entgegen.

Witherby fand die Eier am 20. April 1902 bei Kalah-Muschir in Farsistan, S.W.Persien. Das Nest stand etwa $3 / 4 \mathrm{~m}$ hoch über dem Boden zwischen zwei dichten Zweigen eines Busches. Es hatte die Form andrer Phylloscopus-Nester und war mit Federn ausgelegt. Es enthielt 4 rein weiße Eier, die $15 \times 11$ mm messen. Die Vögel waren gar nicht seheu.

\section{Phylloscopus neglectus lorenzii (Lorenz).}

Phyllopmeuste Lorenzii Lorenz. Beitr. Kenntn. Orn. Fanna Nords. Kaukasus, p. 28. Taf. II, 2,3,4 (1887 - Nordseite des Kaukasus, Breresowaja-Schlucht bei Kislowodsk u. a. Ex Severtzow MIS).

(Phyll. tristis Radde, Ornis Caucasica, 1. 32, 235- errore! Phyll. sindiamus Pleske, Orn. Ross. I, p. 284- partim - errore!).

Enterscheidet sich auf den ersten Blick von $1 \%$. neglectus neglectus dureh viel hedentendore Gröbe und dunklere, mehr ins Rostfarbene zichende brame Oberseite. Die Flügel von 3 mir vorliegenten ó messen 62-63, die eines o $48 \mathrm{~mm}$.

Bewohnt zur Brutzeit nur den Kaukasus. - Die Winteryuatiere liegen walurscheinlich schon in Tlanskaukasien. Die Angaben vom Torkommen in 'Turkestan siud augenschoinlich falsch.

Lorenz faud diese Form hauptsächlich in Höhen von 5-8000 Fuß, in geringer Anzahl anch niedriger. Das Nest wurdę von Lorenz am Errdboden gefunden. Es ähnelte Nestern des 'Zilpzall' und enthielt 5 Eier. Diese sind auf weißem Grunde mit dunkel rotbraunen Punkten und kleinen Spritzern gezeichnet. 


\title{
788. Phylloscopus trochilus trochilus (L.)
}

\author{
Fitis-Laubsängel:
}

Motacilla Trochilus Linnaeus, Syst. Nat. Ed. X, p. 188 (1758 - Ex Fauna Suecica, Aldrovandus, Willughby u. a. m. Einige der (itate sind nicht ahsolut sicher. Das erste Citat ist Fauna Suecica no. 236. Die dort gegebene Beschreibung ist lediglich aus Willughby (Orn. 164) ontuommen. Willughby's Beschreibung läßt ziemlich sicher den Fitis erkennen. Wir brauchen also den allgemein angenommenen Namen nicht zu ändern, obwohl Will. den Gesang falsch beschreibt, ihn offenbar mit dem vom Waldlaubvogel verwechselnd. Als Terra typica haben wir demnach England zu betrachten).

Motucillı Acredulu. Linnaeus. Syst. Nat. Ed. X. 1). 189 (1758- Ex Fanna Suocica 237. Linné gibt in der Fauna Suecica eine gute Beschreibung, die sich m. E. nur auf den Kitissänger beziehen läßt. Da Linné die Motacilla Trochilus nur aus Büchern kannte, bemerkte er nicht, daß es dieselbe Art wie seine Acredula war. Terra typiea Schweden).

Motacilla Fitis Bechstein, Naturforscher XXVH, p. 50 (1793- 'Thüringen).

Sylvia flaviventris Vieillot, Nouv. Diet. d'Hist. Nat. Nour. Ed. XI, p. 241 (1817Frankreich).

Trochilus medius Forster, Syn. Cat. Brit. B., p. 15, 54 (1817- nomen nudum! Nur aus den englischen Namen und dem Zusammenhang läßt sich etwa erraten, daß mit diesem Namen der Fitissänger gemeint sei).

Pliyllopineuste arborea Brehm. Handb, Naturg. Yög. Jeutsehl.. 1. 12: (1831- Naclel- hölzer Deutschlands).

Sylvia melorlia Blyth. in Rennie's Field Natur. 1, 1).42:) (183:- nomen nudum).

Curruca viridula Hemprich \& Ehrenberg, Symb. Phys. fol. bl (1833- "Ägypten“. Die Untersuchung des von Suez stammenden Typus ergab, daß er nicht der östlichen Form angehöre).

Sylvin tamarixis Grespon, Faune Méril. 1, p. 209 (1814- ..Etang de Seanandre", SüdErankreich).

Sylvia angusticauda Gerbe, in Ray, Faune de l'Aube, p. 139 (1813- Paris. - Nach Degland ein junger Fitislaubsänger).

Silvic Meisneri P’ässler, Naumannia 1851. Heft III, p. 56 (Nomen nudum! Nur biologische, nido- und oologische Notizen, woraus zu entnehmen, dab es sich um den Fitis-Laubsänger mit aberrantem Gesange handelt).

Pleyllopmenste arredula, septentrionulis (?partim) Brehm, Vogelfang, p. 332 (1855 ersterer Thüringen, letzterer Lappland. Ungenügende Kennzeichnungen. In der Sammlung befinden sich zwei Stücke aus "Lappland, Mai 1848", ohne genanere Angaben, die als ,septentrionalis" bezeichnet waren. Auf einem, der ein Fitis-Laubsänger ist, ist der Name später ausgestrichen, auf dem anderen, der ein Zilpzalp ist, ist der Name nicht verändert).

Phyllopmenste major Tristram. Anu. \& Mag. Nat. Hist., ser. 4, VIII, p. 29 (1871 -. ..Southern Mediterranean coasts". Sic! Die Typen sind aus Algier!).

..Phyllopneuste citrina Sew. $=P$. viridulu Ehronb." (sic.) Menzbier, Bull. Sor. Imp. Natur. Moscou LVIII, p. 120 (1883 - nomen nudum!).

Engl.: Willow-wren. - Franz.: Pouillot-fitis. - Ital.: Lui grosso. - Schwed.: Löfsångare.

AuBenfahneu der 3., 4.. 5. Handschwingen vor der Mitte merklich verengt; 1 . Schwinge bedeutend länger als die Handdecken, meist etwa 12-16 mm; 2. Schwinge viel kürzer als die 3., zwischen der 5. und 6., ausnahmsweise nur so lang wie die 6. oder sogar etwas kïlzer, somit zwischen der 6. und 7. innestehend; 3. Schwinge am längsten, 4. ebenso limg oder nur etwas kürzer. - onad. in Herhstkleide nach der 1. Mauser: Ohersoite lebhaft grünlich gelhbraun; von der Basis des Oherschnabels bis zum Finde 
der Ohrgegend rin hlaßgelber Supereiliarstreif. Zügel und Ohrgegend etwas dunkler, hräunlicher als die Oberseite. übrige Kopfseiten etrvas fleckig. Sehwingen und S'chwanz dunkelbraun, mit der Farhe der Oberseite gesïunt, Innensïume der Schwingen hräunlich hellgrau. Schwingen außerdem mit brïunlichweißen Spitzensiimmen. Unterseite gelblich weiß, an Vorderhals und Brust die Federsiüume gelh. die Federmitte weißlicher, sodaß eine undeutliche Streifung entsteht, außerdem Brust und Seiten mit brïunlichem, mehr oder minder deutlich fleckenartigen Anflug. Flügelbug. Unterflügeldecken und Axillaren schwefelgelb. Im Winter stoßen sich die gelhlichen Säume ab und das Gefieder verbleicht, sodaß das Frühlingskleid. in den sie nach Europa zurückkebren, auf der Oberseite fast grïnlich olivengrau aussieht, auf Bürzel und Ohersehwanzdecken grünlicher, auf der C'nterseite trübweiß, an Kehle und Torderbrust mit gelblichem, etwas streifigen Anflug. an Brust und Körperseiten etwas brüunlich. Im Sommer wird die Unterseite noch weißlicher, die Oberseite gräulicher. Schuahel hraun, an den Schneiden und der Basis des Unterschnabels gelblich. Iris braun. Fïl.e gelbbraun. Flügel etwa 66-70, manchmal bis 71 und ausnahmsweise $72 \mathrm{~mm}$. Schwanz etwa 53-67, Lauf etwa 18-20, Culmen 11-12 mm. Der junge Herlstrogel ist noch gelblicher als der alte Vogel nach der Mauser. die Unterseite ist ganz schwefelgelh. Das Nestlkeid ist auf der Oherseite mehr olivenhrämlich, Unterseite weißlicher.

Brutgehiet: Von Lappland. Fimnland und Nord-Rublind durch ganz Skandinavien, dic britischen Inseln. Nittel-Furopa. S'panien, Italien, in SüidostEuropa bis Bosnien und Montenegro, dureh Mittel- und Süd-Rußland bis zum Kaukisus. Vom Tale der Petsehora und von Orenburg an nach Nordosten durch eine kaum unterscheidbare Subsperies (ecersmami) vertreten. Auf der sïdlicheren Balkanhalbinsel nur auf dem 1/uge. C̈herwintert im tropischen und südlichen Afrika, in geringerer Anzihl anth sehon in den Mittelmeerländern.

Allbekannt ist der angenehme Lockpfiff, der etwa wie huid klingt und leicht nachzupfeifen ist. Das Lied ist kurz, aber hübsch und besteht aus einer allmählich abfallenden etwa wie didi di die dïe düe dea dea dïe deida da (Naumann) kliugenden Strophe. Echter Fliegentïinger. der sich von teils herumfliegenden, teils im Gelaube der Bäume und Büsche oder auch auf dem Erdboden sich aufhaltenden Insekten und deren Larren nährt. Er bewohnt Laubwälder und gemischte Wälder mit viel Unterholz, Feldhölzer. Parkanlagen. Auwälder und grïßere Gärten. Das Sest steht in der Regel auf dem Boden, meist in kleinen Vertiefungen, entweder ganz frei oder unter einem Busche, wohl.nur ganz ausnahmsweise in Biischen ïber dem Boden Es ist ein länglichrunder, oben geschlossener, lockerer Bau aus Gras, Halmen. IIoos und Gespinsten. innen sehr weich und immer mit einer Menge Federn ausgepolstert, mit etwas uach oben zu angebrachtem, bald sehr kleinem, bald größerem seitlichen Loch. Die 5-7, selten 8 Eier sind rahmweiblich, mit zahlreichen iber das ganze Fi verbreiteten, meist länglichen, blaßroten Fleckchen, oder aber (seltener) mit sinzelnen größeren blaßroten, wder (noch seltener) mit verstreuten dunkleren, rotbraunen Flecken, die aber niemals den dunkelroten. fast schwarzen Zeichnungen der Fier des Zilpzalps ähnelı. Nach Rey messen 73 deutsche Exemplare in Maximum 17.3 $\times 12.7$. im Durchsehnitt 15.26 $\times 12.40$. Mlinimum $13.5 \times 11.2$ und $14.2 \times 10.9 \mathrm{~mm}$. Das mittlere Gewicht beträgt nach demselben Sammler $62 \mathrm{mg}$. Rey erwähnt, daß ihm aus Finnland zugegangene Gelege weißlicher, etwas größer und nit dunklerer Rostfarbe gezeichnet seien. also wohl wie der dritte oben beschriebene Typus aussehen. Sie messen (23 Stïck) im Mlaximum $16.2 \times 12.3$ und $15 \times 12.5$, Durchschnitt $15.37 \times 11.98$, Minimum $14.2 \times 1.19$ und $14.8 \times 11.3 \mathrm{~mm}$. 
(Hier und da wurden ron verschiedenen Beobachtern - auch von mir vor etwa 30 Jahren bei Breslau - Fitis-Laubsänger beobachtet, die ihrem Gesange das dilm delm dilm delm des Zilpzalps anhängten. Pässler, der wohl zuerst darüber schrieb, nannte den so singenden Vogel "Silvia meisneri". Sowohl Pässler als ich fanden von solehen Süngern Nest und Eier. die ler selteneren grubgefleckten Varietät angehörten. Es wurden daher von Sammlern oft diese großgefleckten Eier ohne Kritik als die des ... Ieisnerschen Laubrogels" bezeichnet. Mit großem Ingeschick identifizierte man diese Doppelsünger mit "Sylic syliestris" Heisners, der den Zilyzaly unter letzterem Namen beschrieb. Parrot hörte einen Laubsänger, der wie der Zilpzalp anhub und endete und in der Mitte den Schlag des Fitis hören ließ. Da der Vogel nicht erlegt wurde, ist nicht festzustellen, ob es sich in diesem Falle auch um einen Fitis oder einen Zilpzalp handelte.)

\section{Phylloscopus trochilus eversmanni (Bp.)}

Phyllopneuste eversmumi Bonaparte, Consp). Ar. 1, p. 289 (1850- ex Eversmann. Addenda ad Pallasii Zoogr., Aves III, p. 14, 184\%. „Ex Asia occ. Rossia m." Sic! Eversmann sagt genau: „Hab. in prov. Casanensi et Orenburgensi boreali"). Phyllopnenste gracilis Brehm, Vogelfang, p.332 (1855- ,Sehr gestreckt und lang. im Orient". Der durch die Präparation sehr gestreckte und wirklich "sehr lange" Balg wurde am 3. April 1850 von Oskar Brehm bei Wadi Halfa erlegt. Der Fliigel mißt fast $72 \mathrm{~mm}$, der Schwanz ist enorm lang. Ich halte das Stïck daher trotz der ziemlich grünlichen Färbung für die östliche Form, während der Typus von viridula m. E. entschieden zu P.t.trochilus gehört).

Phylloscopus gatkei (?partim) Seebohm. Ibis 1877, p.92 (P'etschora und Helgoland).

Gino schwer kenntliche und noch wenig gokimnte Forn, deren Verhreitung weiterer studien bedarf. Steht I'. trochilus trochilus auBorordentlich nahe, jedoch lälit sich nicht leugnen, dals die östlichen Stïcke sich fast.

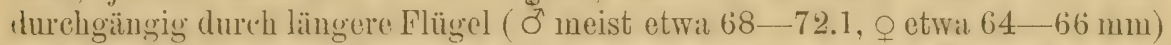
und im Frühling und Sommer gräulichere, weniger grünliche Färbung unterscheiden. In Herbstkleide scheint der Färbungsunterschied sehr unbedentend zu sein, auch mag die weniger grünliche Fürbung zur Brutzeit an stärkerem Ausbleichumgsprozeß liegen. Die 1. Schwinge ist meist länger oder hreiter als bei $P . t$. trochilus und mißt oft $18-18.5 \mathrm{~mm}$. Die 2. Schwinge ist oft länger als bei westeuropäischen Stïcken, bleibt jedoch zwischen der 5 . und 6 . In Ausmahmsfällen ist sie stark verkïrzt und damn nicht länger oder fast sogar kürzer, als die 6. Schwanz etwa 53-60.5 mm. - Dio bedatuerlicherweise im Neuen Nammamn publizierten Notizen Pražális dürften auf Erdichtung beruhen.

Die Verbreitungsgrenze scheint in Nord-Rußland östlich des Timanischen Landrïckens zu beginnen und daun weiter im Süden längs des Lrals dureh die östlichen Teile der Regierungshezirke Perm und Orenburg zu ziehen. Ostwärts brütet die Form am Ob und Jenissei, an der Boganida, bei Bulun nahe der Mïndung der Lena und der Kolyma (Buturlin). In Rumänien mindestens auf dem Zuge. Ein einzelnes Exemplar wurde am 28. August im Beringsmeere erbeutet. Seheint auch in Süd-Afrika im Wrinter rorzukommen und durch Egypten zu ziehen.

Nach Seebohm ist der Lockton anders (Ibis 1877, p. 93); später schien der Autor selbst nicht mehr von dieser Beobachtung ïberzeugt zu sein, da er sie nicht mehr erwähnt. Die Eier sollen denen von S. trochilus trochilus gleichen. 


\section{Phylloscopus tytleri Brooks.}

Phylloscopus tytleri Brooks, Ibis 1872, p. 23 (Kaschnir und Simla).

1. Schwinge fast dopnelt so lang wie die Handdecken, 2. zwischen der 7. und 8., manchmal nur so lang wie die 8., die 3., 4., 5. heinahe gleich lang und am längsten. Oberseite olivengrün, ebenso dio Säume der Schwingen und Steuerfedern. Superciliarstreif blaß schwefelgelb. Unterseite matt gelhlich rahmfarben, Hals- und Körperseiten. sowie Kropfgegend bräunlichgrau verwachsen. Flügelrand, Unterflügeldecken und Axillaren rein schwefelgelh. Innensäiumo der Schwingen granweißlich. Schnabel dunkelbraun, Basis des Unterschnabels hellbräunlich. Flïgel $\delta^{\top}$ etwa $60-62$, o ungefähr $58-60 \mathrm{~mm}$.

Brïtet in den Nadelwäldern unterhalh der Schneegrenze im westlichen Himalaya, von Kaschmir bis Kumaon. - Im Winter in den niedrigeren Lagen der Berge und in den indischen Fhenen bis Ootacamund.

Das Nest nach Cock (rgl. Ibis 1872, p. 30) oben offen und vierzig Fuli über dem Boden am Ende eines Zweiges, Eier weib. Fs liegt wohl sicher eine Verwechslung vor, da wohl kein Laubsänger ein oben offene's Nest bauen dürfte, das $40 \mathrm{FuB}$ hoch steht.

\section{Phylloscopus nitidus nitidus Blyth.}

Phylloscopus nitidus Blyth, Journ. As. Soc. Bengal XII. p. 965 (1843- ('alcutta).

Abbild.: Pleske, Orn. Ross. II, p. 172, Taf. II, Fig. 2; Dresser, B. Europe IX, Taf. 651, Fig. 2.

Die 3., 4. und 5. Schwinge sind immer stark, die 6. ist meist deutlich, mitunter aher auch nicht ausgeschnitten. 1. Schwinge etwa ${ }^{1}-1 / 2$ ihrer Iänge über die Handdecken hinausragend. 2. gleich der T., sehr selten etwas länger, oder gleich der 8., meist zwischen 7. und 8., 3. und 4. gleich und am lïngsten, 5. nur etwas kïrzer. Oherseite einförmig mattgrïn ohue gelben Anflug. Schwingen und Handdecken dunliclbraun, nit der Farbe des Rückens gesïumt. Innensäume grïnlichweil. Flügeldecken wie der Rücken, die mittleren mit undeutlichen, die großen mit deutlichen, cine schmale Querbinde bildonden hellgelben Spitzen. Steuerfedern braun mit mattgrünen Auben- und feinen grauweibliehen Innensäumen und Spitzen. Zägel und Streif hinterm Auge olivenbräunlich grün, darüber ein schwefelgelber Superciliarstreif. Ührige Kopfseiten, Unterseite und Flïgelbug schwefelgelb, Unterflügeldecken etwas holler. Während der Brutzeit wird die Oberseite gräulicher, dic Unterseite blasser. I'lügel von 38 gemessenen ơ und 60 (selten) bis $66.3 \mathrm{~mm}$. Iris dunkelliraun, Schnabel und FïßBe wie bei den anderen Arten.

Das Brutgebiet ist der Kankasus (vermutlich auch die Krim), Transkaspien, des westliche Buchara und I'ersien, wahrscheinlich auch A fghanistan. - Überwintert in Indien rom Himalaya his Ceylon und von Sind im Westen ästlich bis Calcuttil. Am 11. Oktoher 1867 wurde uach Gäthe ein Fxemplar auf Helgoland erlegt.

\section{Phylloscopus nitidus viridanus Blyth.}

Phylloscopnes viridenus Blyth. Journ. As. Soc. Bengal XII, p. 967 (1843- Caleutta und Nepal).

Ficedula Middendorfii Far. intermedia Severtzow, T'urkest. - Jevotn. (in Izv. Obsheh. Moskov. VIII, 2) p. 65, 125 (1873 - Turkestan); vgl. Zeitschr. ges. Orn. IV, p. 70. 
Phylloscopus pseutoborculis (partim?) Severtzow, Ihis 1883, p. 66 (Pamir. Ferghana. Tian-Schan bis Ili).

Abbild.: Hume \& Henderson, Lahore to Yarkand, Taf. XIX; Pleske, Ornithogr. Rossica Taf. II, Fig. 3; Dresser, B. Europe IX, Taf. 65̌l, Fig. 1.

1. Schwinge fast um ihre Hälfte über die Handdecken hinausragend. 3., 4., 5. Schwinge an der Außenfahne stark, 6. weniger tief ausgeschnitten. Das Schwingenverhältnis variiert, meist aber ist die 2. Schwingo zwischen der 7. und 8., oft gleich der 7., selten etwas länger, sehr selten kürzer als die 8. Die 4. ist am längsten, die 3. und 5. sind aher nur sehr unbedeutend kürzer. - Oberseite nicht grü̈, sondern brïunlich olivengrünlich. Supereiliarstreif gelblich rahmfarben, Spitzen der längsten Oberflügeldecken schmal rahmgelb, eine deutliche Binde bildend, die Spitzen der mittleren Deckfedern nicht merklici heller. Unterseite weißlich mit schwefelgelbem Anfluge, also viel heller, als bei nitidus. Sonst wie nitidus. 0 ad. Flügel 57 (nur o, selten) bis 65 , selten bi6 (nur ơ) $\mathrm{mm}$.

Vielleicht schon in Ostpreußeu, wo im Juni auf der Kurischen Nehrung ein Stück erlegt wurde, nistend, jedenfalls von Estland, Livland, Nord-Kurland und den Gouvervements Olonetz (Latscha-See), Jaroslaw, Moskau, Kasau, Perm, Ufim durch den Ural und das westliche Sihirien bis zum Altai, Teile von Turkestan (Kora-Tal, Kopal, Alexander-Kette, Karatau, Tschinas, Fergana, Tian-Schan, Ili, Iskander-Kul), vielleicht auch in Kaschmir und Gilgit, was aber noch nicht erwiesen ist. Osmaston (Journ. Bombay N. H. Soc. XIV p. 816) beschreilot Nest und Ei aus Sikkim, doch liegt vielleicht ein Irrtum vor. - Überwintert in Indion von Hasara bis Sikkim und Galcutta, vom Himalaya bis Ceylon, soll aber in den trockeneren Gegenden des IVestens (Rajputana und Sind) fehlen. Dreimal auf Helgoland erlegt. Trurde oft mit nitidus verwechselt, den er zur Brutzeit geographisch vertritt.

Bewohnt (vgl. Menzbiers und Suschkins Beobachtungen, Ornith. Jahrb. 1898, p. 1) Wälder und Gärten. Das Lied ist laut und wohltönend, aus den Silben tsche tschi rj ri bestehend. Der Lockton wird als psi psi und tiss jip beschrieben. Das Nest steht am Boden oder nahe ïber demselben. És besteht aus Moos und frrashalmen und ist mit Wolle ausgefüttert. Die Eier sind weiß, ungefleckt.

\section{Phylloscopus nitidus plumbeitarsus Swinh.}

Phylloscopus plumbeitarsus Swinhoe, Ibis 1861, p. 330 (zwischen Taku und Pelking).

Phyllopseustes Middendorffiileres, Öfr, af Kgl. Vet.-Akad. Förh. 1871, p. 758, Taf. XV. 1 (Ajan am Ochotskischen Meere).

Phyllopneuste excoronatus Homeyer, Journ. f. Orn. 1872, p. 207, (Nomen uudu Baikal-Gegend).

Ficedula (Phyllopneuste) Middendorffii var. hypolcïna (graminis) (sic) (?partim) Seve Turkest. Jevotn. (in Izv. Obshich. Moskov. VIII, 2) p.65, 125 (1873- Turk

Phylloscopus Seebohmi Hume, Stray Feathers V, p.335 (1877- Tenasserim).

Phylloscopus burmanicus Brooks, Stray Feathers IX, 1). 272 (1880-- Pegu und IIoul

Phylloscopus pseudoborealis (partim?) Severtzow, Ibis 1883, 1).66 (Pamir, Fer. Tian-Schan bis Ili.

Abbild.: Pleske, Ornithogr. Rossica, Taf. II, Fig. 4.

Sehr ähnlich P.n. virilumu', aher die blaßgelbliche Färbung an den Spitzen der grolen Flügeldecken lichter, gelblicher; infolgedessen tritt die durch diese hellen Spitzen gebildete Flügellinde dentiicher hervor, und außerden 
ist im frisehen Gefieder cine deutliche, durch die bellen. hlaBgelhen Spitzen der mittleren Flügelderen gehildete zweite Binde auf dem Flïgel bemerkbar. die aher in Sommerkleide ganz ahgerieben ist. Fröße ettras geringer: Flügel $55-62 \mathrm{~mm}$.

Wegen mehrfincher Verwechslung der verwandten Formen ist die Verbreitung schwer anzugehen. doch scheint diese Form in den istlicheren Teilen von Thriestan rorzukonmen. wo sie aher vielleicht teilweise mit riridume verwechselt wurde. Jedenfills nistet sie ron 'Transbaikalien lis zu den Lifern des Ochotskischen Meeres, sotrie rielleicht anch im uördlichen ('hinil. - Clberwintert in Pegu, 'Tenitsserim his zur Malakki-Halbinsel, in Gohinchina mo ist häufig in Hainan im Oktoher und November.

Nach Dybowskis und Godlewskis Beobachtungen brütet er in Transbaikalien Ende funi und anfangs Juli und baut an Uferrändern und (irabenböschungen in einer kleinen Bodenrertiefung sein Nest, das 5-6 Eier enthält. Diese sind schneerveiß wie die von Ph. fuscata und messen nach Taczanowski $15.4>11.5,15.4>11.3,15.7>11.5$, $15.8 \times 11.5$ und $15.8 \times 11.6 \mathrm{~mm}$. Dr. Rey stellt diese Brutnotizen ganz irrtümlich inter Ph. coronata.

\section{Phylloscopus tenellipes Swinh.}

Pluylloscopus tenellipes Swinhoe, Ibis 1860, p. 53 (Winterrogel bei Amoy).

Acanthopneuste puella Madarász, Termeszetr. Fïzetek XXV, p. 1, Taf. I (1902- Wladiwostok. Typus verglichen).

Abbild.: Pleske, Ornithogr. Rossica, Taf. II, Fig. 5.

1. Schwinge variabel, bisweilen nur wenig länger als, oft aber fast doppelt so lang wie dic Handdecken, 2. zwischen der 6. und 7. oder zwischen der 7. und S. Die 3., 4., 5. gleich lang und die Spitze bildend, oder die 4. ein wenig üher die henachbarten heiden hinausragend. Oherseite olivenbram, auf dem Bürzel und den Oberschwanzdecken mit röstlichem Farbentone. I) groben ()herflügelderken mit immer deutlichen, die mittleren mit bald deutlichen, hald kaum angedeuteten hrïunlich rahmfarbenen Spitzen. Unterseite weiß mit brïunlishem Seitenanflug. Superciliarstreif rahmfarben. Füße hlab fleischforben, nicht braun somst wio phumbeitarsus. Flügel etwa $61-67.5 \mathrm{~mm}$.

Der brïunliche 'T'un des Gefieders und die hellen Beine sind auffallende Merkmale, aluch scheint tenellipes teilweise in denselben Gebieten wie plumbritarsus 7u brïten, er ist daher als besoudere Art zu betrachten. - Sicher tenellipes an der Boganida im Taimyrlande, „bei Hadschi an der sehen Strabe" und hei Wladiwostok im Amurlande zu hrïten. In und Japan wurde es vermutet. - Überwintert in Süd-China und Birma und der nördlichen Malakkahalbinsel.

\section{Phylloscopus lugubris Blyth.}

Phyllopneaste luyubris B]yth, Ann. \& IIag. Nat. Hist. XIT. p. 98 (1843- Bei Calcutta. Ungenügende Beschreibung. Fernere Litt. s. Seebohm, Cat. B. Brit. Mus, V, p. 48); Journ. As. Soc. Bengal XII, p. 968 (1843).

1. Sehwinge sehr groß und hreit, bis zu 11 und $11.6 \mathrm{~mm}$ über die Handdecken himausrigend, aber etwas variabel. 2. Schwinge kürzer als bei den ähnlichen Arten, zwischen der 9. und 10., seltener zwischen der 8. und 9., 


\section{R. Friedländer \& Solnn in Berlin NW. 6.}

In unserem Verlage erscheint:

\section{Das Tierreich.}

Eine Zusammenstellung und Kennzeichnung der rezenten Tierformen.

A Begründet von der Deutschen Zoologischen Gesellschaft. A

Im Auftrage der

\section{Königl. Preuß. Akademie der Wissenschaften zu Berlin herausgegeben von}

Franz Eilhard Schulze.

$-200305$

Die Herausgabe findet in Lieferungen (in Groß-Lexikon-()ktar mit Abbildungen im Texte) statt, die je eine oder mehrere nahestehende Gruppen behandeln, jedoch unabhängig von einer systematischen Folge erseheinen. Jedo Lieferung ist einzeln käuflich.

Bei Subskription auf das ganze Werk tritt eine PreisermäBigung ein.

Aus der' Gruppe der

sind bisher erschienen:

\section{Vögel (Aves)}

Lieferung 1: Podargidae, Caprimulgidae und Macropterygidae. Bearbeitet von $\mathrm{E}$. Hartert ('Tring). 1897. VIII und 98 Seiten mit 16 Abbildungen und Beilage: Terminologie des Vogelkörpers von A. Reichenow, 4 Seiten mit Abbildung.

Einzelpreis Mark 7,-.

Lieferung 2: Paradiseidae. Bearbeitet ron The Hon. Walter Rothschild. 1898. VI und 52 Seiten mit 15 Abbildungen. Einzelpreis Mark $3,60$.

Lieferung 9: Trochilidae. Bearbeitet von, E. Hartert (Tring). 1900. X und 254 Seiten mit 34 Abbildungen.

Einzelpreis Mark 16.-

Lieferung 15: Zosteropidae. Bearbeitet ron O. Finseh (Leiden). 1901. I und 55 Seiten mit 32 Abbildungen. Einzelpreis Mark 4, 0 ?

Iieferung 18: Paridae, Sittidae und Certhiidae. Bearbeitet ron C. E. Hellm (Mïnchen). 1903. XXXI und 255. Seiten mit 76 Abbildungen.

Einzelpreis Mark. 16.

Weitere Lieferungen erscheinen in ununterlnochener Folge. Bestellungen und Subskriptionen können durch jede Buchhandlung hewirlit werden.

Berlin, März 1907.

\section{R. Friedliinder \& Sohn.}




\section{R. Friedländer \& Sohn in Berlin NW.6.}

Iń unserem Kommissions-Verlage erschien 1902:

\section{Aus den \\ Wanderjahren eines Naturforschers.}

Reisen und Forschungen

in Afrika, Asien und Amerika

nebst daran anknüpfenden meist ornithologischen Studien Voll

\section{Ernst Hartert.}

Ein Band von XV und 329 Seiten mit 17 Abbildungen im T'ext und 13 'Tafeln (- Routenkarten, Landschaftsbilder, ethnographische 'Typen, Abbildungen neuer Fische -). klein-4. In geschmackvollem Leinenband.

Preis 25 Mark.

Inhalt:

I. Reise nluch Sokoto und Kano im westlichen Sudan (Westkiüsto. Flußfahrten auf dem Niger und Benue. Ton Loko bis Kano, Sokoto und Gandu durch vorher unerforschto Gebiete, dam zurïck zum Benue. Ioko am Benue). Z/ur Fauma der Canarischen Inseln. Die Ornis der I Los-Inseln. Verzeichnis der hisher lekannten Vögel des Haussalandes. Übersicht der

1 Hanssalaude heobachteten Nutzpflanzen. - II. Reise uach Sumatra, alakka und Indien. (Die Insel Penang. Sumatra. Naturgeschichtliches s Sumatra. Die Insel Salangi. Der britische Sehutzstaat Perak. Assam. Xien.) - III. Reise nach den Inseln des Caribischen Meeres (Reise nach sstindien und Venezuela: St. Thomas. Faumistisches. Porto Rico. Venezuela. caracas. Antinuano. Curaçao, Arula und Bonaire. Flora und Fauna dieser Inselı. Hayti). Die Vögel der Inseln Aruba, Curaçao und Bonaire, neuo Formeti: - IV. Frühlingsausflug nach Marokke und Tonerife. (Reise nach Marokko und den Canaren. Vogellehen. Der Oum Rbiah. Eutdeckung: nener Fische. Tenerife. Orotava.) Notizen ïber die Vögel der Gegend um Mazagan im mittleren Marokko. 


\section{Die Vögel , \\ der paläarktischen Fauna.}

$\underset{\text { der }}{\text { Systematische Übersicht }}$

in Europa, Nord-Asien und der Mittelmeerregion vorkommenden Vögel.

Von

Dr. Ernst Hartert.

Heft $V$.

Seite $513-640$.

Mit 32 Abbildungen.

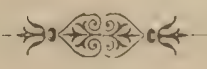

Berlin.

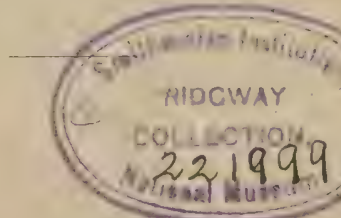

Verlag von R. Friedländer und Sobn. Ausgegeben im Februar 1909. 
Es gab bisher kein Werk, welches die lokalen Formen aller paläarktischen Vögel in knapper Form berüeksichtigt, und überhaupt kein Werk in deutscher Sprac ?e über die Ornis der palïarlitischen Fauna.

Von dem seır kostspieligen Prachtwerke H. E. Dresser's algesehen, haben wir zwar ein vor kurzem erschienenes praktisch eingerichtetes Handbuch desselben Verfassers. Dieses "Manual of Palaearctic Birds" hat aber die Ergebnisse des sultilen Studiums der letzten 15 Jahre unbeachtet gelassen, und bringt fast nur die leicht unterscheidbaren Formen, bietet also nur einen Teil von dem, was wir gebrauchen.

Das vorliegende Werk bemüht sich vor allen Dingen zu zeigen, wals bisher in Unterscheidung der Subspezies geleistet worden ist, und somit auch, wo noch Lï̈cken auszufüllen sind. Das Bekannte ist zusammengestellt, geprïft, gesichtet und Neues limzugefügt worden, wozu die bedeutende von dem Verfasser verwaltete Sammlung, und das nahe gelegene größte Museum der Welt in London, Gelegenheit boten.

Die Beschreibungen sind, wenn nicht anders angegeben, nach der Natur entworfen, also vollstïndig neue Originalbeschreibungen; sie sind möglichst kurz und knapp gehaltev.

Die Nomenklatur ist so konservativ wie möglich, d. b. der älteste ermittelte Name ist für Gattung, Art und Unterart in jedem Falle ohne Ausnahme angewandt.

Das Werk wird in Lieferungen von je 8 Bogen, zum Preise von $t$ Mark für die Lieferung, erseheinen. Das Ganze wird in etwa 12 Lieferungen in 2 Bänden vollständig sein. Nit Heft 6 (Ende der Passeres) wird der 1. Band alogesehlossen, und demselben Titelblatt und ein kurzer Index beigefügt werden.

Während der Arheit, die infolge der in den letzten Jahren rapide wachsenden Tätigkeit der Ornithologen auf dem Gebiete der paläarktischen Fauna einen immer größeren Umfang annimmt, wurde Verf. von vielen Museen und Freunden mit Material und Notizen unterstiitz.t. Er möchte schon hier vorlïufig allen seinen Korrespondenten seinen Dank aussprechen, insbesondere den Herren Valentin Bianchi, Dr. Paul Suschkin, Sergins Buturlin, Professor Reichenow, Pastor Kleinschmidt, Prof. Schauinsland, Othmar Reiser, Dr. Julius vou Madarász, Ritter von Tschusi zu Schmidhoffen, Dr. Loreuz von Liburnau, Prof. Wilhelm Blasius, Dr. Louis Bureau, Prof. Trouessart, Dr. Ménégaux, Joseph Whitaker, Gebr. Ticehurst, Dr. H. O. Forbes, Dr. Hoyle, W. Eagle-Clarke, H. F. Witherby, Prof. Giglioli, C. E. Hellmayr und anderen.

Berlin NW. 6, Fobruar 1909.

Karlstr. 11.

\section{R. Friedländer \& Soln.}




\title{
Die Vögel
}

\section{der paläarktischen Fauna.}

\author{
Systematische Übersicht \\ der \\ in Emropa. Noprl-Asien und der Mittelmenremgion \\ rorkommenden Vögel.
}

Von

Dr. Ernst Hartert.

Heft V.

Seite 513-640.

Mit 32 Abbildungen.

$\Rightarrow\left(\begin{array}{l}2 \\ 0\end{array}\right.$

\section{Berlin.}

Verlag von R. Triedländer und Sohn.

Ausgegeben im Februar 1909. 

mitunter kiam lïnger als die 10. Flügel viel stumpfer als hei mannimestrix,

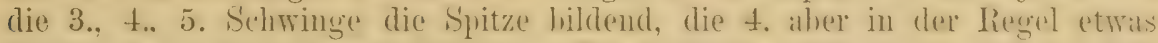

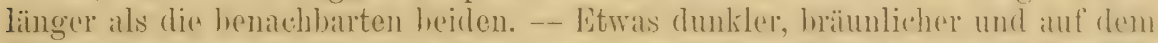

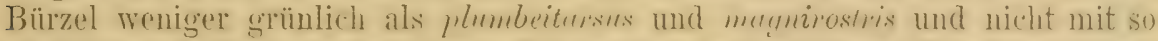
röstlichem Anflug wie tenellipes. Die orolien und mittleren oberflïgelderdien

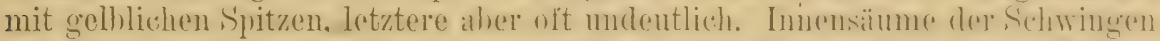

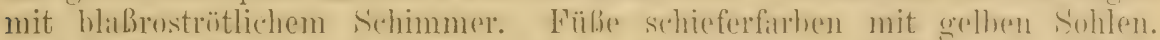

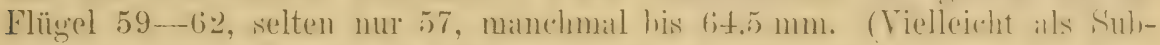
spezies zu der Gruppe von nitidus, viridanus, plumbeitarsus.)

Wurde von Mai bis Juli in Kansu gefunden, muls dort also brïten ebenso im Trin-ling Gebirge. Wahrscheinlich erstreckt sich sein Brutgebiet durch die westchinesischen Gehirge his Tibet und den Himalatai nörllich ron Darjiling. - C̈herrintert in Sikkim. Assam. Bengalen. Birma, nördlich bis zu den Andamanen. Im westlichen Indien scheint er zu fehlen.

\section{- 796. Phylloscopus magnirostris Blyth.}

Phylloscopus magnirostris Blyth, Journ. As. Soc. Bengal XII, p.966 (1813- Calcutta).

1. Schwinge grof. nud hreit, etwa dopuelt so lang wie die Handdechen. Die 2. steht an Länge zwischen der 7. und 8. oder zwischen der 6. und 7.

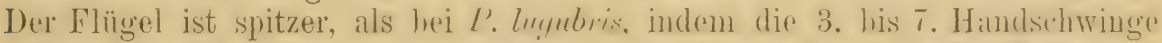

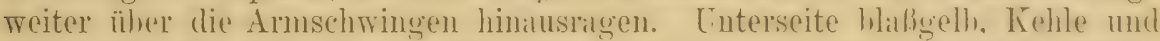

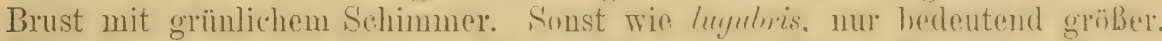
Füße bleigran mit leichtem gelblichen Sehimmer. Flügel $=062-72$ mm.

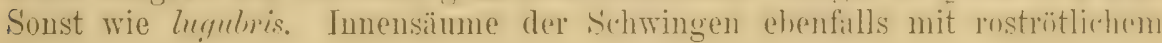
Schimmer.

Angenseheinlich Brutrugel in Kansu, wo Przewalshi Exemplare im Mai und Juli erheutete, sowie im Himalaya his Katschmir. Tergherehumg gut gesimmelter Serien ron den rersehiedenen Brutplitzen nuß zeigen, ub es sich hier un eine oder mehrere F'ormen handelt. - Wrintervogel in Indien östlich vom Punjah, und Rajputana, his Birma, T'enasserim und MalakkiaHalbinsel, südlich bis C'eylon.

Hehrere englische Forscher fanden die Nester in großen Höhen (8500 engl. Fuß u. a.) in Kaschmir an Uferrändern, in Baumlöchern(!?) und an Abhängen. Sie bestehen aus Moos und Farnkrautblättern, mit feinerem Material und Haaren, aber nicht mit Federn ausgefüttert. Die Eier sind kurz oval, manchmal gestreckter, und rein weiß. Sie messen nach Baker (Ibis 1906, p. 260) im Durchschnitt etwa $18 \times 14$, und variieren von 17 bis $19 \times 13.5$ bis $14.8 \mathrm{~mm}$.

\section{Phylloscopus bonelli bonelli (Vieill.).}

Berglaubsänger, Berglaubvogel.

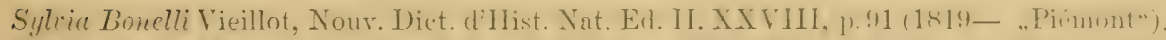

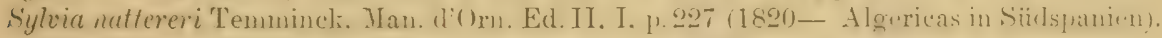
Sylvia albicans Baldenstein, Neue Alpina, II, p. 87 (1827-- Graubïndten).

Phyllopneuste montana Brehm, Handb. Naturg. Vög. Deutschl. p. 429 (1831- 'lirol).

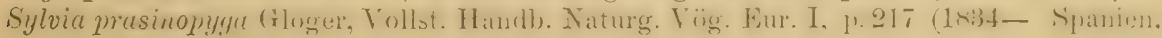
Alpen u, a.).

Phyllopneuste alpestris Brehm, Vogelfang, p. 332 (1855- "Vorberge der Schweiz").

Engl.: Bonelli's Warbler. - Eranzös.: Pouillot Bonelli. -- Ital.: Lui bianeo.

E. Hartert, Die Vögel der paliaarktischen Region. 
1. Schwinge ungefiihr $1 \%$ em über die Handdechen limansragend. 2. Sehwinge in der Regel zwisehen der 6. und 7.0 ansmahmsweise liam so lang wie die 7. oder etwas lïnger als die 6. Die 3.. 4.. und 5. sind etwa

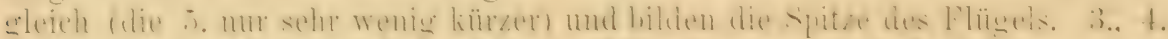

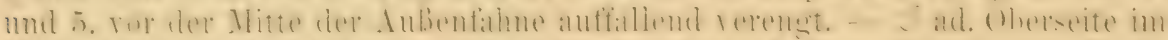

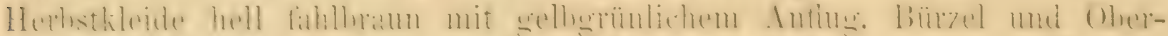

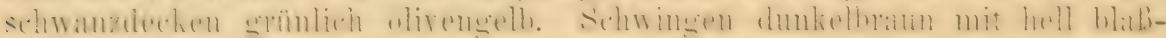
bräunlichen Spitzen- und Innensäumen und grünlichgelben. an deu Arm-

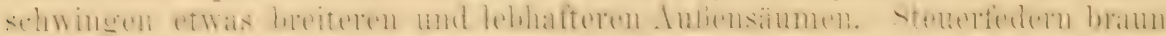

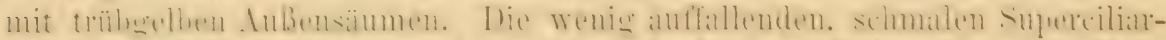

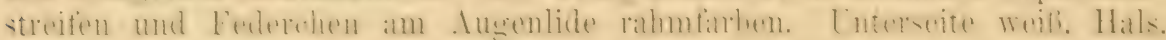

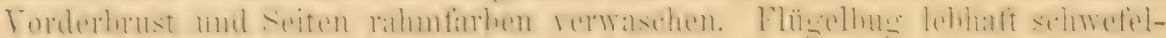

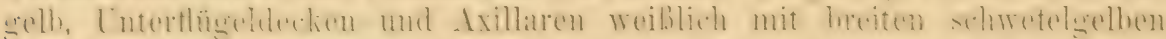

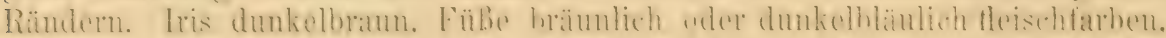

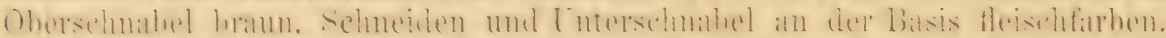

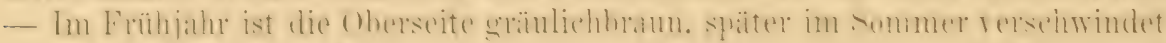
der grünlichgelbe Anflug noch mehr und bleibt nur noeh anf Bürzel und

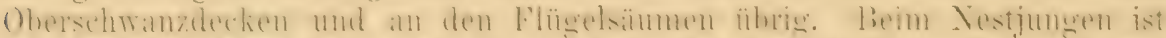

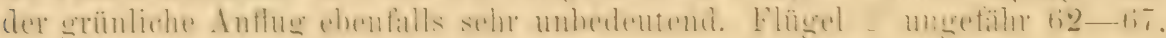
o $57-62$ mu. o wie ô, nul kleiner.

Bewohnt zux Brutzeit die Bero- und Ḧ̈gelländer Mlittel- und Süd-

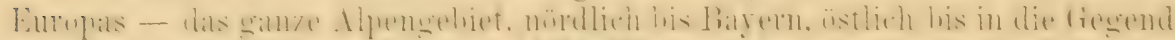

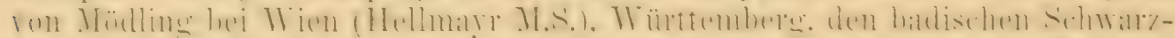

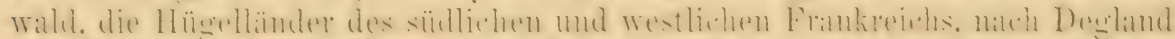

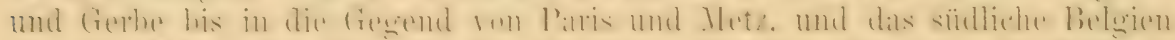

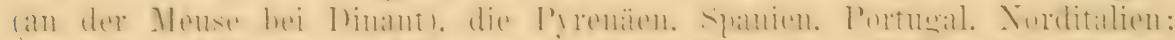

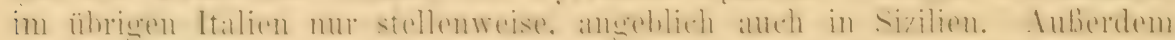
in den bergigen und woldigen Teilen ron 'Tunis, Algier und Marokko, in

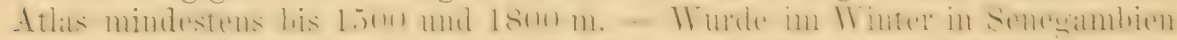
gefunden, übermintert aber vermutlich sehon im Süden der Atlaslïncler.

Bewohner ron lichten Wäklern. Gesang ein kurzes unmelodisches S'chwirren, ron dem des Waldlaubrogels ( $P$. sibilatrix) merklich verschieden, kïrzer, schmeller und schwächer. auch fehlen ihm die den (Fesang des letzteren fast immer einleitenden piepsenden Laute. Burg und andere Schweizer beschreiben auberdem einen nur im Frihijahr gehörten klangrollen, aus gleichlantenden, wie hüi oder tii klingenden Silben bestehenden Gesang. Sicher hört man diesen Gesang im Juli im Engaclin, wo P. bonelli sehr häufig ist, nicht, sondern nur das Schwirren. Lockrul etwas höher und feiner, als der des Waldlaubrogels. Nest auf dem Hrdboden oder niedrig ïber demselben zwisehen Ptianzenstengeln und Steingeröll. Wie das des Waldlaubrogels, ohne Federn. Eier 5-6, Mai und Juni. Maße ron 19 Eiem (10 ron Rey, 9 ron Jourdain gemessen) im 1)urchschnitt $14.9 \times 12$. Mlaximum $15.9 \times 11.9$ und $15 \times 12.6$. Minimum $14.1<12.2$ und $14.8 \times 11.2$. Mittleres Gewieht ron 10 Eiern nach Rey $69 \mathrm{mg}$. In der Färbung gleichen sie oft den etras größeren Eiern von $P$. sibilatrix, oft sind die Zeichnungen brämlicher.

\subsection{Phylloscopus bonelli orientalis (Brehm).}

?? Curuca platystoma Hemprich \& Ehrenberg, Symb. Hhys., Aves fol. ce (1833- SinaiHalbinsel. - Die Beschreibung stimmt rortreftlich auf bonelli, nach Reichenow aber ist der Flïgrel ziemlich kurz, wie anch ron $\mathbf{H}$. \& $\mathbf{E}$. angegeben. Nach Reichenow - in litt. - ist der 'lypus ein augenscheinlich durch Spiritus 


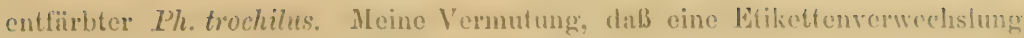
stattgefunden habe, hält li. lïr unbegründet).

Phyllopnenste orientulis Brehm, Vogelfung, ]. 332 (1855- Wadi-Halfa).

Enterschoidet sich von der westlichen form durch lïngere Filiggel, die $6 \pm$ (selten) $-71.5 \mathrm{~mm}$ mossen, wobei die of ron $64-67$, of von 66 bis $71.5 \%$ varioron seheinen. Ich konnto 36 lixemplare in Jondon, Jiver-

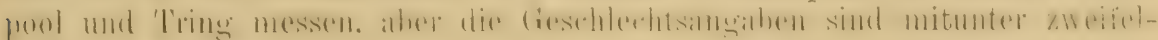
haft oder fehlen gamz.

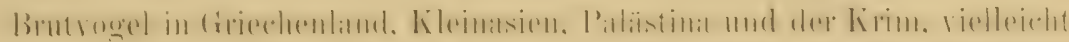
auch atuf Cypern. Wenn die Angabe voun Vorkommen in der Bukowina richtig ist (s. Oru. Jahrb. 1892 p. 201), so dürfte das auch die grobe lín sein. Scheint am Nil zir ühorwintern.

\section{7?). Phylloscopus sibilatrix sibilatrix (lindst.) (Fin. (1:3. 9.4).}

Waldlaubsäinger; Waldlaubvogel, Śchwirrender Laiubsänger.

Motacilla Sibilatrix Bechstein, Naturforscher XXV11, 1).47 (1793- Berge Thiiringens). Sylvia sylvicola MLntagu, 'Truns. Linn. Soe. Loudon IV. 1).35 (1798- Lingland).

Motacilla syleatica 'l'urton, Linn. Gen. Syst. Nat. I, p. 587 (1806- Umbenennung).

Trochilus Major Forster, Syn. Cat. Brit. 13. 1) 15, 5.1 (1817- Als newer Name liir Iseachs Sylvir sylvicola; ohne Beschreibung).

Phyllopnenste megarhynehos Brehm, Handb. Naturg. Vög. Deutschl. p. 425 (1831- in

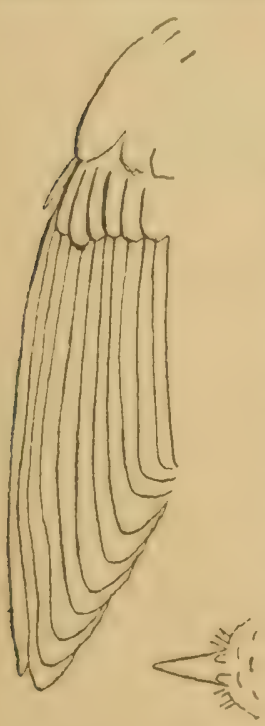

Higur $93(1 / 1)$ Laubhölzern).

Hingl.: Wood-Wren. - Französ.: Pouillot-siffleur. Shlhwed.: Grön Singare. - Ital.: lai verde.

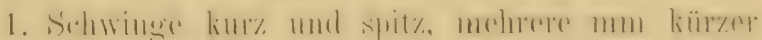
als clie Handdecken, nur selten fast odor ganz so lang wio letztere. ') 3. Schwinge am längsten, 4. ganz wenig kürzer, 2. desgloichon, meist etwas küirer als 4. und immer länger als die 5. AnBenfihnen der 3. und 4. ror der Mitte verengt. Oberseite hellgrün mit gelblichem Schimmer, anf dem Büi\%ol am leblaftesten. Zügolstroif und Fortsetzung desselben hinter dom Auge brïunlich, darïber ein lebhaft schwefelgolber Superciliarstrcil. Flügel und Sohwanz dunkelbritun init gelblichgrïuen tul.jen- und griuwrilien Lmmensïmmen. Kuptseiten schwefelgelb, Unterseite weils, Kehle und Vorderbrust schwefelgelb, ebenso Flïgolbug undSpitzen

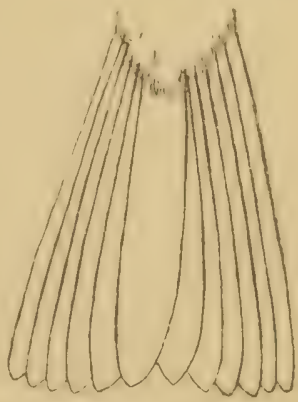

Figur : is $(1 / 2)$.

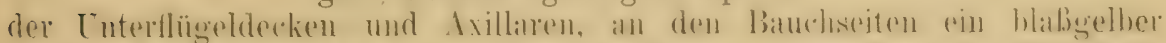

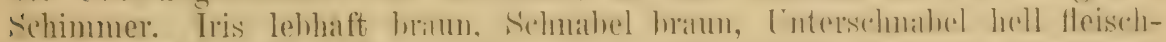

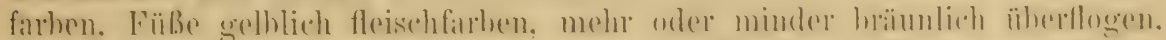

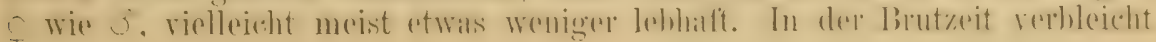

1) In seltenen Ausnahmen $1 \mathrm{~mm}$ lïuger. Ein solehes Stück sandte mil Madarász zur Ansicht und ein gleiches erwähnt Kleinschmidt (Journ. f. Orn. 1903, p.481). 


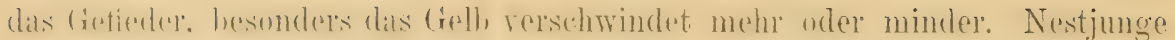

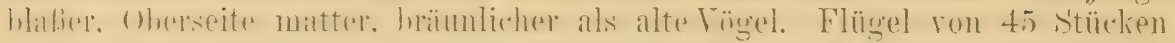

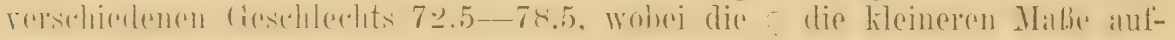
weisen, Schwanz etwa $49-52 \mathrm{~mm}$.

Brutgebiet: Grobbritannien und Irland. Schweden von Upsala südwärts,

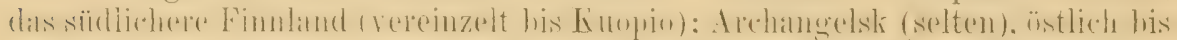
in das Gouvernement Kasan, auf den Vorbergen des Ural. Südwärts über

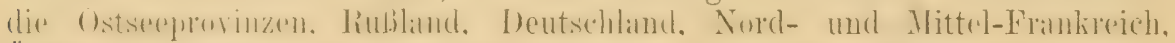

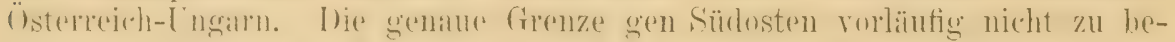
stimmen. Ob die im Kaukasus vermutlich nistende Form hierzu oder zu

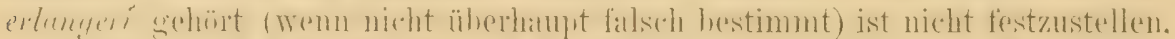

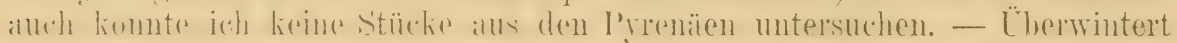
in Afrika, im Westen südwärts bis zum Kongo, im Osten bis Abyssinien und Sïid-Alabien.

Echter Waldbewohner; der vor allem Buchenwälder liebt, aber anch gern in Eichenbeständen, in gemischten und mitunter in reinen Nadelwäldern nistet. Sein Gesang ist ein ron mehreren piepsenden Lauten eingeleitetes Schwirren, wobei er mit Flïgeln und Körper zitternd auf einem Zweige sitzt, dann fliegt er-meistens ab und stößt im schwebenden verlangsamten Hinibergleiten zu einem anderu Baume ein 3-4 maliges sanftes, aber volles pfeifendes djii, djü, djii aus. Man hört dies bisweilen auch allein, oder der Sänger bleibt sitzen und begnügt sich mit dem Schwirren. Lockruf ein flötendes djii, höher als das huid von trochilus. Nester rundlich, wie die der andern Laubsänger, mit kleinem seitlichen Eingangsloch, meist mit sehr viel dürren Blättern, innen weich ausgelegt, manchmal mit Haaren, aber immer ohne Federn. Die 5-7 Eier fundet man ron Mitte Mai bis Mitte Juni. Sie sind auf weißem, mitnuter leicht bläulich oder rötlich angehauchtem Grunde mit tief rotbraunen Flecken dicht bedeckt, teils mit teils ohne violettgraue Schalenflecke; mitunter sind die Flecke fein, punktartig, meist aber groß und länglich, bisweilen Kranzbildung. Durehschnitt von 100 Eiern (67 von Rey. 33 von Jourdain gemessen) $15.87 \times 12.38$, Maximum $18.3 \times 13$ und $17.5 \times 13.5$, Minimum $14.4 \times 12$ und $15.2 \times 11.4 \mathrm{~mm}$. Durchschnittsgewicht nach Rey $72 \mathrm{mg}$.

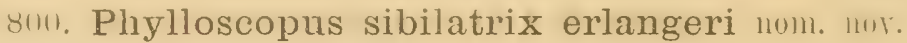

Phylloscopus sibilatrix flavescens (uon Sylvia flavescens Gray, quod syn. Pl. borealis) Èrlanger, Journ. f. Orn. 1899, p. 254, Taf. V, worauf aber Ph. sib. sibilatrix zu bräunlich ist. - Tnnis. V'gl. Journ. f. Orn. 1903, p. 481).

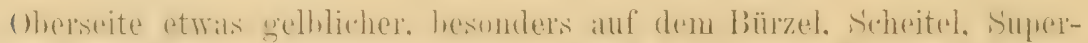

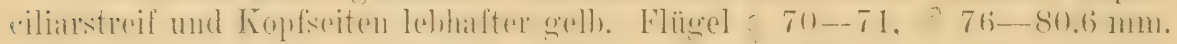
Die o scheinen weniger lebhaft gefärbt und von denen von $P$. s. sibilatrix

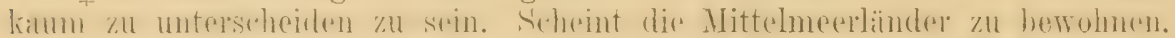

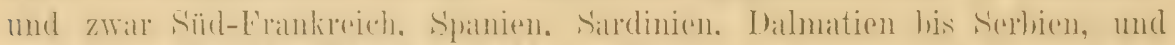

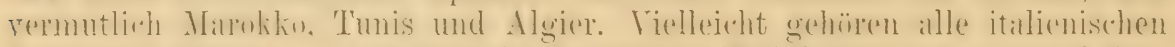

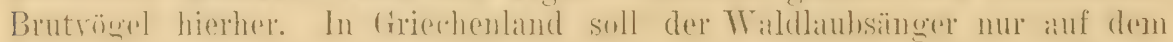
Zuge vorkommen, und zwar sind die dort durchziehenden Vögel Ph. sib.

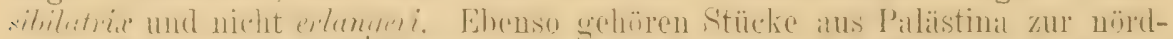
lichen Form, derh will'I'ristran die Art dort anch nistend gefunden haben.

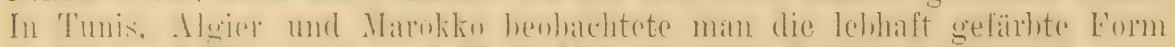

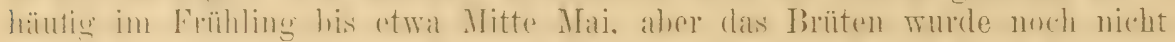

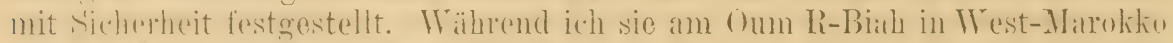

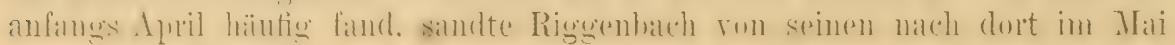


unternommenen Tomen lieine ein, anch Meade-Waldo erwälnt ilner nivht aus dem Atlas. fand sie aher nath mündliden Angahen in den IV äldern des

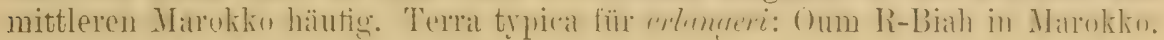

Nester und Eier aus Sïdeuropa gleichen völlig denen der nördlichen Form. Nach meinen von Meade-IValdo und Witherby bestätigten Beobachtungen singt (im April an Oum R-Biah in Marokko) der Vogel anders als im Norden: ich hörte cine flötende, aus den Locktönen ähnlichen Lauten zusammengesetzte Strophe, nicht aber das S'chwirren. Es wäre zu ergründen, ob diese Eigentünlichkeit konstant ist. (Vgl. Aus den IVanderj. e. Naturf., p. 297, 309.)

\section{Phylloseopus borealis borealis (Blik.). (Fig. 95.)}

Phyllopneuste borealis Blasius, Naumannia 1858, p).313 (am Ochotskischen Meer). Phylloscopus sylvicultrix Swinhoe, Ibis 1860, 1). 53 (Amoy in China).

Sylvia flavescens Gray, Proc. Zool. Soc. 1860, p. 349 (Batjau).

Phylloscopus hylebata Swinhoe, Journ. As. Soc. Bengal XXIX, p. 265 (1860- Amoy). ?? Phyllopneuste kennicotti Baird, Trans. Chicago Ac. Sc. I, 1). 313 Tif. XXX Fig. 2 $\left(1869\right.$ - Alaska). $\left.{ }^{1}\right)$

Abbild.: Naumaun, Vögel Deutschl. XII, 'Taf. 375, Fig. 1; Neuer Naumann II, Taf. 7, Fig. 3; Dresser, B. Europe II, Taf. 79.

1. Schwinge sehr klein, spitz, meist otwas kïrzer, seltener ebenso lang;

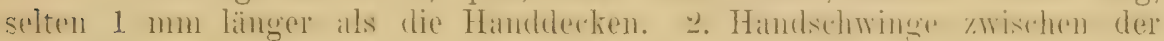

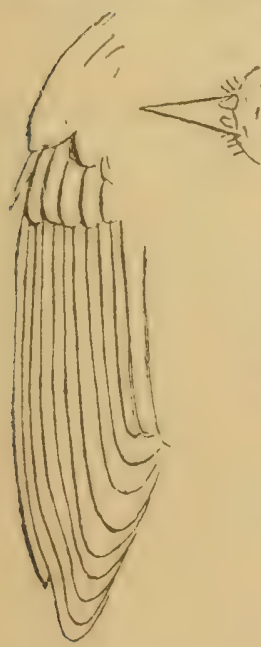

Figur $95(1 / s)$. 5. und 6., mitunter gleich der 6., sehr selten zwischen der: 6. und 7. Die 3. und 4. fast oder ganz gleich und

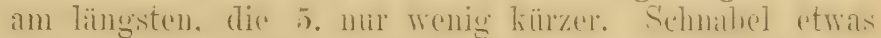
broiter, als bei Ph. collybita und trochilus und die Mundwinkelborsten etwas melu entwickelt. óad. Ganze Oberseite, Zügel und Streif hinterm Auge oliven-grïn, auf dem Bürzel etwas lebhafter. Schringen, Steuerfedern und OberHïgeldecken dunkelbraun, mit der Farbe des Rückens gesäumt; Steuerfedern im frischen Gefieder mit deutlichen weiblichen Säumen an der Spitze und den Innenfabnen; mittlere Oberflügeldecken mit grünlichweißen, große mit gelblichweißen Spitzen, wodurch eine deutliche und eine undentlichere Flïgelbinde entstehen. Unterseite weißlich mit grünlichgrauem Anfluge an Brust und Seiten und außerdem mehr oder minder deutlich blaßgelb überflogen, Unterschwanzdecken etwas gelblicher. Axillaren und Unterflügeldecken blaßgelblich, Inuensäume der Schvingen grauweißlich. Iris braun. Schnabel dunkelbraun, Unterschuabel gelblich, meist mit dunklerer Spitze. Fïße hornbraun. Flügel o $64-70$, soltener bis 72 , o etral $62-65 \mathrm{~mm}$. Schivanz gerade, of o etwa 45-51 mm, Lauf $18.5-21.3 \mathrm{~mm}$. of wie of num meist

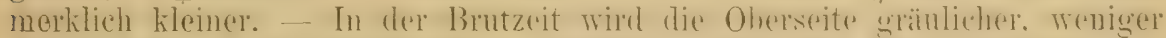

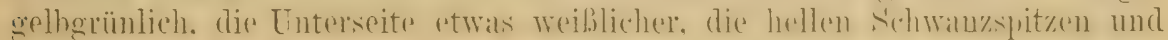

1) Ridgway (B. Middle \& N.-Amer. III, p. 696, 1904) unterscheidet die wie es scheint in geringer Anzahl in Alaska briitende Form als P. b. kennicotti. Sic unterscheidet sich augenscheinlich nur durch geringere Größe: "Flïgel ơ 우 $60-65$, Schwanz $43.5-47.5 \mathrm{~mm}$. 


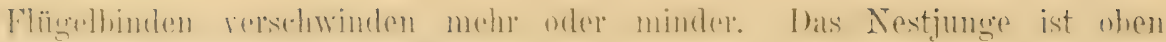
etwas grünlicher, unten gelblich.

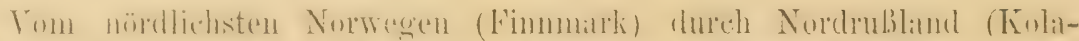

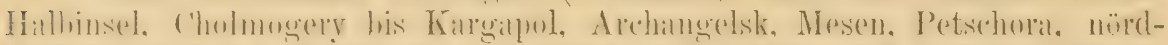
liehste Treile des cionsernements Permo und Sibirien bis Daurien l'Trants-

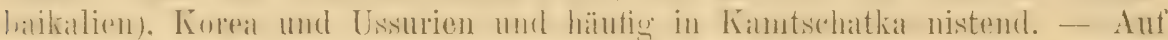

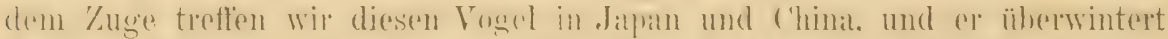

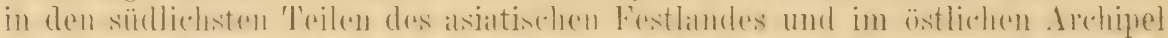

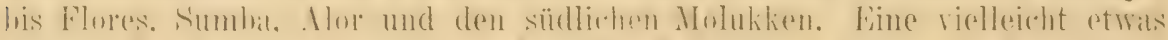

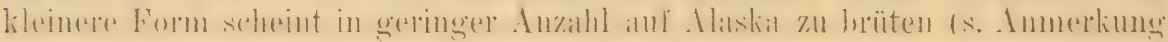
unter der Synonymie).

Bewohnt Gebüsch und Wälder, hält sich gern in den Kronen hoher Bäume auf. Der Lockton ist ein monotones dzit, der Gesang besteht nach Sabanjeff und Dybowsky aus sehnell anfeinanderfolgenden wie tsi tsi tsi tsi klingenden Silben, sodab er also

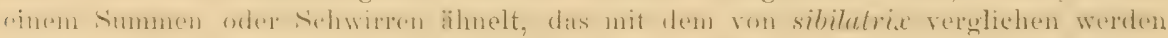
kann, aber lauter ist. J)as Nest steht am Boden im Noose oder dorl. und scheint dem anderer Laubsänger zu gleichen. Federn fand man nieht darin. Die 5--6 Eier fand man im Juni. Sie seher aus wie die von $P$. trochilus, sind aber etwas größer: Maximum (Pleske): $12.5 \times 16$, Durchsehnitt $12.33 \times 15.33$, Ilinimum $12 \times 15 \mathrm{~mm}$.

\section{8(1). Phylloscopus borealis xanthodryas sirinh.}

Phylloscopus :xanthorlvyes Swinhoe, Proc. zool. Soe. Iondon 1863, p. 296 (Amoy).

? Phyllopneuste trinoteria J)avid, Nour. Arch. Mlus. Paris VII, Bull. p. 7 (1870- Mupin); vgl. L'leske. Ornithogr. Ross., p. 169 Anmerkung.

Wie $P$. boreculis horealis, aber Oborseite etwas lebhafter und grünlicher,

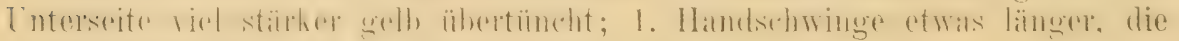
Haudschwingen meist ungefähr 2 mm überragend.

Diese Form scheint P. b. borealis auf den Kurilen, anf Jesso und nach.

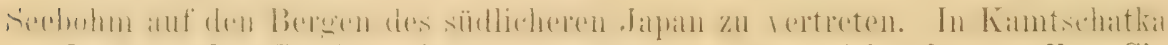
wurclen einzelne Stïcke erbeutet, das Brïton aber nicht festgestellt. Sie zicht im Winter südlicher und wurde in Sïd-China und auf Bormeo erbentet. Die Angaben rom Vorkommen am oberen Chuanche beruhen auf Irtum.

\section{il:i. Plyylloseopus superciliosa superciliosa (lim.).}

Motacilla superciliosu Gmelin, Syst. Nat. I, p.975 (1788- ex Latham, Gen. Syn. II, p. 159 "Russia").

Sylvia bifasciata Gütke, Naumannia 1858, j). 419 (nomen nudum!).

Engl.: Yellow-Browed Warbler.

Abbild.: Niıumann, Vög. Deutsehl. X11I, T'af. 378, Ëig. 1, 2; Dresser, B. Europe Il, 'Taf. 74; Nener Nitumann II, T'af. 5, kig. 2.

1. Schwinge $10-15.5 \mathrm{~mm}$; 2. meist zwisehen der 6. und 7 ., selten zwischen der 7. und 8. Die 3., t. und 5. nahezu gleich und am längsten. - Sad. Oberscite olivengrün, Bürzel und Oberschwanzdecken heller und grïnlicher, Oberkopt dunkler und brïunlicher, in der Scheitelmitte ist

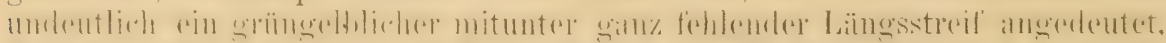

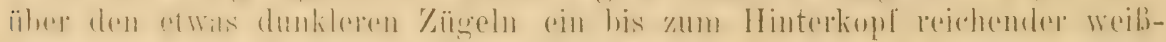

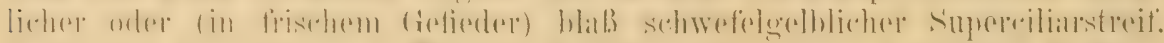

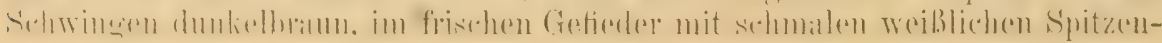




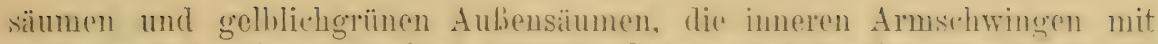

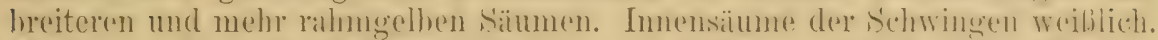

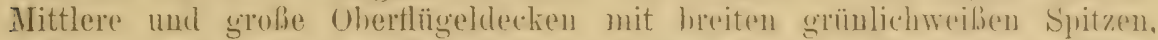
wodurch zwei dentliehe Querhinden gehildet werden. Enterseite weiblich

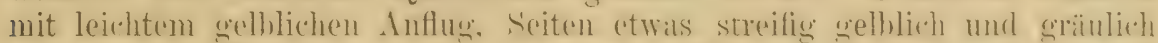

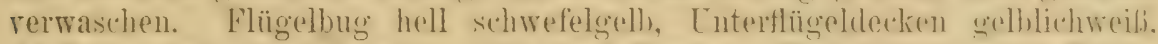

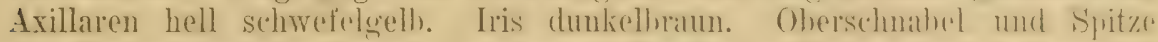

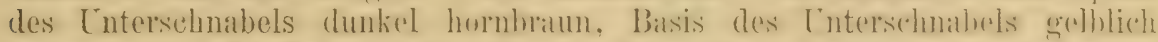

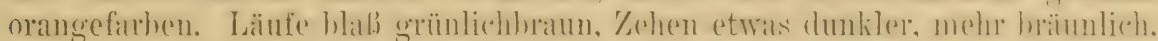
o wie $\delta$, nur etwas kleiner. Erstes Jugendlileid: ()hereate Inäunlicher, dunklerer. Cutersente weiblicher. In Sommer ror der Manser ist die I"nter-

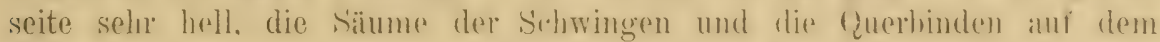
Flügel nutzen sich stark ab. Flügel oे etwa 55-60, ᄋ $51-55 \mathrm{~mm}$. Schwanz, etwa $37-40 \mathrm{~mm}$.

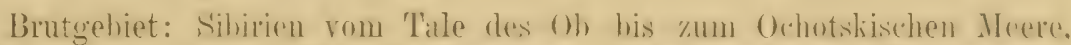
nördlich his fast an die Cfor des Eismeeres (bulun, nahe dor Mündung der

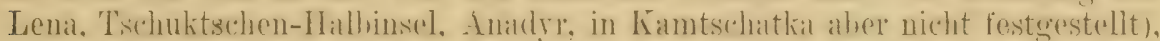
südlich his zum Batialsee. Kultuli. T'ranshabialien. Essurion und nateh

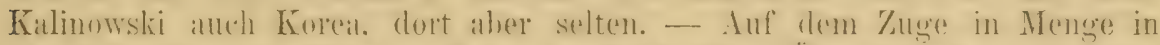
der Mongrolei und Chinat. seltener in Turkestan. Cherwintert in Sïdehina (in Nenge anf Hainan). Pirmal. Issam unnl bengilen, westlirh mindestens bis Muddapux, wo el noch häufig ist. Butlers Angabe vom Vorkommen

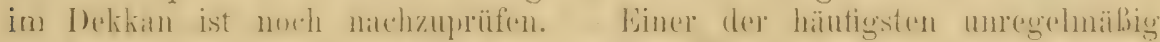

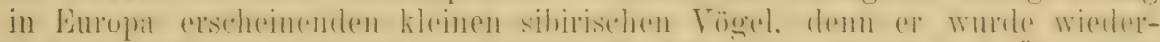

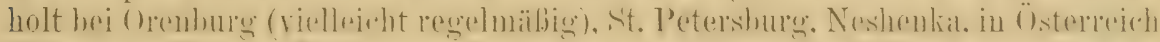

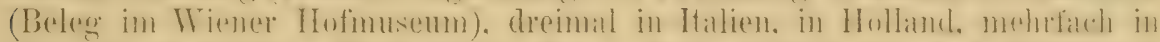

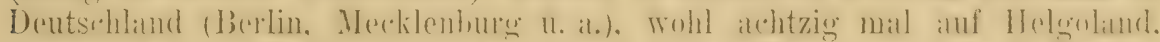

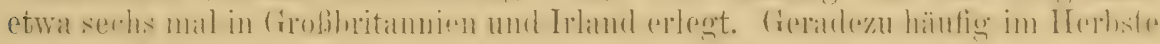
auf der Fail-Insel zwisehen den Orkneys- und Shetlands-Inseln.

Lebt in Wäldern und Buschdickichten. Lockton schrill, langgezogen, etwas an den der gelben Bachstelze erinnernd, etwa wie wiest oder swiet klingend. Gesang nach Godlewski wie die rasch aufeinanderfolgenden Silben filifilifilifili, mit einigen Trillern vermischt. Das Nest gleicht dem anderer Laubänger und ist mit Roh- und Renutierhaaren ausgefüttert. Die Eier sind weil3 mit rotbraunen, kranzförmig um das dicke Ende stehenden Zeichnungen. Als Maße werden angegeben $15.7 \times 11.4$ und $16 \times 12 \mathrm{~mm}$.

\section{1)4. Phylloscopus superciliosa humei (Broulis).}

Abromis temiceps Hodgson, in Gray's Zool. Misc., p. 82 (1844- nomen nudum! Aus den unveröftentlichten Abbildungen im Brit. Mlus. gedeutet).

Reguloides humei Brooks, Stray Feathers VII, p. 131 (1878- „North-West Indiats).

Abbild.: Cat. Birds Brit. Mus. V, 'Taf. IV, Fig. 1. Eier: Cat. Eggs Brit. Mus. IV, Taf. X, Fig. 5,6 .

1. Schwinge variabel wie bei $\ell^{\prime}$. s. superciliosa, aber im allgemeinen etwas lïnger, etwa $13-16 \mathrm{~mm}, 2$. in der Regel zwischen del 7 . und 8 .,

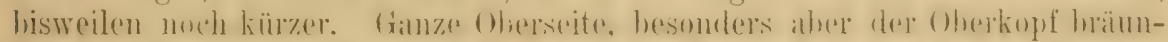

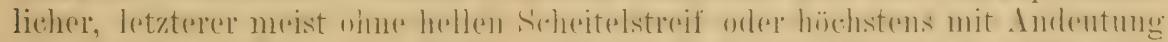

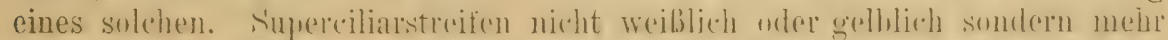

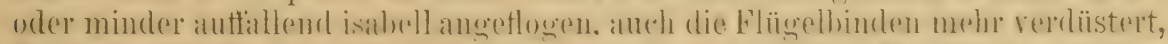

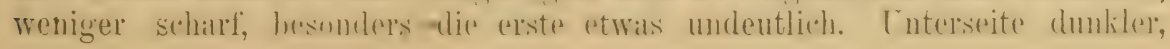


meln trüh gethlichweib mit isahellfarbenem, wit grünlichem Anflug. Sonst wie P.s. superciliosa.

Altai, Thim-thehan ume nordwestlicher Hinnalitya (Käschmir, anseheinend his Nepal, aher nicht mehr Sikkim). - Cherwintert in den Eihenen Indiens ästlich mindestens his Mluddapur, westlich his in den Punjah und dir oistlichen. fruchthatreren 'Teile Rajputanas, südlich his ptwal Belgaum.

Nach Sewertzow im 'Tian-Schan bis 10500 FuB, nach Brooks in Kaschmir in der oberhalb der Nadelholzwälder liegenden Birkenregion, nicht tiefer zu T'al als 8000 engl. Fuß. Lockton ein echtes Laubsänger-artiges "tissjip", klar, scharf, zweisilbig. Nester am Boden, wie die anderer Laubsänger, mit feinen Halmen, MIoos und Haaren ausgefüttert. Die 4 oder 5 Eier sind weiß mit rotbraunen, bald helleren, bald sehr dunklen, spärlichen bis zahlreichen Zeichnungen versehen. Sie stehen in ihrem Aussehen meist zwischen denen von $P$. collybita und denen von $P$. sibilatrix. Maße von 50 Eiern nach Pleske im Durchschnitt $14 \times 11.25$, Iaximum $16 \times 12$, Minimum $13 \times 11 \mathrm{~mm}$.

\section{Phylloscopus superciliosa mandellii (Brookis).}

Reguloides Mandellii Brooks, Stray Feathers VIII, p.389, 481 (1880- Sikkim).

Abbild.: Pleske, Aves Przewalskianae, Taf. II, Fig. 5.

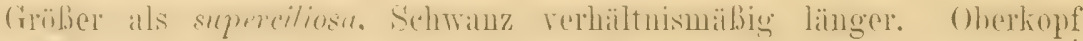

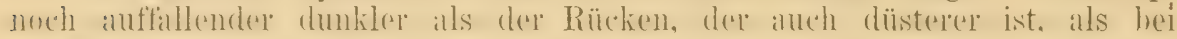

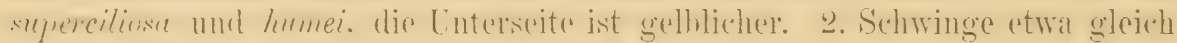
der 9. Flügel of 57-61, o 54-56, Schwanz etwa 45-48, Lauf 18.5-19,

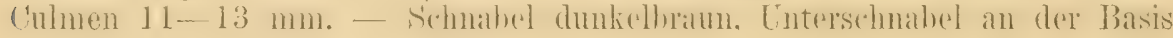
gelblich. Füße hell gelblichbraun.

Am Oberlaufe des Chuanche (Hwang-ho), in Bergwäldern bis über

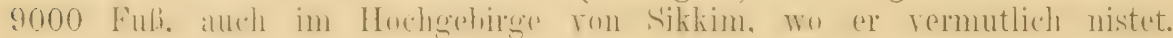
Ferner in den Khasia-Bergen, dort aber wohl nur Wintergast.

\section{Phylloscopus subviridis (Brooks).}

Reguloides subviridis Brooks, Proc. As. Soc. Bengal 1872, p. 148 (Nordwest-Prorinzen Indiens, besonders bei Etawah).

Abbild.: Cat. B. Brit. Mus. V, 'Taf. IV, Fig. 2.

1. Schwinge ungefähr doppelt so lang wie die Handdecken, $11-15$ mm lang. 2. meist zwischen der 8. und 9., selten zwischen der 7. und 8 . oder zivischen der 9. und 10. Die 3., 4. und 5. nahezu gleich und am

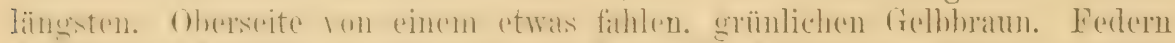

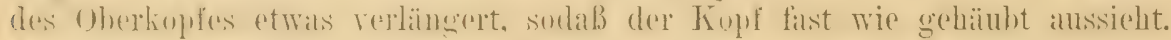

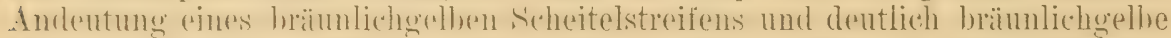

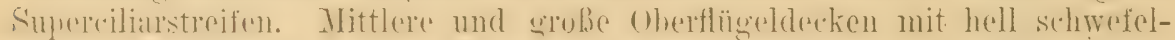

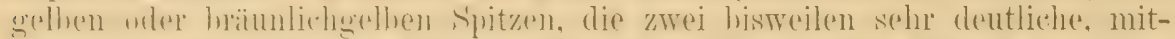

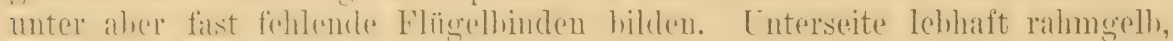
Mitte des Luterkörpers remer blaßgell. Śeiten mit bräunlichem Anflug.

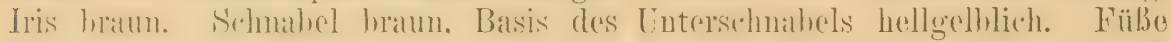
hellbraun. Flügel etwa 58-60, o kleiner, etwa 54-56 mm.

Brïtet in Afghinistm (Hariah) Tal), im nordwestlichen Himalaya, in Gilgit, Kaschmir his Kumam, und ïherwintert in den Nordwest-Prorinzen 
Indiens und im Punjah. Ein verirtes Exemplar wurde am 5. September 1882 von Sarudny bei Oremburg erbeutet (I'leske, Ornithogr. Rossical. 1). 293).

Hält sich in Kaschmir in Höhen von $10000 \mathrm{FuB}$ und höher auf und hat einen scharfen, klaren wie tissjip klingenden Lockton, der aus zwei Silben besteht, von denen die zweite merklich steigt. Junge Vögel wurden im August erlegt.

847. Phylloscopus occipitalis coronata (Temm. i Schleg.).

Ficedula coronata 'Temminck \& Schlegel, in Siebold's Fauna Japonica, Aves, p. 48 Taf. 18 (1847- Japan).

Abbild. der Eier: Journ. f. Orn. 1873, Taf. I, Fig. 9.

An del Schnabelbasis ziemlich starke Borsten. 1. Sehwinge kurz, lanzettlich, etwa ;-; mm länger. als die Handechen, 2. zwischen der 6. und 7., gleich der 7. oder sogar etwas kïrzer, 3., 4., 5. fast gleich lang und am lïngsten, AuBenfahnen der 3.. 4., 5., merklich, die der 6. haum rerengt. - $\delta$ ad. Oberseite mattgrïn mit gräulichem Anflug, auf Büızel und

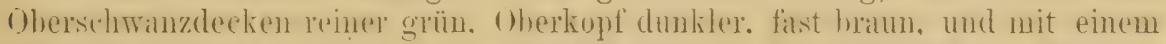

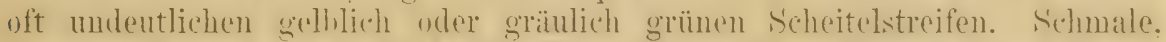
aber seharf hegrenzte golhlichweilie Supereiliastreifen. Spitzen der mittleren

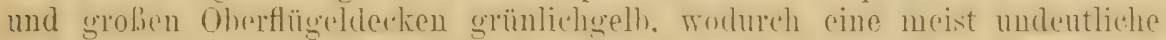

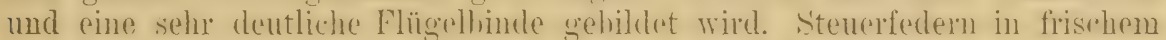
Getieder mit schmalen Weilibhen Syitzen und Innensïmmen. Unterseite

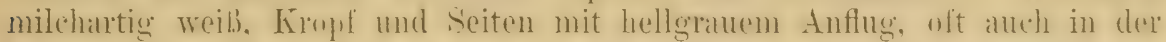

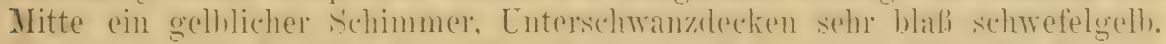

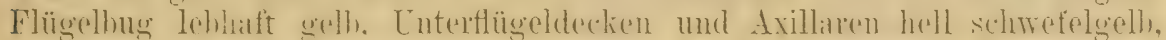

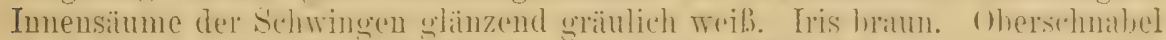

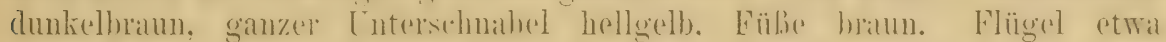
60-64 mm. Culmen 13.5-14, Lauf 17-19.5. Sehwanz etwa 46.5-50 mm.

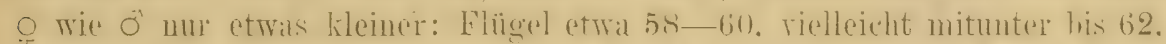
weun das Geschlecht der gemesenen Stärke richtig lustimmt war. Nestjunge wie alte Tägal. nur auf der ()herseite hämulicher. Cuterseite matt weib. In der Brutzeit nutzen sich die hellen Schwanzitzen, somie die Flïgelbinden stark ab.

Nistet in Ostsibirien (['smri-Land mit der Insel Aslobl his ins sïdliche

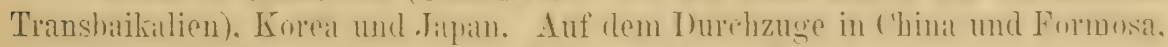
überwintert in Pegu, Tenasserim, Manipur, Java, Malakka.

Nach Pleske legt der Vogel bis 7 weiße Eier. Im Katalog der Eier in British Iuseum (IV, p. 227) sind ebenfalls zwei reinweiße Eier von Hondo (Japan) beschrieben.

\section{Phylloscopus occipitalis occipitalis (Blyth).}

Hippolais swainsoni Hodgson, in Gray's Zool. Misc., p. 82 no. 385 (1844- nomen nudum! Aus den unveröffentlichten Abbildungen Hodgson's gedeutet).

Phyllopnereste occipitaiis Blyth, Journ. As. Soc. Bengal XIV, p. 593 (1845- "Southern India"; ex Jerdon MS.).

Sylvia validirostris Gray, Handlist B. I, p. 216 no. 3064 (1869- ex Jerdon MS., nomen nudum!).

Abbild.: Pleske, Orn. Rossica, T'raf. II, Fig. 6, 7.

Cuterscheidet sich ron roromete durch gleichfirmige Lnterseite. die im frischen Gefieder blabgelb, im Sommerkleide weiblich ist (hei l'. roromuta 
stehon die wethen T'ntersehwanzdecken in Kontrast zu der weiblichen Ĺnter-

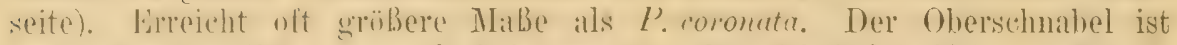

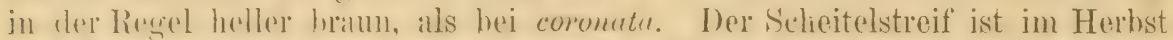
und II inter gelblich. im Sommer mehr weiblich. I) de durch die Spitzen der

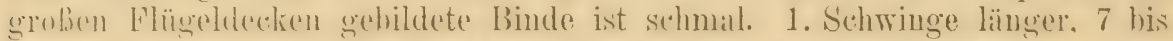
9 mm lïngar als die Ilamderlien. Die 2. Sehwinge ist öfter zwischen der 7. 'und 8. Flügel $0^{7}$ ㅇ $61-67$, mitunter $69 \mathrm{~mm}$.

Briitet in 'Turkestan, iu Kanchmil und dem nordwestlichsten Himalaya

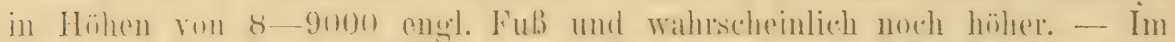
Winter in Indien. rom Himalaya his etwa ledgamm und Nellore. von Sind

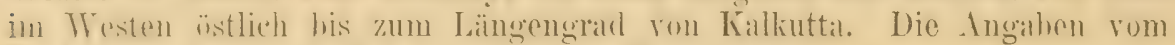
Vorkommen weiter östlich hedïrfen der Bestïtignug.

Die Nester stehen weniger offen als die anderer Laubsänger, in der Regel in Löchern, unter dem Wurzelwerk alter Bäume, in morschen Baumstämmen, in Spalten oder in Steinwällen. Das Nest besteht aus Hoos, feinen Gräsern und dergl. und ist mit Haaren, Wolle und Federn ausgefïttert. Da vom Mai bis Juli Eier gefunden wurden, nimmt man an, daß zwei Bruten gemacht werden. Die 4 bis 5 Eier sind rein weiß, ohne Zeichnung. Die Maße von 15 Eiern sind nach Pleske durchschnittlich $17 \times 13$, im Maximum $17.5 \times 14$, Hinimum $16 \times 12.5 \mathrm{~m}$.

\section{Phylloscopus trochiloides (Sunder.).}

Acanthiza trochiloides Sundevall, Physiogr. Sällskap. Tidskr. I (1838); Übers. in Ann. \& Mag. Nat. Hist. X VII, p. 25 (18.16- Calcutta).

Plyyllopneuste reguloilles Blyth, Journ. As. Soc, Bengal XI, p. 19 I (1842- ohne genaue Lokalititsangabe, wahrscheinlich Calcutta).

Phylloscopus niridipemis Blyth, op. cit. XXIV, p. 275 (1855- 'Tenasserim).

Phylloscopus flavo-olicaceus Hume, Stray Feathers V, p. 504 (1877- ohne genaue Lokulitït).

1. Sehwinge wohl entwickelt, breiter, fast doppelt so lang als die Handschwingen; 2. zwischen der 8. und 9. oder 9. und 10., bisweilen sogar

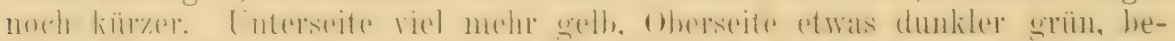

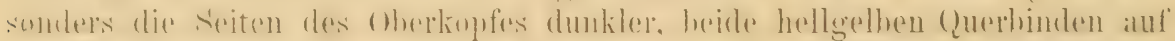

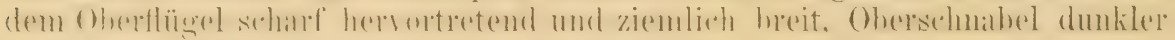
braun, im übrigen wie occipitalis, aber lileiner. Flügel etwa $57-63 \mathrm{~mm}$.

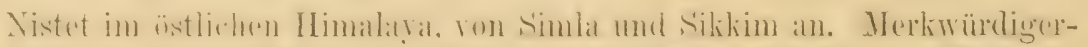

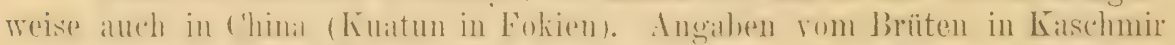

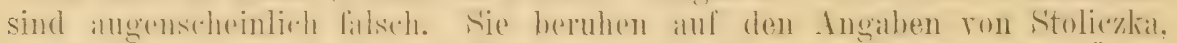

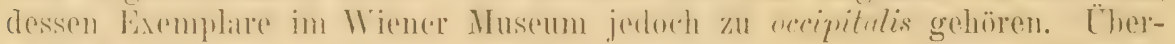
wintert in lichgallen. rtwal rom 87. Iängenglad an, his Assam, Birmah, Tenasserim, sowie in Süd-China. - Vielleicht Subspecies von occipitalis.

Im Ibis 1899 p. 264 sind eingehende Nitteilungen iiber Lebensweise und Nest und Eier aus Fokien gegeben. Die Eier sind weils ohne Flecke.

\section{Phylloscopus ijimae (Stejn.).}

Acantiopneuste ijimae Stejneger, Proc. U. S. Nat. MIus. XV, p.372 (1892- "Seven Islands (of Idzu), Japan").

Ähnlich coronatus, aber der Oberkopf wie der Rücken, ohne helleren

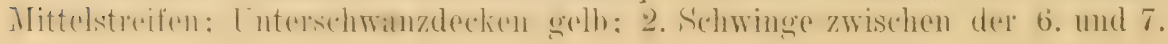




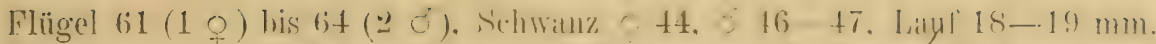

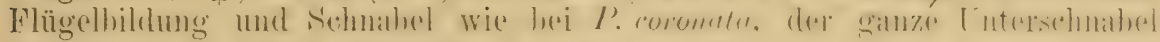
also hellgelb. (Nach Stejneger, 1. c. und in litt.)

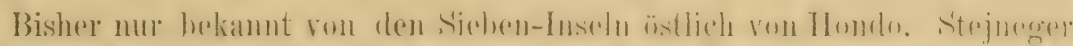

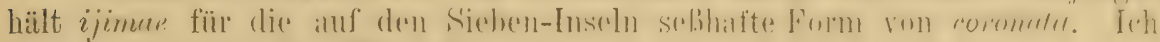
kounte keine Stïcke untersuchen.

\section{Phylloscopus proregulus proregulus (l'ill.).}

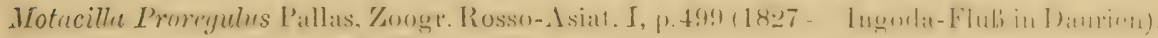
Regulus modestus Gould, B. Europe I1, p. 149 (1837- Dalmatien).

Abrornis chloronopus (jedenfalls Druckfehler für chloronotus) Hodgson, in Gray's Zool. Mise. p. 82 no. 839 (1814 - nomen nudum! Partim! Nur aus den unveröfientlichten Abbildungen zu denten. Hodgson vermengte danach proregulus und maculipennis).

Phylloscopus Pallasii Dubois, Ois. Europe, 2. Série, I p.83 (1868-- partin! Descr. nulla).

Abbild.: Gould, B. Europe II, Taf. 149; Dresser, B. Europe IX, 'laf. 650, Hig. I

Ei : Journ. f. Orn. 1873, Taf. I. Fig. 10.

1. Schwinge ungefähr doppelt so lang wie die Handdecken, 2. meist

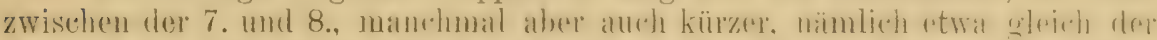
9. - Ot ad. Oberseite lebhaft olivengrün, Spitzen der Federn des Unter-

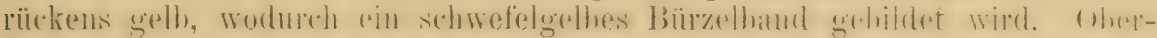

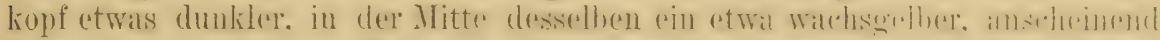

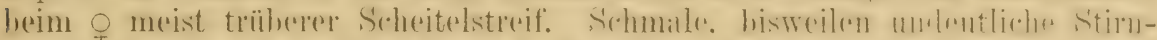

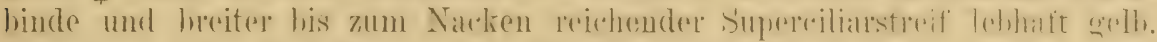

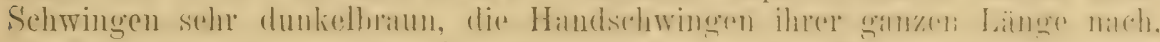
die Armschwingen zul etwa \%: ihrer Länge (an der Basis nielıt) mit gelb-

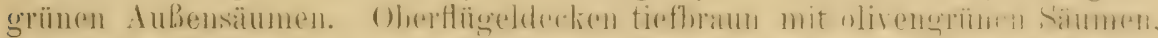

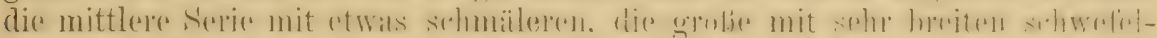

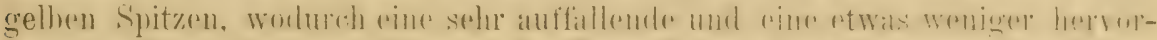

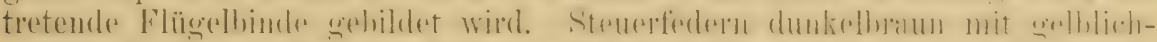

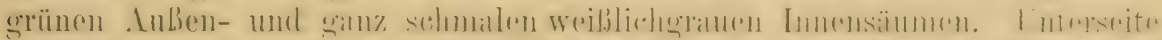

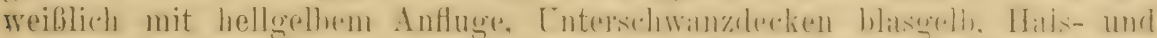

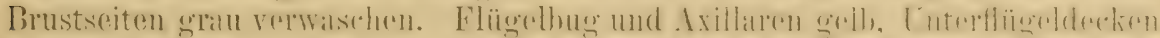

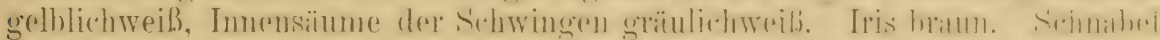

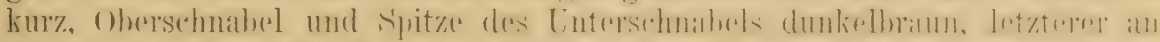

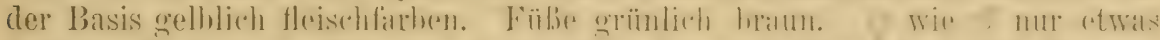

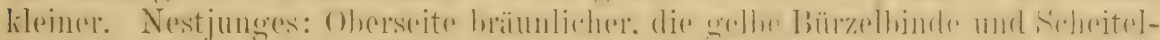

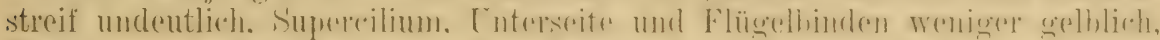

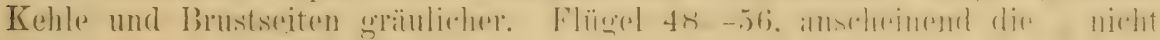
über 50 , o meist $52-56 \mathrm{~mm}$.

Brütet in Ostsibirien vou der Lena bis zum Ufer des Stillen Ozeans,

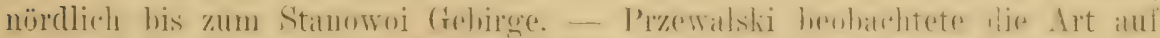

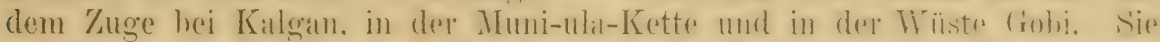

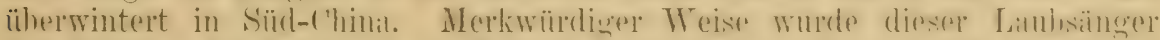

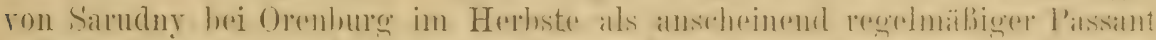

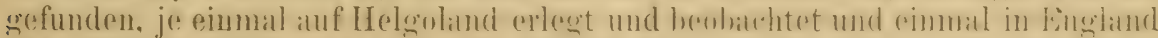

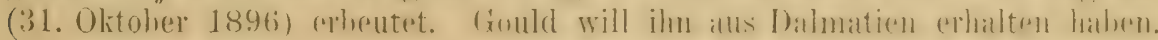

Lebt in W:ildern. Lockstimme nach Brooks fein. goldhähnchenartig. Gesang nach 1) Jbowski laut, melodisch, mannigfaltig und angenélnm. (? Der Gesang ron P.p. newotoni 
wird anders beschrieben). Nester wie die anderer Laubsänger, mit seitlichem Eingangsloch, aber auf Baumästen, mehrere Mleter über dem Boden. Sie sind innen mit Federn und Haaren ausgelegt. Eier 5-6, weiß mit braunroten Fleckeu und einigen bläulichgrauen Schalenflecken. Sie messen von $14 \times 11$ und $14.2 \times 11$ bis $15 \times 10.5 \mathrm{~mm}$.

\section{\$1\%. Phylloscopus proregulus newtoni Gätle.}

Phylloscopus newtoni Gätke, Ibis 1889, p. 579 (Indien).

Ist Ph. p. proregulus äuBerst ähnlich, unterscheidet sich aber dureh

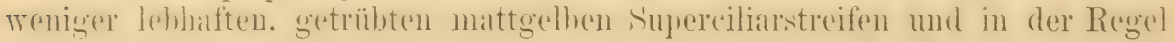

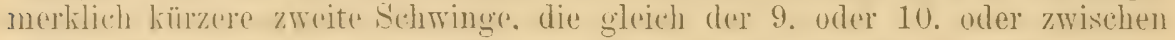

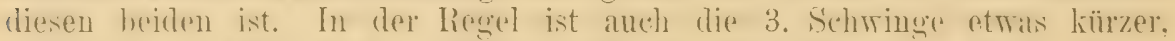

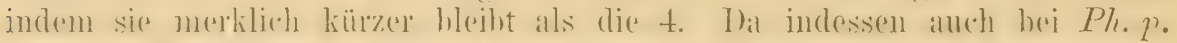

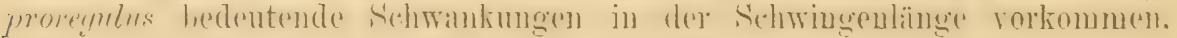
sind einzelne Stiicke mitunter kaum zu bestimmen.

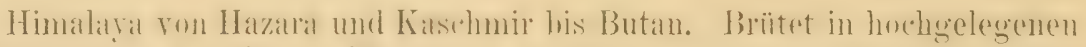
Nadelwäldern und gabt im Winter in niedrigere Latgen. somie nach Assam (Khasia- und Nagi-Berge), Manipur und Tenasserim.

Lockstimme nach Brooks fein, goldhähnchenartig. Gesang nach. Kaptain Cock schwach, dem ron sibilatrix ähnlich(?). Fortpflanzung wie die von P.p.proregulus.

\section{Phylloscopus maculipennis (Blyth).}

Abrornis maculipennis Blyth, Ibis 1867, p. 27 (Nepal oder Sikkim).

ర̄ 0 ad. Oberkopf und Streif durch das Auge olivenbraun, Scheitel-

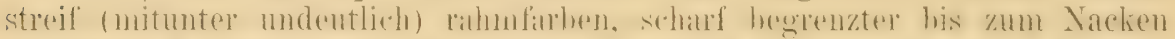

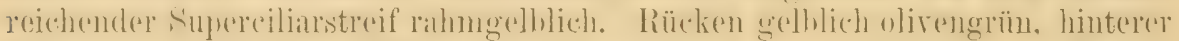

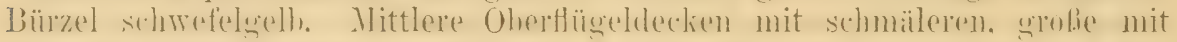

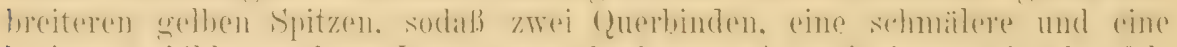

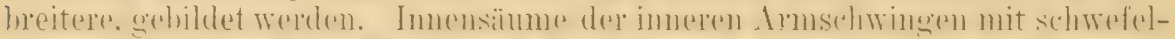

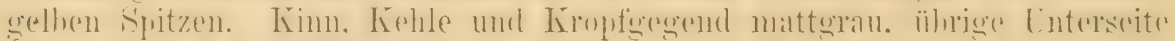

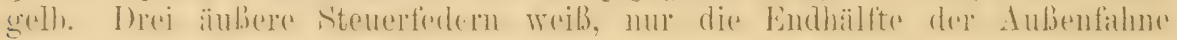

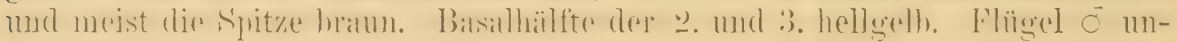
gefähr 58-62, ㅇ etra 55-57 $\mathrm{mm}$.

Himalaya von Butan bis zum Sutlej Flusse.

Brütet in der alpinen Zone und begibt sich im Winter in die niedrigeren Berge. Lockruf ein oft wiederholtes dem der Goldhähnchen ähnelndes Schirpen. (Brooks.)

\section{1t. Phylloscopus pulcher Blyth.}

Abromis evochroa und pulchrala Hodgson, in Gray's Zool. MLisc., p) 82 (1844-- Nomina nuda!).

Phylloscopus pulcher Blyth (ex Hodgson II. S.) Journ. As. Soc. Bengal XIV, p. 592 (1845- Nepal).

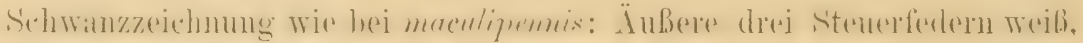

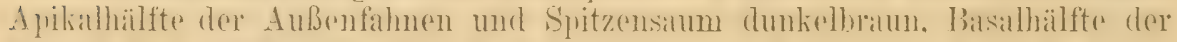

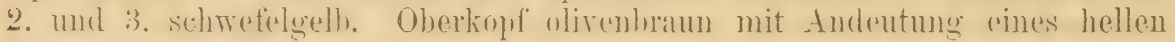
Srhestelstreifens: ähroge Oherseite olivengrün, die unteren Bür\%elfedern mit hellgelblichen Spritzen. Wudureh ein helles Bürzelband gebiletet wirel. Super- 


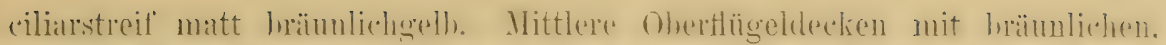

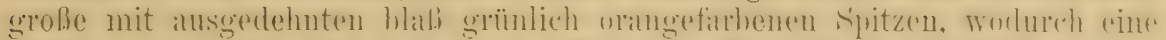

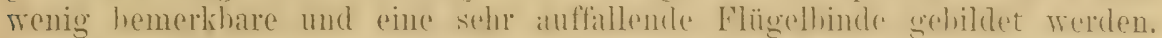

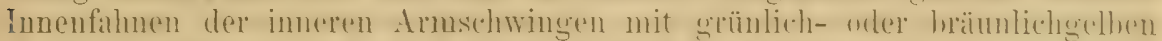

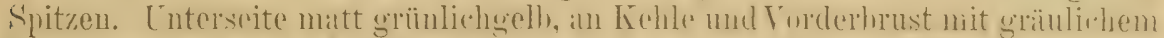

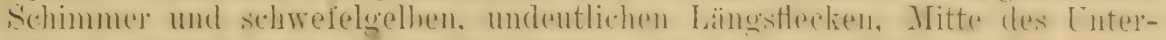
lïrpers schwetelgedh. Interflügeldechen und Axilbaren hlabgelh. Flügelrand

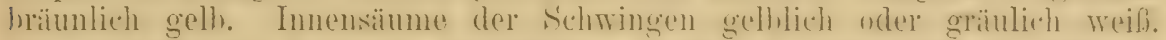

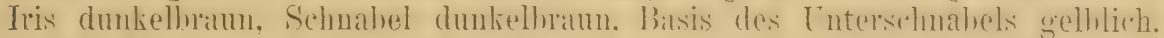

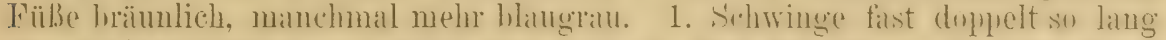

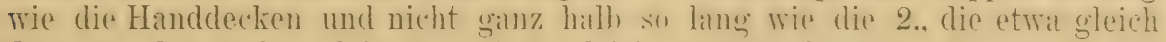
der 10. oder 9. ist. Die 4. und 5. gleich und am längsten, 6. und 3. nur umbedeutend kürzer. Flügel ठे etwa $60-61$, o $54-57 \mathrm{~mm}$.

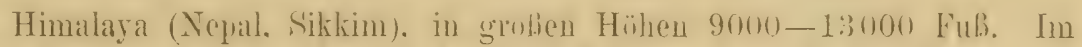
Winter mehr in needrigen Latgen, 4-7000 Fub. - Aueh in den Nagia- und Khasia-Pergen, in Manipur. Birmah. T'masserim. Schau-Staten (Loisampa 5500 FuB), aber vermutlich in diesen Gegenden nur im Winter.

Stimme nach Brooks ein schirpender Laut.

\section{-815. Phylloscopus affinis ('lick.).}

Motacilla Offinis (augenscheinlich Druckfehler für affinis) Tickell, Journ. As. Soc. Bengal II, p.57h (1833- „Jungles of Borabhúm and Dholbúm").

Abrom xanthogaster Hodgson, Gray's Zool. Misc., p. 82 (1844- Tomen nudum!).

Phyllopneuste flaveolus Gray, Cat. Mlamm. B. Nepal, p. 152 (1816- Nomen nudum!).

Abbild.: Pleske, W'iss. Res. Przewalskis Reisen, Zool. II, Vögel, p. 115, 'Taf. III Fig. ō.

3. bis 6. Schwinge an der Außenfahne verengt. ' 1 . Schwinge $4 \mathrm{~mm}$ liürer als die Hälfte der 2. his halh so lang wir letrtere. 2. sleich der 9., 10, oder selten 11., oder zwischen diesen stehend. Die 4. und 5. bilden die Flügelspitze, die 3 . und 6 . aher sind nur sehr unbedentend kürzer. - - a ad. Oherseite olivenfirhen. Aubensïume der Schwingen und Bürzel rtwas mehr grïnlich. Zügel und Fleck hinter dem Auge dunkler, ein schmalep gelher superoiliarstreif -rou der Sinnhelhasis his zum Nacken. Luterseite grelh. Forderhust und Seiten olirengelb remasehen. Flügehand und EnterHügeldecken hlil. schwefelgelh, Axillaten schmutziggelh. Inmensämme der

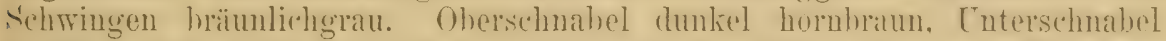
weißlich oder gelhlich hornfarhen, selten an der Spitze haum. Fülie hornbraun. wie $\sigma^{2}$, aber kleiner. Flïgel o etwa $56-62.5$, o $53-57 \mathrm{~mm}$.

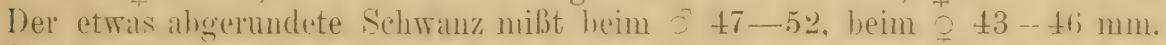
In ahgetragenen Brutgefiedur when wtwas fihler. unten etwas hasser. Nestlileid nach Pleske oben hrïunlicher. Unterseite weniger gleichü̈ligg gefürht.

Berrobut den Himalaya von Kaschnir im Westen, ëstlich dureh das

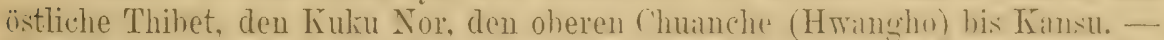
l̈berwintert in Indien. südlich bis zu den P'alni-lBergen. fehlt aher in den Norwest-Prorinzen, dem Punjah. Raljuntania und den mestlichen Teilen CentralIndiens.

Nistet in Kaschmir in Höhen über 10000 engl. Fuß in niedrigem Busch aus Wachholder, Lonicera, Rhododendren u. dergl. Hat einen lauten einsilbigen Lockton. 
Nester etwa einen Fuß über dem Boden in Büschen, wie die andrer Laubsänger, innen mit Federn ausgelegt. Eier in der Regel 4; ein diesem Vogel zugeschriebenes Gelege von Kiuku Nor enthält 7, doch wäre es möglich, daß diese aus zwei Nestern stammen, da dic Angaben des Sammlers ungenau sind. Die Eier mehrerer Gelegesind rein weiß, die anderer teils rein weiß, teils spärlich rostrot geflekt, wieder anderer durchweg geflekt. Eier rom Kuku Nor gleichen spärlich geflekten Eier von P. trochilus. Sie messen $14.9-15 \times 11.8-12.1 \mathrm{~mm}$. Hier aus Kaschmir messen von $15.6 \times 12.5$ bis 14.5 $\times 11.8$, acht Stück im Durehschnitt etwa $15.5 \times 12 \mathrm{~mm}$. (Vgl. Nov. Zool. 1894, p. 671, Ibis 1906, p. 258, 338).

\section{- 816. Phylloscopus subaffinis (Grant).}

Oreopneuste affinis David et Oustalet (nou L'. affinis ['Tick] 1833) Ois. Chine, p. 267 (187T- MIupin \& Szetschwani).

Oreopneuste subaffinis Grant, Bull. B. O. Club X, p. 37 (Januar 1900- Pu-an-ting, S. IV. Kweichu).

Oreopneuste davidi Berezowski \& Bianchi (non Swinhoe ef. sub P. armandii), Ann. Mus. St. Petersburg V, p. 211 (1900- Szetschwan).

Orcopneuste bianchii Sharpe, Zool. Record (!) XXXVIJ, Ares p. 54 (1901); Handlist IV, p. 214.

Unterseite ron einem filhlen Rostgelb. in der Nitte gelblicher, an den

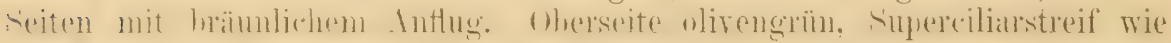

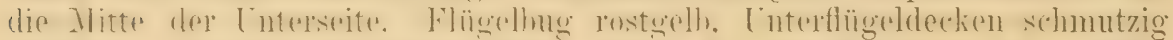

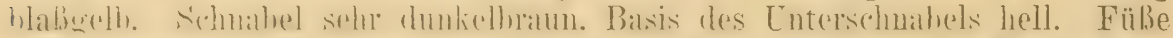

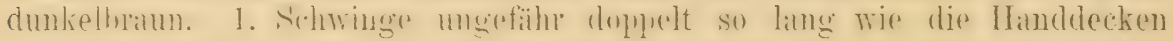
und etwa halb so lang wie dic 2., welche gleich der 9. oder noch kürzer ist. Die 4. und 5. gleich lang und am längsten, 3. und 6. nur sehr wenig kiüzer. 3.-6. an der Außenfahme verengt. Flügel $\delta^{\pi}$ etwa $50-54$. o 48 bis 50, Schwanz etwa 45- 48 , Lauf 19-21. Culmen $12-12.5 \mathrm{~mm}$. Vielleicht Subspecies ron utfinis. (Kuatun).

Westchinesische Gehirge ron Mupin und Szetsehwan bis Fokien

\section{Phylloscopus armandii (Milne-Edw.).}

Abromis Armundii Jlilne-Edwards, Nouv. Arch. Jus., Bull. I, p.22. Taf. 2 Fig. 1 (1865genauer Fundort fehlt; Nord-China, ef. Ois. Chine, p. 265).

Oreopnenste davidii Swinhoe, Proc. Zool. Soc. London 1871, p. 355 (irrtümlich statt. armandii).

Abbild.: Pleske, Ares Przewalskianae, 'T'af. III. Fig. 2; Ei: 'I'af. V, Fig. 10.

3 o ad. 1. Schwinge etwa doppelt so lang als die Handdecken und lath so lang wio die 2.. Welche meist zwisehen der 4. mud 10. steht. manchmal anch einer dieser letzteren gloicht. Die 4. und 5. sind etra gleich

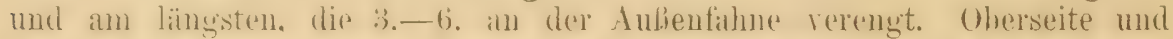
Streif durehs Auge loram, Bürzel und Oberschwanzdecken mit griunlichem Anfluge. Breite, deutliche. arelhlichweife, hinter den Ange weiblicher werdende Supereiliarstreifeu. Ohrdecken bram mit gelhlicher Fleckung. Wangen und Halsseiten fahlhlab zimtbräunlich. Schwing(rnsïmme heller als die oberseite. Kehle schuntrigwejb. Krojtgegend. Brust- und Bauchseiten hrïmlich übertüncht, Nitte ron Brust und Tnterkörper sehwefelgelh, mehr oder minder, hesonders im allgetragenen Brutgetieder, streifig erseheiuend. Enterschwanz- 


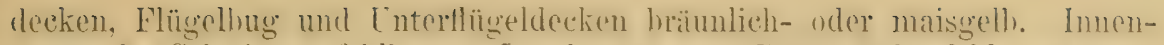
säume der Schwingen fihlhraun. Im abgetragenen Brutgetieder fahler, weuiger

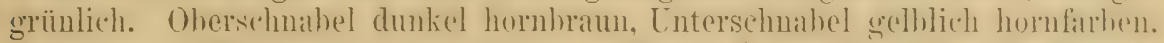

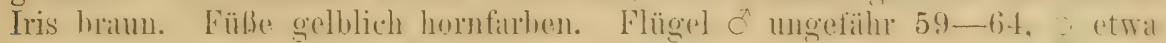
50-56, Schwanz oे ungefähr 56-59, ㅇ 48-52, Lauf 19-22.5, Culmen

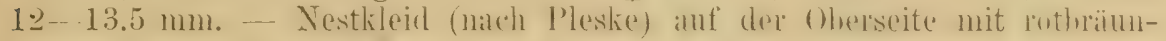
lichem 'Ton, auf der Unterseite stark mit Grau untermischt.

Brïtet in den Gebirgen der Mongolei und Nordehinas, im Nuni-ulaGebirge, am oberen Laufe des Chuancho und in Kansu.

Bewohnt zur Brutzeit die dichten Gebiische an Fluß- und Bachufern, bis in Höhen von 9000 Fuß (Przewalski) und Laubwälder in der Nähe Hießender Gewässer. Am 18. Juni 1880 fand Przewalski das Nest etwa $11 / 2 \mathrm{~m}$ über dem Boden in einem Berberitzenstrauche. Es war kugelförmig mit seitlichem Eingangsloche, aus Grasstengeln bestehend, inmen mit Federn von Phasianus stranchi ausgefüttert. Die 5 Eier sind weiß mit nicht sehr zahlreichen lehmfarbenen Flecken. Sie messen im Durchschnitt $12.9 \times 15.9$, Maximum $13 \times 16$, Minimum $12.5 \times 15.5 \mathrm{~mm}$.

\section{-818. Phylloscopus indica (Jerd.).}

Sylvia indica Jerdon, Madras Jourual L. S. XI, p.6 (1840- Indien).

Phylloscopus giriseolus Blyth, Jouru. As. Soe. Bengal XVI, p. 443 (1847- Am Ufer des Hugli bei Calcutta).

Phyllopneuste obscura Sewertzow, 'l'urkest. Jevotn. (in Izr. Obshch. Moskov. VIII, 2), 1. 124 (1873- Turkestan.); Übers. in Madarász, Zeitschr. ges. Orn. IV, p. 67.

Abbild.: Pleske, Wiss. Res. Reis. Przewalski, Aves 'T'af. II, 3. Eier: Ibis 1903, Taf. X, Hig. 14-16.

1. Sehwinge breit und lang, etwa gleich der Hälfte der 2. oder etwas kürzer. 4. und 5. am lïngstem. 3. und 6. aher nur sehr wenig kïrzer, 3.-6. an der Aulsenfahne verenet. - o ad. Oherseite einfarhig grambram, auf dem Bürzel etwas bräunlicher. Zügrel und deren Fontsetzung hinter dem Auge dunkler, darïher cin zitronengelher, nach hinten zu etwits heller werdender, scharf hegrenzter schmaler Sunereiliarstreif. Flügel und Schwanz erdbran. mit der Farbe der Oherseita gesäumt. Stenerfedern mit sehr schmalen weißlichgrauen Endsäumen. Luterscite wachsgell, Mitte des Lnterkïrper's mehr zitroneugelh. Vorderbust und seiten bräunlich verwischen. Lntersehwanzdecken bräunlich rahmfarthen. Unterflügeldecken und Axillaren blab fahlbrïunlich. Oberschmahel hornbram, Untersehnihel gelhlich, spitzewärts hräunlich. Iris braun. Füle brälunlichgelb. c wir aher etwas kleiner. Jur. und Nestlileid wie beim alten Vogel. Flügel c etra $62-66$, etwa 58-60 mm. Der ein ganz klein wenig algeruulete Schwanz etra 48.5 his 52. Tauf 19-21 mm. Im alggenutaten Brutkleide auf der Oherseite dunkler, gräulicher.

Brutvogel in Afghanistan, Turkestan. Buchara, nördlich his zum Altai, und in Kaschmir.

Kareeff fand das Nest in einer Höle von $6500 \mathrm{FuB}$, einen Fuß über den Boden, in einer mit hohem Gras und Büsehen bedeckten Gegend in einem Nesselgebüsch. Es war mit weichen Federn ausgefüttert und enthielt 3 Eier, die weiß sind mit braunroten Punkten. (Dresser, Ibis 1903, p. 404.) 


\section{- 819. Phylloscopus fuscata (Blyth). (Fig. 96, 97.)}

Phyllopneuste fuscata Blyth, Journ. As. Soc. Bengal XI, p. 113 (1812- bei Calcutta). Horomis fulviventris Hodgson, Proc. Zool. Soc. Loudon 1845, p. 31 (vermutlich Nepal). Phylloscopus brumeus Blytl, Journ. As. Soc. Bengal XIV,- p. 591 (1845- Arracan). Sylvia Sibirica Middendorff, Sibir. Reise, Wirbelth., p. 180, Taf, XVI, 4-6 (1853Stanowoj-Gebirge, auch Sajan).

Abbild.: Pleske, Wiss. Reis. Przewalskis, Ares 'Taf. II, 4. Ei : Journ. f. Orn. 1873, 'Taf. I, 6.

1. Schwinge ganz oder fast so lang wie die Hälfte der 2. Die 4. am längsten, die 5. oft kaum, die 3. etwas kürzer. Die 2. zwischen der 8. und 9. oder 9. und 10., selten so lang oder kaum so lang wie letztere.

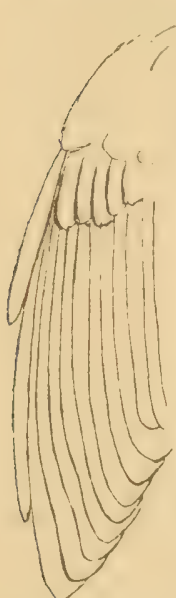

Figur $96(1 / 1)$. 3.-5. an der Außenfahne verengt. Oad. Oberseite braun, auf dem Bürzel mit etwas röstlichem Sehimmer. Zügel und Strich hinterm Auge dunkler, darïber ein rahmfarbener, vor dem Auge blasserer, hinter demsellen mehr röstlicher Superciliarstreif. Flügel und Schwanz dunkler braun, mit der Farbe des Rückens gesäumt. Unterseite rahmfiurben, in der Mitte der Kehle und des Unterkörpers fast weiß, auf dem Kropfe, an den Seiten und Unterschwanzdecken stark mit röstlichem Braun verwaschen. Imnensïume der Schwingen grauweißlich mit rötlich-rahmfarbenem Schimmer. Im Sommer, nach der Brutzeit, oben gräulicher, frisch vermausert lebhafter, brïunlicher. Nestkleid: Oberseite etwas lichter, rötlicher, Unterseite mehr gelbbräunlich. kleiner, sonst wie 0 .

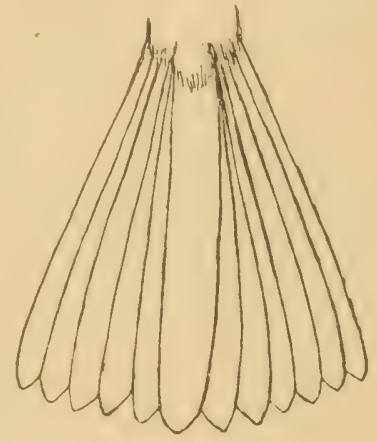

Figur $07(1 / 1)$.

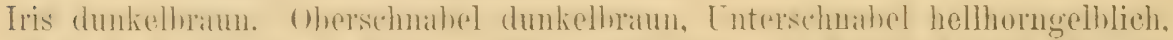

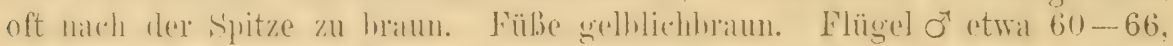

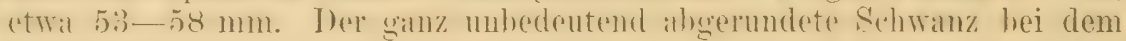
ơ 53-58, beim o etwa $48-50 \mathrm{~mm}$, I a auf $20-22$, Culmen $12-13.5 \mathrm{~mm}$.

Bewohnt das südliche und mittlere Sibirien vom .Jenissei ostwärts bis an die Ufer des Ochotskischen Meeres. An der Lena fand Hall ihn noch oberhalb von Jakutsk. - Auf dem Zuge kommt er in China, Japan und

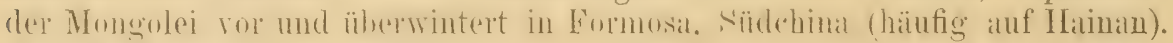
Assam. Birmah, T'matserim. Indien westlich his in die Gegend ron Fitawah.

Lebt in buschreichem Gelände nach Art anderer Laubsänger, hält sich aber mehr in niedrigem Gesträuch auf als jene. Der Lokton ist nicht so flötend wie bei unseren Laubsängern, sondern mehr schnalzend. Das Nest steht entweder am Boden oder einen halben Meter ïber demselben. Es ist nach der Art anderer Laubsänger gebaut und innen mit Federn ausgelegt. Anfangs Juni 5-6 rein weiße Eier, die von $15.3 \times 12.5$ bis $18 \times 12.5 \mathrm{~mm}$ variieren (Pleske).

\section{- 820. Phylloscopus homeyeri (Dyb.).}

Phyllopmenste Homeyeri Dybowski, Bull. Soc. Zool. France 1883, p. 358 (Kamtschatka).

In der Färbung wie P. juscata aber die Oberseite etwas dunkler, ohne

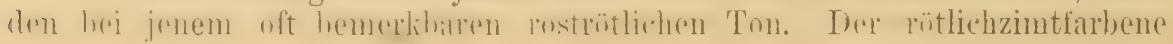




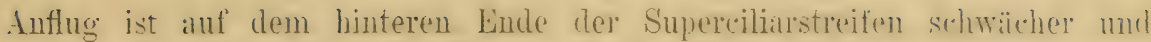
wird an den Halsseiten, der Brust und den Brustseiten rou einem hräunlicheren Ton verdrängt. Der Schmabel ist viel schwäther und Hatch der Basis zu viel weniger breit. Oherschuahel hormbatun, mit holleren fiantun. Unterschublel bis auf eine dunklere Linie längs der Firste gelhlich. Flügel ơ 62.5, O 56.5. Schmanz ơ 54, o 49.5, Culmen ò 12, o $11 \mathrm{~mm}$. (Nach Pleske, Ornithog'r. Rossica p. 409 , mit Abbildung. Ieh konnte dir Art nicht untersuchen. TVahrscheinlich Subspezies von fuscata.) erbeutet.

Die heiden eimzigen bekannten Stücke wurten bei Tigil in Kamtschatkil

\section{Phylloscopus fuligiventer (Hodgs.).}

Horonis ?fuligiventer (von späteren Autoren in fuliginiventer, was grammatikalisch richtig wäre, und fuliginiventvis, je nach ('eschmack, verbessert) Hodgson, Proc. Zool. Soc. Loudon 1845, p.31 (Nepal, worin aber Hodgson augenscheinlich auch Sikkim mit einbegriff).

ơ oad. Oberseite tief dunlel olivenbrann. Schwanz und Flügel noch etras dunkler, mit der Farhe des Rürkens gesämmt. Schmaler Superciliarstreif und schmaler Ring mu das Auge hellhaun. Kopfseiten bram und rahmfarben gemischt. Lnterseite olivenbram, heim so dunkler. heim o heller und melı mit gelhlichgrünem 'Ton. Nitte des Cnterköruers und Kehle heller. fast mäumlichgelh. Schnahel dunkelbram, Basis des Enterschuabels hell. Iris braun, Füße braun. Flügel 54-57, Schwanz etwa 43-47, Lauf etwa 21-22, Culmen 12-13 mm. - (1) diese Art in lie Gittung Phylloseopm. grehört. kömnte angezweifult werien. Seehohm stellte sie mit anderen hier

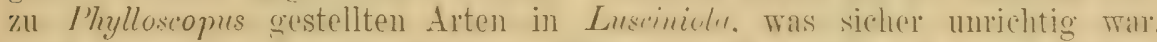
piner der größten Gattungssplittrer. Eugene Oates, hachte sio ohue Bedenken zu Phylloscopus im engeren Sinne, Sharpe zu Oreopneuste, eine von mir nicht ahgetrenute Gattumg. Das fefieder ist sehr woich, atuch der etwas al)gerundete zwölffedrige Schwanz ist ziemlich meich. 1. Shwinge etwa gleich der Hälfte der 2.. 2. gleich der 9. oder 10. Flïgel sehr wenig spitz. indem die Spitze nur 6-9 mm über die mittleren Armschwingen hinauslast. Dir 3., 4., 5. sind etrva gleich lang und am längsten.

Wurde in Nepal und Sikkim, in letzterem in Höhen ron 14000 engl. Ful.) gefunden. Scheint int Winter teilmeise iu niedrigere Lagen zu gehen und hommt dann am Fulje des ästlichen Himalara, sowie in Assam am Brahmaputra (Sadiya) und Dibru (Rungagora) vor:

\section{Gattung HERBIVOCULA Swinhor 1871.}

H. schwarzi steht den Laubsängern sehr nahe, aber der kurze, dlicke. stämmige Sehuahel, die starken Inundwinkelborsten und starlen Lïufe mit kräftigeren Zehen dürften zu generischer Sonderung berechtigen. 1. Sehwinge hreit und lang. etwa doprelt so lang als die Handdectien. fast molel ganz. balh so lang wie die 2., Welche in der Regel zwischen der 7 . und 8. ocher 8. und 9. steht. Dic 4 . ist am längsten. die 5. fast odur retwat so lang. die 3. nur wenig küzer. S'chwauz etwas gerundet, die äulieren Steuerfedern etwa 3 bis $4 \mathrm{~mm}$ hürzes. Die Läufe sind rorn mit dentlich getrennten großen Śbildern bedecht, die nur bei sehr alten Tögelu so gut wie rerschwinden. - Scheint wie die Laubsänger (Phylloscopus) nur eimmal im Jahre zu marisern.

E. Hartert, Die Vügel der parliaarktischen Fauna. 


\section{Herbivocula schwarzi (Radde). (Fig. 98.)}

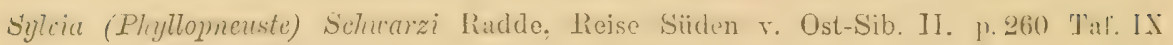
(1863- Tarei-Nor und Bureja-Gebirge).

Arundinax flemingi Swinhoe, Proc. Zool. Soc. London 1870, p. 440 (Tientsin). Phylloscopus Brooksi Hume, Stray Feathers II, p. 505 (1874- Tenasserim). Herbivacula incerta Darid \& Oustalet, Ois. Chine, p. 246 (1877- Peking).

Abbild.: Pleske, Ornithogr. Rossica, Taf. IU, 1, 2; Ibis 1899, T'af. I.

Uadd. ()herseite (im frischen Herbstileide) gelhlich nlirenhratun, Bürzel und Uberschwanzdecken mit rostlarbenem Anflug. Flügel und Schwanz bram.

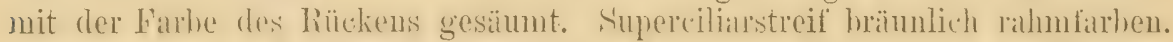
rägel und dessen Furtsetzumg hinter dem Ange hrüunlich rahmfarhen, Wangen und Ohrdecken hiam mit hellen Shehalthinion. Unterseite weiblich mit gelhbratunem Anflige, Geiten stark. Torderhrust schwächer brann verwaschen,

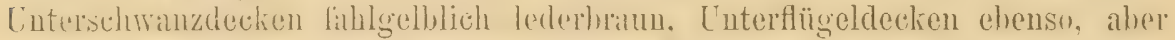
noch etwas heller, immere sehwingensïmme fihl ockerfaben. Iris sepiabram.

Oberschnabel licht hornbraun, Unter-
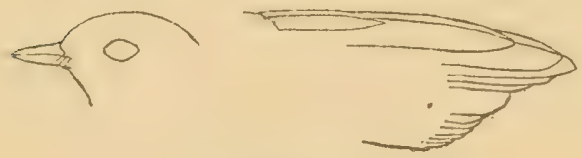
schmabel fahlgelb. Füße und Beine yolblich fleischfarben. In der Brutzeit wird die Oberseite mohr graubraun, der Superciliarstreif blasser,

Figur $98(\% / 3)$. fahler, die Unterseite weiß mit schwachem bräunlichgelben Anflug; der an der Vorderl)rust atwas, an den Seiten viel intensiver ist. Unterschwanzdecken fuhl ockerfarhen. Der junge Togel jm arsten Herhste ähnelt dem

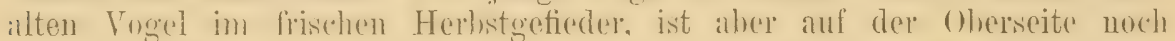

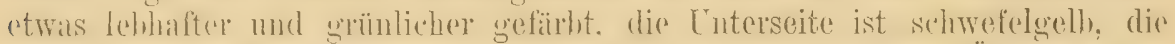
Vorderhrust mit sehwahem Anflug. Seiten mit dunklem Üherzug von gelblichem Lederbraum, o wie $\sigma^{\top}$, nur kleiner. Flügel $0^{\top} 61-65$, ᄋ etwa 56 bis 58, Lauf 21-22, Culmen 12-13, Schwanz 52-60 mm.

Ostsibirien, von Kultuk am Südende des Baikalsees durch 'Trans-

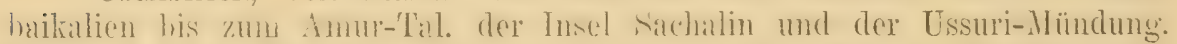

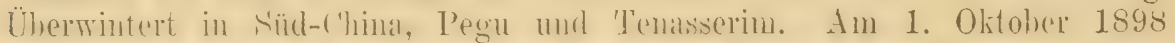

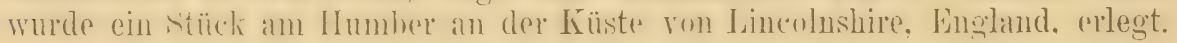

Kommt erst Ende Mai an seinen Brutplätzen an, die er im September wieder verläßt. Nistet in dichten Laubwäldern, das Nest wurde aber augenscheinlich noch nicht gefunden.

\section{Gattmong HOR PITES Hodgs. 1845.}

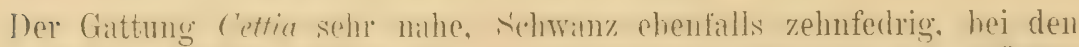
meisten Arten verhiltnismäbig länger. Struerfectern schmäler, die äuberen

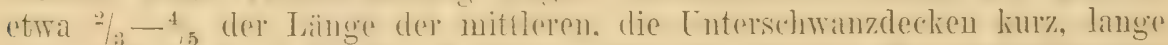

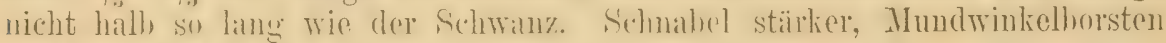

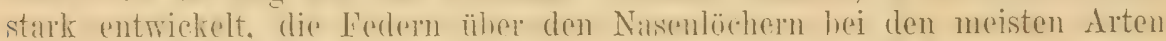

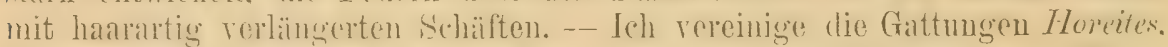

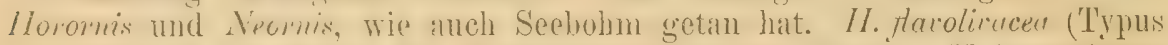

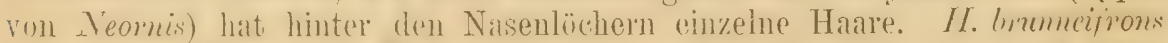
(Typus ron /loreiles) hat rinen etwas mehr sestulten Sehwanz und lipine 
haarartig verlängerten Federn hinter den Nasenlïrhern: cliese haurartigen Verlüngerungen sind aher auch hei $I I$. jortipu's und lmunescens: angedeutet und oft nieht leicht zu hemerken. eine generische Trennung auf Grund dieser Nerkmale ist daher lediglich eine umötige lirschwerung des Studiums. derselben. Alle drei Namen wurden 1845 gegehen, Horrites zuerst. - Nester meist oben offen, einige ïherwilht. Eier etwal wie dir von Cittiu. Mansern nur einmal (im Herbste).

1 f Größer: Schwanz über $60 \mathrm{~mm}$. . . . . . . . H. cantuns, 4 Subsp. . p. 531

Kleiner: Schwanz unter $60 \mathrm{~mm}$. . . . . . . . . . 2

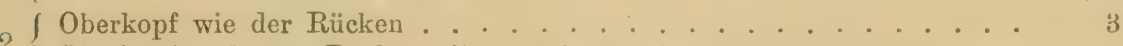

I Oberkopf rotbraun, Rïcken oliven- oder rostbraun . . . . . . . 4

Unterseite grünlich, Seiten mit schwachem olivenbräunlichen Antlug
H. flavolivacea flavolivacea. p. p33

$3\left\{\begin{array}{r}\text { Unterseite rahmgelblich, Seiten deutlich olivenbraun verwaschen a } \\ \text { H. flavolivacea intricatus . p. } 533\end{array}\right.$

Unterseite rahmgelb, Seiten blaßgelblich, ohne jeden olivenfarbenen Anflug. . . . . . . . . . H. acanthizoides, 2 Subsp. . p. 534

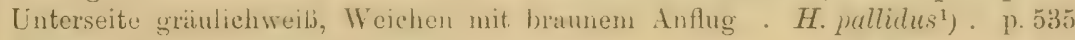

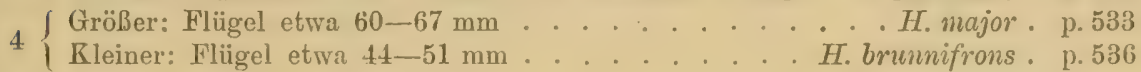

823. Horeites cantans cantans ('Temm. \& S (chl.).

Salicaria cantuns Temmineli \& Sehlegel, Sieholds Fauna Japonica, Ares, p. il Taf. 1! (1847- Japan).

Salicaria cantillans Temminck \& Schlegel, l. c., p. 52 Taf. 20 (1847- Japan). Die o wurden als cantans, die 우 als cantillans beschrieben.

Oald. Oberseite olivenhraun, Bürzel und (Obersehwanzdecken mit röstlichem Anfluge. Sehwingen Inaun mit röstlich olivenhraunen Aufen- und hell hrïunlichgranen, fist weißlichen Inuensïumen. Stenerfedern röstlich ulivenhraun, Außensiume etwas rïstlicher. Federn üher dem Auge und undeutlicher Supereiliarstreif weiblichgrau. Mitte der Lnterseite schmutrig- oder bräunlichweiB, Seiten und Cnterschwanzdecken röstlich olivenhran. Iris braun, FüßBe hell horubrïunlich, Oherschnabel dunkel hornbraun. Basis des Cnterschnahels hellbräunlich. 1. Schwinge üher doppelt so lang als die Handdecken und etwa so lang oder etwas länger als die Hälfte der 2., die etwa gleich der 10. his 12. oder noch etwas liürzer ist. 4. his 6. ungefïhr gleich und am lïngsten. Äußeres Steuerfederpaar etwa 1 em kïrzer als das mittelste. Flïgel etwa 66-70, Schranz 65-70, Jauf 24.5-26. Culmen $14.5-16 \mathrm{~mm}$. O ar. Wie dis $0^{*}$, aher viel kleiner und diher oft fälsehlieh als hesondere Art betrachtet. Flïgel etwa 56.5-59, selten 60), S(hwanz etwa 53-57 mm. - Das Frühlingsgefieder ist weniger lehhaft. mehr olivenfirthen, grï̈ulicher. weniger röstlich. (Üher 100 untersucht.)

Häufiger Brutrogel in Japan, ron Jesso bis Kiuschin und auf Iturup in ren Kurilen. Auf den Riu-Kin-Inseln häufig, aber auf den südlichen wohl

1) Nicht zu rerwechseln mit H. pallidipes Blanford (Journ. As. Soc. Bengal XLI, 2, p. 162. Thaf. VII, 1872). Diese Art ist auf der Oberseite dunkelbraun, auf Bürzel und Oberschwauzdecken mit rostlurannen Auflug; Unterseite weib, Seiten hraun. Wcißlichgrauer Superciliarstreif. Füße weißlich. Flügel (jedenfalls ơ und 우) 47-55, Schmanz 39-45 mm. Sikkju bis Tennsserim, anseheinend nicht über 6000 engl. Fulj. 
nur Tinterrogel. Auf Jesso Zugrogel, auf den südlicheren Inseln, auch auf den Sieben-Inseln, Standrogel. Formosi im Winter. Stücke ron den SiebenInseln sollten genauer untersucht werden.

Wegen des kurzen, kräftigen Schlages in Japan beliebter Käfigvogel. Nester in Bambusgebüsch, bis vier Fuß über dem Boden, die 5-6 Eier dunkel braunrot oder ziegelrot-braun, denen von Cettia cetti ähnlich, etwa 18-19 $>13.5-14.2 \mathrm{~mm}$.

\section{Horeites cantans canturians (Swinh.). (Fig. 99.)}

Arundinax canturians (!) Sriuhoe, Ibis 1860, 1. 52 (im Winter bei Amor, im Sommer bei Shanghai. Neuere Autoren schreiben canturiens, was grammatikalisch richtig ist. Swinhoe beschrieb das ot als canturians, das ${ }^{\circ}$ als minutus).

Arundinax mimutus Swinhoe, Ibis 1860 , p. 52 (Amoy).

Amendinax miniatus Swinhoe, Ibis 1860, p. 357 (Verbesserung des Namens minutus). Homochlamys luscinia Salvadori, Atti Accad. Sc. Torino V, p.511 (1870- Fundort unsicher. 'Iypus untersucht).

Ist viel kräftiger gehant, mit stïrkerem Schnabel und kräftigeren Füßen, und gröber als H. c. cuntuns. Auberdem unterscheidet er sich von

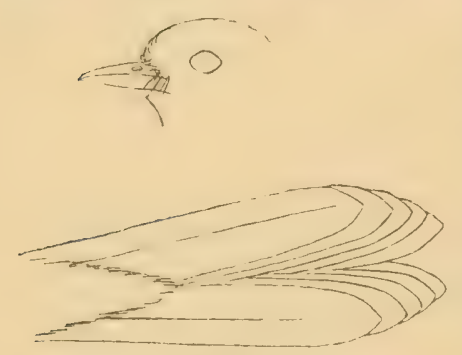

Figur $99\left({ }^{2} / 3\right)$.

H. c. cantens durch die nicht olivenbraune, sondern rötlichbraune Oberseite, Stirn und Oberkopf am lebhaftesten und am rötlichsten. Der undentliche Supereiliarstreif ist etwas gelblicher, die Schrvingensäume sind rotbraun, die Unterseite ist schmutzig weiß, mehr oder minder, an den Seiten immer stark rostgelb, nicht olivenbraun, verwaschen. Flügel ${ }^{\circ} 74$ bis $79,058-63 \mathrm{~mm}$. Im allgemeinen sind Hainan-Exemplare etwas kleiner, aber der Unterschied beträgt nur wenige Millimeter und ist nicht konstant. (Etwa 60 gemessen.)

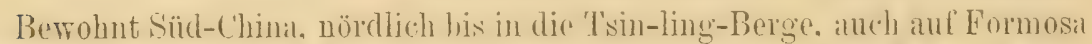
gefunden. Vereinzelt auf den Philippinen rorgekommen. Fin ò aus Cachar (Assaun) im British Museum ist stark rötlich. Kïmnte aher dureh Fenchtigleit verändert sein.

Im Ibis 1906, p. 449 beschreibt La 'I'nuche Nistweise und Eier.

\section{Horeites cantans borealis (Campbell).}

Cettia mimuta borealis Campbell, Ibis 1892, p. 235 (Chemulpo in Korea).

Cettia canturiens septentrionalis Campbell, Ibis 1892, p. 235 ("Russian Manchuria“).

Abbild.: Pleske, Ornithogr. Ross. Taf. IV, Fig. 3 (ठే, sub nomine Cettia canturians).

Wie H.c. canturians, aber etwas blasser. Herbststücke sind otra gefürht wie Stücke rom April und Mai ron $I I$. c. centminns, während Frïhlingsund Sommer-lixemplare so hlab und cräulich werden, wie $I$. c. comburims niemals wircl. Flügel ơ etrva $72-79$. (20 untersucht.)

Südlivhes Essuriland, nördlivh his zum Chanka-See. Insel Iskold, Korea. Mandschurei, südlich bis Chefon. - Wandert südlich. Fin Stürali von Folmosa scheint zu borealis zu gehören.

Hält sich im Dickicht und auf einzelnen Bäumen in den mit dichtem Unterholz bestandenen Gebirgstälern aut. Der Warnungsruf besteht nach Przewalski aus der oft wiederholten Silbe tek. Der laute Gesnng erimnert an die Silben kugu-u-u-u-uk, 


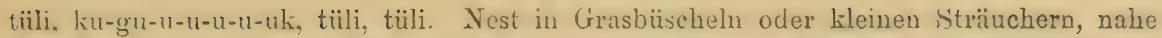
dem Boden, einen tiefen Napf bildend, aus breiten Wasserpflanzenblättern und Halmen. innen mit feinen Stengeln ausgelegt (Godlewski). Lier dunkel tribrosa bis ziegelrot: meist einfarbig, manchmal mit dunkeln Wölkchen und Flecken, die oft am stumpfen Ende einen Kranz bilden. MIaße von 15 Eiern nach 'Taczanowski Maximum $21.2 \times 15.3$. Jurchschnitt $19.1 \times 15$, Mivimum $17.2 \times 14 \mathrm{~mm}$.

\section{-826. Horeites cantans diphone (Kittl.).}

Siylviu diphone Littlitz, Ilém. Acad. Imp. Se. Pentersburg 1830, p. 233 und 'Latel (BuninInseln).

Ähnelt 1I. c. cuntans, ist aber viel kleiner, der Sehnabul verhïltnismäßig lïnger. Oherseite fahl rosthraun mit olivenfarbenem Schimmer, AuBenfahnen von Stenerfedern und S(hwingen mehr l'osthrätulich, der Superciliarstreif

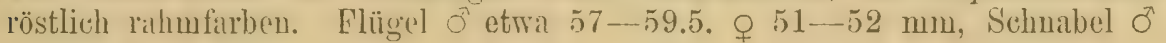
(Culmen) $17 \mathrm{~mm}$.

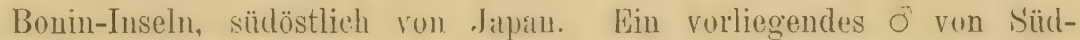
Dionisio, Tulkan-Inseln, dessen Nest und Eier ebenfalls vorliegen, ist in so abgenutztem Gefieder (1. Juni!), daß man nicht feststellen kann, ob es eine typische diphone oder andere nahestehende Form ist.

Kittlitz beschreibt den eigenartigen Gesang. Nest und Eier wie die anderen Formen von Horornis und Cettia. Eier nur wenig kleiner als die von cantans. Zwwei von mir gemessene Eier messen $16.7 \times 13.4$ und $17.2 \times 13.7 \mathrm{~mm}$.

\section{Horeites flavolivacea flavolivacea (Blyth).}

Nenrnis flavolivacea Blyth, Journ. As. Soc. Bengal XIV, p. 590 (1845- ex Hodgson M.S., Nepal).

Neornis cacharensis Blyth, l. c. (1845- ex Hodgs. M.S., keine Lokalität angegeben).

Abbild. der Eier: Cat. Eggs Brit. Mus. IV, Taf. X, Fig. 20.

Ad. Oberseite olivengrün, Flügel und Stenerfedern dunkelbraun, mit der Farbu des Rücliens gesäumt. Schrärzlicher Zïgel- und Angenstreif', darrïber ein hell grünlichgelber Superciliarstreif. Unterseite grünlichgelh. Interschwanzdecken, Seiten, Kehle und Kropfgegend olivenbräunlich rerwaschen. Oberschnabel und Spitze des Unterschnabels dumkelbraun, Untersehnabel lıell, Füße gelhlichbraum. Flügel ó etwa 57-58. ๆ $52-53$, Sehwanz ơ ungefähr $57-58$, $50 \mathrm{~mm}$.

Himalaya rom Sutlej-Tale his Sikkim. in Höhon vou 3500 bis 10000 engl. Fuß.

Nester wurden in Sikkim vom Mai bis Juli in Höhen von 3500 bis 6000 Fuß gefunden. Sie waren kugelförmig; aus Bambusblättern und Gras gebaut und standen in niedrigen Büschen. I)ie Fier sind rötlich schokoladenbraun und messen ungefähr $17 \times 13 \mathrm{~mm}$.

\section{Horeites flavolivacea intricatus subsp. nor.}

Unterscheidet sich von $H$. $f$. Aarolicacen durch weniger grïnliche und nicht so gelbliche Unterseite: Seiten hell olivenhraun. Kehle schmutzig rahmbräunlich. Mitte des Unterkörpers rahmweißlich mit hellgelbem Anflug. Oberseite mit etwas geringerem grünlichen Anflug, mehr bräunlich. Iris rotbraun, Schuabel braun, Unterschmabel hell. Füße hellbram. Flügel of $57-58$, \& $52-54 \mathrm{~mm}$. 
Tsin-ling Gebirge in Schensi. Typus $0^{\top}$ : T'a-pai-schan, in mittlerer Hëhe, 1. Olitolere 1905, im Tring-Museum. Nr. 11050. Außer dem Typus liegen 3 Exemplare aus den Monaten Jumi und Juli vor.

\section{Horeites major Hoore.}

Horeites najor MLore, Proc. Zool. Soc. London 1854, p. 105 (Ex Hodgson M.S. - Nepal. Abbild.: Cat. B. Brit. Mus. V, Taf. VII.

Oberkouf kastanienhranm, übrige Uherseite nebst Aubernsïumen von

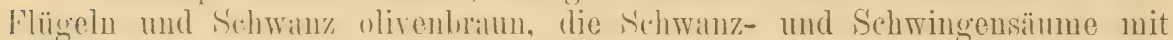

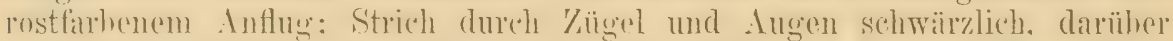
(in hell rostgelhlicher Supreviliasstreif: Ohrdecken mit gramem Anflug. Kinn. Kehle nnd Krophegegend weiblichgratu. Enterschwanzdecken und Körperseiten matt hrämulich ockerfarben. Nitte des Unterkïrpers weil.s. Füße hellbraun, ()herschnahel dunkelhaum, Unterschuabel hell. Flügel etwa 60-67, Sehwanz. $50-55 \mathrm{~mm}$.

Siklim und Nepal. in groben Höhen. Nach Baker atuch aut den hohen Bergen rem Nord-('achall. Woher aber keine Bälge ron mir untersucht werden konnten.

Hume und Oates beschreiben Eier, die ohne Zweifel fälschlich dieser Art zugeschrieben wurden. Dagegen heschreibt Stuart Baker Eier, die er auf den hohen Gipfeln der Nord-Cachar Berge fand. Die Nester sind tief napfförmig, aus feinen Gräsern und Bambusblätteru, meist mit Federn ausgelegt. Die Eier gleichen denen der anderen Arten der Gattung.

\section{8:30. Horeites acanthizoides brunnescens Humu.}

Horeites brunnescens Hume, Ibis 1872, p. 109 (bei Darjiling).

5. und 6. Schwinge ungeführ gleich lang und am längsten, 2. etwa 14 mm kïlzer als dio längste. Oherseite hell röstlichloran mit schwathem. anf dem Bürzel aher dentlicheren olivengrïnlichen Sehimmer. Schwingen mud Stenerfedern lram, mit der Rürdienfarhe gesämmt, dip Sehwingensäume aber lohhafter, dio Inuensäume der śchwingen weib. Zügd- und Supereiliar-

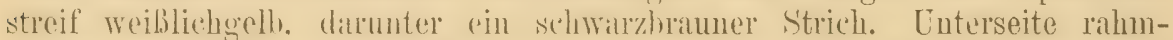

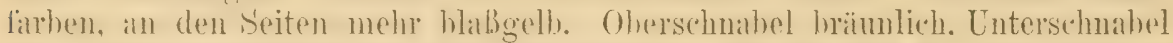
hell, Fübe anscheinend hrïmnlich fleischfarben. Flügel otwa $48-56$, Schwanz

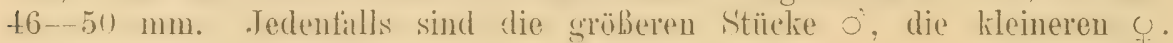
Schnabel etwa $12.5-13.5 \mathrm{~mm}$.

Sikkim und vielleicht Nepal.

\section{Horeites acanthizoides acanthizoides (Verr.).}

Abromis acanthizoides Verreaux, Nouv. Arch. MIus. Paris VI, Bull., p. 37 (1871- ohne genaue Lokalität; terra typica: Westl. Szetschwan; op. cit. VII Bull., p.47, 1872. 'Typus untersucht).

Abbild. des Eies: Cat. Eggs Brit. Mus. IV, Taf. X, Fig. 19.

Wie H. b. Gmunescens, aber der Schnabel etwas kürzer und stärker (lureiter). Was hroim Tergleich einer Seris sofort auffiallt, obwohl die Lnter-

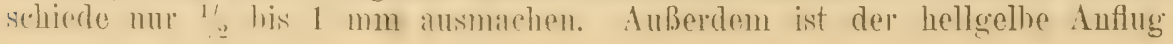


der Unterseite stärker und gleichmäfiger. Iris rothraun. Selnabel braun, Interschuabel gelblich. Füife bräunlichgelh. Flügel ron \& of etwal 5:3-54 mm.

Brïtet in den 'T'sin-ling-Bergen (in hallser Höhe des Tal-pili-Berges) und wurde in Szetschwan vou David und in Folien (Kuatun) fon La 'Touche gesammelt. Hierzu scheint anch der. von Ripmon in den südlichnen schnanStaaten gesammelte Vogel zu gehören.

Nach La Touche in den Bergen von Nordwest-Fokien (5500-6000 Fuß Höhe) brïtend. Nest und Eier wie die verwandter Formen. La Touche vermutet, daß die Nester ursprünglich überwölbt wæren.

\section{Horeites fortipes fortipes (Hodgs.).}

Horomis fortipes Hodgson, Proc. Zool. Soc. London 1845, p. 31.

Drymoica brevicaudata Blyth, Journ. As. Soc. Bengal XVI, p. 459 (1847- Darjiling im Himalaya).

Neornis (Horomis) assimilis Gray, Cat. Mamm. B. Nepal, ed. 2 p. 30 (1863- Nepal).

Ad. Oberseite olivenhraum, auf dem Bürzel etrvas lehhafter. Streif üher deu Zügeln und durch das Auge etwas dmukler, darïher ein hellhräunlichere

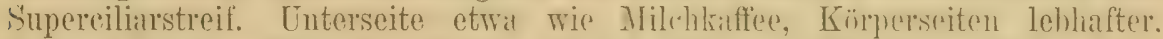
mehr gelbbraum. Nitte vou Kehle und Unterkörper weiblich rahmfurbeu. Iris hellbraun; Sehmabel dunkelbraun, Wurzelhälfte des [nterschmalonls Jull rä̈ulich; Füße hellbraun. $\sigma^{\top}$ Flügel etwa 54-57, Schwanz 54-56, Lauf 20.5-21.5; + Flügel t8-50. Sehwanz ungefühn 48, Iaul 20-21 mm. of wie $\sigma^{\pi}$, nur kleiner.

Nepal, Sikkim, Butau-Doar's, Uber-Assam lis in die Naga- und KhasiaBerge, üstlich bis Ober-Birmal. Nach baker in Nord-Kaltscbar von 2800 Ful. bis über 4000 .

Nistet in Nepal und Sikkim vom Mai bis Juli. Das Nest ist oben offen, wie das von Cettia cetti und innen mit Federn ausgetüttert. Die Eier sind rötlich schokoladenbraun, etwas kleiner als die von Cettia cetti, und messen $13-13.6>17-18.5 \mathrm{~mm}$.

\section{- 833. Horeites fortipes davidiana (Verr.).}

Arundinax davidiana Verreaux, Nowv. Arch. MIus. Paris, Bull. VI, p. 37 (1870 — „MIoutagnes du Thibet chinois". 'Terra typica: Mupin, und nicht Peking! S. Oustalet et David, Ois. Chine, p. 255).

Horomis sinensis La Touche, Bull. B. O. Club VII, p. 37 (1898- Fokien).

Steht H. jortipes fortipes sehr nahe. aber die Seiten sind etwas bräunlicher, nicht ganz so lebhaft gefürbt. die Mitte der Enterscite etwas heller. mehr deutlich weililich. Flïgel ơ 55-58, Q 49.5-51.5 mm. In der Brutzeit verbleicht das Getioder, die Unterseite wird noch weillicher; die Seiten heller braun.

Süd-Kausu. 'Tsin-ling-Borge, bis 'latsien-lu in s'motschwall, und berge von Nordwest-Fokien, wo or mach Lal T'nuche in Höheu von 4-5000 engl. Fuß brïtet.

Stimme nach La 'T'oucho wie 'I'schiii-witschi, 'L'schiii witschiu. Nester nach demselben Autor überwölbt, mit seitlichem Eingang,-sonst wie die der Verwandten. Eier wie die anderer Horeites-Arten. (Ibis 1899, p. 209.) 


\section{Horeites pallidus Brooks.}

Horeites pallidus Brooks, Journ. As. Soc. Bengal XLI, 2, p. 78 (1872- Kaschmir).

1d. Oherseite matt olivenhraun, Sämme der S'chwingen und Steuerfedern rtras mehr losthäumlich, aher" matter als hei $/ 1$. Grumesens. Fin

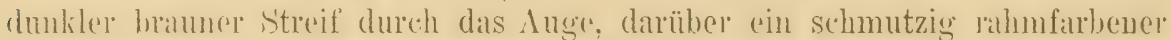
Supereiliarstreif. Cnterseite gräulichweiß. ITeichen mit matt röstlich olivenbraunem Anflug: Fligel of etwa 58-61, ㅇ 51-52, Schwanz $55 \mathrm{~mm}$.

Kaschmir und Hasara, östlich bis Garwhál.

Brooks fand die Art in Höhen ron 5600-8000 engl. Fuß. Er beschreibt den kräftigen Gesang wie folgt: ein eigenartiger langer Pfiff, gegen das Ende hin mit einem Umschlag und gefolgt von dem zweiten 'T'eil der Strophe, der aus 5-6 Tönen in ganz anderm 'Tonfall besteht. Das Nest, das er fand, war kugelförmig, aus grobem Gras, innen reichlich mit Federn gefüttert. Eier dunkel braunrot wie die von Cettia cetti. Ein Ei mißt etwa $16 \times 12.5 \mathrm{~mm}$.

\section{Horeites brunnifrons (Hodgs.).}

Orthotomus (Prinice) brunnifions Ilodgson. Proc. Zool. S'oc. London 1845. 1r. 29 (Nepat). Orthotomus (Horeites) pollicaris \& schistilatus Hodgson, 1. c., p. 30 (Nepal).

Abbild.: Cat. B. Brit. Jus. V, Taf. VIII.

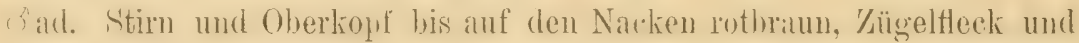

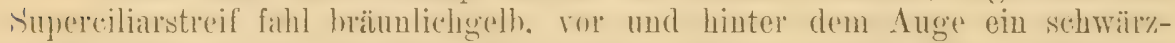

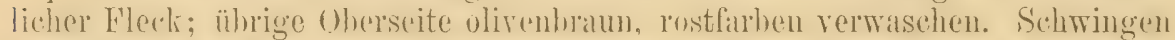
haum. mit der liarhe des Rürkens gexüunt. Stenerfedern etwas mehr rothrïunlich als rler Rücken. Lnterseite aschgran. entlaug der Mitte weißlich,

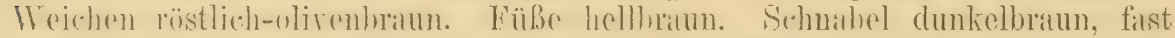

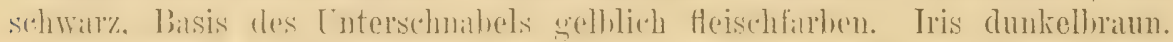

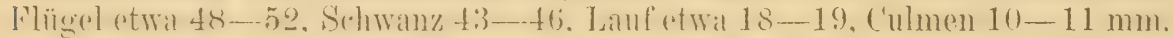
o wie o?, nur etwas kleiner: Flügel etwa $46-47.5 \mathrm{~mm}$. (Der Schwanz dieser drt ist "twas mehr gestuft als bei den ïhrigen Arten der Gattung.)

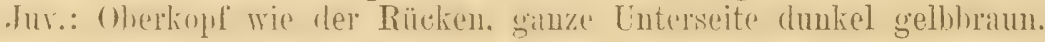

Bewolnt zur Brutzoit den Himalaya in Höhen vou 10-12000 engl. Fuli. ostwärts his Mupin in Szetsehwan (David). Im WVinter in der Brahmatputra-Ebene und den Hügeln des nördlichen Assam.

Osmaston fand die Nester in Sikkim in Höhen ron 10-11000 Fuß. Die Nester sind iiberwölbt mit seitlichem Flugloch nahe der Oberscite etwa 1 Fuß über dem Boden im Gebüsch. Sie sind aus Mloos, Gras und Bambusblättern gebaut, mit Federn ausgefüttert. Es wurden 2, 3 und 4 Eier gefunden. Diese sind wie die andrer Arten: rötlich terrakottafarben oder glänzend ziegelrot, mit einem Ring aus dunkler, rötlich terrakottafarbenen und tiefer liegenden gräulichen Flecken. Durchschnittsmaße von 12 Eiern nach Osmaston $18 \times 12 \mathrm{~mm}$.

\section{Gattung CETTIA Bp. 1838.}

Der stark gerundete Schwanz aus nur 10 sehr breiten und weichen

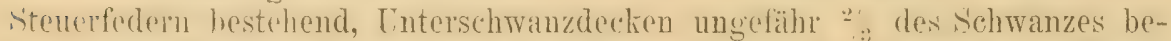

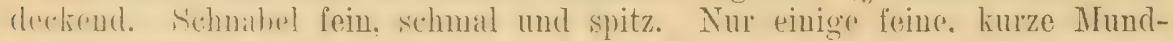
winlelhorsten. In dem gerundeten, hurzen Elügel ist die hreite 1. Selhwinge rtwal gleich de! Hälfte der 2. Die sehr km\%e 2. ist ctwa so lang wie die

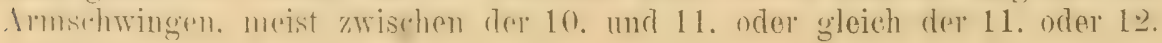




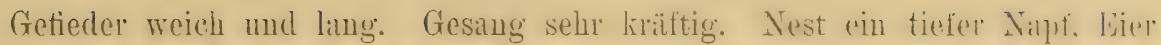
ziegelrot. - Lis seheint nur eine Mauser jährlich stattzufinden, Pleslie rermutet jedoch doppelte Mauser; nähere Untersuchungen darïher sind erroüscht.

\section{Cettia cetti cetti (Marm.). (Hig. 100.)}

Motacilla Sylvia y Curruca fulvescens Gmelin, Syst. Nat. I, p.956 (1788- Provence. Ex Daubenton, Pl. Enl. 655 Fig. 2; ef. Buffon, Hist. Nat. Ois. V, p. 134. Die Abbildung ist ganz unsicher; der nicht gerundete Sehwanz, dic rostrote Farbe u. a. genïgen, die Abbildung anzuzweifeln; dab der Schwanz aus 10 Federn zu bestehen scheint, ist ohne Belang: da der Zeichner auch Sylvien, Ammern u. a. so darstellte).

Sylvia Cetti Marmora, Hem. Acead. Torino XXX, p. 254 (1820- Sardinien. Ex Cetti, Uccelli di Sardegna, p. 216).

Sylvia sericea Temmiuck, Man. d'Orn., 2. Edd, I p. 197 (1820- Brenta, Südspanien; ex Natterer II.S.)

Sylvia Altisonans Bonaparte, Geogr. \& Comp. List, p. 11 (1838- , South of Europe". Basiert auf Gould, B. Europe, Taf. 114).

Cettia (Potamodıs) orientalis 'l'ristram, Ibis 1867, p. 79 (Palästiua. - 'I'ypus untersucht).

Oad. Farbe dor Uberseite ein löstliches Braun, das nach dem IBürzel zu lebhafter und lötlicher wird und anf den Ohersehwinzdecken ann intensivsten ist. Schwingen braun mit schmalen helloreu AuBen- mur Innenfialnen. Steuerfedern dunkelbram. Zï̈relfleck mul dessen Fortsetzung hinter dem

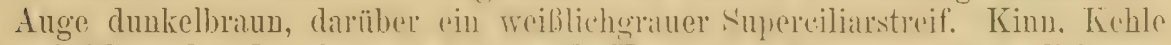

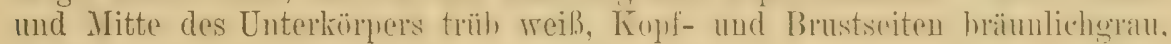
Körperseiten trüb braun, Unterschwanzdecken triib braun mit schmutzigweißen Spitzen. UnterHügeldecken und Axillaren blaß graubraun mit veißlichen Enden. Oberschnabel dunkelbraun. Unterschnabel holl horufarben mit dunkler Spitze. Iris leblaft braun. Füßo hellbraun. Flügel etwa $62-64.5$ (65), Schwanz etwa $61-65$, Lauf 20-22, Culmen 14-15 mm. o wie oे, пul otwas kloiner: Flügel etwa $54^{-+} 59 \mathrm{~mm}$. Das Herbstkleid ist lebhafter, dunklor, im

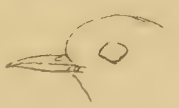
Frühliug wird die Oberseite matter, etwas blassare die I'nterseite weiblicher. Der junge Vogel wie der alte, nur etras matter. - Es scheint, als ob westliche Stücke, besonders marokkanischu, messt kürzere Schwänze hahen. dagegen kleinasiatische - nicht aber solche ans Palästina - lüngere.

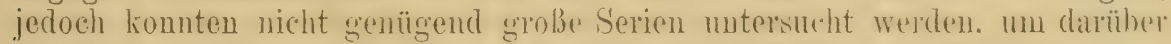

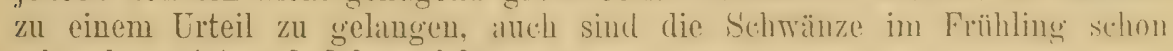
sehr abgenutzt und daher nicht genau zu messen.

Standrogel in Süd-Frankieich, Spanien. Portugal. Mallorka. Süid- und

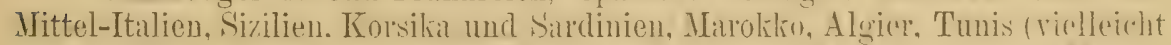
nur nördlich des Itlas nistend). Balkinulhilhinsel (bis Rumänien. Moutrnegro und Dalmatien). Kileinasien. Palästina. . Telenfalls gehören zu dieser Form auch dic Vïgel vou der Frim und ans deun Kamkiasus; datïr spricht

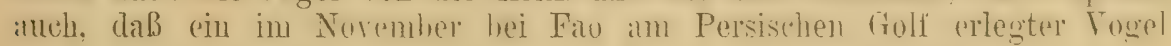
zu der westlichen Form gehört, sowie ein ơ aus dem Elburs-Gebirge.

In der Ebene vie im Hügellande bis über 1000 m, aber nur in feuchten, üppigen Lagen, wo Rohr- und Sehilfidickichte gedeihen. oder dichtes frestriipl unter schattranden 
Bäumen wächst. Schlïplt geschickt durch das dichteste Gezweig und läuft auch rasch am Erdboden entlang. Eriunert in seinen Bervegungen am meisten an die Locustellen. Ein höchst auffallendes Prodult ist der Gesang: ein kurzer metallischer S'chlag, der mit außerordentlicher Kralt ohne Einleitung plötzlich hervorgeschmettert wird und ebenso plötzlich abbricht. Das Nest steht tief rersteckt in dichtem Gebüsch und Gerank. Es bildet einen aus Fasern, Würzelchen, Bast und dürren Blättern zusammengefügten tiefen Napf und erinnert etwas an das Nest der Nachtigall, oft aber ist es mit weißer Pflanzenwolle durchwebt und ähnelt dann dem Nest vom Gartenspötter, innen sind mitunter Federn zur Auspolsterung benutzt. Es steht nie höher als $1 \mathrm{~m}$ rom Boden. Die $4-5$ Eier sind braunrot, graurosa bis ziegelrot, mitunter mit deutlicher dunkler Wölkung um die Mitte herum. 2 von mir in Marokko gefundene Eier messon $17.6><13.9$, andere aus demselben Lande $17.5 \times 1.1-19.2>14.2$ und $19 \times 14 \mathrm{~mm}, 66$ Eier aus Süd-Spanien und Nord-Afrika (47 Jourdain, 15 Rey; 4 Hartert) messen durchsehnittlich $17.88 \times 13.82$, im Maximum $19.4<14.1$ und $18.5 \times$ 14.5, JLinimum $17-13.5$ und $17.1 \times 13.2 \mathrm{~mm}$. Durchschnittsgewicht nach Rey $94 \mathrm{mg}$.

\section{- 837. Cettia cetti cettioides Hume.}

Cettia Cettioides Hume, Stray Feathers I, p. 194 (1873- Sind. - 'Iypen untersucht). Cettic albiventris Sewertzoff, Turkest. Jevotn. in: Jzv. Obshch. Moskor. VIII, 2, p. 131 (1873 - Karatau, 'T'schimkent, T'aschkent).

Cettia scalenura l. c., p. 131 (1873- Aral-See, bei 'L'schimkent, u. a.).

Cettic Stoliczkae Hume, Striny Feather's I1, 1) 520 (1874- Jarkand. - Typen verglichen).

Cetlic var. $\beta$ pallens Sewertzoff, Journ. f. Om. 1875, p. 175 (Nomen nudum!).

Cettia cetti semenovi Sarudny \& Loudon, Ornith. Jahrbuch 1903, p. 174 (Tedschen in Transkaspien).

Abbild.: Second Yarkand Mission, Ares, 'Taf. XI.

Unterscheidet sich vou C. cetti cetti durch die heller braune Oberseite,

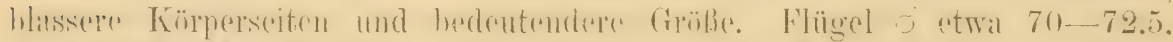

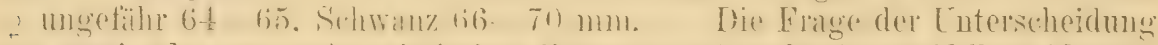

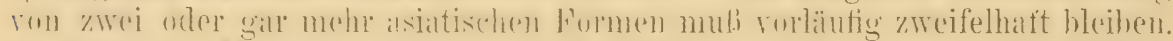

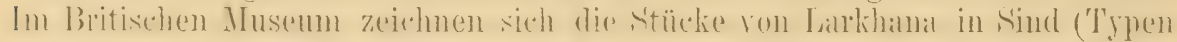

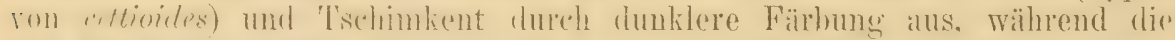

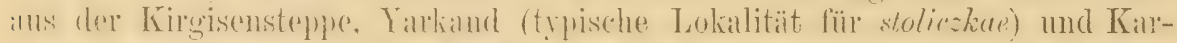

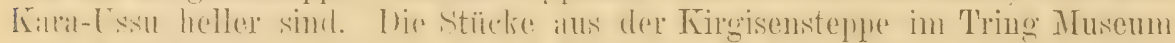
sind nieht ganz so lecll wie die im Britischen Arnsemm. Die wenigen untersuchten Perser (1 aus Farsistan, von Witherby, 1 aus dem nördlichen

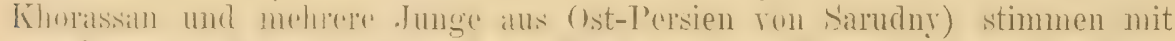

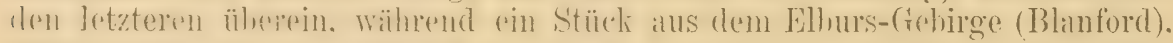
soweit marh dem shlechten Exemplar zu urteilen ist. zur dunkelu westlichen Form gathërt. Dat diesse Vögel wie andere auch individuell varierene. dart

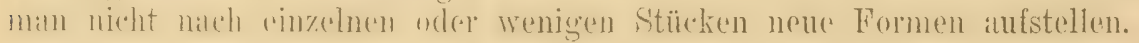

Bmotrogel in 'Turkestan (darkand. Tian-Seham. Flïsse ('haidyk-Gol und

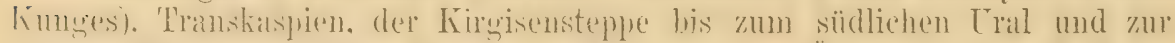

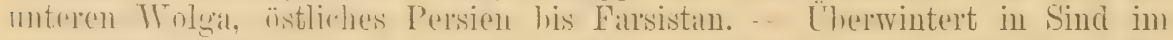
westlichen Tndien (Indus-Tal). aluer anch in Transkaspien und im Wolga-Delta.

4 Eier aus Persien in Jourdains Sammlung sind größser als solche von C. cetti cetti. Sie messen im Durchschnitt $20 \times 14.5 \mathrm{~mm}$. 


\section{('iattung UROSPHENA kiwinh. 1 Ui .}

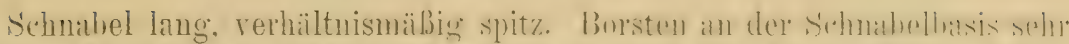

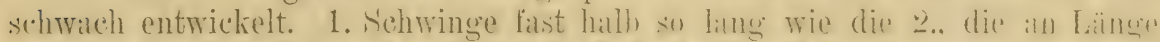

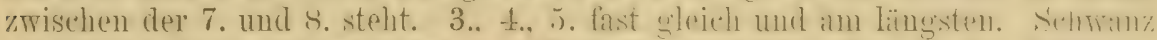

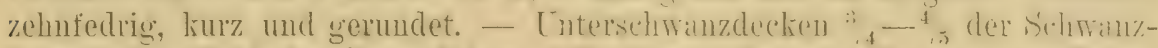
länge. Die rathl der Stenerfedern (10) dentet die naho Vorwandtrehalf mit

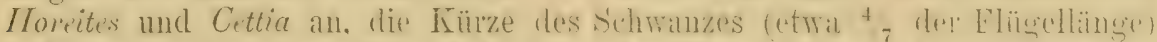

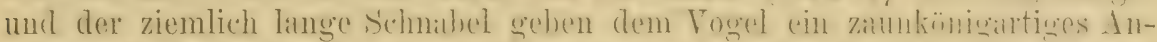
sehen. J)as ron Godlewsti hesehriehene Verhereen in Rerisghtaten und das Durehschlïpfen derselhen erinnert anffallend an die (rowohnheiten der Zaunkönige. - Eime Art. (Dor Name Urosplence wurde von Stejneger 1892 in

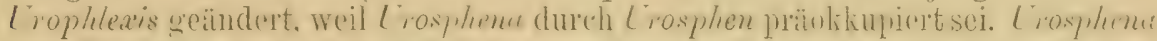
und Lresphen sind aher leicht zu unterscheiden.) Es scheint mix nur "ine Manser im Jahre stattzufinden.

\section{Urosphena squameiceps (Swinl.). (Eis. 101.)}

Triburce squameiceps Strinhoe, Proc. Zool. Soc. London 1863, p. 292 (Kanton). Cettia ussurianus Seebohm, Cat. B. Brit. MLus. V, p. 143 (1881- Ussuri-Tal).

Abbild.: Ibis 1877, T'af. 4.

ơad. Oberseite röstlich olivenbraun, die broiten, hompakten Federu

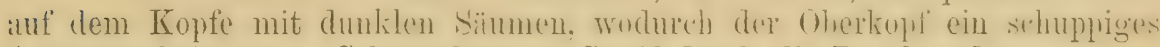
Aussehen bekommt. Schwarzbramer Streif durch die Zïgel und hinter dem Auge fortgesetzt, über diesem dunklen Streifen ein bräunlich rahmfirbener Supereiliarstreif; IVange und ährigen Kopfseiten rahmfarben mit braunen Federsiumen. Unterseite rahmfarben, an den Seiten in röstliches Olivenbraun über-

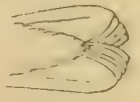

Figur 101.

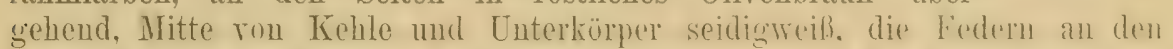

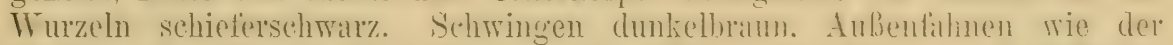

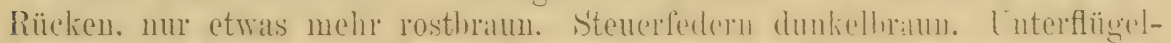

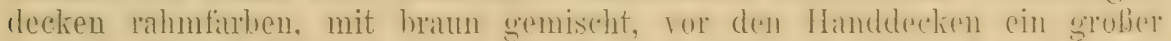

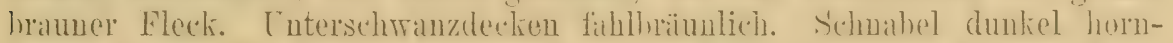

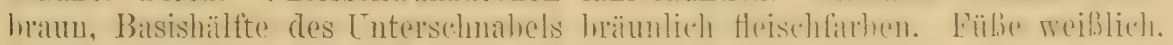

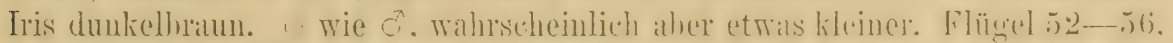

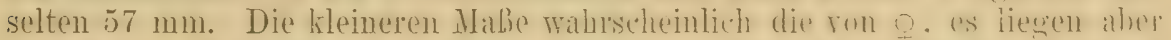

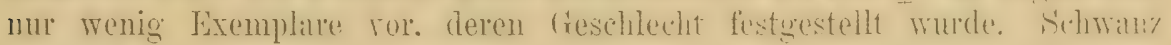
etwa 25-33.5 mm, Culmen 12-13.5 mm, Lauf $16 \mathrm{~mm}$. - Zur Brutzeit wird das Gefieder lichter. mehr matt ulivenhriumlich, die Körperseitem hlisiser. heller. Ein solches Stïck wurde als "nssurianus" beschrieben.

Brötet in Ostsibirien (au den Lferu des Jalnanisthen Meeres. anf Askold. anu Sidemi, alm unteren Cisuri. bei Mracliwostok), in Koreal und anf den!

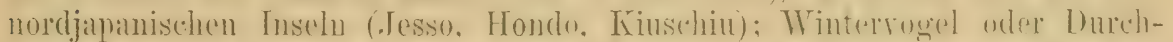

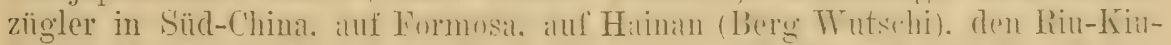

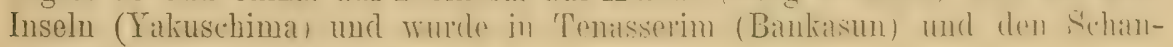
Stanten (Loi-mai) erbentet.

Goldlewski berichtet, daß dieser Vogel sich im dichten Unterholz der Wälder aufhält und besonders Reisighaufen liebt, die er wie die Zaunkönige durchschlüpft. daß er mit lauter schnalzender Stimme lockt und schreit, eifrig singt, und seine Nahrung meist am Boden sucht. Die Eier scheinen noch nicht bekannt zu sein. 


\section{Gattung LUSCINIOLA Gray 1841.}

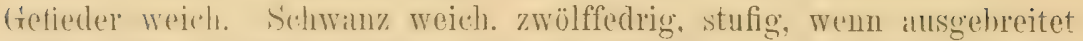

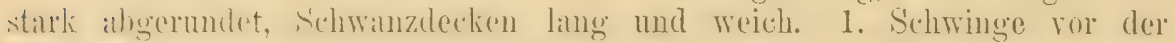
Spitze mehr odre minder ausgebuchtet, riel länger als die Handrlecken, etwal $1 / 3$ bis $1 / 2$ der 2., die merklich kürzer als die 3., und etwa zwischen der 7 . lis 10. ist. Div 3.. 4.. 5. etwa gleich und am längsten. Schnabel schlanki mnd dïmn. Mundwinkelhorsten kurz und schwach, oft kaum bemerkbar. ('Tribure ist nicht von Lasciniola zu tremen.) — Es scheint jedes Jahr eine doppelte Mauser, wenigstens des Kleingetieders, strettufinden.

1 f Rïcken dentlich gestreift. . . . . . . . L. melanopogon . p. 540

I Rücken nicht gestreift. . . . . . . . . . . . . . 2

") 1. Schwinge ungefähr gleich der Hälfte der 2. oder wenig kürzer . . 3

- 1 . Schwinge merklich kiirzer als die Hälfte der 2. . . . . . . . 4

3 K Kehle deutlich gefleckt ............. . . thoracica. p. 541

3 T Kehle mugefuelit oder mit angedenteten Flecken . . L. Luteonentris p p.543

4 f GröBer: Flïgel ơ

4 Kleiner: Flügel 53-56, Lauf $19-20 \mathrm{~mm}$. . . . L. tacsanowskia. 1). 512

839. Lusciniola melanopogon melanopogon (T'(mm.). (Fig. 101.)

..Tamarislien-Rohrsänger".

Sylvia melanopogon (mitunter fälschlich melampogon geschrieben) 'Temminck, Pl. Col. 245, Fig. 2 (1823- Campagna bei Rom. - Abbildung schlecht).

Caricicola Bonelli Brelm, Vogelfang, p. 236 (1855- Italien. Typus von Pisa).

Ital.: Forapaglie castagnolo.

Őad. Oberseite vou einem warmen Braun mit schwachem röstlichen Anflug. hesonders anf dem Bürz,el. Rücken mit schwarzhraunen hreiten
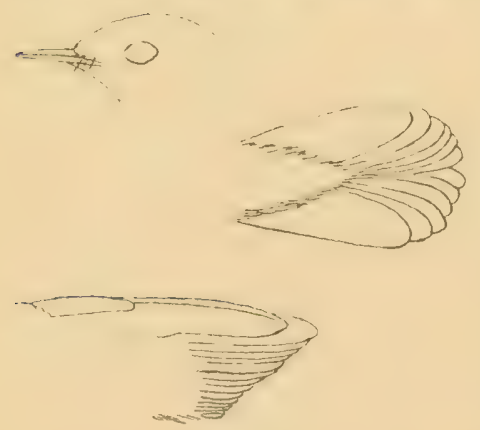

Fig. 102 . Schaftstreifen, Scheitelfederu schwarz mit braunen Säumen. Breiter Zügelstreif und Fortsetzung desselben hinter dem Auge schwärzlich, darüber ein etwas bräunlich getrïbter weißer, von der Schnabelwurzel bis über die Ohrdecken hin sich erstreckender Superciliarstreif, der von der Scheitelmitte durch einen fast rein schwar\%braunen Streifen getremnt ist. Oberflügeldecken und innerste Armschwingen schwarzbraun mit röstlichbraunen Säumen, übrige Schwingen braun mit schmalen, etwas helleren Außen- und Innensäumen. Steuerfedern dunkelbraun mit rostbraunen Aubensäinnen. Kehls und Mitte des Lnterkörpers woiß, Torderbrust, Cnterk̈̈rpere und Unterschwanzdreten hell rosthräumlich. Seiten lebhafter rosthraun. Schuahel dunkelbraun, Basis des Lnterschuahels hellbräunlich. Füße dunkelbraun. Iris braun. Flügel etwa 58-60, Schwanz etra 51-57, Lauf 20, Culmen $14.5-15.5 \mathrm{~mm}$. o wie $0^{n}$, nur wenig kleiner, Flügel etrva 54 bis

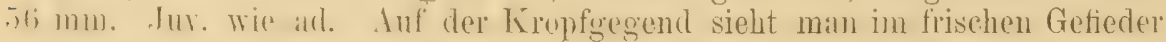

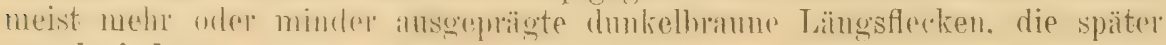
rerschwinden. 
Spanien (Sïdost und Ost), das südliche Erankireich, It:nlien mit seine'n Inseln, von Dalmatien nördlich bis Ungann (zerstreut an der unteren Donau, an Velenezer und Platten-See und einigen anderen Stellen), durch die Ballkanhalbinsel his Griechenland und Cnter-Egypten (Nildeltil). Reiser rermntert. daß die Art aus Cngarn nach Griechenland in dif Winterquartiere zieht: allerdings soll sie aus Ungarn in! Winter fortziehen. andrerseits illor britet sie im Nildelta.

Bewohnt die Ufer ron stehenden und fließenden Gewässern, wo sie mit Schilt, Rohr, Binsen und niedrigem Gebüsch bewachsen sind. Der Gesang ist laut und krächzend und erinnert an den des Schilfrohrsängers. Nest in Schilf und Rohr eingebaut, ans Rohr- und Grashalmen mit 'T'amarisken und Rohrkolben-Wolle, innen mit feinen Rispen ausgefüttert. Die 4-6 Eier findet man in Ungarn im MIai. Sie ähneln sehr denen von Acrocephalus schoenobaenus, sind aber meist heller und grünlicher, mitunter jedoch kaum oder gar nicht zu unterscheiden. 55 Eier messen nach Rey und Jourdain durchschnittlich $17.96 \times 13.02$, NIaximum $19 \times 13.1$ und $17.9 \times 13.9$, Minimum $16.3 \times 12.3 \mathrm{~mm}$ und wiegen im Nittel $83 \mathrm{mg}$. Ein Gelege aus Ungarn, das mir vorliegt, mißt $18.6 \times 13,18 \times 13,17.8 \times 12.3,17.6 \times 13 \mathrm{~mm}$. - Lebensweise und Eier weichen somit von denen der anderen Lusciniolen ab, aber unsere Gattungen dienen zur Orientiorung und Gruppierung nach äußeren Nerkmalen und wir können nicht nach biologischen MIerkmalen allein Arten generisch trennen.

\section{Lusciniola melanopogon mimica Matl.}

"Iduna caspica (r. d. Wolga)" Grabowski, MIus. Homeyer, p. 8 (1893- nomen nudum!). Lusciniola mimica Mladarász, Vorläuf. ïb. einen neuen Rohrsänger (1903, FlugblattTranskaspien nnd Seistan).

Unterscheidet sich von L. m. melanopogon durch mattere, weniger rothraune, mehr olivenlrame Oherseite, hlassere Körperseiten. etwas gribere Dimensionen. Der Schmabel ist etwas lünger. Flügel ô etwa 61-65.5, Schwanz 59-62 mm.

West-Turkestan, Transkindien, Kirgisensteppe his zum IVolga-Deltil. Persien. - Im Winter im westlichen Indien, von Sind his Delhi, Ftawah und Lucknow.

\section{- 841. Lusciniola thoracica (Blyth).}

Salicaria affinis Hodgson, Gray's Zool. Misc., p. 82 (1814- nomen nudum!); Gray, Cat. Mamm. \& B. Nepal, p. 64, 151 (1816- Nepal und ?Cachar).

Dumeticola thoracica Blyth, Jouru. As. Soc. Bengal XIV, p. 584 (1845- "Nepal").

Dumeticola brunneipectus Blyth, Ibis 1867, p. 19 ("Himalaya").

Lusciniola melanorhyncha Rickett, Bull. B. O. Club VIII, p. 10 (1898- Folkien).

Abbild: Cat. B. Brit. Mus. V, Taf. VI, vordere Figur; Eier: Aves Przewalsk. I. Taf. V, 7, Cat. Eggs Brit. Mus. IV, Taf. IX, 5 \& 8 .

of o ad. (Herbstkleid), 1. Schwinge halb so lang wie die 2. oder etwas kürzer. Oherserite rötlich olivenhraum, Sichwanz, mehr aher noch die Schwingen dunkler hraun, mit der Firloc der Oherseite gesiumt. Sehwathe Andentung rines supereiliarstreifuns. Konf- und Halsseiten mit grïnlichem Anflus. Kinn und Mitte des Lnterliarpers weifs; Kehle und Vorderbrust mit asebgrauem Anflug sowie einigen dunkelumunen, wenig bemerkiaren Flecken. Körperseiten lehhaft sepiahraun. Entersehwanzdecken bran mit breiten weiblichen Endsäumeu. Tnterflügeldecken rahmfarben, an der Basis dunkelbrauu. Axilaren weibiol, rahmfarben. Obersehnabel dunkelbraun. I'nterschmabel 
heller braun. Iris braun. Füße hell horn- oder bräunlich fleischfarben. -

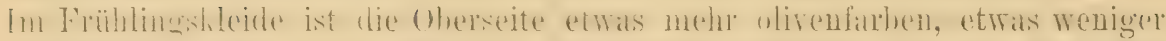

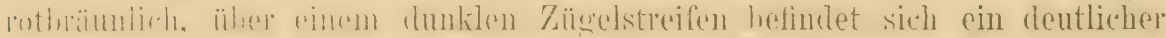

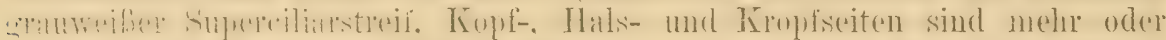

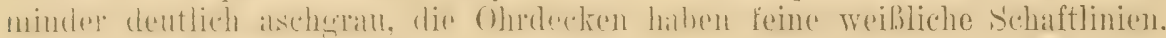

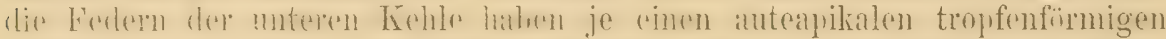

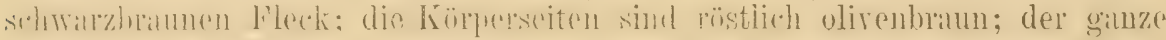

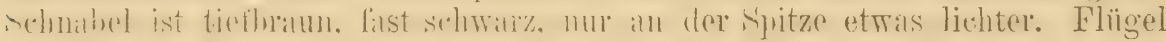
etrva 55-57, seltener bis 59, Schwanz etra 46-53, Lauf 20-21, Culmen

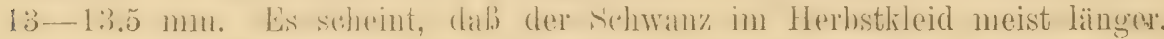

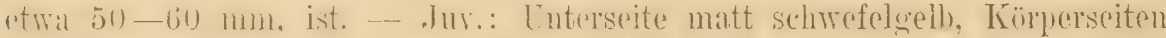

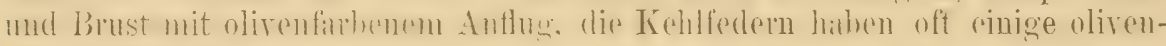
braune Säume.

Seheint zur Brutzeit Mittel-Asien, von den Höhen des Himalaya (9000

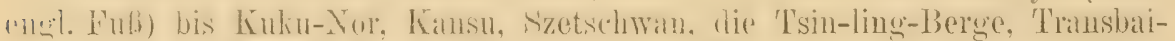

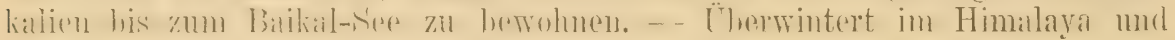
den Bergländern nördlich des Brahmaputra.

An seinen Brutplitizen im sïdlichen Sibirien kommt er erst im Juni an. Der Lockton ist einem Knistern ähnlich, der Gesang scheint den Beschreibungen nach an deu der Locustellen zu erinnern. Das Nest ist itberwölbt wie das der Laubsänger und steht nahe am Boden in Gestrüpp und Reisighaufen. L's enthält 4-6 Eier von weißer, wenig glänzender Farbe, mit braumroten Flecken und Punkten und einigen hlaß bläulichrötlichen Schalenflecken. Sie variieren sehr in der Größe: Taczanowski gibt an $17.2 \times 13.6,18.3 \times 13,18.3 \times 13.5,18.4 \times 13.2,18.6 \times 13$ bis $18.8 \times 13.2$, Pleske $18.5 \times 13.25$ bis $19.5 \times 13.5$. Vom Kuku-Nor stammende, diesem Vogel zugeschriebene Vier messen $16.6-17.2 \times 12.5-12.9 \mathrm{~mm}$. Im Himalaya wurden Eier mit heller roten zablreicheren Flecken gefunden, da aber ihre Nester als oben offen beschrieben werden, bin ich im $1 /$ sreifel, ob sie richtig identifizicrt sind.

\section{Lusciniola tacsanowskia (Swinh.).}

? Motacilla Salicaria (non Linmaeus!) Pallas, Zoogr. Rosso-Asiat. I, p. 492 (1827- „In Rossia et Sibiria" - partim!).

Locustella tacscnoivskia (sic) Swinhoe, Proc. Zool. Soc. London 1871, p. 355 ("TransBaikal").

Dumeticola intermedia Oates, Stray Fenthers IX, p. 220 (1880 - Kyeikpadein in Pegu). Abbild.: Pleske, Ornithogr. Ross. II, Taf. III, 5.

OT gad. (Herbstkleid.) 1. Schwinge merklich kürzer als die Hälfte der

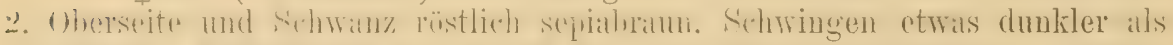

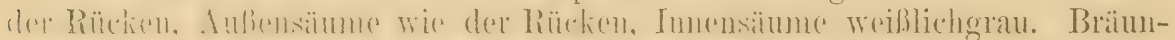

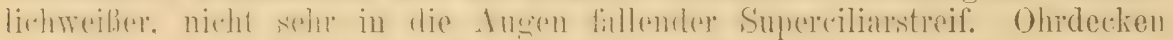

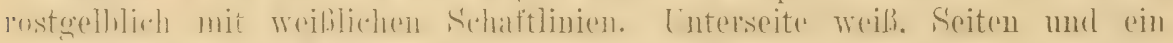

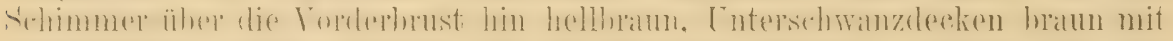

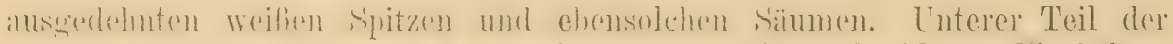
Kehle mituntri: aher wohl swhe seitens, mit einigen dunkieren Fleckehen.

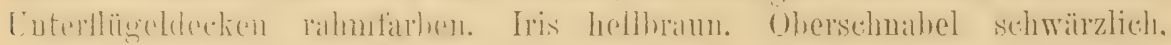

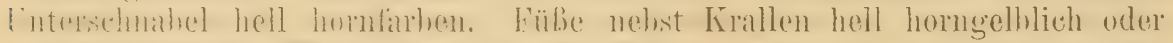

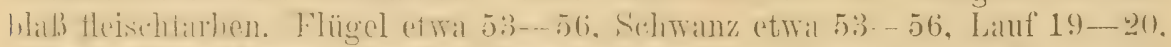
f'ulmen $130-14 \mathrm{~mm}$. In liühlingskleide ist die Oberseite eine flee mehr

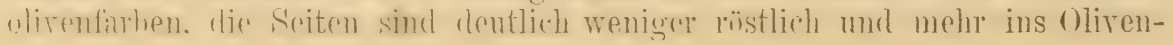




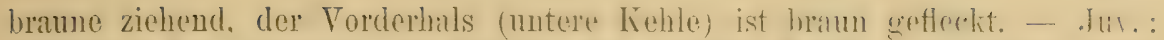

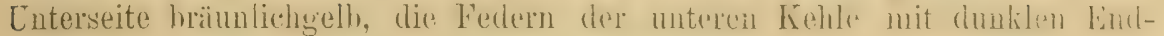
binden, Spitzen der Unterschwanzdecken gelblich.

Nistet von Kultuk am Baikal-See durch Transbaikalien his zum Ussurilande, wandert durch China und überwintert in Birma.

Bewohnt mit langem Gras und Buschwerk bewachsenes Gelände. Der Gesing ähnelt nach Dybowski dem des Heuschreckensängers. Das Nest ist nach demselben Forscher oben offen, besteht aus trockenen Grashalmen, innen mit feinen Gräsern ausgelegt, und enthält 5 Eier, die denen ron Locustella naevia ähneln, aber etwas kleines. sincl. MaBe $18.5 \times 14$ und $17.4>14 \mathrm{~mm}$.

\section{Lusciniola major (Brooks).}

Dumeticola major Brooks, Journ. As. Soc. Bengal XLI, p.77 (1872- Kaschmir).

Abbild.: Pleske, Ares Przewalskianne, 'Taf. I, Fig. 5.

1. Schwinge viel küuzer als die Hälfte der 2. ठㅇ ad. (Frühlings-

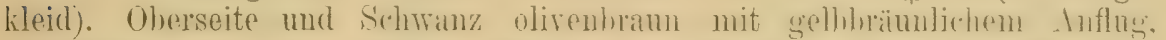
Schwingen bram mit röstlich olivenhramen Sämmen. Tor und unter denu

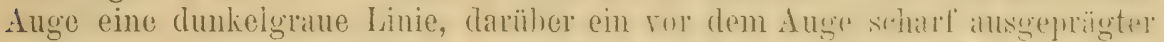

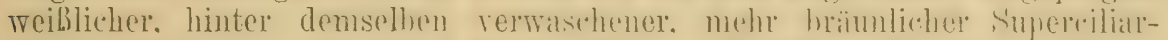
streif. Ohriecken graubram mit weiblichen schälten. Kahle und Luter-

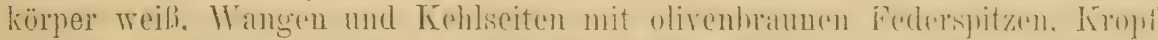

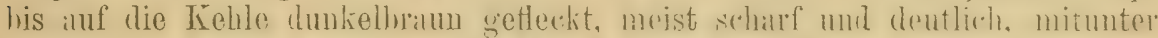

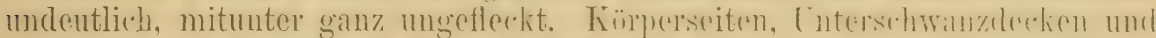

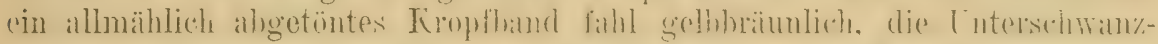

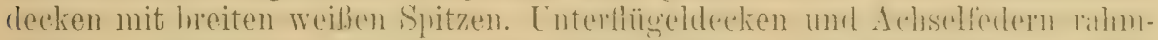

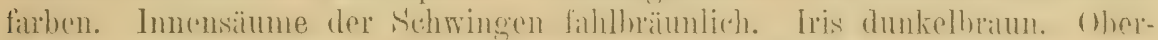

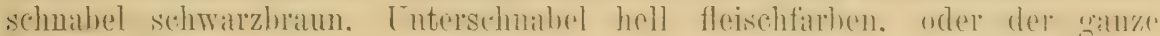

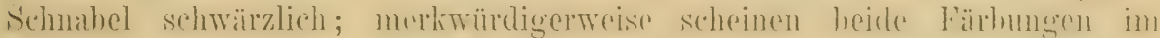

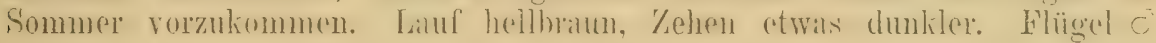
etwa $61-65$, 2 ungefälux 55-60, Sclıwanz etrva $61-68$, Lauf $22-23.5$. Culmen 17.5- $18.5 \mathrm{~mm}$. - Juv.: Oberseite mehr ins Olivenfarbene ziehend,

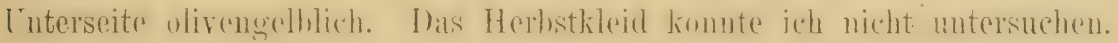

Brïtet in Kaschmir und Ladak in Höhen ron 7-11.000 engl. Fub.

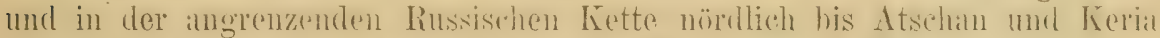
in Ost-Turkestan (aliel keinestalls in der Mromgolei. wie Dresser angiht).

Bewohnt Ackerfelder (besonders Gerstenfelder), dichtes Gestrïpp und hohes Gras. Die Stimme erinnert nach Przewalski an das Geräusch der Spindel eines Spinnrockens.

\section{-844. Lusciniola luteoventris (Hodg's.).}

Tribura luteoventris (sic) Hodgson, Gray's Zool. Misc., p. 82 (1814- nomen nudum); id. Proc. Zool. Soc. London 1845, p. 30 ("Nepal").

Horomis flaviventris Hodgson, Proc. Zool. Soc. London 1845, p. 31 („Nepal").

Lusciniopsis brevipennis Verreaux, Nouv. Arch. MIus, Paris, Bull. VI, p. 65 (1871Mupin).

Horomis enythrogenys Hume, Ibis 1872, p. 108 (unterhalb Darjiling).

Duneticola Mandelli Brooks, Stray Feathers III, p. 28t (1875- "Native Sikkim").

Cettia russula Slater, Ibis 1897, p. 171 (Kuatun in Fokien); vgl, Ibis 1900, p. 51. 
1. Schrvinge halb so lang wie die 2. oder etwas kürzer. - ôad. Ober-

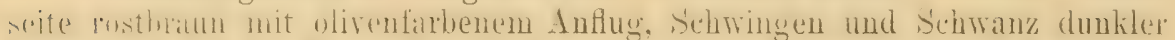
hrann mul nit der Fitrhe des Rückens gesäumt. Kurzer. undeutlicher, rost-

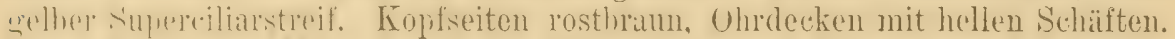
Krinn. Kehle und Mitte der übrigen Interseite weib. Seiten ansgedehnt röstlich lehmfintben. ehenso die L'nterschwanzdecten. die alner breite helle Säume

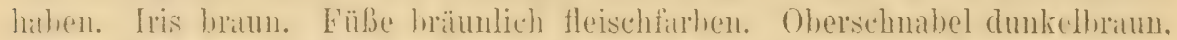
Tuterschnabel hellgellhlich. Das Herlsstkleid zeigt lehhaftere. rotbrüunlichere Farbun. hesonders sind die Kürperseiten mehr röstlich. Mitunter zeigen sich in Kehle und Kropf kleine dunkerhraune Elecke und ein grïulieher Anfug. wie es scheint, nur im Herbstkleide. - Flügel etwa 53-58 (wohl die

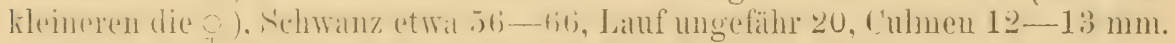
... Jur.: (Nestkleid.) [nterseite mit olirenfarbenen Federemelen: das erste Herbstkleid unten schwefelgelb.

Himalaya: Nepal, Sikkim, Butan (angeblich auch von Simla), bis

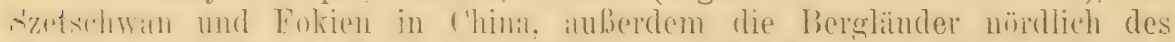

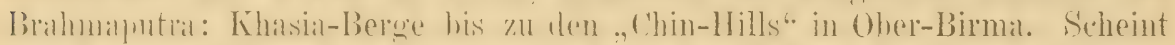

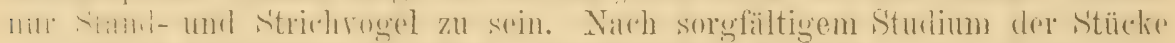

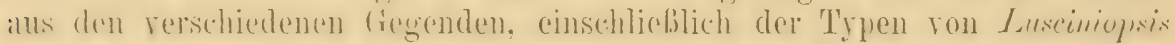
brevipenmis und Cettia russula, kann ich zwar individuello Variation, aher weder gengraphische Formen noch mehrere Spezies unterscheiden.

\section{(xittung LOCUSTELLA Kam, 1829.}

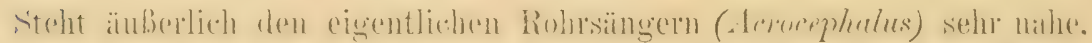

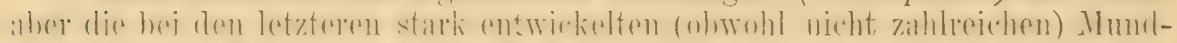

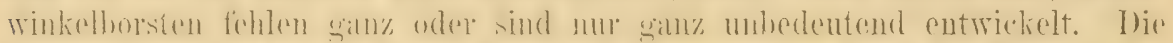

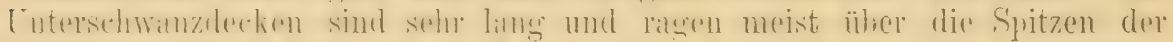

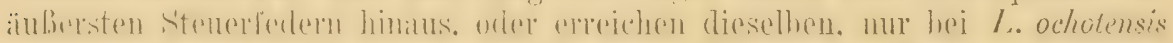
bleiben sie meist hinter denselben zurïck. Wenn anch nieht ansschlag-

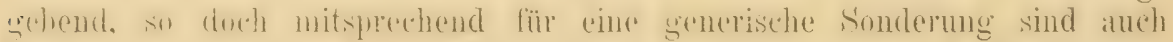

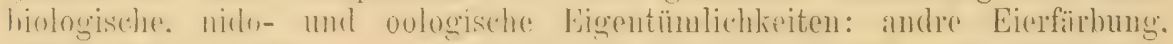

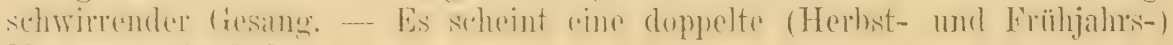
Manser stattzufinden.

(Oberseite scharf und deutlich braunschwarz gefleckt . . . . . . . 2

1 Uberseite einfirbig oder hüchstens mit angedenteter oder verwaschener Fleckung

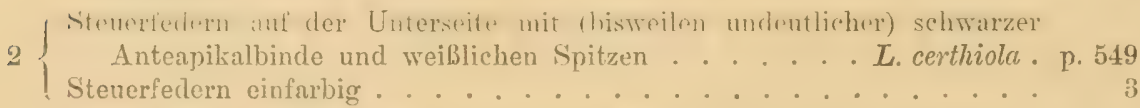

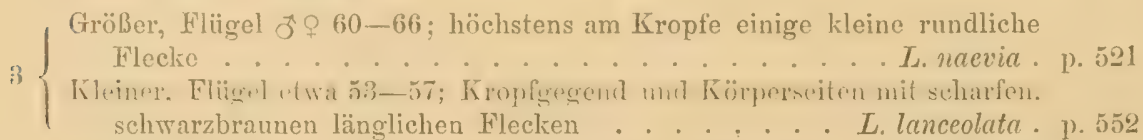

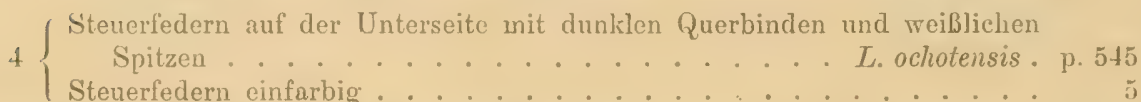

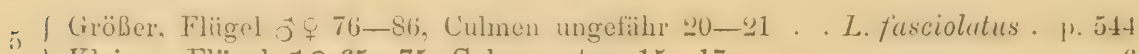

| Kleiner, Flingel $0^{7}$ $65-75$, Culmen etwa $15-17 \ldots \ldots$ 


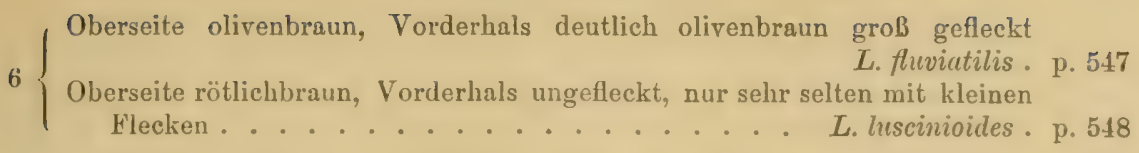

\section{-845. Locustella fasciolatus (Gray).}

Acrocephahus fasciolatus Gray, Proc. Zool. Soc. London 1860, p. 349 (Batjan). Acrocephalus insularis Wallace, Ibis 1862, p. 350 (Halmahera und Morty). Calamoherpe fumigata Swinhoe. Proc. Zool. Soc. London 1863, p. 91, 293 (Amoy). Calamoherpe subflavescens Elliot, Proc. Zool. Soc. London 1870, p. 243 (Daurien).

Abbild.: Cat. B. Brit. Mus. V, Taf. V.

1. Schwinge spitz, meist kïrzer als die Handecken, mitunter jedoch chen so lang oder ein weng länger. 2. kamm länger als 4., 3. am längsten. ơ ad. Oberseite braun (Ridgway's bisterhramn), auf Bürzel und Oberschwanzdecken, am Suhwanz und an den Auliensäumen der Oherflügeldecken und Schwingen etwas ins Rostbraune, auf dem Kopfe mol Hinterhalse mehr olivenfarben. Kurzer, schmaler, hell aschgrauer Superciliarstreif, Ohrogend braun mit weiBlichen Schaftlinien. Kehle und Mitte des Cnterkörpers weiß, Kropt' und Vorderbrust hell aschgratu, Kärpersciten und Schenkethefiederung gelblich olivenbraun, Entersehwanz- und Unterflïgeldecken fahl gelhbäunlich isahellfarben. Iris kaffeebraum. Oberschnabel dunkelbram, Lnterschnabel hellbraun. Füße hellbraun. Flügel etwa 82-86, schwanz etwa $68-75$, Lauf $27-29$, Culmen 20-21.5 mm. qad. wie ô ad., um etwas kleiner (Flügel meist $76-82 \mathrm{~mm}$ ). und in der Regel an der Vorderhust etwas brämnlicher. Herbst- und Frühlingskleid nicht verschieden, doch behalten jüngere rögol einen gelhlichen Schimmer mindestens ein Jahr Iang bei. Juv.: Oherseito viel dunkler, meist mehr olivenhraun, Unterseite maisgelh his schwefolgelb, Seiten bräunlich, Kropf und Torderbrust mit dunkeln Federspitzen, so daß diese Teile etwas wie geschuppt erscheinen.

Brutgebiet Ostsibirien vom Jenissei bis Sachaliu, am Lissuri und Amur. - Zieht auf der Wanderung dureh .Japan und ('hina und üherwintert anf den Philippinen, Nenguinea, Celehes und den umliegenden Inseln, den Molukken und Südost-Inseln (Ceramlaut, Teoor').

In Ostsibirien erscheint er nach Godlewski anfangs Juni. Er hält sich in dichtem, mit hohem Grase durchwachsenen Unterholze auf und ist wie seine V'erwandten ein vortreftlicher Schlüpfer. Der Gesang nerinnert an den Rhytmus einer Mazurka und läßt sich durch die Silben "touti-vouti, routi-touti" wiedergeben." Er singt selten am Tage, häufiger in der Nacht. Nest und Eier scheinen noch unbekannt zu sein.

\section{Locustella ochotensis (Midd.).}

Sylvia (Locustella) Ochotensis Middendorf,, Sibir. Reise II, 2, P. 185, Taf. XVI, Fig. 7 (1853 - Udskoj Ostrog).

Lusciniopsis japonica Cassin, P'roc. Acad. Philad. X, 1858, p. 193 (1859- Hakodadi). Locustslla subcerthiola Swinhoe, Ibis 1874, p. 154 (Hakodadi).

Arundinax blakistoni Swinhoe, Ibis 1876, p. 332 pl. VIII, Fig. 1 (Hakodadi)

Acrocephalus dybowsliii Ridgway, Proc. U. S. Nat. Mus. VI, p. 92 (188t- Kamtschatka. Ex Stejneger MIS.).

?Locustella pleskei Taczanowski, Proc. Zool. Soe. London 1889. p. 620 (kleine Inseln bei 'I'schimulpo, Korea, brütend).

Locustella hondoensis Stejneger, Proc. U. S. Nat. MIus. X VI, p. 957 (I893- Hondo, Japan). Abbild.: Pleske, Ornithogr. Ross., Taf. IV, 1, 2.

E. Hartert, Die Vögel der paläarktischen Region. 
(Ich habe mich nicht davon üherzengen können, daß die Form von Tschimulpo boi Korea versehieden ist. Das mir vorliegende alte ô (Cotypus, Mus. Berlepsch) hat einen nur unbedeutend längeren Schnabel, ein Stück von den Kurilen kommt ihm äußerst nahe und Zugrögel aus China und Japan kommen ihm gleich oder nahe. Sonstige größere Dimensionen haben die Tschimulpo-Exemplare nicht, der angehliche grauere Ton der Oberseite ist nicht maBgebend, weil er auch stücken von den Kurilen im abgetragenen Sommerkleide eigen ist.)

cad. Oherseite röstlich olivenhraun mit wenig bemerkbaren, im frischen Gefieder aber deutlichen, im alhgetragenen Gefieder ganz verschwindenden helleren Federrändern, die aher auf den Oberflügeldecken und Sehwingen deutlicher werden. Kurzer gramweißlicher Superciliarstreif. Zügel und dessen Fortsetzung hinterm Auge wie der Oberkopf; Ohrdecken olivenhraun mit hellen Shchäften. übrige Kopfseiten weißlich mit olivenlnäunliehen Spitzen. Mittlere Steuerfedern wie der Rücken, seitliche mit weißlichen Spitzen und an den Innenfahnen mit wenig bemerkharer dunkler Querbänderung. Lnterseite der Stenerfedern diusterer, die Querbänderung deutlicher, ror den weißlichen Sintzensäumen hreiter. Luterseite weib, mitunter schwach gelblieh angehaucht, Seiten und mitunter einen Selatten üher den Kropf hin hraun, etwas heller als der Rïuken. Am Vorderhalse zeigen sich mitunter, vermutlich nur bei nirbt sehr alten Tögeln, kluine. selten dentliehe brïunliche Flecke. Untersthwanzdecken hellnraun mit breiten weiben Spitzen, mitunter anch vor den Syitzen mit dunkelhramen S'chaitstreifen. Tnterflügeldecken und Axillaren rahmweiblich, an Bug mit dunkelhraunem Basalteile. Innensäume der Schwingen brännlich rahmfarhen. Iris dunkel gelbhraun. Oherschnabel dunkel hornhraun. Linterschnahel gell, lich hornfarben. Fübe hell gelhuräunlich. Flügel etwa 70-74.5, bei $ᄋ$ o und jungen Vögeln nur 63-70, Schrwanz 57-64.5, Lauf 24-25, Culmen $17-20 \mathrm{~mm}$. ㅇ wie o ${ }^{7}$, nur etwas kleiner. - Nateh der Herhstmaner seheint die Enterseite meist etwas gelhlicher, die

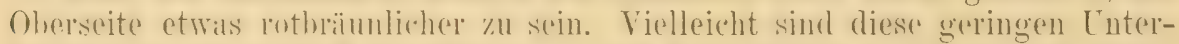
schiede nur jüngeren Vögeln eigen. - Ias Jugendileid ist aluweichend: Oherseite dunkler, mehr hraun, dire Federmitten dunkelhraun. so dibs sie deutlich

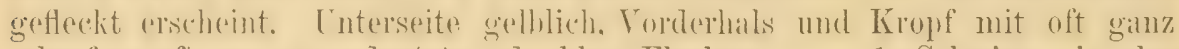
scharfer, oft nur angedeuteter dunkler Fleckung. - 1. Sehwinge in der

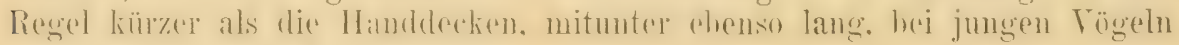
oft etwas länger. 3. am längrsten.

Brutrogel anf Kantsthatkat, an der sibiriseben Küste des Orhotskischen Meeres, auf der Schantar-Insel, auf den Kurilen und kleinen Inseln bei

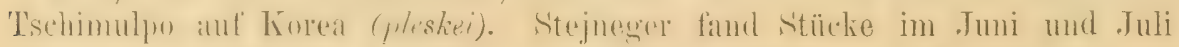
auf der Berings-Insel, wo die Art vermutlich nistet. - Auf dem Zuge in

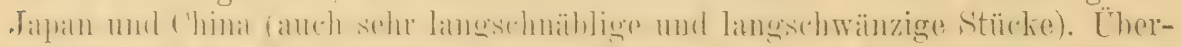

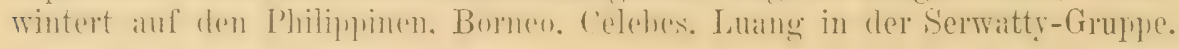

Wird noch bis gegen llitte MIai in Borneo und China angetroffen und erscheint an seinen Brutplätzen in Kamtschatka erst im Juni. Hält sich in dichtem Gebüsch, besonders Weidengesträuch auf. Singt besonders Nachts, Gesang nach Stejueger an das beim Wetzen einer Sense hervorgebrachte, wie witsche, witsche, witsche, witsch klingende Geräusch erinnernd. Nest oben offen, im Grase, nahe über dem Boden, aus trockenem Gras, mit Federn gefiittert. Die 5-6 Eier sind rosa, ohne Flecke, aber am stumpfen Ende mit sehr feinen schwarzen Adern gezeichnet. Gestalt ziemlich länglich, Masse von 6 Eiern nach 'laczanowski: Maximum $21.4>14.8$, Durchsehnitt $20.95 \times 14.3$, Minimum $20.5 \times 14.2$. 


\section{Locustella fluviatilis (Wolf).}

Flußrohrsänger, Flußschwirl.

Sylvin fluviatilis Wolf, Meyer \& Wolfs Taschenb. d. deutsch. Vögelkunde I, p. 299 (1810 - Ufer der Donau in Österreich).

Acrocephalus stagnatilis A. Naumann, Nat. Land- u. Wasser-Vög. nördl. Deutschl. Nachtr. 4, p. 202, Taf. 26, Fig. 53 (1811- Deutschland).

Locustella strepitans Brehm, Vogelfang, p. 233 (1855- Galizien).

Lusciniopsis fluviatilis alticeps, macrorhynchos, macroura A. E. Brehm, Verz. Samml., p. 6 (18t66- Nomina nuda)!

Threnetria gryllina Schaner, Journ. f. Orn. 1873, p. 183 (als passender Name für L. fluviatilis).

Locustella cicada Hansmann, Journ. f. Oın. 1873, p. 434 (neuer Name für L. fluviatilis).

ơ ad. Oberseite einfarbig olivenbraun, die meisten Federn mit bei gutem Lichte sichtbarer feiner Quenbünderung, Schwanz etwas brïunlicher, Schwingen dunkler und brïunlicher, mit etwas helleren und röstlicheren Säumen und äußerst feinen hellen Eundsäumen. Kopfseiten wie der Rücken. aber mit feinen weißlichen Schaftlinien. Mitte des Cnterkörpers und Keble weib oder weiblich, letztere sparsam his dicht olivenbram gefleckt. Krmfgegend olivenbräunlich verwaschen und olivenbram gefleckt. Körperseiten fahl olivenbraun. Lntersehwanzdecen hellhram mit olivenfarhenem Anflug und hreiten weißlichen Spitzen. Unterflïgeldecken fihl hellbrïmnlich, an del Wurzel dunkellraun. Innensïume der Schwingen fihl hräunlichgrau. Iris hellbraun. Fübe und Zehen hräinlich hornfarben. Sehnahel duntelbraun, Unterschnahel hellbraun. Flügel etwa $75-79$, Schwamz 56-64. Lauf 20 his 22 , ('ulmen $15-16 \mathrm{~mm}$. o wie 0 , mur etwas kleiner: Flügel ungeführ 70 - 75, Schwanz bis 54 , Culmen $14-15 \mathrm{~mm}$. - Das Jugendkleid ist anscheinend auf der Oberseite dunkler, mehr rosthriun, und die Fleckung des Vorderhalses sparsamer. 1. Schringe sehr kurz nud spitz, immer liürzer als die Handdeclien. 2. am lüugsten, 3. nur wenig. mitunter kaum kïr\%el' als die 2.

Brutrogel im mittleren und nördlichen RuBlaud, his Mittel-Finnland und bis zum 60." nördl. Br. im Cral, in den Ostsecprorinzen, Polen. Gălizien. im östlicheren Deutschland, Böhmen, Nieder-0̈)sterreich und Cngalm. -- In Rußland ist er in rinigen Gegenden, z. B. lee Meskatu und St. Petershurge häufig. doch glaubt Pleske, - Ornithogr. Ross. 1. 571 - dab or in S'ïd-Ruliland nur Durrhzingler ist (\%). In Dentschland sind die Brutplitt\% in Sehlesien

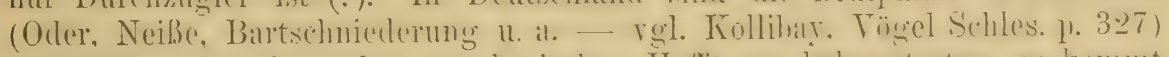

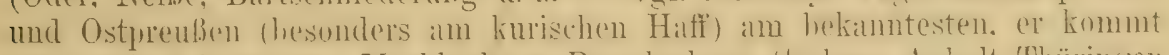

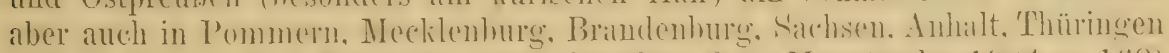

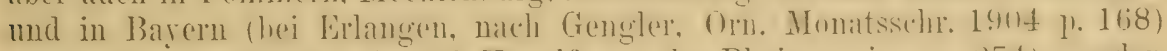

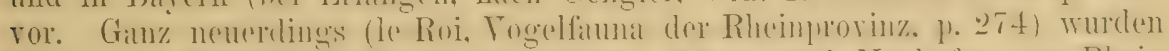

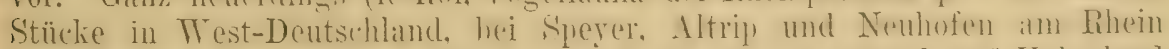
heobachtet und erlegt. - Fimmal anf sereland und cimmal anf Holgolamel

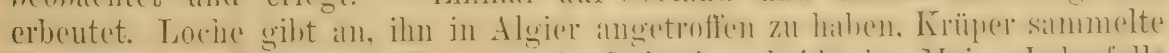

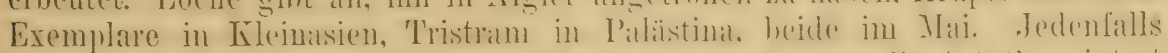
handelte es sich in diesen Fïllen um Inurchzugsriggel, demu lie Art üherwintert in Afrika: Alexander crbeutete ein Stiuck am Zimbesi. [onherty ein of im Dezember 1900 in den Kikuyu-Bergen, 6500 engl. Fuß hoch. 
Der Flußschwirl bewohnt vorzugsweise dichtes Ufergebüsch, außerdem aber auch Jungholz, wie Erlenstockausschlag und Birken, oder sogar dichtes Unterholz im Walde. Er scheint seinen Standort mitunter zu wechseln, vermutlich nach der Höhe des Bestandes und der Verwachsung der Ufergebüsche sich richtend. Je nach der geographischen Lage der Brutplätze trifft er Mitte April bis Mitte Mai ein. Der Gesang, der nach Lindner (Orn. Honatsschr. 1896, p. 207) von einem leisen drrrr, drrrr eingeleitet wird, besteht aus einem fast unbeschreiblichen derrr derr, derr derr, derr derr oder serrrser, serrserr, von dem von Loc. naevia leicht zu unterscheiden, da er mehr in e klingt (der von $L$. naevia in i), auch zwei der Silben rascher aufeinanderfolgen, als die nächsten beiden, so daß man den Gesang allenfalls „zweisilbig“ nennen kann. Das Nest steht an oder in einem Busche, oder im dichten Ptlanzengewirr am Boden. Es ist außen aus groben und breiten Grashalmen erbant, innen mit feinen Halmen und Stengeln, mitunter auch mit Pferdehaaren ausgelegt. Das Gelege besteht aus 4-5, selten 6 Eiern. Aus 3 Eiern bestehende Gelege sind wohl kaum vollzählig. Man findet in Deutschland die Eier von Anfang bis Ende Juni, weiter nach Südosten wohl etwas früher. Die Eier variieren in Färbung und Form, am meisten aber in der Größe. In der Regel sind sie ziemlich konstant eiförmig, mitunter aber länglicher und sogar spitz eiförmig. Meistens ist die Grundfarbe weiß mit sehr schwachem Glanze, über und über mit feinen graubraunen Punkten, die sich gegen das stumpfe Ende häufen und mitunter einen schwachen Kranz bilden, dazwischen eingestreut sieht man hellgraue Schalenflecke. Dieselbe Färbung kommt bisweilen viel gröber, großtleckiger vor, sodaß solche Eier an Grasmückeneier erinnern. Eier anderer Gelege sind hellrosa, fein rötlichgrau punktiert, den Eiem von Loc. naevia gleichend und ausnahmsweise ebenso klein, meist allerdings viel größer. Die schönsten Gelege sind weiß mit schwachem rosigen Hauch und mit lebhaft braunroten Flecken und Punkten, sowie wenigen rötlichgrauen Schalenflecken. Die Maße von 100 Eiern (79 aus der Rödernschen Sammlung, alle aus der Strachate bei Breslau, in Tring-Museum, 18 in Dr. Reys und 3 in Pfarrer Jourdains Sammlung) sind: Durchsehnitt $20.01 \times 15.12$, Maximum $22.3 \times 16$ und $20.9 \times 16.8$, Minimum $18 \times 14 \mathrm{~mm}$. Das Gewicht schwankt nach Rey zwischen 102 und 142 und beträgt im Durchschnitt $121 \mathrm{mg}$.

\section{Locustella luscinioides luscinioides (Sari).}

\section{Nachtigall-Rohrsänger.}

Sylvia luscinioides Savi, Nuovo Giorn. Letter. VII, p. 341 (1824- Pisa).

Pseudoluscinia Savii. Bonaparte, Geogr. \& Comp. List B. Eur. \& N. Amer., p. 12 (1838- Neubenennung von L. luscinioides).

Locustella Wodzickii Brehm, Vogelfang, p. 234 (1855- Galizien. Typus - ganz junger Vogel — vorhanden, Beschreibung verständlich).

Lusciniopsis luscinioides rufescens, macrorhynchos, brachyrhynchos A. E. Brehm, Verz. Samml., p. 6 (1866- Nomina unda!).

Threnetria Acheta Schauer. Journ. f. Orn. 1873, p. 183 (verbesserter Name!).

Locustella luscinioides Geyri Koenig, Journ. f. Orn. 1908, p. 123 (Rheinprovinz).

Engl.: Savi's Warbler. Franz.: Fauvette des Saules. Ital.: Salciaiola.

1. Sehwinge lanzettlich, kürzer als de Handdecken, 2. am längsten, 3. etwals kïrzer als 2. O : ad. Ganze Oherseite nebst Flügeln und Schwanz rötlichbraun mit olivenfurbenem Schimmer, ein heller Superciliarstreif ist nur angedeutet, Kopfseiten rötlichhraun mit rahmfarbenen Schaftstrichen. Auf Bürzel, Schwauz und Schwingen sieht man bei gutem Lichte eine feine Querbïnderung angedeutet. Unterseite falıl rötlichbraun, fast lebmfarben, Mitte der Kehle und des Unterkörpers weiß oder weißich, Spitzen der Untersehwanzdecken etwas heller. Innensüume der Schwingen brïunlich rahmfarben. Der untere Teil der Kehle zeigt mitunter, aber selten, dunkler braune Fleckung. 
Iris gelblichbraun, Obersehmabel dunkel hornbraun, Unterschnabel weiblich horufarben. Rachen gräulich fleisehfarben. Fübe hellhraun. o wie ò, nur etwas kleiner. Flügel ô etwa 69-72, o ungefïbr 65-67, Schwanz cetwa 58-61.5, Culmen o 76-17, o 15-15.5, Lauf 21-22 mm. - Im Sommer verbleicht das Gefieder merklich und wird mitunter auch etwas rithicher, „fuchsiger”. Der junge Vogel nach der ersten Mauser ist auf der Oherseite etwas dunkler und die Unterseite ist in der Mitte weniger weiß und intensiver gefürbt. Der junge Nestvogel ist auf der Lnterseite mehr rötlich, weniger brïunlich, anf der Oberseite etwas dunkler.

Brïtet in Nordwest-Afrika (Agier), Spanien, Frankreich (Südfrankreich, und bei Nantes - an der unteren Loire durch Bureiu hïutig' brïtend heobachtet) Holland und an den Krickenbecker Seen im Kreise Geldern im Rheinland mahe der hollïudischen Grenze (früher in den sumpfigen Gegrenden des östlichen Euglands), in Italien, Sizilien, Lngarn. Galizien, Polen, dem mittleren und siddlichen Rubland bis zum Wolgat-I)elta, an deu Ufern der unteren Donau, in Bulgarien, Rumänien. Aus Schlesien liegen keine zuverlïssigen Augahen vor. Ob hei (nenburg erlegte Stiicke dieser Form oder L. c. fuscu angehören. muß der Vergleich der Lixemplare ergehen. Shelley fand ihn ziemlich häufig in Unterägyjten brütend. - C̈ber den Zug wissen wir so gut wie nichts. Lilford erlegte am 21. Mai 1875 auf Cypern ein Exemplar. Tristram fand ihn im Winter am Nordrande der Sahara, und imm 1. April in Palästina, auch ist er in Ägypten nach Shelley Standrogel mol soll mitunter in Südeuropa üherwintern. Nördlicher wohuende Nachtigallrohrsänger sind indessen Zugrögel und werden vermutlich weiter nach Sïden ziehen, und eines Targes (wie L. Alurutilis) im tropischen Afriki beohachtet werden.

Der seiner einfachen Farbe wegen gar nicht iibel so genannte Nachtigallrohrsänger ist mehr Sumpfrogel als $L$. naevia und $L$. fluviatilis. Er bewolnt sumpfiges Gelände, wo das Wasser am Boden steht und wo man waten mub, mitunter ausgedehnten reinen Rohrwald, in der Regel aher Gelände wo Arundo, Carex, Juneus und Typha aus dem Wasser und Morast wachsen und mit einzelnen Sahlweiden, Erlen, Birken, Myrica und anderen Büschen durchsetzt sind. In Ägypten beobachtete Shelley ibn auch in üppigen Getreidefeldern. Der Gesang ist dem von $L$. nacvia ähnlich, klingt aber gedämpfter und viel tiefer, mehr wie örrrrrrrrr oder ïrrmrrrrr. Das Nest steht in der Regel nahe über dem Wasserspiegel, auf umgeknicktem Schilf oder unten in den Schilfbüschen, selten auf Graskufen. Es besteht ganz aus Schilfhalmen, die in der Mitte feiner und fester gefügt sind, und hat einen ziemlich tiefen Napf. Die Zahl der Eier ist in der Regel 5 und man findet die Gelege von Ende MLai bis Ende Juni. Die Eier haben das Gepräge derer der verwandten Arten. Sie sind weiß, mit bald äußerst dicht stehenden, bald sparsameren graubraunen, rötlichbraunen bis (selten) braunroten Punkten und Flecken bedeckt, die mit bläulichgrauen Schalenflecken untermischt sind; mitunter sieht man auch kurze, feine schwarze Linien. 73 Eier, meist aus Ungarn, einige aus Hoblland und England, gemessen von Jourdain, Rey und mir, messen im Durchschnitt $19.72 \times 14.59$, Maximum $21.5 \times 15$ und $20.7 \times 15.4$, Minimum $17.8 \times 14.7$ und $18 \times 14 \mathrm{~mm}$. Das mittlere Gewicht nach Rey (3 Eier) $111 \mathrm{mg}$.

\section{Locustella luscinioides fusca (Sev.).}

Cettia fusca Severtzow, Turkest. Jevotn. (in Izr. Obshch. Moskov. VIII, 2), p. 131 (1873Syr Darja bei Aris und Tschimkent); Übers. in Zeitschr. ges. Orn. IV, p. 88. 
Enterscheidet sich von L. luscinioiles lusinioides durch hlassere, wenger rötlichbrane, mehr olivenhrame oherseite, blassere Körperseiten und hellere, mehl weißliche Unterschwanzdecken.

T'rauskanpien und Turkestan (Tedschen, Artyk, Askabad, Bagyr, Syr Darja, Djarkent u. a.). - Winteraufenthalt noch nicht festgestellt.

\section{- 850. Locustella certhiola (Pall.).}

Motacilla Certhiola Pallas, Zoogr. Rosso-Asiat. I, p. 509 (1827- „in regionum ultra Baicalem lacum sitarum arbustis et nemoribus non infrequens." Die Beschreibung läßt zu wünschen übrig, ist aber nicht widersprechend genug, um den fast 100 Jahre angewandten Namen zu ändern).

Locustella rubescens Blyth, Journ. As. Soc. Bengal XIV, p. 582 (1845-Calcutta).

? Iocustella temporalis Jerdon, B. India II, p. 160 (1863- am Ganges. Nomen nudum, im Text).

Calamodyta Doriae Salvadori, Atti R. Acc. Sc. Torino III, p. 531 (1868- Sarawak in Borneo).

Locustella minor David \& Oustalet, Ois. Chine, p. 250 (1877- Peking).

.Calamodus phragmitis major v. O. Sib." (sic) Grabowski, in Mus. Homeyer, p. 7 (1893- nomen nudum!).

Abbild.: Dresser, B. Europe II Taf. 94; Ibis 1876 'Taf. II, Fig. 2. — Lier: Journ. f. Orn. 1873, I. Fig. 4-5.

1. Schwinge so lang wie oder länger als die Handdecken, mitunter anch etwals kü1\%(r. 3. Shchwinge am längsten, 4. nur wenig kürzer, 2. zwischen der t. und 5. oder gleirh einer derselhen. Oad. Oherseite lehmbraun, bald etras lehbafter, hald matter, die Federn des Oherkopfes schwarzhaum mit lehmbramen Sïmmen, die am Genick mehr aschgran werden. die des Rürckens und oft anch die des Hintrihalses mit ausgedehnten bratunschwarzen Schalt-

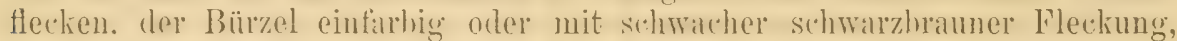
die Oherschwanzdecken wioder mit gröberen sehmilrzlichen schaftfectien. Schwingen gratuhram mit ginz schmalen hellen Spitzensäumen und lohmbraunen Aubenrändern, die inneren Armsehwingen dunkelhraun mit hell lehmbranen Sämmen, die an don Snitzen am hellsten sind. Stenerfedern dunliel olirenfarben mit branschwarzen, ineinanderflichenden, vor der Spitze

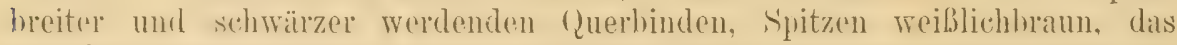
mittelste I'arr lehmbram mit schmaler heller spitze und anteapikalem schwarzen Fleck. Schmaler weißlichbrauner Smpereiliarstreif. Ohrogegenel bellhraun mit

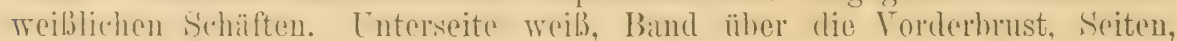
Sehenkel und Unterschwanzdecken hlab lehmgelhlich. Spitzen dor letzteren weiblich Kropfogegend mitunter habluaun gefleckt. Innensïume der Schwingen weiblichgtan. Lnterflügehleckren und Axillaren weiblich. Iris lichthraun, Fübe. Zehen mut Krablen gelhlich hornfatren, Ohersehnahel hornbram, Ränder des-

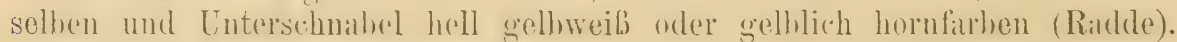
Flügel 64-69, Schwasz ungeführ 50-55, Lauf 20-22,5, Culmen etwa 15-16, nach Pleske zuweilon auch $17.5 \mathrm{~mm}$. क wie 0 . aber kleiner, auBerdem ist die beim alten o nur sehr selten geflectite Kropfgegend öfter und wie es scheint meistens fein braun gefleckt. Flügel etwa $59-62 \mathrm{~mm}$, Sehwanz 48-52 mm. Jux.: Fïrhung der Oherseite etwas lehhafter, Lnterseite hollgellulieh lehmfarhen, untere Kehle und Kropf fast strots mehr oder minder dicht mit dreieckigen srohwarghraunen Flecken besetzt. Es secheint 
daß junge Vögel nach der ersten Herbstmauser auch noch gelbe Lnterseite. haben, die sie aber nach der ersten Frühlingsmauser verlieren.

Brutrogel in Sibirien rom Gouvernement Tomsk (Herm. Johansen) und Jenissei (bei Jenisseisk, Seebohm), im Altui-System und ostwïrts his zu den Ufern des Stillen Ozeans, nördlich mindestens bis zur Amur-Mündung. Überwintert in Indien (Bengalen, Andamanen, C'eylon), Birmalı, den großen Sunda-Inseln und Natuna-Inseln. Am 13. August 1856 auf Helgoland gefangen. Die bisherigen Angahen rom Torkommen in RuBland sind zweifelhaft (vgl. Pleske, Ornithogr. Ross., p. 600).

Bewohnt mit hohen Grasarten und Gebiisch bestandene feuchte und trockene Wiesen und Dickichte an den Flußufern, auch dichte Gebüsche von Artemisia (Przewalski), Chenopodien und Binsen (Radde). In der zweiten Hälfte des Mai scheint er in der Regel erst an seine Brutplätze in Sibirien zurückzukehren. Das Männchen singt auf der Spitze einer Staude sitzend und schwingt sich zuweilen singend in die Höhe. Eine Beschreibung des Gesanges habe ich nirgends gefunden. Die leichtfertigerweise auch, trotz Pleskes Auseinaudersetzungen, im "Neuen Naumann" wiedergegebene Beschreibung von Kittlitz bezieht sich auf Locustella ochotensis. Nach Dybowski baut L. certhiola Mitte Juni sein Nest in einem Grasbüschel. Das Gelege besteht aus 4-6, meist 5 Eiern; dieselben sind mitunter rosa ohne Zeichnung oder mit äußerst feiner, kaum bemerkbarer dunkler Fleckung, etwas dunkler am stumpfen Ende; andere Gelege sind heller rosa, über und über mit kleinen rötlichbraunen Punkten bedeckt, die sich am stumpfen Ėnde häufen oder einen Kranz bilden, außerdem haben sie oft am stumpfen $\mathrm{Pol}$ einige schwarze Adern. 9 Eier vom Argunj messen im Durchschnitt $18.5 \times 13.8$, Maximum $19 \times 14.2$, Minimum $18.3 \times 13,3 \mathrm{~mm}$.

\section{Locustella naevia naevia (Bodd.). (Fig. 103.)}

Heuschreckensänger.

Motacilla naevia Boddaert, Tabl. Pl. Enl., p. 35 (1783- ex Daubenton, Pl. Enl. 531, Fig. 3 \& Brisson, Orn. III, p. 389 . Es ist klar, daß Boddaert der guten Daubentonschen Abbild. den Namen M. naevia gab, den er Brissons "Curruca naevia" entnahm; obwohl Brissons "C. naevia" m. E. ganz unsicher ist, muß daher Boddaerts Name angenommen werden. Übrigens identificierte Buffon [Hist. Nat. Ois. V, p. 149] seine Faurette tachetée mit der oben zitierten Abbildung, obwohl im selben Bande, p. 42 Montbeillard schon die "Locustelle" nach englischen Autoren beschrieben hatte).

Sylvia Locustella Latham, Index Orn. II, p. 515 (1790 — ,Suecia, Sibiria, Europa Anglia").

Muscipeta olivacea Koch, Syst. d. baier. Zool. I, p. 167 (1816- am Bodensee).

Calamoherpe tenuirostris Brehm, Handb. Naturg. Vog. Deutschl., p. 440 (1831Kahla a. đ. Saale, Beschreibung übertrieben; Typus vorhanden).

Locustella sibilans Gould, B. of Europe, im Text zu 'Taf. 102 (1837- nomen nudum!). Locustella avicula "Ray" Gould, B. Europe, 'T'af. 103 (1837- Europa).

Locustella Rayi "Gould" Bonaparte, Comp. List B. Europe \& N. Amer., p. 12 (1838"Gould, pl. 103. Europe generally").

Locustella vera. Loc. anthirostris und "Sylvia lanceolata" (non Temminck!) Brehm, Vogelfang, p. 234 (1855_- "Deutschland“).

Locustella vera major, fruticeti A. E. Brehm, Verz. Samml., p. 6 (1866- Nomina unda)! Locustella gryllus Hansmann, Journ. f. Orn. 1873, p. 434 (Never Name für L. naevia).

Engl.: Grasshopper-Warbler. Franz.: Locustelle tachetée. Ital.: Forapaglie macchiettato. 
1. Schwinge etwas kïrzer bis etwas länger als die Handdecken. 3. am lïngsten, 2. in der Rogel lïnger als die t, nur äuberst selten zwisehen der 4. und 5. Oad. Oberseite gräulich olivenbraun, jede Feder mit braunschwarzem Längsfleck, so daß die Oherseite tiefbraun gefleckt erscheint. Auf
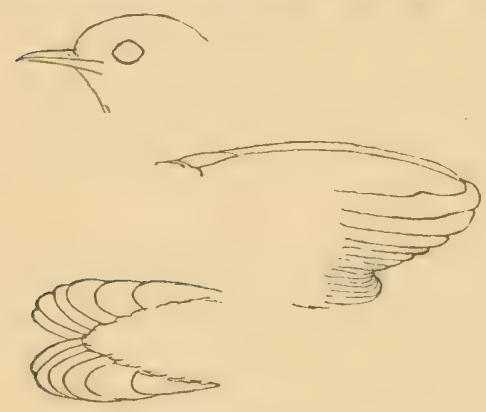

Higur $103\left({ }^{2} / 3\right)$.

Bürzel und Oberschwanzdecken wird diese F'leckung mehr oder minder undeutlich, sie wird auch kurz nach der Mauser durch die damm breiteren olivengraubräunlichen Federränder mehr verdeckt, während sie im abgetragenen Kleide mehr hervortritt. Im frischen Gefieder ist die Grundfarbe mehr braun, nach der Brutzeit blasser, und ist dann, besonders an den Flügeln, stark verblichen. Schwingen olivenbraun, dunkler als der Rïcken, aber nicht so dunkel wie die Federmitten daselbst, mit der hellereu Farbe des Rückens gesäumt.

Steuerfederu wie die Schwingen, mit undcutlichen helleren Sïumen, hei gutem Lichte meist mit angedenteten dunklen Querbinden. Dureh die Zügel zicht ein weißlichgrauer Supereiliarstreif. der hinter dem Auge nur undeutlich fortgesetat ist. Luterseite schmutzig weiß, über die Kropfoegend ein lichtbrames Band, dariiher meist eine Reihe kleiner dunkelbrauner Flecken. Unterschwanzdede'n bräunlich rahmfarben mit dunkelbrauner Federnitten. Iris dunkelbran. Oberschmabel dunkelhriun, Lntersetmabel hell griunlich hornfarthen. Fülie hell bräunlich fleischfarben. - Bei cinzelnen frisch vermanserten Frühlingswögeh (am schënsten an einem alten, am 6. Mai ron

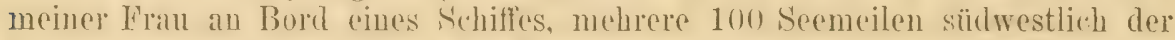
Scilly-Inseln erlegten ) ist die Conterseite schön schwefolgello, die Flecke an dere unteren Kichle sind oft nur wenig ansgehildet oder fehlen gamz. Junge Vïgel sehen drm alten ähnlich, doch scheint die Kohle ausgedehnter und dieliter geflecelt, die Lnterseite bräunlicher voler gelblich, die Cberseite etwals

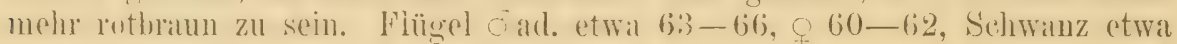
50-56, Lauf 18-21, Schnabel etra 13-14.5 mm.

Brutgebiet: Nittel- und Teile ron Südemrepa: Großbritannien und Irland, Holland und Pelgien, Dänemark, rereinzelt in Süd-Norwegen und Finland, Dentschland, Polen, den Ostseequrovinzen, Süd- und Mittel-RuBland, nordwiirts his St. T'etershurg und zum Onegal-see (nach P'leske stehen Stiücke alus ZentralRubland, hesonders Moskan, in (rö̈be und Fïrbung zwischen I. n. meria und l., n. strminere, Österreich-Lngarn. Sichweiz, Frankreich. Nord-śpanien, Nord- und Nittel-Italien (selten). - In Süd-Spannie'n vermutlich nur I)urchzugstogel und Wintergast, in der Regel alser in Nordafrika (Narokiko und Algier) überwinternd.

Bewohnt feuchte mit Buschwerk bestandene Wiesen, Weidengebüsche, lichte, dicht mit Unterholz durchwachsene Laubwälder, Buschdickichte an Sümpfen, Seen, Flußläufen, T'eichen, mitunter auch dichten Jungwald, (selbst von Nadelholz), Getreideund Kleefelder, ist aber eigentlich nirgends häufig. Am 'Tage sehr ruhig und versteckt, in früher Morgenstunde und Abends aber munterer und dann regelmäßig singend. Der Gesang ist ein eintöniges, wie Sirrrr.... klingendes Schwirren. Das Nest steht am Boden oder sehr nahe über demselben und enthält 5-6 (selten 7) Eier. Diese sind matt rosa, über und iiber mit feinen rostroten bis rotbraunen Punkten und Flecken 
bedeckt, und es messen 37 von Rey gemesserie Stücke im Maximum $18.2 \times 13.4$ und $17.5 \times 13.8$, Durchschnitt $17.1 \times 13.3$, Ninimum $16.1 \times 12.5 \mathrm{~mm}$. Durchschnittliches Gewicht nach Rey $94.5 \mathrm{mg}$.

\section{- 852. Locustella naevia straminea Seeb.}

Acridiornis straminea Sewertzow, Turkest. Jevotn. (in Jzv. Obshch. Moskov. VIII), p. 66 (1873-- Nomen nudum! - Turkestan).

Locustella straminea Seebohm, Cat. B. Brit. Mus. V, p. 117 (1881- Beschreibung)! Abb.: Dresser, B. Europe IX, Taf. 652.

Etrvas kleiner: Flügel $0^{7}$ etwa $57-60$, Flügelspitze in der Regel weniger spitz, indem die 2. Schwinge merklich kürzer ist als die 4. Auherdem ist der Farbenton der Oberseite in der Regel deutlich mehr olivenfarben, weniger bräunlich. In übrigen wie $J$. nueviu naeviu. Die Fleckenzeichnung ist dieselbe.

Vom Ural (Orenburg) ostwärts bis zum Altai, Transkaspien und Turkestan, und im Kaukasus. Aus einem im Juni im nördlichen Sikkim (Himalaya) erlegten Stück wurde geschlossen, dalb die Form anch im Himalaya brüte, was aber noch nicht festgestellt wurde. - Wintergast in den Ebenen Indiens, von September bis April.

\section{Locustella lanceolata (Temm.)}

Sylvia lanceolata 'Temminck, Man. d' Orn. Ed. II, IV, p. 614 (1810 - angeblich von Mainz, was sich als Irrtum erwies. Bruch erhielt sie aus Rußland. ohne Lokalitätsangabe).

Lusciniopsis Hendersonii Cassin, Proc. Phil. Ac. Sci., p. 194 (1858- Jesso, Japan). Locustella minuta und macropus Swinhoe, Proc. Zool. Soc. London 1863, p. 93 (Amoy in Sïdost-China).

Locustella subsignata Hume. Stray Feathers I, p. 409 (1873- Port Blair, Andamanen). Abbild.: Werner, Atlas, Insect., 'I'af. ohne Nr.; Dresser B. Europe II, Taf. 92, Fig. 2; "Neuer Naumann" II, Tuf. I, Fig. 2, 4. - Ei: Cat. Eggs Br. Mus. IV, T'af. IX, Fig. 9.

$\delta$ o ad. 1. Schwinge in der Regel so lang wie oder etwas länger als die Handdecken. 3. Schwinge am längsten, 2. zwisthen 3. und 4., gleich der 4. oder (seltener) zwischen der 4. und 5. - Oberseite lehmbram mit olivenfarbenem Anflug, jede Feder mit braunschwarzem Längsfleck. Schwingen braun, mit schmalen Aubensïumen von der Farbe des Rïckens, innere Armschwingen dunkler, fast schwarzhraun. mit hreiteren hellen Siimmen. Steuerfedern einförmig olivenbrum mit undentlichen helleren Säumen. Fin wenig ausgeprägter, oft kamm benerkbarer lichthaumer Superciliarstreif. Ohrgegend braun mit weiblichen Schäften. Unterseite hlab strobgelh, Nitte vou Kchle und Cnterkörper fast weißlich, Seiten lehmbräunirch. Vorderbrust und seiten mit dunkelhraumen Iä̈ngstreifen, Kehle und Mitte des Cnterhiurper's ungestreift. Untersehwanzdecken hellhram, an den Spitzon lichter und mit dunkelbranuen Schaftstrichen, die den längeren Federn oft fehlen. Oherschnabel dunkelbram, Enterschnabel hell hornbraun: Füfe hab gellbräunlich; Iris braun. Flügel etwa 53-57, Schwauz 44-47. Iauf 18-19. ('ulmeu $12.5-13.5 \mathrm{~mm}$ o wie $\sigma^{\top}$, doch dürften sie kleiner sein (Flïgel 53-54?). - Das Sommerkleid ist natiulich etwas bleicher, das frischvemauserte Gefiecler lebhafter, bräunlicher. Junge Tögel sind mehr gell, auf der Lnterseite, scheinen sich aber sonst nicht wesentlich von alten zu unterscheiden. 
Brutrogel ron Kamtschatka, den Kurilen (Iturup), Nord-Jesso (Nemuro) und Silchaliu durch Silirien, auth in Trestsibirien (Gouvernement Tomsk, nath Johansen, Orn. Jahrb. 1902, p. 166) und selten in Rul.jand: Neves erlegte ein singendes o am 9. Juli 1869 an der Onega. (D)ie Angahen von Blasius üher das Vorkommen in Südrubland dïrften unrichtiog sein. Vel. Pleske Orn. Ross., p. 629.) - Auf dem Zuge in Japan und ('ihna, überwinternd in Birma, Indien his litawah, Tenasserim, Andamanen, Süd-China und Hainan, Bormeo, vermutlich auch auf anderen Inseln.

Wohnt in feuchten Waldpartien und auf Sumpfgelände, nassen, mit Buschwerk bestandenen Wiesen. Auf dem Zuge fand Maack sie in Weidengebüsch an Flußufern, Radde im Seggengras an den Rändern von Wasserlachen. Scheint um den 20. Мai oder später au seinen Brutplätzen einzutreffen. Der Gesang ist ein .ppeifender, vibrierender 'l'on, der an das Schwirren der Locusten erinnert, und an Stärke wechselt". Singt fast den ganzen 'Tag. Das Nest steht an nassen Stellen und wird von überhängenden Grasbüscheln verborgen. Es ist aus trockenen, schmalen Grashalmen erbaut und mit dickeren Halmen vermischt. Am Außenrande sind Blätter von Vaccinien usw. eingeflochten, die Jlulde ist mit feiueren Grashalmen ausgelegt. Die 5 Eier gleichen denen von $L$. naevia, sind aber kleiner. Die Maße von 2 Eiern aus Kultuk sind: $17.8 \times 13$ und $17.4 \times 12.8 \mathrm{~mm}$.

\section{Gattung PHRAGAMATICOLA Jerl. 1845.}

Phragumaticola Jerdon, Madras Journal Lit. \& Sc. XIII, no 31, p. 129 (1845 - ex Blyth. MI.S. Beschreibung der Untersehiede von "Sphenura" und der Färbung, also nicht nomen nudum! No. 31 ist datiert "December 1844", auf dem Titelblatt des Bandes aber steht "1845").

Arundinax Blyth, Journ. As. Soc. Bengal XIV, Teil II, p. 595 (1845 oder 1846 . Da

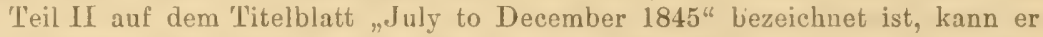
frïhestens Ende 1815, wahrscheinlich aber erst 1816, erschienen sein, also jedenfalls später als der XIII. Band des Madras Journal).

Gekennze'iehnet durch sehr dicken, kurzen, gewölhten schnabel, starke Schnahelborsten (3-4 starke und einige schwache Borsten an jedem Mundwinkel), langen, starkgestuften, schnialfedrigen Sehwanz und lange 1. Schwinge, die fist donpelt so lang, nümlich $18-26 \mathrm{~mm}$ lïnger als die Handdecken ist. Von llevbivondu durch viol bedentendere Gröbse, noch viel stärkere Borsten und den langen, gestuften S'chwanz, von Lusciniolu durch dio Bursten,

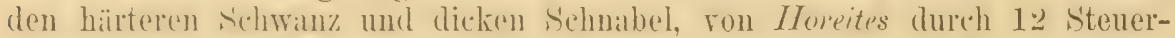

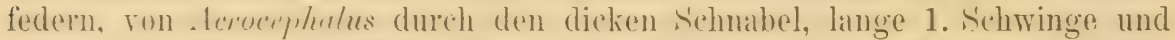
langen Schwinz z.u unterscheiden. - lis scheint nur eine Mauser im Jahre, im Sommer und Herbst, stattzufinden.

\section{5t. Phragamaticola aëdon (Pall.). (Fig. 104, 105.)}

Muscicapa Aëdon Pallas, Reise d. versch. Prov. Russ. Reichs III, p. 695 (1776 - Daurien). Phragamaticola olivacea Jerdon, Madras Joum. Lit. \& Sc. XIII pt. II, p. 129 (1845ex Blyth. M. S., Nellore in Süd-Indien).

Abbild.: Schrenck, Reis. \& Forsch. im Amur-Lande Bd. I, Lief. II Taf. XII, Fig. 1, 2, 3; Pleske, Aves Przewalsk. II, 'Taf. III, Hig. 1; Ei: Cat. Eggs Brit. Mus. IV, 'Tat. X, Fig. 7, Ibis 1904 'Taf. X, Fig. 1, 2.

2. Schwinge zwischen der 6. und 8., 3. und 4. gleich lang und am lïngsten. Farbung fast ganz wie die von Arocephalus anmolinarens. Oberseite im Herbstlicide olivenbrïunlich isibellfarben mit roströtichem Anflug. 
der in der Brutzeit fast versehwindet; Bürzel etwas mehr rostfarben, ebenso die Säume der Armschwingen und Oberflügeldecken. Zïgel weiblich isithell, ebenso die Befiederung der Augenlider. Superciliarstreif nicht vorhanden. Ohrdecken heller als die Oberseite und mit ganz lichten Schaftlinien. Schwingen dunkel olivenbraun, mit isabellfarbenen Innensäumen und schmalen AuBensäumen von der Färbung des Rückens. Steuerfedern etwas dunkler als der Rüicken und mit helleren Süumen. Unterseite nebst Unterschwanz und Unterflügeldecken ockergelblich, Kehle und Mitte des Unterkörpers weißlich, in der Brutzeit heller; blasser; $q$ wie $\sigma^{*}$. Juv. Oberseite etwas mehr

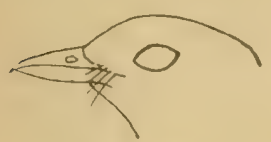

Fig. 104 roströtlich, Unterseite lebbafter ockergelblich. Iris braun. Füße bleigrau, Krallen hornbrätunlich. Oberschnabel dunkel hornbraun, Schneiden desselben sowie Unterschnabel hell hornbräunlich. Flügel ठ ungeführ $81-86$, ㅇ 75 bis

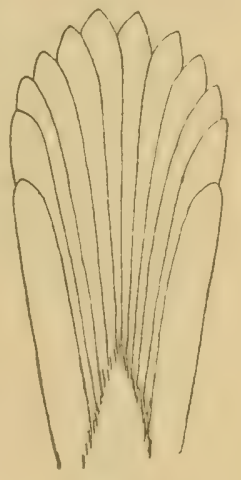

Fig. 105.

77, Schwanz 80--91, die äubere Steuerfecler 18-26 mm kür\%er, meist otwa 85, Lauf 25-28.5, Culmen 17-19 mm.

Brïtet im sïdlichen Sibirien rom Tschulym-Tale im Marinsker Kreise des Gouveruements Tomsk his zum Stillen Ozean, in der Mandschurei und Nord-China (Tsin-ling Berge). - C̈berwintert in Indien, anf den Andamanen, der Malakka-Halbinsel und in Birma.

Bewohnt feuchte, mit Rohr und Gebüsch bestandene IViesen, Fluß- und SeeUfer. Lockruf nach Schrenck wie „tschok, tschok", Gesang laut, schön, manche Strophen an die der Sprossers erinnernd, besonders nächtlich zu hören. Nester in Büschen, wie die der Rohrsänger befestigt, aus Gras gebaut (Dyborski). Die 5-6 Eier sind von der gewöhnlichen Eiform. Grundfarbe schmutzig rosenrot, hell rosiggrau oder roströtlich mit dunkleren bräunlichen Schalenflecken und mit schwarkbaunen Strichen, Kritzeln und Haarzïgen wie Ammern-Eier. Sie messen $24-24 \times 16-17 \mathrm{~mm}$.

\section{Gattung ACROCEPHALUS Naum. 1811.}

Dera allgemeinen Brauche erfahrener Ornithologen folgend vereinige ich alle echten Kohrsänger unter einem Gattungsuamen. Wollte man eine T'eilung rornehmen, mïßte sowohl A. aquaticus wegen seines steiferen Schwanzes, als auch der schmalschnäblige $A$. schoenobaenus von den breitschnäbligeren Formen (aquaticus, palustris u. a.) getrennt werden, dann aber läßt sich avundinaceus nicht ohne Zwang unterbringen, und gleiche Schwierigkeiten bereiten einige asiatische Formen. Eine Trennung ist daher unangebracht. Ich betrachte somit die Namen Muscipeta, Calamoherpe, Calamodus, Calamodyta, Hydrocopsychus, Arnudinaceus, Salicaria, Junco, Eparnetes, Caricicola, Notiocichla und Anteliocichla Oberh. 1905, und sogar Tatare als Synonyme.

Schnabel bald wie der von Lorustella, bald so flach wie bei Hippoluis, bald intermediär. 1. Schwinge meist sehr kurz und spitz. Der zwölfferlrige, meist verhältnismälBig weiche Schwanz ist gestuft octer doch sehr stark gerundet. An der Sebnabelbasis stehen nur wenige Borsten. Am ziemlich langen Latuf sind die einzelnen Selhilder auch hei alten Vögehn noch kenntlich. Cieschlechter gleich, Jugendkleir dem der alten Vüget vollkommen gleich oder doch sehr ähnlich. Klettern und schlüpfen meisterhaft in Rohr und Gebüsch, banen an 
Stengel, Rohr und Zweige hefestigte Nester. Locktöne laut, schmatzend, W'arnruf ein knarrendes rmrr, Gesing laut, schön, fast immer mit sehnarrenden, quarrenden, knarrenden und knisternden Tönen vermischt. Die meisten Arten sind Zugzügel. Doppelte Mauser. Europa, Afrikil, Asien, Australien und einige Inseln des Stillen Ozeans, in Amerika fehlend.

1 f Oberkopf einfarbig. . . . . . . . . . . . . . . 2

$1\{$ Oberkopf nicht einfarbig ................ 8

2 Kleiner, Flügel unter $73 \mathrm{~mm} \ldots \ldots \ldots \ldots$. . . . . . . . . .

|Größer, Hlügel über $73 \mathrm{~mm} \ldots \ldots \ldots$. . . . . . . . . .

3 2. Schwinge länger als die $5 . \ldots \ldots \ldots \ldots \ldots$

\{2. Schwinge kürzer als die $5 \ldots \ldots \ldots \ldots$. . . . . . . . .

Einkerbung der Innenfahne der 2. Schwinge zwischen den Spitzen der Armschwingen und dem Ende der 8., Oberseite mehr isabellbraun, nicht (oder bei A. s. macronyx doch wenigstens uicht so stark) ins (Oliven-

4 braune ziehend ....................... strepera. p. 560

Einkerhung der Innenfahue der 2. Schwinge vor dem Ende der 8., Oberseite alter Vöggel viel weniger röstlich, mehr ins Olivenfarbene ziehend

A. palustris . p. 562

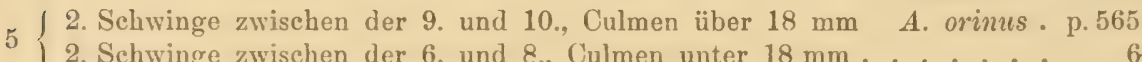

$6\left\{\begin{array}{l}\text { Sehwanz länger, etwa so lang wie der Fliigel, Oberseite röstlicher . A agricola. p. } 561 \\ \text { A. }\end{array}\right.$

Schwanz kürzer, ungefähr $5 \mathrm{~mm}$ kürzer als der Flügel, Oberseite mehr olivenbräunlich . . . . . . . . . . A. dumetorum • p. 563

7 | 2. Schwinge länger als die 5.......... A. arundinacens . p. 556

$7\{$ 2. Sehwinge kürzer als die $5 \ldots \ldots \ldots$. . . . . stentorea. p. 559

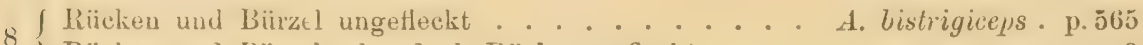

| Rücken und Bürzel oder doch Rücken gefleckt. . . . . . . . 9 9

9 $\left\{\right.$ 2. Schwinge kïzer als die $6 \ldots \ldots$. . . sorgophila ${ }^{1}$ )

| 2. Schwinge länger als die 4................ 10

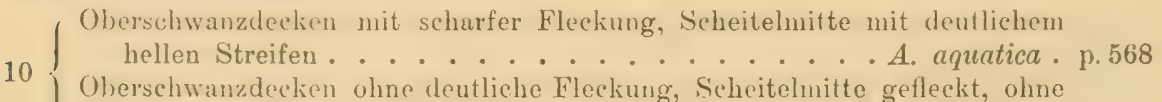
deutlichen hellen Streifen . . . . . A schoenobaenus . p. 566

\section{Acrocephalus arundinaceus arundinaceus (I.).}

\section{Drosselrohrsänger, Großer Rohrspatz.}

Turdus arundinaceus Linnaeus, Syst. Nat. Ed. X, p. 170 (1758- ex Klein, Hist. Av. Prodr., 1750, p. 179, Fig. 3. - Juni 1747 an der Rückfortischen Schleuse bei Danzig geschossen [,juxta deductorium Rickfortanum"].)

Turdus minor Pallas, Vroegs Cat. Coll., Adumbr., p. 2 (1764- "Europa").

Acrocephalus sorgophila (Swinh.).

Calamodyta sorgophila Swinhoe, Proc. Zool. Soc. London 1863, p. 92, 293 (Amoy).

3. und 4. Schwinge etwa gleich und am längsten, 2. zwischen der 6. und 7. Oberseite rötlichbraun, jede Feder mit undeutlichem schwarzen Mittelfleck. Durch die Augen ein dunkell,raner strich, dariuber ein deutlicher hell brangelblicher Supereiliarstreif, darüber wieder ein schwarzbrauner, nach dem Nacken zu rerblassender Streif. Unterseite rostgelblich-weiß, au den Seiten bräunlicher. Flügel $60 \mathrm{~mm}$.

Ein Exemplar wurde von Swinhoe am 20. Mai 1861 bei Amoy in China erlegt und ist bis jetzt Unikum. Ob die Art weiter nach Norden in das paläarktische Gebiet. reicht, bleibt festzustellen. 
Acrocephalus lacustris Naumann, Naturg. Land- und Wasserv. nördl. Deutschl. Nachtr. IV p. 201 (1811 -- Deutschland).

Sylvia turdoides Meyer, Vög. Liv- \& Esthl., p. 116 (1815- Livland).

Turdus Junco Pallas, Zoogr. Rosso-Asiat. I, p. 458 (1827 - Neubenennung von Kleins Vogel und T. minor. Astrachan, Kaspisches Meer, u. a.)

Calamoherpe stagnatilis Brehm, Handb. Naturg. Vög. Deutsehl., p. 442 (1831- „im Mai und August zuweilen auf dem Zuge").

Sylvia turdina Gloger, Handb. Naturg., p. 312 (1842).

Calamodytı mediu MIalm, () fv. K. Vet. Akaul. Förhandl. 1851, p. 159 (Göteborg- Junger Vogel).

Calamoherpe major Brehm, Vogelfang, p. 235 (1855 - „Galizien, selten in Deutschland").

Calamoherpe major megarhynchos \& microrhynchos A. E. Brehm, Verz. Samml., p. 6 (1866-- Nomina nuda!).

Acrocephalus arabicus Heugliu, Orn. N.O.Afr. I. p. 289 (1869-. Suez. 'Typus untersucht). Acrocephalus fulvolateralis Sharpe, Layards B. S.Africa, p. 289 (1877- Natal).

Acrocephalus turdoides var. minor Radde, Orn. Caucas., p. 2:8 (1881- Tiflis).

Engl.: Great Reed-Warbler. Franz.: Rousserolle. Ital.: Cannareccione.

1. Schrvinge spitz und steif, $1 / 2$ - $3 / 4$ der Handdecken; 3. in der Regel am längsten, 2. meist etwas kïrzer, selten ehenso lang, sehr selten etivas länger. Die 4. immer merklich kürzer als die 3. und 2. Außenfahne der 3. vor der Spitze merklich verengt, Innenfahne der 2. mit deutlicher Finkerbung. Oad. Oberseite lebhaft rostgelblich-olivenhraun, auf dem Bürzel etwas beller und röstlicher, weniger olivenbrann. Schrwingen dunkelbraun, wenn frisch vermausert mit helien Endsämmen, außen mit der Farhe des Bürzels, imnen fahl isabellfarben gesïumt. Zügel mit dunklem Fleck vor dem Auge, laüüber ein schmaler, wenig sichtharer, isabell-weißlicher Superciliarstreif. Augenlidbefiederung weiblich. Steucrfedern wie der Rücken, in frischem Gefieder mit deutlichen hellen Spitzensï̈umen. Lnterseite weiblich, Kehle und Mitte des Cnterkörpers fast rein weiß, Kürperseitem. Lnterflügelund Tnterschwanzdecken licht-isibell oder chamois, letztere am lebhaftesten. Vorderhals mitunter mit graubramen Schaftstrichen. Schmabel sehr dunkelbraum. Schneiden und Unterschnabel hell hornfarben, Iris braun. Beine hell brïunlichgriu. o wie of nur etwas kleiner. Frühlingskleid kurz nach der Mauser wie das Herbstkleid, verbleicht aher im Sommer merklich, namentlich auch die Unterseite. Nestkleid: Oberseite gleichmißig rotbraun, Unterseite lebhift isabell. Erstes Herbstkleid etwas rötlicher als hei alten Vögeln, in ganz frischem Zustande mit feiuen helleren Süumen auf dem Rücken. Flügel: ơ etwa 92-100, ㅇ 88-92, Schwanz etwa 72-82, Lauf $28-30.5$, Culmen 22-25 mm.

Brutrogel in Mittel- und Süi-Europa, ron der Pyrenäischen Halhinsel bis Griechenland, sowie in N.-W.-Afrika; nördlich bis zur Nord- und OstSee (Jütland) und in den russischen Ostsee-Provinzen bis fast zum Finnischen Meerbusen; im Osten mindestens bis zum Ural (Orenburg), Kaspischen Heere und Kaukasus. Zu diescr Form dürften auch die lokal im westsibirisehen Steppengebiete nistenden Tögel (Süden des Gouvernements Tobolsk und Kulundinische Steppe - Johansen) gehören. Soll auch in KRleinasien (Krüper) und Palästina (Tristram) brüten, aber mindestens die letztere Angabe ist noch nicht bewiesen. - In Großbritannien und Süd-Schweden ausnahmsweiser Gast. C̈berwintert in Afrika, südrvärts bis Loango, Transvaal 
und Natal. Seheint in Persien durchzuziehen. (Stïcke aus Süd-Arabien und rom Persischen Neerbusen gehören nicht zur östlichen Form.)

Der Drosselrohrsänger ist ein Bewohner größerer Rohrdickichte, besonders der ausgedehnten Rohrwälder an den Ufern von Landseen, Teichen, Haffs und Flüssen, auch wenn das Rohr mit Weiden untermischt ist, und besonders wenn an den Ufern Weiden stehen. Der Gesang ist ein lautes, durch schnarrende Laute verbundenes, immer wiederkehrendes "karre karre karre kiet kiet kiet". das man auch oft in der Nacht hört, wo es dann etwas Großartiges, Bezauberndes an sich hat. Manchmal ahmt er auch andere Vögel nach, aber nicht lange Strophen derselben. Das Nest steht meist etwa $1 \mathrm{~m}$ über dem Wasser im Rohr und ist derart an 2-4 Rohrhalme befestigt, daß diese die Wände des Nestes durchbohren. Ausnahmsweise findet man es auch - z. B. in ungewöhnlich trockenen Jahren -- über trockenem Boden, oder auch bis zu $2^{3} / \mathrm{m}$ hoch in Weiden- und anderen Bäumen. Der tiefnapfige Bau ist bald höher, bald niedriger und besteht aus Gras- und Schilfhalmen, Binsenblättern und Kispen ron Gräsern, mit feineren Halmen, Rispen. Spinngeweben, ganz ausnahmsweise auch Pflanzenwolle und Entenfedern ausgefüttert. Das Gelege enthält 4-5, selten 6, mitunter auch vielleicht nur 3 Eier. Diese sind auf licht bläulichem oder grünlichweißem Grunde mit tiefbraunen, fast schwarzen Flecken und oft zahlreichen solchen Punkten, sowie mit hellgrauen Schalenflecken bedeckt; andere Eier sind hell bräunlichgrün, mit fahlbraunen Flecken und helleren, mehr grauen Schalenflecken, andere (ausnahmsweise) milchweiß mit einigen hellgrauen und wenigen bräunlichen Flecken. 100 Eier (ti0 Rey, 10 Jourdain) ans Deutschland. Holland und Spanien messen im Durchschnitt $22.56 \times 16.24$. Maximum $24.8 \times 16.3$ und $23 \times 17.2$, Minimum $20.9 \times$ 16.2 und $21.2 \times 15.3 \mathrm{~mm}$. Das größte Ei einer Serie aus Sehlesien mißt $24.6 \times 17.5 \mathrm{~mm}$. Gewicht nach Rey durchschnittlich $178 \mathrm{mg}$.

\section{Acrocephalus arundinaceus zarudnyi Hart.}

Acrocephahus arundinaceus zarudnyi Hartert, Bull. B. O. Club XXI, p.26 (November 1907 - Turkestan. Terra typica Djarkent).

Interscheidet sich durch weniger röstliche, etwas mehr olivenfarbene Oherseite, was besoud(r's auf dem Bürzel allfällt. und hlissere Vuterschwanzdecken und Körperseiten.

Vertritt A. a. arundincecus in 'Transkaspien und Turkestan (Amu Darja, Sye Darja. Tsehinas, Fort Alexandrowsk, Bischany, T'sehimkent. Kóulik, Kuksand,

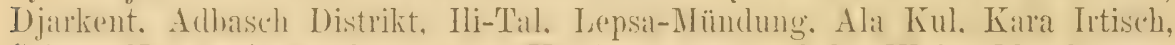
Sitissan-Nor u. a.), westlich his zur Kirgiseusteple und deu Wrigg-Alündungen.

\section{Acrocephalus arundinaceus orientalis ('l'mm. \& Schleg.).}

Salicaria turlina orientalis 'Temminck \& Schlegel, Siebolds Fauna Japonica, Aves, p. 50, Taf. XX B (1847- Japan, Borneo, Makassar und Sumatra).

Acrocephalus magnirostris Swiuhoe, Ibis 1860, p. 51 (Amoy bis Shanghai).

Acrocephalus inexpectatus Berezowski \& Bianchi, Ann. Mlus. St. Péterb. V, p. 210 (1900Hui-hsien in Kansu, West-China).

In der Färbung nicht von A. amulinacens amundinaceus verschieden,

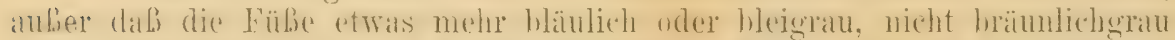
sind. Lie Dimensionent sind dagenen etwas geringer und die 2. Selowinge ist etwas lïrzere, indem sie meist hinter der 4. zurëclihleiht. mitunter songur kürzer ist als die 5., seltener so lang wie oder länger als die 4. ist, immer aber kürzer als die 3. bleibt. Die 4. Schwinge ist nur wenig kürzer als 
die 3., mitunter sogar ebenso lang. Die Flügelspitze ist also etwas gerundeter. Außenfahne der 3. Schwinge ror der Spitze deutlich, die der 4. meist undeutlich verengt. Innenfahne der 2. mit deutlicher Finkerbung. Flügel $\sigma$ etwa 84-89, selten 92, ᄋ etwa 75-83, Schwanz etwa 70-78, Lauf 28-30, Culmen 22.5-24.5 $\mathrm{mm}$.

Brutrogel in Japan, Korea, dem südlichen Ostsibirien, westlich bis zum Argun, den Oasen der zentralasiatischen Wüste, dem nördlichen und mittleren China bis zum Jangtsekiang und Fokien. - Zieht durch ('hina und überwintert in Hinterindien, der Malakka-Halbinsel, auf den groben SundaInseln, Andamanen und Philippinen.

Lebensweise und Fortpflanzung nicht wesentlich von der von $A$. arundinaceus arundinaceus verschieden. Yrzewalski fand die Nester etwa $1 \mathrm{~m}$ hoch an Spiräien. Stengeln befestigt. Die Eier gleichen denen der europäischen Form, nur sind sie etwas kleiner. 18 Eier vom Argun und Lefu messen im Durchschnitt $21 \times 15.3$, Maximum $22 \times 16.2$, Minimum $20 \times 14.8 \mathrm{~mm}$.

\section{Acrocephalus stentorea stentorea (Hempr. \& Ehrr.).}

Curruca stentorea Hemprich \& Ehrenberg, Symb. Phys., Ares, fol. bb (1833- Bei Damietta und am südl. Roten Meere).

Calamoherpe lonyirostris Müller. Nammannia I, 4, p. 27 (1851- Unterägynten); Brehm. Vogelfang p. 235 („Im Morgenlande, uamentlich im Winter in Ägypten").

Calamoherpe macrorhyncha Mäller, Beitr. Orn. Afric. Taf. IX u. Text (1853- Agypten). Acrocephalus tenuirostris A. E. Brehm, Journ. f. Orn. 1855, p. $486^{\circ}$ (am 24. Dezember $1850 \mathrm{am}$ Blauen Nil).

Abbild.: Ibis 1864, Taf. I.

1. Sehrvinge klein und spitz, kürzer als die Handdecken. 2. kürzer als die 3., an Länge zwischen der 5. und 7 ., selten nur so lang wie die 7. Die 3. und 4. fast gleich und am längsten, 5. nur wenig lï̈rzer. Außenfahnen der 3. und 4. vor der Mitte verengt, Innenfahnen der 2. und 3. mit. einer Finkerbung. - otad. Oberseite olivenhraun mit rostfarbenem Anflug. der auf dem Bürzel deutlieher hervortritt. Flügel und Schwanz dunliel olivenbraun. Spitzen und AuBensïune ron der Farhe des Bürzels. Lnterseite. in der Regel etwas lebhafter rostgelb als die vou $A$. anundinaceus unulinucens, nur die Kehle und Nitte des [nterkörpers weißlich. Schnabel dïmn und lang. ('ulmen of etwa $25-27$, 9 etwa 23-25. Flügel $0^{\pi} 80-85$. ? etwa $75-77 \mathrm{~mm}$. Jur. Ohen etwas stärker rostfarhen üherflogen. Cuterseite lehbafter und fast ganz rostgelblich. (Stücke mit einfirllig düstel brauner Unterseite, deren ich eins von Palästina, eins von A. s. Urmmescens aus Indien ror mir habe, sind nicht junge Tögel und seheinen richehr einer selten vorkommenden Aberration anzugehören.)

Standrogel in Ägypten (I)amiettil, üherhaupt Nilscltal. Falum, S'uez, Küste des Roten Ireeres. Natron-'Tal) und Palästinil (See Huleh uml Tutes Meer). Brehm beobachtete ihn im Dezember am Blauen Nil.

Bewohnt die ausgedehnten Rohrwälder im Nildelta, am Roten Meere flache, mit dichtem Gebüsch, besonders ron Avicennia, Schilf und Rohr bestandene Inseln und Gestade. Seine Stimme soll noch lauter und schallender sein, als die von A. arundinaceus. Das Nest und die Eier wie die der letzteren Art. Masse von 4 Eiern nach Jourdain durchschnittlich $21.9 \times 16.05 \mathrm{~mm}$. 


\section{Acrocephalus stentorea brunnescens (Jerd.).}

Agrobates brunnescens Jerdon, Madras Journal Lit. \& Sc. X, p.269 (1839- „in the Caruatic, near 'Trichinopoly, also near Jaulnah, ete.").

Calamodyta meridionalis Legge, Stray Feathers IH, p. 369 (1875- Ceylon).

Abbild.: Henderson \& Hume, Lahore to Yarkand Taf. XVI.

Lnterscheidet sich von A. s. stentorea durch viel stärkeren und kïrzer alussehenden Sehmabel, lïngere Flügel und viel blassere, nicht so braune Seiten. Hlügel ơ etwa 85-95, o etwa 78-82 mm.

Brutrogel in Trauskaspien, Persien, Turkestan, Buchara, Kaschmir und Himalaya, auch im Indus-Tale, Nara und Sind, sowie in Ceylon. - Im Winter in den Ebenen Indiens vom Himalaya bis Ceylon und im Osten bis Birma.

Gleicht in der Lebensweise A. s. stentorea. Bewohner von Rohrdickichten. Nest an Rohrstengeln aufgehängt, Eier wie die von $A$. arundinaceus. Drei Eier aus einem in Buchara gefundenen Neste nach Pleske $21-22 \times 16 \mathrm{~mm} .8$ Eier aus Kaschmir messen durchschnittlich $21.96 \times 15.45 \mathrm{~mm}$. (Jourdain.)

\section{Acrocephalus strepera strepera (Vicill.).}

Teich-Rohrsänger, Kleiner Rohrspatz.

?. Motacillı Salicuriı Linnacus, Syst. Nat. Ed. X, 1) 185 (1758- ex Klein, Willughby, Albin).

(Calamoherpe arundinacen vieler Autoren, nec Turdus arundinaceus L.!)

Sylvia strepera Vieillot, Nouv. Dict. d'Hist. Nat., Nouv. Ed. XI, p. 182 (1817- Frankreich).

Calamoherpe ahorum and arbustorum Brehm, Handb. Naturg. Vög. Deutschl., p. 443 (1831- Thüringen).

Calımoherpe piscinarum Brehm. Handb. Naturg. Vög. Deutschl., p.447 (1831 - Renthendorf).

Calamoherpe Brehmii Brehm, Handb. Naturg. Vög.Deutschl., p. 447 (1831- ex Müller MS. und Bechstein, Gem. Naturgesch. Deutschl. IV, p.669, Taf. 25. Abnormität mit heller Schwanzbinde).

Curruca fusca Hemprich \& Ehrenberg, Symbol. Phys., Aves, fol, ec (1833 - Nordarabien und Nubien).

Sylvia affinis Hardy, Ann. de l'Assoc. Norm. 1841. (Nach mehreren Autoren.)

Calamoherpe pinetorm Brehm, Isis 1848, p.5-9 (Lübs in Mecklenburg - Typus -, Renthendorf, Görlitz, u. a.).

Sylvia (Calamoherpe) horticolı Naumann, Naturg. Vög. Deutschl. XIII (Nachtr.), p. 444, Taf. 370, Fig. 1 (1853- Vielleicht nur teilweise).

Calamoherpe hydrophilos Brehm, Vogelfang, p. 235 (1855- Deutschland).

Calamoherpe crassirostris Brehn, Vogelfang. p. 235 (1855- „Morgenland“. Terra typica: Oberägypten).

Calamoherpe orientulis Brehm, Vogelfang, p. 2:35 (1855- „Morgenland". Terra typica: Oberägypten).

Calumoherpe ambigua A. E. Brehm, Allg. d. Naturh. Zeitung 1857, p. 467 (Valencia und Ilurcia).

Calamoherpe Brehmii canneti \& pygmaea A. E. Brehm, Verz. Samml., p. 6 (1866Nomina nuda).

Acrocephahus Calamoherpe Kleinschmidt, Journ. f. Orn. 1903, p. 492.

Engl.: Reed-W arbler. Franz.: Rousserolle effarvatte. Ital.: Cannaiola. Schwed.: Rörsåugåre. 
1. Schwinge so lang wie oder etwas liürzer oder länger als dic Handdecken; 3. am längsten, 2. ctwas kïrzer als oder so lang wie die 4., die nur wenig külrzer ist als die 3. Aubenfahne der 3. stark, die der 4. undeutlich verengt. Inneufahme der 2. S'chwinge ror der Spitze eingekerbt, diese Linkerbung liegt etwa dem Anfang der Linsehnürung der AuBenfilhne gegeniiber und liegt zwischen den Śpitzen der Armschwingen und dem linde der 8. Schwinge. Oherseite warm isabellbran (nicht ins olivenfuthene ziehend), Untersuite hell rostgelblich, Kehle und Uitte des Tnterkïruers heller; fast oder ganz weiß. Jugendkleid anf der Oherscite mehr röstlich, im ersten Gefieder sind die Federsiume lichter. die Enterseite ist röstlich gelbhraun. Iris braun. Flügel $6 t-68$. ausuahmstweise his 71.5 , Schwamz etwa $55-57$, mitunter bis 61, Lauf 22-2-t, Culmen $17-18 \mathrm{~mm}$. O meist kleiner als ơ,

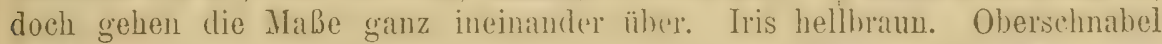
duukel olivenbraun, Lntersehnabel fleischfarhen. FüBe gelblichgrau mit grünlichem Anflug. Rakchen oringerot, viel rötlicher als bei alten A. palustris.

Brutvogel in süd-Schweden (etwa 58"). den südlicheu und mittleren russischen Ostseeprovinzen und Kiew, südwiirts durch Europla bis zum Mittelmeere, und vielleicht auch in den Atlasländern. Die gemane Grenze nach Osten ist schwer festzustellen, doch stimmen lixemplare ans dem Wrolgat Delta schon mit der ëstlichen Form übereiu. In England nur in den sǘtlichen und mittleren Teilen, in Irland soll er eimmil (1843) rorgekommen sein, am 24. Sept. 1906 wurde ein Stïck auf der Fair-Insel, zwischen deu Orkney- und Shetlind-Inseln, erlegt (kngle ('larke). - Überwintert in Afriki (Gambia, Ostafrika bis Sansibar).

Bewohnt in der Regel Rohrdickichte an den Ufern ron Gewässern, aber auch Rohr, das über trockenem Boden wächst, ferner ausnahmsweise Weidengebiissh und öfter sogar fern rom Wasser gelegene Gärten, wo er in Syringen, Weiden und Ligustersträuchern nistet (z. B. Frankfurt a. M.,, vgl. Zoolog. Garten 1891, p. 119). Unermüdlicher Sänger, dessen „tiri tiri tiri, tirr tirr tirr, zeck zeck zeck, zerr zerr zerr, tiri tiri tiri, dscherk dscherk dscherk, heid heid heid, trett trett trett, zipp zipp zipp, räck räck räck" usw. man stundenlang zuhören kann. Nahrung: allerlei Insekten, besonders kleine Käfer, wie Donacien und Rüsselkäfer, Räupchen und andere Larven, Mücken, Fliegen u. a. Nest hängend an Rohrstengeln, Weidenzweigen, Syringen u. a., über dem Wasser meist etwa $1 \mathrm{~m}$ hoch, mitunter bis zu $2 \mathrm{~m}$ über dem Boden. Die Nester variieren sehr in der Höhe und dem Material woraus sie gebaut sind, sind aber fast immer mit feinen Rispen, Gras- und Rohrblüten ausgefüttert. Die Brutzeit ist in der Regel der Juni. Die 4-5 Eier sind auf blaugrünem oder bräunlichgrünem Grunde mit helleren und dunkleren olivenbraunen Flecken über und über bedeckt, oder gräulichweiß mit grauen Schalenflecken und meist großen olivenbraunen Flecken versehen, sowie mit einzelnen schwarzen Punkten und kleinen Flecken. Nur die letztere Varietät ähnelt den Eiern von A. palustris, ist aber meist grünlicher, etwas glänzender und von Kennern nicht zu verwechseln. 100 Eier (Jourdain, Rey) aus England und Deutschland messen im Durchschnitt $18.20 \times 13.62$, Maximum $21.4 \times 14.2$ und $19 \times 14.6$, Minimum $16.3 \times 12.4 \mathrm{~mm}$. Kleinschmidt gibt Maße bis $22 \times 14.5 \mathrm{~mm}$. Das mittlore Gervicht von 55 Eiern nach Rey $90.5 \mathrm{mg}$.

\section{Acrocephalus strepera macronyx (Ser.).}

Salicaria macronyx Sewertzoff, Turkestan Jevotn., in Izv. Obshch. Mloskov. VIII, 2, p. 128 (1873- Russisch!); Übers. in Zeitschr. ges. Orn. IV, p. 78 („V Vit dans les lieux inoudés par le Sir Dar, parmi les roseaux qui baignent dans l'eau et qu'il ne quitte pas." Es kann keinem Zweifel unterliegen, daß die Beschreibung sich auf eine Form von $A$. strepera bezieht).

E. Hartert, Die Vögel der paläarktischen Region. 
Salicaria eurhyncha Semertzoff, t. e., p. 128 (1873- Russisch!); Übers. in Zeitschr. ges. Orn. IV, p. 78 (Manguschlak am Kaspi-See, Turkestan. Partin!! Cf. Pleske, Ornithogr. Ross., p. 527).

Salicaria ilensis Sewertzoff, Fauna der Pamir Kette, p. 75 (1879- Russisch! Partim, teste Menzbier; siehe Pleske, Ornithogr. Ross., p. 521; Ibis 1883, p. 66).

Unterscheidet sich rou A. s. streprea durch weniger röstliche, etwas mehr ins olivenbrïunliche ziehende Oherseite, wodurch er A. palustris sehr ähnlieh sieht, und blassere Körverseiten und Unterschwanzdecken. - Diese Form ist kenntlich, wenn eine Serie verglichen wird, einzelne stücke sind aber kaum zu bestimmen. Sie verdient fernere Beachtung.

Fs ist zuryeit unmöglich, die genaue Verbreitung festzustellen. Sewertzoffs Angahen sind unsicher und verwirrt (siche Pleske, l. c.). Jedenfalls brïtet diese Form aher in T'urkestan und Transkispien (Sir Darja, Tschinas, Teulschen u. a.), Baluchistan und Persien; die angehlich im Altai vorkommenden Vögel dürften dazu gehören. und auch die Stücke ans der Kirgisensteppe bis zur unteren Wolgia sind chenso oder anmähernd so wenig röstlich und unten ebenso hell, doch komnten nur wenigge Sitücke von letzteren Gegenden verglichen werden.

\section{Acrocephalus palustris (Bechst.). (Fig. 106.)} Sumpfrohrsänger.

Potacilla fasciata Bechstein, Gemeinn. Naturg. Deutschl. IV, p.669, Taf. 25 (1795Offenbar eine Abnormität von A, palustris oder strepera?).

Sylvia palustris Bechstein, Orn. Tascheub., p. 186 (1803- Deutschland).

Calamoherpe musica Brehm, Isis 18:8, p. 1283 (Nomen nudum!); Handb. Naturg. Vög. Deutschl., p. 416 (1831 - „Er scheint nordöstlich von hier zu wohnen, besucht im Anfang des Juni die dichten Haselbüsche der hiesigen Gegend").

:Sylvia (Culamohery)e) fruticoln Niumam, Naturg. Vög. Deutschl. XIII (Nachtr.), p. 453, T'af. 370, Fig. 2 (1853- Nach Erinnerung und unvollkommener Abbildung aus den Kunabenjahren benannt).

Calamoherpe philomela Brehm, Vogelfang, p. 236 (1855- Deutschland).

Calamoherpe Pratensis Jaubert, Rev. \& Mag. Zool. VII, p. 65 (185๊ - Neuer Name für den schlecht gewählten Namen palustris. Ex Caire II. S.).

Calamoherpe obscurocapilla Dubois, Journ. f. Orn. 1856, p. 240 (Belgien. Dies Synonym gehört unter palustris).

Salicaria turcomana Severtzoff, Turkest. Jerotn., in Izv. Obshch. MIoskov. VIII, 2, p. 128 (1873- bei Krasnowodsk am Kaspischen Meere); Übers, in Mladarász, Zeitschr. ges. Oru. IV, p. 78 .

Salicaria macroptera Sewertzoff, t. c., p. 128, im Text (1873 - Nomen nudum! Ohne Lokalität. Nach Pleske hierher gehörig); Übers. in Madarász, Zeitschr. ges. Orn. IV, p. 80.

Acrocephalus Frumentarius Kleinschmidt, Journ. f. Orn. 1903, p. 485, 493.

Engl. : Marsh-Warbler. Franz.: Rousserolle verderolle. Ital.: Cannaiola verdognolu.

Flögelform fast ganz wie hei 1. strepere. nur sind die Einsthnürungen rer Fahnen der 2). und 3. Schwingen weiter natch rorn gerïclit, so dab die

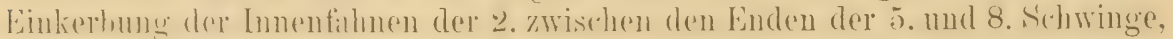
nicht aber hinter dem der 8. Schwinge liegt. Die Färbung der Oberseite ist im Fribjahr viel melı olivenhräunlich. oft fast ins Olivengrünliche ziehend, woran mall die alten Vügel schon im Freien leicht unterscheiden kann, junge Yäger sind alore der Fïrhmg nath nicht sicher zu unterscheiden. Die Mabe 
sind dieselben. Iris lehhaft braun. Oberschmabel olivenbraun, Unterschuabel rötlich fleischfarben. Füße gelblich fleischfarben. Mundwinkel und Rachen orangegelb oder rötlichgelb, heller als bei A. strepera strepera.

Brütet in Europal von Dänemark. den Südufern der Ostsee, Esstluland, den russischen Gouvernements Twer. Jaroslat, Kasim und Orenburg sïdlich bis Süd-Spanien und Italien, Montenegro und Bulgarlen. Auch in den Atlasländern. Ostwärts bis Orenburg, Wolga-Delta, Krim, Krasnorvodsk am Kaspischen Meere, Tiflis, Derbent, Lenkoran. In Süd-England sehr lokal und selten. - Überwintert im tropischen Afrika, südlich bis Natal.

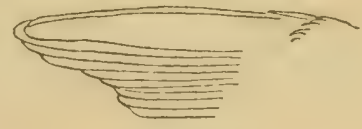

Fig. 106.

Der sogenanute Sumpfrohrsänger berwohnt fast niemals eigentlichen Sumpf, sondern vorzugsweise Weidengebüsch, das mit Nesseln, Brombeergerank, Clematis und dergl. durchwachsen ist, besonders an den Ufern von Flüssen, Teichen und Seen. Man findet ihn indessen häufig auch in rerwilderten, buschreichen Gärten und sehr gern in Erlenhainen, in denen Nesseln, wilder Hopfen und Buschwerk wuchern, und ebenso (besonders im westlichen Deutschland, aber auch u. a. in Bulgarien) vielfach im Getreide und in Bohnen- und Erbsenfeldern. Der Gesang ist von dem von A. strepera grundverschieden: Ein klangschöner, reich modulierter, feiner Gesang, der am meisten an den des Gartenlaubsängers erinnert, aber viel zarter und feiner ist. Individuell singen die Männchen sehr verschieden, viele siud Heißige Nachtsänger, manche sog. Spötter, d. h. sie ahmen die Stimmen anderer Vögel nach. Das Nest steht immer nahe am Boden, oft in Weidenbïschen, mit besonderer Vorliele in Nesseln, deren Stengel die Nestwände ., durchbohren", oder im Getreide. Es ist viel loser und flacher, als das von A. strepera und meist mit Pferdehaaren ausgelegt. Die 4-5 Eier findet man im Juni. Sie sind auf fast glanzlosem bläulich- oder grü̈lichweißem Grunde mit licht bläulichgrauen sèılenflecken und dunkelolivenbraunen und mitunter fast schwarzen, oft knnzentrischen Flecken gezeichnet, weniger variabel, meist heller als die von $A$. strepera, von Kennern immer zu unterscheiden, wenn auch nicht leicht zu kennzeichnen. Mlaße von 130 Eiern (Rey 54, Bau 45, Hurtert 31) im Durchschnitt $18.83 \times 13.67$, Maximum $20.2 \times 14.1$ und $18.4 \times 14.7$ Minimum $18 \times 10 \mathrm{~mm}$. Durchschnittsgewicht nach Rey $100.4 \mathrm{mg}$.

\section{Acrocephalus dumetorum Blyth.}

Acrocephalus.Jumetorum Blyth, Journ. As. Soc. XVIII. p. 815 (1849- Basiert auf Sylvia montana Sykes, Proc. Zool. Soc. London 1832, p. 89, Blyth u. a. nec Horsfield!).

Sylvia (Salicaria) maynirostris Lilljeborg, Ölv. Kigl. Vet.-Akad. Förh. 1850, p.27t, Taf. 19 (Bei Kargopol im Gouv. Wologda, nördl. Rußland).

Salicaria macronyx, earhyncha, sphenura Sewertzoff, Turkest. Jevotn., in Izr. Obshch. Moskov. XVIII, 2, p. 128 (Russisch! Turkestan, partim, fide Seebohm, Menzbier und Pleske); Übers, in Madarisz, Zeitschr. ges. Orn. IV, p. 78, 79, 80.

Sulicaria ilensis Severtzoff. Fauna der Pamir Lette, [1.75 (1879- Russisch! Partim teste Menzbier; cf. Pleske, Orn. Ross., p. 532.

Acrocephalus dumetorum var. affinis Sarudny, Bull. Soc. Nat. Moscou 1890, p. 25 (Transhaspien).

Abbild.: Dresser, B. Europe II, Taf. 86 Fig. 2. - Eier: Cat. Eggs Brit. MIus. IV, Taf. IX. Fig: 1 u. 4.

1. Schwinge unvefüh gleich den Handrlecken veler cine Kleinigheit kürzer oder länger. 2. zwischen der 5. und 6. oder 6. und 7. Die 3. und 4. etwa gleich und am längsten. Außenfahmen der 3. bis 5. vor der Mitte verengt. Innenfahne der உ. mit sebarfer. die der 3. und mitunter auch der to mit undentlicher Andentung ciner Eiukerbung. Olnerseite ristlich 


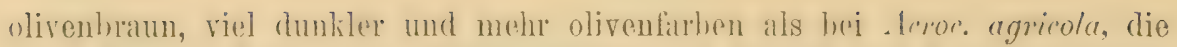
sonst diesulbe Farthe hat. Lrühlingscögel sind hlasser und weniger röstlich.

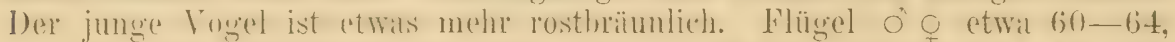
nach Pleske hei einem turkestinischen ò sogar $67 \mathrm{~mm}$, sechwanz etwa $52-58$. I auf 21-23.5, Culmen 15.5-17.5 $\mathrm{mm}$.

Weit rerhreiter: Himalaya, Altai, T'urkestan, Buchara, Transkaspien, If est-Sibirion und run durt in einem Keil nateh Rubland hinein his in das Gouvernement. St. P'etershurg, üher Iloskan bis nach Orenburg, nördlich vermutlich his Archangel. -- Clherwintert in Indien, südlich bis Ceylon und Pegu.

A. dumetorum ist nicht ein so typischer Rohrsänger wie die meisten seiner Gattungsgenossen; der Schwanz ist etwas weniger gestuft; die Art bewohnt Buschwerk, besonders von Weiden und Erlen, an den Ufern von Gewässern oder auf feuchtem Gelände und nassen Wiesen; der Lockruf ist nach Seebohm wie "tick, tick", der Gesang erinnert an den von Acrocephahus palustris und Hippolais hippolais; das Nest ist dem von Acrocephahus palustris ähulich; es steht nahe über dem Boden in Nesseln und Sträuchern. Die Eier kommen in verschiedenen Färbungstypen vor: Sie sind entweder auf hell rosafarbenem Grunde nit grauvioletten oder hell rotbräunlichen und tiefbraunen Zeichnungen versehen, mattweiß mit hellgrauen und olivenbraunen Flecken, oder schmutzig weiß, über und über mit bräunlichen Flecken bedeckt, etwa zwischen den Eiern von $A$. strepera und A. palustris stehend. Form wie die von A. palustris. Maße nach Pleskes Messungen an 24 Eiern im Durchschnitt $17.53 \times 13.86$, Mlaximum $19.5>15$, Jinimum $17>13$ und $17.5 \times 12.75 \mathrm{~mm}$. 19 Eier vom Altai (Jourdain) messen im Durchschnitt $17.6 \times 13.6 \mathrm{~mm}$.

\section{stit. Acrocephalus agricola agricola Jerd. (Fig. 107.)}

Sylvia (Acrocephalus) agricola Jerdon, Madras Journ. Lit. \& Sc. XIII, no. 31, p. 131 (1845- Nellore, Süd-Indien, im Winter).

Salicaria brevipennis \& capistrata Sewertzoff, Turkest. Jerotn, in Izv. Oshch. Mloskov. VIII, 2, p. 127; Russisch! (1873- Turkestan); Übers. in Madarász, Zeitschr. ges. Orn. IV, p. 75, 76. - Nach Menzbier zu agricola: cf. Pleske, Ornith. Ross., p. 552, Anm.

Abbild.: Dresser, B. Europe II, 'Tat. 86, Fig. 1.

1. Schwinge kurz und steif, ausnahmsweise so lang wie, in der Regel aber viel (bis zu $4 \mathrm{~mm}$ ) länger als die Handdecken. 2. zwischen der 6 . und 7.. seltener zwischen der 7. und 8., nach Pleske ausuahmsweise anch zwischen der 8 . und 9., was ich aber nicht beobachten konnte. 3., 4., 5. fast gleich und die sipitze des lilügels bildend. Aubenfahnen der 3., 4. und 5. Shinwinge vor der Mlitte vorengt, Innenfahmen der 2. und 3. mit dentlicher Einkerbung. Ad. im frisch vermauserten Gefieder: Oberseite warm isabell-braun, auf dem Bürzel etwas röstlicher, auf dem Kopfe etwas dunkler. Ein deutlicher, röstlichrahmfarbener Superciliarstreif erstreckt sich von der Schnabelwurzel bis zum hinteren Lnde der Ohrdecken. Unterseite hell isabellfarben, nach

Fig. 107.

der Mitte zu heller, Kelle und Nitte des Cinterkörpers fast weiß. Iris Tratun. Obersehnabel und meist auch Spitze des Lnterschmabels dunkelbraun, Lintersehnabel hell. Füße hellbraun. In der Brutzeit wird die Färloung matter, die ()lerseite brïunlicher, Unterseite weißlicher, Flügel of o etwa 55 his 60.5. Sehwauz etwa 55-60, Lauf 20.5-22.5, Culmen etwa $15-16 \mathrm{~mm}$. 
Brutrogel in der Krim, der Kirgisensteppe. natch timem am 18. April 1907 bej Malcoci crbenteten Stüclie zu urteilen aurh im Donan-Delta. im südlichen und mittleren Lral, in Trimskispien. Ost-P'ersien. 'Turkestan, ()st-Turkestan, dem Altai, im Himalaya von Kaschmir his Nepal, in Tsaidam und vermutlich Tesilen von Tihet. - Überwintert in Indien, ästlich his ('illeutta.

Bewohnt Rohrpartion und Buschwerk in der Nähe von Gewässern. Im Winter sieht man ihn oft in Reisfeldern und im hohen Grase. Die Nester sehen aus wie kleine Nester von Acrocephahus arundinacens und $A$, stentoreus und sind an Schilfstengeln oder Zweigen aufgehängt. Die meist 4 Eier ähneln denen ron A. strepera, die Flecke sind meist klein und fein. Die MIaße sind meist etwas geringer, nach Nelarkorn $17 \times 12 \mathrm{~mm}$. Zwei Eier im Petersburger Museum nach Pleske $18 \times 13$ und $17 \times 12.5 \mathrm{~mm}$. Sechs Eier im Brit. Bluseum messen durehsehn. $17.05 \times 13.08 \mathrm{~mm}$.

\section{Acrocephalus agricola concinens (Siriul.).}

Calamoherpe concinens Swinhoe, Proc. Zool. Soc. 1870, 1). 432 (Peking).

Oberseite morklich weuiger röstlich, mehr ins Olivenfirbene ziehend. Seiten und Unterschwanzdecken etwas bräunlicher. 2. Srhwinge ctwis kürzer, zwischen der 8. und 9. ocler 9. und 10. Der Schmahel srheint in allgemeinen etwas größer zu sein - sonst wie $A$. agricola agricola.

Brïtet in China, mindestens ron den T'sin-ling-Bergen his Folicn und überwintert in Pegu, Tenasserim, Assam.

\section{Acrocephalus orinus Oberh.}

Phyllopneuste macrorhynchus (non Calemolierpe mucrorhyncha Müller 185:3) Hume, Ibis 1869, p. 357 (Deser. nulla. „Interior of the Himalayas"6!).

Acrocephalus macrorhynchus Hume, Ibis 1871, p. 31 (Bei Rampur im Sutlej-Tale in NTV.-Indien).

Acrocephalus orimus Oberholser, Proc. U. S. Nat. MIus. XXVIII, p. 899 (1905).

Dieser Vogel ist bisher Unikum geglieben. Er muß in die Gattung*

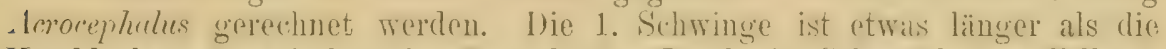
Handdecken. 2. zwischen der 9. und 10. I) breite Schublel ist auffallend, Culmen 19.5 mm. Ohersaite olivenbran, Cnterseite hlab ockerfarben, Nitte von Kehle und Lnterkïrper weißlich. Flïgel 62. Schwamz 56, Laluf 16.5 mm.

Rampur im Sutlej-Tale.

\section{Acrocephalus bistrigiceps Swinh.}

Acrocephalus bistrigiceps Swinhoe, Ibis 1860, p. 51 (Januar 1860- Amoy).

Sulicaria (Calamodyta) Mactlii Selnenek, Reisen Amur-Land I, 2, p.370. Taf. XII. Fig. 4-6 (1860- Südlicher Amur, zwischen dem Bureja-Gebirge und der Mlündung des Ssungari).

1. Schwinge verhältnismäßig lang, immer hedeutend länger cetwat 3.5-5.5 mm) als die Hamddectern. aher nicht dis Hälfte der 2. erredehend. 2. meist zwischen der 6. und 7. oder noch etwas kïrzel als die 7., 3. und 4. etwa gleich lang und am lïngsten; vorilerer Teil del Aufienfahnen der 3.-5. unbedeutend rerengt. Innonfahne der 2.-4. mit riner lileinen binkerbung. - Oad. Oberseite löstlichliaun, auf Bürzel und Ohelschwanzderelien am lebhaftesten (röstlicher). Schwingen und Sihwanz hraun, mit der Rücken- 
farbe cosiumt. Kägelmitte and strich hinterm Ange dunkelbraun, darüher ein hroiter rahmegelher Supereiliarstreif, darüber ein chenso hreiter schwarzbrauner Streif. Sheheitelmitte mit Andeutungere dunklerer, schattenartiger Streifen. Interseite bräunlichrahmfarben, Seiten viol dunkler, etwa lehmbraun. Kehle und Körpermutte am hollsten, fast woib, Lnterflügeldecken,

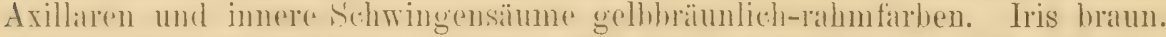

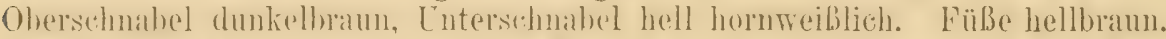
Das Frühlingskleid gleich nach der Mauser diurfe nicht wesentlich ron dem ohen heschrehene'n Herhstkleid ahweichen, in dor Brutzeit aher rerhleicht das Gefieder und wird weniger röstlich. a nur etwas kleiner als o’. Fiügel

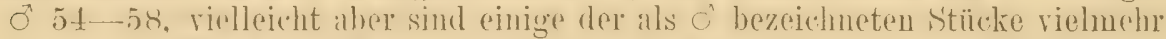
, onath Pleske und 'Takzanowski 51. nath einem o rom Amur 53, Schwanz etwa 50-55, Lauf etwa 20-22, Culmen etwa $14-15 \mathrm{~mm}$.

Briitet in Ost-Sibirien von Transbaikalien his Sachalin und in Japan, vielleicht anch noch in 'leilen von china. - Auf dem Zuge in China, üherwintert in Hinterindien.

Bewohnt augenscheinlich sumpfiges mit Schilfdickichten und allerlei anderem Gestrüpp bestandenes Wiesenland und trifft schon im April und Hai an seinen Brutplätzen ein. Soll fleißig singen, aber wie, haben die Beobachter bisher nicht mitgeteilt. Das Nest hängt $2-5$ Fuß über dem Erdboden und enthält 5, seltener 4 oder 6 Eier, die denen von Acroc. schoenobaenas gleichen und nach Taczanowski und Pleske im Durchschnitt $(25$ Eier) $16.05 \times 12.45$, Maximum $17.5 \times 13.6$, Ninimum $15 \times 11.8 \mathrm{~mm}$ messen. (Die Angabe, daß einige Gelege den Eiern von A. streperus gleichen, muß wohl auf falscher Bestimmung beruhen?)

\section{Acrocephalus schoenobaenus (L.). (Fig. 108, 109, 110.)}

\section{Schilfrohrsänger.}

Motacilla Schoenobaenus Linuaens, Syst. Nat. Ed. X, p. 184 (1758- „Habitat in Europa“. Ex Fauna Suecica 1746 , p. 84 no. 222 , wo es heißt: „Habitat inter Scirpos Scaniae", terra typica also: Süidschweden).

Sylvia phragmitis Bechstein, Orn. Taschenb., p. 186 (1803- Deutschland).

Calamolierpe tritiri, phaymitis, schoenihumesisic) Brihm. 1sis 1828, p. 1284 (Nom. nuda). Calamoherpe tritici Brehm, Handb. Naturg. Vög. Deutschl., p. 449 (1831- Greifswald, Ahlsdorf und Frießnitzer See).

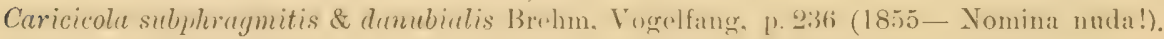

Caricicola brachyrhynchos Brehm, Naumannia 1855, p. 284 (Nomen nudum!).

Caricicola phragmitis acurostris \& juncorum A. E. Brehm, Verz. Samml., p.6 (1866Nomina nuda!)

Calamodus phragmitis minor v. Hâvre, Grabowski, Mus. Homeyer., p. 7 (1893 - Nomen nudum!). Säfsångare.

Engl.: Sedge-Warbler. Franz.: Becfin des jones. Ital.: Forapaglie. Schwed.:

1. Schwinge äuBerst kurz, stoif und spitz, otwa ${ }^{1 / 2}-3 / 4$ der Länge der Handelecken. 3. Schwinge in der Regel am längsten, ¿. meist etwas kïrzer, selten ebenso lang, alusnahmsweise $1 \mathrm{~mm}$ länger. t. merklich kï̈zer als 3. AuBenfahne der 3. vor der Mitte verengt. $\sigma^{\circ}$ ad. Oberkopf gelblichbraun, jede Feder mit schwarzem Mittelstreifen, der an den Federn über dem Supereiliarstreifen hreiter wird. so dab sich dort jederseits ein ziemlich deutlich markierter schwärzlicher Streif hinzieht. Breiter gellolich rahmfarbener Superciliarstreif, durch das Auge eine sehwärzliche Liuie. Rückenfedern 
gelblichbraun mit schwarzbraunem Mittelstreifen, die auf dem Hinterhalse undeutlich sind und auf Bürzel und Oberschwandecken verschwinden, so daß letatere einfurbig sind, übrigens auch lebhafter, mehr lederfarbig elscheinen. Schwingen schwärzlichhraun mit hräunlichgranen Endspitz.n, gedblichloraunen Außen- und blaß bräunlichğauen Innensäumen. Schwanz hraun nit rostbraumen Säumen. Unterscite fahlgelbhräunlich. in der Mitte dor Kehle und des Unterkörpers lichter, fist weißlich, an den Seiten und Lnterschwanzdecken lehhafter. Axillaren weiBlich rahmfarhen. Unterflügeldecken hellerau mit weißlichen Sämmen. Iris bram. Sehmahel schmal wie bei den Locustellen. Oberschnabel dunkelbraun, Lnterschnabel rötlichgelb mit brauner Spitze.

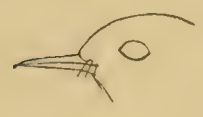

Fig. 108.

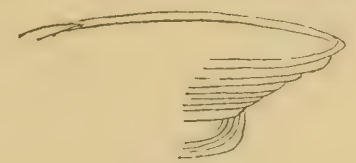

Fig. 109.

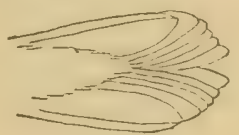

Fig. 110.

Fübe bäulichgrau. In Herbste ist das Gefieder etwas lebhafter gefärbt, mehr rostfarben, im Jugendkleide etwas celblicher, auberdem die untere Kehle und Kropfgegend mehr oder minder dicht diisterbraun gefleckt. Flügel 66-69.5, seltener nur 65, sellost 64, oder his zu $71 \mathrm{~mm}$, Junge kleiner. Schwanz etwa $51-56.5$, Lauf $20-22$, Culmen $14.5-16 \mathrm{~mm}$.

Brütet rou $70^{\circ}$ nördl. Breite in Norwegen, in Rußland von der Mur-

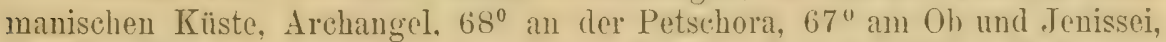
in Westsibirien bis zum Altai, nach Sewertzoff auch im nördlichen Turkestan, durch RuBland, Europa rom äuBersten Westen (Irland, GroBbritamnien) bis zum Osten, südlich bis Italien und vielleicht auch in Spanien, in Griechenland aber vermutlich nur. Durchzugsvogel. - Zieht regelmäBig durch Transkaspien. Ägypten, die Atlasländer (wo das Brüten bisher nur rermutet, aber nicht festgestellt wurde), ïberwintert in Kleinasien und Afrika bis zum Congo, Angola, Damala-Land und Transvaal.

Bewohnt niemals Rohrdickichte, sondern die Uffer von allerlei Gewässern, Gräben und Sümpfen, wo dieselben mit Weidenbüschen, Schilf, Binsen, hohem (rrase und allerlei Sumpfblumen bewachsen sind, mitunter auch Hecken und dichte Gebiische in einiger Ențfernung vom Wasser, und ausnahmsweise Getreide-, Reis- und Bohnenfelder. Während des Gesanges erhebt er sich oft einige Meter in die Luft, um sich dann (ähnlich wie Baumpieper) in schräger Linie singend herabzusenken. Dies habe ich bei andern Acrocephalus-Arten nie gesehen. Der Gesang ist ziemlich wechselreich, aber nicht laut, von schnarrenden Lauten und einem häufigen flötenden "woid woid woid" durchsetzt, sonst dem von $A$. streperus ähnlich. Das Nest hängt in der Regel nicht, sondern steht im Pflanzendickicht, in oder neben kleinen Büschen, in Brombeerranken, Nesseln, im hohen Grase, meist nahe über dem Boden, mitunter aber auch in Hecken und auf Zweigen von Bäumen bis zu 1.50 und sogar $2 \mathrm{~m}$ hoch, in Parks auch in Büschen von akklimatisiertem Bambusrohr. Es ist ein dicker Bau, außen aus Halmen und Stengeln, oft mit Moos, innen mit Haaren und Federn weich ausgelegt. Es enthält meist im Juni, oft aber schon von Mlitte Mlai an - besonders in wärmeren Ländern - , mitunter erst im Juli (vielleicht finden in günstigen Jahren zwrei Bruten statt?), 4-6 Eier. Diese sind auf hellgrauem oder gelblichem Grunde über und über mit helleren oder dunkleren graubraunen und braunen Flecken uud Punkten bedeckt, oft so dicht, dab sie fast einfarbig braun aussehen. Sie erinnern mitunter zum Verwechseln an die allerdings meist größeren Eier ron Iotacilla flaza. Gegen das stumpfe Ende häuft sich oft die Fleckung oder es bildet sich ein Kranz, nicht selten sieht man schwarze Haarzïge und 
Punkte. Die Mlaße von 137 von Rey, Jourdain und Bau gemessenen Eieru, meist aus Deutsehland und England, betragen im I)urchsehnitt $17.67 \times 13,37$, Maximum $20.5 \times 13.2$ und $19.6 \times 15$, Nlinimum $16 \times 12$, Zwvergeier $12.2 \times 9.2 \mathrm{~mm}$. Das durchschnittliche Gewicht ist nach Rey 102 mg. - Nahrung: Insekten, besonders gern kleine Käfer, Raupen, Würmer, Schnecken usw.; im Herbste auch Hollunder- und andere Beeren.

\section{Acrocephalus aquatica (Gm.).}

\section{Binsen-Rohrsänger, Seggen-Rohrsänger.}

Motacilla aquatica Gmelin, Syst. Nat. I, p.953 (1788- Ohne Lokalitätsangabe. Ex Seopoli, Annus I. Hist.-Nat. 1769, p. 158, no. 235; ef. Temminck, Man. d'Orn. 1815, p. 131. Obwohl Scopolis Beschreibung, worauf die Diagnosen von Latham und Gmelin beruhen, recht ungenügend ist, läßt sie sich doch auf vorliegende Art beziehen, und da der Name aquatica von Temminck auf den Binsen-Rohrsänger bezogen wurde, liegt kein Grund vor, ihn zu verwerfen. Als terra typica haben wir Kärnthen oder Venetien anzusehen).

Sylvia paludicola Vieillot, Nour. Dict. d'Hist. Nat., Nouv. Ed. XI, p. 202 (1817_ „en Lorraine et en Picardie").

Sylvia cariceti Naumann, Isis 1821, 2, p. 785 (Thüringen. Naumann unterschied die oben hellgrauen Stücke als Art von den gelblichbraunen).

Sylvia striata Brehm, Beitr. z. Vögelkunde II, p. 286 (1822- Neustadt a.d. Orla).

Calamoherpe limicola Brehm, Isis 1828, p. $128+$ (Nomen nudum!); id. Handb. Naturg. Vög. Deutschl., p. 451 (1831- Erste Beschreibung. Renthendorf auf dem Zuge).

('aricicolu aquatica longirostris \& erassirostris A. E. Brehm, Verz. Samml., 1. 6 (1866Nomina nuda!).

Engl.: Aquatic Warbler. Franz.: Becfin aquatique. Ital.: Pagliarolo.

Struerforlern zugespitzt. I)ic schmale, steife 1. Schwinge in der Regel etwas kïrzer als die Handdecken. 3. Schwinge an längsten, 2. und 3. nur wonig lï̈zer. - Herbstleid: S'heitel brämmlichgelb, jederseits üher dem Supreriliarstreifen mit einem lreiten, infolge der branngelben Federänder nicht änz reinen. braunsthwarzen Streifen. Cbrige Oberseite wie der Scheitel, breit branschwarz gestreift, auf Nacken und Bürzel woniger sebarf. Sehwingen bramgrau mit gam\% schmalen hellglatuen śpitzen. hellbraumen Außen- und fablgelhen Innensïumen: innere Armschwingen sehwarz mit breiten bräunlichgelken Sïnmen. Steneffedern gelblichbraun, die Innenfahnen dex seitlichen und ein Streif entlang den Schäften des mittelsten Pares dunkelbram. Enterseite hell rostgelh, Kohl- und Bauchmitte heller, fist weiBlich. Sehr oft sind Soriten und Kropfgegend, mitunter auch die Weichen allein, sehmal schwarzhram gestrichelt. I)iese strichelung seheint unahlä̈ngig von Alter, Geschlecht oder Jahroszeit, anfzutroten. Das Frïhlingskleid gleicht dem Herbstlikide, ist aber etwas weniger lehluft gefärbt, nicht so rostgelblich, auf dem Rüchen mehr ins Olivengrauc ziehend, und verbleicht in der Brutzeit so, daß die rostfarhenen Farhentüne verschwinden und nur noch auf dem Bürzel bleiben, während der Rüclen licht olivengrau, fast weiblichgrau, braunschwarz gestreift aussieht, die Unterseite weißlich, nur am Klopfe und an den Untersehwanzdecken noch golhlich übertincht. Iris ruBbräunlich. Der schmale, dem del Inoustellen ähnliche Schuabel ist dunkel hormbraun, der Untershmabol gelblich. Füße gelhlichfeischfarben mit hellen Krallen. Dis .Jugendkleid gleicht dem Herhstkleide. Gesehlechter gleich. Flügel etwa 60 - 66.5, S'chwanz 48-51, Lauf 19.5-21, Culmen etwa 12-14 mm. 
Brutrogel in Zentral- und Süd-Europa: Südliches Dänemark. Deutschland, Holland, Frankreich, Spanien. Italien und Sizilien, Österreieh-Cugarn, Galizien, Polen, Süd-Rußland bis in den mittleren [ral. Brütet auch in N.W.-Afrika (Algier, Tunis). Einige wenige Male in England rorgekommen, ebenso auf Helgoland und in Belgien. In S.O.-Europa ma Ägtpten vur auf dem Zuge festgestellt. Scheint in N.W.-Afrikil im Winter vorzulsommen, vielleicht liegen die Winterquartiere aber im tropischen Afrika. Über Griechenland vgl. Reiser, Ornis Balc. III, p. 561.

Bewohnt ähnliches Gelände wie Acrocephalus schoenobaenus: Sümpfe, die mit Seggen und Binsen, allerlei Sumpfblumen, Sahlweiden und anderen Büschen bewachsen sind, sowie ähnlich bestandene Uferstrecken an stehenden und träge fließenden Gewässern, ist aber sehr lokal und nur an wenigen Orten häufig. Der Gesang erinnert an den von $A$. schoenobaenus, ist aber weniger laut, einförmiger, hastiger, die 'Triller kürzer (Ssabanjeff u. a.). Das Nest steht in kleinen, mit dichtem Grase durchwachsenen Büschen, nahe über dem Boden. Es bängt nicht, sondern ist ein ziemlich grober und fester Bau aus Sumpfgräseru, mit feinen Halmen ausgefüttert, etwas tiefer als das Nest von A. schoenobaenus. In Polen findet man Mitte Mai die 5-6 Eier, auch Naumann gibt den Mai als Brutzeit an. Die Eier gleichen denen von A. schoenobaenus, sind aber meist etwas kleiner und oft etwas grünlicher. Durchschnitt von 30 Eiern (17 von Hocke, 7 von Blasius, 6 von Jourdain gemessen) aus Deutschland und Jütland $16.94 \times 12.76$, Maximum $18.3 \times 12$ und $15>13.7$, Minimum $15>13.7$ und $17.6>11.8 \mathrm{~mm}$. 'Taczanowski gibt für Eier aus Polen $16 \times 12 \mathrm{~mm}$ an. Durchschnittsgewicht nach Rey $88 \mathrm{mg}$.

\section{Gattung HIPPOLAIS Brehm (Isis 1828, 1. 1283).}

Der Name Ilippolais wurde ron vielen Autoren in IIypolais verhessert. Fïr $H$. caligatu wurden die Namen Idune und Jerdonia aufgestellt. Die „Spötter" stehen den Acrocephalen sehr mahe, lassen sich aher durch den geraden oder nur etwas gerundeten Schwanz mit kürzeren Tnterschwanzdecken unterscheiden. Auberdem sind der Sehwinz und die Flügel verhältnismäBig länger, die Lïer rosenrot oder lila bis hellgrau, geflecht. Das Gefieder ist meist etwals kürzer, als bei Acrorephalus. Der Schmabel ist breit und flach. Zweimalige Mauser. Gesang laut, wechselreich, unterhaltend. H. caligata und rama hahen kürzere Flügel und gerundeteren Schwanz, neigen also etwas zu Arecephalus, letztere auch in der Fïrbung der Eier! Wollte man Idun trennen, müBte dieser Gattungsname auf letztere beiden Formen heschränkt bleiben. Das andere Extrem ist, Ilippoluis mit Acrorephalus zu vereinigen.

1 Unterseite gelb, Oberseite grünlich . . . . . . . . . . 2

Unterseite weißlich, Oberseite bräunlich oder grau . . . . . . . 3

2 $\int$ 1. Schwinge nicht länger als die Handdecken, 2. lïnger als die 5. H. icterina 5. 57()

1. Schwinge länger als die Ifanddecken, 2. kïrzer als die 5. H. polyglotha p. 571

3 ) Oberseite dunkler, mehr brangrau, Flïgel ïber $80 \mathrm{~mm}$. H. olivetornm 1.572

Oberseite meist fahler, Flügel unter $80 \mathrm{~mm} \ldots . . \ldots 4$

$4\left\{\begin{array}{c}\text { 1. Schwinge meist kürzer, oder doch nur etwa } 1 \text { mm länger als die } \\ \text { Handdecken . . . . . . . . . H. languida p.573 }\end{array}\right.$

1. Schwinge etwa $3-8 \mathrm{~mm}$ länger als die Handdecken ....... 5

$5\{$ 2. Schwinge zwischen der 7. und 9. . . . . . . . H. rama p. 575

2. Schwinge zwischen der 5 , und 7 .................. 6

6 f Flïgel über $63 \mathrm{~mm}$. . . . . . . . . . . H. palliala P. 574

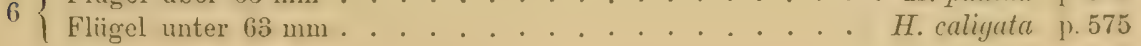


870. Hippolais icterina (Vieill.). (Fig. 111.)

Gartenlaubrogel, (relbe Grasmücke, Bastardnachtigall, Sprachmeister.

Hippoluis (Hypolnis) hippoluis (hypoluis) vieler Autoren, abor nicht Hotacilla hippolais L.! Hypolais philomela neuerer Autoren, aber nicht Motacilla Philomela L. 1758! Die Diagnose „H. supra grisea, subtus cinerea, remigibus primoribus apice obsoletis" kann nimmermehr aul vorliegende Art bezogen werden; sie scheint aus Klein entnommen, aber auch Klein's Lusciria altera (p. 73) ist zweifelhaft, denn er zitiert die deutliche Abb. einer Sylvia curvuca in Frisch).

? Motacilla nigrifrons Bechstein, Gem. Naturg. Deutschl. IV, p. 675. 'Taf. 27 (1795Thüringen. Vermutlich ein anormales Stück des Gartenlaubvogels).

? Sylvia flaveola Vieillot, Nouv. Dict. d'Hist. Nat., ¿. Ed., XI, p. 185 (1817 - Frankreich und Lothringen, Nach den Untersuchungen von Degland \& Gerbe war S. flaveola nach schlecht präparierten Stücken mit durch Präparation deformierten Schnäbeln von S. icterina getrennt worden. Man kann daher diesen Autoren beistimmen, daß der Name nicht angewandt werden kann. Die Beschreibung der Flügelform beweist, daß es sich nicht um polyglotta handelte, und nur die Angabe, daß S. flaveola kleiner sei, als letztere widerspricht S. icterina).

Sylvia icterina Vieillot, t. c., p. 194 (1817- Frankreich, Nancy).

Hippolais ulticeps Brehm, Mandb. Naturg. Vög. Deutseh1., p. 435) (1831- Dentschland).

Hippolais media Brehm, t. c., p. 436 (1831- "wandert durch Mitteldeutsehland, kommt bei Kiel vor, und scheint nördlicher als Deutschland zu wohnen").

Hippolais planiceps Brehm, t. c., p. 436 (1831- „erscheint in der letzten Hälfte des Iai und im August im mittleren Deutschland, brütet wahrscheinlich nicht in unsrer Gegend").

Salicaria italica De Filippi, Mus. Mediol., p. 30,4 (1847-

Sylvia obscura Smith, Illustr. Zool. S.Afr., Aves 'Taf. 112, Fig. 1 und 'Text (1849Port Natal, S.Afrika).

Hypolais hortensis A. E. Brehm, Ill. Thịierleben III, p. 861 (1866).

Hypolais major, xanthogastra A. E. Brehm, Gef. Vög. II, p. 165 (1876- in der Synonymie von Hyp. icterina).

Hypolaris familiaris Taczanowski, Ptaki Krajowe I, p. 217 (1882).

Hypolais ieterina var. Mollessoni Zarudnoi et Nazarow. Bull. Soc. Imp. Natur. Moscou, p. 675 (1888 - Tastuba, Kreis Birsk, Gouv. Ufa, Rußland).

Eugl.: Icterine Warbler. Franz.: Fauvette ictérine. Ital.: Canapino maggiore. Schwed.: Bastardnäktergal,

ôd. Oherseite fihl olivengrünlich oder gelblich graugrün. Unterseite schwefelgelb, ebenso ein liurzer, bald hinter dem Auge aufhörender Superciliarstreif. Schwingen dunkelbraun, Handschwingeu mit fahlgrüulichgrauen, innere Armschwingen mit breiteren und fahl strohgelben Aussensäumen, Innensäume der Schwingen graulweiß. Steuerfedern dunkelbraun, Außensäume wie der Rücken, Innenränder schmal weißlich-

Fig. 111. grau. 1. Schwinge so lang wie die Handdecken oder etwas kïrzer. 3. Schwinge am lïngsten, 4. nur wenig kïrzer. 2. etwas kürzer als oder so lang wio die 4 ., immer länger als die 5 . Iris braun. Oberschnahel hell hornhram, Lntersthnabel gelbrötlich oder hell fleischfarben. Füße bläulichgrau. Flügel etwa 75.5-82, Schwanz 56-59, Lauf 21-22, Culmen $16-17.5 \mathrm{~mm}$. o wie $0^{7}$. Juv.: Oberseite bräunlicher. Unterseite meist matter, blasser. 
Brutrogel im größten Teile Europas; in Norwegen his zum Polarkreise und spärlich etwas nördlich desselben. in Finland his Kúppio, in Nordrubland bis Arehangel, in Ural mindestens his zum 57. Grad nörellicher Breite. Im Westen bis Holland und Belgien und im nördlichen, östlichen, mittleren und südlichen Frankreich; im Süden bis zu den Pyrenïen. Italien und Sizilien (nur sehr selten in Sardinien), im Osten his zum [ral, nach Dresser bis West-Sibirien, Kaukisus, Krim; in Dalmatien noch hä̈tig. jn Rumänien. Bulgarien und Montenegro aber schon weniger zahlreich. in Griechenland, Kleinasien und Nordost-Afrikit nur noch auf dem '/nge. Fehlt im nordwestlichen Fraukreich von der Garome-Mündung und den Departements ('harente. Viemne. Cher, Nièrres. Seine et Marne his fast nach C'alais (L. Burean in litt.); in England in der Regel nur seltener Irrgast, doch wurden mehrere Male Fier gefunden. - Überivintert im tropischen Afrika.

Bewohner von lichten Laubwäldern, gemischten Waldungen und Feldhölzern, namentlich aber von Gärten, Parkanlagen und Fr'iedhöfen. Scheint eine Vorliebe für Birken, Hollunder und Syringen zu haben. Der Gesang ist eine der außerordentlichsten Leistungen in der europäischen Vogelwelt, denn er übertrifft an Mannigfaltigkeit und Abwechselung fast die aller anderen Vögel: eine reiche Anzahl schöner flötender und zwitschender Strophen wechselt mit schnalzenden und schnarrenden Tönen ab, und alles dies wird unermuidlich, fröhlich und hastig vorgetragen, dabei kräftig genug, ohne übermäßig laut zu sein. Einzelne Männchen ahmen (iesänge andrer Vögel nach, zum l'eil aber beruht die angebliche Nachahmung auf Täuschung. Das Nest steht meist in Reichhöhe oder etwas tiefer, mitunter aber auch bedeutend höher. Es ist schön gewebt und geglättet und steht auf allerlei Laubbäumen, mit Vorliebe auf Birken, Syringen, Hollunder u. dergl. Es ist mit den '/weigen oder der Rinde des Stammes fest verwebt und ist außen mit Birkenrinde, oder in Ermangelung letzterer mit weißen Papierfetzen bekleidet, eine Bekleidung, die nur ganz ausnahmsweise ganz dureh Federn ersetzt wird. Die Eier findet man in Deutschland selten vor Anfung Juni. Sie sind beller oder dunkler rosenrot, und die Zeichnung besteht aus meist scharf umschriebenen tiefschwarzen Flecken und Punkten, sowie mitunter dunkel graubläulichen Schalenflecken, seltener findet man Haarzïge oder Kritzeln. 142 (95 Rey, 47 Bau) Eier messen im Durchschnitt $18.35 \times 13.4$, Maximum $20.6 \times 13$ und $19 \times 14.1$, Minimum $17 \times 12.5$ und $18.1 \times 12.4 \mathrm{~mm}$. Durehschnittliches Gewicht nach ßau 92, nach Rey $91 \mathrm{mg}$.

\section{1. Hippolais polyglotta (Vieill.). (Fig. 112. 113.)}

\section{Sänger-Laubvogel.}

Sylvia polyglotta Vieillot, Nouv. Dict. d'Hist. Nat., Nouv. Ed., XI, p. 200 (1817Frankreich. Beschreibuug zweifellos, aber Synonym unrichtig).

Hippolais italica Baldenstein, Neue Alpina If, p. 77 (1827- Piemont).

Hypolais polyglotta major, minor, intercedens A. E. Brehm, Verz. Samml., p. 6 (1866nomina nuda!).

Engl.: Melodious Warbler. Franz.: Fauvette Iusciniole ou polyglotte. Ital.: Canapino.

Abbild.: Dresser, B. Europe 1I, Taf. 80; Nener Naumann II, 'Taf. 4.

Unterscheidet sich von II. ieterinu durch folgende Merkmale: Die 1. Schrwinge stets bedeutend lïnger als die Handdecken, die 2. steht an Lüuge zwischen der 5. und 7 ., der Flügel ist kürzer, etwa $64-70 \mathrm{~mm}$ (45 gemessen). das Gelb der Tnterseite mitunter lebhafter. - H. icterina und polyglotta sind häufig miteinander verwechselt worden. 
Brutrogel in ganz Frankereich mit alleiniger Ausnahme der nördlichsten Departements, nïmlich derer nördlich der Somme, also Somme. Par-de-Cialiais. Nord, Aisnes. Ardennes, Mlense. Mreurthe-et-Aloselle. Tosges. Haute-Saône und Doubs

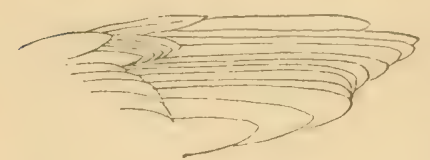

Fig. 112. (L. Bureau in litt.), in Spanien, Portugal,Marokko bis mindestens zum Rio do Oro an der Westküste der Sahara (da dort am 27. und 28. Juli bäufig),

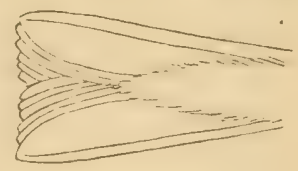

Fig. 113.

Nord-Aluerien und Tumis, Italien his Sï̈ltirol, scheint aher auf Korsika und Sardinien zu fehlon. Finzehne Funde wurden verzeichnet von England, Belgien. Böhmen. Mïhren und Helgoland (23. Mai 1846). Raddes Angahe von einem Vorkommen in Transkiukisien dürfte auf rinem Irrtum bexuhen. zumal dits Belegexemplar nicht mehr im Nusemm zu 'Tiflis vorhanden ist. Überwintert in Senegambien und Ober-Guinea.

Lebensweise und Fortpflanzung wie die von $H$.icterina, doch soll der Gesang den der letzteren Art oft an Mannigfaltigkeit und lieblichen Tönen zu übertreffen. Die Eier sind trotz anders lautender Angaben in der Regel nicht von denen ron $H$. icterina zu unterscheiden, nur im Durehschnitt etwas kleiner. Mittel von 34 Eiern (31 von Jourdain, 3 von König gemessen) $17.75 \times 13.31$, Jlaximum $19.1 \times 14$, Minimum $16.4 \times 12.7 \mathrm{~mm}$. Gewicht nach König $83 \mathrm{mg}$. Pleske gibt den Durchschnitt von. 5 Eiern aus Südspanien mit $17.4 \times 12.2 \mathrm{~mm}$ an. Auch diese Art brütet spät.

\section{Hippolais olivetorum (Strickl.).}

Olivenspötter.

Salicaria olivetorum Strickland, in Gould's B. Europe, II, 'Taf. 107 und 'Text (1837Zante, Jonische Inseln).

Abbild.: Dresser, B. Europe II, Taf. 82 Fig. 2. - Ei: Bädeker, Ei. eur. Vög., 'l'af. 19 Fig. 3.

1. Schwinge immer bedeutend kürzer als die 2., welehe an Länge zwischen der 3. und 5. steht. 3. immer am längsten. Oberseite bräunlichgrau. Ein weibur Supereiliarstreif ist nur angedentet. Federn am Augenlide weißlich. Schwingen dunkelloran nit schmalen weiblichgrauen Außen- und breiteren weißlichen Innensïumen. Steuerfedern sehwilrzhraun mit schmalen. mach der Mitte de's Sthwanzes zn verschwindenden weißen Spitzen, das äußerste Paar ringsum, die folgenden an den Innenfahneu schmal weißlich gesiiumt. Lnterseite weif. Seiten ausgedehnt graubraun verwaschen. Iris

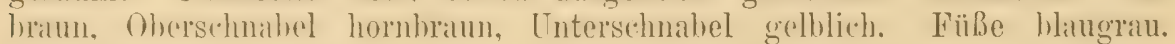
Flügel 85-88.7, Schrvanz 67-74, Lauf 22-24, Culmen 18-21.2 $\mathrm{mm}$. Die Jungen sind etwas düsterer gefürbt und auf dem Rïcken mehr olivenfarben angeflogen.

Der Olivenspütter hrütet im nördlichen Palästina. in Kleinasien, anf den griechis:hen Inseln, in Griechenland und nördlich his in das südliche Dalmatien. Krïper heobatchtete ein Lixemplar bei sliven in Ost-Rumelien; in Italien nur wenigge Matle erbentet (Ligurien, Bari), ron 'Tristram ('inmal hei Koleah in Algier erhentet aher nicht hrïtend gefunden. Die dieser Art zugeschriehenen Lier gehören zu I. $_{p}$. opure. Angahen rom Vorkommen 
in Maroklio heruhen auf Irrtum. Das Torkommen bei Nizza (Arrigoni, Man. Orn. Ital., 1). 308) mud dis bei Talencia (1his 1871. 1. 213) sind durehius unsicher. - Zugrogeel, der ('rst zicmlich spä̈ an seincen Brutplätzen cintrifft und in Afriki ïberwintern mu, wo ihn Jesse in Ahrssinien erbentete.

Lebt vorzugsweise in Olivenhainen, Eichenwäldern und Gärten und ist ein außerordentlich unruhiger Vogel. Der kräftige, sonore Gesang ändert individuell ab, ist aber immer ein nie enden wollendes Geleier, in dem die Silben tschau tschum zizeri bis zum Überdruß wiederkehren (Kollibay, Journ. f. Orn. 1904, p. 111). Die Nester stehen auf Olivenbäumen, nach Lindermayer auch auf Granatapfel-, Nandel- und Maulbeerbäumen. Die 4 Eier sind etwas blasser rosenrot, als die ron $H$. icterina und polyglotta und sofort durch ihre Größe kenntlich. Die schwarzen Flecke sind in der Regel groß und nicht sehr zahlreich. 81 Eier (29 Reiser, 29 Rey, 23 Jourdain) messen im Durchschnitt $20.04>14.81$, Maximum $22.5>14.7$ und $20.5 \times 15.7$, Hinimum $18.3 \times 14.3$ und $19.3 \times 13.8 \mathrm{~mm}$. 'Thienemann gibt an, daß +7 Eier 16.5 bis $19 \times 12$ bis $13.5 \mathrm{~mm}$ messen. Durchschnittliches Gewicht nach Rey 127, nach Reiser $117 \mathrm{mg}$.

\section{Hippolais languida (Hempr. \& Ehr.).}

Curruca languida Hemprich \& Ehrenberg, Symb. Phys. fol. cc (1833-- Syrien).

Hypolais upcheri T'ristram, Proc. Zool. Soc. London 1864, p. 438 („Slopes of Libanon and Hermon").

Sylvia magnirostris Sewertzoff, 'Turk. Jerotn. (in Izw. Ubshch. Mloskov. VIII, 2), p. 123 (1873 - Karatau und westliche Vorberge des 'Lian-Schan); Übers. in MIadarász, Zeitschr. ges. Orn. IV, p. 65.

Acrocepialus sogdianensis Dresser, Ibis 1874, p. 420 (Kokand).

Abbild.: Dresser, B. Europe II, Taf. 83. - Ei: Cat. Eggs Brit. Mus., Taf. X Fig. 2.

1. Schwinge steif und spitzig, etwas kürzer, ebenso lang wie oder ausuahmsweise cine Kleiniglieit läuger. als die Handdecken. 3. an längstun, 4. unbedentend kïrzer, 2. so lang wie die 6 . oder zwischen der 5. und 6 . AuBenfahmen der 3., 4.. 5. Schwinge rerengt. Oberseite luamugan mit kurzem, waiß]ichen Supereiliarstreifen, Cuterseite weißlich. am Ballche mehr bräunlich. Soiten, Lntorschwanz- und Unterflägeldecken brämnlichwrau übertüncht. Steuerfedern dunkler brann als die Oherseite, äußerstes T'alar ringsum weiß gesämmt. die älnigen, mit Ausmalme iles mittelsten Pares mit schmalen weißen Spitzen. Schwingen wie der Schwanz, mit der Farhe des Rürkens schmal gesäumt. die Armschwingen breiter und lichter gesäumt. alle mit schmalen. weißlichen Spitzen. Iris braum. Oherschnabel braun, Cnterschuahel fleischfarhen. Füße braun, Lä̈ufe hellhraum. Flügel etwa 73--78, Schwanz etwa 60-65, Lauf etwa 2:. Culme'n umgefïhr 17-19 mm (28 untersucht).

Brutvogel ron Syrien und Palästiua bis Persien. Baluchistan, Afghamistan, Buchara, Turkestan und Trauskaspien. vielleicht auch in Arahieu. Wo Stücke sogar im Süden im August gesammelt wurden. - Im Winter in Nordostund Ost-Afrika (Abyssinien - auch im August! -, Somaliland, Pare, Litemagebirge).

Bewohnt Ebenen und Gebirge bis ïber $5000 \mathrm{FuB}$, in Buschwerk, lichten Wäldern, Weinbergen und Gärten. Die Nester stehen in Büschen und sind außen mit Spinngeweben und Pfanzenwolle verfilzt. Die $4-5$ Eier sind blaß gräulich rosa oder rötlich grau und sind gefleckt wie die andrer Hippolais-Arten, aber wenig gekritzelt. Sie gleichen denen ron $H$. pallida, sind aber größer und messen nach Nehrkorn $19<14.5$, während 17 Eier im Britischen Museum durchschnittlich etwa $19 \times 13.8 \mathrm{~mm}$ messen. 


\section{Hippolais pallida pallida (Hempr. \& Ehrb.).}

Curmea pallida und Var. Andromedt und maxillaris Hemprich \& Ehrenberg, Symb. Phys. fol. bb (1833- am Nil in Ägypten und Nubien).

Salicaria elacica Lindermayer, Isis 1843, p. 342,343 (Griechenland).

Firerlulı ambignu Schlegel, Kirit. Öbers. eur. Vög., p. XXVI, 53 (1844- Griechenland). Sylvia preglii Frauenfeld, Verh. zool.-bot. Verein, Wien I, p. 54 (1852- bei Almissa in Dalmatien).

Hypolais Verdoti Jaubert, Rev, et MIag. Zool. 1855, p. 70 (Cairo).

Acrocephalus obsoletus Heuglin, Orn. N.O.-Afr. I, p.291 (1869- Tedjura. Typus verglichen).

Acrocephalus obscurus Finsch \& Hartl., v. d. Deckens Reise, Vögel, p. 243 (1870never Name für obsoletus. Ex Heuglin M.S.).

Abbild.: Dresser, B. Europe II, Taf. 80; Neuer Naumann II, Taf. 4. - Ei: Bädecker, Eier europ. Vög., 'Taf. XIX Fig. 4.

1. Schwinge mindestens $3 \mathrm{~mm}$ länger als die Handdecken, 2. zwischon der 6. und 7. oder (seltener) zwischen der 5. und 6., nach Pleske auch mitunter zwischen der 7. und 8. Die Außenfahnen der 3., 4. und 5. Schwinge sind verengt. Oherseite fahl graubraun mit schwachem olivenfarbenen Schimmer, Unterseite und Supereiliastreif weißlich mit rahmfarbenem Anflug und brïunlich üherflogenen Seiten. Flügel etra 6t-69. Schwanz 52-58, Lauf 20-22, Culmen 14.5-17 mm. - Von der Unterscheidbarkeit einer östlichen Subspezies konnte ich mich nicht überzengen.

Brutvogel von Turkestan, Buchara, Transkaspien, Persien, Transkaukasien, Kleinasien, Palästina, Cypern, Ost-Rumänien, Bulgarien, T'ürliei, Griechenlaud his Dalmatien. Teroinzelt, unregelmäßBig in Italien. Eimmal auf Helgoland elbentet. - Im Winter in Sïd-Alibjen. Nordost- und Ost-Afrikia, nach Pleske auch in Baluchistan. Zu dieser Form scheint auch ein im September 1902 bei Vilaflor auf Tenerife ron Thamer erlegter junger Vogel zu gehören.

Bewohner von Gärten, besonders auch Olivenbainen, Orangen- und ZitronenAnpflanzungen. Der Gesang ist sehr einförmig, indem er in der endlosen Wiederholung einer lkurzen, 'den Hippolais-Charakter wahrenden Strophe besteht. Das Nest steht in der Regel in Olivenbäumen und ist ein typisches Spötternest. Die Eier haben eine völlig glanzlose, schwach ins Rötliche oder Rötlichviolette ziehende hellgraue Grundfarbe, mit sparsamen, meist feinen, schwarzen oder tief rotbraunen und einigen tieferliegenden aschgrauen Flecken, mitunter auch mit einigen Strichen und Haarziigen. 105 Eier (63 Rey, 26 Reiser, 16 Jourdain) messen im Durchschnitt $17.88 \times 13.33$, Maximum $19.5 \times 13.8$ und $17 \times 14$, Minimum $15.9 \times 12.3$ und $17 \times 12.1 \mathrm{~mm}$. Durchschnittliches Gewicht nach Reiser und Rey $80 \mathrm{mg}$.

\section{Hippolais pallida reiseri Hilgert.}

Hypolais pallida reiseri Hilgert, Falco 1908, p. 3 (Biskra).

Ist II. $\eta^{\prime}$ pullidu äuberst ähulich, unterscheidet sich aber durch blassere, fahlere, mrh" an " Wüstrurögel" crimernde Oherseite, auberdem ist die 1. Schwinge meist $1.5-2.5 \mathrm{~mm}$ länger. der Schnabel dagegen häufig $1 \mathrm{~mm}$ kürzer. Flïgel $65-68 \mathrm{~mm}$. Von 11 . $\%$. opaca durch geringere Größe (besonder's Schnabel) und blassere Färbung unterschieden.

Bewohnt die Oasen des südlichen Algeriens (Biskra, Tuggurt). 


\section{Hippolais pallida opaca Cab.}

Hypolais opaca Cabanis, Mus. Hein. I, p.36 (1851- Senegal).

Hypolais Arigonis A. E. Brehm, Naturhist. Zeit. 1857, p. 467 (Valencia).

Hypolais cinerascens A. E. Brehm. Ill. Thierteben III, D).865 (1866- als Synonym von H. opaca).

"Hypolais fucescens Selys-Longchamps" Loche, Expl. Sc-Algérie, Ois. I, p. 271 (1867unter den Synonymen von $H$. opaca).

Unterscheidet sich von $I I$. pallida pallide durch bedentendere Größo: Der Flügel ist lünger $(66-71.5 \mathrm{~mm})$, der Schnabel gröber, besonders viel breiter.

Bewohnt Mittel- und Süd-Spanien, Maroklio, Nord-Algier und NordTunis. - Überwintert in Wrest-Afrika vom Senegal bis zum Niger. Soll gelegentlich in süid-Frankreich, nach Giglioli mehrere Male bei Nizza vorgekommen sein.

Lebensweise und Fortpflanzung wie die von $H$. pallida pallicla, aber die Eier sind im allgemeinen wohl etwas dunkler und manchmal etwas rötlicher, jedenfalls aber durchschnittlich etwas größer. 52 Exemplare (39 Jourdain, 13 Rey) messen im Durchschnitt $19.29 \times 13.43$, IIaximum $20 \times 14$, Ilinimum $17 \times 13.6$ und $17.9 \times 12.7 \mathrm{~mm}$. Durchschnittsgewicht nach Rey $92 \mathrm{mg}$, drei spanische Eier nach Jourdain nur $82 \mathrm{mg}$.

\section{Hippolais rama (Sykes).}

Sylvia rama Sykes, Proc. Zool. Soc. London 1832, p. 89 (Dekkan, Indien).

(?) Salicaria obsoleta und morlesta Sewertzoff, Turkest. Jevotn. (in Izr. (O)sheh. MIoskow. VIII, 2), p. 129 (1873 - Perowsk am Sir Darja und am Kaspischen Meere); Übers. in Mad., Zeitschr. ges. Orn. IV, p. 83.

Salicaria tamariceti Sewertzoff, t. c., p. 131 (1873- Sir Darja); Zeitschr. ges. Orn. IV, p. 87.

Iduna albicans Sewertzoff, Bull. Turk. Abt. Ges, Naturw., Anthrop. \& Ethnogr. I, p. 75 (1879- nomen nudum! Vielleicht teilweise zu $H$. caligata gehörig).

Abbild. von Nest und Ei: Dresser, Proc. Zool. Soc. London 187t, Taf. 79.

1. Schwinge sehr lang, meist etwa doppelt so lang als die Handdecken, 2. zwischen der 7. und 8. oder zwischen der 8. und 9., 3., 4. und 5. fast gleich lang und am lïngsten. Flïgel etwa $59-65$ mm. Se:hwanz leicht gerundet. Fürhung wie die von 11. pullida pullidu. - Einige Stücke sind blasser, fahler als andere, doch ist deren Verbreitung unklar und konnte ich unterscheidbare geographische Formen nicht mit Sicherheit feststellen.

Brutvogel in der südöstlichen Nongolei, Kaschmir, Sind, T'urkestan, Afghanistan, Baluchistan, Persieu, Transhaspien. - Uherwintert in Indien, anscheinend auch in Baluchistan und Afghanistan.

Bewohnt die Tamarisken-, Saxaul- u. a. Büsche der Steppenregion, und nistet in niedrigen Büschen. Die 4-5 Eier sind denen von $H$. pallidla ähnlich, nämlich gräulich oder bläulichweiß, höchstens mit schwachem rötlichen Anflug, die Zeichnungen wie bei den-Gattungsgenossen. Sie messen (10 Eier aus I'schinas) nach Pleske im MLaximum $16.5 \times 13$, Durchschnitt $15.6 \times 12.8$, Hinimum $15 \times 12.5 \mathrm{~mm}$.

\section{Hippolais caligata (Licht.). (Fig. 114.)}

Sylnict caligata Lichtenstein, in Eversmann's Reise von Orenburg nach Buchara, p. 128 (1823- Am Ilek am 2. Mai). 
Hippolais swainsoni Hodgson, Gray's Zool. Misc., p. 82 (1832 - nomen nudum!).

Sylvia scita Eversmann, Addenda fase. III, p. 12 (1812- „... in campis et collibus promontoria Uralensia proxime ....").

Jerloniu agricolensis IIume, Ibis 1870, p. 18: (ïuBerst sorgfältige Beschreibung, aber keine Lokalitätsangabe).

Salicaria brevipenis Sewertzoff, Turkest. Jevotn. (in Izv. Obshch. Moskov. VIII, 2), p. 127 (1873); Übers. in Madarász, Zeitschr. ges. Orn. IV, p. 75 (in den krautreichen Steppen, im Saxaulgebüsch im Karatau und in den Vorbergen des 'Tian-Schan).

Salicaria scitopsis und concolor Sewertzoff, t. c., p. 130 (1873- auf dem Schiffe im Kaspischen Meere und am Sir Darja); Mad., Zeitschr. ges. Orn. IV, p.85, 86.

Salicaria microptera Sewertzoff, Stray Feathers III, p. 425 (1875- neuer Name für S. brevipennis 1873).

Iduna platyura Sewertzoff, Bull. Turk. Abt. Ges. Naturw., Anthr. \& Ethnogr. I, p. 85 (1879 - nach Pleske hierher gehörig).

Abbild.: Dresser, B. Europe II, Taf. 84.

Kloiner als H. rama (Flügel nur etwa 57-61), Färbung der Oberseite merklich hräunlicher, Unterseite (hesmolors Seiten) mehr rosthräunlich ver-

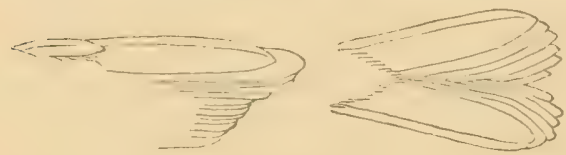

Fig. 114. waschen. Schwanz merklich gerundet, die äuberen Steuerfedern bis $5 \mathrm{~mm}$ kïurzer als die längsten. 1. Schwinge $4-7 \mathrm{~mm}$ läuger als die Handdecken, 2. zwischen der 6. und 7 ., selten nur so lang wie letztere oder minimal külzer, 3.-5. fast gleich lang und die Spitze des Flügels bildend.

Brutvogel in östlichen RuBlaud, mindestens von Olonetz und Moskiau his zur Kirgisensteppe, in West-Sibirien (Jenissei) his zum Altai, Inkestan, Bucharal, Transkispien, auch in Kaschmir. - Überwintert in Nord- und Zentral-Indien.

Bewohnt Buschwerk und Rohrdickichte, sowohl in der Nähe des Wassers als auch auf trockenen, buschreichen Halden. Nistet in Büschen, dicht über der Erde (vgl. Pleske, Ornithogr. Ross. I, p. 375, 376). Die 4-6 Eier sind hell rosa, meist mit sehwachem violetten Anfluge und Zeichnungen wie bei den Eiern der verwandten Arten. 8 Eier aus Orenburg (Sarudny) messen von $15.5 \times 12$ bis $17<13$, 6 Eier aus Mloskau (Lorenz) $15 \times 12$ bis $16 \times 12.5,45$ Eier messen nach Jourdain im Durchsehnitt $15.57 \times 12.24$, Maximum $17 \times 13$ und $15 \times 13.5$, Hinimum $14 \times 11.3 \mathrm{~mm}$.

\section{Gattung SYLVIA Scopoli (1769).}

Die Sylvien stehen der Gattung Hippolais sehr nahe, letztero aber haben eiuen mohr oder minder auffallend breiteren, mehr rohrsingerartigen Schnabel, audere Gervohnbeiten, Nester und Eicr; bei letzteren sind die Goschlechter inmmer sleich, hei Sy/ri, mit wenigen Ausuahmen verschieden. Die 1. Schwinge ist bald sehr kurz und steif, hald gröber und weicher, der Schwanz kïrzer oder länger, fust gerade his deutlich gestuft. Am Mundwinkel hefinden sich immer 3 deutliche Borsten. Kaup schuf fast für jede gute Art rimen Gattumgsnamen (Adophonens, Monuches, Alsoecus, Thumnodus, Livilıis, Earylleolencu), olne Verstïndnis für die wirliliche Verwandtschaft, aus rein theoretischem Formelkram. Unbedingte Synonyme sind $\mathrm{m}$. F. anch Silvia, Cumua, Nisoria, Adomis, Stoparola, Ataphromis, Philacantha. Auch die kmrflüglichen und dahei verhältnismäßig langschwänzigen Melizophilus 
kaun ich nicht tremnen, denn dio sogenannten Pyrophthalme-Arten und Syluiu conspirillate vermitteln den Übergang zu Syliü; die ctwas gröBere Schwanzstufung und das lockerere Gefieder der sog. Melizophilus sind Merkmale, die nur die Bestimmung der Gattungen erschweren würden und künnen nur als Artcharaktere wichtig sein, und daß das Vorhandensein eines nackton, rötlichen Augenlides nicht von Bedeutung ist. zeigt sich dadureh, dab es bei einigen Arten heim of sehr deutlich, heim o sehr wenig ausgeprägt ist, und bei anderen Gattungen, z. B. Pycnonotus.

1. Schwinge viel kürzer als die Handdecken, Kopfplatte ohne alles Schwarz, Flïgel über 68 , Kehle nie rotbraun . . . . . . .

1. Schwinge etwas kürzer als die Handdecken, Kopfplatte bein $\jmath^{7}$ ganz, beim $q$ teilweise schwarz, Flügel $67-74 \mathrm{~mm}$. . . . S. ruppeli .

1. Schwinge so lang wie, etwas kürzer oder etwas länger als die Handdecken, Flügel 58-67, Kopf ohne Schwarz, Kehle und Brust beim of rotbraun........... S. subalpina.

1. Schwinge bedeutend länger als die Handdecken...... 4

Armschwingen mit rostbraunen Säumen . . . . . S. communis .

I Armschwingen ohne rostbraune Säume ............

ÄuBere Steuerfeder mit (beim fa mehr, beim $q$ weniger) Weiß, Schwanz über $66 \mathrm{~mm}$. . . . . . . . . . . S nisoria .

Äucre Steuerfeder ohne alles Weib, Schwanz unter $66 \mathrm{~mm}$. S. borin .

Größte Art, Flügel 79-85, Kopfplatte ơ mattschwarz, ㅇ schiefergrau

S. hortensis .

Etwas kleiner, Flügel 70-78, Kopfplatte ot tiefschwarz, $q$ rotbraun S. atricapilla.

4 Noch etwas kleiner, Flügel $60-70$, Kopfplatte of $q$ matt aschgrau oder graubräunlich, wenig vom Rücken sich abhebend, ohno nackten Hautring ums Auge . . . . . . . . . . . .

Noch kleiner, Flügel 52-63, meist mit deutlichem nackten roten Haut-

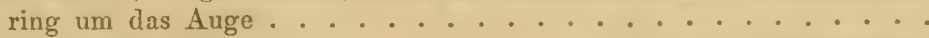

5 I Schnabel riel stïrker . . . . . . . . . S. althaea.

Schuabel viel schwächer .

S. curruca

Kopfiplatte des $\vec{\jmath}$ tiefschwnz, des $\%$ bräunlich schieferfarben, Brust des o nicht mit weinrötlichem Anflug . . . . . . . . . . .

Kopfplatte des 3 mattschwarz, des $q$ hell fahlbraun, brust des of mit weinrotem Anflug, Flïgel 58-63 mm ..... S. mystacea .

Kopfplatte nie schwarz, sondern grnu, bräunlich oder isabell, Flïgel nicht über 61.5 , meist nur $50-57 \mathrm{~mm}$...........

líehle weiß .............. S. melunocephala.

7 Kehle ơ schwarz mit schmalen weißen Spitzen, O schwarz mit so ausgedehnten weißen Spitzen, daß sie fast weiß zu sein scheint. S. melanothorax .

Oberseite in beiden Geschlechtern gräulich- oder rötlich-isabell, Unter-

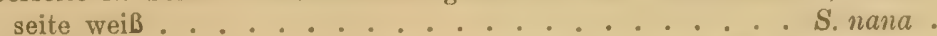

Oberseite in beiden Geschlechtern bräunlich schiefergrau, Kehle und Brust des $\hat{o}$ braunrot, $\subsetneq$ hell rotbräunlich, Schwanz sehr lang und gestuft $(58-72 \mathrm{~mm})$............ S. undata.

Oberseite $\hat{\jmath}$ brïunlich schiefergrau, $f$ fahlbraun, Unterseite $\hat{\jmath}$ braunrot, q hellrötlichbraun, Flïgel $50-57 \mathrm{~mm}$, Schwanz kürzer und weniger gestuft $(55-58 \mathrm{~mm})$. . . . . . . . S. deserticola .

Oberseite ô bräunlich, Kopf grau, $q$ fahlbraun, Brust of weinrötlich, Kehle aber weiß. \& weiß mit nur rötlichem Auhauch, Schwanz etwas mehr gerundet, Flügel $56-59 \mathrm{~mm}$..... S. conspicillata .

Oberseite bräunlich schiefergrau, Unterseite mattgrau . . . S. sarda . p.602

E. Hartert, Die Vögel der parläarktischen Fauna. 


\section{Sylvia nisoria nisoria (Bechst.).}

Sperbergrasmücke.

Motacilla nisoria Bechstein, Gem. Naturg. Deutschl. IV, p.580 (1795- „das mittlere und nördliche Deutschland").

Curruca undata (non Motacilla undata Bodd. 1783) Brehm, Handb. Naturg. Vög. Deutschl., p. 414 (1831- „im nördl. Deutschland").

Curruca undulata Brehm, t. c., p. 415 (1831 - „kommt nur selten im nördl. Deutschland, namentlich bei Ahlsdorf, vor").

Abbild.: Dresser, B. Europe II 'I'af. 68, Naumann II Taf. 76, Neuer Naumann II Taf. 8, Eier: Rey, Eier Vög. Mitteleur., 'Taf. 25, Fig. 20-23.

Engl.: Barred Warbler. - Franz.: Babillarde épervière. - Ital.: Bigia padovana.

Ơad. im Frühling: Oberseite grau mit braunem Anfluge, der auf Kopf, Hals, Bürzel und Oberschwanzdecken laum bemerkbar ist; auf Bürzcl, Obersehwanzdecken, Sehulterfedern und meist anch am Vorderkopfe und üher den Ohrdecken haben die einzelnen Federn schmale weiße, durch eine dunkle subterminale Linie hervorgehobene Säume. Sehwingen dunkelbran mit schmalen fihlhraunen S̈̈umen; Oherflügeldecken wie der Rücken mit ziemlich breiten weißen S̈̈umen. Steuerfedern dunkelgran, die äußeren mit weißen, nach der Mitte zu kleiner werdenden und am 4. Pance rerschwindenden, schräg abyeschnittenen und fast auf die Innenfahne beschräinkten weiben Spitzenflecken; an dem äubersten Palare findet sich auch ein sehr schmaler weißer AuBensaum. Unterseite weiß, Seiten gran angeflogen, jede leder mit subterminaler bräunlichgrauer Bogenlinie, so dab die Lnterseite wie geschuppt erscheint, nur die Mitte des Unterkörpers bleibt ganz oder fast ganz weiß. Iris gelb. Oberschnahel brämulich hornschwar\%, Basishälfte des Unterschnabels hell gelblich fleischfortuen. Füße hell graubram. Flügel etwa 85-90, Schwanz schwalch gerundet, etwa 68-73. Land 23-.25, Culmen 15 bis $18 \mathrm{~mm}$. 1. Schwinge viel kürzer als die Handdecken, oft nur hall, so lang, 2. gleich der 3. oder eine Idee länger, oder zwischen der 3. und t. Frisches Herhstgefieder etwas hrämlicher, sonst wie das Frühlingskleid. o ad. Unterscheidet sich rom durch hrïunlichere oberseite. währoud auf der Cnterseite die Bogenlinion an Kehle, Brust und Lnterkörper fast ganz fehlen und nur an den Cntersehwanzdecken. an don Brustseiten und in den Weichen vorhanden oder wenigstens angedentet sincl. Flïgel etwa $8+$ - $88 \mathrm{~mm}$. - Juv.: Oherseite gräulich braun, die heim ôad. Weiß gesäumten Federn mit fahl rehbraunen Rändern. Cinterseite weililich oder hell rahmfarben, Seiten bräunlich angeflogen. Cntersehwanzdecken mit graubraunen Bogenlinien. Iris graubraun!

Dic Sperbergrasmü̈lie bewohnt Europat vom südlichen Schweden und dem Südufer des Fimischen Meerbusens an durch die Gouvermements Jaroslaw und Kasan his zum südlichen Cral, das ganze mittlere und südliche RuBland, Polen, die Dobrudscha. Bulgarien. IIontenegro, Dalmatien, ÖsterreichUngarn, Deutsehland, I)ïnemark und Oberitalien. In Deutsehland ist sie sehr lokal rerheitet: in Ost- und Mestyreußen ist sie stellenweise sehr gemein, in Pommern und Mecklenburg nicht selten, in Sehlesien selten, stellenweise dagegen häufiger - hier wie anch anderwärts scheint sic ihre Standorte mitunter zu wechsehn -.. im mittleren und südlichen Deutschland zwar regelmäßig 
und stellenweise zahlreich, aher im allgemeinen wohl selten, weiter westlich, also in Hessen, dem Rheiulande usw., ebenso in Frankreich uи rereinzelt, und jedenfills niemals nistend rorgekommen. Auf den britischen Inseln ziemlich oft, besonders in Norfolk, erlegt. - Zugvogel. In Nord-Italien auf dem Zuge häufig. Überwintert in Nordost-Afrika.

Die Sperbergrasmücke lebt in buschreichen Waldungen, Auen, Parkanlagen, großen Gärten in ebenen Gegenden. Die eigentliche Lockstimme ist lauter, tiefer als bei anderen Grasmücken, an die Silbe tschrä erinnernd, ganz charakteristisch aber ist ein eigenes, viel öfter zu hörendes, an den 'Ton des Haussperlings und an den des rotriickigen Würger's erinnerndes „errrrw". Der Gesang ist melodisch, anhaltend, laut. dem der Gartengrasmücke (S. borin) sehr ähnlich, der Sänger verrät sich aber meist durch das hier und da angebrachte "errrrr". Das Nest ist umfangreicher, als das anderer Grasmücken, fester gebaut als das von S. borin, das Äußere ist locker, das Innere ziemlich flach, mit Pierdehaaren und kleinen Wïrzelchen ausgelegt. Es findet nur eine Brut im Jahre statt und zwar im Juni, frühestens Ende MIai. Die 5, ausnahmsweise 6, Eier sind mit denen anderer Grasmücken nicht zu verwechseln. Sie sind auf hell gelblichgrauem, trüb rahmfarbenem, grauweißlichem, milchigem, seiten gelblichem oder grü̈lichgrauen (†runde mit blaßgrauen und ganz blaß fahlbräunlichen Flecken gezeichnet; oft ist die Zeichnung so matt, dalj sie aus einiger Fntfernung nicht zu bemerken ist. Nur einmal fand ich bei Pillau ein Gelege mit großen rotbraunen Flecken und Punkten. 113 Eier in Dr. Reys Sammlung messen im Durchschnitt $21.07 \times 14.41$, Maximum $22.8 \times 15.6$ und $22.5 \times 16.3$, Minimum $19.5 \times 14.5$, cin Riesenei $23.9 \times 17.2$, ein Zwergei $12.5 \times 10 \mathrm{~mm}$. Mittleres Gewicht nach Rey $158 \mathrm{mg}$.

\section{Sylvia nisoria merzbacheri Sehalow.}

Sylvia nisoria merabacheri Schalow, Urn. Jlonatsber. (Januar) 1907. 1.3 (Kaschka-su im zentralen Tian-schan, im September erlegt).

Sylvia nisoria sibirica Johansen, Ornith. Jahrb. (Dezember) 1907, p. 198 (Altai).

Nach Schalow unterseheidet sich die Sperhergrasmücke des Tian-sehan durch längere F'lügel, lichteres Grau an Kopf und Nateken und etwals ausgedehnteres Weiß an den äußeren Stenerfedern. Es lagen dem Autor nur 3 Exemplare vor, er rechnet dazu aber auch ein $\sigma^{\pi}$ von Margelan. Die Flügel sind nach Schalow 91-92 mm. lang. Für dic westlichen Vögel gibt er $83-91 \mathrm{~mm}$ an. Mir vorliegende Stücke aus dem T'ian-schan haben eine Flügellänge von 86-93.5, oin o vom 7. Mai 1884 aus Aidin in Kleinasien hat einen Flügel von $95 \mathrm{~mm}$. Im allgemeinen ist bei den astitischen Stücken (8 aus Turkestan, 1 aus Ḱleinasien). dats Grau an Kopf, Nacken und Bürzel etwals reiner und lichter, die Ausclehmug des Treiß an den äuferen Steuerfedern aber vilriert und ist hei den Asiaten nicht grölier. - Iohansen gibt für seine neue Form an, dals sie mit merzbacheri in der Färbung übereinstimme, aber kürzere Flügel habe. Seine silvirea soll Flïgel von $84-8$ mm haben. Das kürzere Stener und der kürzere Lauf boruhen wohl auf Täuschung (rgl. die MaBo ron Europätrm). Dil der Fï̈gel anch nicht kürzcl sein diüfte (.Johansen urteilte nach 2 Exemplaren!), könuen wil

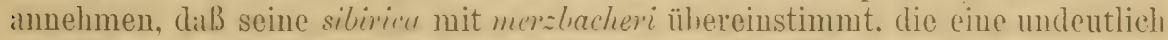
markierte asiatische Subspezies, mit Neigumg \%u lichterer Obarscite und laugen Flïgeln bildet. Sie scheint Asien vom Altai und 'Turkestan his Persien(?) und Kaukasus(?) zu hewohnew. In Kleinasien ist sie vielleicht auch Brutrogel, oder nur Durchzügler. Winterquartiere unbeliannt, viellei.ht 
gehören die in Süd-Arahien überwinternden Stiicke hierher. - So nahestehende Formen sollten nur mach größeren Serien benamnt werden.

\section{Sylvia hortensis hortensis (Gm.) (=orphen auct.).}

Sängergrasmücke, Orpheussänger.

Motacilla hortensis Gmelin, Syst. Nat. I, p. 955 (1788 - ex Brisson, Buffon, Daubenton, pl. 579, 1. Frankreich und Italien).

Sylvia orphea Temminck, Man. d'Orn., p. 107 (1815 - Lothringen, Ardennen, hügelige Gegenden des übrigen Frankreichs).

Sylvia grisea Vieillot, Nouv. Dict. d'Hist. Nat. (Nouv. Ed.) XI, p.188 (1817- „Hollande, Lorraine, Piémont, Provence").

Curruca Vidali und caniceps Brehm, Journ. f. Orn. 1856, p. 455 (Spanien, obwohl dies nicht erwähnt ist).

Curruca orphea griseocapilla A. E. Brehm, Allg. d. naturh. Zeitung III, p. 464 (1857Catalonien, Valencia).

Abbild.: Dresser, B. Europe II Taf. 64. 'Eier: Rey, Eier Vög. Mitteleur., 'Taf. 25, Fig. 25.

Engl.: Orphean Warbler. - Franz.: Faurette orphée. - Ital.: Bigia grossa.

Cal. (Frühling). Oherkopf. Zügel und (Ohrgegend glanzlos grauschwarz. am Geniek in die hell sehiefergrame. leicht hriunlich iuhertinnelite Fürbung der Oherseite ühergehend. Schwingen sehwillzhram, fahlibraun gesïumt, innere Arnschwingen wie der Rücketen. I) ie vine mittleren Steurfedern matt schwarzbram, in frischem cirfieder mit schmilen fahlen Sämmen, die folgenden haben kleine. nach auben zu an Breite zunehmende weibe spitzen, das ïulerste Palar ist woil. mit duukel graubrannem lä̈ngstleck am Ramde der unteren zwei I) rittel der Innenfahne und schwälzlichem schaft. Cnterseite weiblich. Tehle und Kenfgergend mehr oder minder blab hraungelblich. Seiten etwis lehhafter ïhertüncht. Lntersehwauzdecken lehhaft rahmfarhen, in der Mitte etwats brännlicher. Axillaren und Lnterflügreldeclien röstlich fahl mit rosigem Anflug. Iris hell seliwefelgelh his rahmfarben. Schmahel dunkel sechieferfarhen, Basis des Cnterschmahels hliuliehgrau. Fïle hräunlich sehiefergrau. Fliggel retwa 79-84 (spanische scheinen an kleinsten zu scin. mit Fliigeh von nicht mehr als $80-81 \mathrm{~mm}$ ): 1. Sehwinge länger als clie Handdecken, 2. zwischen der 5. und 6.. 3. und t. fast gleich und am längsten; Schwanz leicht gerundet, etwa 66-70, Lauf 23-25, ('ulmen 16-18 mm. - Im Herhstkleid ist die Kehle und Kropfgegend rosig augehaucht, das Schwirrzliche des Oberkopfes mehr dureh graue Sïume und grauen Anfug verschleiert. O Oberkopf nicht so dunkel. sondern nur etwas mehr grau, als die übrige Oherseite, selten schwärzlich. Flïgel etwa $78-81 \mathrm{~mm}$. - Juv.: dem $o$ ad. ähnlich, aher anf der Oherseite etwis hrïmlieher, die Flügeldecken mit rostgelben Kanten.

Die westliche Form der Sängergrasmü̈cle hewohnt das südwestliche Furopa und die $\Lambda$ tlaslïnder Nordwest-A frikits. Sie hrïtet in den haumreichen Strecken Marokkos. Algeriens, Tunesiens, rorzugsweise nürdlich der Atlasherge, auch in Tripolis. Sie leht in Portugal. Spanien, Süd- und MittelFrankreich, in geringer Anzahl his Luxemburg und Metz (in NordwestFrankreich aher fehlend), in der West-Schweiz, in Italien und Sizilien (anf Sardinien und Korsika nicht festgestellt). - In Eugland soll sie zweimal zur 
Brutzeit erbeutet, nach Heubler eimmal 1886 hei Kilrlsuhe gefangen worden sein, aber dies ist ebensowenig zu beweisen wie die dreimiligen Brohathtungen anf Helgoland, wenn nieht ein Belegexemplar vorliegt. - I)al die Alt in südlichen Algerien durehzicht, üherwintert sie rermutlich in Test-Afrikia oder in den Oasen der Salhara. Sharpe giht au, dab sie in Senchambien erhentet wurde. In England zweimal im Herbst erlegt.

Die Sängergrasmücke bewohnt allerlei Buschwerk, Gärten, Wälder mit Unterholz u. dgl., und scheint besonders Hügelland zu lieben. Die Lockstimme ist laut und rauh und durch die Silben tjätt scherrrr, trui-ra ra ra ausgedrückt worden. Der Gesang wird von allen Beobachtern gepriesen und ist auch zweifellos wundervoll, dennoch ist er für mein Ohr nicht so weich und lieblich wie der des S'chwarzplättchens, obgleich er anhaltender, lauter und voller klingt. Das Nest steht in Büschen oder Bäumen, besonders gern in den Kronen der Olivenbäume; es besteht aus allerhand Pflanzenstengeln, Wurzeln und Grashalmen, die im Innern viel feiner werden, die Nestmulde enthält aber weder Federn noch Haare. Die 4-5 Eier sind sehr blaß griinlichweiß, in Sammlungen rein weiß, mit braunen bis fast schwarzen Flecken und Punkten, häufig mit sogenannten Brandflecken und Sehnörkeln, sowie mit blaßgrauen Schalenflecken gezeichnet. Sie erinnern lebhaft an die allerdings viel kleineren Eier von S. curruca. 100 Eier (81 von Jourdain, 19 von Erlanger gemessen) messen im Durchschnitt $19.01 \times 14.41$, Maximum $21.5>14.5$ und $19 \times 15.5$, Minimum $17.5>13.6$ nnd $20.3 \times 13.2 \mathrm{~mm}$. Ein abnorm großes in Newtons Sammlung meist $22.3 \times 17.3 \mathrm{~mm}$.

\section{Sylvia hortensis crassirostris ('retzsehu.}

\section{Östliche Säng*ergrasmücke, östlicher Orpheussïnger.}

Sylvia crassirostris Cretzschmar, Atlas Reise Rüppells, p.49, Iaf. 33 Fig. a (1826Nubien).

Curruca orphea $\beta$. Helena Hemprich \& Ehrenberg, Symb. Phys. fol. ce (1333- Syrien). Curruca jerdoni Blyth, Journ. As. Soc. Bengal X VI, p. 439 (1847- „From southern India"). Curruca musica Brehm, Vogelfang, p. 228 (1855- Seunar).

Unterscheidet sich von S. hortensis hortensis lediglich durch oinen in der Regel (cinzelne Stücke sind nicht zu unterscheiden) längeren Schuabel, mit einem culnen rou 18 - 20.5 mm, auberdem' ist die Enterseite meist etwas weiblicher und entbehrt auch im Herhste des rosigen Hauchs, ist dann vielmehr nur sehwach rostgelblich angehaucht. Flügel wie bei der westlichen Furm, hei einem of aus sïdwest-Persien (ron Witherhy gesammelt) etwa $85 \mathrm{~mm}$.

Trotritt S. hortensis hortensis in (Isten, von Dalmatien und Montenegro an dureh Griechenland und Kleinasien his Palästina, P'ersien. Afghauistan, Buchara und Turkestan. - C̈berwintert in Nubien, Eritrea, Sennar. Kordofan, Somaliland, Alabien und den Ebenen Indiens.

Lebensweise und Fortpflanzung wie die der westlichen Form. Die Eier sind indessen in der Regel größer und glänzender, nicht so rein weiß, in frischem Zustande deutlich grünlich. Die Fleckung ist dreifarbig: aschgrau, grünlichgrau und bräunlich, oft über das ganze Ei gleichmäßig zerstreut, Braudflecken kommen anscheinend nie vor. Sie erinnern gar nicht an Eier ron S. curruca und haben einen ganz eigenartigen Charakter. 100 Eier (78 von Jourdain, 22 von Reiser gemessen) messen im Durchschnitt $20.02 \times 14.92$, Maximum $23.3 \times 15.1$ und $20.6 \times 16.5$, Minimum $18 \times 14.4$ und $20.4>14.1 \mathrm{~mm}$. 


\title{
883. Sylvia borin borin (Bodd. $\left.)^{1}\right)$.
}

\author{
Gartengrasmücke.
}

Sylvia hortensis auctozum: errore, nicht Sylvia hortensis Gmelin!)

Motacilla Borin Boddaert, Table Pl. Enl., p. 35 (1783- Frankreich. Ex Daubenton Pl. Enl. 579, 2, Buffon \& Brisson. Deutl. Abb. des Herbstvogels und Beschreibung). Sylvia simplex Latham, Gen. Syn. Suppl. I, p. 287 (1787- Name für die engl. Var. des "Pettychaps", welch letzterer der Orpheussänger, nach Brisson \& Buffon beschrieben, ist).

Motacilla passerina Gmelin, Syst. Nat. I, p. 954 (1788- Frankreich und Italien. Ex Brisson, Buffon, Daubenton 579,2).

Syleia Aedonie Vieillot, Nour. Dict. d'Hist. Nat. (Nour. Ed.) X I, p. 162 (1817 - Frankreich)

Curvué brachyjhynchos Brehm, Handb. Naturg. Vüg. D)eutschl.. 1).416 (1831- deutsche Fichtenwälder).

Curruca grisea Brehm, t. c., p. 416 (zuweilen Mitteldeutschland auf dem Zuge).

Muscicupe ussheri Sharpe, Proc. Zool. Soc. London 1882. p. 591 ((roldküste. - Exemplar in Mauser).

Engl.: Garden-Warbler. - Franz.: Fauvette des jardins. - Ital.: Beccafico. Schwed.: Trädgårdssångaren.

ơad. Oherseite olivenbram, Schwanz, und Schwingen etwas dunklel Śpitzensïmme der Flügel liehter, weißlicher. Interseite gräulichweiß. Kürperseiten. Kropfgegend und [nterflïgreldecken fahl grehbram, die letrteren reiner, goblhlicher. Kehle und Cnterschwanzdectien nit gelblichem Schimmer, Mitte des Tnterkïrpers fast rein weil, Innensäume der S'chwingen silbergralu. Iris hrann. Schnabel dunkelhornhramn, Basis des Tnterschuahels gelhlichliamun. Füle hleigran. 1. Schwinge kï̈zer als die Handdecten, ausuahmsweise ehenso lang. 2. zwischen der 3. und 4., 3. am längsten. Flïgel etwa 75-84,

1) Fraglich ist:

Bradyornis woodwardi Sharpe, Cat. B. Brit. Mus. III, p.311, Taf. XIV (1877- Natal) Sylvia clarae Kleinschmidt, Orn. Monatsber. IX, p. 167 (1901- 'Tunis).

Die von Sharpe aus Natal, und die von Kleinschmidt aus Tunis beschriebenen Zugvögel sind auffallend groß (Flïgel $80-84 \mathrm{~mm}$ ). Es fragt sich, ob diese großen Exemplare in einem besondern geographischen Gebiete brüten, oder individuelle Aberrationen darstellen. Nach meinen Messungen sind ost- und suidafrikanische Zugvögel durchweg sehr groß, und man könnte vermuten, daß sie einer östlichen großen Subspezies angehören. Westliche, besonders englische, französische, westdeutsche sind in der Regel kurzflügliger, und haben $73-78$, höchstens $80-81 \mathrm{~mm}$ lange Flïgel. Wenn es wirklich eine östliche, größere Subspezies gibt, vermag ich deren Verbreitung vorläufig nicht anzugeben; es müßten erst Serien von Brutvögeln aus den östlichen Wohngebieten untersucht werden. Erlangers Vermutung, das S, borin bei Gafsa in 'T'unesien brüte, beruht auf Irrtum, da die der S. borin zngeschriebenen Eier solche von S.hortensis sind. Folgende IIaße mögen andeuten, wie unsicher die Frage von der Unterscheidung mehrerer Formen noch ist: Flügel alter Vögel aus England in der Regel 73-78 mm; Cauterets in den Zentral-Pyrenäen ơ (Ende Mai!) 81, ㅇ 75; Ingelheim ơ bis 81 , ein of Volkmaritz nur 75 , eive Serie aus Thüringen etwa $76-82$, Vogesen bis 80 , Piemont 80 , Schweden $\odot 76--79,078-80$, Spanien $76-82$, Italien ơ $76,77-80$, ๆ $75-81$, Sardinien of 76 , Ungarn ơ $81-83$, q 78-80, 3 Vögel aus 'L'unesien, Curzola (Dalmatien) und Schlesien nach Kleinschmidt 84, alle westlichen Vögel nach Kleinschmidt kleiner', nicht über 80-81; ô 'Türkei 81; Helgoländer Zugvögel 76--80.5; MLskau 79.5; Kleinasien 75-78; Palästina 78; Nyassaland 81.5, Kibiro 80, Natal 84, Pinetown 83.5, Potschefstrom $83 \mathrm{~mm}$. Westafrikanische Zugrögel kleiner. 
Schwanz fast gerade, etwa 56-62, I uauf 20-22, Culmen 12.5-14.5 mm. - Das Herbstkleid ist in der Regel etwas lebhafter, dunkler, das o gleicht dem O’, höchstens sind dio Seiten etwas hlasser. Das Nestkleid ist röstlicher.

Brïtet von Skandinavien, Nordrußland, Irland und Großhritannien ïher Europa, ist aber in Süd-Europa seiten und kommt beispielsweise in Griechenland nur auf dem Zuge vor, doch find Iilford noch ein Nest in SüdAlbanien (kpirus). In Sibirien bis Krasnojarsk. vereinzelt bis Transkiukasien und Persien ${ }^{1}$ ). - In Kleinasien, Gricchenland. Palästina, Ägypten, sowie in Tunis, Algerien und Marokko anscheinend nur Durehzïgler, dre im tropischen und südlichen Afrika überwintert. Angehlich soll die Art jedoch in Palästina brüten und möglicherweise findet das auch in den Atlasländern statt.

Bewohnt Waldränder, lichte Stellen inmitten von Waldungen, Gehölze, Parkanlagen und Gärten. Der Gesang besteht aus längeren Strophen als der andrer Grasmiicken, ist wohlkliugend, voll und kräftigg, aber nicht so schöu flötend und orgelnd wie der der Schwarzplättchen. Das Nest steht meist $1 / 2-2 \mathrm{~m}$ hoch in Büschen, besteht fast nur aus feinen Halmen und Stengeln und ist groß und unordentlich gebaut, sodaß es oft von Wind und Wetter beschädigt wird. Die Eier, 5, selten 6, mitunter aber nur 4 an Zahl, findet man von Mlitte Mlai an, nach Zerstörung der ersten Brut sogar bis in den Juli hinein. Die Eier sind auf weißem, gelbbräunlichen oder leicht grünlich angehauchten Grunde mit olivenbraunen, schwarzbraunen, lehm- oder leberbraunen, oft hell umrandeten Flecken und Punkten und mit hellgrauen Schalenflecken gezeichnet. Sie sind in der Regel lichter, aber von den hellen Varietäten der Eier von Sylvia atricapilla nicht zu unterscheiden. So dunkelbraune Eier wie bei letzterer Art und die dort so häufigen roten Varietäten scheinen bei S. borin nie vorzukommen. 100 Eier (50 Jourdain, 50 Rey) messen im Durchschnitt $20.05 \times 14.69$, Mlaximum $23 \times 14.8$ und $19 \times 16$, Minimum $18 \times 14.6$ und $19 \times 13.4 \mathrm{~mm}$.

\section{Sylvia atricapilla atricapilla (L.).}

Schwarzplättchen, Mönchsgrasmücke, Schwarzkopf.

Motacilla Atricapilla Linnaeus, Syst. Nat. Ed. X, r. 187 (1758- "Habitat in Europa”. Als terra typica sehen wir Schweden an, nach dem ersten Zitat).

? Motacilla moschita Gmelin, Syst. Nat. I, II, p. 970 (1789 - ex Cetti, Ucc. Sardegna Sardinien. Der Name wurde irrigerweise als Syn. von S. sarda zitiert!).

Cirruca nigricapilla Brehm, Handb. Naturg. Vög. Deutsehl., p. 417 (1831- „bewohnt unsere Fichtenwälder").

Curvuca pileata Brehm, Handb. Naturg. Vög. Deutschl., p.418 (1831- ,scheint den Norden zu bewohnen, besucht im September die Hollunderbïsche des mittleren Deutschlands").

Curruea rubrieapilla Landbeck, Syst. Aufz. Vög. Württembergs (abgerlruckt a. d. Correspondenzbl. d. landw. Ver.), p. 44 (1834- Tübingen).

1) Vielleicht handelt es sich in Sibirien um eine blassere Form, die aber noch zu bestätigen ist:

Sylvia borin pallida Johansen.

Sylvia simplex pallida Johansen, Orn. Jahrb. 1907, p. 199 (Barnaul und Kainsk in Westsibirien).

Unterschejdet sich nach Johansen von Exemplaren aus Livland durch lichtere Färbung, besonders der Oberseite, und "scheinen in allen Dimensionen kleiner zu sein". Dem Autor lagen nur 2 Exemplare vor, wonach eine solche Subspezies nicht benannt werden sollte. Die augegebenen Maße (Flïgellänge 79-82) widersprechen der Vermutung, daß die Form kleiner sei. 
Sylvia Tumanni Müller, Naumannia 1851, Teil 4. 1.26 (am Nilkatarakt ron Ambukol). Sylvia ruficapilla Naumann, Vög. Deutschl. XIII, p.411 (1853- Deutschland).

Sylviu gularis Alexander. Ibis 1898, 1).81 (Capverden. - Nach mit gelben Bliitenstaub beschmierten Stücken).

Sylvia atricapilla Pauluccii Arrigoni, Avicula VI, p. 103 (1902- nach 2 sardinischen Exemplaren!).

Engl.: Blackeap. - Franz.: Fauvette à tête noire. - Ital.: Capinera. - Schwed.: Svarthufvadesångare.

G̈al. (Frühling). Kopfplatte schwarz, Nacken, Zü̈gel, Kopf- und Halsseiten aschgrau. ührige ()herseite griulich olivenbran bisweilen fast aschgrau.

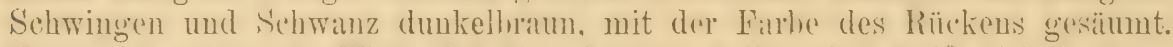

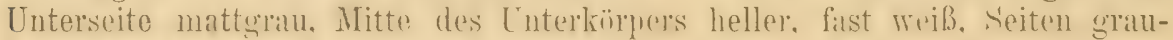
braun rerwaschen. Cuterlügeldechen weiblich his rahmfarhen. Cutersehwauzdecken sraubaun mit breiten schmutzigweilien Sämmen. Iris haum. Oher-

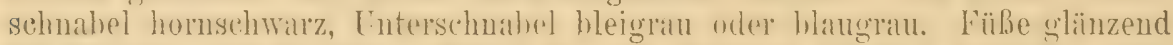

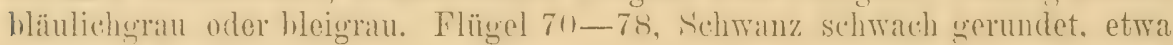
60-65, Lauf etwa 19-21, Culmen $12-15 \mathrm{~mm}$, 1. Schwinge an Läng’e varierond, aher immer die Handdecten ïberagend. 2. zrischen der 5. und 6. oder gloich der 6., Aubensaum der 3. von der Mitte an, der 4. und 5. vor dor Spitzo verongt, 3. und t. an lïngsten. i Topfplatte rosthraun, Nacken

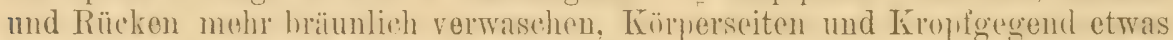
bräunlicher: - Im frischen Herbstileide hithen dis schwarzen Fónffedern der $\hat{o}$ schmale rosthraume Säume, die sich aber bald abmutzen. - Im ersten Jugendlikide hahen heide Geschlechter rothrame Kopplatten, diese ist hrim f blasser als in Alter, daber weniger vom Rï̈rken alistedrend, heim of etwats dunkler als beim 0 .

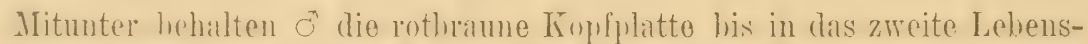

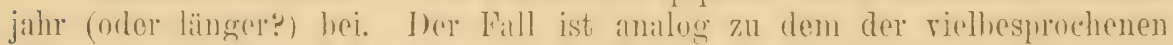

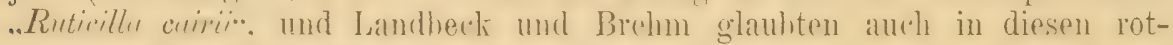
köpfigen $0^{\pi}$ eine besondere Art vor sich zu haben.

Das Schwarzplättchen brïtet in Europa von etwa dem $66^{\circ}$ nördlicher Breite in Skandinavien (in wringer Anzahl anch noch noirdlicher). vom 60. his 62." in Nordrubland his zum Mittelmecre. auf den Azoren und Kanver(en ${ }^{1}$ ) (über Madeira und die Canaren siehe unten, S. a. heineken), in Marokko, Algerien und 'Lumesien, aher nur nördlich des Atlas. in Osten his Kleinasien und Palästina, rereinzelt im westlichen Persien. In Sihirien soll es bei Omsk gefunden worden sein. - Zugrogel. Therwintert in Afrikia his zum Niassa-See südlich, angenseheinlich aber auch schom in dou Oasen der Sahara; teilwoise in Sücl-Eurona. sowice in Nord-Algerien Standrogel.

Bewohner von Wäldern mit viel Unterholz, jungen Kulturen, Parkanlagen, Friedhöfen, großen buschreichen Gärten. Gesang einer der schönsten Vögelgesänge in Europa, nach dem Geschmack vieler Naturfreunde nur von dem der Nachtigall übertroffen; er beginnt mit einem leisen Gezwitscher, das in eine bald kiirzere, bald längere. oft prachtroll orgelnde Flötenstrophe übergeht. Die zwei Bruten finden von Aufang April bis Juli statt. Das Nest steht gewöhnlich wenige Fuß über dem Boden in allerhand Büschen. Es ist aus Gras, Halmen, Würzelchen

1) $\mathrm{Daß}$ die Stücke von diesen Inseln nicht von europäischen zu unterscheiden sind, ist vielleicht auf die spätere Besiedelung dieser Inseln (worauf vieles hindeutet) zurïckzuführen. 
und Fasern gebaut, innen augenscheinlich immer mit Pferdehaaren ausgelegt. Die meist 5, selten 6 oder nur 4 Eier rariieren in Europa besonders zwischen braunen und rötlichen Typen. Sie sind auf gelblichweißem, weißlichem, gelblichem, bräunlichem Grunde mit verschieden braunen Flecken und hellgrauen Schalenflecken gezeichnet, sowie meist mit tiefdunklen, fast schwarzen, heller umflorten runden Fleckchen und Punkten, mitunter auch mit braunen Kritzeln. Sehr häufig sind rötliche Gelege, d. h. Eier, die auf rötlichweißem oder hellroten Grunde mit rötlichbraunen dunklen und helleren Zeichnungen versehen sind. 100 Eier (ఓ00 von Jourdain, 50 von Rey gemessen) messen im Durchschnitt $19.3>14.56$, Mlaximum. $21.5 \times 15$ und $20.6 \times 15.5$, Hinimum $17 \times 13 \mathrm{~mm}$. Das durchschnittliche Gewicht nach Rey $131 \mathrm{mg}$ (Maße und Gewichte wie immer abgesehen ron den bei dieser Art nicht seltenen Riesen- und Zwerg-Eiern). - In Süd-Europa, besonders Cypern, werden diese im Herbst sehr fetten Vögelchen mit besondrer Vorliebe gegessen.

Geographische Formen:

Ein sehr plausibles Bild von der geographischen Variation vermag ich nach dem ron mir untersuchten Material zurzeit nicht zu geben. Weder vermag ich auf dem europäisch-asiatischen Festlande Subspezies festzustellen, noch auch auf den atlantischen Inseln, mit Ausnahme von Iadeira und den Kanaren. Die Färbung wechselt "sehr nach der Jahreszeit und auch indiriduell. Die von Arrigoni belauptete dunklere Färbung der sardinischen Stïcke ist nicht vorhanden, wenn man Serien vergleicht. Die Bewohner der Atlasländer kann ich nicht unterscheiden. Nach Vergleich von 6 Exemplaren kann ich nicht einmal die Brutvögel der tropischen Capverden unterscheiden, ebensowenig ergibt der Vergleich von 30 Brutrögeln ron den Azoren erkennbare Unterschiede. Merkwürdigerweise sind die Vögel von Madeira (und den Kanaren) wirklich düsterer, obrohl 'T'schusi bei Beschreibung seiner S. a. obscura ein nur seln geringes Material von S. a. atricapilla untersuchte und die Beschreibung übertrieben erscheint; weder ist der Schnabel bei $S$. a. obscura schwächer, noch ist die normale S. a. atricapilla oben aschgrau mit nur schwacher bräunlicher 'Trübung. - Der Name der düsteren Inselform ist S. atricapilla heineken. Unter diesem Namen wurde die dunkle Aberration der Madeira-Subspezies beschrieben; er gebührt unbedingt der Madeira-Form, wenn er auch einem aberranten Stücke beigelegt wurde. Nomen. klatur und Kennzeichen sind wie folgt:

\section{Sylvia atricapilla heineken (Jard.).}

Curruca Heineken Jardine, Edinburgh Journ. of Nat. \& Geogr. Sc. I, p. 243 (1830Madeira. Es sei bemerkt, daß der Name heineken und nicht heinekeni lautet; es handelt sich nicht um einen Schreib- oder Druckfehler, ebensowenig wie bei den Namen von Jichahelles; vgl. oben p. 295 und 338).

Sylvia atricapilla obscura Tschusi, Orn. Monatsber. 1901 p. 129 (Madeira).

Sylvia atricapilla capirote Floericke, Aus der Heimat des Kanarienrogels, p. 47 (1905Kanaren).

Nach Vergleich ron ïber 20 Stücken von Madeira kann ich bestätigen, daß diese Vögel eine düsterere Färbung haben. Dies ist besonders auffallend auf der Oberseite der $q$, deren Rücken und Kopffärbung verdüstert ist, sodaß die Kopfplatte weniger auffallend absticht. Außerdem sind die Körperseiten bräunlicher als sonst gewöhnlich. Ebenfalls bei den of ist die Oberseite sehr dunkel, mehr olivenbraun, und auch die Seiten zeigen eine stark braune Färbung. Flügel der ơ $69-72$, $q 68$ bis $71 \mathrm{~mm}$. - Mit den Vögeln von Madeira stimmen in der Regel die von den Kanaren (Stücke von 'Tenerife, Canaria, Palma, Fuertaventura untersucht) überein, manche aber sind heller, und zwar nicht nur solche von Fuertaventura. Es wäre möglich, daß die helleren Stücke z. T. Zugvögel sind. Eine Unterscheidung der Stiicke von den Kanaren ist vorläufig nicht durehfïhrbar. Floericke, der behauptet, ohne Vergleichs- 
material "sofort darüber im klaren zu sein, daß er eine gute klimatische Subspezies" vor sich hatte, schlägt zwar einen neuen Namen ror, gibt aber keine Unterschiede von der Iladeira-Form an. - Außer der diustereren Färbung finden wir folgende Eigentïmlichleiten: Es kommt (häufig auf IIadeira, ebenso auf Palma, und mitunter auf Tenerife) eine dunkle Aberration vor. Beim of erstreckt sich das Schwarz des Kopfes ïber den Nacken, die Koplseiten. Kehle und Kropfgegend, und der Rest der Unterseite ist olivenbräunlich. Das $q$ gleicht auf der Oberseite den normalen $q$, die ganze Unterseite aber ist braun. Merkwürdigerweise kommt diese dunkle Form auch vereinzelt auf den Azoren vor, und (vgl. Nov. Zool. 1905, p. 119) im Mluseum zu Ponta Delgada befindet sich ein Übergang von der normalen Form zu "heineken". Nach R. v. Thanner manserten normale Junge im Käfige in das dunkle heineken-Kleid, aber es gibt auch solche junge Nestvögel, wie ein vorliegendes $\widehat{\jmath}$ juv. von Madeira beweist. Größenunterschiede zwischen der dunklen Aberration und normalen Stücken besteben nicht. - Jie Fier der S'chwarzplättehen variieren auf Iadeira und den Kanaren in einer in Europa nicht bekannten Weise. Besonders gibt es (noch dazu mitunter auffallend große) Eier, die auf weißem Grunde mit rostgelben und äußerst feineu roten Punkten gezeichnet sind, so daß sie selbst geübte Eierkenner nicht ohne weiteres erkennen, weun ihuen diese Varietäten noch nicht bekannt sind.

\section{Sylvia communis communis Lath.}

Dorngrasmiicke.

Motacilla mifa Boddaert, Tabl. Pl. Enl., p. 35 (1783-- ex Daubenton pl. 581, 1. Da Daubentons Bild unkenntlich ist, kann der Name nicht angewandt werden). Sylvia communis Latham, Gen. Syn. Suppl. I, p. 287 (1787- ex Gen. Syn. II, p. 428. Eingland).

Sylvia cinerea Bechstein, Orn. Taschenb. I, p. 170 (1803- Deutschland).

Sylvia cineraria Bechstein, (rem. Naturg. Dentschl., 2. Auf. III, p. 534 (L807 - Europa). Curruce cineraceu Brehm, Handb. Naturg. Vög. Deutschl., 1. 420 (1831- Nadelwälder Deutschlands).

Curruca fruticeti Brehm, t. c., p. 420 (1831- Kiel, Thüringen auf dem Zuge).

Curruca caniceps, Brehm, t. c., p. 421 (1831- einzeln im April bei Renthendorf).

Engl.: Whitethroat. - Franz.: Babillarde grisette. - Ital.: Sterpazzola. Schwed.: Törnsångare.

ơ ad. (Frïhling): Oberseite mit Finschlub der kieineren Oberflügel decken gräulichbraun, Oberkopt und Kinpfseiten mit deutlichem aschgrauen Auflug; Sehwingen dunkelhraun. AuBensäume der Handschwingen schmal fahlbraum, die der Armschwingen und groben Oberflügeldecken breit röstlich zimthraun. Struerfedern dunkolhraun mit schmalen fahlhramen Rändern, äuberstes Patr weil. mit grauem Anflug. Basis und gröibter 'Tril des Innensilumes dunkelhraun, zweites Par mit schmälerem oder breiterem weiBen Spitzensaum. Lnterseite rahmweib, Ściten isabellfarhen. Kropfgegend mit rosigem oder holl weinrïtichem Anflug. Kehle an reinsten weib. Lnterschwanzdecken röstlichweib. Axillaren und Enterflügreldecken fahl bräunlichgrau, Innensiume der Sehwiugen sehr hellgrau. Iris gelbhratum, Angenlidrand blab rötlich. Oherschmabel dunkel hornhraun, Untersehmabel fleischfarbeu, Spitze hraum. Fïbe hellhram, rehen dunkler. - Im Sommer verhleichen die Farben etwas. - Das Herhstlileid ist auf der Oherseite viel brämnlicher. fast zimtfarben, die Wlügelsämme sind etwas mehr rötlichbraun. Jas . Jugendkleid gleicht dem Herhstiloide. aher die Kropfgengend ist nicht rosig, sondern golhbrämulich. I)as Nestkleid ähnelt dem Herist-mnd Jugend- 
kleide, die Kropfgegend aber ist rostbräunlich. 1. Schwinge kürzer als die Handdecken, 2., 3., 4. beinabe gleich und am längsten. Flügel etwa 68-75, ausuahmsweise (1 o Italien) lis 77, Schwanz etwa 63-68, ausnahmsweise

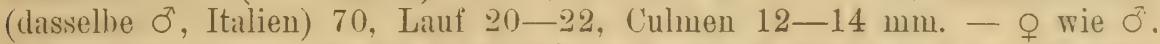
1. Schwinge kürzer als die Handdecken, 3. und 4. gleich und am längsten, 2. gleich der 3. oder unbedentend kürzer.

Brutvogel in Europa, rom $65^{\circ}$ nördlicher Breite in Skandinavien bis zum Mittelmeere, im europäischen Rußland bis Archangelsk und im Ural bis etwa zum $63^{\circ}$ nördl. Breite. - Üherwintert in Afrika. auf dem Zuge in geringer Anzahl auf den Camaren. Scheint auch im Norden ron Algerien und 'Tunis zu brïten.

Bewohnt Hecken, Weg- und Feldränder, verwilderte Gärten, Unterholz im lichten Walde, kurz allerlei niederes, mit Brombeeren, Himbeeren, Nesseln, Dornsträuchern und dergleichen verwachsenes Gebüsch. Der Luckton ist ein schnalzendes tze tze, der Gesang besteht aus einem zwitschernden Piano, dem ein lauteres, rauheres Forte folgt, das oft auch allein und nicht selten in schwebendem Fluge vorgetragen wird. Das Nest ist ziemlich tief und leidlich fest gebaut, am oberen Rande findet man weißliche oder gräuliche Raupengespinste, P'flanzen- und Schafwolle. Es steht immer nahe am Erdboden und wohl versteckt. Es werden regelmäßig zwei Bruten gemacht. Das Gelege besteht aus 4-5, selten 6 Eiern, welche so außerordentlich rariieren, daß eine Beschreibung aller Varietäten hier zu weit führen würde. Die häufigste Färbung sind wohl die hell grüngrauen Eier, die mit grünlichbraunen und aschgrauen Punkten und Flecken besät sind. Andere sind olivenbraun, lehmgelb, weißlich, blaßbläulich, oder gar rosig mit lauter rostfarbenen, oder auch teils matt rotbraunen, teils aschgrauen und schwärzlichen Flecken. Die sehlesische Ëbene scheint besonder's reich an schönen Varietäten von Dorngrasmücken-Eiern zu sein. 100 Eier messen nach Rey im Durchschnitt $18.1 \times 13.8$, Maximum $20.3 \times 14.8$ und $18.2 \times 15$, Hinimum $16 \times 13.2$ und $17 \times 12.6 \mathrm{~mm}$. Nittleres Gewicht nach Rey $114 \mathrm{mg}$.

\section{Sylvia communis icterops Ménétr.}

Östliche Dorngrasmücke.

Sylvia icterops Ménétries, ('at. rais. Caucase, p. 34 (1832- I'alysch).

Curruca cinerea var. persica Filippi, Note Viagg. Persia, p. 162 (1865- Persien).

Sylvia cinerea B. fuscipilea Severtzoff, Journ. f. Orn. 1875, p. 177 (nomen nudum 'Tianschan).

Unterscheidet sich durch dunklere, mehr graubrame Oberseite, etwas schwärzlichere Sehwingen, fahlere, nicht so riotlich-brane Sïume an den Armschwingen, mehr grabbrälunliche Kürperseiten. Etwas größer, Flügel ron $\ddot{\text { ïher }} 30$ alten Exemplinen $74-78$, mitunter bis 80 und 82 mu. Iris nilch Nénétres nankingelh. - Jungre Herhströgel sind auch schon merklich dunkler auf der Otrerseite. Drei Exemplare inus Transkaspien, Beluchistan und Aschabad kamm ich nicht won der westlichen form muterscheiden.

Fisetat S. a communis vom Kaukasus durch Persien. Transkispien, Ostund West-Turkestan sowie in West-Sihirien bis zum Altai und zum Jenissei. Die in Palästina brïtende Form gehört ebenfills licrher, doch scheint dort im Winter anch die westliche Form vorzukommen. Yu letaterer gehören rielleicht anch noch die kleinasiatischen Brutrögel. - Überwintert im sïdlichen Arabien und vermutlich im westlichen Indien. 
10 Eier messen im Durchschnitt $18.42 \times 14.47$, Maximum $19.1 \times 14.6$ und 18.15 , Minimum $17.2 \times 14.3$ und $18.5 \times 14.2 \mathrm{~mm}$. Rötliche Varietäten sind häufig. (Jourdain in litt.).

\section{Sylvia curruca curruca (L.).}

\section{Zaungrasmücke, Müllerchen.}

Motacilla Curruca Linnaeus, Syst. Nat. Ed. X, p.184 (1758-- „Habitat in Europa." Als terra typica betrachten wir Schweden, nach dem ersten Zitat).

? Motacilla Sylvia Linnaeus, 1. c., p. 185 (1758- "Habitat in Europa". Ex Fauna Suecica no. 228. Die Beschreibung als oben aschgrau, unten weiß, die geringe Größe und das Nichterwähnen der rostfarbenen Filügelsäume verbieten, diesen Namen auf die Dorngrasmücke zu beziehen).

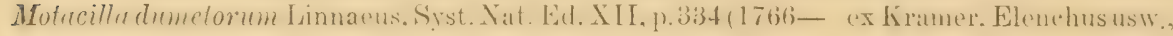
p. 376, et Gessner. "Habitat in Enropa“).

Sylvia Sylviella Latham, Gen. Syn. Suppl., p. 185, 288 (1787- Bulstrode in Buckinghamshire, England).

Sylvia cinerea Latham, Ind. Orn. II, p. 515 (1790- Ex Brissons Parus cinerens u. a. m. - ?partim).

Sylvia garrula Bechstein, Gem. Naturg. Deutschl., 2. Aufl. III, p. 540 (1807- Europa; als terra typica ist Thüringen zu betrachten).

Curuca molaria Brehm, Handb. Naturg. Vög. Deutschl., p. 422 (1831- zieht durch Nitteldeutschland).

Curruca superciliaris Brehm, Vogelfang, p. 228 (1855- „Trandert durch die Lausitz und das Salzburgische $\left.{ }^{*}\right)$.

Curruca septentrionalis Brehm, Vogelfang, p. 228 (1855 - Lappland).

Curruca assinilis Brehm, Vogelfang, p. 228 (1855- Sennaar).

?Curruca obscura Brehm, Vogelfang, p. 228 (1855- Griechenland. - Der Typus ist äußerst klein. Vgl. Reiser, Orn. Balc. III. p. 164).

Sylvia sordida Heuglin, Journ. f. Orn. 1867, p. 294 (Sennaar, ex Württ.).

Engl.: Lesser Whitethroat. - Exanz.: Babillarde ordinaire. - Schwed.: Ärtsmyg.

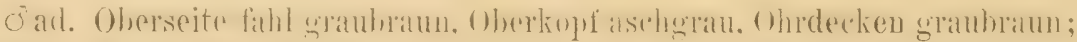
Sehwingen hrann mit fahlbrannen Auben- unel weiblichen Innensïmmen. Cuterseite weib mit hrimulich rahntarbenem Anflug an Brost und Séten.

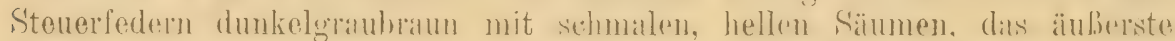

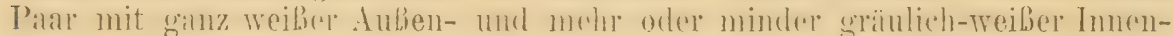

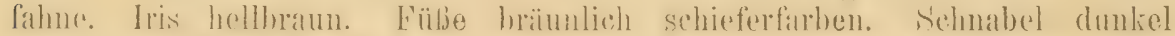

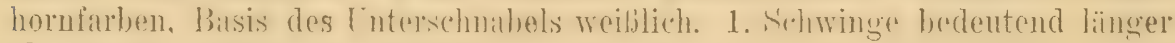
als die Handdecken. 2. Schwinge zwischen der 5. und 6. Flügel etwa 64-67, seltoner bis $69.5 \mathrm{~mm}$. Schwanz etwa $53-60 \mathrm{~mm}$. Lauf 19-20.5, Culmen 12-13.5. o wie o . - Der Nestrogel ist auf der Oberseite braun,

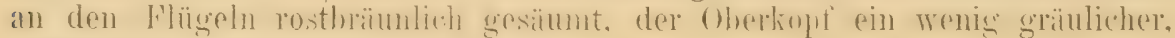
Unterseite mehr bräunlich verwasehen.

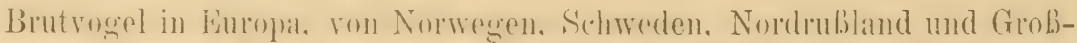
britamnien his zum Mittehmerere, im Osten mindestens his zum trial: an-

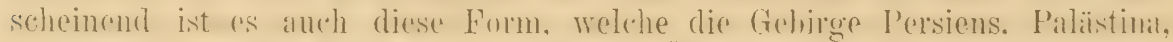
Flemasien und den Kaukasus bewolunt. - Eborwintert in Nordostafrikit, rereinzoln auf dem Zuge in den Atlasbändern. Fahlt als Brutroger iu Frland. -

Bewolnner von Gärten, Hecken, Feldhölzern und lichten Waldungen. Nistet in Büschen, meist nahe über dem Boden, mit Vorliebe in Dornbüschen und Hecken. Das Nest ist sehr leicht gebaut und besteht zumeist aus trockenen Fasern, Hälmchen und 
Würzelchen. Die 4-6 Eier sind weiß mit dunkelbraunen, oft umwölkten Flecken und Punkten und lichtgranen oder gelblichbraunen Schaleuflecken. 100 kier (Rey) messen im Durchschnitt $16.5 \times 12.6$, Mnximum $18.7 \times 13$ und $17.5 \times 14.2$, Minimum $14 \times 12$ und $15 \times 11.5 \mathrm{~mm}$. Der Gesang besteht aus einem zwitschernden Piano, dem ein mohr klapperndes rapides Horte folgt, häufig anch nur aus dem letzteren. Der Lockton ist ein schmatzendes ,tse", ähnlich wie bei den übrigen Arten Gattung, in der Angst wird er mehrfach hintereinander ausgestoßen und mehr schnarrend.

\section{Sylvia curruca affinis Blyth.}

Sylvia affinis Blyth, Journ. As. Soc. Bengal XIV, p. 564 (1845- Indien).

Unterscheidet sich von S. cum cuca cumea nuг dadurch, daß die 2. Schwinge an Länge zwischen der 6. und 7. steht, also nicht länger als die 6. ist. - Einzelne Stücke sind nicht von der westlichen Form zu unterscheiden, auch sind anscheinend (nach Pleste, u. a.) in den Grenzgebieten die Unterschiede nicht immer wohl entwickelt, und sellost in Sibirien hommen Stücke mit längerer 2. Schwinge vor.

Brïtet in Sibirien, nürdlich bis zur Grenze der Traldregrion, üstlich bis Transhaikalien und der Maudschurei. im Süden anseheinend his zum Tian-Sehan und Altai-Gebirge. - Ëberwintert in Indien und reylon. zieht durch Turkestan, Ost-T'urkestan. Ost-Persien, Afghanistan, Beluchistan.

\section{Sylvia curruca halimodendri Suschkin.}

Sylvia curruca halimodendri Suschkin, Bull. B. O. Club XIV, p.42 (Januar 1904mittlere Kirgisensteppe).

Flügel wie bei S. c. affinis, aber der Schnabel kürzer. Oberseite viel blasser und gräulicher. Oherkopf und Hinterhaupt gratu. weniger hräunlich. als bei S. c. curruca. Von S. c. minula durch etwas längeren Schnabel, Flügelformel. nicht sandfarhenen, sundern bräunlichgrauen Rüchen und dunkleren Oberkopf zu unterscheiden. (Nach Suschkin.)

Bewohnt nach Suschkin die saudigen Steppen am Lnterlauf der Fiüsse Irghis und Turgaï in der sïdüstlichen Kirgisensteppe, nördlich vom Aral-šee.

\section{Sylvia curruca minula Hume.}

Sylvia minula Hume, Stray Feath. I, p. 198 (1873- Bhawalpur, Yarkand, Ihansie, Sindh).

Sylvia minuscula Hume, t. c. VIII, p. 103 (1879- neuer Name für minula).

?Sylvia margelanica Stolzmanu, Bull. Soc. Imp. Nat. Moseou 1897, p. 72 (Margelan, Turkestan. - Wegen bedeutenderer Größe abgetrennt. Es wäre möglich, daß irgendwo eine größere Form wohnt, nähere Untersuchungen sind daher erwünscht).

Abbild.: Pleske, Ornithogr. Rossica I, Taf. T, Fig. 5, 6, 7, Dresser, Suppl. Taf. 646, 1.

Meist etwas kileiner. als S. c. curmuca und affinis, Oberkopf lichter grau, Rücken fahler, 2. Schwinge in der Regel zwischen der 7. und 8. seltener gleich der 7. oder 8., vder zwischen cler 6. und 7. Flügel etwa 60-65, solten (? gröBere Subspezies) bis 68 und $70 \mathrm{~mm}$. 
Berrohnt die Stepuen und Wüstemränder am Amu Darja und sir Darja in Transkaspien. Buchara. dus Ferghama-Tal. Afghanistan und Ost-Turkestan. - Cberwintert in Beluchistan. Sind. Baháwalpur und Nordwest-Indien his Jodhpur.

Eier kleiner als die ron S. c. curruca und affinis.

\section{Sylvia althaea Hume.}

Sylvia althcee Hume, Stray Feathers VII, p.60.62 (1878- Ebenen Indiens).

Abbild.: Dresser, B. Europe, Suppl. Taf. 647, Hig. 2.

Ad. (h)erseite dunkelgrau mit brïunlichem Anflug anf dem Rürken. sonst Färbung wie die von S. c. curruca und affinis. 2. Schwinge in der

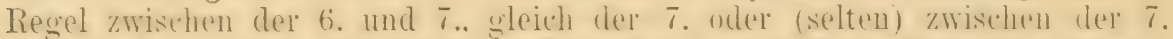
und 8. Aubentithne der ïuBersten stenerfeder weili. Innenfithne dunkillinum mit langem keilfïrnigen Längsfleck am sichafte entlang und schmalem

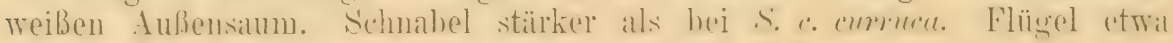
o $65-71$, o etwas kürrzer, Schwanz etwa 58-63 mm.

Brutrogel in Transkiaspien. Ost-Jersien. Buchara. Teilen ron Turliestan. Nordwest-Kaschmir und Gilgit. - Clerwintert in den Ehenen ron Nordwest-

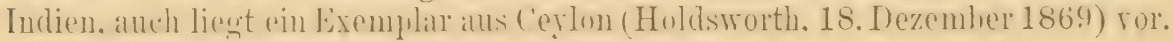

Brütet in Kaschmir in Höhen von 9000 engl. FuB. Die Eier sind nach Dresser schmutzigweiß mit feiner grünlichgrauer Fleekung und etwas größer als die ron S. c. curruca.

\section{Sylvia nana nana (Hempr. \& Ehr.).}

Curveca nana Hemprich \& Ehrenberg, Symb. Phys. fol. ce (1833- bei 'Tor auf der Sinaibalbinsel und Djedda).

Salicaria aralensis Eversmann, Bull. Soc. Nat. Jloseou XXIII, 2, p. 565, Taf. VIII, 1 (1850- Raïm).

Sylvia delicatula Hartlaub, Ibis 1859, p. 340, 'Tal. X, I (Berbera, Jeid, Armati usw., an IVestufer des Roten Meeres).

Sylvia doriac Filippi, Viaggio in Persia, p. 348 (1865- Persien).

"Sylvia chrysophthalma Heuglin MS," in der Synonymie in Heuglins Orn. N.O.Afr. I. p. 306 (1869).

Abbild.: Dresser, B. Europe, Suppl. 'Iaf. 648.

ర̃ad. Oberseite fahl isabellbraun mit grauem Anflug, im frischen Herhstkleide lehhafter. rïtlicher. im abgetragenen brutgefieder fahler. filst gräulieh erseheinend. Wurzel mit zimtrïtlichem Anfluge. Oberschwanzdecken

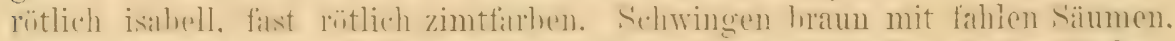

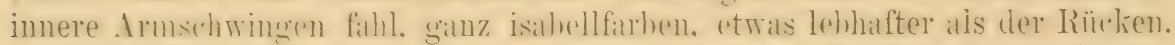

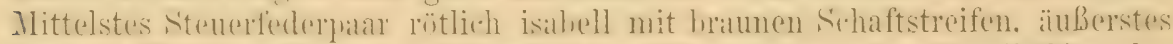
Paar weib mit erdbraunem Längsfleck an Innensaume der Basalhailfte. dazs zweite Palar (rom aufien) dunkelhraun mit gröbtenteils weifer Aubenfalme und weibem Fleck an dere śpitze der Innenfithe, die ährigen dunkelhnaun mit schmalen fahlen Süumen und meist schmalen weißen Spitzensïumen. [nterseite wrils mit matten filngelhen Anflug. Axillaren. Interflügeldecken und Innensäume der schwingen hell fahl isahell. Iris weißlichgelh. Oherwehnahel humblaum mit gelben schneiden, l'nterschnabel horngell mit hammer 
Spitze. Füße strohgelb. Flügel: 1. Schwinge etwas länger als oder weuigstens so lang wie die Handdecken, 2. zwischen der 5. und 6., seltener nur so lang wie die 6. oder zwischen der 6. und 7., 3. und 4. etwal gileich und am lïngsten. Flügel (36 Exemplare) 56-61.5. schwatnz sehwatch abgerundet, etwa 48-55.5, Lauf 18-20, Culmen 9 bis $10.5 \mathrm{~mm}$. o ad. wie 0 , jur. etwas rötlicher, etra wie das Herbstkleid.

Brutrogel in den Wüsten und Stepurn Transkaspiens his zum Sy Darja, in Turkestan, Süd- und Ost-Persien, Balluchistan, Ost-Turkestan bis Alasehan. Ferner die Wüstenstrecken von Sind, Bahláwalpur, Rajputana his in den südlichen Panjab - angeblich in diesen Gegenden sogar Brutrogel. - Der Fund eines stückes bei Bisch-Kopa in der Firgisensteppe durch Saruduy dïrfte nur ein ausnahmsweises Torkommen beweisen. Im Trinter wird die Art in Arabien und an der Kü̈ste des Somalilandes angetroffen. wohei es sich wohl um Zugrögel handrelt. Sie wurde aluch am Sinai und am Südende des Toten Meeres gefunden. oh Brut- oder Zugrogel nicht sicher.

Lebt in sandigen und salzhaltigen Wiistenstrecken, wo Saxaul, Tamarisken und Atraphaxis wachsen. Sarudny fand ein Nest mit Jungen in einem Tamariskenbusche, das an ein Rohrsängernest erinnerte. Die Eier dieser Form scheinen noch nicht bekannt zu seiu.

\section{Sylvia nana deserti (Loche).}

Stoparola Deserti Loche, Rev. \& Ilag. Zool. 1858, p. 394, Taf. XI Fig. 1 („Dans les ksours du sud de l'Algérie").

Abbild.: Koenig, Journ. f. Orn. 1895, Taf. 1 (zu rot); Eier: Journ. f. Orn. 1896, Taf. VII, Fig. 1.

Unterscheidet sich auf den ersten Blick von S. nana nana durch die wundervoll den von ihr hewohnten sanddünen angepabte rïtlich sandfarhene Oberseite. Die Schwingen sind hell fahlhraun, hreit mit der Farbe des Rückens gestumt. innere Armschwingen ganz wie der Rüclien; Bürzel und Obersehwanzdecken rötlicher. Äuliere Stenerfeder wie hei s. numa nanu, 2. schwarzhraun mit ausgedehnter weiber Spitze und weilser Aulienfahne, 3., 4. und 5. schwarzbram mit rötlich isahellfarbener Aulienfahne und weiker Endspitze, dis mittelste. P'ilur raitlich isabell. Cnterseite weil, mit leichtem rahmfarbenen Hauch, Seiten halb sandfarben rerwaschen. Iris lebhatt hellgelb. Schuabel hornbraun, Cnterschmabel und Schneiden hiblöunlichgelb. Flügel (9 Exemplare) $56-59 \mathrm{~mm}$. ㅇ wie ${ }^{\top}$.

Algerische und tunesische Sabara bis Tripolis. In Algerien ron den ausgedehnten Sandflächen zwischen Tuggurt. Quarglit und Gardaia his zu den Flugsanddünen zwischen Biskra und Cmasch. in Tunesien am Djebel Dekaris und bei Galb-es-Assued. im östlichen Tripolis bei Oumsinerma festgestellt. - Am 26. Januar 1901 murde ein Exemplar auf Porto Santo hei Nadeira erbeutet. Fimmal im November hei Cremona in Italieu erlegt. Sharpes Angabe vom Vorkommen auf den Kanaren ist falsch.

Dieser in seiner einfachen Wüstenfarbe so iiberaus zarte und wunderschöne Vogel ist aussehlieBlich Bewohner der Flugsanddïnen der Sahara, wo Limoniastrum, Returaa, Calligonum. Ephedra, Goillonia und Wrïstengräiser in dichten, niederen Büschen eine eigene Pflanzenwelt bilden. Er ist ziemlich seheu, hält sich in den dichtesten Büschen versteckt und ist, wenn er neben dieselben auf den Sandboden hïpft, kaum zu erkennen. 
Der Lockton ist ein feiner, schmatzender Laut, der Gesang, der zuweilen im Fluge vorgetragen wird, eine echt grasmückenartige, durchaus nicht kräftige, sondern leise, geschwätzig murmelnde, ziemlich lange Strophe. Das Nest ist wie alle Grasmückennester oben offen, aber tiefer als die der Gattungsgenossen, so lang wie Rohrsängernester, mit tiefer MIulde. Es steht in den dichten Wiistensträuchern und ist aus Grashalmen, Stengelchen und Blättern, mit grauen Pflauzenteilen, Blïtenköpfchen von Gnaphalium u. a. durchsetzt, innen mit Pflanzen- und 'Tierwolle und Spinnweben ausgelegt. Die einzigen beiden sicheren bekannten Eier wurden von Koenig am 13. April 1893 gefunden. Sie sind auf weißem, leicht grünlich angehauchtem Grunde grünlich olivenbraun gefleckt, mit hell bläulichgrauen Schalenflecken. Sie messen nach Koenig $14>11 \mathrm{~mm}$ und wiegen 0.06 und $0.05 \mathrm{gr}$.

\section{Sylvia ruppeli T'emm.}

Sylvia ruppeli Temminck, Pl. Col. 245, Fig. 1 (1823 - „Kandia“. Errore! Cretzschmar sagt im „Atlas z. Reise, usw., p. 29: „Bewohnt die Küsten und Inseln des roten Mleeres, wo sie buschig sind, wird selten am Nil gefunden. Kommt nach eingezogenen Berichten auf den Inseln des griechischen Archipelagus vor." - Spätere Autoren berichtigten die Schreibweise des Namens, indem sie S. rüppelli schrieben).

Sylvia Räppellii oder eapistrata Riippell, Ins. Senchenberg. II. 1. 181 (18:37- Ägypten). Sylvia guttata Landbeck, Württemb. naturw. Jahresh. V, 2, p. 253, Abbild. (1849Griechenland).

Sylia melandiros Ki rijper. Journ. f. () ru. 1841, p. 279 (ex Lindermayer MS- Griechenland).

Abbild.: Atlas z. Reise im nördl. Afr. v. Rüppell, T'af. 19; Dresser, B. Europe II, Tal. (i).

Eier: Reiser, Ornis Balcanica III, Taf. 3 Fig. 3, 4. Dresser, Eggs B. Europe "Sylviinae", Fig. 22-24.

1. Schwinge etwas kürzer als (sehr selten so lang wie) die Handdecken, 2.. 3., 4. fast gloich und am längsten. óad. Tiigel, Ohorkopl bis auf den Nacken, Kinn, Kehle und Kropf glïnend schwarz, übrige Oberseite hell aschgrau. Ohrgegend glänzend dunkelaschgrau. Ton der Schmabelwurzel bis zu den Halsseiten ein weißer Bartstreif. Unterseite rabmweißlich mit rosigem Schmmor, Seiten lichtgran ühnëuncht. Sehwingen hrüunlichschwarz mit hellhräunliehen Auben- und hreiteren weiblichen Innensätumen. Armschwingen mit breiteren, lichthrämulichen Aub('nsiumen und reißlichen Spitzen. Kleiue Flügeldecken wio der Rücken. grobo wio die Armschwingen. Äubersto Steuerfeder meiß, Basis und unterer T'eil des AuBensaumes der Inuenfahno schwarz, 2. Stenerfeder sehwarz mit einem mehr oder minder ausgedehnten weißen Keilfleck an der Spitze, 3. Stouerfeder schwarz mit woißem Fleck an der Spitzo, die mittleren Paaro grïulichschwarz mit sehr schualen lichton Süumen. Cim das Auge ein nackter rotbramer Ring. Iris dumkelbraun, Füßo rötlich gelhhram, Schuabel schwarz, Basís des Unterschmabels horugelblich. Flügel 67-74, Schwanz gerundet, etwil 60-64. Lauf 20-21, Culmen 14 his $16 \mathrm{~mm}$. - o ad. Federu des Oberkopfes mattschwarz, ausgedehnt graubraun umsäumt, übrigo Oberseite grau mit gelbbräunlichem Śchimmer. Kehlfedern weiß mit schieferfarbener Basis. Sonst wie das $\sigma^{\top}$. Im frischen Herbstkleide haben die schwarzen Kehlfedern des ơ weiße Spitzeu. Juv. dem Q ähnlich, aber Ober- und Unterseite bräunlicher.

Brutvogel in Griechenland, Klein-Asien und Palästina. - Überwintert in Nordostafrilia. Itoche gibt au ein Paar bei Milianah in Algerien brütend gefunden zu haben, doch liegt wahrscheinlich eine Verwechselung vor. 
Bewohnt Buschwerk und Gärten und baut sein aus Grashalmen bestehendes. innen mit Pferdehaaren ausgelegtes Nest in Büschen. Die Eier sind grausveißlich mit dunkel olivenbraunen Flecken so gleichmäßig und dicht bedeckt, daß sie an die ron Acrocephalus schoenobaenus erinnern. 25 Eier messen nach Jourdain im Durchschnitt $17.84 \times 14$, Maximum $19.3 \times 14.6$ und $19 \times 14.8$, Minimum $17 \times 13.3$ und $17.5 \times 13.2 \mathrm{~mm}$. Bewegung und Gesang erinnern an die von S. melanoceplala. Gewicht zweier Eier $85 \mathrm{mg}$.

\section{Sylvia melanocephala melanocephala (Gm.).}

Sylvia melanocephala Gmelin, Syst. Nat. I, 2, p. 970 (1788 - ex Cetti - Sardinien). Sylvia ruscicola Vieillot, Nouv. Dict. d'Hist. Nat. XI, p. 186 (1817- Partim! „Provence, Sardaigne, et aux (anaries").

Sylvia ochrogenion Lindermayer, Isis 1843, p. 34t (Griechenland).

Curruca luctuosa Brehm, Vogelfang, p. 229 (Dalmatien).

Pyrophthalma nigricapilla Brehm, Naumannia 1855, p. 283 (nomen nudum).

Pyrophthalma melanocephala major und longirostris Brehm, Verz. Samml., 1).6 (1866nomina unda!).

Italien: Occhiocotto.

Abbild.: Dresser, B. Europe II. T'af. 62; Eier: Dresser, Eggs B. Europe, 'Taf. Sylriinae Fig. 25-29.

and. Zügel, Ohrdecken und Oberkopf bis auf deu Nicken schmarz, übrige (h)erseite dunkelaschgrau, Sehwingen sehwarzhraun mit aschgranen Aubenund bräunlichweißen oder weißlichbramen Innensïumen. Steuerfedern dunkelschieferfarben mit schmalen grauen Süumen; Außenfihne des äußersten Stenerfederpaares nur an der untersten Basis grau, sonst weif, Innenfahue mit mebr nder minder ausgedehnter, oft his zur Hïlfte weißen Spitze, 2. und 3. Patr mit weißem Spitzenfleck. Cuterseite weiß, Seiten stark mit gran ïherflogen. Unterschwanzdecken weib, nach der Basis zu grau ${ }^{1}$ ). Unterflïgeldecken hellgrau. Iris rotbraun. Schnabel schwarz, Basis des Unterschuabels fleischfarben, nackter Ring ums Auge mattrot. Fïßse hellhraun. 1. Schwinge länger als die Handdecken, 2. zwischen der 7. und 8., seltener zwischen der fi. und 7 . Flügel etwa 57-63, S'hwauz abgerundet, etwa 62-66, Culmen 14-15, Lauf etwa 20-22 mm. - o ad. Oberseite braun mit mehr oder minder gratuem Schimmer. Oberkopf schiefergrau mit braunem Anflug. Linterseite weißlich, Seiten hellbraun, ebenso die Wurzeln der Unterschwanzdecken. Juv. ähnlich wie das $\bigcirc$, mur Ober- und Unterseite bräunlicher.

Brutvogel in Sïdfrankreich, Spanien und Portugal, auf den Balearen, in Italien (in der Poebene nur vereinzelt). auf Korsika. Sardinien. Sizilien, Malta. in Süd-I)almatien, Montenegro, der Türkei, in Griechenland und auf mehreren der griechischen Insehn, und in Kleinasien, außerdem in Marokko, NordAlgerien. Nord-Tunis und Tripolis ${ }^{1}$ ), den östlichen Kanaren. - Überwintert hituptsä̈chlich in Süd-Algerien und Süd-Tunesien, wahrseheinlich auch im südlichen Marokko, und in geringer Anzahl in Pitlïstina, Egypten und Nubien. (Die Vermutung des Vorkommens auf Helgoland ist unbegründet.)

\section{1)}

\section{Sylvia melanocephala subsp.?}

Die Sammetköpfchen, welche Nordwest-Afrika, nämlich Marokko, Algerien, Tunis und Tripolis bewohnen, zeichnen sich durch fast reinweibe Untersehwanzdecken aus, wohingegen die von den östlichen (anaren (Fuertaventura und Lanzarote) wieder mehr gräuliche haben, obne jedoch zu S. m. leucoyastra zu gehören. - Größere Serien guter und frischer Bälge sind zu untersuchen.

E. Hartert, Die Vögel der paliarktischen Fauna. 
Lebt in Buschwerk, Gärten und lichten Wäldern und ist im allgemeinen eiu ziemlich scheuer Vogel. Er scheint Hügelland und die Nähe der Küsten zu lieben. Der Lockton ist ein rauhes, schnarrendes treck, treck, treck; der Gesang ist ein leises, melodisches Geschwätz, dem anderer Sylvien ähnlich; er läßt ihn auch bäufig iw Fluge hören. Das Nest steht in niederen Büschen und Ranken, es besteht aus Graihalmen und Wïrzelchen, Spinnengeweben und dergl. und ist mit feinerem Material und Haaren ausgefüttert. Die 4-5 Eier sind in der Regel grünlich weiß, grau und braun gewölkt und gefleckt. Aus Spanien liegen auch gelbliche und rote Varietäten vor. 100 von Jourdain und Rey gemessene Eier messen im Durchschnitt $17.86 \times 13.6$, Maximum $19.3 \times 14.2$ und $18.2 \times 14.5$. Minimum $15.3 \times 13.4$ und $16.8 \times 13.1 \mathrm{~mm}$. Mittleres Gewicht nach Rey $95 \mathrm{mg}$.

\section{Sylvia melanocephala leucogastra (Ledru).}

Motacilla lencogastra Ledru, Voy. 'T'énériffe usw. I, p. 182 (1810- Tenerife).

$\sigma^{\top}$ ad. Dem von S. melanocephala melanocephala sehr ähnlich aber otwas kleiner, die hellen Endflecke an den Immenfahmen der äuersten Steurrfodern heschränkter und nicht rein weib. sondern mit Gran üherflogen. Flügnl etwa 55-58 mm. o ad. Oberseite dïsterer, als bei $S$. m. melanocephalu, das Wreiß an den äulieren Steuerfedern weniger ausgedehnt und mohr grambraun rerwaschen. - Schnabel wie bei der europäischen Form.

Westliche Gruppe der Kanarischen Inseln: 'Tenerife, Gran camariat. Palma, Hior'o.

\section{Sylvia melanocephala momus (Hempr. \& lihr.).}

Curvuca Momus Hemprich \& Ehrenberg, Symb. Phys. fol.: bb (1829- Ägypten).

Sylvia melanocephala minor Heuglin, Orn., N. O. Afr. I, p. 303 (1869 - Nordost-Afrika). Melizophilus nigricapillus Cabanis, Mus. Hein. I, p. 35 (1851- Nordost-Afrika).

Sylvia bownani Tristram, Ibis 1867, p. 85 (Jordantal - Typus untersucht).

Melizophilus rothschildi Madarász, Termesz. Füzetek XXIV, p.351 (1901- Palästinu - Typus untersucht).

? Sylvia semenowi Sarudny, Ornith. Jahrb. 1904, p. 220 ('Territorium der Bachtiaren in Luristan ${ }^{1}$ ).

ơ ad. Ist von S. melanocephala melanocephulu nur durch etwas geringre Gröbe, weniger gratue, weiblichere Körperseiten und etwas bräunlichere fingelsäume zu unterscheiden. Das o ist etwas mohr braun, der Oherkopf kitum dunkler, als der Rürken. die Kö̈rperseiten weniger olivenbrïunlich. mehr rosthräunlich. Iris gelbbraun! Flïgel stwa $55.5-59.5 \mathrm{~mm}$. Der Typus von s. bowmani hat einen aufallend hellen Rücken.

Brutrogel in Palästina und Syrien, wo er S. mel. melanocephala vertresten dürfte. "Westliches Persien. (S. Ammerkung.) - In Ägyten scheint $\mathrm{el}$ nur Durthzugsogel zu sein und in Alahien (his Aden) und Nubien zu iiberwintern.

1) Sarudny berichtet, daß S. semenowi in den Buschwälderu des 'Territoriums ler Bachtiaren in der westpersischen Provinz Luristan nistet und in der l'rovinz Arabistan überwintert. Aus der Beschreibung sind sichere Unterschiede nicht zu ersehen. Der Autor gibt an, daß seine neue Art weniger wach binten ausgedehnte und nicht scharf getrennte schwarze Färbung des Oberkopfes und auf dem Rücken leichten braunen Schimmer habe. Als Flügelmasse gibt er an: 6 of $51.4-61.1,1$ 옹.3 mm. - Die Form bedarf weiterer Bestätigung. 


\section{Sylvia melanothorax Tristr.}

Sylvia melanothorax 'Tristram Ibis 1872, p. 296 (Jordantal, im Winter).

Abbild.: Dresser, B. Europe II, Tafel 61.

ơ ad. Yügel, Oberkopf und Ohrdecken glïnzend sehwill\%, ührige (H)erseite dunkelasehgrau, Oberschwanzdecken nach der Spitze zu mehr oder mind're schwarz. Schwingen dunkelschieferfarhen mit maiunlichweiben Innen- und Außensämmen. Oberflügeldevien schwärzlich mit hellgramen Süumen, Stenerfadern schwarz mit schmalen weiblichen Sämmen, diss äuberste Paar mit dem größten Teil der Aubenfahne und etwa $1 / 4-1 / 3$ der Spitze der Innenfilune weib, das 2. Pall mit weiber Spitze. Bartstreif weil. Federn der Cnterseite schwarz mit weiken an der Kehle schmäleren Sämmen, die dex Cnterkïrpers und Untersehwanzdecken weiB mit dunkelgraner Basis, ebensu die Unterflïgeldecken. Iris dunkelgell. Füße gelhbraun, Sehmahel schwarz. Wurzel des Lnterschmabels gellikeh. 1. S'chwinge lïnger als die Hauddecken, 2. zwischen der 5. und 6.. 3. und 4. am längsten, Flügrel also rund und kur\%, etwa 58-62. Schwanz geruudet, 52-58, Tauf etwa 19-20, Culmen etwa $13--14 \mathrm{~mm}$. Oad. Oberseite grambraun, auf dem Kopfe mit schwarzen Federwurzeln, Flügel dunkelbrun mit der Rückenfarhe gesäumt. Unterseite bräunlichweib. Lnterschwanzlecken hellhraun mit weißlichen Süumen. Seiten braun. Kropfgegend hämnlich rerwathsen, Kehle und Vorderbrust meist mit schwärzlichen Feclerwurzeln. Kalmm etwas kileiner als das Männchen. Juv. dem o id. ähnlich. aher die Männchen sehon mit mehr S'chwarz an der Kohle.

\section{Brutrogel auf Cypern. Tristram erbeutete ein Paar in Palästina.}

Glaszner fand die Nester in niederen Dornsträuchern im Mlai. Sie enthielten vier Eier. Diese ähneln manchen Varietäten von Sylvia melanocephala. Die Grundfarbe ist schmutzigweiß mit zahlreichen braunen, am stumpfen Ende kranzförmig gehäuften Flecken und einigen tieferliegenden hellgrauen schalenflecken. Andere sind grünlichweiß mit grünlich braunen Flecken über und über bedeckt. Die Maße von 8 Eiern sind $\mathrm{jm}$ Durehschnitt $17.42 \times 13.73$, IIaximum $18.3 \times 13.5$ und $18 \times 14$, Hlinimum $16.9 \times 13.5$. Die Nester messen nach Glaszner: Durchmesser $7.5 \mathrm{~cm}$, Tiefe $4.5 \mathrm{~cm}$ äußere Maße.

\section{Sylvia mystacea Ménétr.}

Sylvia mystacea Hénétries, Cat. Rais. Caucase, p. 34 (1832 - Saliane an Flusse Kur, Kaukasus).

Sylvia rubescens Blanford, Ibis 1874, 1).77 (bei Sehiras und Isfahan, Persien).

Abbild. : Blanford, Eastern Persia, II, Taf. 12; Dresser, B. Europe, Suppl. Taf. 647 (zu lebhafte Farben). Ei: Cat. Eggs Brit. Mus. IV, 'Taf. X Fig. 4.

J ad. (Frühling): Zügel und Oherkonf gränlich mattschwarz, im Narclen allmählich in das hräumlich ühertünchte Gram des Rückens ähergehend. Schwingen dunkelbraun, fahl grauhraun gesïumt. S'teuerfedern braunschwarz. in frischem Gefieder schmal grau gesäumt: das äuberste Par mit grïbtenteils (mindestens zu Hälfte) weilier Anbenfilune und etwa 1 ('m weiter weißer Spitze an der Imnenfahue. die nächsten beiden Parre mit schmalen weißen Spitzenflecken. Kinn und Bartstreif weib. übrige Cnterseite hell weinrötlich, am intensirsten in der Kropfgegend. Seiten matt grambämnlich rerwaschen, Mitte des Unterkörpers weißlich. Enterschwanzdecken matt gräulich, breit 


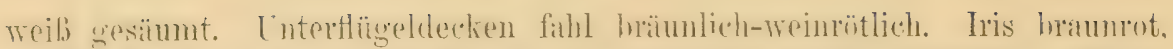
milckte Haut un das Ange orange. Oherschnahel dunkel hormbraun. Basalhälfte dos Untersehnahels gelhlich. Fübe hell rö̈lichbram. Flügel etwal $58-63$, Schwan\% stirk gerundet (äubere steuerfeder his $10 \mathrm{~mm}$ kürzer) etwa 56-60, Culmen etwa 11.5-12.5, Lauf ungeführ $18 \mathrm{~mm}$. 1. Schwinge etwa $2 \mathrm{~mm}$ länger als die Handdecken, 2. zwischen der 6. und 7. -- o ad. Oherseite fahl gräulichbraun. Cuterseite brämlich rahmfarben ohne rötlirhe Färbung, Nitte von Kehle und Unterkörper weißlich. Jur. wie $q$.

Brïtet in südlichen Káakiasns, Transkaukasien. P'ersien, Nord-Afghmistan. Thanskiaspien. in den Flubgebieten des S.r. Darjal und Amu Darja. Die Angahen rom Brïten in Palaistina heruhen an Verwechselungen mit S. melanec. momns. dagegen diirfte die Art auf dem Zauge dort vorkommen, da sie in Nubien (S'chendi), bei Suakim am Roten Meere und im Somalilande überwintert.

Bewohnt buschreiches Gelände wie andere Sylvien, mit undurchdringlichem Buschwerk bestandene Flußtäler und bewaldete Bergbänge. Sarudny entdeckte Nest und Eier. Die Nester standen nahe am Boden in Büschen, sie waren wohl gebaut und so tief, daß sie an Rohrsänger-Nester erinnerten. Die Eier sind nach dem Entdecker rundlich, die Grundfarbe schön weiß, in einem Falle mit einem rosigen Schimmer, fein dunkelgrau, schwärzlich oder braun gesprenkelt, manchmal äußerst dicht am stumpfen Ende, manchmal fehlen die schwarzen Punkte und Flecke. Größe $15 \times 12$ und $17 \times 13 \mathrm{~mm}$. Am 17. Juni wurden schon ausgetlogene Junge beobachtet.

\section{Sylvia subalpina subalpina T'emm.}

Sylvia subalpina 'Temminck, Man. d'Orn. Sec. Ed. I, p.214 (1820- Turin).

Sylvia leucopogon Meyer, Meyer und Wolf's 'Taschenb. Deutsch. Vögelk., Zus., p. 91 (1822- Sizilien. Typus verglichen).

Curruca leucopogon major, minor A. E. Brehm, Verz. Samml., p. 6 (1866- nomina nuda). Abbild.: Dresser, B. Europe II, T'af. 59.

Ital. : Sterpazzolina.

1. Sehwinge so lang wie die Handdecken. seltener etwas kïrzer oder etwas länger. 2. Schwinge zwischen der 5 . und 6. also merklich kürzer als die 3. Ootd. Obersuite aschgrau 'mit haunem Anflug, besonders auf dem Rücken, Schwingen dunkelbraun mit brannen Auben- und bräunlichweißen Innensiumen. Steuerfedern dunkelbrann, äußerstes Paar mit weiber Außenfahme und weißer Spitze der Innenfahne. Das 2. und 3. T'arar mit kleinem, weiben Fleck an der Spitze, die ïbrigen im frisehen Gefieder mit schmalen hellbraunen Sïumen. Schmaler weilier Bartstreif. Unterseite hell weimrïtlich bis dunkel rostrot, Weichen kaum etwas heller, nur die Mitte des Unterkörpers weißlich, Lntersehwanzdeckien bräunlich weiß, rostrot verwasehen. Iris lehhaft gelbbraun oder brälnnliehgelb. Sehnabel sehwarzbraun, Basis des Unterschmabels hellhraun. Fülise lehhaft hell rotbraun. Matt oratugernter nackter Augenring. Flägel 58-61, seltener $62 \mathrm{~mm}$. Schwanz gerundet, etwa 52-55.5, Lauf ungefïhr 20. C'ulmeu etwa $11-12 \mathrm{~mm}$. o ad. Auf der Oherseite wie das o ad., nur mitunter etwas mehr brïunlich vorwaschen, Unterseite weililich, Seiten und Kehle gelbbräunlich überlaufen, mitunter die Kehle mit rostbraunen Federn, nder mit letzterer Farbe übertüncht, also dem ơ ähnlicher. Juv. dem $q$ ähnlich. 
Bewohnt Sardinien. Forsikit, Sizilien. Italien strichweise, die südlichen Alpen bis in das franzissische Savorem. eimmal hei Neuchitel und mehrfach hei Genf beohachtet. diss siiderstliche Erankreich, Spanien und Portugal. Dats angebliche Vorkommen am Gambia (Westafrika) (unthelurt jeden Beweises. -

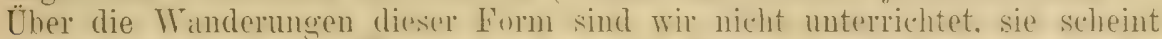
meist Standrogel und strichvogel zu sein. Merkiürdiger Teise wurle in Juni 1894 ein Stück auf St. Kilda erbeutet.

Bewohnt vorzugsweise niedriges Buschwerk, worin sie mit großer Leblaftigkeit umherschlüpft. Lebensweise und Fortpflanzung wie die der rerwandten Formen. 44 Eier aus Korsika und Spanien messen nach Jourdain im Durchschnitt $16.5 \times 12.9$, Maximum $19.1 \times 13.7$, Minimum $15 \times 12.1 \mathrm{~mm}$. (Jourdain in litt.)

\section{Sylvia subalpina inornata Tsch.}

Sylvia subalpina inornata Tschusi, Orn. Jahrb. 1906, p. 141 (Nord-Tunesien).

Flügelform und schwinzzuichnung wie hei S. s. sululfina. aher Kehle und Körperseiten melı rothraun. fast zimtrot. Flügel 0 5 $58.5-62 \mathrm{~mm}$ (9 gemessen). Iris bräunlichgelb.

Brutrogel in Tripolis, Tuuesien. Algerien und Marokko, wite es scheint, von der Küste lis 7000 engl. Fub hoch in Gehirge. In den Oasen der Wïste vermutlich nur Wintervogel.

9 Eier messen nach Koenig und Erlanger im Durchschnitt $17.9 \times 13.55$, Maximum $19 \times 14$, Ninimum $16 \times 12 \mathrm{~mm}$.

\section{Sylvia subalpina albistriata (Brehm).}

Curruca albistriata Brehm, Vogelfang, p. 229 (1855- Ägypten).

Curruca lencopogon orientalis A. E. Brehm, Verz. Samml., p. 6 (1866- Nomen nudum). Abbild. der Eier: Rey, Eier Vög. Mitteleur., Taf. 16, 16-18 (Griechenland).

2. Sehwinge länger als bei S. s. subalpina und S. s. inornata, in der Regel zwischen der 3. und 4., gleich der 3., gleich der 4., nur ganz ausnahmsweise zwischen der 5. und 6. Der weiße Bartstreif etwas hreiter, das Rothraun der Kohle mehr zum Kastanienlıxiun hinneigend, an den s'citen heller, die Jitte des Unterkörpers ansgedehuter meib. Enterschwanzdecken weiß mit nur sehr schwikhem röstlichen Auflug. - Weder bei dieser Furm, noch bei S. S. inornata scheint die bei den ơ von S. s. subalpina häufig (anscheinend besonders bei jüngeren of und im Herbste) rorkommende hell Teimötliche Fürbung anfzutreten. - Aubensiume der Schwingen in frischen Getieder merklich lichter, fihler. Iris lehhaft hräunlichgelh. Gröiber. Flügel (34 ठ) $59-65$, selten bis $67 \mathrm{~mm}$.

Bewohnt Dalmatien, Kroatien, Montenegro, Bosnien, Herzegowina, T'ürkei, (iriechenland, Kleinasien. die griechischen Inseln, Cypern. - In Palästina von 'Tristram beobahtet, in Ägrpten häufig auf dem rouge. je einmal im Somalilaude, in Arabien und Dentrch-()stafrikil nachgewiesen. Scheint in den Oasen der Silhara zu überwintern, da sic inu März und April in Menge chrch Algerien und Tunesien wandert, und berührt auf dem Zuge Italien.

In Griechenland stellenweise sehr häufig. Sie bewohnt dort und in Dalmatien allerlei Strauchwerk, besonders gern wohl immergrüne Buschwälder, aber auch das 
Unterholz höherer Wälder, Kiefern, Gärten. Die 4--5 Eier variieren, indem sie auf weiljem oder grauweißem Grunde graubraun, braungrau, rötlich oder rötlichbraun, mit hellgraneren Şhalentlecken, meist fein und gleichnäbig gezeichnet sind, mitunter anch sind die Oberflächenzeichnungen zu derben Klecksen rereinigt. Man findet die Eier von Ende April bis Ende Mai. 47 Eier messen nach Jourdain im Durchsehnitt $17.02 \times 13.24$, Maximum $18.2 \times 14$, Minimum $15 \times 13$ und $16.4 \times 12 \mathrm{~mm}$.

\section{(113. Sylvia conspicillata conspicillata 'T'(m)!}

Sylvia conspicillata Temminck, Hanuel d'Orn., sec. édit., I, p. 210 (1820 - Ex Marmora, Sardinien).

Curvea conspicillata major \& minor A. E. Brehm, Verz. Samml., 1).6 (1866Nomina nuda!)

Italien.: Sterpazzola sarda.

Abbild.: Dresser, B. Europe 1I, 'Taf. 60 (gut, nur zu dunkel, mehr an S. c. bella erinnernd); Eier: Dresser, Eggs B. Europe, Sylviinae Fig. 31-36 (meist der Subsp. bella angehörend).

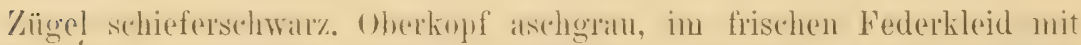
hatunem duflug und ehen solchen Federspitzen. Rürcken gräulich zimmetbratun, Bürzel und ohersehwanzdectene assehgrau mit brannem Anflug. Schwingen dunkelhraun mit lahlbraune'n Anbensibumen, Armschwingen und große Obreflügehlecken mit hreiten rötlichzimtfurbenen AuBensäumen. Stenerfedern mattschwar\% oder hrïnlichschwar\% clas äußerste Pall weil.

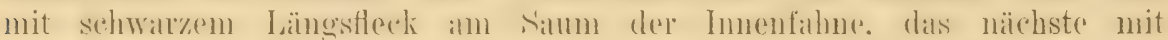

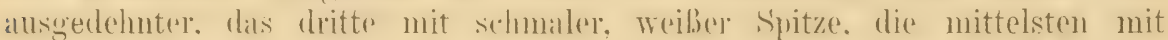
sthmalen, häiunlich weiben Sïumen und granem dnflug. Kehle weib. unterer

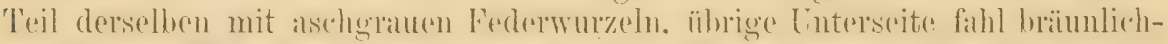
weinfathen. Mitte des Linterkïryer's und die Lnterschwanzdecken heller, fast

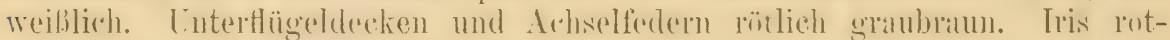
bratun, um das Auge ein schmaler, weiBer Federring. Schnabel schwarz-

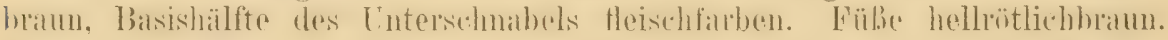
Flïgel etwa 56-59, Sohwanz etwa 51-55, stark gerundet, Lauf etwa 68.5 -20, Culmen 12-13 mm. - 1. Schwinge meist bedeutend, mitunter aber nur etwas länger als die Handdecken; 2. zwisehen der 5. und 6. oder 1. und 7.; 3. und 4. am lüngsten, 5. nur wenig oder gar nicht kïrzer. Q ad. auf der Oberseite mehr fahlbraun, Kopf mit schwachem grauen Schimmer, Unterseite blasser, Kehle weiß, Flügel 2-3 $\mathrm{mm}$ kürzer: Juv.

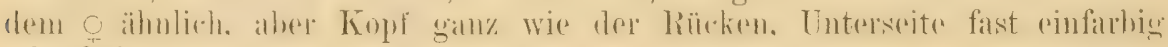
rahmfarben.

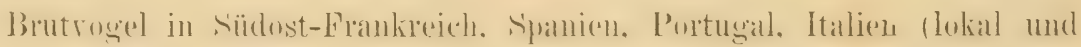
selten), Korsika, Satrdinien, Maltal. Sizilien. (Yyern. Palästina. AuBerdem in Nordwest-Afrikil und anl' Fuertarentura. - 'T'eilweiser '/ugrogel, der vermutlich in den Oasen der Sahara ïberwintert. - In Griechenland und auf den griechischen Insein bisher nicht mit Sicherheit nachgewiesen (rgl. Reiser. Ornis Baleaniea III, p. 562).

Bewohnt zur Brutzeit Ebenen sowohl als Hïgelland, immer aber rorzugsweise offenes Land mit Buschwerk. In ibrer Lebensweise erinnert die Art auffallend an die Dorngrasmücke. Der Gesang ist schwätzend, fast gurgelnd, kurz und wohllautend und wird meist von der Spitze eines Busches vorgetragen, oft auch steigt der Vogel singend grrade in die Höhe und läßt sich dann plötzlich wieder herabfallen. Das Nest steht 
in niederen Büschen, oft ganz am Boden. Es ist ein ziemlich dickwandiger, wohlgrefïgter Bau, besteht aus Halmen, Gespinsten, Rispen und Pflanzenwolle und ist mit feinen Haaren und Pflanzenwolle ausgelegt. Es enthält je nach der Gegend vom Ylärz bis ILai $4-5$ Eier. Diese sind grünlichweiß oder hellgrangrünlich, mit grünlichgrauen oder brïunlichen Flecken und Punkten bedeckt, mitunter heller, fast weiBlich. 109 Eier (57 von Koenig, 32 von Jourdain, 20 von Erlanger gemessen) messen im Durchschnitt $16.28 \times 12.57$, Maximum $18 \times 12$ und $17.2 \times 13.5$, Minimum $15 \times 12$ und $17.1 \times 11.5 \mathrm{~mm}$.

\section{Sylvia conspicillata bella 'Tsch.}

Sylvia conspicillate bella Tschusi, Orn. Monatsber. 1901, p. 130 (Madeira, Kanaren).

Enterscheidet sich ron S. r. conspicillnta durch dumkler grauen (Oherkopf. dumkler braumen Rücken, mehr kastanienbraune Säumung der S'chwiugen heim of und dunkler braune Oberseite beim $\underline{\text {. }}$

Brutrogel auf Madeira, den Kanaren und Kapverden.

Lebensweise und Fortpflanzung wie bei S. c. conspicillata. 29 Eier von Madeira mes.en nach Schmit\% in Durchschnitt $16.9 \times 13.09$. Maximum $17.6 \times 13.5$ und $16.8 \times 14$, Mlinimum $15.5 \times 11.5 \mathrm{~mm}$.

\section{Sylvia deserticola Tristr.}

Sylvia deserticola Tristram, Ibis 1859, p. 58 (Sahara, Süd-Algerien).

Abbild.: Koenig, Journ. f. Orn. 1895, Taf. U, Eier op. cit. 1896, Taf. VII, Fig. 2.

ôd: Oherseite brïunlich schicfergrau, am rotbraunen Angenlide rinige weibe Federn. Rücken mehr oder minder stark rosthraun rerwaschen. Schrongen dunkelbram, Handschwingen schmal gelhbram, Armsehwingen und große Flügeldecken breit rotbrum gesïumt. Stenerfedern schwarzbram mit hrïunlichgraucn bis hellgrauen Säumen, äuberstes Paar weiß, nur diu Wurzel del Aubenfahne und ein keilförmig am Innensanme entlang ziehender. Fleck dunkelbaum; zreites, und mitunter auch noch drittes Par mit weilon śpitzen. Lnterseite weinrötlichbraun, Kinnfleck und ein oft undeutlicher lBartstreif. sowic Mitte des Unterkürpers weißlich. Unterschwanzdecken weißlich rothraun. Tnterfiigeldecken fahl graubram, Axilaren und Innensämme der Schwingen bräunlich rahmfarben. Iris hellhraun his gelbbraun. Schmahel dunkelhraun. Basis des Lntersehnabels bräunlichgelb. Fülie gelblichhaum. Flügel 5:3.5-57 (10 c), Scliwanz atwa 5̌-58, Lauf etwa $17-18$. Culmen etwa 11-12 mm. - 1. Scliwinge etwa 2-4 mm über die Handdecken hinausragend, 2. zwischen der 7. und 8. oder gleich der 7., 3., 4., ¿. etwa gleich lang und am längsten. Jüngere ci sind heller, lichter. forl. (Herseite heller grau, Rücken lichter und bräunlicher, Flügelsäume etwas heller. [nterseite viel hellel: hlab brïunlich weinrot bis fast weiblich. Das rrste Jugendtieder ähnelt dem des . Das Winterkleid ist blasser, bräunliehur. - Das o sieht dem rom S. convpicillata äuBerst ähnlieh, ist aber durch den kürzeren Flügel und kïrzere 2. Schwinge sowie hlab hräunlich weinrote, nicht weiße, Kehle zu unterscheiden.

Brïtet im Atlasgebirge: in Tunis und Algerien in mittleren Höhen. in Naroktio nach Meade-Traldo üher der Bammegion his zu 9000 engl. Ful.) In Algerien bisher mu in den Aures-Bergen hrïtend gefunden, wo sie häufig ist. - Überwintert in der Sahara. 
Bewohnt zur Brutzeit mit Strauchwerk von immergrïnen Eichen, Cistus, Wachholder, Kiefern, Ginster, Rosmarin, Lavendel, Thymian u. dergl. bestandene Berge und findet sich im Winter in den Strüuchern der Wüste. Die Lebensweise erinnert am meisten an die von Sylvia undata - dasselbe Schlüpfen, dieselbe Berveglichkeit, das Singen der munteren Strophe von der Spitze eines Busches, derselbe schwache Flug. bas tiefe Vest ist innen mit weichen Blïten, Pflanzenwolle und Rispen mollig ausgelegt und enthält im Mlai 4 Eier. Diese sind den Eiern von Sylvia undata gleich. 15 Eier messen nach den Angaben von Whitaker und Koenig im Durchschnitt $15.6 \times 12.47$, Maximum $16>13$, Minimum $15>12 \mathrm{~mm}$.

\section{Sylvia undata úndata (Bodd.).}

\section{Provence-Grasmïcke.}

Motacilla midata Boddaert, Tabl. Pl. Enl., p.40 (1783- Benennung des „Pit Chou de Provence" auf Daubentons Taf. 655).

Motacilla provincialis (imelin, Syst. Nat. I, 9, 1.958 (1789- Partim! .. Habitat in Anglia et Galloprovincia").

Sylvia ferruginea Vieillot, Nouv. Dict. d'Hist. Nat., Nouv. Ed. XI, p. 209 (1817- Neu- . benennung von M. provincialis. Verbreitung partim).

Curruca obsoleta Brehm, Vogelfang, p. 229 (1855- Oberitalien).

Melizophilus provincialis macrourus, brachyurus A. E. Brehm, Verz. Samml., 1).6 (1866- nomina unda!)

Franz: Pitchou de Provence. - Ital.: Magnanina.

Abbild.: Dresser, B. Europe II, Taf. 69, obere Figur. Eier: Rey, Eier Vög. Mitteleur., 'Taf. 16, Fig. 24-25 (Spanien).

Òal. Oherseite sehiefergrau mit mehr ocler mindel starkem brannem Anflug. aut dem Kopte etwas reiner gram. Halsseiten lichter, Schwingern dunkelbraun, graubraun gesäumt. Steuerfedern schwarzhraun mit lichteren Säumen, das äuferste Pilar mit dem gröbten Teil der AuBenfahme und mit einem Spitzensium weiß, die folgenden heiden mit schmalen weilien Spitzen. Enterseite kastanienbrammot. Kehle mit weiBen Flecken. Kürperseiten graubrüunlich rerwascheu. Mitte des Cnterkürpers schunutzigweili. Unterschwanzdecken hräunlichgrau. Unterflügeldecken aschgrau, Innensäumı der Schwingen hräunlich. Iris und Ring um das Auge orangegelh. Fülie hellbräunlich. Schnabel schwarzhraun. Basis des Lnterschnahels gellolich. 1. Schwinge hedentend $(5-6 \mathrm{~mm})$ länger als die Handdecken. 2. soln liur\%. sleich der 9.. 10.. oder 8., oder zwischen diesen, 4. und 5. gleich und am längsten, 3. und 6. nur sehr wenig kürzer. Flügel etwil 53-57. Schwanz: iubere Steuerfedern 53-57. mittlere 64-72 1). Lauf etwa 19-20, ('uhren etwa 12-13.5 mm. - o ad. Ähnlich dem ơ ad., aber Oberseite brïunlicher, Unterseite heller, mehr weinrötlich als kastaniemrotbram, übrigens variabel. Jüngere ơ ähneln den o. - Juv. im ersten Gefieder: Dunkel sepiabram mit rostfarhenem Schimmer. Flügel und Schwanz dunkelhraum. Außenfahnen und Spitzon des äuBersten Steuerfederpaares isahellfarben. [utreseite hellrostbröunlich.

Brïtet, und ist augenscheinlich Standrogel. in Südwest-Europlat: SüdFrankreich. Vorherge der Pyrenäen, Spanien und Portugal. Mittel- und SïdItalien mit seinen Insoln. Sardinien, Korsika, in Nord-Italien nur rereinzelt

1) Der Schwanz ist meist an den Spitzen stark abgenutzt, die Masse der mittleren Steuerfederu daher fast niemals ganz genau. 
und zulällig. -- Stücke ron Konsika und Sardinien scheincen kleinel und kaum von denen Nordwest-Afrikas unterseheidball zu sein: 5 of Flïgel jo 1 -5?. Schwanz: äubere Steuerfeder 51-53. in pinem lixemplar aus dem Winter (? Zuzügler aus Italien) 58.5. mittlere etwa 64-66, in dem einen guben S'tücke 72 mm. (Nach Gätle auf Helgoland heohachtet. Belegexemuline aber nicht vorhanden.)

Bewohnt mit niederem, dichten Gebüsch und Gestrüpp bewachsene Flächen. Lockton wie pi-ti-tschu, außerdem hört man ein scheltendes, erschrockenes tscha-tscha. Der Gesang ist ein wohlklingendes Gezwitscher. Flug unsicher. Der lange Schwanz fällt sehr auf. Die 3-5, meist 4 Eier sind grünlichweiß oder schmutzigweiß, mit olivenbraunen und braunen Flecken und Punkten und grauen Schalenflecken. In Spanien sind rötliche Varietäten nicht selten. Die Zeichnungen sind meist groß und grob. 60 von Jourdain gemessene Eier aus Südspanien messen im Durchschnitt $16.46 \times 12.63$, Maximum $17.5 \times 13.1$ and $17 \times 14$, Minimum $15 \times 11.8$ und $15.1 \times 11.7 \mathrm{~mm}$.

\section{Sylvia undata dartfordiensis Lath.}

Sylvia dartfordiensis Latham, Ind. Orn. II, P. 517 (1790- „Habitat in Europa: in Angliae ericetis rarior. Specimina varia a nobis risa, hyberno tempore, aut vere primo deprehensa." Als terra typica haben wir Bexley Heath bei Dartford in England anzusehen, zumal die Beschreibung der Oberseite auch nur auf die englische Form paßt).

Ficedula ulicicola Blyth, in Rennies Field. Nat. I, p.310 (1833- England).

Melizophilus aremoricus Cretté de Palluel, Ornis X, p.42 (1899- Bretagne).

Engl.: Dartford warbler.

Alle von mir untersuchten sicheren Exemplare aus England (4 im British Museum, 3 im Oweus ('ollege in Mamehester, 2 in Witherhys Sammlung) haben die Oberseite trüb scholioladenbram, nur den Oherkopf schiefergran verwaschen und ziemlich deutlich rom Rücken abstechend. Diese brame Farbe erstreckt sich üher den ganzen sichtharen 'Teil der Federn, kamm also nicht durch Abnutzung versehwinden. Bei den südemropäischen (und nordafrikanischen) Provence-Grasmüteken ist der Rücken schiefergrau und hat nu einen, sich mehr oder minder abmutzendeu, und hei alten Vögreln sehr schwachen braunen Anflug: Die Seiten der 'uglischen Stücke habeu eincu braunen, nicht grauen Anflug. AuBerdem sind die englischen Tägel otwas kleiner: Flügel ơ ad. 52-55. Schwanz: äubere Steuerfeclern etwa 55, mittlere 66-69 mm. Mit den englischen Tögeh stimmen nach del Beschreihumg von Cretté de Palluel die der Bretagne ïherein. Die Terhreitumg ron Syleiu undata dartfordiensis dürfte also sein:

Süd-England. nördilich his iu das Themse-Tal. Suffolk, violleicht anch Shropshire. Normanische Inseln (selten) und nordwestliches Frankicich. besonders Bretagne.

Bewohnt (in England wenigstens) fast ausschließlich den Stachelginster, worin er sich trefflich zu verbergen weib, und in dern er auch seine Nester baut. Das Nest besteht aus feinem Gras und Ginsterblättern, innen mit Pflanzenwolle und Moos, oder auch mit Schafwolle ausgelegt. Auch in England werden zwei Bruten gemacht. Die Brutzeit schwankt. Am 17. Mai fand ich schwach bebrütete Eier nnd ausgeflogene Junge. Die ersten Gelege findet man im April, die zweiten im Juni oder Juli. Das Gelege besteht aus $4-5$ Eiern. 44 englische Eier messen nach Jordain $17.51<13.22$, Maximum $19 \times 12.7$ und $17.2 \times 14.4$, Minimum $15.3 \times 13.2$ und $16.6 \times 12.5 \mathrm{~mm}$. 


\section{Sylvia undata toni subsp. nov.}

IDie von mir mntersuchten Provence-Grasmücken ans Nordwestafrika in den Sammlungen zu Iuondou, Tring. Ingelheim und Liverpool sind noch kleiner als die englisehen. ohne dihei aluf der Oherseite so braun zu sein. Nur ein altes. von Loche stammendes bxemplar, hat eine so braune Oberseite wie englische Stücke. Flïgel of $51-54$, Schwanz: ̈̈ußeres Steuerfederpaial 46-53, mittleres retwa 58-68 mm. Typus: Oad. No. 327. im Tring Museum. südlich von Biskira am 14. Januar 190:3 von F. Flürckiger gesammelt.

Algerien, Marokko, Tunis.

In der Sahara sind diese Grasmücken jedenfalls nur Wintergästc, aber sie brïten im Atlas (z. B. bei Hammam R'hira häufig) und vielleicht iiberhaupt im Norden der Atlasländer.

\section{Sylvia sarda 'Temm.}

Sylvia sarda 'Temminck, Man. d'Orn., 2. Ed., I, p.20t (1820- ex Marmora MS.; Sardinien).

Sylvia sardaniae Vieillot, Tabl. Enc. MLéth., Om., II p. 465 (1820- Sardinien).

Sylvia sardonia Vieillot, Faune Frane., p. 203, T'af. 86, Fig. 3 (1828- Sardinien, auch Korsika).

Italien: Magnanina sarda.

Abbild.: Dresser, B. Europe II. 'T'af. 70; Li: Dresser, Eggs B. Europe, T'eil I, "Sylviinae", Fig. 30 .

ond. Oberseite dunkel aschgrau mit leiehtem braunen Anflug, auf

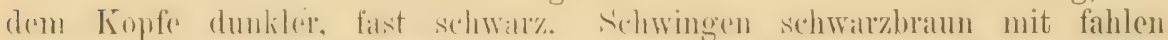
Sïnmen, Struerfordern bräunlichsehwar\% mit sehieferfarbenen Säumen, das

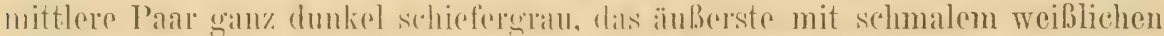
Iubensamm. Kohle his zur Korderburust und Seiten grau, etwas heller als

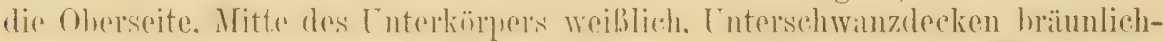

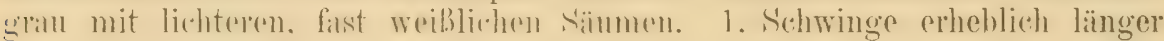
als die Handdecken. 2. in der Regel zwisehen der 7. und 8., 3., 4., 5. fast gleich und am lïngsten. Flügel etwa 56-58.5. Schwanz etwa 62-65. Lauf 20-21. Culmen 11.5-12.5 mm. Iris braun, Augenlidrand rot;

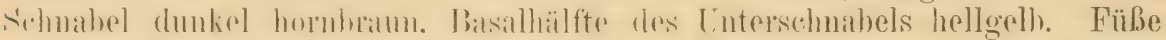
selhbraun. - add. Oherseite atwas hräunlicher. Cnterseite heller, Seiten

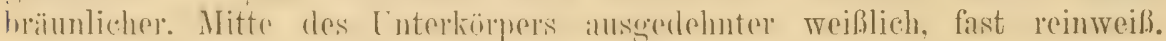
- Juv. Oberseite graubraun, noch etrvas brïunlicher als beim o ad., Unter-

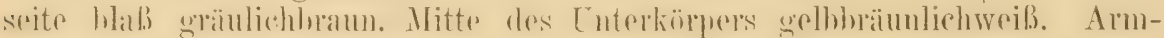
sehwingen rostloraun gesäumt.

Der sardinische Sïnger lurwhlnt dir Inseln des westlichen Mittrhmeerherekens. nimlied die Ballearen. Konsilat und Sardinien. Pantellaria. ('apri. S'izilien. ('uriat all dor tunesisehen Kï̈ste. Inf dem italienischen Festlande ist er selten und nur in Ligurien mehrfach erbentet worden. In Tunis wurde er nieht selten festgestellt, ol er dort nistet. ist aber unbekannt; in Algerien wurde er des afteren erlegt (Biskra, Gil Outaya), das Nisten aber nicht henbachtet. - Rey führt ihn als häufigen Brutvogel im südlichen Portugal ant das Torkommen auf der iberischen Hallinsel scheint anderweitig nicht

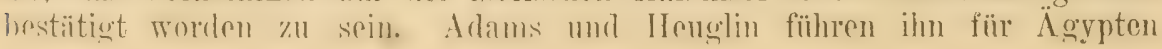


:m. Angaben, div wabrscheinlich auf Terwechselung heruhen und jedenfall: (lor Bestïtigung bediurfen. I) as hehauptete Vorkommen in Griechenland, am Sinai und Palästina ist mit ziemlicher Sicherheit auf Irrtümer zuriekzuführen.

In Aufenthalt, Gestalt und Bewegungen gleicht die Art der S. undata. Der Lockruf ist anders als der von S. undata, ein rauher, krächzender Ton, an den von Sylvia melanocephala erinnerud. Der Gesang ist nach Rey ebenfalls von dem ron S. undata ganz verschieden. Hausmann nennt ihn ein klingendes Liedchen, das mit dem Gezwitscher eines jungen Kanarienrogels Ähnlichkeit habe. - Eier soll man von April bis Juni finden (Arrigoni). Das Nest ist ein fester, starker Bau aus Halmen und Würzelchen, innen mit feinerem Material und eiuzelnen Haaren ausgelegt, nach Jourdain erheblich größer als das von S. undata und steht wohl versteckt und tief in kleinen Büschen nahe am Boden. Die 4-5, meisten 4 Eier sind gelblichweiß, mit braunen Flecken besät, sowic mit (inigen blaßgrauen, kaum auffallenden Schalenflecken. 12 Fier in den Sammlungen von Jourdain und Rothschild messen im Durchschnitt $16.86 \times 13.04$, Iaximum $18.1 \times 14$, Minimum $16 \times 12.2 \mathrm{~mm}$.

\section{Gattung AGROBATES Swains. 1838.}

Von Sylvin durch den stark gerundeten Schwinz mit sehr hreiten, am Eude ahgerundetrin Federn zu unterscheiclen (Fig. 115): Sehnabel lang und gestreckt. 1. Nehwinge breit, an der Inmenfabme rom der Mitte an leicht rengt. meist hedeutend, mitunter kaum länger als die Handdechen. 2. gleich der 5. oder zwischen $(\mathrm{ler} 5$. und 6. seltener zwischen der 4. und 5.. 3. und 4. gleich lang und am längsten, 5. nur wenig kiirzer als die 4. - Der Limf ist rom in deutliche Tafoln geteilt. Die. Jungen glejchen den Alten.

\section{Agrobates galactotes galactotes (T'(mm). (Fig. 115.)}

\section{Rostfarbiger Sänger.}

Sylvia galaclotes Temminck, Man. d'Orn. Ed. II, I, p. 182 (1820- Südspanien).

(Die

Schreibweise wurde meist in galactodes verbessert.)

T'urdus rubiginosus Meyer, Heyer \& Wolfs Taschenb. d. deutsch. Vögelk., Zus. \& Ber., p. 66 (1822 - Algeciras, Gibraltar).

Aedon pallens brachyrhynchos Brehm, Journ. f. Orn. 1856, p. 441 (Spanien).

:Aedon pallens macrorhynchos Brehm, t. c., p.441 ("Syrien und im April in Sennaar".

Belegexemplare nicht in der Sammlung, nur ein typischer Spanier ist als macrorliynchos bezeichnet).

Acdon galactodes communis, major, gracilis A. E. Brehm, Verz.-Samml., p. 6 (1866nomina nuda!).

Engl.: Rufous IVarbler.

Abbild.: Dresser, B. Europe II, 'T'af. 85; Neuer Naumann II, Taf. XII, u. a. m.;

Eier: Seebohm. Brit. B., Taf. 10; Dresser. Eggs B. Europe Phylloscopinae, Fig. $45,46$.

cad. Oherseite lebhaft rostfarben rötlich isabell, anf dem Kopfe etwas dunliler. auf dem Bürzel in das Braumot der ()berschwanzdecken ïhergehend. Treiblich rilmmfarbener Supereiliarstreif. dureh Zïgel und Auge ein schwarzhramer Streif, unterm Auge weililich. (Hhrgegend schmutzig zimtfarhan. Sehwingen sehwarzhaum. Aulien- mul Inuenfahuen zu etwa zwei Drittel ron der Wurzel an hroit rötlich zimtfarhen gesäumt, aubordem die Spitzen der Handschwingen und die Armschwingen ringsum weißlich gerandet. innere Armselwwingen wis der Rüeken. Oherflügeldecken bräunlich oder 
grïulich zintfarhen mit weißlichen Rïndern. Stenerfedern Mnunrot. das mittelste Pan mit mehr oder minder ausgedehnten schwärzliehen Fleck mahe der spitze, oder einfarhig, das nïchste Par mit schwärzlicher Findhinde. das daraffoluende auberdem noch mit weibem Silum. der sich nur mitunter an dem zweiten Paare von der Mitte findet, die ïbrigen drei Paare mit breiter. nach innen zu sehmäler werdender schnerweiber Endhinde und

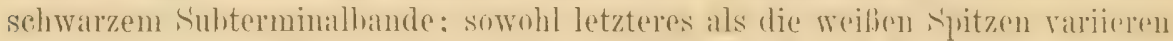
an Ausdehnung. Lnterseite rithnfirloen. Kropfhand und Seiten etwas mehr brämnlich isaleeil. Lnterschwanzdecken. Mitte der Kehle und des Unterköruers

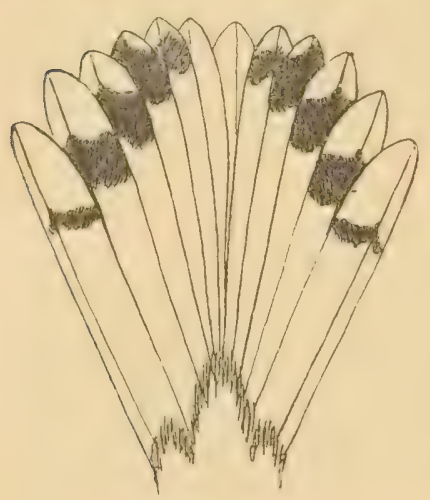

Figur 115. weißlich. Lnterflügeldecken und Axillaren weißlich isabell. Iris braun. Fülie graubraun. Schnabel hormbraun, Basis des Unterschnabels schmutzig fleischfarben. Flügel etrva $86-89.5$, Schwanz etwa $70-75$, Lauf etwa $27-28$, Culmen 18.5-19.5 mm. Herbstkleid wie Frühlingskleid, das abgetragene Gefieder blasser. mehr isabell, das frische Gefieder lebhafter. mehr rostrot. o wie ơ, nur etwas kleiner, Flügel etwa $83-86$, Schwanz $69-72 \mathrm{~mm}$. Die Jungen gleichen den Alten fast vollkommen, nur ist die Oberseite etwas rötlicher, der Superciliarstreif gelblicher, der dunkle Augenstreif nicht so deutlich ausgebildet, mehr bräunlich; am Kropfe sieht man undeutliche Wellenlinien, da die Federn dunklere Säume haben.

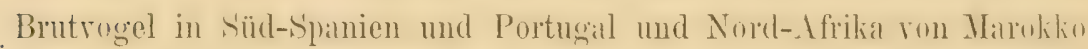
bis Ägypten und Palästina. - Da der Vogel Zugvogel ist - sogar bei Biskra erscheint er nicht vor Ende Mär'z _. muß er in der Sahara oder sïdlich derselhen üherwintern. Vurirte Stürke wurden in Fingland und Island eriegt, mehrfach vereinzelte in Italien.

Die deutschen Namen Heckensänger und Baumnachtigall sind unpassend; der erstere paßt auf andere Vögel besser, der letztere ist geradezu irreführend. Agrobates yalactotes bewohnt vorzugsweise trockene Striche. Cactus-Hecken, ()puntien. TamariskenBüsche, auch Gärten und seltener mit Gebüschen bedeckte Hügelhalden (sog. MaquisVegetation): in Spanien außerdem auch Weinberge und Ölbaumpflanzungen, in Nordostalfrika nach Heuglin IIimosenhaiue. Baumwollfelder, Rohrdickichte und vichtes Interholz. Der Lockruf ist ein schnalzendes tak, tak; der Gesang besteht aus einer kurzen, aufsteigenden Strophe mit grasmüekenartig sehwätzenden und se'hönen flötroden Trinn!n. Die Munterkeit des Vogels läßt ihn sogleich auffallen, obwohl er meist etwas scheu, am Nistplatze allerdings vertraulich ist. Er sucht oft auf dem Boden Nahrung, oft sitzt er auf den Spitzen der Büsche und breitet vielfach den breiteu. bunten Schwanz fäicherartig aus, stellt ihn auf und wippt damit auf und nieder. Das Nest ist groß, locker und schlecht zusammengefügt, außer aus Stengeln und Gräsern auch aus Lappen, Fäden und dergl. bestehend, innen ist es dagegen weich mit Tier- und Pflanzenwolle, Haaren und dergl. ausgefüttert, und enthält außerdem meistens (aber nicht immer) Stücke abgestreifter Schlangenhaut. Es steht in Opuntienhecken, Büschen, Lehmwällen, oft ganz frei, oft wohl verborgen. Das Gelege besteht aus 4, seltener 3 oder 5, Wiern. Diese variieren sehr und sehen oft hellen Sperlingseiern recht ähnlich, andere, ausgenommen die bedeutendere Größe, denen von Anthus campestris. Eine Ähnlichkeit mit den Eiern von Locustella fluviatilis ist nur ganz ausnahmsweise vorhanden und ganz unnötigerweise herrorgehoben worden, denn die Agrobates-Eier sind fast immer größer, fast 
gar nicht rötlich und gröber gefleckt. Sie sind schwach glänzend weiß; schmutzig-, gelblich- oder (selten) grünlich-weib, mit gelblichbraunen, sepiafarbenen, bratunen oder rötlichbraunen. seltener grïnlich oliventurbenen. mejst langgezogenen Flecken bedeckt. auberdem mit blaß aschgranen Schalenflecken. 113 Eier messen nach Jourdains Notizen im Durchschnitt $22.45>16.43$, Maximum $26 \times 16$ und $24 \times 18$, Minimum $19.5 \times 15$ und $20.5 \times 14.3 \mathrm{~mm}$. Durchschnittsgewicht von 31 tunesischen Eiern nach Koenig $162 \mathrm{mg}$, von 5 spanischen nach Jourdain $154 \mathrm{mg}$.

\section{Agrobates galactotes syriaca (Hempr. \& Ehr.).}

Curvuca galactodes var. syriaca Hemprich \& Ehrenberg, Symb. Phys. fol. b b (1833"Syrien". 'T'erra typica: Beirut).

Aëdon Bruchii, Bruchii brachyrhynchos \& macrorhynchos Brehm, Journ. f. Orn. 1856, p. 442 (Griechenland).

:Aelon psammochroa Reichenow. Orn. C'entralbl, 1879, p. 139 (Jassa in Ostafrika. - Es ist unerwiesen und unwabrscheinlich, daB in Ostafrika ein Agrobates nistet, vielmehr scheint es, daß sowohl syriaca als familiaris dort als Zugvögel gelegentlich erscheinen. Ein Exemplar von Ngomeni ist etwas rötlicher, sonst wie syriaca, eins von MLmbasa [Liverpool-Museum] typischer syriaca).

Abbild. d. Eier: Rey, Eier Vög. Mitteleur., Taf. 24, Fig. 25, 26.

Tuterscheidet sich auf den ersten Blick von A. g. yalactotes durch dio ganz verschiedene, rötlich grauhaune Fïrhng der Oberseite, die auf dem Bürzel in das Brammot der Oherschwanzdecken ïbergeht, sowie clurch die oft fast ganz, oft nur teilweise rötlich hraungrauen, nicht wie die ührigen braumoten, mittelsten Stenerfedern. AuBerclem sind die subterminalen hraunschwarzen Binden an den Stenerfedern fast stets viel breiter und das Braunschwarz zieht sich meist noch etwas am Samm der Aubenfahme entlang. Die Sehwiugeu sehen viel mehr grauhraun aus, weil ihre Sämmung schmäler und nicht rothrämlich. sondern graubraun, an den Armschwingen fast weißlich ist. Die Unterseite ist mehr fahl graubräunlich rerwaschen. Die 1. Schwinge, die bei A. $g$. gulurtotes immer bedentend (meist $3-5 \mathrm{~mm}$ ) üher die Handdecken hinimstagt. ist selten bis 4 , oft nur $1 \mathrm{~mm}$ länger, manchmal erreicht sie kaum die Spitze der letzteren. Größe wie bei A.g.galactotes.

Bewohnt die Ehenen Griechenlands. nordwärts bis in die südlichste Herzegonvina und den Sü̈zipfel Dalmatiens. die griechischen Inseln, Kleinasien und das nördlicbe Syrieu, nördlich des Libanon. Diese Form überwintert im südlichen Arabien und nördlichen Somaliland, sowie gelegentlich in Ost-Afrika (Momhassa). Tereinzelt wurde sie in Italien erlegt. Das regelmäßige (oder doch nicht seltene) Vorkommen bei Nizza (nach Gal!) ist durchaus unglaubwïrdig.

Ist in Griechenland Zugvogel, der erst spät, nämlich Ende April und im Mai ankommt. Das Nest steht meist auf Olivenbäumen, meist frei, mitunter versteckt, mitunter auch in Lehmmauern. Es entlält auch meistens ein Stück Schlangenhaut. Eier und Lebensweise wie die der westlichen Form, doch sind unter den Eiern bläuliche Varietäten nicht selten. Durchschnitt von 56 Eiern (30 aus Kleinasien von Jourdain, 4 aus Dalmatien von Kollibay, 22 aus Griechenland ron Reiser gemessen) $21.96 \times 15.96$ - also kleiner als die von A. galactotes galactotes -, Maximum $22.6 \times 16.9$ und $22.5 \times 17.3$, Minimum $19 \times 15.1$ und $20.1 \times 14.9 \mathrm{~mm}$.

\section{Agrobates galactotes familiaris (Ménétr.).}

Sylvia familiaris Ménétries, Cat. Rais. Cauc., p. 32 (1832- am Kur, südl. Kaukasus). Ist A. g. syriace sehr ähnlich, aber die Oherseite ist noch blasser, mit etwas gräulicherem Ton, was beim Vergleich einer Serie sehr in die Augen 
springt. Meist ist wohl anch der Bürzel eine Ider weniger rot and rib Unterseite vielleicht noch blasser.

Transkankisien, rom südlichen Kaukasus an, Persien und Mesopotamien. Thanskaspien, Turkestan, Afghanistan und Baluchistan. - Cherwintert in den trockenen Strichen Nordwest-Indieus. Sindh und Rajputina. Gimmal anf Helgoland erbeutet.

Nistweise und Fortpflanzung wie die von A. g. syriacu. 17 Eier im British MLuseum messen nach Jourdain, in litt., im Durehschnitt $21.48 \times 15.61$, Maximum $23.2 \times 16.5$, Minimum $19.3 \times 15.6$ und $22 \times 15 \mathrm{~mm}$. Zwei außergewöhnlich stark bläuliche Eier sind im Cat. Eggs Brit. Mus. IV, Taf. IX, Fig. 2, 3 abgebildet.

\section{Agrobates galactotes minor (Cab.).}

Aeclon minor Cabanis, Mus. Hein. I, p. 39 (1850 - "Abyssinien“).

Achon meridionulis, A. meridionalis brachyrhynchos und macrorlynchos Brehm, Journ.

f. Orn. 1856, p. 441,442 ("- - bewohnt aber nur den Sennaar").

Aedon galactodes brachypteros A. E. Brehm, Verz. Samml., p. 6 (1866- nomen nudum:). Sylvia oliviae Alexander, Bull. B. O. Club XXIII, p. 15 (1908 - Tschad-See. Typen verglichen).

Ist merklich kleiner als A. \%. galactotes, auch ist die Oberseite im frischen Gefieder otwas lehhafter rot und die suhterminalen schwarzen Binden an den äuleren Steuerfedern sind in der Regel sehr schmal, fast verschwindend. Elügel $77-82$, Schwanz etwa $65-75 \mathrm{~mm}$.

Abyssinien und das nördlichste Somaliland, am Blanen Nil und am sü̈lrande der Sihara ('I'schith-see). Stücke ron Khartum grehören norh daru, diu von Schendi aber nicht mehr.

\section{Gattung. SCOTOCERCA Śundev. 1872.}

Steht Primia und Verwandten nahe, die Nasenlöcher sind aber durch einige nach roln aerichtete Borsten geschützt. Der zehnfehrige Schwanz ist kaum lïuger als der Flügel und alogerundet, mur das seitliche steuer-

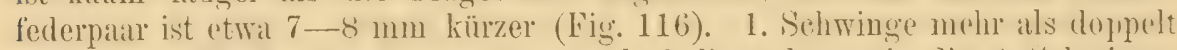
so laug als die Handdecken und mehr als halb so lang wie die ¿. Selowinge. die etwa so lang ist wie die mittleren Armschwingen und etwa ö mm kïrzcr als die 3., 4., 5., die ungeführ gleich lang und am längsten sind. Wir kennen bis jetzt fün geographische Formen.

\section{Scotocerca inquietus inquietus (Cretzschm.). (Fig. 116.)}

Malurus inquietus Cretzschmar, Atlas zu Rüppells Reise, Vögel, p. 55, Taf. 36 (1826„das peträische Arabien").

Curruca Famula Hemprich \& Ehrenberg, Symb. Phys. fol. bb (1833- „in Aegypto utraque“).

Drymoeca eremita Tristram, Ibis 1867, p. 76 ("in deserto Judaico et Arabia Petraea“). Scotocerca inquieta imnesi Nicoll, Bull. B. O. Club XXI, p. 98 (1908- „Wadi Hof near (airo").

oे ad. Obcrseite fahlbraum. auf dem Kopfe mit breiten und scharfen schwarzbraunen, auf dem Mantel schwitcher werdenden und sich allumïhlich verlieronden Schaftstreifen. Über dem Auge ein deutlicher weißlicher Superciliarstreif, hreiter Streif dureh Zügel und Auge duukelbraun. Ohrdecken 
bräunlich rahmfarben. S'chwingen braun, mit fahlhrannen Spitzen und Außen- und Innensäumen. Steuerfedern schwarzhraun, das mittelste Palar von den fablen Säumen her gröBtenteils hraun verwaschen, das äuBerste mit gelbbraunem Außensaum und brälunlichweibemi Spitzensaum. das nächste mit schmaler fahlbrauner Spitze. Kin, Kehle und Kropfgegend weiß mit schmalen braunschwarzen Schaftlinien. UJbrige Lnterseite brïunlich rahmfarben, Mitte weißlich. Iris gelb. Schnabel hornfarben, Füße bräunlich fleischfarben. Flügel 0 etwa $48-50$, ㅇ 46-47, Schwanz ơ ungeführ 50, 9 48, Lauf etwa 19, Culmen etwa $11.5 \mathrm{~mm}$.

Bewohnt das südöstliche Palistinil, die Sinai-Hallinsel und das nördliche Ägypten (Wadi Hof bei Cairo).

Eier weiß, seltener rosa, mit bräunlichroten Punkten und Flecken.

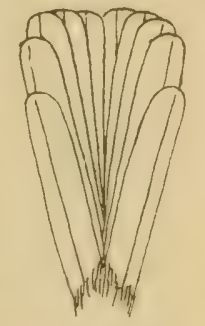

Figur 110.

\section{Scotocerca inquietus platyura (Serv.).}

Ataphromis platyura Sewertzow, Turkest. Jevotn. (in Izv. Obshch. MIoskov. VIII, 2), p. 124 (1873- 'Turkmenen-Steppe östlich des Kaspischen Meeres); Übers. in Zeitschr. f. ges. Orn. IV, p. 67.

Unterseheidet sich von seotoceren inquietus inquietus durch blab rö̈lichisabellfarbenen, nicht weißen Supercilinustreifen, auch die ()hrdecken und Halsseiten sind lebhafter gefürbt, mehr rötlich isabell. Die Oherseite ist gräulicher, nicht so bräunlich. Unterscheidet sich ron $S$. $i$. saharce durch dunklere, mehr gräuliche Oberseite, breitere und mehr schwärzliche Streifung auf dem Oberkopfe, deutliche Strichelung an der Kehle und lehhafter gefürlote Körperseiten.

\section{Transkaspien.}

\section{Scotocerca inquietus striatus (Brooks).}

Melizoplilus striatus Brooks, Ibis 1872, p. 180 (Punjab, Indien).

Abbild.: Dresser, B. Europe IX (Suppl.), T'af. 653, Fig. 2. Ei: Dresser, Eggs B. Europe Taf. Cisticola, etc. Fig. 6.

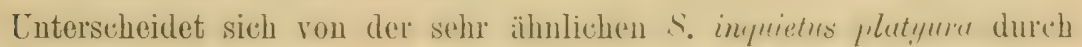
noch dunklere, bräunlichere Oberseite. Die Streifung auf dem oberkopfe ist sehr breit, braunschwarz.

Ost- und Süd-Persien, Persisch Beludschistan, S̈̈̈d-Afghamistim und westlichstes Indien westlich des Indus.

Bewohnt steinige, kahle Hügelzüge. Fortpflanzung wie die von S. i. saharae, doch scheinen die Eier meist feiner gefleckt und teilweise etwas größer zu sein. Die (irundfarbe variiert von weiß bis hell rosa.

\section{Scotocerca inquietus buryi Grant.}

Scotocerca buryi Grant, Bull. B. O. Club XII, p. 22 (1902- Dthubiyat in S. Arabien. Superciliarstreif weißlich wie bei S. i. impuictus, (Oberseite hingegen ureh etwas dunkler als die von S. i. striatı.. Unterkörper lehhafter rötlieb.

Süd-Arabien. (Bisher nur ein Stück bekaunt.) 


\section{Scotocerca inquietus saharae (Loche).}

Mahurus Saharae Loche, Rev. \& Mag. Zool. 1858, p. 395, Taf. XI fig. 2 (Algerien). Drymoica striaticeps Tristram, Ibis 1859, pp. 58, 419 (Algerische Sahara).

Abbild.: Dresser, B. Europe, Suppl. Taf. 653, Fig. 1; Nest und Eier Koenig: Journ. f. Orn. 1895, Taf. XIII.

Unterscheidet sich von S. $i$. inquietus durch die hellere, mehr wüstensundähnliche Fïrhung. Alle Stenerfedern sind hellgesäumt. Die Oberseite ist bräunlich-isabell, Kopffedern mit sthmalen hraunen. die über dem Supercilium mit schwarzen Schaftstrichen, Bürzel und Obersehwanzdechen rötlichisabell. Inreh Zügel und Auge oin schmaler schwarzer Streif. Supereiliarstreif hrïunlichgelb oder hriunlich rahmfarhen. Luterkörper fahlbräunlichgelh (hell wüstensandartign), Weichen mit dunkleren, undeutlichen Streifen, Nitte des Lnterlörpers weiblich, Kehle und Kropf rein weib. Iris blab. grïnlichgelb, Oberschmabel horubram, Unterschmabel gelblich bräunlich fleischfarben. Fübe blab oraugen-bräunlich. Flügel of $46-48$, q $44-46 \mathrm{~mm}$.

Nördliche Sahara von Algerien bis Barka (Cyrenaica).

Bewohnt Sanddünengebiete, die mit Salycornia, Limoniastrum u. a. Wüstensträuchern bewachsen sind, auch sebkha-artigen Wüstenboden. In den dichten Sträuchern hiipft das kleine Vögelehen - oft mit senkrecht hochgestelltem s'chwanze - immer in Bewegung hin und her, oder läuft auch schnell auf dem Erdboden hin. Es hat einen schnarrenden Schreckruf und ein lautes zirpendes Zwitschern, das eine kurze Gesangsstrophe bildet. Das Nest steht in kleinen, meist dornigen, Sträuchern. Es ist rundlich mit seitlicher Öffnung und erinnert in seiner Bauart an Zaunkönigsnester. Die 4-5 Eier findet man von Anfang April bis in den Juni, man kann daher annehmen, daß jährlich zwei Bruten stattfinden. Die Eier sind weiß, sehr selten rosa, wenig glänzend, bald gröber, bald feiner bräunlichrot gefleckt und gepunktet, mit mehr oder weniger helllilafarbenen Schalenflecken. Das mittlere Maß von 20 Eiern (10 Koenig, 9 Erlanger) beträgt etwa $14.97 \times 11.17$, Maximum $16.5 \times 12$, Minimum $13 \times 10 \mathrm{~mm}$. Gewicht etwa $0.05-0.06 \mathrm{~g}$.

\section{Gattung PRINIA Horsf. 1821.}

Die Gattung Priniu, voll der Burnesia nicht zu trennen ist, umfaßt eine Anzihl tropischer, in Afrikit. Intien his Java und China lebender Vëgelehen ${ }^{1}$ ). Der' zehnfedrige lange, Schwanz ist stark gestuft, viel länger als der Flügel (Fig. 117). 1. Sichwinge lïnger als die Hälfte der 2., duppelt so lang als die Handdecken. Gefieder lang und seidenweich. Schuabel spitz, leicht gekrïmmt, an der Mundspalte jeder'seits 2 Borsten. Nester mit seitlichem Eingangsloch. Zweimalige Mauser.

\section{Prinia gracilis gracilis (Licht.). (Fig. 117.)}

Sylvia gracilis Lichtenstein, Verz. Doubl. Berlin, p. 34 (1823-- Nubien).

Abbild.: Cretzschmar, Atlas zur Reise Rüppells, Taf. 2 Fig. b.

Oberseite fahl grauhraun, mit breiten dunkelbraunen Schaftstrichen, Kopfseiten heller, mehr hell fahl gelblichbraun, wenig scharfer Superciliarstreif

1) Vgl. auch: Prinia catharia Reichenow, Orn. Mlonatsber. 1908, p. 13 von „Tatsieng-lu-ting in Szetschwan". Oberseite braun, verwaschen dunkelbraun gestrichelt, Bürzel nicht, Kopf deutlicher gestrichelt. Weißer Superciliarstrich. Unterseite weiß. Seiten hellbraun. Steuerfedern braun mit verwaschenem dunklen Subapikalfleck. Flïgel 43, Schwanz 67, Schnabel 11, Lauf $17 \mathrm{~mm}$. (Nach Reichenow.) 
und Unterseite weiß mit rahmgelbem Anflug, Seiten bräunlich rahmfarhen verwaschen. Schwingen braun, mit der Farbe des Rückens gesäunt, die S:̈ume der Armsehwingen breiter und etwas bräunlicher. Stenerfedern fahl graubraun, die mittlereu matt dunkel gebändert, Endsäume schmal weißlich, davor ein breiteres braunsehwarzes Subapikalband. Iris gelblichbraun. Schnabel zur Brutzeit schwarzhraun, nur die Basis des Untersehmabels hell. Füße gelblich fleischfarben. o wio 0 ; juv.: Farben etwas matter, sonst wie der alte Vogel. Flügel etwa $45-48.5$, fast immer über 45 , Schwanz ungeführ 55-62, aber selbst bei den ältesten $\delta$ anscheinend nicht länger, Lauf etwa 17-18, Culmen etrva $10.2-12 \mathrm{~mm}$.

Berrohnt das Niltal von Dongola nach Süden (Dongola, Kerma, Naikhala, Schendi), scheint aber auch in der Libyschen Wüste zu leben, da ein von Charles Rothschild gesammelter Balg aus dem Natron-'I'ale südlich vou Kairo augenscheinlich zu dieser und nicht zu der dunkeln Form des Deltas gehört. Nach Reichonow u. a. auch bis Erythrea und Nord-Somaliland.

Die Vögel bewohnen sandige, mit spärlichem Gestrüpp und Gras

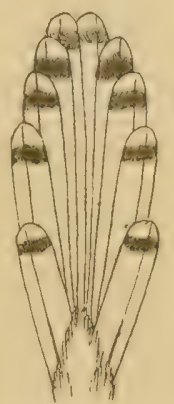

Figur 117. bewachsene Strecken, in denen sie gewandt umherschlüpfen und klettern. Der Schwanz wird häufig senkrecht in die Höhe gerichtet. Der Lockton ist wohlklingend, etwa wie "quick, quick", der Gesang ist laut und schmetternd. Das Nest bildet einen ovalen Beutel mit seitlichem Eingangsloch. Die 3-4 Eier sind auf weißem oder rahmfarbenem Grunde fein rotbraun gefleckt. Größe wie die von P.g. deltae.

\section{Prinia gracilis deltae Rchw.}

Prinia gracilis deltae Reichenow, Journ. f. Orn. 1904, p. 307 (Nildelta).

Abbild.: Dresser, B. Europe III, Taf. 97.

Enterscheidet sich von I’. y. macilis durch merklich dunklere Fürbung: der Oherseite mit breiteren schwarzbranen Schaftflecken, Körperseiten mitunter mit angedeuteter Strichelung. (Die Unterschiede sind lieim Tergleich von Serien sehr anffallend, doch sind mitunter Stücke von $P$. q. grarilis nahezu ebenso dunkel, 7. B. ein Exemplar von Schendi.)

Lnter-Ägypten, Palästina und das südliche Kleinision. Stücke aus Kleinasien sind meist bräunlicher auf der Oberseite und haben rotbräunliche Seiten, gleiche Lxemplare aber finden sich auch in Palästina und Ägypten.

Die Wier sind weißlich oder rahmfarben, mit braunroten Fleckchen. 15 von Jourdain gemessene Eier aus Palästina messen im Durchschnitt $14.37 \times 11.18$, Maximum $15 \times 12$, Minimum $13.6 \times 11$ und $14.2 \times 10.6 \mathrm{~mm}$.

\section{Prinia gracilis yemenensis subsp. nov.}

Unterscheidet sich von $P . g$. deltue durch sehr breite, $5-6 \mathrm{~mm}$ weite, schwarze Anteapikalbinden der Steuerfectern, sowio im allgemeinen etwas gräulicheren Grundtou der Oherseite, auch scheint der Schwanz nicht ganz die Lünge desjenigen von $P$. g. deltar zu erreichen. Typus im Tring Museum Oे Nr. 8 Scheik Osman hei Aden 20. XI. 1898. gesammelt von Ogilvie Grant.

Südarabien.

E. Hartert, Die Vögel der paläarktischen Fauna. 


\section{Prinia gracilis lepida Blyth.}

Prinia leprida Blyth, Journ. As. Soc. Bengal XIII, p. 376 (1814- "Indus Territories")

In der Färbung ganz wie $P$. gracilis gracilis, nur ist die schwarze Subapikalbindo an den Steuerfedern meist nicht so scharf, aber der Flügel liürzer, nïmlich 43.5-46.3, in der liegel unter 45 mm, Schwanz lämger, bei alten ơ bis zu $74 \mathrm{~mm}$.

Süd- und Ost-Persien, Baluchistan his Sind, Punjah, Rajputani, Cutch und fuzerat. Auch im Tale des franges mnd in Assam. (Stïclie aus dem Ganges-Tale scheinen etwas dunkler zu sein.)

Gleicht in der Lebensweise den verwandten Formen, aber die Eier sind anscheinend immer hell grünlichweiß oder bläulich, mit rotbraunen, bald gröberen, bald feineren Zeichnungen.

\section{Gattung CISTICOLA Kaup 1829.}

Line gut charikterisierte Gattung mit zur Brutzeit kurzem, stirk gerundetem, fïtherförmigem zwölffedrigen Sehwanze (Fig. 118). 1. Schwinge mindesteus doppelt so laug als die Handdecken. aher nicht hall, so lang wie die 2. Die 3.-5. oder 3.-6. Schwinge etwa gleich lang und am längsten. Schmabel spitz, gebogen. Gefieder voll und weich. Zweimalige Mauser. Schwanz im Winter und hei jungen Tögeln länger! Die Nasenlächer liegen frei. am Mundwinkel stehen einge kurze Borsten. Die Gattung ist vorzugsweise afrikanisch. Man unterscheidet üher 50 tropisch afrikanische Formen, die z. 'I. sehr der Revision bedürfen. In Indien erkennt man 3 Arten an.

\section{Cisticola cisticola cisticola (Temm.).}

Cistensänger:

Silvia cisticola Temminck, Man. d'Orn., 2. Ed., I, p. 228 (1820- Portugal und SüdSpanien).

Cysticola Schoenicola Bonaparte, Geogr. \& Comp. List B. Europe \& N. Amer., p. 12 (1838- "Southern Europe". Neuer Name für Silvia cisticola).

Cisticola europaea Hartlaub, Ibis 1863, p. 325 (nomen nudum!).

Oa ad., Frïhlingskleid: Oberseite sehr dunlielhraun, jede Feder grelhhraun gesäumt, diese Säume auf dem Oberrïcken mit weiBer Beimischung, der Nacken einfarhiger erscheinend, weil die Federmitten nicht so dunkelbraun sind, Bürzel einfarbig rostbraum, Oberkopf braun mit nur schmalen hellen Säumen, daher fast eiufarbig aussehend. S'chwingen dunkelhram mit fablbraunen Sätumen, die an den inneren Armsehwingen breiter sind und noch glänzend weiße, selı schmale Aubenränder zeigen. Stenerfedern dunkelbraun, das mittelste Parr fast einfarbig und nur mit helleren Säumen, die übrigon mit weißen, nach der Mitte zu schmäler und schmutziger werdenden Spitzen und hraunschwarzen Subterminalbinden, vor denen äuberst selten und nur an den Innenfahnen rostfarhene Flecke angedeutet sind. Unterseite gelblich weib, Seiten hell rostfarbig, hraun verwasehen, Unterschwanzdecken rostgelh. Iris hraun. Obersehuabel dunkelhraun, Unterschmabel gelhlichweiß. Füße hellgelblichnraun, fast brïunlichweiß, Rachen innen sehwarz. Flügel 49-52, Schwanz: mittelstes Steuerfederpaar etwa 36-40, äußerstes 8-13 mm kürzer; Lauf $16-18$, Culmen etwa $10-12 \mathrm{~mm}$. - o wie $\sigma^{\pi}$. aber kleiner, 
der Oberkopf in der Regel etwas deutlicher gestreift: Elügel etwil $\pm 6- \pm 8$ mm. Rachen immen dunkelgelh. - Herbstkleid auch der alten or mit dentlichen, breiten rostfurbenen streifen an den Federn des Oberkopfes. so dab derselhe dentlich gestreift erscheint. - Iur.: Wie das Herbsthleid. aber die Federsäumo auf del Oberseite lebhafter, der Bürzel lebhafter gefïrlot. auferdem die mittleren Steuerfedern läuger, bis zu 18 mm. (Es ist zwcifellnaft, ob alle alten of im Frühjahr ciuen fast ungefleckten Oberkopf crhalten.)

Bewohnt Süd-Europa: In Süd-Frankreich die an das Nittelmeer grouzenden Departements, Spanien und Portugal, Italien (mittlere und sïdliche Teile), die Inseln des Nittelmeers, Griechenland, forner Kleimasien, I'alästina und Ägspten. In anderen Gegenden durch rerwandte Formen verticten.

Der Cistensänger bevorzugt in den Ebenen und im Hügellande feuchte Stellen, die mit Binsen, holıem Grase, Schilf, niederen Büschen und dergl. bewachsen sind, auch Getreidefelder. Er schlüpft hier meisterhaft umher und verschwindet bei vermeintlicher Gefahr in dichten Pflanzenwuchs meist auf Ximmerwiedersehen, weun man nicht Zeit und Geduld hat lange mäuschenstill zu warten oder ihn aus einem Grasbüschel oder dergl. heraustreten kann. In der Brutzeit steigt er sehwebend auf und Hliegt ruckweise und sehr rasch über einem Binsenstück oder dergl. hin und her, wobei er seinen einförmigen, leisen, wie zic zac zic zic zic zic klingenden Gesang hören läßt. Sein Nest hängt in Binsen, (rrasbïscheln, kleinen Strüuchern und selbst im Getreide. Es ist ein länglicher, beutelförmiger Bau mit der Öffnung nach oben und in die dichten Pflanzenbüschel hineingewebt. Die Eier findet man mindestens von April bis Juni, woraus zu schließen ist, đaß mehrere Bruten stattfinden. Die Eier variieren außerordentlich und sind entweder weiß oder blaß rötlichweiß mit bald feinen sehr dunkel rotbraunen Punkten oder mit größeren heller rotbraunen Flecken und einigen lila Schalenflecken, hellblau mit den gleichen Zeichnungen wie die weißen Eier, einfarbig blau oder einfarbig weiß. 57 Eier aus Malaga messen nach Rey durchschnittlich $15.57 \times 11.56$, IIaximum $16.5 \times 12$ und $15>12.3$, Ninimum $14.8 \times 16.6$ und $15.4 \times 10.6 \mathrm{mmn}$, und das durchschnittliche Gewicht beträgt $58.5 \mathrm{mg}$. 80 Eier aus Spanien von Jourdain gemessen, messen im Durchschnitt $15.51<11.59$, Naximum $17.1 \times 12$ und $16.3 \times 31$, Minimum $14>11.5$ und $14.7 \times 10.2 \mathrm{~mm}$.

\section{Cisticola cisticola arquata (Müll.). (Fig. 118.)}

Sylvia arquata Müller, Journ. f. Orn. 1856, p. 224 (Nord-Algerien).

Cisticola cisticola mauritanica Whituker, Bull. B. O. C. XIV. 1903, p. 20 (Algerien und 'Tunis; Typus des ơ Batna, Algerien).

Ist C. c. cisticola sehr ähnlich, unterscheidet sich aber durch etwas dunklere, weniger röstliche Färbung: Der Oberkopf scheint auch im Frühjahr immer recht deutlich gestreift zu sein, die Ränder der F'edern des Rückens sind ziemlich weißlich, der Bürzel nicht so rostfarben, sondern etrvas mehr bräunlich.

Hierzu dürften alle noriwestafrikauischen Brutvögel (Marokko, Algerien, 'Tunis) gehören, nur einigo Stücke von Tanger (Nord-Marokko), die ich im Britischen Museum untersuchte, erschienen mir

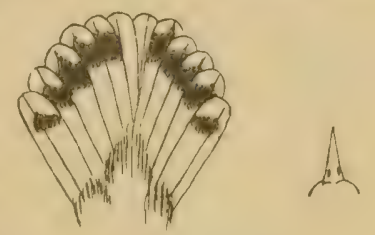

Figur 118. zweifelhaft und eher zur südeuropäischen Form zu gehören. - Whitaker (B. Tunisia I p. 123-125) läßt diese Form auch mitunter in Süd-Spanien rorkommen, was ich nicht für richtig halte, und nimmt an, daß die 
südeuropäische Form im Winter in den Atlasländern hä̈nfig sei und mïglicherweise auch brüte; auch dies kann ich nicht bestätigen.

20 Eier aus Tunis maßen nach Erlanger im Durchschnitt $15.57 \times 11.62 \mathrm{~mm}$.

\section{Cisticola cisticola aridula With.}

Cisticolı aridula Witherby, Bull. B. O. Club XI, p. 13 (1900 - am weißen Nil, 60 Meilen südlich von Khartum).

Unterscheidet sich von C. c. cisticole und C.c. uropygialis durch die sehr lehhaftr Fïhung der Oherseite. Die Fedtern des Oherkoples habeu anch bei den of im Frïhling einc tief schwarhyanne Farbe mit hell rostgelhlichen Ränderu. der Rücken ist fast ebenso scharf gezeichnet, der Nacken melı fahlhraum. Bürzol lehloft und ziemlich hell. Fine helle, semmelgellor Aheration mit schmalen Schaftstreifen scheint nicht selten zu sein, dem nach einem solchen Stïcke wurde aridula beschrioben und ein zweites gleiches lixemplar wurde von N. (!. Rothschild mol A. F. R. Wollaston hei Schendi erbentet.

Lobt am Nil südlich von Dongola bis zum Weißen Nil. Stücke von Kerma (I) nngola) möchte ich auch noch dizu rechuen. doch nïhern sie sich 7. T. C. c. cisticola.

\section{Cisticola cisticola uropygialis (Fras.).}

Sylvia (Cisticola) "typus" Rüppell, Neue Wirbelt. Abyss., p. 113, ohne Beschreibung, wurde zitiert, doch ist das Wort "typus" wohl nicht in nomenklatorischem Sinne gebraucht).

Drymoicu uropygialis Fraser. P'roc. Zool. Soc. London 1843. p. 17 (Acera an der Golrikiiste).

Die tropisch afrikanische Form des ('istensïngers unterscheidet sich von C. cisticula cistirole im Inrutgefieder lediglich dureh etwas lebhattere restfarhenen 'Ton des Bürzels und der ührigen Oberscite, im Winterkleide ist ehoufills die Oherseite merlilich lehhafter gefïrht. Auberdom finden sich mitunter an den äuberen Stenerfedern vor den subterminalen schwarzen Binden rostgelbe Flecke wie bei der indischen Form.

Tropisehes Afrikil. - Die genaue Terbreitumg vermag ich nicht anzugehen: Stürke aus West-Ifrikia (Goldküste, Senegamlien), Somaliland, ans 'T'oilen von Deutsch-Ost-Afrika (Bulioba. Ussuri, [rigi-See), die ich untersuchte, dürften sicher zur gloichen Form gehören. ${ }^{1}$ )

$\left.{ }^{1}\right)$ In anderen Teilen Afrikas finden sich noch andere Formen, doch ist es noch nicht in allen Fällen sicher, wie weit diese rein geographische Vertreter (Subspezies) von C. cisticola sind, oder neben cisticola-Formen vorkommende Arten. - Serien aus Angola, Damaraland und Transvaal zeigen im abgetragenen Gefieder eine sehr fahle Färbung und haben meist keine scharfe Anteapikalbinde an den Steuerfedern; andere Stücke aus denselben Gegenden scheinen sich nicht von uropygialis zu unterscheiden, haben auch eine deutliche Anteapikalbinde. - Z đrei südarabische Stücke sind sehr hell, äußerst ähnlich aridula; es wäre wünschenswert, Serien aus Südarabien zu vergleichen. - C. hindei Sharpe (Bull. B. O. Club VII, 1896, p. 7) aus der Asi-Ebene, von Machakos, Nairobe und den Kikuyu-Bergen in Britisch-Ostafrika ist eine auf der Oherseite sehr lebhaft gefärbte, mittelgroße Form olue scharf abgegrenzte Subapikalbinden, die cisticola zu vertreten scheint. - C. ayresii Hartl. (Ibis 1863, p. 325, 'I'af. 8) aus Natal mit schwarzen Steuerfedern ohne Subapikalbinden diurfte eher mit terrestris als mit cisticola verwandt zu sein. - C. textrix und terrestris, beide aus Süd-Afrika beschrieben, scheinen besondere Arten zu sein. 


\section{Cisticola cisticola cursitans (Frankl.).}

Prinia cursitans Franklin, Proc. Zool. Soc. London 1831, p. 118 (Hindustan).

Prinia subhemalayana Blyth, Journ. As. Soc. Bengal XII, p.377 (1844- neuer Name falls der N.-Indier verschieden).

Cisticola omalura Blyth, Cat. B. ILus. As. Soc., p. 145 (1849- nomen nudum!); Journ. As. Soc. Bengal XX, p. 176 (1851- Ceylon).

Cisticola munipurensis Grodwin-Austen, Proc. Zool. Soc. London 1874, p. 47 (Manipur).

Im Brutgefieder zeigen sich an den Inuentihnen der seitlichen Stenerfederu immer eleutliche rostgethe Flectie vor de'n subterminalen schwarzen Binden, die weißen Endbinden sind in der Regel etras breiter.

Indien und c'eglon, Andamanen, Nihoharen. Malakial his zu den gyofen Sunda-Inseln.

928. Cisticola cisticola brumniceps (Temm. \& s.hleg:).

Salicaria (Cisticola) brunniceps Temminck \& Schlegel, in Siebolds Faun. Japon., Aves, p. 134, 'I'af. 20 (18500- Japan).

Sehr auffallend durch die Färbung des Schwanzes im Brutgefieder: an den seithehen Stemertedern ist dic Innenfahne zwischen dem subterminalen schwarzen Bande und der hraunseluwarzen Basis so ausgedehnt hell rostgelb. daß diese Färbung otra die Hälfte der ganzen Feder einnimmt; das mittelste Parr hat dort wenisstens dinen restgellon Sohimmer. I)as Herbst-

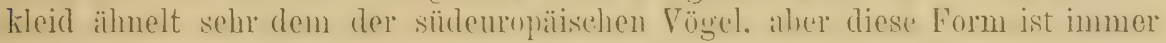
ziemlich groß, Flügel के $54-57.5 \mathrm{~mm}$.

Japan und die Liu-Kiu-Inseln. (Nicht auf den Kurilen.)

\section{Cisticola cisticola tintinnabulans (Swinh.).}

Calannanthella tintinnabulans Swinhoe, Journ. As. Soc. N. China Branch, I1; 1859; cf. Swinhoe, Ibis 1860, p.51, 131 (Amoy, Shanghai, Formosa).

ÄuBorst nahe C.c. Grumiceps, aber etwas kleiner. (Flïgel etwa 50 bis $5 t \mathrm{~mm}$. Stücke ron Hainan rielleicht meist noch etwas kleiner), die rostgelben Mittelfelder an den Imenfihnen der Stenerfeden etwas briunlich ang'ehaucht.

China, Formosa, Hainan.

\section{Cisticola cisticola fuscicapilla Wall.}

Cisticola fuscicapilla Wallace, Proc. Zool. Soc. London 1863, p. 489 ('limor).

Eine düster gofärbte Form, in Alter mit fist ganz einfarbig dumbelbraunem Oberkopfe, die die kleinen Sunda-Inseln bewohnt.

\section{Gattung RHOPOPHILUS Gigl. \& Salval. 1870.}

Diese eigenartigo Form erinnert an Proparus und Verwandte und an Scotocerca, die Cisticolen und Prinien einerseits, an Crateropus und Junthocincla amdrerseits. Schmahel hïrzer als der Kopf, stark mit lirummer Firste. Nis'ulücher frei ron Federn, mit einem starken Hautackel zngedeckt. 
Mnundwinkel mit kurzen Borsten, Federn der stiru. des Kinns und der Kehle in Hiale auslinuf(nod. Gefieder limg und weich. Schwanz zwölffedrig, beiwahe dopnelt so lang als der Flügel, gestuft (Fig. 119). Flïgel kurz, 1. Schwinge mehr als halh so lang wie die 2.. die viel linzer ist als die mittleren Armsehwingen, 4.-7. Schwinge fast gleich und die Spitze des Flügels hildend. Lailuf an der Vorderseite in fünf deutliche sehilder geteilt. Nur 2 Formen im mittleren paläarktischen Asien.

\section{Rhopophilus pekinensis pekinensis (Swinh.).}

Drymoeca pekinensis Swinhoe, Ibis 1868, p. 62 (Peking).

Abbild.: Gould, B. Asia 1V, Taf. 3.

cad. Oherseite rötlich graubraun, die einzolnen Federn mit breiten schwarzhramen Seluaftstreifen, die am Hinterhalse weniger scharf und hräunlicher sind, Oherschwanzdecken ungestreift. S'chwingen dunkel grauhraun mit helleren siumen. Mittleres Steuerfederpaar grïulichbram, die ührigen schwarzhraun. mit nach aufen an Auschenung zunehmenden. weiblichgrauen, in die dunkle Grundfathe ühergehenden Sjutzen. Supereiliarstreif fahl brïunlichgrau. Ohrodecken ein wenig dunkler. Schmaler Bartstreif schwar\%. Federn ror dem duge schwarz mit luamgramen Sipitzen. Lnter-

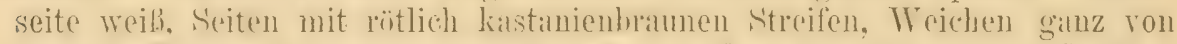
letzterer Farbe. Cutersehwanzdecken granweifs mit rötlichbratunen Streifen.

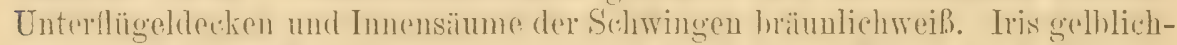

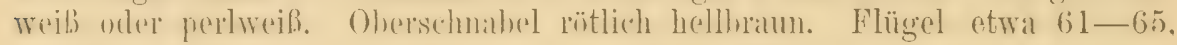
Schwanz etwa 97, Lauf etwa 32-34, Culmen etwa 13.5-14.5 mm.

Bewohnt die mit Buschwerk und Wald hestandenen Gehirgsaüge des nürdlichen ('hina und der südristlirhen Ifongolde: T'sin-ling, Berge hei P'aling. Schensi, Tal des Chuanche, Ala-Schan.

93.. Rhopophilus pekinensis albosuperciliaris (Hume). (Fig. 119.)

Suyc ullosuperiliaris Hume, in Henderson \& 11 une, Lahore to Tarkand, 1. 218, Taf. XYIII (1873- Yarkand-Ebene bei Koschtak).

Rhopophilus prinensis iar. major P'rewalski, IIongol i Strana T'munt II, P. 32 (1876Zaidam).

Rhopuphilus deserti Pryewalski, Izv. I. (ieugr. Obtsch. XIII, p. 285 (Chaidu-gol, Lob)Nor und Tarim-'Tal).

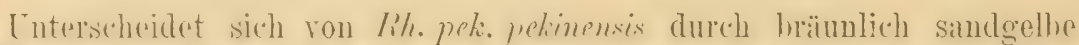
Grumblfathe dere Oberseite mit etwas schmäleren sehwarzhramnen Streifen. Auch die mittelsten Steuerfedern sind filbl grauhraun, chenso die AúBenfahnen der heller braunen s'chwingen. Ohrdecken hell isahell. Körperseiten wit viel heller rostroten Streifen. - Nach Pleske sind die Stücke aus Ziridam, namentlich an den Banchseiten, etwas dunkler; falls unterscheidhan müBtew sie den Nimen mujor tragen. Die Gesehlechter scheinen gleich zu sein, die Jungenen elonfills wie die alten, nur etwas weniger lehhaft gefärlot. Flügrel $66-71 \mathrm{~mm}$.

'Turkestan südlich des Tian Schan von Yarkand bis zum Lob-Nor, Tarim und Zaidam. 
Bewohnt wie die chinesische Form dichtes Gebüsch, in dem er gewandt herumschlüpft, und versteht es meisterlich, auf dem Boden zu laufen. Im Herbst und Winter in kleinen Flügen. Der Lockruf besteht nach Przewalski „aus einem Pfiff und einem besonderen schnarrenden Ton". Den Gesang nennt derselbe Forscher einen wohltönenden Pfiff. Przewalski fand anch das Nest in einer Höhe von 4 fiuß über dem Erdboden in einem dichten Nitraria-Gebüsch. Es besteht aus Grasstengeln mit Schafswolle und Roßhaaren. Rückbeil jun. sandte vom LobNor Eier als zu Rhopophilus p. albosuperciliaris gehörend, die den Eiern kleiner Sylvia-Arten ähneln. Sie sind weiß, schwach glänzend, mit braunen und mattbraunen Flecken und Punkten und hellbraunen und grauen Schalenflecken. Drci Eier messen $15.5 \times 12.4,16 \times 12.4,16.5 \times 12.7 \mathrm{~mm}$. Ein anderes Gelege in Jourdains Sammlung mißt sogar nur $14.6 \times 13.1,15.3 \times 12$, $14.7 \times 13,14.6 \times 13 \mathrm{~mm}$. Ob diese Eier richtig sind, wage ich nicht zu entscheiden, doch kann ich wegen ihrer Kleinheit Zweifel nicht unterdrücken. Dresser bildet im Ibis 1908 auf Taf. X, Fig. 3, ein Ei ab, das diesem Vogel angehören soll, und sehr einem kleineren Lerchenei ähnelt, es fehlt aber völlige Sicherheit über seine Herlzunft (rgl. Ibis 1908, p. 486).

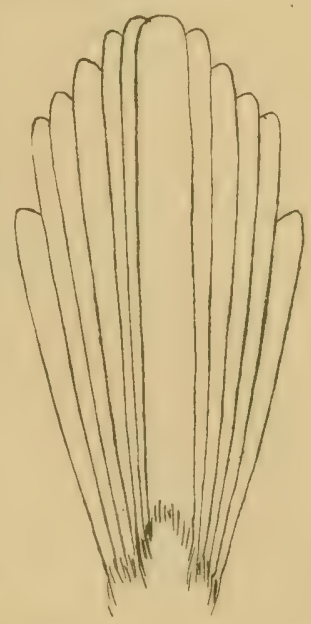

Figur 119.

\section{Gattung PROPARUS Hodgs. $1841^{1}$ ).}

Sehliebt sich durch den kräftigen kurzen meisenartigen Schnabel mit gebogener Firste an Rhopophilus an, ohwohl die Formen alle viel kileiner sind. Die Nasenlöcher sind Ieicht von Federborsten überdeckt. Das Gefieder ist sehr weich und roll, dio 1. Sehwinge etwas länger als die Hälfte der 2., der Schwanz leicht gestuft oder stark gerunclet. Der Nagel der Hinterzehe ist bei den meisten Arten sehr stark und groß. Ich vereinige folgende Arten unter obigem Gattungsnamen:

1 f Unterseite und Flügelränder gelb ......... P. chrysotis . p. 619

\{ Unterseite und Flügelränder nicht gelb ............. 2

2 I Breiter weißer Superciliarstreif . . . . . . . P. vinipectus . j.617

| Ohne weißen Superciliarstreif ................. 3

3 Kopf \& Kehle mit schwärzlicher Strichelung . . . . P. striaticollis . p. 618

$\left.{ }^{1}\right)$ Die Gattungen Proparus, Moupinia, Leiothrix, Inuthocincla und Pomatorlinus enthalten eine Anzahl ausschließlich paläarktischer Formen und diese durften daher, nebst ihren nächsten Verwandten, hier nicht fehlen. In Dressers Mlanual sind sie fast alle fortgelassen, obwohl er die Höhen des Himalaya ïber $6000 \mathrm{FuB}$ und China nördlich des Yantsekiang als paläarktisches Gebiet bezeichnet. Außer den hier behandelten Arten und Subspezies reichen aber auch noch Angehörige sonst tropischer Genera bis in bedeutende Höhen im Himalaya hinauf, deren Geschichte man in Oates, Fauna Brit. India, Birds, I nachlesen möge. Es kämen eventuell in Betracht: Stachyrhis nigriceps, Oates p. 162, Drymochares stellatus, p. 187, D. cruralis, p. 188, Ixops (Actinodura) nepalensis, p. 203, Siva strigula, p. 208, Iuhina gularis, p.211, Pteruthines crythropterus, p. 224, Pt. xanthochloris xanthochloris, p. 227, Pt. xanthochloris pallichus (s. David \& Oustalet, Ois. Chine, p. 215), Myzornis pyrhura, p. 233, Minla igneitincla, p. 245. Stachyridopsis davidi Oustalet, Bull. MLus. Paris V, 1899, p. 119 (Szetschwan) Jxulus rouxi Oust., Bull. Mus. Paris II, 1896, p. 186 (Junnan). Uiber weitere chinesische Formen vgl. man David \& Oustalet, Ois, Chine. 
4 Kopfplatte braumot. . . . . . . . P. ruficapilla . p. 618

I Kopfplatte grau ................ 5

$5\left\{\begin{array}{l}\text { 3.-5. Schwinge mit weißgrauen Außenfahnen } \cdots \ldots \text {. cinereiceps . p. } 617 \\ \text { Alle Handschwingen mit braunen Außenfahnen } \ldots . \text { P. nipalensis . p. } 616\end{array}\right.$

\section{Proparus nipalensis hueti (David).}

Alcippe cinerea (non A. cinerea Blyth) David, Nouv. Arch. Mus. Paris VII, Bull., p. 14 (1871- Szetschwan, Mupin).

Alcippe Hueti David, Ann. Sci. Nat. 5 ser. XIX, art. 9, p.4 (1874- West-Fokien). Alcippe davidi Styan, Ibis 1896, p. 310 (neuer Name für cinerea David).

$\sigma^{\pi}$ oad. Oberkopf bis auf den Oberrücken aschgrau mit einem weinfarlenen Hatueh: Kopf- und Halsiveiten etwas heller, mu das Auge weibliche Federn, ohne aloer einen dentlichen wriben ling zu hilden; bei einigen

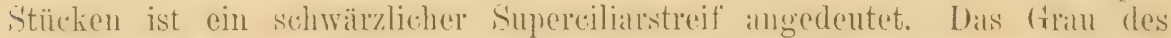
Hinterhalses gent anf dem Rüchin in das gadhliche Olivenhraun des Bürzels und der oherschwanzdecken äber: Schwingen donkelhraun, Anbenfahmen

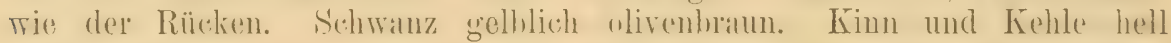

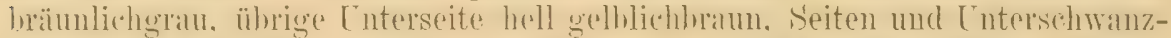
decken hell röstlich olivenhraun. Mitte des Luterkörpers weiBlich. Innen-

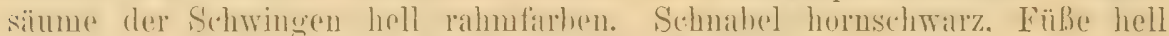

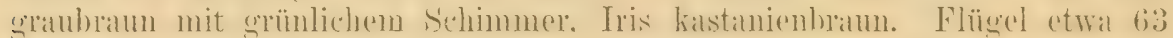

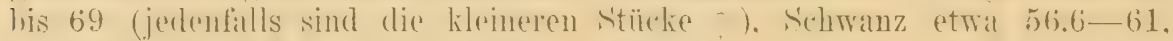
Lauf 21-22, Culmen 12--13 mm. ㅇ wie ó.

West-Szetschwan, Hupeh, Kiangsi und Fokien. Die von Styan angegehenen Cuterschiede zwisthen Vägenn von Folien und denen aus den Bergen von Szetschwan finde ich nicht bestätigt.

Gesellig, munter und beweglich, oft in Gesellschaft anderer Vögel. Die Nester sind lose aus Bambus- und anderen Blättern, Gras, Moos, Kiefernnadeln, Farnwedeln und dergl. zusammengefügt und mit Kiefernnadeln oder Pflanzenfasern ausgelegt. Die 3-4 Eier sind hellrosa, mit blaß bläulichgrauen Schalenflecken und tief dunkel rotbraunen Flecken und Haarzügen. Sie messen ungefälı $18-19 \times 15-16 \mathrm{~mm}$.

\section{Proparus nipalensis nipalensis (Hodgs.).}

Siva nipalensis Hodgson, Indian Review 1838, p. 89 (Nepal).

Abbild. d. Eier: Cat. Eggs Brit. Hus. IV, Taf. IV, Irig. 1-4.

Von $P$. nipalensis hueti durch den gelblichen, nur an der Wurzel des Oberschnabels dumbelgrauru holmahel, etwas deutlicheren weiben Augenring, deutliche sehwärzlishe, bis fast auf den Rücken fortgesctzte superciliantreifen, schmutzig rabmweibliche Krale und gavingere Gröbe leieht zu unterseheiden. Junge Vögel sind unten mehr rostgelblich.

Himalaya, jedenfalls bis in Höhen von etra $7500 \mathrm{FuB}$. Andere Subspecies sind: $P$. nipalensis morrisonia Stvinh. aus Formosa (niemals auf dem Festlande vorliommend) einc schwarzschniblige. sonst aber in der

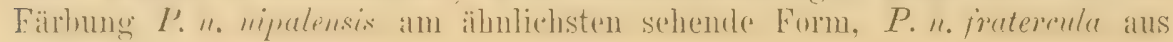
Junnan, u. a. m.

Die Eier sind glänzend weiß oder blaß rosa, mit heller oder tiefdunkel rotbraunen, bald größern, bald kleineren Flecken. Sie messen etwa $18-20<14-15.5 \mathrm{~mm}$. 


\section{Proparus vinipectus vinipectus (Hudgs.).}

Siva vinipectus Hodgson, Indian Review 1838, p. 89 (Nepal).

ô ad. Oherkopf, Zügel, Konfiseiten und Rïcken weimritlich hraun, orler etwa wie Schokolade mit Nilch, Bürzel und Oherschmanzdecken lelhaft rotbrame. An den Seiten ron Hinterkopf und Hals ein breiter hram-

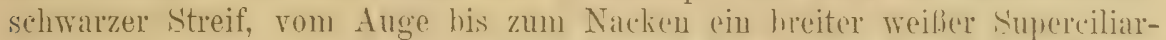
streif. Schwingen schwärzlich, Ankenfinhen der dritten bis tünften Handschwingen hellgrau, die der Armschwingen simt den Obertlügeldechen lobhaft rostrot. Steuerferern haun. Aubensïmme rostgelh rerwaschen. Kimu, Kehle und Vorderhust schmutzig weif. mit mehr oder minder undentlichen kurzen bräunlichen Streifen, übrige Unterseite filhlbaun mit weinrötlichem Sehimmer, in der Mitte heller. Iris, Sehnahel und Füßse hranis. Flïgel

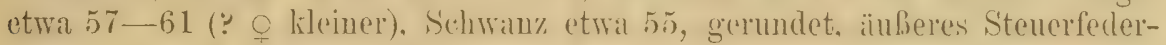
paar etwa $9 \mathrm{~mm}$ kürzer, Culmen 10.5-11 $\mathrm{mm}$.

Himalaya rom Sutlej-Tale bis Sikkim, in Höhen bis zu $11000 \mathrm{FuB}$

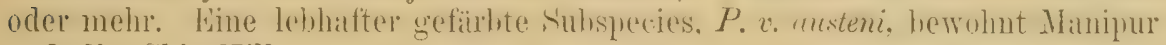
und die Chin-Hills.

Baut ein napfförmiges Nest aus Bambusblättern und Gras und die Eier sind blaugrünlichgrau mit olivenbraunen und tiefer liegenden grauen Zeichnungen. ILaße $17-18 \times 13-13.5 \mathrm{~mm}$. (Cat. Eggs Brit. Mus. IV, p. 44. Taf. III, 19.)

\section{Proparus vinipectus bieti Oust.}

Alcippe (Proparus) Bieti Oustalet, Ann. Sci. Nat, ser. 7, XU, p. 283, 304, Taf. IX Fig. 2 (1892- Ta-tsien-lou).

Unterscheidet sich voll $P$. vinipectus vinipectus durch weißliche Zïgel, hellere Oberseite und dunkler lirame, fast sehwarze Kopfseitem. Fiögel bis $62 \mathrm{~mm}$.

Bei Ta-tsien-lu im westlichen Szetschwan.

\section{Proparus cinereiceps (Verr.).}

Siva cinereiceps Verreaux, Nour. Arch. Mus. Paris VI, Bull., p.37 (1870 - „Mont. du Thibet chinois").

Abbild.: David \& Oustalet, Ois. Chine, 'laf. 73. Ei: Cat. Eggs B. Mus. IV, Taf. 1V, Fig. 11.

o o ad. Oberkopf und Nacken seidig aschgrau, Stirn etwas dunkler

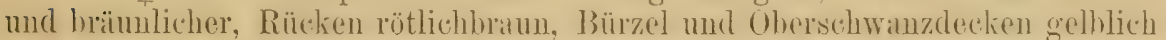
rosthraun. Śchwingen hraun, Aufenfahnen der 3.-5. Meiblich alschgran, dio der 6. und 7. schwärzlich, die der drmschwingen rütlich olivenfuben. Stenerfederu braumgrau mit olivenfurbenen Außensïmmen. Ohrgegend hellgrau mit Teinrötlichem Anflug und seidigem Schimmer. ebenso die Unterseite: an der Kehle eine dunkle Strichelung angedentet; Enterschwanzlecken und Wrichen ockerbräunlich. Innensäume der Sehwingen weißlich. Iris geth. Schmabel schwarz. Füße im Balg hellbraun. Flügel etwa 57-59, Schwamz 55-62, 
starle gerundert. das äußere Steuerfederpar etwa $15 \mathrm{~mm}$ kïrzer, Culmen etwa 10.3, Lauf $22 \mathrm{~mm}$.

Mest-Szetschwan und Tsin-ling (Sïd-Schensi), nach Lar Touche bis Fokien ${ }^{1}$ ).

3 Eier aus Fokien (La Touche) sind lell grünlichblau mit dunkel graugrünen und grauen Zeichnungen. Haße: $18 \times 13,18.1 \times 14$ und $19 \times 13.8 \mathrm{~mm}$.

\section{Proparus striaticollis (Verr.) ${ }^{2}$ ).}

Siva striaticollis Verreaux, Nouv. Arch. Mus. Paris VI, Bull., p. 38 (1870 „Mont. du Thibet chinois").

Abbild.: David \& Oustalet, Ois. Chine, p. 222, Taf. 71 (Schlecht).

Oherseite olivenhrann, am Halse in eine gränliche Farbe übergehend mnd auf dem Konfe und Nacken mit schwärzlichen Strichen. Unterseite grau, seidenartig glänzend, an der Kehle mit schwärzlieher Strichelumg, Weichen olivenfirben verwaschen. Zügel schwarz. Stenerfedern dunkelgrau. Schwanz ahgerundet. Schwingen hraun, die äberen Handschwingen aschgrau, die folgenden schwarz, die imeren drmschwingen olivenfarben gesäumt. Iris gelblichweiß. Schnabel olen graublaun, unten weißlich. Füße gräulich. Flügel 55, Schwanz, 50, Lauf 23, Schmahel $7 \mathrm{~mm}$. (Nach David \& Oustalct. l. c.)

Armand David erhentete ein Stück bei Jupin in einer Höhe von $4000 \mathrm{~m}$, zwischen Vifeiden und verkiüppelten Rhododendron-Büschen an der Grenze der Buschvegotation.

\section{Proparus ruficapilla (Verr.).}

Siva muficapilla Verreaux, Nouv. Arch. Mus. Paris VI, Bull., p. 37 (1870 - „Nont. du Thibet chinois").

Abbild.: David \& Oustalet, Ois. Chine, Taf. 72 (Schlecht).

$\sigma^{\top}$ o ad. Oberkopf spitz über den Nacken hin verlaufend braunrot, seitlich von eiuem schmalen fast undeutlichen schwärzlichen und darunter von einem hreiteren aschgrauen Streifen hegrenzt. Stirn und Zïgel asthgrau, Federn ummittelhar um das Auge weiß. Rücheu rötlichbraun, Bürzel und Oberschwanzdecken gellohaun. Shehwingen und Schwauz wie die von $P$. cinereireps. Ohrgegend scidig weinrötlichbraun. Kehle weiß mit einigen undeutlichen gräulichen Längsflecken. Brustseiten weinrötlichgrau, Weichen gelhhraun, Mitte der Brust und des Unterkörpers weißlich. Iris braum. Schmahel hellhraun, Unterschnahel gelblich. Füße (im Balg) hellbraun. Flügel o 58.5, ㅇ 51-52, Schwanz etwa 50, Lauf 20.5, Culmen $10.5 \mathrm{~mm}$. (3 Exemplare.)

Trest-Szetsehwan und Süd-Schensi bis zn den südlichen Tsin-ling-Bergen. In Bambusdickichten und dichten Hecken.

1) Dies Vorkommen ist eigentümlich, da zwischen Fokien und Szetschwan, bei Itschang in W. Hupeh, eine andere Form: P. fucatus Styan (Bull. B. O. C. VIII, 1899, p. 26) vorkommt.

$\left.{ }^{2}\right)$ Nahe verwandt ist $P$. guttaticollis (Bull. B. O. C. 1897, p. ๖ั) aus Fokien. 


\section{Proparus chrysotis Blyth.}

Proparus ? chrysaeus Hodgson, Gray's Zool. Misc., p. 84 (1844- nomen nudum!).

Proparus chrysotis (sic) Blyth. Journ. As. Soc. Bengal XIII, 1).938 (184t- ex Hodgsun ISS., Himalaya, jedenfalls Nepal).

(Gefieder an Kopf und Hals seidenartig glänzend, ïußerst weich; Mundwinkelborsten stärker entwickelt, als sonst bei Proparus, daher von Oates zu einem besonderen Genus, Liopumes, erhoben.) - Õ ad. Oberliopf und Zügel grauschwarz. Koptseiten und Federn um das Auge weilograu. Rücken, Shapularen, Bürzel und Oberschwamzdecken olivengrau, letztere grünlich verwaschen. Schwingen schwärzlich, Außenfahnen der fünf äußeren Handschwingen gelb, die Armschwingen mit hreiten orangefarbenen Aufensüumen und weißen Spitzen, die innersten beiden mit breiten weißen Innensïumen, die der ïbrigen Schwingen schmal blabgelb. Steuerfedern schmärzlich, Außenfahmen an den Wurzelteilen zu zwei 1)ritteln orangegelb gesäumt. Kinn und Kehle glänzend aschgrau, ganze übrige Unterseite lehbalt tiefgelb. Schnahel bleigran. üher den Nasenlöchern gelblich, Füße (im Balg) hell gelbbramm. Iris (nach Jerdon) braum. Flügel etwa $49.6-5+5$ (die kleimen Stüclie, 49.6-50.5, sind anscheinend die O), Schwanz etwa 45-48, Latuf 21. Culmen $9-9.6 \mathrm{~mm}$.

Sikkim und Nepal in Hühen bis 9000 Fuß oder höher. Auch NagaBerge und Manipur.

Nach Jerdon baut dieser Vogel ein eiförmiges Nest aus Bambusblättern und Gras und legt weiße, rotbraun gefleckte Eier. Neuere Beobachtungen scheinen nicht vorzuliegen.

\section{Proparus swinhoii Verr.}

Propants swinhoii Verreaux, Nouv. Arch. Mus. Paris VI, Bull., p. 38 (1870- "Tibet chinois", Mupin); op. cit. VIII, Taf. II, Fig. 2.

Unterscheidet sich von $P$. chrysotis durch einen weißen, nach dem Nacken zu in Gelb ühergehrnden Streifen in der Mitte des Oberkopfes. Kehle gräulichschwarz, Kopfseiten seidig weiß. -- Inürte der geographische Vertreter (Subspezies) von $P$. chrysotis sein.

Findet sich in den Wäldern der hohen Berge von Mlupin und WestSzetschwan bis an die Grenzen der Provinz Kuliu-Nor, einmal rom Abhé David in den zentralen 'Tsin-ling-Bergen in der Provinz Schensi angetroffen.

Nach Armand David hat dieser Vogel meisenartige Bewegungen und ist nicht mit den anderen Proparus rerwandt, was m. H. aber der Bestätigung bedarf.

\section{Gattung MOUPINIA David \& Oust. 1877.}

Der Schwanz länger als der Flügel. weichfedrig und so stirk gestuft. dab) das äuBere Steuerfederpatr nur hall so lang wie das mittelste ist. Sonst wie Propames. Eine Art bekannt.

\section{Moupinia poecilotis (Verr.).}

Alcippe poecilotis Verreaux, Nouv. Arch. Mlus. VI, Bull., p. 35 (1870- MIupin); t. c. VIII, Taf. 2, Fig. 4.

Pyctorhis gracilis Styan, Bull. B. O. Club VIII, p. 26 (1899- Szetscbwan). 


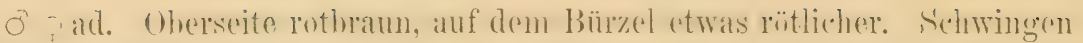

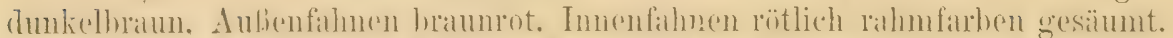

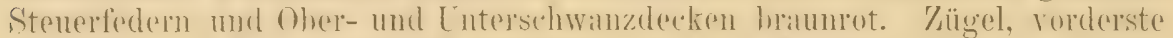

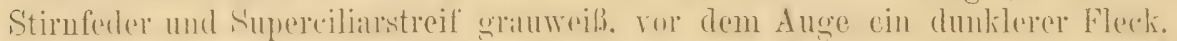

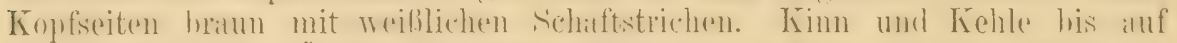

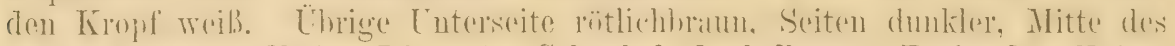
Unterkörpers weißlich. Iris rot. Schnabel dunkelbraum, Basis des Unter-

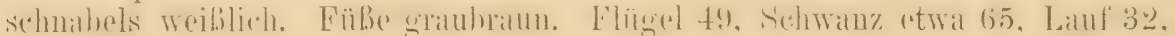
Culmen $11 \mathrm{~mm}$. (Ein Exemplar.)

Nordwest-Szetschwan (Hupin, Lung-an). David fand sie in Höhen von $3000 \mathrm{~m}$, in dichten Gebiischen.

\section{Giattung LEIOTHRIX Swains. 1831.}

Gekennzeichnet durch den merkwürdig geformten Schwanz: derselhe

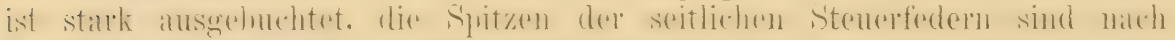

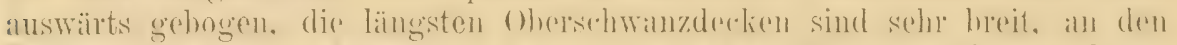

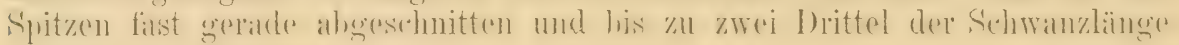
verlängert. (Fig. 120).

\section{Leiothrix lutea lutea (Scop.). (Fig. 120.)}

Sylvia hutea Scopoli, Del. Flor, et Haun. Insubr. II, p. 96 (1786- China. Ex Sonnerat,

Voy. Indes Or. \& Chine $\mathrm{H}$, p. 205, Táf. 114, Mésange de Nanquin).

Turnagra sinensis Gmelin, Syst. Nat. I, p. 897 (1789- China).

Parus furcatus Temminck, Pl. Col, 287, Fig. 1 (1824- China).

(Furcuria malabaricus Lesson ist im Cat. B. VII, p. 644 irrtümlich als Synonym zitiert!

ơad. Oberseite gelbgrünlich olivengrau, Oberschwanzdecken etwas

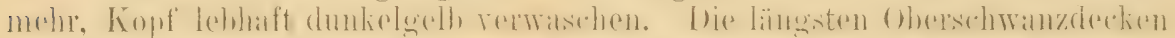

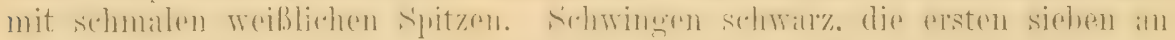

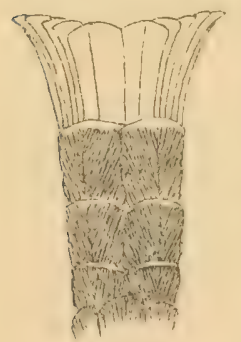

Figur 120. den Außenfahnen hochgelb, die imeren an der Basis orangerot, die folgenden 2 oder 3 mit in der Mitte schwarzer, an der Basis und Spitze orangeroter AuBenfalne, dio darauf folgende mit ganz ununterbrochenem breitem tief orangeroten, fast karminroten Außensaum, dio darauf folgenden Armschwingen mit schwarzer Außenfahme, dio an der Basis grünlich ist, und vor dem grünlichen Wurzelteil einen orangegelben Fleck hat, imerste Armschwingen gelbgrünlich olivengrau. Stenerfedern olivengräulich, Spitzen und größter 'T'eil der Außenfahuen gläuzend hlauschwarz. Zügel und Federn ums Auge gelblichweib. Ohrgegend blaß gelblichgrau, breiter Bartstreif dunkelgrau. Kehle

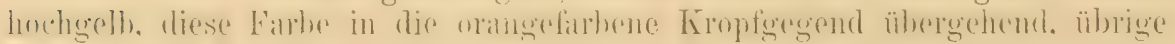

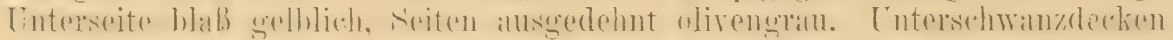

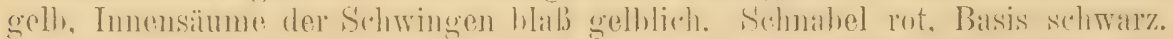

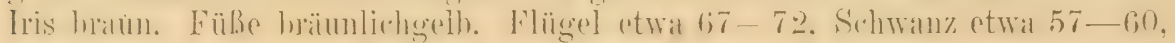

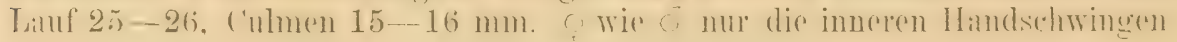
mit orangegelben statt karminroten Außensäumen.

In den Bergziigen des siidlicheren Chima bis Szetsehwan und Mupiu. Lebens- und Nistweise wie bei $L$. $l$. calipyga. 


\section{Leiothrix lutea calipyga (Hodgs.).}

Bahila calipyga Hodgson, Indian Reviev II, p. 88 (1838- Nepal).

Abbild. d. Ei: Cat. Eggs Brit. Mus. IV, 'Trf. IV, Fig. 13.

Ganz wie L. lutea lutea, nur die Basis der Außenfalnnen der inneren Handschwingen ohne Orangerot.

Himalaya rom Simla his Butall, Khasiat-Berge bis ()ber-Birmal, hesonderes in Höhen von 5-8000 engl. Fuß.

Man sieht diese Vögel meist in Schaaren, sie sind aber scheu und unruhig. Nahrung Früchte, Beeren, Insekten. Das ơ singt im Frühling sehr schön. Der Gesang erinnert an den von Sylvia hortensis. Das Nest ist napförmig, aus Blättern, Hoos, Stengeln und Würzelchen erbaut. Es enthält $3-4$ blaß grünlichblave, mit braunen und rötlichen Flecken gezeichnete Eier, die im Durchschnitt etwa $22<16 \mathrm{~mm}$ messen.

\section{Gattung CRATEROPUS Swainson 1831.}

Tögel meist ron Drosscelgübe mit langem. weichen Gefiecler. Sehmahel drosselattig, leicht gebogen, Nasenlächer ron einer Membran gesehützt, aher frei von Federn. Federn des Vorderkopfes kurz, steif und hart. Erste Schwinge länger als die Hälfte der 2., 2. bedeutend kïrzer als 3., 4.-6. mahezu gleich und am längsten. Der zwölfedrige Shohamz bald nur so lang wie der Flägel, mreitfedrig. gerundet, bild viel längrer als der Fü̈gel. schmalfedriger und sehr stark sestuft (Fig. 121). Ietztere Gruppe, der die paläratischen Formen amgehören, wirt meist als dryye generisch gesoudert, Was aber mpralitisch ist, da sie nicht seharf getreunt ist. Weil mehrere Arten den Ühergang vermitteln. 'Tropren Afrikis und Indiens, nur wenige Formen reichen in die malärritische Region hinein.

Färbung rötlich isabell .............. C. fulvus . p. 623 Färbung gräulich, Flïgel ïber $100 \mathrm{~mm}$......... C. squamiceps . p. 621 Färbung graubräunlich, Elügel unter $100 \mathrm{~mm}$. . . . . . C. caulatus . p. 622

\section{Crateropus squamiceps squamiceps (Cretzschm.).}

Malums squamiceps Cretzschmar, in Rüppell's Atlas z. Reise, Vögel, p. 19 Taf. 12 (1826- Akaba).

Arygu Ruppellii Lesson, Traite d'Orn., 1) 4112 (18:31- Neubenennung von M.squamiceps). Crateropus squamatus Gray, Gen. B.I, fol. $5 \mathrm{I}_{\text {.. (18 (18- }}$ - Schreibfehler für squamiceps). Crateropus chalybeus Bonaparte, Compt. Rend. Paris XLII, p.765 (1856- See Tiberias in Nord-Palästina).

Cad. Oherseite fahl hraungrau, Federn des oberkopfes und Hinterhalses mit tropfenlörmigen tiefhramen Mittelflecken, erstere heller unsäumt, Rücken mit blalumen Schaftstrichen, die auf Bümel und Oberschwanzdecken fast oder ganz, rerschwinden. Schwanz und Flügel wie der Rücken. Ohrdecken wie der Rücken, aber etwas glinzend, in der Mitte dunkler. Lnterseite fihl gratulraun. Seiton brïunlicher, Mitte des Lnterhörpers weißlicher, Kehle fast ganz weib. unterer 'Teil der Kehle, Kropf und Kropfseiten mit mehr oder minder deutlichen dunkeln Schaftstriehen. Die Iris scheint zu Valrieren, denn auf den Etiketten finde ich .. rötlich grauhraun, licht erzgell, gelblichgrau ins Bronzefarhene spielend *, in Büchern ..rötlichbraun". Schnabel schwärzlich kornfarben, an der Basis gelblich. Der Typus rou chulybeus hat schwarzen Schnahel. Fübe hellbraun, Zehen dunkler. Flügel etrva 108-112. Schwanz etwil 135-145, Lauf etwa 33-36. Culmen etwa 


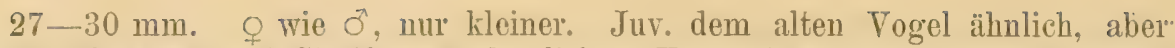
die Fleckung und Streifung undentlieher, Unterseite mehr isabell, Schnabel schwärzer, Iris mattgrau.

Pallistiua und Nord-Arabien rom S'ee Tiberials lis zur Sinai-Halbiusel und dem foulf ron Akibad, alleh Maskit. — Stücke aus dem mittleren TrestArabien (s. Neumanu, Orn. Monatsher. 191)4, p. 311) neigen zur südlichen Form, C. s. yemensis.

Lebt in buschreichen Ebenen und hält sich viel am Boden auf, auf' dem er meisterlich zu laufen weiß. Nahrung zu großem 'Teile aus Beeren und Früchten bestehend. Nest ein großer, zumeist in Dornbiischen angebrachter oben offener Bau. Eier 4-6 an Zahl, dunkel grünlichblau, stark glänzend. 17 Eier messen nach Jourdain im Durchschnitt $25.47 \times 18.42$, Maximum $28 \times 19$ und $26 \times 19.2$, Ninimum $23.3 \times 18.5$ und $26 \times 17.3 \mathrm{~mm}$.

\section{Crateropus squamiceps yemensis (Nemm.).}

Argya squamiceps yemensis Neumann, Orn. MIonatsber. 1904, p. 29 (Wüste zwischen. Scheich Osman and Lahadsch).

Seh" viel dunkler, mehr bram. S'chuahel gröftenteils gelhlich, hei einem (anscheinend jungen) Exemplar aber schwarz.

Süd-Arabien.

\section{Crateropus caudatus huttoni (Blyth). (Fig. 121, 122a.)}

Malacocercus Huttoni Blyth, Journ. As. Soc. Bengal XVI, p. 476 (1847- Kandahar). Crateropus Salvadorii De Filippi, Viaggio Persia, p. 346 (1865- Schiras).

Abbild.: Blanford, Eastern Persia II, 'T'af. XII, Fig. 1.

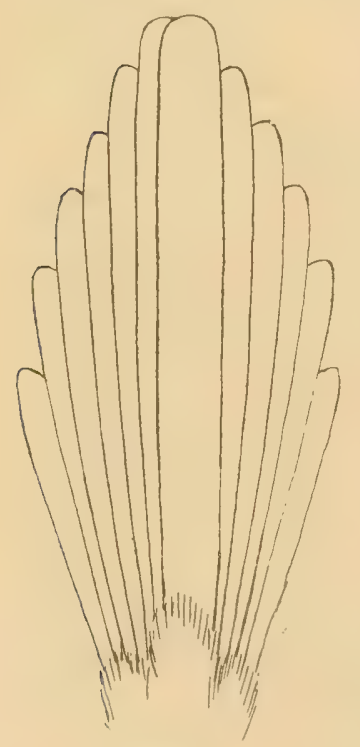

Figur 121

Oberseite fahl graubraun, jede Feder in der Mitte mit breitem dunkelbraunem Längsfleck, Bürzel und Oberschwanzdecken schwächer gefleckt, meist nur mit Andeutungen der Flecke. Kopfseiten braunrötlich, Kehle weiß oder weißlich, übrige Unterseite bräunlich rahmfarben, Seiten dunkler und mit mehr oder minder deutlichen Längsstreifen. Schwingen fahl gräulichbraun mit helleren Säumen, Steuerfedern fahl gräulichbraun mit dunkler braunen Schäften und mehr oder minder undeutlichen schmalen etwas dunkleren Querbändern. Iris braun. Füße gelb. Schnabel braun, Basis gelblich. Flügel etwa 87 bis 91.5, Schwanz etwa 115-124, Lauf 28, Culmen etwa $25-27 \mathrm{~mm}$. 오 wie $0^{x}$, aber kleiner, Flügel etwa $80-82 \mathrm{~mm}$. - Juv. wie der alte Vogel, nur die Seitenstreifung nicht entwickelt, die Fleckung der Oberseite nicht so scharf.

\section{luchistan.}

Süd- und Ost-Persien, Afghanistan und Ba-

Bewohnt buschreiches Gelände und wird meist in kleinen Flügen bemerkt. Hält sich viel am Boden auf.

Nest ein tiefer, geräuniger Napt. Èer kurzoval, einfarbig dunkel grïnlichblau, glatt mit starkem Glanze. Sie messen etwa $16 \times 20$ bis $17 \times 22 \mathrm{~mm}$. 
948. Crateropus caudatus altirostris subsp. nor. (Fig. 122 b.)

Unterscheidet sich auf den ersten Blick von dem ihm am nïchsten stehenden C. c. huttoni durch kürzeren und viel höheren Schnabel, kïrzere Flügel, viel schmälere dunkle Streifung auf Kopf und Rücken. Die Brustseiten anscheinend ganz ohne Streifen, Seiten heller. Flügel nur $76-78 \mathrm{~mm}$. (2 im Tring, 3 im British Museum.) 'Typus Fao 1893, gesammelt von W. D. Cumming.

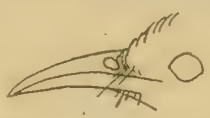

a

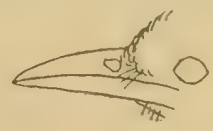

b

Figur 122.

An der Nordspitze des Persischen Golfs, an der Mündung des rereinigten Fuphrat und Tigris. (Vielleicht weit rerbreitet im Tale ohengenannter Ströme.)

\section{Crateropus caudatus caudatus (Drip.).}

Cossyphus caudatus Drapiez, Dict. Class. d'Hist. Nat. X, P. 219 (1826- Ex Dumeril Indien).

Timalia chataraea Franklin, Proc. Znol. Soc. London 1831, 1. 118 (am Gauges zwischen Calcutta und Benares).

Chutorhea eclipes Hume, Stray Feathers 1877, p. 337 (,N. W. Punjab, Trans-Indus and lower valleys of the surrounding hills").

Dunkler, mehr rötlichbraun, besonders an den Kopf-, Hals- und Körperseiten, und erheblich kleiner, als C. c. huttoni.

Indien vom Himalaya his Süd-Indien und ron Sindh und Rajputana bis Behar, Lakkadiven und Rameswaram Insel.

\section{Crateropus fulvus fulvus (Desfont.).}

Turdus fulvus Desfontaines, Mém. Acad. Roy. Sci. 1787, p.498, Taf. XI (1789-- Gafsi, I'unis).

Mahurus mumidicus Levaillant jun., Expl. Sei. Algérie, Atlas, Ois., Taf. 9 bis Fig. 1 (1850Algerien).

Abbild.: Dresser, B. Europe, III, Taf. 98, Fig. 1.

$\mathrm{O}^{\top}$ ad. Oberseite von einer braunrötlichen Sandfarbe, Oherkopf dunkler, Kopf und Hinterhals mit dunkelhraunen Schaftstrichen, die auf dem Rücken verschwinden. Schwingen und Schwanz etwas brïunlicher mit lichteren Säumen. Unterseite heller, etwas gelblicher, Mitte der Kehle weiß, Mitte des Unterkörpers weißlich. Schnabel dunkelbraun, F'üße hellgrünlich graubraun. Iris nach Angaben in den meisten Büchern braun oder rothraun, nach König weiß, auf den Etiketten zweier junger Vögel aus Marokko von Riggenbach als rot bezeichuet. Flügel etwa 98-102, Schmanz etwa 125 bis 135 , Lauf ungefähr 32-34, Culmen $25-26.5 \mathrm{~mm}$. -.- o wie $0^{7}$ nu etwas kleiner, Flügel etwa $5 \mathrm{~mm}$ kürzer. - Jur. etwas dunkler auf der Oberseite, auch die Unterseite etwas gesiittigter, soust genau wie die alten Vögel.

Tripolis, Tunis (wohl nur ausnahmsweise nördlich des Atlas), SüdAlgerien (nur südlich der Aurès) und Sïd-Marokko (Marrakesch, Rahamma bei Mogador).

Bewohner buschreicher Wïstengegenden. Mleist in kleinen Flïgen. Lärmend, oft ein eigentümliches Rätschen, oft ein lautes hoch anfangendes, absteigendes, lang- 
gezogenes, nach König wie hi, hu, hu, hu, hu klingendes Pfeifen ausstoßend. Nester in dichten Büschen, große oben offene Näpfe. Eier 4-6, anfangs April bis Mai, bald länglieher, bald rundlicher. glänzend blaugriin ohne "yeichnung. Nach Erlanger messen 25 Eier im Durchschnitt $24.24 \times 17.9$, Mrximum $26.5 \times 19$, Minimum $22 \times 17 \mathrm{~mm}$, ein Doppelei $28.5 \times 20.5 \mathrm{~mm}$.

\section{Crateropus fulvus acaciae (Licht.).}

Sphenura Acaciae Lichtenstein, Verz. Doubl., p. 40 (1823- Nubien).

Abbild.: Cretzschmar in Rüppell's Atlas, Taf. 18; Shelley, B. Egypt., I'af. I.

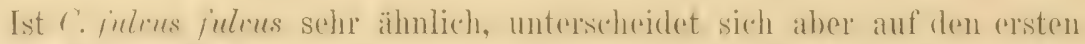
Blick durch deutlieh gran übertünchten (Herlinf und Nakken mit dunkel-

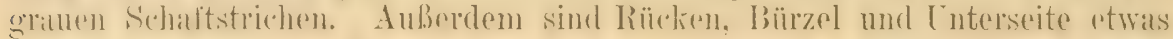

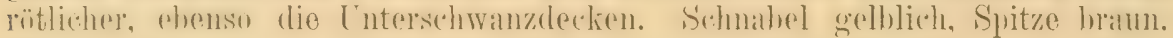
Iris hellbraun, gelb oder grau. Flügel ot ungeführ $94-98$, o $5-9 \mathrm{~mm}$ kïrzer. Juv. wie alte Vögel, Schuabel aber schwärzlich.

Nubien. etwa von Wadi Halfa bis Chartum und Küste von Fritrea.

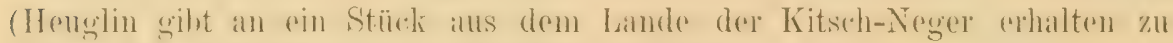
haben, eine Angabe, die der Bestätigung bedarf.)

Lebensweise wie die von C.f. fulvus. Eier nach Heuglin $23 \times 18 \mathrm{~mm}$.

\section{Gattung IANTHOCINCLA Gould 1835. (Fig. 123:---..)}

Unter obigem Namon fassen wir eine gröBere Gruppe etwa drossel-

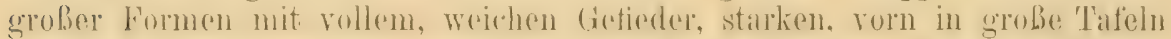

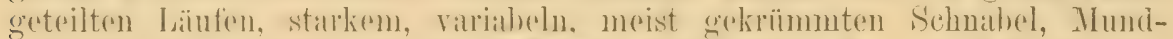

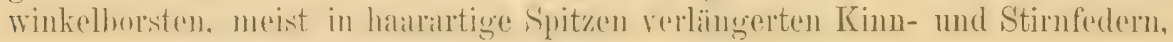

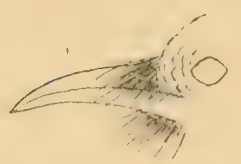

a

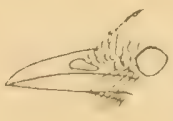

b

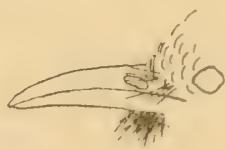

c

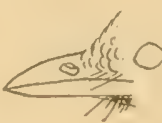

d

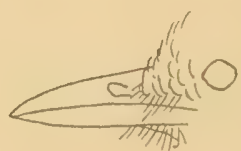

e

Figur 123.

liumen germuleten Flügeln zusammen. I)ie 1. Sohwinge ist etwa ron clel halben Länge des Flügels, rlie Sehwingen nehmen stufenweise an Länge zu, bis zur 5.- 7., wo sie die Elügelspitze erreichen. Min könnte die hier unter Ianthocincla grefisten Formen atuch mit Gurrulare Lesson (18:31) vereinigen, doch ist es tunlichst nuter Gurmlux dir langhäubigen Formen (lencolophus, moniliger, belangeri, pertonelis usw.) nit weniger gestuften Schwänzen zu balassen. Ton lanthorinclu mit diumn bedeekten Nasenlächern und wenigg ge-

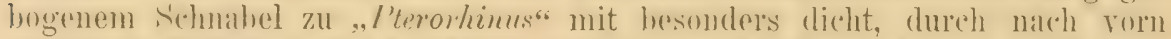
gerichtete Federn hedecktem Nares und etwas stärker gekrïmmtem Schnabel "inerseits. zu .. Trochulopterone" mit weniger bederkten Nasenlöchern, .Balax" und ,Kusnalionir" mit längerem, gehogenen Schnahel und ehensolehen Nasenlüchern finden sivh alle Üherg̈̈nge (Fig. 123 a.-.e). Viel eher könnte man zwei oder mohr Gattumgen nach del Form des Schnabels alloin abteilen, aber auch dieser sehwert die Ühersicht mehr, als es sie erloichtert, weil es an scharfen 
Grenzen fehlt. — I)ie .. Lärmdrossehn" oder "Latughing Thrushes" treiben sich in kleinen scharen laut lärmend und pfeifend umher, und nähren sich meist am Boden von Iusekten und Frïcliten. Sie bauen offene Nester und legen meist ungefleckte, selten gefleckte blaue (wenige Arten weibe) bier. Sie sind nicht Zugrägel und hewohnen die Tropen Asiens, vou wo eine Anzahl Arten in die Hochgebirge Mittel-Asiens und in China his in paläarktisches Faunengebiet reichen.

1) Außenfahnen der Schwingen leuchtend rot...... I. formosum . p. 634

I Außenfahnen der Schwingen nicht rot ........... 2

Oberrücken ganz einfarbig ................... 5

Oberrïcken fast einfarbig (dunkel zimmtbraun mit helleren Säumen)

I. koslowi . p. 629

Oberrücken mit rundlichen weißlichen Flecken an den Spitzen der Federa 3

Oberrücken rotbraun mit schmalen Schaftstrichen .... I. lineatum . p.635

Oberrücken fahlbraun mit weißlichen Spitzen und breiten schwarzen

2) Subapikalbinden ............. I. lunulata.

Oberrücken braun mit schwärzlichen Endsäumen . . . . . . .

Oberrïcken rotbraun mit schmalen dunkelbraunen Spitzenrändern und hell gräulich olivenfarbenen Anteapikalflecken ..... I. affinis .

Oberrücken schwarzbraun mit breiten aschgrauen Federsäunen, Flügel über $120 \mathrm{~mm}$.............. I. vaddelli .

Oberrücken kastanienbraun mit hellgraubraunen Federsäumen, Flïgel unter $120 \mathrm{~mm}$............. . . . lunceolatus .

3) Kehle schwärzlich. . . . . . . . . I. occllatum p. 626

Kehle rostrot mit weißen Federspitzen ....... I. maximus . p. 625

$4\{$ Alle Steuerfedern mit rotbraunen Spitzen . . . . . I. vufogularis . p.634

Mittlere Steuerfedern einfarbig, äußere mit weißen Spitzen I. subunicolor - p. 633

- I Innere Armschwingen mit weißen Spitzen . . . . . . . . . 6

I Innere Armschwingen ohne weiße Spitzen ........... 7

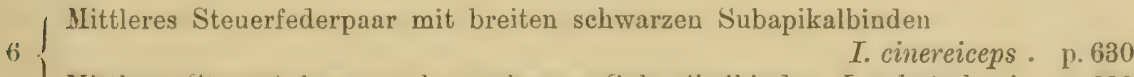

Mittleres Steuerfederpaar ohne schwarze Subapikalbinden I. sukatschcuci - 1).629

7 K Kehle reinweiß ...................... . . . . . . . . 637

\{ Kehle nicht weiß .................... 8

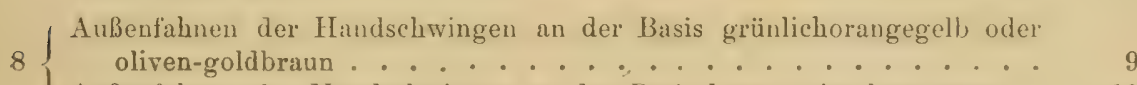

Außenfahmen der Handschwingen an der Basis braun oder braungrau . 10

$9\{$ Breiter weißer Bartstreif . . . . . . . . . henrici 1. 1.632

Kein weißer Bartstreif ................ elliotii . p. 631

$10\left\{\begin{array}{l}\text { Unterschwanzdecken lebhaft hell rostfarbeu . . . I. perspicillatus . p. } 636 \\ \text { Unterschwanzdecken fahl gräulich aschbraun . . . I. davidi . p. } 630\end{array}\right.$

\section{-952. Ianthocincla maximus (Verr.).}

Pterorhintes maximns Verreaux, Nouv. Arch. Mlus. Paris VI, Bull., p. 36, Taf. 3, Fig. 1 (1870- "Hontagnes du Thibet chinois").

ơ ad. Oberkopf und Hinterhaupt schwarzhraun mit undeutlichen helleren Spitzen. Federn an Hinterhals und Torderrücken gelbbraun mit hreiten schwarzen Fudbinden, an deren Spitze ein runder rahmfarhener Fleck steht, äußerste Basis hellgrau; Federn des Rückeus kastanienfurben mit breiten

E. Hartert, Die Vögel der paläarktischen Fauna. 
schwarzen Eindhinden, an deren Spitze ein runder weißer Fleck steht, Basis ehenfalls hellgrau: nach den Oherschwanzdectien zu nehmen die schwarzen Endbinden an Ausdehnung ab. Oherflügeldecken kastanienfarben mit weiBen Spitzen und sthwarzen Subterminalbinden. 1. bis 3. Haudschwinge ganz schwarz mit weißen Suitzen, die folgenden mit granem Wurzelteil der Außenfahnen. au den Armsehwingen ist die Außenfahne kastanienbramu, uach der Spitze in Gratu ühergehend, imerste Armschwinge ganz rotbrann mit weiber spitze. Mittelstes stenerfederpar rotbram mit schmaler weißer Spitze, die äuBeren Paare an der Wrurzel der Aulienfiahne grau, an der Innenfahne sehwarz und shau gebündert. dann schwarty mit breiter weiber Spitze. Lndeutlicher. cuperciliastreif rostgelh. Tor den Augen ein grober weißer Zügelfleck. die ïuliersten federspitzen sehwarz. Ohrdecken rostrot. Kinn und Kehle rostrot mit weiben Federspitzen, ührige C'nterseite rostgelb, Brustseiten mit schwarzen

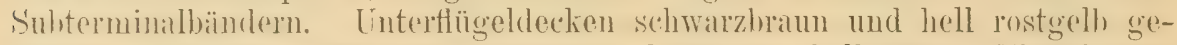
mischt. Iris gelh. Sehmahel hornhraun. Fïbe sehr hell braun. Filïgel etwa 138 140, Schwallz (twal 180). Lauf 40-43, ('ulmen etwa 33-38 mm. Nasenlöcher deutlich von Federin überragt.

Berge von West-Szetschwan und Süd-Kansu.

In den hohen Bergen von Mupin und Jaotschi in Höhen von 3-4000 m.

\section{5:3. Ianthocincla ocellatum artemisiae (David).}

Cinclosona Artemisiae David, Ann. \& Mag. Nat. Hist. (4) VII, p. 256 (1871- MIoupin in West-Szetschwan).

Abbild.: Gould, B. Asia III, Taf. 45.

ơ o ad. Oberkopf schwarz, Hinterhals rostbraun, mit helleren ockergelblichen Federspitzen und suhapikaler sehwarzer Binde. C̈hrige Oherserite

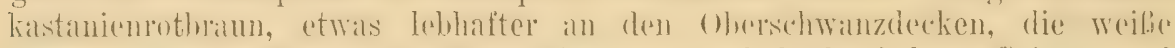

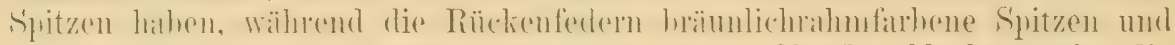
wie jene subapikale sehwarze Bänder haben. Oberflügeldecken wie die

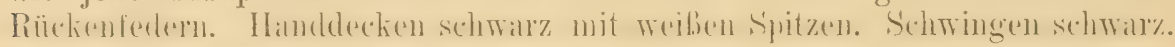
Außenfahnen der Handschwingen zum gröBten 'Teil grau, die der Armsehwingen kistanienhram, Syitzen weib. Mittlere steuerfedern kastanienhraun. mit schmalen weiben linden, die äbrigen braun mit ausgedehnten weiben

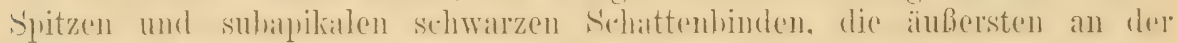
Bassis der Anbenfahne kistanienbraun und ditror gratu. Endentlicher, gratuer Sunpereiliarstreif. Zügel. Federn unterm Auge und Kinn brämnlieh rahmfarben. Federn um das Auge, Ohrdecken und Kehle schwarz. Hinter den Ohrodedien ein rahmfinthener Fleck. Halsseiten und Forderhais brïunlich rahmfirthen mit sehwarzen Gurerinden. Brust griulicher mit undentlieheren

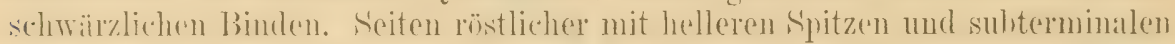
schwallzen Binden. L'nterkärper. Sichenkellnefiederung und Entersehwandechen

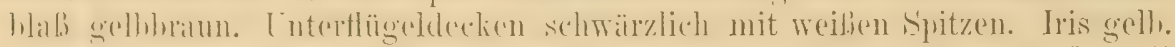

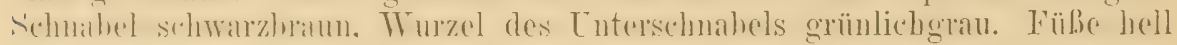
fleischfarben. Flügel ot etwa 122, of 118, Schwanz ô etwa 150 , o 116. Lauf etwa 47, Culmen 28-32 mm. Nasenlöcher wie bei I. maximus.

Bergwälder von Szetschwan und Kuku-Nor. 


\section{5t. Ianthocincla ocellatum ocellatum (Vig.).}

Cinclosoma ocellatum Vigors, Proc. Zool. Soc. London 1831, p. 55 (Himalaya).

Abbild.: Gould, Cent. Himal. B., Taf. 15.

Unterscheidet sich von Ianthocinda ocellatum artemisice durch kitstanienbraume Ohrdecken. Kimfleck, Zügel und Supereiliarstreif lehhaft rostgelb. Brustbänderung viel breiter. Flügel etwa $130-133 \mathrm{~mm}$.

Nepal und Sikkim, in Höhen von 8-10000 engl. Fuß. I, p. 54.)

(Über die Eier vgl. die Notiz von Hume, in Nests \& Eggs Ind. B., second ed.,

\section{-955. Ianthocincla lunulata Verr.}

Ianthocincla lumulata Verreaux, Nour. Arch. Mus. Paris VI, Bull. p. 36, 'Taf. 3, Fig. 2 (1870-- „Montagnes du Thibet chinois").

Oad. (Herhstlkleid): Oherkopf und Nacken matt rötlich schokoladenhraun, ührige Oherseite gelhbraun, die Federn mit lichteren rostgelhen Endbindeu und schwarzen Anteapilial-Binden. Kleine oherflügoleckén einfarbig gelbbram, große und mittlere wie die Rückenfedlern. Handdecken schwarz mit weibgranen Spitzen. Schwingen mattselwwal\% mit weißen Spitzen, dußenfahnen der Hamdschwingen aschgrat, die der Ammsehwingen gedhlich olivenbraun. Mittelste stenerfedern selblieh olivenhraun mit schmalen weiben Fuden und hreiten schwarzen Anteilpikal-Binden, äußere grau mit ctwa 1 em weiten weiBen Spitzen und 2-3 cm weiten schwarzen Antealnikal-Binden. rä̈gel und hreiter Riug um das Auge weil. Ohrdecken und Kiehle kiam heller, als der Oberkouf, Kronf und Brustseiten ehenso, aber mit weiben Endbinden. Weichen und Unterschwanzdecken bränulich lostgellh mit aingen schwïrzlichen Punkten, Mittu des Unterkïrpers gräulichweiß. Innousïume der Schwingen aschbräunlich. Iris ggelblichweib his weiß. Oherschuahel gräulich horubram, Enterschnahel heller. Fülje hellhraun. Flügel etwa 108-115. Schwanz 130-140. Lauf etwa t2. Culmen ungefilhr 30-32 mm. o. und juv. wie $\sigma^{\top}$, vielleicht o kleiner. - Im Sommer bleicher, die Spitzen der Federn des Rückens fast weiß.

Trestliches Szetshwan und Kansu his zum Kuku-nor und in den Tsinling-Bergen.

\section{Ianthocincla lanceolatus lanceolatus (Verr.). (Fig. 123c.)}

Pterorhinus lanceolatus Verreaux, Nour. Arch. IIus. Paris VI, Bull., p. 36 (1871- „Montagnes du Thibet chinois").

Abbild.: Nouv. Arch. Mus. Paris Bull. VII, p. 40, 'Taf, 2.

Federn des Oberkopfes kastanienhram mit etwas helieren Säumen, die les Rückens dunkel kastanienbraun mit hellgranen Sümmeu, welche auf dem Bürzel breiter werden, die Oberschwanzdecken graubaun mit aschgranen Rändern. Schwingen dunkelbraun. die änberen und imneren mit brangrauen, die mittleren mit hrumen Aufensüumen. Schwanz cinfarhig olivenhraun. Ohrdecken rahmfarben, bald mehr bald minder breit schwaraliam his dunkel kistanieubrium gestreift. Fou der Sehnahelwurzel zicht sich an den Seiten der Kehle hald ein hreiterer hraunschwarzar, hald ein gräBtenteils in Flecken 
anfogelister, oder doppelter und mehr Kastamienbrauner Streif entlimg. Luterseite rahnmweib, Kropfgegend mit dunkelhraunen Schäften, Seiten, oft bis fast in die Nitte des Kürpers mit tief kastanienhramnen, rötlicher kistanienbraun eingefiliten Längstlecken und Streifen. Unterschwanzdecken sthmutzig rahm-

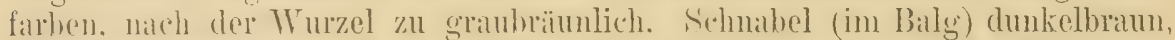
Füßse hell grathraun. Iris nach I)avid blaßgelb. Innensïmme der schwingen blab rostrot. Flügel von \& Exemplaren 94-110 (remutlich sind die kleineren stiucke die p). Sehwanz etwal 125-145, Lanf 38-40. ('ulmen $27-29 \mathrm{~mm}$. Schnabel merklich gebogen.

Hohe Berge von West-Szetschwan, Mupin und Süd-Schensi.

Standrogel, den man in der Regel in kleinen Flügen an Waldrändern umherstreifen sieht. Das Nest gleicht in der Form den Drosselnestern, steht in dichten Büschen und enthält nach David 5-6 grünlichblaue Eier.

\section{Ianthocincla lanceolatus bonvaloti (Oust.).}

Baliax Bonculoti, B. lanceolutus rar. Bonvaloti Oustalet, Ann. Ści. Nat. (7) VIT, p. 2iis. 274 (1892- So in Tibet, errore!); Nouv. Arch. Mlus. Paris, ser. 3, V, p. 192 ('Tara in libet).

Unterscheidet sich (nach Oustalet) von $I$. lanceolatus lanceolatus aus Szetschwan (West-Chinil) dadurch, daßs die Zügel und der vordere Teil der Wangen schwarzbraun iihertuincht sind, die Kehle fein gestrichelt, die Mitte der Brust ganz mit bramuen Lüngsstreifen bedeckt. Schnabel und Fülie sollen dunkler und kräftiger erscheinen, der Schwawz 183, Flügel 115-120 mm lang sein. - Ein zweites Exemplar soll die dunkle Färbung der Kopfseiten weniger ausgepräigt reigen und sein Schwanz 140, sein Flïgel nur $110 \mathrm{~mm}$ lang sein.

Tara in Tibet. - Andere Subspecies sind: 1. lanceolatus yunnanensis Rippon (Bull. B. O. (Guh, XV, 1).96, 1905) aus West-Yumian, dessen Cnterschiede (weder die von lanceolatus noch die von bonvaloti) aus der ungenïgenden Diagnose nicht zu ersehen sind, und I. lanceolatus vidorine Rippon (l. e., p. 97) vom Berg Victoria, suidliche Chin-Hills, Birma.

\section{-958. Ianthocincla waddelli (Dress.).}

Babax vaddelli Dresser, Proc. Zool. Soc. London 1905, I, p. 54, Taf. IV (Tsangpo-'Tal).

$0^{\pi}$ ad. Oberseite bräunlich aschgrau mit breiten schwarzbraunen Längsstreifen die auf (lem Bürzel schmäler werden, so dable letzterer fast ganz grau erscheint. Schwingen schwarzhraun, die mittelsten fast einfarbig. die äubern und inuern mit aschgranen AuBensïumen. Steuerfedern schwarzhraun mit undentlichen grauen Spitzen und Sämmen. Kopfseiten wie die Oberseite. Cnterseite heller aschgrau als die Oherseite, Kinn und Kehle fast ('infarbig; nur mit dunkeln Schälten. Schenkelbefiederung und Tnterschwanzdecken einfarbig, übrige Unterseite mit rotbraunen, am Sehafte fast schwarzen Streifen. Iris graumeiß. Schnabel und Füße schwärzlich hornfarthen. Flügel etwal 135-142, Sichwanz etwa 165, I tauf ungeführ 42, Culmen $35-37 \mathrm{~mm}$. Schnabel stark gebogen, - o wie ơ (6 verglichen).

Bewohnt das obere Brihmaputra-Tal in sïdlichen Tihet und die Gegend von Gjangtse, nördlich von Sikkim. 
Lebt wie die Verwandten, läuft raseh am Boden und ist schwer zu schießen. Nester mit 2 und 3 Eiern wurden am 27. Mai 1905 bei Gjangtse in Tibet gefunden. Die Nester waren aus kleinen Zweigen, Gras und Wolle gebaut und mit feinen Grashalmen ausgelegt. Sie standen in alten Weidenbänmen und niedrigem Buschwald. lie Eier sind grünlichblau und messen ungefähr $32 \times 23 \mathrm{~mm}$.

\section{-959. Ianthocincla koslowi (Bianchi).}

Kaznakowia koslowi Bianchi, Bull. Ac. Petersb. (5) XXIII, p. 45 („1905“, erschienen Jan. 1906 - Dze-tschu, Nebenfl. des Mekong, siidöstl. Tibet).

Abbild.: Aves Exped. Koslowi, Taf. III, Fig. 1.

Fürbung der Hauptsache nach zimmthraun; Oberseite dunkel zimmthraun mit mehr oder minder helleren Federsäumen; Federn der Stirn mit sthwarzen Schäften, die des Nackens und der Halsseiten mit gratuen Sïumen; Handschwingen mit grauen Anßeusïumen; Stenerfecleru fust einfarbig zimmthraun. Kopfseiten aschgrau. Zügel dunkler, Superciliarfedern mit zimmtfurbenen Sehaftstreifen; Federn unter den Augen und am Kinn mit hell rimmtfarbenen Spitzenflecken, Ohrdecken bräunlich zimmtfurben. Oberster Teil der Kehle grau; Vorderbrust, Brust, Körperseiten, Entersehwanzdecken. Luterflügeldecken und Schenkelbefiederurg hell zimmtfarben mit heller'"n Säumen, Federn in der Mitte der Brust mit hreiten granen Säunen, die in der Titte des Unterkörpers mit sehr breiten röstlichgrauen Säumen. Schnahel und Füße sehwarz. Flügel of 112.5-122, o 106.5(1), 115-117, Schwanz 148-157, o 155 (144 eimmal), Lauf ơ 38.5-41.5, o 38-40.5, C'ulme'n ก $33-38$, o $33.5-37 \mathrm{~mm}$. (Nach Bianchi.)

\section{Südöstliches Tibet, am Dze-tschu, einem Zufluß des Mekong.}

\section{Ianthocincla sukatschewi (Bere\% \& Bianchi) ${ }^{1}$ ).}

Trochalopteron Sukatschewi Berezowski \& Bianchi, Aves Exp. Potan. Gansu, p. 59, Taf. 1, Fig. 1 (1891-- Tanneniwälder hoher Berge in Kansu); Übers.: Journ. f. Orn. 1897 , p. 67.

OTad. Oberseite graubraun mit weinrötlichem Schimmer, auf Bürzel und Oherschwanzdecken in ein brïunliches Fuchsrot ïbergehend. Handsebwingen dunkelgran, Außenfahnen hellgrau mit weinrötlichem Schimmer, Armschwingen dunkelgrau mit braunen Außenfahnen, die innersten mit ausgedehnten, nach außen an Größe abnehmenden weißen Spitzen. die an den äußeren Armschwingen und an den Handschwingen nur noch augedeutet sind. Mittelste Stenerfedern gelblich graubraun, nach dem Ende zu mehr grau und mit kleinen weißlichen Spitzenflecken, die vier äußeren Paare an der Wurzel grau. in der Mitte sehieforschwarz, an der Spitze grüulichweiß. Zügel. Stirnborsten und halbmondförmiger, vom Mundwinkel unter den Waugen her bis hinter die Ohrdecken ziehender Fleck braunschwarz. Tangen und Wurzelhälfte der Ohrdecken bilden einen großen weißen Fleck. Unterseite weinrötlich-graubraun, an Kehle und Kropf undeutliche dunkle Streifen; Bauch, Weichen, Schenkelbefiederung und Unterschwanzdecken bräunlich

1) (Trochalopterum hennickei Prazák, MLnatschr. Ver. z. Schutze d. Vogelw. XXII, p. 327 (1897 - "An der Mündung von Yuen in den Tungting-See ${ }^{6}$ ). — Es scheint, daß diese vermeintliche Art, die eine Form ron $I$. sulatscheni sein soll. nicht existiert und nur der Phantasie des verstorbenen Autors entsprungen ist.) 
fuchspot. I'nterflïgraldecken gelbbraun, vor den Haudschwingen ein großer sehwarzgrauler Flerk. "Iris dunkel zimmetfurben. Läufo blabrosil-glau".

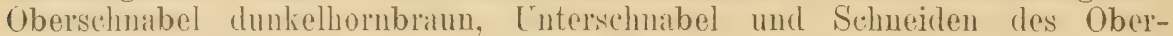
schnabels gelblich. ㅇ wie ơ. Flügel ơ 99-108, ㅇ 97-106, Schwanz ơ 143-160, 132-158. Lauf 37-39, ('ulmen o 23-28, o 22-26 mm. (Beschreibung natch einem ô (Cotypus) im Tring-Museum. Maße nach Berezowski \& Bianchi.)

„Diese seltene, meist paarweise anzutreffende Art ist Standrogel in den Tannenwäldern hoher Berge in Kansu, besonders dort wo Bambus dazwischen wächst." Auch wenn mau die Gattung Trochalopteron trennt, gehört diese F'orm durch die bedeckten Nasenlöcher und ihren Zeichnungscharakter unbedingt zu Ianthocincla.

\section{-961. Ianthocincla davidi (Swinh.). (Fig. 123a.)}

Pterorhinus davidi Swinhoe, Ibis 1869, p. 61 (Peking).

Abbild.: David \& Oustalet, Ois. Chine, Taf. 50. Gould, B. Asia Taf. XXIII.

Oे. Oberseite fahl gräulich aschbraun, über dem Auge ein undeutlicher kurzer bräunlichweilier Suprereilicarstreif. Zü̈gelfedern schwärzlich mit anteapikaler brïunlichweilier Binde. Sehwingen braun, Außenfahne'n der Handschwingen hell brämnlichgrau. innere Armsthwingen und Ober- und Interflügeldecken wie der Rüicken. Steuerfedern schwarzbraun, vor den Spitzen meist einige undeutliche Querbindern. die seitlichen an der änfersten Bassis, die mittleren gröbtenteils aschgrau, welehe Farhe allmählich in das Sehwarzbraun der Spitzen übrergeht. Kinnfleck schwarz, übrige Unterseite heller als der Rücken, imm hellsten an Kehle und Brust. Schnabel fahlgelb. Fïbre hellbraun. Iris hraun. Flügel etwa 92-10:3 (jedenfalls sind die mit Flügellänge von etwa $92 \mathrm{~mm} \rho$, die mit $97-103 \mathrm{o}$ ), Schwanz etwa 120-130, Lauf 30-35, ('ulmen etwil 23.5-30 (jedenfalls sind auch hier die kleineren Maße die von $ᄋ$ ). - o in der Färbung wie $0^{7}$. - Nasenlöcher von in halaratige Sjitzen rerlängerten Federn ganz bederkt, Schnabrel gekriimmt.

Sü̈löstliche Mongolei, Ordos, Mlaschan. Kinnsu. Kuku-Nor, Oberlauf de's Chuanche, Schensi, Peking.

Bewohnt dicht verwachsene Gebirgsschluchten und wurde ron Przewalski bis zu Höhen ron $9500 \mathrm{Fuß}$ gefunden, in Kansu im "Gebüsch der alpinen Zone". Lin munterer, beweglicher Vogel, der äußerst gewandt in den Büschen herumklettert, äuch viel am Boden läuft, und meist nur niedrig und auf kurze Strecken hin fliegt. Stimme ein lauter angenehmer Pfiff, der kurze Gesang besteht aus Variationen des Lockrufes. Im Mai wurden schon Junge in Kansu und am Chuanche gefunden. "Das Nest ist ein wenig solider Bau, der aus trockenem Grase, Würzelchen oder feinen Zweigen erbaut und inwendig nicht ausgefüttert wird; es steht im dichten Gebüsche, nicht hoch über der Erde." Przewalski fand 3 Eier im Gelege, Rückbeil sandte vom Kuku-Nor Gelege ron 5 und 6 Eiern. Die Eier sind bis auf die viel geringere Größe denen von Garrulax pectoralis und moniliger gleich, nämlich glänzend blaugrün und länglich eiförmig. Pleske gibt als Maße $25-28 \times 19-19.5$ an. 6 Eier im Hiuseum zu Tring messen $27 \times 18.7,27 \times 19,27.1 \times 19,27 \times 19.4,27.4 \times 19$ und $27.5 \times 20.4 \mathrm{~mm}$.

\section{Ianthocincla cinereiceps styani (Oust.).}

Trochnlupteron Styani Oustalet, Bull. Mus. Paris 1898, p. 226 (Ta-tsien-lou in Szetschwan und Yunnan).

Stirn und Oberkopf bis in die Nitte des Nackeus schwarz, übrige Obrescite röstlich olivenbraun. Schwingen an den Innenfahmen grauschwar\%. 
Handschwingen mit hellgrauen, Armschwingen mit röstlich olivenbraunen Anßenfahnen, schmalen weilsen Spitzen und breiten schwarzen Anteapikalbinden. Handdecken sehwarz. Mittlere Stenerfederu wie die Armsehwingen, änßere mit übor 1 (:m weiten weißen Enden und unch breiteren schwarzen Anteanikalbinden, das änBerste Pall anberdem noch in der Nitte mehr oder minder gratu. Zügel und kurzer Streif bis über das Auge weiblich, breiter, aus schwarzen Federspitzen bestehendor Bartstreif. Unterseite fahl rostbrilunlich, an der Brust mit weinrötlichem Anflug. Schubel (im Balg) bornfarben, Füße hellbraun. Flügel etwa 94-98. Schwanz etwa 106-118, Lauf ungeführ 38, ('ulmen 22-25: Schuabel sehr gerade. breit und stunpfspitzig.

Ta-tsien-lou im westlichen Szetschwan und Yunnan.

\section{Ianthocincla cinereiceps cinereiceps (Styan).}

Trochalopterum cinereiceps Styan, Ibis 1887, p. 167, 'Taf. 6 (Käfigvogel).

Trochalopteron ningpoense Darid \& Oustalet, Naturaliste XII, p. 186 (1890- Ning-pu).

Unterscheidet sich auker anderen minder auffallendon Charakteren dadurch ron I. c. styguni, dab der Oberkoplf nicht schwarz sondern dunkel aschgrau ist, die Ohrgegend rostrot.

Chinesische Provinzen von Tsche-kiang und Fo-kien.

Ein Ei aus Fo-kien im Britisch Museum ist blau und miBt $24.1 \times 18.8 \mathrm{~mm}$.

\section{-964. Ianthocincla elliotii elliotii (Verr.).}

Trochalopteron elliotii Verreaux, Nouv. Arch. Mus. Paris VI, Bull., p. $36(1870$ „Mone tagnes du Thibet chinois").

Abbild.: Gould B. Asia III, Taf. 42.

ơad. Oberseite fahl erdhraun, auf dem Bürzel und den Oberschwanzdecken olivenfarben verwaschen. Fedorn des Hinterhalse's und Mantels im frischen Gefieder an den Spitzen mit glänzenden graurveißen Punkten; Oherkopf fihl bräunlichgratu. Schwingen dunkel schiefergrau. Anßenfihnen an der Wurzel glümzend grünlich nrangefarben, an den Spitzon weißlich graublau; Armschwingen mit den Außenfahnen fist ihrer ganzen Ausdehnung nach glïuzend griülich orangegelb, die letzten Armsehwingen fist ganz blaugran. Steuerfedern unten schwarz, oben an den Außenfahnen ginulichgoldbraun, innerstes Paar ganz vou letzterer Fïrbung oder nur damit gesïunt oder verwaschen, sonst aschgrau, Innenfahuen aschgrau, das inittelste. Palr mit ganz schmalen, die übrigen mit etwa $1 \mathrm{~cm}$ weiten weilien Spitzen, die ron unten wie ron oben gesehen sehr auffallen. Zügel schwarzbraum. Kehle und Kopfseiten fahl graubraun, in frischem Gefieder mit feinen silberweißen Spitzen, Brust und Seiten rötlichgraubraun. Nitte des Lnterkörpers, Bauch und Unterschwauzdecken braumrot. Iris rahmfarben. Sehnahel schwarz. Füße fahl braumrötlich. Flügel etwa 9:3-100, bei oinem Stïcke aus Ta-tsien-lu 105, Schivanz 115-125, Lauf' etwa 36 37.5, - c'ulmen etwa 20-2.2 mm. o wie $\sigma^{\pi}$, nur eiu bißchen kleiner: Flügel. etrva 90--95 $\mathrm{mm}$ (30 gemessen). Erstes Jugendkleid wie das der Alten, nur die Firben etwas matter, und es fehlen die feinen silherweißen Punkte auf Mantel, Kopfseiten und Kelle.

Schensi, von den Tsin-ling-Bergen bis Szetschwan. 


\section{Ianthocincla elliotii prjevalskii (Menzh.). (Fig. 123h.)}

Trochalopteron prjevalskii Mlenzbier, Ibis 1887, p. 300 (Kansu).

Wie I. elliotii elliotii, nur die mittleren Steuerfedern ganz grau oder nur mit schmalen gellogrüulichen Säumen, die Gesamtfärbung etwas gräulicher uncl heller, auberdem etwas gröber: Flügel y etwa $103-106$. o $105-106 \mathrm{~mm}$ (6 gemessen).

Kansu, nördlich der Tsin-ling-Berge bis Kuku-Nor.

Przewalski fand diese Form in den dichten Laubrväldern der Gebirgstäler, im Sommer in Höhen bis zu $11000 \mathrm{FuB}$. Er schildert den Vogel als munter und bereglich und sah ihn meist in kleinen Flügen von 4-7 Stück. Das Nest steht meist unter Reichhöhe in Büschen und bildet einen ziemlich großen oben offenen Klumpen von Bast und Reisern, innen mit feinen Würzelchen ausgelegt. Die 4-5 Eier sehen kleinen Singrdrossel-Eiern fast zum Verwechseln ähnlich. Sie sind grünlichblau mit rotbrauneu und fast schwarzen Punkten und kleinen Flecken, meist am stumpfen Ende. 5 Eier im Tring-MIuseum messen $24-25 \times 19-20 \mathrm{~mm}$.

\section{Ianthocincla elliotii bonvaloti (Onst.).}

Trochulopterum Bouvaloti \& T. Ellioti var. Bonvaloti Oustalet, Ann. Sci. Nat. (7) XII. p. 275, 276 (1892- Tioungen in Ost-Tibet); Nouv. Arch. Mus. Paris (3) V, Taf. 3, Fig. 1.

Oherseite dunkler, düsterer grau, ohne glänzende gräuliche Sipitzenpunkte, alle Farhen weniger lebhaft. Flïgel nach Oustalet $103 \mathrm{~mm}$.

Üstliches Tihet (('hatou, 10. Mai 1890. Gajung 13. Mai 1890).

\section{Ianthocincla henrici (Oust.).}

Trochalopterum Henrici Oustalet, Ann. Sci. Nat. (7) XII, p. 274 (1891- So in Tibet): Nouv. Arch. Mus. Paris (3) V, Taf. 3, Fig. 2 (Figura mala).

Garrulax tibetanus Dresser, Proc. Zool. Soc. London 1905, p. 54, Taf. V, Fig. 2 (Tsangun-

T'al. Figura optima).

Oberseite aschgrau mit olivenfarbenem Tou, Zügel und Kopfseiten kastanienhraun, schmaler Superciliar- und hreiter Wangenstreif ralmmeiß. Schwingen schwärzlich, Außenfahnen aller und beide Fahnen der inuersten beiden Armschwingen aschgrau, Basis der mittleren Handschwingen matt oliven-goldhraun mit leichtem grïnlichen Schimmer: Handdecken schwarz. Steuerfedern schieferfarben mit nach außen zu hreiter werdenden weißen Spitzen: an dem äßersten Paare etwa $1 \frac{1}{2} \mathrm{~cm}$, am mittelsten kaum $2 \mathrm{~mm}$. Cnterseite etwas leller und fihlbrïunlicher als der Rücken, Unterschwanzdecken, Bauch und Scheukelbefiederung lehhaft kastanienbraun. Iris matt rot. Schnabel und Füße orangebräunlich. उे wie f. Flügel o 115, 2 110, Schwanz o 140 his 150, Latuf ungefähr 37, Culmen $22-23 \mathrm{~mm}$. Jux. wie alte Vögel. Im September starke Mauser.

\section{Östliches Tibet (So: $3700 \mathrm{~m}$, Tsangpo-Tal 12100 engl. Fuß).}

Lebt in Pappel- und Erlengebüschen und kommt in die Nähe der Dörfer. Man sieht ihn in Gesellschaften von acht oder mehr Individuen, er ist beweglich und laut, läßt oft einen flötenden Ruf wie wo-hi, wo-hi hören, weiß sich trefflich zu verbergen und fliegt selten weit und meist nahe am Boden entlang. 


\section{Ianthocincla affinis blythii (Verr.).}

Irochalopteron blythii Verreaux, Nouv. Arch. Mus. Paris IV, Bull., p. 37 (1870- „Montagnes du Thibet chinois").

Abbild.: Gould, B. Asia III, Taf. 41.

onad. Zïgel und breiter Streif überm Auge schwarz, Oberkopf schwar\%brann, Ohrdecken schwarzbraun mit Andentungen silberweißer Federsäume. Hinter den Obrdecken ein weiBlicher Schimmer. Federn des Rïckens rotbraun mit breiten hell gräulich olivenfarbenen Siumen und ganz feinen dunkelbraunen Spitzenrïndern. Hinterhals fast einfarbigg rotbraun, Bürzcl cinfarbig olivenfarben, Oberschwanzdecken braunrot. Schwingen schwïrzlichgran, Außensïume bräunlich goldiggrrün, nach der Spitze zu hellgrau, Handdecken schwarz. Steuerfedern goldig braungrin, Spitzen etwa $2-3$ c'm aschgran. Federn am hintern Augenlide und breiter Bartstreif weiß. Kinn und obere Kehle in der Mitte schwarz. Übrige Unterseite rütlich zimmetbraun mit sehmalen aschgrauen Federsüumen, Treichen und Schenkelfedern einfarbig und etwis brïunlicher, Unterschwanzdecken rotbraun. Iris kastanienbraun. Fülbe braunrot. Schnabel schwarz. Flügel etrva 100-110, Schwanz ungefïhr 125, Lauf etwa 40, Culmen etwa 22-23 mm. O wie $0^{3}$, juv. wie ad. Kuku Nor.

Hochgelegene Tälder der chinesischen P'rorinzen Szetsehwan und

\section{Ianthocincla affinis affinis (Blyth).}

Garrulax affinis Blyth, Journ. Ass. Soc. Bengal XII, p. 950 (1843- Nepal. Hx Hodgson MS.).

Abbild.: Gould B. Asia III, Taf. 37 (Trochalopteron affine).

Unterscheidet sich von I. affinis blythii dadurch, daB sich an den Halsseiten hinter dem oberen Teile der Ohrdechen ein weißer, ron einem größeren brämnlichweißen gefolgter Fleck befindet. Außerdem ist der Oherkopf, und besonders die Stirn, noch weniger schwärzlich. mehr braun. Flügel 103-115 mm, die kleineren Maße gehören offenbar $q$ an.

Himalaya in Nepal, Sikkim und Bhutan, in Höhen von 8-13000 engl. Fub, in Rhododendron-Dickichten und an den Rïnderu der 'Tanmenwälder.

\section{Ianthocincla affinis oustaleti subsp. nov.}

Unterscheidet sich von I. affinis affinis, mit dem er durch das Vorhandensein des weißen Fleckes an den Kopfseiten übereinstimmt, durch schrvarze, bis auf den Nacken reichende Kopfplatte; auBerdem haben die Federn der Kehle und Brust viel dunklero graue Säume, so dal. diese Teile dadurch dunkler aussehen. - Typus aus Tsékou, vom Missionär Soulié gesammelt, No. 349, im Tring Musoum, eingetauscht rom Pariser Musem.

Yunnan ('Tsékou).

\section{Ianthocincla subunicolor (Blyth). (Fig: 123 d.)}

Trochalopteron subunicolor Blyth. Journ. As. Soc. Beng. XII. p. 952 (1843- nomen nudum!); op. cit. XIV, p. 599 (1845- Darjiling).

ơad. Oberkopf hraungran mit schmalen schwiirzlichen Federsäumen, stirn heller, gelblich, ührige Oberseite hell olirenhraun mit schwärzlichen 
Sïumen; Schwingen schieferschwar\%, Aufenfahnen goldig grängelb, an den Armsthwingen nach den spitzen zu bläulichgrau. Mittlere steuerfedern goldgeelbich olivenbram, aiubere nur an den Wurzeln der Aubenfahnen von cliesere Farbe, sonst schwärzlich mit wriben Endsätumen. Kohle und Kroptgregenel hell ramchbrämulich, ïbrige Cuterseite hell fihl brämulichgelb, jede Feder mit dunkelbranem Endsaum. Seiten und Lnterschwanzdecken olivenhräunlich. Iris rethratun, Sechnahrel dunkelhratun, Füße rötlichlratun. Flügel etwa 89-95, die kleineren Stïcke jedenfalls o. Schwanz etwa 100-105, Lauf ungeführ 35, Culmen etwa $17-19 \mathrm{~mm}$.

Nepal und Sikkim bis $11000 \mathrm{engl}$. Fuß.

Baut ein oben offenes Nest wie die Gattungsgenossen und legt ebensolche grünlichblane, ungefleckte Eier.

\section{Ianthocincla formosum (Verr.).}

Trochalopteron formosum Verreaux, Nouv. Arch. Alus. Paris V, Bull., p. 35 (1869"Thibet oriental").

Abbild.: Op. eit. VII, p.43, Taf. 2; David \& Oustalet, Ois. Chine, Taf. 59.

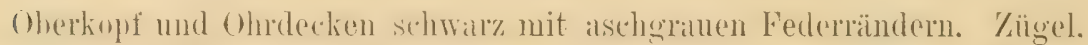
Śnperciliarstreif, Kélhle und Halsseiten schwarz. Rücken rotbraun, Bürzel

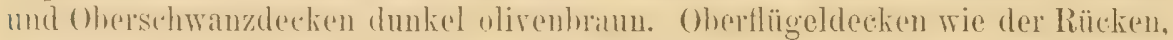
die groben uit rotem Sehimmer; Handdecken rot mit feinen weißgranen shaftstrichen. Sohwingen schwarz, Aufenfahmen lenchtend rot, mit Ausnihme der inneren Armsehwingen, die ganz schwarz sind. Mittlere Steuerfodern matt karmoisinrot. die iibrigen sebwïrzlieh. an den Aubenfianem matt kimmosinnot. Brust rothraun, einige der Federn mit sehwiilzlichen Spitzensïumen, Unterkiorper und Unterschwanzdedien olivenhraun. Iris grambatun. Sehnahel sehwar\%. Fübe rothraun. Flïgel etwat 102, Sehwanz 115, Latuf 40, Culmen $25 \mathrm{~mm}$.

In den waldigen Bergen des westlichen Stzetsebwan (cbina). (Andere Arten mit prachtroll roten AuBenflügrehn sind I. pherenicea phoenicen (Gould) ans dem mittleren Himaliya, I. phoenicen bakeri Hart. ans den Bergen siidlich des Brahmaputra, I. ripponi aus den Sehan-Staaten.)

\section{Ianthocincla rufogularis rufogularis Gould.}

Ianthocincla rufogularis Gould, Proc. Zool. Soc. London 1835, p. 48 (Himalaya). Cinclosoma Rufimenta Hodgson, Asiatic Researches XIX, 1, p. 148 (1836- Nepal).

ôad. Oberkopf bis an den Nacken schwarz, übrige Oberseite samt ()herflügeldecken rötlich olivenbran, jede Feder mit schwarzem Endsaum. (herschwanzdecken riotlicher und mit rostrotem statt sehwallzem Endsaum. Handdecken schwarz. Schwingen hraunsehwallz, die äubersten Handsehwingen mit gränlichweiben, die ührigen mit schwarzen, an der Wurzel olivenbraunen Aubenfahnen, die nath der Spitze zu einen weißen Saum haben, der von Feder zu Foder an Ausdehnung ahnimmt. Armschwingen mit olivenhramen, hreit sehwarz gespitzten Außenfuhnen und schmalen weißen Endsäumen. Stenerfedern rotlrann mit breiten rostroten Syitzen und ausgedehnten schwarzen Anteapikallinden. Rustroter, wenig ührer $1 \mathrm{~cm}$ ausgedehnter Kinnfleck; ülnige Untersrite weiblich graur. Kehle am hellsten, ganz oder fast einfarbig, Brust und 
Seiten mit bräunlichem Anflug, die einzelnen Federn mit schwarzem s'pitzenfleck, Mitte des [nterkörper's ungefleckt. Lnterschwanzdecken lehhalt kastanienbraunrot. Tor dem Auge ein grober rüstlich rahmfirloner Fleck; Ohrdecken schwarz mit wenigen kleinen weißgrauen Flecken; hreiter sehwilrzer Bartstreif, übrige Kopfseiten rötlich olivenbraun. Obersehnahel hornhram, Interschnahel gelhlich. Füße hellbram. Flïgel etwa 94-97, Schwanz etwal 104-107, Lauf 33-35, Culmen 24-25.5 mm. - ơ ad.: Kopffedern olivenbram mit schwarzen Spitzen, Brust und Seiten etwas hrämnlicher. Flügel etwa 2-4 mm kürzer. engl. Fuß.

Mittlerer Himalaya: Nepal, Sikkim, Butan, in Höhen von 5-8000

Nest ein oben offener Napf, Eier glänzend weiß, messen etwa $18-20 \times 23-29 \mathrm{~mm}$.

\section{7t. Ianthocincla rufogularis assamensis sulsp. nov.}

Ganze Kehle in der Ausdehmung von $2 \mathrm{~cm}$ oder darïber rostrot Ohrdecken meistenteils bratun. Kleiner: Sichubel etwa $2 \mathrm{~mm}$ kürzer, Flügel etwa 91-94 mm. - Typus Õad, Margherita 12. 1. 1902. Von Dr. H. N. Coltart gesammelt. (Nr. 12102 im Tring-Huseum).

Assam: Patkai-, Khasia- und Garo-Berge.

\section{Ianthocincla rufogularis occidentalis sulsw. nor.}

Oherseite hlasser, fahler, Ohrdecken weder hram noch schwar\% sondern rostrot. Kinnfleck wie hei $I$. r. mogultri. - Typus o Dehra Dun. Kaschmir. aus der Narshall-Sammlung, Nr. 11 109. Tring-Museum. (Man rgl. Sharpe,

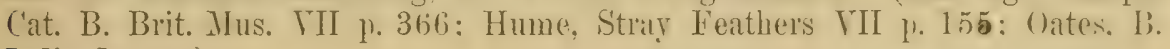
India Ip. 86.)

Nordwestlicher Himalaya von Kumaon bis Kaschmir.

\section{Ianthocincla lineatum lineatum (Vig.).}

Cinclosoma lineatum Vigors, Proc. Zool. Soc. London 1831, p. 56 (Himalaya). Cinclosoma setifera Hodgson, Asiatic Researches XIX, p. 148 (1836- Nepal).

Oberkopf his Vorderrïcken graubram oder braungrau mit etwas steifen. dicken schwarzen Schäften. Mittelrücken rothraun mit weißlichen Schäften. Bürzel und Oberschwanzdecken asehgrau mit olivenfarbenem Schinmuer. Schwingen bram, Außenfahnen lebhaft rotbraun. Stenerfedern olivenhraun mit rotbraunem Schimmer, die mittleren mit Audeutungen ron dunklerer und hellerer Querbänderung und undentlichen grauen Spitzen, die ïhrigen mit deutlichen liellgrauen Enden und breiten oder nur ganz schmalen schwarzen anteapikillen Binden (erstere vermutlich ö. letztere o.). Zügel und Federn um das Auge weißlich mit rotbramen Spitzen. Kopfseiten brammot: Unterseite braumrot, mitunter mit undeutlichen oder doch nur schmalen gratuen Federrïndern, Brust mit glänzenden weiBlichen Sehäften. T'nterkürper und Enterschwanzdecken mehr oliren-graubraun. Iris hraun oder rotbraun. Schnahel horuhraun, Unterschuabel heller. Fïße hellhraun. Flügel etwa $74-i \tau$. Schwauz etwa 90, Lauf 27, Culmen etwa 18.5-20.8 mm.

Himalaya von Nepal. 


\section{Ianthocincla lineatum grisescentior sulsp. nir.}

Abbild.: Hume \& Henderson, Lahore to Yarkand, Birds Taf. VIII.

Auf Konf und Hinterhals im allgemeinen etwas mohr aschgrau. smost wie I. l. lineatum, auf der Unterseite aber merklich verschieden: die bei 1. l. lineatum undentlichen oder doch nur schmblen gräulichen Anbensäume der Brustfedern sind heiter und lichter, so dab neben dem hellen Schafte nur ein hreiter, hraumoter Längsstrenif hleiht. die Kehle ist ganz grau mit selumalen braumpoten Stricheu, ehenso sind die Kopfseiten grau, so dab die

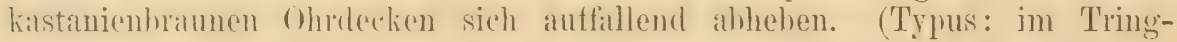
Museum No. 1548. Simla 15. XI. 1880, gesammelt von H. J. Elwes.)

Westlicher Himalaya: Kumanon, Simla, his Kaschmir in Höhen ron $5000-8000$ engl. Fub.

Das Nest steht etwas über $1 \mathrm{~m}$ hoch bis zu $2 \mathrm{~m}$ in Büschen und Bäumen. Ws besteht aus trockenem Gras, Stengelchen nnd trockenen Blättern und ist mit Würzelchen und feinen Gräsern ausgelegt. Es enthält vom April bis Juni 3 (bis 4) Eier von geringem Glanze und grünlichblauer Farbe. Sie messen $21-28 \times 17.5-20 \mathrm{~mm}$.

\section{Ianthocincla lineatum gilgit sulsp. nov.}

Noch viel griulicher als $I$. l. grisescention. Kehle grau mit weiblichen Längstleclien. Brust gelhlichgran mit rahmweiben Sehäften, die ron nul schmalen hell brammoten Streifen cingefaßt sind, Treichen blaßgrau mit mur schwachem hrïunlichgelhem Auflug. Oherseite etwas lichter, gräulicher. Junge Tügel wie die alten. Typus sad. Gilgit 3. II. 1880, von J. Ścully gesammelt.

Hohe Berge des nordöstlicheren Kasehmir: Gilgit (5-_-60no FuB), Chitral, Baltistan bis 10500 Fuß.

\section{Ianthocincla perspicillatus (Gm.).}

Turdus perspicillatus Gmelin, Syst. Nat. I, 2, p. 830 (1789- China. Ex Duubenton. Pl. Enl. 604, Buffon IU, p. 368).

Garmlax rugillatus Swinhoe, Ibis 1860, p. 57, 358 (Fu-tschau).

Abbild.: David \& Oustalet, Ois. Chine, 'laf. 52.

Şad. Stirn, Umgehung der Augen und Ohrdecken einc rerbundene s.hwarze Fläche bildend. Oberkopf und Nacken bräunlich grau mit etwas dunkleren Federrändern, dies Grau in die graubraume Färbung der übrigen Oherscito ïhergehend, Bürzel etwas lichter unil mit schwachem rostgelhlichem Anflug. Schwingen dunkelbraum, Außenfahmen und innere Armsehwingen wie der Rücken. Mittleres Par und Wurzelhüfte der äußeren Stenerfedern rötlichbraun, Rest schwarz. Kinn. Kehle und Halsseiten grau mit schwachem bräunlichen Anflug und etwas dunkleren Federränderu, ührige Unterseite rïstlich rahmfurben, Bauch und Unterschwanzdecken lebhaft hell rostfarben. Iris braun. Schmahel horngrau.. Füße hell rötlichbraun. Flïgel oे etwa 130-135, o 126- $130 \mathrm{~mm}$, Schwanz ungefïhr $16 \mathrm{~cm}$, Iauf 42-44, Culmen otra $28-29.5 \mathrm{~mm}$. - ? wie c, juv. wie ad. Nördlicher wohnende Stücke sind vielleicht etwas heller und mitunter grölier. (34 untersucht.)

Bewohnt Sür-China, noldwärts bis in die Tsin-ling-Berge (Ta-pai-schan). 
Dex. lebhafte, laute Vogel bewohnt Gartenland, Buschwerk, Bambusdickichte. Er nistet in Bäumen und Büschen. Das Nest besteht aus Zweigen und W urzeln und enthält (April, Ilai, Juli) bis 4 Eier ron bläulichweißer Farbe. Sie messen etwil $27-30 \times 20.5-24 \mathrm{~mm}$.

\section{Ianthocincla albogularis Gould. (Fig. 12: e.)}

Intherinclu albogularis (iould, Proc. Zool. Sor. London 18:35, p. 187 (Nepal, Himalaya).

Ad. Oberseite vliven-gratubran, Schwingen dunkelbraun, InBenfahnen wie der Rücken, an den Handschwingen hedentend heller. Stenerfedern etwas mehr in's gräuliche als der Rücken. dic äulecen mit ausgedehutun weißen Spitzen und schwarzen anteapikalen Schatten. Kleiuer schwarzer

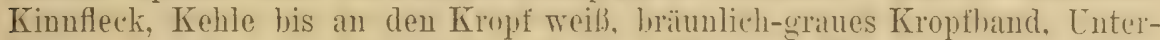
kiirper lostgelb. am lehhaftesten in den Weichen. Mitte heller, weißlich. Flügel etwa $120-130 \mathrm{~mm}$. - Termutlieh in mehrere Subspezies teilhar. wenn genügendes Material verglichen wird.

Himalaya vou Hasara bis Sikkim, in Höben ron wenigen tausend his zı $9000 \mathrm{FuB}$, im Osten wieder in den Gebirgen. die Szetschwan von Kuku-Nur und Tihet tremen. (Aus den letzteren Gegenden untersuchte ich keine stücke.)

Baut sein Nest in Büschen und legt grünlichblaue Eier.

\section{Gattung POMATORHINUS Horsf. 1821.}

Schuahel seitlich homprimiert, sichelartig gebogen, so laug wie der Kopf oder läinger (Fig. 124). Das von einer Haut etwa zur Hälfte ülerdeckte Naseuloch ist gatnz frei ron Federu. Die Kinufedern zeigen haarartige Terlängerungen, es fehlen aber steife Mundwinkelhorsten. Fülie stark und Beine lang. Schwanz stark gestuft, das äußerste Stenerfederpan ctwa : his ${ }^{3}$. der Schwanzlïnge. Im allgemeinen wie Imthocincla. - Gesellig, laut. Nester an Ahhängen, am Boden, grofe überwölhte Klumpen. Eier weib. ungefleckt. - Über 30 Arten von Indien bis Australien.

1 f Zügel und Ohrdecken schwarz ......... P. ruficollis . p. 639

I Zïgel und Ohrdecken rostfarben oder bräunlich ......... 2

$2 \int$ Kropfgegend ungefleckt oder mit nur undentlicher Fleckung P.crythrogenys . p. 637

Kropfgegend scharf gefleckt ......... P. macclellandi. p. 638

\section{Pomatorhinus erythrogenys erythrogenys Vig.}

I'umatorlinus erythrogenys Vigors, Proc. Zuol. Soc. London 1831. P. 173 (..Himalaya." Beschreibung und Abbildung Goulds zeigen unverkennbar die nordwestliche Form mit ganz weißer Kehle).

Abbild.: Gould, Century Himal. B., Taf. 55.

ơad. Oberseite olivenhraun mit einem leichten asthorauen Anflus. Flügel dunkelbraun, innere Armschwingen und Sïume wie cler Rüchen, Aubensïume der Handschwingen etwas heller. Schwanz wie der Rücken. Stirn. Kopfseiten. Hals- und Körperseiten. Schenkelhefiedermug nnd [nterschwanzdecken rostfarben. Zügel mit weiBem Eleck. Kurzer Bartstreif dunkralgrau. Kinu, Kehle und Mitte der Lnterseite weib, am unteren Tcil der Kehle meist einige graue Federspitzen. Iris hlabgerh, weib oder grüulichweib. 
S'chnabed hell horngeblich. Basis des Oherschnabels gräulich. Füße bräunlich fleischfarhen. Flïgel etwal 9s-101, S'chwanz etwal 100-105, Lauf etwa 36, Culmen etwa $35-36 \mathrm{~mm}$. O wio 0 . Nestjunges ganz rötlichbraun mit weißer Kehle.

Nordwestlicher Himalaya, von 2-10000 oder 12000 Fuß hoch.

Nest ein großer überwölbter Klumpen am Boden oder an Abhängen. Eier wei $B$, 20 Eier messen durchschnittlich etwa $28 \times 20 \mathrm{~mm}$ (Oates).

\section{8.. Pomatorhinus erythrogenys ferrugilatus Hodgs. (Fig. 124.)}

Pomatorhinus fervegilatus Hodgson, Asiatic Researches XIX, p. 180 (1836- Nepal. Deutlich die graukehlige Form beschrieben); vgl. Oates, Fauna Brit. Ind.. Birds I, p. 124, 125 .

Unterscheidet sich von P. erythrogenys erythrogenys dadurch, daß die

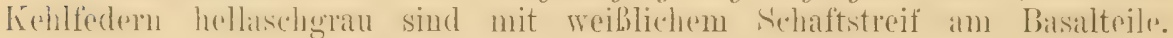
AuBerdem ist die Oberseite etwas dunkler, ebenso die

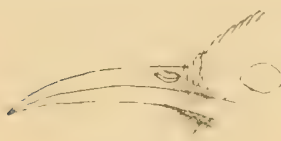

Figur 124. Seiten. - Eine sehr in die Augen springende Subspezies. Mir scheinen die Strieke ron Nripal unledingt zol clieser Form zu gehören. Line dritte Form. I'. erythrogenys imberbis Salvad., bewohnt Birma.

Sikkim und Nepal.

\section{Pomatorhinus macclellandi gravivox I)arid.}

Pomatorlinus gravivox Darid, Ann. Sci. Nat. XVIII, art. 5, p. 2 (1873- Sïd-Schensi); David \& Oustalet, Ois. Chine, Taf. 49.

ơ $\mathrm{O}$ ad. Oberseite mit Einschluß von Flügeln und Schwanz olivenbraun,

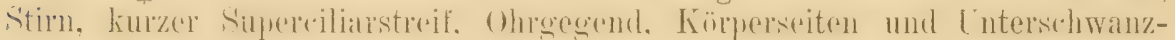
decken gelhlich rostfirhen. Breiter Bartstreif sehwarz. Fudern zwischen

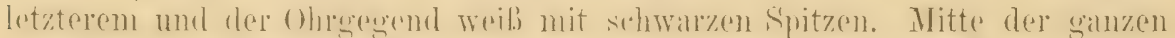

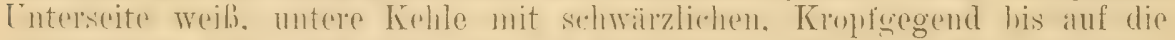

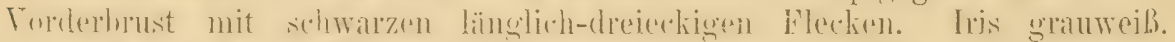

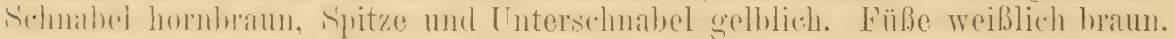
Flügel etra 90-95, Schwanz 90-100, Lauf etwa 36-38, Culmen etwa $35-38 \mathrm{~mm}$.

Bewohnt die Berge des suidlichen Schensi und östlichen Kansu, und

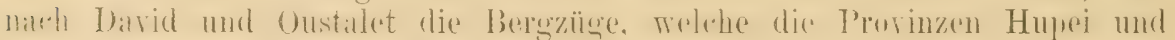
Hunan trennen, sowie Junnan.

Nach Darid scheu und flüchtig, mit lautem, sonoren Gesange. Nährt sich von Insekten und lebt in dichten Wäldern.

\section{- 984. Pomatorhinus macclellandi dedekensi (ust.}

Pomatorhinus macclellandi var. Dedekensi Oustalet, Ann. Sc. Nat. Zool., sér. 7, XII, p. 276, 304 (1892- 'Tibet und Ta-tsien-Iu!).

? Pomatorhinus macclellandi var: Armandi Oustalet, op. cit., p. 277 ("Aio, Tibet, " irrtümliche Angabe: Ta-tsien-lu! Cf. Oustalet, Nour. Arch. MIus. Paris, sér. 3, V, p. 199, Taf. IV). 
Diese Formen bedïrfen weiterer Aufklïrung! Es lagen Oustalet vin .,dedekensi" nur 2 Exemplare vor, 1 aus Tibet. 1 aus Tatsienlu, von , comendi. nur 1 aus Tatsienlu! Sie sollen sich von $P$. m. gravivox durch dunklere, mehr ins Olivenfarbene ziehende Olnerseite, tiefer" schwarze Flecke der Torderbrust unl lebhafter gefïrbte, etwas mehr rütliche Seiten unterscheiden; ded kensi soll größer als gravivox sein: Flügel 100, Schwanz 110-120, Lauf 38, c'ulmen 34, mpundi dagegen kleiner: Flügel 85, Schwanz 105, Culmen 26. Lauf $31 \mathrm{~mm}$.

Ost-Tibet (T'songhai) und (?) Tatsienlu in Szetschwan.

(P. macclellandi macclellandi unterscheidet sich sehr anffallend durch olirenbräunliche Seiten, ebensolche und weniger zahldreiche Flecke an der Vorderbrust. Er bewohnt Assam.)

\section{Pomatorhinus ruficollis ruficollis Hodgs.}

Pomatorhinus ruficollis Hodgson, Asiat. Res. XIX; p. 182 (1836- Nepal).

$\delta^{\top} \mathrm{q}$ ad. Oberseite rötlich olivenbraun, der Oberkopf etwas dunkler und mehr braum, an den Halsseiten joulerseits ein rostroter Fleck. durch ein mehr oder minder deutliches rostrotes Naclienhand verbunden. Sidhingen

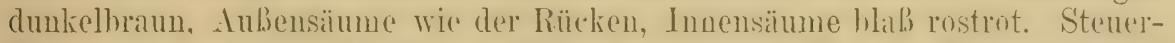
federn braun. mit der Farbe des Rückens gexiumt. Ton der S'dmalrelwurzel his zu den Halsseiten cin hreiter weilger Supereiliarstreif. Zï̈gel und hreiter hinterm Auge fortgesetzter Streif sehwarz. Kinn und Köhle weif. Krople und Brust weiß mit wehr oder winder rötlich-olivenhranen Streifen. Seiten.

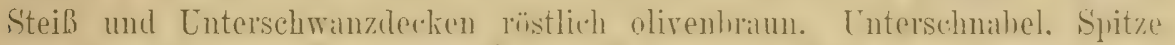
und Schneide des Oberschmahelis lohhaft hormgenlh, Rest des Oberschnahels schwarz. Iris rot. Fübe brïunlichgrall. Flügol etwa $76-85$. Schranz ctwa 81-90, Lauf etwa 31-32, Culmen 24-25 mm. o wie on, nur kleiner, doch liegen nur sehr wenige zuverlässig sezierte Stücke vor.

Himalitya: Nepral. Siklim, auferdem die Bergzüge sïdlich des Brabmatputra: Katschar, Khasia-Berge, Iranipur, isstlich lis ('hina (siehe P’. ruficollis styani).

Brïtet im April und 11 ai, baut ein großes, rundliches Nest am Boden und legt 5 weiße Eier, die etrra $25 \times 17 \mathrm{~mm}$ messen.

\section{- 986. Pomatorhinus ruficollis styani Seeb.}

Pomatorhinus styani Seebohm, Ibis 1884, p. 263 (Lushan im Jangtsetale).

Die meisteu Stïcke aus dem Tale des .Tangtsekinng. die meisten ans Jumnan, die aus Fu-tschan, die Meln'zahl der Stïelie aus Szotschwan und das ron mir untersuchte Exemplar aus Kansu unterscheiden sich ron den trpischen mpicollis aus Indien dureh etrias hlassere Oherseite. weniger rosthrame. mehr olivenbraune Streifung der Brust und meist auch etwas geringere Grölie (Flügel 75-82 mm), hesonder's scheint die Kralle der Hinterzehe meist kleiner zu sein. Trotzdem ist die Tnterseheidung und Terbreitung der Suhspezies stymi unsicher. demn es kommen in chini, hesonders in szetschwan. anch viele, Stïcke vor, welche denen ans Siklim gleichen, andere sind intermediär, und außerdem gibt es auch in Sikkim und in den Bergen von 
Assimm Cherginge und einzehne Stücke, die chinesischen ..styani* gleichen; der 'Typus von $P$. styani ist keineswegs extrem, sondern intermediär.

Bewohnt Süd-China bis Szetschwan und Junnan.

(Ganz mit Unrecht wurde mit $P$. ruficollis auch $P$. stridulus Swinhoe vereinigt, der sich durch die viel hreitere, lehhaft braunrote Bruststreifung. liïzeren Schnabel, geringe Milke. sowie dadureh unterseheidet, dab der olivenbraune Schwanz im Gegensitz zum rothriunen Rëlchen steht.)

\section{Gattung TURDUS L. 1758.}

Eine der hekanntesten Togelgruppen, deren Mitglieder fast über dir gamze Erde rerbreitet sind. Das Genus ist vielfach zersplittert worden, aber diese Versuche sind meist liagglich gescheitert, hesonders was die Trennung ron Thumes mit gleich oder doch sehr ähnlich, und ., Merule" mit ungleich gefärbten Geschlechtern hetrifft. Mehr Berechtigung hat noch "Georichla" oder ,Orecinele", doch kann man auch daron ahsehen. Unhedingte Synonyme. zum 'Teil aus Kimps wissenschaftlicher spiclerei hervorgegangen, sind ircenthornis, Ixocossyphus, Planesticus, Iliacus, Hylocichla (die kleinen nordamerikanischen Formen, mustelinus, yuttutus, uliciue, fuscescens umfassend). ('ichloides, Copprichus, Thorreocinch, Cíchloselys u. a. - Der Baul der Drosseln ist ziemlich ühereinstimmend. Der kraiftige Schnabel ror der Spitze mit einem kleinen ,Zahn"; Nasenlöcher fast frei vor den nach rom vorgeschohenen Federschneppen der Stirn. In dem langen, spitzen Flügel ist die 1. Schwinge meist bedeutend kïrzer als die Handdecken, rerhältnismäBig am kleinsten bei 'T. torquatus, dubius, muficollis, naumanni, philomelos, musicus u. a., etwas länger bei $T$. castanca, celcenops u. a., bei T. merula, albocinctus fast oder ganz so lang wio die Handdecken, bei T. anitus sogar etwas länger. Meist bilden die 3. und t. Sehwinge die Spitze des Flügels, seltener sind (T. mernlu.

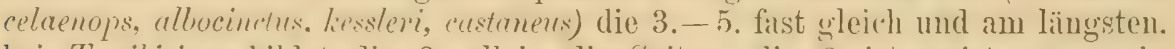
bei T. sibiricus hildet die 3 . allein die Spitze; die 2 . ist meist nur wenig kürzer als die 3. und lïnger als die 5. und 6.. mitunter (T. memelu, T. anritus) aber kïrzer als die 5. und 6. Sehwamz schwach gerundet oder fist gerade. aus 12 , nur bei $T$. verius und mehreren (uicht allen!) ihrer Subspezies aus 14 Federn bestehend. Lauf von einer nur ganz unten geteilten Schiene hedeckt. - Alle Drosseln bauen offene Nester und legen gefleckte Lier.

\section{Übersicht der Arten, of \& od $^{2}{ }^{1}$ ):}

(Nestjunge sind oben und unten gefleckt, junge Vögel in Fällen wo die Geschlechter gleich sind, wie die alten, wenn die Geschlechter verschieden sind, wie die $q$ ).

1 f Ganzes Gefieder schwarz ........ T. merula ôad. \& subsp.

I Gefieder nur teilweise schwarz oder ohne Schwarz . . . . . . 2

, Innenfahnen der äußeren Steuerfedern zimmtrot . . . . . . . . . . . . . . . . .

2 Innenfahnen der äußeren Steuerfedern ohne Zimmtrot . . . . . . . 5

1) Mehrere nordamerikanische Drosseln sind dann und wann in Europa und Nordasien vorgekommen:

1. Turdus ustulatus swainsonii Cabanis (Tschudi, Faun. Per., Aves, p. 188, 1814-46): ()herseite olivenbraun: Kehle und Kropf leh,haft rahmfarben, dunkellraun gefleckt, iibrige Unterseite weiß, Weichen und einige Flecke an der Brust olivenbraun. Flügel etwa 


\section{R. Friedländer \& Sohn in Berlin NW 6.}

In unserem Verlage erscheint:

\section{Das Tierreich.}

Eine Zusammenstellung und Kennzeichnung der rezenten Tierformen.

A Begründet von der Deutschen Zoologischen Gesellschaft.

Im Auftrage der

\section{Königl. Preuß. Akademie der Wissenschaften zu Berlin heransgegeben von}

Franz Eilhard Schulze.

sind bisher erschienen:

Die Herausgabe findet in Lieferungen (in Groß-Lexikon-Oktav mit Abbildungen im Texte) statt, die je eine oder mehrere nahestehende Gruppen behandelu, jedoch unabhängig von einer systematischen Fulge erscheinen. Jede lieferung ist einzeln käuflich.

Bei Subskription auf das ganze $W^{r}$ erk tritt eine PreisermäBigung ein.

Aus der Gruppe der

\section{Vögel (Aves)}

Lieferung 1: Podargidae, Caprimulgidae und Macropterygidae. Bearbeitet von.E. Hartert (T'ring). 1897. VIII und 98 Seiten mit 16 Abbildungen und Beilage: T'erminologie des Vogelkörpers vón A. Reichonow, 4 Seiten mit Abbildung.

Einzelpreis Mark 7,-.

Lieferung 2: Paradiseidae. Bearbeitet ron The Hon. Walter Rothschild. 1898. VI und 52 Seiten mit 15 Abbildungen. Einzelpreis Mark 3,60.

Lieferung 9: Trochilidae. Bearbeitet ron E. Hartert (Tring). 1900. $\mathrm{X}$ und 254 Seiten mit: 34 Abbildungen.

Einzelpreis Mark 16,-.

Lieferung 15: Zosteropidae. Bearbeitet ron O. Finsch (Leiden). 1901. XIV und 55 Seiten mit 32 Abbildungen. Einzelpreis Mark 4,80.

Lieferung 18: Paridae, Sittidae und Certhiidae. Bearbeitet von C. E. Hellmayr (München). 1903. XXXI und 255, Seiten mit 76 Abbildungen.

Einzelpreis Mark $16,-$.

Weitere Lieferungen erscheinen in ununterbrochener Folge. Bestellungen und Subskriptionen können durch jede Buchhandlung berwirkt werden.

Berlin, Januar 1909. 


\section{R. Friedländer \& Sohn in Berlin NW 6.}

In unserem Kommissions-Verlage erschien 1902:

\section{Aus den \\ Wanderjahren eines Naturforschers. \\ Reisen und Forschungen}

in Afrika, Asien und Amerika

nebst daran anknüpfenden meist ornithologischen Studien voll

\section{Ernst Hartert.}

Ein Band von XV und 329 Seiten mit 17 Abbildungen im Text und 13 'Tafeln (- Routenkarten, Landschaftsbilder, ethnographische Typen, Abbildungen neuer Fische -). klein-4. In geschmackvollem Lèinenband.

$$
\text { Preis } 25 \text { Mark. }
$$

\section{Inhalt:}

I. Reise mich Solioto und Kano im westlichen Sudan (Westküste. Flußfahrten auf dem Niger und Benue. Ton Loko bis Kano, Sokoto und Gandu durch vorher unerforschte Gebiete, dann zurïck zum Benue. Loko am Benue). Zur Fauna der Canarischen Inselı. Die Ornis der Los-Inseln. Verzeichnis der bisher bekannten Vögel des Haussalandes. Übersicht der im Haussalande beobachteten Nutzpflanzen. - II. Reiso nach Sumatra, Malakka und Indien. (Die Insel Penang. Sumatra. Naturgeschichtliches aus Sumatra. Die Insel Salanga. Der hritische Schutzstaat Perak. Assam. Indien.) - III. Reise nach den Inseln des Caribischen Neeres (Reise nach Testiudien und Tenezuẹla: St. Thomas. Faunistisches. Porto Rico. Venezuela. Caracas. Anfiniano. Curaçao, Aruba und Bonaire. Flora und Fauna dieser Inseln. Harti)* Die Vögel der Inseln Aruba, Curaçao und Bonaire, neue Formen. - IV. Frühlingsausflug nach Narokko und Tenerife. (Reise nach Marokko und den Canaren. Togelleben. Der Oum Rliah. Entdeckung neuer Fische. Tenerife. Orotara.) Notizen über die Vögel der Gegend um Mazagan im mittleren Marokko. 


\title{
Die Vögel
}

\section{der paläarktischen Fauna.}

\author{
Systematische Übersicht \\ der
}

in Europa, Nord-Asien und der Mittelmeerregion

vorkommenden Vögel.

Von

Dr. Ernst Hartert.

Heft VI (Doppelheft).

Seite $641-832$

Mit 10 Abbildungen.

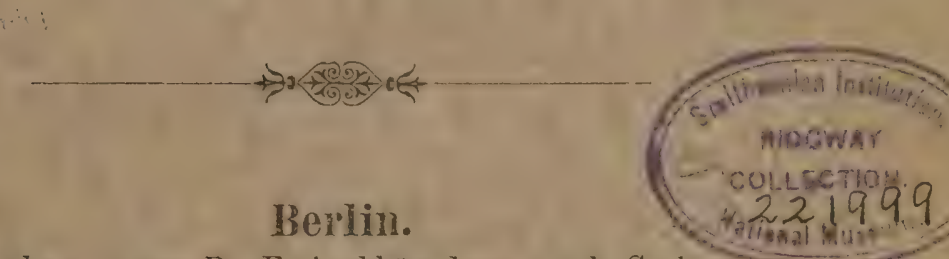

Verlag rou R. Friedländer und Sohn. Agents in London: Witherby \& Co., 326 High Holborn. 
E gah lisher kein Werk, welches die lokalen Formen aller paläarktischen Vögel in happer Form berücksichtigt, und überhaupt kein Werk in deutscher Sprache üher die Ornis der paläarktischen Fauna.

Ton dem sehr kustspieligen Prachtwerke H. E. Dresser's abgesehon, haben wir zwar eiu ror limzem erschienenes praktisch eingerichtetes Handbuch desselhen Verfassers. Dieses .Manual of Palaeartic Birds" hat aher die Frgehnisse des subtilen Studiums der letaten 15 .Jahre unbeachtet gelassen. und bringt fast um die leicht unterscheidharen Formen, bietet also nur einen Toil von dem, was wir gebrauchen.

Das vorliegende Werk bemüht sich vor allen Dingen zu zeigen, was hisher in Euterscheidung der Subspezies geleistet worden ist, und somit auch, Wo noch Lücken auszufüllen sind. Das Bekannte ist zusammengestellt, geprift, gesichtet und Nenes hinzugefügt worden, wozu die bedeutende ron dem Verfasser verwaltete Sammlung, und das nahe gelegene größte Museum der Welt in London, Gelegenheit boten:

Die Beschreibungen siud, wenn nicht anders angegeben, nach der Natur entworfen. also rollständig neue Originalloeschreil)nugge ; sie sind möglichst kur\% und knapp gehalten.

Die Nomenklatur ist so konservatix wie möglich, d. h. der älteste ermittelte Name ist für Gattung, Art und Unterart in jodem Falle ohne Ausnahme angewandt.

Das Werk wird in Lieferumgeu vou je 8 Bogen, zum Preise von 4 Mark für dic. Lieferung, erscheinen. Das Ganze wird in etwa 12 Lieferungen iu $\rightleftharpoons$ Bänden rollständig sein. Nit dem Doppel-Heft 6 (Hude der Passeres) ist der 1. Band ahgeschlossen, und demselhen Titelhlatt und ein kurzer Index beigefügt.

Wäluend der Arbeit. die infolge der in den letzten Jahren rapide machsenden Tätigkeit der Ornithologen auf dem Gebiete der paläarktischen Fanna sineu immor größeren Umfang aunimmt, wurde Verf. von vielou Museen und Freunden mit Material und Notizen unterstützt. Wr möchte schon hier vorläufig allen seinen Korrespoudenten seinen Dank aussprechen, iusbesonder den Herren Talentin Bianchi, Ir. Paul Suschkin, Sergius Buturlin, Baron Jumdon, Profresor Roiehenow. Pastor Kleinschnidt, Prof. Schaninsland, Othmar Reiser, Dr. Julius ron Nadarász, Ritter ron Tschusi zu Sohmidhoffen, Dr. Lorenz vou Liburuau, Prof. Wilhelm Blasius, Dr. Louis Burean, Prof. Trouessart, Dr. Ménégaux, Joseph Whitaker, Gobr. 'Ticehurst, Dr. H. O. Forhes, Dr. Hoyle, W. Eagle-Clartio. H. F. Witherhy, Prof. Giglioli, C. F. Hellmayr, Graf Zedlitz und anderen.

Berlin NW 6, Juni 1910.

Karlstr. 11.

R. Friedländer \& Sohn. 
Kehle und Kropf braunrot, Seiten weißlich . T. ruficollis muficollisiô. 3). 659

3) Kehle, Kropf und Seiten braunrot ....... T. naumanni ơ . p. 657

Kehle in der Mlitte weißlich oder röstlich rahmfarben, mehr oder minder gefleckt

4 Seiten weißlich oder gräulich

T. ruficollis ruficollis $\uparrow$. p. 659

I Seiten rostrot mit weiBlichen Ferlersïumen . . . T. nanmanni . 1.65i

i) $\{$ Innensäume der Schwingen größtenteils rostrot . . T. Tuscatus ơㅇ. 1). 658

Innensïtume der Sehwingen ohne ausgedehnte rostrote Färbung . . . . t

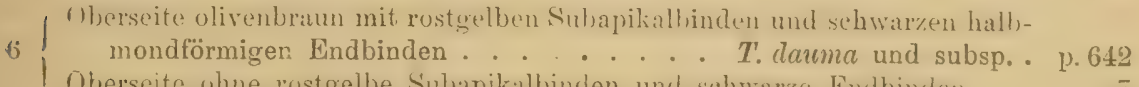

Oberseite ohne rostgelbe Subapikalbinden und schwarze Endbindent. . T

7 Seiten mit Kastanien-, Rot-oder Rostbraun . . . . . . . . . . 8

I Seiten ohne Kastanien-, Rot- oder Rostbraun . . . . . . . . . 16

$8\{$ Kehle und ganzer Kopf schwarz . . . . . . . . . . . . . 9

Kehle und Kopf nicht schwarz . . . . . . . . . . . 10

9) Rahmfarbenes Brustband ........... T. kessleri o . p. 662

I Kein rahmfarbenes Brustband ..... T. celaenops ơ und subsp. . p. 657

10 Ischenkelbetiederung und Tnterflïgeldecken rostgell T. hortutmm ơo p p. 654

I Schenkelbefiederung und Unterflïgeldecken nicht rostgelb...... 11

11 Kehlseiten, Kropf und Weichen gefleckt ..... T' musicus ơ + p. 653

Kehlseiten, Kropf und Weichen nicht gefleckt. . . . . . . . . 12

12 Uberseite ganz oder nahezu einfarbig . . . . . . . . . . . 13

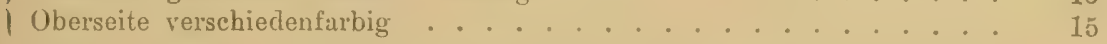

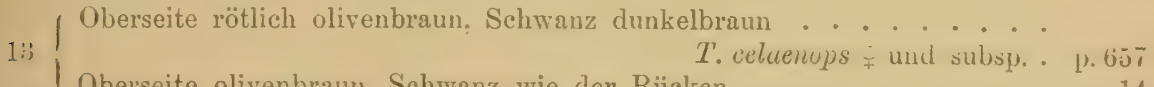

l Oberseite olivenbraun, Schwanz wie der Riicken......... 1. 14

14 ( Deutlicher weißer Superciliarstreif . . . . T. obscurus ơo . p. 656

IOhne Superciliarstreif ............ T. chrysolats ơ o . p. 656

$45-105$ mm. Nordanerika, anf den Zuge in Xittel- und siidanerika; ein halb Dutzend mal in Europa: Italien, Tirol, Belgien, Helgoland (1 sicheres stiick), Eriedrichsruh in Lauenburg.

2. Turdus aliciae aliciae Baird (Rep. Pacific R. R. Survey, IX, p. 217, 1858Illinois): Kehle nicht lebhaft rahmgelb, sondern weißlich. Nördliches und östliches Nordamerika, im Winter südlich bis Peru; wurde nördlich von Jakutsk in Ost-Sibirien; und mehrfach in der Tschuktschen-Halbinsel erbeutet.

3. Turelus yuttete pellusii Cabanis (Wiegmanus drebiv f. Naturg. 1847, 1, p. 205): Ion T. sucainsonii und aliciue durch roströtlichen Schwanz unul Oberschwanzalecken unterschieden. Östliches Nordamerika, im Winter südlich bis Florida und Texas. Vereinzelt in (irönland, Klein-Zerbst im Auhaltisehen, fraglieh in der Schweiz, in Italien und auf Helgoland, sowie einmal im Schwarzwald vorgetiommen. (Das Vorkommen ron Turdus fuscescens anf Helgoland ist zweifelhaft, die Angaben ron Funden dieser Art in audern Teilen Europas wohl auf Verwechselungen mit andern Arten zurückzuführen.)

4. Turdus migratorius miyratorius Linnacus, Syst. Nat. Wd. XII. 1, p. 292 (1766ex Catesby, (arolina): Größe etwa wie die von T. pilaris; Kchle weiß, schwarz gestreifu, ïbrige Unterseite rostrot, Bauch und Mitte des Unterkörpers weiß, Oberseite graubraun. Bewohnt das östliche und nördliche Nordamerika, im Wiater südwärts bis Florida, Texas, Bermudas und ansuahmsweise Cuba. Vereinzelte Stiteke wurden in Europa grefunden: Helgoland, Irland. England, Meiningen, ()denburr, Wiener Wildpretmarkt, Böhmen, Dalmatien.

E. Hartert, Die Vögel der paläarktischen Fauma. 


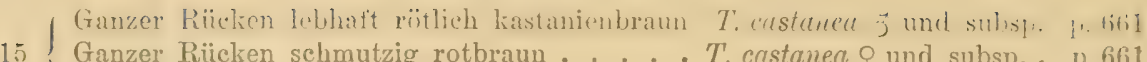
Ganzer Riicken schmutzig rotbraun ..... T. castanea o und subsp.. [p. 661

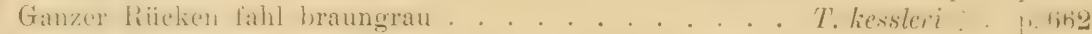

16 S Seharfe weibe nder rahmfurbene Querbinde iiber din Lnterseite des Fligen! 17

\{ Keine scharfe Querbinde über den Unterflügel . . . . . . . . 18

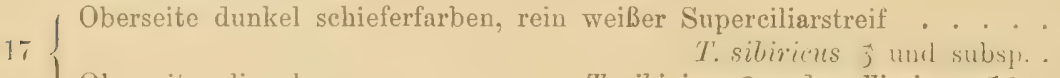

Oberseite olivenbraun . . . . . T. sibirious 우 und mollissimus ơo . 1).644

$18\{$ Axillaren rein weiß . . . . . . . . . . . . . 19

\{ Axillaren nur teilweise weiß oder olne Weiß . . . . . . . . 20

19 Oberseite einfarbig graubraun ..... T. viscivorus to 0 und subsp. . p. 647

Oberseite nicht einfarbig: Nacken und Bürzel grau, Vorderrücken dunkel kastanienhrann. . . . . . . . . . . . . T. pithris; . plifli

Schwanz einfarbig ................ . . . 21

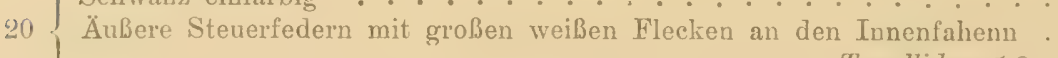
T. pallidus Oิๆ - p. 655

21 Brustseiten mit dunkelbraunen oder schwarzen fächerförmigen Spitzenflecken 22

\{ Brustseiten ohne fächerförmige Spitzenflecke......... 25

22 Kehle einfarbig schwarz . . . . . . . . T. carlis วૅ. p. 652

Kehle nicht einfarbig schwarz . . . . . . . . . . . 23

23 Unterflïgeldecken und Axillaren lebhaft rostfarben... . T. carlis $q$. 1.652

Unterfïigeldecken blaß ockergelb . . . . . . . . . . . . 24

$24\left\{\begin{array}{l}\text { 1. Schwinge viel kürzer als Handdecken, 2. länger als } 6 \ldots . . . . . \\ \text { T. philomelos ơ und subsp. . p. } 650 \\ \text { 1. Schwinge mindestens so lang wie die Handdecken, 2. viel kürzer als 6. }\end{array}\right.$ T. auritus ơ . 1). 649

$25 \int$ Brust und Unterkörper weißlich . . . . . . . . . 26

\{ Brust und Unterkörper braun oder schwarz, meist mit weißen Säumen . 27

$26\{$ Kehle schwarz . . . . . . . . T. ruficollis atrogularis ô. p. 660

\{ Kehle weißlich, schwarzbraun gestreift... T. muficollis atrogularis ㅇ․ p. 660

Oberseite schwarz mit neißem Nackenband ... . T. albocinctus of . [. 663

27 Oberseite braun mit weißgrauem Nackenband . . . T. albocinctus 0 . p). 663

Oberseite schwarz oder dunkelbraun, olne helles Nackenband . . . . 28

Mit breitem weißen Kropfband ......... T. torquatus ơ. p. 663

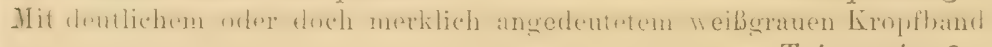

T. torquatus $q$ - 1).663

T. merula ㅇ․ [1.666

\section{Turdus dauma aureus Hol.}

Turdus aureuts Holandre, Faune dép. Moselle, in Annuaire de la Moselle 1825, 1).60 (Beschreibung eines bei Metz im Sept. 1788 gefangenen Stückes).

Turdus varius Pallas, Zoogr. Rosso-Asiat. I, p. 449 (1827- Krasnojarsk am Jenissei und bei Bargusi. Ex Gmelin sen. und Steller).

Turdus squamatus Boie, Isis 1835, p. 251 (Helgoland; nomen nudum. Ex Temminck MIS.). Turdus Whitei Eyton, Rarer Brit. B., p. 92 (1836 - bei Christchurch in Hampshire). Oreocincla leancii Swinhoe, Ibis 1863, 1). 275 (Formosa).

Abbild.: Secbohms Mon. Turd., Taf. I. Li: Ibis 1908, Taf. IV, 2-33.

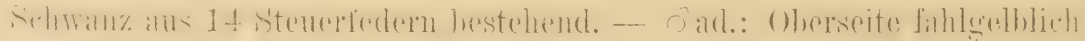
olivenbraum, jede Feder mit breitem schwarzen Endsaum, vor dem sich ein

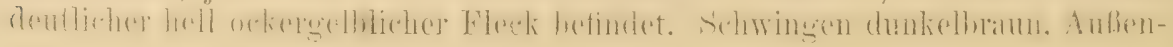


säume gुolbhrämulich, an den Haudschwingen in der Ylitte am sednniilsten, an den Armschwingen hinter der Mitte rerberitert und nicht bis zur spritze rejehend, doch halon die Amsehwingen anch noch schmale gathhratums Śpitzen. Die dem Körper nahen Oberflügeldecten wie der rë̈rken, dis

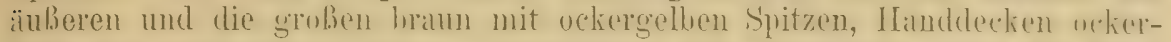

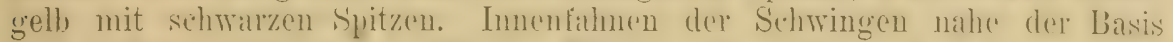

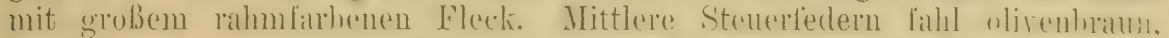
die äulieren mehr odre minder sehwarzhram verwaschen und mit all dusdehumg wathseluden. mitunter undentichen weiben syitzen. Interseite weib, hesonders an der Brust mit hell weliergelblichem Anflug, die rinzeluen Federn mit halhnondfümign sehwarzen Enden. nur dio Nitte des Lntex-

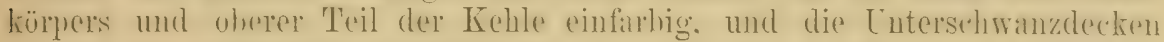

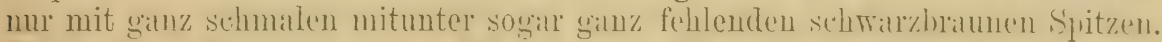

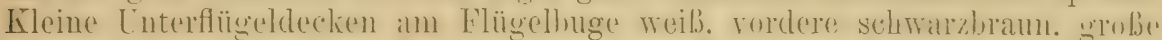

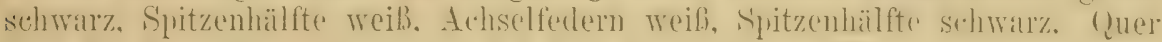

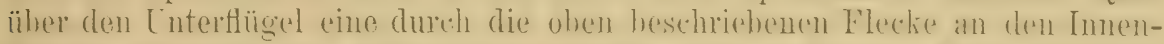

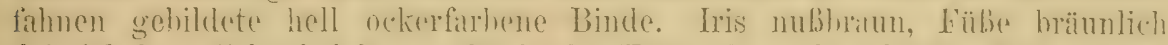

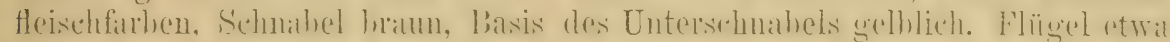
152-162; der Schwanz ist stark gerundet und mißt etwa $112-118 \mathrm{~mm}$, die Stenerferlern sind am linde rerichnälert; Laluf 35-39. ('nhmen 27 his $31 \mathrm{~mm}$. - q wie $\sigma^{\pi}$. - Im frischen Herbstkleide ist die Färbung mehr ockergelblich, im Frühjahr mehr gräulich, blasser.

Ostsibirien vom Süiden des Baikal-Sees bis an den Stillen Ozean und

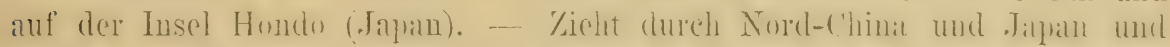
kommt im WVinter in Süd-China und auf Formosa vor; einzolne Stïcke

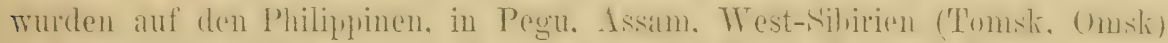

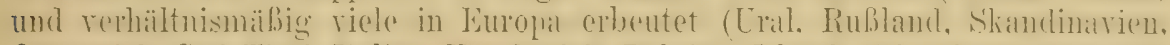
Osterrich, Sür-Tirol. Italien, Flankreich. Belgien. Irland, Sehottlaud, England,

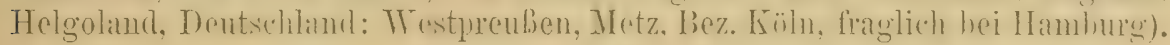

Die früher nicht sicher bekannten Eier wurden neuerdings von Alan Owston in größerer Anzahl gesammelt. Nach seinen Befunden brütet $T$, $d$, aureus auf den Bergen des mittleren Teiles der Insel Hondo (Fudschi, Sajami) in Höhen von 1500-3000 engl. Fuß und höher. Die Nester stehen 10-20 Fuß über dem Boden in Eichen, Kirschbäumen, Mimosen, u. a. m., und bestehen aus grünem Moos mit Fichtennadeln. Die 4-5 Eier sind auf mäßig glänzendem, ganz hell bläulichgrünem, fast hell grünlichgrau ausschendem Grunde bald äußerst schwach und fein, bald gröber und lebhafter, mitunter fast über und über hell rotbraun gefleckt. Die sehr fein punktierten Exemplare erinnern oberflächlich an Gavulus-Eier. 45 Eier messen nach Jouxdain im Durchschnitt $32.24 \times 23.93$, Maximum $34.7><24$ und $33.3 \times 25.3$, Jinimum $30<22 \mathrm{~mm}$. Durchschnittliches Gewicht von 24 Eiern nach Jourdani $513 \mathrm{mg}$.

\section{Turdus dauma major (Ogava) $\left.{ }^{1}\right)$.}

Geocichla major Ogawa, Annot. Zool. Japon. V, p. 178 (1905- Insel Amami in der Riukiu-Gruppe).

1) Außer T. dauma major gibt es noch eine Anzahl tropischer Vertreter:

Turdus dauma horsfieldi (Bonaparte), ebenfalls mit 14 Steuerfedern, aber viel kleiner als T. $d$. aureus. - Berge von Java und Lombok.

Turdus dauma dauma Latham (Ind. Orn. I, p. 362, 1790), viel kleiner als T. d. currens und mit nur 12 Stenerfedern. - Himalaya, bis in Höhen von 6000-7000 Fuß 
Unterscheidet sich von T. clauma aureus durch bedeutendere Größe,

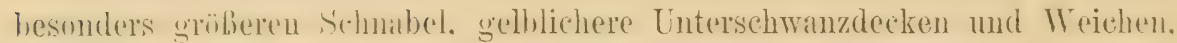
namentlich ahere dadureh, dab der Schwamz nur aus 12. anstatt 1 t. itreurefedern besteht. Flïgol etra $162-170 \mathrm{~mm}$.

Insel Amami (Amami-Oschima) in der Riu Kiu Gruppe.

\section{Turdus mollissimus Blyth.}

Turdus mollissimus Blyth, Journ: As. Soc. Bengal XI, p. 188 (1842- Darjiling).

Turdus oreocincloides. Hodgson, in Gray's 'Zool. Mlisc., p. 43 (184.1- nomen nudunı).

Oreocincla rostrata Hodgson, Ann. Nat. Hist. XV, p. 326 (1845 - Nepal).

Turdus Hodgsonii Homeyer, Rhea If, p. 150 (1849- Himalaya).

Geocichla dixoni Seebohm, Cat. B. Brit. Nus. V, p. 161 (1881- Himalaya).

Abbild.: Seebohms Mon. Turdidae I, Taf. IX. - Ei: Cat. Eggs Brit. Ilus.! IV'. Taf. VI, Fig. 13.

Oे a ad. Unterseite wie die ron $T$. danma anrens und T. d. clauma, aber

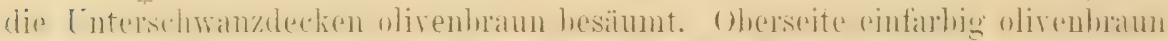

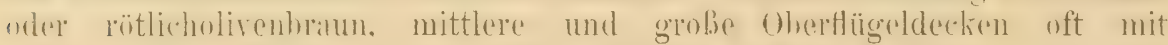

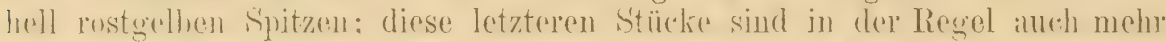

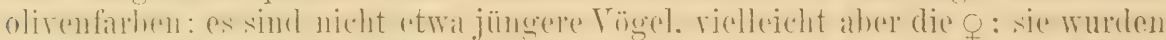

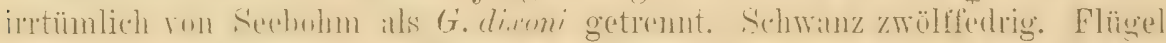

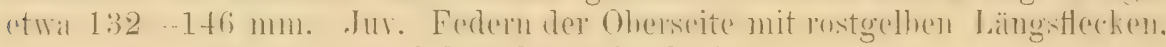
die dunklen Fndsäume anf der Unterseite breiter.

T. mollissinus bewohnt den Himalaya von Chamba nach Osten und die

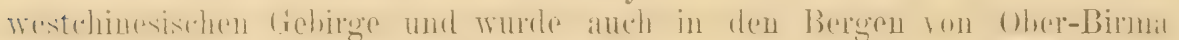

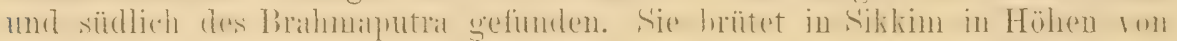
10-12800 ongl. FuB, in Szetsehwan in solchen von 9-10000 FuB und zicht im Winter in nicdrige Lagen.

Das Nest wurde in Sikkim gegen Ende Juni gefunden. Es bestand aus fest zus ammengefügtem Moos mit einer dïnnen Ausfütterung ron feinen schwarzen Farnund Mooswurzeln. Die Eier gleichen rötlichen Varietäten ron Amsel-Eiern.

\section{Turdus sibiricus sibiricus Pall.}

Turdus sibiricus Pallas, Reise d, versch. Prov. RuB. Reichs III, p. 694 (1776- Daurien). Turdus leucocillus Pallas, Zoogr. Rosso-Asiat. I, p. 450 (1827- Sibirien).

Iurdus atrocynaeus Homeyer, Isis 1843, p. 604 (Insel Rügen).

Turdus mutabilis Bonaparte, Compt. Rend. Paris 38, p. b́ (185̌4- ex 'Temminck MIS., Java, descr. nulla!).

Oreocincla inframarginata Blyth, Journ. As. Soc. Bengal XXIX, p. 106 (1860 - AndamanenInseln).

Abbild.: Dresser, B. Europe II, Taf. 12. Eier: Ibis 1901, 'Taf IX, Fig. 13-16.

ơad. Ober'seite dunkel schiefergrau, mit dunkleren, fast schwarzen

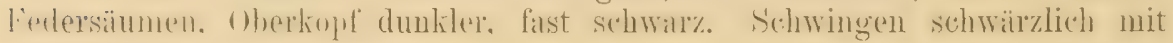

oder höher. Angeblich 1854 in Italien erbeutet, doch ist die Geschichte des Stïckes nicht ganz sicher; Giglioli selbst, Arrigoni und Seebohm bezweifeln es. Andere Angaben beziehen sich auf $T$. d. aureus.

Turdus dauma neilgherriensis Blyth. - Südindien. Außerdem mehrere australische Formen, u. a. m., über welche man Seebohm, Cat. B. V und Monograph of the Turdidae I vergleichen möge. 


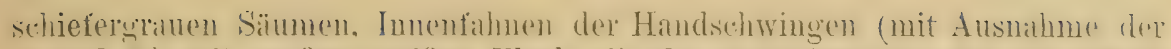
1. und 2.) mit grobem weiken Fleck. die dor Irmschwingen fiat zul Mälte

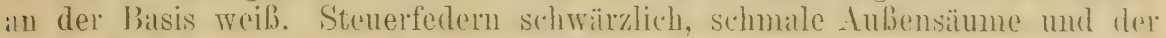

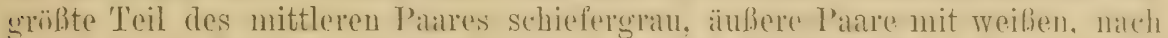

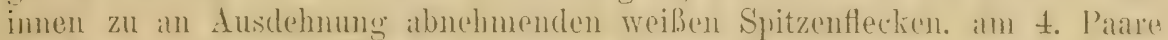

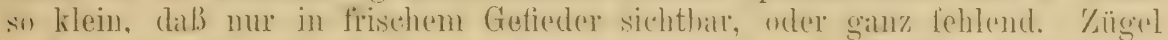
und Ohrdecken schwarz. Dreiter Nupereiliarstreif weil. Luterseite schilur-

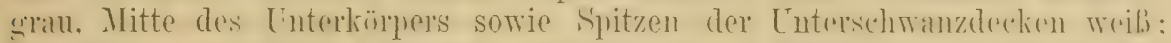
bei vielen, vermutlich jüngeren. Stïcken ist die Jitte del Cuterseite ans-

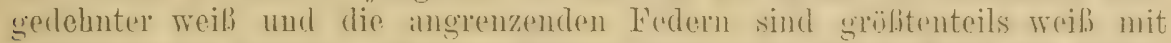

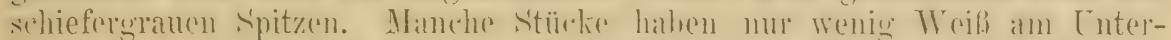

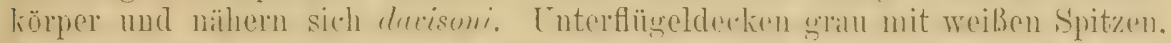

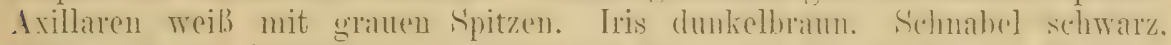

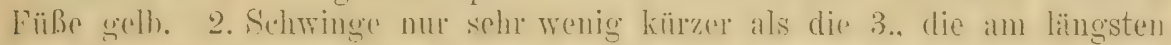
ist, 4. etwas küuzer; Flügel etwa 116-122; Schwanz etra 84-90; Laui ungefähr 30 , Culmen $22-25 \mathrm{~mm}$. - o ad. Oberseite olivenbraun, Ober-

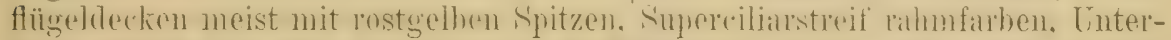

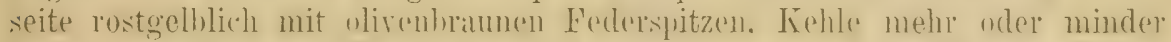
rinfarbig und hasser, Seiten mit olivenbräunlichem Anflug, Nitte des Unterlïrpers weils. [ntersebwanzdecten weif, nach der Wrumel zu breit ulivenbraun gesäumt. Schuabel braun. - Juv.: dem o ad. gleichend, die $0^{\text {r }}$ aber gräulicher.

Brïtet in den Finßtïlem des mittleren sibiriens (Jenissei. Letuil) nahr. dem Polarkeise. (Die Annahme vom Nisten am Kuku-Nor in Tihet - C'it. Eyggs Brit. Mus. Ir 1\% 112 - ist unbegriudet). ... Trandert dureh Daurien. [ssurien, ('hina mel üherwintert im fernen süd(en, besonclers auf . Tara. Bnrnen.

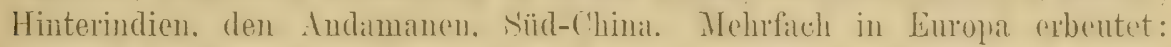
zehmmal in l)entschlind, zweinal in Belgien, zweimal in Holland, je (ximmal -in Bulgarien und Erankreich, ein-oder zrvoimal in England.

Das Nest steht in Büschen und besteht aus Gras, mit Erde zusammengekleistert, innen mit feinen Gräseru und Blättchen ausgefüttert. Die Eier ähneln am meisten denen der Misteldrossel und haben meist eine bläuliche Grundfarbe. 9 Eier messen im Durchschnitt $29.33 \times 21.08$, Maximum $31 \times 21$ und $30 \times 22$, Minimum $26 \times 19.4 \mathrm{~mm}$.

\section{Turdus sibiricus davisoni (Hume).}

Turdulus davisoni Hume, Stray Feathers V, p. 63 (1877- Berg Muleyit in Tenasserim, Birmah).

Abbild.: Seebohm, Mlon. 'l'urdidae I, Taf. 31; Ei: Dresser', Eggs B. Europe, I'af. T'urdinae A, Fig. 20.

ठ̊ad. Wie das von $T$. s. sibiricus, aber überall dunkler, schwärzlicher.

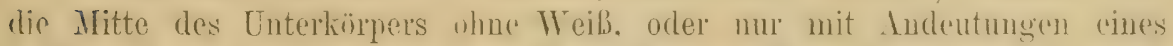
woißen Streifens. Im allgemeinen anch etwas gröifer. Flügel und Srehwauz

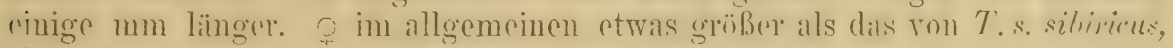
aber nicht immer zu unterscheiden.

Nistet auf den großen japanischen Inseln. - Zioht im Winter nach Birma und Tenasserim.

Die Nester wurden auf Hondo in Kirschbäumen, Fichten, Kastanien, "Gumi" (Eleagnus umbellata) $11 / 2-11 / 2 \mathrm{~m}$ hoch gefunden. Lier wurden vom 12. IIai bis 
28. Juli genommen. Sie sind in der Regel feiner gefleckt als die ron T. s. sibivicus, selten bläulich und in der Regel etwas gröłser. 31 Eier messen nach Jourdain im Durchschnitt $29.63 \times 21.1$, Haximum $33 \times 212$ und $30.1 \times 22.3$, Minimum $26.3 \times 20$ und $27.2 \times 19.5 \mathrm{~mm}$. 10 Eier wiegen durchschnittlich $367 \mathrm{mg}$ (Jourdain).

\section{Turdus pilaris I.}

Wachholderdiossel.

Turdus pilaris Linnaeus, Syst. Nat, Ed. X, p. 168 (1758- Europa. T'erra typica: Schweden, nach dem 1. Zitat).

Turlus subpilaris Brehm, Handb. Naturg. Vög. Deutschl., p. 384 (1831- Ahlsdorf bei Herzberg u. a. O. in Deutschland nistend).

Thurhes juniperorum Brehm, t. c., p. 385 (1831- bei Ahlsdorf' u. a. O.).

Turdus fuscilateralis Brehm, Vogelfong, p. 159 (1855 - keine genauo Lokalität).

Turdus pilaris major, minor, alticeps, tenuirostris, brachyrhynchos, superciliaris A. E. Brehm, Verz. Samml., p. 5 (1866 - Nomina nuda!).

Turdus Socius Kleinschmidt, Journ. f. 0rn. 1903, p. 458 (never Name für Turdus pilaris mit rorausgesetzten Subspezies).

Engl.: Fieldfare. - Franz.: Grive litorne. - Ital.: 'Tordelagazzina. - Schred.: Björktrast.

ơad. im Herbste: Oberkopf und Hinterhals aschgrau, die Federn des

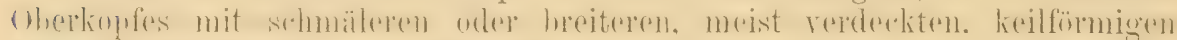

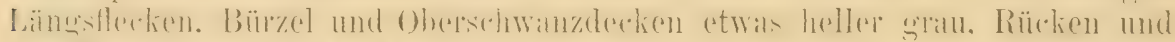

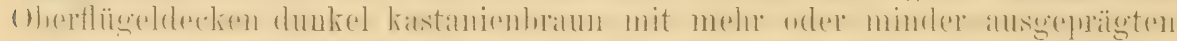

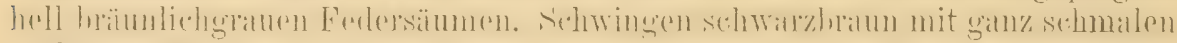

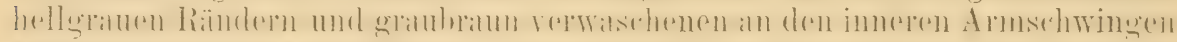

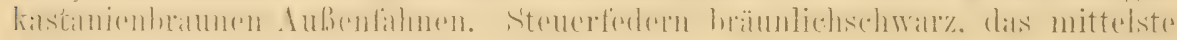

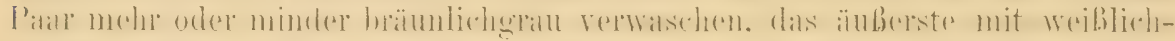

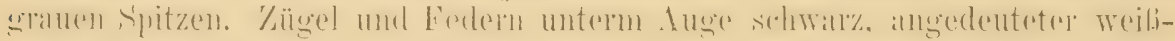
licher Superciliarstreif. Ohrdecken grau mit weißlichen Schäften. Kinn,

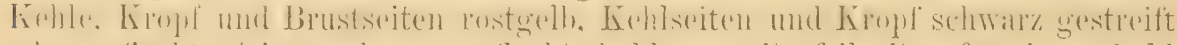

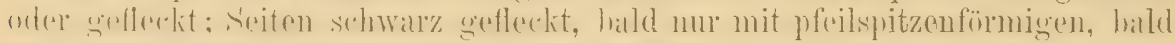

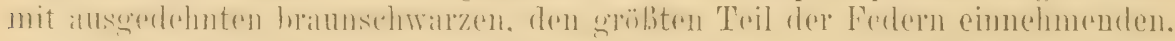
nur von weißen Säumen umgebenen Dreiecken. Unterer Teil der Brust,

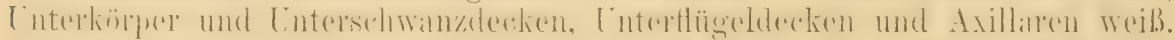

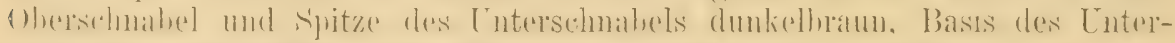

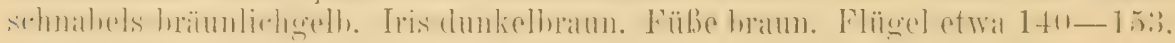
Selıwanz etra 110-115, Tauf ungeführ 32-35, Culmen 22.5-24.5 mm. q wie o, nur im allgemeinen etwas kleiner. - In der Brutzeit verbleicht

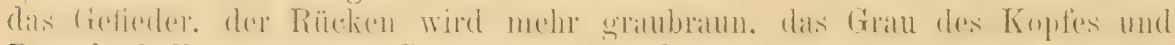
Bürzels heller, und der Schuabel ist größtenteils gelb. - Juv. im ersten

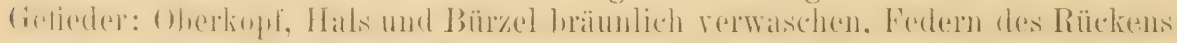
mit rostgelhen streifen mel sehwärzlichen Spitzen. Vorderhoust und Seiten

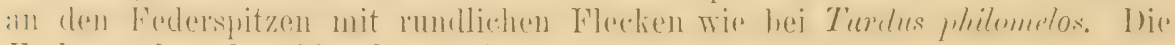
Färbung der alten Vögel ist sehr variabel.

Brütet in den Wäldern Nord-Europas und Nord-Asiens, nördlich bis in

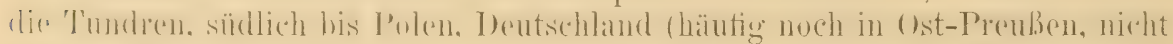

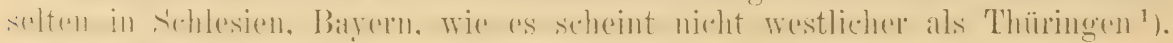

$\left.{ }^{1}\right)$ Die Angaben rom Briten in Holland, den Ardennen und den Alpen bedïrfen sicherer Bestätigung, die ron Wallis gemachte Beobachtung eines bei Gavarnie in den Pyrenïen britenden Paares dïrfte auf Irrtum beruhen. 


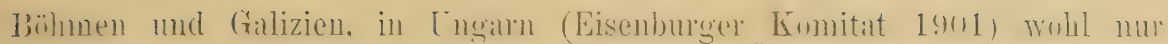
vereinzelt, östlich bis zur mittleron Lena. - Überwintert schon in Süd-

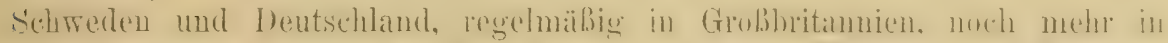

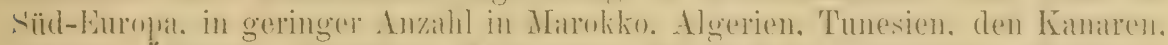

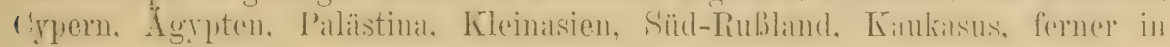
Timkestan, Yaidam und vereinzelt im nordwestlichsten Indien.

Im allgemeinen Bewohuer von Wäldern und Gehölzen, im hohen Norden aber auch hier und da in baumloser 'J'undra brïtend. Die. Lockstimmen sind ein lautes scha-scha-schak-schak, woran man die Art schon von weitem erkennt, und ein hohes gedehntes zieh oder ziek-ziek. Der Gesang besteht aus einem Schackern, Plaudern YWitschern und kurzen pfeifenden Tönen und ist mit den herrlichen Gesängen anderer Drosselarten nicht zu vergleichen. Das Nest steht bei uns auf allerlei Nadel- und Laubbäumen, im Norden vorzugsweise auf Birken, Erlen und Kiefern, in der Tundra auch am Boden. Sie bewahren den Hang zur Geselligkeit anch während der Brutzeit, denn mau findet die Nester meist kolonienweise, selten cinzeln. Das Nest ist groß und das iibliche Nestmaterial ist dureh und durch reichlich mit Erde verkleistert und mit Grashalmen ausgelegt. Die Gelege bestehen aus 4-6, selten 7 Eiern. Diese gleichen sehr oft denen der Amseln derart, daß man sie nicht unterscheiden kann, sie variieren aber noch bedentend mehr und sehr oft sind die Flecke lebliafter rotbraun und größer; Gelege von ziemlich dunkelgrüner Grandfarbe und dicht mit rotbraunen Flecken bedeckt sind häufig, ebenso grïnlichblaue mit großen braunroten Flecken und helleren bläulichroten Schalenflecken, während audere wieder blaß grünlichgrau und ïber und über mit blasser rötlichbramer Wölkung bedeckt sind. 5̃9 Lixemplare messen nach Dr. Rey im Durchschnitt $28.4 \times 21$, Maximum $33.5 \times 23.4$, Minimum $26.3 \times 20.5$ and $28 \times 19.5 \mathrm{~mm}$, und das durchschnittliche Gewicht ist $0.383 \mathrm{~g}$.

\section{Turdus viscivorus viscivorus L. ${ }^{1}$.}

\section{Misteldrossel.}

Thrlus viscivorus Linnaeus, Syst. Nat. Ed. X, p.168 (1758 - Europa. Ex Ray, Willughby, Aldrovandus).

Turdus major Brehm, Handb. Naturg. Vög. Deutschl., p. 379 (1831- Dentschland).

Turdus arborens Brehm, t. c., p. 380 (1831- Thüringen).

Tiurdus meridionalis Brehm, Vogelfang, p. 159 (1855- Partim! "Algerien und Südeuropa") (siehe T. v. deichleri).

1) Ich habe vorläufig nur eine Form der Misteldrossel in Europa angenommen, dies ist aber nicht ganz korrekt. Die Exemplare von den Britischen Inseln, die aus Mitteldeutschland, die aus den Alpen, vom Rhein und aus Hamburg sind auf der Oberseite brauner, besonders aber auf dem Bürzel mehr rostbräunlich. Dahingegen sind die aus Schweden, Rußland, Ostpreußen, der Herzegowina und eine Serie von Zugvögeln aus Italien und dem Balkan oben heller. Man sollte daher eine westliche (dunklere) und eine östlichnördliche (hellere) Subspezies unterscheiden. Da mir aber aus vielen Gegenden ein ganz ungenügendes und oft in verschiedenen Jahreszeiten gesammeltes Material vorliegt, die Formen sehr wenig verschieden sind, auch einzelne Stücke, nicht mit der Regel iibereinstimmen, rermag ich die Verbreitung der beiden Formen nicht mit genügender Sicherlueit anzugeben. Linné kannte 1758 die Art nicht, sondern benannte sie nach Ray, Willughby und Aldrovandus - als nymotypische Lokalität fïr T. viscivorus ist daher nicht Schweden, sondern Westeuropa, am besten England, anzusehen. Da sich auch die Namen von C. L. Brehm auf die dunkle F'orm beziehen; würde die hellere einen neuen Namen bekommen müssen. Ohne Untersuchung von Serien aus den verschiedenen Brutgebieten erscheint mir eine solche Benennung vorläufig zu gewagt. 
Turdus viscivorus medius; alticeps, planiceps A.E. Brehm, Verz. Samml., p. ¿) (1866nomina nuda!)

Turdus Arboreus Kleinschmidt, Journ. f. Orn. 1903, p. 456 (neuer Name für T' viscivons mit seinen Formen).

Engl.: Mistle-thrush. - Franz.: Draine. - Ital.: Tordela. - Schwed.: DubbelT'rast.

1. Schwinge ungeführ halb so lang wie die Handdecken, 2. gleich der 5. oder wenig kürzer oder länger, 3. und 4. am längsten. - ò q ad. Oberseite

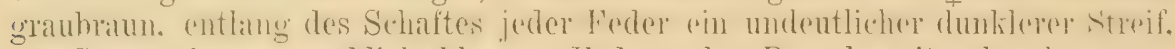
die Säumu kitum merklich blassere. Forlern des Bürzels mit sehmalden rest-

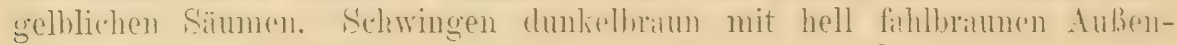

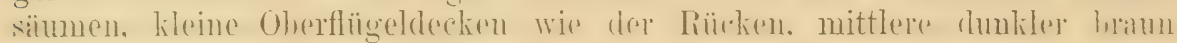

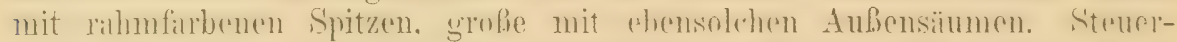

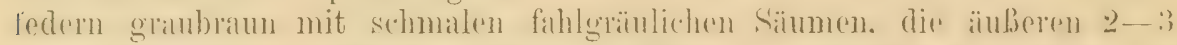
mit unregremäbig geformten weifun Gudferelen. Cnterseite rahmbarben, an

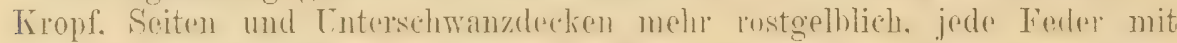

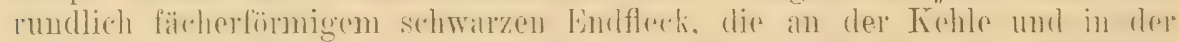

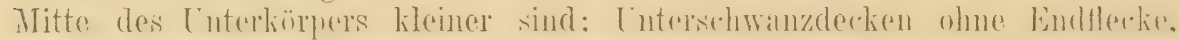

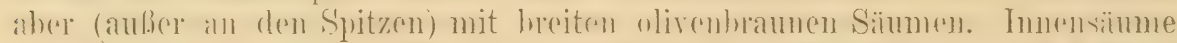

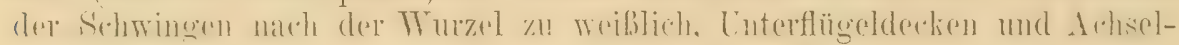

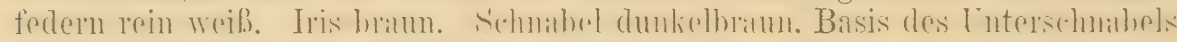

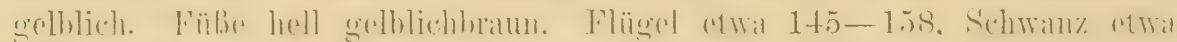
105-120, Tauf 22-24, Culmen 24-26 mm. - Während der Brutzeit

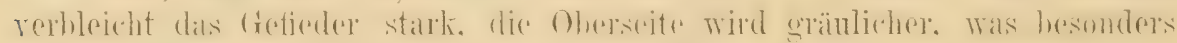

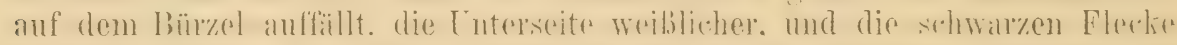

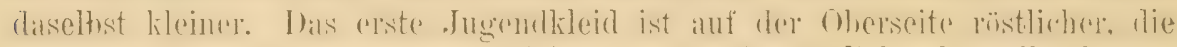

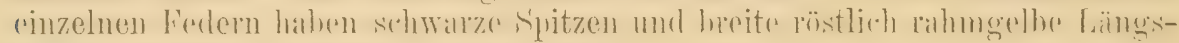
flecken, Kopf und Seiten sind gräulicher.

Brutvogel in Nord- und Zentral-Europa, in Sïd-Emropa nur auf den Gabirgen. aher auf Korsika. Sardinien und Sizilien, im Osten his Mrst-Sihirifn und zum Ural. - Überwintert in den Mittelmeerländern.

Die Misteldrossel ist ein Waldbewohner und bevorzugt hohe Nadel- und Buchenwälder. Die Lockstimme ist ein sonderbar schnarrender, langgezogener 'Ton, der etwa wie schnärrrrrr klingt. Das ô hat einen melodischen, lauten Gesang, der an Kraft und Klangfülle dem der Amsel kaum nachsteht. Das Nest steht selten so niedrig wie das der Singdrosseln und Amseln, oft dagegen bis $10 \mathrm{~m}$ hoch und darüber, mit Vorliebe auf Kiefern, aber auch oft auf Laubbäimen. Das Nest ähnelt einem großen Amselnest, ist also mit trockenem Gras ansgelegt, außen aber weniger sauber und ordentlich gebaut, Bastfasem, Hloosstücke und dergl. baumeln oft lang herab. Die 4-5 Eier sind auf gelblichgrauem, hellbräunlichem, seltener blabs grünlichgrauem oder bläulichgrauem Grunde mit Flecken und Punkten von rotbrauner Farbe und verwaschenen blals rötlich oder bläulichgrauen Schalenflecken gezeichnet. 86 deutsche Exemplare messen nach Rey im Durchschnitt $29.5 \times 22.2$, Maximum $31.4 \times 22.6$ und $30 \times 23.5$, Minimum $28.1<21 \mathrm{~mm}$ und wiegen durchschnittlich $0.420 \mathrm{gr}$.

\section{Turdus viscivorus deichleri Erl.}

[Turdus meridionalis Brehm, Vogelfang, p. 159 (1855- Partim! „Algerien und Südeuropa“. Die angegebenen Mlerkmale passen durchaus nicht auf den algerischen Vogel; in der Sammlung befinden sich als meridionalis bezeichnete Stitche 
aus Ungarn, Spanien und Algerien, der Name kann daher nicht sicher anf rorliegende Form bezogen werden).

Turdus viscivorus deichleri Erlanger, Orn. Monatsber. 1897, p. 192 (Gebirge des mittl. 'Tunesiens, loc. typ.: Ain-bou-Dries).

Von T. viscivoms viscivorus ohne Schwierigkeit dureh den krältigeren und längeren Schmahel zn unterscheiden. I) Fe Fügel der mir ronlienenden 20 Brutvögel aus Marokko, Algerien und 'Tunis messen etwal 1 tis - $15 x$.

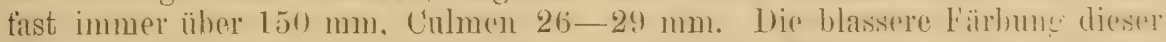

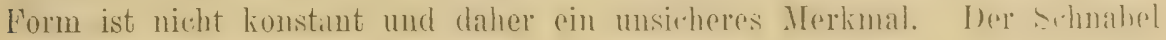
scheint tiefer schwarz zu sein.

Brutvogel in den Bergwildern (hesondris den Kixterngehülan) van Marokko, Algerien und Tumesien, und dort anscheinend Standrogel.

\section{Turdus viscivorus bonapartei Cab. $\left.{ }^{1}\right)$}

Turdus Bonapartei Cabanis, Journ. f. Orn. 1860, p. 183 (Himalnya).

[nterseheidet sich dureh die hedentende Flügellänge: Flïgol 160 his $173 \mathrm{~mm}$, und ist im allgemeinen anch sonst etwas größer. Die Färbung

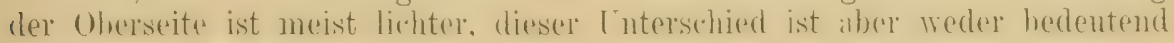
noch ganz konstant.

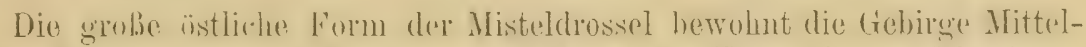

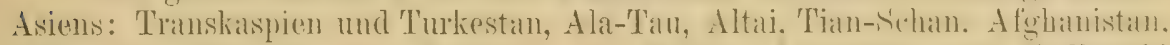

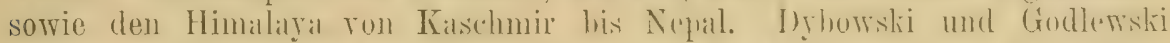

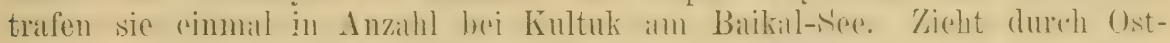

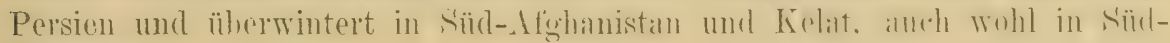
Persieu.

\section{Turdus auritus Verr.}

Turdus auritus Verreaux, Nouv. Arch. AIts. Paris, VI, Bull. p. 34 (1870- 'Typus von Hupin).

Abbild.: Nouv. Arch. Mus. Paris, IX, Taf, 5; Eier: Pleslie, Aves Przewalsk. I'af. V, 1. Ibis 1903, Taf. III, Fig. 4, 5.

Erinnert auf den ersten Blick sehr an 7 ? philomelos, unterseheidet sich aber hei wirklicher Untersuchung wio folgt: 1. Sehwinge so lang wie die Handdecken oder länger, 2. virl kürzer als 3., 4., 5. und 6.. nur rinige mm länger als die 7.. die 3.. 4. und 5. heinahe gleieh und am längsten. Hinter den Olurkecken ein seharf markiorter, auffalleuler schwarzer Flerk. Mittlere und grobe Oberflïgeldecken auscheinend immer mit scharf markierten lahmegelhen Spitzenflecken. Die Elecke der Enterseitu meist ctwas gröBer, schwillzhicher. rundlicher und auffillender. an die ron T. riscrirms erimernd. Cnterflügeldecken, Axillaren und allyemeine Färhung wis bei T. philumeles. Flügel

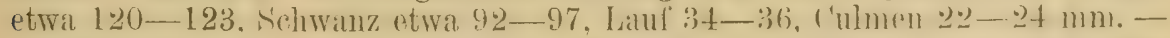

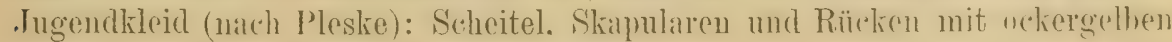
Schaftflecken, der Bauch feiner gefleckt.

1) Kleinschmidt (Turdus pseudohodgsoni, Falco 1909 p. 20) trennt die Nisteldrosseln aus West-Turkestan ('Taschkent und Merw) als intermediïr zwischen T. v. viscivorus und T. v. bonapartei. Für letztere gibt er ein F'lïgelnaß von 169, für pseudohodgsoni 162 an. Unsere Stücke aus West-Turkestan (Issik-Kul haben Fliigel von $163-172 \mathrm{~mm}$. 
Kansu, 'Tsinling, West-Szetschwan; anseheinend in geringer Anzahl in (len Ebenen (Peking) überwinternd oder durchziehend.

Diese seltene Drossel bewohnt nach Przewalski die Waldzone der hohen Gebirge ron Kiansu. Im Frühling lassen die ơ eifrig ihren schönen Gesang hören, der an den der Singdrossel crimnert. Mitte Mai wurden zwei Nester gefunden, eins auf einem Baumstumpfe, das andre $7 \mathrm{Fu}$ hoch auf einem Weidenaste. Sie enthielten 2 und 4 Eier. Letztere ähneln Misteldrosseleiern, sind ziemlich rundlich und die Färbung ist entweder fahl weinrötlich oder hell fahl olivenbräunlich mit feineren und gröberen rostroten Punkten und Fleckchen und einigen hell violettgrauen Schalenflecken. IIaße ron 5 Eiern nach Pleske: Durchschnitt $26.8 \times 20.1$, Maximum $28 \times 21.5$, Kinimum $25 \times 19 \mathrm{~mm}$.

\section{Turdus philomelos philomelos Brelim.}

(T. mesicus auct, errore!) Singdrossel.

(Turdus musicus Linnaeus, Syst. Nat. XII, p. 292, 1766, non T'. musicus 1758!)

Turdus minor Brehm, t. c., p. 382 (1831. Non T. minor Gmelin 1788!)

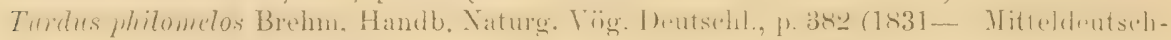
land auf dem Zuge).

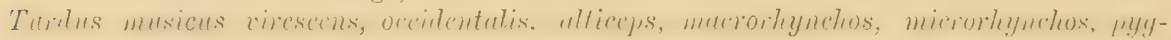
maeus A. E. Brehm, Verz. Samml., p. 5 (1866 - Nomina unda!)

Turdus Bragi Kleinschmidt, Journ. f. Orn. 1903, p. 460 (neuer Name für die Singdrossel mit ilsen Formen).

Engl.: Song-'Thrush. - Franz.: Grive. - Ital.: Tordo bottacio. - Seliwed.: T'alltrast.

1. Schwinge etwa $10-15 \mathrm{~mm}$ lang, 2. zwischen der 4. und 5., 3. und 4. am längsten. O๋ad. Oberseito olivenbraun, an Bürzel und Oberschwanzdecken etwas heller werdend und leicht ins Aschgraue ziehend. Zügel mit hell rostfurbenem Strich. Kopf- und Halsseiten hell gelblich rostfurben,

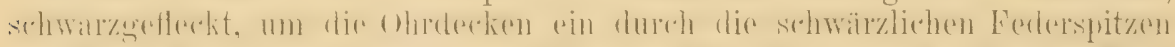

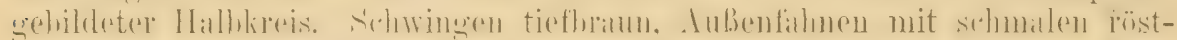
Iichen Kanten. Innenfahnen nach der Wurzel zu fahl ockerfarben; imnere

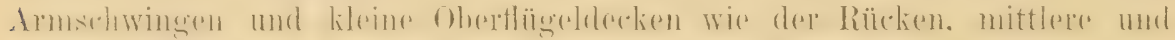

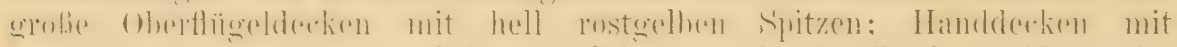
dunkleren, fast schwarzen Spitzen. Schwanz wie der Rücken. Unterseite weiß, Kehle, Kropf und Seiten blaß rostgelb, Weichen olivenfarben ver-

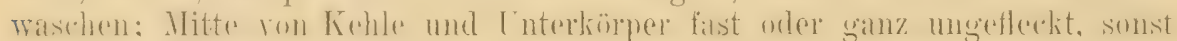

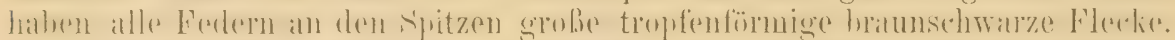

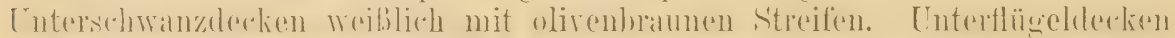

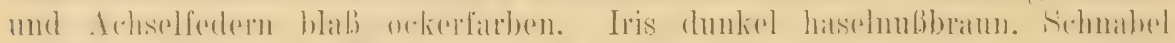
schwärzlich, Basis des lintersehnahels gelhlieh, Fübe bläulich oder bräunlich fleischfarben. Flügol etwa 115-122, Schwanz etwa 82-90, Lauf $32-35$. Culmen 21-23 mm. - Geschlechter gleich. - Junge Vögel im ersten Gefieder sind auf der Oberseite etwas mehr rötlich braun und die Federn

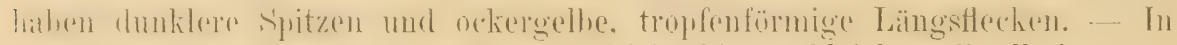

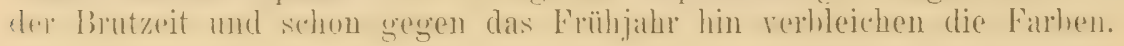

Brutvogel in Europa im allgemeinen (in Großbritannien aber nur auf dem Zuge), im Norden bis etwa zum $60^{\circ}$ nördl. Breite, im Süden bis zu

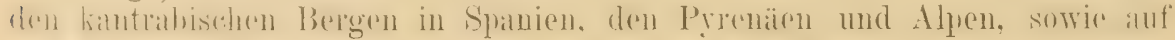

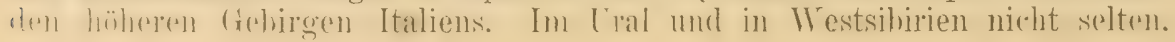




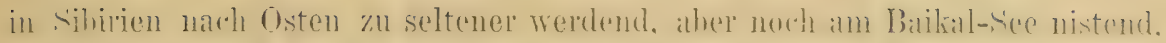

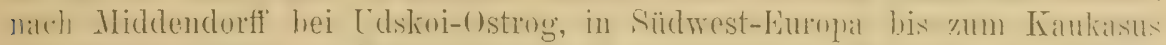

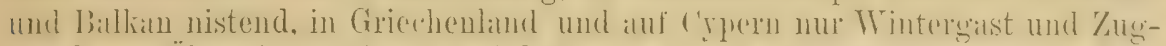

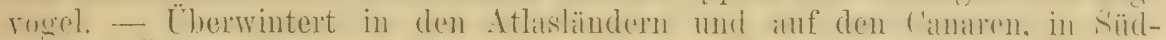

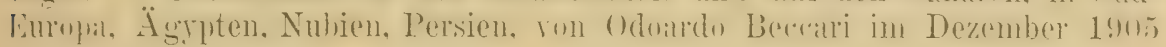
in Erythrea erbeutet.

Die Singdrossel bewohnt die verschiedensten Waldungen, sofern sie nur Unterholz haben, ihre Nahrung aber sucht sie rorzugsweise am Boden. Letztere besteht aus Wïrmern, Schnecken, Larven und Insekten, sowie aus allerhand reifen Beeren und weichen Friichten. In dicht bewohnten Ländern nistet diese Art auch in Gärten und Stadtparks. Lockton ein scharfes „zip", woher der Name Zippe. Der Gesang ist wechselvoller, als der der Amsel, besteht aber meist aus oft wiederholten, kurzen MIotiren, die weniger voll sind als die der Amseln. Das große, festgefügte Nest hat einen sehr tiefen Napf, der mit einer festen, aus mit Speichel angefeuchteten Holzmulm bestehenden Masse ausgestrichen ist. Die 5 bis 6 (selten 4) Wier sind glatt, tief grünblau, mit feinen oder gröberen schwarzen Punkten oder Flecken, selten mit Schnörkeln und Haarzügen, noch seltener ungefleckt, mitunter anch mit rötlichbraunen Schaleuflecken. 50 Eier messen nach Rey im Durchschnitt $27 \times 20.2$, Haximum $30 \times 20$ und $26.2 \times 22$, Ninimum $24.5 \times 19.5$ und $26 \times 18.7 \mathrm{~mm}$, mittleres Gerricht $0.317 \mathrm{~g}$.

\section{Turdus philomelos clarkei Hart.}

\section{Britische Singdrossel; British Song-Thrush.}

Turdus phitomelos clarkei Hartert. Bull. B. O. Club XXII, p. 54 (Jan. 1909- Grol3britannien).

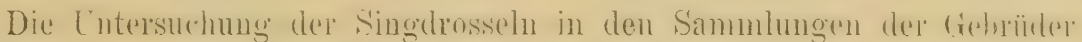
Ticehurst, von Lervis Bonhote, des Museums zu Limburgh, des British

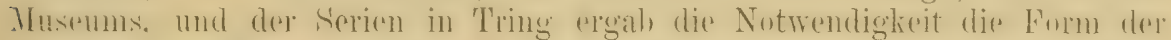
Britischen Inseln zu sondern. Ich benannte sie zu Ehren des Hermu TVm.

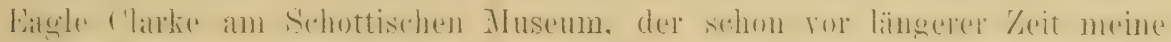
Aufmerksamkeit darauf lenkte. - Bei $T$. $p h$. clarkei ist die Oberseite von

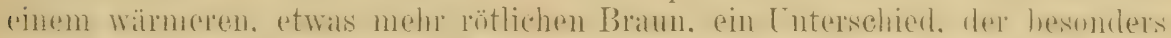

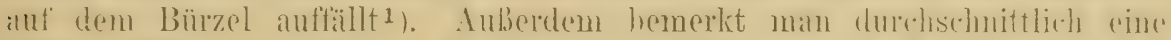

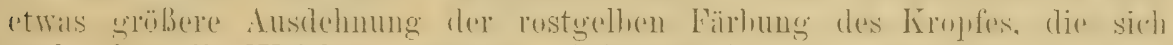
auch über die Weichen erstreckt. Mitunter ist die Untersoite auffallend

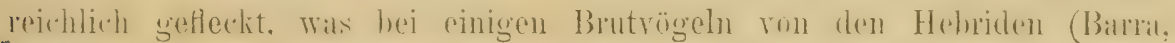
'Tewis) sehr in die Augen springt; da diese Stücke auch eine besonders

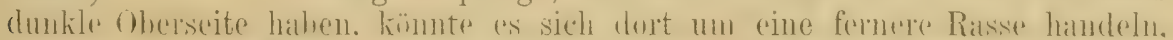

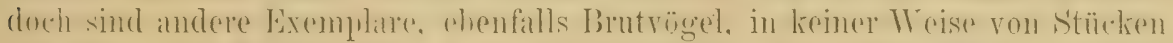

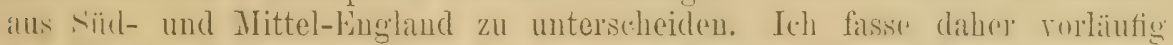

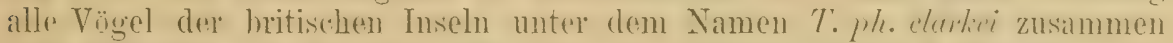
und betrachte als trpischen Fundort das mittlere Fngland (Trince Die

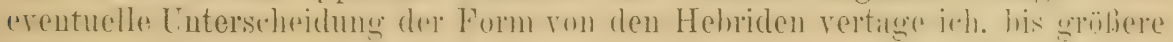
Serien vorliegen.

$\left.{ }^{1}\right)$ Bei kontinentalen Stïcken ist die Oberseite mehr olivenbraun, besonders der Bürzel mehr grünlich-gräulich. Natürlich variiert auch dieses, und es gibt auffallend grabürzeliche Exemplare (besonders sah ich solche aus Cypern, Marokko, Sardinien, Persien, Erithrea), doch konnte ich nicht feststellen, ob sic ein gesondertes Brutgebiet bewohnen, möchte dies aber bezweifeln, zumal Brutvögel aus dem Ural nicht auffallend grïnlich sind. 
S̈(h) häntis anf den Inseln des Britischen Reiches, von Schottland und

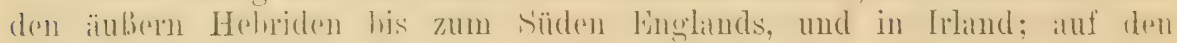
Shetlands nur selten nistund. -- Auf dem Zuge ist aluch T. philomelos philomelos in England nicht selten, besonders an den Küsten.

Die englische Singdrossel ist hauptsächlich Stand- und Strichvogel, der nux sehr teilweise die Inseln verläßt. Sie ist in England völlig Gartenvogel geworden, und brütet außer in Wäldern und Parks auch in kleineren Gärten und Dörfern und Städten, nicht selten an Häusern in Efeu und Weinranken. Den Gesang kann man an schönen T'agen schon um die Jahreswende hören. Den eifrigen englischen Sammlern gelang es, sonderbare Varietäten von Eiern zu erbeuten, u. a. melrere Gelege weißer Eier mit hell rostroten Flecken; vermutlich kommen solche auch anderswo ausnahmsweise vor. 41 Eier aus England messen nach Jourdain im Durchschnitt $28.46 \times 20.95$, Maximum $31.1 \times 20.5$ und $28 \times 23$, Minimum $25.2 \times 21.3$ und $27 \times 19.2$, Zwergeier $19 \times 15.2 \mathrm{~mm}$.

\section{Turdus cardis T'emm.}

Turdus cardis 'Temminck, Pl. Col. 518 (1830- Japan).

Abbild.: Seebohm, MLon. Turdidae, II, I'af. 128. - Eier: Cat. Eggs Brit. MIus., Taf. VI., Hig. 1 und 4.

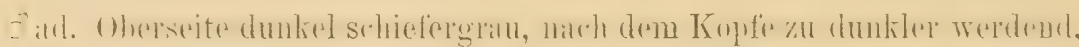
so daß Kopf und Nackon roin schwarz sind. Flügol und Sehwanz otwas

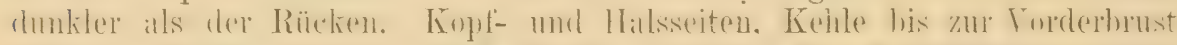

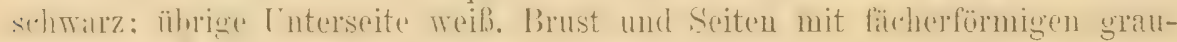

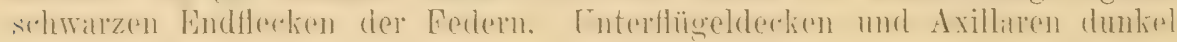
schiefergrau. Oft ist ein kleiner weißlicher Kinnfleck vorhanden. Unter-

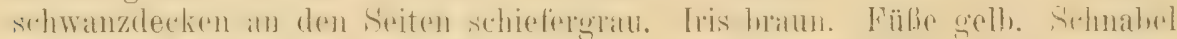

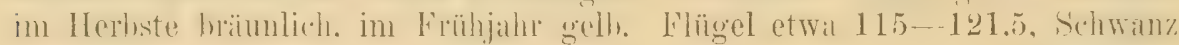
70-78, Lauf etwa 30, Culmen etwa $20-22.5 \mathrm{~mm}$. - o jur. Obersoite

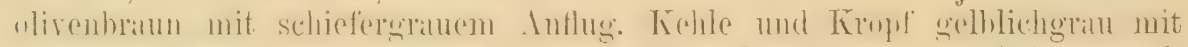

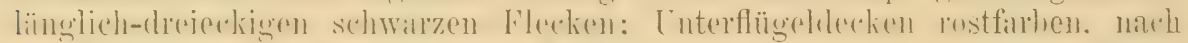

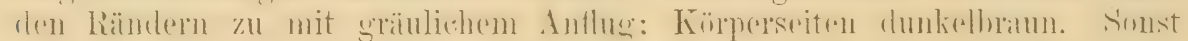
wie ơad. - Etwas ältere, aber nicht ganz alte $\delta$ haben deu Kopf weniger rein schwarz als alte Vögel und an der Kehle einige braune Striche. Obrrseite olisenbratun ohne graturn Anflug. Sïmme der Silnwingen and

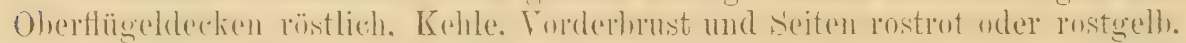

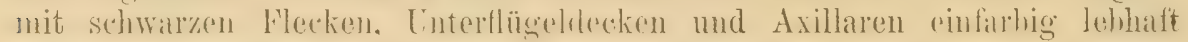

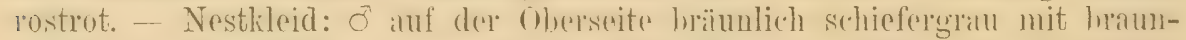

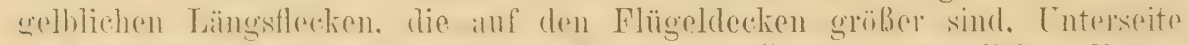

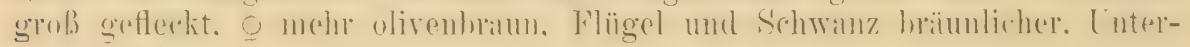
seite rostfarbener.

Scheint nur auf den großen japanischen Inseln von Jesso bis Kiu-schiu z.1 brüten, wurde auf Korea erbeutet, zieht durch das mittlere China und ïherwintert in Süd-China nnd auf Hainan.

Wegen ihres schönen Gesanges ist diese Drossel in ihrer Heimat ein beliebter Käfigvogel. Die Eier variieren wie die der meisten Drosseln ziemlich stark. Die Grundfarbe ist rötlichrahnfarben oder hell blaßgrünlich, die Zeichnung besteht aus hellerem oder dunklerem Rötlichbraun und mattgrauen Schalenflecken. Die tier gleichen kleinen Eiern ron Turdus viscivorus und messen etwa $26-29.5 \times 18-22 \mathrm{~mm}$. Das Nest besteht aus Moos und Würzelchen, ist mit Erde fest verkittet und innen mit feinem Gras, W Wirzelchen und Haaren ausgefüttert. 


\title{
1000. Turdus musicus L. (T. iliacus anct., errore!)
}

\author{
IVeindrossel, Rotdrossel.
}

Thurlus musicus Linnaeus, Syst. Nat: Ed., X, p. 169 (1758- „Habitat in Europae sylvis". Terra typica: Schweden, nach dem ersten Citat, Fauna Suecica 189: Die Diagnose und Beschreibung - alis subtus ferrugineis, linea superc. albicante - passen nur auf die Weindrossel.)

Turlus iliacus Linuaeus, Syst. Nat. Ed. XII, p.. 292 (1766- Non Linnaeus, Ed. X, p. $\left.168,1758^{1}\right)$ ).

Turdus manvis P. L. S. Mäller, Natursyst. Suppl., p. 141 (1776- Ex Buffon und Daubentons, "Le Mauvis". Europa.)

Turlus Illas Pallas, Zoogr. Rosso-Asiat., I, p. 457 (1827- Rußland und Sibirien).

Thurlus betularum Brehm, Handb. Naturg. Vög. Deutschl., p. 386 (1831- "Ziemliclı selten in Deutschland").

Turdus vinetorum Brehm, t. c., [1.386 (1831- Deutschland, „kommt aus dem Norden zu uns".)

Trurlus gracilis Brehm, Vogelfang, p. 160 (1855- wie vorige.)

Turdus alticeps, planiceps, obscums, concretus, gracilis A. E. Brehm, Verz. Samml., p.5. (1866- Nomina nuda!)

Turdus illuminus 'Tobias, Abh. naturf. Ges, Görlitz, IV, 1, p. 32 (1850 - Lausitz. Eine auffallend große V'arietät. S. Naumann, Naturg. Vög. Deutschl., XIU, p. 28ち, 286, T'af. 356, Fig. 1).

Turlus coburni Sharpe, Bull. B. O. Ulub, XII, p. 28 (1901- Island).

Turlus Borealis Kleinschmidt, Journ. f. Orn. 1903, p. 464.

Engl: Redwing. - Franz: Mauvis. - Ital.: Tordo sassello. - Schwed.: Rödvinge-'Trast.

1. Schwinge 8-13 $\mathrm{mm}$ lang, 2. zwischen der 4. und 5., 3. und 4.

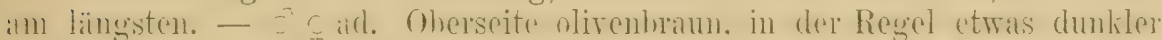

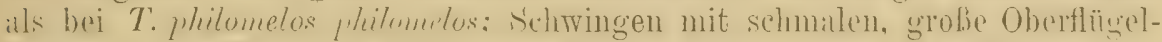

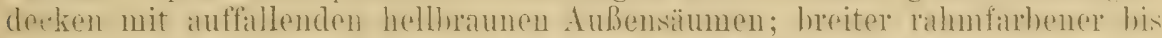

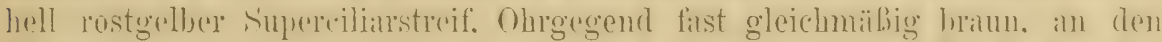
Halsseiten cin hell rostgelber, diror cin mehr rahufarbenel Flecti: roun der

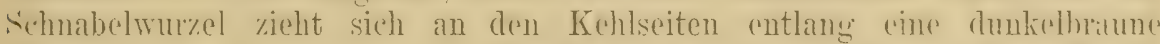

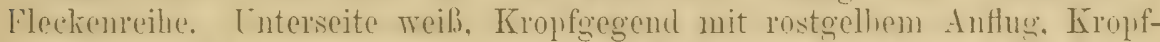
spiten brann. Kehle mit wenigen sehmalen, hropforgend und Seiten des Lutrohiirpers mit hreiten olivenbaunen hängsstreiten und Flecken -- diese immer lïnglicher, meln streifenatig, als bei T. pluilomelos. Suiten unter den Flüguln leh-

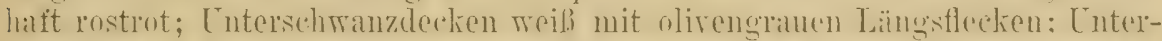
Hügeldecken und Achselfedern lostrot, hasser als die Sriten. Elügel etwa 111 his 119, Schwanz ungefähr 80, Lauf 30, Culmen $21-23 \mathrm{~mm}$. - Jur. wie das ron T. philomelos, und Interflügeldecken und kaum rostroten Seiten intolge der helleren. fast nur dureh den deutlichen meiblich rahmfarhenen supereiliustreifen zu unterscheirlen. - Im Frïhjalni und summer wird die Oberseite matter, mehr olivenfarben. - Die Ausdohumg der Rostfarbe an deu S'eiten sowie die Fleckenzuchmug der Unterseite varieren sehr.

Brutrogel in Nord-Europa und Nord-Asien: Faröer. Island ²). nördliches Norwegen und Schmeden, Nordrubland südlich bis Memel in ter Nordostecke

1) Turdus iliacus 1758 ist ein Gemisch von Sing-, Wein- und Misteldrossel, daher unanwendbar.

2) Sharpe trennte isländische Brutrögel als Turdus coburni ab, die ron ihm angegebenen Kennzeichen sind aber rein individueller Natur. Hantzsch glaubte die 


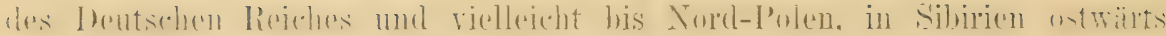
bis Bulun an der unteren Lena. Vereinzelte Fälle des Briitens wurden aus

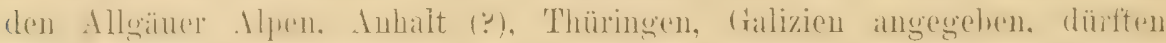
jedoch nicht alle einwandsfrei sein. - Vereinzolte Vorkommen werden aus

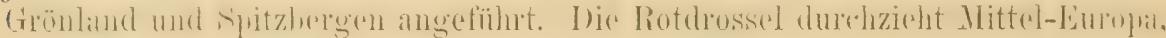
überwintert in Süd-Europa und kommt südwärts bis Algerien, Madeira, Canaren (vereinzolt) vor, im Osten bis Persien und Nordwost-Indien.

Die Rotdrossel bewohnt die IVälder des Nordens, besonders die niederen Tamnen und Buschdickichte ron Birken und Erlen. Dort baut sie ihr Nest meist niedrig iiber dem Boden, mitunter auch am Boden selbst, neben Steinen, auf Zäunen und Mauern, besonders gern nahe an Stämmen und in Astgabeln. Das Nest besteht aus Gras und feinen Zweigen und ist mit Erde rerkittet und ausgeschmiert, innen aber mit feinen Grashalmen gefüttert. Die 5-6 Eier findet man Ende Mai oder im Juni. Diese sind kleiner als die aller andern europäischen Drosseln und gleichen in der Zeichnung Eiern der Amsel und Wachbolderdrossel, ändern aber nur wenig ab. Die Grundfarbe ist bläulichgrün, ausnahmsweise blau oder gelblichgrau, die Zeichnung besteht aus einer meist gleichmäßigen, dichten rotbraunen Wölkung. 50 lappländische Eier messen nach Rey im Durchnitt $25.8 \times 18.7$, Maximum $21.8 \times 19.8$ und $26.2 \times 20$, Ninimum $23.5 \times 19$ und $26 \times 17.5 \mathrm{~mm}$, und wiegen in Mittel $0.260 \mathrm{gr}$. Der Lockruf ist zweisilbig und besteht ans einem tiefen dück, von einem langgezogenen zih oder schnarrenden zirr gefolgt. Der Gesang ist zwitschernd, schwatzend, mit pfeifenden Tönen gemischt.

\section{Turdus hortulorum S'cl.}

,Therdus pelios" (errore, non Bonaparte!) Cabanis, T'aczanowski, Oustalet, etc. Turdus hortulorum Sclater, Ibis 1863, p. 196 (Amoy in Süd-China).

Turdus Campbelli Swinhoe, Ann. \& MLag. Nat. Hist. (4), XII, p. 374 (1873- "Chefoo"). Turdus chrysopleurus Swinhoe, Ibis 1874, p.444, Tat: XIV (Chefoo in Nord-China).

Abbild.: Seebolım's Monograph 'Turdidae II, 'Taf, 134. Eier: Ibis 1903, 'Taf. III, Hig. 7-9.

Orad. Ganze Oberseite, einschließlich Schwanz und Flügol, rein asch-

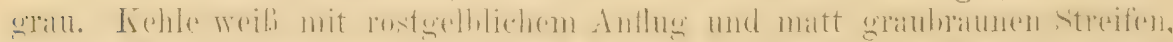

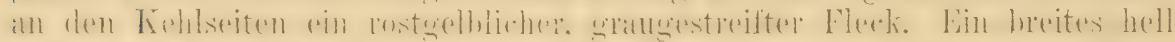

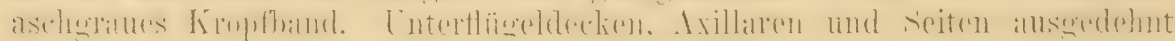
lobhaft rostrot, nicht ganz so rötlich wie bei $T$. musicus (iliacus auct.), aber riel lobhafter, dunkler und rötlicher als bei 7 . philomelos. Mitunter ist die

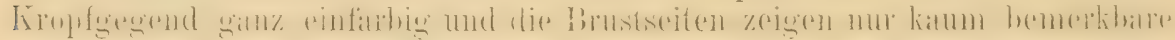
graue Spitzenflecke, manchmal aber sind die Hals- und Kropfseiten stark

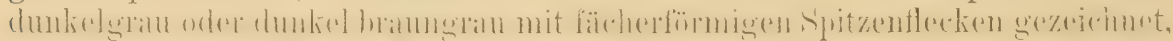

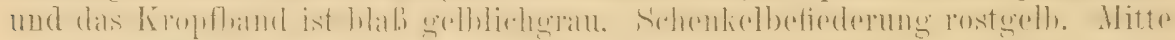
von Unterkörper und Brust und Unterschwanzdecken weiß. Schnabel im

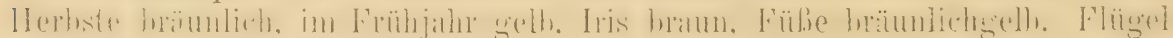
etwa 114-116, Schwanz ziemlich konstant etwa 84, Lauf 30-32, Culmen $21-23 \mathrm{~mm}$. : Oberseite in der Regel bräunlicher, Kehliseiten, Kropfgegend (und meist auch die Brustseiten) immer dentlich gefleckt, auch die Mitte der Kehle scharf, wenn auch fein gefleckt. - Junge Vögel sind auf der

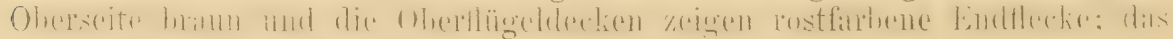
Nestkileid ist nicht hekannt.

isländische Form wegen olivenfarbener Oberseite sondern zu können; diesen Unterschied finde ich nicht bestätigt, doch kann man beim Vergleich von Sommervögeln mit im Herbst und Winter erlegten zu solchem I'rugschluß gelangen. 


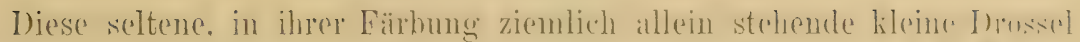

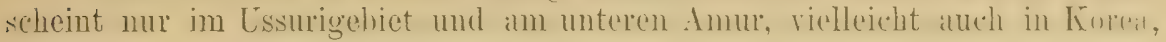
zu brüten. Sie ïberwintert im sïllichen China.

Ein von Jankowski am Sidemi gefundenes $\mathrm{Ei}$ sah wie ein Amselei aus: seegrün mit zahlreichen hell rotbramen und einigen noch blasseren Flecken bedeckt und maß nach Taczanowski $25<19 \mathrm{~mm}$. Es frägt sich, ob dies Ei richtig war. Von Dörries derselben Gegend gesammelte Gelege sind Misteldrossel-Eiern ähnlich, grïnlichgrau mit rostroten Flecken und messen $26 \times 20 \mathrm{~mm}$. Das Nest zeigt keine Besonderlieiten und ist innen mit feinen Gräsern ausgelegt. Der Gesang wird als der schönste aller ostsibirischen Drosselschläge beschrieben und die Sänger sind unermiidlich in ihrem Vortrage.

\section{Turdus pallidus Gm.}

Turdus pallidus Gmelin, Syst. Nat. I, 815 (1789- Ex Latham, Syn. II. 1, p. 32; Am Baikal-See).

Twrdus dantias T'emminck, P1. Col. 515 (1830- Japan. Figura pessima).

Turdus advena Swinhoe, Ibis 1860, p. 56, 358 („Schreibfehler für daulias).

Turdus obsoletus Brehm, Journ. f. Orn. 1862, p.391 (Japan).

Abbild.: Gould, B. EuropeII, Taf. 80; Temm. \& Schleg. Fanna Jap., Aves, Taf, 2 6. Ei: Cat. Eggs Brit. Mus. IV, Taf. VI., Fig. 11.

ôad. Oberseite röstlich olivenbraun, Oberkopf mehr gräulich, ebeuso

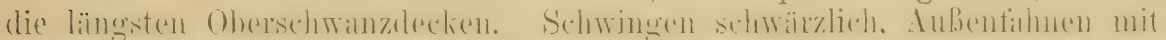

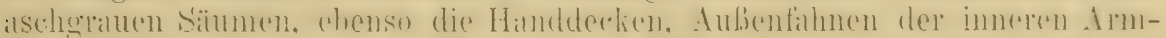

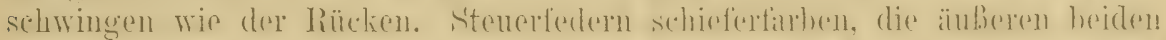

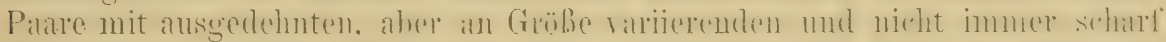
abgegrenzten weiben spitzen an den Inuenfilmen. dis folgende Palar mit

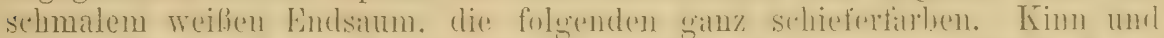

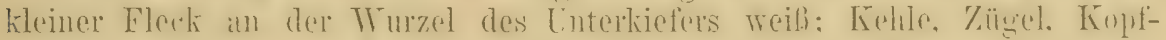

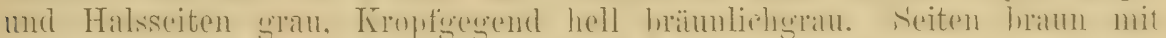

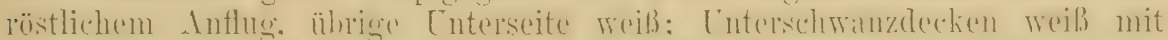

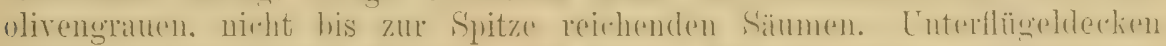

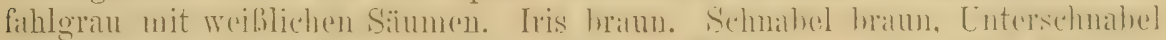

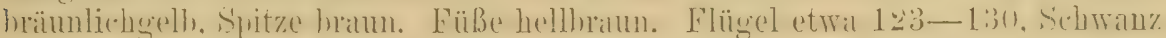
95-98, Lauf $31-32$, Culmen 22.5-24.5 mm. - o ad. wio das ó, nur der

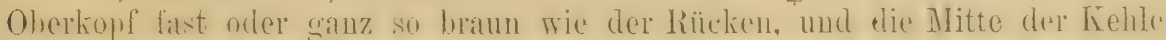

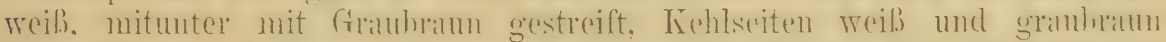

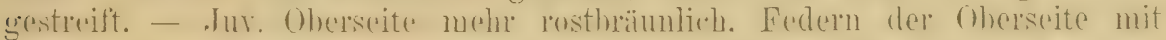

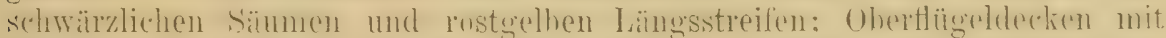

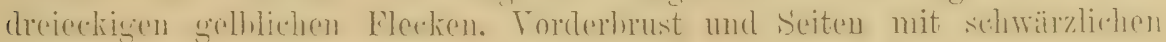
Flecken and Spitzensäumen.

Scheint nur in den Ussuri-tändern am unteren Amur und in der Mandschurei zu brüten, wohl auch auf der kleinen Insel Askold. - Auf

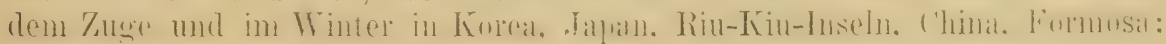
angeblich in Assam, doch köunte dies auf Verwechslung mit der dort vermutlich heimischen $T$. feae beruhen.

Am Lssuri wird das Nest aus allerlei Kräutern zusammengefügt. Die Eier ähneln denen von T. obscurns sind aber länglicher. Sie sind auf blaß blaugrünem Grunde rötlichbraun gefleckt, bald fein längsgefleckt, bald mit wenigereu und größeren Flecken gezeichnet. Drei Eier messen 29.2-19.5, 30.2 $<20.4$ und $32 \times 20 \mathrm{~mm}$. (Taczanowski). Fier in Nehrkorns und der British II useums Sammlung gleichen regelrechten Amseleiern und messen $25-27 \times 20 \mathrm{~mm}$. 


\section{Turdus obscurus Gm.}

Thurdus obscurus Gmelin, Syst. Nat. I, 2, p.816 (1789- Ex Latham, Syn. Av. II, 1, p. 31: Wälder jeuseits des Baikal-See).

Turdus Seyffertitzii Brehm, Lehrb. Naturg. europ. Vög. II. 1).972 (1824- Ahlsdorf). Turdus rufulus Drapiez, Dict. Class. d'Hist. Nat. X, p.443 (1826- Java).

Tiurdus pallens Pallas, Zoogr. Rosso-Asiat. 1, p.457 (1827- "Circa fluvios Dauuriae

vere, circaque Baïcalem lacum, in alpestribus sylvis, tota aestate frequens. “)

Tiurdus Werneri Géné, Mem. Ac. R. T'orino XXXVII, p. 296, Taf. 2 (1831).

Turdus modestus Lyton, Proc. Zool. Soc. London 1839, p. 103 (Malalkka).

Turdus davidianus Milne-Edwards, Nouv. Arch. Mus. Paris 1865, Bull. p. 26 (China).

Merula subobscura Salradovi, Ann. Mus. Civ. Genov. (2) I, p. 143 (1889- Kasen-Berge in Ober-Birma. Vermutlich Aberration ron 'T' obscumus).

Abbild.: Dresser, B. Europe II, 'Taf. 8; Eier: Ibis 1901, 'T'af. 1X, Fig: 5-8.

ôad. Oberseite röstlich olivenbraun, Oberkopf mit grauem Auflug und

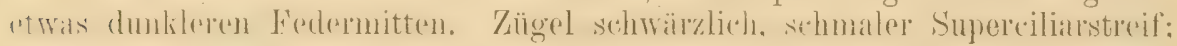
dreieckiger Fleck unter dom Auge, Kinn und kleiner Fleck an der Basis des Interkirfers weils. Kónle bis auf den Kront. Kopt- und Halsseiten

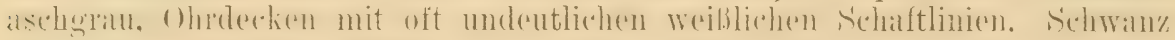

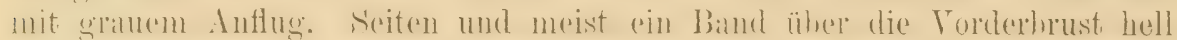

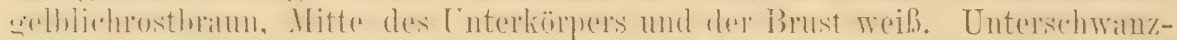

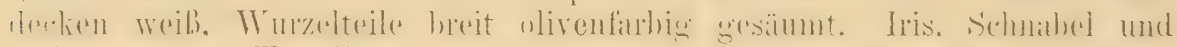
Füße wie bei $T$. pallidus. Unterflügeldecken bräunlich fahlgrau. Flügel etwa 124-130, Schwauz 84-91, Lauf 31-33, Culmen 21-23 mm.

Oberkopf braun wie der Rücken, Kehle weil., an den Kohlseiten braune

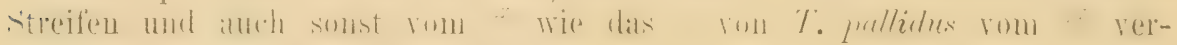
schieden. - Juv. dem o ähnlich.

Brutvogel in Sibirien, vom Tale des Jenissei bis Kamtschatka, am Baikal-See, in Daurien, seltener in den Ussuri-Ländern. - Wandert durch China (häufig) und Japan (selten), nach Süd-China und Formosa, den

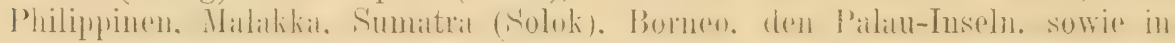
das östlichere Indien und die Andamanen. Vereinzelt in Turkestan (nach

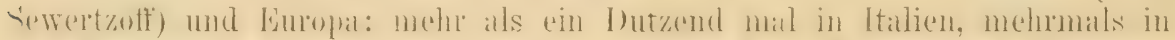

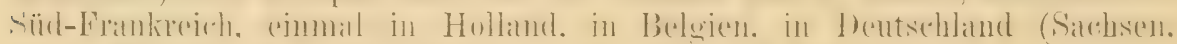

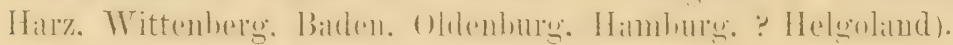

Der Gesang ist schön, klar, flötend, aber kurz und wenig abwechselnd. Die Nester stehen meist ziemlich hoch in Nadelbäumen; sie gleichen denen der Wachliolderdrossel, sind dick mit Erde ausgeschmiert, darüber mit feinem Gras gepolstert. Die Eier gleichen denen der Amseln und Wachholderdrosseln und variieren ebenso. 28 Eier (20 von Jourdain 8 von 'Taczanowski und Rey gemessen) messen im Durchschnitt $27.16 \times 19.62$, Maximum $30.5 \times 20$ und $26.2 \times 20.7$, Minimum $23.5 \times 17.5 \mathrm{~mm}$.

\section{Turdus chrysolaus 'Temm.}

Turdus chrysolaus 'lemminck, Pl. Col. 537 (1831- Japan).

Turdus jouyi Stejneger, Proc. U.S. Nat. Mus. X, p. 4 (1887- Insel Hondo, Japan. Vgl. Sharpe in Seebohms Mlon. 'Turdidae II, p. 171).

Abbild.: Seebohm's Mon. 'Turdidae II, Taf. 137. Eier: Cat. Eggo Brit. Mus. IV, Taf. IV, Fig. 15 und 18.

Unterscheidet sich von T. obscums durch lebhaftere Färbung, stetes

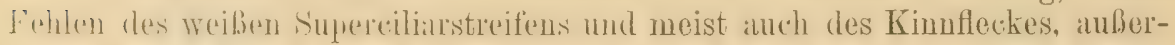
dem ist der libugel etwals kïrze und die 1. Schwinge in der Regel länger 
and heiter. (Oberkonf wie die ïhrige Oberseite, Fehle dunkler, mit schwärz-

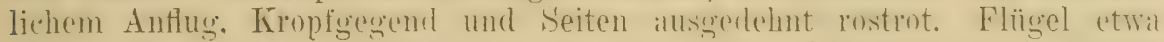
122-126, selten bis $129 \mathrm{~mm}$. - 우 und juv. rom ôad. wie bei $T$. obscurns unterschieden.

Brutrogel auf Satualin. den Kintrileu und den jatpanischen Insehn mit Aus-

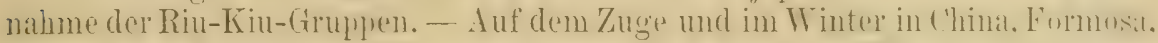

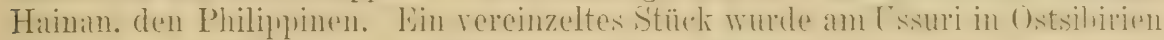
erbentet. - Obwohl T. cluysolaus in anderen Gebieten britet, als T'obscums,

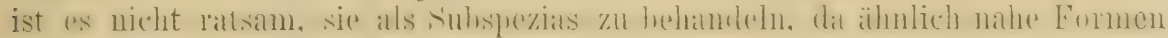
(z. B. in Afrika) nebenciuander vorkommen kömmen.

Die Nester sind aus grobem Haterial, Gras, Bast, Fasern gebaut, die Eier ähneln Anseleiern und sind sehr variabel, anch rötliche Varietäten sind nicht selten.

\section{Turdus celaenops celaenops Stejn.}

Turlus celcuenops Stejneger, Ścience X, p. 108 (1887) und Proc. U. S. Nat. Mus. 1887 p. 484 (Jijake-schima Sieben-Inseln von Idzu).

Abbild.: Seebohms Monogr. 'Turdidae II, Taf. 136.

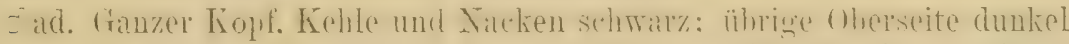

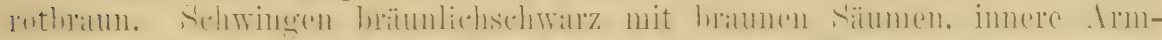

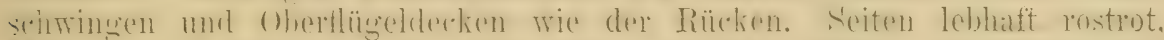

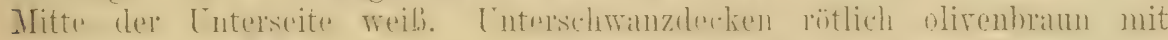

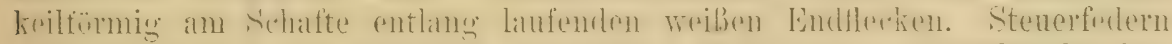

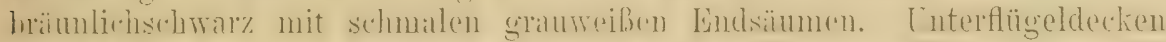

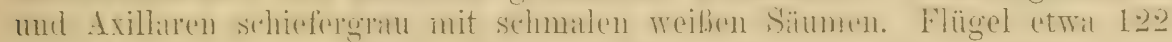
bis $123 \mathrm{~mm}$. - o. Etrvas kleiner (Flïgel 114-117 mm), Oberkopf nul

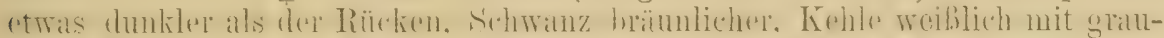

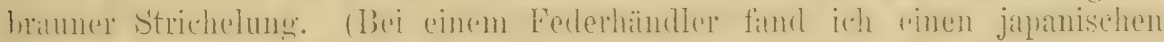
Balg ohne genaueren Fundort, der ein Bastard ron $T$. celcenops und T. crysolans zu sein scheint.)

Bewohnt die ciehen-Inseln ron Idzu und Fatsidsehio südlich ron Hondo.

Die Eier sollen in der Färbung denen von T. cardis sehr ähnlich sein.

\section{Turdus celaenops yakushimensis (Ogawa).}

Merula celcenops yakushimensis Ogawa, Annot. Zool. Japon. V p.180 (1905- Yakuschima).

Sehr ähnlich T. celcenops celaenops, unterscheidet sich aber durch etwas

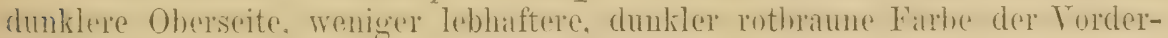
brust und Seiten, und etwas größere Maße: Flügel o etwa 126-127.5, ㅇ. 116-122 $\mathrm{mm}$.

Insel Jaku (Jakushima), sïdlich von Kiu-Sehiu.

\section{Turdus naumanni T'emm.}

Turdus naumanni Temminck, MIan. d'Orn. I, p. 170 (1820 - "Les parties orientales; se montre en Silésie et en Autriche; plus commun en Hongrie").

Turdus abrekianus Taczanowski, Journ. f. Orn. 1876 p. 193 (Ex Dybowski JIS. - Südl. Ussuri-Land, Ost-Sibirien).

Abbild.: Seebohms Mlonogr. Turdidae II, Taf. CXLIII. Eier: Dresser, Ibis 1903, Taf. III, Fig. 1, 2. 3, 6.

E. Hartert, Die Vögel der palïarktischen Fama. 
Oad. Oberseite braungrau, oft ohne, meist aber mit mehr oder minder

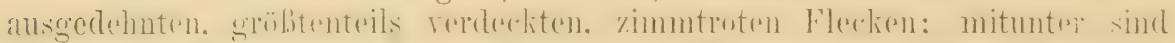

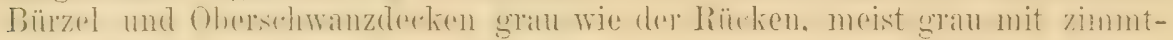

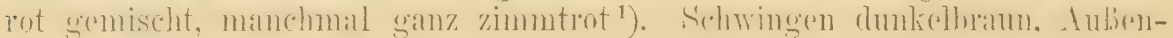

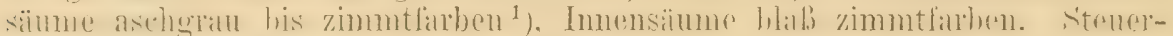

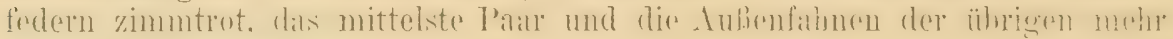
oder minder graubraun.

Oberdecken wie der Rücken, an den Seiten der Kehle meist einige

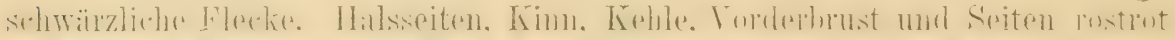

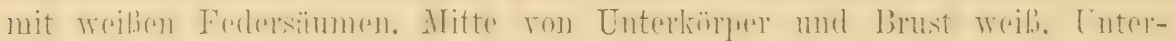

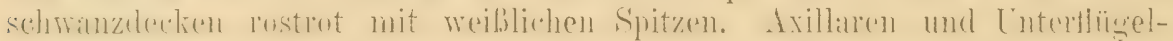
decken hell rostrot mit oder ohne sehr schmale weißliche Säume. Iris braun.

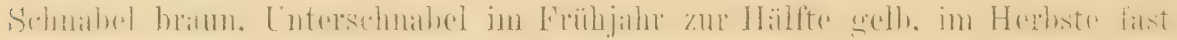
ganz bräunlich. Füße hellbraun. Flügel etwa 130-140, Schwanz etwa 95-100, Lauf 52.5-54, Culmen etrva 23-24.5 mm. O wie ơ, aber Kehle

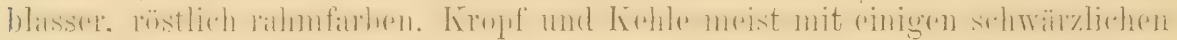
Flecken, Flïgel ungefäh $5 \mathrm{~mm}$ kürzcr. - Im Frühjahr treten die zimmt-

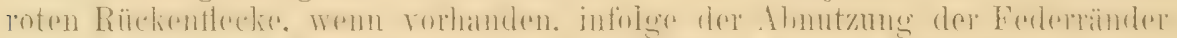

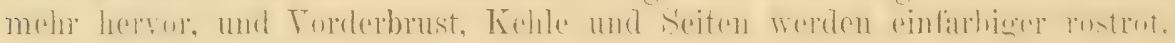
- Juv. im Nestkleide: Rückenfedern mit schwärzlichen Spitzen und bell röstlichen Mittelflecken; Kehle und Brust hell röstlich mit rundlichen schwarzen Flecken.

Naumanns Drossel ist Brutvogel in Sibirien vom Jenissei nach Usten

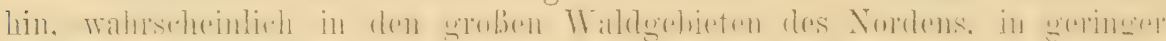
Anzahl am Baikal-See, vielleicht im allgemeinen südlicher als $T$. fuscutus, aber am Jenissei in denselben Breiten. - Als Zugrogel in den Amurund Ussuri-Ländern, in der Nongolei, in Korea, im Winter im Süden der Mandschurei, in Nord- und Mittel-China und seltener in Japan. Darison

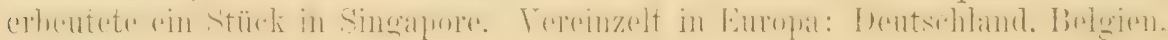
Holland, Osterreich, Ungarn, Italien, Süd-Frankreich.

Die ron Popham gefundenen sicheren Eier gleichen denen von T. dubius.

\section{Turdus fuscatus Pall.}

? Turdus dubius Bechstein, Gem. Naturg. Dentschl. IV, p. 240, Taf. V b (1795- Coburg. Bezieht sich wahrscheinlich auf diese Art, doch sind einige Angaben nicht recht passend).

Turitus fuscatus Pallas, Zoogr. Rosso-Asiat. I, p.451, 'Taf. XII (1827— ,in sylois alpinis Daunriae").

1) Die auffallende Variation dieser Drossel hat wahrscheinlich ihren Grund größtenteils in individueller Abänderung, aber es sind auch andere Möglichkeiten vorhanden, von deuen eine die ist, daß T. naumanni, wie wir sie heute vor uns haben, aus der Vermischung ron zwei früher getrennten Formen entstanden ist. $\sigma^{\widehat{t}}$ mit dunkel kastanienbrauner Vorderbrust und Seiten sind sicher nur Aberrationen, es kommen jedoch Stïcke vor, die man für Hybriden mit $T$. fuscatns halten muß. Ein naheliegender Gedanke ist, daß T. naumanni und T. dubius geographische Vertreter (Subspezies) sind, aber nach unserer heutigen geringen Kenntnis von ihrer Verbreitung zur Brutzeit können wir dies nicht als sicher annehmen, auch spricht das anscheinend verhältnismäßig häufige Vorkommen ron Bastarden dagegen, denn zum Entstehen letzterer ist ein Zusammenwohmen. nicht geographische Vertretung erforderlich. 
Turilus cunomus Temminck, I'l. Col. 514 (1830- Japan).

Abbild.: Seebohms Monogr. Turdidae II, Taf. 145, 146. - Eier: Ibis 1901, Taf. IX. Fig. 1-4.

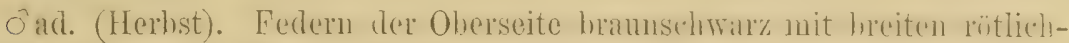

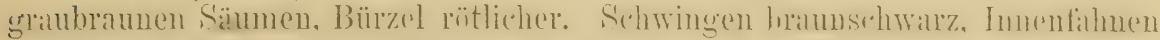

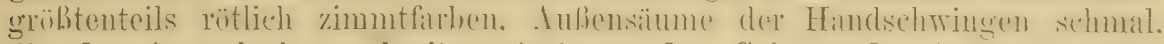
die der Armschwingen breit rostrot, an den Spitzen der imnorsten Arm-

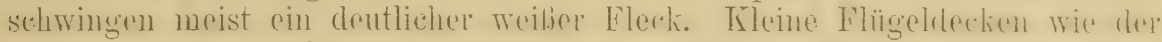

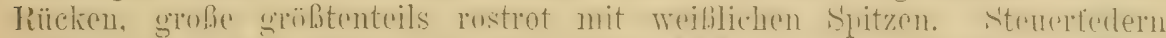

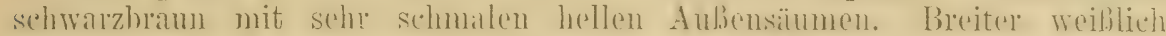

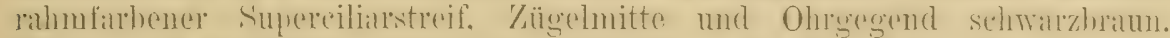

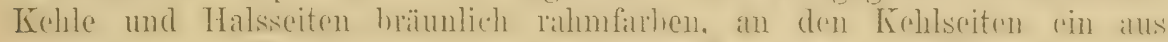
sehwarzhaunen l'muliten bestehender Bantstreif, atuch an den Halsspiten und

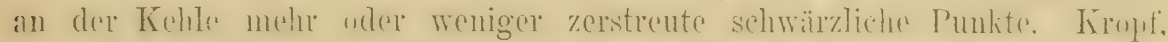
ganze Vorderbrust und Seiten schwarz mit breiten weißen, die schwarze

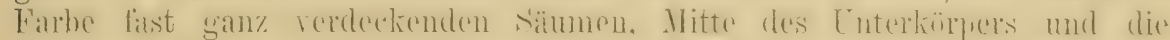

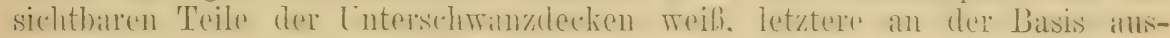

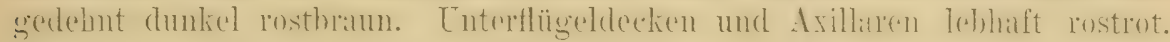
Iris braun. Schnabel braun. Füße hellbraum. Flügel etwa 128-134.5, Schwanz 95-98, Lauf 32-33.5, Culmen 32.5-34 mm. Im Frühjahr werden Oberseite, Brust und Seiten schwärzlicher, da sich dio hellen Säume abstoßen, der Bürzel ist in der Regel rötlicher. Der Schmabel wird gelblich mit brauner Spitze. - o ad. Rücken nicht so schwärzlich,

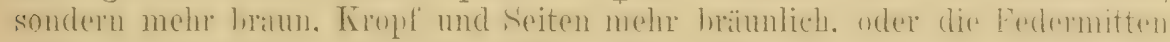
nicht so ausgedehnt schrvarz. Flügel etwa 122-12s mm. - Im ersten

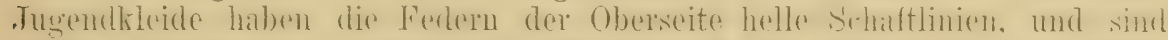

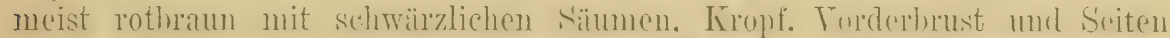
sind weifs oder rahmfarben mit lundlichen Fleclen. - Das frefieder ist sehn

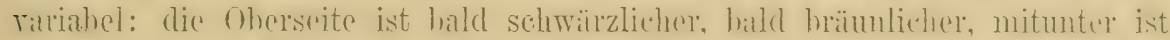
anch der ganze Rïrken stark mit Restrot vertaschen. lisweilen sugar last

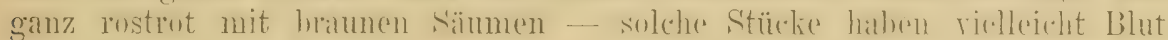
von $T$. naumami in sich, eine Art, die sich ohne Zwoifel mitunter mit T. frescatus rerbastardiert.

Brïtet in Sibirien, nördlich bis fast an die Mündung der Lena, am

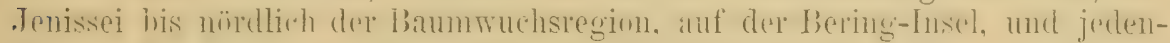
falls in Kamtschatka und vielloicht im Norden von Sachalin. - Auf dem Zuge und im Winter in Menge in Korea, Japan, der Mandschurei und Mongolei, in ('hinal his Amoy und Formosil. Assam unt Nordmest-Indion.

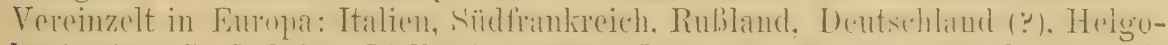

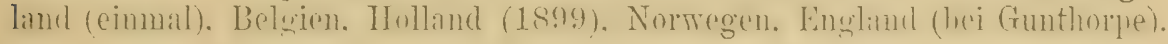

Der Lockton ähnelt nach Seebohm dem ron T. musicus (iliacus auct.), andere Angaben beruhen wohl auf Irrtum. Das Nest steht am Boden oder in Büschen und Bäumen nahe über der Erde. Die von Popham gefundenen Eier ähneln denen ron T. pilaris oder ron T. merula merula. Die Eier in Nehrkorns Sammlung (Fundort "Ost-Asien"!) ebenso die vom "Altai"(?) in R. Blasius' Sammlung sind unzuverlässig. Neun sichere Eier messen nach Jourdain im Durchschnitt $27.15 \times 19.85$, Ilaximum $30.6 \times 19.5$ und $27.1 \times 21.1$, Minimum $24.1 \times 19.2$ und $24.2 \times 19 \mathrm{~mm}$.

\section{Turdus ruficollis ruficollis Pall.}

Turdus ruficollis Pallas, Reise rersch. Pror. Russ. Reichs III, p. 694. (1776- „Hab. in summis jugis Davuriae larycete obsitis"). 
Turdus erythrumes Hodgson, Gray's Zool. Misc., p. 83 (1844- nomen nudum).

Turdus hyemalis Dyborski, Journ.f. Orn. 1872, p. 439 (Kultuk am Baikal-See, Beschreibung der Var. mit braunem, wolkenartig gefleckten Brustschilde).

Abbiid.: Dresser, B. Europe II, Taf. 8.

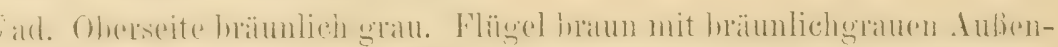
nul undentlich rostbraunen Innensäumen. Seliwanz wie bei $T$. numm

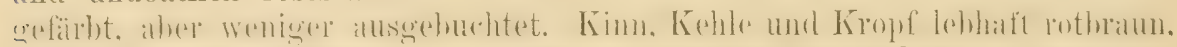

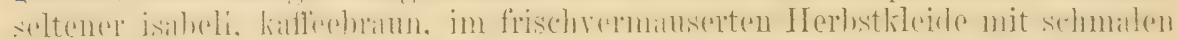

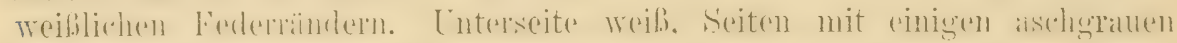
Strichen, Basis und Säume der Unterschwanzdecken meist rostrot. An deu

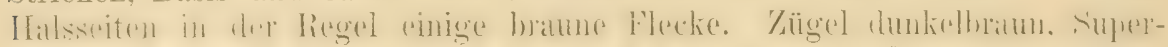

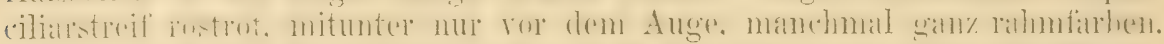

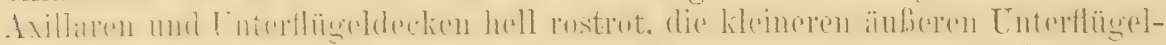
decken mehr oder reniger ausgedehnt hellgrau. Iris braun. FüiBe braun.

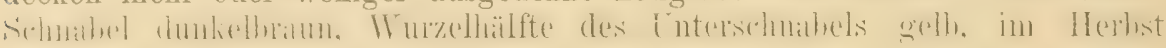
mehr braun. Flügel etwa 134 bis 140 , Schwanz etwa $100-106$, Tauf $33-34.5$. Culmen etwa $24-25 \mathrm{~mm}$. - o. Auf der Oberseite etwas brüunlicher als

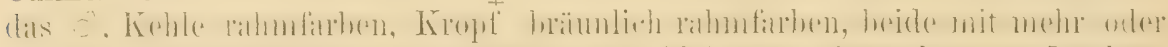

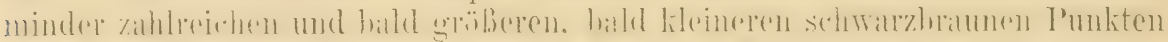

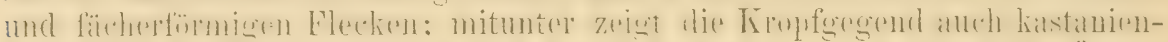

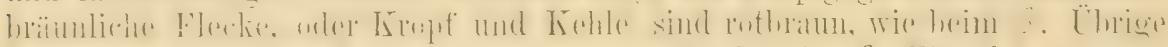

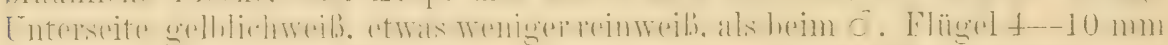

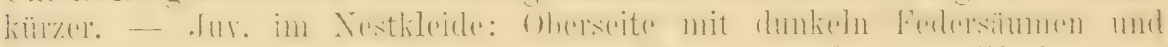
gelblichen Schaftflecken, Brust mit großen schwarzbraumen Flecken. Ein sonst normales von Dr. Coltart in Assam erlegtes of hat rostrote Feder-

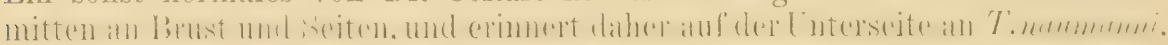
Es scheinen Bastarde mit T. atrogularis vorzukommen, doch düften die o

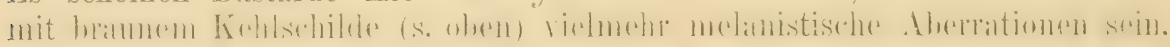

Hänfig in Ost-Sibirien, wo sie in den Zirbel- und 'Tannenwäldern der Gebirge nistet, doch sind die Nester und Eicr noch nicht beschrieben. -

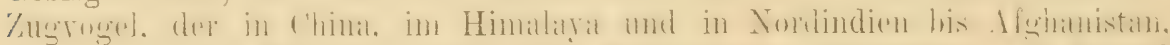

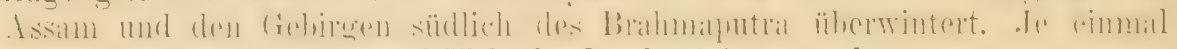
als in Deutschlard und auf Helgoland erbentet angegehen.

\section{Turdus ruficollis atrogularis 'temm.}

Twdus atrogularis Temminck, Man. d'Orn. I, p. 169 (1820- „Habite: rarement en Autriche et en Silésie ...").

Turclus Bechsteinii Naumann, Vög. Deutschl. II, p.310, Taf. 69, Fig. 1, ơad. (1822Deutschland. Naumann glaubte, dieser Vogel sei Bechsteins 'T. dulius. Der von ihm abgebildete junge Vogel scheint T'. sibiricus zu sein).

Herulc lencogaster Blyth, Journ. As. Soc. Bengal XVI, p. 149 (1847- Assam. Nach einer Abbildung!)

Turdus mystacimus Sewertzoff, Turkest. Jevotn., in Izr. Obshch. Moskov.VII, 2, p. 64, 118 (1873- Turkestan); Übers. in Mladarászs Zeitschr. f. ges. Orn. IV, p. 48-50.

Merula relicta Zarudny \& Korejew, Oru. Monatsber. 1903, p. 129 (auf dem Zuge(!) bei Dscharkent in Turkestan).

Abbild.: Dresser, B. Europe II, Taf. 2. - Eier: Ibis 1901, Taf. IX, Fig. 9-12.

otad. Wie das von T.r.mficollis, aber Kinn und Kehle bis auf den

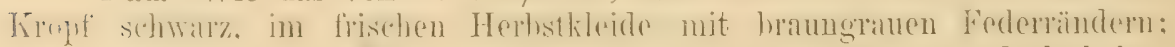
häufig erstreckt sich das Schwarz auch auf Kopf und Nacken, doch haben 


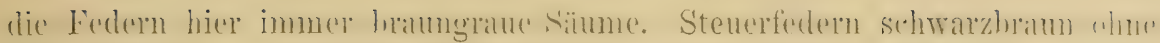

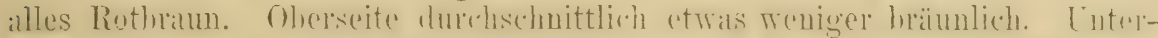

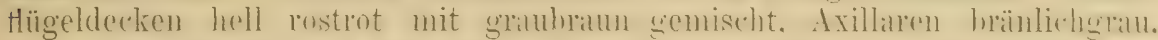

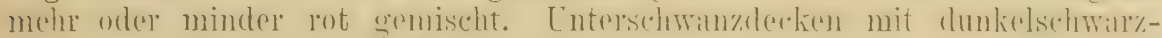
braunen statt rotbraunen Wurzeln und Säumen. o und juv. wio die von

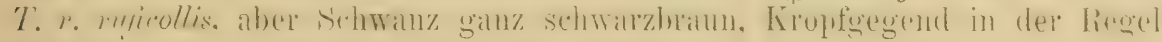
dunkler und schärfer braunschwarz gefleckt.

Nistet in Westsibirien, in den Täleru der Flüsse Ob und Jenissei, sïdwïrts bis zum Altai und nach Sawertzoft im 'lian-Schan. - A uf dem Zuge

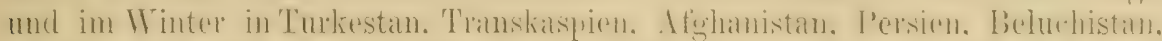

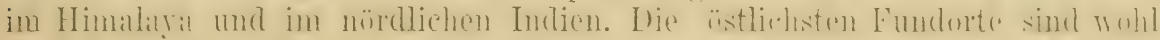

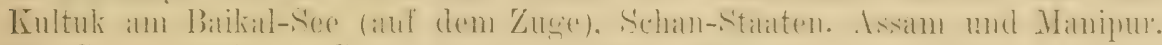
Ein Stück wurde in Süd-Arabien erbeutet. Mehrfach in Europa: Finland,

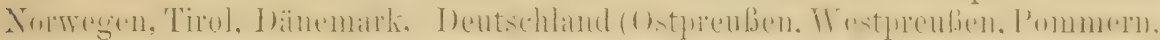

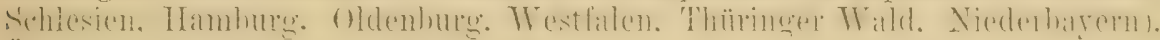
Östorieich, England, Schottland.

Augenscheinlich schließen die Brutgebiete von 'T. r. micollis und T. r. atroguluris sich vollkommen aus. Die angeblichen Bastarde dieser Form könmen ebensowohl Aberationen oder Rüchschlägo soin, und an den

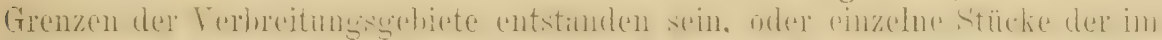

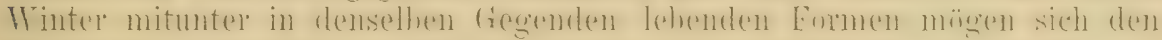
Scharen der anderen angeschlossen und mit ihmen verbastardiert haben.

Nach Popham brütet diese Drossel in den großen Nadelwäldern am Jenissei. Das Nest ist aus Gras gebaut, dick mit Erde ausgeschmiert und schließlich wieder mit feinen Gräsern gefüttert. Es steht in Fichtenbäumen, etwa 1-2 m ïber dem Boden. Die meisten Eier sehen aus wie kleine Amseleier, andere gleichen melr deu Eiern ron 'I', viscivorus. 27 Eier messen nach Jourdain im Durchschnitt $29.18 \times 21.3$, Jaximum $30.6 \times 20.4$ und $30.2 \times 23$, Minimum $27.4 \times 21.6$ und $28.8 \times 20.4 \mathrm{~mm}$. Der (resang ähnelt nach Popham dem ron T. philomelos, ist aber noch abwechslungsreicher, und die einzelnen Strophen werden nicht so oft wiederholt.

\section{Turdus castanea castanea (Gould).}

Merula castanea Gould, Proc. Zool. Soc. London 1835, p. 185 (Himalaya, wahrscheinlich aus Sikkim oder Nepal).

Turdus rubrocanus Hodgson, in Grays Zool. MLisc., p. 83 (1844- nomen nudum.)

Abbild.: Gould, B. Asia IU, Taf. 5. Seebohm, Mlonogr. Turd. II, I'af. 114. Eier: Cat. Eggs Brit. Mus. IV, Taf. VI, Fig. 16, 17.

ơad. Kopf und Hals bräunlich aschgrau, nach hinten zu und au Kehle

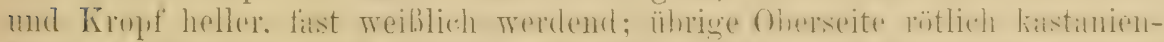

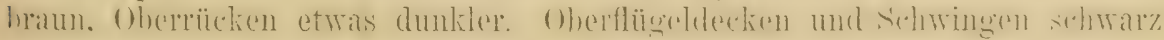
mit schmalen braunen Säumen. Stenerfedern schwarz, das äußerste

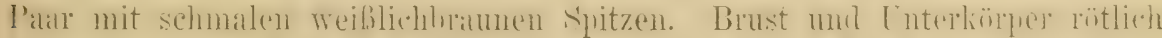

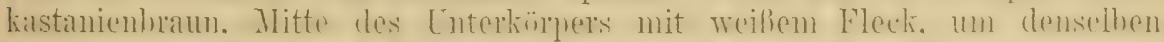

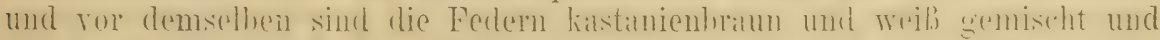

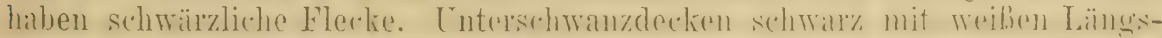

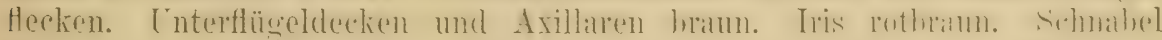
wachsgelb. Füße hellgelb. Flïgel etwa 134-141, Schwanz 107-114, Isauf 32.5-34, Culmen 27.5-29.5 mm. - o ad. Alle Farben weniger

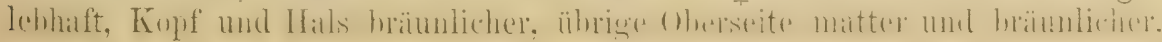


Flïgel und Schwanz braun. Nitte des Unterkörpers brïunlich. - Juv.:

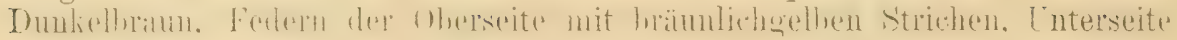
woiß mit schwarzen Tedersïmmen, Körperseiten dunkel kastanienbraun.

Himalaya von Ratvalpindi (Kaschmir) bis Sikkim, in Assam und den Bergen südlich des Brahmaputra.

Brütet in Höhen ron $6000-9000 \mathrm{Fuß}$, anscheinend zweimal im Jahre, da im April und Juni Eier gefunden wurden. Nester an Erdwänden, aus Moos, mit einer Unterlage von abgestorbenem Farnkraut, mit etwas Erde versehmiert und mit feinen Gräsern ausgefüttert. Die Eier gleichen Amseleiern und sind grünlichweiB, mit braunroten Flecken und Spritzeru über und über bedeckt, oder sparsamer und gröber rotbraun gefleckt. 10 Eicr messen $27.5-33 \times 19-23.8 \mathrm{~mm}$.

\section{Turdus castanea gouldi (Verr.).}

Nerula Gouldi Verreaux, Nouv. Arch. Mus. d'Hist. Nat. Paris VI, Bull. p. 34 (1871West-Szetschwan).

Abbild. op. cit. 'Iaf. 5; Seebohm, Monogr. T'urd. II, Taf. 116.

Ähnlich T. c. castunea, aber der Kopf und Hals mehr dunkel braun-

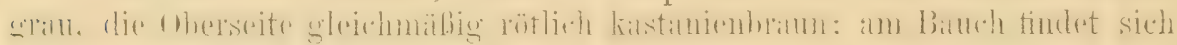
nur sehr wenig WVeiß, die Unterschwanzdecken sind bräunlichschwarz mit

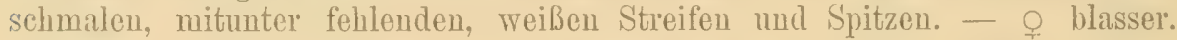
Flügel von 8 o $139-146$, von 5 o etra ebenso. - Juv.: Gefleckt, schou im Nestkleide unterscheiden sich die Geschlechter auffallend.

Bewohnt die westchinesischen Gebirge vou West-Szetschwan bis Kansu und 'T'sin-ling (Ta-pai-schan).

In Bergwäldern, im Winter in niedrigeren Lagen. Giesang dem der Amsel ähulich, aber rauher. Ende Juni fliegen die Jungen (nach Przewalski) aus.

\section{Turdus kessleri Przer.}

Turdus kessleri Przewalski, Jlong. i. Strana Tangut,, p. 62, Taf. X (1876- Kansu): übersetzt: Rowleys Orn. Nisc. II, p. 199; Taf. LIV, II.

Eier: Pleske, Ares Przewalsk. (p. 21), 'T'af. V, F'ig. 2.

Abbild.: Seebohm, Monogr. Turdidae II, Taf. CXV.

ơad. Ganzer Kopf und Hals bis auf den Nacken, Kehle bis zum

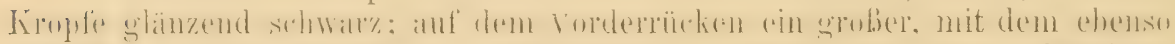

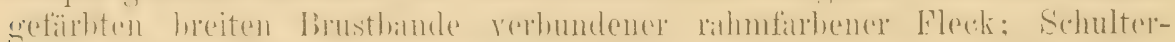

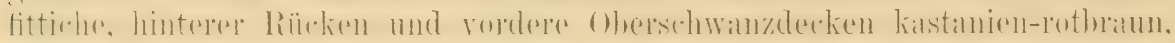
die längsten Oberschwanzdecken graubraun mit zuweilen undeutlichen

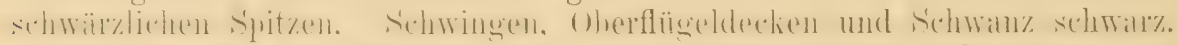

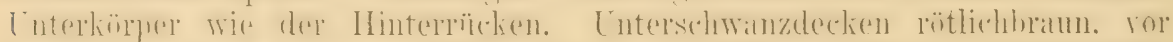

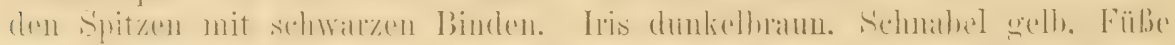
braun. Flïgel von 8 o $153-163$, Schwanz otwa $130-140$, Lauf $34-38$, Culmen 25-27 mm. - o ad. Das Schwarz an Kopf, Flügeln und Schwamz ist matt, unrein, und die Federu baben schmale bräunliche Säume, das

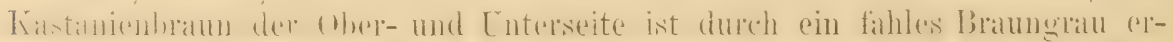

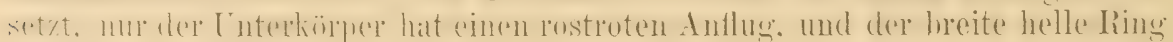
an Brust und Vorderrïcken fehlt. Schnabel braun. - Nestkleid: Kopf und

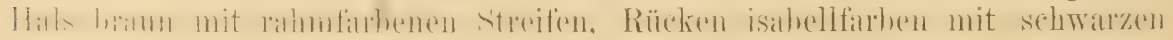




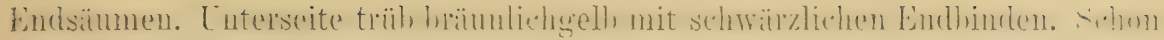
im Nestkleide unterscheiden sich die Geschlechter auf den ersten Blick.

Von West-Szetschwan (Ta-tsien-lu) bis Kansu, Tetung-Gebirge, oberer Ditschu, Kuku-Nor und Ost-Tibet.

Bewohnt die Waldregion der Hochgebirge und die dichten Wachholderbestände der alpinen Zone bis 12000 Fuß ïber dem Meere. Der Gesang erinnert an den der Singdrossel, die Lockstimme klingt wie tschok, tschok, tschok. Die Nester wurden an Felsen und überhängendem Gestein oberhalb eines Bachbettes gefunden; sie "waren aus Grasstengeln gebaut und eins thatte in der ILulde Haare and Federn von Perdix sifanica. Die Eier sind denen ron Turdus pilaris ähnlich, nämlich auf hellgrünlichem Grunde bald dunkler, bald heller und lebhafter, dichter oder sparsamer rostrot gefleckt. 10 Eier ( 6 von Pleske, 4 von mir gemessen) messen im Durchschnitt $31.51 \times 22.7$, Maximum $34.5 \times 23.5$, Hinimum $30 \times 21.5 \mathrm{~mm}$.

\section{Turdus albocinctus Royle.}

Turdus albocinctus Royle, Ill. Himal. Bot., p. LXXVII (1839- Himalaya).

Turdus albicollis t. c., Tat. VIII, Fig. 3 (1839- non Vieillot!).

Turlus collaris Soret, Rer. Zool. 1840, p. 2 ("Vient de Calcutta" - unrichtig).

Merula nivicollis Hodgson, in Grays Zool. Misc., p. 83 (1844- nomen nudum!).

Abbild.: Seebohn, MLon. Turdidae II, Taf. 82.

కౌad. Oberseite glänzend schwarz, Unterseite schwarzbraum, ringss um

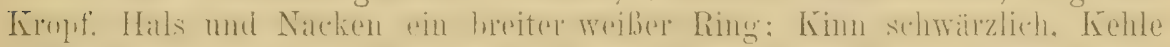

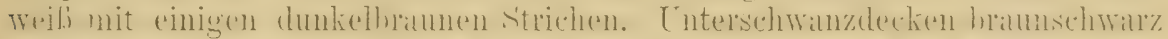

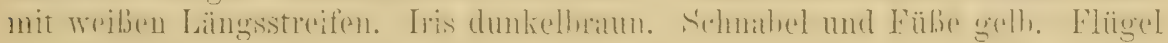
von 4 ơd etrva 138-142, Schwanz etra 112-118, Lauf 34-35, Culmen 26-28 mm. - - ad. Ober- und Unterseite rötlich dunkelbraun, der Ring

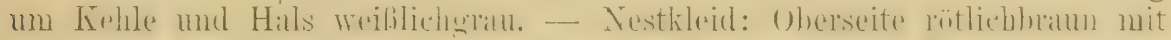

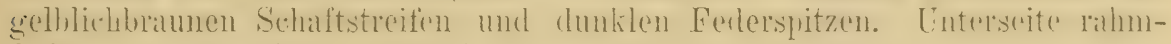
farben mit dunkelbraunen Endsäumen, Weichen röstlich.

Diese Drossel — die keimestreg's mit Turdus torquatus, sondern vielmehr mit $T$. kessleri am nächsten verwandt ist - bewohnt den Himalara rom (1)t-Kilschmir his Sikkim, und rielleicht noch weiter nitch osten hin.

Nistet östlich von Simla in Höhen von 8000-10000 engl. Fuß, in Sikkim sogar bis zu 12500 Ful hoch in Eichenbüschen oder am Boden. Die Nester sind nach Usmaston große Bauten aus Mloos, mit feinem Grase ausgelegt, denen der Jisteldrosseln nicht unähnlich. Gelege von 3 und 4 Eiern wurden am 23. und 24. ILai gefunden. Die Eier sind blaßblau, uiber und über mit rötlichbraunen Flecken bedeckt und mit einigen wenig bemerkbaren hellgrauen Schalenflecken. Von 7 Fiern mißt das größte $30 \times 21.2$, das kleinste $28 \times 20.9$, die übrigen 5 durchschnittlich $29.2 \times 21.2 \mathrm{~mm}$.

\section{Turdus torquatus torquatus $\mathrm{I}_{\mathrm{s}}$.}

Turdus torquatus Linnaeus, Syst. Nat. Ed. X, p. 170 (1758- „Europa“. Als terra typica betrachten wir Schweden).

Merula montana Brehm, Handb. Naturg. Vög. Deutschl., p. 375 (1831- „bewohnt die hohen deutschen Gebirge, doch nicht die Alpen Tirols". Die Sammlung enthält Stücke von Hummelshain und Pommern).

Merula collaris Brehm, t. c., p. 376 (1831-- Zugvogel in Deutschland).

Engl.: Ring-Ouzel. Franz.: Nierle à plastron. Schwed.: Ring-Trast. Ital.: Nerlo con petto bianco.

ald. in Herbste: Oherseite hramblehschwary mit sehmalen blab gran-

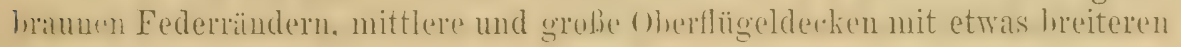




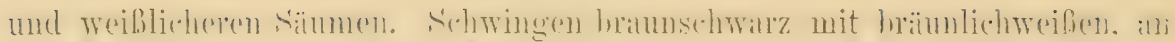

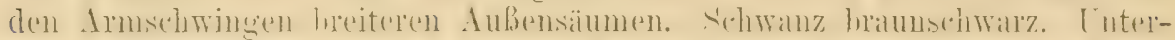

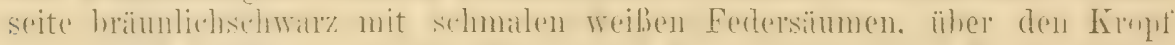

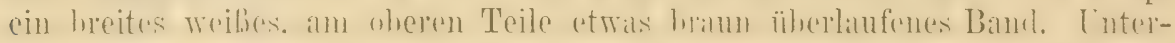

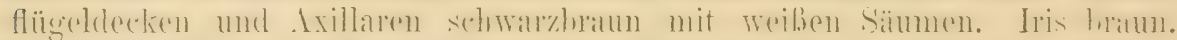

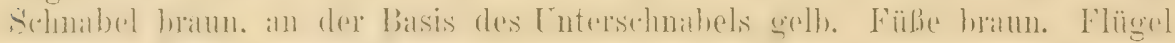
etwa 136-145, Schwanz etwa 112-118, Lauf 32-35, Culmen 25-26 mm. - o ad. Das Kopfband woißlich fahlbram mit braunen Federsäumen, die hellen Federränder etwas breiter, Gesamtfarbe brännlicher, Flïgel un-

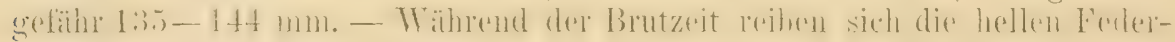
rïnder auf der Oberseite ganz, auf der Unterseite molu oder weniger ah und später im Sommer wird das Gefieder bräunlicher. Der Schnabel wird im Frühjahr orangegelb mit brauner Spitze. - Der junge Vogel im ersten Gefieder hat auf der tiefloraunen Oberseite weißliche Schaftstriche und die Federn der Unterseite sind dunkelbraun mit weißlichen Querbinden.

Die nordische Ringamsel brïtet in Nor(-Europa: in den Gebirgen Skandinaviens bis zum Nordkap, in Großbritannien, Irland und auf den Orkney-Inseln auf Hügeln und Mooren. - Auf dem Zuge in fast ganz Europa bis zum Mittelmeere, in geringer Anzahl im Winter auch in Nordwest-Afrika. (Das Brüten dieser Form in den Alpen ist zu bezweifeln; es wurden zwar am Pilatus am 4. April 1906 [Dr. G. v. Burg] ans einer Schar mehrere alpestris und zwei ô voul T. t. torrucutus erlegt; vom Col de Riou in den Zentral-Pyrenäen, wo alpestris nistet, erhielt das Tring-Nuseum noch am 5. Mai erlegte torquatus - da aber in den Wohngebieten der Alpenform die nordischen Vögel anf dem Zuge vorkommen und sie im hohen Norden erst spät zur Brut schreiten, sind diese und ähnlicho Vorkommnisse lieine Berveise für das Brüten in Mittel-Luropa. Angaben vom Brüten in Dentsch-

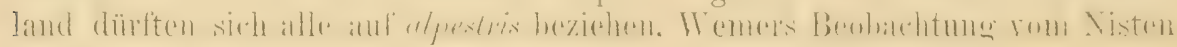
im Münsterlande u. a. m. bedürfen durchaus fernerer Bestätigung:)

Brätet in melhr oder minder offenem Gelïnde, wo nur Birken, niedrige Büsche und vereinzelte Bäume stehen, nicht im dichten Walde. Die Lockstimme ist mitunter ein kurzer Pfiff, öfters ein kurzes, scharfes tack-tack-tack. Der Gesang ist angenehm Hlötend, dem der Amsel nicht ganz unähnlich, aber noch kräftiger und viel eintöniger, indem dieselbe Strophe immer und immer wiederholt wird. Das Nest steht meist am Boden, besonders gern an grasbewachsenen Abhängen. Es ähnelt dem der Amsel und ist innen mit Grashalmen ausgelegt. Die $4-5$ Eier, die man im Mai und Juni findet, variieren wenig, denn sie sind in der Regel grünlichblau mit rotbraunen Flecken, seltener bräunlichgrün. Sie gleichen den bläulichen Varietäten der Amselund Wachholderdrosseleier. 100 Eier aus Großbritannien und IrIand messen nach Jourdain im Durehsehnitt $30.32 \times 21.54$, Naximum $33.5 \times 22.5$ und $31.3 \times 23$, Hinimum $26.2 \times 21.2$ und $26.3 \times 19.6 \mathrm{~mm}$. Rey gibt das mittlere Gewicht mit $0.423 \mathrm{~g}$ an.

\section{Turdus torquatus orientalis (Seeb.).}

Mernla torquata orientalis Seebohm, Ibis 1888, p. 311 (Kislowodsk im Kaukasus).

Sehr ähnlich T. t. torquatus, die weißen Federsäume an der Cnterund Oberseite meist noch sehmäler (also in keiner Wreise an T.t. alpestris erinnernd), aber die weißen Süume der Armschwingen und großen Ober-

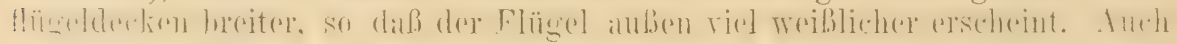
die lichten Innensäume der Schwingen sind ausgeprägter. Flügel ron 10 o $137-147 \mathrm{~mm}$. 
Nord- und Süd-Kankasus, Nord-Persien (Elbur's-Gebirge) und das angrenzende südliche, gebirgige 'Transkaspien.

Lebt in Kaukasus zur Brutzeit in der Rhododendronregion, bis zu 10000 FuB über dem Nleere, und in 'Tannenwäldern, und geht im Winter in die 'Täler' hinab. Nester am Boden und unter Rhododendronbiischen.

\section{Turdus torquatus alpestris (Brehm).}

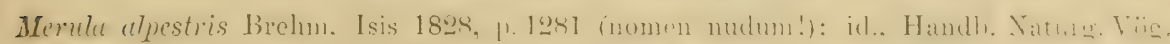

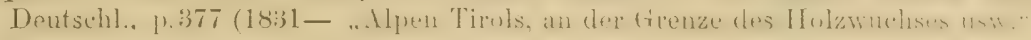
Erste Beschreibung).

Merula vociferans Brehm, Naumannia 1855, p. $28 \mathrm{~L}$ (nomen nudum!).

IFerula maculata Brehm, Vogelfang, p. 159 (1855- Alpen).

Menule maculata, insignis, vociferans Brehm.Journ. f. Orn. 1856, p. 446 (ohne Fundorte) Abbild.: Seebohm, Mon. 'Turdidae II. 'Taf. 85; Neuer Naumann I, Taf. 19, 1.

Von T.t. torquatus dadurch unterschieden, daß die Federn der Unterseite stets viel breiter weib gesïumt sind, und in der Mitte größere oder

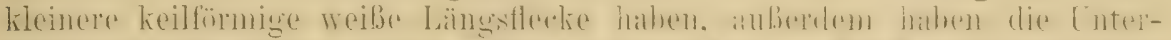

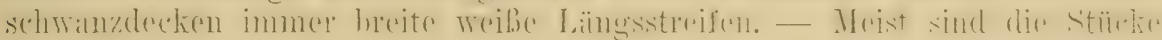
diesor Subspezies auf den ersten Blick zu erkennen und es ist erstaunlich. dab sie ein halbes Jahrhundert unbeachtet blieb, mitunter aber sind die weißon Federmitten sehr beschränt, und wenn bei solchen lixenuplaren auch noch die Federsïume in der Brutzeit abgenutzt worden sind, können sie bei oberflächlichem Vergleich leicht mit Stücken ron T. t. torquatus verwechselt werden.

Brutvogel auf den Gebirgen Mittel- und Süd-Europas: Pyrenäen, hohe

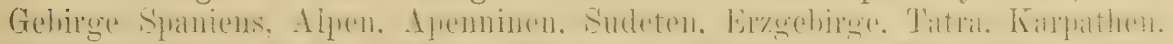

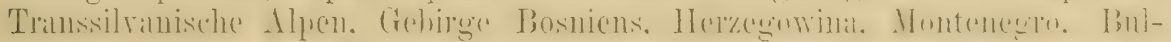

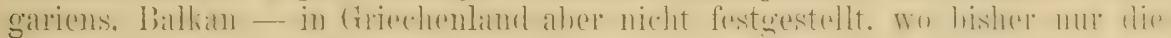
nordische Form im Winter beobachtet wurde. Kommt auch auf dem Zuge in Ungarn vor und ist dort mehrfach mit orientalis verwechselt worden. Im

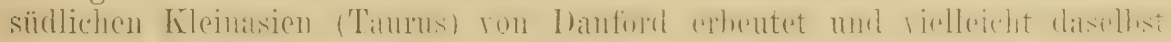
nistend. Soll in Luxemburg und Belgien, im Sanerlande und bei Osnatbrïck, bei Echternach und in der Eifel gebrütet haben -, doch bedürfen

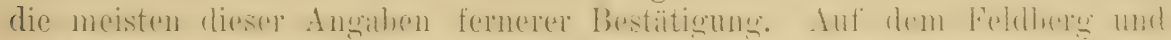

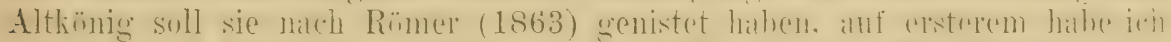

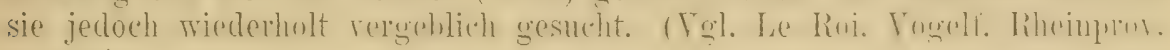
p. 284.)

Die Alpenamsel lebt in hochgelegenen Nadelwäldern, in der Rhododendron- und Knieholzregion. Das Nest steht in der Regel auf Nadelbäumen. 42 Eier (32 aus Transsylvanien, 8 aus der Schweiz, 2 aus Spanien) messen nach Jourdain im Durchschnitt $30.74 \times 22.23$, Maximum $34 \times 22.2$ und $30.6 \times 24$, Minimum $28.9 \times 21.2$ und $29 \times 20.3 \mathrm{~mm}$.

\section{Turdus merula merula Lim. ${ }^{1}$ ).}

Amsel, Schwarzdrossel.

Turdus Merula Linnaeus, Syst. Nat. X, p. 170 (1758- „in Europae sylvis". - Als Terra typica betrachten wir Schweden: ex Fauna Suec, erstes Zitat).

1) Synonymie, Beschreibung und Verbreitung ron Nr. 1017, 1019, 1020, 1021. 1023, 1024 und 1025 sind von Carl E. Hellmayr bearbeitet. 
Merula nigra Leach, Syst. Cat. Mamm, \& c. Brit. Ilus., p. 20 (1816- nom nud.).

Merula pinetorum Brehm, Handb. Naturg. Vög. Deutschl., p.372 (1831- „in den Nadelwäldern des nittlereu Deutschlands").

MI. truncorum Brehm, 1. c., p.373 (1831- "in den Laubhölzern Deutschlands").

M. alticeps Brehm, 1. e., p.373 (1831- „erscheint nur im Winter in unseren Wäldern und an unseren Quellen").

II. Camiolica Brehm, 1. c., p.374 (1831- „bewohnt den Fub der tyroler, kärthner und krainischen Alpen").

1I. vulgaris Selby, Illustr. Brit. Orn., 2. edit., I, p.167 (1833- "Ihis bird is well known as a native of the British Islands").

M. major Brehm, Vogelfang, p. 158 (1855- Europa).

Turdus Menegazziamus Perini, Uecelli Veronesi, p.56 (1858- Berge der Provinz Verona).

Merula vulguris gracilis, tenuirostris, microrhynchos A. E. Brehm, Verz. Samml., p.5 (1866- nomina nuda!).

T. menula var, montana Dresser, Birds Europe II, p.99 (1872- Pisa, Toscana).

Merula rubricollis Zonghi Lotti, Avicula II, p. 146,164 (1898- Italien, Var. von T.merulu). Turdus Termus Kleinschmidt, Journ. f. Om. 1903, p. 140 (Amsel und Verwandte).

Engl.: Blackbird. Franz.: Merle. Ital.: Merlo. Schwed.: Kolstrast, Solsvärta.

کึad. Einfarbig schwarz, die Flügel etwas matter als das übrige Gefieder.

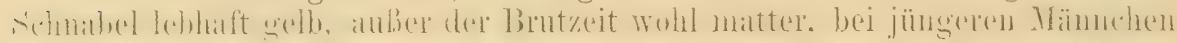
şanz oder teilweise braun. Flügelspitze von der 3., 4. und 5. Handschwinge gebildet, 2. Schwinge gewöhnlich zwischen der 6. und 7., bisweilen kaum

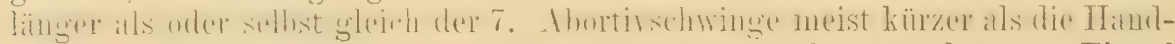
decken, manchmal aber ebenso lang oder sogar noch etwas länger. Flügel 124-134, Schwanz 105-117, Schnabel etwa $23 \mathrm{~mm}$. o ad. (aus Schweden).

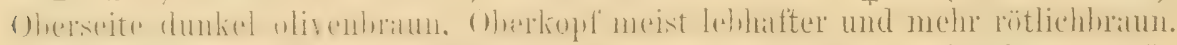

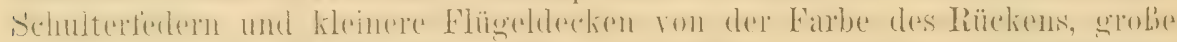

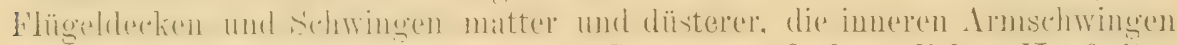
mit der Rückenfurbe überwaschen. Schwanz ruBschwärzlich. Kopfseiten dïster braun, dunkler als der Oberkopf, dio Ohrdecken häufig mit feinen,

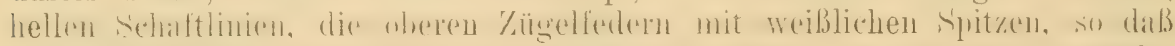

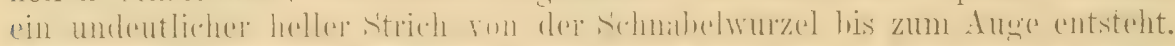

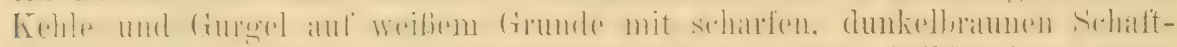

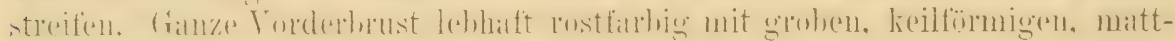
schwärzlichen Flecken, die auf den Spitzen der Federn stehen. Rest des

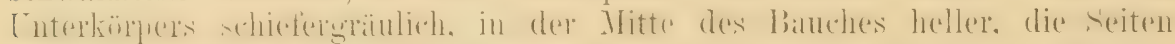

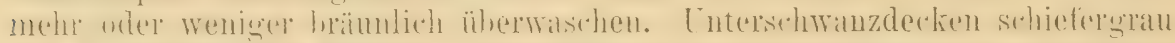

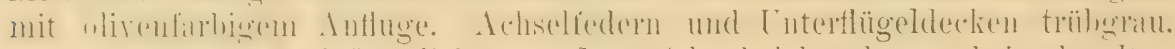

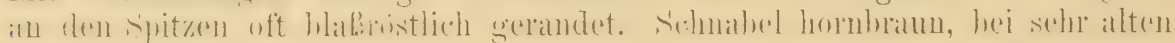
Vögeln blaßgelb. Flügel 120-128, Schwanz 105-112 mm. Junge Vögel im Nestkleid (vor der ersten Mauser) sehen dem Veibchen sehr ähnlich,

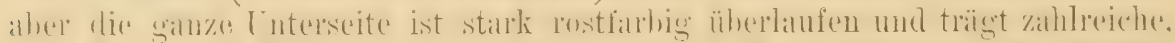

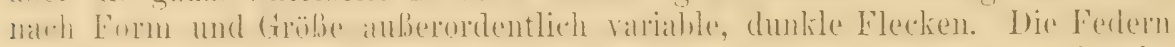

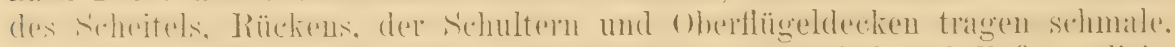

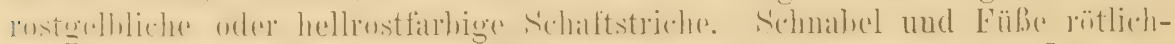
grau, Mundwinkel und Augenlid trïb orangegelb. [150 untersucht.]

Die Schwarzamsel brütet in Schweden und Norwegen (nordwärts bis

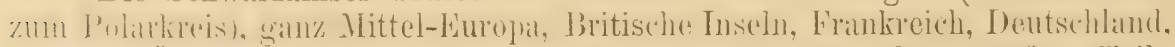
, thweiz,

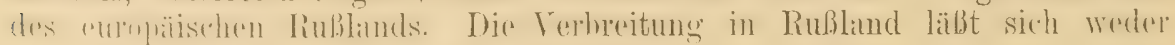
mach Osten noch nach Sïden zurzeit genau begrenzen. 
(Trotz des ansehnlichen, untersuchten Mlaterials ist es nicht unmöglich, daß hier unter dem Namen T. m. merula mehrere geographische Formen vereinigt sind. Vögel aus Großbritannien sind im allgemeinen kurzflügeliger und die Weibchen zeigen düsterere Färbung, besonders mohr olivbraunen Anflug auf der Brust. In Italien (T'oskana) findet man häufig weibliche Amseln mit ganz lebhaft rostfarbiger Unterseite. Sie murden als var. montana bezeichnet. Daneben kommen aber (anscheinend als Brutvögel) normal gefärbte Stücke, ja auch solche mit grauer Unterseite und bloß schwachem olivenbräunlichen Anflug auf der Brust vor, wie sie sich gelegentlich auch in der Schweiz, Tirol und Deutschland finden. Bei der Schwierigkeit Brut- und Zugvögel auseinanderzuhalten, bedarf es eines weit umfangreicheren Materials als mir zu Gebote stand, um die geographischen Formen der Amsel in West- und Mittel-Europa definitiv festzustellen. Dagegen sind die Brutrögel der Balkanhalbinsel (T. m. aterrima) sicher als besondere F'orm abzutrenuen.)

Stand- und Strichvogel außer im hohen Norden und Nordosten, wo sie im Winter versehwindet. - Früher allgemein, jetzt nur noch in dünner bevölkerten Gegenden scheuer Waldrogel. Im Westen in allon Parks, Gärten und Anlagen, selbst inmitten der Städte, und einer der bekanntesten aller Vögel. Gesang nicht so wechselvoll wie der der Singdrossel, weil immer in gleicher Tonhöhe bleibend, aber reicher an prachtvoll flötenden Strophen. Lockton ein tiefes tack, seltener ein kurzes "srih", Angst-, Warn- und Kampfruf ein lautes Ketern. Nest in Büschen und Bäumen, meist niedrig oder doch zu erreichen, mitunter am Boden (an Böschungen) oder gar in einer Höhlung unter der Oberfläche, oft in Eifeu und Weingerank. Das Nest ist innen immer mit feinen Grashalmen ausgelegt und enthält $4-6$ Eier. Sie sind grün oder grünlich mit braunen Flecken und variicren ungemein. Sehr selten sind ungefleckte Gelege. 100 Exemplare messen nach Jourdain und Rey im Durchschnitt $29 \times 21.39$, Maximum $35>21.5$ und $34 \times 24$, Ninimum $24>19$ und $25 \times 18 \mathrm{~mm}$. Durehschnittsgewicht nach Вau $427 \mathrm{mg}$.

\section{Turdus merula hispaniae Kleinschm.}

T'urdus hispanice Kleinschmidt, Falco 1909, p. 22 (,Sparien“; kein genauer Fundort).

Stumpfthïgelig (bei den vier von Kleinschnidt untersuchten stilchen ist die 3.-5. Schrvinge kürzer als bei $T$. m. memla) und verhältuismäßig langschwänzig: Flügel der 3 untersuchten alten of $12.3-12.7 \mathrm{~mm}$. Lin ón.

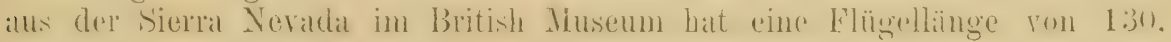
einen Sehwanz von $110 \mathrm{~mm}$. Ein mil vorliegendes $\mathrm{o}$ ist denen vou $T$ '. cubrerce ähnlicher als unseren, aber etwas bräunlicher und blasser. - Zahl der Eier im Gelege 3-4.

Spanien. - Die Tatsache, daß — wie es scheint — kein Museum Serien

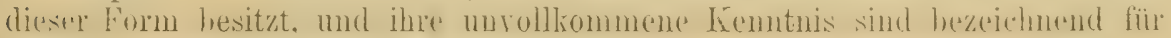
unsere Kenntnis der spanischen Vogelwelt.

\section{Turdus merula cabrerae Hart.}

Turdus merulc cabrerce Hartert, Norit. Zool. VUI, p.313 (1901- „Kanaren", Typus von Tenerife, cfr. Nov. Zool. IX, 1902, p. 326).

Merula canariensis (ex Hellmayr MS.) Madarász, Annal. Mus. Nat. Hungar. I, p. 559 (1903- Terror, Gran Canaria).

ôd. Unterscheidet sich vou den europäischen Formen durch tieferes, glänzenderes Schwarz des Gefieders, merlich kïrzere Flügel. etwas kürzeren Śchwauz und kräftigeren, im allgemeinen wohl alt:h ein wenig längeren

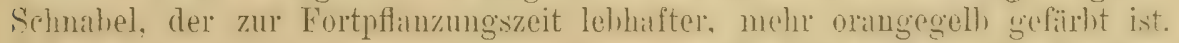

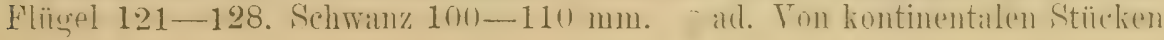




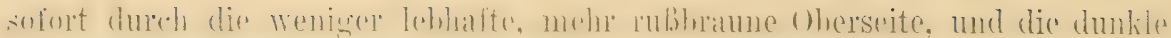
Unterseite zu unterscheiden. Brust und Bauch sind dëster rußbraun, die

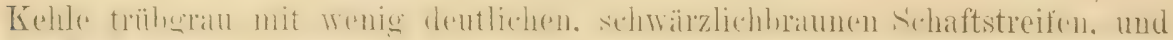

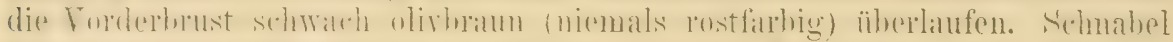

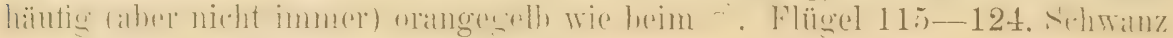
94-108. (44 Exemplare untersucht.)

Madeira und westliche Gruppe der Kanarischen Inseln (Tenerife, Grum Canaria, Palma, Hierro und Gomera).

Singt schlechter als die kontinentale Form und legt meist weniger (2-3. manchmal gar nur cin) mitunter aber bis 5 und 6 Eier. 19 Eier messen nach Jourdain im Durchschnitt $29.82 \times 21.69 \mathrm{~mm}$. - (Zwischen Vögeln von Gran Canaria und Tenerife besteht kein Unterschied; auf Madeira finden sich bisweilen langschwänzigere Individuen, das Gros stimmt aber mit den kanarischen Stiicken überein. Nur drei Weibchen (je eins ron Iladeira, Hierro und 'Tenerife) zeigen eine Andeutung von schwärzlichen F'lecken auf der Vorderbrust, welche in der Regel einfarbig; ungefleckt ist.)

\section{Turdus merula azorensis Hart.}

Tiurlus merela azorensis Hartert, Norit.Zool. XII, p:116 (1905- Santa Cruz, Graciosa.)

Oad. Ähnlich T. m. cabrerae von den Kanaren, aber der Schwanz merklich kürzer: und der Flïgel stumpfer und mehr abgerundet. Flïgel 117-125, Schwanz 90-102 mm. qad. Wie T'.m. cabrerce, oberseits rußbraum, aber die Kehle meist weiblicher und schärfer dunkel gestreift, die

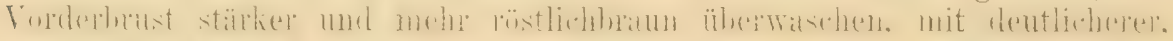

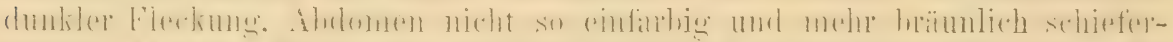

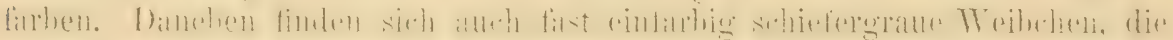
T. m. mantritanica sehr ähnlich sehen, aber durch viel lï̈reren Schwanz, abweichen. Flügel 112-122, Schwanz 90-100 mm. Schnabel matter als bei T. mo calrerae o, Oberschnabel stets mehr oder minder braun gefürbt. (21 Exemplire untersucht.)

\section{Azoren.}

Häufig, von der Küste bis anf die Höhen der Berge. Der Gesang wird als ein rollerer, getragenerer, als der der europäischen Amsel geschildert. Zahl der Eier 2-3. Die Eier gleichen denen der andern Formen.

\section{Turdus merula mauritanicus Hart.}

T'urdus merula mauritanicus Hartert, Novit. Zool. IX, p.326 (Juli 1902- Mhoiwla bei Mazagan, Marokko).

OTad. Unterscheidet sich ron T.m.calverae, dom es in dem tiefon, giënzend

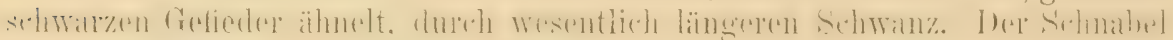
ist in der Regel kräftiger und länger. Flügel 126-132, ausnahmsweise nur 121-125, Schivanz 120-130 mm. (Oft ist die 6. Schwinge filst so lang wie die 5.) o ad. Ton Tr, m. calrerae leicht durch dunkelnufarbige

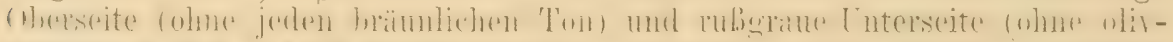

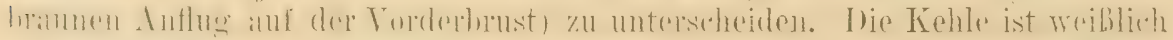

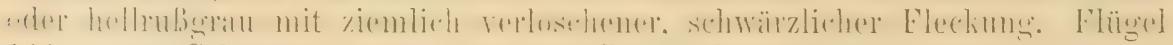
118-127, Schwanz, 110-120 mm. Schnabel anscheinend immer orangefarben. (Untersucht: 32 Exemplare aus Marokko, 17 aus Algerien.) 
Das südlichere Marokko (bei Mazagan, Mogador, sïdlicher Atlas),

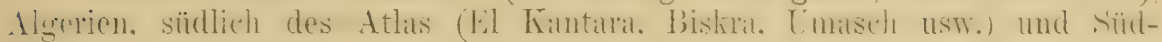
Tunesien (bei Gafsa).

Bewohnt in Harokko dichtes Gebüsch, Orangenhaine, Bergwälder, im südlichen Algerien Wälder, Gärten, Anlagen, Palmen-Oasen. Nistet in Büschen, in den Oasen mitunter auch auf DattelpaImen. Die Eier gleichen denen der europäischen Form. Der Alarmruf ist noch rauher als bei uns, der Gesang abgerisseuer, weniger klaugroll.

\section{Turdus merula algira (Mad.).}

Merula algiva Madarász, Ann. Mus. Nat. Hungar. I, p. 559 (1903- Bône iu NO.-Algerien).

Wie T. m, manitanicus, aber bedentend kleiner: Flügel ơ 119-124,

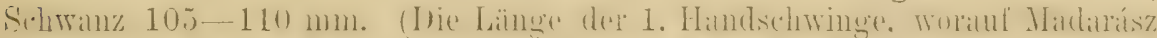

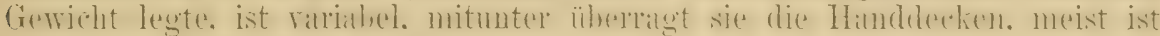
sie kï̈rzer oder gleich lang.)

Nord-Tunesien, Nord-Algerien, Nord-Narokko (Tanger').

Angstruf und Gesang wie bei T. m. mauritanicus. Nester in Büschen und Bäumen wie in Europa.

\section{Turdus merula aterrima (Mad.).}

Merulı aterrima Madaráš, Ornith. Monatsber. XI, p. 186 (1903- Wladikaukas, Kaukasus).

on ad. Weicht von schwedischen Amseln kaum durch reineres, aber oft

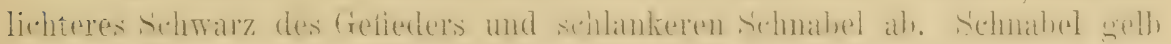
wie bei T. m. merula. Flïgel 123-134, Schwanz $105-115 \mathrm{~mm}$. o ad. Weicht auf den ersten Blick von $T$. m. merula durch viel mattere, fullere Unterseite ab. Die Kehle ist reiner reiß und die schwarzbraunen Streifen

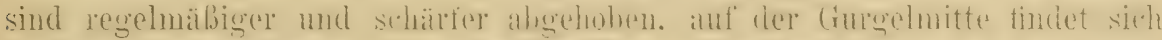

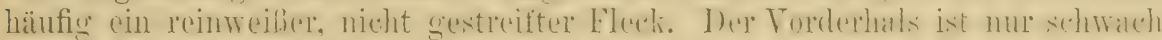

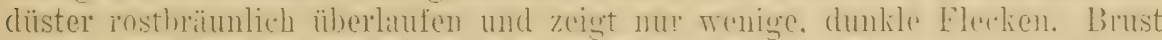

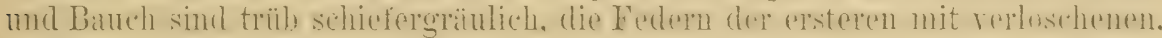
helleren Randsäumen. Flügel 118-125, Schwanz 95-110 mm. [Untersucht 42 Exemplare.]

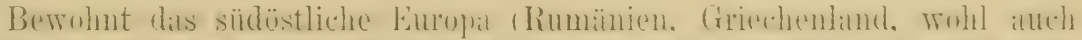

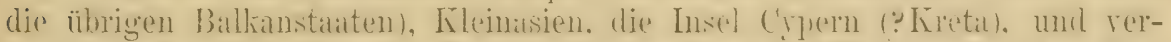

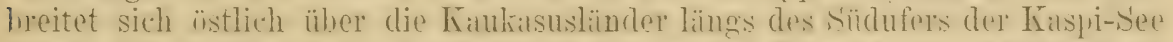
durch das nordiranische Randgentirge lis in die fresend ron Aschabial in

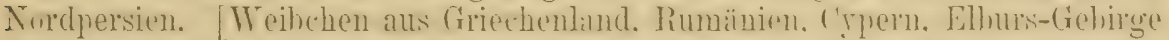

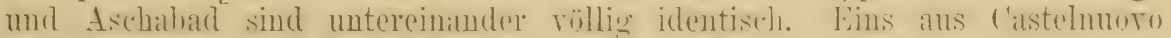
(Bocche di Cattaro, Dalmatien) stimmt gleichfalls völlig überein.]

\section{Turdus merula syriaca Hempr. \& Ehrbg.}

Turdus merula var. syriaca Hemprich \& Ehrenberg, Symb. Phys. Aves, fol. bb (1828Syrien).

? Turdus dactylopterus (Bonaparte MIS.) G. R. (iray, Hand-List Birds I, p. 255 (1869Syria, nom. nudum.).

ơad. Gleich 'T. m. merula, nur mit etwas längerem und melur ge-

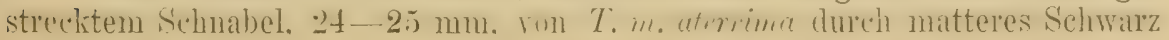


und längeren Sehnabel untersehieden. Flügel 127-131, Schwanz 115 bis $120 \mathrm{~mm}$. Q ad. Älinlich dem von T. m. cubrerae, aber auf Kehle und Brust

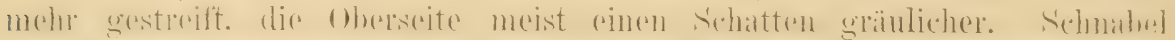
schlanker und wohl ein wenig länger. Von dem o vou T.m. aterima dureh

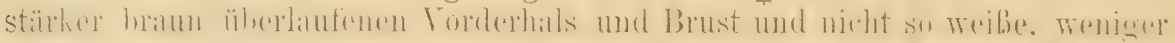

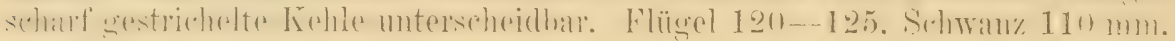
[Untersucht 8 Exemplare.]

Syrien, Palästina und das südliche Persien (Disful, Schuschter usw. im sïdiranischen Randgebirge).

(Die Verbreitung . dieser Form läßt sich zurzeit nicht mit Sicherheit feststellen. Ein $q$ aus Damiette, Ägypten, gehört auch hierher, doch ist es möglicherweise kein einhcimischer Brntrogel. II'elche Form in Ostpersien lebt und wieweit T. m. syriaca nach Norden verbreitet ist, vermochte ich gleichfalls nicht $z$ oruieren.

\section{Turdus merula intermedia (Richm.).}

Menula merala internedia Richmond, Proc. U.S. Nat. Mus. XV1II, 1895, p.585 (1896Aksu, Tian Schan, Ost-Turkestan).

ธad. Weicht von T. m. aterrima und T. m. syriaca durch die bedeutendere Grölie, besonders längere Flügel und stärkeren Schnabel ah. Flïgel 132-140, Schwanz 120--133, Schnabel etra 26-27 mm. qad. Ähulich dem von ' $T$ '. m. syriaca, aber viel größer. - Flügel 130-138, Schwanz 118-129 mm. [Untersucht 30 Exempliure.]

Gebirge von Turkestan und der Mongolei.

\section{Turdus merula maxima (Seeb.) ${ }^{1}$ ).}

Merula maxima Seebohm, Cat. B. Brit. Mus. V, p. 405 (1881- Partim! Kaschmir: die dazu gezogemen Stücke aus Jarkand gehören zu T. m. intermedia).

Die größste der palïiarktischen Amseln! ỡad. (Brutrogel). Dunkel rußbraun, Flügel und Schwanz rein schwar\%. Iris dunkelbraun. Schnabel gelb, an der Basis sehwarzbraun. Füle tiefbraun. Nach Lentnant Whitehead (in litt.) gibt es auch rein schwarze ô mit ganz gelbem Schnabel, sie

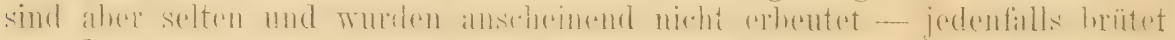
das ${ }^{*}$ in der Regel in dem oben beschriebenen Gefieder. Flïgel (3 cord.) 156-160, Schwanz 135-139, Lauf 36. Culmen $28 \mathrm{~mm}$. o ad. Sehr dunkel-

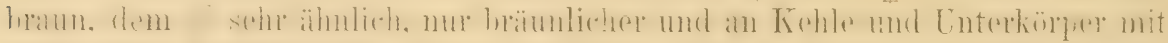

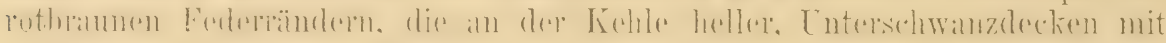
fahlbraunen Spitzen. Filügel (3 o) $150-155.5$, Schwanz $123-130 \mathrm{~mm}$. - Nestgefieder: Unterseite fahl rothraun mit schwarzer Querbänderung, Ohersoite schwarzbraun mit fahlgelbbraunen Schaftstreifen.

1) Im tropischen China, nordwärts bis Shaughai und Szetschwan lebt T. merula mandarimus Bonap. 1850. Die Färbung des Gefieders ist nicht glänzend schwarz, sondern ein mattes, sehr dunkles Rußbraun. Das ơ ad, zeigt einen kleinen weißlichen Fiunfleck, und an den Federn der Kehle und des Vorderhalses Spuren heller Randsäume, daß o hat die Kehle auf weißlichem Grunde breit schwarzbraun gestreift, im iibrigen gleicht es dem ot. Fliigel 148-155, Schwanz 110-120 mm. Schnabel gelb. 
Briitet in Hölıen von 10-12.500 engl. Fuß in Zentral-Kaschmiv und den Bergen rou Peschatrar (Sofid Kuh an der allehanischen firenze und

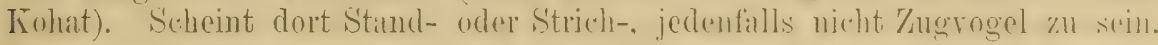

Leutnant Whitehead fand diese Amsel in Kohat im Mai und Juni im Wachholdergebüsch brïtend. Die Nistweise gleicht der unserer Amsel. Die Nester standen meist in Wachholderbüschen, gelegentlich in einer Aushöhlung am Felsen. Dem Gesang schien die Klangfülle und Variation des Amselgesanges zu fehlen, auch sangen die of nicht fleiBig. Der Lock- und Warnruf klingt wie tschut-ut-ut, kurz und raseh. Der zeternde Alarmruf wurde nur in der Nähe des Nestes mit Jungen vernommen. Die ơ sind sehr scheu. Die meisten ô brüten im nicht ganz rollen Alterskleide.

\section{Gattung MONTICOLA Bri 1822.}

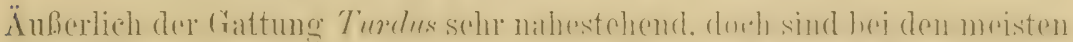

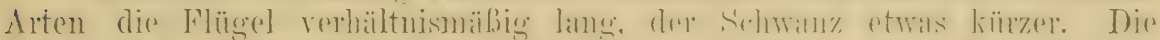

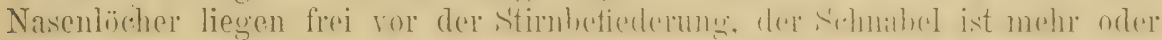

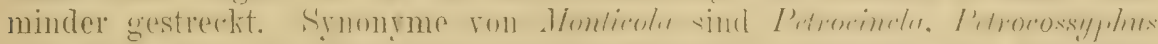

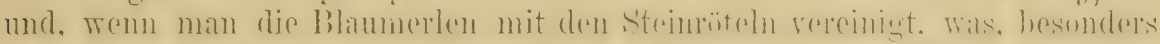

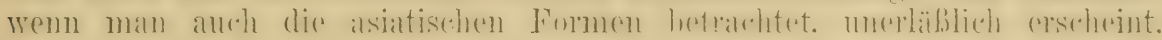
auch Petroptila, Orocetes, Cyanocinclu. - Europa, ganz Afrika, Asion. Tobensweise und Nistrveise mehr wie hei Suxicolu als bei 'Turdus.

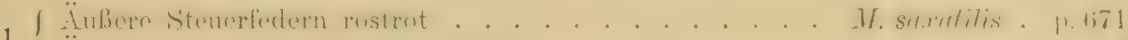

१ Äußere Stenerfeclern nicht rostrot . . . . . . . . . . ב

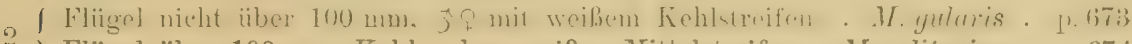

2 I Flügel über $100 \mathrm{~mm}$, Kehle ohne weißen Mittelstreifen . M. solitarius . j). 674

An den Südgrenzen der paläarktischen Region leben ferner:

1. Monticola erythrogaster Vigors 1831: ơ dem von M. solit. philippensis ähnlich, aber Kehle dunkelblau, Oberseite reiner und lebhafter blau; $q$ dunkler als das ron M. s. philippensis. - Himalaya und Gebirge von Assam.

2. Monticola cinclorlynncha Vigors 1831: Kaum größer als M. gularis: ô, Oberkopf und Kehle blau, übrige Unterseite und Bürzel rostrot, Armschwingen mit weißer Binde. - Himalaya, 4-8000 engl. Fuß hoch.

\section{Monticola saxatilis (L.).}

Steindrossel, Steimrötel.

Tudus saxatilis Linnaeus, Syst. Nat. Ed. XII, p. 294 (1766- „Hab. in Helvetiae, Austriae, Borussiae montibus". Ex Kramer, Frisch, Brisson, Gesner. Als terra typica betrachten wir: Helvetia).

Lanius infaustus $\beta$ minor Gmelin, Syst. Nat. I, p. 310 (ex Linnaeus, Brisson, Gesner, Frisch. - Europa).

Saxicola montana Koch, Syst. d. baier. Zool. I, p. 185 (1816- Baierische Gebirge: Vilstal im Regenkreise).

Petrocossyphus Gourcyi Brehm, Handb. Naturg. Vög. Dentschl., p. 370 (1831- Italien und Österreich).

Petrocossyphus polyglottus Brehm, 1. c. (1831- Südseite der Alpen, wahrscheinlich bei 'Triest).

Monticola saxatilis gracilis A. E. Brehm, Verz. Samml., p.4 (1866- nomen nudum!).

Engl.: Rock-Thrush. Franz: Merle de roche. Ital.: Codirossone.

ơad. Ganzer Kopf und Hals bis auf den Oberrïcken lebhaft hell

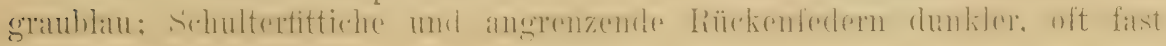


s(hwarz $\left.{ }^{1}\right)$, meist mit bräunlich weißen Endsäumen, vor denen eine schwärz-

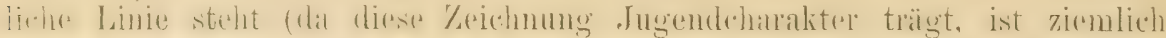

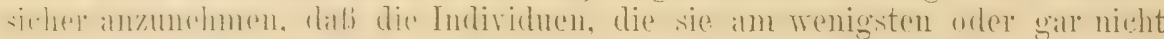
zoigen, die ältesten sind). In der Mitte des Rirckens ein großer, aber an

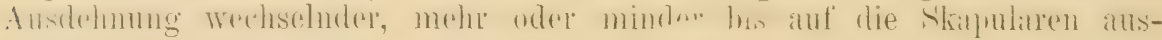
codehnter weißer Fleck: Unterer Bül\%,nl und vordere Obersehwanzdecken

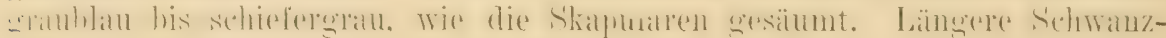
decken und Steuerfedern, mit Ausnahme des mittelsten Pares, das braun ist. und einiger ebenso gefärbter Außensäume nahe den Spitzen, rostrot.

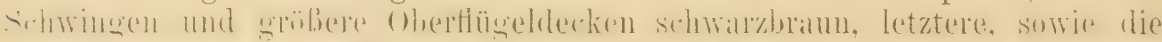

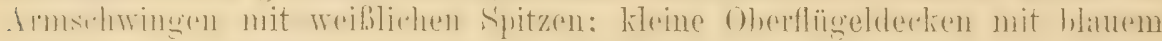
Shimmer. Unterseite von der Kropfgegend an, einschließlich der Unter-

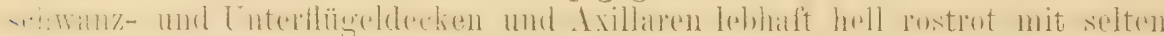
oder nie, ganz fehlenden, aber oft sohr sparsamen schmalen weißen Federsïimeu. Iris braun. Schmabel schwarz. Füße dunkelbraun. Flügel 117 bis 125, selten bis 127 und 128, Schwanz etwa 62-70, Lauf etwa $26-28$, Culmen etwa 24-26 mm. - o ad. Oberseite blaBbraun, Schïfte und

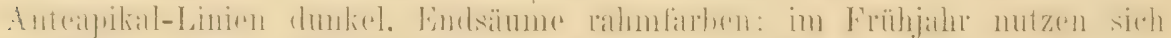

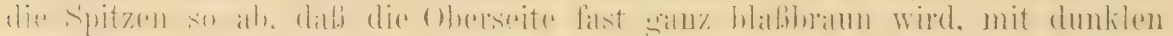
Schaftlinien. Unterseite blaß rostgelb, mitunter fast reiß, die Federn vor den Spitzen mit schwärzlichen halbmondförmigen Biuden. Unterschwanzdecken blaß rostrot. Schwanz wie beim o; Kehle weißlicher als die ت̈brige Unterseite, die schwärzliche Zcichnung reduzierter. Schuabel braun. Malie wie beim ơal. Das erste Jugendkleid ähnelt dem des o ad. ist aber hlasser und die dunklen Sämme der Unterseite sind breiter, aber weniger schurf gezeichnet, die Federn der Oberseite haben schwärzliche Spitzen und

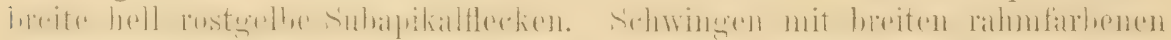
Śpitzen und Säumen. Schnabel braum. Junge ơ haben eine braune, mehr oder minder blau verwaschene Oberseite mit breiten bräunlich rahmfarhenen Federenden, die Kehle wie beim o; Unterkörper hell rostrot mit breiten

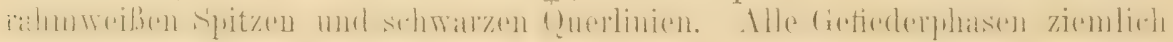
viliahel.

Bewohnt die Gebirge Nordwest-Afrikas, Süd- und Mittel-Europas, den Kankasus, Kleinasien, den Libanon und Hermon, Persien, T'urkestan, die

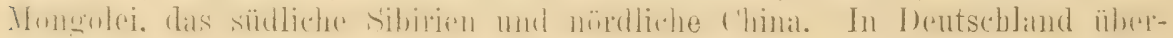

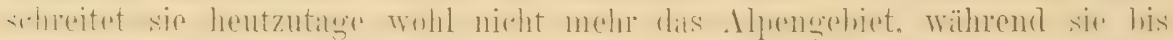

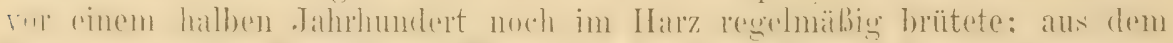

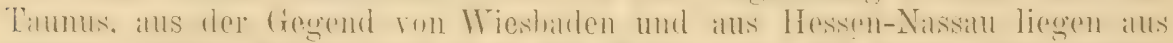

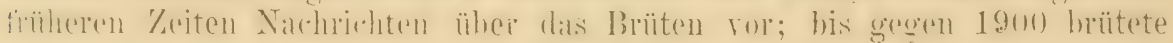
sie noch in den felsigen Tälern des Mittelrheins (bis Linz) und seiner

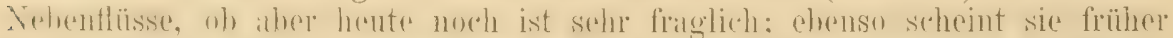

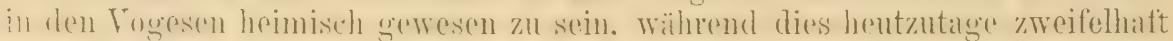

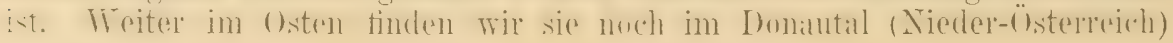

1) Hitunter sind rliese Teile kaum dunkler als der Kopf; besonders oft finden sich solche helle Stücke in Inner-Asien, wo aber in den gleichen Gegenden auch oft Stücke rorkommen, die vollkommen europäischen Exemplaren gleichen. Das Blau des Kopfes und Halses ist oft, aber nicht durchschnittlich, bei turkestanischen Stücken auffallend hell, variiert aber auch in Europa, ebenso wie die Ausdehnung des weißen Rïckenfleckes. Ich konnte nicht feststellen, daß es mehrere Formen gibt. 
bei Krems, Stein, Dürrenstein, bei Mödling (Hellmậr) und anseheinend auch in Nähren, als Brutrogel der ungarisehen Gehirge und nach T'aczanowski im südwestlichen Polen im Olkuscher Distrikt. In Nordwest-Afrika brütet sie nur in höheren Lages im Atlas. - Wandert durch die Silhara und Egypten, überwintert in West- : as Ost-Afrika, im nordwestliehen Indien und in China. Vereinzelte Stïcke wuider "uf Helgoland und in England erbentet.

Die Steinmerle trifft im April an ihren Brutplätzen ein. Sie ist ein scheuer Vogel, aber ihr kräftiger, an Flötentöneu reicher, drossel-ähnlicher Gesang verrät sie bald. Sie singt meist von der Höhe eines F'elsens herab, oft aber sehwingt sie sich singend in die Luft und schwebt mit ausgebreiteten Flügeln auf ihren Sitz zurück. Sie bewohnt felsiges Gelände und alte Burgruinen und erinnert in ihrem Wesen viel mehr an den Steinschmätzer als an Drosseln. Das Nest ist lose gefügt und besteht aus Pflanzenstengeln mit einer inneren Ausfütterung ron feinen Wïrzelchen und Halmen. Es steht an Felswänden, zwischen Felsblöcken und hohem Gemäuer, in Ritzen, Löchern oder unter überhängendem Gestein. Es enthält (nicht vor Mitte MLai) 4-5, mitunter 6 Eier. Letztere sind dünnschalig und von blaugrüner Farbe. Mitunter haben sie am stumpfen Ende einzelne oder viele kleine rotbraune Punkte und Flecken. 92 Eier messen nach Jourdain und Rey im Durchschnitt $25.96 \times 19.5$, Maximum $30 \times 20.8$ und $29 \times 21$, Minimum $23.2 \times 16.9 \mathrm{~mm}$, und ihr Durchnittsgewicht ist nach Rey $0.284 \mathrm{~g}$.

\section{Monticola gularis (Swinh.).}

Oroecetes gularis Swinhoe, Proc. Zool. Soc. London 1862, p. 318; Ibis 1863. 1). 93, Taf. III (Peking).

Òad. Oberkopf und Nitcken sowie kleine Oberflïgeldecken kobaltblau. Ohrgegend, Rücken und Schulterfittiche schwarz, in frischem Gefieder mit schmalen brannen Säumen. Bürzel und Oberschmanzdecken rötlich kastanienbraun. Schwingen brïunlichschwillz mit schmalen bellen Säumen, Armschwingen an der Basis der Außenfahnen mit großen weißen Flecken, große Oberflügeldecken mit schmalen bläulichen Außensüumen. Schranz dunkelaschgrau mit bläulichem Hauch. Zïgel und Unterseite rütlich kastanienbraun, Nitte des Unterkürpers. Unterschwanz- und Unterflïgeldecken heller. Kehle und Kropf mit rahmweißem. alm Krrople breiterem Nittelstreifen. Schnabel dunkel-, Füße hellhraun fleischfarben. Flügel ungefïhr 97-99, Schwanz etwa 65-67, Lauf 24, Culmen $24 \mathrm{~mm}$ (2 gemessen). - o ad. Oberseite brïunlichgrau. Kopf und Hinterhals einfarhig und mit bläulichem Schimmer, Rücken mit hreiteu, hellumsiumnten sıhwarzen Fndhinden, Bürzel und Oherschwanzdecken auberdem noch mit schwarzem Mittelfleck, hellem Schaftstrich und weiBicher Binde zwischen den schwar\%en Zeichnungen. Flügel mattbraun mit hellen Süumen, Schwanz brïunlichgrau. Unterseite weiß mit breiten schwarzen Anteanikalhinden nud einer chensolchen Qnerbinde in der Mitte jeder Feder, Kehle und Kropf mit weißer, am Kropfe rerhreiterten Mittellinie, Mitte des Lnterkïrjers weib. Lntersehwanzdecken тeiß mit schwarzen Streifen. ' Iris braun. S'chnahel dunkelhraun, Füße fleischfarben, Flügel $92 \mathrm{~mm}$ (1 gemesson).

Ussuri-Tal in Ostsilbirien, Mandschurei. Nordehina. - In Kimubodscha im Winter gefunden, auf dem Durchzuge in der Malilkia-ITalbinsel.

Soll sich nicht in felsigem Gelände, sondern in dichten Wäldern, wo sich viele abgestorbene Bäume finden, aufhalten. Gesang sehr schön.

E. Hartert, Die Vögel der paläarktischen Fauna. 


\section{MIonticola solitarius solitarius (L.).}

Blaudrossel, Blaumerle.

Turdus solitarius Linnaeus, Syst. Nat. Ed. X, p.170 (1758- ex Willughby, Raius, Edwards, u. a. "Habitat in Oriente." T'erra Typica: Italien nach dem 1. Zitat; der Name solitarius wurde später auf die östliche Form mit rotem Unterkörper übertragen).

Turdus Cyamus ${ }^{1}$ ) Linnaeus, Syst. Nat. Ed. XII, p. 296 (1766- Hab. in Italiae, Cretae rupibus." Neuer Name für T. solitarius).

Thrdus azureus Crespon, Faune méridion., p. 179 (1814- ㅇ, Montpellier).

Petrocossyphus cyamus niacrorhynchós A. E. Brehm, Verz. Samml, p. 4 (1866- nomen nudum!).

Engl.: Blue Rock Thrush. Franz, Merle blen, Ital.: Passera solitaria.

c’ad. Dunkolgraublau, die Unterseite etwas heller, Unterflügeldecken

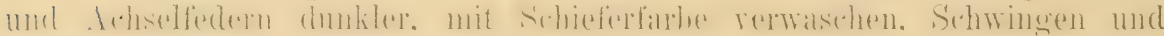
Schwanz duukel schioferschwarz aus schmalen bläulichen Säumen. Im frischen Gefieder haben die Federn der Ober- und Unterseite mehr oder

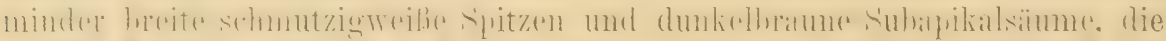

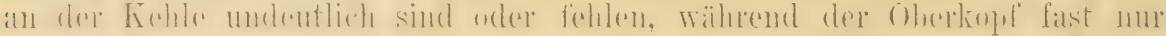

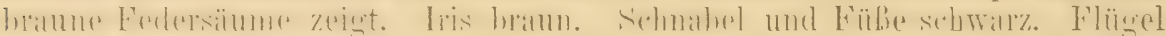
122 - 130, ausnahmsweise bis 132 oder nur 120 mm, Schwanz 81-83, Lauf etwa 28-30, Culmen 26-31 mm. - o ad. Oberseite bräunlich schiefer-

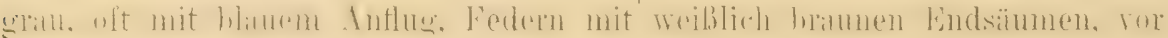

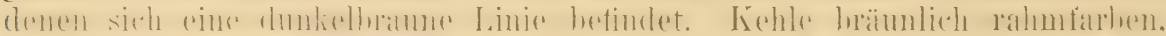

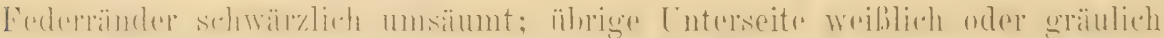
baum. mitunter mit dentlichem graublanem Anflug, alle Federn mit dunkel-

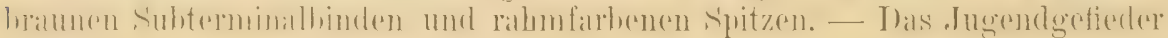
wie das des $\rho$, die $o^{\top}$ aber mit mehr Blau.

Bewohnt Nordwest-Afrika, Sïd- und Mittel-Europa bis in das Alpen-

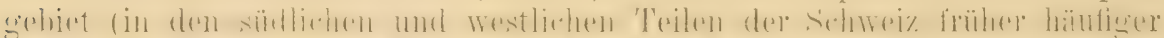

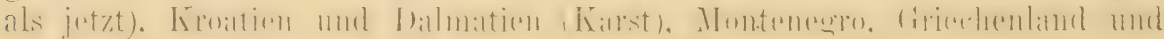

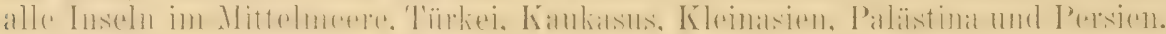
Vereinzelt bei Andernach 1865, Tetzlar 1869, Netz im Sommer 1906 ,

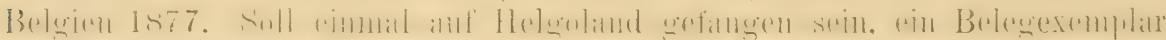

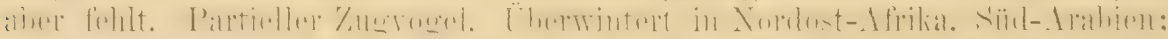
da sio die westliche Sahara noch auf dem Zuge berïhrt, jedenfalls auch in

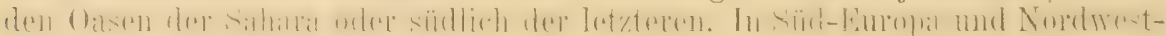
Afrika auch Standrogel.

Die Blaumerle berohnt felsiges Gelände und Gemäuer in felsigen Gebirgslandschaften. Sie erimert in ihrem ganzen Wesen an Sixicolen, nicht an Drosseln. Der Lockton ist wie bei dem Stemrötel ein tiefes täck täck, anch hört man ein feines uit. Die lanten, Hlötenden, durch schnarrende Lante verbundenen schönen Strophen werden mehrere Iale wiederholt, weshalb der Gresang weniger abwechslungsreich klingt als der von $M$. saxatilis. Das Nest steht in Felsenspalten, unter überhängendem Gestein, in Löchern und Nanern oder hohen Gebäuden und ist dem des Steinrötels ähnlieh. Die Eier sind in der hegel etwas heller und viel öfter mit braunroten Punkten und kleinen Flecken rersehen, 106 Eier messen nach Jourdain n. A. im Durehsehnitt $27.57 \times 19.91$, IIaximum $30.4 \times 19$ und $28.3 \times 21$, NInimum $23.2 \times 20$ und $27.6 \times$ $18.3 \mathrm{~mm}$. Gericht $0.311 \mathrm{~g}$.

1) „Cyanus" wurde oft in ,cyanents" geändert. 


\section{0:30. Monticola solitarius transcaspicus Hart.}

Monticola cyanus transcaspicus Hartert, Bull. B. O. Club XXIII, p. 43 (Jan. 1909Tedschen, Sirax, Aschabad).

Wie 1\%. s. solitarius, aber das ơ viel blasser blau, das $o$ blasser und mehr gräulich. Flügel von 6 o $116-122 \mathrm{~mm}$.

Bewohnt augenscheinlich zur Brutzeit Transkaspien (violleicht anch

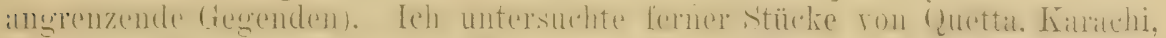

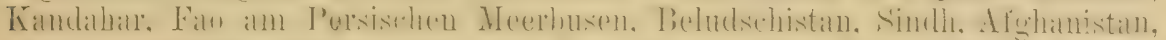

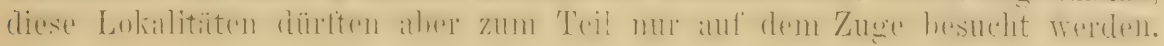

\section{Monticola solitarius pandoo (Sykes).}

Petrocincla pandoo Sykes, Proc. Zool. Soc. London 1832, p. 87 (Ghats in Vorderindien; $\widehat{\top}$ ). Petrocincla maal Sykes, ibidem (q).

Petrocincla affinis Blyth, Journ. As. Soe. Bengal XII, p. 177 * (1843- Darjiling; Beschreibung eines Stückes mit Rot an Unterschwanzdecken).

Turdus (Monticola) erythropterns Gray, Proc. Zool. Soc. London 1860, p. 350 (Gilolo. Mit Rot an Unterflïgel- und Unterschwanzdecken).

Monticola cyanus tenuirostris Johansen, Orn. Jahrbucl 1907, p. 200 (nach einem ơ aus dem, Siebenstromgebiet ${ }^{6:}$ [Ssemirjetschje]).

Wie die europäische Form, aber kleiner: Flügel 5-15 mm kürzer,

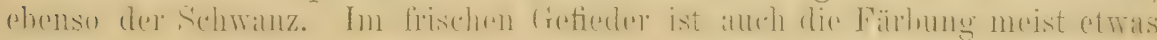
dunkler. - Die Läuge der 5. Schwinge ist variabel, Stïcke, bei denen sie länger ist als die 2. sind aber vielleicht bei der asiatischen Form etrvas weniger selten. - Schon in Vorderindien findet man mitunter, aber selten

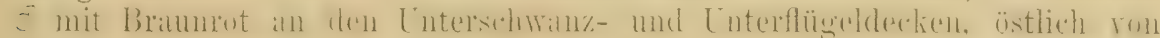
Caleutta werden solche häufiger, nur im südlichen China scheinen sio vor-

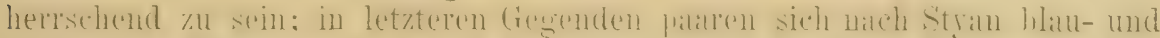

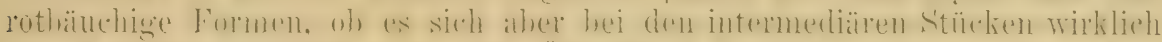

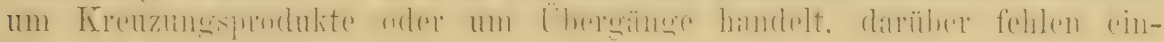
gehende Beobachtungen.

Turkestan ${ }^{1}$ ), Afghanistan ${ }^{1}$ ), Kaschmir (und vielleicht andre Teile des Himalaya), 'Tibet, West- und Nittel-China. - Im Winter in Indien, Ceylon, Birmah, Süd-China.

\section{Monticola solitarius philippensis (I'. I. .'. Müll.।.}

Turdus Philippensis P. L. S. Müller, Natursystem, Anhang 1. 14,2 (1776-- ex Buffon; Name rermutlich aus Brisson. Diagnose unsinnig, aber - zumal in Anbetracht der notorischen Farbenblindheit des Autors - sicher Daubentons Tafel entnommen).

Tiudus manille Boddiert, Tabl. Pl. Enl., p. 39 (1783 - ex Daubenton Pl. 636).

Turdus manillensis Gmelin. Syst. Nat. I, p. 833 (1788 - ex Brisson \& Buffon).

Turrlus Evemita Gmelin, Syst. Nat. I, p. 833 (1788 - ex Brisson \& Buffon).

$0^{7}$ ad. Oberseite etwas lebhafter blau, Brust, Unterkörper; Unterschwanz-

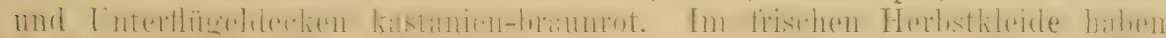

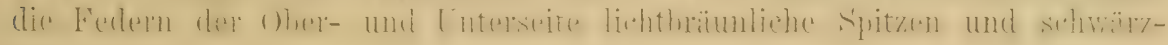

1) Die genaue Abgrenzung, zumal gegen die Gebiete von M. s. transcaspicus ist noch festzustellen. 
liche Subnilikn-Linien, die sieh aber abnutzen, so dia man im Sommer keine Spur davon sieht. Flügel von 56 o $118-126$, alusnahmsweise 127.5 oder nur 112 uud $116 \mathrm{~mm}$. o. Tnterseite merklich hrïunlicher, Oberseite meist etwas dunkler als die von M. s. solitarin.s. - Die in den Winterquartieren und Süd-China gesammelten ô hahen mitunter hane Federn am Unterkörper und sind somit intermediär zwischen M. s. philippensis und pandoo; wo solche Stücke briiten ist meist unbekannt.

Brutrogel in Südost-Silirien (Küstengegenden hei Wladiwostok), der Mandschurei. Ost-C'hina, Korea, Japan, den Bonin-Inselu, anseheinend anch auf den Rin-Kïn-Inse'n und Formosa. - Cherwintert in Süd-china, auf den Riu-Kin-Inseln, Formosa, den Philippinen, südlich bis Cochin-China, Siam, Malakkil, Javil, Natuma-Inseln, C'elehes und umliegende Inseln. Termate und Tidore.

Scheu und vorsichtig, vortreftlicher Sänger. Godlewski fand ein Gelege von 6 frischen Eiern am 26. Mai. Letztere maßen $27 \times 19$ bis $28 \times 20 \mathrm{~mm}$.

\section{Gattung MYIOPHONUS 'Temminck 1823.}

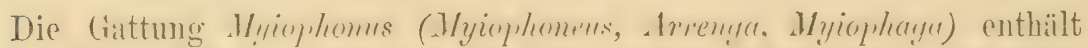
etwa ein Dutzend Formen, welche die Tropen Asiens ron Formosia und Tava bis Nord-China, T'ibet und T'urkestan hewohnen. Der starke Schnahel ist höher als hreit und an der s'pitze hakenförmig gehogen, die rundlichen Nasenlöcher liegen vor deu Stirnfederu. Der Sechwanz ist leidht abgerundet, das Kleingefieder lang und worch, die FüBe sind liriftig. der Lauf gesshient. Die systematische Stellung ist musicher, doch seheint die Gattung den Drosseln wahe zu stehen, möglicherwerise wäre sie mehr in die Nähe von Imutherincla (p. 624) zu bringen.

\section{Myiophonus temminckii temminckii Vig.}

Myiophoneus temminckii Vigors, Proc. zool. Soc. London 1831, p. 171 (Himalaya).

Myiophoneus tibetanus Madarász, Ibis 1886, p. 145 ("Zentral Thibet". 'Typus untersucht - junger Vogel).

Abbild.: Gould, Cent. Him. B., 'Taf. 21.

onad. Gher-und Luterseite matt glanzlos sehwarmhlum. jede Feder mit ctwas verbärteter glänzender graublaurer spitze. so dib der Togel gauz gefleclit erscheint, diese Fleckung anf der Cuterseite und dem liürken am grïßten, anf dem Hinterkopf und Hals kileiner; auf Bürzel und Oberschwanzdecken mohr hau und daher muaffïlliger, an der mittleren Reihe der Oberflügeldecken sind die Flecke fist rein weiß, Banch und Cintersehwanzdecken einfarbig schwar\%blan. Zügel schwall\%. Stirn und kleine Oherflügeldecken reilehenhlan. Schwingen schwar\%. Aubenfahnen und Steuerfedern dunkel veileheuhlau. Fedem an den Soiten des Luterkörpers und auf dem untern Teil des Bürzels mit verdeckten weilon Aubenfahnen. die des Luterkïrpers mit weißen schaftlinien. Iris lran. L'nterschnahel und S'chneidenränder sowie ein 'T'eil der Seiten des Olnerschnabels wathsgellh, ühriger Oberschnabel braunschwarz. Füße schwarz. Flügel von 8 o $178-185$, Schwanz etwa 140-150, Lauf etwa 55, Culmen etwa 37-38 mm. - - o ad. Wie ơad, nur etwas kleiner. Flügul ron 10 o ungeführ 161-172 mm. Jux. Fast cinfarbig hläulich 
schieferbraun, nur Flügelsäume und Schwanz mehr violett, die Kehlfeclem mit etwas helleren Schaftstrichen. Die Federn der Körperseiten und der Bürzels einfarbig obve Weiß.

Brütet im Himalaya und dem angrenzenden mittlereu Tibet, rom äubersten Westen des Himaliya bis Assam und in den Berglïnderm südlich des Brahmaputra, im Sommer in Höhen his üher 11000 engl. F'uB, im Winter in niederen Lagen. - Eine nahe Suhspezies (1. t. engenei Hume) mit etwas grö̈brem und mehr gelbem Schnahel und ohne weiße Flecke an den mittleren Oberflïgeldecken. berrohnt T'eile ron Birma und Siam.

Lebt vorzugsweise an Bächen und Rinnsalen und soll vorzugsweise von Gehäusschnecken leben, Der Gesang ist laut und flötenartig. Baut ein großes Nest aus W urzeln und Mloos an F'elsen, unter umgestürzten Baumstämmen und dgl, mit Vorliebe hart an Wasserfällen und Gießbächen und enthält im April bis Juni 3-5 Eier. Letztere sind rahmfarben, rötlichweiß oder grünlichweiß und mit blaß rotbraunen Schalenflecken und mitunter mit einigen dunkel rotbraunen Flecken bedeckt, die meist dicht und deutlich, mitunter undeutlich erscheinen. 16 Exemplare aus den Bergen Assams messen im Durchschnitt $35.75 \times 25.23$, Maximum $40.1<25$ und $35.5 \times 26.6$, IIinimum $22.5 \times 25.2$ und $33>24.6 \mathrm{~mm}$.

\section{0:34. Myiophonus temminckii turcestanicus Sar.}

Myiophonens temmincli turcestanicus Sarudny, Orn. Mlouatsber. 1909, p. 168 (russisches Turkestan).

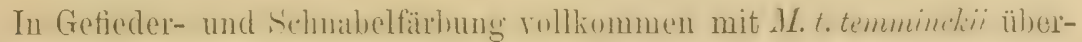
cinstimmend, aher etwas grölser: Flügel 190_-200, S'chwanz 15t-160,

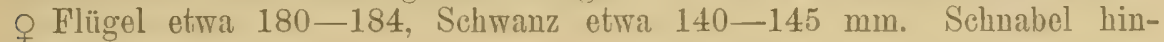
gegen etwas kleiner. Issik-Kul).

Russisches Turkestan (Ferghanagehiet, Tschirtschikflul, Aksu, Buchara,

Ein vorliegendes Ei von Issik-Kul mißt $36.9 \times 25.4 \mathrm{~mm}$.

\section{Myiophonus caerulea (Scop.).}

Gracula caerulea Scopoli, Del. Florae et Faunae Insubr. II, p. 88 (1786- ex Sonnerat. Merle bleu de la Chine, Voy. Ind. Or. et Chine II, p. 188, Taf. 108: China). Turdus violaceus Gmelin, Syst. Nat. I, 2, p. 829 (1789- ebenfalls ex Sonnerat).

Myiophoneus nitidus Gray, Fase. B. China, p. 4. 'Taf. 1 (1871- China).

Myiophonens brevirostris Lafresnaye, Rev. \& Mag. zool. 1852, p. 460 (China).

Ähnlich .K. temminchii temminclii, aber Schnibel kleiner und ganz schwarz. Die Flecke (besonders atuf der Unterseite) etwas gröber. Gröbe im allgemeinen etwas geringer. Flïgel nicht ühser und allerhöchstens $178 \mathrm{~mm}$, bei o etwa 160-163, Culmen etwa $31-33.5 \mathrm{~mm}$.

Süd- und Mittel-China, nördlich bis zu den T'sin-ling-Bergen und Südwest-Kansu nistend.

Bewohnt die Laubwaldzone der Gebirge. Eier wie die von M, temminckii, nur im allgemeinen etwas kleiner. 


\section{Gattung SAXICOLA Bechst. 1802.}

Synonyme: Vitiflora, Oenanthe, Campicola, Iromolaea, Lencotal. Eine Gronze zwischen Saxicolet und "Dromolaca" ist absolut nicht zu ziehen. Am nächsten stehen die afrikanischen Genera Mypmecocichla, 'Thamnolaea u. a. - Fast allen Arten ist auffallend weißer Bürzel und Sehrvanzwurzel eigen, seltener sind diese Teile rostfarben. Die Arten lebeu zumeist in steinigem

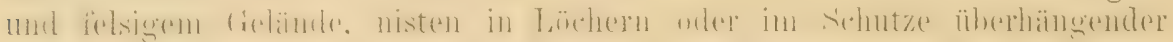
Steine u. dgl. und legen hellblaue oder hellgrünliche, schwach rostrot ge-

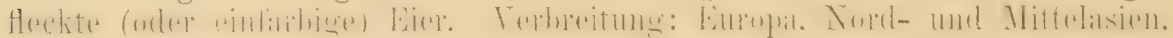
Afrika, anch ${ }_{\text {en }}$ Grönland und Alaska (eine Art). - Schnabel schlank, schwarz,

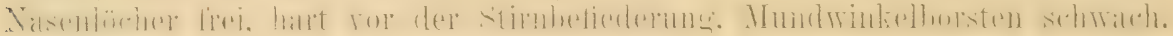
Lüufe mit einer ununterbrochenen Schiene bedeckt. Junge sehwach oder gar nicht (S. leucumis \%. B.) gefleckt.

\section{Übersicht der alten ot im Frühling:}

Rücken schwarz, Schwanzwurzel weiß . . . . . . . . . . 2

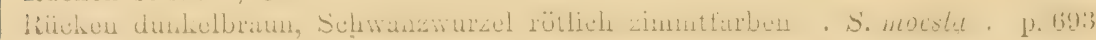

Rïcken und Kopf aschgran . . . . . . . S. oenanthe . 1. 679

Rïicken weder schwarz noch aschgran ............ 9

- f Unterkörper weiß oder weißlich . . . . . . . . . . . . 5

2 Unterkörper schwař . . . . . . . . . . . . . . . . 3

3 f Aftergegend weiß . . . . . . . . . . . . . . . 4 4

3 Aftergegend schwarz . . . . . . . . . . . S. lencurus . p.697

$4\{$ Glänzend blauschwarz, Flïgel ïber $100 \mathrm{~mm}$. . . . S. lencopyga - p.699

\{ Braunschwarz, Fligel unter $100 \mathrm{~mm}$........ S. opistholenca . p. 697

Oberkopf glänzend blauschwarz wie der Rücken, Flügel über $100 \mathrm{~mm}$

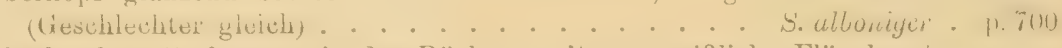

5 Oberkopf mattselıwarz wie der Rïcken, seltener weißlich, Fliigel unter

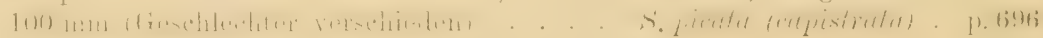

Oberkopf niemals schwarz (Geschlechter verschieden) . . . . . . 6

6 J Innensäume der Schwingen weiß oder weißlich . . . . . . . . 8

6 Innensäume der Schwingen schwarz oder dunkelbraun . . . . . . . . T

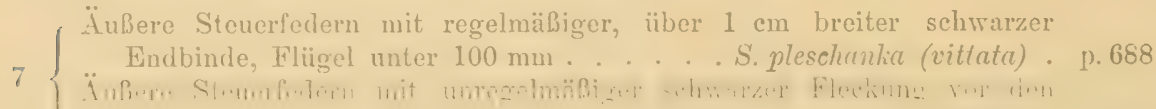
Spitzen oder ganz weiß, Hlïgel ïbor $100 \mathrm{~mm}$. . . . S. monacha . p. 701

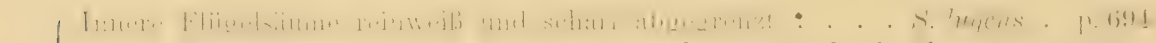

$8\left\{\begin{array}{r}\text { Innere Flïgelsäume breit trubweil, nicht so scharf abgegrenzt } \\ \text { S. persica . p. } 696\end{array}\right.$

$9 \int$ Oberschwanzdecken fahl bräunlich orangefarben . S. xanthoprymma . p. 692

Oberschwanzdecken weiß . . . . . . . . . . . 10

Oberflügeldecken sehwarz (Geschlechter rerschieden) . . . . . . . . 11

10 Oberflügeldecken fahlsandbraun oder isabell (Geschlechter gleich) S. isabellina . 1).691

11 Äußere Stenerfedern größtenteils schwarz. . . . . . S. deserti . p.683

11 Äußere Steuerfedern weniger als zur Hälfte sehwarz . . . . . . . 12

1.) Kehle weiß oder Kinn und Kehle schwarz . . . . . S. hispanica 1).685

T Kehle und Kropf sehwarz . . . . . . . . S. melanolenca . p. 690 


\section{Saxicola oenanthe oenanthe (I.).}

Grauer Steinschmätzer.

Motacilla Oenanthe Linnaeus, Syst. Nat. Ed. X, I, p).186 (1758- Europa. Als terra typica ist Schweden, nach dem 1. Zitat, angenommen).

Motacilla Vitiflora Pallas, Zoogr. Rosso-Asiat. I, p. 472 (1827- Rußland und Sibirien. Neuer Name für M. oenanthe).

Oenanthe cinerea Vieillot, Nour. Dict. d' Hist. Nat., Nour. Ed. XXI, I).418 (1818neuer Name für Motacilla oenanthe L.).

Vitiflora septentrionalis Brehm, Handb. Naturg. Vög. Deutschl., p.403 (1831- "Norden" und Mitteldeutschland).

Vitiflora grisea Brehm, t.c., 1. 405 (1831- mittleres Deutschland).

Vitiflora cinerex Brehm, t. c., p. 405 (1831- Sardinien).

(?) Saxicola oenanthoides Vigors, Zool. Voy. Blossom, p. 19 (1839- angehlich von Nordwest-Amerika).

Saxicola ocnanthe alpestris, melanoptera, crassirostris, maritima (partim!), und macrorhynchos A. E. Brehm, Verz. Samml., p. 5 (1866- nornina nuda, nach den Stücken der Sammlung alle hierher gehörig).

Saxicola Borealis Fleinschmidt, Journ. f. Orn. 1903, 1).389. (Neuer Name fïr Sax. ocnanthe mit allen seinen Formen).

Eugl.: Wheatear. Franz.: Motteux, Cul-blanc. Ital.: Culbianco. Schwed.: Stenskrätta.

Abbild.: Kleinschmidt, Berajah I, Taf. 1, 3, 4, 5, 6.

1. Schwinge $10-16 \mathrm{~mm}$, etwa $2-3 \mathrm{~mm}$ kïrzer als die Handdecken. 3. am längsten, 4. nur wenig kiurzer, 2. in der Regel zwischen der 4. und 5., mitunter so lang wie die 3. Die 3. und 4. Schwinge vol der Nitte stark eingeschuürt. Über Variation vgl. Berajah, Taf. I. ơad. Oberseite grau

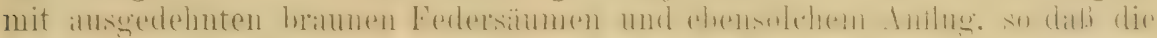

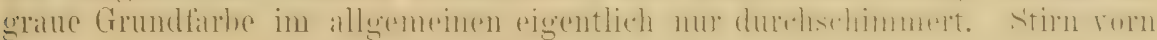
etwas lichter. Tou den Zïgeln bis kurz hinters Oln eine weiße Linie. Zügel, Linie vou dort bis ans Nasenloch und grober Ohrfleck schwarz, an

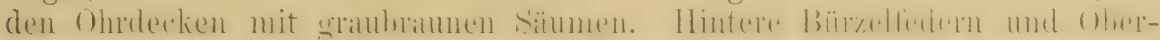

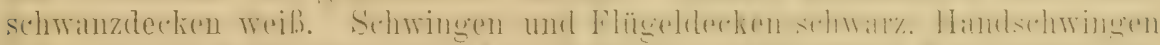

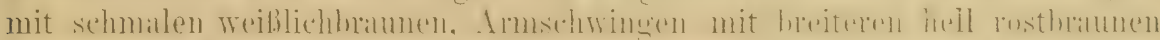

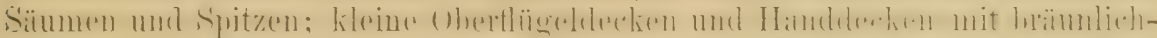

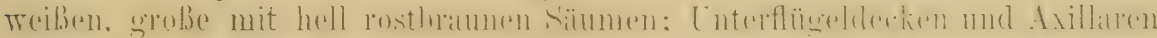
mit hreiten weißen Rändern. Mittlere Stenerfedern schwarz, Basis (etwa $2 \mathrm{~cm}$ ) weiß, clie übrigen weiß, Spitze (etwa $15-20 \mathrm{~mm}$ ) schwar\% mit schmalen veißen Endsäumen. Unterseite vou der Kehle bis zur Brust hell

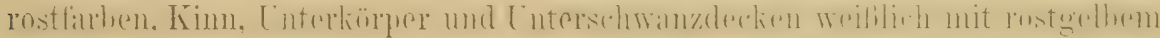
Anflug. Aus diesem Kleide entwickelt sich ohme Mauser, lediglich durch

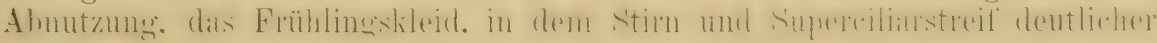
weiß sind, übrige Oberseite grau, Schwanz und Flïgel schwarz, fast ohme

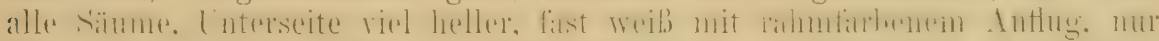

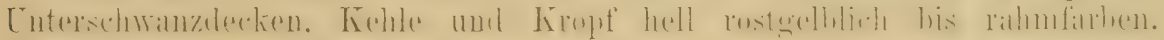
Flügel 95-99, mitunter nu 89 (cin Stïck) bis 94, Selıwanz etra 51-59, Culmen etwa 16-17, $\mathrm{m}^{\text {' }}$ unter - besonder's bei Stincken von Sardinien bis $19 \mathrm{~mm}$. Iris braun, Schnabel und Füße schwarz. — o ad. Im Herbstkleide ist 'die Oberseite braun, fast dunkel zimtbraun, Stirmand lichter,

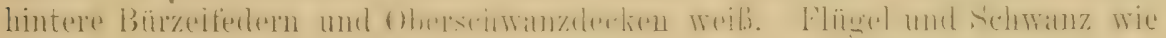
beim $0^{2}$, nur die Säume etwas bräunlicher, nicht so lohhaft gelärbt. Im Frühjahr ist die Oberseite viel bhasser und bekommt einen grïulichen 
Schimmer, die Flügel sind nicht so dunkel sehwarz wie beim ond. - Nestkleid: Oberseite fuhlhram mit helleren Lindfecken und schwärzlichen Lindsümmen, die weiben Oberschwanzfedern mit brïmnlichen Linden. Unterseite rahmfarben, Kehle und Brust mit braunen Federsäumen.

Brutgehiet: Gimz Buropa und Britisehe Inseln, in Spanien und Portugal aher nur nördlich der Cantahrischen Gehirge, Kleinasien, Syrien, Persien his Turkestan und Nordasien bis zum Bedringsmeere, survie nördliehes Alaska; die Tögel ans Alaskil sollen (Ridgway, B. N. und Middle Amer. IV, p. 10) nicht zu leucorhoa gehören, aber größer sein als europäische Stïcke Angahen. die uhne weitere Studien zweifellaft bleiben, da sie nach Lntersuchumg eiues ganz geringen Naterials gemacht wurden. (Üher Kaukasus und Kleinasien siehe unter rostrata.) - Wandert durch die Sahara und Arahien und üherwintert in tropischen Afriká wohin die siliristhen Stïcke ziehen, ist fraglich. doch dürften die in Nordehina rorkommenden dazu ggehören.

Die Variabilität, besonders in den $\mathrm{Maßen}$, ist ziemlich groß. Interessante Angaben siehe in Kleinschmidts Berajah I. Die Flïgelläuge erreicht oft fast $100 \mathrm{~mm}$, größer ist sie mir nicht vorgekommen; die große grönländische Form hat in der Regel einen Flügel von merklich über 100 , da aber auch Vögel mit Flügeln unter 100 vorkommen, sind einzelne Stücke manchmal kaum zu unterscheiden. Die kürzesten Flügel fanden Kleinschmidt und ich bei englischen und pyrenäischen Brutrögeln und einigen marokkanischen Zugvögeln; indessen gibt es auch in Mittel-Europa Flügel von kaum 93-95 mm und es konnten keine genïgenden Serien von Brutrögeln untersucht werden. Die Schwanzlänge harmoniert mit der Fliigellänge. Die Schnabellänge ist ebenso variabel: die kurzschnäbligsten Stücke, die ich untersuchen konnte, stammen aus Skandinavien, Sibirien und Ilittel-Europa, in denselben Gegenden kommen aber auch langschnäbligere Individuen vor; die längsten Schnäbel fand ich außer bei den sogenannten rostrata bei Sardiniern und Griechen, aber auch lier keine Konstanz. Die Färbung ändert mehr nach der Jahreszeit ab, doch ist der Rücken mitunter lichter als gewöhnlich, so daß z. B. Stücke aus Süd-Europa und vom Norden u. a. m, zurveilen nicht von der sogenannten argentea zu unterscheiden sind; es scheint, daß englische Brutrögel eine ebenso lichte Unterseite bekommen, wie die vom Kontinent - es ist auch in Erwägung zu ziehen, daß in Gegenden mit mehr Sonnenlicht und trocknerem Klima das Gefieder mancher Vögel rascher ausbleicht und sich anscheinend auch rascher abnutzt.

Der Steinschmätzer findet sich in Nord-Europa und Sibirien oft an den Meeresküsten, steigt aber auch im Gebirge bis in Höhen ron über $2500 \mathrm{~m}$ hinauf. Er ist nicht überall zu finden und wohnt in offenen Gegenden mit ihm zusagenden Nistgelegenheiten, seien dies nun Felslöcher, Mraverreste, Ėrdhöhlen (Ǩaninchenbaue u. dgl.), hohl liegende große Steine, selbst Holzklaftern usw. Weiter im Süden scheint er nur Gebirgsrogel zu sein (Süd-Europi). An den angegebenen Orten baut er sein wohlverstecktes Nest aus Wurzeln, Halmen und Gras, das er innen mit Haaren und Federn auslegt. Im Mai findet man die 5-7, meist 6 Eier. Diese sind hellblau, mitunter sehr blaß, fast weiß, oft dunkler, und haben mitunter kleine dunkel rotbraune Punkte und Fleckchen. 100 Eier messen nach Rey und Jourdain im Durchschnitt $20.76 \times 15.55$, Haximum $23 \times 16.1$ und $22 \times 16.5$, Мinimum $19 \times 14.5$ und $19.3 \times$ $14 \mathrm{~mm}$. Hält sich am Boden auf, läuft sehr rasch, fliegt niedrig und lockt üit-tack oder nur schmatzend tack, tack. Der kurze Gesang enthält gepreßte, rauhe Töne, mit zwitschernden und pfeifenden Lauten verbunden; oft steigt das singende 0 einige Meter hoch in die Tuft.

Ungeniigend bekannte und zurzeit noch nicht sicher abzugrenzende Formen sind:

a) Saxicola oenanthe argentea Lönnberg.

Saxicola oenanthe argentea Lönnberg, Arkiv för Zoologi V, no.9, p.22 (1909- Bura, Kjachta, Kiran südlich des Baikalsees). 
Lönnberg benannte wenige Stücke von obengenannten Plätzen wegen hellerer Oberseite und breiterer weißer Stirn. Die gleichen Unterschiede finde ich (wie auch schon Kleinschmidt, Berajah 1, 1905, p. 5 hervorhob) an Stüeken von Transkaspien und aus Turkestan, auch ist bei diesen die schwarze Schwanzbinde in der Regel (aber nicht immer) einige Millimeter schmäler, der Flügel meist lang, d. h. über $96^{3} \mathrm{~mm}$, der Schnabel meist 1-2 mm länger. Die Form, die nach dem geringen vom Autor verglichenen Material nicht hätte benannt werden sollen, ist in ihrer Verbreitung noch zweifelhaft und namentlich die Abgrenzung gegen rostrata schwierig. Nordsibirier scheinen mir nach den untersuchten wenigen Stïcken nicht dazu zu gehören, doch dürfte diese Form im Winter bis Gilgit (Nord-Indien) und Sindh ziehen, vielleicht gehören auch größtenteils die in Ost-Afrika überwinternden dazu.

\section{b) Saxicola oenanthe rostrata Hempr. \& Elurbg.}

Saxicola rostruta Hemprich \& Ehrenberg, symb. Phys. I, fol. aa (183is- Ober-Ägypten Nord-Arabien, Syrien).

Saxicola libanotica Henprich \& Ehrenberg, t. c., fol. bb (1833- Syrien).

Abbild. von Köpfen: Kleinschmidt, Berajah I, Taf. III (ebenda auch 'T'ext).

Unter dem Namen S. rostrata wurden Stücke aus Syrien, Nord-Arabien und Ober-Ägypten beschrieben. Nun finden wir allerdings unter den ostafrikanischen Zugvögeln Stücke mit riesig langen Schnäbeln (bis zu fast $20 \mathrm{~mm}$ ), auch ist der Schnabel in der Regel bei Brutvögeln aus dem Libanon und Nord-Arabien etwas länger (17 bis $18.5 \mathrm{~mm}$ bei $\sigma^{7}$ rom Hermon). Ferner sind offenbar die Schwingensäume und Flügeldeckenränder im Herbstkleide bei den ơ sehr licht. - MIan kann somit wohl annehmen daß auf den Bergen Syriens und Arabiens eine Form mit langem Culmen und hellen Flïgelsäumen lebt, die dureh Ägypten wandert und in Eritrea, Somaliland bis Sansibar und Deutsch-Ost-Afrika ïberwintert. Die Abgrenzung der Form ist indessen noch unsicher. Wahrscheinlich gehören zu derselben auch die kleinasiatischen Brutvögel (ein ơad, verglichen) und vielleicht die des Kaukasus.

S. oe. lencorhoa und S. a. seebohmi sind deutlich abgegrenzte Formen.

\section{Saxicola oenanthe leucorhoa (Gm.).}

Motacilla lencorhoa Gmelin, Syst. Nat. I, 2, p.966 (1789- ex Buffon [Motteux du Sénégal V, p. 249]. Senegal).

Vitiflora major Brehm, Vogelfang, p. 224 (1855- „Mittel-Afrika und Holland‘6).

Saxicola oenanthe maritima (partim!) A. E. Brehm, Verz. Samml., p. 5 (1866- nomen nudum!).

Abbild.: Kleinschmidt, Berajah I, 1905, Taf. 1, 2, 3, 4 (Ei: 'Taf. 6).

Ähnlieh S. oe ornuthe aber Untersoite. hesonders Kehle, Kropf und Torderhrust in Herlistileide sehr lehbaft rostfarhen und auch in der Brutzeit nicht so hell werdend wie bei S. oe. oenanthe. AuBerdem moist bedeutend größer, Flügel 5-12 mm länger (ctwa 98-111). Lauf etwa 2 mm länger. dabei Śchnabel nicht länger. Die brannen S'chwingeusïume scheinen erst spät zu verschwinden.

Brïtet in Grönland und Nordust-Amerika mestlich der Davis-Straße bis Tabrador (? (Quebec). Auch lie auf Island und deu Farüel brïtenden Tögel werden dazu gerechnet und stimmen aluch in der Fïrbung ganz übereiu, seheinen abex (auf Island wenigstens) nie so lange Flügel zu haben (nie über 100?) und kïrzeren 'Tarsus; leider liegrn keine grofen Serien ron Brutrögehn, sondern meist nur Zugrögel ror. - Wiundert dureh WestFuropa (auf dem Zuge häufig in Hngland, vereinzelt in Deutschland und 


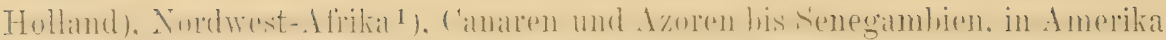

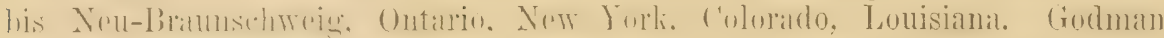
will auf den Azoren (Corvo) ,S. oenanther" brütend gefunden haben, aber wohl kaum diese Form!

Brïtet wie S. oe. oenanthe in Steinritzen und Felslöchern, auf Island in künstlichen Wällen und Steinhaufen, Wänden von Vichställen und verfallenen Gebäuden. Die 5-8 Eier findet man im Juni und selbst noch im Juli. 23 Eier von Island und Grönland messen nach Jourdain im Durchschnitt $21.4 \times 15.7$, IIaximum $23 \times 16.2$ und $22.3 \times 16.5$, Minimun $20 \times 15.3$ und $20.5 \times 15 \mathrm{~mm}$. Nach Schlïters Erinnerung (siehe Berajah I, p. 16) ist ihm bei Gelegen dieser Form außer der Größe auch die hohe Zah] der Eier im Gelege aufgefallen; dies wird ron Feilden für die Faröer bestätigt. Jourdain sah ein Gelege von 9 aus Island. Slater und Hantzsch aber erwähnen Gelege von 4-5. - S. oe. lencorhoc wandert natürlich später als $S$. oe. oencenthe, in England zieht sie ron Mitte April bis Mitte Mai durch, wenn die einheimische oenanthe schon brïtet.

\section{Saxicola oenanthe seebohmi Dixon.}

Saxicola scebohmi Dixon, Ibis 1882, p. う63, Tat. XIV (1)jebel Mahmel, Algerien).

Abbild.: Journ. f. Orn. 1895, 'J'af. IlI; Ei: Berajah I, Taf. YI.

ơad. Unterscheidet sich von dem ron S. oe. oenanthe dadurch, dab das Sehwarz der Ohrdecken ïber dic ganze Kehle ausgedehnt ist, und daß die Flügel reiner schwarz sind: die Schwingen sind tiefer schwarz, die bei oenanthe durch die breiten Sämme gröbtenteils weibeu Arillaren sind tiefschwarz, mit nur sehr schmalen weiben Räncleru; die Unterflügeldecken haben ebenfalls schmillere Silume, die oft fast gan\%, verschwinden. Die 4. Schwinge ist so lang wic die 3., oder kaum kürzer. wodurch die Flïgelspitze etwas stumpfer erscheint, der Scbnibel ist in der Regel $1-2 \mathrm{~mm}$ länger. Fliigel von 15 add. 92.5-99.5 (meist 95-97) mm. Die Oberseite ist etwas lichter. - I)as o ist dem von oencuthe sehr ïhnlich, aber dio Oberseite ist im Frïhjahr lichter, otvas mehr fahlgelblich, die Axillaren und Unterflügeldecken haben schmälere helle Sïtume, der Lnterflïgel ist dunkler. Meist ist auch die längere 4. Śchminge ein gutes Kennzeichen. - Das Nestkleid ist lichter und gelblicher, als das ron S. or. ouanthe. (24 untersucht.)

S. oe sechohmi ist aus Höhen von etwa 1700 his $2000 \mathrm{~m}$ in den Aurès-

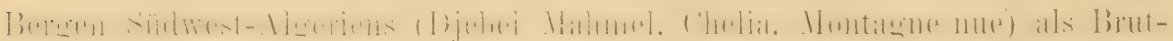
rogel bekannt, dürfte aber auf rielen hohen Bergen des Atlas rorkommen,

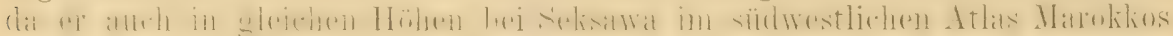
von Riggenbacl, und bei Tilula und Saraliten von Dodson gefunden wurde.

Bewohnen zur Brutzeit Berghänge und Plateaus, wo auf grasigem Grunde zahlreiche Steine und Felsblöcke liegen, oder die von felsigen Rïcken durchzogen sind. Sie leben dort nach Art unsrer Steinschmätzer, ihr Lockton ist ein vielleicht etwas kiirzeres iiit, dem ein sehr leises tack angehängt wird, und das oft fehlt, wenn man es nicht rielmehr ïberhört. Der Gesang ist eine kurze, etwas rauhe Strophe, wie beim europäischen Steirischmätzer, die das of bald im Sitzen, bald indem er sich in die Luft erhebt, hören läBt. Das lockere Nest steht unter großen Steinen und es scheinen etwa fïnf Junge ausgebritet zu werden. Ein Ei mißt $20.5 \times 15 \mathrm{~mm}$. Es ist einfarbig hellhlau. - Dr in den Höhen, in denen diese Vögel brïten, im Winter tiefer Schnee liegt, dïrften sie sicher ilıre Brutplätze dann verlassen, wir wissen aber nicht, wo sie sich im Winter aufhalten.

1) Das angebliche Vorkommen in Nordost-Afrika beruht auf Irrtümeru. 


\section{Saxicola deserti deserti 'lemm.}

Saxicola deserti 'Temminck, P1. Col. 359, Fig. 2 (1825- Ägypten).

Saxicola gutturalis Lichtenstein, Nomenel. Av. ALus. Berol., p. 35 (1851- Arabien. Ägypten. - Nomen nudum!).

Vitiflora paradoxa Brehm, Vogelfang, p. $22+$ (1855- Ägypten. Vgl. Journ. f. Orn. 1856$, p. 451$)$.

Sexicola homochroa Tristram, Ibis 1859, p. 50 ( $q$ - tunesische Sahara).

Saxicola paraloxa major \& minor A. E. Brehm, Verz. Samml., p. 5 (1866- nomina nuda).

Saxicola albomarginata Salvadori, Atti Soc. T'orino, p.507 (1870 - tunesische Sahara).

ờal. Oberseite isaboll, auf Rücken und Bürzel lebhafter, auf Kopf und Nacken mit graubräunlichem Anflug. Ein oft undeutlicher schmaler Streif an der Stirn und sehmaler Superciliarstreif weiß. Bürzel und Oberschwanzdecken weiß, mehr oder minder isabell verwaschen. Schwingen schwarzbraum, Aubenfahnen fast rein schwarz, mit an den Armschwingen dentlichen, an den Handschwingen schmäleren, undeutlichen weiblichen Säumen, Innenfahnen dïster braun und mit breiten weißen Säumen, die an den Handschwingen etwa so weit wie die Einbuchtung reichen. Äubere

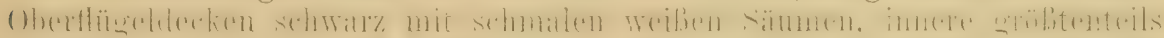
meiBlich. Basis der' Stenerfederu ein Drittel bis zur Hälfte weiß, der Spitzenteil schwarz. Kinn, Kehle und Kopfseiten bis zu den Seiten der Torderbrust schwarz, übrige Unterseite rahmfarben, Brust hell isabell. Lnterflügel weil mit schwarzer Basis, Axillaren schwarz mit weilsen Spitzen. Im Herbstkleide sind Oberseite und Brust etwas dunkler, die hellen säume der Sohwingen deutlicher, die Kehlfedern haben oft (? anch bei ganz alten) weile Hudsäume; das Gefieder wird zur Brutzeit blasser, nul das Sehwarz erscheint tiefer. Flügel etwa $87-92$, eimmal 93 , moist $88-89 \mathrm{~mm}\left(46^{\circ}\right.$ gemessen); Schwanz etwa 63-69, Culmen etwa 17.5 (seltener mur 17) bis 19.5 (seltener 20-21). Lauf etwa 25-26 mm. - o Oberseite wio beim ठే; Unterseite blaß rahmfarben, Kropf und Brust isabell, Kehle häufig mehr oder minder schwärzlich, Unterflügeldecken und Axillaren fast ganz weiß. Juv. im Nestkloide dem o ähnlich, aber das Kleingefieder der Oberseite hat blassere Flecke ror den Federspitzen, die Federn der Brust haben

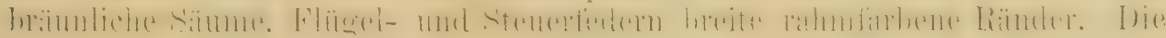
schwarze Kelıle der or erscheint schon in der ersten Mauser! - 1. Sehwinge so laug, etwas kïrzer oder länger als Handdecken, 3., 4., 5. deutlich rerengt, 3. und 4. am längsten, 2. wie die 5, oder lï̈rzer, ausuahmsweise länger.

Bewohnt die Saharal rom Kap Blanco (2. $2^{n}$ ) bis Ägypten ${ }^{1}$ ) Nubien und

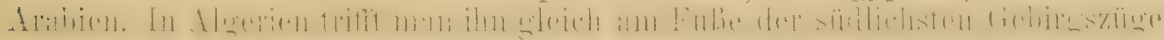
und er geht an gecigneten Stellen soweit in dio Wïste hinunter. wie diese ornithologiseh bekaunt ist. Ist Stand- und höchstens Strichrogel, trotzdem gehört nach sorgfältigem Vergleich ein am 17. X. 1885 an der Küste ron Norfolk. England (Holderness) erlueutetes o dieser Form an. Ebenso wahrscheinlieh das italienische Stück, das Giglioli erwähnt.

Eehter Wüstenbewohner; am hïufigsten in sandiger und lehmiger Steppe, sowie an den Rändern. weniger inmitten ansgedehnter Sebliha (Salzsteppe) und nur vereinzelt in der reinen Steinwiiste. Dem Gebirge und ausgedehnten Sanddïnenmeer durehaus

1) Stiicke ans dem Natrontal gleiehen rollkommen denen der westlichen Sahara, andere aus Ägypten stehen teilweise der östlichen frorm näher. 
fehlend. Ist gar nicht scheu und belebt die Sandsteppe vorzüglich. Der Lockton ist ein etwas klagender, heiserer Pfiff, der wie ein gezogenes twüi oder bwiiji klingt. Die kurze charakteristische Strophe wird leise schwätzend eingeleitet und klingt etwa wie twü twïititü, die letzte Silbe eigenartig schleifend ausgezogen. Das Nest wird unter Erdschollen, Steinen oder Wurzeln, in verlassenen Ërdröhren, besonders an Uferwänden, mitunter auch tief unter dichtem niederen Geäst eines WVüstenbusches errichtet; es besteht aus Halmen und Wurzeln und ist mit wenigen Haaren und Federn ausgefüttert, mitunter besteht es fast nur aus Federn. Die 3-5, meist 4 , Eier sind in der Regel ziemlich rundlich, schwach glänzend, zart blaugrün mit moist zahlreichen rotbraunen Punkten. 43 Eier (24 Koenig, 15 Erlanger, 4 Hartert) messen im Durchschnitt $19.92 \times 14.9$, Maximum $21.5 \times 15.5$ und $21 \times 16$, Minimum $18.6 \times 14 \mathrm{~mm}$.

\section{Saxicola deserti atrogularis Blyth.}

Saxicola atrogularis Blyth, Journ. As. Soc. Bengal 1847, p. 131 ("Upper Provinces, Scinde etc. ").

Saxicola salina Eversmann, Bull. Soc. Imp. Nat. Mloseou XXIII, 2, p. 567, 'Taf. VIII, 2 (schlecht) (1850- Kirgiseusteppen).

Saxicola montana Gould, B. Asia IV, T'In. 30 (1865- "Libet").

S. oenanthe var. indica Temminck MS., teste Finsch, Notes Leyden Museum XXII, p. 152 (1900).

Saxicola oreophila Oberholser, Proc. U. S. Nat. Mlus. XXII, p.221 (1901- neuer Name für S. montana). - (Der Name S. montana wurde Stücken der asiatischen Form gegeben, bei denen die Innenfahnen der Flïgel nicht einen schmalen weißen Saum haben, sondern bei denen das Weiß an der Wurzelhälfte der Innenfahnen bis an den Schaft reicht. Merkwürdigerweise sind auch solche Stücke oft größer als die, welche nur einen weißeu Saum haben. Indessen finden sich häufige Übergänge in der Ausdehnung des Weiß, wie in den Maßen, auch konnte ich nicht feststellen, dảß die sogenannte montana ein besonderes Brutgebiet hat. Ich bin daher überzeugt, daß ,montana" nur eine individuelle Abweichung darstellt.)

Sehr ähnlich S. deserti deserti, aber etwas dunkler, Oberseite, besonder's Konf und Hals, zu gleicher Jahreszeit viel hrämlichere im Herlsst stark

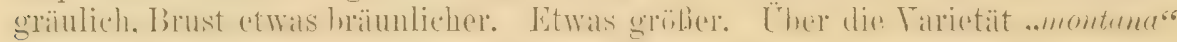
sieho Bemerkung in der Synonymie. Flügel vou 50 o meist etwa $92-93$, zweimal nur 88, öfter 95-96, mitunter bis $101.5 \mathrm{~mm}$; Flügel rou übor 96

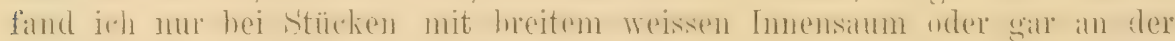
Wrurzelhälfte his an den Schaft reichendem Weiß der Innenfahnen der

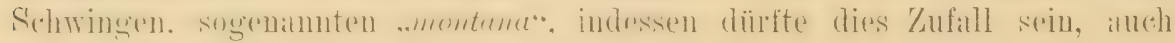
sind nicht alle letzteren so grob.

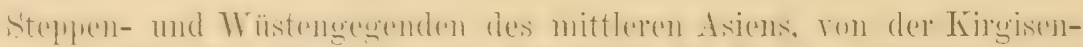

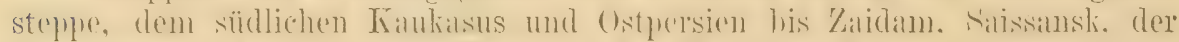

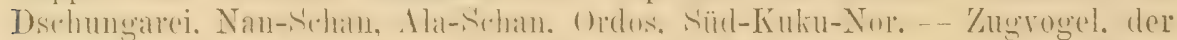

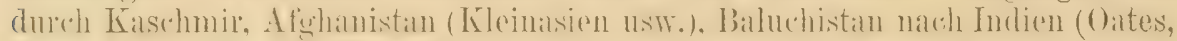

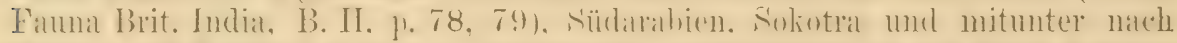

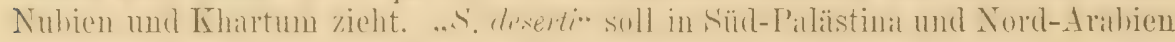
Standrogel sein; ich vermute, daß — wenn die Angabe richtig ist - es sich

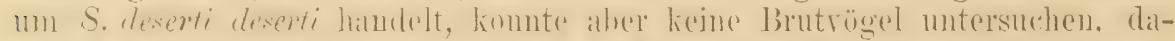

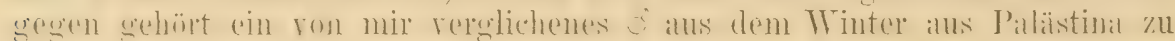
S. d. atrogularis. Wahrscheinlich gehören die meisten in Europa vor-

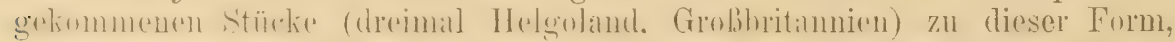

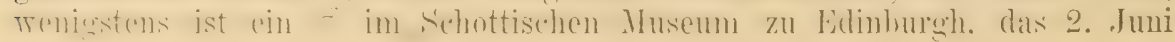


1906 anf den Pentland Skerries zwischen den Orkmey Inseln und Schottland gefunden wurde, ein typischer atrogularis.

Scheint mehr steiniges und felsiges Gelände zu bewohnen als die westliche form, auch Salzsteppen zu lieben. Sieben Eier (Kuldscha, Turkestan) messen nach Jourdain im Durchschnitt $20.23 \times 15.11$, Mlaximum $20.6 \times 15.5$, Hinimum $19.5 \times 14.7 \mathrm{~mm}$.

\section{Saxicola hispanica hispanica (L.).}

\section{Mittelmeersteinschmätzer.}

Motacilla hispanica Linnaeus, Syst. Nat. Ed. X, I, p. 186 (1758- „Hispania“. Ex Edwards, Orn. nor. I, T'af, 31 und 'lext, wo ein schwarzkehliges und schwarzohriges ơ von Gibraltar als ô und $q$ abgebildet und beschrieben sind).

Motacilla Stupazina Linnaeus, Syst. Nat. Ed, XII, I, p.331 (1766- .. Habitat in Hispania, Italia". Ex Aldrovandi, IVillughby, Edwards, Brisson. Absolut auf die westliche Form mit weißlicher Kehle bezüglich).

Titiflora rufa Stephens, Shaw's Gen. Zool. X, II, p. 569 (1817- "Gibraltar und Bologna“. Neuer Name für Mot. stapazina, nach denselben Autoren kompiliert. 'Zweifellos die westliche Form).

Oenanthe albicollis Vieillot, Nouv. Dict. d'Hist. Nat., nouv, ed., XXI, p. 424 (1818Süd-Hrankreich, Spanien, Italien).

Saxicola aurita Temminck, Man. d'Orn., 2. Ed., I, p.241 (1820- Süd-Europa. Die Beschreibung stimmt besser auf die östliche Form, trotzdem bezieht sich der Name ganz oder größtenteils auf die westliche, weißkehlige Form, wie die Zitate und die Verbreitung beweisen, zumal auch, daß der Autor Edwards' Tafel 31 [siehe oben unter M. hispanica], die einen übertypischen westlichen Vogel von Gibraltar darstellt, sehr exakt nennt).

Sylvia rufescens Savi, Orn. Toscana I, p. 223 (1827- Toscana, Rom usw. Westliche weißkehlige Form).

Saxicola atrogularis Dubois, Ois. de l'Europe, 2. sér., I, p. 56 (1868-- Portugal, Spanien, Italien, Pyrenäen, Süd-Frankreich, Kaspisches Meer, Tirol, Senegal, Ägypten, Nubien, Abyssinien. Taf. 56. Die Abbildung - besonders Ausdehnung des Schwarz an der Kehle des $\sigma^{\star}-$ stellt die schwarzkehlige westliche Form dar, Beschreibung fehlt, Verbreitung Mischmasch).

Saxicola occidentalis Salvadori, Ann. Mus. Civ. Genova (2) III, p. 116 (1886- "Questa è la forma occidentale della Monachella gola nera").

Vitiflora assimilis (partim!) Brehm, Vogelfang, p.224 (1855- „Süd-Frankreich und Ägypten". Weißkehlige Form).

Saxicola rufa longirostris (partim), brevirostris, crassirostris, aurita brevi- und longirostris (partim), aurita occidentalis(?), nigribarbata crassirostris, tenuirostris A. E. Brehm, Verz. Samml., p. 5 (1866- nomina nuda!).

Saxicola caterinae Whitaker, Ibis 1898, p. 624; B. Tunisia I, Taf. III (noch ein Name für die schon mindestens fünfmal sicher benannte westliche weißkehlige Form).

oad. im Herhstlileide: Oherseite lehhaft hell ockerfarben. an der Stirn etwas heller, am Bürzel in Treif ühergehend: Schulterfitticbe teilweise schwarz, nämlich die nach dem Rücke'n zu liegenden Federn wie letzterer, die nach dem Elügel zu sich betiudlichen schwarz, die Ausdehumng der beiden Farben nicht ganz loustant. Schwingen bäunlich schmarz, die Innenfabmen brämnlicher, die Aubenfibnen reiner schwarz. Handschwingen, Handdecken und kleine Uherflïgeldecken schmal weiblich ockergelb gesäumt, Armschwingen und gröBere Oherflïgreldecken hreiter und wrehr fahl ockerfarben gesïumt: Innensïume der Schwingeu mehr oder minder deutlich weißlich oder fahlgrau. Mittelstes Steucrfederpan schmirz, mur an der Wurzel etwil $1-1^{1,2}$ ('m weil.) die ïhrigen steuerfudern weiß mit schwarzer 


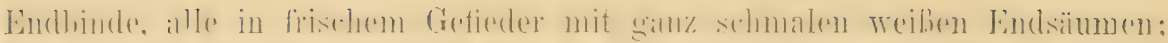

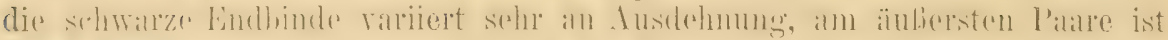

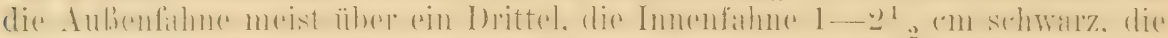

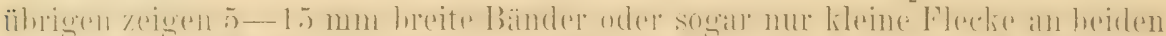

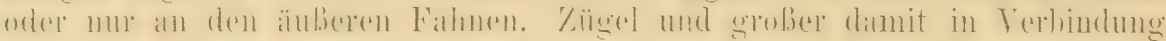
stehender Fleck unter und hinterm Auge schwarz. Unterseite ribmgelb bis fahl ockerfarben, an der Brust und am Kopf lebhafter ockerbraun; die Kehle ist entrveder bis zum Kinm himauf rahm- bis hell ockerfarben orler etwa $15-20 \mathrm{~mm}$ weit schwarz und rou der Kropfgegend durch einen meist sehr

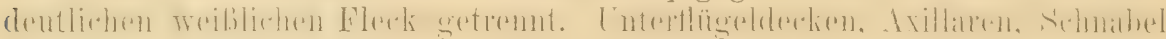
und FüBe schwarz, Iris braun. Durch Alonutzung und Ausbleichon wird dies Kleid im Frihjahr gauz anders: die Oberseite fahl ockerfarben bis fast weiBlich rahmfarben, Flïgel fast ganz schwarz. Unterseite rahmfarben bis fast woib. Flïgel an 60 o $89-94$, Sehtanz 64-69, Lauf 23-24.5. Culmen 16-19 mm. - o ad. Oberseite nicht lebhaft hell ockerfarben, sondern

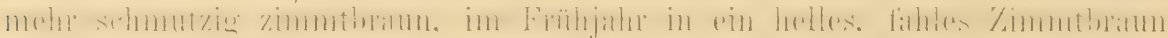
übergohend, Oberdecken wie der Rücken oder etwas dunkler. Unterseite

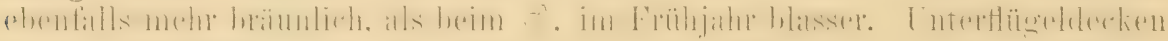
schmutzig fahlbraun, nur nach der Trurzel zu sehwarz. Flügel in der Regel 2- $4 \mathrm{~mm}$ kïrzer. Daß bei dieser Folm o mit schwärzlicher Kehle vorkommen, liounte ich nicht feststelleu, jedoch sind ơ im ersten Herbstkleide dem $ᄋ$ sehr ähnlich, nur daß die Grundfarbe der Obrdecken und Kehlfederu schwarz ist, und die Unterflügeldecken schwarz mit fahlbraumen Sümmen. - Nestkleid: Oberseite hellbraun, Federräuder dunkelbraum, Federmitten

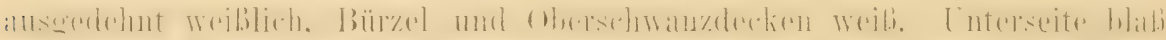
rabmfarbeu, Kropf und Vorderbrust mit braumen Federsäumen. Flïgel und Schwanz wio bei den alton Vögoln im Herbstkleide. - 3. und 4. Schwinge gleich und am lïngsten, 5. etras kürzer, 1. zwischen der 5. und 6., seltener länger als die 5., 1. etras länger als die Handdecken, 3. und 4. immer. 5. mitunter nur undentlich, oft aher ebenso stark vor der Mitte verengt.

Brutvogel in den Mittelmeerländeru West-Furopas: In den Mittelmeerprovinzen Südfraukreichs, rereinzelt bis in das südliche Saroyen, in Portugal und Spanien, Italien bis in die Südabhänge der Alpen, Südtirol, südlich des Brenner und Istrien, auf den Inseln und in Nordwest-Afrika: Marokko, Algerien, Tumesien und 'I'ropolis; hauptsächlich nördlich des Atlas, inmitten desselben, auf nicht zu hohen Plateaus, und an den Südabhängen, jedenfalls niemals in der eigentlichen Wüste brütend. - Zugvogel, der die Testliche Sahara durchwandert und südlich bis Senegambien beobachtet wurde. \%weimal rerflogen in England und Helgoland.

Ilan findet diesen Steinschun̈tzer in allerlei steinigem Gelände, Steinbalden, Feldern, kurzgrasigen 'Triften, an Wegen, sehr häufig auch in Weinbergen, wenn nur Steine, Mlaueru u. dgl, Plätze vorhanden sind. unter denen und in deren Löchern und Ritzen er nisten kann. Meade-Waldo will ihn zwar ausnahmsweise in großen Höhen im Atlas beobachtet haben, aber in der Regel geht er nicht sehr hoch ins Gebirge. In seiner Lebensweise stimmt er ganz mit andern Steinschnätzern überein. Der Gesang besteht aus einer kur\%en, aus pfeifenden und gepreßten, schnarrenden Lauten zusammengesetzten echt steinschmätzerartigen Strophe, und wird in zuckendem, wippendem Fluge sowohl als im Sitzen rorgetragen. Das Nest steht unter. Steinen, in Ritzen und Löchern an Felsen und Uferwänden, in M[auern, an rerlassenen Gebäuden usw. Es ist ziemlich lose gebaut, die Ausfiitterung enthält meist, aber nicht immer Pferdehaare und es 
enthält im Mai 4-5 Eier. Letztere sind auf licht blangrïnem, mattglänzendem Grunde mit matt rotbraunen, meist auch einigen blaßvioletten Schalenflecken, Flecken und Punkten gezeichnet. 60 Eier (34 Jourdain, 13 Koenig, 7 Erlanger, 6 Hartert) messen im Durchschnitt $19.83 \times 15.28$, Maximum $21.5 \times 15.1$ und $21<16$, Minimum $17>14 \mathrm{~mm}$.

\section{Saxicola hispanica xanthomelaena $H(m n)$. \& lihrly.}

Saxicola xanthomelaena Hemprich \& Ehrenberg, Symb. Phys. Aves, fol. c, aa, no. 6 (1833-Ägypten. Besehreibung des Herbstkleides der schwarzkehligen Form).

Saxicola aurita var. libyca Hemprich \& Ehrenberg, 1. c., no.9 (1833- Ägypten. IVeißkehlige Form).

Saxicola eurymelaena Hemprich \& Elirenberg, t. c., fol. bb, no. 3 (1833- Syrien. Schwarzkehlige Form, im Sommerkleide).

Saxicola amphileuca Hemprich \& Ehrenberg, 1. c., no.4 (1833- Syrien. IV eißkehlige Form, im Sommerkleide).

Saxicola albicilla Müller, Naumannia 1851,4, p. 28 "Abyssinien". Frihlingskleid der schwarzkehligen Form); id. Beitr. z. Orn. Afr., Taf. 3.

Saxicola stapazina brachyrhynchos und macrorhynchos, aurita longirostris und brevirostris (partim!) A. E. Brehm, Verz. Samml., p. 5 (1866- nomina nuda!).

Unterscheidet sich ron S. hisp. lispanica wie folgt: Im frischen Herlost-

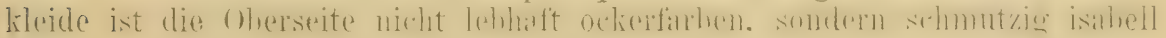
(etwa wie Fig. 23 anf Taf. III in Ridgways Nomel. Col.), und im Sommer wird die Ober- und Unterseite ganz, weiß, wenn nicht durch noch weitere

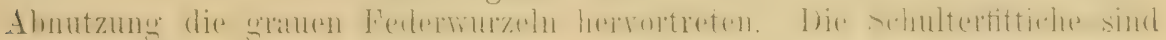
meist ganz schwarz. Bei den sehwarzkehligen ơ geht das Schwarz weiter nach unten (je nach Präparation und individuell von $2-3 \mathrm{~cm}$ varierend) und ist nach unten zu nicht so dentlich weib begrenzt; im allgemeinen ist auch ein feiner schwarzer Stirmand deutlicher zu bemerken, als bei der westlichen Form, und das Schwarz geht in schmaler Linie über das Auge, doch ist dies nicht konstant. Die Imuensäume der Schwingen sind nie deutlich weißlich, sondern nur fahlbraun oder ganz so schwarz wie der Rest der Schwingen. - Bei den o sind Stücke mit dunkler Kehle sehr häufig; die

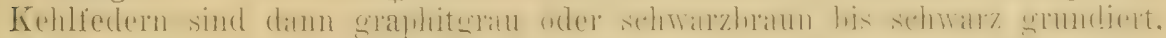
und die Kehle ist nach Abutzung der hellen Federsäume schwarz. Die

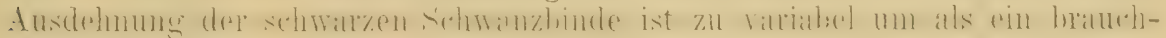
bares Merkmal zu dienen, doch sind Stücke mit fast gauz weißen inneren

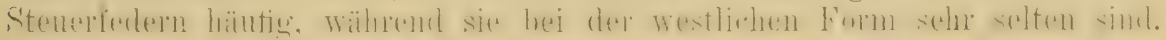

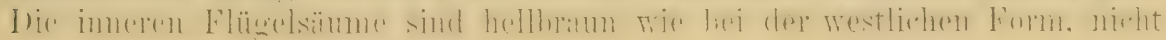
fast reinschwarz wie bei den $0^{2}$.

Ton Palästina und Kleinasien, sowie von Sïd-Rußland (Krim) und Bulgarien, durch Griechenland, Türkei bis Montenegro, Dalmatien und Kroatien, vielleicht auch noch im siidlichen Italien (Apulien, Calabrien, Sizilien?) nistend. - In Herbst und Frühling dureh Ägypten und Nubien bis zum östlichen Sudan und Abyssinien wanderud. Nicht selten auch auf dem Durehzuge in Italien, Tripolis, Tunis und Algerien.

Lebensweise und Fortpflanzung ganz wie bei der westlichen Form. 100 Eier (57 Jourdain, 39 Rey, 4 Reiser) messen im Durchschnitt $19.47 \times 14.92$, Dlaximum $21.6 \times 14.7$ und $21.5 \times 16$, Ninimum $17 \times 15$ und $17.3 \times 14 \mathrm{~mm}$. Im allgemeinen sind die Eier wohl etwas glänzender und im Durchschnitt gröber gefleckt, doch gibt es auch bei der westlichen Form ebenso grob gefleckte und bei der östlichen fein gefleckte, bei beiden kommen auch mitunter ungefleckte Stücke vor. 


\section{Saxicola hispanica gaddi Sar. \& Loud.}

Saxicola gaddi Sarudny \& Loudon, Orn. Jahrb. 1904, p. 219 (West-Persien).

$0^{\pi}$. Unterscheidet sich von weißkehligen $0^{\pi}$ der S. hispanica xanthomelnenu dalurch, dals die schmarze Ohrgegend mit der der Schulterpartie durch einen ansgedeluten schwarzen Fleck verbunden ist. „Betrachtet man den Togel vou der Serite. so wired der Vogel von der Oberschnahelwurzel bis zum Schwanze weif arscheinen, unterbrochen vou einem durehgehenden (hreiten) schwalydn Streifen," Die schwarzen und weiben Farben sind sehr rein.

Bekannt nach drei weißkehligen on aus West-Persien (Arabistan, Luristan. Masanderan) und cinem ebensolehen aus Sakutaly in Georgien (Transkiakiasien) im Tring Musem. - Ein mir vorliegendes sehön schwarz und weibes sehwarzkehliges o aus Luristan scheint sich in keiner Weise von Stüclien aus auderen Gegenden zu unterseheiden. Weitere Forschungen sind nötig, um zu zeigen, oh ..guddi: rine nur bei weißkehligen on arkennbare Subspezies oder Aberration ist.

\section{Saxicola pleschanka pleschanka (Lepect.).}

Motacilla Pleschanka Lepechin, Nov. Comm. Petr. X1V, p. 503,.Taf. 24 („1770“, nach Hase 1771 erschienen - Saratow an der Wolga) (Übers. Hase, Lepechins Reise I, p. 229. Gute Beschreibung).

Motacilla leucomela Pallas, Nov. Comm. Petr. XIV, p. 584, Taf. 22, Fig. 3 („1770“, wohl richtiger 1771 - untere Wolga, Altai, Daurien).

Saxicola Morio Hemprich \& Ehrenberg, Symb. Phys. Aves I, fol, aa (1833- OberÄgypten und Arabien).

Saxicola atricollis Miüller, Naumannia 1851, 4, p. 28 (Abyssinien).

Saxicola hendersoni Hume, Ibis 1871, p. 408 (Yarkand).

Saxicola talas Severtzoff, Turkest. Jevotn., in Izv. Obshch. Moskov. VIII, 2, p. 55, 119, Taf. 8, Fig. 1, 3, 4 (1873-- Russisch!); Übers. in Zeitschr. f. ges. Orn. IV, p. 51 ; ef. Stray Feathers III, p. 429.

Abbild.: Dresser, B. Europe II, Taf. 33, 1. Eier: Rey, Eier Vög. Mitteleur., 'Taf. 57, Fig. $17-20$.

( Saxicola vittata Hemprich \& Ehrenberg, Symb. Phys., fol. ce (1833- NordArabien).

Saxicola leucolaema Antinori \& Salvadori, Atti Acc. Torino VIII, p. 32 (1872Bogosland).

1) Saxicola melanogenys Severtzoff, Turkest. Jevotn. (in Izv. Obshch. Mloskov. VIII, 2), p. 120 (1873- Turkestan. Russisch! Üher's. Zeitschr. ges. Orn. IV, p. 54).

Saxicola melanotis Severtzoff, t. c., Taf. VIII, Fig. 5 ( (َ), 6 (q).

Saxicola somalica Sharpe, Proc. Zool. Soc. London 1895, p. 486 (Somaliland).

Abbild.: Dresser, B. Europe IX (Suppl.), Taf. 637.

ơall. in abgetragenen Brutgefieder: Kopf', Hinterhals, Bürzel und Oberschwanzdecken. Brust. Lnterkörper und Tutersehwanzdecken weiß, das

1) Diese Namen beziehen sich auf die weißkehlige Aberration, die sich nur durch die weiße Kehle unterscheidet.

Sie wurde in T'urkestan, Transkaspien (Sarudny), Ost-Persien, einmal in Gilgit, und im Winter in Nord-Arabien, Bogosland, Somaliland und Ost-Afrika (Escarpment in den Kikuyu-Bergen, 6500 engl. Fuß hoch, Dezember 1900, WV. Doherty) vereinzelt angetroffen, und am 19. September 1909 in Schottland erlegt. 
übrige Kloingefieder cinschließlich eines sehmalen Stirnstreifens und der Zü̈gel, der Unterflügeldecken und Axillaren schwar\%. Kehle mitunter weiß (,vittute"). Schwingen braunschwarz. Mittelstes Stenerfederpar an der Wurzel ungefühn zu $2 / 5$ weiß, sonst schwarz, die übrigen weils mit schwarzer Endbinde, alle mit sehr schmalen Spitzensäumen; die schwarze Binde variiert von $2 \mathrm{~cm}$ an den änßeren und etwa 7-10 $\mathrm{mm}$ an den inneren Pataren (immer ist sie an den äußersten am breiteston) bis zu $1 \mathrm{~cm}$ an den äußeren, und Üherbleibselu von Binden in Gestalt einzelner F'lectie an den iuneren Steuerfederm. Iris braun, Schuabel und Füßse schwar\%. Im Herbstkleide haben die Federn der Oberseite breite isabellbrame, die Armschwingen hreite fahl isabellfarbene Säume, die Unterseite unterhalh des Kropfes ist bla B, isabellfarben. Flügel (etwa 36 ठ ) $90-97.5$, Schwanz 60)-65, Tauf 22.5-24.5, Culmen etwa 15-17 mm. - Q ad: Oberseite erdhrau, unterer Bürzel und Oberschwanzdecken weiß. Flügel dunkelhraun, Vorderbrust und Kehle fahl graubrïunlich his schwar\%, Stenerfedern weiß mit schwarzbrauner Endhinde, wie beim on, aher durchschnittlich etwas hreiter. In frischen Herbstlkeide haben die Rückenfedern hlaß isabellfarbene Süume und der Tinterkörper ist hell fahl isabell, fitst rahmfarben. Das cjur. ähnelt dem o, aber die Kehle ist immer, aufer an den Federspitzen. schwarz, und der Rücken ist schwär\%licher. - Die ziemlich bedeutenden Größenunterschiede bei beiden Geschlechtern seheinen rein individuell zu sein. - - 1. Sehwinge etwas kürzer. gleich, oder etwas lïnger als die Handdecken, 3. und 4. meist gleich und am längsten.

Südrußland von Orenburg und dem Mittellauf der WTolga bis zur Krim und dem Kaukasus, Transkaspien, Turkestan, Persien, Afghanistan, westliches Thibet, Mongolei, Süd-Ost-Sibirien, Nord-China, Gilgit und Nord-Kaschmir. - Auf dem Zuge in Nordostafrikit und Arabien. vereinzelt auf Helgoland. in Italien, und wahrscheinlich auch Algerien.

Sichere und erhebliche Unterschiede von seinen Verwandten in bezug auf die Lebensweise konnte ich nicht eruieren. Der Gesang wird als verhältnismäßig fein und leise beschrieben. Das Nest steht in Löchern und Höhlungen nahe am Boden und enthält 5 Eier von blaß grünlichblaner Färbung und mit rotbräunlicher Fleckuug. 41 Eier messen nach Jourdain (25) und Rey (16) im Durchschnitt $19.29 \times 15.08$, Maximum $20.8 \times 15.2$ und $18.8 \times 16$, Minimum $17.1 \times 14.9$ und $18.5 \times 13.5 \mathrm{~mm}$. Das mittlere Gewicht ist nach Rey $137 \mathrm{mg}$. - (Man hat S. pleschanka als die "östliche" Form vou $S$. lugens aufgefabt, was ich fïr gewagt halte, namentlich im Hinblick unf den ganz verschiedenen Färbungscharakter der $q$ und die Verbreitung.)

\section{Saxicola pleschanka cypriaca Hom.}

Saxicola cypriaca E. v. Homeyer, Zeitschr. f. ges. Oru. I, p.397 (1884- Cypern).

ơad. Uniterscheidet sich von dem von S. pleschanka pleschanka dadurch, dall es etwas kleiner, die schwarze Findbinde des Schwanzes meist hreiter, die Irurzel des mittelsten Steuerfederpanes nur 18 his hërhstens $20 \mathrm{~mm}$ weit weib. und die gin\%e Tnterseite vom Kropfe an hlab rostgelb. selhst in der Brutzeit nicht so weil. wie hei S. p. plesehanliu ist. Flügel von 20 untersuchten alten $\sigma^{\pi}: 84-90$, hei einnm $3111 \% 81 \mathrm{~mm}$, doch sind bei demselben die Spitzen schon abgeutat, so dab dis Mab \% klein sein mul. Schwanz etwa $56-62 \mathrm{~mm}$.

Cypern, anscheinend Standvogel.

E. Hartert, Die Vögel der palïarktischen Fauna. 
Zwischen dem 6. und 20. Mai fand Glaszner zahlreiche Nester in Mauerlöchern, 1-3 m über dem Boden. Sie enthielten 4-5 Eier. Diese sind ziemlich gleichmäßig. hell grünlichblau, reichlich heller oder dunkler rotbraun, besonders um das stumpfe Fnde herum gefleckt und mitunter mit deutlichen blaß lila Schalenflecken. Fast durchweg sind es die am stärksten gefleckten Steinschmätzereier, die ich kenne. 50 an das Tring-1luseum gesandte Exemplare messen im Durehschnitt 19.39 $\times 1+4.60$, Maximum $20.6 \times 14.6$ und $20.4 \times 15.4$, Minimum $18 \times 14.8$ und $18.9 \times 14 \mathrm{~mm}$.

\section{Saxicola melanoleuca melanoleuca (Giïld.).}

Muscicapa melanolenca Güldenstärt, Nov. Comm. Petrop. XIX, p. 468, Taf. 15 (1775Georgien) $\mathbf{1}$ ).

Saxicola barnesi Oates, Fauna Brit. Ind., Birds II, p. 75 (1890- „Baluchistan und Afghanistan and eastwards to Persia").

Saxicola finschi var. turanica Zarudny, Mém. Ac. Imp. Sc. Petersb., ser. VIII, X, no. 1, p. 236 (1900 - turanisches Tiefland. Russisch).

Saxicola finschi turcomana Loudon, Orn. Jahrb. XV, p. 173 (1903- Schreibfehler statt turanica).

Abbild.: Dresser, B. Europe II, Taf. 28.

Tat im frischen Horbstkleide. Oberseite: Kopf, Hals und Rücken brätunlich isabell, Bürzel und ()herschwanzderken weib nit rahmfatrenem An-

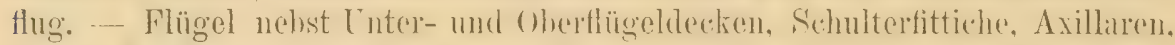

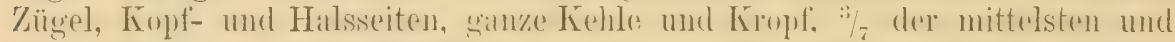

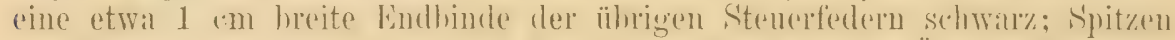

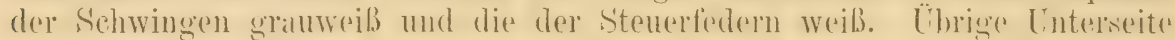

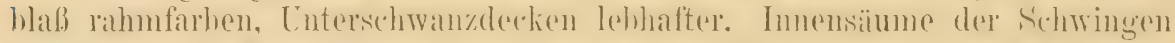
graubram, sich kaum ron den mattschwargen Sohwingen ahhehend, mitunter

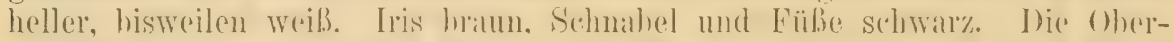

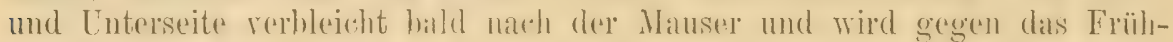
jaho hin fast weiß. Flügel 87.5-95, Schwanz 64.5-69.5, Lauf etwa 25, ('ulmen 17 - 18 mm ( 41 gemessen). - Oad. Ohersegte fihlhaum (fast dunkel

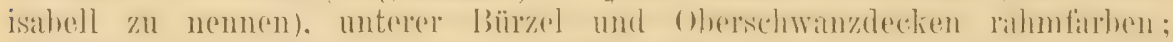

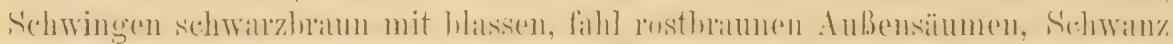

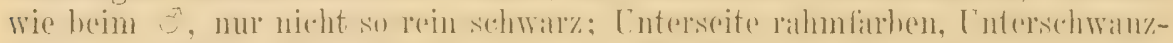

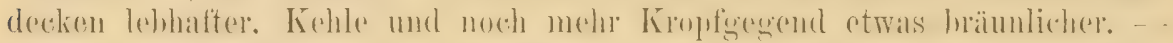
Etwas kleiner, als das 0 . - Nestkleid in beiden Geschlechtern dem des o

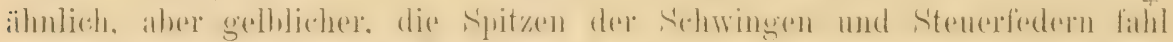

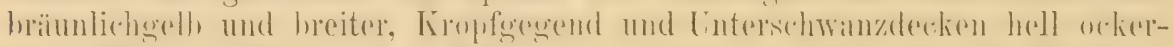

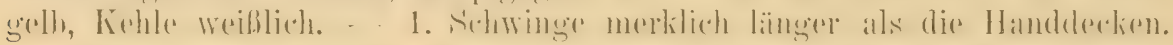

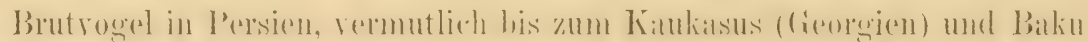

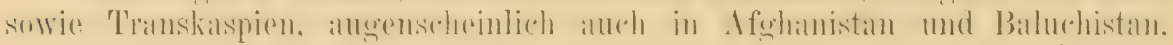

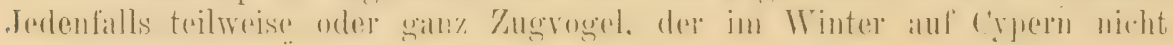
selten ist und in $\ddot{A}$ gypton beobachtet wurde.

\section{Saxicola melanoleuca finschii Heugl.}

Saxicola Finschii Heuglin, Orn. N.O.Afr. 1, p.350 (1869- nach einem angeblich aus Sibirien stammenden of des Bremer Museums beschrieben. - Typus untersucht).

Õ: Wie das von S. melanolenca melanoleuca, aber kloiner: Flügel ron 12 o nur 85-90, bei einem ơ aber $92 \mathrm{~mm}$. - o in der Regel mit

$\left.{ }^{1}\right)$ Dieser Name wurde bisher immer fälschlich auf die östliche Form ron S. hispanica bezogen. 
Schwarzer Kehle: meist ist del untere 'Teil der Kiehle ganz schwarz mit hellen Federsäumen, (lor ohere 'Tril wriblichur, gauz weibliche Kehlen wie hei s. $j$. Lumesi sind offenhar seltrn: anBerdrm scheint dio Oberseite etwils gräulicher und dunkler zu sein.

Brut-, und anschemend Standroger in Palästina, Ș̣rien (Nordarahiun) und Kleinasien.

In seiner Lebensweise anderen Steinschmätzern gleichend. Nest aus trockenem (trase und mit Federn ausgefüttert. in Fulsenspalten; im IIärz und April Eier, die blalj bliulichweiß, frisch mit rosigem S'chimmer. und mif rotbraunen Punkten gezeichnet sind.

\section{Saxicola isabellina Crotzschm.}

Saxirola isaliellina Cretzschmar. Atlas zu Riippells Reeise, Vïgel, ]. 52. 'Taf, 34, b (1826Nubien).

Saxicola saltator Ménétries, Cat. Rais. Cauc., p. 30 (1832 - „Sur les bords arides de la mer Caspienne").

Suxirola squalida Erersmaun, Addenda ad Pall. Zoogr.. p. 16; (1835- ô „prope uppidum Indersk", 우 „in monte Bogdo").

Saxicola valida Lichtenstein, Nomencl. Av. Mus. Berol., p. 35 (1854- nomen nudum, wohl Versehen statt squalida).

Abbild.: Dresser, B. Europe U, 'T'af. 22.

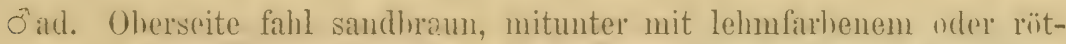
lichbranem Anflug. Yägelstrich sehwilrzich, Supereiliasstreif weiblich. ()berschwauzdecken weil). Schwingen dunkelhraun, sandfurben gresäumt. Steuerfedern bräunlichschwalrz, das mittelste Parl an der Wrurzel zu einem I)rittel vder etwas weniger weif, die übrigen gut zur Hälfte oder merklich dartiher weib, so dab nur etwat $20-26 \mathrm{~mm}$ an den Syitzen schwarz hleiben. ()hngegend dunkler als der Rücken, brätulicher. T'nterseite rahmfarben, mehr oder minder isibell verwasthen; Krouf und Vorderhrust isabell. Unterthügeldecken und Axillanen weiB, Imnensïmme der Selnwingen l'alhmfarben. Iris dunkelbriun. Schmahel und Füße schwarz. Flïgel etwa ( 10 gemessen) 99-105, selten nur 96 (so kileine augebliche o wohl meist falscb buzeichnete o) oder 106. Sehwanz etwa 57 -6:2. Lauf:30-33, Culmeu 19-22.5, meist etwa $20 \mathrm{~mm}$. - o ganz wie $d$. nur etwas kleinel: Flügel hei über 20 o 94-97 mm. Ein angebliches o (obrvolıl von einem der besten Simmler) mit Flügel 11$) 1$ clürfte doch ein ò sein. - Nestlileid: Kloingetieder der Oherseite mit lichteren Krilflecken ror den Sinitzen und dunklex"en Fudsäumen, Kropfgegend mit schmalen luaunen Federsäumen. Oherschwanz-

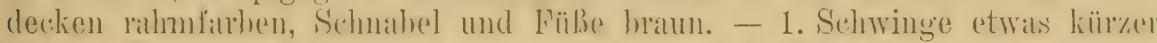
als die Handedeken. seiten so lang wie letztere. 2. etras länger als 5.. udet

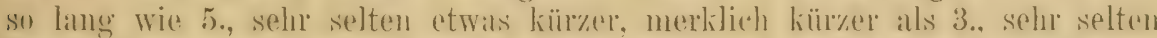

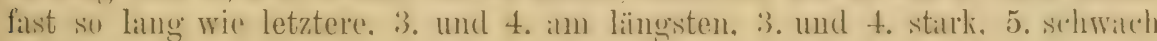
verengt.

Wrait verhneitete Art, die ron den südostrussischen Sitejuen und Klein-

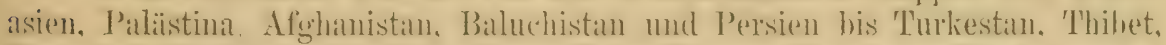
Mongolei, Ostsihirien und Nordwest-China Brutrogel ist. - Kangrogel, der in Nordust- und ()st-Ifrikil. Sïdaribirn und inn westlichen Indien überrintert.

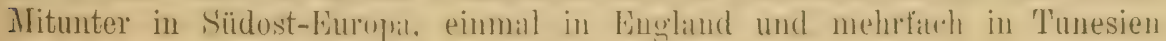
und Algerien erbeutet. 
Bewohnt Ödland, Felder, buschreiche Ebenen usw. und brütet in Löchern, besonders in von Nagetieren verlassenen Höhlen. Eier wie die von S. oenanthe, doch meist etwas größer und glänzender. Nach Rey messen 21 Stïck aus den südrussischen Steppen im Durchsehnitt $21.71 \times 16.09$, Maximum $24.5 \times 17$ und Minimum $20.7 \times 16.2$ oder $22.4 \times 15.7 \mathrm{~mm}$. Nach Jourdain messen 33 Eier aus Kleinasien, Astrachan usw. im Durchschnitt $22.3 \times 16.6$, Maximum $25.1 \times 17.3$, Minimum $19.5 \times 15.6 \mathrm{~mm}$.

\section{Saxicola xanthoprymna chrysopygia (De Fil.).}

Dromolaea chrysopyyia De Filippi. Arch. Zool. Genova II, p.381 (1863- Demavend, Persien).

Saxicola kingi Hume, Ibis 1871, p. 29 (Jodhpur).

Abbild.: Dresser, B. Europe IX (Suppl.), Taf. 638, Fig. 1.

ơad. (Herlost): (Oherseite isahell-hraun, auf dem Bürzel in die fahle brämnlichorangenfirhene Färhung der Oherschwanzdechen ïbergehend; rorderste Stimfedern. Zïgel und schmaler Simpereiliarstreif hellgrau, Federn um das Ange weiblich. ()hrgegend dunkler und mehr haun als der Rüclien. Halsseiten blabgrau. Schwingen dunkelbram, ()berflïgeldecken bramschwan, Handsehwingen mit schmalen schmutziggratuen, Almsehwingen mit breiteren fahl rötlich zimmtfarbenen Aubensïumen und alle mit weiBgrauen spitzen. (benso die gröberen (Oberflügeldecken, die kleinen dagegen braun mit ausgedehnten grauen säumen: Haudelecken mit woiflichen Sïumen. Steuerfedern hräunlich orangofarhen, änbere an den Spitzen ungefïhr zu einem Viertel. mittelste zur Hiilfte bis zwei I) rittel braunsehwarz, mit etwal 3-4 mm breiten bräunlich orangefarbenen Eudsüumen. Tinterseite bräimlich grauweiß. Kehle weißlicher. Brust hräunlicher, Wrichen sehr fahl orangebräunlich verwaschen. Cunterschwanzdedien etwas heller als die oheren. Innensämme der Schwingen sehmutzig weiligrau; Lnterflügeldecken dunkelgrau mit ausgedehnten weiben Spitzen, Axillaren weiß nit dunkelgrauer Basis. Iris hraun, S'chmabel und Fübe sehwal\%. In Fröhjahr wird die Oberseite dunkles

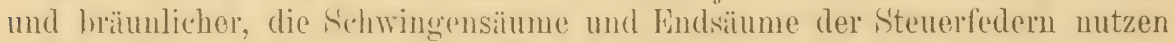
sich mohr ader minder ah, dor Bürzel wird heller, elsenso die Unterschwanzdecken, die Unterseite schmutriger. Brust brïmlicher. Flügel etwa 90-96. Schwanz etwa 62-66, Lauf 25-26, Culmen $18-20 \mathrm{~mm}$. o ad, wie $\sigma^{\circ}$.

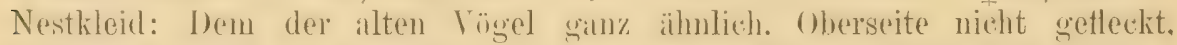
Enterseite nieht mit dmokeh Fedorsümmen, aher Bür\%el heller, Flügeddecken mit isabell-rahmbarhenen Spitzen, Brust mel Unterkörper rahmfarben, Sehnahel

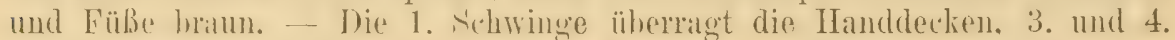
am längsten, 2. kiüzer als 5. Die 3.-5. und mitunter die 6. ror der Mitte verengt.

Brïtet in sïdlidhen 'T'anskaspien, in (Ost-Persien und Persisch Balurhistan, wurle in Baluchistan und dem südlichen Ost-P’ersien (S'eistan) ron

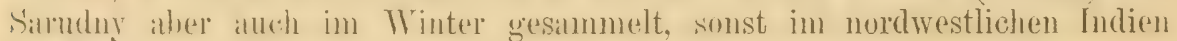
bis Sindh und Gujarit, ostwïrts bis Jodhpur überwinternd.

Bewohnt öde, steinige und felsige Gegenden. Sarudny fand im sïdlichen 'Transkaspien am 25. Mai 1892 ein Nest mit Eiern. Die Eier sind weiß mit hellblauen Schimmer und feinen. blaß braunroten Fleckchen am stumpfen Ende. Ein Ei in Dressers Sammlung mißt (s. Ibis 1903) ungefähr $19 \times 16.1 \mathrm{~mm}$. 
105(). Saxicola xanthoprymna xanthoprymna Hempr. \& Whrhg.

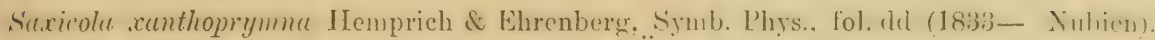
Śaxicola erythropygia Taylor, Ibis 1867, p. 61 (Ägypten).

Abbild.: Dresser, B. Europe II, Taf. 31 (sub nomine S. moesta), 32 Fig. 1.

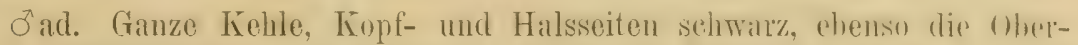
und Tinterflügeldecken und Axillaten; Basis des Sohwanzes woil. _ _ sonst wie S. x. chrysopygiu, nur die Oherseite dïsterer grambraun und die Cinterseite vielleicht etwas weilhlicher. - o ad. Den von S. a. chrysopngia seh" ähnlich, nur Ohrgegend und Kehlseiten dunkler und mit sehwïrzlichem Sohimmer, Wurzelteile der Steuctedern brälunlich orangetarben, an der äubersten Basis in Weiß ühergehend, Wurgeldrittel des mittelsten l'ares größtenteils weiß. Ein? Òjuv. gleicht dem qad., nur ist die Schwanzhasis fast rein weib. Flügel cines bei Simakin erlegten Pares im 'Tring Musem: ơ 93.5 , ㅇ $91.5 \mathrm{~mm}$. - Iris braun.

Diese seltene Art wurde hisher nur in Ägyten und Nuhien, sowie an der Küste des Roten Neeres gefunden (Sauakin, erlegt ron Oherst Giftard).

\section{Saxicola xanthoprymna cummingi Whit.}

Saxicola cummingi Whitaker, Bull. B. O. Club X, p.17 (1899- Fao am Persischen Golf, ठే).

Saxicola hawkeri Ogilvie-Grant, Bull. B. O. Club XXI, p. 94 (1908- Berber in Nubien, ?).

Abbild.: Ibis 1902, Taf. 3 ( ð).

$\checkmark$ wie das $S_{\text {. }} x$. xunthoprymun, aber die Basis der Steuerfedern hräunlich orangefarben anstatt weib. - Das o wie S. $x$. chrysopygia, nul die Oberseite dunkler hram, auch Kopfseiten. Kronf und Treichen etwas bräumlicher.

Ess sind hisher nü drei Stücke bekaunt: Kin Pärchen von Faro an del Nordspitze des persischen Meerbusens und ein o ron Berber in Nubien. Jetzteres wurde im Januar, also wohl sicher im Winteryuatier erlegt. Ob hei Fao (oder in anderen Teilen Persiens) Brutrogel, ist noch nicht festgestellt.

\section{Saxicola moesta Licht.}

Saxicola moesta Lichtenstein, Verz. Doubl. Mus. Berlin, p. 33 (1823- Ägypten). Saxicoln philothamma 'Tristram, Ibis 1859, p. 58. 299, Taf. 9 (Algerische Sahara). Saxicole ruficeps oder vielmehr muficapilla IIs. im Berliner Museum, teste Ibis 1850. p. 299 und Journ. f. Orn. 1899 p. 234.

Abbild.: Whitaker, B. T'unisia I, Taf. 4.

oad. im Herhste: Oherkopf und Hinterhals hräunlichgrau. Rücken dunkel sehieferfarben, Bürzel und Oberschwanzdeckon hell fahl rostrot, Schwingen braun mit weißlich fahlbraunen Außensäumen. Flügeldecken dunkelbraun mit brïunlichwoißen Süumen. Steuerfedern dunkelbraun, iußerste. Basis der heiden mittelsten, üher ein Drittel his einhalb der ührigen an der Wurzel blaß rötlich zimmtfarben. Weißlicher Superciliarstreif. rä̈gel, Kopfmol Halsseiten, Kehle (mitunter mit weisser Beimischung) und Brustseiten bräunlichschwar\%, übrige Tnterseite weiß, äußere Lnterflügeldecken weiß, an der Wurzel schwärzlich, übrige Unterflügeldeclin und Axillaren schwärzlich 


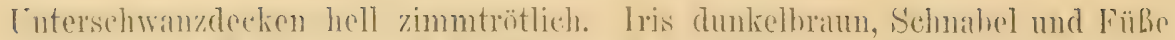

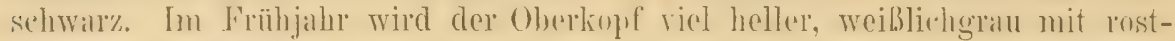
fathener Beimischnng. der lï̈cken variert, bleibt mitunter granbraun, wird aher meist dunkler und oft fast rein schwalrz, Bär\%el und Oherschwan\%decken, ebenso die Schwanzwurel, werden heller und mitunter fist weib: in stark alggenutztem Sommergetieder werlen die Flïgelsäume selmüler und die Fedem des Oberkopfes stossen sich so ilh, dali die Koptmitte. Wril list nur noeh die Federwurzeln hleiben, dunlielgrau aussiolst. Flügel etwal 90-99. also recht variahel, Sehwanz 6t-71. Lauf etwa 26-29. C'uhmen 19-21 $\mathrm{mm}$ (20) algerisch-tunesische. 5 ans Paliistinal gemessem). - o ad.: Oherkinf und Hinterhals zimmetrot. Rücken und Oberflügeldecten rötlichgrau, letztere mit fahl hell zimmetrötlichen Sïumen. unterer Bä̈zel und Oberschwanzdecken hell zimmetrötlich. Steuerfedern wie heim of, uur die syitzenhälifte niecht sn dunkel, sondern mehr braun. Konfseiten wie Rïeleu. C'nterscite rahmfarhen, Kehle oft mit gräulichenr Sichimmer. Vorderbust und Unterschwanzdecken hell rostrot. Das Gefieder verïndert sich nur wenig dureh Abnutzus und Ausbleichen. Kleiner als das ơ. Flügel meist etwa 5 mm kï̈"\%er. Nestlileid: (Oberseite gräulich zimmtfarben, Ferlermitten undeutlich heller und rïtlicher. Bürzel und Oberschwanzdecken zimmentrich weis. Unterseitr schmutzig fahl rahmfatron, Brustfedem rätlicher und mit undeutlichen granhramen sïumen. Flïgel wie heim c ahere die sülume hreiter und mehr

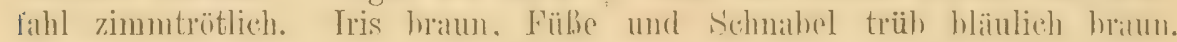
o dunkler als $0 .-$ 1. Schwinge länger als die Handdecken, 3.-5. beimahe gleich und alm längsten (sehr stumpfflüglig), 3.-6. vor der syitze stark verengt.

Sahallal, von süb-Algerien und Tunesien, Tripolis, Cyrenaiea his Ägrpten, (Lyhisehe Wüste) Nordarahien und Süd-T'aliastina. - Östliche und westliche Stiicke sind nicht zu trennen.

S. moesta ist Standvogel in der sandigen, lehmigen und steinigen Steppe, mit Vorliebe dal, wo der Boden salzhaltig ist, in der sogenannten Seblka, fehlt aber unbedingt den Sanddünen sowohl als dem Gebirge. Obwohl nicht uiberall anzutreffen, ist er doch an vielen Orten, z. B. in der Nähe von Biskra und Sidi Okba, südlich von Biskra bis fast nacl 'Tuggurt hinunter, in Süd-Tunesien und der Cyrenaica häufig. $\mathrm{Er}$ ist durchaus nicht scheu. Die Lockstimme ist ein ganz eigenartiges rollendes iljürrr, iirrr, ürrr; aus diesen Tönen und einigen pfeifenden Lauten setzt sich der krältige, angenehme Gesang zusammen; beim Neste hört man noch ein zeterndes brrr-dje. Die Nester stehen in Röhren, meist (oder stets) verlassenen Höhlen von Nagern, sind über metertief vom Eingange entfernt; oft sind die Röhren gebogen, gewinkelt vder gezweigt. Das Nest besteht meist hauptsäellich aus Schafwolle dureh kleine 'Lweiglein zusammengehalten, ist außen mit Lappen und Fäden umgeben, innen mit allerlei Haaren und Federn, in einem F'alle mit einer Menge Schlangenhaut ausgelegt. Die 4-5 Eier sind licht grünlichblau bis bläulich weiß, mit feinen rotbraunen Punkten und Fleckehen. 7 Eier (5 Whitaker, 2 Hartert) messen im Durchschnitt $23.41 \times 16.32$, Iaximum $24 \times 17$, Minimum $23 \times 16$ und $24 \times 15.5 \mathrm{~mm}$.

\section{Saxicola lugens lugens Licht.}

Saxicola lugens Lichtenstein, Verz. Doubl. Mus. Berlin, p. 33 (1823- „Nubia").

Siscicola erythraea Ilemprich \& Ehrenberg. Symb. Phys., Ares, fol. ce (1833- NuralArabien).

Saxicola lugens major \& minor A. E. Brehm, Verz. Samml, p. 5 (1866- nomiua nuda). Abbild.: Dresser, B. Europe II, Taf. 33, 2. 
O̧ad. Oberkopf und Nacken weib, mehr oder minder mit fahlem Grambatun verwasthen, in ganz frisehem Gefoeder ist dio Grumbathe der

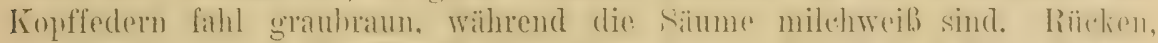

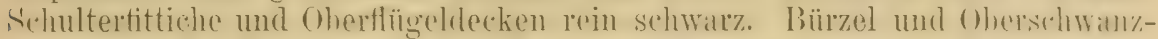

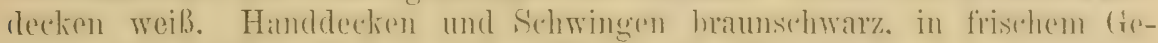
fieder mit weilien Spitzen. Immenfahnen dex Schwingen, mit Ausmahme

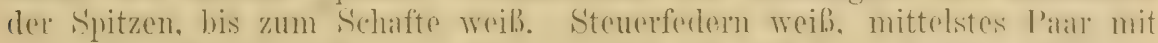
schwarzer Spritzenhïlfte, die ïhrigen mit $10-12 \mathrm{~mm}$ loreiten, mitunter schmäleren sehwarzen budbinden nud alle mit sehmalen weilen spitzensämmen. Zügel, Kinn, Kéhle. Kopf- und Halssciten schwarz, ahenson die Arillaren und Unterflügelderelien. Chrige Unterseite weilh, Cutersehwanzdecken fahl ockerfarhen. Iris haum, Schnahel und Fübe schwarz. Flügel (8 ठ̋) etwa 91-96.5, Schwanz 63-67, Lauf 26, Culmen 18.6-19.9 mm. - o ad. Ganz wie das ơad., nur vielleicht nicht ganz so tief schwarz auf dem lï̈cken, und etwas kleiner: Flügel 89-91 mm. - Jur. Nestkleid:

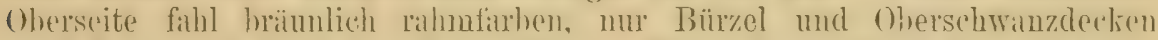
weib, Kehle und Brust lohhaft rahnfithen. Listes Jugendkleid: Die schwarzon Rü̈kenfedern nit fahl rostgellon Sümmen. ehenso dic Oherflügeldecken und Sehwingen; Kehle weili, Brust mahmfahen. - 1. Schwinge üheragt die Handdecken.

$$
\text { Ägypten, Nubien, Nordarabien und Palïistina. }
$$

\section{Saxicola lugens halophila Tristr.}

Saxicola haloplita 'T'ristram, Ibis 1859, pl). 59, 301 ( $q$, Algerien).

Saxicola kocnigi Erlanger, Journ. f. Orn. 1899, p. 282 ('Tunesien).

Abbild.: Koenig, Journ. f. Orn. 1895, T'af. 4, Taf. 5, Fig. 1; Eier: Journ. f. Urn. 1896, Taf. 7, Fig. 4.

ơad. Dem von S. lugens lugens äußerst ähnlich, aber leicht dadureh nuterschioden, dalfi die Innenfilmen der Schwingen nicht his an den Schaft meils sind, sondern nur einen hroiten weiben Sam hihen; auberdem sind die Linterschwanzdecken hlasser, im Frühjahr nicht viel mehr als gesättigt rahmfarben. - I lo @ sind von denen der östlichen Form ganz verschieden: Dir ()herseite, mit Ausnahme ron Bürzel mol Oherschwanzdecken, ist filhl graulram, Flügel schwarzhaun. Interscite weib mit rabmfarbenem Anflug, Enterselowanzdeclien hell fahl röstlich: Kehle sthmutzigweig his schwalry, meist sedmutzigweil. mit rubfuhenem Anflug nder schwar, am Kimn und

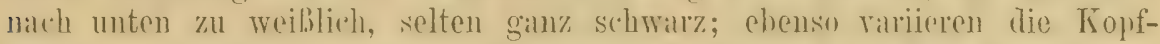
seiten ron braun liss schwarz. Mam nimmt gewöbulich an, dab die schwalrlichligen: die ältesten seien. aher hicrfür liegt keinerlei Boweis ror.

Nërdliche algerische und tunesische Sabara, Tripolis und C'yrenaikal. Wie weit diese Form nach Osten geht, wissen wil nicht; cin am 24. Februar 1909 hei Ahuroaseh (Gizil) in Ägypten ron Nicoll erlegtes on ist wohl als verflogen amzusehen.

In 'Tunesien und Algerien nur südlich des Atlas, wo or die kahlen; aus zerkliifteten Felsen bestehenden Hiigel, die I'fer trockener Flußbetten. steinige Sahara mol Wegränder bewolnt, daher häufig sïdlich von Lil Kantara und um Biski'a herum, aber selten in der eigentlichen Wüste, wo er nur ganz vereinzelt in salzhaltigem Gelände, bis 'Tuggurt hin, und selbst bei Wargla und Hadschira vorkommt. - Der 
prachtrolle Vogel belebt die öden steinigen Gegenden in hervorragender Weise. Sein Gesang ist feiner, zwitschender als der der andern Steinschmätzer, meist kurz, soltener länger ausgedehnt. Er wird meist im Sitzen vorgetragen. Das Nest steht meist tief in Höhlen, Rissen und Spalten im Felsgestein oder an den Ufern von Flußbetten oder Wegrändern und ist von Steinen oder Erdschollen überdacht, seltener in Erdlöchern in der Wüste. Vor dem Neste findet man in der Regel Steinchen aufgeschichtet, wie bei S. leucurus. Das flache Nest besteht aus allerlei Pflanzenstengelchen, Würzelchen und Gräsern und ist mit Haaren und Wolle ausgefüttert. Es enthält (im April) 4-5 Eier. Diese sind sehr bell grünlichblau, fast weißlich, mit rotbraunen Flecken und Punkten und vereinzelten blaßvioletten Schalenflecken. Sie sind meist gedrungen bauchig. 20 Eier aus Algerien und Tunesien (11 Jourdain, 5 Koenig, 1 Hartert) messen im Durchschnitt $20.16 \times 15.61$, Maximum $20.8 \times 16$ und $20 \times 16.4$, Minimum $19 \times 15$ und $19.7 \times 14.9 \mathrm{~mm}$.

\section{Saxicola persica Seeb.}

Saxieola persica Seebohm, Cat. B. Brit. Mus. V, p.372 (1881- Schiras in Persien). (S. Sarudny, Hém. Soc. Russe Géogr. XXXVI, no. 2, p. 445. Russisch!).

Von S. picatr mit lellem Oherkopf (Aberration eapristrala) wie folgt unterschieden: Kopfplatte hell tahl graulnam und nicht am Hinterkopfe s.harf ahgeschuittron, sondern üher den Naclien hin ausgedehnt. Untersehwanzdecken dunkler, fast lohbaft zimmtarhen, Innensäume der Schwingen hreit waiß, 1. Sohwinge etwas kï̈\%er. Ton S. lugens untersehieden durelı: bräunliehere Kopfplatte. weniger ausgedehnte und nicht so rein weibe immere Flügelsäume, hreitere solıwarze Sehwanzhinde, dunklere Unterschwanzdecken und etwas längere Flügel. Flügel $96-98.5 \mathrm{~mm}$. (3 0$)$. - Juv: Oberknpf und Rücken fahlbraun. Kohle rahmwoiblich. Vorderinust fahl hräunlichgelb mit dunkleren Federsäumen.

Persien (Schiras, ()stpersion, Persisch Baluchistan). -- Vielleicht ïstlichste Form voul S. lugrns, doch enthalte ich mich vorläufig jeder Meinungsiuberung ïher dic wahre Verwandischaft, zumal ieh das fy nicht aus eigenor Anschauung kenne.

\section{Saxicola picata Blyth ${ }^{\mathbf{1}}$ ).}

Saxicola picate Blyth, Journ. As. Soc. Bengal XVI, p. 131 (1847- zwischen Sind und Firozpur); Abbild.: Dresser, B. Europe IX, Suppl., T'af. 26.

Saxicola capistrata Gould, B. Asia IV, 'laf. 28 (1865- Nordwest-Indien).

(Es scheint mir keinem Zweifel zu unterliegen, daß ,S' picata" mit schwarzen Oberkopf und "S. capistrata" mit weißlicher Kopfplatte ein und dasselbe sind, der Fall ist derselbe wie bei Saxicola lencopyga, Saxicola monticola - vgl. Reichenow, Vög. Afr. III, p. $716^{\circ}$ - und Myrmecocichla nigra Reichenow III, p. 706. Ahnliche Variation finden wir an den Kehlen bei Sax. hispanica und S. pleschanka (vittata).

Carl. Oherseite schwarz. Bürzel und Oherschwanzdeclien weiß; mittelstes Steverfederpatar schwar, Basis zu etwa ${ }^{3}$ is weiB. ïlnige Stenerfederu weif. mit schrvalzer, "twal $1-1^{1} / 2$ em breiter schwarzer Endbinde und schmalen weißen Spitzensïumen. Kehle und Kropt, sowie Unterflügeldecken schwarz.

1) Verwande nordostafrihanische tropische Formen mit fahl graubraunen Oberlö̈fen sind: S. lnyentoides und S. lngubris. Listere ist in Winter in Süd-Arabieu nicht selten. (Vgl, Reichenow, Yög. Afr. IIT, p. 729.) 
Unterschwanzdecken röstlieh rahmfarhen; Innensäume der Schwingen dunkel rauchbraun; ührige Unterseite weiß mit schwachem graurosa Aufuge, äußerste Federwurzeln grauschwarz. Hosenfedern sehwar\% mit weißen Spitzen. Gegren das Frühjahr hin wird die Unterseite rein wciB, die Luterschwanzdecken fast weiß, und die weißen Śpitzen der Stenerfedern nutzen sich ah. Dis Kopfplatte zeigt mitunter einige weiße Feclern, seltener ist sie ganz filh bräimlichgrau oder weiß. Iris braun, Schnahel und Füße schwarz. Flügel von 30 ơ 90-96, Sehwanz 68-71, Lauf etwa 25, Culmen 16-17.8 mm. o ad. Oherseite dunkel erdbram, Kehle und Vorderbrust fahlbraun, Kehle meist mehr oder minder sehwärzlich; übrige Unterseite weilb, Unterschwan\%decken wie beim ö. Schmabel dunkelbraun. Juv.: Oherseite braun, fahler und mohr rötlichbraun als beim oad., Kehle und Brust fahl blabbraun; unterer Bürzel und Oberschwanzdecken weiß. Nestkleid ehenso, nur mit helleren Fodermitten auf Kopf, Rücken, Oberflïgeldeckeu und Brust. -1. Schwinge hedentend ( $1 / 2 \mathrm{~cm}$ oder mehr) länger, als die Handdecken.

Brutgehiet: Ostpersien, Baluchistan, Afghanistan, nördlich bis 'Transkaspien, südlich his Sindh und Raijputana. - Nördlicher wohnende Vïgel sind Zugvögel, die in Nordwestindion überwintern.

Bewohnt steiniges und felsiges Gelände, von den Ebenen bis in Höhen von 6000 engl. Fuß, selten bis $9000 \mathrm{FuB}$ (Ibis 1909, p. 217). Guter Sänger, der seinen Gesang im Sitzen und im Fluge erschallen läbt. Nester in Löchern an den Seiten von Bachbetten, unter Steinen oder in Steinhaufen. Das Nest besteht aus Gras und Federn und enthält 4-6 Eier. Diese sind blaßgrüulichblau mit hell rotbraunen Punkten und Fleckchen.

\section{Saxicola opistholeuca Strickl.}

Saxicola opistholeuca Strickland, Jardines Contr. Orn. 1849, p. 60-10 und Taf. (,Northern India").

1. Schwinge etwa $1 / 2 \mathrm{~cm}$ lünger als die Handdecken. - otad. Das gesamte Gefieder sehwar\%, nur die unteren Bürzelfedern, (H)er- und V'nterschwanzdecken, Steißgegend und größter Teil des Schwamzes weiß; mittelstes Stenerfederpar zur Hälfte, die ïbrigen größtenteils weiß mit etwa $1 \mathrm{~cm}$ breiter schwarzer Endbinde und im frischen Gefieder mit schmalen weißen Spitzen; Sehwingen mebr bräunlichsehwar\% mit etwas helleren Sïmmen, Innensäume weißlich fahlbrikuv, Flügel nur etwa 90-94. Schwanz 66-69, Lauf etwa 23, Culmen 16-17 mm. - o. Oher- und Unterseite hraun, Ahdomen heller und fahler, sonst wie ơ. - Schnahel und Füße schwal'z.

Scheint Teile von Turkestan (..die kultivierten I)istrikte von S. W. Thurkestan"), Kaschmir und (hitral zur Brutzeit zu bewohmen. — Überwintert in Nordwestindien vom Pandschab bis Nagpur, Sind bis Etawah und in Afghanistan.

\section{Saxicola leucurus leucurus (Gm.).}

T'urlus lencurus Gmelin, Syst. Nat. I, 2, p. 820 (1789 - Gibraltar. Ex Latham, (icn. Syn. II, 1, p. 344, Taf. XXXVIII).

Saxicola cachinnans Temminck, Nan. dOOrn. I, p. 236 (1820- neuer Name für Turdus leucurus).

Dromolaen leucura maynirostris, parvirostris, nigerrima A. E. Brehm, Verz. Samml.. p. 5 (1866- nomina nuda!). 
ôd. Große, stumpf- und kurzflüglige Art. 1. Schwinge bedentend länger als die Handdecken, 3.-5. gleich und am längsten, 3.-6. verengt.

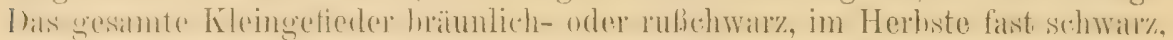

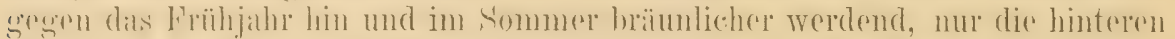

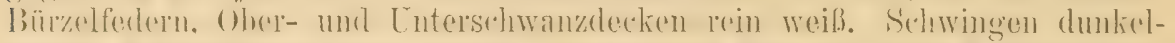

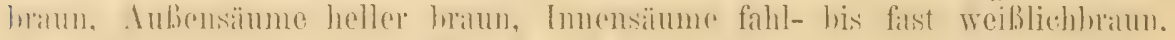

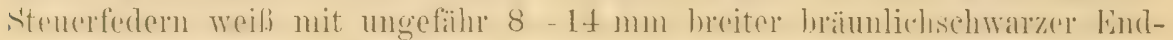

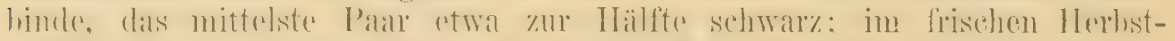

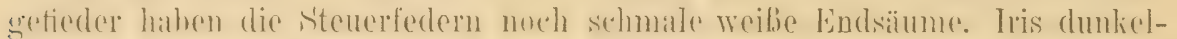
braun, Füße und Schmabel schwarz. Flügel etwa $96-100 \mathrm{~mm}$. - o ad.

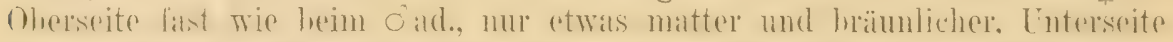

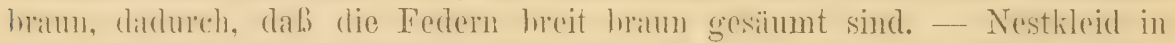

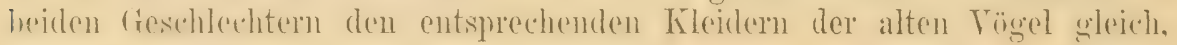
nur etrvas matter.

Nistet regelmäbig in Portugal und Spanien (vielleicht mit Ausmahmo?

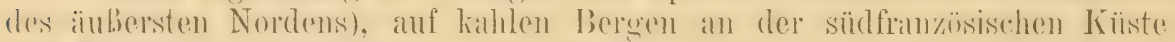
(lwi Marseilla, Nizzal) und an dor Rivielal di J'onente his fímul; soluent

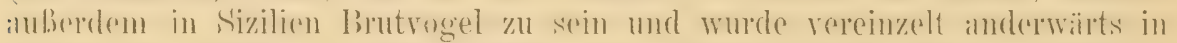
Italien fostgestrllt. - Die Angahen rom bröten in Griechenland beruhen wohl auf einem Irrtum und wurden vou Buch zu Buch abgeschrioben,

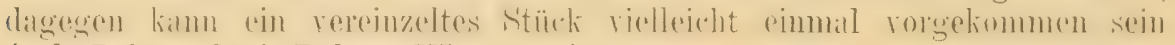
(vgl. Reiser, Ornis Balcan. III, p. 558).

Die Lebensweise ist dieselbe wie bei S.l. syenitica. Auch die siideuropäische Form ist Standvogel; die Angaben vom Wandern nach Afrika dürften auf Irrtum beruhen. 40 spanische Eicr (30 Key, 10 Jourdain) messen im Durchschnitt $25.14 \times 17.81$, ILaximum $26.3 \times 18$ und $24.7 \times 19.4$, Minimum $23.3 \times 17.7$ und $23.6 \times 17 \mathrm{~mm}$.

\section{Saxicola leucurus syenitica Heugl.}

Saxicole syenitica Houglin, Journ. f. Om. 1869, p. 155 (El Kab in Ägypten).

Abbild.: Dresser, B. Europe II, I'af. 36; Koenig, Journ. f. Orn. 1895, T'af. 6.

ơad. Dem von S. leucurus leucurus sehr ähnlich, aber das Sehwar\%

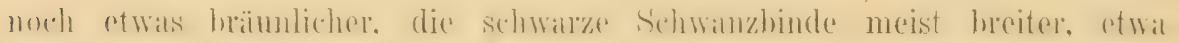
12-15 mm. Flïgol vou 12 o $96-101$, von 2 anderen uur $92 \mathrm{~mm}$. o. Viel brïunlicher und fahler, als das von S. l. leucurus. Die Oberseite

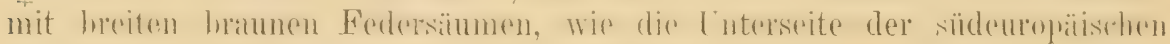
Stiicke, Unterseite heller und fihler, nicht so rötlich.

Bowohnt 'Tripolis, 'Tunis (auscheinend nur südlich des Atlas brïtend)

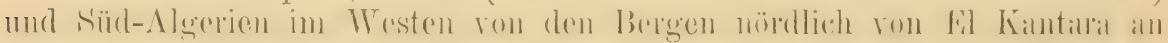

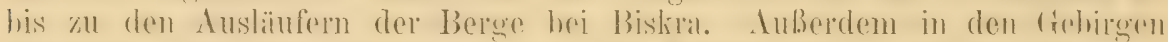

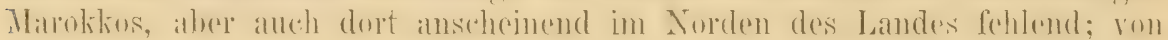
'Tanger zwar erwähnt, aber es handolt sich da wohl um ein verflogenes spanisches Exemplar.

Bewohnt kahle Felsgebirge, die sich nur einige Meter hoch am Nordrande der Wiiste erheben, ebensowohl wie solche, die bis zu Höhen von 5 bis 6000 engl. Fuß ansteigen (Marokko, nach Whitaker). Der prachtrolle schwarz und weiße Vogel entziickt alle Beobachter, zumal zur Brutzeit, wenn er auf exponierten Felsblöcken um das o herumtrippelt und ron dort seine muntere Strophe ertönen läßt, oder singend mit ausgebreitetem Schwanze langsam zu seinem Sitze hinabschwebt. Er ist mitunter 
- auch vor der Brutzeit - ganz vertraut und furchtlos, moist aber scheu und vorsichtig. Der Gesang beginnt mit zischenden und knarrenden 'Tönen, die in eine kurzo aber hübsche geschwätzige Strophe übergehen, die wieder knarrend endet; man kann ihn mit dem der Blaumerle vergleichen, doch ist er nicht so laut. Das Nest steht in Spalten und Rissen an den Felswänden oder Steinblöcken, oft metertief im Gestein. auch unter Blöcken oder Erdschollen und in Löchern, nach Graf Zedlitz auch mitunter an Gebïuden (Bordjs). Es besteht aus Halmen und Gräsern, mit Haaren zusammengefilzt, mit Wolle und Federn ausgefüttert. Vor dem Eingang befindet sich fast in allen Füllen eine erstaunliche Menge lose aufgeschichteter Steine, die mitunter auch dem Neste als Unterlage dienen. Diese sollen wohl vielmehr einen Sehutz gegen Sand oder Witterung, als gegen tierische Feinde bilden. Es enthält 4-5 hellblaue bis fast weiße Eier mit mattrotbraunen Punkten und Flecken, zumal um das stumpfe Einde, sowie meist einigen blaß lilafarbenen Schalenfleckchen. 57 algerisch-tunesische und marokkanische Eier (22 Koenig, 17 Erlanger, 18 Hartert) messen im Durchschnitt $23.5 \times 17.22$, Maximum $25 \times 17.1$ und $22.2 \times 18.1$, Minimum $21<16 \mathrm{~mm}$.

\section{Saxicola leucurus riggenbachi Hart.}

Saxicola lencurus riggenbachi Hartert, Faleo 1909, j. 36 (Rio de Oro).

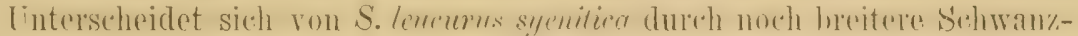
binde: hei 4 Stiicken $16-20 \mathrm{~mm}$. Außerdem sind die beiden mittelsten Stenerfedern 45-46 (gegen 35 - 42) mm weit, schwil\% - Teider liegt mm

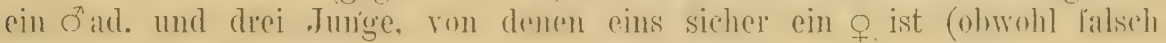
bezeichnet) vor; danach wäre das of sehr dunkel.

Rio de Oro, an der Westküste der Sahara, otwa unterm Wendekreis des Krebses. Im Juli 1902 von F. W. Riggenbach gesammolt.

\section{Saxicola leucopyga (Brehm).}

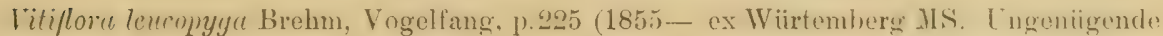
Diagnose, doch wird der Name durch Untersuchung der 'Typen und dureh A. E. Brehm, Journ. f. Orn. 1858, p. 66 [ "Lutucoa leucopygaia"] sicher).

Dromolaca lencocephala A. E. Brehm, Journ. f. Orn. 1858, p.62 (Ober-Ägypten - Iypus von Assuan, - Nubien, Sinaihalbinsel).

(Dromolaea monacha und nigra bei Loche: irrtümlicherweise.)

Abbild.: Dresser, B. Europe II, 'Taf. 35.

1. Schwinge hedentend lïnger als die Handdecken, 3.-5. mugetihl gleich und am lïngsten. I)as ganze Gefieder glänzend schwar\% mit Ausnahme des Bürzels, der Ober- und Cinterschwanzdecten, des Stribes mind der Basishälfte der Stenerfedern des mittelsten Paiares, welche Teile weili sind; häufig haben mehrere ${ }^{1}$ ), selten alle steuerfederu ror (ler Spitze lïnglichn sehwarze Flecke, das mittelste Paar hat im frischen Gefieder schmale wriline Endsiume. I)ie Kopfylatte ist ebensooft weib wie schwarz, mitunter sicht man auch anf weiben Kopfplatten einzelne schwarze und in sehwalten Konfplatten einzelue weiße Federn. Innensäume der Schwingen dunkelliaun. Das im frisehvermauserten Kleide tief glinzend blau-schwarze Grefieder wird in der Brutzeit etwas matter, fast hrämnlich. Ansuahmsweise zeigen sich einzelne weilie Federn ann Kropfe und an den Sehultern. Flügel hei 20 o 101-112, Schwanz ctwa 68-72. Lauf 25.5-27, Culme'n 20-24 mu.

1) Anscheinend haben jüngere Vögel immer schwarze Flecke an den seitlichen Steuerfedern. 
- ? wie ơ nur etwis kleiner: Hlügel 95-102.5 mm. Nestkleid: Matt-

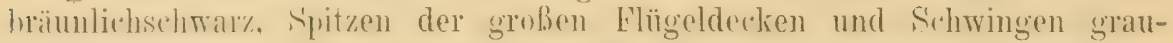

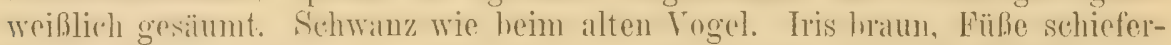
larben. Schnaluel hramu. -- I)ie Jungen sollon niemals weilie Köpfe haben, (lab aher die alten Tügel alle in hïherem Alter weibe Käpfe liekommen. ist eine ganz willkürliche Annahme.

Nubien und Ägypten (etwa his Assuan nilabwärts), das peträisehe Irahien und südliche Palästima mol his ungeführ zum 18." sïdlich; Sahara ron Ägypten dureh die Cyremaical und Tripolis (häufig) his Sü̈-Tumesien und Süd-Algerien ${ }^{1}$ ).

Bewohnt felsige Höhenzïge und steinige F'lußbetten in der Sahara, sowie abgulegene „Bordjs" (Rasthäuser an den Karawanenstraben) in Tunesien und Algerien; tritt in letzteren Ländern nur südlich des Atlas auf, und zwar noch südlicher als Saxicola leucurus syenitica, in Algerien z. B. erst im Mlzab-Gebiete und bei Wargla. Lebensweise der von $S$. leucurus ähnlich; die 4 Eier nach Loche bläulichweiß mit rötlichbraunen Punkten, $22 \times 17 \mathrm{~mm}$ groß; von neueren Forschern nicht gefunden. Nest in Spaltien und Löchern, auch an Gebäuden.

\section{Saxicola alboniger Hume.}

Saxicole Alboniger Hume, Stray Feathers I, p. 2 (1873- Grenzhïgel von Sindb).

Abbild.: Saxicola albonigra Blanford, Eastern Persia II, Taf. XI; Dresser, B. Europe IX (Suppl.), T'af. 638, Fig. 2; Ei: Dresser, Eggs B. Europe, Taf. Saxicola, Fig. 6.

Geschlechter glejeh! Ganze ()herseite reinschwa\%, nur Bürzel und ohersehwanzdecken weils: Flügel etwas mohr hräunlich schwar\%: mittelste Stenerfedern an der WVurelhälfte weib. die ïbrigen weil. mit 11 - 14 mm hreiter sehwallzer Endbinde und alle in frisehem Gefiedel mit $1-1.5 \mathrm{~mm}$ hreitem woißen Endsaum. Kohle, Kopf- und Halsseiten selhwar, ülrige Luterseite weiß: Innensäume der Schwingen rubhraun. Iris hrann. Schuabel und Fübe

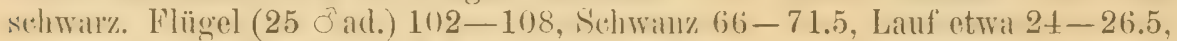
('ulmen 19-20 mm. O Flügel 99-106 mm. Jur. (Nestlileid): W'ie die Iten, nur matt hrämlichsehwar\%, anstatt tiof reinschwar\%. - Die 1. Steuerfecler ïbrrragt die Handdecken bedentend: $3-7 \mathrm{~mm}$.

Brutvogel in Persien (Ostpersien). Afghanistan und Baluchistan, jedenfalls auch in Gilgit und Sind.

1) Offenbar sind die westlichen Vögel kleiner, die östlichen größer: In Palästina sind die Schnäbel größer (Culmen ơ 23-24), die Flügel von 4 ơ messen 106-108 mm, die von $3 q$ 101-102. In Ägypten variieren die Schnäbel von (Culmen) 22-24, die Fliigel sind aber länger als bei den Stücken aus Palästina: 106.5-112 mm!, ㅇ 101 bis 102.5. In T'unesien und Algerien sind die Schnäbel kïrzèr (Culmen 20-23), die Flügel der ơ messen 101-106, q 95-100 (102?) mm. Unter den von mir untersuchten alten Stücken aus Palästina hat nur eins keine schwarzen Flecke an den seitlichen Stenerfedern, bei den $\ddot{A} g y p t e r n$ fehlen sie mitunter. aber nicht oft. dagegen fand ich deutliche schwarze Fleckung bei den Stïcken aus Tunesien und Algerien nur bei iïngeren Vögeln. - Da die angegebenen Unterschiede nicht recht konstant erscheinen und die geographisehe Begrenzung etwaiger versehiedener Formen z. Z. unsicher ist, halte ich eine Benennung der westlichen und der östlichen Form für nicht augebracht, ehe größere Serien aus allen Zwischengebieten, z. B. auch aus der Libyschen Wiiste, untersucht sind. 
Scheint im Frühjahr und Sommer die Berge, im Winter die I'äler zu bewohnen. Nistet in Höhlungen an Felsen. Am 14. Mai 1901 fand Sarudny ein Ei, das sehr blaß grïnlichblau ist und nur wenige matt ausgeprägte rotbräunliche Fleckehen an stumpfen Ende zeigt. Es mißt $23.5 \times 15.8 \mathrm{~mm}$.

\section{Saxicola monacha Temm.}

Saxicola monacha Temminck, Pl. Col. 359, Fig. 1 (1825- ot! Nubien).

Saxicola pallide. Cretzschmar in Rüppells Atlas z. Reise der Vögel, p. 51. 'Tat', 34, Fig. a (1826- ! Nubien).

Saxicola gracilis Lichtenstein. Nomenel. Av. Mus. Berol., p. 35 (1854- nomen nudum!). Saxicolt semenori Bianchi \& 'Zarudny, Ann. Mlus. Petersburg V, p. 187 (1900- ()stPersien. - qad. frisch vermausert).

Abbild.: Dresser, B. Europe II, T'af. 34; Shelley, B. Egypt., 'Taf. 2.

1. Schwinge etwas länger als die Handdecken, 3. und 4. ungefähr gleich und am lïugsten, 2. und 5. viel kïrzer und gleich. Schnabel laug und schlauk. Oad. Oherkopf bis zum Nacken, unterer Bürzel, Cnterkürper, (Oher- und Linterschwanzdecken weiß. Steuerfedern weib, Spitzenhälfte des mittelsten Paares und meist einige Längsflecke an den Spitzen der äuBeren Patare, mitunter auch an den Innenfahnen braumschwarz. Das übrige Gefieder schwar\%, im frischen Gefieder sind die Spitzen der Sohwingen weißlich und die Federn auf dem Rücken und an der Kehle und Vorderbrust schmal schmutzig weiß gesäumt. Flügel (S ơ) etwa 102-106, Schwanz etwa 72-75, Lauf 23-24, Culmen etwa 22-23 mm. o: Oberseite fahl hraun, gegen das Frühjahr hin blasser, unterer Bürzel und Oberschwanzdecken gelhbräunlich weif. Schwingen und Oberflügeldecken dunkelbrimu, Steuerfederu hell ockerfarben. im Frühjahr fast woißlich gelbbraum, Spitzen des mittelsten Paares zu fast zwei Dritteh, und schmale Spitzen der ührigen schwarzhraun. Unterseite fahl gelhhraum, im Frühahr rahmfarben. Vorderbrust und Seiten etwas dunkler.

Ober-Ägypten, Nubien, Küste des Roten Meeres (Sauakin), Palästina. his Ost-P'ersien, Afghanistan, Baluchistan und die Grenzhügel von Sind.

\section{Gattung PRATINCOLA Koch 1816.}

Die Gattumg I'ratincole (Sym. Fruticolu, Rubetru) ist im System nicht ganz leicht unterzuhringen. Bei l'. mubetra ist die 1. Schwinge nur so laug wie, oder wenig länger, als die Handdecken, hei allen anderen Arten übertrifit sie die Handdecken sehr bedeutend. Schnibel meist etwa halb so lang wie der Kopf, verhältuismäßig kïrzer und hreiter als hei Saxicola, die Mundwinkelhorsten kriiltig entwickelt. Dadurch erimnert dic Gattung an die echten Fliegenfünger, in der Lohensweise aber steht sie den Śaxicolen nahe, denen ich sie aluch hier amreihe. Verbreitumg: Europa, Asien und Afrika - in ästlichen Archipel bis Neu-Guinea. - P. Prubetra mausert zweimal, die ïhrigen Arten nur einmal im .Jahre.

Übersicht der $\widehat{c}$ :

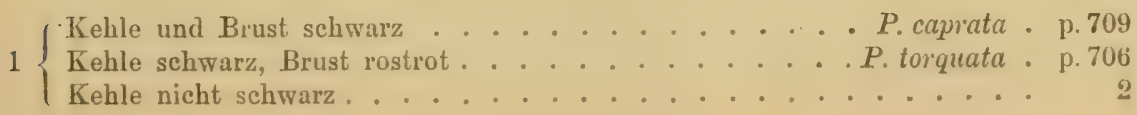


6) I Kehle und ïbrige Unterseite weil oder hell rahmfarben $P$. macrorhyncha a p. 704

| Kehle weiß oder rostfarben, Brust rostfarben ... . . . . . . 3

3 Steuerfedern etwa zur Hälfte weiß . . . . . P. rubetra p. 702

Steuerfedern ganz schwarz oder schwarzbraun .......... 4

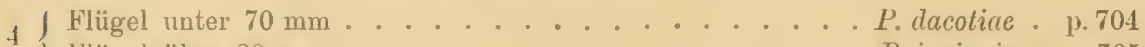

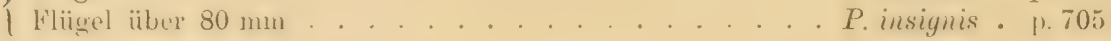

\section{Pratincola rubetra rubetra (L.).}

\section{Braunkehliger Wiesenschmätzer, Braunkehlchen.}

Motacilla Rubetra Linnacus, Syst. Nat., Ed. X, I. 1. 186 (1758 Europa. 'Terra typien Schweden, nach dem 1. Zitat. Einige der Zitate Linnés beziehen sich auf P. vubicola).

Motacilla seneyulensis Linnaeus, Syst. Nat., Eł. XI. p.3333 (1766-- Senegal. Ex Brisson). [Sylvia zya Scopoli, Annus I. Hist. Nat., p. 158 wurde als Synonym zitiert, aber die Beschreibung paßt durchaus nicht.]

Motacillu fervida ('melin, Syst. Nat. I. 2. p.968 (1789- Senegal. Ex Buflon \& 1 ) aubenton. Pl. Enl. 583, 1).

Saxicola orampes Brehm, Isis 1828, p. 1282 (nomen nudum!).

Saxicola pratorum Brehm, Isis 1828, p. 1282 (nomen nudum!).

Saxicola septentrionalis Brehm, Isis 1828, p. 1282 (nomen nudum!); Handb. Naturg. Vög. Deutschl., p. 408 (1831- bei Kiel und Renthendorf).

Saxicola crampes Brehm, Handb. Naturg. Vög. Dentschl., p. 409 (1831- „wandert durch Nitteldeutschland").

Rubetia major Gray, List Gen. B., p. 22 (1840- nomen nudum!).

P'ratincolu Pratensis Kleinschnidt. Journ. f. ()rn. 1903, 1).387 (Nume für den „Formenkreis“).

Engl.: Whinchat. - Franz. 'I'arier. - Schwed.: Buskskvätta. - Ital.: Stiaccino.

1. Schwinge so lang wio oder minimal lïnger als die Handdecken, 3. und 4. gleich und am längsten, 2. und 5. nur wonige mm külzer. - of ad. Federn der Oherseite bransehwar\% mit hell rothraunen Sïmmen, anf dem Rücken an den Spitzen etwas heller, unterer Bürzel etwas rütlichex.

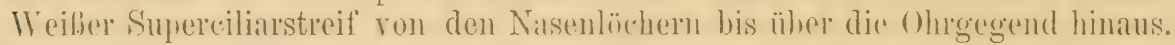
Sehwingen chukelbraun, auben schmal hell rothraun, innen röstlich rahmfinben

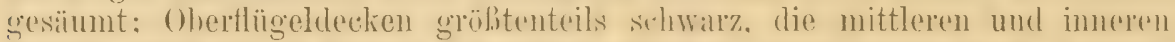

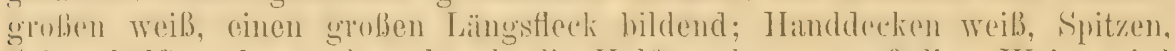

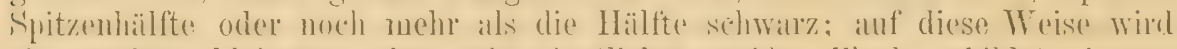

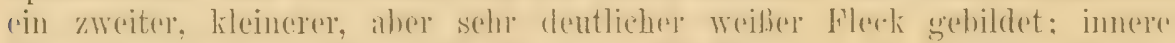

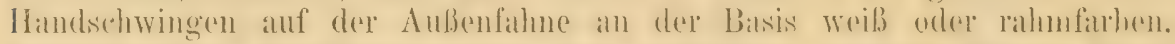

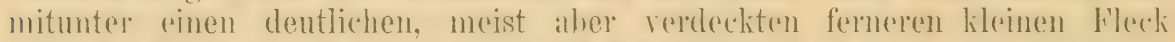
bildend. Stenerfedern schwarzhram, das mittelste Palat nur an der äuBersten

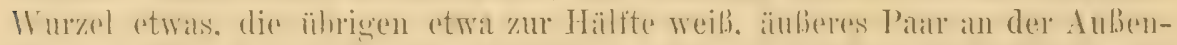

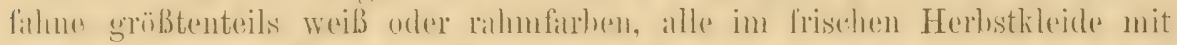

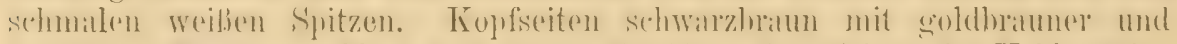

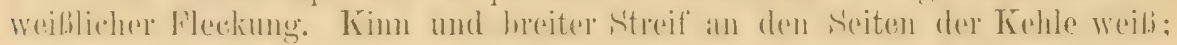

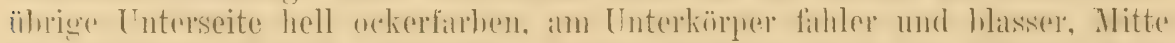

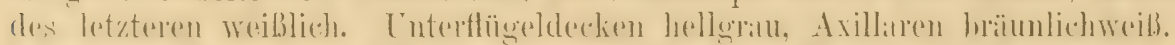

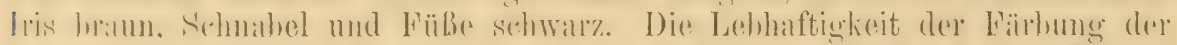

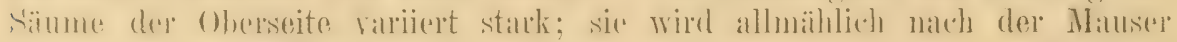

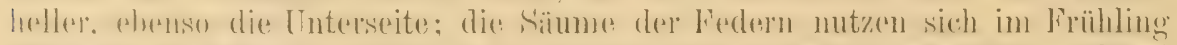

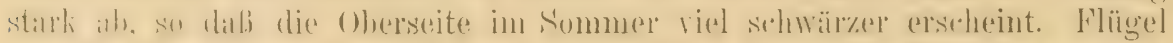

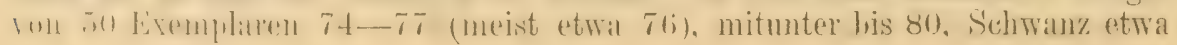




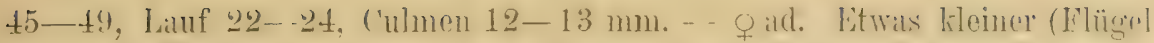

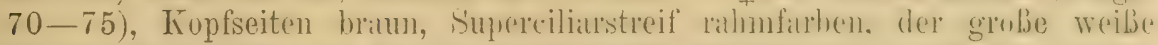
Schulterfleck fehlt und ist nur durch weibe ledersilume angedentet, Enterseite blasser, Kropfgegend entweder ainfarbig uder mit einer Reihe kileiner dunkelhrauner Schaftlecke. -- Nestkleid: Oinerseite rosthraun mit breiten sehwarzbraunen Längsflecken und rahmfarhenen s'baftstreifen. Unterseite rahmfarhen; Kropif und Torderbrust mehr odkerfarben und nit dunkelbraunen Federsäumen, sonst wio das 0 .

Brutrogel in Europal rom 70." in Skandinavien, Rubland. Grolshritannieu und Irland, bis zum Nittelmeere, in spanien alser nur nördlich der Cautitbrischen Bergkette, in Italien nur in Gebirge, in Griechenland nur als Zugvogel bekinnt: in Sïd-Dalmatien (? und anderwärts) dureh die folgende F'orm vertreten. - Zugrogel, der durch die Sahalra ins tropische Afrika wandert.

Im allgemeinen Bewohner des ebenen, fruchtbaren Wiesenlandes, in Süd-Europa aber im Gebirge bis zu $2000 \mathrm{~m}$. Lockton ein gedämpftes, schnalzendes "teck, teck", allein oder in Verbindung mit einem weichen "tzau" oder "hju“; Gesang eine aus zwitschernden und pfeifenden Lauten zusammengesetzte kurze Strophe, die mit eigenartigen gepreßten Zischlauten endet. Viele Beobachter konstatierten auch eine große Nachahmungsgabe. Das Nest steht mitten im Grase oder am Fuße eines Busches oder einer anderen hervorragenden Pflanze; es ist wohlgefügt und besteht aus Grashalmen, MLos und Würzelchen, innen meist mit Haaren ausgelegt. Die 5-6 gedrungenen Eier sind tief blaugrün, meist mit feinen, mitunter kaum bemerkbaren hell rostfarbenen Pünktehen und Fleckehen sparsam gezeichnet. Man findet sie im Mai und Juni. 100 Eier (22 Dentschland nach Rey. 6:3 (irobhritanuien nach Jourdain. 15 Finland nach Sandman) uessen nach Jourdans Berechnung im Durehschnitt 18.72x14.41, Maximum $21.5 \times 14.5$ und $18.6 \times 15.4$, Minimum (Zwergeier niemals mit berechnet) $17 \times 14.2$ und $18 \times 13.5 \mathrm{~mm}$.

\section{Pratincola rubetra spatzi Erl.}

Pratincola vubetra spatzi Erlanger, Journ. f. Orn. 1900, p. 101 (Gafsa in T'unesien). Pratincola mbetra dalmatica Kollibay, Orn. Jabrb. 1903, p. 43 (Dalmatien).

Im allgemeinen heller, die Federränder der Oherscite hissser, mehr fihl genhlichbran als rothram, und die Unterseite hlassere Diese Intersehiede

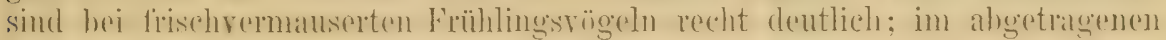

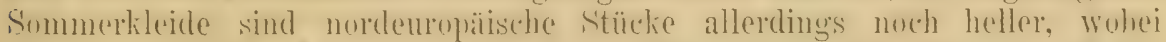

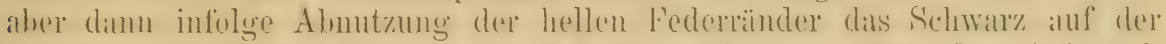

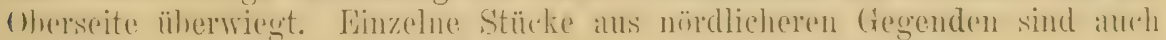
in frischem Gefieder sehr blaß und $I^{\prime}$. $r$ spatzi nahekommend.

Verbreitung noch ganz ungervil\}. Brutrogel in Süd-Dalmatien. Das

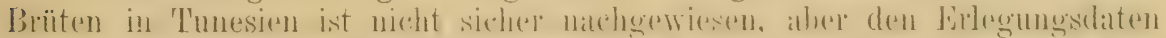

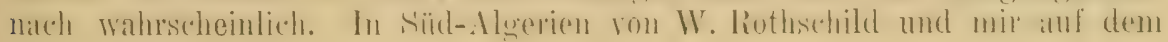
Zuge erbentet.

\section{Pratincola rubetra noskae 'l'seh.}

Pratincola rubetra noska 'Ischusi, Orn. Jahrb. 1902, p. 234 (Nord-Kaukasus).

Äußerst ähnlich $P$. rubetra spatzi, aher die Federrïnder der Oberseite

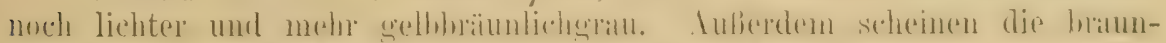

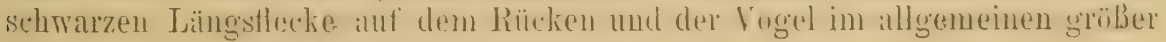


zu sein. Flügel des Typus (O) in al)genutztem Zustande 80--81, alsu wahrscheinlich etwa $82 \mathrm{~mm}$.

Kaukasus - wahrscheinlich auch im nordwestlichen Persien. (Kleinasiatische Brutvögel habe ich nicht untersucht.)

\section{\$ 1067. Pratincola rubetra margaretae Job.}

Pratincola rubetra margaretae Johansen, Orn. Jahrb. 1903, p. 232 ('Tomsk in Westsibirien).

? Fratincola mubtra altuica Johansen, Orn. Jahrb. 1907, p. 199 (Kireis Bijsk im Altai).

Natch der Beschreibung des Autors von P. rubetra rubetra "durch kürzeren Schmabel, blassere Färbung der Ober- und Unterseite, gröbere Flockung der Oherseite, weilse Endfärbung (sic) der 2. und 3. Stenerfeder an der Innenfithe und Fehlen des weißen Flïgelspiegels" unterschieden. - Diese Furm muß der katukasischen $P$. z. noskae sehr ähnlich sehen. I) a die Schnabellïnge variiert, ist der angebliche (ich henutze diesen Ausdruck, weil der Autor nur je 1 ¿ aus Livland und Sibirien vergleichen komnte!) Unterschied von 1 mm nicht ron Bedentung. Fr heschreiht die 2. und 3. Stenerfeder als "am kinde breit weil. gesäumt", und sagt, dal. nur die kleinen Deckfedern weiß sind und der ...ppiegel gïnzlich fehlt". .. Flügel 76. Schwanz "a. $49 \mathrm{~mm}$ ". - Unter dem Nimen 1'.r. altaica beschreiht der Autor ainen Vogel im abgetragenen Sommergefieder: die ['nterschiede. die er angibt, sind die des abgenutzten Sommerkleides im Tergleich zum frischen Frühlingsrogel, uи findet sich ein sehr deutlicher Flïgelspiegel, der bei maryuretae fehlt. Fine Vergleichung genïgenderen Naterials mub die Lnterschiode noske gegen-

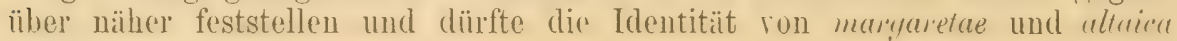
wohl beweisen.

\section{Westsibirien: 'T'omsk und ? Altai.}

(Piratincola macrorhyncha Stoliczka, Journ. As. S'oc. Bengal X LI. 2. p). 2:38 (1872). - Wintervogel in den nordwestlichen T'eilen Indiens (Punjab, Rajputana, Gušerat, Sindh, Cuteh) und ist rielleicht im paläarktischen Asien Brutrogel. Vgl. Outes, Fauna India, Birds II, p. 63. Die Kehle ist weib in beiden (ieschlechtern, dir inneren fiuhnen der Steuerfedern sind weiß mit schwarzbraunen Spitzen.)

\section{Pratincola dacotiae Meade-Walde.}

Pratincola dacotiae Meade-Waldo, Ibis 1889, p. 504, T'af. 15 (Fuertaventura).

1. S'chwinge fast 1 em linger als die Handdecke'n, 3.-5. fast gleich und am lüngsten, 2. (twa $8 \mathrm{mmn}$ kïrzer. Cad. Oberkopf und Rüicken grïulieh schwarzbraun, jede Feder schwarz mit breiten graburaunen Sïumen. die sieh in Frihhjahr almutzen. so dab die S'tüicke damn ohen bräunlichschwary. alussehen. Bürzelfedern ohne sehwarze Mitte, daher der Bürzel graubraun.

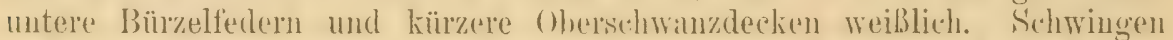

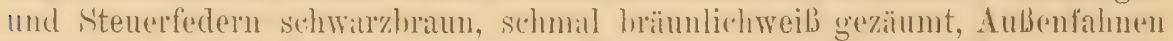
der letzten Armschwingen an der Basis ansgedehnt weib. Oherflügeldecken sehwarghram, weißlichbraun gesiumt, die groben l)eckfedern über den letaten Armschwingen weib, so dia dort der hekamnte den Pratimolu-Arten eigene weibe

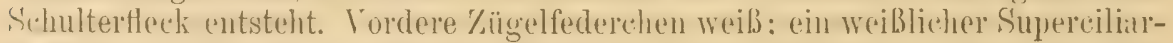
streif kium mehr als angedentet; Kopfseiten hrïunlichsehwallz, chenso die seitlirhen Kehlfedern: Uitte der oheren und ganze untere Lehle weils. ebenso die 


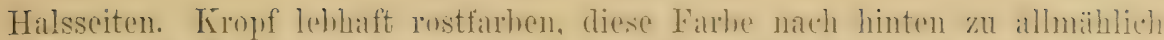

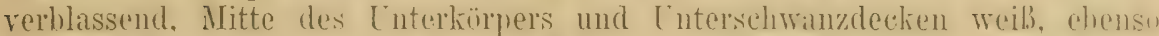

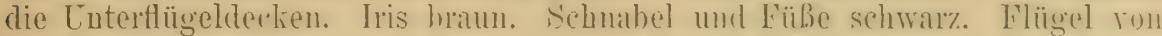
16 o $60-63$, Schwanz etra 48-51, Lauf 21-22, Culmen 14-15.5 mm. ad. I)em c ähnlich, aher die Federmitten der Oherseite nieht schwarz.

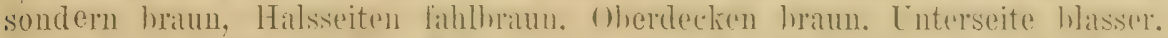

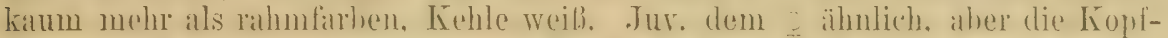

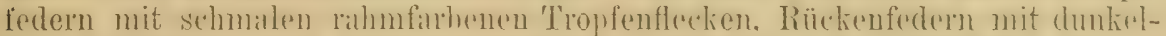

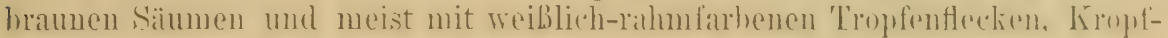
und Brustfedern braun gerëndert.

\section{Insel Fucrtarentura (östliche Canaren).}

Mausert augenscheinlich nur einmal (und zwar im Mlai, nach der Brutzeit), wie die Schwarzkehlchen, denen er trotz seiner weilen Kehle näher verwandt ist als den Wiesenschmätzern. Ist Standrogel und brütet schon im Jauuar und Februar bis April. Fr bewohnt die windgeschiitzten, mit Büschen, Gras und Heidekraut bewachsenen Barraneos und Flußtäler. Die aus feinen Grashalmen bestehenden und mit Haaren ausgefütterten Nester stehen in tiefen Löchern und Felsen, in Mauern, unter Steinen oder Büschen und enthalten 4-5 Eier. Diese sind glatt. gläuzend, von bauchiger Gestalt, bläulich grïn mit blaß rötlichbraunen Fleckchen und Punkten, die mitunter auf die Ungebung des stumpfen Poles beschränkt sind. Die vier Eier im Tring-IIuseum messen $18 \times 13.8,18.2 \times 14$ und $18.6 \times 14.1$, Polatzek gibt $16-18 \times 13.5-14.7 \mathrm{~mm}$ an. Nahrung rorzugsweise Dipteren. Die Lockstimme erinnerte Polatzek an die von Sylvia atricapilla, der Gesang wird ron 'Thanner als ruhig, kurz und dem von Sylvia conspicillata ähnlich beschrieben.

\section{Pratincola insignis Blyth.}

Saxicola insignis Hodgson, Gray's Zool. Misc., p. 83 (1844- nomen uudum). Pratincola insignis Blytl, Journ. As. Soe. Bengal XVI, p. 129 (1847- "India").

Abbild.: Pleske, Wiss. Res. Przewalskis Reisen II, Vögel 1, Taf. I, Fig. I, 2

ơad. Winterlikid: Oberseite schwarz mit breiten, graubraunen Feder-

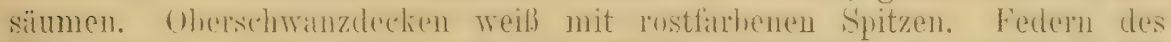
Hiuterbalses an den Suiten mit etwas Meils. Shehwingen braunschwarz mit

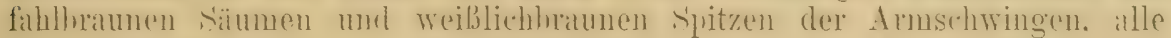
mit weißer Basis, die an den Haudsehwingon nur den 3.-4. Teil, an den

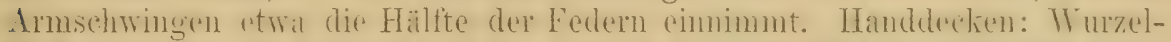

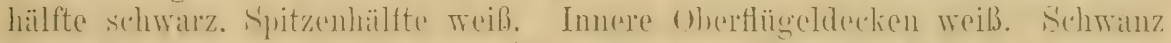

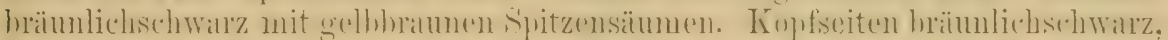

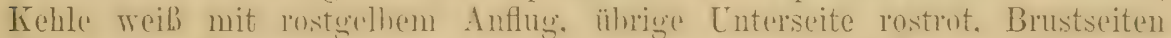

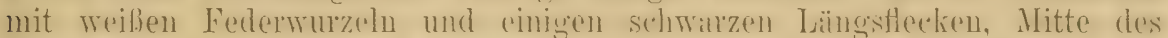

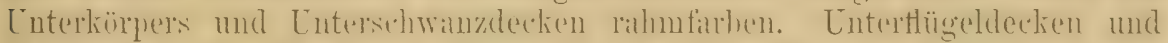

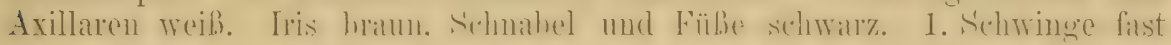
$1 \mathrm{~cm}$ länger als die Handdecken, 2. zwisehen der 6. und 7., 3. und 4. gleich lang und am längsten, 3.--6. verengt. Flügel von 3 ऊ $86-91$, Schranz

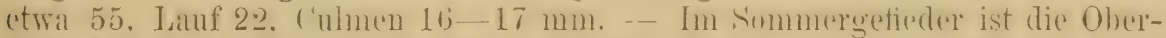

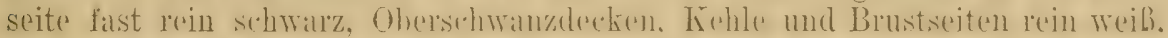

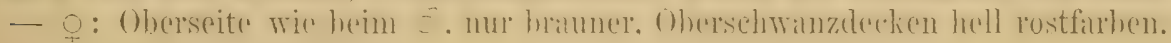
Unterseite matt rostfarben.

Da die russischen Forscher Stïcke am Saissan-Nor und im Ala Schan

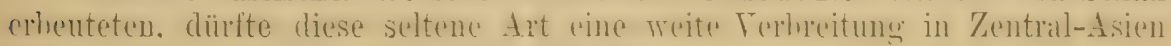
laben. - Sie ïberwintert in Nord-Indien. 


\section{Pratincola torquata rubicola (L.) ${ }^{1}$ ).}

Schwarzkehliger Wiesenschmätzer; Schwarzkehlchen.

Motacilla Rubicola Linnaeus, Syst. Nat. I, I, p.332 (1766- Europa. - Ex Aldrovandi. Albin, Brisson, Willughby. Als terra typica ist Frankreich anzusehen, ex Brisson, aus dessen 'Text und Bild Linné seine schlechte Diagnose und Aufenthaltsangabe entnahm).

Sylvia muscipeta Scopoli, Annus I. Historico-Nat., p. 159 (1769- Kärnten).

Saxicola fruticeti Brehm, Naturg. Vög. Deutschl,, p. 411 (1831-.. Wien, wandert durch Mittel-Deutschland).

Saxicola media Brehm, t. c., p.411 (1831- mittleres Deutschland).

Saxicola tytis Brehm, t. c., p. 412 (1831- Mittel-Deutschland).

Pratincola Atricapilla Kleinschmidt, Journ. f. Orn, 1903, p. 384 (neuer Name für P. mbicola und Subspezies).

Engl.: Stonechat. - Franz.: Tarier rubicole, Traquet pâtre, Ouistrac. - Ital.: Saltinpalo. - Schwed.: Buskskvätta.

1. Schwinge bedentend lïnger als Handdecken, 3.-5. etwa gleich und am längsten, 6. unbedentend, 2. viel kïrzer. - óad. Herbstkleid: Federn der Oberseite schwarz, breit rosthraun gesiumt, untere Bïrzelfedern und Oherschwanzdecken in der Vitte weiß, an den Spitzen mit längliehem schwarzem I'leck und rotbraunen Ś̈̈mmen. Schwingen bräunlichschwar\%. Handschwingen und Handdecken mit schmalen fahlbraunen, Armschwingen mit breiteren lehhaft hell rothraunen Süumen. Flügeldecken wie der Rü̈ken. die die inneren Armschwingen bedeckenden Flügeldecken nelost der Basis der AuBenfahnen der innersten Armselnwingen weib, rinen groben waiben schulterfleck bildend. Stenerfedern schwar\% mit sebmalen braumen Außensïmmen, Aubenfahne des äuBersten Patres mit breiterem wrißlichbraunen Samm. Zügel, Krhles und Kopliseiten schwalrz mit brannen S'̈̈umen; Halsund Kreptseiten weib) mit hell rosthraunen Federspitzen. Ülorige Cinterseite rostfarben, dir Brust am lebhaftesten, Nitte des Unterkïrpers und C'ntersehwanzdecken heller, fast rahmfarben. Innensäume der 'schwingen rahmfarben, Enterflügeldereken und Axillaren sehieferschwarz, erstere nit hreiten weißlichen Sänmen, Außenfahnen der letzteren weiß. Iris braun, Sehnabel und Fübe schwar\%. Nach der Herbstmanser findet kein Federwechsel mehr statt, aher im Frühjahr nutzen sich die brannen Federsäume der Oberseite derartig ah, daß Kopf, Kehle und Rï̈cken fast schwar\% die Halsseiten ganz. und die Oherschwanzdecken fist ganz weil. werden und scharf hervortreten. Flügel von 36 o $64-70,5$, meist etwa $65-67,5$, Schwanz 47-51, Lauf etwa 21-23, Culmen 14-15 mm. - o ad. Oberseite bräunlicher, nicht si) rein schwart, Bürzel und Oherschwanzdeden wie der Rücken, ohne Weib, Hals- und Kropfseiten gellich, nur im ganz abgetragenen Sommergefieder einen weiben Fileck aufweisend, Kehle weniger schwar\%, nach dem Kinu zu stets braun, ïbrige Unterseite matter rostbraun. - Nestkleid: Oberseite dunkelhraun mit rahmfarbenen, dunkel umrandeten Keilflecken an den Spitzen der Federn, Oberschwanzdecken rotbraun. Kehle brïunlich weib, ührige

1) Über die afrikanischen Formen siehe Reichenow, Vög. Afr., p. 732, Hartert, Journ. f. Orn. 1910, p. 175. - Der Name torquata (Muscicapa torquata Linnaeus, Syst. Nat., Ed. XII, I, p. 328, ex Brisson II, p. 379, Taf. 36 Fig. 4) hat die Priorität, da er rier Seiten vorher publiziert wurde. Er bezieht sich auf die südafrikanische Form des schwarzkehligen Wiesenschmätzers. 
Tnterseite bräunlich rahmfarhen, an der Brust etwas lebhafter und mit schwäzzlichen Federsäumen.

Kontinentales Europa rom südlichsten Schweden his zum Mittohneere und dessen Inseln, östlich bis Griechenland, Kreta, Polen und SüdruBland (Podolien), ferner in Marokkn, Nord-Algerien und Nord-Tunesien. Überwintert in Ägrpten, Palüstina und vermutlich in der südlichen Sahara, da er durch Algerien und Nachbarländer durehzieht. (In Deutschland seh. lokil, meist im Westen weniger selten, im Nordosten mur vereinzelt.)

Bewohnt vorzugsweise sonnige, steinige, mit Brombeergerank und Buschwerk bestandene Halden und Hïgel, Bergwiesen, junge Kiefernschonungen, mit Gebisch bewachsene Böschungen, Wegränder, verwildertes Gemeindeland u. dgl., nicht aber üppiges, feuchtes Wiesengelände. Lockton aus einem kurzen Pfiff mit folgendem Schnalzlaut, Gesang aus zwitschernden, abgebrochenen, mit einigen Pfeiflauten vermischten Strophen bestehend. Nest änßerst versteckt, unter Büschchen, neben Steiuen, in dornigem Gerank v. dgl., gebaut wie das von $P$. rubetra. Eier 5-6, bläulichgrün, viel grünlicher und sehr viel heller als die von $P$. rubetra, mit rotbräunlichen, meist blassen, unscharf begrenzten und oft ineinanderfließenden Wölkchen, Flecken und Punkten bedeckt. Zivei Bruten scheinen die Regel zu sein. - Zugvogel, der früh ankommt und lange verweilt, im IVesten Deutschlands (am Rhein) auch vereinzelt äberwintert. 38 Eier aus Deutschland und Griechenland (Rey, Reiser, Jourdain) messen im Durchschnitt $17.94 \times 14.14$, Maximum $20 \times 14.5$ und $17.6 \times 14.9$, Minimum $16.5>$ 13.5 und $16.9 \times 13.2 \mathrm{~mm}$.

\section{Pratincola torquata hibernans Hart.}

Pratincola torquata hibernans Hartert, Journ. f. Orn. 1910, 1. 173 (England, Typus Tring).

$\sigma^{\top}$. Unterscheidet sich von Pr. rubicola im Herbstkleide durch die dunklereu, mehr rotbraunen Federsiumme der Oberseite, atuch etwas dunklere. an der Brust rein kistanienbraune Fïrbung der Unterseite: diese mehr rotbrame Färbung ist sogar schon an Nestjungen bemerlibar. Im abgetragenen Sommerkleide nicht leicht unterscheidbar, doch bleibt fast immer meli von den rotbramen Federsäumen auf der Oberseite übriğ, und die Körperseiten werden nie so hell. Flügel von 20 o $66-68 \mathrm{~mm}$.

Standvogel auf den Britischen Inseln.

Nistweise, Lebensweise usw. wie bei $P . t$. rubicola. Hält sich im Winter vorzugsweise auf den Hügeln und im Gestrüpp in der Nähe der Küsten auf. 42 Eier aus England und Irland messen nach Jourdain im Durchsehnitt $18.61 \times 14.53$, II aximum $21.3>14.4$ und $19>15.1$, Minimum $16.5 \times 13.5$ und $16.9 \times 13.2 \mathrm{~mm}$.

\section{Pratincola torquata maura (Pall.).}

Motacilla maura Pallas, Reise d. versch. Prov. Russ. Reichs II, p.708 (1773- Ural und zwischen den Flüssen Tobol und Irtysch).

Parus Varictagus (ersichtlicher Druckfehler für variegatus) Gmelin, Reise d. Russland III, p. 105, T'af. 20, 3 (1774- von Schamachie (= Schemacha im südl. Kaukasus) aus überall, d. h. nach Persien zu).

Iotacilla Tschecantschia Gmelin, Syst. Nat. I, 2, p.997 (1789- „Sibiria“. Ex Lepechin, Tagebuch Reise d. versch. Prov. Russ. R. II, p. 186, Taf. 8, 1. Die Lokalität ist der südliche Ural).

Saxicola Hemprichii Ehrenberg, in Hemprich \& Ehrenberg, Symb. Phys., fol. aa (1832Ägypten).

Saxicola assimilis Brehm, Naumannia I, Heft 2, p. 28 (1850- Nubien). 
Herhsthleid viol heller: dir sehr hreiten Fedorsäme der oherseite hell

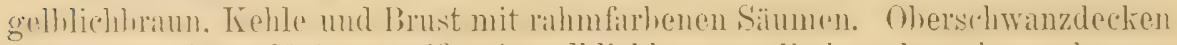

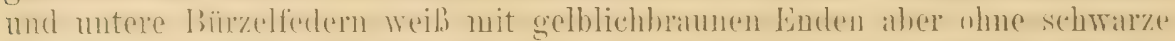

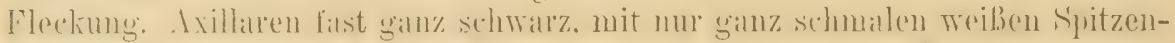
sïumen. steurefedern an der Wru\%el an beiden Fahnen weib in wrehsehder Ausdehnung: meist ist etwa der halbe Schwanz von der Wurzel her weiß,

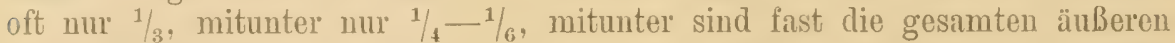
Stenerfedern weiß mit nur einer 3-5 mm breiten Endbinde und einem

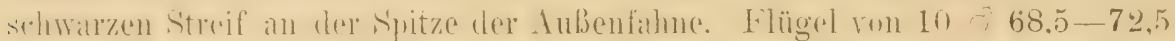
ausnahmsweise $74-78 \mathrm{~mm}$. Schnabel ziemlich schlank. Das Weiß der

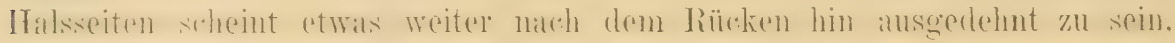
der Unterkörper wird im Frülijahr fast ganz rein weib.

Brutrogel in Transkaukasien und im Kaukasus, sowie am untern

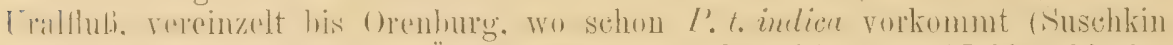
in litt.), auch in Persien. Überwintert in Nordostafrika von Nubien bis ins

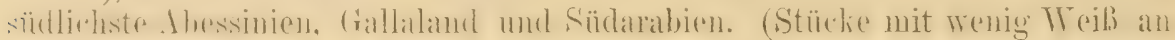

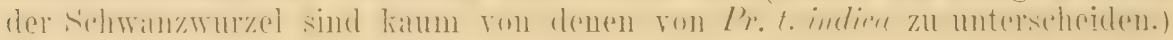

\section{Pratincola torquata stejnegeri Parrot.}

Pratincola rubicola stejnegeri Parrot, Verb. orn. Ges. Bayern VIII, p. 124 (1908-Iterup und Jesso nördl. Japan).

Oberschwanzdecken wie bei $P$. $t$. manre, aber Sehwanz ganz schwarz, oder doch nur an der äuBersten Basis $2-3 \mathrm{~mm}$ woit weiß. Schnabel

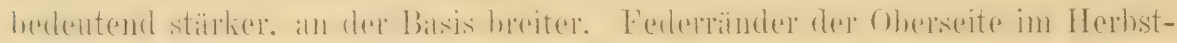
kleide dunkler, mehr rotbraun, als bei $P$. t. manra und indica, das $o$ im Herbste viel dunkler. Flügel vou 30 ơ etwa $67-70.5 \mathrm{~mm}$.

Vertritt P.t. indica in Ostsibirien (östlich des Altai, Lena, 'Transbaikalien,

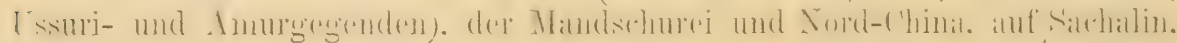
don Kurilen, Jesso und wahrscheinlich Hondo. - Im Winter auf /den RiuKiu Insoln, Hainan, Formosi, in Birmall und Indien.

Ein Gelege von 5 Eiern aus T'ransbaikalien hat nach T'aczanowski folgende Maße: $17.5 \times 13.8,17.5 \times 13.4,18.8 \times 14,19.4 \times 14,19.2 \times 14.3$, ein solches aus Ussuriland mißt $16.3 \times 13.1,16.3 \times 13.2,16.4 \times 13.6,17.2 \times 13.6,16.5 \times 13.3,17.1 \times$ $13.4,17>13.2 \mathrm{~mm}$.

\section{Pratincola torquata indica Blyth.}

Saxicola saturatior Hodgson, in Gray's Zool. Misc., p. 83 (1811- nomen nudum). Pratincola indica Blyth, Journ. As. Soc. Bengal XVI, p.129 (1817- Indieu).

Pratincola albosuperciliaris Hume, Stray Feathors I, p.307 (1873- Andamanen).

Die westlicheren Stïcke, die rom Altai westwärts in Westsibirien bis

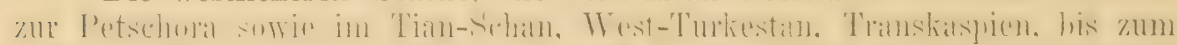

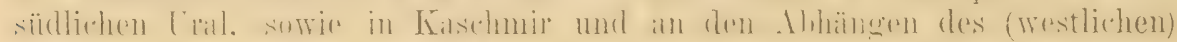

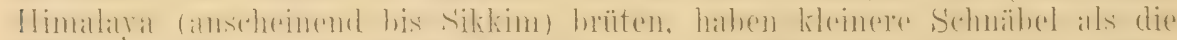

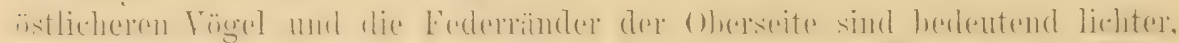

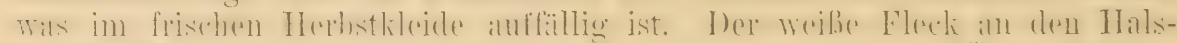

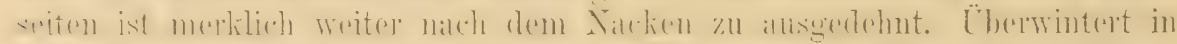

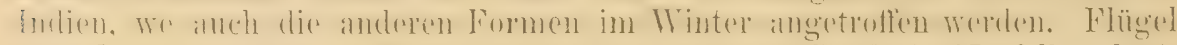
$(30$ ơ) $67-72 \mathrm{~mm}$. Am 2. IX. 1904 wurde ein Stück in Norfolk erlegt. 
Ein Gelege ron 5 Eiern von Aksu (südlicher Tian-Schan) mißt $16.7>14,16.3 \times$ $13.6,17.6 \times 14,17.3 \times 13.3,16.5 \times 14$, fünf Eier eines Geleges von Nainital im westlichen Himalaya messen $17 \times 14,17.2 \times 13.4,17 \times 13.5,17 \times 13.6,17 \times 13.3 \mathrm{~mm}$ (Jourdain).

\section{Pratincola torquata przewalskii l'leske.}

Pratincola man va var: Przeualstii Pleske, Wiss. Res. Przewalskis Reisen, Vögel, 1, p. 46. Taf. IV, Fig. 1, 2, 3 (1889- Gansu - nistend - und Ost-Turkestan).

Von den ïbrigen Formen der Art durch bedeutendere GröBo unterschieden, sonst ganz wie $P$. torquate stejnegeri; ebenso dunkel; der weiße

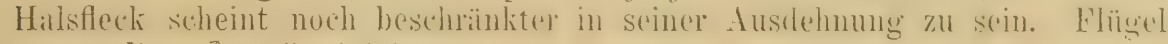
von 6 alten $\sigma^{7} 72.5-75.5 \mathrm{~mm}$.

Brïtet in Kansu und am Nordabhange der Russischen Kette in Ost'Turkestan. sowie remmtlich in gamz Tibet. - Auf' lem Yuge und im Wrinter

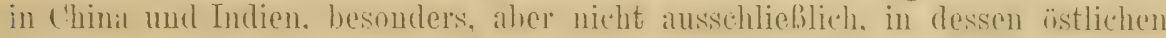
Ieilen. zumal in Assam und Bimmals. aber atuch in (iilgit und Kumaon. -

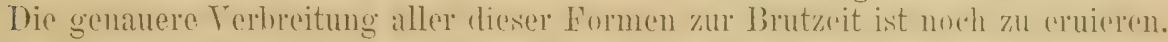

(Pratincola leucura Blyth, Journ. As. Soc. Bengal XVI (1847- Sind). - ơ: $P$. torquata maura äußerst ähnlich, aber die Stenerfedern, mit Ausnalıme des mittelsten Paares, an den Innenfahnen schneeweil mit brauner Spitze. Das Rotbraun der Unterseite auf einen großen vom unteren Rande der schwarzen Kehle auf die Brust reichenden Fleck beschränkt, Unterkörper und Seiten weiß. \&: Durch den bräunlichgrauen Ton der Federränder der Oberseite und hellere Unterseite, besonders weiße Kehle, von allen Formen von $P$. torquata sofort zu unterscheiden. - Indien, aber vielleicht daselbst nur Wintervogel, dessen Brutplätze möglicherweise im paläarktischen Asien liegen. Wahrscheinlich eine fernere Subspezies ron P. torquata (vgl. Oates, Fauna Brit. Ind., Birds Il, p. 63).)

\section{Pratincola caprata rossorum Hart.}

Pratincola caprata rossomm Hartert, Journ. f. Orn. 1910, p. 180 (Trinskaspien).

Abbild.: Dresser, B. Europe IX (Suppl.), Taf. 6.1.

Flügelbau wie bei $P$. mibicola. - $\sigma^{\star}$. Oberseite, ganzer Kopf und Hals, Kuhle. Blust und Weichen. Flügel mul Sohwanz glanzlos schwarz. Grubel Sehulterfleck faus den grolien Deckfedern der innersten Armschrwingen. den

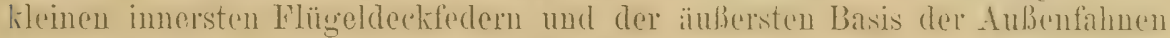
der immersten Armschwingen gebildet), unterste Bürzalfeclem und ()her-

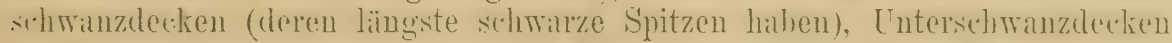

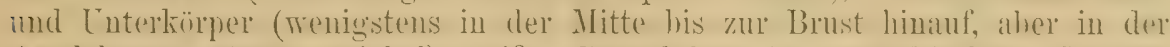

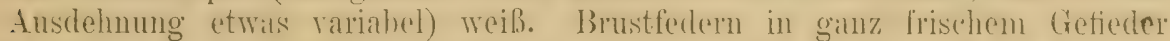

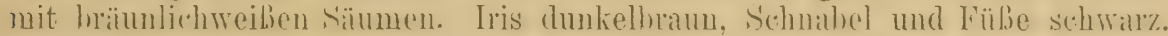

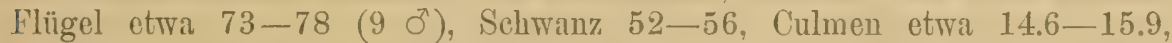
Lauf 21-22.5 mm. o ad. Oberseite braun (dunkler oder heller) mit

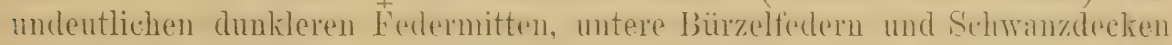
röstlich zimmtfithen. Schwingen und Ohorflügeldecken dunlielhram mit fabliöstlichen Sämmen. Cutersuite hellbraun, Keble fast weiblich lraun. Wie dunkleren stü̈ke scheinen meist jüngere Individuen zu sein. - Fistes

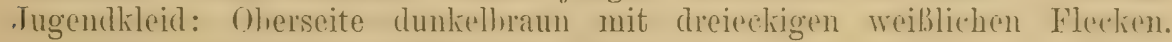
Unterseite braun mit rahmfarbenen Flecken. 
Trinshisplun, I'Prsien, Afghinistan und Kaschmir, sowie Nordwest-Indin

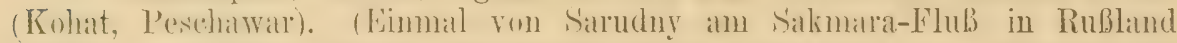
erhentet.) In den Elhenen Nordwest-Indiens remutlich nur Wintervogel, im westlichen Himalaya aber anscheinend anch brïtend.

Die Grenzen der Brutgebiete dieser und der folgenden Formen sind schwer zu bestimmen, da letztere in der Literatur nicht unterschieden wurden. - Nest sehr versteckt, meist in Vertiefungen oder Löchern, oder in Büschen am Errdboden, ein tiefer, weich ausgefütterter Napf. Eier sehr blaß grünlichblau mit rotbraunen feinen Wölkchen und Flecken. Gesang nach Brooks besser als der von P. torquata indica.

\section{Pratincola caprata bicolor (Sykes).}

Saxicola bicolor Sykes, Proc. zool. Soc. London Juli 1832, p. 92 („Decean“, d. h. Plateau zwischen Narboda und Kistna).

Saxicola erythropygia id., loc. cit., p. 92 ( $q$ des S. bicolor).

Motacilla sylvatica Tickell, Journ. As. Soc. Bengal II, p. 575 (1833- Borabhum und Dholbum im westlichsten Bengalen).

Wie P. c. rossorum, aber beim $\sigma^{\top}$ nicht der gröBte Teil des Unterkörpers, sondern nur die Analgegend oder doch nur ein geringer 'T'eil des Unterkörpers weiß. Mitunter etwas größer, doch nicht so groß wie $P$. c. atrata.

Vorderindien bis zum Dekkan und mittlere Teile des Himilaya.

\section{Pratincola caprata caprata (L.).}

Motacilla Caprata Linnaeus, Syst. Nat., Ed. XIl, 1, p.335 (1766 - Luzon. Ex Brisson III, p. 442, 'Taf. 24).

Saxicola fruticola Horsfield, Trans. Linn. Soc. London XIII, p.157 (1821- Java).

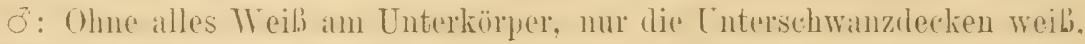

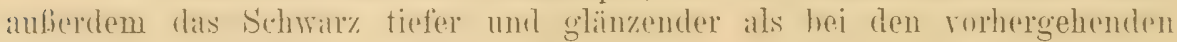
Eormen.

Bewohnt die malayischen Inseln von Jara bis Sumba, Timor und den Sïdwest-Inseln. Celehes und die Philiphinen. Zur selhen Form gebören auch die hinterindisehen stücke, ungefihl bis zum 90. Längengrad westwirts.

(Von tropischen Formen schließen sich ferner südlich und östlich noch an:

1. P. caprata atrata Blyth: Wie P. c. bicolor, aber mit bedeutend größerem Schnabel und auch sonst kräftiger, größer, Flügel 78-82 mm. - Ceylon und die Gebirge des südlichsten Indiens (Oates, Fauna B. India, Birds II, p. 60).

2. P. caprata aethiops (Sel.): Wie P.c. atrata, aber das Schwarz der ot tiefer und glänzender, das $ᄋ$ mit weißen Oberschwanzdecken und gräulicher. - Neubritannien und Neuguinea (Nov. Zool. 1907, p. 467).)

\section{Gattung OREICOLA Bp. 1854.}

Steht der Gittung Pratincola sebr uhe, doch ist der Schwanz länger und mehr gestuft, da die äuberen Steuerfedern ungefähr 1 em hürzer sind als die mittelsten, auch sind die Steuerfedern mehr zugespitzt. Synonym ist lihodophila 1863. Außer der in zwei Formen bis ins paläarktische Gebiet reichenden $O$. jerrea lebt in Indien die schwarz und weiße (). jercloni und in 'Timor die ähnlich gefürthte $O$. melanolenen mit dickerem Sohnahel. 


\title{
1079. Oreicola ferrea ferrea (Gray).
}

Saxicola ferrer Gray, Cat. Mamm. B. Nepal \& 'Thibet coll. by Hogdson, p. 71, 153 $(1816$ - Nepal).

Abbild.: Hume \& Henderson, Lahore to Yarkand, 'l'af. 12; Ei: Cat. Eggs Brit. IIus. IV, 'Taf. VI, Fig. 19.

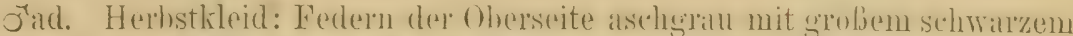

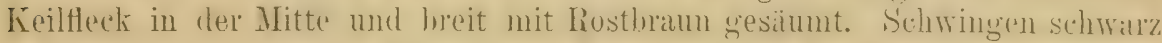
mit sehr schmalen, all den innern drmschwingen hreiterem und lehhifter

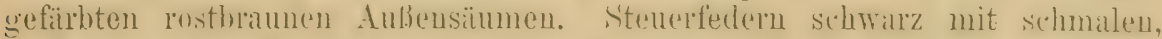

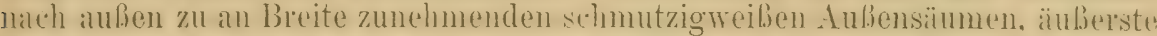

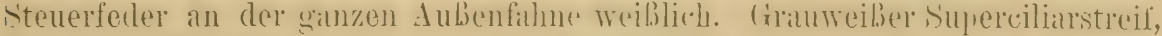

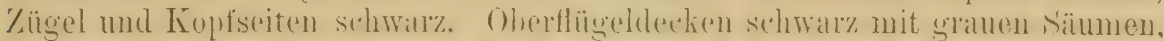

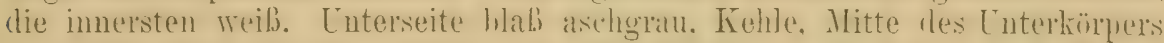

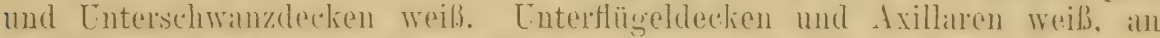

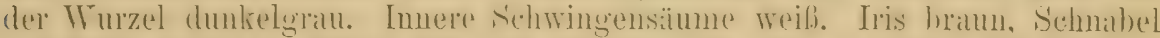

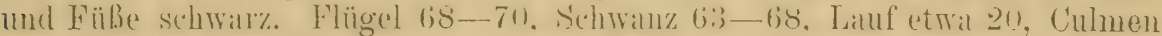

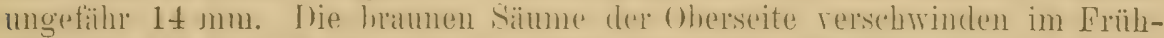

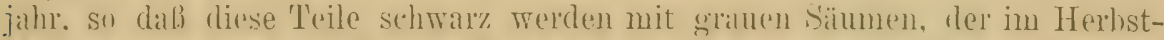

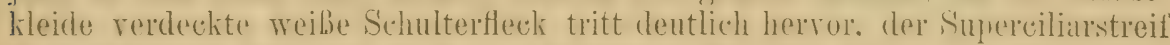
wird schmäler aber rein weiß, die Unterseite fast rein weiß. - o ad. Ober-

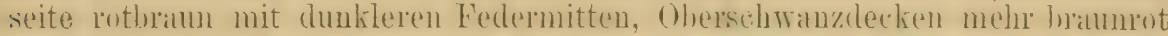
und cinfirbig. Schwingen dunkelhram mit rosthramen Sämmen, der weiße schulterfteck ist nicht rorhanden. Stenerfedern hraun, Aubenfahnen ganz uder gröbtentrils rostrot. Enterseite rahnfarben, Brust und Treichen bram. Im ahgetragenen Fleide ist die Oberseite nicht so röstlich und die dunklen Federmitten treten deutlicher hervor, die Unterseite wird weiblicher:

.Jur. (Nestlileid): Braun mit rahmfarbenen his hell röstlichen Keilflecken mahe den Spitzen der Federu, Luterseite rahnfarbu mit branen Feclersätumen.

Bewohnt den Hinalaya (ron Kaschmir und dem Industale bis Silikim), im Śmmmex in Höhen ron t-9000 engl. Fub, im Winter in den Täleru.

Baut ein napfförmiges Nest aus Gras, kleinen Zweiglein, Wïrzelchen und Moos, mit Haaren ausgefüttert. Es steht am Boden, im Schutze von Steinen, Erdklumpen oder unter Büschen und neben Grasbüscheln, auch an Uferwänden oder Mauern in Vertiefungen und Löehern. Es scheinen zwei Bruten stattzufiuden, da man die $4-5$ Eier rom April bis Juli findet. Die Eier sind blaß bläulichgrün mit blaßroten und rotbraunen Wölkchen, Flecken und Punkten, denen ron Pratincola torquata rubicola und indica sehr ähnlich. Sie messen etwa $17-19 \times 13-15.6 \mathrm{~mm}$.

\section{Oreicola ferrea haringtoni subsp. nov.}

\author{
Ei: Cat. Eggs. Brit. Mus, IV, T'ef. VII, Fig. 18.
}

Enterscheidet sich von 0 . jerren jerrea durch den hedentend künzeren Schwanz. ơad. Schwanz 57-61,5, Flügel 65-68 mm.

Mupin und andere 'Teile ron S'zetschuan bis Fokien in Südost-c'hinil, anßerdem Birmah und die Bergländer sïdlieh des Brabmaputra.

Eier dunkler blau als die von 0 . ferrea ferrea und stets ungefleckt, denen der Heckenbraunelle ähnlich. - Benannt zu Ehren von Oberst Haringtou, der mich auf die konstante Verschiedenheit der Eier aufmerksam machte. Typus: - 3 ad. Lien-kiang bei Fu-tschau in China. 18. Januar 1887, im Tring Museum. 


\section{('attung TARSIGER Horlgson 1845').}

Unter obigem Namen vereinige ich, wie Sharpe es früher tat, 'T. chrysaeus,

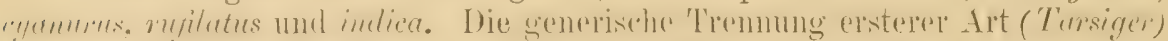
ron den ïhrigen (lanthia) ist nicht durchführbar. denn die formosinische

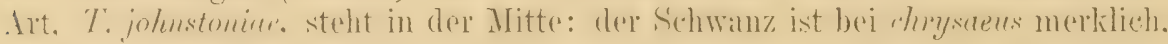

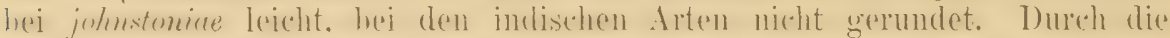

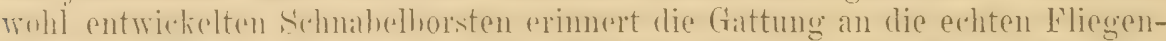

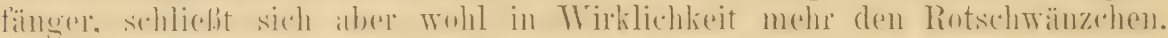
Rot- und Blankehlehen an. - Geschlechter verschieden.

\section{Übersicht der $\widehat{x}$ :}

1 f Sehwanz gelh, an den spitzen schwarz oder olivenhraun T. chrysueus. p. 71.

Unterseite rostrot, Superciliarstreif blan ..... T. Myperythra . p.714

2 Unterseite rostgelb, Superciliarstreif weiß . . . . . . T. indica . 1.713

Nur die Weichen rostfarben . . . . . . . . . . . 3

3) Supereiliarstreif blau . . . . . . . . . T. muflatus . 1) 713

3 | Superciliarstreif iiber den Zügeln weiß ...... T. cyamums . p. 712

\section{Tarsiger cyanurus (Pall.).}

Motacilla Cyanurus Pallas, Reise d. versch. Prov. Russ. Reichs II, p. 709 (1773- Jenissei). Abbild.: Temminck \& Schlegel, Siebolds Faun Japonica, Ares, Taf. 21.

ơad. Oberseite und Kopfseiten trüb blau, in frischem Gefieder mit

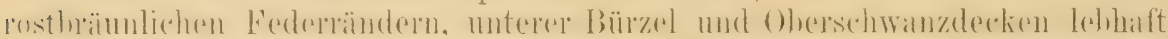

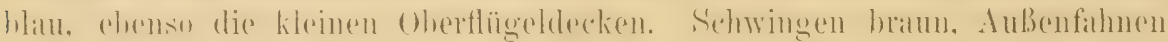

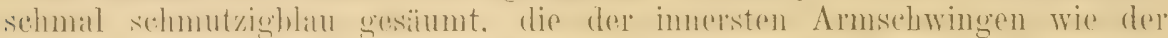

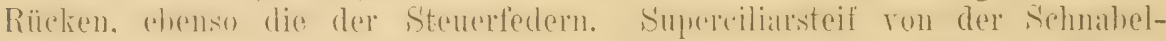
wurzel bis zum Auge weiß, von da ab blau: alle diese Federn weiß mit

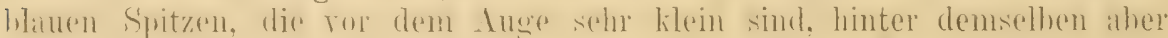

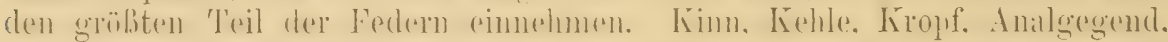

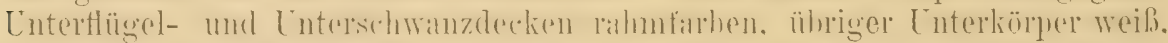

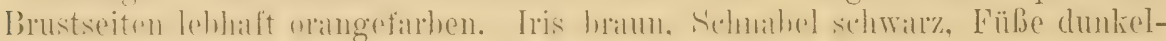
braun. Flügol von 12 o $78-80$, Schwanz etwa 58-60, Lauf etwa 21-22, Culmen 13-13.5 mm. - o. Oberseite olivenbraun, im Fiül-

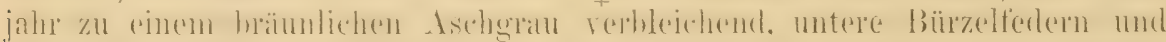

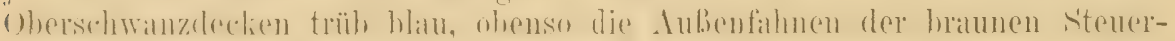

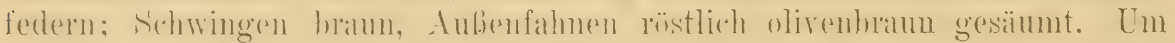
die Augen ein bräunlichweißer Federring: Unterseite wie beim $0^{\pi}$, nur die Kropfgegend bräunlich. - ơjuv. wie o ad. und in diesem Gefieder nicht selten schon brïtend, - Juv. (Nestkleid): Oberseite braun mit hell ocker-

1) Hier schließt sich am natürlichsten die tropische Gattung Notodela an, von der ein Vertreter im Himalaya bis 9000 engl. FuB Höhe beobachtet wurde: Notodela leucura (Mnscisylvia leucura Hodgson, Proc. zool. Soc. London 18th, p. 27, Nepal): ơad. Oberseite blauschwarz, Stirn und kurzer Superciliarstreif kobaltblau. Schwanz schwarz mit großem weißem Fleck an der Basis, mittelstes Steuerfederpaar ganz schwarz. Unterseite schwarz mit bläulichem Schimmer, an den Kropfseiten ein verdeckter weißer Fleck. Flügel etwa 90-95̌ mm. \& Röstlich braun (Cat. B. Brit. MIus. VII, p. 23; Oates, Fauna Brit. India, Birds II, p. 112). Eier lachsrötlich mit blaßgranen Zeichnungen. 


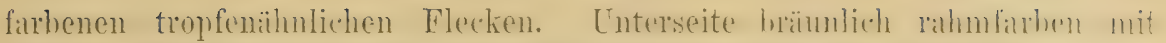

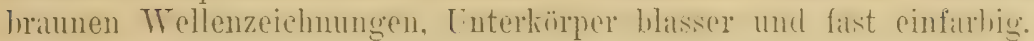

Britet vom Gouvernement Perm in Rußland (mittlerer Ural) durch ganz Sibirieu his zum ()chotskischen . Inere und in Kinntsehatlia (rereinzolt

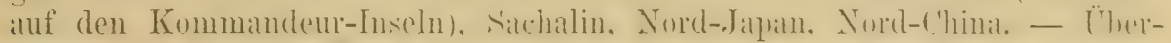
wintert in Süd-China, and Hainam, Formosil und den Riu Kin-Inseln, und kommt auch mitunter in Indien vor: E. C. Stuart Baker erlegte ein ô ad. in den Bergen von Nord-Cachar am 14. Februar 1896.

Lebt in Wäldern und Buschwerk und erinnert in seinem Wesen an die Rotsehwänze. Der Lockruf ist kurz und scharf und soll an die Silben keke keke oder toctoc erinnern. Das Nest steht in kleinen Vertiefungen am Boden, an Steinen und Böschungen. Nehrkorn (Katalog Eiersamml. p. 27. 1899 ) beschreiht die Eier folgentermaßen: "Weißer Grund, sonst gefärbt wie unsere vibecula, $18-19 \times 15 \mathrm{~mm}$. Als Fundort gibt Nehrkorn "Ost-Sibirien", wie leider immer ohne Gewährsmann, an.

\section{Tarsiger rufilatus (Hodgs.).}

Nemura milatus Hodgson, Proe. zool. Soc. London 1845, p. 27 (Aug. 1845- Nepal).

Abbild.: Dresser, B. Europe II, 'Taf. 55 ơ (Sub nom. Nemura cyanura).

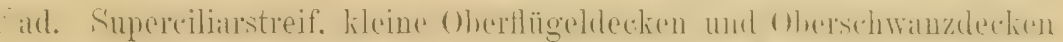

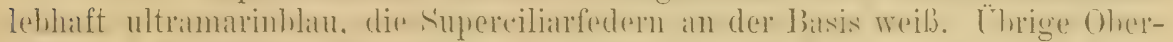

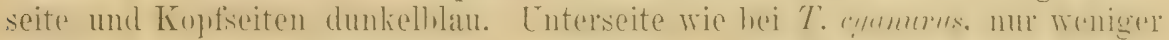
rahmfarben, und schmutziggrau verwaschen. Flïgei von 14 of $80-84.5$, Schwanz etwa 66-68, Jauf etrva 24, Culmen 14-15 mm. o ad. Oberseite

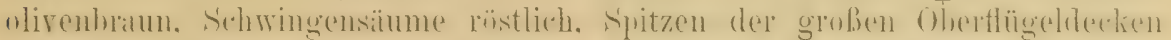

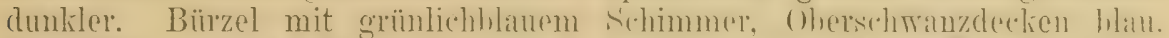

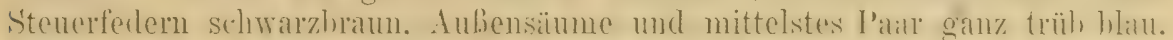

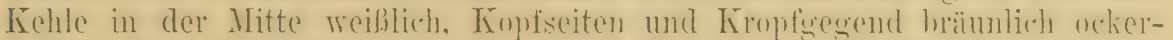
farhen, ährige [nterseite schmutzig woib. Brustseiten lahlaft röstlich orange-

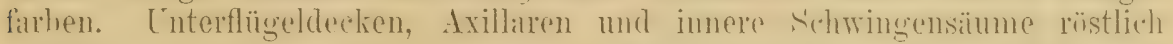
rahmfarbon. Dem o von $T$. cyanums ähnlich, aber das Blau der Stener-

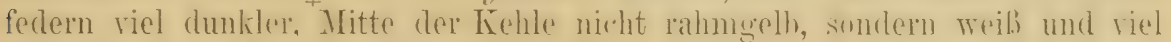
dunkler olivenbraun umsäumt. - Juv. Oberseite braun mit rostgelben,

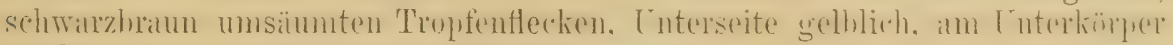
weib und mit dunkelbraumen Federsäumen.

Bewohnt den Himalayı in Höhen von 8-16000 engl. FuB, und die "hinesischen Gehinge: Szetsohwan. Tsin-ling lierge. In Minter in tiofuren Lagen.

Brüten nicht selten ehe sie das Altersgefieder angelegt haben. Nest in Löchern an Böschungen und Uferwänden, unter gefallenen Stämmen oder Baumwurzeln. 4 Eier im Mai und Juni, blaugrünlichweiß mit feinen blassen rotbraunen Flecken um das dicke Ende. 12 Eier messen im Durchschnitt $18 \times 13.9$, Maximum $19 \times 14.8$, Hinimum $17 \times 13.2 \mathrm{~mm}$.

\section{Tarsiger indica indica (Vieill.).}

Sylvia indica Vieillot, Nouv. Dict. d'Hist. Nat., Nouv. Ed. XI, p. 267 (1817- ex Sonnerat, Voy. Ind. II, p. 208, Indien).

Nemura flavo-olivacea Hodgson, Proc. zool. Soc. London 1815, p. 27 (Nepal).

Tarsiger superciliaris Moore, Proc. zool. Soc. London 1854, p. 76 (Febr. 1855- Nepal). 


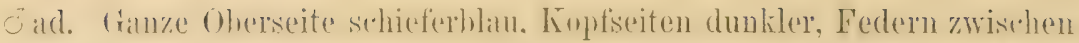

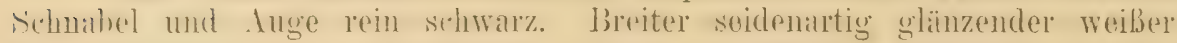

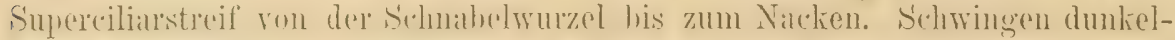
bran mit selhlich olivenhaumen Auben- und röstlich rahmfarhenen lnnensïmmen. Stenertedern sehwarzhaun mit hamen Anfeusäumen. Unterseite

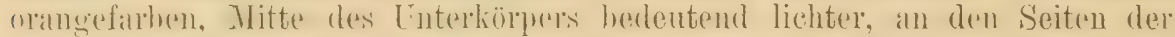

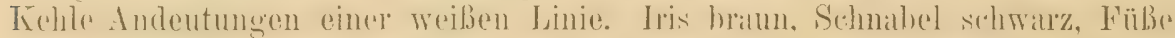
braun. Flügel von 6 ơad. 81-82, Schwauz 68-71, Lauf etwa 30, Culmen etwa 23-23.5 mu. - o ad. Ganze Oberseite olivenbraun, mehr oder minder

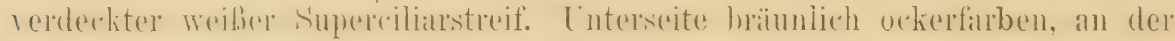
Brust am lebhaftesten, Mitte des Unterkörpers weißlich.

Himalaya in Nepal und Sikkim, wo Pearse ihn 12500 engl. Fuß hoch

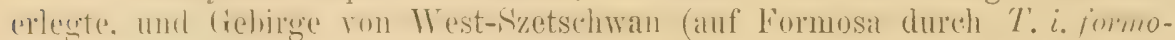
sames vertreten).

\section{Tarsiger hyperythra (Blyth).}

Ianthia hyperythra Blyth, Journ. As. Soc. Bengal XVI, 1, p. 132 (1847- Darjiling).

Abbild.: Jardine, Contr. Orn. 1849, Tafel zu p. 88-16, Fig. 2.

ơd. Stirn, Superciliarstreif und kleine Oberflügeldecken lebhaft ultramarimblau. iibrige OHerseite dunkel purpurblatu, auf den Obersehwanzdecken hellel. S'chwingen und Sebwanz schwar\% mit hlauen Sämmon. Zügel und Kopfseiten tiefhliu, erstere fast schwarz; Tehhnitte und ührige Unter-

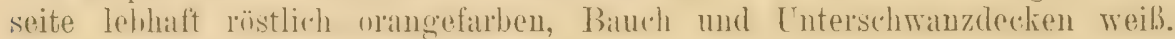
Flïgel von 3 o $79-82$, Schwanz etwa 60 , Iauf $25-26 \mathrm{~mm}$. - o ad.: Oherseite einschlieblich der Aubenseite der Flügel rostgelhlich olivenbram. untere Bürzelfedern matt blan, Oherschwanzdecken und Aubenfahnen der Steurefedern dunklor hlau. Enterseite ockergelblich, Brust dunkler, mehr olivenbrïumlich, Nitte des [nterkör]ers. Banrh und Iintersehwanzdecken wrib.

Sikkim, von Kapt. Pearse noch bei Gnatong, 12600 engl. Fuß hoch, erbeutet, auch in den Khasia-Bergen südlich des Brahmaputra.

\section{Tarsiger chrysaeus Hodgs.}

Tarsiger chrysaeus Hodgson, Proc. zool. Soc. London 1845, p. 28 (Aug. 1845- Nepal). Abbild.: David et Oustalet, Ois. Chine (p. 233), 'Taf. 29.

Schwanz stark gerundet. - ơad. Oberseite des Kopfes, Hals, Nacken und Rürckenmitte dunkel olivenhraun mit griunlichgelhen Federsüumen; ührige Oberseite einschlieblich der letzten kurzen Armschwingen, Supereiliarstreif und ganze Unterseite orangegelh, im frishen Gefieder an vielen Federn mit feinen schwärzlichen lindsämmen. Breiter. Stroif an den Kopfseiten von den Zïgeh durehs Auge bis zur Ohrogegend hin selhwilrz. Schwingen bramschwarz mit olivengelben AuBen- und zitronengelben Innensäumen, vorletzte Armsehwingo mit breiteren. mehr goldgelben Aubensatum. Sitemerfedern orangengell), alle, mit $\mathrm{l}-\mathrm{L}^{1 / 2}$ (:m breitem schwarzen Endsaum, auberden dis Aubenpalr mit hallischwalzer AuBeufahne, und das mittelste fast ganz schwar\%. Iris dunkelhram. Schnabel hellgelh, Obersehuabel mit Ausuahmo

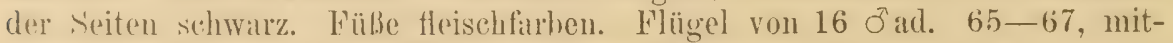
unter bis 70 und 71 (bei Stüeken von Sikkim und Nepal, die aber nicht 


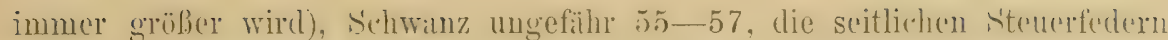
etra 5-8 mm kïrzer, Lauf 27-29, Culmen $13.5-15.5 \mathrm{~mm}$ - - o ad. Ganze Oberseite und Aubenseite der Flügel, sowie mittleres Steuerfederpar

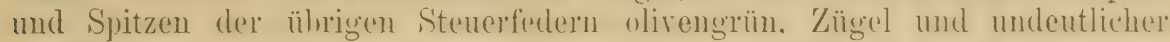

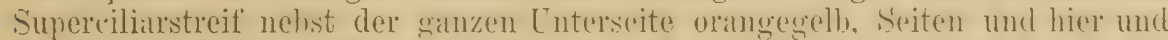
da Fedreä̈me sehmutzig olivenbram. - Jur. (Nestleid): Oherseite dunkel

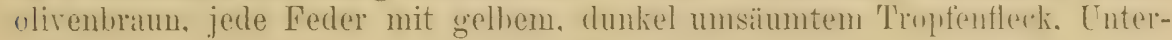
seite gelb mit dunkel olivenfarbenen Federsäumen.

Himalaya ron Chamba his sikkim, Berge südlich des Bralmantutlat und Bergländer WV est-Chinas: Szetschwan, Mupin, Tsinling-Berge.

Brütet schon in Höhen von etwa 5000 engl. FuB, reicht aber auch bis $12500 \mathrm{FuB}$ hinauf (in Sikkim). Lebt in buschreichem Grelände und nistet in Vertiefungen an alten Baumstämmen, am Boden oder an Böschungen. Die Eier sind nach Brooks, und nach von Eingeborenen gesammelten Stücken (Sikkim, Cachar) einfarbig blau und messen $18-20 \times 12.5-14 \mathrm{~mm}$. Nehrkorn beschreibt sie ebenso, mißt aber $19>16 \mathrm{~mm}$.

\section{Gattung CHAIMARRORNIS Hodgson 1844.}

Chaimarrornis Hodgson, Gray's Zool. Mise, p. 82, descr. nulla (Typus leucocephala). Chaemorrornis Jerdon, B. India II, p. 143, diagnosis. - Chimarrhomis auctorum recent. - Rhyacomis Blanford. Journ. As. Soc. Bengal XLI, 2, p. 51, 1873 ('Typus fuliginosa). - Nymphaeus Hume 1873 ('Typus fuliginosus).

Von Plocnicurn: dureh (im Terhältnis zur Fiügrellänge) hedentend kïrzeren

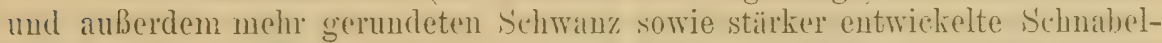
horsten unterscheidhan. Gefieder reich und weich. 1. Schwiuge ungefäh donnult so lang als die Handdecken, 2. zwischen der 6. und 7.. 3. und t. gleich und am längsten, 5. nur wenig kïrzer, 3.-6. verengt. Zwei Arten im paläalktischen Geliete, auBerdem C. bicolor auf den Bergen ron Luzon (Philippinen).

Kopfplatte weiß, ganzer Unterkörper braunrot ....C. lencocephala ơ . p.715 Kopf, Rücken und Unterkörper graublau ....... C. fuliginosa ô . p. 716 Kopf und Rücken braungrau, Unterkörper grau und weiß quergefleckt

C. fuliginosa 우 . p. 716

\section{Chaimarrornis leucocephala (Vig.).}

Phoenicura leucocephala Vigors, Proc. Committee zool. Soc. London I, p. 35 (1831Himalaya).

Abbild.: Gould, Cent. B. Himal. Its., Taf. XXVI Fig. 1; David \& Oust., Ois. Chine, Taf. 24.

Abbild. d. Eier: Ibis 1904 Taf. VII, Fig. 4,5 (nicht 1,3, vergl. p. 485).

Oे ad. Kopfplatte his zum Nacken seidenurtig weiß; Kinn, Kehle und Kropf, Stirn, Zügel, Kopfseiten, Hals, Rücken, Schulteru, S'chwiugen nebst Oberflügeldecken und $1-2 \mathrm{~cm}$ breite Endbinde der Steuerfedern schwar\%. ferner fast die ganze Spitzenhälfte der Aubenfahne der äuBersten Stenerfeder schwarz gesämmt. Ührige Lnterseite, Bürzel, Schwanzdecken und der Rest der Steuerfedorn kiastanienäbnlich braumrot. Unterfü̈geldecken mattschwarz mit mehr oder minder braumoten Spitzen. Iris hraun. Schnahel, Fübe und Schenkelbefiederung schwar\%. Flügel an 250 (meist ron den Tsin-ling-Bergen) 98-106, Schwau\% etwa 80-85, Lauf 32-34. Culmen 


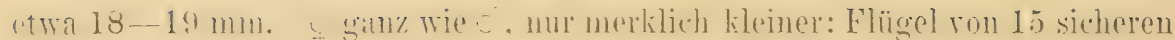
o $88-96 \mathrm{~mm}$. - Juv: Oberkopf weiß mit Dunkelgraubraun gemischt,

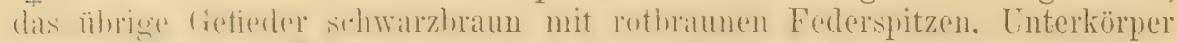
Inamu. Flïgel und sehwanz wie beim alten Vogel. - Nordehinesische stücke neigen zu ctwas hedeutender Gröbe als sulehe alus dem Himalaya, der Enter-

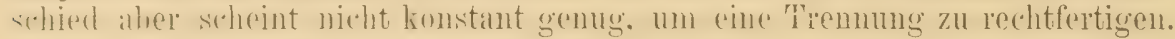

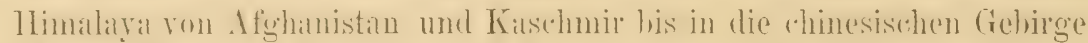
nileh Kansu. 'Tin-ling. Szetsehwan. his zum Irawaddy und .Jangtse Filusse.

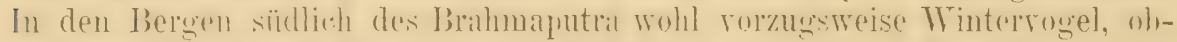

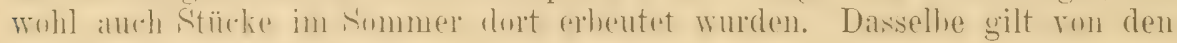
Schan-Staaten und Arrakan. (Die von Baker aus Cachar beschriebenen Eier sind unsicher).

Lebt an den Ufern der Bergströme, im Sommer im Himalaya in Höhen ron 10-20000 engl. Fuß, im Winter bis zu 3000 Fuß talabwärts. Der Lockton wird als ein tiefer Pfiff beschrieben. Sollen etwas andere, heftigere Schwanzbewegungen haben als unsere Rotschwänze und den Schwanz häufig ansbreiten. Das große napfförmige Nest ähnelt dem unseres Rotkehlchens und ist aus Moos, Mooswurzeln, Stengelchen und dergl. gebaut und mit Haaren gefüttert. Es steht an den Uferwänden der Bergbäche und enthält (im Mai) 3 Eier. Diese sind licht hellgrün oder grünlichweiß mit rotbraunen Flecken und einigen graulila Schalenflecken. Sie ähneln täuschend den weniger gefleckten Varietäten von Copsychus und Kittacincla (Schamadrosseln) oder, mit Ausnahme der Größe, Eieru von Muscicapa striata (grisola). Drei Eier messen 24-24.7 X $17.5-17.7 \mathrm{~mm}$.

\section{0s7. Chaimarrornis fuliginosa fuliginosa (Tig.).}

Phoenicura fuliginosa Vigors, Proc. Committee zool. Soc. London I, p. 35 (1831Himalaya).

Phoenicura plumbea. Gould, Proc. zool. Soc. London I, p. 185 (1836- Himalaya).

Phoenicura rabicaude Hodgson, Gray's Zool. Mlisc., p. 82 (1844- Nomen nudum. T'este Sharpe!)

Phoenicura lineoventris Hodgsou MI. S., teste Sharpe.

Abbild.: Hume \& Henderson, Lahore to Yarkand, Taf. 15. Ei: Cat. Eggs Brit. Mus. IV, 'laf. VII, Fig. 20.

Ō ad. Das ganze Gefieder blangrau mit Ausuahme der Steuerfedern, des

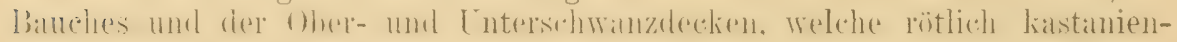

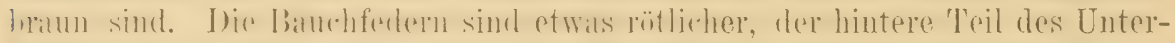

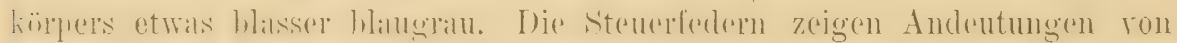
braunen Spitzen. Vordere Stirnfedern und Zügel etwas düsterer, im ab-

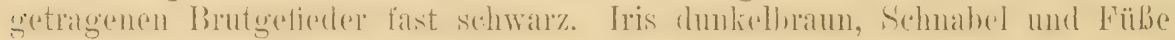
schwarz. Flïgel $(20$ J $)$ etwa $75-82$, Schwanz etwa 55-60, Lauf 22-24,5, Culmen etwa 14-15 mm. - o ad. Oberseite aschgrau, mehr

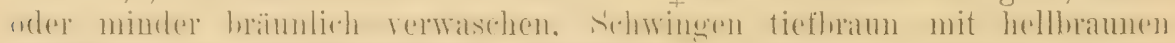

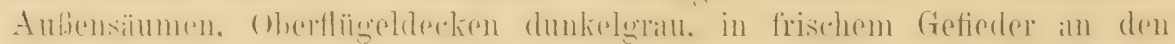
sintzen mit je comen weiben Fleck, an clen gröberen mit weifem Endsaum.

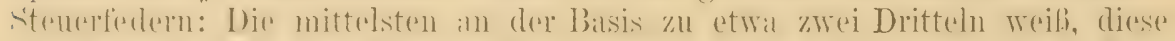

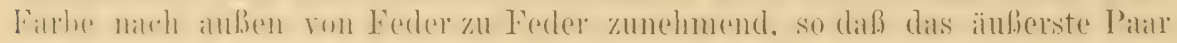

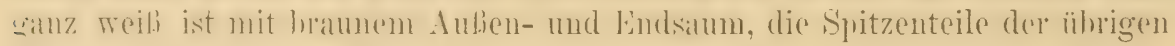

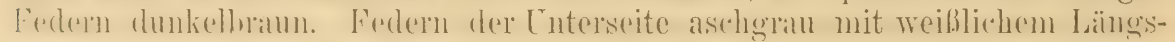

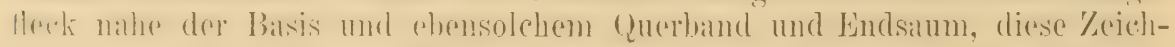

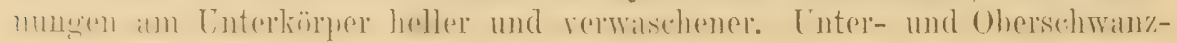




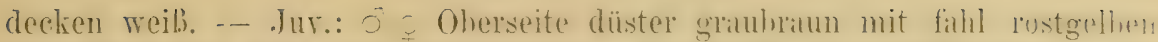
Lïngsteckchen nahe den Federspitzen. Unterseite fahl weililichloram mit dunkeln Federsiumen. Enterkïper weiblich. Flïge] nud Srhwanz wiv heim on ad.

Himalaya von Kaschmir bis Assam, im Sommer in großen Höhen bis zu 13000 engl. Fub. Außerdem China ron Futschau und Fokien bis zu

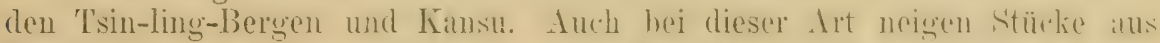

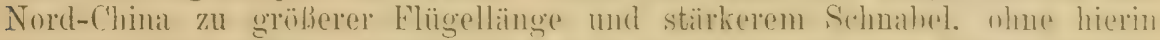
lioustant ahzuweichen. Anschemend anch in den Beregen von Hainan nistend. - Auf Formosil durch C. fuliginosa affinis (Grant) vertreten, deren ơ nicht sicher unterscheidhar ist. Während dis - sich durch düsterer gratue Cnter-

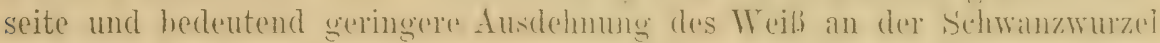
unterscheidet.

Hält sich wie C. leucocephala an den Ufern von Gebirgsbächen auf. Das Nest steht in Vertiefungen an Uferwïnden und Felsen und besteht aus Würzelchen, Bast, Moos, mit Haaren und Wolle ausgekleidet. Es enthält im Mai und Juni 4-5 Eier. Letztere sind grünlichweiß, reichlich mit fahl rotbraunen Flecken und einigen lila Schalenflecken gezeichnet. Sie ähneln bis auf die geringere Größe und meist sehr reichliche Fleckung ganz den Eiern ron C. leucocephala. 25 Eier messen $17-19.5 \times$ $13-15 \mathrm{~mm}$.

\section{Gattung PHOENICURUS Forster 1817.}

Synonymo: Phoenicura, Ruticilla, Adelura.- Dio ,Rotschwänze", von denen nur zwei Arten ( $P$. setisticeps und $P$. coeruleocephala) lícine roten Schwinze haben. hilden cine in sich wohl ahgeschlossene und rernüntfiger-

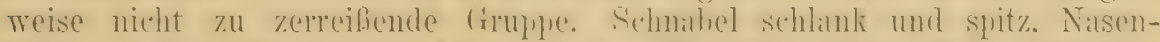

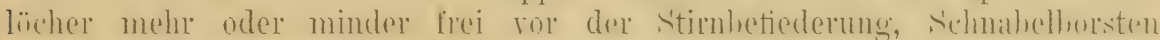

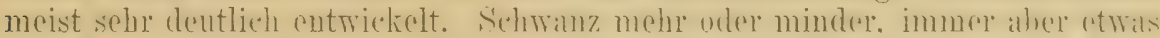

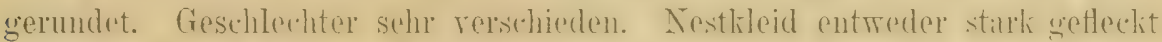

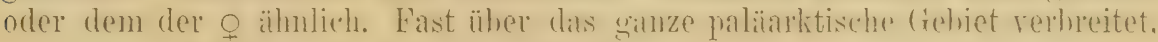
außerdem in Afrika, in Amerika aber fehlend.

\section{Übersicht der alten $\sigma^{t}$ :}

1 Sehwanz größtenteils rot . . . . . . . . . . . .

\{chwanz schwarz .............................. 8

2 Schwanz mit iiber $1 \mathrm{~cm}$ breiter schwarzer Endbinde. . P. frontalis . p. 728

2 Schwanz oline Endbinde oder nur mit Andentung einer solchen... 3

$3\{$ Basis der Armschwingen an beiden Fahnen weiß ........ 4

\{ Basis der Armschwingen nicht oder nur am Außensaum weiß..... 5

1 Flügel unter $8 \mathrm{~cm} \ldots \ldots$. . . . . . . . . . . . . . . 725

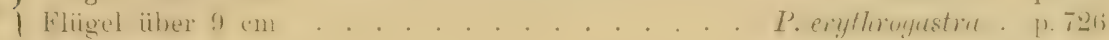

5 $\{$ Kehle schwarz . . . . . . . . . . . . . 6

$5\{$ Kehle rot .......................... 7

2. Schwinge gleich der 6 . oder länger, 3-5. verengt. P. phoenicurns - p. 718

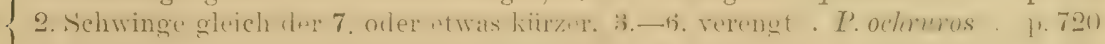

2. Schwinge gleich der 8. oder noch kiirzer, 3.-6. verengt . P. hodgsoni - p. 72.1

7 / Kopfseiten mit breitem schwarzen Streifen...... P. erythronota . p. 727

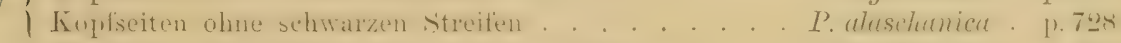

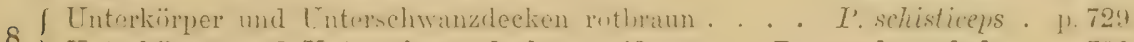

8 Unterkörper und Unterschwanzdecken weiß . P. coeruleocephala . p.730 


\title{
1088. Phoenicurus phoenicurus phoenicurus (L.).
}

\author{
Gartemrotschwanz.
}

Motacilia Ploonicums Limnaeus, Syst. Nat, Ed. X. p. 187 (1758- „Habitat in Europa”. Als terra typica betrachten wir Schweden, nach dem ersten Zitat und der der Fauna Suecica entnommenen Diagnose).

Motacilla Erithacus Linnaeus, 1. c., p.187 (1758 - „Habitat in Europa“, ex Fauna Suecica no. 225. Beschreibung des $९)$.

Motacilla titys $\left.{ }^{1}\right)$ Linnaeus, 1. c., p. 187 (1758- "Habitat in Europa", ex Fauna Suecica no. 227, wo deutlich ein $q$ von $P$. phoenicurus beschrieben ist).

Phoenicurus Ruficilla I'orster, Syn. Cat. Brit. B., p. 16 (1817- Neuer Name für Sylria phoenicurus).

Phoenicurus muralis Forster, t. c., p. 53 (1817- Wieder anderer Name für den Gartenrotschwanz).

Ruticille sylvestris Brebm, Handh. Naturg. Vög. Deutsehl., p.363 (1831- .Fichtenwälder Deutschlands").

Ruticilla arborea Brehm, t. c., p. 363 (1831- "Scheint eigentlich nördlich von uns zu wohnen - wenigstens kommt er bei Kiel vor - brütet aber auch hier ...").

Ruticilla hortensis Brehm, t. c., p. 364 (1831- „Er hält sich vorzüglich gern in Baumgärten auf ...").

Phoenicura muraria Swainson, Swainson \& Richardsons Fauna Boreali-Amer., Birds, p. 489 (1831- Anderer Name für "Motacilla phoenicura auct.").

Ficedula Rutacilla Eyton, Hist. Rarer Brit. B., Cat. p.10 (1836- Ex Raius, wohl Schreibfehler statt Ruticilla).

Erithacus Arboreus Kleinschmidt, Journ. f. Orn. 1903, p. 353 (Nener Name für die vorl. Art in ihren verschiedenen Formen).

("Sylviu phoenicums aegyptiace Kittlitz" wurde irrtïmlich von Olphe-(ralliard zitiert. der Name existierte aber nicht.)

Engl.: Redstart. - Franz.: Rouge-queue. - Ital.: Codirosso. - Schwed. : Rödstjärt.

3.-5. Schwinge verengt, 2. etwas länger als die 6 . oder gleich der 6 . sehr selten kïumer: 3.- -5. die Spitzo des Flügels hildend, 6. etwa 5-7 mm

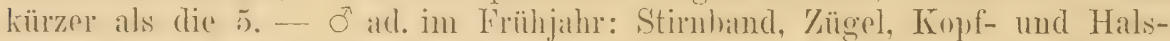
seiten (rom Auge ahwärts) und gimze Kehle his zum Kropf schwarz, üher dem schwarzen Band an der Vorderstim ain weißer, in einen angedenteten Superciliarstreiten fortgesetzter Stirnfleck, der an Ausclehnung etwas rariiert. Ülrige ()berseite nchst den kleineren Flügeldecken aschgrau. Bürzel, Obersehwanzdecken und Stenerfedern rostrot, das mittelste Steuerfederpar dunkelhraun mit rostroten AuBensïmmen. S'bwamzfedern und grobe Oberflïgeldecken dunkelhraum mit hellhramen Sämmen. IJnterseite rom Kropf an rostrut. am Unterkörler heller werdend, letzterer in der Mitte weib oder weililieh. Untersthwanzdecken bedentend heller als Steuerfedern und Brust. Iris dunkelhraun, Fübe und Schnahel hraunschwarz, Stohlen gelblich. Im frischen Herhstkleide ist das Weiß der Stim durch aschgraue Federsäume fast ganz rerdeckt, die Federn des Rüekens haben rothraune Kanten, die der untern Kehle und Brust weiße Endsäume; hei jüngeren ô sind die hramen Kanten der Ohnrseite ausgedehnter, ebenso die hellen Süume der Unterseite. dip auch nicht so weiß. sondern hrätmlich ralmfarben sind und das Schwar. der Kehle mitunter ganz rerdecken. Flügel von 69 of (30 Hartert, 39 Klein-

1) Die Schreibweise wurde später meist in "tithys" geändert und der Name über ein Jahrhundert lang irrtümlich für den Hausrotschwanz angewandt! 
schmidt) 76 -83, selten 84, eimmal nach Kleinschmidt $85^{1}$ ), Sehwanz 57 - $\nmid 1$, Lauf 20.5-21.5, Culmen 13.5-14.5 mm. - o ad. Oberseite graubrau, Flügel, Bürzel und Sehwanz wie heim ò. Unterseite fahl röstlichbramu, am Unterkörper ins Ralumfarbene ühergehend. Mitunter sieht man Spuren schwarzer Kehle und nicht selten ist die Brust roströtlich bis rostrot: oh letztere Stürke wirklich ..hahnenfedrigg " oder hesonders alte o sind, ist zweifelhaft. Über Varriation und Tandlumg des Gefieders u. a. m. s. Berajah , Frithacus Arboreus" 1908 und 1910. An letzterem Orte ist eine Aberration mit weiBem Fleckehen in der Jitte der Kehle als aber. natorpi beschrieben.

Nestkleid: (Oherseite braun mit schwarzen budsüumen und röstlich rahmfarbenen Anteatpikalflecken, Enterseite rahmfarben mit dunkelbraumen Federrändern, Wreichen rostfarben. Sehwingen breit rosthraun gesäumt.

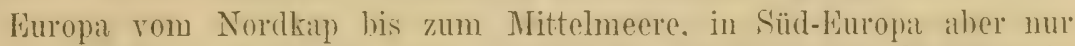
auf den Gebirgen, in Spanien nur nördich des (antabrischen Gebirges, in Griechenland nur anf dem Zuge. Fast ganz RuBland mit Ausmahme der steppengegenden und der Krim. Östlich lis Irkutsk und zum Sü̈den des Baikal-Sees. - Zieht dureh den Kaukasus'²), Kleinasien und Ägrnten und ïberwintert in West- und Nordost-Afrika bis zum weißen Nil und Bukobil.

In allen Grebieten Zugvogel. Bewolnt Kopfweiden, Baumgärten, Alleen, Anlagen und Wälder, aber nicht reinen Nadelwald. Lebhaft, unruhig mit dem Schwanze auf und nieder schüttelnd oder zitternd. Lockstimme ein heller, etwa wie fuid klingender Pfiff, dem meist ein schmatzendes teck teck angehängt wird. Der wechselnde, angenehme Gesang ist an der charakteristischen Einleitung sofort zu erkennen, die aus einem gezogenen, ron zwei kurz angeschlagenen Lauten gefolgten Tone besteht. Das Nest steht in Baumlöchern, mit Vorliebe in denen der Kopfweiden, hin und wieder auch an Fels- und Erdwänden und in Gebäuden, häufig an Mauern. Das meist aus 6 (ausnahmsweise 7-9) Eiern bestehende Gelege findet man im Mai. Die Eier sind einfarbig glänzend blaugrïn, mittunter, aber selten, mit einigen braunroten Punkten und Fleckchen. 100 Eier (61 Rey, 39 Jourdain) messen in Durchschuitt $18.28 \times 13.89$. Maximum $21 \times 14.5$ und $18 \times 15$, Minimum $16.1 \times 13.1$ und $18.2 \times 12.7 \mathrm{~mm}$. Durchschnittsgewicht $107 \mathrm{mg}$.

\section{Phoenicurus phoenicurus algeriensis (Kileinschm.).}

Evithacus algeriensis Kleinschmidt, Orn. Monatsber. 190t, p. 197 (Lambèse).

Abbild.: Berajah 1908, Taf. I, 3; vgl. auch Text.

ơ: Unterscheidet sich von Ph. phoenicurus phoenicurus dureh etwas stumpferen Flügel, in welchen der Abstand zwischen der 5. und 6. klejuer, nämlich nur 4 l)is höchstens $5 \mathrm{~mm}$ (austatt $6-7$ ) gro 3 ist, die 3. - 5. fast gleich lang sind und die 2. fast immer merklich kïrzer oder doch nicht länger ist als die 6. Die Farben sind anseheinend durehweg lehhaft, doch kommen ehenso lebhaft gefïrhte Stïcke auch in Sücl- und Nord-Furopa häufig vor. Die Sïume der Armschwingen sind anscheinend nicht so braun, sondern mehr lahmfarben.

Brutrogel in Algerien (Steineichen bei Batua [Lambèse] und nördlicher Atlas), vermutlich aber auch anderwärts in Nordwest-Afrika.

1) Ich finde die größten .Iaße (und zwar vielfach) bei ostafrikanischen Zugrögeln.

${ }^{2}$ ) Das Brüten im Kaukasus "unterm selben Dache" mit mesoleuca beruht jedenfalls auf Verwechslung mit Stücken letzterer Form in abgeriebenem Gefieder oder solchen, die den weißen Flïgelspiegel nur angedeutet hatten. Die Angaben rom Brüten in Palästina und Cypern halte ich für unrichtig. 
1090. Phoenicurus phoenicurus mesoleuca (Hempr. if Fhr.).

: Motacilla samamisica Hablizl, Neue Nord. Beyträge IV, p.60 (1783- Gilanische Gebirge Nordpersiens).

Syltie mesolewe Hemprich \& Ehreuberg, Symb. Phys fol. ee (1832- Djedda in Arahien). (Vgl. auch Kleinschmidt, Berajah 1908); R. mesomela Loche, Schreibfehler. Ruticilla Bonapartii v. Müller, Beitr. Orn. Afr., 'Taf. XIV und Text (1854- Abessinien). Ruticilla marginella Bonaparte, Compt. Rend. 38, p.8 (1854-- Abessinien und Senegal, letzterer Fundort fraglich).

Der Flügol des alten - hat im Horhstikeide hroite weibe duldensïume an den Alm- mul sehmale an den Handschwingen. so dab dort ring grobel

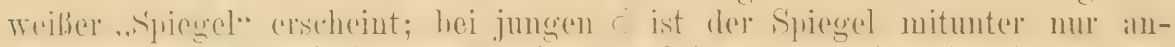

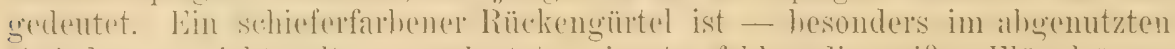
inctieder - nicht selten angedentet; mitunter fohlen die wriben Flïgensiume anch scheinbar alten of fast ganz und in sehr abgetragenem Kleide ver-

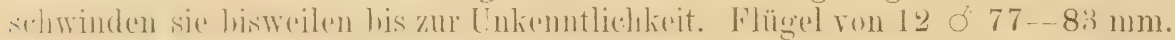
- q nicht sicher von denen von $P . p$. phoenicums zu unterscheiden, mitunter aber mit Andentung des Flïgelspiegols, mud hei alten Stünken sind (H)erseite und Kopfseiten mehr grau.

Brutrugel in der Krim, in Kankiasus. 'Transkankasien, Kleinasien und Persien. - Zieht durch Syrien, Ägypten und Arabien und ïberwintert in

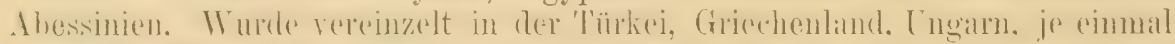

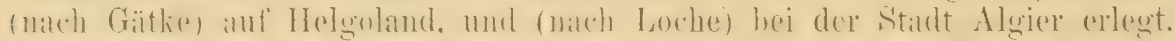

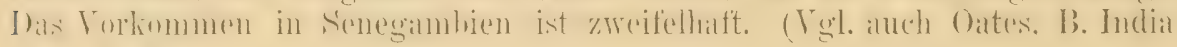
II 1. U1.)

Lebensweise und Eier wie die von $P . p$. phocnicurus. 10 Eier messen nach Jourdain im Durehschnitt $18.9 \times 14.35$, Maximum $20.2 \times 14.3$ und $19.4 \times 15.5$, Minimum $17.5 \times 13.6 \mathrm{~mm}$.

\section{Phoenicurus ochruros gibraltariensis ((im..' $)$.}

Hausrotschwanz.

Motacilla gibraltariensis Gmelin, Syst. Nat. I, 2, p. 987 (1789- Gibraltar. Ex Edwards, nude Brisson, Buffou, Latham).

Motacilla atrata Gmelin, t. c., p.988 (1789- Ex Latham. Fundort unbekannt).

Motacilla erythrourus Rafinesque, Caratt., p.6 (1810 - Teste Seebohm).

Ruticilla atra Brehm, Handb. Naturg. Vög. Deutschl., p. 365 (1831- Deutschland).

Sylvia Tites $\beta$. campylonyx Hemprich \& Ehrenberg, Symb. Phys., fol. dd (1832Nubien).

Ruticilla Cairii Gerbe, Dict. Univ. d'Hist. Nat. XI, p. 259 (1848 - „Basses Alpes").

Ruticilla montana Brehm, Vogelfang, p.415 (1855- Unteralpen und Kärnthen).

Ruticilla inomata Madarász, Zeitschr. f. ges. Orn. I, p. 119 (1884- Ungarn. Beschreibung des cairii-kleides. Frühere Beschreibung fand ich nicht).

Erithacus titis Brehmi Kleinschmidt, Journ. f. Orn. 1892, p. 198 (schon im 1. Herbste schwarz werdende $\widehat{\jmath}$ ).

Ruticilla tithys paradoxa Olphe-Galliard, Orn. Jahrb. III, p. 158 (1892- Aus Brehms Brief vom 1. Dezember 1863. Dasselbe wie "Brehmi").

1) Phoenicums, Ruticilla oder Sylvia titys, tithys, titis, tythis, tites, thitis und thytis (!) der Autoren, aber nicht Motacilla titys Linné 1758, oder gar 1766, wo der Autor selbst sagt, sein titys sei das of von phoenicurus! 
Evithacus Domesticus Kleinschmidt, Journ, f. Orv, 1903, p. 357 (Name für den Hausrotschwauz und seine Subspezies).

Ruticilla nigra Giglioli, Bull. B. O. Club XIII, p.79 (1903- Sardinien. Ersichtlich Melanismen!).

("Motacilla ochracea Gm." wird von Olphe-Galliard zitiert, der Name existiert aber nicht).

Engl.: Black Redstart. - Franz.: Rouge-queue noir. - Ital.: Codirosso spazzacamino.-- Schwed.: Srart-Rödsterjt.

Bau des Flïgels wesentlich anders als bei Ph. phoenicurus: 2. Schwinge bedentend kiurzer als die 6. und zwall gleich der 7. oder wanig litizer oder länger; Außenfahne der 3.-b. verongt. - on ad. Oberseite aschgrau, dic Rörkenfedern ror den Spitzen breit schwarz, so dab in stark abgenutzen

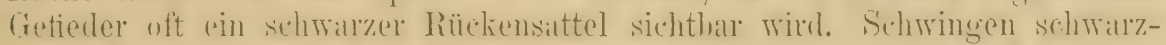
hraun, Handsehwingen sehmal grau, innere Amsehwingen hreit weil gesïunt.

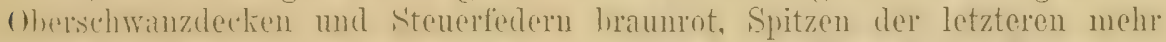
nder minder dentlich haum wie das mittelste P'all. Stim, Zügel. Kopfseiten.

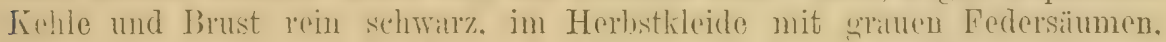
Enterlö̈per weidogran. die Federn dunkelgrau mit hreiten weiblirhen Sämmen. Cuterschwanzdecken hell rostlarhen. Unterflügeldecken sehwarz mit sehmalen, Axillaren und grabere Luterflügrelecken gratu mit hreiteren weifen Sümmen.

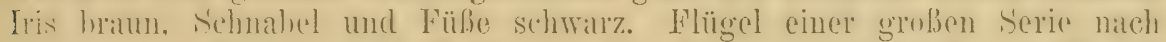
moinen und Kleinsthmidts Messungen 85-91, ansmahmsweise nur 82 und 83, Schwanz etwa 62-68, Iauf etwa 23-25, Culmen $13.5-15 \mathrm{~mm}$. ad. Oherseite graulatan (mehr grau als hei den asiatischen Formen). Cutersaite heller: Nitte des Unterkïrpers am lichtesten, mitunter fast weiblich. Schwingen dunkelhram mit fahlhraumen Sämmen. Schwanz wir heim 5. - Dats Nestleleid ist nicht gefleckit. gleicht vielmehr dem des ?.

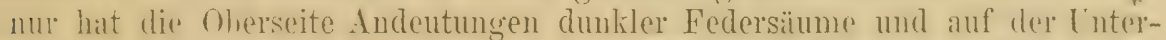
suite sind lutztere deutlich ausgebildet. - Wie bei Cimpodurne, Sylvin atricapille und andern Tägeh mausern die jungen Tügel im ersten Herhste trilweise (in rielen Gegenten grölitenteils) in ein clem ähnliches, meist nur dureh brïunlichere Flügel zu unterseheidendes Kleid und hrüten in

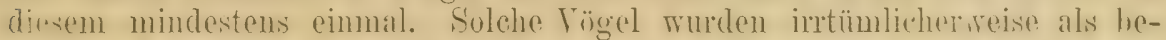
suldere Art unter dem Namen Ruticille cririi leschriehen und eine ganze Liceratur hexchätiote sich mit dieser Frage; andere Individuen nehmen schon im ersten Herbste das ... Alterskleid" an, sind aber in den viel hreiteren und hrïunlicheren Fodersïmen kenntlich. Erstere bezeichnete Kéleiuschmidt als

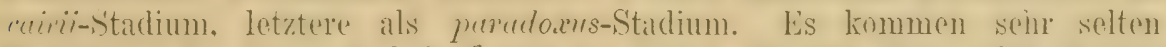
Zwischenstufen ron. nämlich 0 , die im ersten Herhste meln oder minder rerdechtes S'chwarz an Kehle und Brust haben. Bei ringen cler astatischen Subspezies findet dasselbe statt.

Europa, nöpllich his zur Nord- und Ostsee, östlich his ins südwestliche Rubland und Polen his Traschau, Rumänien und Bulgarien, südlich his ans Mittelmeer. Tareinzelt. vielleicht nur zufälig, in der Krim (Suschkin, in litt.). In Mitteleuropa in den Fhenen ehenso wie im Gebirge his in Hähen von 2-3000 m. in Sü̈leuropa Gehirgsogel. Ścheint auf Sardinien und Kórsika nur Zugrogel zu sein, iu Sizilinu aber zu brüten. Das Brïten in Norlwestatrika (Manchko und Algerien) ist noch nicht sicher festgestellt, ehensowenige in Fngland, wo Hausrotschwänze aber hänfig durelogiehen und sogn äher-

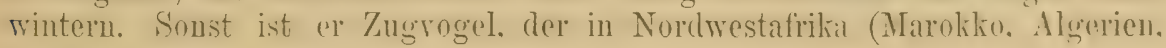

E. Hartert, Die Vögel der paläarktischen Fauna. 
I'unesiens und Noldostafrika. sü̈lärts his ins südliche Nubien überwintert und auf dem Zuge auch noch in Kleinasien heobachtet wurde. In Skatudimarien rerein\%lt roregehmmen, eimmal auf Island. - Im westlichen Deutschlamel und in belgien nicht selten üherwinternd. Im nordiistlichen ebenen Dentsehland selten mol lokal. Wr mag dort in spaiterer Zeit pingewandert sein. weil er sieh dasellst nur an Gebänden anfhïlt, da soine natürlichen Aufenthaltsorte (Felsen) fehlen.

Der Hausrotschwanz bewohnt Häuser, altes Gemäuer und dergl., im Westen Deutschlands und jn Frankreich selbst größere Städte, während seine ursprünglichen Nistplätze sicher Felswände und Schluchten waren, an denen er im Gebirge noch heute vorzugsweise nistet. Seine Lockstimme wurde treffend mit fid teck teck übersetzt, der Gesang ist äußerst eigenartig, aus zwitschernden und heiseren Lauten zusammengesetzt und teilweise so gequetscht klingend, daß man glaubt, die Kehle sei zu eng für ihn; es gibt aber auch einzelne bessere Sänger, die mehr flötende Strophen singen. Das Nest steht in allerhaud Löchern und Höhlungen an Felsen oder Gebäuden, auch auf Balken unter Giebeln, in Veranden und Scheunen. Es besteht aus einer unordentlich zusammengehäuften Menge ron Halmen und Wurzeln und ist mit Haaren, Federn, Wolle und dergl. dicht ausgepolstert. Es enthält 5-6 Eier. Diese sind meist reinweiß, mitunter aber auch deutlich, wenn auch sehr hell blau, und haben bisweilen feine braunrote Punkte. Es werden regelmäßig zwei Bruten im Jahre gemacht. Die Eier der ersten findet man aufangs Hai oder auch schon Ende April. 82 Eier messen nach Jourdain, Rey und Reiser im Durchschnitt $19.44 \times 14,37$, Mlaximum $21.4<16.1$, Jinimum $17>14.5$ und $17.2>13.3 \mathrm{~mm}$. Durchschnittsgewicht nach Bau $119 \mathrm{mg}$ (Rey gibt $167 \mathrm{mg}$ an, doch scheint dies ein Irrtum zu sein).

\subsection{Phoenicurus ochruros ochruros (fime).).}

Motacilla Ochruros S. G. Gmelin, Reise d. Rußland IIT, p. 101, Taf. 19, Fig. 3 (1774Persische Gebirge).

Ruticilla erythroprocta Gould, Proc. Zool. Soc. London XXIII, p. 78 (1855- Erserum).

Abbild.: Gould, B. Asia IV, Taf. 37; Berajah, Erith. Domesticus, I'af. I, Fig. 2.

Bildet cinen Übergang von P.o.gibraltariensis zu phoenicuroides. Ö: Cnterkïrper (etwal ain Drittel bis fist die Hälfte der Lutrescite) rustrut wie der Siehwanz oder mit Grau und Sehwally vermischt. hesonders an den

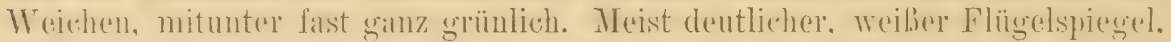
mitunter alher sind die weißen Schwingensäume merlich schmäler als hei gibrulturensis. Rö̈cken dunkler als bei letzterex Furm. die Federn schwarz

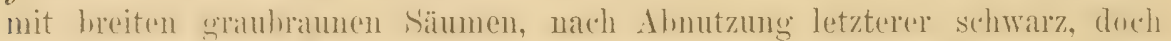
hleiht immer die Kopfplatte mehr oder minder ausgedehnt grau. stiru dunkelgran. mitunter aber, besonders im abgetragenen Kleide mehr oder minder weib. Cnterflïgedecken schwarz mit glanen Sïmus!n, Achselfedern

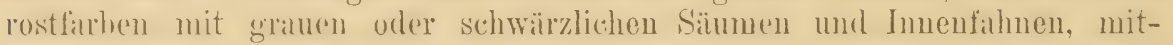
unter schwallz oder dunkelgran mit heller graluen Sämmen und um sehr geringer rostiarhener Beimischumg. Die seitlichen steuerfederu ohne dunkle Fndhinde oder nur mit Audentung einersolehen. Flügel rou 9 $082-87$ mm. O meist etwas bräunlicher als die der europäischen Form.

Kaukasus, nördliches Kleinasien (Armenien), Nordwest-Persien.

Brïtet an Felswänden, auch an Gebäuden, Die Eier sind blaugrün wie die rom Gartenrotschwanz oder weiß mit blauem Schimmer (s. P. o. gibraltariensis). 


\section{Phoenicurus ochruros semirufa (II mur. if Fhı.).}

Sylvia semimfa Hemprich \& Ehrenberg, Symb. Phys. fol. bb (1832- Agypten).

ơ: Sehr mahe P. o. ochmuros, der Nacken und Rücken bis zum Bürze!

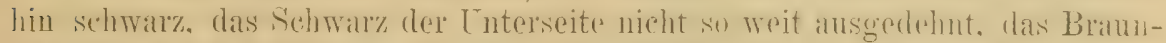

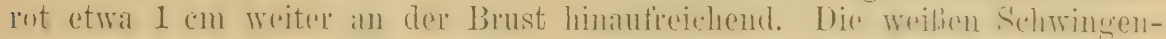

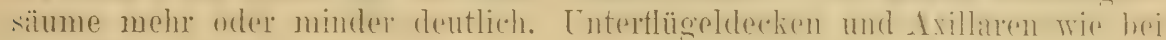
P. ochmeros ochmeros.

Gehirge Syriens und l'alïstinas, Euphmat-Tal: in Heglten aul dem Zusir.

2 Eier aus dem Libanon im British Museum gleichen denen von Phoenicurus ph. phoenicurus. Sie messen $18.1 \times 14$ und $18.6 \times 14 \mathrm{~mm}$.

\section{Phoenicurus ochruros phoenicuroïdes (1Inore).}

Ruticilla phoenicuroüdes 1 Ioore, Proc. Zool. Soc. London XXII, p. 25, Taf. Ares LVII (1855- Nordindien).

? Ruticilla pectoralis Heuglin, Journ. f. Orn. 1863, p. 165 (Bahr el abiad und Gazellenfluß. Obwohl Heuglin selbst später pectoralis als Synonym zu phoenicurus zog, muß man nach dem Vorhandensein eines "schwarzen Brustschildes" vermuten, daß es sich um phoenicuroides handelt. Typus anscheinend nicht vorhanden).

Ruticilla semenowi (partim?) Sarudny, Oın. Jahrb. 1904, p. 213 (Persische Prorinzen Luristan, Arabistan, (?) Mlasanderan. Beschreibung alter Vögel, aber sehwer verständlich, weil mit $P \cdot p \cdot p h o e n i c u$ us verglichen).

Abbild.: Berajah „Erithacus Domesticus", I Fig. 3, VI mittlere Reihe.

ô Oberseite dunkelgrau, in frischem Gefieder mit aschgranen (bei

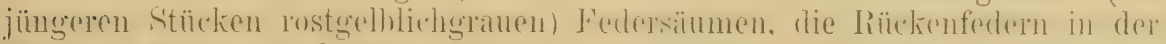

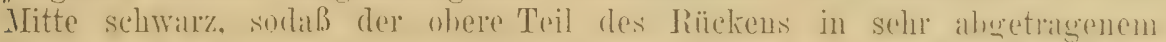
Kleide mehr oder minder schwäl'zlich ist. Kehle his ühore den Kroul hin

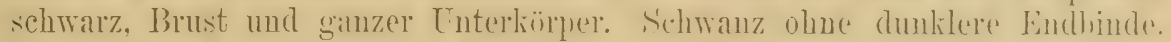
Stim (über dem schwaran Bande an dre Vurderstin) im Erïhjuhr fast immer weiBlich. Unterflügeldeclien und Axilliareu rostrot! Flïged run 16 o $80-85 \mathrm{~mm}$. O ctwas heller und fithler. Testhleid lichter und genlhliehor als bei dex europäischen Form, wolurch bei letzterem dio duntern Federsäume etrvas dentlicher hervortreten.

loritet im südiranischen Randgebirge, in Nordost- und ()stpersien, Persisch Baluchistan, Afghanistan, im sürllichen Trauskaspien, in Turkestan, nordwärts bis zum sïdlichen Altai und Sajan, südlich his zum westlichen Irimalaya (Kaschnnir, in Höhen ron übel 10000 engl. Fuls). - Ühermintert. in dem westlicheren Indien, Südarabien und Somaliland.

Eier nach Kleinschmidt (in litt.) wie die von 1092.

\section{Phoenicurus ochruros rufiventris (Vieill.).}

Oenanthe rufiventris Vieillot, Nouv. Dict. d'Hist. Nat, Nouv. Ed., XXI, p.431 (1818Ex Levaillant, Ois. d'Afr. IV, Taf. 188 Fig. 1, 'I'ext p. 83, wo deutlich die östliche schwarze Form mit roten Unterflïgeldecken beschrieben ist. Fundort fälschlich Südafrika. Als terra typica ist Indien anzusehen).

Phoenicura nipalensis Hodgson, Gray's Zool. Misc., p. 83 (1844- Nomen nudum! Moore, Proc. Zool. Soc. London XXII, p.26 (1855- Indien). 
Ruticilla indica Blyth, Cat. B. IIus. As. Soc., p. 168 (1849- Neuer Name für Phoenicura atrata Jardine \& Selby [nec Gmelin], Ill. Orn., 'Taf. 86, Fig. 3, wo vortrefflich die große schwarze Form abgebildet ist).

Ruticilla mufiventris pleskei Schalow, Journ. f. Orn. 1901, p. 454 (Nan-schan).

Abbild.: Kleinschmidt, Berajah „Writhacus Domesticus“, Taf. I.

Das o unterscheidet sich auf den ersten Blick von dem von $R$. $o$.

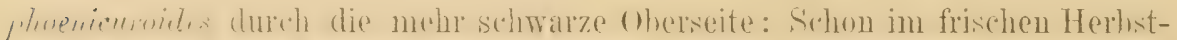

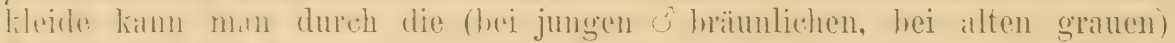

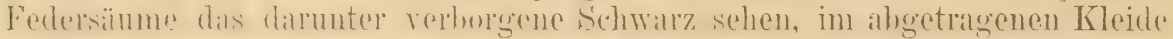

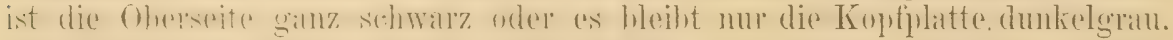

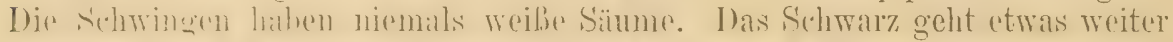
an der linst hinunter. Interflüguldectien und Axillaren immer rostrot. Etrvas größer, als phoenicuroides. Flügel von 10 alten ơ $84-91 \mathrm{~mm}$ - -

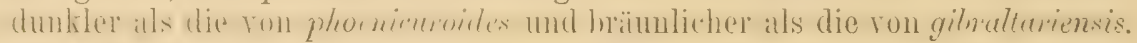

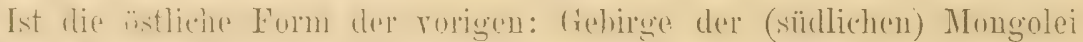

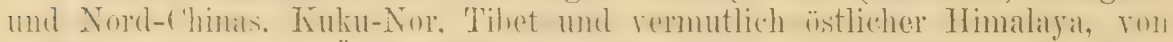
Siklim astwïrts. - C̈herwintert inn norliestliehen Indien (Assim, Manipur).

Die mir rorliegenden Eier zweier Gelege von Kuku-Nor sind weiBlichblau, viel heller als die ron $P h$. ph. phoenicurus, auch größer, und ohne alle Zeichnung. Sie messen 19.6-20.5 $\times 14.7-15.4 \mathrm{~mm}$. Pleske beschreibt von Przewalski gefundene Eier mit feinen, kaum merklichen braunen Pünktchen und mißt $19.5 \times 14.5 \mathrm{~mm}$.

\section{Phoenicurus hodgsoni (Moore).}

Phoonicura ruticilla Hodgson, Gray's Zool. ILisc., p. 82 (1844- Nomen nudum!); Phocnicura ruticilloides Hodgson MS., teste Seebohm, Cat. B. Brit. Mus. V, p. 344.

Ruticilla Hodgsoni Moore, Proc. Zool. Soc. London XXI, p. 26, 'Taf. Ares 58 (1854Nepal).

Abbild.: Kleinschmidt, Berajah „Erithacus Domesticus" 'Taf. I, Fig. 5.

1. Schwinge fast doppelt so lang als die Handdecken, 2. zwischen der 8. und 9. oder gleich der 8., 4. und 5. fast gleich und am längsten,

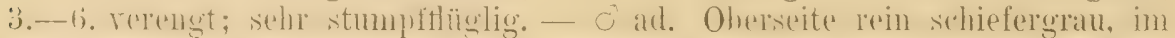

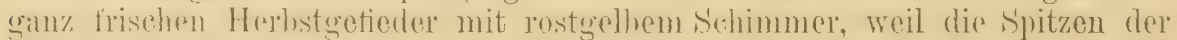

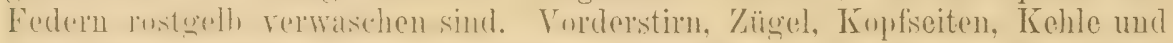

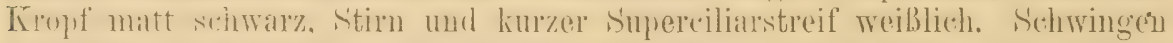
dunkelhamm. Armschwingen an den dubenfahmen hreit weib. Stenerfedern

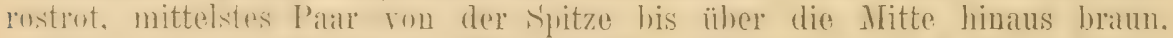
mit selmalem rostarbenem Mittelstreifen. Cnterkärper und Brust. Ober-

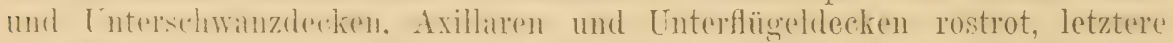

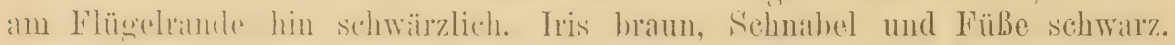
Flügel vou 7 alten ơ etwa 83-87, Schwanz etwa $69-70$, Lauf 25-26, Cuhmen 1.5-16 mm. - ad. Oherseite gräulich hram, Unterseite fihl gram-

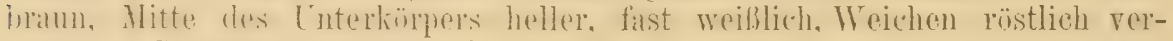
waschen, Sehwanz wie beim ơ.

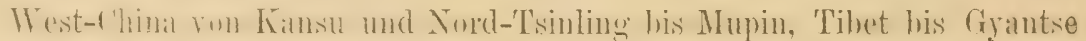
112000 (mgl. Fuli) mel Kambil-1)schong. - Auf dem Yuge und im Winter in Verbal. Sikkin, Butan und den Bergen ron Assam und Manipur. (Angahen vom Vorkmmon in Afghanistan und Kasehmir beruhen anf Irrtünern.) 
Bei Gyantse gemein, briitet in Mauer- und Erdlöchern. Das Nest besteht aus Gras und Moos und ist mit Federn ausgefüttert. Die Eier in Dressers Sammlung sind einfarbig hellblau. Sie messen nach Jourdains Xlessung $20.4 \times 15.3$ und $20.2 \times 15.3 \mathrm{~mm}$ (vgl. Kleinschrnidt, Ornis XIII, p. 197).

\section{Phoenicurus aurorea aurorea (Pall.).}

Motacilla aurorea Pallas, Reise d. versch. Prov. d. Russ. Reichs III, p. 695 (1776"In salicetis circa Selengam et collaterales fluvios, usque ad Sinarum fines"). Sylvia (Phaenicumus) Reevesii Gray, Zool. Jise. p. 1 (1832- China).

Abbild.: Kleinschmidt, Berajah 1908. Ei: Cat. Eggs Brit. Mus. IV, Taf. VII, 5.

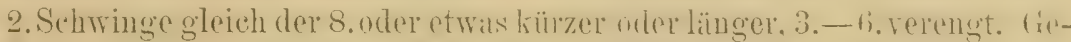

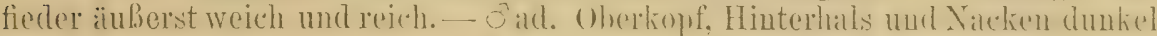
aschgrau, im Fribling dureh Ahnutzung dex dunklen Forlersitzen heller werdend. Rüleken. Schulterfittiche. Oberflügeldecken und Sohwingen sehwarz,

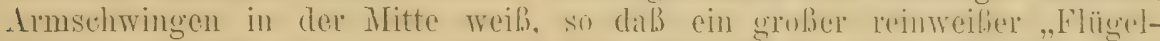

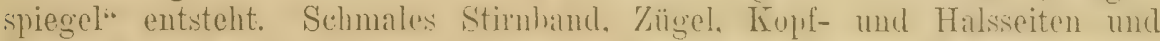

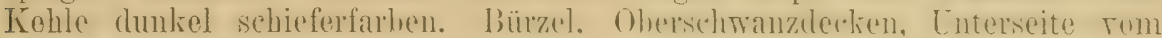
Kroplf his zu den Lnterschwanzdedien. Enterflügraldecken und Axillaren rostrot. Steuerfedern rostrot, das mittelste Paar schwarz, dic äußeren an den

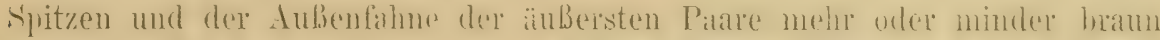

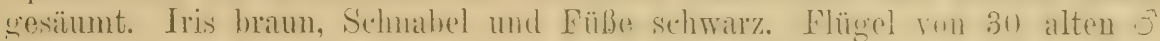
72-75, Schwanz etwa 63-66, Lauf 22-23, Culmen 14-15 mm. - o ad.

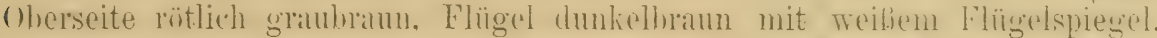

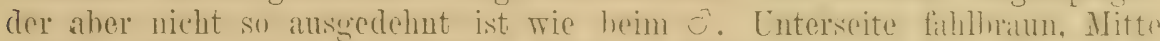

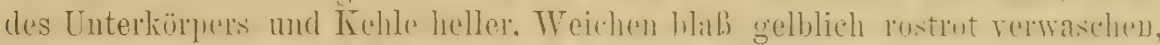

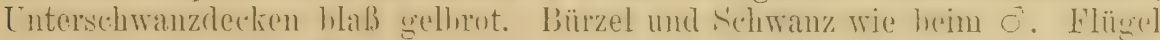
etwa 70-72 mm. Hinige o sind unten vom Kropfe an stark gelbrot verWatsehen. - Nestkleid: Ohrerseite gefleckt: hratum mit schwärhehen Endrïnmen.

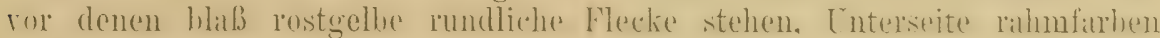
mit dunkelbraumen Endsäumen.

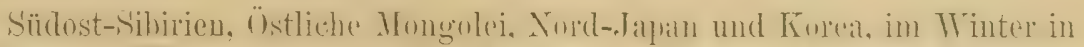

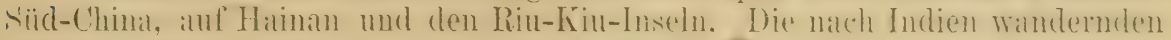
Stücke gehören fast alle zu $P$. a. lewcoptera.

Bewohnt buschreiche Gehölze und Gärten und brïtet im Mai. Das Nest steht in Baumlöchern, in Felsenspalten, unter umgestürzten Bäumen, in Steinhaufen oder an Gebäuden. Es besteht ans Moos, Rinde und Hälmchen und ist mit Haaren und Federn ausgefüttert. Die Eier variieren: Sie sind entweder lichtblau, oft fast weißlich, wie die von Saxicola oenanthe, oder dunkler blau wie die von Phoenicurus phoenicurus, oder weiß mit roten Punkten oder mehr verwaschenen braunroten Zeichnungen, also fast wie Rotkehlchen-Eier. 29 Eier messen nach 'Taczanowski ron $18 \times 12.2$ und $17.8 \times 13.8$ bis $19 \times 15.4$ und $20 \times 14 \mathrm{~mm}$.

\section{Phoenicurus aurorea filchneri (Parrot).}

Evithacus auroreus Filchneri Parrot, in Filchners Exped. China-Tibet, Zoolog.-bot. Ergebnisse, p. 130 (1907 - Kin-tschou \& Ping-liang, N. China. Typen verglichen),

In der Finhung in keiner Weise untersehichen, doch anshomend etwas gröber: 10 ganz alte ö aus den Tsin-ling-Bergen haben Flügel rom $74-77$,

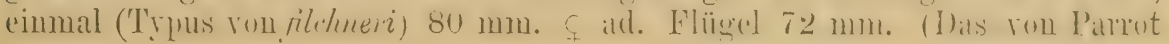




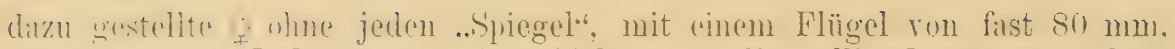
ist ein $q$ ron $P$. hodgsoni; wir erhielten $q$, die völlig denen aus andern Gegenden steichens.) Gröbere Serien sind (rwänscht, um die Form zu bestätigen.

Gebirge ron Nord-China, anscheinend in Süd-China (wo dann auch $P$. aurorec aurorea vorkommt) überwinterud.

\section{9!. Phoenicurus aurorea leucoptera Bjyth.}

Phoenicura lencoptera Blyth, Journ. As. Soc. Bengal XII, 1, p. 962 (18t3- Malakka).

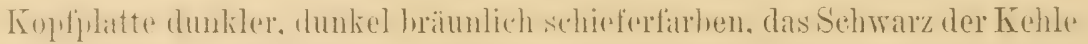
reiner, tiefer und ungefähr $1 \mathrm{~cm}$ weiter nach der Brust hin ausgedehnt.

Erscheint im Winter im östlichen Indien, (Bhutan, Assam, Berge südlieh des Brahmifutra) in den Schan-Staten und auf der Malakka-Hall-insel. - Brutheinat noch nicht hekinnt, rermutlich in nordwestlichen ('hina.

\section{Phoenicurus erythrogastra erythrogastra (Güld.).}

Motacilla erythrogastra Güldenstädt, Nov. Comm. Petr. XIX, p. 469, J'af. 16, 17 (1775Kaukasus).

(Motacilla) Ceraunia Pallas, Zoogr. Rosso-Asiat. I, p. 478 (1827- Im Text vorgeschlagener Name für erythrogastra "si sit distinguenda", nämlich ron aurorea!).

Abbild.: Kleinschmidt, Berajah, 1908.

o ad. Oberkopf und Hinterhals rahmweiB, im frischen Herbstkleide

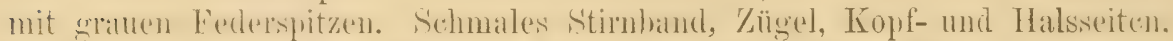

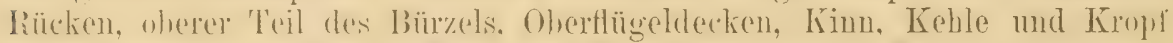
mattschwar\%, when dunkier. Kehle und Kropf mehr schieferfarben. Schwingen schwarz. Jiasis wrils. die weribe Fathe an den Handschwingen etwa ein Viertel. iln den .Armsthwingen etwa drei Tiertel eimnehmend. Untere Bä̈relfedern und oherschwanzdecken kistanienhram, Stenerfedern ebenso, das mittelste

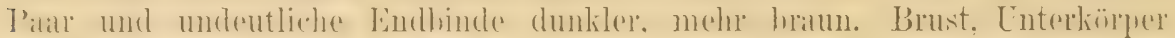

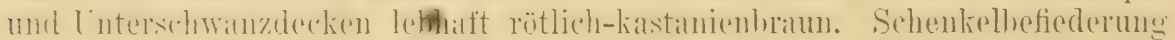

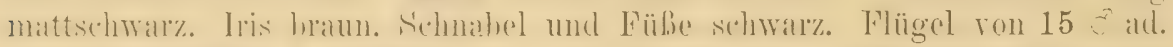

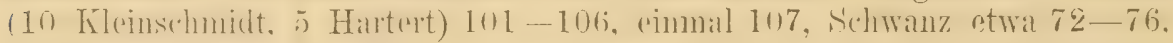
Culmen 16-17.5, Lauf $26 \mathrm{~mm}$. - o ad. Oberseite und Flügel graubraun, letztere whe Treils. Cinterseite leeller und mit rïtlichem sechimmer, zuweilen

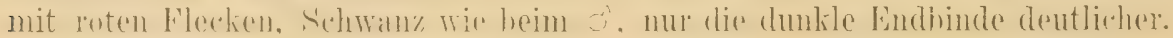

Kaukasus und Transkaukasieu.

\section{Phoenicurus erythrogastra grandis (Gould).}

Ruticilla grandis Gould, Proc. Zool. Soc. London X VII, 1849, p. 112 (1850 - "Afghanistan \& Thibet").

Ruticilla tricolor Gould, teste Bonaparte, Consp. Av. I, p. 296 (1850- Errore).

Ruticilla Tigorsi Moore, Proc. Zool. Soc. London XXII, 1854, p. 27, Taf. Ares LX (1855- Nordindien, ․ 'Typus ron Bhutan).

Ruticilla erythrogastra Subsp. Severzowii Lorenz, Beitr. Orn. Fauna Nords. Kaukasus, p. 23 (1887- Asien, namentlich Ferghana).

Abbild.: Kleinschmidt, Berajah, 1908. 
ơ ad. Unterscheidet sich auf den ersten Blick von der kaukisischen Form durch die hellere Firrbung: Das Schwarz der Oherseite ist nicht so intensir, sondern matter und mebr bräunlich und reicht nicht so weit auf den Bürzel nach hinten: Oherschwanzdecken, Bürzel und Sichwanz heller und lehhafter rostrot. letztere nur mit Andeutungen ron dunklerer lindlinde ocler ganz ohne solihe. Kéhle mehr gräulich, Unterkïrper heller rustrot. Der weiße Fleck an der Basis der Handschwingen ist größer. - o ad. Heller und etrats mehr sandfarben. 25 on ad. aus 'Turkestan messen: Fiügel 100- (zwei mal) 106. 5 andere ehendiher (Semiretschensk) nar.h Kleinschmidt 102.-107, 1 von Gilgit 105.5, 2 aus 'Tsaidam 102-103.5, 2 aus Kansu 1075-108. 2 ron Kinnsu und Kuku-Nor nitch Pleske 103 und 105, $1 \mathrm{rom}$ Niridschin-Gol in Nord-Tibet nach demselhen Autor sogall $110.5 \mathrm{~mm}$. frrabere Serien kïnuten vielleicht argehen, daß Stüeke aus Nordust-Tibet und Kinsu etwats gröbere Dimensionen aufweisen; zwei mir rorliegende o haben auch etwas stirlkce Schuäbel, doch ist der Cnterschied äulierst crering. - Nestkleid: Nicht gefleckt, sondern dem des ïhnlich: Ohorseite hellbrann mit etwas dunkleven Federsäumen, Luterseite blab rostgelh. Kohle, Kropf und Brust mit dunklen Federsäumen.

'Turkestan vou Semiretsehensk bis Ost-Turkestan und Kaschmir (Laddak in Höhen ron $1600($ engl. Eul. brütend), Himalaya bis Siklim, liebirge der Nongolei his zum Altai und Trausbaikalien, Tihet, Amdes und Kinsu.

Dresser beschreibt Eier vom Issik-Kul in I'urkestan als gesättigt einfarbig blau und $22 \times 15.5$ und $21 \times 15 \mathrm{~mm}$ messend.

\section{Phoenicurus erythronota (Eversm.).}

Sylvia erythronota Eversmann, Addenda ad Pall. Zoogr. Rosso-As. fasc. II, 1) 11 (18+1Altai).

Ruticilla rufogularis Noore, Proc. Zool. Soc. London 185t, p. 27, Taf. Aves LIX (Nordindien).

Abbild.: Dresser, B. Europe IX, Taf. 643; Kleinschmidt, Berajah 1908.

2. Schwinge zwischen der 7. und 8., 4. und 5. ann längstesn. 3.-6. dentlich verengt. dad. ()herlinf hellgrau, atu den Seiteu weililich, im Herbstgefieder

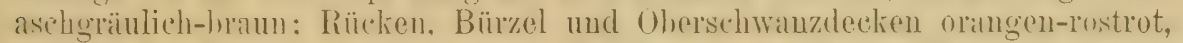
erstere im frischen Gefeder durch die breiten aschgrauen Federsüume fast ganz grau (rscheinend. Simualer Stimstreif, Zügel, Kónf- und Halsseiten, Kimn und Skatpulaten schwar\%, ein breites sehwarzes Band bildend. Schwingen dunkelhraun. Handsehwingen schmal bräunlich. Armschwingen hreiter weiß gesiumt, Tnneusïume rilhnfurben. ()herflügeldechen schwarz mit weiblichen Ribndern, die mittlere šerie weib, ein weibes Tängshand hildend. Handdectien wreil. mit sehwarzhramen Spitzen. Stenerfelern orangen-rostrot, Auliensum

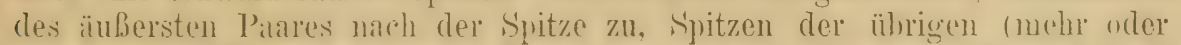
mindel deutlich) und mittelstes Patr hrann. Kehle, Brust und Seiten lehbift orangen-rostrot, im frischen Kileide mit weibgramen Fiederspitzen, Mitte des Lnterkïruers rahmfirthen, Lntersehwanzdecken hlaß orangenrot. Cinterflügeldeclien und Axillaren weib. an der MTural schieferschwarn. Sidhahel und

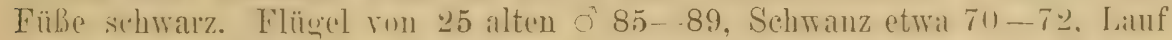
21.5-23.5, Culmen 14-16 mm. - o ad. Oberseite graubraun, auf dem Bürzel in das Rostrot der Oherschwanzdecken ïhergehend. (oherflügeldorken 


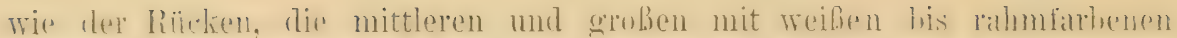

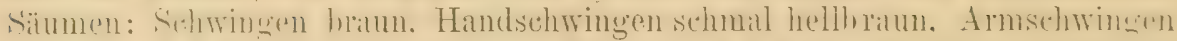

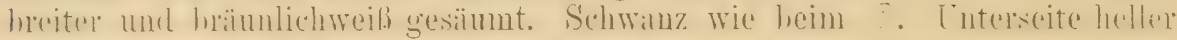

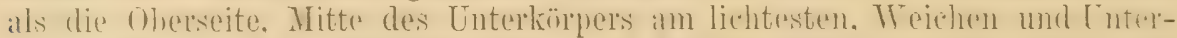

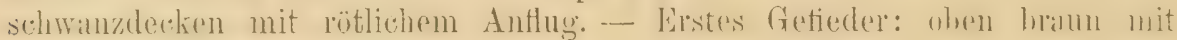

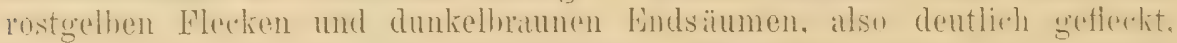
Bürzel rut mit schwilrzlichen Federsilumen. (Oherschwanzdectien rot. I'nterseite rahmfuhlen mit schwïrzlichen Wellenlinien, Bauch fist einfarhig:

Scheint weit verbreitet zu sein und von 'Turkestan bis zum Altai,

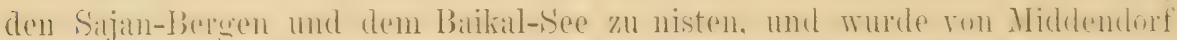

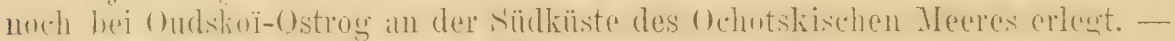
Anf dem Zuge dureh Turkestan. Transkitspien und ostpersion. üherwintert im Tillim-Becken, in Süd-Turkestan. Kaschmir, isstlich his Kotokhali. Afghimistan,

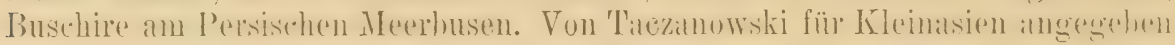
und von Sarudny im Gouvernement Orenburg im Ural erlegt.

Hält sich in buschreichem Gelände auf, liebt im Herbst und Winter die Berberitzen-Beeren. Nehrkorn erwähnt Eier aus "Sibirien" (ohne Fundort und Gewährsmann), die denen von Pratincola torquata rubicola ähneln. Neuerdings sandte Tancré ganz ähnliche Eier vom Issik-Kul an Dresser (S. Eggs Birds of Europe, III \& IV, Tafel "Pratiucola etc.", Fig. 7,12.)

\section{Phoenicurus alaschanica (Przew.).}

Ruticilla alaschanica Przewalski, Mlongol i Strana Tangut II, p.40, Taf. IX, Fig. 2 (1876- Ala-schan); Übers. in Rowley, Orn. Misc. 1I, p. 175, Taf. LIV, Fig. 2.

3., 4., 5. Schwingo dentlich, 6. weniger scharf verengt. - o ad. Ober-

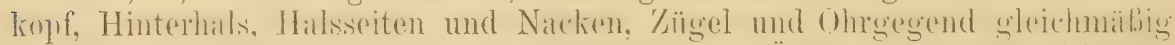

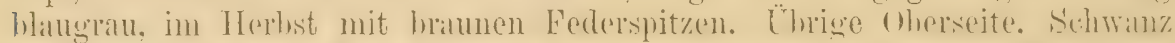

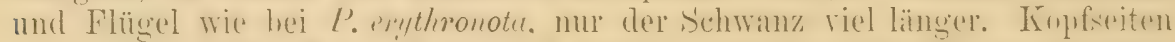

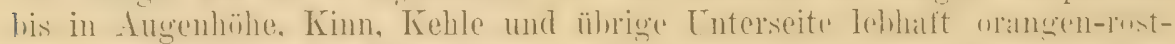

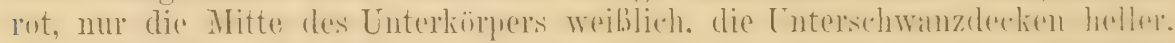

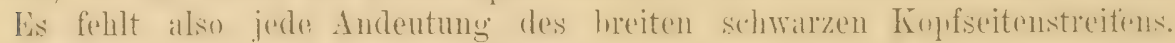
Flïgel von 5े ò ad. 89-95 (Pleske gibt nur 87-92 an); Schwanz er-

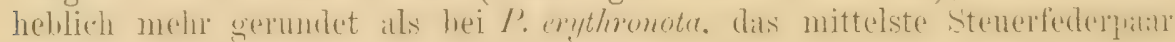
verlängert; Schwanzlänge $82-87 \mathrm{~mm}$ - - O In der Fürbung wie das von $P$. erythronota. Flügel eiues vorliegenden Stückes 87, Schwanz $79 \mathrm{~mm}$.

Nordost-Tibet vou Zaidam bis Kansu und den Ala-schan-Bergen und

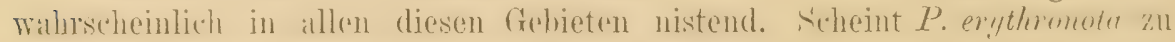
vertreten und wiire vielleicht als Subspezies letzterer anzusehen.

\section{Phoenicurus frontalis Vig:}

Phoenicura frontalis Vigors, Proc. Committee Zool. Soc. London I, p. 172 (1832-Himalaya).

Ruticilla melanura Lesson, Rev. Zool. 1840, p. 265 (Himalaya).

Phoenicura tricolor Hodgson, Gray's Zool. Misc., p. 83 (1814- Nomen nudum!).

Abbild.: Gould, Cent. Himal, B., Taf. 26; Berajah „Asiat. Gebirgsrotschw.", Hig. 4.

2. Schwinge ungefähr gleich der 8., 4. und 5. gleich und am längsten, 6. nur sehr wenig kürzer. O̊ ad. Oberseite mattblau, im frischen Herbst- 


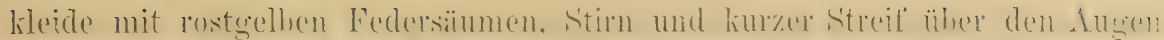

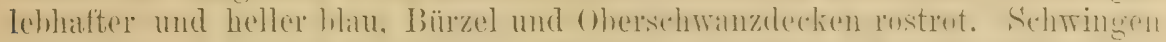

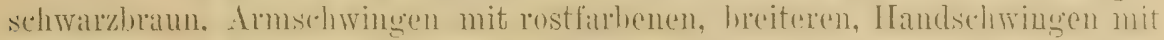
aschgranen, sehmäleren sïmmen. Mittelstes struerfeclerual sehwarz, Banis moist etra $1-2 \mathrm{~cm}$ rostrot. Übrigo Steuerfedern rostrot mit $1-1 \frac{1}{2} \mathrm{~cm}$

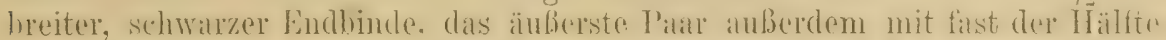
der Aubenfalnere sehwal\%. Kopf- und Halsseiten und Kohle dunkelhlan.

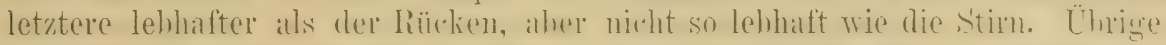

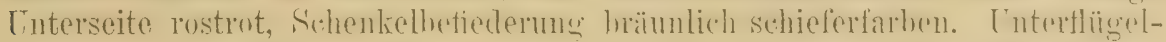
decken hell rostfarben. Flïgel von 30 o 85-90, eimmal 91, Schwanz etrra 68-74, Lauf 22-23, Culmen 13-14.5 mm. - o ad. Oberseite dunkel-

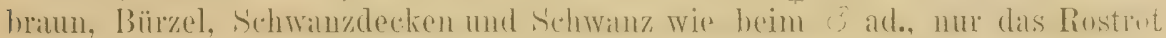

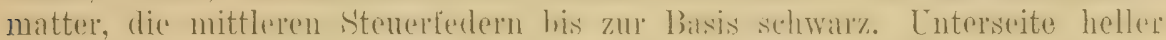
und gelhlidher haum. Mitte des Cuterhärpers fahl rostgelh. - Nestkleid: Oherseite dunkelhaum mit dunkleren, fast schwatren Gudsiamen, vor denen

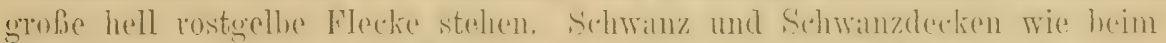

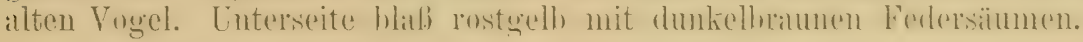

Himalaya von Kaschmil bis China, in Höben von ïber 5000 und bis $1 \pm 000$ ('ngl. Ful. IT est-chiul, Tsin-ling-Berge und Sïdwest-Kansu. - In. Winter in den Bergen und Hügelu südlich des Brahmaputra.

Rüickbeil sen. sammelte mehrere Gelege am Kuku-Nor, die durch den mitgesandten Vogel identifiziert wurden. Diese Eier sind blaß grünlichblau mit blaß rostroten Flecken bald deutlicher bald minder deutlich bedeckt. Sie haben die Form typischer Rotschwanzeier und messen von $20.6 \times 15.6$ und $21.5 \times 15.6$ bis $23<15.5 \mathrm{~mm}$. Von Möller aus Sikkim gesandte Hier sind einfarbig blaßblau und messen $21 \times 15 \mathrm{~mm}$, ebenso ein zweifelhaftes Gelege aus Sikkim in Humes Sammlung. Von Przewalski gesammelte und von Pleske auf Tafel 5 der "Aves Przewalskianae" abgebildete Eier haben weißen oder nelkenrötlichen Grund mit braunroten Flecken. Diese waren von einem dazugehörigen $q$ begleitet. Den von Przewalski entdeckten Eiern ganz ähnliche wurden von Osmaston im Tons-Tale im Himalaya gesammelt. Spätere Forschungen müssen ergeben, ob $P$. frontalis Eier von verschiedenen Typen legt, oder ob ein Teil der Eier unrichtig bestimmt war.

\section{Phoenicurus schisticeps (Gray).}

Phoenicura schisticeps Hodgson, Gray's Zool. Hisc., p. 83 (1814- Nomen nudum!). Ruticilla schisticeps Gray, Cat. Jamm. B. Nepal Coll. Hodgson, p. 69, 153 (1816- Nepal). Ruticilla nigrogularis Moore, Proc. Zool. Soc. London XXII, 1854, p. 29, 'Taf. Aves LXI (1855- Nepal).

ơ ad. Oberkopf lebhaft graublau, im frischen Herbstkleide durch schwärzliche Federtünder verilunkelt. Rürken und, thapularen sehwarz, im

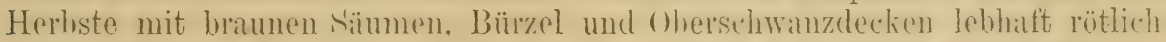
kastanienbraun. Steuerfedern sedwarz, alle mit Ausuahme des mittelsten Patres an der Basis zu einem Drittel rütlich kastanienhaum. Soluwingen und ein Teil der oberen Flügeldecken schwar\%, die mittleren und innersten großen nehst den Rïndern der immersten Almschwingen weili, so dab ein breiter weiber Längsstreif auf dem Flügel zebildet wird. Vurderste Stirnfelern, Zügel, Kopf- und Halsseiten und Kehles sthwatz, unterer Teil der Kehle mit grofem weiBen Fleck, der mitunter kleiner oder ahwesend ist. Übrigo Lnterseite nehst Unterschwanzdecken liastanionbaumber, lianchmitte weiBlich. Lnterflügeldecken und Axillan weil.) mit sehiefergramer Basis. 


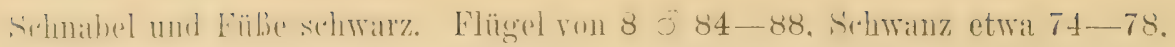
Lauf etwa 23, Culmen 15-16 mm. - o ad. Oberseite braun, Bürzel und

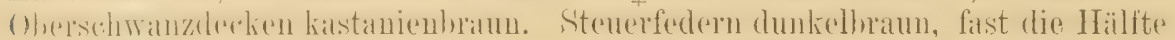
der äuBeren Paare matt rotbraun. Flügel wie beim ơ, aber braun statt

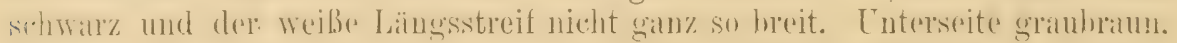

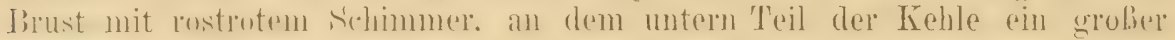
weiber Fleck. Lnterkingere in der Mitte weiblich. Cuterschwanzdecken ristlich. Nepal.

Gebirge von Kansu bis Tibet und Hoch-Himalaya von Sikkim und

Brütet in der Waldzone hoher Gebirge. Nach Pleske fand Pylzow in Kansu am 11. Irai 1873 ein Nest in einer Felsenspalte; es war aus Moos gebaut und mit Rehhaaren und Federn ron Crossoptilon ausgefiittert. Es enthielt 4 frische Eier. Diese sind nach Pleske "hell nelkenrötlich-fahl mit leichtglänzender Schale und zuweilen mit kaum merklichen bräunlichen Punkten". Maße: $19.5-20 \times 14.5-15.5 \mathrm{~mm}$. (Aves Przewalskianae I, 'Taf. V, Fig. 6.)

\section{Phoenicurus coeruleocephala Vig.}

Phoenicura coeruleocephala Vigors, Proc. Committee Zool. Soc. London I, p. 35 (1831-Himalaya).

Ruticilla lugens Sewertzoff, Turkest. Jevotn. (in Izv. Obshch. Moskov. VIII, 2), 1. 121 (1873- Turkestan) (Russisch!); Übers.: Zeitschr. Ges. Orn. IV, p. 58.

Phoenicura caerulea Hodgson IIS., teste Seebohm, Cat. B. Brit. Mus. V, p. 353.

Abbild.: Hume \& Henderson, Lahore to Yarkand, Taf. 14; Kleinsehmidt, Berajal. 1908; Ei, Cat. Eggs Brit. MLus. IV, 'l'af. VII Kig. 8.

2. Schwinge ungeführ so lang wie die 8., 4. und 5. gleich und am

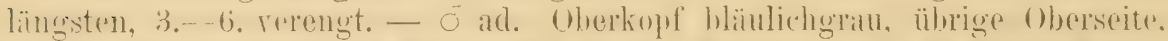

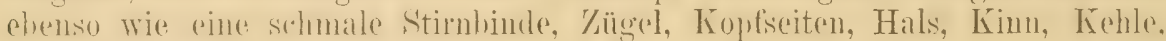

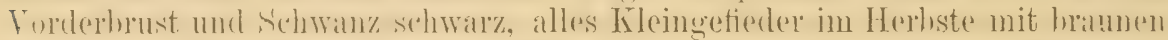

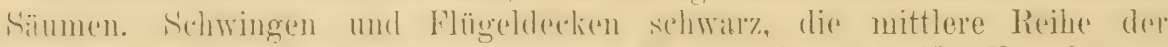

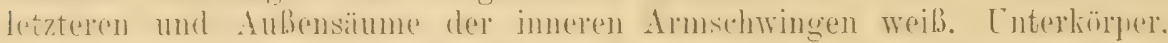

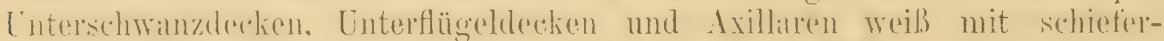

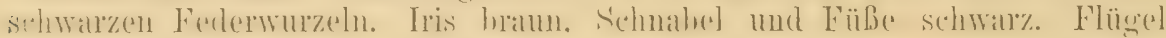
ron 12 ad. 81-85.5, Schwanz etwa 67-68 mm. - o ad. Oberseite

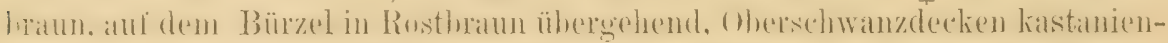

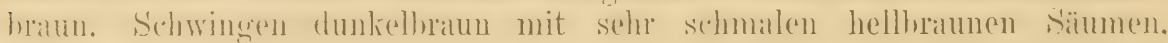

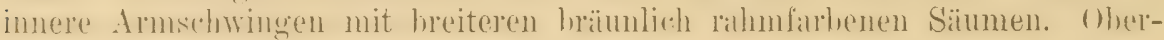

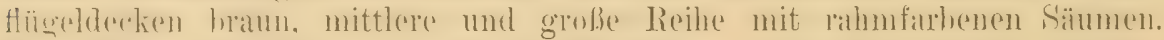

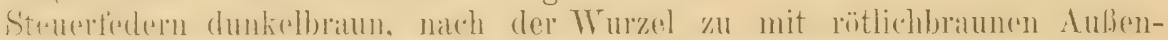

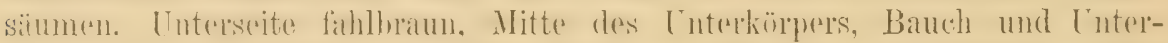

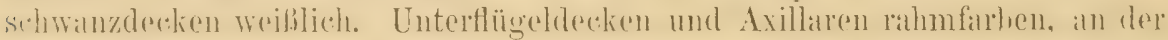

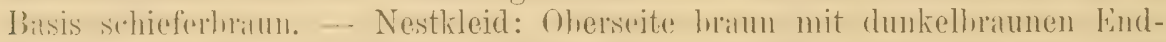

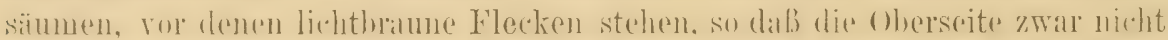

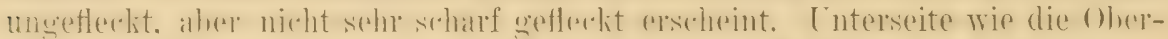

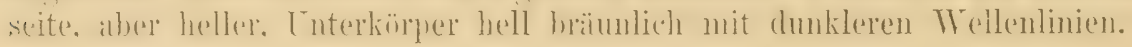

Turkestan bis Afghanistan und Himalaya von Gilgit bis Bhutan.

Zu der Brutzeit in großen Höhen von $10000 \mathrm{FuB}$ und mehr, im Winter in niedrigeren Lagen. Das Nest ist in Höhlungen an Felswänden gebant und enthält im Mai oder .Juni 5 Fier. Diese sind rahnufarben mit einer dunkleren Zone nahe dem stumpfen Ende (Wardlaw Ramsay). Hume beschreibt ein blaues Ei, zweifelt aber selbst die Eehtheit an. 


\section{Gattung DIPLOOTOCUS Hartert 19(1).}

Änberst nahe Phornicums, aher rundflügliger und kurzsthwänziger, sumin

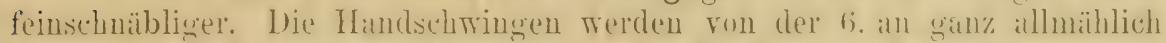
lï̈zer, die 2. Schwing ist katum länger als die längsten Armsehwingen und

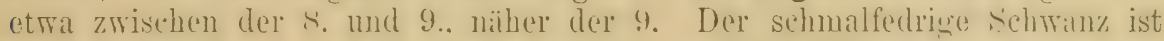

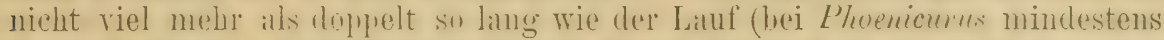
3 mal so ling). Aufenthalt nicht auf hohen Bäumen, sonclorn im Gestriip) und am Boden, wie bei Pratincola, womit Diplootocus indessen keineswegs näher rerwandt ist. Nur eine Form in Nordwest-Afrikit. - Vine Mauser.

\section{Diplootocus moussieri (Olphe-Galliard).}

Erythacus Moussievi Olphe-Galliard, Ann. Soc. Agric. Lyon IV, p. 101, Taf. II (1852Provinz Oran in Algerien).

Phoenicurus vittatus Olphe-Galliard, Faune Orn. Eur. Oce. fasc. XXIX, p. 44 (1891Umbenennung von Ruticilla moussieri!)

Erithacus Diplootocus Kleinschmidt, Berajah 1908 (Synonym von E. moussieri).

Abbild.: Kileinschmidt, Berajah 1908; Eier: Journ. f. Orn. 1896, Taf. VII, 3 a, 3 b.

ard. Oberseite. Zügel und ()hrgegend rein schwarz. im Heristhleide mit mehr vder minder dentlichen bramen Federsïmmen. die sich in Frühjahr allmählich almutzen; attral $3- \pm$ mu hiuter dem Śchuabel zicht sich quer über die Stim ein 3-4 mm lueites weides Bancl. das an heiden Suiten in einen schmalen Sunerciliatrstreifen üherout. der sich an den Halkseiten in einem groben seidig weiben Fleck fortsetzt: diese beiden Flecke sind in der Regel am Hinterhalse durch ein schwares Feld grotrennt. mitunter aber fast rereingt: der gläuzend reilie diademartige Quedrstrich an der , Stim ist ausnahusweise in der Mitte muterlnoenen; unterer Bürzel und ()bersehwanzdechen rostrot. Schwingen schwilrz, bei jüngeren ơ hräunlicher. Handschwingen von der 7. an und Basis der Amuschwingen an den Aubenfahnen etwa zur Hälfte weili. Steuerfedern lostrot, das mittelste T'aar schwarzbram.

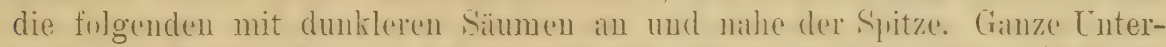
seite, Cnterflugeldecken und Axillaren lehhaft rostrot, am Tuterhïruer allmühlich heller werdeud, Nitte des letzoteren und Bauch am hellsten. mitunter katum melur als rahmfarheru. Iris lebhatt dunkelhraun, Schuahel und Fübu schwarz. Flügel von $25 \sigma^{\pi}: 65-70$ (nach Kleinschmidt 15 ơ: 66-70), Schwanz 46-50, Lauf 23-24, Culmen 13-15 $\mathrm{mm}$. - o ad. Auffallend variabel: Oherseite fahl gränlich hraum, am unteren Bürzel in das Rostrot der ()her-

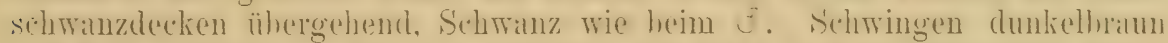

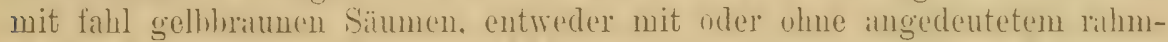
Teiben Flügelspiegel. Cnterseite fahlhram mit leichtem rostfarbenen Sehimmer (in dor Mitte des [nterhioruers rihmfurbeu) oder rostrot. hei aimem von Riggenbach im marokkanisehen Atlis am 17. April gesammelten umd ..fem. sect., Brutyogel* hereichneten stück so lehlaft wie hei d: dies stück hat anch schwarze (oherflugeldechen. sehwälzere Schwingen und zeigt auf Kopt und Rücken Sohwarz, hat aher keine Spur ron eimem Flïgelspiegal. Flügel der O etwa 63-67 mm. - Nestkleid: Nicht scharf getleclit, smodern aul

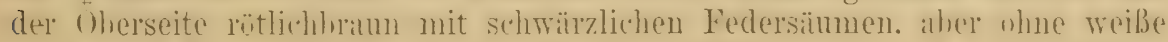

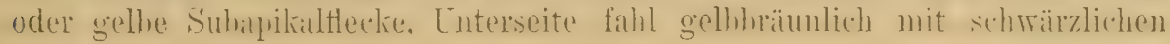




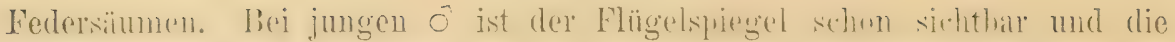
Schwingen sind schwärzlicher.

\section{Marokko, Algerien und Tunesien ${ }^{1}$ ).}

Der reizende "Diademrotschwanz" ist Brutrogel in den Gebirgen der Atlasländer, an geeigneten Orten hier und da, aber nicht überall, nahe der Neereskïste, bis zu den Südabhängen des Atlas (Aurès). In Marokko will ihn Meade-WTaldo bis in Höhen von 9000 engl. Fuß beobachtet haben. Im Winter zieht er sich von den hohen Bergen in die siidlichen Täler des Landes und die Oasen der nördlichen Sahara zuriick. Der Lockton ist ein scharfes tsit, tsit-kärr, das o lockt anscheinend nur $\ddot{i}$ ï ï; die Locke

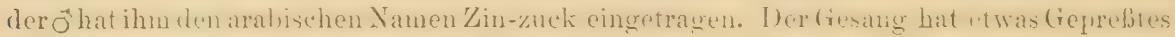
an sich; er besteht aus anmutigen, trillernden und gepreßten, heiser zwitschernden Lauten und ist eine unbedeutende Leistung. Das Brutgebiet sind im allgemeinen Halden und Hügel, die mit Steineichenbüschen, stacheligem Wacholder, Callitris, Rosmarin und Lavendel und mit einzelnen Aleppokiefern bestanden sind, aber auch mitunter Wegränder und grasige, steinige Höhen und Felsen mit vereinzelten Büschen. Das Nest steht am Erdboden, mit Benutzung eines schiitzenden, bergenden Grasbuischels oder Krautes, mitunter auch in Büschen. Es enthält Ende April und im Mai 4-5 Eier. Diese sind glänzend, entweder licht blaugrün (etwas lebhafter und leuchtender als Eier von Phoenicurus phoenicums) oder weiß mit blaugrünem Schimmer, etwa wie die bläulichen Varietäten von Phoenicurus ochruros gibraltariensis oder sehr blasse Eier von Saxicola oenanthe. 42 Eier (30 Koenig, 8 Jourdain, 4 Hartert) messen im Durchschnitt $17.78 \times 13.7$, Iaximum $20 \times 15$, Minimum $16 \times 13 \mathrm{~mm}$. Durchschnittsgewicht nach Koenig $96 \mathrm{mg}$. Das Nest besteht aus Halmen und Würzelchen und ist mit Haaren und Federn ausgepolstert. Wahrscheinlich finden zwei Bruteu statt.

\section{Gattung LUSCINIA Forster 1817.}

Die Abgrenzung der Gattungen wurde bei diesen Vögeln immer sehr verschieden beurteilt. Seebohm und viele andere Autoren vereinigten unter dem Namen „Erithacus" die Nachtigallen, Blaukehlchen, Rotkehlchen, die Larvivora-Gruppe und "Calliope". Bei dieser Behandlung fehlt jedweder Grund, die Rotschwänze (Phoenicurus) zu trennen, was aber geschah. Andere trernen Luscinia (Nachtigallen), Cyanecula oder richtiger Cyanosylvia (Blaukehlchen), Erithacus, Calliope, Larvivora und Icoturus; letzterer Name umfaßte $L$. Komadori und namiyei, mïßte aber anch olne Zweifel die nahe verwandte alkalige einbegreifen, die ganz unrichtigerweise als östliches Rotkehlchen angesehen wurde. Wenn man Calliope und Larvivora trennte, mußte $L$. davidi unbedingt zu Lavvivora gestellt werden, nicht zu Calliope, wie schon die Struktur der Kehlfedern zeigt. Die Ähnlichkeit eines $ᄋ$ L. calliope und einer persischen Nachtigall ist, abgesehen von dem längeren Schwanze der letzteren, verblïffend. "Icotumus" ist strukturell typische "Lavivora", welche durch $L$. davidi und die Schwanzzeichnung zu Calliope hinüberführt. Die Blaukehlchen haben die Schwanzzeichnung von L. ruficeps.

Alle hier unter Jascinia vereinigten Sänger haben einen mehr odor minder dentlich abererundeten schwanz, lange läufe. lehen liel am Boden,

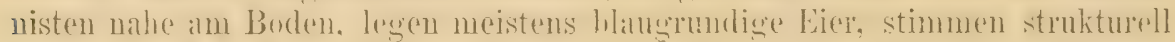

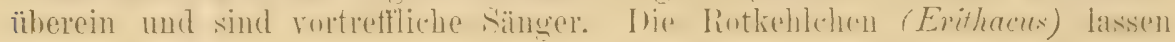

1) Die Angaben rom Vorkommen in Europa sind zweifelhaft. Eine frühere Beobachtung von Irby in Südspanien wird von ihm selbst später ignoriert. Lr schreibt, er habe nie ein in Spanien erlegtes Stïck gesehen! In Florenz befindet sich ein Stïck, das von den Gebrïdern Gal auf dem Markt in Nizza erworben und im Fleisch an Giglioli gesandt wurde. Auf Helgoland wurde er nach Gätke 1842 erlegt, das Belegexemplar aber ist verschwunden. 
sich allenfalls generisch ahsondern. Dic Rotschwänze (l'hoemirmms) liaben im allgemeinen länguren sthwanz und Elügel, weicheres Gefieder, dentlichere Schnabelborston und andere Lebens- und Nistweise.

\section{Übersicht der $\sigma^{x}$ :}

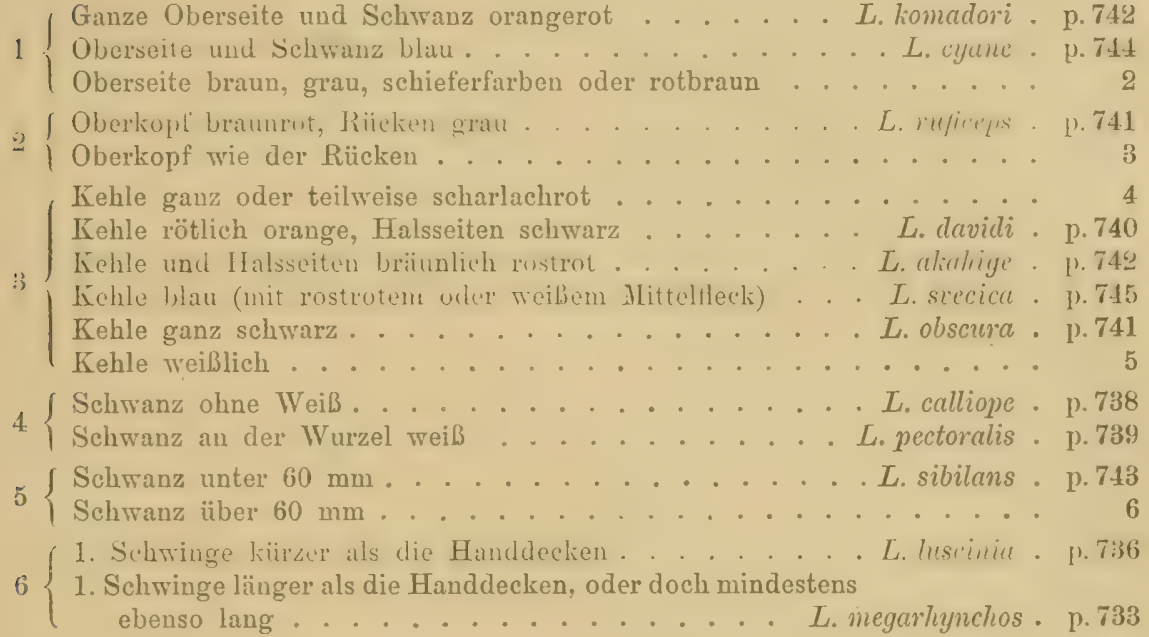

\section{Luscinia megarhynchos megarhynchos Brehm.} Nachtigall.

Luscinia megarhynchos Brehm, Handb. Naturg. Vög. Deutschl., p. 356 (1831- Deutschland).

Luscinia media Brehm, t. c., p. 357 (1831- mittleres und nördliches Deutschland).

Luscinia Okenii Brehm, t. c., p. 357 (1831- mittleres und nördliches Deutschland). Luscinia peregrina Brehm, t. c., p. 358 (1831- wandert nach Brehm in Deutschland nur durch. trotzdem ist in der Sammlung auch ein Nestjunges aus Ablsdorf als peregrina bezeichnet).

Sylvia Schuchii Schinz, Wur. Fauna I, p.181 (1840- Griechenland).

Luscinic minor Brehm, Naumannia 1855, p. 281 („in Italien“, Nomen nudum!).

Luscinia vera Brehm, Vogelfang, p. 145 (1855- Deutschland).

Luscinia vera intercedens A. E. Brehm, Verz. Samml., p.4 (1866- Nomen nudum!). Luscinia occidentalis Sewertzoff, Turkest. Jevotn., in Izv. Obshch. Moskor. VII, 2, p. 120 (1873 - Europa, östlich bis zum Uralfluß, Wolgamündung und Turkestan, wo die Farben etwas anders sein sollen) ${ }^{1}$ ); Übers. 'Jeitschr. ges. Orn. IV, p. 55.

Engl.: Nightingale. - Franz.: Rossignol. -- Ital.: Russignuolo. - Span.: Ruiseñor.

1. Schwinge länger als die Handdecken oder mitunter nur ehenso lang. 2. wie die 5. oder etras liürzer, 3. und 4. am längsten. - O o ad. ()berseite riotlich hram, längere Oherschwanzdecken kastanienhraun, im IIerbste dunkler, im Frïhjalı lichter und etwas rötlicher. Schwingen dunkelhraun, Aubensätume und Oberflügreldecken wie der Rücken. Yügel dunkel graubratun, Federu um das Auge weiblichbraun, Ohrdecken etwas hlasiser und

1) Diese Angaben müssen auf Irrtümern beruhen. 
fahler als der Rücken. Unterseite umrein weiß, über den Kropf ein blaß

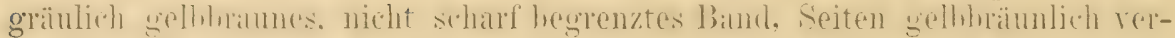

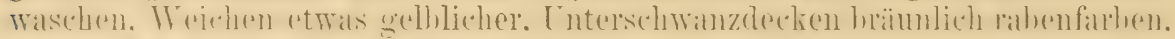

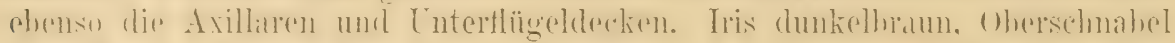

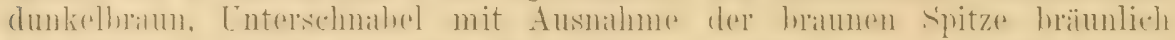

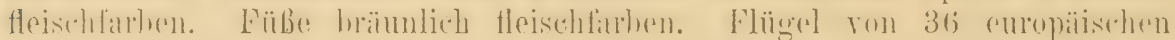
7ad meist 84-87, mitunter bis 89, selten nur 80-82, Schwanz etwa 68 bis 72, Lauf etwa 26-28, Culmen etwa 16-18 mm. - o ad. Genau wie

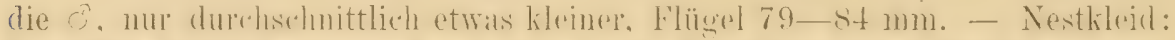

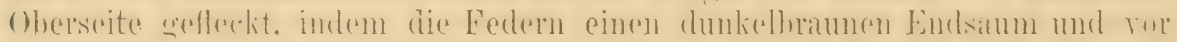

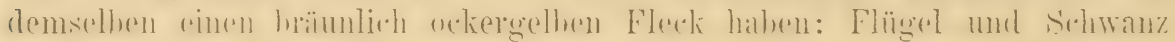

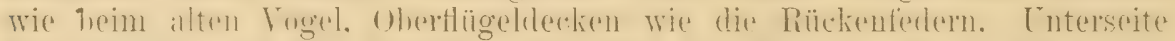

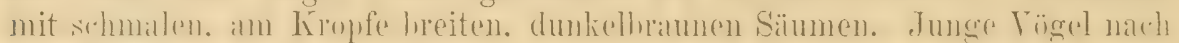

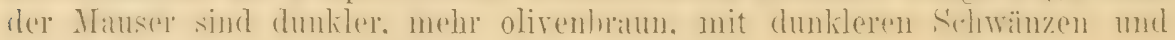
hellen Spitzen an den größeren Oberflügeldecken.

Die Nachtigall berwohnt Mitteleuropa von den Ufern der Nordsee bis

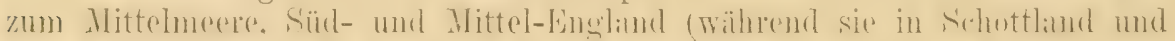

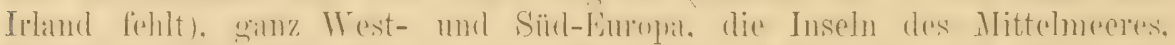

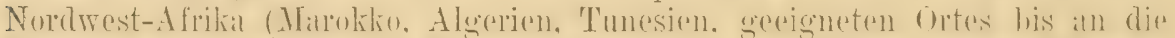

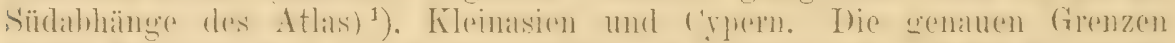

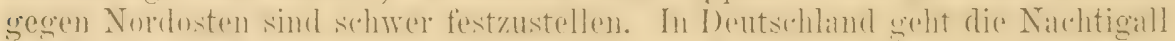

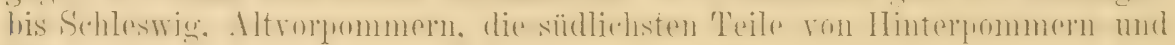
Westpreußen und Posen, in Polen bis an die Treichsel, die sie nur in sehr

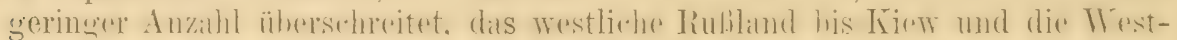

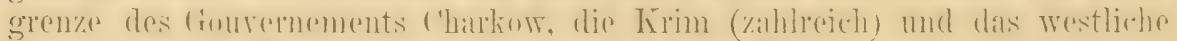

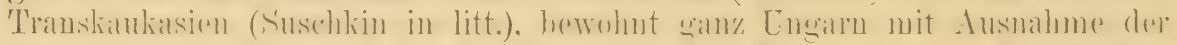

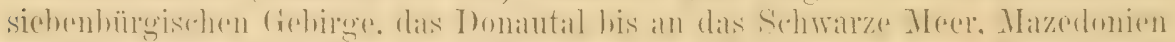

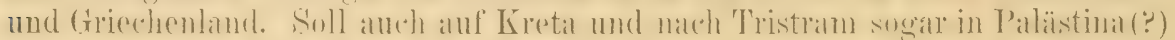
brïten. - Auf dem Zuge durchwandert sie die Sahara und ist im Winter

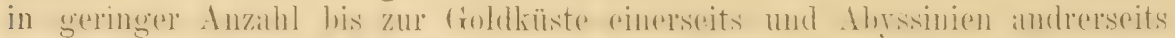

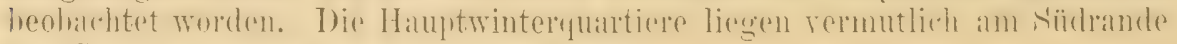
der Sahara und in deren südlichen Oasen.

Die Nachtigall bewohnt zur Brutzeit lichte Laubwälder mit viel Unterholz, tiefliegende Feldhölzer, buschreiche Parkanlagen, Promenaden, Gärten, Ufergebïsche, wenn sie viel Unterholz und einzelne hohe Bäume haben. Sie liebt üppige Vegetation und Feuchtigkeit und meidet ganz trockene Orte, sowie Gärten, in denen das trockene Laub entfernt wird. Sie kommt in Deutschland und England etwa in der zweiten oder ersten Woche des April an und macht sich bald durch ihren Gesang bemerkbar, der in der ganzen Welt nur von dem des Sprossers übertroffen wird. Die Lockstimme ist ein flötendes wihd, entweder allein oder mit angehängtem schnarrenden karrr. Das tiefnapfige Nest steht stets nahe am Boden, meist nicht höher als einen halben Meter, oft hart auf der Erde, sehr selten bis in Manneshöhe oder höher in dichten Büschen. Der Unterbau besteht aus dürren Blättern, das eigentliche Nest aus trockenen Hälmchen, Moos, Blättern und Würzelchen und ist mit feinen Wurzeln, Rispen und

$\left.{ }^{1}\right)$ Vielfach haben nordwestafrikanische Brutrögel - deren ich neun sichere Exemplare untersuchte - kürzere Flügelspitze, auch konnte ich nicht mehr als $85.5 \mathrm{~mm}$ Flïgelliinge leststellen. da sich aber auch in IVesteuropa oft Stïcke mit $87 \mathrm{~mm}$ Flügellänge und in Osteuropa solche mit nur 83 finden und die Merkmale nicht konstant sind, auch ehenso stumpifliiglige Stüeke in Mitteleuropa vorkommen. ist eine Trennung nicht. möglich. 
oft mit Pferdehaaren ausgefiittert. Es enthält im Mrai 5, seltener $\$$ bis 6 Eier. Diese sind braun, etwa wie Fasanen-Eier. Die Grundfarbe ist mitunter auch braun, meist aber ein leichtes Blau oder Blaugrün, auf der kaffeebraune Wölkung und Flecken so dicht stehen, daß sie die Grundfarbe fast oder völlig verdecken. IIanche Eier sind nur durch etwas bedeutendere Größe von Blaukehlchen-Eiern zu unterscheiden, mitunter fehlen die Zeichnungen und die Eier sind licht blaugrün oder blau. 100 Eier (50 Jourdain, 50 Rey) messen in Durchschnitt $20.58>15.56$, Naximum $23.2 \times 16.1$ und $20.5 \times 16.5$, Minimum $18.2 \times 14$ und $20 \times 13.9$, Doppelei $24 \times 16.2$, Zwergei $16.7 \times 12 \mathrm{~mm}$. Durehschnittliches (xewicht. nach Rey $150 \mathrm{mg}$.

\section{Luscinia megarhynchos golzii (Cab.).}

Lusciola Golzii Cabanis, Journ. f. Orn. 1873, p. 79 (Turkestan).

Luscinia Hafizi Sewertzoft, Turkest. Jevotn. (in Izv. Obshch. Moskov. VIII, 2), p. 120 (1873 - 'Turkestan); Übers. in Madarászs Zeitschr. ges. Orn. IV, p. 56.

1. Sehwinge wie hei der westemantischen Naldhtigall, die Handelechen überragend oder gleich denselben; 2. gleich der 5., 3. und 4. fast gleich

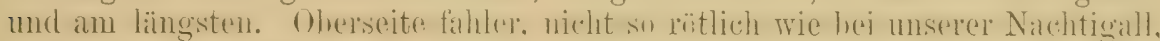

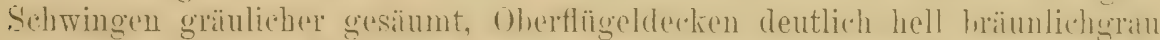
gesïumt. Flïgrel und Schwan\% weniger rötlich und länger. Cnterseite weif-

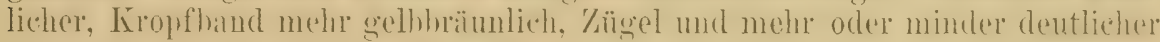

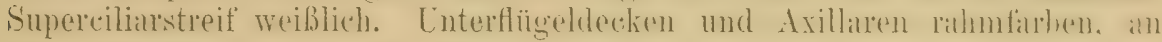
den Innenfahnen nach der Wurzel zu olivenbraun. Flïgel von 15 ơ und 0 91-95, einmal 96, einmal 97, Schwanz 82-88 mm. - Nestlileid gefleckt

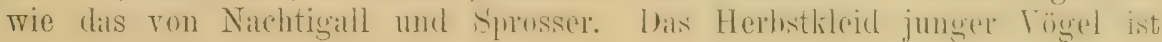
dunkler als das alter Vögel.

Bewohnt 'Turkestan, von der Kirgisensteppe und Transkaspien bis in den Westlichen Tian-behan und nördlich bis zum f'arhatgatai. - Im Winter nicht selten in sïdarabien, zweimal in Indien (Oudh) und in geringer . Inzilhl im Innel'n von Afrika beobachtet.

Lebens- und Nistweise wie die ron L. luscinia und L. m. megarhynchos. Der Gesang ist nach Radde von dem der Nachtigall und des Sprossers durch den Mangel jeglichen schnarrenden Anschlages und seine Strophen-Armut sofort zu unterscheiden. Er steht dem seiner Verwandten bedeutend nach. Die Nester bestehen, wie jene, großenteils aus Eichenblättern. Das Gelege enthält 4 olivengraugrüne Eier, die denen der Nachtigall gleichen.

\section{Luscinia megarhynchos africana (Fischer \& lichw.).}

Lusciola africana Fischer \& Reichenow, Journ. f. Orn. 1884, p. 182 (Klein-Aruscha am Kilimandscharo).

Abbild. d. Ei: Cat. Eggs Brit. Mlus. IV, Taf. VII Fig. 14 (Exemplar aus Schiras)

Steht L. m. golzii ann nïehsten. unterscheidet sich aber dureh dunklero Oborseite, die der der dentschen Nachtigall gleichkommt oder noch etwas diisterer ist, etwas dunkleren Schwamz und weniger deutlich hell gesïmmte Oherflïgeldecken, dunklere Zügel und fast gö̈nzlich f'ehlenden Superciliarstreif. AuBerdem sind Kropf und Körperseiten etwas mehr grabüunljch verwaschen. Schwanz kürzer. Flügel 84-89, Schwanz $73-79 \mathrm{~mm}$.

Brutvogel in Persien, vom südlichen Kankasus und Transkaukasien ${ }^{1}$ ) bis Schiras. Fimmal in der Krim nachgewiesen (rermutlich diese Form!) (In

1) Es sind die angeblichen „Übergangsexemplare von $L$. megarhynchos zu hafizi“ die hier "nicht selten" sein sollen. 


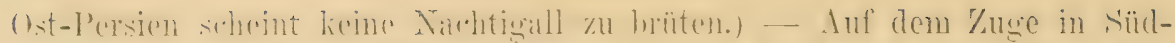

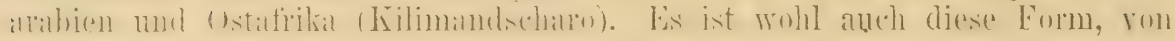
der Madarísz ein Stück in Ungarm orlangte.

Vier Eier aus Teheran in Jourdains Sammlung messen $21 \times 16,21 \times 16,22 \times 15$ und $21.7 \times 15.3 \mathrm{~mm}$.

\section{Luscinia luscinia (L.).}

Der Sprosser.

Motacilla Luscinic Linnaeus, Syst. Nat., Ed. X, p. 18t (1758- „Europa“. Ex Fauna Suecica no 221! Als terra typica haben wir daher Schweden anzusehen, wo nur der Sprosser brütét. Linné sagt ausdrücklich, er habe dio kleine. Nachtigall nicht in Lande beobachtet. Die hinzugefügten Zitate sind nicht richtig).

Motacilla luscinia $\beta$ major Gmelin, Syst. Nat. I, p.950 (1789- Europa. Ex Brisson, Frisch u. a.).

Motacilla Phitomela Bechstein, Naturg. Deutschl. IV, p. 536 (1795 - „... einzeln in Schlesien, Böhmen, Pommern, bei Wittenberg, Halle und Dessau. In Ostreich, Pohlen und Ungarn ist sie in manchen Gegenden häufiger als dic gemeine Nachtigall").

Motacilla Aëdon Pallas, Zoogr. Rosso-Asiat. I, p. 486 (1827- Südrußland, Wolga, Kaukasus und Persien - letzteres wohl Verwechslung mit einer andern Form).

Philomela magna Blyth, in Rennie's Field Nat. I, p.307 (1833- Nomen uudum).

Luscinia major (ex Brisson) Brehm, Handb. Nat. Vög. Deutschl., 1.355 (1831- „Ungarn, Polen und Schlesien").

Luscinia eximia Brehm, Vogelfang, p. 144. (1855- "Ungarn").

Luscinia hybrida Brehm, Vogelfang, p.145 (1855- Polen).

Luscinic major pomarina, Melpomene A. E. Brehm, Verz. Samnl., p. 4 (1866Nomina nuda!).

Luscinia infuscata Sewertzoff, Turkest. Jevotn., j). 121 (in Izv. Obsheh. Moskov. VIII, 2) (1873 - Turkestan, Ural-Mündung; Übers. in Madarász' Zeitschr. ges. Orn. IV, p. 57.)

Lusciola Böhmi Reichenow, Journ. f. Orn. 1886, p. 115 (Narungu errore: Fundort Simbilo bei Kakoma in Ugunda, Deutsch-Ostafrika. Typus untersucht).

Engl.: Thrush-Nightingale: - Schwed.: Näktergal.

Der Sprosser unterscheidet sich von der Nachtigall durch folgende

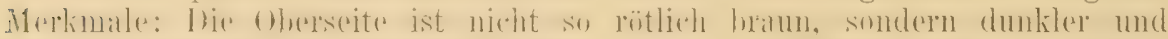

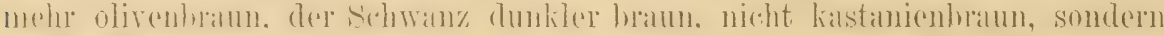

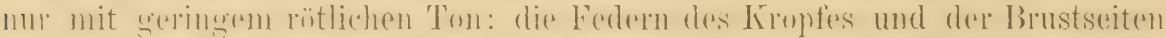

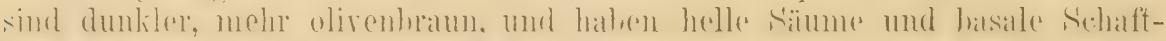

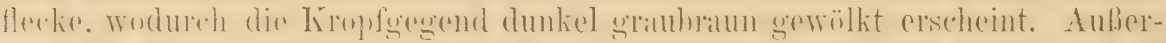

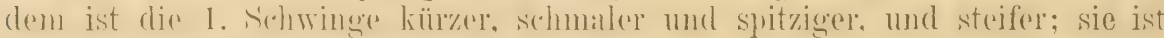
meist nur wenig mehr als halb so lang wie die Handdecken, und wenn sie

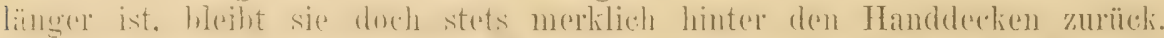
1)ie längste von mir germessene surosserschwingre nilit $12 \mathrm{~mm}$. die kürzeste einer Nachtigall zwar nur 15, letztere ist aber breiter und weicher ${ }^{1}$ ). Die

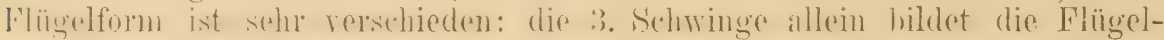

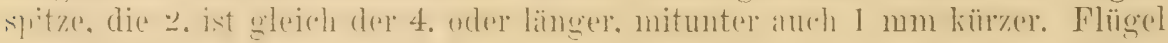

1) Man darf sich nicht durch Herbstvögel täuschen lassen, bei denen die 1. Schwinge noch nicht völlig ausgewachsen ist! 
von 20 Exemplarem 81 -92 mm. Schmahel wit hei der Nachtigill, nur oft etwas kräftiger und kïırzer.

Bewohnt die Küstenstriche Nordost-Dentschlinds. nïmlich einen schmalen Streifen entlang der Ostsee. rem nördichen Mechlenburg durch Nenrorjommern, Lsedon, Wollin, den nördlichen Treil von Hinterpommern. West-

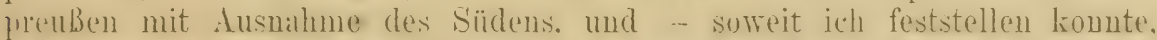
dats ganze - ()stuenßen, Jütland, die dänischen Inseln, Süd- und MittelŚchwedru, das stidlichr Fimbind, die rusischen Ostseeprovinzen, Polen (ïstlieh der Treichsel fast allein, westlich derselhen selten). Galizien, Siehen-

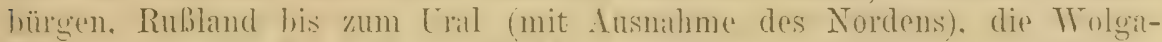
Mündungen, die Krim (niteh Susehlin, in litt., ganz sicher, aber nicht in

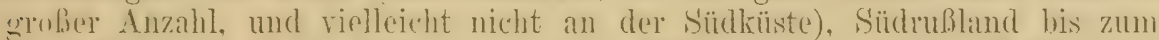
Tord-Kanthasus, nach Situnin auch hei Tiflis. lis Orenhurg und sï̈lwestsibirien (nath Suschkin. in litt.. noch hei Tjumen, ästlich his 'Tomsk und den nordwestliche'n Forhergen des Altai). In Turkestan (nich Semertzoti

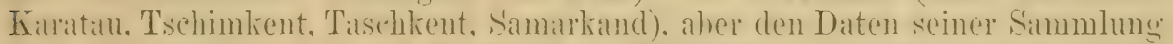
nach (Suschkin iu litt.) nur Zugrogel. - Windert im Herbste nach Ostafrilia (Gomaliland. Kilimandxeharo, Kikurn-Berge, Massailamı, D)eutsehostafrikit. simbesi). Teroinzelt in Westrurojia, eimmal in England festgestellt letzterer wahrscheinlich ein entwichener Kätigvogel.

Ich habe mich nach langem Schwanken entschlossen, den Sprosser als Art zu behandeln; er kommt zweifellos in Polen und Posen, auch in Vorpommern, sowie in Teilen Rußlands neben der Nachtigall brütend vor, was für mich bestimmend ist. Dasselbe mag hier und da freilich auch in kleineren Gebieten bei geographischen Vertretern der Fall sein, deren Wohngebiete nicht durch Heere, Wüsten oder hohe Gebirge getrennt sind, aber selten haben solche so laute und leicht unterscheidbare Gesänge, nach denen man sie leicht bestimmen kann, ohne Exemplare zu sammeln. Das rereinzelte Vorkommen in Westeuropa ist bedeutungslos, da das Brüten dort nirgend nachgeriesen worden ist, und bei dem einmaligen Vorkommen in Eugland kann es sich leicht um einen entwichenen Käfigvogel handeln. Im südlichen Kaukasus hat Radde zwar Hafisnachtigall (afiricana!) und Sprosser festgestellt, letztere aber nur bis zum 27. April und daun erst wieder am 15. August gesammelt, während er erstere alleiu im Mlai und Juni erbentete. Es könnte also sein, daß seine Sprosser noch auf dem Zuge waren, doch brïten sie nach Satunin (Suschkin in litt.) auch bei Tiflis, während sie im Nord-Kankasus allein rorkommen.

Der Sprosser bewolnt dieselben Örtlichkeiten wie die Nachtigall, scheint aber noch mehr feuchtes Gelände zu lieben und findet sich daher u. a. mit Vorliebe in Erlenhainen, an Flußufern und auch in Weidendickichten, im Norden in Birkengehölzen. Die Lockstimme ist dieselbe, nur klingt das flötende whit schärfer und höher, wie auch das angehängte Schnarren. Der Gesang ist der schönste der Vogelwelt und übertrifft den der Nachtigall durch seine Tiefe und Kraft und die häufig darin rorkommenden Glockentöne; ein nicht seltenes schnarrendes, den Strophen angehängtes zerrr fällt auf, der Rhythmus ist ein anderer, der Gesang enthält mehr aber kürzere Touren, die sanft lullenden, ziehenden "seelenvollen" 'Töne der westlichen Nachtigall fehlen fast immer, der ganze Schlag aber klingt erhabener, langsamer, getragener. Wer nur die geringste Ahnung von Vogelgesängen hat, kann die beiden Gesänge nicht verwechseln, wenn er beide kennt. Lebensweise und Fortpflanzung wie bei der Nachtigall. Das Nest steht keineswegs "meist nahe am Wasser." Die Eier gleichen denen der Nachtigall und sind nicht zu unterscheiden, nur daß sie anscheinend durchschnittlich etwas größer und schwerer sind. 72 Eier (23 Rey, 49 Jourdain) messen durchschnittlich $21.77 \times 16.25$, J Laximum $24.2 \times 16.1$ und $22.5 \times 17.1$, Jinimum $20.1 \times 15.3 \mathrm{~mm}$ and riegen im Nittel $166 \mathrm{mg}$. 


\section{Luscinia calliope (Pall.).}

Motacilla Calliope Pallas, Reise d. versch. P'rov. Russ, Reichs III, p. 697 (1776„... a Jenisea usque ad Lenam").

Turdus cantschatkensis Gmelin, Syst. Nat. I, 2, p. 817 (1789- ex Latham: Kamtschatka: Thrush, Gen. Syn. II, p. 28. - Kamtschatka).

Calliope Lathamii Gould, B. Europe II, Taf. 118 und Text (1837- Neuer Name).

Erithacus ignigularis Dubois, Ois. Europe, T'ext zu Taf. 61 (1862- Never Name).

Calliope yeatmani 'Tristram, Ibis 1870, p. 444 ("Pilhubeet", Zentralprovinzen Indiens).

Abbild. d. Ei: Journ. f. Orn. 1873 'Taf. I Fig. 13.

ơad. Oberseite und Schwanz röstlich olivenbraun. Schwingen dunkel-

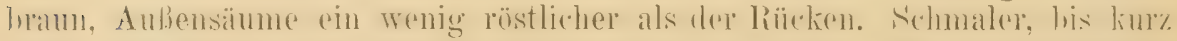
hinter diss Auge rejehender Supereiliarstreif und hreiter Wangenstreif meils: Zïgel und Federn um den vorderen 'Teil des Auges schwarz, Kinn und

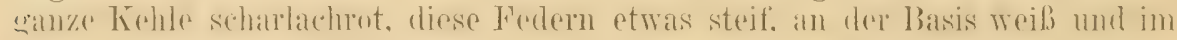
frisch vermaluserten Kleide auch mit feinen weiben bindsïumen, der rote Kehlflecti ron dem weilion Wangenstreifen durch eine schwarze Linie aptrennt und nach der Brust zu mehr oder minder deutlich sehwarz umrahmt.

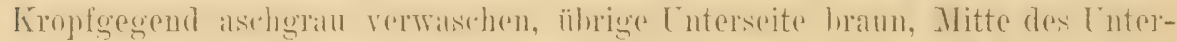

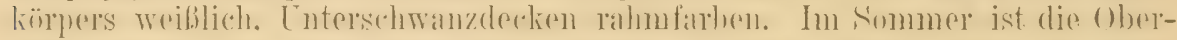
seite blasser und cotwas gräulicher; (־ nur) jungere rögel hahen hell rost-

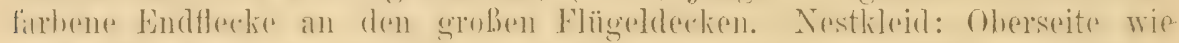

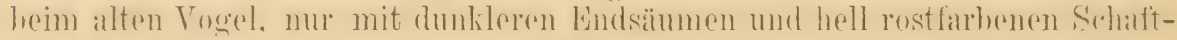
flecken. Unterseite wie beim $q$, Brust und Seiten bräunlicher und mit

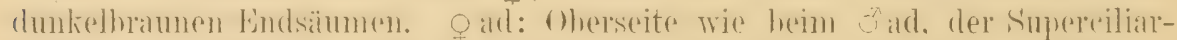

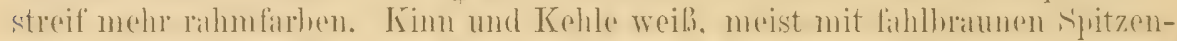

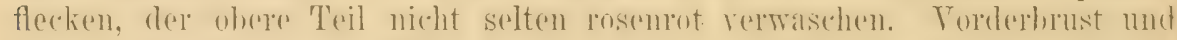

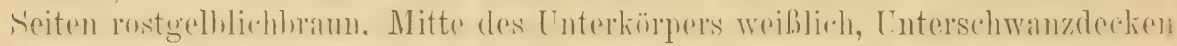

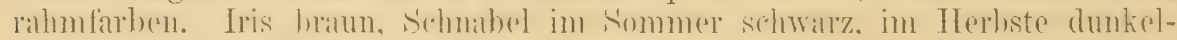
braun, an der Basis hell. Füßo braun oder graubraun. Flügel von 30 ô 74-83 mm. Da nur wenige Brutvögel gemessen werden komnten, war

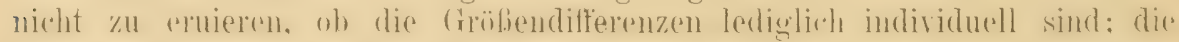
Wintervägel von den lin-Krin-Inseln sind fist alle sehr klein. Sehwany etwa 57-65, Lanf otwa 31-33, Culmen 15-18.3 mm. 1. Schwinge bedentend länger als die Handdecken, 2. zwischen der 6. und 7., 3., 4., 5. nu wenig verschieden und die Flügelspitze bildend, 3.-5. verengt.

Brutvogel in Sibirien bis Kamtschatka, auf der Berings-Insel und den

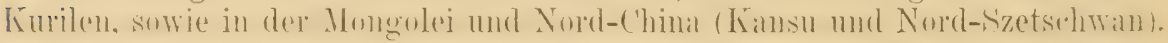
- Kugvoged, der im Winter his Indien und Tenasserim. Süd-('hina. Hainan.

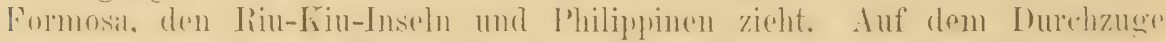
auch in Japan. Vereinzelt in Luropa vorgekommen: Im Ural, Kaukasus.

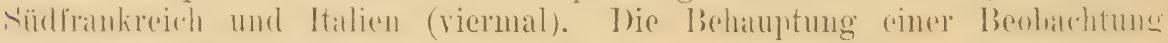
in England bleibt umerwiesen.

Lebt in buschreichem Gelände, besonders an Flußufern und Bächen, im Gebirgean dichtbewachsenen Hängen und in der Nähe des Wassers. Der Gesang wird als wunderschön und kräftig beschrieben, die Strophes als lang. Man hört ihn besonders in den Abend- und Morgenstunden, mitunter auch im Dunkel der Nacht. Im Juni findet die Fortpllanzung statt. Das Nest ist ein länglich runder Klumpen mit seitlichem Eingangsloch und besteht aus Gräsern, Stengeln und Würzelchen, und mitunter einigen dïrren Blättern. Das Gelege enthält fünf Eier von lebhaft grünlichblauer Farbe. mit 
blassen rotbraunen Fleckchen und Spritzern. Meist sind diese Zeichnungen sparsam und auf das stumpfe Ende beschränkt, uitunter über das ganze Ei rerbreitet und bisweilen fehlen sie ganz. 16 Eier messen nach Taczanowski von 20.4-22 $<15-16$, ein Riesenei $25.50<16.6 \mathrm{~mm}$.

\section{Luscinia pectoralis pectoralis (Gould.).}

Calliope pectoralis Gould, Icones Avium T'eil II, I'af. 1 mit T'ext (1838 - "Himalaya". Ohne Zweifel westlicher Himalaya!)

రోad. Oberseite bräunlichgrau, Oberkopf, Bürzel und Oberschwanzdecken dunkler und mehr braun. S'chwingen dunkelbran mit heller braunen

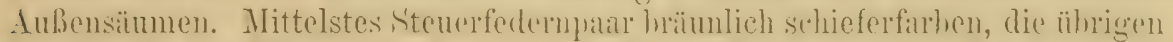
schieferschwarz, Wrumelhailfte und rundliche Flecke an den s'pitzen weils. Ton der Obersehnabelwuzel bis hinter die Augen ein hreiter weiber Sunerciliarstreif: Zügel, Kopfseiten, Seiten der Kohlule, Krople und Vorderhrust rein schwarz, Kinn und Yitte der Kehle in der Tünge von etwa 2 c'm, lohhaft

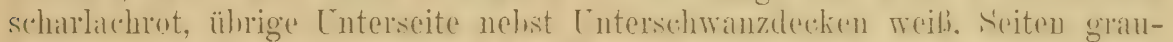

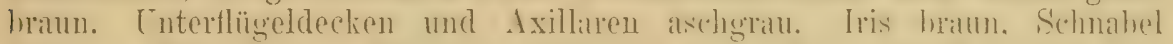

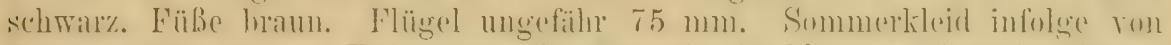

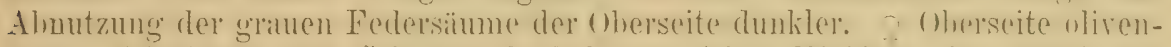

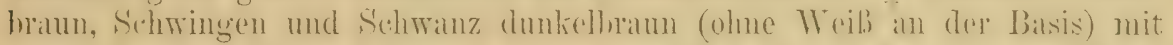

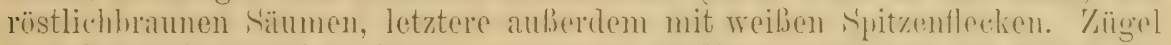

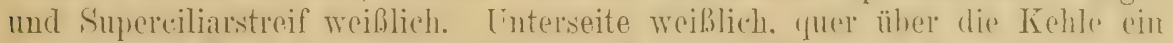
graubraunes Band. Seiten brïunlich. - Nestlileid: Oherseite luaun mit rost-

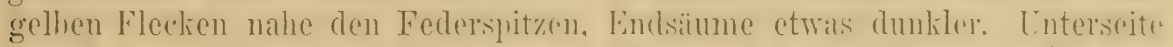

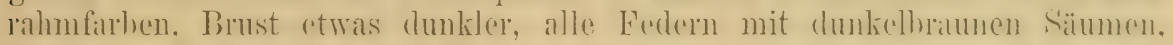

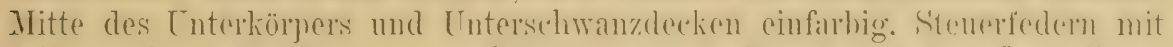

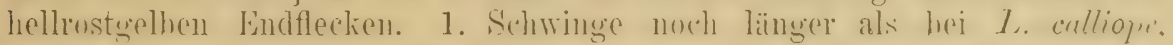
2. gleich der 10. oder zwisehen der 9. und 10., 3., 4., 5., 6. nur twenig verschieden und die Flïgelspitze bildend, die hedentend kïrzer ist ails her I. calliope, 3.-6. an der Außenfahue verengt.

\section{Westlicher Himalaya von Gilgit und Kaschmir bis Nepal.}

Brütet in Höhen von 10000 engl. Fuß und höher, kommt abor im Irinter in mittlere und niedere Laigen und wurde gelegentlir.t, am Fube der Berge bis Oudh gefunden.

Über die Nistweise sind wir nicht sicher unterrichtet. Ein angebliches Nest der Art war napfförmig, oben offen und enthielt lachsfarbene Eier, die Identität ist aber zweifelhaft.

\section{Luscinia pectoralis ballioni (Sew.).}

Calliope Bullioni Sewertzotî. Turkest. Jesotn. (in Izv. Obsheh. Mosliov. VIII. 2). 1) 12.2 (1873- Tian Schan); Übers. iu MIadarászs Zeitschr. f. ges. Orn. IV, p. 60.

Ist $l$. . 1 . pectorelis äuBerst ähnlich, aber (besonders im Summerkleide) auf der Oberseite hlasser, mehr fahl graubrïunlich: mittlere steuerfedern graubraun, Sehwingensiume fihlhbaun. Flügrel ron is ce $72-7+\mathrm{mm}$.

Brïtet in Turkestan (Ferghana, Tischkan, Tian Schan). 


\section{Luscinia pectoralis confusa subsp. nor.}

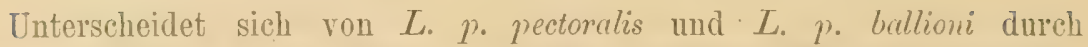

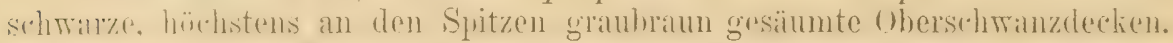
Auberiem sind dio steurededern schwarz und die oberseite dunkler, hesonders

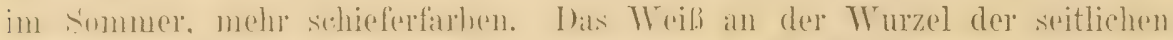
Stenerfedern meist etwats atuscedehnter, mehr als die Hälfte der Federn einnehmend. Flügel bis zu $77 \mathrm{~mm}$ gemessen. Typus ơad. Sikkim, Janual 1876, von H. J. Ellwes gesammelt.

Im östlichen Himalaya, (Sikkim und Bhutan) in großen Höhen.

\section{Luscinia pectoralis tschebaiewi (I'\%ew.).}

? Calliope pectardens David, Nour. Arch. JIus. Paris VII, Bull. Cat. no. 167 (1861Mupin; vgl. Ois. Chine, p. 236).

Calliope tschebaiewi Przewalski, Mongol i Strana 'Tangut II, p. 44, Taf. IX, Fig. 1 (1876-

Kansu); Übers. in Rowley's Orn. Hisc. II; p. 180, Taf. 54.

Abbild.: Aves Przewalskianae I, Taf. I, Fig. 3, 4; Eier ebenda Taf. V, Fig. 9.

ơad. Ähnlich dem von L. p. pectoralis, aber der rote Kehlfleck weiter alusgerehnt, an de'n Soitru der Kehle ein weiber Bartstreif, die Sechwanz-

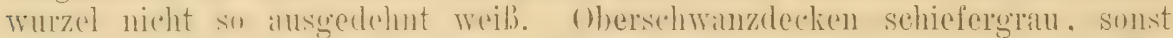
Oberseite wie bei $L$. $p$. confusa. Flügel von $60^{\pi} 75-79 \mathrm{~mm}$. Das o scheint sich nicht sicher vou dem der verwandten Formen unterscheiden zil lassen.

brütet in Kinsu, am oherem ('huanche und I)itschu und ist Trintergast im aistliehen Himalạ̧a, in Assamn, den Bergen sïdlich des Brahmaputra und Nord-Birma.

Przewalski fand am 17. Mai 1880 ein Nest mit 4 frischen Eiern. Es stand auf der Lrde, unter einem Spiräenbusche. Das Nest war rund und hatte eine seitliche Öffnung(!) Eier bläulich grün mit oder ohne schwach roströtliche Flecke. Maße $20.5 \times 15-15.5 \mathrm{~mm}$. "Beim Singen erhebt sich das ơ nach Art der Blaukehlchen in die Luft. In erregter Stimmung hält es den Schwanz senkrecht. Auf der Erde läuft der Vogel äußerst schnell."

\section{Luscinia davidi (Oust.).}

Calliope Davidi Oustalet, Bull. Jlus. Paris 1892, p. 222 ('Ta-tsien-lu in Szetschwan).

Abbild.: Nouv. Arch. Mus. Paris sér. 4, III 'Taf. XI.

ठึ ad. Oberseite bläulich schieferorau, einschließlich der Oberflügel-

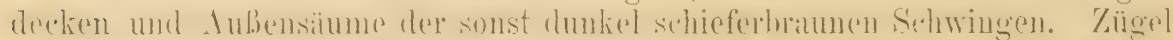

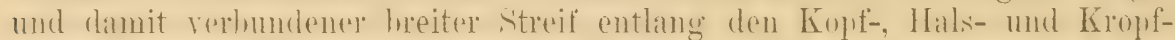

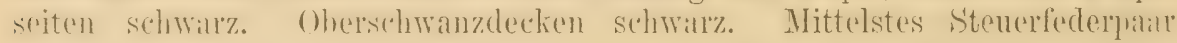
ganz schwarz, die übrigon an der Wurzel weiß - dio seitlichen zu etwa einem Drittel, die mittelsten zu ${ }^{4} / 5$. Kinn, Kehle und Kropf bis an die

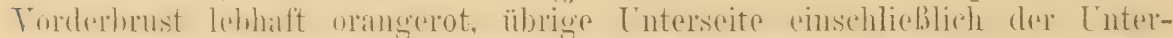
schwanz- und [nterflügeldedien sowie der Axillaren hlab isibell. Mitte des

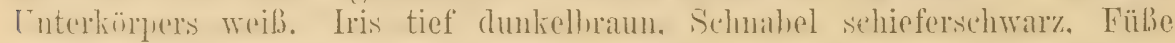
horngrau. Flügel $71-73$, Schwanz etwa 56, Lauf 27-27.5, Culmen 15 oder $16 \mathrm{~mm}$ - o (nach Oustalet) Oherseite hraum, etwas mehr olivenfiuhen als bei dem von $L$. calliope und die Unterseite etwas mehr rotbrïunlich. Ta-tsien-lu in Szetschwan und Tsin-ling Berge (Brntvogel). 


\section{Luscinia obscura (Beres. \& Bianchi).}

Lavivora obscura Beresowsky \& Bianchi, Aves Exp. Potanin. Gansu, p. 97, 'Taf. I, Fig. 2 (189t- Kansu); Übers.: Journ. f. Orn. 1897, p. 70.

ơ ad. Oberseite dunkel schicfergrau, Oberschwanzdecken glanzlos sellwarz. Schwingen mattschwar\% mit schmalen dunkelgranen Anbensänmen. Handschwingen an der Basis einge mm weit schmutzigweib gesilumt (An-

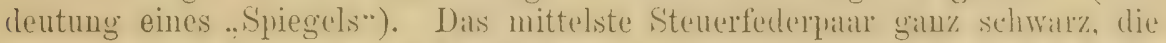
angreuzenden etwa zu zwei I)ritteh weil.s. Spitzendrittel schmallz. die weibe Basis an Ausdehnumg abmehmend his das seitliche Pall nur etwat zu einem

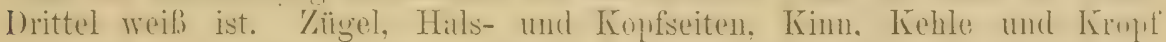

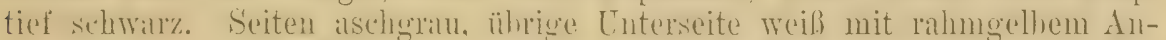

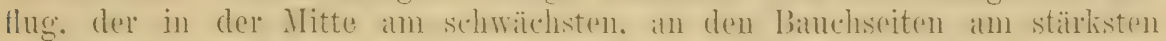
ist, Entersehwamzlecken mit Gran rerwaschen. Enterflügeldeclien grau mit weiben Syitzen, Axillaren dunkelgram. immere Lnterflügrldecken mitunter hell

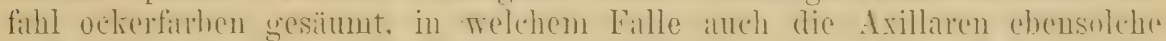

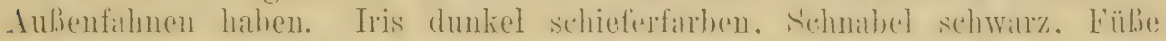

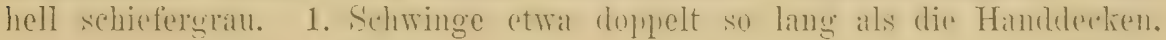
t. und 5. gleich und am längsten, 3. und 6. nur wenige mm kürzer, 2. zwischen der 7. und 8., 3.-5. an der Außenfahne verengt. Flügel unserer 3 meBbaren Stücke 70-71.5 mm, Schwanz 5̃ -53, Lauf 26-29. Culmen 16-17 mm. o und juv. unbekannt.

Nistet im südwestlichen Kransu im Bambusdickicht der Nadelholzznnc,

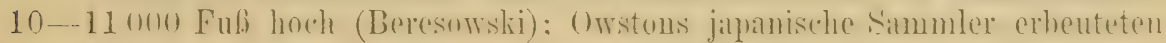
vier $\sigma^{\star}$ auf dem Berge 'Tai-pai-schan im 'T'sin-ling' Gebirg'e.

Der Gesang wird als "Hlötenartig und ausgezeichnet" beschrieben.

\section{Luscinia ruficeps (Hart.).}

Larvivora muficeps Hartert, Bull. B. O. Club XIX, p. 50 (1907- T'sin-ling Berge).

Abbild.: Ibis 1907, Taf. XIII.

ठad. Oberkopf und Nacken bräunlich orangerot, übrige Oberseite nehst Flügoldecken und Aubensänmen der sonst dunkel schiefurfublenen Schwingen schiefergran, Oherschwanzdeclien schieferschwarz. Stenerfectern bräunlich orangerot. die Spitzen zu etwa einem Drittel und Aufenränder. auberdem diss mittelste Paall ganz schieferschwarz. Zügel und breite Streiten unter den Augen, die dureh ein die Kehle halhkreisförmig umschliebendes Band rerbunden sind, schwarz. Kehle rein weiß. Federn hinter dem schwarzen Kropfhand und Śeiten grau. Nitte des Enterliniper's und Lnterschwanzdecken weiß, letztere teilweise mit schiefergraturn Aubemrindern und rahmfarbenem Sehimmer. Tuterflügelelecken aschgrall mit weiben Sipitzen und Sämmen. Inncusämme der Schwingen schmal röstlichweib. Iris rötlichbraun, Schnabel schieferschmarz, Fiilie rötlich gellhraun. 1. Schwinge etwa $1 / 4$ länger als die Handdecken, 2. zwischen der 6. und 7., 4. und 5 . am längsten, 3. nur sehr wenig kürzer, 3.-5. deutich verengt. I'lïgel etwa 79-81, Schwanz etwa 52-56, Lauf 27, Culmen 16--17.5 mm. Oberseite und Schwanz olivenhraum, an Kopt und Oberschwanzdechen etwis röstlicher. Schwingen dunkelbraun, Aubeufahuen wie der Rücken. Cnter-

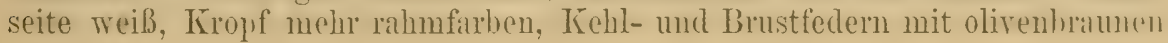




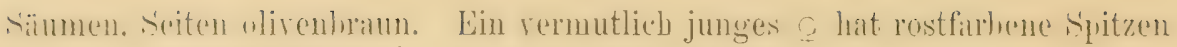
an den großen Oberflügeldecken. Flügel $80 \mathrm{~mm}$.

$3 \overbrace{}^{\pi}$ und 20 in sehr abgenutztem Gefieder wurden auf dem Tai-paischan-Berge in der T'sin-ling Kette in China im Juli 1905 erbeutet.

\section{Luscinia akahige ('Temm.).}

Sylvia akahige 'lemminck, Pl. Col. 571 (1824- Riu-Kiu-Inseln1)).

Abbild. Ei: Cat. Eggs Brit. Mus. IV, Taf. VII Fig. 1.

ơad. Oberseite dunkel rötlichbraun, auf dem Kopfe rötlicher. Steuerfedern kiastanienhratun. Stirn. Yä̈gel, Federn ums Augu. Konf- und Hals-

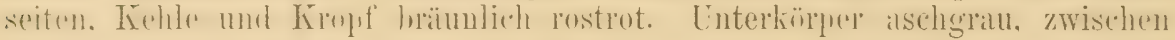
dem Orangerot des Kropfes und der Brust meist ein mehr oder minder rntwirkeltes sehwarzes Band. Seiten olivenbramu, verwaschen, Nitte der Lnterscite und Lntrischwanzderlen weil.s. selten hräunlichgrau. [nterflügeldecken

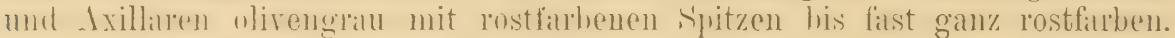
Schnabel (im Balge) holnschwarz, Füße braun. Flügol von 15 ơ $74-78$, einmal 79, Schwanz 50-54, Lauf 28-29.5, Culmen etwa $15.5-17 \mathrm{~mm}$. - zad. Oberseite etwas weniger rötlich, mehr olivenbraun, Stirn, Zügel,

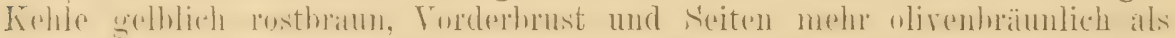
grau. - 1. Schwinge bedeutend länger als die Handdecken; 2. zwischen der 7. und 8. oder der 8. und 9., 4. am längsten, 3. und 5. nur sehr wenig kürzer; Verengung der Schwingen variabel, meist aber an der 3. und 4. am deutlichsten.

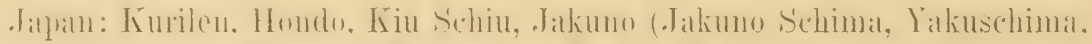

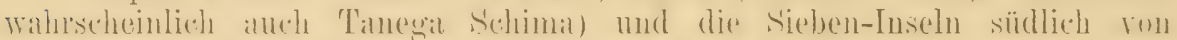

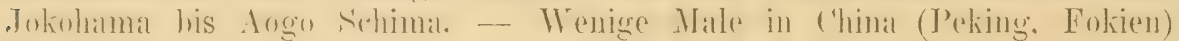
festgestellt, dort jedenfalls aber nur vereinzelt auf dem Striche.

4 auf Fatsidschio (Hachijio), Sieben-Inseln, am 30. Mai 1901 gefundene, von Alan Owston erhaltene Eier sind glanzlos blaugrünlich-weiß mit einigen kaum sichtbaren, feinen braunen Punkten. Sie messen $22.9 \times 15.8,21.9 \times 16.5,21.8 \times 16.3$ und $21.6 \times 16.4 \mathrm{~mm}$. Das Nest stand etwa anderthalb Meter hoch in einem Baume, Beschreibung desselben liegt nicht vor. 2 Eier ron den Sieben-Inseln im British Museum sind ron gleicher Größe, nur wenig mehr blau und zeigen keine Punkte.

\section{Luscinia komadori komadori (Temm.).}

Sylvia kiomadori T'emminck, Pl. Col. 570 (1824- „Korea". Errore!).

Õad. Ganze Obersoite einschließlich des Schwanzes gesättigt und

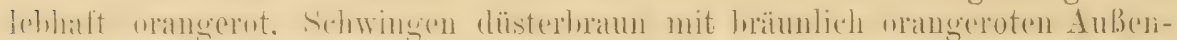

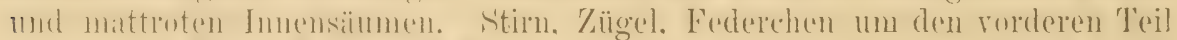

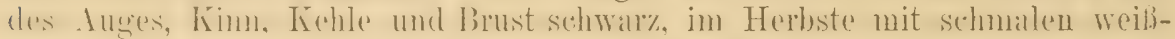

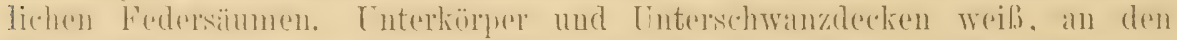

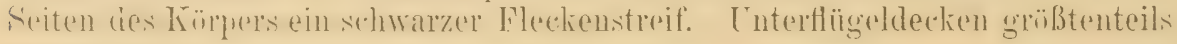

1) Diese Angabe dürfte falsch sein; da die Namen verwechselt wurden - ,akahige“ ist der japanische Name für L. komadori, "komadori“ der für L. akahige - liegt vielleicht auch eine Verwechselung der Fundorte vor: L. komadori kommt nur auf den Riu-Kiu-Inseln vor, L. alahige dagegen nicht. 
schwallz, Axillaren weib mit schwarzer Bassis. Schnabel braunschwarz. Fülie

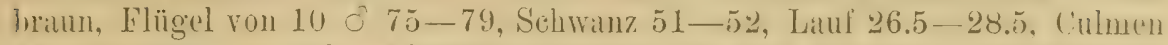
17-18 mm. - 2akl. Oherseite braunrot his zum Sichnibel, Oberschwantdechen und Schwanz etwas lehhafter. Zügel hräunlirh. Cnterseite weib, die Federn mit aschgrauten Sïumen. Mitte des Cnterkürpers und Cnterschwanzdecken fast rein weib. Flügol $1-3 \mathrm{~mm}$ kürzer: - Juv. im Nest-

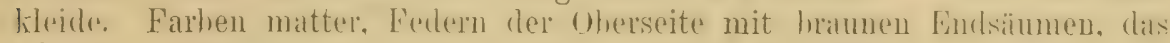
o dem o ähnlich, nur mit Schwarz an Kinn und Kehle. - 1. Schrvinge hedentend lïnger als die Handdecken, 2. gleich dex 7. oder etwas länger. 3., 4., 5. nur wenig verschieden und am längsten. 4. und 5. dentlich, 3. und 6. undeutlich verengt.

Bewohnt lediglieh die nürdliche Gruppe der líu-Kin-Inselkette, näm-

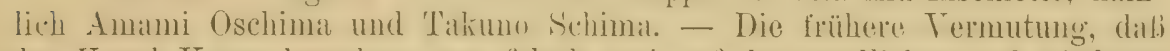
dere Togel Kiorea hewohne, wall falsteh und auf' den uördlichen und mittleren japanischen Inseln wird el nur im Käfig gehalten.

Vier von Alan Owston erhaltene Eier, die auf Amami Oschima am 28. März 1906 gefunden wurden, gleichen riesigen Rotkehlchen-Kiern. Sie sind rötlich rahmfarben oder hell Heisehfarben mit dunkler Wölkung, die am stumpfen Ende mehr gehäuft ist. Sie messen $23.9 \times 16.5,23.6 \times 16.7,23.5 \times 17$ und $23.3 \times 16.7 \mathrm{~mm}$.

\section{Luscinia komadori namiyei (Stejn.).}

leoturus namiyei Stejueger, Proc. U. S. Nat. MLus. IX, p.645 (1886- Okinawa in der Riu-Kiu-Inselgruppe).

ऽ`ad. Dem von L. Komadori komadori äußert ähnlich, aber die Seiten gleichmïßig hä̈unlichgrau, chenso die Cuterflïgeldecken umd Axillaren. - o ad. Von dem von L. l. komadori durch graubraun verwaschene Unterseite verschieden. Gruppe.

Bewohnt die Insel Okinawal (Okinktwal S'hima) der mittleren Riu-Kin-

\section{Luscinia sibilans (Strinh.).}

Lavivora sibilans Swinhoe, Proc. Zool. Soc. London 1863, p. 292 (bei Macao in China).

1. Sehwinge hedentend lïnger als die Handdecken, 2. zwischen der 6. und 7., 3.-5. ungefäln gleich und am längsten, 3.-5. merklich verengt. - E pad. Oberseite rötlich olivenhnaun, Oberschwanzdecken rötlicher.

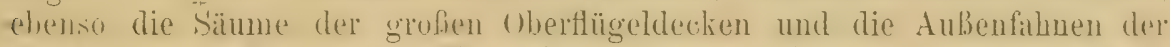
dunkelhramen Śchwingen. Stunerfedern kistanienfarhen. Enterseite weil. Kehle mit sehmalen dunkrlhramen Federsämmen, in der Mitte mitunter fast einfarhig. Federn an Kropt and Brust mit hreiten olivenluaunen Sïumen.

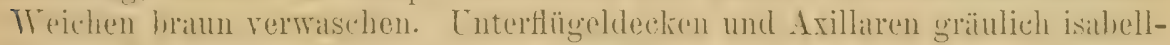

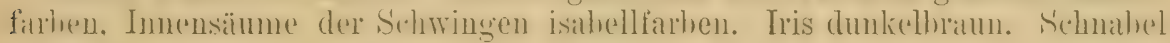
dunkelbraun. Füße graugelblich. Flügel von 3 ○ $64-68,3$ o $67-7: 3$, Schwanz ơ etwa 49-52, o 47-48, Lauf 23-25, Culmen 14.5-16.5 mm. - Jur.: Oherseite mit hell rustharbenen Fleckeir. Flägeldecken mit rostfarbenen Säumen und Querflecken, Unterseite mohr roströtlich.

Dieser in Sammlungen seltene Vogel hrïtet in Sïdostsibirien (Sideni-

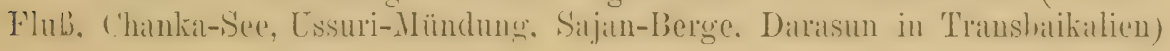




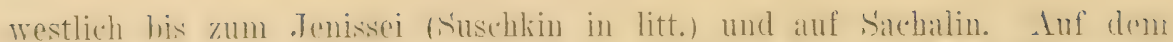
Zuge wurle "l' in Korea heohalditet und ïberwintert in sö̈d-c'hina und Hainall. Das Vorkmmmen in Japam ist ansehemend mech nicht hewiesen. Lebensweise und Fortpflanzung unbekannt.

\section{Luscinia cyane (Pall.).}

Motacilla Cyane Pallas, Reise d. versch. Prov. Kuss. Reichs III, p. 697 (1776- Daurien, zwischen den Flüssen Onon und Argun).

Larvivora gracilis Swinhoe, Ibis 1861, p. 262 (Fokien, China).

Erithacus cyaneus Seebohm, Cat. B. Brit. Mus. V, p. 303 (1881).

Abbild.: Radde, Reis. S.O.-Sibir. II, Taf. X, 1-4. Ei: Ibis 1908 Taf. IV, Fig. 6.

1. Schwinge 3-5 mm länger als die Handdecken, 2. gleich der 6.

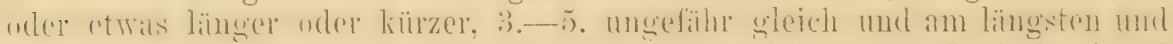
schwach verengt. - otad. Oberseite trïb dunkelblau, am Vorderkopf und

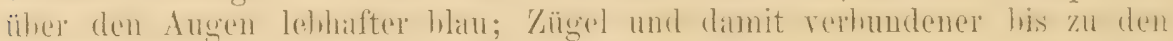
Brustseiten reichender Streif zwischen der blauen Ober- und der weißen

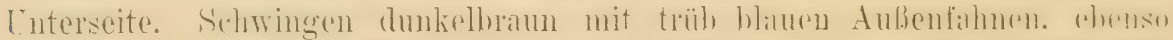

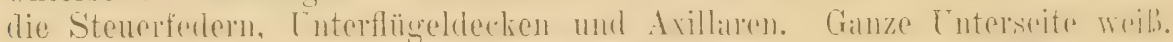

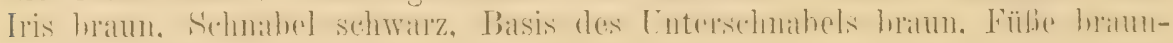
gelblich. Flügel 73-77, Schwanz etwa 47-50, Lauf 26-27, Culmen etwa $16-17 \mathrm{~mm}$. In der Brutzeit verbleicht das Gefiedel etwas. Jüngere

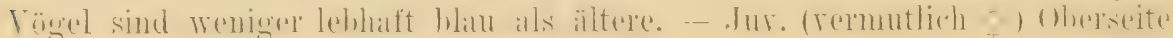

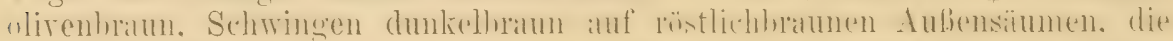

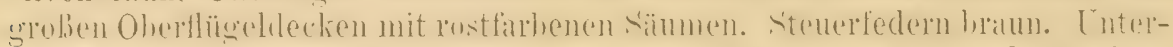

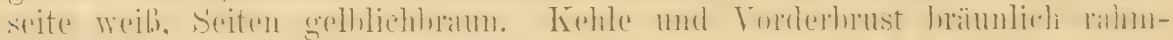

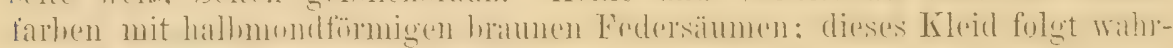

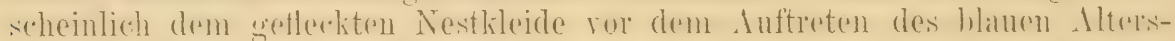

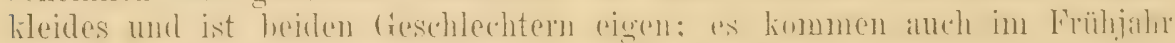
(nicht etwa in der Mauser befindliche) oc. ror, die in der blauen Oberseite größere oder kleinere olivenbraume Partien zeigen, — o ad. Oberseite wie

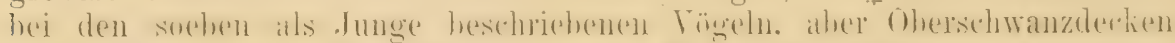

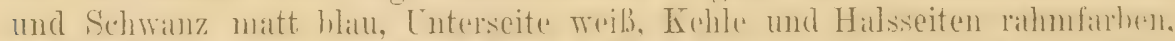

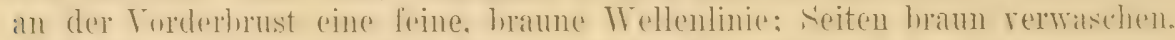

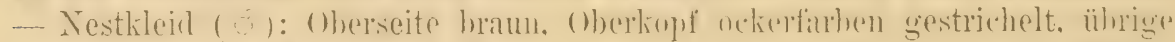

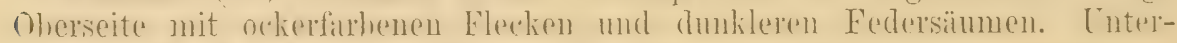

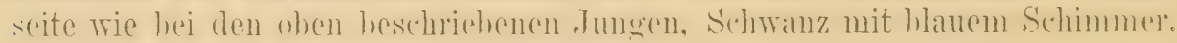
Über die Mauser bin ich nicht genügend unterrichtet.

Brutrogel in Ost-, Vibirien (nath Susthkin. in litt. westlieh his Krasnojarsli)

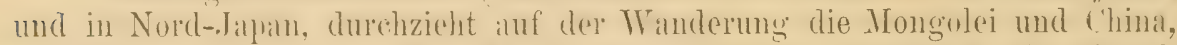
nud ühertrintert in der Malakka-Halloinsel, Borneo, westwärts his Bimah

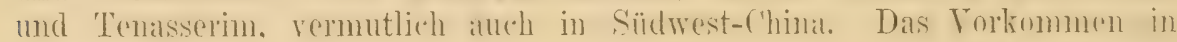
Sikkim ist zweifolhaft.

Lebt am Brutplatz in dichten Wäldern, besonders gern in Schluchten und an Berghängen und hält sich viel am Boden auf. Soll einen prachtvollen, wegeu seiver ILannigfaltigheit unbeschreiblichen (iesang haben, Ingran (Il)is 1908, p. 13i) nennt ihn aber nur ein "musikalisches Geschwätz". Das Nest steht an Abhängen und Böschungen auf dem Boden und besteht aus Moos und andern Bestandteilen aus seiner Umgebung und ist (nach Godlewski) überdacht mit seitlichem Eingang. Es enthält im Juni 5-6 einfarbig blaue Eier. Die Eier zweier Gelege messen nach 'Taczanorvski $18.2 \times 15$ und $19 \times 13.7 \mathrm{~mm}$. 
(Im Himalaya, aber anscheinend nicht in großen Höhen, lebt Luscinia brumea (Hodgs.) ठ̋ad. Oberseite dunkelblau, Superciliarstreif weiß, Zügel und Ohrdecken schwarz, Unterseite lebhaft orangerot, Mitte des Unterkörpers und Unterschwanzdecken weiß. q. Oberseite nebst Schwanz olivenbraun, Unterseite gelbbräunlich, Mitte der Kehle und des Unterkörper's weiß. Nest (in Höhen von 8000 Huß) an Böschungen, wie Rotkehlchen-Nester, Eier einfarbig blau.)

\section{Luscinia svecica gaetkei (Kleinschm.).}

Erithacus gaetkei Kleinschmidt, Journ. f. Orn. 1904, p.302 (Norwegische Hochgebirge, 'Typus ron Helgoland).

Unterscheidet sich von L. svecica svecica nur durch bedentendere Größe, besonders längere Flügelspitze. und etwas dunkler luame (h)erseite und ist

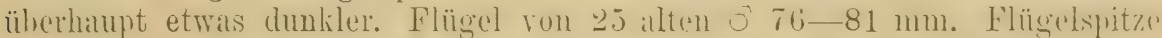
d. h. Entfernung der äuBersten Spitze rom Ende der mittelsten Armschwingen 17-20 mm, gegen 15-17 bei 1,. s, svecica.

Brïtet in den Gehrigen Norwegrens (Fille Fjold, Dnre Fjeld), gुenane Grenze makh Norden und Osten noch uicht festgestellt. - Zicht in Menge

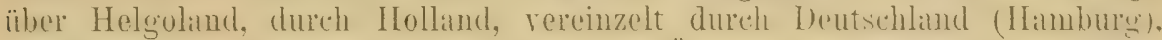
Grobbritamuien, Frankreich und suanien. (Cberwintert remutlich in Wextoder Nordwest-Afrika.) Zugzeit Ende April und Mai, also sehr spät.

\section{Luscinia svecica svecica (L.).}

Schredisches oder 'l'undra-Blaukehlchen.

Notacilla svecica Limmaeus, Syst. Nat. Ed. X, p. 187 (1758- Partim. „Habitat in Europae alpinis." Dem Namen und 1. Zitat - Fauna Svecica 220 - nach ist Schweden und Lappland als terra typica zu betrachten, wo nur diese eine Form rorkommt. In der Fauna Suecica ist ein rotsterniges Blaukehlchen beschrieben "Habitat 'l'ornoae \& alibi in Westrobotnia \& Lapponia in salicetis \& alnetis". Von den Zitaten bezieht sich Frisch - das letzte - auf das weißsternige Blaukehlchen, die andern auf junge Vögel oder $q$ irgend eiver der Formen).

Motacilla Coerulecula Pallas, Zoogr. Rosso-Asiat. I, p. 480 (1827- Neubenennung von Linnés svecica. Hab. „... in omni Rossia et Sibiria". Also "partim". Roter Stern beschrieben).

Cyanecula orientalis Brehm, Handb. Naturg. Vög. Deutschl., p. 351 (1831- „Berrohnt Asien, kommt auch in Egypten vor, waudert durch Italien" ... Wien. Später übertrug Brehm den Namen auf Stücke mit rotem, weiß eingefaßtem Stern!).

Cyanecula v. Calliope suecoidles (partim?) Hodgson, Gray's Zool. MLise., p. 83 (1832Nomen nudum!).

"Sylvia caeruligula Pallas"Blyth, Cat. B. Mus. As. Soc., p. 167 (1849- Errore).

Cyanecula dichrosterna Cabanis \& Heine, Mus. Hein. I, p. 1, Anmerkung (1850„Nordöstliches Afrika und Arabien." Typus von Suez untersucht. Stiick mit weißeingefaßtem roten Stern).

Cyanecula suecica vera und ?bicolor A. E. Brehm, Verz. Samml., p.4 (1866- Nomina nuda!).

Cyanecula suecica var. occidentalis (?partim) Sarudny, Vögel des Ortschik Tales, in Mat. z. Kenntn. d. Flora \& Fauna d. Russ. Reiches Zool. T'eil I, p. 146 (1892russisch!).

Engl.: Red-spotted oder Aretic Bluethroat. - Franz.: Gorge bleue ì tache rouge. - Ital.: Pett' azzurro a macchia rossa. - Schwed.: Blåhake-sångaren. 
ôad. im Frühlingskleide: Oberseite sepiabraun, Stirnfedern bis in

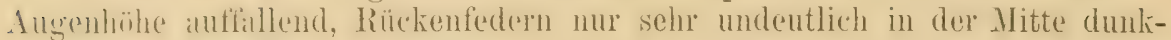
ler und an den Riandern heller: von der Schnabelwurzel bis lintr hinter das Auge cin rihmgelhlich-weiber Supereiliarstreif. Zügel selhwirzlich, selten, und zwall anschemend nur in alogenutztem Gefieder, mehr vder minder deutlieh

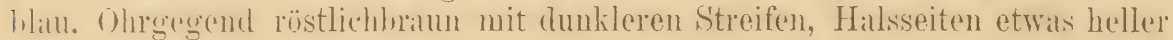
als die Oberseite und nach vorn zu von der blauen Kehle durch einen mehr oder minder deutlirhen weiblichen Streifen getrennt. Oherschwanz-

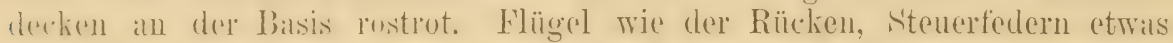
malu als zur Hälfte (his zu zwei Drittelni) rostrot. der s'pitzenteil und das

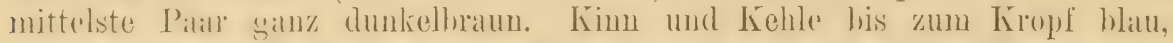

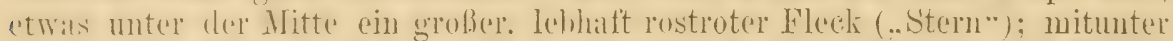
ist len rote stern weilh eingefalbt, sehr selten ist er weib mit rotem Mittelpunkt. Bisweilen hathen die roten Sternfedern biane Spitzen, so dab der Stern fint rerdeclit ist; bemplare mit völlig fehlendem Stern sind, wie es sheint, nicht bekiunt. I):s Bliun der Kehle unten durch ein mehr oder minder

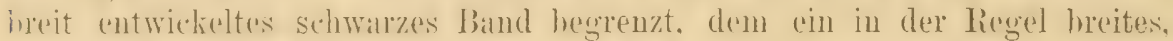
mitunter alueh rerht sehmales und eigentlich nur angedentetes rothraunes Band forgt. Clorige Conterseite weif mit rahmfarbehem Anflug. Weichen und

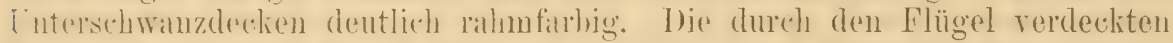

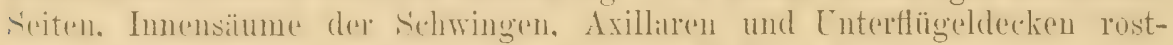

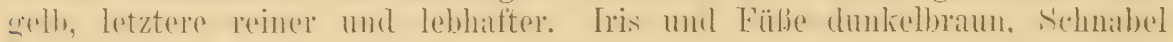
fist whwarz. In Herlostledede ist das Braun der Oherseite einen Ton mehr

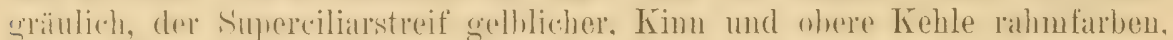
dat wo im Frühjihr der ... Stern" steht rostrot mit rahmfirthenen Federsäumen,

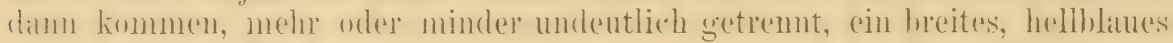
und schwarzes Band, dem das meist breite restrote Brusthamel folgt. An derl Seiten der Fehle stehen schwarze und blaue Federn, mitunter ist der where Teil schwilrzlich. Die Kehle vom Krinn his zum hropte allein malusert zul Ausgang des Winters oder im März in das oben beschriebene Hoch-

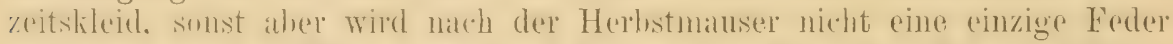
mehr vermansert. Bei gilnz alten of komment mitunter schon hei der Herhstmiluser das volle Frühlingskleid zum Forschein und soldhe Stïcke scheincon

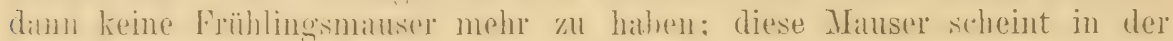

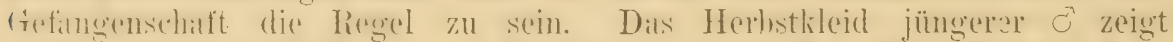
deutliche rostgelle silume an den śpitzen der wroben Flügeldecken, fahlhratume Sïmme an den Flügelfedern, and" dem Bürzel einen rostfarbenen Schimmer. - o ad. Oberseite wie beim ơad., Kehle abor weißlich, an

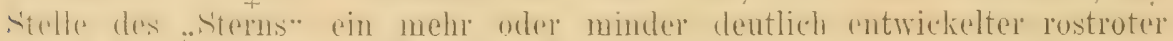

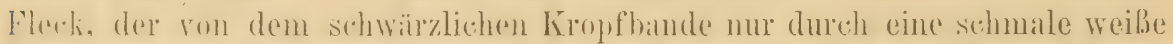
Linie geterennt ist: dis schwarze Kropfland enthiilt oft einige hane Federn. Kuhle mitunter dunkelbram gafleckt. S'eiten des oberen Teiles mit meist muleutliehem blanen Streifen, die des unteren Teiles mit hreitenn sthwarzen Streifen. Brust oft braun gefleckt. Sonst wie das ơ. Einzelne (sehr alte oder hahmenfedrige) of gleichen den ơ fast vollkommen. of juv. wie ơdad, alher das Brusthand mehr getterkt, Kehle rahmfirben, ohne Blan oder Rostrot. - Flïgel vou 32 alten o $74-77$, Schwanz etwa 55-58, Lauf 27-28, Culmen $15-16 \mathrm{~mm}$. O Flügel etwa $71.5-73 \mathrm{~mm}$. Die 2. Schwinge ist an Lüng'e gloich der 6. oder häufiger noch zwischen der 6. und 7. - Nest-

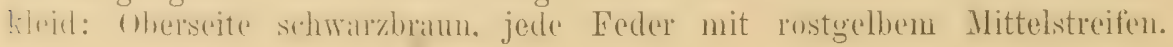


()herseluwandecken restrot, Shwanz wie heim alten Togel. Cuterscite rahmfarben, jede Feder hreit schwarz umsäumt, Ablomen weiblich mit nur wenigeu Andeutungen sthwarzer Federsämme, ül)rigens ziemlich variabel.

Zu dieser Form rechue ich die Blaukehlchen, welche in Schwedon,

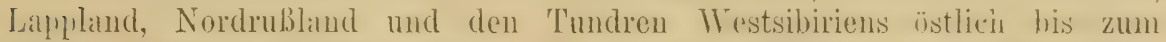
Jenissei (66 nördl. 13r.) hrïten. - Sie ziehen im Winter nach Norelıstafriki, herïhren auf dem Zuge das istliche Europa (his Transkaspien) und scheinen gelegentlich auch im westlichen Indien zu überwintern.

Das schwedische Blaukehlchen bewohnt feuchtes, mit Buschwerk bestandenes Gelände, und namentlich auch die Tundren Nordrußlands und Westsibiriens. Das Nest steht wie das der deutschen Form im dichten Wurzel- und Pflanzengewirr am Erdboden. 100 Eier (61 aus Schweden, Finnland und Nordrußland von Jourdain, 39 aus Lappland von Rey gemessen) messen im Durchschnitt $18.54<14$, Maximum $20.7 \times 1.4$ und $19.3 \times 15$, Minimum $17>14.2$ und $17.3><12.8 \mathrm{~mm}$.

\section{Luscinia svecica pallidogularis (Sar.).}

Cyanecula suecica pallidogularis Sarudny, IIat.z. Kennt. d. Fauna und Flora d. Russ. Reichs, Kool. IlI zwischen p. 171 und 312 (1897- "Orenburg und wahrscheinlich der 'Turan.“ Russisch! Übers. im Auszuge in Orn. Monatsber. 1898, p. 83,84$)$.

ơ. Kehle blasser, als die von L. s. svecica, übrigens variabel wic hei allen Blaukehlehen. Steru grob, rostrot. Oberseite nur undedentend heller als bei L. s. sereice oder abeuso, aber anscheinend nicht so hlab wie hei discesso

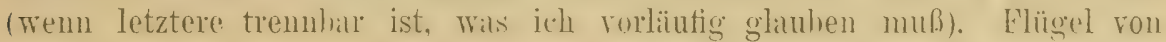
17 of $71-75$, die 2. Schwinge zwischen der 7. und 8. oder zwischen der 6. und 7 .

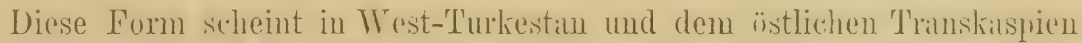
(Semirjetschensli, Issik-Kul, Tian-Schau, Syr-Darjil) und bis zum südlichen Ural

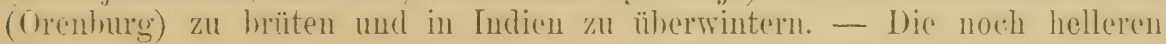
Stricke, die in denselben Gegenden auf dem Zuge vorkommen. scheinen aus

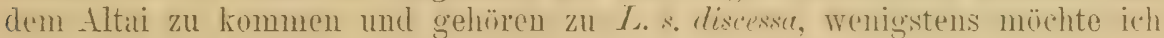
sie rorläufig nicht mit pallidogularis zusammenziehen.

\section{Luscinia svecica discessa (Mad.).}

Cyanecula discessa Madarász, Termész. Füzetek XXV, p.535 (1902- 'Transkaspien).

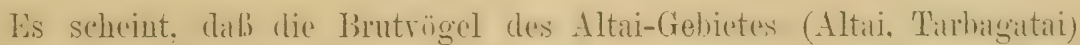
noch etwas kleiner sind als die Turkestans. Das Blau der Kehle ist bedentend blasser als bei $L$. s. srecica, die Oborseite fahler braun. Dies ist die kleinste, hellste und stumpiftügigste blatukeblehenturm. Flügel ron 14 alten ठึ $69-74$, Flügelspitze $12-14 \mathrm{~mm}$. 2. Schwinge zwischen der 7. umel 8., mitunter zwisehen der 8. und 9. \%/u dieser Form scheinen nath Iileiusehmiclt (in litt.) anch Tägoel ron 'Tomsk zu ggehören. Sie durehzieht 'Jurkestin und Tramshaspien. - Gröbure Serien ron Brutrïgeln simet zu

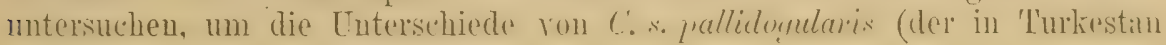
brütenden Form) zu bestätigen. 


\section{Luscinia svecica robusta (But.).}

Cyanecula suecica robusta Buturlin, Psoreia i Rusheinaia Okhota (Jagen \& Schießen) 1907, März, no. 6 und Orn. Monatsber. Mai 1907, p. 79 ("Kolyma's Delta“).

Große, dunklo, intensiv gefärbte Form mit großem rostroten Stern.

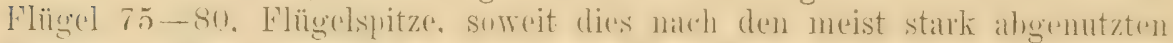

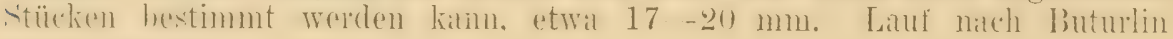
$27.5-28.5 \mathrm{~mm}$.

Buturlin gibt für seine robusta an: „Verbreitung von der unteren Tunguska und Ionjero bis zum Anadyr". Die Typen stammen ron der Mlündung des Kolyma-F'lusses. Die ron mir untersuchten Typen gleichen völlig den Brutvögeln ron der unteren Lena. Sie unterscheiden sich durch bedeutendere Größe und intensivere Färbung ron der schwedisch-nordrussisch-westsibirischen $L$. s. svecica, aber es bleibt festzustellen, wie sie sich ron der norwegischen $L$. $v$. gaetkei unterscheiden; es scheint, daß der Schmanz meist etwas kïrzer, nämlich nicht über $56 \mathrm{~mm}$ lang ist, während er bei gaetkei 56 bis $60 \mathrm{~mm}$ lang zu sein ptlegt. Das Blau der Kehle ist dunkel, der Rücken dunkel, der Schnabel lang. - Im Winter zieht die große nordostsibirische Form nach Birmah. Assam, Hinterindien und China. Es dürfte auch diese Form sein, die mitunter in Alaska bemerkt wurde; die nördlich von Irkutsk brütenden Vögel mögen auch noch dazu gehören. Es ist wahrscheinlicher, daß noch andere Unterschiede bestehen. als daß diese Form der der norwegischen Gebirge gleicht; Ähnlichkeit westeuropäischer und ostasiatischer Formen ist eine bekannte Erscheinung, völlige Gleichheit ist in

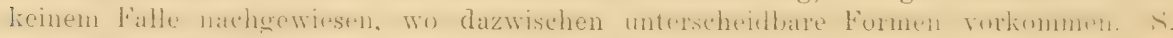
u. a. Falco 1905, p. 68 .

\section{Luscinia svecica cyanecula (Wolf).}

Weibsterniges Blaukehlchen.

Sylvia cyanecula WVolf, in Neyer \& Wolfs 'T'aschenb. d. deutsch. Vögelk. 1, p. 240 (1810deutliche Beschreibung des weißsternigen Bl. allein! „Im Anhaltischen, in Thüringen, Franken, der Wetterau").

Sylviı Wolfii Brehm, Beitr. z. Vögelk. II, p.173 (1822- Beschr. der sternlosen Varietät. Deutschland).

Cyanecula obscura Brehm, Handb. Naturg. Vög. Dentschl., p. 353 (1831- Rhein und Elbe, u. a. O.)

Cyanecula lencocyana Brehm, t. c., p. 353 (1831- Deutschland).

Cyanecula longirostris, major, minor Brehm, Naumannia 1855, p. 280 (Nomina nuda!)

Engl.: White-spotted Bluethroat. - Ital.: Pett'azzurro a macchia blanca.

ơ ad. im Hochzeitskleide: Leicht von dem von $L$. s. svecica und den andern vorhergehenden Formen zu unterscheiden, weil es in der auch dunkler hauen Kehle einen wie Atlas glänzenden reinweißen Stern hat: dieser Stern weehsert an Ausdehumg, ist aher fist stets arhehlich likeiner als der rote Stern von $L$. s. svecica und ist nicht selten verdeckt oder frhlt gänzlich ${ }^{1}$ ). IDe Oherseite ist kaum etwals (lunkler braun. Dils : ist nicht immer sicher ron dem anderer Fonmen zu unterscheiden, doch geht der schwarze Fleck an den Seiten der Kehle in der Regel weiter zum schniblel hin. die untere Kohle zeigt keine'n lenstruten Fleek und an den seiten der uberen findet sich selten Bban. - F'lügellänge sehr rariabul:

1) Nur im Herbste hat der Stern oft einen röstlichen Anflug, im Frühjahr erlegte Stïcke haben anscheinend imner rein weißen oder fehlenden Stern. 
36 alte $\sigma^{\pi}$ messen $71-81 \mathrm{~mm}$, die kleinsten o sind je ein Brutrogel von

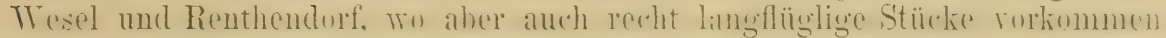
- heirle hahen alhgenutzte Schwingen, dünften also etwas zu klein gremesiren sein. Flügel von 80 und $81 \mathrm{~mm}$ sind selten, meist messen sic etwa $74-77 \mathrm{~mm}$, mitunter kommen Zwerge von Flïgeln von nur 69 und $70 \mathrm{~mm} \mathrm{vol}$.

Brütet in Mittel-Fureprat Frankreich. Belgien. Hulland, niedere Teile der sehweiz (anscheinend vereinzelt in der Lumbarlei). Dentschland. Öster-

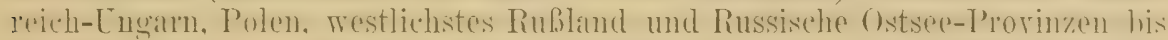

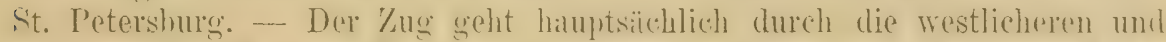
mittleren Teile kurnas (Spanien. Südfrankroich, Italien) nach Nordwest-Afrika (Manoklo, Algerien. Tumesien), in geringerex Anzahl nach Nordnst-Afrika.

Bewohnt Sümpfe, sofern in denselben Buschwerk vorkommt, Fluß-, Teich- und Seeufer, alte Ausstiche wie Kies- oder Lehmgruben, und zwar fast ausschließlich dicht rerwachsene Weidengebüsche, ist daher lokal verbreitet, stellenweise gar nicht selten, anderwärts nicht zu finden. Hält sich viel am Boden auf und schlïpft meisterlich durch das dichteste Buschwerk. Lockstimmen wie "fied, fied" und "tack tack". Gesang äußerst wechselreich, mit einigen schönen flötenden Tönen, alle Strophen durch ein zischendes Schnurren verbunden; außcrdem sind die meisten ô hervorragende "Spötter". Der Gesang wird meist im Sitzen, gewöhnlich auf einem.Busche, mitunter in schnurrendem Herumtrippeln am Erdboden, manchmal auch in schwebendem, kurzen Fluge rorgetragen. Das Nest steht im dichtesten Pflanzengewirr, im Wurzelwerk und hohen (irrase, im Schutze ron Büschen, an Böschungen und dgl., immer sehr versteckt und äußerst schwer zu finden. Es besteht aus Würzelchen und Halmen und etwas MInos auf einem ziemlich unfangreichen, leicht zusammengeschichteten Unterbau von trockenen Blättern und ist mit Wolle und Haaren ausgefüttert. Die 5-6 Eier findet man regelrecht wohl kaum vor dem 20. April, aber meist im Mai. Sie sind sehr variabel, selbst in der Gestalt ändern sie von der gewöhnlichen Eiform zu ganz dickbauchiger und länglich dünner ab. Die Grundfarbe ist ein mattes Blaugrün oder Grünlichbraun, worauf rötlichbraune Wölkchen und Flecke stehen; häufig ist diese Wölkung so dicht, daß sie die Eier völlig bedecken, so daß sie rollkommen kleinen Nachtigall-Eiern gleichen, manchmal so spärlich, daß sie den Eiern von Pratincola vubicola stark ähneln. 100 Eier (88 aus Holland ron Jourdain und 12 von Rey gemessen) messen im Durchschnitt $18.91 \times 14.24$, Maximum $20.5 \times 14.5$ und $19.2 \times 15.1$, Minimum $17.1 \times 14.3$ and $19.1 \times 12.5 \mathrm{~mm}$.

\section{Luscinia svecica volgae (Kleinschm.).}

Erithacus volgae Kleinschmidt, Falco III, no. 2, 1).47 (1907- untere Wolga. Typus ron Sarpa).

ơd. Stern wohl meist weiß (aber variierend und mitunter rostrot mit weißem Riumle oder ganz dunkel mstrot. Sitülie mit rostrotem Stern sind ron L.s. srecica kaum zu unterscheiden, doch ist der Stern kleiner, besonders schmäler: Flügel von 14 Stïck $70-74$, einmal $75 \mathrm{~mm}$. Das Blan der Kohle bei frischremanserten Frïhlingsvögeh hasser, im Sommer tiefer blau. Die Zïgel mitunter mit etras hlatem sebimmer. Sonst wie L. s. cyanecula.

Das Brutgehiet dieser. Form scheint die Ehenen Siidrußlands (Poltawa, Charliow, Lntere Wulga - remutlich nördlich his Moshiulu) und des westlichen Transkaspiens zu umfassen. Im Winter in Ägypten. 


\section{Luscinia svecica magna (Sar. \& Loud.).}

Cyanecula wolfi magna Sarudny \& Loudon, Orn. Jahrb. 1904, p. 225 (Luristan, Typus von Bidesar in Arabistan).

Kehle ganz blan oder mit kleinem weißen Stern. Unterschoidet sich

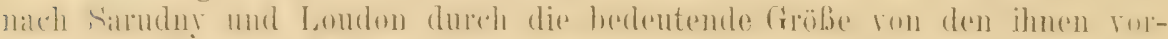

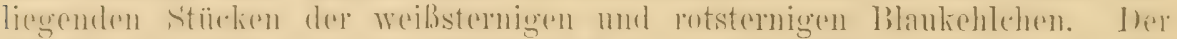

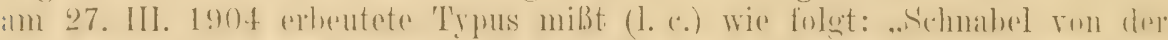

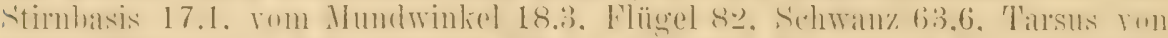

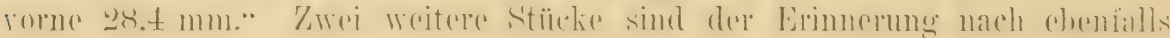
anffallend giob.

Arabistan, Südrest-Persien. - Wahrscheinlich ist es auch diese Form, dio in Armonien briitet.

\section{Luscinia svecica abbotti (Richm.).}

Cyanecula abbotti Richmond, Proc. U. S. Nat. MIus. XVIII, p.48t (1895- Nubra-Tal in Ladakh).

Stern der alten of weiß oder rostrot, weißs mit rostrotem Anfluge oder

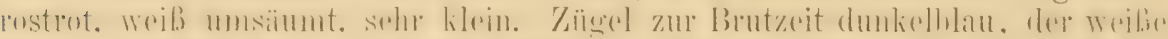

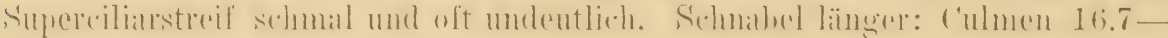
$17.5 \mathrm{~mm}$. Flïgol $72-74 \mathrm{~mm}$, da indosson nux abgenutzte Sommerrögel

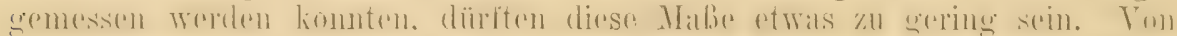
L. s. svecica und seinen näheren Verwandten dureh den viel kleinoren Stern zul unterscheidon.

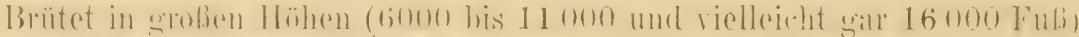

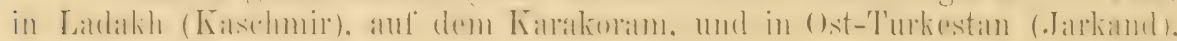
Pamir und Alai-Gebirge.

L. brunnea (Larvivora brumnea Hodgson 1837, Erithacus brumneus Cat. B. Brit. IIus. V, p. 302, Larvivora brunnea Oates, B. India I, p. 182) bewolnnt Indien.

\section{(xattung ERTTHACUS Cuvi"x 1801.}

Synonyme: Erythacus, Dandalus, Rubecula, Rhondella und "Erithacus Dandalus" Kleinschm. - So gern ich auch in der Vereinigung von Gattungen recht weit gehe, kann ich es doch nicht für nötig halten, die Rotkehlchen mit den Nachtigallen, Blaukehlehen, Larvivora u. a. m. zu vereinigen - es bleibt in dem Falle stets die Inkonsequenz der Isolierung von Phoenicurus $(-$ Ruticilla), die man dann unbedingt auch mit hineinzieheu müßte: dadurch aber würde die Übersicht nicht erleichtert, sondern erschwert werden.

Steht Luscinia sehr nahe, das Gefieder aber ist weicher und reicher.

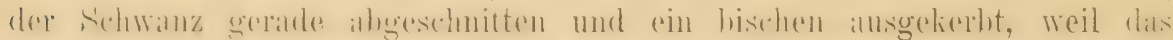

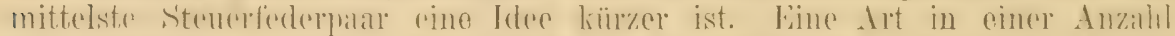

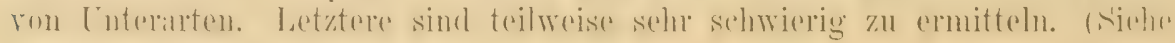
Journ. f. Orn. 1903, p. 346.)

\section{Erithacus rubecula rubecula (L..).}

\section{Rotkehlchen.}

Motacilla Rubecula Linnacus, Syst. Nat. Ed. X, p. 188 (1758 - „Europa“. Als terral typica ist Schweden zu betrachten, nach dem 1. Zitat: Fauna suecica no 232).

Dandalus pinetorum, foliom und septentrionalis Brelım, Isis 1828, p. 1280 (Nomina nuda!) 
Rubecula pinctorum Brehm, Handb. Naturg. Vögel Dentschl., p. 360 (1831 - „unsere Fichtenwälder").

Rubecula folionum Brehm, t. c. p. 360 (1831- deutsche Laubhölzer.)

Rubecula septentrionalis Brehm, t. c. p. 361 (1831- in Deutschland Durelizugsrogel, auch bei Kiel).

Erithacus rubecula major Prazák, Journ. f. Orn. 1897, p. 249 (Gebirgsform).

Engl.: Continental Robin. Franz.: Rouge-gorge. Ital, : Pettirosso. Schtred.: Rödhake-Sångaren.

or q ad. Vorderstirn, Zügel, Kopf- und Halssoiten, Kinn, Kehle und

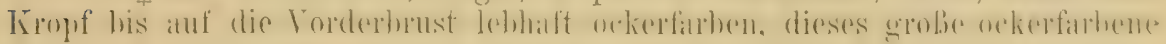
Fold von ciner auf der Stin weniger, an den Seiten der Vorderbrust am

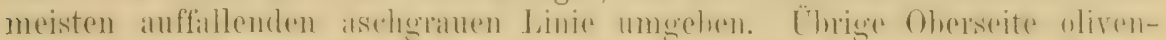

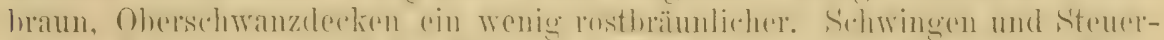

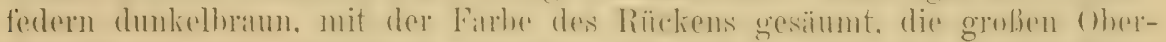

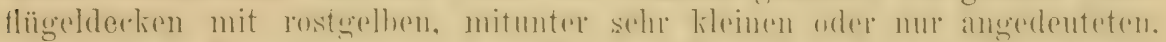

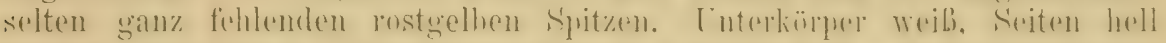

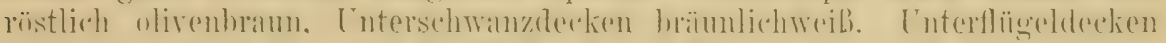

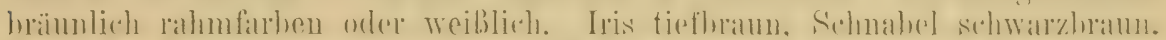

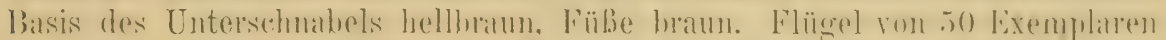
$71-75$, seltener (wohl nur o) 69-70, Schwanz etwa 57-62, Culmen 12.3-15, Lauf etwa 25-27 mm. - o im allgemeinen kleiner, sonst ganz.

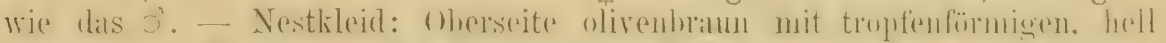

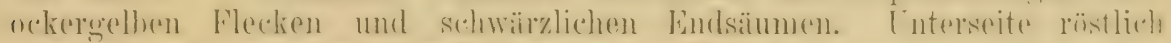

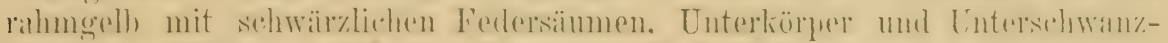

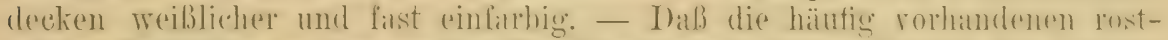

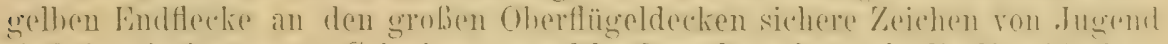

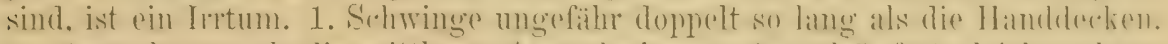
2. etwas bänger als die mittleren Amosehwingen, 4. und 5. fast gleieh und am längsten, 3. und 6. nur wenig kürzer, 7. bedeutend kïrzer als die 6. und

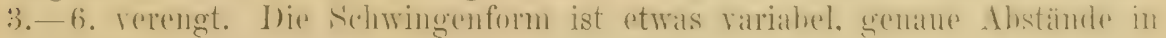
mm sind nicht anzugeben, sie entspricht aber fast immer del oben angegebenen.

Das Rotkoblchen brütet in Emopa, etwa vom $68^{\circ}$ nördl. Breite, vom Atlantischen Ozean im Westen bis zum Ural im Osten, ankerdem im sïdliehen Westsihirien und in der Kínlturzone Wrest-Turkistaus. Von wo irh ron Kutsehento am 10. Juni und 25. August gesammelte stiucke untersuelite. — Ühermintert in Peesien, Ägypten und in den ()asen der nördliehen s'ahara.

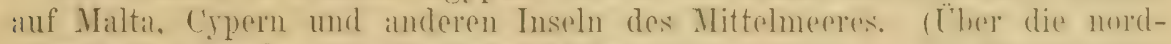
atlantischen Inseln und Norelwest-Afriká siehe unten.) - In Skandinarion

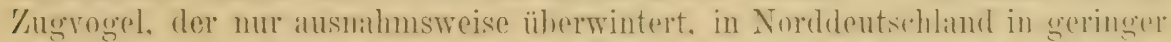

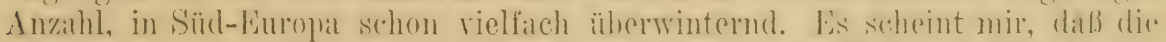

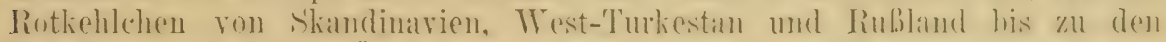

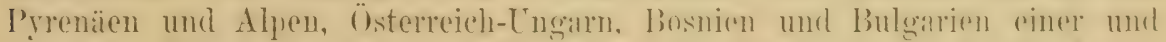
derselhen Form angehören, während in Cirolihritannien und Irland, im Kaukasus, in Persien. auf Sirdinien und in Nordwestativik dentlieh unter-

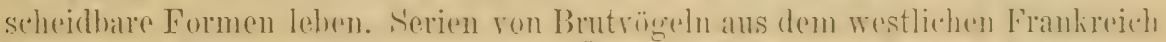
kounte ich leider nieht untersuchen. Gher die folgenden formen linnnte inh mach dem von mir untersuchten Material nicht zu sicheren shehliissen zelaugen:

Spanien: Es scheint, daß spanische Brutrögel (im Winter kommt auch das typische nord- und mitteleuropäische Rotkehlchen vor) eine lebhafter gefärbte, mehr 
braunrote Kehle und Vorderbrust haben, während die Oberseite mehr olirenbraun sein dürfte, als bei den englischen Rotkehlchen. In Spanien anscheinend nur im Gebirge (Jourdain in litt.).

Italien: Im Winter findet sich das nordische Rotkehlchen, während manche Stiicke - wahrscheinlich Brutrögel - den spanischen Exemplaren gleichen oder der Form ron Sardinien sehr nahe kommen.

Griechenland: Ich konnte keine Brutvögel untersuchen. Nach Reiser gleichen sie den zentral- und nordeuropäischen Vögeln ,im Gegensatze zu den südwesteuropäischen“.

Madeira: Reichenow trennt die Form ron Mladeira im Journ. f. Orn. 1906, p. 153 unter dem Namen „E. r. microrhynchus" ab, nach 2 Bälgen von Honte, die sich durch auffallend kleinen Schnabel und weniger grünen, mehr bräunlichen Ton der Oberseite auszeichnen sollen. Nach Untersuchung von 12 Exemplaren von Monte und anderen Plätzen auf Madeira kann ich diese Unterschiede nicht bestätigt finden. Einzelne Stïcke haben jedoch eine ziemlich dunkle rote Kehle, die meisten aber gleichen solchen aus Nord-Europa. Flügel $69-72$, einmal 73 , einmal $68.5 \mathrm{~mm}$.

Gomera, Palma und Hierro (westliche Canaren): Die Fürbung der Kehle und Vorderbrust ist meist dunkler, als dies bei Mittel-Europäern im allgemeinen der Fall ist, einige der 6 untersuchten Stücke sind aber nicht zu unterscheiden. An E. $r$. superbus kommen sie übrigens nicht im Entferutesten heran. Scheint etwas größer als Stïcke von Madeira- Flügel 70-75, einmal $68 \mathrm{~mm}$. (Auf Fuertaventura dïrfte das Rotkehlchen nur Zugrogel sein.)

Azoren: Im allgemeinen ist die Oberseite recht dentlich mit Grau ibertiuncht, dies aber ist auch bei nord- und mitteleuropäischen Stücken oft der Fall, und die meisten Stücke sind nicht zu unterscheiden. Flügel $71-75$, einmal $76 \mathrm{~mm}$. Das Rotkehlchen ist Brutrogel auf Santa Maria, San Miguel, Terceira, San Jorge, Pico, Fayal und Graciosa.

Die Formen ron Spanien und Italien, sowie die von den westlichen Canaren werden vermutlich eines Tages nach Untersuchung reicheren Materials (oder ohue fernere Kenntnis nach meinen obigen Bemerkungen ron einem homo nominum novorum cupidus) benannt werden.

Das Rotkehlchen lebt in Wäldern mit reichlichem Unterholze, dichtverwachseuen Hecken, Parkanlagen und buschreichen Gärten. Es hält sich viel am Boden auf, sitzt aber während des Singens immer hoch, oft in beträchtlicher Höhe. Die Lockstimme ist das bekannte "Geschnicker" oder nur ein ein bis zweimal wiederholtes .djick, djick", außerdem hört man oft von ruhig dasitzenden Vögeln ein dünnes, langgezogenes "Sih". Der Gesang wird verschieden beurteilt; jede Strophe wird von hervorgewürgten, dünnen. scharfen Lauten eingeleitet, denen ein angenehmer Triller folgt, der wieder mit dünnen, berausgequälten 'Tönen abschließt, gute Sänger singen länger und lassen dem Triller lautere, schmelzende, schwermütig klingende Flötentöne folgen. Das Nest steht meist am Boden, an Böschungen, Grabenrändern, in halb vermoderten Baumstïmpfen, an Baumwurzeln, am Fuße von Stämmen, auch im Gerank von Lauben und Gartenhäusern, seltener in Mauerlöchern und Kopfweiden. Es besteht größtenteils aus Moos und ist mit feinen Würzelchen und Haaren, oft auch mit Federn ausgefïttert. Es finden jährlich zwei Bruten statt. Die 5-6, selten 7 Lier sind rahmfarben gelblich oder rötlichweiß, sehr selten mit griinlichem Schimmer, mit rotbraunen Flecken und Punkten, besonders am stumpfen Ende, und gräulichen Schalenflecken, oder aber mit braunrötlichen Wölkchen über und über bedeckt. 150 Eier (81 Bau, 55 Rey, 14 Jourdain) messen im Durchschnitt $19.36 \times 14.79$, Maximum $21.6 \times 15.7$ und $20.5 \times 16.3$, Hinimum $17.5 \times 1 \pm \mathrm{mm}$. Kleinschmidt gibt für ein abnorm großes Ei $22.5 \times 15.2$ an. Mittleres Gewicht nach Rey $133 \mathrm{mg}$.

\section{Erithacus rubecula melophilus Hart.}

Rubecula familiaris Blyth, Field Naturalist I, p. 421 (1833- nomen nudum!). Erithacus qubecula melophilus Hartert, Nov. Zool. 1901, p. 317 (britische Inseln). 
Unterscheidet sich von $E$. $n$. mbecula durch gesättigtere, viel mehr rosthame Oherseite und viel dunklere, mehr resthrïunliche hehle. Auberdem sind die Kïrperseiten illsgedehntre und gesittigter rusthrann, si) dab

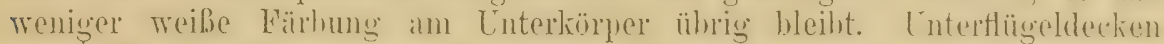
rostgelblich, an Liande rostrot gefleckt. [intersehwanzdechen hell rostlarhen. Schuabel merklich dicker und plumper. Flügol vou 36 or o $71-76 \mathrm{~mm}$. Flügelspitze otwas stumpfer, gerundeter, jedoch variabel.

Großbritannien und Irland, von den Orkneys und Hebriden bis zur Insel Wight. - Stïcke vou den Normannischen Inseln, wo die Art häufig ist. komnte ich nicht untersuchen, doch kïmnte dort die kontinentale form seßhaft sein.

Standrogel auf den britischen Inseln. Die Jungen sollen von den Alten im Herbste von den Brutplätzen vertrieben werden, daß sie aber Zugvögel sind, scheint ein Irrtum zu sein. Ist in England ein zahmer, vertrauter Vogel, der nicht nur in Wäldern, sondern auch in Gärten ïberall brütet. Nest bäufiger erhöht, als in Deutschland, gern an und selbst in Gebäuden, in offenen Baumhöhlen, im Efeu, in Heuschobern. Allgemeiner Liebling des Volkes. Herbstgesang sehr lebhaft und früh beginnend. Die Eier sind im Durchschnitt etwas größer: 100 Eier messen nach Jourdain (in litt.) im Durchschnitt.19.87 $\times 15.53$, Maximum $22.3 \times 15.5$ und $20.5 \times 17$, Minimum $18 \times 16.6$ und $20.4>14.1 \mathrm{~mm}$.

\section{Erithacus rubecula sardus Kleinschm.}

Erithacus Dandalus sardıs Kleinschmidt, Falco 1906, p. 71 (Sardinien).

Oherseite dunkler, mehr olivenfarhen und weniger rosthrämulich, als hei E. r. mberulu, Gröle wie hei letzterer Form. Kohle und Vorderhrust nahrzu so rothräunlich wie hei $E$. $r$ melophilus. Oberschwoundeclinn und Wumel der. Steuerfederu kanm oder gar nicht röstlicher als der Rücken.

Standvogel auf Sardinien, wo im Winter anch E. $r$ mibecula vorkommt, und in den Bergwäldern von Korsika in Höhen von über 2-3000 FuB. Flügel von 11 alten Vögeln nach Kleinschmidt (in litt.) 70-74 mm. (Ich kounte zwar leine korsikiuischen Brutrögel vergleichen, nehme aber an, daß sie derselben Form angehören.)

\section{Erithacus rubecula witherbyi subsp. nw:}

Kehle und Vorderbrust so bräunlichrot wie bei E. r. meloplitus, Oberseite etwas dunkler als bei $E$. r. mubcule, aber nicht so dunkel olivenbraun wie bei $E$.r. sardus und nicht ganz so rostfarben wie bei $E$. r. meloplitus. Unterflügeldecken ebenso rostgelb und rastront gertfeckt wio bei melophilus. Schnabel gestreckt, nicht so plump wir be letzterer Eum. aher meist etwas länger, als bei $L$. $r$. rubecula. Flügel von 4 onad. 69-71, von 2 o etwa $67.5 \mathrm{~mm}$. Offenbar kleiner als melophilus. 'Typus ỡad. Hamman R'Hira, Nordalgerien, 27. IV. 1904, No. 100, von H. F. Witherby gesammelt. Im Tring Museum.

Brut- und angenscheinlieh Standrogel in mïrdlinhen Atlis: Nördlichstes

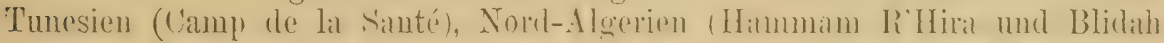
Glacière). und im Atlas in Marokkn. I)ie Form der Flügelspitze ist valriahel. scheiut aber im allgemeinen stumpfer zu sein. - Vielleicht könnten die spanischen Brutrögel mit dieser Form vereinigt werden. 
Scheint, wie die meisten Atlas-Vögel, spät zu briten. Vgl. Witherby, Ibis: 1905, p. 184. E. r. rubecula ist zur Zugzeit in Algerien anzutreffen, bei Alger lsäufig.

\section{Erithacus rubecula superbus Koen.}

Erithacus superbus Koenig, Journ. f. Oru. 1889, p. 183 (höhere Regionen Teneriffas). Abbild.: Journ. f. Orn. 1890, Taf. III. Eier ebenda, Taf. VIII, Fig. 4.

Oberseite dunkler, mehr olivenbraun, als bei E. r. mbecula, viicht an-

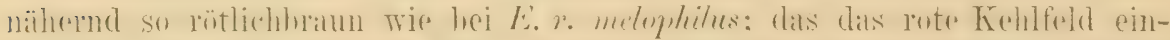
fassude gratue band meist etwas mehr anf die Malsseitem ansegedehnt, häufig hat anch ein grober 'Teil der oherseite einen asehgraurn Influg. Das Rot der Kehle und der Vorderbrust sehr dunkel, noch rötlicher als bei E. $r_{\text {. }}$ melophilus. Körperseiten sehr hell, Unterkörper bis zur Brust weib ohne

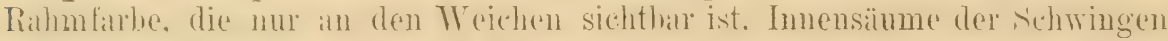
lebhaft gelhlich ocherfarhen. 2. Sehwinge kitum läuger als die Armsehwingen,

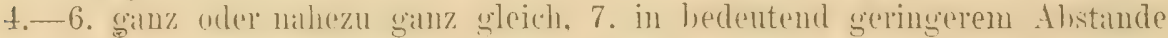
von der 6. und fast oder mitunter völlig so lang wie die 3., die Flügel-

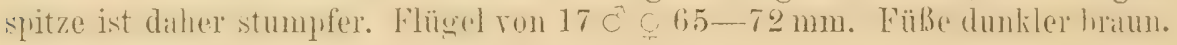

Bewohner der Berge von 'Tenerife und Gran Canaria, in Höhen von $400-2000 \mathrm{~m}$.

Das Brillantrotkehlchen lebt im Unterholze der Wälder, wo der Boden üppig bewachsen und feucht ist, oder in der Nähe ron Quellen und Bächen. Geeigueten Ortes brütet es auch in Gärten. Das Nest steht anscheinend sowohl am Boden, im Heidekraut und Hoos, als in Büschen (Lorbeer, Palmen, Orangen) doch liegen hierüber wenig Mitteilungen ror. Die $4-5$ Eier sind oft, aber nicht jmmer sicher von denen von E.r.mbecula zu unterscheiden. Während bei den europäischen Rotkehlchen nur selten und meist nur einzelne grünliche Eier vorkommen, haben bei $E$. r. superbus sehr häıfig alle Stücke eines Geleges eine blaß blaugrünliche Grundfarbe, oder sind milchweiß. und die Zeichnung ist meist eine gröbere. (S. die oben zitierte Abbildung.) Dies. trifft aber nicht immer zu und manche Stücke sind ununterscheidbar. Der Gesang scheint immer kurz und abgerissen zu sein, etwa wie bei sehr schlechten Sängern in. Europa. 26 Eier von Teneriffe (20 Jourdain, 6 Koenig) messen im Durehsehnitt $19.99 \times 15.06$, Maximum $22.4 \times 15$ und $20.3 \times 16$, Ilinimum $18.9 \times 14.9$ und $19.4 \times 14.5 \mathrm{~mm}$.

\section{Erithacus rubecula hyrcanus Blanf.}

Withacus hyreanus Blanford, Ibis 1874, p. 79, (Provinz Ghilan in Persien).

Abbild.: Eastern Persia II, Tal. XV, Fig. 1; Dresser, B. Europe IX, Taf. 644.

Oberseite stark rötlich, aber nicht so lebhaft rotbraun, wie bei $E$. $r$. melofhilus. smmlem mit mehr gräulicher Beimiselnug. Längere oherschwanz-

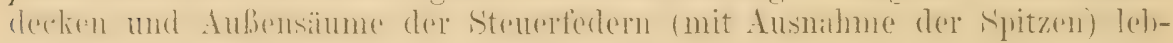
haft rostfarbig. Kehle und Vorderbrust fast und mitunter volliommen so lebhaft wio bei $E$. $r$ superbus. Weichen braun, Nitte des Unterkörpers rein weiß. Schnabel länger und dünner; Culmen etwa $17-17.5 \mathrm{~mm}$. Flïgel spitz, etwa wie bei $t$. r rubecula geformt.

Nord-Persien. Dio in Transkaspien brïtenden Stücke (Aschabad, Merw, an den Flüssen Murgab und T'edjen) gehören vermutlich zu dieser Form. Sie dürfte anch in Armenien rorkommen, dem ein ơ von Batum am Kaspischen Meere gehört entschieden hierher. Scheint in Süd- und Ost-Persien nicht zu brüten, wurde aber im Herbst und Winter zu Fa am Persischen Neerbusen gesammelt. 


\section{Erithacus rubecula caucasicus But.}

Erithacus rubecula cancasicus Buturlin, Oru. Monatsber. 1907, p. 9 (Kaukasus und Transkaukasien).

Steht zwischen E. r.rubecula und E. r.hyrcanus. Letzterem ähnlicher

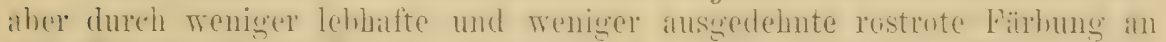

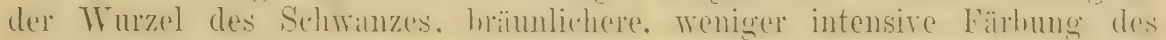

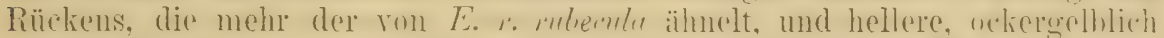

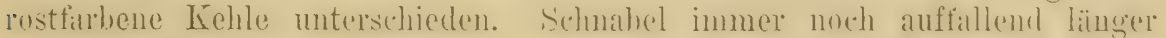
als bei rubecula, aber meist kïrzer als bei hyrcanus; Brutvögel im abgetragenen Gefieder sind mitunter schrverer von E. r. rubecula zu unterscheiden. Sehr schön gekennzeichnet von Dresser, B. Lurope IX, p. 47 (,Obs.") aber falsch gedeutet.

Kankasus; Brutvogel an der Nordseite und Südseite. Bei Lenkoran iiherwinternd.

\section{Gattung IRANIA De Filippi 1865.}

flureh den sehe hreitferdrigen wohl abgerundeten Sechwanz ron Lnwinin,

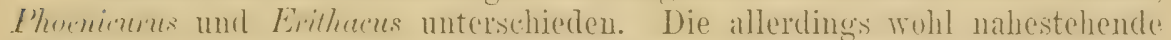
afrikanische Gattung Cossypter hat eine ganz andere Schwingenformel und

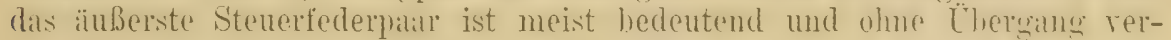
kiüzt. Schnabel sehmal und spitz. 1. Schwinge nur 2-4.5 mm lïnger als die Handdecken, 2. gleich der 6. oder zwischen der 5. und 6., 3. und 4. gleich und am lïngsten, 3.-5. an der Spitze der Außenfahue verengt.

\section{Irania gutturalis (Guérin).}

Cossypha gutturalis Guérin, Rev. Zool. 1843, p. 162 (Abyssinien).

Irania Finoti de Filippi, Arch. Zool. Anat. usw., Genova II, p. 381 (1863- Persien). Saxicola albigularis Pelzeln, Sitzber. A. Wiss. Wien XLVIII, p. 150 (1863 - Kleinasien). Irania albigula Serrertzoff, Turkest. Jevotn. (in Izv. Obshch. Moskor. VIII, 2) p. 122 (1873- westliches 'lurkestan). Übers. in Zeitschr. ges. Orn. IV, p.61.

Abbild.: Dresser, B. Europe IJ, Taf. 53, 5t; Ei: Dresser, Eggs. B. Europe, 'Taf. Pratincola, Ruticilla usw, Fig. 26.

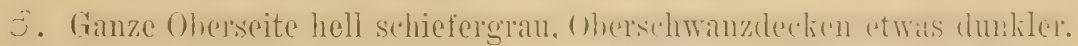

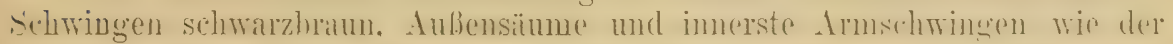
Rücken. Steuerfedern schwarz. Superciliarstreil weib. Zü̈grel. Konf- mul Kehlseiten weil. Nitte der Kehle weili, einen dreied ligen, nath unten zu

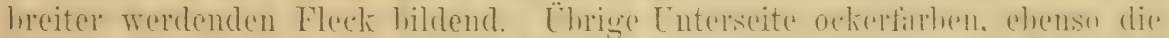
Enterflügeddecken und Axillaren. Unterschwanzdedien, Banth und Vitte des untern Teiles des Lnterkïrpers weiß. Sehenkelhetiederung grau. Iris hraun.

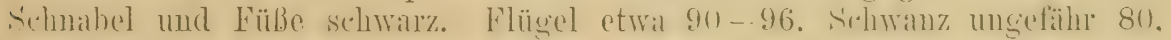
Lauf 25, Culmen 18-20 mm. Die Unterseite wird im Frühjalı blasser und rariert anffallend stark individuell. vielleicht nich derne .17ter. Mitunter - vielleicht nur bei jüngeren Stücken - reicht das Schwarz der Kopfseiten in einer mohr oder minder geschlossonen Binde um den

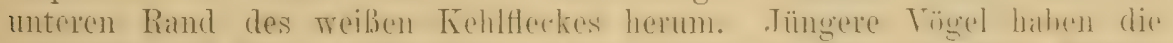

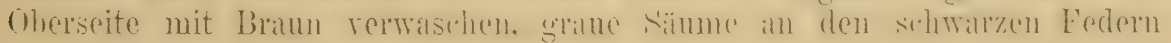
der Kehlseiten und weißliche an den Brustfedern. - o ad. Oberseite 
bräunlich gran einschließlich der Zügel, Kopf- und Kehlseiten, Ober-

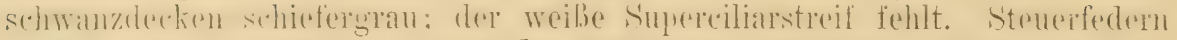
nucht so roin seluwall wie beim of Kehlseiten und Brust fahlgralu mit hell

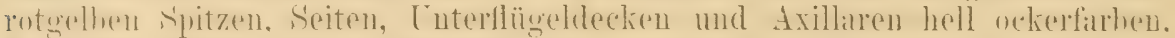

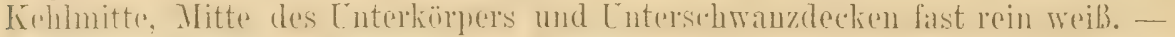

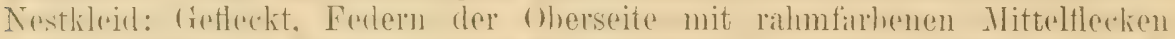

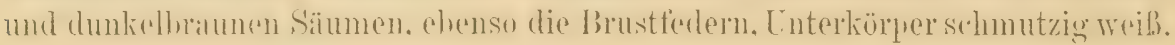

Brutvogel in Kleinasien, Palästina, Persien und West-Turkestan. Ich

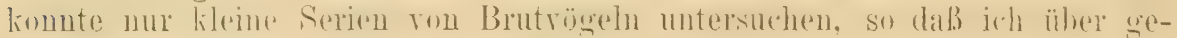

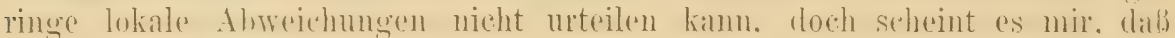
nur eino Form anzuerkennen ist. - Im Winter in Süd-Arabien und Abyssinien, sogar bis 'Taweta in Ost-Afrika.

Gebirgsvogel, der felsiges, steiniges, mit Buschwerk und Bäumen bestandenes Gelände bewohnt. Der Gesang besteht aus prachtvollen glockenartigen Tönen und würde mit dem der Nachtigallen wetteifern, wenn ex länger wäre. Soll häufig den Schwanz ausbreiten, wippen und aufrichten - an die Schwanzbewegungen von Agrobates (S. 603, 604) erinnernd. Das Nest steht niedrig in Büschen oder Bäumchen und nach Danford in lockeren Steinmauern. Es besteht aus trockenen Halmen, Zweiglein, Rindenstücken und Gräsern, und ist mit Pflanzenwolle, feinen Gräsern, IVollenfäden und Lappen ausgefüttert. Die 4-5 Eier werden im Mai gelegt. Sie sind hell grünlichblau vder bläulichgrïn und mit gelblich rostbraunen Fleckehen bedeckt. Sie messen etwa $20-22.5 \times 15-16 \mathrm{~mm}$.

\section{Gattung HODGSONIUS Bp. 1850.}

Durch kurze stumpfe Flügel und langen stark gestuften Schwanz

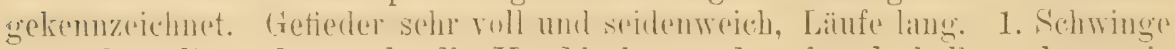
etra doppelt so lang, als die Handdecken und mehr als halb so lang wie die 2., welche höchstens otwa $1-2 \mathrm{~mm}$ länger ist als die Armschwingen, 4. und 5. gleich und am längsten. Eine Art, Geschlechter rerschieden.

\section{Hodgsonius phoenicuroides (Gray).}

Bradypterus phoenicuroides Hodgson, Gray's zool. Mise., p. 83 (184t- nomen nudum!) Gray, Cat. Mamm. etc. Nepal pres. Hodgson, p. 70, 153 (Nepal).

Dumeticola cyanocarpa Hume, Ibis 1872, p. 108 (q Sikkim).

Callene hodgsoni Jerdon, Ibis 1872, p. 132 (ex Mloore MS., Nepal).

Abbild.: Hume \& Henderson, Lahore to Yarkand, Taf. 6. (Schwanz falsch gezeichnet).

Oad. Oberseite schieferblau, Afterflügel mit großen weißen Feder-

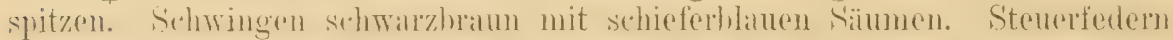

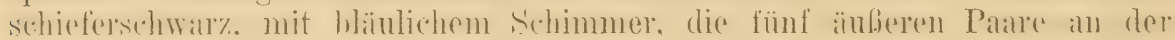

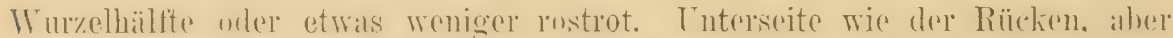

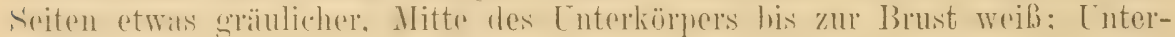
schwanzdecken mit breiten weißen Spitzen. Iris braun. Schuabel dunkel

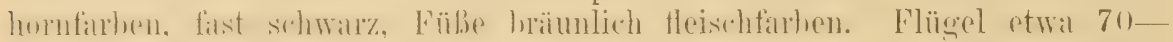

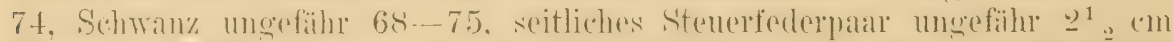

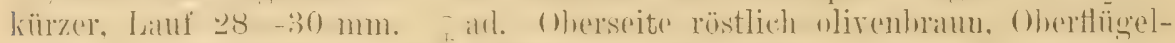

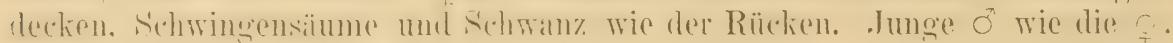
Himalaya vou Kaschmir his Butan, auBerdem das angrenzende Tibet 
und die westehinesischen Gebirge bis zu den 'Tsin-ling-Bergen und SüdKansu $\left.{ }^{1}\right)$.

Osmaston entdeckte Nester und Eier im Tons-Tale im westlichen Himalaya zwischen 10000 und $12000 \mathrm{engl}$. Fuß. 12 in der ersten Hälfte des Juni gefundene Nester enthielten je 2-3 Eier. Die Nestel stehen in niedrigen Büsehen 1-3 Fuß über dem Erdboden im offenen Buschwalde. Sie sind tief napfförmig und bestehen aus groben Grashalmen, mit feinen Halmen ausgefüttert. Die Eier sind einfarbig dunkelblau. 18 Eier messen im Durchschnitt $22 \times 16$, Maximun 21-17, Minimum $20.8 \times 15,5 \mathrm{~mm}$.

(Nicht allzu weit entfernt ron dieser Gattung dürften die tropisch indischen Genera Notodela und Callene stehen. Erstere geht mit Notodela leucura (Hodgs.) bis in Höhen von fast 9000 engl. Fuß. Das $\vec{f}$ ist oben schwarzblau, unten schwarz mit einigen blanen Säumen, Stiruband und kurzer Supereiliarstreif lebhaft kobaltblau; an den äußeren Steuerfedern große weiße Partien, an den Seiten des Halses ein verdeckter weißer Fleck, q braun. Vgl. Uates, Fauna Brit. India, Birds II, p. 112.)

\section{Gattung GRANDALA Hodgs. 1842.}

Die systematische Stellung dieser Gattung wird verschieden beurteilt. Sie scheint mir nicht allzuweit von Ruticilla und Monticola zu stehen, ist aber sehr eigenartig. Seebohm und Kleinschmidt rereinigten Grandala mit Sialia, einer ähnlichen rein amerikanischen Gattung, in deren Nähe sie auch Sharpe noch 1903 stehen lieB, während Oates ihr eine Stellung zwischen "Adehura" - einem echten Phoenicurus aber mit schwarzem Schwanze - und Notodela einräumt. Ich stelle sie zu den aberranten Gattungen, an das Ende der "Erdsänger".

Der Flügel ist sehr lang und spitz, ein idealer Wandervogel-Flügel ${ }^{2}$ ), derhe scheint sein besitzer absolut nicht zu wandern. 1. Sehwinge klein und

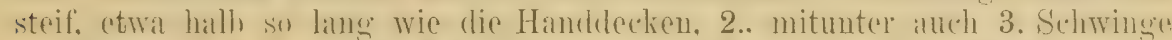
am längsten, 3. nur etwa 2 mm kür\%er uder ehense lang. Filügelspitze etwil $7 \mathrm{~cm}$, also fast halb so lang wie der Flügel. Schwanz etwa $1 \mathrm{~cm}$ weit ausgeschnittell. Lauf geschient, etwa ein Viertel so lang wie der Schwanz, Gefieder sehr dicht (pelzig), voll und glatt. Schmabel dïun und gerade, etwa halb so lang wie der Kopf. Geschlechter verschieden.

\section{Grandala coelicolor Hods's.}

Grandala coelicolor Hodgson, Jouru. As. Soc. Bengal XII, p. 447 (1843- NepaI).

Grandala chistacea Hodgson, Tafel zu oben genannter Seite, 147.

Abbild.: Gould, B. Asia IV, Taf. 34.

ơad. Ober- und Unterseite indigoblau, im Herbste fast glanzlos und

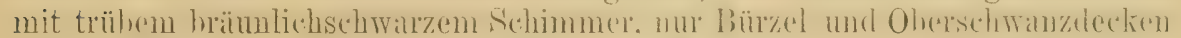

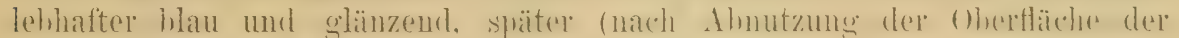

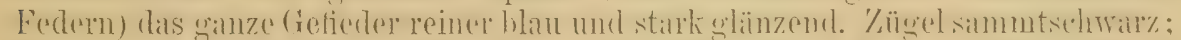

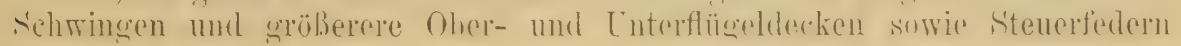

1) Nach dew untersuchten Material scheint'es, daß chinesische Stiicke dunkler sind, als solche aus dem Himalaya, da aber erstere aus dem Frühjahr und Sommer, letztere fast nur aus dem Herbst und Winter stammen, konnte ich nicht zu sicheren Resultaten gelangen.

$\left.{ }^{2}\right)$ Solch langspitzige $W$ anderflügel finden sich mitunter auch bei anderen Hochgebirgsvögeln. 


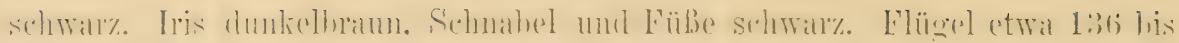
147. Schwanz etwa 93-100, Lauf 30, Culmen 20-23 mm. - ad. Obel-

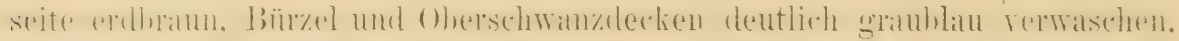

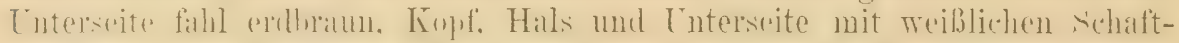

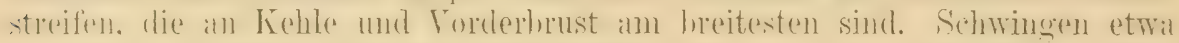
1/s ron der Basis mit einer weißen Binde, die an den Innenfahmen schon an der 6. oder 7. undentlicher wird, von der 5. an an der Außenfahme fehlt

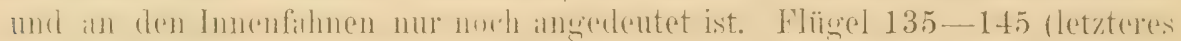
vielleicht $\left.\sigma^{x} j u r.\right)$. Juv. Dem c ähnlich. - Es seheint als ob im allgemeinen die Stücko ron Kansu und vom oberen Hwang-ho etwas kleiner seien (o'

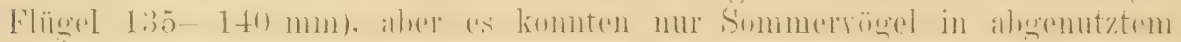
Gefierler untersucht werien.

Himalaya von Garhwal bis Sikkim, 'Iibet und die Gebirge ron NordwestChina his Kinsu.

Dieser prächtige Vogel bewohnt die höchsten Regionen der Gebirge. Er wurde noch in Höhen ron 17000 und nicht niedriger als $12000 \mathrm{FuB}$ gefunden, in wild zerrissenen Felspartien an der Schneegrenze und auf spärlich mit kriechenden Alpenkräuteru bewachsenen Alpenwiesen. Przewalski sagt: „auf dem Boden erinnert der Vogel au den Steinschmätzer und z. 'T. an den Mauerläıfer, der Flug aber ähnelt dem der Schwalben und Bienenfresser. Die Stimme besteht aus einem lauten abgebrochenen, piependen 'Tone. Ende Juli mauserten die Alten".

\section{Gittung FNICURUS T'emminck 1824.}

(Enicuns wurde meist in Henicums verbessert.) - Systematische Stellung der Gattung nicht sicher. Oates stellt sie zu den "Ruticillinae", denen sie in der Schienung des Laufes und der Fußbildung ähnelt. Der

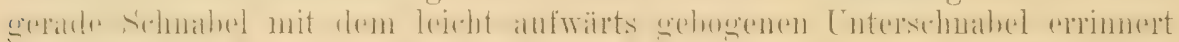

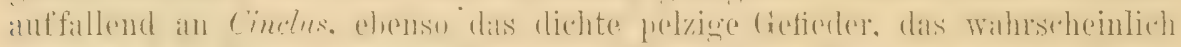

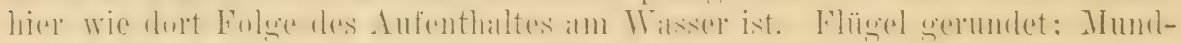

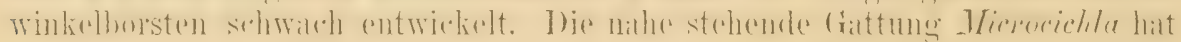
einen, an den von Cinclus erinnernden, moschusartigen Geruch. Nach der Form

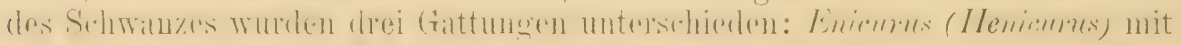

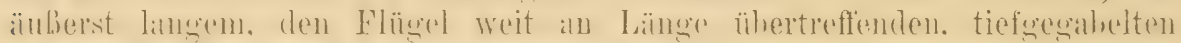

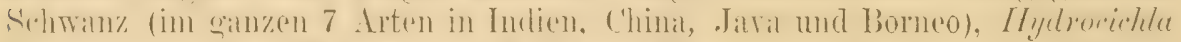

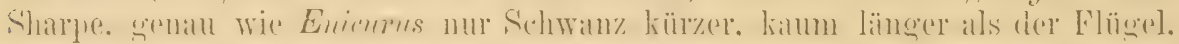
mit 3 tropischen Arten, und Microcichla mit nur einer Art, deren Schwanz

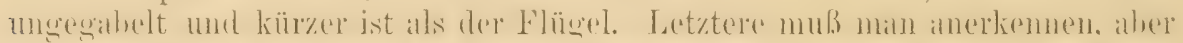

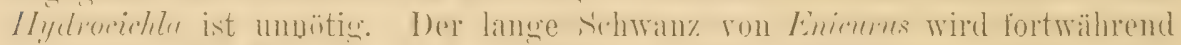

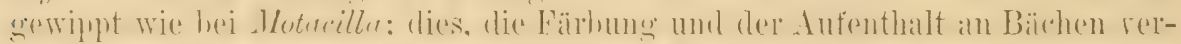

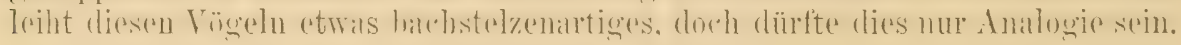

\section{Übersicht der Arten:}

\footnotetext{
(Rücken schwarz, weiß gefleckt . . . . . E. maculatus (guttatus) . p. 759

1 Rücken schiefergrau ............... E. schistacens . 1) 760

Rücken einfarbig schwarz ................. . . . . 2

$2\{$ Äußere Steuerfeder etwa $4-5 \mathrm{~cm}$ kïrzer als die 2. . . . E. sinensis . p. 759

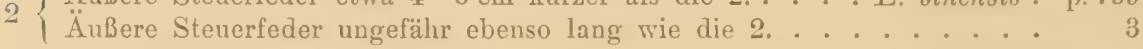

$3\left\{\begin{array}{r}\text { Nur Stirnbinde (allerhöchstens bis zu } 1 \mathrm{~cm} \text { breit) weiß; Kropf weiß } \\ \text { E. immaculatus . p. } 760\end{array}\right.$

Breiter Stirnfleck weiß: Kropf schwarz . . E. leschenculti (indieus) . p. 760
} 


\section{4t. Enicurus maculatus maculatus Vig.}

Enicums maculatus Vigors, Proc. Committee Zool. Soc. Loudon I, 1830-31, p. 9 (1831- Himalaya).

Enicurus Fuliginosus Hodgson, As, Res. XIX, p. 190 (Nepal).

Abbild.: Gould, Century B. Himal. Mts., 'T'af, XXVII.

o o ad. Bis in die Mitte des Kopfes reichende runde Stiruplatte weiß.

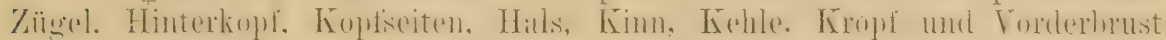
rein sammetschwarz. Rückenfedern schwarz mit weißen Spitzen, die des

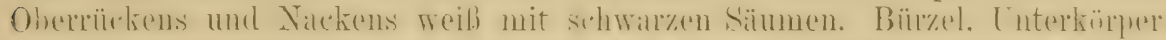

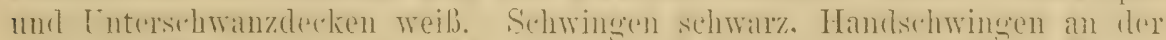

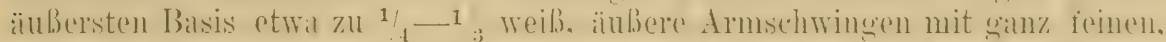

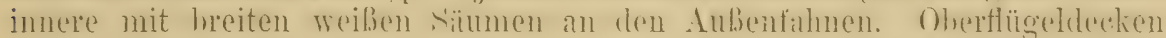
schwarz, die größte Serie weiß, mur an der Wurzel schwarz. Zwoi äußere

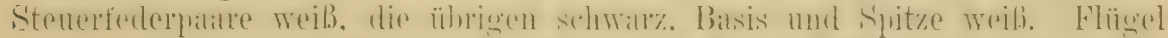

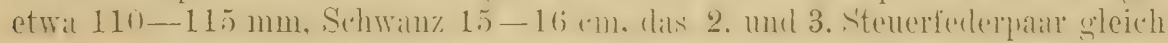
und am längsten, das äuBerste $4-5 \mathrm{~cm}$, das 4 . etwa 6 , das 5 . etwa $7-8$, das 6. sogar $9^{1 / 2}-10 \mathrm{~cm}$ kïrzer. Latuf etra 30, Culmen 23-25 mm. Füße weißlich, Schnabel schwarz, Iris braun. Juv. Ober- und Unterseite rußig braum, Brust mit weißlichen Schaftstreifon.

Himalaya von den Hasara-Bergen im Westen bis Nepal im Osten von wenig über 2000 bis in Höhen von 12000 engl. Fuß.

Diese Vögel laufen schwanzwippend an den Ufern der Bergströme und Bäche nach Art der Bachstelzen umher und fliegen aufgescheucht, ein feines Pfeifon ausstoßend, eine Strecke am Strome entlang, oder rerschwinden im Dickicht. Das Nest steht in der Nälue des Wassers, an F'elswänden oder in kleinen Vertiefungen, in der Regel ron oben geschiitzt. Es bildet einen tiefen, sauberen Napf und besteht aus allerlei Pflanzenteilen, von denen halb verrottete Blattgerippe einen großen Bestandteil bilden. Vielleicht finden zwei Bruten jährlich statt, da man vom April bis Mitte Juni Eier findet. Letztere, 3-4 an Zahl, sind blaß grünlich weiß oder rahmfarben und mit blaß rotbraunen oder fahl ockergelben Flecken und Spritzern bedeckt. \Гaße $23-26 \times 16-18 \mathrm{~m}$.

\section{Enicurus maculatus guttatus Gould.}

Enicurus guttatus Gould, Proc. Zool. Soc. London 1865, p. 661 (Sikkim?).

Abbild.: Gould, B. Asia IV, T'af. 69.

Wie $E$. maculatus maculatus aher kleiner und die weißen Flecke auf rler Oberseite viel kleiner und rundlicher.

Östlicher Ilimalaya: Nepal. Sikkim: fermer die Gehirose Astams südlich des Brahmaputra. Scheint nicht so hoch im Gebirge zu gehen wie $E$. m. maculatus.

Sieben Eier aus den Bergen von Cachar (April und Mai, gesammelt ron Stuart Baker) gleichen denen von $E$. maculatus maculatus und messen $20.5 \times 15.5,20 \times 16$, $20.7 \times 16.5,20.5 \times 15.7,22.5 \times 16.8,22.3 \times 16.5$ und $22 \times 16.6 \mathrm{~mm}$.

\section{Enicurus sinensis Gould.}

Enicurus sinensis Gould, Proc. zool. Soc. London 1865, p. 665 (Schunghai).

Abbild.: Gould, B. Asia IV, Taf. 70 (sub nomine E. chinensis).

ơ o ad. Stirn bis in Höhe des hinteren. Augemrandes, Basis der

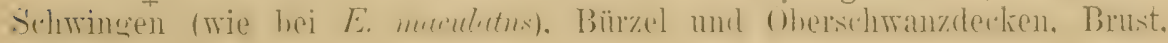




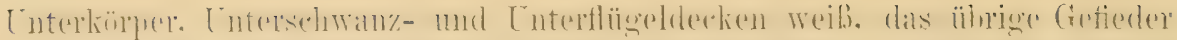

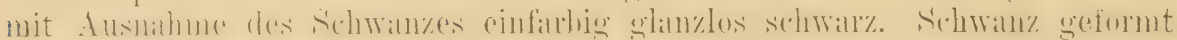
und gefürbt wie der von E. maculatus. Iris, Füße und Schmabel, ebenso die Maaße wie bei E. maculatus; nur Culmen $25-27 \mathrm{~mm}$. - Jur. wie das ron $E$. maculatus.

China, von Hainan und Süd-China bis zu den 'T'sin-ling Bergen.

\section{Enicurus leschenaulti indicus sulsil. nor. ${ }^{1}$.}

Unterscheidet sich voll $E$. sinensis dadurch, daß die äuBerste Steuerfecter nur 2-5 mm kïrzor ist als die folgende, anch ist der Schnabel ein wenig diclier. Flügel von 20 ठ大 $105-117 \mathrm{~mm}$; ich komnte nicht mit Sicher-

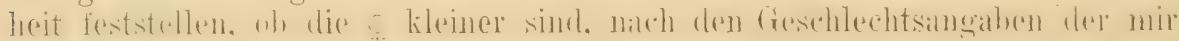
rorliegenden Stitcken ist dies aber nicht immer der Fall. (Typus ơ ad. Margherita in Ober-Assam 19. Januar 1902, ges. von Dr. Coltart.) Von

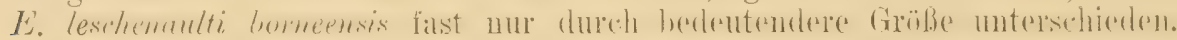

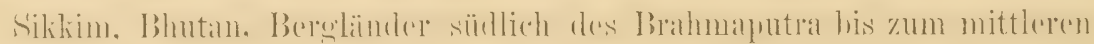
Tenasserim. Wie hoch diese Art im Gebirge hinaufreicht, konnte ich nicht feststellen, vermute aber, daß sie noch in großen Höhen lebt.

[Enicurus schistaceus Hodgson (As. Res. XIX, p. 189, 1836, Nepal): Stirnbinde weiß, Oberkopf, Oberhals und Rücken schiefergrau, Kopfseiten, Kinu und oberer 'Teil der Kehle schwarz (Östlicher Himalaya, Berge südlich des Brahmaputra, Manipur bis Tenasserim und Perak in der Malakka-Halbinsel und Süd-China), und Enicurus immaculatus Hodgson (t. c. p.190): Wie schistaceus, aber Oberkopf, Hals, Rücken und Kehle schwarz (Himalaya, Berge sïdlich des Brahmaputra bis Birmah), dürften nicht als paläarktische Arten zu betrachten sein.]

\section{(wattung MICROCICHLA Shape 1883.}

Von Enicurus dadurch unterschieden, daßs der Schwanz kiurzer als der

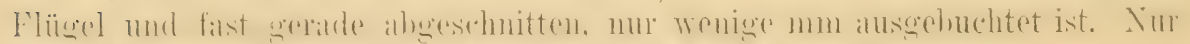

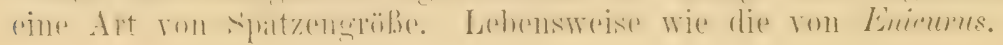

\section{Microcichla scouleri (Vig:).}

Enicums Scouleri Vigors, Proc. Committee Zool. Soc. London I, 1830-31, p. 174 (1832 - Himalaya).

Enicurus heterurus Hodgson, in Gray's Zool, Mis., p. 83 (1844- Nomen nudum!)

Enicurus nigrifrons Gray, Proc. Kool. Soc. London 1859, p. 102 (Darjiling - ex Hodgson MIS.).

Abbild.: Gould, B. Asia IV, I'af. 71.

on ad. Stirn 9-10 mm weit weiß, Rest des Kopfes, Hals, Kropf

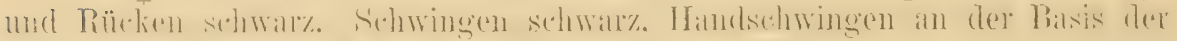

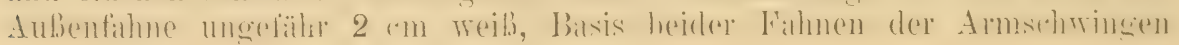

1) Enicurus leschenaulti leschenaulti Vieillot, Nouv. Dict. d'Hist. Nat., nour. éd., XX. p. 269 (1818 - Java) bewohnt die Inseln Java und Bali. Sie steht E. leschenaulti indicus sehr nahe, letztere unterscheidet sich aber dadurch, daß sie an den Spitzen der

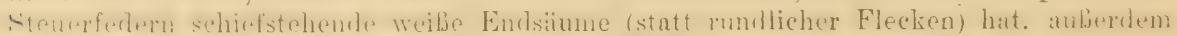

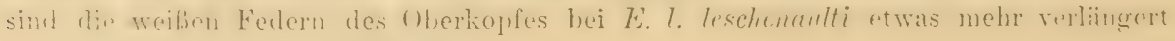
und laben weuiger schwarze Spitzen. 


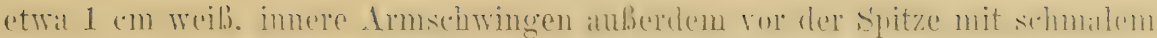
weißen Außensaum. Kleime und mittlere Flügeldecken sehwarz, große

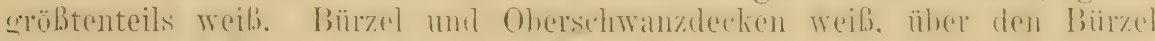

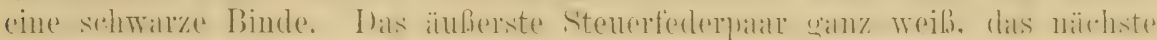

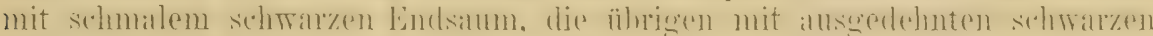
Spitzen, die rou Feder zu Feder an Ausdehnung zunehmen, so dab von den

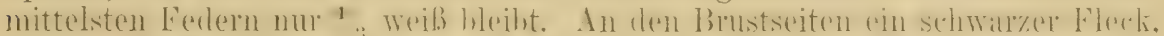
Brust, Unteikörper und Untersch tanzdecken weiß, Weichen mit einigen

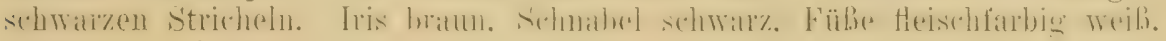
Flügel (10 ఠ 0$)$ etwa $71-78$, Schwanz etwa 48-50, Lauf 25, Culmen 14-15 mm. - Juv. Stim matt schwarz wie Oberkopf, Hals und Rücken,

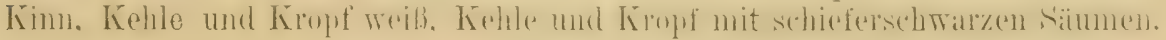

Himalaya und östliche Naga-Berge bis ins mittlere China: Szetschwan, 'I'sin-ling-Berge. Bis in Höhen ron über 11000 engl. FuB ${ }^{1}$ ).

Ward fand schwer bebritete Eier in Kaschmir an 19. Juni. Fr beschreibt. sie als schmutzig weiß mit rötlich braunen F゙lecken.

\section{Fanilie ACCENTORIDAE (PRUNEIIDAE).}

Die „Braumellen" und ..Flüevögel" werden bezüglich ihrer systematischen

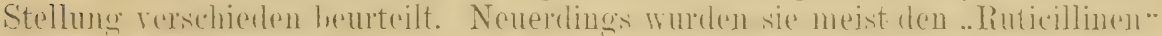

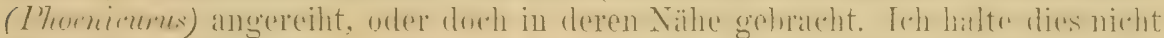

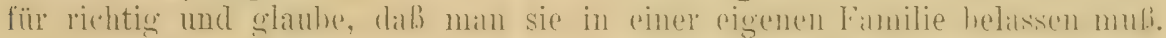
Der Schnabel ist eigenartig: hart, an der Basis ziemlich breit, seitlich wie

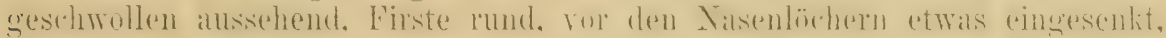

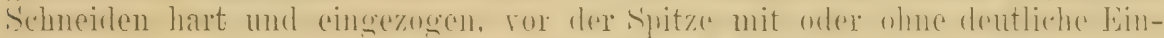

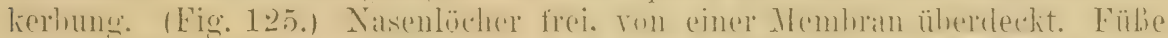

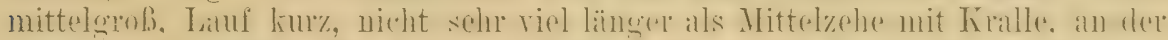

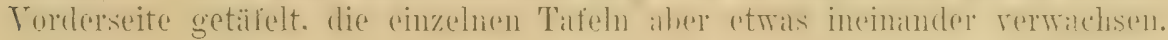
1. Schwinge kürzer oder länger als die Handdecken, 3. am längsten, 4. und 5. etwas kürzer als oder so lang wie die 3. Schwanz kïrzer als der Flügel, gerarle oder seicht ansegeluchtet. Gefieder dicht und fest. Hüpten ratseh und

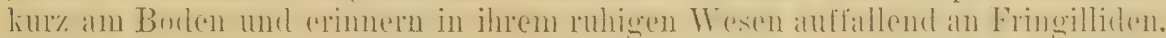
durchaus nicht an "Turdiden". Die Zeichnung ist mehr fringillidenartig (Passer!) als an die irgend welcher "Turdiden" erinnerud. - Man hat für

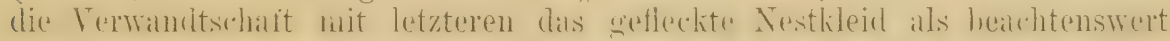

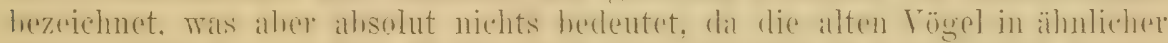

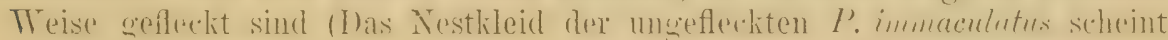
umbekaunt zu sein). Der Magen ist muskulös wie bei Körnerfressern. Die Beziehungen zu den Fringilliden sind beachtenswert.

1) Eine etwa größere Form mit weiter ausgedehntem weißen Stirnfleck lebt in Formosa. Ich nenne sie

Microcichla scouleri fortis subsp. nov.

Stirnfleck $12-15 \mathrm{~mm}$ weit weiß, Flügel von 16 ơ etwa 75 -81, Culmen meist 1-1 1/2 mm länger. Typus ơ no. F. 92 Tapposha, Formosa 19. Januar 1907. '/4 dieser Form scheinen mir auch die südchinesischen Stücke (Futschau, Fohien) zu gehören. La Tonche entdeckte Nest und Eier in Fokien. Das Nest ähnelt den größeren Testern von Enicumıs und enthält ebenso wie jene zahlreiche Blattgerippe. Die Eier sind weiß mit blaß braunroten Zeichnungen und eins hat außer lebhafter rotbraunen Zeichnungen auch fahl lila Schalenflecke. Sie messen ungefähr $19.5-18.5 \times 14-15 \mathrm{~mm}$. 


\section{Gattung PRUNELLA Vieillot 1816.}

Der Name Accentor 1802 ist leider 1797 schon in anderem Simme

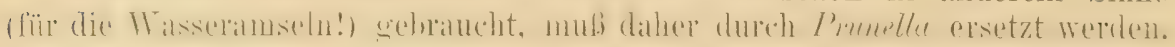
Ich veroinige ohme Bedenken die Geuera "Accentor" und Prunella (Tha'valens) (d. b. die Alpen- und Heckenbraunellen). Ebensoviel Sinn hätte es, die Formen mit längerer 1. Schwinge zu sonderu, was aber auch nicht

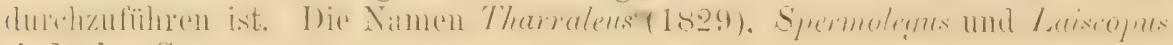
sind also Synonyme.

Übersicht der Arten:

1 Steuerfedern an der Spitze mit weißen Fiecken ......... 2

Stenerfedern an der Spitze ohne weiße Flecke.......... 3

$2\{$ Ganze Brust gestreift . . . . . . . . P. himalayanus . p. 766

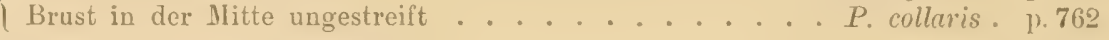

$3\{$ Oberseite günzlich ungestreift ......... P. immaculatus . p. 775

Oberseite gestreift ................. . . . 4

Scharfer weißer Superciliarstreif . . . . . . . . . . . . 5

4 Breiter ockerfarbener Superciliarstreif . . . . . . . . . . . . . 6

Ohne scharfen oder auch nur deutlichen Superciliarstreif . . . . . 7

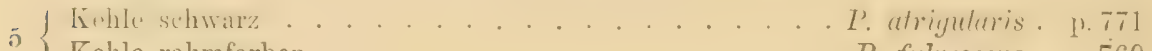

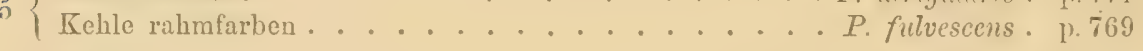

6 \{ Kehle einfarbig. . . . . . . . . P. montanella . p. 768

6 Kehle gestrichelt oder gefleckt.......... P. strophiatus . p. 767

7 Kropf und Brustseiten rötlich zimmtfarben . . . P. mbeculoides . 1. 767

I Kropf und Brustseiten nicht rötlich zimmtfarben . . . . . . . 8

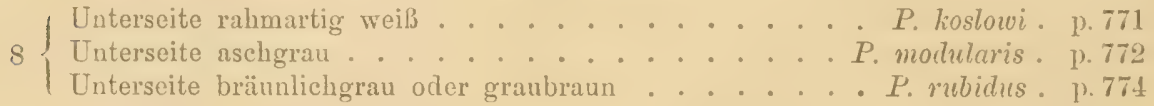

\section{Prunella collaris collaris (Seop.).}

Alpenbraunelle, Alpentlühevogel.

Stumus collaris Scopoli, Annus I Historico-Natur., p. 131 (1769- Kärnthen).

Motacilla alpina Gmelin, Syst. Nat. I, 2, p. 957 (1789- „Habitat in Alveruiae et Delphinatus alpibus". Ex Buffon und Latham).

Accentor major Brehm, Handb. Naturg. Vög. Deutschl., p. 1008 (1831- „Nordseite der deutschen Alpen").

Accentor alpinus communis A. E. Brehm, Verz. Samml., p. 8 (1866- nomen nudum!).

Èngl.: Alpine Accentor. Französ.: Fauvette des Alpes. Ital.: Sordone.

òad. Obersoite matt aschgrau, Oberkopf mit deutlichen, Hals und

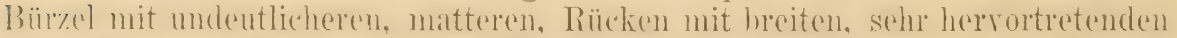

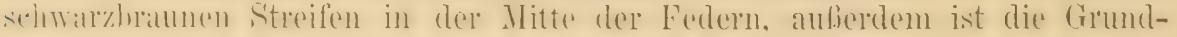

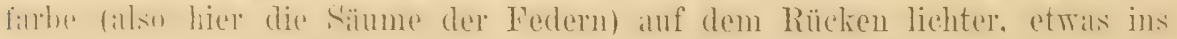

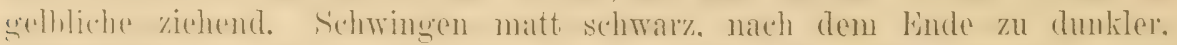

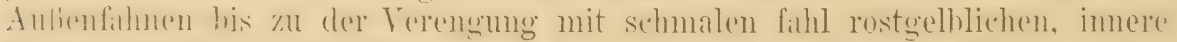
Ammshwingern mit hreiteren und rotwas rötlicheren süumen, die inmersten

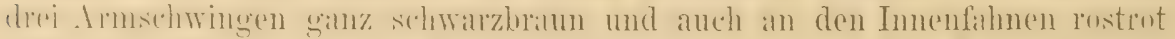

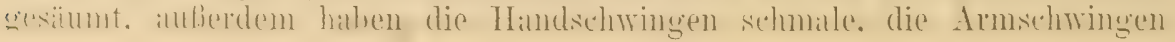




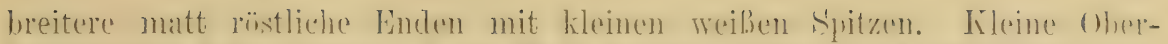

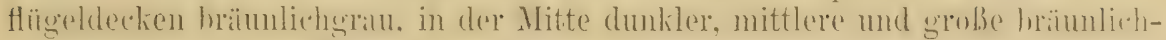
schwarz, nach der Wurzel zu melu braungrau, jede an dex Spitze mit

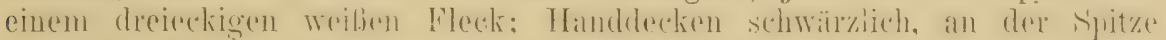
der Außenfahme mit schmalem weißen Randstrich. Kehlfedern weis mit

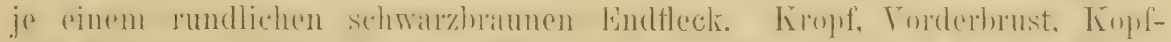

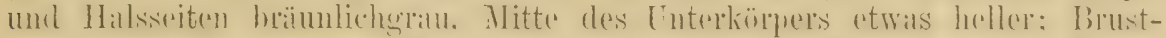

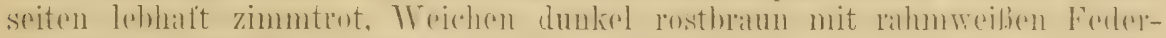

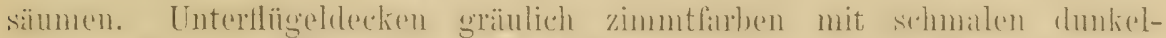

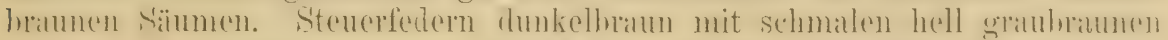

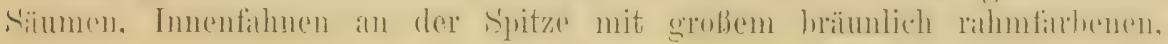

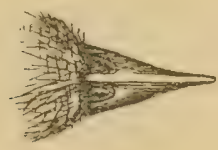

Figur 125.

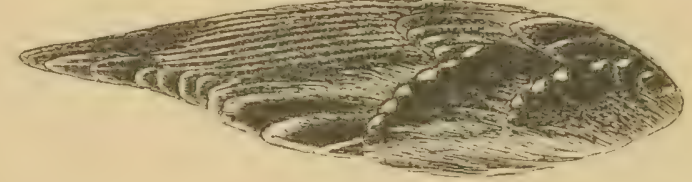

Figux 126.

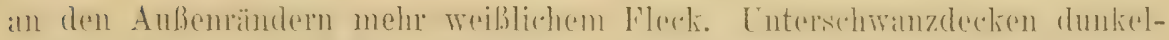
braun mit breiten woißen Säumen. Im Sommer erscheint das Gefieder-

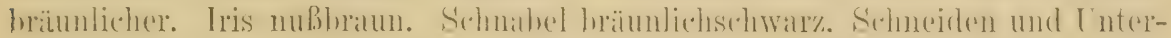
schnabel an der Basis gelb. Füße rötlichbraun. Flügel etwa 103-108, Schwanz etwa $65-70$, Lauf $25-26$, Culmen $16-17.5 \mathrm{~mm}$. Q wie o nu०

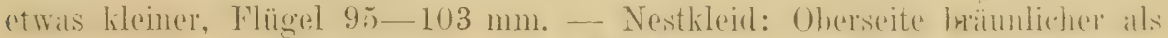

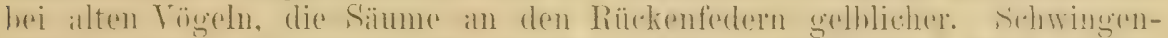

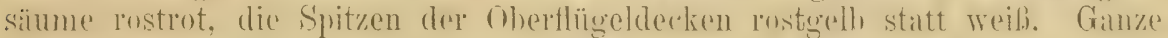
Luterseite rostgellulich mit bramen Streifen. - 1. Sehwinge kïm\%er als die Handdecken, 3. am längston, 4. gleich oder $11 u 1^{\circ} 1-2 \mathrm{~mm}, 1$. und 5. 2-4 mm kïrzer, 3-6 an der Aubenfahne verengt.

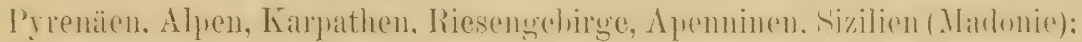

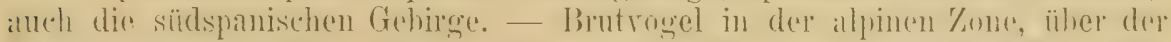

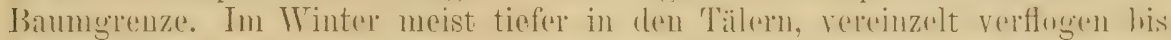

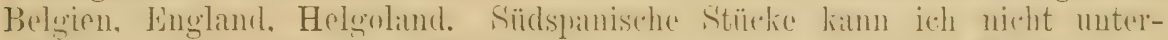
scheiden. ()b in Sardinien Brutvoged oder nur ansmathmsweise Erscheinmeg, scheint nicht sicher festzustehen.

Dic Alpenbraunelle lebt wie die Heckenbraunelle meist am Boden und ist keineswegs scheu zu nennen. Der Lockruf ist ein etwas trillemdes trü, trï, trü, der Gesang aus flötenden und trillernden Tönen zusammengesetzt, klangreich aber leise, anspruchs Ios. Das Nest steht in Felslöchern, unter flachen Blöcken und Steinen, mitunter auch unter dichten Rhododendron-Büschen. Es ist aus Moos, Würzelchen und feinen Halmen gebaut und mit Haaren, Wolle und Federn gefüttert. Die 4-5 Eier gleichen denen ron $P$. modulavis, sind aber viel größer. 63 Eier ( 47 Jourdain, 17 Rey) messen im Durchschnitt $23.04 \times 16.6$, Maximum $26.7 \times 17.1$ Hinimum $20.5 \times 15 \mathrm{~mm}$.

\section{Prunella collaris subalpinus (Brehm).}

Accentor subalpinus Brehm, Handb. Naturg. Vög. Deutschl., p. 1009 (1831- Dalmatien). Accentor collaris reiseri 'I'schusi, Orn. Monatsber. 1901, p.131 ("Von Dalmatien und Iontenegro bis Griechenland und in den transsylvanischen Alpen." Terra typica: Griechenland, weil der Autor zuerst angab, die neue Subspecies sei dorther). 
Ist $P$. c collaris sehr : thmlich, abor die Oberseite reiner grau, fast ohne

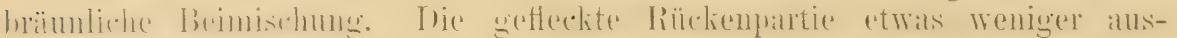
gedehnt; Brust heller, etwas reiner grau, die rotbraune Fleckung an den

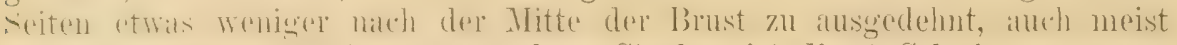
ein wenig heller. (Bei 8 untersuchten Stücken ist die 4. Schwinge ganz so lang wie die 3. Bei $P$. c. collaris sind Stücke mit gleich langer 4. seltener, als solche, bei denen sie $1-2 \mathrm{~mm}$ kïrzer ist.)

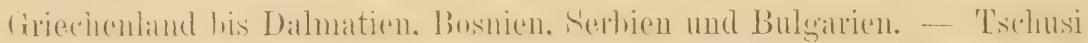

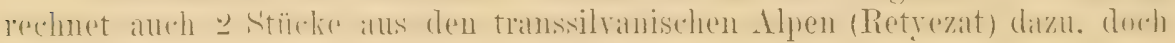
bedarf dies weiterer Bestätigung (?Kreta).

5 Eier messen im Durchschnitt $23.7 \times 16.54 \mathrm{~mm}$ (Jourdain, in litt.).

\section{Prunella collaris caucasicus $\left(\right.$ (Tsch. $\left.^{1}\right)$.}

Accentor collaris caucasicus Tschusi, Orn. Nonatsber. 1902, p. 186 (Wladikawskas, Terek-Gebiet, Nord-Kaukasus).

Accentor collaris hypanis 'T'schusi, Orn. Jahrb. 1905, p. 135 (Kl. Labafluß, Kuban-Gebiet, Nord-Kaukasus).

Oberseite so hell wie bei $P$.c. subalpinus, aber mit einem dentlichon

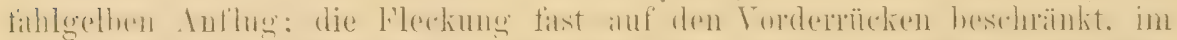

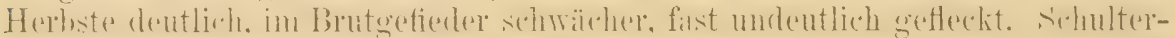

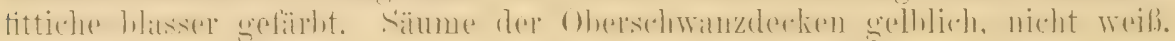
Das Rostrot an den Seiten mehr oder minder ausgedehnt.

Kaukasus und Kleinasien (Taurus).

\section{Prunella collaris rufilatus (Sew.).}

Accentor mfilatus Sewertzoff, Sapiski d. Turk. Abth. d. Ges. der Lieb. d. Naturk. I, 1, p. 45 (1879- Turkestan).

Accentor rufilatus turcestanicus Reichenow. Orn. Monatsber. 1907, p. 29 (Aksu in OstT'urkestan).

Abbild.: Pleske, Ares Przewalsk., Taf. IV, Fig. 4.

Oberseite noch fahler, die Rückenflecknng nicht ganz so dunkel und daher weniger scharf hervortretend. Schulterfittiche fahler, an den Außen-

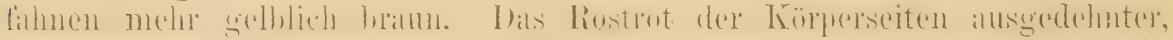
nach vorı zu die gauzen Federn eimnehmend, nach den Weichen zu weiße Sïume lassend, an der Brust fast oder ganz geschlossen. 3.-5. Schwinge fast ganz gleich.

Turkestan: Alai-Tag, Pamir, westlicher Kwenlün, Issik Kul, Tian-Schau,

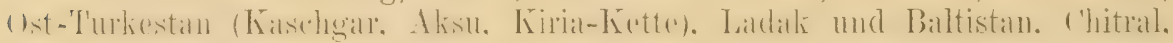
Samana, Safed Koh. - Stïcke von Vernoy, Aksu, Issik Kul, Gilgit, Samana,

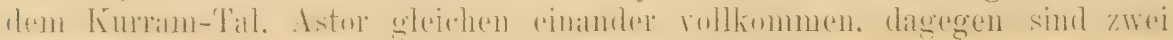

1) Stumus montanus Hablizl, Neue Nordische Beytr. IV, p. 53 (1783- Samamisische Alpen, I'roriuz Ghilan in Nordpersien), unde "Sturnus moritanus" (wohl Druckfehler) Gmelin, Syst. Nat. I, 2, p.80t (1789) bezieht sich sicher auf eine Alpenbraunelle, vermutlich die kaukasische oder eine eigene persische Subspezies. Fralls sie mit der kaukasischen identisch ist, wie Radde annahm, muß letztere den Namen $P$. collaris montanus tragen. 


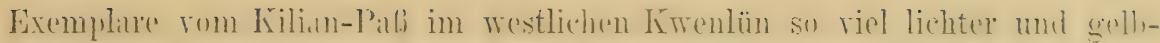
licher, daß man darin eine andere Form vermuten muß; es ist indossen

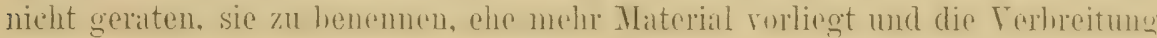
klar ist.

Nach Whitehead Wintergast in Samana-Gebirge, der bis 6000 Fuß herabkommt. In der Safed Koh Kette von demselben Beobachter als häufiger Brutvogel festgestellt. Nester in Felsenspalten oder unter vorspringenden Felsen an steilen Wänden. Ende Juli wurden Junge gefunden, am 1. Juli 3 frische Eier. Diese gleichen denen der europäischen Alpenbraunelle und messen $22.5 \times 14.5 \mathrm{~mm}$. Die Nester bestehen aus Gras und Wurzeln und sind mit Moos und feinen Haaren ausgefüttert.

\section{Prunella collaris tibetanus (Bianchi).}

Ac. collaris tibetamus Bianchi, Ann. Mus. Zool. Acad. Petersb. IX, p. 128 (1904- OstTibet).

Abbild.: Bianchi, Aves exped. Koslowi 1899-1901, Taf. III, Fig. 3.

Riickenfleckung wieder viel schärfer als bei $P$. c. rufilatus, melı wie bei den enropäischen Formen, aber die Flecko breiter, Süume der Rückenfedern und Bürzelfedern otwas fihl gelblichbran, Oberschwanzdecken roströtlich. 'Säume kaum heller, mit oder ohne schwarzbraunc Schaftstreifen. Seitenferern dunkel rostrot mit meiben S̈̈umen. Die weiben Endflecke an den mittlereu und groben Oherflïgeldeden im frischen Herhstkleide größer. helle Spitzen der inneren Schwingen ausgedehnt. Schwanzspitzen zimmtröstlich, an den Innenfahnen der äußeren Steuerfedern weißlich.

Gohi (Church-Gebirge), Kansu, in Ost-Tibet am oheru Chuauche und Ditschu, in den Burchan-Buda-Bergen, und Kuku Nor.

Bewohner der Alpenregion. Nach der Brutzeit in Flügen.

\section{5t. Prunella collaris erythropygius (Srriuh.).}

Accentor erythropygius Swinhoe, Proc. Zool. Soc. London 1870 p. 124, Taf. 9 (Kemeih in Seuen-hwafoo in Nord-China).

Ähnlich P. c. tibetanus aber durchweg dunkler: Rö̈chen kaum dunkler, Bürzel und Oherschranzdecken mehx rothritun, Brust dunkler gratu.

Gehirge Japans (Nippon), Ost-Tibiriens (Lssuri- und Amurand) und Nord-Chinas (Mandschurei) his zu den Tsin-ling-Bergen (Ta-pai-schatu).

\section{Prunella collaris nipalensis (Blyth).}

Accentor Nipalensis Blyth, Journ. As. Soc. Bengal XII, p. 958 (1813- "Kâchar region of Nepâl". Ex Hodgson MS.).

Accentor Cacharensis Hodgson, Proc. Zool. Soc. London XIII, p. 34 (1845- Nepal).

Abbild.: Gould, B. Asia IV, Taf. 44.

Wesentlich verschieden von allen andern F'ormen von $P$. collaris: Oberseite dunkel braungran, der Rïcken breit schwarz gefleckt, Federsiamme in der Mitte des Rückens matt rostgelblich. Bürzel dunlel bramgran mit hald sebwächerem rostgelben. hald stärlerem rothranum Anflug, längste ober-

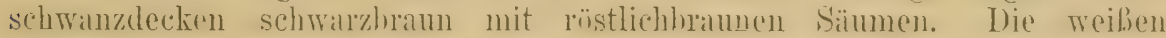
Spitzenflecke der Flügeldecken klein, im abgetrigenen sommerlikide oft 


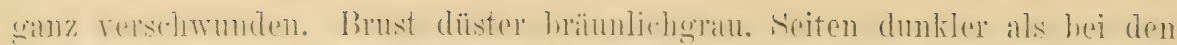

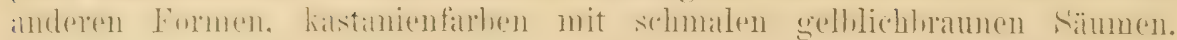

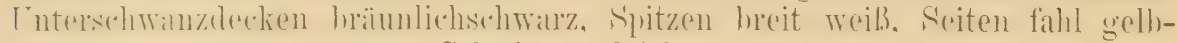
bräunlich gesïumt. 3.-5. Schwinge gleich.

Himalaya: Kumaon bis in den östlichen Himalaya und das westliche Szetschwan ('Ia-tsien-lu). In Höhen ron 12-14000 FuB. Dịe wenigen

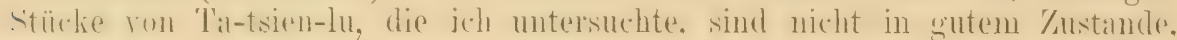

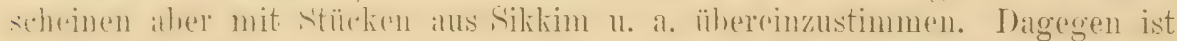
eine Serie von den hohen Bergen östlich ron Ta-li (T'alifu) im westlichen Jünnan anf der (b)erseite, hesonders anf Kopf. Hals. Rë̈cken und Bürzel, viel dïsterer. Weniger ristlieh, aluch in der Kropfgegend etwas gräulichere Ich benenne diese Form

Prunella collaris ripponi subsp. nov.

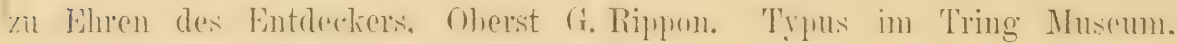
5. April 1902 Gyi-dziu-shán, 10000 Fuß.

\section{Prunella himalayanus (Blyth).}

Accentor Himalayanus Blyth, Journ. As. Soc. Beng. XI. p. 187 (1842- Himalaya). Accentor altaicus Brandt, Bull. Acad. Petersb. I, p. 365 (1843- Altai).

Accentor variegatus Blyth, Journ. As. Soc. Bengal XII, p. 958 (1843- Neuer Name für himalayanus, weil mehrere Arten den Himalaya bewohnen!),

Abbild.: Gould, B. Asia IV, T'af. 49.

Flïgel und Schwanz denen von P. collaris nipalensis und erythropygins

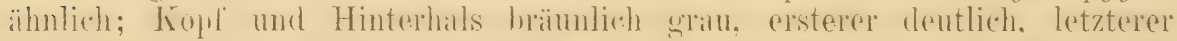

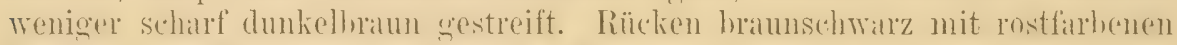
Streifen (jede Feder rosthram mit schwarzam Längsfleck). Bürzel mid Ohersthwanzoleckn hräunlichgrau his gräulichhram. arsterer sehmal und oft undeutlich. letatere breit dunkel graburam gestreift. Hinter dem Auge ein kurzer

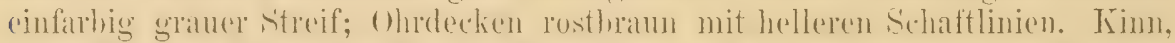

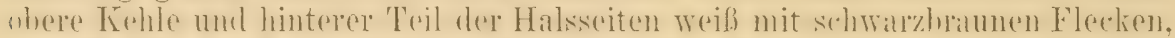

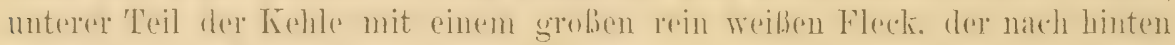

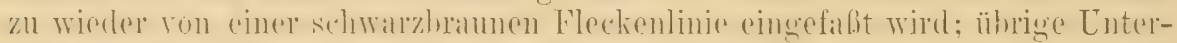

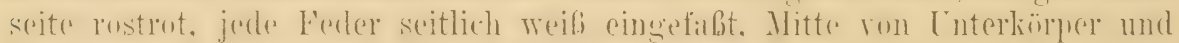

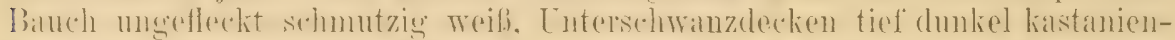

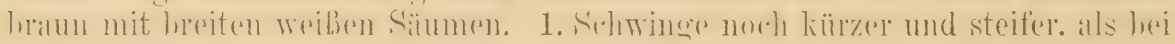
P. collaris, nur etwa $1 / 2$ bis allerhöchstens $2 / 3$ der Hauddecken, 2., 3. und 4. fast gleich lang und am längsten. Iris nach Hume rot (nach Ward dunkel-

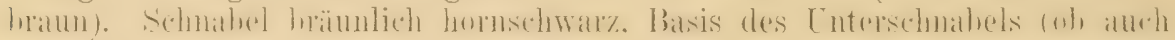
im Frühjahr?) hellhraun, Füße braum. Flügel $87-96 \mathrm{~mm}$. - Nesthleid:

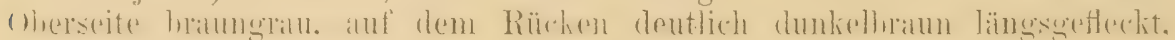
Unterseite fahl gelbbräunlich mit dunkelbraunen Längsflecken.

Tom Altai, den Sajgan und Chamardaban Bergen bis nach Turkestan (Tian Schan, Karakoram, östl. Kindukusch) und zum Himalaya, dort aber noch nicht sicher als Brutrogel festgestellt.

Eier, die dieser Art angehören sollen, gleichen denen von P. modularis bis auf die etwas bedentendere Größe. 


\section{Prunella rubeculoides (Moore).}

Accentor rubeculoides Hoore, Proc. Zool. Soc. London XXII „1854", p. 118 (1855- Nepal, ex Hodgson MS.).

Abbild.: Gould, B. Asia 1V, Taf. 46.

ơad. Oberseite: Kopf und Hals erdbraun mit helleren und mehro grä̈ulichen Federrändern. Rücken- und Schulterfedern röstlich hraun mit

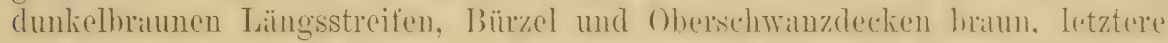
mit etras lichteren Säumen. Schwingen und Schwanz dunkelhrann mit helleren Sämmen. Fleine und mittlere Elügcoldecken hraun mit gräulivben Rändern, grobe mit zimmthö̈nlichen Anbensämuen und weiblichen Spitzen. Kopfseiten einfarhig hraun. Kehle graubran mit etwas helleren Fencrö̈ndorn. Krope und Brustsciten lebhaft rötlich zimmentaben. übrige Cuterseite nehst Enterflügeldecken und Axillaren weilb mit rahmfartunem Anflug. Wreichen und Enterschwanzdecken rötlich rahmfarben mit hrannen Streiten. Iris lehhaft hellbraun. Schnabel schwarz. Füße rötlich braun. Flügel etwa $80-84$, Schwanz etwa $65-70$, Lauf $25-26$, Culmen $15-16 \mathrm{~mm}$. - o wie $\sigma^{\circ}$ nur etwas kleiner: Flügel $74-78 \mathrm{~mm}$.

Weit verbreitet im Himalaya, von Kaschmir und Ladak bis Siklim und Butau, in Höhen ron ïher $1+000$ FuB. in sïd- und ost-Tihet (in der Hochehene von Gyantse ïherwinterud), und Trest-chinat Mrest-szetschwan Schensi und Kansi. - In diesen weiten Gebieten scheint nach dem untersuchten Material die Form ïberall gleich zu seim, ohne gengraphische Variation.

Ward fand in Ladak Nester in Büschen im Mai und Juni, gibt aber keine Beschreibung der Eier.

\section{Prunella strophiatus strophiatus (Blyth).}

Accentor strophiatus Blyth, Journ. As. Soc. Bengal XII, p.959 (1843- Ex Hodgson MS., Nepal).

Abbild.: Gould, B. Asia IV, Taf. 47.

$\sigma^{\top}$ oad. Oberseite rötlichbraun, jede Feder mit breitem schwarzen Mittelstreifen, die auf Bürzel und Oberschwandeclien undeutlicher worden. (Oherflügeldecken wie der Rücken, mittlere und grobe śere nit hlab ockerfarhenen Spitzen. Schwingen und Schwanz dunkelbaun, rötlichbraun gesïmmt.

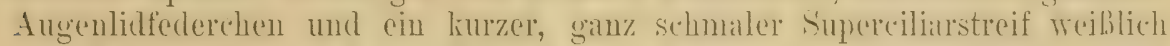

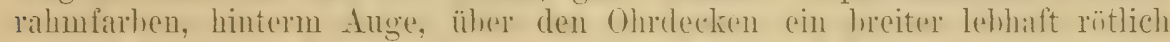
zimmtfarhener Stroif. Zü̈gel. Federu unterm Auge und Ohredecken schwirzhran. letztere an ihrem hintern Teile rötlich zimmtfarben gestreift. Forlern der Halsseiten gralu mit schwarzen Streifen. Kehle weililieh rahmfarluen mit einigen schrillzen Flerken, hreites froufhand lehlallt rö̈tich zimmt-

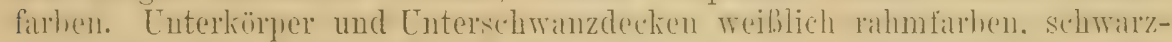

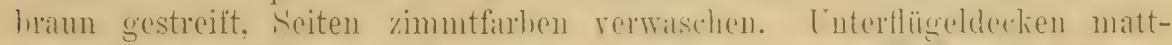

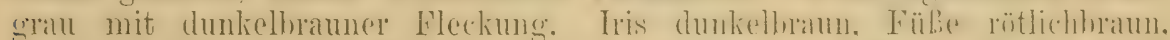

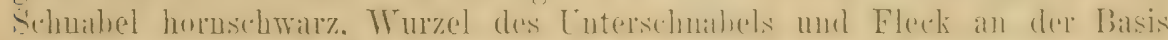

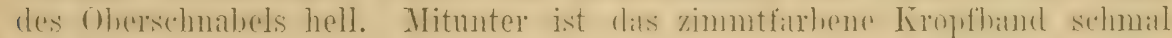
schwarz gestreift: dies scheinen teilmeise o, teils jüngere Stücke zu sein. Flïgel o $65-70$, o etwa 59-63, Schwanz 60-64 mm. - Nestkloid:

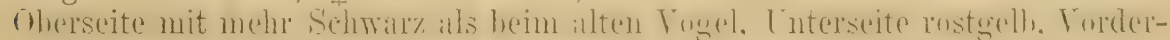

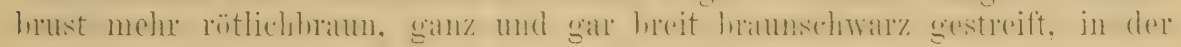




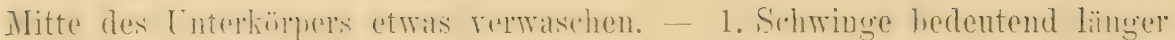
als die Handdecken, 2. zwischen der 6. und 7. oder der 7. und 8., 3., 4. und 5. wenig rersehieden und die Flügelspitze bildend.

Östlicher Himalaya, bis Kumaon.

Brütet in großen Höhen, bis zu $13000 \mathrm{Fu}$ u über dem Meere, findet sich aber im Winter tiefer abwärts, bis zu 5000 Fuß. Das Nest steht im Grase oder niederen Gestrüpp und ist wie das der Heckenbraunelle aus Moos und Würzelchen gebaut, mit Schaafswolle und Yaks- und anderen Haaren ausgefüttert. Die 2-3 oder 4 Eier wurden rom IIai bis August gefunden und sind einfarbig grünlich blau. 9 Eier messen nach Osmaston im Durchschnitt $20 \times 14.2$, Maximum $20.4 \times 15$, Minimum $19.2 \times 14 \mathrm{~mm}$.

\section{Prunella strophiatus multistriatus (Darid).}

Accentor multistriatus David, Ann. \& Mag. Nat.Hist. (4) VII, p. 256 (1871- Mupin).

Wio P.s. strophiatus, aber die Oberseite nicht so rötlichbraun, sonderu mit einem matteren, etwas gräulichen Ton, der Bürzel mehr olivengrau. Dex Streif hinterm Auge und das Kropfluand nicht so lehbalt rötlieh zimmtfarben, sonderu etwas blasser, letzteres wohl auch im allgemeinen etwas schmäler.

Gehilge ron t'hinal Schensi (Tsin-ling Bergo). West Szetschwin, Kansu und am oberen Hoang-ho.

\section{Prunella strophiatus jerdoni (Brooks).}

Accentor Jerdoni Brooks, Journ. Ac. Soc. Bengal XLI, Part. II, p. 327 (1872- Kaschmir und Dhurmsala).

Oberseito nicht so rotbraun, sondern mehr ins olivenfarbene ziehend, die schwarzen Flecke etwas matter, nicht so tiefschwarz, daher nicht so scharf hervortretend, auf dem Kopfe noch matter, fast undeutlich. Der Streif hinterm Auge noch heller als bei $P$. s. multistriatus, auch die Unterseite noch blasser.

Westlicher Himalaya, ron Faschmil his Simla, in Höhen ron 9000 Fuli und höher brütend.

Versteckt und ruhig lebend, so daß man ihu leicht übersieht. Nistet nach Whitehead ziemlich häufig im Safed Koh Zuge, in Höhen ron 9000-12000 engl. FuB, im Walde und im Wachholder-Gestrüpp. Der Warnruf klingt wie tir-r-r.

\section{Prunella montanella (Pall.).}

Iotacilla montanella Pallas, Reise versch. Prov. Russ. Reichs II, I, p. 695 (1776- Daurien). Accentor Temmincliii Brandt, Bull.-Ac. N. Sci. Pétersb. II, p. 39 (1848- Neuer Name für 'J'emmincks - nicht Pallas' - A. montanella, falls verschieden).

Abbild.: Dresser, B. Europe III, Taf. 100.

ơ o ad. Oberkopf dunkelbraun, mit angedeuteter Streifung, an den Seiten fast schwar\%. Rï̈cken rothram, Federmitten dunkler und hräunlicher.

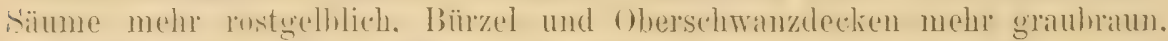
versehwommen dunkler geflecht. Sehwingen hraun mit rothranen, in den

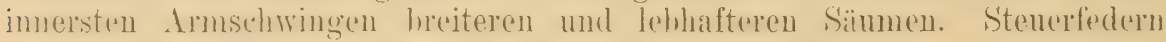
braun mit etwas helleren Säumen. Breiter, bis zum Nacken reichender, 


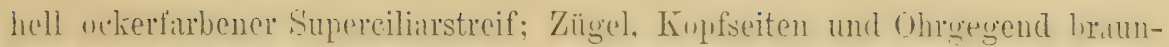

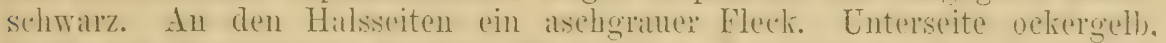
Mitte des Cuterkinpers blasser, oft weiblich, Kürpersoitru hram gestreilt. Die dunkelhrame Färhung der Euderwurehn reicht an den Federn der Torderbrust weiter nateh den Spitzen zu, so dab diese Fïrhung dort in ahgetragenem Gefeder etwals hervortritt. Lnterflügeldectien hlab bis weilolich

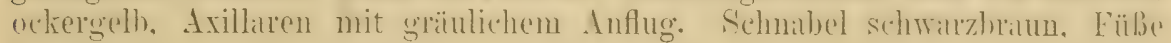
fleischfarben. Iris gelbbraum. Hlïgel o $75-78$, o $70-72$, Schwanz o etwa $67-71$, q $60-61$, Lauf $19-21 \mathrm{~mm}$, Culmen 13.5-15 mm. — Erstes Jugcudkleid (nach Titezanowski): Oherseite erdhraum. Rücken und Skiljularen mit groben dunkelbaunen Elecken in der Mitte der Federu. Supereiliarstreifeu schmutzigweil. mit brannen Flecken. Kopfsciten hlass braun, Mitte der Ohrgegend mehr ader minder ackerfarhen. Lnterscite schmutzig isabellfarhen mit groben dreiedigen bramen Flecken anf Kropt und Brust, und ebensolehen kleinen an den Seiten der Kohle. - Das frische Herhstgetieder der alten Vägel ist dunkler und mehr rothram, der supereiliarstreif lobbaft ockerfurben, im Frühjahr mird das fietieder hasser. die Federränder des Rückens mehr graubrüunlich, der Supreciliarstreif hlassere fast weiflich.

Sibirien vom Ural bis zum Berings-Meere, südlich bis zum Altai, Sajan, Thamardahan, Transhaikalien und nach Bianchi IT est-Tian-S'han, anf dem Zuge oder in den Winterepuartieren in Norel-China und Korea. Tereinzelt in Europa: Cralgebirge, nach Norelmann Durchzïglep in der Krim, mehrfach in Italien, wach J'elzcln eimmal in Cisterreich festgestrilt.

Gesang kurz und anspruchslos. Das Nest besteht aus kleinen Zweigen und Grashalmen und ist mit Moos und Haaren ausgefüttert. Es enthält 4-6 Eier, die denen der Heckenbraunelle ähneln, nur etwas heller und kleiner zu sein scheinen. 31 Eier messen nach Jourdain (in litt.) durchschnittlich $18.55 \times 13.75$, JIaximum $20.6 \times 14.2$ und $19.1 \times 14.4$, Minimum $17 \times 13.2$ and $17.2 \times 12.6 \mathrm{~mm}$.

\section{Prunella fulvescens fulvescens (Serv.).}

Accentor fulvescens Sewertzoff, Turk. Jevotn., (in Izv. Obshch. Jloskor. VIII, 2) p. 66, 132 (1873- 'Turkestan); Übers. in Madarászs Zeitschr. ges. Orn. IV, p. 92.

Abbild.: Dresser, B. Europe, Taf. 65t, Fig. 1.

ơad. Oborseite fahlbraun mit dunkelbraunen Längsstreifen, die auf Bürzel und oberidhwandecken undentlich worden oder verschwinden. Oherkionf dunkler hraum und nur indentlich gestreitt. Hinterhals mit gratuem Schimmer. Schwingen edhram mit fihl gelhlichbramen Sïumen. Grobe und mittlere (Oberflügeldecken mit weiflichen budsämuen. Stenerfedern luaun mit fahl grä̈ulichbraunen Rändern. Supereiliarstreif von dex Stirn his

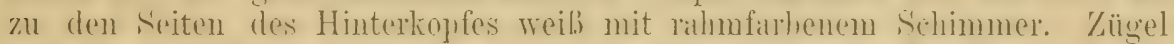
und Koprseiten dunkelhraun. Cnterseite thamois, an der Kohle und in der Mitte des Cuterkïruers klarer, last weiflich, Trichen mehr viler minder

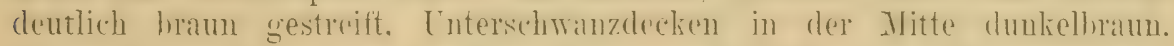
In der Brutzeit nutzen sich dio fahlbraunen Federsäume stark ab und die

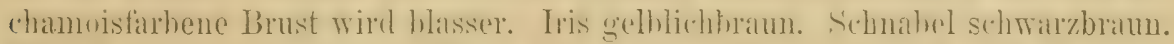

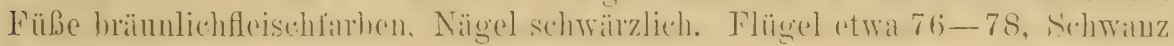
68-70, Lauf ungefähr 20, Culmen 15-15.8 mm. - Das o gleicht dem

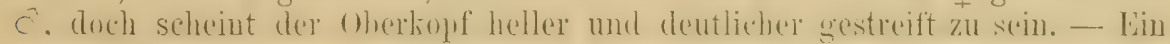

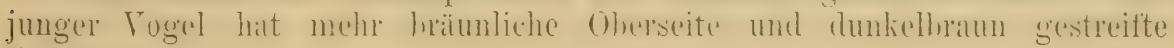
Vorderbrust. 
Der vorliegenden Literatur nach ist $P$. julvescens verbreitet ïber Wrest-

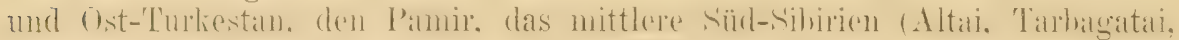

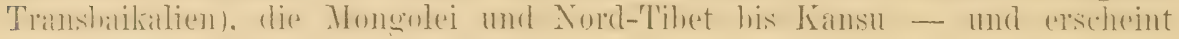
im Tinter in Kaschmir und Sikkim.

Alle diese Vögel gehören jedoch augenscheinlich nicht einer und derselben Form an. Es lassen sich nach dem von mir untersuchten, spärlichen

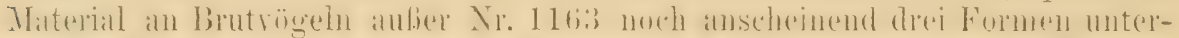

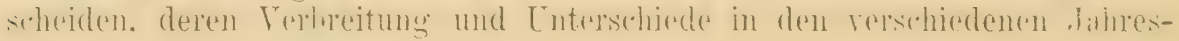
zeiten aber noch ferneren Studiums bedürfen:

Prunella fulvescens fulvescens (Sew.).

'lurkestan. Siehe obige Beschreibung.

\section{Prumella fulvescens dresseri, nom. nov.}

Accentor fulcescens var. pallidus Dresser (von pallidus Menzbier 1887!), B. Europe IX. p. 105 (1895- Karakasch-Tal in Ost-Turkestan. Aus Sewertzoffs MS.).

Brutvögel aus dem Karakasch-Tal und den Chotan-Bergen im südlichen (ost-Turkestan sind erhehlich hlasser, fahler als solche ans dem russischen 'Turkestan, und scheinen eine wohl unterscheidbare Rasse zu bilden.

\section{Prunella fulvescens dahuricus (Tacz).}

Accentor dahuricus Taczanowski, Journ. f. Orn. 1874 p. 320 (Staros-Suruchaitujewskij am Argun-Flusse).

Tharrhaleus tetricus MLadarász, Ann. Mus. Nat. Hungar. VII p. 175, Taf. IV, Fig. 1 (1909 Saigan-Berge, Nord-Mongolei).

Wie ich mich durch eigene-Anschauung überzeugte, ist der Typus vou ,Tharraleus tetricus" dunkler, als turkestanische Stïcke, und zwar sowohl anf der oherseite. Wo der Kopf eintarbig dunkelhram erscheint, als an der brust und den Körperseiten, und die Weichen sind sehr dentlich gestrichelt.

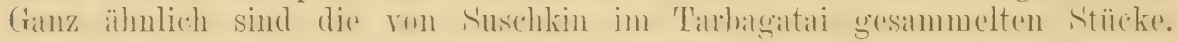

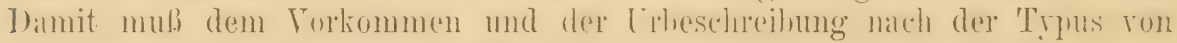

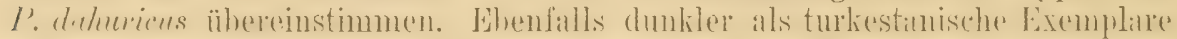
ist ein $0^{7}$ aus dom Juni, rom oberen Dit-schu (Ost-Tibet), und Bianchi (in

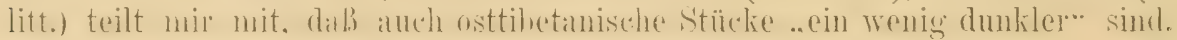

Eier wie die von $P$. modularis, 12 Eier messen nach Jourdain (in litt.) im Durchschnitt $19.74 \times 14.86$, Maximum $21.2 \times 15.3$ und $20.3 \times 16$, Minimum $18.8 \times 14 \mathrm{~mm}$.

\section{Prunella fulvescens ocularis (Radde).}

Accentor ocularis Radde, Ornis Caucasica, p. 244, Taf. XIV (1884 - Küs-jurdi im Talischer (iebirge, in einer Höhe von $8000 \mathrm{FuB}$ ).

Von allen anderen Formen ron $P^{3}$. fulvescens leicht zu unterseheiden: Die Streifung des Rückens ist eine sehr scharfe, die Striche dunkler braum, die Federsämme hlaB: Die ockerbrïunliche Vorderbrust erscheint mehr in Form eines Bandes, ron dem bleicheren Rahmgelb des Unterkörpers und der Kehle schärfer abgesetzt, nicht nur die Weichen, sondern die Körperseiten von der Brust bis zu den Bauchsciten sind dunkelbraun gestreift, nur einen breiten einfarbigen Streifen in der Mitte übriglassend. 
Persien, von der russischen Grenze am Küs-jurdi in Talisch, Gilan und

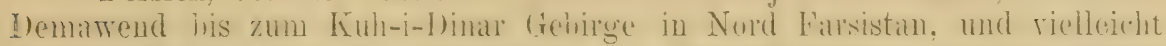

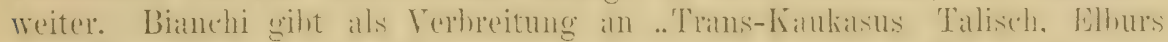
und West-Persion". - Diese Form wurde sohr leichtfertigerweise für" identisch mit $P$. julvescens gehalten.

\section{Prunella atrogularis (Brandt).}

Accentor atrogularis Brandt, Bull. Acad. Petersb. II, p. 140 (nicht 40!) (1814- Semipalatinsk).

Accentor Huttoni Moore, Proc. '/20ol. Soc. London XXII „1854“, p. 119 (1855- Simla Afghanistan).

Abbild.: Dresser, B. Europe, IX, Taf. 654, Fig. 2.

ôad. Oberseite broccolibraun (blaß gräulich rostbraun) mit schwarzhraunen Läugstleckén, Konf dunkler, an den Suiten des Oherliopfes (über dem Supereiliarstreifen) und an der Stirn fast riufarhig schwarzhamun, Bürzel und oherschwanzdecken mit versohwommenen dukelhamen Federmitten. An den hinteren Halsseiten ein aschgraure Fleck. Fibwingen und Stener-

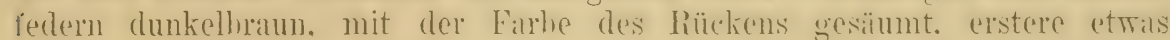
rötlicher und lebhafter. Vom Schnabel bis zu den Halsseiten ein breiter firhl rostgelher Supreiliarstreit. Zïgel. Federn untem Auge. Ohregegend und

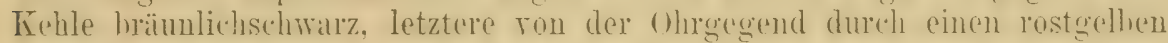
Streifen getrennt und in Herhstleide mit fahl rostgellen Federsintzen. Uhrige Cuterseite fahl rostgelh, suiten und Untersohwamadechen dunkelhram crestreift. Mitte des Unterlörpers rahmfarhen. fast weiblich. Solnahel schwärzlich, Iris dunkel-, Füße hellbraun. Flügel von 20 ठ $72-75$, zweimal 76 ,

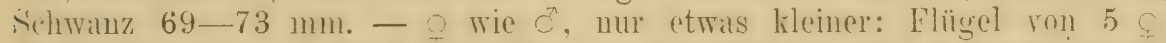
(i9.5-71.5 mm. - Nestkleid: Oherseite relsoliwommener, weniger lebuat.

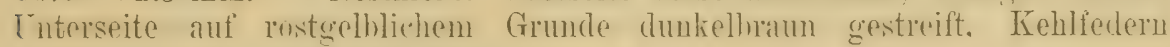
schwärzlich mit rostgelben Säumon.

Weit verbeitet in Kentral-Asien: Altai, I)sungurei, semirjetschensk, Turliestan (der ganze Tim-Sihan). im Winter und auf den Zuge lis orenhuy im sïdlichen [ral. Afghtnistau. Tordmest-Himaliya und P'mjah.

Vier Eier messen nach Jourdain $19.7 \times 14.8,18.5 \times 15.1,18.3 \times 14.6$ und $17.5 \times 14.7 \mathrm{~mm}$. Zwei Eier von Kuldscha im Britischen Museum gleichen denen ron P. modularis, nur sind sie einen Schein grïnlicher.

\section{Prunella koslowi (Przw.).}

Accentor Koslovi Przewalski, Nor. bidi. ptitz. Centr. As., Zap. Imp. Akad. Nauk, LV, [. 83 (1887 - Alaschan).

Tharraleus pallidus IIenzbier, Ibis 1887, p.299, Taf. IX. (Khobdo in der nordwestl. Mongolei).

Oे Oad. Oberseite hell bräunlich isabell, mit auf dem Rücken deut-

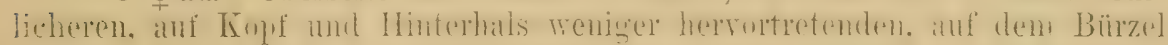
ganz und auf don Obcrsehwanzdecken fast fehlenden Schaftflecken.

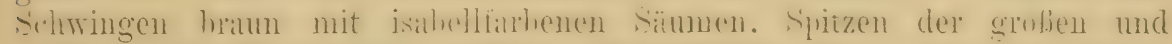

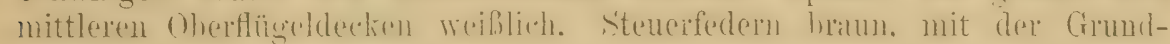
farbe des Rückens gesäumt. Kehle bräunlich rauchgrau, im frischen

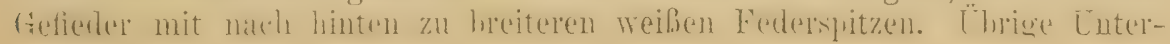




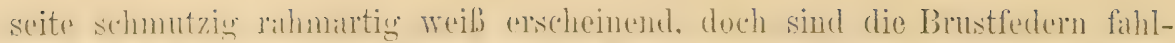

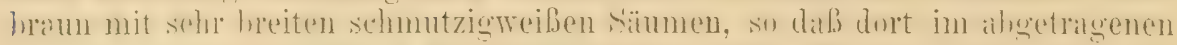

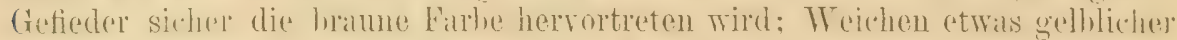

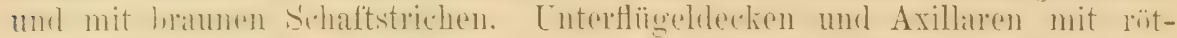

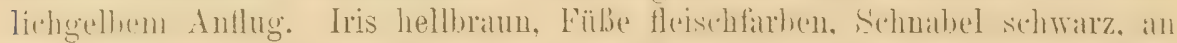
der Basis heller. Flügel 67-75, Schranz 68-73, Lauf 19-20, Culmen 14-15.5 mm. - Jur. nach Menzbier bräunlicher. 1. Schwinge viel längee

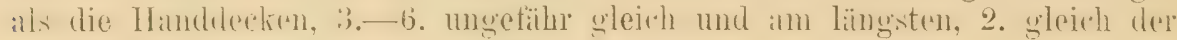
7. oder ein renig lüuger, Außenfahmen der 3.-5. verengt.

Gebirge der Mongolei: Kobdo, Gobi, Alaschan. Bisher liegen nur Winter-Exemplare vor:

\section{Prunella modularis modularis (L.).}

Heckenbraumelle.

Motacilla modularis Linnaeus, Syst. Nat. Ed. X, p. 184 (1758- „Habitat in Europa“. Terra typica Schweden nach dein 1. Citat: Fauna Suecica 223).

Motacilla plumbec Pallas, in Vroeg's Cat. Verzam. Vogelen, Adumbrat., p. 4 (176tHolland).

Accentor pinctorum Brehm, Handb. Naturg. Vög. Deutschl., p. 457 (1831- Nördl. Europa bis Renthendorf brütend).

Tarrhaleus modularis verus A. E. Brehm, Verz. Samml., p.8 (1866- Nomen nudum!)

Französ.: Mouchet. Ital.: Passera scopaiola. Schwed.: Jerns̄parf.

o oad. Oberkopf und Nacken braungrau mit dunkel schrvärzlich-

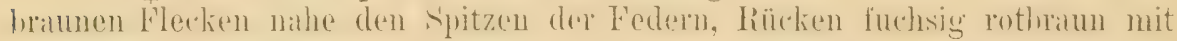

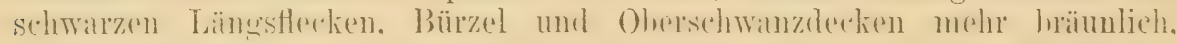

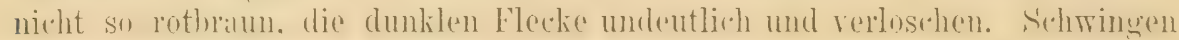
dunkelhran. Handschwingen nut sehmalen. Armschwingen mit hreiteren,

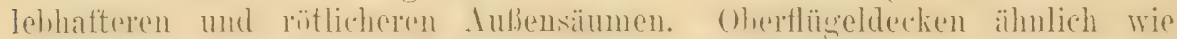

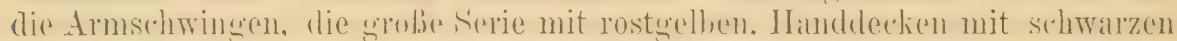

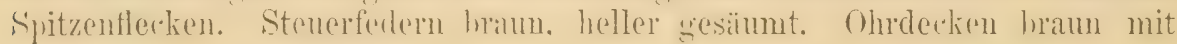

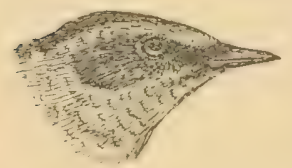

Figur 127.

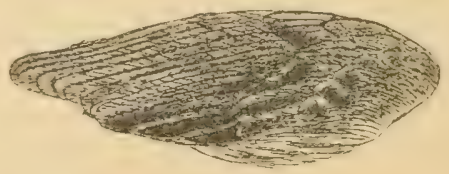

Figur 12S.

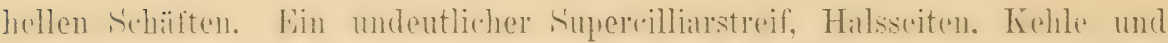
brust ascheran. Küruerseiten hell rostfarben mit dunkelhraunen Lüngsistreifen.

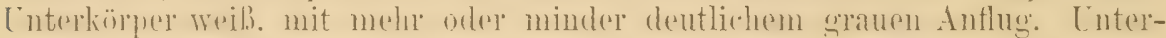
schwanzelecken hann mit hreiten weiblichen his hell restfarlenen Säumen.

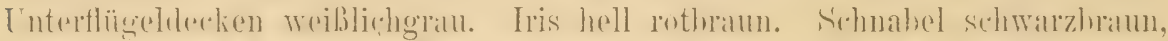

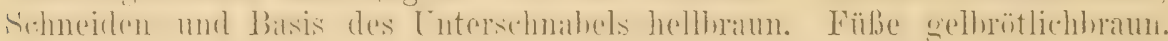
Flïgel von $300^{7}$ o $67-70$, selten $71-72$, Schwanz etwa 56-61, Lauf otwa 20, Culmen 13-14.5 mm. - o wie o $0^{7}$ - Nestkleid: Federn der Oberseite gelblichbraun mit schwarzen Längsflecken, Kopf mehr graubraun.

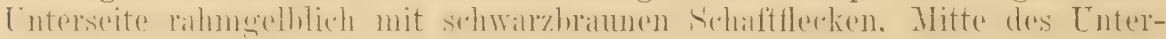
körpers einfarbig weiBlich. Das oben beschriebene Herbstkleid wird im

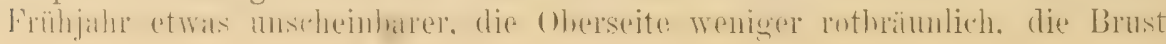


dunkler gran, mehr wie bei A.m. occidentalis. -1 . Sehwinge $1-2$, selten bis $3 \mathrm{~mm}$ länger als die Handdecken, oft kaum so lang wie letztere, 2. immer merklich, meist 4, mitunter nur 3, nicht selten $5-6 \mathrm{~mm}$ länger als die 7., deren Abstand ron der 6. mindestens $5 \mathrm{~mm}$ beträgt. 3.-6. Schwinge mit verengter Außenfahne.

Die Heckenbraunelle bervohnt Europa ron der Nordgrenze des Waldwuchses (etwa $70.0^{\circ}$ ) bis zum Mittelmeere, osträrts bis zum Ural und schwarzen Meere. In Spranien und P'ortugal angeuscheinlich nur im Norden. in Italien, Korsikil und Sardinien nur im Gehirge nistend, in s'ür-Italion und und Sizilien, Griechenland und Nazedonien nur Wintervogel. - In Nord-

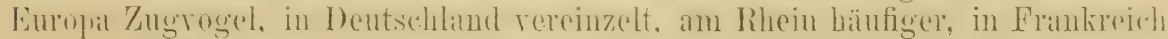
schon vielfilch in Kleinasien und Palästina vermutlich nur im Winter rorkommend. Auf den Britischen Insehn durh eine sedentirre From vertreten. Serien alus West-

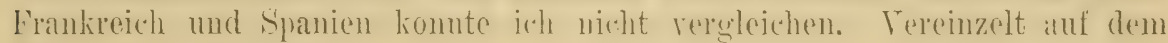
Zuge in Ost-England.

Lebt in Wäldern ron Laubholz, Fichten und Tannen, besonders im Gebirge, wenn sie viel Unterholz haben, meidet aber offene Kiefern- und Buchenhochwälder, dagegen ist sie häufig in Gärten, Buschwerk und Hecken. Man sieht sie meist still, in ganz kurzen Sprüngen am Boden Nahrung suchen, nur beim Singen sitzt das of oft hoch auf Bäumen. Die Lockstimme ist ein unauffälliger, etwas klirrender, mehr silbiger Pfiff, auch hört man oft ein ganz leises, kurzes tü oder tütü. Der Gesang ist ebenfalls nicht gerade laut, wenig abwechselnd und aus einigen kurzen Strophen zusammengesetzt. Er erinnert etrvas an den des Zaunkönigs. Nahrung Insekten und Sämereien. Das Nest steht nahe über dem Erdboden, in Fichten- und anderen Büschen, Hecken und Reisighaufen. Es ist ein mäßig tiefer Napf aus grünem MIoos und feinen Zweigen und Stengeln, die Ausfütterung aus feinen Halmen, Haaren und Wolle, mitunter auch einigen Federn. Das erste Gelege findet man etra Mitte April, das zweite im Sommer. Die 4-5 Lier sind einfarbig grünlichblau, tiefer blau als Rotschwanz-Eier und meist größer, rundlicher, anch noch weniger glänzend. 83 Eier messen nach Rey im Durchschnitt $19.5 \times 14.4$, Maximum $21.2 \times 15.1$, Minimum $17.5 \times 14$ und $19.5 \times 13 \mathrm{~mm}$. Das mittlere Gewicht nach Rey $120 \mathrm{mg}$.

\section{Prunella modularis occidentalis (Hart.).}

Curruca Eliotee Leach, Syst. Cat. Indig. Mamm. \& Birds in Brit. Mus., p. 24 (1816England. Nomen nudum!)

Accentor modularis occidentalis Hartert, British Birds 1910, p. 313 (Britische Inseln).

Engl.: Hedge Sparrow.

(Prazák, Orn. Monatssehr. 1896, p. 189 behauptet, daß die Art ron Britannien nach Japan hin immer mehr braun wird, „so daß die sehr lichten britischen Vögel vielleicht als besondere Subspezies, die als sclateri bezeichnet werden könnte", getrennt werden könuten. Da nun englisehe Vögel aber im Gegenteil dunkler sind, ist anzunehmen, daß die ganze Redensart nur der Phantasie des unglaubwürdigen Autors entsprungen ist.)

$0^{7}$ o ad. Kehle und Vorderbrust dunkler grau, Mitto des Unterkörpers niclit so dentlich wriblich, Grundfarhe der Körperseiten etwas dunkier. infolgedessen die hreiten hraunen Streifen nicht in sehanf herrortreten. Thie Oherseite ist im allgemeinen etwas weniger lekhalt geförbt, nicht sil rothrïunlich. Bei den sind diese geringen Firthungsunterschiede in allsemeinen weniger sichthar. I)er Schubinel ist durehsehnittlich merklich 
kräftiger; dicker: (Vgl. P'arus major neutoni, Evithacus rubeula melophilus).

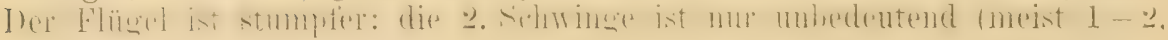
sehr selten $3 \mathrm{~mm}$ ), mitunter gar nicht länger als die 7 ., deren Abstand von der 6. etras geringer ist. - Die Flügelform aller untersuchten britischen Stïcke, mit Ausnahme eines typischen $P$. m. modularis von der Westküste (Herbst) ist wie oben beschrieben. Der Fïrbung (nicht der Flügelform) nach sind mitunter koutinentale Stücke, z. B. Schreiz, Pyrenäen (andere sind typisch hell!) nicht sicher ron occiclentalis zu unterscheiden.

Großbritamien und Irland.

Der "Heckensperling“ der Engländer ist Standrogel auf den Britischen Inseln ron den Kavalinseln bis zu den Orkneys und Hebriden. Lir ist einer der häufigsten und bekanntesten Vögel und lebt in Wäldern, Parks, Gärten und Hecken, ja sogar auf Klippen am Meere (Kanalinseln), die kaum einige Sträucher aufweisen. Lebensweise wie die ron A. m. modularis. Eier 4-6. Nest mitunter auch hart am Boden. 27 englische Eier messen nach Jourdain (in litt.) im Durchschnitt $19.8 \times 14.47$, Maximum $21 \times 14.3$ und $20.6 \times 15.1$. Ninimum $18.4 \times 14$ mm. Ein Riesenei $23.1 \times 14.5$. Spareier $12.5 \times 8.9$ und $12.6 \times 9.5 \mathrm{~mm}$.

\section{Prunella modularis orientalis (Sharpe).}

Accentor orientalis Sharpe. Cat. B. Brit. IIus. VII, p. 652 (1883- "Apparently from the eastern shores of the Black Sea to Persia“. Terra typica: Batum.)

Ähnlich P. m.modularis, aber die Fleckung auf dem Kopfe nicht ganz.

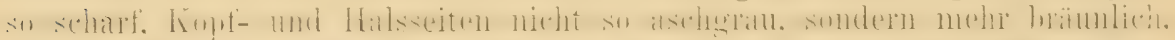

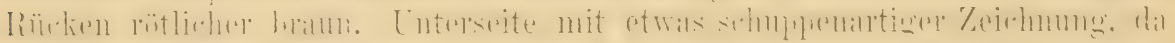
die Federn der Brust dentliche weißliche Sämme baben, der Unterkörper mehr bräunlicbgrau mit weißen Säumen. 3. Schwinge ungefülur gleich der 7 .

Südlicher Kaukasus und Transkaukasien.

\section{Prunella modularis blanfordi (Sar.).}

Accentor mubidus (non 'lemm. \& Schl.!) Blanford, L. Persia II, 1) 202.

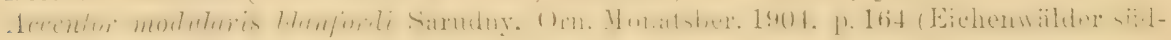
westl. ron Isfahan).

Unterscheidet sich ron $P . m$. modularis und $P$. m. orientalis durch voll-

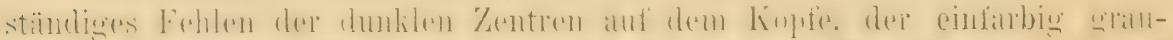

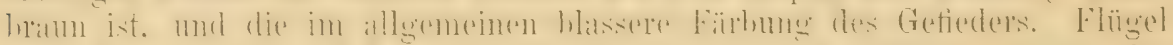

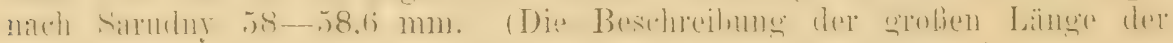
1. Schwingo inub auf einem Schreib- oder Druckfehler beruhen.)

Gebirgswälder sẗdlich und südwestlich von Isfahan im mittleren Persien (Kumische).

\section{Prunella rubidus (T'emm. \& Schleg.).}

Accentor modularis rubidus Temminck \& Schlegel, Siebolds Fauna Jap., Ares, p). 69, Taf. 32 (1850- Japan).

Accentor fervidus Sharpe, Cat. B. Brit. IIus. VII, P. 653 (1883- Hakodate, Japan). Abbild. d. Eies: Cat. Eggs Brit. ILus. IV. 'T'af. VII, Fig. 21.

of O. Oherseite der ron $P$. moclularis ähulich, aber Kopf und Hals einfarbig rötlichlowu. etwa hell sehokoladenfarben, Rücken viel rötlicher, 
Federmitten dunkel kastanienbraum, Süume rötlich rostbraun. Bürzel und Oberschwanzdecken gelblich erdbraun mit etwas dunkleren Tedermitten. Flügel und Schwanz wie bei $P$. modulcuris, nur die Süume etwas rötlichor.

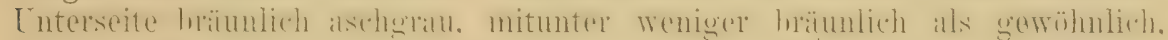
Weichen mehr oder minder rostrot mit dunkleren Federmitten. Ohrdecken rotbraun mit brïunlichgelben Sehaftlinien. Flügel von alten Vögeln Geschlecht zweifelhaft — $66-71 \mathrm{~mm}$.

Japan (Jesso, Hondo, Kiuschiu und Kurilen). — Vielleicht als Subspezies von $P$. modularis aufunfassen.

Briitet auf dem Fudschi-Jama in Höhen von 8000 Fuß, in Buschweidendickichten. Eier wie die ron $P$. modularis.

\section{Prunella immaculatus (Hodgs.).}

Accentor immaculatus Hodgson, Proc. Zool. Soc. London XIII, 1815, p. 34 (Nepal). Accentor mollis Blyth, Journ. As. Soc. Bengal XIV, p. 581 (1845- Darjiling).

Abbild.: Gould, B. Asia IV, Taf. 45.

o o ad. Oberkopf und Nacken dunkel aschgran, die Federn mit mehr

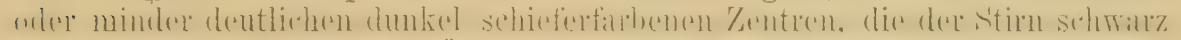

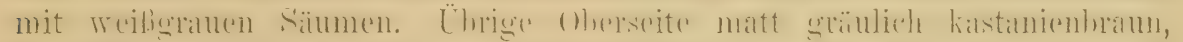

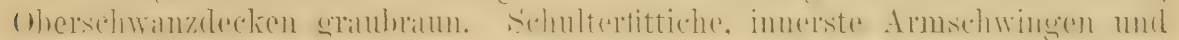

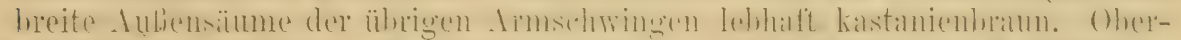

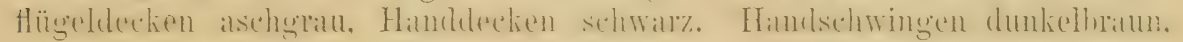
3.-6. mit schmalen hellgrauen Außensäumen. Schwanz braun mit sehr

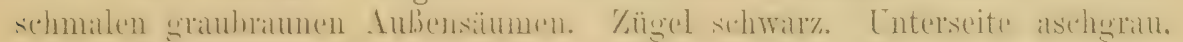
untere Hälfte des Abdomens, Bauch, Weichen und Untersehwanzdecken

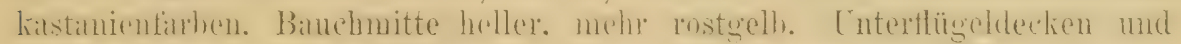

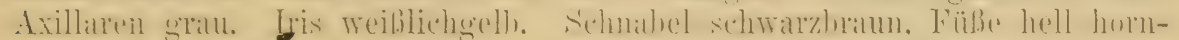
braun. Flügel von 12 alten Vögeln 77-80.5, Sehwanz 58-60, Lauf 20-21, Culmen $15-16.1 \mathrm{~mm}$.

Nepal und Siklim bis West-China (Szetschwan).

\section{Familie TROGLODITIDAE.}

Familie kleiner lis mittelgrolber Vögel mit kurzer, aller wohl antwickelter

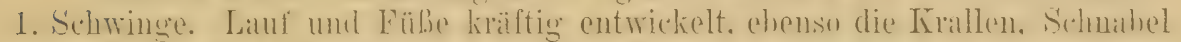

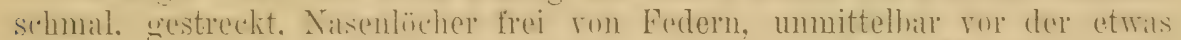

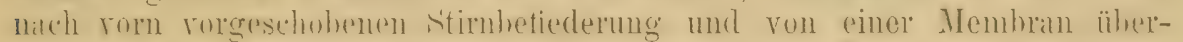

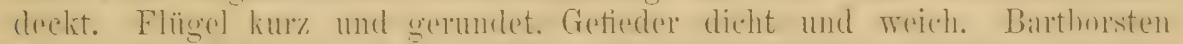

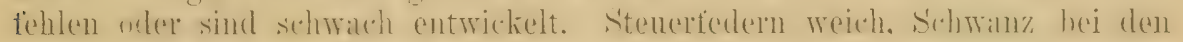
meisten altweltichen Formen sehr kurz. Zahl der Stenerfedern variabel.

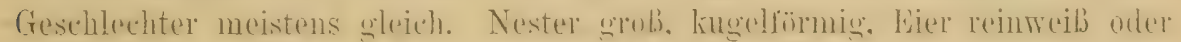

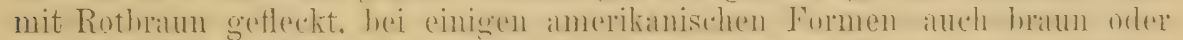

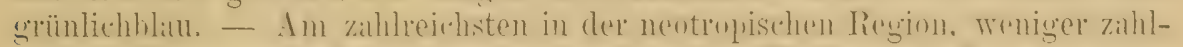

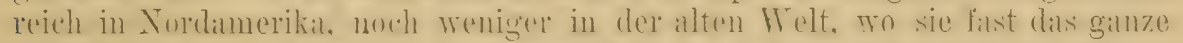

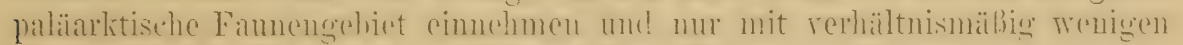

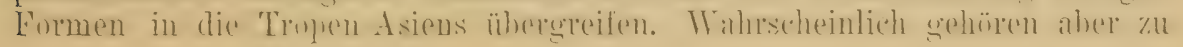




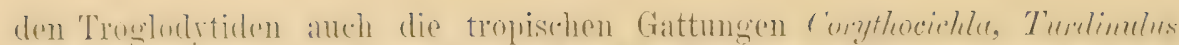

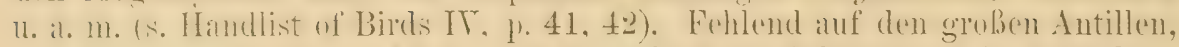

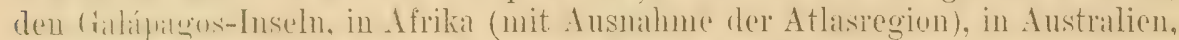

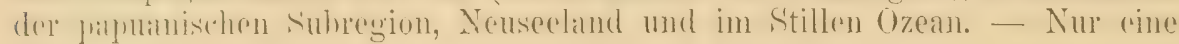
Mausel:

\section{Gattung TROGLODYTES rieill.}

Die Zaunkönige. Man hat die amerikanischen Troglodytes von den

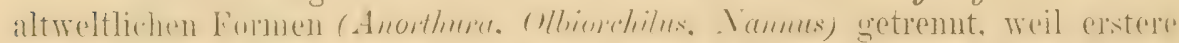

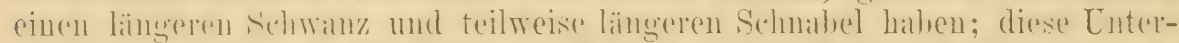
schiode sind \% wall in den Extremen anffillend, hei einigen Formen alder zu

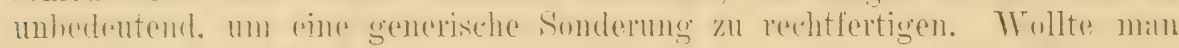

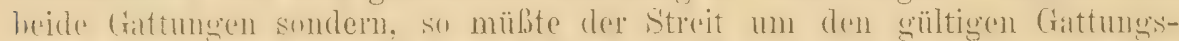

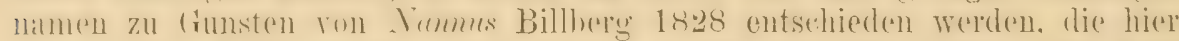

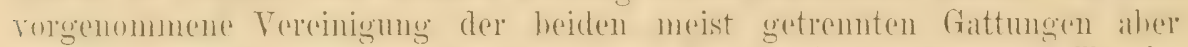

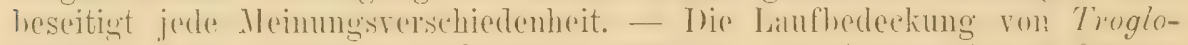

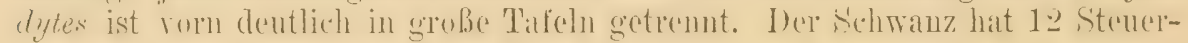
fedeln. Dio Jungen sehen den Alten ähnlich.

Außer den hier besprochenen palïarktischen Formen des Zamukönigs. diurfte es noch nahe verwandte Subspezies in den nicht mehr recht paläarktischen Gebirgen von China (und Hinterindien?) geben. Eine solche wurde bereits von Sharpe als Anorthura talifuensis (Bull. B. O. Club XIII, p. 11, Tali-fu in Jumnan) beschrieben, und auf den Bergen voll Formosa

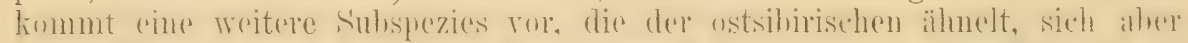

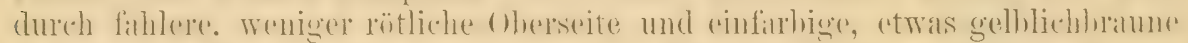

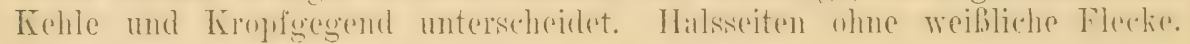
Diese Form benenne ich nach drei o vom Berge Arisan:

\section{Troglodytes troglodytes taivanus sulsi. u.}

Fermer gohört eine Anzahl nordamerikanischer Formen als Subspezies

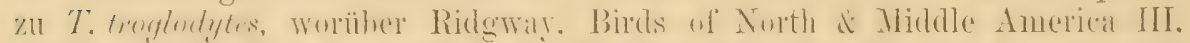
1914. 1. 595-6ut Auskunt giht. Er füht folgente Formen an: himalis

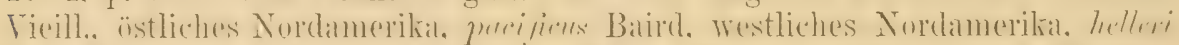

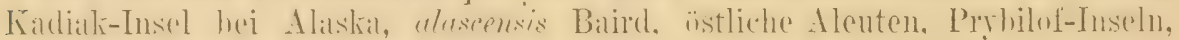
Teile von Alaska, meligemes Oberh., westlichste Aleuten. - T. t. hiemalis ist weniger leicht vou ' $T$. $t$. troglodytes zu unterscheiden, als manche der' paläarktischen Subspezies.

\section{Troglodytes troglodytes islandicus Hart.}

Troglodytes troglodytes islandicus Hartert, Bull. B. O. Club XXI, p. 25 (1907-- Is]and).

Wio T. t. borealis aber noch größer. Flïgel von 2 ơ 57.5 und $61 \mathrm{~mm}$.

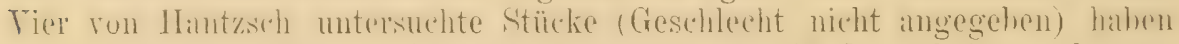
nach letzterem Filugel ron $54-55 \mathrm{~mm}$, seine Maße scheinen aber zu

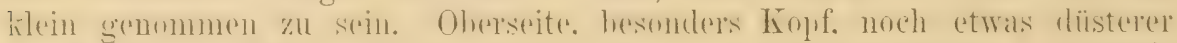
braun. Culmen 15-15.8, Lauf $20-21 \mathrm{~mm}$. „Füße rötlichgrau“ (Slater). Island.

Sehr seltener Standrogrel, besonders iu wasserreichen Teilen der Insel. Brutzeit Juni und Juli. Vier Eier im British Museum nach Jourdains Hessung $19 \times 14$, $19 \times 13.5,18.3 \times 14$ und $18 \times 13 \mathrm{~mm}$. 


\section{Troglodytes troglodytes zetlandicus suhsi. 11.}

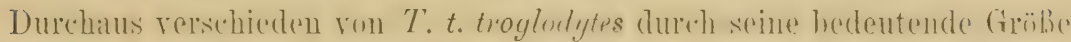
und überhaupt nur mit T. t. islandicus, borealis und livtensis zu vergleichen.

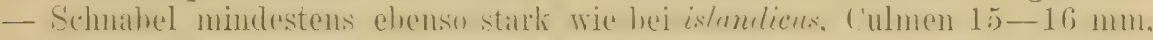
Flügel abel kïrzer: bei 3 ơ ad. 52-53.3, bei einem o $48.1 \mathrm{~mm}$. Von $T$.

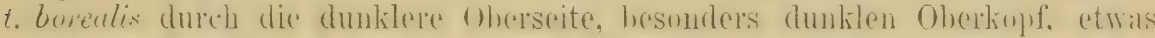
dunkleren Flügel und etwas düsterere Cuterseite, hesomders aber dureh den

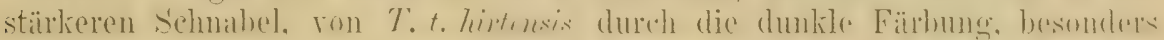

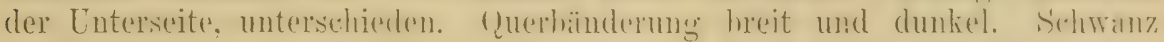
ơ $37-39$, o 34, Lauf $19 \mathrm{~mm}$. Trpus òd. Dumrossness, Schetlandsinseln,

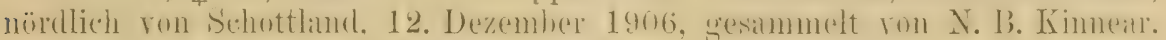
No. 59 F im Königl. Sehottischen Museum zu Edinburgh.

Häufiger Standrogel anf den [xlsigen, sturmumhransten SehetlandsInseln, wo er sehr furchtlos auftritt und in Felsenspalten und unter der Rasendecke über den Abhängen nistet.

\section{Troglodytes troglodytes borealis lisch.}

Troglodytes borealis Fischer, Journ. f. Orn. 1861, p. 14, Taf. I. (Faröer - Vogel und Eier abgebildet).

Steht zwischen $T$. t. islandicus (bziv. zetlandicus) und 'T'. t. troglodyles. -

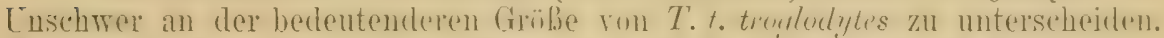

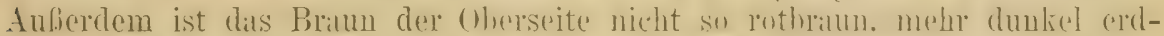

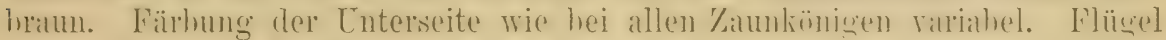
einer Serie von ते $49-55 \mathrm{~mm}$. Knud Andersen gab $53.75 \mathrm{~mm}$ als das

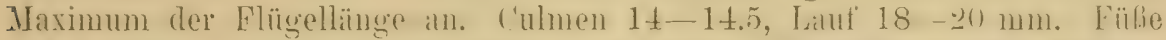
viel kräftiger, Hinterzehe viel stärker und länger. Flügelform etwas rariahel.

Earöer.

Nach Feilden iiberall auf den Faröer häufig, wo nicht viele Katzen gehalten werden. Der Gesang viel kräftiger und wohlklingender als bei uns. Nester in Mauern und Bootshäusern, auch in Höhlen und an Felsen. Sie bestehen äußerlich immer aus Heu, darauf folgt eine Schicht aus MIoos und das Innere ist mit Federn und Daunen weich gepolstert. Die Eier sind durchschnittlich bedeutend größer als solche rom europäischen Festlande. 41 Fier messen nach Jourdain im Durchschnitt $18.34 \times 13.57$, Iaximum $19.3 \times 14.2$, Minimum $17 \times 13$ und $17.2 \times 12.5 \mathrm{~mm}$.

\section{Troglodytes troglodytes subsp.?}

Eine Serie von Zaunkönigen von den Hebriden und von Fair Island (zwischen den ()rkner- und Schetlands-Inseln grelegen) ergah. dab sie zwischen T. t. troglodytes aus England und T.t. zetlandicus stehen, meist aber kaum von borealis zu unterscheiden sind. Sie sind sehr variabel, in der Regel monhl etwas dunliler" als T. t. Lorealis von den Farierer. während Flügrel- und Schnahellänge mrist dieselhe ist. Indessen sind cinige Stildke genat so hell wie solche von den Faröer, von denen nicht sehr viele untersucht werden komnten, andererseits sind sie auffillend variahel (Exemplare ven den Grkiners

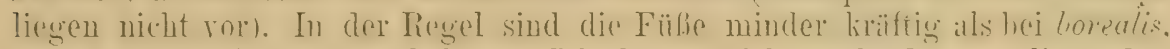
aber stärker als bei troglodytes. Ich kann mich nach dem vorliegenden

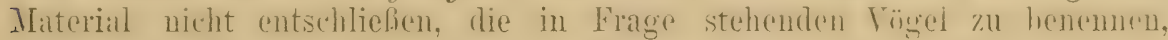

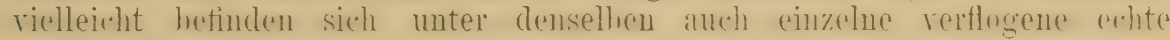
troglodytes. 


\section{7i. Troglodytes troglodytes hirtensis Ser $_{\text {. }}$}

Troglopytes hirtensis Seebohm, Zoologist 1884, p. 333 (St. Kilda).

Abbild.: Ibis 1885, Trf. III.

Wie T.t. borealis, auch auf der Oberseite ganz ebeuso gefärbt, doch ist die Unterseite viel weißlicher, die Unterschwanzdecken entbehren der

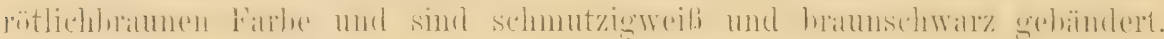
Flïgel von 3 alten Vögeln $53-54$ mm.

Insel St. Kilda, westlich der Hebriden.

Lebt an den Felsen der sturmumwogten, baum- und strauchlosen Iusel St. Kilda, westlich ron Schottland. 33 Eier messen nach Jourdain im Durchschnitt $18.11 \times 13.7$. Maximum 19.1 $<14.1$ und $18.3 \times 14.2$, Minimum $17 \times 13.2$ und $17.2 \times 13 \mathrm{~mm}$. Eiu Gelege im Tring Museum mißt: $19.4 \times 14.3,18.6 \times 14.4,18.8 \times 11.2,18.5 \times 13.5$ und $18.3 \times 14 \mathrm{~mm}$. Die Eier sind also viel größer als die ron T. $t$. troglodytes.

\section{7\%. Troglodytes troglodytes troglodytes (L.). (Fig. 129.) Zaunkönig:}

Motacilla Troglodytes Limnaeus, Syst. Nat. Ed. X, p. 188 (1758 - Europa. Als terra typiea betrachten wir Schweden, nach dem 1. Zitat: Fauna Svecica 232).

Troglodytes Europea Vieillot, Nouv. Dict. d'Hist. Nat., Nour. Ed., 34, p. 511 (1819Europa).

Troglorlytes punctatus Boie, Isis 1822, p. 551 (Nomen nudum!).

Troglodytes parvulus Koch, Syst. baier. Zool. I, p. 161 (Neuer Name füir Motacilla troglodytes L.).

Troglodytes vulgaris Fleming, Brit. An., p. 73 (Neuer Name für Mot.troglodytes. Heimat Großbritannien und Shetlands Inseln).

Troglodytes Regulus Mleyer, Meyer \& Wolf, Taschenb. deutsch. Vögelk., Zusätze usw., p. 96 (1822- Neuer Name für "Sylvia Troglodytes").

Troglodytes domesticus und sylvestris Brelm, Isis 1828, p. $128 \pm$ (Nomina nuda!); id. Handb. Naturg. Vög. Deutschl., p. 454, 455 (1831 - Deutschland).

Anorthura communis Rennie, IIontagus Orn. Dict., 2. Ed., p. 570 (1831- Neuer Name). Troglodytes tenuirostris und bifasciatus Brehm, Vogelfang, p. 238 (1855-- Deutschland). Troglodytes Naumanni Brehm, Vogelfang, p. 238 (1855- "Sïdfrankreich und Böhmen"). Troglodytes verus Burmeister, Syst. Uebers. d. Thiere Brasil. III (Vögel), 2, p. 137 (1856- Neuer Name für "unsern Zaunkönig").

Troglodytes europaeus crassirostris, pygmaeus, taeniotos, Naumannii, punctatus und maculatus A. E. Brehm, Verz. Samml., p. 6 (1866- Nomina nuda!)

Troglodytes Linnéi IIalm, Götheb. Bohusl. Fauna p. 169 (1877- Bohuslän \& Göteborg).

Troglodytes parvulus bergensis Stejueger, Zeitschr. ges. Orn. I, p. 10 (1881-. "Westküste Norwegens").

Engl.: Wren. -- Franz: Roitelet. - Ital, : Scricciolo. - Schwed.: Gärdsmyg.

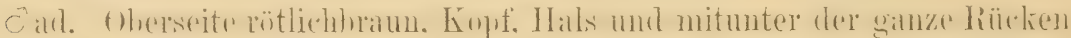

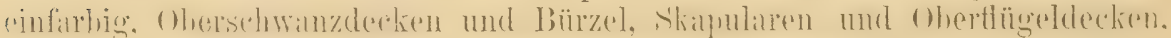
meist auch der untere, und nicht selten der ganze Rücken schmal dunkcl-

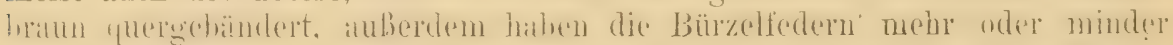

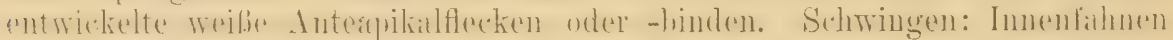

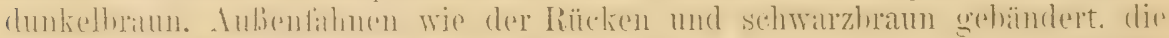

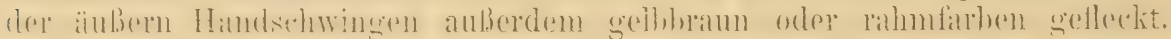
Mittlere Serie der Oberflügeldecken an den Spitzen mit kleinen weißen Flecken. Steuerfederu rotbraun mit (an dem mittleren Paare etwa 10-12)

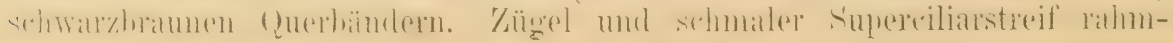




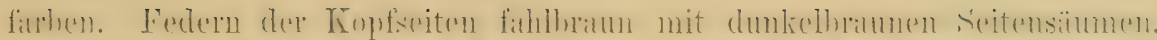

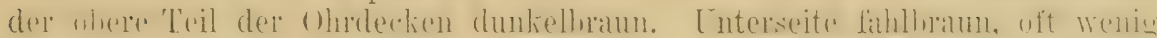

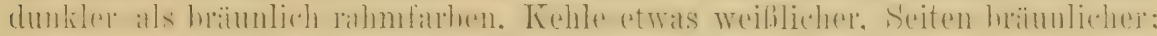
Bauch und Weichen immer schwarzhraun gebändert, die dunklen Querbänder durch weiße oder weißlicho Nebenbänder hervorgehohen; büufig geht die Bänderung, mehr oder minder undentlich und schmäler werdend, rom Unterkörper bis zur Brust himauf, öfter aber ist die Brust und der größte 'Teil des Unterkörpers ganz einfarbig oder die Feder'u ron Kehle und Torderhrust durch etwas dunklere Seitensäume ric gestreift erscheinend, bisweilen das Abdomen bis zur Kehle hin fein punlitiert. Unter-

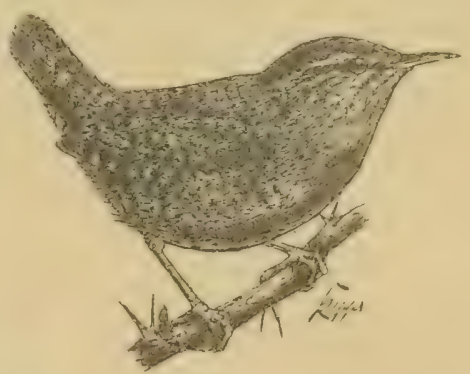

Figur 129.

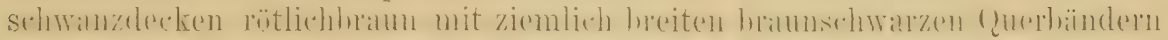

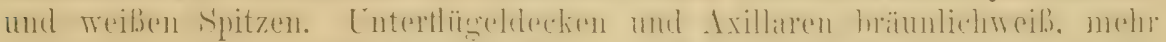

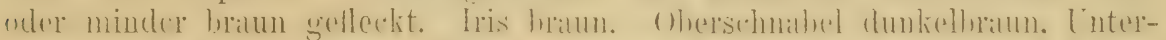

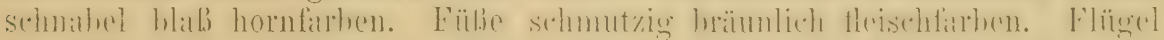
etwal t7-50, Sehwanz 32-35, Lauf 17-18, Culmen 12.5-13.5 mm. 2. Schwinge so lang wie die längsten Armschwingen, selten länger. o acl. wie ơ ad., nur ein wenig kleiner, Flügel ungefïh $45-47 \mathrm{~mm}$. Nestrleid: Dom der alten Vögel älunlich, nur Oberkiopf und Hals etwas

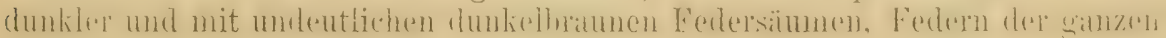
Unterseite mit dunklen Endsäumen.

Europa rom nördlichen Skandinavien bis zu den Gestaden des Mittelmeeres und von den britischen Inseln bis zum Ural. - Im Norden Zug-

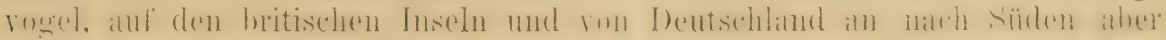
Stand- und Strichvogel. In Südeuropa anscheinend mehr Gebirgsvogel.

Der Zaunkönig bewohnt mit Vorliebe gemischte Wälder, Hecken und buschreiche Gärten und hält sich besonders gern in der Nähe des Wassers, besonders ron kleinen Waldbächen auf. An den englischen Küsten und auf den Normannischen Inseln lebt er auch an spärlich mit Büschen bewachsenen Uferwänden und sucht auf dem zur Ebbezeit trocken gelegten Meeresboden zwischen Steinen und Tang nach Nahrung. Er hält sich meist am Boden und in niederem Gebiisch, Reisighaufen und Zäunen auf, die er mit großer Hurtigkeit, den Schwanz senkrecht emporgehoben, durchschlüpft. So schlüpft er durch die engsten Ritzen und Löcher und verkriecht sich oft in Mauselöelier, unter Wurzeln und Stïmme, Steine und dergl. Seine Stimme ist ein lautes Schnurren, das etwa wie tzrrrrr, tzrrrrr klingt, oder auch, seltener ein hartes tjik. Der Gesang, den er auch bei Selnnee und Eis im Winter hören läßt, besteht aus einigen hell schmetternden Reihen, die gewöhnlich in einen Roller ausklingen. Das Nest steht an Uferwänden, Böschungen, Felsen, in niedrigen Strohdächern, Reisighaufen, Heuschobern, im Epheu an Häusern und Bäumen, im Gewurzel gestürzter Bäume oder frei in Büschen und Hecken. Es ist kugelförmig oder etwas länglich, mit kreisrundem seitlichen Einflugloch. Es besteht mit Vorliebe aus grünem Moos, oft auch aus Farrnkraut, seltener aus Gras und dïrren Blättern, im Park zu Tring sahen wir Nester, die größtenteils aus Emu-Federn gebaut waren. Das Innere ist nicht selten mit Federn ausgefüttert. Das Gelege besteht meist aus 6, wohl nur ganz ausnahmsweise auch aus mehr Eiern. Diese sind glanzlos weiß mit feinen braunroten Punkten und kleinen Fleckehen, nicht selten auch ganz weiß. 100 Eier (72 Rey, 28 Jourdain) messen im Durehselnnitt 16.19 $\times 12.54$, MIaximum $18.9 \times 13.2$ und 
$17.4 \times 13.5$, Minimum $14.7 \times 11.7$ und $15.7 \times 11.5 \mathrm{~mm}$. Zwei Bruten sind in milderem Klima die Regel, in Norden scheint aber meist nur eine stattzufinden. Außer den zur Brut benutzten Nestern baut der Zaunkönig auch andere, vie zur Eiablage gebrauchte Nester, sogenannte Spielnester. Sic sind anscheinend nicmals mit Federu ausgefüttert und viel dünnwandiger, leichter, oft nicht einmal fertig gebaut. Dies sind nicht nur verlassene, lialb fertige Nester, sie werden auch mitunter zum Schlafen benutzt. Jedenfalls sind sie ein vortreffliches, wenn auch unbeabsichtigtes Mittel, den Nestersucher von der richtigen Fährte abzuleuken.

\section{Troglodytes troglodytes kabylorum sul,sp. nor.}

Unterscheidet sich von T't. troglodytes durch krïftigeren Sehmabel, wie T. t. cypriotes. 2. Schrvinge nicht länger, als die längsten Armschwingen, sondern wie bei $T$. $t$. troglodytes. Unterkörper wie bei letzterem in der

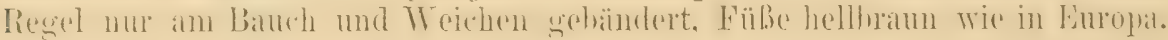
Oberseite wohl im allgemeinen etwas matter. Bei zwei marokkanischen

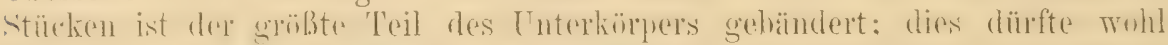
Zufall sein, dir die Bänderung ja aluch in buropla vielfach abündert. Tyjus Ōad., N0. 8, bei der Stadt Algier 25. Februar 1909 erlegt.

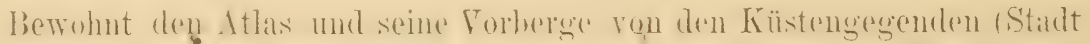

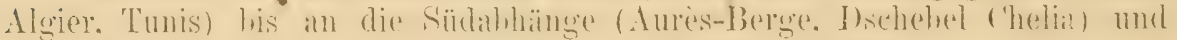
Marokko (bis Tamarut und Fensu im siidwestlichen Atlas).

Lebensweise und Fortpflanzung wie beim europäischen Zaunkönig.

\section{Troglodytes troglodytes cypriotes (Batr).}

Anorthura cypriotés Bate, Bull. B. O. Club XIII, p. 51 (1903- Cypern).

Unterscheidet sich von T.t.troglodytes durch merklich längeren Schnabel sorvie dadurch, daß die 2. Schwinge immer deutlich lïnger ist als die lïngsten Armschwingren. Auberdem geht die Bänderung der Conterseite hoi den

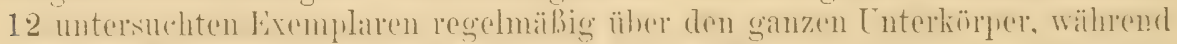

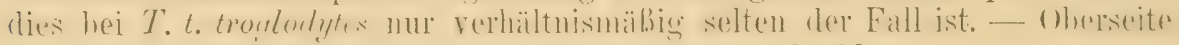
kaum etwas woniger rotbraun. Füße anschoinend dunkler.

Gebirge Cyperns.

Glaszner fand Gelege von 5 Eiern Ende April und anfangs Mai. Die Nester befanden sich etwa einen halben $m$ hoch an den Ufern ron Gebirgsbächen. Die Eier haben sehr feine, bei einigen Stücken kaum sichtbare rotbraune Punkte. Maße: $16.8 \times 12.4, \quad 16.5 \times 12.5, \quad 16.3 \times 12.5, \quad 15.9 \times 12.5, \quad 15.5 \times 12.5$ und $15.3 \times 12.2$, $15 \times 12.5,15 \times 12.3,14.9 \times 11.55 \mathrm{~mm}$. Ein drittes Gelege - Nest anderthalb m über einer Quelle in einem Erdloch - ist größer und mehr hell rotbraun gefleckt. Es mißt: $16.4 \times 12.2,16.1 \times 12.1,15.7 \times 12.4,15.1 \times 12.8$ und $15 \times 12.4 \mathrm{~mm}$.

Ich bin außer stande anzugeben, zu welcher Form die Zaunkönige aus

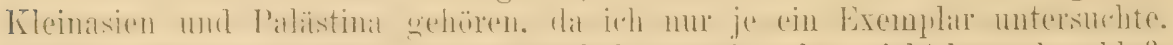

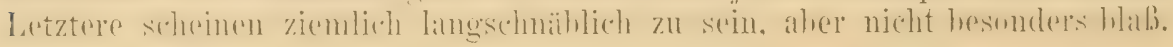

\section{Troglodytes troglodytes hyrcanus Sar. d Luul.}

Troglodytes parvulus hyreanus Sarudny \& Loudon, Orn. Monatsber. 1905, p. 107 („Bewohnt die Wälder der an das Kaspische Meer angrenzenden persischen Provinzen Ghilan, Masanderan, Asterabad“).

Trogtodytes talyschensis Buturlin, Nasita Okhota 1908, Heft IX-XI (Talysch). 
Steht zwischen T.t. pallidus und T.t. troglodytes. Nicht so rostfarbig wie letztorer, dunkler als T.t. pallidus.

Nord-Persien bis T'alisch, Nord- und Süd-Kaukasus. Hierzu scheinen mir auch Vögel von der Südküste der Krim zu gehören.

\section{Troglodytes troglodytes pallidus Hume.}

Troglodytes pallidus Hume, Stray Feathers III, p. 219 (1875- Kaschgar. Kurze, aber richtige Kenuzeichnung).

Troglodytes tianschanica Sewertzoff IIS, teste Sharpe Cat. B. Brit. D[us. VI, p. 273 (1881- Turkestan).

Troglodytes parvulus subpallidus Sarudny \& Loudon, Orn. Monatsber. 1905 p. 107 ("Gebirge von N.O. Persien, besonders der Provinz Chorassan, von wo sie sich offenbar weit nach Osten in das System des Parapamisos-Gebirges rerbreitet"). Nach Untersuchung von zwei Bälgen und Bianchi in litt. nicht von $T$. $t$. pallidus zu trennen.

Von allen andern Formen durch die blassere, auf Kopf, Hals und Vorderrïcken immer ungebänderte und grau angehauchte Oherseite unschwer 7.u unterscheiden, Kehle, Tropf und Brust weiBlich hrïunlichgran. nugebändert oder nur mit schwachen Audeutungen von Bänderung an der Brust. Flügel von 20 Bälgen $47-50.5$, zweimal (Dschirkend und Tasehlient. wo auch Stücke mit nur $47 \mathrm{~mm}$ kurzen Flügeln vorkommen) $52 \mathrm{~mm}$.

Turkestan, Transkaspien und Nordost-Persien.

\section{Troglodytes troglodytes zagrossiensis Sill. if Lutul.}

Iroglodytes parvulus zagrossiensis Sarudny \& Loudon, Orn. MIonatsb. 1908 p. 29 (S. W.-Persien).

Diese ron mir nicht untersuchte Form unterseheidet sich nach Sarudny und Loudon ron T. to troglodytes durch ...hellere Firthung des rostfarthigen Gefieders", ron T. p. heypeanus durch weniger grïuliches und mehr rostfarhiges Gefieder, ron T.t.pallidus durch reniger gränliche Fïrhung und gröhere Zeichnugen. Es ist alst eine helle rostfirthige Form, gegenuiber der hellen, mehr gräulichen Form Turkestans (pallidus).

Südwestliches Persien: Gebirge des Zagrosch-Systems.

\section{Troglodytes troglodytes nipalensis Blyth.}

Troglodytes nipalensis Blyth, Journ. As. Soc. Bengal XIV, p. 589 (1845- Nepal. Ex Hodgson MS.)

Troglodytes subhemalayamus Hodgson, Gray's Zool. Misc., 1).82 (1832 - Nepal. Nomen nudum. Druckfehler für subhemalachanus).

In allgemeinen die dunkelste Form ron allen, hesonders auf der I'nterseite. wo die schwarzhnane Querbändermug hreit und regelmibigentwickelt ist nud hei alten Vügeln oft his ans Kim reicht. Supereiliarstreil schmal, hann.

Sikkim und Nepal, meist in Höhen über 10000 Fuß. 


\section{Troglodytes troglodytes tibetana (Waltom).}

Anorthura tibetanc Walton, Bull. B. O. Club XV, p.93 (1905- Tibet).

Zwei bei Kamba Dschong in südlichen Tibet, in einer Höhe ron

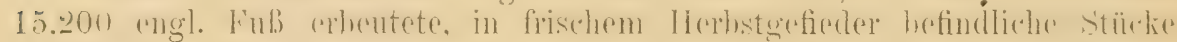
stehen $T$. $t$. nipalensis sehr nahe, haben aber eine trübere, weniger rotbraume Färbung. Der Unterkörper ist nur sehr schwach rotbraun und merklich

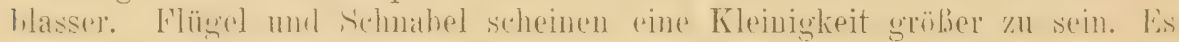
ist mehr Material erwünscht, um die Unterschiede zu bestätigen.

\section{8.,. Troglodytes troglodytes neglectus Brooks.}

Troglodytes neglectus Brooks, Journ. As. Soc. Bengal XLI, II, p. 328 (1872- Kaschmir). 'Anorthura maqrathi, Whitehead, Bull. B. O. Club XXI, p. 19 (1908- Safed Koh. - Die zwei vorliegenden Stïcke wurden im August in Höhen von 8500 und 12500 Fuß gesammelt; sie haben fast einfarbige Oberseite und aschgräuliche Kehle, da aber beide jung sind, müssen die vermuteten Unterscheide erst an einer Serie alter Vögel bestätigt werden).

TVie T.t. nipalensis und ebenso häufig (aber nicht immer!) his ans Kimn gobündert, digegen etwas hlasser, hesunders an der Kohle lichter und

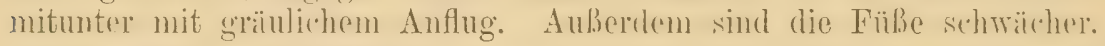

Westlicher Himalaya (ron Simla an) bis Kaschmir. Über den Safed Koh an der westlichen Gronze vou Kaschmil siehe oben unter , magrathi“.

Brütet in gewaltigen Höhen, kommit aber im Winter bis 5500 Fuß talabwärts. Lebensweise, Nest und die teils gefleckten, teils einfarbig weißen Eier ganz wie bei T. t. troglodytes.

\section{Troglodytes troglodytes dauricus Dỵ. \& 'Taı\%.}

Troglorlytes dauricus Dybowski \& Taczanowski, Bull. Soc. Zonl. France 1884, p. 155 (Daurien).

Steht $T$. $t$. fumigatus uahe, unterscheidet sich aber dureh weniger tief rot-

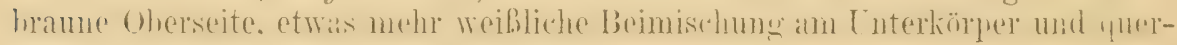
gewellten Kropf und ebensolche Kehle.

Daurien ('T'ransbaikalien).

\section{Troglodytes troglodytes tarbagataica (Suschk.).}

Anorthura tarbagataica Suschkin, Bull. B. O. Club XVI, p. 58 (1906- Östliches Tarbagatai-Gebirge.

Fragliche, nach zwei Nestjungen mit noch nicht röllig entwickelten

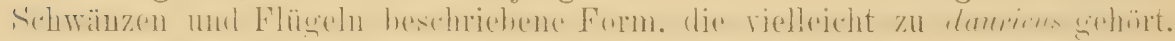
Die Oberseite ist keineswegs so dunkel wie bei mipalensis, allerdings viel dunkler als bei pallidus und ron ungefähr derselben Färbung wie bei damicus. Es fiägt sich, ob die aschgräuliche Färbung des Supereiliarstreifens, del

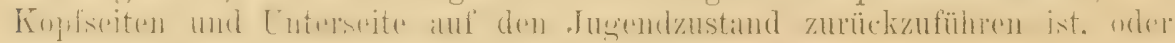
ob es sich um eine eigene Subspezies handelt.

Tarbagatai-Gebirge an der nordöstlichen Grenze der Dsungarei. 


\section{Troglodytes troglodytes peninsulae ('lark).}

Oltiorchilus fumigatus peninsulac Clark, Pror. U. S. Nat. MLus. XXXII, p. 474 (1907Fusan in Korea).

Olbiorchilus fumigatus amurensis Clark, t. c., p.474 (1907- „Amur")

Steht zwischen 'T. t. fumigatus und $T$. t. dauricus. Ist nicht so dunkel wic jumigutus, mit weniger Rothram aul der ()herseite ind etras matter. Die Oberseite ist lebhafter und tiefer brann als bei dauricus, Kehle und Kronfgegend ungehïndert. Mittlere Flügeldecken mit kleinen rundlichen oder dreieckigen weißen Flecken.

Unterel Amur (Sidemi, Wladiwostok) und Korea. (Ich kam ein Exemplar aus Korea nicht ron snlehen atus der Gegend von Whadiwostok

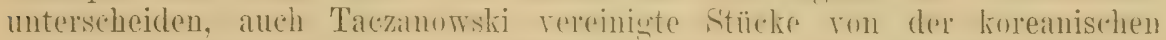
Grenze mit denen ron sidemi mol Biandhi hezudehnete sie anf unsern biketten mit denselben Namen.)

\section{Troglodytes troglodytes idius (Richm.).}

Olbiorchilus fumigatus idivis Richmond, in Blackwelder, Research in China, Carnegie Institution Publication I, 2, p. 498 (1907- Schantung und Chi-li, China).

Abbild.: Ebenda Taf. LIX. (Sehr hübseh anzusehen, aber viel zu weißlich und hell!)

Heller als fumigatus und ein wenig lichter als peninsulae, aber lange nicht so hell wie pullidus; die hellen Stricjic der Kopfseiten auch an den Halsseiten entwickelt. Wohl entwickelte reife anteapikale Quersiume an den mitteren Oherflügeldechen. Flügel 51-52.5. Schwanz etwa 33.5. Lauf 18, Culmen $15 \mathrm{~mm}$. (Typus untersueht). - Steht peniusulae sehr nahe. seleint sich aber durch etwas hellere fïrhung im allgemeinen und die weißen (?uerlinien an den mittleren Flügeldecken daron zu unterscheiden. Intersuchung größeren Materials erwünscht.

Provinzen Schantung und Chi-li in Nordwest-China.

\section{Troglodytes troglodytes szetschuanus sulsil. nor.}

Schwanz bedeutend kürzer, etra 27-31 mm, Färbung der Oberseite etwiss düsterer. Weniger rätlich. Lutesseite weniger rötlich, sonst wie $T . t$. juminums. (25 Stïck mutersucht.) Tiel dunkler als idius, Halsseiten ohne weißliche Flecke.

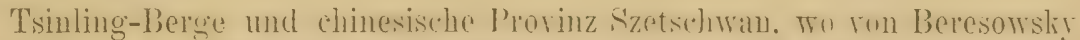

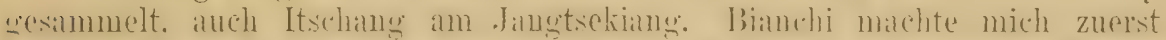

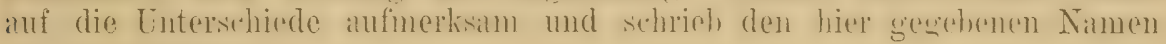
anf die Etiketten.

\section{Troglodytes troglodytes fumigatus 'T'mm.}

Troglodytes fumigatus Temminck, Ilan. d'Om., 2. Ed., IIT, p. 161 (1835- Japan).

Abbild.: Cat. B. Brit. MIus., T’af. XVI, Fig. 1.

Unterscheidet sich anf den ersten Blick vou den westpaläarktischen

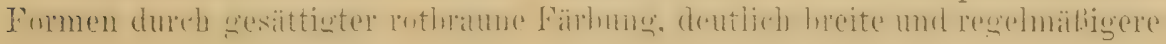




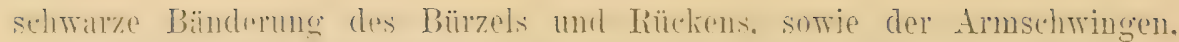
und scharfe mindestens his zum Kropfe reichende dunkelhraune Bänderung

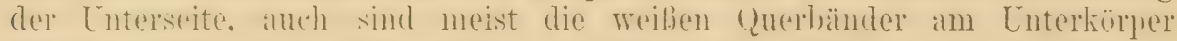

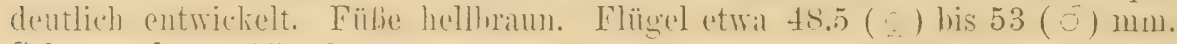
Sehwanz lang: $35-37 \mathrm{~mm}$.

Bewohnt die großen japanisehen Inseln: Jesso, Hondo, Kiuschiu. (Ein Vogel von der Insel Askold soll hierher gehören?)

Lebenstreise wie bei unsern Zaunkönigen. Brütet im Gebirge und findet sich im Winter an Bächen im Hügellande.

\section{Troglodytes troglodytes ogawae sulsp. nor.}

Ähnlich T. t. fumigatus aber mit merklich düsterer, dunkler brauner Oherseite, hesonders anf Kopf und Bürzel. Im allgemeinen ist auch der Schnabel länger. Benamnt zu Ehren des rerstorhenen tüchtigen japanischen ()mithologen Ogawa, der sebon 1905 (A. Annot. Zool. Japon. V. p. 194) anf die Cntersehiede anfmerksim machte. 'Typus: is Jakuschima 30. Sept. 1904. No. 1121.

Japanische Inseln .Jakin und Tinnega (Jakistschima und Tanegashima) südlich vou Kiuschin.

\section{Troglodytes troglodytes kurilensis Stejn.}

Troglodytes fumigatus kurilensis Stejneger, U. S. Nat. MIus. XI, p 548 (1888Schiaschkotan, nördliche Kurilen).

Ähnelt T. t. pallescens, ist aber mehr rotbräunlich. Ähnelt auch T. $t$. finmigatus, ist aber nicht so dunkel und gröber, hesonder's mit gröberem Sechnibel

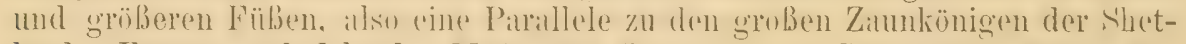

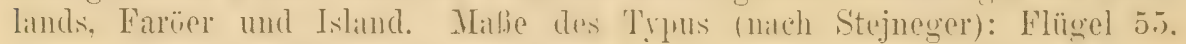
Stenerfedern 37. C'ulment rom Ende der' Stirnbetiederung 1t. Lanf' 19.5. mittlere Zehe mit Nagel $19 \mathrm{~mm}$.

Kurilen (Schiaschlotan, Iturup).

\section{Troglodytes troglodytes pallescens (Ridgw.).}

Anorthura pallescens Ridgway, Proc. U. S. Nat. Nus. VI., p.93 (1883- Kommandeur Gruppe der Aleuten).

Auffallend große, helle Form. Schuabel groß und krumm. Oberseite

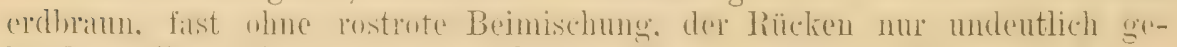

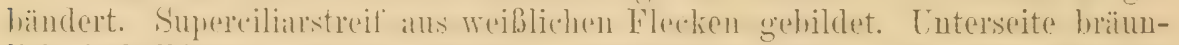

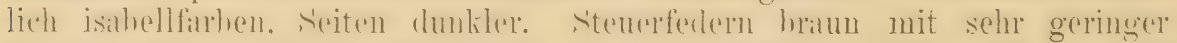

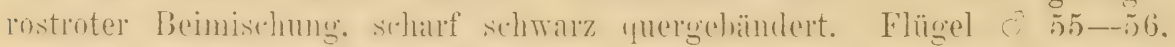
ㅇ 51-52 mm, ., Schnabel" (nach Taczanowski) o 16, o 17-19.1, Schwanz Oे 35,38 , \& $32 \mathrm{~mm}$.

Standroger and den Kimmmateur-Inseln (Bering-Insel. Kupfer-Insel, Miednyi) und Kamtschatka. 


\section{Gattung SPELAEORNIS David et Onstalet 187.}

Synonym: Urocichla Sharpe 1881. - Spelaeornis wurdo für dio Arten

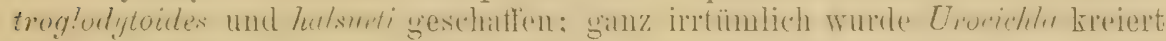
für" die "Pnoepyga longicandata" Moores, die freilich keine Pnoepyga, wohl aber ein Spelacomis ist. - Der abgerundete Schwanz mit stark verkürzten

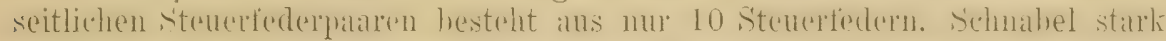
und kurz. Lauf geschient, nur wahe den Zehen deutlich geteilt. S. caudata (früher irrtümlich mit Pnoepyga vereinigt) hat einen kürzeren Schwanz. Gattungssplitterer werden sie wohl, leider, eimmal generisch sondern.

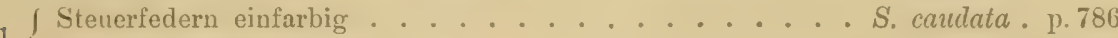

1 \{ Stenerfedern gebändert ................... 2

, $\int$ Oberseite fahl graubraun . . . . . . . . S. halsueti . . p.786

\{ Oberkopf schwarzbraun, Rücken rostbraun ..... S. troglodytoides . p. 785

Außer den in den folgenden Zeilen beschriebenen drei Arten kennen

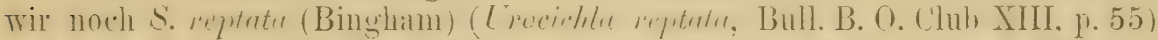

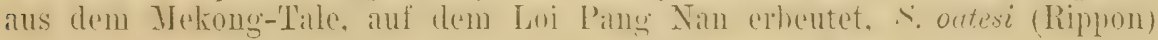
(Urocichla oatesi, Bull. B. O. Club XIV, p. 83) vom Mount Victoria in den südlichen ('hin Hills in Birma. und S. sumliri ()ustalet (Bull. Mus. Paris 1898. ṇo. 8, p. 257), eine prächtige kleine Art aus dem nördlichen Junnan, wo palianlitische und tropische Famen sich remischem (Ahilh. Nor. Zoul. 1910, Taf. VII), und S. longicaudata Moore (Proc. Zool. Soc. London 1854, p. 74, Sharpe, Ca B. VI, p. 263) aus den Bergen siidlich des Brahmaputra.

\section{Spelaeornis troglodytoides (Verr:).}

Pnoepygr troglodytoides Verreaux, Nouv. Arch. Mus. Paris VI, Bull, p. 34 (1870"Montagnes du 'Thibet Chinois").

Abbild.: David \& Oustalet, Ois. Chine, Taf. 16.

¿ Oherlopf und Hinterhals sehieferschwarz, uuregelmälig graureili quereartellt: ïbrige Oherseite rosthram, jede Feder an der Spitze mit schwarzem Fleck und weiBer Anteapikillinie. Schwingen dunkelhraun, äubere Fihnen fihl rothram quer gebändert, innere Amschwingen auf heiden Fahnen gebändert und mit kurzen hellen sichaftherden. Stenerfedern schwarzhian

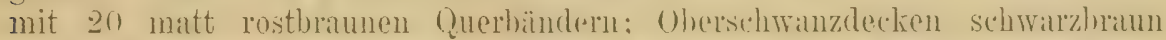
mit fahlbranen Qnerbäntern. Zü̈gel grauhramn, fahl rostfarhen gefleckt. Ohrdecken rosthaun. rom Mundrinkel allsgehent rin schwarzgefleckter Bartstreif. Kimm und Kehle bab gelbhraun, ührige Lnterseite lehbaft gelblich rostbraun, jede Fodor mit schmaler schwärhicher Endlinie, ror der cin kleiner.

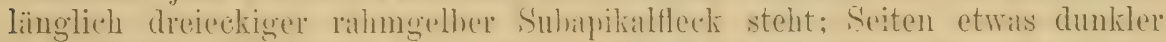
und ungefleckt. Entersehwanzdecken chenfalls dunkler und mit weniger deut-

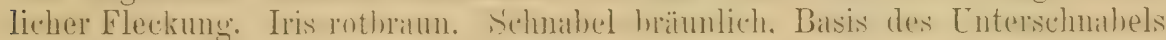

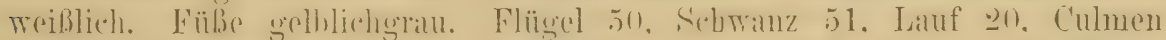

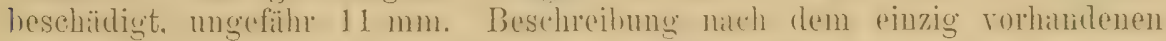
Stücke.(q) im Pariser Mluseum. Père David erwähnt zweier an Verreaux gesandter Stücke, woron eins anscheinend nicht erhalten ist.

Mupin und westliches Szetschwan.

Lebensweise nach David wie die der Zaunkönige.

E. Hartert, Die Vögel der paliarktischen Fauna. 


\section{Spelaeornis halsueti (Darid).}

Pnoepyge? Halsueti Darid, L'Institut, III, no, 114, \& Bull. Soc. philomat. 6. sér., XII, p. 19 (1877-5 "Chensi“. Typus von den Tsinling-Bergen).

Abbild.: David \& Oustalet, Ois. Chine, 'Taf, 15.

ơad. Oberseite etwas fahl olivengranbraun, jede Feder mit bräunlich

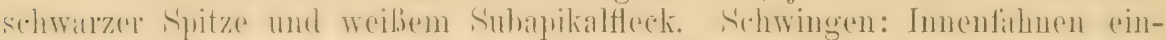

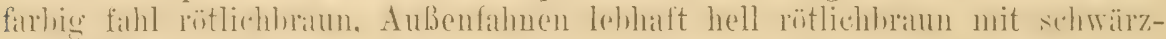

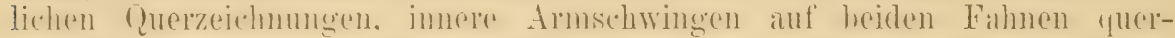

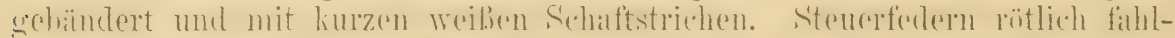
braun mit gransehwarzen (2uerbïndern. Zï̈gel sehmutzigweib, ohrgegend

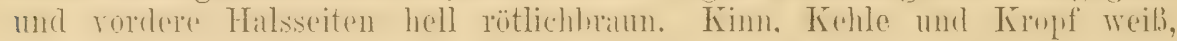

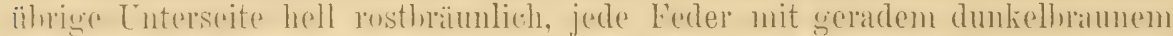

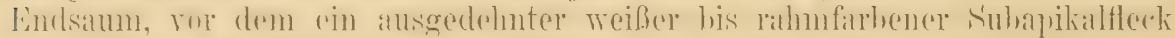

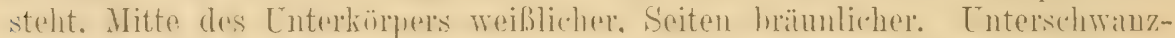
decken woiblich mit mehreren hräunlichen (Querbänderm. Iris rot. 1)her-

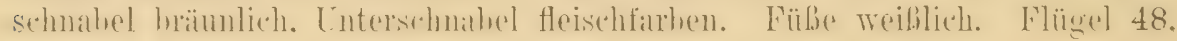
Schwanz 51, Lauf 20, Culmen $12 \mathrm{~mm}$.

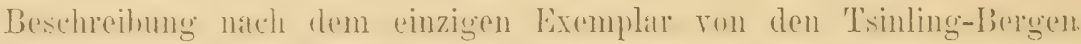
im nördlichen China, im Pariser Museum.

\section{Spelaeornis caudata (Blyth).}

Tesia caudata Blyth, Journ. As. Soc. Bengal XIV., p. 588 (1845- Darjiling).

Abbild.: Nov. Zool. 1910, Taf. VII, Fig. 3.

ô ad. 'Oberseite röstlich olivenbraun mit schwärzlichen, auf Kopf

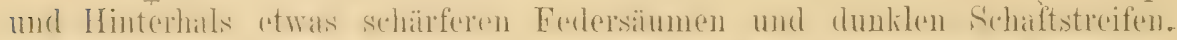

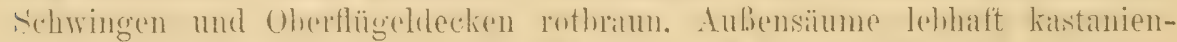

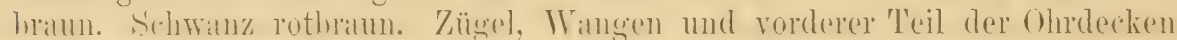
ascherau. linterer 'Teil der letzteren hräunleds; unter den Trangen eine

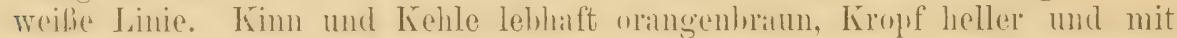

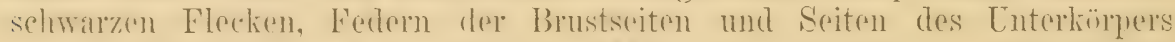

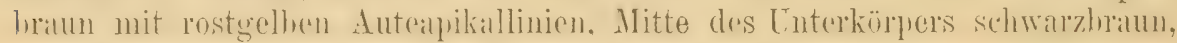
jerle Feder mit hreitem weilien subathihalhande und ehensolehen, bald hreiten. bald sehr sehmalen, oft muregelmäbijgen weifen sehaftstreifen. Setmahel

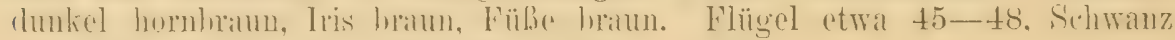
etrva 29-32, Lauf ungeführ 19, Culmen $12 \mathrm{~mm}$.

Lebt in großen Höhen im Himalaya in Sikkim.

\section{Gattumg PNOEPYGA Hoilgson 1845.}

Wesentlich rerschieden von Troglodytes: Nasenlöcher in einer großen

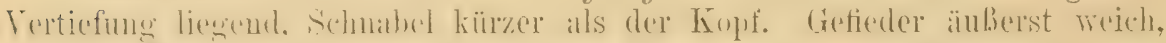

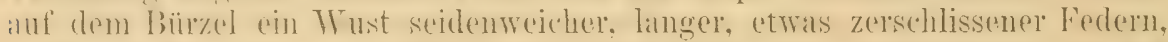

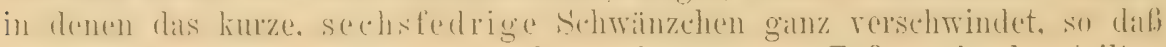
man Mühe hat, es zu finden. Lauf von einer nur am Fuß zweimal geteilten

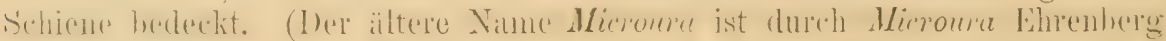
prïokimpiert.) 


\section{Pnoepyga squamata (Gould).}

Microura squamata Gould, Icones Arium Taf. und Text (1837 - „Himalaya Yountains and Nepal"t).

Tesia albiventer Hodgson, Journ. As. Soc. Bengal VI, p. 102 (1837- Nepal).

Tesic rufiventer (o) Hodgson, t. c., p. 102 (Nepal).

Pnoepyga concolor \& micolor Hodgson MIS., teste Sharpe (!).

ऽ`ad. Oberseite dunkel rostbraun mit schwarzbraumen Federsäumen,

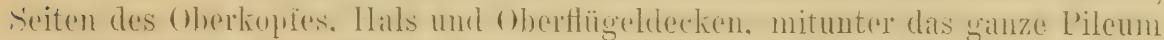
und der gröbte 'Teil des Rü̈clens (dies remutlich jüngere Tögel) mit rost-

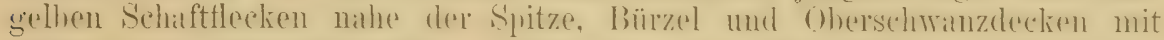

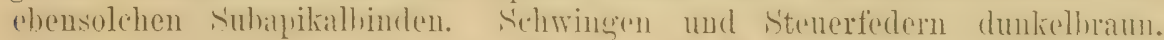
erstere lneit rosthraun gexïunt. Kéhle weil. mit sehwach entwickelten granhraunen Federrïndern, ülrige Cnterseite weil.s mit dunkelhramem \%entrum

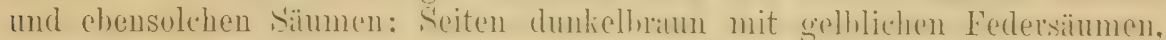

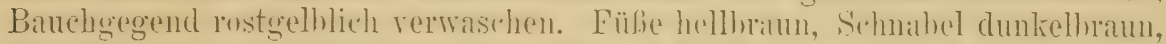
[nterschmahel mit Ausmahme der Spritze Heischfarhen. Iris bramu. Flügrel etwa 59-63, Lauf etwa 24, Schwanzfedern ungefïh 18-20, Culmen 13 bis $13.5 \mathrm{~mm}$. - o Unterseite gelbbraun, gezeichnet wie beim ơ. - Juv. Ohne Zeichnungen: Oberseite rotbraun, Unterseite düster braun.

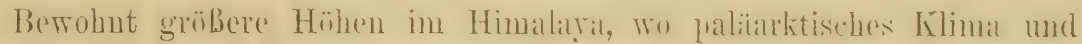
chensulehe Florat und Fannal herrsehen. und verhreitet sich wach Osten his in die westchinesischen Gebirge (Mupin). farbig weiß.

Nest aus Hoos nahe dem Boden an Baumstämmen oder Felsen, Eier ein-

\section{Pnoepyga pusilla pusilla Hodgs.}

Pnoepyga pusilla Hodgson, Proc. Zool. Soc. London XIII 1845, p. 25 (1845- NepaI).

O̊ad. Dem von P. squamata äußerst älınlich, nur auf der. Oberseite eine Nuance wenigere rosthraun und last ohne die rostgelhen l’unlite, dir auf die Flügeldecken und Suitzen der Armschwiugen beschränkt sind. Flügel etra 48-52.5 mm. - - . Wie das von $P$. squamata aber ebenso viel kleiner wie das $\sigma^{n}$, Oberseite etwas mehr olivenbraun. Iris dunkelbraun,

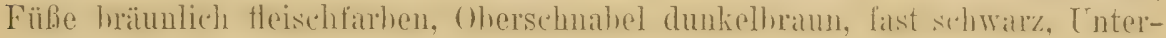
schnabel hellbraun.

Scheint die mittleren Höhen des Himalaya zu bewohneu, ebenso die Berge südlich des Brahmalputra und West-C'hima: Tatt-trien-lu in MestSzetschman und Tsinling-berge (Til-pai-schan). Westlich his Kuitun (Eokieni). In dex Malakiahahhinsel. und aut Sumatra dureh melnere Subspezies roltreten, auf Java und Flores durch zivei einander sehr ähnlicho Formen, in denen die Geschlechter gleich sind.

Das kugelförmige Nest ist in die lebenden Noosbehänge alter Baumstämme eingebaut, oder aus grïnem Moos an Zweigen und dgl. befestigt. Die 2-3 Eier sind rein weiß.

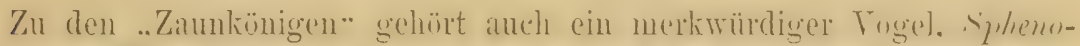

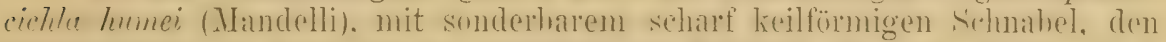

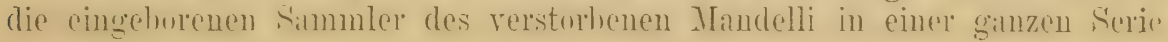




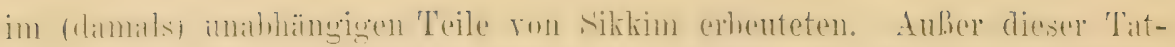
sache und seiner Beschreibung wissen wir nichts von dem Vogel. Da er scrither nicht wieder sofunden wurke, kïmnte man den Sehlub zichen, dals

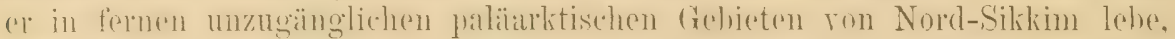
das Nuseum zu 'Tring aber besitzt einen Balg (rermutlich auch aus der

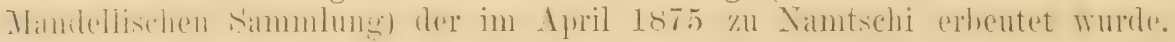
das Kloster Namtschi liegt aber nur etwa 5700 engl. Fuß hoch. - Be-

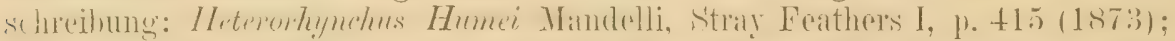

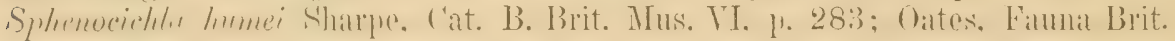
India, Birds I, p. 336. Abb.: Nov. Zool. 1910, Taf. 7. - Eine rerwandte

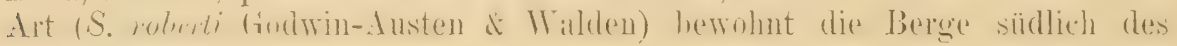
Brahmaputra.)

\section{Gattung CINCLUS Borkh. 1797.}

Synonyme: Accentor 1797, Aquatilis 1813, Hydrobata 1816, Hydrichla Billberg 1828.

Die Wasserschwätzel sind Verwandte der Zaunkönige, mit denen sie

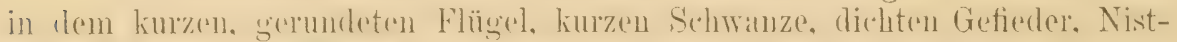

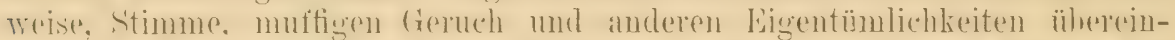

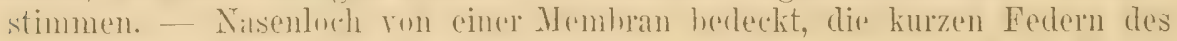
Torderlioples bis auf die Nisenhochberleckung sich erstrechend. Treine Mund-

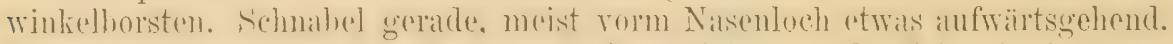

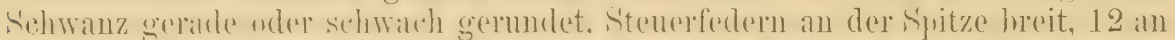

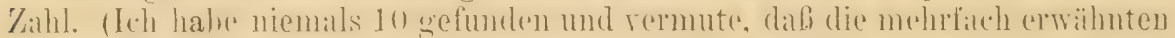

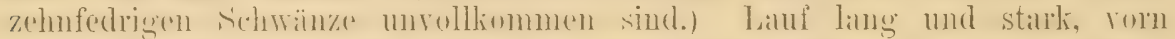
gesehient (nur nahe don Zehen (ine dentliche binteihng in 2 Schilder),

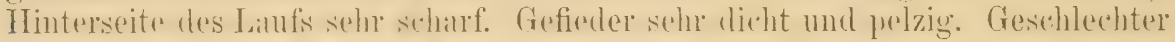

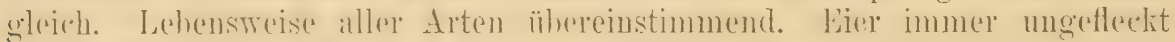

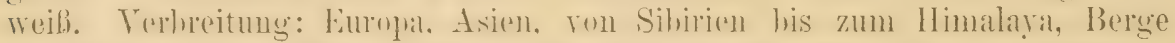
sü̈llich des brahmatputral, Jalpatn. ('hina bis Formosal; westliehes Nordamerikil, in Sïdamerilia die Inden und Berger von T'uemman in Nord-drgentinien.

Ober- und Unterseite einfarbig braun . . . . . . . . C. pallasii . p.797 Oherseite mit dunklen Eedersäumen, Liopl und Hinterhals aber einfarbig, kehle

weiß, oder wenn braun doch eine Schattierung heller als Unterkörper

C. cinclus . p. 788

\section{Cinclus cinclus cinclus (L.).}

Stumus Cinches Linnaeus, Syst. Nat. Ed. X, p. 168 (1758- „Habitat in Europa“. Als terra typica betrachten wir Schweden, nach dem 1. Zitat: Fn. srec. 216).

Cinclus septentrionalis Brehm, Lehrb. Naturg. aller eur. Vög. I, p. 287 (1823- Norwegen und im Winter im Thüringer Walde - letztere Angabe irrtümlich, wie Naumannia 1856 p. 187 auseinandergesetzt).

Cinclus melanogaster Brehm, t. c. p. 289 (1823- "Scheint den Nordosten der alten Welt zu bewohnen und kommt im Winter an die Küsten Rügens". Schwanz nach Brehm zehnfedrig, ist aber unvollständig).

Abbild.: Dresser, B. Europe, II, Taf. 20, Fig. 2.

Schwed.: Strömstare.

ऽ̊ad. Oberkopf und Hinterhals, Kopf- und Halsseiten schokoladen-

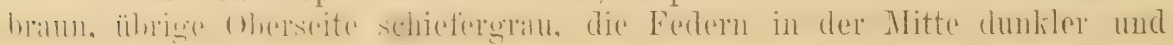




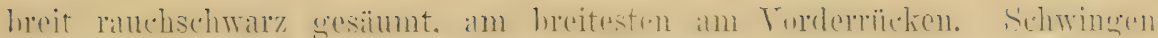

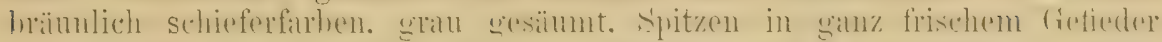

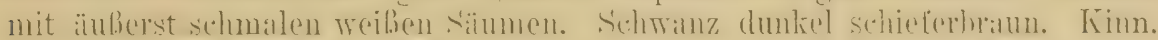

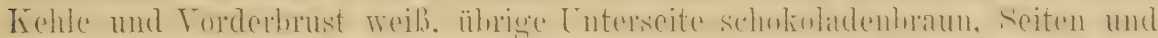

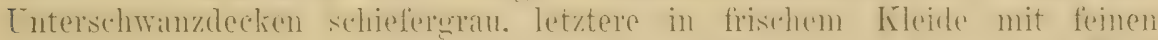

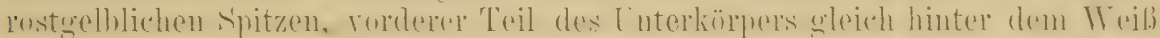
etwas rötlicher, sehr selten (o aus Lappland 3 . Juni) wirklich rostrot wie bei aquaticus. Iris dunkelbraun, Fülße hellbraun, Schmabel hornschwarz. Flügel 94--98, Schwanz 55-59, Lauf 28-30, Culmen 21-22 mm. o tie 0', nur etwas kleiner: Flügel etra 88-91 mm. — Nestkleid: Ganze

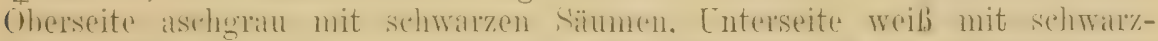

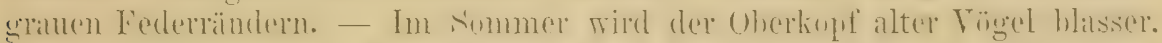

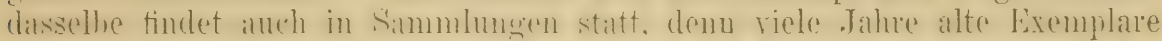

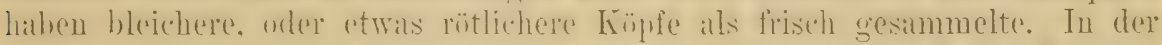

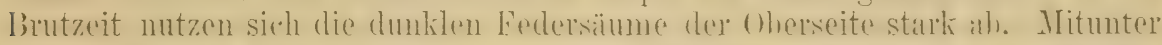

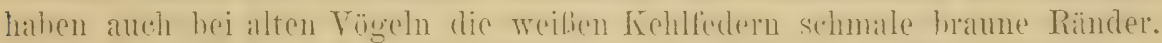

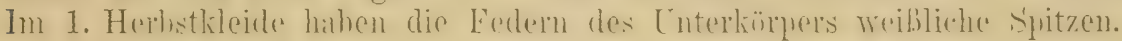

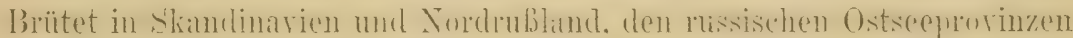
und an der Rominte in Ostpreußen (wenigstens bestimmte ich s. Z. ein dort im Erïhjahr erlegtes Stück als ,melanogaster"6) angeblich auch in

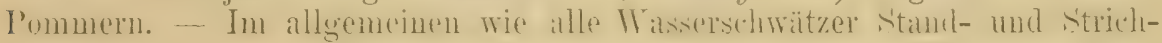

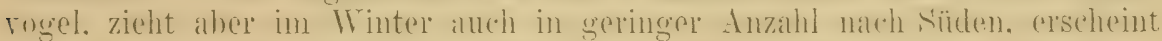

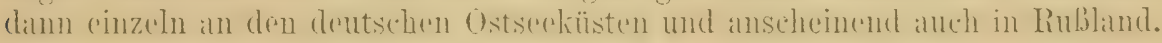

Nistweise und Biologie wie bei C.c.aquaticus und allen andern Formen der Gattung. 5 t Eier (28 Wasenius, 26 Jourdain, in litt.) messen im Durchschnitt $25.94 \times 18.7$, ILaximum $30.6 \times 19.5$ und $27 \times 20.1$, Minimum $22 \times 17 \mathrm{~mm}$.

\section{Cinclus cinclus britannicus T'schusi.}

Cinchus Europaens (partin) Leach, Syst. Cat. Ind. Mamm. Birds Brit. MIus., p. 21 (1816 - Nomen nudum!); Olphe-Galliard, Faune Orn. Eur. Occ. fasc. XXX, p.12. ?? Turdus yularis Latham, Suppl. Ind. Orn., p. XV (1801- Cumberiand in Nordengland. "Penrith Ouzel" Latham, Suppl. Gen. Syn. II, p. 177. Beschreibung eines jungen Vogels, der aber nicht gut ein junger Cinclus sein kann. Der Name ist daher mehr als zweifelhaft).

Cinchus cinclus britannicus Tschusi, Orn. Jahrb. XUI, p.69 (1902- Großbritannien).

Engl.: Dipper, Water-ouzel.

Oberseite wie bei $C$. c. cinclus, aber der vordere Teil des Unterkörper's mebr udre miuder allsgedehnt zimmtrot, diese Farhe mitunter his anf die

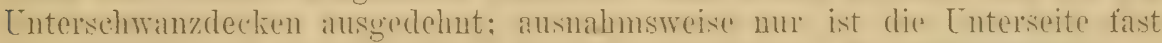

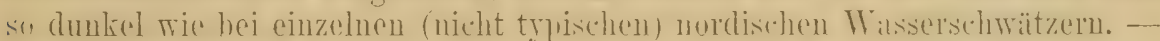

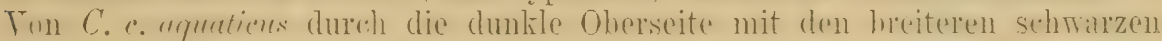
Sïunen unterschieden. Finzelne dunkelste bisenplare mitunter C. r. cinclus ziemlich ähnlich. ausmahmsweise heller nirht ganz bereht rou dunklen aquaticus zu unterscheiden, eine Serie aber auffallend charakteristisch.

Grobbritannien.

100 Eier messen im Durchschnitt $26.13 \times 18.1$, Haximum $29.5 \times 19$ und $24.3 \times 19.9$, Minimum $22 \times 15.5 \mathrm{~mm}$. Durchschnittsgewicht von 20 Eischalen $230 \mathrm{mg}$ (Jourdain in litt.). 


\section{Cinclus cinclus hibernicus subsp. nov.}

Unterscheidet sich von C.c. britannicus (GroBbritannien) und C. c. cinclus

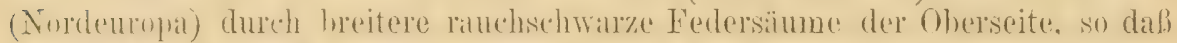
der lï̈cken in frisch rermansertem Gefiecler fist ginz schwarz erscheint, ron

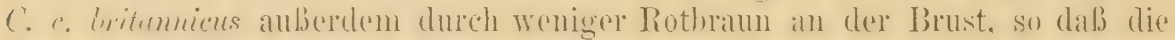

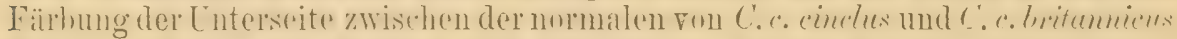

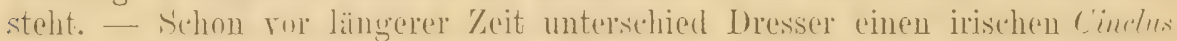
von der englischen Form, indem er ersteren zu C. c. cinclus rechnete. Ich komnte, Dank der Liehenswärdigkeit von Herm Barrington und Dr. Sranti 6 irischo Exemplare moterstlehen. die alle in der oben angegehenen Fïrhung der Oberseite von britamicus abweichen; 5 davon haben die angegebene

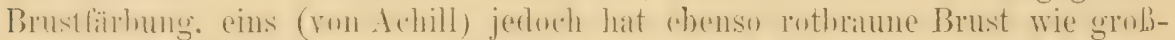

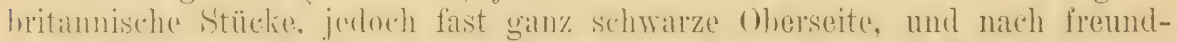
licher Mitteilung barringtons ist dies rin ausnahmswoise gefärhtes struck, das

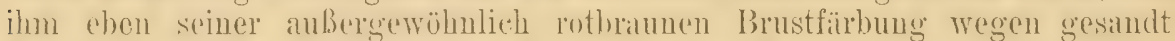

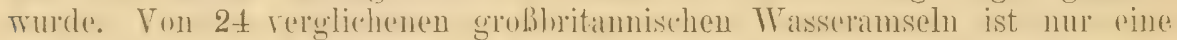

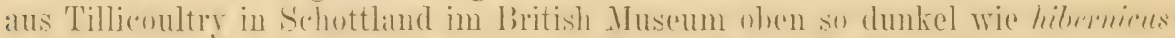
und in der Brust fast so wonig rothraum: ähnliche Tariationen liommen aber auch bei C.c.cinclus, aquaticus, meridionalis u. a. vor, anch kann es sich ja um ein rerflogenes Individum handeln. - Typus rou (. c. hibernicus

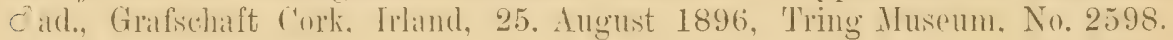

Irland.

\section{Cinclus cinclus pyrenaicus Dress.}

Cinclus melanogaster pyrenaicus Dresser, Ibis 1892 p. 382 (Basses Pyrénées und Gèdres in den Central-Pyrenäen).

Äuberst ähnlich ('. a rinclus, aher Oberkonf und Hinterhals nicht ganz. so dunkel, etwas fihler hrimu und die schwarzen Sïume der Rüleken- und

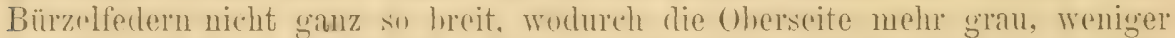
dunkel arseheint. Hinter dem weilien Brustschilde folgt gewiohnlich ain rosthraumer Fleck, mitunter aber ist der sanze Lnterlörper ehenso dunkel wie bei C. c. cinclus, so daß einzelne Stücke bisweilen kaum von letzterem zu unterschriden sind. Nicht kleiner, sondern etwa ehenso groß: Flügel 85-95, mitunter 96 mm. (Cutersucht wurden 25 Stück. ron denen aber nur wenige zuverlässige Geschlechtsbestimmung haben.)

Weit verbreitet in den Pyrenäen.

\section{Cinclus cinclus subsp.?}

Spanische Trasseramseln (Sierra Nerata und Sierra Guadarmara), jectenfalls Brutrögel. scheinen nicht zu pypreniens zu gehören, da der rordere Teil des Lnterkinpers mehr rotbraun ist, auch scheint der Oherkopf etwas mehr rotbräunlich und der Rücken bräunlicher zu sein. Ich konnte indessen nur alte Sitücke (von A. E. Brehm und Samnlers gesammelt) untersuchesl, deren Oherkopf rerblichen zu sein scheint, und vermag nicht anzugrhen, wie sich dieselhen ron deutschen r.c. aquations unterscheiden, Tromit sie indessen wegen der geographischen Torbreitung nicht wohl üherein-

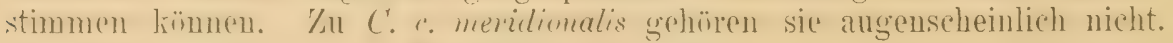
Flügol von sieben alten Vögeln 94-100 mm. 


\section{Cinclus cinclus sapsworthi Arrig.}

Cinchus cinclus Sapsworthi Arrigoni, Atlante Ornitologico, p. 150 (1902- Korsika). Cinclus cinclus sardus Hartert, Bull. B. O. Club XIV, p. 51 (1904- Sardinien).

Unterseite wie bei C. c. cinchus, Oberseite ebenfalls der des letzteren sehr ähnlich, aher Oherknpi und Hinterhals heller, nicht so schokendadenbraun. etwas gräulicher. Finzelne Stürcie von uputicus mitunter kinm unterscheidhar. aber durchschnittlich ist sapsworthi merklich kleiner als C. c. cinchus und

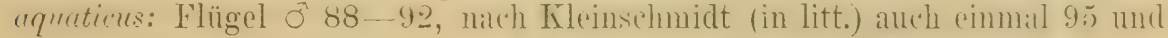
einmal 96 , 오 $81-83 \mathrm{~mm}$.

Brütet in Korsika und Sardinien. - Ein Wintervogel von Korsika, gehört zu C. c. meriliomedis in -trpischster Form. Im ILuseum zu Florenz betinden sich zwei Herhstrïgel ans dem Armo-Tal und Piemont. die sapsurorthi nichts an Dunlelheit der Färbung nachgehen, auBerdem zwe' Herbst- und Wintervigel von Florenz und Rom. clie der sardinischen Form äuberst nahe

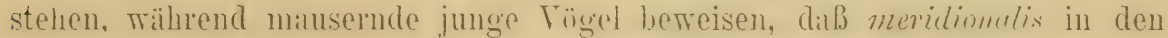
italienischen Gehirgen loütet. Lis ist diesen Formen mehr Aufmerksamkeit zu widmen, doch scheint mir einstwoilen, dab die sogenannten melunomester ans Italien nur ausnahmsweise dunkle meridionulis sind, vielleicht aher handelt es sich auch teilweise um Mischformen oder verflogene sapsworthi.

\section{Cinclus cinclus aquaticus Bechst.}

Wasserschwätzer, Wasseramsel, Wasserstar.

(? Partim) Tringa Merula Schaeffer, Mus. Orn., p. 52 (1789- Ohne Vaterlandsangabe! Ich nehme Anstand Schäffersche Namen einzuführen, da er die binäre Nomenklatur nicht durchführte; von etwa 200 Namen sind sieben nicht binär und eine binäre Benennung bezieht sich auf eine Haustaubenvarietät).

Cinclus aquaticus Bechstein, Orn. Taschenbuch I, p. 206 (1803- Deutschland).

.Cinchus Europaeus (partim) Leach, Syst. Cat. Ind. Manmm: \& Birds Brit. Jus., p. 21 (1816- Nomen nudum!).

Hydrobata albicollis (partim!) Vieillot, Nouv. Dict. d'Hist. Nat., Nouv. Ed., I., p. 219 (1816- "Se trouve dans les Pyrénées et les Alpes, en Angleterre, en Suède, en Hollande, en Sibérie", usw.).

Cinchus medius Brehm, Isis 1828, p. 281 (Nomen nudum!); id. Handb. Naturg. Vög. Deutschl., p. 395 (1831- Thüringer Wald).

Cinclus mupestris Brehm, Naumannia 1855, p. 282 (Nomen nudum!); id. Naumannia 185̌6, p. 188 (Sächsische Schזreiz, Thüringer Wald, ein Stück aus Dalmatien - das allerdings nicht mit dem dort heimischen meridionalis übereinstimmt).

Cinclus peregrinus Brehm, Naumannia 1856, p. 187 (Thüringer Wald, aber nicht dort brütend, auch 19. VIII. 1855 im Aschachtale in Oberösterreich).

Cinclus aquaticus verus und obsoletus A. E. Brehm, Verg. Samml., p. 5 (1866Nomina nuda!).

Cinclus cinclus tsehusii Kileinsehuidt \& Hilgert, Faleo 1907, 1) 104 (Rheingegenden. -Nach Untersuchung von 11 rheinländischen Vögeln finde ich die angeblich dunklere Färbung nicht bestätigt. Es sei bemerkt, daß Hilgert nicht ein Stïck des ,echten aquaticus" vergleichen konnte und Kleinschmidt nur nach 3 rheinischen Bälgen urteilte, was bei so variablen Vögeln nicht genügt).

Franz.: Nerle d'eau, mit welchem Namen natürlich auch andere Formen bezeichnet werden. 
Unterscheidet sich von C. c. cinclus dadurch, daß der vordere T'eil des

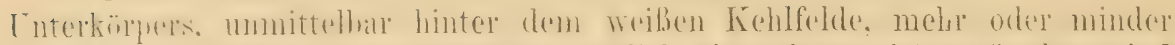

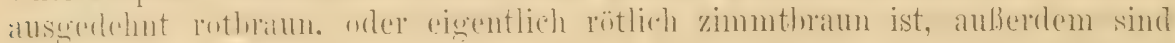

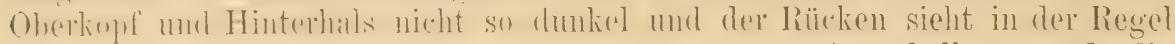

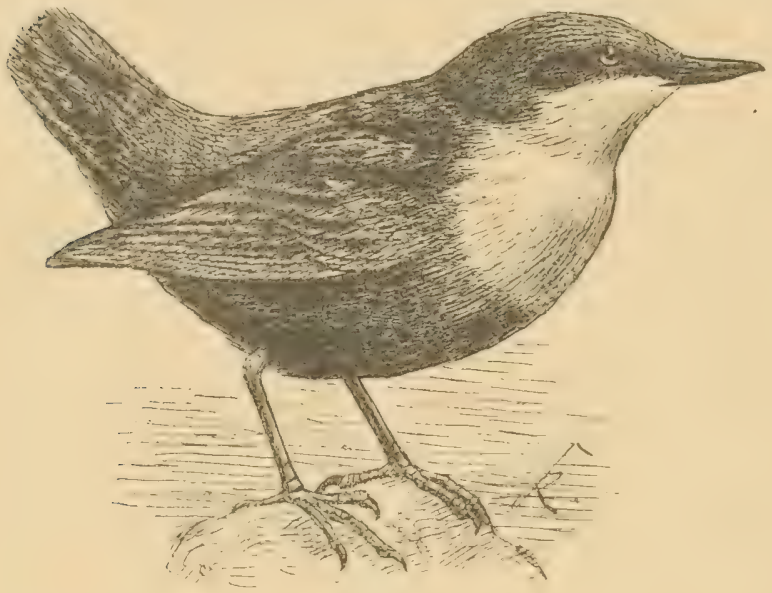

Figur 130. etwas heller aus, da die schwarzen Federsäume nicht so breit sind. Die individuelle $T$ ariation ist nicht unbedeutend; dunklere Stïcke erinnern mitunter sehr an $C_{\text {. }} c$. cinclus und der Unterkörper hat bisweilen ebenso lehhaftes Rostrot wie C. c. mericlionalis. Flïgel vou 56 Exemplaren $85-97.5 \mathrm{~mm}$, wobei Maße unter 90 fast immer $\circ$ angehören.

Deutschland, vom Riesengebirge bis in die Rheingegenden, Belgien,

Frankreich, mit Ausnahme der südwestlichen 'T'eile (w0 meridionalis vor-

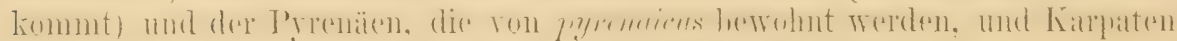
bis zu den transsilranischen Alpen und Nord-Rumänien.

Lebensweise und Fortpflanzung aller Formen von C. cinclus ist diesclbe. Sie bewohnen schnellfießende Bäche und andere Gewässer mit klarem Wasser, die zur Winterszeit wenigstens teilweise offen bleiben, sind daher fast ausschließlich Gebirgsvögel, und fehlen ausgedehnten Ebenen. Ihre Nahrung suchen sie aus dem Wasser, in das sie mit wunderbarem Geschick tauchen, und das sie mit Hilfe der Flügel pfeilschnell durcheilen können. Die Nahrung besteht aus Krebstierchen, Wasserinsekten und deren Larven, kleinen Schnecken und in sehr geringem Grade auch aus kleinen Fischchen. Sie singen auch bei. strenger Winterkälte ihr aus zwitschernden, zerpenden, klirrenden und pfeifenden Lauten zusammengesetztes, munteres Liedchen, das mich immer an den Gesang des Zaunkönigs erinnerte. Auch die Lockstimme, die man meist in Fluge hört, ist der des Zaunkönigs ähnlich und nicht allzu lant. Sie klingt etwa wie $z$, tzrrb, zerb. Das Nest steht nicht immer in unmittelbarer Nähe des Wassers, sondern bisweilen hunderte von Metern davon entfernt, meist aber an und über den Bächen, die diese Vögel bewohnen. Es wird an Felsen, unter Bräcken, in größeren Höhlen auf Felsvorsprüngen, oft unter Wasserfällen, in Spalten, an Gemäuer, unter Baumwurzeln, im Geäst: niederer Bäume, in alten Müblräderu und an den Radstuben der Mühlen. Es ist je nach des Ortes Gelegenheit meist länglich; rund und selbst eckig, indem es mehr oder minder den vorhandenen Hohlraum ausfüllt. Es besteht aus allerlei Pflanzenteilen, Gras und Halmen und Würzelchen, in der Regel aber größtenteils aus Moos auf einer Unterlage ron Stengeln, und ist mit Hälmchen und dürrem Laube ausgefüttert. Das Einschlupfloch ist seitlich und entspricht reichlich der Größe des Vogels. Die 4-6 Eier sind reinweib, glatt aber fast glanzlos, unter der Lupe fein gerunzelt, am spitzen Ende zugespitzt, am stumpfen breit gerundet, mitunter fast gleichälftig oder ganz länglich. 20 Eier aus Deutschland messen (Jourdain in litt.) im Durchschnitt $25.12 \times 18.46$, Maximum $26.3 \times 19$ und $26 \times 20$, Jinimum $24 \times 17.5 \mathrm{~mm}$. Mittleres Gewicht nach Rey. $246 \mathrm{mg}$. 


\section{Cinclus cinclus meridionalis Brehm.}

Hydrobate albicollis (partim!) Vieillot; Nour. Dict. d'Hist. Nat., Nour. Ed., I, p. 219 (1816- „Pyrénées, Alpes, Angleterre, Suède, Hollande, dans le Jutland, aux îles Féroë, en Russie, en Sibérie, et même au Kamtschatka. Du côté du Midi, en le voit en Espagne, en Italie, en Sardaigne, ete." -- Der Name albicollis bezieht sich somit ebensowohl auf C.c.pyrenaicus, aquaticus und andere Formen, wie auf die des Alpengebietes und Sïdeuropas, wir können ihn also nicht für C. c. meridionalis annebmen).

Cinclus meridionalis Brehm, Naumannia 185̄6, p. 186 (Kärnthen).

Cinclus rufipectoralis Brehm, t. c., p. 186 (Kärnthen).

Ital.: Merlo acquaiolo.

Steht C. c. aquations äußerst nahe, doch sind Oberkopf und Hinterhals

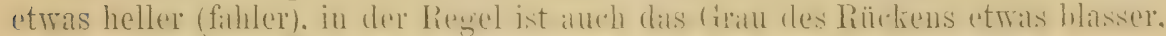

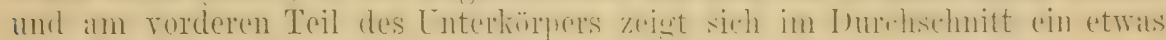

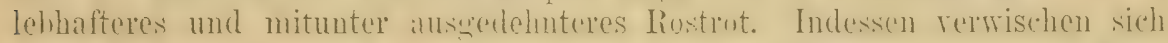

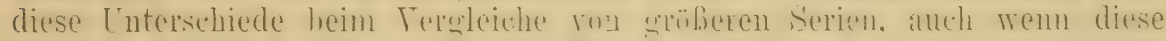

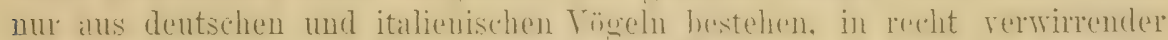
Treise: sie bestehen. sind ahere an einzelnen Strïcken nicht inmer nachweishan

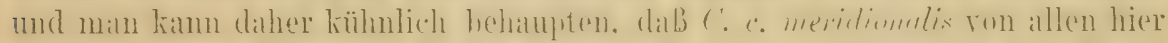

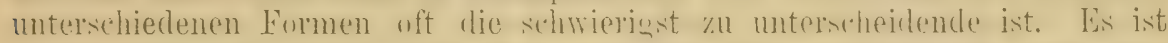

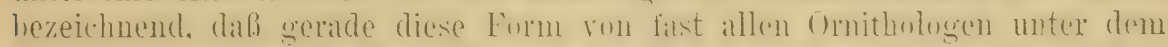

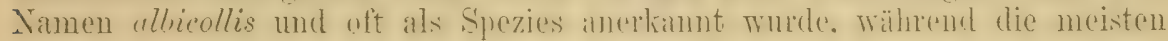
derselhen außerdem nur noch C. c. cinclus und aquaticus untersehieden, und

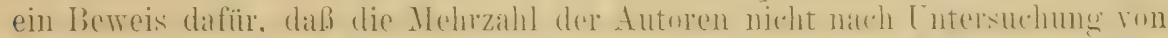

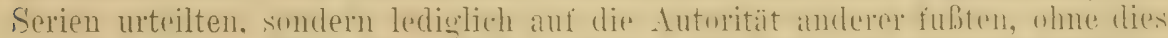

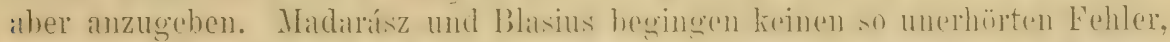

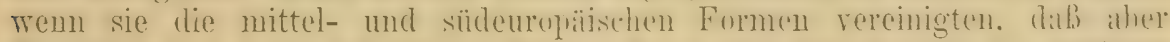
Inadarisz dies anch mit der nurdischen form tat. war freilich ein grölierer In'tum.

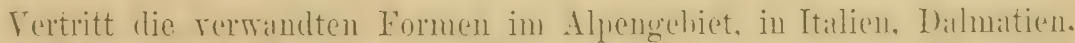

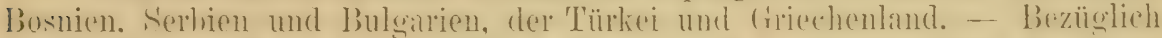

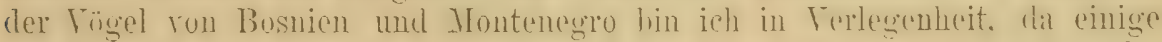
kaum von aquaticus zu trennen sind, indessen wird es am besten sein, sie alle mit meridionalis zu vereinigen, wie dies auch ron andrer Seite, u. a. von Bianchi auf unsern Ftiketten geschehen ist. Reiser zälult alle Griechen zu meridiomalis, ehenso die Bulgaren, withrend ar ron den Monte-

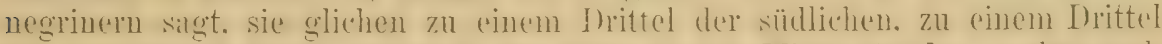
der nordischen Forne. Während der Rest in der Mitte stünde - alson auch hier z.um Teil deutliche meridionulis. Woulte man dire montenegrisehen n. a. Stiicke als besondere intermediaire Sulsuegies trenuen. würde uns dies nicht weiter führen, dá sie teilwreise gut mit meridionalis, teilweise besser. mit "unutinus ühereinstimmen, nicht aher der Durehschnitt intermediär erscheint.

\section{Cinclus cinclus minor Tristr.}

Cinches minor 'Tristram, Ibis 1870, 1).497 (Algerien; bei Blidah).

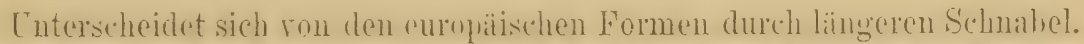

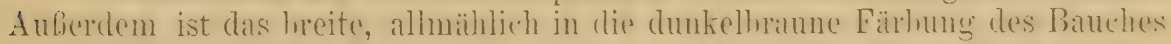
ähergehende Brusthand heller und rütlicher. lebhaft rötlich zimmtfarhen. 


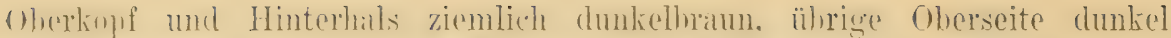

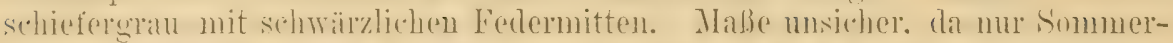

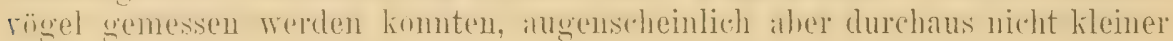
als C.c. aquaticus: o Flügel etwa 98, o ungefähr 82-90 mm. Culmen ơ 23-25 mm. (Typus ein kleines o.)

Atlasgehirge. Bisher mur bei Blidah. am Oued-el-Kehir, und anf dem 1) schehed ('helia, in Algerien und im mankiknisehen Atlas festgestellt.

\section{Cinclus cinclus caucasicus Mad.}

Cinchus cancasicus MIadarász, Ann. Mus. Hung. I, p. 560 (1902- Nordkaukasus).

? Cinclus olympicus Mladarász, Orn. Honatsber. 1903, p. 6 (Troodios Gebirge auf Cypern. Ich vermag drei Frühlingsvögel nicht von caucasicus zu unterscheiden. Besser präparierte Serien sind nötig zu entscheiden, ob vielleicht das Braun etwas weiter über den Rücken reicht).

Unterscheidet sich von C. c. aquaticus durch nicht rotbraune, sondern trïh zimmthraume Fïrbung des oberen 'Teiles des Luterhöruers. der in ganzen dunkelbram ist und nur nate dex Brust zu dunkel zimmthräunlich wirel: ron

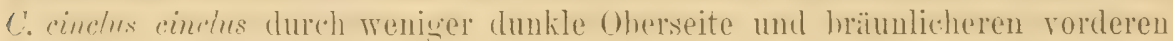
'Teil des Unterkörpers, sowie etwas weniger Grau an den Seiten; von C. cinclus cashmeriensis dureh nicht so dunklen und woniger einfarbigen Unterkörper; von $C$. cinclus persicus und rufiventris durch dunkleren Unterkïrper. Flïgel von 16 cad. $89-94$, eimmal 97, durchschnittlich etwa 90-92, ron 11 o $84-87.5 \mathrm{~mm}$.

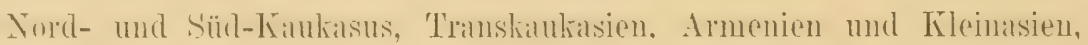
Crpern, Nord- und Ost-Persien. - Diese Form variiert wie alle Wasserschwätzer exingermalien in der Färbung der Unterseite; wemm man rene Serie veroleicht, ist sie lejeht nach den angegebenen Kómzeichen zu tremuen.

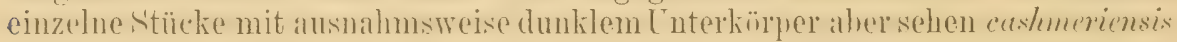
sehr ähnlich, andere mit anBergewöhnlich rötlicher Lnterseite sind sehwer ron

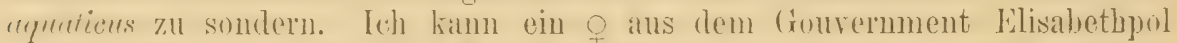
in 'Transkaukision (von I)r. Suschkin gesaudt) nicht sicher von C'. co cinclus' unterscheiden. Lis ist nath einem einzolnen Stïck nicht zu entscheiden, ob es sich um einen abnorm dunklen caucasicus oder einen verffogenen

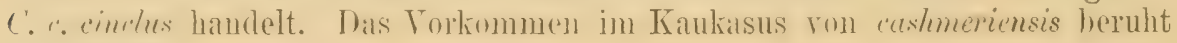
auf Iritum.

\section{Cinclus cinclus rufiventris Tristr.}

Cinchus aquaticus var. rufiventris et albiventris Hemprich \& Ehrenberg, Symb. Phys., fol. bb (nomina nuda!).

Cinclus rufiventris Tristram, Fauna \& Flora Palestine, p. 51 (1884- erste Beschreibung. "Litany River and Lebanon").

Lats Weib der Kropfgegend reicht his auf die Brust, Luterkïrper fahl rötlichbrann, nicht so ]ehhaft und rötlich wie bei persicues, nicht so dunkel

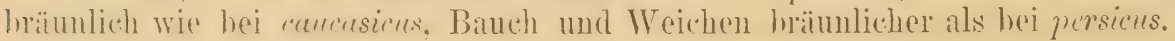
Flïgel ơ 93 , ๆ $84 \mathrm{~mm}$.

Libanon. - Es konnten nur zwei alte Vögel in frischem Gefieder mintersucht werden. 


\section{Cinclus cinclus persicus With.}

Cinchs cinchus persicus Witherby, Bull. B. O. Club XVI, p. 17 (1906 Südwest-Persien. Typus: Berge bei Hal Aimir, 6000 Fuß).

Grôßer als C.c.rufiventris, der ganze Unterkörper fahl rostfarbeu, etwas

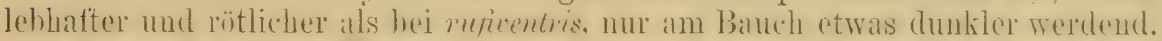
Ias braun des Rürkens reicht his an den Bïrzel. Flügel 103-105 mm.

Die Gehirge ron sü̈dwest-Persien, die ron Palästina durch die EuphratEbene und die syrische Wüste getrennt sind.

\section{Cinclus cinclus cashmeriensis Gould.}

Cinchus cashmeriensis Gould, Proc. Zool. Soc. London 1859, p. 494 (Kaschmir. - Kehle weiß).

Cinclus sordidus Gould, t. c., p. $49 \pm$ (Kaschmir, - Kehle braun).

Cinches przewalskii Bianchi, Bull. Brit. Orn. Club XV, p.91 (1905- Ost-Tibet. Keble braun).

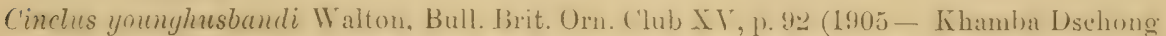
in Tibet. Kehle braun. Angeblich größer als sordidus, was aber nicht zutritit. Verf. bat übersehen, daß der von ihm untersuchte "C. sordidus" sich in derartig abgenutztem Gefieder befindet, duß3 die Flügelspitzen felılen und der Flügel daher nicht meßbar ist).

Abbild.: Gould, B. Asia IV, Taf. 23 und 25.

Lnterscheidet sich in seinem regrelrechten Kleide ron lémenaster mur durch

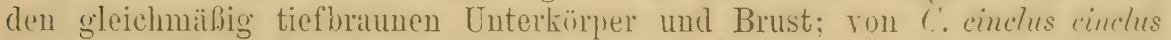
dadurch. daß, das Braun des Hinterhalses sich über den Oberüchen rrstrecht und dal.' die Könperseiten ganz oder fast ganz so dunkel sind wie die Brust. nicht aher dentlich sohiefergrau; rou C: caquations, meridionalis und anch cancasicns und Terwandten durch den gleichü̈Big tiefbraumen Lnterhïrper und ebensolche Brust.

AuBer dieser gewöhnlichen Färbung kommt eine mit rauchbraumer Koble und Kroplgegend ror, die der Tarietït summens Dresser hei C. c. lemomster entspricht, ahere cine noch dunklere Kehle hat; diese Fïrbung wurde als C. sordidus beschrieben und später wiedorum als C'. yomnghelumdi und C. praewalskii.

Schlieblich hefinden sich im Rothschildsehen Muscum zwei alte Vägel. of und - , ron Kaschmil; die den Enterkörper braun und weif remischt hahen, somit also den Ühergang zu der Varietit mit weißem Abdomen hilden. Letztere. (l. h. mit ganz weibem Tnterkürper - dem typisehen l'ucogaste' eutsprechend - scheint nicht rorzuliommen, oder ist. wenigstens noch nicht festgestellt worden.

Kaschmir, im ganzen Himalaya und Tibet bis Kansu.

Lebt selbst im Winter anscheinend nur in großen Höhen, über $9000 \mathrm{FuB}$ und wurde selbst inmitten des Winters noch $14000 \mathrm{FuB}$ hoch angetroffen.

\section{Cinclus cinclus leucogaster Bp.}

Cinclus leucogaster Bonaparte, Consp. Av. I, p. 252 (1850- ex Eversmann IIS.; Westsibirien. Abdomen und Kehle weiß) ${ }^{1}$ ).

1) Mit Ausnahme deren von C. leucogaster und triznae konnte ich sämtliche Iypen untersuchen. 
Cinclus subsp. Zaicalensis Dresser, Ibis 1892, p. 385 ("Baikal district". Abdomen braun. Kehle weib).

Cinclus saturatus Dresser, B. Europe IX, p. 20 (1895- Irkutsk und 'Tunka im BaikalDistrikt. Abdomen braun, Kehle weißlichbraun).

Cinchus bilkevitchi Zarudny, Orn. Jahrb. XIII, p. 57 (1902- Altai. Genau wie saturatus).

Cinclus kiborti Mladarász, Ann. Ilus. Hungar. I, p. 559 (1903- Krasnojarsk. Wie saturatus).

Cinclus cinclus bianchii Suschkin, Bull. B. O. Club XIV, p. 43 (1904- Sajan Gebirge bis zum Baikalsee. Wie C. lencogaster, nur Kopf und Oberrücken etwas hell, was oft rorkommt).

Cinclus cinclus middendorffi Suschkin, 1. c., p. 43 (1904- Sajan Gebirge. Wie saturatus).

Cinclus biedermani Reichenow, Orn. Mouatsber. 1909, p. 41 (Tschulesmanfluß - auf Karten 'l'schulyschman - im Altai. Ganz wie baicalensis).

Cinclus lencogaster triznae Sarudny. Orn, Mlonatsber. 1909, p. 180 (Kara-'Tau-Gebirge und Umgebung, T'urkestan. Die angegebenen Unterschiede ron „C.l. leucog(tster" sind individueller Natur; gerade ron Dscharkent, wo nur Stücke mit grauerem Bürzel usw., vorkommen sollen, liegt mir das allerbraunbürzligste Stück vor).

రo ad. Zügel, Strich unterm Auge, Ohrgegend, gauzer Oberkopf,

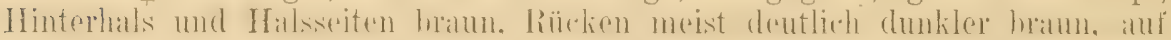
dem Unterrücken in die Fürbung des Bürzels übergehend, der mehr oder minder grau erscheint, da die Federn dunkelgrau sind, in der Mitte hraun

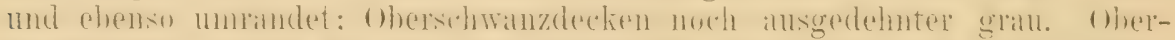

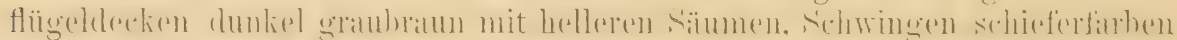

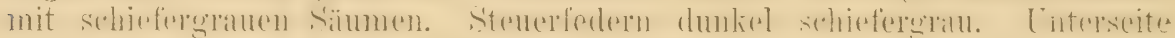

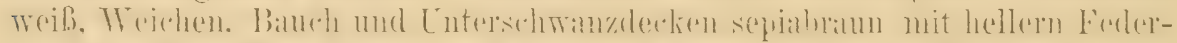

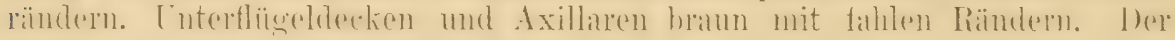
Banch ist bald dunkler bald heller braun, und diese Farbe wechselt etras an Ausdehnung. - Die oben beschriebene Form ist anscheinend die vorherrschende, und scheint in 'Turkestan fast allein vorzukommen - von dort kenne ich nur ein Fxemplar, das der von Dresser als sordidus beschriebenen Varietät, koines das seinem baicalensis gleicht. In Westsibirien und in den

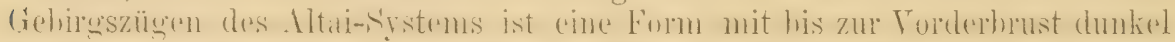

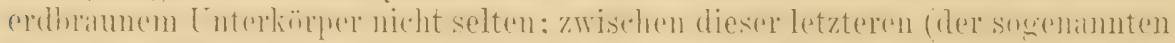

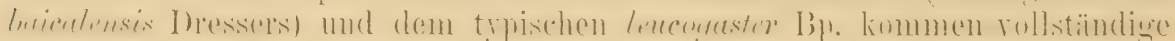
Übergängo ror: sie wurden von Taczanowski und Dresser beschrieben und erwaihnt und mir liegen solde bemplare bon Buchtall mat-Flusse und vom

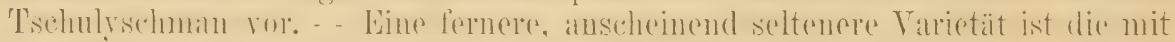

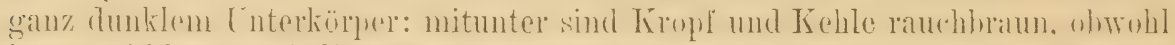

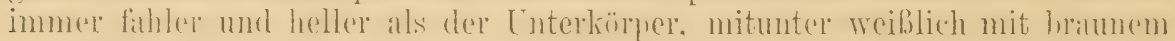

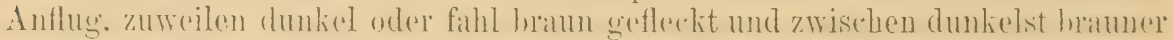

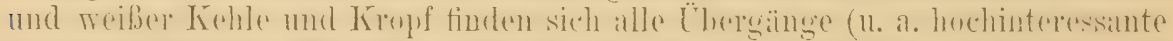

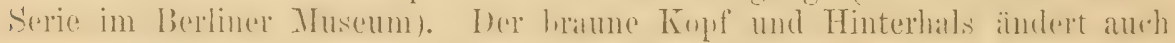
ab: meist ist er rötlich erdbraun, mitunter fahler, wie verblichen, bis zu ganz fahl mausgrau, besonders an den Halsseiten mit fast weißlichen Partien: diese helle Fïrbung zeigt sich besonders im abgetragenen, aber

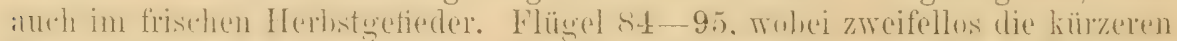

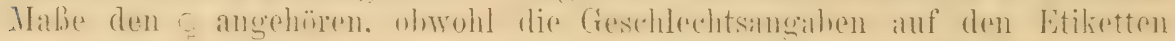
nicht immere dimit iihereinstimmen. Ich untersurlate ungefïh so stiick, davon lagen mir 55 zu gleicher Zeit in Tring vor, nämlich 33 aus Sibirien (Baikal, Altaigebiet, Westsibirien) und 22 aus Turkestan. 


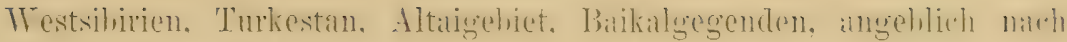
Osten bis zum Stanowoigebirge.

\section{Cinclus pallasii pallasii Temm.}

Cinclus Pallasii Temminck, MLan. d'Orn., 2. édit., I, p. 177 (1820_- „Krim?" ; errore! Jedenfalls ein ostsibirisches Stück, das Pallas olne Fundortsangabe nach Leyden sandte).

Abbild.: Gould, B. Europe II, Taf. 85; T'emm. \& Schl., Siebolds Fauna Joponica, Aves, 'l'af, XXI c.

ơ od. Oberscito schokoladenbraum, Bürzel und Oberschwanzdecken

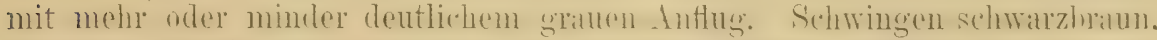

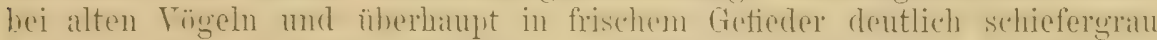
gesäumt. jüugere Tägel mit feinen weiblichen Aufenrïndern und spritzen.

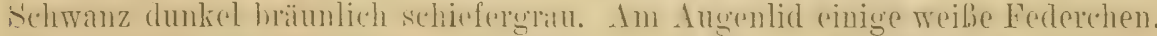

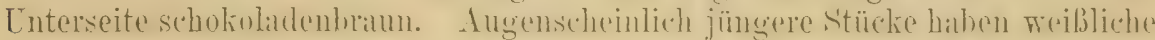

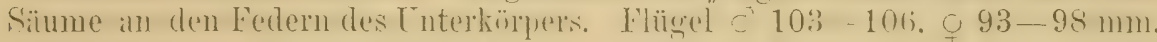
Schwanz etra $66-68$, Lauf $30-32$, Culmon etra $22-24$ mm. - Nest-

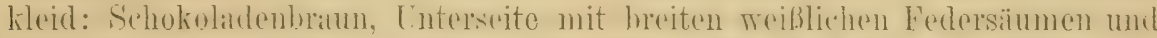
dunkleren anteapikalen Spitzen. Olnerseite mit fidilluamen Säumen. Etwas variahel, mitunter clunkler, oder riistleher. Nateh Tarzanowshi mitunter mit Aschgrau au Kopf und Kohlo.

Ostsibirien: Edsloi-Ostrog. Amur- und Lssurigegenden. Mandschurei.

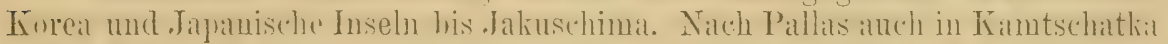
mol auf den Alenten. was aber nenerdius nicht hestïtiont wurde und daber

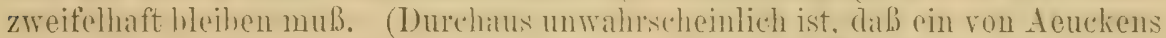
anf Helgoland heobachteter einfarbig dunkel gefärhter Tasserschwätze dieser Folm angehört hat!)

Die tier gleichen vollkommen denen von C. c. aquaticus. Sie messen nach Nehrkorn $25-26 \times 17-18 \mathrm{~mm}$.

\section{Cinclus pallasii souliei Oust.}

Cinclus Pallasi (T'em.) var. Souliei Oustalet, Ann. Sc. Nat., Zool., 7. sér.. XII, „1891", p. 299 (1892-. 'Ta-tsien-lu \& Mupin).

Cinchus siemsseni Martens, Orn. Monatsber. 1903, p. 187 (Fu-tschou, Provinz Fokien).

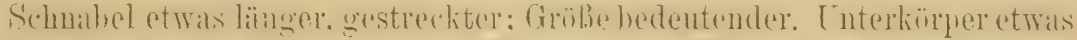

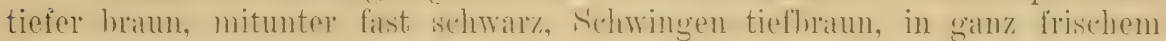
Gefieder mit äuferst schmilen rosthanmen Aubensïmmen, alier ganz ohne den

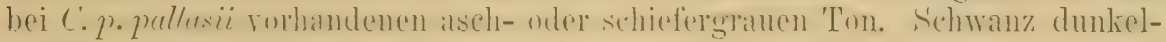
braun, nicht schieforgratr. Flïgel ơ ad. etra 115-120, o $105-112 \mathrm{~mm}$. (1 aus Ta-tsien-lu, 1 vom Jang-tse-Kiang; eine Serie aus Fokien, 7 aus den

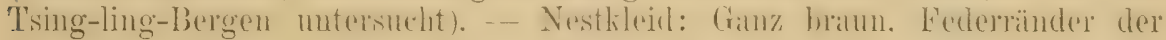
Unterseite schmal rotbraun, Oberseite dunkler als bei C.p. pallasii.

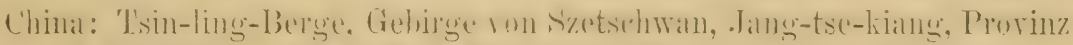

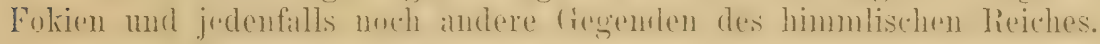

Auf den Bergen südlich des Bralımaputra und in T'eilen von Birmah wohnt eine Form, die C.p. souliei ïhnelt, aber kleiner ist. Sie hat braune Flügel (ohne Grann) wie dic lotztere, ist anch meist nicht gam\% so clunkel, 
aber viel dunkler braun und gröBer als tenuirostris. Auch dio Jungen sind intermediair: sie sind rirl dumkler und brïunlicher als die von temirostis, dascuen heller als snlehr rou jallesii. T)iese Form wïrde zu benemuen sein. doch rernag ich lieine sicheren Untersehiede ron der sonst wohl markierten

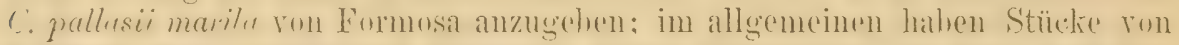
Furmosil wohl sehlankeren Schmalned. dieser Cutersehied ist aher noreh unsicher. (Vgl. Swinhoe, Ibis 1860, p. 187.)

\section{Cinclus pallasii tenuirostris Bp.}

Cinclus Asiaticus Swainson, Fauna Bor-Amer., II, Birds, p. 174 (1831- nomen nudum!). Cinchus Pallasii young? var: maculatus Hodgson, Gray's Zool. Misc., p. 83 (1844nomen nudum!).

Cinclus tenuirostris Bonaparte, Consp. Av. I, p.252 (1850-- Zentral-Asien. Ex Gould JIS.). Cinchus tenuirostris liorrejewi Sarudny, Orn. Mionatsber. 1909, p. 19 ("Gebirge des Semiretschje Gebietes und Bassin des Tschirtschik Flusses." — Soll „bleicher" und "rostfarbiger" sein, doch konnte ich aus dem Himalaya Stücke vergleichen, die bleicher sind, als Stïcke aus dem Semiretschje Gebiete).

Abbild.: Gould, B. Asia IV, Taf. 21, Cent. Him. B., 'T'af. 24.

Auf den ersten Blick von pallasii und souliei durch viel helleres, fahlures und atrats lötlicheres Branir zu unterscheiden, anberdem kleinel, mit kï̈z(ren Flïgeln und gestreckterem verhältnismäbig dïmnerem und längrerem Schnabel. Flïgel $91-101 \mathrm{~mm}$, die kleineren ziveifellos o, doch konnten nur wenige zuverlässig sezierte Exemplite untersucht Ferden. - Nestleisl: ron dem ron mellesii mur somlici dadureh untersehieden. dab die hellen omesist

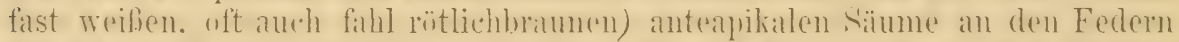

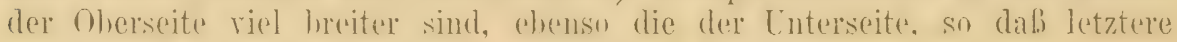
vorwiegend weiß oder weißlich mit bramen Federsäumen erscheint.

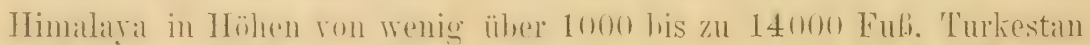

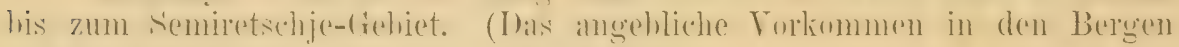
siidlich des Brahmaputra beruht auf Irrtum.)

Lebens- und Nistweise wie bei den europäischen Wasserschwätzeru. Nest aus Mloos, Farnkräutern und Würzelchen. Eier vom Dezember bis Mai gefunden. Eier nach Oates etwa $25-26 \times 18-19 \mathrm{~mm}$. Vier Eier aus Kumaon (Himalaya) messen $26.6 \times$ $19.1,28.1 \times 17.9,27.1 \times 19$ und $28.3 \times 18.6 \mathrm{~mm}$.

\section{Gattung TESIA Hodgson 1837.}

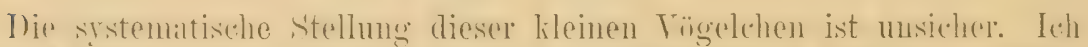
war der Ansicht. man müsse sic ihres limzen Schwänz.hens, seicligen fofieders

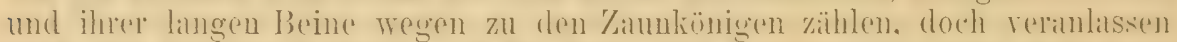
mich der hreitere sidnubel und die deutlichen Mundwinkelhorsten dies nicht

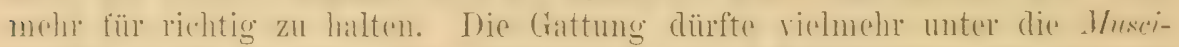

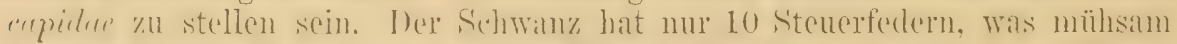
festzustellen ist, da el meist unvollständig ist. Inuf rorn geschient. - (lligure ist Sprnonym von Tesia (S. Nov. Zool. 1910).

\section{Tesia castaneocoronata (Burton).}

Sylvia? castaneo-coronate Burton, Proc. Zool. Soc. London III, 1835, p. 152 (1836Fundort nicht angegeben, ist aber Himalaya). 
Tesia flaviventer Hodgson, Journ. As. Soc. Bengal VI, p. 101 (1837- Nepal).

Cryptolopha Dejeani Oustalet, Bull. Mus. d'Hist. Nat. 1896, no. 6, p.316 (Ta-tsien-luTypus rerglichen).

Oligura castaneoventris (Burton) Hartert, Nov. Zool. 1907, p. 337 (Lapsus calami!).

Abbild.: Gould, B. Asia IV, Taf. 2.

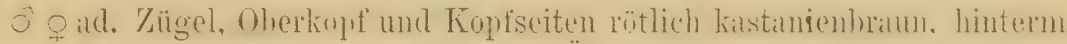

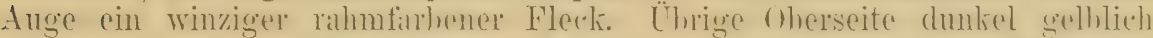
olivengrün. Schwanz und Schwingen dunkler, olivenhran, mit dur Farbe des

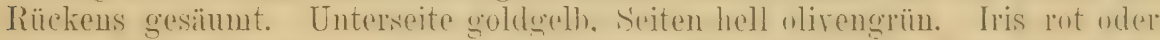

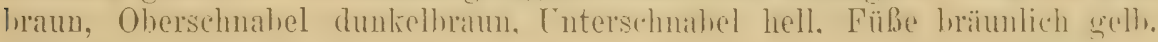
Flügel 48-52, Schwanz 25-28, Lauf 22-24, Culmen 11-12 mm. Juv.: Oberkopf wio Rücken, Unterseite trüb rotbraun.

Bewohnt den östlichen Himalaya, nämlich Nepal und Sikkim von

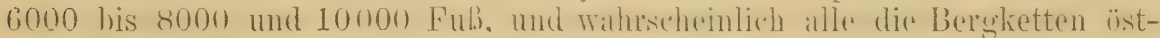

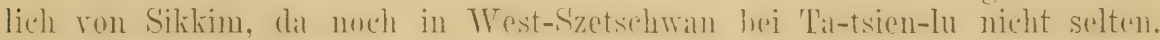

Lebt im dichtesten Buschwerk unter Bäumen und hat eine laute schrille Stimme. Bewegt sich nach Art des Zaunkönigs am Boden. Das Nest wurde „eingewebt in und hängend von einem Aste von Viburnum rubescens" etwa einen Meter vom Boden gefunden. Es bestand aus Moos und war mit feinen Würzelchen und zuletzt mit einigen F'edern ausgefüttert. Die Eier sind länglich oval, mit geringem Glanze, fast einförmig terrakottafarben oder matt kastanienbraun, am dicken Ende mit einer schwachen Kappe von Flecken. Sie messen ungefähr $18 \times 13.5 \mathrm{~mm}$ (Usmaston 1903).

\section{Familie HIRUNDINIDAE.}

Trohl die an dentlichsten abgegrenzte Familie der Osines oder aigentlichen Singrögel (s. pas. 1). Sic sind gुenïgend gुekemzeichnet durch den limzen, dreiechigen, Hachen Schnahel, riesige Jumdëftumug. schr limzen Lauf. schwachen Füße mit kräftigen Krallen, sehr langen nemuschwiugigen Flügrel mit völlig rechzierter 1. Sohninge, die nicht sichthar ist und nur hei gुonauerer Lutersuchung in Gestalt cines steifen. spitzen Federehens entcleclit merden himu. Anch der unerfahrenste Anfinger rermag eine Seluwalle als

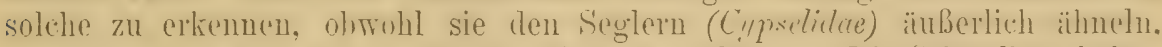
ron denen sie sich jedoch struliturell weit "ntfruen. I)ie Sichwalhen hahen nur eine Mauser. Sie halten sich meist in der Luft anf, da sie ihre allein aus Insekten besteheude Nahrung im Fluge 7 sirh nchmen. Sie sind fast kosmopolitisch. die nördlich wohnenclen Arten sinch alle echte Kugrägel.

Die ausführlichste Auskunft ïber alle Schwalben findet sich in der grobartigen Monographie der Schwallon von Sharpe \& Myatt. Wo alle Arten in Lebensgröße und meist ausgezeichnet abgebildet sind.

\section{Gattung CHELIDON Forster 1817.}

Die's ist die meist Ilimulu genamute Gattmug der aggentlichen Schwalben

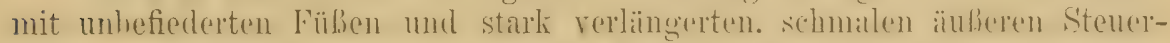
fecleru. - Irrtümliehermejse wurde der Name Cheliden für dio Hausschwalhen

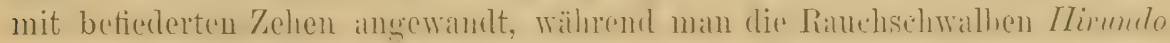

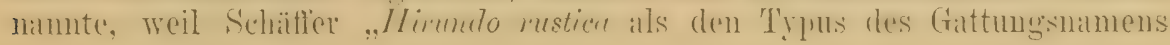


fixiert habe". Dies ist aber nicht richtig. Schäffer bildete zwar die Rauch-

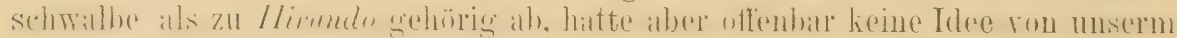

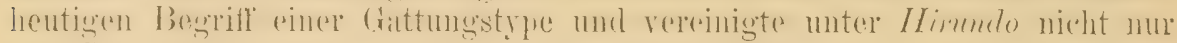
alle Schwalben, sondern auch noch Sogler (vgl. Mus. Orn. 1789). Der erste, der die eigentlichen Schwalben generisch zerteilte war Forster in seiner greulichen Arbeit Synoptical Cat. of Brit. Birds, 1817, und er nannte dic

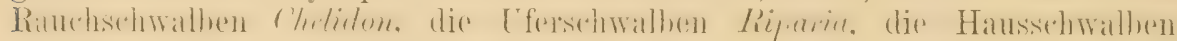
Hirundo. Diese Nomenklatur muß beibebalten werden. Cecropis, Uromitmus und Lillia sind unbedingte Synonyme von Chelidon.

Bürzel schwarzblau wie der Rücken............ C. rustica . p. 800 Bïzel rothraun. . . . . . . . . . . . . C. dentriar 1.804

\section{Chelidon rustica rustica (L.).}

Rauchschwalbe.

Hirundo mestica Linnaeus, Syst. Nat., Ed. X, p. 191 (1758- „Habitat in Europae domibus intra tectum". - Als terra typica betrachten wir Schweden nach dem 1. Zitat: Fauna svecica 244).

Chetidon Procne Forster, Synopt. Cat. Brit. B., p. 17 \& 55 (1817- Descriptio nulla). Hirundo domestica Pallas, Zoogr. Rosso-Asiat. I, p. 528 (1827- Neuer Name für den nach Ausicht des Autors nicht passenden Namen ron Linné. Ganz Rußland und Sibirien).

Cecropis pagorun Brehm, Handb. Naturg. Vög. Deutschl,g p. 138 (1831- Bei Renthendorf und "wahrscheinlich uördlich rom mittleren Deutschland").

Cecropis stabulorum Brehm, Vogelfang, p. 47 (1855- Ungarn und Kärnthen).

Hirundo rustica vulgaris, funaria, latirostris, minor A. E. Brehm; Verz. Samml., p. 3 (1866- Nomina nuda!).

Hirundo mistica sawitzkii Loudon, Orn. Jahrb, XV, p. 54 (190t-Transkaspien \& Turkestan anf dem Durchzuge, rötlichgelbbäuchige Individuen mit weißbäuchigen zusammen beobachtet).

Engl.: Swallow. - Franz.: Hirondelle de cheminée, - Ital.: Rondine, - Schwed.: Ladusvala.

Oे o ad. Oberseite glänzend schwarzblau, Hinterhals und Vorderrïcken mit verdecliten weifon Federmitten. Sehwingen ranchsehwarz. Anbenfihnen und spitzen mit dmukelblinlichem flaschengrounen Glanz. Stim his in Angenhöhe und Kohle rothram. Zägel mattschwall\%. C̈her den unteren Teil der hehle und Krople ein hreites biuschwarzes. meist mit rothramen Flecken gemischtes Band. Chrige Enterseite weil.) mit mehr uler mindere starkem rötlich isiblocll-

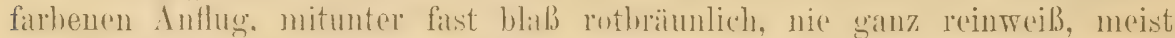

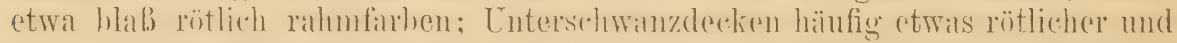

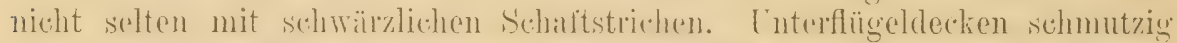
nder brïlunliehweids und mehr oder minder rötlich isibell ühertüneht. Steuer-

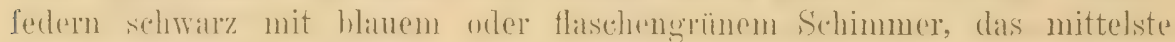

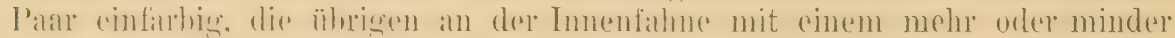

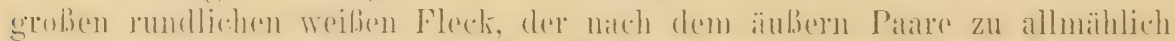

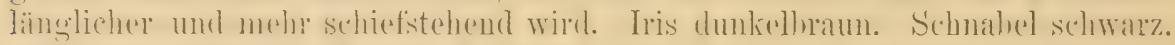

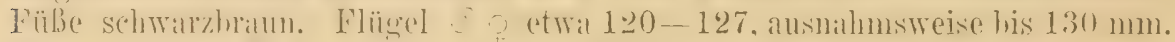
Jie geringsten Itafe (mitunter liaum 119) found ich lee a die aber auch mit-

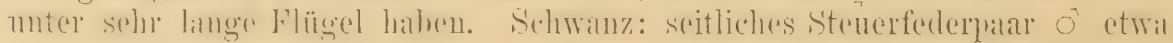
105-110 und sogar 120, o 95-100, selten mehr, mittelstes Paar 45-48, 
Liaf ungefïhr 5, Culmen 11.5-13 mm. - Nestkleid: Oberseite matter.

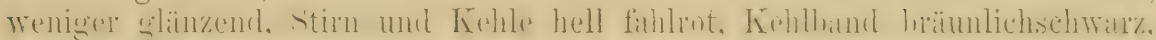

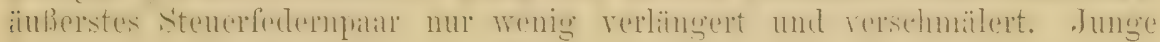
Vögel haben die seitlichen Stenerfedern viel kïrzer und breiter.

Ganz Europa und Nordwest-Afrika bis in die Oasen der nördlichen

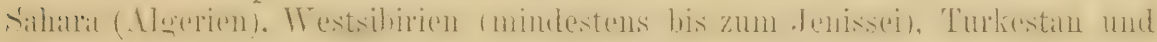
Himalara, Afghanistan, Bahuchistan, Persien und Ḱleinasien. - In allen

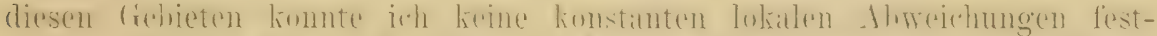

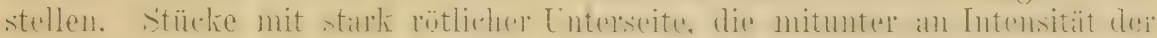
von C.r.transitiva nichts nachgibt, kommen überall vor, sind aber meist nicht häufig und nirgend konstant. Im allgemeinen sind Stïcke aus Maroklio, Algerien und Tumesien nicht sehr langflüglig, der Flügel mißt mitunter nur 118, selten bis 127 , wälnrend in 'I'urkestan Flügel ron 127 nud darüber häufig sind, in keinem Falle jedoch sind diese Unterschiede konstant genug, um daraufhin wenigstens nach dem untersuchten Material - eine subspezifische Einteilung vornehmen zu können. Auf der andern Seite sind die nicht wanderuden Formen in Ägypten und Palästina lionstant verschieden. Die Schwalben sind in den oben gemannten Lündern Zugvögel, die durch den ganzen dunklen Kontinent bis Südafrika, und durch Zentralasien uach Indien und seinen Inseln wandern. Zweifellos ziehen die am nördlichsten wohnenden am weitesten nach Sïden, während die Brutvögel der Atlasländer rermutlich nur in die Oasen der Sahara streichen, um dort zu üherwintern.

Die Rauchschmalbe ist ein so allgemein bekannter Togel, daß ich mich äber ihre Lebensweise sehr liurz fassen darf. Ihr Lockton ist das heimatliche wit wit oder ziwit ziwit, mitunter auch ein gedehnteres wiwit und ängstliches zibist. Der Gesang besteht aus einer angenehmen, mit kurzen Trilleru vermischten, locker plaudernden, schwätzenden Strophe, der man immer gern zuhört, obwohl sie nicht zu den prächtigen Gesängen gehört. Das Nest steht im Innern von Gebäuden, besonders Viehställen, Scheunen, W agenremisen, Teranden, unter Torwegen, Brücken, selten an den Außenwäuden von Gebäuden, und danu nur, wenn das ïberhüngende Dach vollkommenen Schutz ron oben gewährt, und sehr selten (wenigstens heutzutage) an F'elswänden Dis Nest klebt an der. Wand und ist in der Regel halbkugelförmig: mit der flachen Öfnung vorn am obern Rande, doch steht es auch mitunter frei auf Balken und ist vou oben offen. Das Material besteht aus Klumpen lehmiger Erde, die im Schnabel herbeigetragen wird und mit Speichel vermengt ist. Jedes einzelne Klïmpehen steht nach außen zu hervor, so daß das Nest einer Anhäufung zahlloser kleiner gleichgroßer Hügelchen gleicht, auch hängen und stecken meist einzelne Halme aus der Erdmasse herror. Die Ausfütterung besteht aus Federn, Haaren, Faden, Heu und Halmes, und ist locker und lose zusammengepackt. Die ersten Gelege bestehen meist aus 5, die zweiten aus 4 Eiern. Die in der Regel gestreckten, länglichen Eier sind 
glanzlos $\pi$ eiß, die Keichnung besteht aus dunkel rostbraunen, entweder gleichmäßig verteilten und dann meist feineren, oder um das dicke Ende gehäuften Flecken und. Punkten und selten fehlenden grauen oder violettgrauen Schalenflecken. Die Zeichnung variiert stark. 100 Eier (50 Rey, 50 Jourdain, in litt.) messen im Durchschnitt $19.74>$ 13.7, Maximum $23 \times 13.6$ und $20 \times 15$, Minimum $16.75 \times 12.75$ und $18 \times 12.25 \mathrm{~mm}$.

\section{Chelidon rustica transitiva subsp. nov.}

Steht zwischen C.r. rustica und C. $r$ savignii, indem die Unterseite.

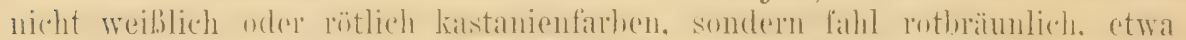

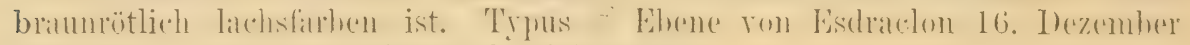
1863, по. T. $2057 \mathrm{im} \mathrm{Liverpooler} \mathrm{Musem.}$

Palästina; Stand- und Strichvogel. - Tristram berichtet, daß. niemand

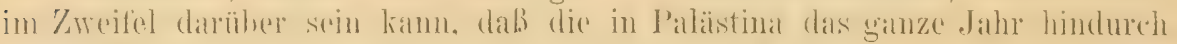

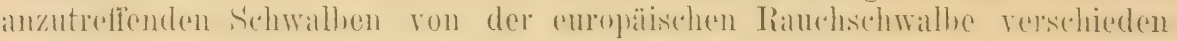
seion. Er nennt sie Hinundo savignii, während Sharpe \& Wyatt richtig

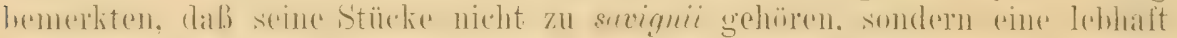
gefürbte Form rou C. mestica seien. - Nach Tristram soll auch C. metica (mit weiblichere Cuterseite) in l'alästina nisten, aber im Trinter nimuls amzutreffen sein ; jedenfalls ist diese Form nur Inurehzugsrogel. In süd-

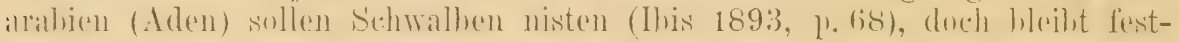
zustellen, zu welcher F’orm dieselben gehören.

\section{Chelidon rustica savignii (Steph.).}

Hirundo Savignii Stephens. in Shaws Gen. Zool, X, p.90 (1817- Egypten).

Hirundo cahirica Lichtenstein, Verz, Doubl. Ilus. Berlin, p. 58 (1823- "Cahira et Arsinoitis". Stephens und Lichtenstein zitieren die Abbildung ("Taf. 4, Fig. 4) in der "Description de l'Egypte" ron Savigny ohne Namen, die damals schon erschienen war, die Explication des Planches ron Andouin, worin der Name riocouri zuerst gebrancht wird, erschien aber erst 1826).

Himudo Riocouri Audouin, Explic. des Planches de la Deser. de l'Egypte, I, 4, Ois., p. 270 (1826- Egypten). (2. Ed., Olitar-Ausgabe, 1828, XXIII, p. 339.)

Hirundo castanea Lesson, Traité d'Orn., p. 268 (1831- Egypten).

Hirundo Boissoneauti T'emminck, Man. d'Orn., 2. Ed., IV, p. 652 (1840- ? Partim, alle Lokalitäten -- Spanien, Griechenland, Tripolis - falseh!).

Hirundo rustica orientalis Schlegel, Krit. Uebers., p. XVIII (1844- „Macedonien, Egypten (östl. Sibirien?)" Neuer Name für ,cahirica", „savignyi" und ,riocouri").

Hirundo Boissoneautii latirostris, microrhynchos, minor A. E. Brehm, Verz. Samml., p. 3 (1866 - Nomina nuda!).

Abbild.: Sharpe \& Wyatt, Monogr. Hirund., 'Taf. 39. Ei: Cat. Eggs Brit. Ilus. III T'af. VII, 3.

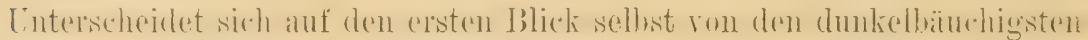
Varietäten von C. mestica mestica durch die lobhaft rötlich kastanienbrame Unterseite, die im Horbst und Winter am lebhaftesten ist, in der Brutzeit

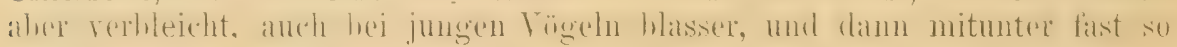
bleich wie bei alten transitiva ist. Die Flecke an den Stenerfedern sind nicht weib, sondern blaßrot.

Ägypten und Nubien. Stand- und Strichvogel. - Alle Angaben vom

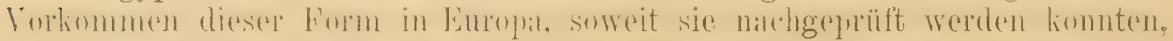

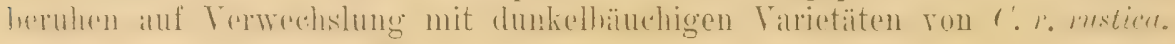


Nester in Wohnhäusern, Hütten, Gewölben, Moscheen und Brunnen. Die Eier gleichen denen von C. $r$ rustica. Vier Exemplare aus Egypten messen nach Jourdain (in litt.) $19.5 \times 13.5,20.3 \times 13.5,18.2 \times 13.2$ und $20 \times 14 \mathrm{~mm}$.

\section{Chelidon rustica gutturalis (Scop.).}

Himundo gutturalis Scopoli, Del. Flor. \& Faun. Insubr. II, p. 96 (1786- „In nova Guiaua

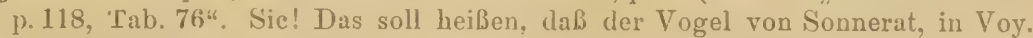
Nouvelle Guinée, p. 118, 'laf. 76 beschrieben und abgebildet wurde. Fundort ist Antigua auf der Insel Panay in den Philippinen).

Hirundo panayana Gmelin, Syst. Nat. I, p.1018 (1789 - Ebenfalls aus Sonnerat, 1. c.). Hirundo Jeucan Sykes, Proc. Committee Zool. Soc. London II, 1832, p. 83 (Juli 1832 ${ }_{\text {"Dukhun"). }}$ D

?Cecropis vusticoides Boie, Isis 1844, p. 174 (Java. - Nomen nudum!).

Hirundo rustica var. rufa Middendorf, Sibir. Reise, Vög., p. 188 (1851- Partim?). Hirmudo fretensis Gould, Handb. B. Austral. I, p. 110 (1865- Nordküste Australiens). Hivundo frenata (lapsu calami) Blyth, Ibis 1866, p. 336 (Sollte fretensis heißen).

Hirundo andananensis Bearan, Ibis 1867, p.316 (Andamanen. Ex Tytler MS.).

? Hirnndo kantschatika Dybowski, Bull. Soc. Zool. France VIII, p. 356 (1883- Kamtschatka. "Abdomen et sous-caudales blanes", sollte vielleicht "d'un roux intense" heißen? S. Sharpe \& Wyatt, Ilonogr. Hirund. I, p. 244!).

"Hivundo rustica, borealis" Dybowski \& Taczanowski, Op. cit. IX, p.152 (1884- "Subtus alba". "Kamtschatka).

Abbild.: Sharpe \& Wyatt, Monogr. Hirundin, T'af. 40.

Unterscheidet sich von C.r.metica durch das merklich in der Mitte unterhrochene. unvollkommene hlauschwarze Kropfband, anderdem ist sie kleiner, Flügel nur etra 110-120 mm, seitliche Stenerfederu $1-2 \mathrm{~cm}$ kürzer: Unterseite woiß, oft so reinweiß, wio es bei C.r.rustica solten rorkiommt, mitunter aher so stark rötlich, disf die Lnterscheidung von helleren

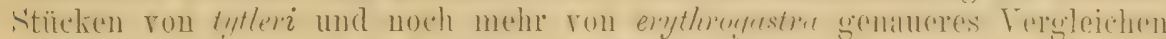

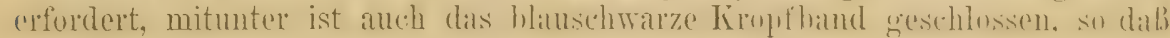
dann die Unterscheidung von C.r.melica schwer füllt.

Scheint südlicher zu wohnen als tytleri, in don Amur und Ussuri-

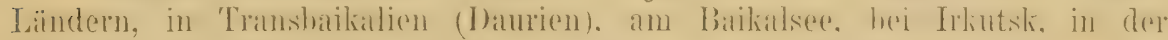
Nandschurei, Nord-China, Koren, Japan. - Im Winter in Indien, dem

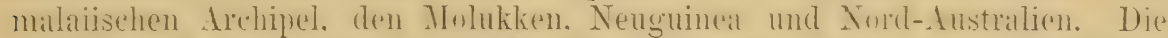
angehlich in Kamtschathal erhenteten Exemplare sind rermutlich hellhäuchige tytleri gewesen.

Lebensweise und Fortpflanzung, wie bei C.r.rustica.

Chelidon mustica enythrogastra ist die amerikanische Form der Rauchschwalbe. Sie steht zwischen tytleri und gutturalis; die Unterseite ist fahl rotbraun - übrigens variabel wie bei den anderen Formen -, das Kropf-

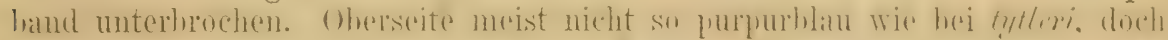

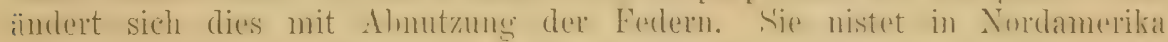

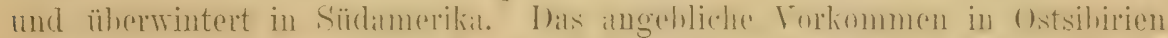

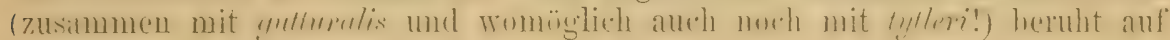
intümlicher Bestimmung: 


\section{Chelidon rustica tytleri (Jerd.).}

Firundo Tytleri Jerdon, B. India III, p. 870 (1864- Indien, brütend).

Hirundo saturata Ridgway, Proc. U. S. Nat. Mus. VI, p.95 (1883-- Kamtsehatka; ex Stejneger MIS.).

"Hirundo rustica, baïcalensis" Dybowski \& 'Taczanorski, Bull. Soc. Zool. France IX, p. 152 (Baikalgegend).

Abbild.: Sharpe \& Wyatt, Monogr. Hirundin., 'Taf. 41.

Ähnlich C.r. gutturalis, mit breit und vollstïndig unterbrochenem,

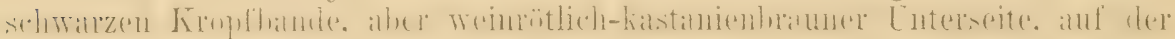
Oberseite meist mehr purpurn als erylhrogastra. (Siehe unter Nr. 1221.)

Kamtschatka und Nordost-Sibirien, im Winter in Süidchina und Indien.

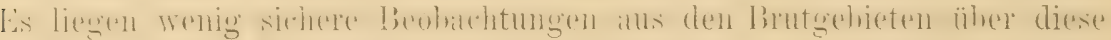
Schralbe vor und die Angaben über das Vorkommen sind vielfach verwirtt. Sicher ist, daß sie in Kamtschatka häufig brütet, und vermutlich ist dies auch in Sibirien nördlich und westlich ron Kamtschatkí der Fall, sogar noch bei Udskoi Ostrog an Uda-Flusse, wo aber die genanen Grenzen des Brutgebietetes mach Testen und Süden zu (gegen die von C.r. gutturalis) liegen, ist noch nicht sicher festgestellt. Das Vorkommen zusammen mit C. $r$. gutturalis ist wohl ausgeschlossen ${ }^{1}$ ), (das Brïten bei Irkutsk nicht bewiesen, deun in Kamtschatka kommt diese Schwalbe erst anfiugs Juni an, ein angeblich am 31. Mai erlegtes Stïck kann also noch auf dem Zuge gewesen sein! Das Vorkommen in Südamerika muß auf Terwechselung mit dunkelbänchigen erythrogastra beruhen.

\section{Chelidon daurica rufula (T'emm.).}

Himundo rufula Temminck, Man. d'Orn. 2. Ed., III, p. 298 (1835-Egypten, Sizilien fälschlich auch für Siidafrika und Japan angegeben. Sïdafrika nach Leraillant, dessen Abbildung und Beschreibung sich jedenfalls anf vorliegende drt bezieht und nicht auf C. cucullata, dessen Fundort aber, wie so oft, falsch ist. Das hinzugefügte Synonym "Himudo capensis Gmelin" ist unrichtig).

Lillic Temmincli Hume, Stray Feathers V, p. 259 (1877- Neubenennung des ron Temminck beschriebenen mediterranen Vogels).

Abbild.: Sharpe \& Wyatt, Mlonogr. Hirund., I'af 64.

Oे o ad. Konfplatte glänzend schwarzblan, von einem zimmtroten Bande

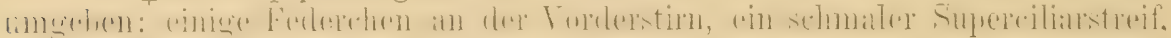
nach hinten breiter werdend und mit einem breiten Nackenband rerbunden,

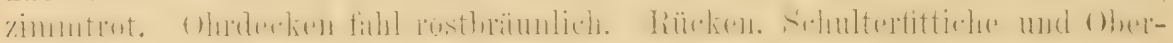
flügeldecken schwarzblau, auf dem Tordervëicken dadurch, dab die weilsen

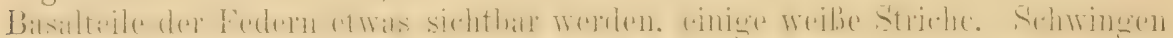

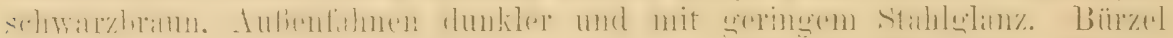

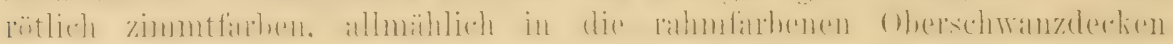

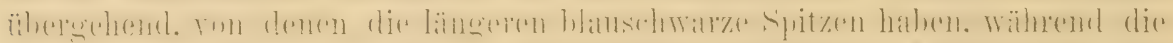

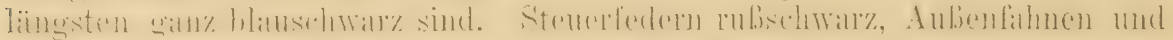
inmerstes Parr an beiden Falmen mit stahlfarbenem Schimmer, nicht selten

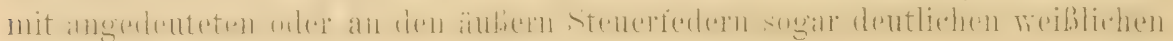

1) Sollten C.r.tytleri und gutturalis zusammen brüten, so wäre zu ermägen, ob erstere nicht einfach eine schr ausgesprochen dunkelbäuchige Varictät ron gutturalis bildet! 


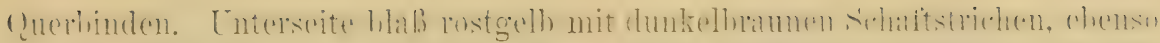

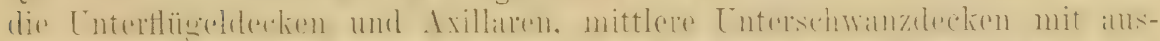

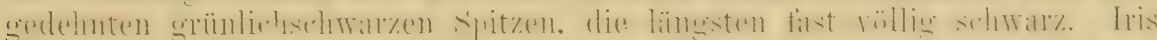
dunkelbraun. Schmabel schwarz, Fäßo braun. Flügel etwa 118-126, wobei die o im allgemeinen kleiner sind, Schranz etra 103-110. Culmen 8.5-10.5 mm. - Juv: Nicht so lebhaft gefürbt wie die alten Tögel, die bei jenen zimmtrote Farbe am Hinterkopfe und an den Halsseiten blaB

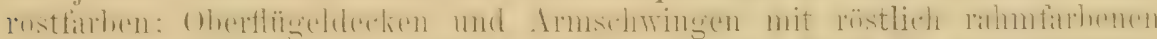

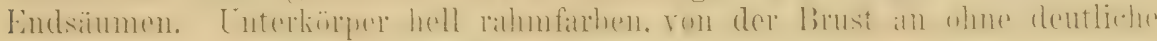
Schaftstriche. Seitliche Stenerfedern kürzer und breiter.

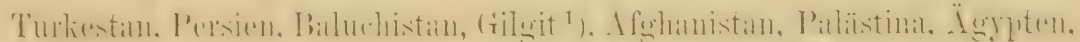

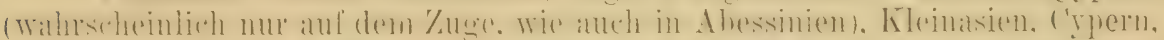

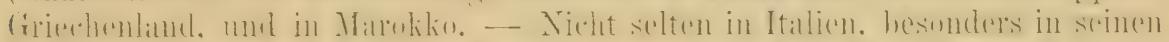

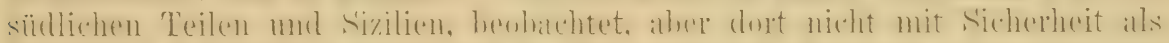

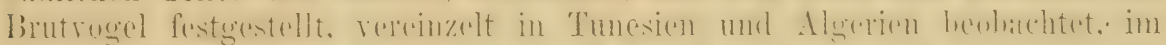

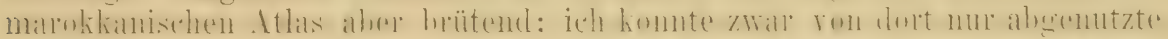

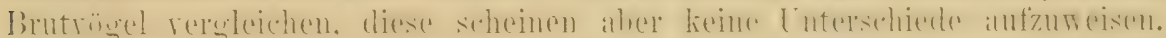
Eimmal auf Helgoland, einmal auf Fair Island zwischen den Orkney und Shetlands, am 16. Mai 1909 an der südenglischen Küste, anch in Südfrankroich beobachtet.

Diese Schwalbe ist in Kleinasien und Griechenland Zugrogel, vielleicht auch in ihren andern Brutgebieten. Die Nester stehen an der. Decke von Höhlen, oft fast im Dunkeln, unter iiberhängendem Gestein und Felsblöcken oder Brïckenbogen. Sie sind aus feuchter Erde gebaut und retortenförmig, d. h. es führt eine bis $18 \mathrm{~cm}$ lange retortenförmige Röhre zu dem eigentlichen Neste, das mit Halmen, Wolle und Federn ansgefüttert ist. Die Eier sind rein weiß, schwach glänzend, wie die der Hausschwalbe (H. urbica), bald rundlicher, bald mehr zugespitzt. 36 Lier (24 Jourdain, 12 Rey) messen im Durchschnitt $20.05 \times 14.24$ Maximum $21.5 \times 14.7$, Jinimum $19 \times 13.5 \mathrm{~mm}$.

\section{Chelidon daurica nipalensis (Hodgs.).}

Himendo Nipalensis Hodgson, Journ. As. Soc. Bengal V 1836, p. 780 (1837- „Central region of Nepal").

Hirundo alpestris japonica Temminck \& Schlegel, in Siebolds Fauna Japon., Aves, p. 33, T'af. 11 (18t7- Japan).

Cecropis aretivitta Swinhoe, Proc. Zool. Soc. London 1871, 1.346 (Peking).

Abbild.: Sharpe \& Wyatt, Monogr. Hirundin., Taf. 67.

Ähnlich C. daurica rufula, aber das zimmtrote Nackenband in der Mitte muterhrochen, dies schwarzhlaue Konfohitte also mit dom Rüldien rerbunden.

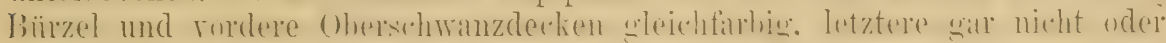

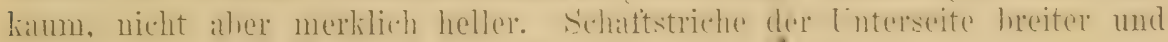

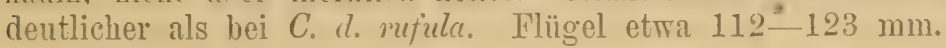

1) Die wenigen rorliegenden Stücke aus "Nepal" (?) und Afghanistan (ohne Geschlechssangabe!) sind etwas kleiner - Flügel 112-118 $\mathrm{mm}$ - scheinen aber sonst nicht abzureichen. Falls eine kleinere, den westlichen Himalaya (? und Zentralasien) bewohnende Subspezies zu unterscheiden ist, würde sie

heißen mïssen. (Hirundo rufula B. scullii Seebohm, Ibis 1883, p. 168, Gilgit und Nepal). 
Brutrogel im Himalaya, China, Korea und Japan (aber nicht so weit nördlich wie Jesso), im Winter in don Ebenen Indiens und Birmas.

Baut Nester wie C. d. rufula und befestigt dieselben unter überhängenden Felsen, an Felswänden, in Höhlen, in den Verandas oder unter Dachvorsprüngen der Häuser. Eier weil. Zwwei Bruten.

\section{Chelidon daurica daurica (L.).}

Hin $u n d o$ daurica Linnaeus, Mantissa Plantarum. p. 528 (1771- „Sibiria").

Hirundo alpestris Pallas, Reise versch. Prov. Russ. Reichs II, App., p. 709 (1773Altai und andere sibirische Gebirge).

Lillia intermedia Hume, Stray Feathers 1877, p. 263 (Sadiya in Assam).

Abbild.: Sharpe \& Wyatt, Monogr. Hirundin., Taf. 65.

Nitckenband unterhrochen. Bümzal nur unlentlich gestrichelt. Interseite blaß rötlich, schmal gestrichelt. - Von vufule durch das unterbrochene

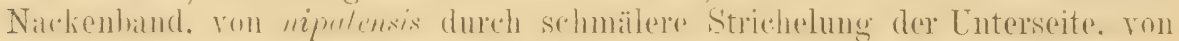

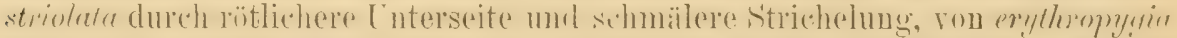

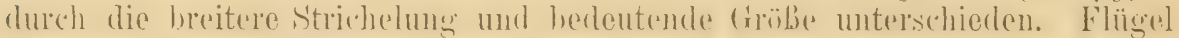
lang, mindestens $125-138 \mathrm{~mm}$.

Ostrihirien, westlich his zum Irtisch, 'Transhaikalien, Amur- und ['ssurigegrnden. Nongolei, Alathan und Kansu. Fimmal in zwei Exemplanen (im

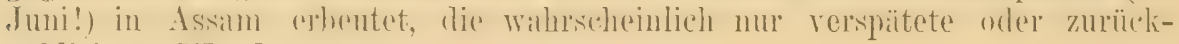
gebliebene Wanderer waren.

Die Nester gleichen, wie sich Godlewski ausdrückt, einer der Länge nach durchgeschnittenen Flasche, und werden an der Decke ron Verandas oder andern Gebäuden, sowie an ïberhängenden Felsen befestigt. Die 5-6 Eier werden nach demselben Beobachter im Juli gelegt und die Jungen verlassen die Nester erst kurz vor der Abreise im September. Die Eier eines Geleges aus Transbaikalien messen nach Taczanowski $21.8 \times 14.2,21.7 \times 14,21.4 \times 14,21.2 \times 13.4$ und $22 \times 14.2 \mathrm{~mm}$.

\section{Chelidon daurica striolata (Temm. \& S'hleg.)}

Cecropis striolata Boie, Isis 1814, p. $17 \pm$ (Nomen nudum! Ex Kuhl MS.).

Himundo striolata Temminck \& Schlegel, Siebolds Fauna Japonica, Aves, p. 33 (1847Java).

Abbild.: Sharpe \& Wyatt, Monogr. Hirundin., Taf. 66.

Lnterseite $\mathbb{F}$ (xiß uder last weiß, Strichelumg hreiter als bei allen anderen Formen, lostrutes Nalchenband hreit unterhrorhen wie hei allen asiatischen Formen. Eitwas hreiter gestrichele und in der Regel weiblicher als mipulensis, aber ungefïhr von derselhen Gribe und vielleicht nicht immer mit sicherheit zu unterscheiden.

Eine südlichere Form, die ron den Beroündern südlicb des Brahmat-

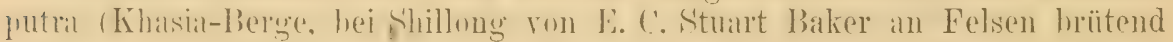

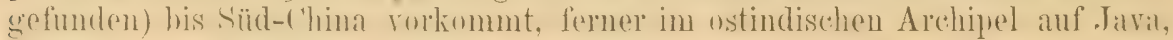
Flores, Sumbit. Trotter und Alor gesammelt wurde, aber dort jedenfalls nur Wintergast ist.

\section{Chelidon daurica erythropygia (Syk.).}

Hirundo erythropygia Sykes, Proc. Committee Zool. Soc. London 1832, p. 83 (Poona in Indien).

Abbild.: Sharpe \& Wyatt, Monogr. Hirundin., Taf. 68. 
Eine kleine tropische Form. Bürzel ungestrichelt rostrot, Unterseite weißlich rahmfarben, fein gestrichelt.

Bewohnt die Ebeneu Indiens vom Fuße des Himalaya bis zu den

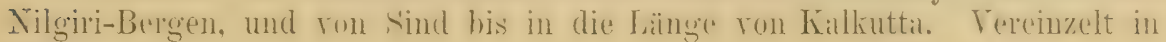
Ceylon.

Nist- und Lebensweise wie bei den größeren Vertretern, Nester' unter 'Torbogen, Verandas, an Mauern und Felsen, Eier rein woil.

Mehreve der tropisch afrikinnischen sedhwalhen könnten als Tertreter ron Chelidon durrieu angesehen werden. wie C: senegulensis und C. cucullate, dench ist es rorlïufig gewagt, sie als Sulswezies aufzulassen. Reichemow. Vögel Afrikas, II p. 412, 415, 416 gibt über diese Formen Auskunft.

Auf den rortwiegend tropischen japanischen Riu Kriu-(Liu-Kiu)-Inseln lebt eine von der typischen Chelidon jumanicu juranicu nur durch etwas he-

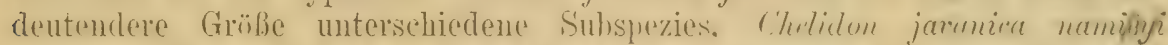
Stejneger (Proce L. S. Nat. Mus. IX, 18s6. 1. 646). I) ie spitlichen Steuerfedern sind nur einige mm, nicht lang fadenförnig verlängrast, die Cuterseite ist rauchbräunlich, Kehle und Stirn rotbraun.

\section{Gattung HIRUNDO L. 1758.}

(Irrtïmlich vielfach Chelidon Boie (1s22) genamnt, doch wurde der Name Ghelidon schon 1817 für die Raunchschwathe eingeführt. Ton llone $185+$ in Ielichon geëudert, von Reichenow 1889 Chelidonuria getauft, nach Elimination der mit anderen Gattungsnamen versehenen Arten bleiht aber der Time Himento L. für die Hausschwalbe übrig, der üherdies ron Forster bei seiner 1817 vorgenommenen Teucinteilung auf diese Gruppe heschrïnlit wurde.) - Enterscheidet sich rou Chelidon Forst. und allon inderen Schwalhengrattungen durch dicht befiederte Läufe und Zchen, aulierdem ist der Schwanz nur gegahelt, die seitlichen Steurefedern simd aber nicht auffallend verlïngert. Nester ans Frde. Fier weiß. Brutheimat: Europa. Nordwestafrika, Asien.

\section{Hirundo urbica urbica (L.).}

Hausschwalbe, Mehlschwalbe, Fensterschwalbe.

Hirundo urbica Linnaeus, Syst. Nat., Ed. X, p. 192 (1758 - "Habitat in Europa". Als terra typica betrachten wir Schweden, nach dem 1. Zitat, Fauna svecica 245).

Hintndo domestica Leach, Syst. Cat. Indig. Mamm \& Birds Brit. MIus., p. 19 (1816Nomen nudum!).

Hirundo Lagopoda Pallas, Zoog. Rosso-Asiat. I., P. 532 (1827- Partim! Siehe unter H. $u$. whiteleyi).

Chelilon fentestrenum Brehm, Handh, Naturg. Vïg. Dentschl. 1. 140 (1831- Mittleres Deutschland).

Chelidon rupestris Brehm, t. c., p. 140 (1831- Heiligenblut am Fuße des Großglockners in Kärnthen, an Felsen nistend). 
Chelidon tectorum Brehm, Vogelfang, p. 47 (1855- Dentschland).

Chelidon urbica vulyaris, latirostris, septentrionalis A. E. Brehm, Verz. Samml., p. 3: (1866- Nomina nuda!).

Engl.: House-MIartin. - Franz.: Hirondelle de fenêtre. - Ital.: Balestruccio. - Schwed.: Hussrala.

ơ ad. Oberseite glänzend schwarzblau, die Wurzeln der Federn weiß

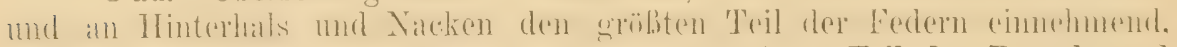
so daß dort meist etwas Weib hervorguckt; unterer Teil des Bürzels und

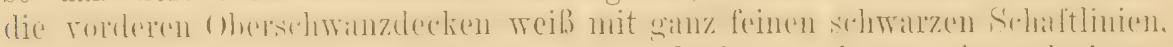

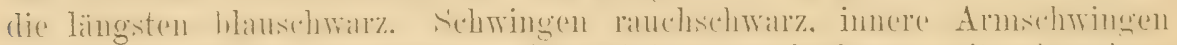

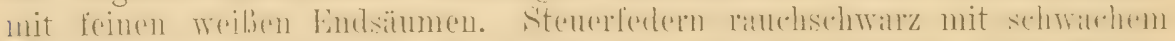

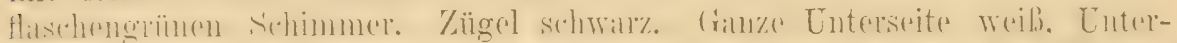

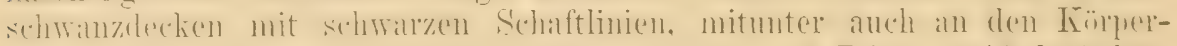

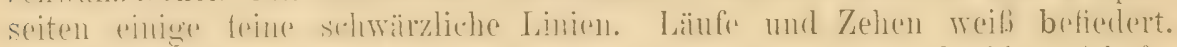

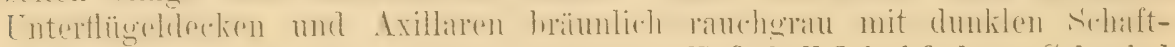

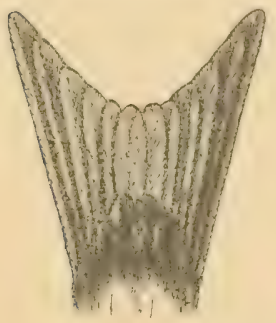

linien. Tris dunkelbraun. Füße hell fleischfarbon. Schnabel schwarz. Flügel etwa 108-114, bei einem ô aus Turkestan 115. Schwanz ungefähr 65-68, mittelstes Stenerfederpaar 17-20 mm kïrzer; Lauf 9-11.5, Culmen

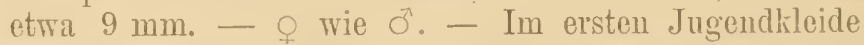
und Nestgefieder ist die Oberseite dunkelbraun, nur auf dem Rüeken mit etwas schwarzblauem Schimmer, Bürzel graubraun mit an Ausdehunug wedselnden hreiten weifen Futersäumen, die innern Armschrringen haben breitere weiße Säume, Kehle und Seiten sind bräunlich verwaschen. - Zwei grichische Exemplare (12. April, ob

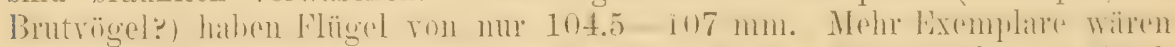
zu untersuchen. - Auch persische Brutrügel sind anffillend klein: 1 Stürk

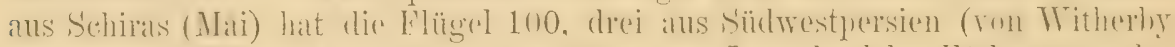

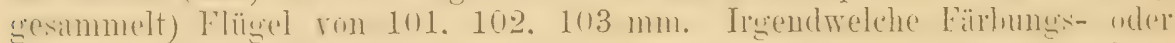
sonstige andere Unterschiede von $H$. u. urlica kanu ich nicht bemerken.

Europa, etwa rom 70. Grade in Sliaindinarien sïdwärts bis zum Mittel-

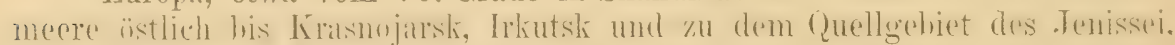
Persien (?) (s. oben!) und Turkestan bis zum Kren-Lün ${ }^{1}$ ). Im Winter bis

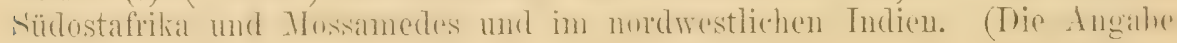
vom Brïten auf den Canaren beruht wahrscheinlich auf einem Irrtum. Brutzeit erst im Mai!)

Lebensweise wie die anderer Schwalben, Lockruf ein kurzes tr tr oder tzr tzr, Gesang nicht so kräftig und meist weniger anhaltend als bei der Rauchschwalbe. Tester mit äußerst seltenen Ausnahmen an der Außenseite ron Gebäuden, sowie an Felswänden, besonders an Kalk- und Kreidefelsen (England, Frankreich, Ungarn, Tunesien u. a.). Das Nest halbkugelig oder in Ecken unter Dachvorsprüngen eingeklebt und dann nur wenig mehr als viertelkugelig, außen sauber gearbeitet und mit einem ovalen oder fast ganz runden Einflugsloch am oberen Ende. Ausfütterung größtenteils aus Federn. Eier rein weiß, schwach glänzend, in der Regel ziemlich spitz. am dünnéren Ende. 100 Eier (55 Rey, 45 Jourdain, in litt.) messen im Durchschnitt $18.8+\times 13.27$, Maximum $21.6 \times 13.7$ und $21.5 \times 14.7$, Minimum $16.75 \times 13$ und $18.75 \times 12 \mathrm{~mm}$. Es finden zwei, angeblich mitunter sogar drei, Bruten jährlich statt.

1) Für 'Turkestan von Servertzoff unrichtig als „lagopoda" angeführt (Suschkin in litt.). 
1229. Hirundo urbica meridionalis subsp. nor.

Unterscheidet sich von $H$. $u$. urbica durch dio bedeutend geringere Größe: Flügel von 4 Exemplaren (3 aus Algerien, 1 aus Marokko) 100, 101, 103.5 und $106 \mathrm{~mm}$. 'Typus òd. 8. Nai 1908, Hammam R'Hira in Algerien, im Tring Museum (Nr. 337, R. \& H. coll.).

Brutrogel in Nordwestafrika: Algerien (terra trpiea), jedenfalls aber anch in Marokko und 'Tunesien. - Ob andere sïdliche Schwalben hierzu gehören, ist noch festzustellen. Ëber griechische und persische Stücke siehe ohen.

Brutzeit im Mai, denn anfangs Mai beobachteten Rothschild und ich sie erst beim Bauen ihrer Nester.

\section{Hirundo urbica whiteleyi (Swinh.).}

Hivundo Lagopoda Pallas, Zoogr. Rosso-Asiat. I., p. 532 (1827- Partim! „In omni Rossia et Sibiria!“ Pallas beschreibt zwar, wie er sagt, ein daurisches Exemplar, sein Name "Lagopoda" ist aber ein neuer Name für H. urbica, wie er ja auch Hirundo rustica neu benannte, und bezieht sich ebensowohl auf $H$. ubica aus Rußland wie auf ostsibirische Stiicke).

Chelidon whiteleyi Swinhoe, Proc. Zool. Soc. London 1862, p. 320 (Pekin).

Chelidon lagopus Sharpe, Cat. B. Brit. Mus. X, p.93 (1885- Grammatikalische Verbesserung von "lagopoda".

Abbild: Sharpe \& Wyatt, Honogr. Hirundinidae, Taf. 5.

Untorscheidot sich von $H$. urbica urbica dadurch, daß alle Oberschwanz-

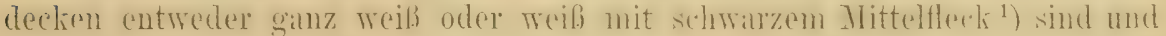
der Schwanz viel weniger, nur etwa $1 \mathrm{~cm}$ tief, gegabelt ist. Flïgel ron alten Vögeln 110-112 mm.

Ist weiter nach Norden und Osten verbreitet. Bei Krasnojark nach Suschkin (in litt.) u. a. mit $H$. $u$. urbica, wie anch an andern Punkten der Grenzzone, „ohne Bastarde zu bilden", vom Jenissei nach Osten zu allein, his zum Essuri und Sachalin. nördlich his zum Kulrmat-Delta (Buturlin). Nilch T'allis auch in Kamtschatka, dort ahere ron spriteren forscheren nicht

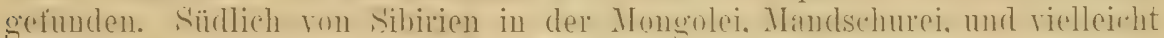
Nord-('hina. - C̈herwintert in Sïd-China und wurde anch in Birmat henhatehtet.

Nistet an Häusern, nnter Dächern, wie $H$. $u$. urbica, aber die Fluglöcher scheinen breiter, größer zu sein. Drei Eier im Britiseh IIuseum messen $18 \times 13$, $19 \times 13.2$ und $18.6 \times 13.1$ (Jourdain in litt.), 'Taczanowski gibt an $16.7 \times 125$, $17 \times 12.8,16.8 \times 12.3,16.8 \times 13$ und $17 \times 13 \mathrm{~mm}$.

\section{Hirundo urbica cashmeriensis (Gumld).}

Chelidon cashmeriensis Gould, Proc. Zool. Soc. London XXVI, 1858, p. 356 (1858Kaschmir).

Abbild.: Sharpe \& Wyatt, Monogr. Hirundin., 'Taf. 3.

Ähnlich H. u. wrlca, aber etwas kleiner, Flügel ungefähr 5-6 mm kïrzer, Schmanz nicht so tief gegahelt, Cnterseite ctwas graubrïunlich in-

${ }^{1}$ ) Beide Färbungen und Zwischenstufen kommen in denselben Jörfern briitend vor: 
gehancht. I.ïngere ['nterschwanzdecken hratun mit ansgedehnten weilien Säumen. Flügel etra 97, (eimmal) bis 103 und (einmal) $104 \mathrm{~mm}$.

Himalaya und westehinesische Gebirge bis Kansu (ein Stück nach (iighlioli in Italien erlegt, aher ron Silvadori und Arrigoni angezweifelt).

In Höhen von 6000 bis 12000 und 13000 engl. Fuß. Nistet nach Art ihrer Verwandten an überhängenden Felsen.

Eine H. u. cashmeriensis sehr uahestohende Form bewohnt die Hügel

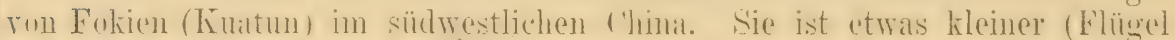

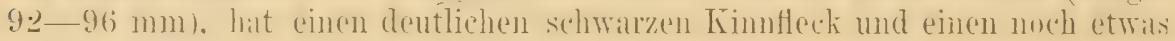
weniger gegabelten Schwanz. Ich nenne sie:

Hirundo urbica nigrimentalis subsp. nov.

Typus im Museum zu Tring, ơad. Kuatun 30. April 1897, von J. La 'Touche gesammelt.

\section{Hirundo urbica dasypus (Bp.).}

Chelidon dasypus Bonaparte, Consp. Av. I, p.343 (1850- Borneo!).

Chelidon blakistoni Swinhoe, Proc. Zool. Soc. London 1862, p. 320 (Hakodate in Japan).

Abbild.: Sharpe \& Wyatt, op. cit. T'af, 4.

Leicht ron $H . u$. urbica zu unterscheiden: Oberseite weniger blauglänzend. Schwingen und schwanz tiefer schwarz, der Schwanzausschnitt muter I cm ticf. Kinn mohr oder minder deutlich schwarz. Unterseite nicht reinweiß. Brust und Seiten ranchfarhen verwaschen, letztere mit mehr oder minder dentlichens schwïzlichen sehaftlinien. S'chwingen 104-110 $\mathrm{mm}$. Vou II. ". reshun rinsis durch weniger stank metilliseh hlauglänzenden Rürken. brïunlichere [nterseite und lïngere Flïg(') unterschieden.

Brütet auf den japanischen Inseln. - Die Typen (ein Paar) wurden ron I)iard anf Bormeo gesammelt. wo sie wahrsheinlich überwinterten, diese Form aber bisher niemals wieder beobachtet wurde.

Nistet an Felswänden. Eier wie die von H. u. urbica. Zwei Examplare im British Mluseum messen (Jourdain) $20 \times 13.8$ und $19.7 \times 13.7 \mathrm{~mm}$.

Mirnendo nipulinsis (Delichon nipalensis Moore. Proce. Zool. Soc. Iondon 1854, p. 104, 'Taf. IXXII) herwhnt den THimalaya ron Naini Tal bis zu den Daphla-Bergen im nürdlichen Assam. seheint aber nicht äber 8000 engl. Fuß zu steigen. Der Schwanz ist gerade, gar nicht ausgeschnitten, die Federu des Bïrzels und rordere oberschwamzdecken haben sehmale ranchwhware Lindsiume. Kopfseiten, Finn und ein 'Teil der Kehle sind sthwar, die Unterschwanzdecken schwarzblau. Flügel etra $90-95 \mathrm{~mm}$.

\section{Gattung RIPARIA Forst. 1817.}

Synonym: Clivicola Forster 1817, Cotile Boi 1822, Cotyle Boie 1827, Bit,lis Lesson 18:37. I'tyonoqugne Rehh. 1850. Ptionomegne Blanford 1873. Krimnochelidon Walden 1876. 
Unterscheidet sich von Hinndo durch die unbefiederten Lüufe und

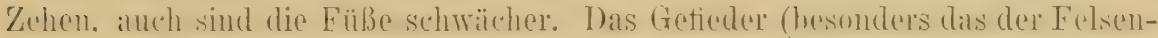
schwalleens ist sehr weich, der Schwan\% nur ausgebuchtet, nicht gegahlelt zu nemen (Fig. 13:3). Der l'hug ist weicher. schattenhafter. Nan ist rersucht, zwei (rittungen zu trenuen: die Cferschwalben. welche Lïhren in Ceroünke graben. un darin zu nisten, und die Felsensehwallon, welehe Eirdnester an

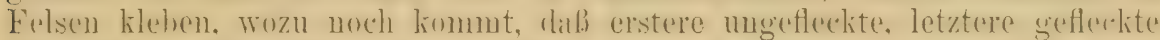

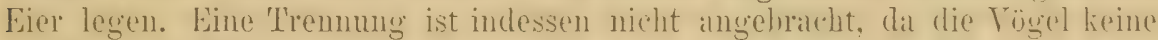
strukturellen Luterschiede zeigen. lis wurde angenommen, dab erstere ein kleines Büschel ron Federchen am untern terile der Hinterseite des Liatufes Int. das den Felseuschralhen fehlt, allein dirses Mterkmal ist hei den afrikanischen Formen uicht stichhaltig. I) Ee Eierfïhmug ist auch unvesentlich, wie wir bei Cheldon sehen, wo ein T'eil der Arten einfarbige, andere grefleckte Fier logen, heiht also wur die Nestanlage, nach der allein man doch nicht Gattungen trennen kann. - Das Genus Ripuriu ist üher Afrika. Europa und Asien, sowie in einer Art ( $R$. riparia) auch iiber Amerika verbreitet.

f Steuerfedern ungefleckt ........................ 3

1 \{ Steuerfedern mit weißen Flecken ............... 2

(2) Obere Kehle gefleckt ............. R. rupestris . J. 815

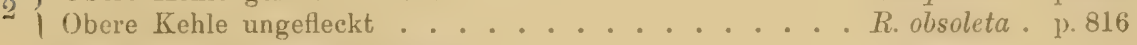

3 Kehle weil, dunkles Kropfband ........... R. riparia . p. 811

3 Kehle bis Vorderbrust graubraun ............ kaludicola . p. 813

\section{Riparia riparia riparia (L.).}

Uferschwalbe.

Hirundo viparia Linnaeus, Syst. Nat. Ed. X, p. 192 (1758- „Habitat in Europae collibus arenosis abruptis". - Als terra typica betrachten wir Schweden, nach dem 1. Zitat: Fauna svecica 247).

Riparia Europaea Forster, Synopt. Cat. Brit. B., p. 17 (1817- Descriptio nulla!).

Hirundo cinerea (non Latham!) Vieillot, Nouv. Dict. d'Hist. Nat., Nouv. Ed., XIV, p. 526 (1817- Europa).

Cotyle fluviatilis Brehm, Handb. Naturg. Vög. Deutschl., p.142 (1831- Flußufer des mittleren Deutschlands).

Chelidon micror hynchos Brehm, t. c., p. 143 (1831- "Wohnt wahrscheinlich nördlich von Deutschland, besucht unsere Gegenden nur selten auf dem "Zuge").

Cotyle riparia vulgaris, minor A. E. Brehm, Verz. Samml., p.3 (1866- Nomina nuda!). Clivicola riparia maximiliani Stejneger, Bull. U. S. Nat. ILus. No. 29, p. 378 (1885Name für die amerikanische Form der Uferschwalbe).

Backsrala.

Engl.: Sand-Mlartin. - Franz.: Hirondelle de rirage. - Ital.: Topino. - Schwed.:

ad. Oherseite erdhraun. auf Hinterrïclen und Bürzel eine Schattierung hasser. in frischem Gefieder mit sehr schmalen weiblichen Sï̈mmen an den Spitzen der Armsehwingen, an den Stenerfedern und an Bürzel und oherschwanzdedien. Schwingen und steuerfedem riel dunkler hram, die imern Armschwingen mehr wie der Rürcken. Zä̈gel dunkelbraun. L'nterseite weib. Brustseiten. Achselfedern und hreites Firopfband dunkelhraun. Linterflïgeldecken bram mit etwas helleren Sïumen. Iris braun. Sichnahel und FüßBe schwillzlich. Flïgel meist 102-108 nach Ridgway in Amerikil his 111. in der Sammlung Kileinschmidts anch aus Marhurg his 111, Schwanz otwal 50-55, Lauf 10-12, Culmen 8-10, Schranzgabelung etwa 6--10 mm. 


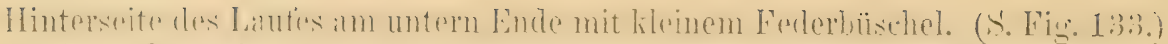
-- Juv. Oberseite mit schmalen, an den innern Armschwingen, Bürzel und

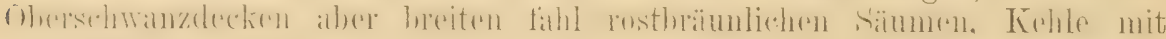

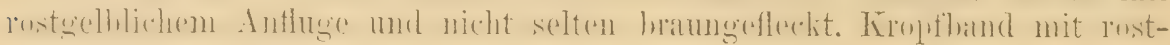
farbenen Federsäumen.

Europa rom $70^{\circ}$ nördlicher Breite und der Kola-Halbinsel bis zum

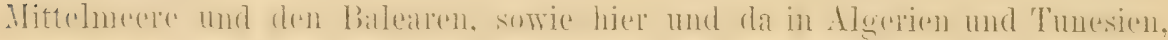

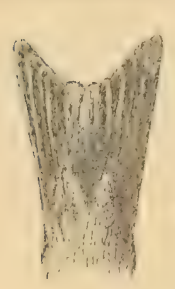

Figur 133. ostrvärts bis Sibirien, Palästina, Persien und vielleicht noch weiter, doch sind weder in Sibirien, noch anderwärts in Asien die Grenzen gegen die verwandten Formen sicher festgestellt. - Auf dem Zuge bis Ost- und Südafrika und Indien.

Anßerdem brïtet die Uferschwalbe in Nordamerika ron den arktischen Gebieten bis Nord-Mexiko und wandert im Winter nach Südamerika. Weder den amerikanischen Ornithologen, noch Sharpe und meiner Wenigkeit gelang es, die amerikanischen Uferschwalben von der europäischen in befriedigender Weise zu treunen. Manche Stïcke sind allerdings dunkler und schwer von ijimae zu unterscheiden; fermere Studion sind noch erwïnscht.

Überall Zugrogel, der aber zu verschiedenen Zeiten wandert, z. B. in England schon im JIärz und früh im April, in Deutschland fast niemals ror Anfang Nai erscheint. In Anbetracht der Unmasse von Individuen, die in Europa nisten, ist sie im tropischen Afrika verhältnismäßig selten, und überhaupt nur in Senegambien festgestellt, von mir im Haussalande nur gesehen, aber nicht gesammelt, so daß eine Verwechselung mit verwandten Formen nieht ausgeschlossen ist. Wolnt da, wo steil abfallende Erdwände ihr Gelegenheit zum Nisten bieten, also vorzugsweise an Fluß-, See- oder Teichufern, Durchstichen, Lehm- oder Sandgruben. Dort gräbt sie bis $60 \mathrm{~cm}$, mitunter sogar meterlange und ausnahmsweise noch längere schmale Röhren, an deren Ende sich eine längliche Errveiterung befindet, die ein von Stroh, Heu, Würzelchen, Wollefäden und Federn leicht zusammengehäuftes Nest enthält. Ich fand die Nisthöblen auch uuter der Rasenbedeckung unmittelbar über den flachen Steinen, die eine Festungsmauer krönen. Mitunter werden auch Mlauerlöcher zum Brïten benutzt, in Norwegen die aus trockenen Rasenstïcken bestehenden Dächer der Bauernhäuser. Vgl. auch Journ. f. Orn. 1887 p. 253. Die 5-6 Eier sind meist ziemlich zugespitzt und fast völlig glauzlos, reinweiß ohne jede Fleckung. 100 Eier (Rey) messen im Durchschnitt $17.3 \times 12.5$, Maximum $19.75 \times 12.5$ und $17 \times 13.5$, Minimum $15-25 \times 12$ und $15.5 \times 11.75 \mathrm{~mm}$. In Jourdains Sammlung ein Li ron $20.5 \times 13 \mathrm{~mm}$ aus England. Gewicht durchschnittlich $76 \mathrm{mg}$ (Rey). Nester fast immer kolonienweise, anscheinend zwei Bruten im Jahre. Lockstimme ein leises Schnarren, und aus schnarrenden, kaum zwitschernden Tönen besteht auch der sogenannte Gesang.

\section{Riparia riparia littoralis (Heugl.).}

Cotyle littoralis Lichtenstein, Nomencl. MIus. Berol., p.61 (185t- Nomen nudum!). Cotyle littorelis Heuglin, Orn. NO.-Afr. J, p. 166 (1869- Erste Beschreibung. Dongola) Cotile shelleyi Sharpe, Cat. B. Brit. Mus. X, p. 100 (1885- Ägypten).

Sehr ähnlich R. r. riparia, aber merklich kleiner, die Kropfbinde etwas

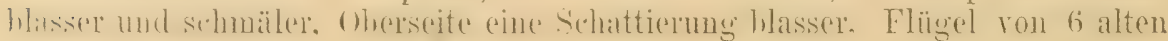
Vögeln $90-97 \mathrm{~mm}$. 
Ägypten und Nubien (Giseh bei Kairo, Neu-Dongola, Schereik). - Ein Vogel ans Keren in Bogosland sieht fast aus wie $R$. r. littoralis, hat aber einen Flügel ron $100 \mathrm{~mm}$. Vielleicht gehört er einer andern Subspezies an.

Fortpflanzung wie bei R. r. riparia. 7 Eier messen nach Jourdain im Durchschnitt $16.37 \times 12.17$, Haximum $18.3 \times 12.5$, Minimum $15.3 \times 12 \mathrm{~mm}$.

\section{Riparia riparia diluta (Sharpe \& Wyatt).}

Cotile diluta Sharpe \& Wyatt, MIonogr. Hirumd. I, p. 63 (1893- Tschimkent bei 'l'aschkend).

Sharpe beschrieb eino Uferschwalbe aus Taschkend, die sich durch

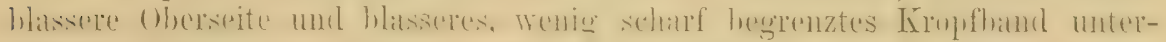

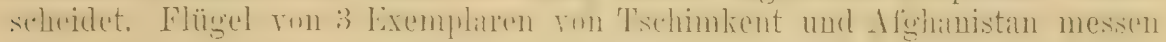
97.5, 104, $106 \mathrm{~mm}$. Zu dieser Form scheinen auch Brutrögel von Kobat

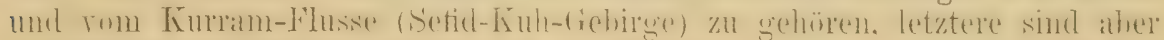

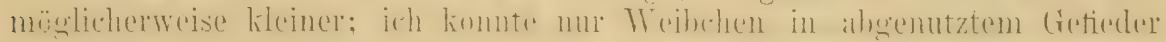
untersuchen, deren Flïgel 96.8, 94 und $93 \mathrm{~mm}$ messen. Zur selben Form

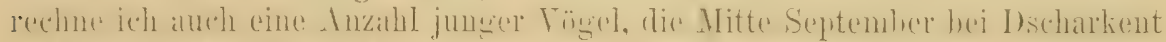

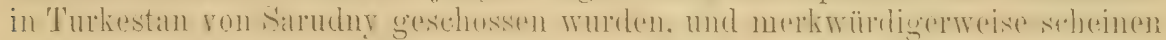
auch die Brutrögel von der Lena in Sibirien - alte Brutrögel, im Juni 1903, bei Zarkarminski von Hall gesammelt - dazı zu gehören. Flügel రొ ㅇ 100-105 mm. (Tol. Ibis 1904, p. 437.)

Danach würde diese Form cino Verbreitung rom nördlichen Sibirien bis Nordwestindien haben, die Grenzen gegen $k_{0} r$ ripuria und $l_{0} r$ rijimae

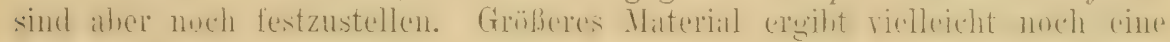
weitere Thennumg.

\section{Riparia riparia ijimae (Lönnb.)}

Clivicola riparia ijimae Lönnberg, Journ. College Science Tokyo, XXII, Art. 1t, p. 38 (1908- Sachalin).

Östlich der Lena in Ostsibirien, wo die helle dilute vorkommt, tritt

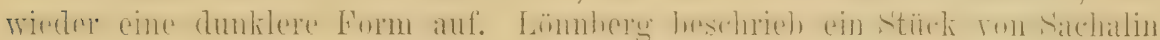
unter dem Namen ijimae. Es ist auf der Oberseite dunkler, und besonders ist anch das Brustband sehr dunkel. Die Stenerfedern und Oherschwauz-

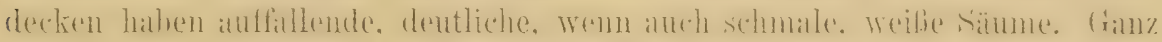

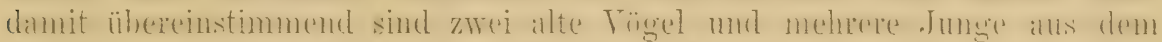

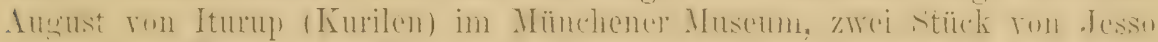

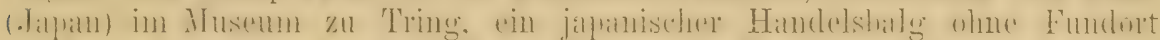

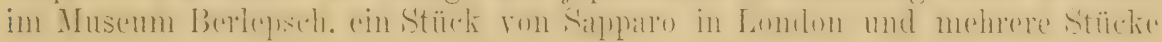
von Kamtschatka. Dieso Vögel seheinen im frischen Gefieder immer helle Sïume auf dem Bürzel, den Schwanzdecken und an den Steuerfedern zu baben, jungo Vögel ebenfills rostfarbene Ründer, wie bei K. r. riparia. Die Verbreitung dieser Subspezies ist noch unsicher, doch scheint sie ron

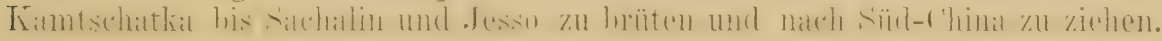

\section{Riparia paludicola minor (Cab.).}

Cotyle minor Cabanis, Mus. Hein. I, p.49 (1850- Nordost-Afrika).

Abbild.: Sharpe \& Wyatt, Mlonogr. Hirundin. Taf. 12 (Unterkörper zu bräunlich!). 
$\mathrm{O}^{7} \mathrm{~g}$ ad. Oberseite erdbraun, Armschwingen in frischem Gefieder mit

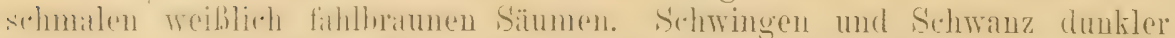

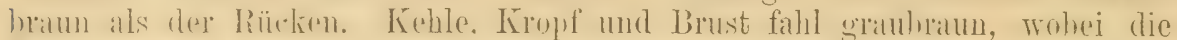

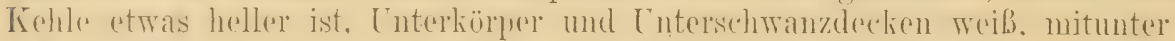

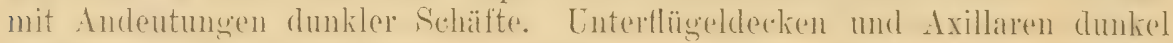

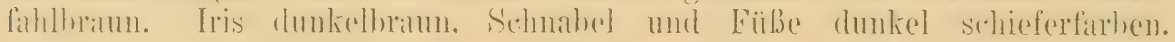
Flügel von 12 alten Vögeln 95-102.5 mm. Schwanz ungefähır 45-47 mm. - Junge Vögel haben rostfarben gesäumte Federn auf der Oberseite.

Brutruged an den Tfern des Nils in Nubien und dem ägrptischen Sudinn.

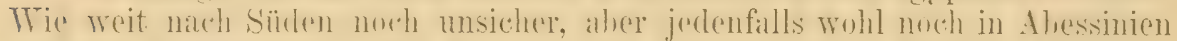

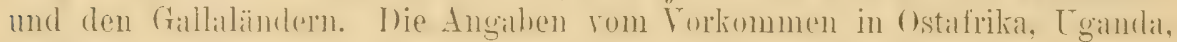
am Victoria Nyansa dürften sich auf andere Formen beziehen. - Bis auf

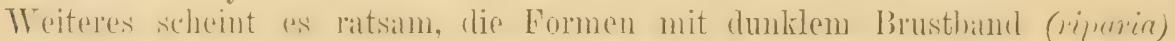

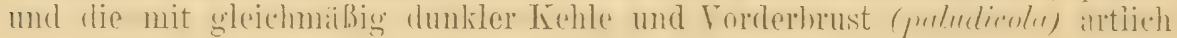
zu trennen, da sie anscheinend am Nil nebeneinander hrüten.

Nistet am Nil in Kolonien wie unsre Uferschwalbe. Nisthöhlen etwa $60 \mathrm{~cm}$ tief. Am 25. Mär'z fand N. C. Rothschild bei Schendi 5 schwach bebrittete Eier von reinweißer Farbe. Maße eines der Eier $16 \times 12.5 \mathrm{~mm}$.

\section{Riparia paludicola mauritanica (Meade-Iraldo).}

Colile manritanica Mleade-TValdo, Bull. B. O. Club XII, p. 27 (1901- Wad Iloorbei [=Oum-er-Rebia] Marokko).

Sehr ähnlich R.p.minor, aber bedentend größer. Die Färbung der

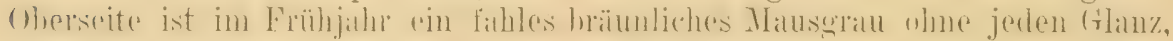
aher die friseh vermatuserten Sehwingen und stenerfedern sind ganz dunkel,

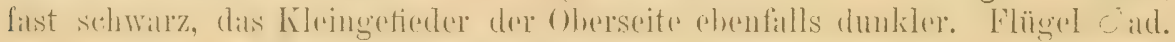
103-109, o 101-108, Schwanz 45-47.5, Schwanzausschnitt höchstens 4, Lauf etwa 10, Culmen ungefähr 8-9 mm. - Juv. Oberseite mausgrau

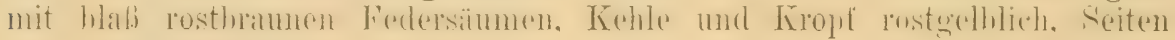
ebenso verwaschen.

Bisher nur von den Ufern des Oum-er-Rebia im westlichen Marokko bekannt.

Scheinen in ihrem Brutgebiete Standrögel zu sein, nisten schon im Februar. Am 21. und 22. Februar enthielten die Nester einer von Riggenbach entdeckten Brutkolonie 3-4 Eier. Letztere gleichen denen unsrer Uferschwalbe und 4 Gelege messen: $16.75 \times 12.6,16.75 \times 12,5,16.4 \times 12.7 ; 16.9 \times 12.4,16.9 \times 12,17 \times 12.4 ; 17 \times 12.4$, $17.3 \times 12.9,17.1 \times 12.9,16.9 \times 12.5 ; 17.7 \times 13.1,18.1 \times 13.3,18.5 \times 13.5,18.4 \times$ $13.5 \mathrm{~mm}$. Die Mauser alter Vögel beginnt schon Ende IIa i und im J uni.

\section{Riparia paludicola paludicola (Vieill.).}

(Hirundo paludicola Vieillot, Nouv. Dict., Nouv. Ed. XIV, p. 511, 1817, Ex Levaillant) ist dio südafrikanische Vertreterin von $R$. p. minor und manritanica. Sie ist ungefähr so groß wio mantanica, aber Keble und Kropf

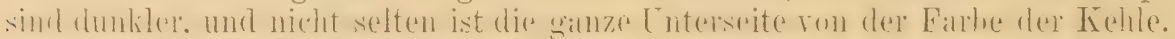
'/wischen $R \cdot p$. paludicola und mauritinica einerseits und minor andrerseits wohnen andere Unterarten. 
In diese Gruppe gehört auch die tropisch indische, bis Süd- und Nittel-China sich erstreckende Riparia chinensis, die wahrscheinlich als

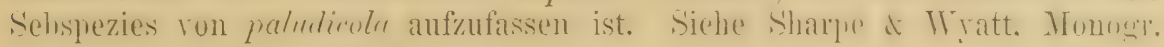
Hirundin. I, p. 81, Taf. 14.

\section{Riparia rupestris (Scop.)}

Felsenschwalbo.

Hirundo rupestris Scopoli, Annus I Historico-Nat., p. 167 (1769- Tirol).

Hirundo montand Gmelin, Syst. Nat. I, 2, p. 1020 (1789- Ex Buffon VI, p.6t1: Savoyen, Auvergne, Dauphiné).

Hirundo Rupicola Hodgson, Journ. As. Soc. Bengal V, p.781 (1836- Mittel- und Nord-Nepal).

Hirundo inomata Jerdon, Madras Journal XIII, p. 173 (1844- Ootacamund in Indien). Cotile obsoleta sarda Arrigoni, Avicula 1902 p. 103 (Sardinien). moutana.

Engl.: Crag-Martin. - Franz.: Hirondelle de rochers. - Ital.: Rondine

ơ qad. Oberseite von einem etrvas fahlen gräulichen mausbraun, die Federn mit undentlichen lichteren Sünmen. Schwingen. bestunders nach den Śpitzen zu, dunkelhran mit sehwarhem frlanze. Oherflügedecken dunkler

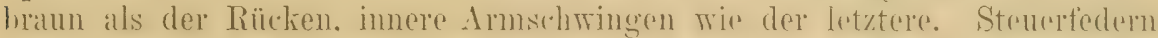

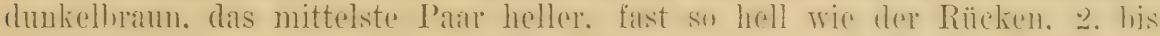
5. Pan mit grolicm, ovalen, weiben Fleck an der Innenfahne. Tropfoceiten wie der Rüctien, nateh der Kehle zu etwals hell gestrichelt: Keble lis zom

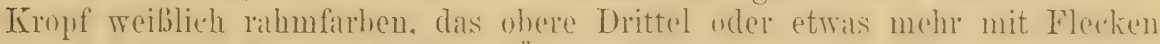
ron der Fathe des Oberkenfes. C̈hrige Cnterseite fahl gräiulich rustluam.

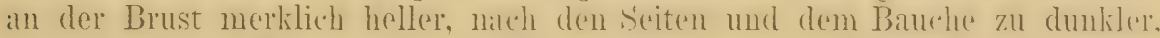
mehr graubraun. Seiten mit undeutlichen dunkleren S.haftlinien, Untersedswanzdecken dunkel graubraun mit fahl blaßbraunen Säumen. Unterflügeldecken und Axillaren braun. Iris dunkelbraun, Schnabel schwarz, Füße bräunlich fleischfarben, Zehen dunkler als Lauf. Flügel meist 128-134, mitunter nur 124 nder his 136 . Schwanz. 55 bis 58, Lauf etwa 11 , Culmen 10-11.6 mm. Geschlechter gleich, o keinesweg's durchweg
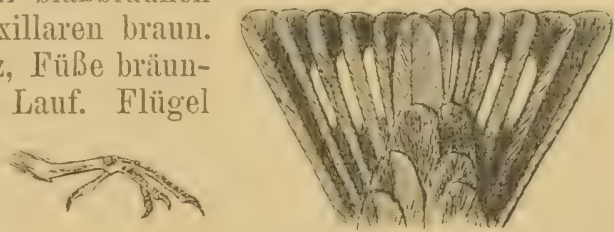

Figur' 134. kleiner. Hinterseite des Laufes bei dieser Art und bei lí, olsceletn ohne Federbuischel (Fig. 134). - Nestkleid: Federn der (herseite mit hreiten blak

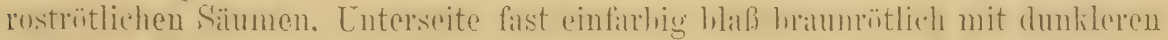

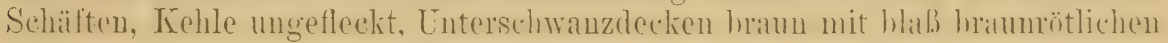
Säumen.

Brütet in den Atlasländeru, von den Südabhängen und Ausläufern des

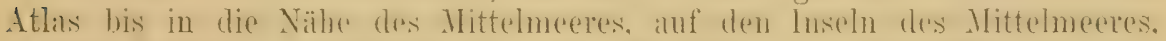

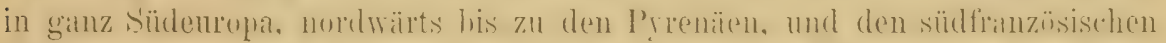

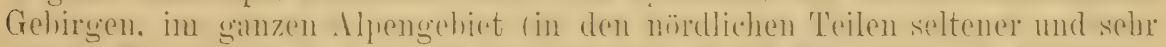

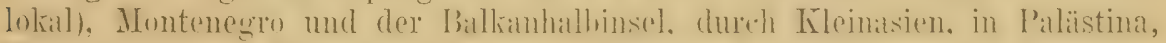

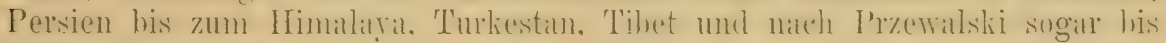

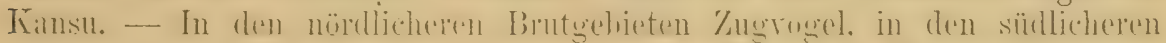

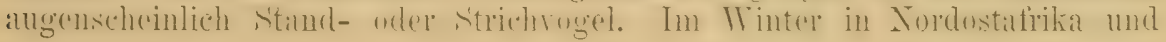




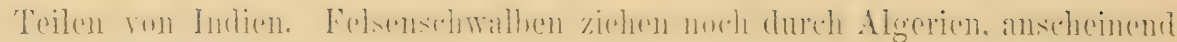
aber nicht seha weit nach Süden, da im tropischen Westafrika noch nicht beobachtet. Tor etwa einem Jahrhundert erhielt Wolf ein Stïck aus der Oberpfalz.

Die Felsenschwalbe ist Gebirgsrogel und kommt sowohl in geringen Erhebungen als im Hochgebirge bis ïber $2000 \mathrm{~m}$ vor, im Himalaya sogar noch einmal so hoch. Felsenwände mit Höhlen oder doch Plätzen, an denen sie unter überhängendem Gestein nisten kann, sind ihr Bedürfnis, nur ausnahmsweise britet sie unter weit rorstehenden Hausdächern, z. B. in Andorra. Die Nester ähneln, die Eier gleichen denen der Rauchschwalbe. Im allgemeinen ist nach Rey die Fleckung der letzteren feiner, viele Eier aber siud nicht zu unterscheiden. 56 Stïck messen nach Jourdain (in litt.) im Durchschnitt $20.11 \times 14$, Maximum $23.2 \times 14.5$ und $20.7 \times 14.7$. Minimum $19 \times 13.4$ und $19.2 \times 13.1 \mathrm{~mm}$. Die gewöhnliche Stimme ähnelt den Silben tschri, tzri und gleicht der der Uferschwalbe, ist nur lauter und schriller, der Gesang ist ein schnarrendes Gezwitscher, das fast nur aus den Locktönen besteht.

\section{Riparia obsoleta obsoleta (Cab.).}

Cotyle obsoleta Cabanis, Mus. Hein. I, p. 50 (1850- Nordostafrika).

Cotyle cathirica A. E. Brelum, Journ. f. Orn. 1853, p. 452 („Von Kairo an durch ganz Ägypten).

Ptionomrogne Pallida Hume, Stray Feathers 1873, p. 1, 417 (Sindh \& MLekran-Küste). Riparia mpestris reichenovi Zedlitz, Orn. Monatsber. 1908, p. 177 (Nordarabien).

Abbild.: Sharpe \& Wyatt, Mon. Hirundin. I, Taf. 16. Ei: Cat. Eggs Brit. ILus. III, Tat. III. : ב.

Unterscheidet sich von R. rupestris durch folgende Morkmale: Kim

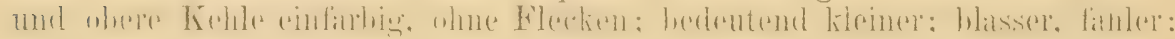
die Flecke an den Steuerfedern sind meist, aber nicht immer, rundlicher, nicht so länglich wie bei mpestris, dio äußerste Steuerfeder, die bei mpestris immer einfarbig zu sein seheint, lat oft eime Andentung eines weißen Fleckes, und mitunter ein deutliches rundes weißes Fleckchen. Flügel ron über 30 Exemplaren 113 (selten), 115 bis $122 \mathrm{~mm}$. - Der Farbenton der Ober- und Unterseite variiert natürlich nach der Jahreszeit. Die Mauser findet nicht erst im Winter oder Herbst, sondern unmittelbar nach der Brutzeit, im Juli und August statt, denm im August erlegte Stücke zeigen schon ein röllig vermausertes frisches Federlileid; solche Stücke haben eine

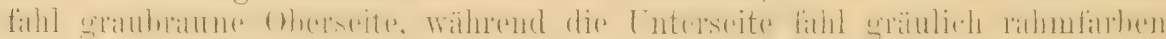
erscheint, am Unterkörper dunkler und gräulieher werdend, an den Unterschwanzdecken fahl graubraun. Schon im Winter, noch mehr aber im Frühling, verbleicht dic Oberseite, während die Unterseite fast (melr oder minder schmutzig) weißlich wird, Bauch und Unterschwanzdecken fahler. Graf Zedlitz (Orn. Momatsber. 1908 p. 177) unterscheidet vier Subspezies, die er mpestris, obsoleta, mesilla und reichenowi nennt. Nach sorgfültiger

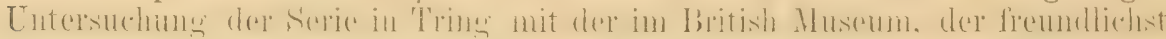
geliehenen Stiicke der Zedlitzschen Sammlung und anderer rom Sinai im Münchener Museum, kann ich diese Tremung nur teilweise billigen. Graf Zedlitz glaubt (in litt.), daß dio blasseren Stücke, die er reichenowi nennt, die

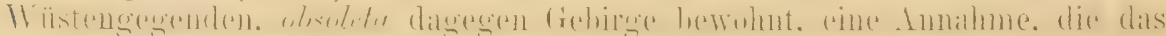
von mir untersuchte Material nicht bestiitigt, auch dürfte es schwer sein zu entscheiden - falls eine Trenuung möglich wäre —, zu welcher Form der Typus, ein altes ausgestopftes Stiick mit uugenauem Fundorte (rgl. Mus. 
Hein. I, p. 50 und Heine \& Rehw., Nomencl. Mus. Hein. Orn. p. 31 !) gehört. Graf Zedlitz' R. r. pusilla ans dem Hochlind von Eritreal (Flügel genam. (l. h. gestreckt gemessen 118,5 mm) ist eine wohl unterscheidhare dunklere Form, doch frägt es sich, ob sie von K. urabica Rehrv. (Vüg. Afr. III, p. 818) verschieden ist. Letztere konnte ich aus Süddilialien (Aden, wo sie brütet, Iil Hotil). Sukotria und Nord-Somaliland untersuehen; sie ist rou olsoleter nur dureh die dunklere Firrhung zu unterscheiden, weniger aber mit den südafrikanischen julignla und andersoni zu vergleichen, die viel gröbre und noch dunkler sind und einen noch weniger ausgesehnittenen Sehwamz halben. Der Typus ron pusilla ist noch dunkler als der von arabicu, doch mïßte eine Serie vorliegen, um zu errveisen, daß dies konstant ist.

Höclust auffillend sind zwei Stïcke ron $R$. obsoleta, dio Witherby in Sïdwest-Persien sammelte, ein oad. rom 2. April aus Kotal Dockitar, und eiu junger Vogel vom 11. Juni von Baseht. Sie sind auf der Oberseite hlasser, Teißlicher. als alle andern von mir untersuchten Stïcke, was nimentlich auch heim Tergleich des jungen Vogels mit einem jungen stüek rom 6. Juli aus Palästina aufä̈llt. Trotzdem möehto ich mehr Maiterial abwarten, um diese rermutlich wohl unterscheidbaro Subspezies zu bestätigen.

Der Gedanke liegt nahe, Riparia obsoleta als Subspezies von R. mepestris aufzufassen, beide Tögel hrüten aher nach Tristram in Palästina in derselben Höhle, beide scheinen in derselhen Gegend in Persien und Baluchistiun rorzukommen, oine suhspezifische Behandlung ist daher gewagt und reitere Feststellungen sind abzuwarten. R. fulioulu und unders:oni halsen ungefleckte KehIen, sind aber in der Größe $R$. mipestris ähnlich, auch von gesä̈ttigterer Färbung.

Ripuria obsoletu hewohnt Nubien und Ägypten, Nordarabien (Sinaïhalbinsel) und Palästina, sowie Persieu. Afghanistan und Baluchistan, nstwärts bis Sind.

Rip. obsoleta ist vermutlich kein Wandervogel, sondern Stand- und Strichvogel. Sie lebt wie $R$. rupestris und nistet in derselben Weise, ist aber mehr Bewohner kahler Felsenrïcken in wüstenartigem (ielände, als Hochgebirgsvogel, obwohl sie z. B. in Palästina dieselben Giegenden bewohnt wie die europäische Felsenschralbe. Eier gefleckt wie die ron rupestris. Acht Eier messen nach Jourdain (in litt.) im Durehsehnitt $18.43 \times 14.75$, Maximum $19.5 \times 16$, Мinimun $17.1 \times 12.2$ und $17.1 \times 12 \mathrm{~mm}$. 


\section{Alphabetisches Register.}

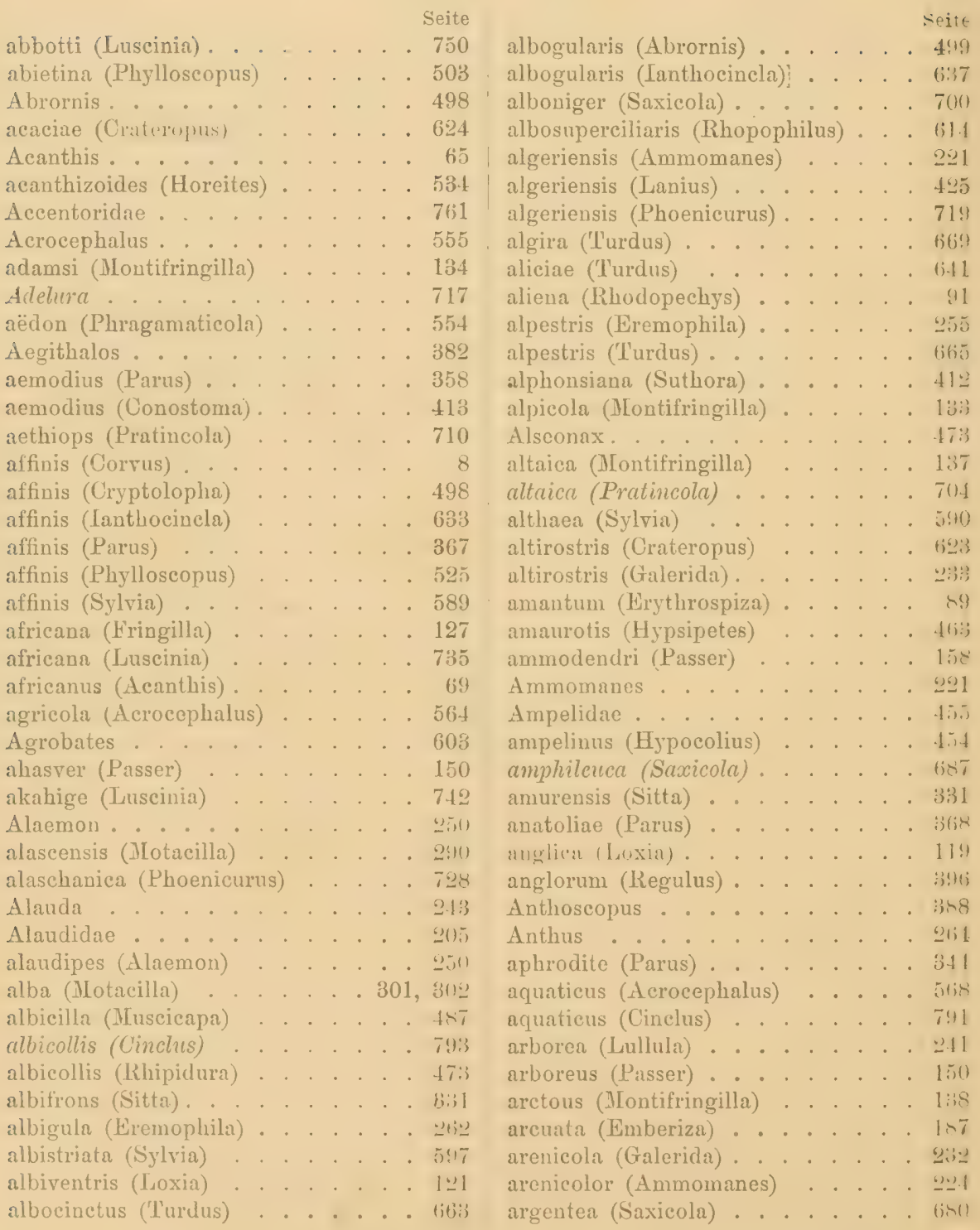


Argya ......... . 621

aridula (Cisticola) . . . . 612

armandii (Phylloscopus) . . . 526

arynitta ('isticola) . . . . . 611

arrigonii (Passer) . . . . 157

arsinoe (Pyenonotus) . . . . 461

artemisiae (Ianthocincla) . . . . 626

arundinaceus (Acrocephalus) . . 556

Anundinax . . . . . . . 554

arvensis (Alauda) ........ = 1

asiatica (Cinnyris) . . . . . 2

asiaticus (Cinches) ........ . 88

assamensis (Ianthocincla) . . . 635

assimilis (Parus) . . . . . 379

ater (Parus) . . . . . . 356

aterrima (Turdus) . . . . . 669

atlas (Eremophila) . . . . 257

atlas (Parus) . . . . 358

atrata (Pratincola) . . . . 710

atricapilla (Muscicapa) . . . . 480

atricapilla (Sylria) . . . . 583

atricapillus (Garrulus) . . . . 32

atricapillus (Parus) . . . . 376

atrogularis (Prunella) . . . . 771

atrogularis (Saxicola) . . . . 684

atrogularis (Turdus) . . . . 660

atcheri (Lanius) . . . . . . 430

aurantiaca (Pyrrhula) . . . . 97

aurantiiventris (Chloris) . . . 63

aureola (Emberiza) . . . . . 173

aureus (Turdus) . . . . . . 642

auvita (Saxicola) ...... 685

auritus (Turdus) . . . . . . . 649

auroren (Pboenicurus) . . . . 725

australis (Alauda) . . . . . 249

axillaris (Phylloscopus) . . . . 504

azorensis (Turdus) . . . . 668

azoricus (Regulus) . . . . . 396

Babax ........... 624

badius (Lanius) . . . . . . . 437

baetica (Calandrella) . . . . 218

baicalensis (MLotacilla) . . . 304

baicalensis (Parus) . . . . 380

ballioni (Luscinia) . . . . . 739

balcanica (Eremophila) . . . . 262

balearica (Loxia) . . . . . 120

barbara (Petronia) . . . . 143

barbatus (Pyenonotus) . . . 460

beavani (Parus) . . . . . . 361

beema (ILotacilla) . . . . . 290

bella (Sylvia). . . . . . 599

behringianus (Corrus) ..... 5

berezowskii (Yarus) . . . . 354 bianchii (Certhia) . . . . . 3 3.1

bianclii (Lanius) . . . . . . . . 424

bianchii (Parus). . . . . . . 37!

biarmicus (Yanurus) . . . . . 403

bihlicus (Palsser) . . . . . . . . 149

bicolor (P'ratincela) . . . . . . 710

bicornis (Eremophila) . . . . 263

biddulphi (Podoces) . . . . . 3s

bieti (Proparus) . . . . . (117

bifasciata (Loxia) . . . . . . . 12:3

bilopha (Eremophila) . . . . . . 2.7

bimaculata (Melanocorypha) . . . 210

bistrigiceps (Acrocephalus) . . . . 5is

blakistoni (Anthus) ..... . 28.

blanfordi (Montifringilla). . . . 135

blanfordi (Parus) . . . . . . . . 341

blanfordi (Prunella) . . . . . . T7t

blythi (Carpodacus) . . . . . . 102

blythii (Ianthocincla) . . . . . (i3:)

boarula (Motacilla) . . . . . 298

bogdanowi (Lanius) . . . . 145

bokharensis (Parus) . . . . . 344

Bombycilla . . . . . . . 45i

bonapartei ('lurdus) . . . . . 649

bonelli (Phylloseopus) . . . . . 513

bonvaloti (Ianthocincla) . . . . 629

bonvaloti (Ianthocincla) . . . . (1032

borealis (Horeites) . . . . . . 5:52

borealis (Lanins) . . . . . . . 12:;

borealis (Motacilla) . . . . . . 291

burealis (Parus). . . . . . . 3is

borealis (P'hylloscopus) . . . . 517

borealis (Troglodytes) . . . . . 77

borin (Sylvia) . . . . . . . $58 \pm$

bottanensis (Pica) ...... . .

brachydactyla (Calandrella) . . . 215

brachydactyla (Carpospiza) . . . . 145

brachydactyla (Certhia) . . . . . 32:;

Brachypodidae . . . . . . . . $45 !$

brachyura (Galerida) . . . . . 234

brandti (Eremophila) . . . . . 257

brandti (Montifringilla) . . . . . 137

brandtii (Garrulus) . . . . . . 33

brandtii (Parus) . . . . . . 369

brevirostris (Acanthis) . . . . . 77

brevirostris (Acanthis) . . . . 70

brevirostris (Cinnyris) . . . . . 31:

brevirostris (Parus) . . . . . 374

brerirostris (Pericrocotus) . . . . 465

brevirostris (Petronia) . . . . . 144

brittanica (Certhia) . . . . . . 320

britannica (Sitta) . . . . . . . 332

britannicus (Acanthis) . . . . . 68

britannicus (Cirsclus). . . . . T 


\begin{tabular}{|c|c|c|c|c|c|}
\hline britannicus (Parus) & & & & & \\
\hline brunnea (Larvivora) & & & & & \\
\hline brunneinucha (Montifri & & rilla) & & & \\
\hline runnescens (Ácroceph & alu & & & & \\
\hline brunnescens (Horeites) & & . . & & & \\
\hline brunniceps (Cisticola) & . & . . & & & \\
\hline unnifrons (Horeites) & - & . & & & \\
\hline utius (Passer). . . & . & & & & \\
\hline cephalus (Lanius). & . & & & & \\
\hline chanani (Emberiza) & . & & & & \\
\hline rkii (Cryptolopha). & & & & & \\
\hline rtoni (Callacanthis) & . & & & & \\
\hline ryi (Lanius) . . . & . & & & & \\
\hline aryi (Scotocerca) & & & & & \\
\hline ivryi (Coccothraustes & & & & & \\
\hline
\end{tabular}

cabaret (Acanthis) . . . . 80

cabrerae (Turdus) . . . . . 667

caerulea (Myiophoneus) . . . . 677

caeruleus (Parus) . . . . . . 347

caesia (Emberiza) . . . . . 182

caesia (Sitta) ....... 331

cairii (Phoenicurus) . . . . 720

calandra (Emberiza) . . . . 165

calandra (MIelanocorypha) . . . 208

Calandrella ....... 214

Calcarius ....... 200

caligata (Hippolais) . . . . 575

calipyga (Leiothrix) . . . . . 621

Callacanthis ........ 205

Calliope ........ 732

calliope (Luscinia) . . . . . 738

Campephagidae ...... 466

campestris (Anthus) . . . . 267

campestris (MLtacilla) . . . . 294

camtschatkensis (Luscinia) . . . 738

canadensis (Sitta) . . . . 335

canaria (Serinus) . . . . 83, 84

canariensis (Corvus) . . . . 6

canariensis (Fringilla) . . . . 129

eanariensis (Phylloscopus) . . . 501

caniceps (Acanthis) . . . . . 70

cannabina (Acanthis) . . . . 73

canneti (Emberiza) . . . . 197

cantans (Horeites) . . . . . 531

cantarella (Alauda) . . . 246

canturians (Horeites) . . . . 532

eapellanus (Corvus) ...... 11

caprata (Pratincola) . . . 709, 710

eaptus (Anthus) ...... . 269

eardis (T'urdus) . . . . . 652

carduelis (Acanthis) . . . . 67

carnipes (Hycerobas) . . . . 60

caroli (Gralerida) . . . . . . 234
Seite

carolinae (Galeriđa) . . . . . 238

Carpodacus ........ 98

Carpospiza ........ 145

caryocatactes (Nucifraga) . . . 25

cashmeriensis (Cinclus) . . . . 79.5

cashmeriensis (Hirundo) . . . 80!

caschmirensis (Parus) . . . . 34n

cashmirensis (Sitta) . . . . 3:44

caspius (Anthoscopus) . . . . 340

caspius (Garrulus) . . . . . 31

cassini (Pyrrhula) . . . . $\$ 6$

castanea ('Iurdus) ...... 661

castaneiceps (Emberiza) . . . 186

castaneocoronata (Tesia) . . . . 798

castaneoventris (Parus) . . . 355

caterinae (Saxicola) . . . . . 685

caucasica (Galerida) . . . . 231)

caucasica (Sitta) . . . . . 333

caucasicus (Cinclus) . . . . . 794

caucasicus (Erithacus) . . . . 755

caucasicus (Prunella) . . . . T $7 ; 4$

caucasicus (Sturnus) . . . . 46

caudata (Spelacornis) . . . . $75 t$

caudatus (Aegithalos) . . . . 382

caudatus (Crateropus) . . . . 62:3

celaenops (Turdus) ...... . 657

centralasiae (Emberiza) . . . . 1!19

Cephalopyrus . . . . . . 393

Certhia ........ 316

Certhiidae . . . . . . 316

certhiola (Locustella) . . . . . 50

cervicalis (Garrulus) . . . . 34

cervina (Anthus) ...... 277

cerviniventris (Muscicapa) . . . 489

cetti (Cettia) ....... 537

Cettia ......... 5336

cettioides (Cettia) . . . . . 538

ceylonensis (Culicicapa) . . . 495

Chaimarrornis ..... . 715

Chaunoproctus ....... 115

cheleënsis (Calandrella) . . . . 220

Chelidon ........ 799

Chelidorynx . . . . . . . 491

chendoola (Galerida) . . . . 236

Chersophilus . . . . . . . 252

Chimurhornis . . . . . . 715

Chloris ........ 61

chloris (Chloris) ...... 61

chlorotica (Chloris) . . . . 63

Cholornis ........ . 405

chrysieus (Tarsiger) . . . . . 711

chrysolaus (Turdus) . . . . 656

chrysophrys (Emberiza) . . . 189

chrysopygia (Saxicola)..... 692

chrysotis (Proparus) . . . . . 619 
Seite

cia (Emberiza) . . . . . . 183

Cinclus ........ . 788

cinclus (Cinclus) . . . . . 788

cinctura (Ammomanes) .... 225

cinctus (Parus) ...... 365

cineraceus (Spodiopsar) . . . . 48

cinerea (Alauda) . . . . 247

cinerea (Emberiza) . . . . 178

cinereiceps (Ianthocincla) . . 630, 631

cinereiceps (Proparus) . . . 617

cinereocapilla (Hotacilla) . . . 292

cinnamomea (Passer) . . . . 162

cinnamomina (Galerida) . . . 235

Cinnyris ........ 312

cioides (Emberiza) . . . . . 185

ciopsis (Emberiza) . . . . 186

cirlus (Emberiza) . . . . 175

Cisticola . . . . . . . 610

cisticola (Cisticola) . . . . 610

citreola (Motacilla) . . . . . 296

citreoloides (Motacilla) . . . . 298

citrinella (Acanthis) . . . . 81

citrinelia (Emberiza) . . . . 167

clarkei (Turdus) . . . . . 651

clot-bey (Rhamphocorys) . . . 206

Coccothraustes ....... 55

coccothraustes (Coccothraustes) . . 55

coelebs (Fringilla) . . . . 125

coelicolor (Grandala) . . . . 757

coelivox (Alauda) ...... . 249

coeruleocephala (Phoenicurus) . . 730

collaris (Coloeus) . . . . . 17

collaris (IIuscicapa) . . . . 483

collaris (Prunella) . . . . . 762

collurio (Lanius) . . . . . . 439

collybita (Phylloscopus) . . . . 501

Coloeus .......... 15

coloratus (Calcarius) . . . . 201

commixtus (Parus) . . . . 346

communis (Parus) . . . . 372

communis (Sylvia) ..... 586

concinens (Acrocephalus) . . . 565

confusa (Luscinia) . . . . . 740

Conostoma . . . . . . . 413

consobrinus (Anthoscopus) . . . 391

conspicillata (Suthora) . . . . 410

conspicillata (Sylvia) . . . . 598

cooki (Cyanopica)....... 24

corax (Corrus) . . . . . . 2

coreensis (Galerida) . . . . 236

cornix (Corvus) ....... . 9

coronata (Dendroica) . . . . 311

coronata (Phylloscopus) . . . . 521

coronatus (Anthoscopus) . . . . 392

corone (Corrus) corsa (Certhia) ....... 320

corsicana (Acanthis) . . . . 82

corsus (Parus) . . . . . 343

Corritae . . . . . . . . 1

Corrus . . . . . . . . 1

Cotyle .......... 810

coutellii (Anthus) . . . . 281

crassirostris (Erythrospiza) . . . 89

crassirostris (Parus) . . . . 374

crassirostris (Sylvia) . . . . 581

Crateropus . . . . . . . 621

cristata (Galerida) . . . 227, 228

cristatus (Lanius) . . . . 443-447

cristatus (Parus) . . . . . 363

Cryptolopha . . . . . . 496

cucullatus (Telophonus) . . . 452

Culicicapa . . . . . . . 495

cummingi (Saxicola). . . . 693

curruca (Sylvia). . . . . . 588

cursitans (Cisticola) . . . . 613

curvirostra (Loxia) . . . . . . 117

cyane (Luscinia) . . . . . . 744

Cyanecula ........ 732

cyanecula (Luscinia). . . . . 748

cyanomelana (Nuscicapa) . . . 493

cyanophrys (Suthora) . . . . 410

Cyanopica ....... 23

Cyanoptila ........ 473

cyanurus (Tarsiger) . . . . 712

cyanus (Cyanopica) ..... 23

cyanus (Parus) ....... 352

cypriaca (Saxicola) . . . . 689

cypriotes (Parus) . . . . . . 359

cypriotes ('Troglodytes) . . . . 780

cyrenaicae (Galerida) . . . . 239

dacotiae (Pratincola) . . . 704

dahuricus (Prunella). . . . 770

dalmatica (Pratincola). . . . 703

dartfordiensis (Sylvia) . . . . 601

darwini (Lanius) . . . . . 449

dasypus (Hirundo) . . . . 810

dauma (Turdus). . . . . 642,643

daurica (Chelidon) . . . . 806

dauricus ('Troglodytes) . . . . 782

dauuricus (Coloeus) . . . . 18

davidiana (Horeites). . . . . 535

davidiana (Moutifringilla) . . . 134

davidi (Ianthocincla) . . . . 630

davidi (Luscinia) . . . . . 740

davidi (Yarus) . . . . . 370

davisoni (Turdus) . . . . . 645

debilis (Passer) ....... 162

dedekensi (Pomatorhinus) . . . 638 


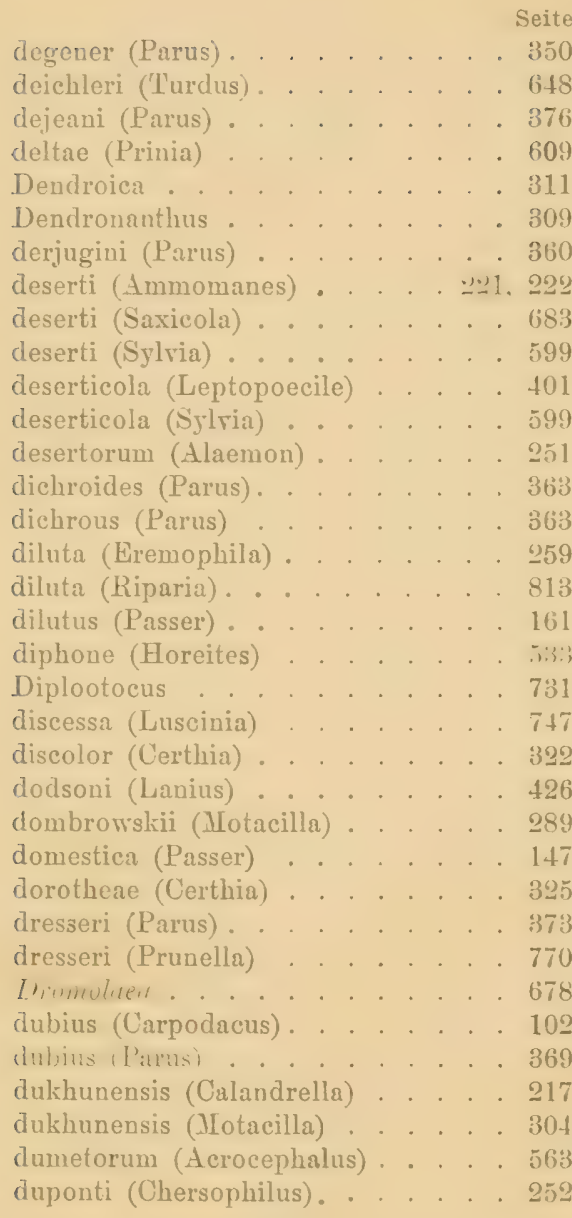

edwardsii (Carpodacus)

104

elegans (Émberiza) . . . . . . . 174

elegans (Lanius) . . . . . . 427

elegans (Lophobasileus) . . . . . 402

elegans (Loxia) . . . . . . 124

ellioti (Galerida) . . . . . . . 240

elliotii (Ianthocincla) . . . . . . . 631

elwesi (Eremophila) . . . . . . . 260

Emberiza . . . . . . . . . 164

Enicurus . . . . . . . . 758

enigmaticus (Passer). . . . . . . 154

enucleator (Yinicola) . . . . . . 114

Eophuntat. . . . . . . . 57

epruletta (Pyrrhoplectes). . . . . . 98

Emmphila. . . . . . . 253

erlangeri (Galerida) . . . . . . 237

erlangeri (Phylloseopus) . . . . . 516

Erithacus . . . . . 750 erythaca (Pyrrhula) ........ . . . . . .

erythrina Ccarpodacus) . . . . 111;

erythrocephala (Pyrrhula) . . . . . :

erythrochroa (Anmomanes) . . . . 20.2.

erythrogastra (Phoenicurus) . . . T:2ii

erythrogenys (Emberiza) . . . . . 1ti:!

erythrogenys (Pomatorhinus) . . . 15:i

erythronota (Phoenicurus) . . . . 72i

erythronotus (Lanius) . . . . . . 45i

erythropleurus (Zosterops) . . . . 31:

erythropygia (Chelidon) . . . . . m(11;

erythropygius (Prunella) . . . . . . Titi

Erythrospiza . . . . . . . . तs

europaea (Pyrrhula) . . . . . . 14

europrea (Sitta). . . . . . . . 32!!

europaeus (Aegithalos). . . . . . . : int

emymelaena (Saxicola) . . . . . . ssi

erersmauni (Phylloscopus) . . . . . . .

excelsus (Parus) . . . . . . . 34 .

excubitor (Lanius) . . . . . . 41

exiguus (Petronia) . . . . . . . 14:3

exilipes (Acanthis) . . . . . . . $\rightarrow 1$

exsul (Phylloscopus). . . . . . . . . Mis

familiaris (Agrobates) . . . . . . (601.

familiaris (Certhia) . . . . . . 317

faroensis (Sturnus) . . . . . . . $4-1$

fasciolatus (Locustella) . . . . . . 545

ferrea (Oreicola) . . . . . . . . 711

ferreirostris (Chaunoproctus) . . . 11.

ferrugilatus (Pomatorhinus) . . . 6 63s

ferrugiuea (Yuscicapa) . . . . . . $47 !$

filchneri (Phoenicurus) . . . . . $7 \pm 5$

finschii (Saxicola)...... . ti!n

Hammea (Acrnthis) . . . . . . Ti

flammiceps (Cephalopyrus) . . . . . 394

Hava (Eremophila) . . . . . . 2.is

Hava (Motacilla) . . . . . . . 2a

flarescens (Cullula) . . . . . . 녀ㄴㅡㅡ

flaricollis (Gymnoris) . . . . . 145

Havipectus (Parus) . . . . . . 354

Havirostris (Acanthis) . . . . . 76

flaroliracea (Horeites) . . . . . . 5i3:)

flückigeri (Passer) . . . . . . 15R

fluriatilis (Locustella) . . . . . . 547

formosum (lanthocincla . . . . . 63.4

fortipes (Horeites) . . . . . . 53.5

fortis (Mlicrocichla) . . . . . . itil

fraterculus (Ammomanes) . . . . . .

Fringilla . . . . . . . . . 121

Fringillidae . . . . . . . 54

fringillirostris (Acanthis) . . . . . Tis

frontalis (Phoenicurus) . . . . . T.:

frugilegus (Corrus) . . . . . . . 13 


\begin{tabular}{|c|c|c|c|}
\hline fuliginosa (Chaimarrornis) & . & & \\
\hline fuliginosa (Muscicapa) . . & • & & \\
\hline fuligirenter (Phylloscopus) & & & \\
\hline fulrescens (Prunella) . . & & & \\
\hline fulvifacies (Abrornis) & . & & \\
\hline fulrifrons (Suthora). & . & & \\
\hline fulrus (Crateropus) · - & • & & \\
\hline fumigatus ('lroglodytes). & & & \\
\hline fusca (Locustella). . . . & & & \\
\hline fucata (Emberiza) . . & . . & ${ }^{\circ}$ & \\
\hline fuscata (Phylloscopus). & & & \\
\hline tuseatus (Turdus). & & & \\
\hline fuscicupilla (Cisticola). & & & \\
\hline
\end{tabular}

gaddi (Saxicola)

[2: tu kei (Luscinia)

galactotes (Agrobates)

Galerida

irarrulus .

garrulus (Bumbycilla)

gibraltariensis (Phoenicurus) . . . . :-0

grimenteus (Lanius)

gigliolii (Montifringilla) . . . . . 13̈!

gilgit (anthocincla) . . . . . 1i3ı

githaginea (Erythrospiza) . . . . . is

glandarius (Garrulus) . . . . . . 299

gliaszneri (ciarrulus). . . . . . . : :

glancogularis (Aegithalos) . . . . . 3 388

godlewskii (Emberiza) . . . . . . . 185

golzii Luscinir) . . . . . . . . 735

gonduli Turdus) . . . . . . . titi2

gracilis (Prinial). . . . . . . tios

graculus (Pyrrhocorax) . . . . . 36

(irandalit. . . . . . . T5\%

grandis (Crpodacus) . . . . . . 101

grandis (Motacilla) . . . . . . . . :09

grandis (Phoenicurus) . . . . . T2t

granti (sturnus) . . . . . . . . . 43

grarivox (Pomatorhinus) . . . . . 63

grebnitskii (Carpodacus) . . . . 10i

griseigularis (Passer) . . . . 1.i:

griseonucha (Montifringilla) . . . 140

griseisticta (Muscicapa) . . . . 178

griseirentris (Pyrrhula) ..... 95

grisescentior (Ianthocincla) . . . . 1336

guillemardi (Loxia) . . . . . . . 1:1

gularis (Monticola) . . . . . . . 473

gularis (Psittiparus) . . . . . . . . 413

gularis (Suthora) . . . . . 4119

gulgula (Alauda) . . . . . . . $1 !$

gustari (Anthus) ........ . . . .

guttata $(A$ lauda) ...... . . $24 !$

guttatus (Enicurus) . . . . . . . .

gutturalis (Chelidon) . . . . . . sul; gutturalis (Irauia) . . . . . . . . . . . .

Gymuoris . . . . . . . 114

Laematopygia (Montifringilla) . . 137

Haematospizi . . . . . . . . 1113

hafizi (Luscinia) . . . . . . . . . $7: 35$

halimodendri (Sylria) . . . . . . . in!

halophila (Saxicoln) . . . . . . . . 1945

halsueti (Spelaeornis) . . . . . . Tst

haringtoni (Oreicol $\Omega$ ) . . . . . . 711

harterti (Alauda) . . . . . . . . 947

harterti (Certhia) . . . . . . . . . \$25

harterti (Galerida) . . . . . . . 2:s

heinei (Calandrella) . . . . . . . . 219

heineken (Sylria) . . . . . . . isi

hellmayri (Parus) . . . . . . . . 375

hellmayri (Petronia) . . . . . . . 143

Hemichelidon ....... 473

hemispila (Nucifraga) . . . . . 25

hemprichii (Pratincola) . . . . . . Toi

hendersoni (Podoces) . . . . . 38

Henicurus . . . . . . . . Tis

hennicliei (Trochalopterum) . . . . . 1529

henrici (Ianthocincla) . . . . . . (iij?

hensoni (Hypsipetes) . . . . . . 464

hensoni (Parus) . . . . . . . 875

Herbivocula . . . . . . . . 50!

hibernans (Pratincola) . . . . .

hibernicus (Cinclus) . . . . . . . 790

himalayana (Certhia) . . . . . . 3200

himalayanus (Prunella) . . . . . Tito

himalayensis (Loxia) . . . . . . 1:1

himalayensis (Regulus) . . . . . . $\quad 3: 7$

himalayensis (Sitta) . . . . . (3iti

Hippolais . . . . . . . . . . 569

hirtensis (Troglodytes) . . . . . . 778

Hirundinidae . . . . . . . . . . Ty!

Hirundo . . . . . . . . . . . 807

hispana (Loxia) . . . . . . . . . 119

hispaniae (Turdus) . . . . . . . . 66i

hispanica (Saxicola). . . . . . (isi

hispaniolensis (Passer) . . . . . . 15\%

hispanus (Corrus) . . . . . . . . . . .

hodgsoni (Certhia) . . . . . . 321)

hodgsoni (Motacilla) . . . . . 307

hodgsoni (Phoenicurus) . . . . . $7 \pm 1$

hodgsonii (Muscicapa) . . . . . 4ts

Hodgsonius . . . . . . . . T5t

holboelli (Acanthis) . . . . . . . T.

homeyeri (Lanius) . . . . . . . . 4:01)

homeyeri (Phylloscopus) . . . . . 524

homeyeri (Sitta) . . . . . . 3301

Horeites . . . . . . . . . . .

hornemanni (Acanthis) . . . . 81 


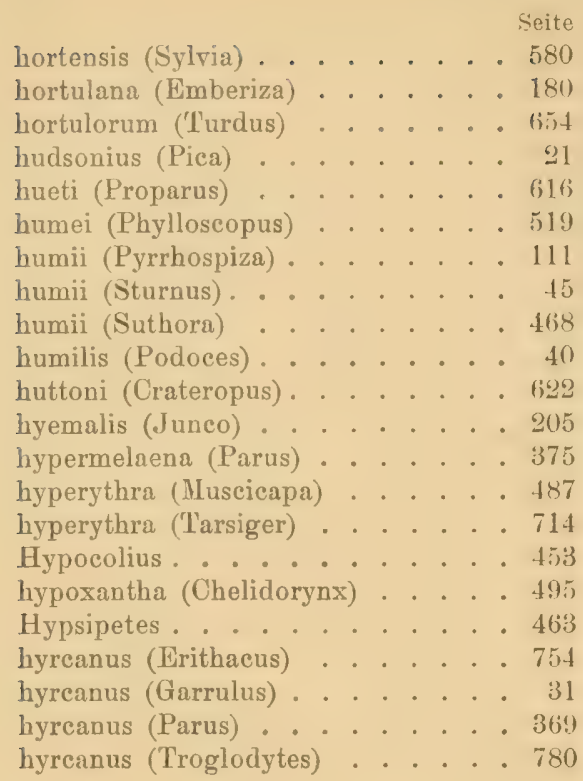

Ianthia

712

Ianthocincla ........ 624

ichnusae (Garrulus) . . . . . 30

Icoturus . . . . . . . . . 732

icterina (Hippolais) . . . . . . 570

icterops (Sylvia) . . . . . . 587

idius (Troglodytes) . . . . . . 783

ignicapilla (Regulus) . . . . . 398

ijimae (Phylloscopus) . . . . . . . 522

ijimae (Riparia) . . . . . . . . 813

iliacus (Turdus) . . . . . . . . 653

illex (T'chitrea) . . . . . . 472

immaculatus (Prunella) . . . . 775

incei (T'chitrea) ...... . 471

inconspicua (Alauda) . . . . . 249

indica (Dendronanthus) . . . . . 309

indica (Haematospiza) . . . . . . 110

indica (Phylloseopus) . . . . . . 527

indica (Pratincola) ..... 708

indica (Tarsiger) . . . . . 713

indicus (Enicurus). . . . . . $76(i)$

indicus (Oriolus) . . . . . . 53

indicus (Passer). . . . . . . 151

infaustus (Perisoreus) . . . . . 34

inornata (Sylvia) . . . . . . 597

inquietus (Scotocerca) . . . . 606

insignis (Pratincola)..... 705

insularis (Parus) . . . . . . 359

intermedia (Alauda). . . . . 248

intermedia (Cryptolopha). . . . 497

jntermedia (Petronia) . . . . 14t
Seite

intermedia (Turdus) . . . . . . . 670

intermedius (Parus) . . . 345

interni (Regulus) . . . . . . 396

intricatus (Horeites) . . . . . 5333

Irania . . . . . . 755

irbii (Aegithalos) . . . . . 38t

isabellina (Ammomanes) . . . . . 2:3

isabellina (Galerida) . . . . . . . 233

isabellina (Saxicola) . . . . . . . 691

isabellinus (Lanius) . . . . . . 444

islandicus (Troglodytes) . . . . 776

italiae (Passer) . . . . . . 15

italicus (Parus) . . . . . . . 374

imanowi (Galerida) . . . . . . 236

jakuschima (MIuscicapa) . . . . 491

jankowskii (Emberiza) . . . . 186

japonensis (Corvus) . . . . . 12

japonensis (Regulus) . . . . . . 397

japonica (Alauda). . . . . . . 248

japonica (Bombycilla) . . . . 457

japonica (Certhia). . . . . 319

japonicus (Coccothraustes) . . . . 57

japonicus (Anthus) . . . . . . 252

japonicus (Garrulus) . . . . . . . 32

japonicus (Nucifraga) . . . . . . 27

japonicus (Zosterops) . . . . . 315

jaxartensis (Anthoscopus) . . . . 391

jerdoni (Anthus) . . . . . 270

jerdoni (Prunella) . . . . . . 768

jerdoni (Sylvia) . . . . . . . 581

Junco . . . . . . . . 205

kabylorum ('Troglodytes) . . . 780

kamschatkensis (Nucifraga). . . . . 27

kamtschatica (Pyrrhula) . . . . 95

kamtschaticus (Corvus) . . . . 5

kamtschatkensis (Parus) . . . . . 381

kamtschatkensis (Pinicola) . . . 115

kansuensis (Montifringilla) . . . 136

kawarahiba (Chloris) . . . . . 63

Kaznakowia . . . . . . . . . 624

kessleri (I'urdus) . . . . . . 662

khamensis (Certhia) . . . . . 321

khamensis (Eremophila) . . . . 260

kittlitzi (Chloris) . . . . . . 65

kleinschmidti (Anthus) . . . . . 284

kleinschmidti (Galerida) . . . . 231

kleinschmidti (Garrulus) . . . . $\quad 30$

kleinschmidti (Parus) . . . . . 378

kobylini (Lanius) . . . . . . . 441

koenigi (Fringilla) . . . . . 128

koenigi (Lanius) . . . . . 426, 
Seite

komadori (Luscinia). . . . 742

korejewi (Parus) ....... 372

korejewi (Passer) . . . . . . 159

koslowi (Ianthocincla) . . . . 629

koslowi (Prunella) ...... 771

krüperi (Sitta) . . . . . 336

krynicki (Garrulus) ...... 32

kukunoorensis (Calandrella) . . 221

kundoo (Oriolus) ....... 53

kurilensis (Pyrrhula) . . . . 9 95

kurilensis (Troglodytes) . . . 784

lahtora (Lanius) . . . . 430

lanceolata (Locustella) . . . . 553

lanceolatus (Ianthocincla) . . . 627

languida (Hippolais) . . . . 573

Laniidae . . . . . . . 414

Lanius . . . . . . . 414

lapponica (Calcarius) . . . 200

Larvivora . . . . . . . 732

latirostris (Muscicapa) . . . . 477

laurencei (Corvus) . . . . . 7

leautungensis (Galerida) . . . 236

ledouci (Parus) . . . . . 360

Leiothrix . . . . . . . 620

lepida (Prinia) . . . . . 610

lepidus (Uragus) . . . . . . 88

Leptopoecile ........ 400

leschenaulti (Enicurus) . . . . 760

leucocephala (Chaimarrornis) . . 715

leucocephala (MIotacilla) . . . . 291

leucocephalos (Emberiza) . . . 169

leucogaster (Cinclus) . . . . 795

leucogastra (Sylvia) . . . . . 594

leucogenys (Pycnonotus) . . . 463

leucomelanura (Muscicapa) . . . . 489

leucophaea (Calandrella) . . . . 219

leucophrys (Anthus) . . . 269, 270

leucopsis (Motacilla). . . . . 304

leucopsis (Sitta) . . . . . 337

leucoptera (Loxia) . . . . 123, 124

leucoptera (Phoenicurus) . . . 726

leucopyga (Saxicola) . . . . 699

leucopygos (Lanius) . . . . . 428

lencorhoa (Saxicola) ..... 681

leucotis (Pycnonotus) ..... 462

leucura (Pratincola) . . . . . 709

leucurus (Saxicola) ..... 697

levantina (Sitta) . . . . . 333

lidthi (Garrulus) . . . . . 28

Limonidromus ....... 309

linaria (Acanthis) . . . . . 77

lineatum (Ianthocincla) .... 635

littoralis (Anthus). . . . . 284
Seite

littoralis (Riparia) . . . . . 818

Locustella . . . . . . . 544

longipennis (Calandrella) . . . 216

longirostris (Eremophila) . . . . 260

longirostris (Parus) . . . . . 373

longirostris (Pyrrhospiza) . . . 111

loochooensis ('Kosterops) . . . 315

Lophobasileus ....... . 402

lorenzii (Phylloscopus) . . . 50t;

Loxia . . . . . . . . 116

lucionensis (Lanius) . . . . . 447

lugens (\Lotacilla) . . . . . 308

lugens (Parus) . . . . . 368

lugens (Saxicola) . . . . . 694

lugubris (Mlotacilla) . . . . . 301

lugubris (Parus) . . . . . . . 368

lugubris (Phylloscopus) . . . . 512

Lullula . . . . . . . 241

lunulata (Ianthocincla) . . . . 627

Luscinia . . . . . . . 732

luscinia (Luscinia) . . . . . 736

luscinioides (Locustella) . . . . 548

Lusciniola . . . . . . . 540

lutea (Leiothrix) . . . . . 620

luteola (Emberiza) . . . . . 171

luteoventris (Lusciniola) . . . . 513

macclellandi (Pomatorhinus) . . 638

macedonica (Aegithalos) . . . 385

macrodactyla (Certhia) . . . 319

macronyx (Acrocephalus) . . . 561

macronyx (Anthoscopus) . . . 393

macrorhyncha (Galerida) . . . 232

macrorhyncha (Pratincola) . . . . $70 t$

macrorhynchos (Nucifraga) . . . 26

maculatus .(Anthus) . . . . 273

maculatus (Enicurus) . . . . 759

maculipennis (Phylloscopus) . . . 524

madeirensis (Anthus) . . . . 271

madeirensis (Petronia) . . . . 141

madeirensis (Regulus) . . . . . 399

maderensis (Fringilla) . . . . 128

magna (Galerida) . . . . 235

magna (Luscinia) . . . . . . 750

magnirostris (Eophona) . . . . 58

magnirostris (Hypsipetes) . . . 465

magnirostris (Phylloscopus) . . . 513

major (Acanthis) . . . . . . . 69

major (Aegithalos) . . . . . 386

major (Horeites) . . . . . . . 534

major (Lusciniola) . . . . . ótis

major (Parus) . . . . . . 341

major (Turdus) . . . . . . . 643

malabarica (Galerida) . . . . 240 
malaccensis (Passer) . . . . . . 161

maltne (Passer) . . . . . . . . . . 157

mandarinus ('lurdus) . . . . . . . 670

mandelli (\$ontifringilla) . . . . . . 134

mandellii (Phylloscopus) . . . . . 520

mantschurica (Suthora) . . . . . $\$ 10$

margaretae (Pratincola) . . . . . 704

margaritae (Chersophilus) . . . . 253

manra (Pratincola) . . . . . . . 707

mauritanica (Certhia) . . . . . . 325

mauritaniea (Pica) . . . . . . 22

mauritanica (Riparia) . . . . 814

mauritanicus ('Turdus) . . . . . . lifis

maxima (Melanocorypha) . . . . 211

maximal (T'urdus) . . . . . . . (6)

maximus (Ianthocincla) . . . . ( (i25)

mediterranea (Acanthis) . . . . . T5

megarhynchos (Luscinia) . . . . . 7333

melanocephala (Emberiza) . . . . 170)

melanocephala (MLtacilla) . . . . . 2995

melanocephala (Sylvia) . . . . . . 5193

Melanocorypha . . . . . . . 쁜

melanogriseus (Motacilla) . . . . . "

melanoleuca (Saxicola) . . . . . ti9()

melanolophus (Yarus) . . . . . : 362

melauopo (Motacilla) . . . . . : 300

melanopogon (Lusciniola) . . . . . ill)

melauops (Emberizal) . . . . . 177

melanops (Muscicapa) . . . . . . 191

melanothorax (Sylvia) . . . . . . iš

melanoms (l'icit) . . . . . . @1

melanura (Eophona) . . . . . . . 5.

melophilus (Erithacus) . . . . . Ti2

menzbieri (Sturnus) . . . . . . . . 44

meridinoalis (Cinclus) . . . . . . 793

meridionalis (Galerida) . . . . . 230

meridionalis (Hirundo) . . . . . . so!)

meridionalis (Lanius) . . . . . . . 42!

merula ('l'urdus) . . . . . . . . 66.'

merzbacheri (Sylvia) . . . . . 57!

mesoleuer (Phoenicurus) . . . . . . T20

metallica (Nectarinia) . . . . . $31: 3$

michalowskii (Parus) . . . . . . 3rill

Microcichla . . . . . . . T(iil

microrhynchus (Erithacus) . . . . 7.i2

migratoria (Eophona) . . . . . . . i!

migratorius (T'urdus) . . . . . . 641

miliaria (Emberiza) . . . . . . 16is

mimica (Lusciniola) . . . . . . . it1

minor (Acanthis) . . . . . . . 70

minor (Agrobates) . . . . . . tiui

minor (Anthus) . . . . . . . . . 269

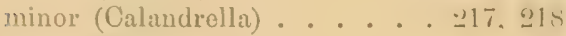

mimar 1 ('hloris) . . . . . . (i)

ninor (Cinclus) . . . . . . . 793 minor (Garrulus) . . . . . . . . 31

minor (Lanius) . . . . . . . 41 i

minor (Parus) . . . . . . . 345

minor (liparia) . . . . . . . s1:3

minor (Sturnus) . . . . . . . . .

minula (Sylvia) . . . . . . . . 5

mitratus (Parus) . . . . . . . . 34

Iniotiltidae ......... . . 31

moabiticus (Passer) . . . . . . . . 1i

modestus (Parus) . . . . . . . 3-

modularis (Prunella) . . . . . . . 7 i

moesta (Saxicola) . . . . . . . lị

mollis (Lanius) . . . . . . . . . . 4. 4

mollissimus ('Iurdus) . . . . . . 6 (it

moltchanowi (Parus) . . . . . 366

momus (Sylvia) . . . . . . . 5,9

monacha (Saxicola) . . . . . 70

monedula (Coloeus) . . . . . . . 1

mongolica (Melanocorypha) . . . 21:

mongolicus (Hrythrospiza) . . . . . 8!

montana (Eremophila) . . . . . . Li:

montana (Passor) . . . . . . 161

montana (Saxicola) . . . . . . TR.

montanella (Prunella) . . . . . . Tbis

montanus (Parus) ....... . ¿*il

Monticola . . . . . . . . $t ; i 1$

monticolus (Parus) . . . . . . . 347

Mlontifriugilla . . . . . . . 131

montifringilìa (Fringilla) . . . . . 1301

montium (Sitta) . . . . . . $\$ 34$

moreletti (Fringilla) . . . . . 1파

Motacilla . . . . . . . . . 2ni

Notacillidae . . . . . . . 2013)

Moupinia ...... . . . li!!!

moussicri (Diplootocus) . . . . . . 7331

mugimaki (Huscicapa) . . . . . . . 1!12

multipunctata (Nucifraga) . . . . .

multistriatus (Prunella) . . . . . T

muraria ('lichodroma) . . . . . . . 307

murina (Pyrrhula) . . . . . . . . 96

Mluseicapla . . . . . . . 173

Muscicapidae . . . . . . . . . 469

musicus (Turdus) . . . . . . . . (65)

musicus ('lurdus) . . . . . . 15,53

Iycerobas . . . . . . . . 150

Myiophoneus . . . . . . . . lizti

mystacea (Sylvia) . . . . . . . 595

nacria (Locustella) . . . . . . .

nagaensis (Sitta) . . . . . . 3334

namiyei (Luscinia) . . . . . . . 7.13

nana (Acanthis) . . . . . . 75

nana (Sylvia) ........... . 590

narcissina (Nuscicapa) . . . . . . 490 


\begin{tabular}{|c|c|c|c|c|c|c|c|c|c|c|c|}
\hline & & & & & & & & & & & suile \\
\hline aumanni ('I'urdus) & & & & &.$\quad 1557$ & olivetorum (Hippolais) & & & & & . $\quad \therefore i: 2$ \\
\hline Nectarinia . . . & & & & & . $: 31: 3$ & ombriosus (Parus)... & & & & & 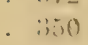 \\
\hline Nectariniidae . . . & & & & & 311 & opaca (Hippolais) . . & & . & & & 575 \\
\hline neglectus (Coloeus) . & & & & & is & opistholeuca (Saxicola) & & & & & 6997 \\
\hline neglectus (Phylloseopus & & & & & intiti & ()rencos):al . . . . . & & & & & 711 \\
\hline eglectus ('Troglodytes) & & & & & $7 x 2$ & orientalis (Acrocephalus) & & & & & 2,58 \\
\hline cola (Moutifringi & illa) & & & & . $1: 36$ & orientalis (Acanthis). & & . & & & 71 \\
\hline neumanni (Muscicapa). & & & & & .177 & orientalis (Corvus) . . & & & & & 1.3 \\
\hline neumayer (Sittr) ... & 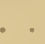 & & & & $.3: 34$ & orientalis (Phylloscopus) & & & & & 51.1 \\
\hline newtoni (Parus) ... & & & & & . $3-4: 3$ & orientalis (Prunella). & & & & & 774 \\
\hline ewtoni (Pliylloscopus) & . & & & & . $\quad 2 \pm 1$ & orientalis ('Turdus) . & & & & & 6itit \\
\hline eans (Galerida). & . & & & & .227 & orinus (Acrocephalus). & & . & & & 5155 \\
\hline atalis (Hirundo) & . & & & & . $\mathrm{kll}$ & Oriolidae . . . & & . & & & i) \\
\hline s (Lanius). . & & & & . & $4 i 3 t i$ & Oriolus ..... & & . & & & il \\
\hline ensis (Certhir) & - & & & & $3: 2$ & oriolus (Oriolus) & & : & & & 51 \\
\hline lensis (Cholidon) . & & & & & . $8(0.5$ & orphea (Sylvia) ... & & . & & & (xill \\
\hline ensis (Procarduclis) & ) & & & & .112 & usca (('immyris). . . & & . & & & $31: 3$ \\
\hline palensis (Proparus). & & & & & . filti & othmari (Emberiza) . & & & & & 198 \\
\hline palensis (Prunella) & & & & & . $\quad 265$ & ais..... . & & . & & & 25:? \\
\hline palensis (Pymrula) & . & & & & 97 & oustai Tanthocincla) & & & & & ti:3:3 \\
\hline palensis (Suthora). & & & & & 408 & ni (Nuscicapa). & & & & & $4 ! 11$ \\
\hline palensis ('Troglodytes) & & & & & $7 \lll 1$ & i (Parus)... & & & & & \\
\hline soria (s)lvia). . . & & & & & $a 7 s$ & & & & & & \\
\hline tidus (Phylloscopus). & & & & & 511 & & & & & & \\
\hline (Ilontifringilla) & & & & & $1: 2$ & pallasi (Èmberiza) & & . & & & $1: 4$ \\
\hline na). & & & & & $2(1)$ & fallisii (Cincius). & & . & & & 797 \\
\hline us) & & & & & 45 & ii ('lurdus) . . . & & . & & & (iil \\
\hline (Pratincola) . & & & & & 703 & ens (Troglodytes) & & . & & & 781 \\
\hline oracensis (Seiurus & & & & & 311 & pallida (Alaemon) . & & . & & & 251 \\
\hline (Lanius) . . & & & & & $4: 48$ & pallida (Galerida). . & & & & & 231 \\
\hline ucitraga... & & & & & . 25 & pallida (Hippolais) & . & . & & & $\therefore 7.4$ \\
\hline uttalli (Pica) & . . & & & & 2 & ida (Lullula) . & & . & & & 243 \\
\hline & & & & & & 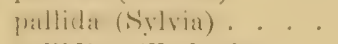 & & . & & & 83 \\
\hline & & & & & & Emberiza) . & & . & & & 197 \\
\hline oscura (Anthus) . . & & & & & $28: 2$ & ostris (Lanius) . & & . & & & 129 \\
\hline obscura (Leptopoecile) & & & & & 401 & ularis (Luscinia) & & . & & & 7.17 \\
\hline obscura (Luscinia) & & & & & 741 & is (Horeites) . . & & & & & 5331 \\
\hline urus (Parus). & & & & & 348 & us ('Troglodytes). & & . & & & $7 \times 1$ \\
\hline arus ('lurdus) . & & & & & 656 & us (Turdus). & & & & & 605 \\
\hline (Rhodospiza) & & & & & 91 & (Fringilla) & & & & & 129 \\
\hline a (Riparia). . & & • & & & . 816 & (Farus). . & & & & & 350 \\
\hline ) . & & & & & . 366 & ('Kosterops) & & & & & 315 \\
\hline nthocine & & • & & & .6335 & rin). & & & & & 811 \\
\hline ella). & & . & . & & 773 & is (Acrocephalus) & & & & & 513 \\
\hline oscopu: & & & & & . 521 & s (Emberiza). & & & & & $1 ! 19$ \\
\hline cincla) & i). & . & • & 62 & (i) 1627 & ris (Parus) & & & & & 370 \\
\hline otensis (Locustella) & . & & & . & .545 & deri (Podoces) & & & & & 39 \\
\hline uros (Phoenicurus) & . & . & & . & .722 & o (Monticola). & & 0 & & & 4i75 \\
\hline cularis (Motacilla) . & & & & . & 307 & turus . . . . . & & & & & (1):3 \\
\hline ularis (Prunella) . & & & & . & 770 & par (Emberiza) . & & . & & & 181 \\
\hline enanthe (Saxicola) . & & & & & . 6779 & paradisi ('T'chitrea) . & & & & & 470 \\
\hline etes) & & & & & . 465 & $\mathrm{xa}$ (Cholornis) & & & & & 4116 \\
\hline oglodytes) & & & & & 784 & loxornis . . . & & & & & 411. \\
\hline s). & & & & & $34 ! 3$ & lae... & & & & & $: 3: 3$ \\
\hline okinawae (Parus) . . & - • & & & & 316 & l'arus. & & & & & $3: 11$ \\
\hline
\end{tabular}




\begin{tabular}{|c|c|c|c|c|c|c|c|c|c|c|c|c|}
\hline & & & & & & & & & & & & Seite \\
\hline this) . & & & & & & . 69 & Podoces ..... & & & & & 37 \\
\hline (Muscicapa). . & & & & & & - 485 & poecilotis (Moupinia). & & & . & & 612 \\
\hline rostris (Ammomar & & . & . & & & . 223 . & polatzeki (Calandrella) & . & & . & & 217 \\
\hline sekii (A egithalos) & . . & & & & 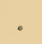 & . 387 & poliogyna (Loxia) . . & & & . & & 121 \\
\hline Passer . . . . . & . & & & & • & . 146 & poltaratskyi (Sturnus) . & - & & . & & 44 \\
\hline Passerina .... & - & & & . & . & 202 & polyglotta (Hippolais) & . & . & . & & 571 \\
\hline pastinator (Corvus) . & • & & & & • & 14 & Pomatorhinus .... & & & . & & 637 \\
\hline I'astor . . . & . & & . & - & . & - 47 & porphyronotus (Sturnus). & . & & . & & 46 \\
\hline ctoralis (Luscinia) . & - & & & - & - & . 739 & raetermissa (Galerida) . & & & . & & 239 \\
\hline kinensis (Alauda) & . & & & - & . & - 248 & pratensis (Anthus) . . & & • & . & & 275 \\
\hline kinensis (Parus) & & & . & & - & . 358 & Pratincola ..... & & & & & 701 \\
\hline sis (Rhopophilt & & & . & & . & . 614 & princeps (Tchitrea) . & & & & & - 471 \\
\hline nus (Anthoscop & & - & . & & & . 389 & Prinia....... & & & & & 608 \\
\hline ata (Eremophils & & & & & . & . 261 & prjervalskii (Ianthocincla) & & & . & & 632 \\
\hline alae (Troglodyte & & & . & & & . 783 & Procarduelis .... & & & & & 111 \\
\hline anica (Antbus) & & & & & & . 282 & Proparus . . . . . . & & . & . & & 615 \\
\hline ericrocotus . . . & 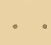 & & . & & & - 466 & rrhula . . . . & & . & . & & 112 \\
\hline erisoreus . . . . & . & & . & 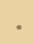 & & 34 & proregulus (Phylloscopus) & & . & & & 523 \\
\hline rsica (Calandrella) & . & & . & & & 220 & Prunella . . . . . & & . & & & 762 \\
\hline Motacilla) . & • & & & & & . 306 & Hypsipetes) . . & & - & & & 464 \\
\hline cola). . & 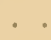 & & & & & . 696 & ii (Eremophila) & & & . & & 259 \\
\hline ica (Sitta) . . & . & & & • & & . 333 & kii (Lanius) . & & & & & 420 \\
\hline cus (Cinclus) . . & 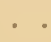 & & & & & . 795 & kii (Pratincoln). & & . & & & 709 \\
\hline cas (Parus) . . & . & & & - & & . 351 & skii (Sitta) ... & & & & & 337 \\
\hline ata (Emberiza) & & & & & & . 177 & ii (Suthora). & & & & & 409 \\
\hline Cophona) & . & & & & & . 58 & aroa (Melanocory & & ha) & & & 210 \\
\hline (Motacilla) & & & & & & . 306 & pseudohodgsoni (Turdus) & & & & & 649 \\
\hline tus (Ianthoci & & & & & & . 636 & us . . . . . & & & & & 412 \\
\hline$\cdot \cdots$ & & & & & & . 141 & Pterorhinus ..... & & . & & & 624 \\
\hline a (Petronia) & & & & & & . 141 & (Phylloscopus) & & . & & & 524 \\
\hline notus (Parus) & & & & & & . 361 & is (Carpodacas) & & . & & & 103 \\
\hline ensis (Monticola & & & & & & . 675 & rrhospiza) . & & . & & & 111 \\
\hline uscinia) & & & & & & . 736 & is (Sturnus) & . . & . & & & 46 \\
\hline & & & - & & & - 650 & (mberiza) . . & • & . & & & 188 \\
\hline nmoman & & & - & & & $1-226$ & a (Pnoepyga) . . & & . & & & 787 \\
\hline Ammo & & & & - & & - 224 & (Serinus) . . & & . & & & 85 \\
\hline s (Hodgs & & & & - & & - 756 & (Petronia) & & - & & & 144 \\
\hline es (Lanius & & & & - & & - 443 & otus . . . . & & . & & & 459 \\
\hline des (Phoen & icus & & & & & - 723 & i (Urocynchramus) & & & & & 205 \\
\hline is ... & . & & & - & & . 717 & naicus (Cinclus) . . & & . & & & 790 \\
\hline (Phoenicu & & & & & & - 718 & $\mathrm{ax} . . .$. & & & & & 35 \\
\hline cola... & & & & & & 554 & (Pyrrhocorax) & & & & & 35 \\
\hline crocephal & & & & & & 566 & us (Passer) . & & & & & 151 \\
\hline Phylloscopus . . . . & & & & & & 499 & plectes ... & & & & & 98 \\
\hline Pica & & & & & & 19 & piza. & & * & & & 110 \\
\hline (Pica) . . & & & & & & 19 & lla . . . . & & - & & & \\
\hline ta (Saxicola) . & - & & & & & 696 & a (Pyrrhula) . . & & . & & & 93 \\
\hline is ('Turdus) . . & & & & & & 64 & nus (Emberiza) . & & . & & & 197 \\
\hline cola . . . . & • & & & & & 113 & pyrrhuloïdes (Emberiza) . & & - & & & 198 \\
\hline Scotocerca) & & & & & & 607 & pytyopsittacus (Loxia). & & & & & 122 \\
\hline a (Saxicola) & & & & & & 688 & & & & & & \\
\hline i (Podoces) . . & & & & & & 39 & & & & & & \\
\hline (Parus) & & & & & & 351 & olais) & & & & & 575 \\
\hline beitarsus (Phyllos & & & & & & 511 & rayi (Motacilla) . & & & & & 294 \\
\hline Pnoepyga . . . . & & & & & & . 786 & Regulus . . . . & & & & & 394 \\
\hline
\end{tabular}


Seite

regulus (liegulus) . . . . . . . 394

rciserj (Emberiza) . . . . . . . . 199

reiseri (Hippolais). . . . . . . 574

restrictus (Parus) . . . . . . . 380

Rhamphocorys . . . . . . . . 206

rhenanus (Parus) . . . . . . 377

Rhipiduriz . . . . . . . . . . 472

rhodochlamys (Carpodacus) . . . 100

rhodochroa (Carpodacus) . . . 102

Iíhodopechys . . . . . . . . . . 90

rhodopepla (Carpodacus) . . . . 10:3

Rhopophilus .......... 613

Rhorlospizar. . . . . . . . . 91

Rhyucormis.......... . 715

richardi (Authus) . . . . . . . 265

riggenbachi (Galerida) . . . . . . 231

riggenbachi (Saxicola) . . . . . . 6999

Riparia .......... 810

jiparia (hiparia) . . . . . . 811

ripponi (Prumella) . . . . . . 766

roborowskii (Montifringilla) . . . . 139

robusta (Luscinia) . . . . . . 748

rosea (Carpodacus) . . . . . . 105

roseata (Carpodacus) . . . . . 108

roseatus (Anthus). . . . . . . 279

roseus (Aegithalos) . . . . . . 384

roseus (Pastor) . . . . . . . 47

rossorum (Pratincola) . . . . . 709

rostrata (Saxicola) . . . . . 681

rostratus (Acanthis) . . . . . 80

rothschildi (Nucifraga). . . . . 27

rubecula (Erithacus) . . . . . 750

rubeculoides (Prunella) . . . . 767

rubescens (Procarduelis) . . . . 112

rubetra (Pratiucola) . . . . . . 702

rubicilla (Carpodacus) . . . . . . 99

rubicilloides (Carpodacus) . . . 100

rubicola (Pratincola) ...... 706

rubidiventris (Parus) . . . . . 362

rubidus (Prunella). . . . . . . 774

rufescens (Calandrella). . . . . 217

ruficapilla (Proparus) . . . . . 618

ruficauda (Muscicapa) . . . . . . 485

ruficeps (Luscivia) . . . . . . $7+1$

ruficeps (Psittiparus). . . . . . 412

ruficeps (Suthora) . . . . . . 407

ruficollis (MLontifringilla) . . . . . 135

ruficollis (Pomatorhinus) . . . . . 639

ruficollis (Turdus) . . . . . . . 659

ruficolor (Galerida) . . . . . . 238

rufidorsalis (Passer). . . . . . 150

rufogularis (lanthocincla) ..... 634

rufilatus ('Tarsiger) . . . . . . 713

rufilatus (Yrunella) . . . . . 764

sufipectus (Parus) . . . . . . . 359
Seite

rufitergum (Garrulus) . . . . . . 30

rufiventris (Ciuclus) . . . . . . . 794

rufiventris (Ploenicurus) . . . . 793

rufonuchalis (Parus) . . . . 561

rufula (Chelidun) . . . . . . 804

rufus (Phylloscopus) . . . . . . 501

rupestris (Riparia) . . . . . 815

ruppeli (Sylvia) . . . . . . . 592

russicus (Panurus) . . . . . . 4 40:

rustica (Chelidon). . . . . . 800

rustica (Emberiza) . . . . . 188

Ruticilla ........ . . 717

rutila (Emberiza) . . . . . . . 172

rutilans (Passer) ........ 161

saharae (Passer) . . . . . . . 163

saharae (Scotocerca) . . . . . 608

sahari (Emberiza) . . . . . . 190

sala (Alauda) . . . . . . . 250

salicarius (Parus) . . . . . . . 376

sanguinea (Rhodopechys) . . . . 90

sanguinolenta (Uragus) . . . . 87

sapsworthi (Cinclus) . . . . . 791

sarda (Sylvia) ....... . . 602

sardonius (Corvus) . . . . . . 10

sardus (Corvus) . . . . . . 6

sardus (Erithacus) . . . . . 753

sardus (Parus) . . . . . . . 358

savignii (Chelidon) . . . . . . 802

saxatilis (Nonticola) . . . . 671

Saxicola . . . . . . . . 678

sayana (Parus) . . . . . . 367

schach (Lanius) . . . . . . 451

schisticeps (Phoenicurus) . . . 72 )

schmitzi (Motacilla) . . . . . . 301

schoeniclus (Emberiza) . . . . 194

schonobaenus (Acrocephalus) . . . 566

schwarzi (Herbivocula) . . . . . 530

scotica (Loxia) . . . . . . . 120

scotica (Parus) . . . . . . . 365

Scotocerca . . . . . . . . 606

scouleri (Microcichla) . . . . . 760

seebohmi (Calandrella) . . . . 220

seebohmi (Saxicola). . . . . 682

Seiurus . . . . . . . . 311

semenorvi (Sylvia). . . . . . . 594

semirufa (Phoenicurus) . . . . 723

semitorquata (Muscicapa) . . . . 483

senator (Lanius) . . . . . . . 431

senckenbergianus (Passer) . . . . 152

senegallensis (Galerida) . . . . . 233

senegalus ('Ielophonus) . . . . 452

sericea (Pica) . . . . . . . 22

Serinus .. . . . . . . 82 


\begin{tabular}{|c|c|c|c|c|c|c|c|c|c|c|}
\hline & & & & Seite & strenera (Acrocephalus) & & & & & seite \\
\hline severtzovi (Carpodacus) & & & & . 100 & striata (Juscicapa). & & . & & & 475 \\
\hline sharpii (Corrus) . . . & & & & 10 & striaticollis (Proparus). & & . & & & (i18 \\
\hline ca (MLelanocorypha) & & & & 211 & striatus (Scotocerea) . & & . & & & 1507 \\
\hline iea (Muscicapa) . & & & & 478 & striolata (Chelidon). & & . & & & \\
\hline ica (Uragus) . . & & & & $86 i$ & triolata (Emberiza). & & . & & & 191 \\
\hline ricus (Corvus) . . & & & & 4 & triolatus (Anthus) . & & . & . & & $2660^{\circ}$ \\
\hline iricus (Perisorens) & & & & 35 & trophiata (Muscicapa) & & . & & & 181 \\
\hline iricus (Turdus) . . & & & & 134.4 & strophiatus (Prunella). . & & . & & & 767 \\
\hline ilans (Luscinia) . . & & & & $74: 3$ & Stumia . . . . . & & . & & & $4 !$ \\
\hline atrix (Plyyllosenpus) & & & & . Бli & Sturnidae . . . . . & & . & & & 41 \\
\hline (Aegithalos) . . & & & & - $3+6$ & sturnina (Sturnia) . . . & & . & & & 49 \\
\hline Illima (Motacilla) & & & & 289 & Sturnus . . . . & & . & & & 41 \\
\hline plex (Passer) . . . & & & & $1+1 \%$ & styani (Ianthocincla) . & & . & & & $(i 30)$ \\
\hline ianus (Phylloscopus) & & & & 50.5 & styani (Pomatorhinus) . . & & & & & (i3:) \\
\hline is (Enicurus) . . & & & & 7.39 & subaffinis (Phylloscopus) . & & . & & & $5:-1 ;$ \\
\hline nsis (Garrulus) & & & & 33 & subalpina (Sylvia) . . . & & . & & & \\
\hline asis (Sitta) . . & & & & - . 3333 & subalpinus (Prunella) . . & & & & & $76: 3$ \\
\hline nica (Chloris). . & & & & $.63,43.1$ & halus (Propyrrhul & & & & & \\
\hline phia. . . . . & & & & . . 473 & sonata (Motacilla). & & . & . & & $3(15$ \\
\hline tta.... & & & & 328 & lor (Ianthocincla) & & . & & & (6:3:3) \\
\hline idae . . . . & & & & . 328 & us (Phylloseopus) & & . & & & 520 \\
\hline Iris (Pericrocotus) & & & & . 16 in & sewi (Ianthocincla) & & . & & & 629 \\
\hline arius (Jlonticola) & & & & .67 .1 & rata (Emberiza). . & & . & & & $17 \pi$ \\
\hline rus (Parus) . & & & & . $31 ; 7$ & superbus (Erithacus) . . & & . & & & $7 \div 1$ \\
\hline (Leptopoecile) & & & & . $\quad 100$ & superciliaris (Muscicapa). & & . & & & $48 s$ \\
\hline (Cinclus) ... & & & & 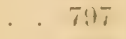 & ciliusá (Parus) . . & & . & & & 370 \\
\hline (Pratincola . . & & & & 7113 & liosa. (Phylloseopus) & & & & & is \\
\hline ligera (Huscicapa) & & & & $4 \times \div$ & iosus (Lanius) . & & & & & 417 \\
\hline pelaeornis . . . & & & & 7h.; & erflua (Galerida) . . & & . & & & $2 ! 34$ \\
\hline logus (Coloeus) & & & & 16 & a..... & & . & & & 406 \\
\hline orcus (Lanius). & & & & $1: 3: 3$ & (Luscinia) . . & & . & & & 745 \\
\hline (Acanthis) & & & & 73 & ei (Cyanopica) & . & . & & & 2.1 \\
\hline Anthus) . & & . & & $27 !$ & ii (Proparns) . . & & . & & & $61 !$ \\
\hline Acanthis). . & & & & 71 & ea (Saxicola) . . & & . & & & (iGs \\
\hline diopsar . . . & & & . & $4 x$ & sylvestris (Phylloscopus) & & & & & $5(1) 1$ \\
\hline diogenys (Fringilla) & & & & $1 \geq 7$ & Sylvia . . . . . & & . & . & & $i 76$ \\
\hline phala (Emberiza) & & & & $17 i$ & Sylsiidae . . . . & & . & . & & $f(j)$ \\
\hline ta (Pnoepyga) & & & & $7 x T$ & synoica (Uarpodacus) & & . & . & & $11 \mathrm{~K}$ \\
\hline unmeiceps (Urosphena) & & & & 5334 & syriacr (Agrobates). & & . & - & & 601.5 \\
\hline amiceps (Crateropus) & & & & 1921 & syriaca (Sitta) . . & & . & . & & 338 \\
\hline amiceps (Hypsipetes) & & & & 165 & syriaca ('T'urdus) & & & & & 6699 \\
\hline agnatilis (Parus) . . & & & & 371 & syriacus (Serinus) . . . & & . & & & 85 \\
\hline ejnegeri (Hypsipetes) & & & & $4(i-4$ & szetschuauus ('Lroglodytes) & & & & & $7 \times 3$ \\
\hline jnegeri (Pratincola). & & & & 7108 & & & & & & \\
\hline ri ('Zosterops) . & & & & 315 & & & & & & \\
\hline ephalus) & & & & 5...9 & tacsanowskia (Lusciniola) & & & & & \\
\hline (za) . . & & & & $17 !$ & a (Certhia)... & & & & & $3: 1 i$ \\
\hline iczkae (Ac & & & & 77 & ensis (Yasser) . & & & & & 161 \\
\hline oscopus) & & & & $3: 11$ & is (Motacilla). . & & & & & 20,3 \\
\hline iczkae (Carpodacus) & & & & $10 ! 9$ & itaica (Troglodytes) & & & & & in: \\
\hline iczliae (Certhia). . & & & & 322 & ata (Galerida)... & & & & & 235 \\
\hline czkae (Passer) . & & & & 159 & rigrer . . . . & & & & & 712 \\
\hline (mberiza) . & & & & 184 & rica (Aegithalos). & & & & & \\
\hline aminea (Locustellia) . & & & & $\therefore . . ;$ & itreat..... . . & & & & & $f(i)$ \\
\hline
\end{tabular}


Seite

tegimae (Pericrocotus) . . . . . $\$ 67$

teleschowi (Eremophila) . . . . 261

temminckii (Myiophoneus) . . . . 676

tenellipes (Phylloscopus) ... . . 512

teneriffae (Parus) . . . . . 350

teneriffae (Regulus) . . . . . 397

tenuirostris (Cinclus) . . . . 798

tenuirostris (Galerida) . . . . 230

Telophonus ....... 452

tephrocephalus (Cryptolopha) . . 496

tephrocotis (Montifringilla). . . 140

tephronota (Sitta) ..... 339

tephronotus (Aegithalos) . . . 387

tephronotus (Lanius) . . . . 451

Tesir . . . . . . . 798

teydea (Fringilla) . . . . . . 129

thanneri (Emberiza) . . . . 167

theklae (Galerida) ..... . 237

thibetana (Acanthis) . . . . 72

thoraeica (Lusciniola) . . . . 541

thura (Carpodacus) ...... 101

tianschanica (Certhia) . . . . 321

tianschanicus (Parus) . . . 353

tibetana (Troglodytes) . . . . 782

tibetanus (Corrus) . . . . . 4

tibetanus (Parus) . . . . 346

tibetanus (Prunella) . . . . 765

'lichodroma ....... . 326

tigrinus (Lanius) . . . . . . 442

T'imeliidae . . . . . . . . 469

tingitanus (')rvus) . . . . . . . 6

tingitanus (Passer) . . . . . 149

tintinnabulans (Cisticola) . . . . 613

titys (Phoenicurus) . . . 718, 720

toni (Sylvia) . . . . . . 602

torquata (Pratincola) . . . 706-708

torquatus ('lurdus) . . . . 663

trauscaspicus (Monticola) . . . 675

transcaspicus (Passer) . . . . 157

transfuga (Gymnoris) . . . . 145

transitiva (Chelidon) . . . . 802

trifasciatus (Carpodacus) . . . . 104

tristis (Phylloscopus) . . . . 503

tristis (Regulus) . . . . . 398

tristrami (Emberiza) . . . . . 192

trivialis (Authus) . . . . . . 972

trivirgatus (Aegithalos) .... 385

Trochalopteron ....... 624

trochiloides (Phylloseopus) . . . 522

trochilus (Phylloscopus) . . . 507

Troglodytes ........ 776

troglodytes ('l'roglodytes) . . . 798

Troglodytidae ....... 775

troglodytoides (Spelaeornis) . . 785

tschebaiewi (Luscinia) . . . . 740
Site

tschitscherini (Sitta) . . . . \$3?

tschusii (Acanthis) ...... tir

tschusii (Corvus) . . . . . 14

tschusii (Emberiza) . . . . . 198

turcestanicus (Myiophoneus) . . . . (;i7

Turdidae ...........46!

Turdus . . . . . . . 1540

tytleri (Chelidon) . . . . . . . 80.1

tytleri (Phylloscopus) . . . . 510

ultramarinus (Parus) . . . . 34t

ultramontana (Certhia) . . . . . . $3 \pm 4$

umbrinus (Corvus) . . . . . . 8

uncinatus (Lanius) . . . . . . 131

undata (Sylvia)...... . $(600$

unicolor (Sturnus) . . . . . . . 16

unicolor (Suthora) . . . . . . 407

Uragus . . . . . . . . 86

uralensis (Sitt $\Omega$ ) . . . . . . . 3330

urbica (Hirundo) . . . . . . . s(t)7

Urocynchramus . . . . . . . 901

uropygialis (Cisticola) . . . . 612

Urosphena . . . . . . . . . . 539

ussurianus (Corvus) . . . . . . 4

ussuriensis (Chloris) . . . . . 1it

ralentini (Cryptolopha) . . . . 497

variabilis (Emberiza) . . . . . 191

varius ('orvus) . . . . . . 4

varius (Parus) ...... 35t

venustulus (Parus) . . . . 35.

verreauxi (Carpodacus) . . . . 10!

villosa (Sitta) . . . . . . 336

vinacea (Aegithalos) .... . 38s

vinaceus (Carpodacus) . . . . . 104

vinipectus (Proparus) . . . . . 617

violacea (Sturnia) . . . . . 50

rirens (Dendroica) . . . . . 311

viridanus (Phylloscopus) . . . . . 510

viscirorus (l'urdus) . . . . . . . 6.47

vittata (Saxicola) . . . . . 6sio

vittatus (Lanius) . . . . . . . 411

volgae (Luscinia) . . . . . . . 719

vulgaris (Sturnus) ....... 11

waddelli (Innthocincla) . . . . 628

walteri (Montifringilla) . . . . 138

webbiana (Suthora) . . . . . $\$ 10,411$

whitakeri (Garrulus) . . . . . 33

whiteheadi (Sitta) . . . . 335

whiteleyi (Hirundo) . . . . . 80!

witherbyi (Erithacus) . . . . . 703 
Alphabetisches Register.

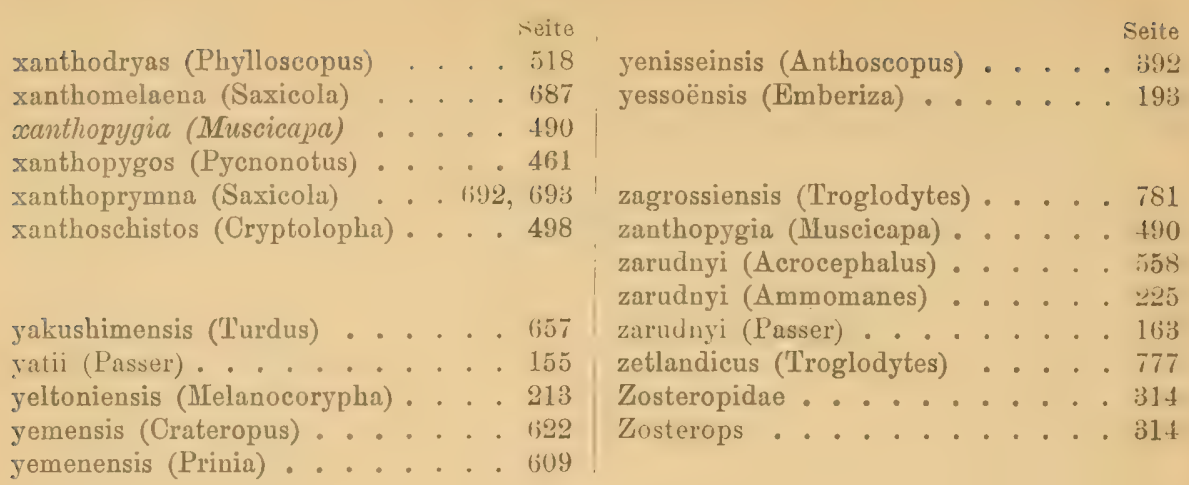




\section{R. Friedländer \& Sohn in Berlin NW 6.}

In unserem Verlage erscheint:

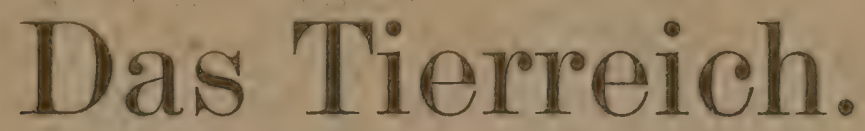

Eine Zusammenstellung und Kennzeichnung der rezenten Tierformen.

Begründet von der Deutschen Zoologischen Gesellschaft.

Im Auftrage der

Königl. Preuß. Akademie der Wissenschaften zu Berlin heransgegeben von

Franz Eilhard Schulze.

- Expos

Die Heransgalie findet in Lieferungen (in Grob-Lexikon-Oktav mit Ablildungen im Texte) statt, die je eino oder mehrere nahestehende Gruppen behandeln, jedoch unabhängig yon einer systematischen Folge erscheinen. Jede lieferung ist einzeln käuflich.

Bei Subskription auf das ganze Werk tritt eine PreisermäBigung ein.

Aus der Gruppe der

sind bisher erschienen:

\section{Vögel (Aves)}

Lieferung 1: Podargidae, Caprimulgidae und Macropterygidae. Bearbeitet von E. Hartert (I'ring) ․ 1897. VIII und 98 Seiten mit 16 Abbildungen und Beilage: Terminologie des Togellö̈pers von A. Reichenow, 4. Seiten mit Abbildung.

Einzelpreis Mark 7;-

liefermg 2: Paradiseidae. Bearbeitet ron the Hon. Walter Rothschila. 1898. VI und 52 Seiten mit 15 Abbildungen. Einzelpreis Mark $3,60$.

Lieferung 9: Trochilidae. Bearbeitet von E. Hartert (Tring). 1900. X und 254 Seiten mit 34 Abbildungeu.

Einzelpreis Mark 16,--

Lieferung 15: Zosteropidae. Hearbeitet rou O. Finseh (Leiden). 1901. XIV und 55 Seiten mit 32 Abbildungen.

Einzelpreis Mark 4,80 .

Yicterung 18: Paridae, Sittidae und Certhiidae. Bearbeitet ron (:. E. Hellmayr (Mïnchen). 1903. XXXI und 255 Sieiten mit. 76 Ahbildungen.

Einzelpreis Mark 16,-

Weitere Lioferungen erscheinen in ununterbrochener Folge. Bestellungen und Subshriptionen können dureh jede Buehhandlung hervint nerden.

Berlin, Juni 1910.

\section{R. Friedlinder \& Soln.}




\section{R. Friedländer \& Solm in Berlin NW 6.}

In unserem Kommissions-Verlage erschien 1902:

\section{Aus den \\ Wanderjahren eines Naturforschers.}

\section{Reisen und Forschungen}

in Afrika, Asien und Amerilsa

nebst daran anknüpfenden meist omithologischen Studien

V011

\section{Erust Hartert.}

Ein Band von XV und 329 Seiten mit 17 Abbildungen in Text und 13 Tafeln (- Routenkarten, Landschaftsbilder, ethnographische 'Typen, Abbildungen neuer Fische -). klein-4. In geschmackvollem Leinenband.

$$
\text { Preis } 25 \mathrm{Mark}
$$

Inlialt:

I. Reise nuch Solont, und Kino im westlichen Sudan (Westliüste. Flubfahrten auf dem Niger und Benue. Vun Loko bis Kano, Sokoto und Gandu durch vorher unerforschte Gebiete, dimn zurïck zum Benue. Loko am Bonue). Zur Fauna der ('auarischen Inselu. Die Oruis der Los-Iuseln. Verzcichuis der bisher hekannten Vägel des Hanssalandes. Thersicht der im Haussalande heohachteten Nutzpflanzen. - II. Reise nach Sumatra, Malakka und Indieu. (Die Insel Pentung. Sumatra. Naturgeschichtliches aus Sumatra. Die Insel Salanga. Der hritische Śchutzstaat Perak. Assam. Indjen.) -- III. Reise nach den Inseln des Camihischen Meeres (Reise wach Westindien und Venezuela: St. Thomas. Fumnistisches. Porto Rico. Venezuela.

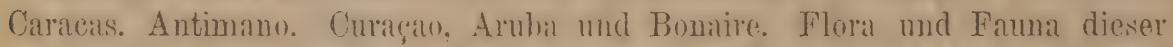
Insehn. Hayti). Die Vügel rer Insehn Aruha, ('uraçao und Bouaire, neue Formen. - IV. Frïhlingsausflug nach Marokion und Teuerife. (Reise nach Marolks und den Canaren. Togellebeu. Der Oum Rhiah. Entdeckung nouer Fische. Tonerife. Orotavia.) Notizen über die Vügen der Cegenend um Mazagan im mittloren Marokko. 






4 
